$f=k$

1. कर

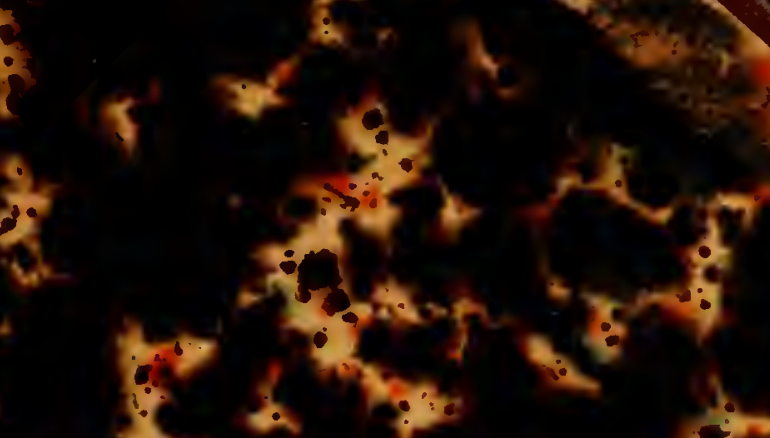

$r_{1}+t^{2}$

$\frac{1}{4}$

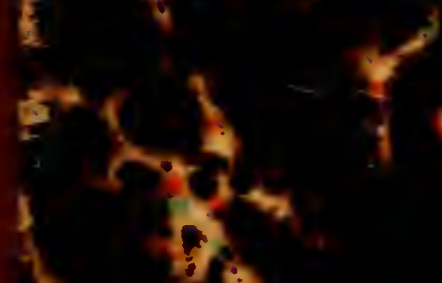

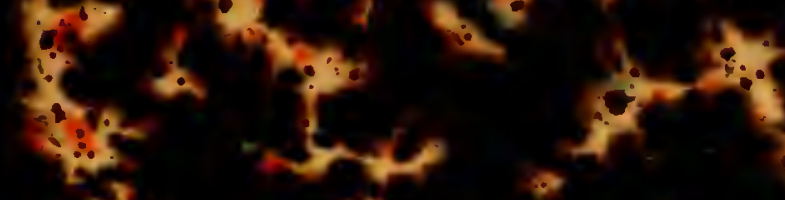

- $x^{2}+x^{2}+4$

$-3^{2}+3 x+3$

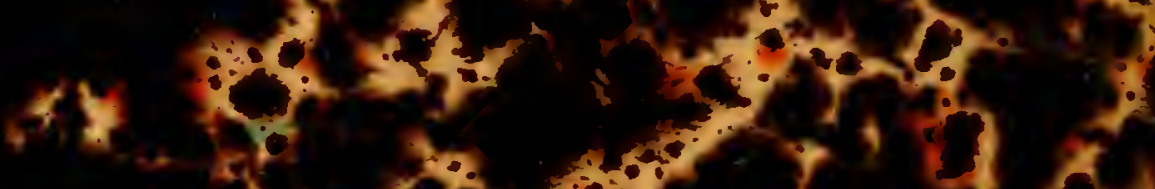

द. 9.

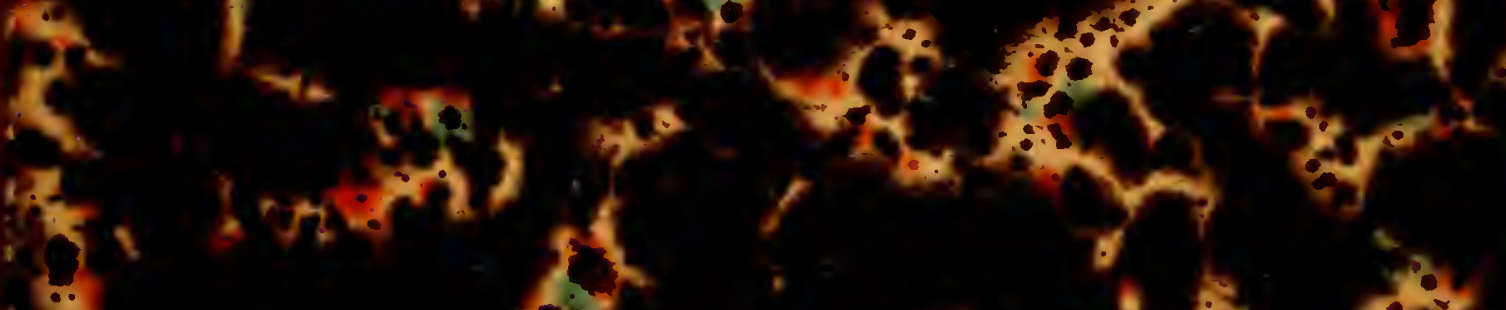

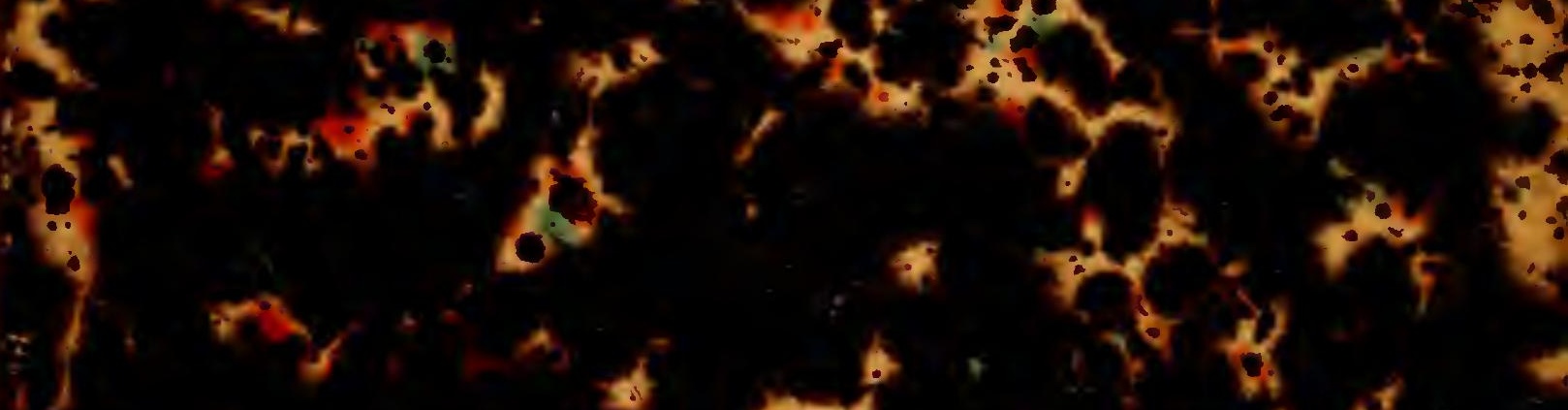

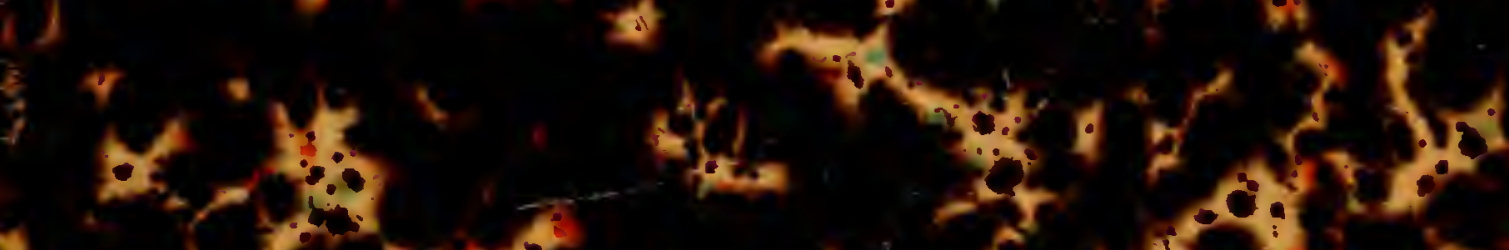

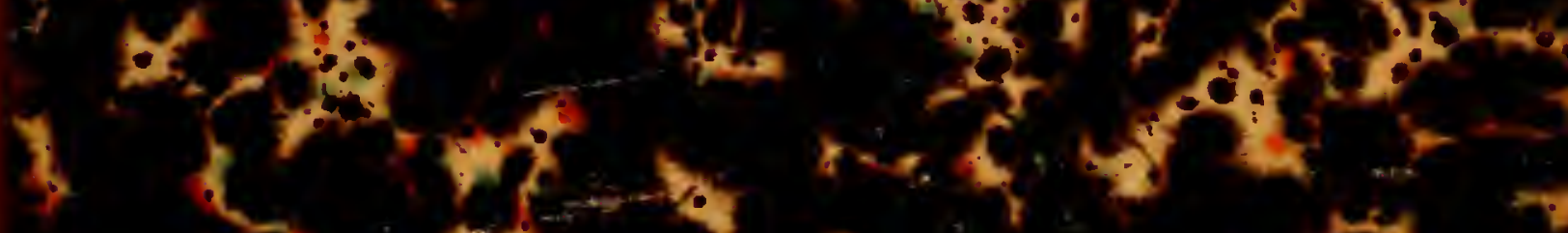

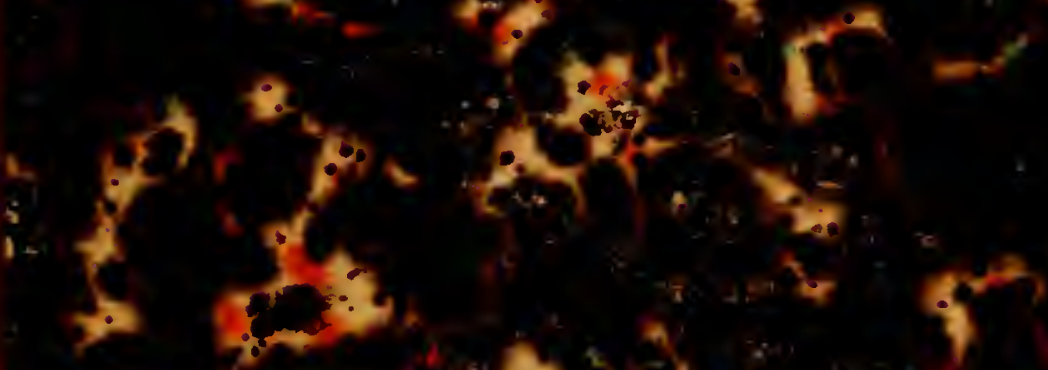

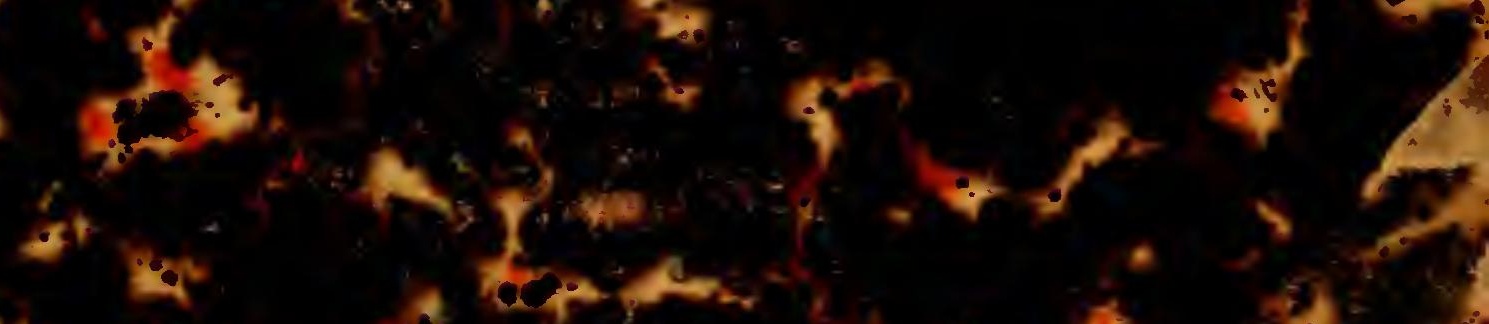

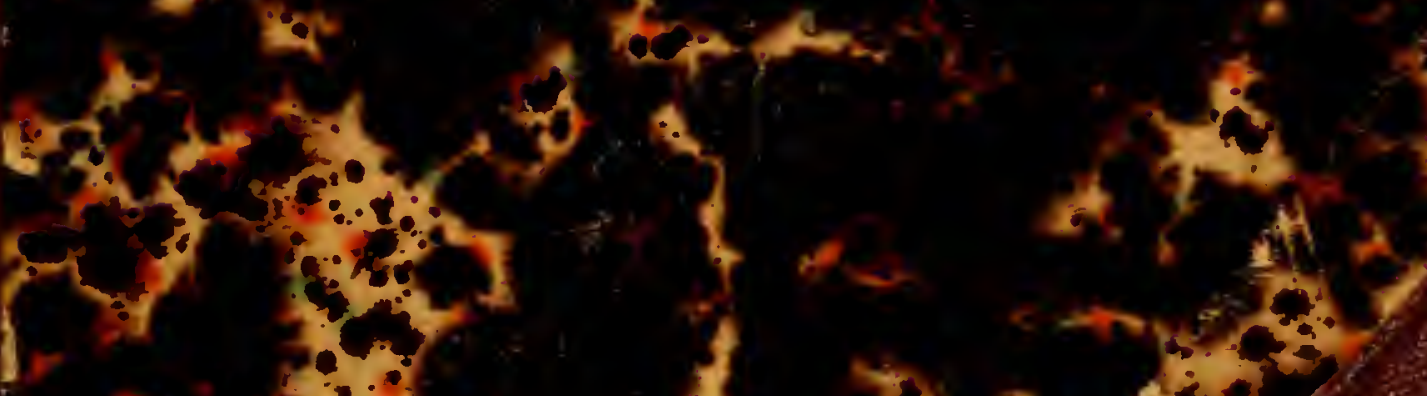

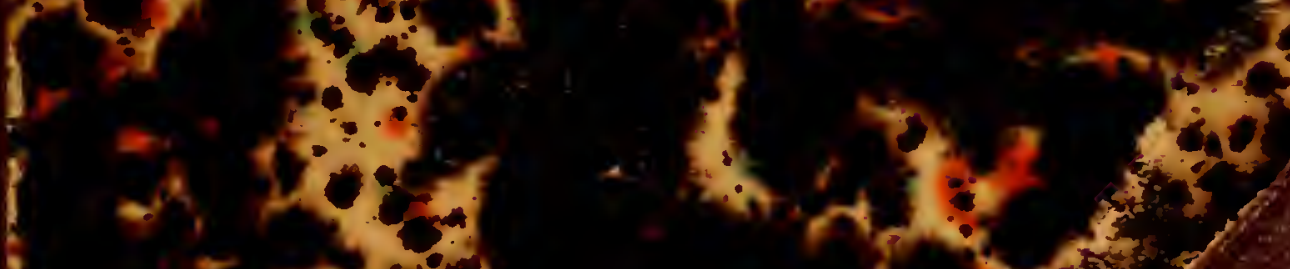

4. 


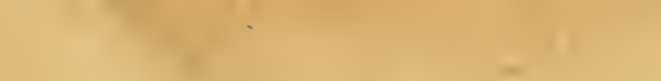







\section{Die Raturfrärte.}

(Sine

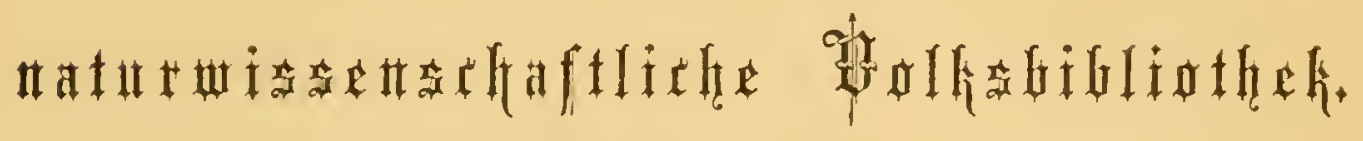

geder P3and koftet broldiint 3 Palark.

" " $\quad$ gefuntd. 4 อglark.

$" \quad, \quad$ wird einzelin verkatuft.

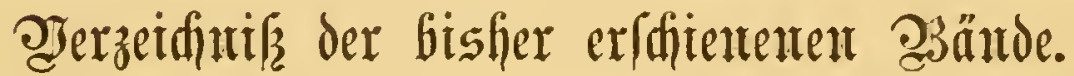

I. Sand. Dite Sehre vom Sdiafr. B̈emeinfaß̧lide Dar=

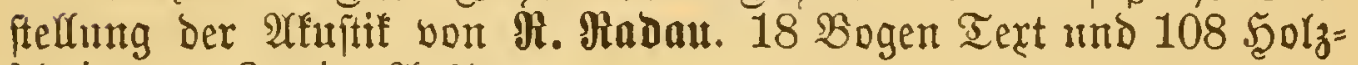
i山nitten. Zुweite $\mathfrak{Y}$ urflage.

II. Fandu. Sidit und Trarbe. Eine gemeinfaß̧lide Dar=

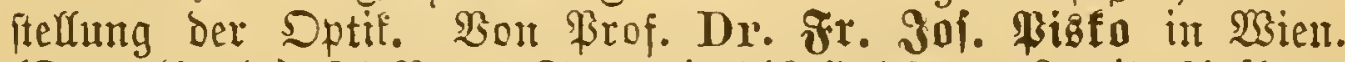

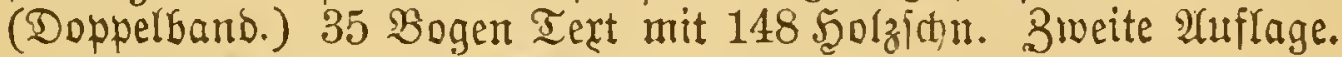

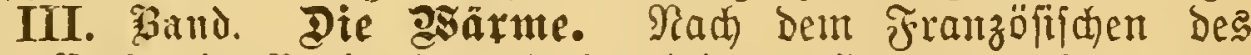

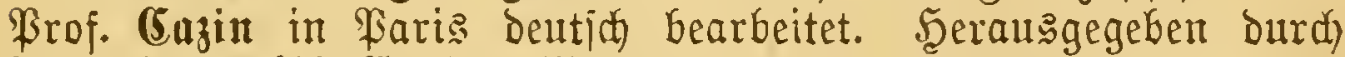

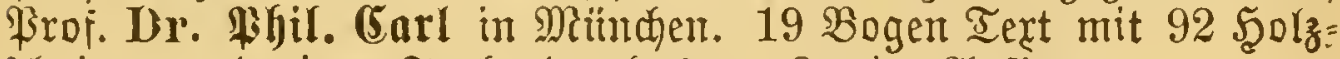
(d) nitten mb einer Farbembruftafel. 3meite 2ruflage.

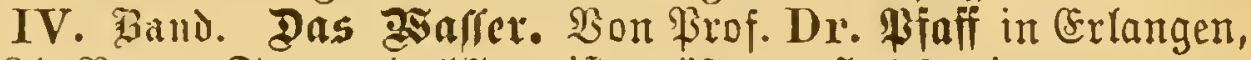

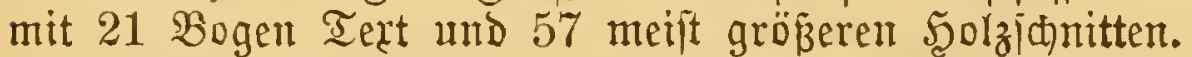

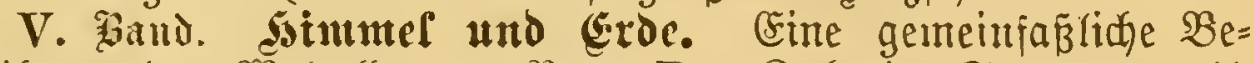
fatreibung des Meltalfe von Prof. Dr. 3ed in Stuttgart. 19

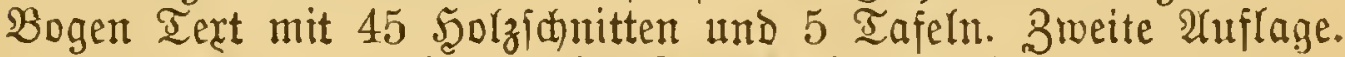

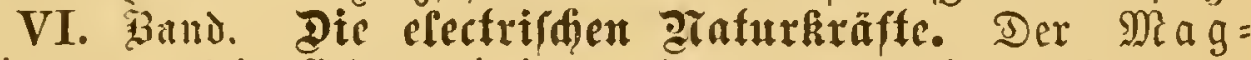
netismus, bie Electricität, ber galvanifde Strom.

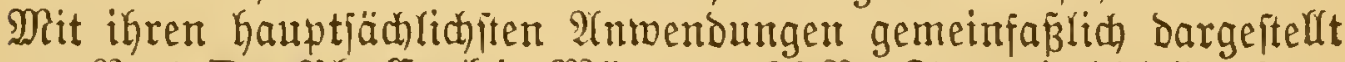

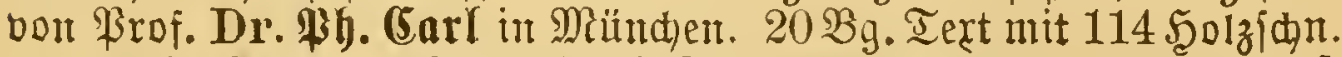

VII. Sando. Die vulkani/dien Errdieinutuen. Son Frof. Dr. Friedr. Pfaff in Errangen. 21 Bogen Text mit 37 Şolzimn.

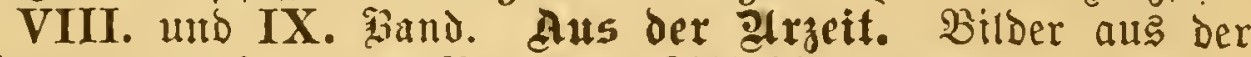
Sd)opfungageididte von Prof. Dr. Bittel in Mümden. 2 I Teile.

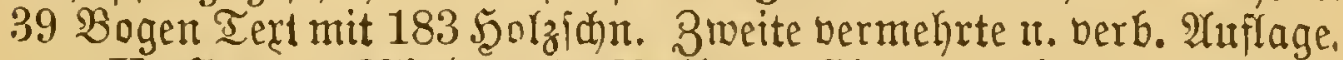

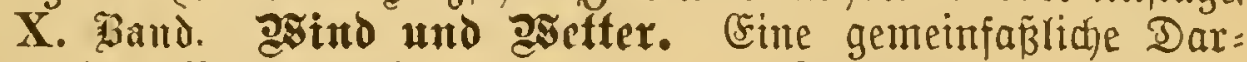
ftelfung Der Meteorologie non Frof. Dr. Qnmmel in Errangen. 25 Bogen Terct mit 66 Solzichnittert.

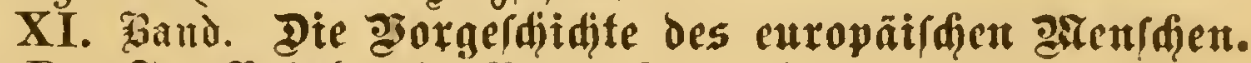
Bon Dr. Fr. Rakel. 19 Bogen Iex̧t mit 92 5eorźchnitten. 


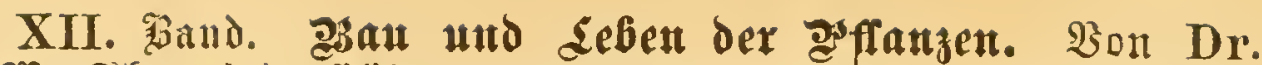

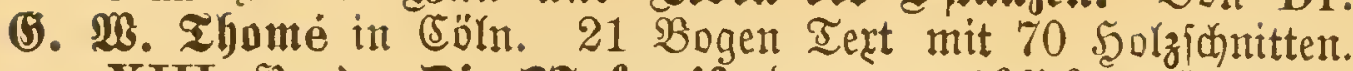
XIII. Gand. Die gitedantk des menfdifiden storpers.

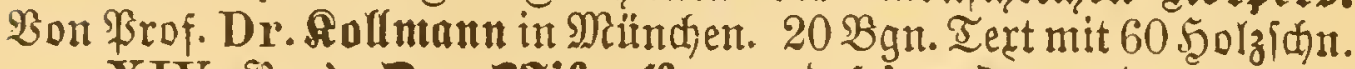

XIV. Gand. Das Difikrofkop und Teine Antwendung. $30 n$

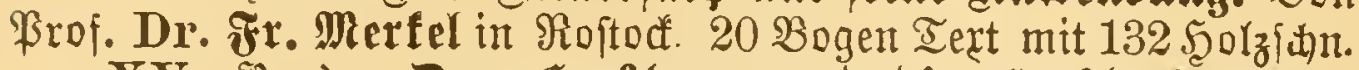

XV. Gand. Das Spektrum und die Spefitralanalyle. Bon Dr. P. 3ed, $\mathfrak{B r o f}$. Der $\mathfrak{B h y}$ fif am Bolntedutum in Stutt= gart. 15 Bogen Text mit 33 Seolzjdnttten und eitter Tafel.

XVI. Band. Qarwintsmus and Egierproduftion. Bon Brof. Dr. (5. C. R. פartmann. 19 Bgn. Tert mit 46 Scolzldnitten.

XVII. Gand. Giels und Eroboden. Bon Juofrath, łrof. Dr. Ferdinand Senft. 26 Bugen. Tert mit 17 Solzfdyntten.

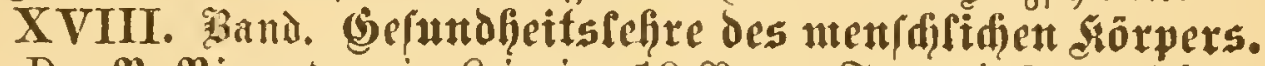
20n Dr. P. Riemeyer in Reipzig. 19 Bogen Tert mit 31 Julzidn.

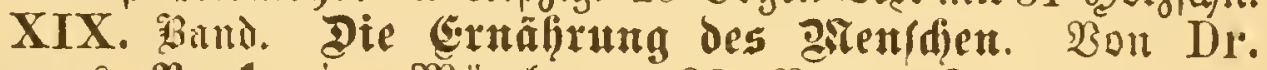
Sobannes Ranfe in Miunduen. 26 Bogent Sert und eine Bhotonraphie von $\mathfrak{s}$. v. Riebig.

XX. Gand. Die giafurkräfte in ifirer Anwendutg auf die Sandwirtfidiaft. Bon Dr. to. Gantm, Minifterialrath it Wien. 22 Bogen Tert mit 64 Solgjhnitten.

XXI. gand. Qrganismus der sutekten. Bon Brofefior

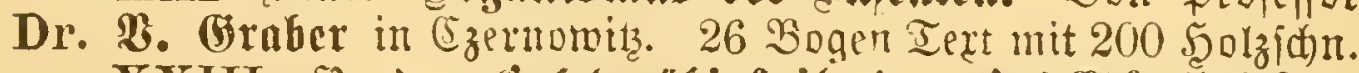

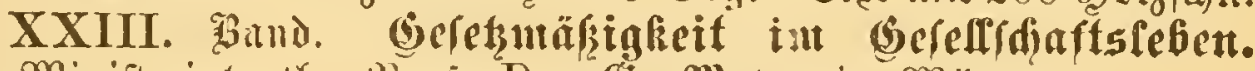
Bon Minifterialrath, Prof. Dr: (5. Mayr in Miindsent.

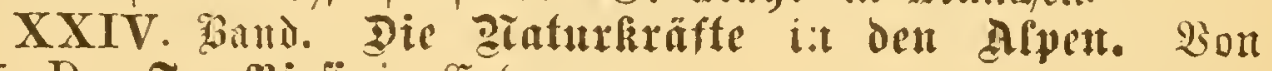
Brof. Dr. Fr. Bjafi in Erlangen.

XXII. Gand. (Doppelband.) Leben ber Sulekten. Son Prof. D1. 23, Graber in Czernomits. I. Şälfte.

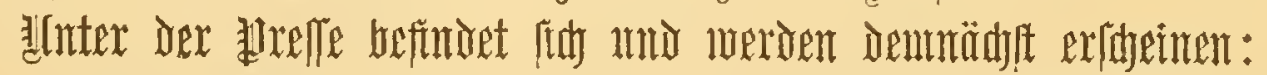

XXII. gand. (Doppelband.) seben der anteliten. Wion Prof. Dr. B. Sraber in Czernomit. II. ちälfte.

XXV. Gand. Erfinftung Der Energie. Won Dr. Arebg in Franfiurt.

焉

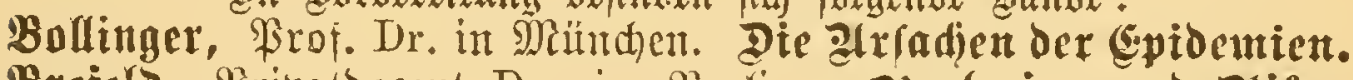

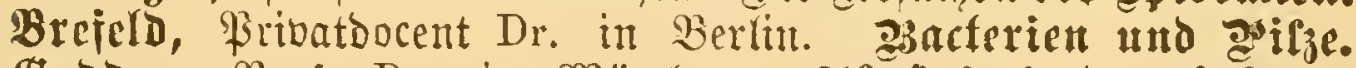

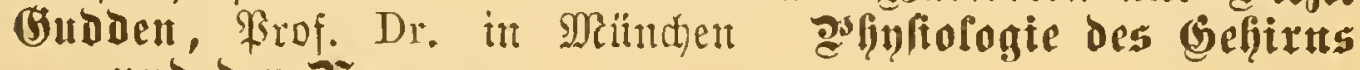

Hnd der gĭerven.

Geller, Broj. Dr. it Riel. Die đ̌arafiten.

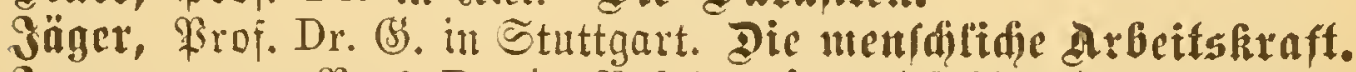

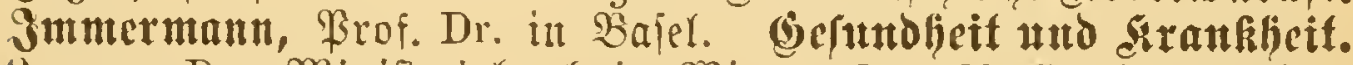

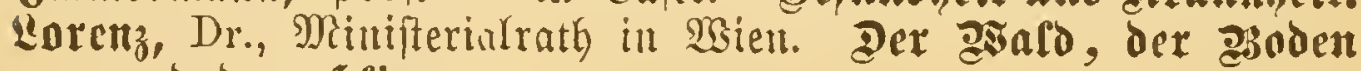

und das silima.

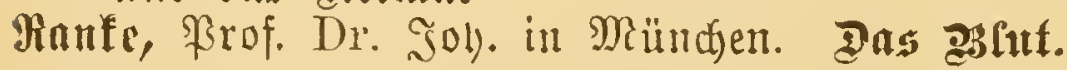




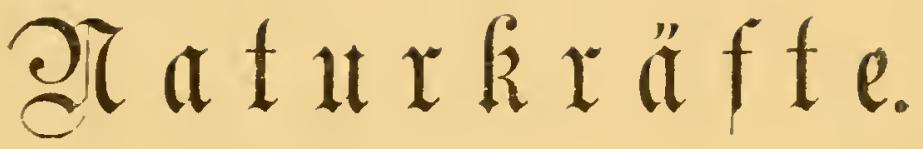

3meiumbzwanzigiter Band.

(Doppelbanio.)

(Erite $\mathfrak{g}$ älite. 



\section{I $\mathfrak{i} \mathfrak{f} \mathfrak{e} \mathfrak{i} \mathfrak{t} \mathfrak{e} \mathfrak{H}$.}

\section{Bont}

\section{Dr. בְitus (ôraber,}

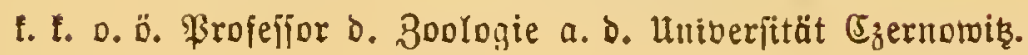

\section{Bweiter Elfieil.}

(Doppelbans.)

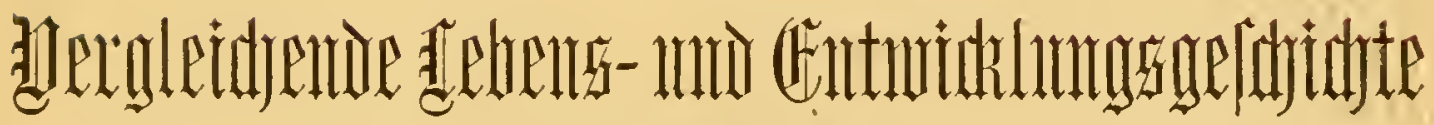

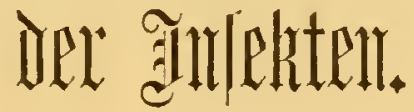

I. Şülfte.

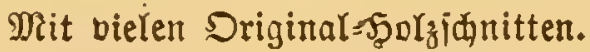

\section{Mïndyen.}

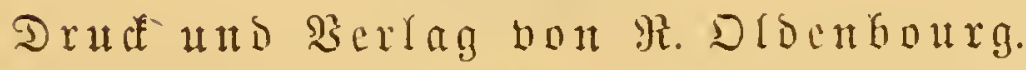


Ieberjeşungared porbegalten.

$$
11515
$$




\section{di $\mathfrak{n} \mathfrak{h} \mathfrak{a} \mathfrak{t}$.}

I. Sapitel:

$\mathfrak{U m} \mathfrak{i} \mathfrak{a} \mathfrak{u} \cdot$. . . . . . . . . . . . . 3

II. Rapitel:

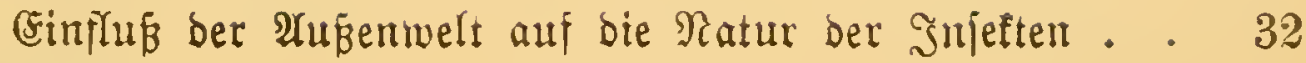

III. Sapitel :

Bauinoufrie ber Эnfeften . . . . . . . . . . 95

IV. Rapitel:

Anbermeitige ben Selbitichus und bie Bertheibigung be= trefiende (Einridungen und Borfebrungen ber Serfe 205 V. Rapitel :

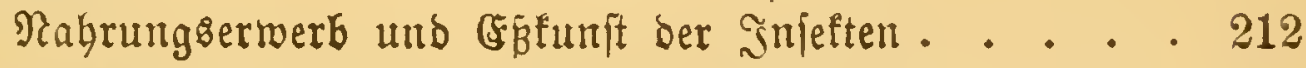
VI. Rapitel:

Sejellidaftaleben ber Rerfe . . . . . . . . . . 225 



\section{Dergleithende sebensgefhidhte.}





\section{1. $\mathfrak{s} a$ pitel. \\ $\mathfrak{U} \mathfrak{n} \mathfrak{j} \mathfrak{d} \mathfrak{a} \mathfrak{H}$.}

Das ganze gewaltige Seer Der gefpicf́ten Serfe, wie

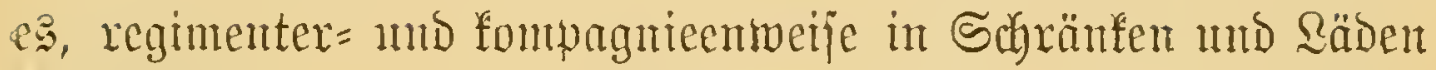

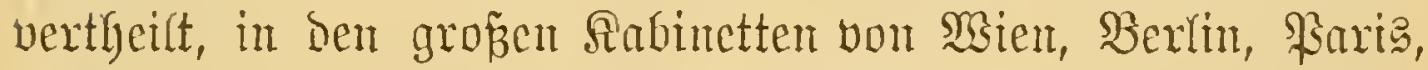

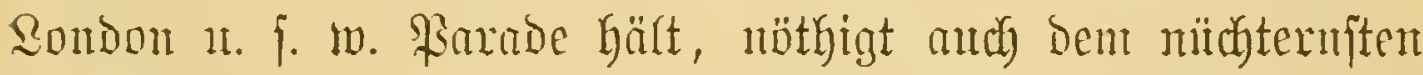
Beobachter, Dex fich zum erftemmale biejex zahlreichen und

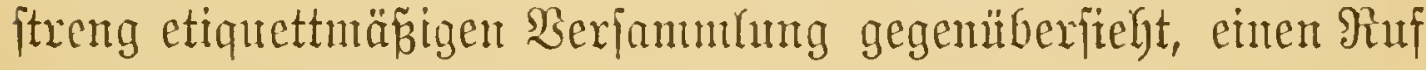
Des Eriftunten ab.

Und dies fund mur Reichen, Nhumien, Skelette.

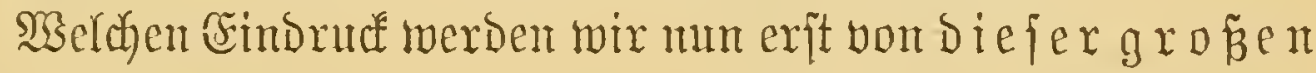
Welt Der $\Re$ leinen befommen, went wir fie auf ifrem natürlichen Schumlah bie Funftionen Des Rebents verridyten fehen. Welch' ein $\mathfrak{A}$ blick mur hebeligen Majajinen in Brang gerathen, wem die vielgliebrigen Beine ihr taftmäpiges Spiel begimen, bie Fłngräber bie

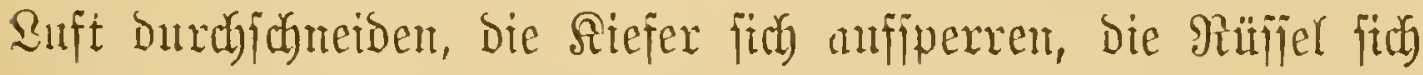

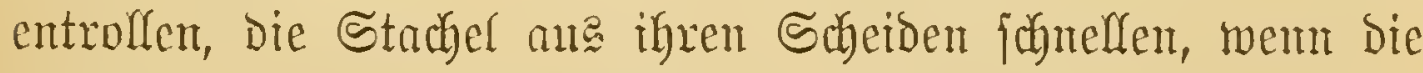
Liber ber Stigmen fich aufthum, bie Luft ben ganzen \&eib amfdhinellt, bas æöhrentherz pulfint, wem der gierige Darm inmer nen gefüllt zu werden verlangt und wenn cholidf, bei ungender Reife Der Fortpflanzutgandgane, Der Bejejlechtatricb,

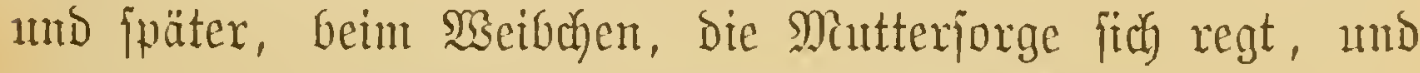

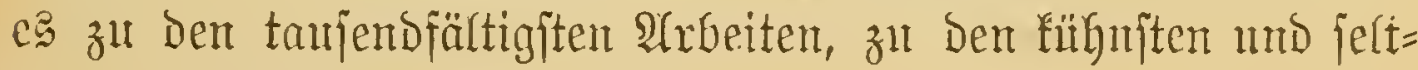
famjten Erfintoungen ampornt! 


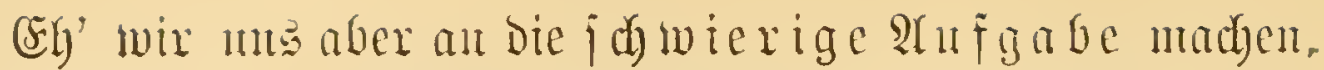

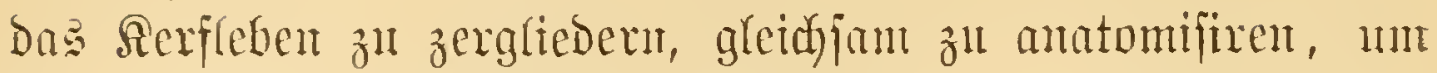

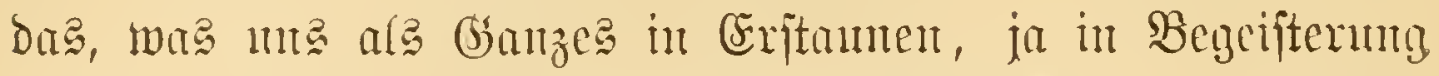
verjest, das mir aher it umerer Bejuränfung als joldhes

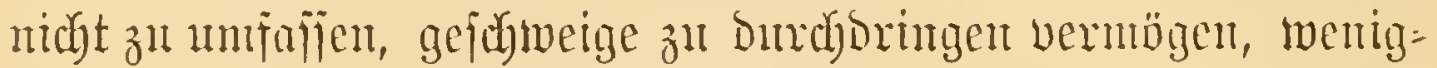

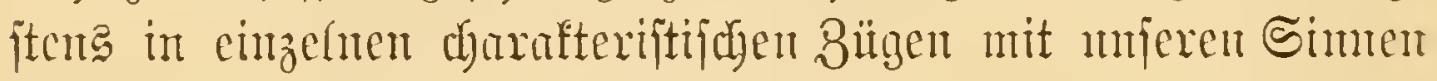
feitzulfalten mo mo nöglidi) and in jeinent inneren

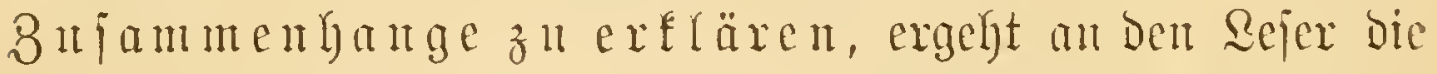

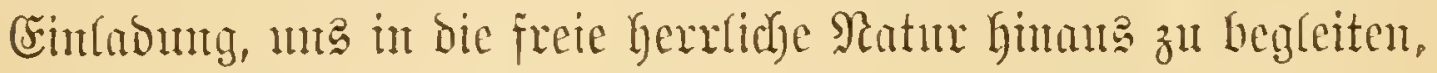

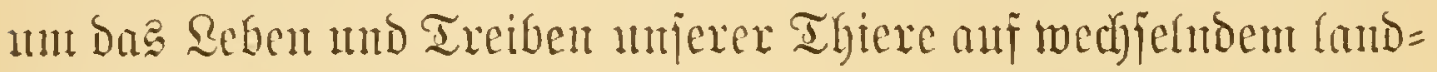

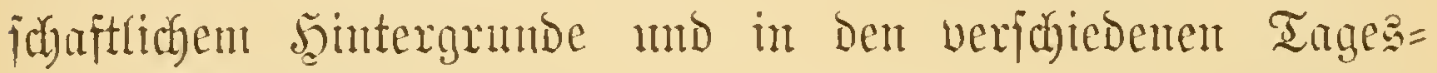

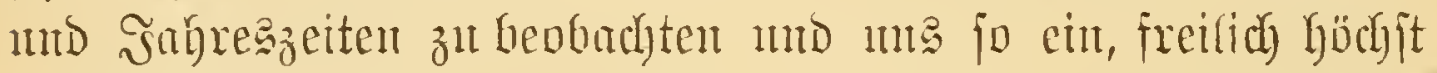

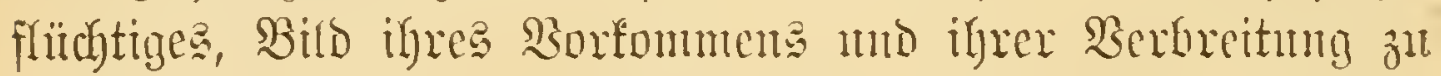

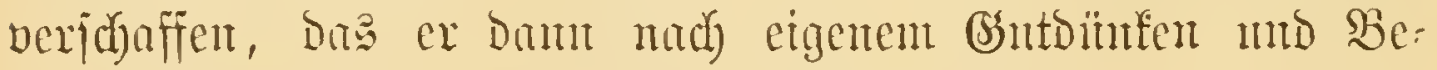
Dürinis (id) vervolffommuten uto ermeitern mag.

Ein blaner âtriltag, und hener der erite, an Dent wir mperer llutwerjitätäjtad, weldye Dort, ans der Fente fo ma=

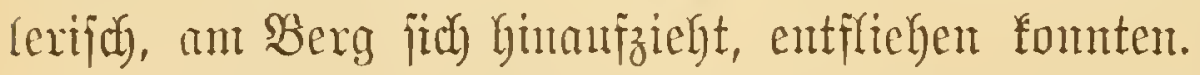

Mir ftehen in einer meiten jumpfigen Crrlenan Des Pruth,

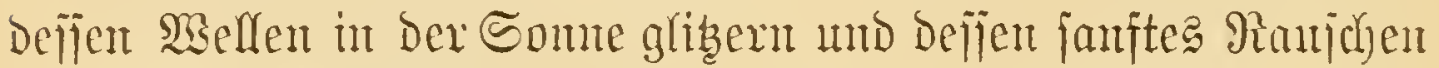
in biejer Eimpanteit wie Eximenntg herüberffingt an bie

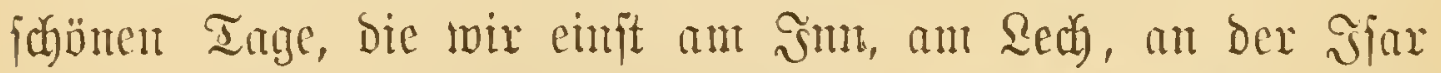

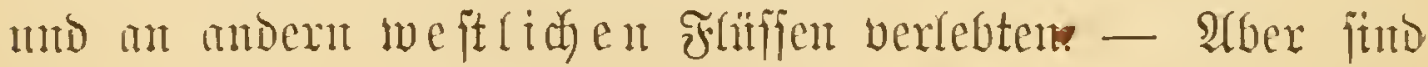
wir allein?

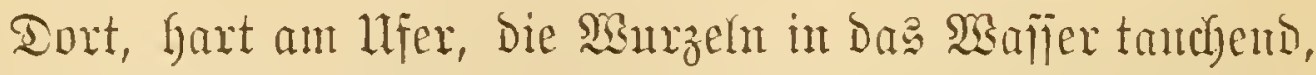

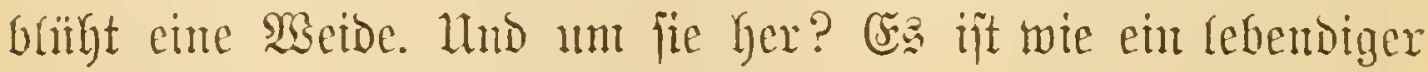

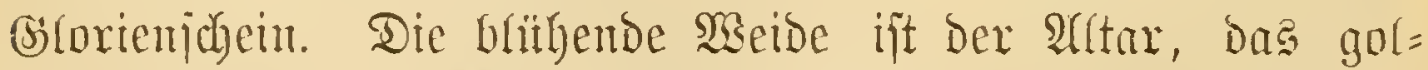

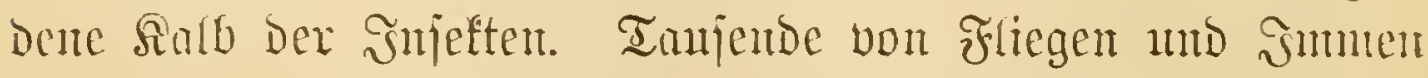
unfreijen, mijumen fie - jie jteigen anf mto nieber in nu=

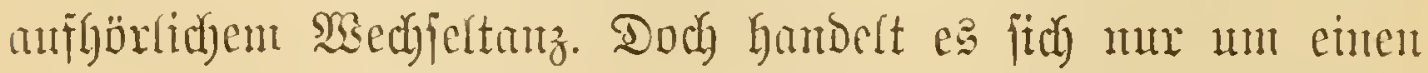

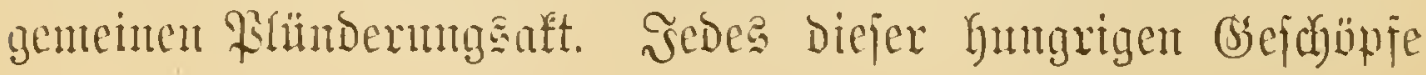




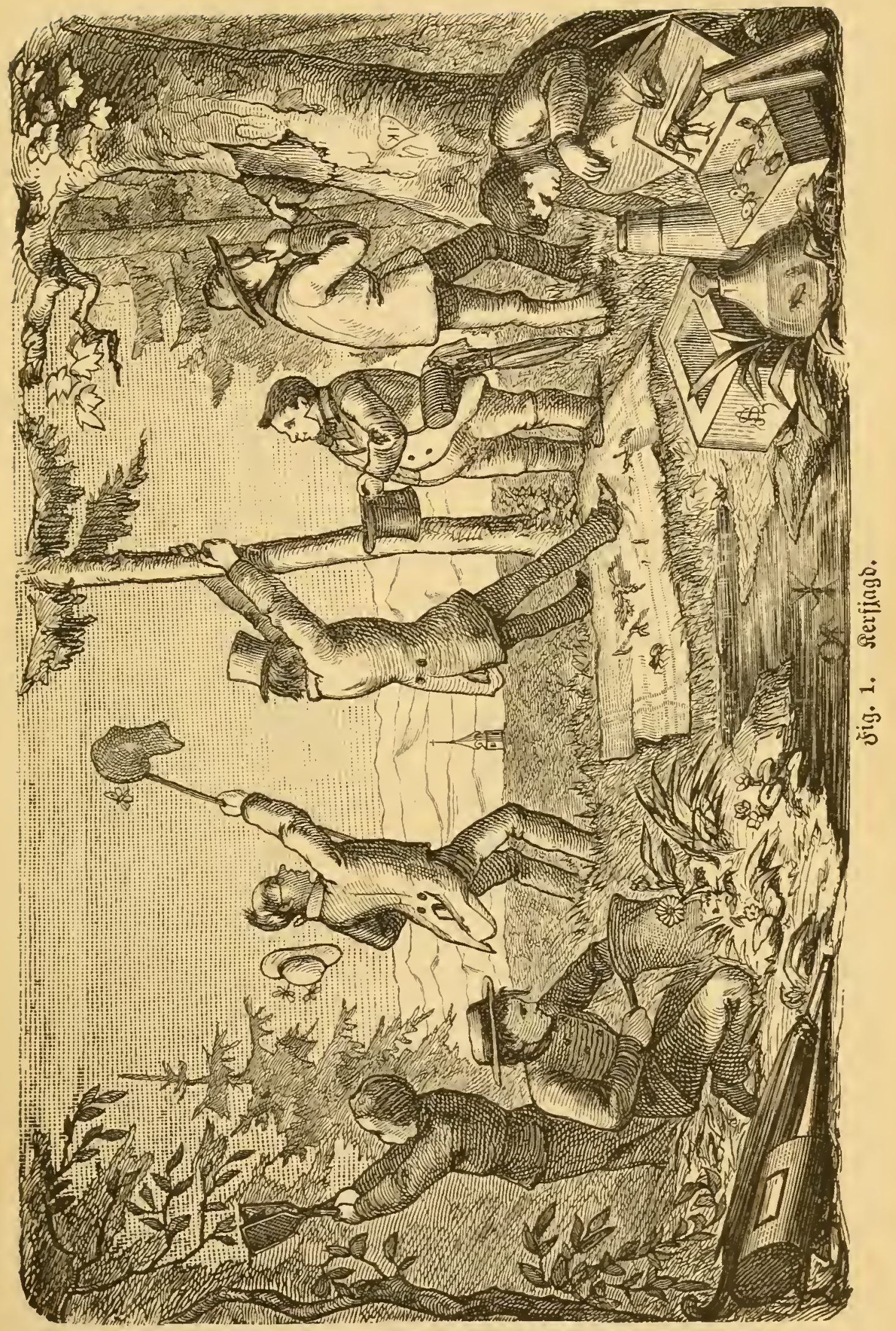


judtht jeinen Theif zu friegen, judft, undy langer Fajtenzeit, jeinen 2rppetit zu ftillen. Reines Der zahtreichen gologejpren=

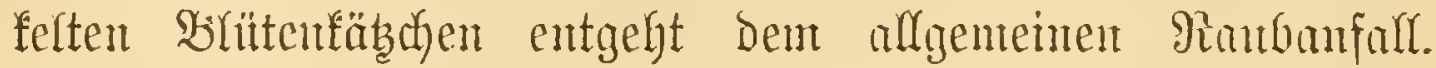

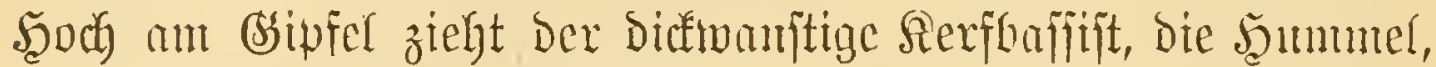

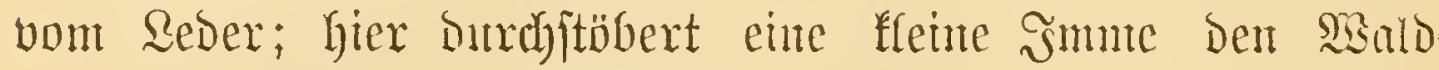
bon Stanbfäben; eine Şonigbiente foumt angeflogen, Den

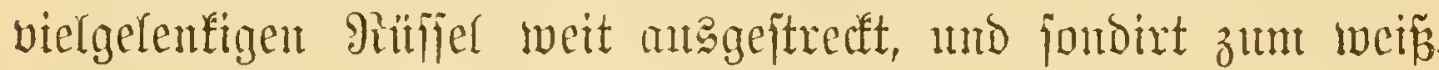
Bsott wie vielten Share jeden B̉ïtenpolftex, oft bänzen mebrere

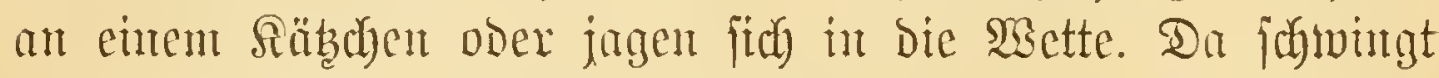

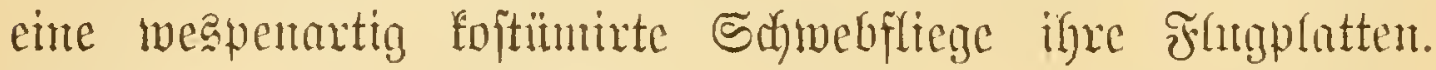
Wie Durch Zauberhand gehalten, fteht fie - in ber $\Omega_{11 f t}$ zu=

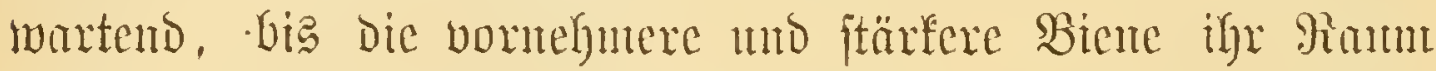
madet. Şier wräjentirt fich bie roitgelbe fleintöpfige Coeno-

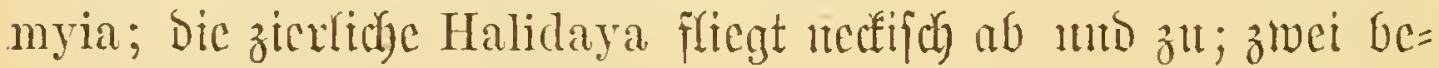
finnte Stedybremfengattuntgen, Die Haematopota und bie

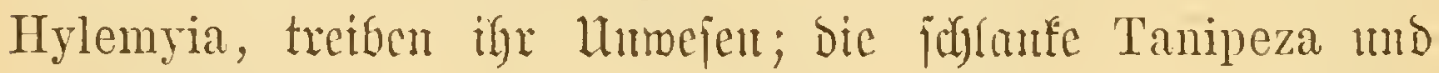
die Micropeza itorziren "arrogant" umber; an Stmme remten Dan die buntflitigeligen Tadbybromien anf mb ab, twährent oben, in ber firone, neben bex herretidfent Myodina

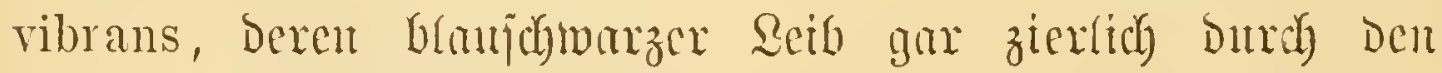
Sdyleier Der frlïgel gläuzt, einige fntebelbärtige Holopogon nidyts Steringeres im Schilbe fülyren, als bet ber exptent bejten

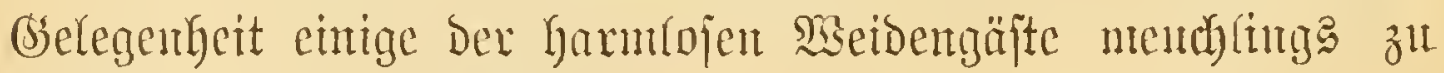
exdoldhen utro ausazifangen.

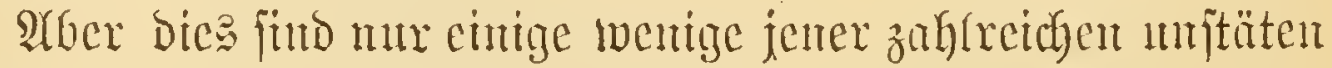

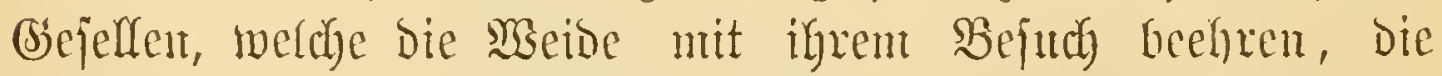

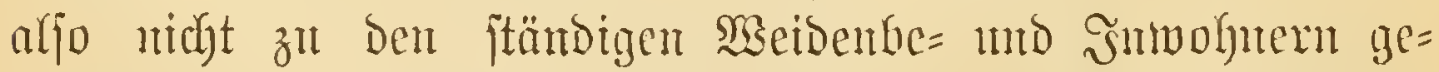

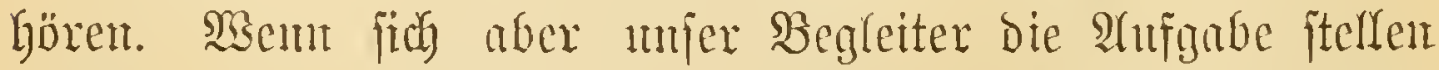
wollte, alle bie leţteren zu jummeln und fentmen zu lernen,

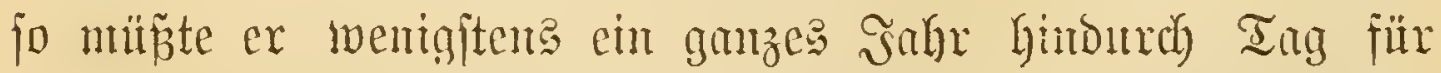

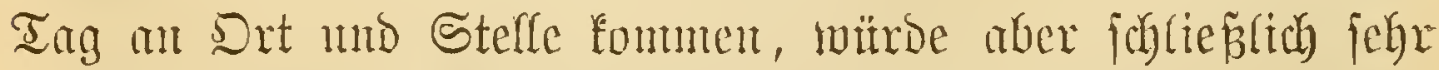

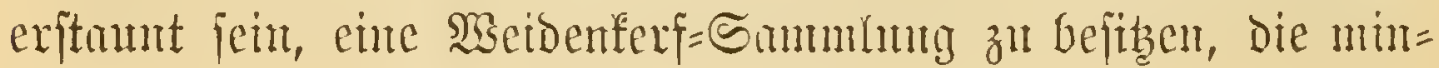

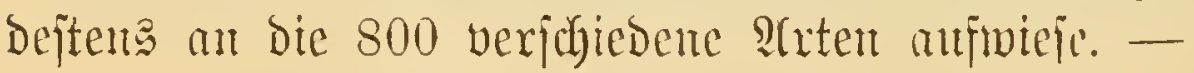




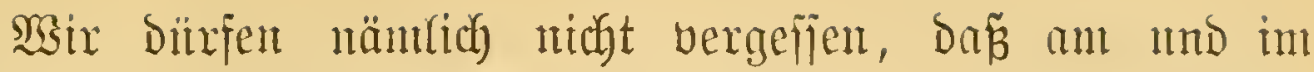

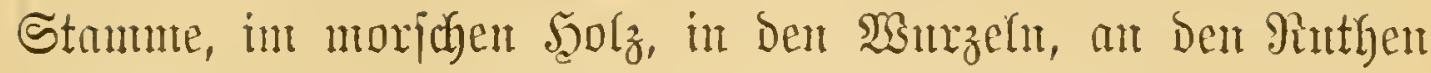

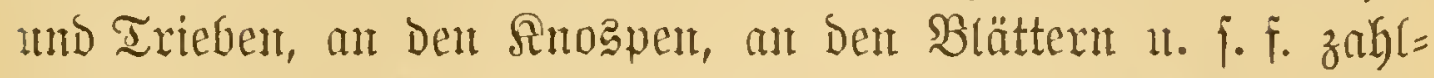

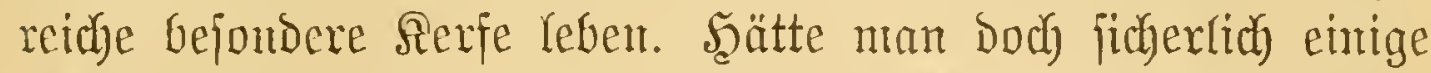
Sonate genug Daxan zu thut, mu alle bie Sinfeftent zu

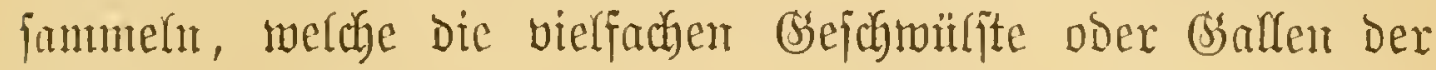
Beibenblätter berurjachen, benen wir, bevor mir meiter gchen,

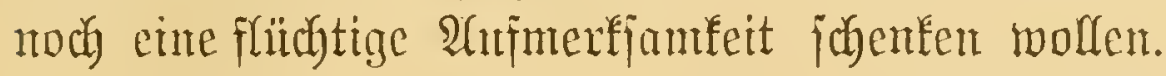

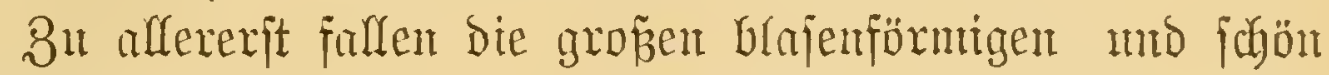
rothbacfigen Gaffen an ber Mittelrippe in bie Angen. Sie rübren vom 2urftich ciner Blattmeane (Nematus helicinus

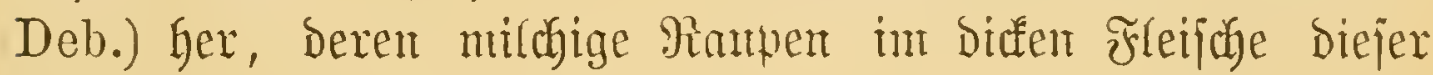

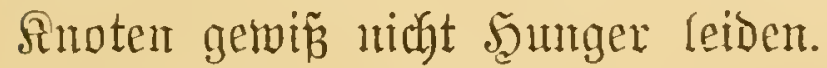

Benden wir bie Blättex um, fo lonmen wix angejichts ber vielen Schauartifel in Serlegenteit, wohin wir ben Blicf zuerft richten jollen. Da hängen zmtächjt an furzzen Stielen

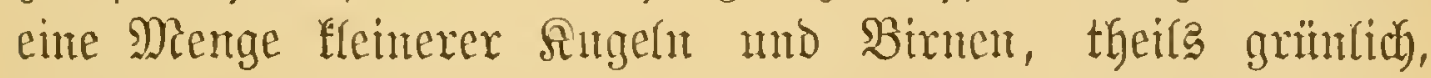

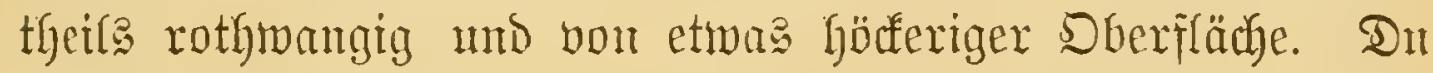
briabit ie anf und fundejt in Der reiten Şöhlung die Rarbe einer andern Blattmeape, des Nematus viminalis.

Sebr harte, fujt holzige Graller, in mebrere Bsentäd)er abgetheilt, gebören Dann einer Der vielen Ssalfminten (Cecidomyia cupreae) an. Später befonmen igre Sarven (sejelfichaft burd)

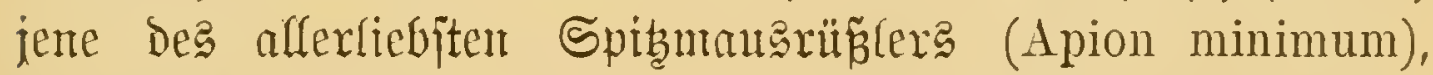

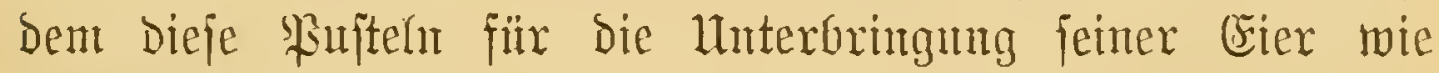
getwünjoft foument.

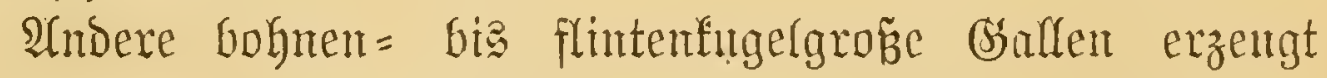
ferner Der Nematus intercrus Gmel., während Die Daneben bef̈ndidyen Gellgrümen, behaarten Aepfeldyen Dent $\mathrm{N}$. pedunculi entitammen.

Rodh wären Danu bie unterfeitiget SBattrippengallen eines Räjerdjeng (Balaninus brassicae) zu bemerfen, jowie,

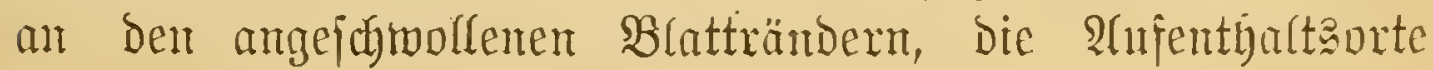




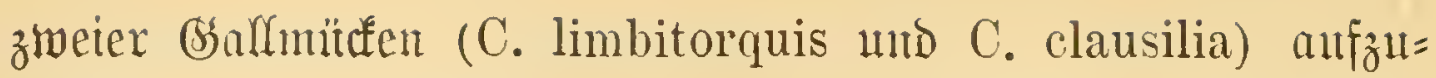
Decten.

Das Sprüchwort, wer jurbt, Der findet, beftätigt fich aber

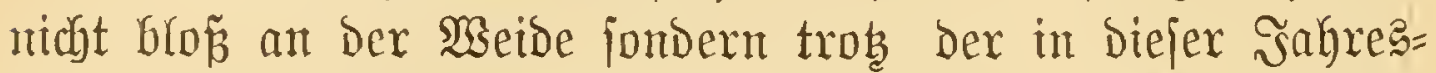
zeit noch felgr Darniederliegenden Entmidfung Der Pfflanzentwelt auch an andern Bsegenjtänden, bie wir auf Jnfelten abjuchen.

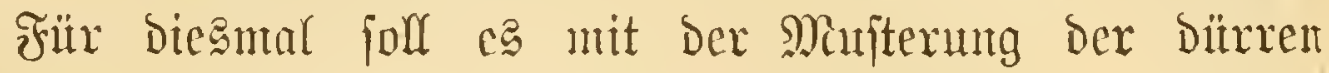

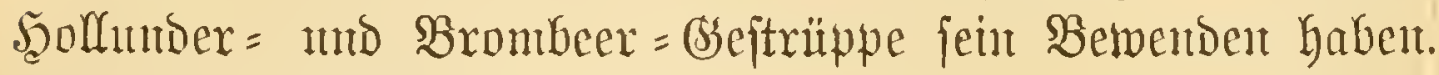
Şat fich ein Sind die Unterhaltung gentadyt, an ihren Stantgen bas Mart herauszuhohren? Fajt jede zeigt näntich auf Der Schnttfflädre ein Rod), Das jebr weit in bie Tiefe geljt.

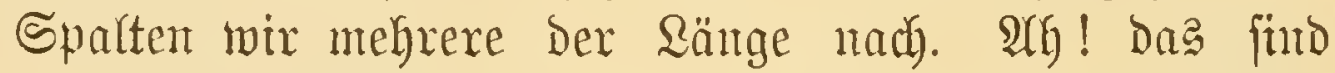
ja förmliche Rerffabinette. Da in cinten hatte cinte fleinte

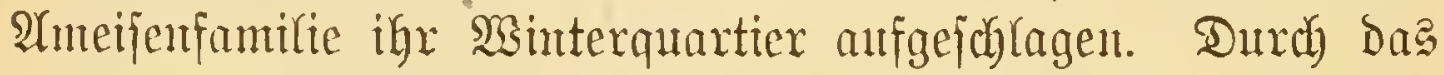
Miark eines zmeiten windet fich ein langer Grang, unb vou Stelle zu Stelle liegen bramte fantenäluntiche Iöintdyen -

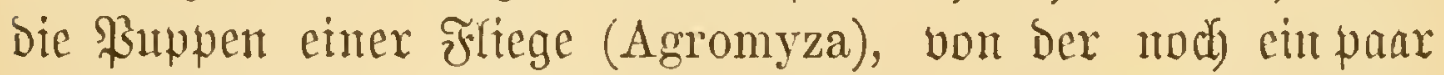
Maden bei ifrem Mintirgejdäaft find. Şier im britten Stengel,

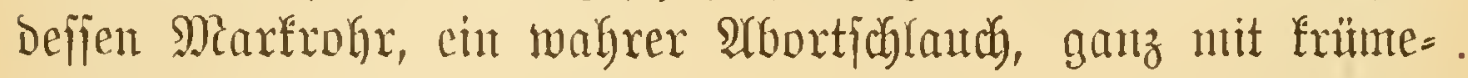
ligem jotwarzent Roth erfüllt ift, habent wir bie zierlidy ge= flodytenen Wiegenförbe cintger S̉lattweapen vox uns. Wir

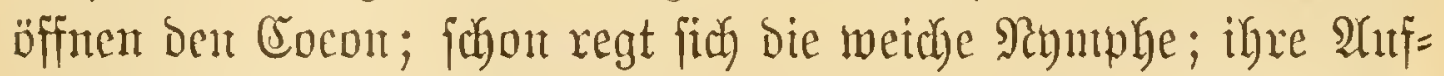
erftelyutg ijt make. Stber was ift Dent in diejem SBrontbeer= zmeig? Eine ganze Rette fingerhutartiger, gelber Seiden= bürfen. SBix find au bie Simberfube einer Snmenjpecies (Colletes?) gerathen. - Sa jei genug. Wir thaten zmar mux

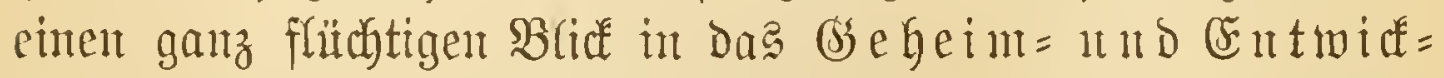

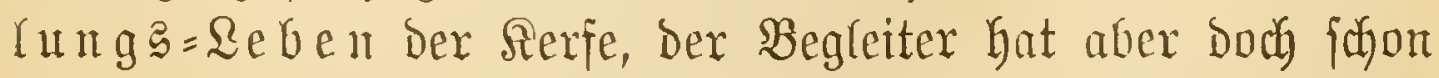

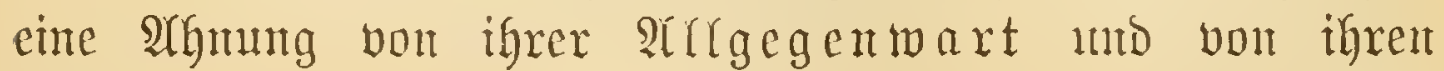
Rünjter. -

Der Şeimweg führt nth an Grartengeländen vorüber.

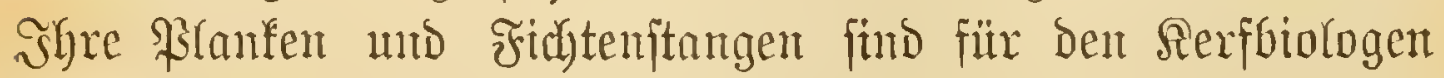
ebenfo widhtig, wie bie mit Şieroglnphen bebecten Pinrantioen 


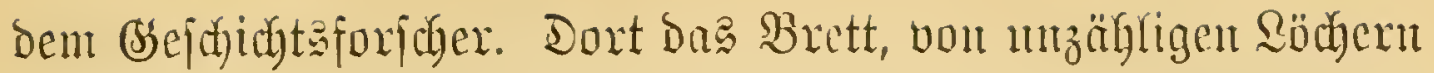

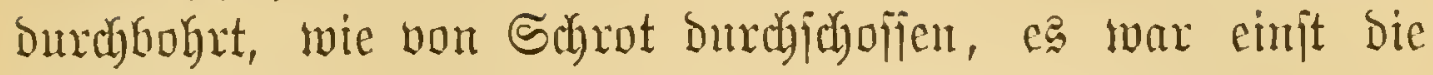

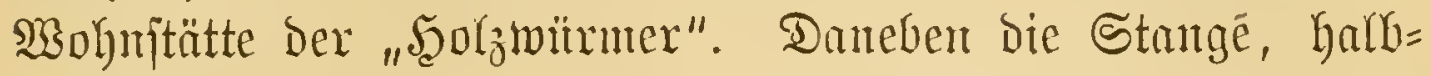
entrinbet, mit Den fertfanften Rumen befdyrieben, wird noch gegenwärtig von Borfenfäfern bearbeitet. Yuber was i it

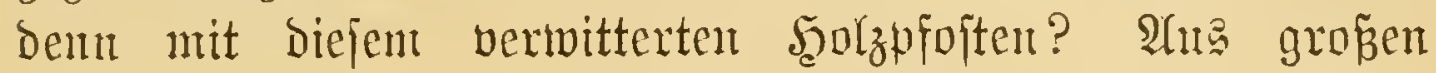

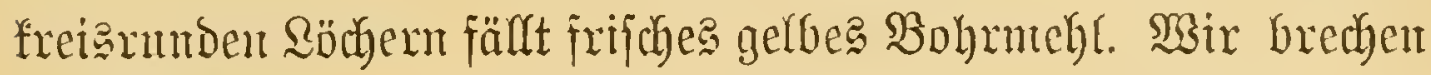

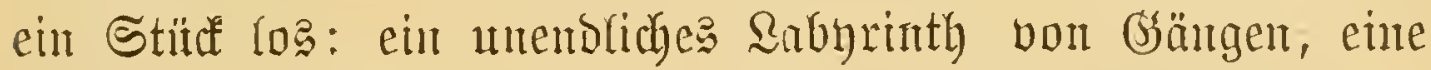

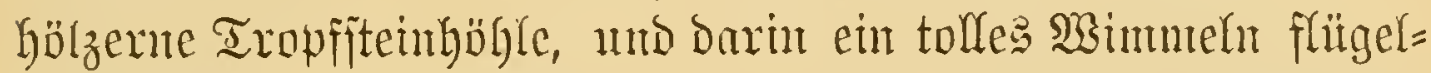
lojer Sierfe. SMin haben ben Şolzpalajt bon 2 meijen aufgebertt.

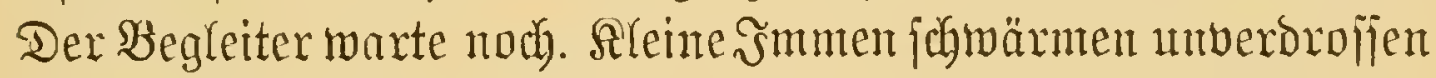
an ber Brettertwand. Was wollen bie Kier?

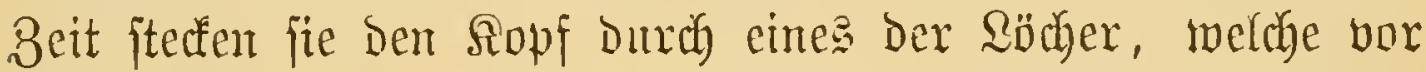
Snhren bie Şolzmürmer auggenagt mo für fie vorbereitet.

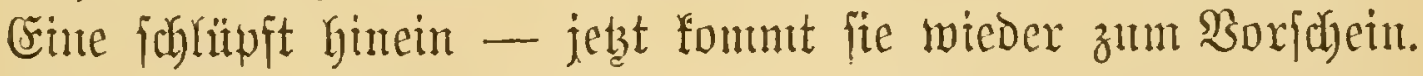

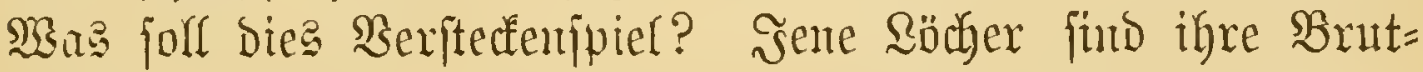

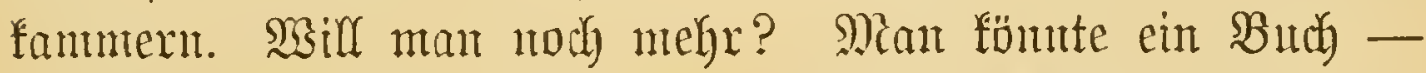
ja eine Bibliotgef jureiben nur über die Rerfgefdyidgtent an

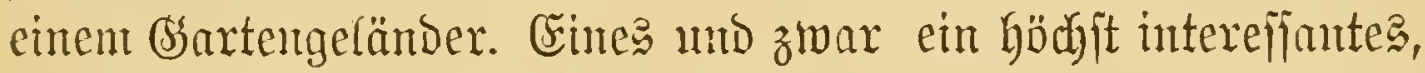
ein walbres Jumel von Rerfbiologie, ift ja wirffich fduon ver= öffentlicht worden, nämltidy von \$rof. von siebold über die gallifache wespe, bie hart vor uns Spähne von Schindel=

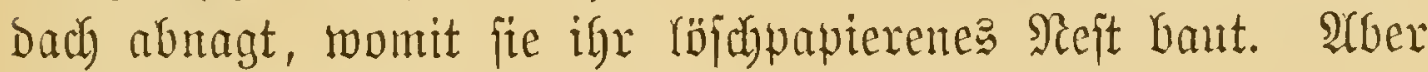
reižen wir un jest log von biejer Bauberivelt. -

Die zweite Rerfichau halten wix zu Rf̈̈ngften ab. Feld und

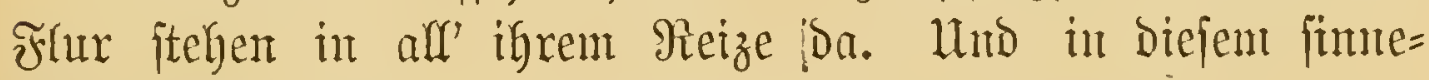
bejtriffenden Feit des Brïnen und ber Bhüten follen wir

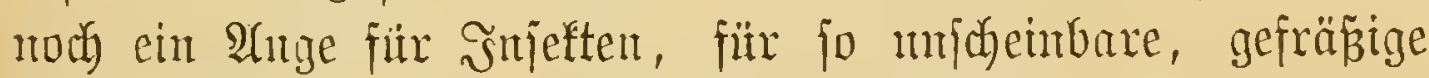
Skelette haben? Atber juchen jie nicht nit ben Bsemächjen zu riba= rifiten; ja ahnen bie taujenbfarbigen Sdymetterlinge, bie bunt=

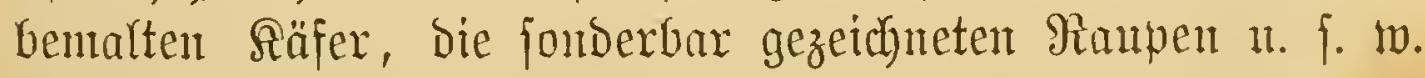

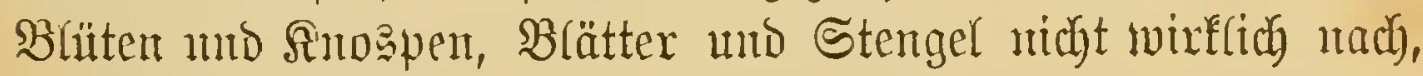

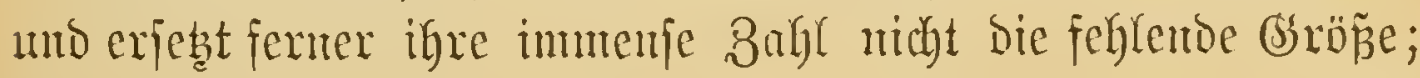


Ind würocu wix แns, die twix von Rinbgeit anf getwognt find,

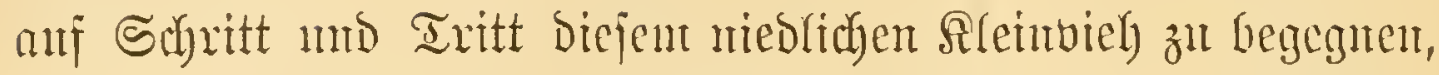

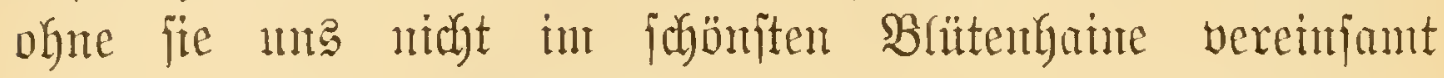

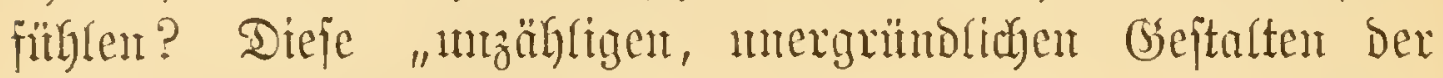
Wünthen", die enten Rleift, emem Werther, in foben Siraje träumend, Das Serz jo waxm madjten, fund fie nidyt

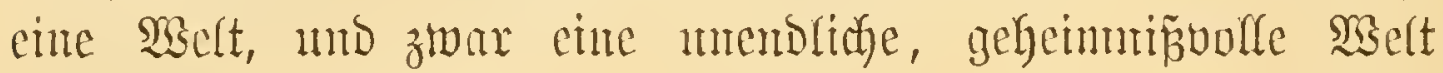
fïr jith?

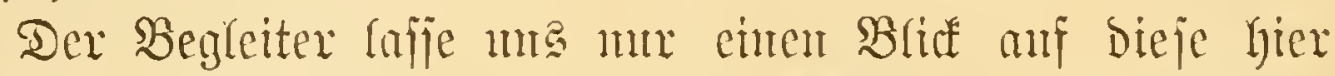

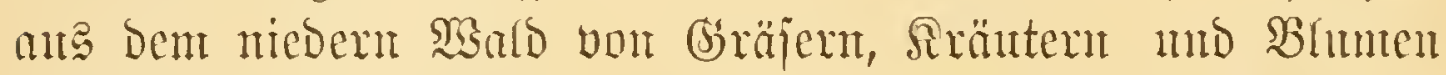

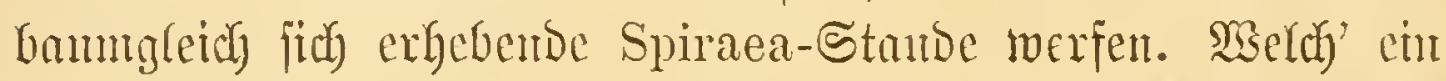
Reben auf biejer einzigen Bhmentwarte! STie viele Ianfande

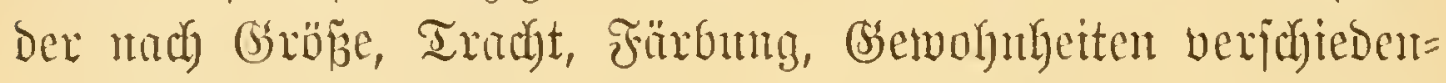
artiglten (sä̈ite mögen tugtäglich), ja ftimblich fonmen umb geben,

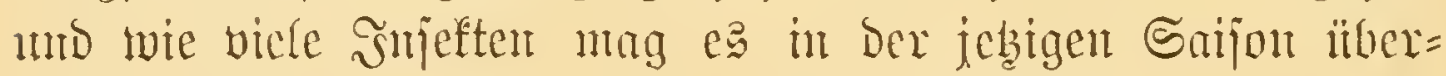

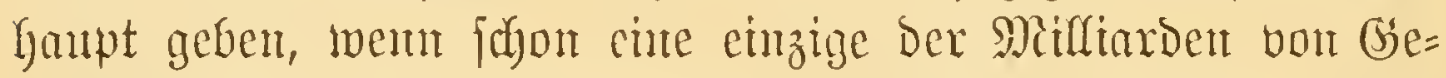

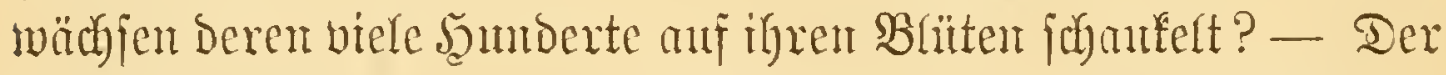
Anbricf all' diefer Spyraea-Sierfe hat in Der I gat etwas $\mathfrak{B e}=$

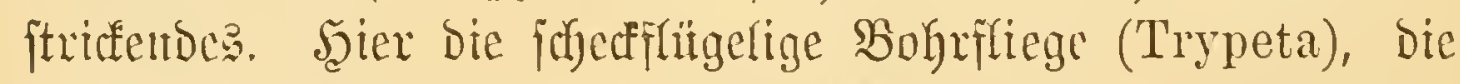
wollige Argyromoeba, Die Lutgrinijiefige Prosena, bie zottige

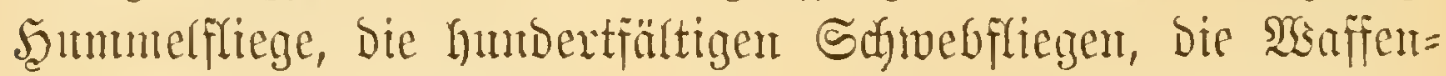

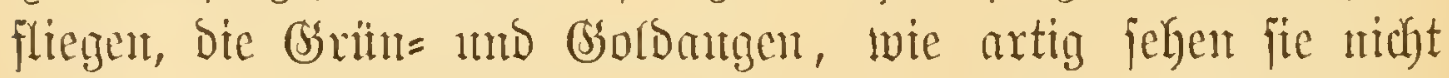

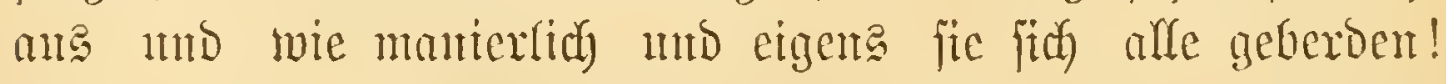

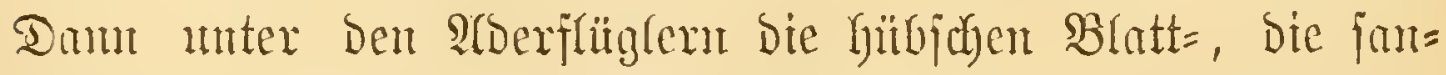

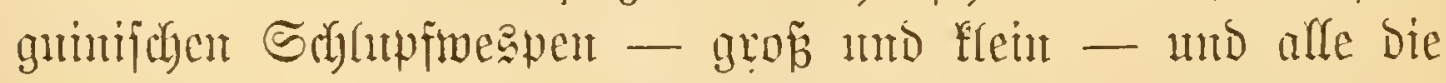

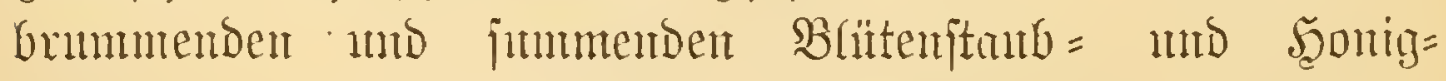

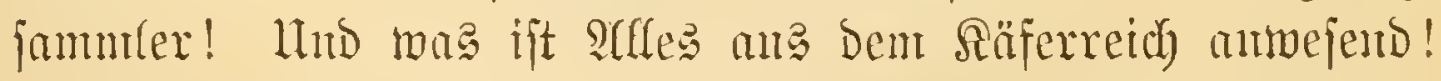

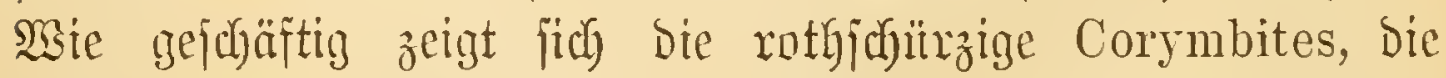
ganzze grope Sippliforft Der Cantharis, Der Ebaeus, der jchmtale Dasytes, Der Antholomus, Die Ragonychia, Die bald

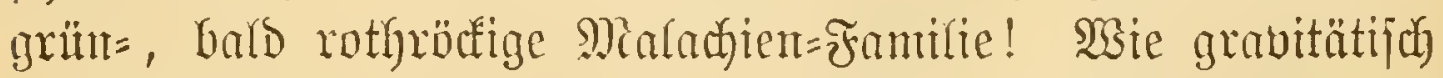
ftorginest Dam die Böfe, die Pachyta in ifyen Domberms frabatten, Die Strangalia nuit ifren prödytigen Frlitgeldecffen 


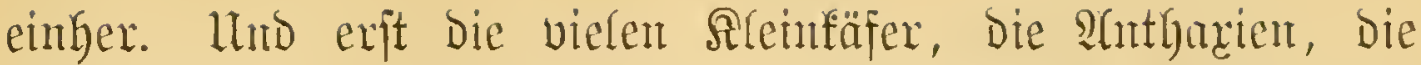

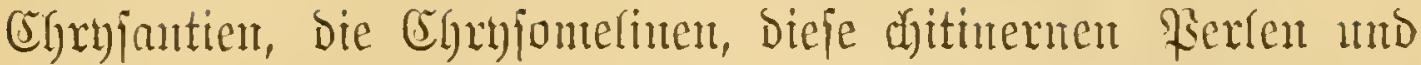

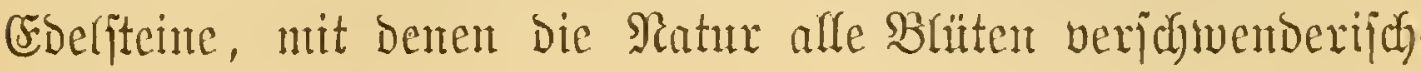
überictüittet.

Went aber $\cdot j($ d)on an Der Dberfläd)e Der Bsetwädyje eint jo reiches, ja verjatwenderijhes Sierfleben fich offentart, twas mag fiw erjt in ben fieferen Bonen, bis zum mo mter ben

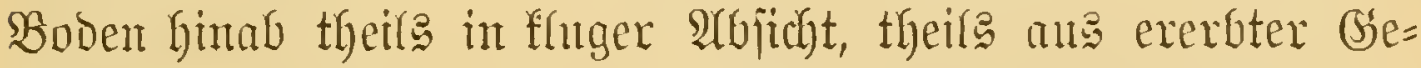
wohntheit verborgen haltent. Sollte aber Der Begleiter nod)

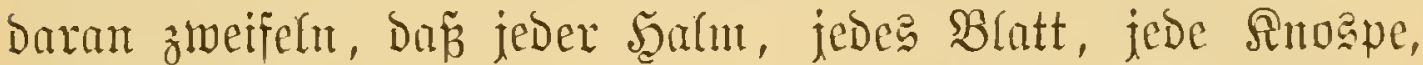

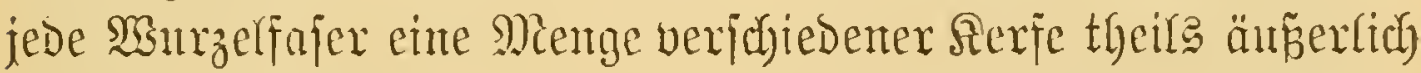

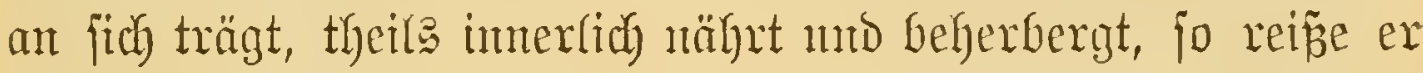

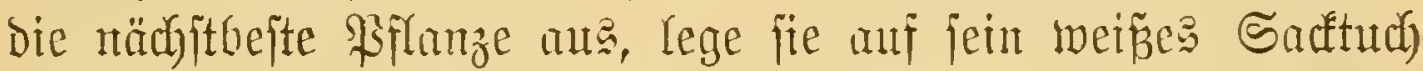

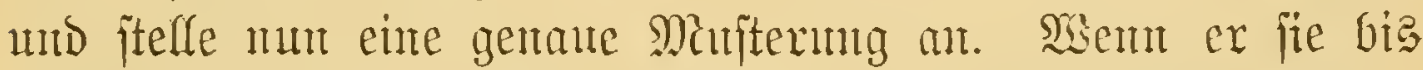
zum letben fleiten Räupchen und zur Leb̧ten Made abfudjent will, wird er an einem Iage mit feiner Altfgabe gemiés nicht jertig werden.

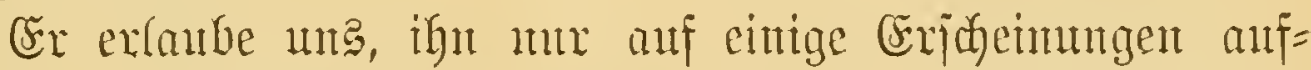
merffan zu madhen. Şier an Dent Şatnt fiebjt du ein lärtg=

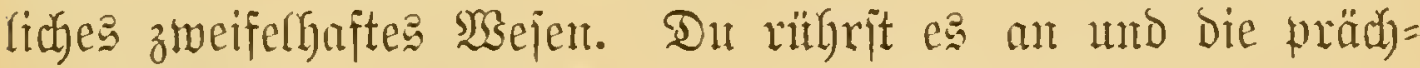
tige Brranotte (Crambus perlellus) entfaltet bie vorber jorg=

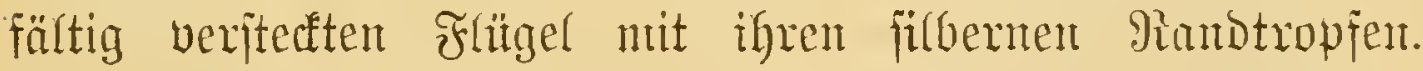

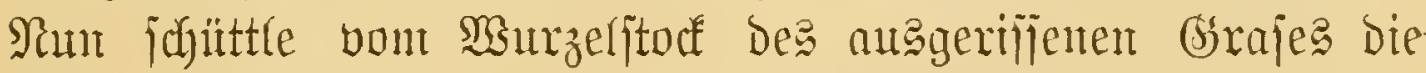
Eroe ab: es falfen manjebntiche gäupchen herms - jeme

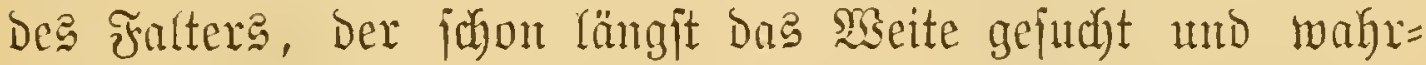

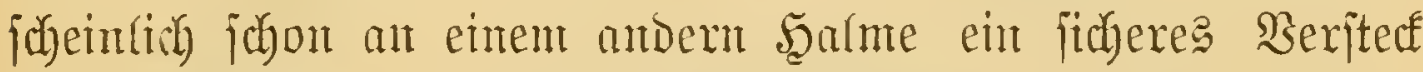

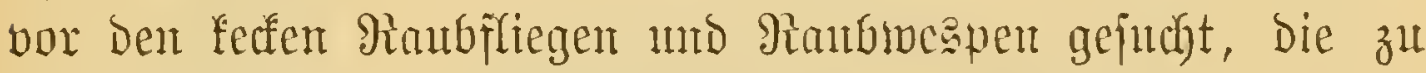
Diejer Tageszeit Das Şerumbunmelnt in Der freien fontigen

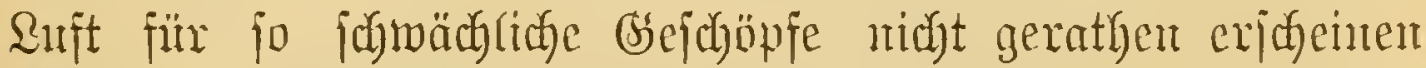

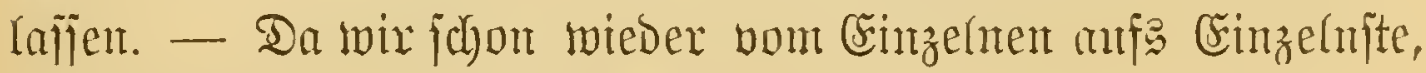

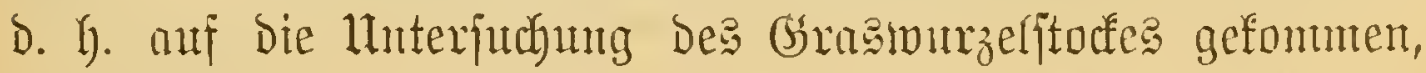
fo machen wir noch anf bie ginnen von Atychia, auj jente ber Croulen, jowie anf Die vielen Engerlinge, Trahtwinnter, 

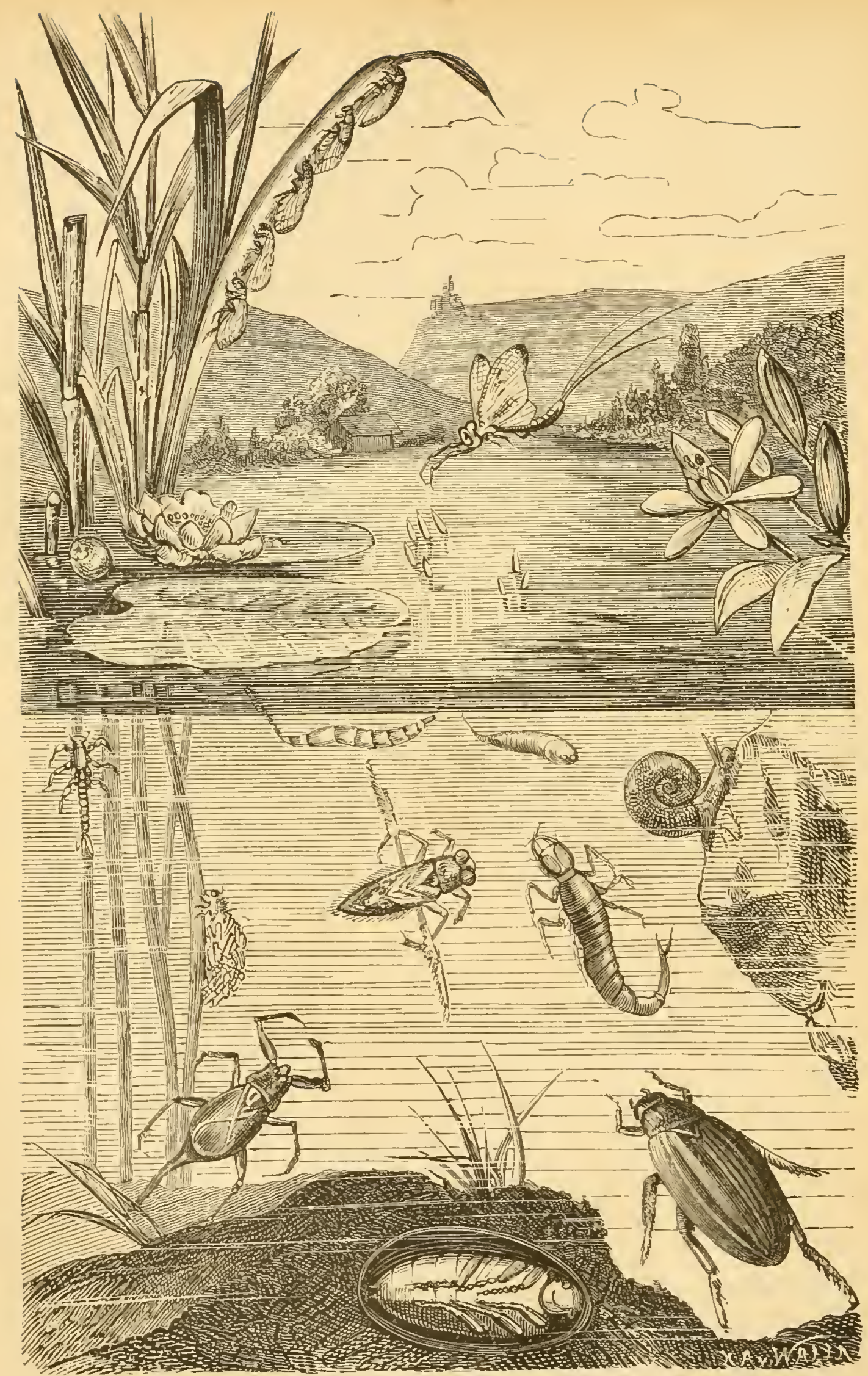

vig. 2. majierter ie.

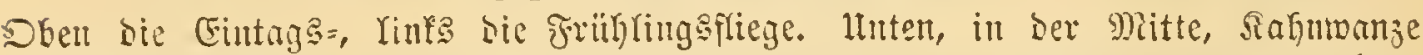

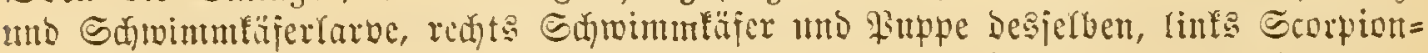
manze unb hö̆ger, an ben Etengelu fletterno, eine siärber= mo Ribclfenlarve. 


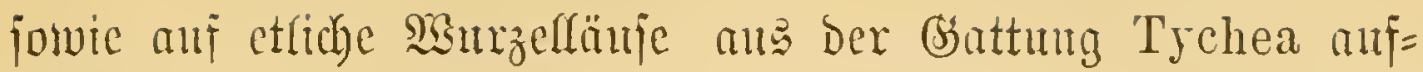
merfian.

Itber bas Serfijanmeln anf freier jonniger $\mathfrak{F}$ htr ijt fïr Die Danter feine jehr angenehnte Huterhaltung. FFlübtent wir

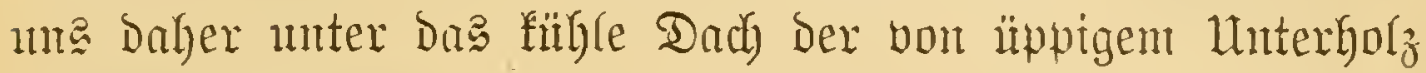

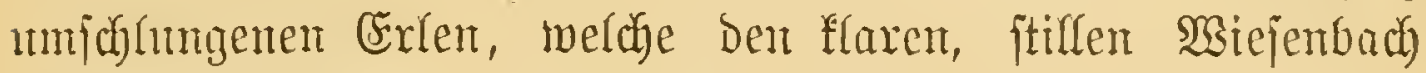
murjäumen. Bsibt es ja anth hier gemug zu jeljen; ja twir be= Gaupten, es jei gerabe hier, an bicjem Lanjedigen Drte, Das

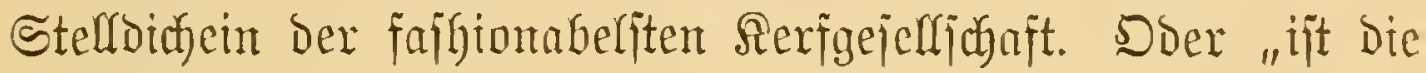

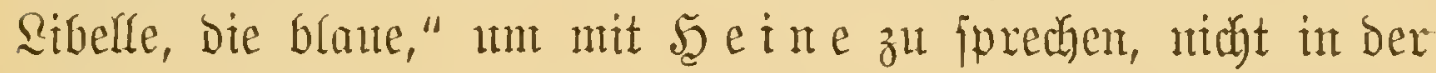

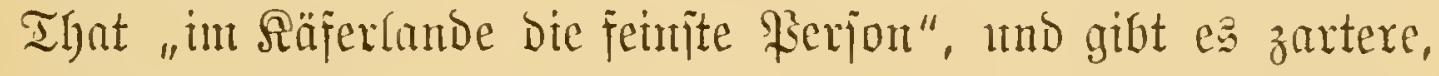

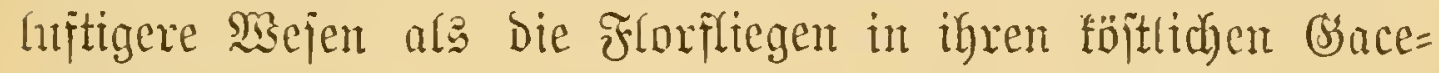
fletbern? Und twas nidht biejer jaftiggrïne, mit Den beran=

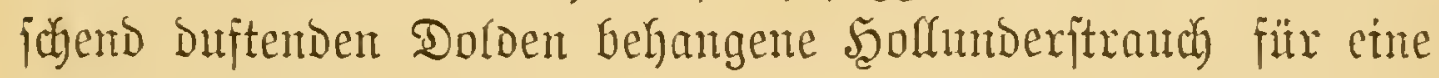
nette Sippidaft beherbergt. Scine Stengel find itellemweife ganz blau von - zwei Blattlausarten, Die, ifre Dinment

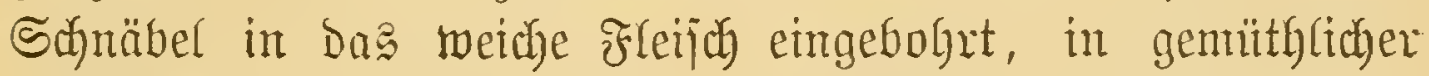
Irägheit jür ein $\mathfrak{B a n}$ joblinme Bejellen, Den SBlattlanslömen und Dic Syrrphus- Zarven fich - mäjten, währento ganze Schmärme von Siflafterfäfern die Bläten und B̧lätter ab= metDen, in meldyen leb̧teren bie brantmen bsänge Der Agro-

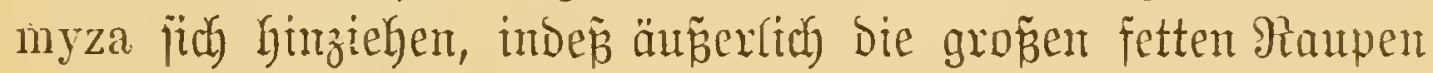
von Sphinx ligustri, Bombyx caja, Macrophysa albicincta,

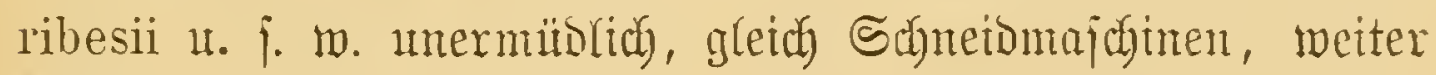
$\mathfrak{f} \mathfrak{n} \mathfrak{n}$ ent.

Aher thun toir mu cinen Blicé in bag șajier, über

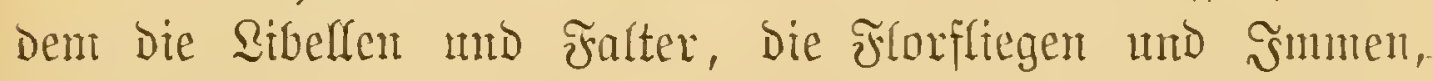

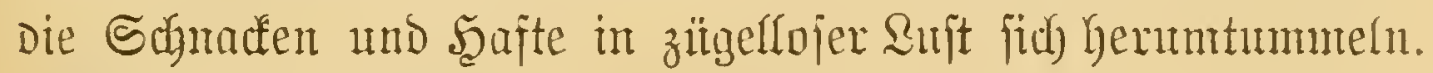
Merfmüroig, aud hier geben Rerfe Den Ton an. Schon an Der Dberffäclye. Etcllenweije ijt fie wie beitrent mit winzigen

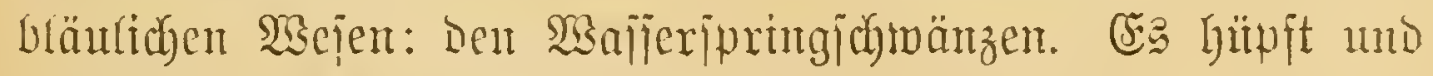
tanzt in wildem Taumel Durdjeinander wie ein eleftrijges

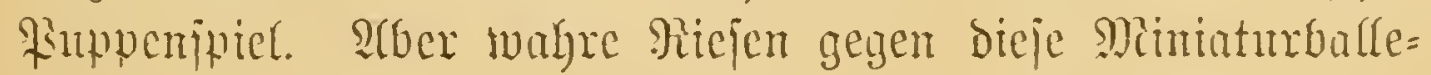


rinen, dic Magajerläujer - fahren ruffweije, mit ihren vier Ginteren Eximtenbeinen lange idymale Schatten werfent, anf

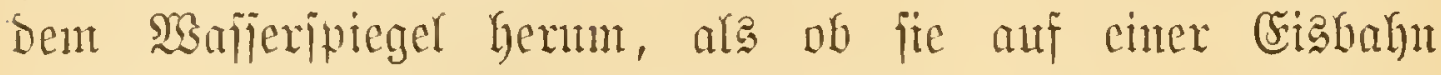
wären, währemb bie taforemmejierartigen arme zum Ranbe fitch angitredfen. 2(utd) cintige Schricken, zuntal flcine Doldyartige

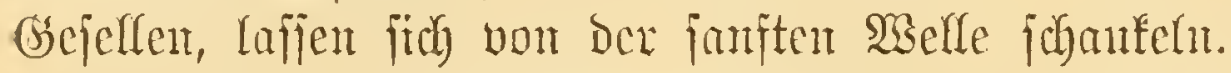

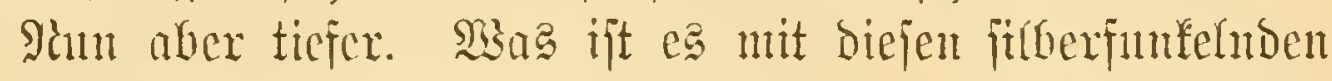
Balfons, bie, wie Durch ein imeres Triefwerf bencat, in ben

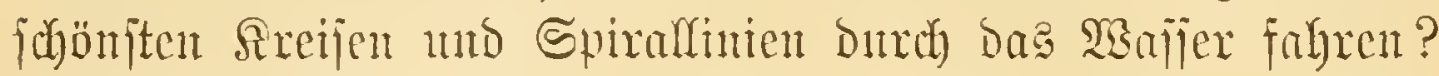

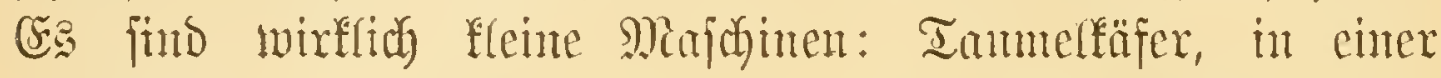

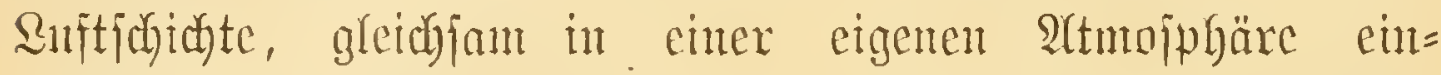

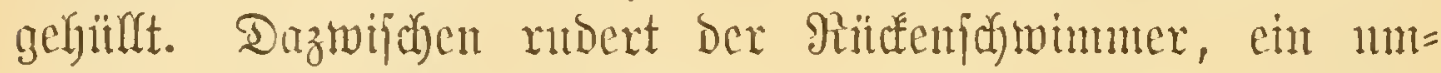
gefipnter Ragn; Dic Stabwanze, mittelit bor immenjen âfiter=

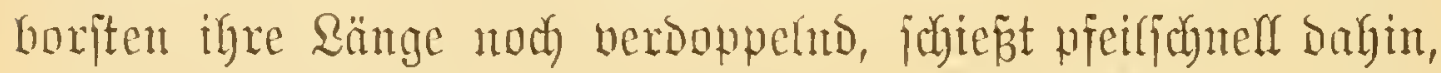
während bie Scorpion= und andere Rantwanzen fopfïfrer in bie Tiefe itenern. Das reidyjte Reben regt fict) aber ant und im

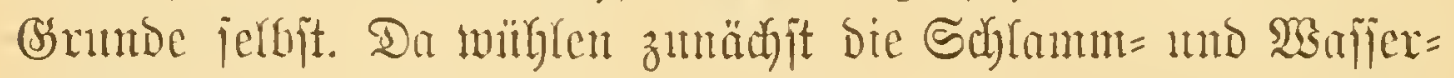

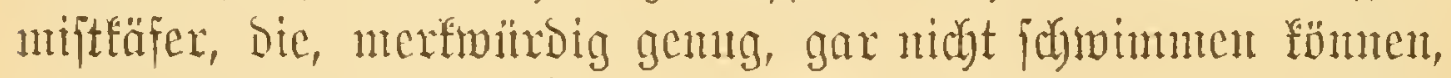

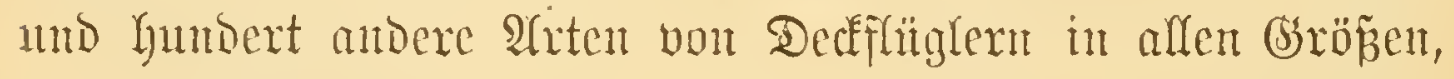
aber in ber Färrunng mo ber ganzen Iracht jebr iiberein= ftinuments.

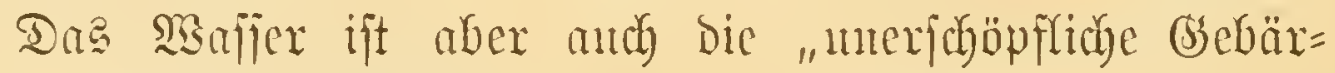
mutter" fïr vicke $\Omega$ uffterfe.

Seben wir cimmal etlidbe Siefol anf. Huzäglige flache Sarven rutjeden ïber ben Stein ober wimmeln im janbigen Antergrumb. Mair geben jie in unjern Trinffecher. Sie foblän=

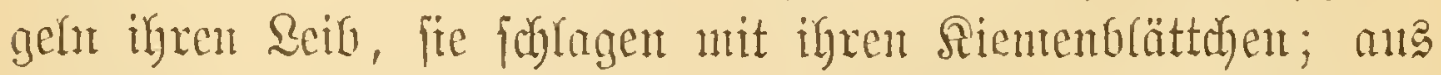

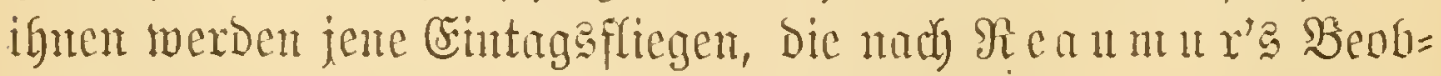
adbtungen meift zu ganz bejtimmten Iagen mo Stunden, und

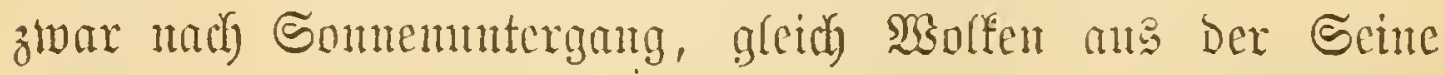
fteigen mo oft zorfyodj mit ifrest $\mathfrak{A}$ ejern weit und breit

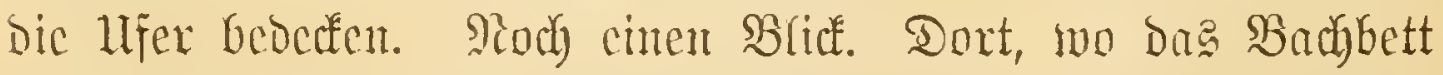

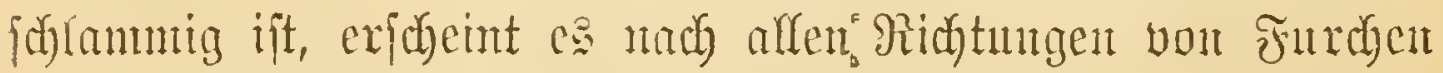




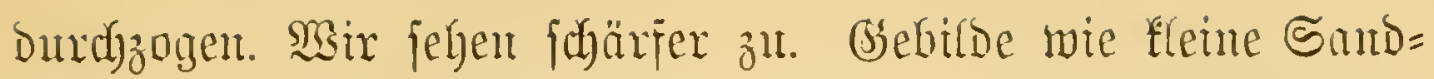

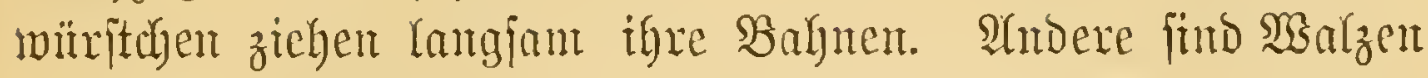

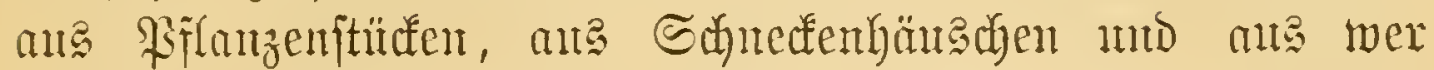

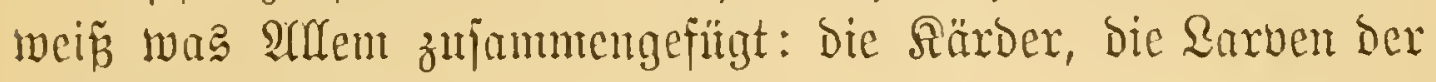
Frülylingesfliegen!

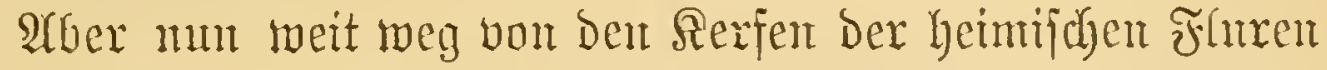

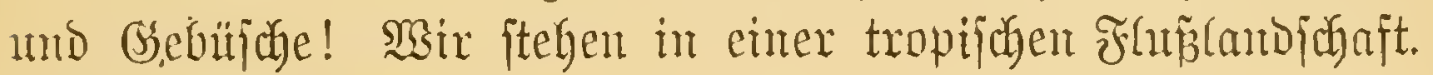

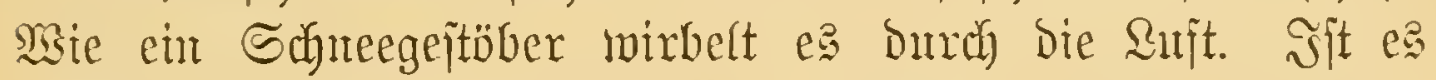
möglidh, ift hiex die Frutchtbarfeit ber Natur fo hod gejteigert: bie Tagfalter, bet mis mtr einzeln, ober wie bie reizenten Bläulinge bod) mux in fleinen Trupps Durdy die gelfen Sornt felder hermijegelnd, fie flattem, vout ben feudten Sambuänfen

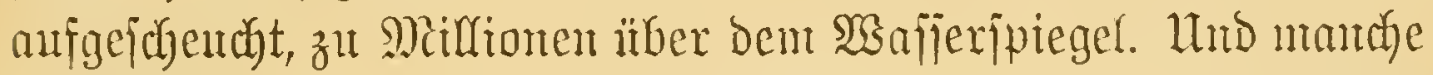
wic grof, wie farbenpräbtig! Sie exfeben in Mrwald, wie

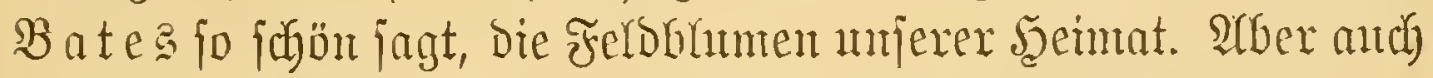
Die andern Rerfe! Dieje Sibellen mit fajt halbichulatangen,

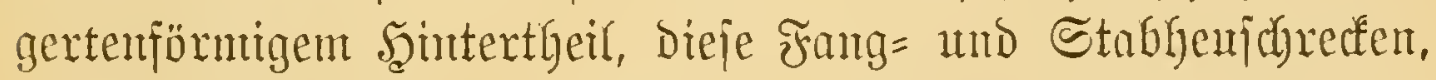

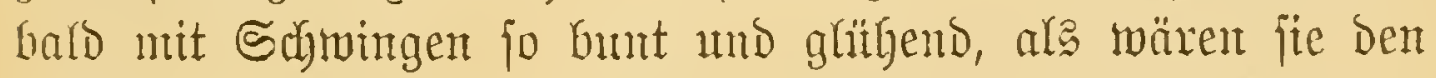

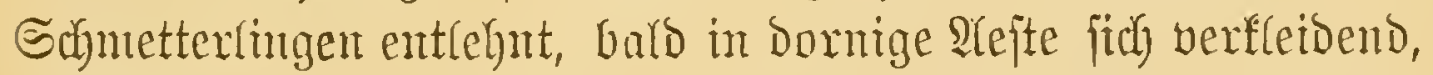

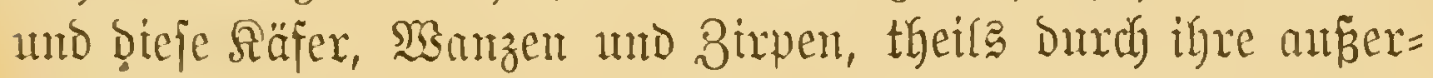
orbentfiche Ioilette, ihre in allen Farben des Regentogents

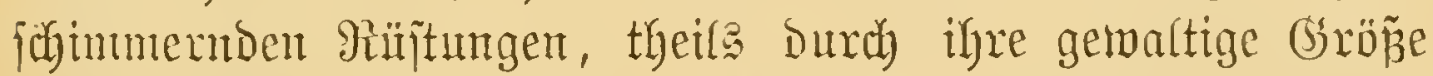
herborragend, find fie etwa Den Rolibri's nidgt ebentürtig mo

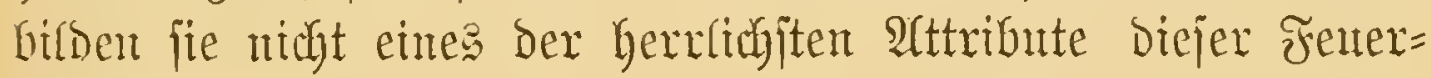
flinate?

Der Sejer mag uts mu, wieder auf hemijichen Boden zurïlfgefehrt, an bas Meer begleiten. Dort bie mit Delbäunten hepffante Stembanf freeft jich weit hinaus in die embloje

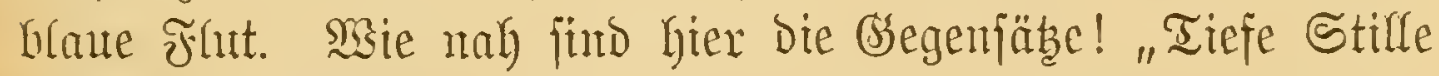

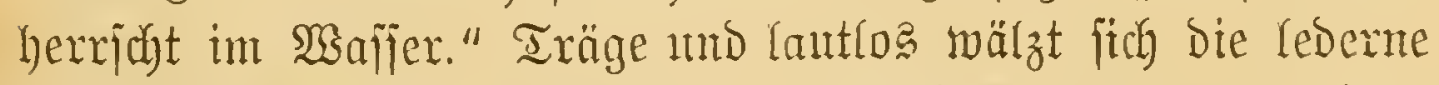
Seegurfe Durh den Shlamm; Der Seeigel, zmijhen Steinen

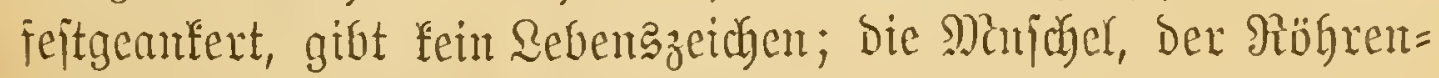
wnum ift ein Bild Der Seridglofjentheit; bie Nanffichnecte, der 


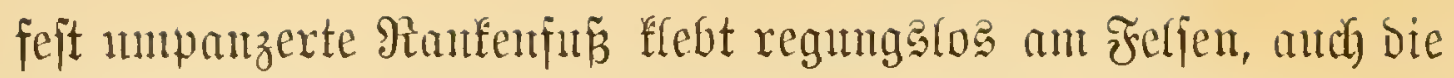
farbenglïhende Antemone hat firb, Der Flut harrent, ein= gezogen - und bieje materijden flechten= und mobsartigen Meberzüge, bieje jeltjamiten aller Thiertotonten, welde alle uferfteme bededfen - fïhren jie nicht ein puppenthaftes Tram = leben? atber bicr oben anf ber Steinbanf, anf ven magern

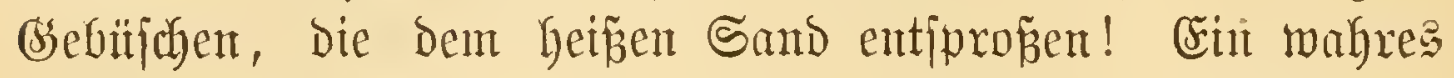
Şälfenconcert flutgt an mifer $5 \mathfrak{h r}$. Taujende vou Sdhnarr=

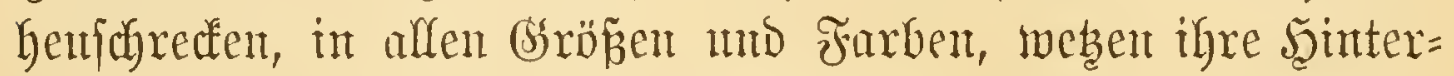
beine an ben gerippten Frïgeh, während bie Cicabon mit ihrem

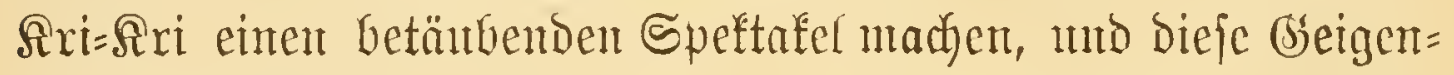

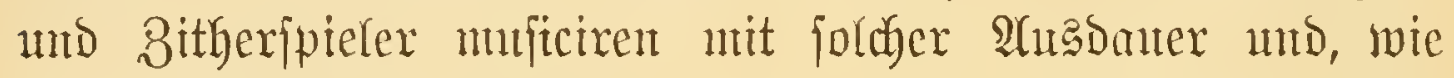

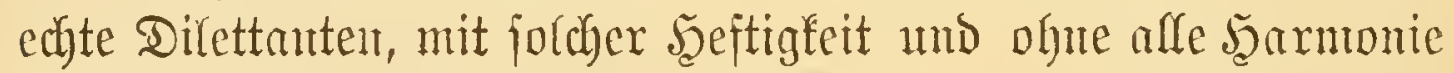
Durcheinander, Dañ in Der That bie Steine rajents werden fömtntent.

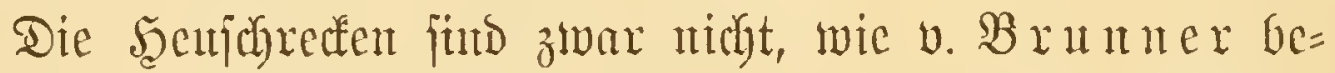
hantet, bie volfonmenten Jnjeften, aber Doch ficherlidy jene, weldye Den medhaniflyen Egarafter, Das ftarre Sebelprincip Dex

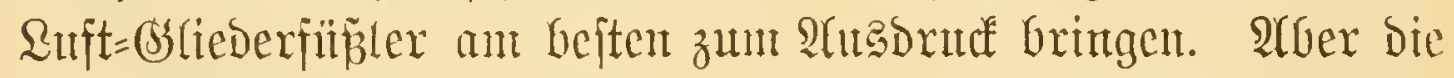
Senfobrecten und Cicaden fint nichts weniger als eigentliche See= ftranbferje, wix meinen aljo Snljeften, die vorzugganeije ober

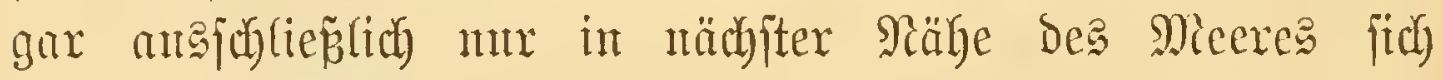

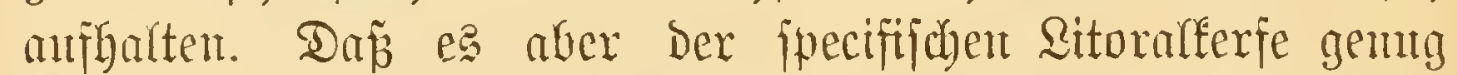
gibt, wird ente flitudige Mujterutg Darlegen, bie auß mebr= fachen Srünben cin bejonderes sntereije gemährt. Sebr cr=

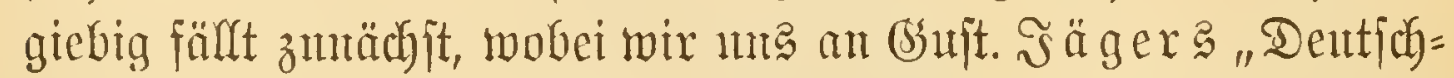
lands Thicrwelt" Galten, eine Huterjuthutg der Strandpflanzen

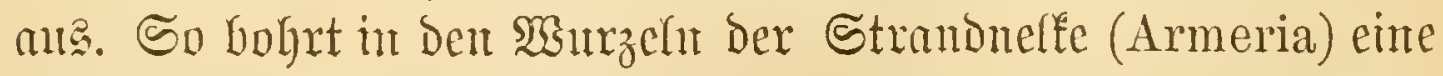
(Ślagflüglexranpe (S. philantiformis), wälyrent in Den Britten eine Motte nagt und unzählige fleite Báafentöpje (Phloeotrips statices) Gerumlanfen. $\mathfrak{A}$ w Dex Mieerjenf nährt jeintent

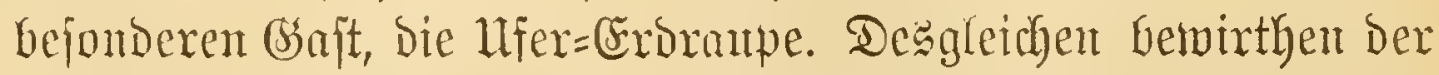

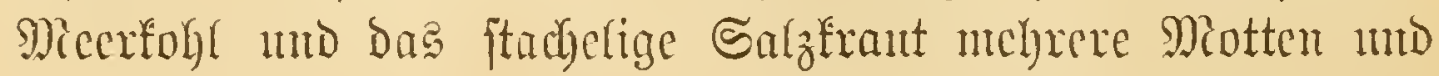




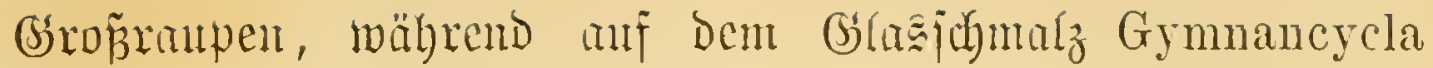
canella und eine Gelechia leben. Die joböne Runpe Dcs wrärbtigen Papilio hero ijt gleidgfalle cinte Rüjtenbewohnterin mo zwar añ Dem Stramblafer.

Mandye Raxitäten findet ipeciell Der Räferiremb am Dïnengras. Sater ijt ber idwarge ichnellende Cardiophorus zu Şanje, Der glänzende Baridius, Der cyanflaue Orobitis, Die jitbrig Gejultppte Itoplia, bie 13 flectige Hippodamia, Der halbfinglige Phalacrus, Der Olibrus, Disopus, die Anisotoma und toic je alle heipen.

Selbijt ber vom Ffutwajier durchtränfte utid gejalzene Sand ijt nidyt frei bon bergleidyen Bsethier, und ncben ganz jpecifijacn Seegejdöpfen, neben fleiten Arnbben,

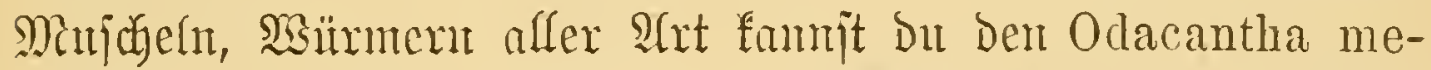
lanura, Den Dromius longipes, den Malachius spinosus, Den

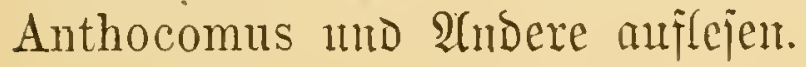

Saenn hicx aber faftijach nidyt bloz eine Berübrung, fondern eine Bermijumg bex terrejtrijuen un Der marinen $\mathfrak{F}$ a n $\mathfrak{n}$ itattfindet, warsm leben bie Serje midyt aud in Meere jelbjt? (5s ijt wirffich eine

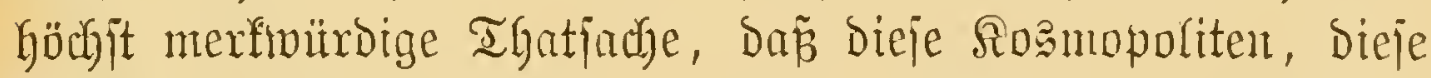
Erobürger erften Ranges, Die fonjt allüberall in unzähligen

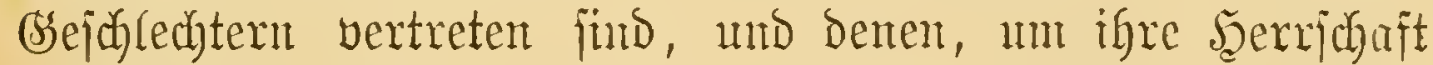
atszubreiten, feine Nühbe zlt groz ijt, gerabe vor bicjer

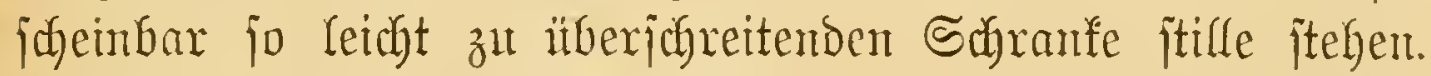

Dies ift um jo anffallender, als, wie wir an ben Ufertwangent (Salda), an gewijien Salmenmaben uno be= ponders an Den frei anj Dem Mecre rubernden Helobates jehen, Das gejalzene sanjer fïr bie Rerfe nidyt unbedingt töbtlich ijt.

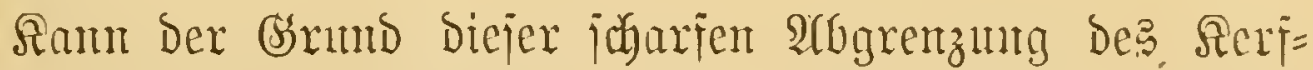

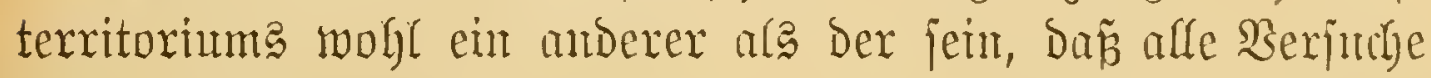
firch im lifermajjer einzubürgern, theils, für die $2 u f t=$ Sn=

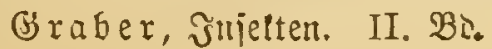


feften mit volffonmener Berwandung, an ber grežen Tiefe,

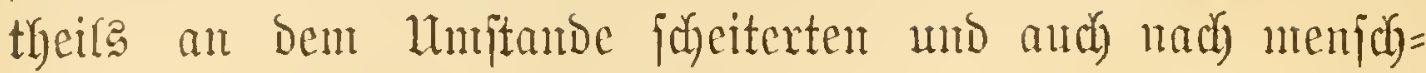

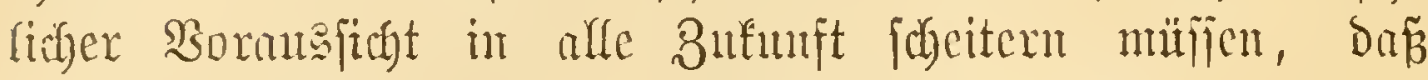

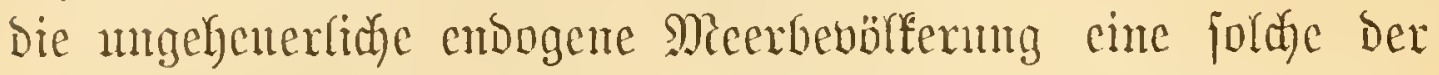

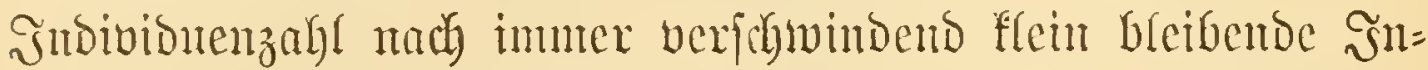

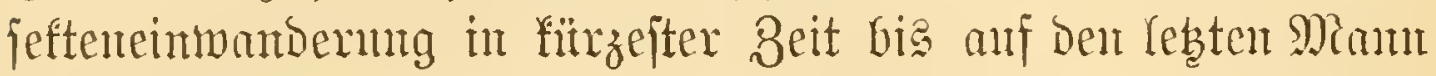
vertilgen würoe.

Die Serfe füd und breiben anf bie suft, das feite Samb

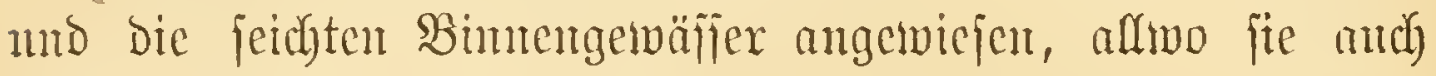
bas geworden, was je jebt finto uto was ihnen mumehr, madjoent fie bas Meer vor Rangent verlafien, verbietet, jemals

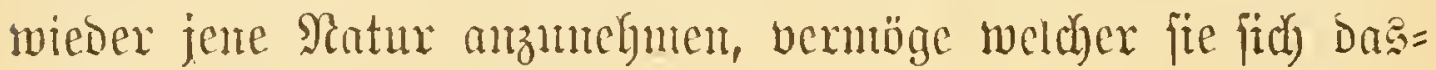
jelbe zunïcécobern fömuten.

Son mijerm Etandplats am iftrifhen Seegeftade, mo ge=

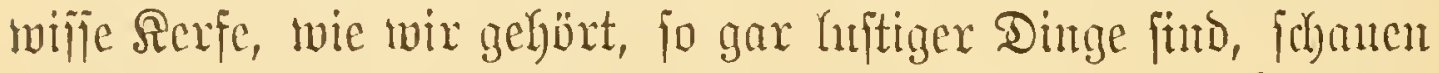

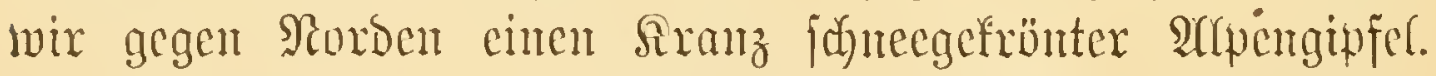
Do c a and bort oben Juffeften gibt? Steigen wir hinanf. Unfere Minfifanten begleiten uts. Heber Dex Banmurenze, in

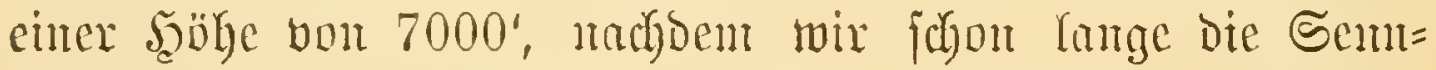

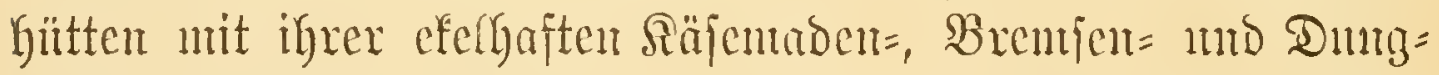

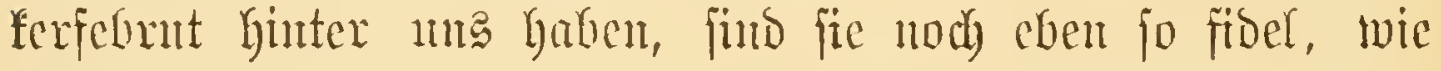
Dort unten, an bieidgen Fel unter biejen jovialen Yelplern füt ein Panr, z. B. Der Stenobothrus pratorum mo variabilis, die twir f(c)on ant Meere

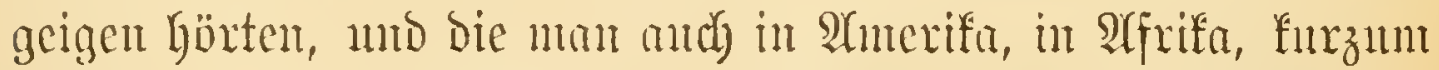

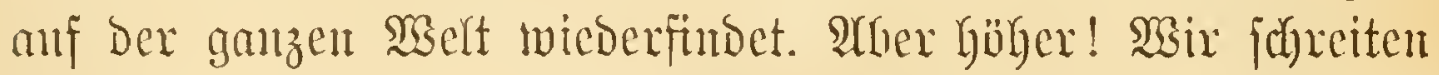

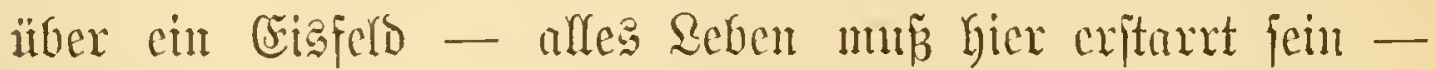
Da jieb! bie minntiöjen Bamerinen, die wir mif Dent Wiejen=

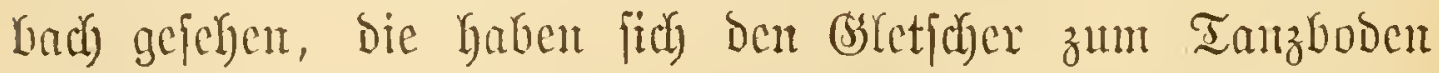

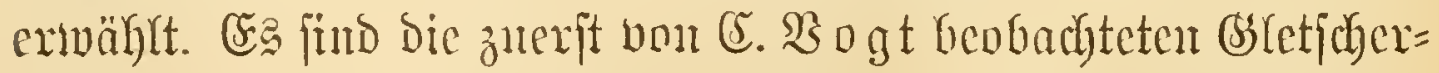
flölye (Desoria glacialis). 8" Mrallionen fpringen fie umber

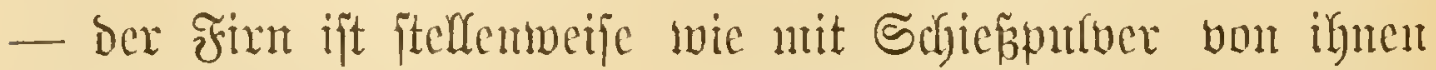
beftrent. Nant, Gaben bie Rerfe feine zälye Natur? Sadyts 


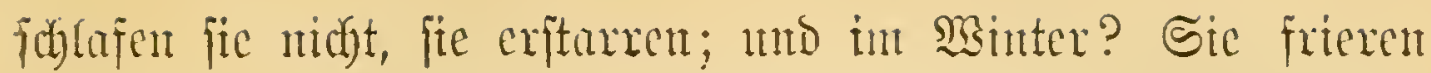

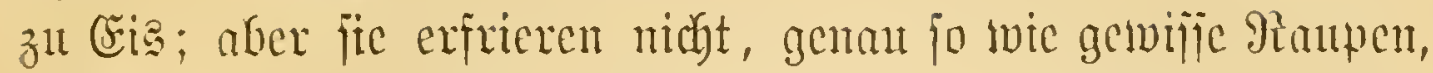

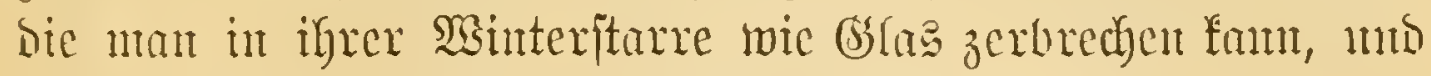
bie endidif Dod wieder ifre Ditern feicur.

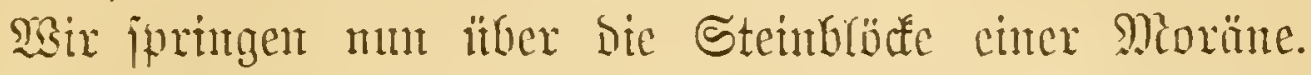
Der Injeftenjanmler wird aber bas fpantmende Stcimmlegen

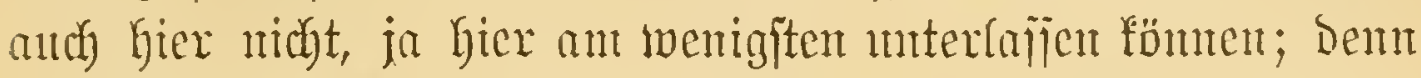
two fättoen bic Rerfe, wirb ex jid fragen, in bicjen Regionen

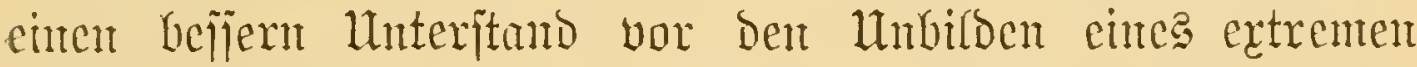

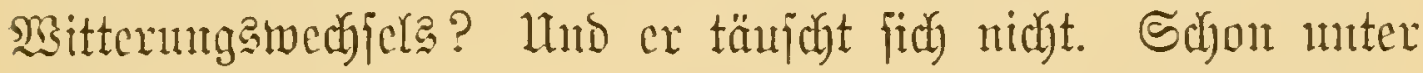
bent erften finten wir eine jehr zahlreiche und rejpeftuble sese=

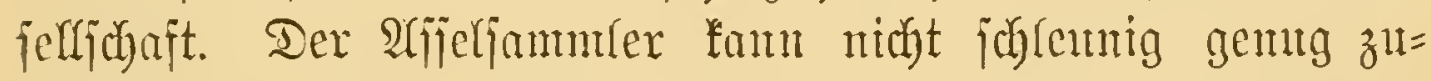

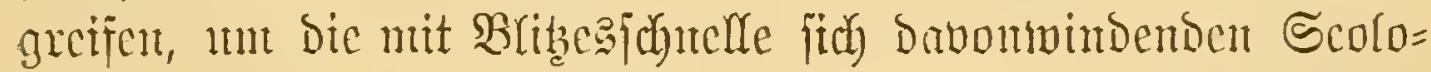
pentor zut fajien, währent bcr Epintenjäger feine Schtfï̈̈ler bequenter in igrent Befpimiten abfängt. Seltjan, was hics fïx Morogejellen, bie fich gegenjeitig untbringen, unter

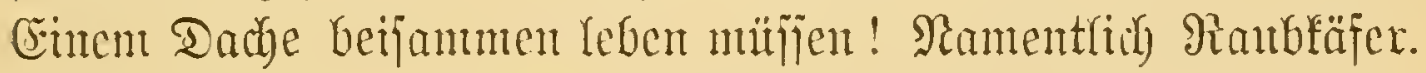
Şier bie jrbönte, glänzent fintwarze Feronia maura, der Carabus alpestris, Hoppei, ber Cychrus und waz bieje flint $=$

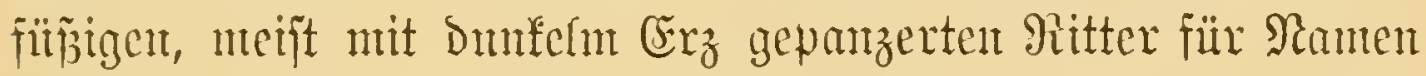
fiifyrent.

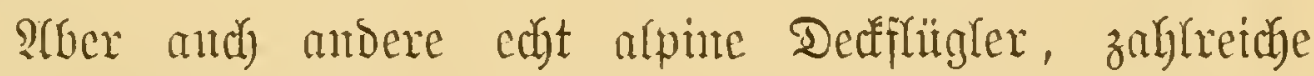

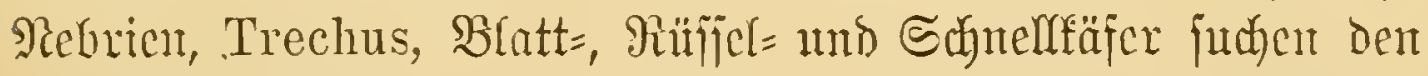
gleichen Interitand, und arg mürbige Bertreterin Der $\mathfrak{A}$ meijen, waldye anf Dem Fladyland die pribilegirten Stein= nutermolner, ift bie brantrothe Myrmica sulcipodis zltyegent.

Itn aud Dem Falterjammlex cinc Frentide zut madyen, wollen

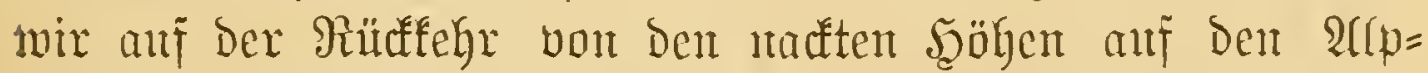

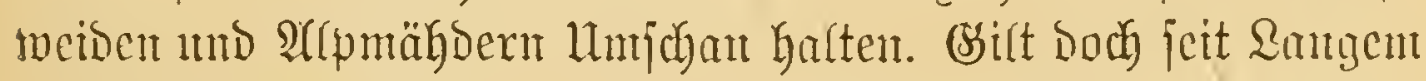

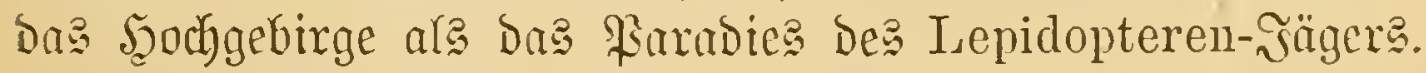
Sit eriter Sintic füto es aber gerwijן Spanter uns Motten, tweldac unten int Thal, wo jee vout unzähligen Singoögefn 


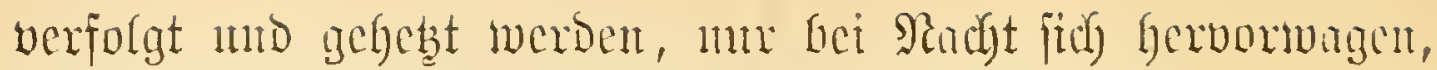

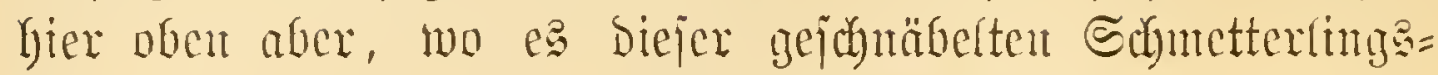

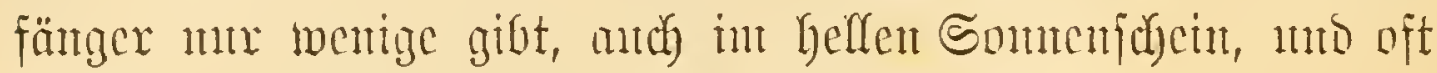
in ganzen Ect)wärmen, fich jebcrt lafjen.

(bsteich hier an ber FelEmand und fanm babon zul unter=

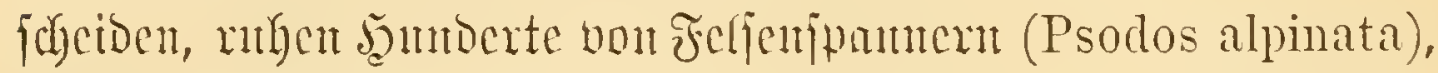

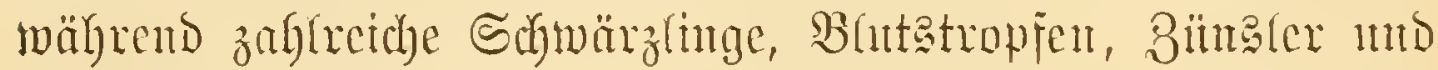
Erdenten, mb Darnuter bic Godalpine Erebia glacialis, muter

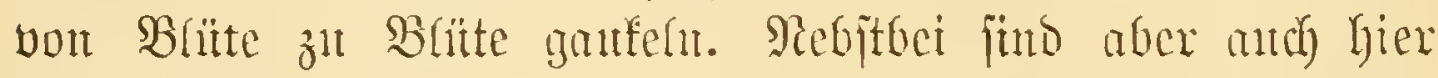

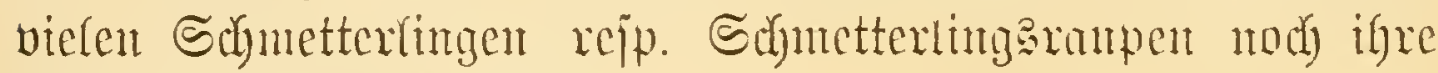
bejombern Iijac bereitet.

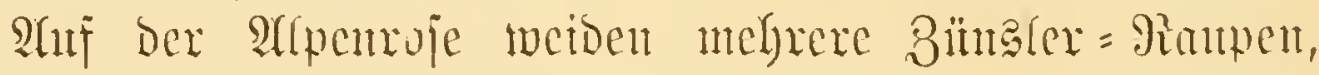

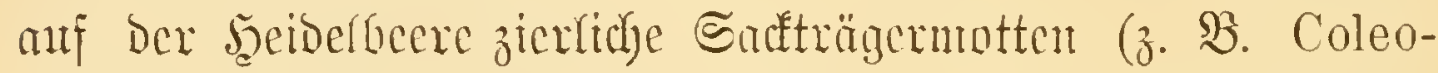
phora vacciniorum); an den B(ättern Der jierlict)en Etem=

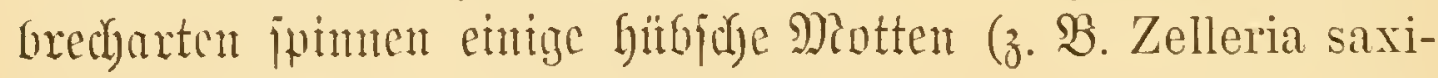

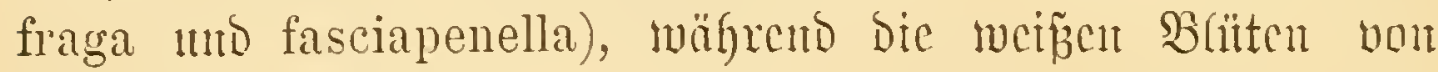
zwei Federmotten (Pterophorus) jerfreficn werden. Des=

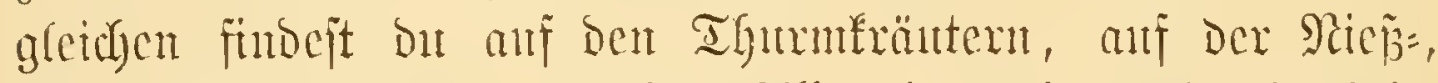

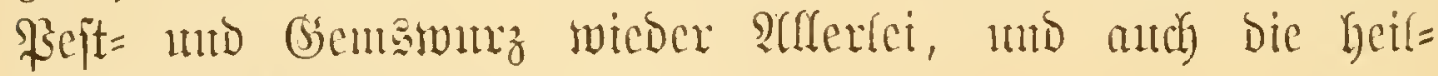
bringembe Arnica bat ihren Stanmgait.

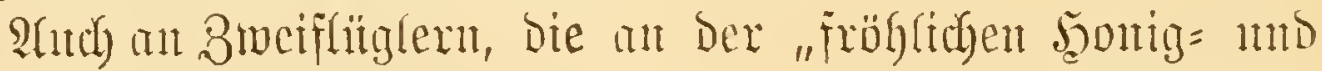

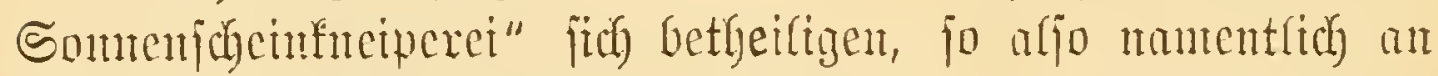

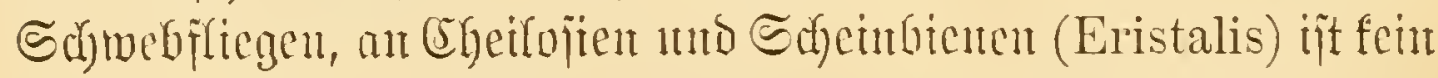
Manger, und bie prächtigen Saphrien uto Asilus fajfen ben ïbrigen Berginjeften and hice feine Ruthe.

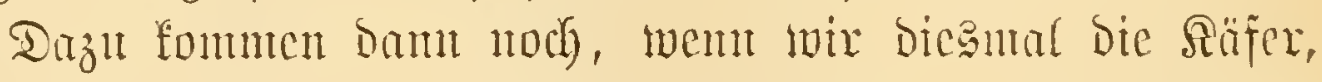

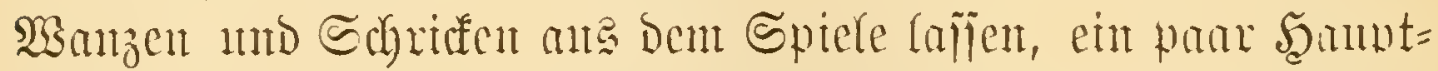

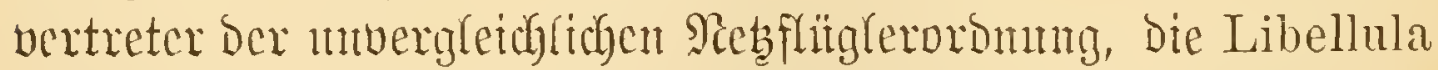
coerulescens, die Aeschna juncea und borealis, wälgrcud bie

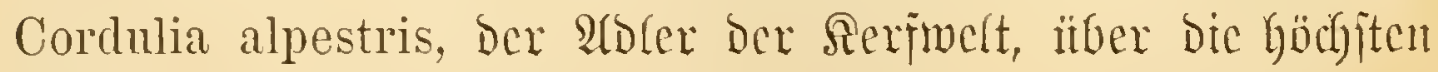
Fetzzintu entrorjabcht.

Das wären cintge dex anffallenditen Srnjeften, weldye den

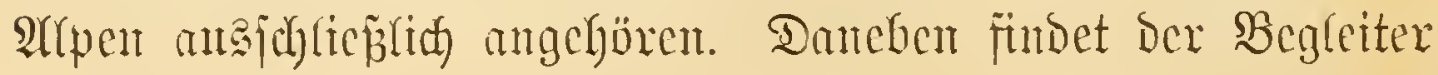




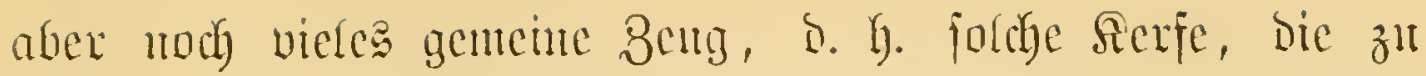

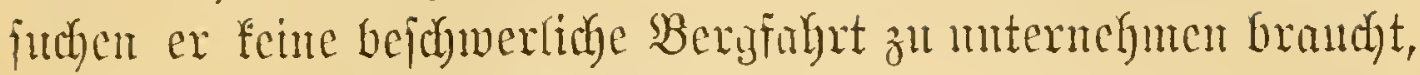
Da ex jie, theils mf Dem Mittelgebirge, theifs mten, anf bent

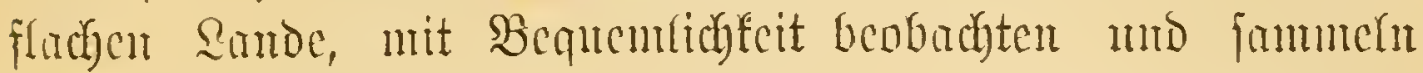

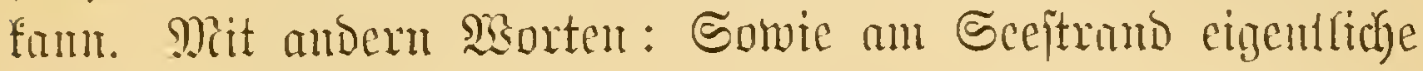

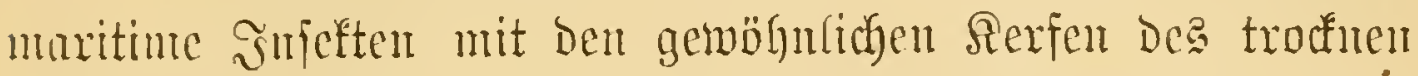

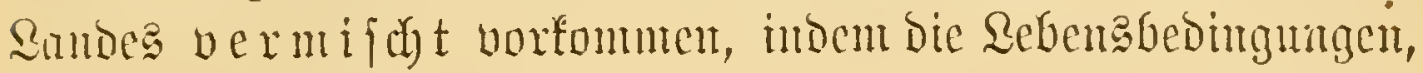
werbe ben eritern z. Th. nothwentig find, mif manche ber

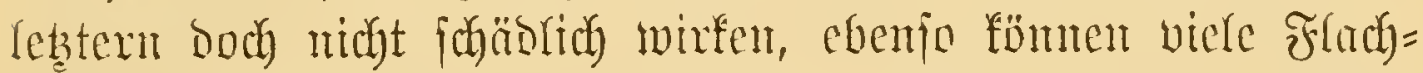
randferje die bejonderen Inujtände, weldhe anf Den Şöhen

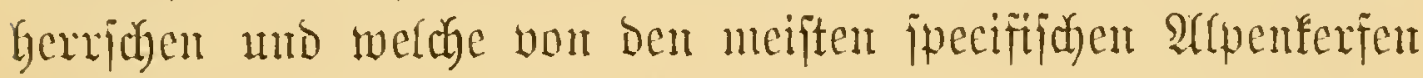
midgt wogl entbegrt werben fönten, gleidffalls vertragen, mo

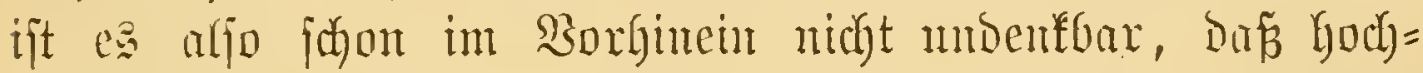

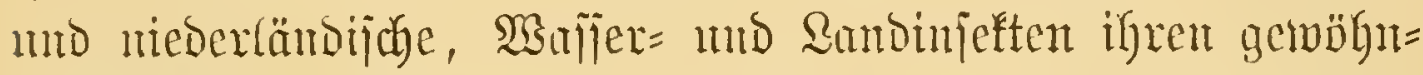

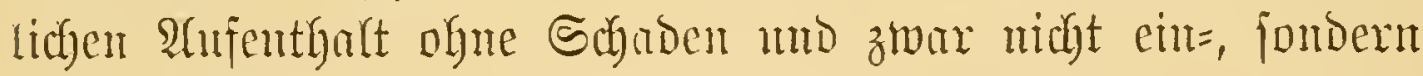

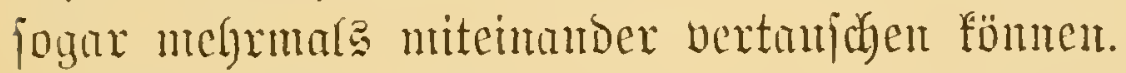

Den beiten Beteg für eine folche Acclimatifation ber

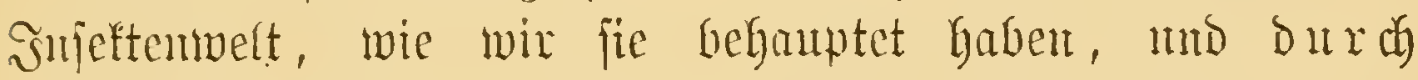

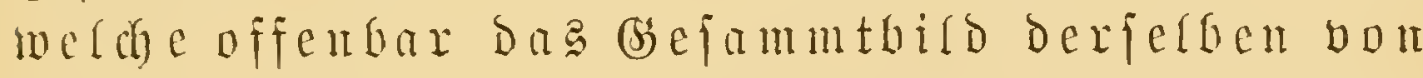
Beit zu 8 eit un von 5 rt zuS

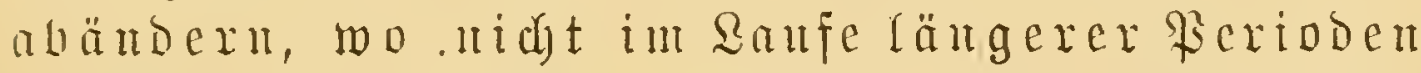
vou (b) $x_{\text {m }}$ a a folgende Erjicheimmg.

Der Mienjud, Diefex glüfflichjt organifinte und wamber = fuftigite aller Erdenbemohner, vermag unter ben wideritre=

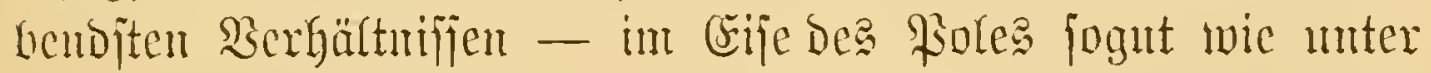

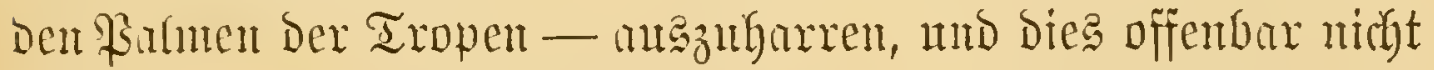

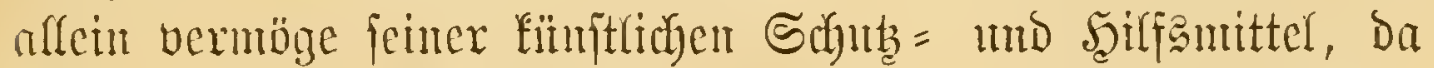

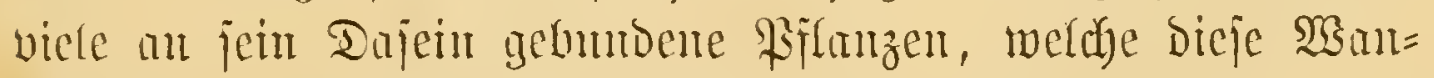

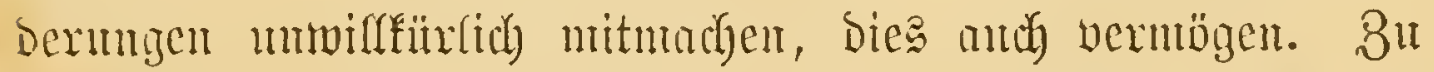
Dicicn geztoungenen Begleitern bes Menjohen, weldye nit

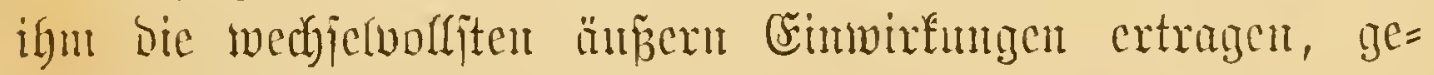

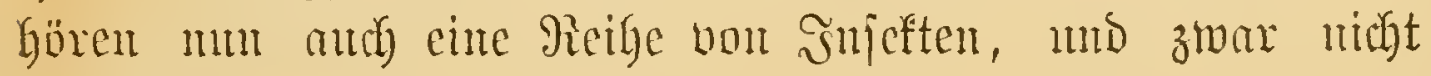




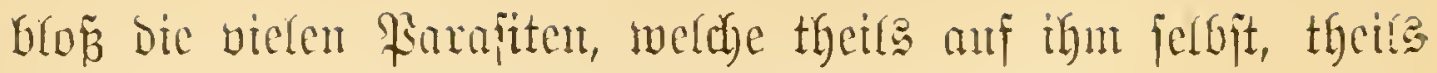

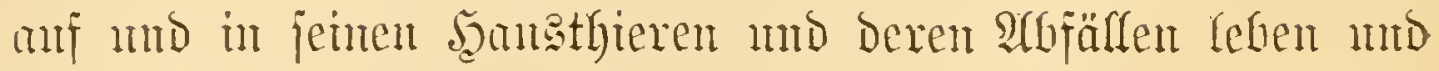

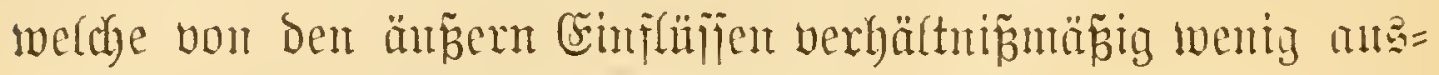

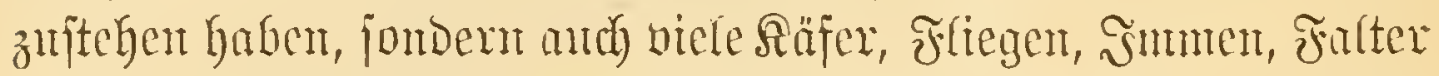

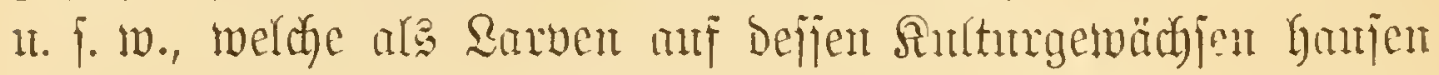

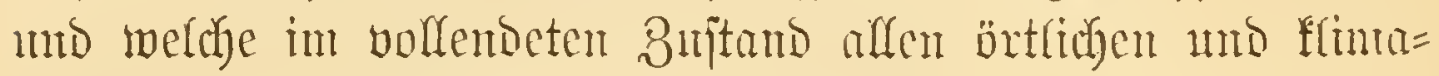

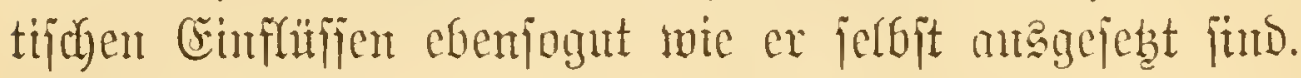

Speciell in bie Mrpen aber jün mit Dem's)ienjichen,

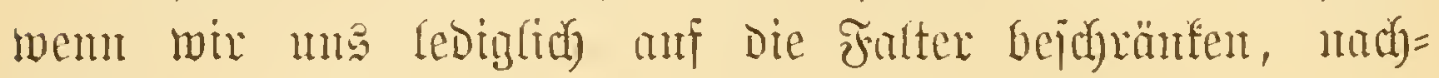
meislich cingedrungen: Drei verjediedente Armutweiplinge, Der

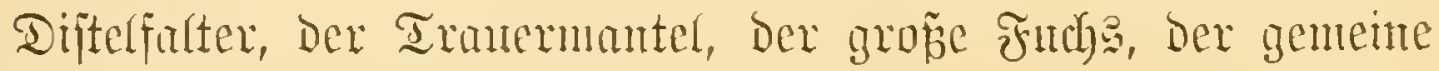
Schedfalter, Die Bammatantle m. m. A.

Bon diejer cinen jobeinfar unboentemben Thatjache fömten twix mu zu Erflänmg émex ambern meittragen= Derent ïhergehen.

Eine vergleidyende Betradytming Der Berbreitming Der Rerfe

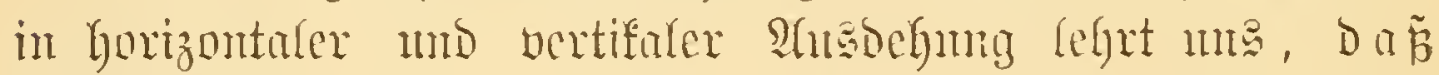

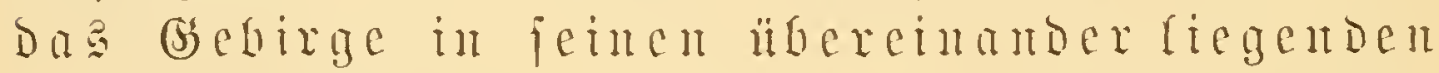

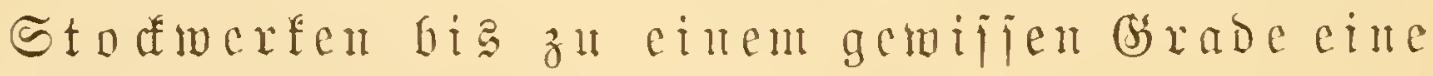
siededrolum defjem darbietet, was am dem Fladande, in veridicdenen Breiten, nebenein=

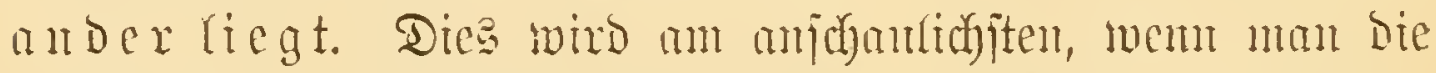

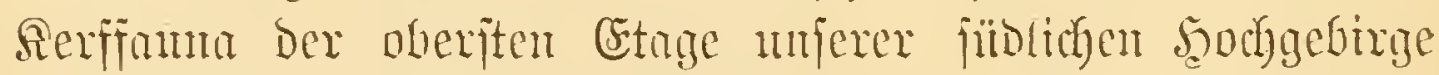

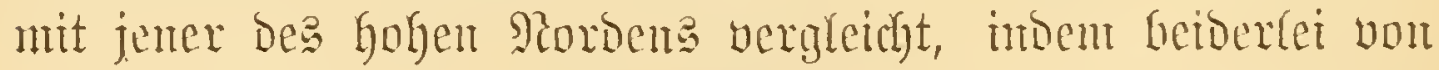
cumber jo weit abriegente Gebicte eine gange Reibe midht

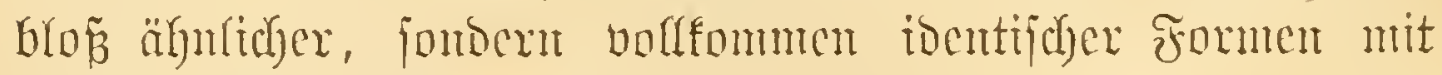
einturber gemein batent.

Mnter Den Räfern gehören z. B. hiehcr: Miscodera arctica, Patrobus septentrionis, Amara erratica, Quenselii mid rufocincta, fermer Sphaerites glabratus, mehrere Dasytes mo Polydrus, Dom vou Bocffäfern eintige Taxotus, Pachyta mo Strangalia, jomie cmofich bie alfbefumte Lina alpina. 
Son Fultern:

3rwei Bläulinge, eine Argymnis, 5 Eroenten, 4 Tag= eulen, twährent, Antore bei Seite gelajjen, von ben 6 alpinen Psodos- umb Den 7 Gnophos-2raten je 2 and boreal finto.

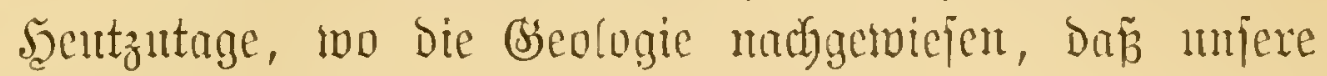

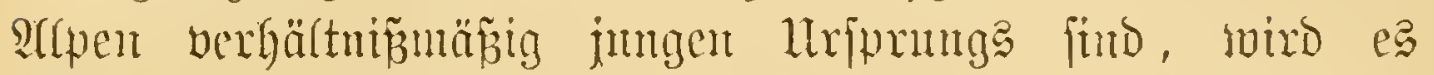

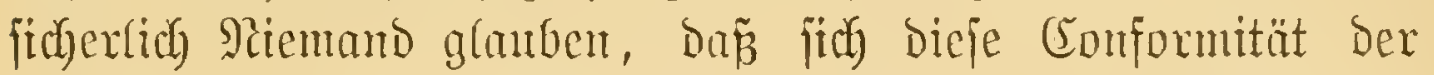

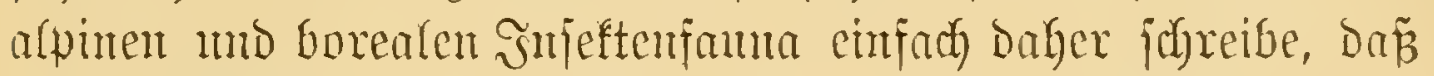

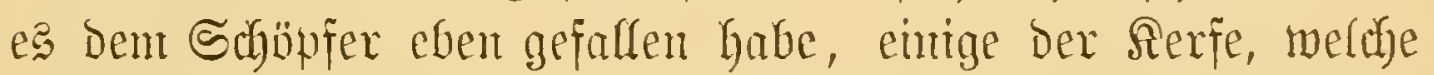
im hohen Rorden jefon jeit Rangem exiftinten, jpäter and

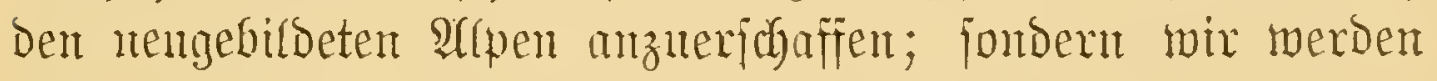

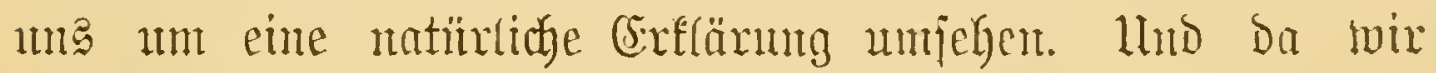
anf Der einen Seite, wentigftens vou ben Siäfern, nidgt ant=

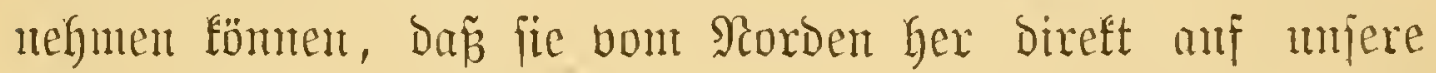
Ulpengipfel losgepilgert jeien mo, von ber antoern Seite, and

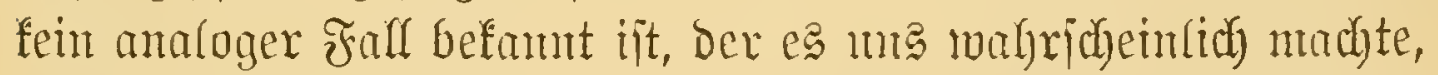

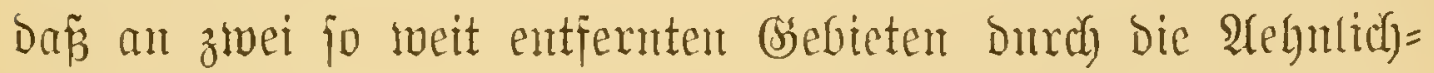

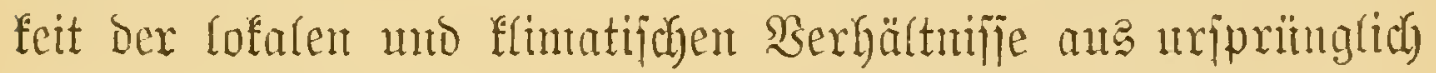
ungleidartigen Aerfen, wir jagen uthat itberbaupt antore, jontern genan idontijche Formen alfmälig erzogen wutroen,

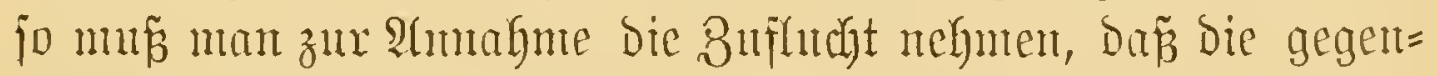
wärtig anseintandergerijienen ober bišcontimuridichen gleithen Fnumen des Rorbens und Sitben elgentals zujammentingen

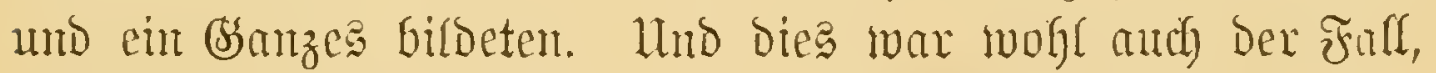

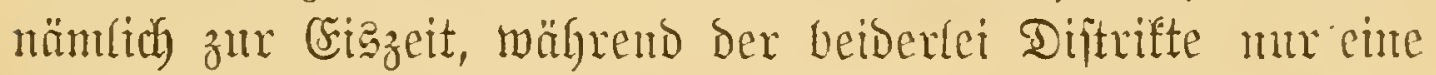

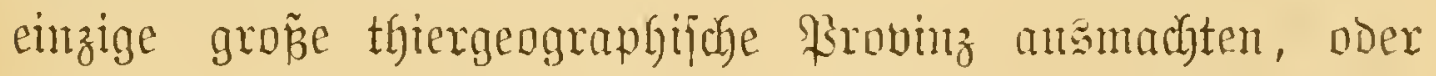

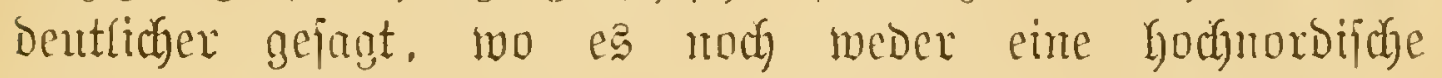
noch eine hodgalpine Reri= und ïberfant Thterwelt gab, indem jene Bemogner, weiche wir hente dort antreffen, now anf Dem flachen Mittellande beijanmen wohnten. Die Thei= lung ober Beriprengung bicjer ciazeitfichen Aerfoelt erfolgte aber beim allnäligen şereinbrechen Der toürmern 2tera, two jene Jnifften, Denten es anj Dent alten, immer geizer mer= 


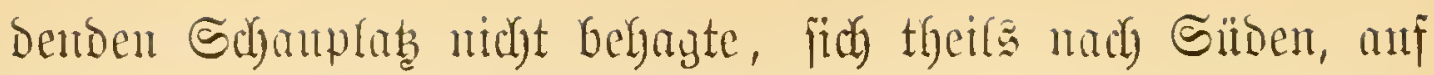

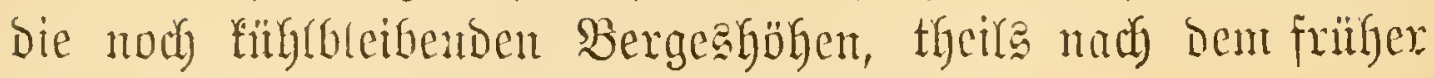

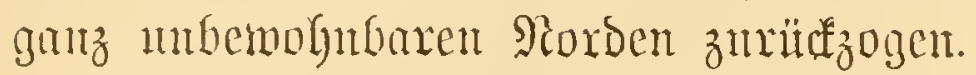

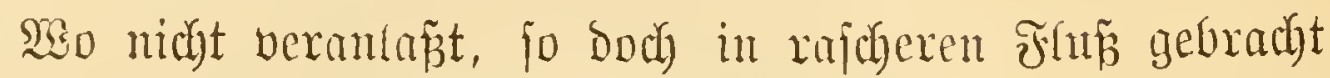
wurde aber diefe alfgeneine Rerfölferwandernng bes mittel=

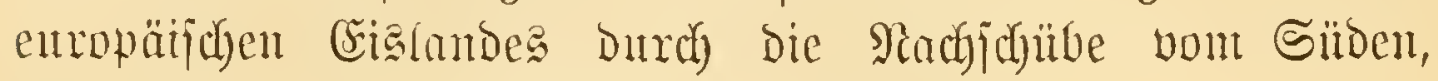
bejonders aber von afiatifben Fathlande her.

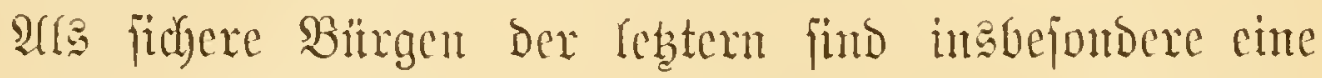
Sieife von Sdymetterlingen zu ncmen, dic Den Sitbatpen

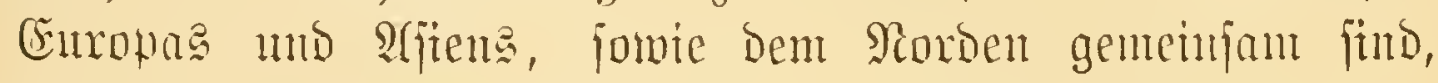
während fie in ben Brwiflenegionen nirgends gefunden werden.

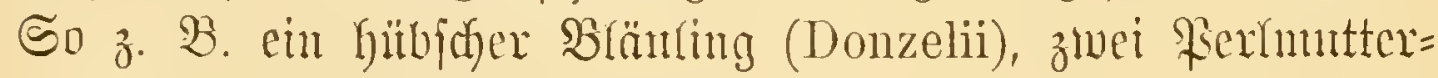
falter (pales and thore) weitcre cinc Crocute (recursa) und żmei Spanner (Gnophos sordaria mid obfuscaria).

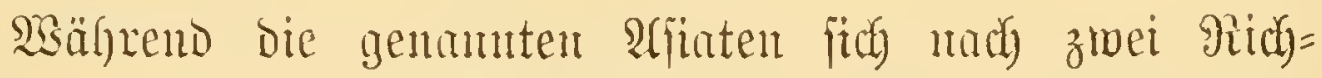

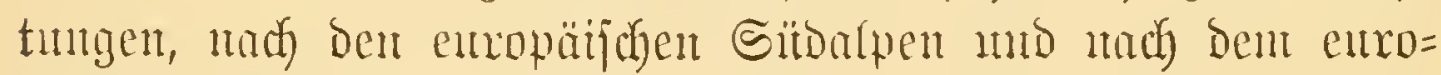

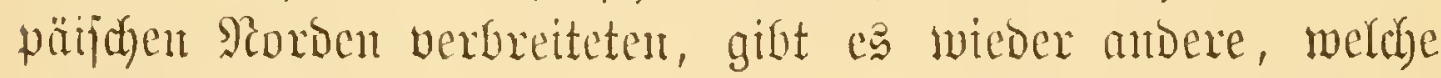

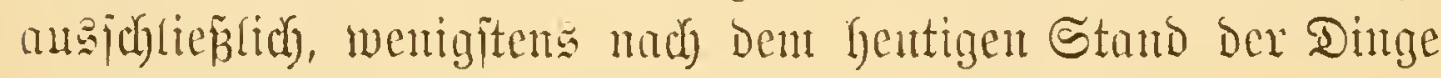
zu untheifen, nur bie erjtere Ridytutg einjdylugen.

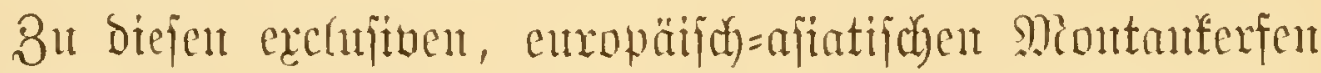

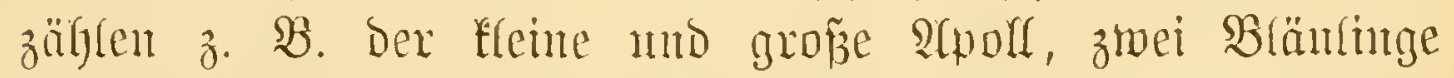
(eros und admetus), ein Rer.mutterfarter (amathusia), mefrere

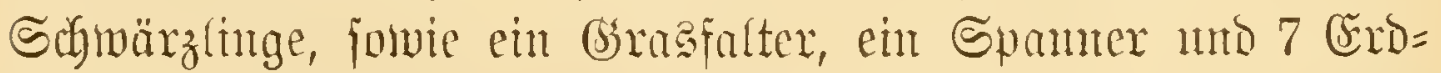

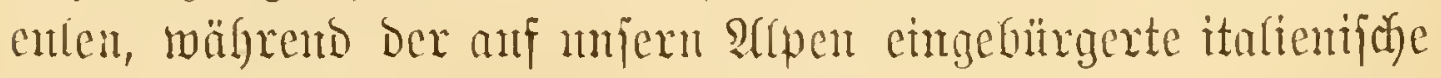

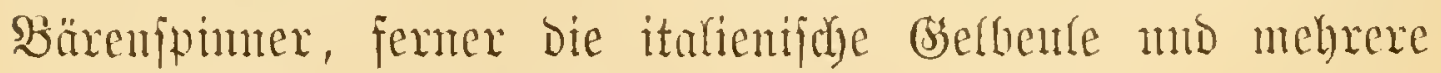
mocte an bent tiefern Suben, z. B. ars Corjifu, Sardinien mo Sicitien, zh me gefonmten finto.

Ier aejer, den wir zux Bemunberung bes muntanten Serflebens anf bie lachenten âpennatten geführt, darf es

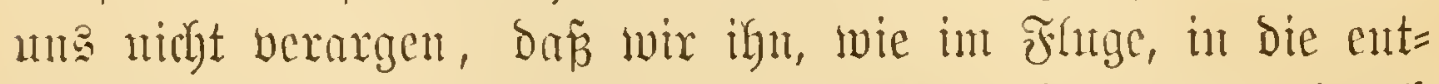

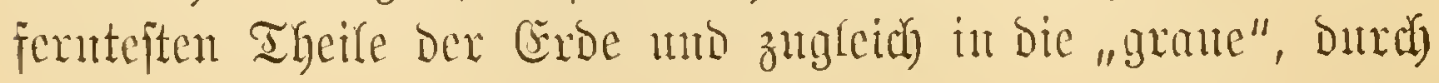


Die Betrantunty Des Sente aber hell exlendytete Sorzeit verjebt haben; ja wix extanben ms nod), ehe wir vom fierf=

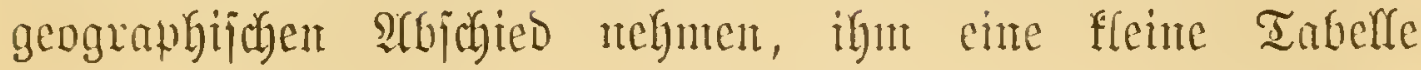

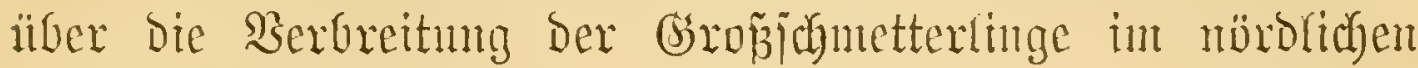
Emropa beizuriägen.

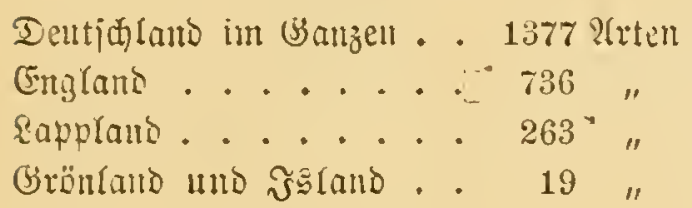

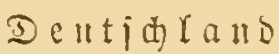

in einer 5eöhe von 3000': 899 Trten,

" 4000^: 527 "

"6000': 210 "

über ber Sdneegruze: 36 "

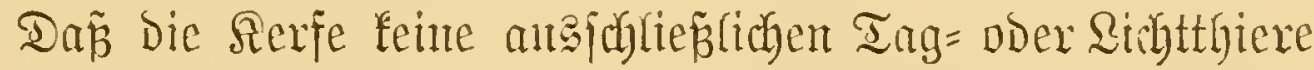

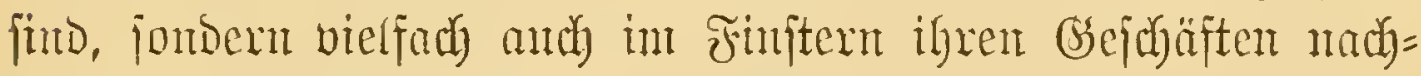
gehen, Dą jehen wir bei ben f̧olgwürmenn und überfanpt bei Den B̧Flanzen=Entoparajiten, Dann bei Den Ameijen, Dhrmitrmen,

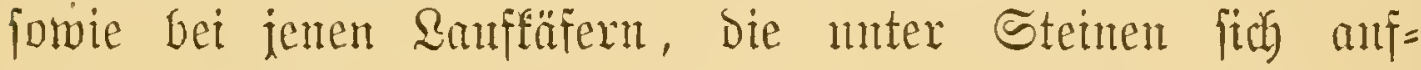
halten. Sind aber nit biejen bie গachtferfe fanon ex= fdyöptt? Begeben wir ung mit enter Błendaterne in Dagjelbe

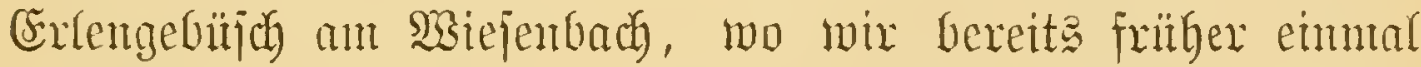
gewejen. ভchon von \$seitent hören wir fonderbare Töne

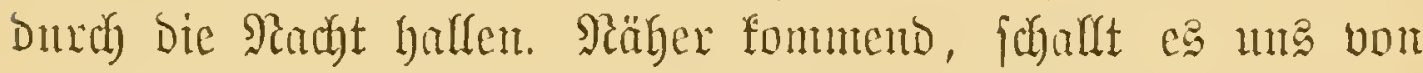

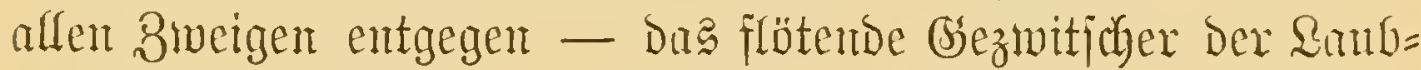

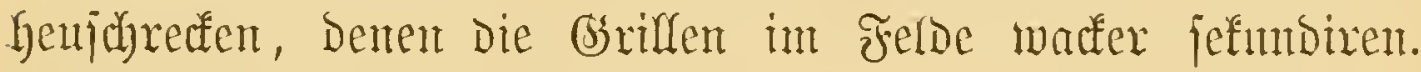
Belendyten wir bie Scencrie. (sinte wahre Bsejpenfterwelt. Alm bas sidut tanzt in wildem Reigen ein ganzex Cyon ser

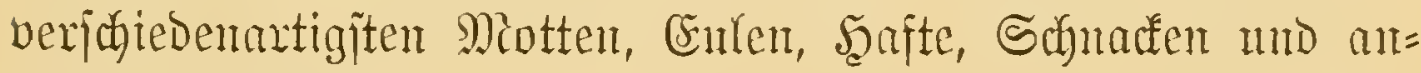
berer sladytuögel.

"Itno finifternb verzefrten die Flammen Der Serzent

"Die Säfer mo ifre liebenton Serzen.

"Die eimen bǖtent das Reben eint,

"Die andern mar bie Flïgelein."

(פeine.)

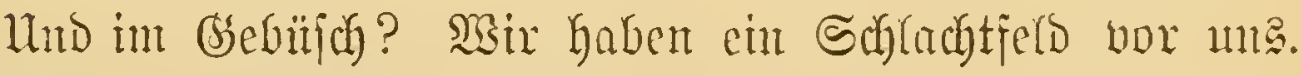

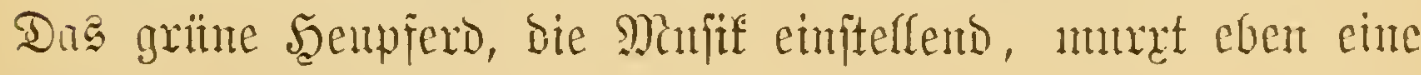

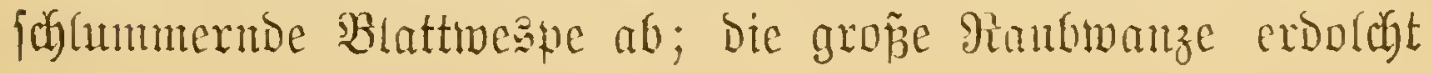


cine Rmup; Dex goldglänzende Sanffäfex, cin gemeinex Ranb=

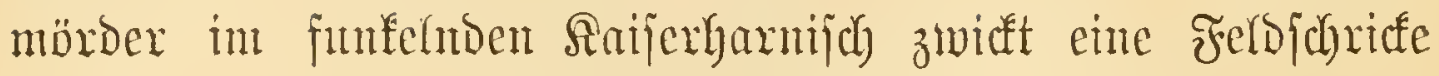

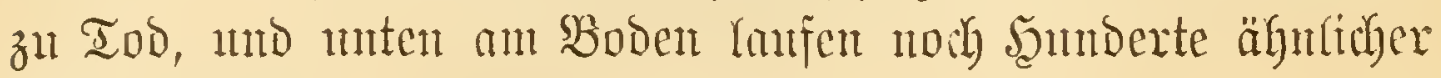
Spiȩ́̃gejellen.

Die zarten Bienthen unt Fliegen, weldye theils mit Den fimbaden, theile mit den Arment einen Bweig unt= Tpannens, wie Beeven an Den Bsefträuct)en bängen, Die lieb=

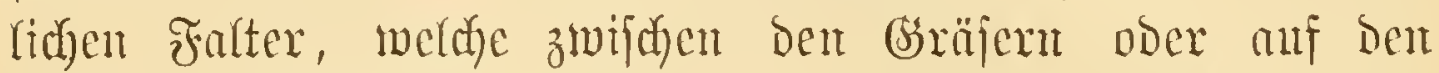

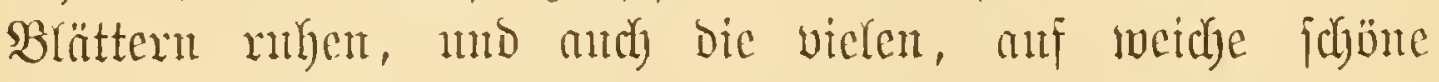
Bhumen gebetteten Räferdyen fund wahrbaftig zu bedauern, da

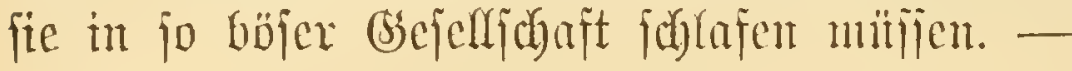

Sallicpen wir die Raternc. Sit a

"Renditfeafferdyen fliegt hir: und her,

"Das wie ein Girberfternein funleyt;

"Es glänzt fein gritne sidat, ie mehr

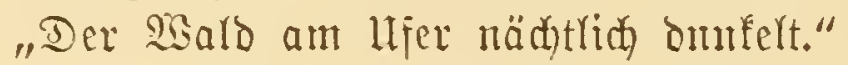

(ङुhr. હdnefler.)

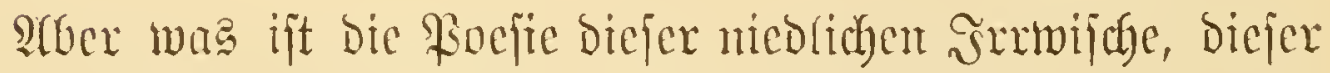
tanzenden eleftrifhen Brenner gegen Das helyre Flammenfeit Dex Feuterfliegen in Den Mrwäldern ber Tropen! -

Mitten Geran an bor fibünten Saifon des Serflebens ipringen wir mu greidy in bas andere Extrem. SWag ift e马 bemn mit ben Jnjeften in Winter, aljo während jenter vier Yangen Monate, wo, in unfern Bonen, die Eroc ben Rflanzen= frefjern nidyte bieten fam, mo fid) baher and bie fleijdy=

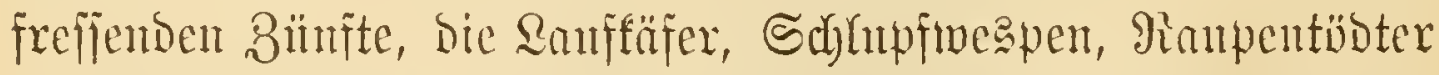

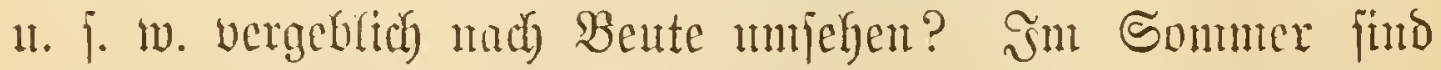
Die Rerfe zahllog wie der Samb an Micere, im Mainter

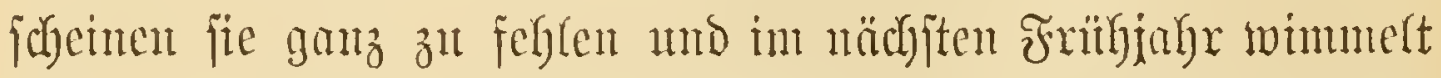

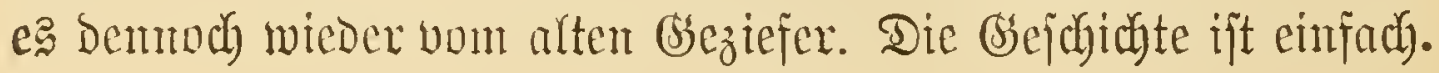




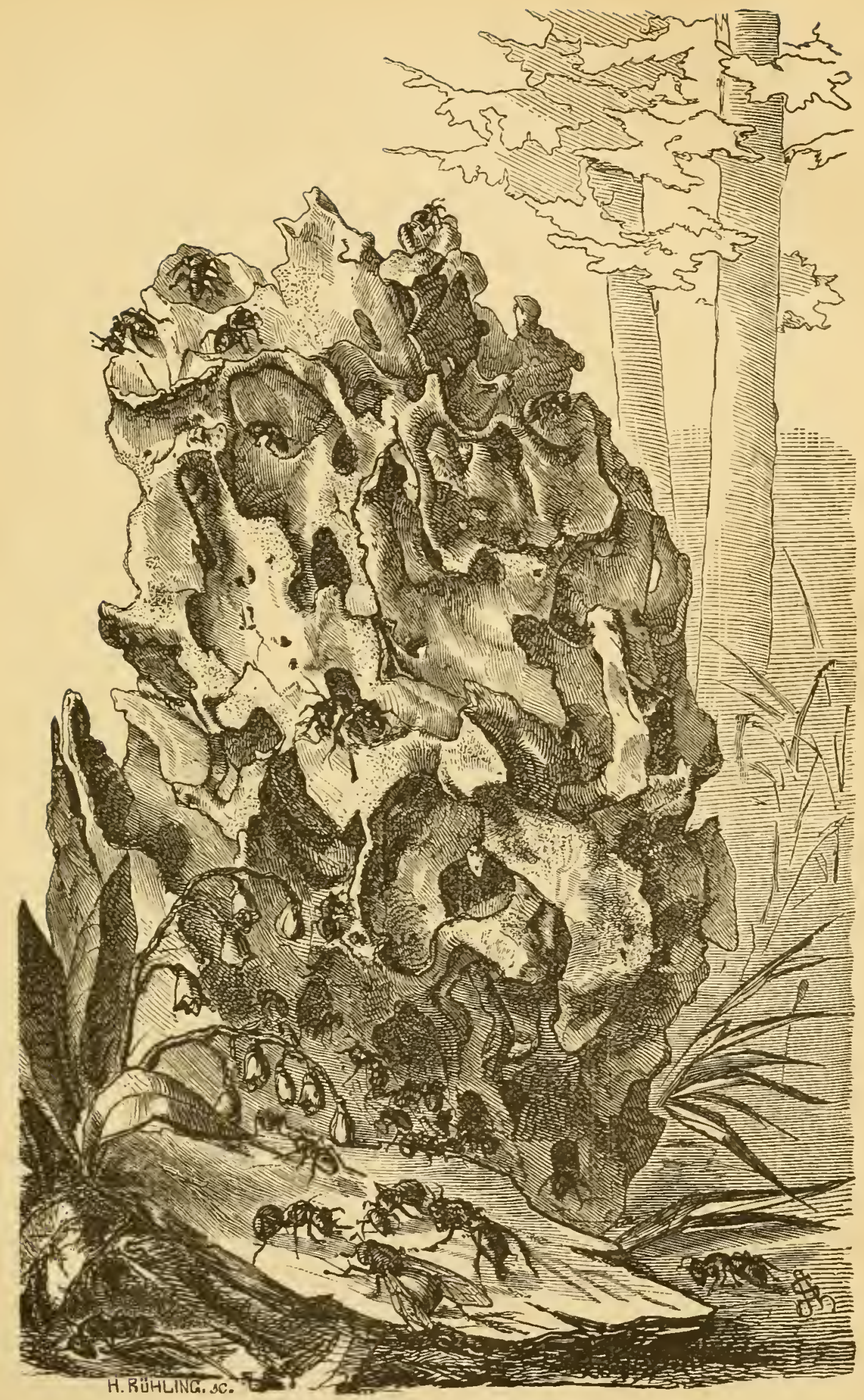

Fig. 3. 2umeijenbau aus eitrem Budjenftanm. 


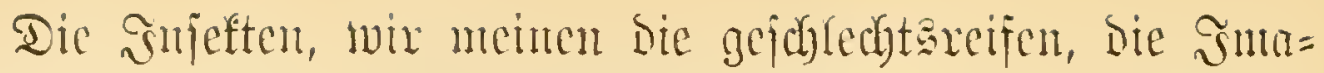

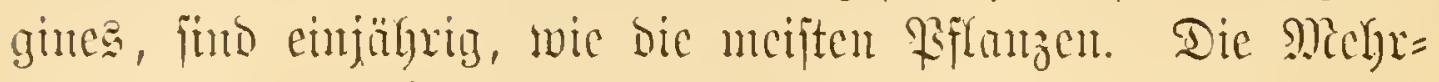

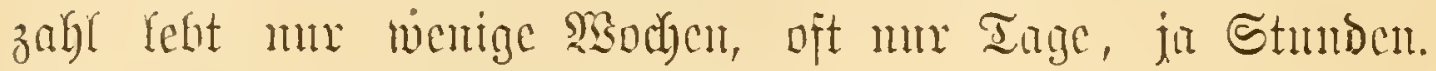

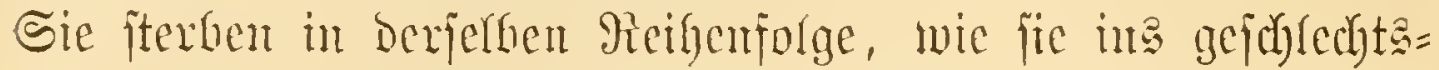
reife Sater cintraten. Sm Sonmer oft megrexe Bruten Ginter= cinnocr. Der cintretende Futtermangel nub sie Sälte bein

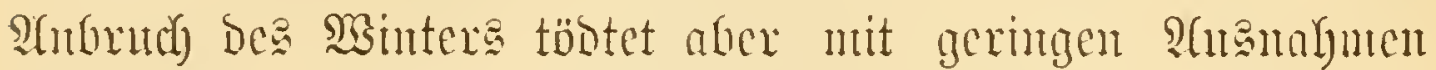
andi) jene, bie untex günftigeren lturitänden noch eintige Beit

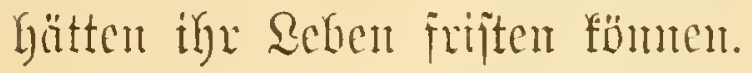

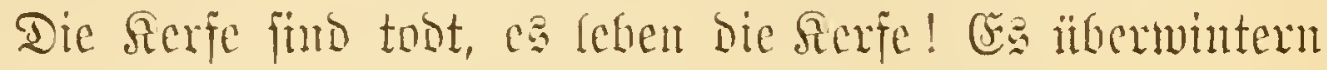

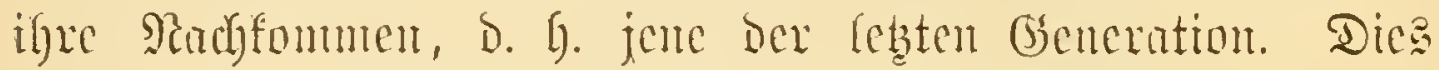

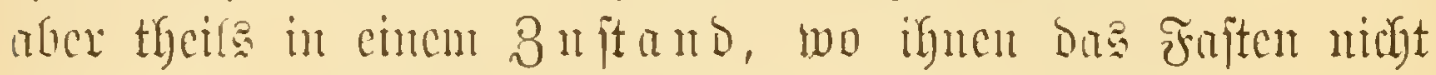

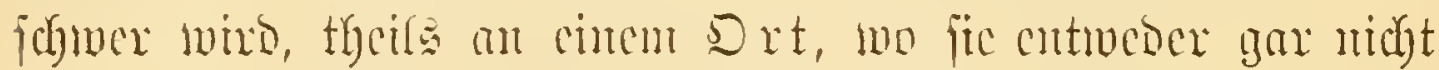

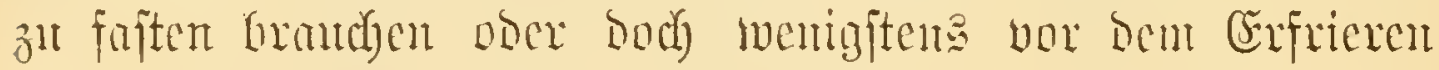
geforitibt jitto.

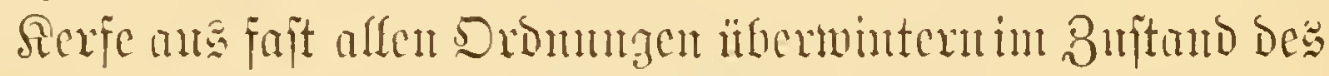

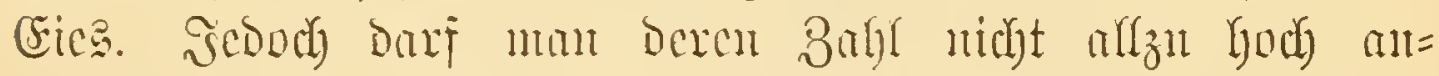

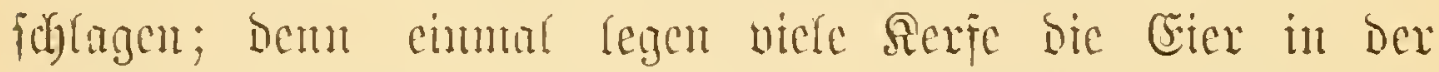

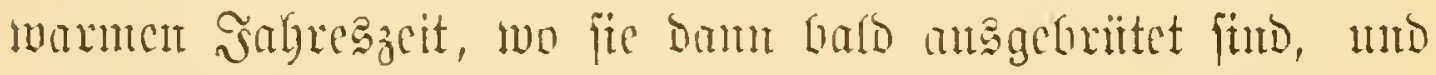

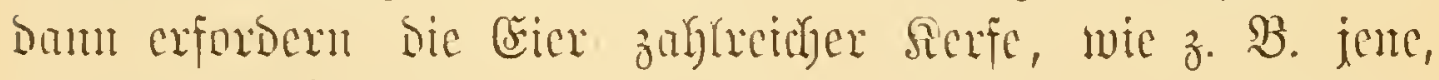

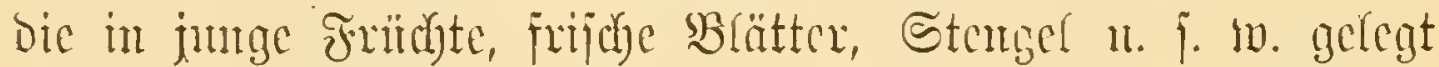

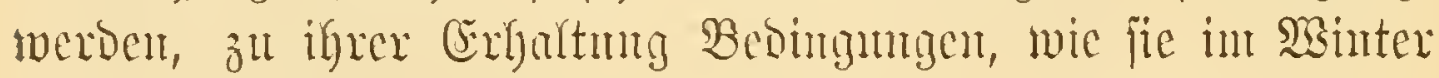
nivit vorkanoen find.

Die Sagerpläbe Der meiften itherwinternoen eter expdyeinen

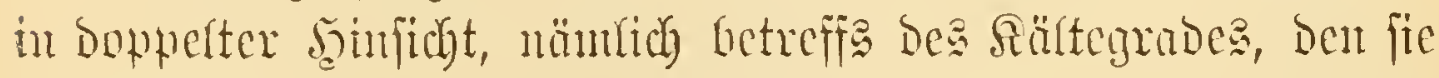

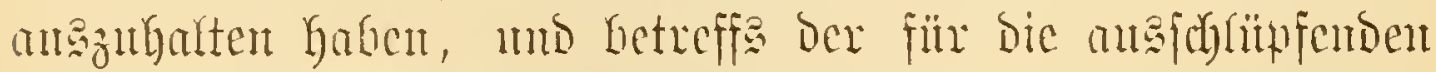

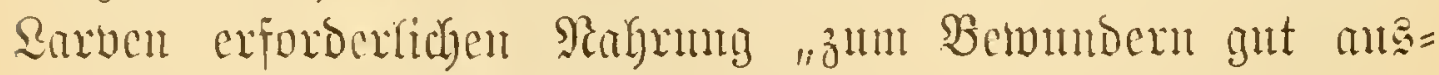

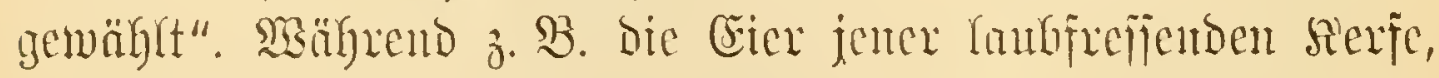

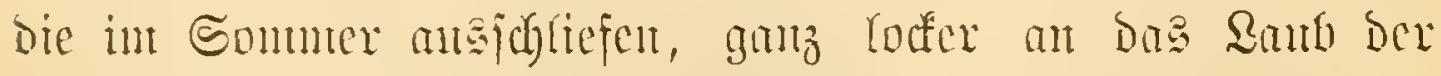

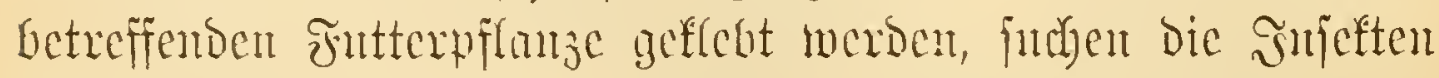

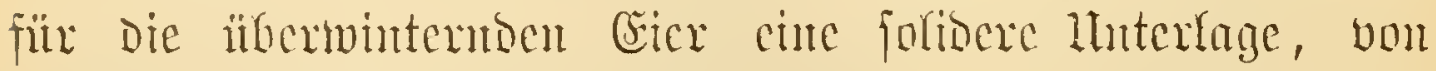

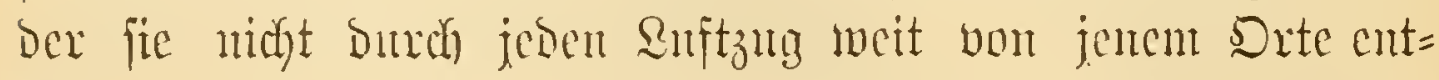

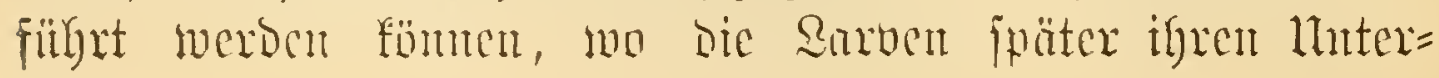


Yalt finden jollent. Rintgel= mo Schmamminimereter, worïber unten bus Rähere, illutrixen bies.

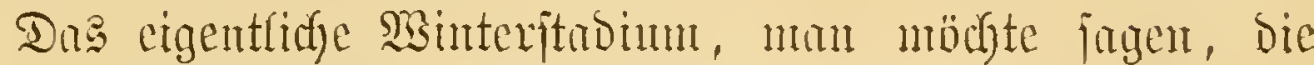
eigens fïr Die grulge = oder Sighumerzeit ber Serje ex=

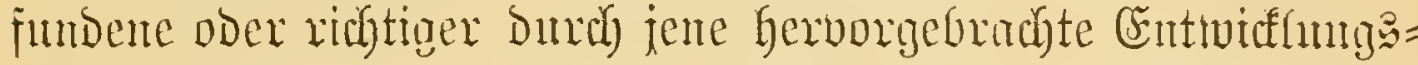

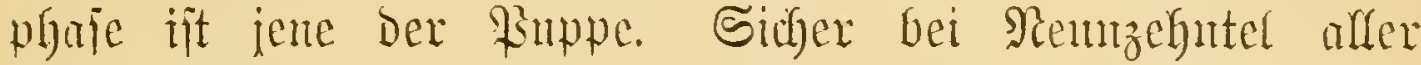

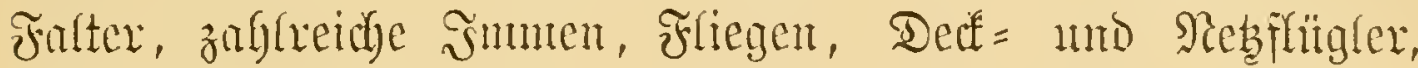
aljo furgum alle Rerfe, bie itbergant eine volffommene Şer=

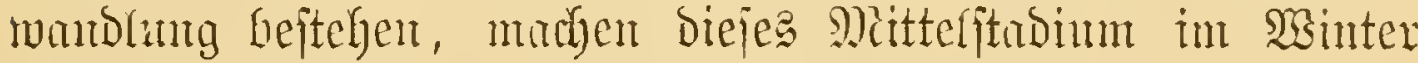

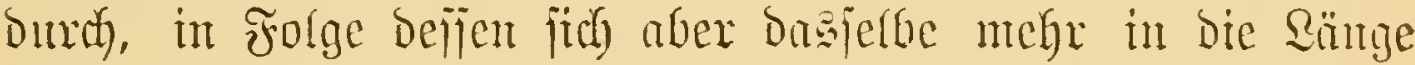
jiegt, als went es im Sommer afjolvirt wird.

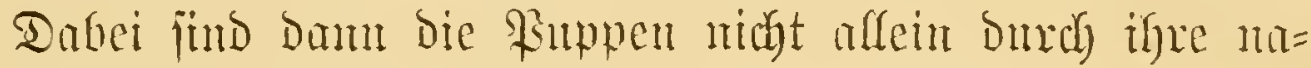

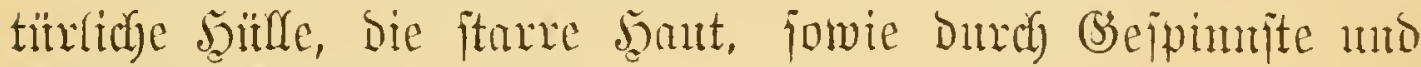

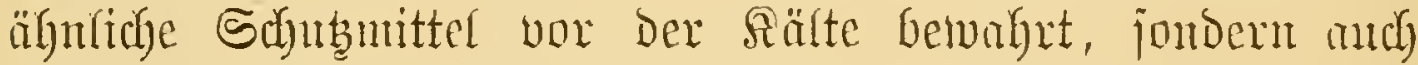

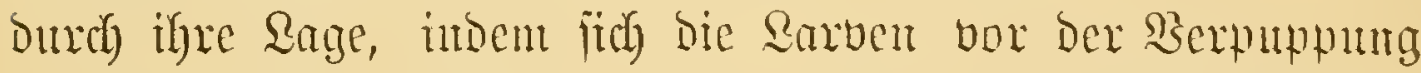
in Spalten, Bammitüme, miter Steme, Raut, Mroos ober

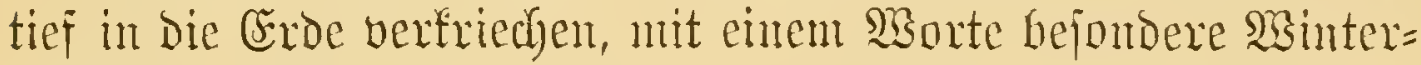
quartiere anfintertuen.

Siele Rerfe itberwintern aber aud als Sarben, alfo in cutem 3ujtun, wo ihnen jont bas Mielefien zun madyt ift. Soldhes beritelyt fide eimmal von ferbit fïr alle

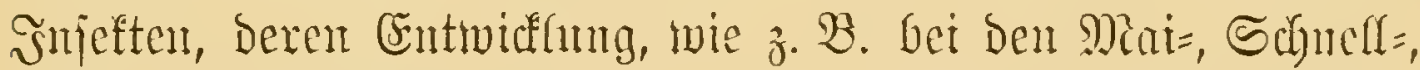

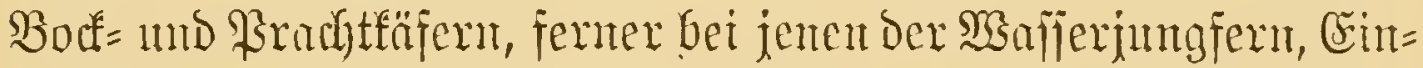

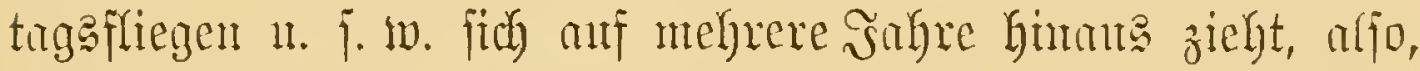

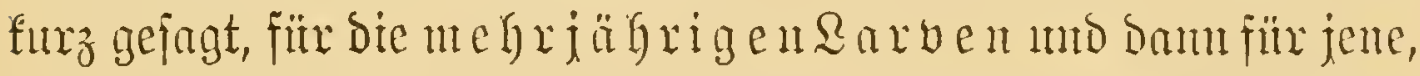

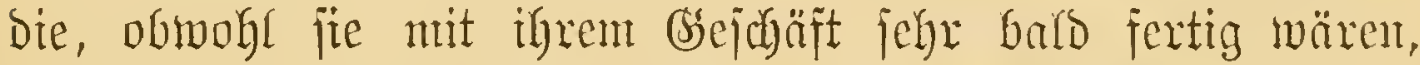

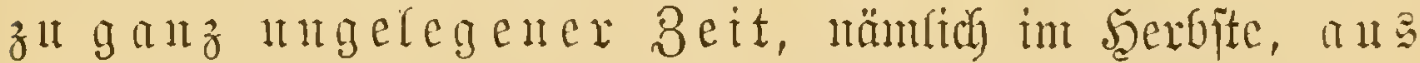

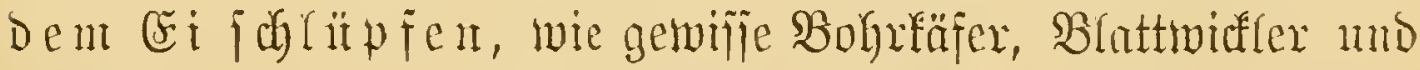

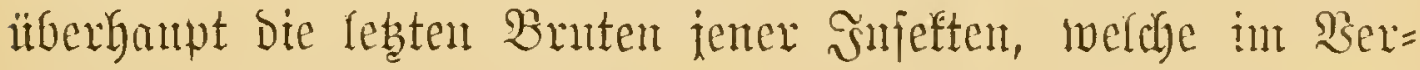
lanf Des Sommers cine Teilye von Generationen hervor=

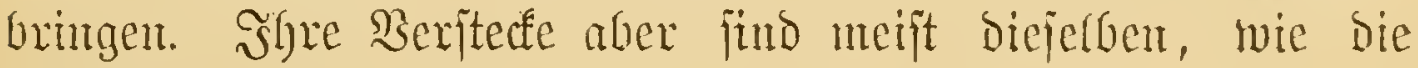
Der Puppen. 


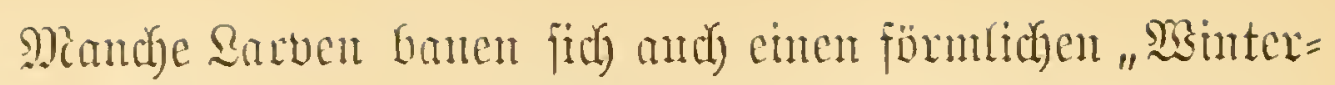
palajt". Seocr feunt bie grop̃en arf Den Bätmen hängenden Gejpimite Des Groldafters, in Denen Tanjende junger Räuthen, in hejondere Grentäbcr abgetheilt mo bicht zujammengedrängt, Der itrengiten Sälte troben. Ânch Die Ranten bes Şage=

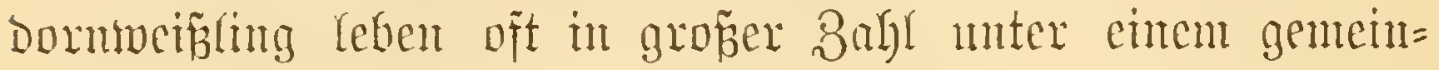

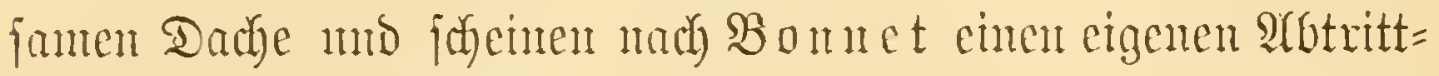

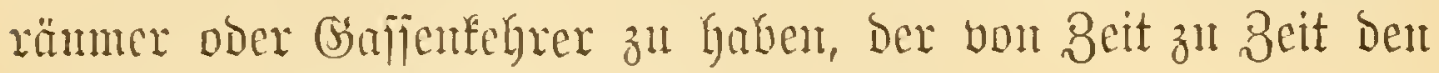
Ilumath Der Gejelfichaft bei Seite juaffit.

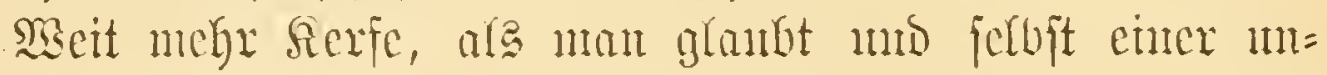

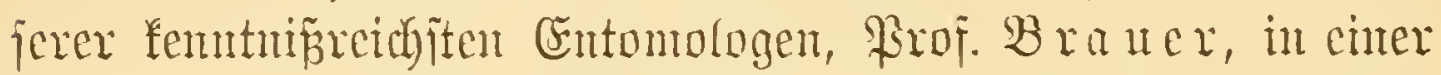
eigenen abhamblnng nambaft madyt, itberwintern in boll= fonmenen Buitand. Sirbig loat eine Bufanmenitelfung ge=

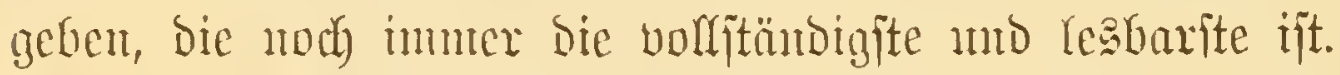

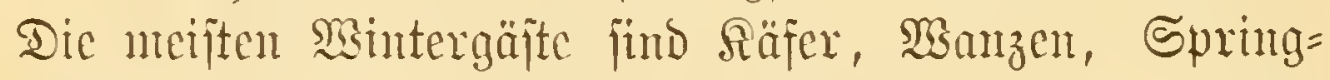

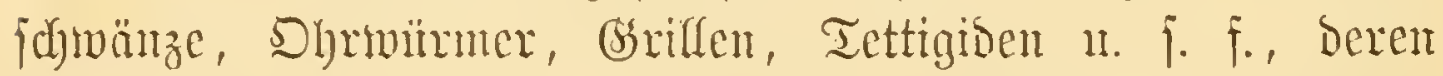

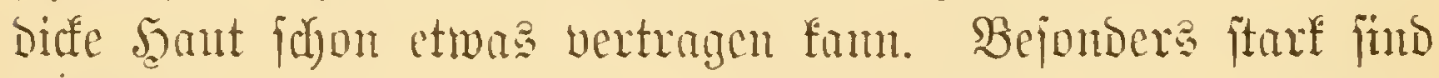

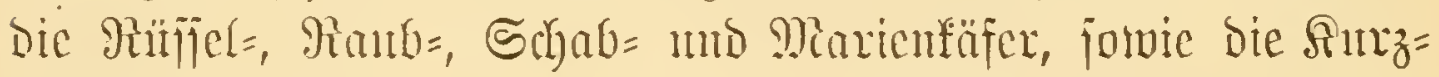
flitglex, Eroflähe w. ¡. w. vertreten. Dieje warten aber in ber

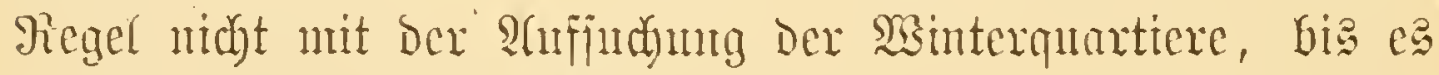
zu fpät ijt, bis fie bie Sälte ïbermant, jombern fehen fich)

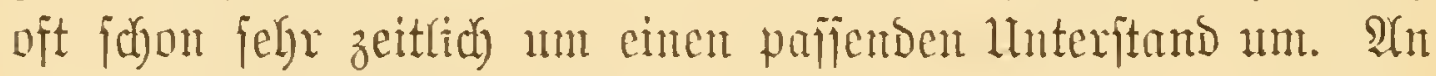

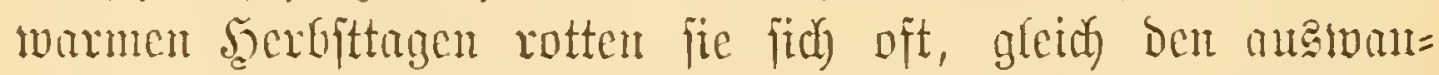

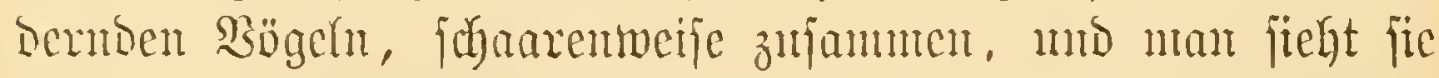

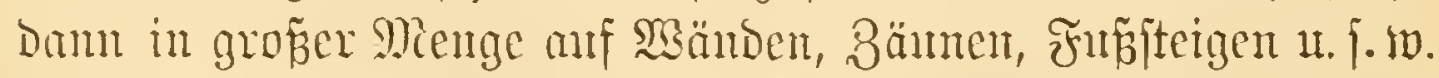

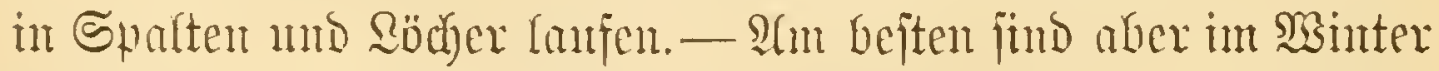

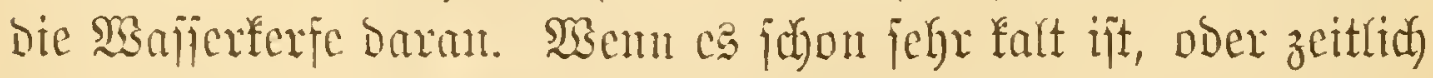
in Frühjahx, während Die Sambinjeften nod in tiefen Shlafe

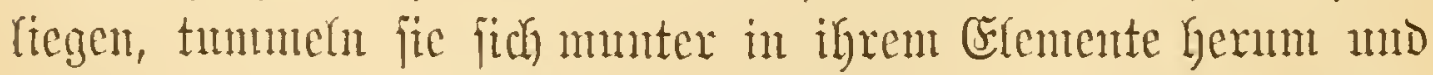
haben, went bie Beiten johlimmer werden, in Schlanme ober

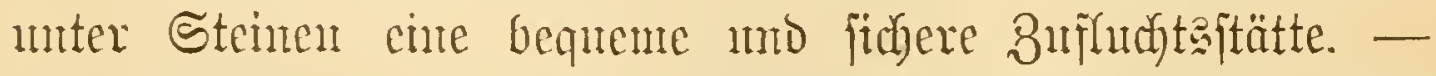

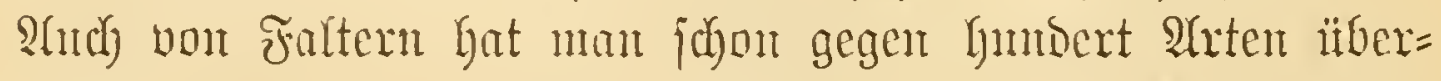
wintern jelgen, am hänfigiten Fïchje, Trantermantel, Citronen= 
vogel, etfiche Cullen (Xylina, Cerastes), Epanter (Larentia), Züm utto Gépiptchent.

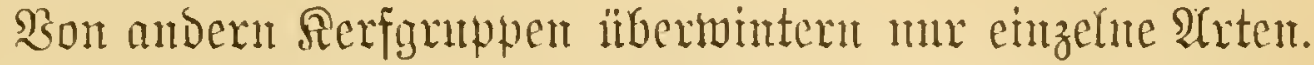
Unter Den Nebflïglern z. B. manthe Sibelfen (Lestes fusca), bic Perlfftege (Chrysopa vulgaris), von ber twir heuer tagtäglidy einige an Den Mautu mperer Stubierjtube hängen fahen, mb bam gemifije Micromus-ভpecies. Sothmentig ift bie Heberminterung

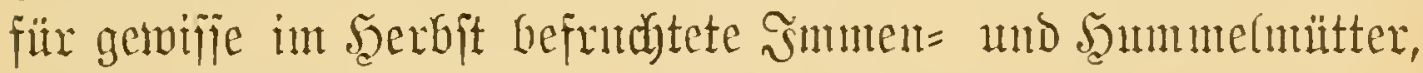
weldye Stanmbalterinten igres Geidyledites fint. Bei Dor

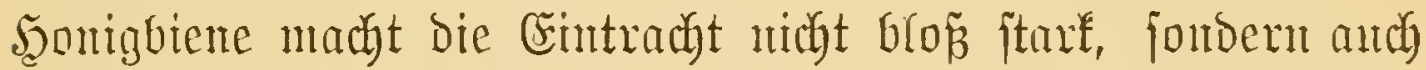

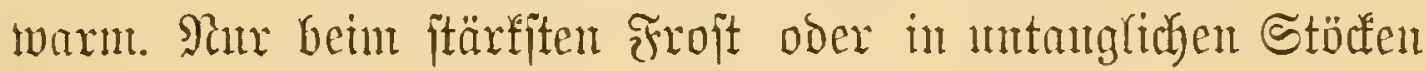

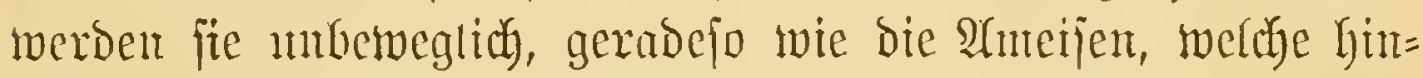
gegen bei mirberem Master häufig auf bem Schnee herum= ipazieren.

Man wiro vielleidyt glauben, dap jo fleine Msejen wie Die Rerfe in Winter gax Gald ifre Märme gegen bie $11 m=$

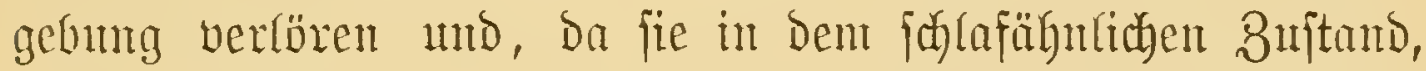
in ben fie verfalfen, mentig ober gar midyt athmen, alfo aud

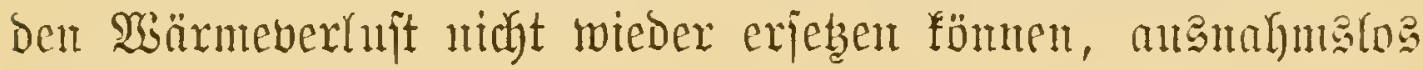
z"ll Cis erftarrten.

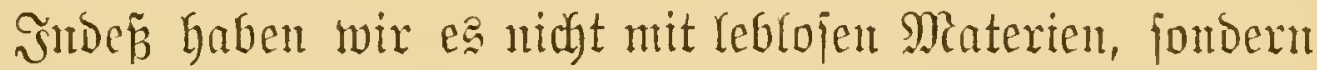
unt Drganienten zu thun, bie gemäp ifyrer ganzen Conjti= tution auf die Sälte. Fegr verjojieden reagiren. Durah $\mathfrak{B} e r=$

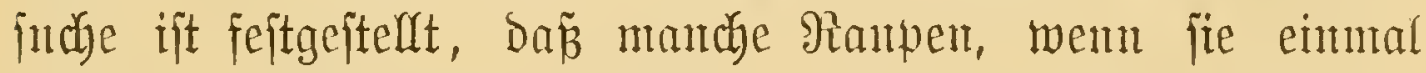
gefrieren, nidyt wieder aufwadjen, mbere bagegen kemertei Schaden mefmen. Grab und Dauer der Siälte, weldye Serfe ertragen fömen, wären aber Durd neuerlidye Experintente

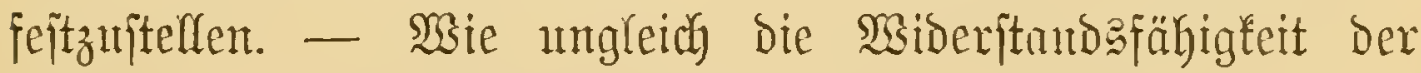
Serbtgiere gegen $\mathfrak{3 a ̈ r m e e n t z i c h u n g ~ i f t , ~ D e m o n j t r i r t ~ a n t ~ a n = ~}$

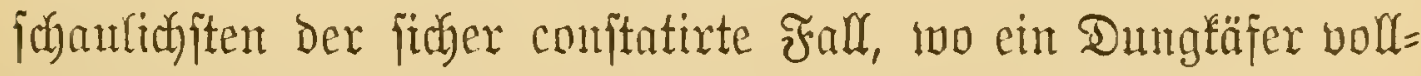
fommen exitarut gefunden wurde, während feine ruingigen Sdjmarober= Mithen ganz nunterer Dinge waren. 


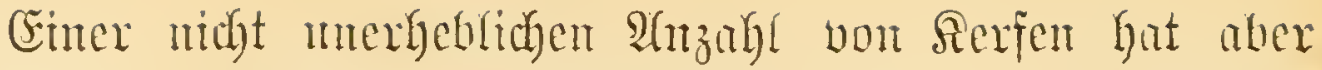

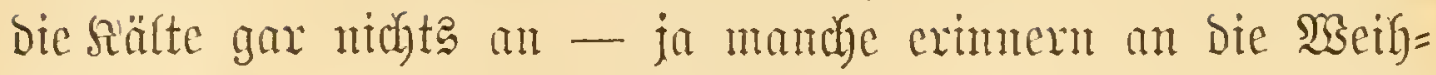

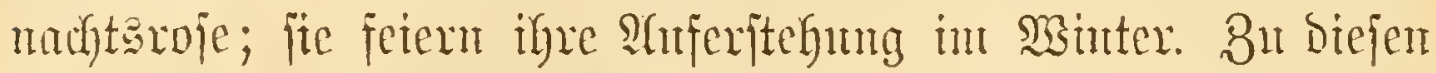

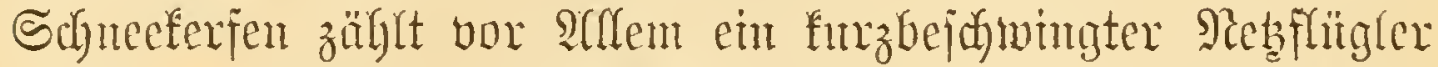

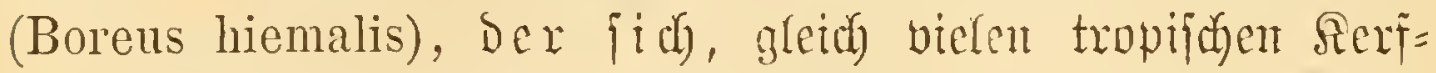
larben, im $\subseteq$ ommer einfapjelt, Dam ber genteme Baber oder Schneetwm, weitere der Schneejpringidumanz un cine Mïlfe (Chionea araneoides). Die Minter= (Trichocera

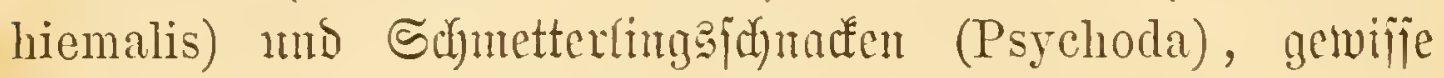
Mrusctoen, Dung = mto Ranbfäfer, bie Bimnberbärenranten unb bie Frojtipanter fund gleidjăfa gegen bie Siälte gefeit.

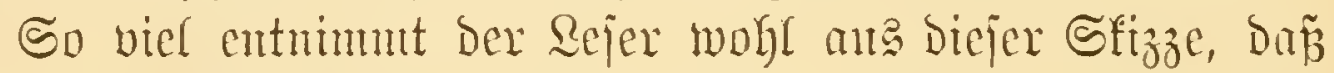

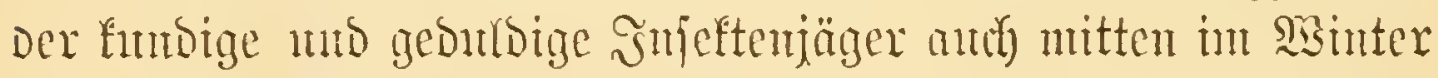

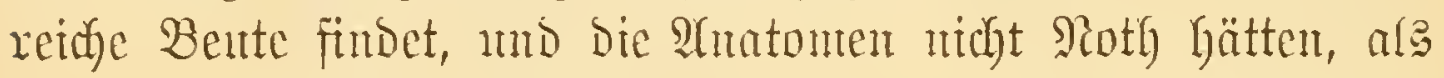

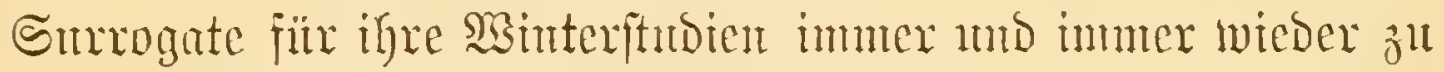

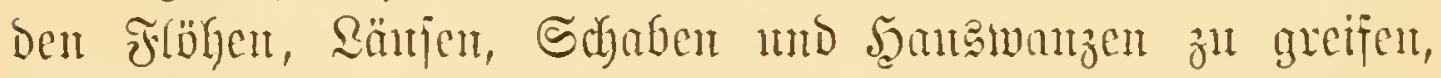

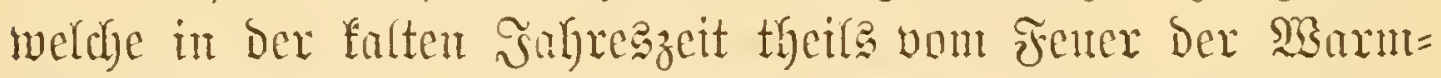

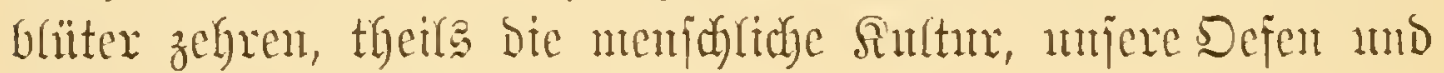
Betten, jith zut Nitbe ntachen. -

\section{E⿰亻⿱丶⿻工二口ipitel.}

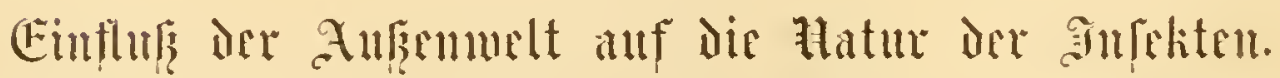

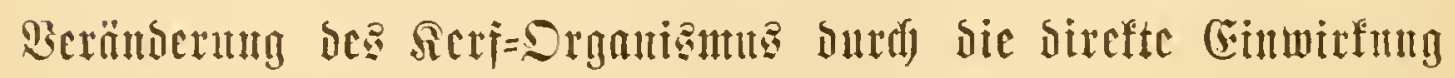

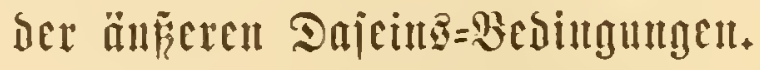

Sein Raturgejes find wir gentigter, ohne weitere Betweife fiir waldx anzundymen, als bas ber conjerbativen Bererbung,

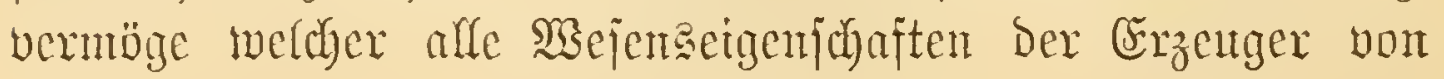




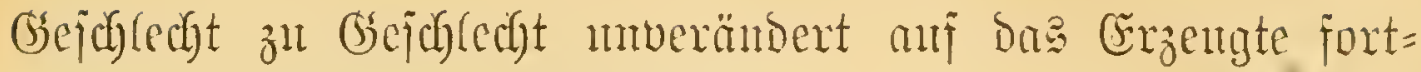
gepffanzt ober ïbertragen werden.

Trobbem ijt biejes Gejech, wentigiten in biejer ftarren

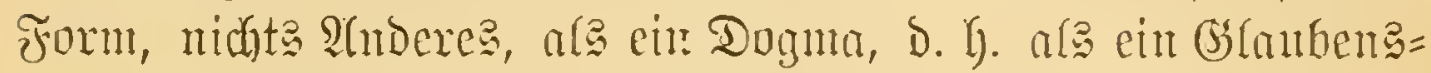

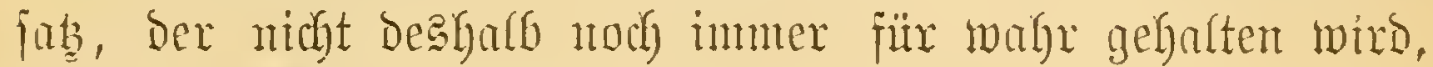
meil ex wirffich wahr ijt, jombern Deshalb, weil ex jobor jo

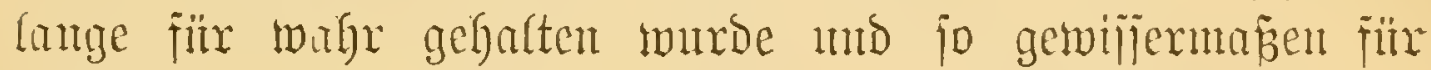
verjährt angejeben wird, während man ifn im bsegentbeil ars antiquirt betrachten jollte.

Daj Der Eab von der comftanten oder unveränderlichen Sererbung jpeciell für bie Jnjeften abfolut jaljd ijt,

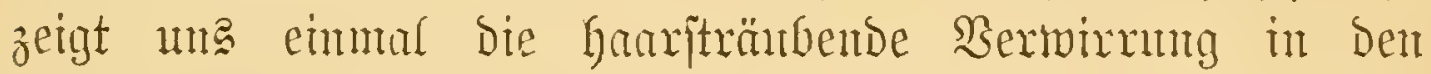

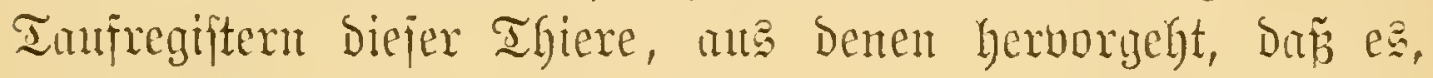
bei gerwifjen Gruppen menigitens, "ganz einterlei ijt, ob man in einer beitimnten geife einander äbntidyer Formen cin furzas oder ein längeres Stïn mit eincu bejonderen Ramen beebrt und als Species (D. h. ale biejammtheit ober Collectiblegriff aller mit gemeimjumen Form = unto

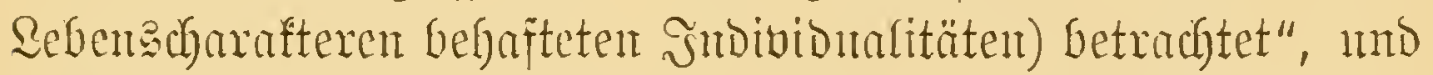

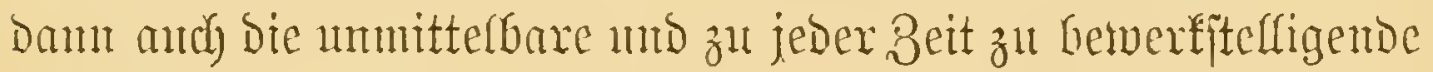

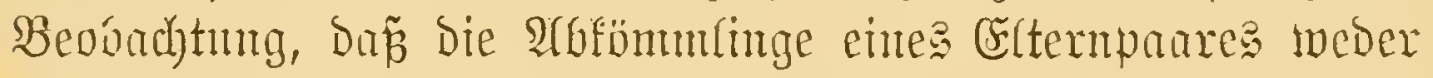
unter fid nod) mit ben Erzeugen abjoht gleid, fondern

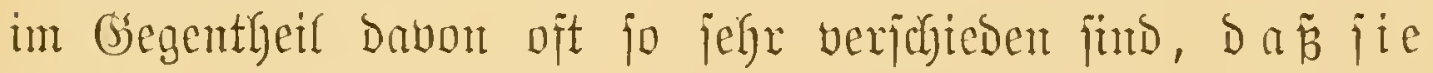
merr eimer fremben art, als ibrex cigenen

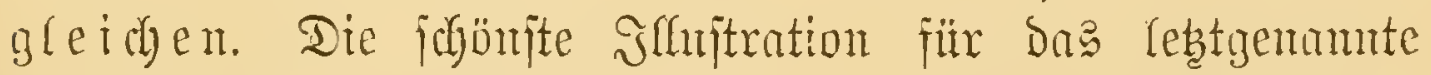
Factum gibt nadjitebende Figur. a ijt ein Iagfalter ans

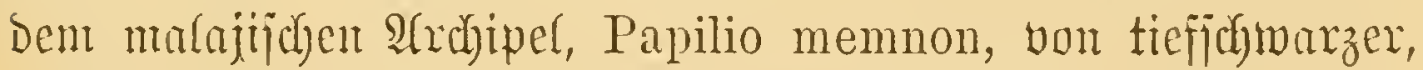

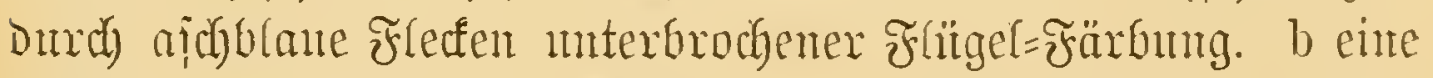
Durct) Den ¿öffelartigen Anfang der Şinterjchmintyen, jowie Durch Die wein unt lebergelb gejtreiften Frïgel wohl unter= juicedene ambere ârt berjelbent bsattıng: P. coön.

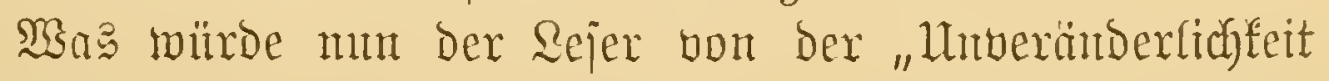

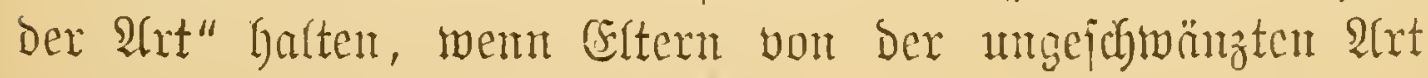
(3) raber, Jilleften. II. $\mathfrak{B}$ o.: 


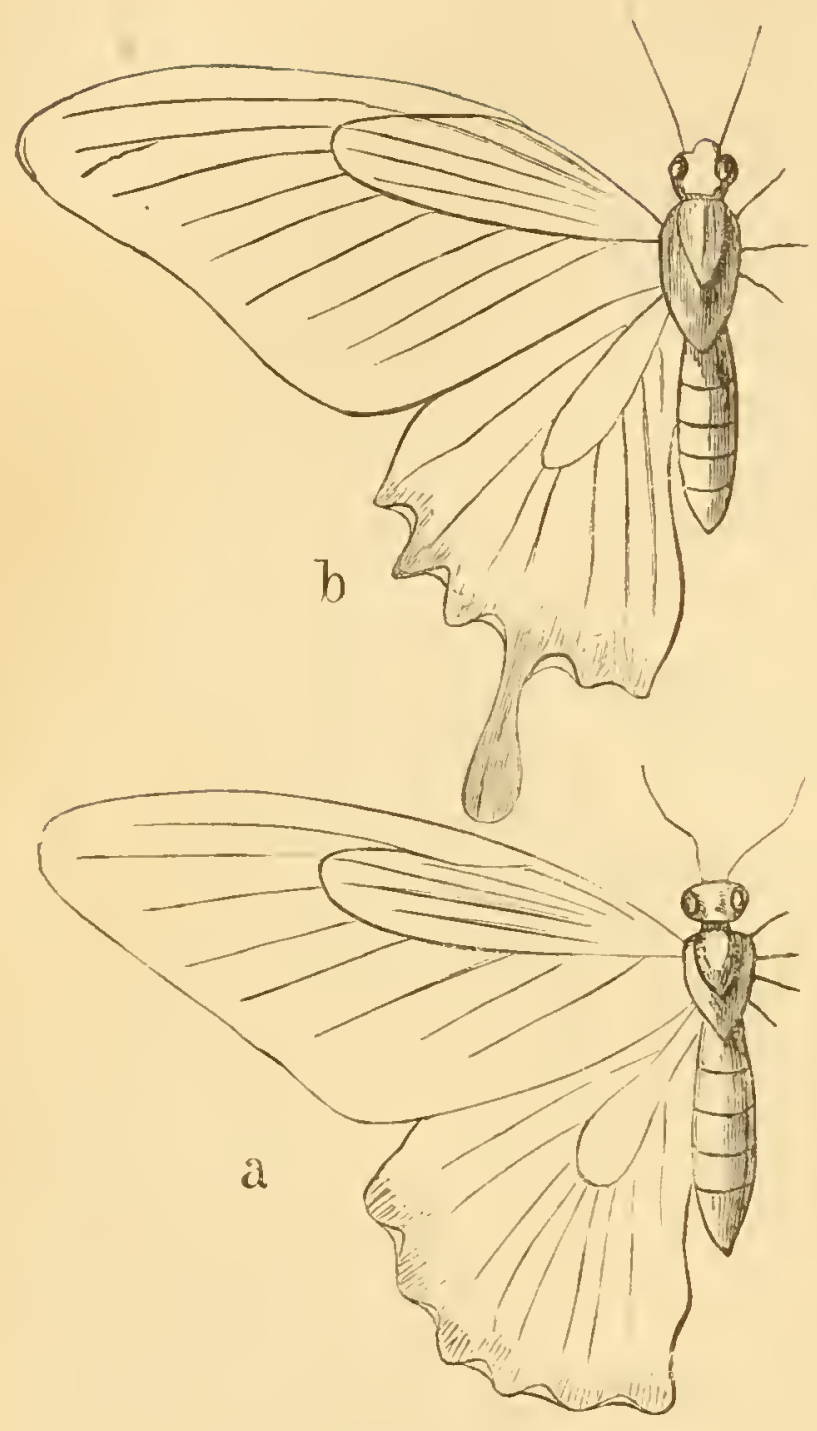

Fig. 4.

a. Papilio memnon. b. P. coön. tuti bex Dunfeln Fär: funty deg P. memnon finder bout ber ge= jehwänzten $\mathfrak{A}$ at mo dex helfer Färbung des P. coön herborturädyten? Sffentar witrde cr Die Inrridgtigfeit diejes Snbees für lyutläıtglidu crivicjen anfelyen. Hut biejer bon vormeberem getwin vout Sientand ex= wartete Fall trifft wirt: = (ide) zul, obex ridytiger gejagt, bie gefdywäntze Falterform b ift gar fein P. coön, fontiderit un eine abondortidac Sacifanat Deg P. memnon, bie aber bent $P$. coön jo jelyr gleicht, ba die Getreffende Figntx fïr beiderlei Formen antereint.

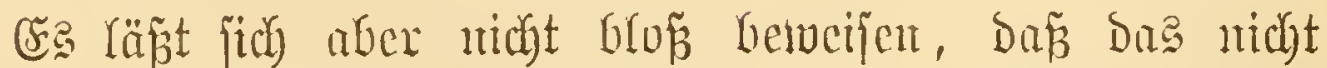

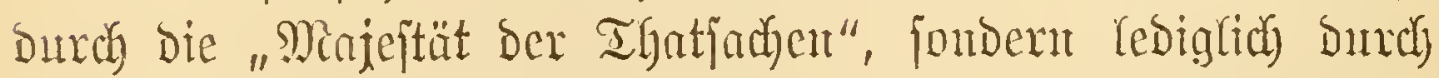
bie "Sognnogentic ber Scebräer" beglanbigte Dognta Der

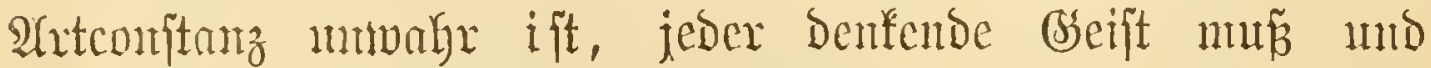

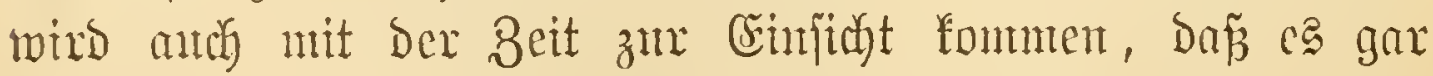

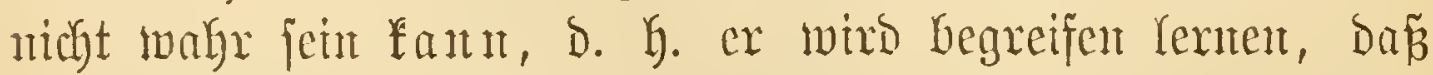
jeber Yehendige Sörper, ber ja nichts âtoeres are "eit com= prexes Büntol von elementaren Sräften" baxftellt, gegcnüber bon medyfelnden än 


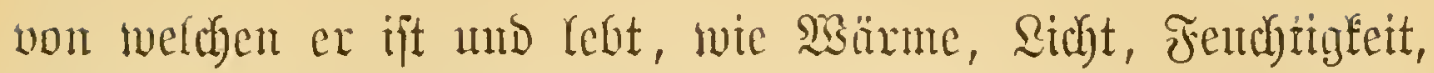

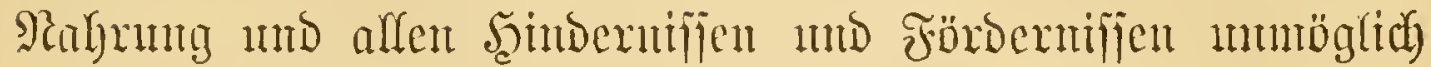

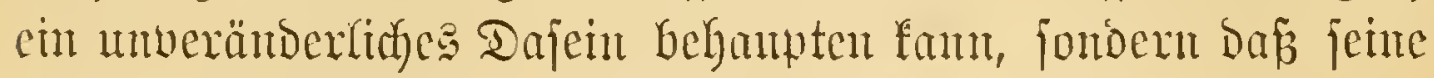

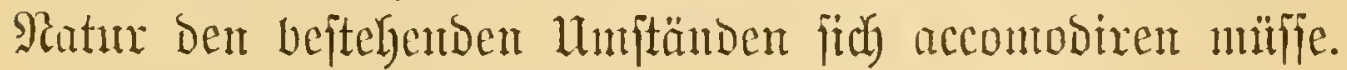

Şat ntan aber erafte Belege Dafürx, Dañ "bie Mreife zu

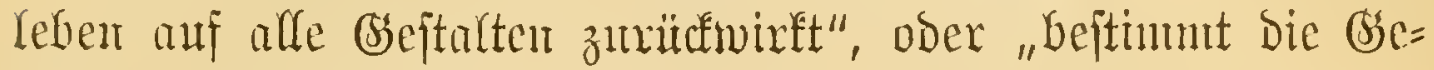

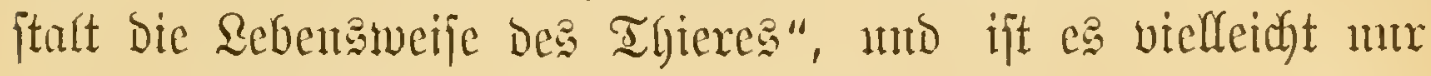
eme Den Drganisment infyärirende ßermantgfaltigung

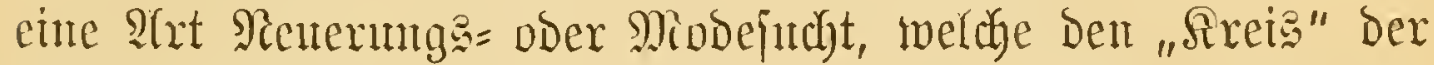

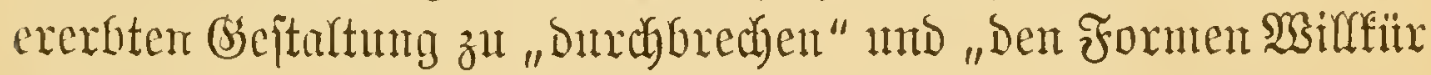

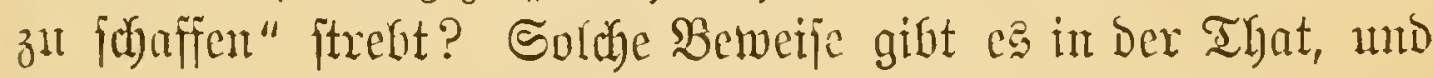
men aud, da man ihrer bei bex bisherigen uatoen

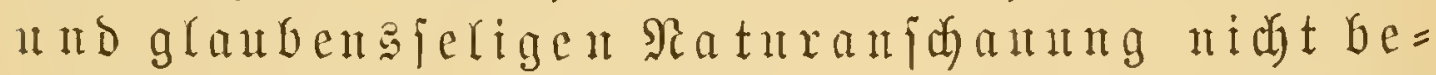
burfte, vor ber Scand unx mentige, fo funt jie soch aus=

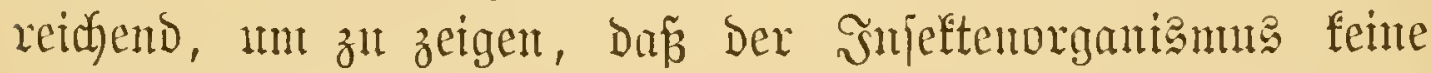

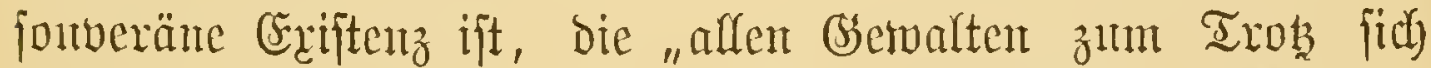
crhält", fonbers ein, freilich hödyjt verwidfeltes, Miolecular= aygregat, bas ben allgenteinten befebent fid) gleidjfalls fïgen

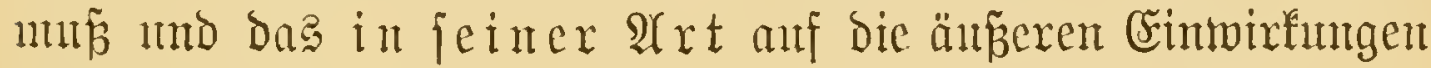
geradejo, wie etwa Daz Ifermometex auf bie sisärme und Das Lach́nแ anf Die Säuren reagirt.

Wix fagen, in jeiner $\mathfrak{A}$ rt; wohl zu bebenfen fint aber

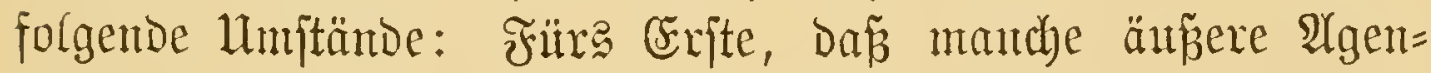
tien, die un gehr wirffam exjdyeinen und bou benen wir uns cine beoentende Finmirfing anf Den Rerforganizmus verfprechen, Denfelben, feiner Natux halber, mentg berülyren; fïrs 3weite, In jelbft Dex Sndividuen einer Species, ja cines und Des= jerben $\mathfrak{s}$ dividum

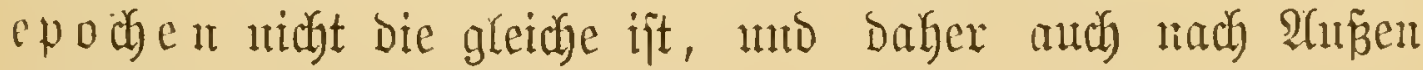

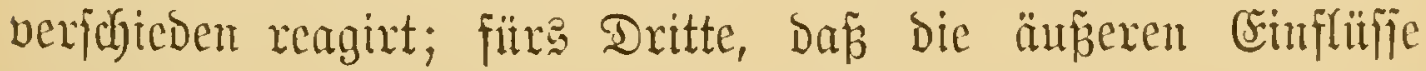

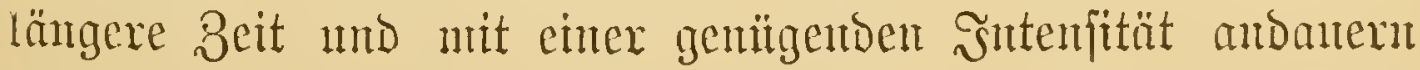

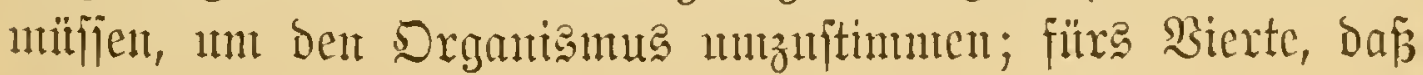


Die bemeften Seräntormtgen, theils, weil jie zut geringfügig,

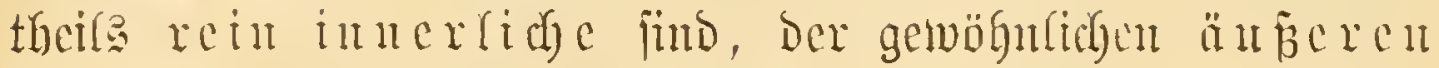

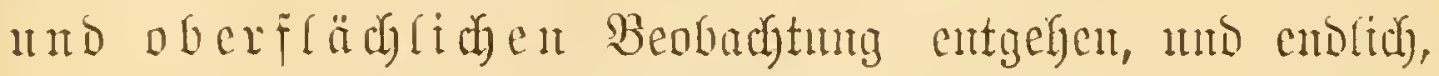

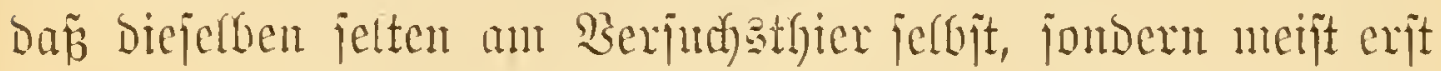

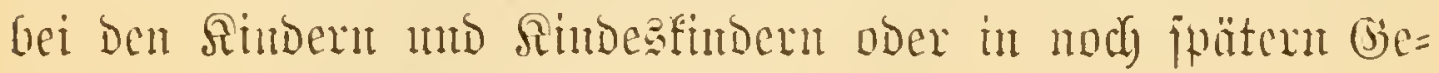

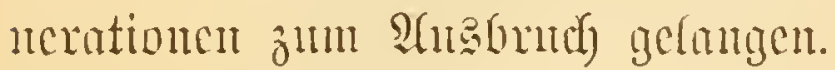

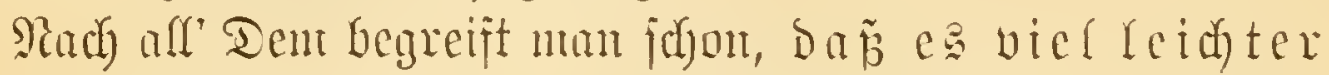

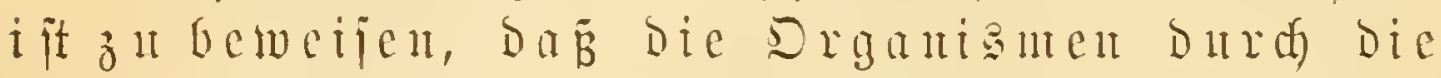

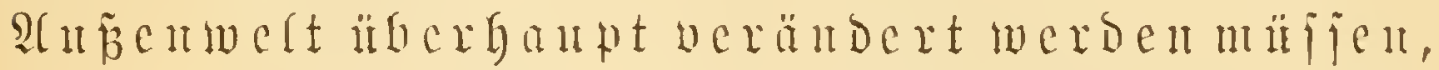

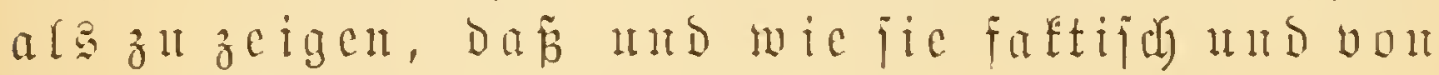
Fall zu Fall berändert werden.

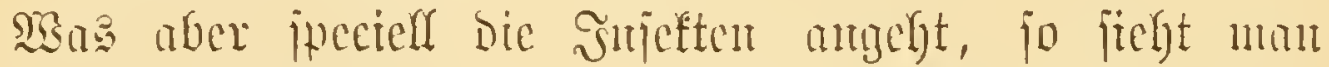

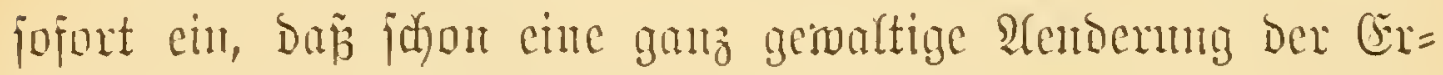

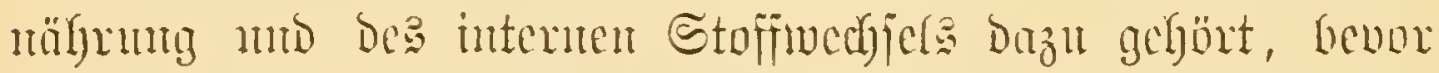

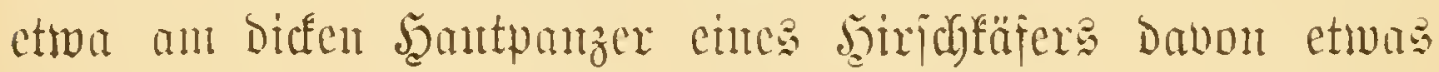
veripünt wird, und man bur aljo, went bei ingent eincr

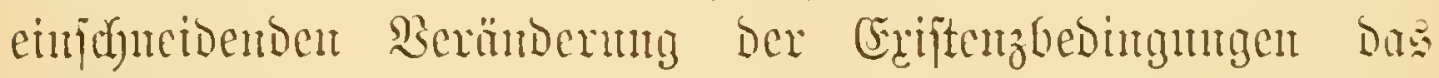

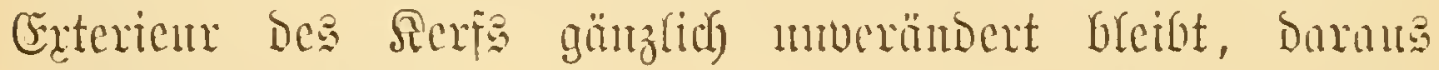

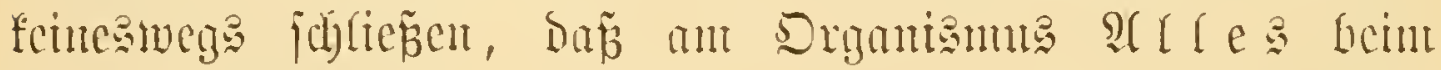
Saten geblieben jei, urd don nidut bei Den fonmenden

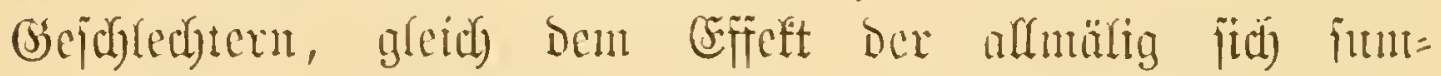

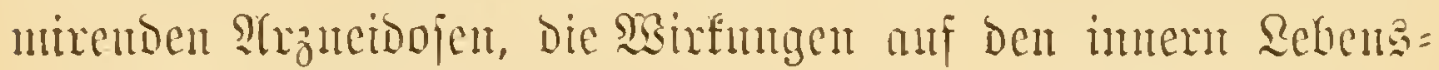

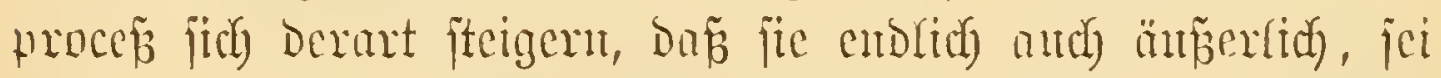
es in was inmer fïr cinter seftalt und alt was inmer fïr cinem Theile, jun Durifgrnd gefangen. - Şält mun

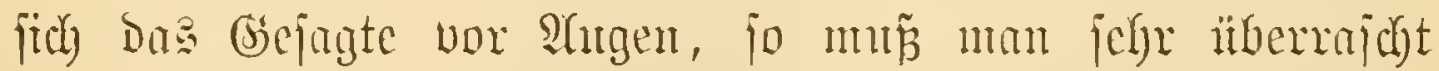
jein zu jehen, wie gewijie Agentien, bie ntan arj bie \&arben

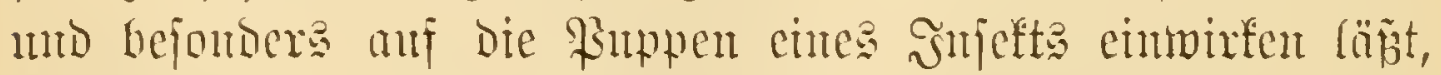

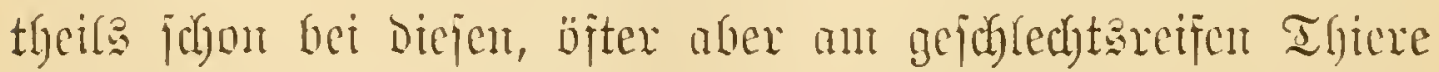

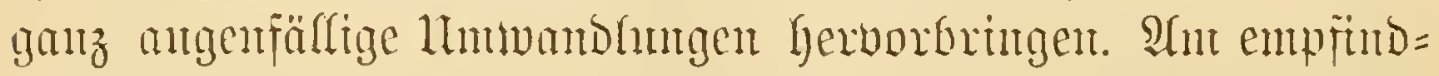
lichjeten erweijen fid aber bie grop̈en Ingidnetterlinge, beren Flügel vou $\mathfrak{B}$ ates als Tajefn bezeidjuet wurden, anf weldjen

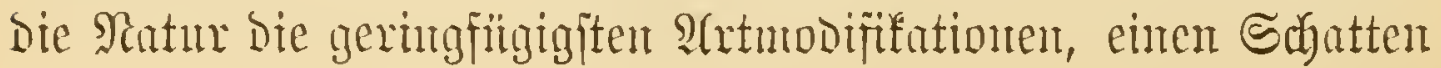


wou Farbe, cinen Etrich oder Fleaf n. Dgl. getvijemthaft cin= injeibt und regiftrixt.

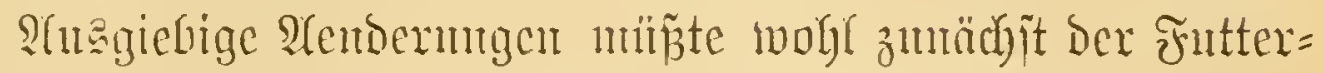

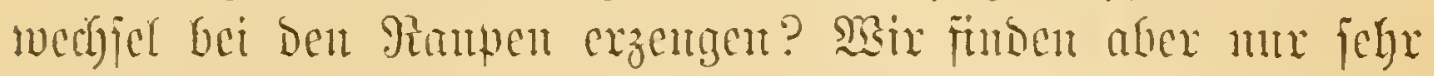

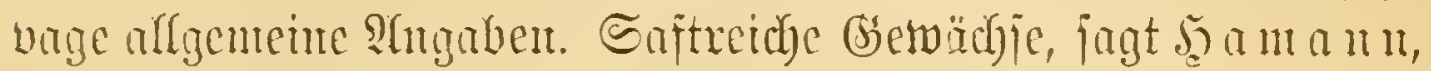
fige incu bic Farbe zu crbögen, und e lajjen fich leidft ans

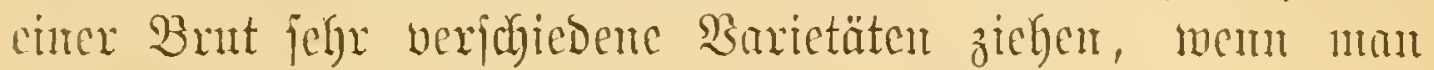
"weit anseinander ftehende" Riflanzen füttert; Der Bären= jpinter peciell wäse cit jebr empfindidyes sojeft. Die Raupen vou Elloparia fasciaria jeieut ferter anf Fidjten grüu,

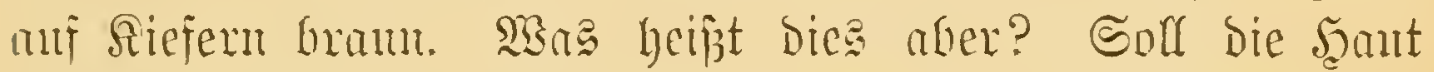

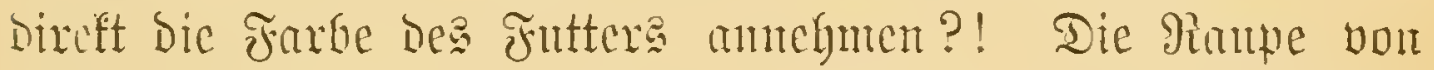
Xylomiges conspicillaris wedjjele bie Farbe gleid)falla mit jener

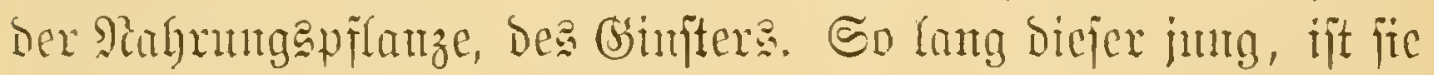
grïn; went bie gelben Blïten foumen, crjochent je ant in

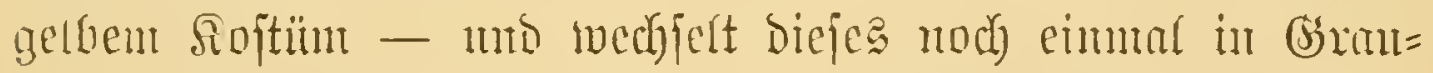

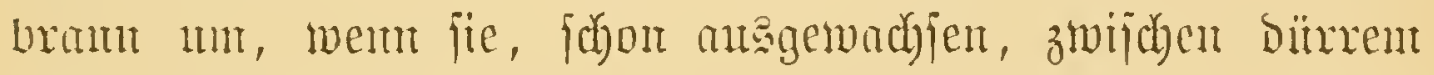
Sante fich berwegt. Alum Das ift ja zum Breifen, aber midjt,

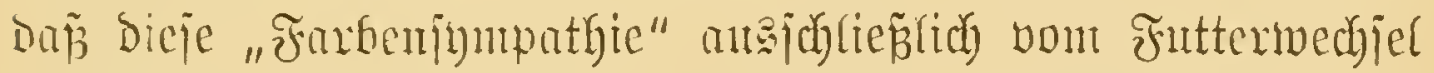

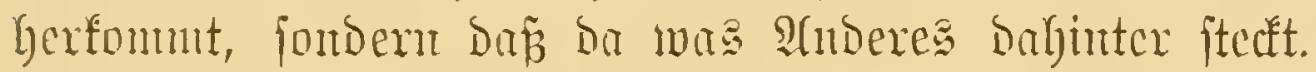

SDer follte es body wahr jein, was jüngit 2 egdig be=

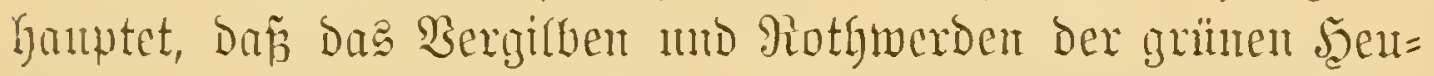

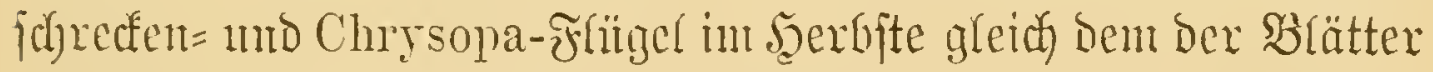

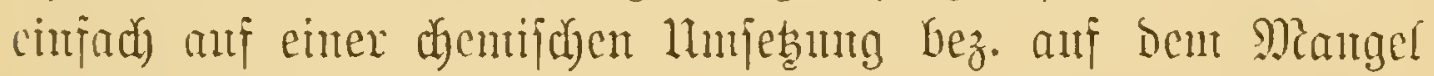

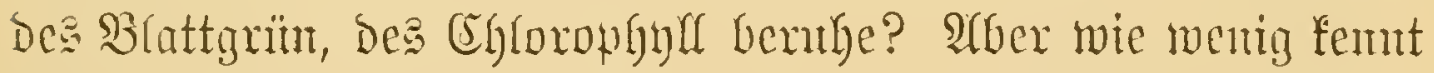

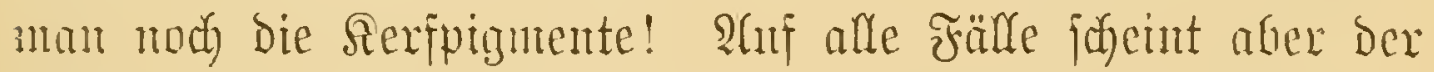

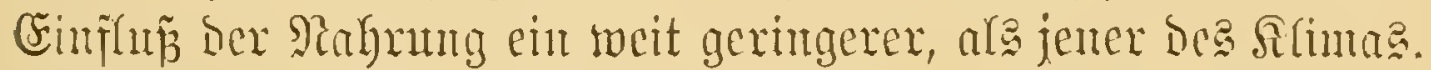

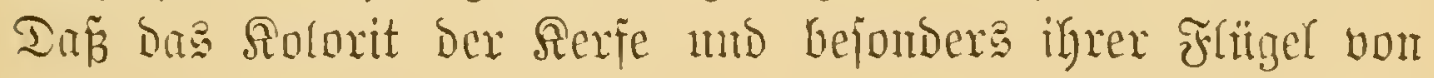
Den Rolen gegent die Iropen zu inmer heller, lebhafter un glïhender werde, ijt cure befaunte Thatjadye, unto bie roth= Gemalten Fittiche manther ïber viele Breitengrabe vortommender Ŝrjeftenartent fpiegeln bic jich iteigembe Temperatux in

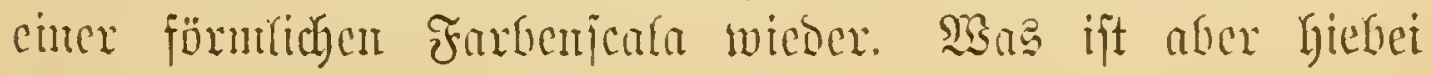




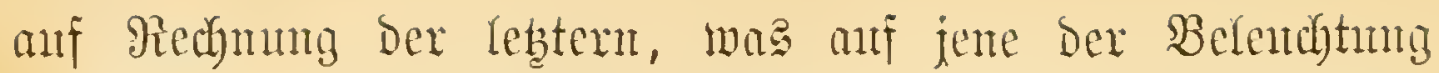

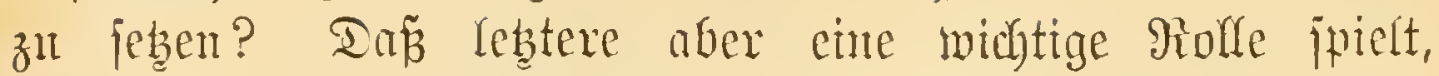
betweifen folgembe zwei ßerjuthe. Biegt man bie Rampen Des Siffilferfalters in zeritrenten Richt, fo werben bic frifgel bes Schmetterlings fajt ganz fohinmerlos. Sene bes gropent Futhjes

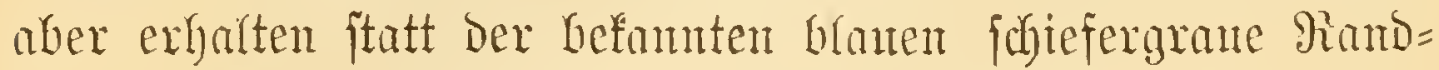
flecten, wenn die Ranpen unter gelGent Btaje herambachjen.

Die erjten ftrengeren Berjuche ïher die Temperatm: eintwirfung anf Sedmetterfinge jheinen vou mijeren Brazer

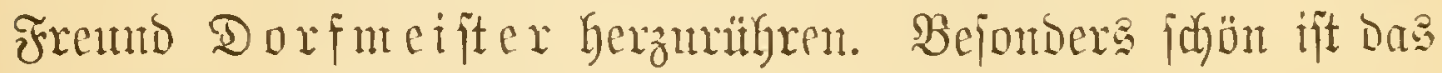
Experiment mit Euprepia caja gefuntgen, wo er ganz beliebig

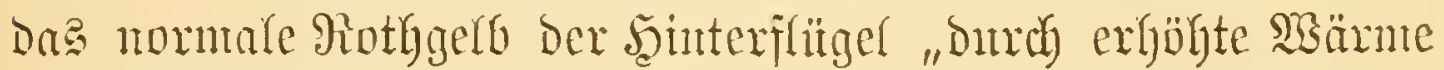
in Mennigroth", "Durdh exniedrigte in Dfergelb" verwandeln fomte.

Das ift einfach; cin eigente Berwanotnie hat es aber mit Dem jog.

$$
\text { Saifon=Dimoxplismu, }
$$

D. h. Der nach Den Jahreeszeiten wedffelnden Fürbung Des Reţfalters (Vanessa levana L.) und einer Geife anberer Tag=

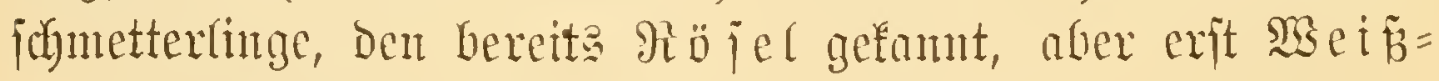

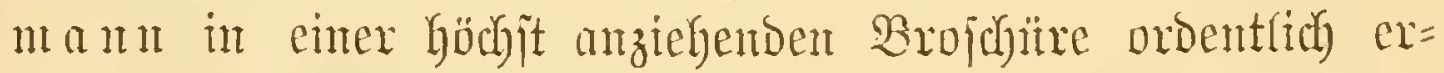
f(ärt und Daburch zugleich) cine Majie Ridyt anf Dent untür=

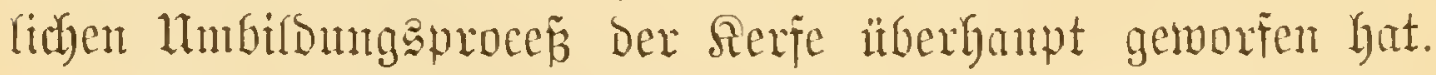

Inten rwerden wir hören, Dañ

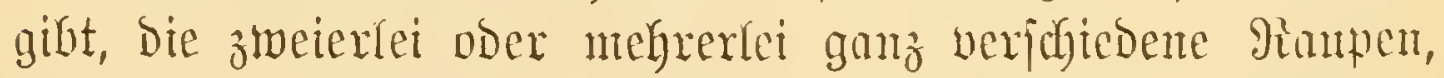
Sinpen mo toas das allerinterefijantefte, bismcilen aud -

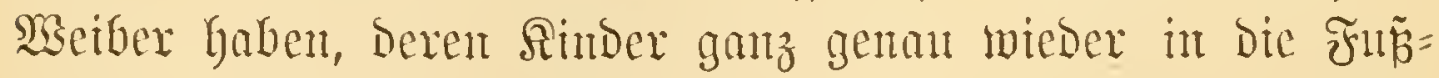
itapfen Der Mutter treten. Dies ijt ber gemöhnliche Di= rejp. Rolymorngismuts.

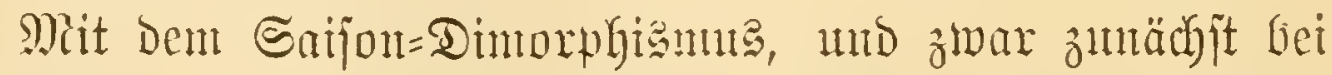
V. levana, ftegt $\mathfrak{c}_{\mathrm{s}}$ aber jo. Dicjer Falter, aus Dent bohl=

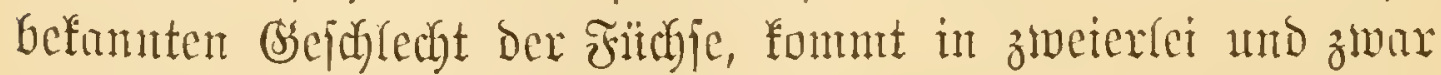
in einander fo fadroff gegentitberjtelyendon Forment vor, Daj 
man fie lange füx veridjiedente $\mathfrak{A}$ reten bielt, bis es gelantg, beidertei Typen anß derịelben But anfarzichen.

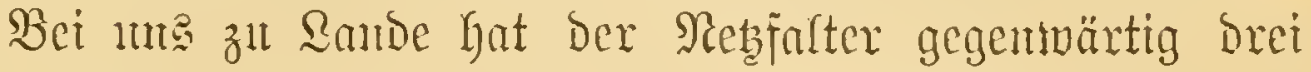
Generationen, er ijt polygonenont, ober, wie wir es freilid) auf ichlectst Denttidy heipen mollen, dreibrïtig. Die erite (Se= reration, von ithertwinternden Brtppen herrïfrento, fliegt in

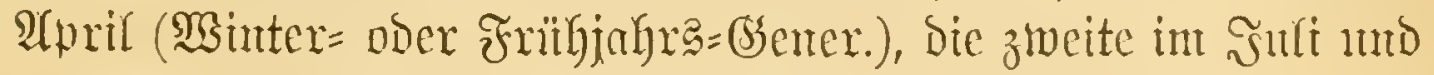

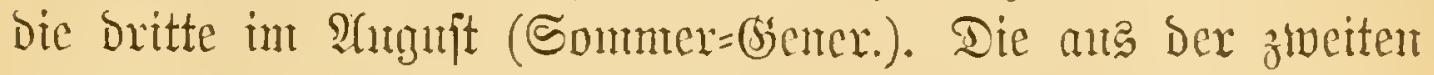

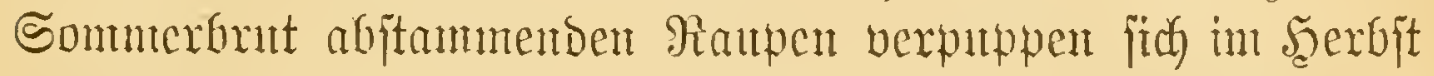

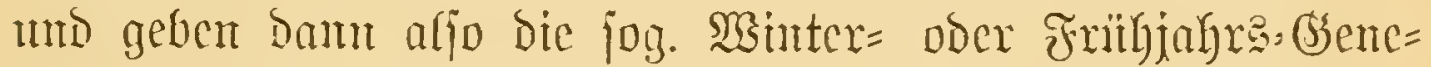

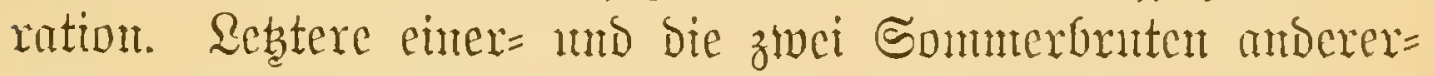

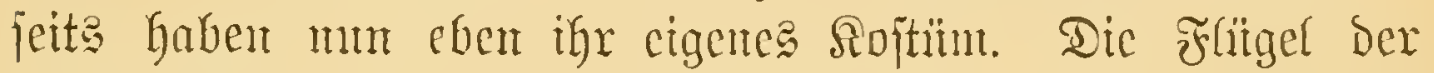

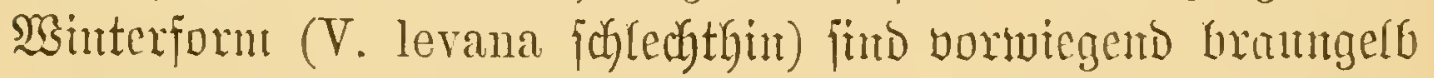
mit finwarzen und weinen Flecfen, jente Der sommerform (V.

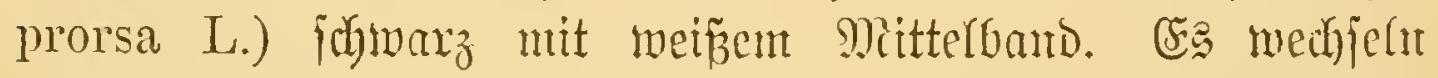

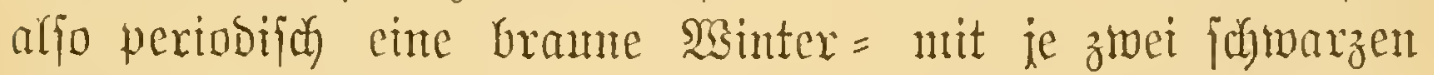
Sommergenerationen ab. Die Art bat jich in zwei $\mathfrak{A}$ (ima Barietäten gcipalten obex ipectalifint.

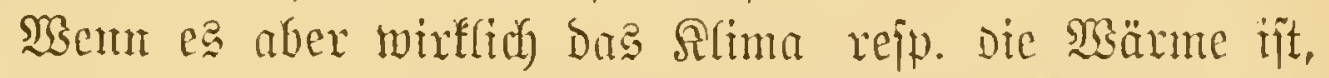

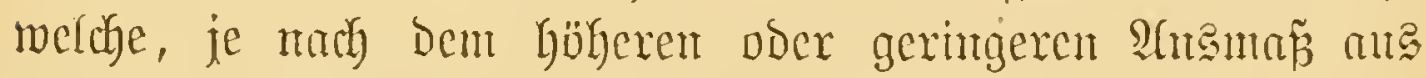
Raupen bezm. Sitppen Derjelben Befdaffentheit, Das cintutal

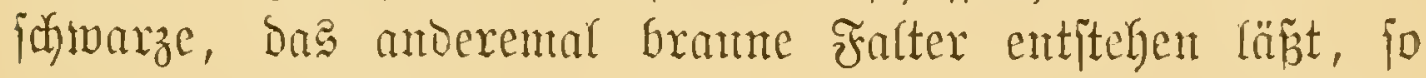

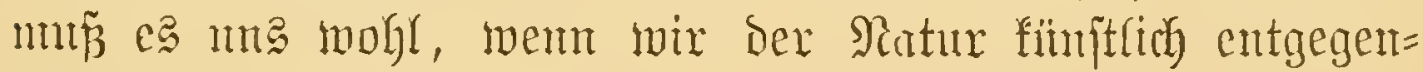
urbeiten, b. h. aljo, wenn wir diesinterformen warm und bie Sommerformen falt befandelu, gelingen, fie in eintuber zu verwandeln? Saeifinann fing mit Dent

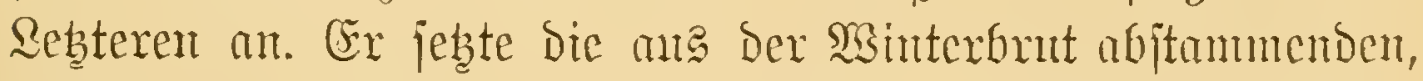

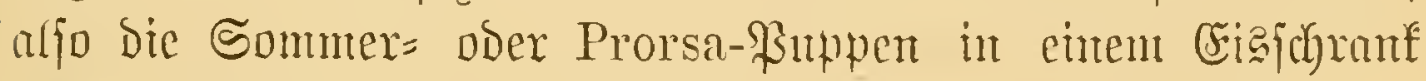
Durchi) 4 Sagden eitrer Temperatur von $0-1^{0} \mathrm{R}$. aut?.

Das Rejultat war bei 20 Berjud stgteren: 5 Prorsa und 15 Levana. Die grope Majorität latte aljo dent crumar= turgen entiprochen, fie soax auf Den fitujtlidyen 柋inter cin= gegangen; cintige aber bieben bei ber siaturregel - jie er= 


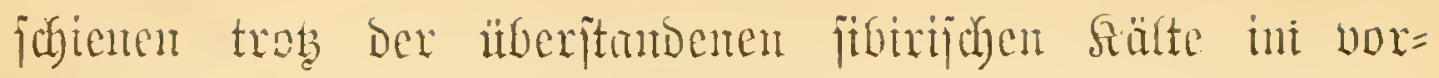
gejefrebenen Eommerfleide. So wax as and anderemale.

Bei Antmendung geringerer Sälte wax and bie Babl

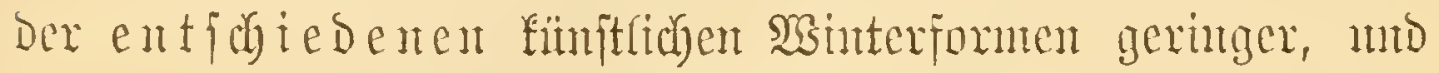
fanten eine Reife vou 3wijhenformen (var. porima) zum

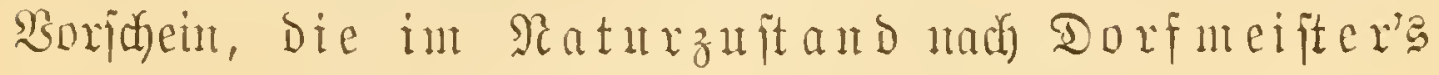

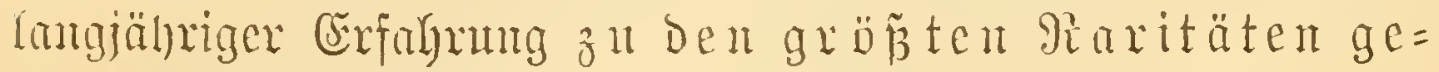
$\mathfrak{h} \ddot{B} \mathfrak{x} \mathfrak{e n}$.

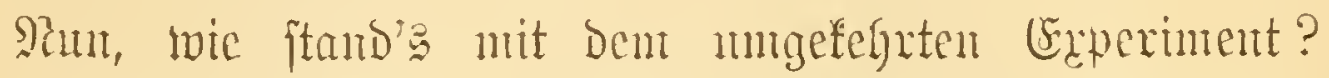

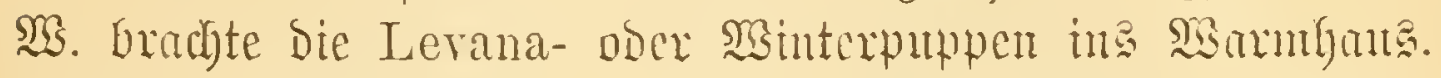

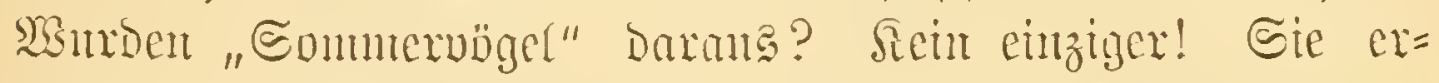
fchienten in Dex Sistutertradyt. Die Levana bleibt Levana. S⿱:

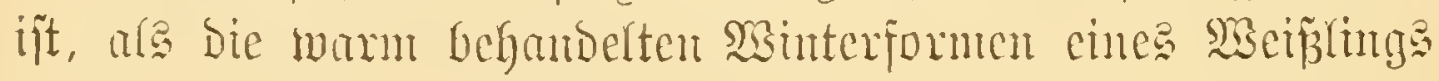

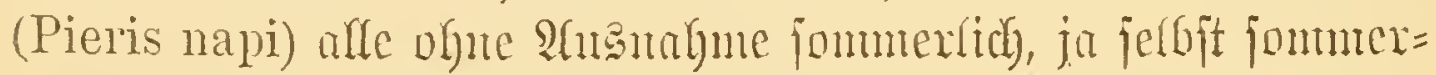

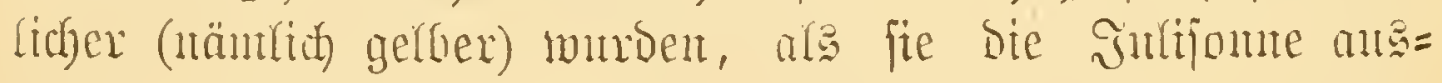

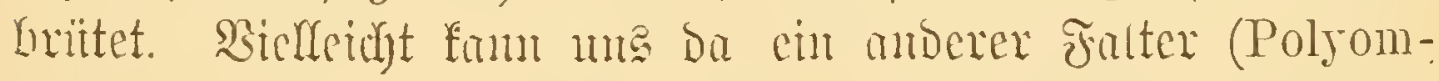
matus Phlaeas) cimen sisulf geben. (Ex geht vou Sapplanto Gis Eicilien. Dort ijt cr bei bcr Sïnze bes Sonmtrs "ein=

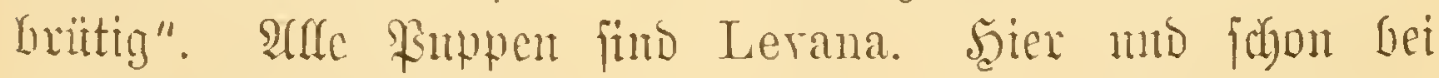
Ints in Dentichland fonmet es aber zu ztwet Generationen:

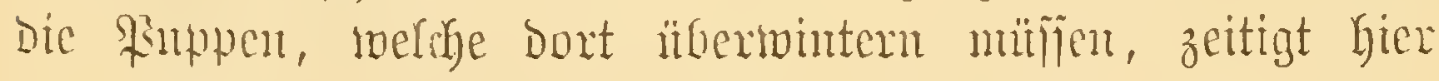

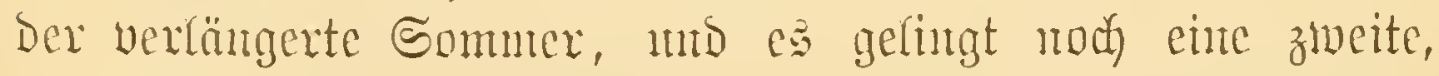

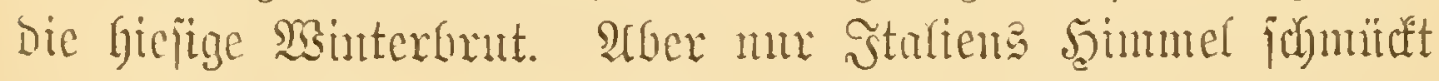
Die Sonturerform mit mberen Tinten; rjer zu Sande ijt

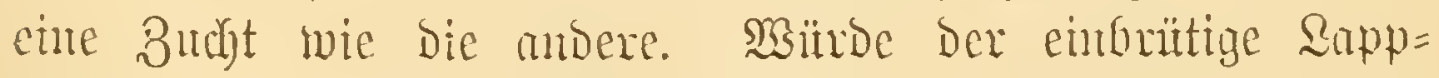

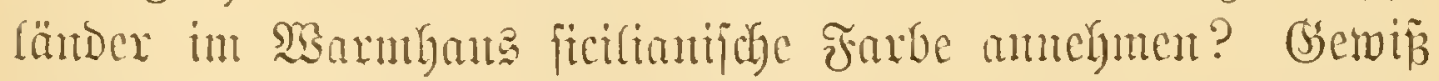
ebenjomenty, wie dic einforittige Âpenvarietät (Bryoniae) Des

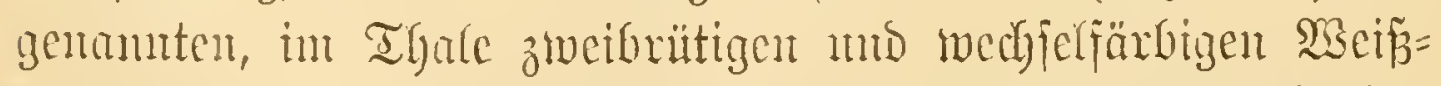

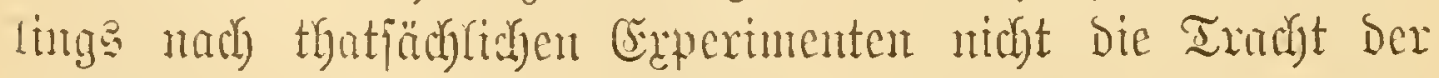

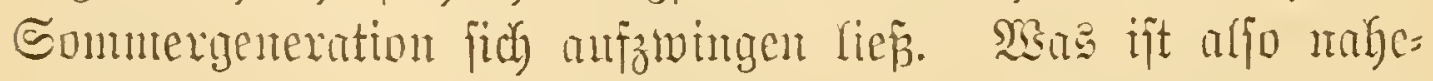
Liegender, twarmu bie dharafterfefte Levana bie Eommerntäe

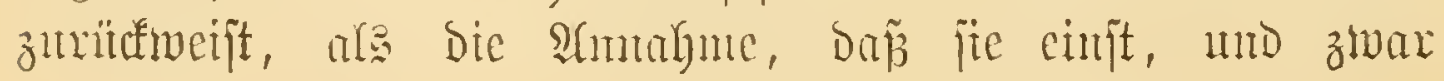




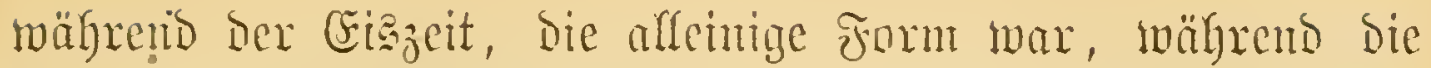
Prorsa, weldye ifren Crgarafter jo feidgt gegen jene vertanjabt,

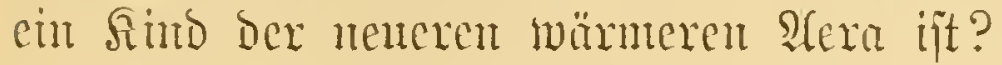

Diejer Fall madyt mus zngleid) mit zmei miahtigen

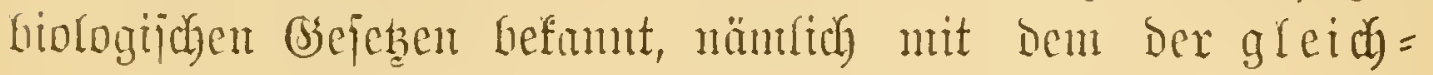
alterigen mb bem ber gleidzeitigen Bererburg. Der gleirhalterigen, injoferne bie an ber Sommergencration nach und

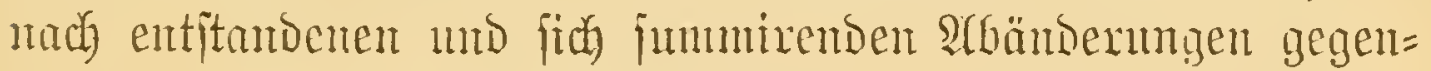
märtig mur Dent volffonmenen Falter, nidyt aber bie Ranpen mo Sisupen betreffen, aljo jtets mur bei jenem (Dem jog. cor=

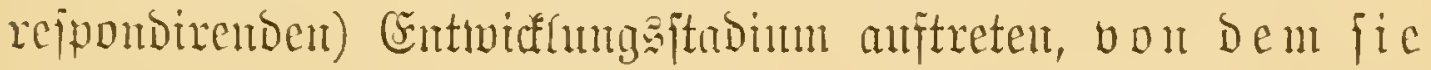

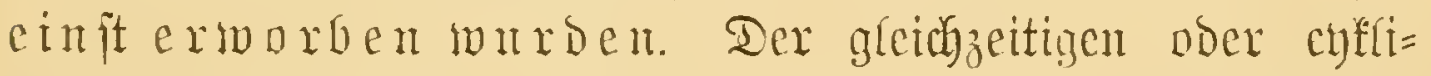

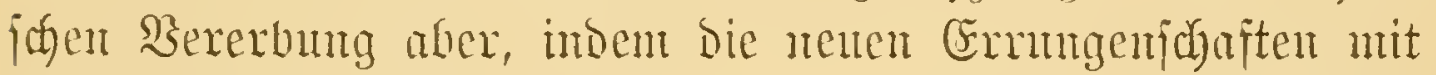
Heberfpringung Der Etamm= ober SBinterform, unt bei ber

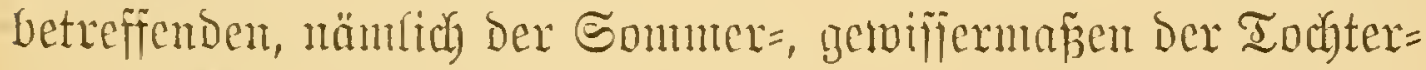
refp. Enfel=Gsentration fich eimitellen.

Da bie Entitehung einer cigenfärsigen Sonmergeneration

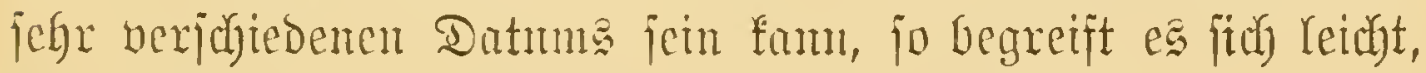

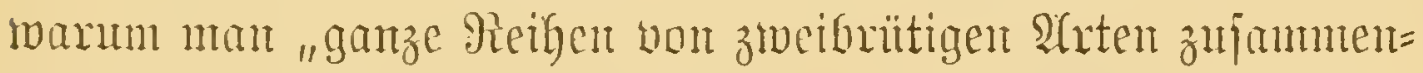
ftellen fant, weldye den Hebergang von völiger Heberein= ftimmung beider benerationen ourcl faum zu fonterfende Unterichtede lindurch (Polyommatus) bis zu Differenzen im

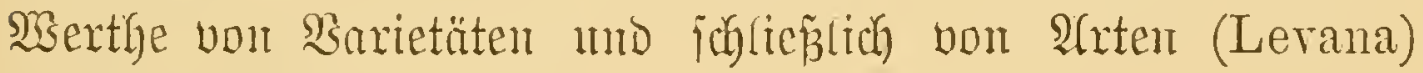
veramidantlidyen".

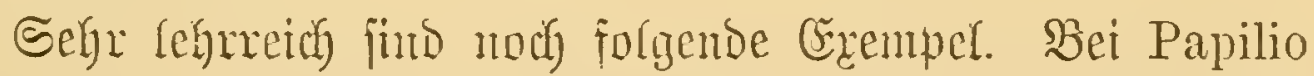
Ajax, einem jaifondintorphen $t=$ =riitigen Falter, fpaltet fich

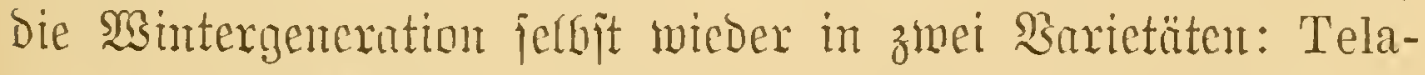
monides uto Walshii, wäfremb bie Snmmerform (Marcellus)

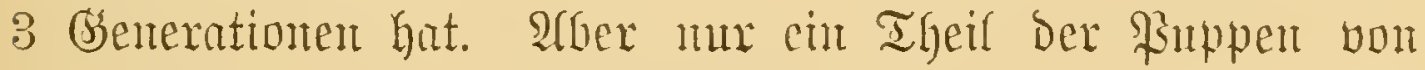
Der erjten mo zweiten Sommergeneration gibt bic britte; Der andere übermintert mit Der Brut Der letstgenament ober Scerbitfamilie, ein Foll, ber un ben vou Pleretes matronula 


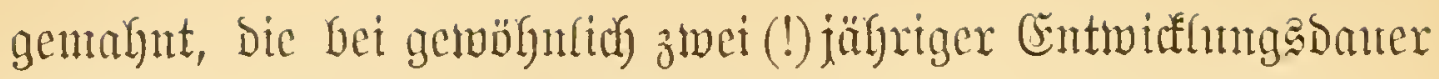

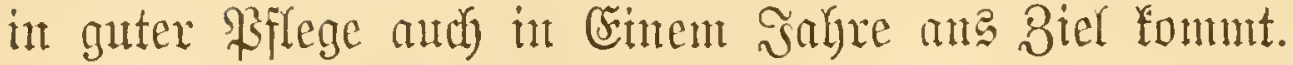

Befonder: interefiant ijt ber zmeifadje Saifon = Dimor=

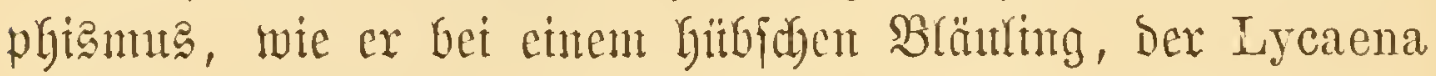
agestis, beobarbtet ijt. Seine breterlei Formen, A, B und C wollent wix fie nemen, vertfjeilen fid in Dentidyland und Stalien uach folgentom Saljema:

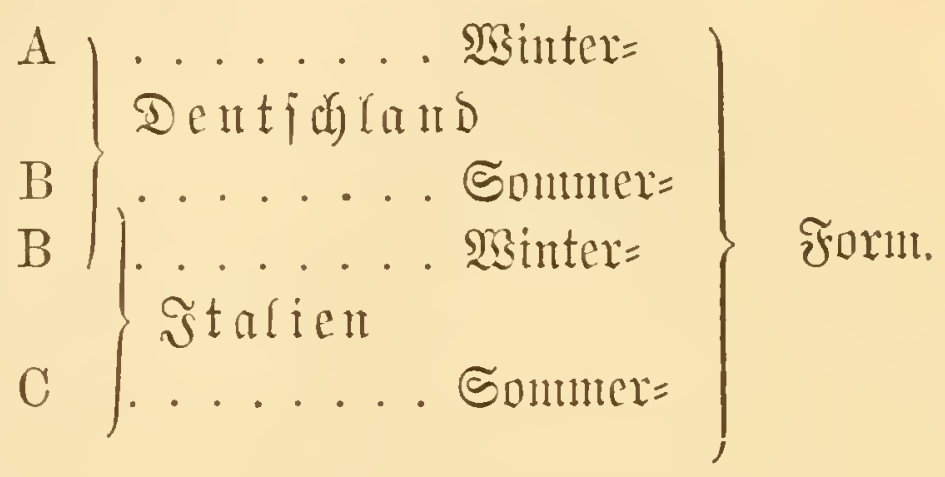

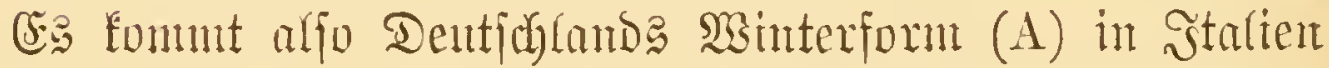
ïberlyant nidgt vor, wälyrend bie Sommerform von Dentich)= land (B) in Ştalien nicht bie Somnter=, fondern bie șinter=

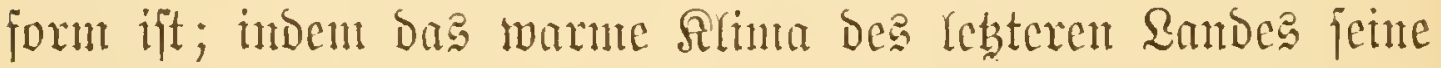
bejombere Sommerform hervorbrathte, ebenjogit, wie bas falte von Dentfidaland cine jeparate Sinterform ins Da= jein rief.

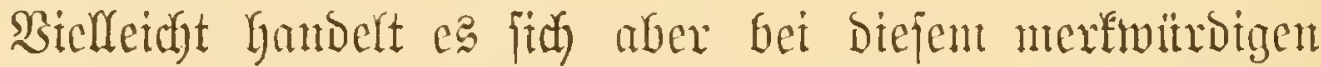

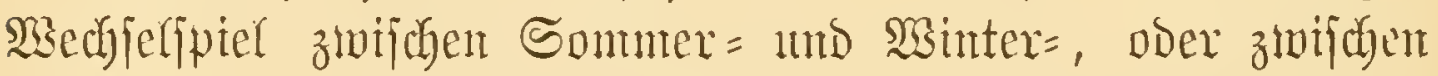

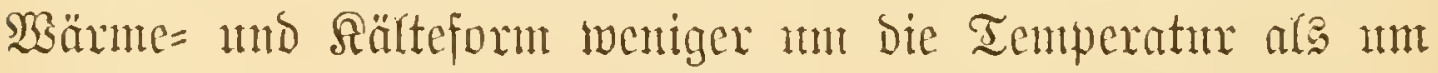

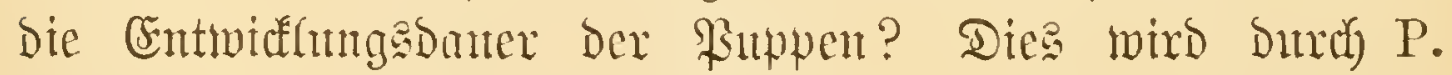
phlaeas verneint, Deren bei nut: tutb in Stafien abweichembe Sontmerformen betreffe der \$supwenzeit fid völlig gleidjptehen.

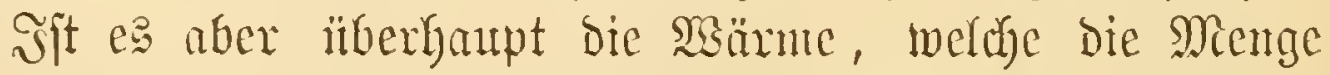

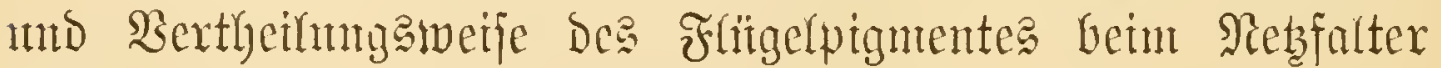
un mit terbar beptinmet mo beeinfluntst?

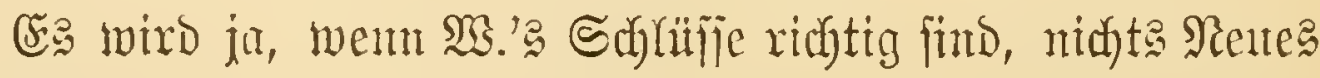
erzengt, jonbern un bas arte wicder ins Dajem gernfent. 


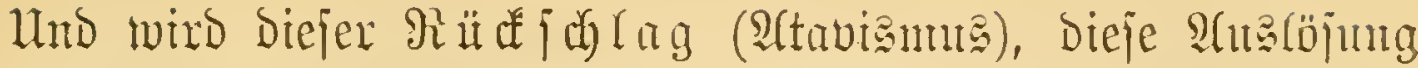
Des eimjtmalig moeränderten, jebt aber mu medx in ber

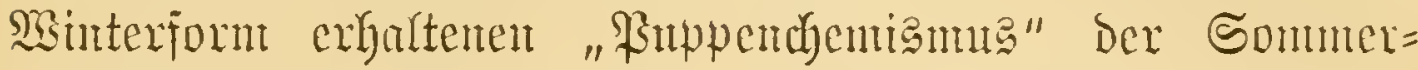

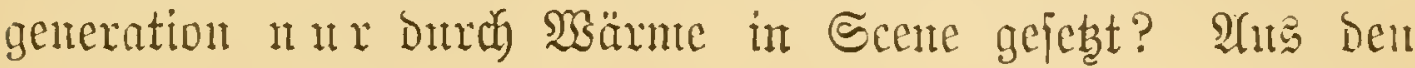

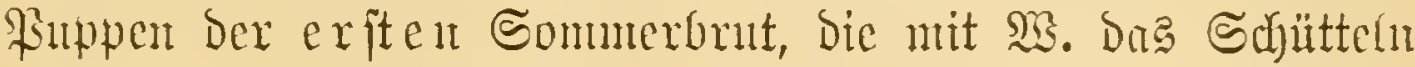
ciner langen Eifentbahnfabrt theilten, famen, uno ztwar anf ntebrere Mionate verzettelt, lanter Levana zunt Borjdyein.

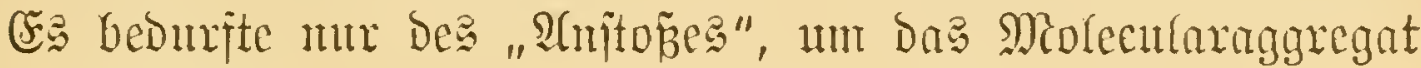

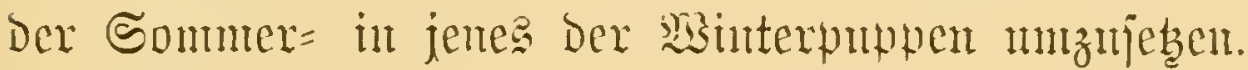

$\mathfrak{U}$ ber, werden bie Rejer einmenten, biagher war ja lebig=

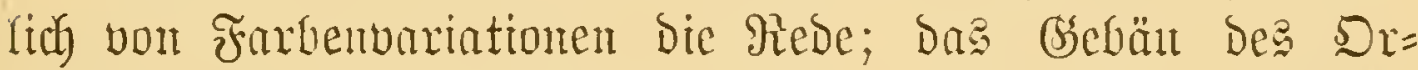

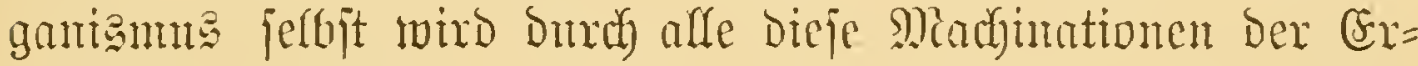

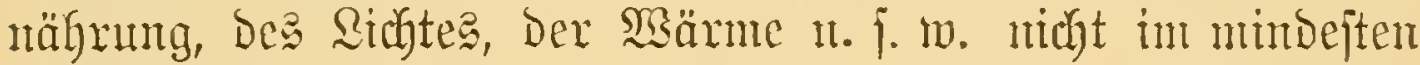

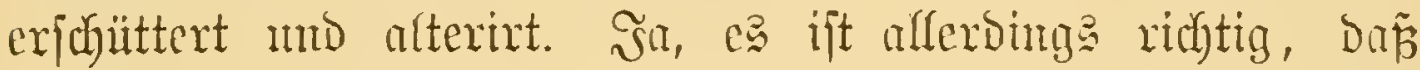
feinerlei anffallende Bsejtaltberämberungen bemerłt wurben, viel= leidyt $z$. Th. Deshalb nicht, weif man ifnen gar nicht gentaner

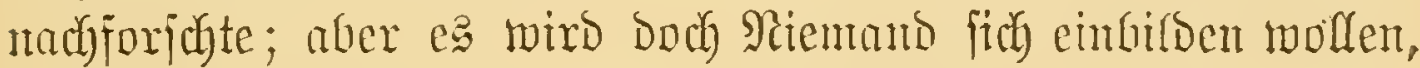

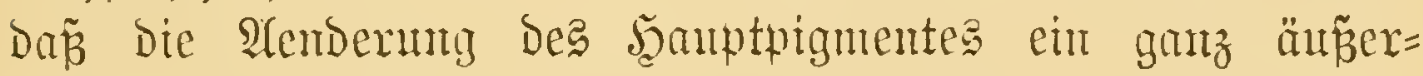

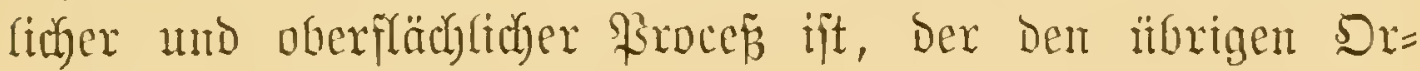

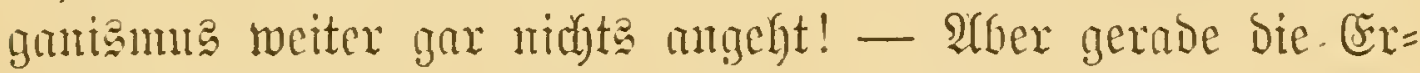

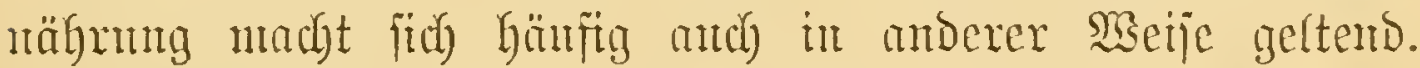

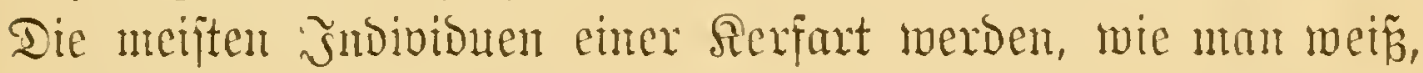

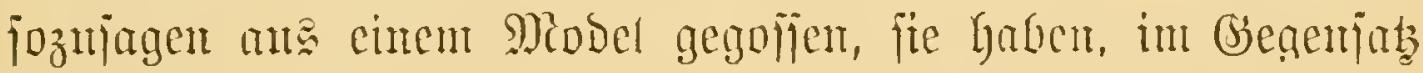

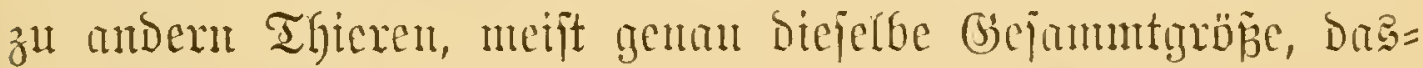

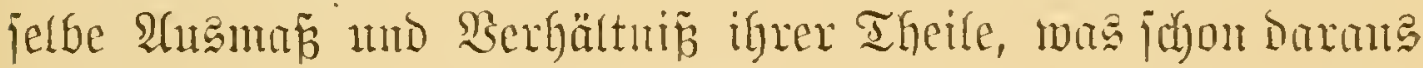

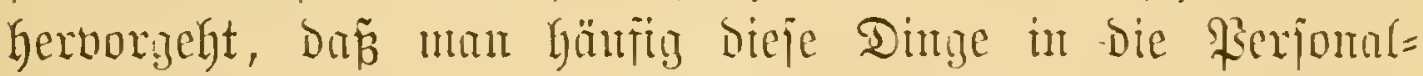

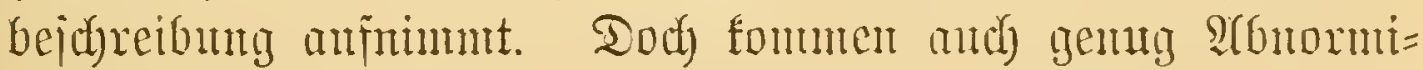

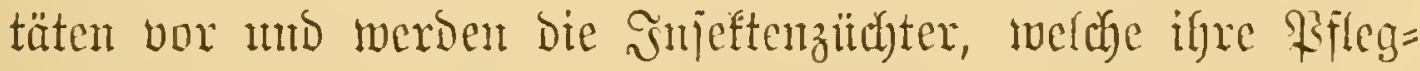
linge öffter fajten lajjen, gor midht jelten mit wahren 3 merg= geftalten itberrajobt, jo ba

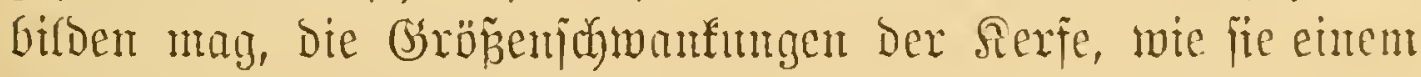
int Freien begeguten, wären reite Saturjpiele. Und wird

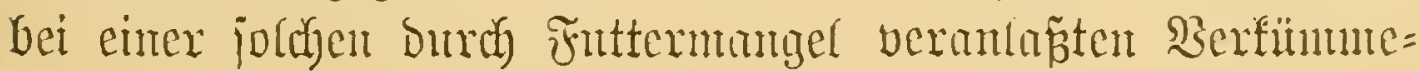


rung Des ganzen Sörpers nidht and Die Syarmonie Der Theile zu Echaben fommen, wird nidyt gelegentfich bie Şantocefe

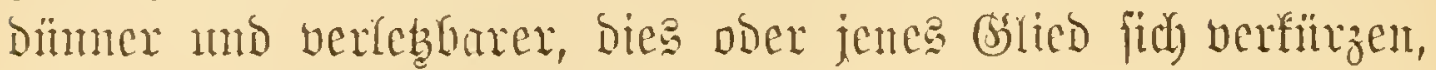

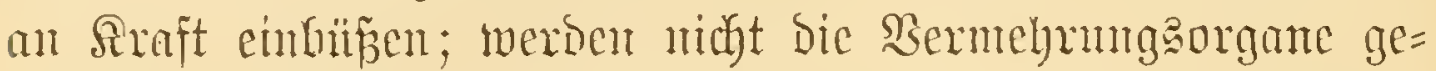

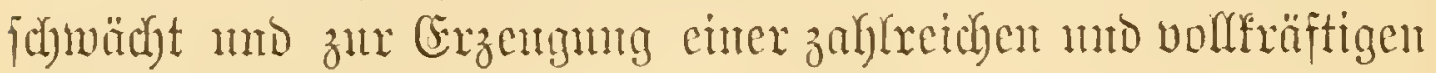
Pactifommeniflaft untanglict)?

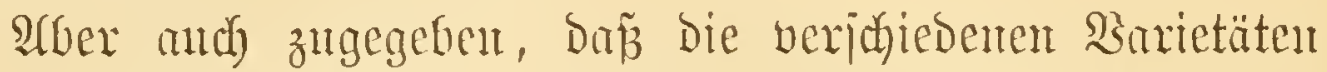

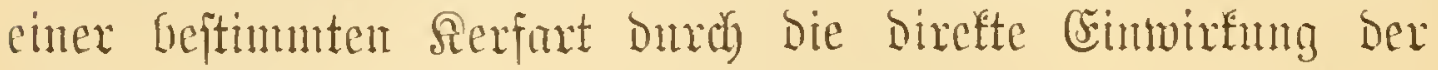

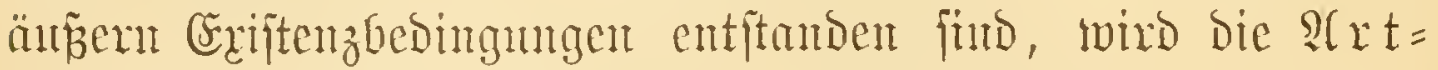

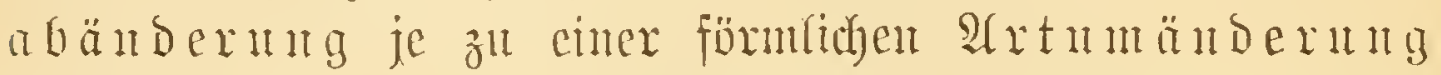
fid fteigern, D. h. wird je Sinsivisuen hervorbringen, bie mit

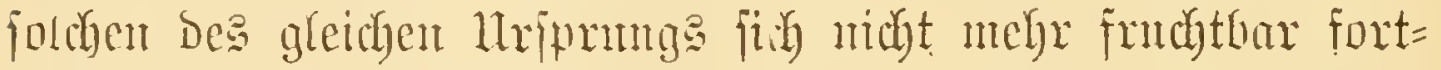
pflanzen, bie funz gejagt, inge anererbte Eigentart gegen ente frembe bertmichen?

Ein forker Fall ift bisher bei Snffeften allerbinge nod)

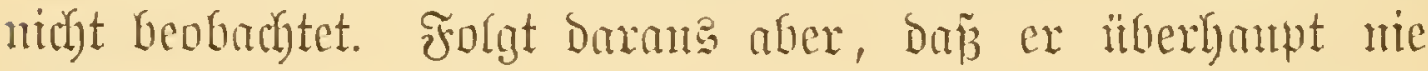

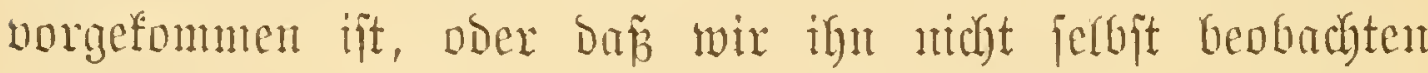
fömnten, wem wix in bie Sage gejełst wïroen, bie gejanmte

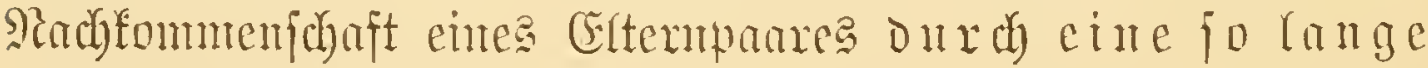

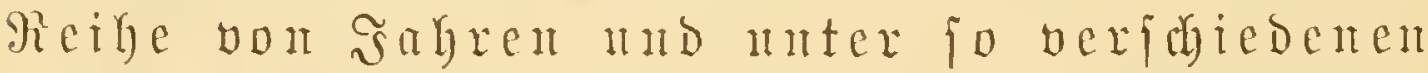

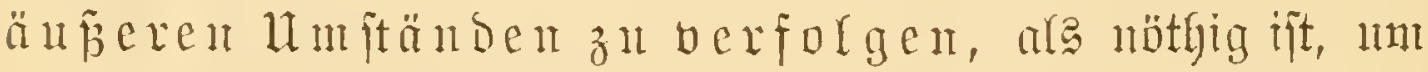
cine fo bebentento äbübung herworzubringen? Dies zu längnen wäre gerabe jo, ale ob ntan einent Mathenatifer midgt glantben wollte, wem er bie Summe einter mentidfen Pieige

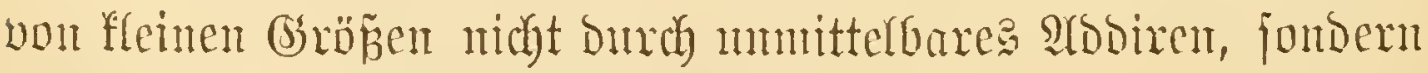
mitterît eines abgefiuzzten Sarfïl

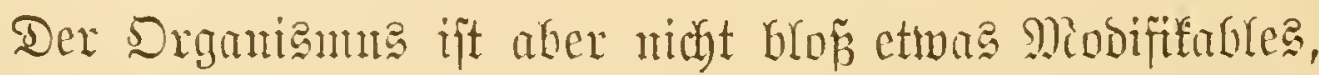

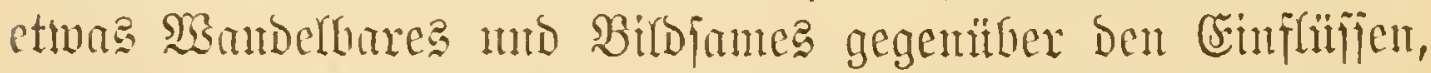

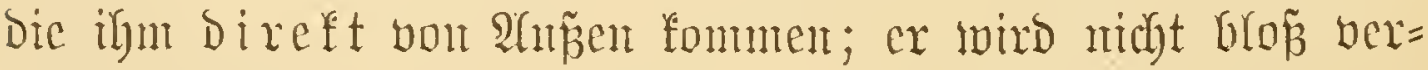
ändert, geitaltet und umtgejtaltet, ex vexümbert jid jecrojt, ja

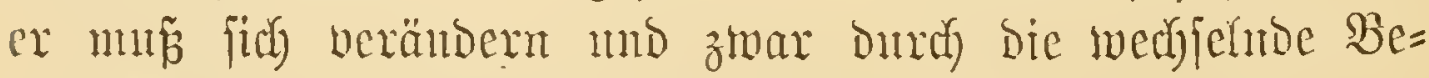
thätignng feinex verjodedenen 


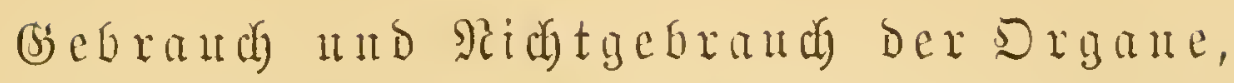

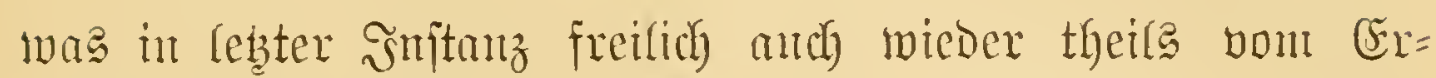

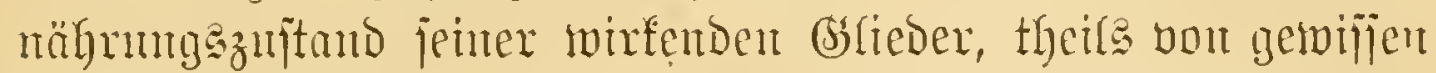
änperen Hnjtänden abhängt, bie bald bieje, bald jene Seite Der origaijchen Thätigfeit in simpund nehmen, eimen Theil

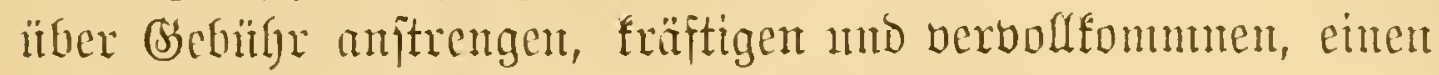
andern wieber rajten mo baburch allntälig verfitmutern, ja veridgintoen lafjen.

Man verändere, fagt $\Omega$ amarł, bie Thätigfeit eince Thieres, mo man toiro jeine Struttur verändern; man ver= änbert aber feine Thätigfeit, memi man die 14 iftände ver= ändort, Die e马 zur Thätigfeit arfporten.

Bon weldhen Thieren nibdyten jidh aber mefre und trif= tigere Betweije für Die Ridhtigf́cit biejer Behantung beibringen

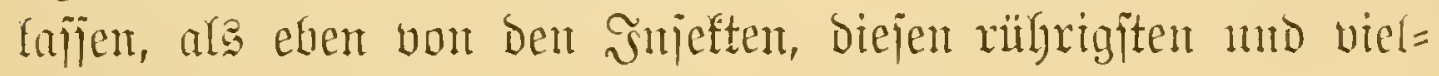
jeitigiten allex animalijofen Majchinen?

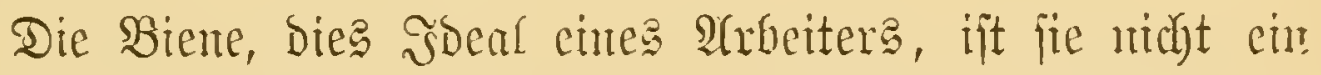

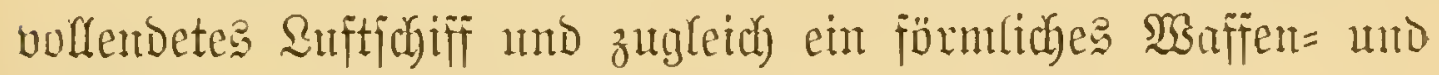

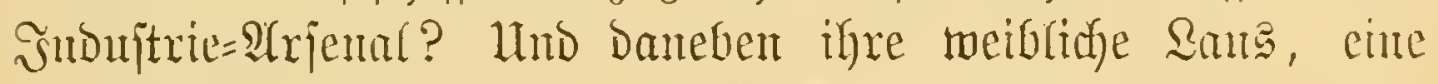

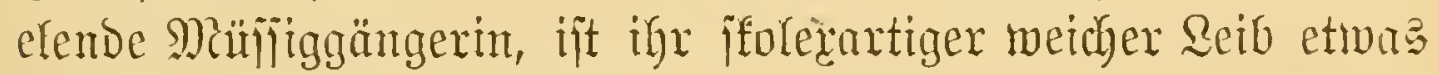
Anderes als eine Cierbitdje, mo fömte aljo ber Gebranch

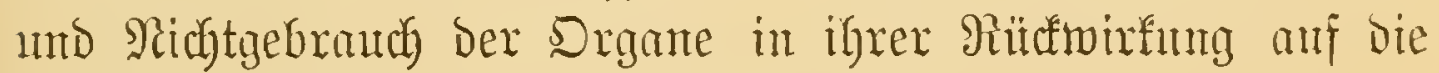
ganze Reiblicheit bejier illujtrint weroen?

Sa, füto denn aber Biente mo Bienentang beshalb jo

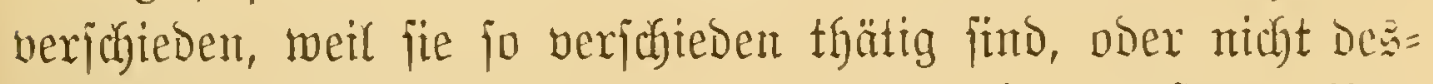
halb, weil fie jobon von alfent Âfang, ben äıñeren llm=

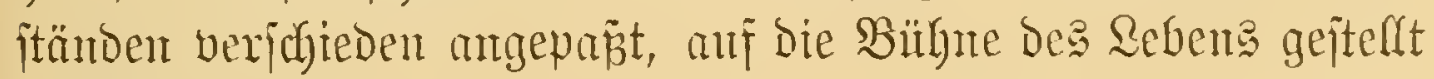
murben?

Die gefanmte Rerinnorphologie ijt ein eingehentor mb Detaillirter Semeis gezen eine joldhe präbeftintute ober vorus = 


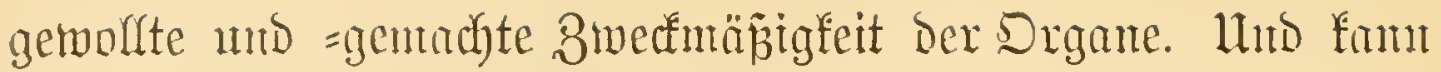
bics überlyant andors fein?

fonnte die Biente eme Biente fent, bebor e马 Santig zu

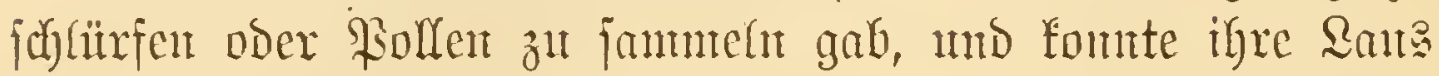
cine Raus fein, bevor fie ferbit war? Docr glankt vielfeidyt

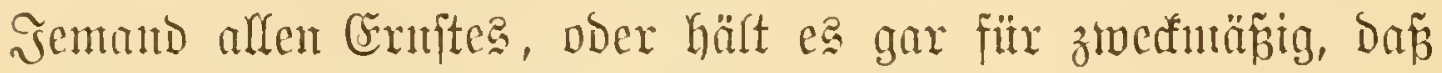

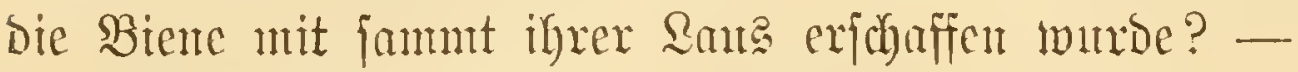

Suber neburen wix cutuen andern Fall. Die Mäund ben Der

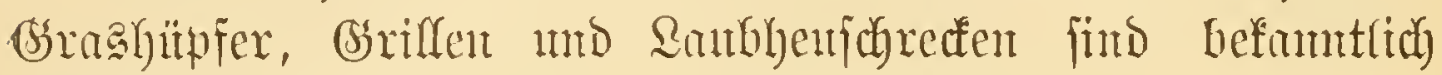
Minfifer, und fie fiedeln jo regelutäpig, jo lant und gevandst,

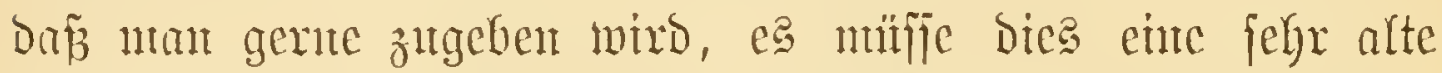

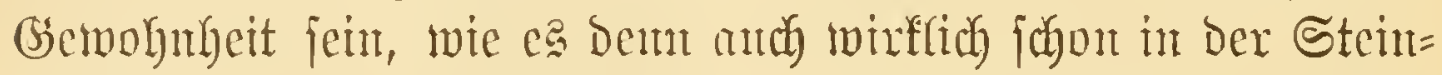
fohlenzeit berlet Bioliniften gab. Into mas ift's benu mit

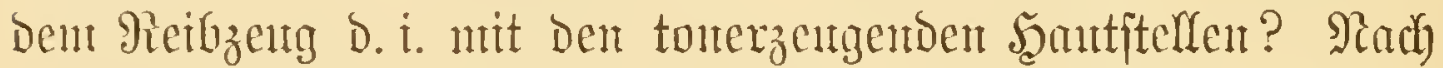
Randois' Darftellung wären dies ganz exquifite Drgane,

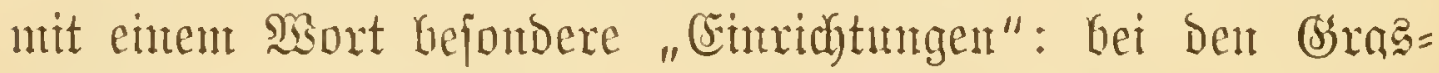

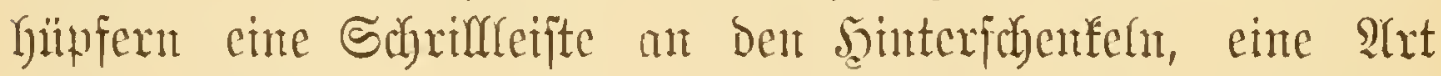
Feile, beftehend ats einer "gernblintigen" Reibe febernder

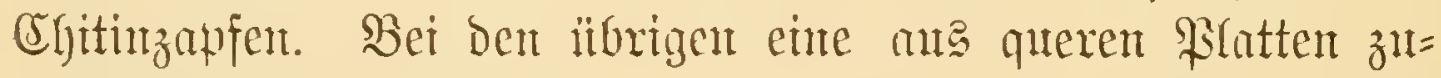
fanmengefeste "Birpaber", ant Grunbe Der Dedent. Erf. Darwin hat aber verumthet, Daj̃ dieje "Sibrillzapfen" ınd "Bixplatten" nux modificirte Şantraugigfeiten wären, and wir jelbit baben bann ftreng betwiejen, daj erjtere

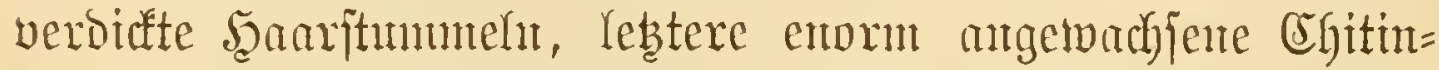
jdÿ̈ppdyen, aljo Dinge find, wie ntan fie anf jebent entiger= naf̧en Dicfen Serfpanzer antriffit. Dody was bemeijt dies;

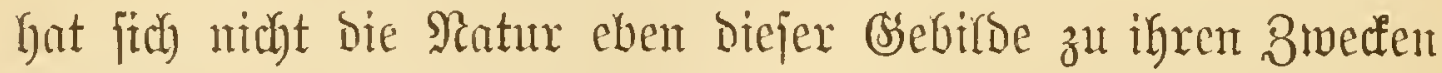
bedient? Man thue cinen Blict anf Fig. 6, weldye bas ver=

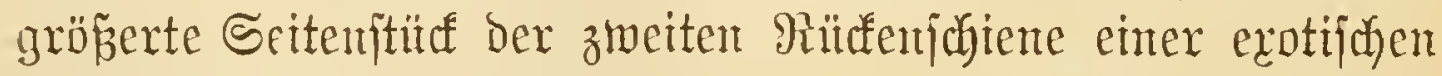
Raubrentarede (Fig. 5 a) Darjtellt.

Dicjer unjebeinbare Santifled ift ein wabres Spottbirs

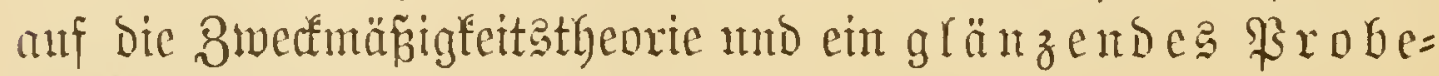

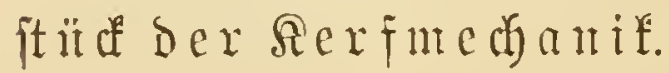




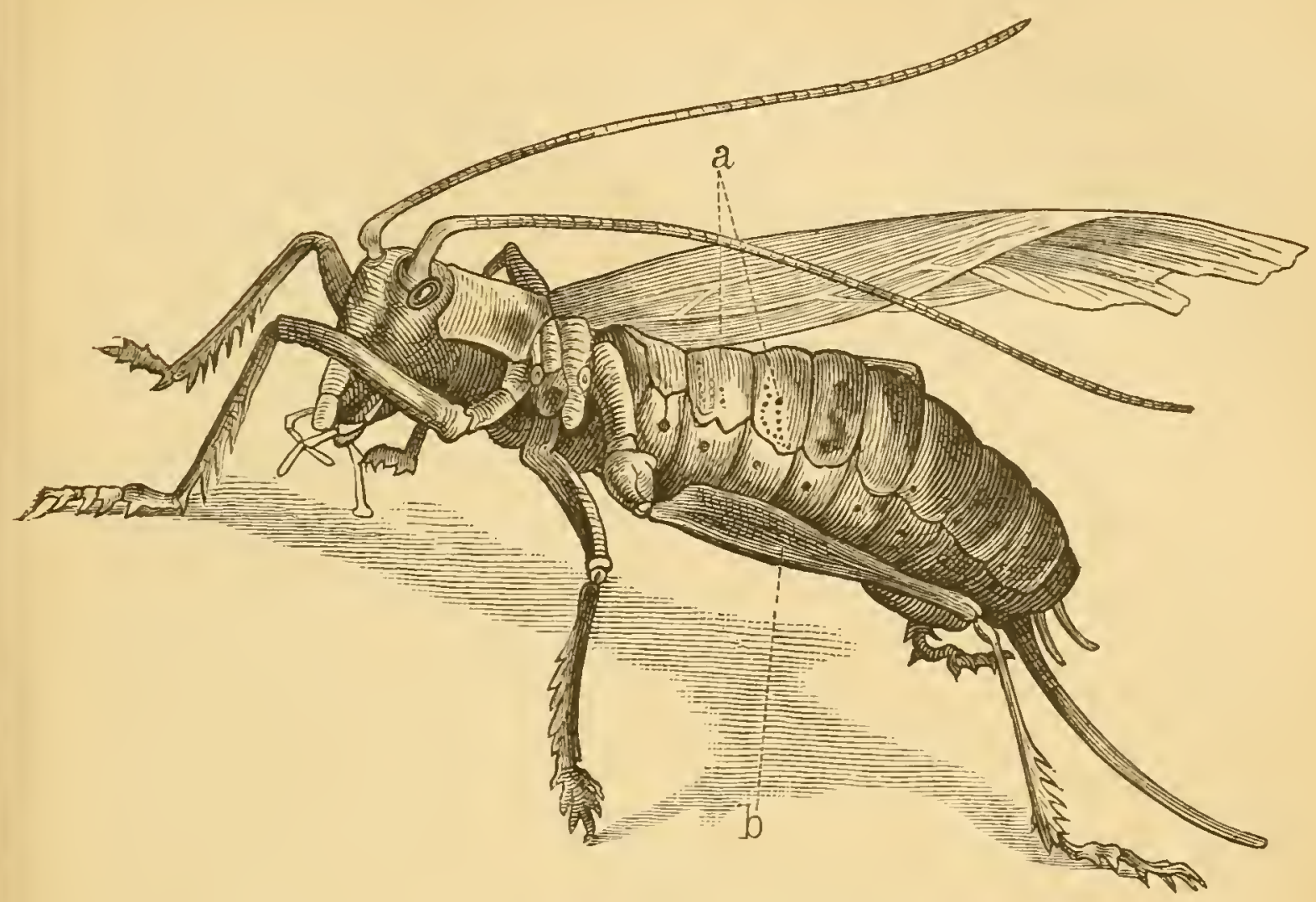

Fig. 5.

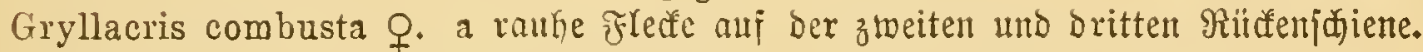

Şm Wald volt Şaarent, Die ung entgegenitarren, fiebt man zhei ßeifen. von Etrünten ( $\mathrm{v}$ แ⿰丿丨 $\mathrm{h}), \mathfrak{a b}=$ geftumpfte Şaare mit bick angejchwollener $\mathfrak{B u r z e l}$ : Schrillzapfen! Dod wie an= orbentfich gefterdt, wie weit entfernt, ein kunftgeredytes Toninftruntent zu jein! Uno unten bei d und c Şanke, wabre Safriffapfen = Ean= Didaten! Woher bieje $\mathfrak{U n}_{\mathrm{n}}=$ oromung, Dieje Itnregel=

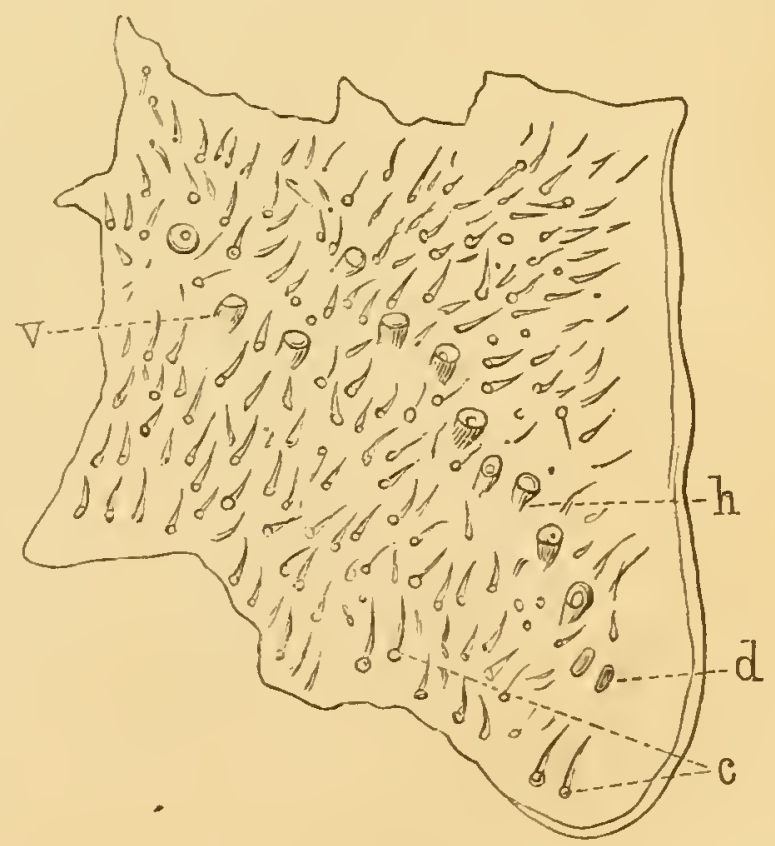
Fig. 6.

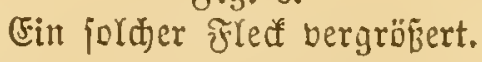

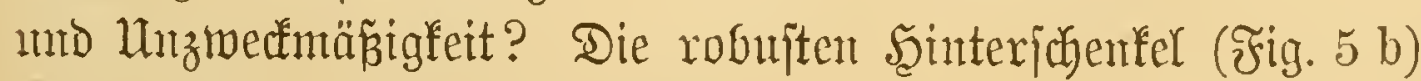
fegen öfter an Den Sörperjeiten. Manthe Şaare brectyen ab, 


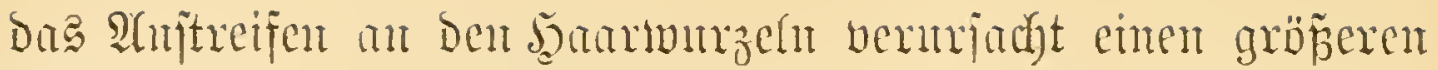

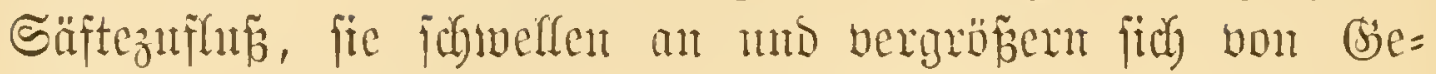

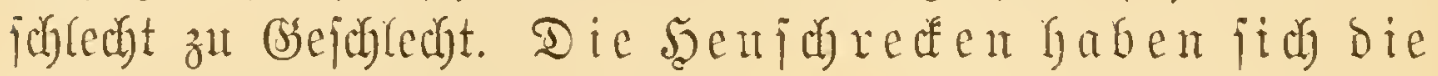

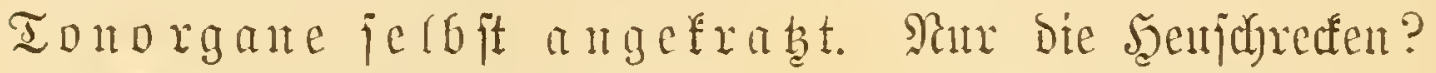

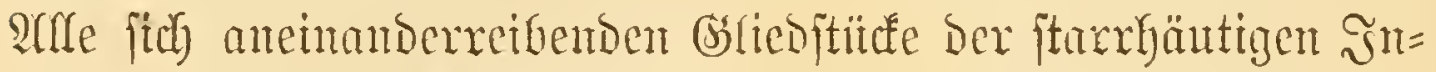

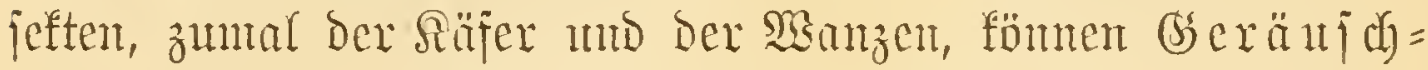

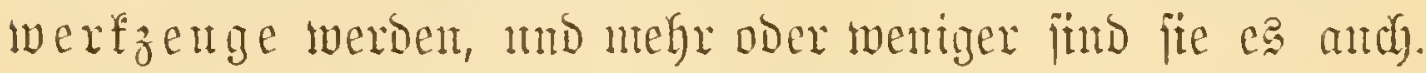

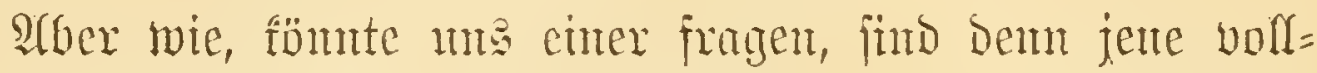
fonmenten afler Tongerätge, bie fri=friantigen uoghefaiteten Irommeln (Fig. 7 rt u. Fitg. S) Der Cicaben entitunden, weldye

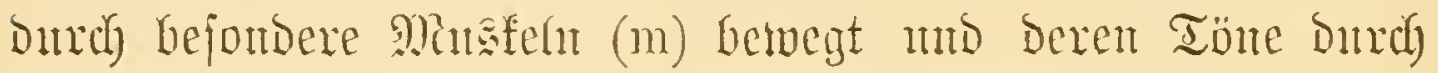

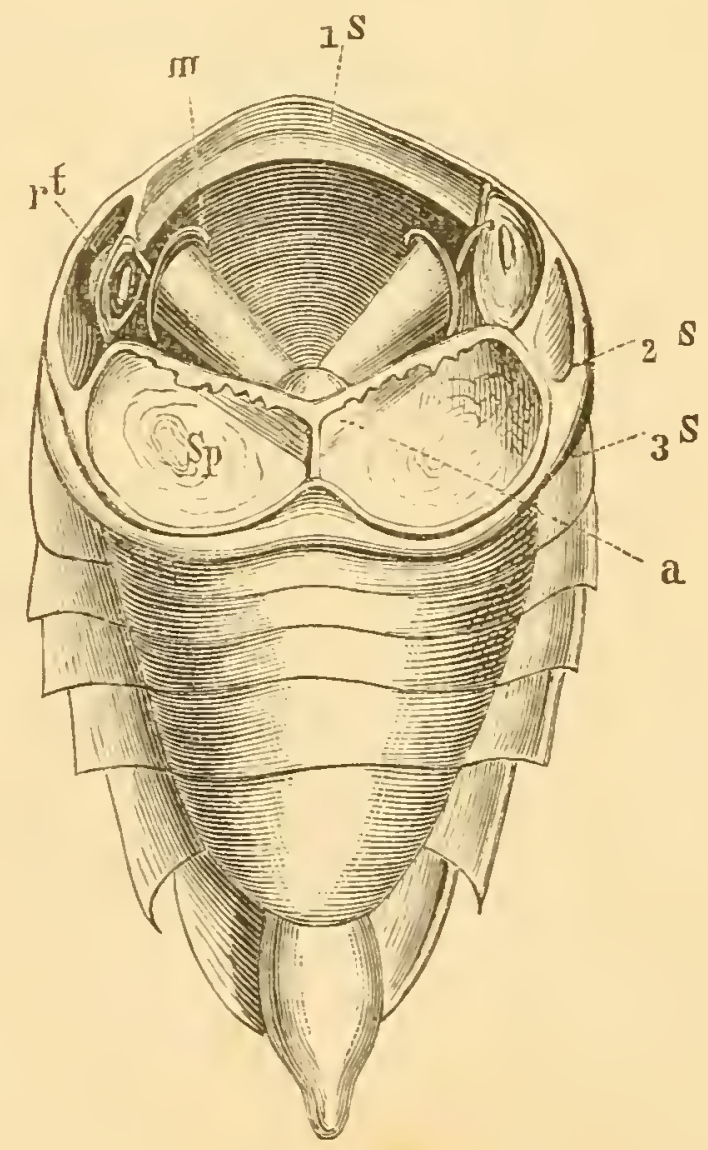

ช̛ig. 7.

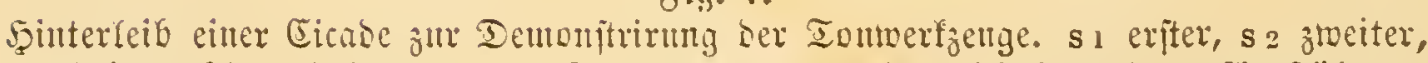
s 3 brittcr Şinterleifsring. tr Trommefn, von einer idjalentartigen 2lusftiilpung

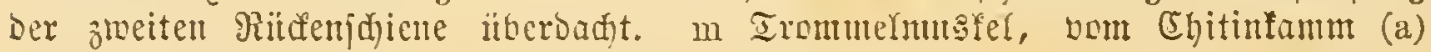
entipungens. Sp Esiegel. 
eigene Refonanzlöben (Sp) berjtärft nuld modulint werden?

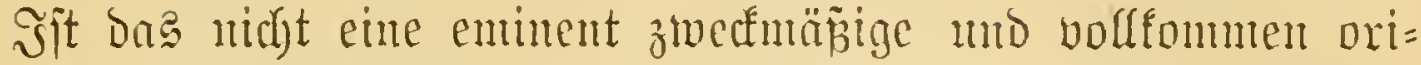

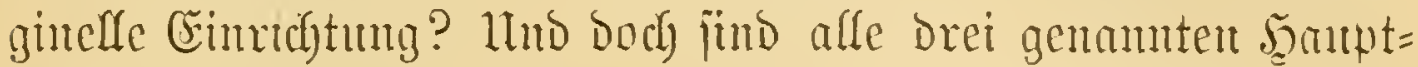

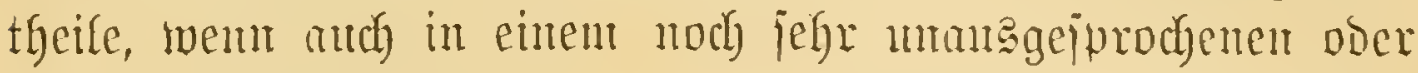

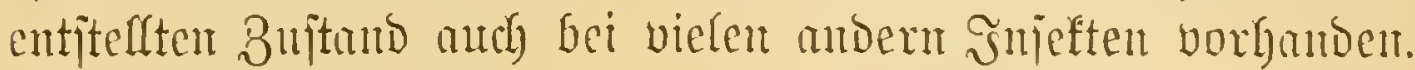
Die Trommel fïrs erite ift bei den Jyentigredfen bus - Dlgr,

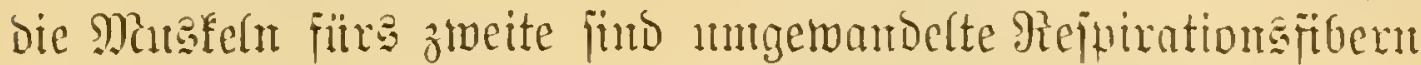
unb bei ben eben genantent als Trommelpanner in $\mathfrak{B e r}=$

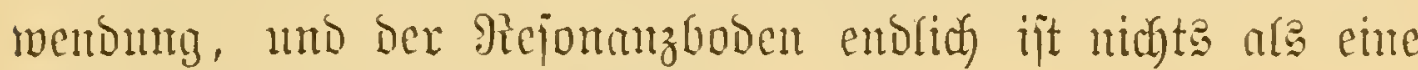

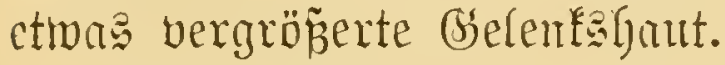

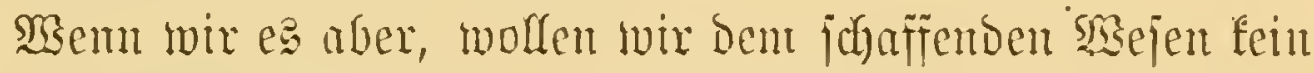

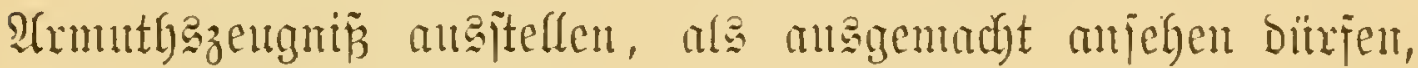
Dañ bie oben ertoühute Gryllacris ifgr höchjt primitives Reif= jentg jich jelbjt angejegt gat, ijt es gemin nicht jo gar mijumig

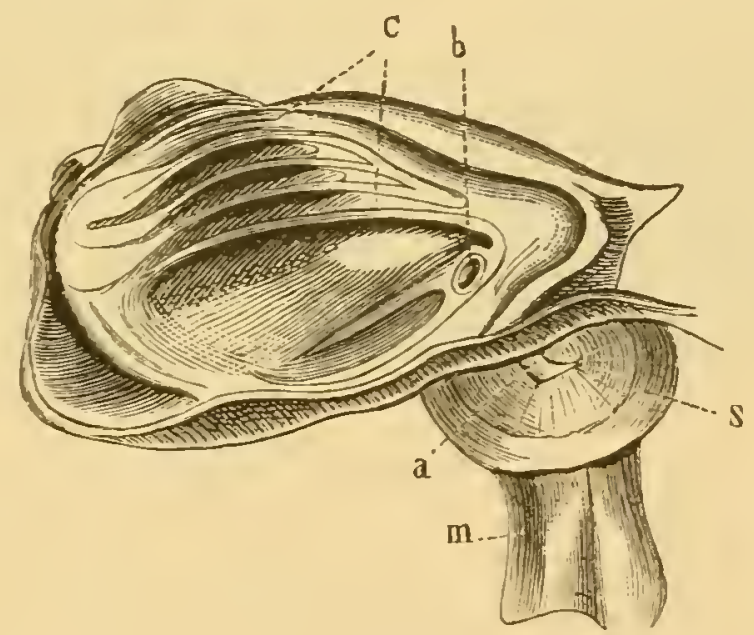

子ig. \&.

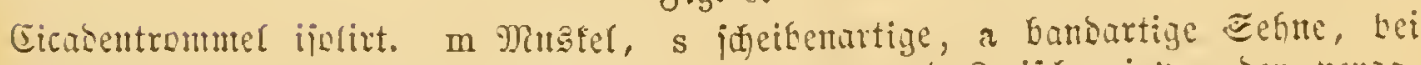

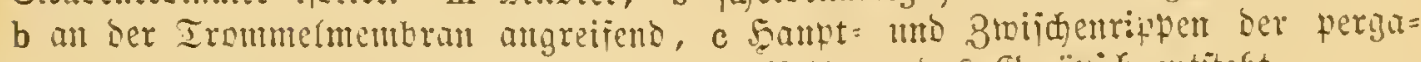

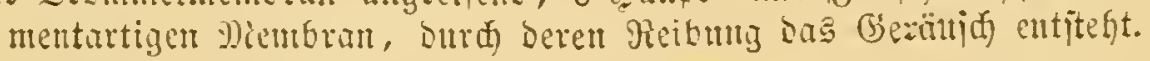

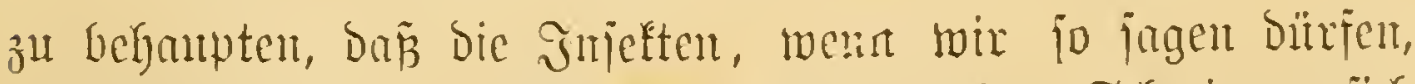

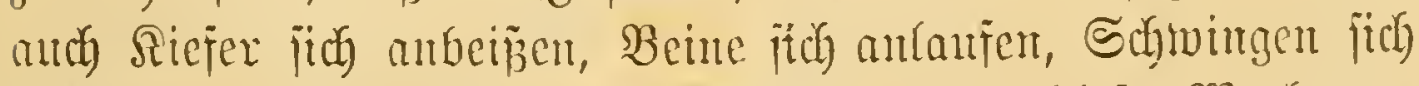

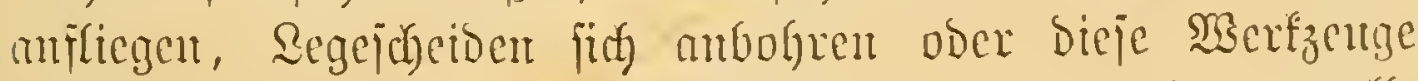
burch fleip̃ige Betfätigung mo llefung boch jefre verwollfommmen $\mathfrak{E}_{\mathfrak{b}}$ ut $\mathrm{n}$ en.

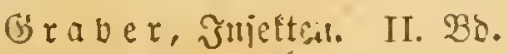




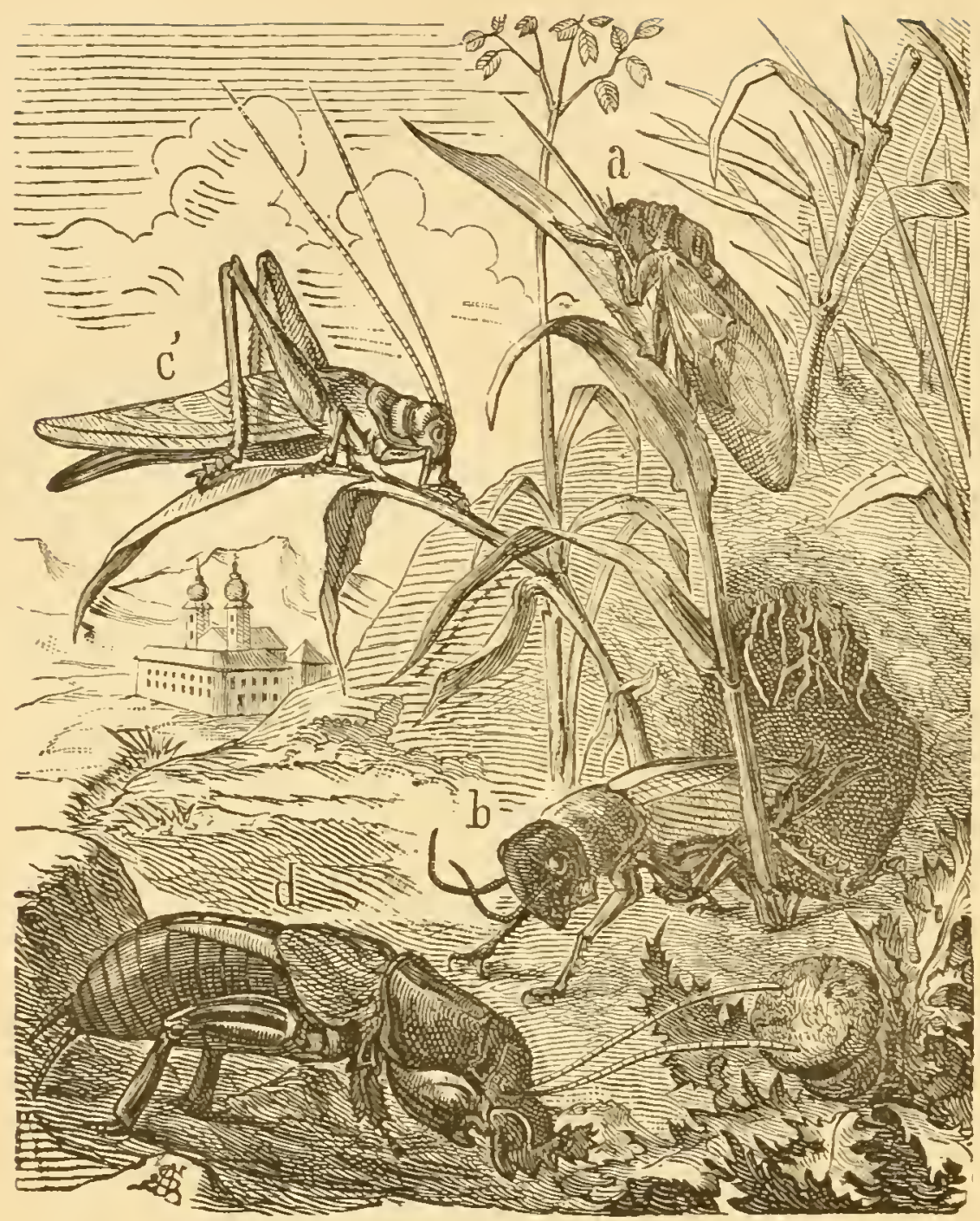

Fig. 9.

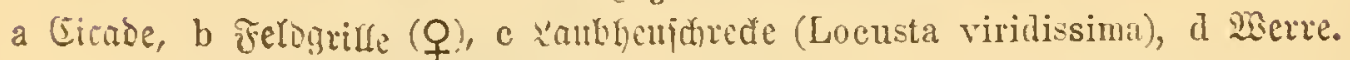

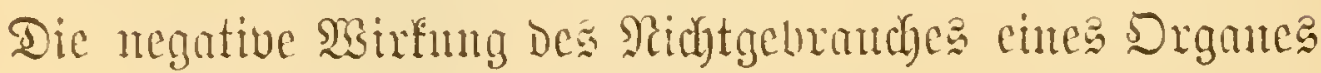

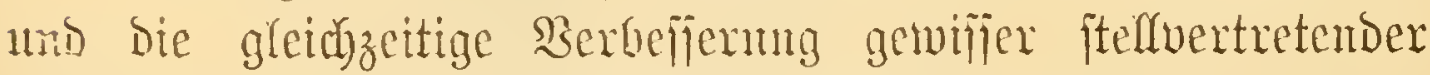

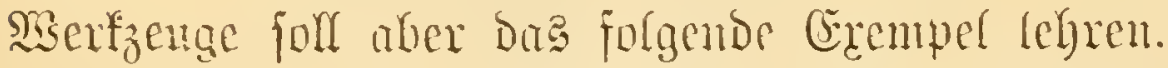

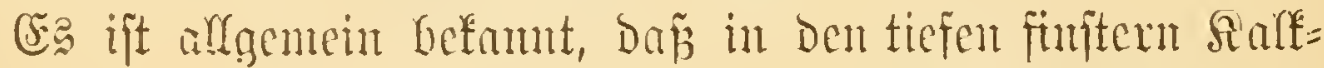

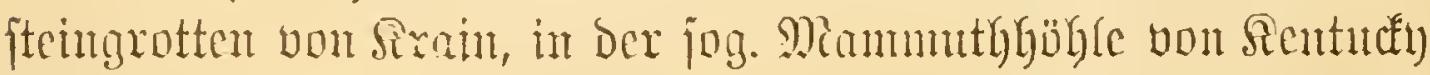

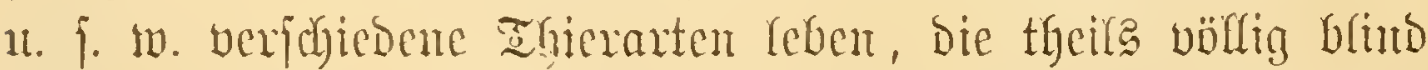

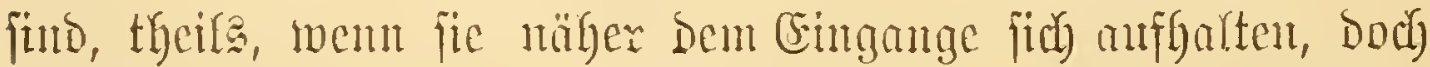

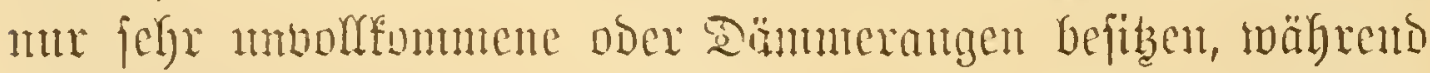
gantz make verwante Epecies, bir man in der ltmgefnutg

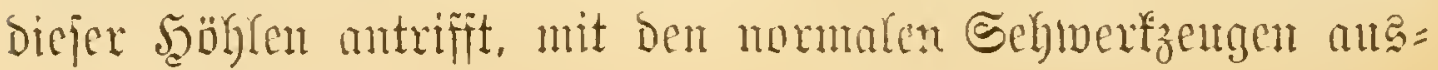


geriiftet fints. Riegt mun bei biejem Sachberbalt etwas näher

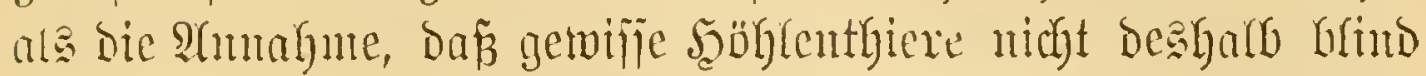

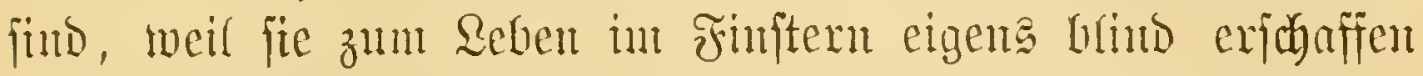
murben, fondern ans dem Grmobe, weil fie, feit fie ans was

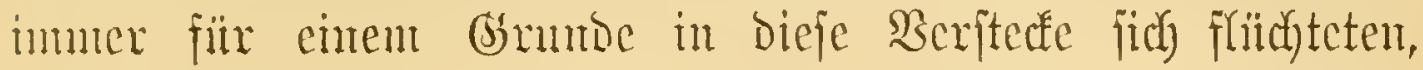

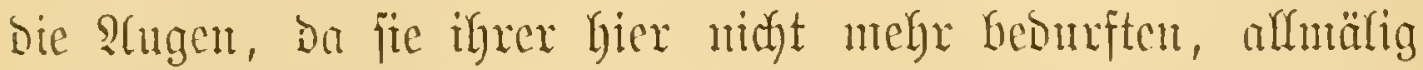

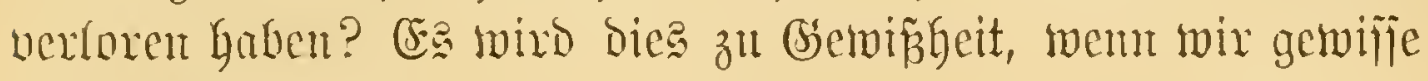

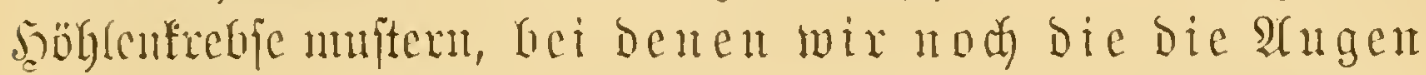
tragenden Sticle a utreffen, währemb die erfteren jelbit wölfig berjdymunden finto.

lluter diejen ફ̧öhlen= rutimen girnt es. mut and viele Эnifekten min hejon= bere Raubläfer, wovon Dem Sejer citter, tuäm(idf) bie Leptodera Hohenwarti, anf beijtehentoer Figur wox= geitellt wiro. Diejes fajt frimentartige, in DCr 2 CDela bergergrotte baujente Serf ift nicht blo pröllig angen= fondorn, wie die meijten

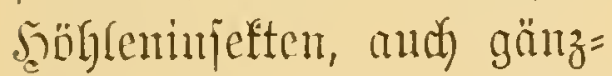
(idi) frügerros. Dod wurben bieje betion grojen M)(ängel compenjint burch sie allmälige ßerlängerung ifrer Beinte uno Fühler,

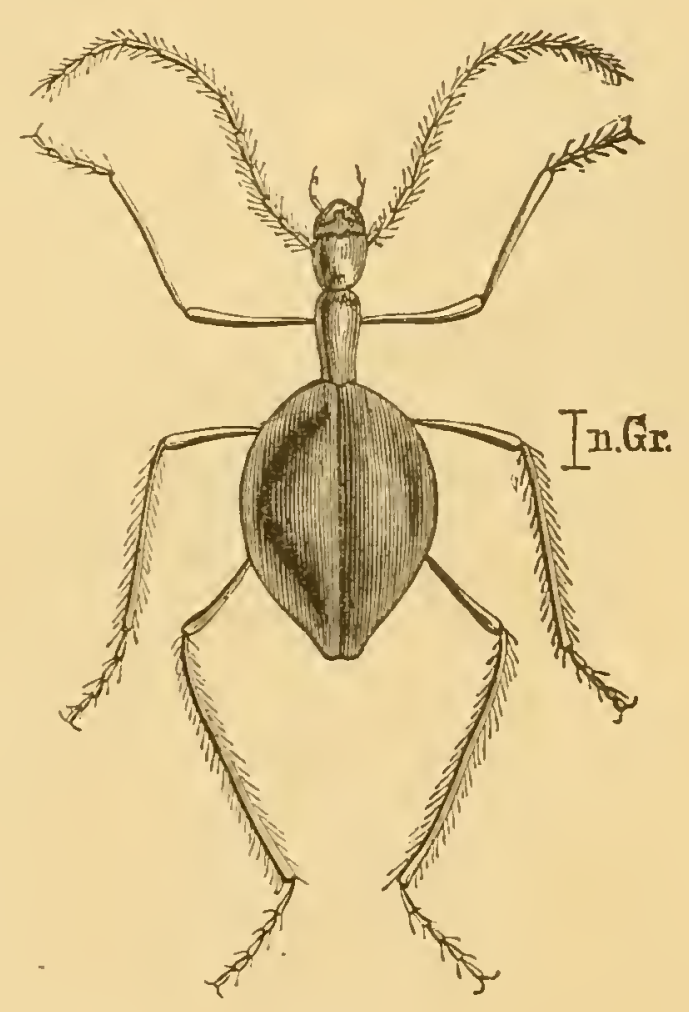

Fig. 10.

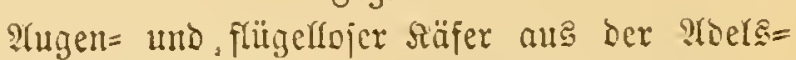
bergergrotte (Leptodera Hohenwarti).

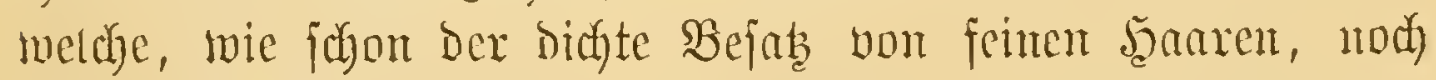
mebs aber bie munttelbare Beobadtunt betweift, zugleid) mit

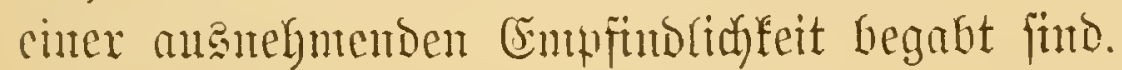

Das im berfen orame fliegende undegende sierfift alfo im finfern eim vorfictig fareitendez 
und taftendç, wir mödten fagen, das soeal eincs blitidengewoxden.

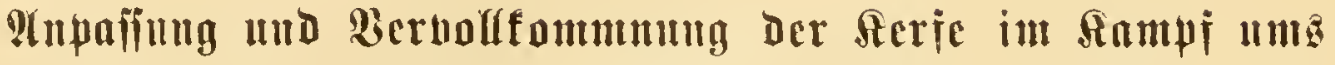 Taiciu.}

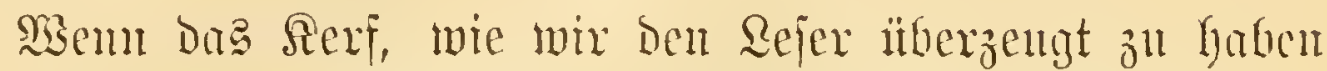

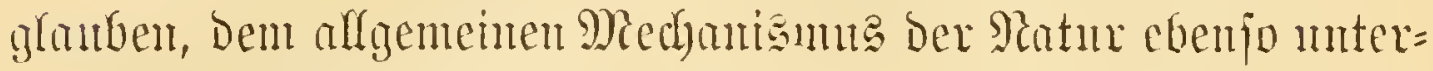
than und vou ifn ebenfo abyängig ift, mic irgend ein anderes Raturwefen, jo hat ber muere Bildungatricb, wie ifn Bicle

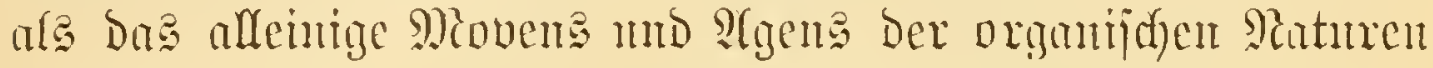

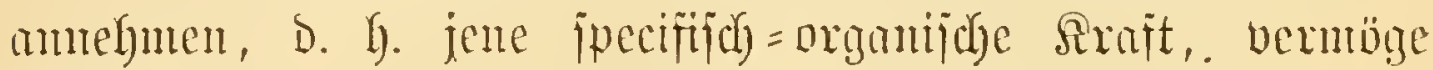

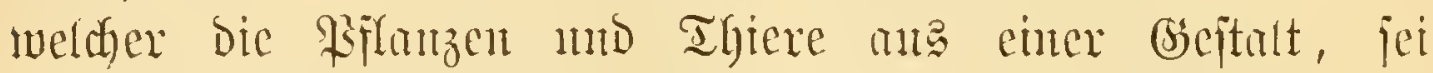

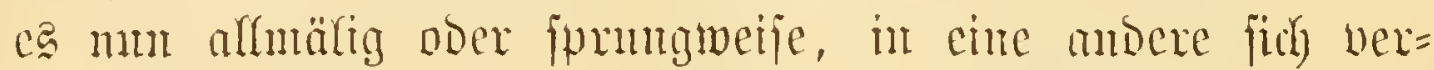
toundelu, offenbar feine Exiftenzberedytigung. Demn mozn ijt bieje

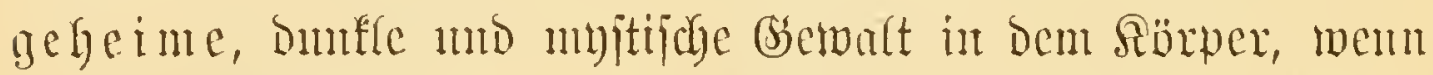
fie fich gegenüber Der offentumbigen "äuzeren" Siatux" madyt nicht zu behannten vermag? SDer bambehn fie vick

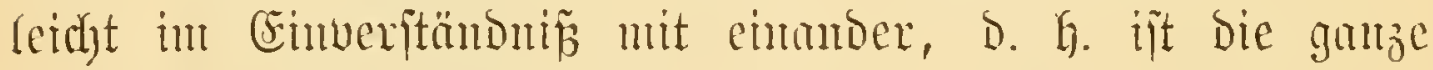

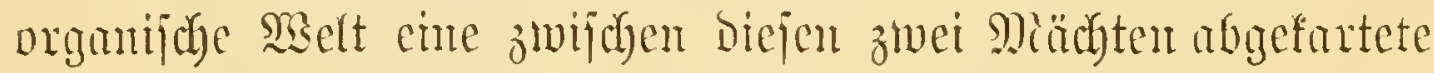
ober verembarte Gadje?

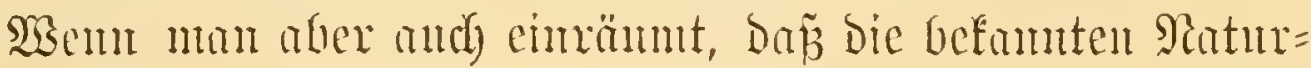

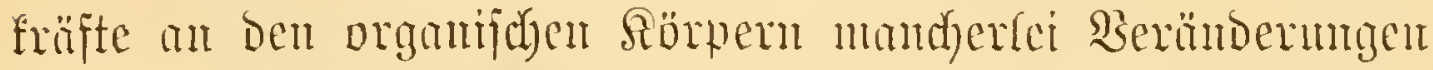

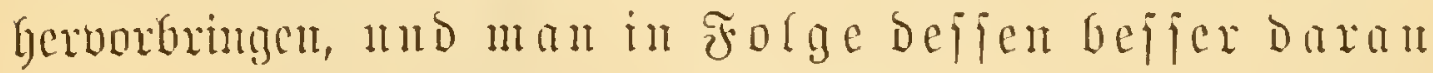

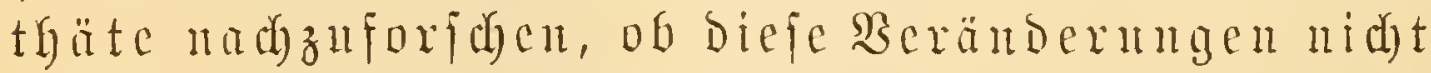
vielleidyt nody gröbex find, ober mit der 3 eit bod gröfex werden fönten, wie man glaubt,

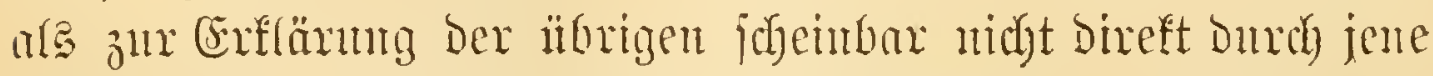

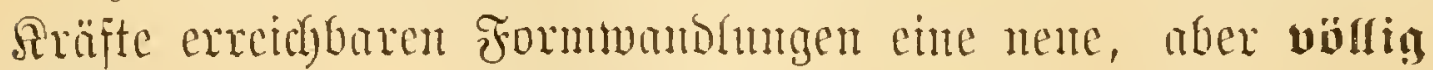
mubcannte ltrjache in bie Redbung einzufübren, fo fam man monerjeits body and Senen nidyt Huredyt gehen, meldes bc=

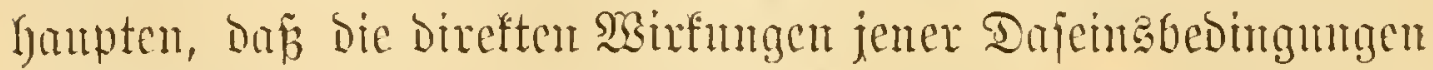
in SGazen zicurlich geringfügiger art fund, und Die Daburd) hervorgebradbten Bariationen, in Der Regel menigjtens, theils 


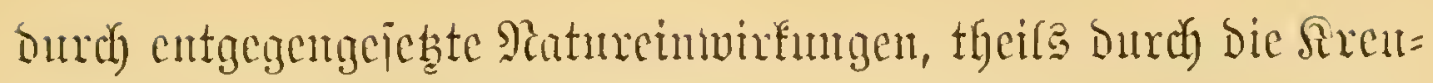
zimg ber betreffenton Fnbivibuen mit ambers gearteten wieder

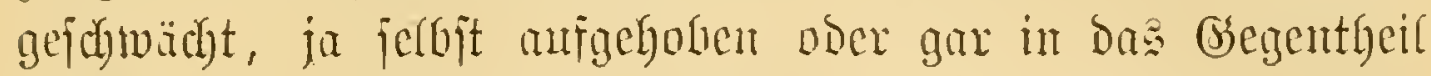

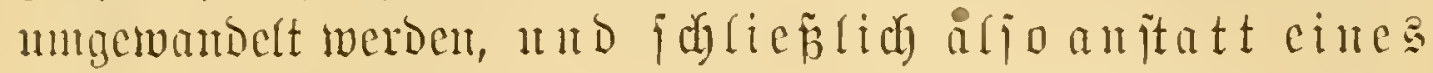
unajhaltion jortidreitemben Bicbugafujpes

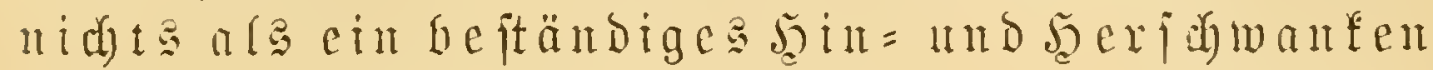

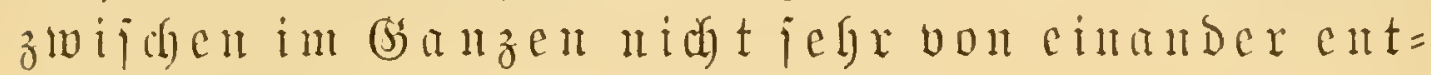
feruten obrazen herang o dume.

Sebsterer Crimwnrf wäre and in Der That ridytig, mem

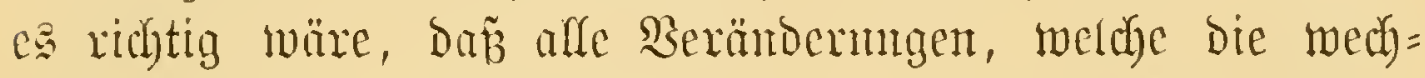

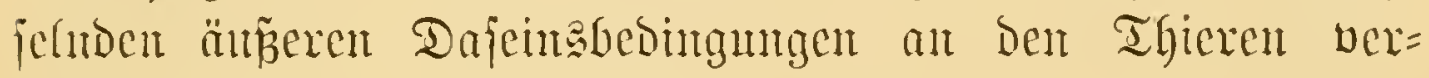

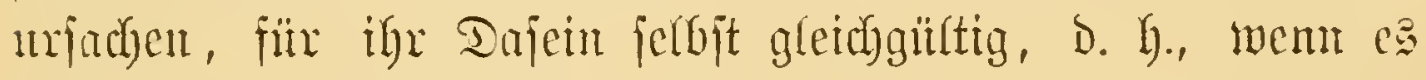

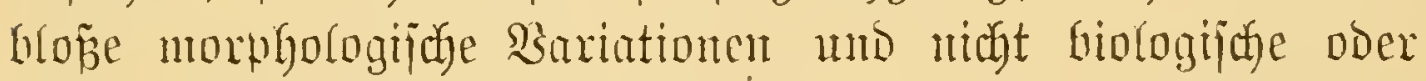
foldhe wären, weldye irgend cinen f̈̈rdernden oder hemmenden Cinfluz anif bas Reben umb \$sohlergehen ihrer Träger haben.

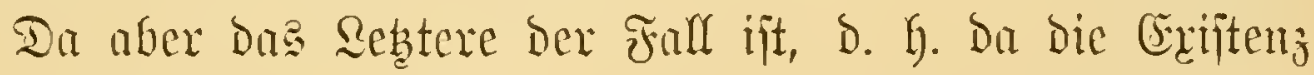

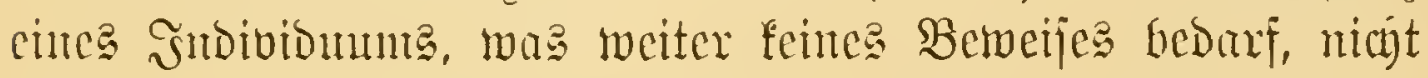

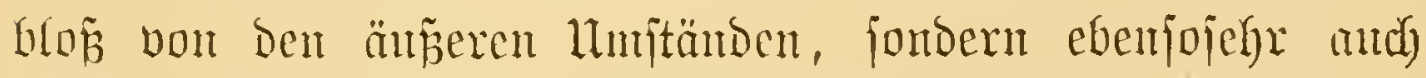
von ber Bejdgaffentheit jeiner verichicbenen Drgane abgängig ijt, Durch Die jene \$erhältuijīe anj Dasjelbe wirfen, und mit Denen es linwiedentm jelbit anf jene reagirt, fo ent = und bejteht jenes zuerit bon Darwin flar ausgejprodyene Medjel= wergältuin, Das man als natürriche Buthtwabl in "siampf uns Dajein" umichrieben hat, und bieje ijt e马, welche "un=

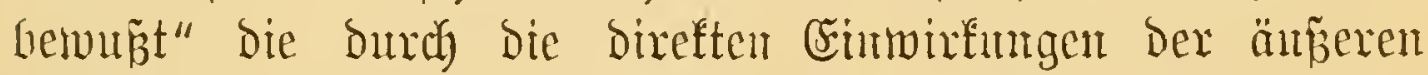
Sehenamutänbe herborgebrachten Sartationen ebenjo jorg=

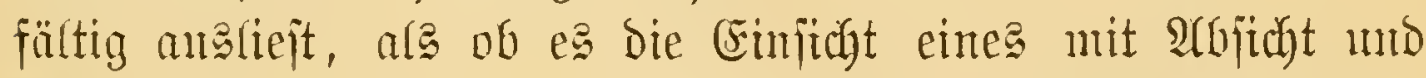
fluger Berechumg vorgehenden Bühters oder Bilonere thäte.

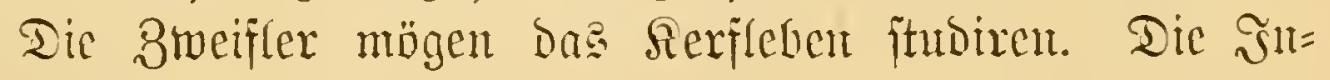
joften fund "Intuehener Der Bernehrung". So leben in Den Sïmpfen Mexifo's ein faar 永anzenarten (Corixa mercenaria ImD femorata, Notonecta unifasciata u. $\mathfrak{A}$.), me(d)e jäl)ritid) jo folojiale Miengen von Eiern an bie Bimjen ablegen, da 


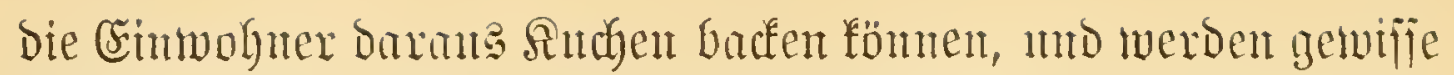

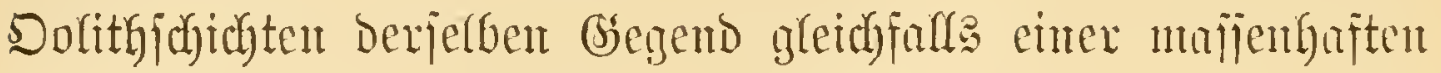

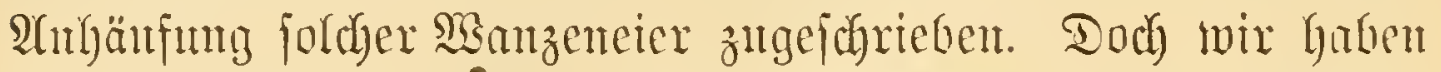
näber liegento Belege. Die Biententöntgin fantn jühr(id) gegen 100,000 Radyfonnen exzengen, Daz Termitentweib bei 12 Millionen, mo wer zälylt bie Jubresbut einer Blatt= lat? ? -

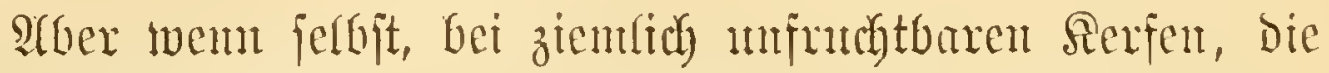
vielfeidyt nur 10 ober nody wentiger Eier legen, alle weiblidyen

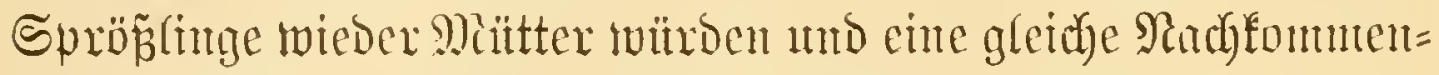
jufaft exzielten, die Sintoestimber ebenfalls mo jo fort mo

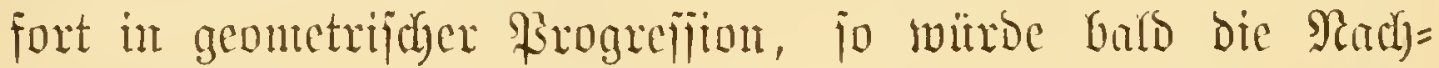

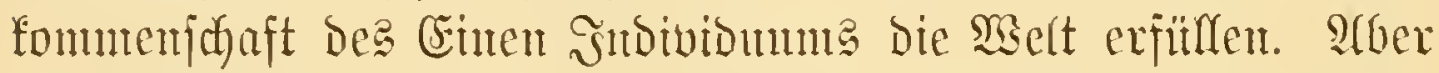

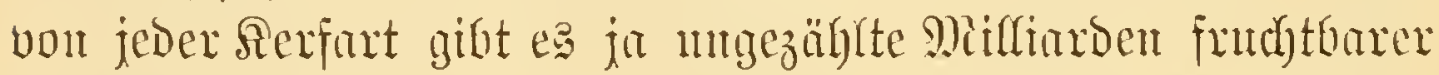

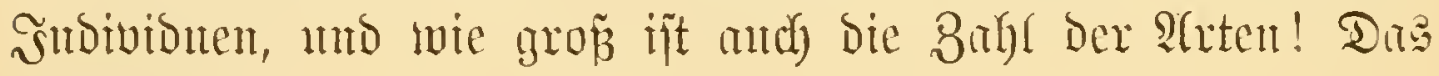
Sryiller'jiche

"Panm jür Alle Gat Die Groe"

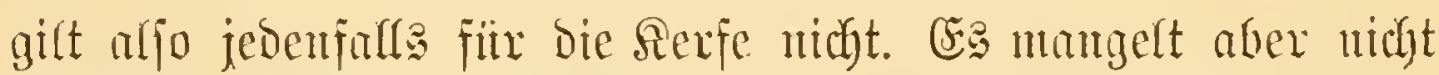

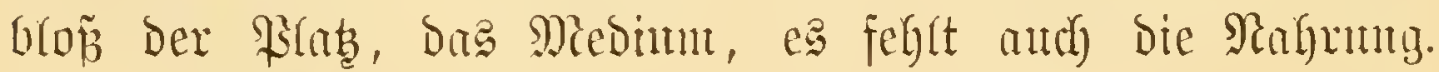

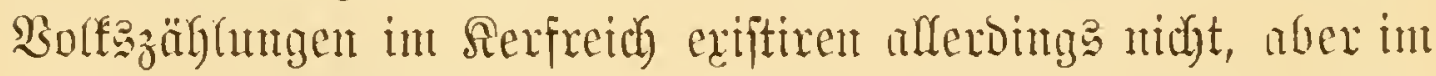

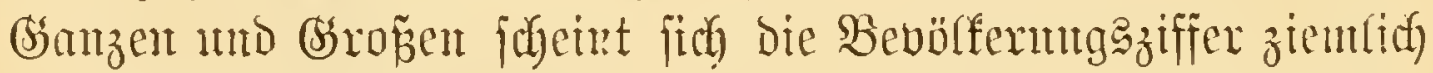

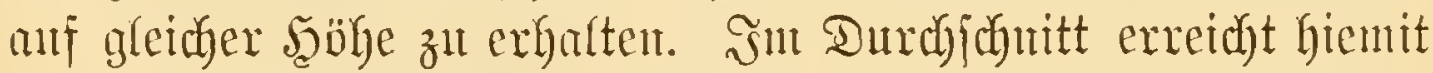

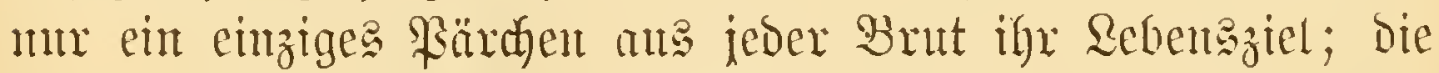

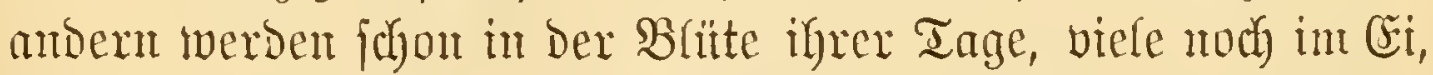

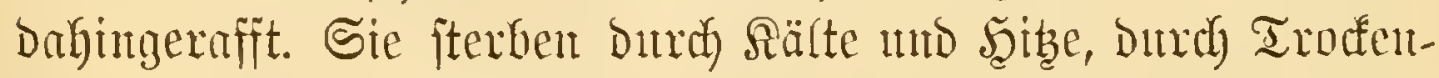
hett und sä̈jie; dic meiften aber eines getwaltianten Todes

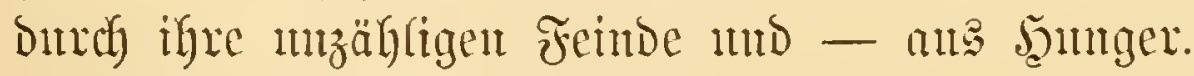

Und weldyes find Dent die Gsiüffidyen, weldye in biejem ent=

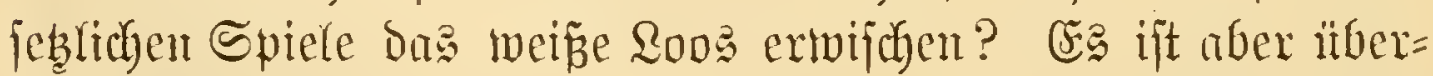
Gaupt feit Rotteriejpiel, wo mu Der Bufall Gerridgt. Sein,

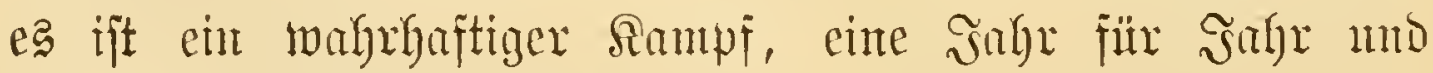

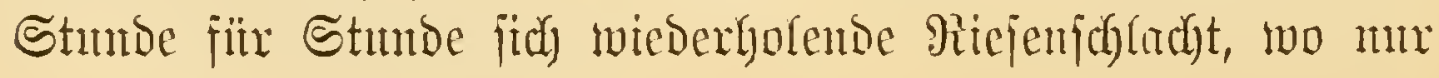


Den gefündoiten, Dem fräftigiten, Dem Geftbewaffueten, Dent

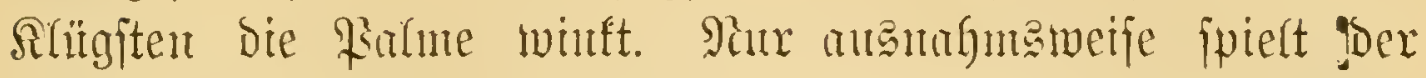
Bufall woht atth eitrem Mintocren ben Sieg in die Şäntoe.

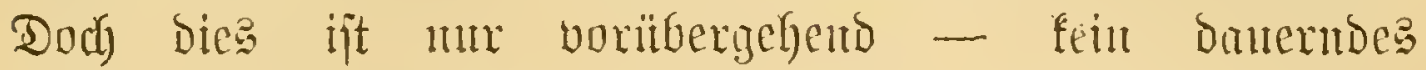

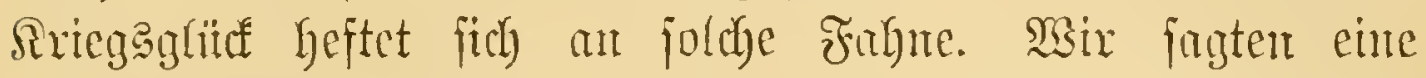

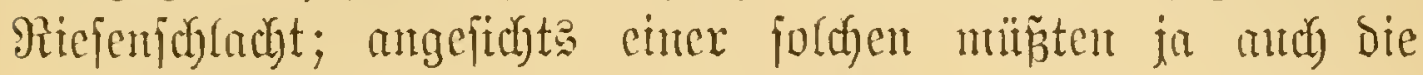

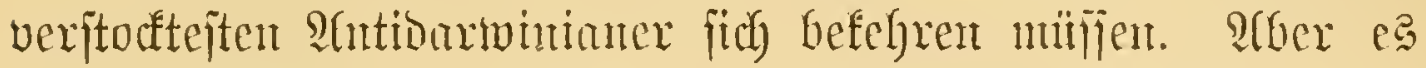

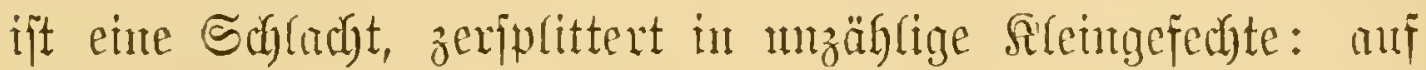
jeben Blatt, in jeber Bhme, in jeden Bammitamm, unter jeben Stein, furzum anf jebem Fleft ober mo mter ber Erbe, wo Serfe hanfen, und too hanfen fie nidht? - vollziegt

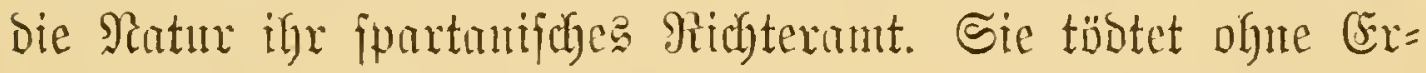

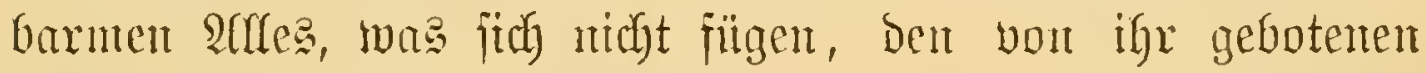

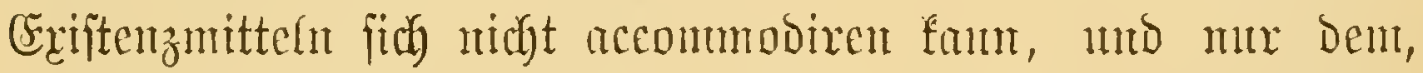
Der unter feinen zahfreichen Mitconcurrenten die vortheil=

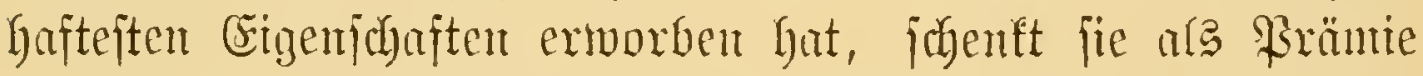

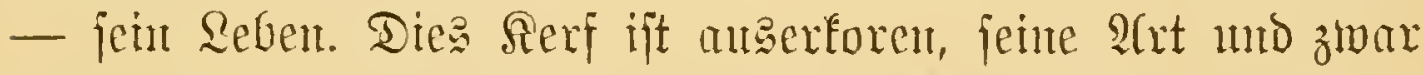

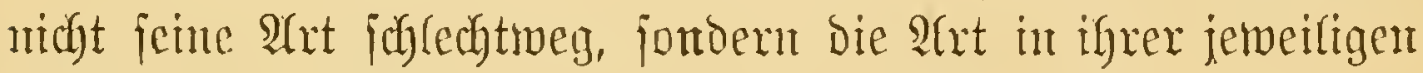
bejonderen indibibueflen Tithtigfeit fortzunflanzen.

Die Marheit der It mithit ebenjo gemiñ, als irgend ein anderes

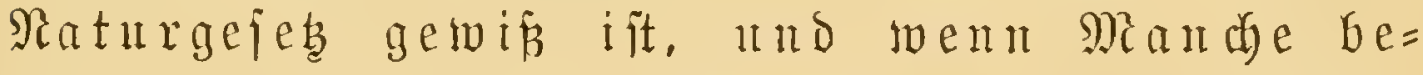

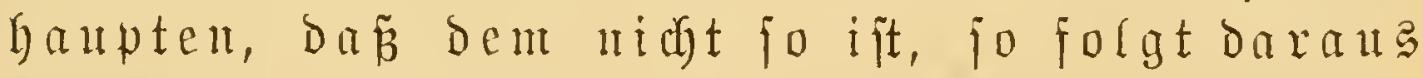

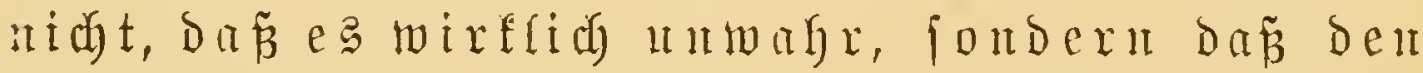

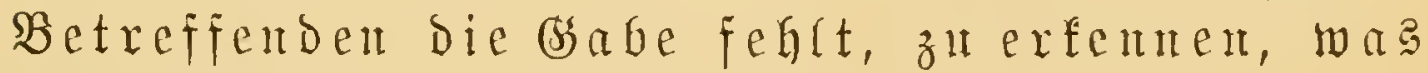

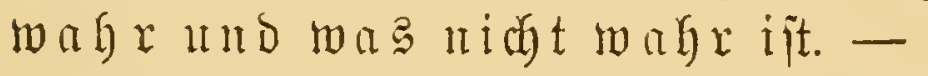

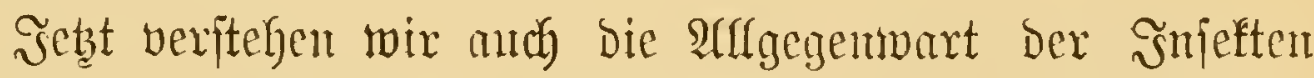

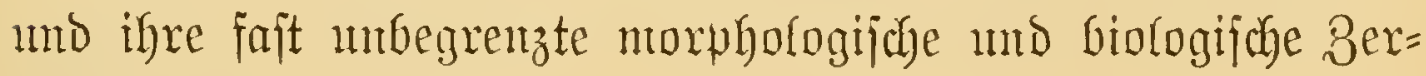
\{plitterutg.

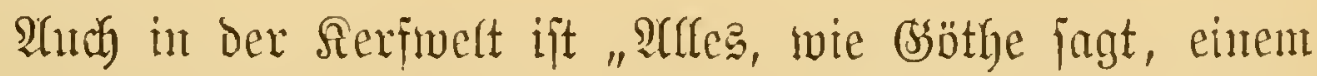

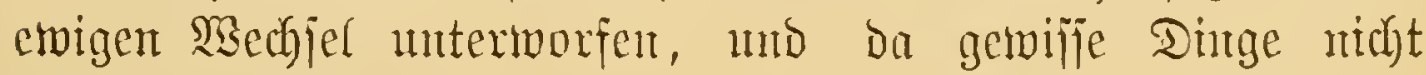
neben einutoer bejtegen fümten, fo verorä̈gen fie eintander." 


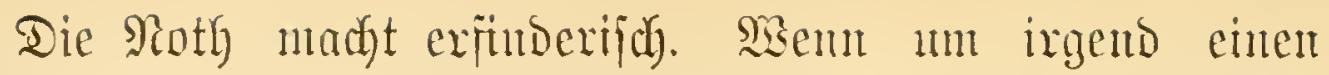

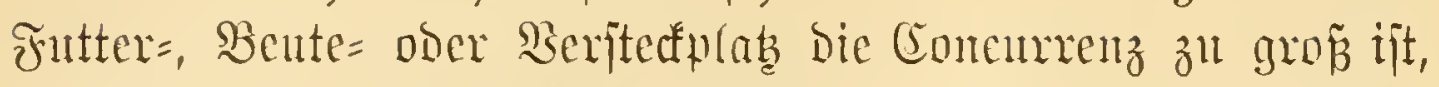
jo mitifien bie Heberzähligen weichen, fich wo anders umfehen,

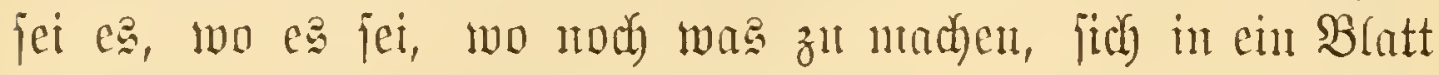
einwihglen, in cinen $3 \mathrm{meig}$ verfriechen - vielleidyt im Mijt

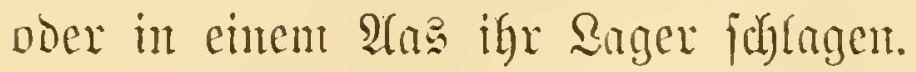

Mnd Das Edhluprejultat? Die fiunjtidye ober methobifdye

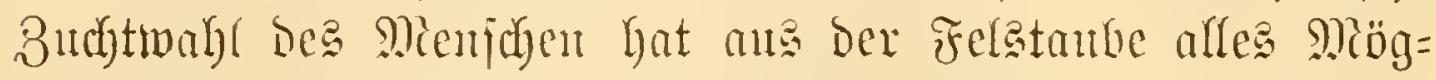

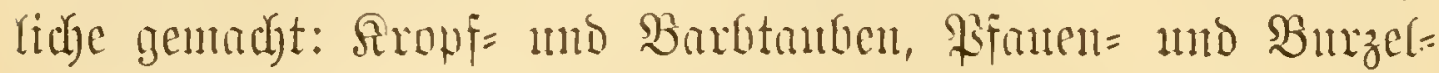

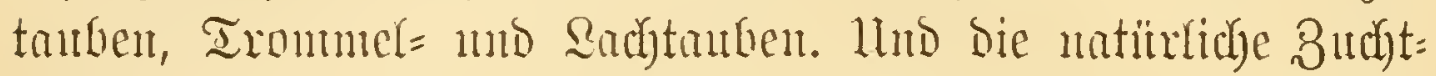

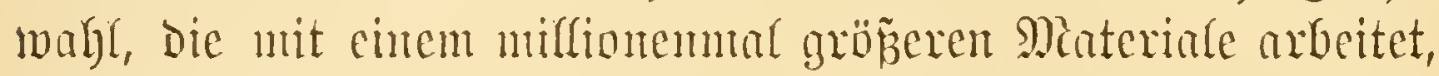
weldye ju ifren Erperimenten itber mbeichränfte Mittel ver=

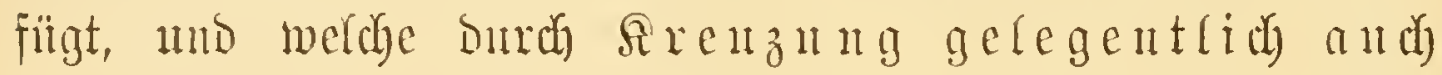

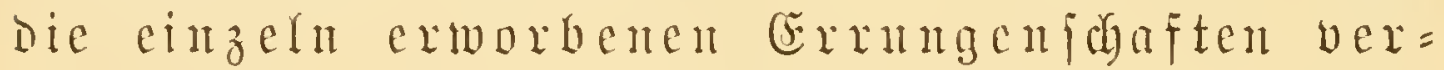
friedener Thiere nd benerationen in einem einzigen Jubivionn concentrixenfan, bieje foll die Serfivelt nicht vormärts bringen? *) -

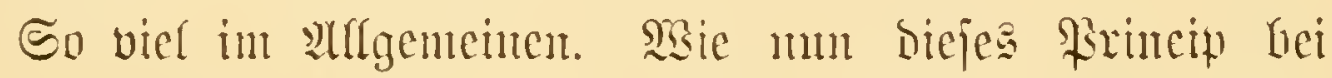
jebem einzeluen Rerf nto bei jedent Drgan besjelben fid

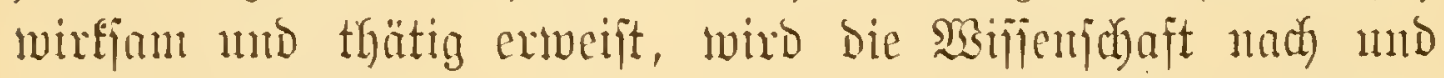

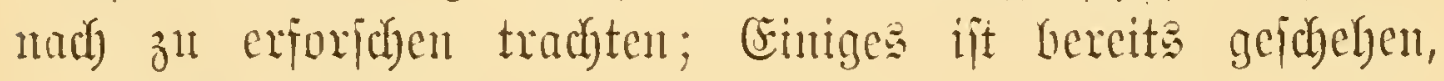
Inld Dabnu folf ber Sejer jutächjt Gärent.

*) Dieje Concentrinng und Combinimng gemijier Durth eine greige von Generationen an einzetnen Snswionen berielben anj= tretensen vortheifhaften Charaftere in einem einzigen Mitghied ber ganzen Etammreige ijt miemals idnöner, als non Böbthe betreffes

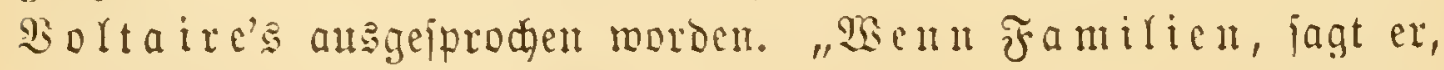

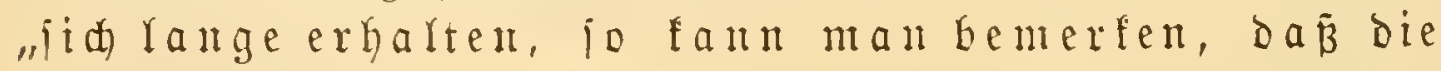
"Patur endide ein Jnbinioun herborbringt, bas bie

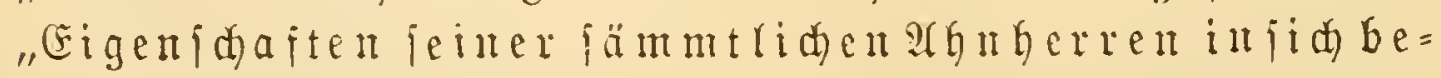

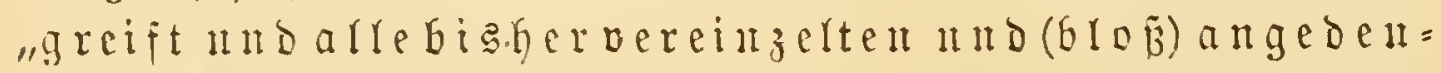

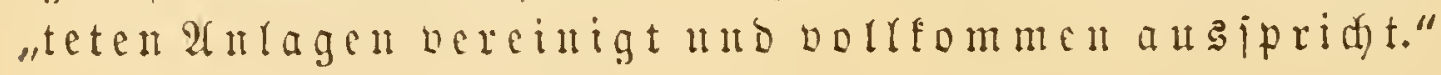




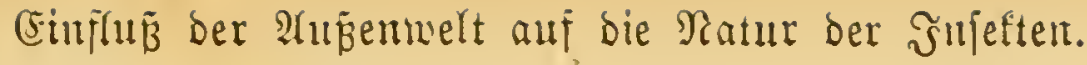

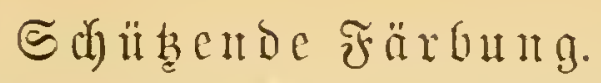

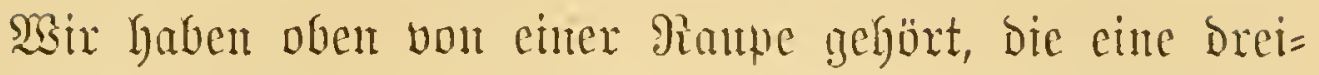

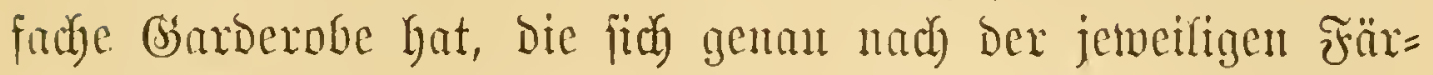
bung ifrer Alahrumbarfanze Kleibet. Eine andere, Eupithecia absinthiata, ein polyphage? Thiex, foll auf Dem gefbriibenten Senecio jacobaea gelb, auf rothen Eentumren röthlich) und

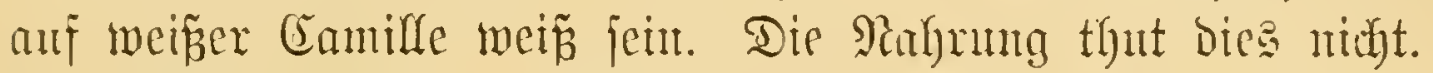
Misas hat es aljo Dantit anf fich? Die Patur hat biejen (be= idjüpjen einen widhtigen Dient ermiejen. Şbre der jemeifigen

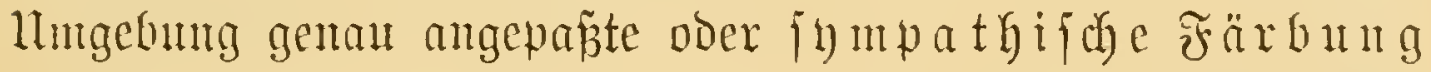

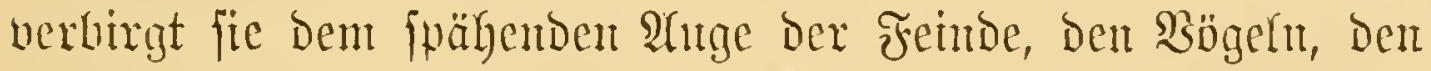

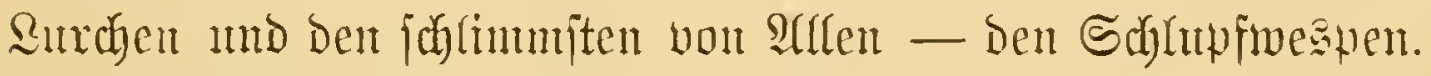
Die blope Farbe ober Beidnung ifrer zarten Şant ijt ifnen ein ebenjo guter, ja vie(fach jogar ein bejjerer Sdyus, als ber

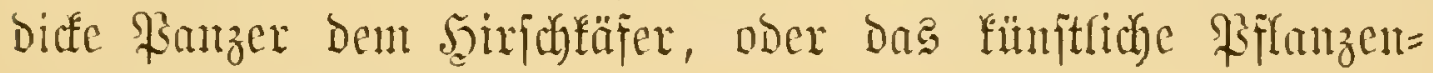
futteral Dex Riäroerlarbe.

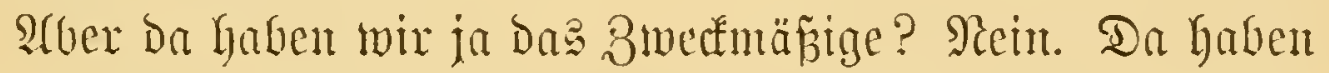

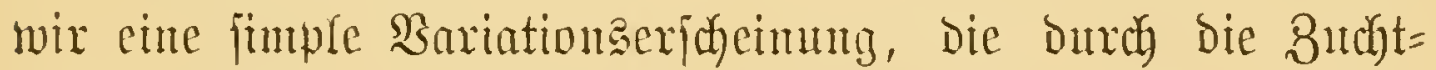

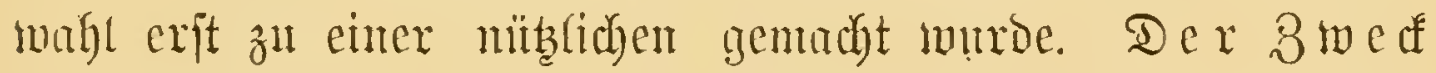
fommt erfit hintendrein, d. h. Die Natur färbte z. $\mathfrak{B}$. Die Brras= Serfe nidgt grün, un fie Dadurd dem Artblicf ifrer Feinde zu verbergen, fondern viełe haben biejes "zotweef= mäpige" Sileid mur Darum, weil bie Ratur mitteljt ihrer Werfzenge, bie oben genanten șmeftenfrefjer, bie meiften andern Serfe, welche ca nicht hatten, auterottete, it ähn=

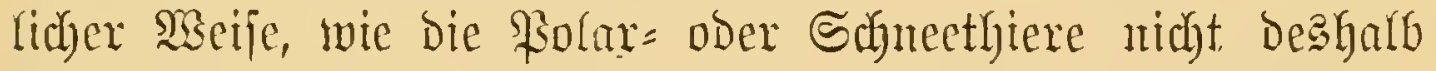
jich wein tragen, damit fie von ifrer Untgebung möglichjt swenig aljtechen, fontoern barum, weil jene, welde nidht mit

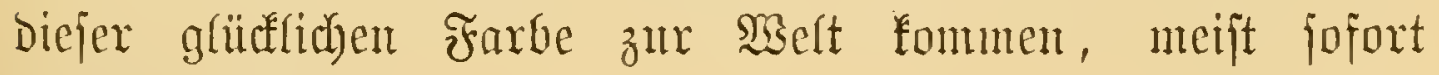
vertilgt werdert.

Atber wie weit verbreitet, wie mannigfaltig mon z. Th.

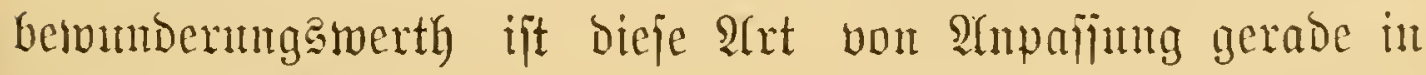
Der Jineftenflajie! 
Es gibt Rerfe, fagt Miduelet, bie jul jagen judenten:

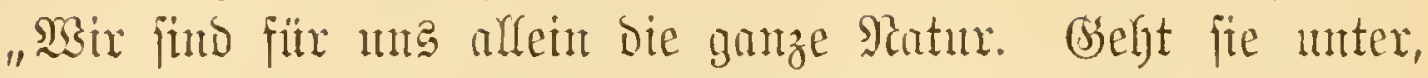
jo weroen wir je jpielen und afle

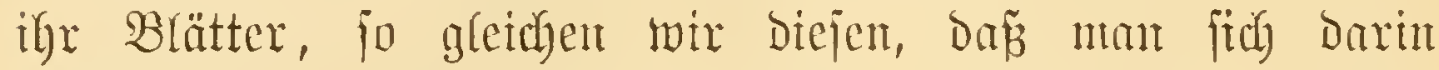

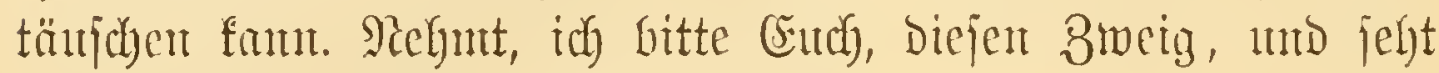
- es ijt ein Jineft!"

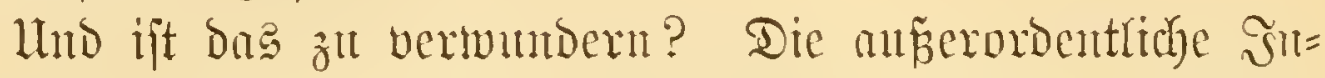
bividuenzahl exlantet eine anperorbentlidye Menge bon $\mathfrak{S a}=$ riationen. Die anzerorbentlidye Berfolgunty ber §nfeften aber

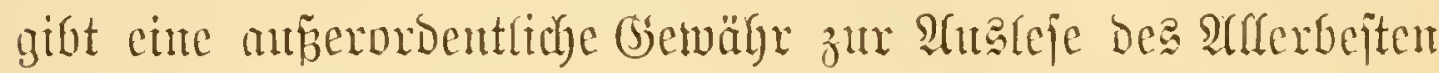
unto Sorthcilfaftejten.

Şalten bir zuntäbjt utit

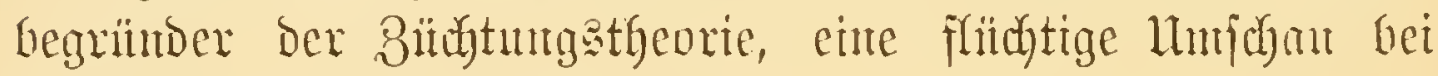
Den einzelten Dromutuen.

Butüabjt bei ben Decfflitglexn.

Biele Tigerfäfer erimern an bie farbentwedfelnden Rimpen. Die Cicindela campestris Der "grofigen Mfer" ift grïn; Die maritima ber fandigen Seegejtade fleidet fitu "blaźs bronce= gelf"; Das fammotartige Grün Der gloriosa twetteifert mit Der Farhe des majen Mioojes anf Den Steinten ber b̉erg= wäjīer, uno einer (C. heros), von olivengritner Farbe, läp̈t jith vom najjen Sdylamm jaziger Miaxidyen mir - Durdy jeinten Sibutten mterjacheiden!

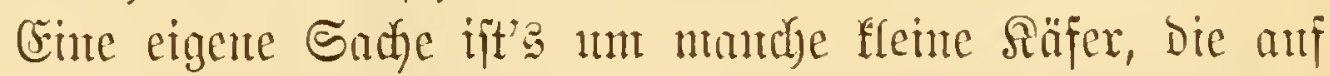

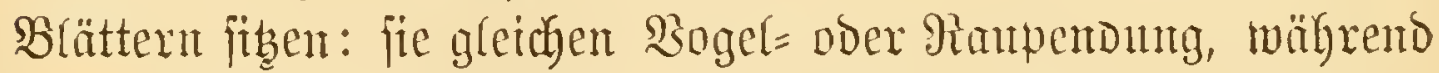
andere, gewiffe Schilbfäfer, int "gefälligen Echein" gliţernder Thantropfen Nichts zu fürdyten haben.

Antfillend ijt bie Farbenmummerei vieler Schntetteringe. Die Iagfalterflitgel, oben meijt briffant, unten ganz mifheintbar,

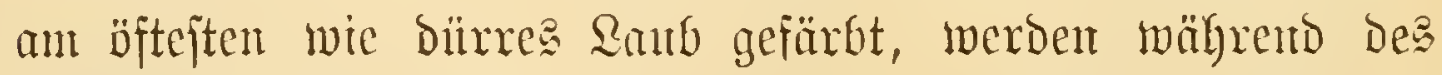

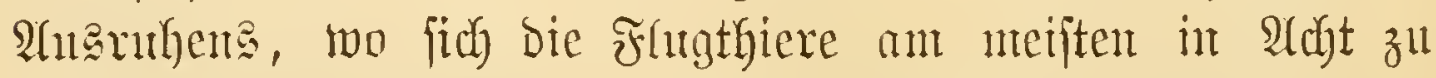

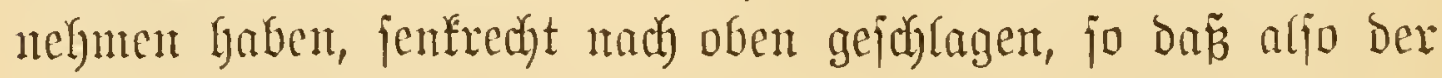
"gefälyrliche Gśanz" Der Dberjeite verborgen ijt. Bei Dent 
Ḧbrigen aber, Die bie Serbungen burfö̈rmig tragen, fütoet

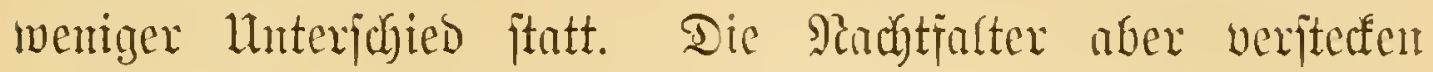
bie oft lebgaft gefärbten Şinterflitgel mnter Den Dunfferen Sorderidhtwingent.

Cimen Fall Der munderjamiten Berffcionng aber, Der gegentuber jelbjt bie Supaijungen Der Stabhenjurecken nto

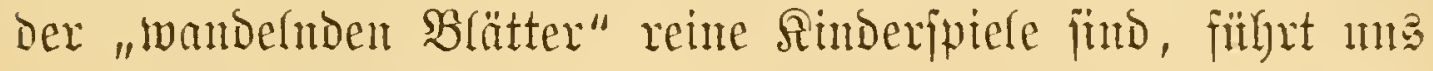
Die indijche Kallima inachis mo bie malatifice K. paralecta vor Afugen.

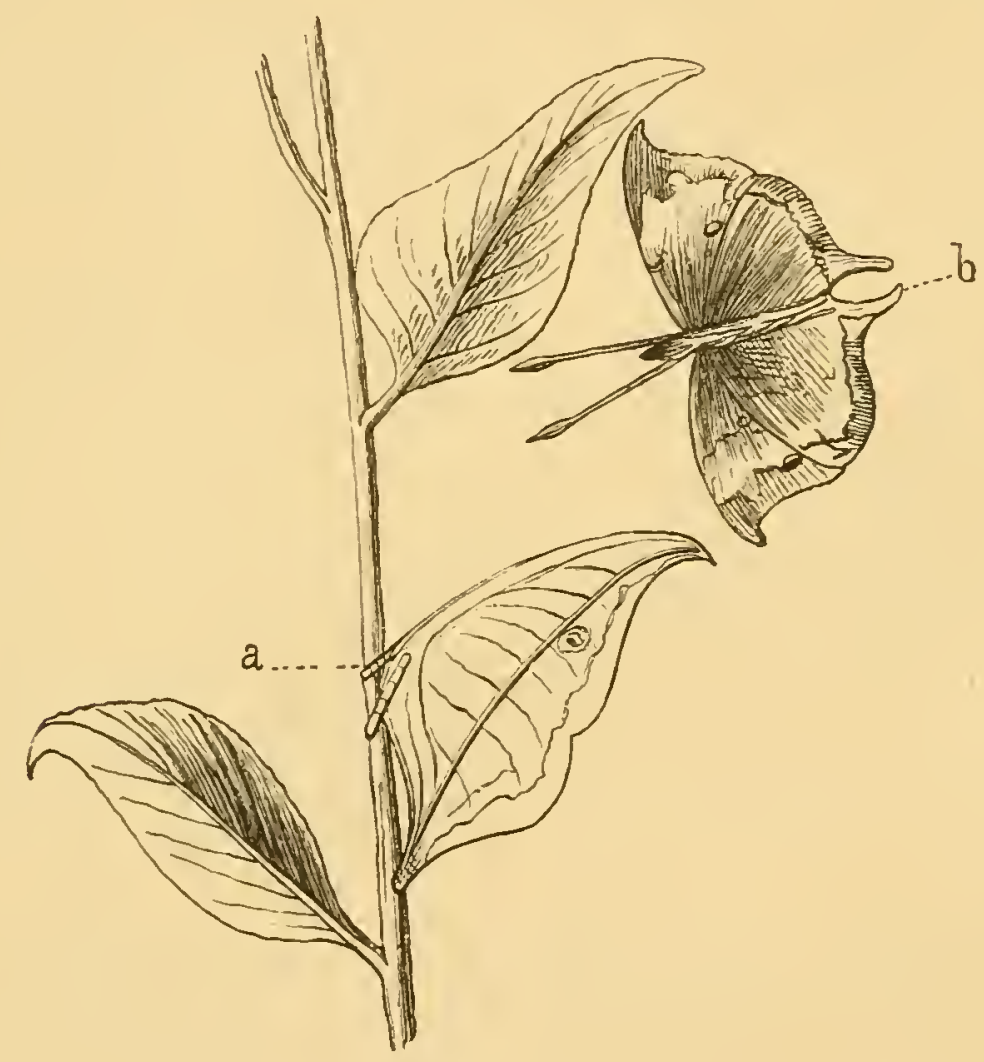

Fig. 11.

Blattjumetterling aus Eumatra (Kallima paralecta) in halber GiröB̈e. b fliegento, a mit zujammengelegten flïgeln auj eincm belaubten 3weig jizento.

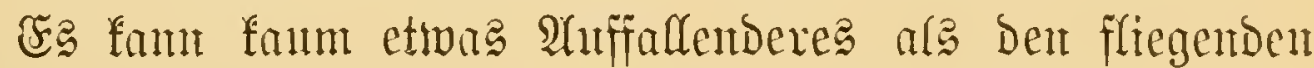

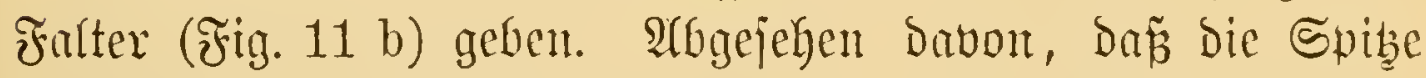

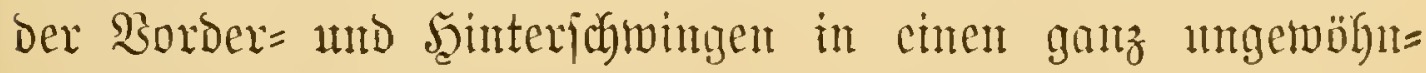
lidyen. Bipfelfortjab maslänft, zeigt beren Dberjeite an eiment hellblanen Felde cin breites Sboldband, das ben 


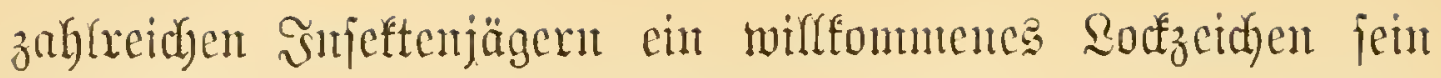

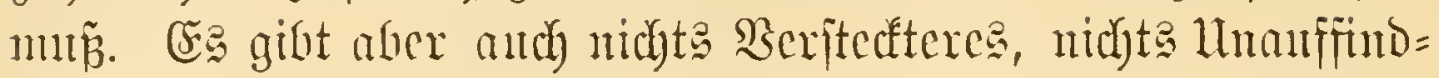

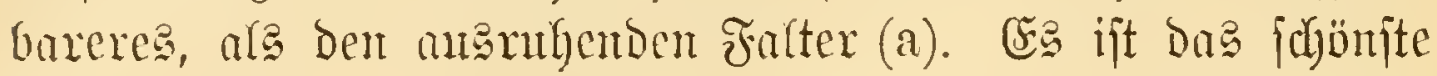

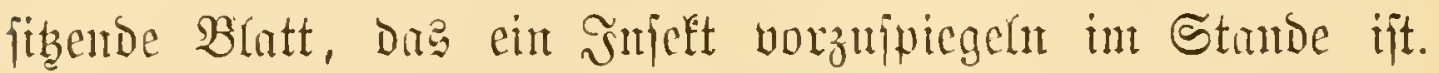

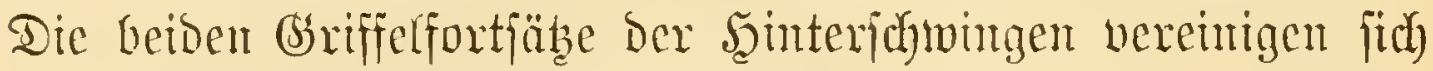

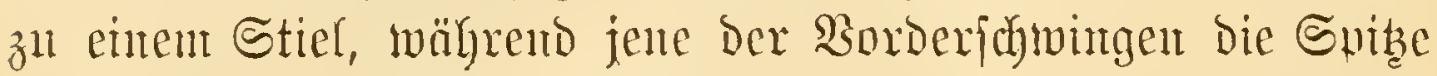
jener wirffidyen Blätter nadyulgmen, zwijd)en Denen Der Falter, Bcine und Fühlex cingezogen, fich berborgen bält. 2(ber bie Farhe Der Flïger? Das fadreiento folorit ifrer Dberfeite ijt vollfommen unjidytbar; bic allein fidtbare Unterjeite aber

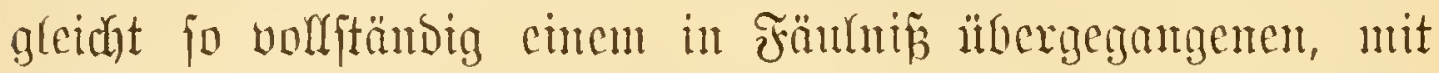

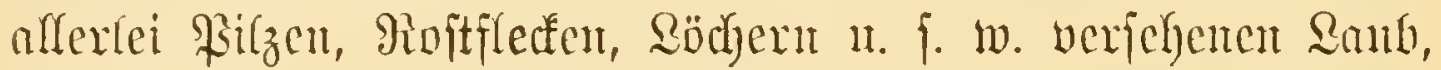

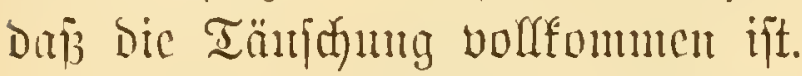

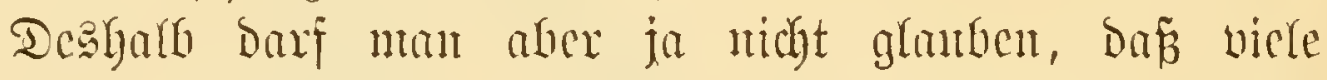

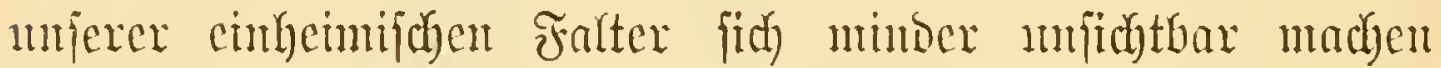
fümuten. So gleidht bic Binfelutotte volffommen cinen getïpfelten trocfente sidgen= uto die fmaragogrüne Thecla rubi cinem jungen Şintheerblatt, wälyend bie Bryophila glandifera mo

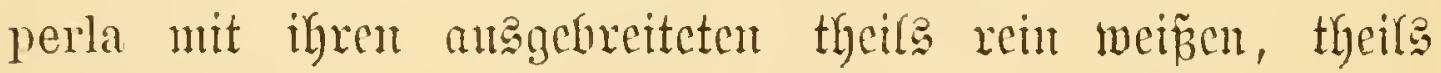

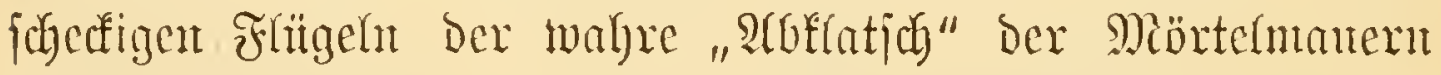

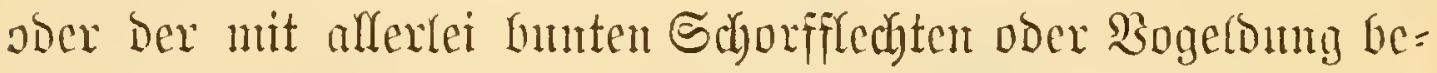

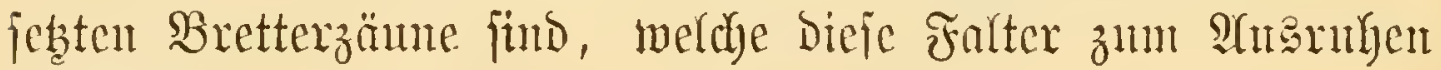
anfinchen.

S(ud biclen Sdhnabelferfen, won Denen zwar bie meiften

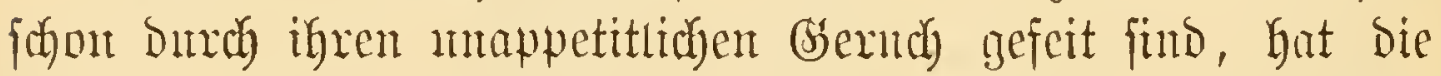

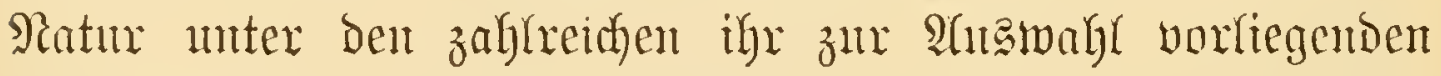
Farhemmitern mu jene gelaijen, welde jie an wentigften auffulfend utadyen. So z. $\mathfrak{B}$. Dem Coreus paradoxus, den Sparimanu boobadete. Er jtand in Schatten eines

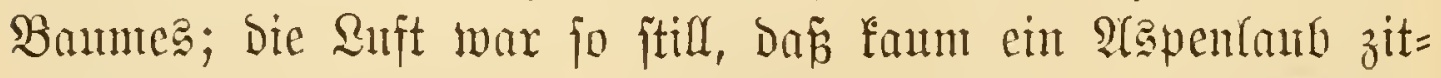
terte; um fo grö̈̈ex wax feinte Bermunderutg, alz ein Kémes

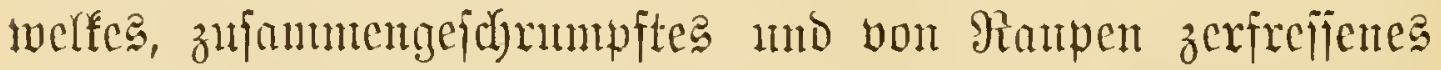
Blatt, wie cr meinte, vont Bante flatterte: unjere $\mathfrak{s a n z e ! ~}$ 
Und jeben bie meijten anf Bäumen lebendent Tingis = ImD

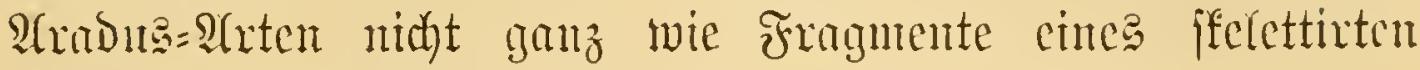

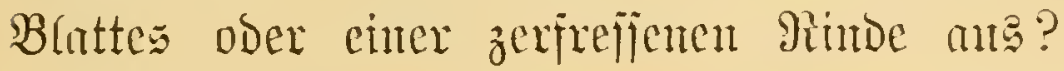

Irber ein wahres Mitfeis crfañt ma, wemt wix jehen,

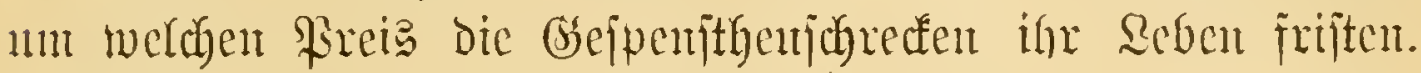
Schon Die Datmatinijhe (Bacillus Rossii). Sie juant zmar

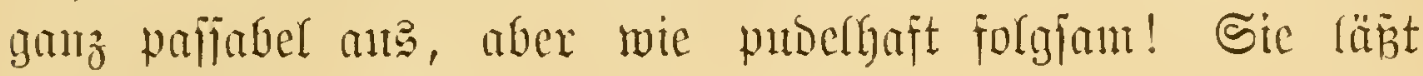

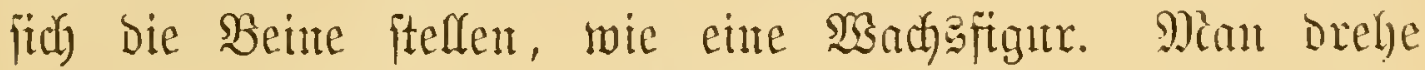
Die rechtjeitigen vor $=$, die lintegfeitigen rücfwärts; man frïmme jie bogenförmity; ntan itreffe bie Mittelbeine gerabe alls, dan jie roie zmei Drähte jenfredyt von Rumpfe abjtehen: fie jtebt wic cine Statue, jie gefordyt wie eine Marionette. Wir haben um ein joldes Thier viel Summer gebabt - wir

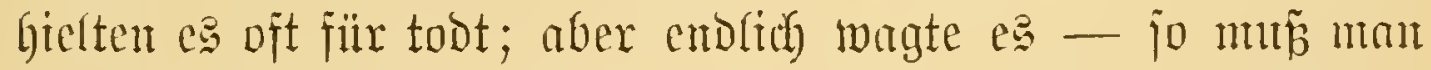
jagen - dody, wieder ein Rebengzeiden von fid zu geben. Und von ben exotifach Stabgentidgreffen begreift man foum,

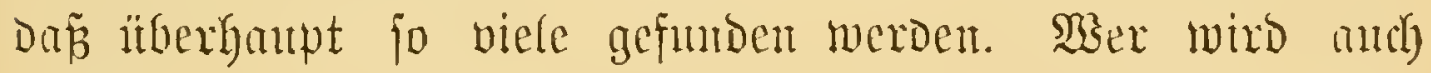

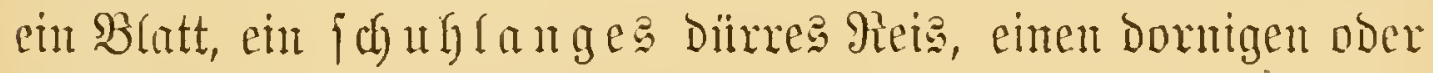
gor (Ceroxylus laceratus) cinen mit Sriechmoos berwadjencm aljt fïr ein lebendiges s\$sejen halten?

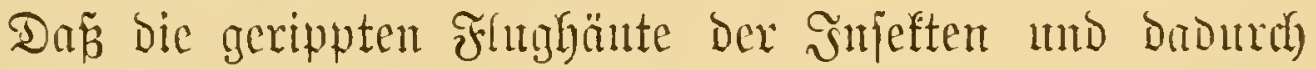
Die Rebteren jelbit Die Bsejtalt cinte Blattes antelumen fömen,

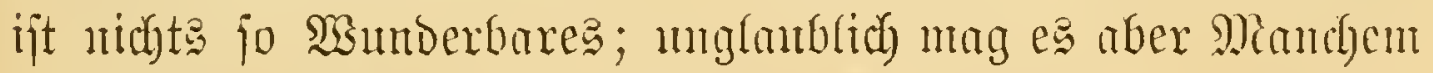

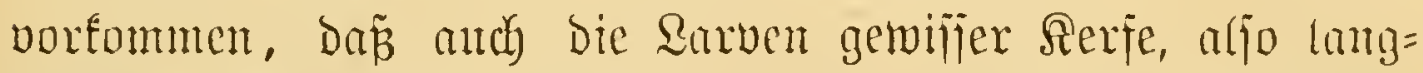
itrectige murmartige $\mathfrak{s e j e n , ~ c i n e r ~ a ̈ b r t i c h e n ~ B e r f l e i d u n g ~}$ fäbig fino.

SEem man bie erwadjenen naften Ranten gervifix

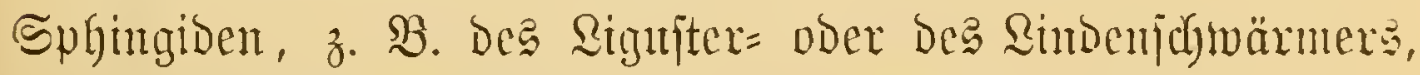

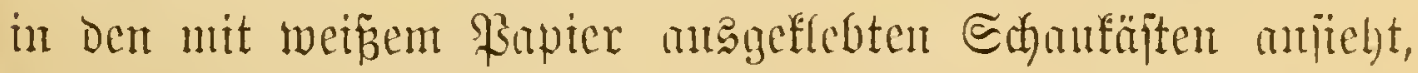
jo meint man, Dar ca foum ctwas Bunteres geben fömus, und Dañ bieje lebondigen Furbenfäjtchen, dieje mit ben grell= farbigiten Sä̈nbern, Streifen, Striclyen und filcren bemalten 


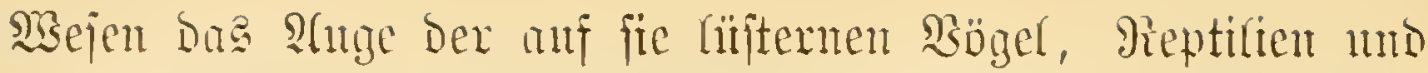
andern Feinde in hohem Grande auf fich zögen.

Mie ganz mbers jehen aber bieje Dinge anf ihrem

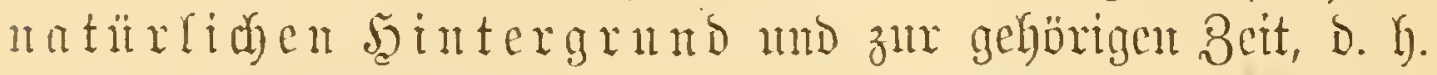
im dänmerigen Bwielicht, ans einigex Entfermung betruchtet, ans! Sic fint ihrer llungebung oft jo gennu angepañt, Dañ

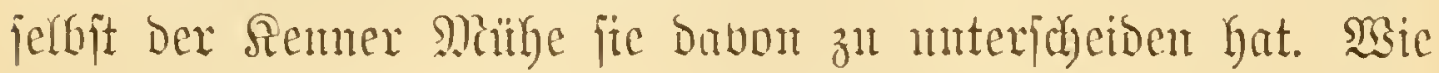

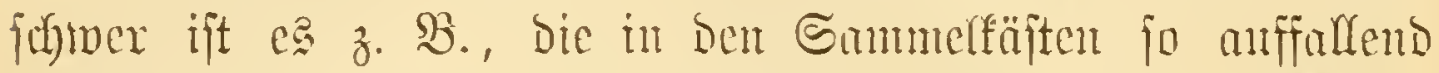

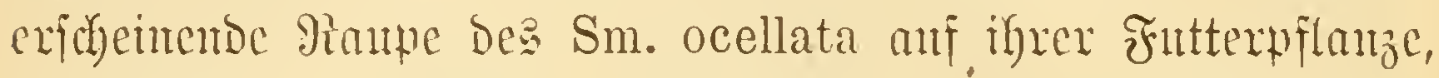

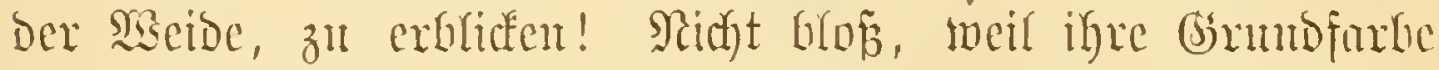
nit der ber Blätter übereinfinment, fondern noch mehr beshalb,

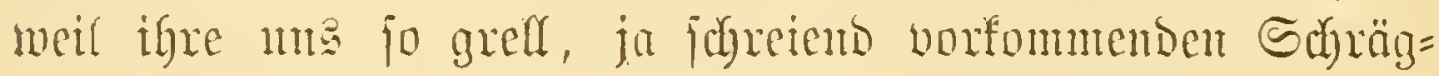
ftriche anf bas gentulejte die Rippen Der Meidenblätter mo Deren Salagidatten an in antroger Meife, wie bie weituerbreiteten Sängajtreifen der Sutyriben=, Bieriben= umb Secperisen = Rampen gleidffan bic ichntalen Stenget mo Blätter Der Srräfer mo Crmeiferen miberipiegeht, auf benen fie fidh aufgalten.

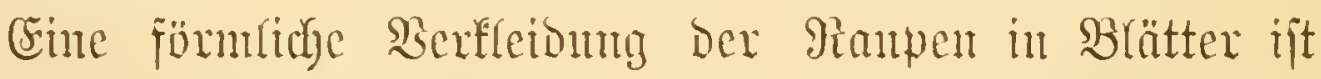

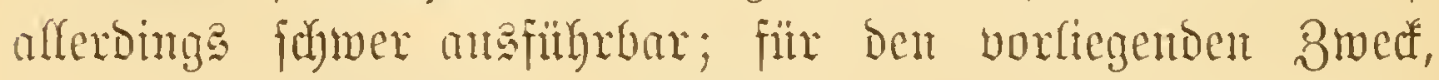

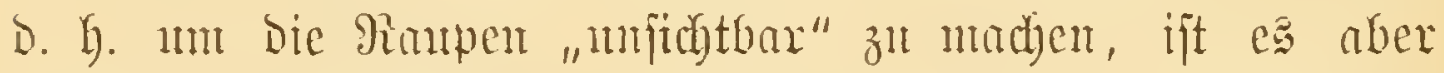

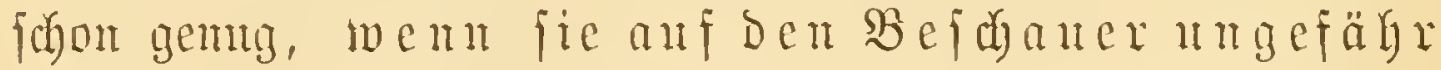
Die

Nod) anziehenter als bus Stmbium ber fertigen Raupen=

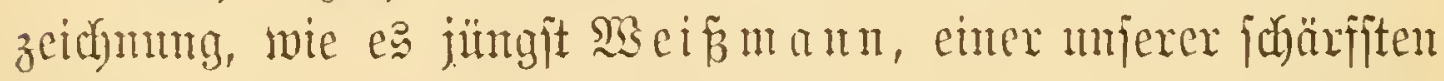

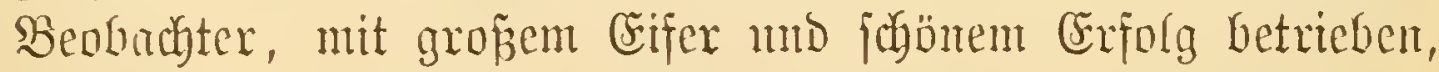
ift bas ifres allmältigen Serdens mo ber an ifnen gleidjan

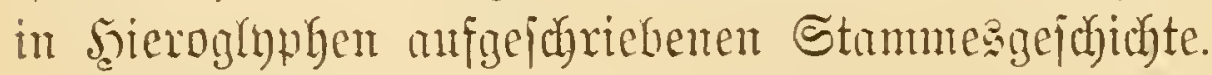

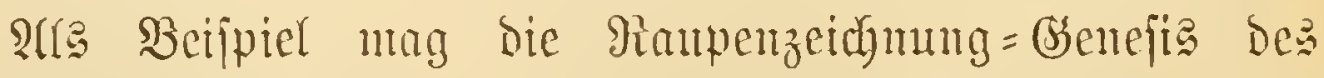
留cinfihtuärmers (Chaerocampa elpenor) hier ftelyen. Dic

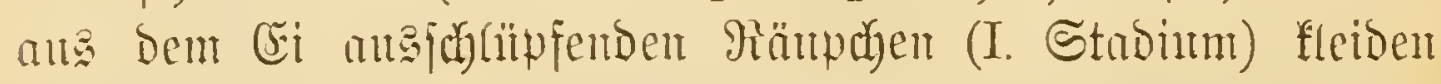

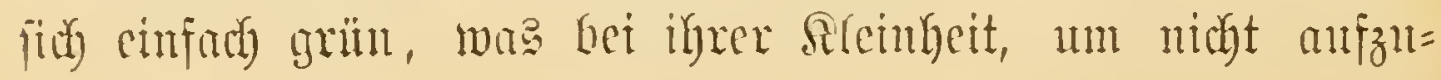


fallen, aud volffoumen ansreidgt. SRard Der erjten Şäutuntg (II. Stabium) zeigt fich beiderjeits des gitufens ein tweipes

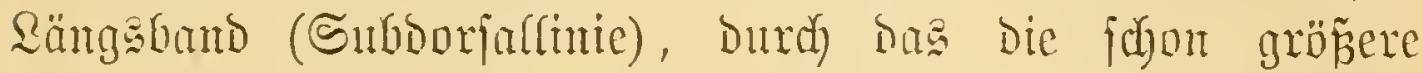

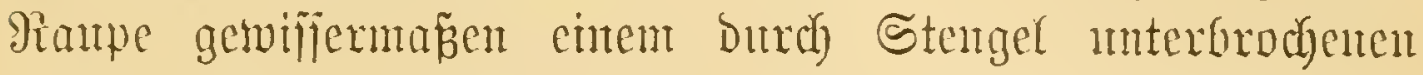

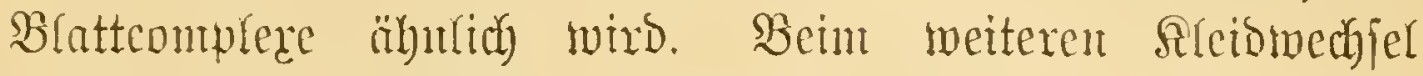
(III. Etabium) jchminden dieje Bänber wieder, und ans ifgren Heberweften entiftelgen anf Dent bierten uns fïnften Reibesringel die befinntent ms einem Dutfeht Rent, einem hellen Spiegel=

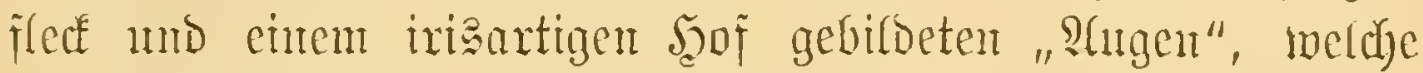

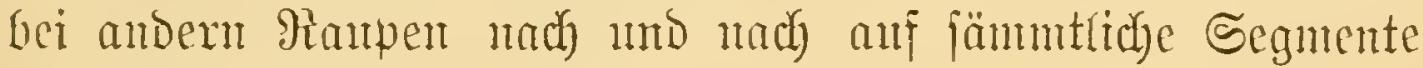
ïbertragen weroen.

Das Lebrueiche an ber ganzen Sache ift aber midyt allem

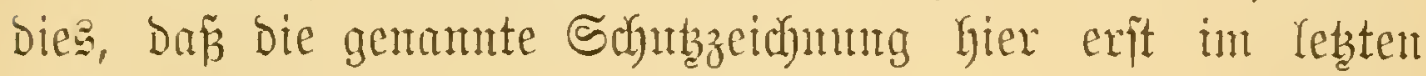
uto am längiten dauernben Stabium anftritt, wo bie fajon

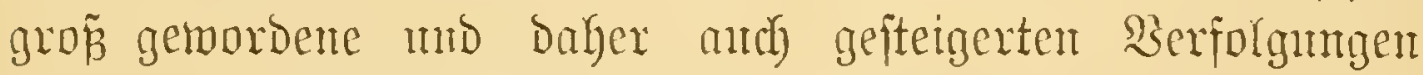
ansgejeşte Fante biejelbe am nöthigiten hat, fondern nod

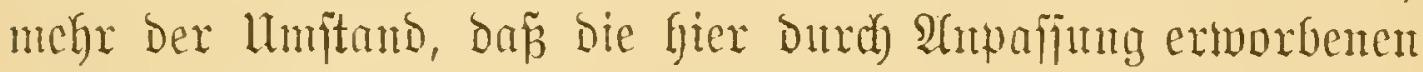

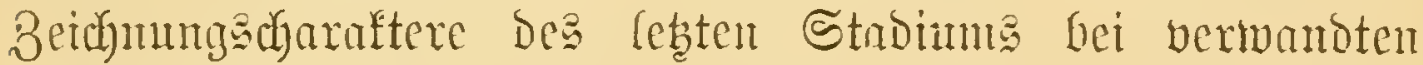
Shten mb Brattutgen joun in fritheren ober jüngeren Stabien firic einjteflent. So fommt Die Ch. Syriaca fodon mit Dem

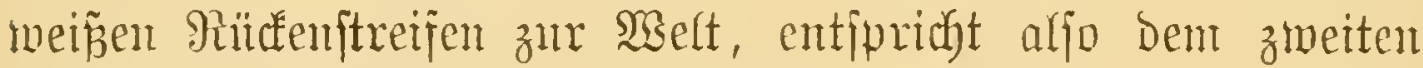
Stabinm von elpenor, während Ch. bisecta bic $5 \mathrm{r}=$ rungenfigaften bes febeten elpenor-Stubiums, näulich bie ge= wijien ?zingflecte jogar jobon int exiten an fich trägt.

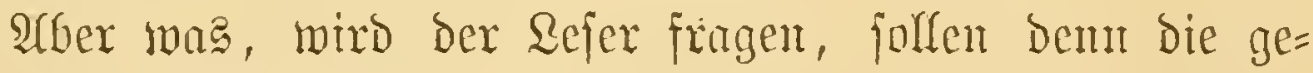

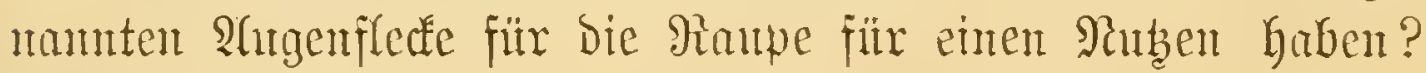
Ex ijt hantogreiffich.

SEem ntan bie betreffenden Thiere reizt, fo ziehen fie Die orei engen $\mathfrak{B}$ rufitringe in Dag ertweiterte vierte Segment

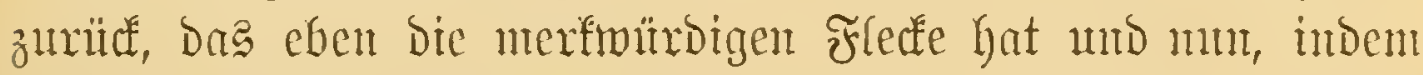

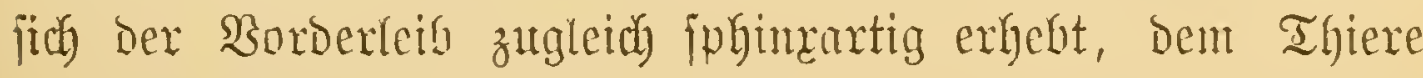

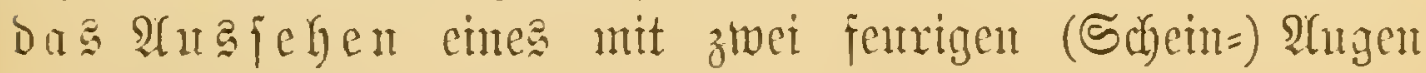
verjebenen llngeheners verteigt. 


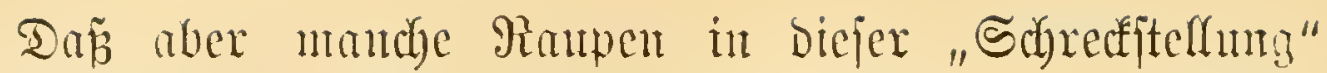

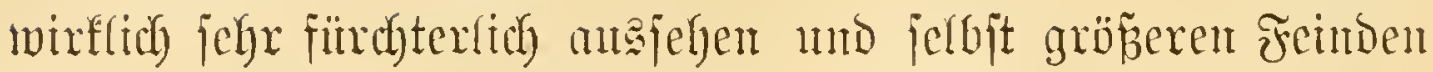

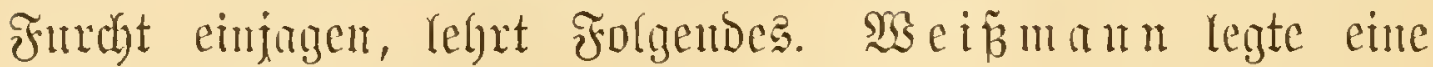

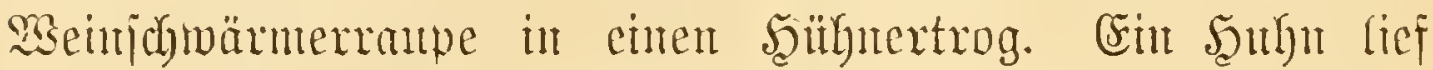

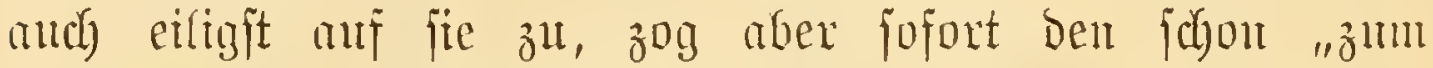

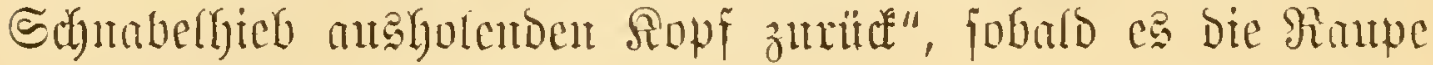
in Der Siälye erft recht anjah.

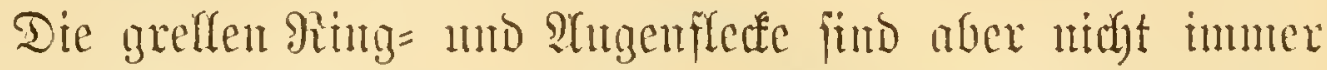

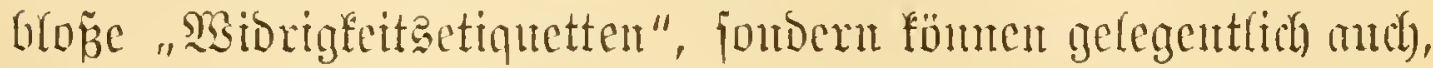
fo gut wie bie Räntge = Imb Duterbämber, in bie Rategoric Dex

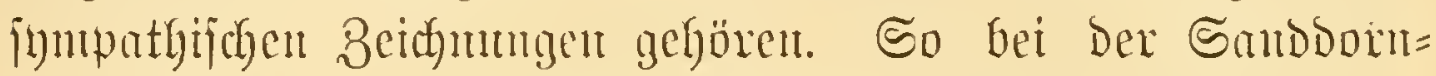
ratpe, dic ique pomeramenfarbencu Seguent= flecte exit daun befommt, went die Beereu ber Futtexpflauze jid gelb färbeu. -

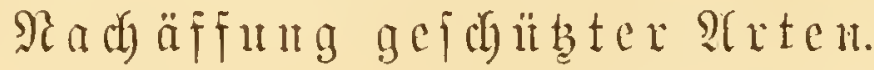

Saemt dic Ratur, wie twix an Papilio memnon faben,

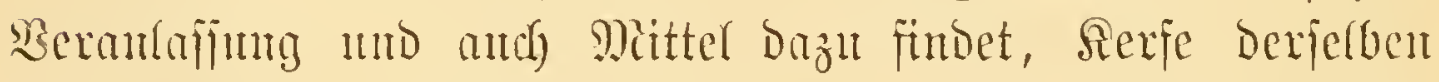

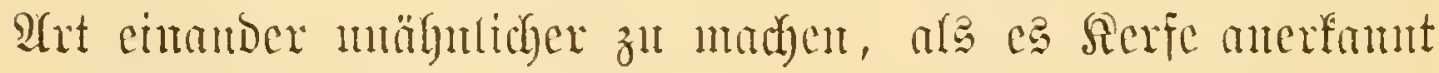
verfactedener Species find, jo wird mant ifre fitherfich and nicht bie Fäbigfeit abjpredyen, Den entgegengejebzten Para=

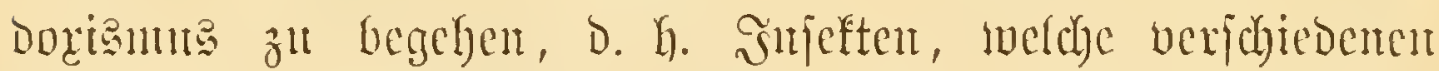

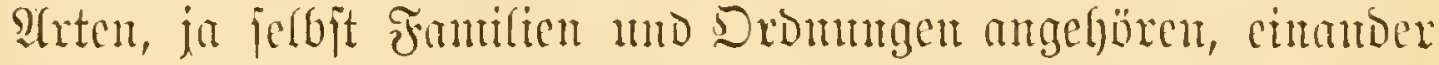

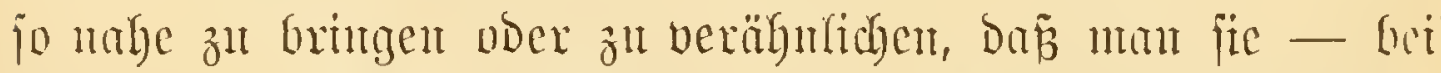
flürbtiger äup̃erer $\mathfrak{B e r g l e i c h u t g ~ - ~ a l g ~ S u g e h o ̈ r i g e ~ c i n e r ~ m o ~}$ Derjelben ât hiumehnen mag.

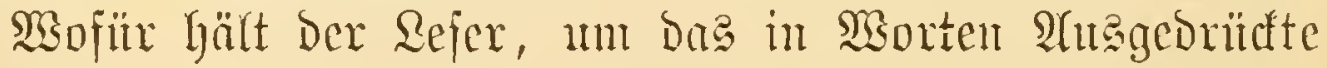

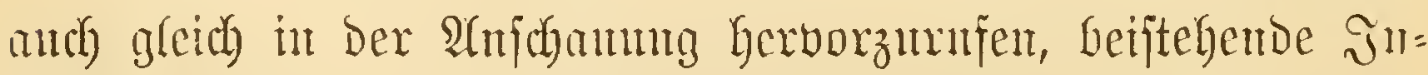
jeften? Ssemiás fïr Sdymetterfinge. Das erjte (Fig. 12 A) ift aber cin Nebeflïglex, alfo cin Berwander der Scafte und Sibellen, Das andere aber (B) ift ein Echnabelferf, eme

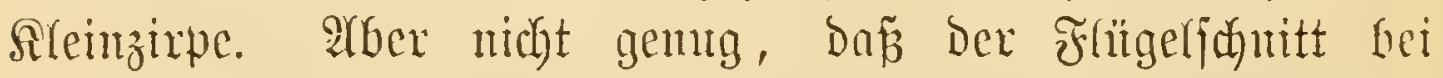
Beiben etwas Falterhaftes hat, Der Nebflügler und bie Birpe 
almen jich twieder unter cinamber mady. Die Contouren ber

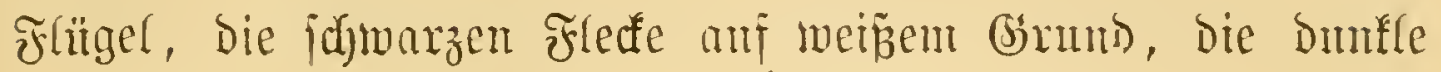
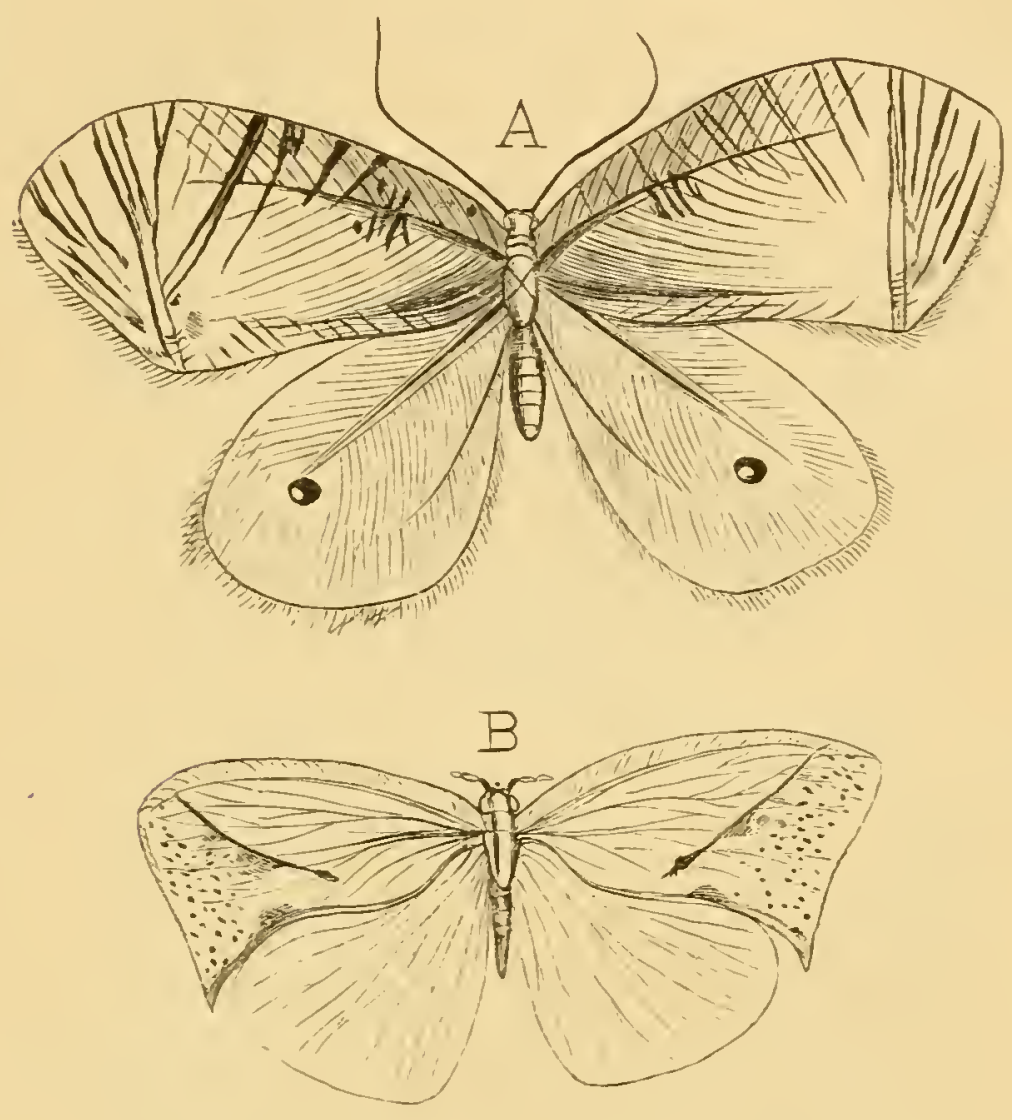

Sig. 12.

A Ein Reţfïgler (Psychopsis mimica). Wiener Şojmnjeum. B Fine (5icadide

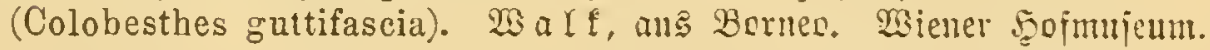

Duerbinde, âfes wieberholt fich, und bie llebereinjtimnung ijt complet, wem bie Frlügel wie bei einer Miotte an Den 2 eib angelegt find.

Wie fommt bie? Die Eridjcinnt fam eimen breifachen

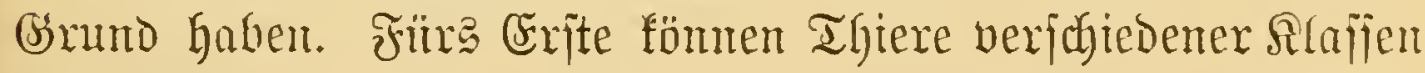

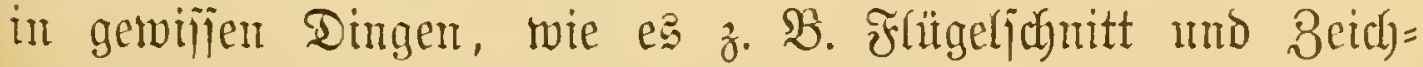
mung ijt, einfach deghalb überciritimmen, weil ifnen dex

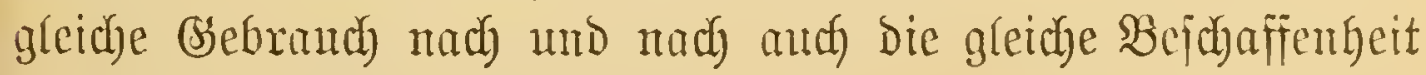

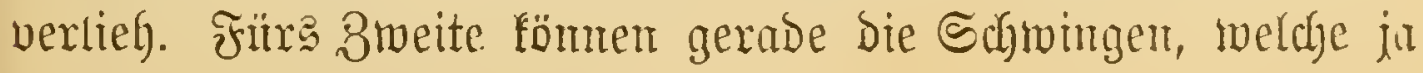

(j) $\mathfrak{x} \mathfrak{b} \in \mathfrak{x}$, J゙njeften. II. $\mathfrak{B} \mathfrak{d}$. 


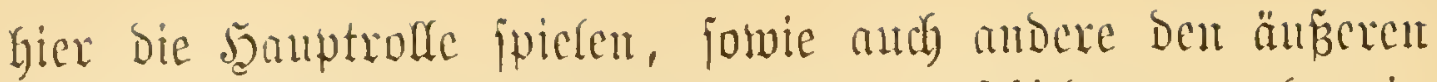
Jabitus bcitimmende Theile zweicr verichiedenter, aber in

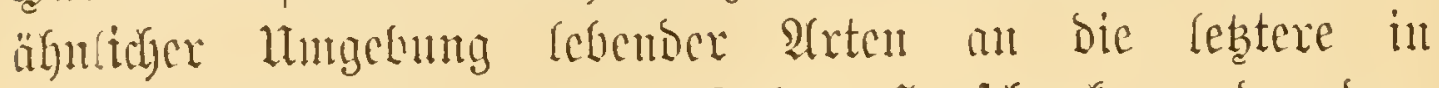

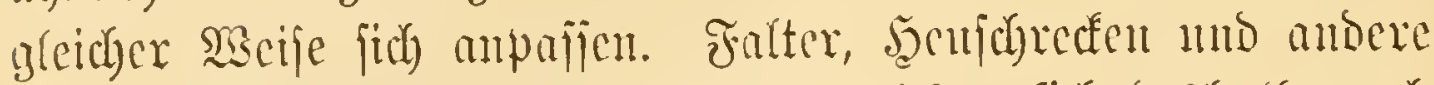

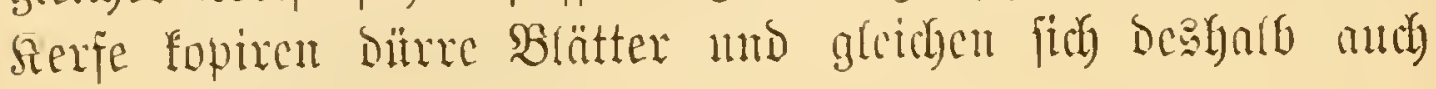
unter cinander.

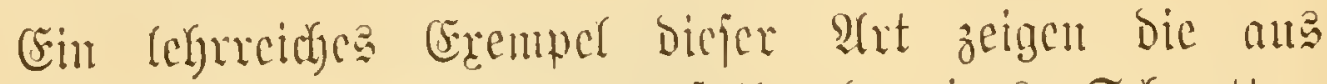

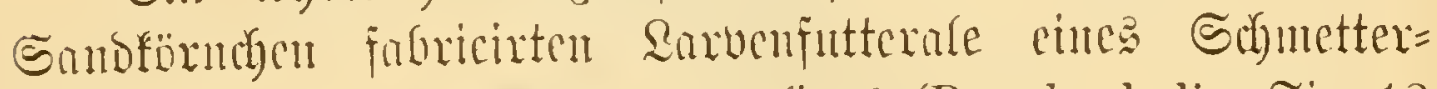

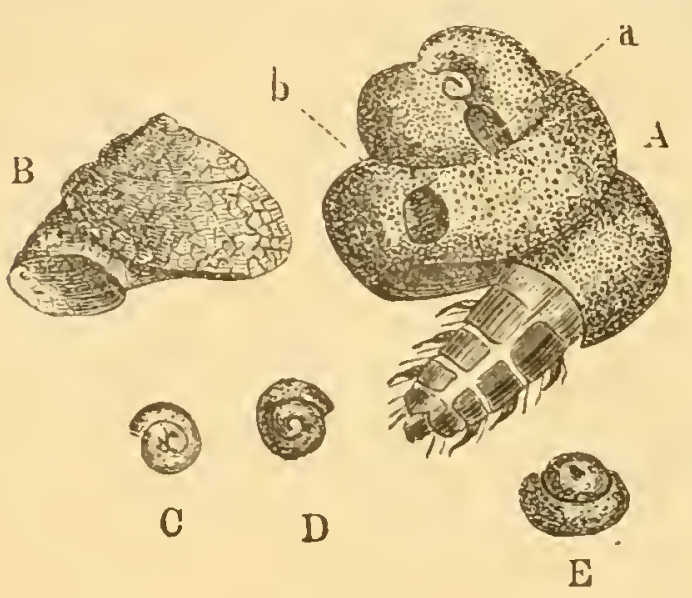

ชิig. 13.

D Rampenjauf von Psyche helix sieb., rat.

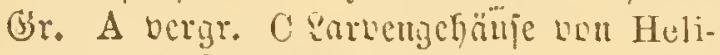
copsyche Shuttleworthi Br., mat. (br.

$D$ vergr. (nad) $v$. Siebold). fing: (P syche helix, Fig. 13 A, D) und riner Frïlfing: flicge (Helico psyche Shuttleworthi, Fig. $13 \mathrm{~B}, \mathrm{C}$ ), wovon exitere an fteinigen $\mathfrak{P l a ̈ b c u , ~}$ retztexe im șajicx (j. B. im (5) miferfec) vorfommen. (5. find contete Sillueften= \{äufex, mux Das cine redyt:,

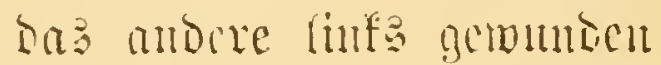
mo mite der Epibe (a) mit

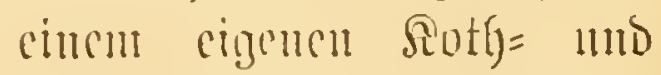
zugleich Fraglodi) verjelyen,

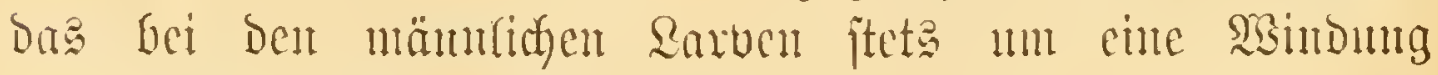
ticfer liegt.

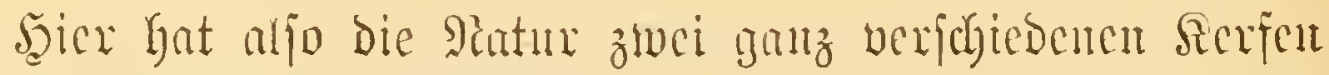
greiche Feftungen angezundutet.

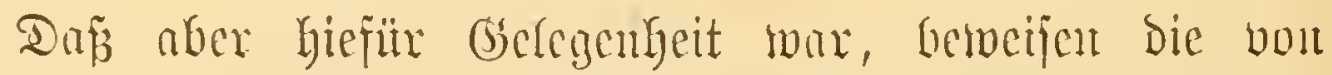

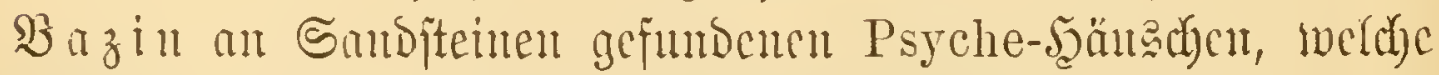

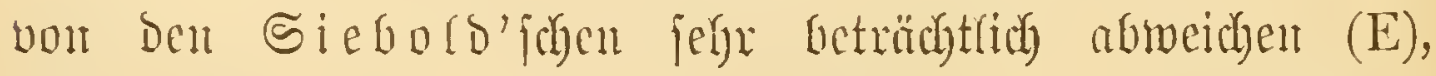
forvie Denn anth b. Sicbold jelbit fie "anjerordentlib" bariatiel ment. Waen trobsocm cin Schmnrober (Chalcis nigra Koll.) 3ugang findet, Der buref Das Roch b entichlitpit, jo ipridgt bies mur fïr bie Rfriffigfeit bes lebteren. 


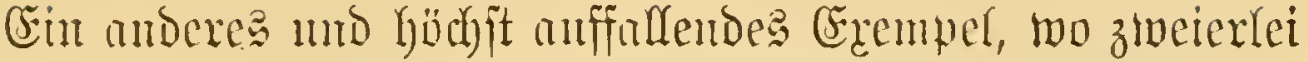

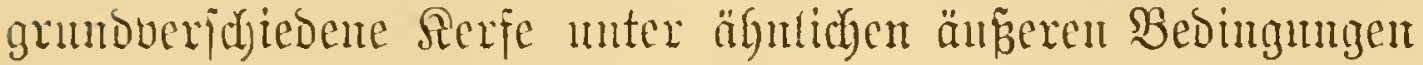

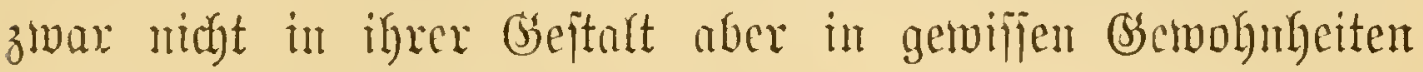

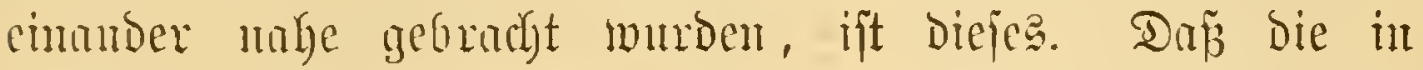
Fing. 14 vorgeftellte Rarve des âmeifanlöwen burch eime

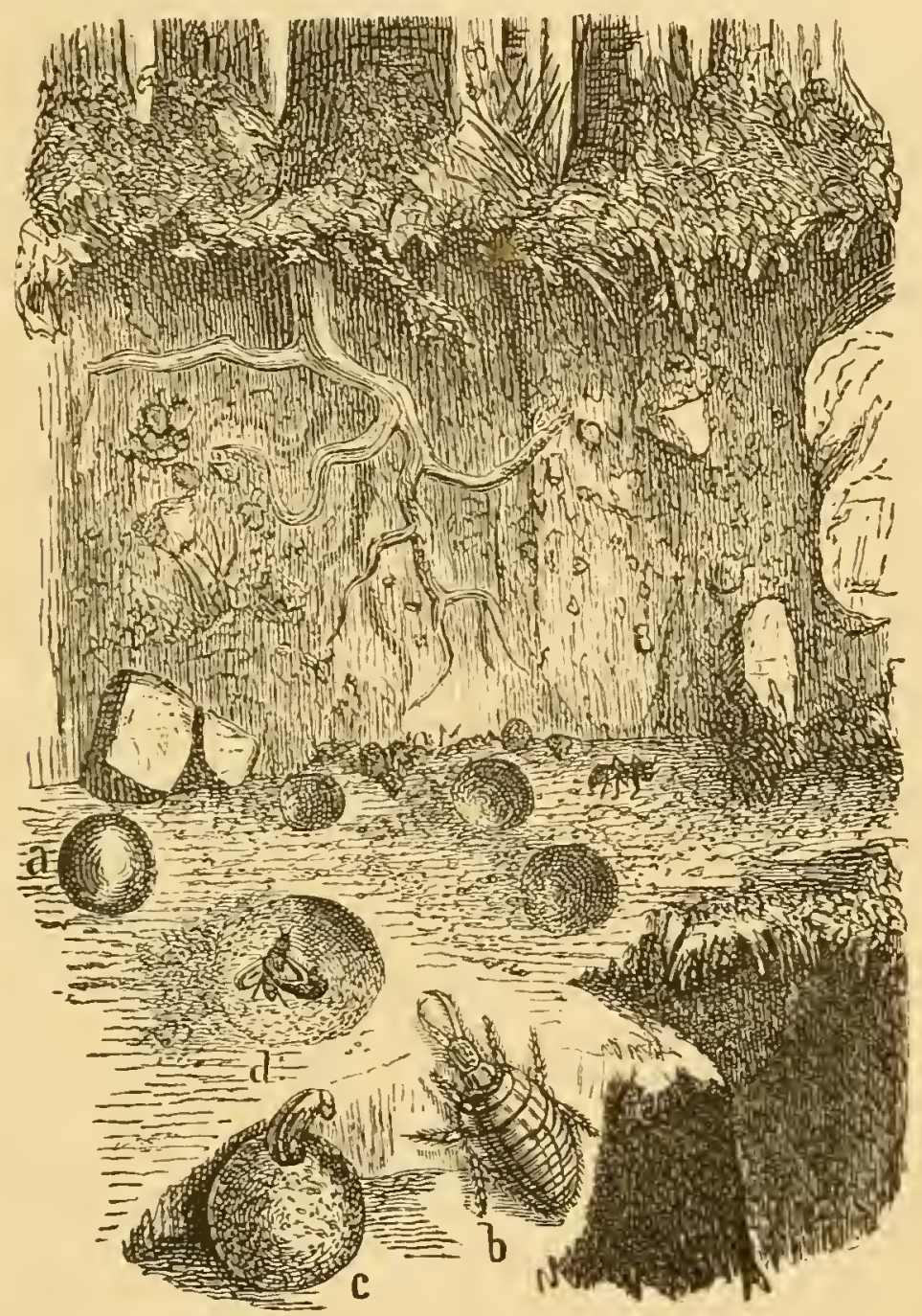

jig. 14.

Zur Sebenggejdidhte Des Mmeijenłötven (Myrmecoleon formicarius! b Die Sarve in nat. (Sr.; a fein Santrixter; in d trie er mit ber fiefergange ein Serf ergrcift; c fiuppe desfelben, beren fugeliger Escon äußerlid mit Gand infruitirt ijt.

Beife nicht io ferneliegendor limitände dazll veranlä́t murde, anjtatt nad) Beute hexumzu(anfar, biefclbe iu

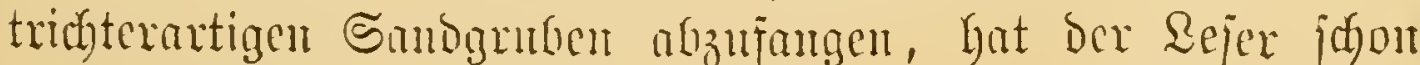




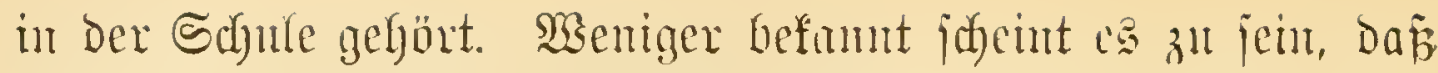
die Made enter Fliege (Leptis vermilio, Fig. 15) gentu sie= jelbe Jnouitrie betreibt. Ces ijt nu jo

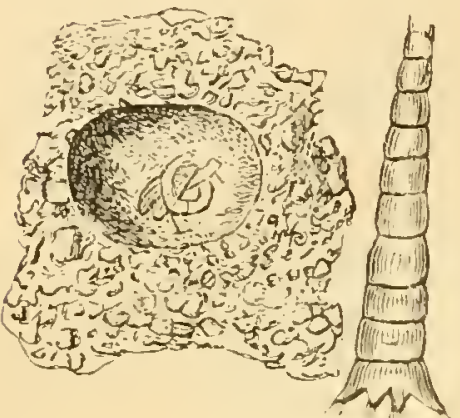

శ̧ig. 15.

Leptis vermilio, redts vergrößert. merfwürdiger, ba ber lesteren alle die zun Eandgraben jo gejeridten Љand = twerfagerätlye des aneijenlömen fellen. woun fie and ganz toolyl in Etumbe ift, Die un ibre Iridfter geratgenden Serfe mit ifrem langen biegiamen

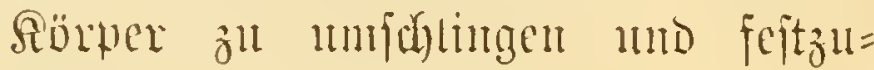
b)alten.

Die lebten Beijpiele mathen mas arjo anjerantidy, wie

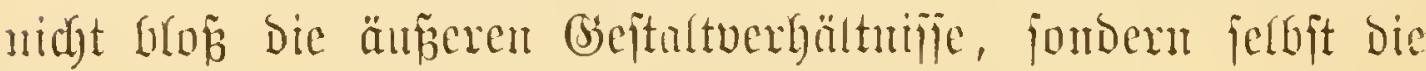

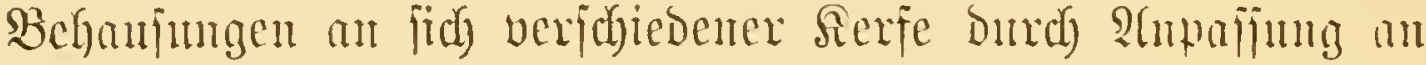
ähnliche Dajeinsbedingnugen cinntocr gleich werden fönnen.

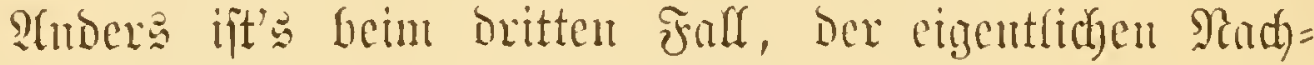

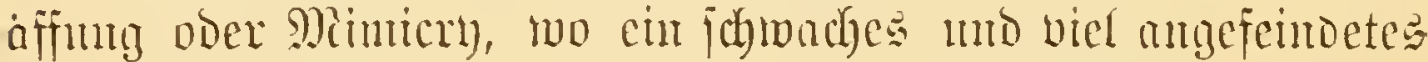

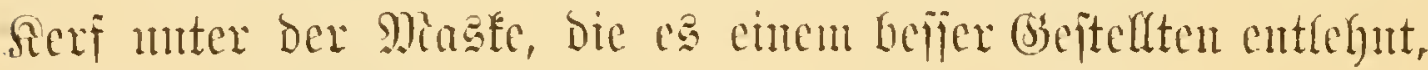

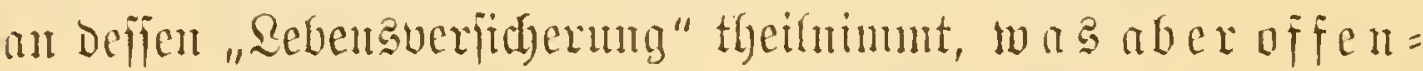

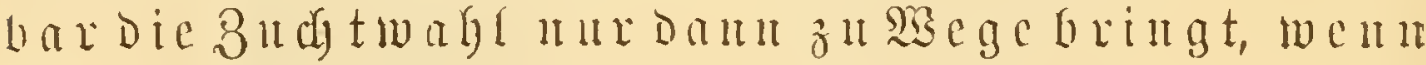
die betreffender $\mathfrak{T}$ giere fdou bou geatux a

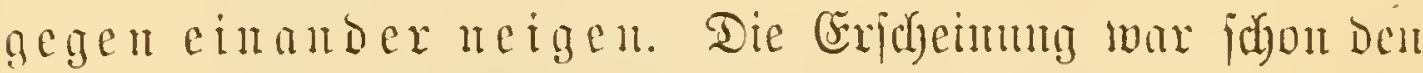
ärteren Sentomologen befamet, ijt aber exit burch $\mathfrak{B}$ a tes mo gisalcace den Publifum veritündlich mo geläufig worden.

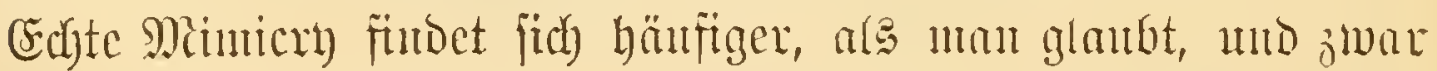
bei alfen Dromungen. - 3 ben bänfigften Tagfalteru હün=

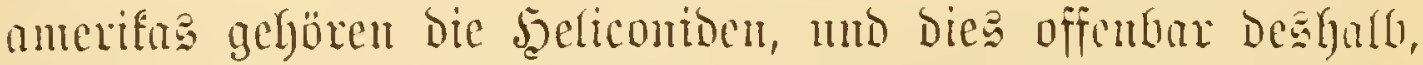
weil fie trob ibres fummelfaft=langjanten Fuges von Den

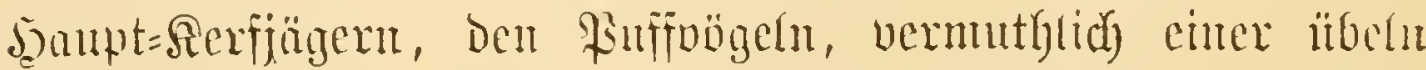

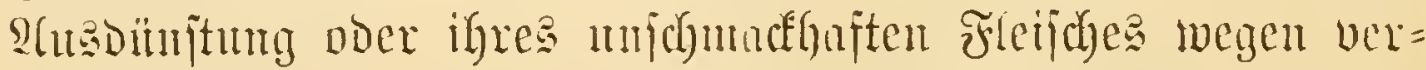

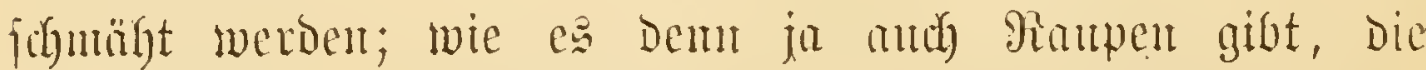

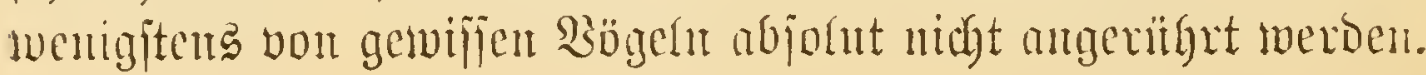


Falter ciner andern Grmpke, bic biefen Seeliconiden gliden, möroen aljo, ferbit olgne beren miderlidye Eigenjuaften, glecthfalla ungeitraft herumfiflegen fömen, falfs jie an 3 athl bedentend geringer wären, und fo von den anf Den 3 weigen

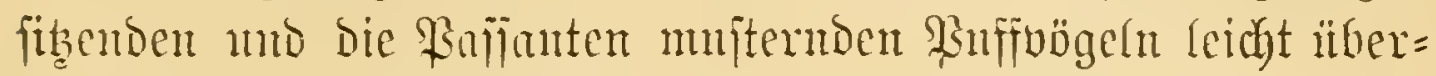

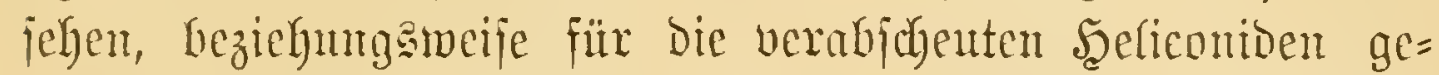

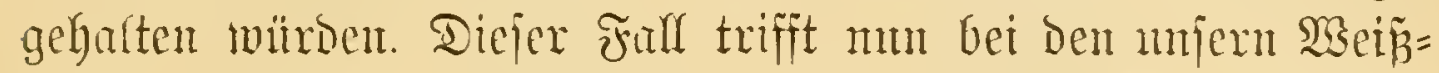
lingen nabeitebenden Reptalioen wirkfich zu. Die einzelnen

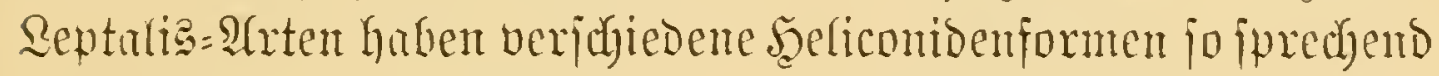

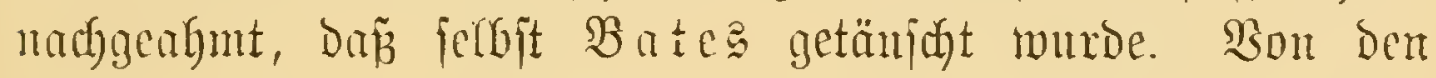

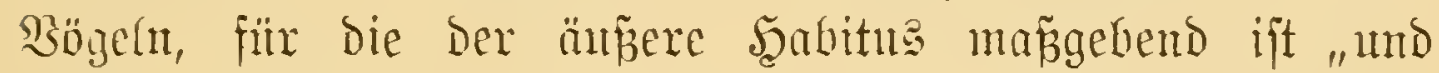
weldye nicht Den cingelnen Fall priffen", find jie mmpnefyr verichont, als fie unter ber Menge ifrer Morbilber fait ver: ichminden und and Deren Flugmeife angenommen haben.

Hebrigens fopiren fitc bie Selicontoen and unter eintantor geradejo wie getwijie Rapilios. P. romulus z. B. fliegt im Sicide Des P. hector und wurde früber fïr defien $\mathfrak{s e i f}$ ge= halten. P. liris und aenomaeus, zmei jehr biftulfte Arrten, find fanm in Der Sanmlung, geformeige im Ffung zu unter=

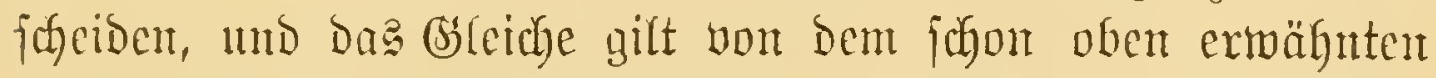
P. memnon und cöon. Mantbe Papilios find aber ferbit Plagiate uto zmar gemeinjan mit Diadema-2Irten von Den

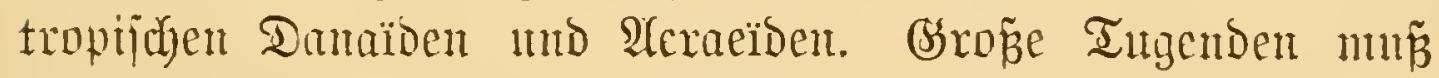

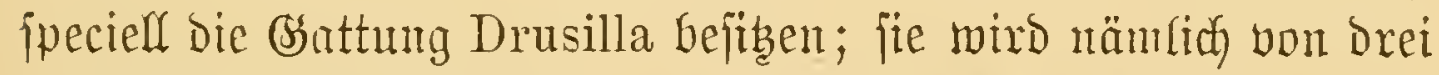
(Gejulectetern: Melanitis, Hyantis umb Papilio fopint.

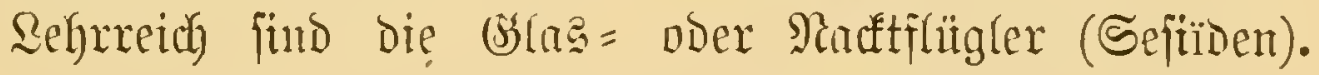

Die Ratux hat ihnen alfmälig bie Schuppen genommen, um jie saburch gemijjen andern itets nactiflitgeligen smieften, meldye Durch Den Bejü von gefährifichen Stedyinjtrumenten gegen bielerlei Radjftellungen gefeit juns, aljo namentfich ben

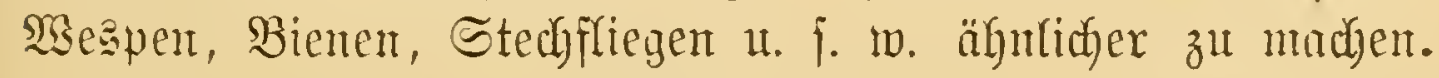

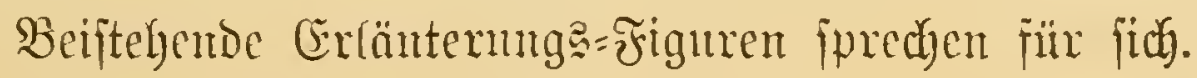


Der SBlaşflïgler in Fig. $16 \mathrm{~B}$ imitirt ben 3meiflïgler in Fig. $16 \mathrm{~A}$, wobei insheịnoere die folbigen Fithler uno

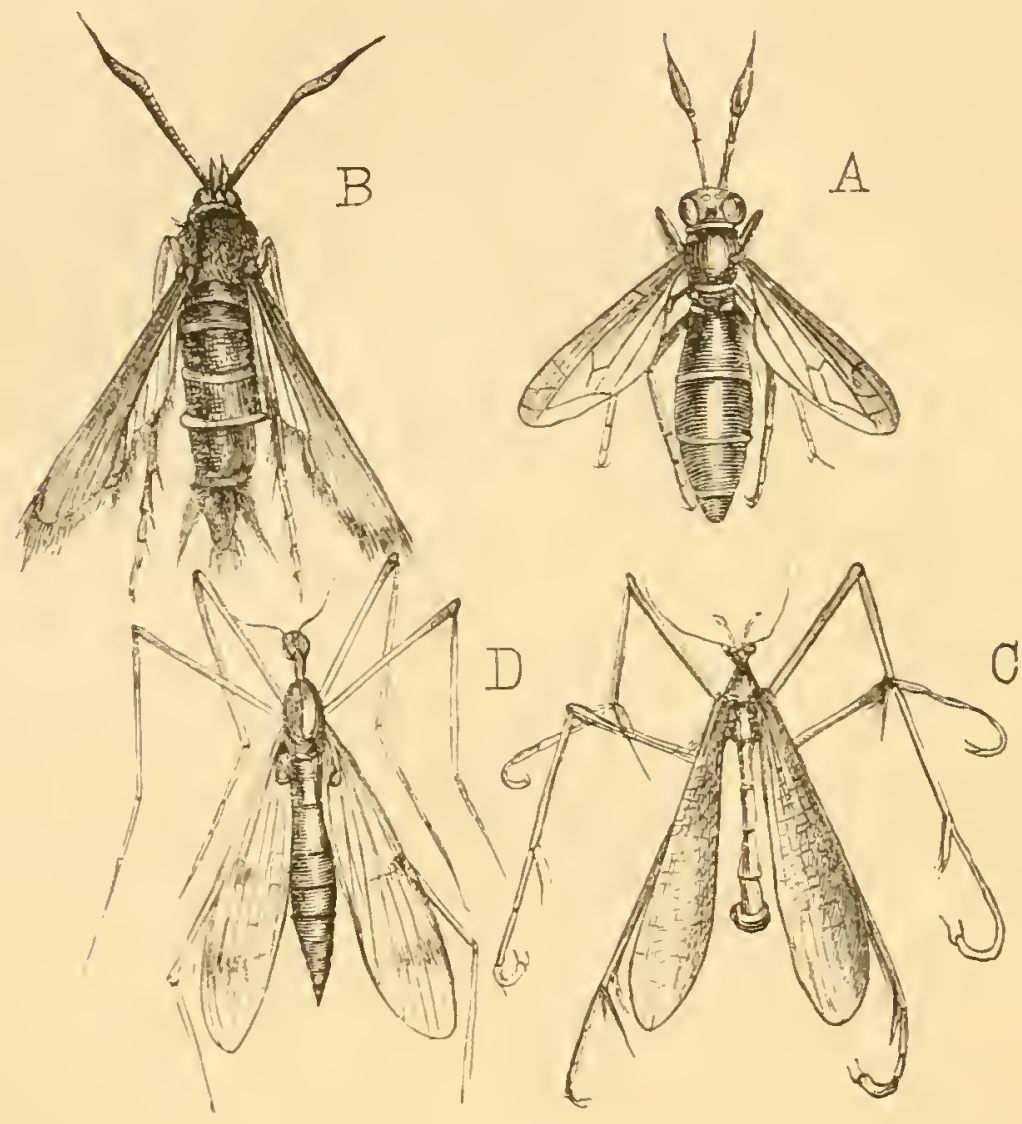

Fig. 16. Bcipiele von Dimicry.

A 3weiflïgler (Ceria conopsoides). B Falter (Sesia tabaniformis Rott), nat. (Sr. C Metzfligler (Psittacus Hageni Br.) D Zweifliigler (Limnobia santhoptera Meig.), nat. (Sir.

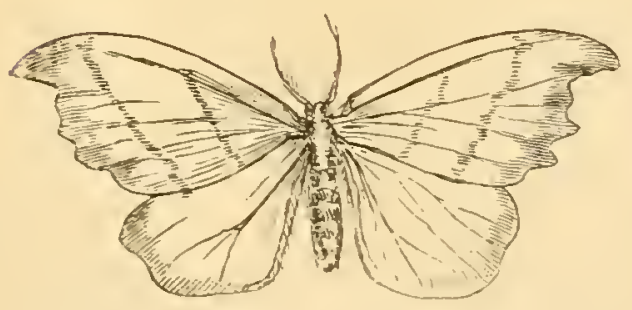

Fig. 17.

Ein ๔pimer, Der fog. ङid)ler (Drepana lacertinaria), nat. Brr.

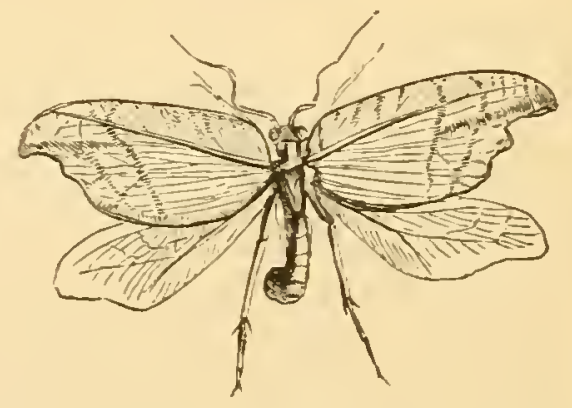

isig. 18.

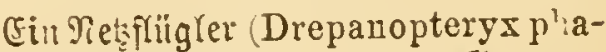
laeroides L.), nat. Brr.

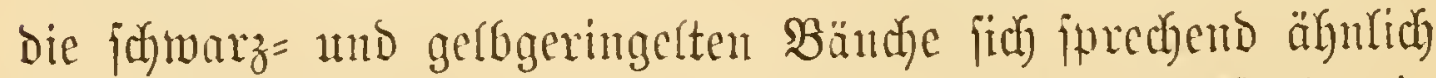

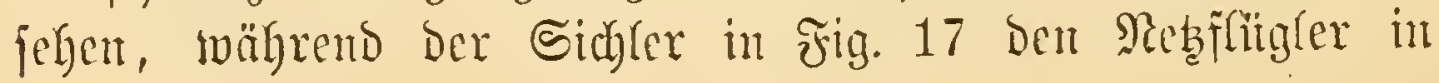


Frig. 18 zum Borbito hat. Man vergleidge bei lebsteren

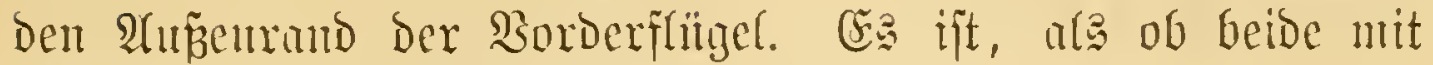
Demiferben Sucheijen auggejdragen wären.

Freilidid roird bie Satur anth einige Beit expermentirt haben, bie e

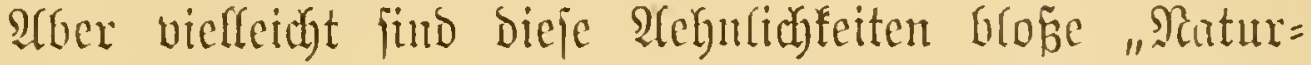
fpiele"? Mhan fömnte dies glanben, went beiberlei Rerfe nidgt wirkfich and in Reben beijammen wären, bie eriteren

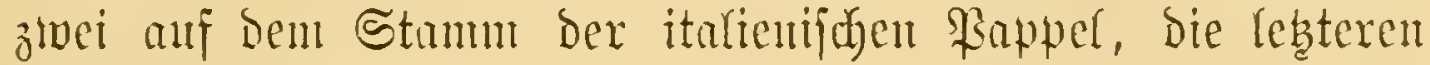
auf ber Mlme.

Had madjoen wir eimual, wentigitens betreffe ber eritern

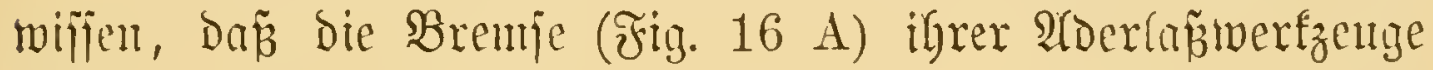
hutber von vielen Thieren gefiurdetet und geflohen wird, jo

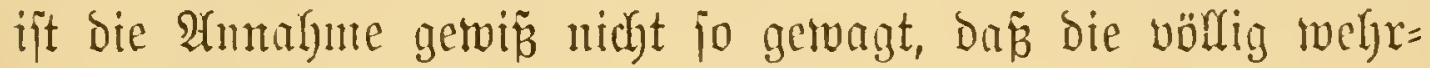

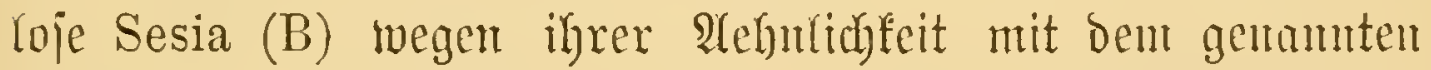

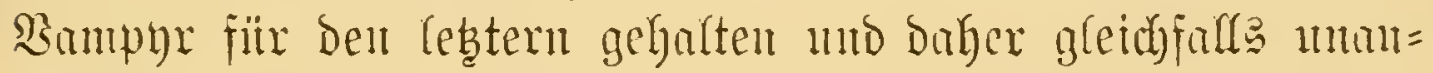

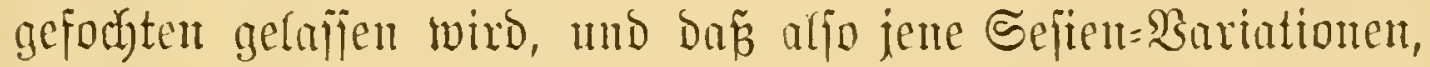

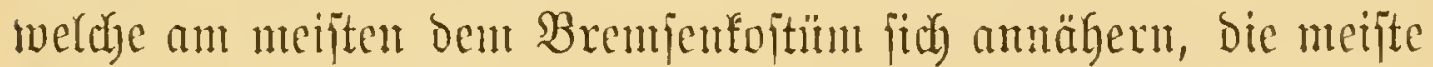

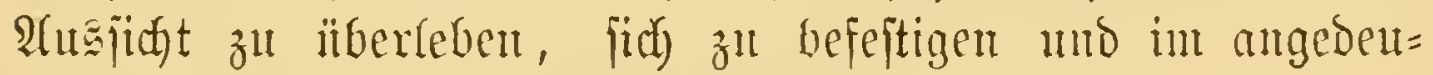
teten Sinne fid zu verbej̈ern haben.

Die Räfer fopiren jid meijt untereinander. So rafien

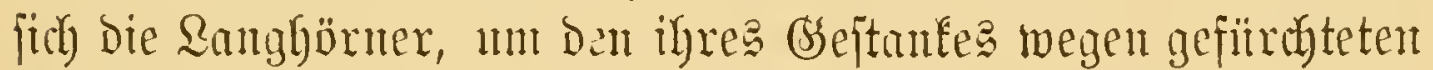

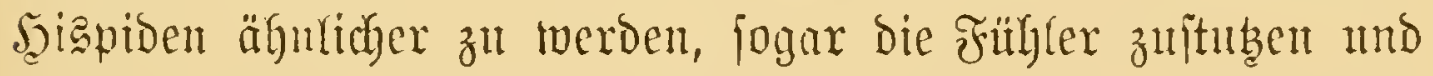
fäulig machen! 2uch ben jteingarten âtntyribiben möbten fie es gleich thum; bejonders aber ben Tigertäferm, bie audh (Tricondyla) unter ben Griflen einen Der merfwuirbigften Doppergänger lguben (Condylodera tricondyloides). Âtr) Sanzen find ans einem naheliegenden Ssrunde ein beliebtes Borbild, [mo cin jübamerifunijher Bodfäfer (Charis meli-

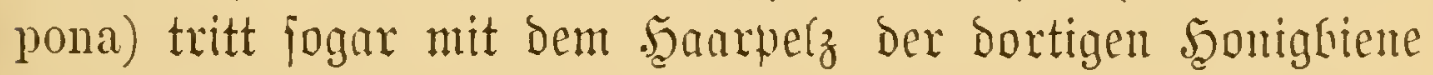
auf, währent ein antoerer Bocf (Odontocera odyneroides)

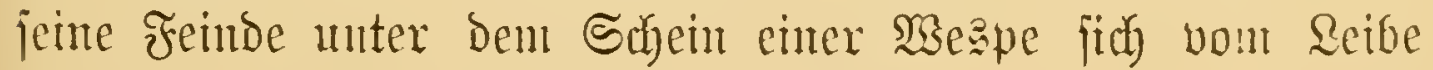
hält. - S⿱ 
jehen, Yehret Die Mergleidyung von Fig. $16 \mathrm{D}$ mit $\mathrm{C}$, weldye

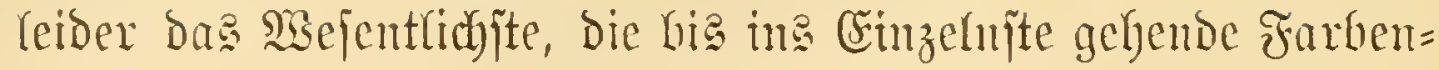

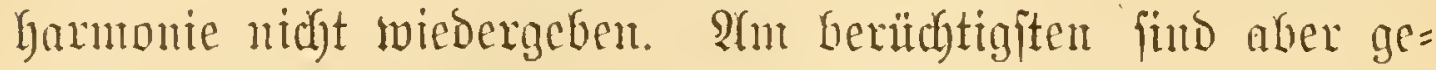

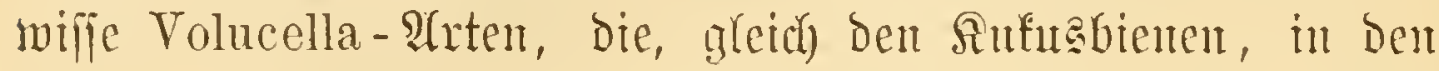

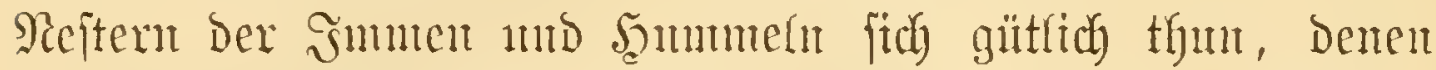

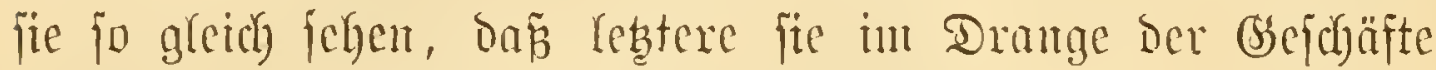
woht öfter für Jhresgleichen betrad)ten mögen! (5s ijt bies Diejelbe Prelferei wie bei gewijien Entbreaspen, weldhe, um ihre Beute, das Grillengents Sphacura, reichter zu ïbcrliften,

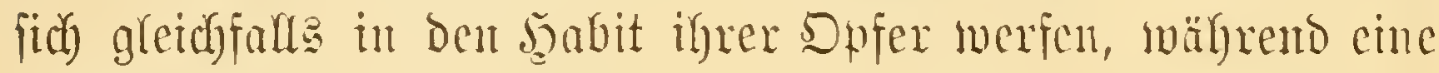

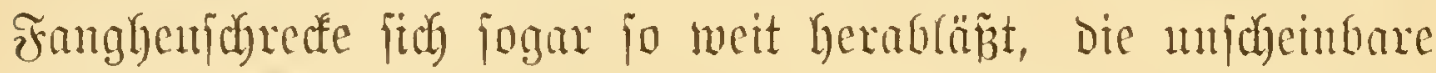

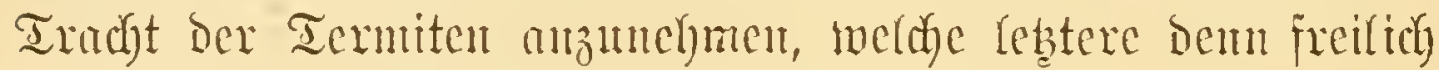
Dieje Controifte thenex gentug bezahlen miijjen. -

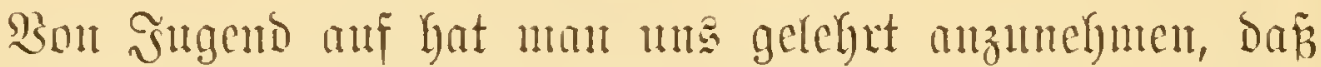

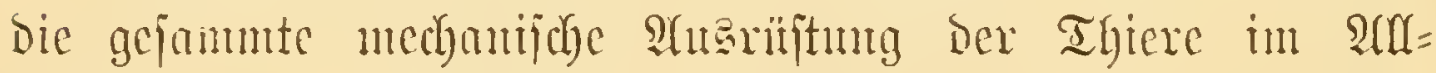

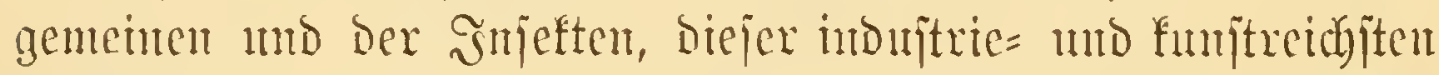
im Bejontoren, fïr das jeweilige Bsejuäft, weldes fie be= treiben, anf bos afferbeite mo zwecfuräpigite "berechnet" jei. Hnd wie jollte bies and ambers jein? Sehen wir bock Die fliegentoen mit Fittichen, Die lunfenden mit langen SBeinen,

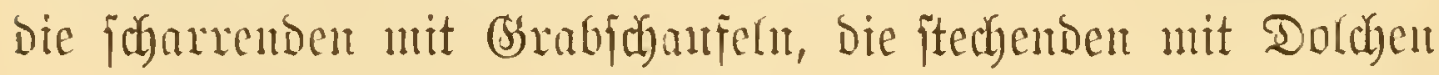

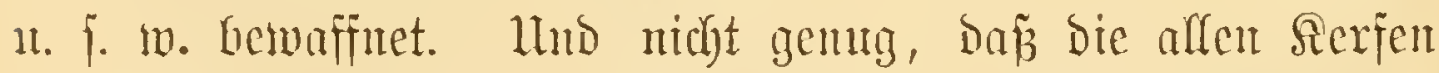
gemeinjanten Theile mb Sslieder, wie z. B. Die Mambuerf=

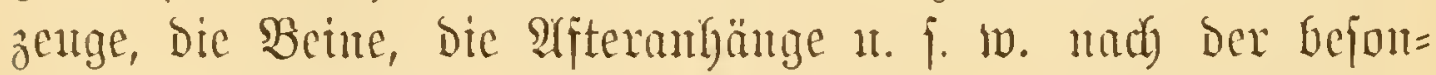

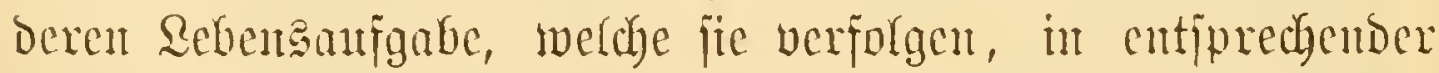
Wcije zugeridgtet oder abaptirt find, fommen bei mond hen,

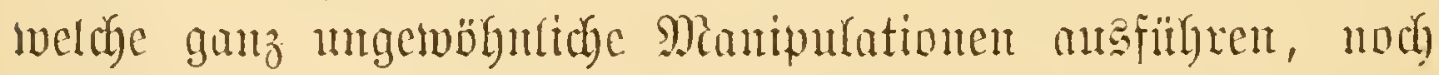

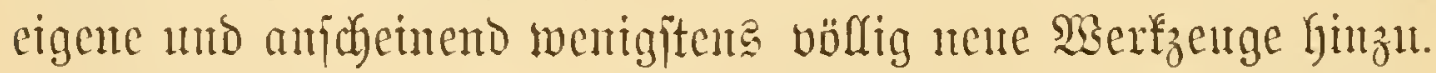

Der Rejer mutere cimmal ben änp̈eren Ban ber Tiger=

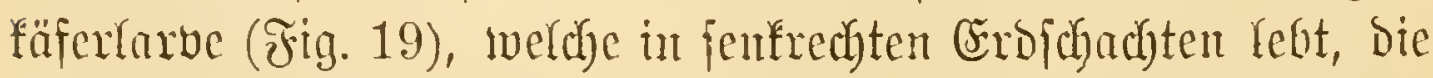
mur mentg breiter ars fic jelbjt fün. SBie fantu fie mit ber S⿹ Jurtigfeit, wie fie bies thut, in bicjen tiejen Brallerieen auf= 


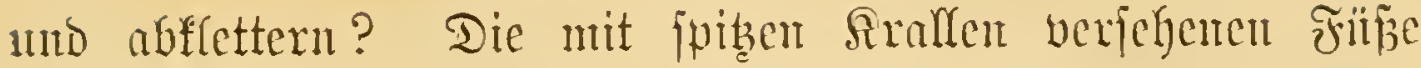

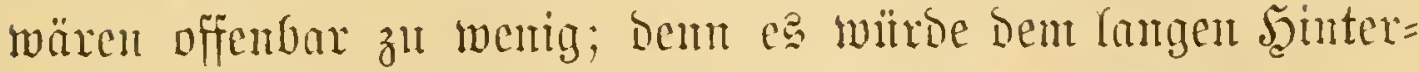
theil an Der nötfigen Stüłse gefrect)en. Eine joldye hat ex aber mid zwar vou

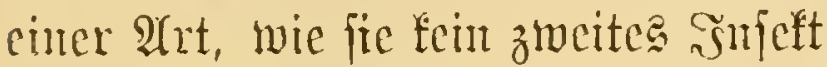

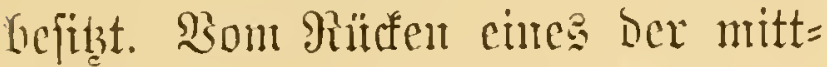
leven Bandf)ringel entipringen mebrere längere und fitrzere nach anfwärts

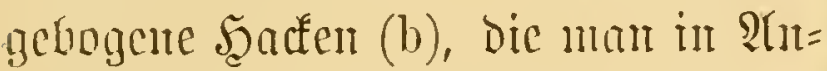
jehung des (Schrauches, Den da? Thier Davon madyt, midyt bejier als mit ben Steigcifen Dex Fenermelyrlente ber= gleichen fantr.

Rebmen wir nod Dazu, Dañ ber

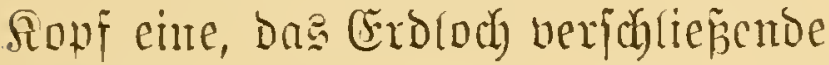
Fallyinze bildet, wer mbid)te dam molgl an biejem merfinitroigat ose= jchöpr etwas ausitellen, wer möchte

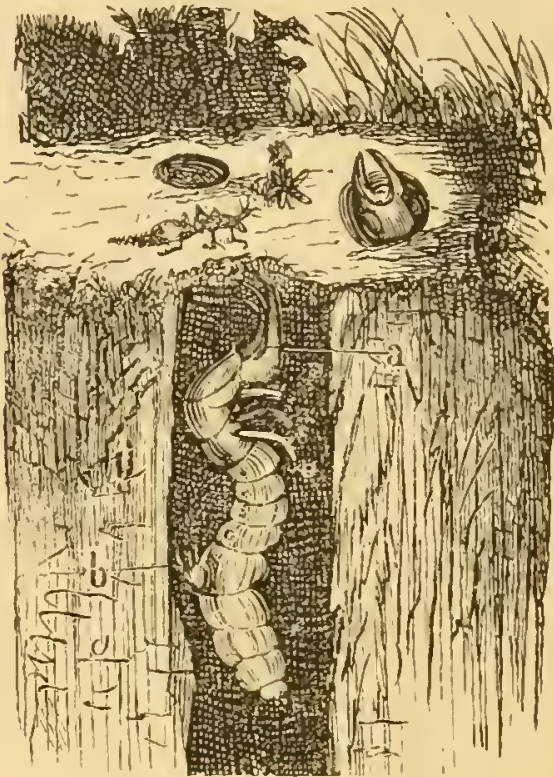

Fig. 19.

Rarvel ber Cicindela campestris

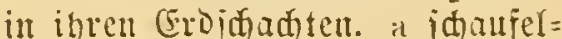
artiger §opi, mit jammt Dem Riicfenidirlo eine Den Fingang veriftiefende fallthïr bildend: b sranmerhaden ses Bandes. Mat. Bir. mǟjiger gebilbet wïnjchen?

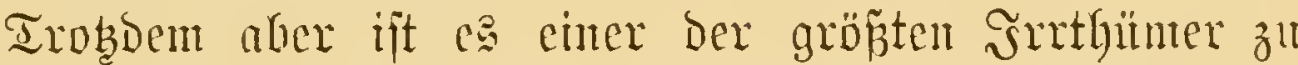

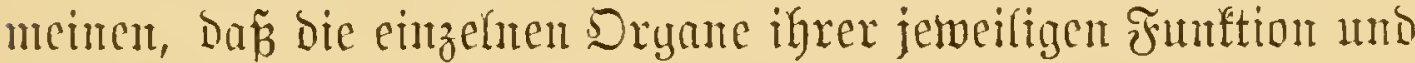

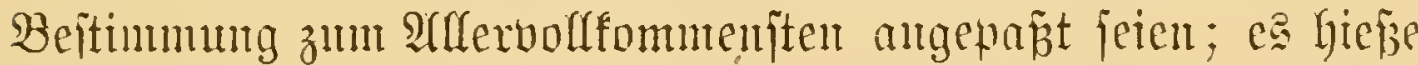

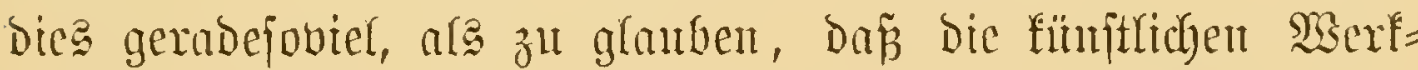
zenge, bie wir un felbjt anfertigen, nicht Dumb befiere nut vollfommentere erjebt werden fömten. Und fo wie wir mit

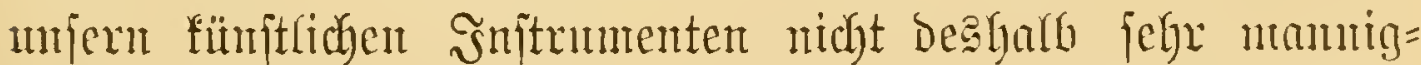

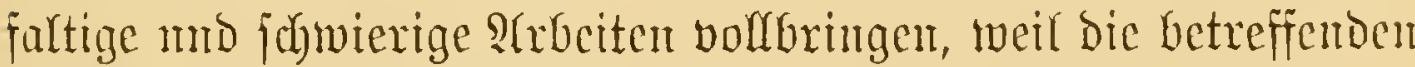
Werf́zenge bie żmectmänjigjten find, fombern Deshalb, weil wir

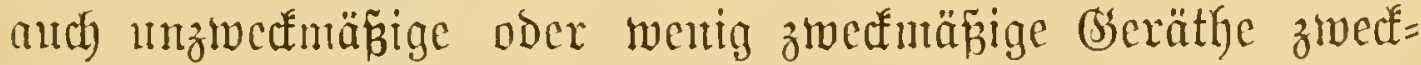
mäp̃ig zut gebrauthen verītehen, ebenjo verhält es fich bei ben

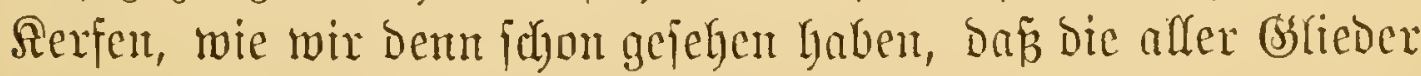

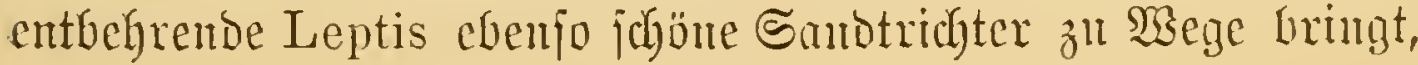




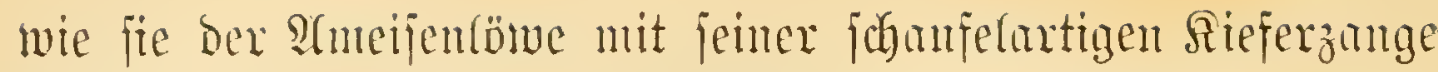

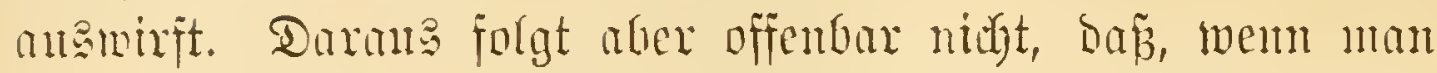

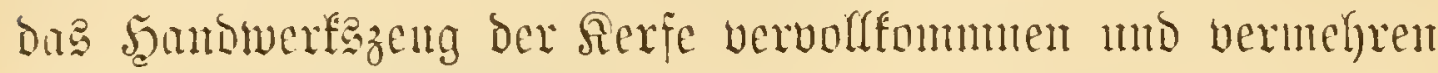
mödyte, fie einestheis nidyt bas, was fie jebt judon leiften, bequemer und bejier volfuringen, nmo andererjeits med

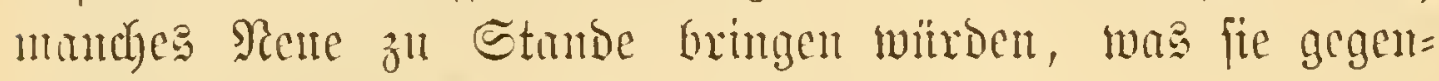

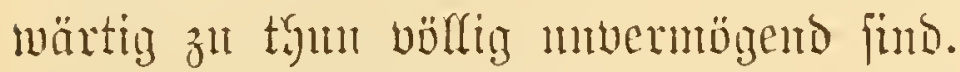

Aber bie verjefiedenen Grande der 3 solfonmenteit Gin=

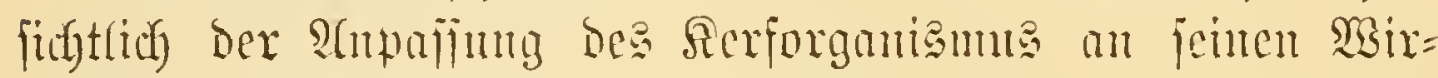
fungatreis find ju bei ben einzelnen Formen felbit wath $=$

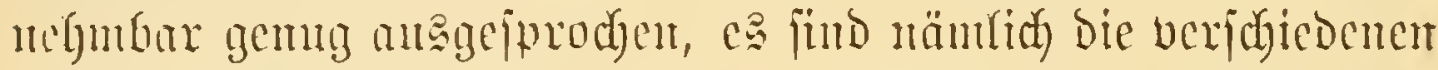

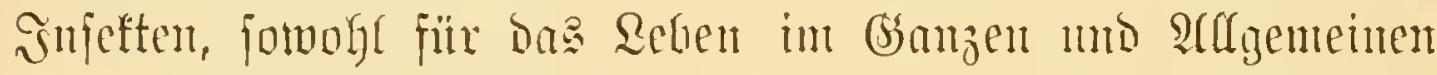

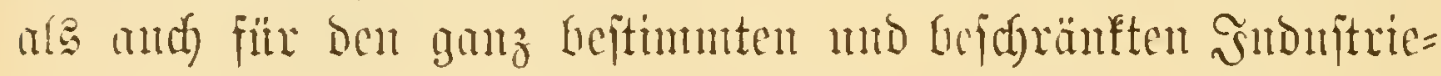

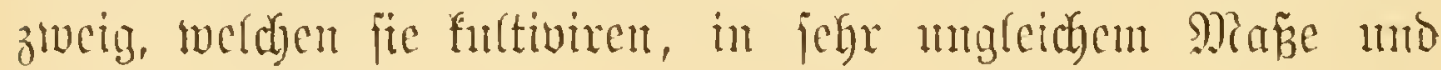
Gritose argenañt.

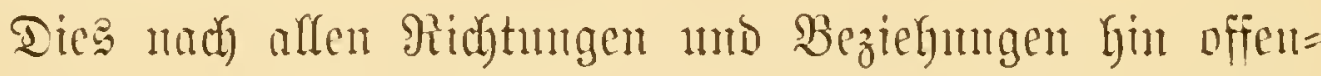

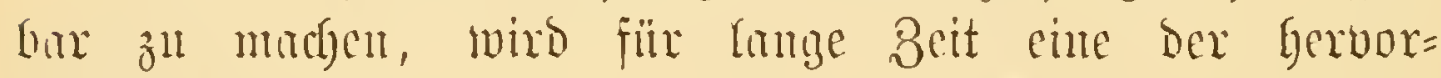

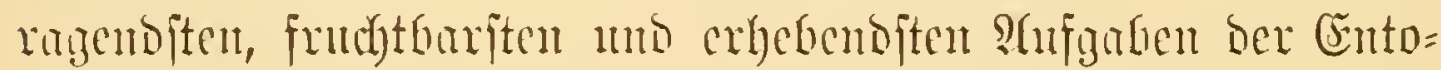

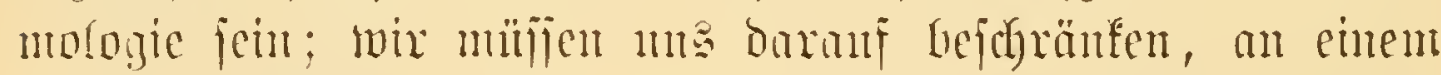

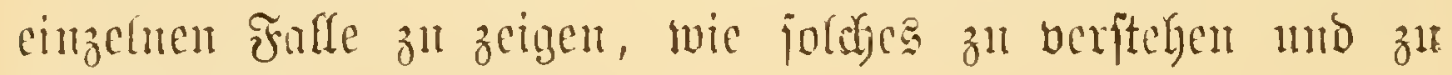
madyen ijt.

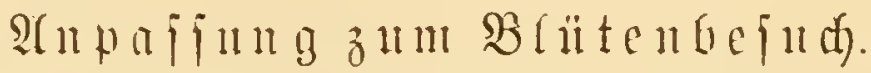

Dan Bamen mo Snjeften "fïr cinanocr" fint, bat

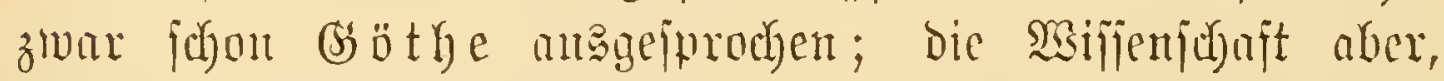

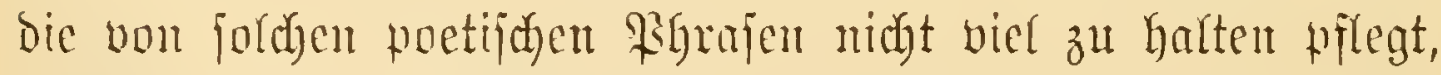
gelungte erit in alferiüngiter Beit zur richtigen mo all=

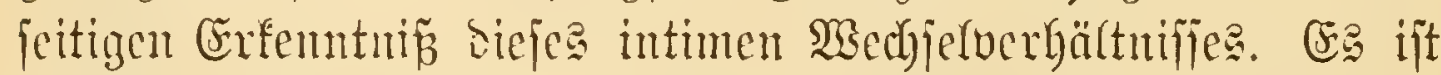
einfad). Biele Bumen hebierfen Der Aerfe zur Befrudbtung.

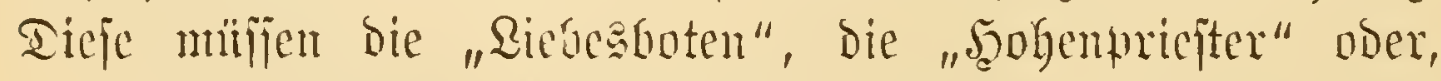
swenn man wiff, ifre Sinplerinnen madyen. Sie leigen Den

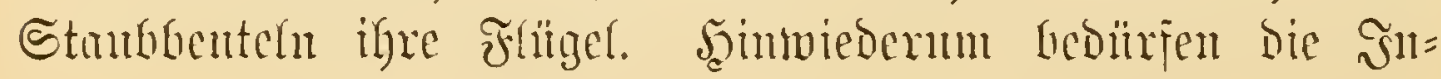




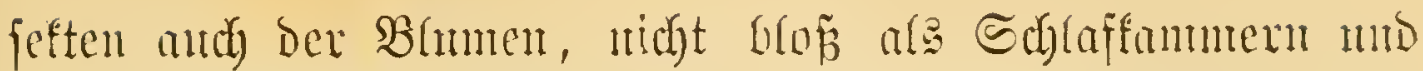

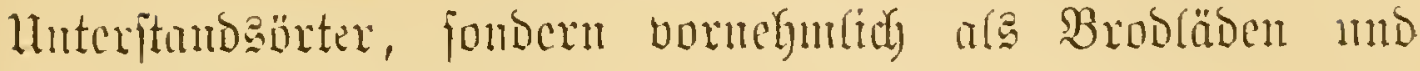
Irinffallen. Snbem jie das esine thm, verrichten fic bas

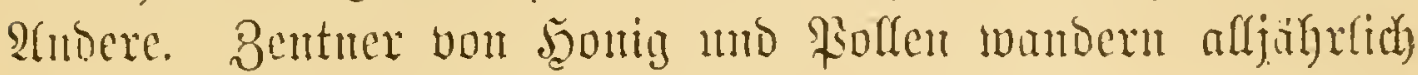

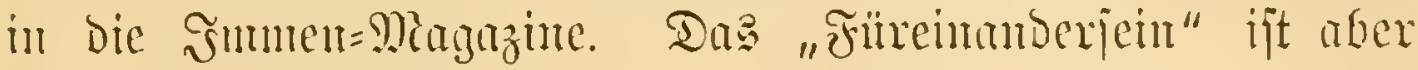

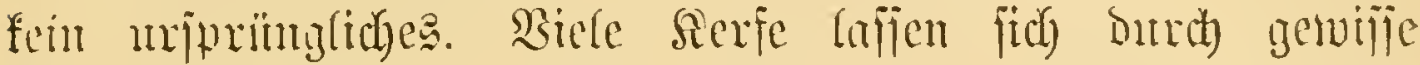

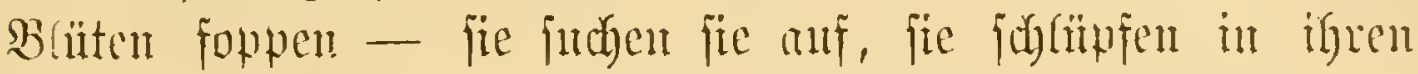

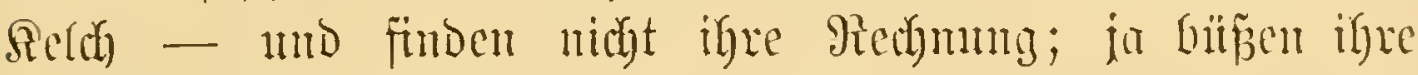
frumbjofaftlide Bifite mit bem Tod. Den Bumen, welde min burd Snterventivn ber fierfe funther werden, hat bie

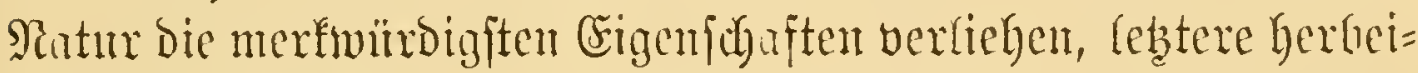
zntodfen: Trittbretter, Stiegen, Igüren, Bijure, Franjen, Sibleier, Sabutfelbalfen, verfithrerifde Farben und vor alfem

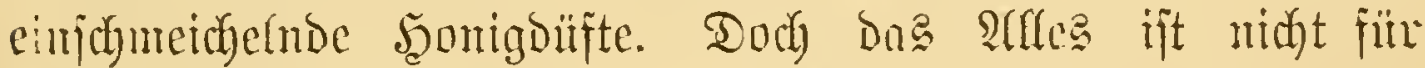

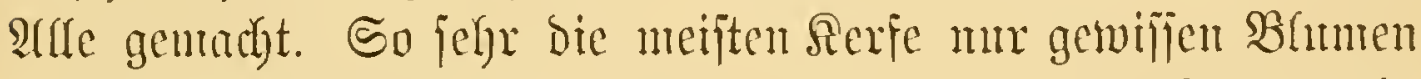

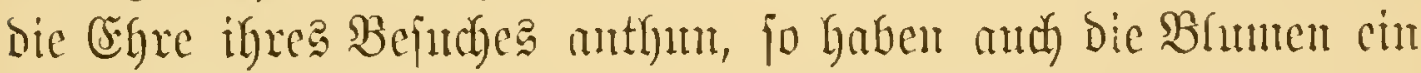

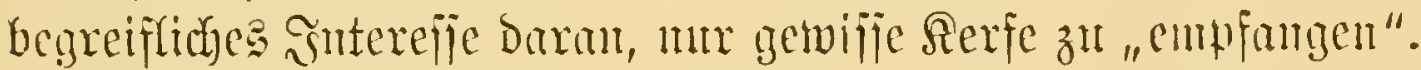

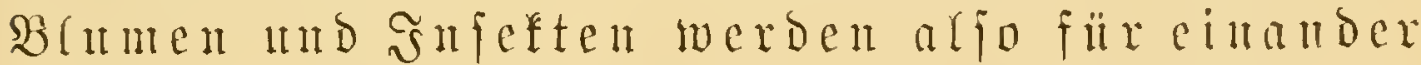

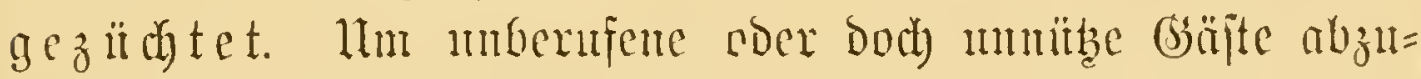
halten, werfehen fith bie Bhmen mit afferlei mo uit jebr

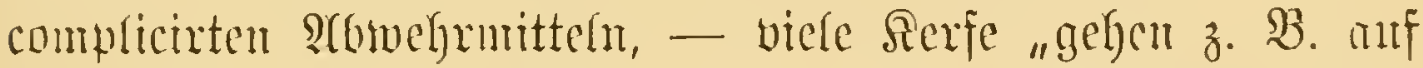
den Rem", Den die BBüten ober andere Bfflumzentheile ab= fortoern.

Auf ber ambern Eeite betrifft bie Epecialifunng, bie Can=

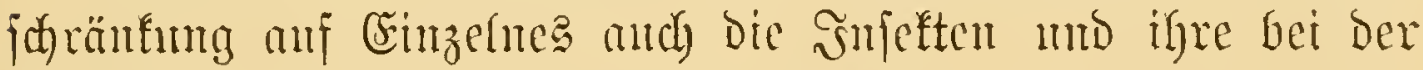
Bhumenplünderung betheiligten Werfaenge, wortiber in bem

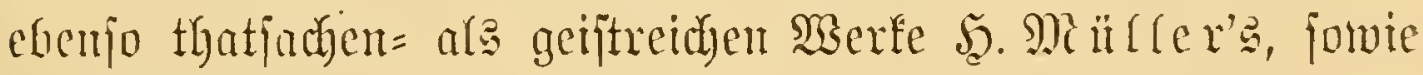

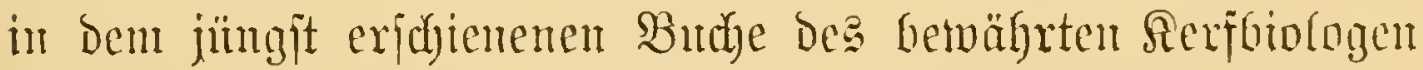

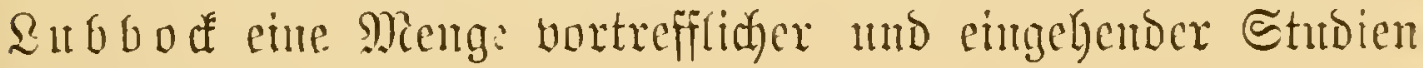
żl verfolgen wären.

Unter Den einzelnen ferforommugen fonmen aber Gichet vo:t ben magenden zumeift mur bie Räfer; bon ben fongenton bie Ffliegen, Bienen mo Siljuctterfinge in Betratht. 
1tur mit bent erfterent anzufantgen, fo fund hier nädjpt bent

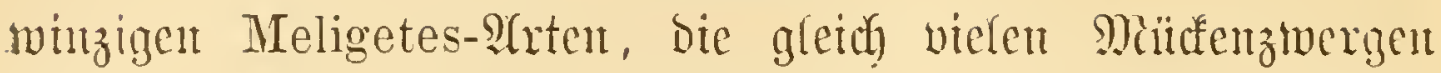

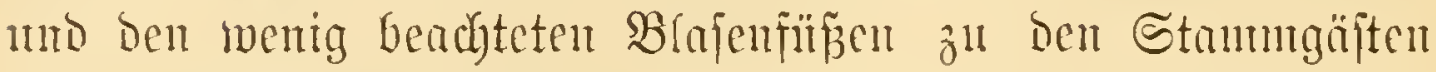

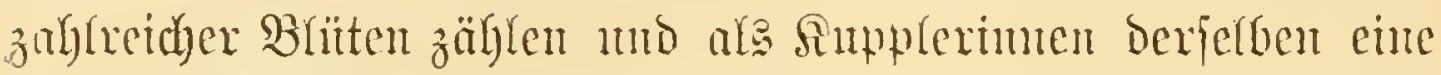

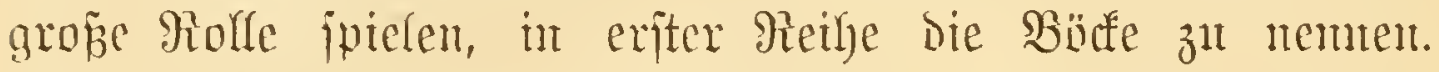

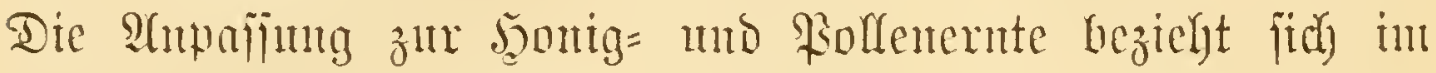

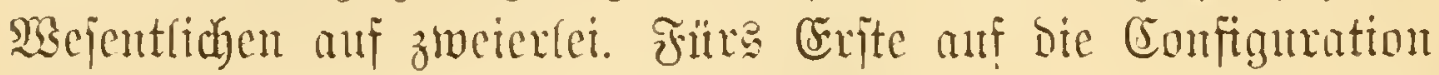

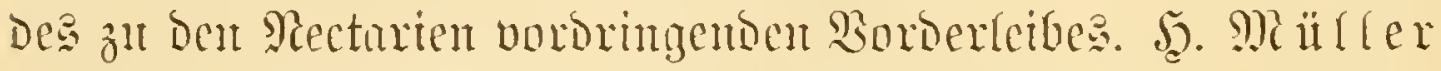
bat bei einer Sulte von arten Leiopus nebulosus, Clytus arietis L., Leptura livida F., Strangalia attenuata L. ge=

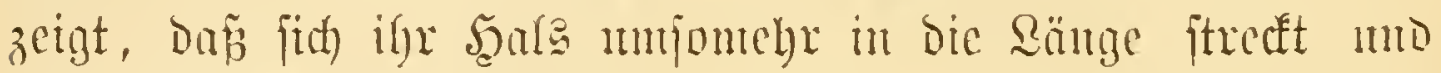
Ginter bent fiopfe cimformüt, je tiejer jie in bie Bhmen=

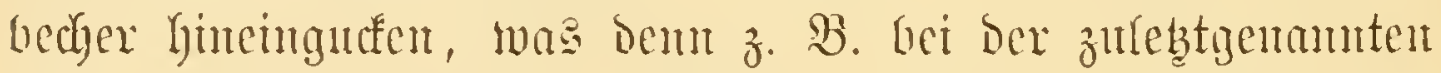

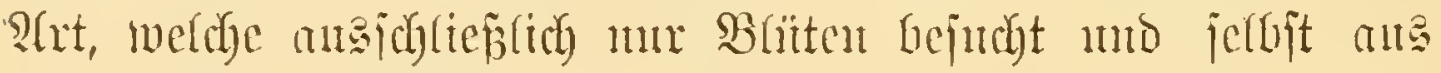
Den langen $\mathfrak{B}$ (umtentüfren Dex Scabiosa arrensis ben Fentig

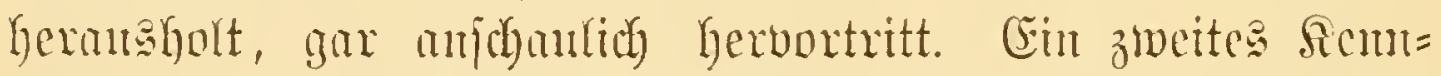

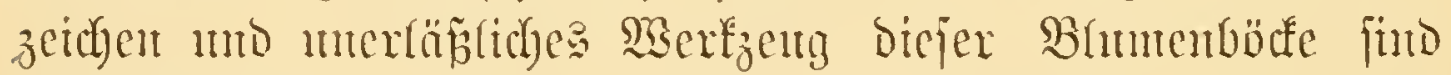

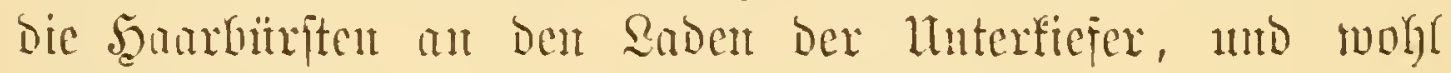

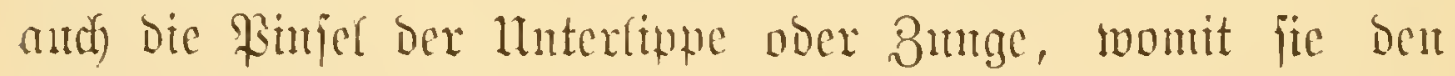

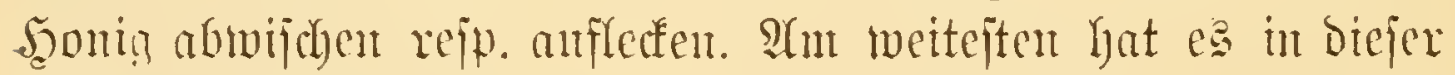

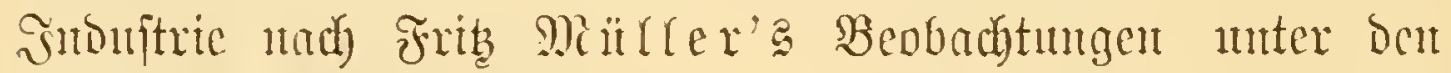
tropifoch Säforut bejondors cine Nemognatha gefract, seren 1nterfiejerlaben, zu żwei ipiben rimtigen Borjten aus=

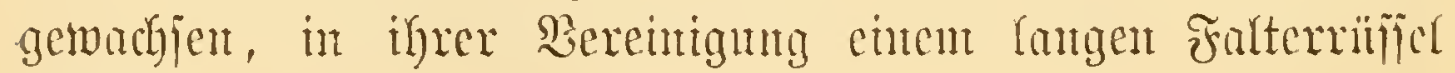
gleichert.

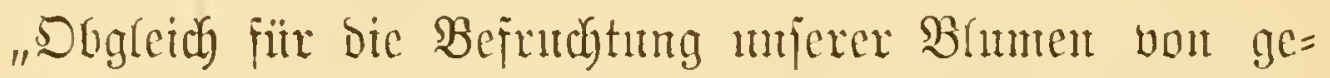

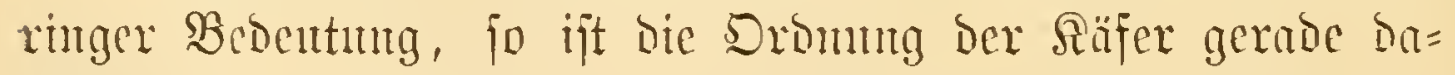

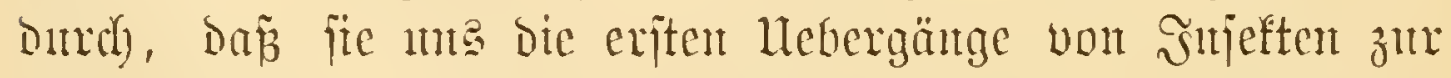

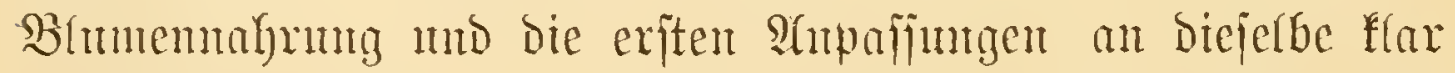

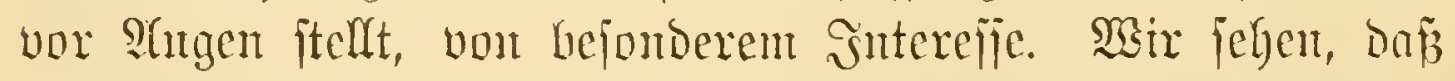

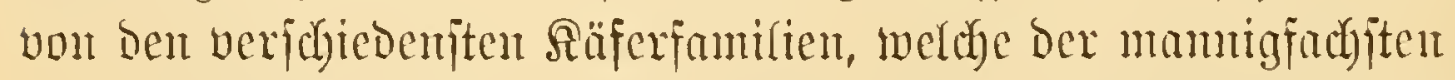

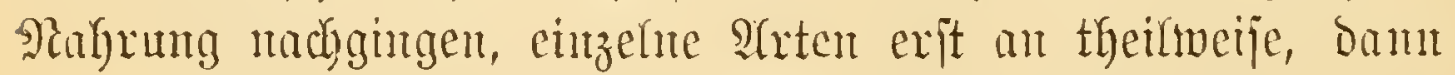

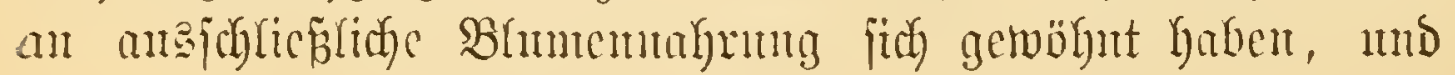




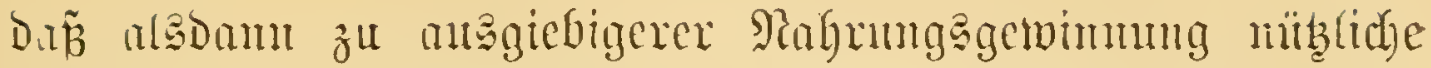

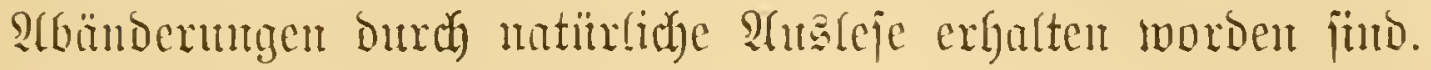
Dex Hebergang zux Bhmemtahrumg mus bei Den einen in frülycren, bei Den andern in juäteren Beitepodyen exfolgt jein;

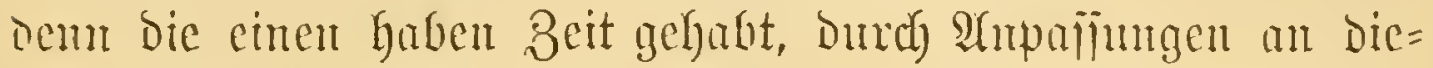

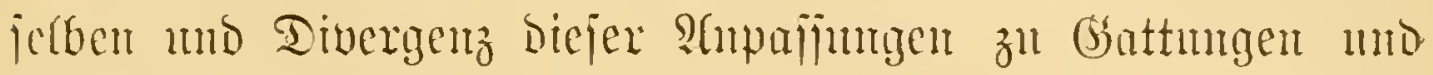
Familien hevanzumadjen, dic moern bejtegen nod als bumentiebende Arten neben Bejerwifterarten, meldye bie B่̧menahrung verjduähen."

Angemein lefrreid) ift bie Ampajing des 3meiflïgler=

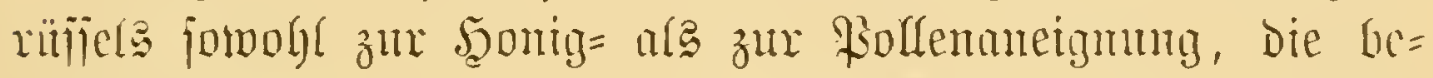

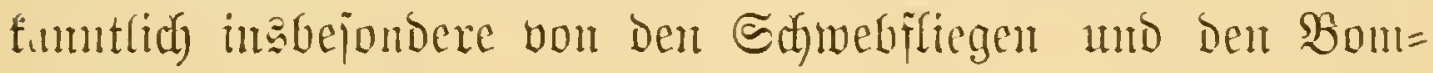
bylion in ansagebigjter MBeije betrieben wiro.

Das wetrefiende Drgan bejtegt hefanutlich ans cinct mefre minder voritrectforen Snugrimuc, in welcher jich jugleids

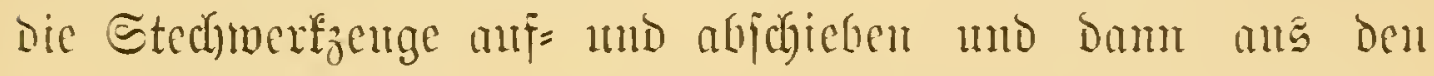
beiocn jefwammigen Endappen, weldye an die zu bejangende

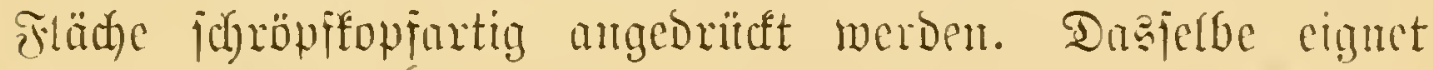

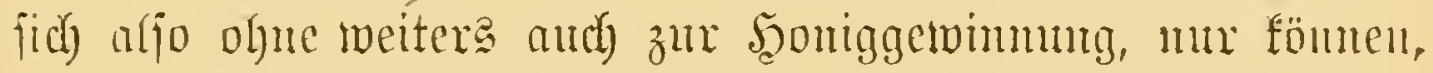
wie wir es bei den $\mathfrak{B}$ hmentfliegen in der ßegel finden, die

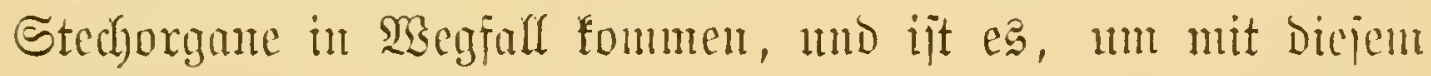
Gujtrument and zu tiejeren Bhamenfeldyen bequemen Butrit

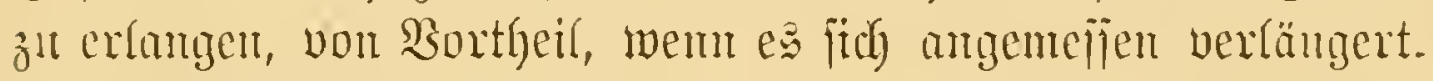
Daj joldyes aber feine Sexerci, bemeijen, wie bured ber= gleidyende Mejiungen leidgt zu confitatiren, Die vielfachen \&ängen= variationen jomofl des Gsejunntriijjels als ber einjelnen Bejtundtyeife.

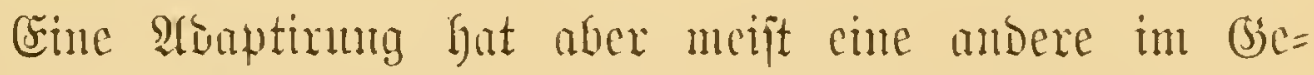
jolge. So jegen roir bei mehreren langritjieligen Bhumen=

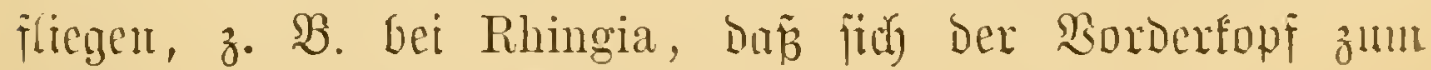

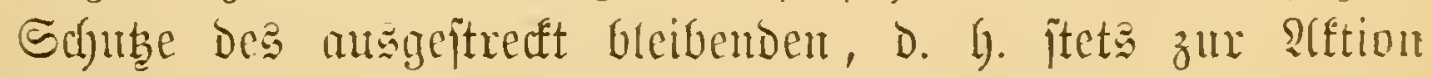

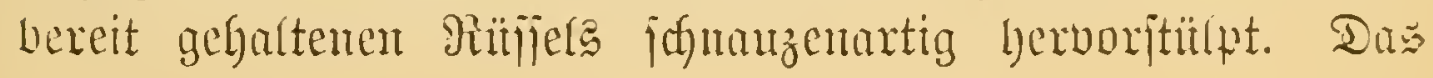




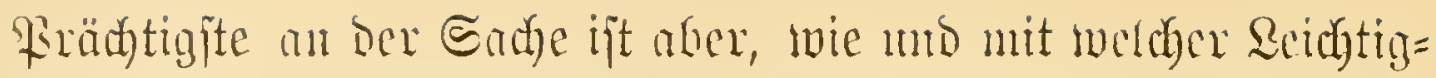
feit ber ztweilabige Endfncpf, weldyer fïr gemölunlidy jum Sangen verwentet wird, in einen faserenflaptenartigen, in=

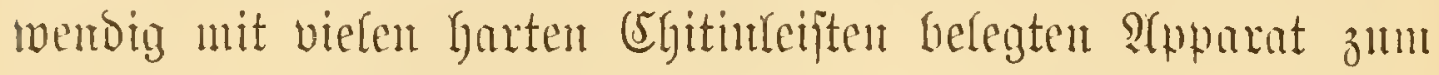

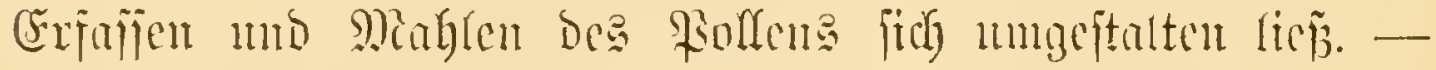

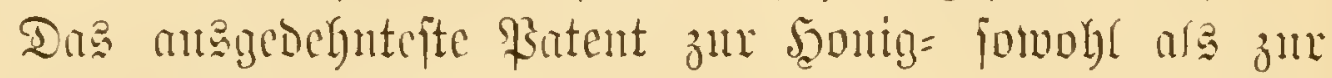

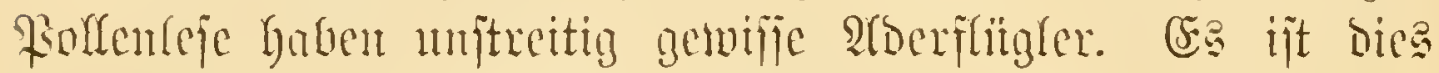

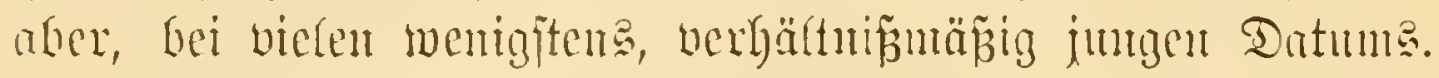

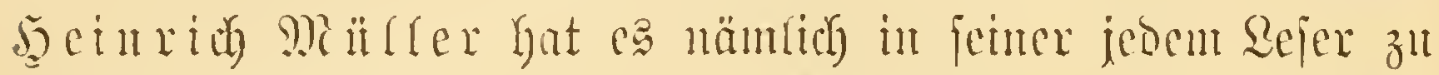

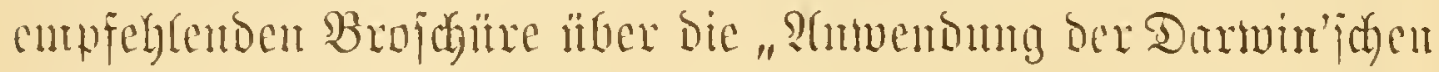

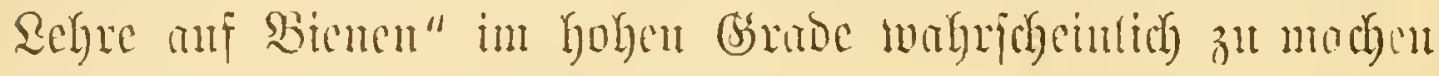
verjtanden, Daj mpere hentigen Bienen von gemijien Grabl=

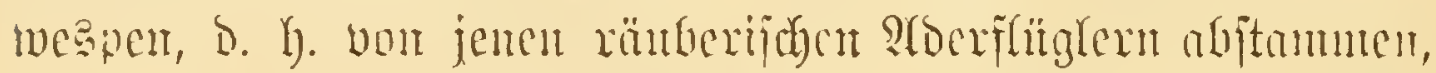

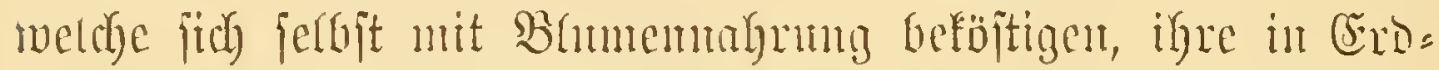

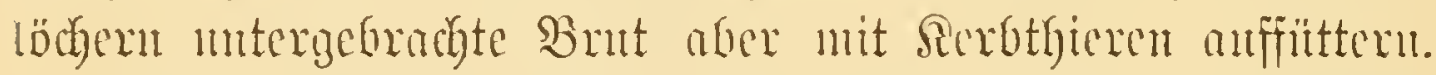

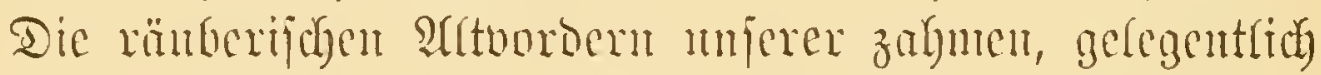

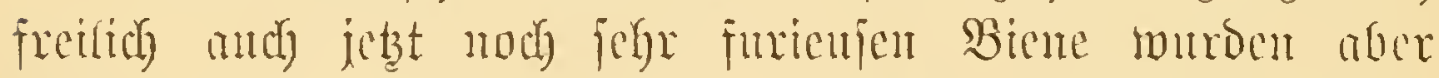

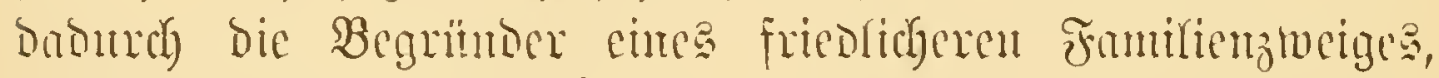

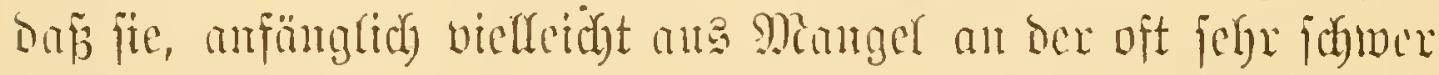

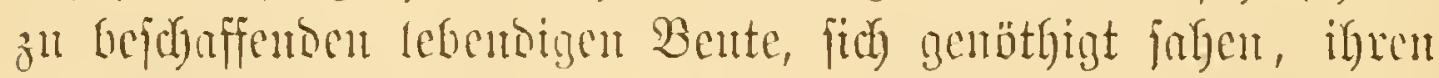

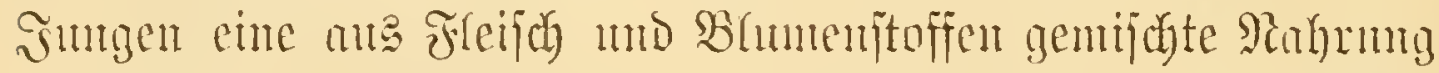

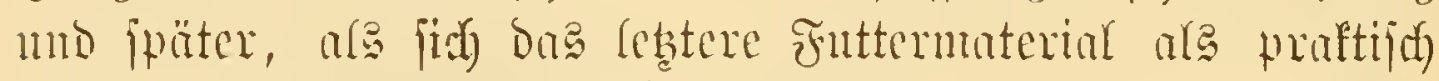
ermies, ats

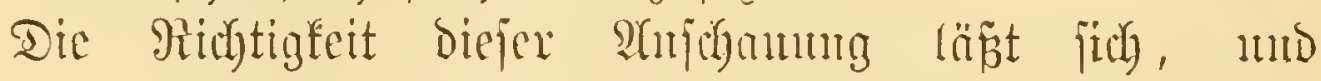

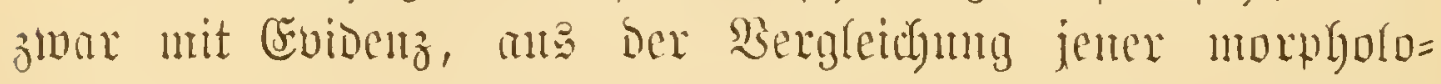

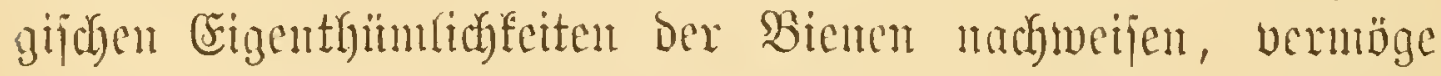

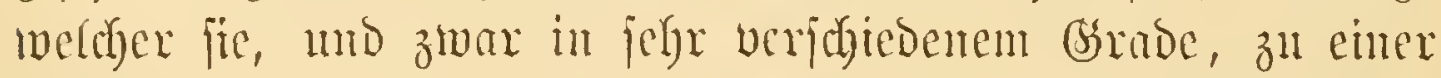

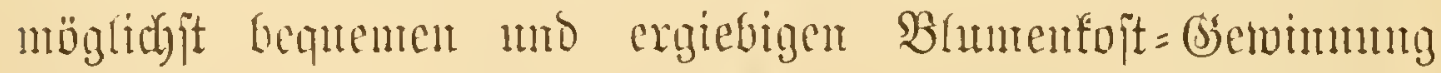

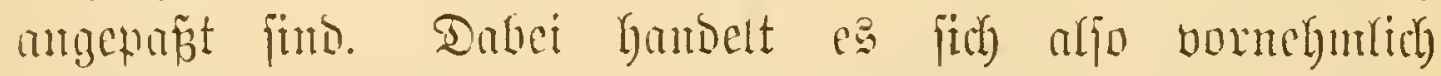

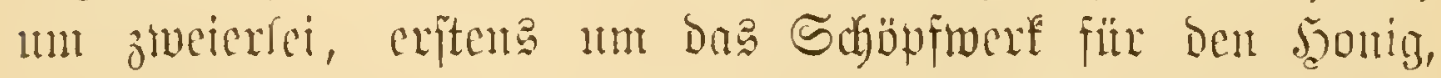
D. i. Den Riijiel, und Dann um Den Pollenjammelapparat,

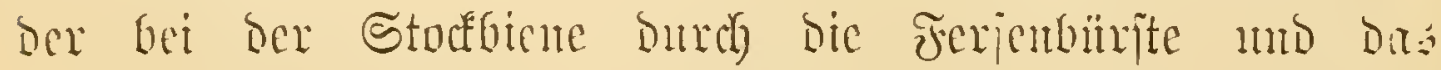

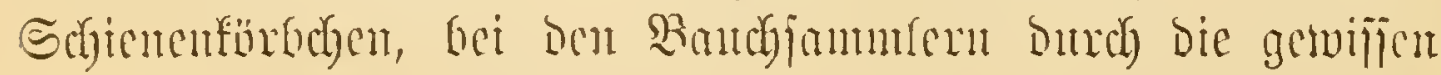




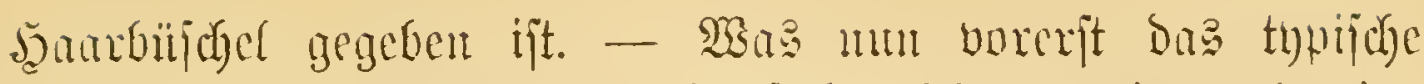

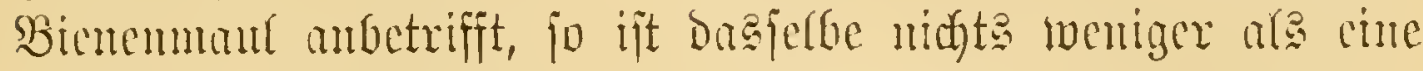

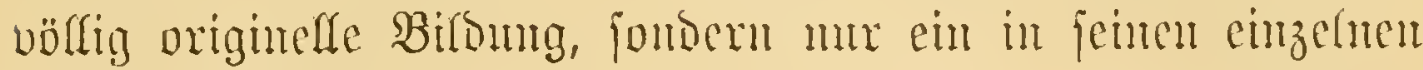

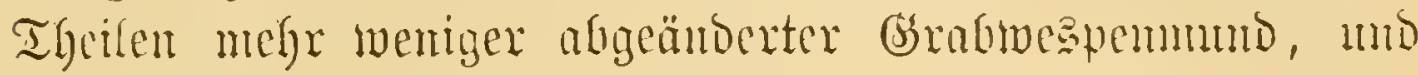

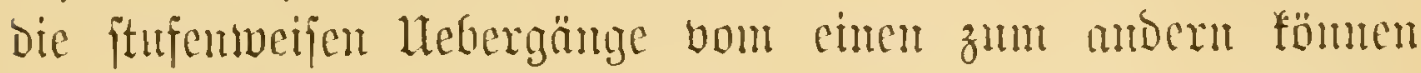
jogar an ben verjebiedenen nod heute lebenden Bienengattungen beliebig borgemiefen twerden.

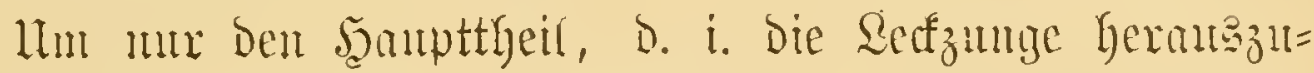
greifen, jo ift bicfelbe beim Gemts Prosopis eme $\mathfrak{u m b}_{j}$ zrveilappige Relle, bie vou jener dex Grabuespen abjolut uidet zu utericheibeu ift. Bei Macropis

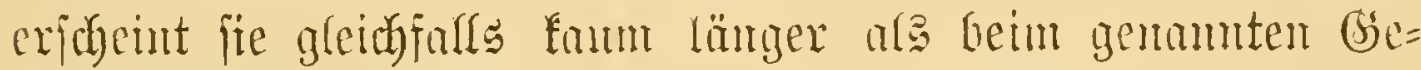

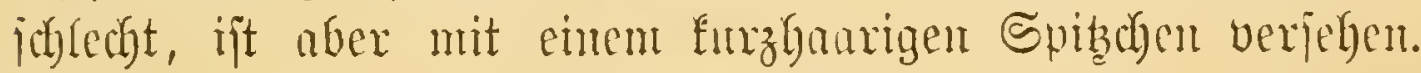
Bei Andrena ijt fie jobon weit länger al breit, bei Halictus jogar lantzenförming mo mit einzelnten ḩaarquirlent. 3um vielringligen $\mathfrak{B} แ r m$ verlängert fie fich bum allmäliz bet Panurgus, Halictoides, Chelostoma, Stelis; mo mit Di-

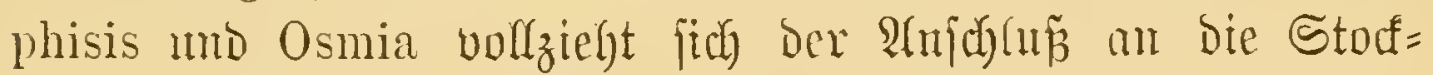
bienen= rejp. an bie jymmelantuge.

2htch che andere roidgtige Eigentyüm(ichfeit ber Bienen= zmuge, nämlich die "viererlei Bengungen un Strefungen", vermb̈ge beren fie fich in thätigen Bujtanbe mi das längite gevvoritreufen, im untbätigen aber, un den nagenden

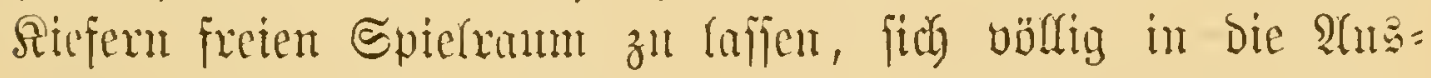

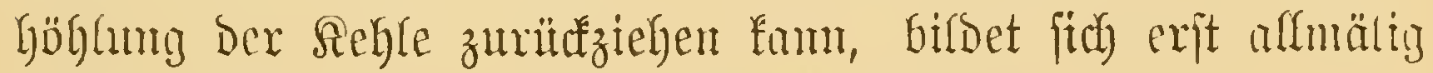

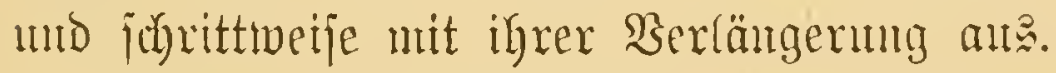

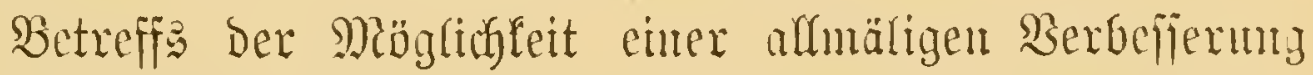

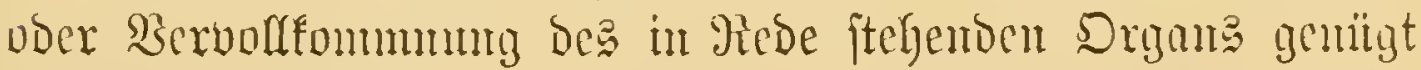

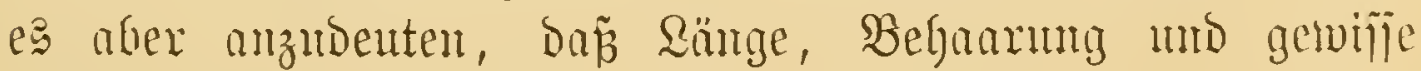

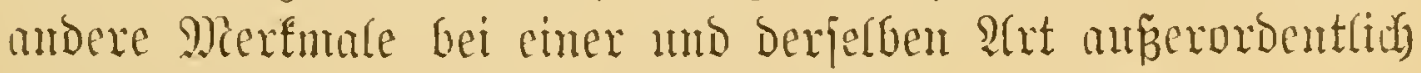

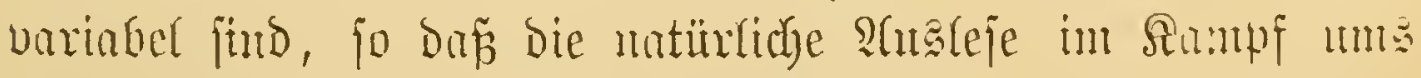

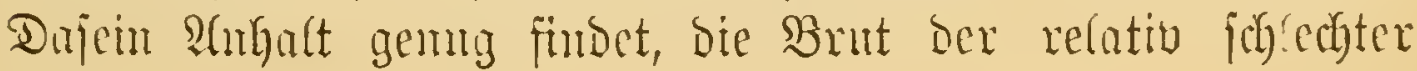


gexiifiẹten Sarietäten anşurotten und ben vortheilfafteren Den Ėieg z̆l veridjuffen.

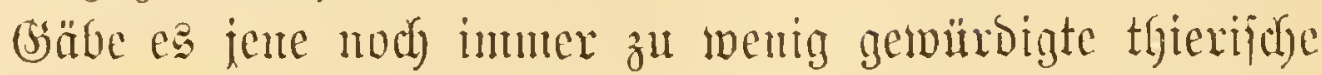

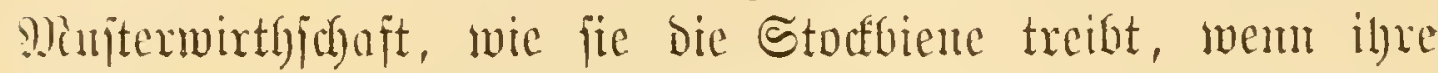

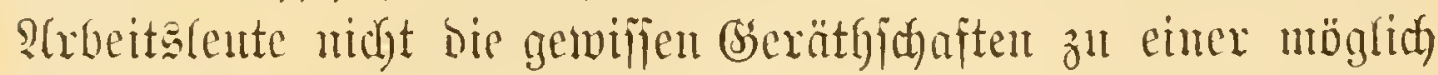

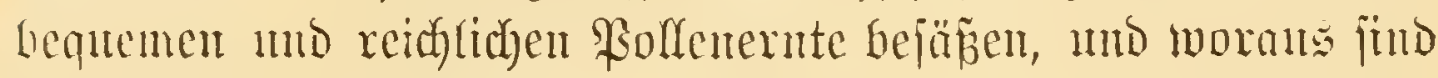

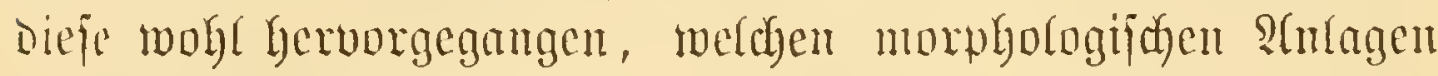
Dex Biene verdanfen unir

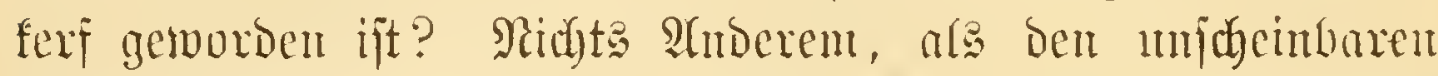

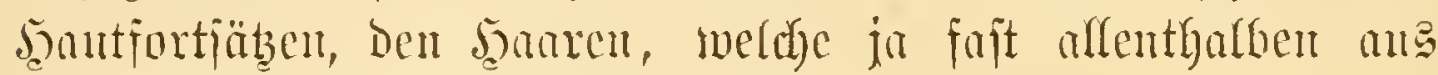

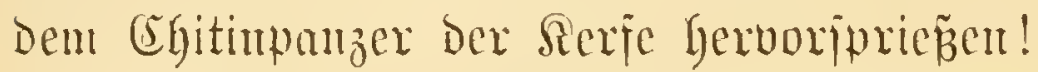

Mir werden gleid) fehen, wie joldyes gemeint ijt.

Die Mrbiente, fo burf man die Srofopianten menten, benädgtigen fid Des Pollens in Derjedben primitiven Sht, wie Die Grabuespen und andere Bhumenitantifrefier, d. h. fie

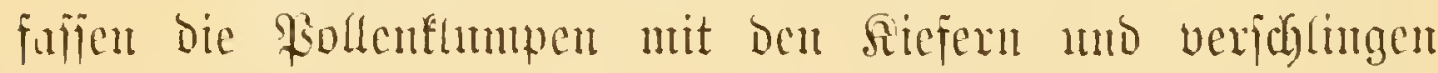
Dumon fo viel, als ju ifrem eigenen luntergalt uo Dem ifrex Brut, Dex jic Den nusgejpiecnen Rollenbräı vorjeben, ex= forderlidy ijt.

Sffenbar ift aber biejs Micthode, abgejeben von ihrer

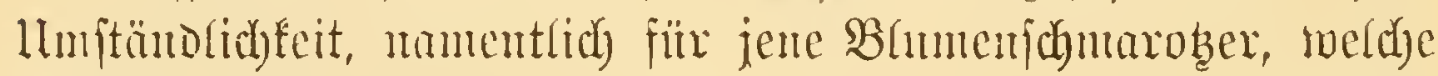

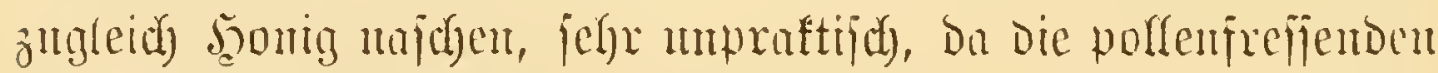

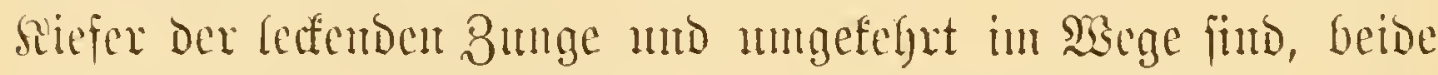

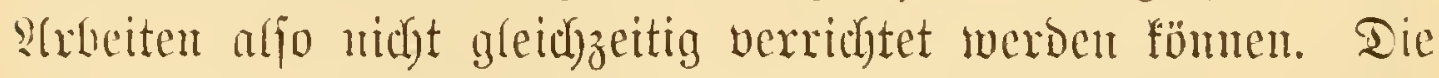
Shatur hat Deshalb énen anden Mcodus begünjtigt. Bicle

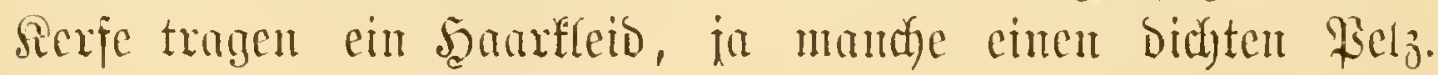

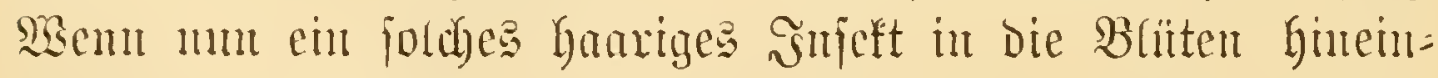

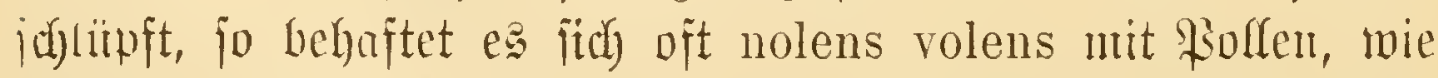

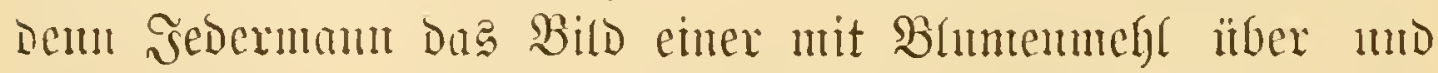
itber bejtäubten Şumnel gegenmärtig jein wiro. Sommt eine

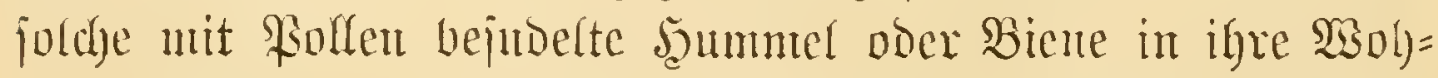

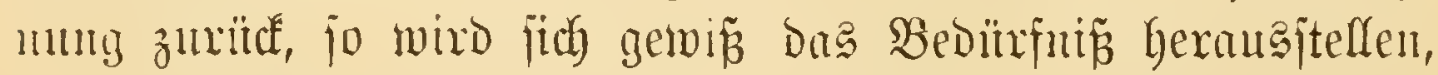
mit Den Beinen ihren Sanapelz zu bürjten, Da wir wijen, 


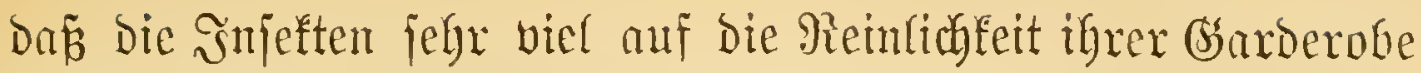
halten. Dex abgejdenerte Blitenjtaub wird aber bem un=

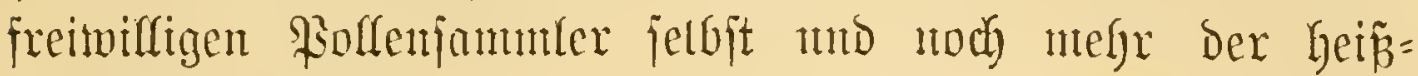
huntgerigen Brut ein gefundenes Frejijen fein, und es ijt jebr nabeliegend, Daz fich bieje Serfe it Zufunft bet igrent Bhumentifiten mux mehr mit Dem Şonigleafen befaffen, da fie

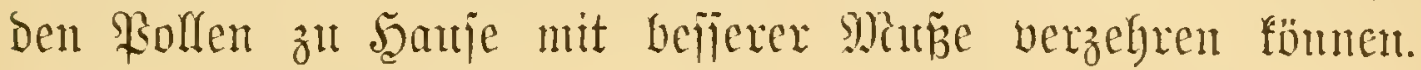

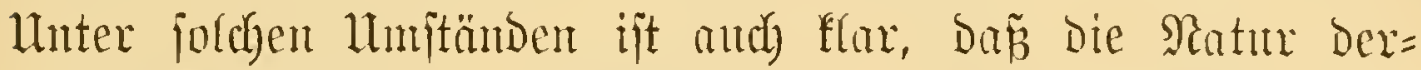

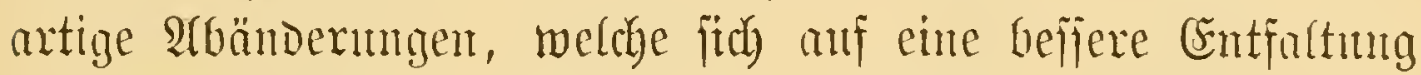
Des pollemjanmelnoen Şaarfleides beziegen, fräftigjt unter= jtïben wiro.

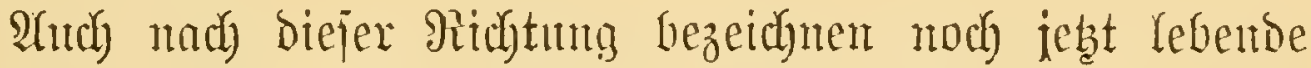
Bientengattungen bie widbtigiten Entwidfungestufen.

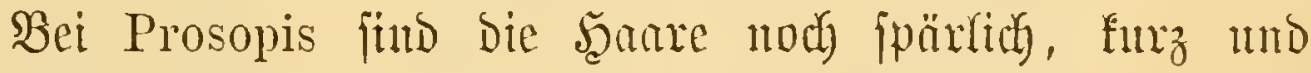
Durityegs einfach. Desgleichen bet Sphecodes mo Nomada,

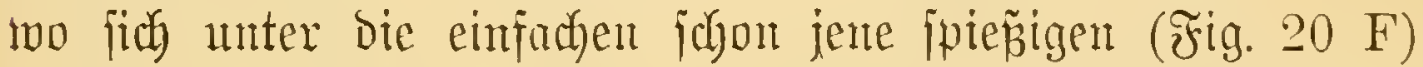
mifichen, an weldyen ber Solfen fich jo leid)t verfängt. Mannig= fardye Hebergänge żt jtärtferer $\mathfrak{B}$ egaarung zeigen bant Andrena

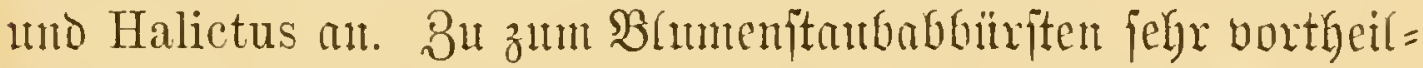
haften Duterbinden verbidytet fie fich bei Colletes und Megachile.

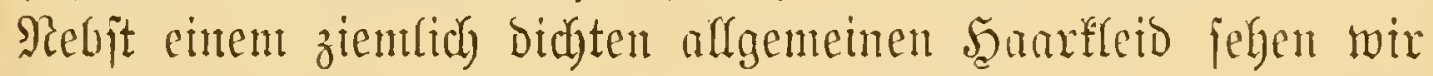
banu bei Osmia nody eine als jpezifijdyen Sammelapparat

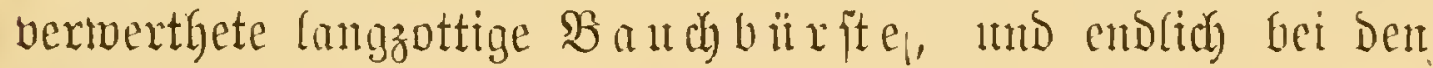

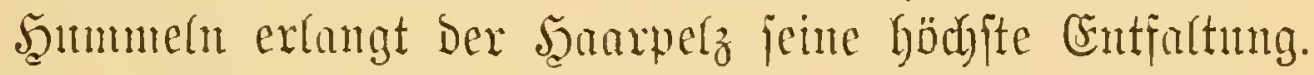

Noch lebrueicher ift bie Mupaijung ber Şinterbeine.

Wieder bezeichnet Prosopis den niederjten Grab. Şgre

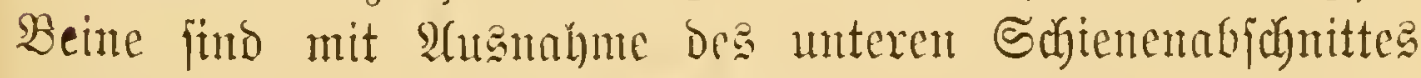
(ひ̌ig. $20 \mathrm{~A} \mathrm{u}$ ) แntr mit winzigen Şärchen beffeidet, ertweifen fich) aljo zum \$ollenabfegen als böllig unbrattdbar und iteben mu, wie aud ber lange, jtarf befrallte Fun zeigt, als (Srabinjtrumente in Sermembunty. - Eatuen fleiten હdyritt weiter ift Dagegen Die zutg(eid) Durd) grofize Bariabilität a ugezeiducte (ื) $\mathfrak{a b e r , ~ \Im n i e t t e n . ~ I I . ~} \mathfrak{B}$. 
Sphecodes, beren Seinterbeine aber ifrer ganzen \&änge nach, auswendig ftärfer als inwendig, und bei ben allein jaul = mertiden seibden bedentend mehr als bei den

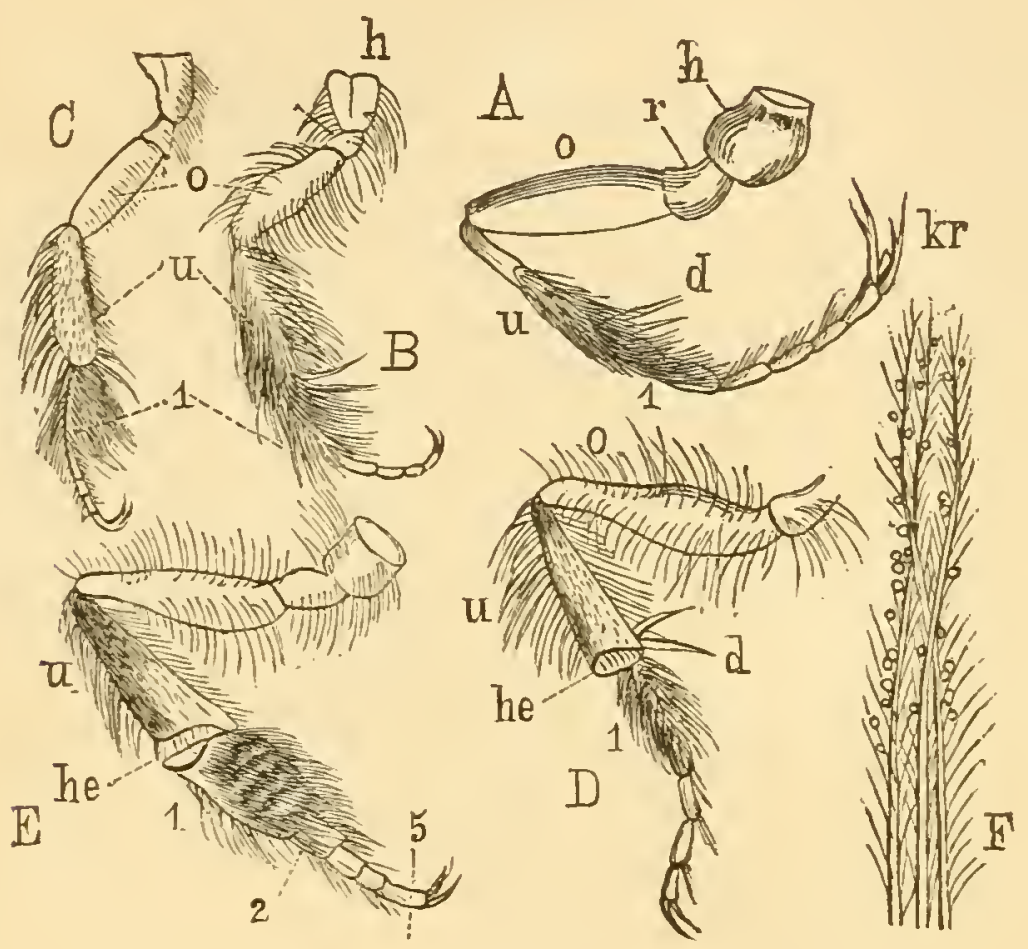

Fig. 20.

Şinterbeine verjajiesener pollenjammelnber Bienen von ber Эnnenjeite.

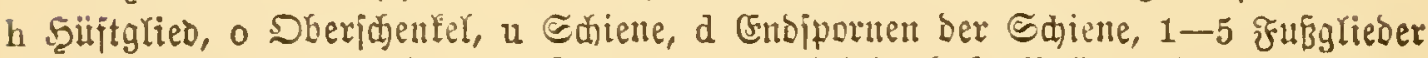

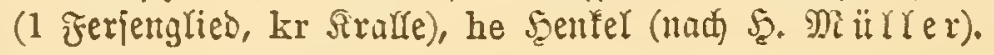

A Prosopis variegata 오

B Panurgus Banksianus $\mathrm{k}$. 9

C Macropis labiata Pz. 오

D Bombus Scrimshiranus k. $\Varangle$

E şonigbiente.

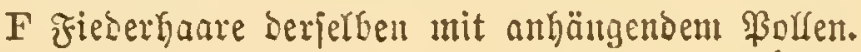

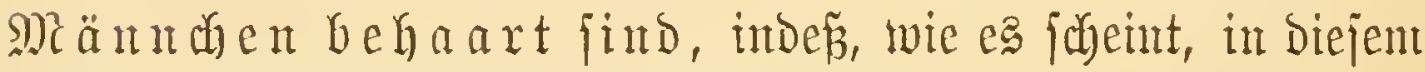
Simne gleidfalls noch unbentbet bleiben.

Einen gröperent Fortid)ritt Gezeidynen Dann bie nament(ich)

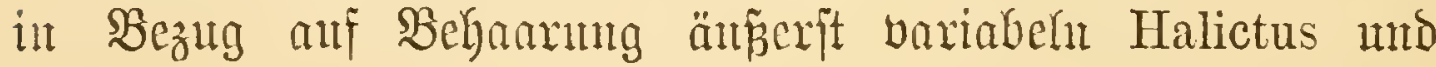
Anarena to bie Schiene bereits Durd ifren Didften Sanmelgarbejag vor Den itbrigen Beingliebern fid herbor=

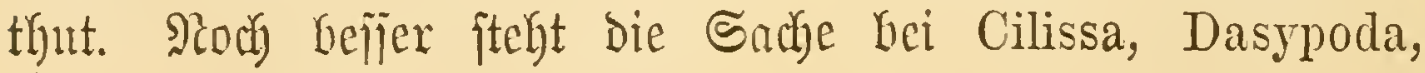


Panurgus (Fig. 20 B) und Macropis (C), two bie beidexjeits von eintent Zam langer Borften umrandeten Schienten (u) fabon

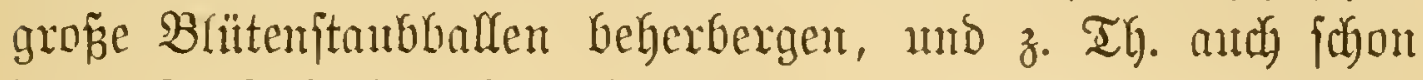

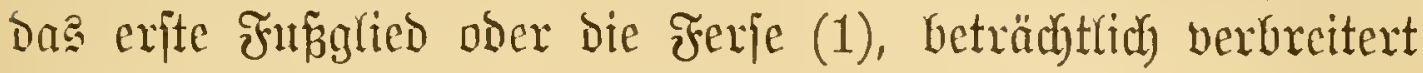

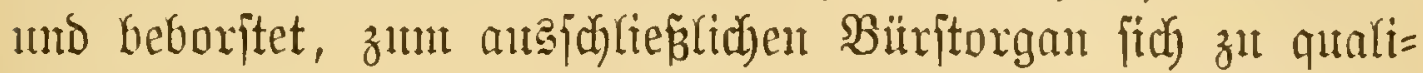

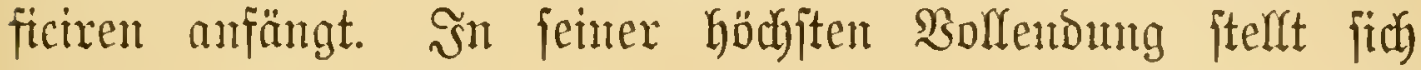

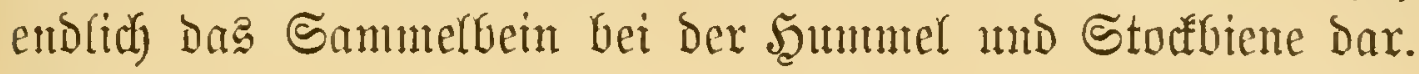
Bei beiden ijt bie Schiente ansmendig mit eintent vörrig glatten, aber vou einem Bsebege elajtijtyer Borjteu un= fablofienen, heimahe löffelförmigen I Iheil, Dent jog. Rörbdhen, verfehen, während bie Ferfe cine wahre Bürfte vorjtellt, bie bei ber Şummel mit gleidymäñig vertheilten fteifen Borjten bejest ijt (D), während leţtere an ber Bienenferje (E 1) jid jogar reihentweije wie an mjern fünjtlidyen Reibbürjten vertheilen.

Die eimzelnen Stabien Der Sammelbeinentwiffung roären aljo, furrz repetirt, bie: zuterit völlig glattes Grablein, bann

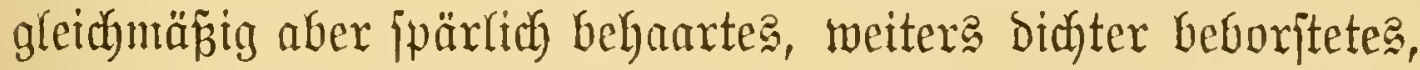
bereits zun Fegen un Âfitappeln Des Pollens geeignet;

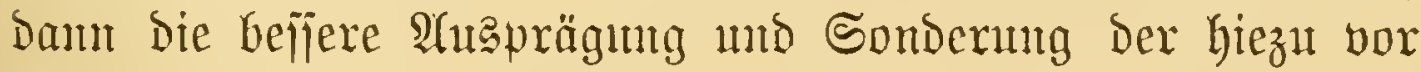
armem geeigneten Endobjanitte. Sujiene ntio Ferje verbreitern

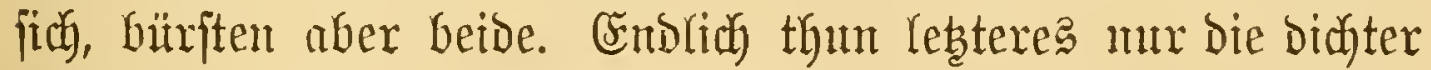
Geboriteten Ferjent, währent die Sdytente zun exchufiuen Pollen= träger wiro.

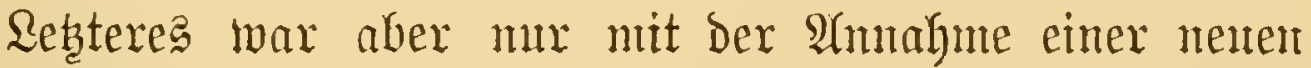
(Sewohnheit möglich, Dañ nämlich Der Den Şinterbeinen zur

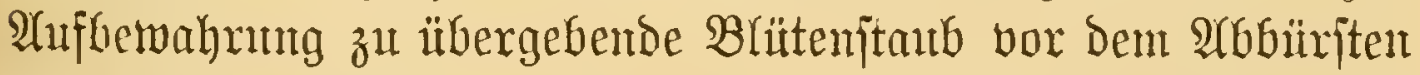

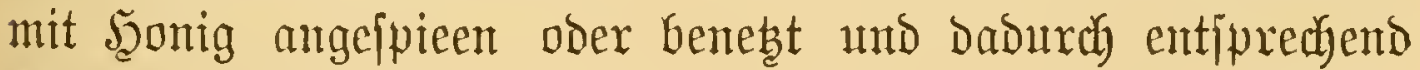
flebrig gemadyt wurde, was fpeciell bei jogenamuten $\mathfrak{M i n d}=$

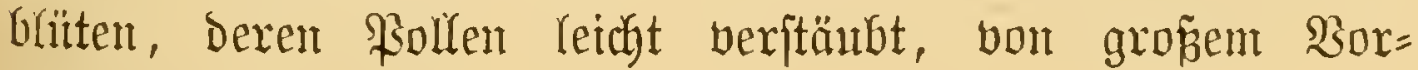
theil ijt.

So viel einjtweiten won Den Bienen. Die bezitglichen

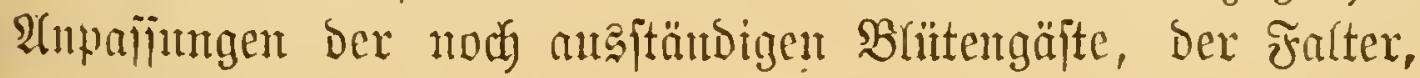


mïroen ohe Bweifel nidgt weniger intercijant zu verjolgen jein. Dody bieje Serje waren biager weniger ju emitgaftem

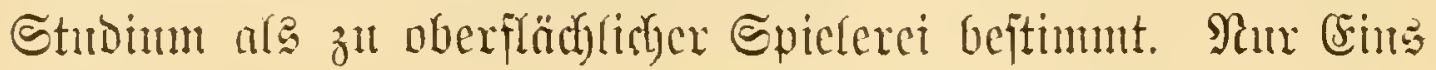

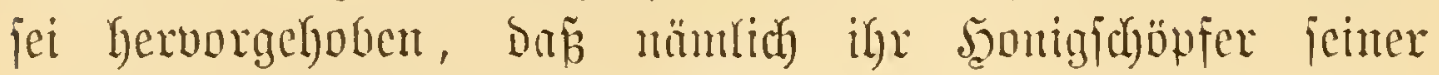
fpiralfebcrartigen Form wegen und weil hter anf feine Acben=

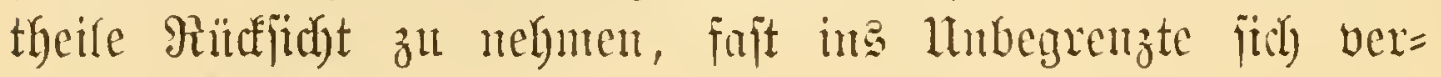
läıgern ḱumı.

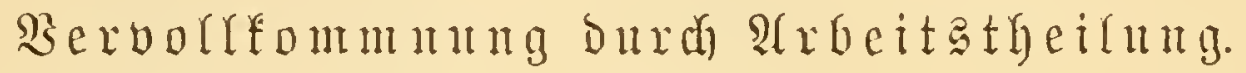

Sit ber Schmetterling mit jeinem juinmernden Frlügel=

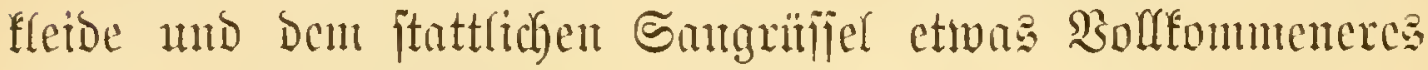

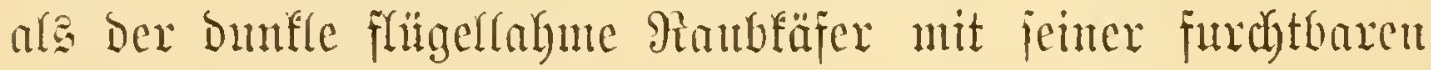

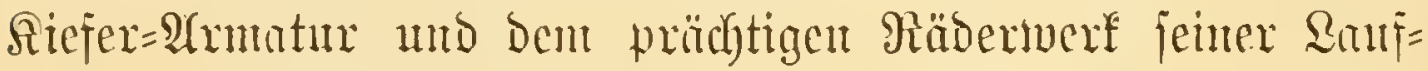
beine? Beide jüto volffonmen in ifrer art, für igr Element,

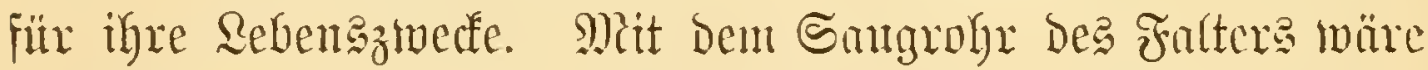

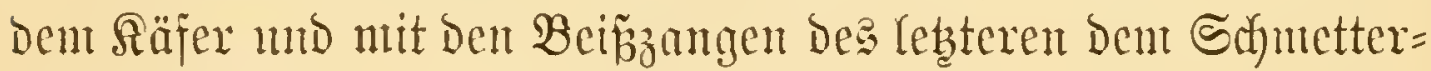
ling nidgt gebient. Und was mürbe biejer anf Den Shatment

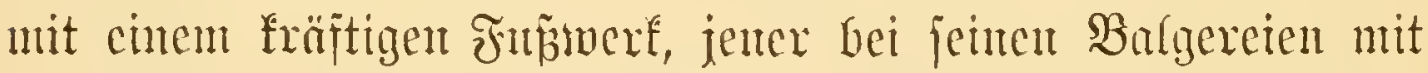
Dem eiteln zerbredylidjen Tand Der Falterjd)wingen anfangen?

San bicjent Beifpiel jehen mir bas gemölntiche gejultat, bas bie matürlinge 3uthtwabl zu

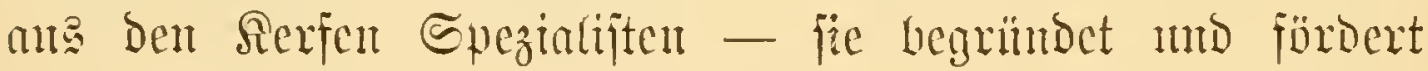
Den Sartifularisuns, Das vielfeitigite Rajtenmejen. Das ijt

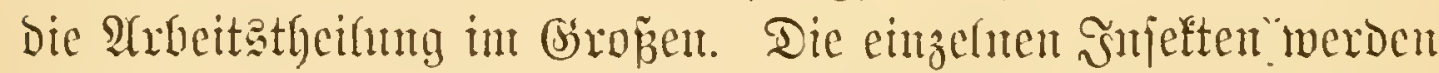
Dabei, wie wir gejehen, nidyt vollfonmener. - Das Miaterial

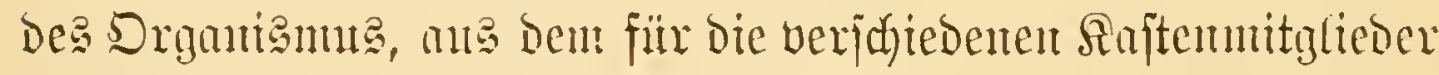

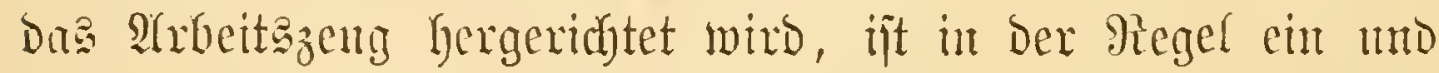

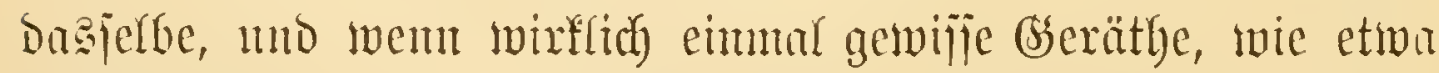

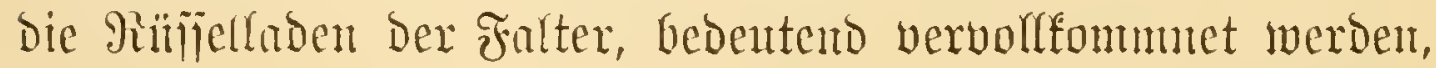
jo müjien es bafiur anbere cutgelten, Dic, wie bie Dherficfer

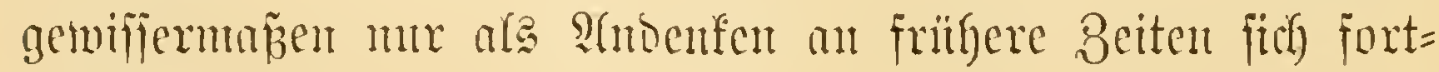
curgulten. 


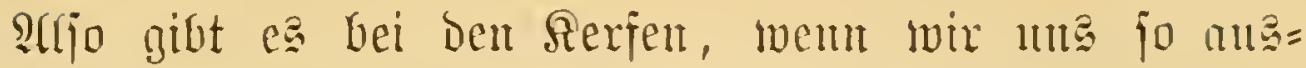
Drinden bitrjen, mur eine partielle Berbollfonmmung, mur eine

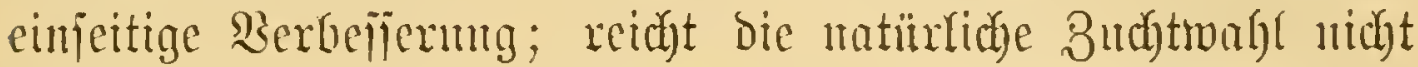
fo weit, Den gejammten Drganismus auf eine hö̆gere Stufe zu erheben?

Dañ jie joldyes vermag, da haftiger alfieitiger Fortidyritt möglid) und cxijtirt, bafïr legt

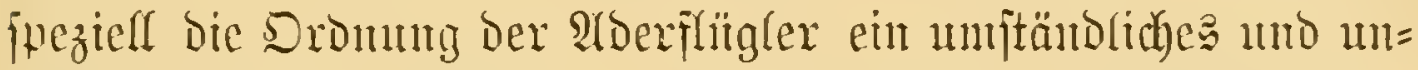

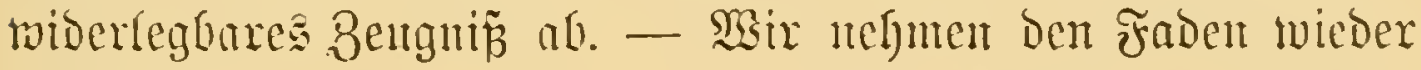
Dort ani, wo wix ifn - im früberen Rapitel - gelajjen

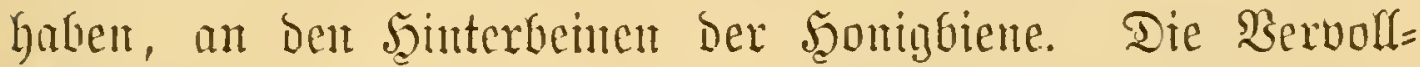

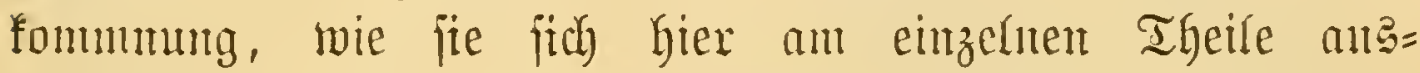
furidgt, fann nirgenos jejönex erläutert weroen. Das Bienen= Şinterbein war anfänglich Den übrigen gleidgeartet, eine einfache Bemegungaggliedmnäe. Spätex ward jie zugleich, aber ohne an Der biagcrigen Fouftion erheblich einzubüzen,

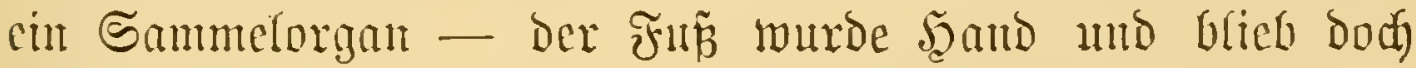

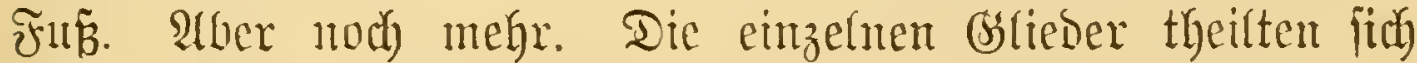
in Die Irbeit: Die Shjiene ward Sanmelförbdyen, Die Ferje

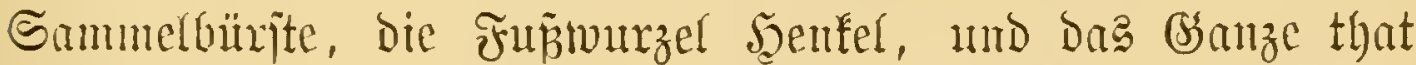
fcinen Dienjt wie ehemaks, wo ifm Dieje Pebentwerrifytungen noch nicht aujgetiitroet waren. Sit bies nidht abjolute Bervoll = fommuntur?

\section{Dasfelbe gilt bon Den Mumbtheilent.}

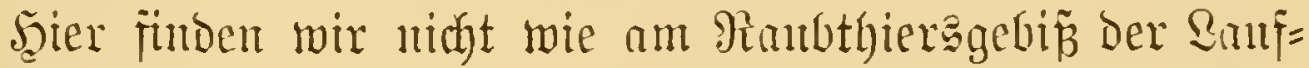
fäjer oder an Gangrohr der Falter mur Ëmerlei. Der Munduparat bex Biene ijt eime Bereinigug, cime $3 \mathfrak{3}$ ammenfajung des sejten, was dic iubigen Jnjeften in biejer fidtug einzelner= wortien. Pats Den Sainterfiefern tward die lange 3 untge

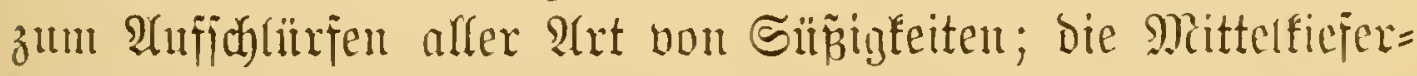
laden, jene mijhliepend, jind das complete Santyrohr der

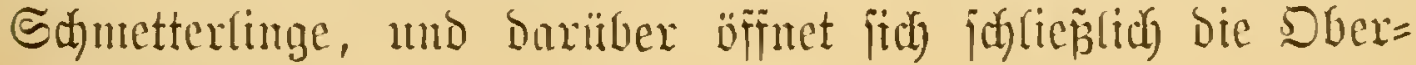




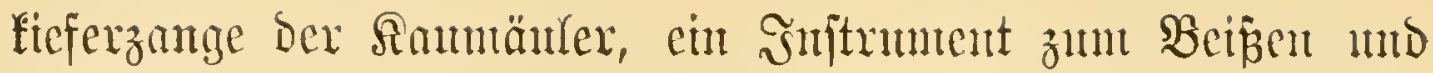
Laftragen ebenjo geeignet, wie zum Schaben uto Grlätten

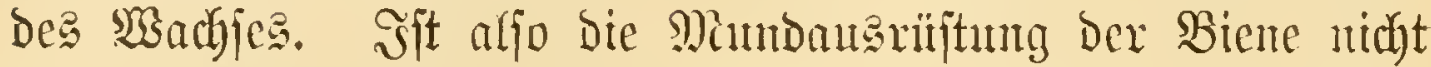

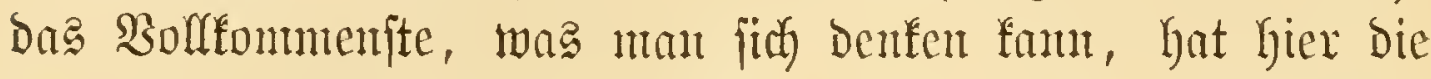

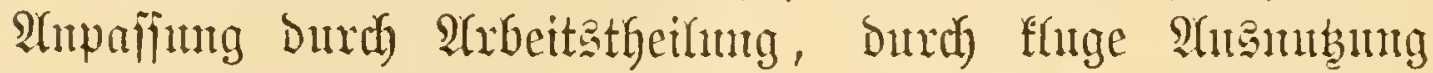

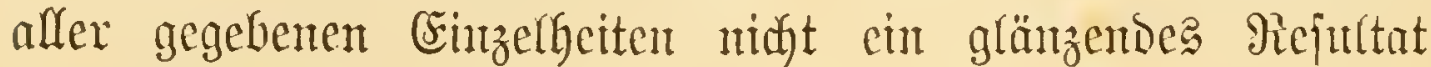
exzielt?

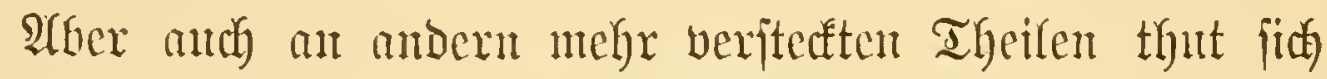

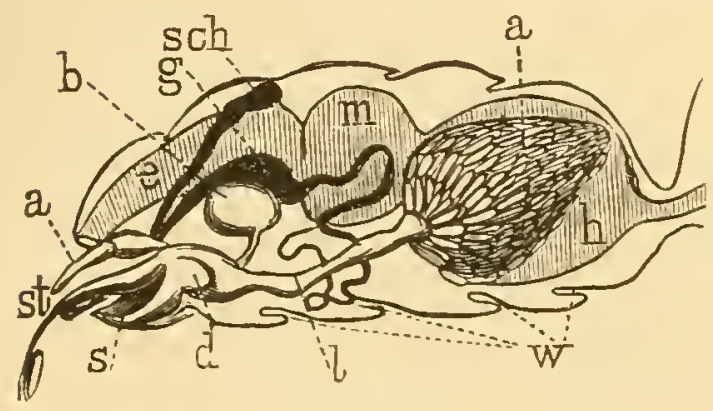

ริig. 21.

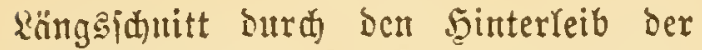
Sontigbiene (nad) Reufart). h Şonig= magen, m Mittel=, e Enbsarm, a Eier= ftoct, 1 Eireiter, b Eamentaide, s Edeibe, st Stadtel (Regeröhre), g Giitortife mit Blaje, sch Edmierbrïfe, w eingeid)lagene

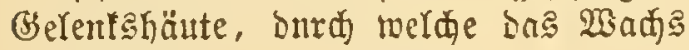
ansjudwitzt, a Aiternubänge.

jăbupflidy. Die Der Scheide (s) anthängende Samentajche (b),

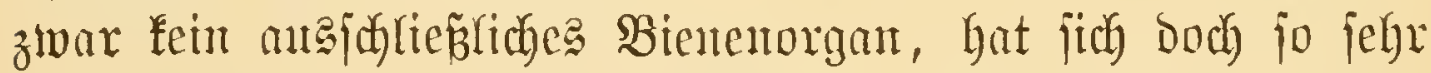
ermeitert, dañ fie eine fïr Sabre antareichende Spermamente

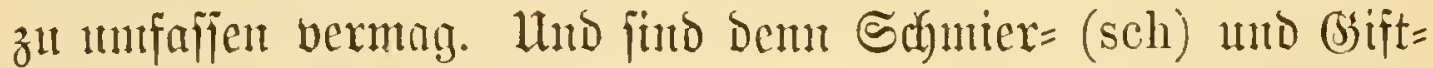
Driffen (g) nidyt gleidafalle roidytige Buthaten ober Differenzi=

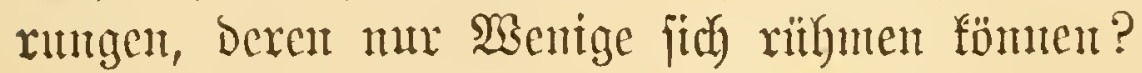

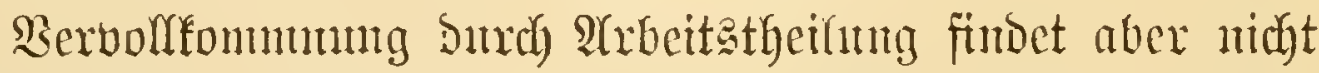

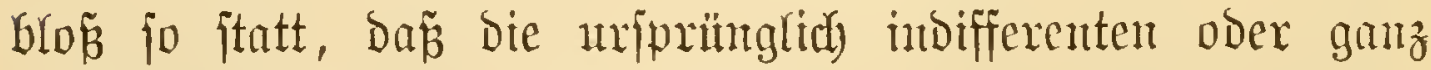
feiernden Igeile immer befier entfaltet und zut neuen Reiftungen gefdhicft gentadyt unt herangezogen werden, alfo mit Eintent

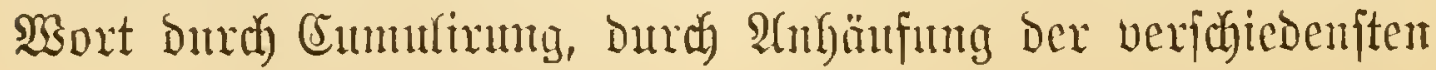


Serfitiufe des Rebens auf eintem mo Demjelben Snbibioum,

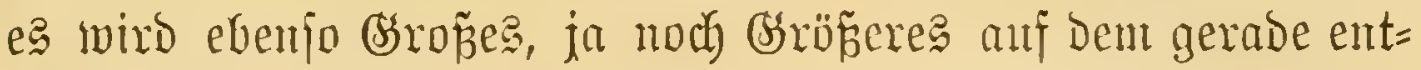

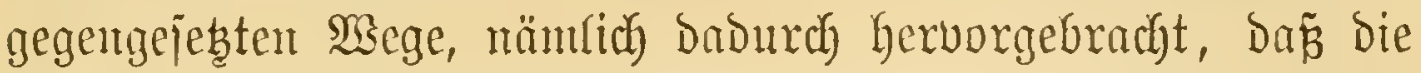
grope Rajt gewifier Funftionen, weldye eine Gebentende firaft=

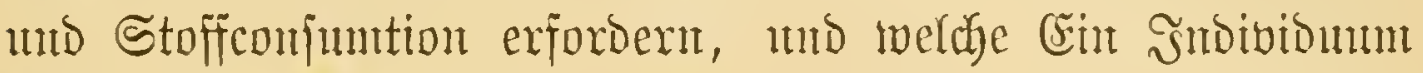

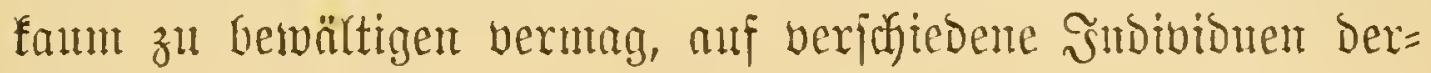
felben $\mathfrak{A}$ rt vertheilt wird, bie nut, in biejer weijen $\mathfrak{B} e=$

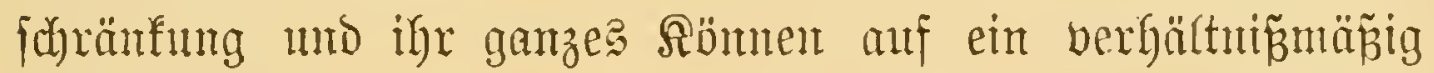

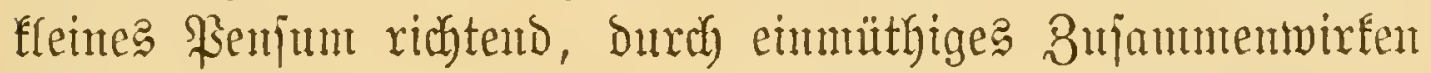
und gegenfeitige Unterftithung ihre (Exiftenz fid aunerordentlid erleidgtern mo zugheich auf eime höhere Stufe erheben. Dieje vou Polynorphismus begleitete arbeitstheilung wiro aber nirgends jübuter offenbar ala bei Den jtaatenbildenden Injeften.

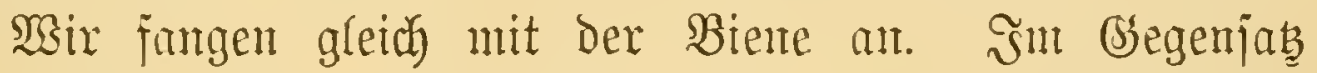
zux grop̃en Mebrheit Der Rerfe, Die ifrer Rebentaufgnbe

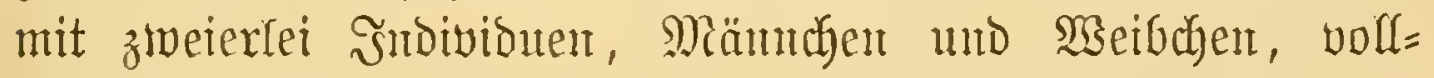
fomment geredgt werben, fommt hier noch ein britter, ber Arbeiterjtand, Dazu, Der befanntlich in jebent Bienenjtant weitaus ber zahlreidyjte ift, indem ani 20-30,000 jolcher mur 2-300 Miämuchen oder Drofnen uno - Das ift Das

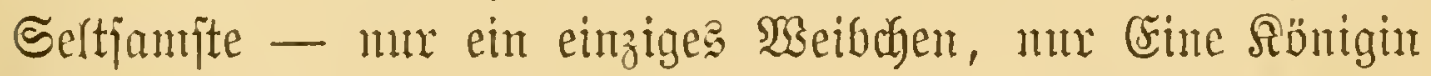

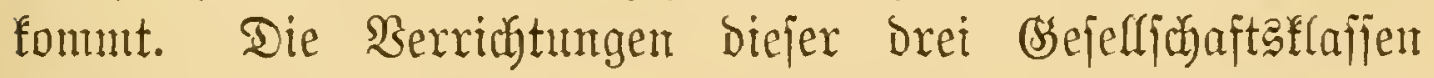
jund ftreng unteridfieden und flajpificirt. Die Rönigin ijt

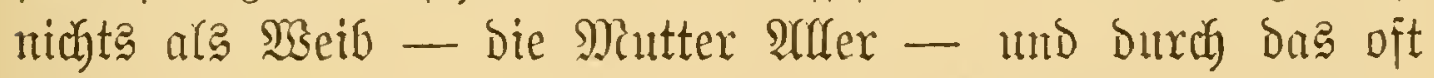
4 bis s sahre mauggejebt fortbanternde Bsejuäft bes Crier=

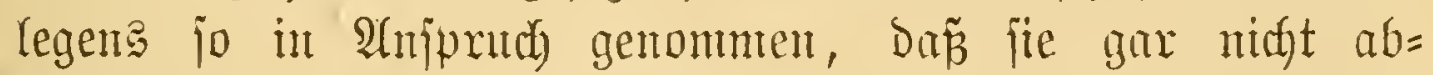
fommen fant, fich bie bod gerabe ifr jo mothmendige Aahrumg jelbit zu janmeln, jondern von ben $\mathfrak{A}$ rbeitern, ilgren allezeit

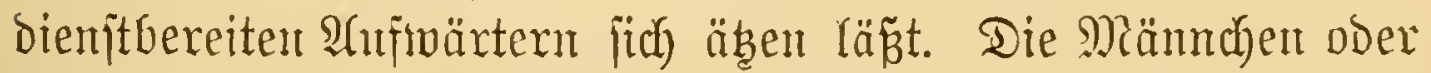

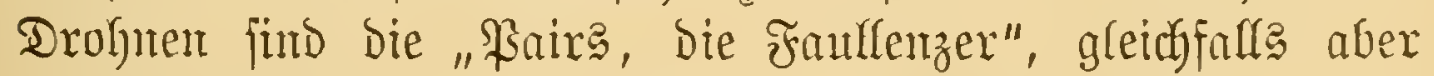
mur furze Beit von Den Rentenl Der Arbeiter lebend, Da jie bald nach Dem Şochzeitgfluge, als weiter völlig entbebrlich,

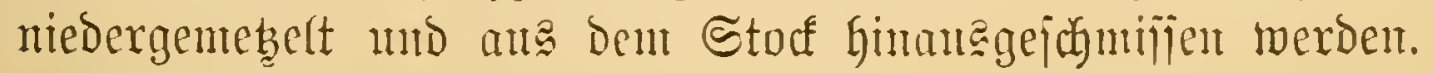




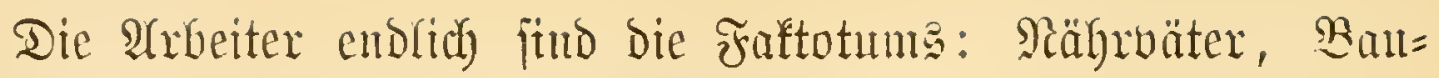

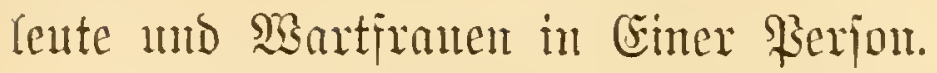

Die Drganijation Der Drei Bienenmejen ijt mit biejen soliegentheiten ziemlidy in Finflang. Beflügelt find alle und bleiben es, da ja and die jtänbige Seanbhüterin, bie Siönigin,

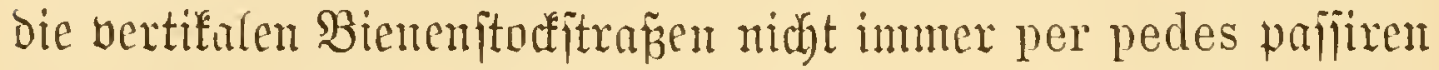

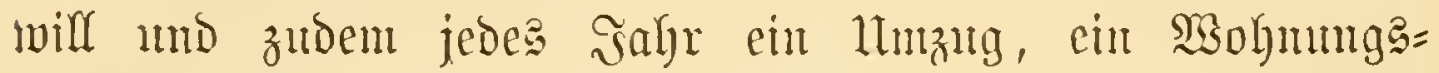
wedbjel jtatthat, bei weldyen bie Flïgel abjolut nidyt feblen Dürfen.

Sonjt ift felbitueritändich bie Arbeitübiente an beiten

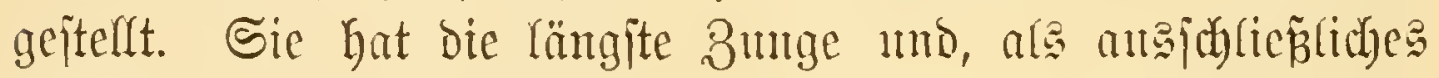
Eigenthum, anjer ben Sanmelfürbchen noch die Bürite. Die feinen weit bou cintmber jtehenden Facett $=$ ober Fernangen und Den Stadjel theilt fie mit Dem meiblidyen Dberlyant, Dejjen Safwerpunft, um mit $D$ afeu zu reden, in Yangen zu=

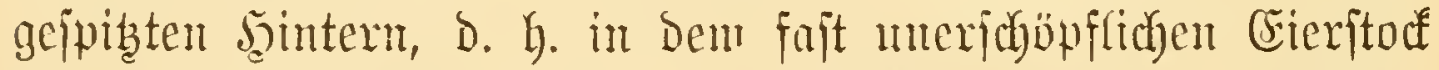
uno in ber getwijen, für alfe Sulektenmeiber fo wiattigen Iajche liegt. Sangen grifijel brautht jie femen, oa fie fo gut wie bie noch furzzüngigeren Drohnen Andere für fith joböpfen

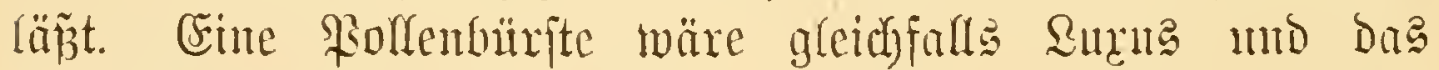
Sanmelförbchen leidgt entbehrlidy; don lebeteres bejut fie Demnoth. - Das Mäunchen verräth fich auf Der Stelfe durb

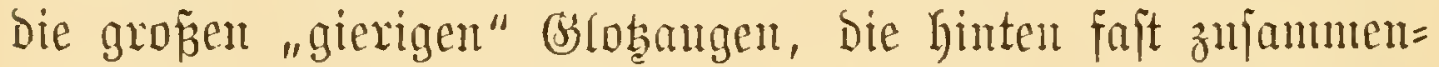

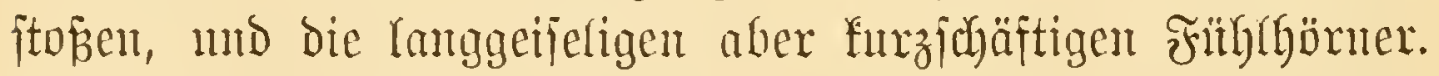
Sount ijt der Şinterleib plump und gedrungen mo jtatt bes Stadyels eime mäbtige idharigezalynte Sneinzange vorlyanden. Sammelförbdyen mo Bürjte fehlen bagegen.

Sit Das nidyt alles in fibüniter Dromung, ein wahres

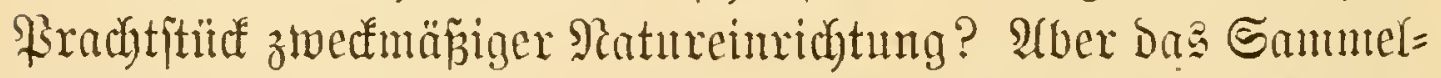
förbchen Der Sonveränin, ein gemeines Merf́zeng Der $\mathfrak{A}$ rbeit! Bielleidht muste fie jid vor Beiten jelbjt anf bas Felo bequemen - vielleidyt war jie einjt eine ârbeiterin, jo gut wie alle andern Serfmeifer. Ind die Arbeiterimus? Antgen und 
Stachel fund genau wie bei der Fiurfitir. Das gibt zu Denfen. Ferner ijt ja Der Stadyel ein Regeinjtument, ein untrüg=

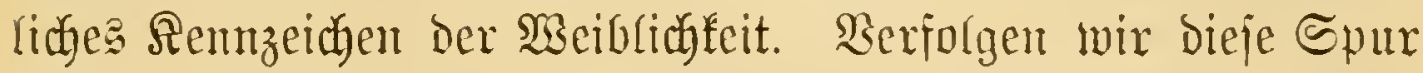

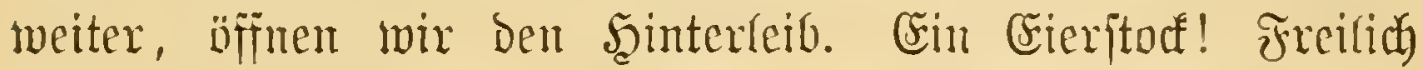
nur bem Rumbigen fich entfjilfend, menige manjebnlidye mo

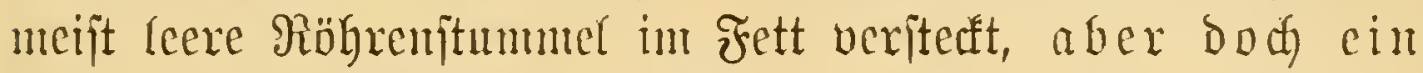
Eierftocf. Slur Eins vermiñt man, das gemijie Sperma=

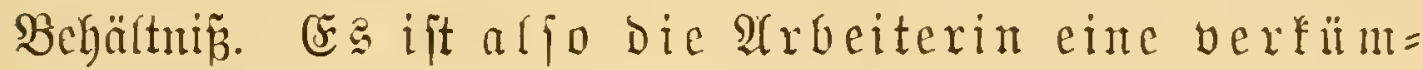
merte Rönigin und die $\Omega$ önigin ift eine emau= cipirte $\mathfrak{A}$ rbeiteriut.

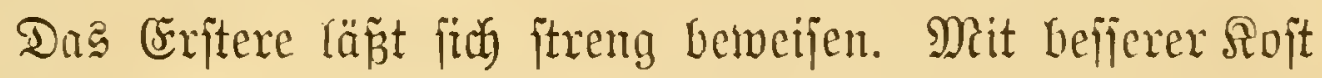
gefüttert und in einer bequeneren Siege erzogen miro ans ber Prolctarierlarve cine Sönigin - ja bismeilen braudbt es foldhen

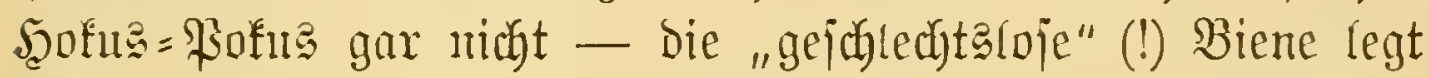
mitunter Eier, ofme alfes meitere 8 uthu, es weroen aber,

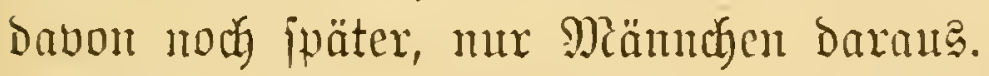

Sind mun, fragen wir bie Teleologen, die Arbeita=

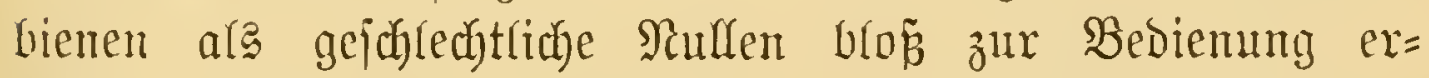
¡daffen worben oder vielleidgt zur gelegentfichen âdugilfe,

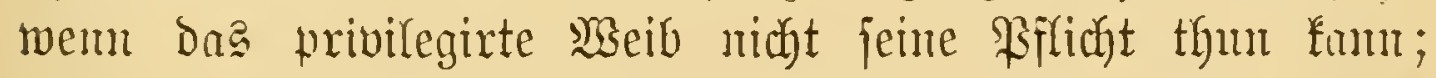
i fiteruer die Drobuenbrütiget, der Ueberfun

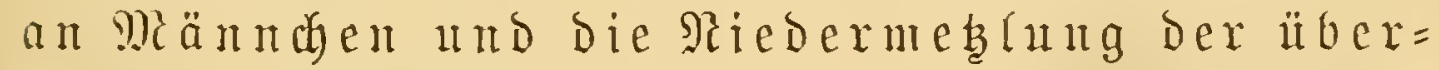
zähligen Thronfandibatimen ein 8 wefmäzig= feitsargument?! - Die Arbeitabiene allein wirft den ganzen alten, längit fojiji fein jolfenden Dogntenplumber üfuer Den Şaufent.

Alber wie fam's Denn zun heutigen Bienenregiment, wie wurden bie $\mathfrak{A}$ beiterinnen entweiblibyt und wis bie Monarchie gejuaffen? Die Ratur erperimentirte an ber uriprünglich

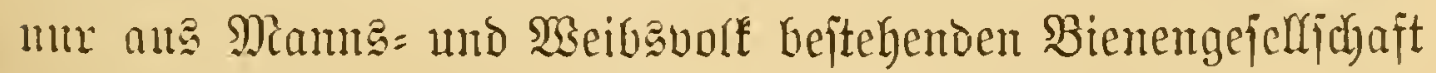
jo lange herum, fie tremute fo lange das Sdymanter in ber Gcichledytajphäre ber 2 cibchen - unterorüate bei ben cinen, jteigerte bie Frudytbarkeit und jpäter zugleich bie (siferjutht 
bei Den anderen, bis es eben fo fan, wie es hente ift - und ïbrigets Danert ja ber Rampf unt bie alten Redhte nod) fort,

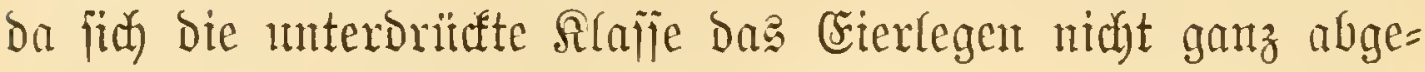

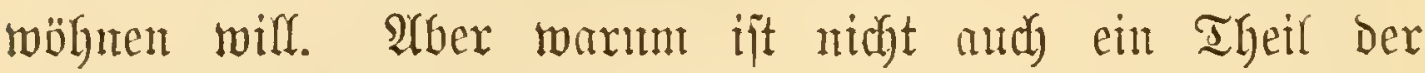
Männd den gefnechtet worben? Man brand feit Kerigelefrter

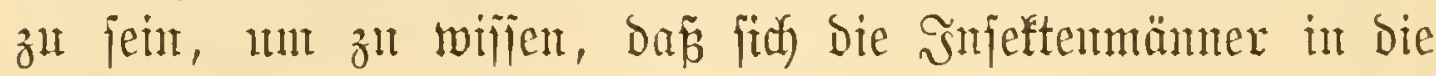

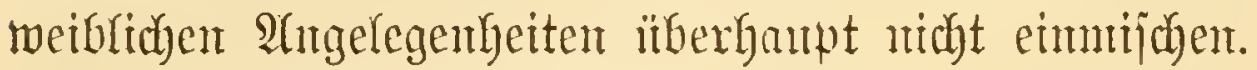

Die Perfonalftandennufterung in Den ïbrigen Serfitanten bietet zum Brejagten mur Die weitere Bejtätigung.

Betreffe der MeEpen hat v. Siebold dent Standpunft flar gemadyt, wentigitens bei Polistes gallica. Einen Dritten

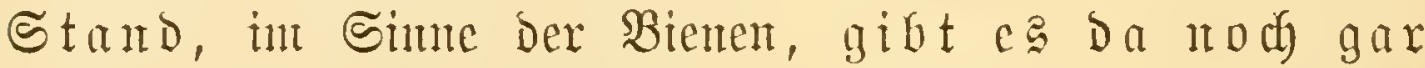

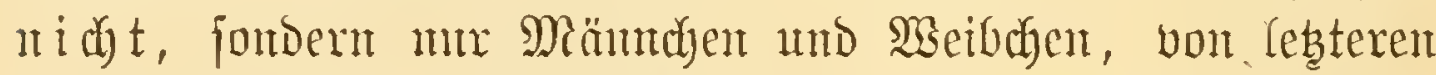
aber cine gröpere mo flcincre Sorte, bie aber fouft, mäntich

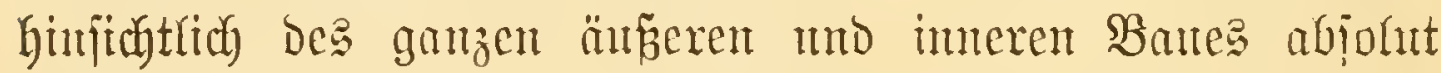
nicht zu unterjheiden fint, went gleid, mo das mag ntan

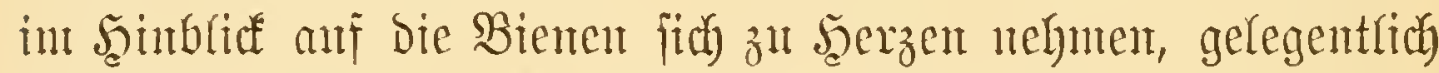
eine Sermegrutg Der 6 Eirögren anf 7 ober 8 ober einte

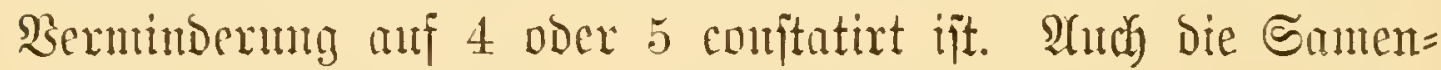
tajche und baher and bie Befrudtungefägigfeit ift gemein=

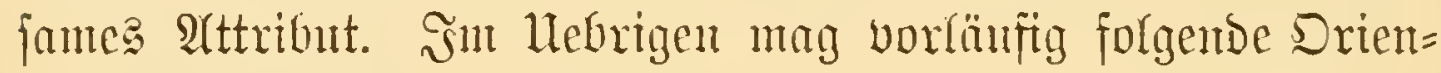
tirung austrichent.

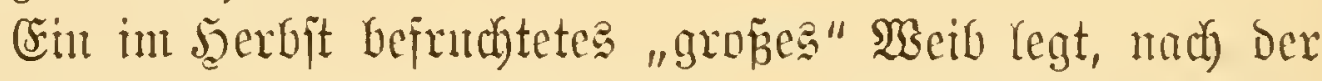
Heberwinterntg, Den Grumb zu eiment menen Stant. Diefe

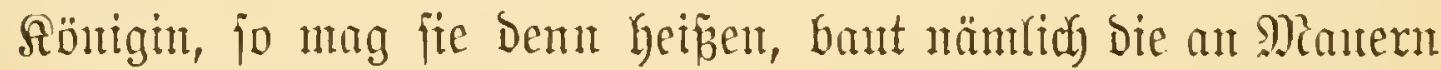
uno Bretterzänten bäufig zu beobadhtende löidgpapierene Zell= wabe mb belegt, nady mo nadi), jowie die 3elfen fertig werden, jede mit einten Cit. 2́n biejer erjten Brut entiteljen

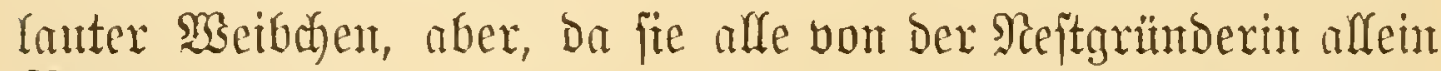

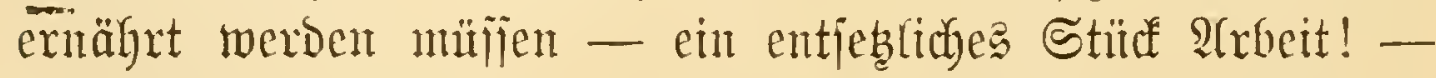

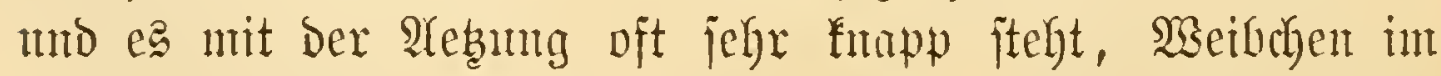
wahriten Simne, mäm(ich lauter fleime. Da leb̧tere beim

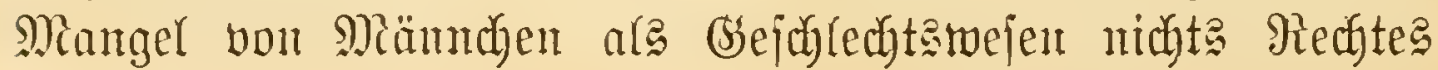




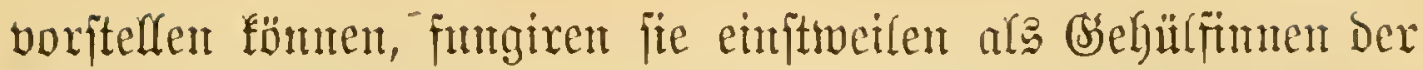

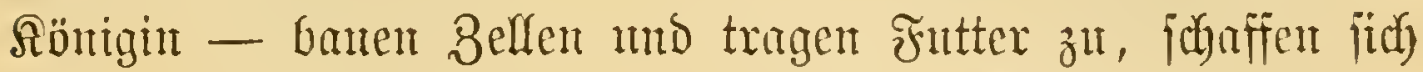

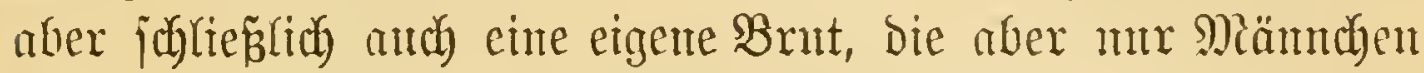

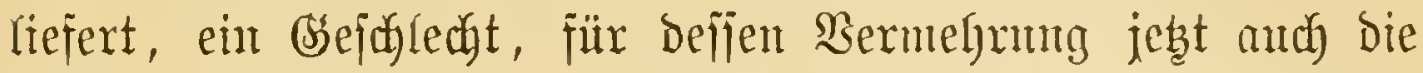

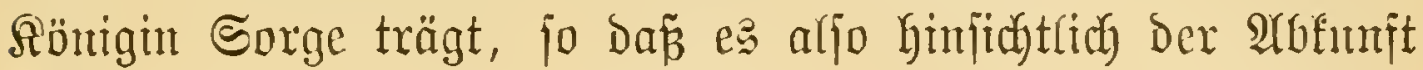

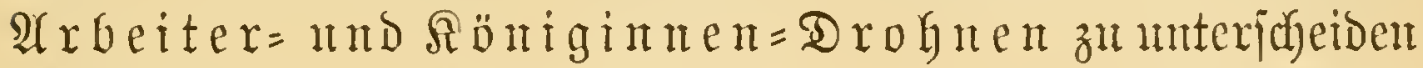

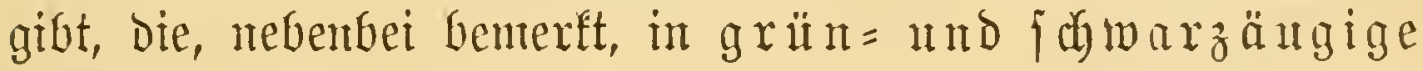

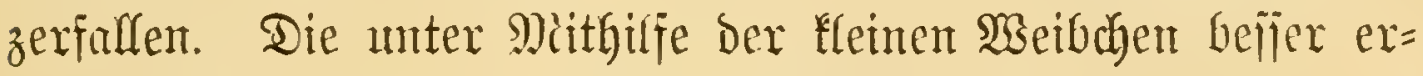
nährten Schroeftern Der fpäteren Bruten find mun eben bie gropen, weldye nach gejolehener Befruchtung überwintern uno Die Sache von vorne anfangen. So iniegelt fith aljo in b̧ats= halt von Polistes ber $\mathfrak{H}$ rzuftand der Bienen wieder; ihre fleinen

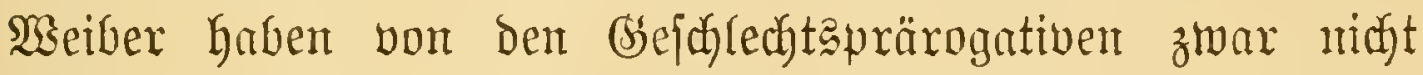

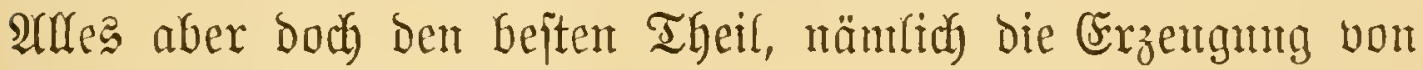

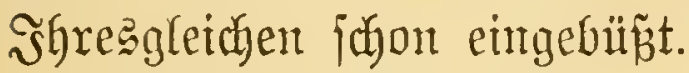

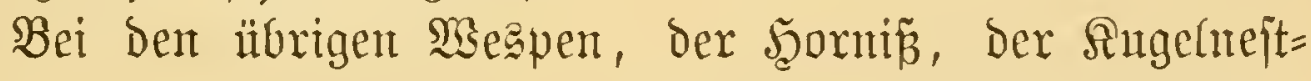

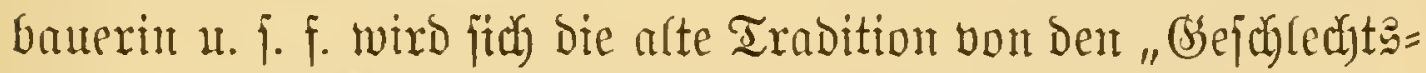
lojen" nod) fo lange fortichleppen, bis auth bier eimmal grïnd= (id) anfgeräumt wirb. Dies wäre bejonders bei ben Şummeln

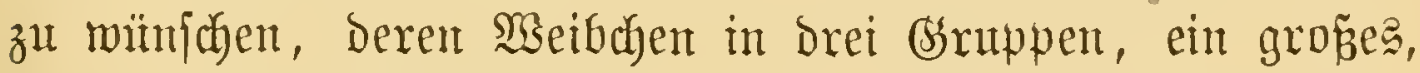
ein wahres Riejentweib, Die "Brrïnderin", Dann bie mittel= gropent und bie fleinen zerfallen, bie, wie idy exit fürzlidy mid überzeugte, Gimjichttich des Stachelapparates twenigitents nidyt

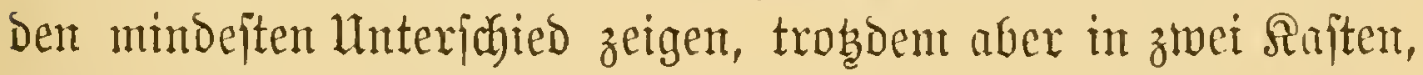

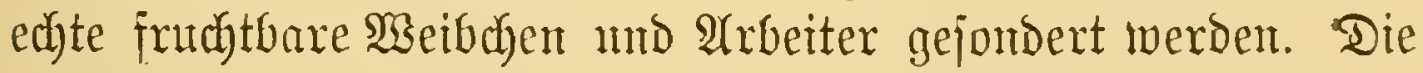
mittelgropenen (e gibt aber ntegrere ßariationen!) follen die fleinen erzengen umb die Riejendamen erjt im Seerbite, bard nach Der mäntrtichen Brut, zun ßorjchein fonment.

Rehrreidy ift die bstiederung und bie jetweifige phyitiche Araräjtung in ben Ameijen itanten. 'Wie bei bent Bienen

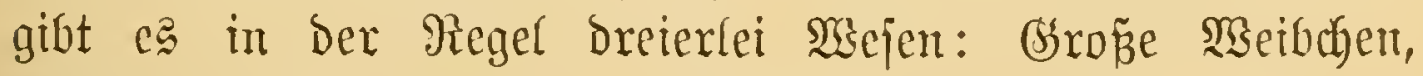
Mäuntyen und $\mathfrak{A}$ rbeiter. Exitere ztwei fonmen itets ge= flügelt ans Der Puppe, verlicren aber dieje fitr ifre nteift 


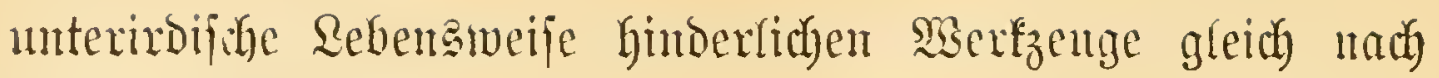
Dem Şachacitaflnge.

Die $\mathfrak{A r b e i t e r}$ hingegen, weldye bei ihren heutigen (Jjemohn= heiten überhaupt niemal: Der Fluggliebmä̧en besürfen, haben Diejelben bereits gäızlid abgelegt. Utm jo interefinuter ift bie

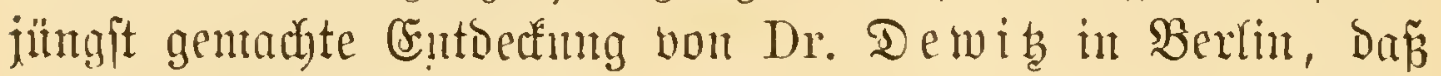

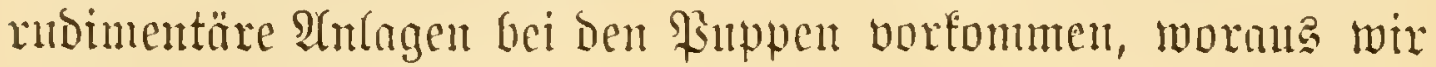
offenbar erjehen, dañ bie arbeiterameijen elymals jo gut wie die vollfommen angebildeten $\mathfrak{x e i b c h e n ~ g e f l u ̈ g e r t , ~ i h n e n ~ a l j o ~}$ ähnlicher al gante maren. -

(Ein midtiger Fortichritt in ber garzen Strbeitstbeifung

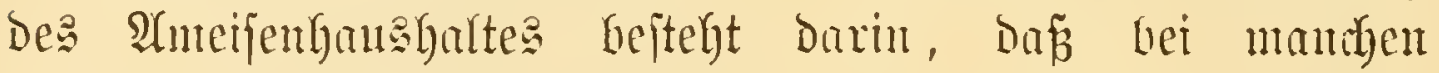
unter ben Shrbeitern zmeierlei, mehr wentger a

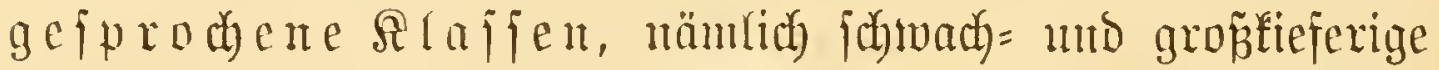

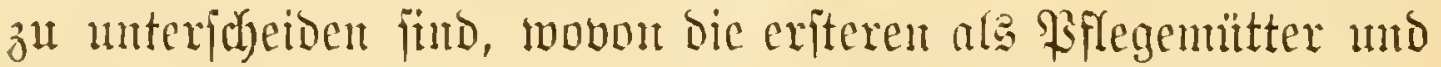

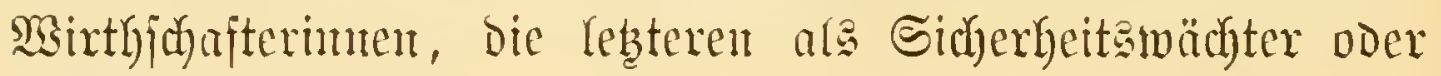
Sorbaten funtgirent.

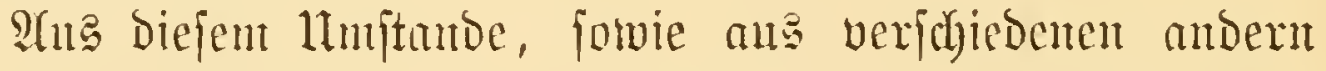

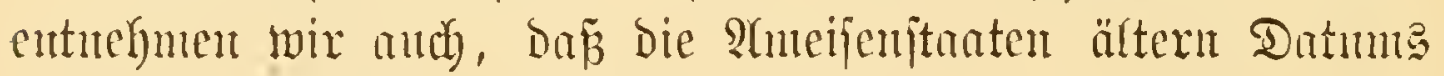
als jene der Bhmentespen futr.

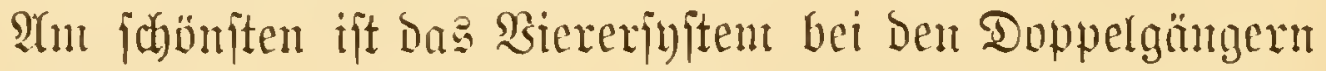
Der Ameifen, den Termiten, ansgeprägt.

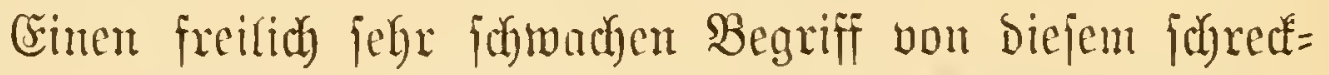

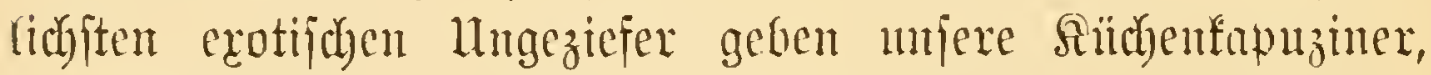
Die "Sibwaben", mit benen fie and wirflidy in naher Buts= verwantidyaft ftegen. Der Sejer wird Shelegenheit gehabt

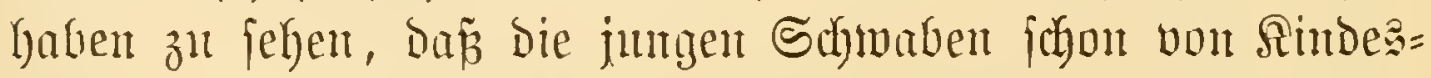
beinen auf mit ben alten fich herumtreiben mo biejen auch bis anf bie erit juecejijue herborfwrojienden Frlügel gleichent. Sarven im Sinne ber ambern Socialferfe gibt es da gar micht mo Dasferbe ift aud mit ben Termiten Der Fall, ein $\mathfrak{l} m=$ ftuns, Der Yjuffichtefich Der Dentung Der einzefuen Termitentrau=

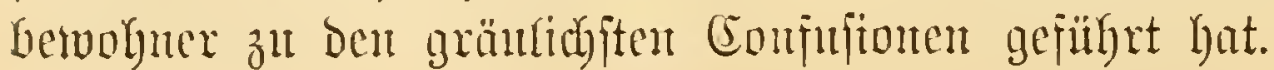




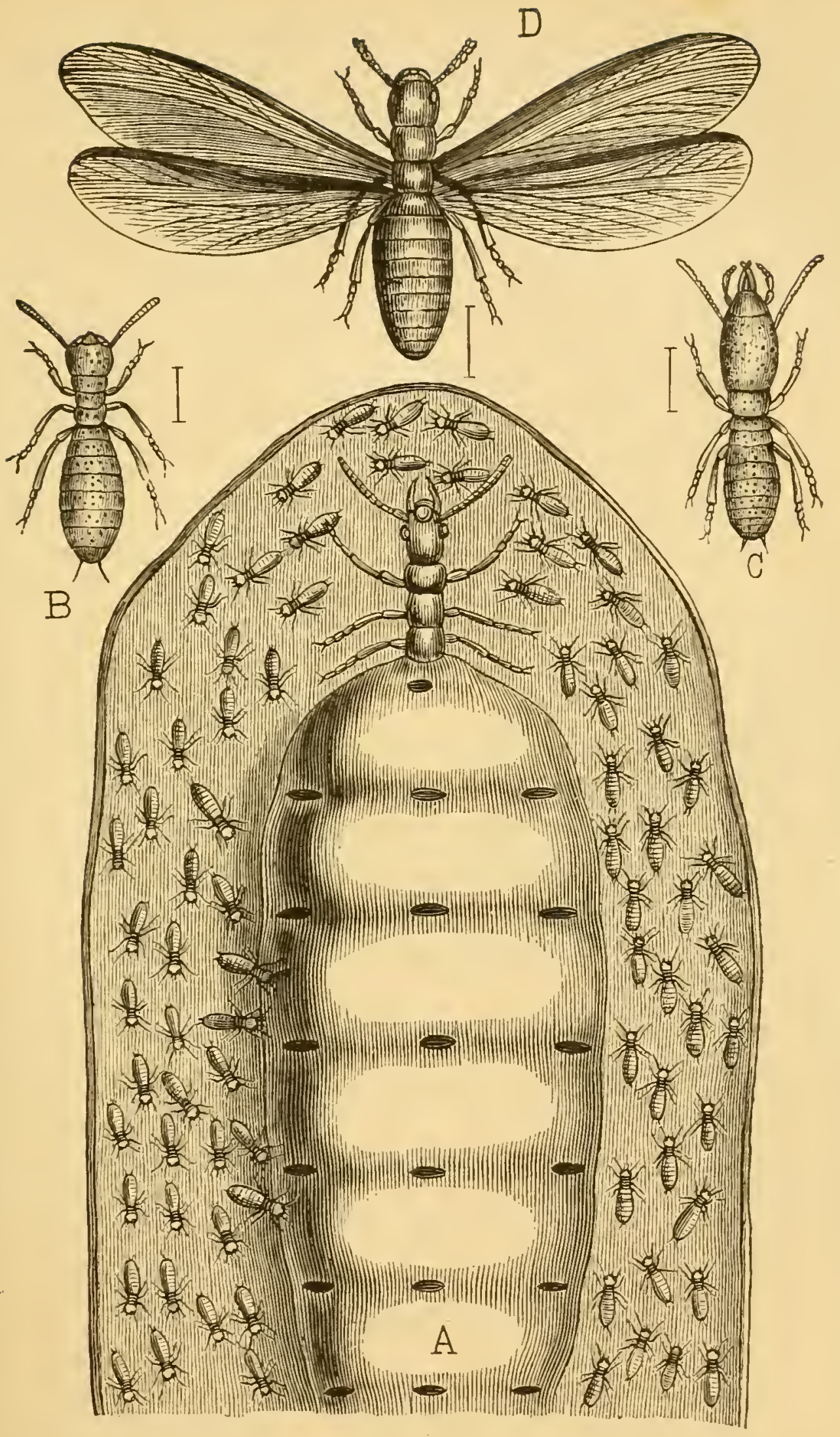

Fig. 22. Termiten (Termes lucifugus).

A Rönigin mit ber inugen Brut, B 2trbeiter, C Eorrat, D Männden. 


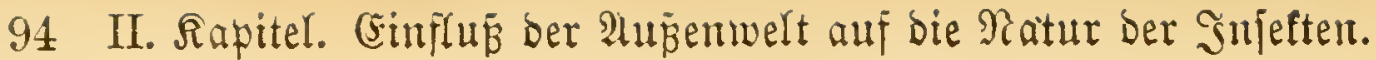

Unter Den majorenten Termiten pheint es im. Ange=

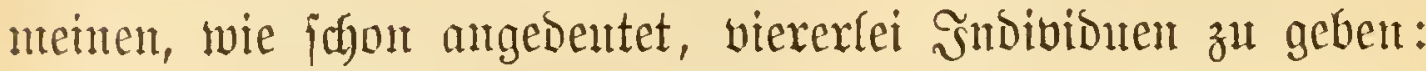

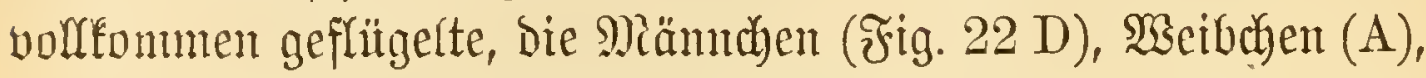
theils ohne, theirs mit Stummerffügeln, die aber, wie foldhes aud bei andern Snjeften febr bäuftig, bei Den Sarven grö̈Ber fein fömen, und Dam $\mathfrak{A}$ rbeiter, welche in 2 (nnmen (B) reip. Banlente uno in Solbaten (C) zerfallen.

Das früher gebranthte $\mathfrak{s o r t}$ "Riefendame" hätten wir fïres Termitentweib arfiparen follen. Es ift dies gerabezu

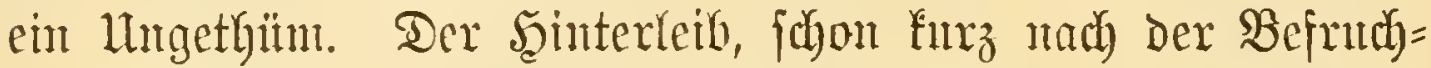
tung zum Beriten angebebnt und Mialionen von Eiern bergens, vergröpert jith uody fort und fort, und die Bauleute haben volfauf zu thum, Den bacfofenartigen Throu= ober Brutfaal cutfprechend zu ermeitern.

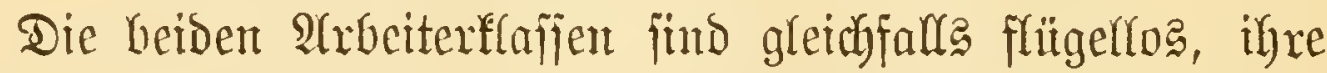
Stärfe liegt aber natïnlidy nidyt im Seintertbeil, fondern in

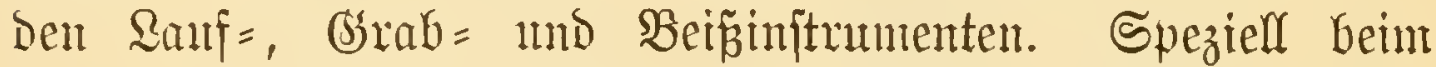
Rriegercorps fints bie Riefer von gemaltiger Stärfe, unto bie

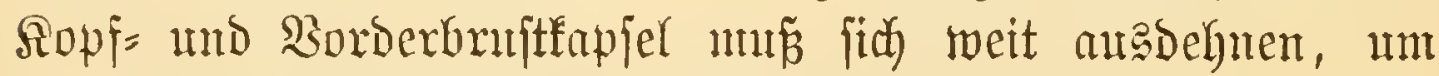

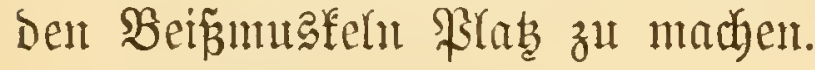

Legpès mill gefunden haben, Daż fich fowohl das Gsenie= ars das Snffanteriecorps aus $\mathfrak{B e i b l e m}$ und Mämlein refrutice; dody lebtere werben wohl and hier ibrem Princip

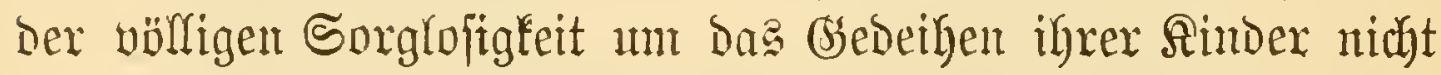

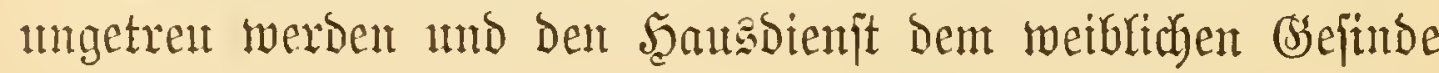
itbertajien. 


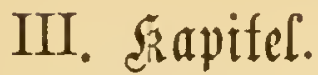

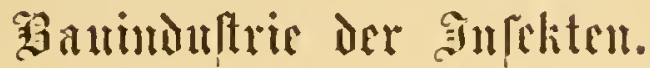

Man mag von ber Rangitufe, welche Die Sechäfitf̧er in

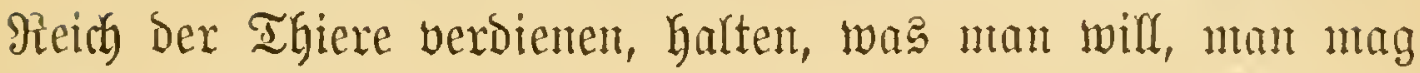

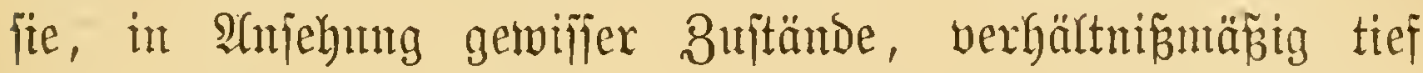

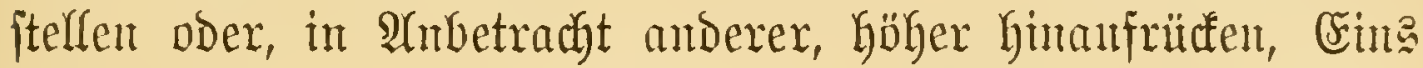

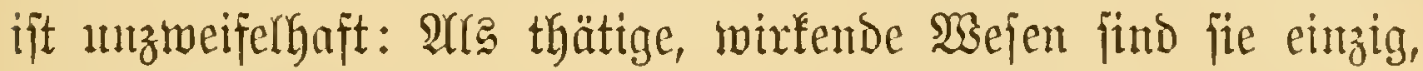
unvergleidylidy; bie Şandungen, weldye fie verrichten, uno bejon=

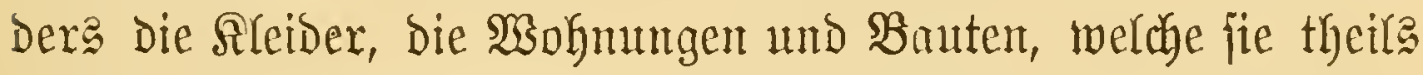

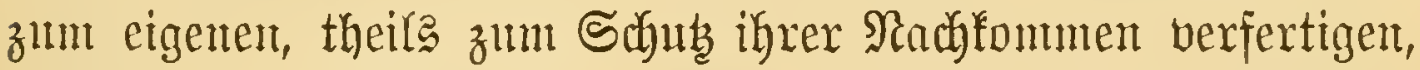

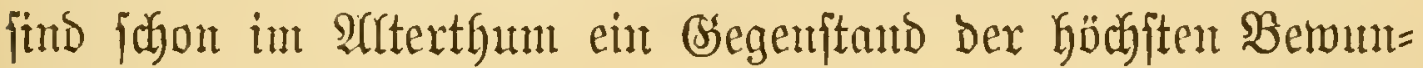
Derutg gewejen, mt went wir bie Sache redgt faffen uno beim rechten Santen nemen, D. h. wern wix me eimntal vor=

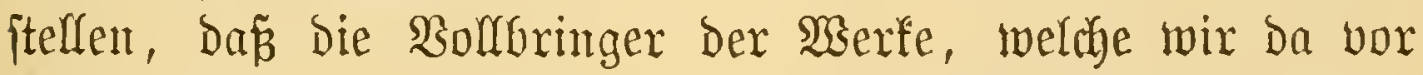
Augen habeu, in Bergleid) zu us Bejchautern nidbt von fo gar fleiner, ja unturfehntidyer Statır wären; jo würden uts ifre Thaten nod mefr impontren, ja e马 würde auth Dem gemeinen Mante flar werden, da z die Jnfelten, hin= fictutid beffen, was ein und burd fid felbjt herborzubingen vermag, arlen andern Thieren weit überlegen find. Doex two ift Das $\mathfrak{W e j e n , ~ w e l d e s ~ j o ~ j u b ̈ n e ~ W i e g e n , ~ w i e ~ b i e ~ S c h n e i d e r = ~}$

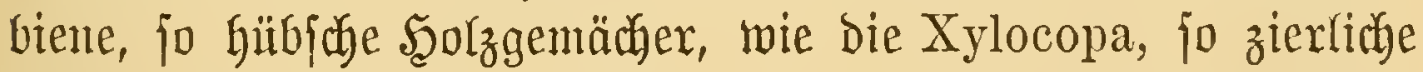
Erogalferieen wie die Andrena, fo mutnexjame Rartenthätfer

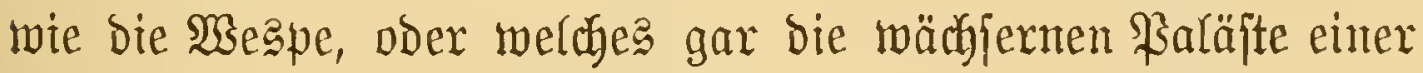
Stodfoiene oder Die "brzantinifaben Dome" Der Iermiten zu Stantbe brächte?

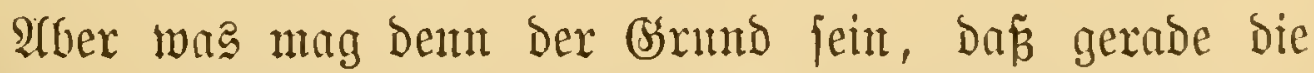

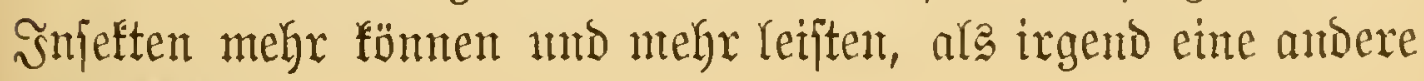
Thierkiajie? 
Bei Der Unterfudyung Diejer Frage, von weldher wir voratsjeben, Dáp fie unfern Rejer nod) weit mehr interejitut als bas rein Thatjächliche und Sejobreibente der Snjeften=

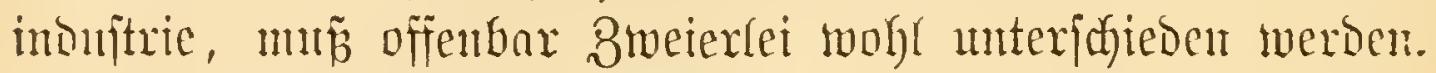
Die Frage nach Der Miöglidyfeit Der tedmijhen ober medha=

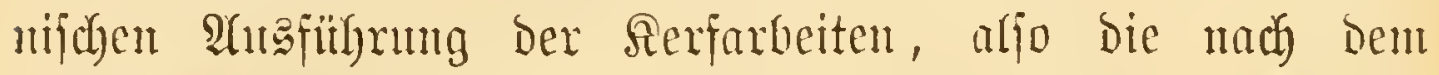

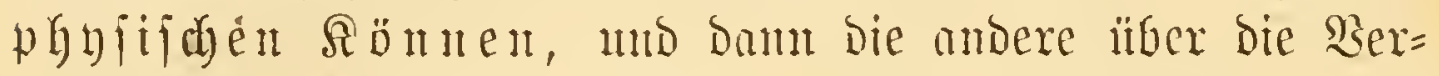

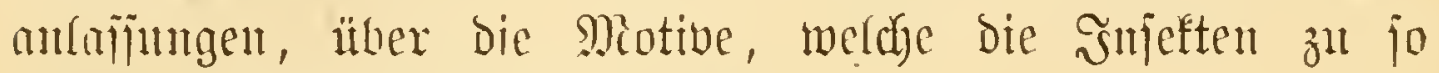
arffälligen Serrichtıntgen antreiben.

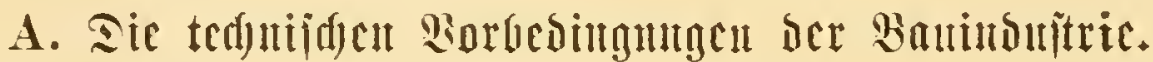

ङie find von zmeierlei 2 trt. Cie betreffen erittich die Materiatien, Die Stoffe, ats Denen bie verjofiedenen Snduftric= artifel, zuntal alfo bie Bauten hergejtellt merben, und bunn

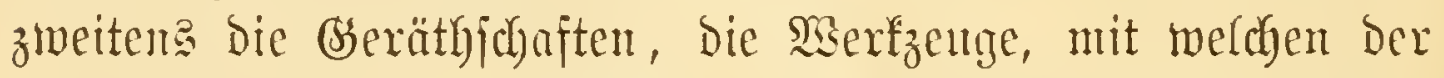
rohe Stoff geformt, zugerichtet und überhaunt zut einem be= ftimmten Snoujtriez̧wed verarbeitet wiro.

Huterjuchen wix zuerjt bas Material. - Daż biejes nicht blof eine Şauntbedingung zum Banten ijt, fondern

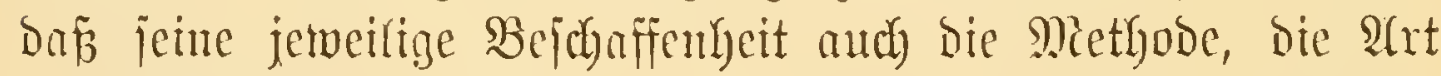
ober Manier des Baneng und Danit zugleid) Den Baujthl

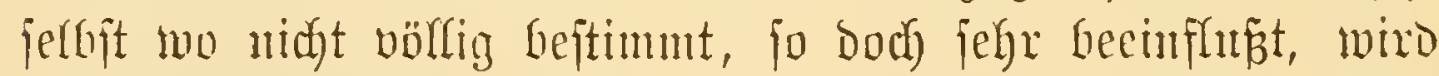

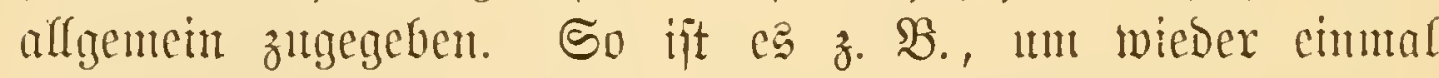

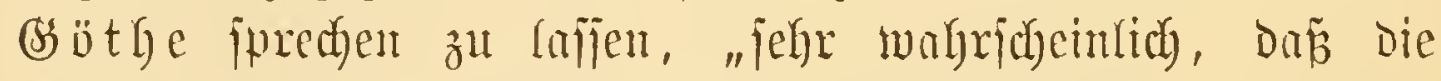

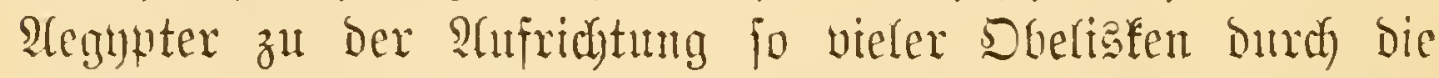
Form der (hiezu benubsten) Grantitböcfe getracht murden, Deren Rarallefipede öfters (nad) atrt einer Ruramide) diagonal getheilt finto", unto bie Form der hohen, jüulengetragenen Şiutten Der Malayen, wie fie $\mathfrak{B a r l a c e}$ abbildet, erjacheint gleichfalle durd die Natur des Bantburahres gegeber. Wie jehr bies and für bie ฐnjeften gilt, fönnte man an tamjenden von Beijpielen erhärten. Esine Midflerrante, Tortrix ribeana, Die anf Den B̉lättern Der Binfe lebt, lant, 


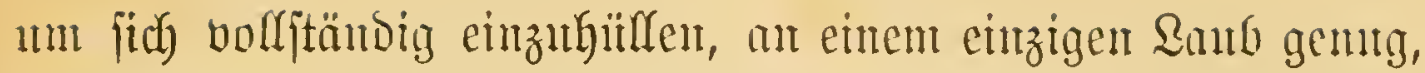
bejien Seitenränder jie mit Fäben an einamber ziejt mo jo zul cinter föblyt einfadyen Scïlje mmojeitultet. Das (Ssleidue fann mun vout jenen exotijchen Raupen int Fig. 23 jagen, die, eine neue Art mandelnder

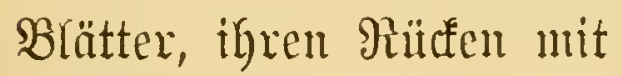
einent cinzigen $\Omega a n b$ zu= becten, bem fie aber früber den Stiel abbeiz̄en, da berjelbe als Sobutbmaterial feinen Werth Gat anto fie mix an Dex freien Betvegung Gundern würde. Anders fteht's bei Der Gelechia subocella (Fig. $2 \pm$ F), die

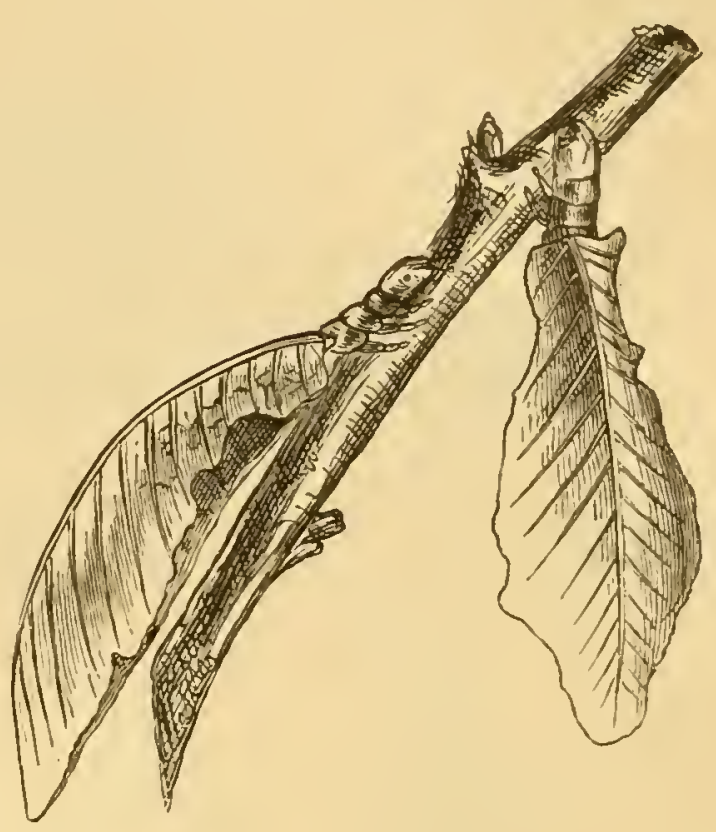

Æig. 23.

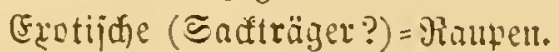
eines näberen Bejchanens wohl würbig ift. Dieje Panue lebt anj Den Blüten von Driganum, tveldye befanntlich eine zarfige Iridgterfrone baben, Die mit Reichtigfeit von Bhätenboben

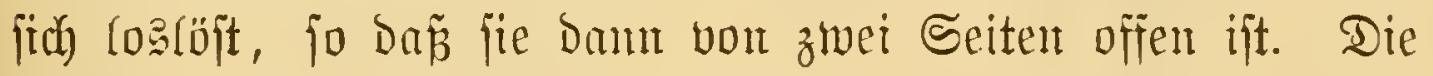

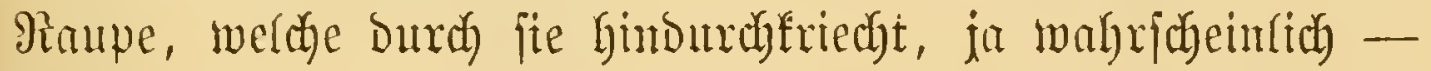

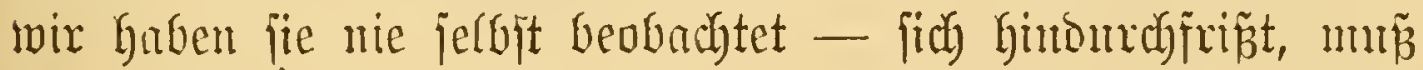

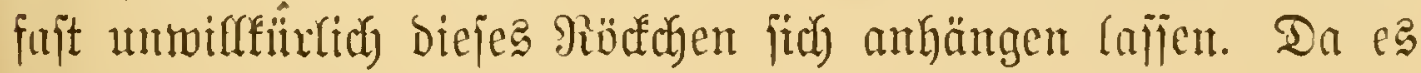
aber zu fleut ijt, um Das Thier ganz zu befleiden, jo werden mebrere über cinander gejdyoben. SRod complicinter wird dies Rleid bei mbern Sadträgern, die anf গRabelbämmen

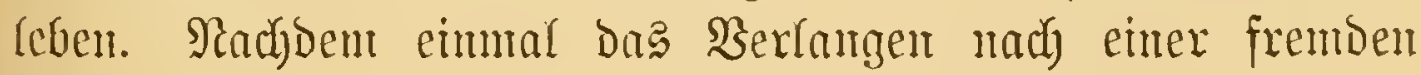
Sillle erwedt, fönnent fie die Sadbe mmöglidy moers an=

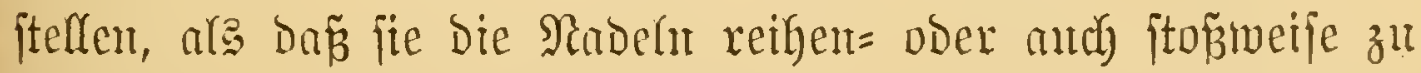
einem 巨ax zufammenjpumen, während vieder der Brasmotte (F̃ig. $24 \mathrm{~A}$ ) Eeine anbere $\mathfrak{W a h l}$ gelajien ift, alg von beu 
Iangen linearen $\mathfrak{B l a ̈ t t e r n ~ m o ~ S c a r n e n ~ i b r e s ~ F u t t e r p f l a n z e ~}$

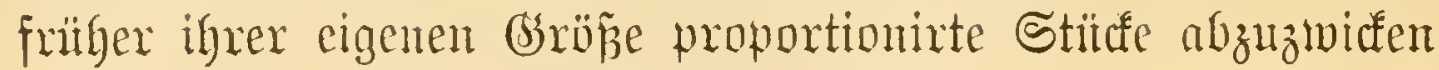
und Dann wie oben zu verfabren.

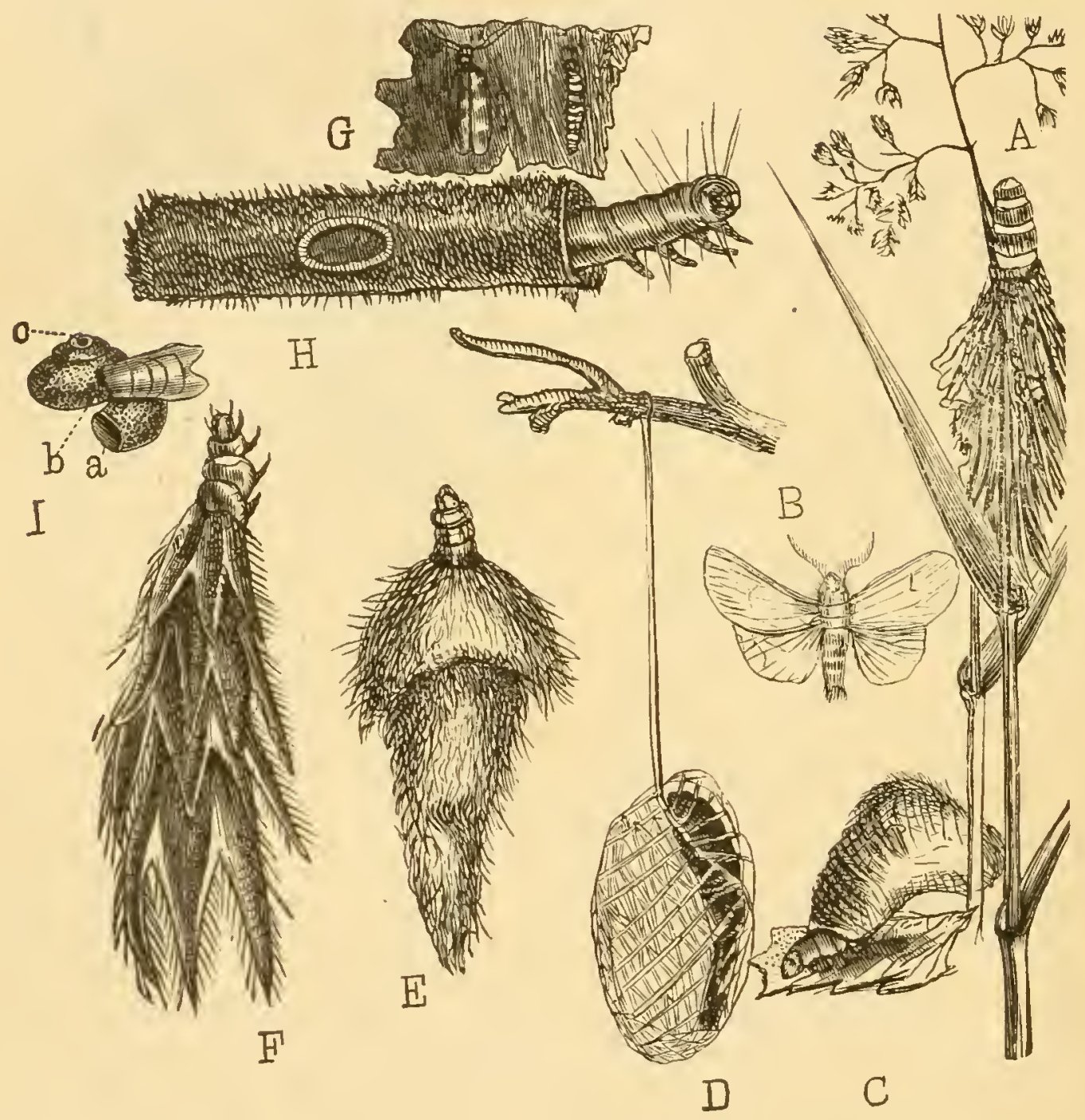

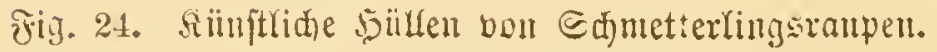

A von Psyche graminella, b Der zugehörige Edjutterling; C u. E Earven von Coleophora, einer Matte (D (Socon eincr Grajitianiphen Miotte); F Gclechia subo-

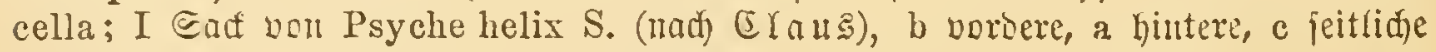

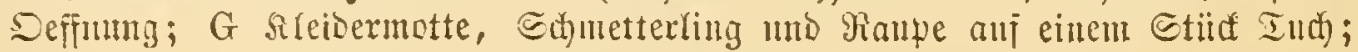
H Faupe vou Tinea tapezella in ifrem fytteral.

Exyon an Diejan wenigen Bcijpiclen fobeint genugfan ex=

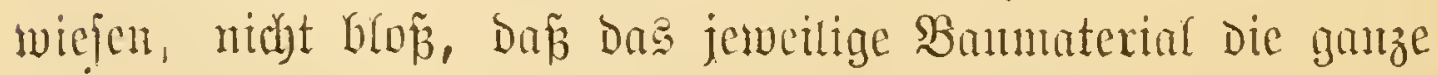
Façu des betreffenden Fubrifatis becunflüt, fondern, was 


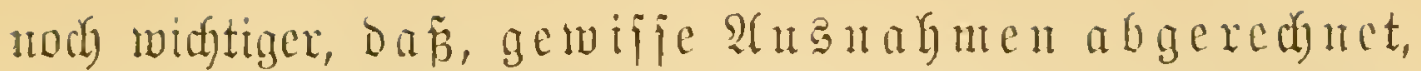

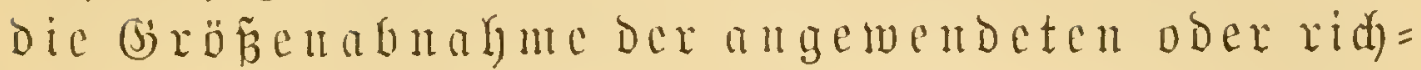
tiger Dex zu Gebote fteluenen materialien noth= wendig and eime complication eime berboll= foumung des $\mathfrak{B}$ anderfaldengerobruft.

Und follte Das, was fïr bie Ranbbanfunft richtig ift,

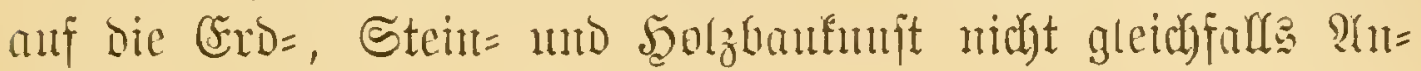

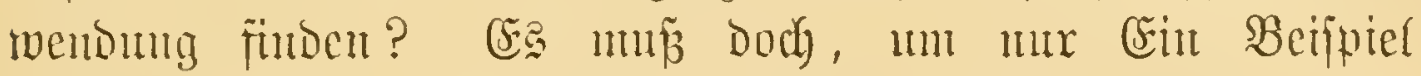

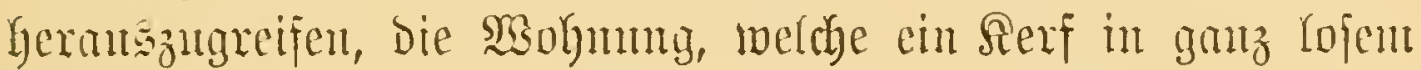
Sand fid bereitet, nothwendig anders ansfallen ale jene, welche in einem zähen (Eroreid) gegrathen wird. Sober, anf

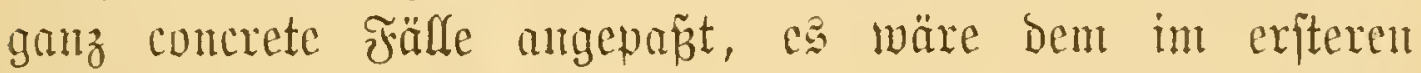

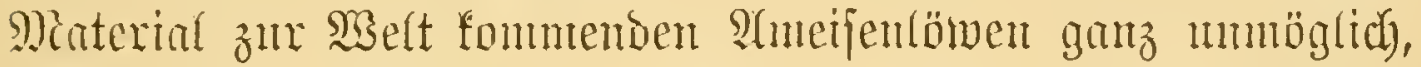

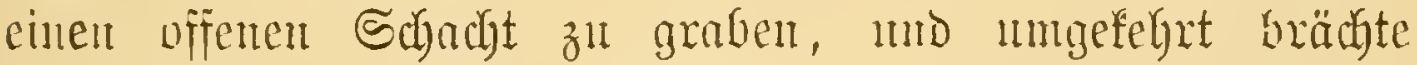
Die Erobiene in Loferen Smbe feine ordentliche Ballerie ju Stante.

Went aber, in Affgenteinen iventigitens, bie Berjachicon=

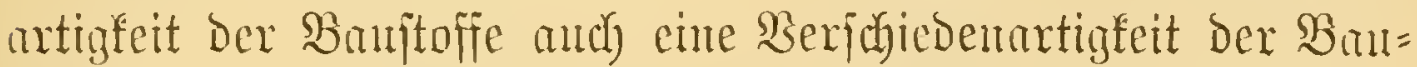
methoden mo ber Banftyle mit firid bringt, weldye Thiere jollten Dan Mantigfaltigeres volforingen als bie Rerfe? C5:

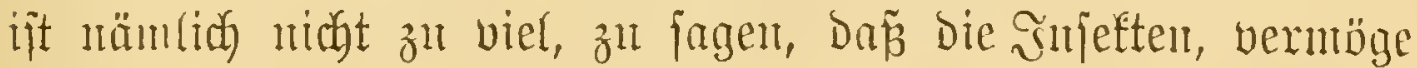
igrer miberjeffen Serbreitung, mit affem baten fömten, was bie Satur ïberhamt an Ganfähigem Minterial herbor= bringt. MSie vieffältig fün füre Crrjte bie einzehnen Beftano=

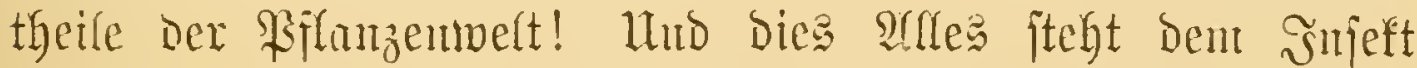

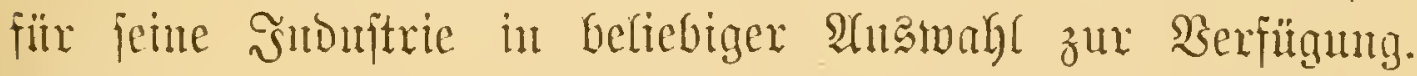

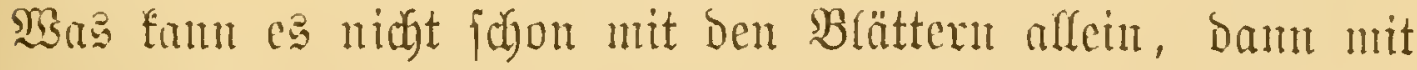

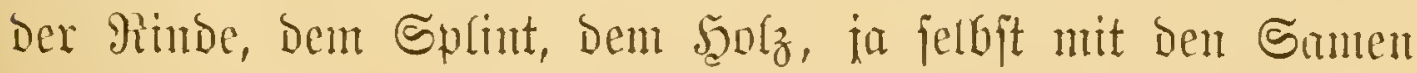

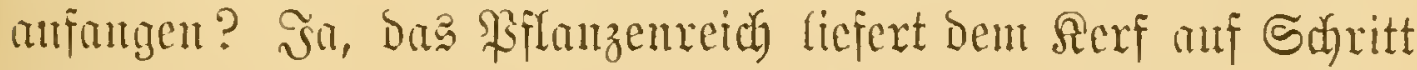
mo Tritt jo vielertei und jo gecigutete, gleichjan eigens

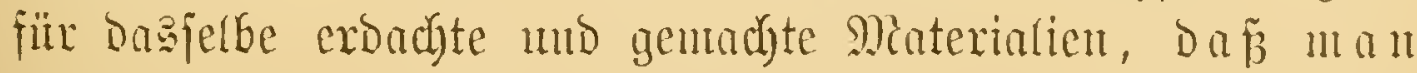

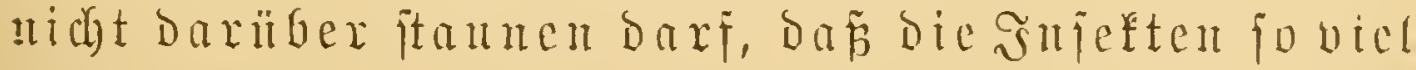
Sudutrie haben, fonderu vielmegr dariber jich 


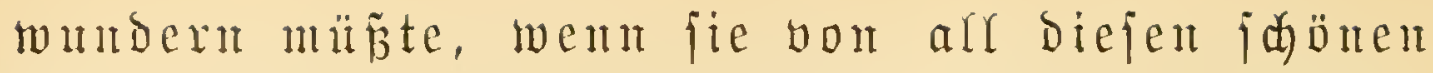
Gelegenbeiten feinen jo weitgebenden Bebrand nu a diten.

Wie mannigfacke mo vorlocfende Bangelegenteiten! lietet ferner bas Eroreich theils Den unmittelbax Darin laanjenden Rarven ntro \$stppen, theils jenen Serfen Dar, welde ifye Crier diejer ficherjten aller Brutjtätten mbertranen. Wie

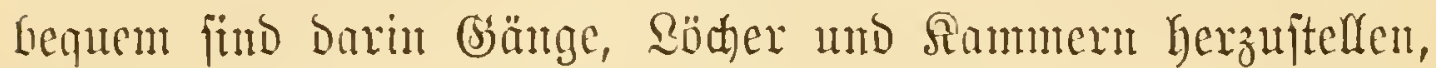

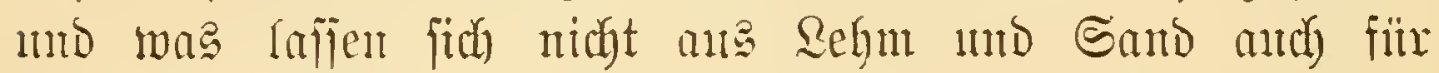

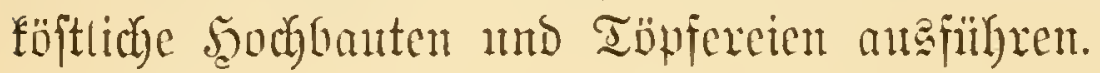

Autch Das Thierreich gitut Mantberlei. Die Sarve

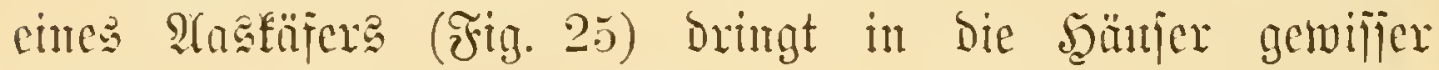
Sofmeden cin, mm Den vermejenden S̈nfaber anjafrej̄en, mo warum jollte fie aljo bas lecre (semady nidgt and fïn
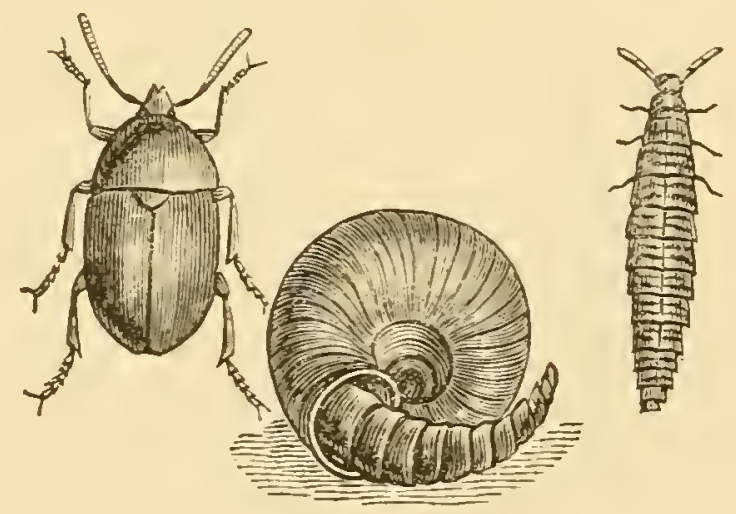

Fig. 25.

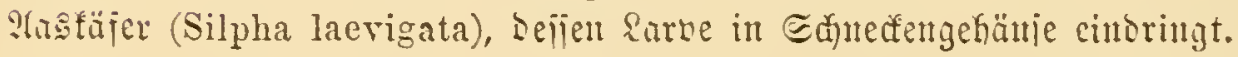

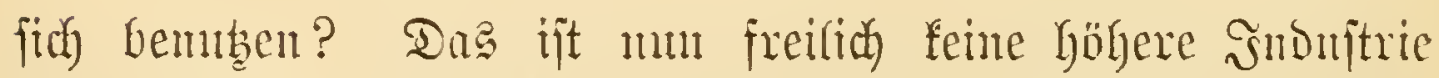

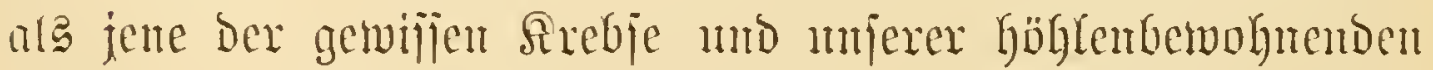

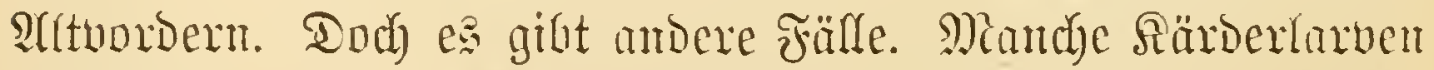

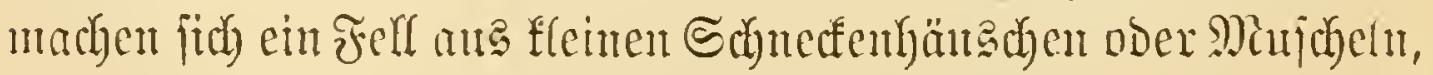
bie fie in ifrex mmittelfaren lungebung anflejen, wohei alfer=

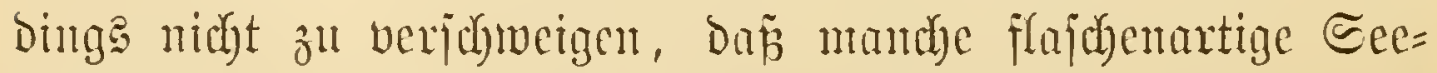
S(d)wämme (Haliphysema, Gastrophysema), bie ber \&aie gax 
nidyt für erbte Thiere gerten lajjen wiro, igren naften fejt= fibenden Rörper, gleidffals mit allerlei fremben Thierjfeletten bepanzert unb bejpifft zeigen, was aber, da bieje bsejchöpfe feinerlei Breifwerfzenge und and - trote ifres Entbecters

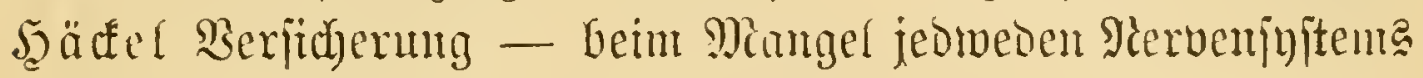

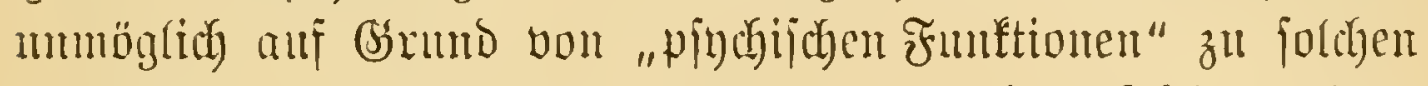
Syandungen veranlä́t werden fömen, mu den jefagenden Beweis liefert, da voll angejultrte Dinge gewijiermazen jid von jelbit ma raten.

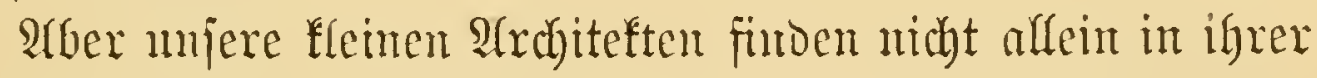
nädbjten llngebung jenes Bammaterial, bas ifyrer jemeiligen Ratur am angemejienften ift, ifr Drganisme jelbit zwoungt ifnen mandbertei Stoffe anf, Die theirs ummittelbar zum Banen

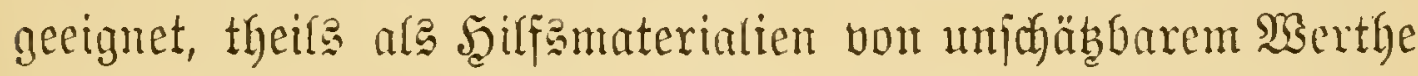
jind. SDer warum jollte unjere Stodfbiente, roie viele ifrer Stanmberwansten, mit fremben Materiatien bauen und bie

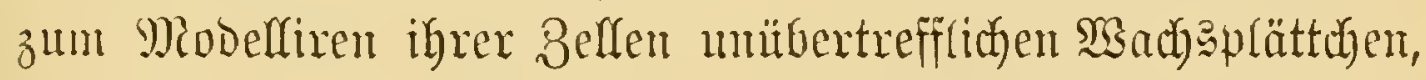
Die jie ofnehin, weil jie igr himberlid), mit Den Beinen

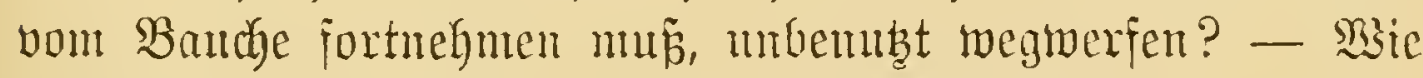
verlodfend ijt es fermer fïr mand)e Andere, Den flebrizen Epeithel als Bindenittel zur Berfittung verjediedener lojer Theile anzunenden, die z. Th. wohl fdyon bon miefähr, wenl fie mit biejem secret bemegt werben,

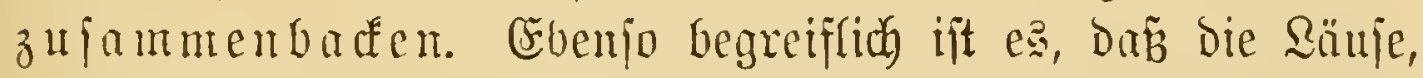
bie Florfliegen mo Anbere, weldye einen äfnlithen Sittitoff aus Den (jeja)ledt to Dazu gebrautben, ihre Crier theils unmittelbar, theils an longen, aus jenem fabenziehenden Rlebftoff gebirbeten Stielen

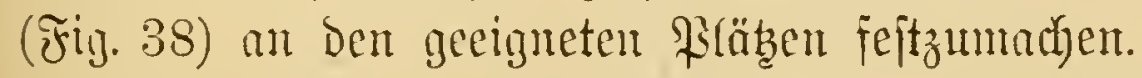

şix baben den Rerfipeidyel ars eir bedentjames Bau= material Gervorgehoben, und Daran wird and STiemand etwas

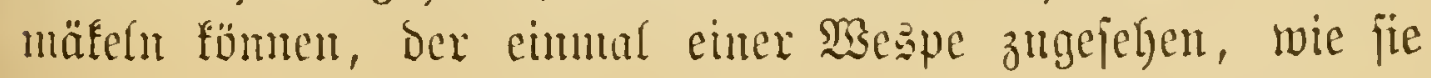


Dic mit Den Riejern abgejabuten Şolzipähne obex gimben=

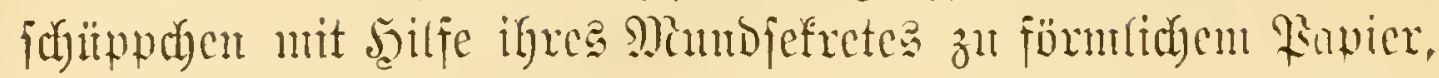
ja gelegentfich, wie twir mody hören twerden, jelbit junt

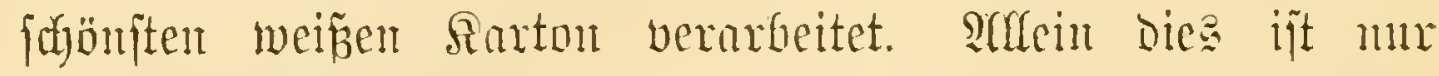

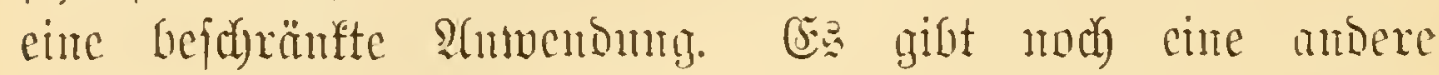
Modififation, die faft für die gefammte sau= induftrie bou fundanentaler Bedentung ift: wir meinen ben Spimitofi, ben bic Sarven viefer Snjeften,

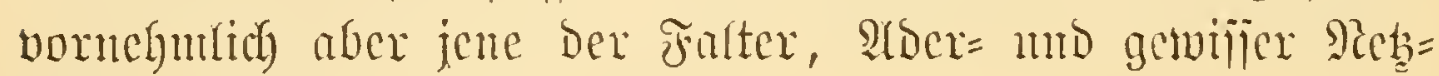
flügler ans dem Maunde lajient.

Dás viele Tanfente dex gentannten Snjeftentarven fïr fïch

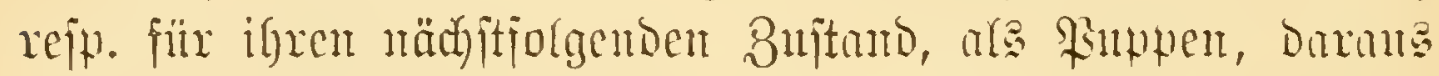
bie ntamigfaltigften, Danerhafteften mo zugleidy and bie

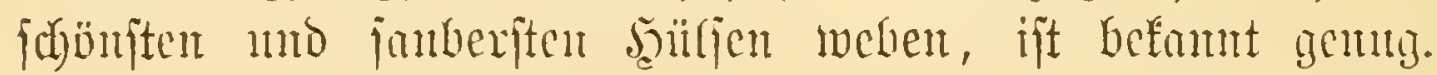

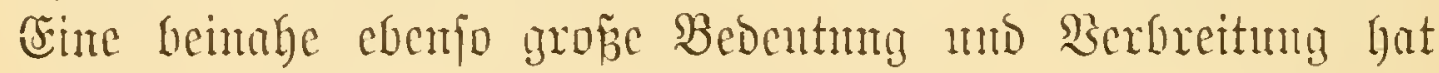
aher sex Spimfaden als Şiffumittel für andere Snouftrie= zweige, ja, wix getrandu un zu beganten, Da es ofue ígu faft gax feine ferfindutrie gäbe.

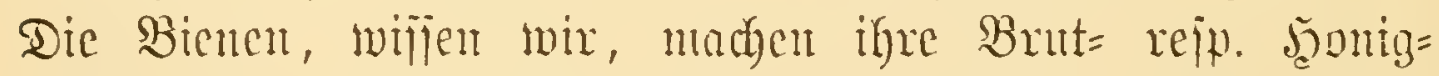

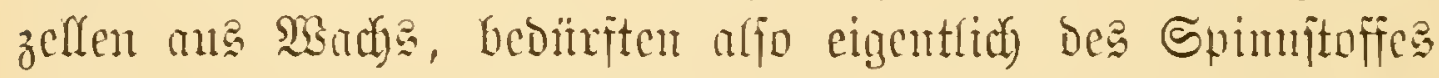

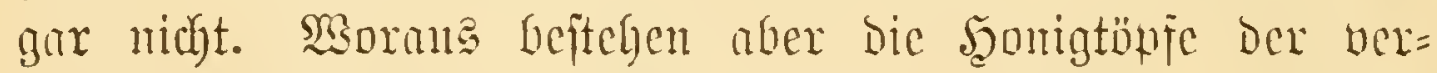

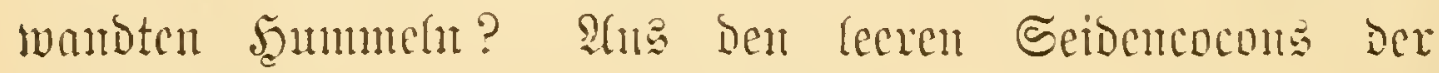

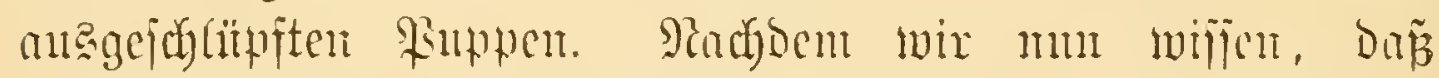
anch) bie wäbjemen Biencuzelfen mit cinem ment and nut

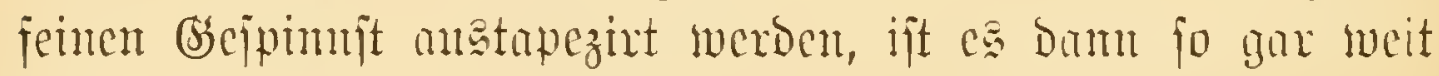
hergegriffen, fith borzujtellen, dañ bie llrjache, warmun dic

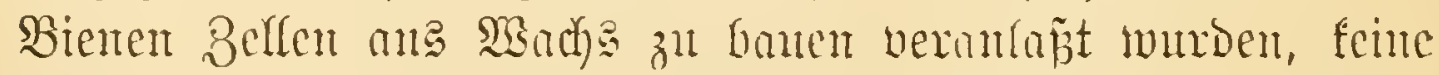

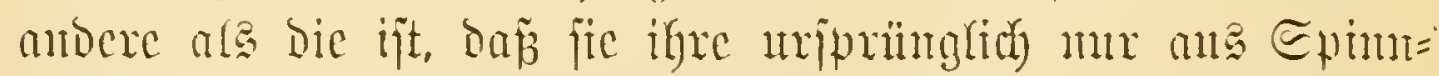

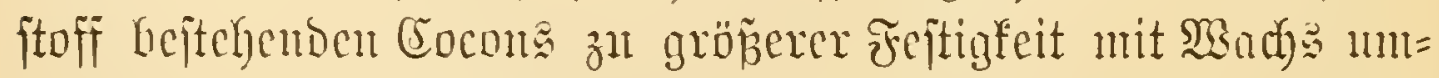
manerten, eine errjheimng, sie aber im Smafe Der Beit jich

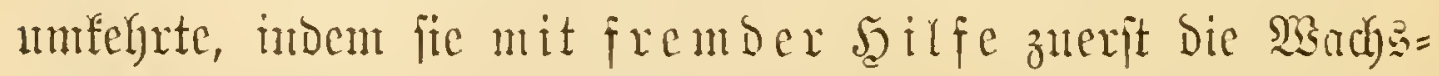

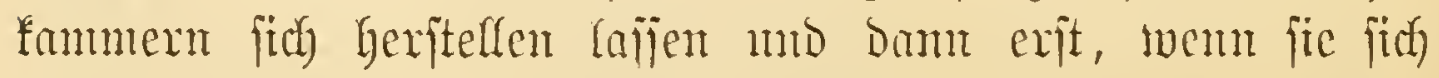
Darim bermandeln, Den imeren Hetrerzng madyen, Dex un $n=$ 
mehr aber a ud, nadoem der fefundäre an Stelle bes primären Stoffes gejebt ift, leidyt entbehrt werden fönte. -

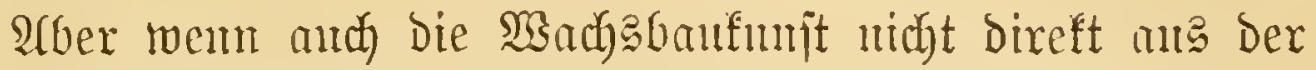
Spinubanfunft fich entwickelt bätte, jo ift lebtere dody in andern Fällen das sine qua non dex Bamindutrie.

Man ziege eine färderlarbe getwaltian aus ifrem Futteral

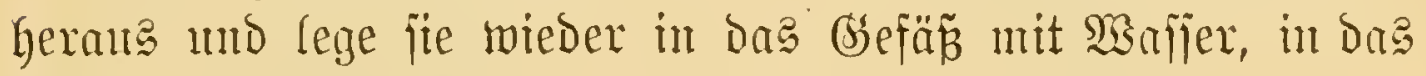
man zugleidy eine Menge furzer Streifen ans fteifen Rarten=

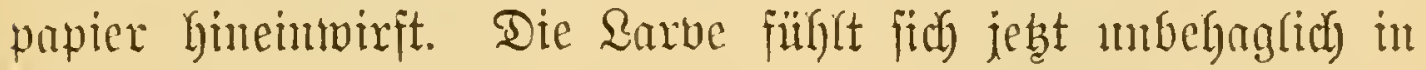

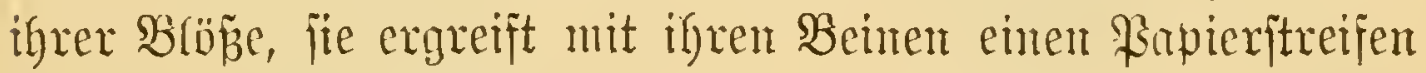
nach Dem andern, bringt fie in die geeignete Sage mo madyt ị ein nenes (sichäns. Wäre dies aber mỏglidy obue dent freilidy fait unjidytbaren Spimfaben, ber igr wie ein von einem aufgebängten finänel fich abroidfentoer Sarn aus

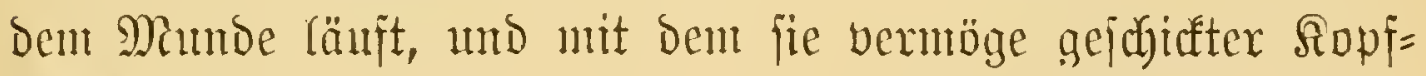
und Rörperbemegurgen die lojen Papierjtüte theils an förper anbindet, theis and unter einander verfiüpt?

Sdjöne Exempel, was für artige mid complicirte Sadjen

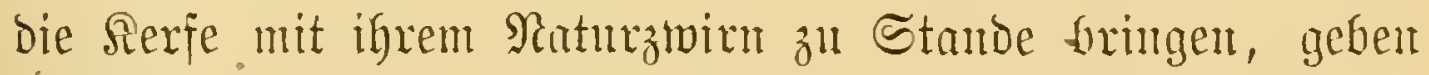
beiftehende Bilder. Das erfte (Fig. 26) zeigt ein Eidbenlaub,

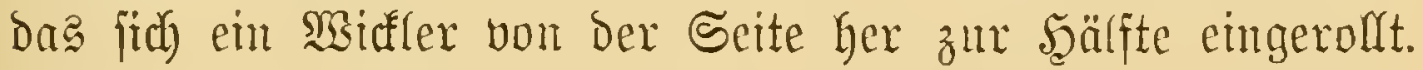
Dies zu thum heftet ex eine Reibe von Fäben an das einzu= rollende SBlattitïcf und ipannt jie gegen den flachen Blatttheil heribber, two ex fie anleimt. - Die zweite Figur (27) zeigt

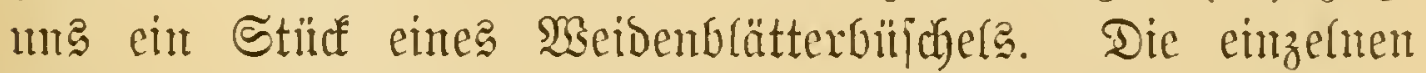
Blätter fund mit beiben Rändern nach innen gegen bie Mrittel= rippe gerollt. IIm aber bem ganzen Sambcomplex meryx Scalt

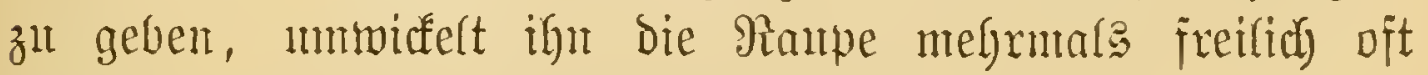

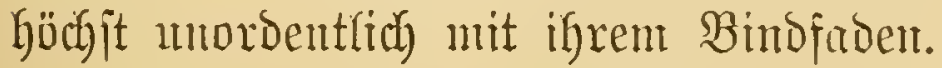

Menu aber Der Spinnitoff in ber gejammten Rerfindutrie eine jo widbtige Rolle jpict, jo wixd fich ber sejer getwiz 
Fïr Den Spparat interefïren, in weldyem er abgejondert und entiprectend verarbeitet miro. An Gejten ijt Das Ranpen=

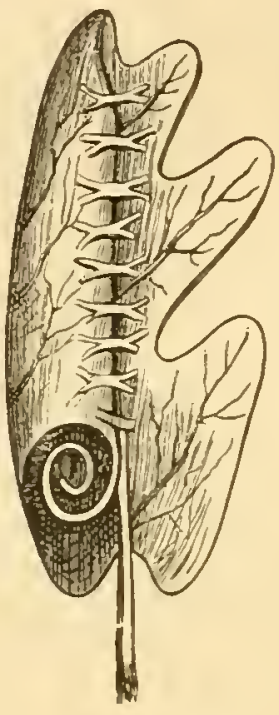

Fig. 26.

Fabrifat des (Gidenblattmiater

(Tortrix viridana).

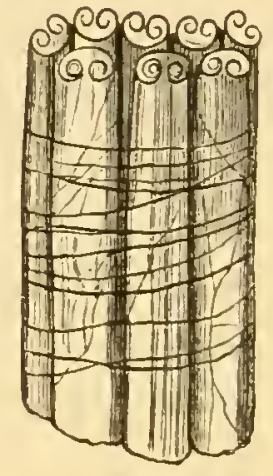

Fig. 27.

Tabrifat des siseidenblatmiaflers.

Fpimorgan erforidyt. (5es bejteht (Fig. 28) ans brei Theilen:

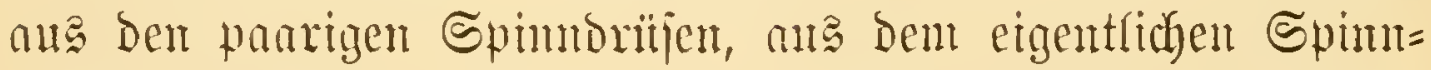
apparat und Dem Reitungarohr. Die Spintorïjen find bald gauz gerabe gejtreafte, bald zicfzacfürmitg gefrimmte ober bei jegr

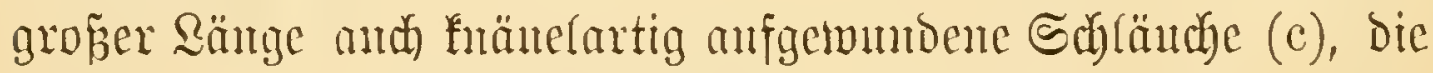
vorme in ein tweiteres $\mathfrak{B c h a ̈ l t n i \tilde { s }}$ (b) übergchen, von dem Dam

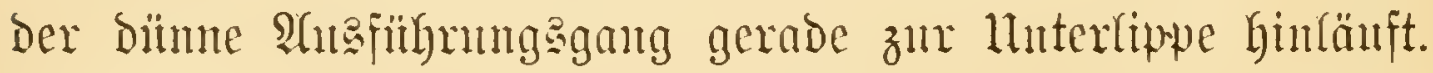
Shren femeren Bun hat exit menlich $\mathfrak{F}$. Scelut in ber Zeit=

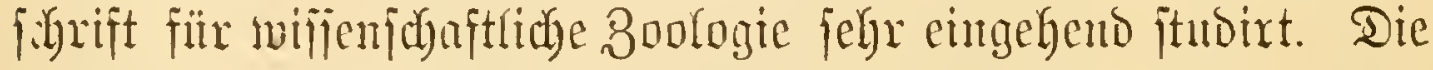

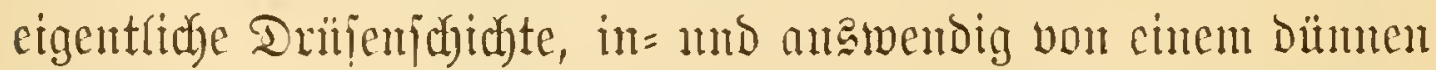

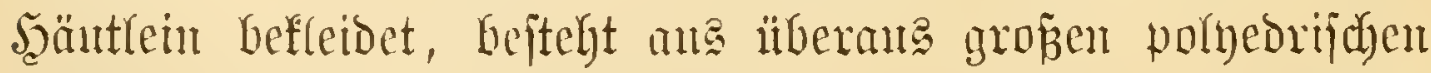
Belfen mit viel verzmeigten Sernen, von benen je ein Pant

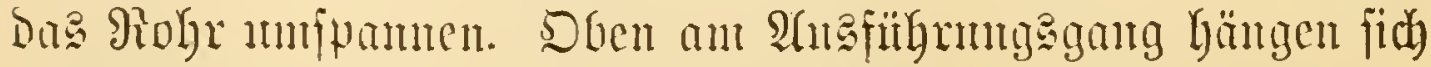
nod) fleine bereits bon Serold gefannte Tranbendrïfen an, cine Combination, wie fie ja aud den Spinnen 
eigenthümlidh. Dar eigentliche Epinninitument liegt ant

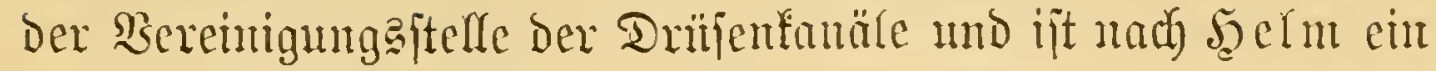

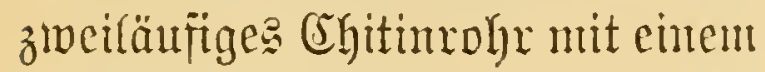
beweglidfen Boden (e), ber Duraty eigene Mirafeln gehoben und ge= jenft werdert farm. Durch diejer Fabenzieler, wie wir bie Sorridtung nemen, hat ca bie Epimerin in der Seand, die Diffe und anth z. Th. Die Form bes Doppelfadeng zur regulirent. Die jog. Epule, d. h. bas hohle CGitimührchen ber lluterlippe (sp) ijt weiter nidyts ala ein berweglicher Reitumgafintal, Durch weldyen Der bereits Definitio gejormte Faben lyervorfonmt.

Die Spinmoriifen fint zmar jugon an ber jungen $\Re$ aupe vor= handoen mb merden vieffach and jothon von ifgr in $\mathfrak{A}$ miprud $\mathfrak{g e}=$

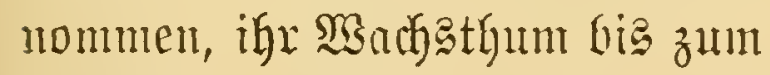
vollendeter $\mathfrak{A}(t)$ r ijt aber fein gleichnääpiges, jondern ein be= julemigtes. Beim Seideripinner

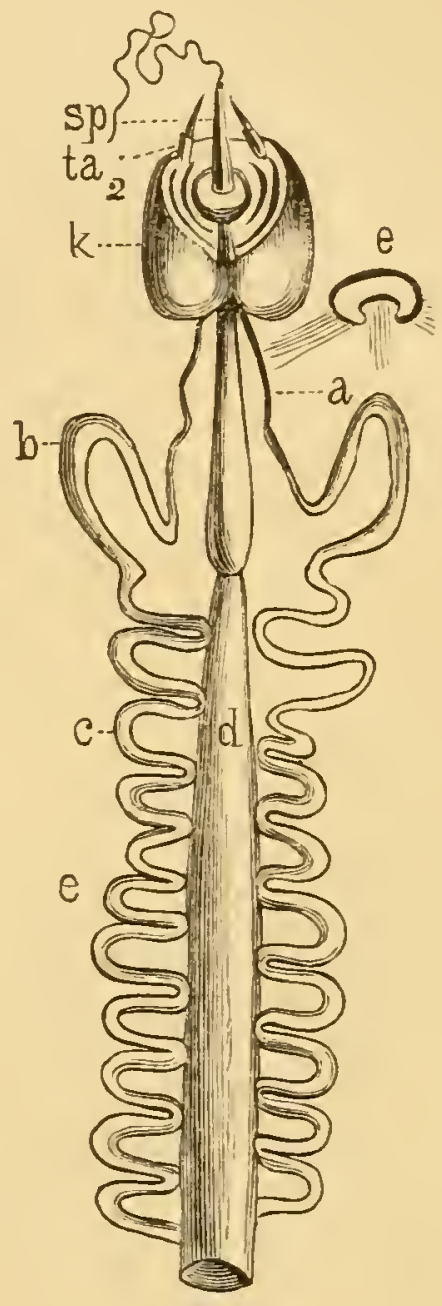

Fig. 2S.

Spinnorgan yon Saturnia pyri.

d Darm, c Epintbrüjert.

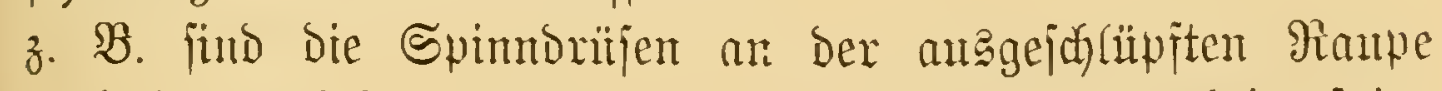

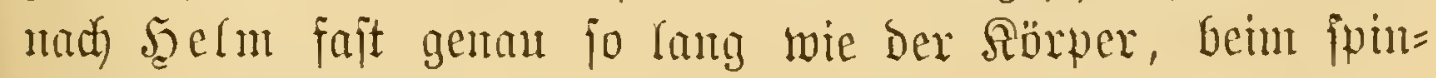
nenden Thier aber fajt 5 mal jo lang und relatio aud viel

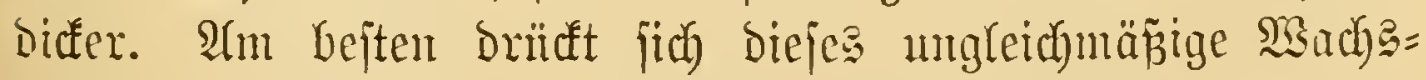

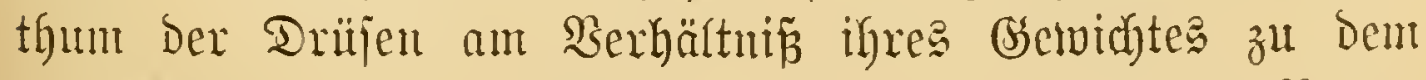
Des Sörpers aus. Mährend z. $\mathfrak{B}$. Gei Der jungen Tratpe auf $100 \mathrm{mgr}$. Sörpergewidyt mux eirca $3 \mathrm{mgr}$. Drïfengewidyt fonmt, find es bei Der atsgetvachjenen uidyt mentiger als 39 , 
inden anf ein Rettogewidyt ber Raupe im Betrag von circa 1366 mgr. 541 mgr., aljo ungefälyx ber britte Thyeil allein auf́ bie Drüjen entfälrt.

Das nod) weidye Secret ber Spinnoriijen ift befanntlich

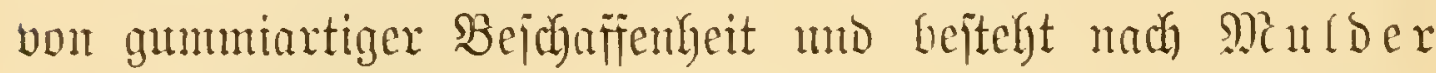

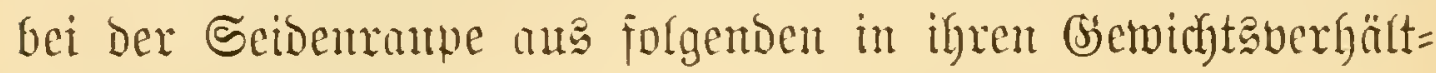
nijien aber etwas fabanfenten Subjtanzen:

\begin{tabular}{|c|c|}
\hline Scibenfajeritofi & 53.67 \\
\hline ¿cint & 20.66 \\
\hline Eimein & 24.43 \\
\hline Madys & 1.39 \\
\hline Frarbjtoff & 0.0 \\
\hline Fett mb Şarz & \\
\hline
\end{tabular}

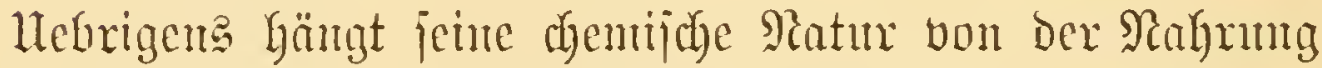
weit wentger ab, als man meinen fönte, indem $z$. $\mathfrak{B}$. Der Bombyx Pernyi, gleidggiltig, ob man ifn mit sichen= ober Buchenlaub füttert, eine ganz älutiche Seide wie bie Miantheer= raupe liejert.

Sidrtiger ars bie Materialien, weldye Der Serfintutrie

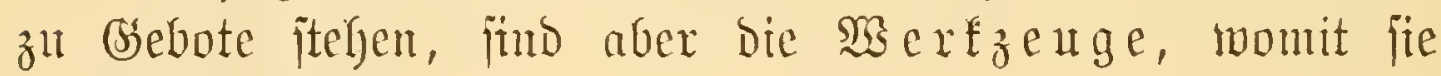
bearbeitet werder.

Dber was miliste etwa Den Yanbhüttenbanenden Aneifent Der Iropen ber reidyjtheblätterte Banm, wenn jie nidyt im

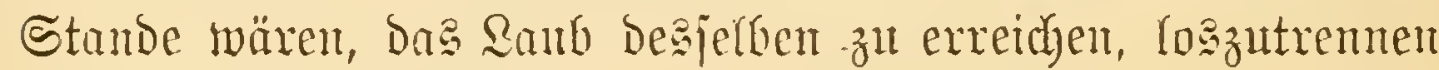
und geljörig zuzuridjtem?

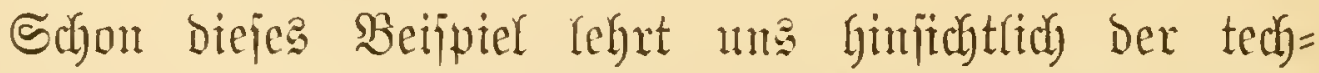

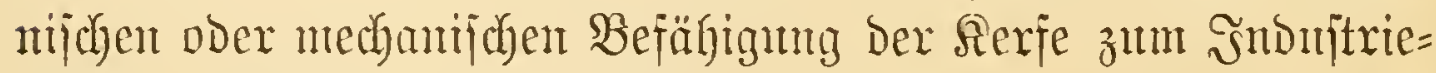
betriebe 8meierlei mtericheiden: Erjtens bie allgemeinen Betriebsuttel, o. h. jente, welche alle mit mechani=

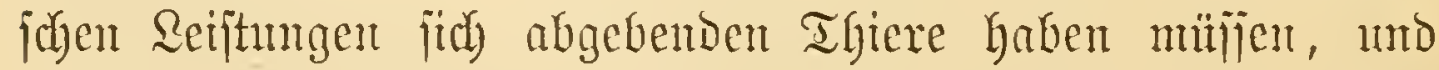
dann bie ipecifijact ondutriegeräthe, D. h. iene 


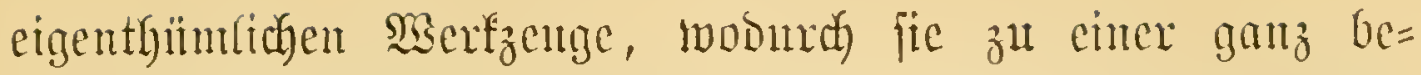

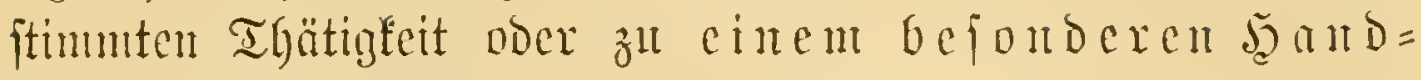
werf befäligigt merder.

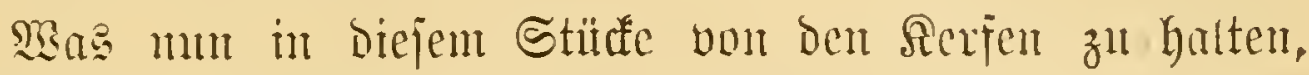

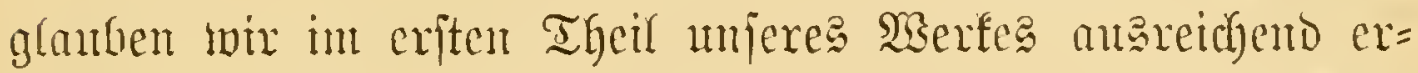
örtert zul haben: Die Snfeften firto nicht blof zut medyant=

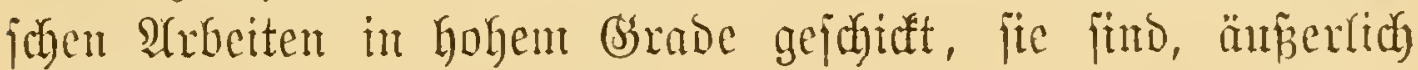

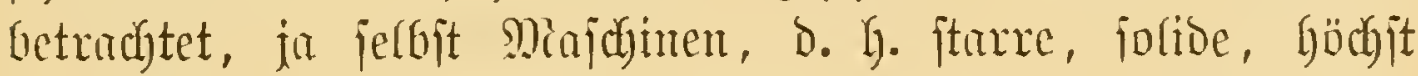

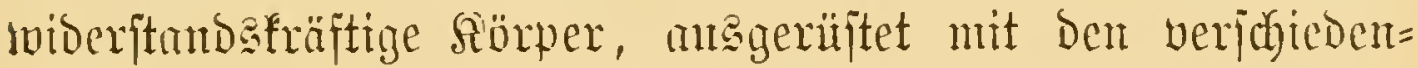
artigiten ḩebeltwerken mo einem mendich) intenfiben und viel= jeitigen Srientirungâfyjtent.

Bon gröp̈tem Belung fïr bie angeneine Arbeitätübtigfeit

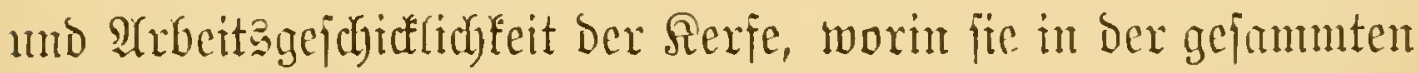
Thierheit merreidgt mo merreidforr bajtehen, ift aber vor

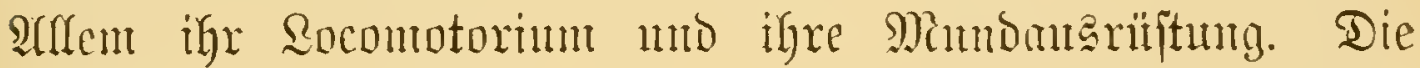

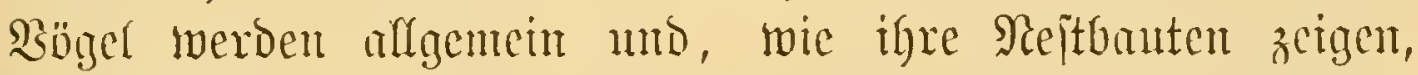

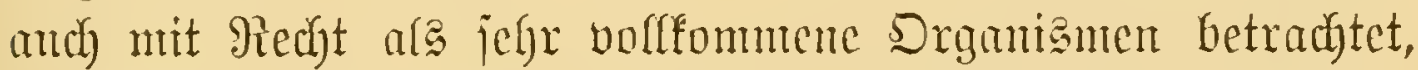
und boch ijt Dus nädithejte Snjeft ein meit bejierer uto viel= feitigerer Miectanifer. Melymen twir z. $\mathfrak{B}$. eine Gralumeape. Rerje töbten und fie Den Jungen heimtragen, foum freilicid)

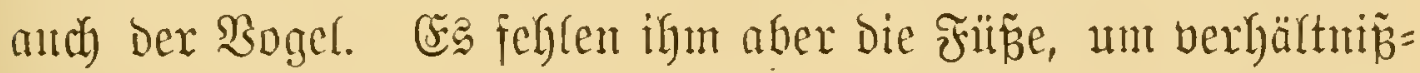

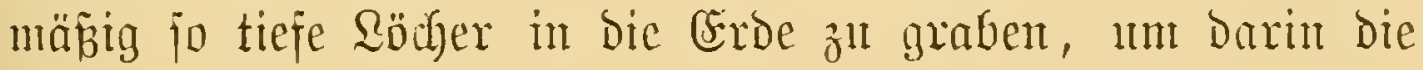
Sungen fither anfubetwahren, umb es fehren ifm and bie

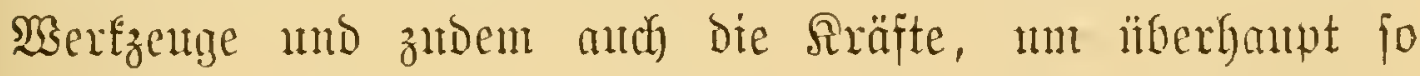
herfulijche $\mathfrak{2}$ rbciten zu verrichten. So jahen woir jüngit

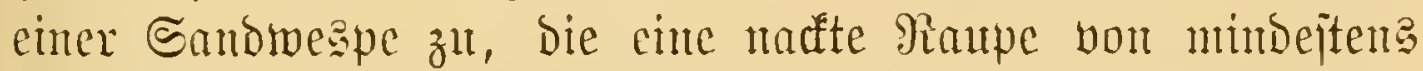

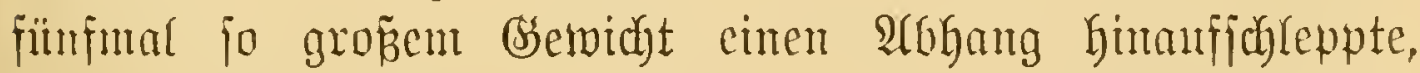

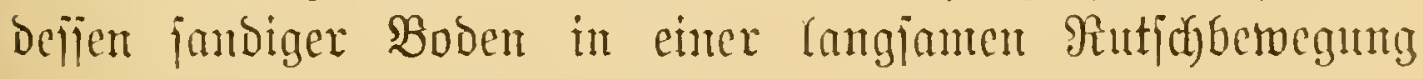
begriffen war, weldye mehrere ftarfe Säfer mit fich fort=

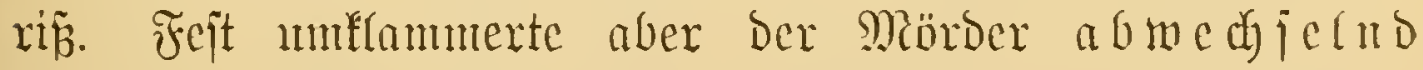
nit dem rechten und linfen Borberbein jeine Beute von

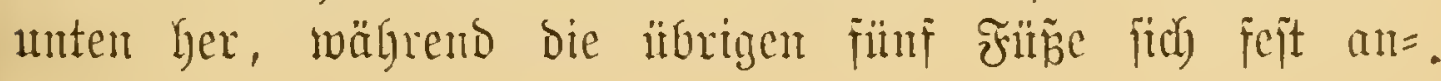


ftenmen, um bem Strome zu wideritelen, mb ex wax

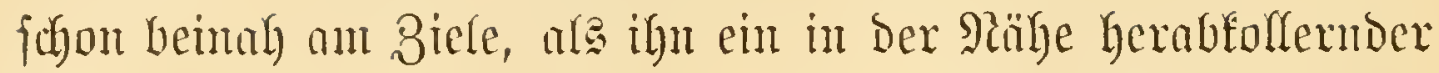

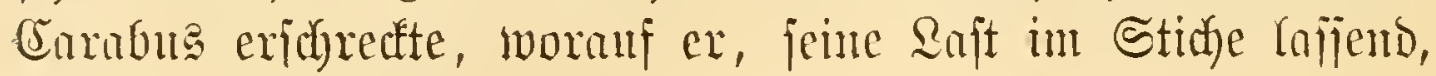
untwillig Davou flog.

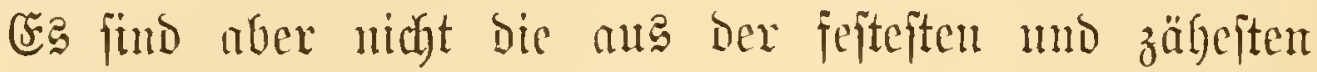
Materic hergeftellten Bricomazen allein, weldye bic Serje zu

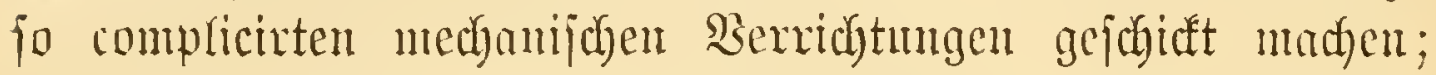

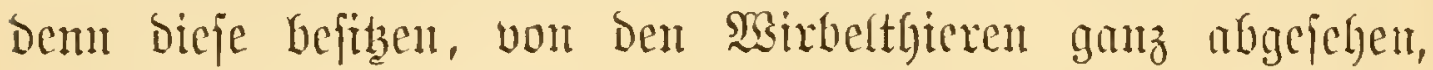
ja aud andere Arthropoden, wie Dic Sirebje mo Spimten, jouberu twas fpeciell die Snfelten zu ciner fo betwubems= werthen Snduftrieentwiafung befübigte, das wax eben die

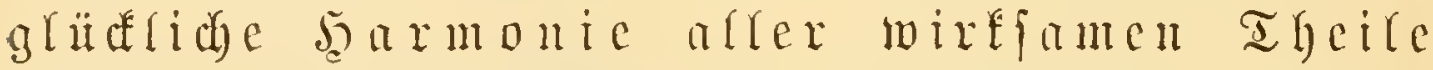

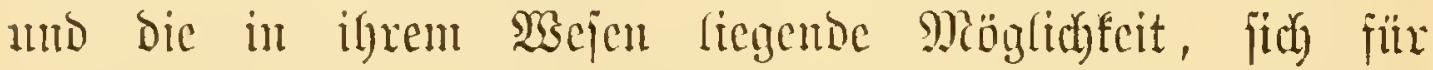
ganz ipecifijace mo bejtimmte âteiteleijtungen ımzu= wandeh, womit wir besn beim zweiten Sisuft urferex Frnge anlangen.

Seber vou ben Sejern hat wohl cimmal, und nidyt objue Bermundermy, einem Bilbhaner zuncjegen, wie er oft mit nidhts Shberem als mit peinen Fingen - Den cinzigen voll=

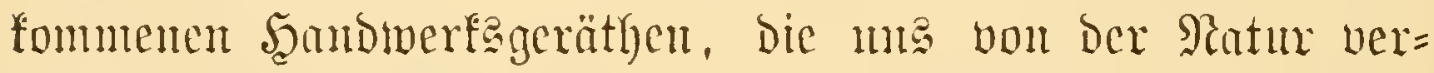
riehen - einem §immen Thon bie complicirtejten und wohl= gefälfigiten Formen gab, wie wir fie mit all Den mantig=

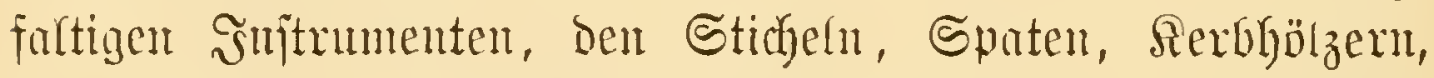

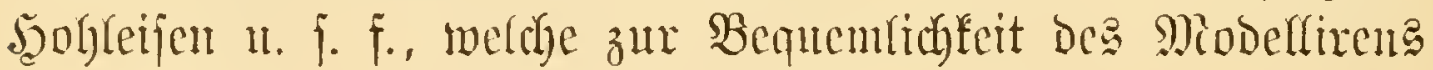
erfunden fün, nicht "rund und fertig" brädyten.

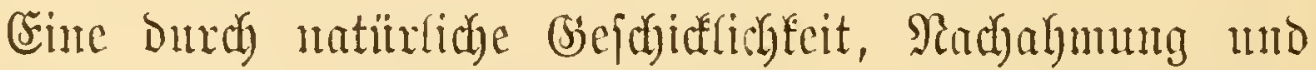
llebung ermorbene "Fintgerfertigfeit" firm aber nidbt broz

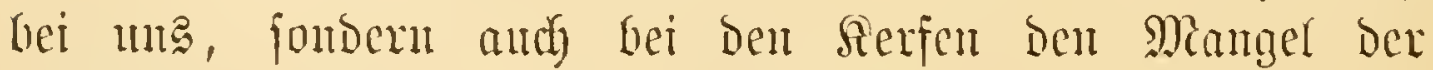
fïnjtlidyen Şiffämittel ganz wohl erjegen, wie mix ja von Den berïhmtejten Serfardyituften, Den Bicuen, wifjen, Dañ fie

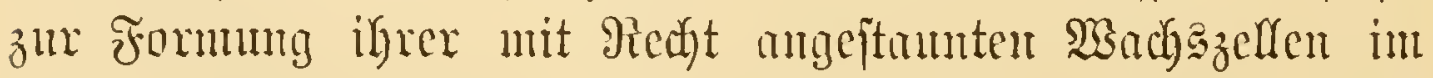
(B)runde genommen feine andern $\mathfrak{s e r f z z e u g e ~ a n m e n d e n , ~ a l s ~}$ 
jene, werche anth andere nub völlig induitrieloje Sarjeften be=

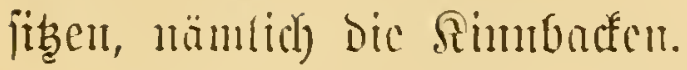

Der Bergleich Der Bienenfiefer mit mujern Fingern ift

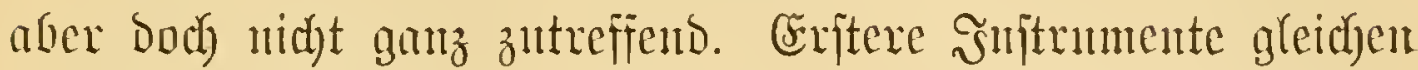

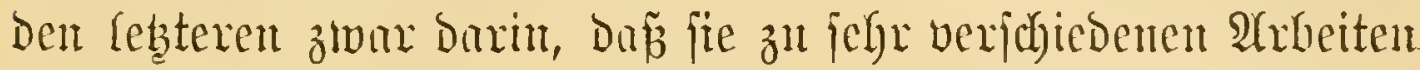

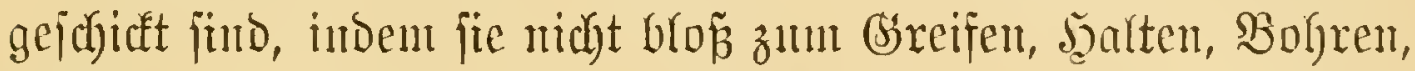

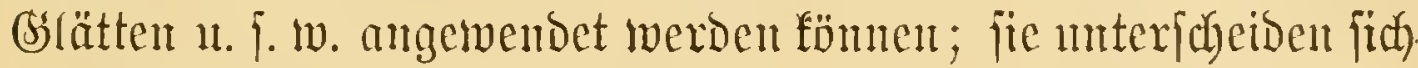

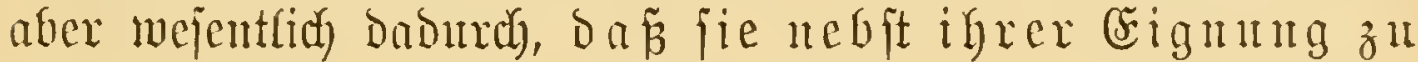

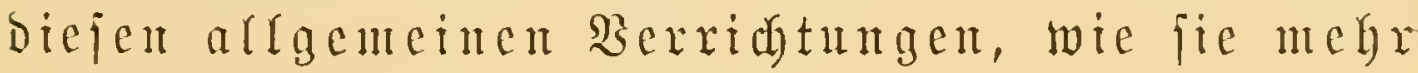
oder minder alle Rerfiefer zu Stamb brimgen,

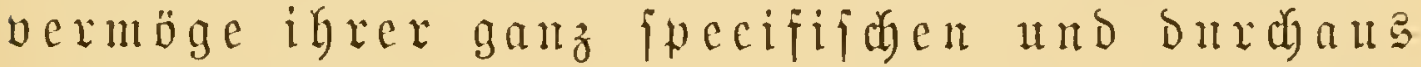
originellen Form nod bie befähigung zu einer ganz hejonderen aeiftud bejigen, wie jie weber unjere finger, nod die Riefer ober irgend welde Drgane anderer Sufeften ub Thiere übergant

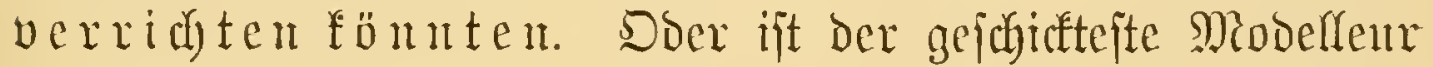

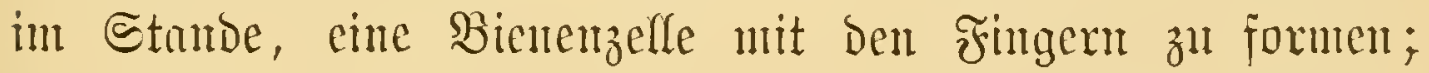
ja, vermag dies jelbjt eine semmuel, deren Riefer von ben: Miobelliximftrumenten Der Bienen mux in ganz nebenfäblichen

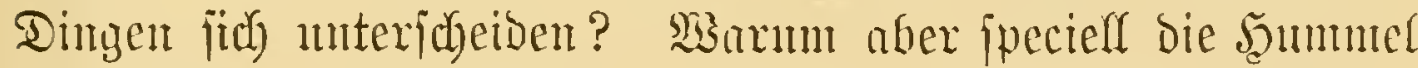

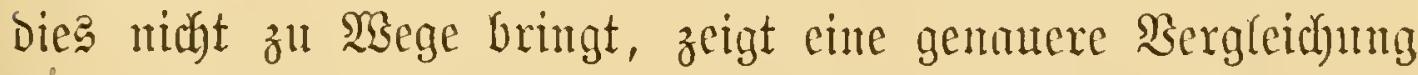

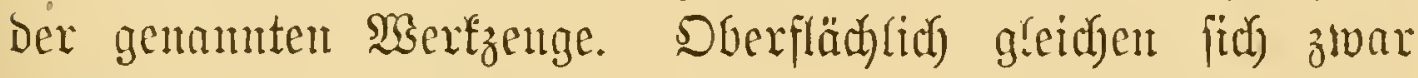
Bienen= und Şummelfiefer ganz und gar. Beide haben die

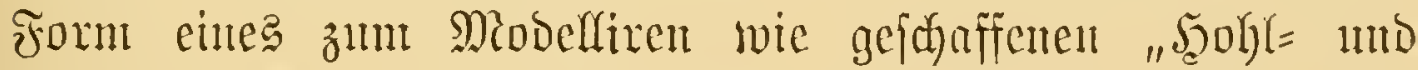

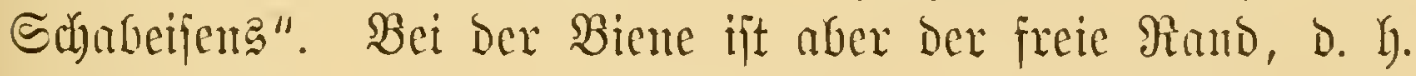

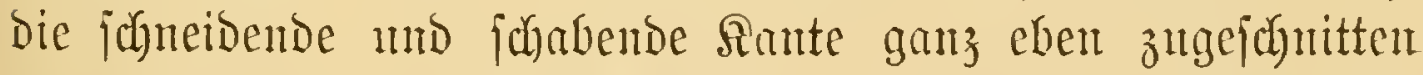

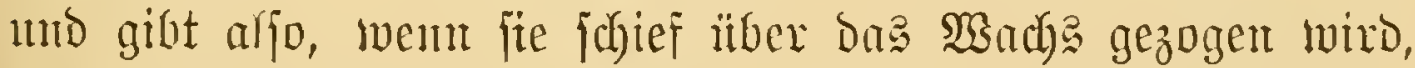
eine vollfommen glatte Fläd)e, wä̈hrend ber Symmelfiefer

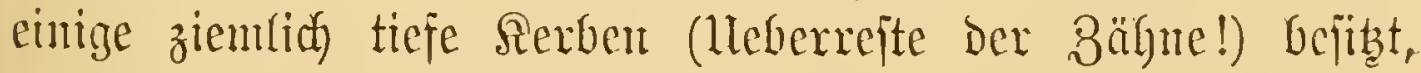

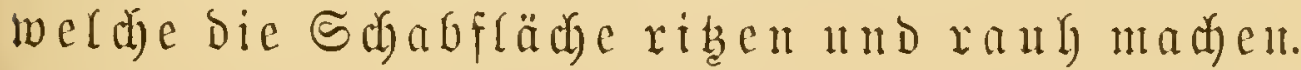

Die Biene hat aljo nicht beahalb ihre ganz aparte mito

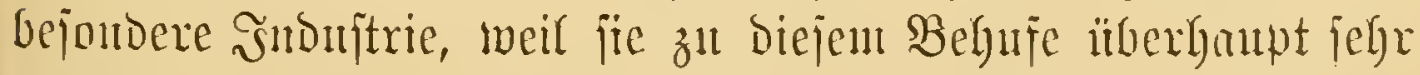

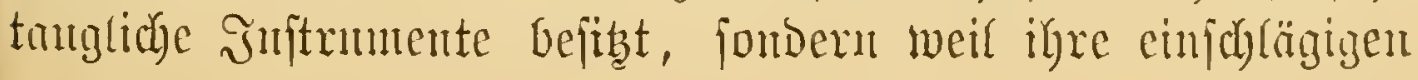


Gerätbidhaften chen von einer ganz exceptionelfen mo cigenen Qut finto.

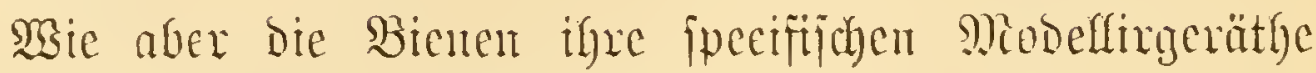
haben, jo haben sie Bortentäfer je inre Gejonderen jous=

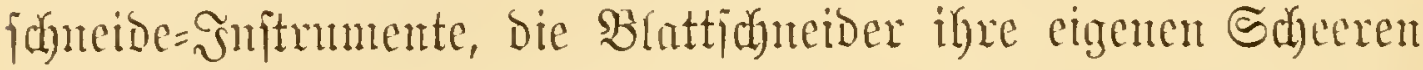

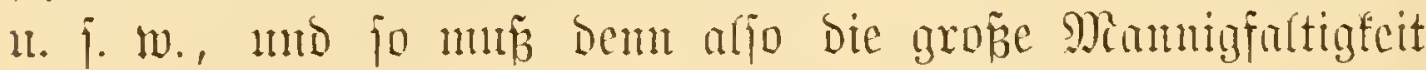

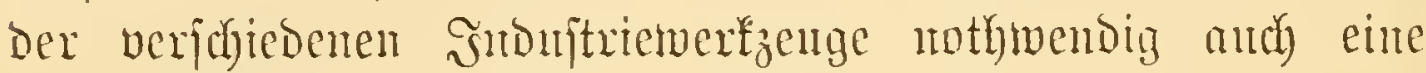

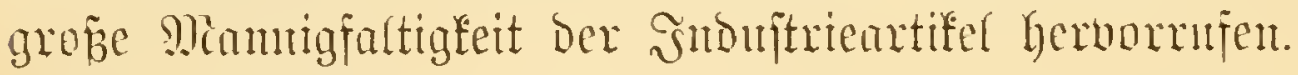

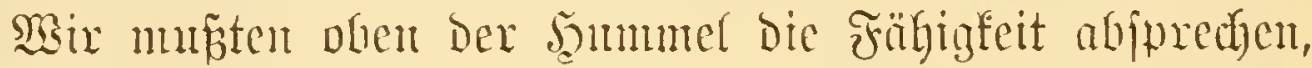
Bienenjellen zu bamen. Sie fam dies aber nidyt blon des=

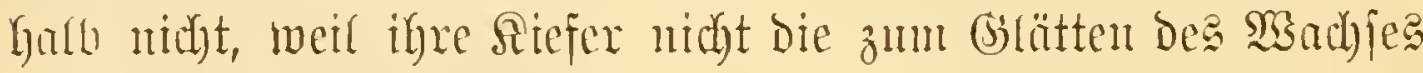

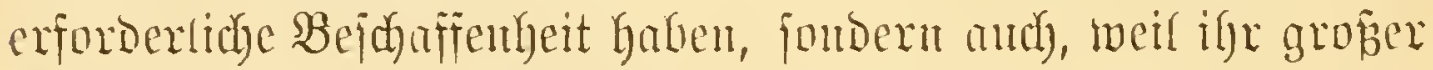

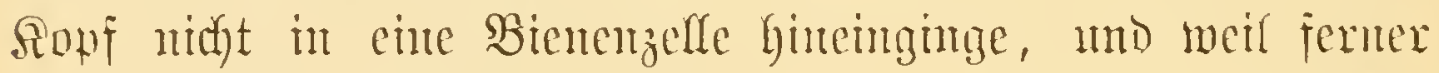
mande andere $\mathfrak{B a r f z e n g e , ~ w i e ~ z . ~} \mathfrak{B}$. Dis Seme mo fithler,

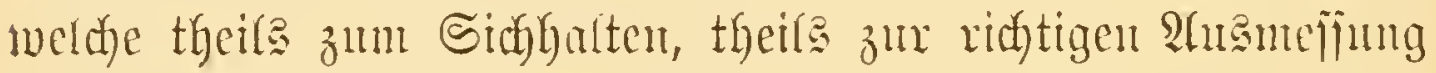

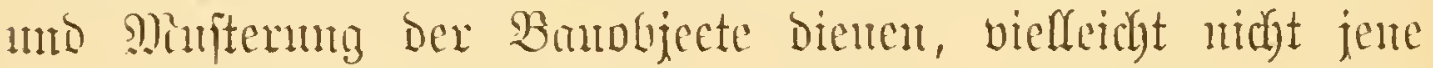

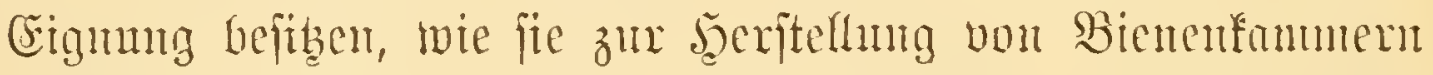

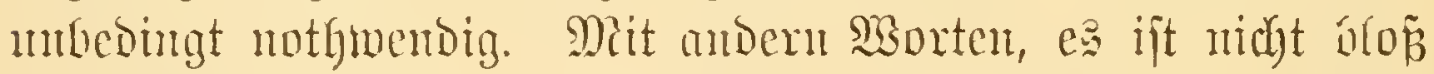

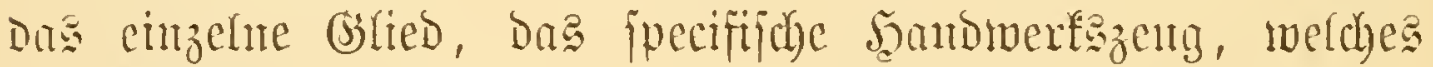

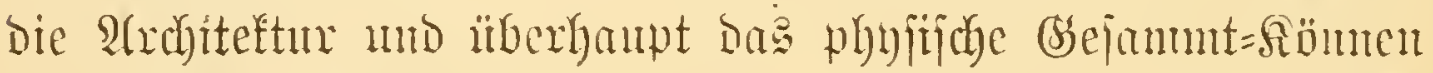
eines Rerjes bejtumnt, jonbern die Sefammtorganifation, Dus

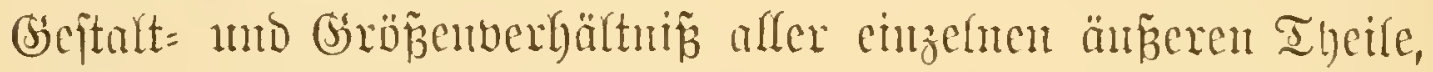

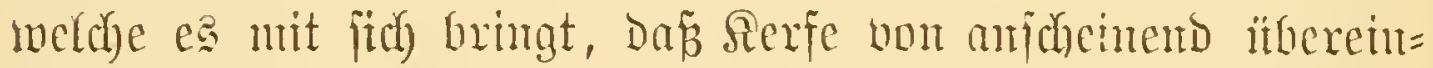
ftimmenden Ban Demudy jebes in jemen arbeiten mo Reijtungen meble ober wentiger origitell erịdseint.

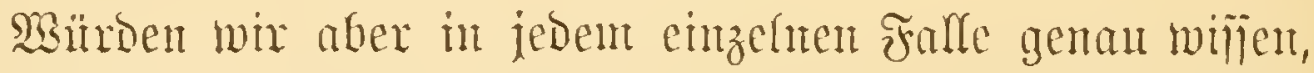

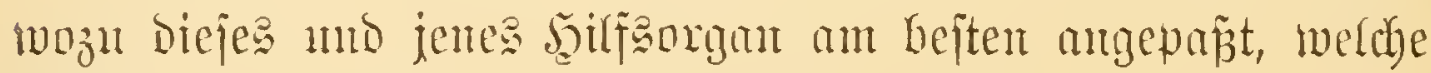
2ret von Thätigfeit ing aljo an angemejienften ijt, fo mïroen

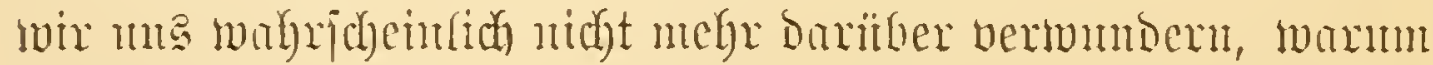

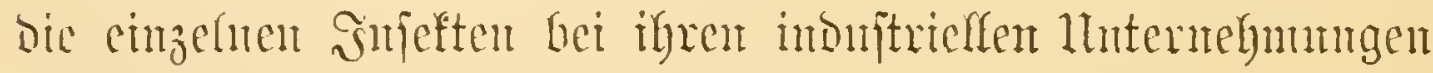
gerabe jo mo midyt anders verfalyen. 


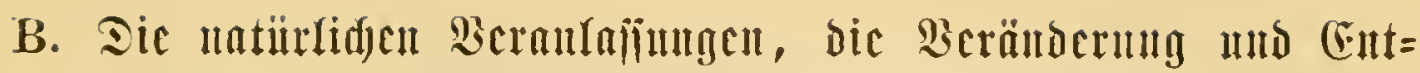 witfnug ber Banimbutrie.}

Bei ben befunten Experintente, so man einem ent=

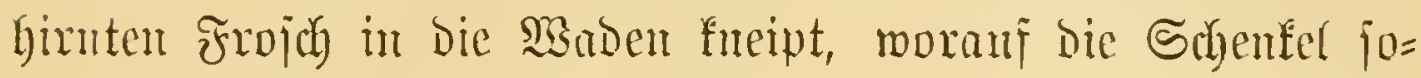

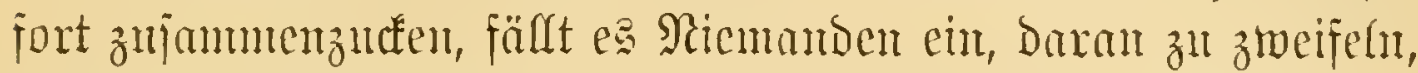

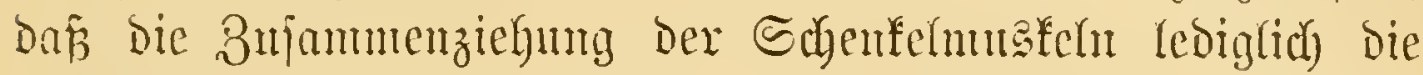
ummittelbare und nothwendige Folge ober Reaftion anf ben

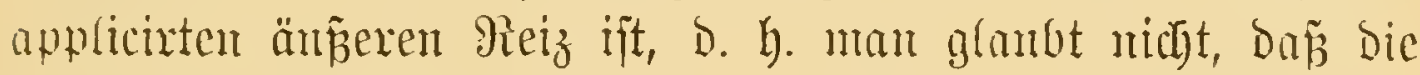

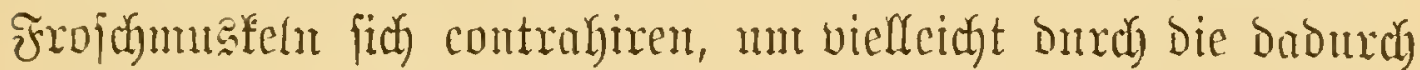

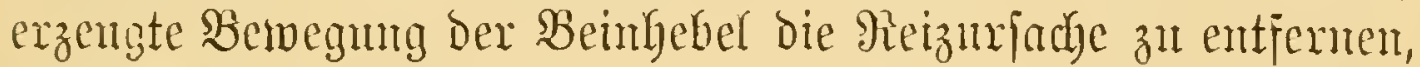

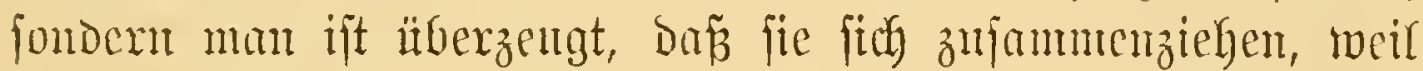

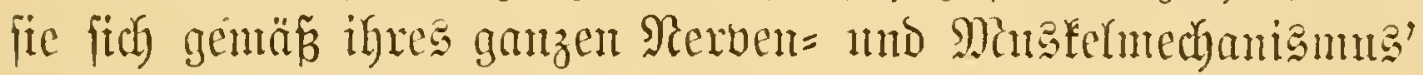
zujammenziehen mïjien, un zwor mit berjerben Sethwendigteit,

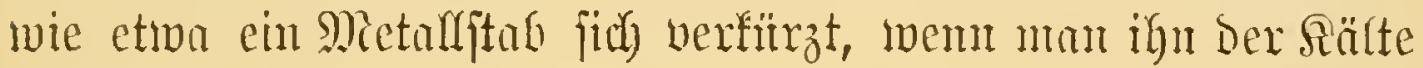
anispetst.

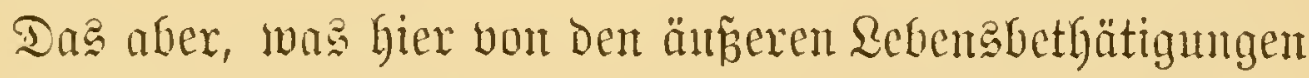
eines eimzenen thierijhen Drgntes gilt, das gilt von Den

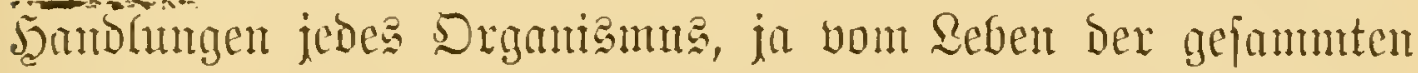
Thierwelt. Affes, was die Thiere mternebmen nub ver= richten, thum fie, ftreng genonmen, weber millfïrlich nody

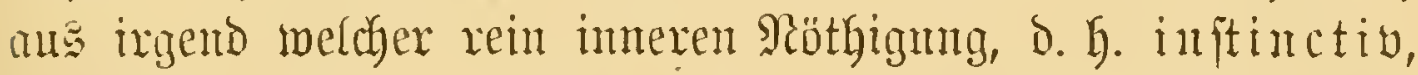

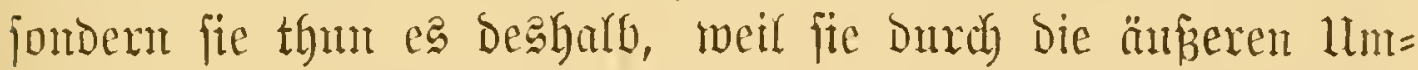
jtände Dazu gezmungen find, und fie thut es gerabe fo und nicht moers, weil cinex beftimuten Summe und Combinatiou vou äuferen Eintoirtugen oder

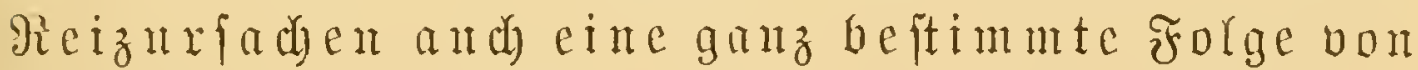
gentionen oder Bexäuderugen des beeinfǘten Srganismusutipricht.

Dicje Reaftionen, Dieje Bjegentwirfungen eines lebentig

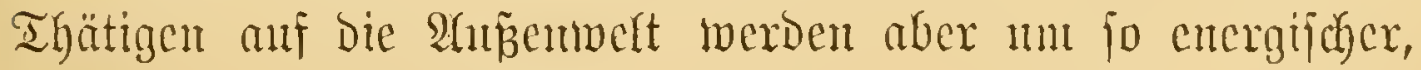
vieljeitiger mo mantigfaltiger ausfallen, je intenfiver mo ver= 


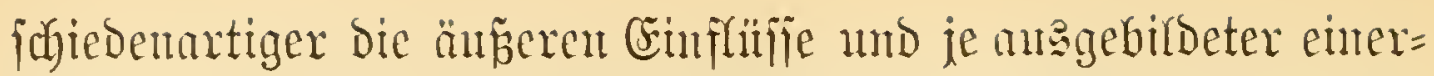
jeits bif biejelben empjangenden und verarbcitenden Simne und Sieizapparate mo andererjeits je volfommener jene bilfo

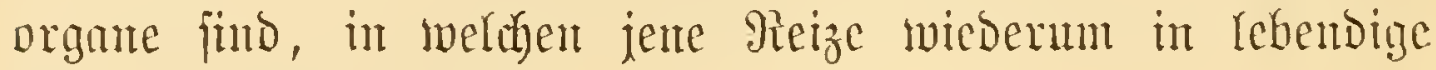
Rraft umgejebt twerdent.

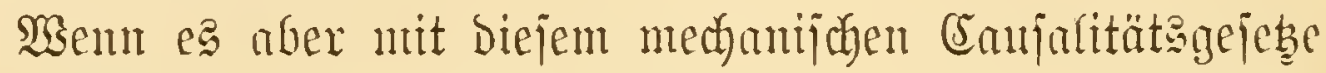

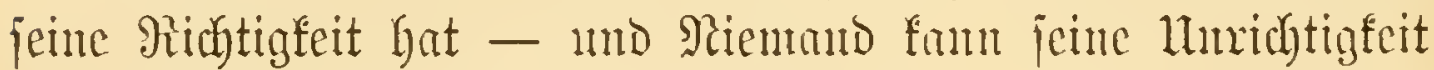
besweijen - un wenn es ferner richtig ijt, daz bie Jujuften

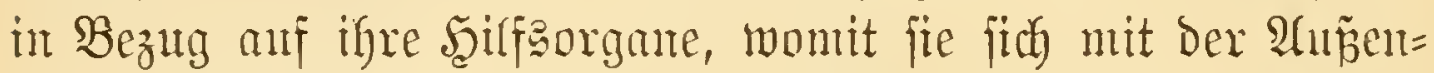
welt in Sechjelverfehr jebsen, Den meijten wo nidyt allen I I jieren überlegen jüb, wälgremb fie anbererjeits auch vermb̈ge ifrer univerjellen Serbreitung in bie alferverjajiedenartigjten Sagen und Berbältutije fommen, jo ift es leicht begreiffich, dañ jie anjebeinend jo jeltjame und jo merfwüroige Bexribtungen volt= bringen, Serrichtungen, wie jie eben ein anderes Ifier, Das

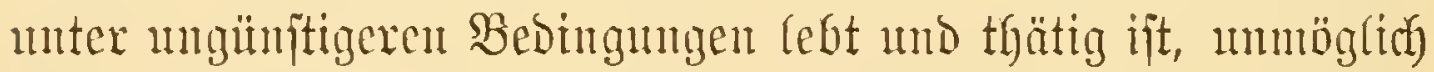

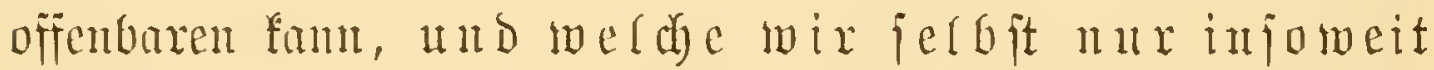

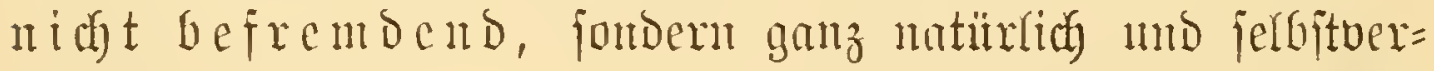
ftämolid finden, als wir bie natürlichen Uriad en derjelbea zu entziffern vermögen.

Aber verrathen Dem bie meijten Sandimgen der Serfe

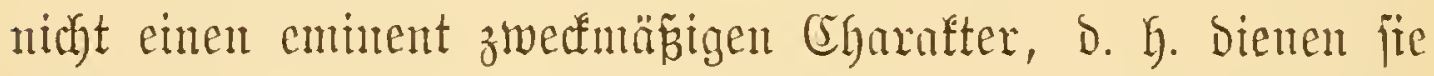
nirgt theila zu ihrer eigenen Wohlfahrt, theils zu Der ifrer

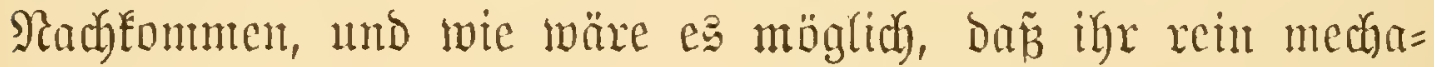

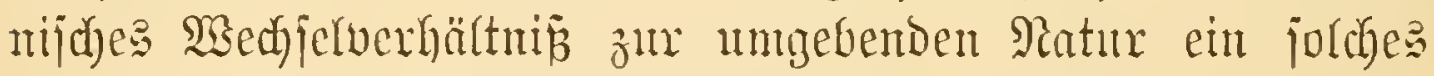

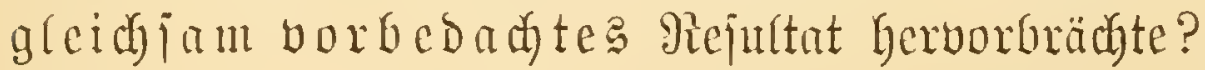

Daranf ermidern wix mit Der Bsegenfange, mämlict wie

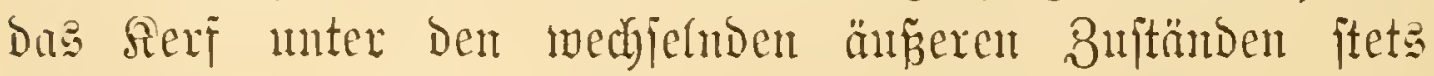

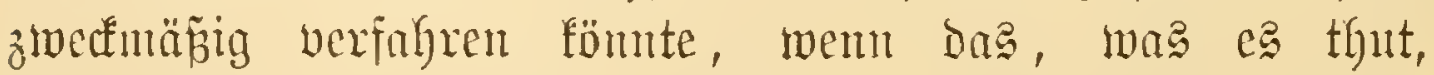
uidft cben Durch bieje, bou Fall zu Fall fïch ämbermben Unijtünde bebingt uno biejen lumftünton genan angenejien wäke? 
Dod) Der Rejer fant biffig von um verlangen, Daż wix Das, was wir da im Âfgemeinen bebautet, igm wenigftens an

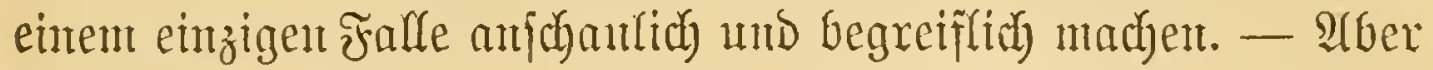
hier ijt es gentur fo wie bei ber Frage nad) Der (Entitehung und Untbilloutg Der Drganismen jelbjt. Şnt Bsanzent läp̧t es

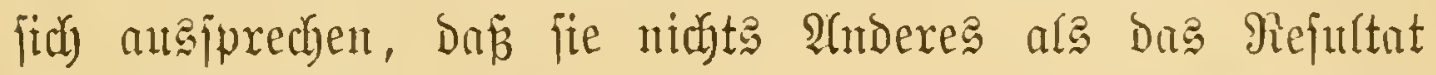

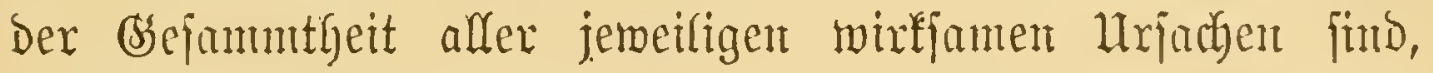
im Detril aber nidit anziüfren und ftreng betweijen, mb bies einfach beshalb nidyt, weil wix midgt alle Faltorent gentan

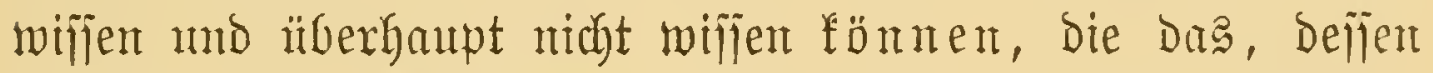
MSerben wir erflären folfen, bewirkt haben. Dem m das

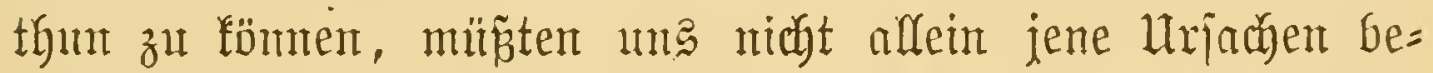

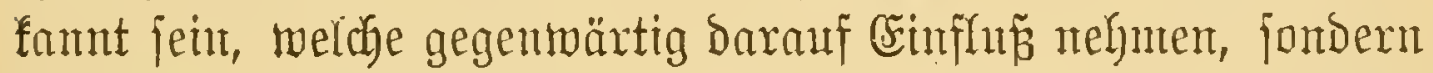
wir müpten aud Die fentnen, die feit feinem SSerben thätig

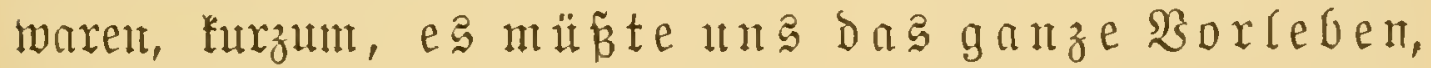
die Summe aller antecedentien ber betreffenden Thiere belanut fein.

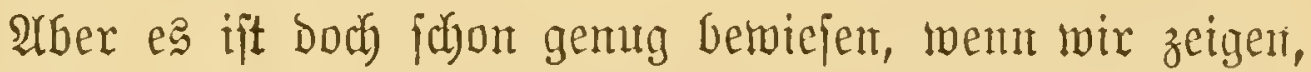

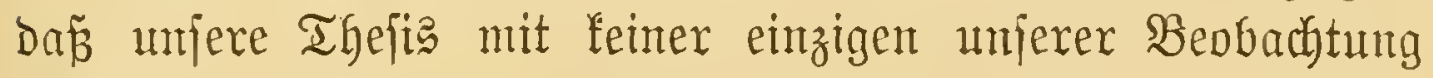

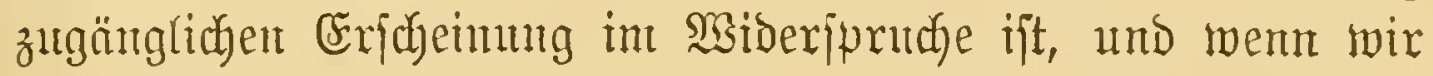

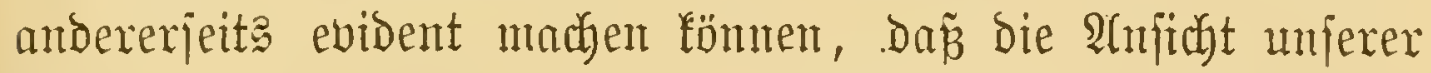

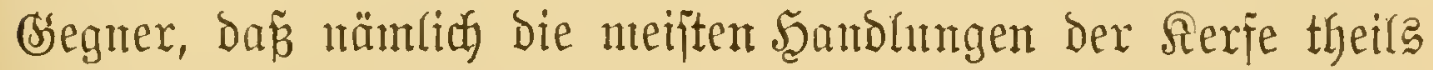
aus einem inneren Thatentwange, D. i. Dem Inftintet, theile aus böllig freier Selbjtbejtimmunt Gerborgegen, allen biejen

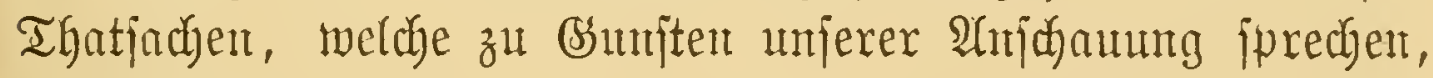
wideritreitet.

Berjuthen wir es mu, die Sache an einigen Beifpielen

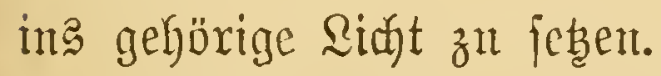

Die induitriellen Unternehmungen und insucjondere die

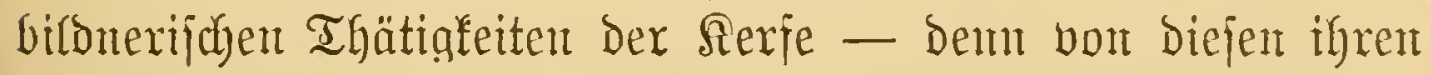

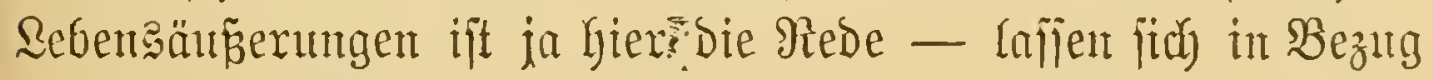
auf Den zeitfichen Bufammentyang ifres sejejeyens in zmei atbtheilungen bringent.

(3iraber, 3njelter. II. Bo. 


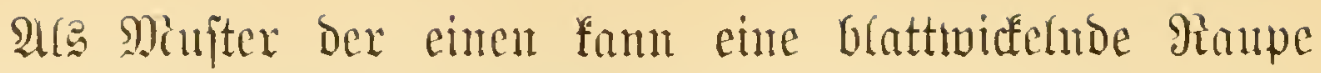
geiter. Der Ketreffende Faltex legt die Crier jedesmal ober Dody in Der Aregel auf bie nämlide Fntterpflanze. Die ans= friechenden granen rolfen ober fpimen bie Bätter zufammen,

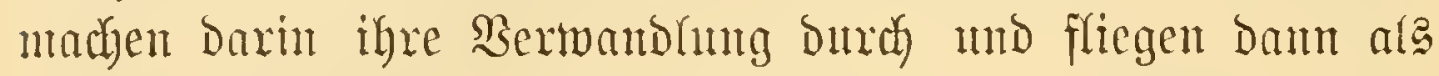

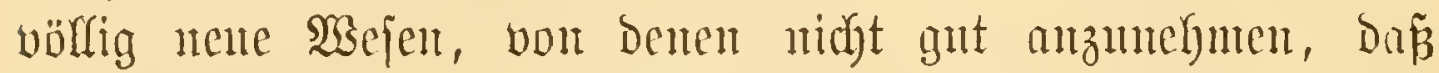

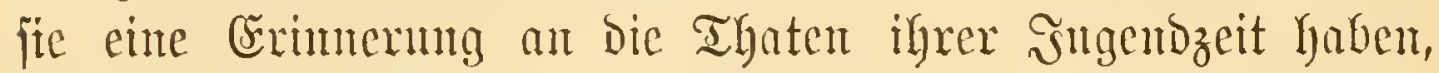
Davon. Zur gehörigen Zeit fommen fie aber trobsen wieber

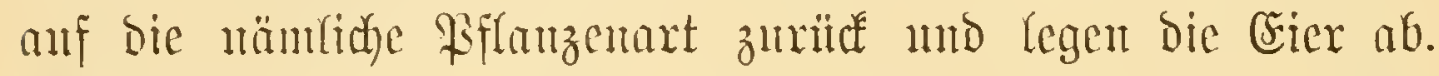
Die Raupen aber, weldye biefer zmeiten Bseneration ange= bören, und weldye von bem, was jene Dex eriten thaten, in Der giegel nidets zul felyen hefommen, madhen es bod) genan jo wie bie erfteren; ifye Şamblungen itedyen aljo anfer jedem

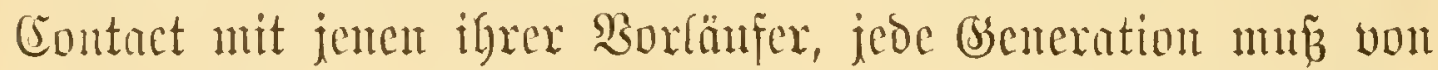

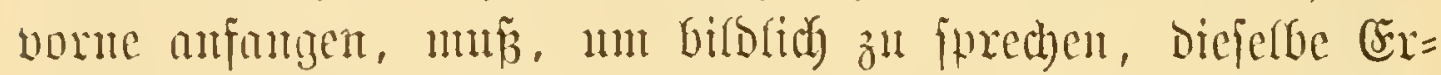

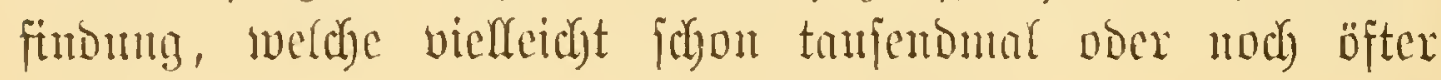

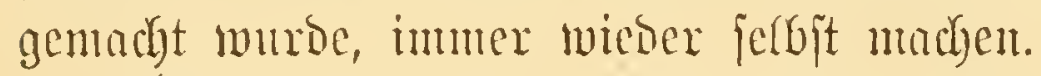

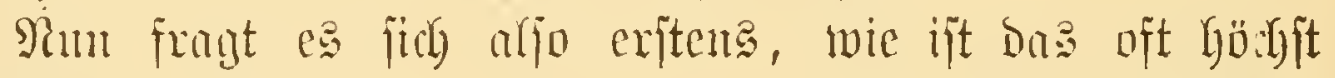
kumituolle Sinttrolfen, wie wir es z. B. Gei ber T. viridana fanden, zu Stande gefonmen, uno ziveitens, warmm madyt e? cinte Bsencration völlig unabgängig ber anbern mach?

Belendyten wix zunädyft bie erjte Frange Durdy ein Beijpiel. Ein Jnbividum ciner nod) ganz barbarifgen Ration,

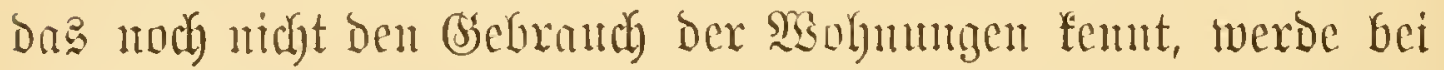

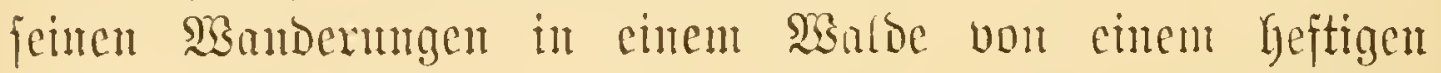

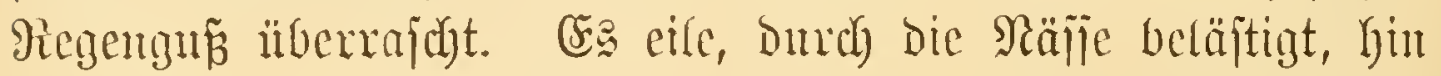
unb biescr, und gerathe mun zufüllig muter einen jelgr bidat belantuten Bann, wo Der Regen weniger Durderingt als an

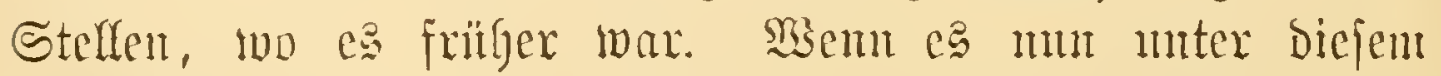

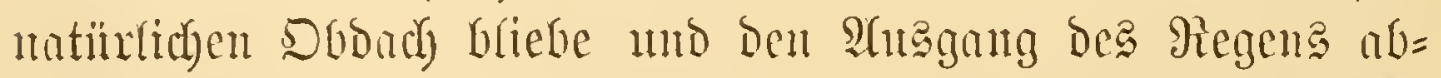

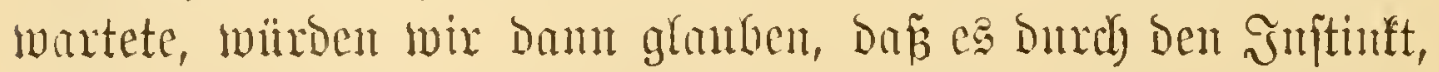
D. h. Durch irgend weldyen rein imeren Irieb bazu veranlaf̧t

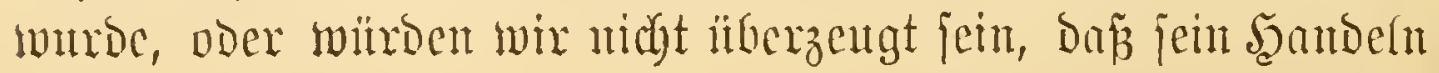




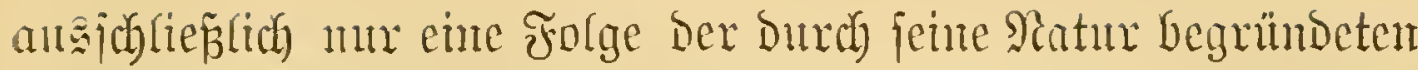
Inlujt gezent bie Näfje jei, welche ifnn mer bem einen Bann weniger beläftigte ala unter jonen, burch weldye er frither hingejdyritten?

Itnd men er mu ferner theirs mittelft der âtgen, theils

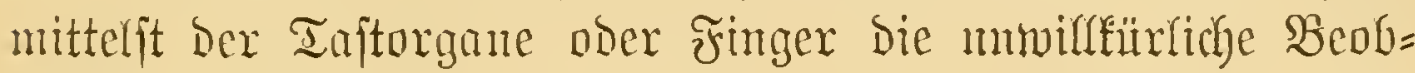

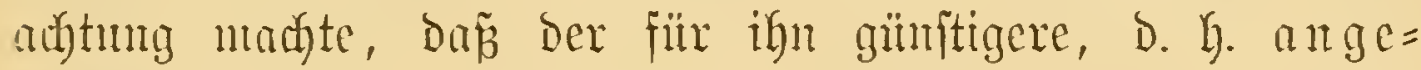
mely mere Bam Dichtere Zweige mo reichere Blätter als bie umjtelyenden Bäıne hahe, mo wenn fitu bieje Beobachtung jefre oft und jebegntal miederholte, went ex bährento eines Regens in Walde ift, fömten bant die einander ftets in berjelben Drbunntg fich folgenben uno jich häufenten $\mathfrak{S o r}=$

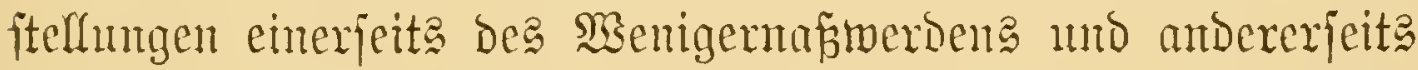
des Didfterbeblättertjents in jeinent Reizapparat nicht jenent Buftand herborbringen, als defien un wahruebmbares und abjolut nothinendiges Rejultat bie combination ober

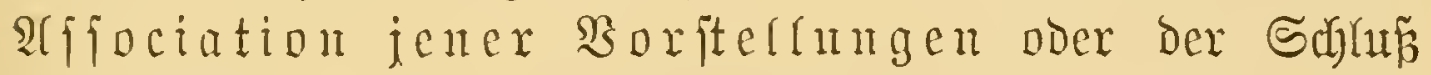

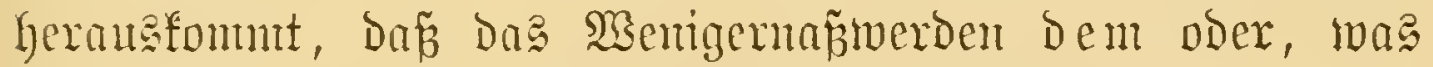

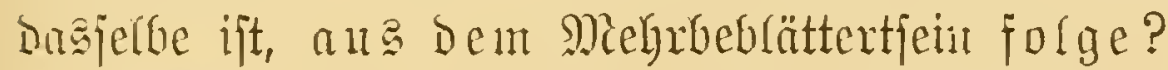

Witroen wir $\mathfrak{c}_{\text {S }}$ Dant weiters nicht als eine nothmendige Conjequenz ans dem Soratsgegangenen betrabten, wenn Das=

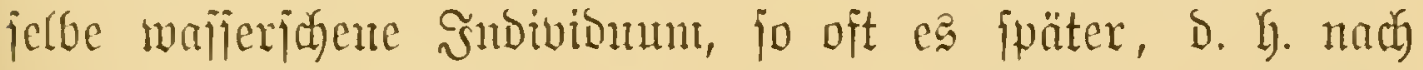

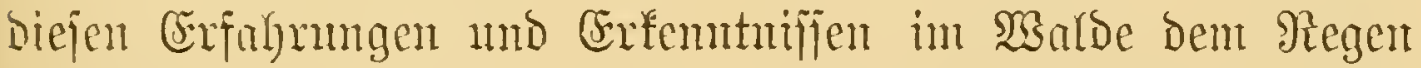

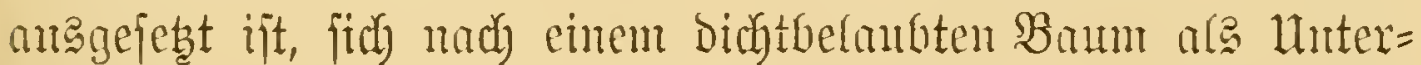

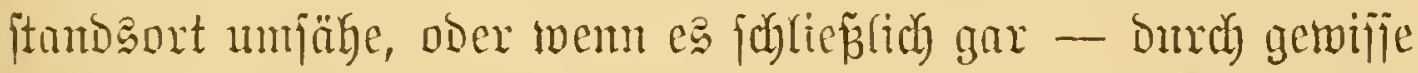

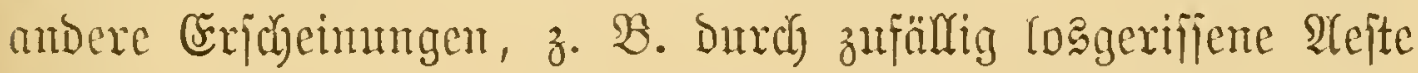

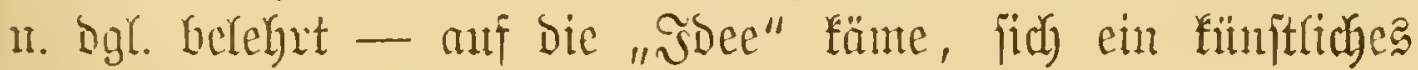
Sunbourly zut bereiten?

Sollte mut das (sejagte, mutatis mutandis, midat aud oon Den gewifijen (Setwohntheiten Der blattwidfelnden Raupe gelten?

Stellen wir ma biejelbe vor, hebor fie dieje Bsemolytheit bejan, aber zut ciner Zeit, soo fie bereits anf Blättern lebte.

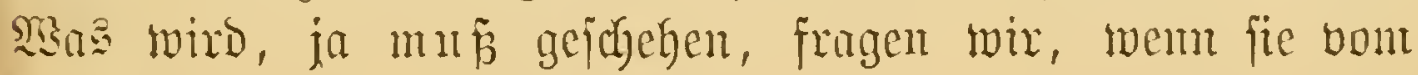


Regen beläftigt wird? Sie wird unulyig werden, fie wirb fir bon einer Seite zan andern betwegen, mo wem jie ctwa zufälig an bie Unterfeite Des Blattes fonmt, wo fie von Regen wentigex ober gar nidyta leibet, jo wiro fie jo lange Dort bleiben, bis fie andere Bntiände wieder anf bie sber= jeite treiben. Und soem fie jebegmal, wem ea regnt,

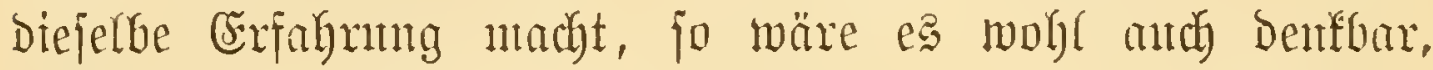

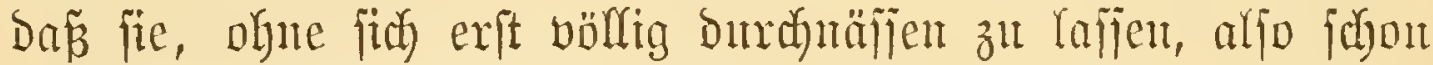
bet Den exiten Durat ifre Sinne wahrnehmbaren Sorboten

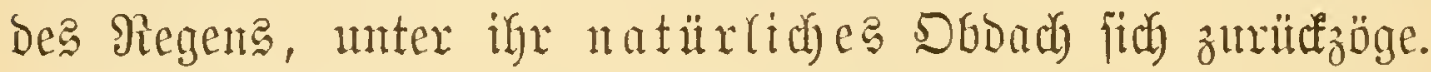
Das jadeint einfach; aber bie Blattrolfe? Sant, wir wollen felyen.

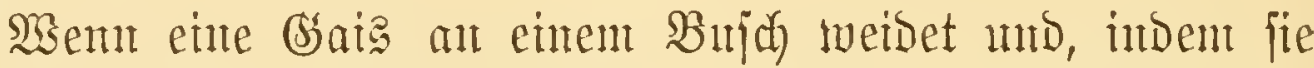
bies thut, einen 8 weig zu fid herunterbiegt, jo wirs hiebei

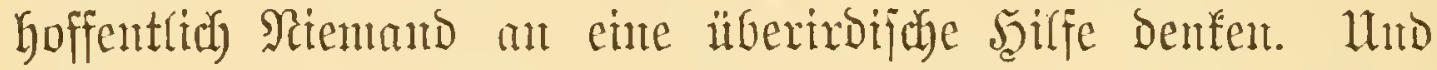
follte ca bei einer Rintpe, die ali Der Mitte Des Blattes jitht, wä̆hrent bie Riefer feinent Rand exfafjen, nidjt vorfonment, oder

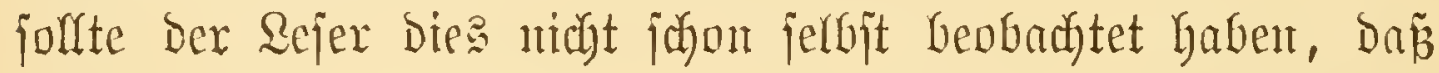
Derjelbe Durah Das (semidy) Des Daran hängenden Я̈̈rwer: un=

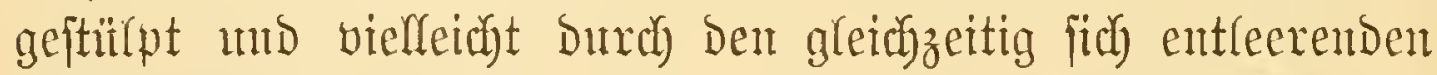
flebrigen Speidjel and fixtrt merbe; ja, fam es bei ben tanfendälttigen Methoden, wie die Rerfe frejlen, uicht anth

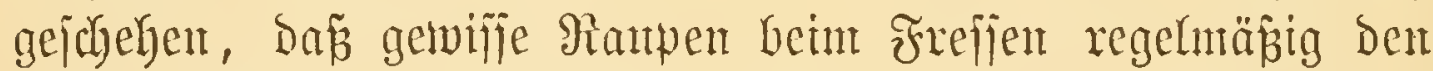

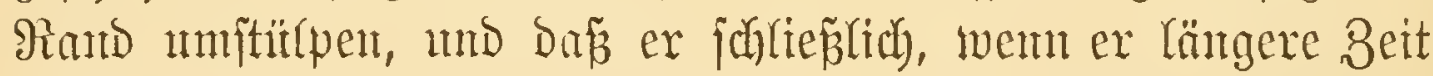
in biejer Stellung gehaltent wit'd, fie fpäter ntidyt melyr ver=

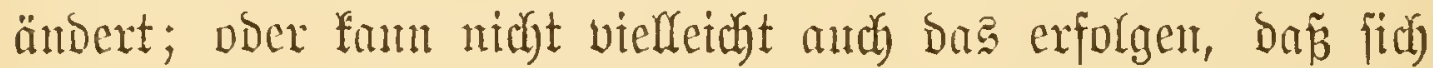

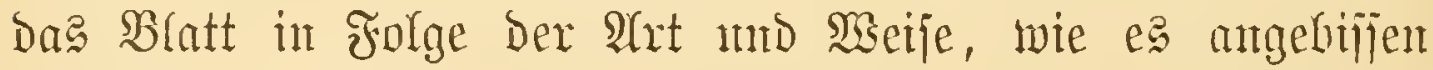
ober burd) bie Elfirentente befentibtet mird, jo zu jagen "von jelbft" anfrollt?

Hnd wem mu eine folde giaupe, fo oft fie "aus Bufall"

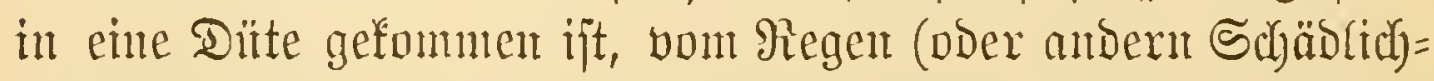
feiten) verjajont bleibt, wälyrend fie, wenn jie anf Den flachen Blatte liegt, banon beunmugigt wird, fann fie, gleich bem 


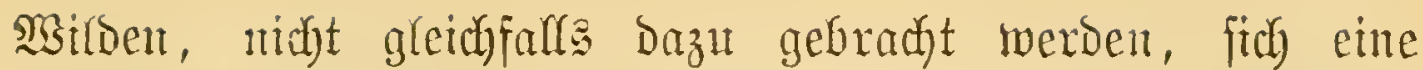
Danernde Blattrolle zn madyen? Doer wer in ber şelt

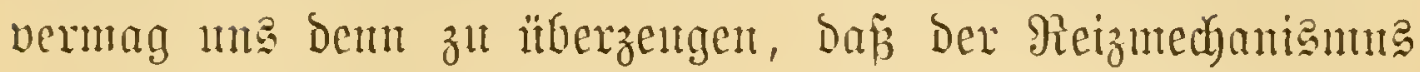

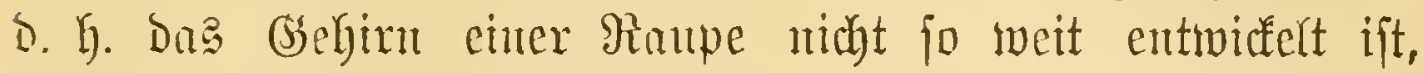

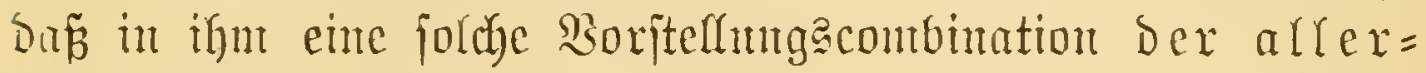
cinfachiten $\mathfrak{A} x$ bon Statten gehen fönte. Die Raune

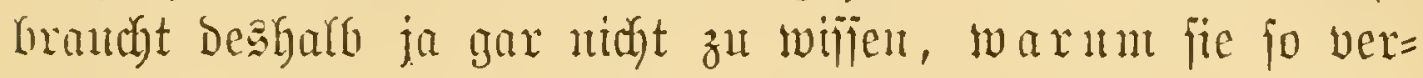
fägrt, ja nicht eimmal, baj jie es thut, und toer berutag bies and immer zu controlixen? - es ift gemtg,

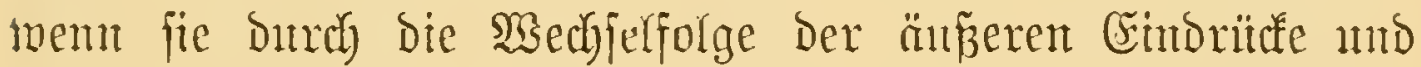
Der Durch lesetere vermajadyten Empfinoungen rejp. Sorjtellungen e zas thun gezwuntgent wirb.

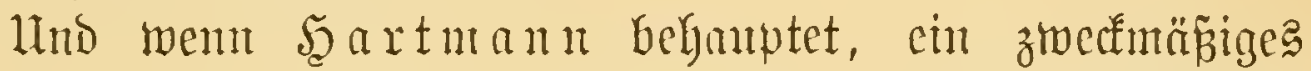
Sgandeyt olyne cin eigenes oder burch eine frembe Intelligenz

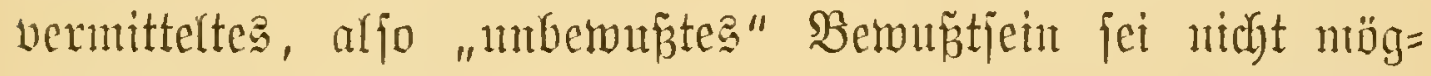
(idc), jo ijt bies eben eine Der Natur Der Sache uad) unbeweis= bare Befauptung; Dem wir fönten nur vou Dent etwas hetweijen, bou bem wir etwas wijjen; an das Untbetwnétjein= gejpenft fonn man, wie an alles Smaginäre, mux gla uben.

Nun die zmeite Frage. SGie fam die Erfindung, weldye die Ra the - wie wir gejehen, nidyt allein, fondern

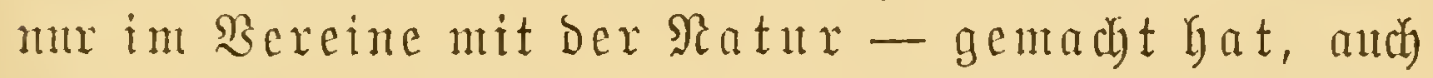
Den Raupen ber nächjten und aller folgenten Ssenerationen zu Sinte foumten, finzun, wie form einte foldhe vereinzelt anftretende semolntheit beftändig reproducirt und endlich

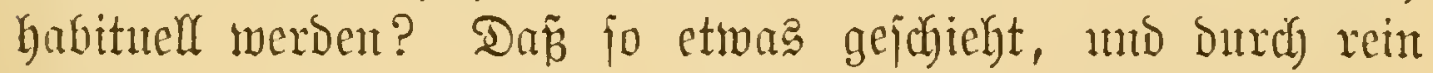

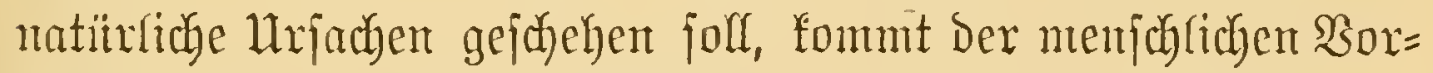
ftellungsmeije beim erjten Anfchein freitidy jebr frentoartig und Deshalb, wie vieles Rene mo Mngemohnte, Yeidyt wo nidyt unfap̧bar Doch unglanbuilrbig vor. Wrir jagen, beim exften

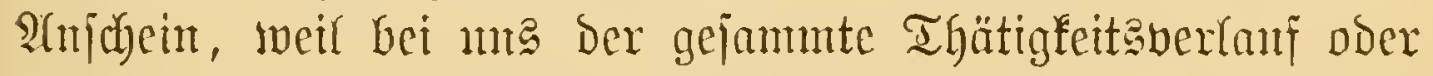

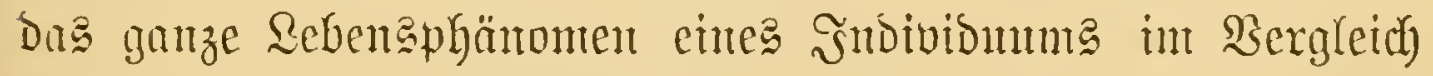
zll Den cines andern itberhaupt mb ipeciell zut Dem feiner 
Sinder oft mehr Berjojedenartigfeit are Heberemitinmung offenbart. Des Grumb Davon ijt aber fein amberer als bie relativ grof́ce Serjojiedenartigfeit ber unjer ganzes Thun be= ftimmenden Dafenghedingmuen, welden Der Rulturmenjid bei Der Bieljeitigfeit jeines Wejeng ausgejebt ijt; Dem bei Solfa: flajfen mo ganzen Böffern, welde nod) anf einer niedrigeren Strife ber Entwiofunty fteben, nimmt and Das Reben ber anf

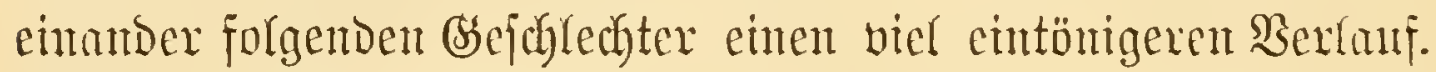
Der Sejer ftelle fid aber eimmal vor, baj zwei von einamber

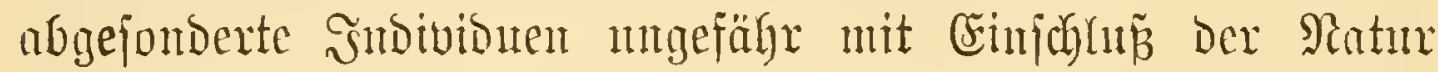

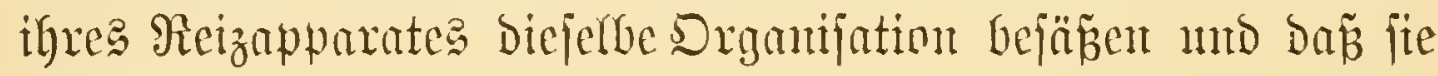

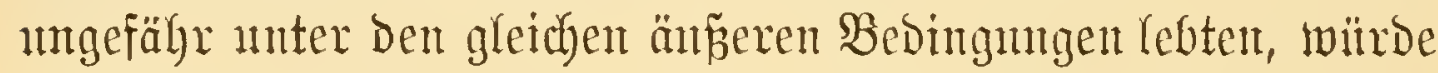
Dannt nicht and ihre gantze Thätigfeit ungefülyr biejelbe fein?

Dod) twozn melgr borausjeben wollen, are zu mieren Betweife nothmendig ijt. Scier handelt es fith jo nidft nut

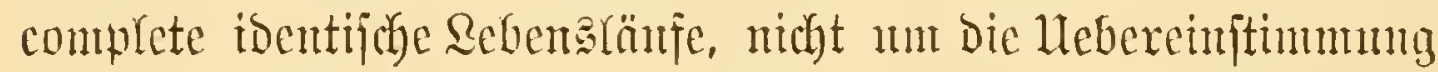

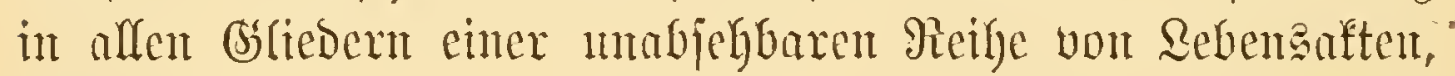
fontorn mur un bie Congruenz einer einzehten Rebenzuer= richtung.

Nun Denfe Der Rejer an miere Rampen. Cine einfadbe Bergleidyung Der Bseneration A mit ber Bsencration B wiro ihn Yefren, baj fie förpertich von cinamber kaum, ja meijt gar midgt zu menterjeciden fund, und von biejer Scite anz

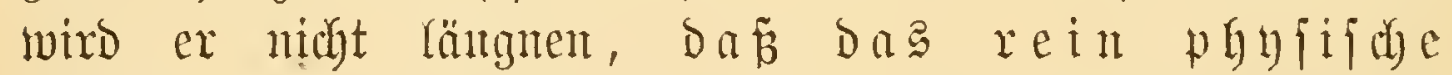

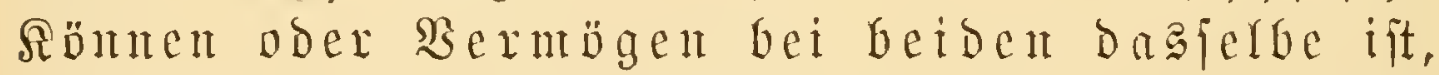
Daz fomit Das, was bie erjte Brut leiftet, and vou ber zueiten verrichtet werden famm.

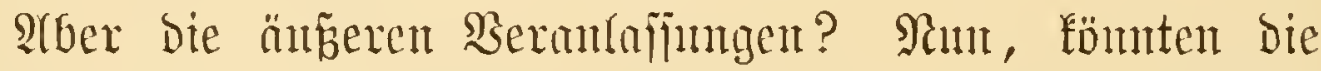
ibentijacher gebadyt werden? Die Raupen B fommen, Dunf

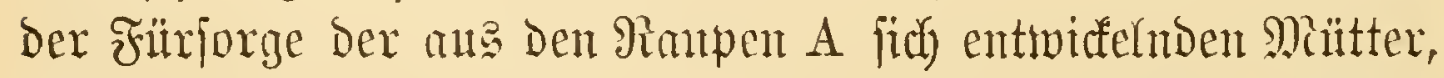
genan an berjelben Stelle, D. h. anf Der mämlichen Pfflanze anto meift and anf Den gleichen Theilen der Bfflanze wic bie

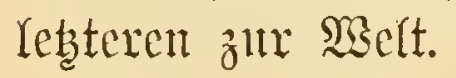




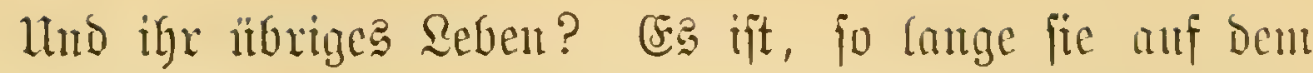

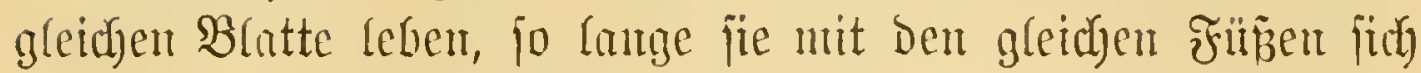
autheften, mit ben gleichen Riefan frefjen und vermöge ifres

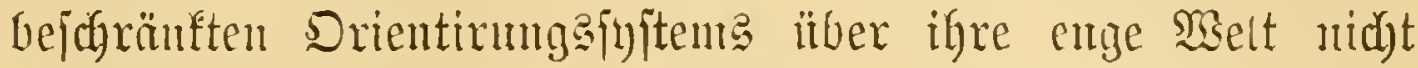

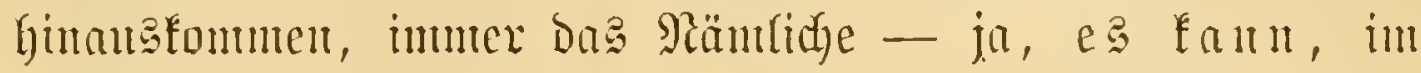

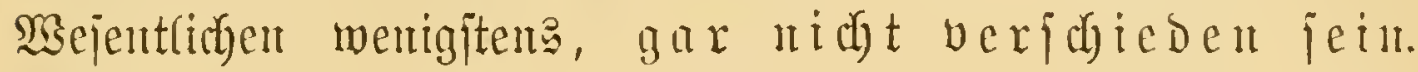

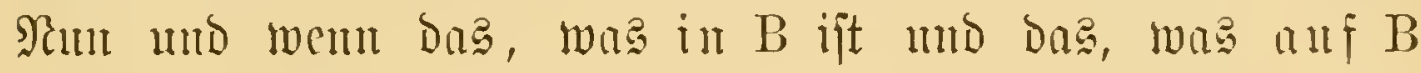
twirft, $k_{u r z} u m$, twem bas ganze B genau fo wie bas A ijt, warum jollte das $B$ nidjt aud biejelben Blattrollen wie Das A madyen? -

Doch) wir wolfen ohne Riuffyalt reben. B wird mur dam bie gleidyen Sriffel mie A fubriciren, wem bei ifym an

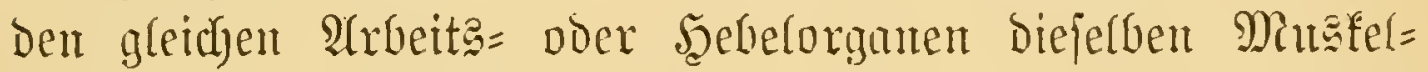
contractionen, und zwar and in Derjelben Reihenfolge wie bei A arâgefüfrt merden. Damit bies aber gejuege, min eriten B genal Dasjelbe Reizorgan wie A haben; - Denn diejes regulirt die motorifaen Nervenftröme - und miijien zmeiten?

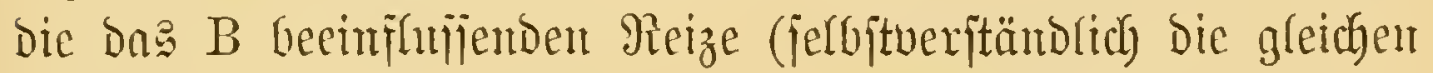
Rerceptio= oder Simmeamertzenge vorangejebt) Diejelten wie bei A jein; bent bieje löjen ja eben, unter Bermittlung des Sentrulorgan, bie motorifdyen Ströme ans. -

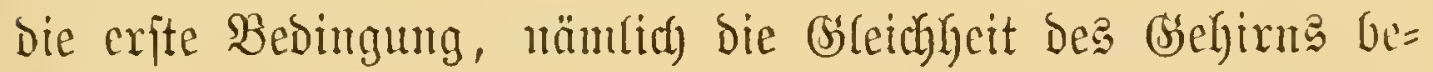

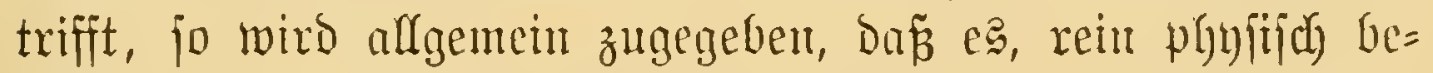

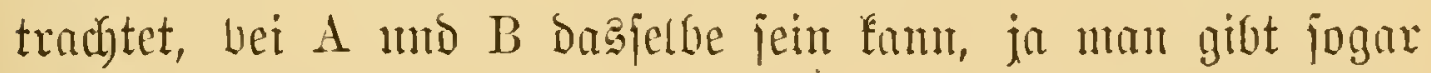

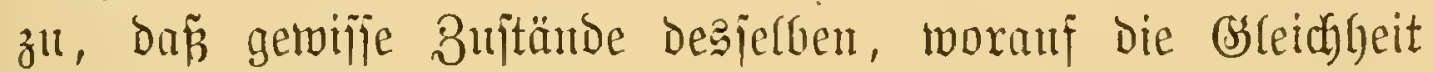

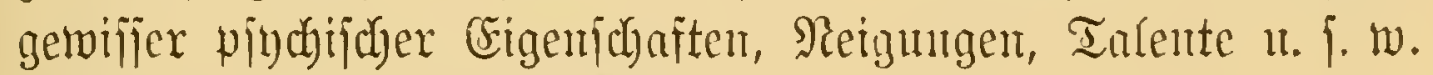
beruben, vererbt werden fömtuen.

Und Da ferner, wic oben marhgetwiejen, and bie ztweite

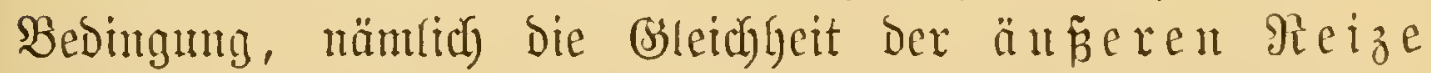

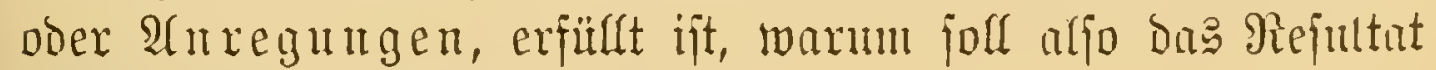
nicht beibemale dasjelbe jein?

Radj Dem Mitgetgeilte! dürjen twir uns aber bie $\mathfrak{B e r}=$ erbung Der jog. Serjuntinfte nidyt jo Denfen, Daj ber ganje 


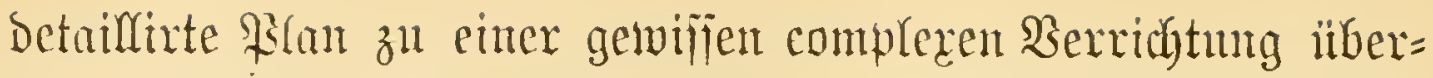
tragen wird - uto an eiter foldyen auth vou Dartwin ver=

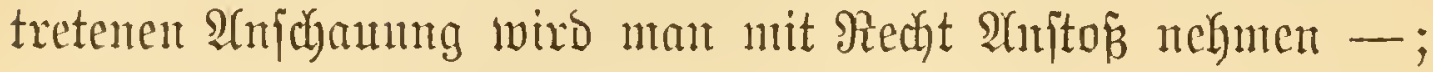
es gejoielyt nichts anderes, als was bei ung ald

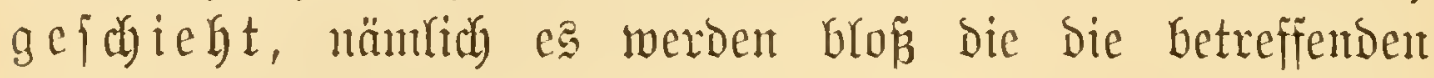
Senthungen executiremben Drgate bererbt, aber ehen unter foldyen unjtäuioen, Da unter ben gleit)en Ámegungen zux gleidjent Âction antge= trieben ineroent.

3ux gleidyen action?

Die Entwidfungamethode biejer interejantejten aller bio=

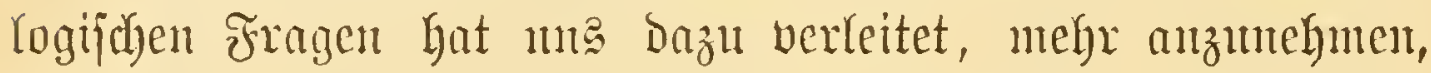

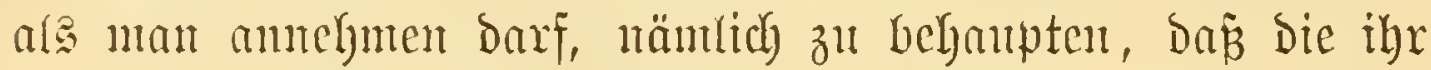
Eentralorgan theils bireft, theirs indireft beeinflujienden gieize

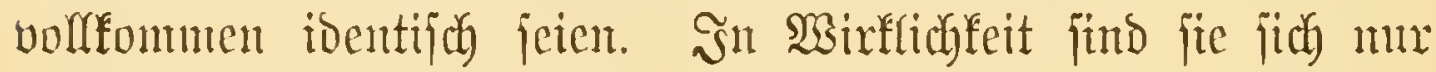
mehr ober weniger älunlid, uno mehr fömen alfo auch, bas minjijen soir jelbjt cinräumen, die giejurtate nicht jein.

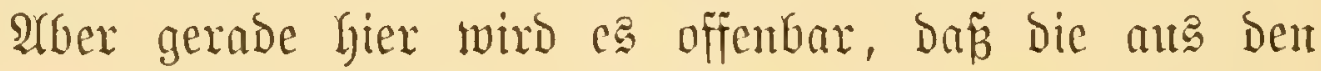

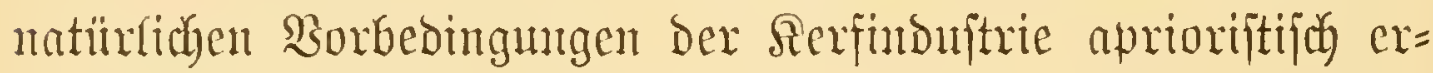

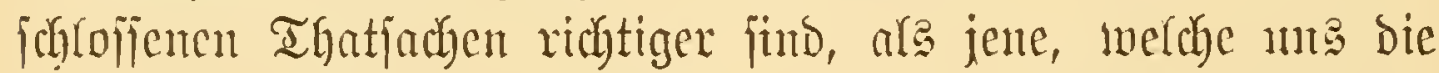
mit einer vorgejapten Meinng an bie Beobachtung gebenden

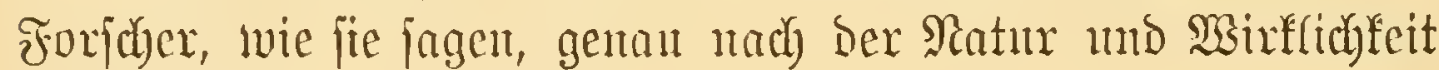
bejchreibert.

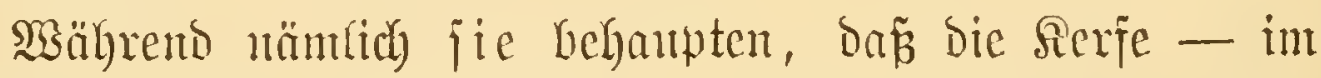
fanteienden Bsegenfatze zu un - inmer Das dsteiche thut, fömen wix beweijen, da je jie jefr verjedicben ver = fahren, nux abex in deuferben brabe wentger verjacben ars wix, als bie jie bejtimenden inneren und äuneren âtregungen weniger ver= jofieden ars bei uns jitt.

Das folgende Beifpiel mun sinftweilen ftatt vieler bienen. Anf Der Birfe rebt cin goldgrüner Rüiffelfäfer, ber

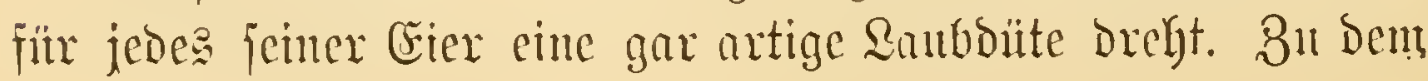




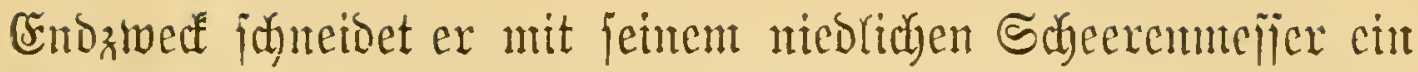
Blatt (F̛ig. 29) ungefähr in Defien Mitte Der Breite utad,

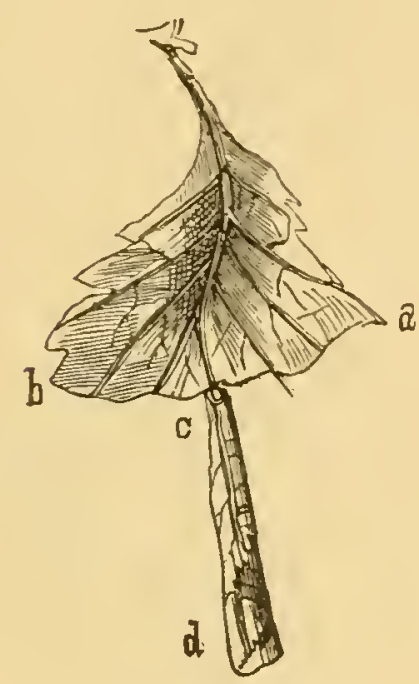

Fig. 29.

Bíattrolle des Birfenriijiclfäiers.

(Rhynchites betuleti Fabr.)

Ilat. Bir.

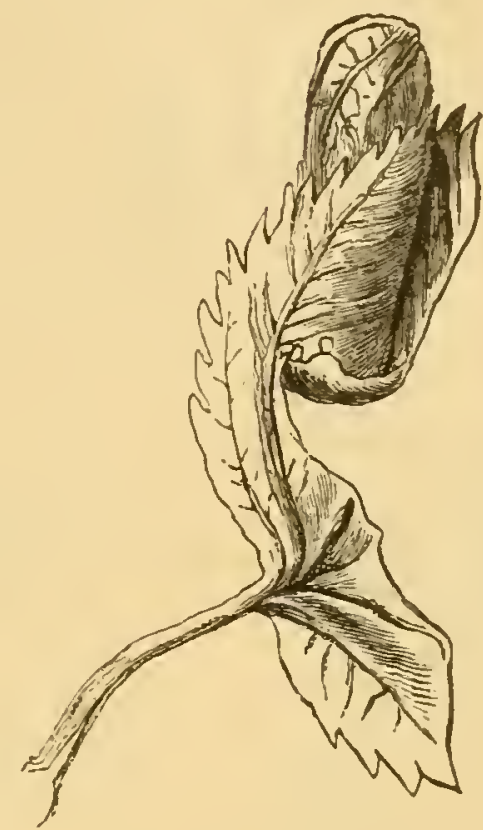

Fig. 30.

Blattrolle eines Sajeljtraudiritifel= fäfers (Apoderus coryli L.). Nat. (3).

aber nidyt gerablinig, jondern - jo jagen Mandje - in einter

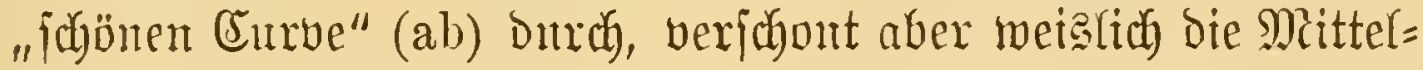
rippe. Sänga ber Yeţteren wiro nämlich das abgetremte fpiţe Blattente auf eine jebr fimple art bermittelift der langen

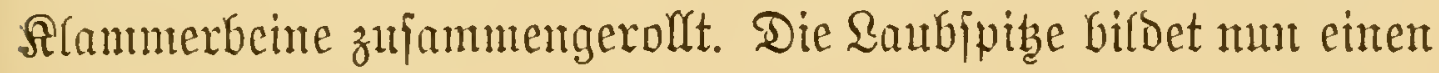
gar artigen Tubus, ber vom fladjen Blatttheil herunterbängt.

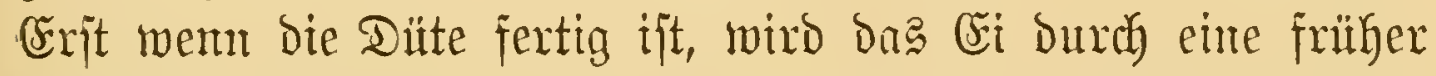
gemadyte Deffinutg in fie hineingelegt. - Sit bas nicht mumberfan gemug, mamentlich went es wahr ift, da jo bie Blatt=

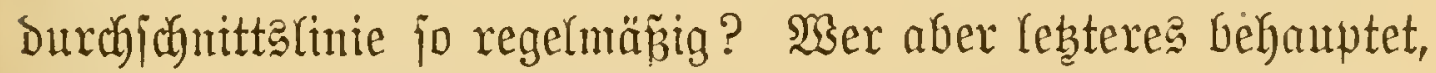

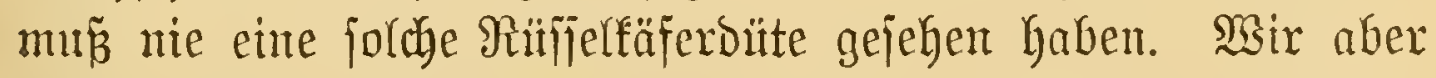

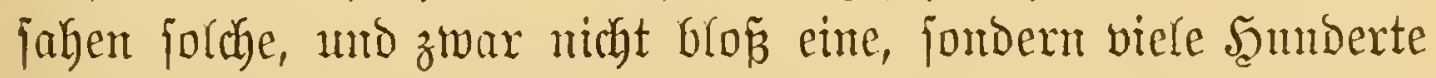
an einem einzigen Strauch, und wir haben ung itberzengt, was soir midyt anders erwarteten, da a näm(ich feine dev 
andern grid), mid ztwar weder ber Form nod ihrex Sage refp. ifyer Erzengung nath. Die einen waren mefr oder wenigex gelungene $\mathfrak{B a l z e n ,}$ andere eben joldye Segel; bie einen

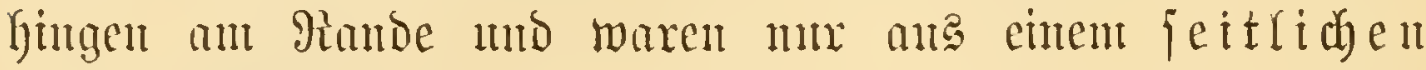
B(attantafdutte gemadyt, älntid) wie bei Fig. 30, andere

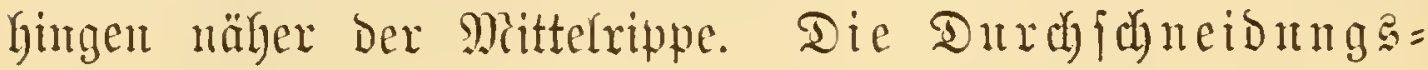
linie aber bejaj alfe nux exbenfliden uregel= mäzigen, mely weutger zidfadfärmigen Formen,
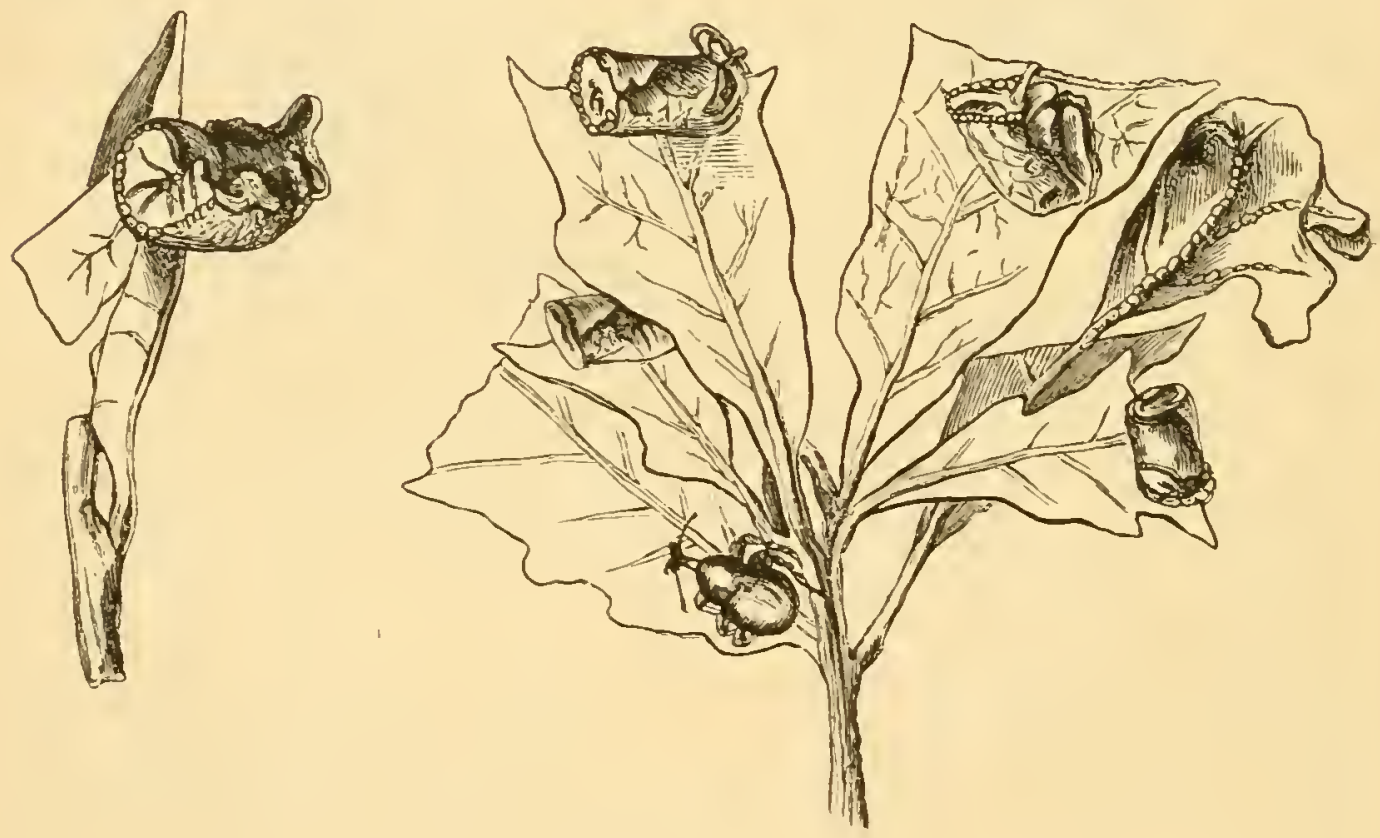

Fig. 31 .

Irommelartige Brattrolfen eincs Eid)enriffler: (Attelabus curculionides). 9lat. Gr.

niemals aber war jie weder eime fada a ferexabe nod) cine regelmä̈ige Curve. Das Sntereffantejte war

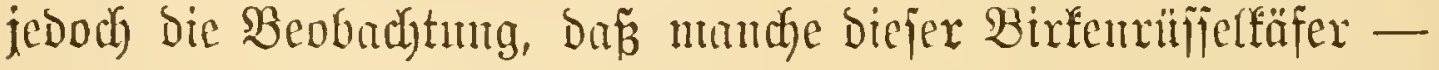

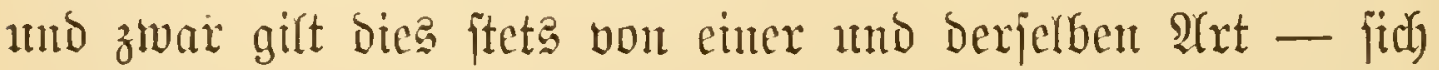
gax nicht Die Mïlye nelgnten, Das Blatt entzmei zu fägen, jontorn bie Ditte anf Die nänlidye printitive $\mathfrak{A}$ rt mie bie meiften blattwidfeluden Raupen durd) Fintrollen bes gejammten Blattes heritellen, ober, was aber eine jeltenere Erjobeinuty, 


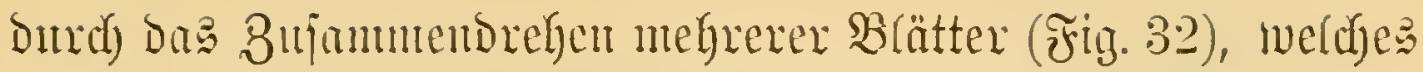
lebstere \$erfahren getwijfermañen cine Copie von jentu des

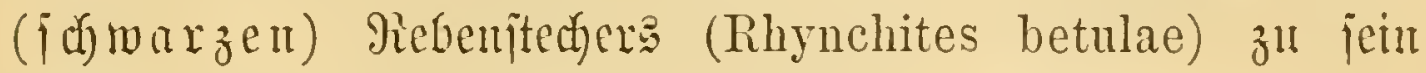
icheint, welder lestere binvicberm gelegentfidi aud do Berfabren Des Birfenrün̈lers befolgt. -

Da mu ber Grutud, toarum die einen Fnbivibuen fo genat ut foris= fältig zut Werfe geben und in Folge bejien jo juböne und jo volffommene Arbeiten liefern, wälyrend andere bie Sache jehr voh angfühlen, viel= fach menigitenz uidit in Der Ratur Des Materials ober im Mangel Der nötfigen 马eit gejurut weroen fum, jo ijt dod zux Evidenzex= wiejen, da b́ daz Bautaleut bei den einzeluen Jubividuen Eimer art, ja jelbjt ermex $\mathfrak{B r u t}$, etwas hö d) ft $\mathfrak{B} e r a ̈ u b e r=$ riches ijt.

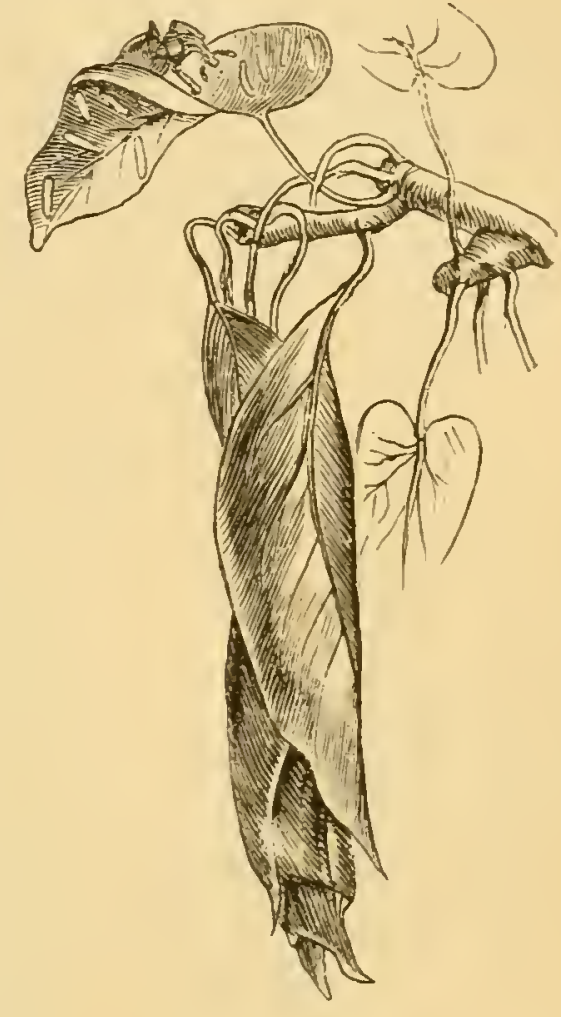

jig. 32.

Blattrolle Des Mebenitedier: (Rhynchites betulae L.).

Damit haben wir aber bie natürfiche Grumbbedingurg

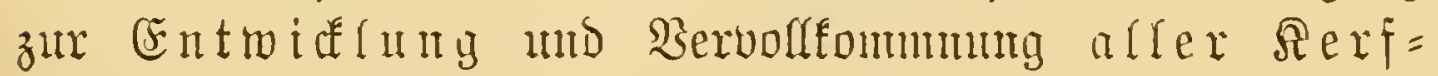
indu it rie aufgedect.

结ir Denten mu flüchtig an.

Bon Den Cricru, weldje cu Birfenrïf́ler legt, gejen, wie Эeder zugeben mñ

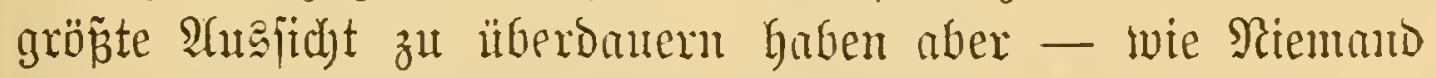
läugnen wird - (ceteris paribus) jente, weld)e in ben an jorgfältigiten gebrehten Düten liegen. Da Dieje mu, wie jelgjtwerjtändlich, von den zu biejem Şambiverf am meiften Befähigten herrithren, jo merden eben die aus biejen Ëien 


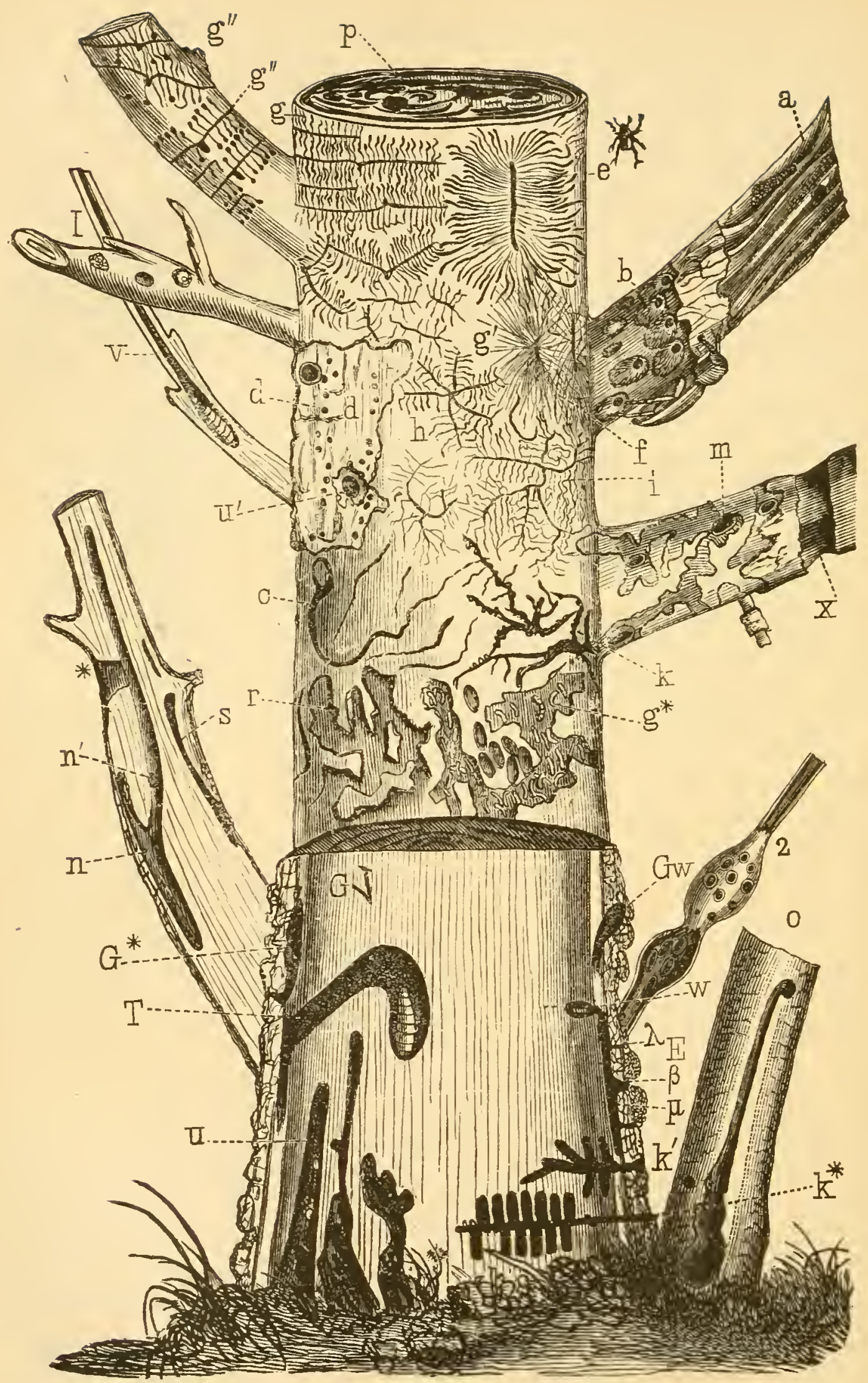

Fig. 33. 


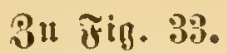

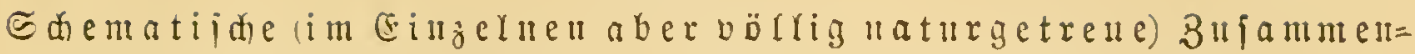
fte [ ung ber widtigiten Diethoden ber $\mathfrak{B}$ a uminirer.

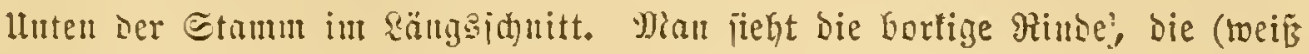
gehartene) Canbinmzne, jerner ben Ep(int, die eigentride Bajtidinte mo entrid Den 5olgériper.

Sben ijt ber Єtamm, Eis anf Den Baft, worin bie meijten Minten verlaujen,

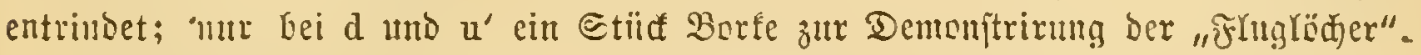

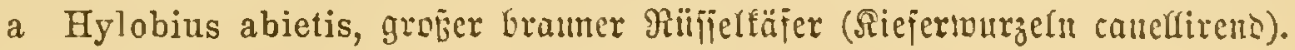

b Pissodes notatus, fleiner bramer Rïfjelfifer (mit jäncı Bajtwiegen).

c $n$ herzyniae, Şarzriifielfï̄er.

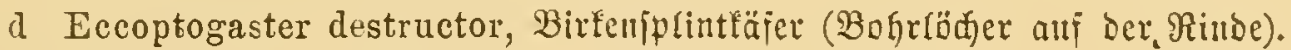

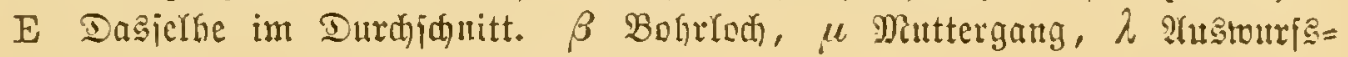
(od), w Miege (im Splint).

e Eccoptogaster multistriatus, Pappelrindenfäfer.

f $n$ rugulosus, Pilammenbauminbenfäjer.

g, g' Hylesinus fraxini, buter (siden=Baftëfer (mit their.s twagamigen, theils gabeligen, theils ganz. urregelmäb̈igen (sanginjtemen).
g" $\quad$ minor, fleiner Riejern=Bättäier.

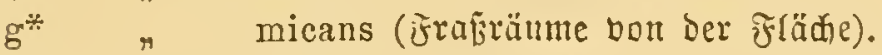
G* $\quad$ piniperda (Borfentwiege im Durdjinnitt).

b Bostrichus chalcographus, 6załniger Borlenfäfer (mit regelmäb́igen Stern= gängen).

i " curvidens, Lammahniger Tamenborfentäfer (mit unregel= mäß̊igen Cterngängen).

k $\quad$ bidens, 2zahniger riefernborfenfäjer (mit ganz unregelmä̈igen Sanginjtenten).

$\mathrm{k}^{\prime} \quad n$ dispar (mit unvolfommenem jolgidad)tityjem).

$\mathrm{k}^{*} \quad "$ lineatus (mit jehr volfommenem, reiterartigem Solziळad)t= initem).

1 Saperda populnea, Mpenbod.

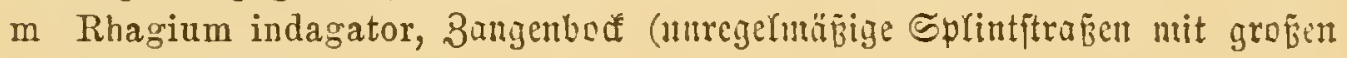
Fłluglöđlern).

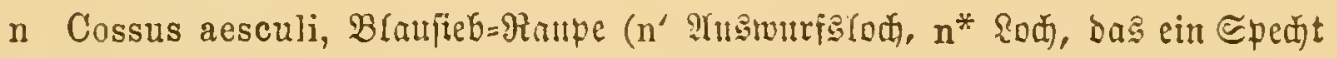
ausgebactit).

- Sesia speciformis, SIfasfligler.

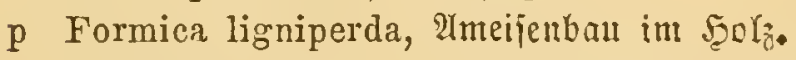

q Cecidomyia salicis, Weibenruthen=(Saffmiide:

r Callidium variabile (unter Siriłbaumrinbe).

s Cryptorhynchus lapathi, Erremriijeltäjer.

T Callidium insubricum, शhornbofi.

u Saperda Carcharias, grof́er $\mathfrak{B} a p p e l b o d$ (u' Bohrlöđer).

$\mathrm{v}$ Cerambix linearis (iu Sajelruthen).

$\mathbf{x}$ Lamia amputator, ztweiflecfiger Bimmeridrüter (Rinbe unt Splint ring= föruig umidneibent). 


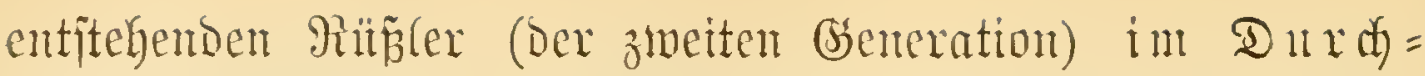
fow nitt wolfommener ars bie der eriften, jene ber britten wieber volfenmener ars bie ber zweiten n. $\%$ w. arbeiten, und wenn wir, wag toir fönnen, and antegmen, daj die

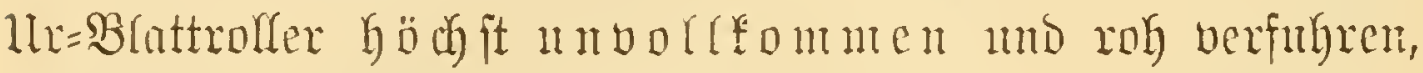

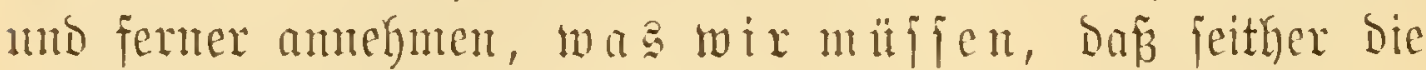

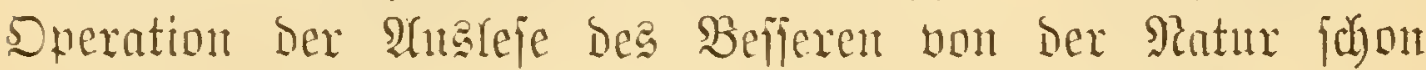
oftmals vorgenommen tourbe, jo jeben toir midgt blofís ein, warm bie bentigen Blatturbeiter relativ jo viel Runftertig= feit entfalten; man fïmte fich jogar Darifler vermmoen, Danj fie es in diejer langen Beit nidjt jon weiter genrad

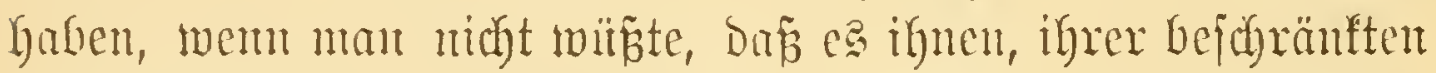

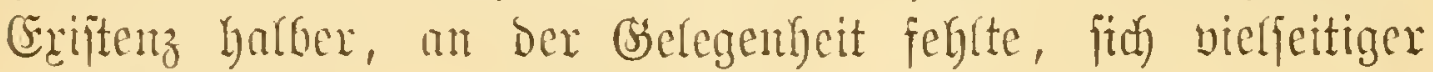
ant

Somie aber bie subivionen enter ant anf einer jegr ungleidyen Stufe ibrex Induitrieentmidfung jteben, jo verbält es fich und in nod weit ansigebebnteren maje bei ver=

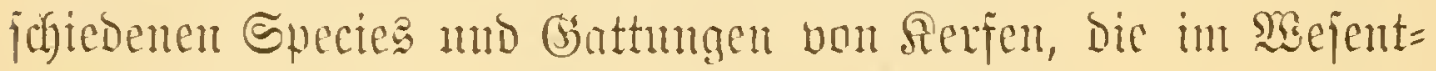
lidjen einem nd Demjelben Sandwerf obliegent.

Bei Den biverjen lnternermmugen in Ranb mo Eroe,

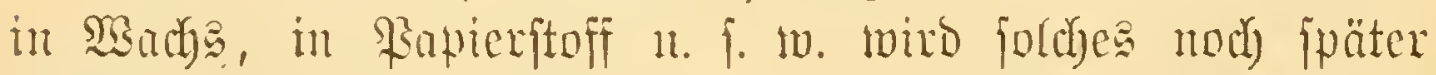
nadjgetwicjen; bejombers Dentrich tritt cs bei Den Solzminimern

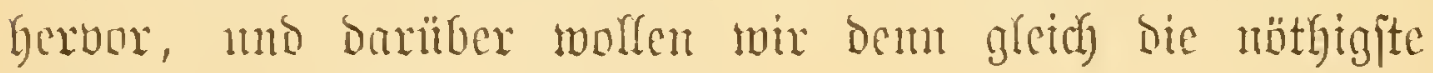
Crrläuterung geben.

Die Sier ber Banmminirer werden theirs num äuñerlid m sie Rimbe geflebt, theils mittelit eigener Bobrintrumente tiefer abgejebt, ober gar in fribger anggearbeiteten fanmern

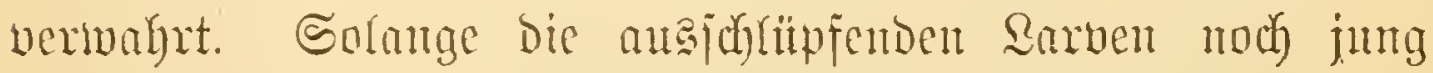

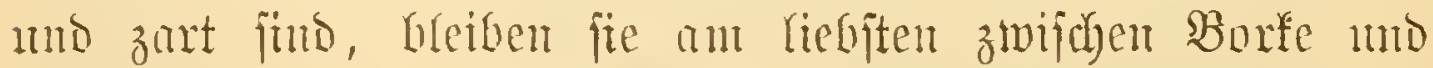
Cambinm, D. i. in Den weidyeren Sagen, ja vicle, wie bie meiften Borfen= nub Bodfäferlarven, gehen niemale weiter, wäbrend andere, mit ftärferen Riefern, in Den Splunt mo in Das feftere Solz fich Gincinbeipen, was alles in Fig. 33, 


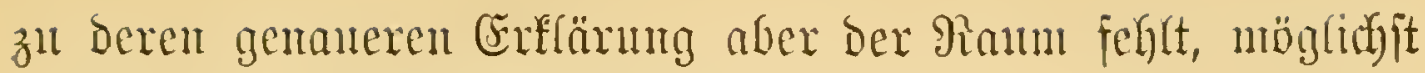

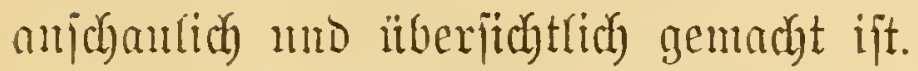

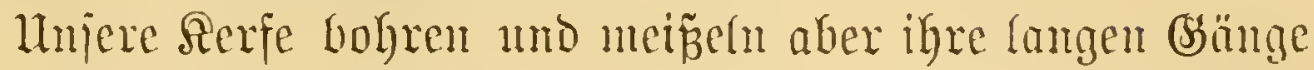
nidyt, um jith zul verjtedfen, fonbern fie madyen, jognt wie viele andere, in Blättern, Stengeh, Samen n. j. w. mintrende

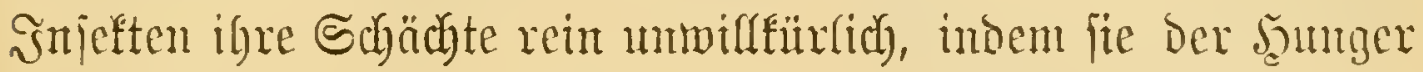
Dozu antreibt, immer meiter zu frefien. Das Bobrmehl aber, Das fie durd) Den Mumb aujuefunen, fommt nach erfolgter Extraction feiner mentgen Nahrungaheitandtgeile mieber als

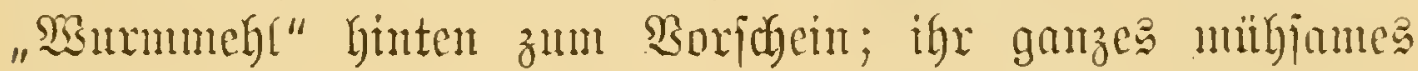

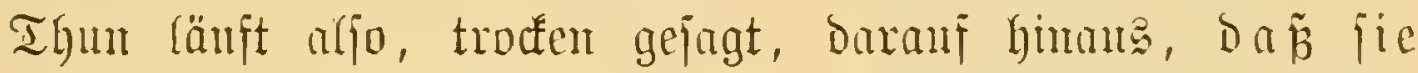

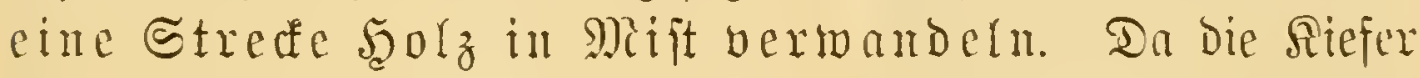

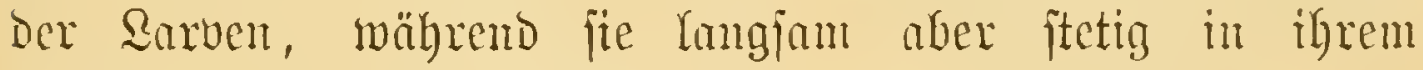
Schadfte vororingen, jowie jie jelbjt bejtändig wadjen, jo ijt auch $\mathfrak{H}(a r$, Da $\tilde{\beta}$ Yetzterer $(\mathrm{C}, \mathrm{T})$ immer weiter wird. Sift bie

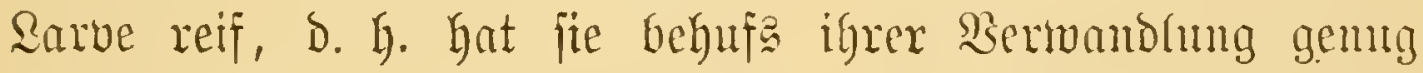
aus bem Şolz herangezogen, fo hat fie anth bas Biel ifrer

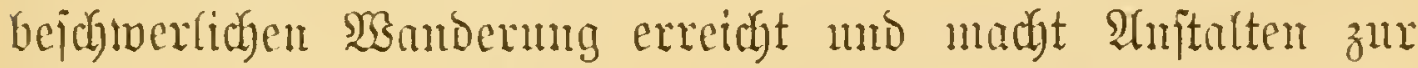

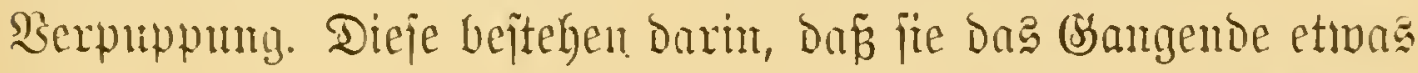

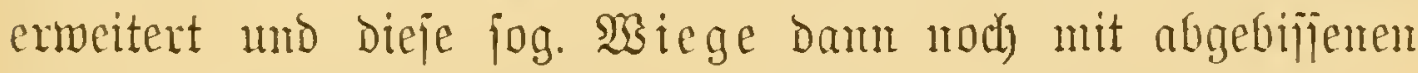

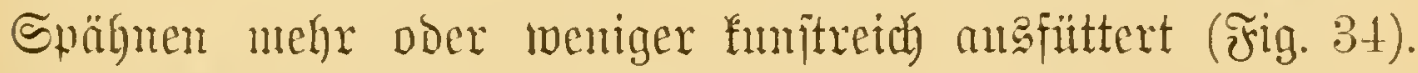
Das vollendete Snjeft beipst jidf Dam entmeder bireft bou

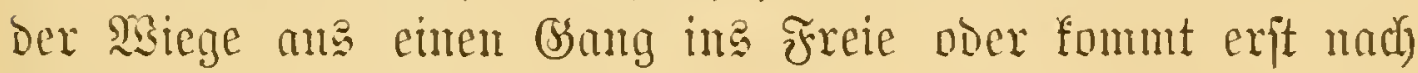
längeren Jrufahrten dortfin.

Die meiften Şolzwärmer leben einfiedrerija, D. h.

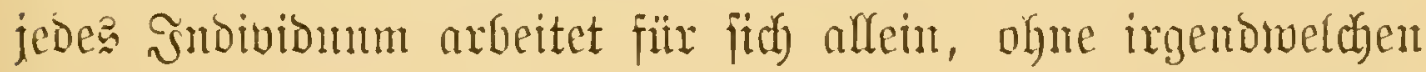

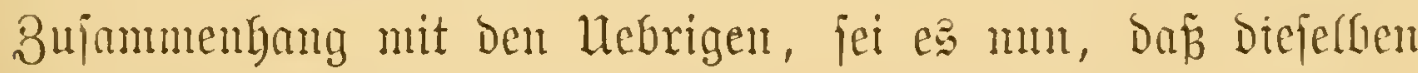
ans einzeln an ober in ben Baum gelegten Eien entiteben,

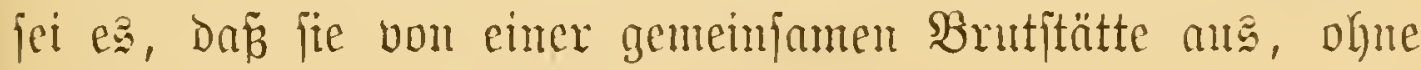

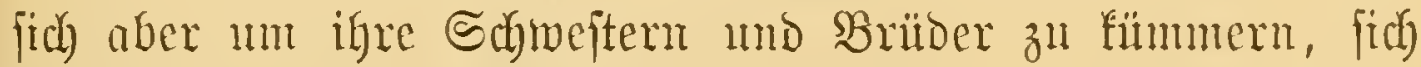

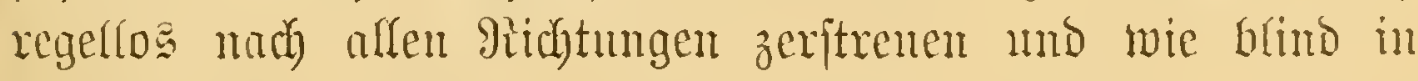
Den Ing poer richtiger in bas Dunfer des Sammes hinein=

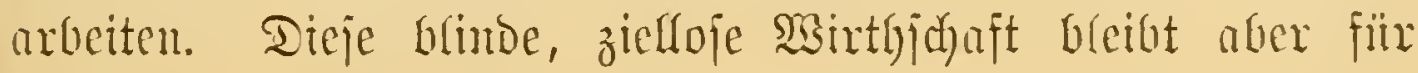


Die Betreffemben nidyt ohyte üble Folgen, wie man fofort

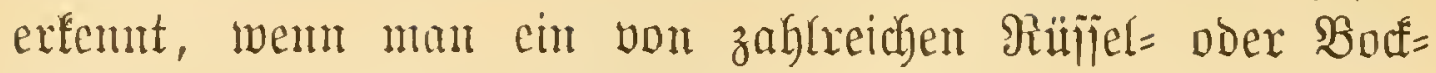

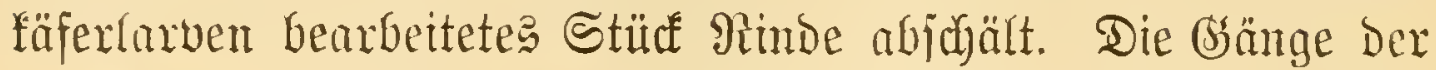

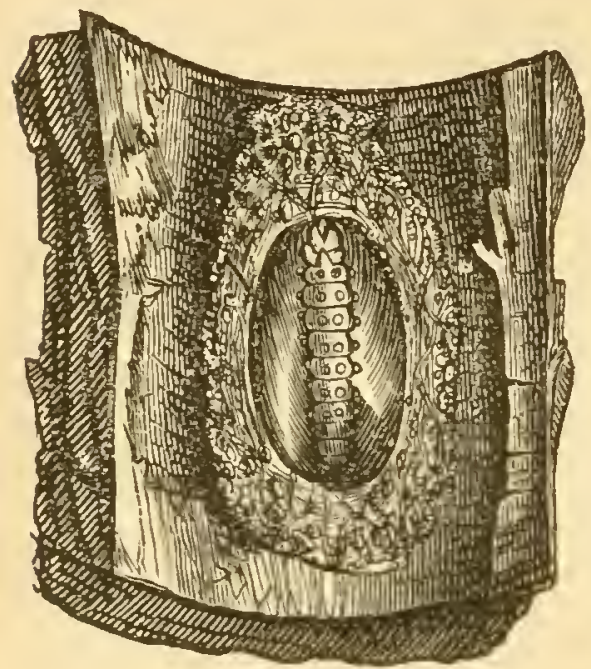

Fig. 34 .

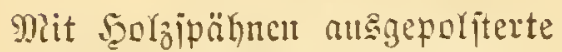
miege von Rhaginm indagator, nat. (3) eutzelnen Thiere laufen nteijt wirx Durch einander uto es trifft jid

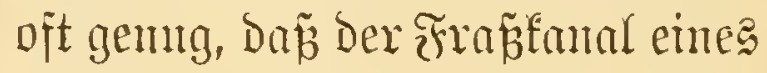
Sndividume in einen leeren, D. h. bereits bon cinem ambern ant: $=$ genagten Ranm einmitmbet.

Şier mun es bam aber notly= mentig verbungern, wern $\mathfrak{e}^{\mathrm{S}}$ fid nidyt etwa mit Dem Soth jeiner ßorgänger befrcunden twill. Dicje ફ̧olzminirer jteben aljo, gantz burdjitäblich) genommen, einamior im $\mathfrak{W e g e}$ mito es mag oft geutg vortommen, Dañ eine ganze Brut

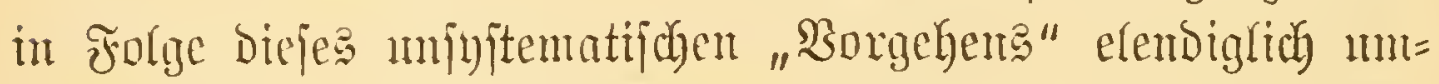

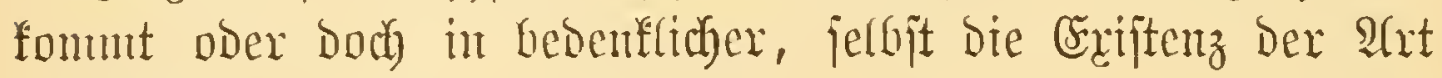
gefähroentor Wscife Decimirt miro.

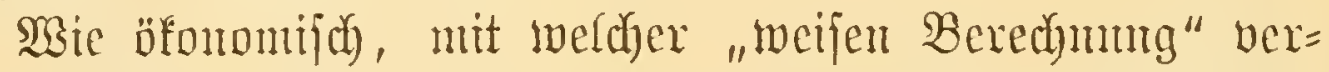
fahren Dagegen die "fozialen Milgler", bie meiften Borten=

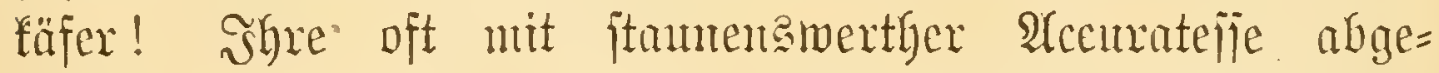
jirfelten for angin iteme find ben zeritrenten Bobrlöchern anderer Şolznager ebenjojehr überlegen, wie etwa die Bell= folonien Der Sentigbiene den eimfamen Erolödyern ber Grabl= wespent.

3" näherer Erörterung mag Der (Erzfeind unferer Sadel= wälder, ber jog. Burbonuter, ein Mufter jein. Nach bem

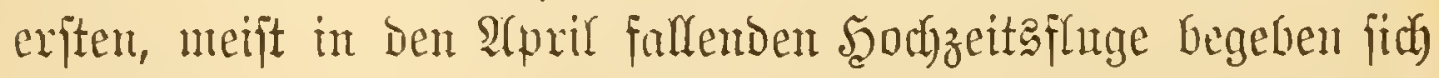

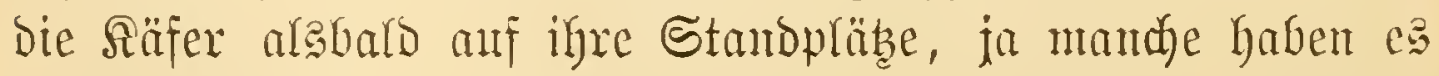

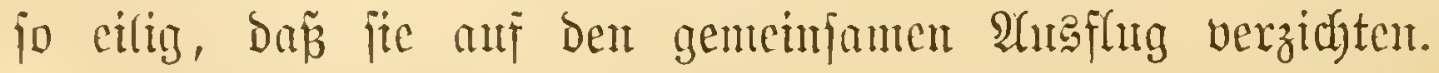

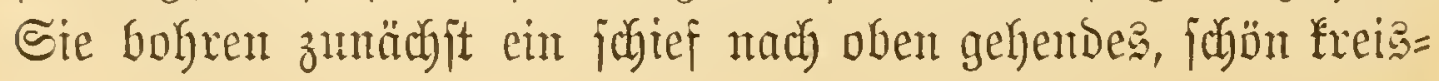




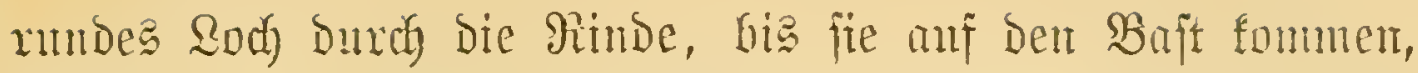

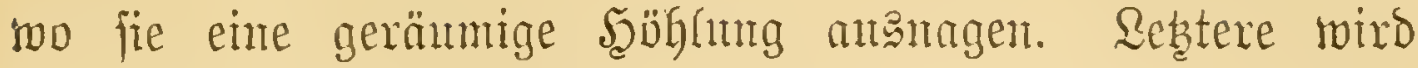
ans maheliegenten Grimben bie Rammelkamex genamt.

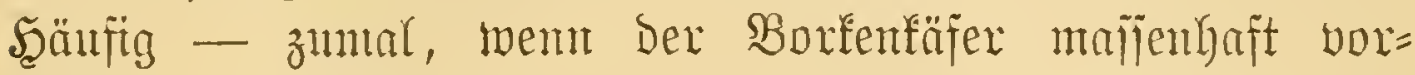
fonme, und in Folge Defjen Rlabuangel eintritt, gerathen

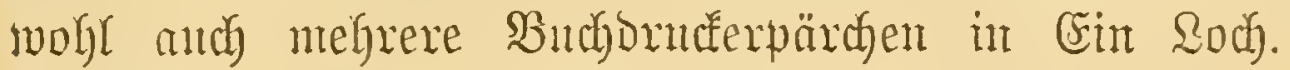

[5?

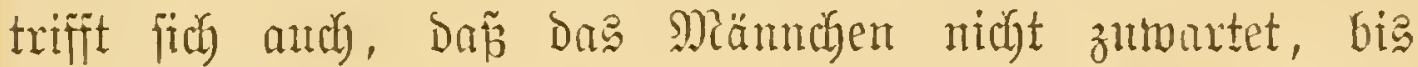

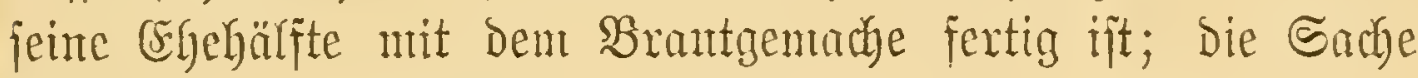

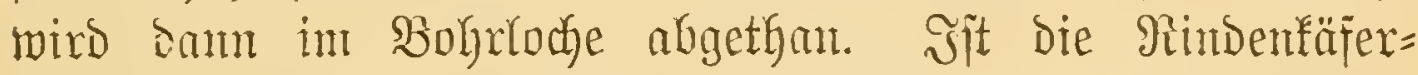
mutter befrudbtet, fo bohrt fie, im Baft, einten gerabe nach phen gehemben final, Dent "Mouttergang", an bem jie, anf betoen Seiten, in genan abgemejienen Entjermugen flente

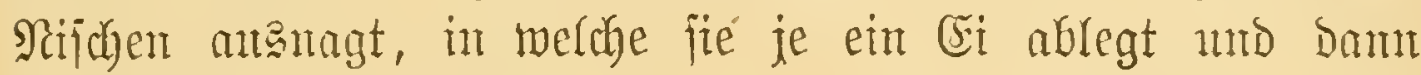

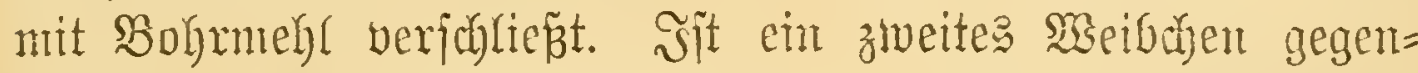
wärtig, jo ntadyt bies Den Brang in gerabe entgegengejebter

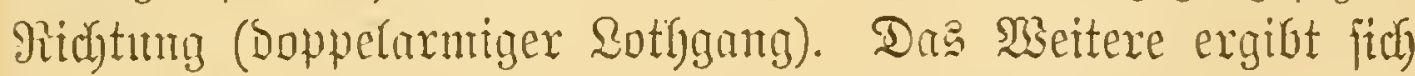

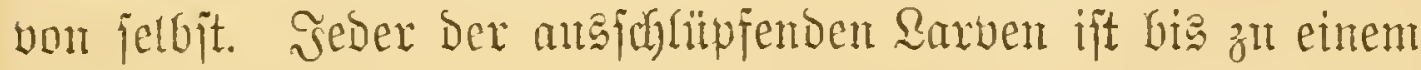

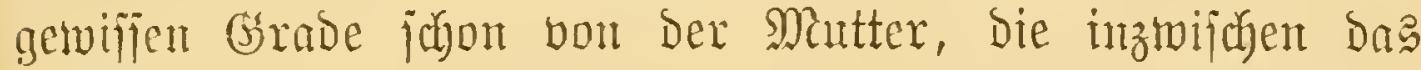
Beitfiche gejegnet, Dex Blats und bie Richtung angerwiejen,

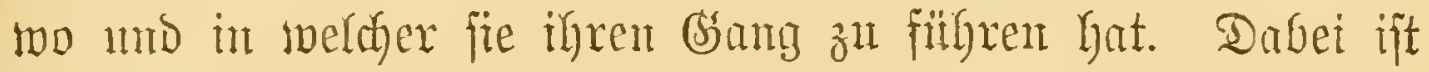
mod) Dicjes midatig. Solange bic Seiten= oder Rarvengänge, nake bent Santyange, zientich yart meben einamber berlanfen,

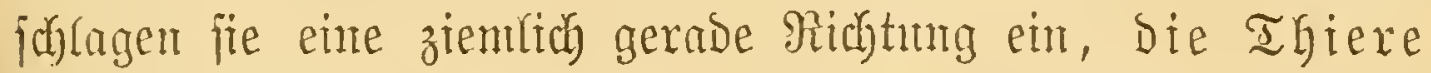
find hier eben gezwnugen, genan gleichen Solyitt

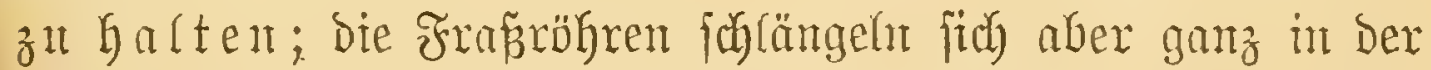

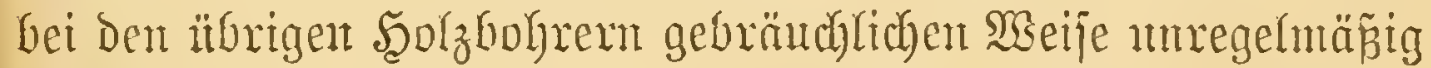
hin mb her, fobald fie, in ifrem vorwiegent xabiäxen

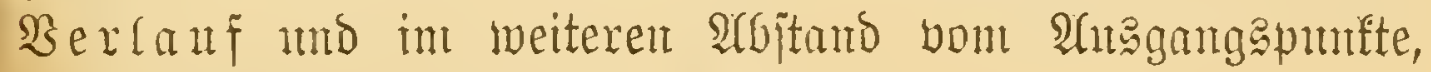
eitren gröp̃erent Spielram erlangen.

Slock jierficher ala Der gemeite "Borfen"täfer, aber in gleidyen Style, arbeiten getwifie "Splint"fäfer, wie z. $\mathfrak{B}$. Eccoptogaster multistriatus (びig. 33 e) an Pappeln, E. destructor an Birfen, E. rugulosus (f) an verjofiebenen Dojt=

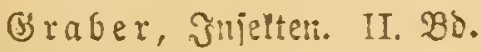




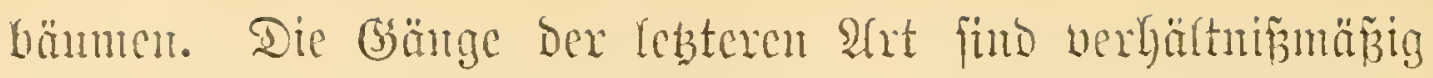

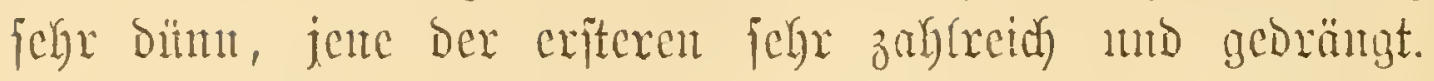

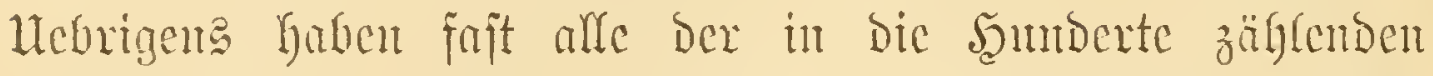
Borfenfüferarten and ifre bejonderen Grangjorment. Schr

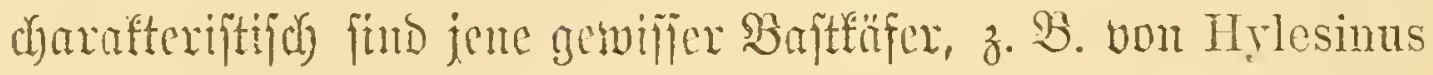

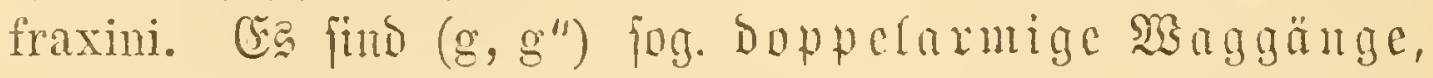

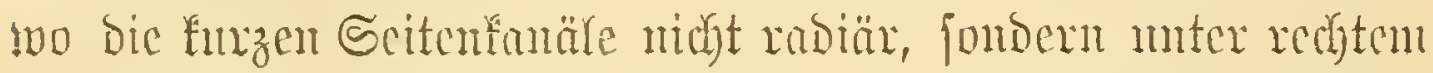

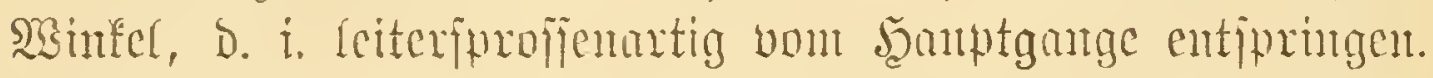

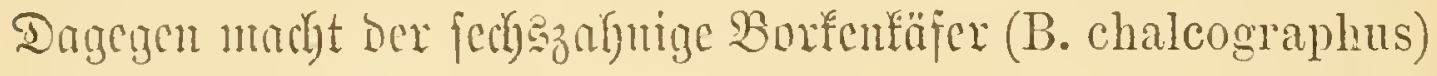
antigezeiduntet fübüte Stcutgänge (h).

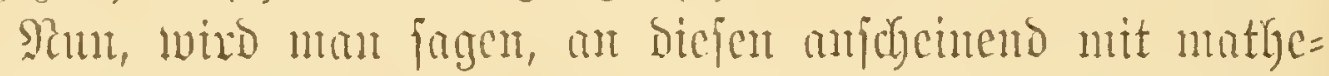

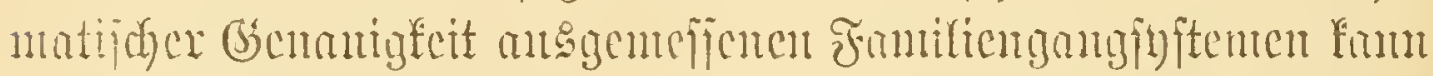

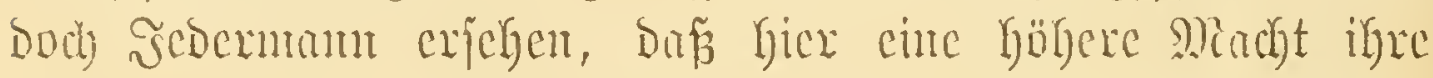
Samb mit in Epiefe hat, ober woher foll bie Rimben=

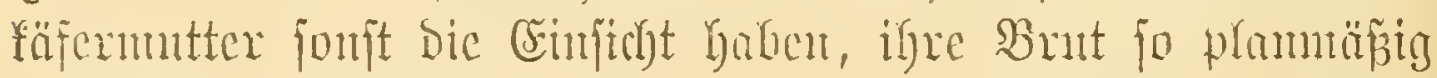

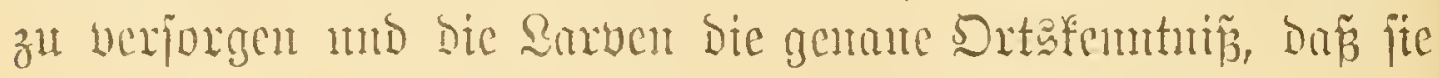
nivat anf cine faljobe Fäbre getangen? Dagegen jei mu

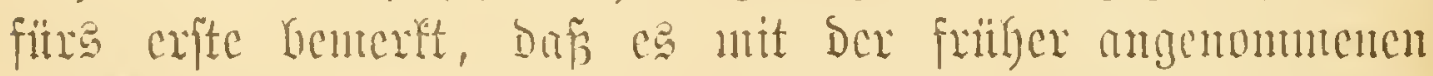

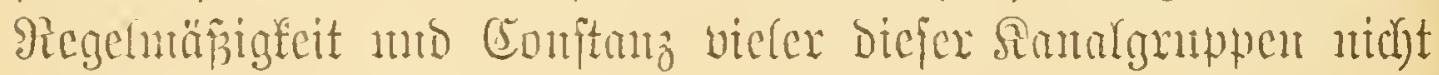
fo biel anf fid hat.

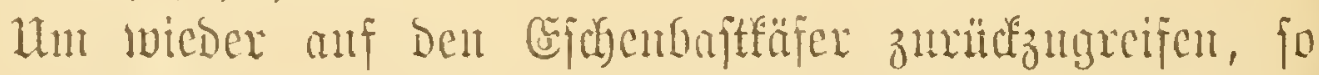

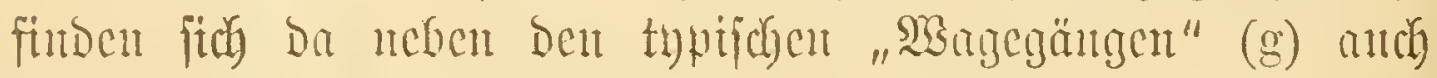

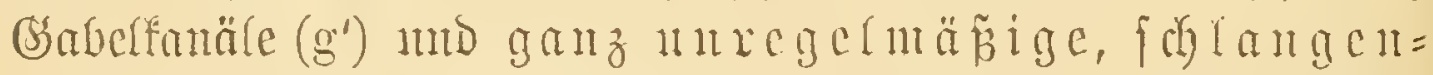

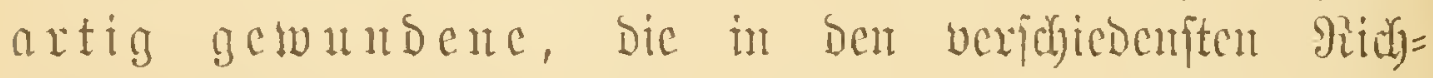

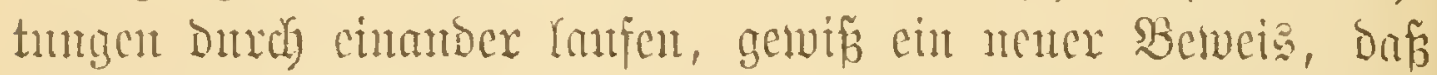

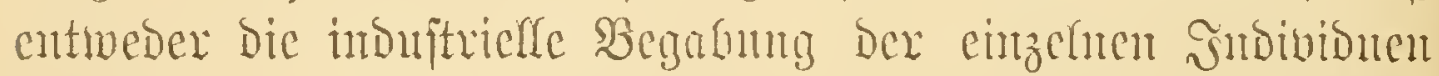

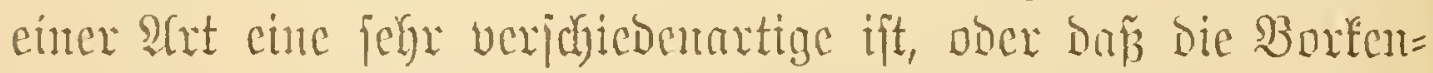

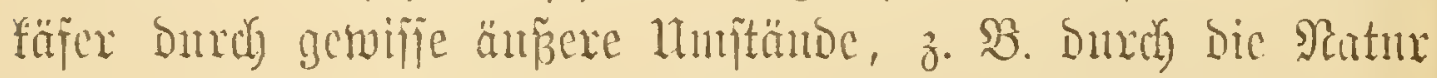

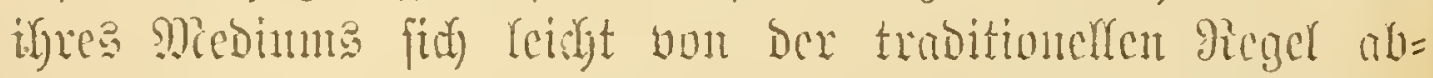
bxitigen Yaffent.

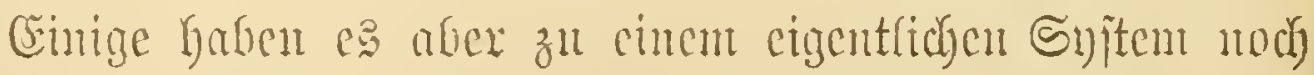
gar uidht gebradjt. Schr lebrucidi ift Hylesinus micans.

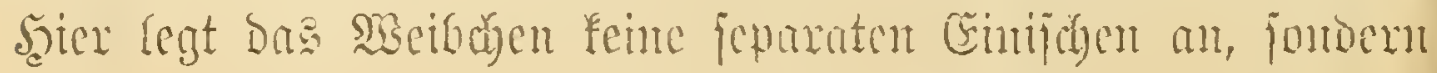




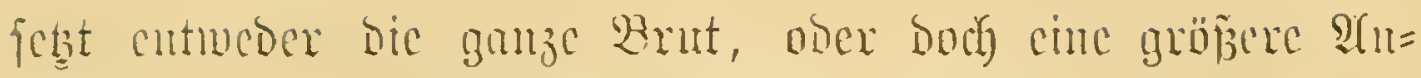

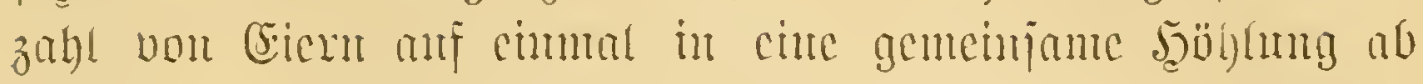

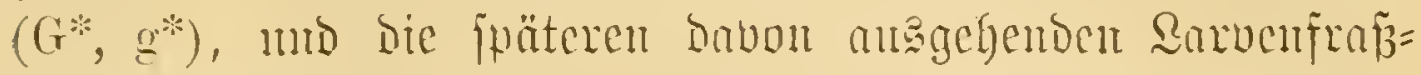

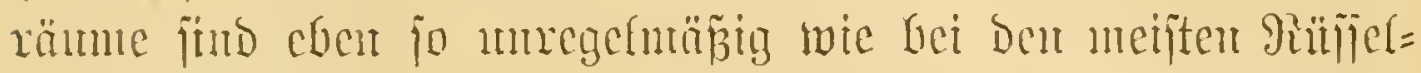

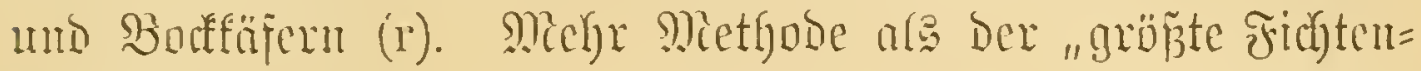

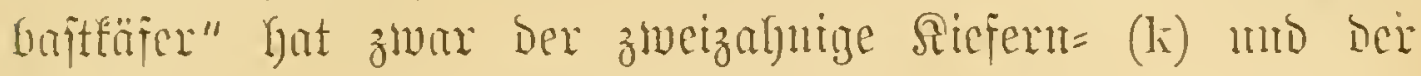

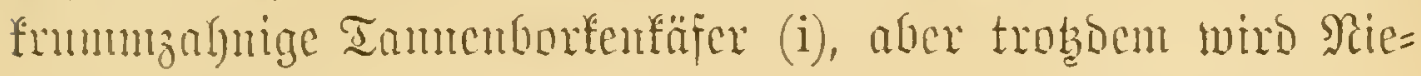

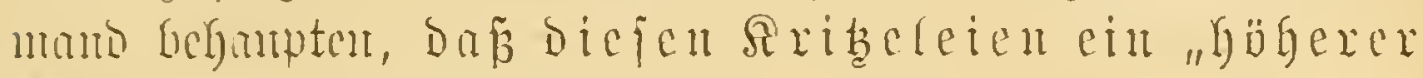

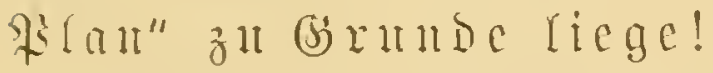

Achntidy wie bie Rimben= haben übrigens and bie cigent=

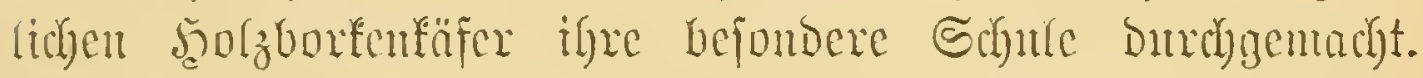

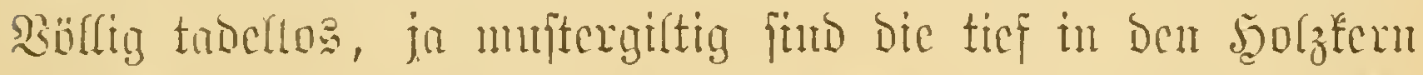
cindringenden reiterartigen Sanarfujteme von $B$. lineatus $\left(k^{*}\right)$. Shroce Strten, toie z. SB. Der befinnte B. dispar unjerer

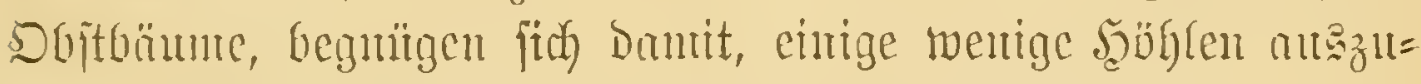

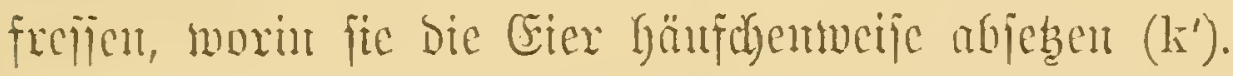

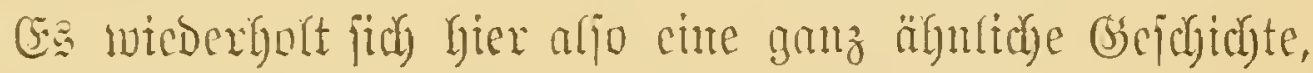
wie bei H. micans: Beibe ftchen gleidjau erift auf bem Rumfe, das auf tuger Separation gegrün=

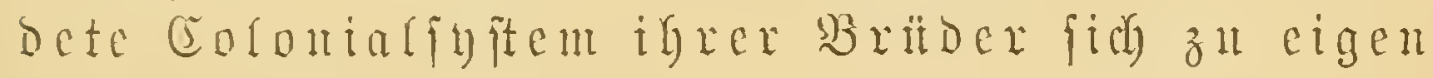

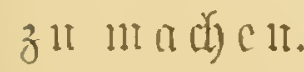

Shlu fund wir anf jene fierje vorbereitet, bie in ifrem gantzen Thyu bem Nemichen näber jtégen, als dice bei

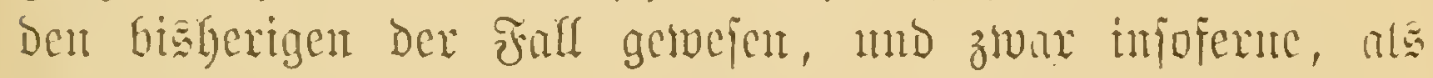

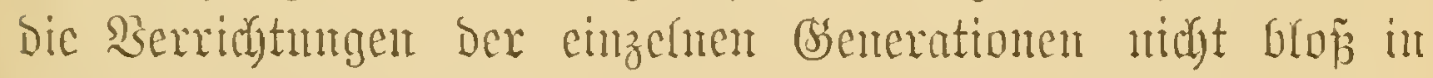

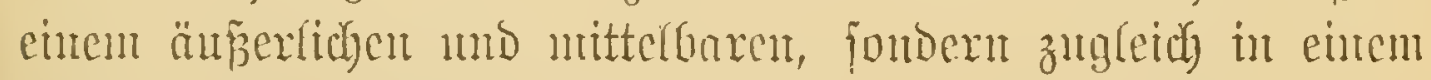

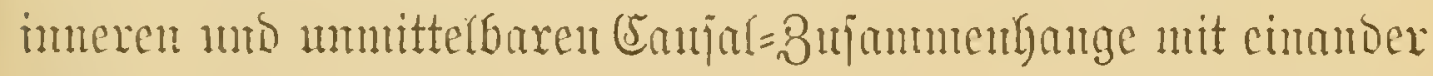
jtergen, indem die Thätigheitânorm Dex Generation B nicht b!ó

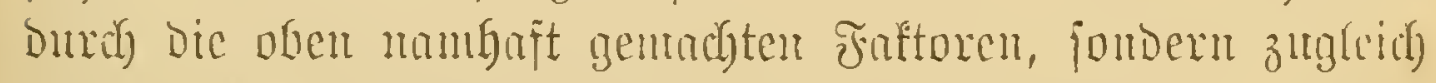

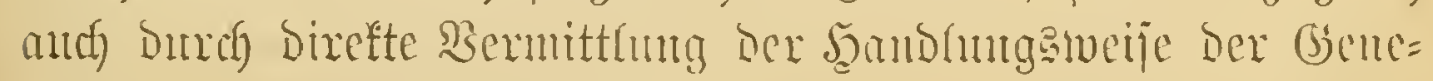
ration A becinflunt mind. 
MGie Der Sejer merft, haben mix in exjer Sinie die

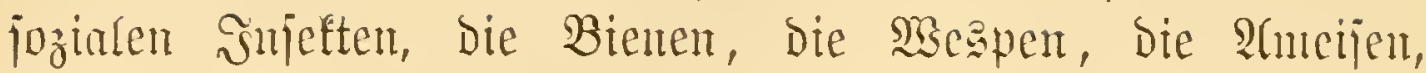

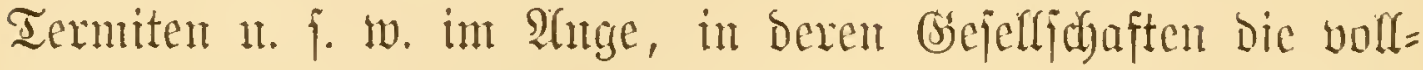
ftändig ertwadjencu Rinder Des fïr Snjeften fo jertencn Bsiüces

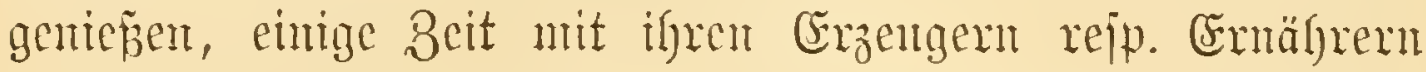
zrfammen zu lebon mo von innen alles Das zu profitiren,

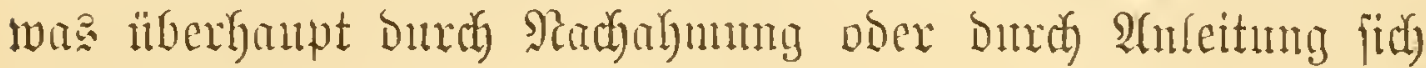
ertuerben lǟjt.

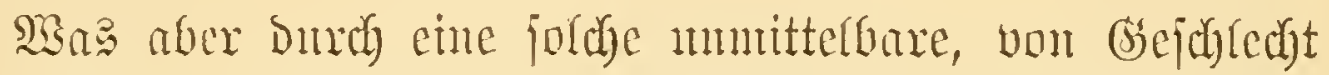

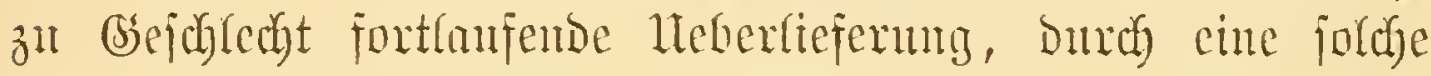

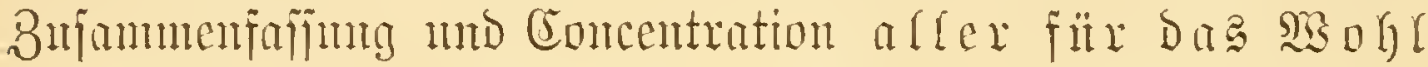
einer $\mathfrak{A}$ t güntigen Antecedentien cinex ganzen

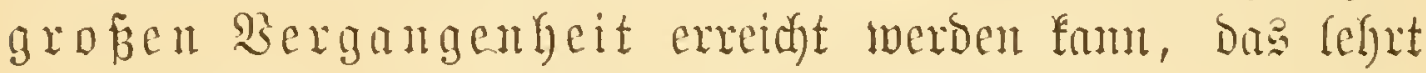

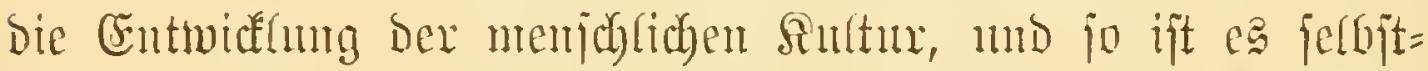

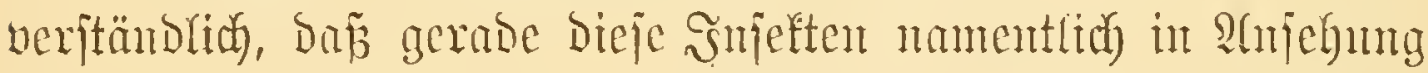

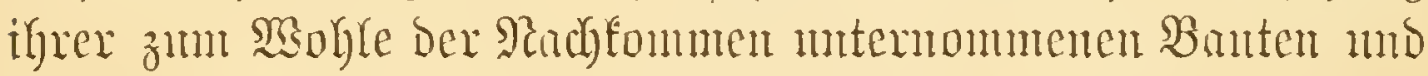

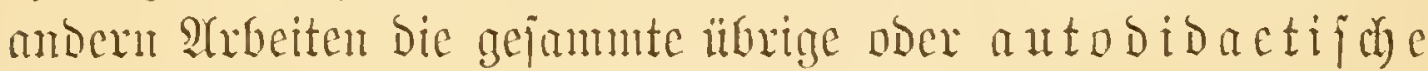

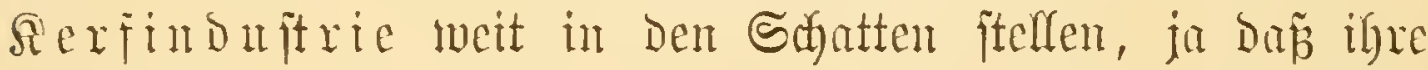

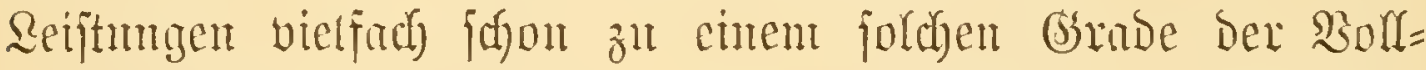

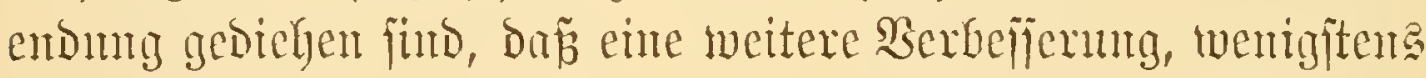
nuter Den bejtelenden Serbältnijjen, fanm mely möglidy ift.

Mnteridgteten nuto Denfenden Entomologen minjte Das Sejugte genug fem; dic andern werben cinen doppelten Bencis fordern, erftens nämrich, daf́ die Snjeften überhant

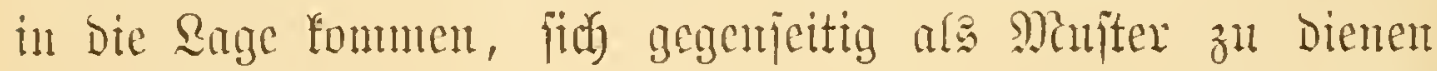

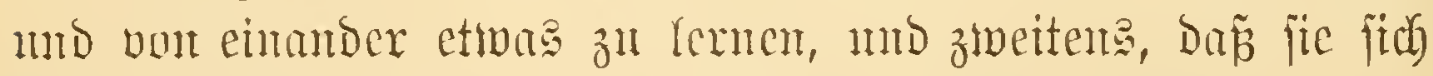

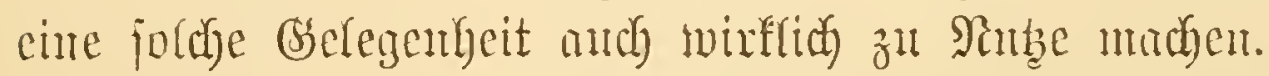

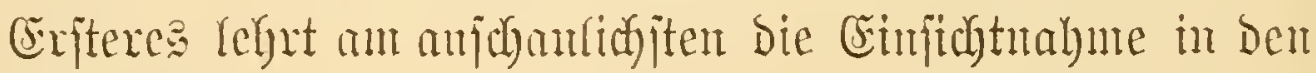
Bicucuranaryalt.

SBenn die jungen Bienen ihre Bellen verlajjen, fo fünen ïe Den Stoct nicht leer mo angejtorben - wie dics ctwa

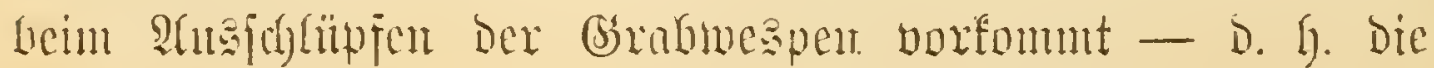


mene Generation tritt nidgt anf, went bie ältere jodyon ben Schauplas berlajpen hat, fie tritt ma und zwax midyt plöblich utD anf eimnal, jonbern cinzeln und alluälig in Dic Reifhen Der andern ein, bie Rücfen ber nadi mb nady mit Tod ab= gehenoen Mritglieser Der Stantagemeinjachaft megiüllent.

Sollte es aljo Der Rovizin, weldye bei ifrem Eintritt in bie SBelt fofort von Inrjenton jachentubigex älterer Sdumeftern untgeben ift, meldye nolens volens bas ganze ge=

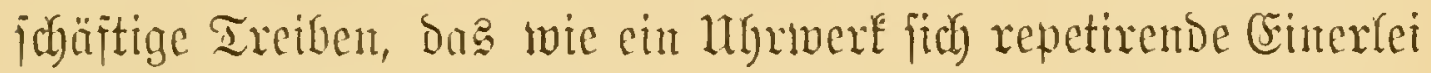

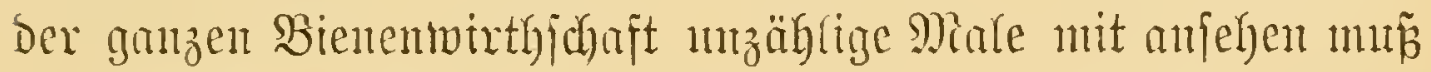

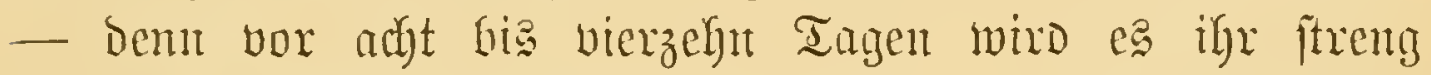
verboten, ifre Geburtaftätte zu verlajfen - an Der Gelegentheit

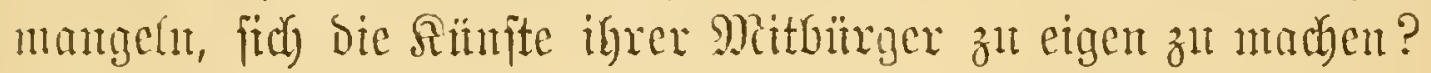

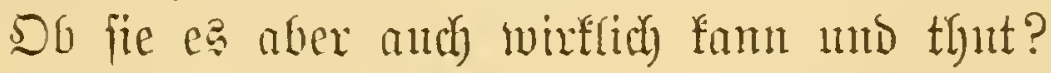

Dá̉ Die jungen Bienten, wie alle Sinfeften, einen Irieb

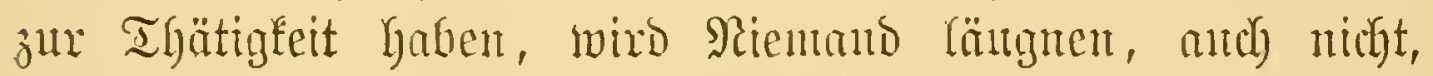
Daz bei ifnen biefer Trieb jefr heftig ift, wie wir Dem

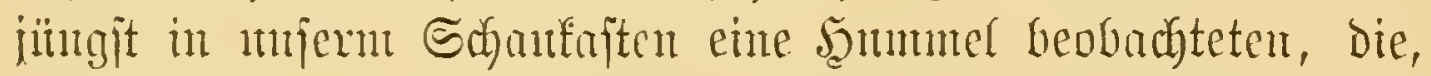
in Ermanglung eines anderu bsegenjtandes, womit fie fith bätte die Santgemeile vertreiben fönuen, ein zufällig dort liegentocs Polistes-ঐiejt ununterbrochen während breiex Stmmen (!) wie einen Ball herumrollte. SWem aber bie junge Biene thätig jein muñ, mo wenn jie offenbar zn Keiner Bejdyäftigung bejier gejdjict ijt, als zu ber, weldye fie bie andern rejtändig

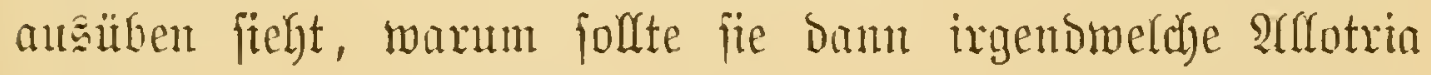

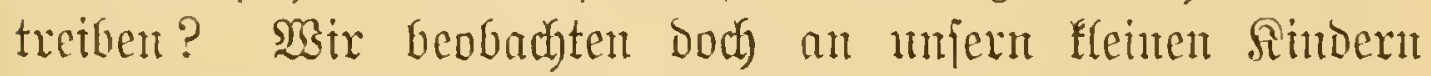

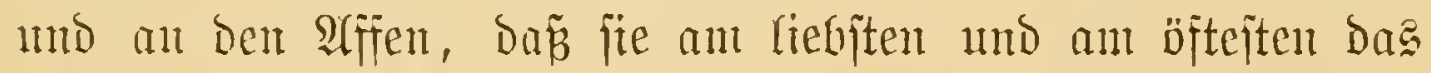

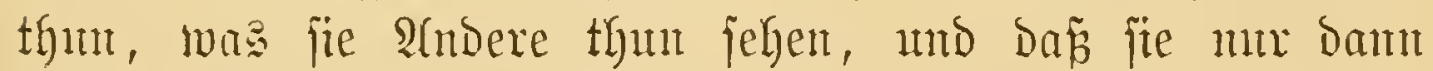
etroas anderes thut ober eine eigene errfindutg madyen, wem ite - was aber in vielföpfigen Bienenalunnat un=

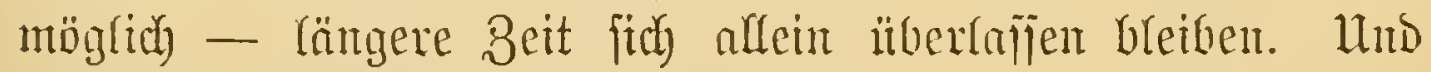
ijt Dies ïberhaut anders Dentuar? \$senn bie junge Biene

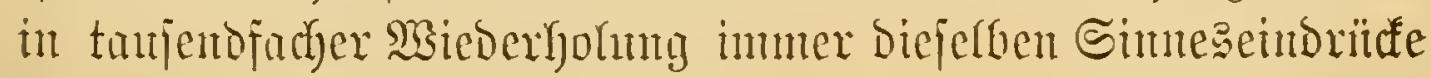




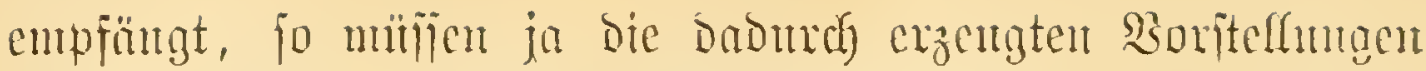

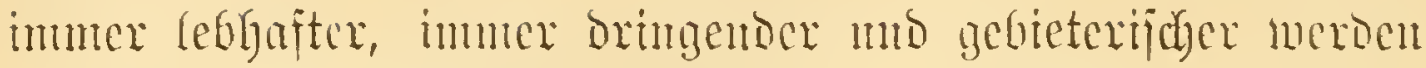

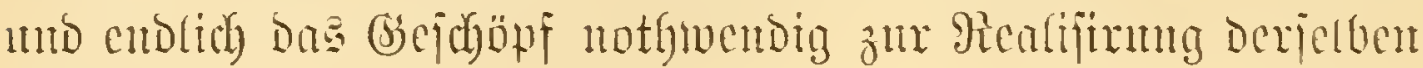
antreibert.

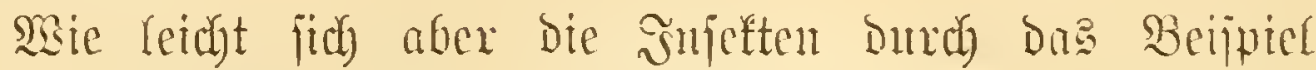
moerex beftimmen lafjen, bavon mag ber folgente, won Siebold bei Polistes beobadytete Fall cinen Begriff geben.

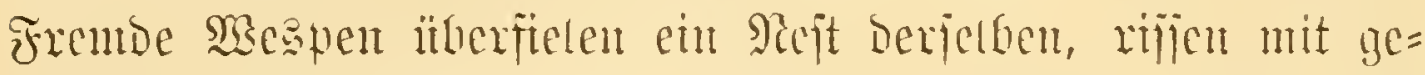

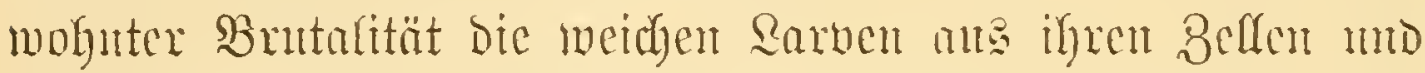

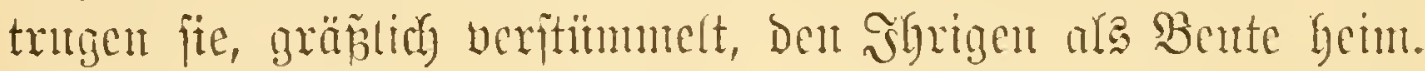

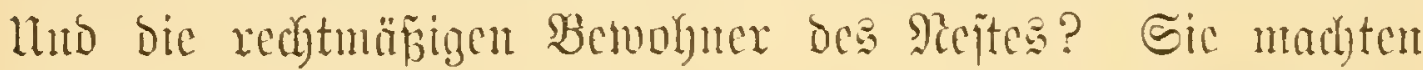

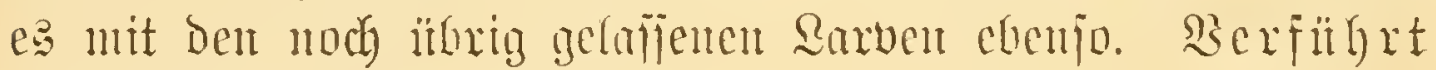

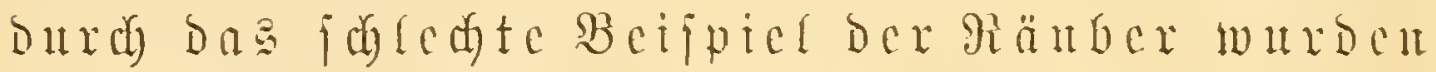
jie zu Mebrocu ifrex cigencu Riuber!

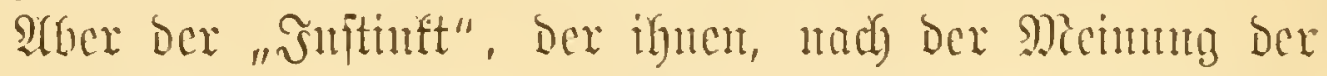

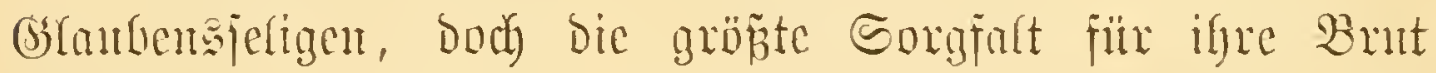

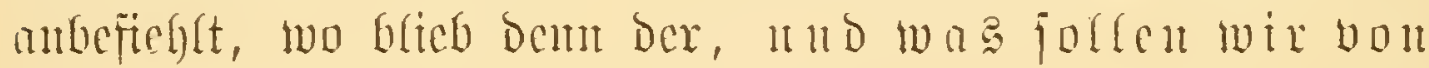

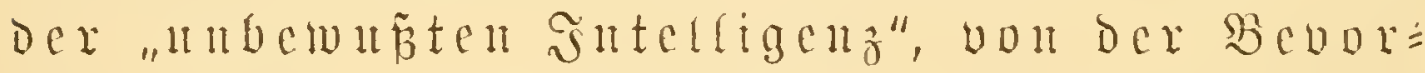

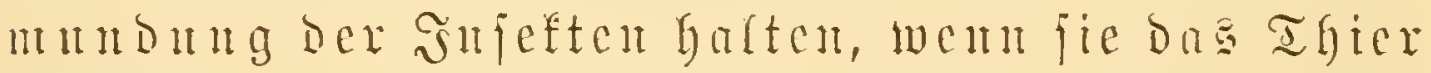

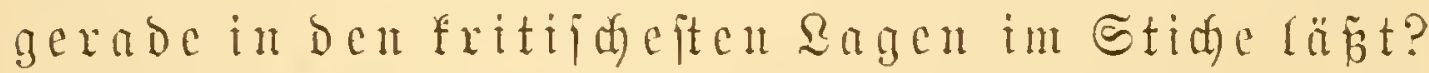

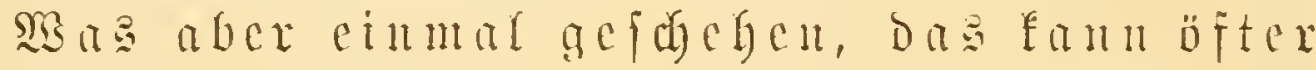
erfolgen, mo was, fragen wix, wïrde dam me den Polistes-

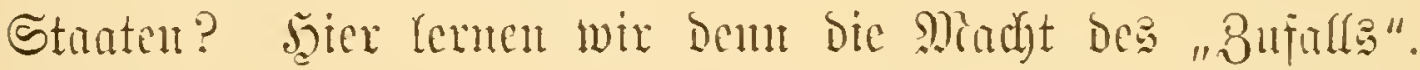

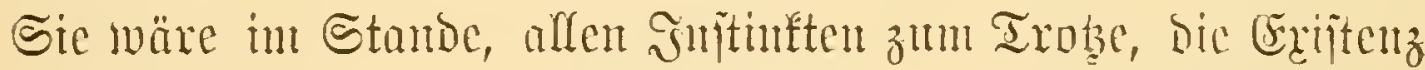

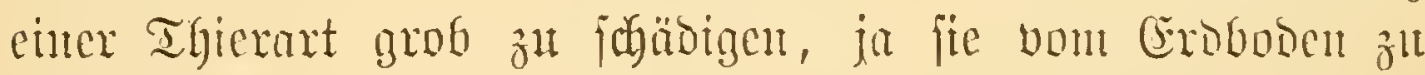
vertilgen. Riegt aher siefleidgt bieje Selbitzerftörmng int

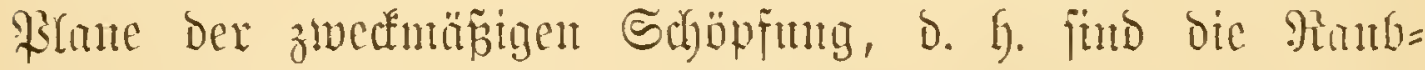

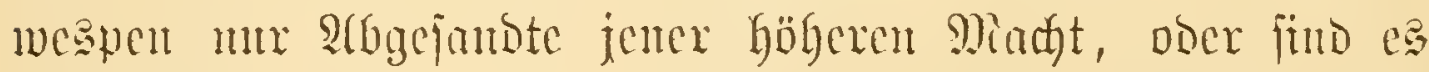

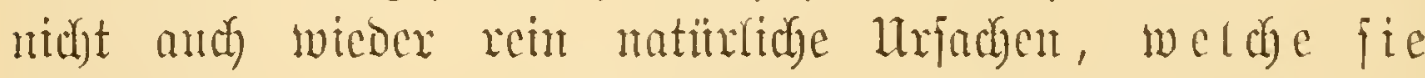
z'wangen, ifren Frttterfedarf fich anf Sojten Der PolistesButt ju verichaffen, jowie benu jebc, aud bie gering=

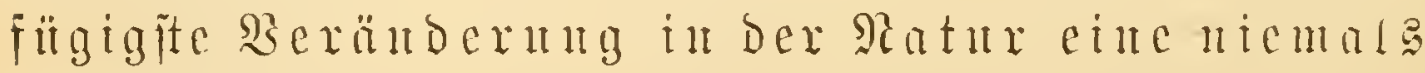
endeube Reige anderer 


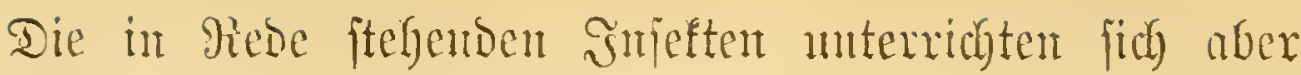

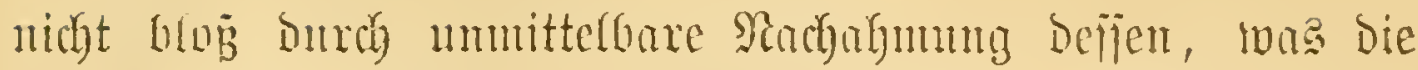

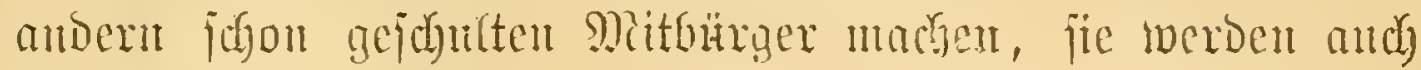

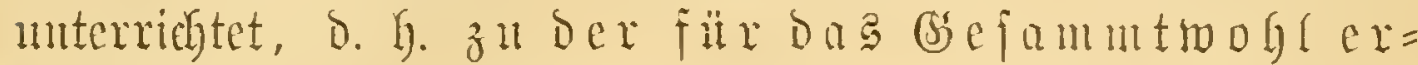

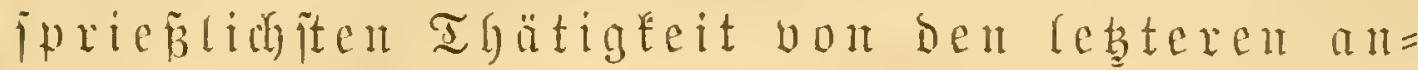
gebaltea un exzogen.

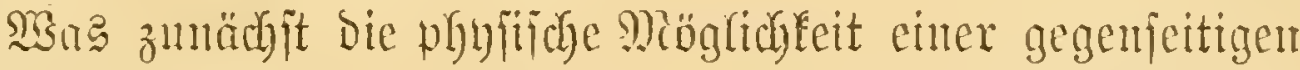

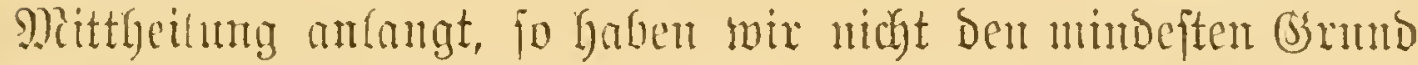
baran zu zweifeln, wenn wir anch in das nähere Detail igrer

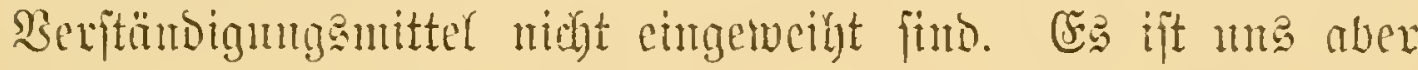

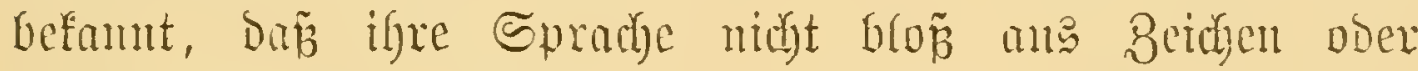

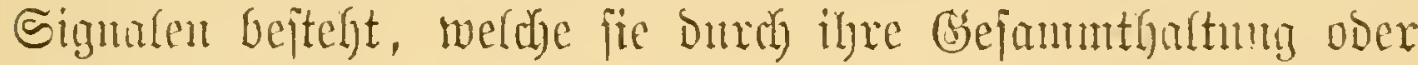

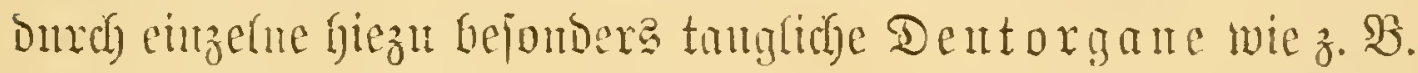

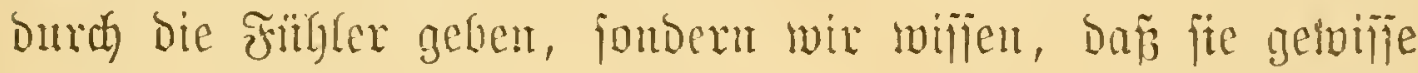

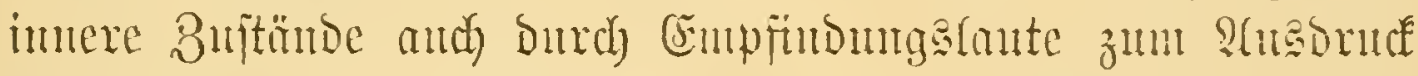
bringen, mo zwar theils burdy bie rajhen Belwegnugen Der

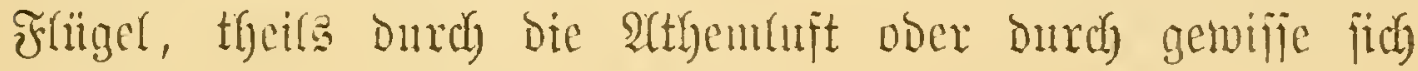
gegen cinnonder reibende Sfelettbeftundtheile.

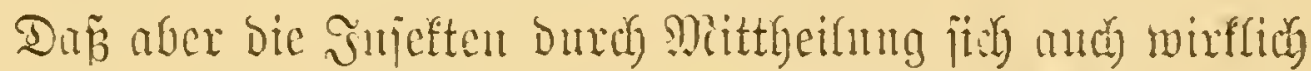

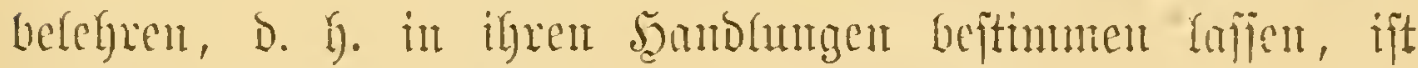

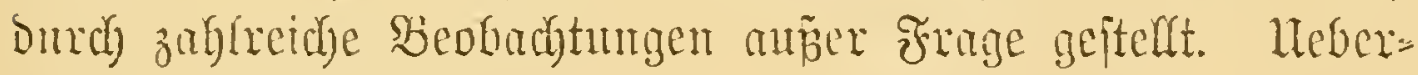

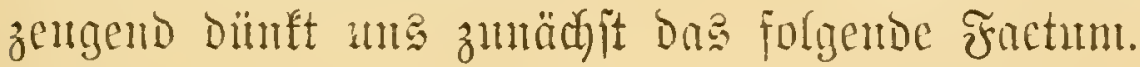

Salmen, ein jubedifber Reijender, tijhte eimmal bent fein Bimmer bejuchoen 2meijen einen Topj mit Theriaf anf. Später leerte er ifn ate und hing ifjn an einem Spagat ant

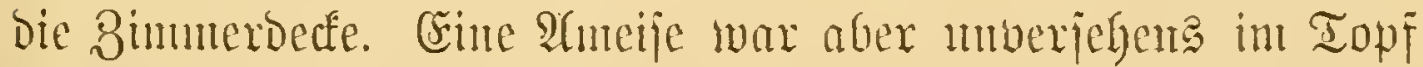

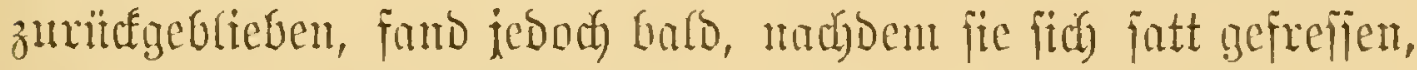

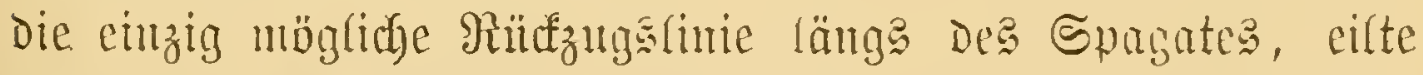

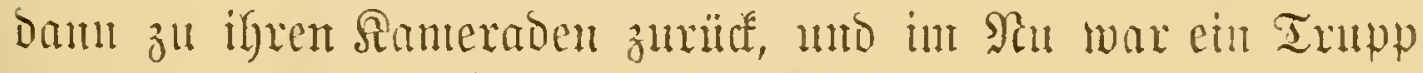
auf Den Beinen, fletterte unter Anfïlynum Dex Botichafterin

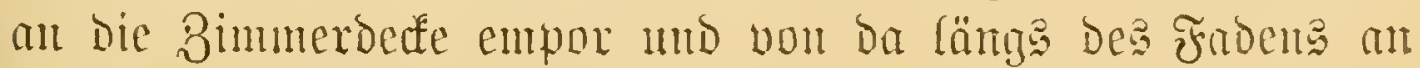
Dus exjefite Biel. 
Sömte aber bieje Erjobeinung midyt aud anf bloper

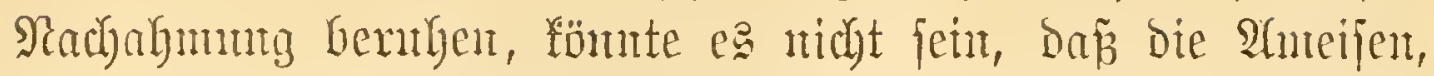

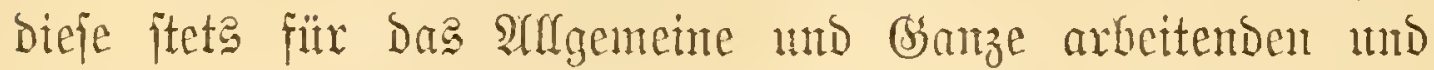
thätigen und au bcjtänige (bejerrjaft gemöhuteu

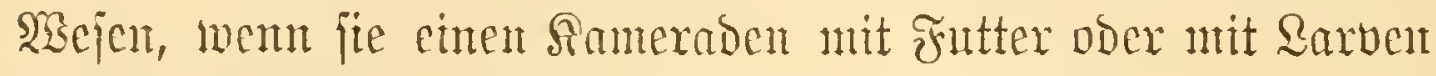

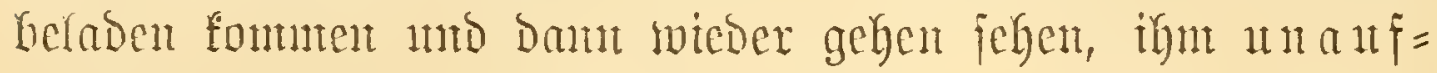
gefordert Folge Ceif́teten?

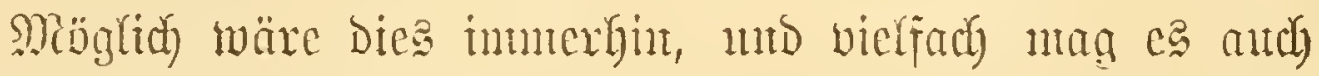
wirffich fidj jo berbalten. Wenn wix biez abex zugeben, wie

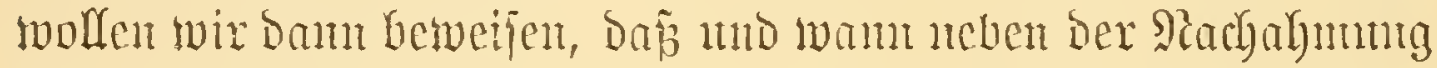

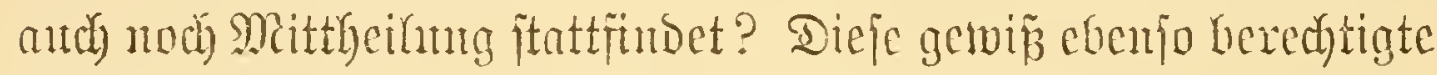
als fïr bie gejanmte Sierfotolngie hodyinterejounte Frage hat

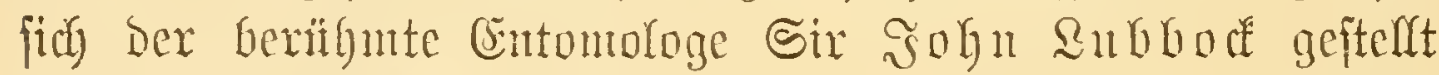

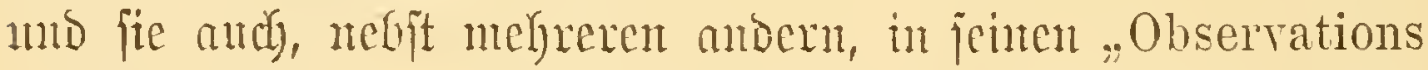
on Ants, Bees etc." (ber Sontonter Linean Society Vol. XII.)

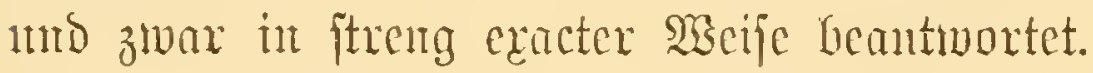

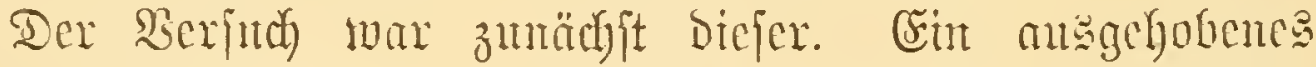

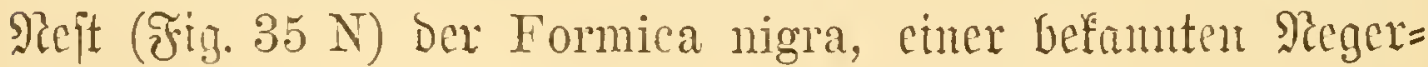

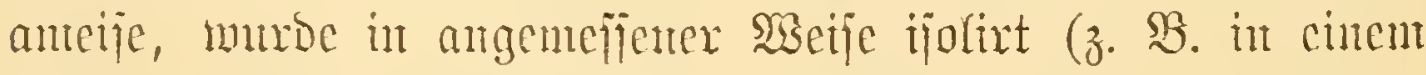

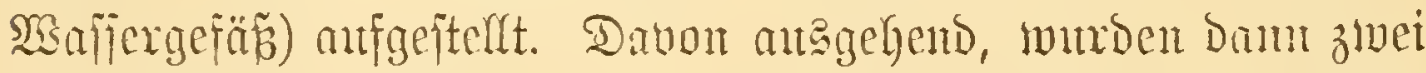

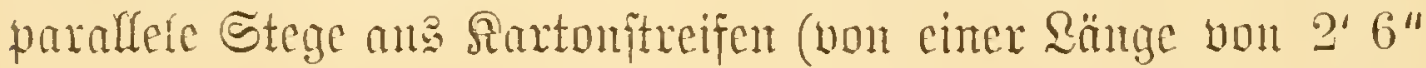
mind in eineut Sigftand vout cirea $6^{\prime \prime}$ ) von eintander

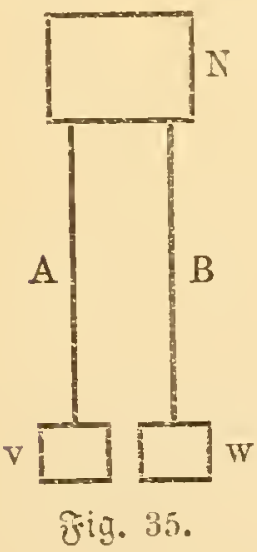

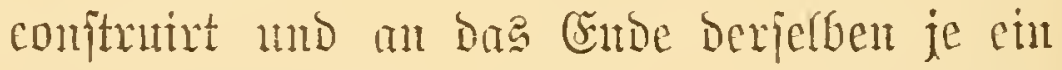

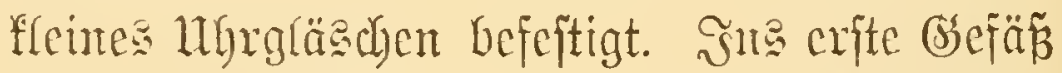
(v) gab bant 2. viele Sarben biefer Sfmeife (wenigitents 200-300) unt ints ojweite (w) mur wentige, nämlidy ztwei bis orei, forgte aber bafïr,

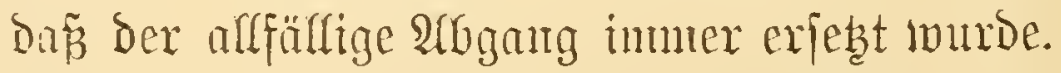

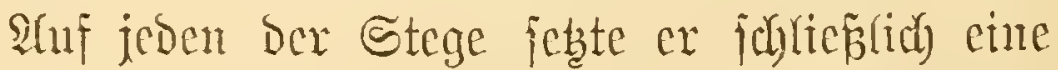
anteije, welche, um fie won son üthrigen zut untericheisen, entipredyend bezcidynet muroe.

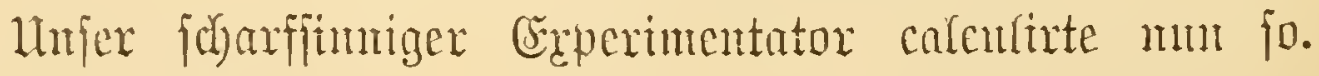

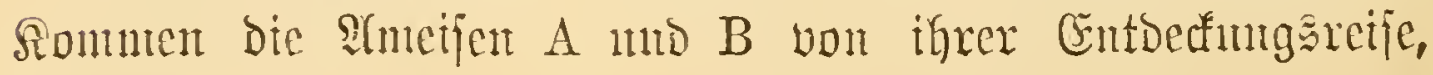




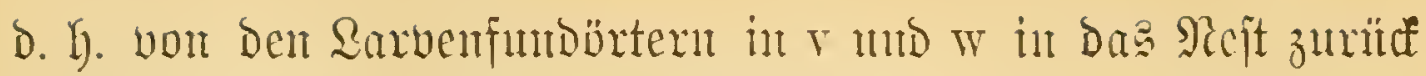
unb begebent fich dann nenerdings an bie frïbern \&läbe, jo werden fie, wie bas bie Regel, von andern begleitet werden.

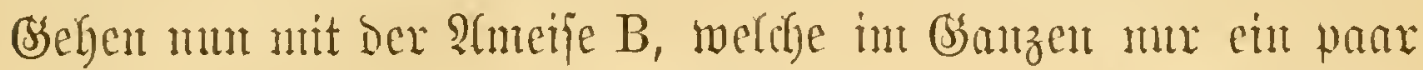
Sarven zu holen bat, im Durefjidntt eben jo viefe Samernden, als mit Der 2 (nneije A, welde ein reiches sarventager entbect

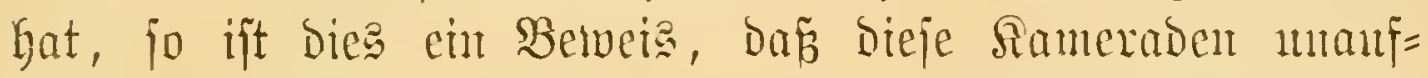
geforbert mitlanfen; Denu jonjt, went fie ausoritufficid cinge= raben witrben, mitzupazieren, hätte ca doch feinen Sint, Dan bie Antije B zun Trmaporte Der menigen Rarven eben jo viele Salferabelfer mitbräd)te, ars bie âmeije $A$, in beren 2rotbeilung ca jefre wiel zut thut gift.

Bringt hingegen bie $\mathfrak{a}$ meije mit ben vielen Zarven melyr

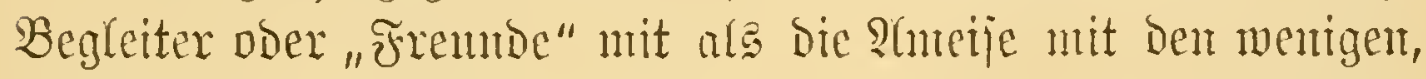

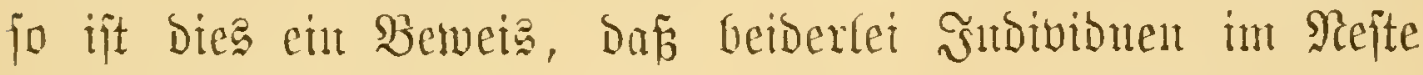
ifre șeijungen extgeilen, Dañ aljo von ber exjteren jehr viele

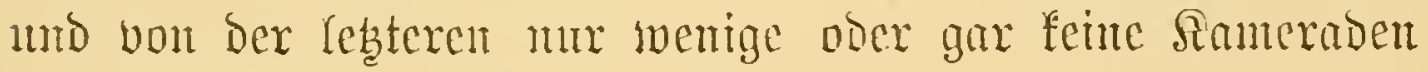
zur Şilfelcijtung anfigefordert werdent.

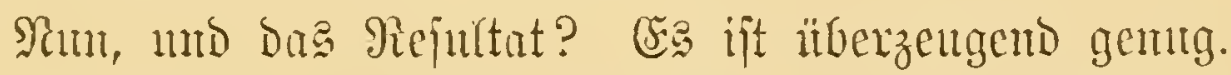

Bei zmanzig Beobadytungefällen bradhte die Almeife mit bent vielen Rarven unt in adbt Fällen wentger als 10 Same= raben mit, wägremb die ameije mit Den wenigen Sarben in eben jo vielen Fäflen vou gar Nientand begleitet war.

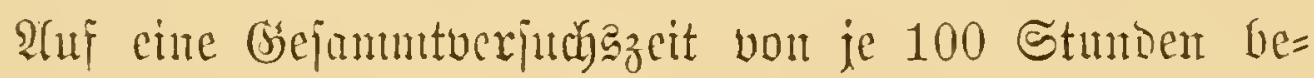
redbut, machte

A 1127 sejudye mo bradjte int Bsumen 539 Soflegen,

B 1040 " $\operatorname{mir} 167$ " mit.

Dẩ mit $B$ in einigen wentigen Fällen Dod) weit mehr

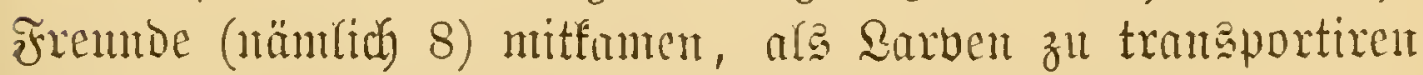

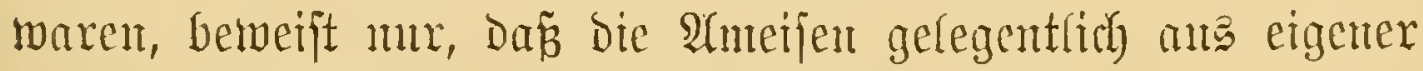
Jntitiative mitgehen; Dent cin angorïcfliches Serbot, fie zn be= gleiten, dürfte bie pribifegirte Sarventrägerin faum extheilen, 
wäbrend ntan ans ber ungenten wedjelnden Bahl ber $\mathfrak{B e}=$

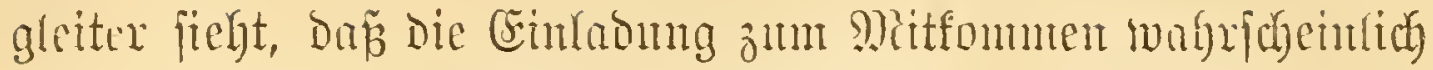
mu cine jummarijche ober jo zu veritehen ijt, Don eben mux jene avifict werben, die gerabe un bie Sage fund.

Michrmals hatte anbood zu beobachten Gelcyentyeit,

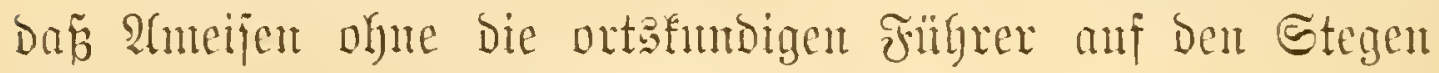
exfdyienen mb fich zu ben ßarven begaben. Bein zufällig

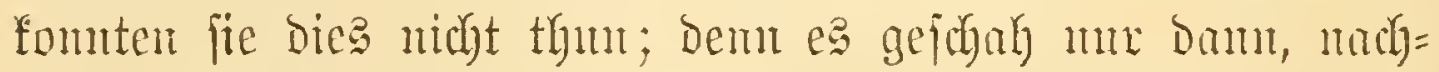

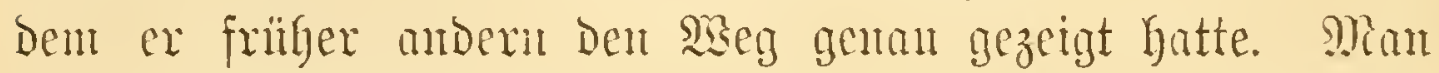
nut Den andern Die Route, sueldye fie zu Den Sarven eintzifhlagen baben, genun anjagen, oder baj̃ rebtere, gleich unjen Spür= Yumben, Durdy die Saje geleitet werben, unent fie Den Spuren nadgelyen, weldye ifje Sorgänger, bie betanntlich ein jebr juarjes Secret abjonbern, hunterlajicn haben.

Dies ficher zul entidyetben und den gerabe in ber fierf=

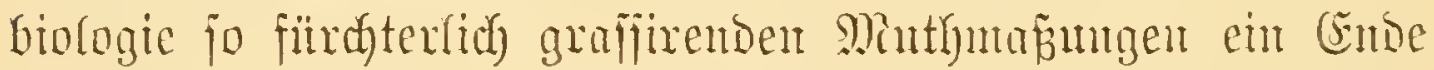

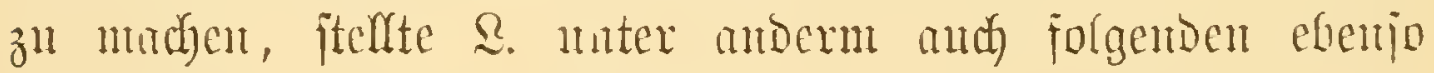

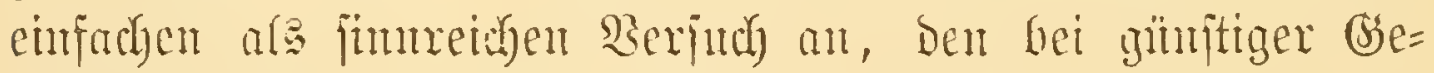
legenteit zul rviederbolen ber sejer emgelnoen wird.

Bou 9keit (Fin. $36 \mathrm{~N}$ ) ging biesunal mu ein einziger Steg (m) ans. Diejer Steg gabelte jid aber umb zinar jo,

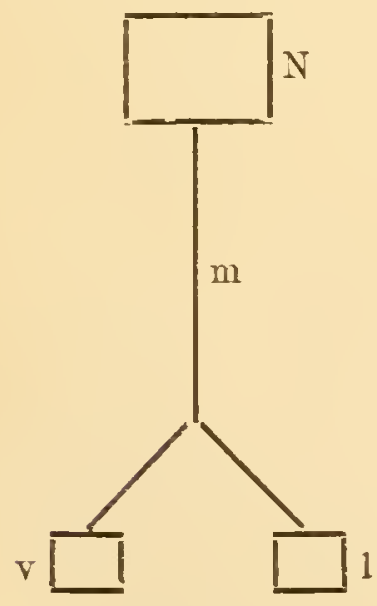

ᄎìg. 36.

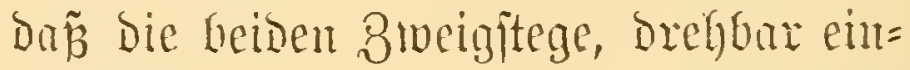
geridstet, reidst in ifrer Stellumg jiut

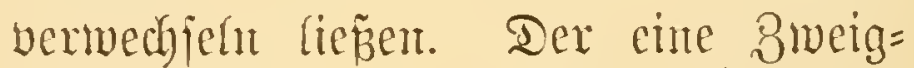

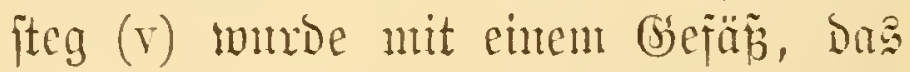
viele, ber andere (l) mit cinem gleidgen, das gax feine Rarven entljielt, ver: bumben.

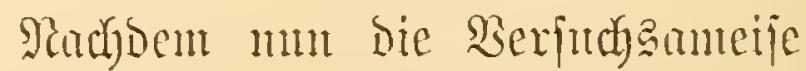

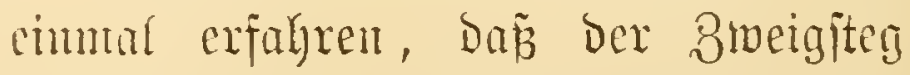
linfer Sants zu keinent exflentidyen Biele fïlyre, jolug fie jedesnal, wern fie, un 


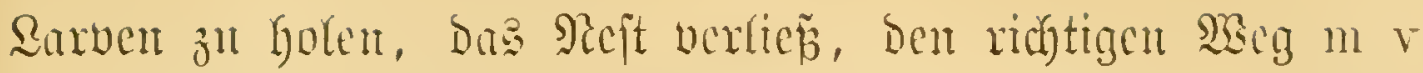

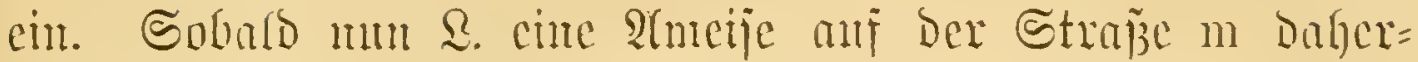

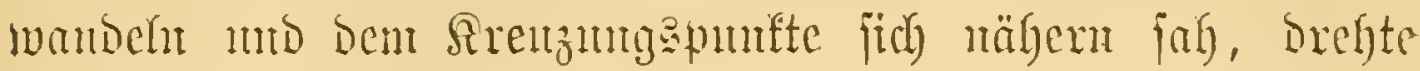

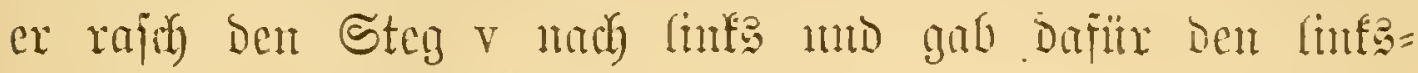
jeitigen anf jeine Stelle.

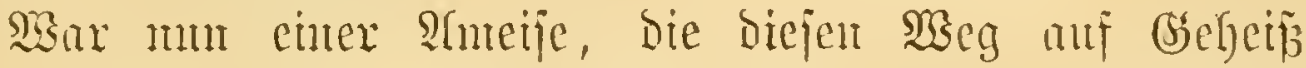

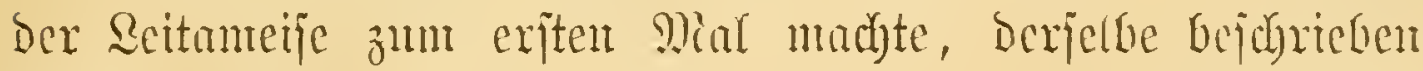

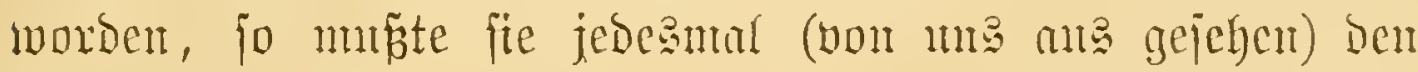

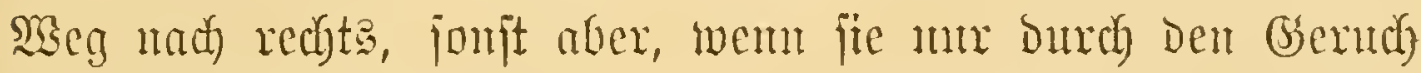

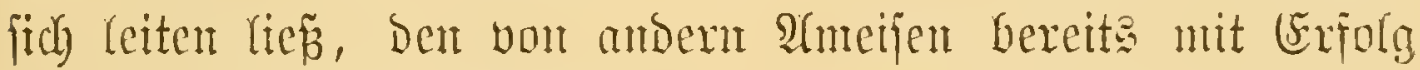
betretenen Giang v einjolagen, mbefiumnext Darmm, ob, Diejer madi redyts obcr linteg füfre.

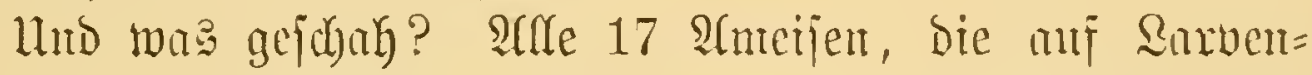
tran aport anggejantst worben, famen an bas redfte Biel, b. h.

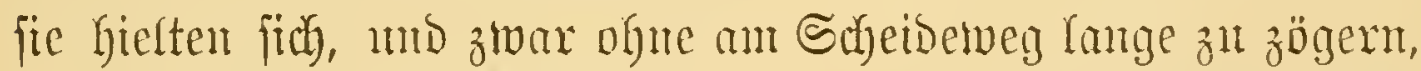
an bie Bahn ifrer Sorgänger, modyte bieje mur redyts ober linfers liegent.

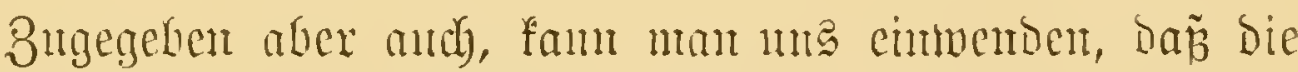

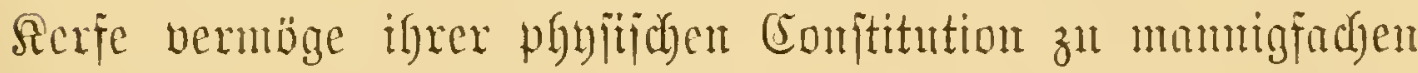

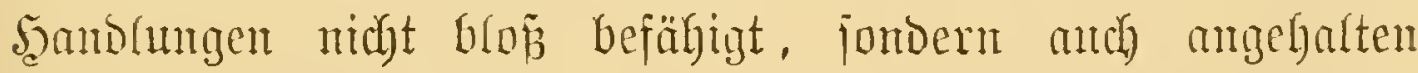

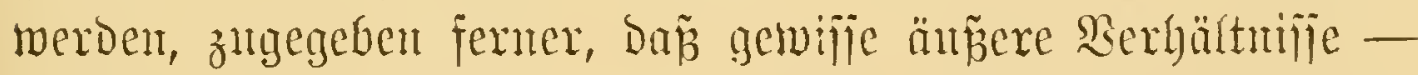

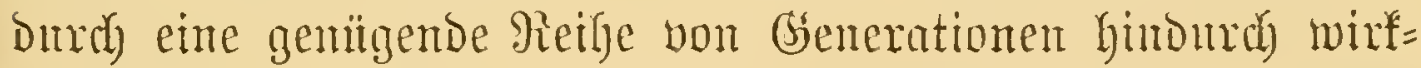
jan - bie Entwidtung gemifjer (bemohnheiten un Fertigfeiten

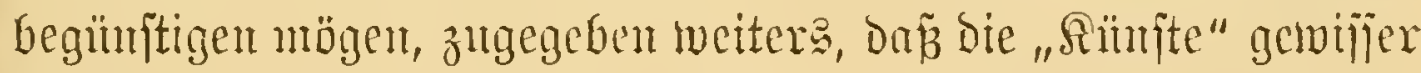

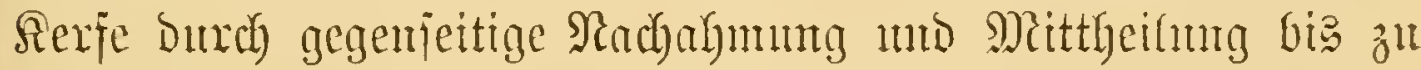
eimem hohen, ja bemubermatwerthen Grabe gefteigert werden

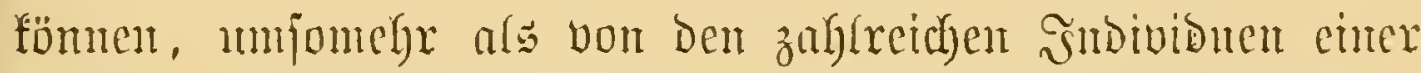
Brut in ber géegel mu bie talentirteiten umb geidjuftejten am Qeben breiben und bei der Fortpflantzung bieje igre Tugenden

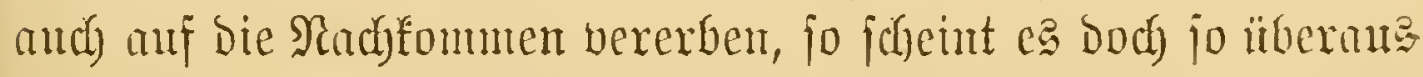

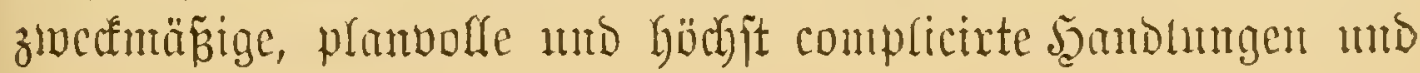




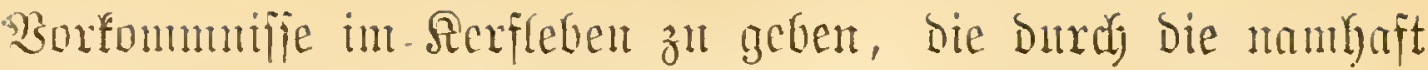
gemadbten Mrjadyen nidft erflärt werben fönten, bei benen alfo in ber That eine frembe Sntelligenz in Spiele fein nuñ.

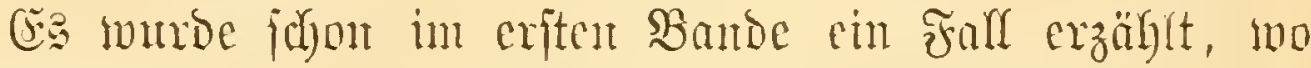

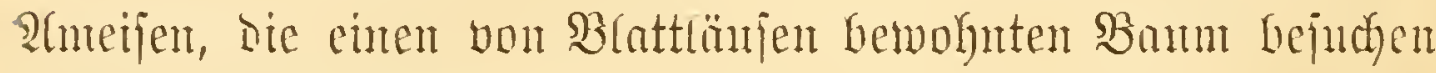

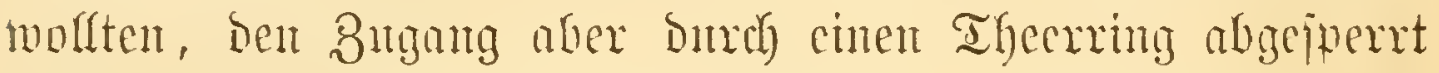

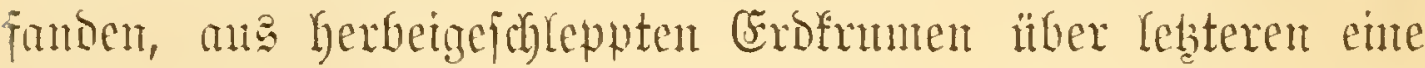

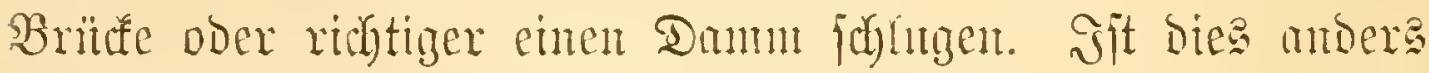

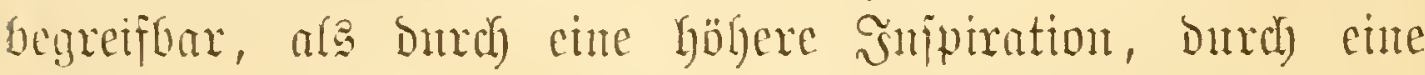

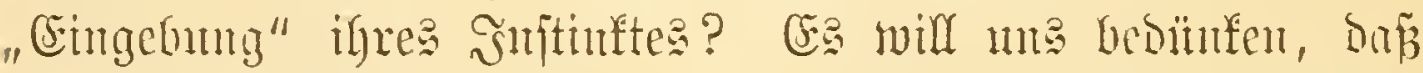

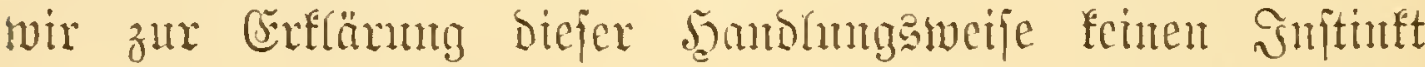

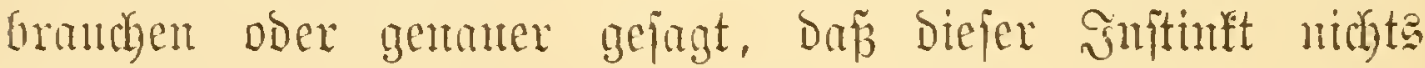

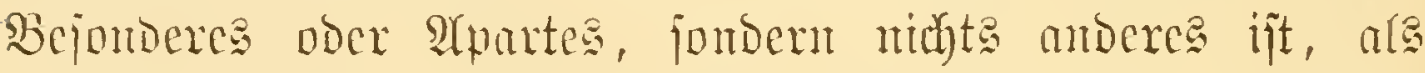
eine jener Dund bie Drganifation bebingten Brhinnfinctionen,

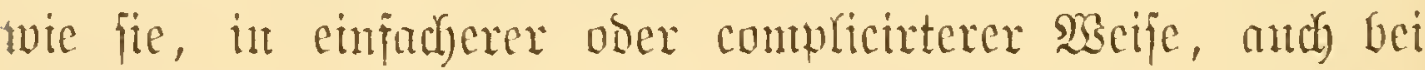

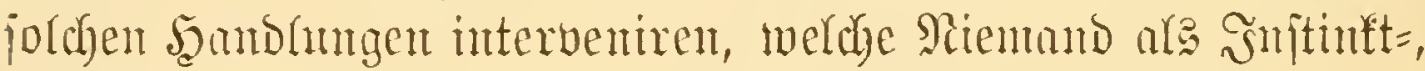
fonbern als reinte Beritandestbätigfeiten bezeichntet.

Cäme ober bie ambere ber zm Theerritg fommenden

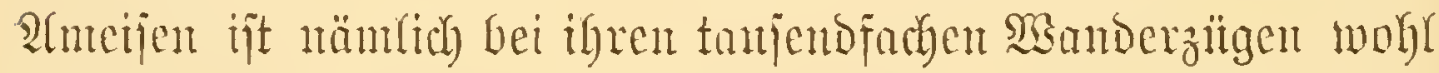
jabou fritiger cimmal anf eimen flebrigen ober najjen Stoff, z. B.

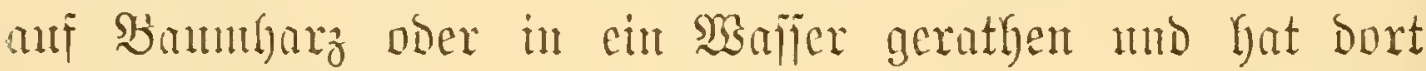
ifre Nïthen gehabt. Sic hat aber vielleidyt in bicjer fiblichen Situntion nach langen Milthen ober and bon ungefäbr cine troctene Stelle, ein Steindben, einen Şalm ober etwas ber = gleiden erreidyt, was ify daz Reben rettete nut ans andere $\mathfrak{H}$ fer $\mathfrak{l}$ )alf.

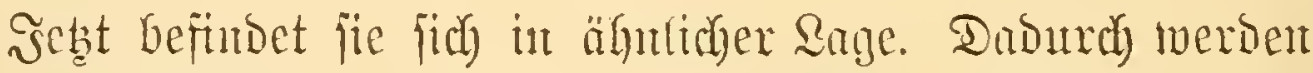

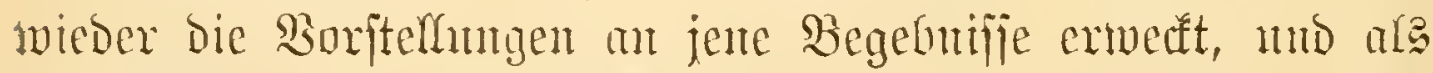
Das gejultat ber Begentitberftelfung mo Combinntion biejer Boritellutgen mit Den gegenwärtigen Wahrnehnumgen reift

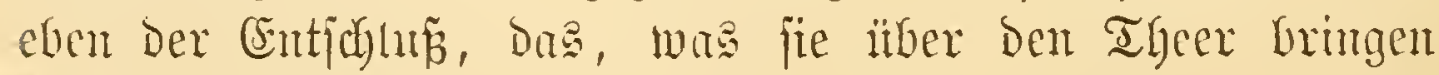

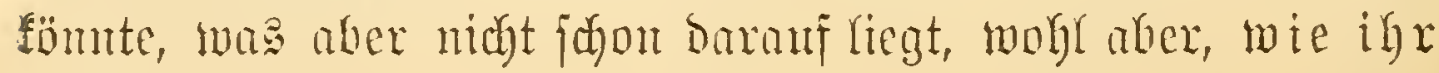




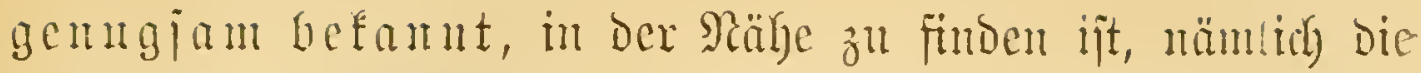

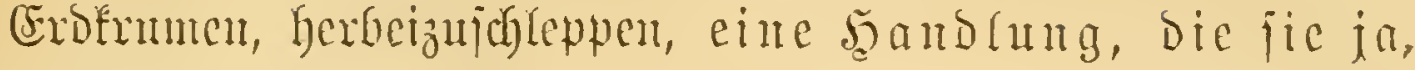
freitich zu ctwas moru Bwerfen, bei ihren Rejtbauten, unzählige Nale jobu veruidytet hat.

Selyr inftufutiv fïr bie in Rebe jtelgende Frage dünft me and folgende Beobadjtung.

Q m nemes Bammaterial an einen Bretterzan flog, ifgr now fleine? SReft von bent abgebrödfelten Biegel einer Mianer toeg un befejtigten huntin mit Siegellace ein frembes, wenigitens drei=

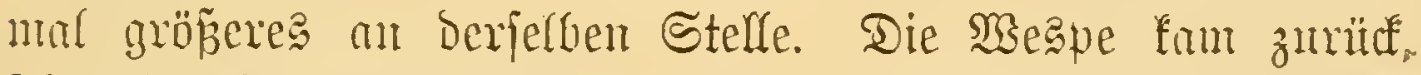

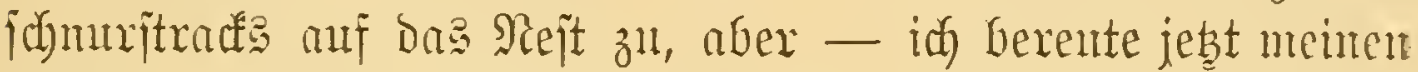

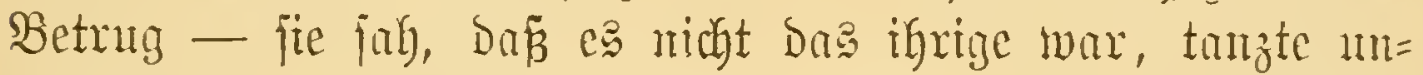
geduldig an ber Manu'x anf utb nicber, als wollte fie bas

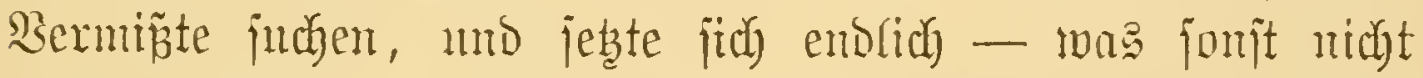
reidgt borfommt - nebent Das untergejchobente, so id jie and

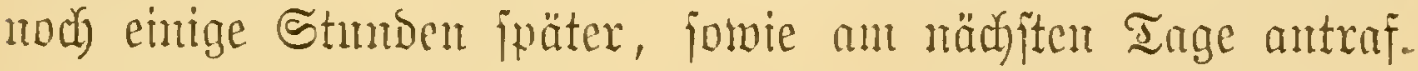
Sie jujien fidy bon ber alten Stätte nidyt tremten ju fibmen,

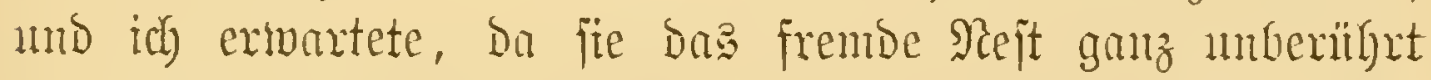

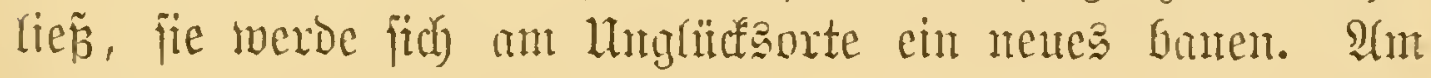

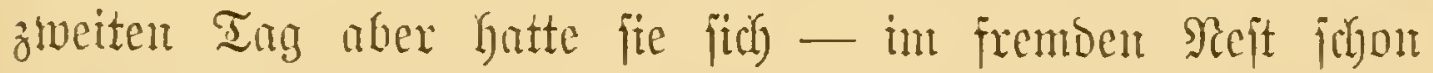

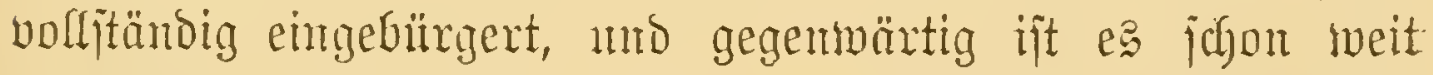

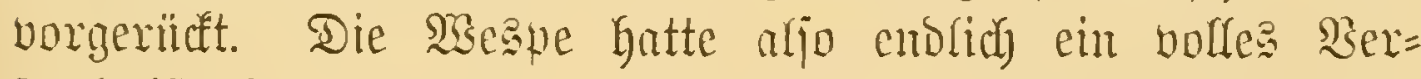
jtündnip der Eadrage erworber. SRadjom der erite

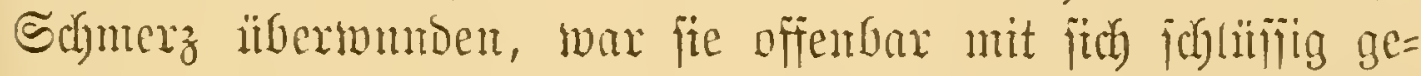

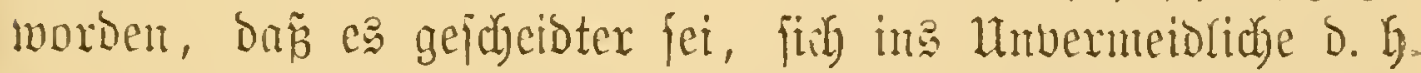

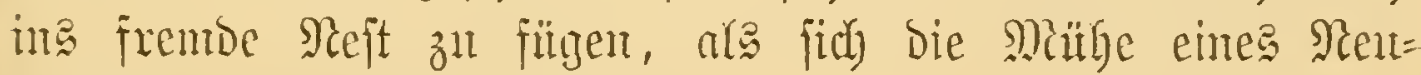

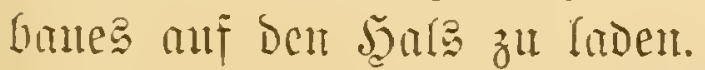

bुier uno in allen äbulichen fällen zeigt es fich flar,

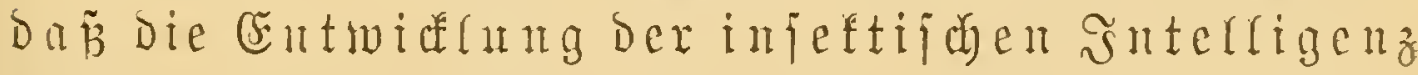
genan an bie gleiden Bebingungen wie bie nujerer

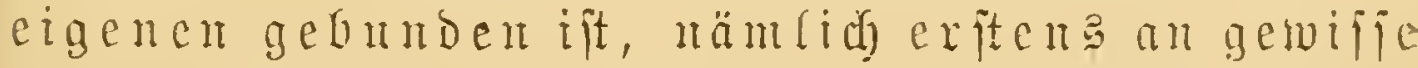

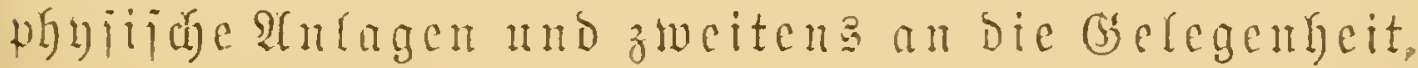




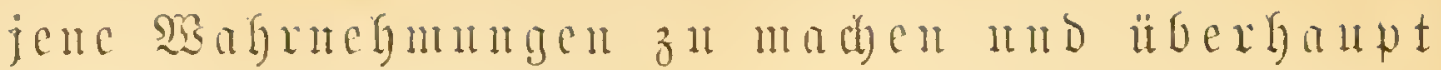

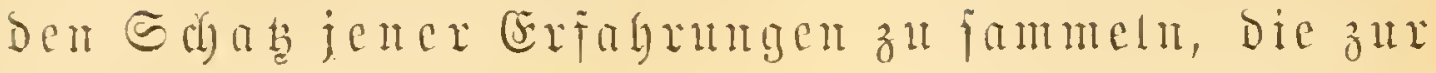

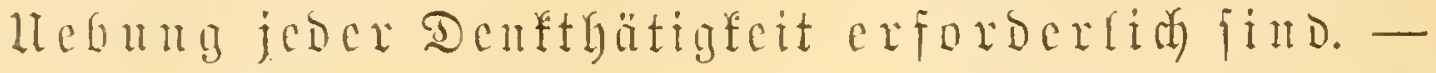

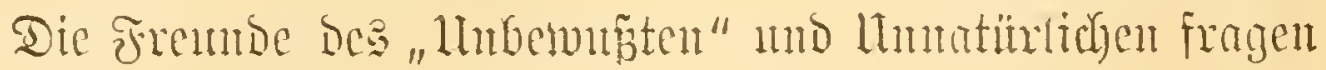

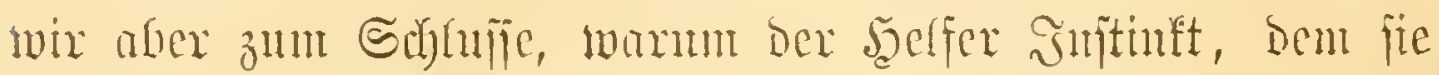

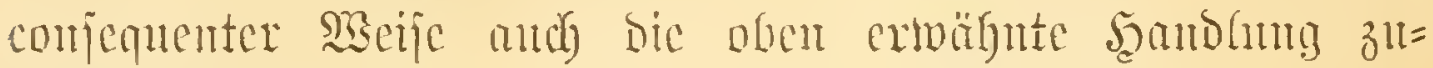

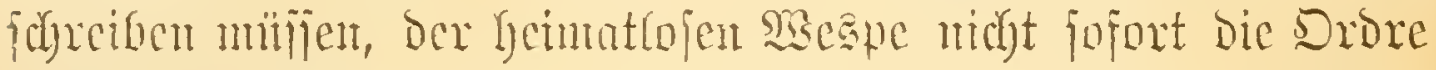

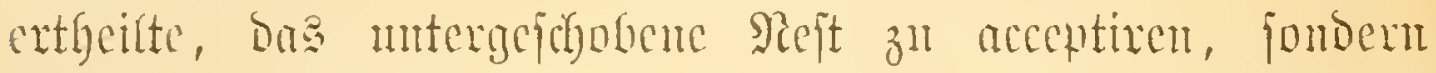

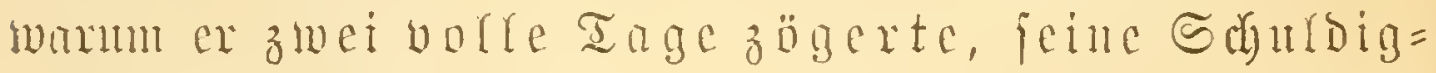
feit $3 u t h u$ ?

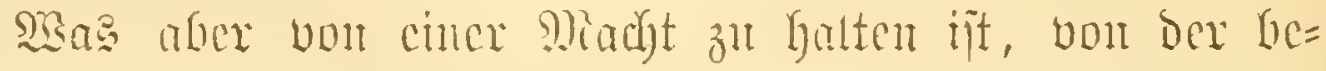

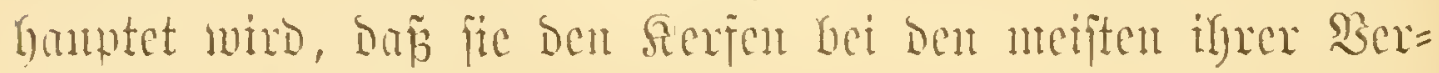
ridutungen beijtebe, bie aber in alten einzeluen Fällen, wo

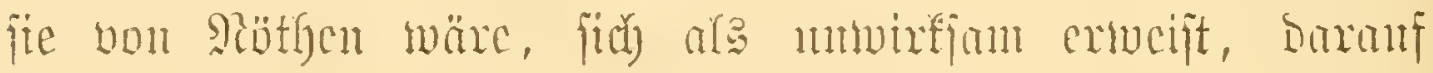

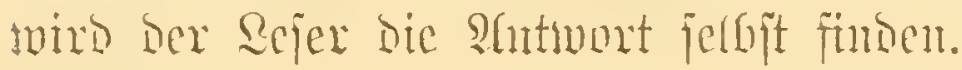

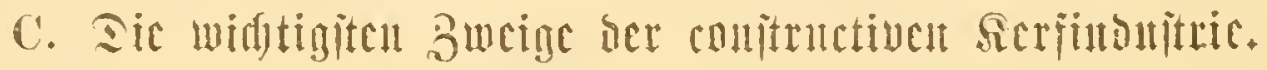

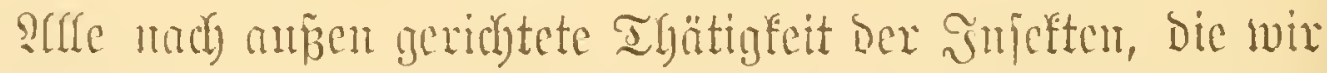

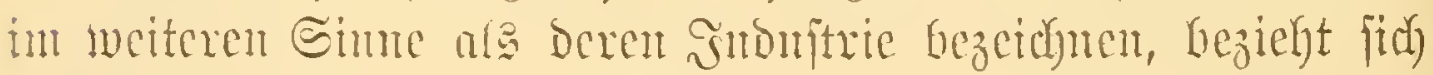
entweder mif ibr cigenes

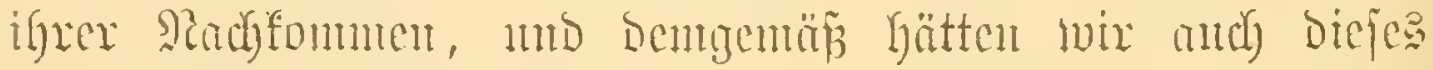

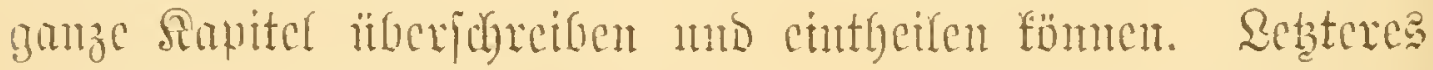

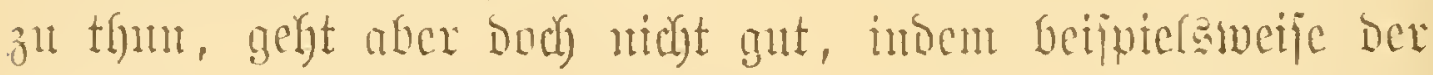

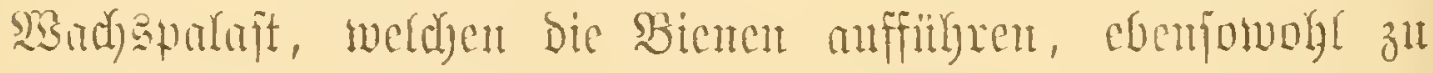

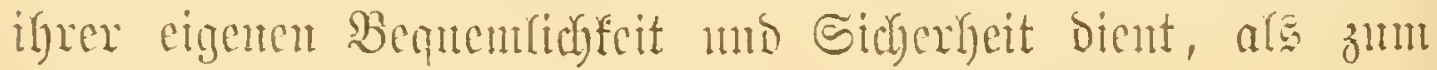
Sayme ihnex sutut.

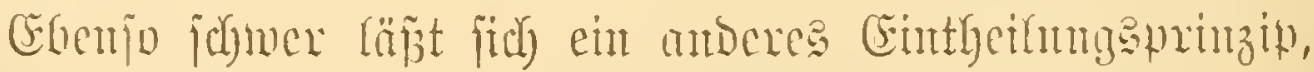
meldyen cutweder dic Ratur ber Materic, als weldyer bie

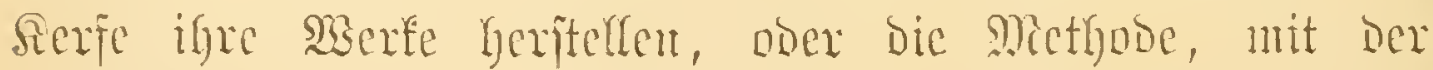

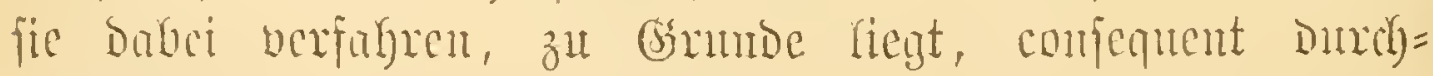

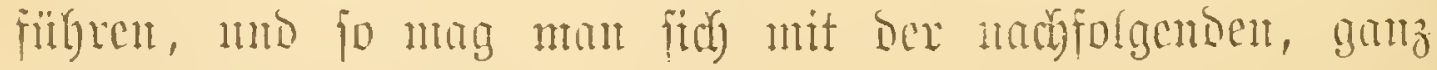

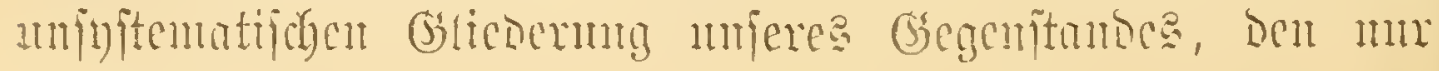




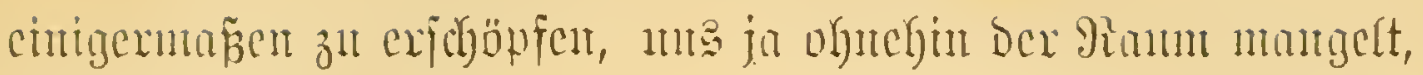
żlfrieden geben.

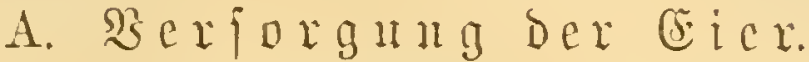

Dic meijten Sicrfe legen bie Crier einzeln mo zwwar in

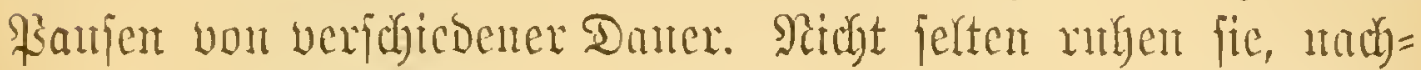

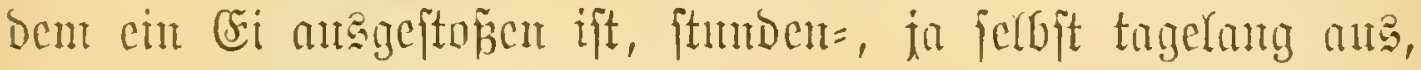

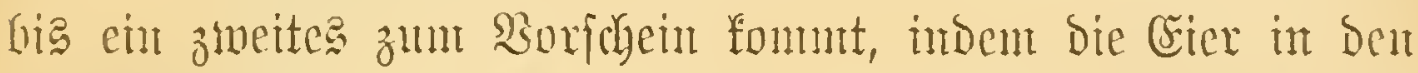

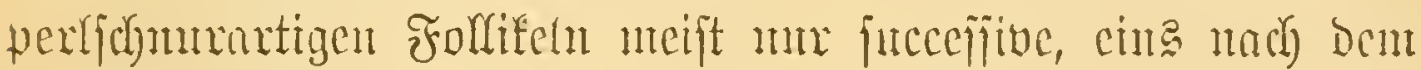
antocrn, abreifen.

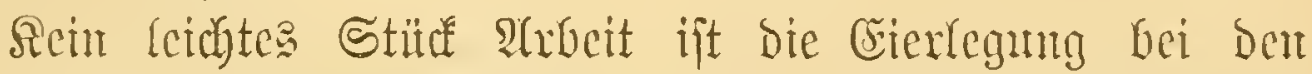

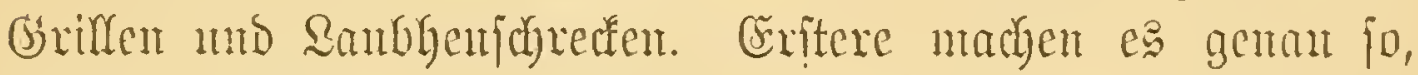

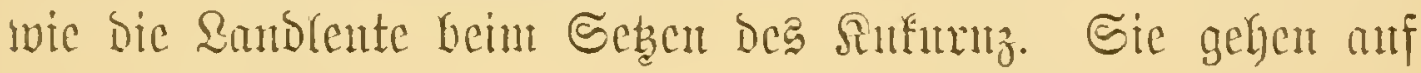

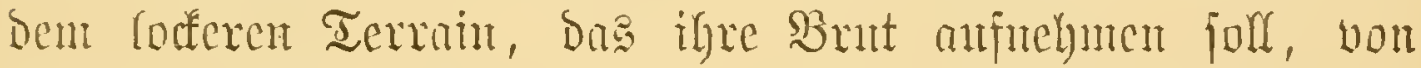
Steffe zu Stefle, bämment jich boct) anf mo bohren ifyren Sege=

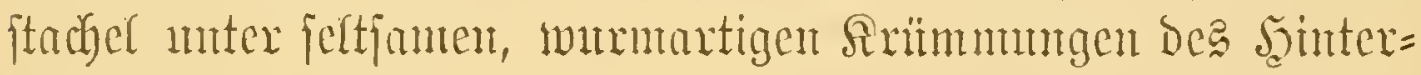
leibes in Dos Eroxcid).

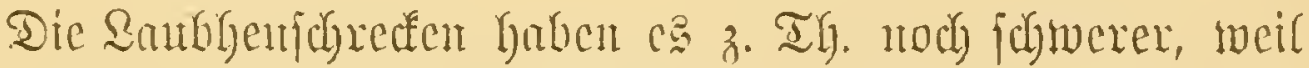
fie mit igrent meift jägentigen Regeinftrument erft cine Definung

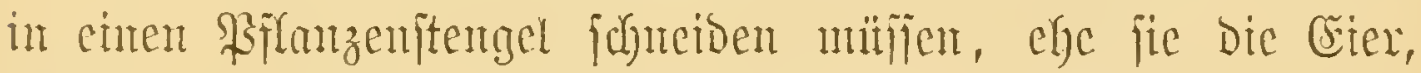
Gald eimzelu, ballo particimeije, unter Dadj mo Fad bringen. Sutcrefiant ift and bas burch beiftelyende Fig. $37 \mathrm{er}=$

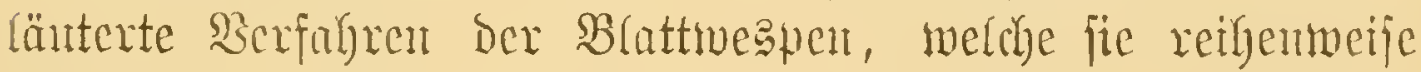
an bie Blattrippen abjeben.

Sente Sierfe, meldye, wie bie Edylupimespen mo andere Schmarober, ifre Cricr in oder an gatz beftimmte Thiere

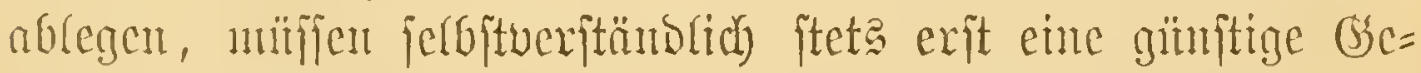

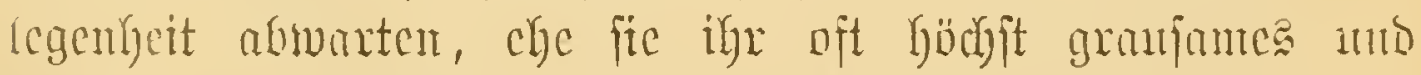

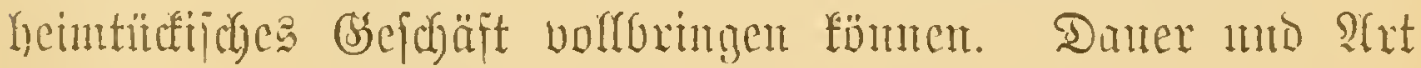

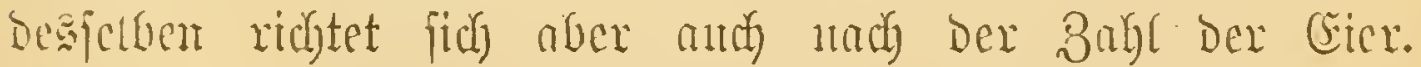

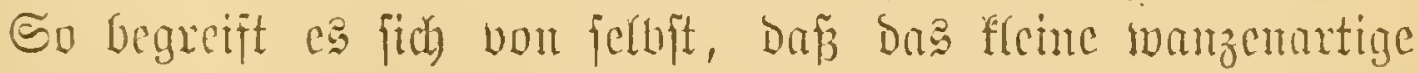
Jnjeft (Alcyrodes proletella Latr.), Das minociten $1 / 4$. probucint, oder gax die weije inteije (Termes bellicosus), 
Die täglid bei 80,000 fertig bringen joll, biejetben in gröperent

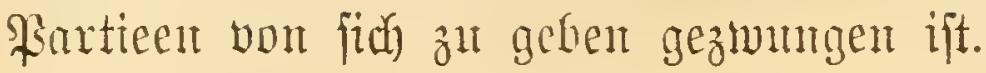

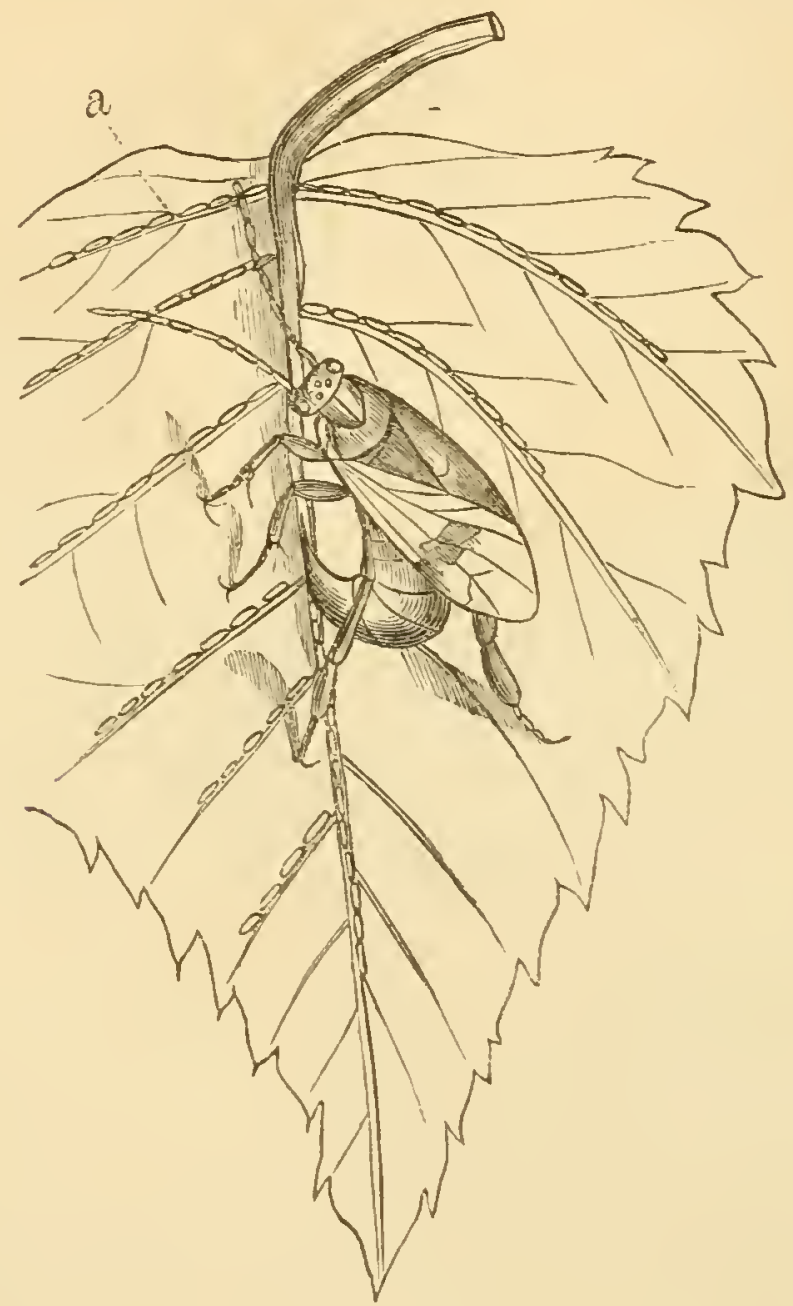

ซig. 37.

Cirr (a) Yegenbe Brattmespe (Nematus septentrionalis), bergröp̃ert.

Mintche Injeften, wie z. B. Die gentante Ternite, bie

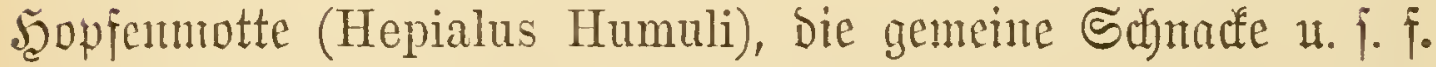
treiben bie Cater mit cinter Bebemenz hervor, ale ob fie mit einer Bitdje abgejifoijen witrdent. Dies ijt aber rebiglich

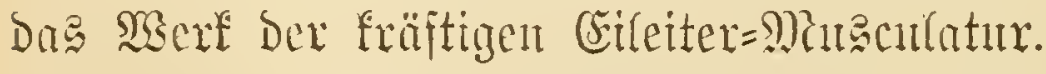

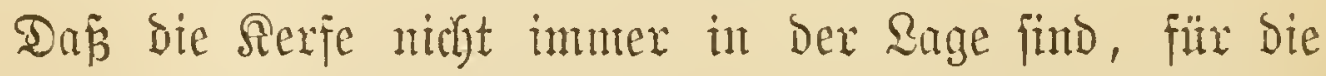

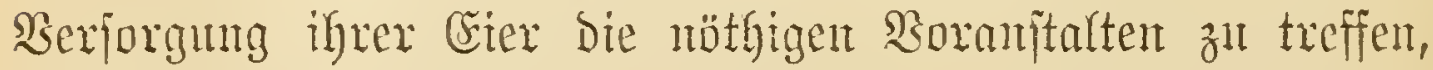

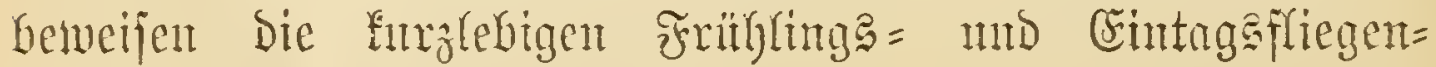


larben, welige, memt fie von Den Beburtalvehen überrajdyt merben, dic Eier aud anf trocfenten Boden fallen laffen, two

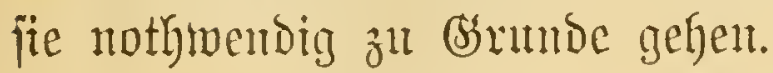

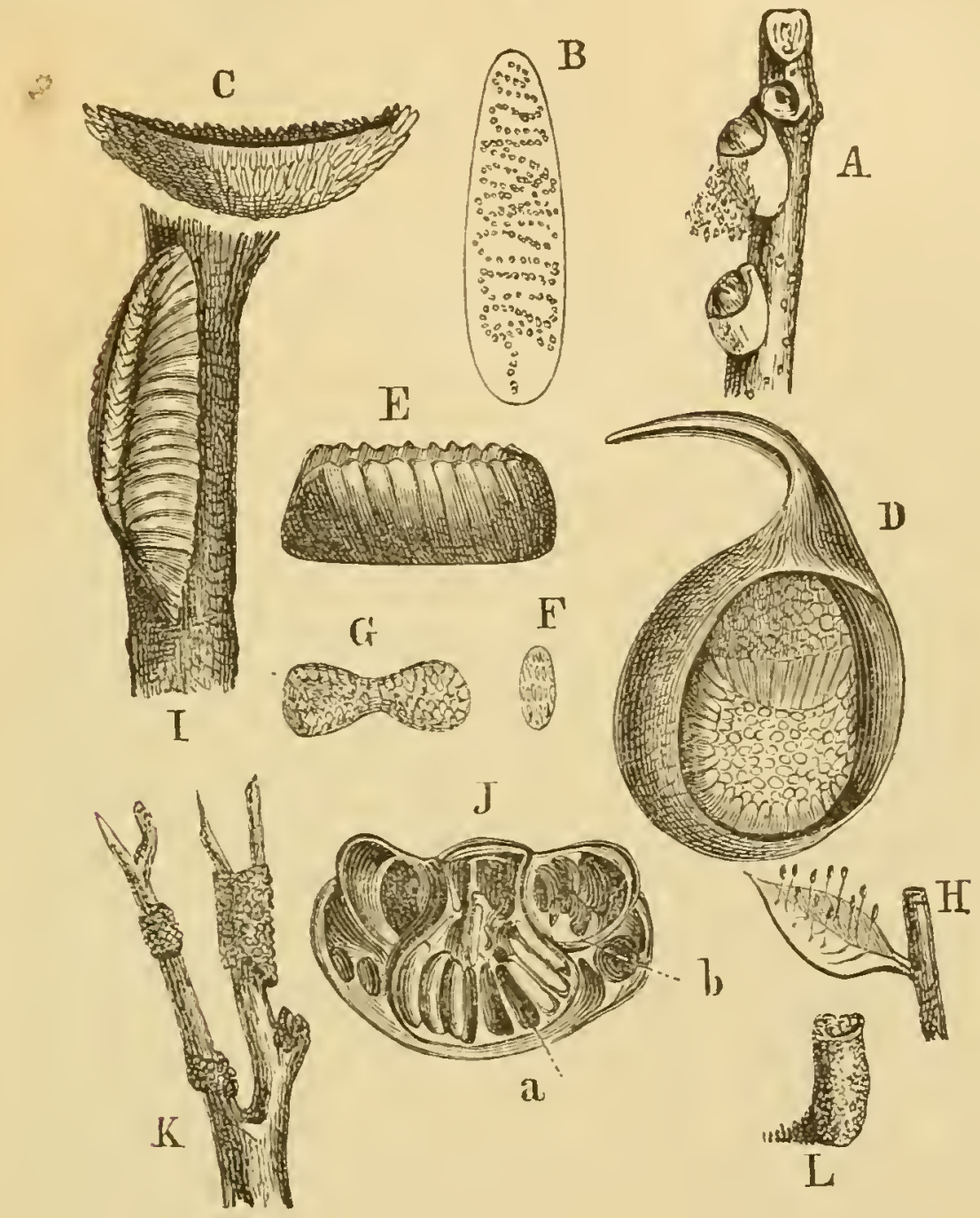

ช̛ig. 38.

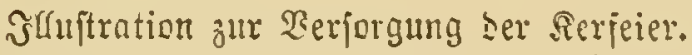

A ๔airtaus (bon ber :

B said) einer Miäcie.

C Rahnjörmiger Raid) einer Ednade (fduematija).

D Ciercrcon beg Gdtrimmfäfers.

E cierbiidfe bon Blatta.

F, G \&aid von Friiflingsfliegen.

H Bejtielte Fier bon Chrysopa.

I Eierpafet der Binttesanbelerin (Mantis religiosa).

J Suerjanitt burf basjerbe; a innere gefäd)rte fapjer, b äufere Inctere Utmbïrrntug.

K CFier be: Ringelipinners.

L Eierjad einer @dnarrheujidecte.

(B) $x$ a ber, Fulfeften. II. Bos. 
Dagegen legen manthe andere Snjeftent für bie Eier,

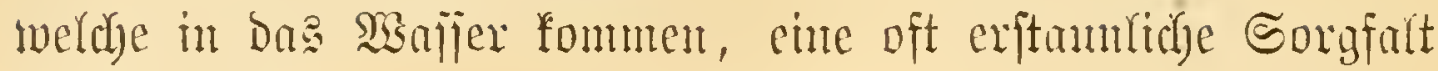
ant Den Tag.

Durch Itmrälfung mit ciner ans ben Sittorüfen ftun= menten Bsalferte bilben zunäd)jt manche, freilidy gautz" un=

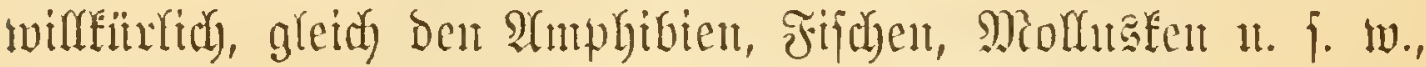

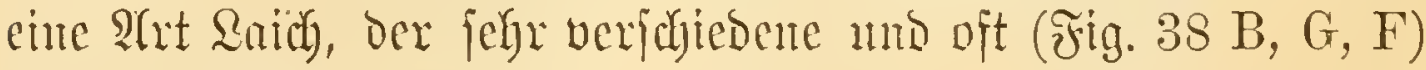
felyr jierliche formen hat.

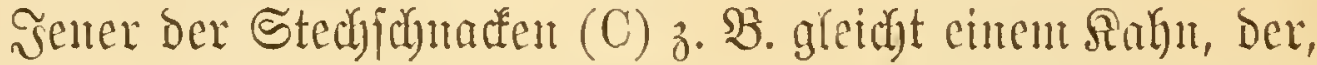

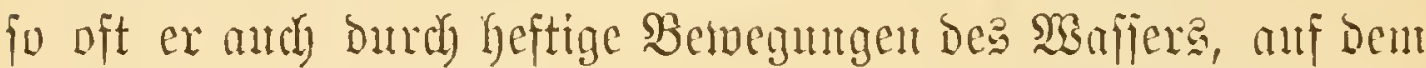

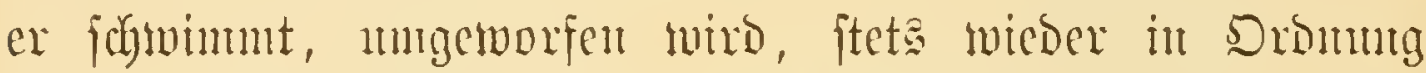
fonmt. Das Conftructionsuerfafren Diejer afrethe ijt mad) Ai e a nun folgemoes.

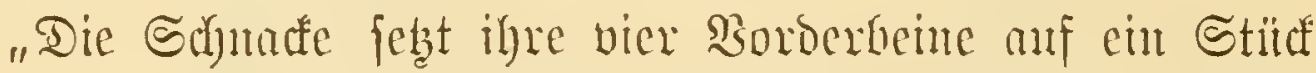

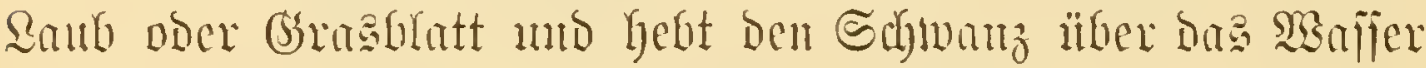
cmpor. Dam frenzt fie bie beion Syinterbeine mo hält in

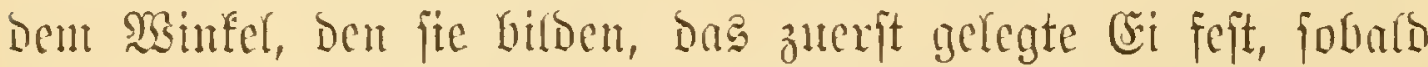

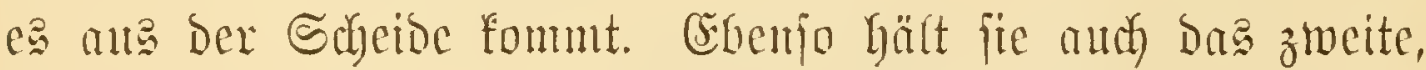

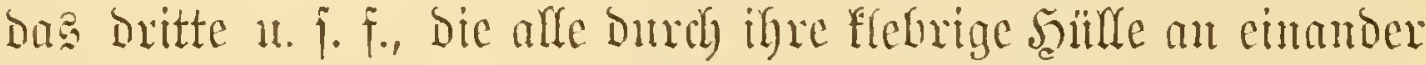
haften. Diejes thut fie fo lange, Gie fic fithlt, bar fo viel mit eimander verbunden fumb, als Gimeidgt, nm bem fleimen Rachen Den ntöthigen Boben zu gethen. Dann thut fie bie Beine ans cinamber und hält bantit mu bie ganze shajpe,

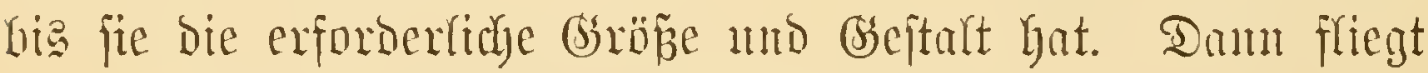
fie bavon mo itberläjpt fie igrent Schicfal."

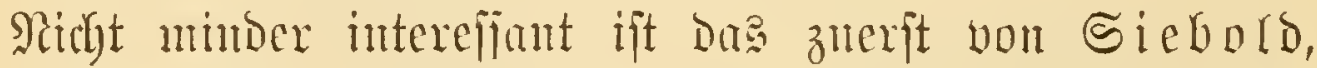
Dent unerreidyten Meifter biologifiber Beobadytungen, cou= ftatirte Merfulgren der medrichen "Seejungferm" (Agrio).

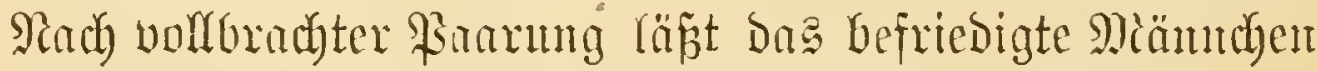

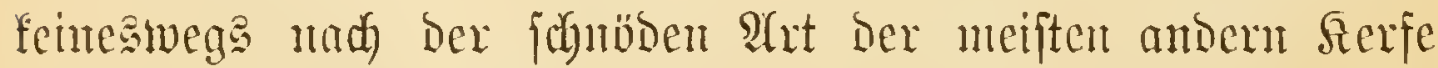

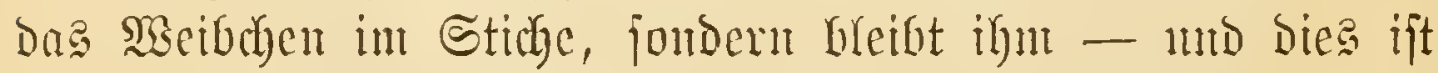
gantz wörtfich zu mebmen - cinte Stübse and fiul bie nächjte 3eit. Die "Ŝtulgänglidefeit" Des Ecejumgfergatten äunert fid 


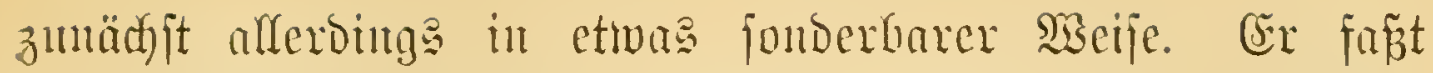
Das Scibchen mit jeincr getwaltigen Nifterzange an Alacten

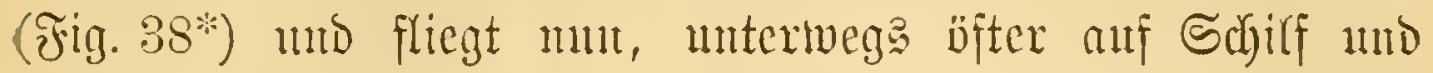

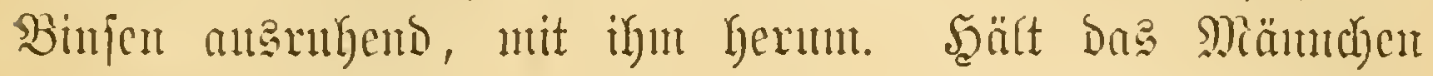
anf einer ber lebetereat längere Zeit jtill, jo frümmt alzhald

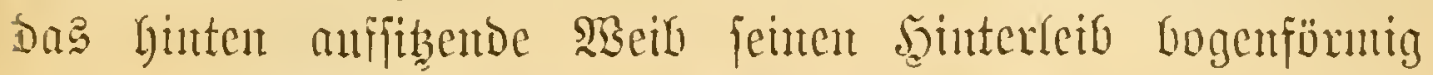

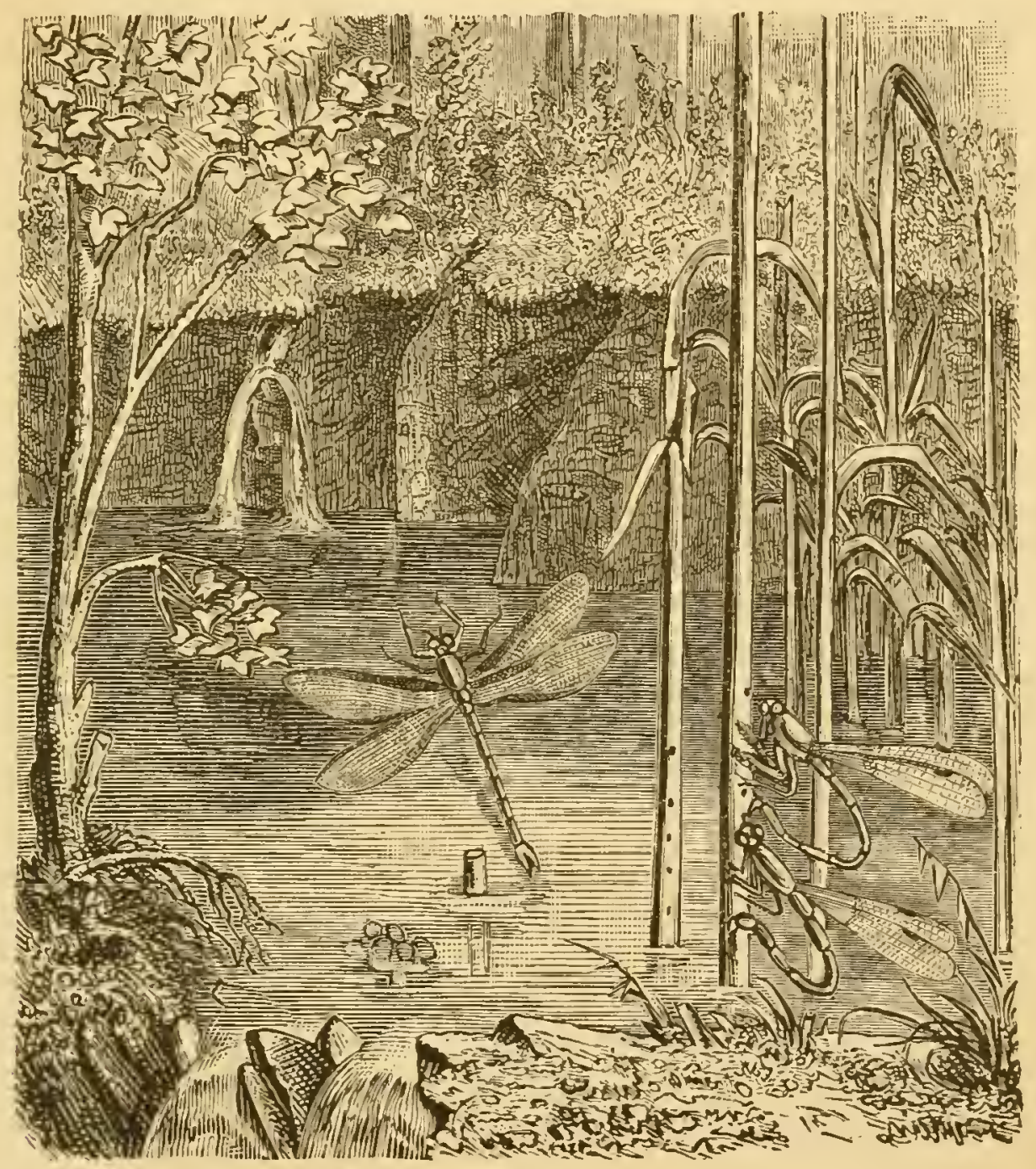

Fig. $35^{*}$.

Fierlegente 2isajierjungicru.

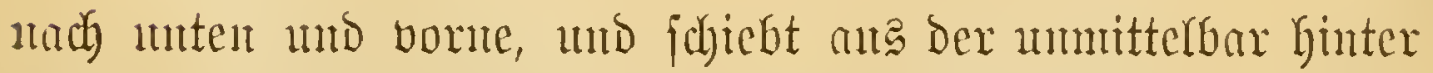

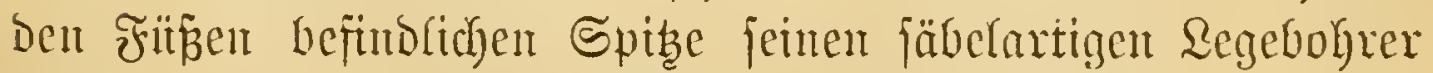
herbor, Dex null in Die Rimbe Dex Bimfe einoringt, sooranf 
Durch Den gebilbeten Spalt ein Cai in bie geräıntige Sutftzelle

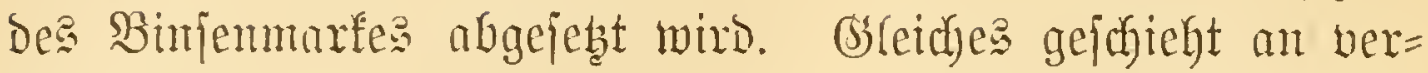
jujiedenen moern Binien, bis ber ganze Borrath exjdyöpit ijt.

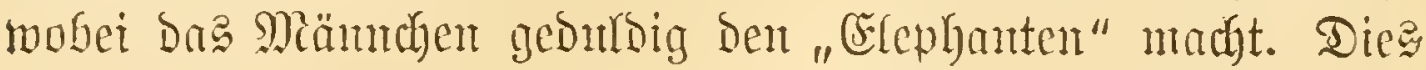

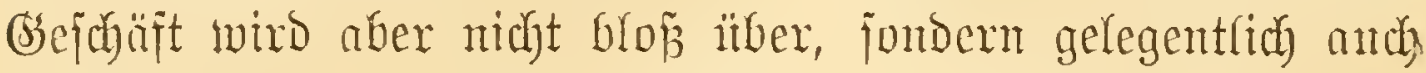
unter Sajajer betrieben, wobei das fectjame und von einer int

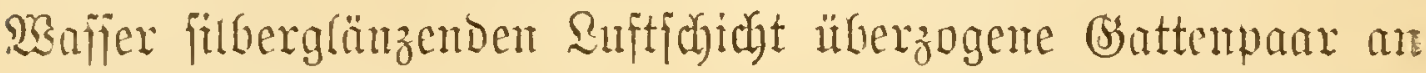

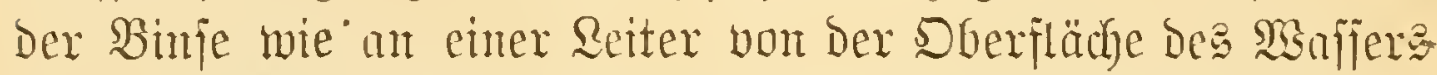

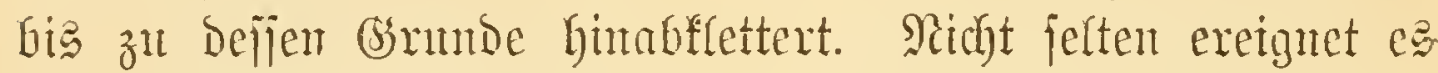
fidy, Dnf zwei ober melyrere Raare an eine Stange gerathen. Sie wijien aber cinanber prädhtig anşuweichen.

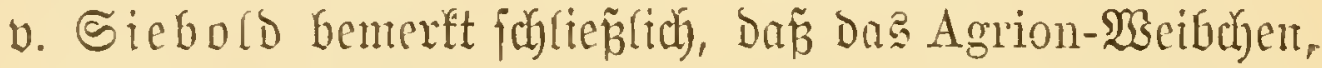

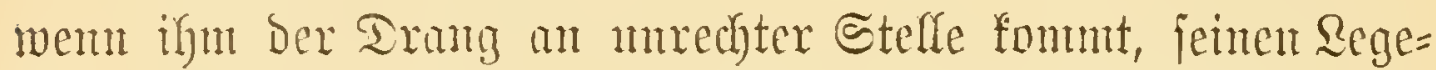

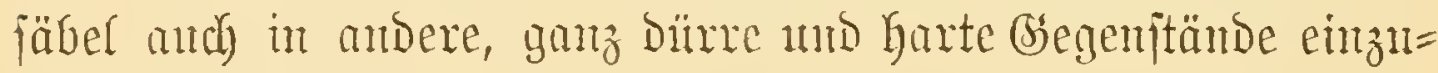
bohren verjutcht.

Daz gewifije Epimten ifje Cater in einen jelgitgemobentr Bentel einfdrlicãen, Den fie Dam entweder, nn ign unter be= ftändiger Antrficht zu haben, mit fich hermmïlyren ober, nto bam oft mit Crobe mufleiftert, anf Bfflanzen anlleften, jo jelbit anf hohe Bänme Ginanftrigen, bürfte Den Rejern hin=

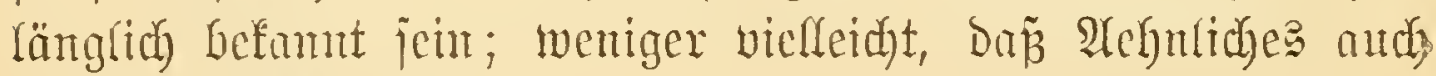
manthe ฐnjeften thum.

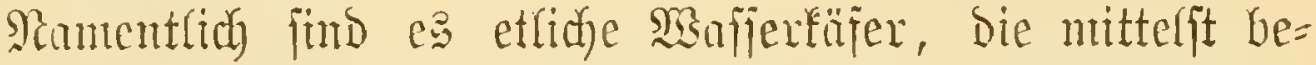
jonderer afferjerifterien Dermitige Eiercocons wehen, Deren Bisejtalt mo Berfertigungasweife gleid interefijant ift. Bein

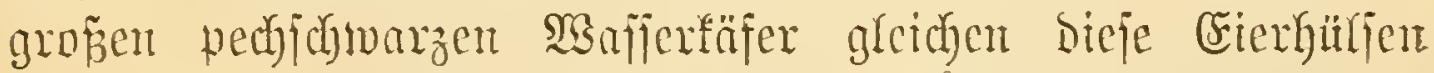

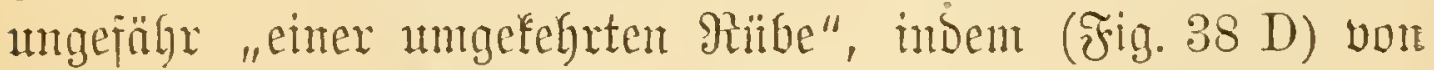

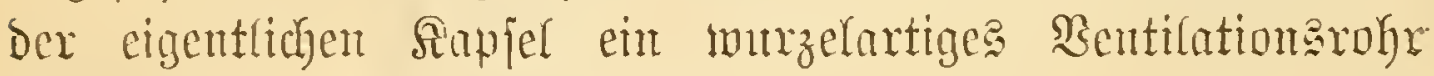
entipringt. Die Conjuntion biejer Alrche ift mm bieje. Buerit überfpint do Therer feinen Banch. Şit bies ge=

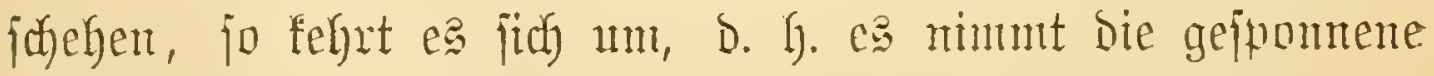

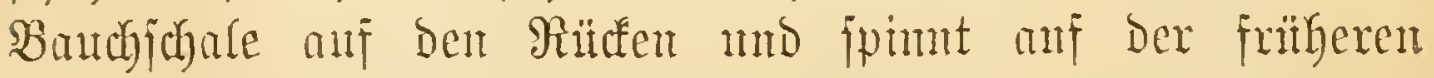

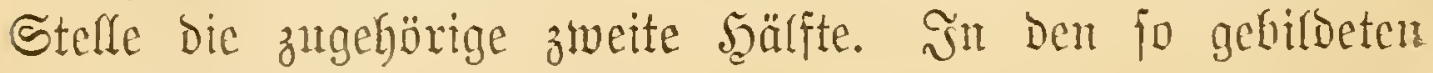




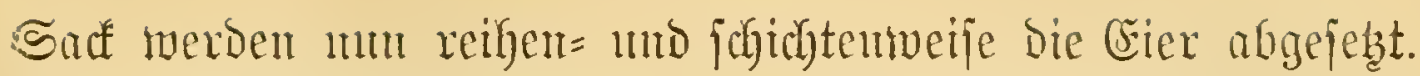

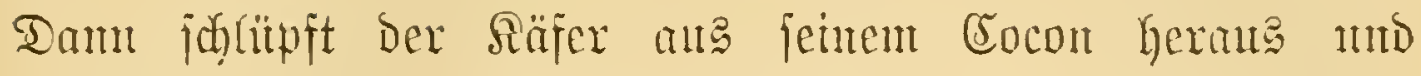

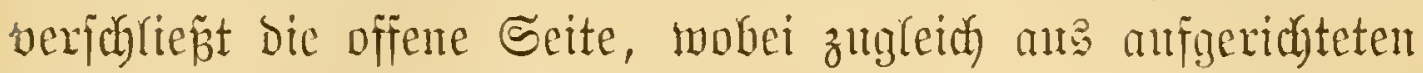

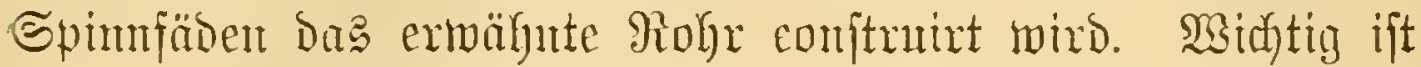

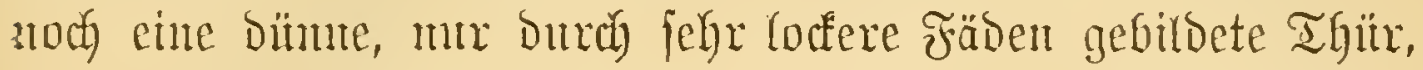
burch weldye jpäter bie jungen Sarben hervorjdyärmen. Der gefrïmmte Fortfas joheint vornehntidy Dazu geeigntet, bie

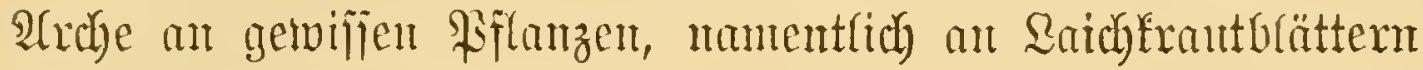
vor Ânfer zul Yegen.

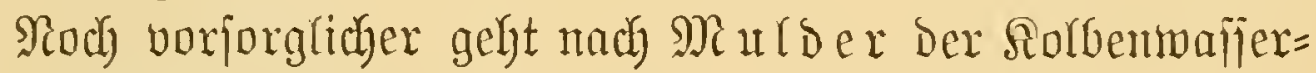

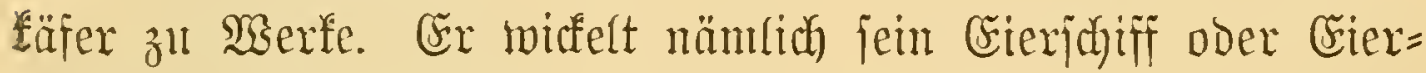

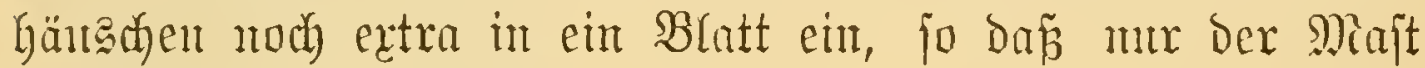
ober Ramin herworfiegt.

Alebuliche Eierbeyälter finden wir anth bei ben $B$ lattinten, weldye jie aber bejtändig mit jich herumführen, jomie bei ben Fanghenfdrecten, bie fie an Stengel mo Steine befejtigent.

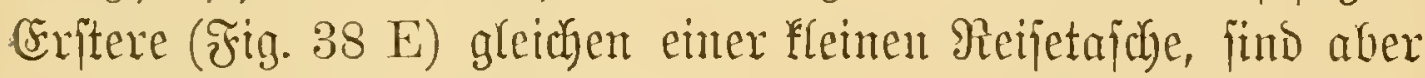
mit jo viefen boppeiten Duterfädhern verjeben, als Eier vorganden.

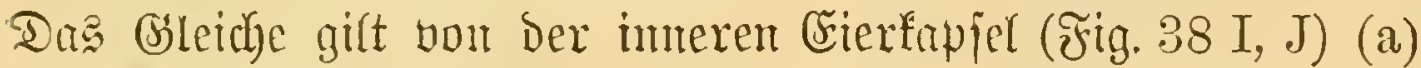
Der Mantis, Die aber, zum Schnt gegen bie Winterfälte, noch bon einem bejonderen blättertg=ichanntigen $\mathfrak{s a ̈ r m e n t a n t e l ~ ( b ) ~}$ unigeber ijt.

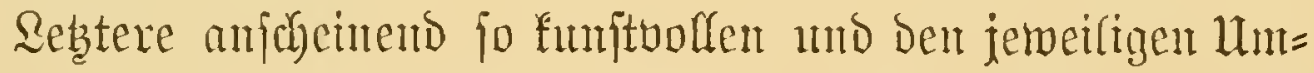

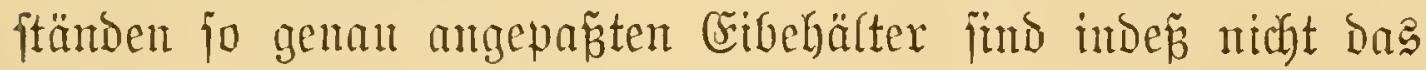
freie sigenthümliden $D \mathfrak{r g a n i}$ ation ihres inueren

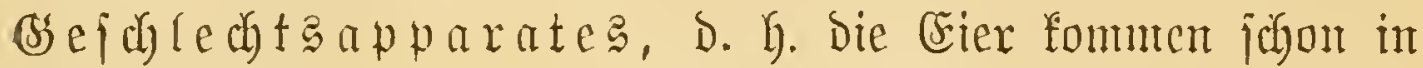
ber bejchriebenen $\mathfrak{B} e i j e$ georduet unb verpact ans Der weiten scheide herbor.

Fajt ebenjo pajfio verhalten fitr) die Schildoünfe, für Deren

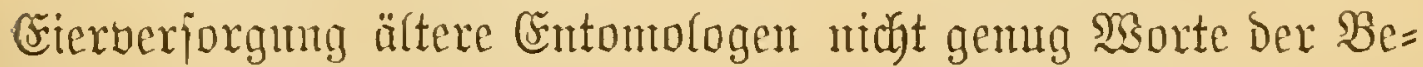

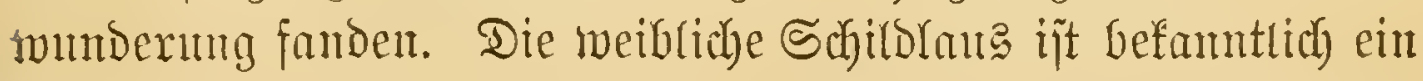

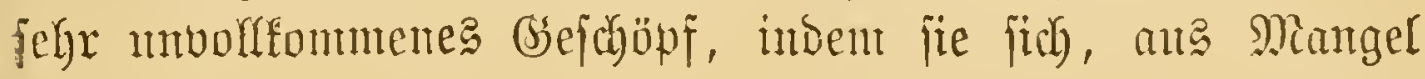




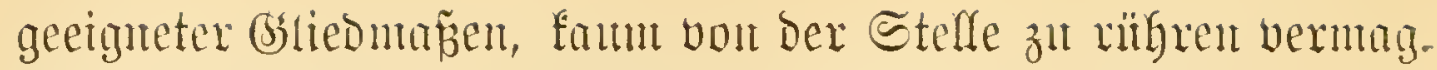
Sit mun igre 3eit gefonmen, fo fdjebt fie die Eiex in ber

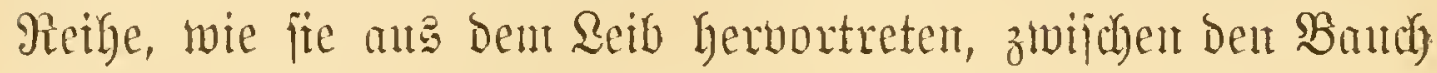

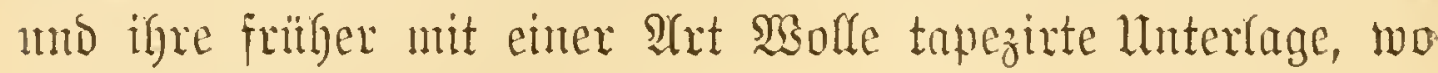

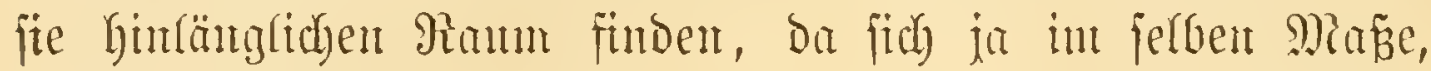

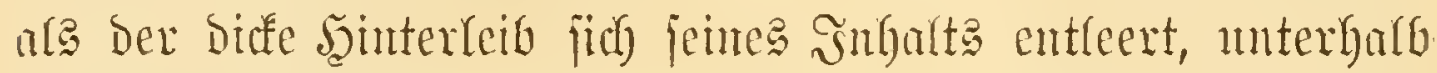

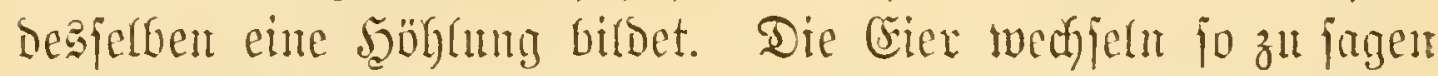

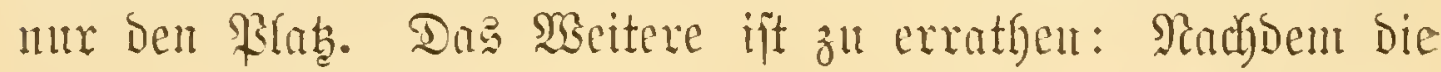

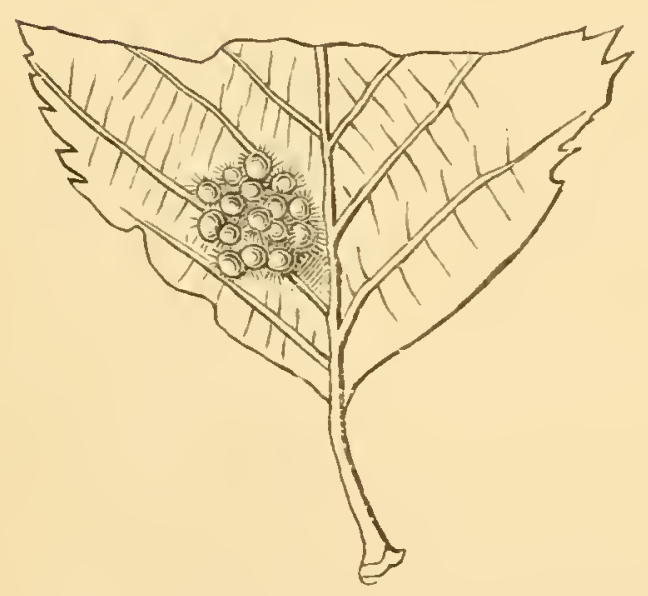

isig. 39.

Cier cirtes Sơnutterlimg (?) añ einem Crenblat, nat. Gir.

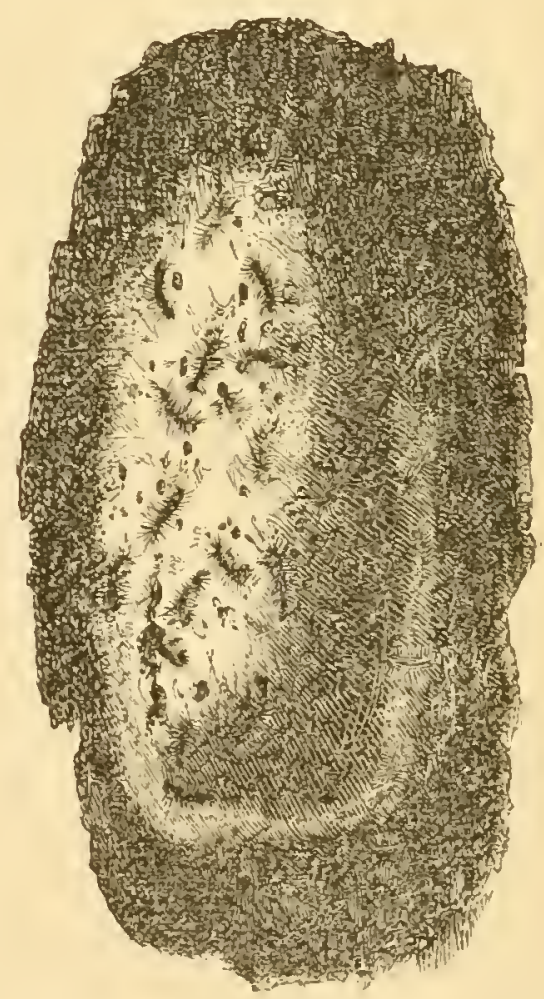

Fig. 40.

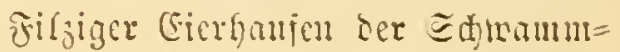
cule, mat. Grr.

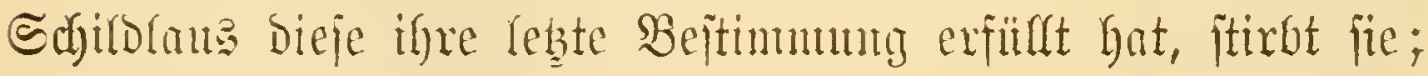

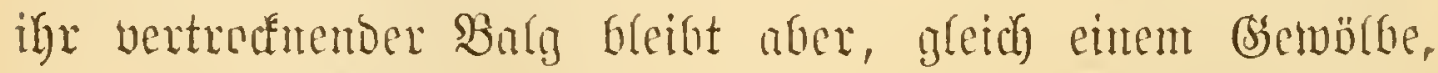

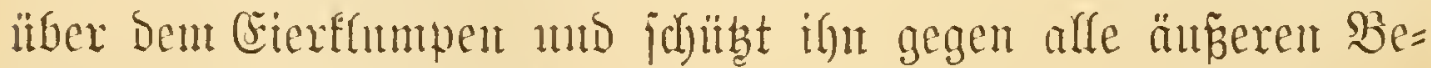

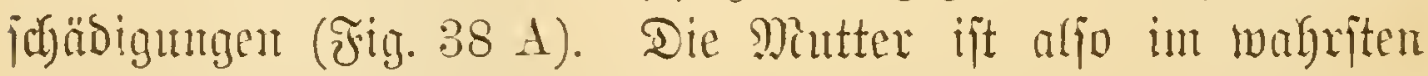

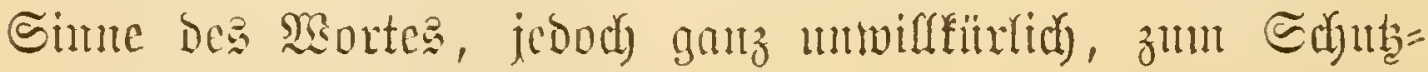
mantel igrer finder getworden. 


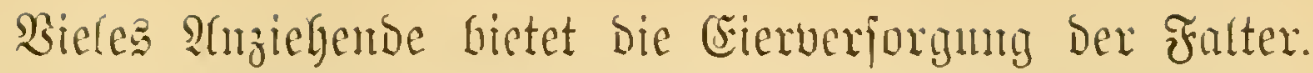
Biele thun alferbing mishts weiter, ars ba

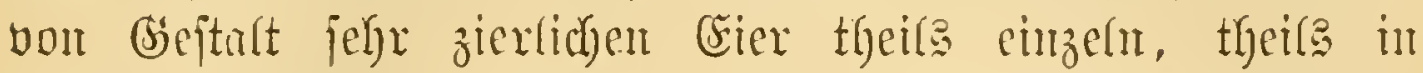

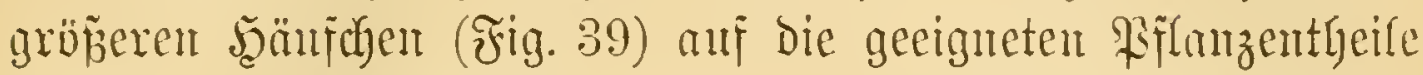

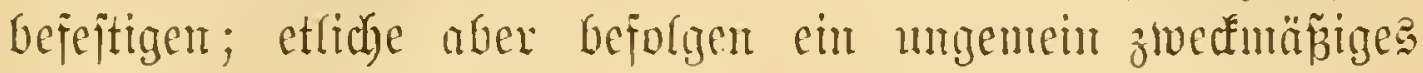
Berfabren, bent fie bent and in erfter Rinie ifre enorme Serbreitung verbanfen.

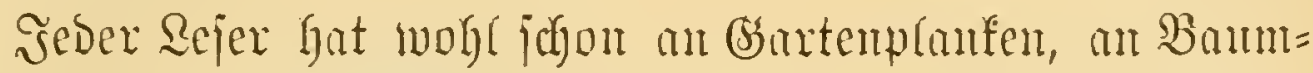

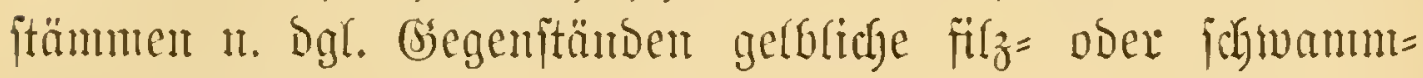

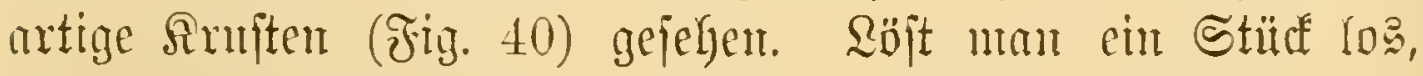
fo fonmen umregelmäñig zeritrente mohntornartige Eier zum Borjcheit, bie in biejer llnterlage wie in eintent Flonnten= bettchen eingewicfert jinto. Das Snterejijantejte ijt aber, Dan die Enle, meld)er fie antgeljören, fith die Freben für dieje马 Sijien jelbit von Leibe rupit.

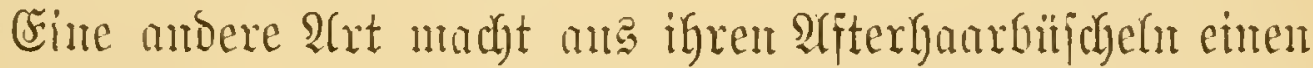
lantgen Edymeif, Den fie Dann, Madjoem die Eier barin ab= gejest, jpiralförmig un cinen Bweig herumjchlutgt.

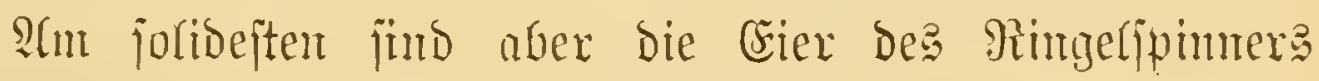
verpart. Sie werden, gleid) einer Rerlen= jdymur, einte bart ant anders, un eitren Banmzmeig gelegt mo mit einem jeber Wittermng trobenden Sitt feit zujanmen= geleimt (Fig. $38 \mathrm{~K}$ ).

Dies find Dinge, bie fidh alle recht

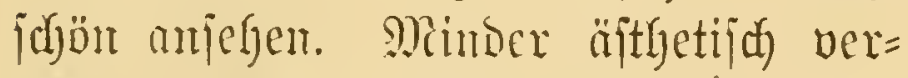
fahren Dagegen getuifie Dungfäfer, bie uts jo recht anjdyantich madjen, wie

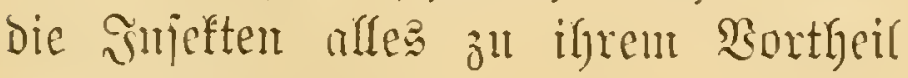
zu gebrauchen wijīen.

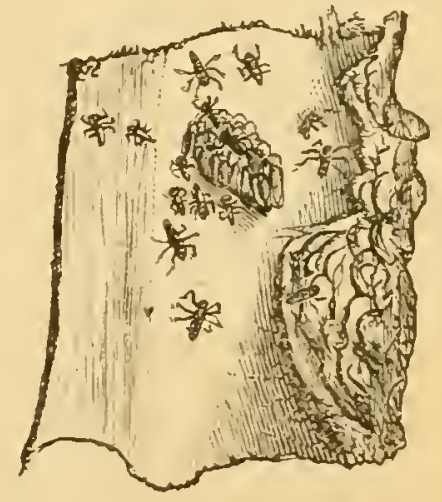

Fig. 41.

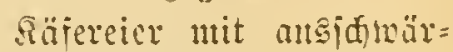
menoer Birut, nat. Bir.

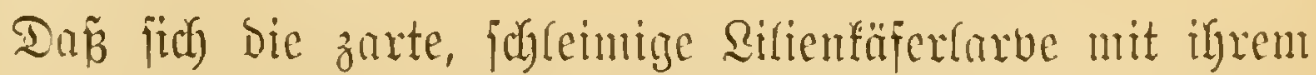
eigenen Mijit zubecft, jieht ber Rejer anz Fig. 42. Mujere 


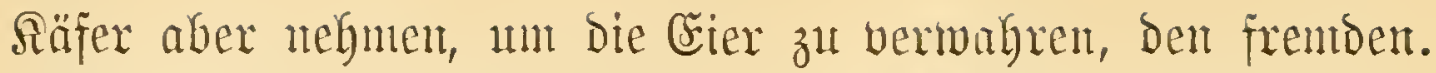
Frither formen fie jesody Darang fleine fingelt, bie fie Dann

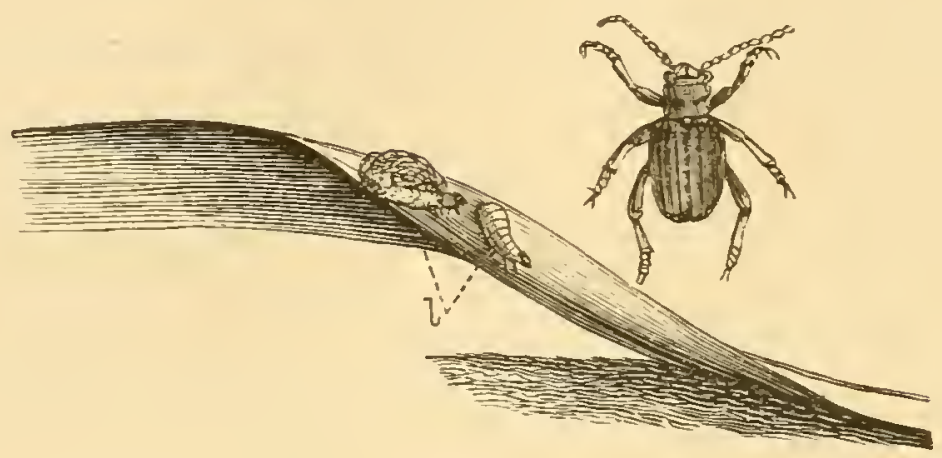

Fig. $4 \%$.

Silientäfer (Lema merdigera) fammt Rarven (eime nit ifrem foth bebeat) auj einem Giras, llat. Gir.

jorgfültig in Erojpalten rollen, ein Gsejäät, bei bent fie cintander getreulich zur Seite jteben.

Selbitichub ber Ruplen.

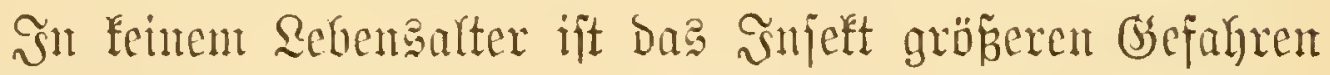
unto Âtrgriffen antigejest als in Dem bes eigentfichen $\mathfrak{B e r}=$

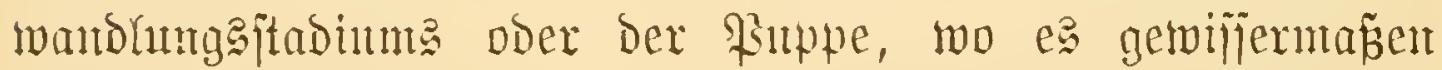

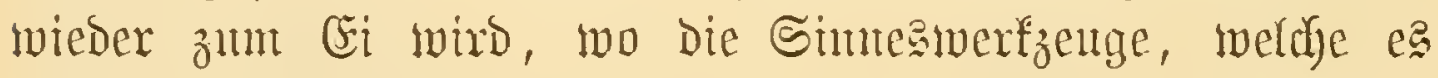
itbex bie ifm drobenden Bsefahren unterridenten follen, mo bie Drgane Des Drtawerkfels mo Der Bertheibigutg, nit Denen es berfelben entflieben ober fid begren fömte, ihre Igätigkeit einjtellen, wäbreno bod fein von reichlichem Fett

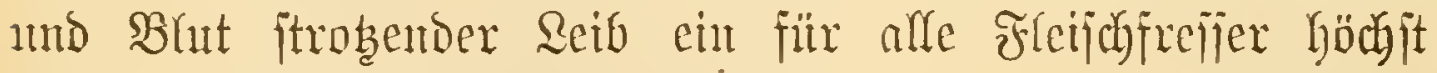
begehrensmerther ssegenjtand ift, und andererjeits ber in ber Itntbildung begriffene und wentg wiberjtandaknäftige Drga=

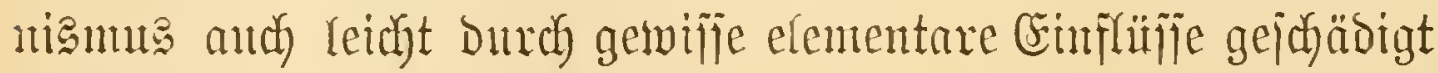
uverden ḱtut.

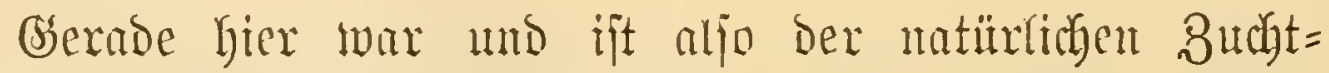

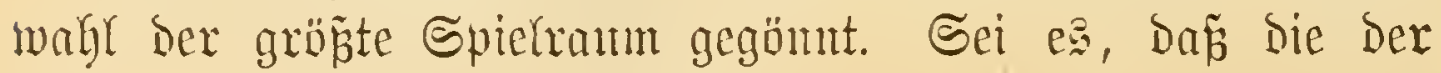




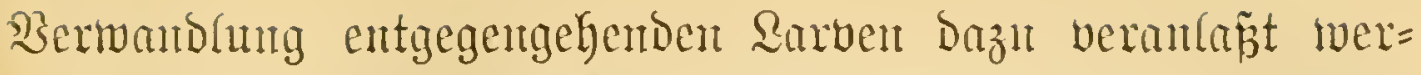

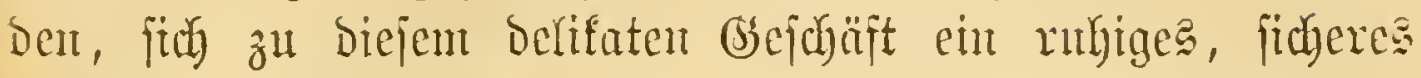

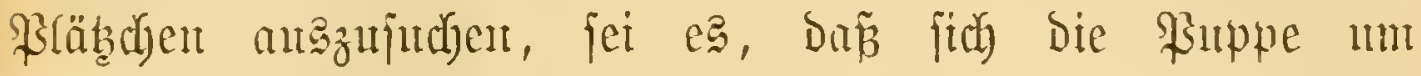

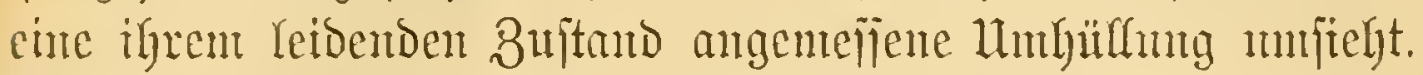

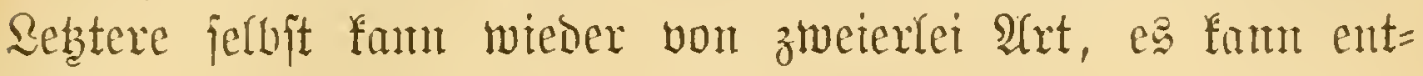

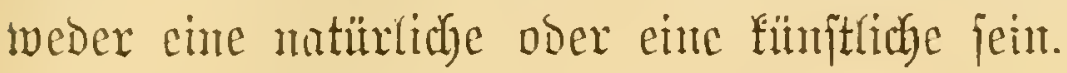

Fine natïrliche ijt $\mathfrak{z}$. B. Die biffe, fruftenartige Schale ber Tagfalterpuppen ober der abgejtoz̃ente Rarventualg, in bent fith bie weidhen Situmplyen Der 3wciflügler, cintger Feber= 倘aben, Säfex

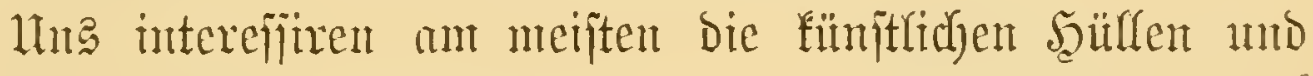
vor allen jente Seidengepinmite ober Cocons, weldye fith

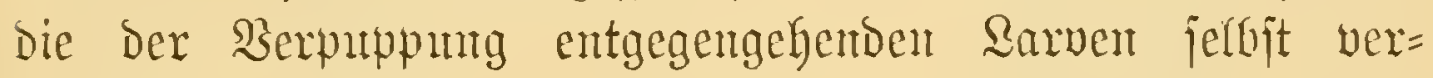
fertigen.

Cintem guten Renter biejer Dintge würde es cin Reidbtes

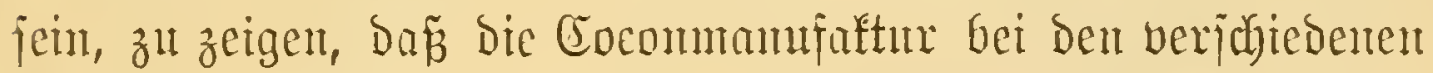
Sinjeften, weldye fie ansüben, in jebr ungleidjem (s)rabe ent=

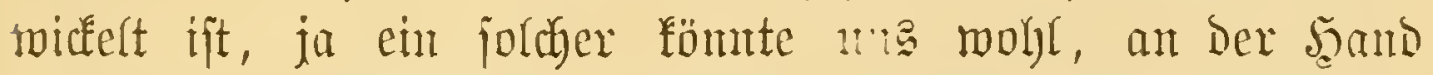

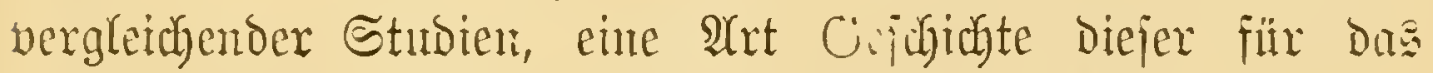
ganze Rerfleben jo bebentjanten Fertigkeit liefern. -

Uns ijt es mur gejtattet, bie allerwidytigiten Stabien biejer Snduntrie furz anzudenten.

şir fangen mit ben niedrigiten, D. i. ntit jenen an, wo

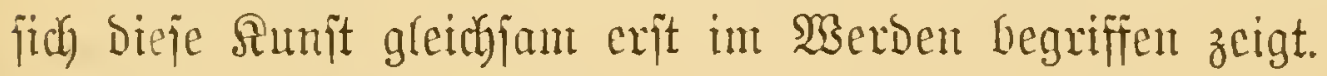

Cringe Serfe, wie z. B. Die geöhrte Eidycn= und Die

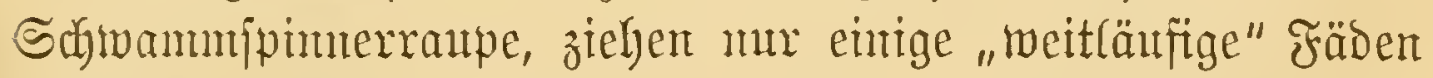
unt jith, worin fie jith zwax halten, aber nidht verbergen fömten. Difenbax gebt biejen zu früh Dex Faben aus, un ifr erites Defut endigt mit Der Shtíage des Rahmens, inter= Galb weldyem $z$. B. Der Seidentmurm erjt Den eigentfidyen Cocon

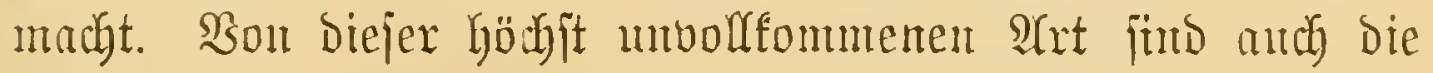

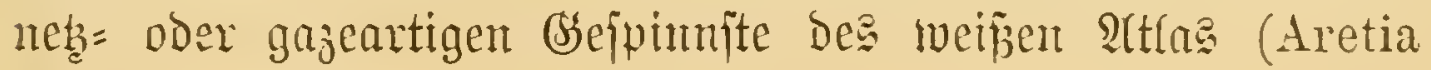


Salicis), Des Rainfarren=Battfäfers und einiger Miotten

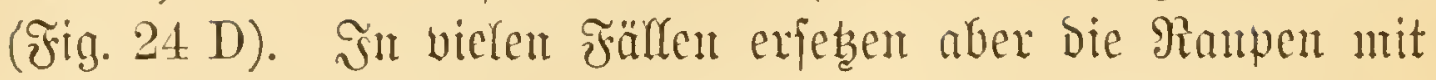
frembartigem snaterial, was ihnen an eigenem Spimmaterial verjagt ift. So verftreidjen jene Des Ringelfpintuers und

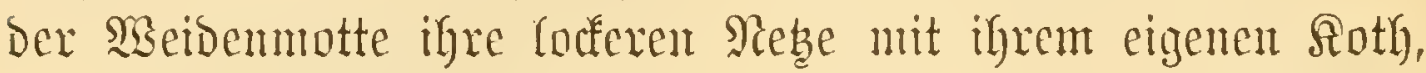

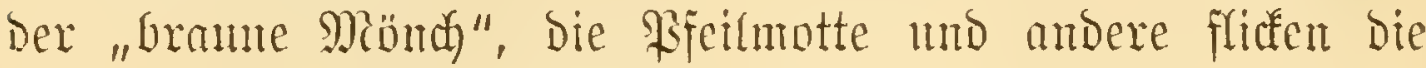

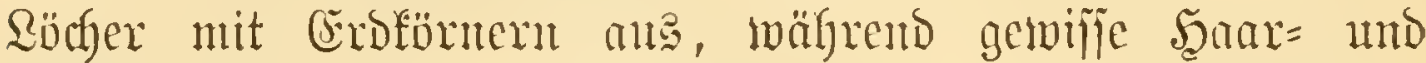
Bürjtemranpen, wie z. B. Noctua aceris, Der "@roốfopí,

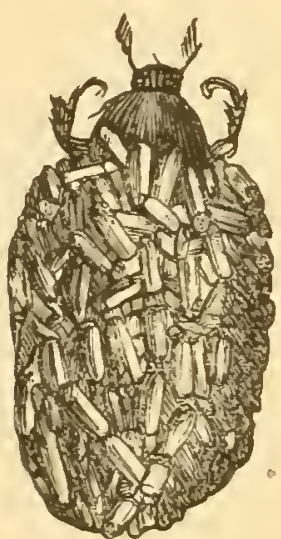

Fi.j. 43.
TH: Sen cigenen Sothballen jujammen= gerïgtes Pruppengefäm;e ses Mictall= golofïjurs (Cetonia aenea), mat. (3r.

Biener 50 immjenm.

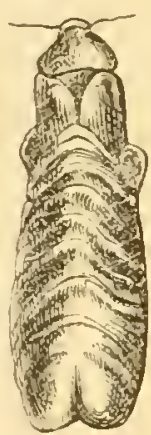

ivig. 44.

Ein Brattfäjer (Clythra quadripunctata) ams feinem ger̈̈ltelten, aus Erose ğufanmen= gefitteten Fuppengefänts hervorgefents, nat. Gr. 然iener Sojmujem.

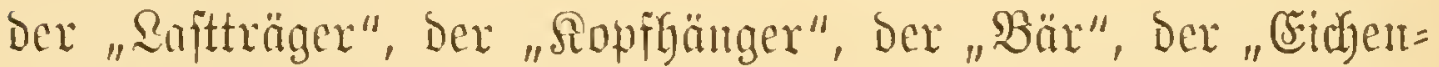
ipinter" mb andere unf bie gewif originelle Methode ge= leitet wurden, in igre meift fefre fojüttern betwebe die şanre

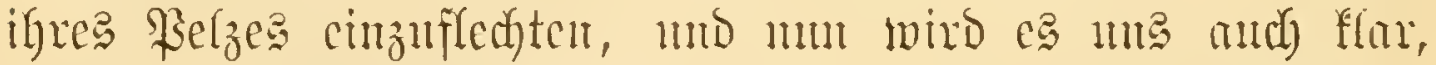
waxm anf bielen biefer bomooften şänptex fo fonberbare

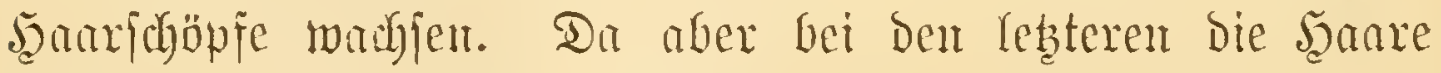

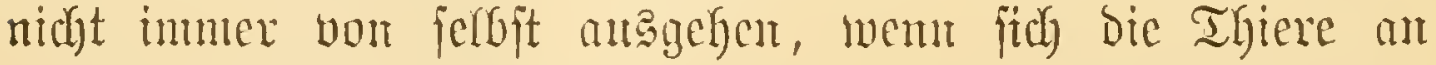

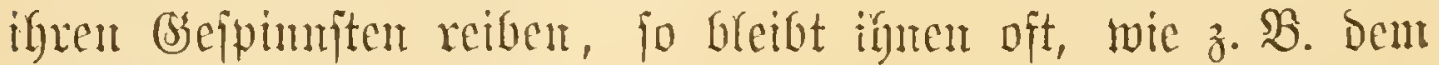

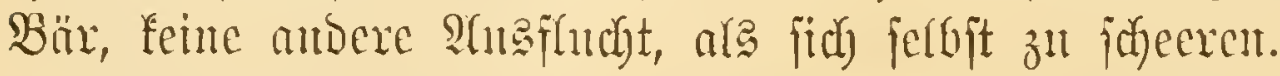

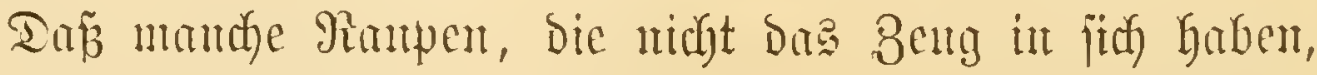

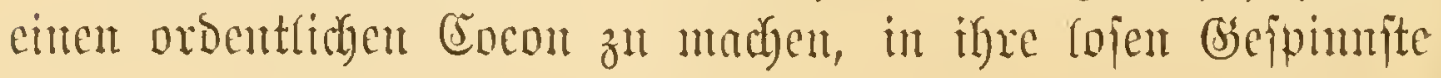




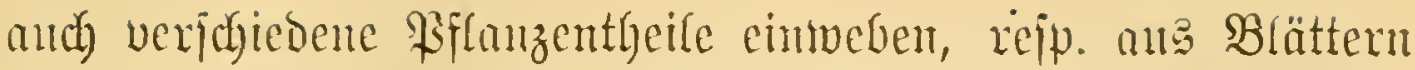

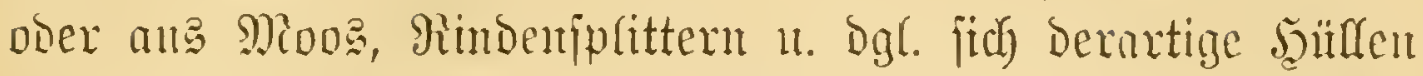
improvifiren, wird dem Rejer gewiez nidyt bejrentend bünfen. Einen ftamentwerthen (brab von Ruritjertigfeit legt bierin

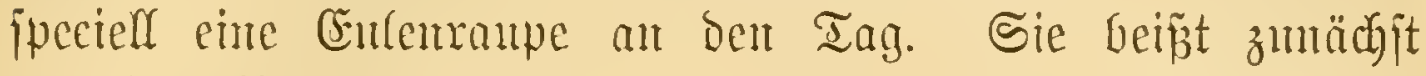
aus bex Rinte, woranf fie lebt, riententige Stinfe ab. Dann macht jie daran zmei breiecfige Platten, die jie

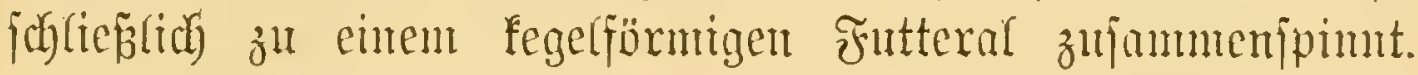
Pod wraftijcher verfälyt ein Büntaler (Hercyna strigularis),

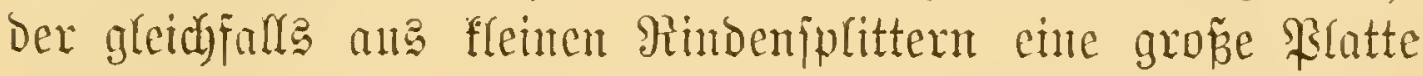
fubricint, beren frei abjtebende Seitentbeile ex dann nit Spin= fäben gegen cintander ziegt, woburch ein gar niebliches, falynt= artiges Ssebäns entiteht.

Un mu anf bie volfonmeneren Seibenthüljen zu fonmen, jo fund bieje nach Form, Farbe, Brejïnge und anderweitiger Bejunffenheit ungemein verjhicoen. SBab bie Bejtalt antangt, fo haben zwar die meiften einten obalen ober elliptijchen Muriż,

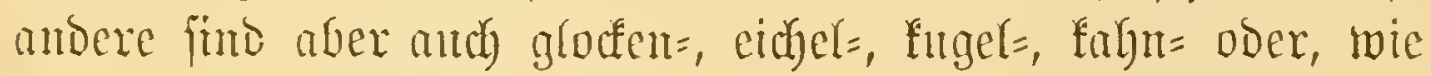

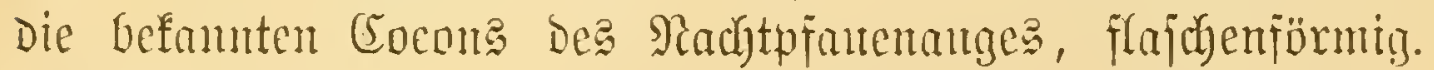
Die Farbe ift ztwar in ber Aiegel weiz̈, gelb, gran oder bram, man feunt aber and jobronze, blane, rothe, ia jelbit zierlich

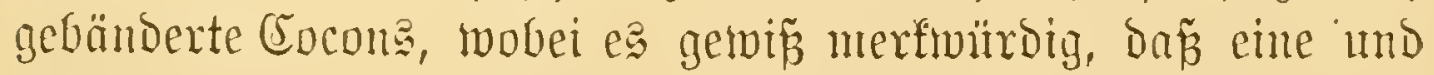
bieferbe Epimbriije verjchieben gefärbte Seide liejert.

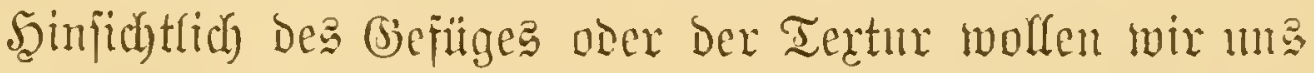

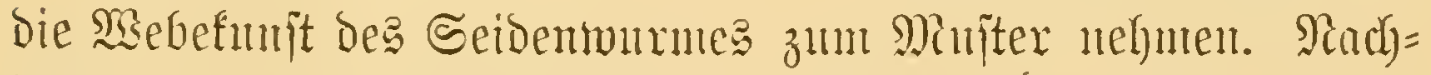

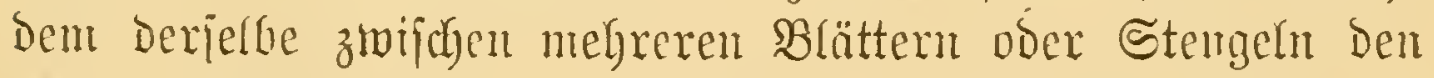
fchon erwälhnten wergartigen Rahmen ausgefpamnt, legt er Den

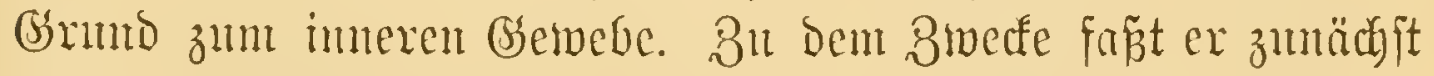

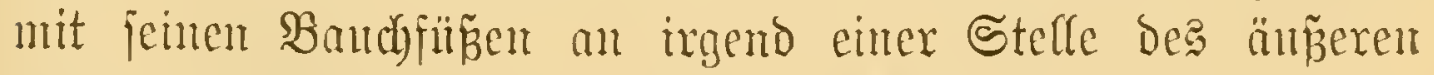

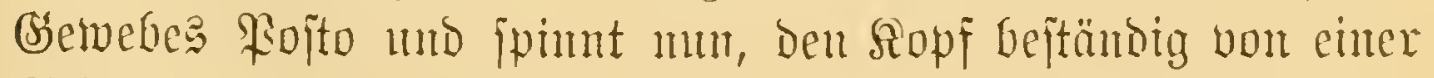
Seite zut andern bewegend, eime Sage Seide anf ber entgegen=

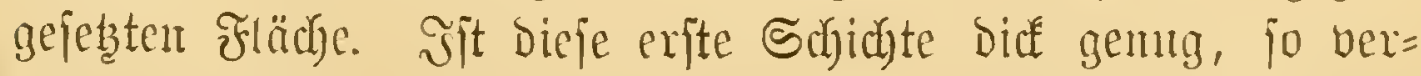
ändert bie Spinmerin igre Rage mo micderholt basjelbe $\mathfrak{S e r}=$ 
fahren anderawo. Syicranf überzieht fie jede Sage nach der

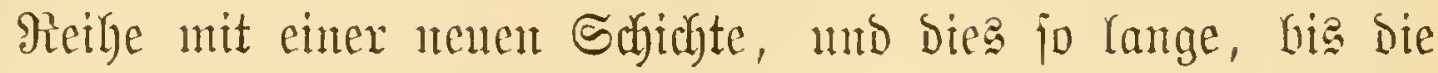

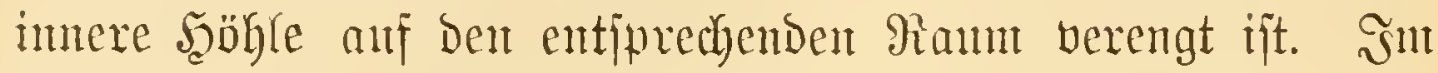
Ganzen werben wenigitens 6 sagen über emander geidjidrtet, von beren ftüntweifen Bujanmenjebung man fich an bejten

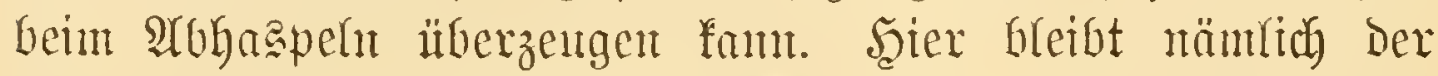
Socon oft lange an ciner Stelle liegen, bis endich, nach Sulauf bes Faben anf ber betreffenden Seite, bie şülje auf

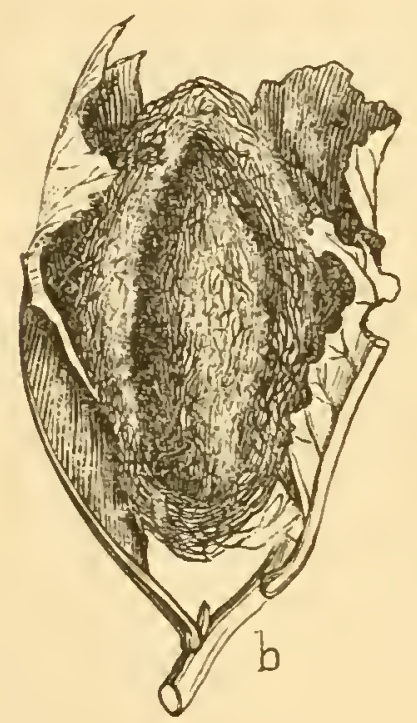

ऊig. 45 .

Cocon Ics Ringelifimer: (Clisio. campa neustria L.), nat. (jr. Mant fieht Den eigentliden Encon mittelit

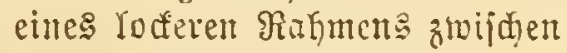
Blättern bejeitigt.

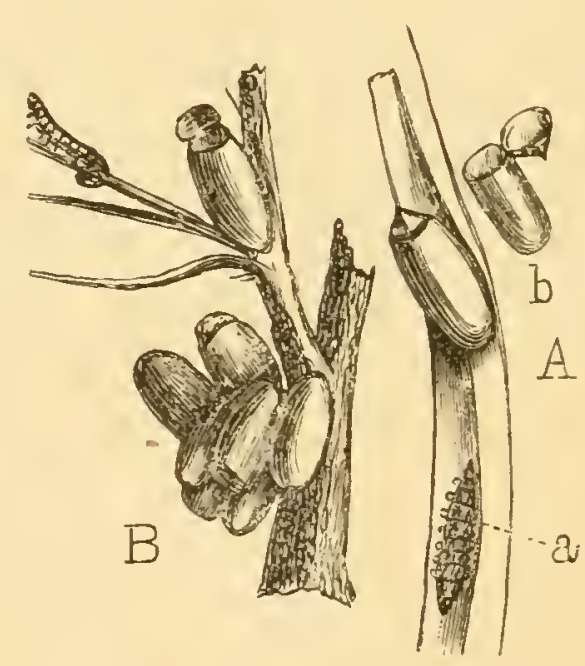

Fig. 46.

A Ricicrmüffe (Tipula pini). a Sarve, b mit Dedel aujitringente Fuppenthïlje.

B Błattwe Epe (Lophyrus pini). Cocon gleidi)= falfs mit Dedfel.

eine antore gedreft twird. Die Bsejanmuttänge Des Fabents heträgt oft eiutige $\mathfrak{I}$ arfent $\mathfrak{F} u \tilde{p}$.

Heber die einzehnen Msebentetfoden der verichiebentent

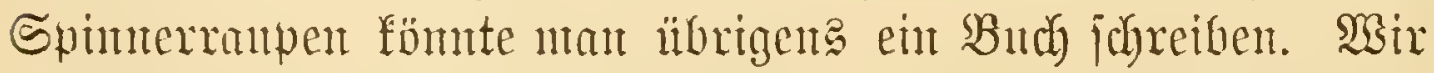

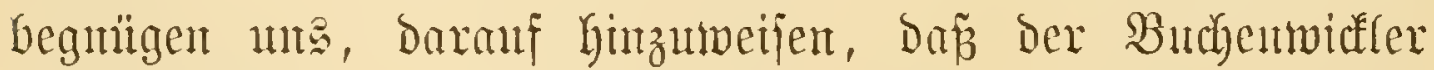

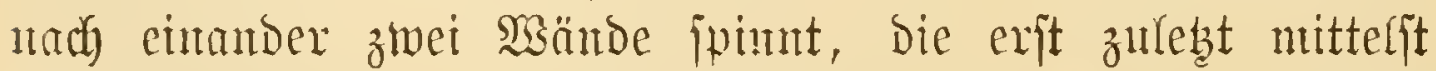
Silgnturen verGutben werben, währent eine fleine, auf Dem

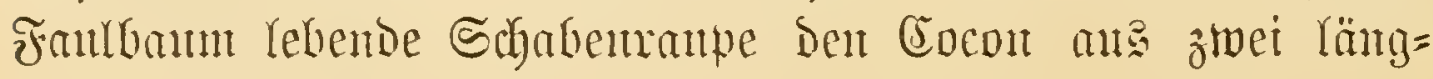




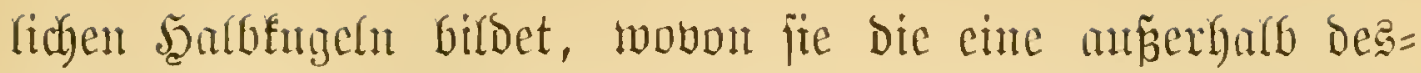
jelben ftelyend madgt und fich erft bei ber Berfertiguntg Der andern Së̈fte in bic exftere lineinbegibt.

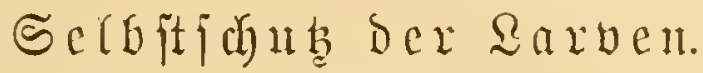

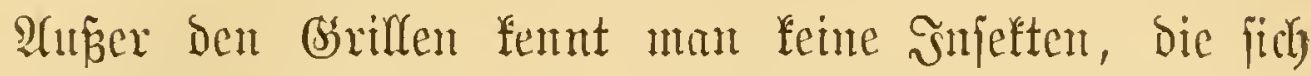

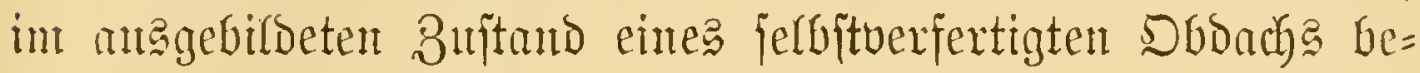
Dienen; und Da and bie Rörder Der gentanten bon ben noch jutgen Thieren gegraben werden, jo fant man jagen, Da ja bie S̃magines gauz für jüb) allein überhanpt midgt bauen. Sie thum bies aber nicht, eimmal tweil jie cas nidyt zut thut braudjen, Da

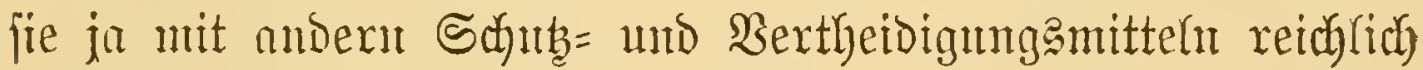
ansgejtattet und zumal auch leidgt in ber Rage find, int

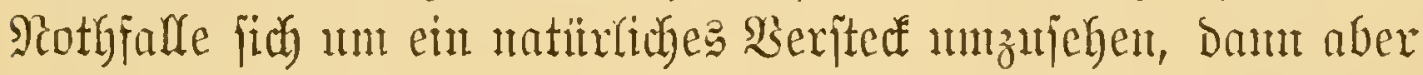

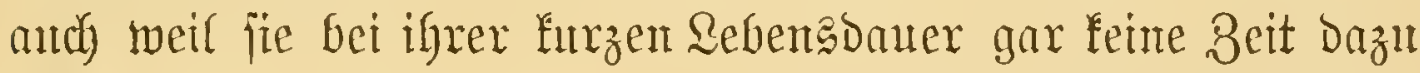
haben, indem jie ja in biejer allerespodbe volfanf mit ber Berjorgutg ihrer Brut bejääfigt find.

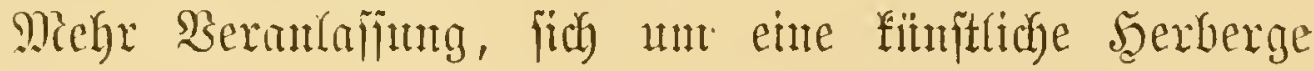

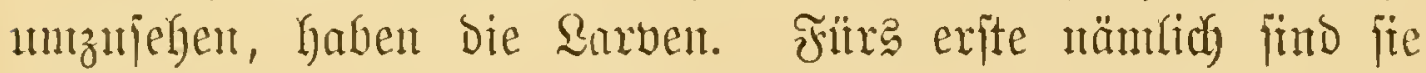
ifres weidjeren Rörpers wegen biel mehr angriffent nus= gejebt, fürs zweite haben jic wentige, ja oft gar feine

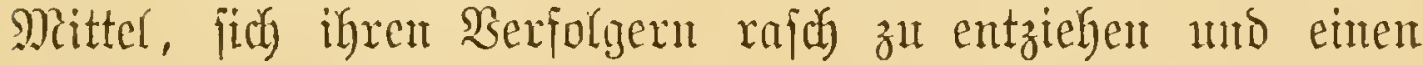
geeigneten Uuteritand zu juchen. Füres dritte endrich Dauert

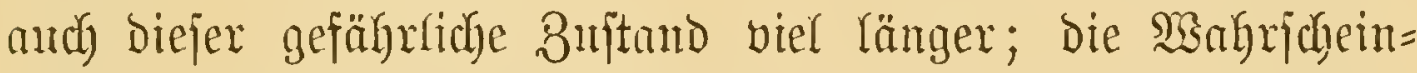
richfeit eines gewaltjamen Todes ijt aljo bei ihnen viel größ̈er als bei bett Smagines.

Da inder bon ber conftructiven Thätigkeit der Larven

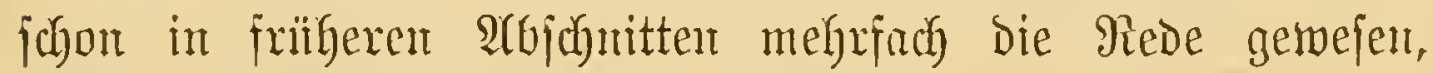
milifen wir uns hier bei ber Anappheit des Ranmes anf eintige Bujäbe bejhräntent.

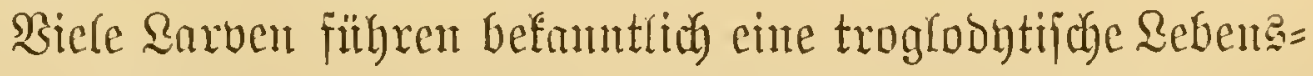
weije, und haben es Darmter ipecicll der Aneijenlöwe uno 
Der Tigerfäfer zu einer gewifjen Berillyntheit gebradyt. Inter Den Falterrapen, bie ja mit geringen SHandamen alle anf Biflanzen leben, ift bagegen biejes Sambwert faft gax nidat im

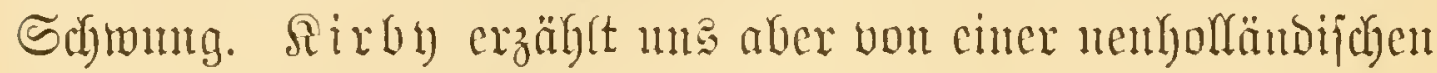
Baupe (Nycterobius Mac-Leay), Dexen Rebengmeife viel Aehn= (ich feit mit jener der befannten Mintripinnen zul haben jobeint. Dieje Sierfe mathen watzige Şöhlen in gemiffen Bäımen, namentfich Banksia, und bejdutben Den Eingang gegen bie Augriffe ber Fumglyenflyrecten uno anderer morogieriger ßevfe

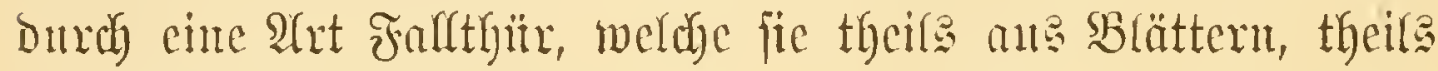

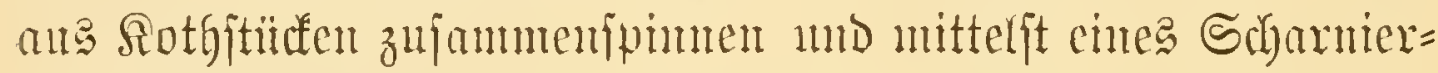
gelenfes an oberen Ende bejejtigen. Dicje Saghnumgen ver=

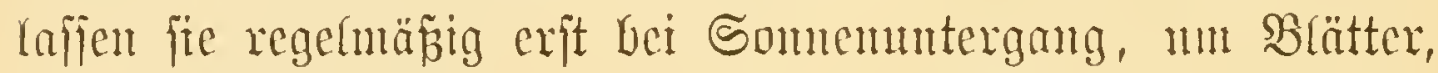
von Denen fie reben, zu jammehr. Sebztere fordeppent fie in

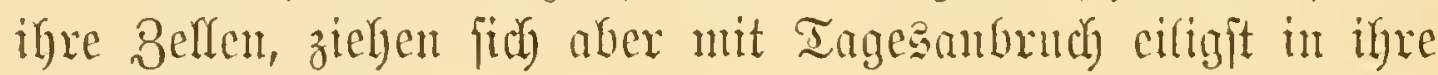
Schächte zuriä.

Ein merkwürbig verjtedtes Sngendeblen fïlyren mady neneren Seobad)tungen bie Singcicaden. Das seibchen legt die cier in bie Rimbe des Bammes, anf bem es fith gernde

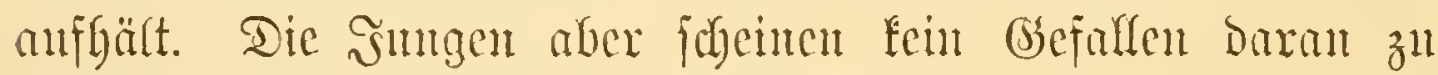
finden, gleid) andern Rimbengebornen in bem Mebiun zn bleiben, wo fie zux sedt fommen, fondern flettern an Den Stänmen lyerab mb graben fich, Den zarten wanzeltwerf nadygehend, am Brmbe berjerben mittefit igrer hacfenartigen

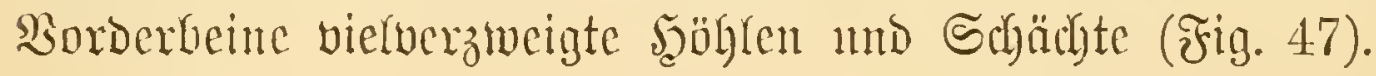

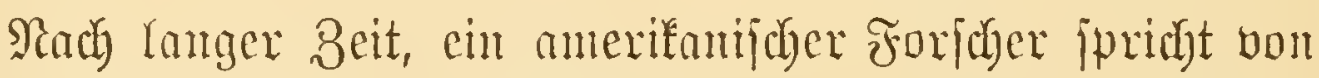

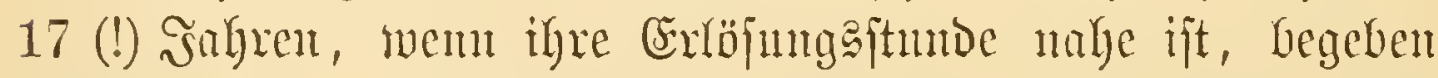

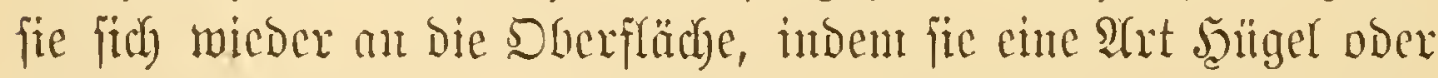
befjer cinen Thum (a) anfwerfon, in Deffen leidyt gefrimunter Spize (c) Die \$erwandung ins vollfommene Snleft exfolgt, bas Dann burch cine an Fure ifres Banes gelegene Seiten=

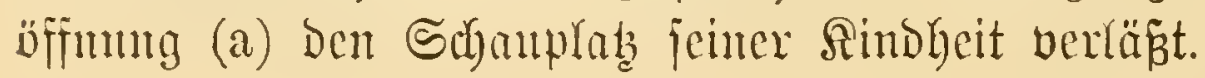


Die meiften Ģebäufe und Fntterale madyen die Larven fufauntich theirs gan, theils zum Theile ans ihrem Spint= jtoff. Retiterer bietet ignen aber and einen andern Sortheif.

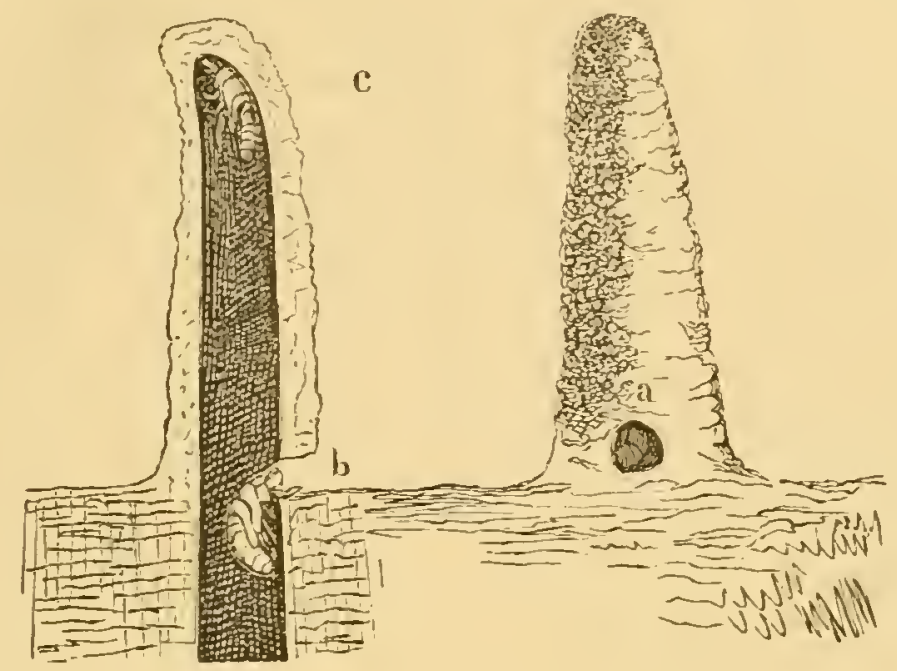

Fig. 47.

Cicasenbau, a Fluglod, c Fupp, verff.

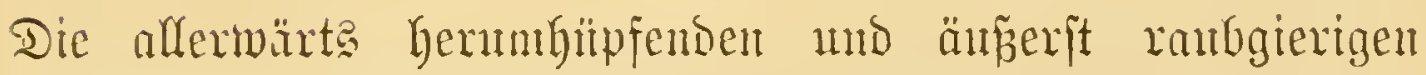
Eprungipimten bitrften bem হejer in Erimernug jein. Ein Fangnes wie andere mathen fie nidyt, unb Der flïthtige Beobadbter wird ïberbant nidyts von Spimfäben bei ihnen merfen. Ilno trob̧oem zielgen fie fajt bejtändig "ein

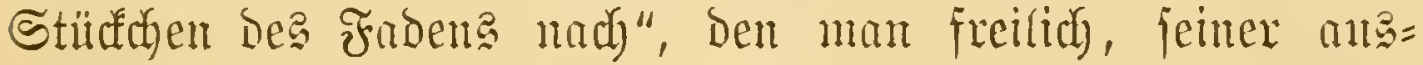
nehmenden Bartheit wegen, un in Reflex Der Somre fiegt, Der aber trobsom rimlänglidy jtark ijt, Das Thier zu halten, toent es fich baran, langfamer ober fihnelfer, anf ben Boden

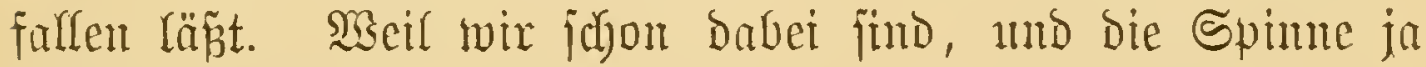
eigentlich body mur eine bejondere Grattung Snjeft ijt, jo fömten wir un nidjt verjagen, eime anf bie $\mathfrak{x}$ iefen= unterjacionng bezügliche Beobachtung mitzutheilen, bie woir unlängft an ciner joldyen Sprumgipime madbten.

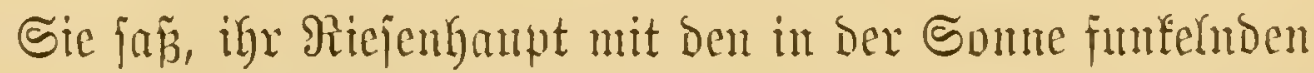
$\mathfrak{U}$ ugen hock erhoben, anf Dem Bripfer eines Birfenzmeiges. 
Dex saind bewegte ifn aber fehr heftig; mo die Spime tradjete offenbax von biejem exponirten Poften megáfommen. Sie lies fich falfen; Denn fanm zwei Boll tiefer breitete fich ein Blatt ans. Säährend fie aber fiel, Drelyte ich Den Bweig

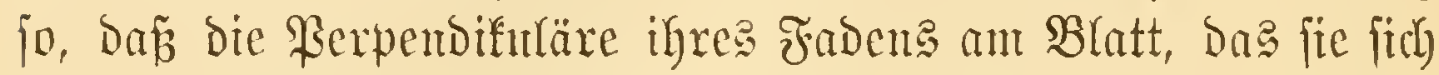

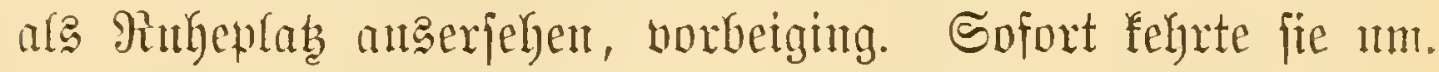
Später, ars das Blatt wieber unter ifr lag, verjuthte fie es

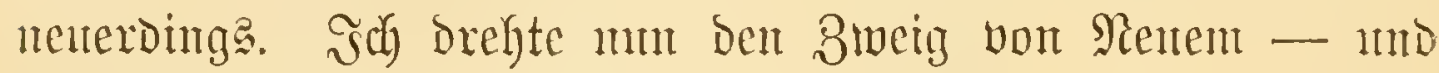
jie fletterte abermals an Seil empor.

Dffenbar befand fich anjere Tumerin in einer ähnlidyen

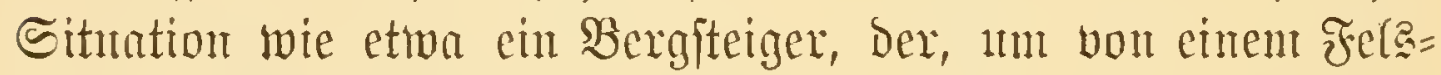

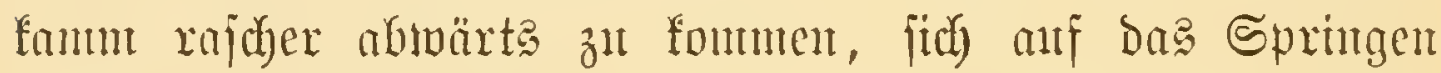
verlegt, ber aber, falls man ifn ctwa an eimem Seife bielte,

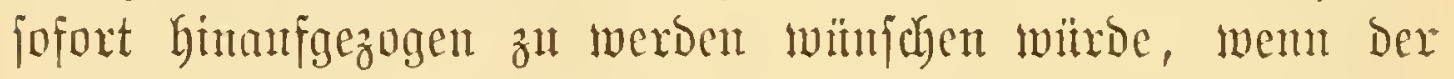
Sorjprung, Den er jidh als exjte Staffel auterjeben hatte,

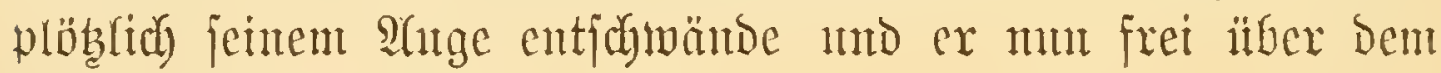
atgrambe jofruebte. -

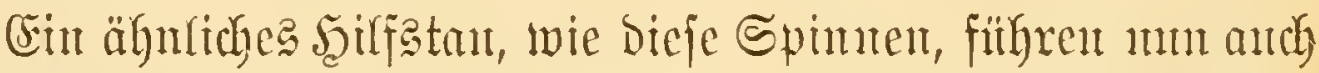

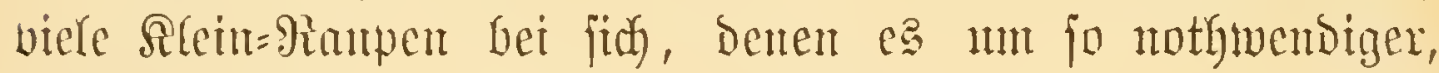

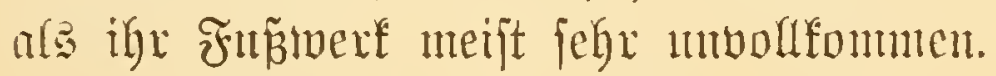

Dody wir baben ja noch Eintiges von ben Futteralen

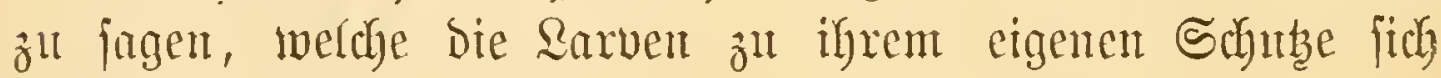
anfertigen.

Eim gar artiges, ats purer Seibe gemoben, zeigt 4ms ente Mrottemratpe, Die man jeitlidy in Frithjulyr an ber ltuter= jeite der Binubaumblätter antrifft. Dieje Seitljen find fajt jollfang, aber, wie der $\mathfrak{L}$ eib ifrer $\mathfrak{B e m o h n e r , ~ f a j t ~ f o ~ d i u m ~}$

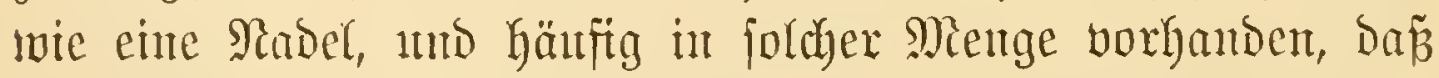
Das Blatt ganz ftrmppig ansfitegt. Das Snterejiantejte ijt Die $\mathfrak{A}$ rt und $\mathfrak{B}$ eife, wie diejer fleine $\mathfrak{A}$ raber fein bemeghidges Belt in anfredftex Stellung erbält. Dies gejuieht theils

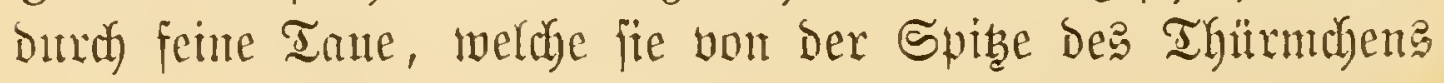


anf bie Brattflädye ipannt, theile mo noch wirffamer baburch,

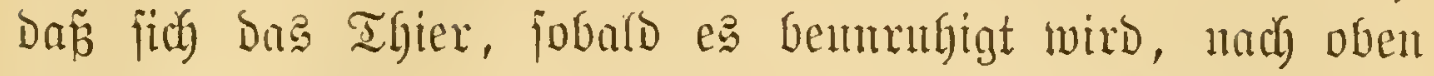

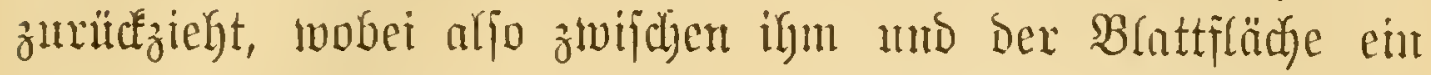

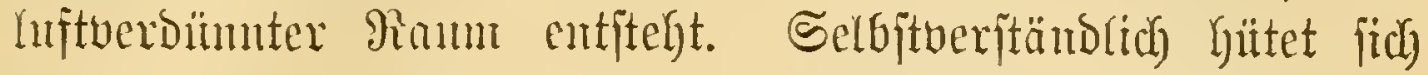

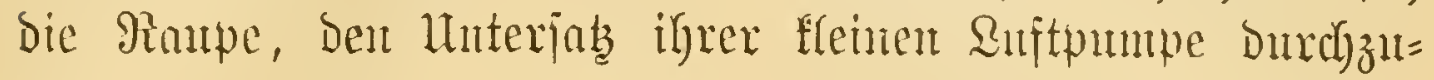
beiß̄en.

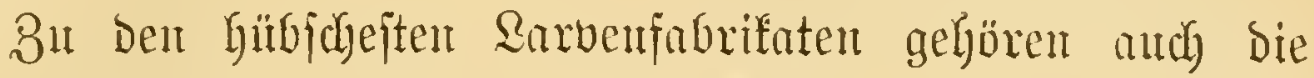
affer jorgjamen รู) fich) Die Rletibermotten ma

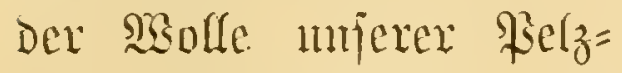
röcke, Miöbelítoffe เ. j. w. anfertigen.

Da biejer : vou friileftem Ŝtter Dem Reibe des Rerieg genta anjizt, jo liegt es ani ber

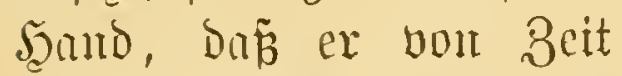
żl Beit vergröpert wer=

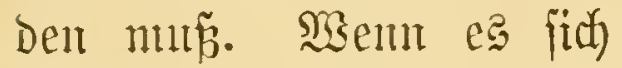
mux ım einte Berlängrumg hantoelte, ginge bie Sache jefyr einfady, es braudyte mx ein menter Ring an= gejerat zut weroent. Das

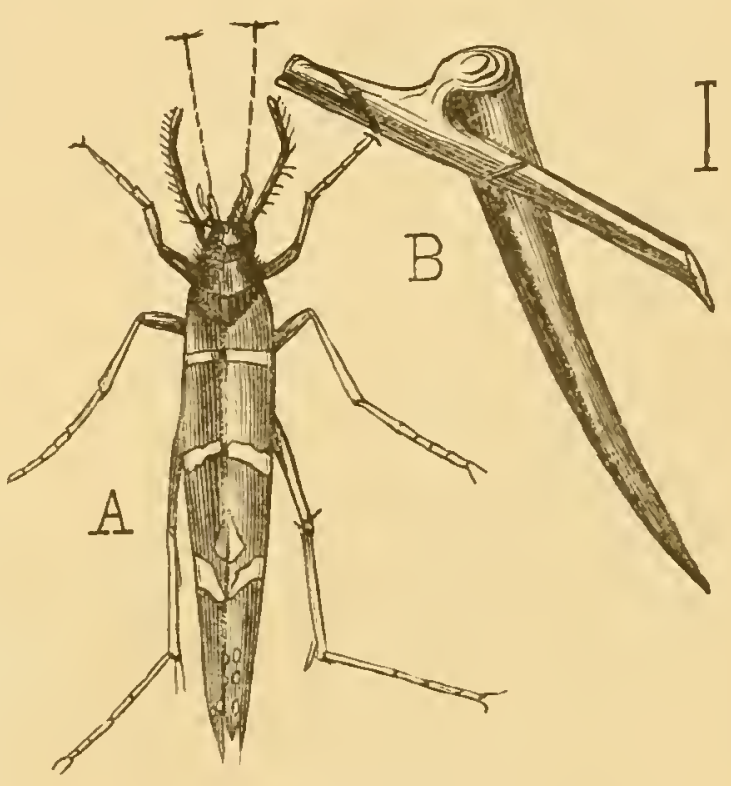

Fig. 48.

Gine Friiflingsfliege (Nystacida trifasciata Trev.) mit sem föderartigen sarven= gehäuje, vergr.

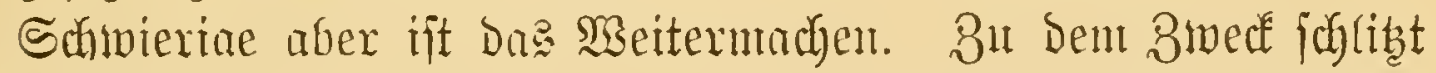
Dic. Schabe Das Futteral, an zwei gegenitberliegenden Seiten anf und idyaltet bam ziwei Streifen bou Der erforderlichen Brröże eitr. -

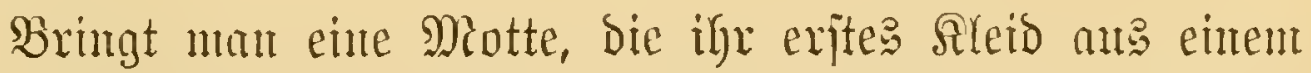
rothen Tud madyte, jpäter auf ein blaues, fo exhalten matïrlich and bie jpäteren Einjojiejel bieje Farbe. Dod wer wird Dem an joldyen Thorbeiten Bjefallen finden!

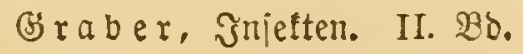




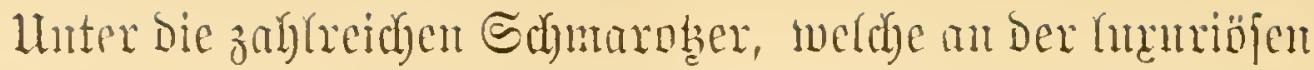

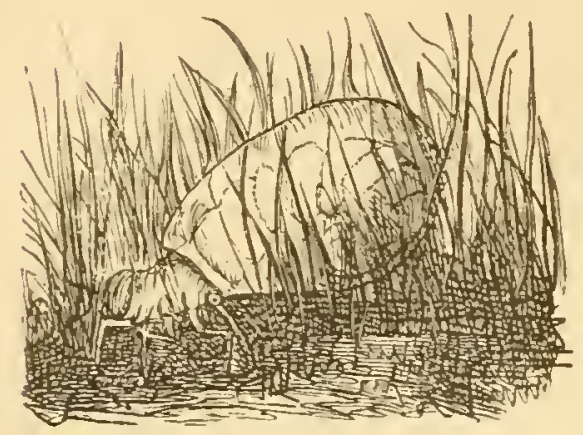

jig. 49.

Eiue Brattfäierlarve (Chlamys plicata) mit ifrem aus Piflanzen= haaren gemobenen Futteral. Tafel Der Storfbieme fortwelgen, gehört audicin cine Miotte (Galleria cerella), Die, bant ifrem ver=

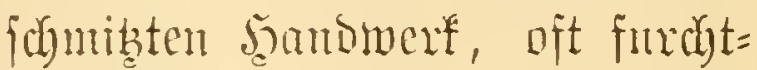
Gare Serheerungen anridytet, ohne

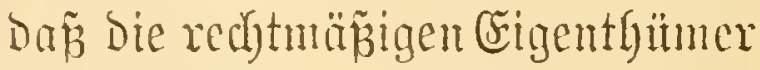
etwas gegen jie menternelymen

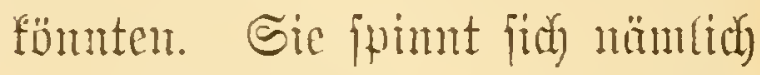

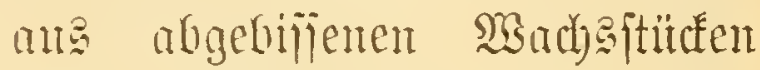
lange Gallerien żlianmen, bie

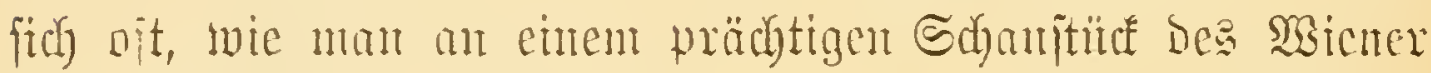

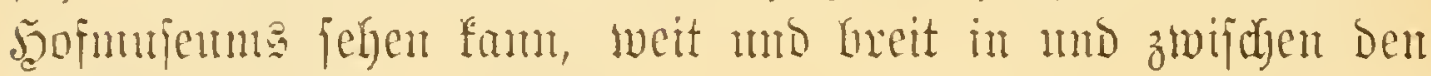
Sibaben verjweigen.

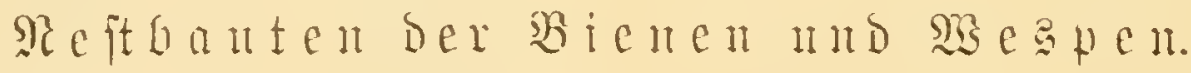

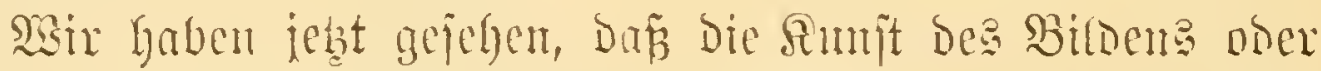

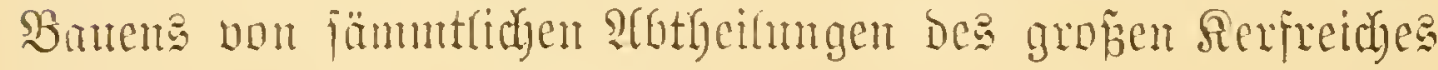

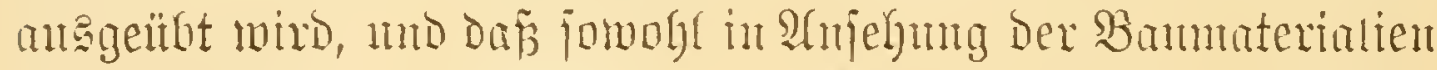
als auch ber Bammethoden dic allermannigfartigiten siserfe verrichtet werden.

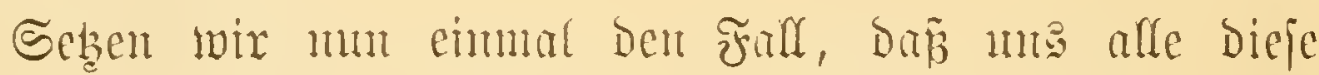

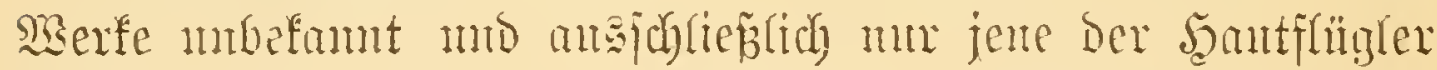

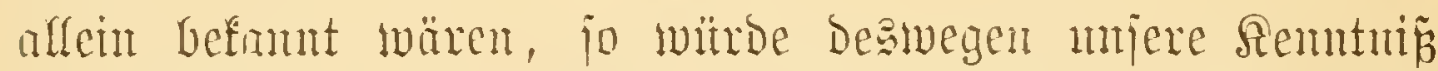

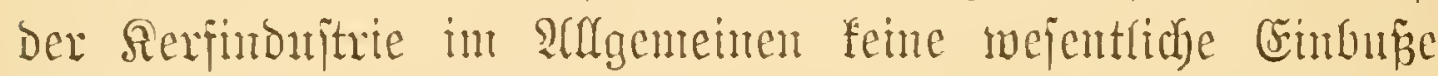
exleident.

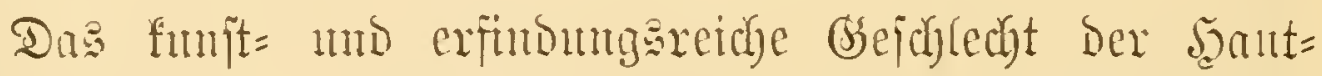

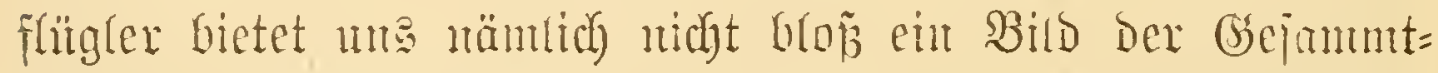
indijtrie ber übrigen fierfe mb bies in den afferverifhiedenjten

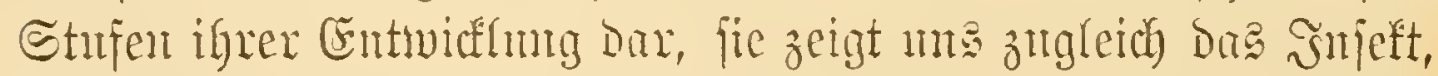
und zwar als gejelliges, als corporatives skejen, anf Der Szöhe

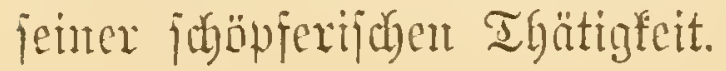




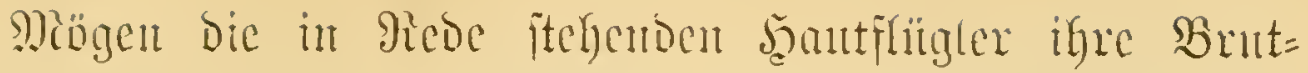
ftätten graben ober frei arff̈̈lfren, mögen jie biejelgen jernex it ober ans was inmex fïr cintem siateriate herifellen, das

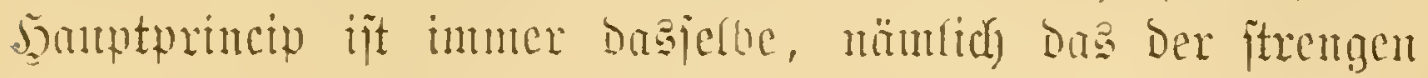

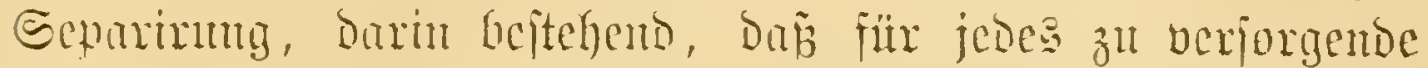
Cit, rejp. Fïr jede ju verjorgento sarve cin bejomberer afrge=

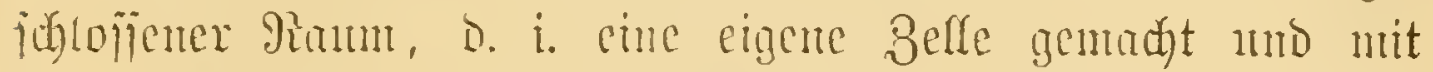

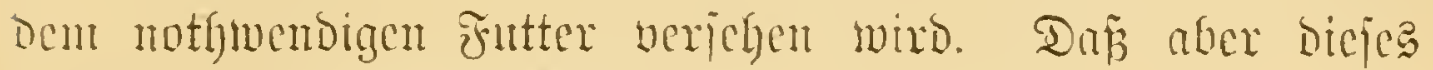
Sirincip anth bas vollfonmentite ijt, mas man jich benfen

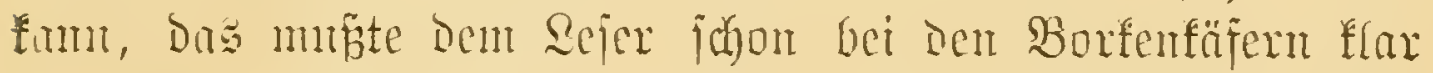

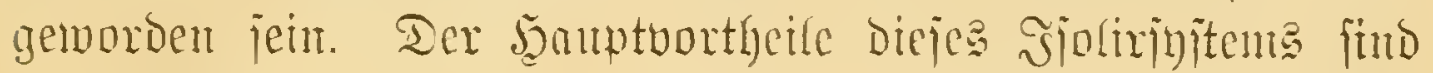

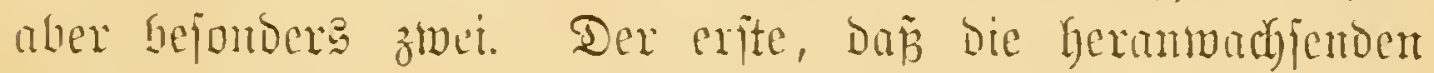

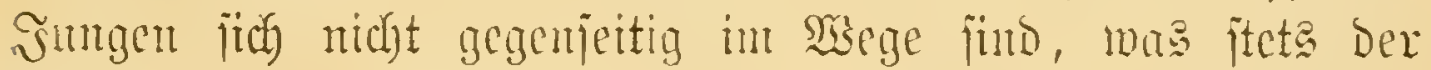

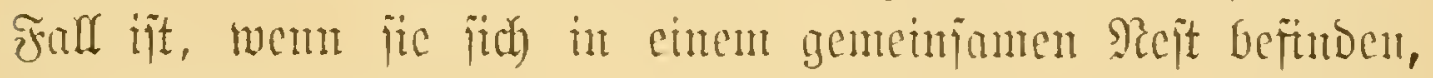

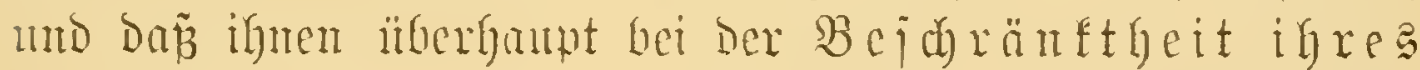

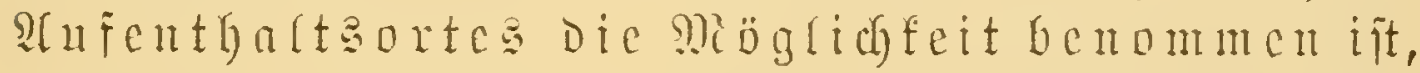

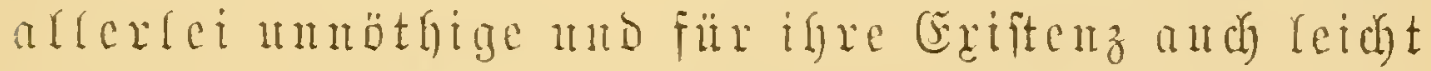

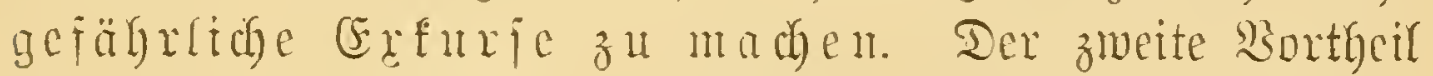

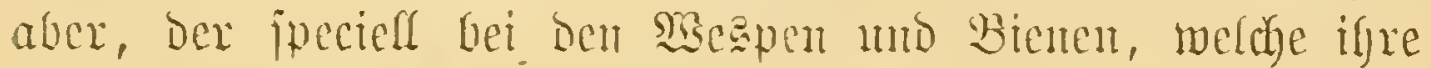

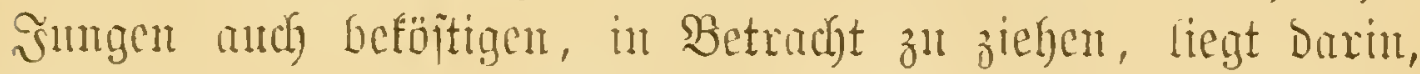

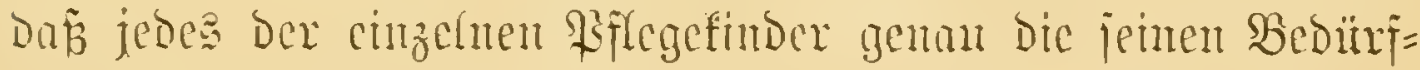

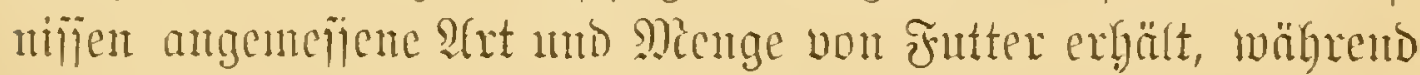

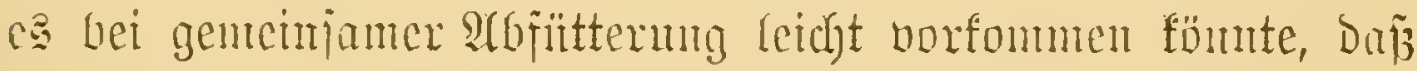

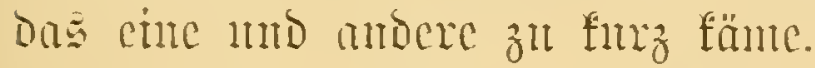

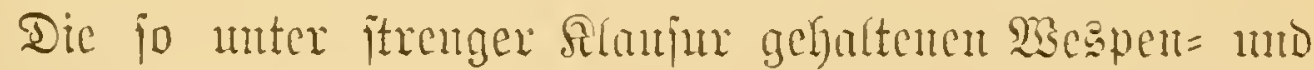
Bientenfindor füfyren mu żwar cin verzweifelt cintöniges Seben - ja jie leben eigentlidy gar nidft, jomoen fie vege= tiren intr, D. h. fie haben nichts weiter zu thut als in aller

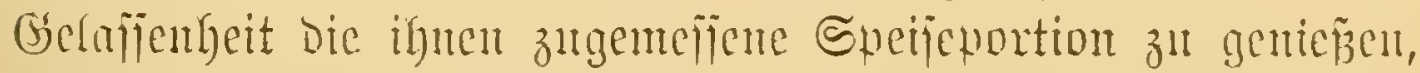

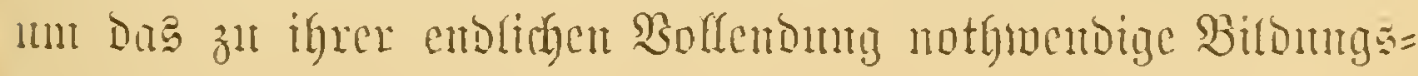
material zall gewimn - aher ca geht bicjen Seäftlingen in

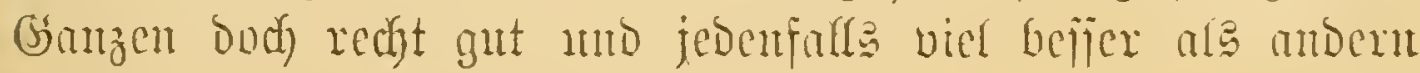




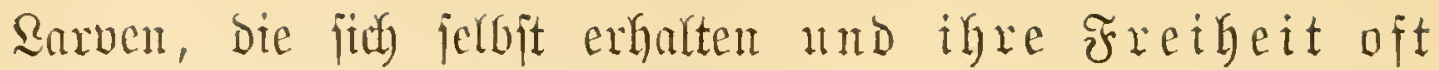
thener bezalgen mïjen.

\section{Banten der jolitären Jummen.}

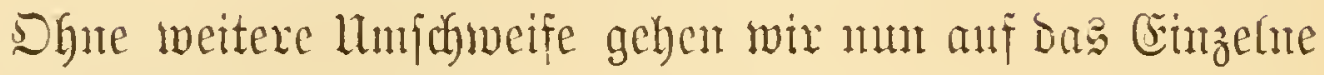

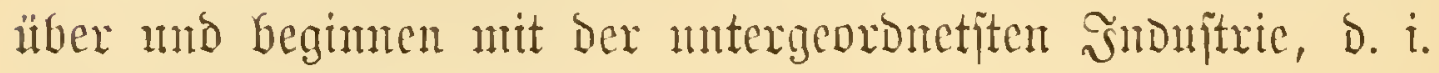

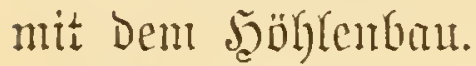

Aut robeften werfalyren die Miord= ober Brabluespen.

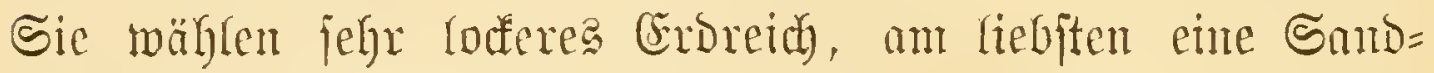

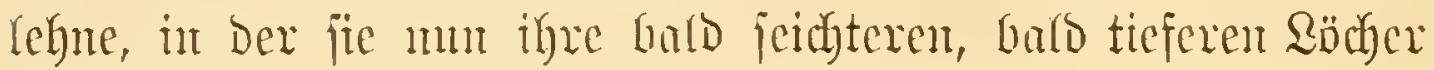

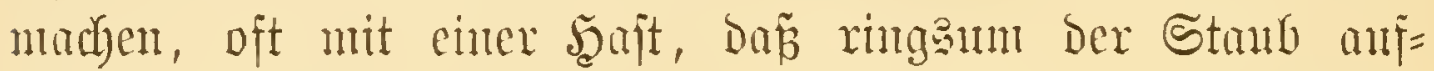
fliegt. Dieje Eile ift leidyt zu begreifen, Dent jie Graudben für jedes esi cinen eigenen uto jwax einen zientich geränntigen

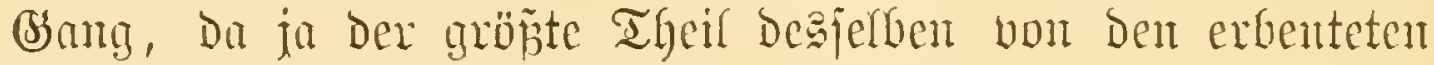
Serfon cingentonmen wird, weldye die gathung ber ans fahlitufenden Rarben Girloen.

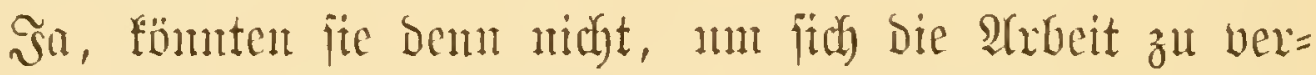

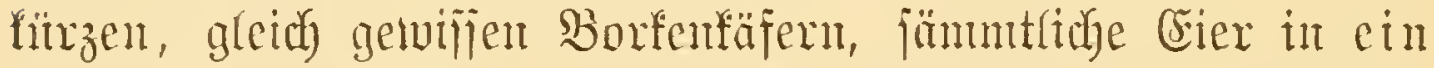

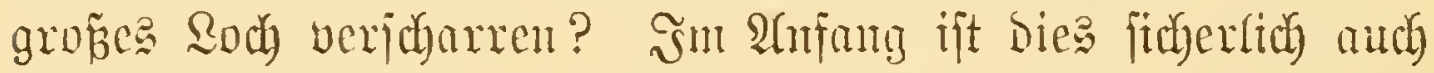

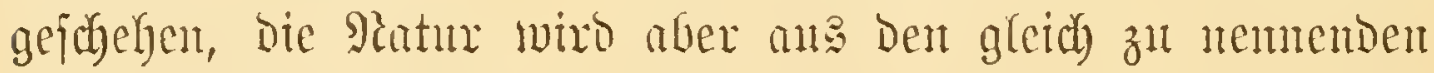

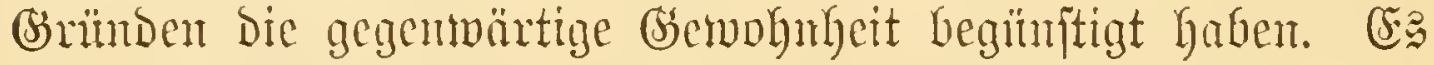

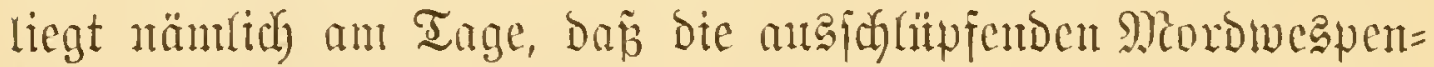

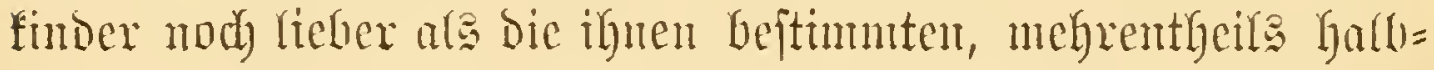
todten mo jum Theil jon verwejenden Injeften ifre eigenen

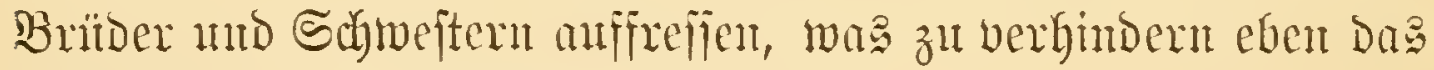
gegenmärtige Sijolinfujtem geeignet ijt.

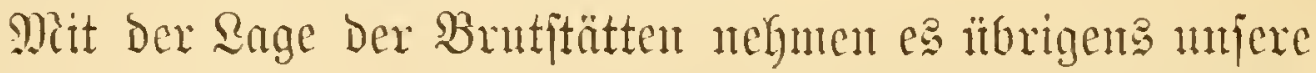
Bräber an menigiten genan; ja fie bohren fich oft, wentigftens

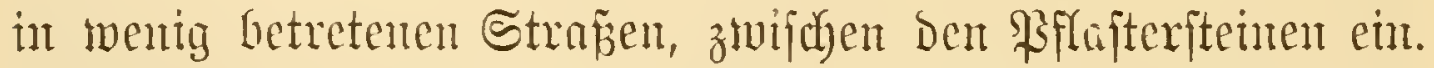

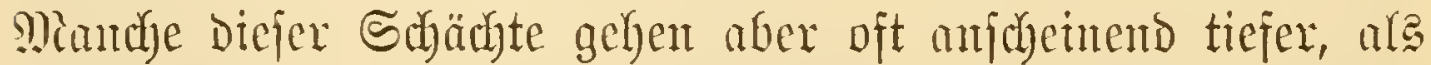

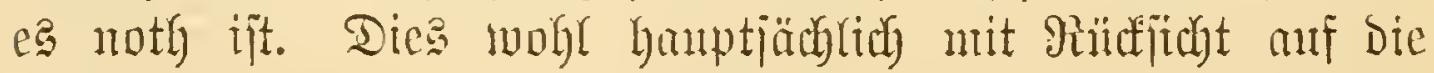
vielen Sinnajiten, die nit bejonderer Sorliebe in Diejen meijt twogl verproviantirten Interftumbsörtern jich anfiedeln. 


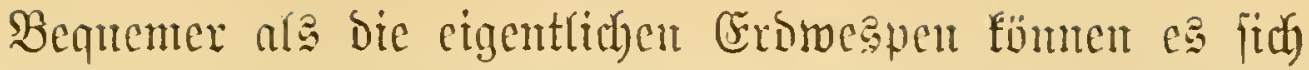
Die Erobientr, D. h. jene Stachelträger machen, die ihre Brut

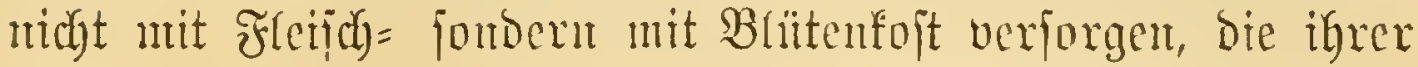

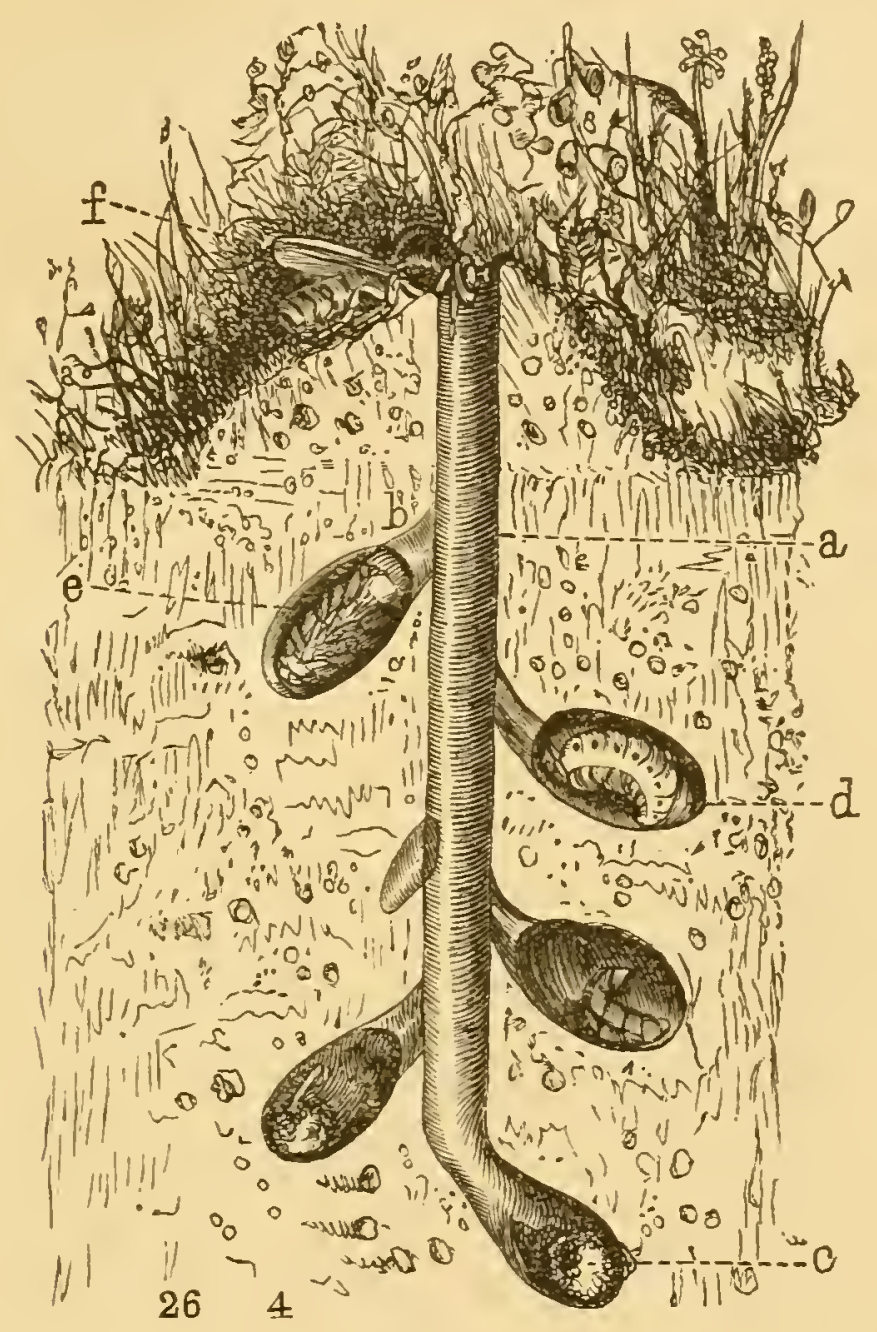

Firig. 50.

Frozelfenjyitem einer Trauerbienc (Andrena vicina Smith) mad (Fuerton. a Şuuptgang. Эn ber unteriten Belle ein Bollentumpen mit Daranigelegtem Fi.

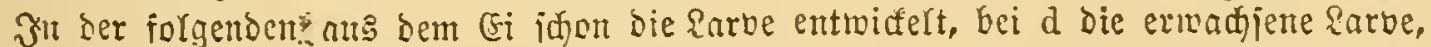
bei e die ßrmpe (welde aljo in ber älteften Belfe liegt, bie zugleid bie oberite ijt). Rat. Grr.

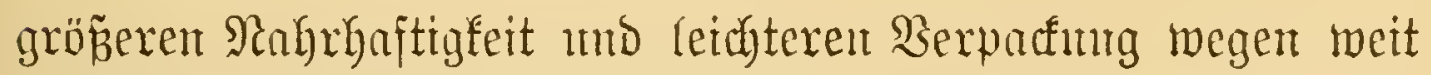

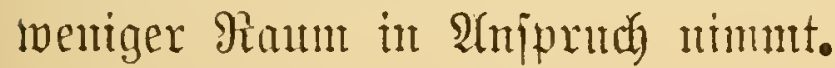

Alferbings gibt es auth Bienten, bie für icbes cri eine Separatgöble madyen, in beren Grumbe man, wenn man fidy 


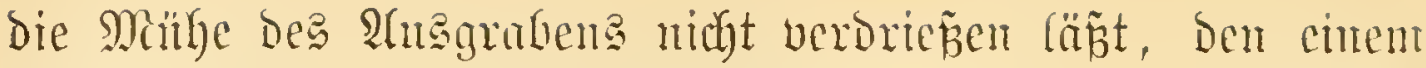

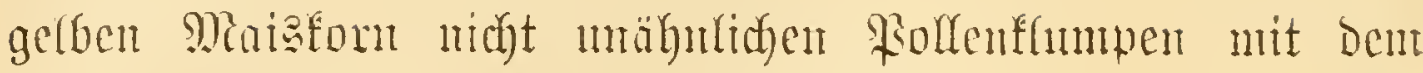

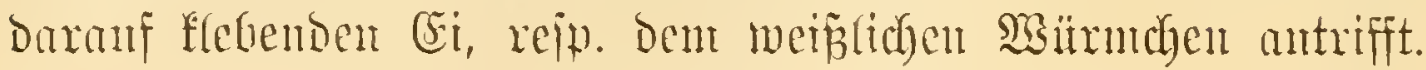

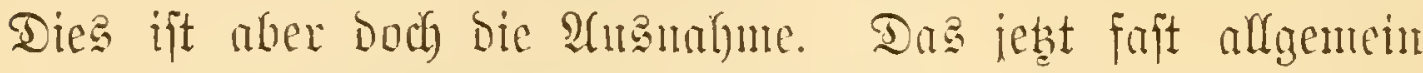

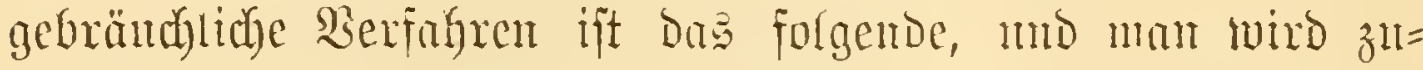

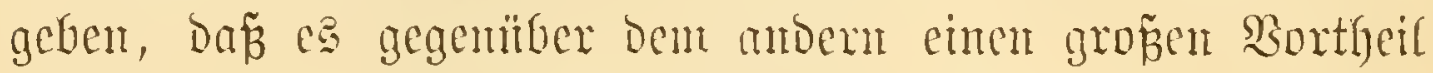
gewälyrt.

Hut es furz zu jagen, jo handelt es fich um einen $8 \mathrm{weig}=$

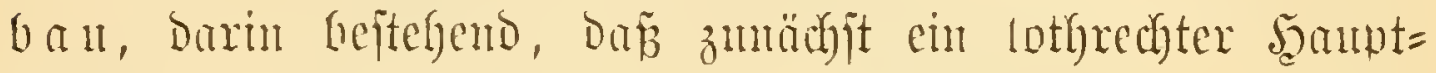
ichadyt von ber exforderlichen Tiefe angelegt wird, bon beut nus Dam Seitengänge mit ben ertweiterten Brutränmen oder Bellen atsgegraben werden.

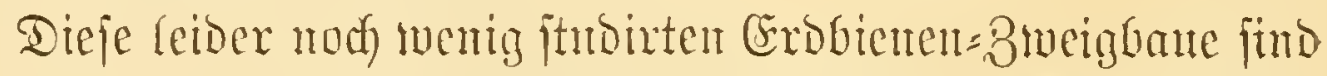

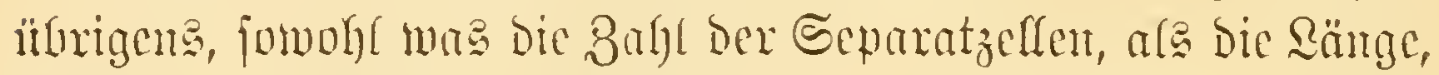
Form mo Rivgtung Der Bugäuge betrifft, änéperft numnig=

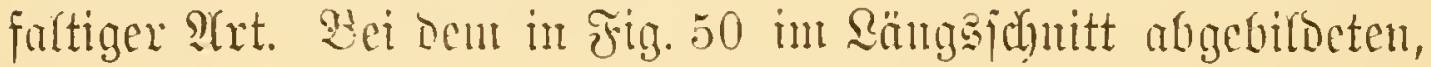

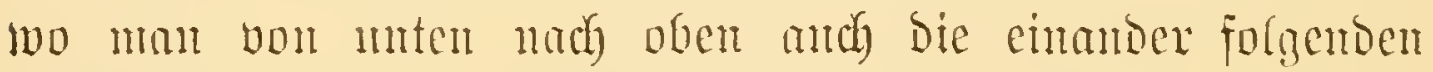
Entwiof́lungajtndien jehen fum, itehen bie Bellen änperjt

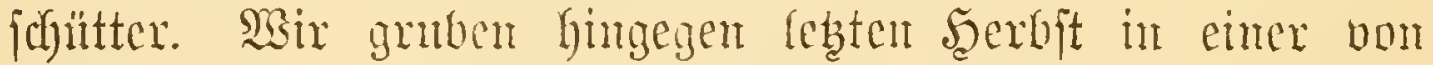

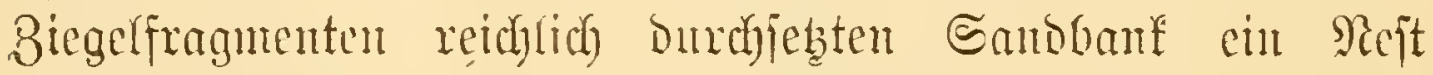

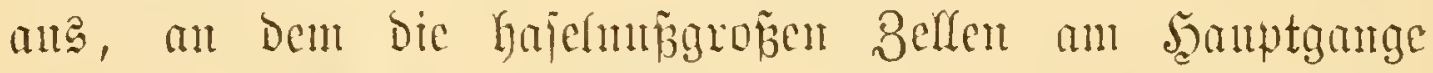

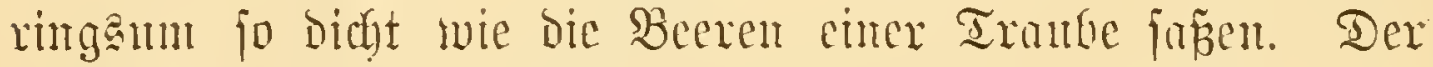

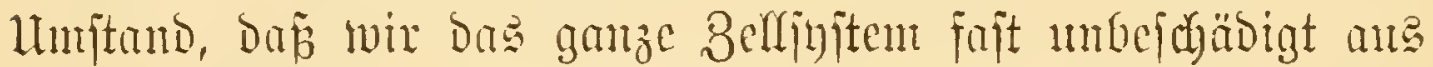
Den mugebenden locferen (Eroreid) Geranghefanen, Gemeijt

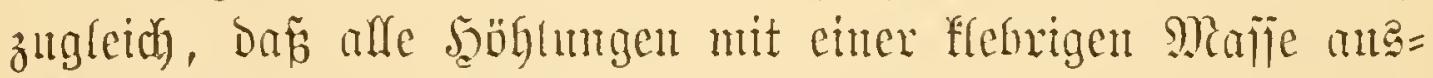
gefleibet werden; Dem mux burch eine folde fomten bie zu= nächjt antiegenden Steirfragmente jo fejt berfittet uorden fein. Dex gefammte hiex in gede ftehende $\mathfrak{B}$ an soax beiränfig einent

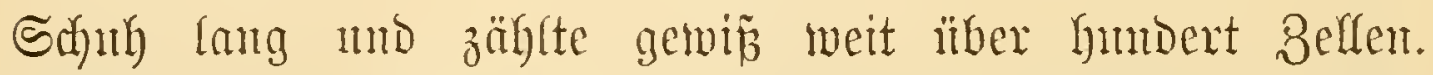

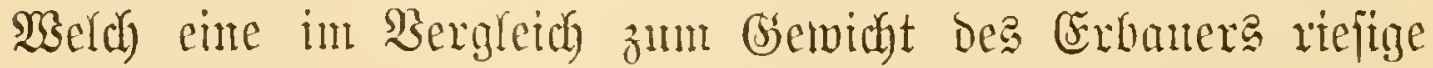
Dunantität Erode muñte Derjelbe alfo anggehoben, mo wie viele Tanfende von $\mathfrak{B}$ (üter murpte er abgefucht mo genlümbert haben un alfe bie Brutgenüb)e ju verproviantiren! 


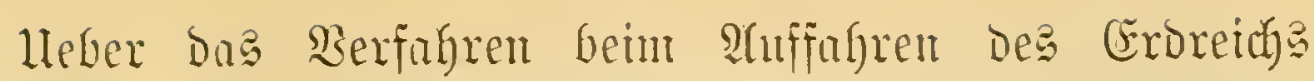

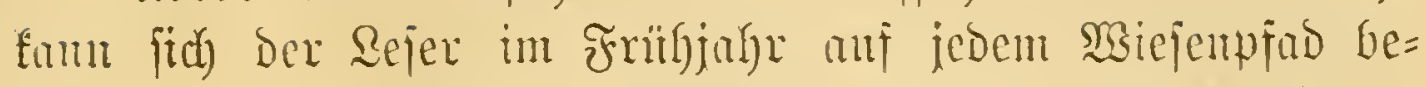
lefren. Son Stelfe ju Stelle fiefter er $1 \mathrm{~mm}$ bie in 2frbeit be=

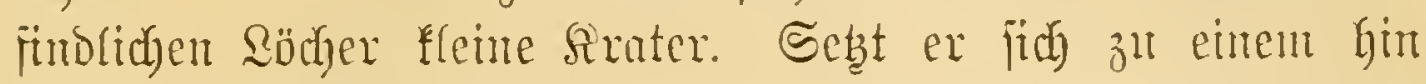
und gibt jorgfältig Darauf adyt, jo bemerft ex, falls das Thier nidyt abmefent, ïber fitrz ober lang an ser Tiefe eime oft jebr bebentende Crolabung Gervorfonmen und quäter die Riene, welde mit bem Ropre Das Benty vor fich herictiebt.

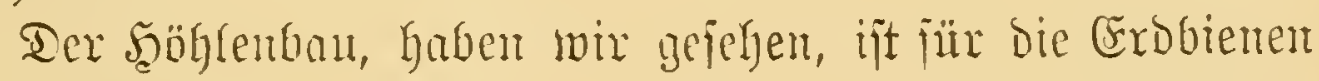

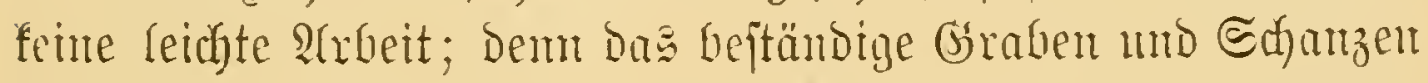
foitet eine gewaltige ânitrengung. aber mjere soinembe haben, mie wir uns nenerbings anf einem eben beendeten Spaziergang itberzentent, nody ganz moere siöthen.

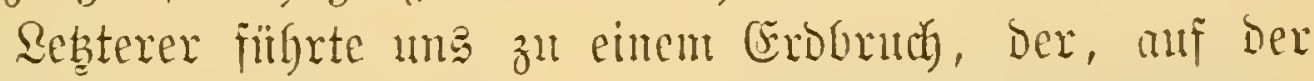

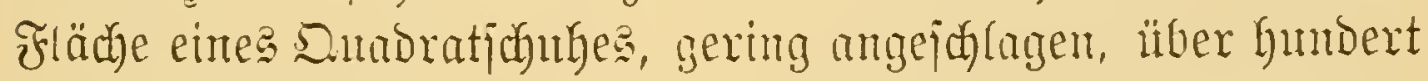
fleine frijule södfer zeigte, weldye alfe in Dent lebzten adyt Tagen gebohrt morden jein musten. Und dies jelbjtberjtändict)

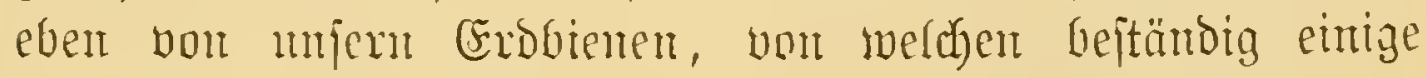

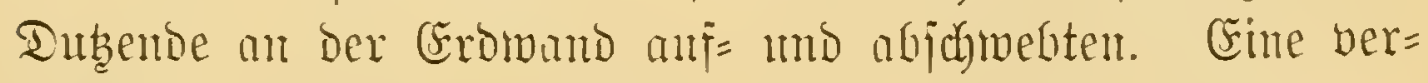
folgte idy, nadjem idh ifr früber Den Şinter(eib rotg Gemalt gatte. Sie frod in eins ber Röd er - aber es fam ifr barms eine andere entgegen - fie hatte fich geirrt. Sie

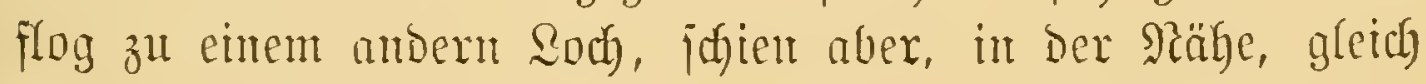

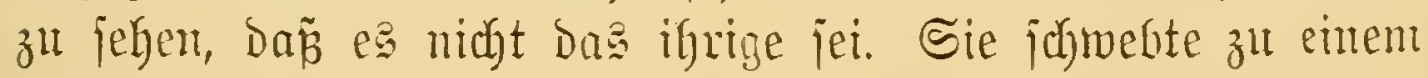
Dritten, bierten, fünften Stoffer - aber inmer vergeben: Sch beobachtete jie mintejtens cine Siertelitumoc. Sie judyte und judjte, jie flog bon oben nach muten, von rechts nach linfs, und in allen möglidyen Ridytungen, fajt vor jedon Etollen etroas vermeilent. alber roie, fragen roir, follte jie unter dent

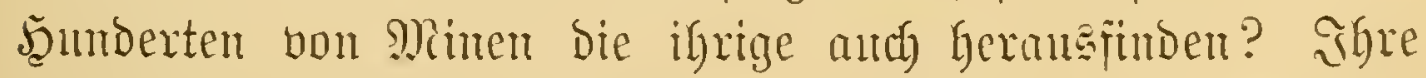

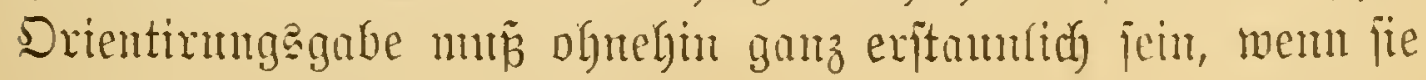

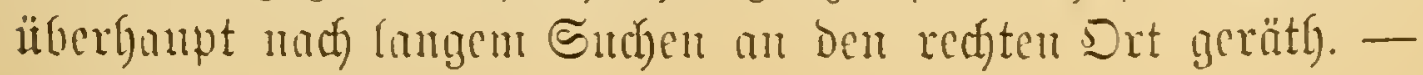




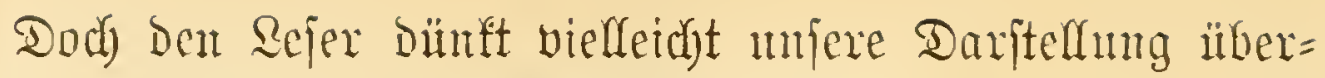
trieber. Bredyen wix baher eine Edyolfe Erde los. Dex

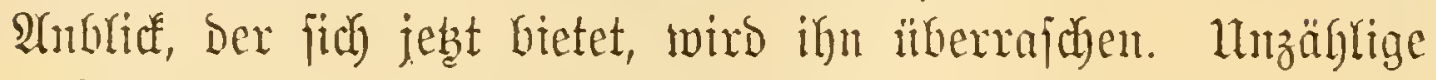
Bellräume, wie an einem Schwamm, einter hart ant andern,

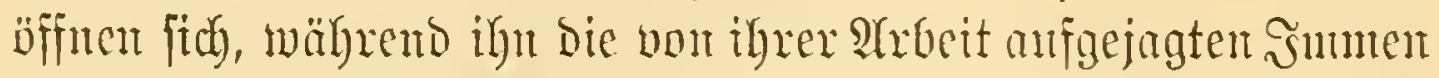
will mrijchwärmen. Itnd in jeber biejer miedlichen, fein ans=

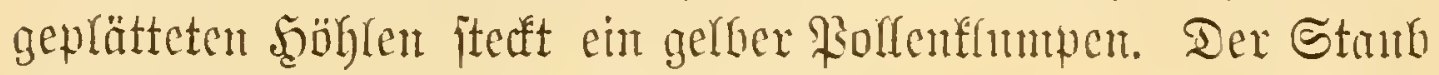
Dex Brïten, bie ï bex Den Erbabjtmz frensing lachen, ijt zum grozen Ibeile faftifd unter bie Eroe gewandert.

Murfern wir mut eimmal cinige Şmoerte biejer Belfen

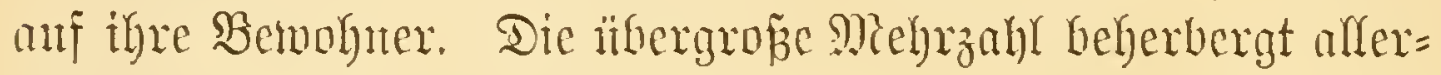
bings nux eine einzige Nadae, und zmax (5. Stuti) in Den ver=

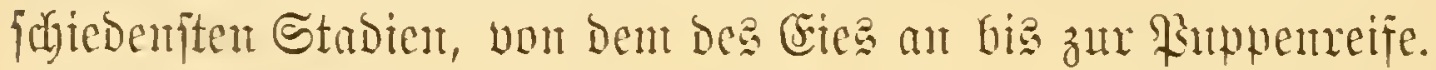
Sn cinigen wentigen aber jtecfen beren zwei - nol hier jichjt bu gar eine Sinmer, wo brei sarwen anf cincur einzigen

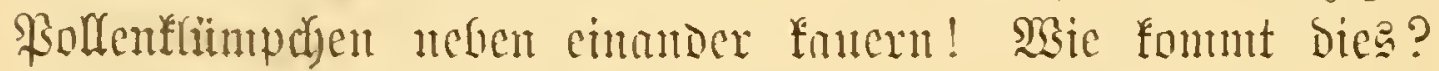
Anzumelymen, da

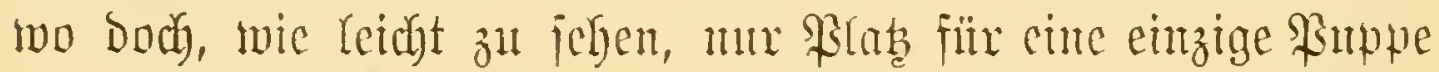

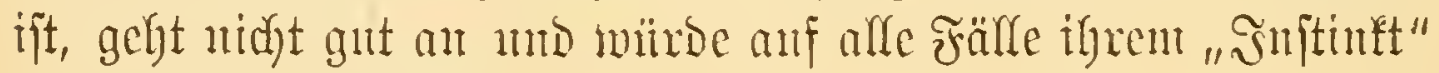
wentig ergre madyen.

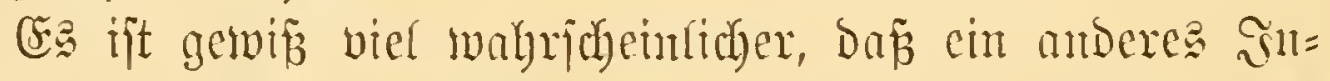
bividum ein (si eingejdunnggelt hat; Dent, wohlgenterft,

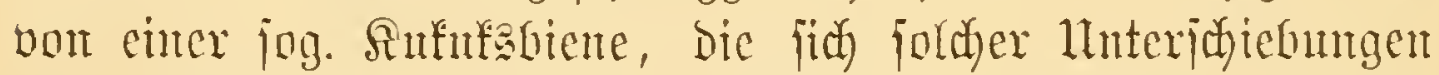

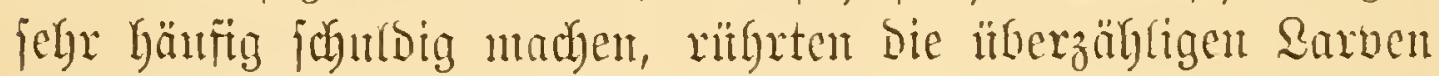
midht her.

Aher wär' es and), jo mu

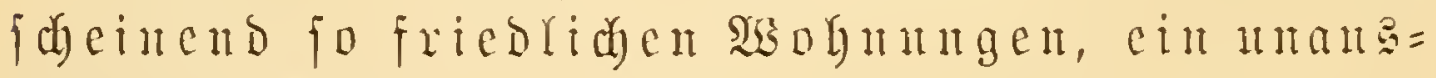

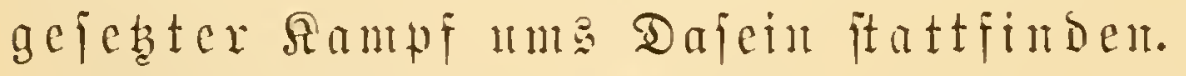

Bei ber Errflärnng Der Rerfbanten nimmt man viel zn twentig

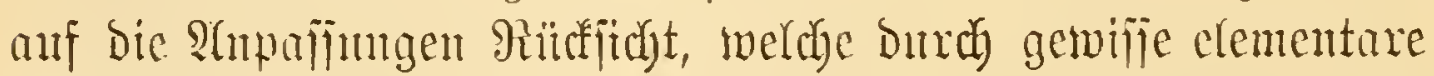
Ereignifje, fermer Durch die jemeiligen Bodentuerhältuifje und Durch manche ambere lumptänbe gefordert werocn.

Nan begreift, ba 
Den Griflentödfern menigitens an Eingang nad) oben füthren,

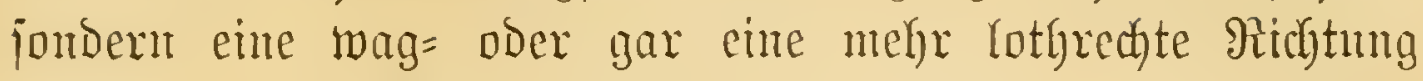

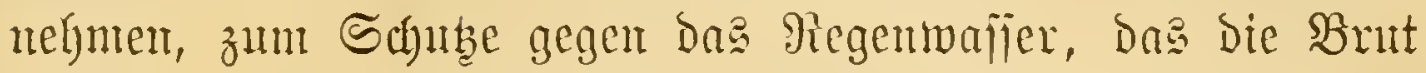
erjänfen witroe, cutjpredyend gejdütst werden mitjen. Die Mimirfpimen haben zu bem Bweá igre eigenen Thüren. Die meijten. Bienen veritehen aber bieje Runt noch nidyt, fondern jie beritopfen einfach die Mïndung. Ssejchiegt bies

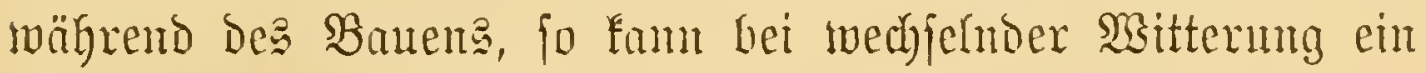
folder Sorgang bie atrbeit jebr auffalten; gejujicht es aber,

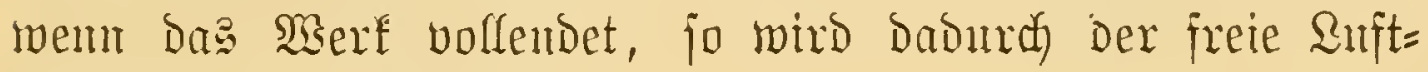
verfebr zu fehr bejoräntt.

Nan höre man, was dic jog. Manrermespe (Odynerus

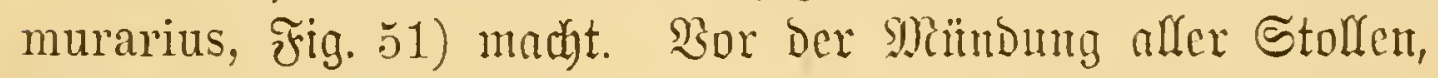
bie alt pomig gelegenen (Fro = britchen, hjer im Brutgthal 子. B. Käufig żu finden, löthet fie eirten ans verfitteten Sand beitebenden, brumenrobrartig gef́rïmnten Tubus an. Afuf= gefaller ijt biejer jeltjame Borbau allen Entomologen; aud ber unfinmigiten (ers=

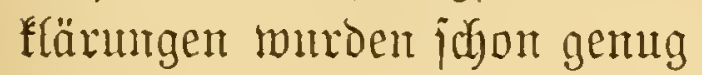
gegeben. Naut, was ijt es aber Damit? Sidjer wifjen wir's

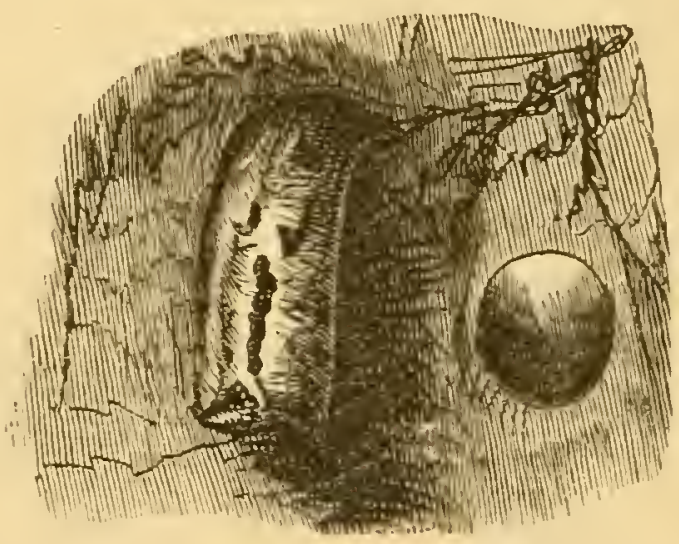

Fig. 51.

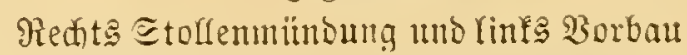
ber Maurerwespe (Odynerus murarius), nat. Br.

allerbings nidyt; wir glauben aber nidyt weit fehl zut greifen,

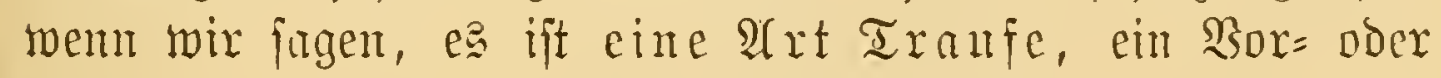

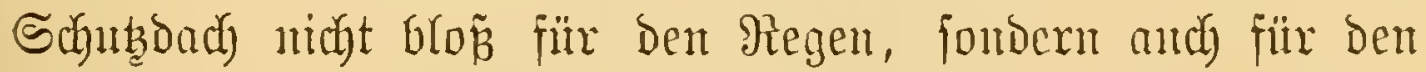
bejtä̈rbig von Den (eromänton fidc) ablöjenden Sand, meldyer Dent Gantg verjaütten lönte.

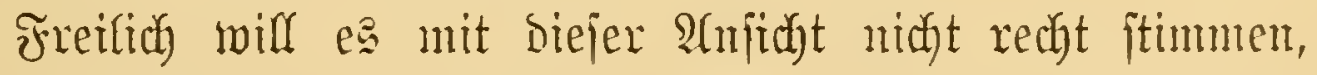

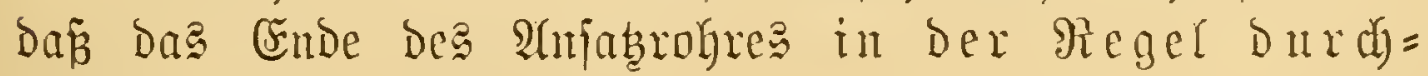
brodhen genrbeitet ijt. 
Bei biejen Refteru ift and zu exjeben, wie die AReigun g

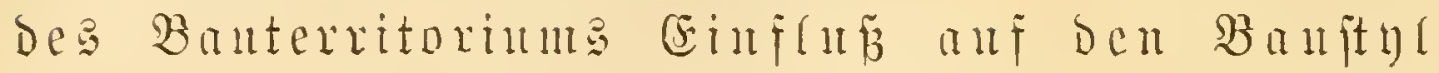
gewinnt, ein Lunfanto, ber ja bei ben Banten vou Menjeden= ganb läugit jutgegeben ijt. -

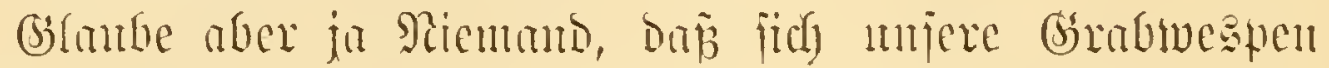
Daranf feiften, iffe Brut gerabe ocr errde anzunertraten. C5. fommt ifnen meniger mif Den bejomberen Dot mid anf Dus bejombere Material, als anf bie Tanglidyfeit besfelten

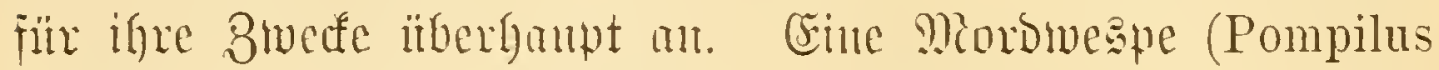

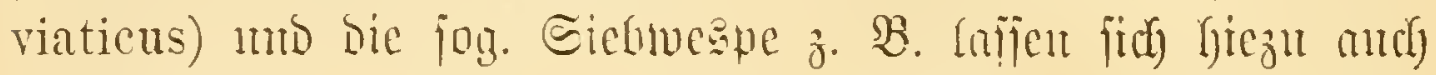

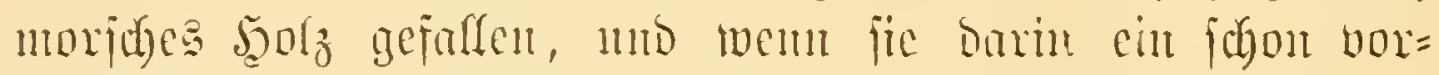
gearbeitetes Roch finten, ift's ifnen nod licher.

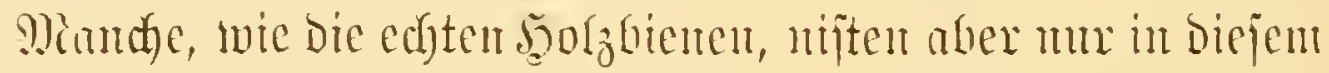

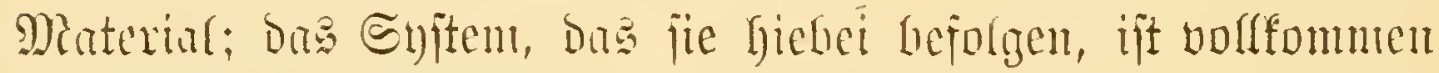
Der Ratur bes bemutzten Stoffes angepañt. Sie magen einen

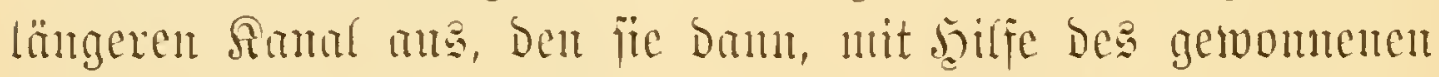

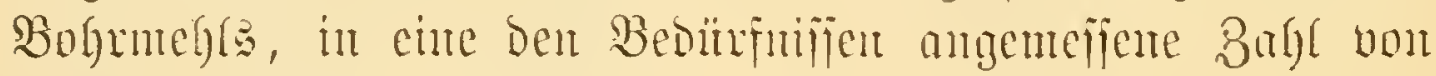
Fädhern abthilles.

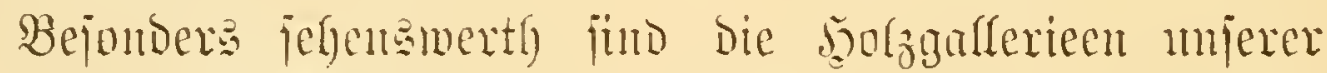
Xylocopa. Die Rnnmiviünde, melde fit madyt, gleidfen in

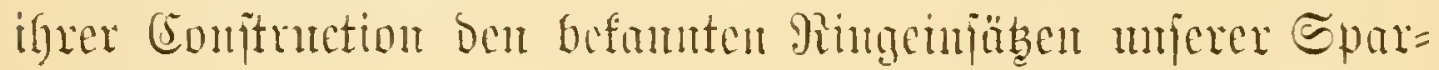

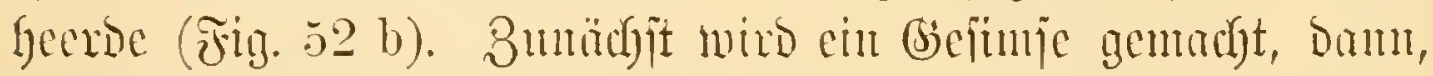

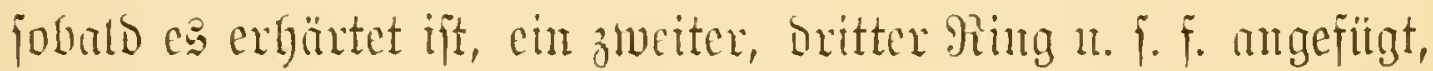

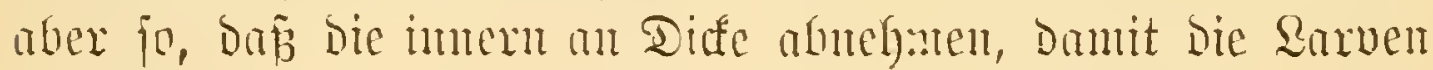

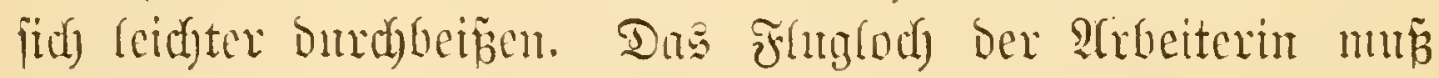

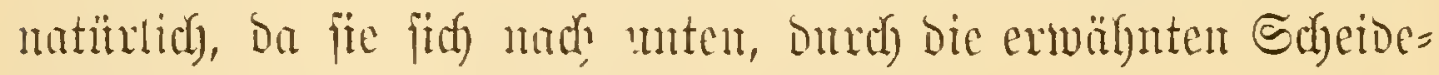
sünde, ben 琶eg verjperrt, oben liegen.

Da aber Die Ŝluajfen Der mutern mid juerft gemadyten Beffen frither als bie obern flügge werben, mb es midyt jein

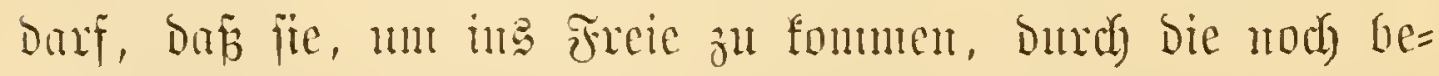

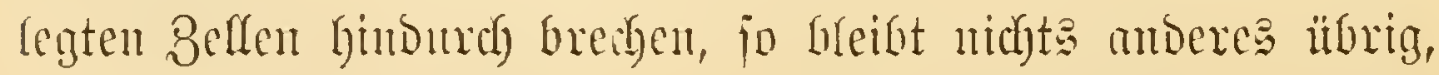

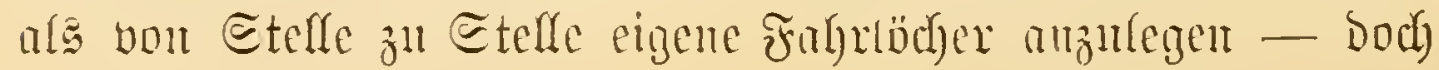




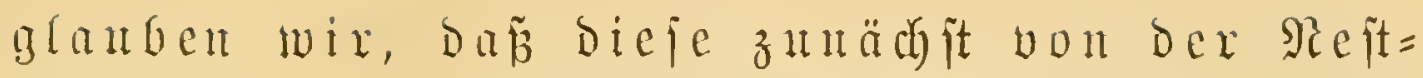
bauerin zu igrem eigeneu 8 wef́e, mäm(tich zun (ent=

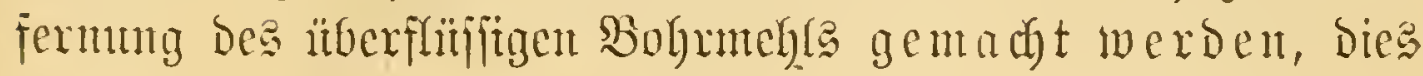
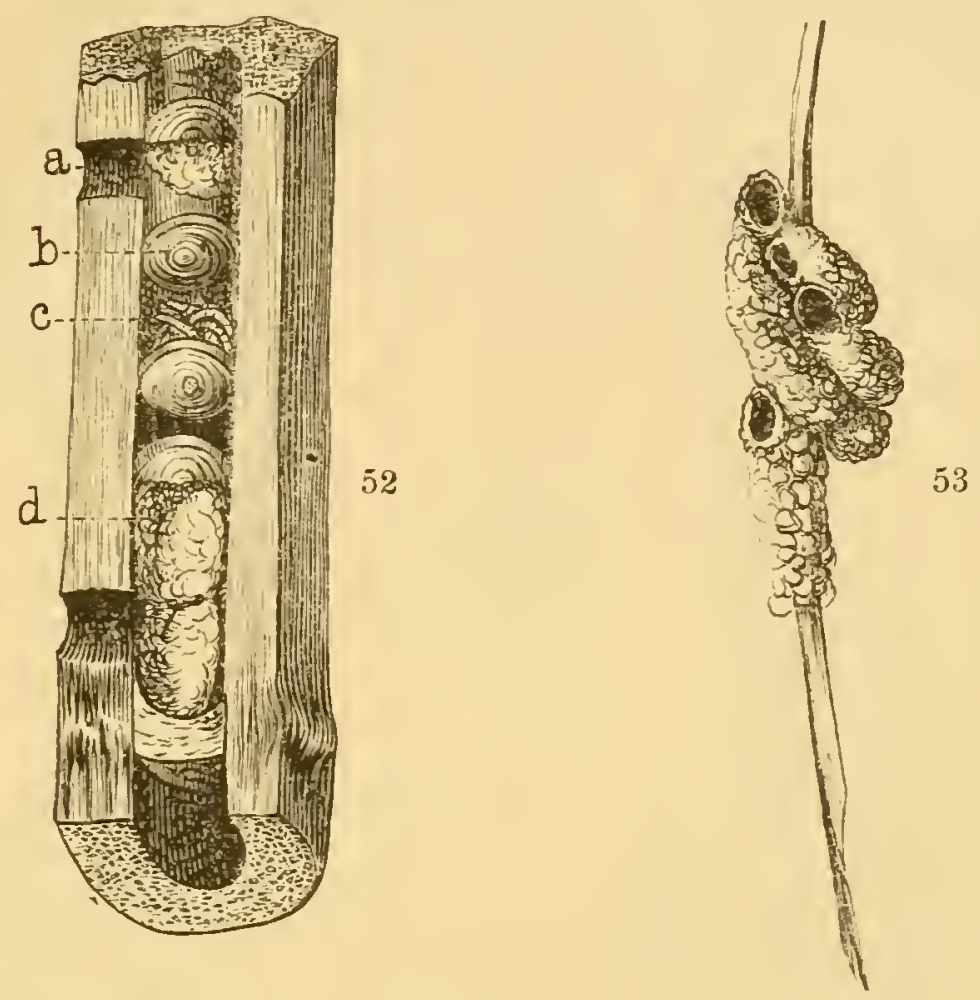

Fig. 52.

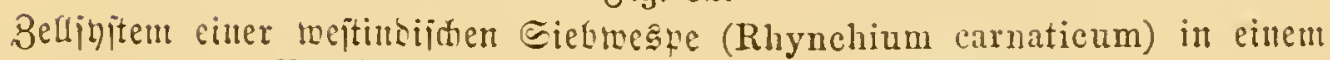

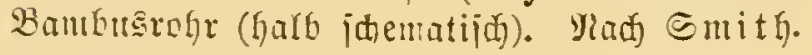

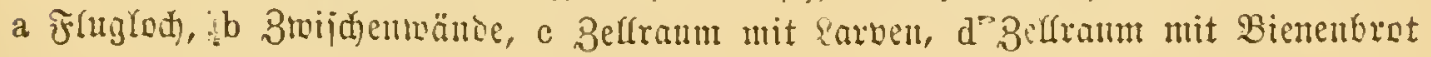
eriiiflt; $1 / 2$ nat. Grr.

Fig. 53.

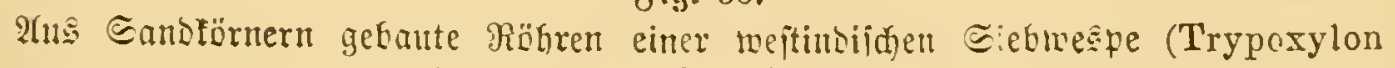

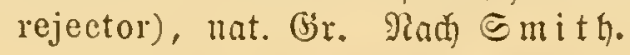

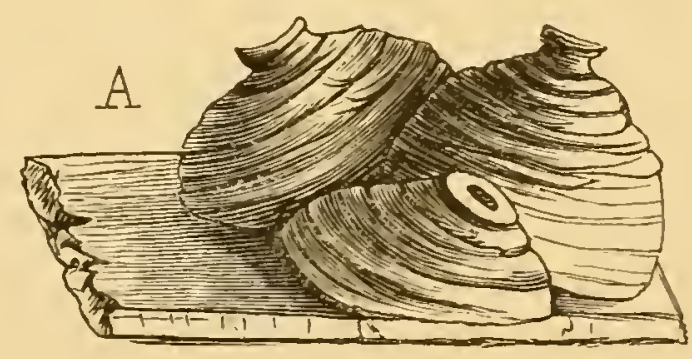

Fig. 54.

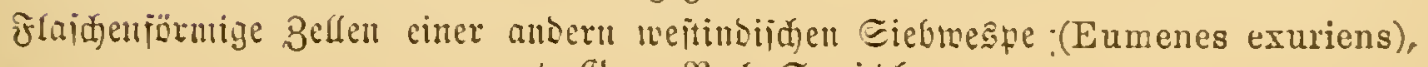
nat. (Srr. Rad) Smith. 
umjontehr, ala het etfichen exotijhen Şolzh bienen (X. chloroptera),

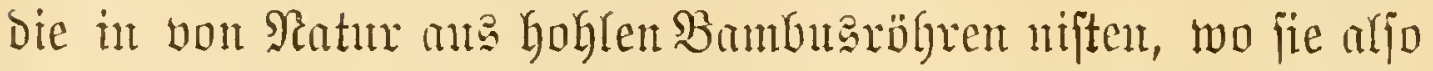

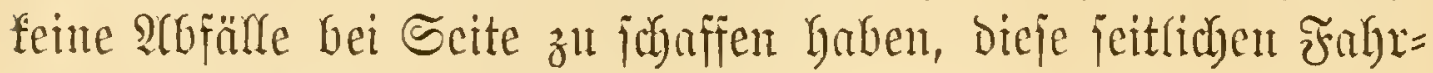

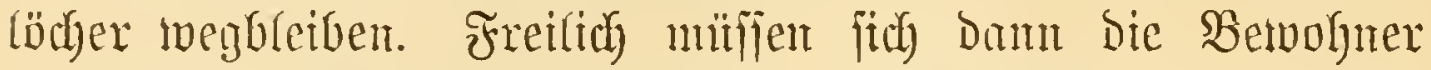
ber nieberen Stocfwerfe gebulden, bis die ber oberen ats= geflogen (

Sa, worats mathen aber Dant bie Bambub=Bienen ifhe

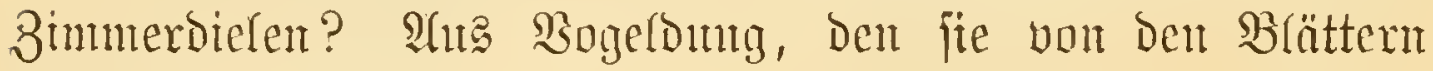
abungen! -

Die jebst bejprodyenen Bruträıme find im Banzen bod jebr rober Satur, wahre Rroletarierwohnungen. Manthe

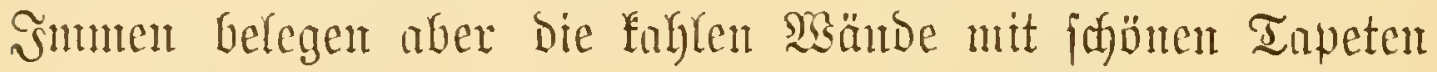

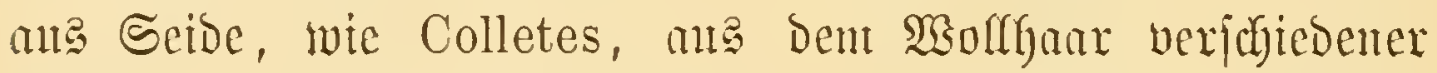
Blätter, wie z. $\mathfrak{B}$. Apis manicata, ober, und dies am ëftejten,

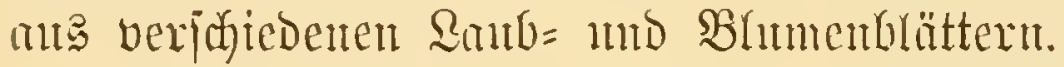

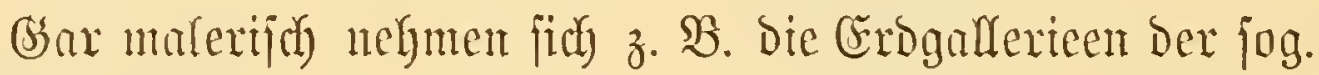
Moryntenen ans, bie man un bie Erntezeit nidut felten in

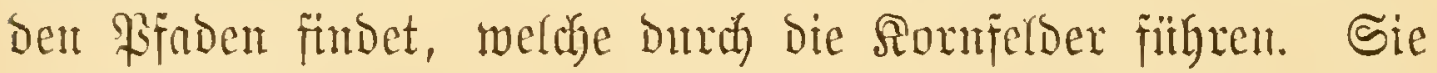

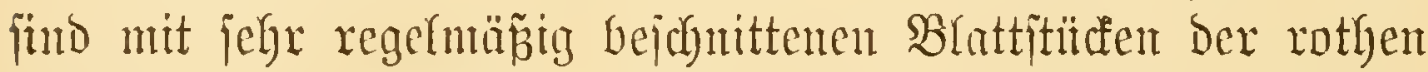
Alatichroje atggejüttert, wobei bie Biene bus ßerjahren be=

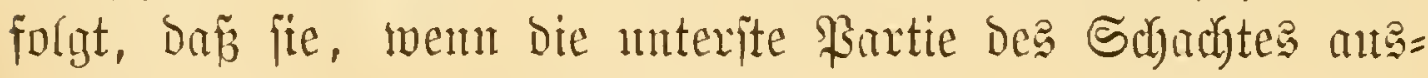
geffeidet und mit âbung verjorgt ijt, die baritber empor=

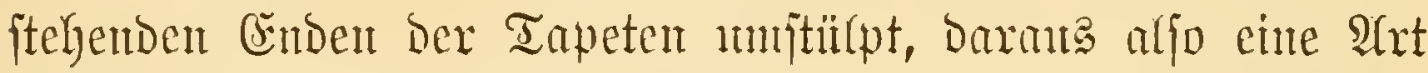

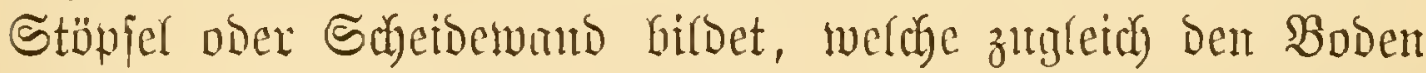

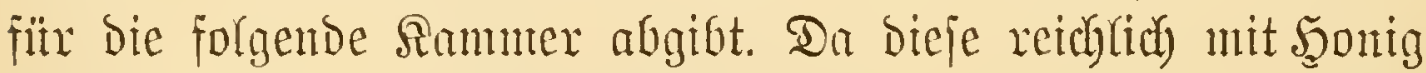

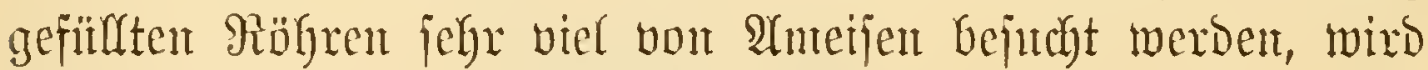

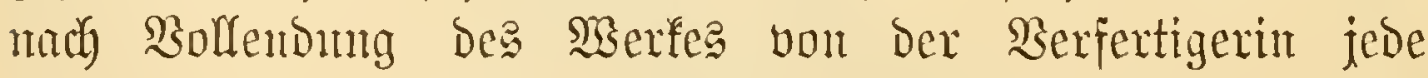

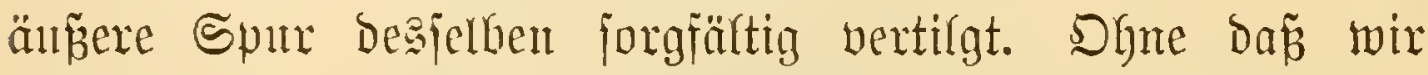

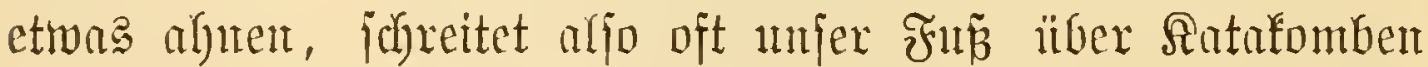

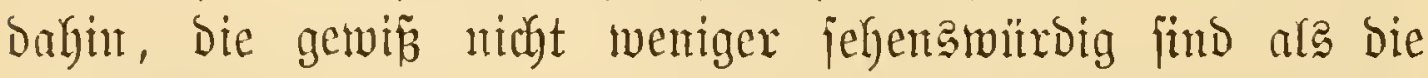
unterirbijchen Gräber, weldye Der Menich gebaut hat, ja, infoferne und weit interefinter, als fie nidgt Bebanfungen 


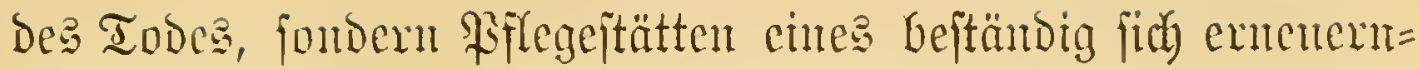
Den Rebens funt.

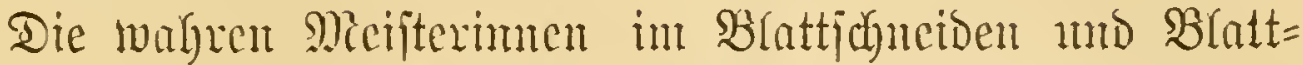

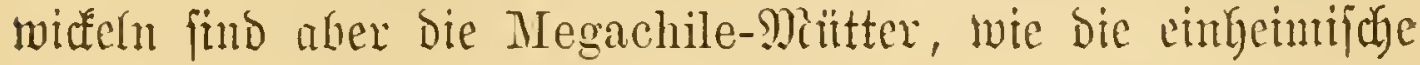
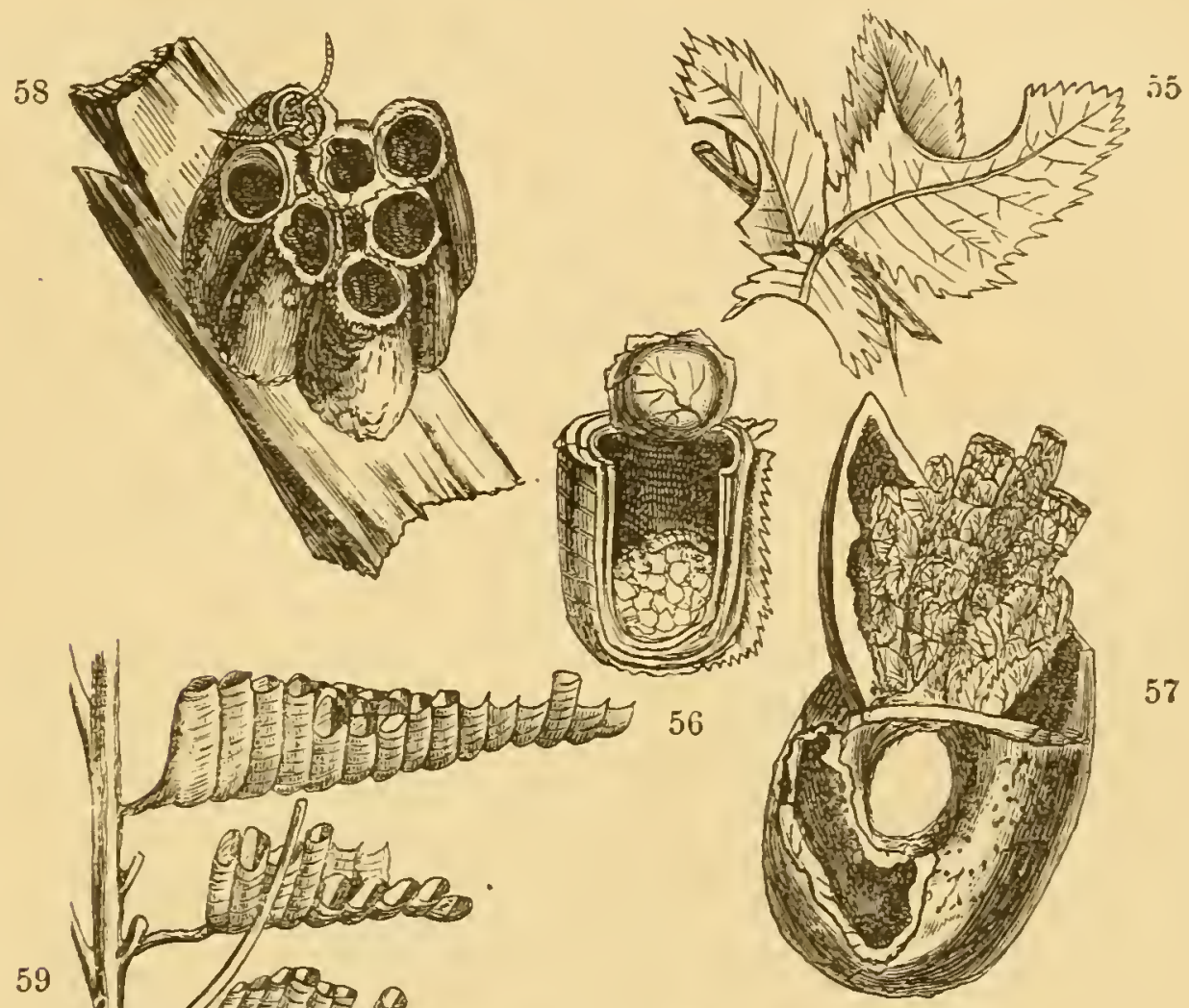

59

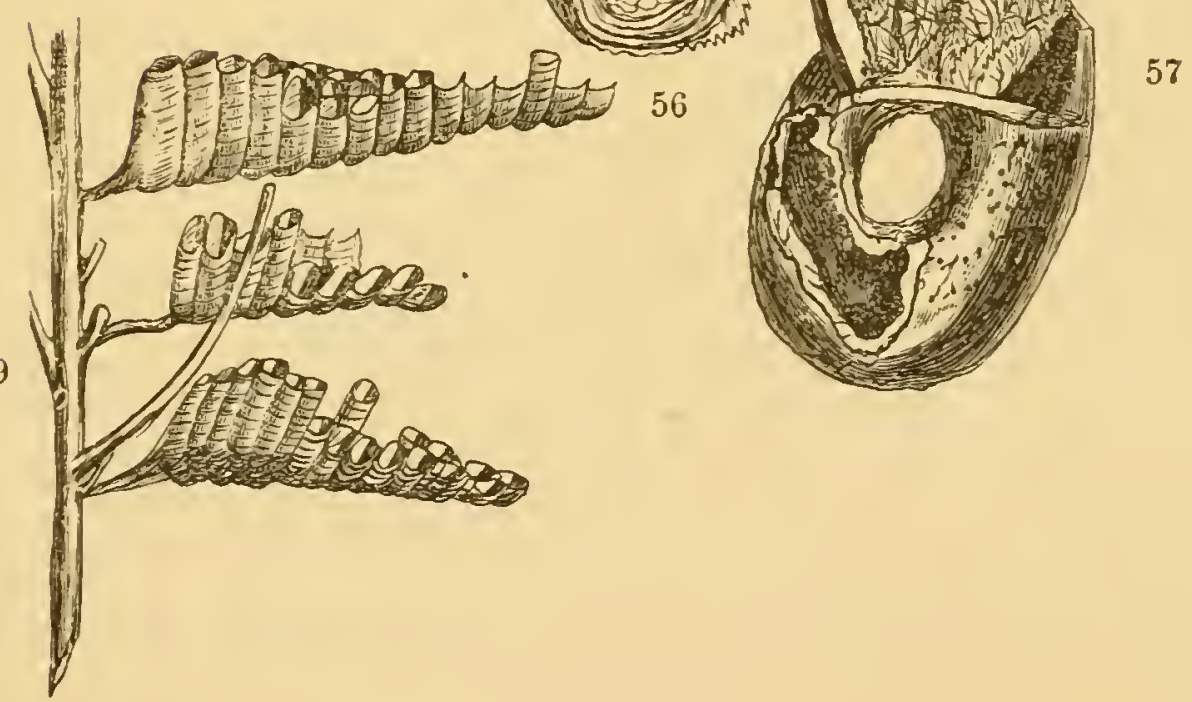

Fig. 55-57.

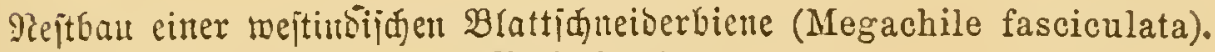
Rad) 巨mith).

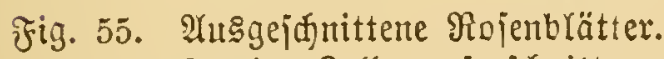

" 56. Fertige Belle, aujgeidnitten, zun Theil mit Bienenfrot gefüllt.

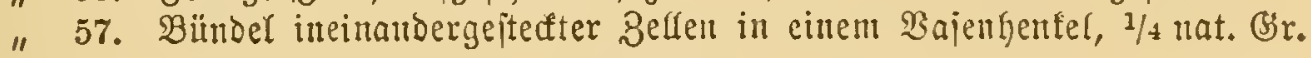

Fig. 58.

Nejt einer mejtindijđen Eicbrespe (Rhynclium nitidulum Fabr.), 1/2 nat. (3r. Rad ธmith.

₹ig. 59.

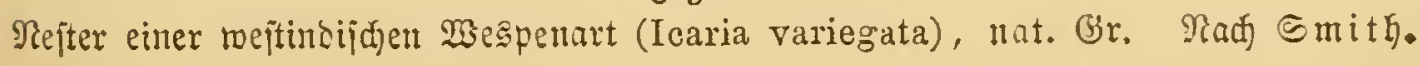


M. centuncularis und bie mcitindifte M. fasciculata. Die

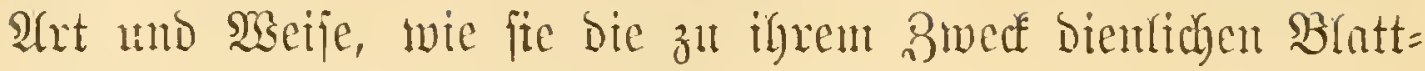
abjanitte zuriffen, zeigt Fig. 55 ; Fig. 56 aber eine einzelue Brutzelle, vielleidgt die fumftreidyjte, Die itberfant cin Snjeft Gereitet. Sie beftegt an mehreren fünerhntartigen b̧itflen, wovon eine bie antore murfüngt. Das Schönite ijt Der ans einent bejonbern Stïn gefornte zinfelrutoe Decfel mit jeinem Examicumant

Dieje füptlithen sisienen werden aber nicht eintzeln, fondern in ganzen langen Bsebinden mutergebradyt. Meijt legt fie die Berfertigerin in Erd= ober in Bammbögten, verjchmägt aber and andere fich Darbietende (belegenfyeiten nidyt. Sulth fand, wie bies in Sletnen Fig. 57 vermichantidnt, ein ganzes Biuntol joldyer Dütenjäbe in abgebrochenen Secufel eines Sortentopfes.

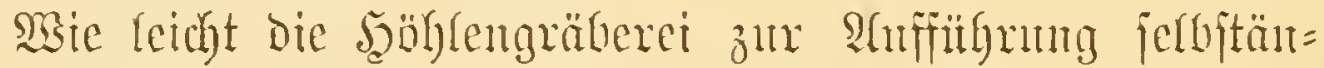

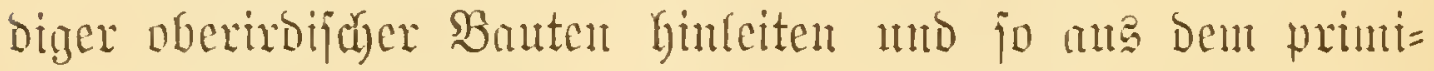

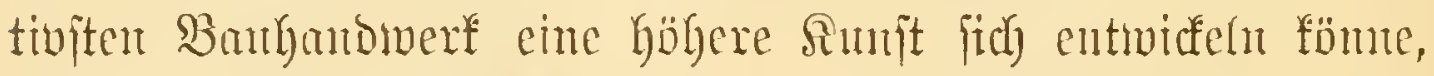
jehen woir beim Odynerus, Der jeine Erojtolfen gleichjam ïber fein Territorim hinats verlängert. \$on Der leţtern Methode

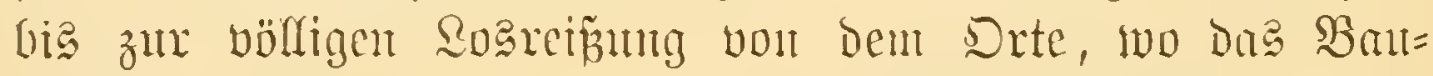

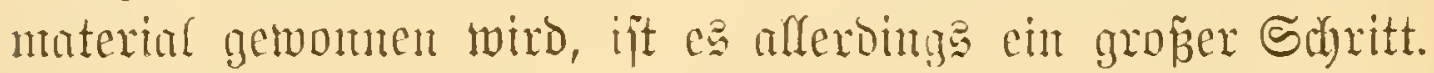
Sther eben ber bebentende Sortheil, Der mit einer joldyen eman=

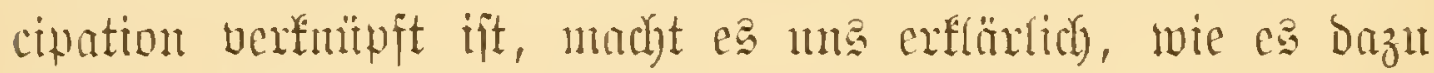
fommen founte, wie alfo, un es furz zul jagen, an ben Minenten Slantrer wurben. Eint foldyer, und ztwar zutgleich einer, ber mody in ziem(id) rohem Etiele arbeitet, ijt Die sö̈rtel=

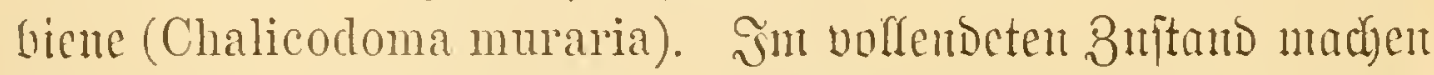

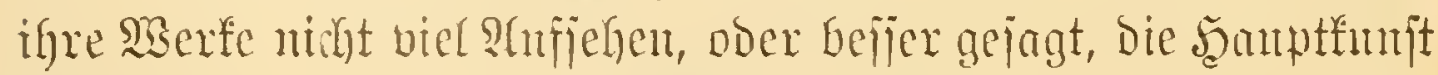
bejtebt chen barin, fie möglidyjt munffäflig zu machen. Dies

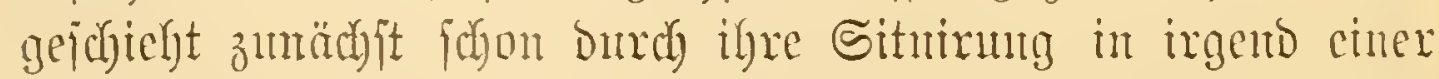

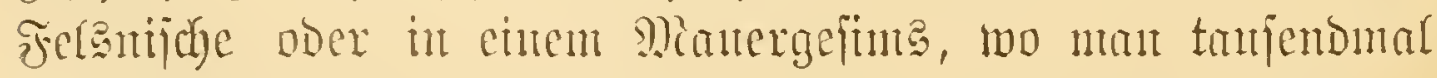

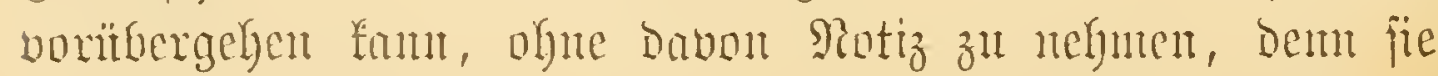




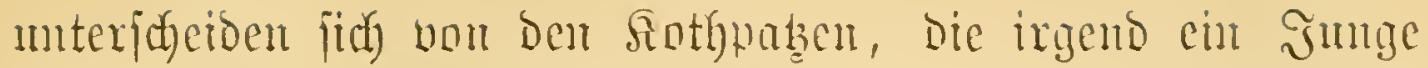

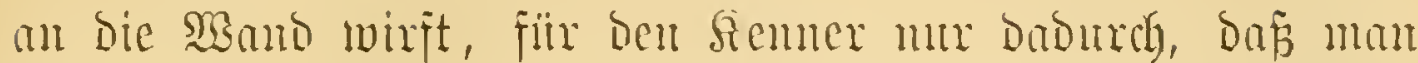

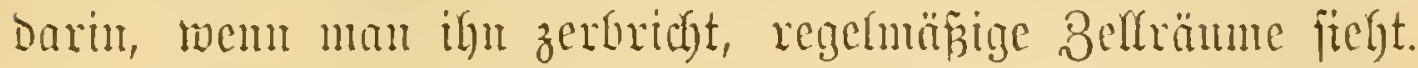

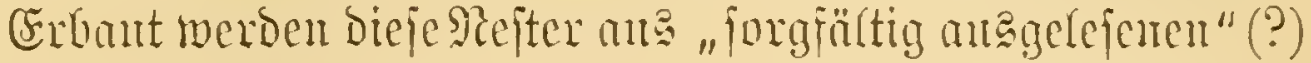
Emblönern, die die Biene mit inrem Epeider verfittet. Das Sanze bejtebt an mebreren bis zu adyt meben cutandor licgen= Den Bellen (Fig. 60), Die aber, mie es jodrint, jebe fïr fid extra

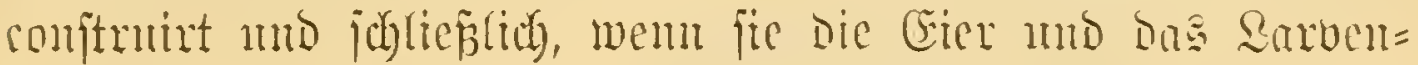

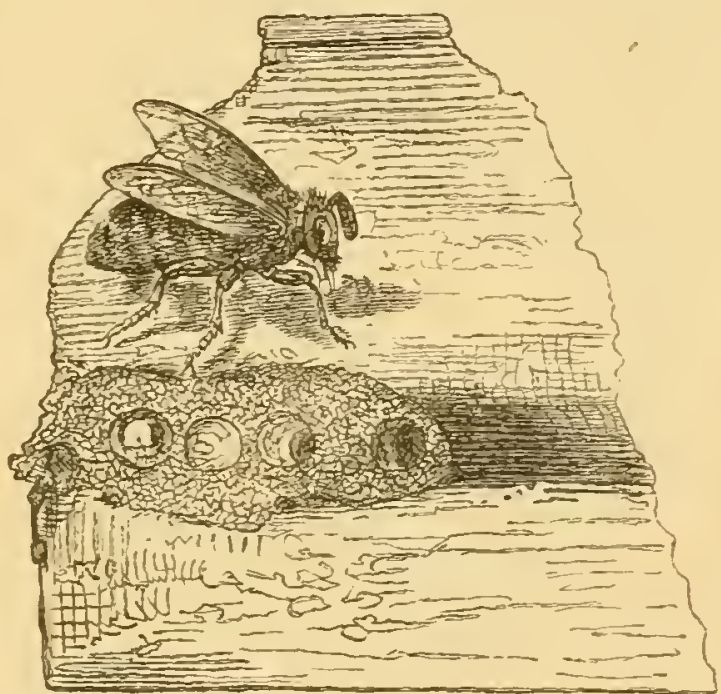

jigi. 60.

Mejt ber Mërtelf́ene (Chalicodoma muraria), rat. (brr.

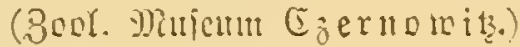

futter anfgenommen baben, einen gemeinjanten shmonf be= fomment.

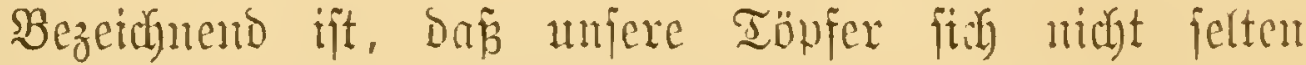
Damit begnïgen, cin vorjähriges seeft zu repariren ober gar bie Unverichämtheit begehen, cine Solfegin ans bem ifgrigen zu vertreiben; Reteteres woht unr bam, weun fic bis zur Zeit, wo ifnen die Criablegung hat bevorftelyt, feinen eigenent Ban zu Etambe (uxad)ten. Inter foldyen llm=

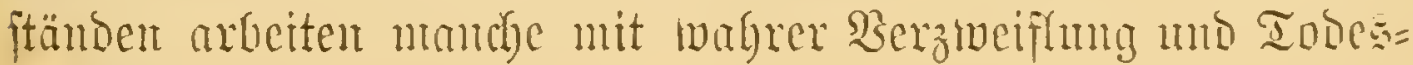




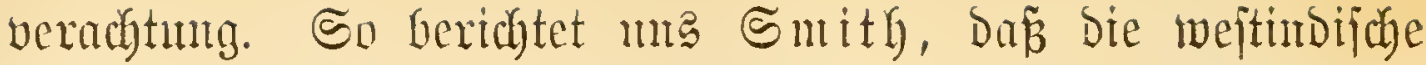
Megachile lanata, eime Schwefter mjerer eintyemijoben

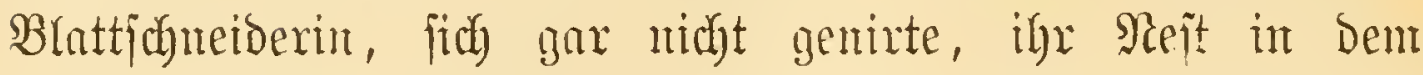

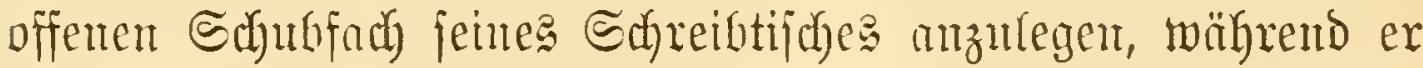
Dabei $j \mathfrak{a} \tilde{\beta}$.

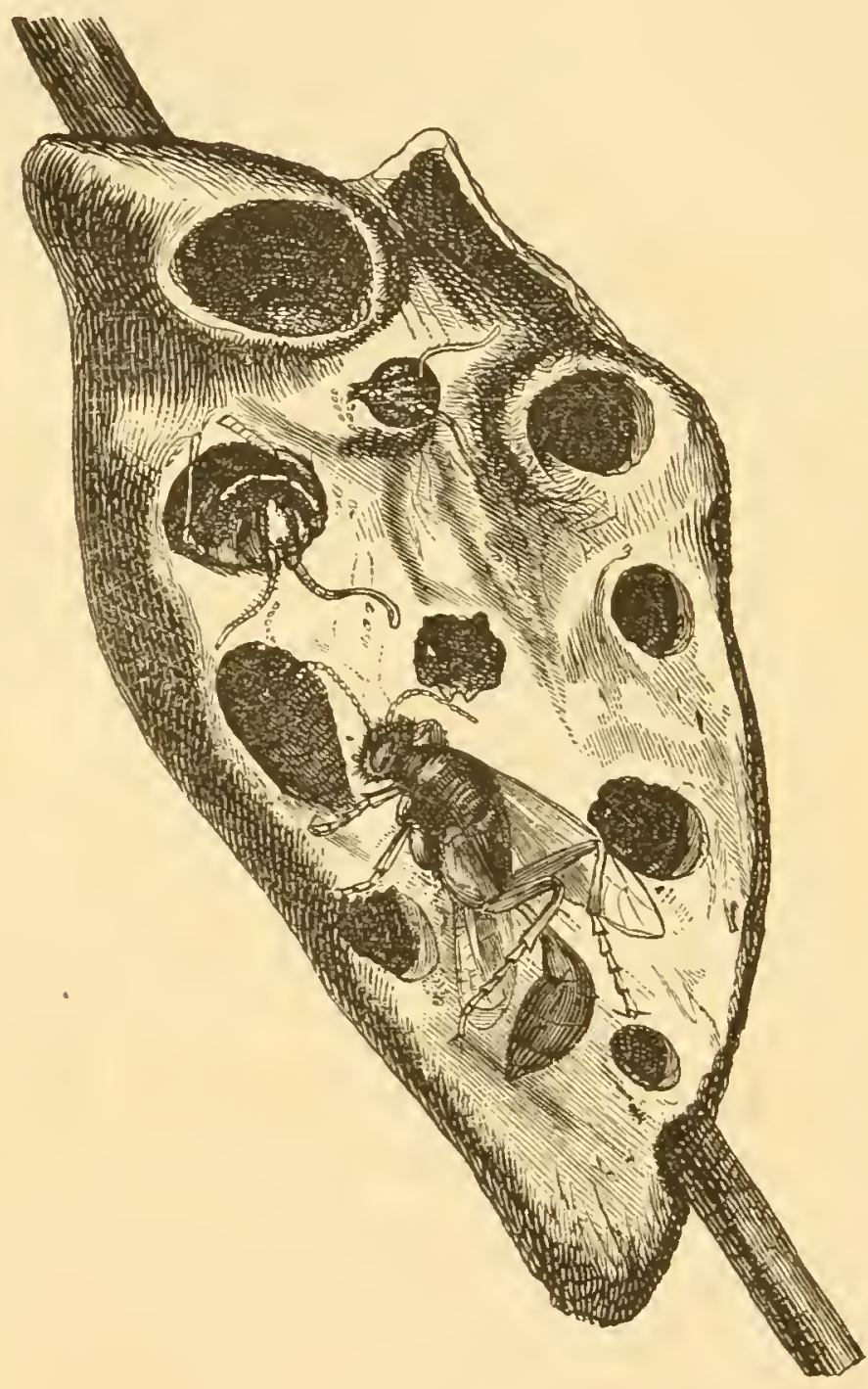

รig. 61.

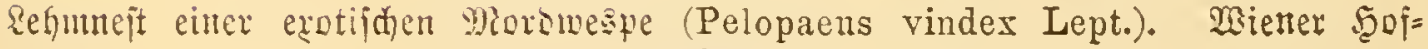
мијеนт.

Der Baunt, weun er mux eimigermaf̧en verited liegt, ift ifr überbaupt gleichüultig. Sntth fand foldye sejter in Săbüffellöbern, in ubrgebänfen, ju cimmal in einem Siegel= ring, Deffen Stein heranggefallen war. - 


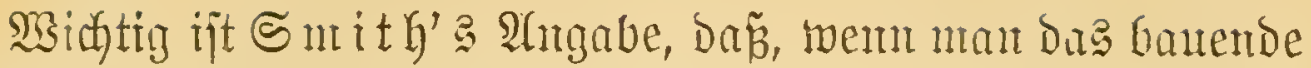

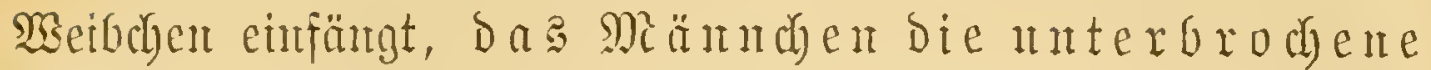

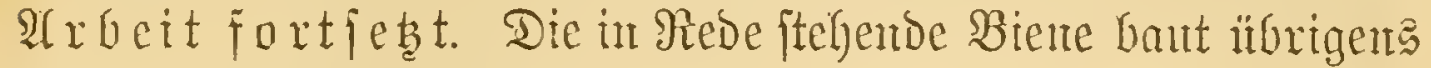
nidgt nit Sumbënnern, fon= Deru, gleidr) Der Mérizaty Dex ïbrigen Manteriuten, mit Rebut. Mcan fiebt jie oit an Sebutgruben, wie fie mit Seiffe Der Riefer unt Borberfïne fleine Baflent Forme und Dam Danit fort fliegt.

\section{Siel ?rnuloges mit} Den Nejtern Der Miörtel= bienen haben jente ber zahl= reidjen Pelopaeus = 2irten, wobon Fig. 61 ein Militex gibt. Sie fdreinen z. Th.

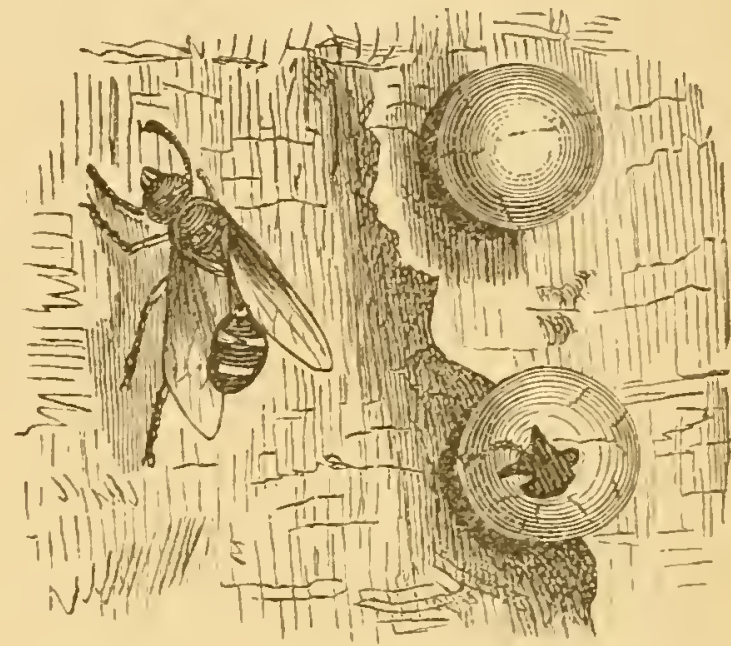

Fig. 6\%.

Fin gcid) loijenes unb eir anjgebrodenes (cint= zelliges) Neit von Eumenes porniformis, nat. Bir.

jehr bejobränften Beijtę zul jein. Smith exzählt nämlid vou einer weitindijden Form, P. madraspatanus, die ifre

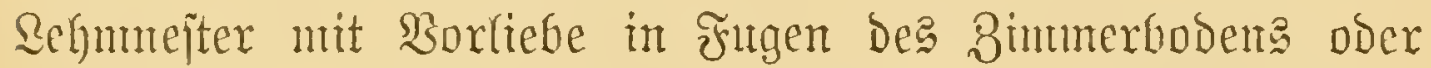
in Thürecten anbringt, mo obmohl fie an Diejen Drten ofit zu wieberbolten Malen zeritört werden, ifre Recon= Ftruttion Doch inmer mieder an berjelben Etelfe begitmen.

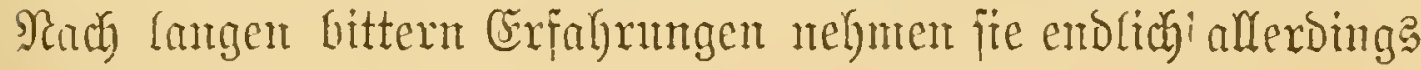
Bexmunft at.

Cimer ber gewanotejten Töpfer ift cine wejtindijote Sieb= we apenart (Rhynchium nitidulum). Die wände ifrex funty= artigen Bellen (F̌ig. 58), weldhe jie gerne an Ighitrpfoften

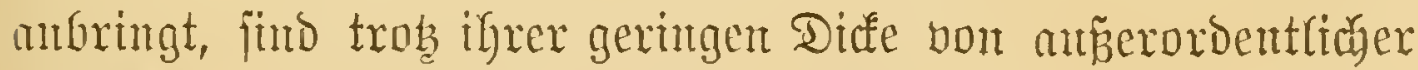

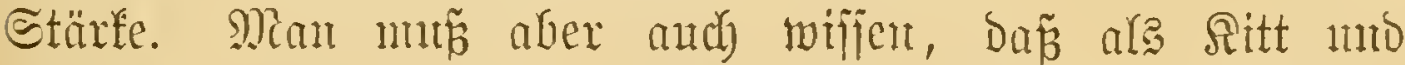
Frimin nicht blof Der Epeidel, jombern atd bas vogelleint= urtige Secret gewijifer 䄮łlanzen, wie z. $\mathfrak{B}$. von Ficus religiosa 
unto Der Acacia Catechu bentust wird. Da die ARefter Diejer

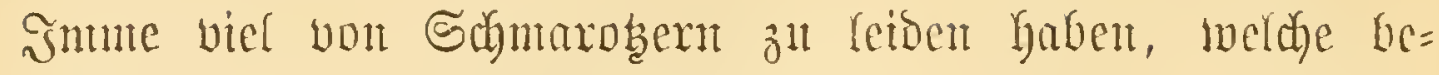

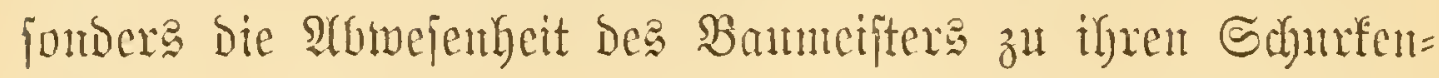

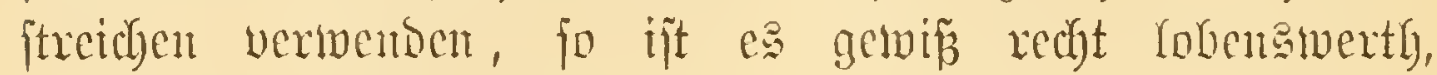

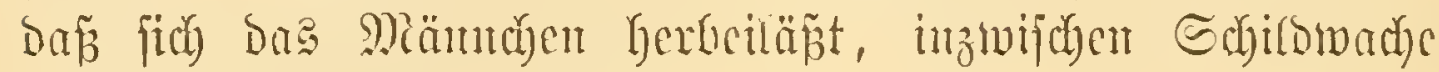
zul fteken. -

\section{Banten ber aefelligen Jumment.}

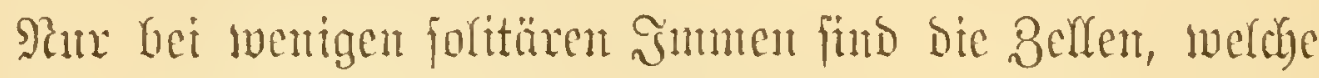

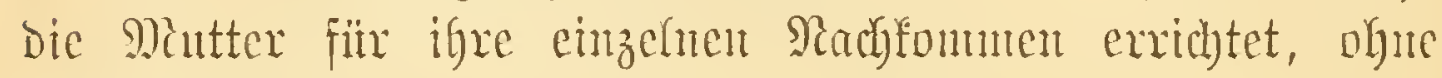
allen Bujanmentyang. Dies z. B. Gci monthen Göglentgrabenden Sanowespen, Dam, nuter ben Freifantem, bei Eumenes pomiformis, beren einzeln an siaterwänte hefejtigte fingel= förmige Bellen Fign 62 wiedergibt. B̉ei cintgen andern

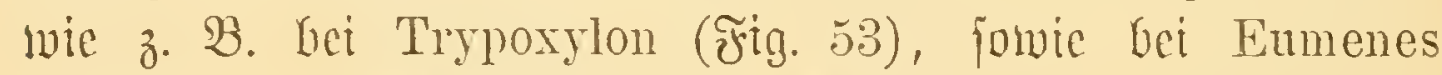

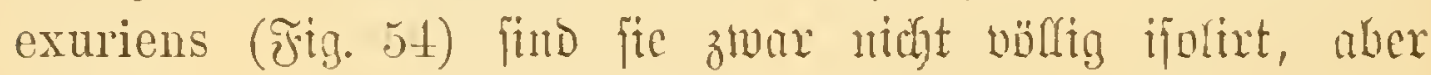

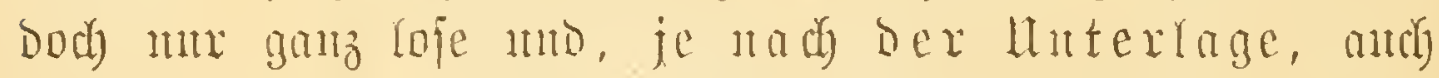

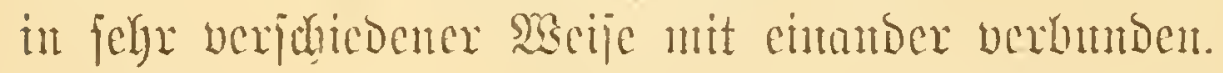

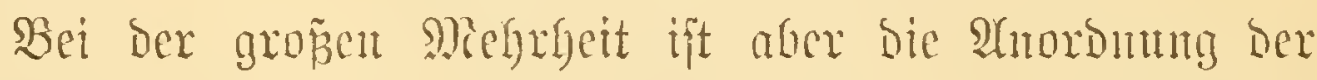

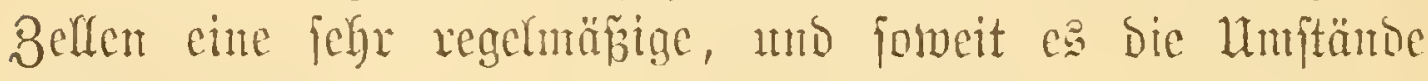

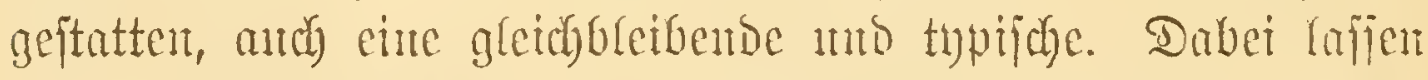

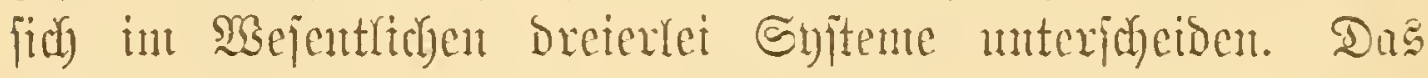

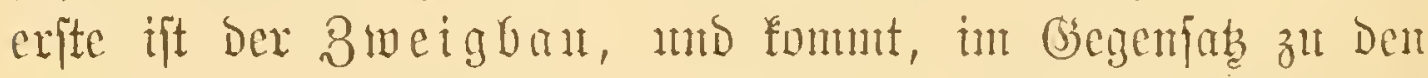

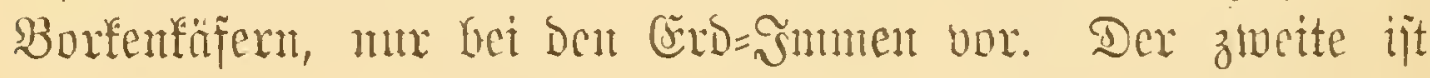

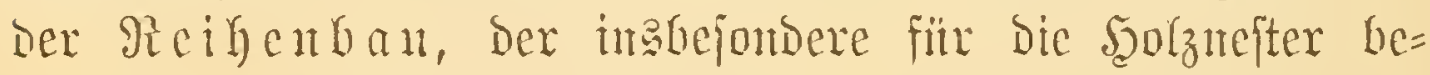
zeidynend ift, mo namentlich dort, wo bie Beffen in Dintuteren Zweigen antagenagt werden, Durrely die Ratux bes Banortes

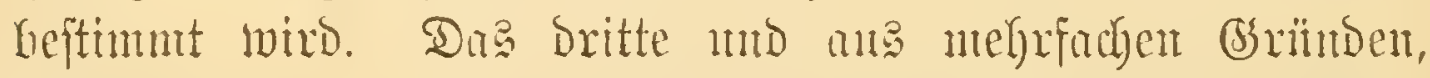

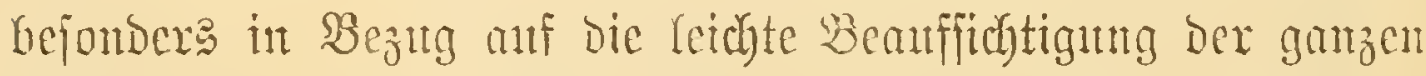

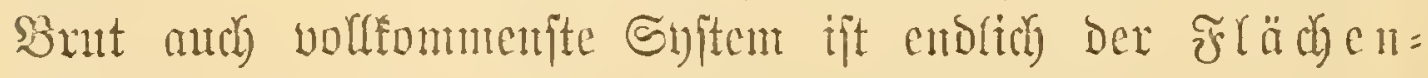
oder Wabentan, bei dent alfo, wic wix bies an den Refmeitern bon Rhynchium (F̌ig. 5S), Pelopaeus (Fig. 61), 


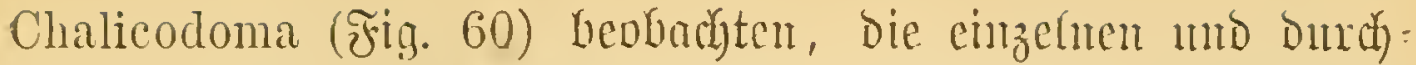

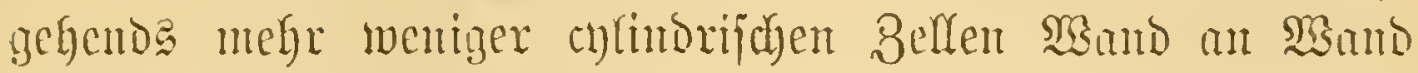
meben einamer gebant werden.

Sergleid)en wix num Den Sejtban=Styl Der gejelligen J̈nnen mit bem ber jolitären, jo findon wir feinertei mejent=

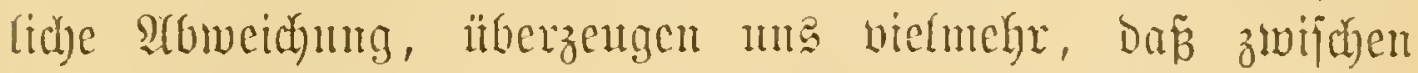

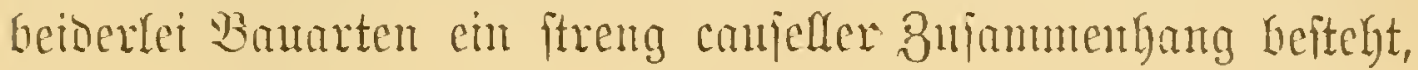
D. h. jo wie dis gefelligen sumen, wie wir oben gezeigt, vou jolitäreal abjammen, jo ftammt

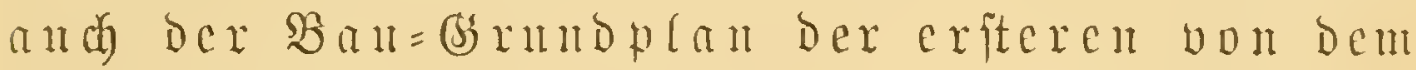

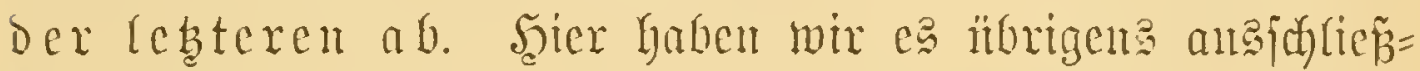

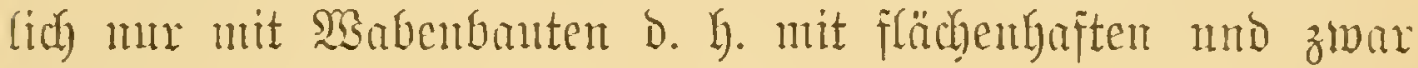

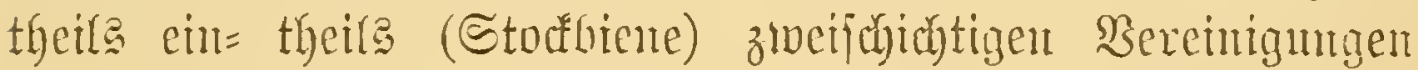

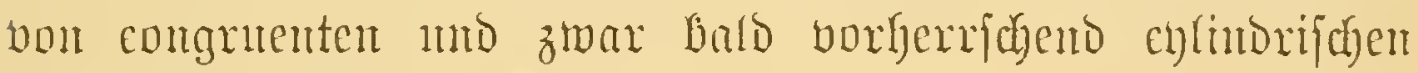
bats prismatijatsen Belfen zut thun.

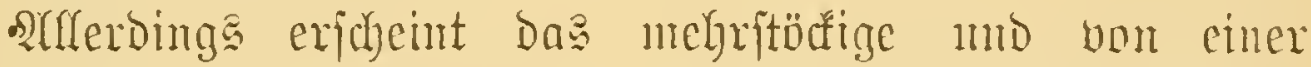

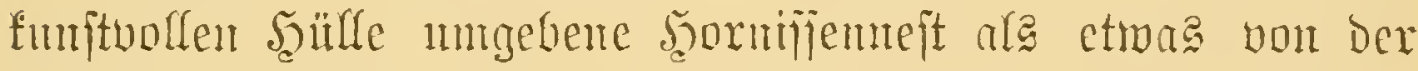

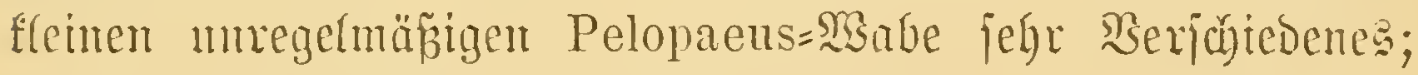
Dns füt aber, wie fid zeigen wird, eben Combinationen mo 3utfatest, wie fie

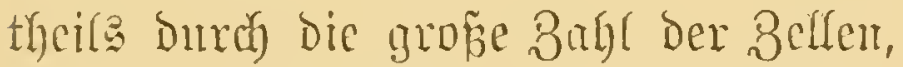
theils ourch getwifife andore llmitünde, veraulapt muxben.

Das NGiratigite furcibt zunächit immer, zu crklären, wic es ithergant

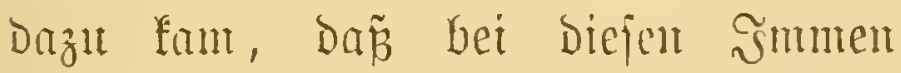
mehrere Subibiduen an ciucm Bate arbeiten.

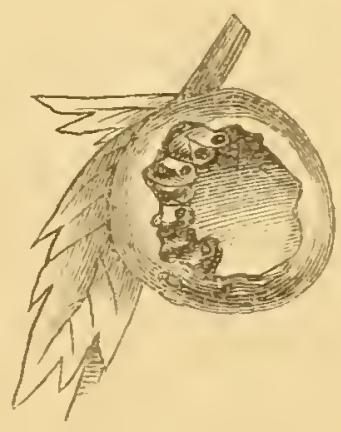

Fig. 63.

Ichmzeffen eincr Osmia in ciner Cidhengaffe.

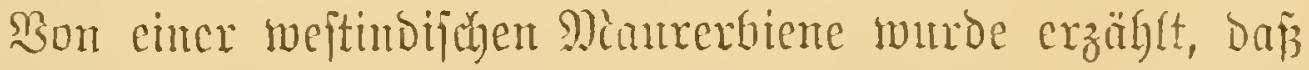

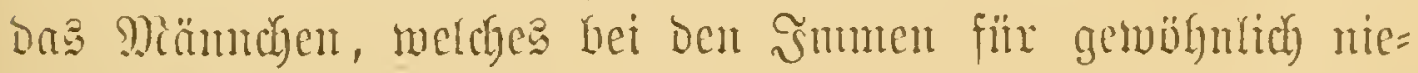

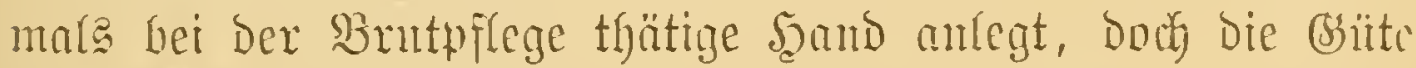

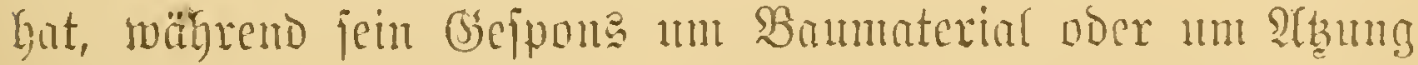

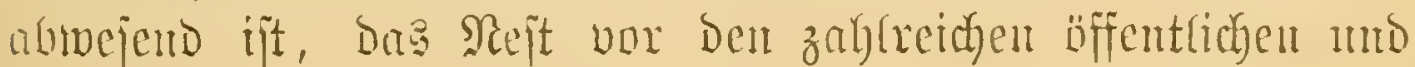


geheimen Feinden zu hüten. Eine ähnlidye Igcilnng der Arbeit fömte auch ohne Die Miännchen, auf weidhe nidht zu

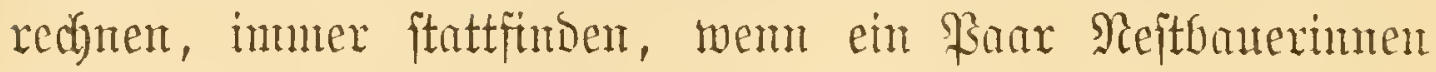
gemeinjante Sadje machten, D. h. twent fie ihre siciter ent= weder hart aneinander banten, ober, da dies eine ifre Fö̆hig=

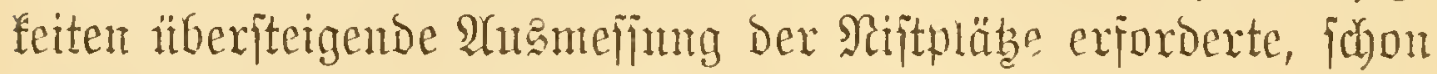

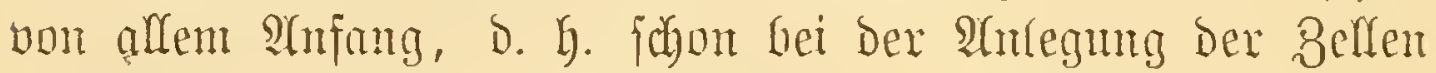
gemeinjan vorgingen, wobei es Dam jeber Betheiligten frei=

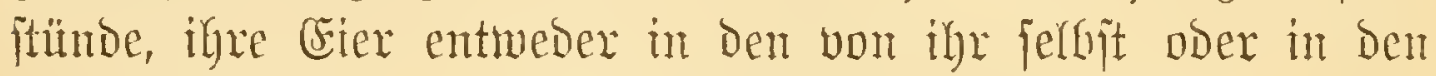
von Dex Sollegin gentaden Sammexn anfatbewalyren.

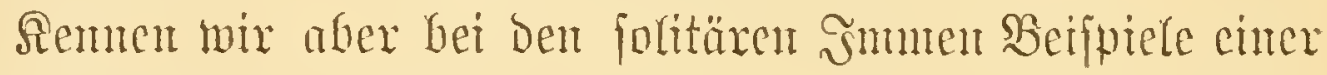

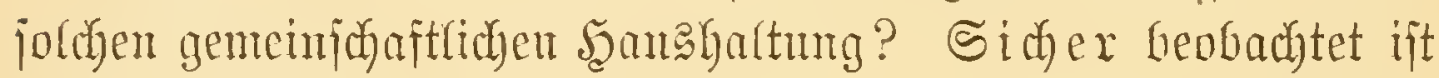
freilich fein Fall; Dod hat es fich oben bei ben Erobienen al jehr

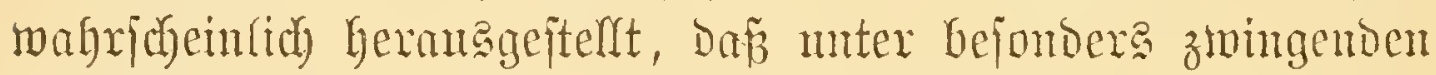

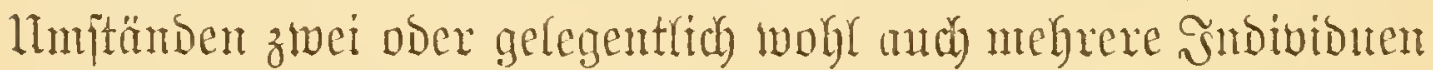
einent cinzigen Sduañt benthen. Man aber eine freimillige

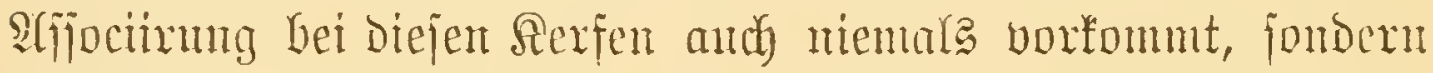
einzig und allein nur bei Den ftrenge jo zu nementen ge= jelfigen Smmen, jo exflärt fich bies volljtänbig aus ifrer jibrigen Rebene ober ridytiger Drganifationsmeije.

alle jolitüren Ŝmmen fommen in ifren Bellen erit zut Ricife, wenn bic (arbanerin längit gejtorben mo jie verlajien loat.

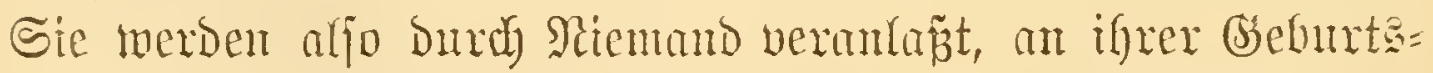
ftätte alich finnftig zat verweilen und diejelbe für ifre Bscuteration

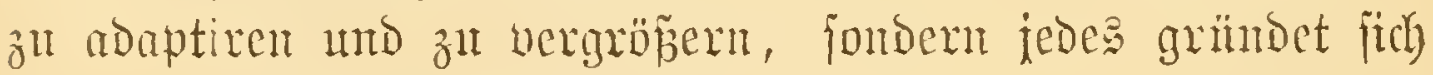
wisber einent eigenen Şeerd.

Anders bei ben jocialen. Ein bald frei, bald in feiner

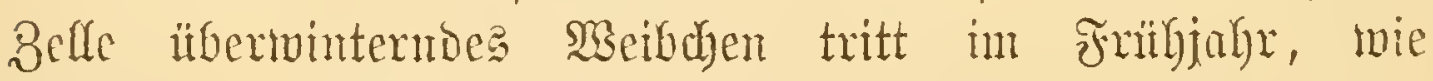

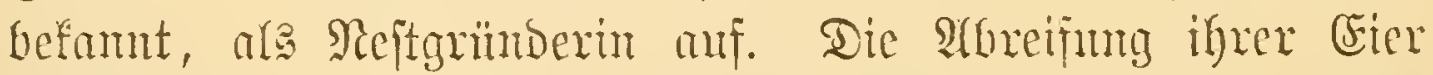

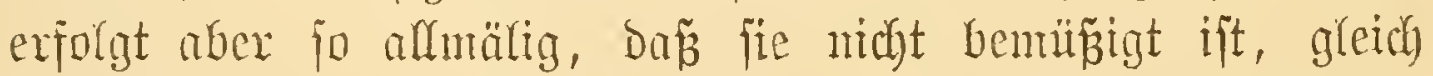
fïr alle die Bellen jelbjt zul banen. Sie madht, wie Polistes z. B., zuerit mir einige wenige, belegt fie mit Eiern, "verjorgt bie herantwadjenden Rarven mit genïgender Sojt, während fie 


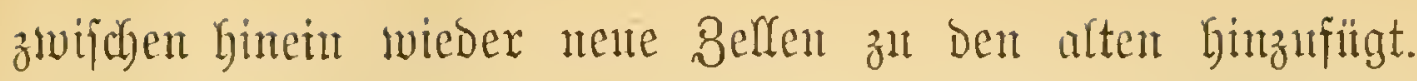
Nam fonmt der für Die Exiftenz Der Rotonie enticheidende

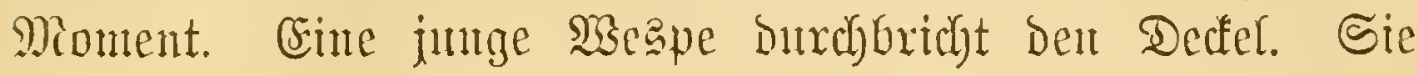
fönte, wenn fie nach furzer Beit zum freien Bebrantd ifrer

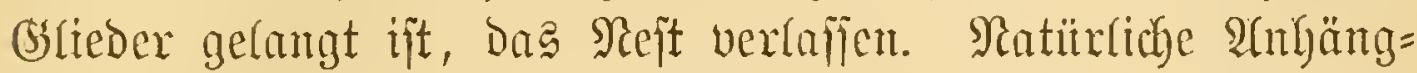
liaffeit an das verwanote SSejen, Das fie zuerft erblict, Das

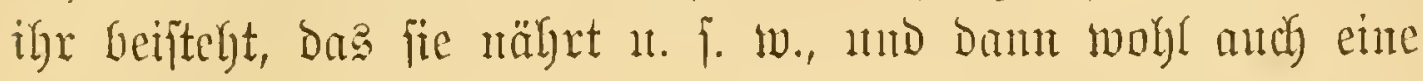

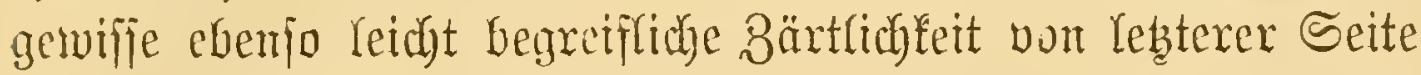
ïben aber anf Das Rind (in Der Regel!) einen jtürteren 3wang als, ale ber Irieb nach Freiheit. Sie ruleibt alfo und bird fo unter Der Dberleitung Der Mutter Deren Selferin. So geht es autd) mit ben ïbrigen, bie allmärig Dent Bereinte zunadyen, Der mit Dex jteigenden Sopizahl mb Dem fort= johreitenden Ssedeifen bes Familienhanjes immer inniger mo fejter wirb.

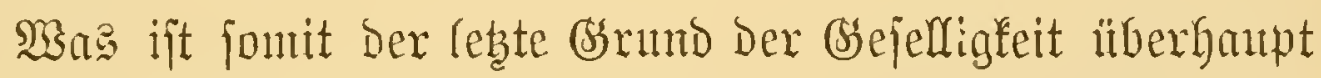
und Des gejelligen Bauens ingepondere? Die Mögrichleit Des

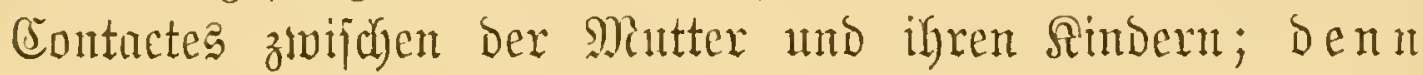
die lesteren affociten jich nid t diret uter einamer, jouberu mit der eriteren. Hnd wowon hämat bie Miöglichlect Diejes Contactes ab? Sou zmei $\mathfrak{H m}=$ ftänden: Erriteng von einen immerlichen, näntlid von ber

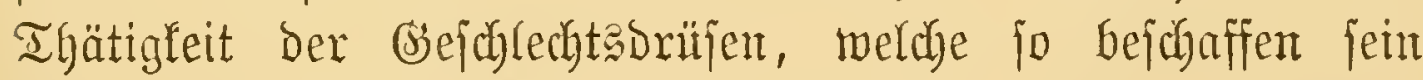

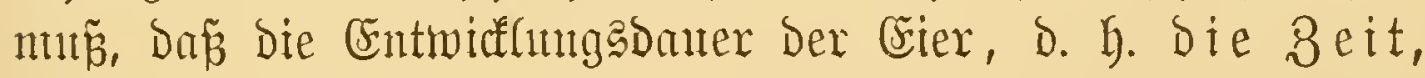
weldye zwifden den ablegen der exiten un

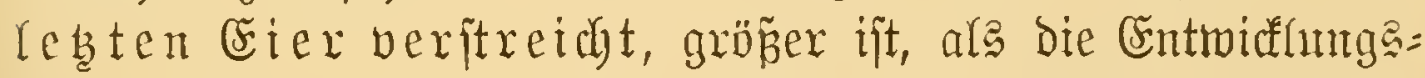
Daner Der jüngiten Sarven. Sebtere aber wirb, zum Theil

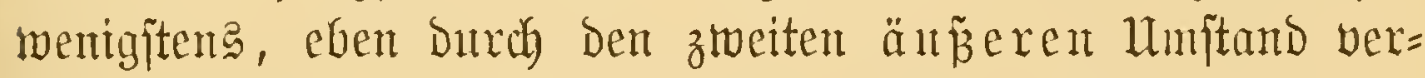

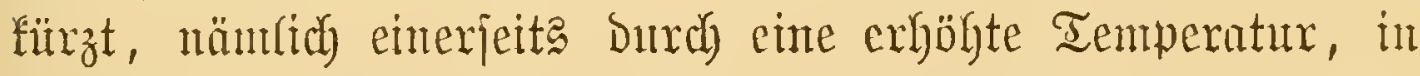
weldyer bie Altabrütung exfolgt, und andererjeits Durch eine geiteigerte Sorgfalt Der Mutter betreffs Der Ernährung.

Eine - völlig im Sexeid Dex Mäglidfeit gelegene-Bextangamug ber Eiabreifugbei 


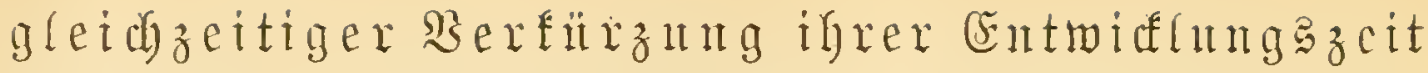
toitroe alfo olye 3 weifel aud die politären sumen anf bie högere Stufe ber bejelligheit exhebent.

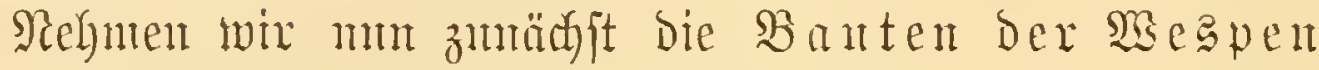

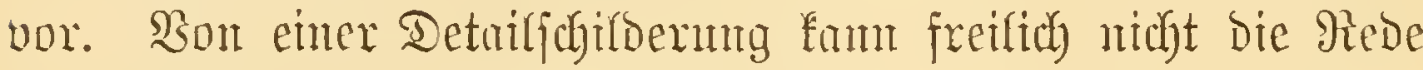
jein; ein furzer Heberbliff joll ma aber Yehren, wie nument=

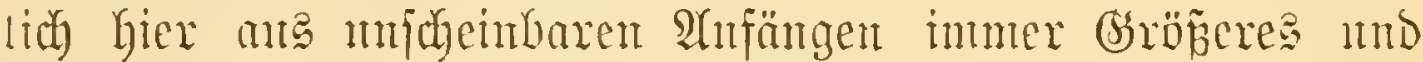
Bollfommenteres herborging, wobe wix bie Satnm bie mannig=

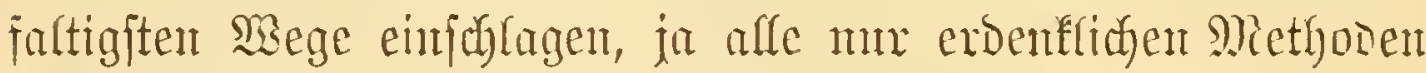
verjutchen mb durchprobiren felyen.

Sign die Banmaterialien jünd felr mannigfaltig. SPeift

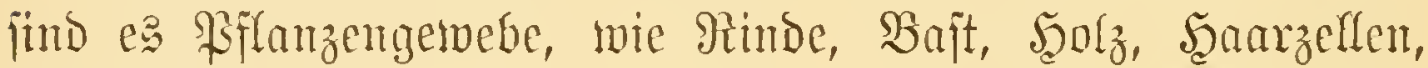

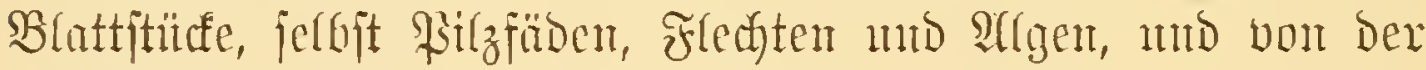
Bejchaffenheit biejer einzelnen Stoffe hängt and bie jemeilige Farbe mo die Fejtigkeit, jotvie, als meitere Folge ber lebzterert,

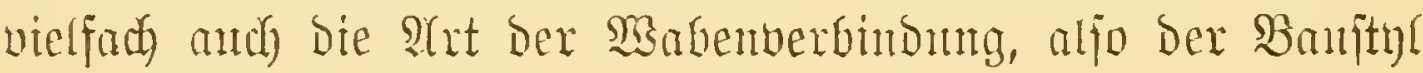
af. CEnc S(rt, Polybia cayensis, madyt aber, mas bördyjt

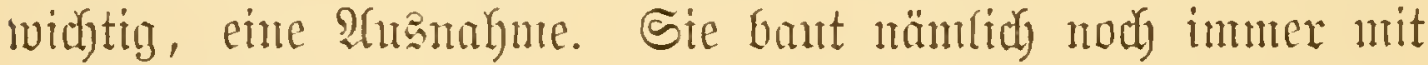
Dent gleichen Stoff, den alle folitären Jmmen vertwenden, mit erde.

Die gentanten Biflanzenfragmente werden zunächjt mit

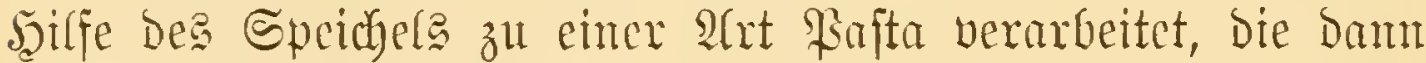
nittelft Der Ricfer in bandförmige Streifen alsgezogen wirb.

Sintuendig befonmen bie Bellen nod) cinten bejonderen dyituäbulichen Şantbeleg.

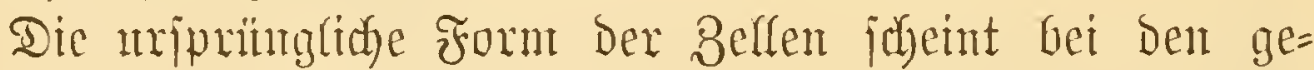

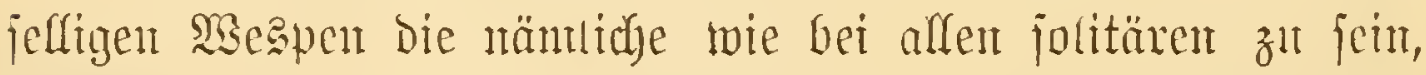

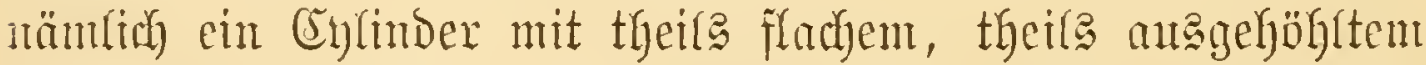
oder concavem Boben. Die erjten Zellen z. B., weldye die Polistes gallica (Fig. 64) anlegt, find alle von diejer bseftalt.

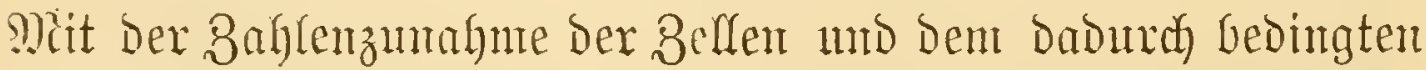
engeren Berfande berjelben gehen fie aber altmälig von felbit 


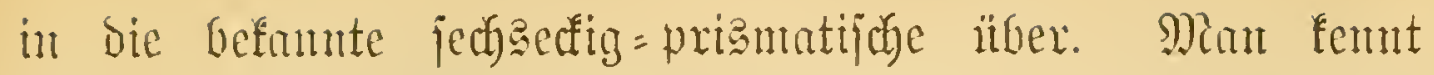

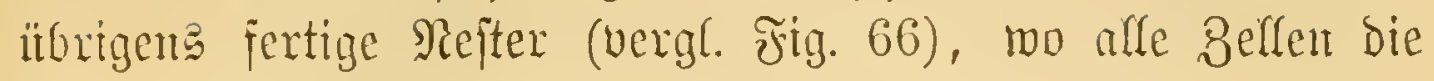

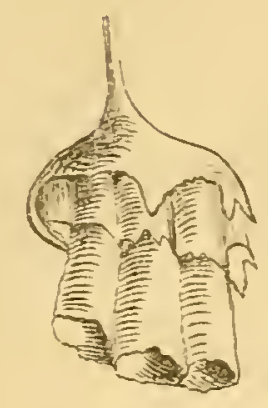

66

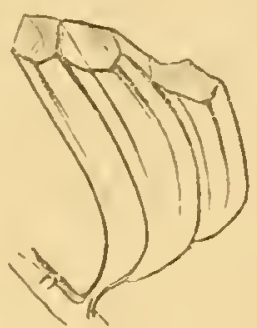

65

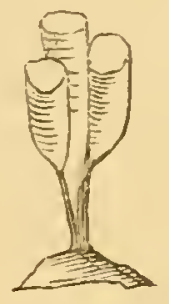

61

Fig. 61-66. Mespentejter.

jig. 61. Polistes gallica (sie eriten Beffen cylintorija), nat. (Br.

65. Icaria guttatipennis (iđ)ou Die erjten Bellen prizmatija), nat. (Fir.

" 66. Jertige Điejt von Mischocyttarus labiatus ans lanter cblinorijhen Beffen, mat. Gir.

Urform beftben, und andere, bei benen mitten unter ben

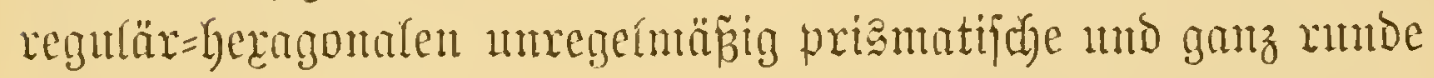
borfommen. Bon einer abjoluten mathematifchen Regularität

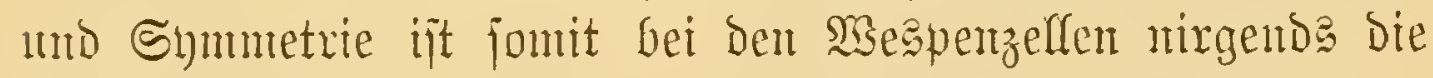
Rede, und wenn fie dentud angendunentirb,

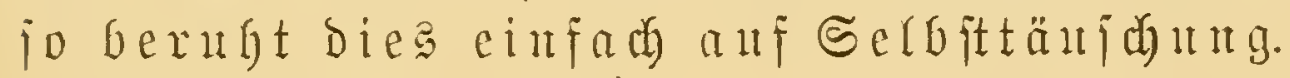

Die Bellen einer Wabe find aber nidyt bloźp ber Form, jonbern and Der (sröpe nach jebr variabel. Und went man

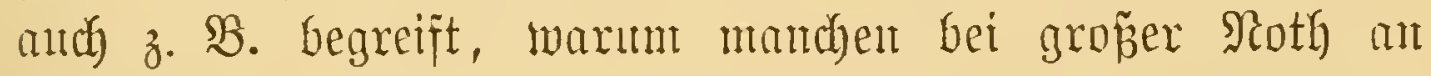
Brutrännten nidyt bie ber Ränge der Ruppen entfpredyende Tieje gegeben wird, und it Folge befijen der Cocon Der leb̧teren

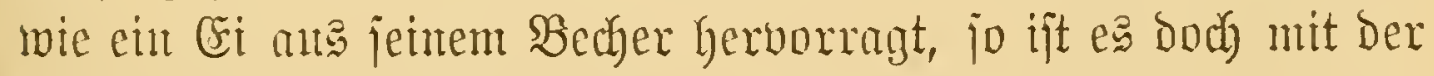

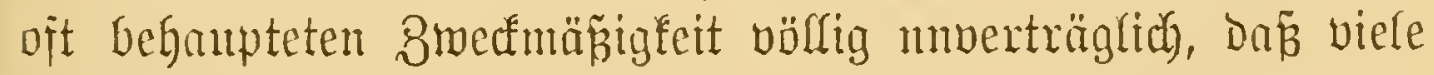
Bellen, mamentlich in ber Mitte der Wabe, of̣t un die Şälfite żt tiej ausfallent.

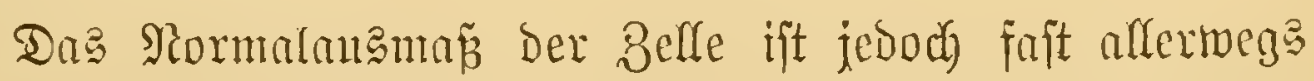
Dex Grö̈pe igres Bemolgners ziemlidy gentu angepañt. 
Die winzige Leipomeles lamellaria z. $\mathfrak{B}$. Gant Zeffen f(x)mäler wie ein Strohbalm (näntlich mux $1.33 \mathrm{~mm}$. Greit),

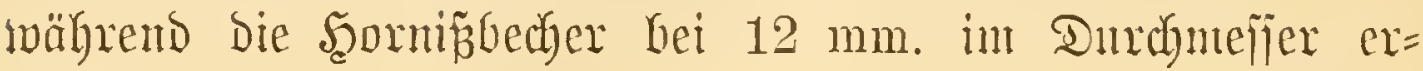
reichen.

Was mu bie "Belltafelu" ober

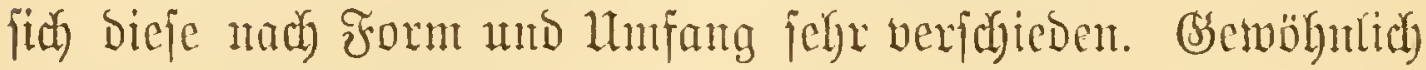
find fie allerdings flach, manthe aber anth concab oder, was häuffiger, und felbjt bie zur Rugelflächentuölbung (Synoeca cyanea), convex.

Der Umfanty Der Waben längt zumeift vou der Zahr ber 3elfen af. So macht Myschocyttarus (Fig. 66) mux gantz fleine

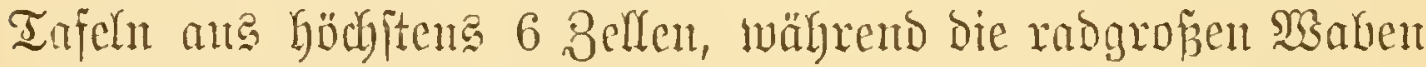

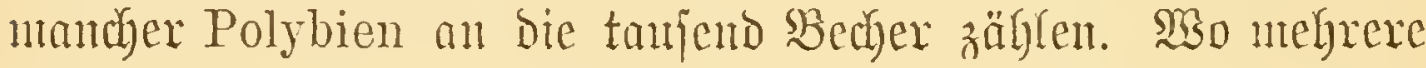
Saben über einntoer bängen, nehmen fie entweder von ofien nady unten bejtänoig an lunfung zu, oder fie swachjen erit und nebmen Dann wieder ab, suie bie Saralleffreije anf einen

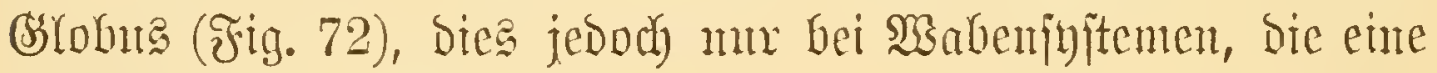
gemeimiante byitle haben.

Das Snterejiantejte ijt Der eigentfiche Bmitul ber Sespen= mejter. SRaturgemäp theiren wir biejchen in ein= mo in melyr= wabige eim, wohei bann wieber foldye obne mo joldye mit beitllest zu unterjobeiden futro.

Das primitivite ift bas eintwabige, huiflenloje Rejt. Dod

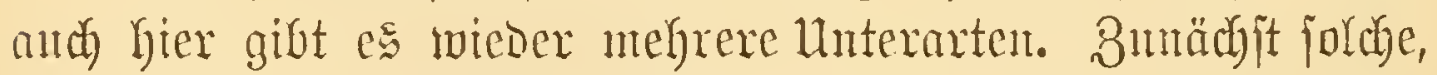

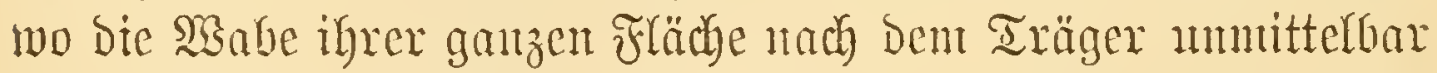
fich anfdyliefst (Fig. 67). Dies ift alfo eine Miethode, Die gar nidat einfacher fein fömute. Sie wiro von Apoica pallida

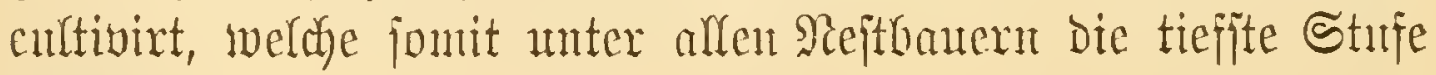
cimmintmit.

Bei andern wird bie $\mathfrak{B a b e}$ durd bejondere Bfeiler ober Stüken an Iräger hefeftigt, und żwar entweber burch Seiten= pfeiler, wie hei Icaria variegata (Fig. 59), ober burch central 
oder anch cxcentrifich vou ber Bodenfläche entjpringende, wie bei Den Diberjen Polistes-2Yrten.

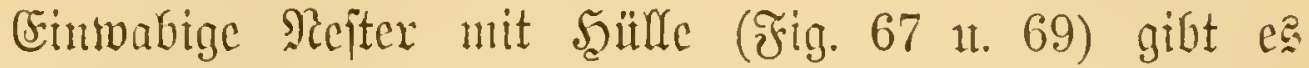
mentige, fie jegen aber, wie z. B. jente der anf $\$$ butenden Polybia palmarum, ungemein ziextidy ats. Dns

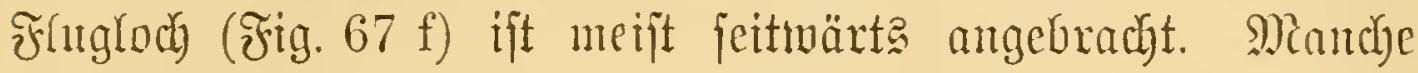
cintwabige sejter find aber entweder unalugebante mehr $\mathrm{r}$ wabige, ober fie fömen bies soch werden, soem fïch unter günjtigen Umptünden bie Ropulation Derart fteigert, da ja bie

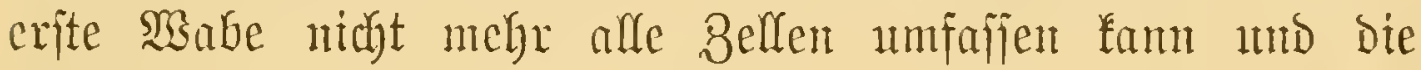
sintage einer ziveiten Etage fordert.

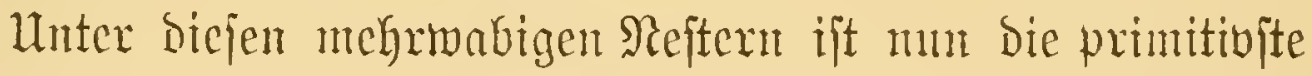
Art bie, bei weldyer bie cinzeluen Belltafeln jede fïr fich an

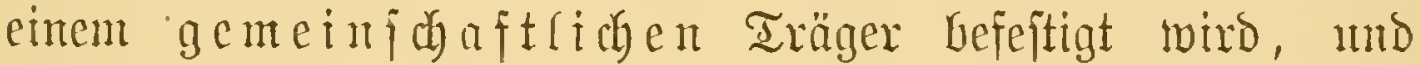
zwar cutweder Durdi) Seitenpfeiler (Fig. 59 u. 70) oder jo,

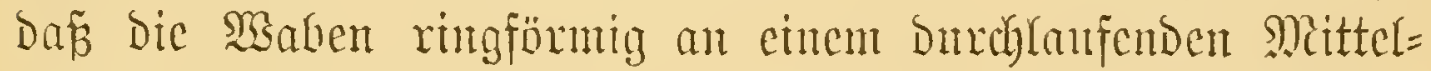

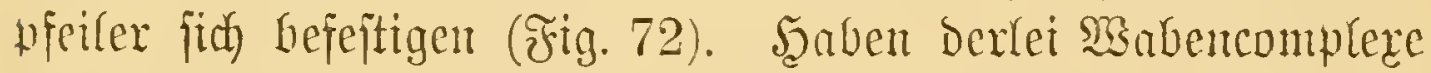
feine Şülle, D. h. Fteljen fie nidyt unter einem gemeinfanen

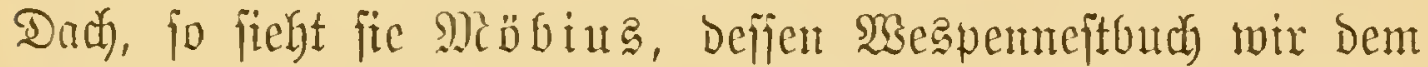
Sejer angelegentfichjt empjehlen, nidht füx cinheitliche Bante an. Man wird aber bod uidht bie Mäglicbeit länguen, da $\mathfrak{B}$ Segpen, die fo nah an einander baucn, ent= weder derfelben Familie angehören, d. h. Sinder

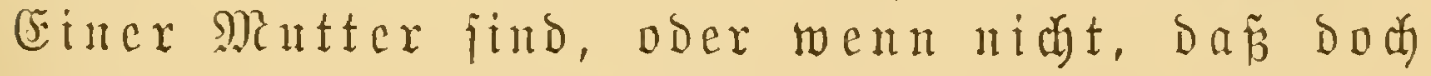

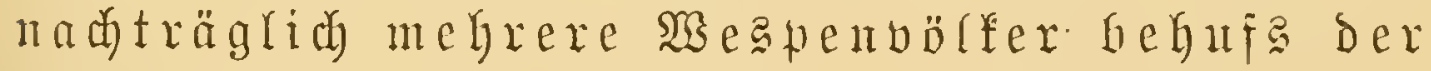
beritellung einer gemeinjamen umbürung jid affocitren tönten.

Şas nun bie gedecten Refter betrifft, jo fei fofort ex=

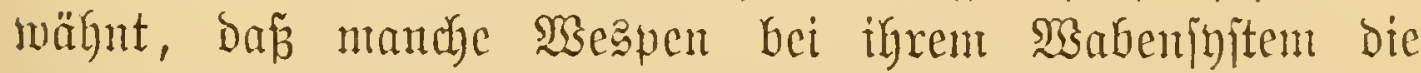
Scülfen weglaffen, ment jerbes Durch einte natürliche Decke

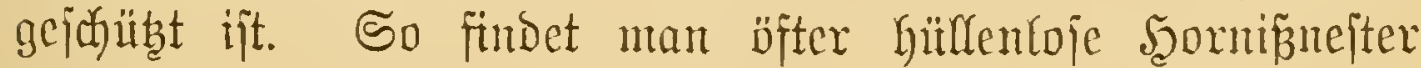
in hohgen Bäıntu, wägrend dic şeappen, melche in Der 


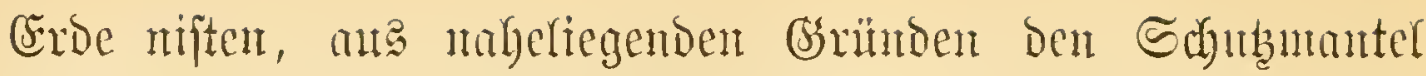
micht entbehren fömen.

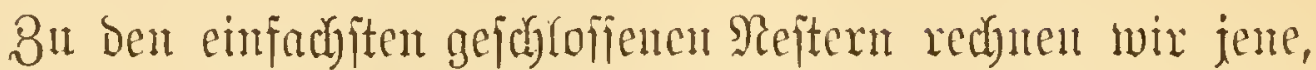

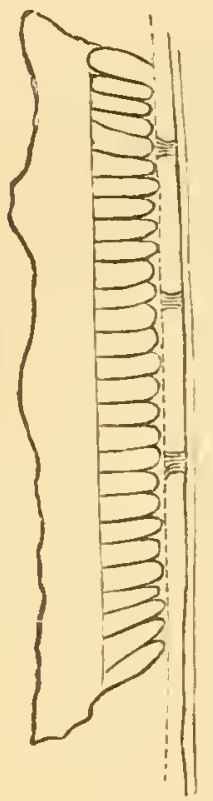

68

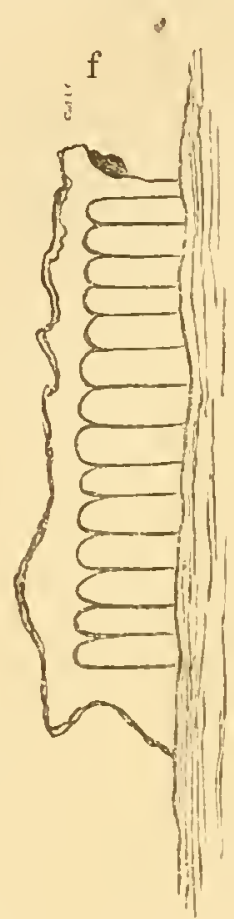

67

Fig. 67.

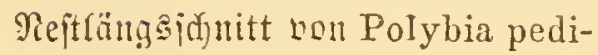
culata (in ber billfe ein jeitlidyes Fathreds), nat. (sir.

Jig. 68.

Gbenjo von Polybia sednla, nat. (Gr. Mad Miöbiแ3. bei weldyen bie Maben, wie oben, ijolirt an cinem âte jteljen. Beijpiele bieten der Chatergus apicalis (Fig. 70) und bie be= riifyute Tatua mario (F̂ig. 72),

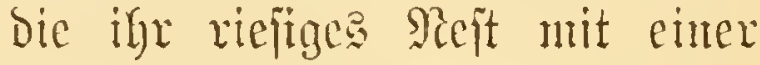
ichön gerieften Saillle nungibt,

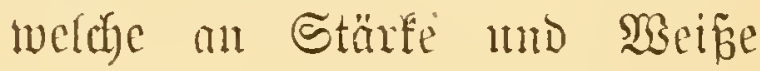
Dem beiten Carton gleidhtommt. SOSir fomment mut zu Dent jtrenge jo zu nemenden $\mathfrak{W}$ aben= ibjtenen, D. lo. zu jencu Reftern, bet welchen bie Belftafeln nicht Duref) natiinlidye, fondern burdy fitnftltche Iräger zu eincm cinbeit= lidyen Bsebänoe verbunden merden. Dies gefroicht jtets anf bie ?art, Dá̃ die eimzehten $\mathfrak{B a b e n ~ e t a g e n =}$ artig mo zwax natïrlidy immex bout oben mad untert an cinamber gefïnt merben. Fes ijt aljo eint horizontaler Şäınge ober Säntentiant.

are die einfachjte Miethode jeben wir Dabei bie an, wo bie erfte, am natïr(id)en Iräger bejeftigte Befltajel zum Boben ber zweiten wird. Da jich aber bie Beflen ber erjteren ftets

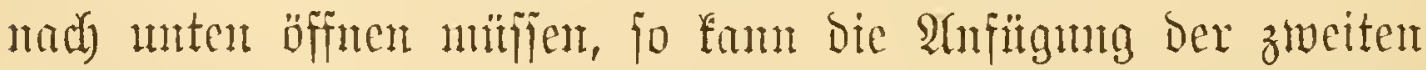

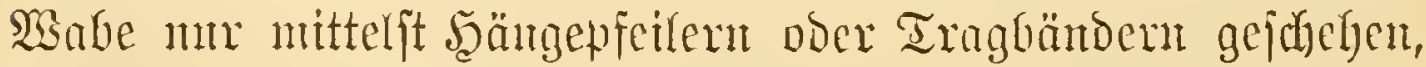

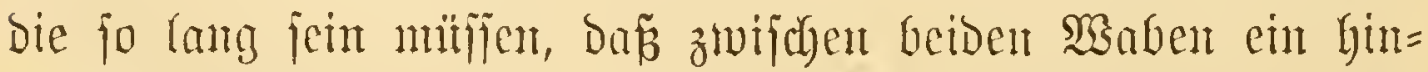
reichender Splehramm für bie arbeitsente übrig breibt. Die 


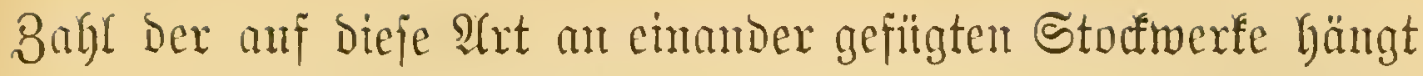

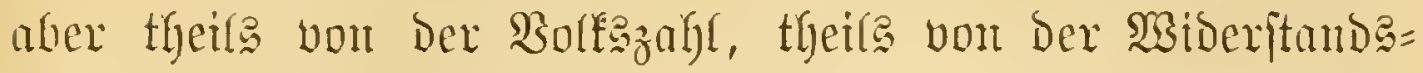
fähigleit des natiurltchen Trägers ab. Sit leteterer etwa

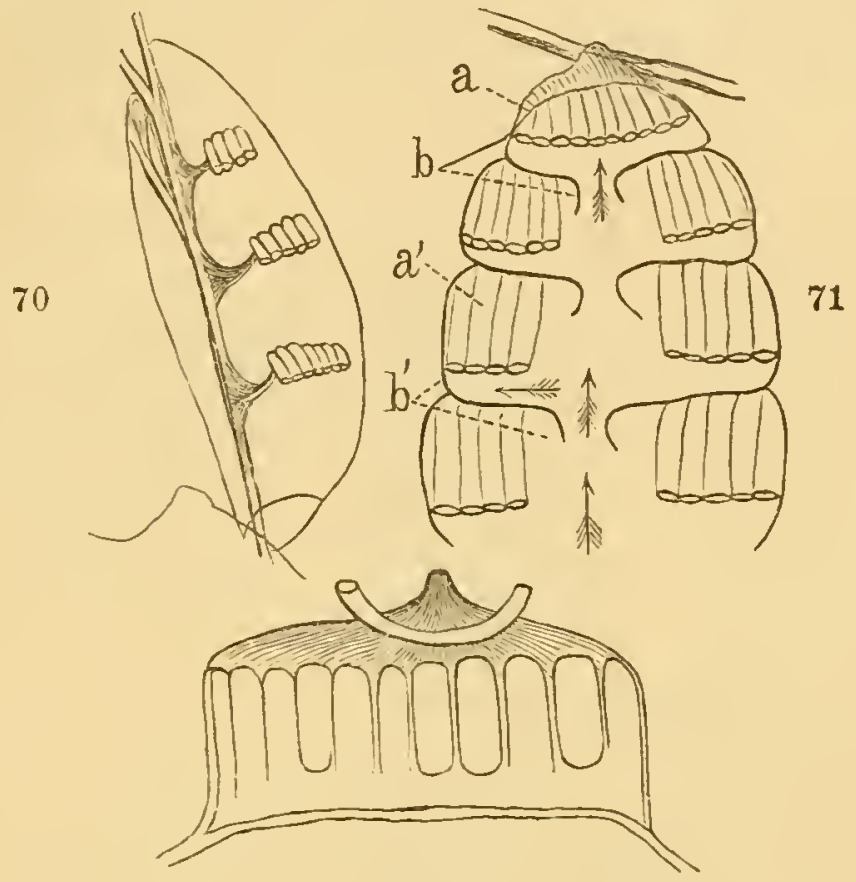

62

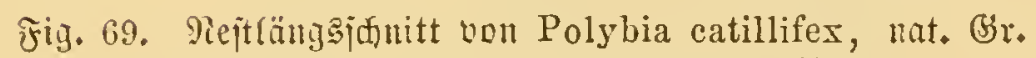

" 70. E.tenio vou Chatergus apicalis, verfl.

"71. Ebenjo von Polybia rejecta.

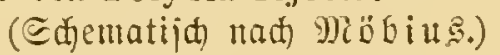

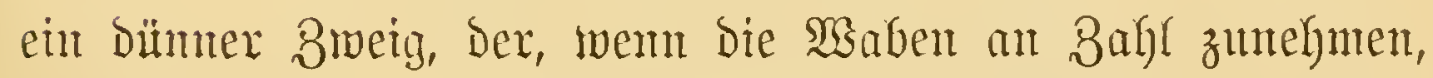
jich bedenffich biegt, jo wird Dex Bau abgej(d)lofjen und ein

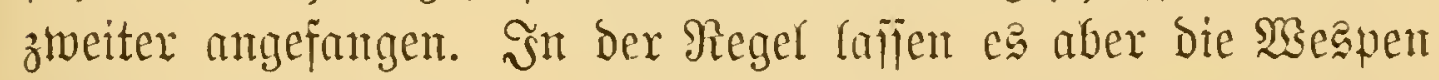

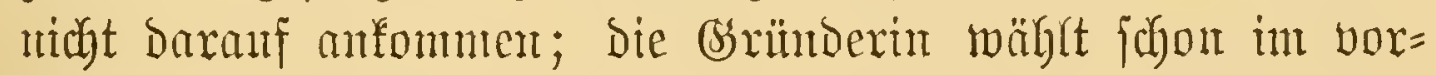
Ginein eine pafjente Stübe ans.

Es ijt eviouent, Dañ bei biefer Banart eine genteinfame Saïlle nidgt unbebingt nothwe to $i g$ ift, und wenn man aud bisher feine hüllenlofen fand, fo mirb man fie vielleidyt nodh

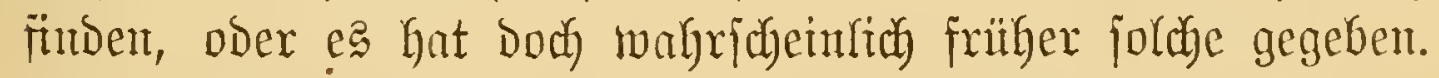
DDex, fragen wir, wenn eintwabige Nefter ob ne beulle

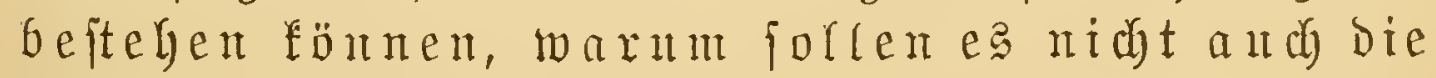
mehrmabigen? 


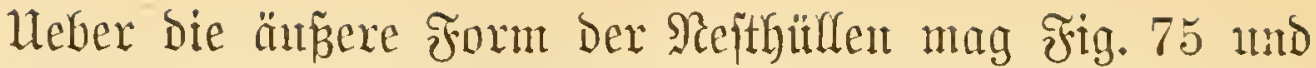

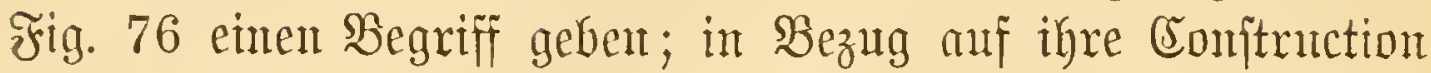
werben aber mebrere Sujteme befolgt. Şänfig bejteben fie and einem einzigen Blatt; andere Nale and mehreren, Die zwiebelichalenartig ïbereinandergreifen, oder es wird, wie bet

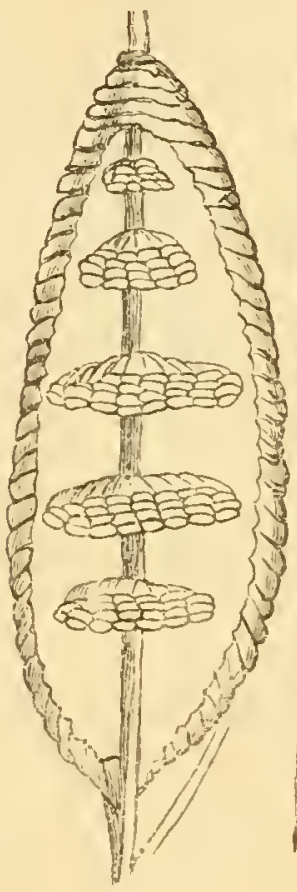

72

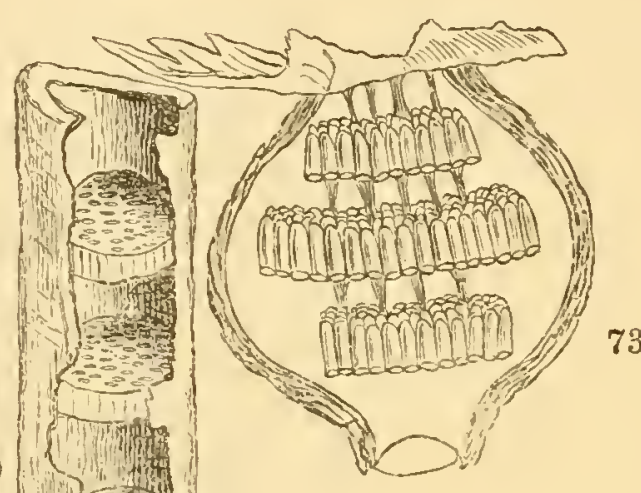

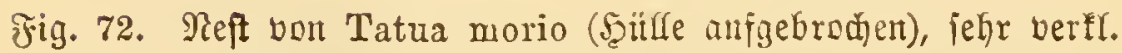

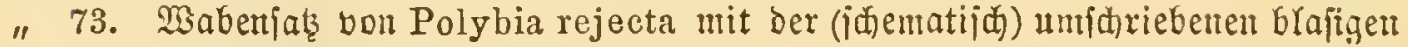
Silife einex Sorniburarg, bertf.

"74. Sornifwaben in einem Gohlet Baum.

Dex Şornif́, Dex Mantel aus eigenen Belfen zujanmengefïgt

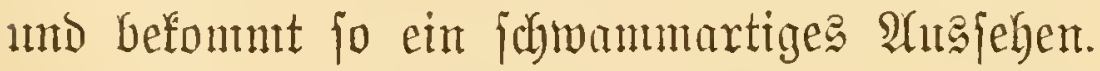

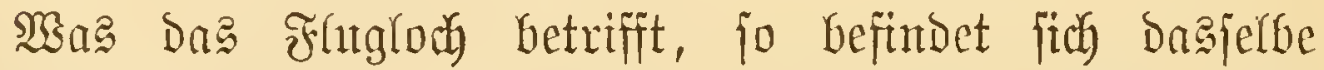
faft Durchgehends am unteren Pol. Bei etfichen bejtebt aber

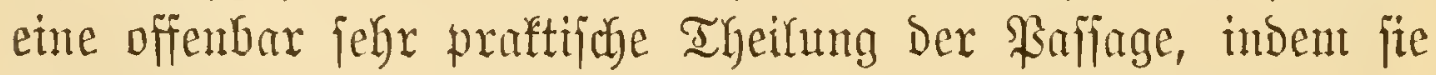

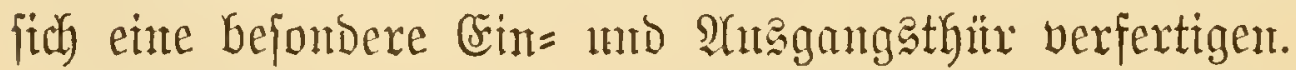

(Ssfeichen die Yebtbejprodyenen Nejter cinem umgefebrten mehritöutigen Şauje, Dejīen offene Etagen burch Säulen ver= 
bunden, unb bou einer gemeinfanen Ringnuaner umgeben fint, fo jeben mix uns in Bezuly auf bie jebt zu ex= wähnenden vergebens un eine Artalogie in ber menjchlichen Buntednil mut. - Mian betrachte Den Aufrip eines Nejtes eitter ber zablreidyen bei uns reiber fehlenben Polybia-Species

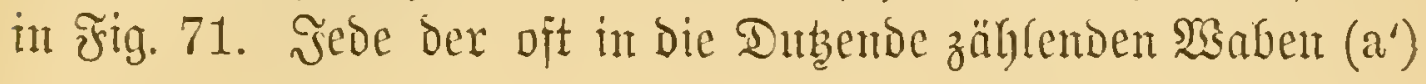

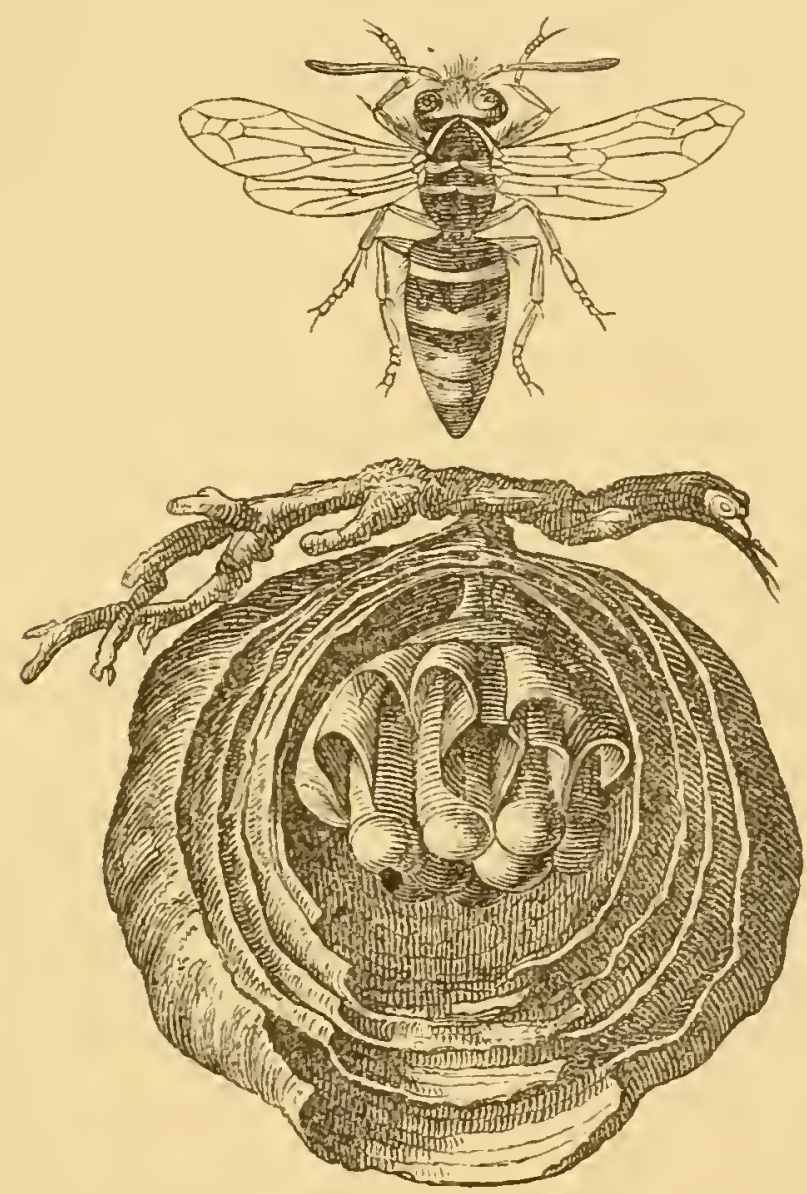

Æig. 75.

Reft der gemeinen sespe.

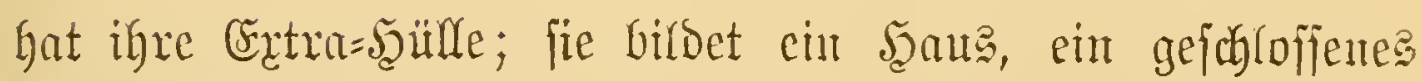

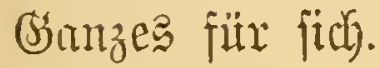

Dabei hat Dann jebe cinzelue Alotheilung entweder ifre bejondere Seitcutthüx, d. h. Dic einzenten Stoctwerfe find

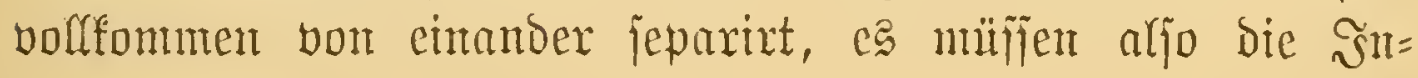




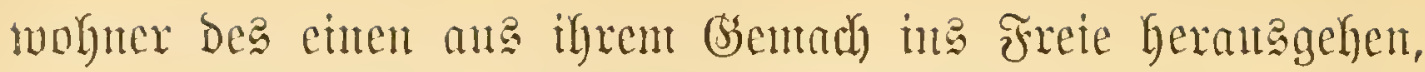

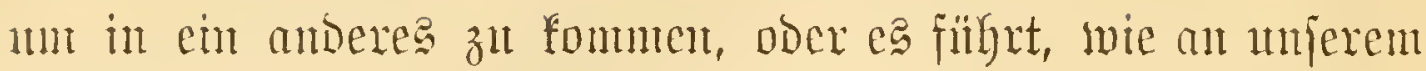
Beippiel, burdy che greige von Igoren, eine geneimfante Strup̃e vom unteriten Stodfwerk zum Giebel cmpor.

Das Sanze ijt ïbrigens feinex Conftrutetion und bifto=

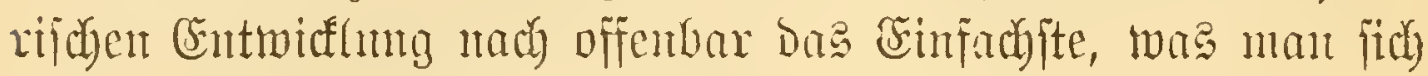

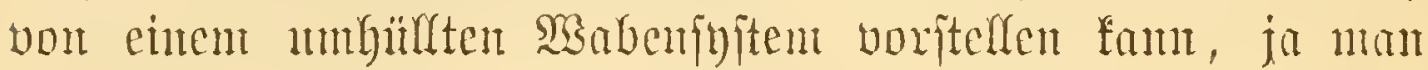

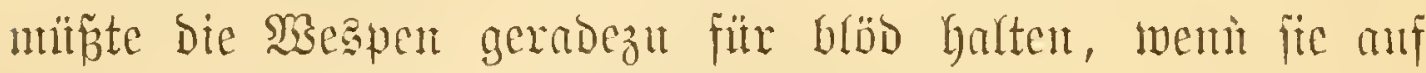
Dieje fimperfte alfer Baurten, die ftreng genommen uid)t eimal bas erfordert, was mau ciucu Pran ueunt, nicht verfallen wären.

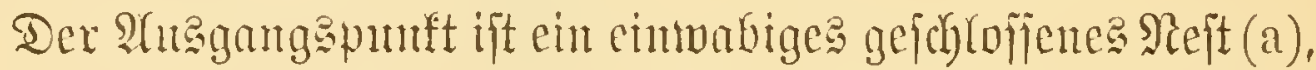

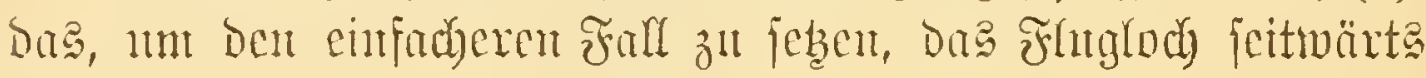

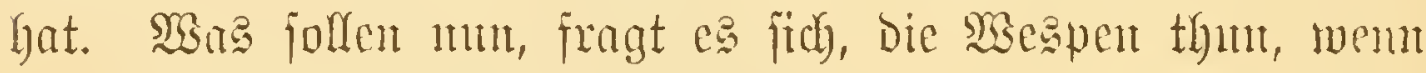

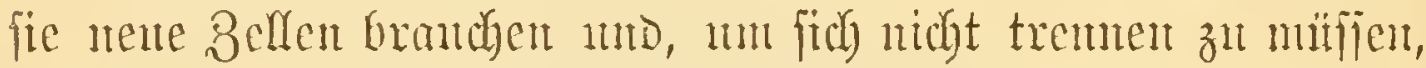
Diejelben mit Den alten SReft in irgend cine Serbintong bringen wollen? Sie branthen abjolut nichts zu exfinton, fo wentg wie die andern, weldyc die teas ङäulen au bie offene alte hefteu, ja ignen ift die Sadbe nodh viel näher gelegt. Sie branthen mur Den Şüll= boden des eriten Reftes (b) zu Dem zu verwenten, wozu fie Den natürlichen Iräger, Den $\mathfrak{A}$ t, Das Brett noer Dergl. ver= tocndeten, furzum fie haben mu das zweite Rejt an Das erfte zu hältgen.

Fit aber, wie in Fig. 71, in erften 'seft bas Finglod) in ber Mitte Des Selllbodents, fo banten fie die Beflen éven

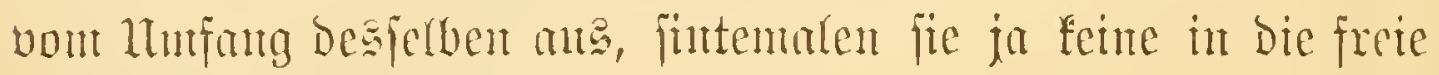
Suft conftumixen töunen.

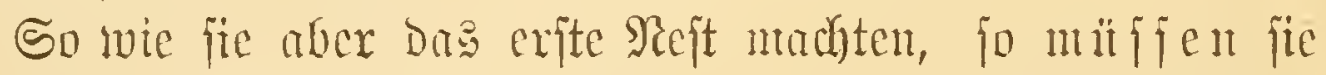
gewohnheitsgenän and bas zueite formen, D. h. fie werden unter ifu wieber Dic än

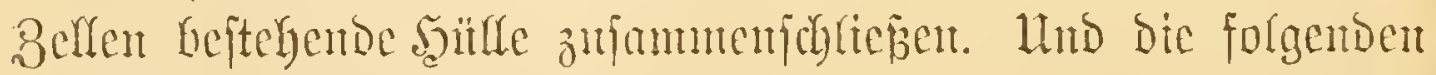
Estagen? Dody genetija berbienten fie ja gar nicht biejen 


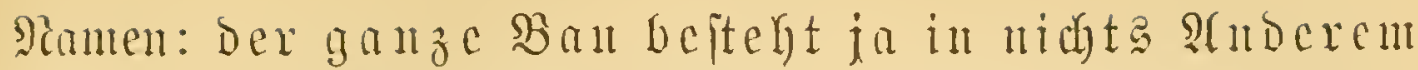

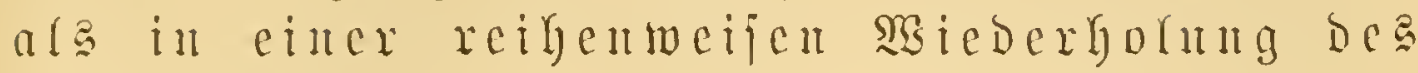
eriten sejte

9)it biejer Crrfenuturíp fällt un freilich bie ganze com= Whicirte bou Möbius aufgejtellte Syjtentatif ber zujammen=

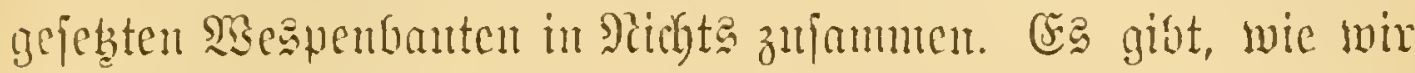
Dice fibon Cingange betonten, in şejentfichen nur zoweierlei

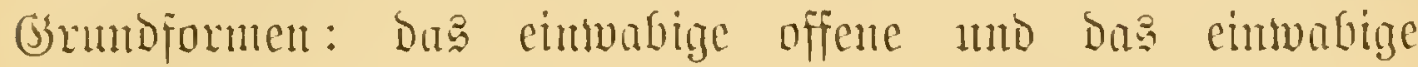

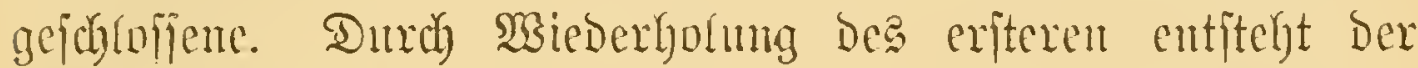

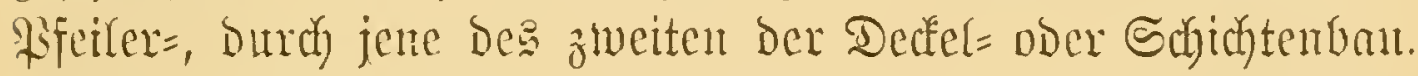

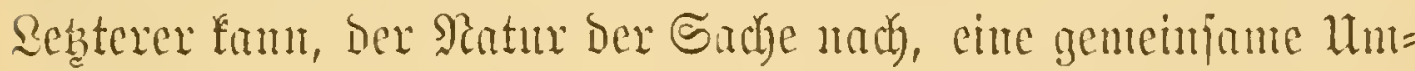

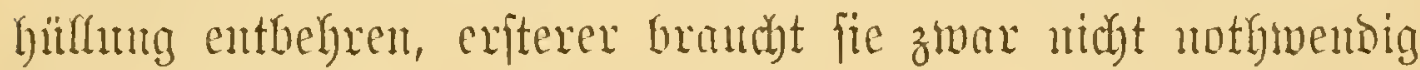

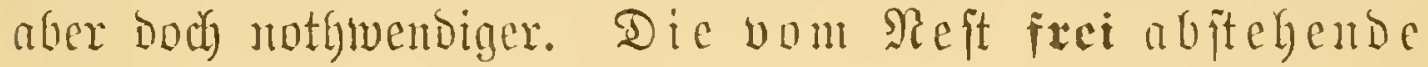

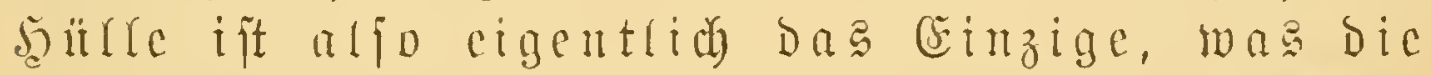
gejerrigen vor ben jolitären woras gaben.

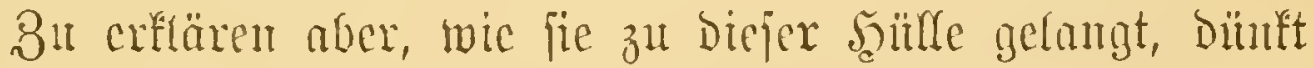
ults eirte zul leid)te Sache, ats bar wix Den Rejer Dantit behelfigen möchten; cr miro jogar das heraugfutoen, was etwa in Bufimift noch an biejen jo viel Gerwunderten Berken zu verbeijern gibt.

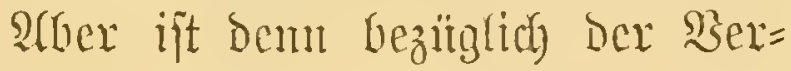
Gimbung Der Bellwaben ïberbant nod eine Miethode Denfrar, bie von ben

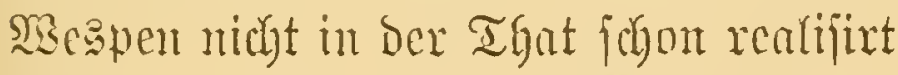
märe? SMinn möbde wirffich meinen, Dar e

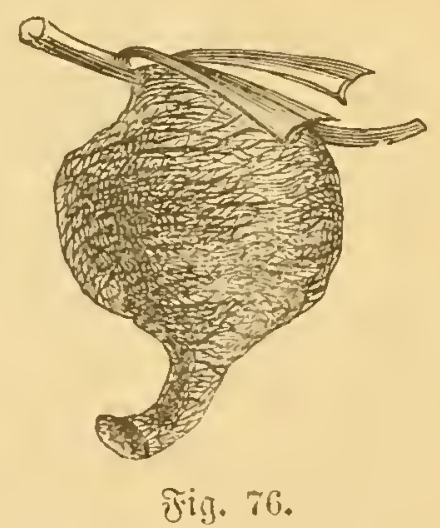

Reit vorr Polybia ampul. laria, jefre verfl.

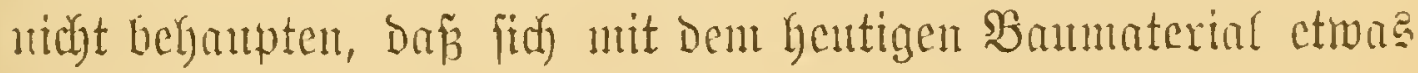
wejentfich Nente madyen laije.

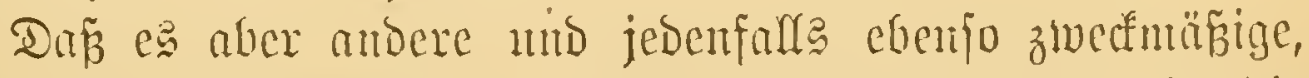
son nidjt beijere Methoden gibt, are fie gegentwärtig bic

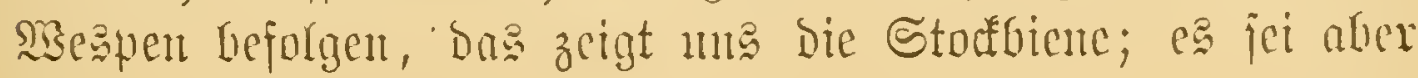




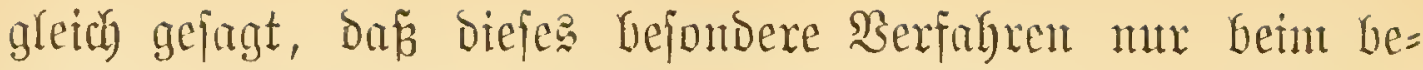

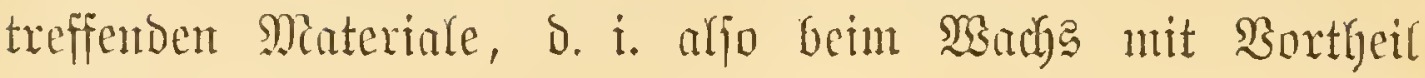
anzutwention ift.

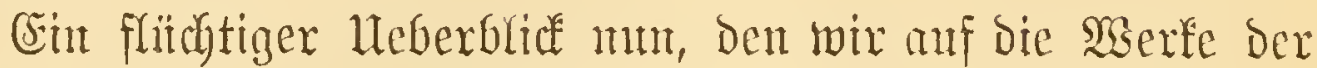

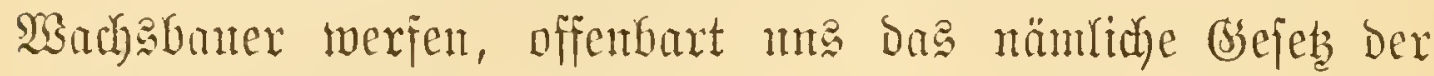

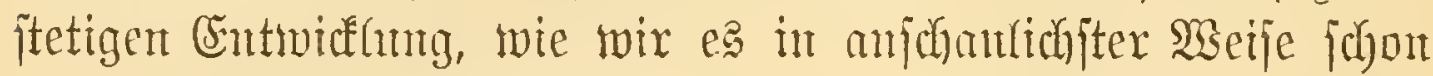
bei ben Mespen erfantut.

Es gibt $\mathfrak{B a b j b i e n e n , ~ z . ~ B . ~ D i e ~ m e f t i n t i f i c h e ~ A p i s ~ f l o r a l i s , ~}$ bie, gleidi) ben Polistes, nux eine eimzige offente Infel won Beffent banen, uno manthe, wie bie Melopona's, ftehen in ifrer Sumft fogar nody tiefer und etron anf gleidyen Jun mit ben Miörtelbienten, Da fie ifhre Bellen midgt hart an eimander fïgen,

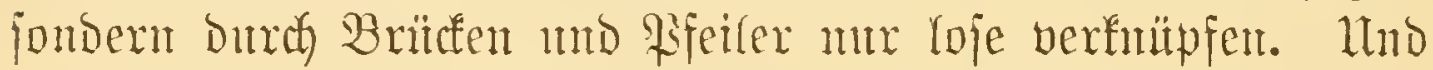
Da bieje Melipona's-Zellen nityt edfig, fondern fejfel= oder topf= artig find, jo baben wix Damit einen menen Betweis, Dan der Prismenban nichts Primüres, fombern nux cin SBerf Des fortichreitenden engern Bujammenritufents ber mriprünglid nutublichen Bellen ift.

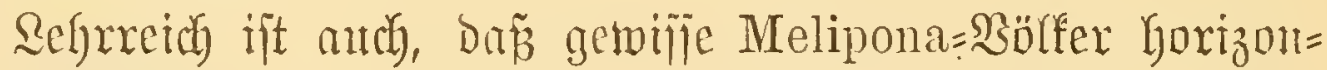
tale Wraben machen, bie fie, gentut wie bie Şornif́, Durch) (othredste Bfeiter mitjamment verbinben.

Ëment böldig nenen Baufthl treffen wir, wie gejagt, exit

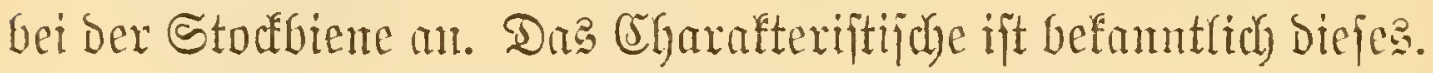
Die Studebienen füfren bie Belfen nidyt vollfommen frei anf, pondern jie arbeitent wenigjtens bie Böben dexjelben aus foltben

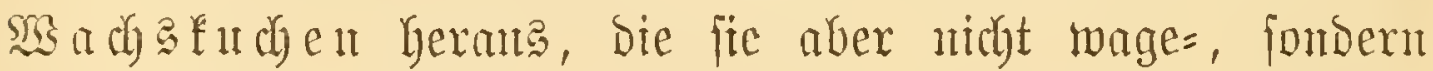
(othredyt an bie Decke ifrer Niftgöhle rejp. Des Sorbes lyängen.

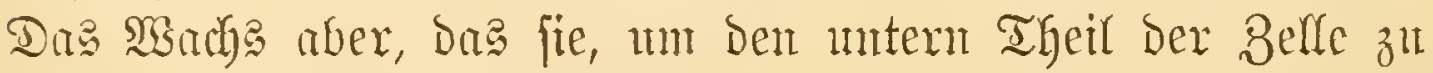
machen, ans Dent Anthen heranghtagen, vermenden fie zugleidh, um Den obern Theil zu verjertigen.

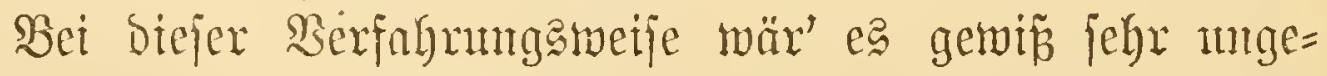

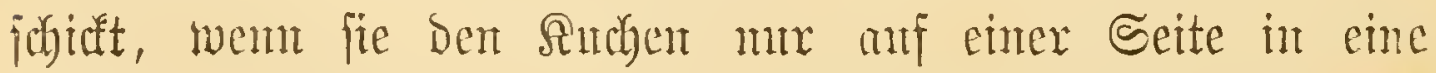

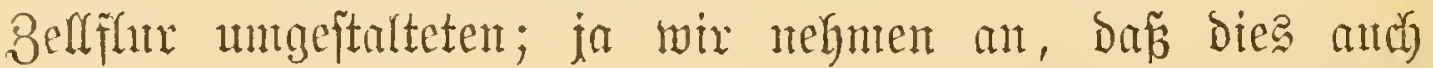




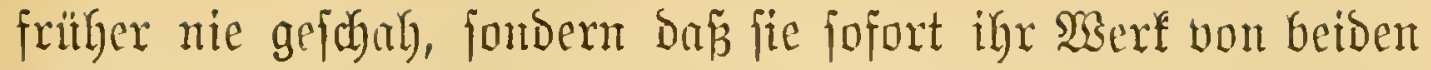
Seiten begamtu.

Mrjprünglich mögen 'Die einumber zugefehrten Böben der beiberjeitigen Bellen, wie bei den Saespen, eben oder napf= förmig uno sie Bellen jelbjt cylindrifoch gemejen fein.

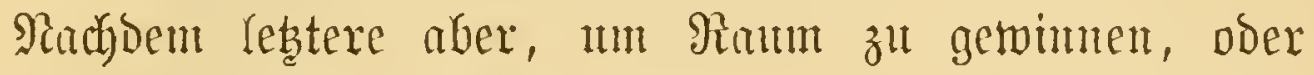
ridhtiger, um $\mathfrak{B a c h s}$ z̆ fparen, inmer enger an eimanber ge=

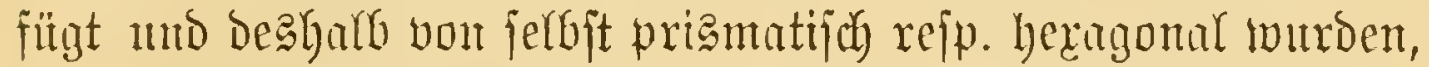

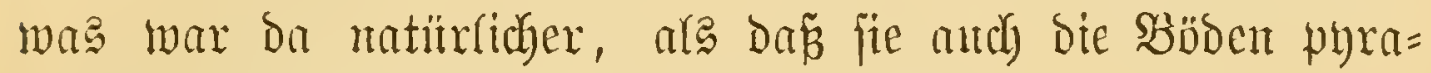

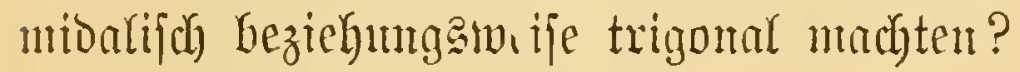

Und infoweit ift benn die zweifinidige Wabe ber Stoffiene in der That das Soeal eines Bell= uejtes.

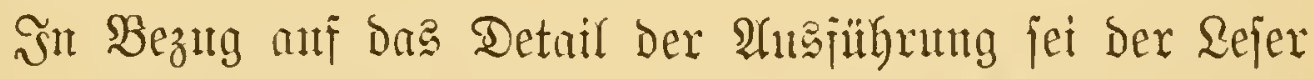

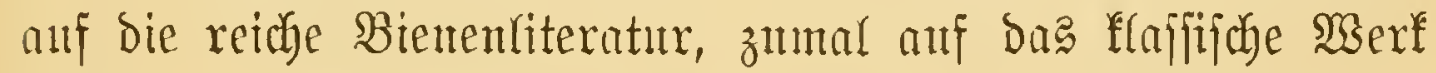

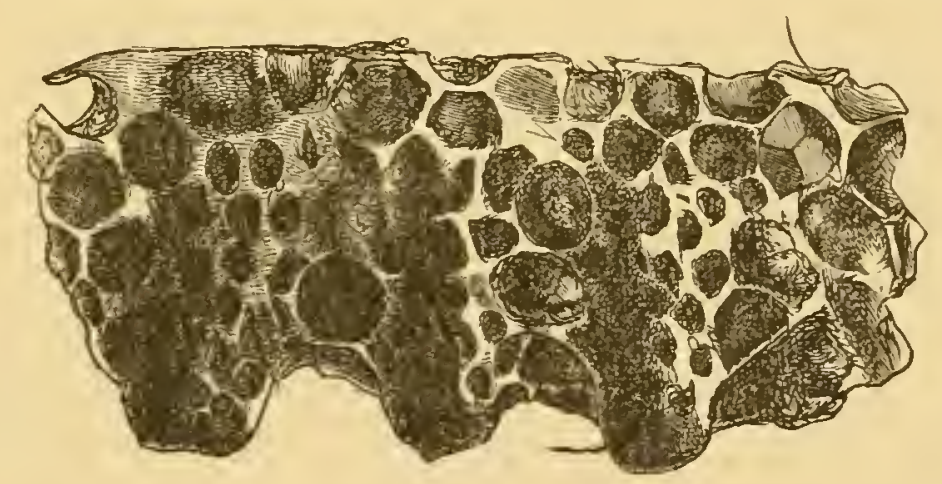

Fig. 77.

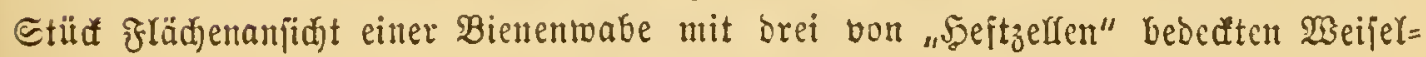
loiegen, nat, Bjr.

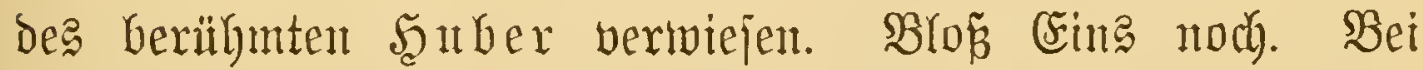

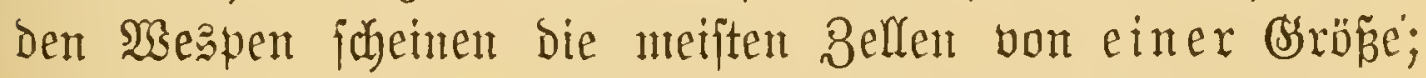
hei Den Bienen Dagegen hat bie meitergehende Differencirung Des ganzen Bolfathume, wir meinen befien ftrenge Sonderumg in eiertegende $\mathfrak{B c i b c h e n , ~ i n ~ M r b e i t e r ~ u n t ~ i n ~ M a ̈ n n c h e n , ~ f i c h ~}$ auch an BelfGan bertörpert. Für bie Arbeiter werben nämtich

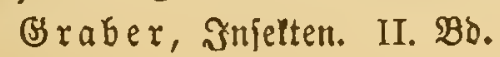


flemere Bcllen gemadyt als für bie Drohnen; währent bie mentgen Siönigimnen ganz riefige Bsemächer, bie jog. Sacifel= wiegen, befonmen, bie (Fig. 77) tropffteintartig wom untem Rand Der Waben herabhängen, während bie andern beiben

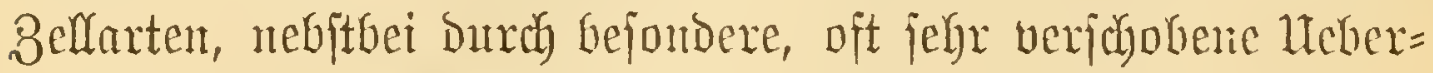
gangezzellen verfmipt, vielfach vermijat vorfomment.

\section{Zefter der Eqummeln.}

Das ftrenge Belfenfyjten, wie ca bie meiften jolitären uno gejelligen Fmment cultiviren, hat, - wie jebe Cimfeitigfeit, neben den nidbt zu mterichäbenden Bortheilen and jeine Schattenjeiten. Sinte Der am meiften ins Semotht falfenton

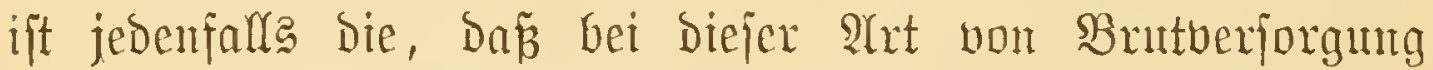
vicle Zeit mo Rraft rediglidy anf bie Beiftellumg Der crfarder= liden Woburäume verloren geht, bie zum Theil befier zum

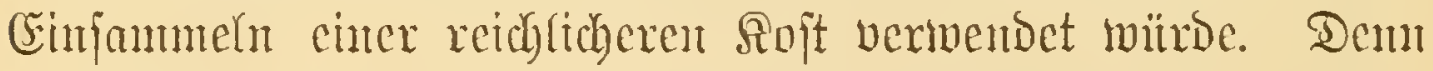
wo (S)entächer hereitet werden, weut fie aber barin hungern mitijien?

Und in ber That gibt es and Sinnten, weldye westiger

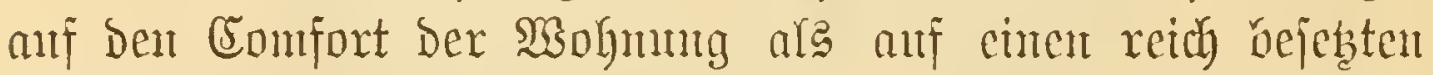

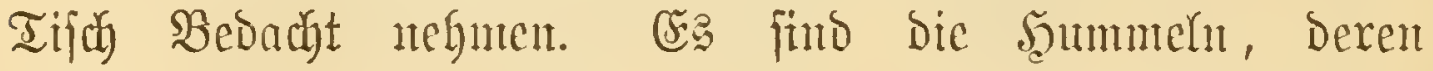
Nefter zugleidy bie meijte Âtalogie mit Den gleidrnamigen

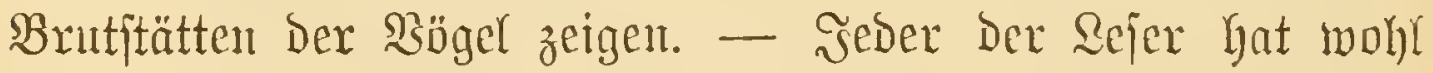

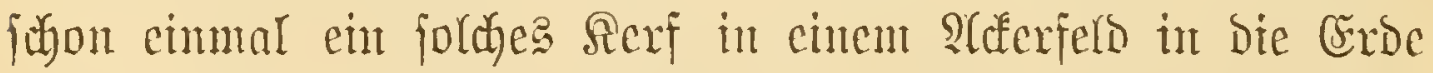

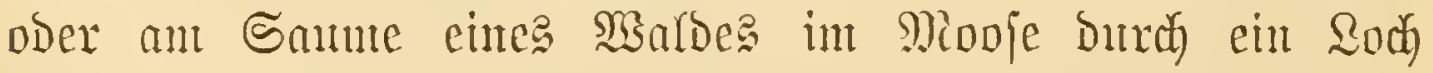
verjumintou fehen. Folgt ex, mit bent Spaten in Der Şand, Den unterirbifdyen Schadjte, fo fonmt ex, frilher ober jpäter,

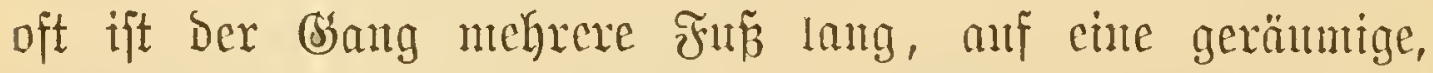

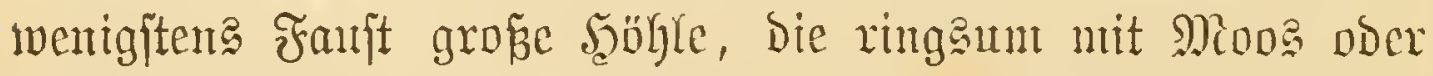
mtDern Sflanzen megr weniger funftooll ausgejdylagen ift.

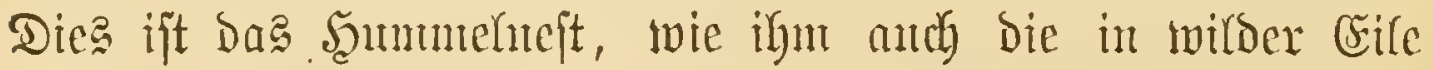




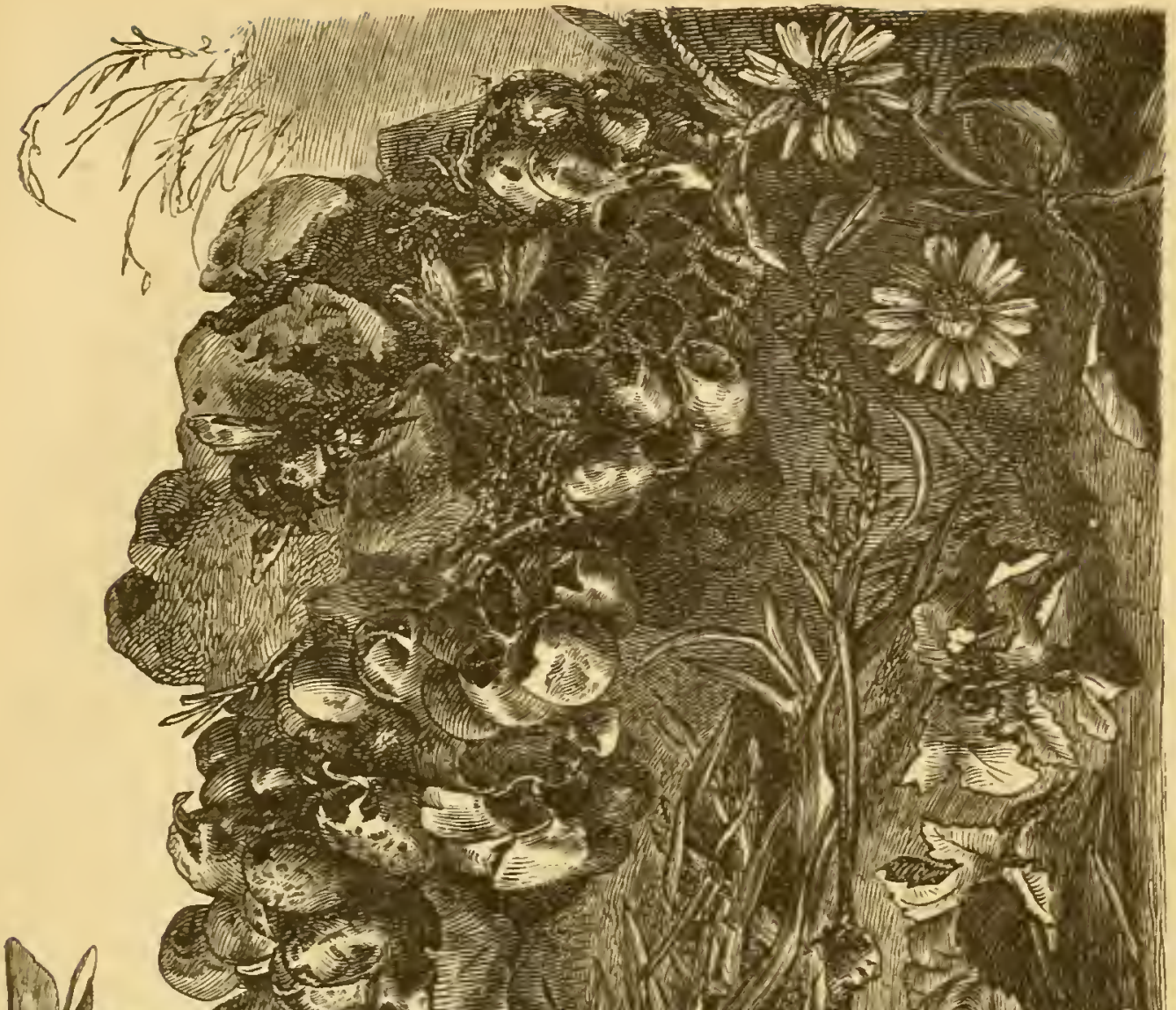

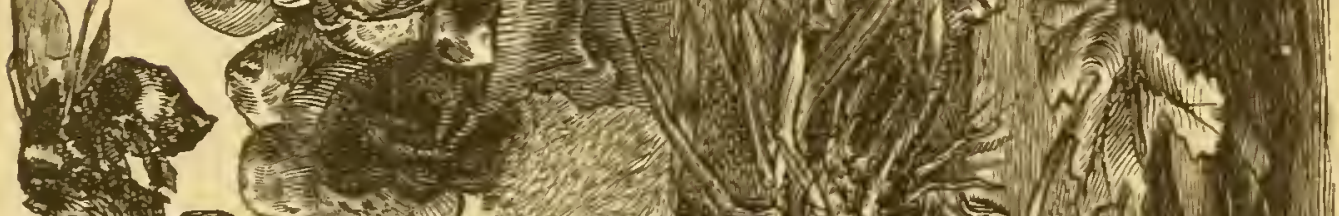
(1)

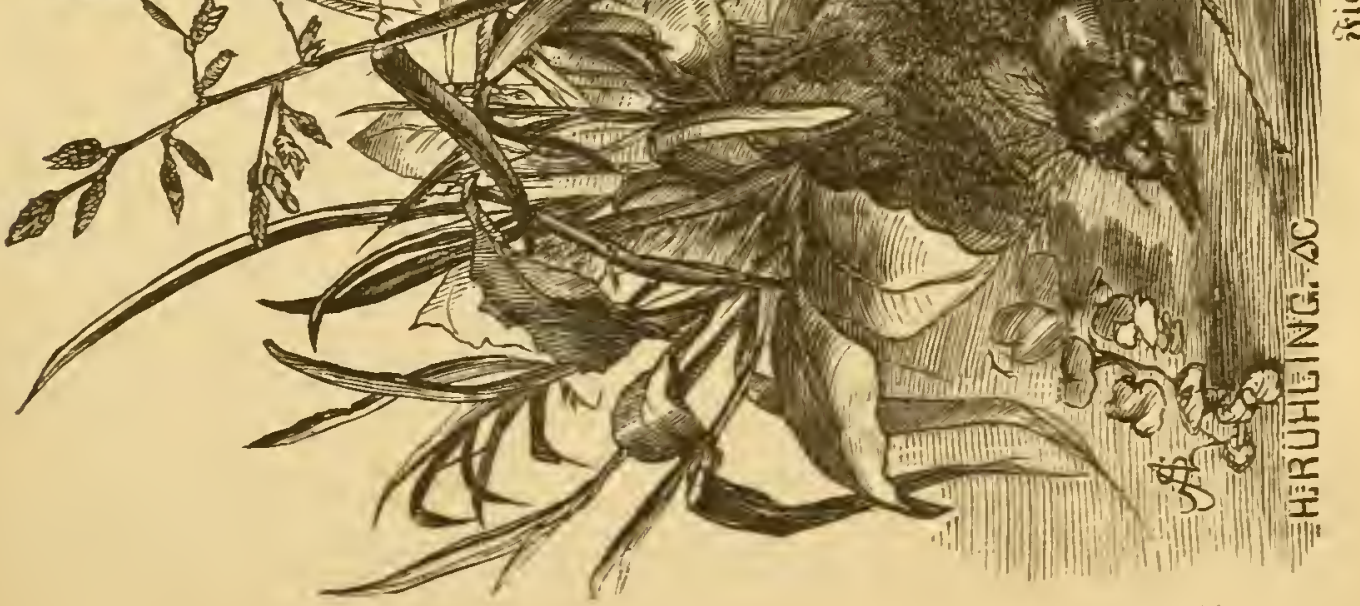


herborftürzenden Betwohner fagen merden. - So artig mun oft

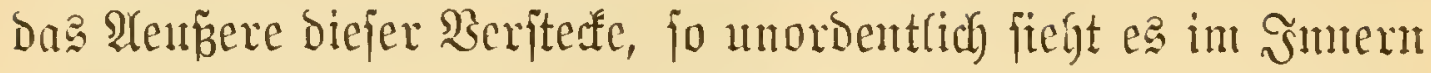

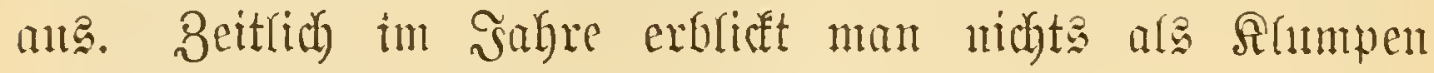

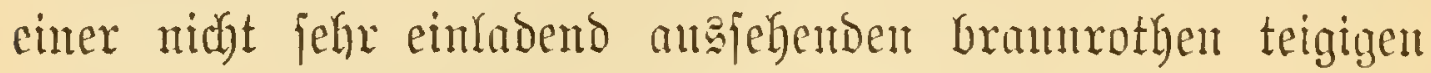
Mafje: cin rohes Gemenge von Rollen und Şonig. Bridyt man fie ans eintunder, fo getwahrt man Darin fleine beb̆hlungen

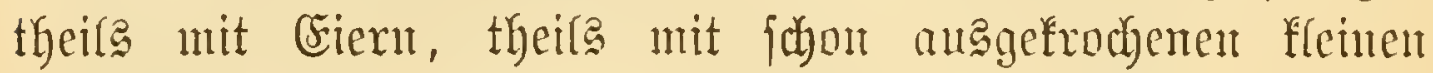

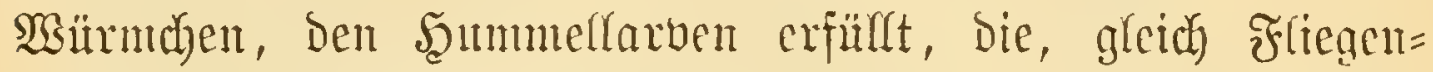

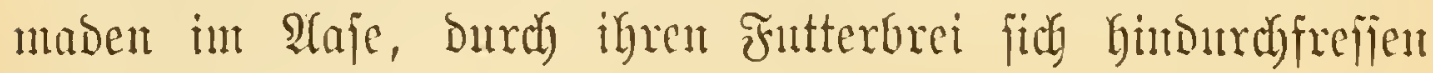
(ซ̧ig. 78 limf

Später, gegen Den Sonmer Ginein, foumnt Dam zut biejen inzwifhen gautz jubanmig gefrejjenen mo bereits ber=

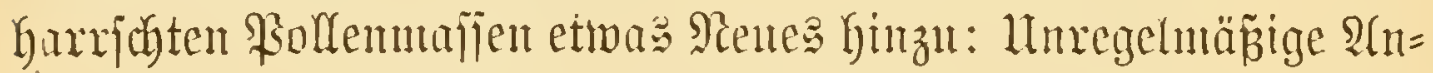

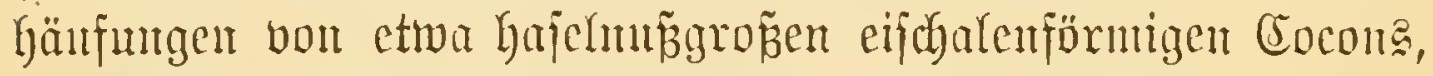
swelde bie ertwähnte Analogie mit cintem Sogelneite noch crlgöhen.

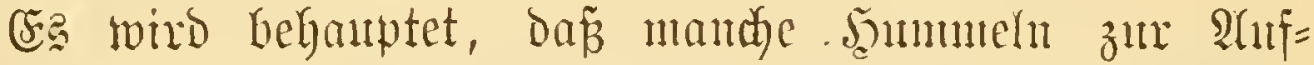

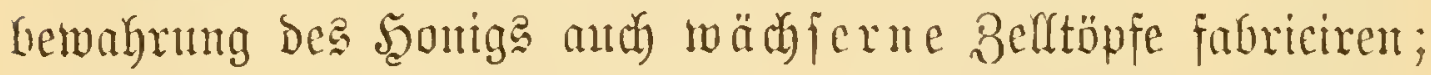

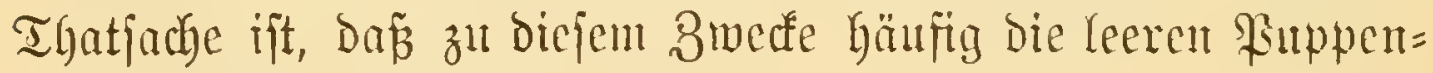
fidalen bentst werbent.

\section{Ziejter der Zlmeijert.}

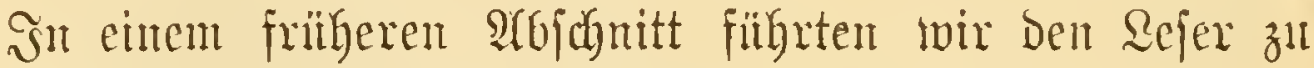
einem Eroabhang, Defien zuhlreithe Belffanmern zat einer

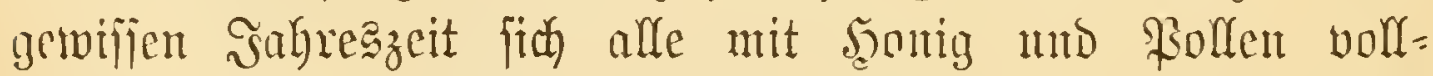
gejtopft zeigten. (Eine jeboch berfonmiegen wir Damalz: Daj Dicje unterirbijdyen Speider von zahlreichen Âteifen befud th

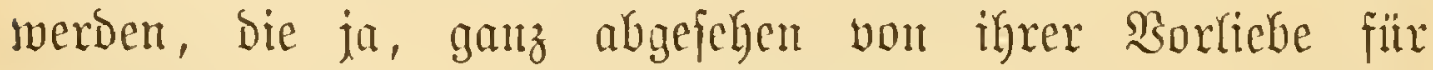

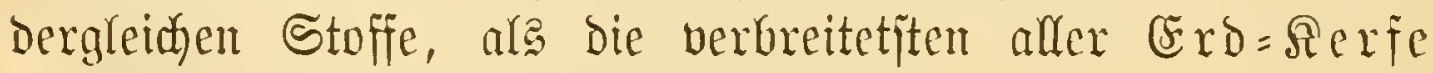
fo recht eigent(ich hieber gebören.

Sommen wir mu zu biejen Erowolymugen Der Bienen nächjtes sabr, went igre Erbater fie verlafien lyaben, fo 
bietet iid) cin menes nod) bewegteres Schanpiel dar: bie

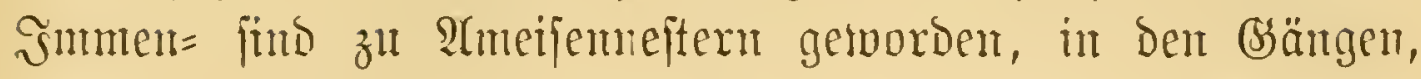
weldge mit vieler Nällye bie Erobiene gegraben, laufen mu=

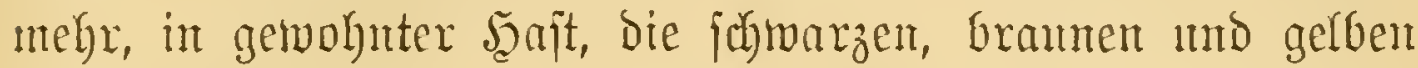
Echmalbrinfte, und in Den netten Sämmerchen, wo eimit, auf ciner Bätenjtunfungel, die Smmenmade ifrer $\mathfrak{B}$ ollendung entgegenreifte, da Yiegen mu Şäufdyen von unzähligen Eiern, Sarven oder Piuppen umjerer obligaten Spaziergänger.

Dies ijt bie saedjelmirthjed aft im šnjeftenteben; bies Beijpiel zeigt uns audh), wie menig von manthen jog. "Bauten" Der âmeijen zu halten ift, bie ju vielfach and ganz anf eigene

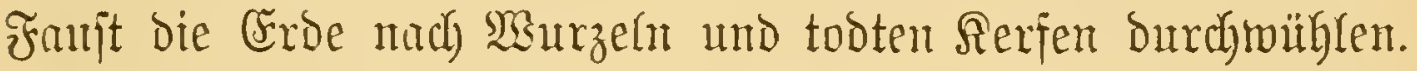

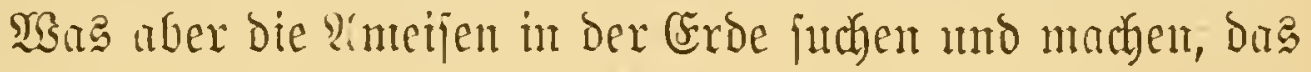
juchen und machen jie unter Anderm auth im Şolz. Dan

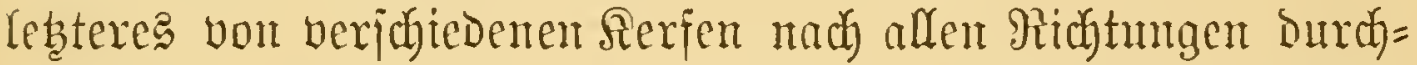
grabcu und jo, lantgian aber jtetig, in Moder vertwandelt svird, wiffent wix. Brechen toir mu, twie roir vorber eine Grofibolle entfernten, ein Stïn cines arten Baumftammes

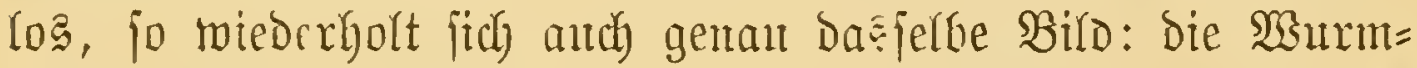
löber find von Ameijen mb ifrer reidfen Brut bewohnt, bie

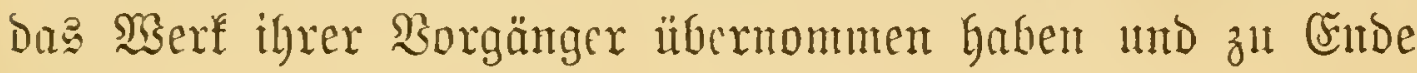
fïbren.

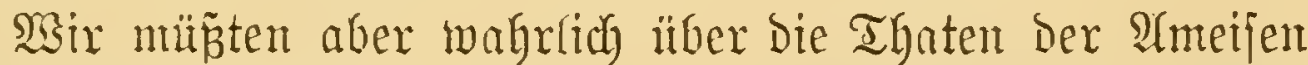
juhlecht unterrichtet jein, wenn wir ben Lejer glauben madjent

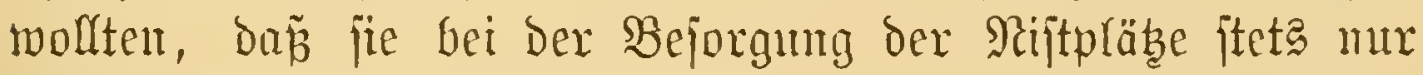

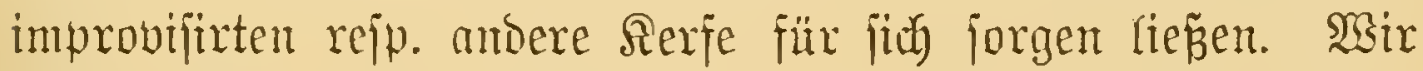

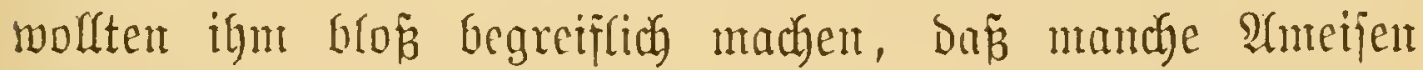
hinfichtlich ifgrer Buuthätigkeit auf einer jebr nieberen Stufe jich befinden, und daż pacciell bei manthen von ifnen bie Beranlajijungen zum Bauen jebr nabelieçende jind.

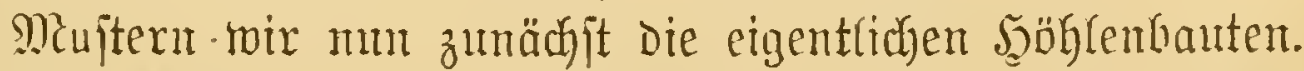

Die NAlegung cinte mentigitens in jeinen Dimenjionen gropartigen Erd=Tiefbane hatten wir jüngit zu beobachten 


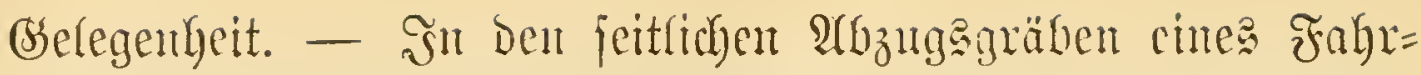
tocges, ber eintige Schulge tief in cintent ziemlidy haxten $\mathfrak{B S a r d}=$

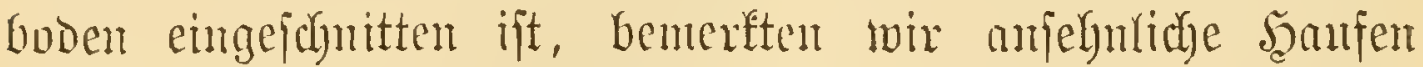
einer cigenthüntlich frimerigen Eroc, bie bon ber, welche vou des: Strapentäntorn herabzufallen pflegt, wejentlich

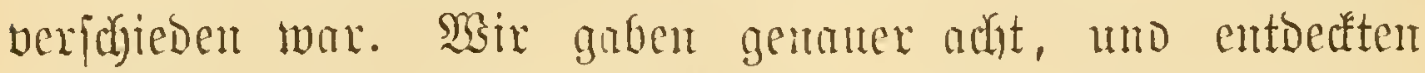

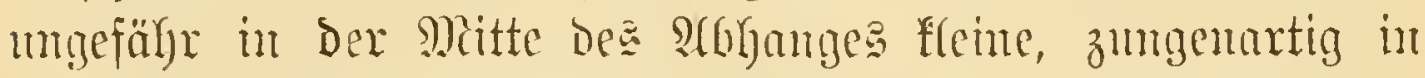
bie Tiefe gehende Sdyutthatben, ganz benen ähntidy, die man vor den Mümbungen Der Bergwerfätollen mutrifft. Itnd

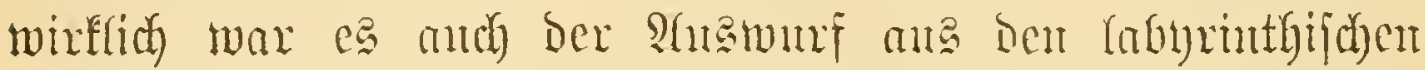

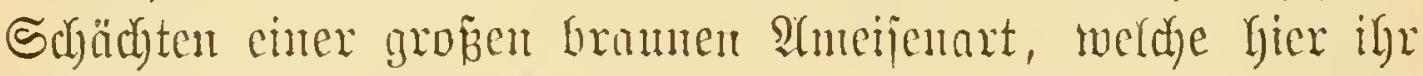

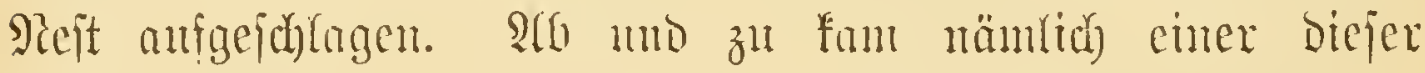
frimfen Suappen an bent Etolfen hervor, in ben weit anf=

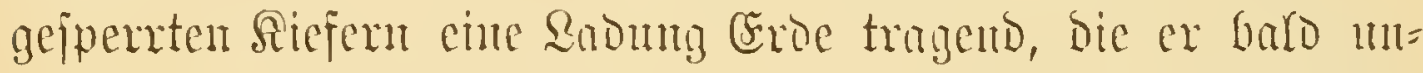

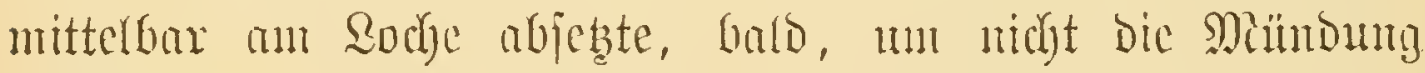
zu verjperren, weiter Ginn? anf Den gand Der denloe trug.

Mie grof uno weit verzmeigt aber die Ssänge bicje Bergbanes bereits jein munten, fonnte nun an Der Menge

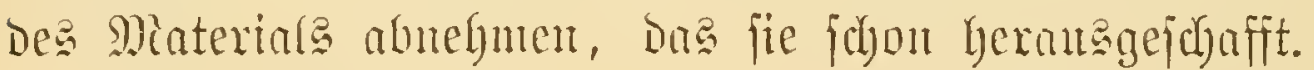

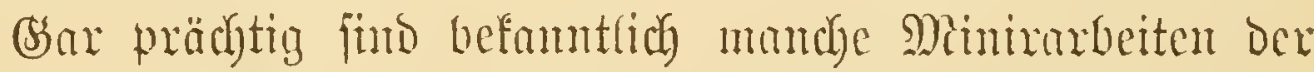

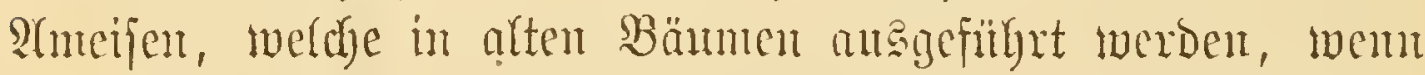
auch Die gang und gäben Bejdyreifnungen Der "Stoctwerfe",

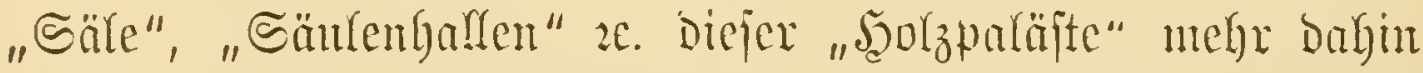

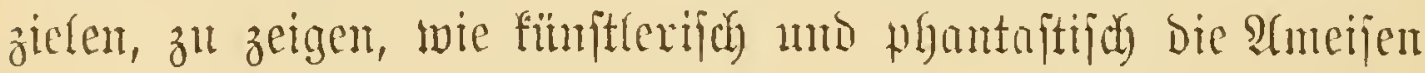
bei berartigen Banten zu Werte geben, als da

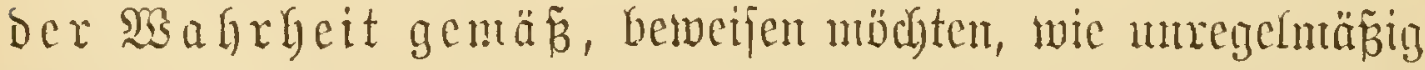

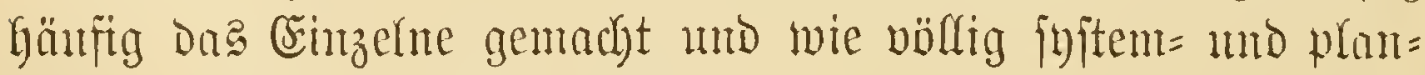
los bag branje angelegt wird.

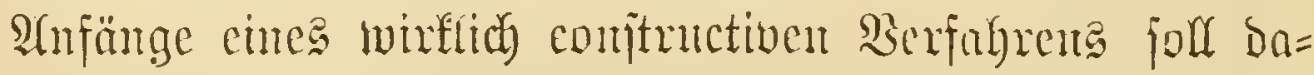
gegen unter andern unfere gelbe Siejentmeije an Den Iang legen.

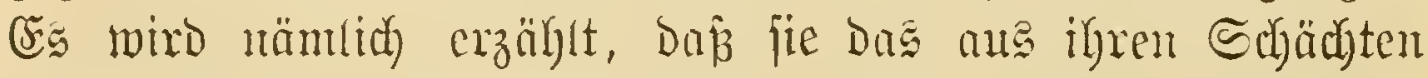

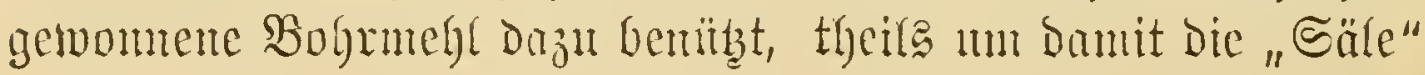




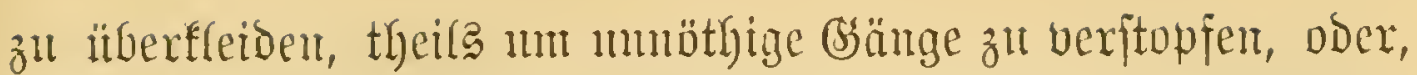

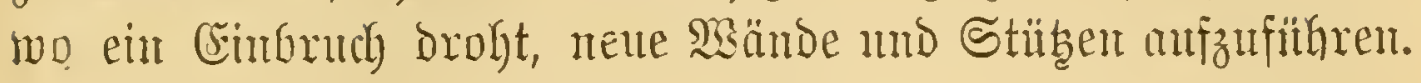

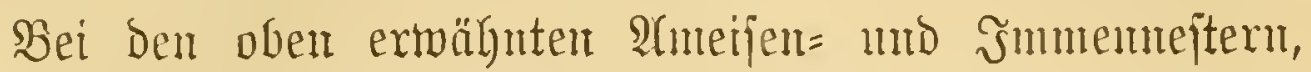

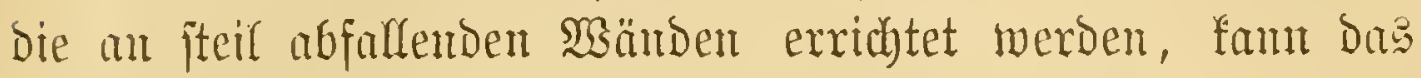

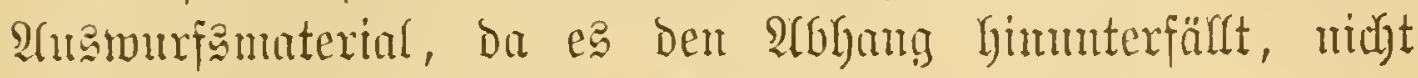

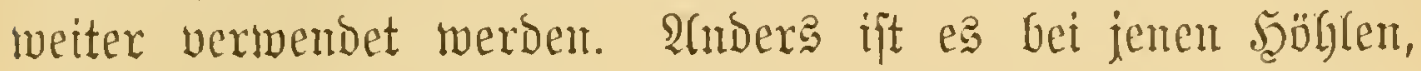
bie in einem megr flathen Terrain gegraben twerden. Şiex thïrmt jith allmälig und olye, bá bies anfang beab=

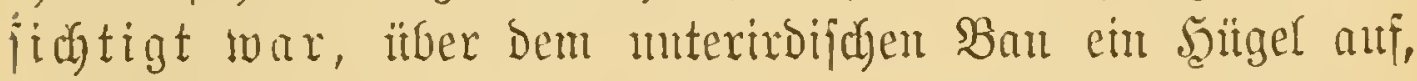
Der, wem die fubterranen Bänne in igm fortgejegt werben, jelbjt zu einen Ban, und ztwar vorzitglid) zu einem Brutofent mird, indom hier Eier, Sarvent und \$uppen Den für ihre

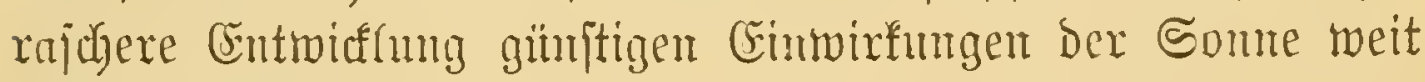

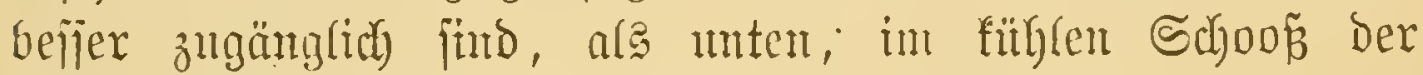
Eride. -

Die meijten in ier Crobe pder in ement Darin wurzelnten Baumitrunf niffenden $\mathfrak{A}$ meijen madyen mu mudf in ber That einen jolchen, mehr weniger funjtollen Sberban. Buan befonders (ebrreich ijt es aber, wahrzmelymen, wie dos Material, aus

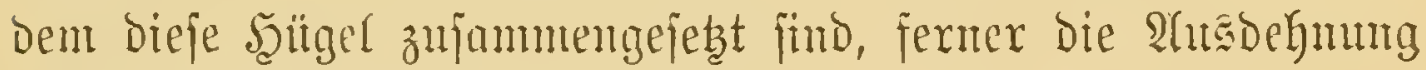
und bie imere Struftur Derjelben mit ber jerweiligen Boben= bejchaffentheit fitch) änbert.

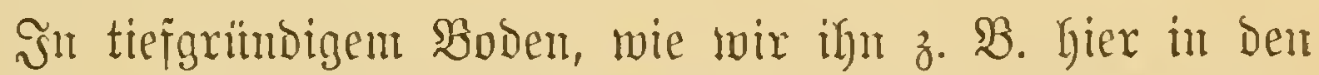
Saubwäldern des Prnththates baben, bejteben alfe atmeijen= Gügel, mo man findet Danunter förmlidje Berge, anta purer Erde, mb die Bsänge oringen oft eben flaftertief in den Bobent ein.

S̃n ben SRadermäldern Der 2lipen aber, auf fteinigem Terrain, Dem fich fobmer etwas abgeminnen läp̧t, werden

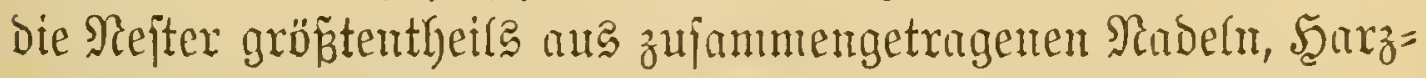

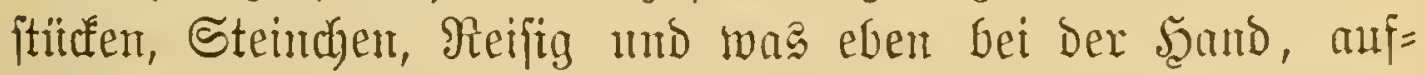
getfürnt, und mit einem fo Loferen mo gemifdgten Miateriale 
möbte es wohl fajwer halten, fo faubere mo glatte Wände herzuftellen, wie wir fie nou manthen Eronameifen marben fehen.

Went aber gewiffe Armeifen mit Rabeln bauen, wär' e马 Dann fogar mas Bejonderes, wemn andere, welche Rantböllber

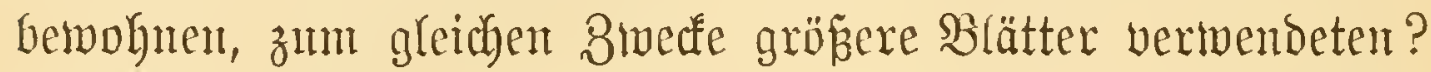

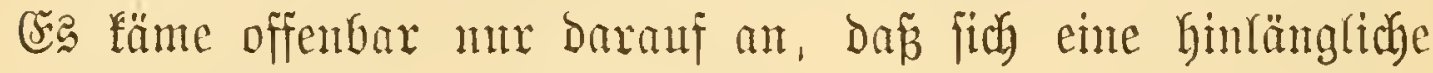

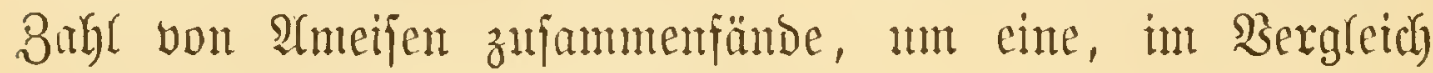

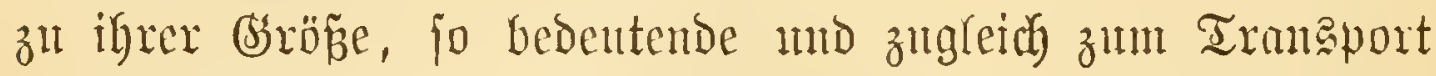
fo unbequente 2 ajt an Drt und Stelfe zu tragen mo bort gebörig zu abjuftirent.

Und in Der That fah $\mathfrak{B a n}$ a

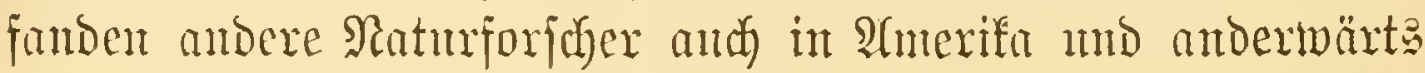
foldye Saublinttest.

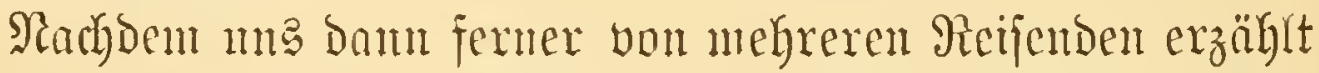

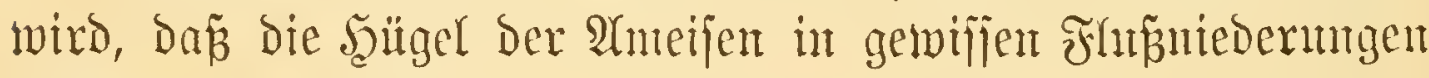

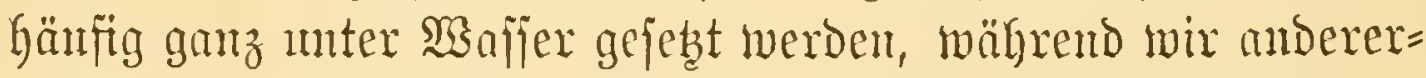

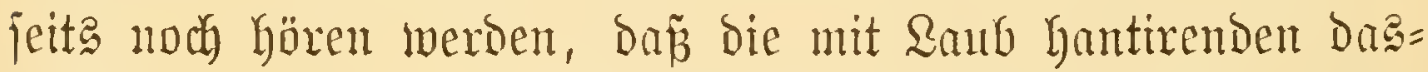
jelbe oft mühjan von den Bänmen herabholen müfjen, was

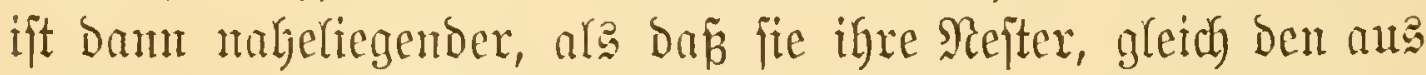
Palnenblättern geffochtenen Şängenatten Der alten đỏnaranmen Des Drinocco= Delta's, gelegentlich anif ben letzteren jerbjt er= ridyten? -

\section{Banten ber Termiten.}

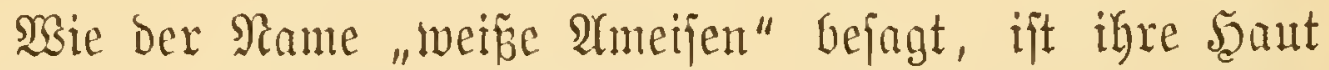
gegenüber ben farbigen Ameijen fehr pigmentarm, und fanon

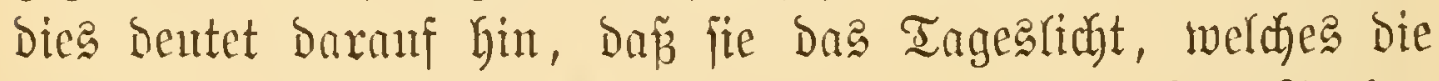
Scant Der andern Jnfeften mit oft fo malerifben Farben

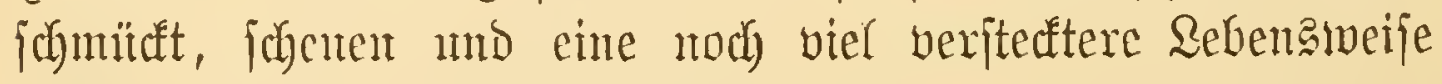
fïlren, wie igre Namentavettern.

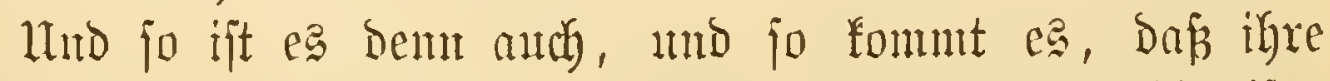

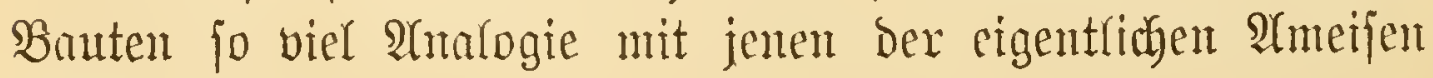
ljabent. 


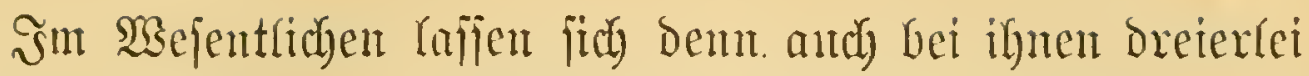

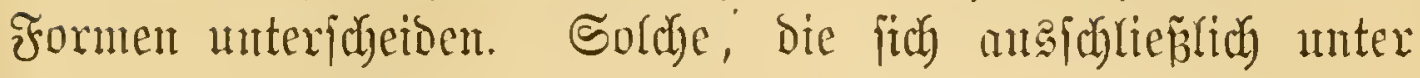
ber Erobe befinden, joldhe, die zugleidh einen lyägelartigen Dberbau haben, unb eine Dritte Brattung, melche man als Baummejter bezeidyuten fanm.

Die zmeite Form hat jeit Smeathman mo $S_{a b a g e}$ an meijten von fid reden gemadt, und mit biejen Banten, Den folofijalifen und arditeftonifid bollendetiten Werfen ber Snjeften überhaupt, wollen wir bent auth biejes Sapitel bejalię̧en.

Die großzartigiten Termitenpaläfte fadeinen in gewiffen Steppengegenden $\mathfrak{a}$ rrifa's vorzufommen. Sie gleidyen getwal= tigen Seuldyobern, indem fie nibyt felten, bei einem Grumb=

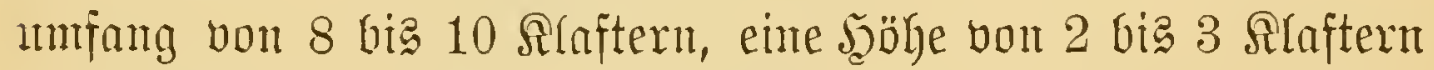
mo Darüber erreichen. Stelfenmeije itegen jie gart neben eimander, und der in bie Riederumgen herabjteigende Reifende

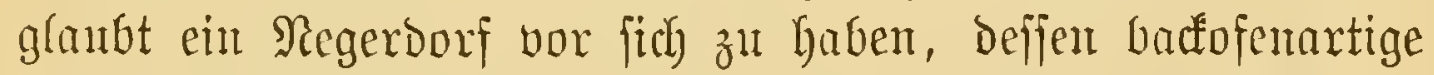

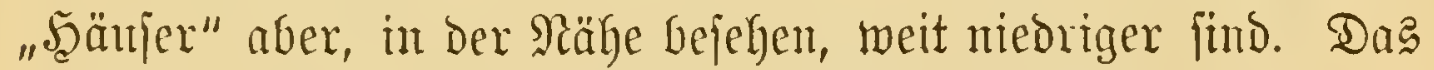
Material ijt mit dem Speid)el vermifhter mo mohl gefneteter Thon und bie Färbung von bar Hungebung oft fefre abjtechent.

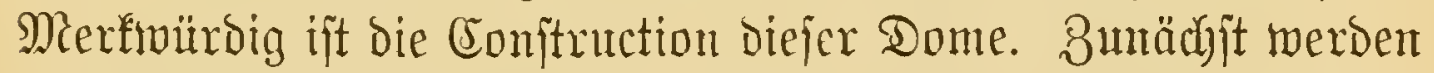

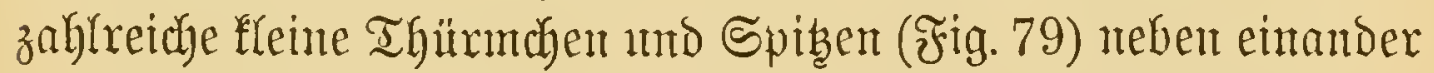
errichtet, worauf bie 3wif henräıme allmälig ausgefülut werden. Dies gibt Den Unterbau, Das (5rogejdyos. Nun fommen Darüber neue $\mathfrak{A} u f$ jäbe, bie fpäter abermals bereingt merden, das erjte Stodfwert.

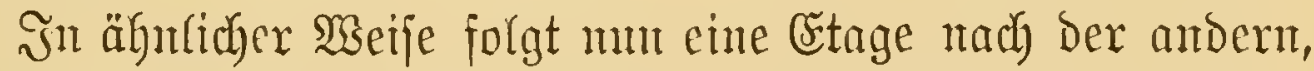

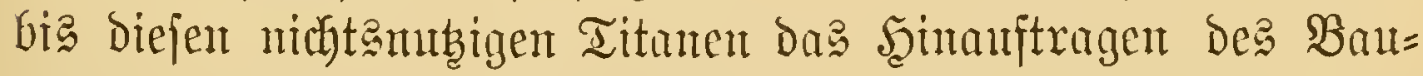

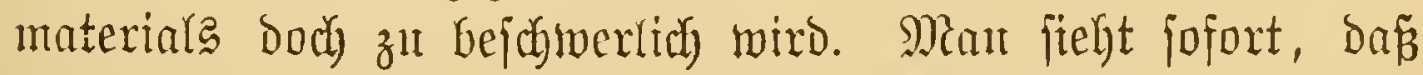
es fich Giex nidbt um ein einfaches Familienthaus wie beim Bienenitocf, jondern un eine wahrhaftige Stabt, wo nicht unt einen "Bundesftrat" Gambelt, Dejien einzelne Commmitüten 
aber, frei von allen Separationsychioften, Dod) nur eine einzige gruze Martergejellichaft aumachen.

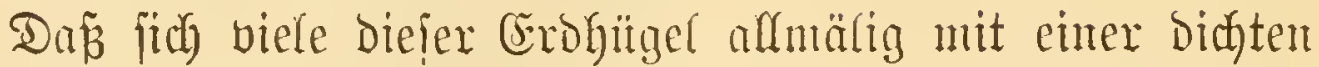
Segetation bebecfen, fann Den Termiten mu erwünjdyt feir.

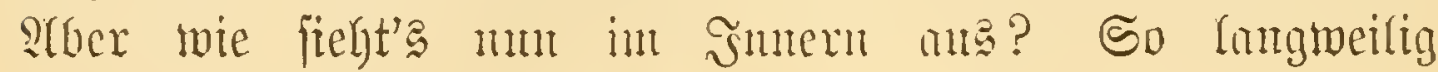

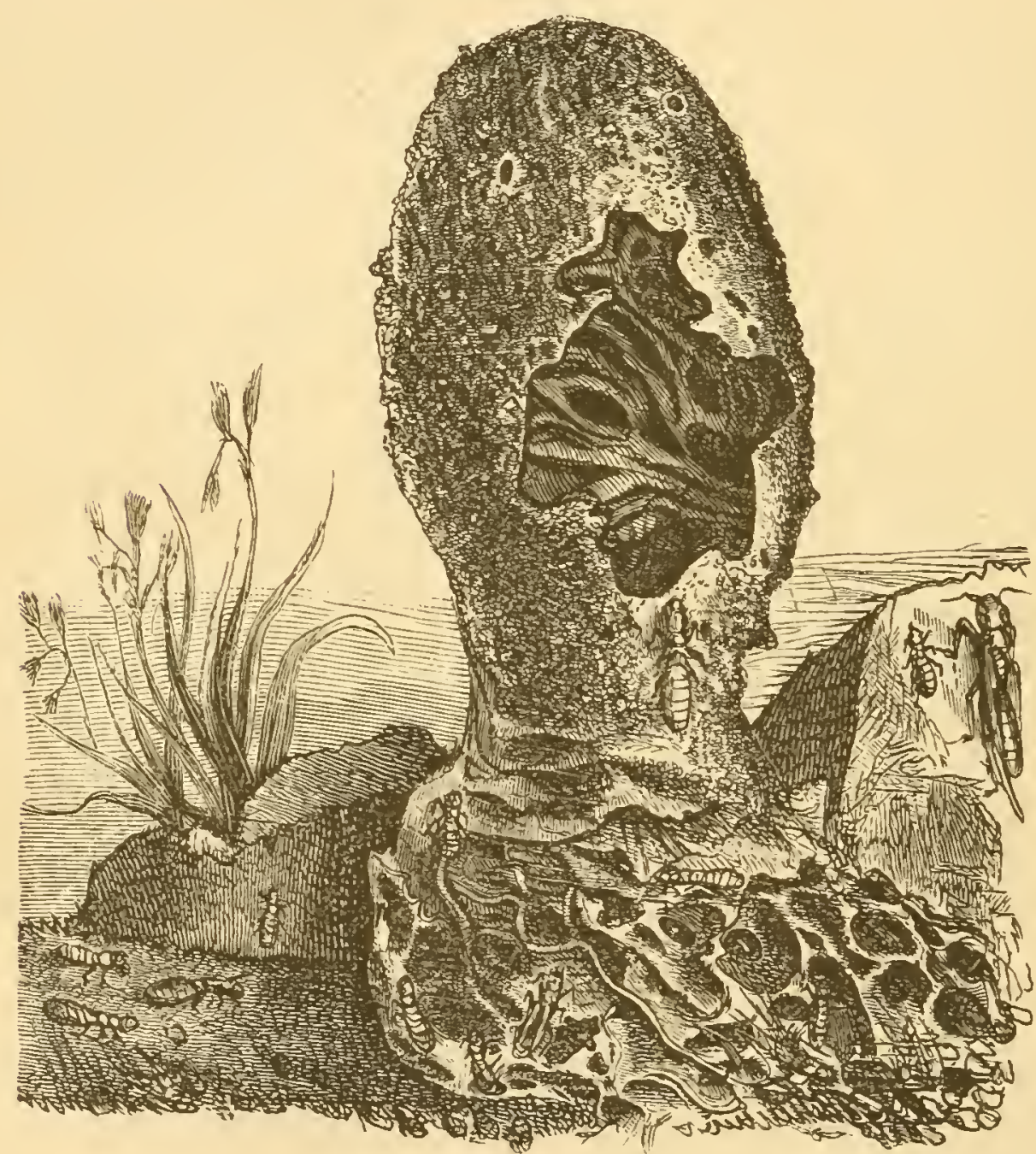

Fig. 79.

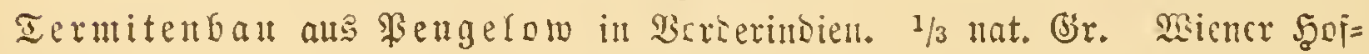
แщјещ.

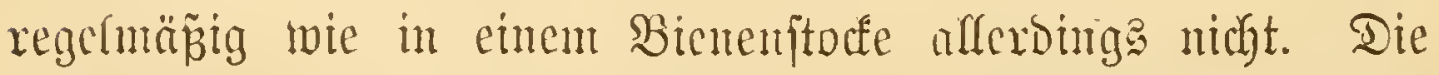
Termiten bauen eben fein modernes Beflengefängnižs, funbern

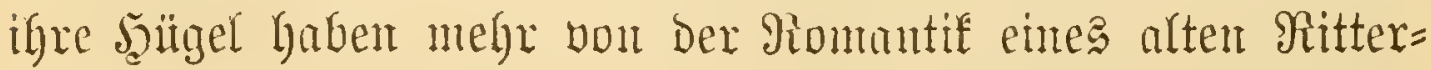

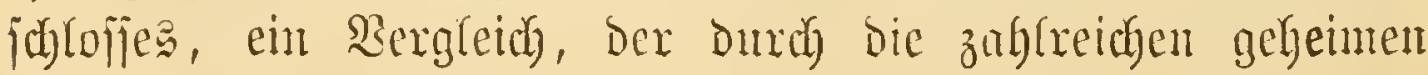


Sänge ober Saupröhren, welche allerwärte bou ben Seller=

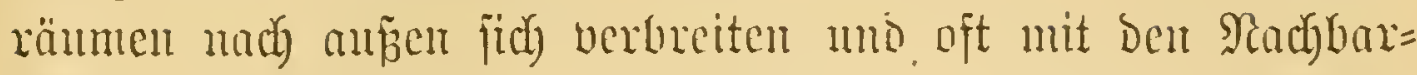
banten conmuniciren, wod) erfägt wird. Betwohnt miro in Dex Regel mur Der mutere Theif; Der obere oder die Sulupel

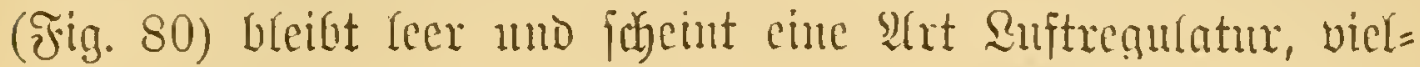

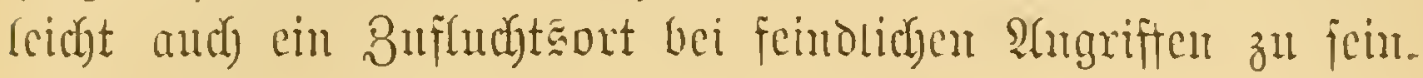

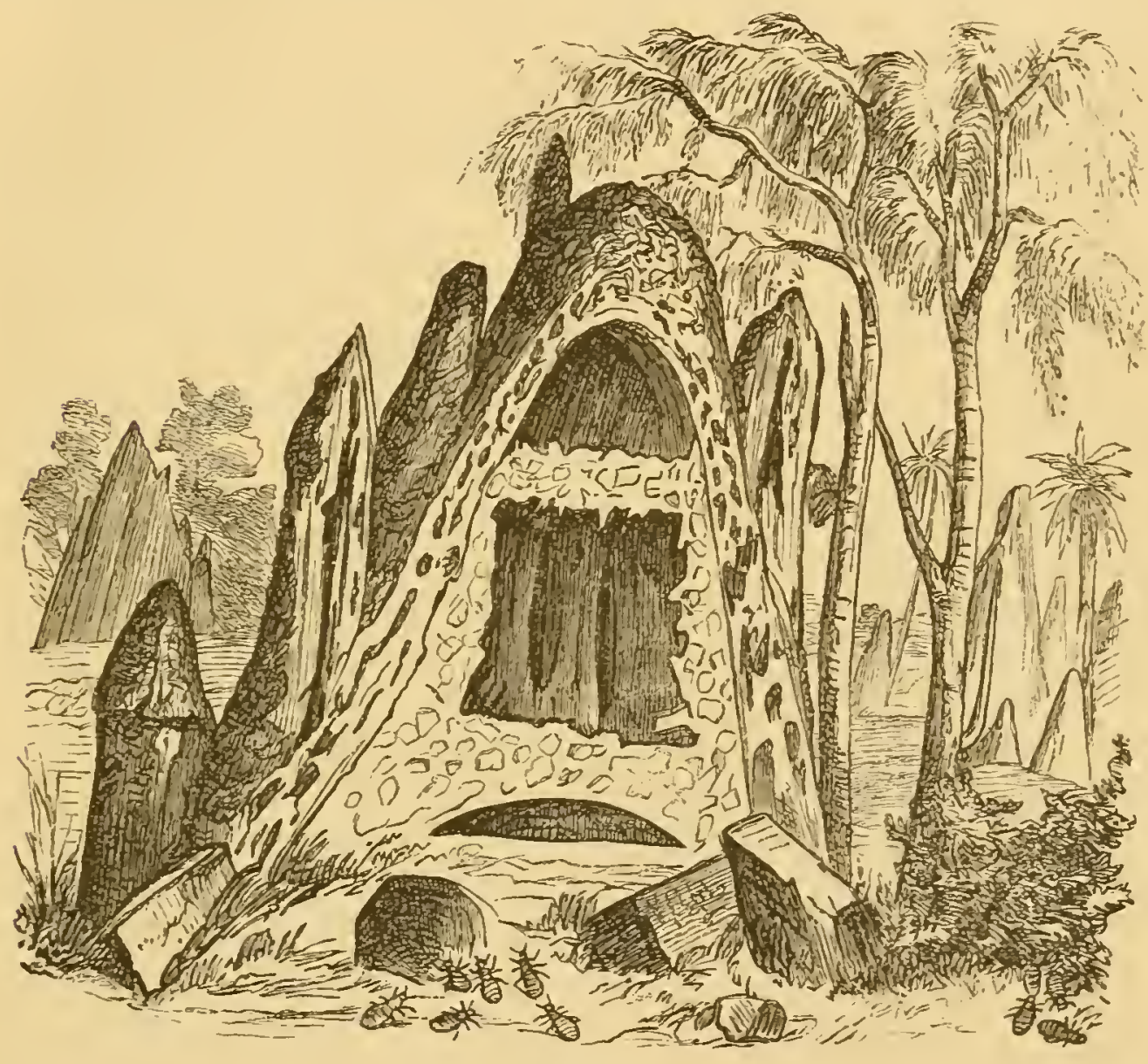

Fig. 80 .

Termitenbau. Sben bie Sumper, unten Die Bruträume (Söniginzellen). Saá Smeathman.

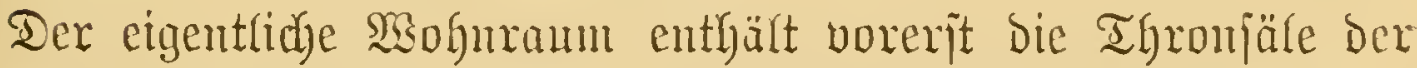

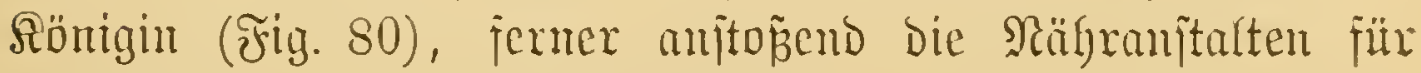

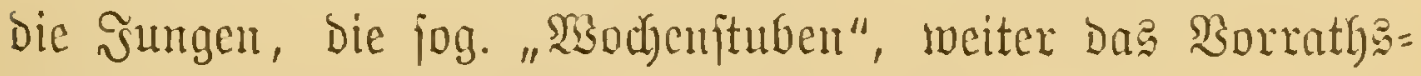
haus obcr bie Miagazine und Dam ringăm nod) ein unent=

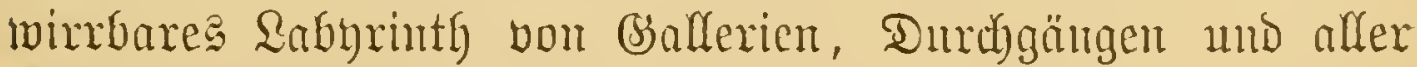

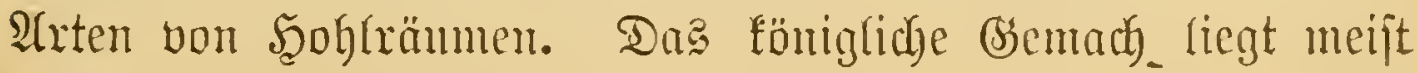




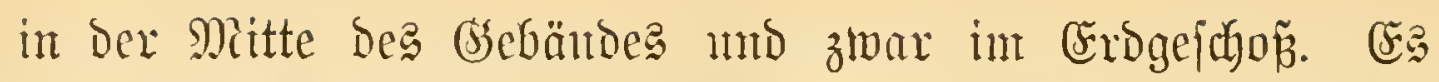

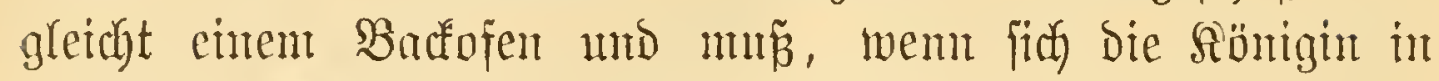
gejegneten lumftänden Gefundet, fortwägrend crmeitert werocn. Die Wodbenfuben bejtehen nidyt aus Thon, wie Die übrigen

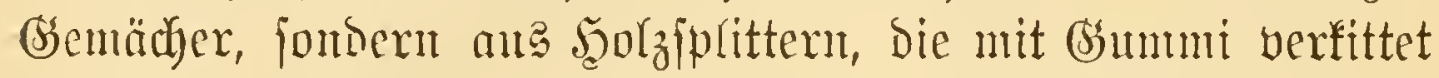
twerden. Rebztere findet man wentgitus mit allerlei Pflanzen=

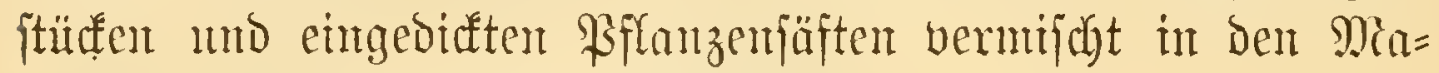
gazinen bepronirt.

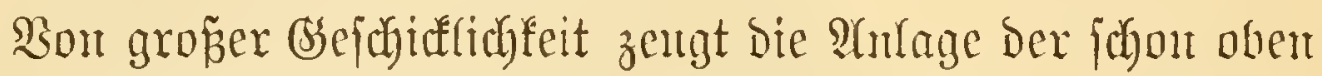

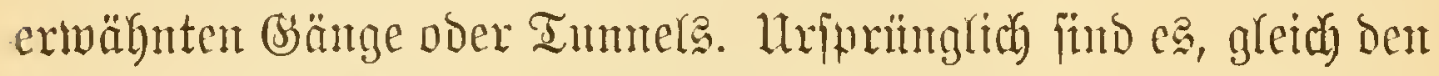

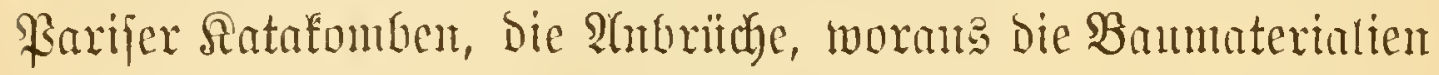

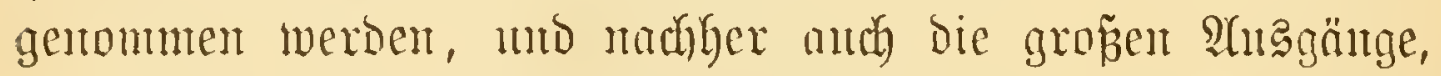

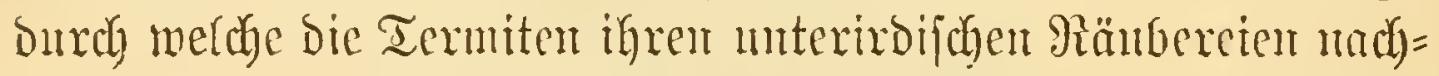

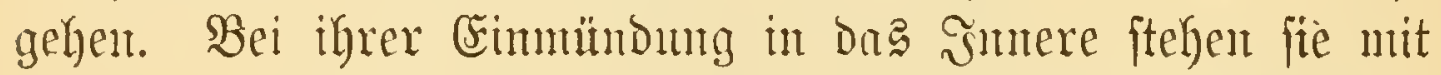

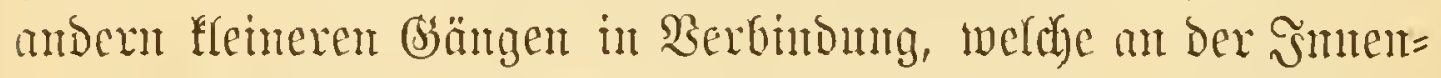

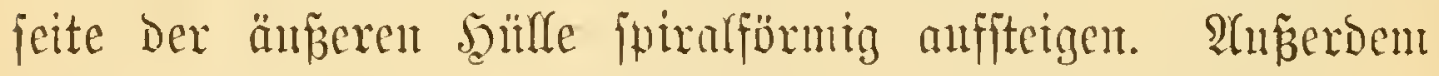

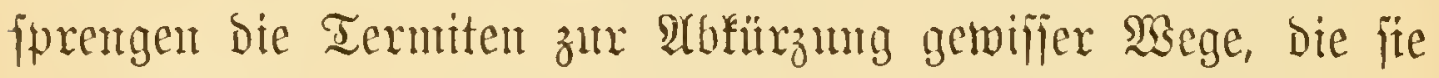
z. B. behufe Der Tranglocirmtg Dex Brut zu machen haben, eine $\mathfrak{A} r t$ "Ailejerftiege" ober Brilde, vou ber alte mb neuere

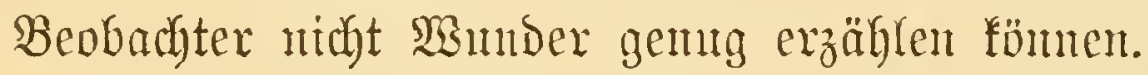

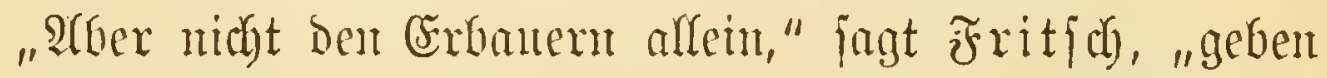
bicje Termitenterge Sifnes mo Brutraum, fondorn aud feind= lidye Sdyanen wirfficher ameifen erobern fich Theile biefer Burgen und man fundet fie oft bejebst mit ocn fremben Ein=

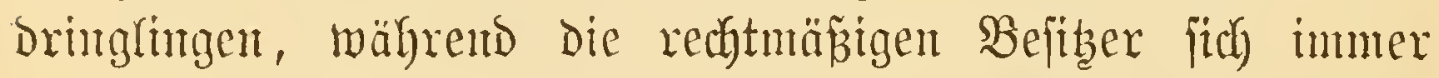

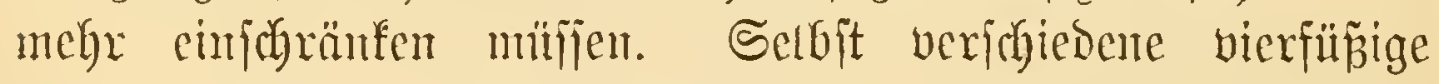
Thtere foblagen Darm ihr Rager auf, indent fie vom Grumbe

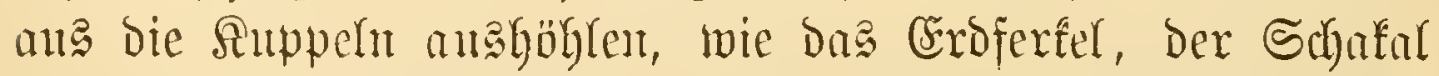

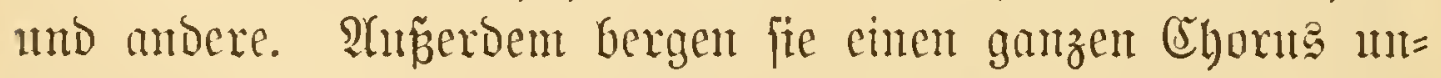

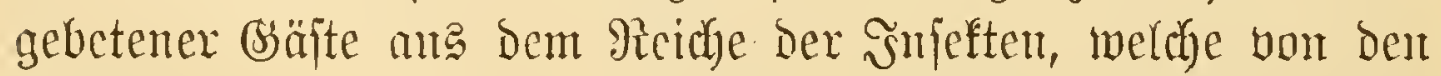

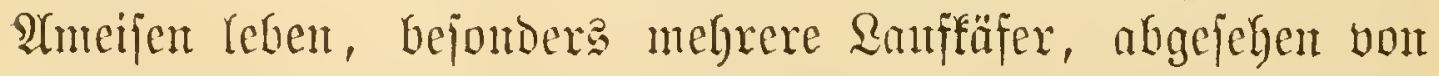
jenten $\mathfrak{A}$ rten, die ignen befrembet füb." 


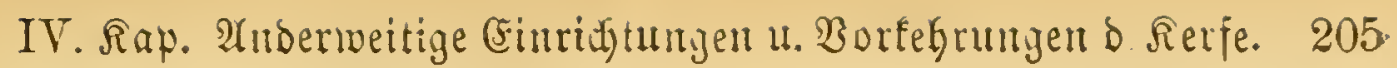

\section{IV. ¿apapite?.}

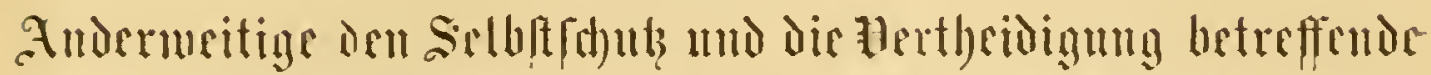
(Eimrid)tumber and Horkebrungen der sierfe.

Man Eam nidyt vorurthei(ślog nnd müd)tern gemtg an Das Studium Des fierffehen herantreten.

Siele Snjetten, haben wir gejehen, befitzen eine Derartige

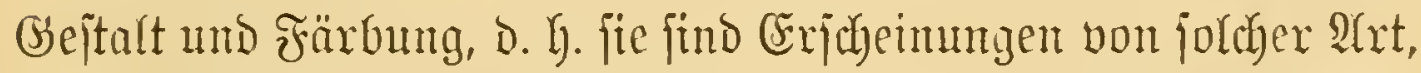

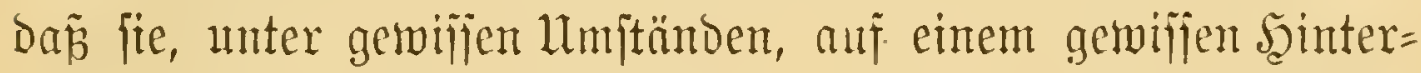

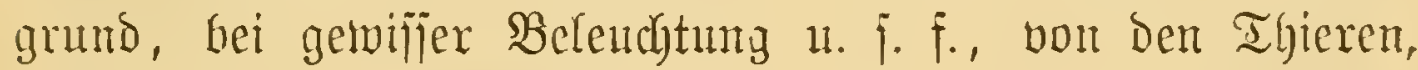

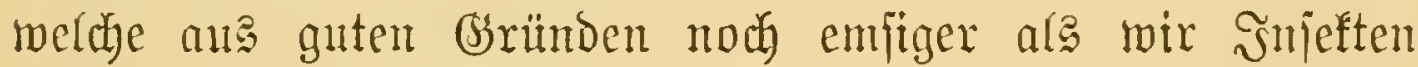
juchen, midit gejeben merben. Andere haben mieber cinten fo Dicfen Szarnijh, Daż ifnen micht beizufonmen, oder jo gefähr $=$

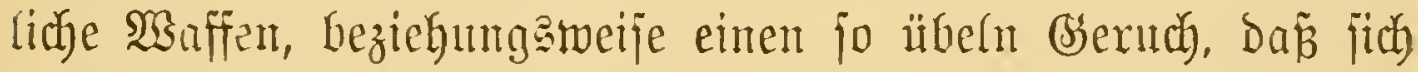
die meijten Şnfeftenfeinde nicht gerne mit ihnen eintajien.

ante bieje (rigenjafaften murben ifmen aber nidyt eigens zum Selbitiduke gegeben ober aneridjaffen, fonden fie murden

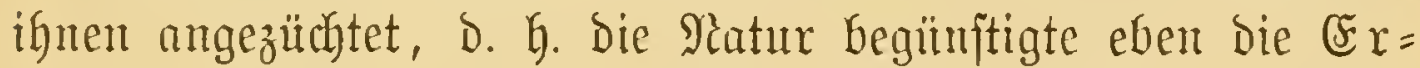
haltug jolcher theifs urjprünglicher, theila ourd) gemijie

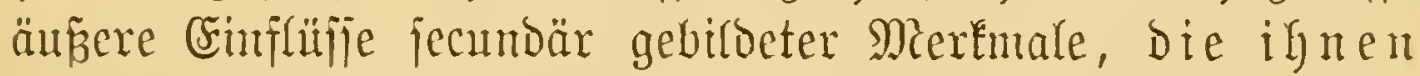
fïr igr Dajein am nïblidjten, oder jagen wir lieber am

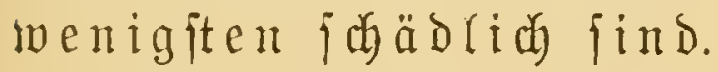

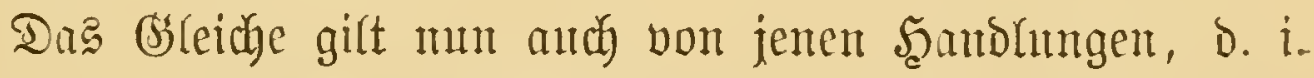
von jenen cigenthitutlichen Stellungaverändernngen bes fierf= förpers, wodurch derferbe einter brohenden Biefahr entzogen oder fich zu vertheibigen befähigt mird.

Manche Rerfe haben fo zarte Nerven, fie find jo übernas

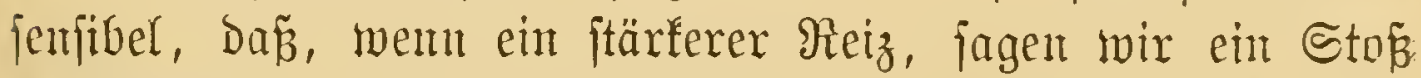

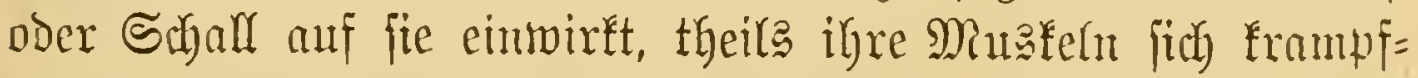
haft zufammenzieljen, thei(z gemifie Drïjen zur Cuntleerung, 海res Secretes veranlant werben. 
Das füt alfo ober waren bod) uriprünglich burch bie Drganifation bedingte Reflerthätigfeiten, die von vorme herein

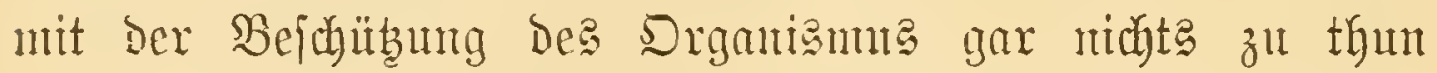
haben, bie aber, went fie unter Mmitänton Demjelben nübzich

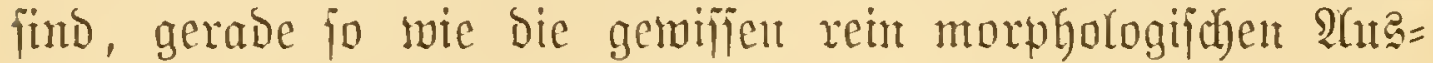
zeichunngen, ourch untïrliche Ausleje erbalten, bezielyungameije

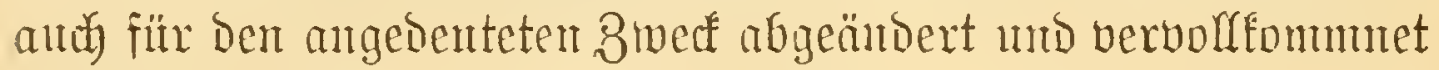
werdelt.

Sh und want aber Derlei Rebensäunerungen, woz th a th d) mandie $\Omega$ autprodutionen gehöxen, für bie Bejchübung

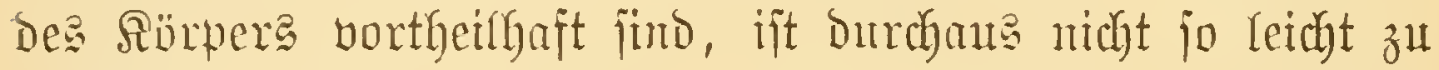

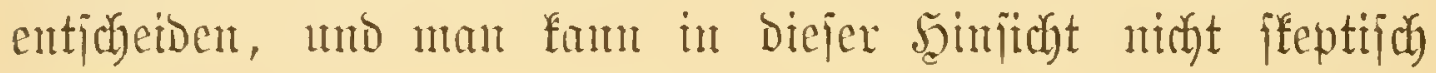
genug jeint.

Die nachjolgende finze Slizze einiger eimjulägiger Er=

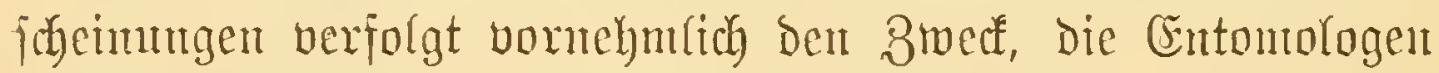
zu uäherer Früfung berjelben einzuladen.

Mis beginnen mit Dem "Sidbtobtitellen", was aber Der \$ryjlologe einen Starrframpf, cinen Tetants nenten mürde;

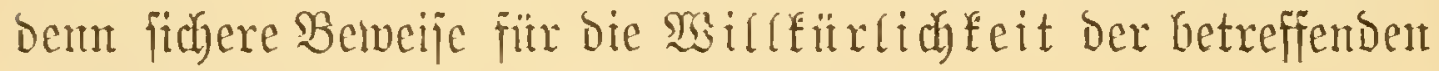
Sorgäuge fütb nur wentige beigebradbt.

Biele Rïfer, Aleochora, Silpha, Agathidium u. f. f., ziehen fith, went fie exjegreett werden, anf das ntöglichjt

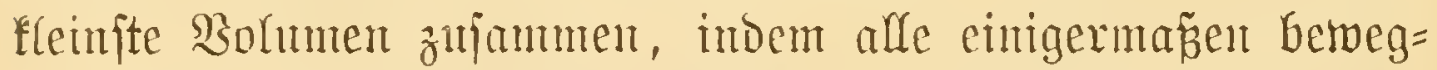

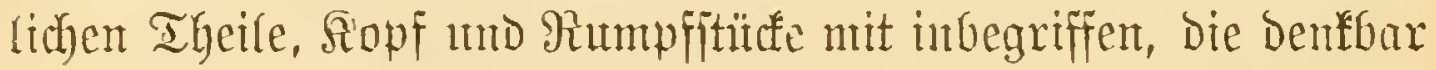
grö̈̆te Bengungalage einmehnen, wodurd fie mituntex einem fleinen Steindyen ober einem andern Yeblojen Sojefte ähulich werden utb fo bas $\mathfrak{A}$ utge ber Feinde weniger auj fich ziełen.

Speciell eintem, bent Anobium pertinax, hat man biejen Starrframt ala Troh magelegt; allein bie mefrifuch ver=

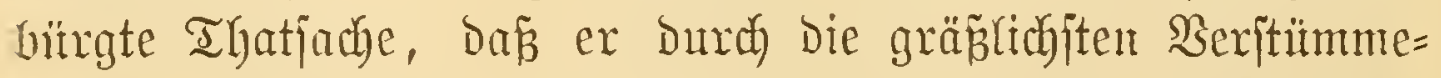
rutgen un Tortmen nicht zum 2ufgeben jeiner Bockgeinig= 


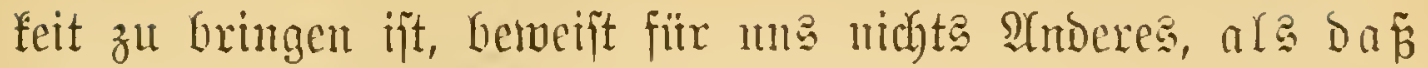
ex cben feiner Muafeln nicht Serr ift.

Sndere ntögen, einem antiqutrten Princip zu Riebe, ihn ars heifigen Miärtyrer verehren!

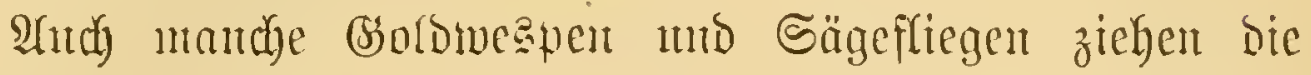

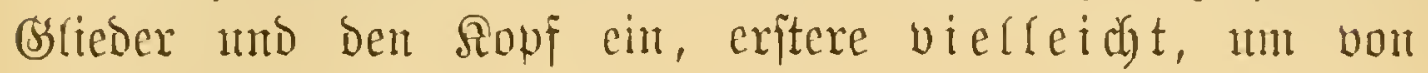

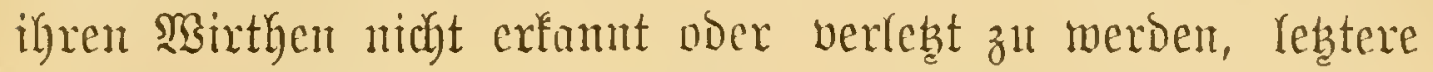
möglichermeife, um Den Âtrgriffen Der Sdhlupfmeâpen zut ent= gebert.

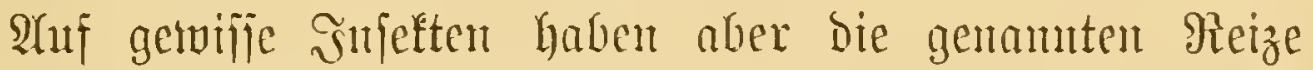
cine gerabe enttgegengejegte Wrirtung, fie verumfadyen Stred So z. B. heim Roṕkäfer mb bei Hoplia, melche lebstere Die lantgen Şinterbeinte gar fontiju in bie Şöge rect.t.

Snmiemeit Das "Siibfaflentaffen" nebjt ber gleidfzeitigen

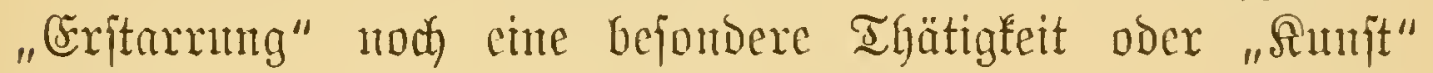
vorauejegt, wäre experimentelf fejtzuitellen.

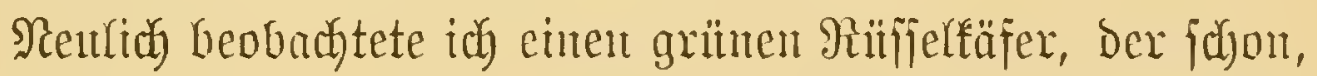

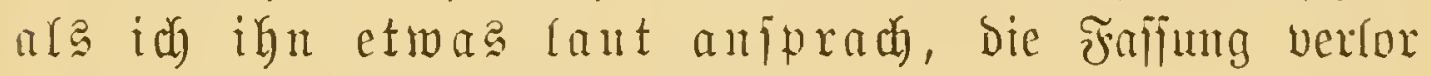
und von feinem Blattfits herabtollerte. -

ungemein viele Snffeften jobeinen fith in gereizten $3 \mathrm{u}=$ itand Durch mefr oder meniger penetrant riedyente, theirs

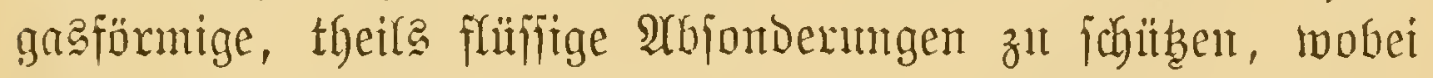
zumeilen and bie glcidyzeitig aus ifrex Rublage tretenton Drüfen als Sabredfmittel bienent ntögen.

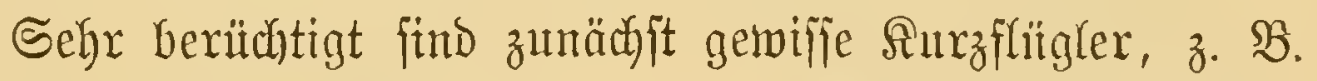
Der Staphylinus brunnipes, Defjen am $\mathfrak{A}$ fter gelegene Stiul= brüje fich in cinen gabelförmigen Fortjab verlängert.

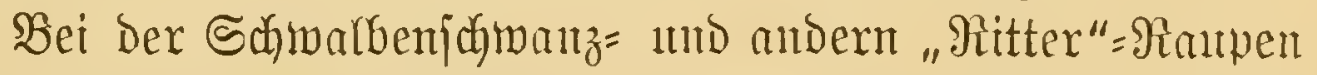

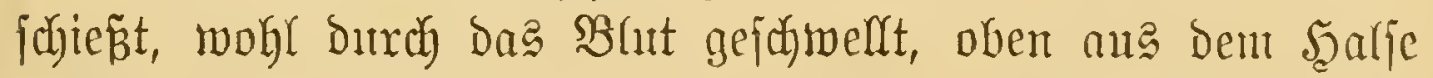
cin Şorn Keraus, Das ein mady Fenthel riechentos Secret sntleeren foll. Es mird bies den fie hänfig moleitirenden Miüfen und ভchlupfmespen gelten. 
Bei einer Sägemespe will $\Re$ irby ctwas Alebnlidyes

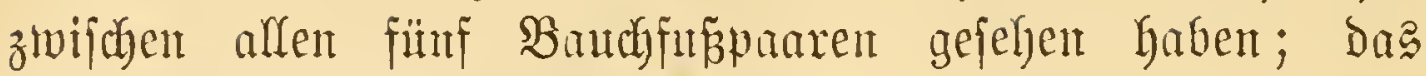

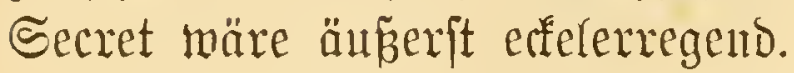

Die fathenfige Diffe Larbe Der Chrysomela populi hat gleidyfalle nidyt wentger ale 9 Panre joldjer Stinforitfen; jie joll aber, nady De Beer, bie Secrettropjen nady bem Brebratch rateder einzieben.

Die mifanbere Rontöbie nit Dem Bombarbierfäfer -

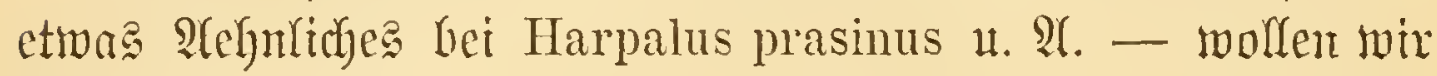

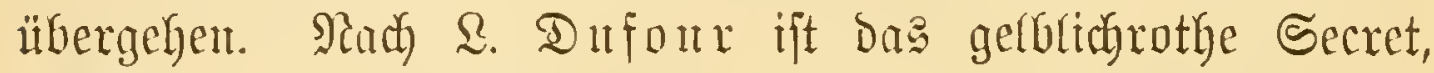

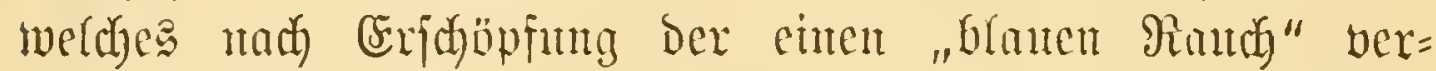

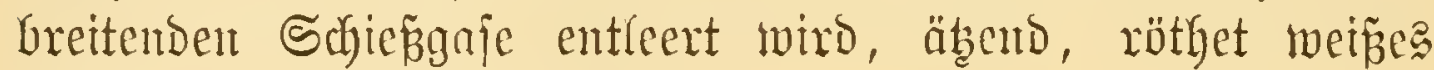
Papiex mo Gremt Die Seaut.

@elyx belicbt ijt bei Den Rerfent and die Sitte bes 2ิnjpucfent.

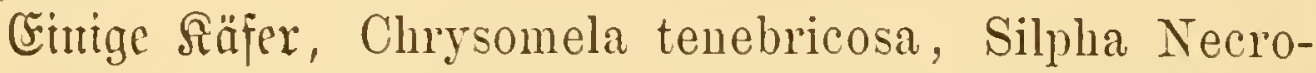
phorus etc., geben fajt regelmäp̈ig, wemn mun fie antgreift, cin

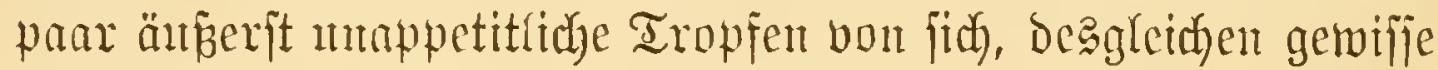
Rampen, Deren flebriger Speidyel fanm wegzubringen.

Eimen gerabeju giftigen Beifer idstendern einem manthe

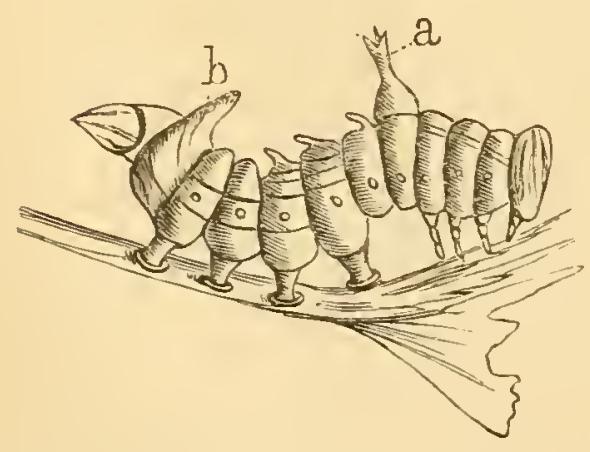

Fig. 81.

Yuf ber (5ide Yebenie Raupe von Hybocampa Milhauseri Fabr. mit felt= famen Rüưenjortjätzent $(a, b)$. ¿anffäfer und bies oft aus weiter Entfermutg entgegen; nach ver= Iäplidyen Nachridyten brad)te Der= jelbe mebrutale heftige altgen= entzüntungen hervor.

Eigenthümlidyes meís ferner Mac $\mathfrak{e} \mathfrak{a} \mathfrak{l}$ von eimer Fidyten= blattwe spenraupe (Pteronus pini) zil erzälylen. Reizt man cine, jo fpritgt fie einem einen $\mathfrak{S} a \mathfrak{r} z=$ tropfen entgegen; unt faum ver= fiegt man fith's, jo folgent alle antwefenden Rameruben "ifhrem 


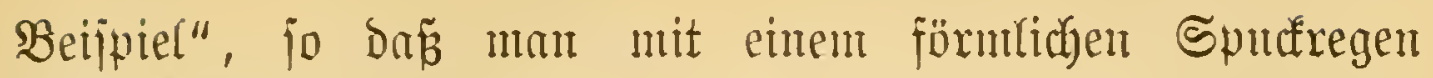
traftirt wird.

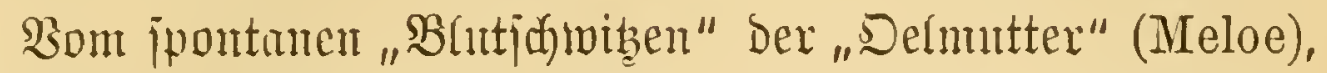
Der Pintelien, gewijijer Coccinellen mo ájutiden (A. crabroni-

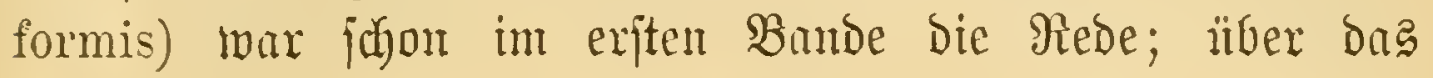

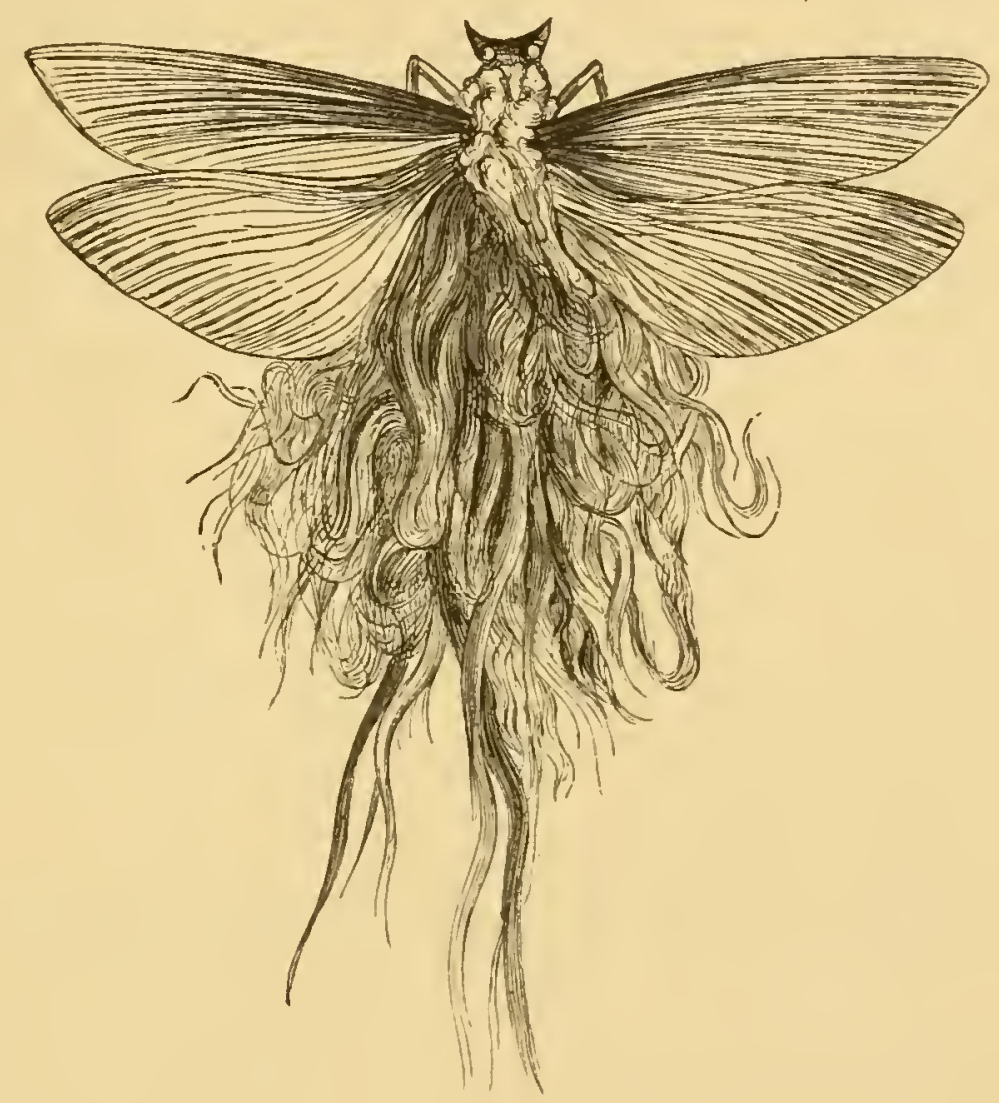

Fig. S2.

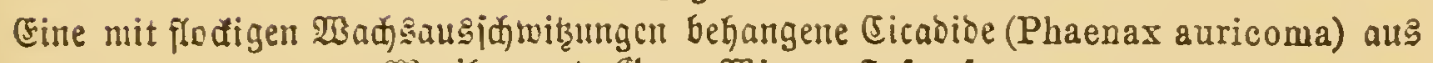

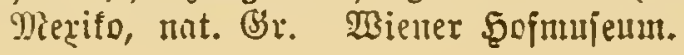

Mechanifhe meiźs man aber vorläufig ebent jo routig, wie betreffe der meijtent übrigen Algjonderungen.

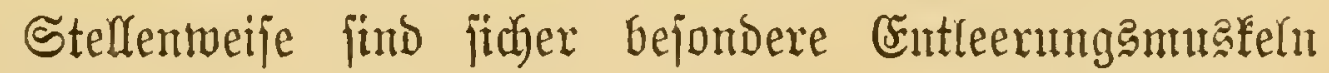
zugegen, jo höbjt wahricheinlia bei ber bon De beer beob= adyteten $\Omega_{a r v e}$ von Tenthredo lutea, bie ifr $\mathfrak{g}$ antfecret in förmlidyen Strahlen heraugipribst.

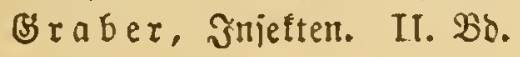




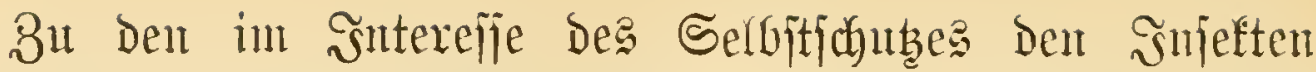

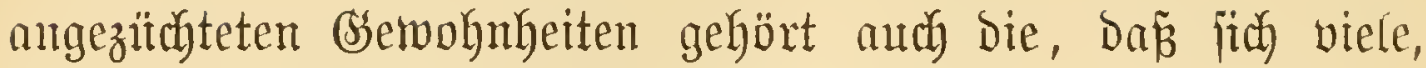

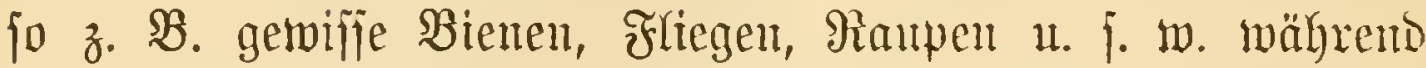
Des Inges theile in Bhamenteldyen (Apis florisomne, campanularia etc.), in ber crobe ober in (Sraje ver=

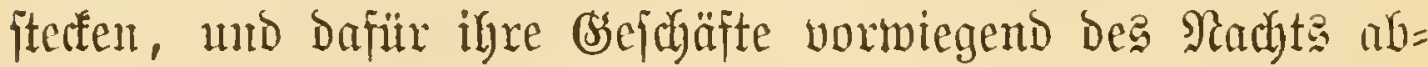
thun. Das wäre aljo eine Urmajinng an die Tageszeiten und zun Igeil jener zu vergleidhen, bie wir bei den heöblen= thieren antreffen.

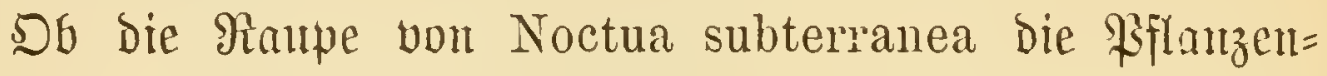

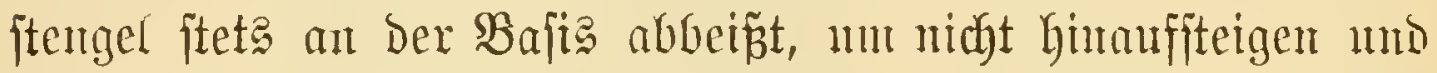
Den Blicfen ber Feinde jidh ausjetgen zu mitjien, mag man Durch Berfuche prïfen.

Eine Der merfmüroigiten Bermitaltungen zux Berthei= bigung ift Dom bie folgende.

Der gewiffe $\mathfrak{A}$ thang vieler Säugetbiere, wonit fie fich Die vielen Parafiten von Seibe halten, wird jeder unjerex

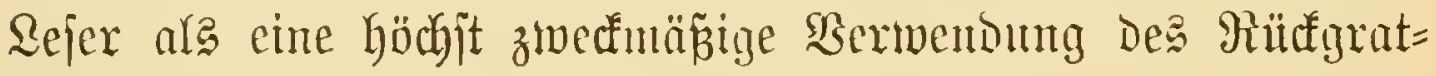
endes zul jüäben wifjen.

Die Ranpe Des Brabelfotwanzes hat aber, und zun greichen Behuf, D. i. - in exjter Sinie menigiten - zur

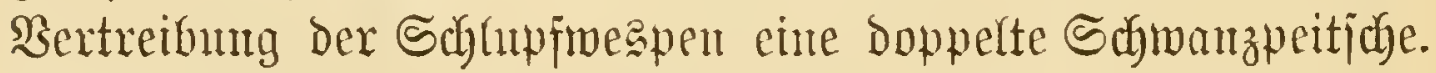
sebe bejteht aus einen hohlen berben Safaft mo bann ans Der äunerit biegfanen Bseifer, weldye in Sseptult eines röth) lidyen Fabeng aus Dem Stiel herborgeiduellt mirb.

Noch übertroffen wirb intoefjen unjere $\mathfrak{B}$ edelträgeriu Durch

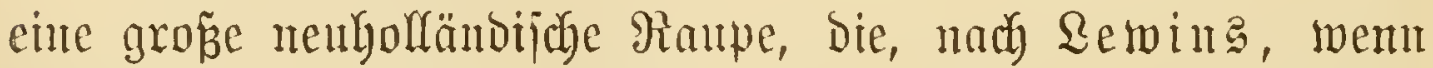

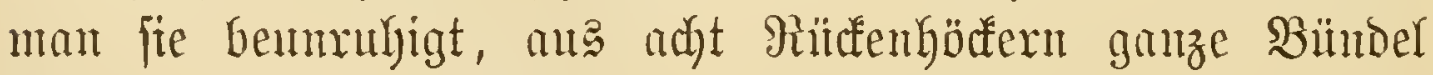
fpiber Rjeile Gerborjchiepst.

Bar Seltjames ijt nodj von dex Rante mierer Buthen= motte (ð̧ig. 83) zu vermeroen.

Die Bejuaffenheit und zumal bie Qärge ifrer Brult= beine $\left(b_{2}, b_{3}\right)$ wird im Segenfats zu der gemöhnlichen Form 
Diejer $\mathfrak{A}$ nhänge Sebermann fofprt in die Angen fallen. Sein Stauten fteigert fith abex nod, wenn ex bet Stephens leejt, da gelegentlich menigitens, Dazu bienen, un die Milben zu ent= fernen, weldye Schmarober befumtlich Den Snjetten jebr viel zu jubaffen geben.

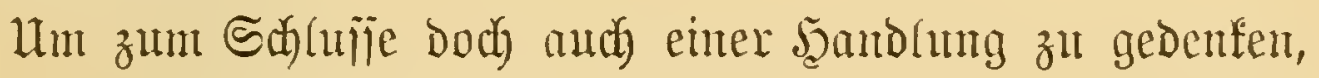

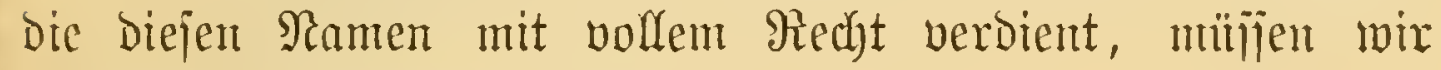
aberntal: Der Bienen gedenten.

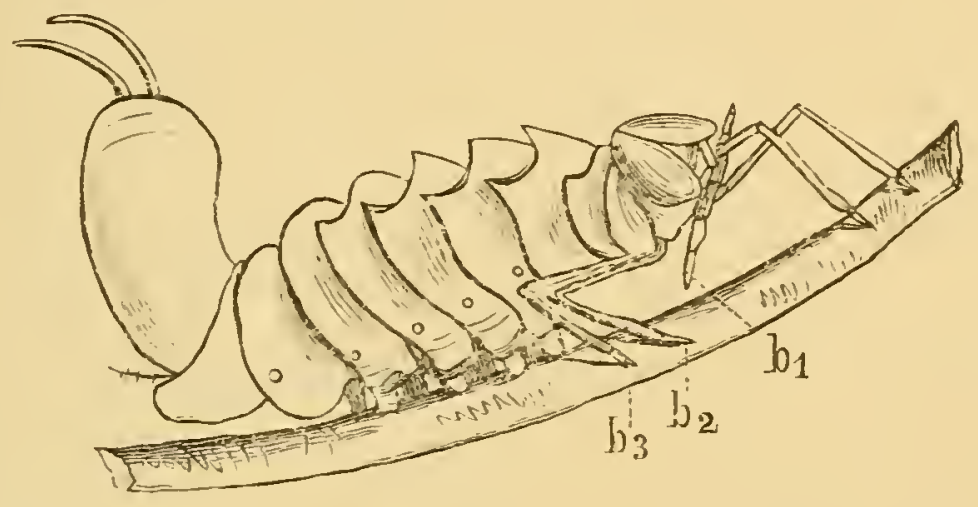

Fig. 83.

Budenipinnerraupe (Stauropus fagi).

$\mathrm{b}_{2}, \mathrm{~b}_{3}$ Die jtelzenartig verlängerten Mittel= unD Şinterbeine; trägt nud) einte Ełtwanzabel.

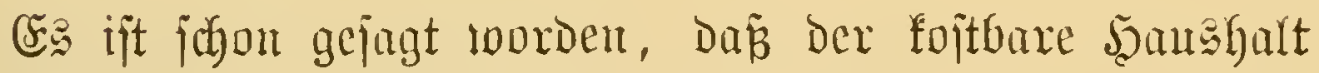
Diejer Rerfe viele ungebetene Bääte herbeiluct, und zu Den

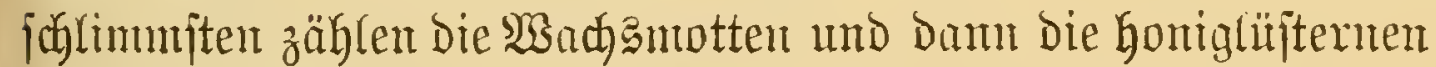
Todtenfopfidjwärmer, weldye beide vormiegend das Dumfer der Radyt zu ifren Streifereien benuzent.

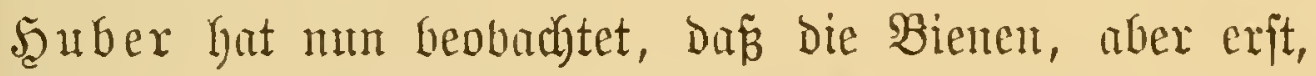
nachoem jie burd wieberholten Srhaben fing geworden, gegen

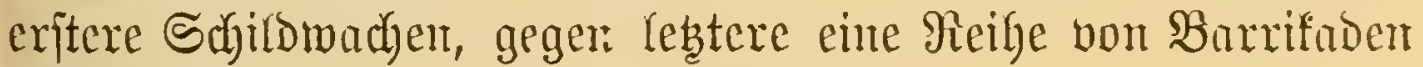
aufiftellen. 


\section{V. 被pited.}

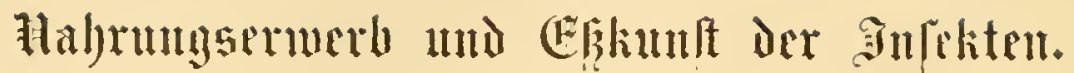

Sisir Denfen uidyt in entfenteften Daran, Dem ฉejer enten

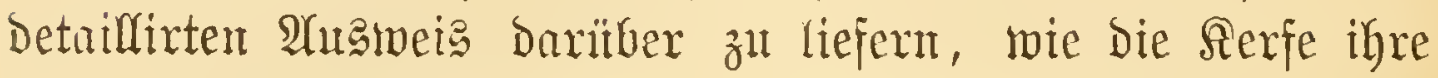
erite und widgtigite Sclbjterbaltungatgätigkeit volffübren; Denn

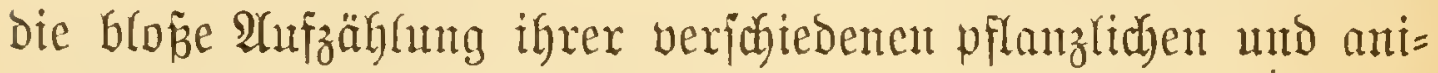

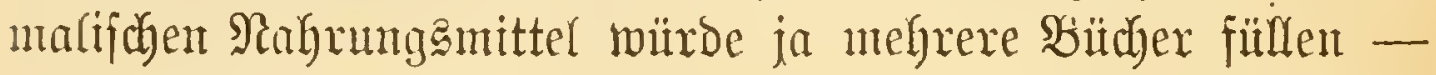
wir bejaränfen uns daranf, in aller Bsebrungenbeit eintige Fragen zu ventiliren ober Dod) antzuregen, bie auf bie Ent=

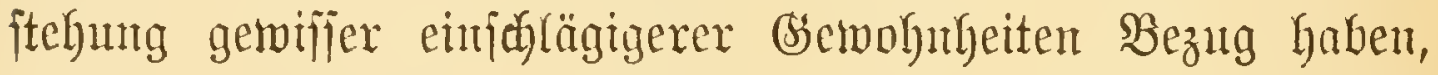

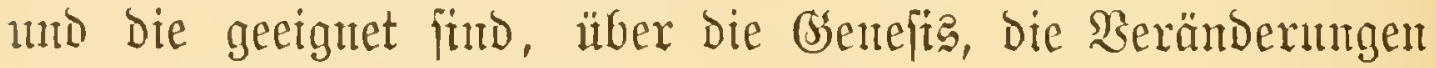
und $\mathfrak{B}$ ervolffommmmgen ber betreffenden Sndujtrie überhaupt einiges Richt zu verbreiten, was um fo nothiwembiger, als man, mad) alter guter Sitte, gerabe in biejem Stïcfe, mux allzugern mit ben blozenen Thatjachen jidh zujueden gibt, nidyt bedentend,

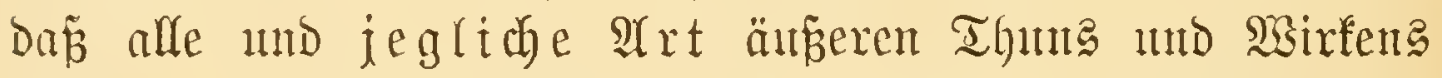
für bic exf(ärende গatunforidhung gleid) belangreid und interejiant ijt.

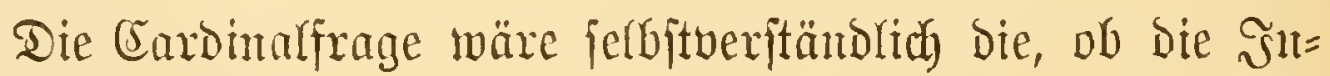
jeften zuerjt Bffanzen= ober Freifjyfrefjer waren, und Dant,

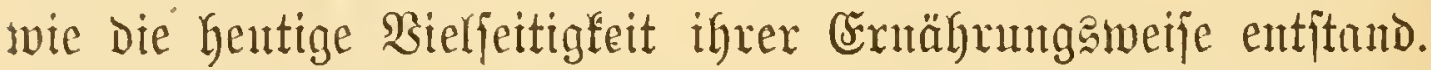
Die Beautwortung ber eriteren Frage febt abor mieber bie

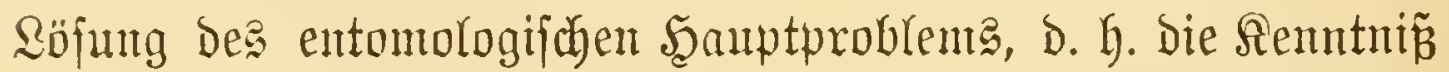

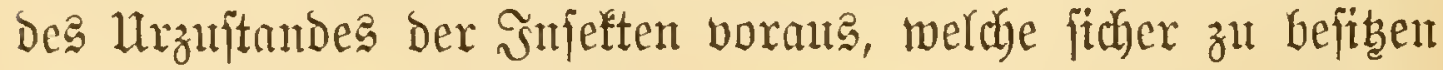

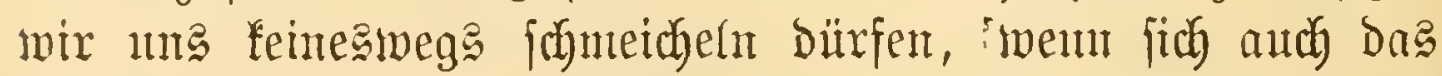
Bünglein melgr ben carni= refp. onutboren Sippen, Delt

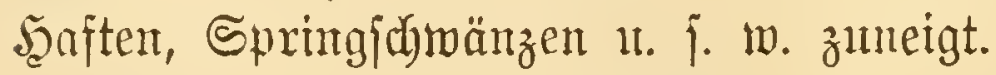

Die zmeite Frage fündet, ganz im allgenteiniten, ihre Röfung Durch Den Rampf um? Dajein, Durch den bie wohl fabon jeit ältejter Beit in zahllojen Sndividuent ver= tretenten Mitglieber Diefer Rlajie nach umb nach, und zum 


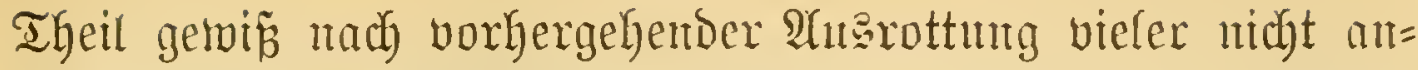
pajiungä̈ähiger (Sejhlechter, gezmutgen. wurden, mit ber Natur

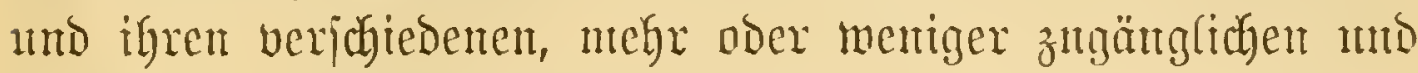

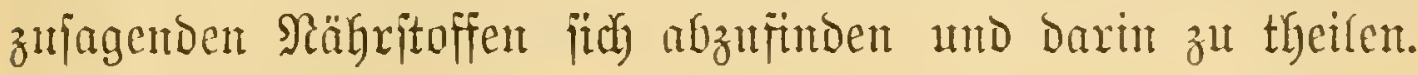

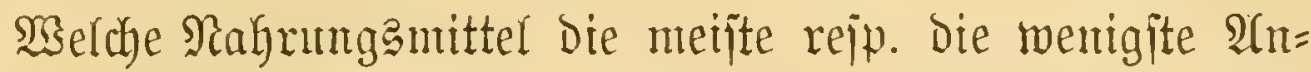
ziehutug erobert und bejest wurben, waun und welche §erje etwa zuerit

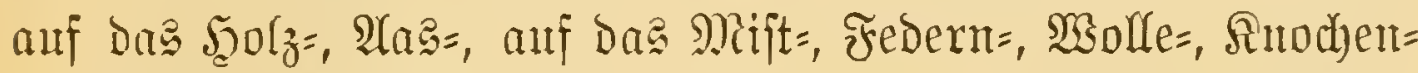

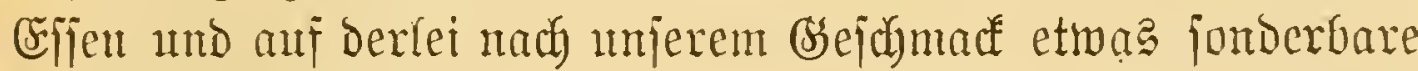
und zum Theil anth fehr moderne Specialitätent verfielen, furz alfe bieịe Fragen, welche Das Detail angehen, fönten wir, and) nur mit einiger $\mathfrak{B a h r i c h e i n l i d f l e i t , ~ m e n i g i t e n s ~ i n j o l a n g e ~}$ nidht löjen, als man nidgt aud diefes Bsebiet dem exaften Wlammäp̃igen Experiment untermirft, b. h. fo lange nidyt erforidht ift, inmiemeit die Eutährungagemohnheiten unter

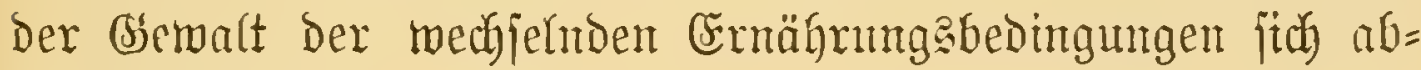
unঠ ımänderı.

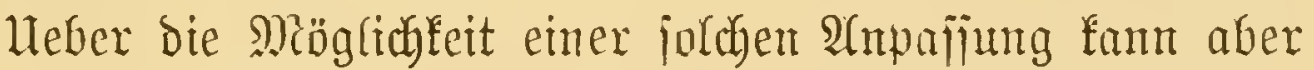
ichon nad) ben bisherigen mebr zufällig als abjidytlich gemtadyten Erfabrumgen fein 3meifel fein, wem man gleidy miemals ber=

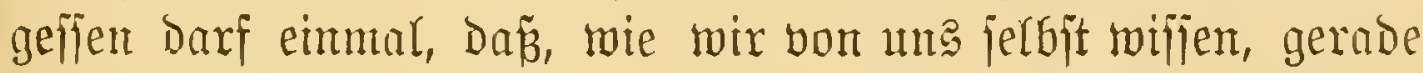
Dieje Bsemohnheiten fich auperordentlid) tiej eintwurzeln und

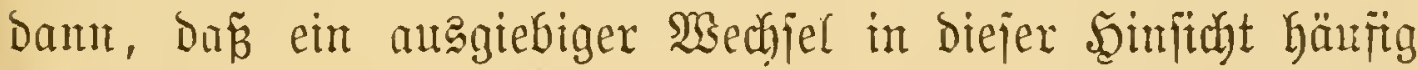

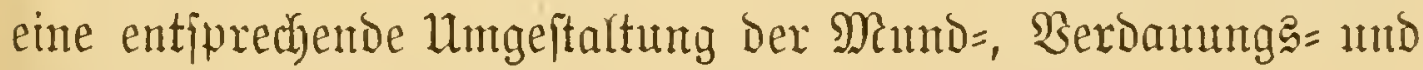
überbaut Der crnägrungąmerłzenge voratsjest.

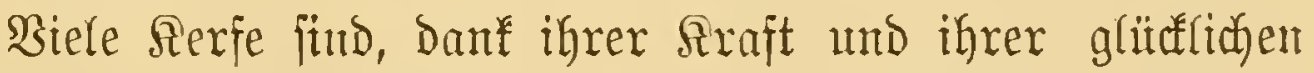
Eonjtitution überhaunt ichon von Natux aus Biel= too nitht

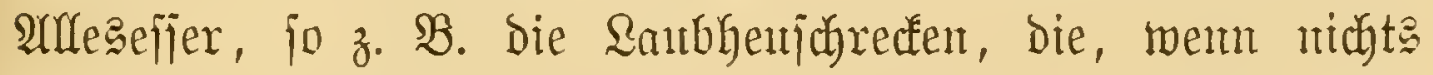
Fleijudiges zugegen, nach Gras und Blättern greifen, ober

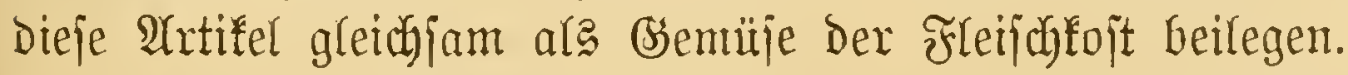

Yuch viele Sägefliegen ober Blattmeapen madyen wentig

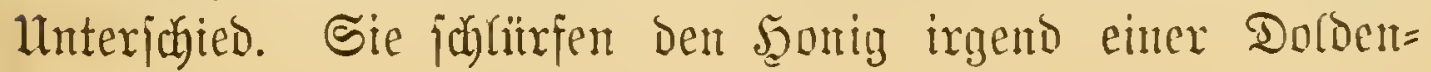


pflanze und öffnen bam auf einntal, wenn eine Miüce ober ein ähnlidjes fantwadyes Snjet ifnen zu nake fonmt, bie Rieferzange und zerreipent fie.

So hat man and den Ptinus rubellus, einen befannten Şolzefier, in einer 2 tpothefe bie Canthariben veripeifen fehen und Der Rerfoieb, Ptinus fur, frifist ohne Unterjated trockene Thterbälge und Pflanzen, und verjamtäbt jelbft, jo wirb erzälylt, den Tabat utidyt.

Selbft Ranpen werden hie und Da, mas bei igren fräf= tigen Riefern aud nicht zu vermumbern, von Mrorbluft iiber= fallen, und bie einter Ente (Noctua derassa) fowie von Cosmia

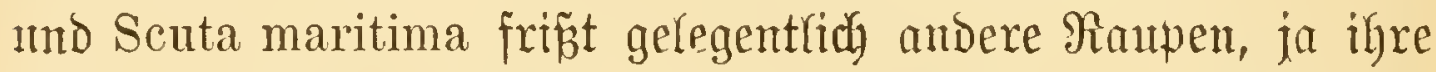
eigene Brattuntg. Desgleichen nimmt Die Made Der Molfgmotte

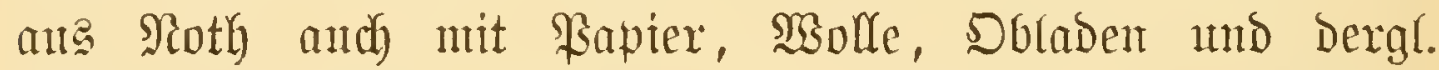
Speiereien vorlieb, und $\mathfrak{R}$ e a m $\mathfrak{x}$ erzählt von einer andern, bie, und ohne es gerabe nöthig zu haben, über ein Facfet Çhocolade herfiel und dem an ftärfiten riechenden am meiften zulurach.

Den julagentoften Betweis, Dás unter Den Rerfen Kein Roftzwang befteht, liejern wohl gemiffe Rleinfdymetterlinge, wie Die Aleider=, $\mathfrak{R e l} z=$, Möbel=, Miehlfpeimnotten n. ;. w. Sind bieje Schabenthiere vielleidyt eigens unjeren Rleidern und Mehltruben anerfchaffen worben? So was zu behaupten,

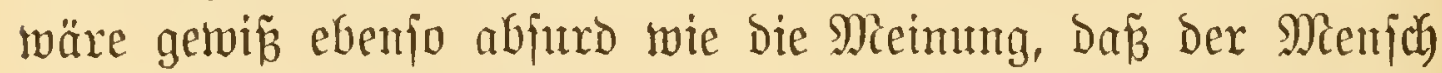
jeine \$arajiten, die Flöhe, Wanzen, Länje, Eingemeidemürmer u. \{. w. Gei feiner Entitelyung zur Mitgift befam.

Melchen Sinfluñ eine ftarfe Bermelyrung mo bie baburch bebingte Rreisfteigenung Der biakerigen Confumartikel auf bie

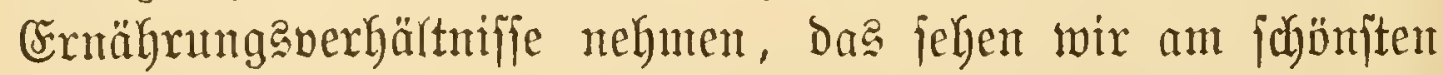
bei Der Nonnenraupe. Ŝn Fahren, wo fie nidyt befonders

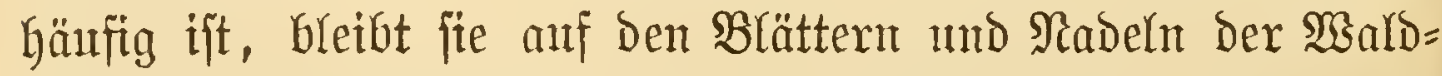
fäıme, ja begnügt fich meift mit Fichten allein. Bu Beitent 
aher, wo fie mafjenthaft auftritt und in Folge beffen bie $\mathfrak{W a l}_{\mathrm{S}}=$ bäıme bald gä̈tzlich abgemeidet finto, fällt fie ohne Bebenfent

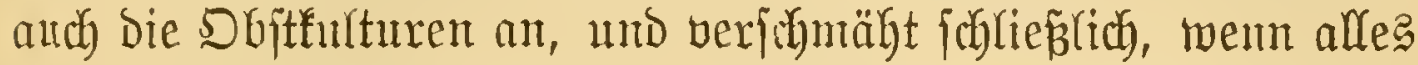
vertilgt ift, jelujt giftige Brartenpflanzen wie den Sabebaum unto Den Wafjerjachierling nicht.

Biele Ranpen urtheilen übrigens gar nidyt nady Dent

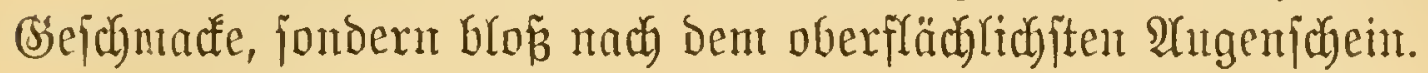

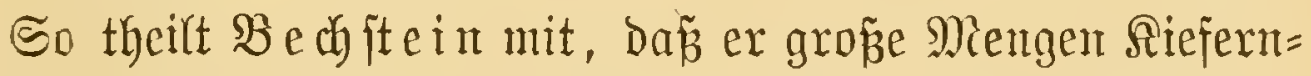

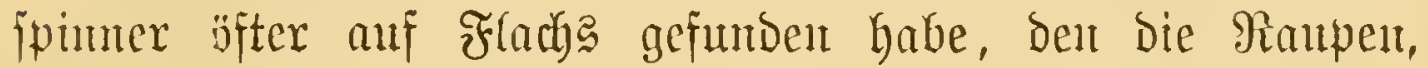

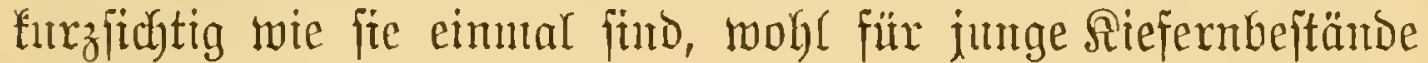
hintahmen! -

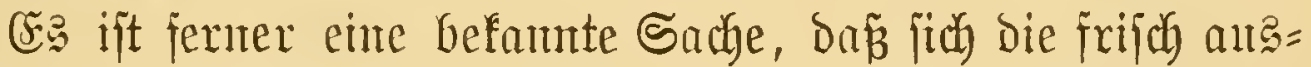

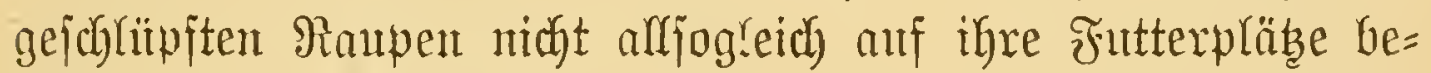
geben, und in ber alfererften Beit aud (eid)t mit einer fremben

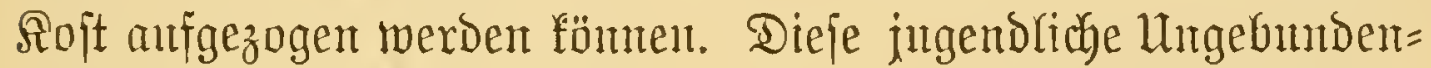
heit, bie mir übrigens and an unjeren Sindern beobacbten,

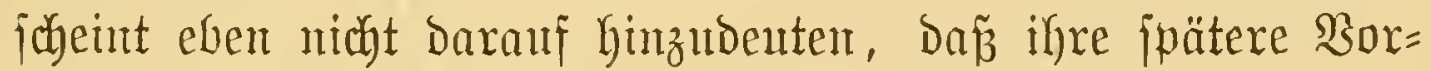
liebe für getwifje Rränter eine ganz urfprüngliche ift.

Man hat aber and $\mathfrak{B e r j u d h e ~ g e m a d y t , ~ a ̈ l t e r e ~ \Re a u p e n , ~ b i e ~}$

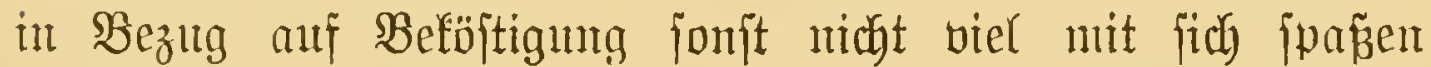
lajfen, nach und nach an frembe Dintge zu gemöhnen. Utnd żum Theil wentigfters, mit Erfolg. Einige gemöbnten fich

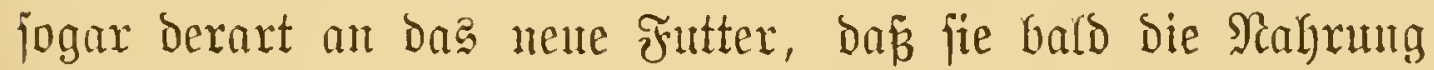

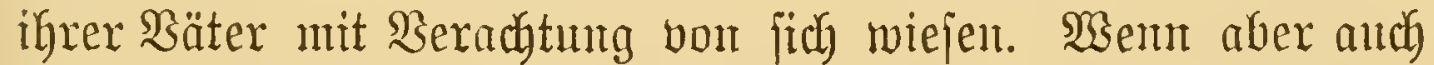
bei Derartigen Experintenten viele Thiere orauf geben, fo be=

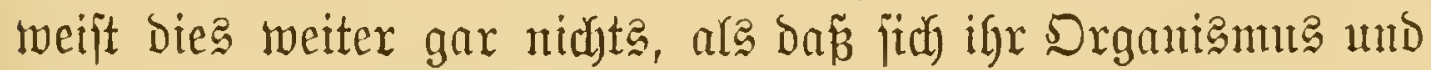

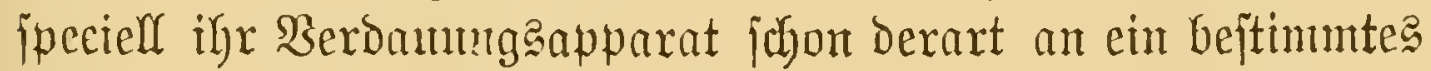

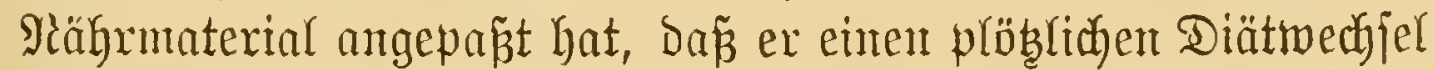
nicht mehr vertragent $\mathfrak{k} a n$.

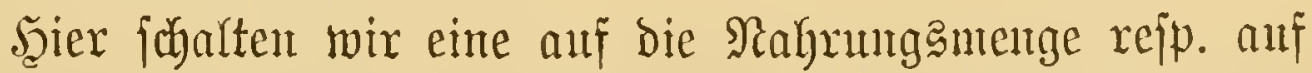
Deren $\mathfrak{A b h a ̈ n g i g f e i t ~ v o n ~ b e n ~ j e m e i l i g e n ~} \mathfrak{T}$ emperatırverbältnifjen bezügliche nenere Unterfuthung von $\mathfrak{A}$ egenex ein. 


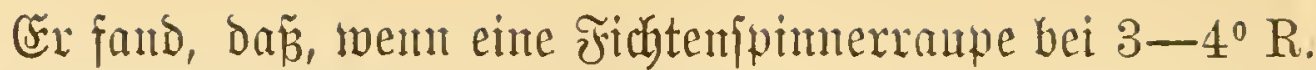

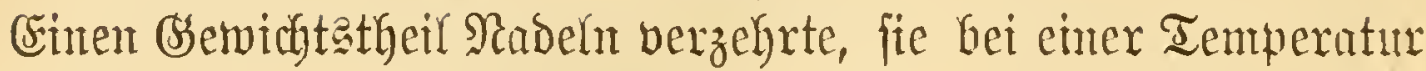

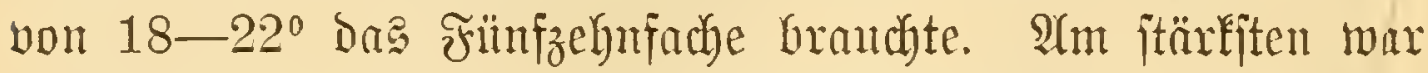
Der Scunger bei $20-22^{\circ}$; bei nod grö̈perer $\mathfrak{3 a ̈ r m e ~ v e r r i n g e r t e ~}$ jich bie E⿺辶卬

Strenge genommen gehärt inder bie Frage, wount bie âtere ifyren 2lppetit ftillen, gar midyt in Das Gébiet Der Binlogie;

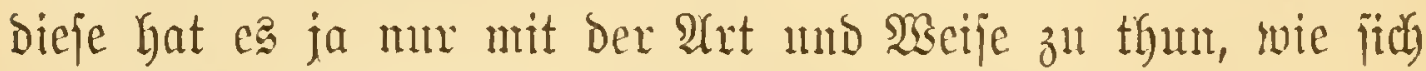

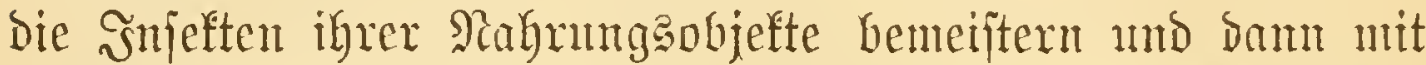

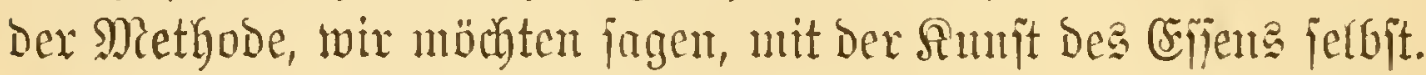

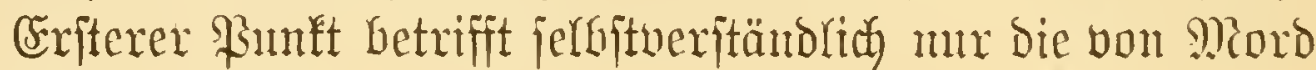
utto Raub Yebenden.

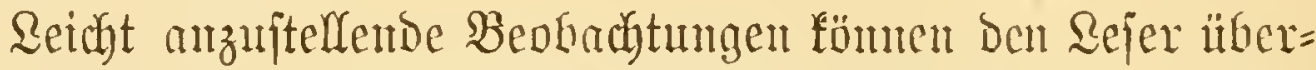

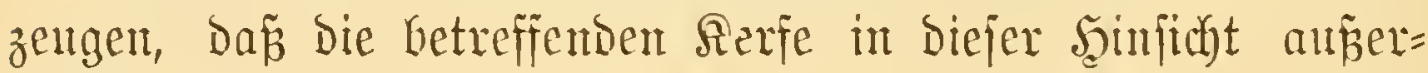
ordentlid) verjobieden zu Merfe geben. Man benfe z. $\mathfrak{B}$. an gewifie Staphylinen, bie ihr Dpfer aus cinem Şinterhalt überfallen, an bie Caraben, Imeijen n. \%. ., bie fich fiilgn und feef bemifelben entgegenitellen, weiters an bie \&anbhen= jayrecten, bie Söwen gleid, ihre Bente in Sprung, ober, wie bie Ribellen, bie Moromeapen 1t. a. in rajuent F̂th erhajuen.

Wie ungleidh und manuigfartig ift baun der arfet ber $\mathfrak{B} e=$ wältigung ferbjt, zum Theil alferbings von ben jemeiligen Angriffämerfzentgen abhängig, bis zu einem gewifjen Grabe aber Dody in Der ererbten oder angelernten Gemohnheit Des

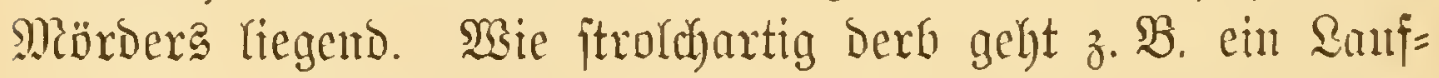

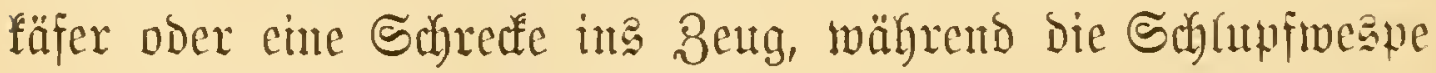
wie fpieletto, ob Der nichts bäjes ahmenden Raune idyebents,

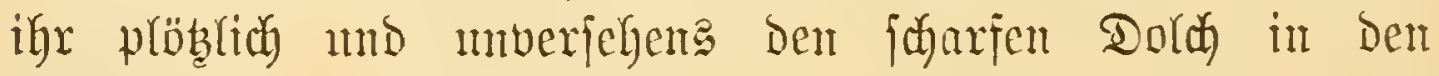
Qeib ftöṕpt!

Ituto glantbe man doch ia midyt, baj etwa alfe Rerfe ify edres Şanowerf gleid vortheilhaft ausübten.

8n einer gewifien Sirtnojität mögen es manthe, bant ber Iangen Hebung und des guten Beipiefs ifrer Rameraden, 
gebradt haben; eine abjolnts Bollfonmenbeit exiftirt aber

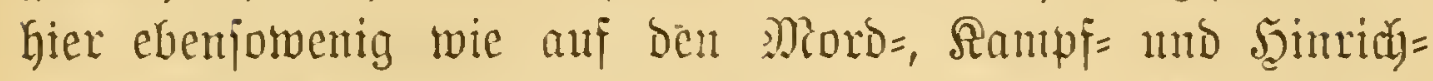

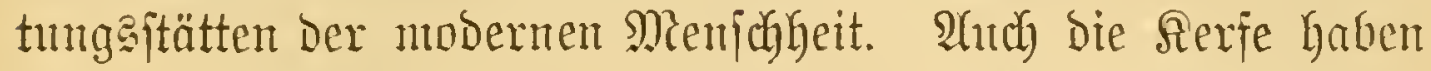
noch am Morohandwerf zu Cernen und viele, namentlich bie

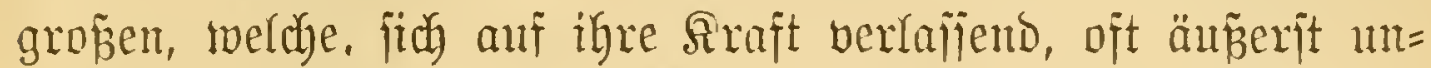

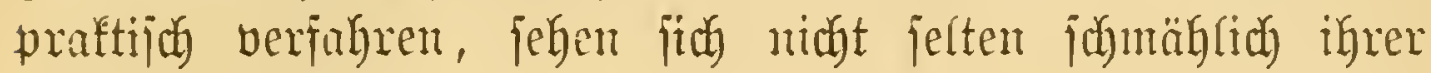
Bente beraubt.

Wic weit Sierfe in biejer Şimficht einer fïmitlichen Drejītr fähig wären, ijt alleroings nidht abzufehen, wie meit es aber mantche in Der itrengen Schule Der SRatur fabon gebracht und andere mit ber Beit e bie Rarben des Tigerfäjer: mo Ameijenlömen, die, ohne ifre

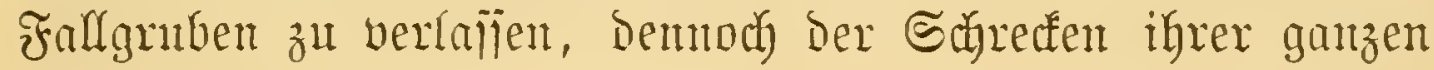
Hningebung fint.

Un mu bie hohe biologifale Bebentung Des zlweiten

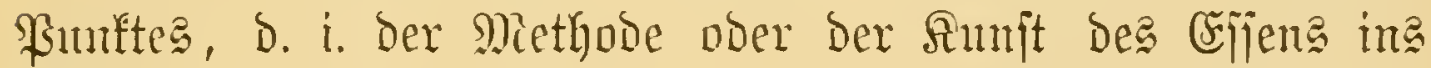
gehöriae Sicht zu jeben, fei frilher cine Bemerfung erlanbt, bie mant, will man über die complicirten Borgänge bes ßerí = rebens überbaupt Allarbeit haben, nidgt oft genug wieberbolen und beherzigen Fam.

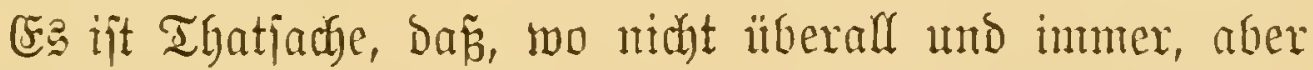
Doch Ftellenweije und zeitweife Den an einem bejtinumten Drt

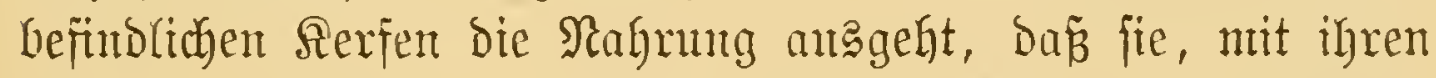
huntgrigen Mägen vor leeren Tifchen bajtehen und in Folge belien jammt ifrer fajon vorgandenen ober zu ermartenden Brut elendiglich umfommen.

Wem dies aber ridytig ift, b. h. genauer gejagt, mem Den Serjen nidyt eine unerjöbofliche, fondern mux eine be= jobränfte Futterquantität zux Berfïgung ftegt, dann ift es

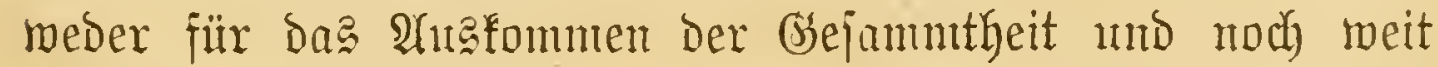
weniger für die Extitenz Des Einzelnen gleidgiltig, wie fie mit Dem biaponibeln Materiale hatshalten, fonoern es bängt 


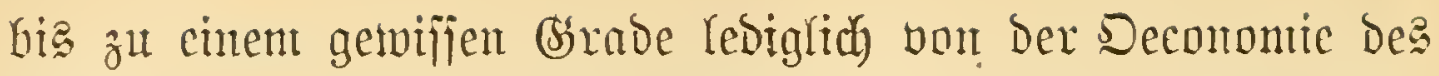

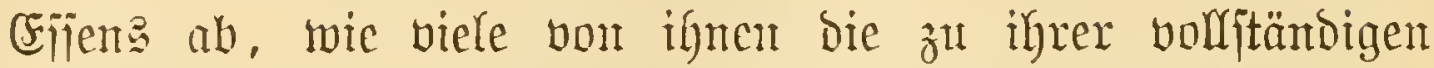
Entwiffung und zux Beugung exforberlichen Stoffe befommen, und wie viele frïlyer baranfgehen.

Der ganze Gegenjtand, jo widftig wie ciner, - ja

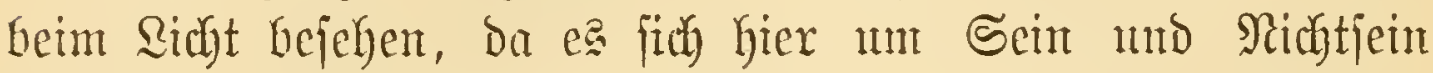
hanbelt, ber allerwidytigfte, wilrbe ein Stubium für (ith) ver= langen.

Crinzelnes, wie z. B. Die Methode Des Sentig= umb Pollen= cijens, ift un anderer Etelle jobn flithtig ermähnt worben;

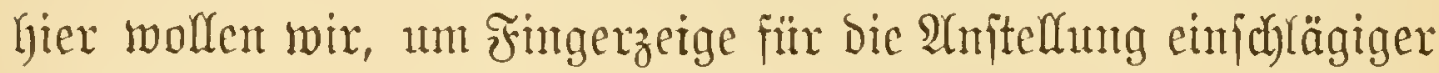
Forichungen zu geben, ant eine zweite Specialität, nämlich anf die Methode bes Blatt= ober Satrirejiens aufmerfiam mathen.

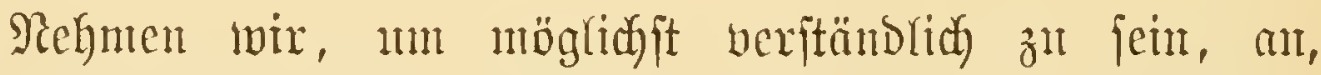

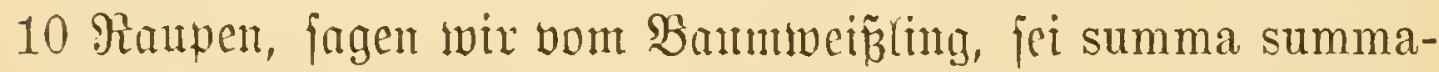
rum eine Bflanze ober ein Bammżneig mit je 10 Blättern zur Diapojition geitellt, und zluar Dergejtalt, Dan jode Raupe ifr jeparates Blatt hat, Deffen Material, wenn jie es bis zum lesten gejt verzegrt, eben zu igrer vollen Entroiffung Gimreichte.

Dieje: Penjum, ein Blatt vollfonmen afzumeiden, exforbere

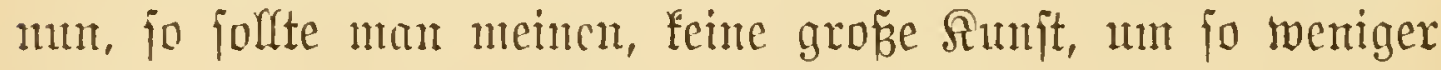

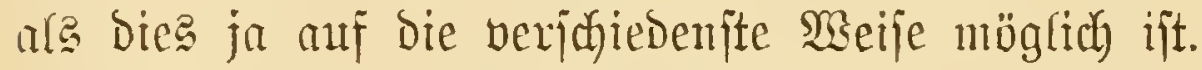

Into trobsom, wic wentige Serfe verjtehen Diejes fimpelfte aller Probleme, und als wie namenlos albern entpuppt

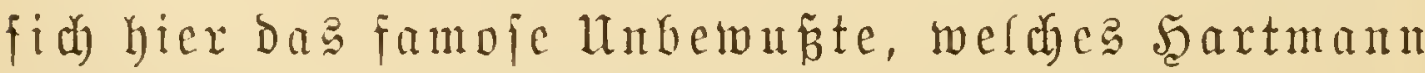

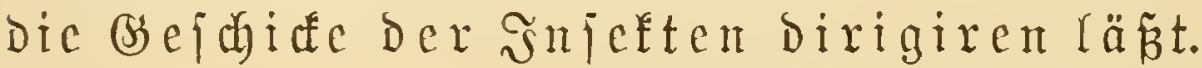

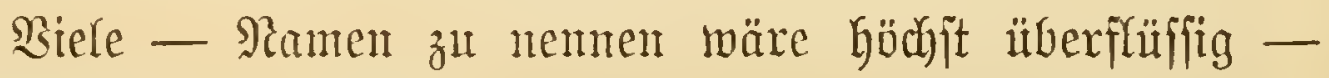
fangen auf bie Denfluar bummite Weije, nänlich Damit an,

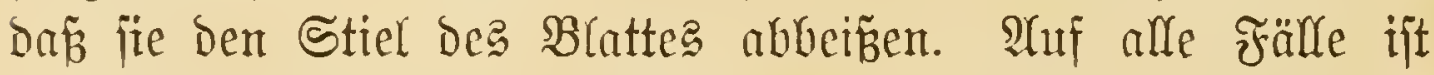
ein Thier Dann jhon geliefert. 


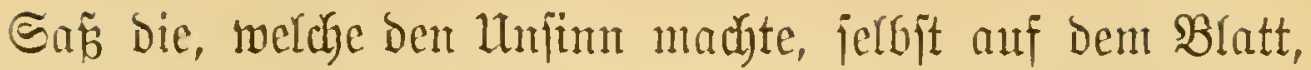
jo fällt fie mit igm ju Boden, und ift im âtrgemeiuen, Da diejes bald verdorrt, broblos. War fie aber, als ber Dumme Streich gejdyaly, midyt anf Dem Blatt, jondern am Stengel nebenan, jo bejtegt afferbinge die Miöglichefeit, Da ïe anf ein amberes der 9 nod) übrigen $\mathfrak{B}(a ̈ t t e r$ fonmt. $\mathfrak{D a}$ aber, nach umferer Borauşeb̨utg, 9 Blätter mur für 9, niemals aber für 10 Ejfer ausreichen, jo múp Esine, jei es mu bie Edyuldige ober eine Unjhuldige, das Reben lajjen.

Nehmen wir mu einen andern, gleidhalls jebr gemöhn=

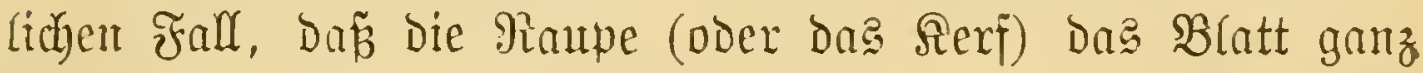
unxegelmäp̃ig abweibet, näntlich bald hier bald bort ein Sod

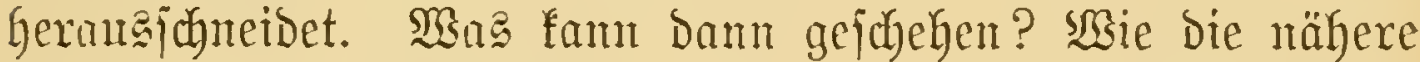

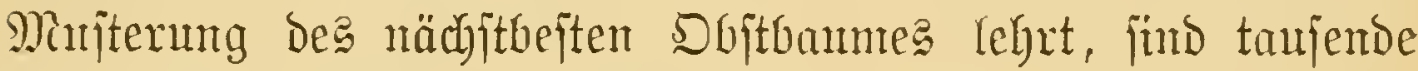
mo abertanfento von Niöglichfeiten.

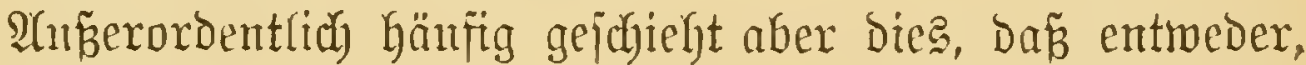

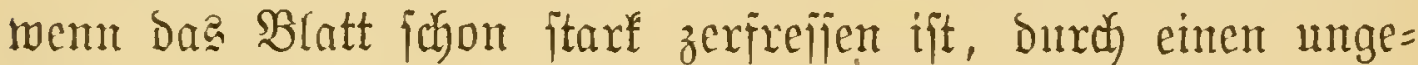
idjiften Edynitt ein Thail Dabon ganz loggetrennt wirb, ober

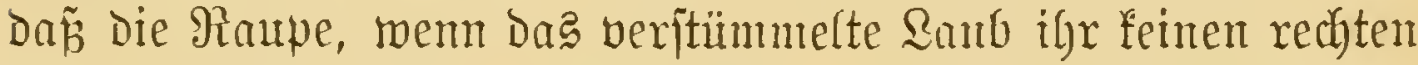
Şalt oder feinen gröperen Stich) läñt.

Die Conjequenz ift aber heibemale bie gleidye wie oben:

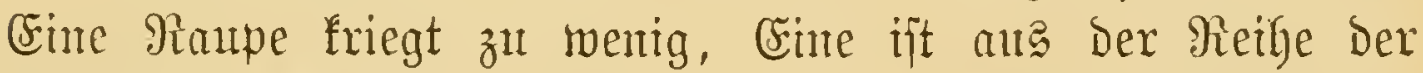
Beugenden geftrichen, wobei es Dann vollfommen eincrei ift, of bie juhuldtragende viefleidgt unr bie gröbern Blattrippen -

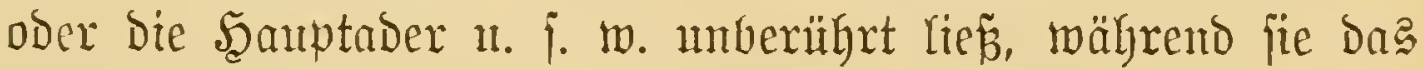
weidjere Parentanm ganz gemijienthaft ausnagte.

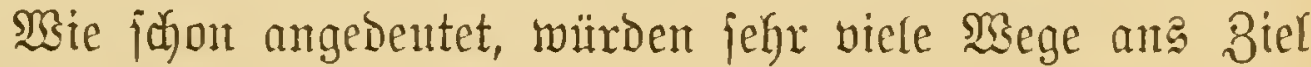
fülfren, mo zntmeilen geht es aud "znfüllig" mit einem mintor

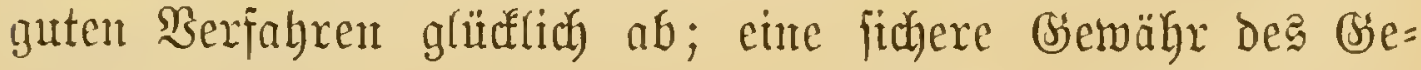
lingens gibt aber bod) mir cine Methode, mo Das ijt bie, Das Blatt bom Rambe her, und of the es irgendmo früber zat dur $x$ d $($ ö dyern, abumeiden. 
Selbitueritändolich Yäpt aber auch bieje Methode wieder viele Miodificationen zu, weldye, unter ben befonderen hiex möglichen Umitänoen, als bals mehr bard wentiger vortheilfaft fid Gerausftellen.

Wählen wix, um bies näh)e zu exläıtern, Den folgenden

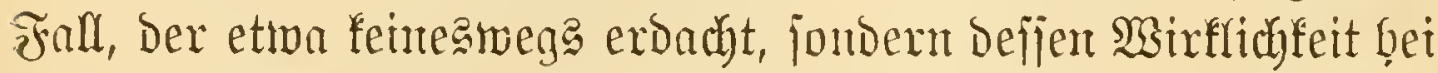
ber geradezut unendichen Miannigfaltigfeit Der einfichlägigen

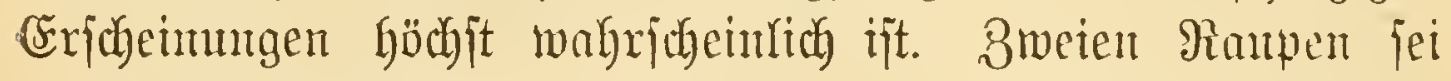
nur ein einziges Blatt angewiefen; jede branche aber zu ibrer vollen $\mathfrak{A}$ trabiloung wentigitens $3 / 4$ Des ganzen.

Mïrben beide Raupen in gleicher Beit gentan gleidy

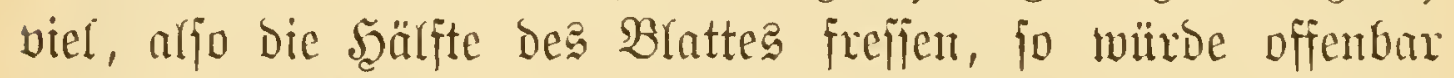
feine gemug friegen. Wie wix aber bei unferen eigenen gemeinfamen Schmantfereien tagtäg(ich) beobadohten, ijt biejer

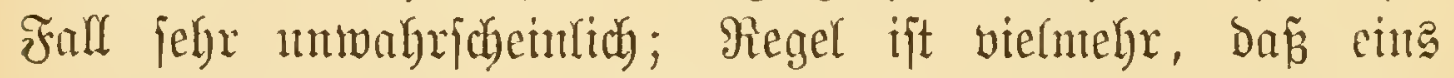
mely als bas andere befoumt, mo zwax befindoct jich ceteris

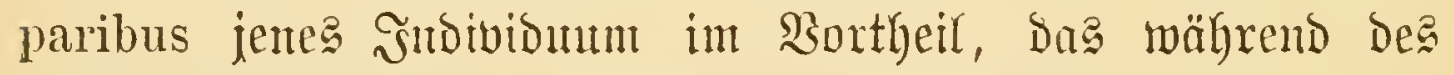
(sijens bie mentigite Beit mit anbern Berridhtungen berliert.

Rebmen wir mu an, die Raupe A freffe eine Beit lang an Der Spibe des Brattes, es verleide jie aber hier, fie

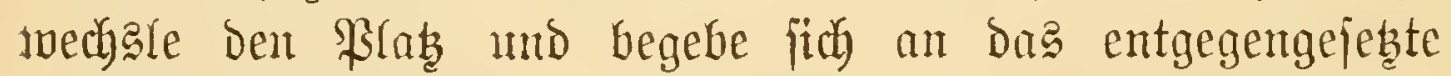
Iafelente; Die Raupe B hingegen bleibe unnterbrod)en bei ifrer $\mathfrak{A}$ rbeit und bemege fich niemals weiter, als p? bic in Folge der jucceffiven Wegntahme bes Futters gröper wer=

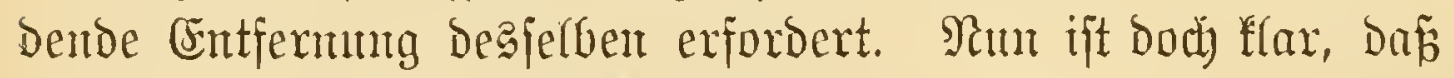

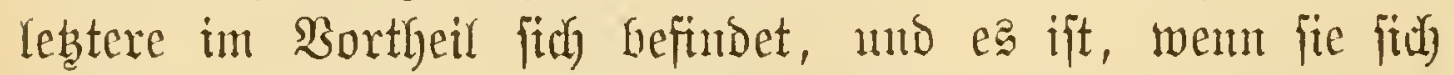

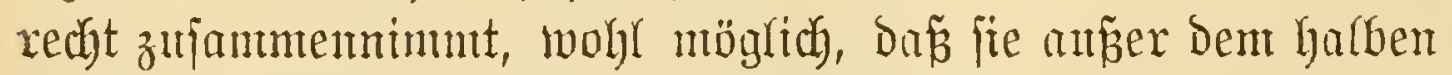
Blatt, das ihr gebülyrt, nody die şälfte des fremben aththeila itch erohert. -

Die thatfädylid erfolgten Aqupajiungen aber, und zinar fowohl jene, weldye fich auf bie Drganifation, als bie, weldye fich ant Den (sebranth, auf bie gefjörige Anmentutg ber be= treffenden Cinmidatungen, aljo anf Die Methode des Effens 
bezielgen, zeigen fid aber hiex nidft wenigex betwmbermswerth als bie, welche wir beim Pollenfegen und bei ber Şonig= geminnung femen lernten.

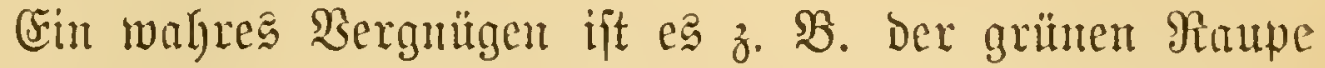
einer Seideneule zuzufehen. Sie reitet anf Dem Blattrand. Die $\mathfrak{B a n d}=$ und bie Ginteren Brujtfüfpe bienen zur Fixirung

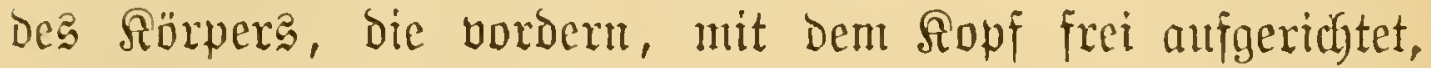

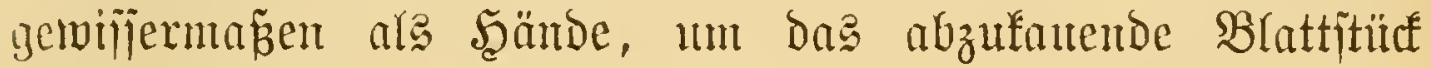
bereit zu halten. Die fadarfzähnigen Riefer jahneiden mu,

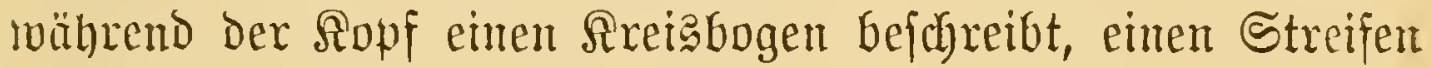
nach Dem andern herants, wobei aber inmer bon ber näm= lidben Stelle anggegangen wirb. Sit der gentachte Blatt=

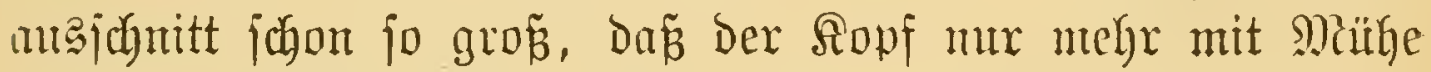
an Das äunerfte Crnde reidut, Dam rutjut bie Raupe jo regetmäp̈ig, twie Durch eine Stellịgraube bemegt, eine Strecte

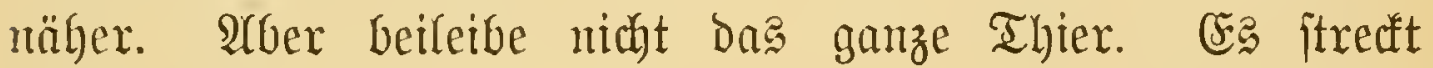
(ïc) zunädjit nur der Şorberleib um die Ränge eines

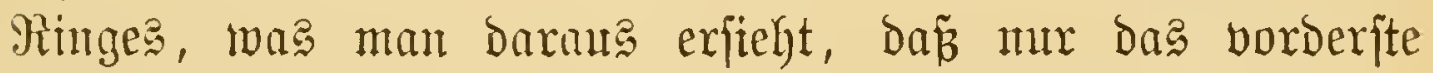
Band funpaar vorrüat, während bie übrigen exjt fpäter, nach mo nach, D. h. mady Miażgabe Des vorme gefdaffenen Spiel= raumes fich vom łilate rälyren.

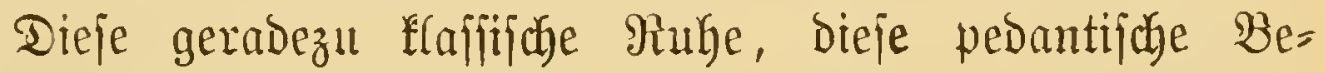
jahränfung der Siraftaußgaben allein fann aber in Fällen,

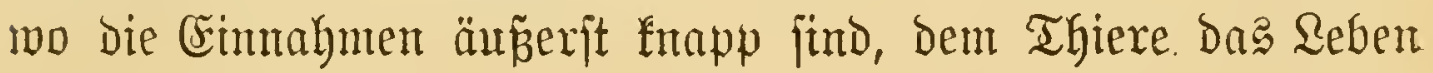
retten.

Schon aus biefer cinen Mittheilung fieht man, was für mannigfache und für bie Seleftionatheorie ähterert mid)tige Beobadytungen in ber Ridytung jïrb anftellen liepenen.

Noch interefijanter würoen aber förmliche mit geeigneten Snitrumenten zu unternegmende Experimente fein. So wäre ว. B. zut uterjudyen, wie fich bie Blattfrefier benelymen, wem

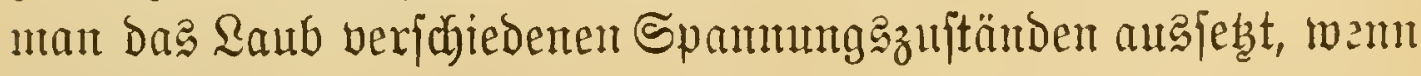
man bie Blätter eitrollt, zmei ober melyrere, fei es mit der 
Unter $=$ ober Dherjeite, zufanmenflebt ober jouftwie bejombere

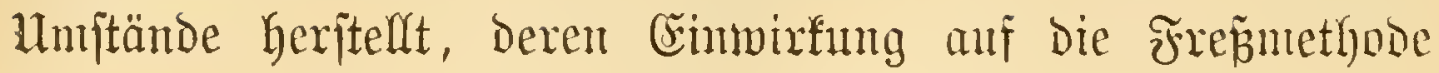

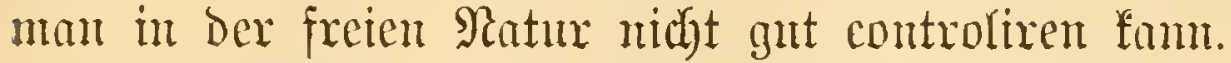

Dies ijt aber mur einte ganz bejdyränfte Seite der ganzen S̃ndujtrie des $\mathfrak{B}$ Battfinuen?.

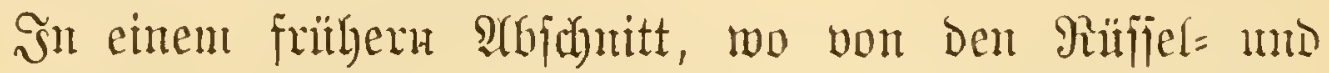
Borfenfäfern un Dergleidyen Şolzmagern bie Rede gewejen, mušten soir itanuen über dic urzähligen Modififationten, Deren

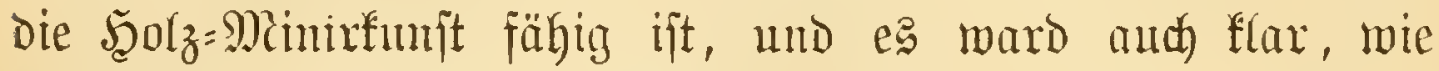

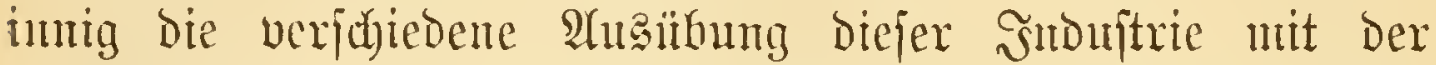
Frudutbarfeit mo mit Der Serbreitung Der betreffenden fierfe verfloditen ift.

Mindeftens eben jo mannigfaltig und vielfach nod) meit

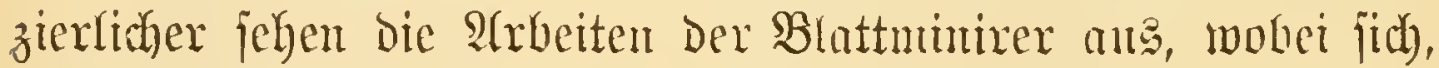

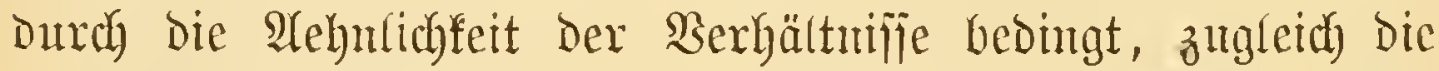

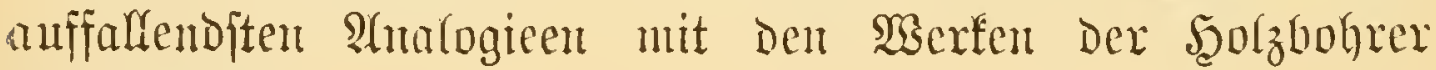
berangitellen.

Prächtige Erräuterumgsobjckte geben die in alfen Bsennifjegärten mafjenlyaft zu findenden Blätter des Sonchus asper uno gemiffer Lappa-Âten ab, Deren wou einer wingigen

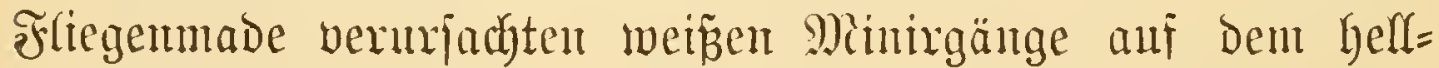

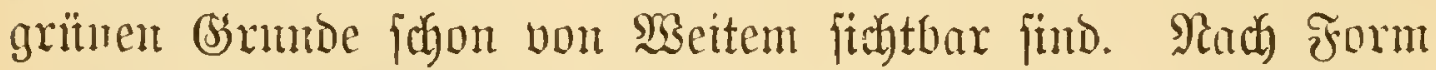
und Berlauf haben dieje Blattminen eine höbjt auffallende

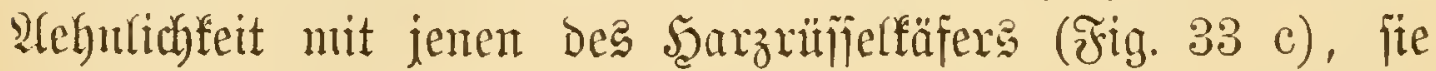
wedhfeln aber nach Lage und Ridhtung zwijhen Den meitejten Extremen. Meift find fie julangenartig gemunden. Mian jiegt aber aud), wem man einige humbert Blätter Durchmujtert, ganz kerzengerabe und wieber andere, bie eincu eimfacthen ober

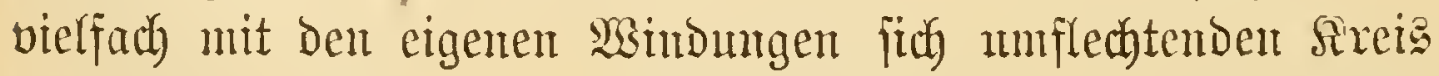

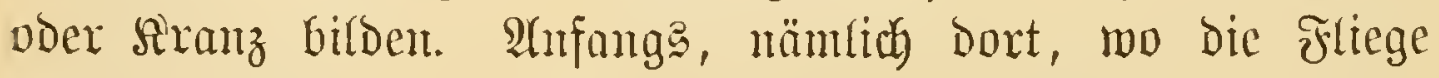
Das (5i ablegte und bie fajt nod) mifrostopifach fleine Larve

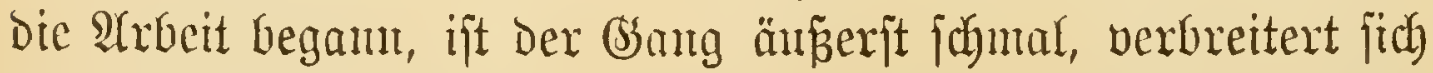
aber zujehends gegen Das Endo Der ganzen Rebensbahn, allmo 
ex in eine balo längliche, bald flectenturtige Cromeiterung, bie

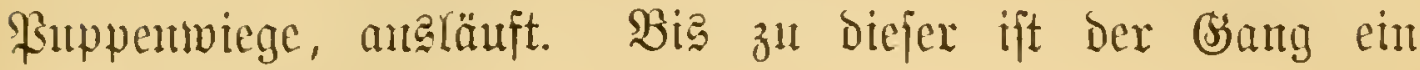
jog. oferjeitiger.

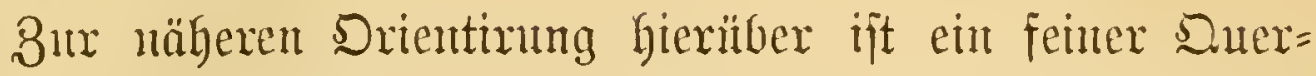
fichnitt exforberlich. Das eigentliche grüne Saftgewebe oder Blatmarf exfcheint Gier von beträratticher Dicfe. Sben nud

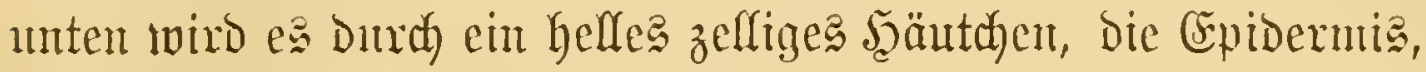

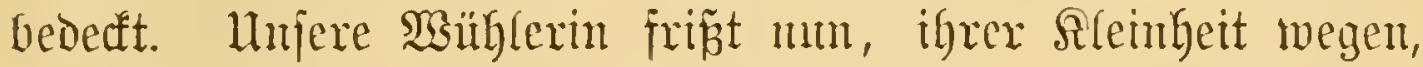

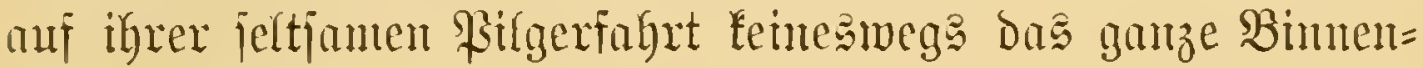
gemebe auf, fonbern jie begnïgt fich mit Der oberflächlichjten

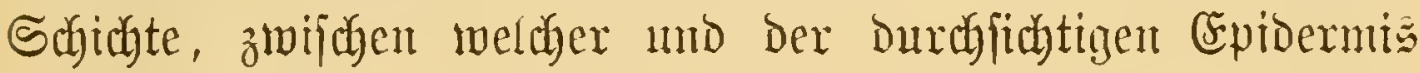

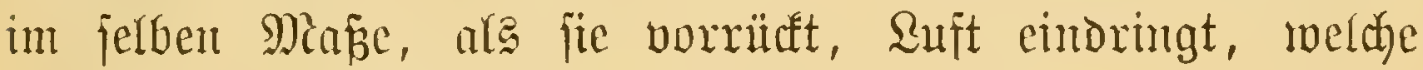
eben Dent Gang die jübermei f̌ce Färbung gibt.

Bsanz eigens und woht eines bejonderen Stubiums werth ijt der Bau biejer Rarve und Der meijten Blattnimirer über:

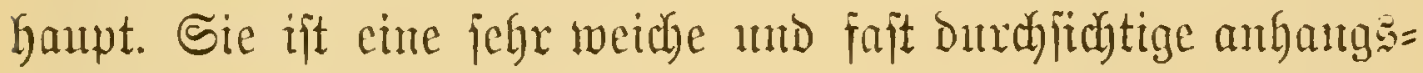

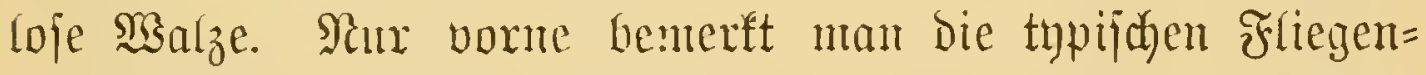

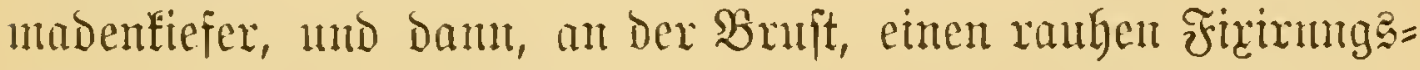
Göfer. Fermer ficht mun vorne mb hinten cim Sarar

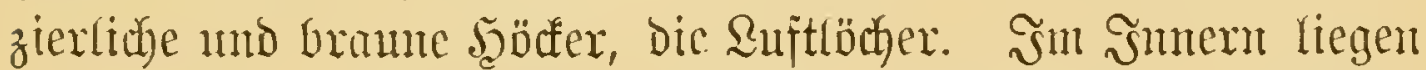
Dann noch, unregetmäpäig zeritreut, diffmandige, zelfartige Sörper von unbefanter $\mathfrak{B e b e u t u n g . ~}$

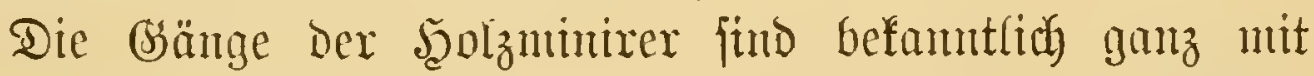
Dem fog. Wsurmuchl angeitopft; Dem beim geringen $\mathfrak{N a ̈ h} x=$ werth Diejes Materiale jebzt es viel Murath ab. Indors hier,

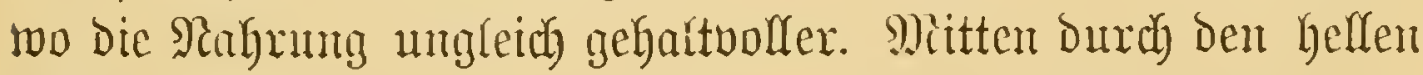
(Goung ziegt fich mux eine bünne, bald perlfchmurartige bald contimuirlibje dunfle Rotglinie, welche bei Den fog. Fflect= ober

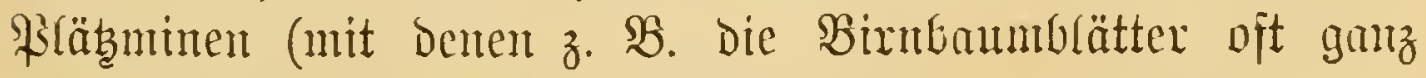
getigert find) in zierlidben Spixalen um das Eentrum, D. i.

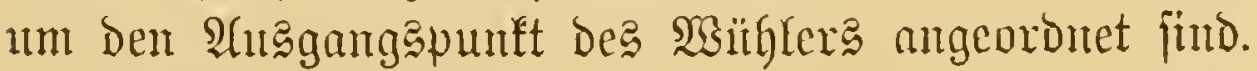

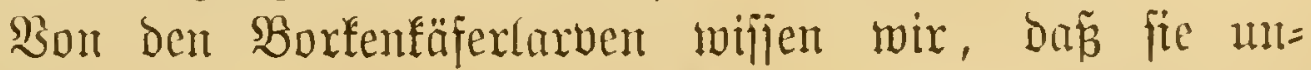
mittelbar vor der Bexpuppung Dem Brang, Der biäher im 
meicheren Banmgemebe, zum Theil im Bajt verlief, eine ambere Direftion geben, indem jie fird weiter nad) anzen in bie Borte

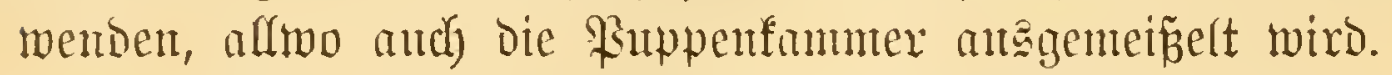

Yehnliches ijt von unjerer Slattmühlerin zut vermelden.

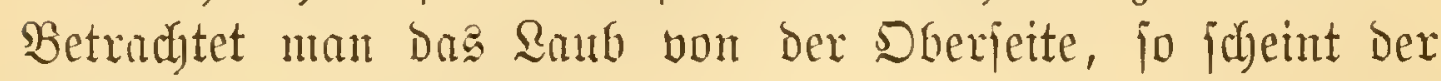

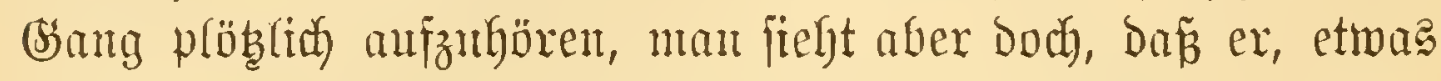
tiefer muten, jid fortjebt. Wendet num bas Batt, fo wird alles $\mathfrak{H}(\mathfrak{a r}$. Das Brangende jammt ber "Miege" befindet jich an ber Unterjeite, D. h. Die Made hat fith ein bejieres Merjted gejud)t. Dabei liegt Das braune Tomentüppdren meift jo

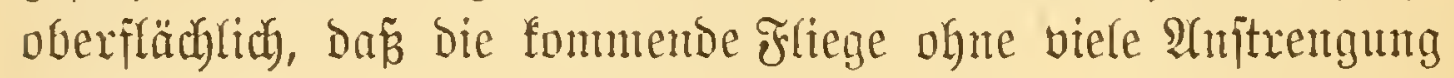
Durch) Die Dïnte Epibermis ing Freie gelungt.

Nant, bas ift bod alles in jojomfter Dromung, wird mant

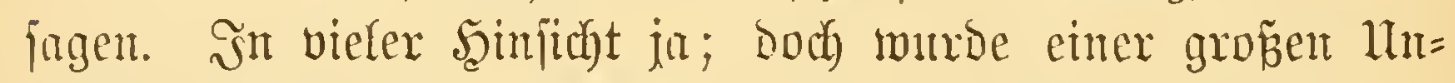

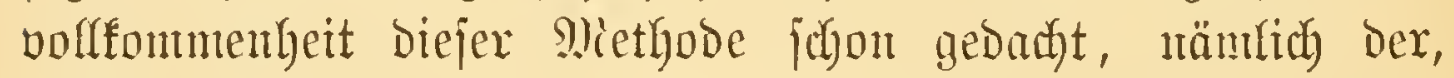
Dá̧ bie Made biameifen einen förntityen circulus vitiosus

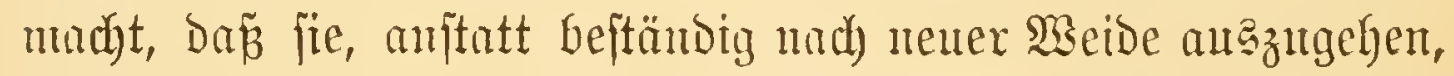

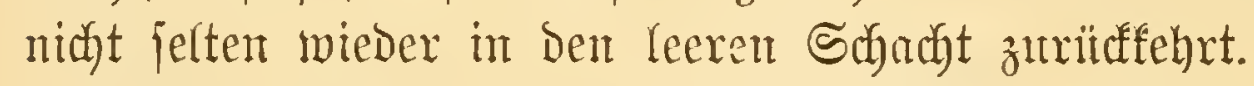

Unjere hohe Meinntg von Den Rünjten biejer Rerfe tvird aber an meiften in ben Fall herabgeftinmt, ment mebrere Derjelben gleidrzeitig anf Einen Bhatte arbeiten.

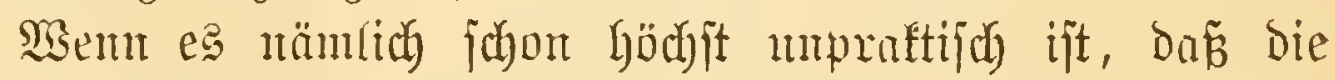
ganze Bejellichaft jich obne alle Drommtg anf ifrem Terrain zerftrent, jo wird es gerndezu gefülyrlich, wem die einzelnen Sntoividuen, was in Dex That umzählige Miare gejdieht, auf

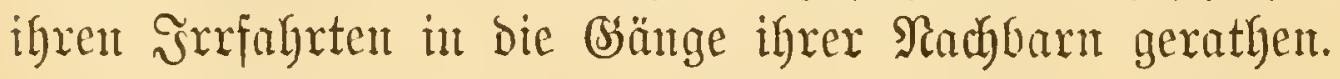

Reider dürfen wix uns nidyt ins Detail einlaffen. Seit geraumer Beit mit Dem હammelu joldyer Minirjtüre be=

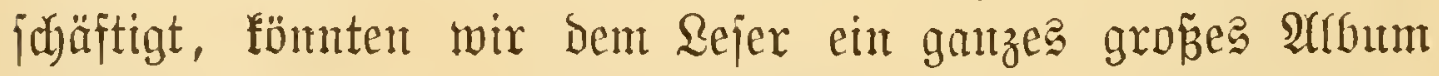
vorlegen, das nichts anderes entfält als eine autobiographirte

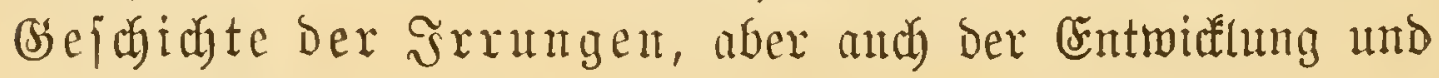
Der Bervolfonummutg Der Serffünite. 


\section{Sapapitel.}

\section{(berellidaftaleben iex 䈍erfe.}

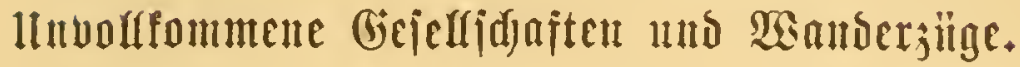

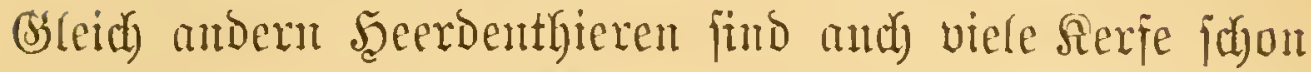
von Ratur aus auf Bsejelligfeit angewiejen, mb amitatt jüb

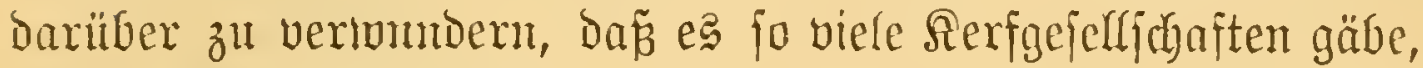
min̈te man eher fragen, marmu es jo mentige gibt. Die meiften Snjeften hinterlajjen ja eitre zahlreiche Familie, Dexen

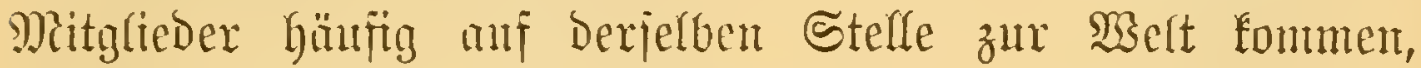

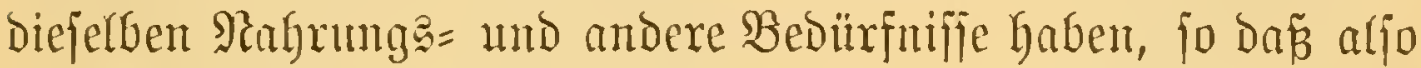
gar fein Brrund vorlyanden ift, rorum, wem fie überbaut beifammen bleiben fönnen, j̈e ats einander gehen, fich meiben und zeritrenen follen; namentlidy bant, went die $\mathfrak{B e r}=$

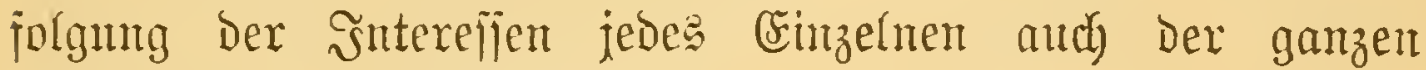
Ssenteinfichaft zat Bsute fonmt.

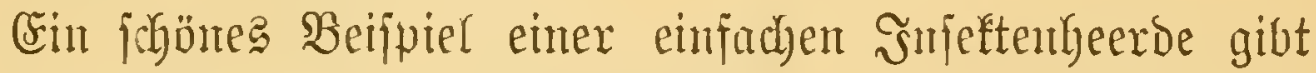

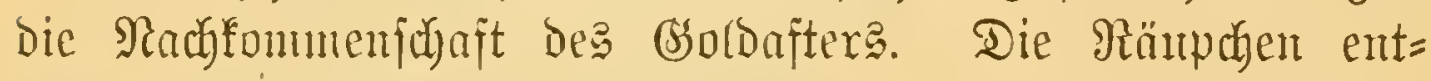
ftehen alfe ans eintem genteinfamen, mit Fitz überzogenen

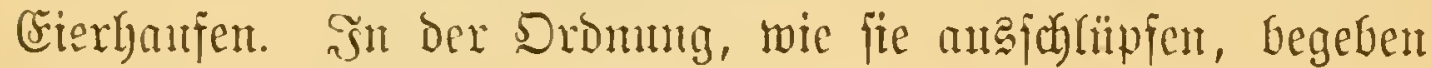
jie fict) anf ein Blatt, ftellen fith in Reif' mo (silied mid beginuten ifgr Tagemerk. Sobald Dann ifgr şunger und bic innere Seibenmannfaftur hinlänglid) Stofi erhalten hat, errichten fie über ifgrer Tafel ein Seibengezelt, bas nad) und nach in mehrere bemäd)er abgetfeilt miro. Soll biefent

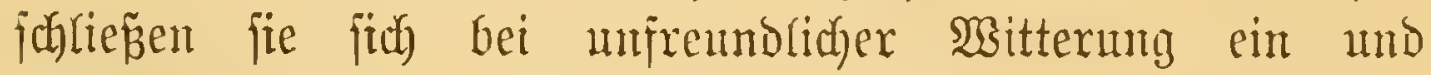
überwintern aud). Şm Mai ober Şmi aber, zur Beit Der Berpuppung, verlajīen fie es für inmer - Jebes geht

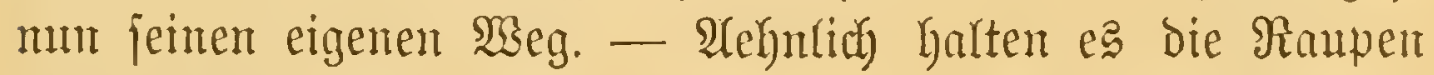
von Papilio cinxia, nur da pa fie mit ifrem Sommergezelt herumziehen, b. h. jo oft jie ben aus Bäättern, bejtebenten

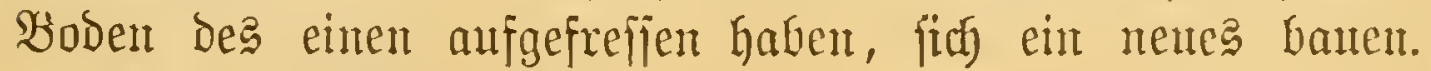

(3) raber, Injetten. II. BD. 


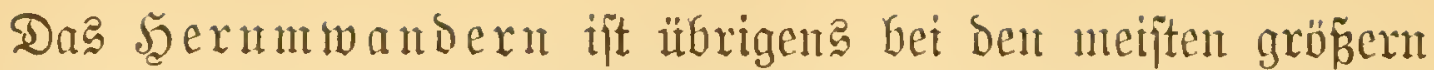
ferfcorporationen itblich oder jagen wir lieber notbwendig, da ja ein befdränter Weideplas für viele sfjer nur auf furze Beit ansreidyt. So wie aber bie Slieber Siner Fantite, jo werdent bäufig zablreidye Familien Durch die sleichbeit ber Rebens=

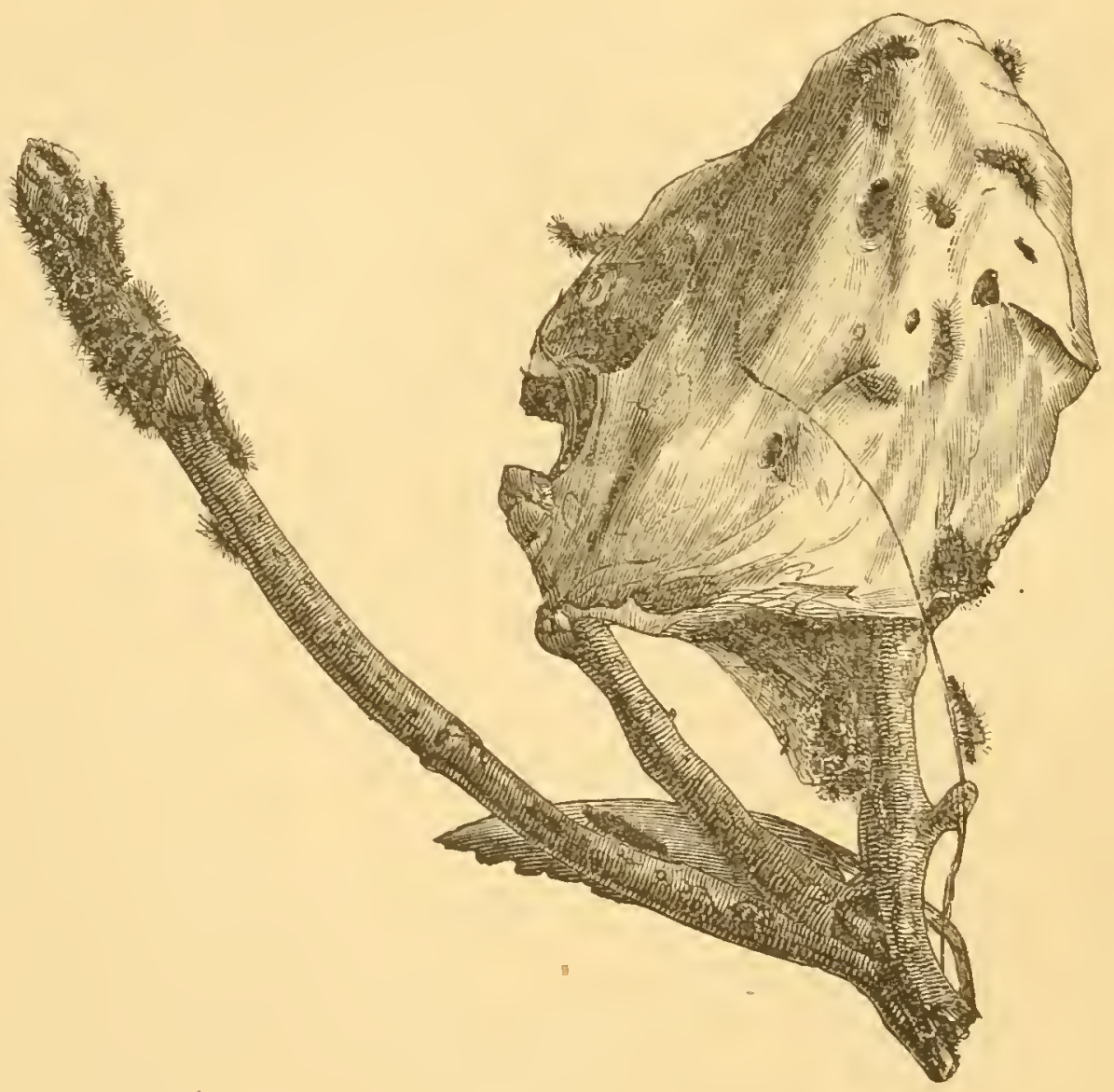

Fig. 84.

Minterueft des Groldafters, nat. Bir.

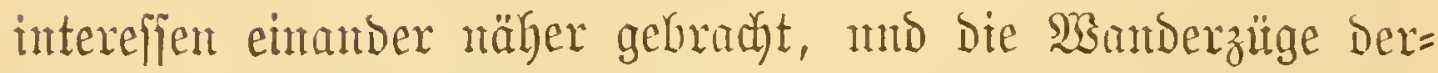
artiger Mafjenteerben zülylen zu den gropartigften Er: \{dyeinungen in Rerffeben.

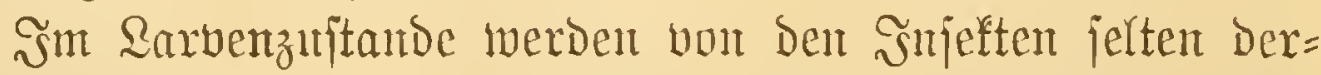
artige Mafjemmzüge unternommen. CEnten merfwüroigen Fall ciutes folchen hatte aber eimjt Dr. Dohrn bei ciner Eijenbahn=

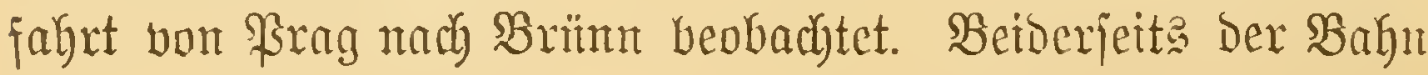




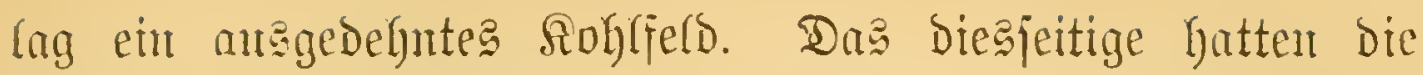
Rohlraupen (P. brassicae) eber abgemeidet und fie manberten, vermuth(ich Durch einige Spione verleitet, quer über bas Bahn= geteife ani das andere. Dahei waren mu bie Mafjen ber

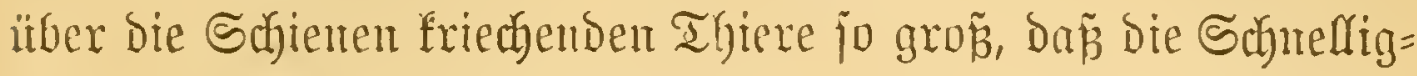

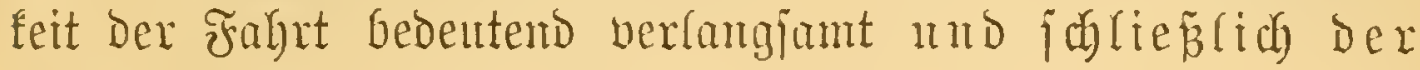
ganze 8 azun Stehen gebrad twate.

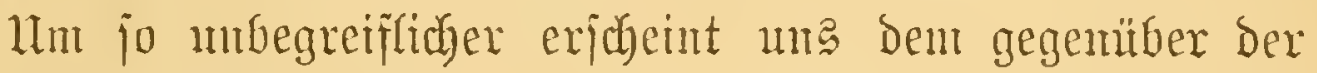
Starrfinn gewijijer mberer, 3 . $\mathfrak{B}$. Der Rieferranpen, bie nadh

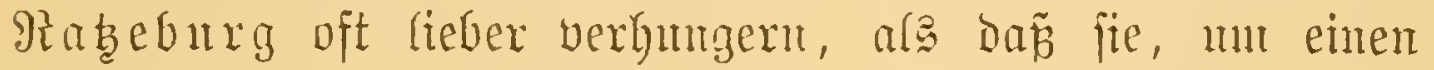
frijchen Banm zu erreidyen, ein par Echritte jich weiter bemïhten.

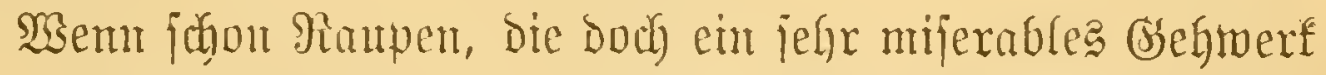

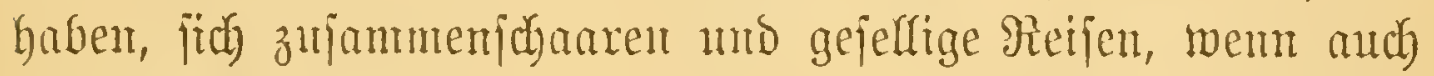
mux anf fleme Dijtanzen, untexnefmen, jo roird man jo etwas Den geflügelten Şrieften un jo eher zutrauen.

Schou in alten Chronifen fundet man Bexidyte von Mafienzügen Der Sametterlinge. So joll im 16. Sahrhmbert

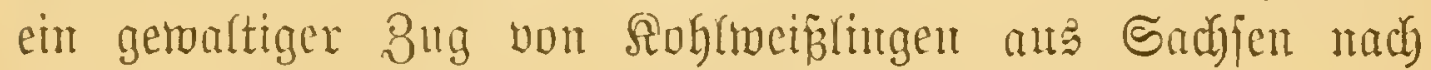
Bayern eingefalfen jein. S̈l ber ßegel gehen bieje Falter= manbernngen aher aus märmeren in fältere Diftrifte, uno fleimere Büge werben andich oft unternommen, un geeignetere Brutjtätten aufzujucher.

ßon bejonderem Şnterejie fund bie Den lebztgenannten

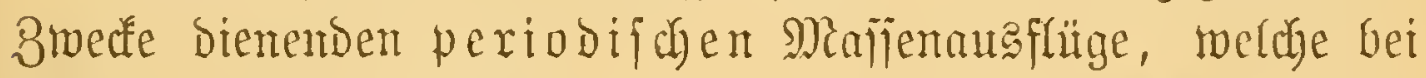
Den anterifanifacen $\mathfrak{A}$ rten Urania leilus und Marius beob)= adjtet fint. Sie ziehent brei bis bier Wodjen lang alle Miorgen "vou 9 bis 12 Mhr" (!) Demt Fune Der Corbiflereu

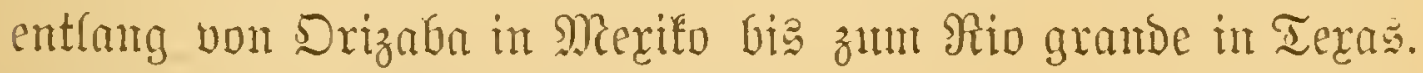

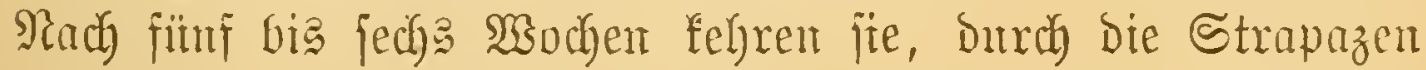

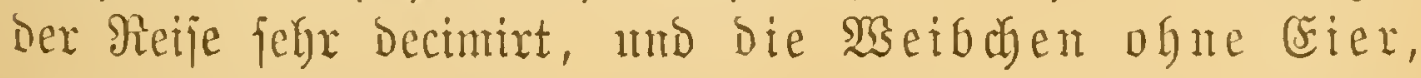
mieder nad) ifrer Secimat zunitc. Das Heberrajchente an ber Sache ift, eimmar, robher jührlich bieje Mafjen von Faltern 
fommen, da bie Brut anper Land getragen wird, und Dam, was bie exmatteten Thiere wieder in ifrer Semat eigentlia

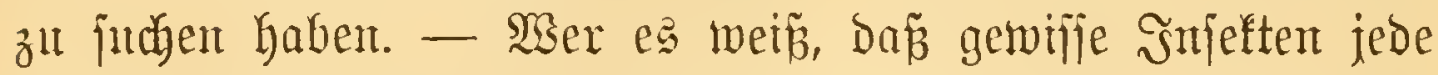
Selegentheit ergreifen, un auf Roften antoerer ihre unerfätt= richen Rülte zu befriedigen, Der wiro fich Ceicht vorjtellen, Daf

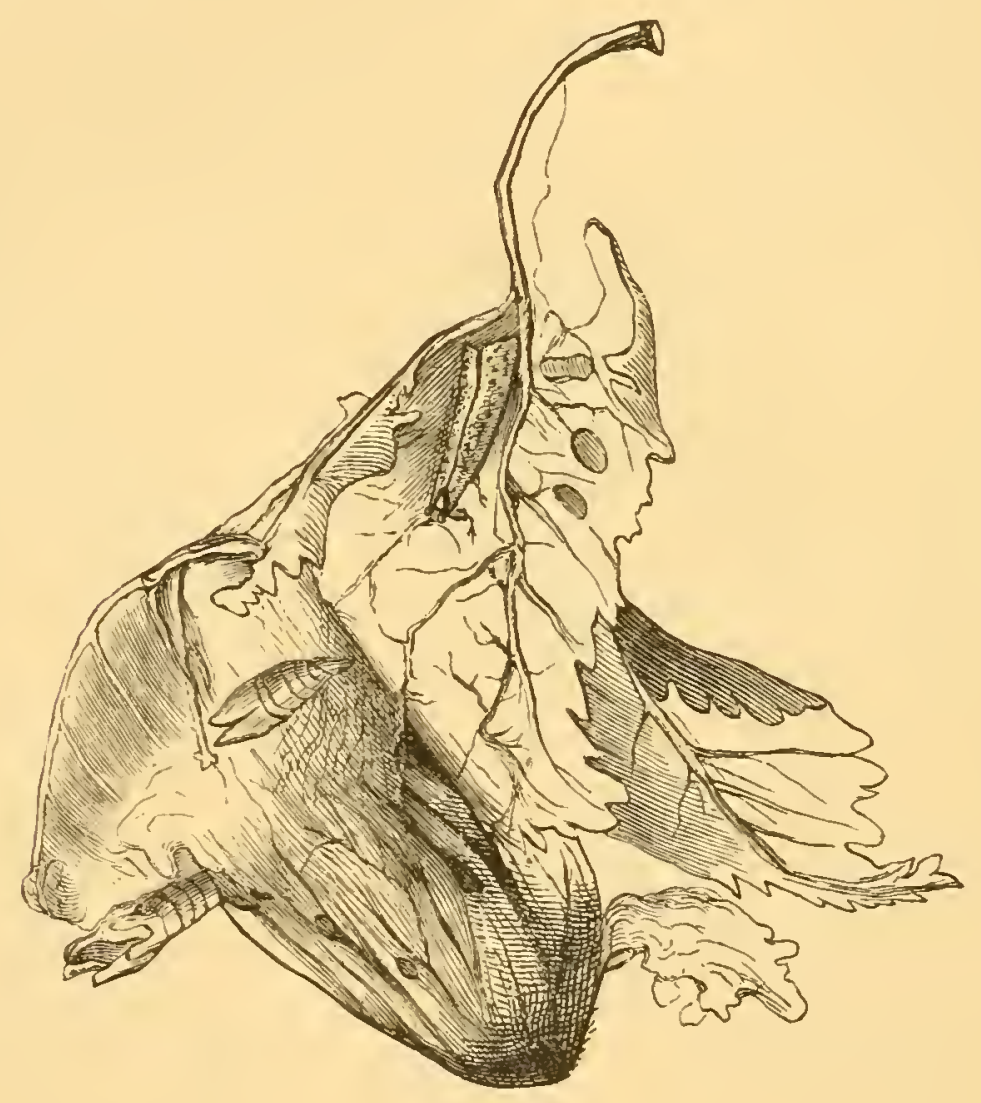

Fig. 85.

Iraubenfirjdeumotte (Tinea padella Heyd.), nat. Br. Wiener Şofmujeun.

unjere Mantorer nidgt jo gunt im Frieben ziehen fömuen, fonderm, jowie jie fich erheben, alghald bon einter Menge

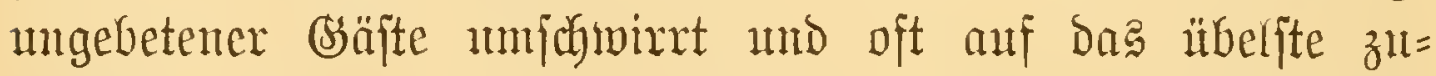
geridjtet werben. Sor allent find es Ribellen, Sandweepen

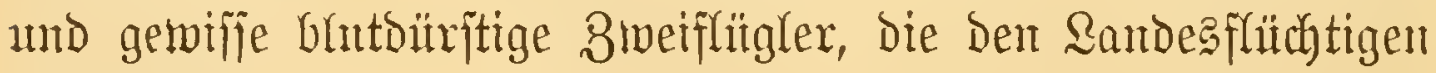
nadjagen.

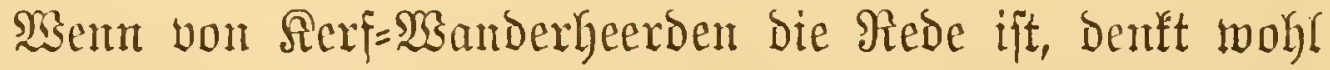

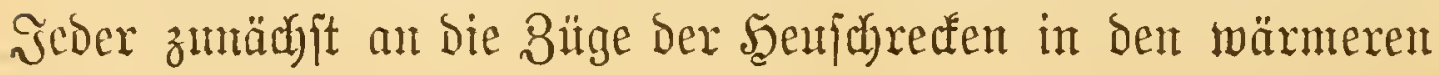


Sänbern, Snjeften, die aber anth fältere Dif́trifte beimijudben, ja jogar - wie dies z. B. mit Der tartarifanen $\mathfrak{B a n t b e r =}$ heufdyrecfe in Sildotirol der Falf - fith Dort Danerno nieder= Iaijen.

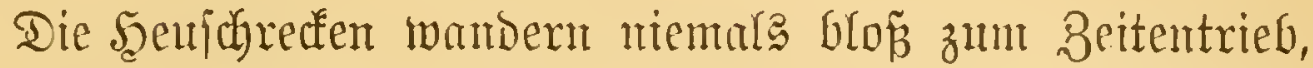

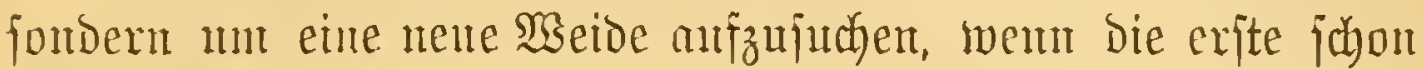

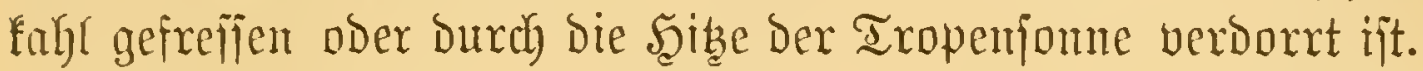
Şäufig merben aber ganze Sdymärme, von ibrer uriprüngliden

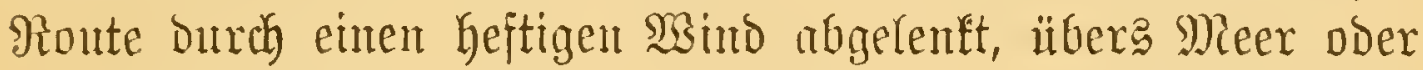

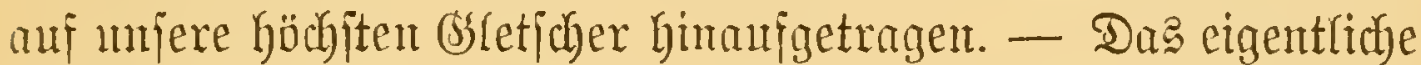

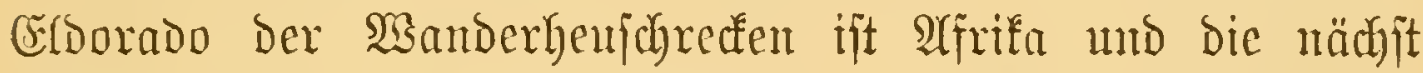

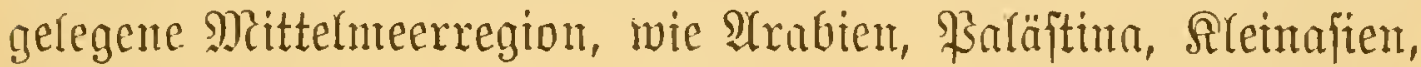

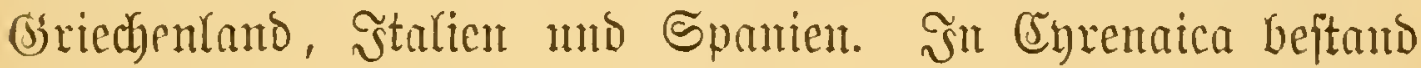

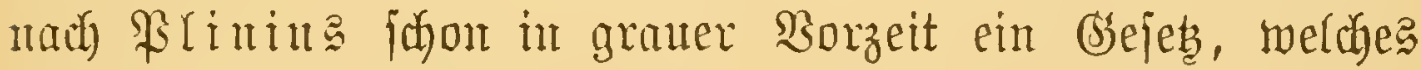
jährlich eincn breimaligen firieg, näntich gegen bie Čier, gegen Die Larven und gegen bie flugfühigen Thiere anorbnete, und cin äbuliches bejtand auf Remnos, bas nach $D$ rojiug im Fahre 3800 v. Chr. "von jo unzähligen Myriaden biejer Rerfe

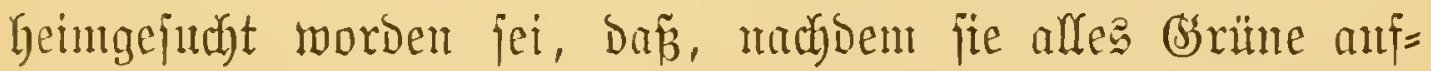
gezehrt hatten, fie in bas Mleer geflogen, Dajelbit "erjoffen", unb nadjoem fie an ben Strand zurïfigemorfen waren, Durch ihre Seidhen eine furchtbare Bejt verurjachten". Aluch int

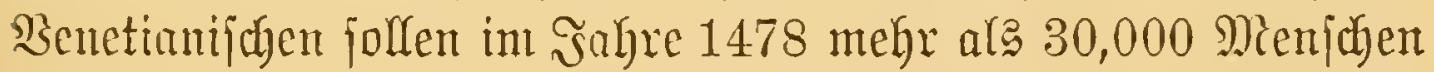

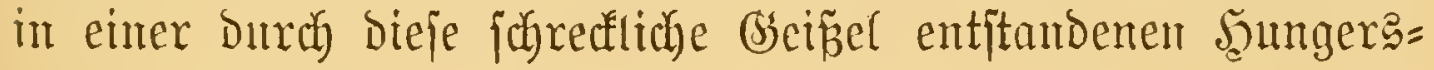
noth untgefonment jein.

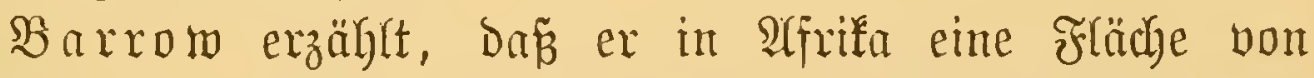
ungefägr 2000 engl. Suabratmeilen Dabon bedectt fano. Und ars dieje Riejenheerde Durih einen Sturm ing Meer getrieben worben, häuften fich Dort ilyre Seichen zut einer 50 Mieilen langen Bant auf, won Der ein Bsejtant ausging,

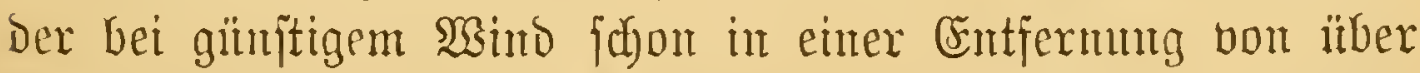

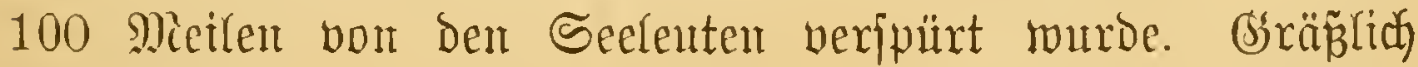
twar and bie im vorigen Sahrhumbert verurjadyte Sertwïftung 


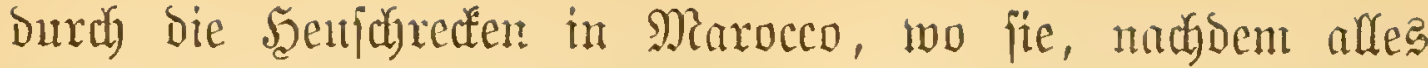
liebrige verzelhat war, felbft bie bittere Rimbe des \$ome=

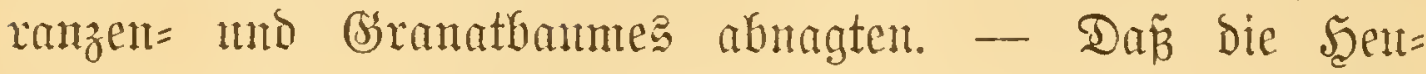
(c) recten nidyt aus eigener Sraft fo weite Ruftreifen madyen fömen, jondern baj fie mit bem șinde jegeh, heweift eine Schildorung vou Rapitän St of e 200 engl. Micilen won ben canarijaten Snfeln - trat plöblict), bei feiner Ueberfahrt nach Savamtah, eine SSindjtille cin umb

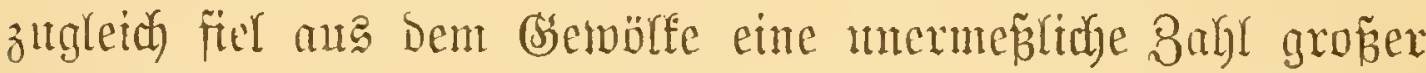

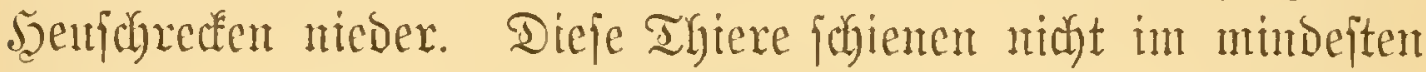

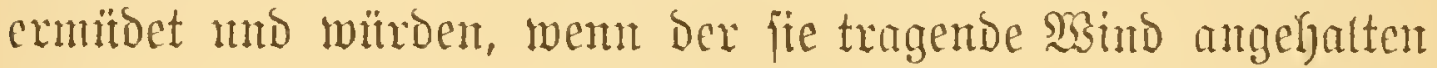
hätte, möglicherweife ïber Den ganzen Deean gefommen fein.

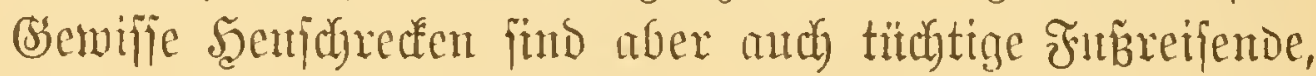
bies aber mar während ifyrer sutgent - wo fie nod nicht fliegen

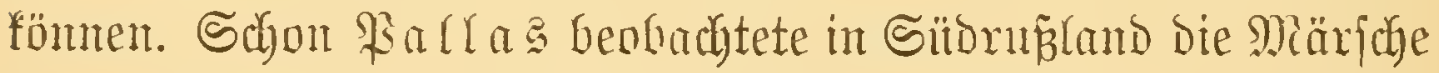
cincr and bei m? lebenden Schrecte, nämlich von Caloptenus italicus. Sie jteben jebr zeitig auf, foburd dex Frithtyau

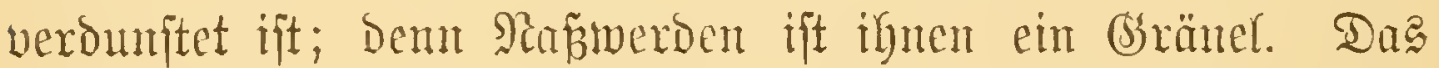
ganze Corps gleidyt fajt einen reyelredyten armeifenheer. Sie wandern zwax nicht in Reify und sified, abex boch in

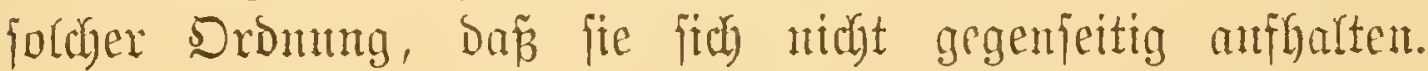
saeroen fie ans einamber gefprengt, jo vergattern fie fid fidjlen= nigit wieber und ziehen weitex - oft humbert Faben an einem

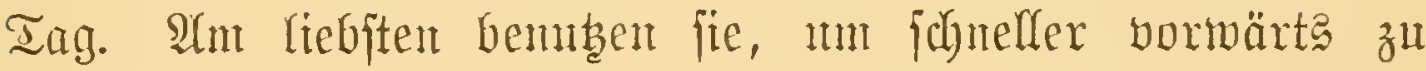
fonmen, gebahnte Strajen, wijfen fich aber aud alt febr

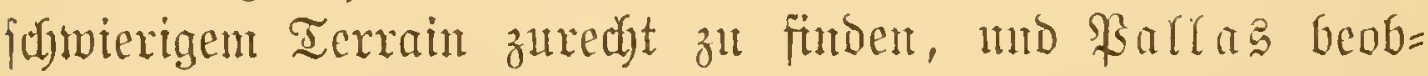
uchtete andy, wie fie einen ïber einen Sumpf gelegten $\mathfrak{B a n n =}$ ftanm als Brübe bentsen. 2(m Shend rajten fie bann anf Den (befträuchen, Die, wie jüngft Der 2lfrifareifende Fritich an Gryllus devastator Licht. beobadytet, won ibnen fo woll =

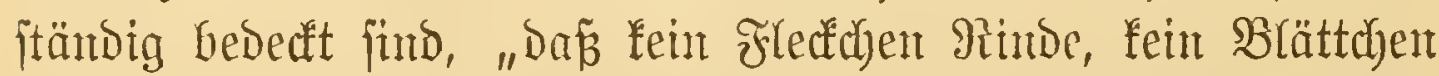

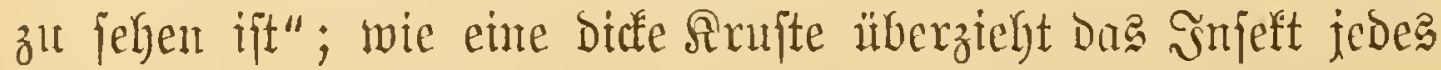
2eftchen, und alles brün ift am Morgen verjabuntoen, 
wenn die ungebetenen Bsäjte fidy aus dem Stanbe gemadbt habent.

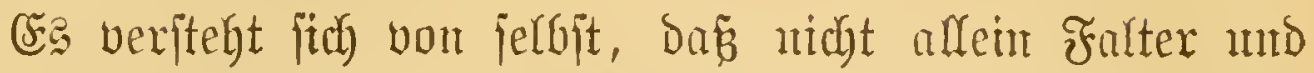

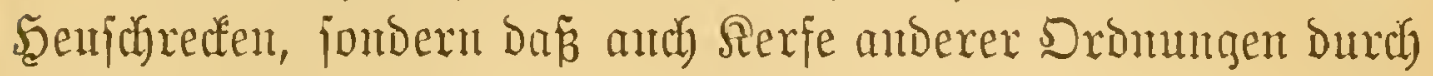
Fntternoth ober Durch gewifife andere igre Exiftenz bedrokende

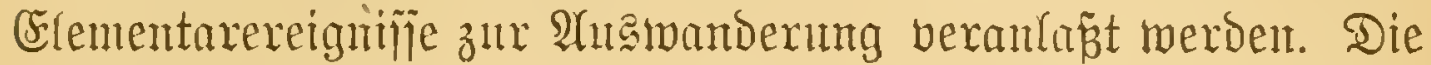

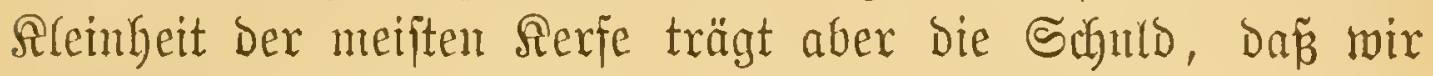
von igren Wamberungen in ber Regel menig Notiz nehmen.

Son Den vielen Beifpielen, wie fie ung die ältern Entono=

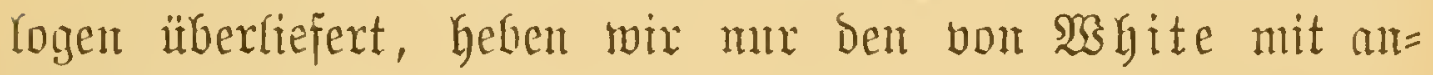

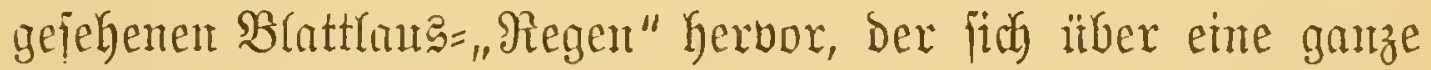
(Srafichaft ergons.

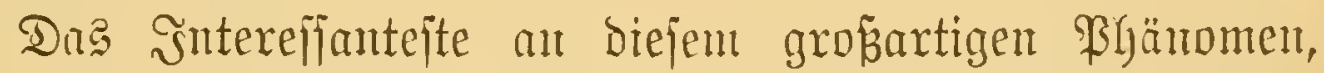
Das jeinen abergläubifduen Beitgenoijen midut geringen Schrecfen

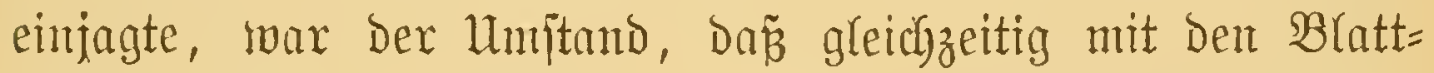
länjen and) igre befannten Feinse, nänlid die Marien=

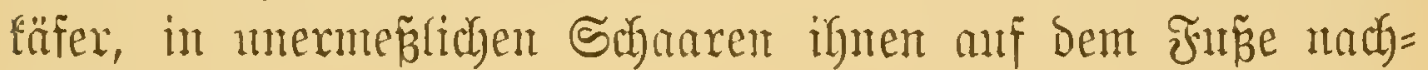
jolgten.

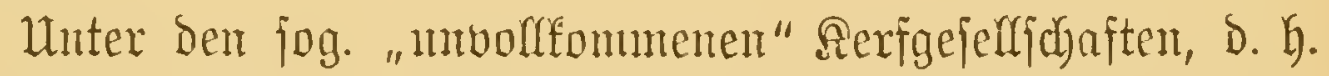
aljo unter jenen, bie nidyt jo jtreng und einheitfich mie etwa bie Bienen, 2(nteijen u. j. w. oxganifirt jind, idyeinen nächjt

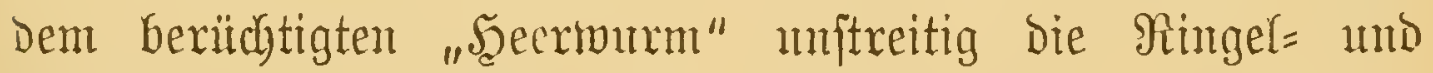

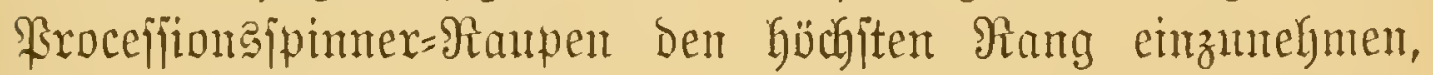
bies menigitens in $\mathfrak{B e z u n g}$ auf bie mufterbafte Dromung,

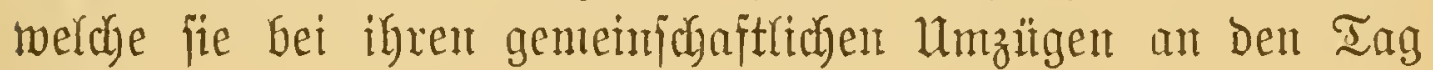
regen.

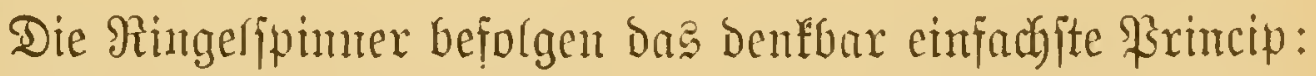

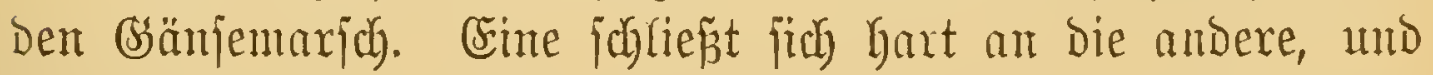
jo ijt Der gauze lange Bug megen ibrex Färbung nicht un= ähnlich einer "goldenen Sdfur", Die jidt) auf einem (d)uee= weizen Bande, dem wälyrend des (seheng gewobenen Teppid, bahin mintot. 


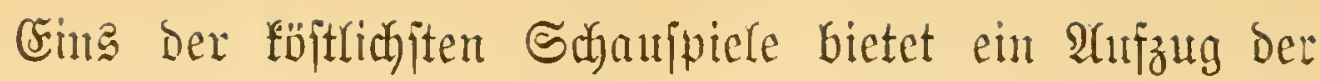
im übrigen mit Recht gefürdeten Proceffiongapinter. Sie

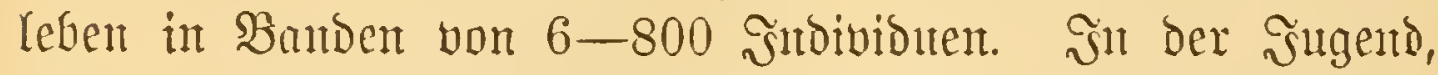
wo fie noch flein jint und baher leidyt ein natïr(idyes \$erftef funben, Gaben fie feinen fejten $\mathfrak{B}_{0}$ hnjth. Später tweben fie ein gentemfante Belt, von Dem ans Dann and bie Büge unternommen werden.

Daz. Regintent verläp̈t jein Dutartier meift exft nach

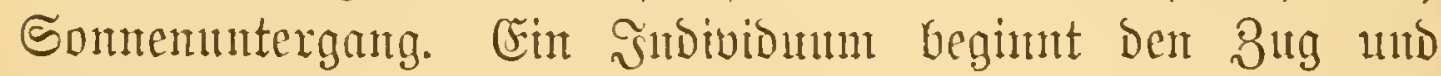
wird als Reitthier anterfant, infofern bie übrigen gentu bie

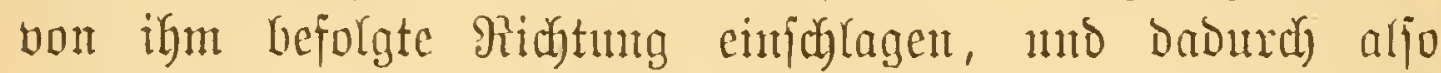
ifren Miflen Dent des Anführers untertwerjen. Drei oder

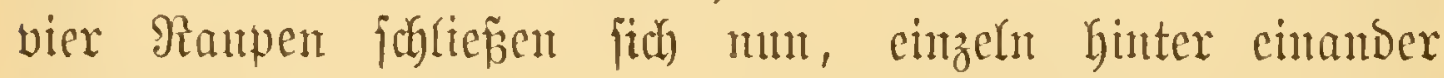
friechend, Dem Reittfier an. Die sweiter rüctwärts folgenten Shlieber Der ganzen langen Rette find aber zujammengejeb̧t. Und zwar fonmen zuerit ntelgrere zu zwei, Dant joldye zu brei,

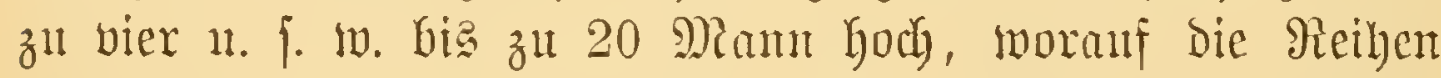
ebenjo fuccefitue twieder abfallen. Die ganze Gy a g ord

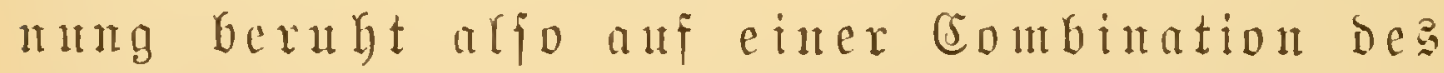
regeluäzigen heinter= und Sebeneinandergelens.

Die Drduntg Der Dinge füfrt uts mu zu Den eigent=

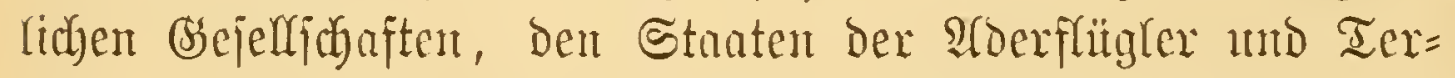
miten. Sine auth mu halbmegs erjöbpende Schilderung Derjelben witrde aber alfein ein bicfes Burb fülfen; Darats utag Dex, Sejer benn jelfit urtheilen, joaj er billigerweife von uts nicht mely forbern faum, ala cine ditrftige Sfizze

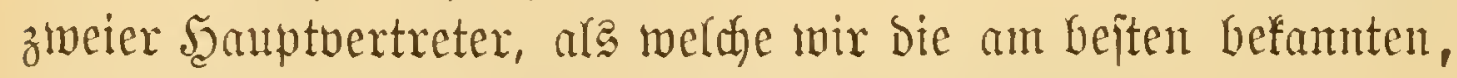

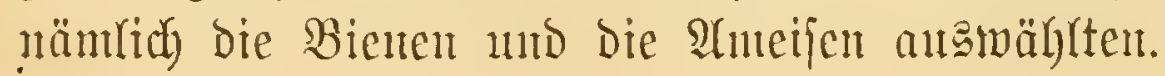

\section{Dex $\mathfrak{B}$ i}

Silt Den fryjtallulauen Fluten Der füblichen Meere, Da haujent mb regen fith Igtere von wahrhaft vermunderfantm

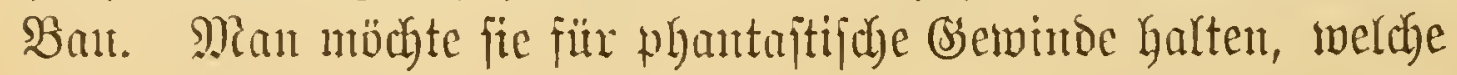


Die Sajaden, unten in ber Tieje, ans ben zartejten, Duftigiten und malerifdeften Meergebilden nit Yeidjter Şanto zujammengefügt und bie fie ban, gleich \angfdumänzigen Guntgläuzenden Drachen, in bie Şöhe jteigen und in bent MEellen flattern und gaudéfu lajien.

Und in Der That find biefe Rettenqualfen feine cin= farben Thiere nach ber gewöhutlichen Sorftellung. Dic biel=

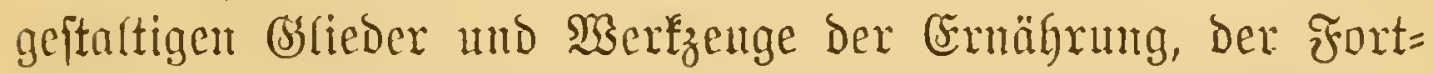
prflanzung, der Bemegung, Des Shubes, Der Bertheidigung unto meldyes bie Drgane zun Betriebe eines mïglidaft biel= jeitigen und energijuen Rebens alle finto, expheinen hier nidjt als an und für fitch mijelbjtündige, Dem gropent Granzen, Dent fif bienen, ftreng untergeoronete, furzun eimberleibte Theile, fondern fie find mo zwar hehufs einer möglichjt

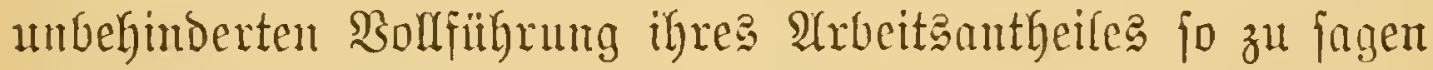

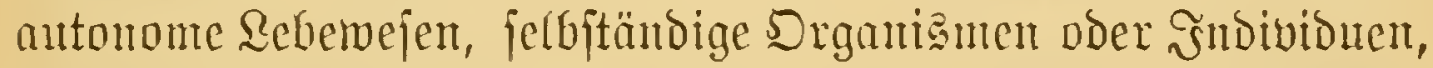

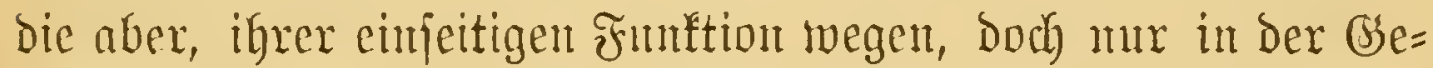
meinjchaft mit Den übrigen bejtehen fömten, und man fönnte

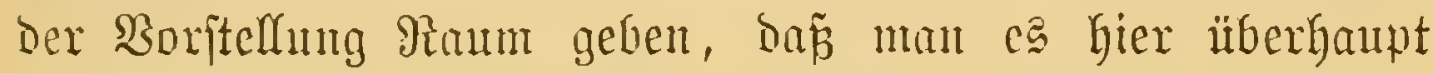
nidyt mit einer indibiouellen Eingeit, jombern ntit einem

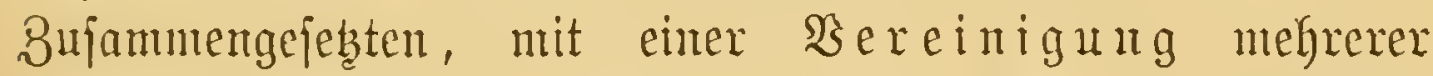
Geterogener Fnoiviouen, furgut mit einem porymorphen Corlectiowejen oder Thierjtoc zu thun habe.

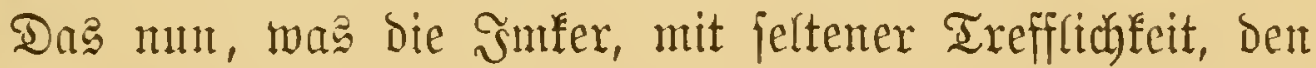
"Bien" heipen, das ijt in mehr als einer Beziehung mit Dem befariebenen Suaflentat, mit Dem Siphonophor ber= mantot. Währetto aber die individuefle Bierbeit bes lestern er entitebt ja aus einem einzigen (ci - unr auf ciner freilid bis auf den benffar äuzerjten Runkt gebrachten Sonderung oder Differenzinung eines intividuelfen Bunzen berugt, indem jeine cinzeluent Theile, die Schminmglodfen, die Miägen, die Fangfäben, die Bentitalien n. \{. f. faft this zum Berfall

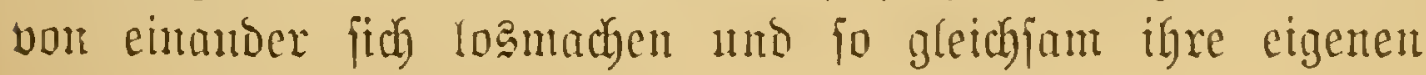


Serren voritellen, ijt hingegent Der Bienorganismus, wie wohl

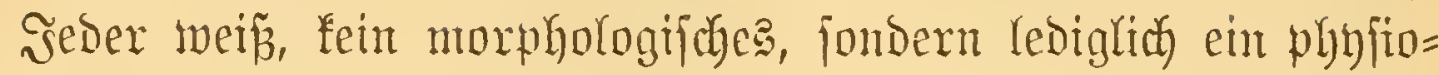
logijiches Bsanzes, gebildet Durch bie ftrenge arjociation einer Reihe veridiedener Sndividualitüten, mit amoen saorten eine ihren fie exzengenoen Dberbante unverbrübdid anthängliche

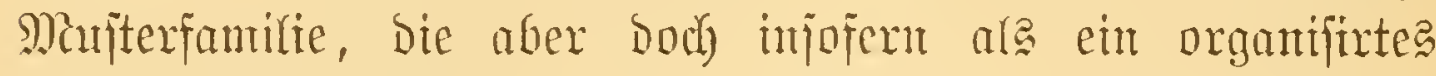
Eintheitfiches exidyeint, are die Strefungen jedes Crinzelnent ebenfogut anf ein gemeimjames Biel, die möglidfite Fördermm

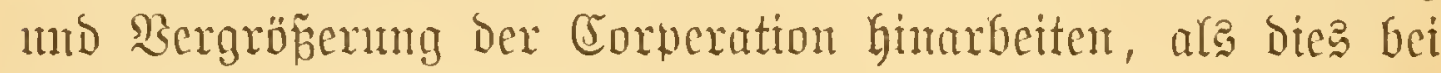
Den Disereten Siphounfforengliebern Der Fall ijt.

Begeben wir un mu gleidy mitten anf ben Schanplabs Der Bienentyätigfeit. Der Bien ijt in erjter Sinte ene Brut=

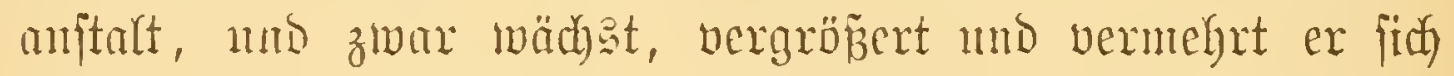
mit ḩirfe oer indibidutelen Fortpflanzung jeines widhtigiten Drgatr: Der Rörigit.

Bon ben exiten warmen Senztagen Eis in bie fobönfte

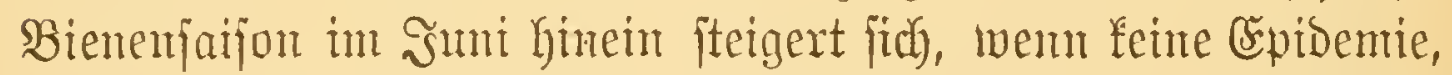

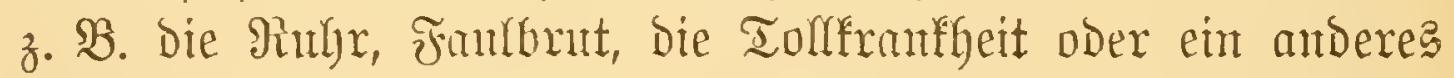

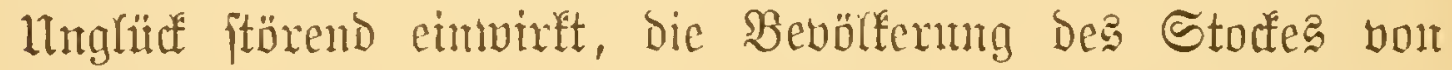

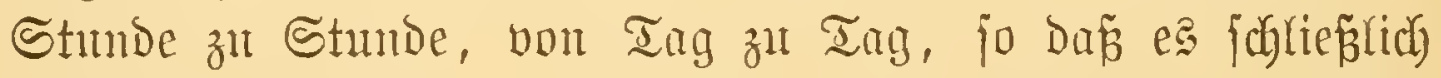

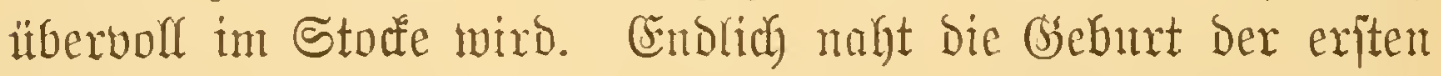

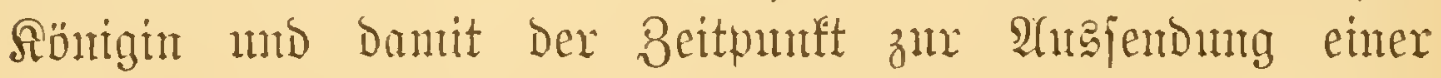
Solonie, zutr Entrajtung Des Mutteritantes. Die Röntgin= Todbter ithernimmt Das Regintent im Lebteren, bie Rönigin= Mutter aber, mit eimer Schar von Getrenen, zicht ans, um

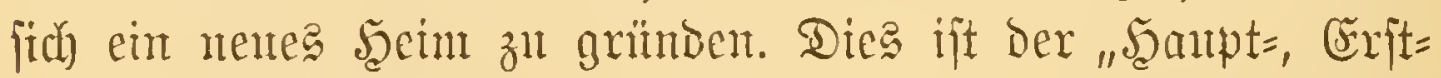
ober ßorjdywarm".

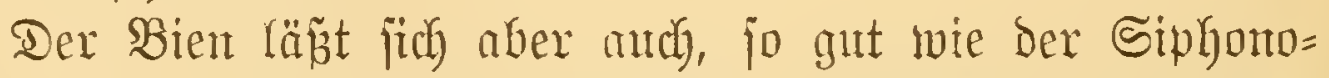

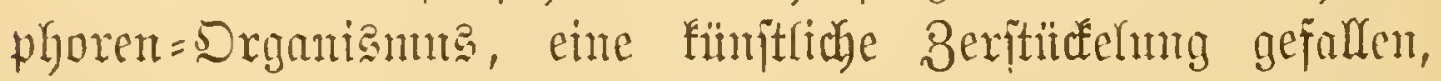
wem man in jeden Iheilitant cine bejondere Regentut einjebt, während andererjeits, wem bei eitem ber häufigen Sriege zmijhen zwei Bientmbölfern eines jeine Şerricherin

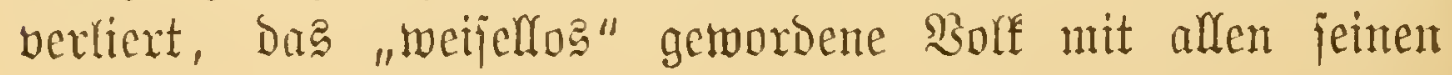




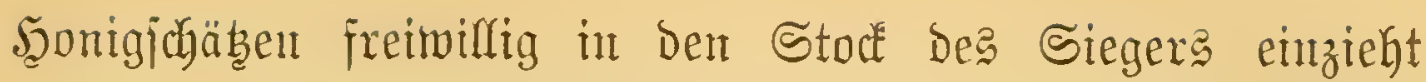

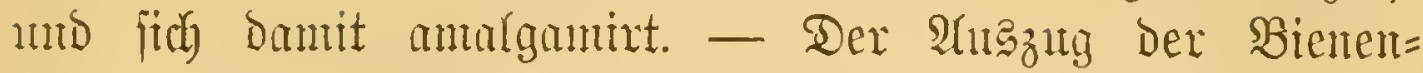

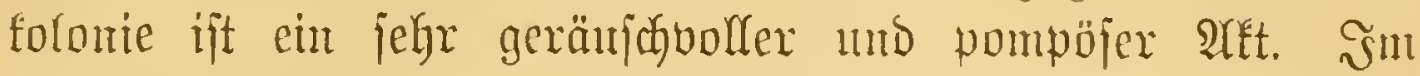
Stocfe herricht eine roilde Alifregung mo in Folge befjer anch einte "unerträgliche" Şibe. Die Temperatur fteigt nämlich vit woul 28 bis alif 30 ja $32^{\circ} \mathrm{R}$, fo Dás die Bienen "ganz in Sahtwein gebabet find".

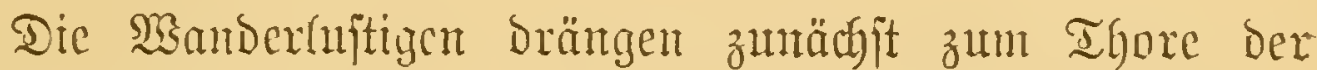
Stadt, zum Frugloch, vor Dem fith barb ein bichter Rlumpen amfanmelt, Der Durch bie zeitweilig heimféfrenden $\mathfrak{A r b e i t e r ,}$

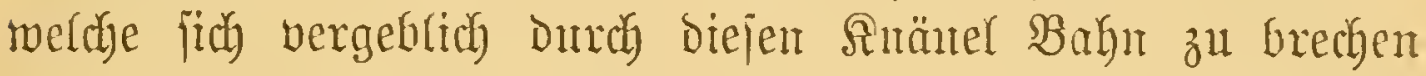
juchen, noch vergröpert wiro. Wem bie Hurulje im smmern

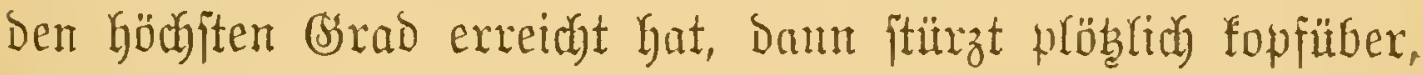
fopfunter, wie ein S⿱: engen Deffunt herauggepres̈t wird, ein Sdutwarn von $10=$ bis 15,000 Bienen, Die Rönigin unter ifnen, herbor, mobei ein weithin hörbares, freubiges Summen, Der Schtwarmgefang, extönt.

Diejer milde Taumel, bieje ungezügelte Frende an Der ex= langten Freibeit und an ber भitŝficht auj einen nenen fröhlichen Berein bauert jedod) mur furze 3cit, oft fanm eine Biertel= ftunde, "Dann fonmt ber Bien wieber zu jitr)" - er fanmert ¡ith), Dic Röntain umbrängend, an einem Saumajt ober an einer

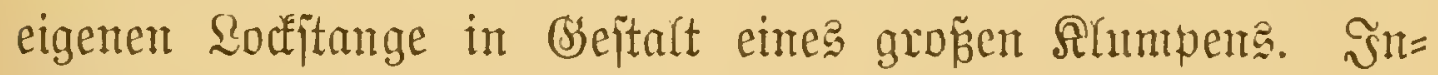
zwijact fint auth bereits anjalten zux Emancipation von ifrem Tyramen, Dem - Menjichen getroffen. Sie rollen fith wieder, wie vor uralter Zeit, ifren jelbittänoigen Şeerd gründent

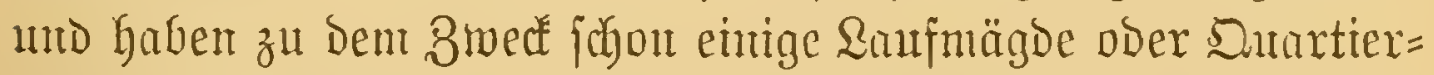
meifter auf Recognoscirung nach einem hoblen Baumftanm,

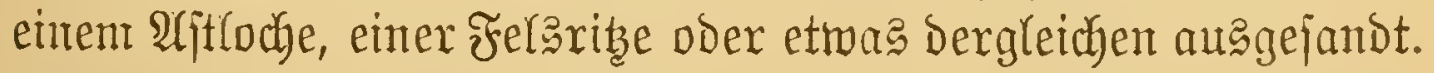
Es ijt abar zu jpät. Bevor bieje noch ßapport exitatten, tritt wieder, um mit C. Bogt zu iprechen, Der Menju mit 


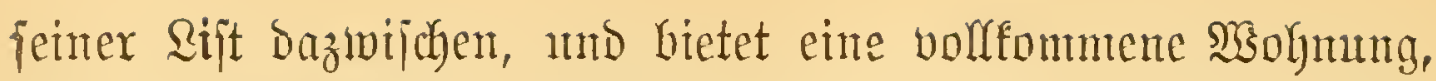

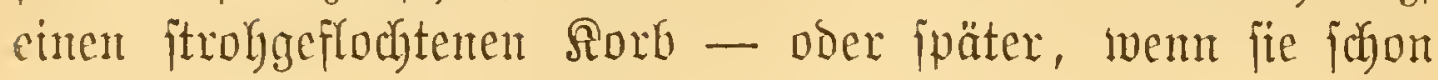
gefangen find, oft gar einen Kleinen Bstagpalajt an, und jo gerathen bie Bienen wiedex in mijere \&eibeigenfyaft. Doib gebent

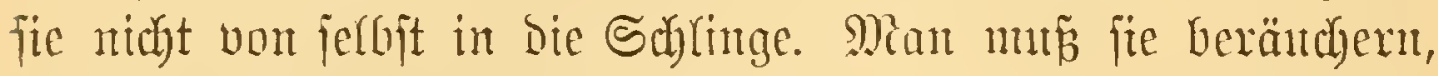

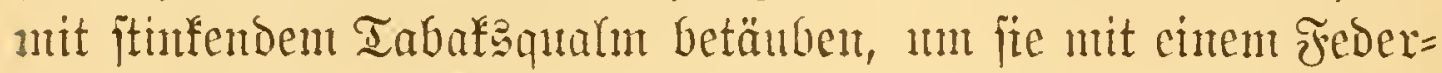
wifich in ben untergebaltenen Rorb zu bringen, oder, went

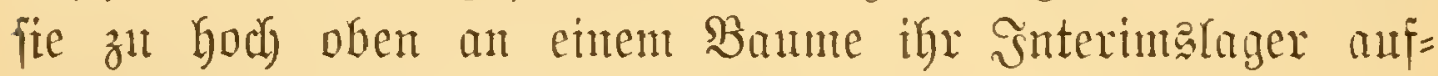

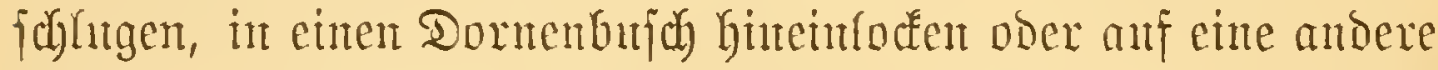

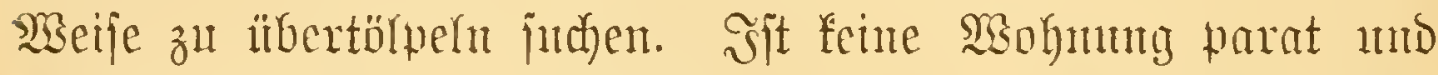
madyen fie Miene, Das şeite ju juthen, jo fühlt man einjt= weilen igr Miütgdyen Durdy Befprengen mit Majper. - Dod

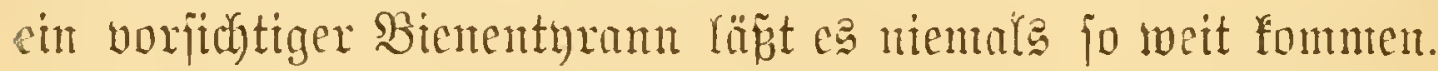

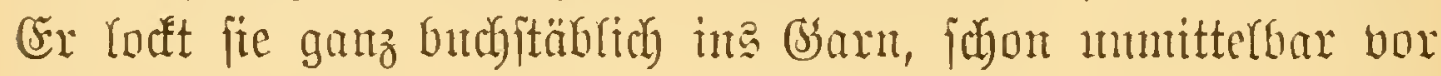
Dem Mutterforbe. - Dic Şmfer verjtehen aber noch ganz andere Rürifte. (Fin itarfer Bienemitat jujicft nach Dent

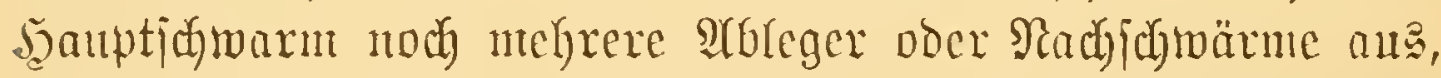
Die, went fie cingeln ju fichwady find, in einen gröperen ver= einigt oder wie's im Sinferlatein heint, copulirt werden. Daju fund mehrere Mietgoden erfonnest worden. Die einfachite ift, zwei Stöcfe mit ihren Mündungen berart über eintander zu regen, Dañ bie, jo zu fagen auf ben Sopf gejtellten, Bienten bes untern fich in ben oberen hinanf zieben. Dabei ift's freilich gut, eine Der beiben Rönginnent frither einzufangen, 3. $\mathfrak{B}$. "mit cinem Biterglas angufdyöpfen", Da die Bienen

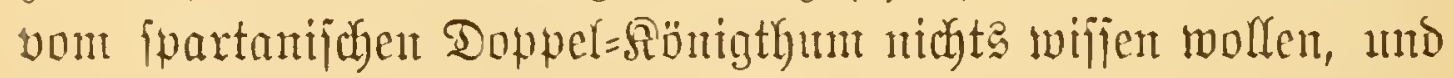

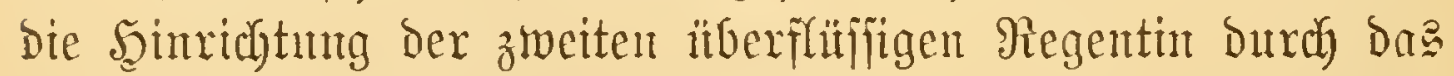

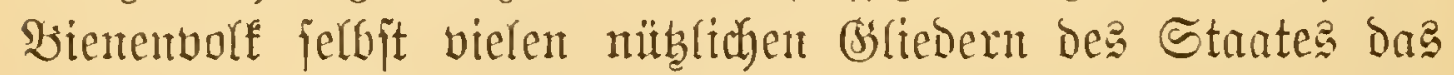
Reben fojtet. 8 u ber fibon won ben Sriechen geübten, aber

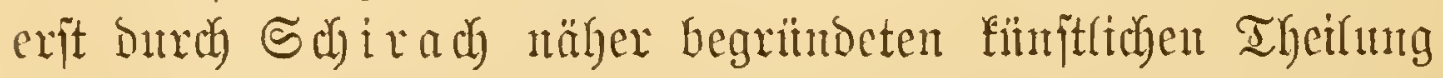
ober Sdyärmebildung eines Biententodes ijt übrigens die Bsegenwart mehrever Süniginnen nidut nubedingt erforberfich. Mian Guandyt bloź, sun eine cinzige Methode zut erwälynen, 
einen Strohjtod mit einter Drahtfaite entzwei zu jodneiden, fo

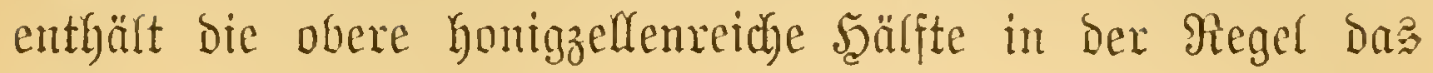

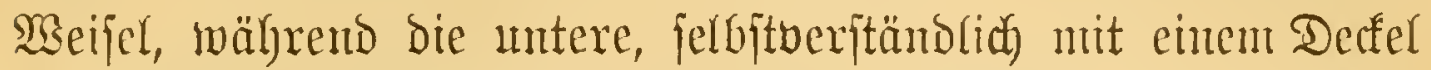
zu verjekenbe vorniegend Brutzelfen beherbergt, aus benen, wenn die Bienen gut gefüttert weroen, auj bem fodou int

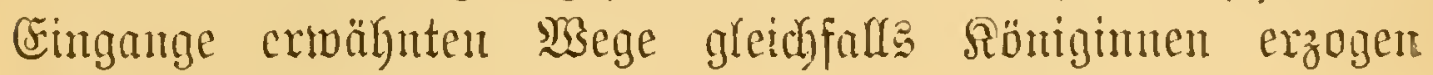
werdeı fömen.

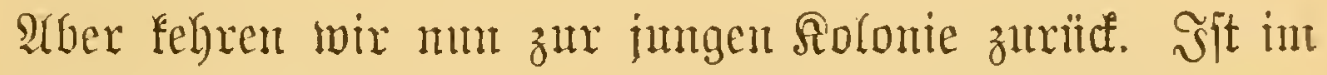
Storfe alles in Dronung, D. h. ift bie Sönigin mit eingefangen,

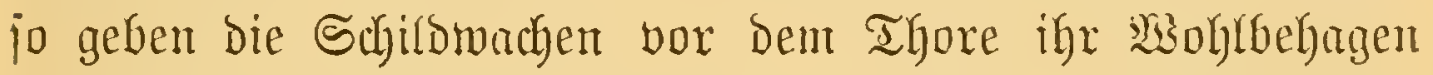
Durch aller(ei pofitriche Bervegungen, bas jog. "Rräịentiren" oder "Sterzer" fumb. Bismeilen merden aber die Eni= granten bon Secimweh ergriffen und febren mieber in Den. Niutteritant zurïá, was Dant zut eimem heftigen Bürger= friege fülyrt.

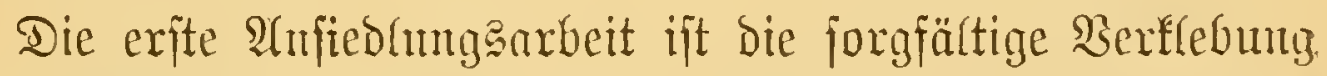

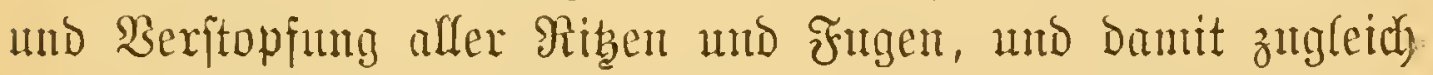
Die abfolute Berfinfterung Des Stocfes. Dies gejobieht mit ben jog. Stopfrache, Propolis, bas fie unttelitt ihrer Siefer von ben.

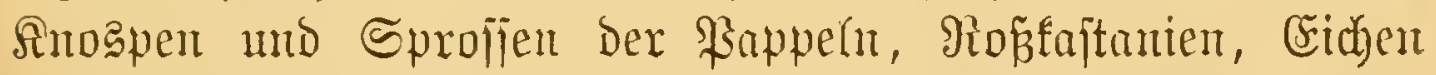
u. j. m. abtraben. Der Bientenjtant jaheint näm(ich mtr im

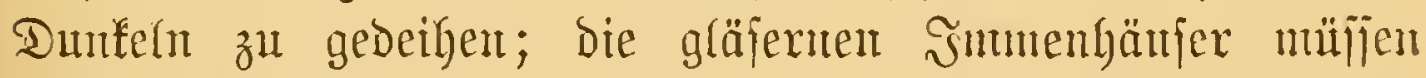
Daber mit Schiebern berfehen fein, fouft werkfeben jie bis Ssiastafeln. Zmingt man fie, beim Ribht zu arbeiten uns ifre

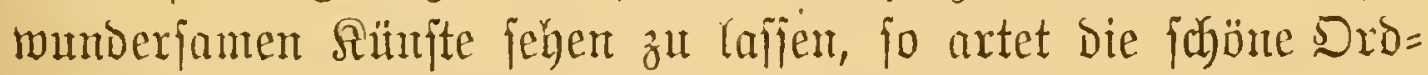
mung Der Dinge bald in Die mildejte Unarchie aus. Wie bie? fommt? Die Afeinftanten ber Polistes lieben Das Somnenlidyt,

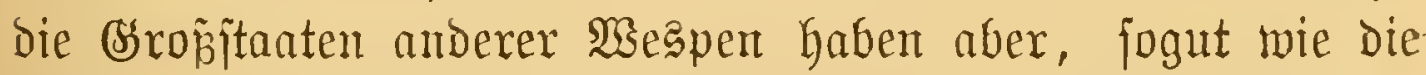
Bienen, ihre $\mathfrak{s a b e n}$ dem Ridyt entzogen, ia befanntfich mit einer oft mehrfachen Ringmauer ungeben. Sie mollen Danit

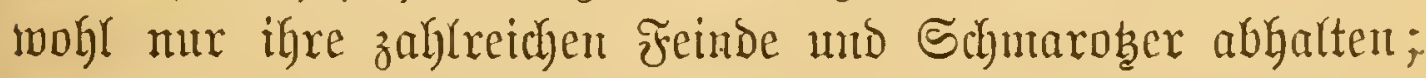
dem mux fo begreifen wir, weshalb gewifje Weapen ihre 
ohmeden gut befryirmte Burg zu nod) grö̈perer Sidferbeit in bie Erbe bautr. -

Fiir die Bienen fonmt aber eis anberer unitund in

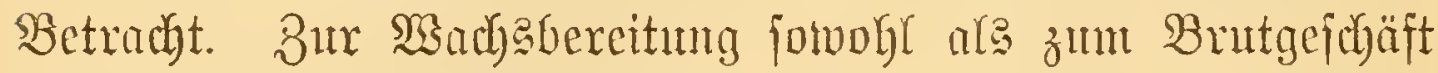

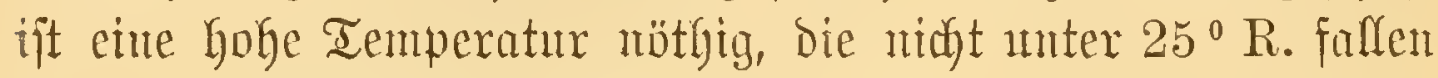
Darf, un bereu Erzeugutu eiue arljeitige her= metijue atofperung des arbeitarames exfordert. Das erwähnte Stopfmady oder bienentarz, wegen femes

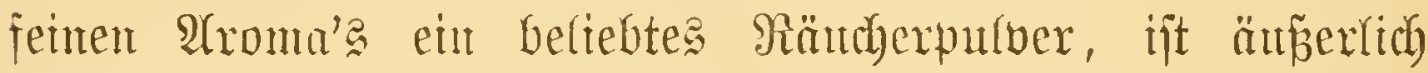

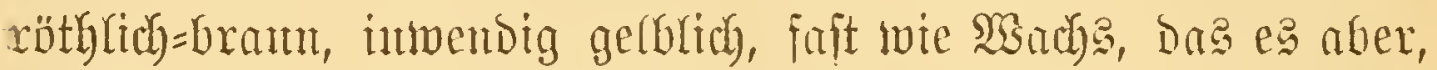

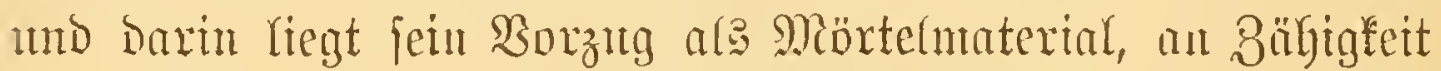

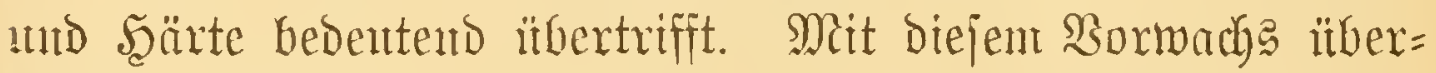

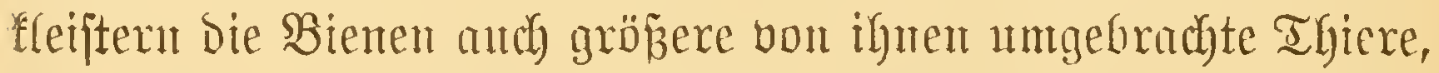

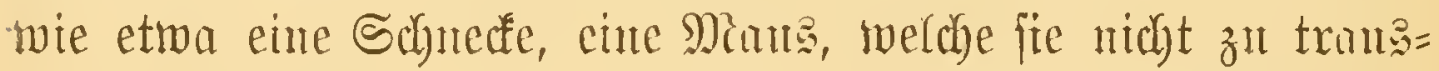
portiren vermögen, $n$ m fid bor Dem Bermejungsomite zu foüben.

Rach Diefen Borbereitungen beyinut die Sauptarbeit, Dte bäushiche jowohl, der Bellban, als die anf dem Felde, Das Sammelgeidäat. Die Feldarbeit ift Die Grundage des

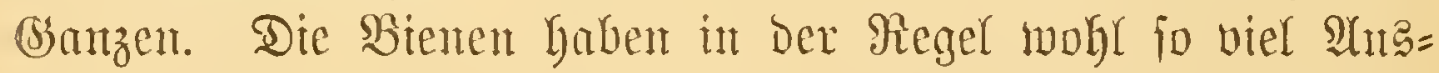

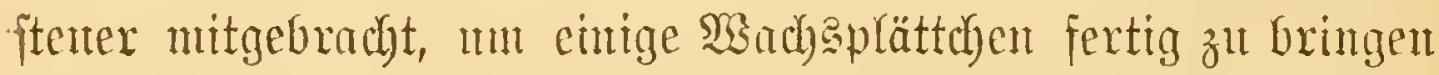
und Deu Srumb zux exften Mabe zu Yegen, falls man ihnen nidjt einige fertige Sitchen in ben Stock gibt; - bies ift aber

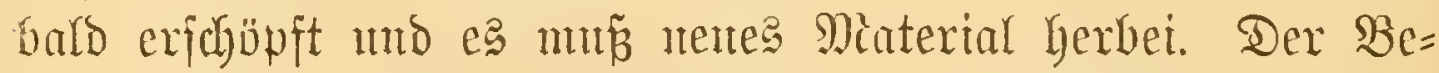
Dorf ift ein riefiger. Fürs erjte ijt begreiflidjermeife jebe Qrbeitshiene, Die von früh bis ipät alle ihre Aräfte anfpannt, unb befonders bie R̈̈nigin, Der Collectibbegriff Des ganzent Sorfes, cine fturfe Ejijerin. Dam berfdrlingt Der Wabenban

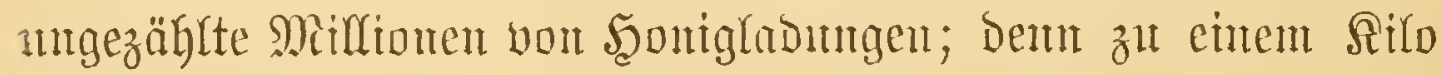

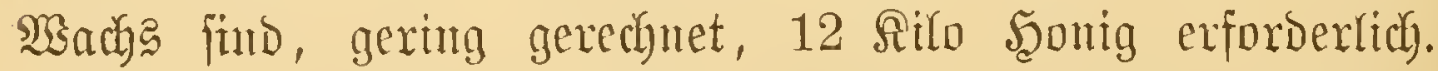

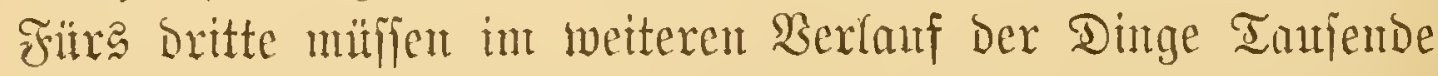

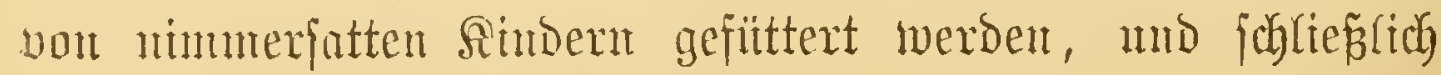


foll alth eint Errfectfiches für bie Beiten ber Noth utro für Dent MSinter evïbrigent.

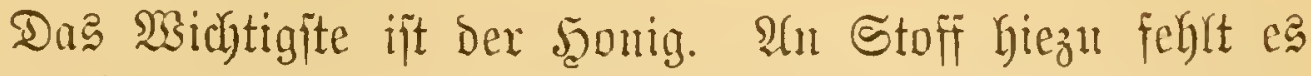

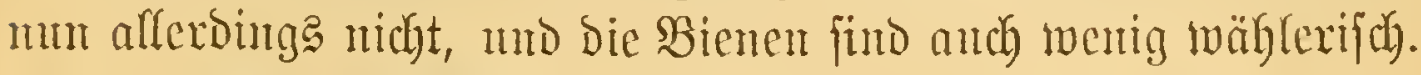

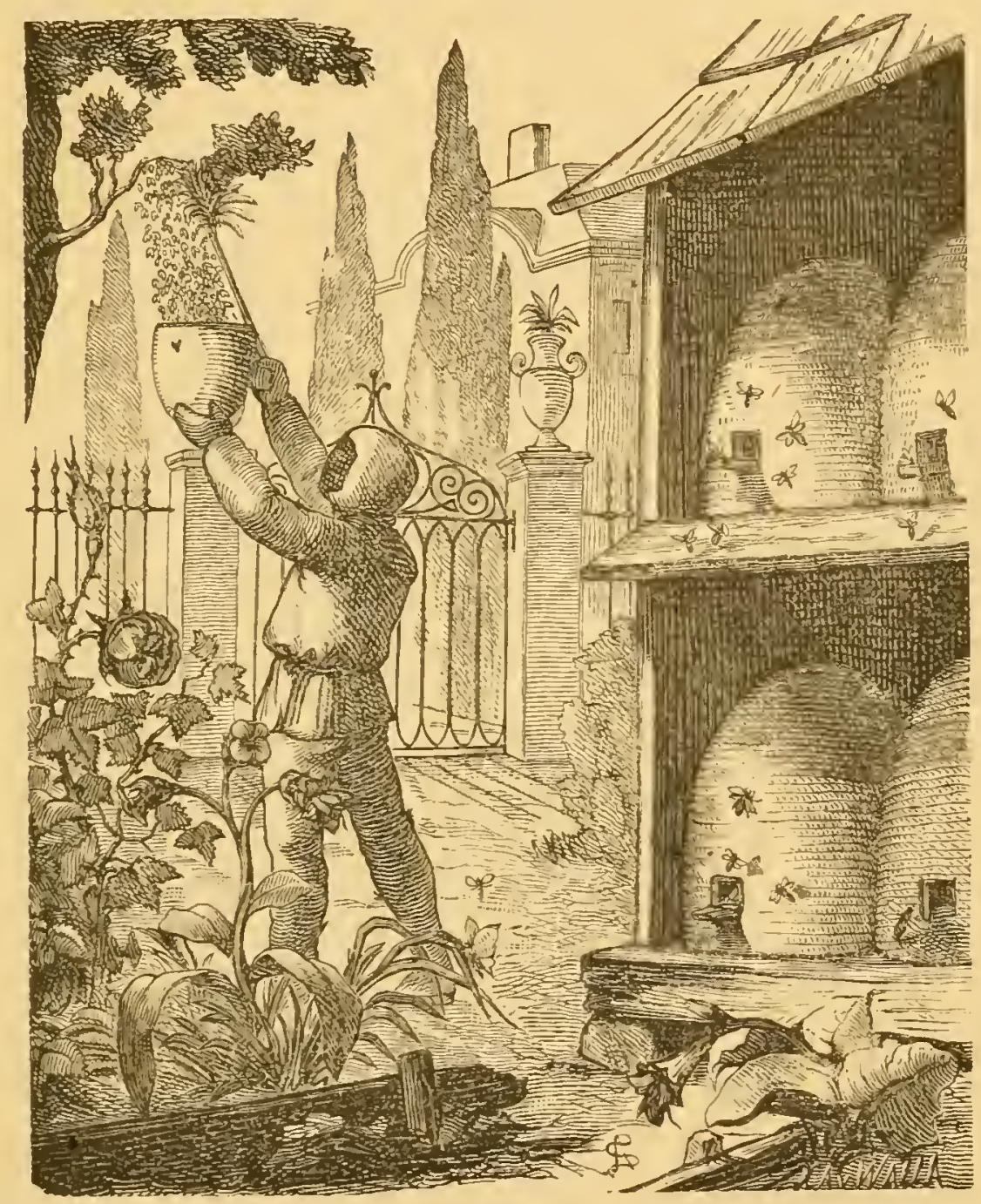

Fig. 86.

Finfangen eines Bienenfidnarmes.

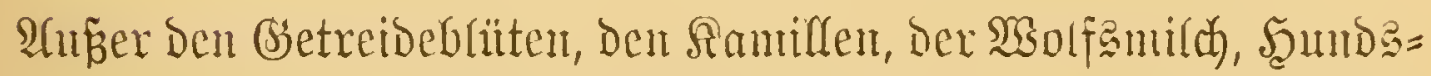
bume, Dem Wermuth, Der Siç̧wurz und einigen anderen, beren Şonig fie nidyt außfteben fömen, haben fie Tamjende ber=

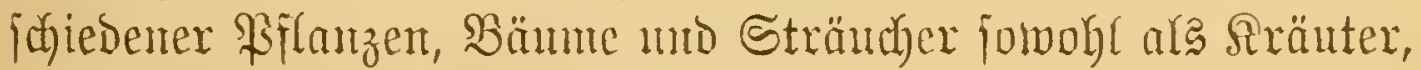
auf ifrem Sammelzettel. Dodi wixd alles genau portixt ein= 


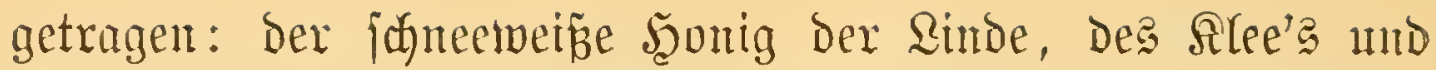
Altgentrojtes, Der bräunliche Der Setidefüle, Der goldgelbe

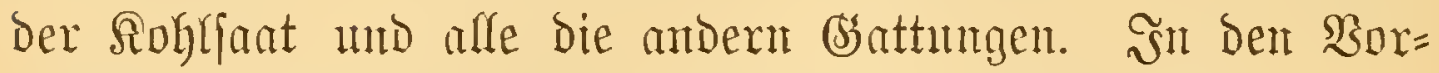
ratheszelfen dagegen fommt alles wieber burdyeinander.

Die Bienen nefmen aber aud antore Sinpigigfeiten. Der

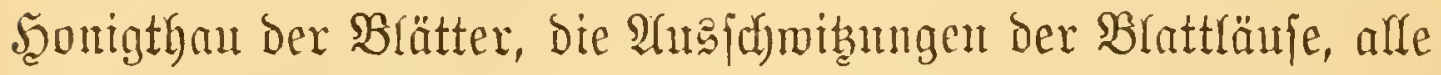

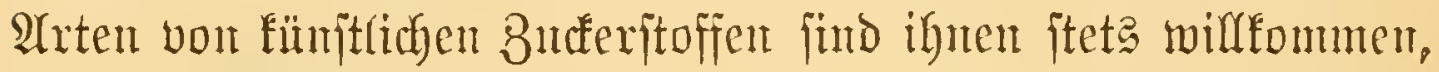

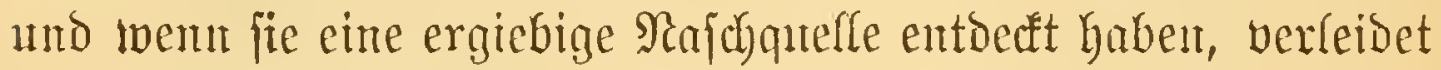

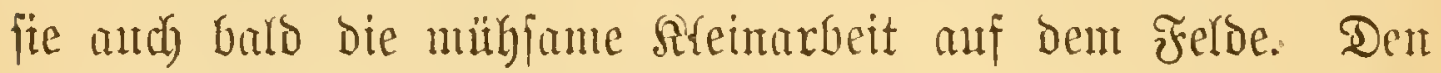

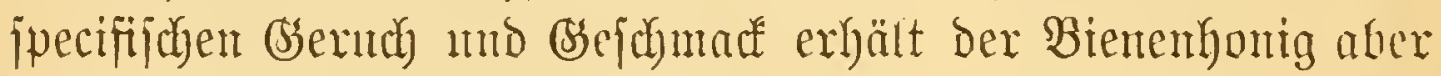
erft durch die Biene jelbjt, o. h. Durdh die Beimengutgent des Speichels und Magenfaftes. Sind Die Sentigtöpfe voll, jo

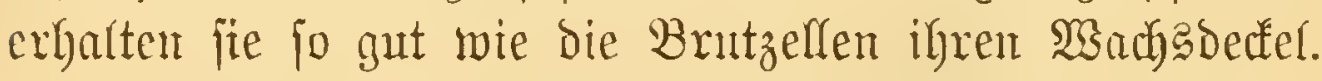

Bon einem Sohlenhydrat allein, wie eben ber Şonig ein fordes ift, fönnten indé bie Bienen unmöglich Yeben, fie

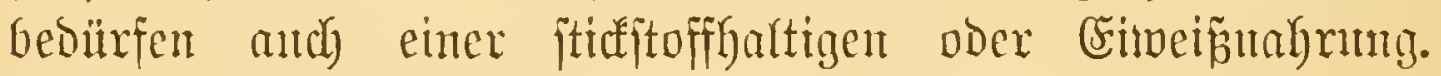
Dieje, alfo bas wahrbaftige Bienentrob, liejert mun bar

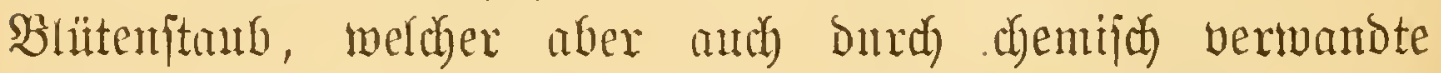

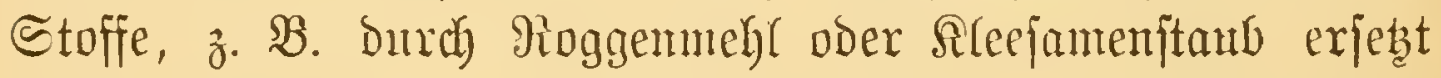

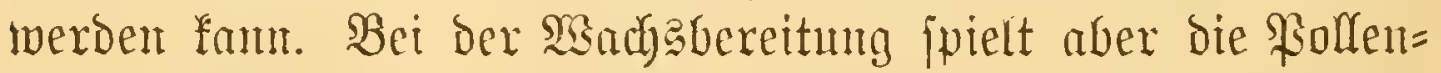
nahrung gar Keite oder unr eine geringe indirefte Rolle.

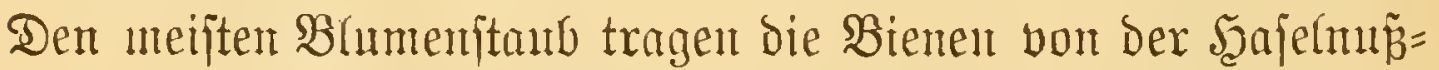
itaude und ber Sanlweide heim, jonft fint noch befonders die

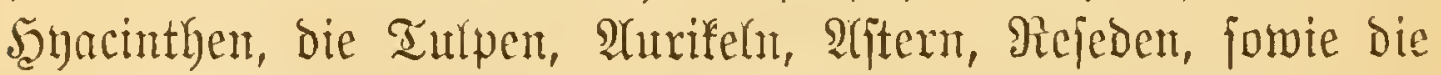
Siappeln ergiebig. Aud hier wird. jedesunal nutr cinerlei ge= fanmelt; in ben Brobfanmern aber fommen bie verjohieden=

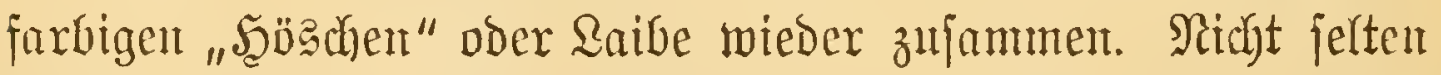
wird eine und biefelbe Belfe zur einen Şälfte mit Pollen, zux andern mit Sconig gefüfll, wie benn überhanpt eine über= reidye Ernte oder Der Mantgel an Befechirr zu mantherlei Alı słunftamitteln führt.

Während bie "Schnitterinnen" auf Dem Felde fleipig funt,

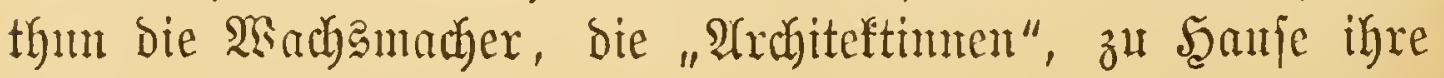


Schurbigfeit. 2ange hat ntan geglaubt, e马 wären bię zmei ganz verichiedene Rajten. Die Arbeitabiente ift aber alles in allem. Nur in gemiffer Ridjtutg findet eine Theilung Der Bejouäte itatt. Die jungen, b. h. Die eben erbrüteten Bienen nüjien nämlid mindeitents 18 Iage Das Şaus Güten, während meldyer

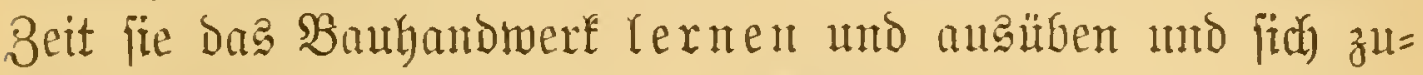
gleich) fïr bie, wie es idjeint, heiffichere Feld= ober Eammel= urbeit vorbereiten. Dies murbe burch (Einfeben einer Brut= tofel italienifjer Bienen in einen beutichen Stod conftatirt.

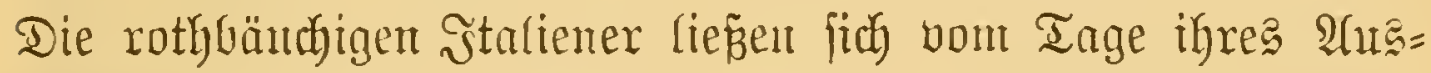
judiutpfens an exjt nad) 20 Tagen auperhalf bes Stodés jefent.

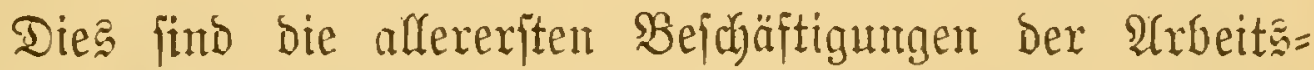

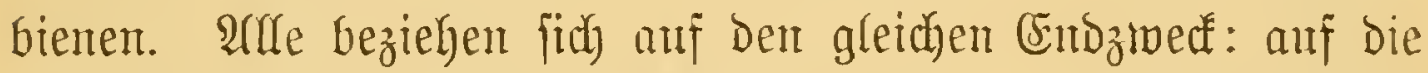

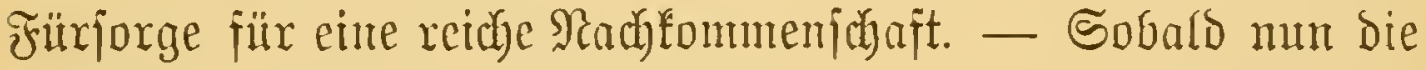
nöthigen Brutzellen vorbereitet füro, fdhreitet aud Die Siöntigin=

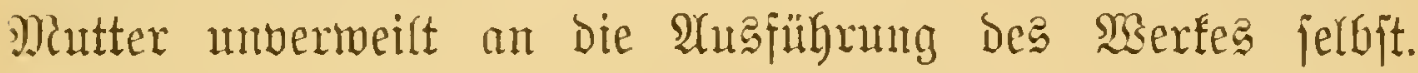
Sange Zeit Gindurd werden mur Arbeitereier gelegt; Dem biejer Stanto bildet ja Das Fumbament der ganzen Géefll= juaft, mb bie anfreibentoe Thätigfeit der Samutelbienent

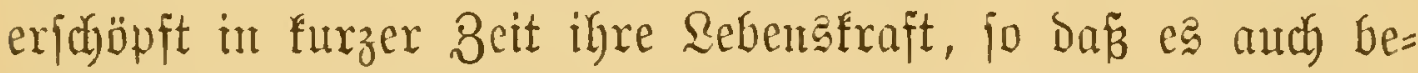

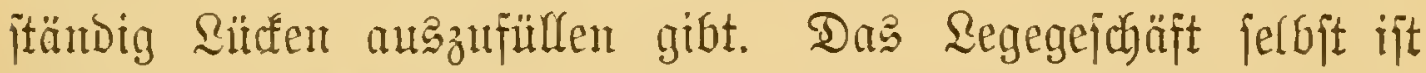
einfacd); mun läp̃t e? aber von allerlei Durch bie Begleiterimen Der Rönigin anfgeführte Myfterien ungeben jein, bie ja über=

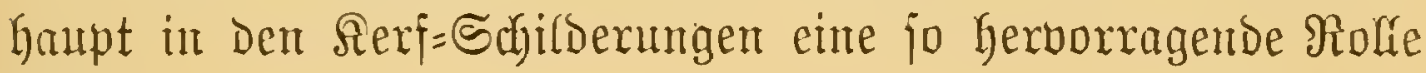
ipielen.

Buterit unterjudyt Die Rönigin Die Befdraffenheit Dex Brut= zelfen mit bent Ropf. Sjt allez in Sronung, D. h. ift bie Belle leer und gehörig geglättet, jo jtenunt jie jich nut bent

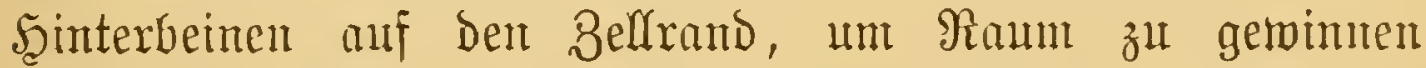

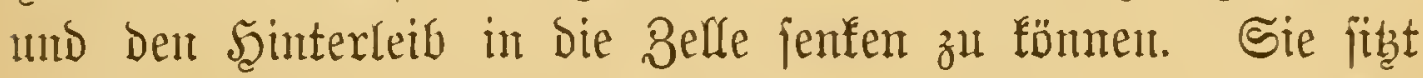
mun förmlidy, "fajt wie eine Şenne in Nejt", in ber Belle, mit bem Sberleib heranggufento und mit Den ausgeipreiztent (5) raber, Jniften. II. Bb. 


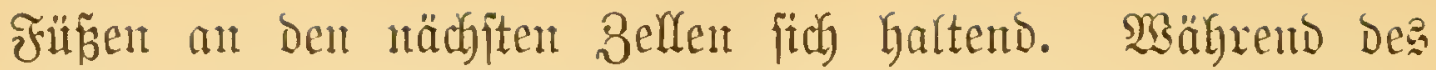
Regens wird jie allerbings von den Arbeiterinnen, Den "Şebanmen" Gebient, D. h. gejitttert, ob aber and gelect't,

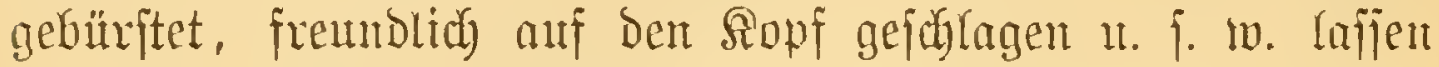
wix bahin geftellt. - Sie legt nidyt blof in gantz vollentote,

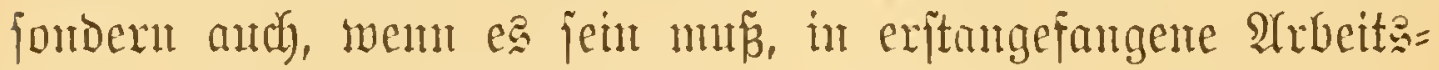
zellen. Bei Den Weijelwiegen veritegt jith Rebzteres von felbit, Denn in bie fertigen fiönigglogen woilroe jie ja nit

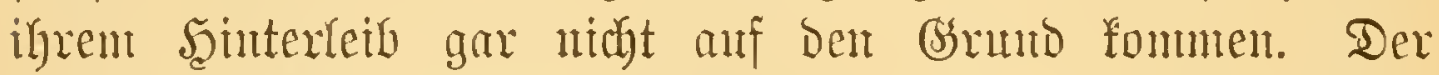
ganze Regeaft Danert bei 9 Sefunden; fie joll aber von Beit ou Beit etwas panfiren. Bismeilen hat fie es aher fo eifig, Duj mehrere Eier in eine Belle mo manche auth auf ben Boden fulfen, wo fte dant von don Martfranten aufgelejen

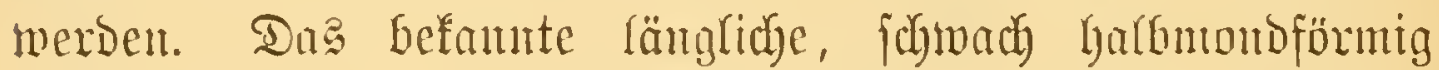
gebogene und vou einer klebrigen Sdyidht umgebene Bienenei mird mit jemem abgenlatteten seinterpole añ bom Boden ber Belle fejt geleimt. Jnben es aber reift, jenfte? jich allmälig anz jeiner anfredjten Stelluma gegen ben Bobdu uno nady ber an vierten Iage erfolgemben Berjtming Der

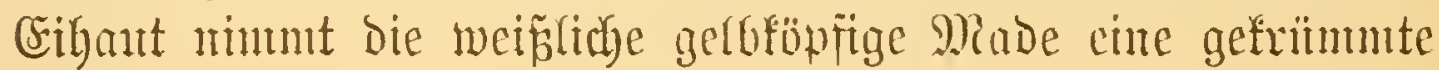
Rage eint.

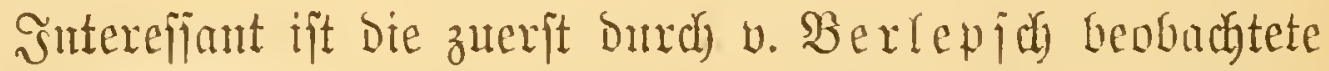
Burferbemegung Dex jungen Maden. Sie mudyen ungefähx in żwei Stumben cinen ภreizlauf.

Wie jhon gejagt, legt die Sinutigin lange Beit hindurch

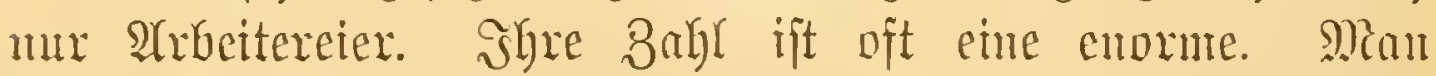

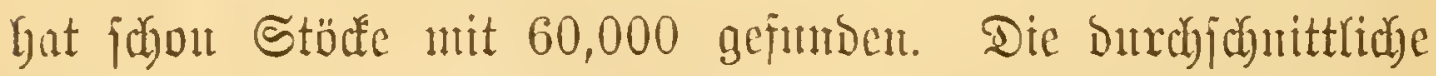

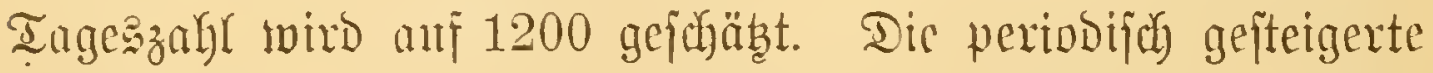

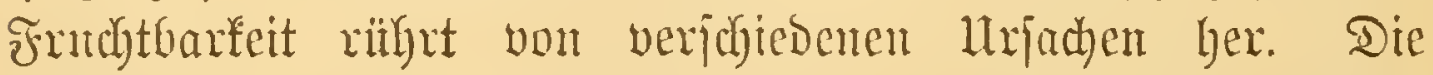

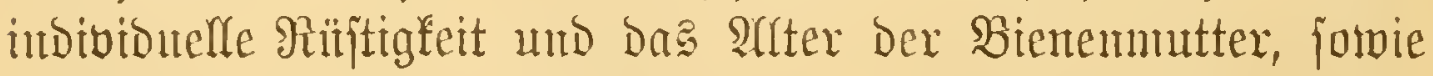

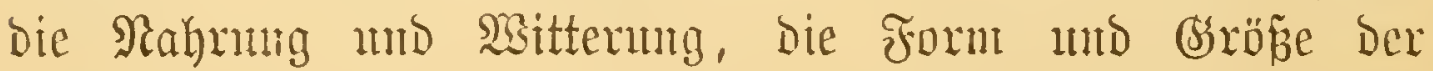

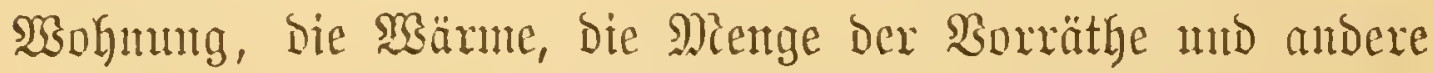

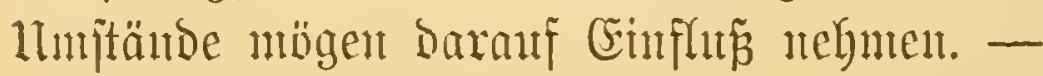


Errit wem das $\mathfrak{B}$ olf gehörig ftarf ift, ment Dex Bien ber Fortpflauzug iu weiteren, ftatriden Sinne fich) nägert, exjt bann exjcheinen auth bie zwei anderen

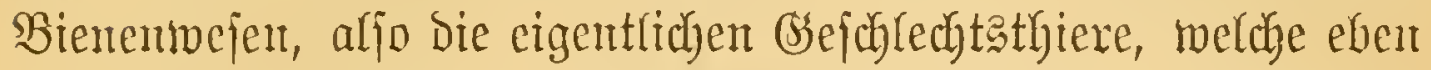

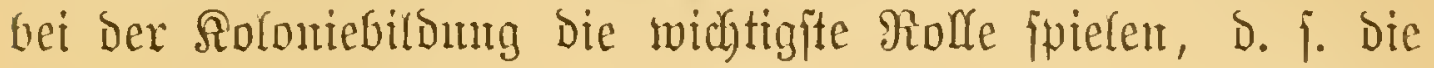
Drohnem mb Rönigimen, anf Dem Schamlab. 3uerft bie

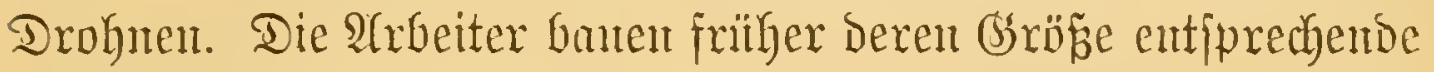
unfangreidyere Bellen, weldhe Daut vou ber R̈ungin belegt werben. Die grof́en flajchenförmigen Weijetwiegen ljingegen,

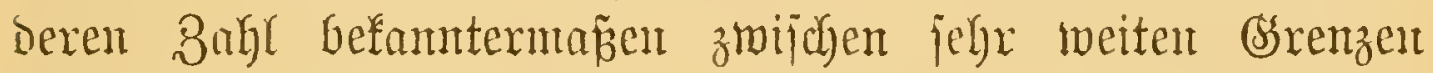
(3 und 20) jobwanft, aber in Iffgemeinen Der Stärfe bes

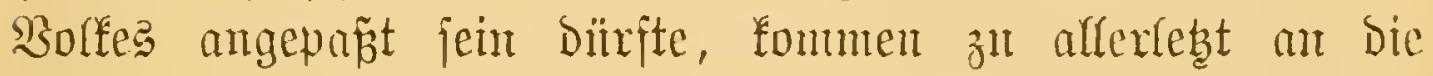

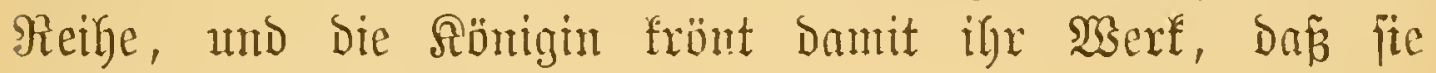
in jede ein (si abjegt.

Num mïfijent wix aber, ch' wir auf bie meiteren Ereignifje im Bienenftodfe cingeben, Dex Ernährung ber Drei Bienen= wejen und Deren Brut unjere Aufnerffamfeit midmen. Die Urbeiterin exmäbrt fidy in Der Regel jelbjt ntm ztwar mit ben

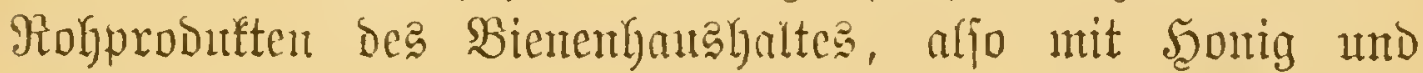
Sollen, ans Denen ber jog. Epeifejaft bereitet wird, eine

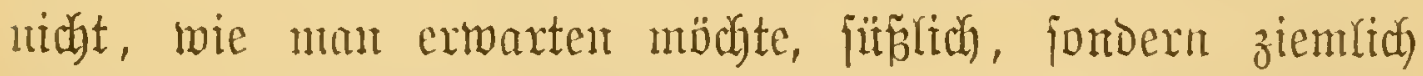

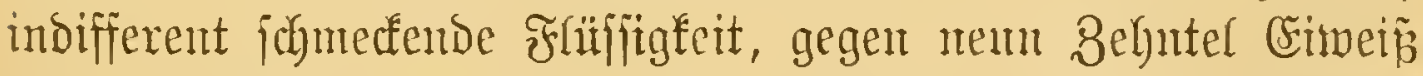
und Fajerifofi enthaltent. Die Rionigin und bie Drobnen Dagegen werden bon Den Grbeitern geäbt und zwar mit

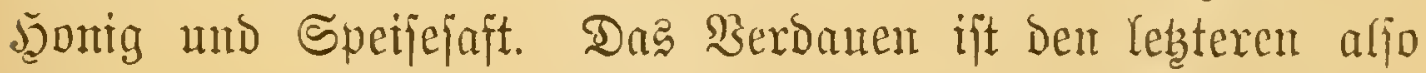

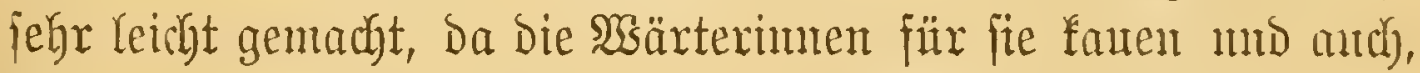
swent wir jo fagen bürfen, vor=verdauen und ihnen $b a s$ (5r= brochente eingeben. WSas mu bie Brut betrifft, jo befommt bieje währent ber erften zwei, Drei Tage bie gleiche Rojt, nämlich

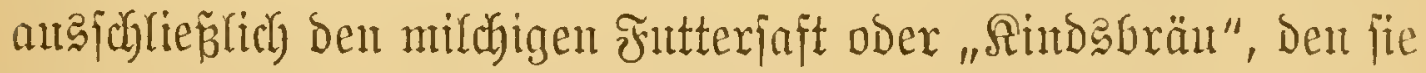

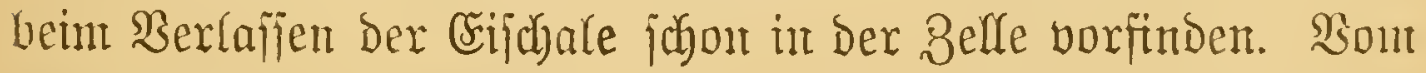
oritten Tage an ändert fitrd aber bie Sache infoferne, als bie

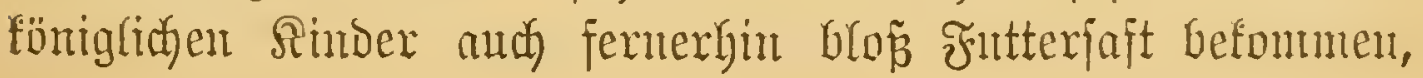




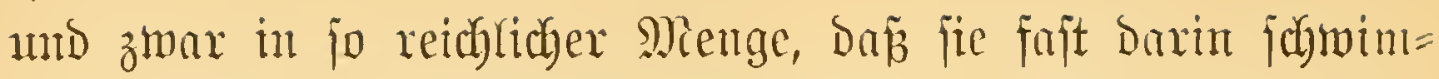
men, während bie Drohnen= mb AYGeitermaden biefer feinen

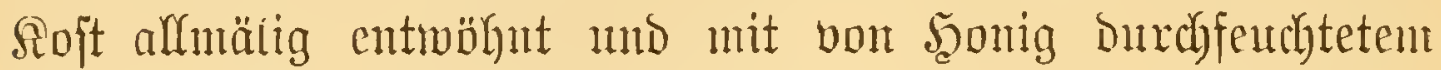
Brod ernährt werden, das je jelber verarbeiten müfjen, jo

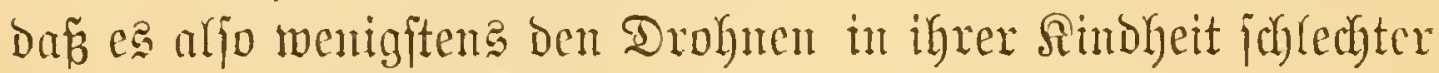
geht, als in reifen âtter, wo fie gleichfarls föniglich bebient werden; trobsoem wird wentg Uturaty ergengt - zu Defien Entleernng ïbrigens auch Die - Deffum fehlt. Dieje Brut=

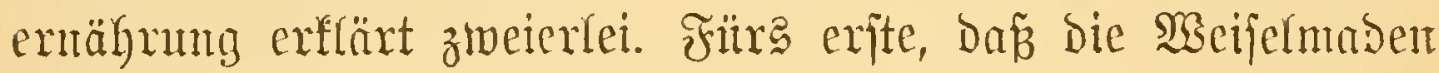
bei ihrer reidylichen und nahrhaften Soft jedon nach 17 Iagen 'ntrwickelt f̈nd, während die Drohsten 21 mb die Arheiter gar 24 ober gelegentlidy nod) mehr Tage Grandyen. Fürs ztweite aber, Dá̃ ang Den Maden Der MEeijerwiegen, die in Den eriten Tagen von ben Sirbeitermaden abjolut

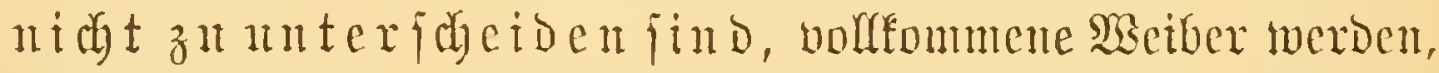

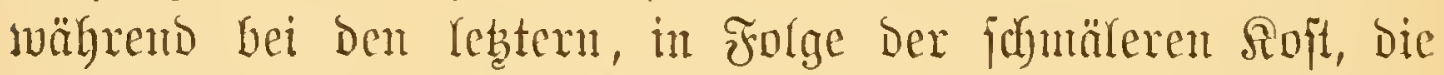

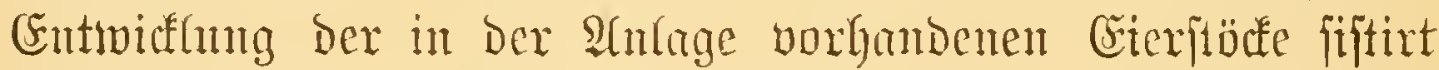
wirb. Die Richtigfeit Des Sisfagten jeigt am beften bas

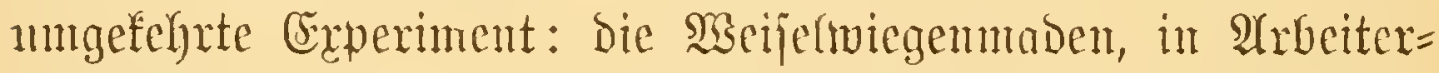
zelfen verjebt mD mit einfachem $\mathfrak{U}$ rbeiterbrod ermährt, werden Arbeiter, bie Arbeiterzellemmoden aber, in Den erjten Tagen

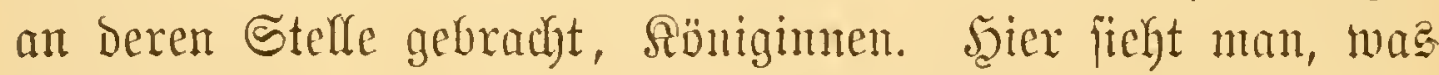

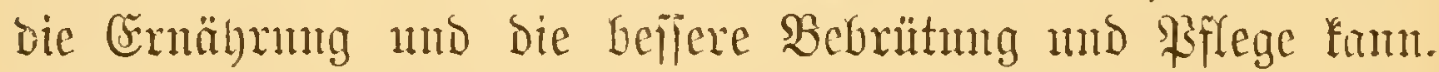

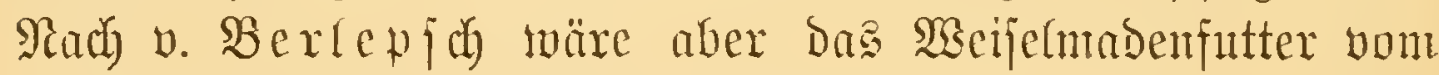
ordinären Futterjaft etwas verjajieden.

Dic Birmemaden wachjen jebr fandell. Sard 5 bis 6 Iagen füllen jie fochon die ganze Belle aus. Şits fo weit mit ihnen, Dan fpimen fie, gleidh) andern 5̧autflüglem,

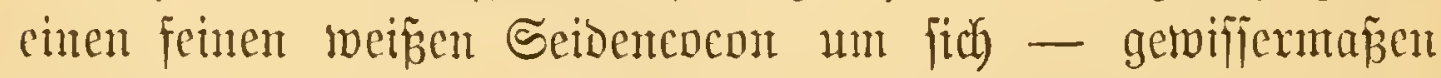

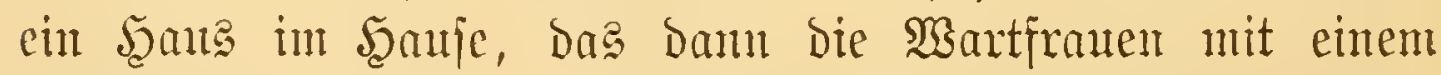

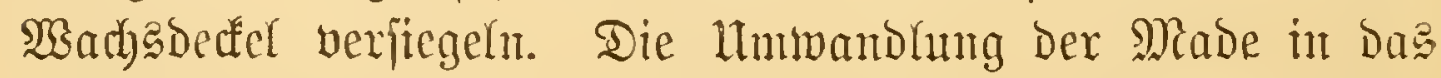

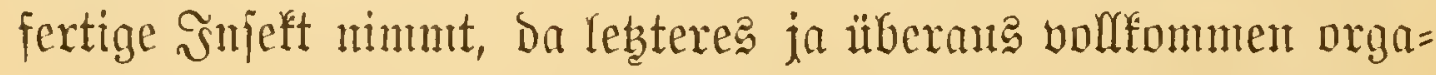

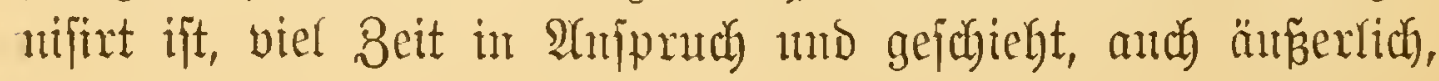


gantz allntältig, D. h. Die jog. Nanmphe behält nicht immer Die gleiche Bseitalt, wie etwa cine Falterpuppe, jondern gegt,

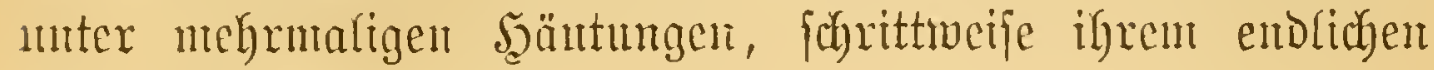
Bicl entgegen.

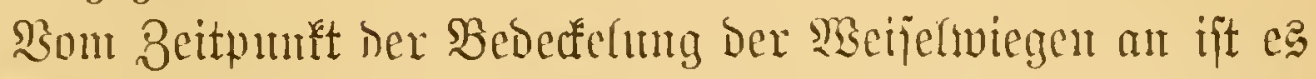

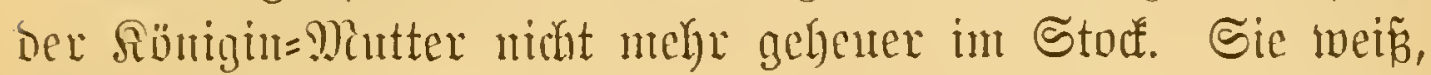

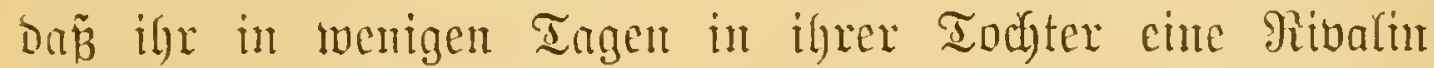

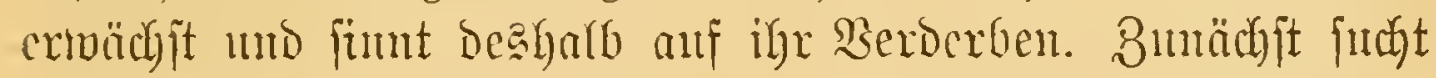

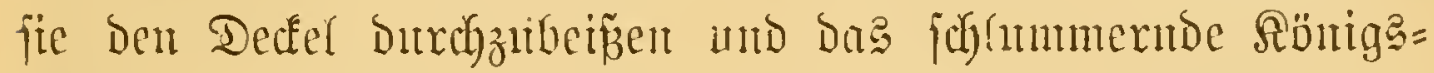
find zu erooldyen. Da zeigt fid uber zum erftemnte bie

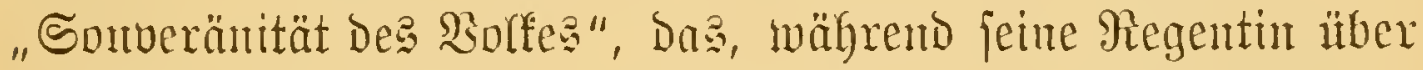

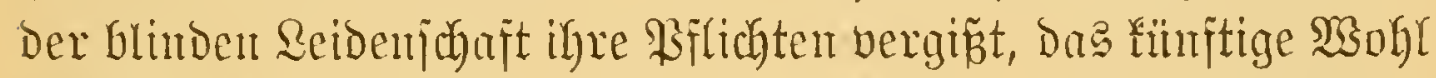

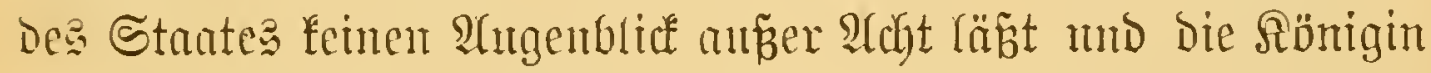

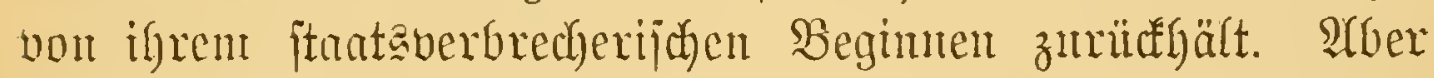
Dieje Dulbet's nidyt länger mehr an ber alten Stätte, und da fie jich nicht bermfen füblt, abjutounfen ober bie Seerrichaft

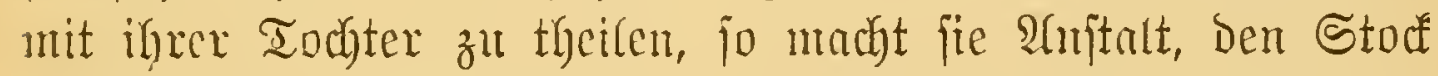

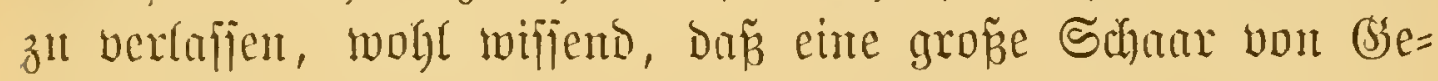

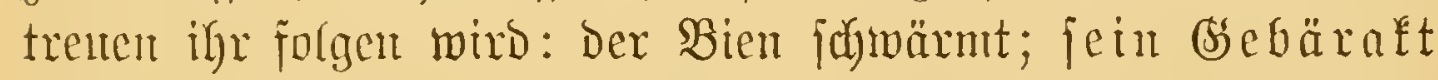
i it volfzogen. Und wälremb der junge Stant fith nell

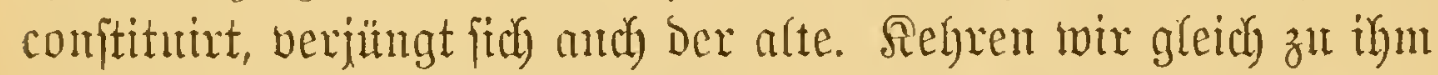

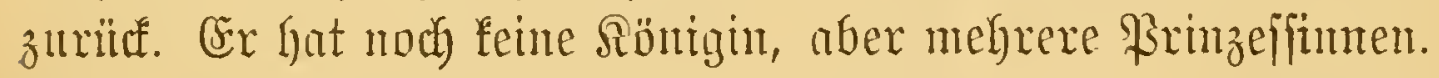

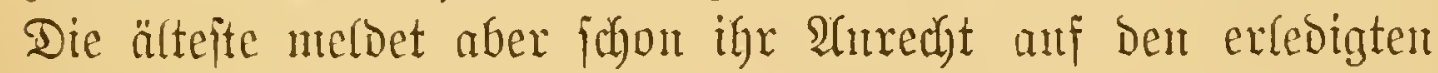
Tyron an, freilidy auf edbt. bientenmäbige MSeife. Son Zeit zu

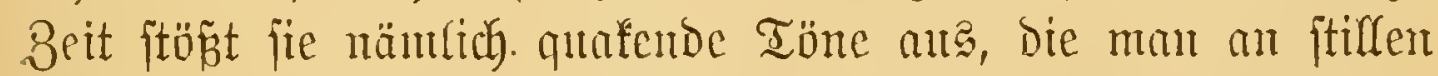

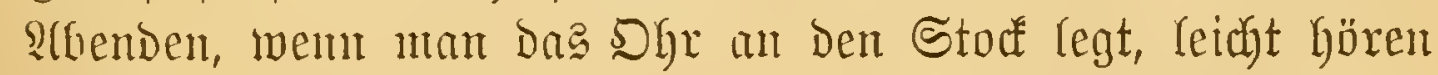

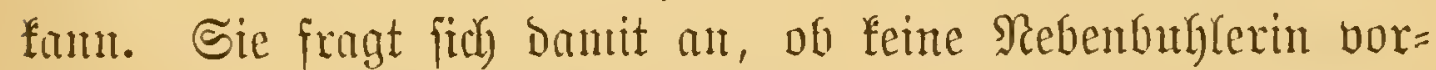
handen ijt. Errbält jie feine Antwort, fo öffnet fie Daz Sieged

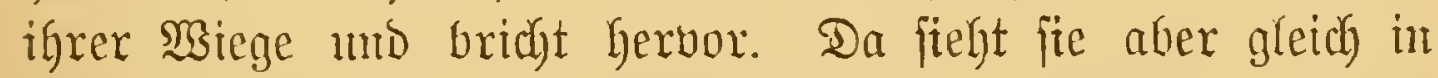
ifrer nädbften Ulmgebung bie anbern Rogen, weldye ibre jüngern

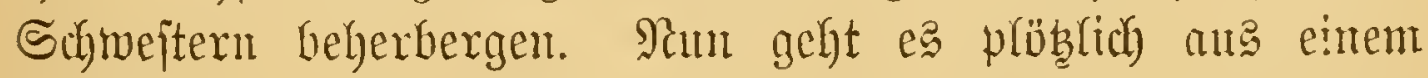
andern Tout: fie fängt lant "tüht, tüht" zu rufen an,

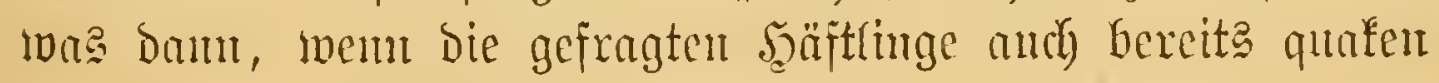


fömen, ein recht ftimmungsoolles Frage = und $\mathfrak{A}$ (ntmortipiel

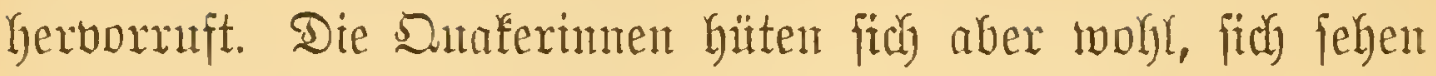
ju laffen, uto werden, went bie Söntgin fie attaquiren will, vom ßonfe in Edjut genomment. Sobard aber bie junge Regentin an Dem ftärferen Sunfen Die barbige Reife einer Schwejter erfennt, madyt jie es ganz ifrer Montter nadb,

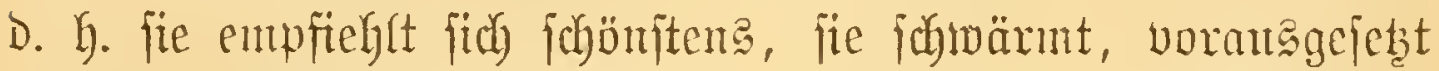

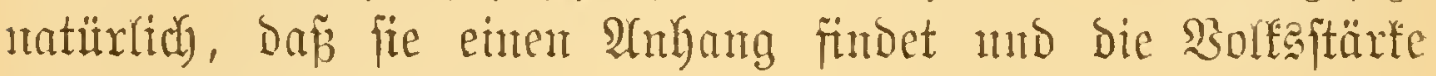
Dies verträgt. Sift lebtere felyr grofi, jo miederlyolt fich ber

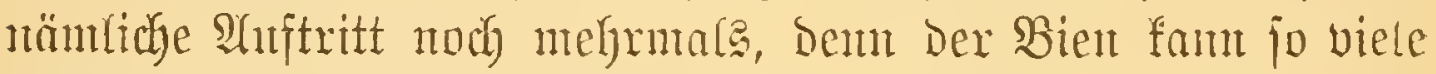
Sclytuärme entfenden, ale Röniginnen cubrïtet werben.

Sit aber eimnal Das Sabuämen cingeitellt und fino noch melgrere Thron= Pirätenoentimen borfanton, bann werocu

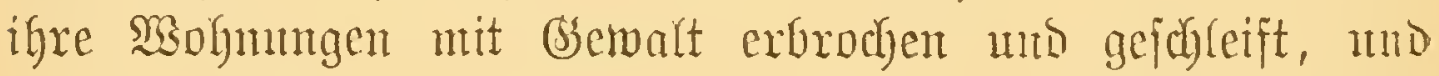

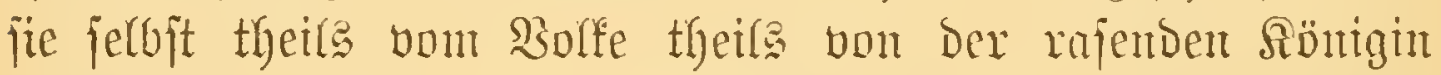

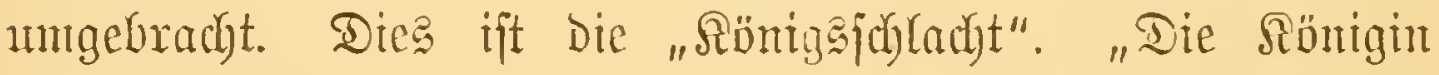
aber herricht jest unumiduräulft, und basjelbe Solf, weldyes fanm und feinen abjoch vor bem Werbrechen fumb that,

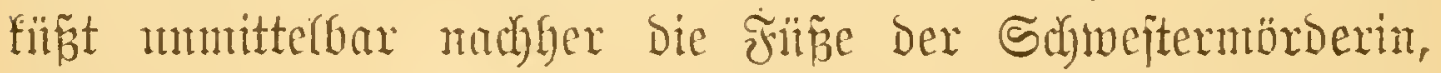
füttert ïe aus Dem cigenen Mintroe mito elyt und liebt

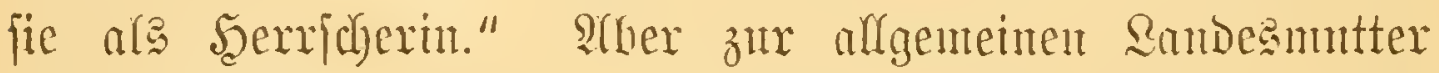

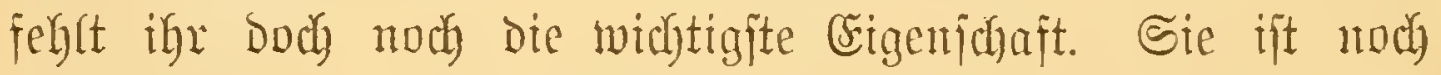

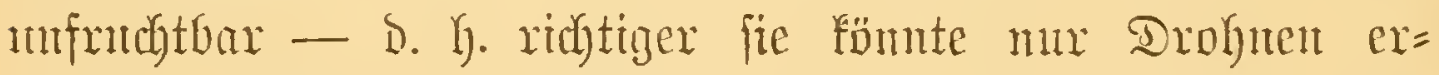
zentgen. Dos ift, jo möbten twir fajt jagen, bie Jronie Des

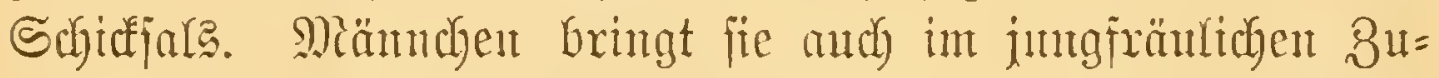

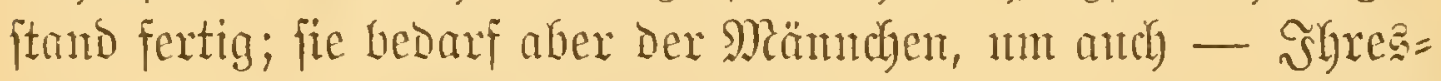
gleidyen, D.'i. SYrbeiter mo Rönigimen zut machen. Die

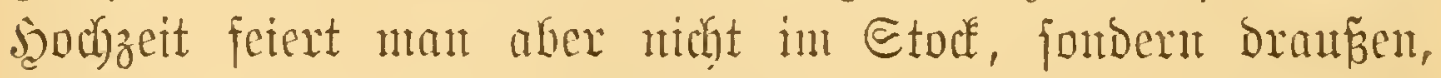

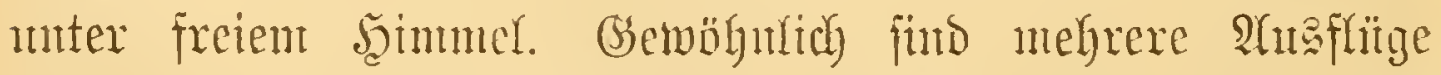

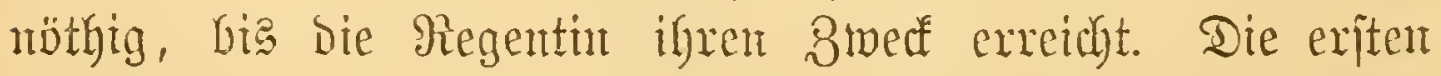
bienen melyr zur eigenen Srientirung, Denn ihr ijt ja bie $\mathfrak{M e l t}$

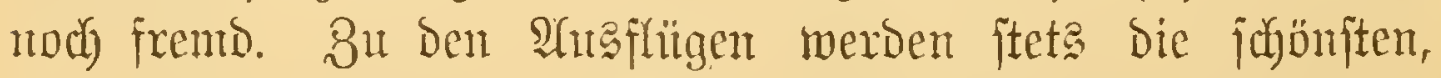

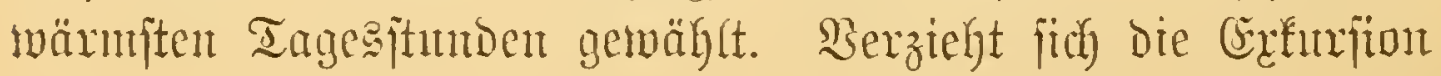




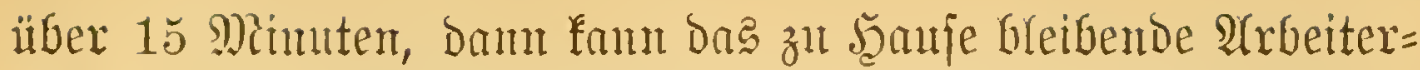
volf anf Die glïffliche \&öjung jeiner wichtigiten Exiftenzirage

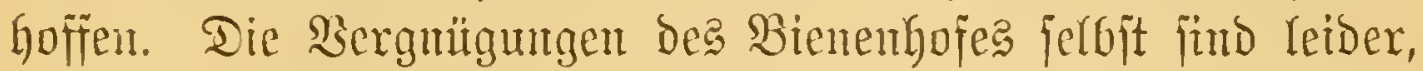
weil zu weit unjerem Schanlab entritet, in ein mourch)= Sringliches Dumfel gegüllt. Sofort nady erfolgter Befrudutung zielgt bie Röntigin in Den Stocf ein, wo mu bie alfgemeine Fuldigung exfolgt. Die Drofnen bagegen fegren zum Theil in jehr befeftem, viele in ganz flïgelfahmen 3ujtand heim wo jie aber bald ale weiter völliy umilbe Sślierer bes Strates erfant und aud befandelt werden, und diez offentbar anf Bejehl, ober boch unter Beiftummung Der Siönigin; Denn in meijellojen Stöcfen muterbleibt bieje Drohnemjal ad t.

Mit Diejen Glutigen Sifte Der Selbjtbilfe wollen boir

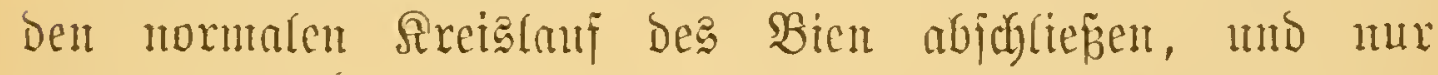

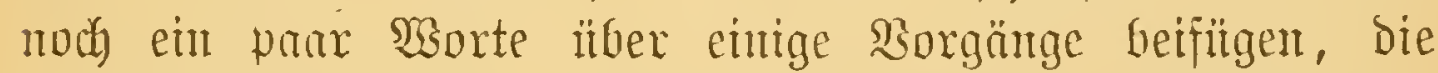
Dex itationären Regel, Der gewölnulichen Rebensjchablone ber

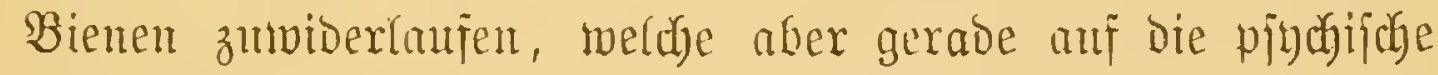

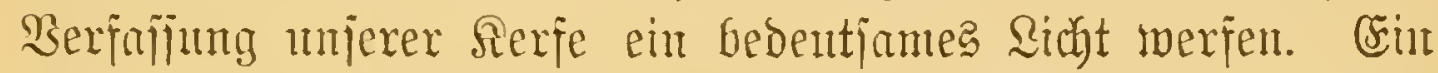
jolcher aufperordentlicher Fall ift unter anderm Der SBerfujt

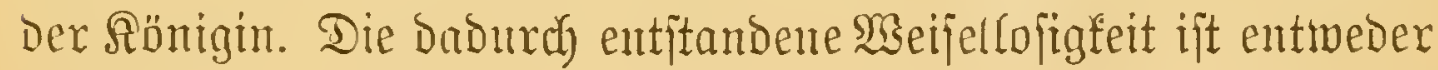

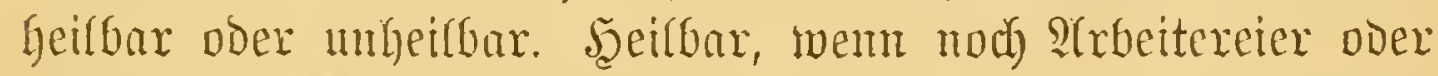
ganz junge 2trbeitermaden vorfandon find. Fn biejem Fall werben bie betreffende Belle und bie Nachbarzellen nieber= geriffen und ringa un bie nen zu junaffende gegentin eine

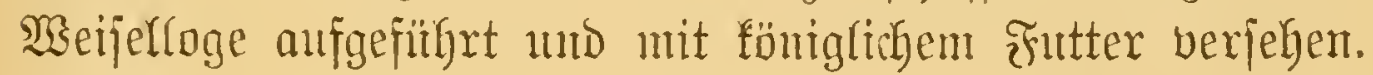

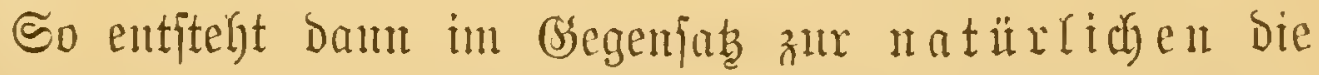

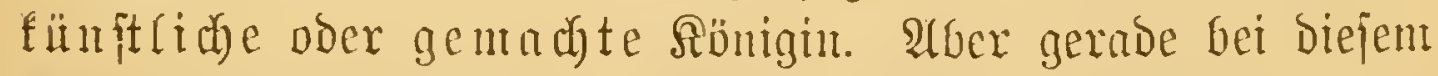

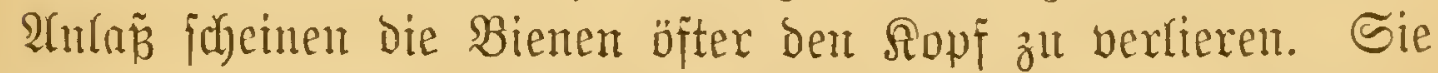
wollent nämlich öfter bas gleiche Experiment aild nit Drohnen=

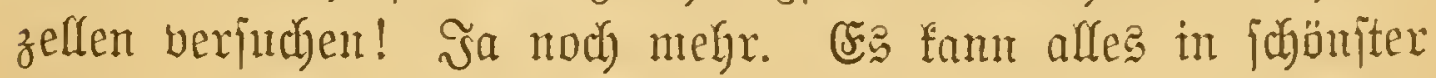
Dromutg iein, fie haben ihre hoffmungevolfe Meijelbrut, fütteru ife aber mit - troduen Brod, jo baj 


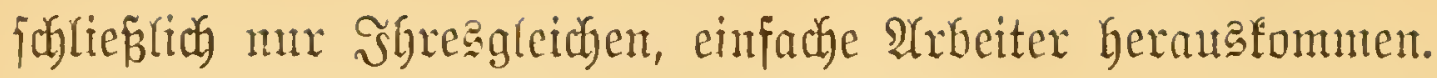
- Dodi Dies alfes find mur Aleinigfeiten gegenitber Dem Folgenden. Die von Der Brantfahrt zurüdffommende Siönigin wirb biameifen am Ff(nglock umzingelt und "abgeftodben"! Und rismeilent findet eine joldye Menterei antid int Stode itatt, wenn Die Röntigin, leere Bellen für ifre Eter fuchend,

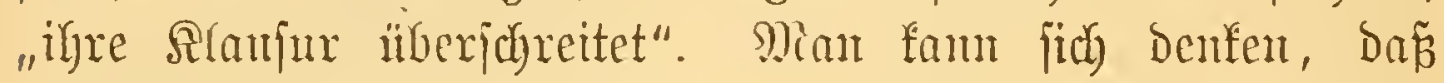

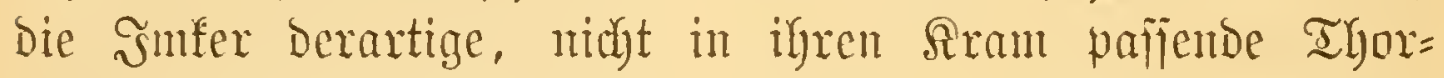

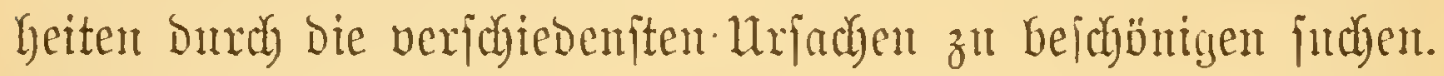

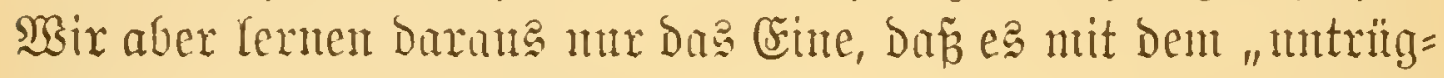
lichen Snjtinft" eine jullimme Sache jei, Dafis bie Bienen Durdh

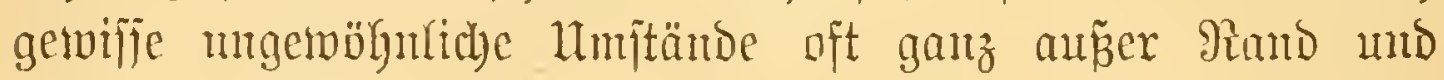
Band gerathen, furzum da b die Stantaraijon ber

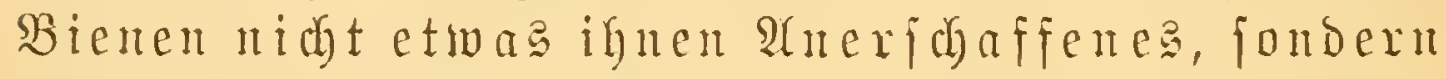

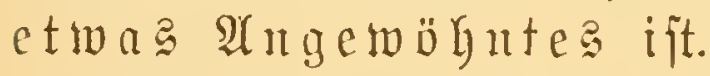

Und wer, fragen wir am Edylnije noch, wer itelft besn manthe Bienemmaden, wie man bies bäntifg beobadbtet, anf

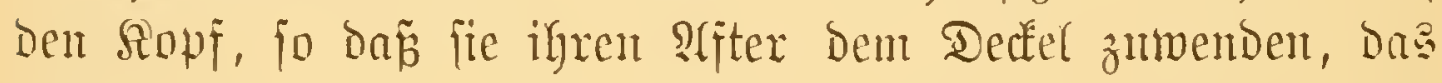
Siegel nidbt löjen uno elendiglid) untfonmen miijien; Dod nidyt ba? "Untherwniste"?

\section{$\mathfrak{A}$ me i jen jtaten.}

Die Ameijen füb-Die Soryphäen, Die "Primaten" der

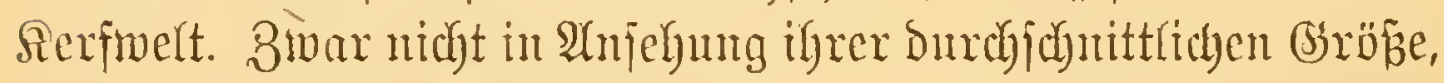
Denn bieje ift eljer flein zu nemten, and nidyt bezüglid) Der whyjifchen Begabung; Denn auper Der fräftigen Rieferzange, ifrem Antwerjalapparat, haben fie seiter nichts jo gar Seervor= ragendes und entbehren ja meift iener Drgane, welthe bas

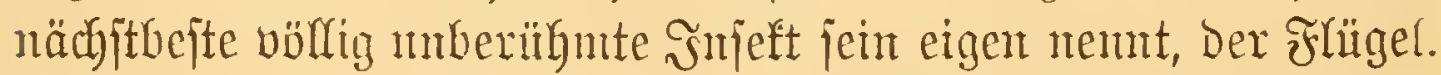

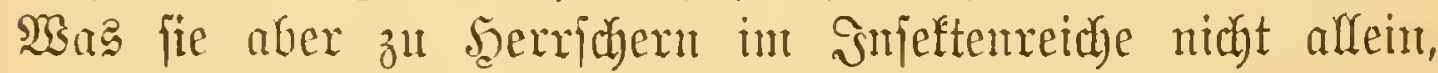

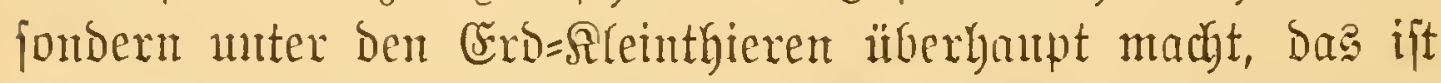

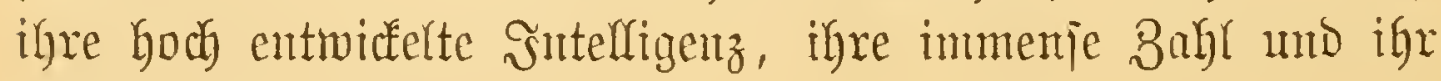
$\mathfrak{B}$ ahlfprud : viribus unitis. 


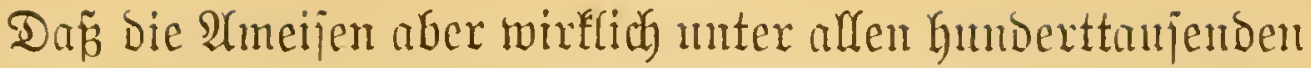
ifrer Briiber oben anjteben, Dafür furedyen ihre Thaten. Man

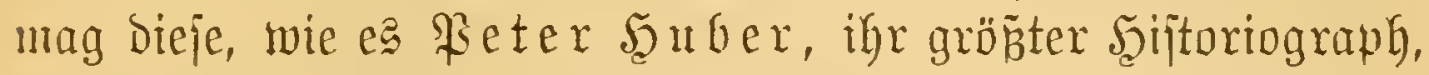
gerathen un getyan, mit nod jo müdyternen Aatgen anjeben, fie

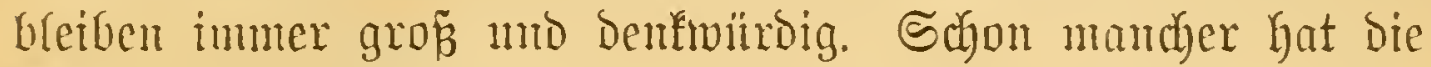
Imeijengefdidyten anderer für Fabeln, für Probulte ber er= bibten Einbiloung mo Dem groéen Latreille ergangen, die betreffenden $B e n b=$

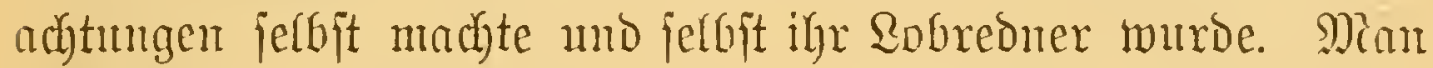

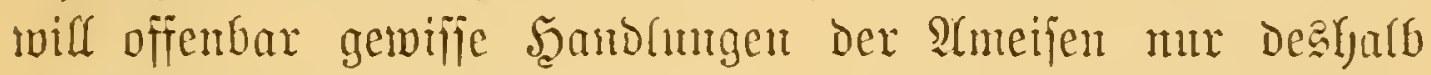
nidht verificiren, weil jie allzu hart an unjere eigenen anftreifen,

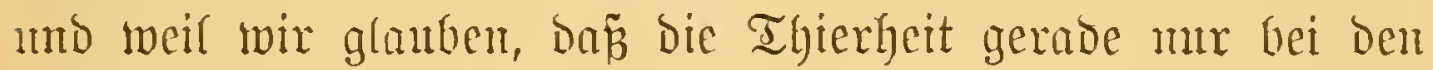
Säugern igren Ģipjelpunt erreid)en mü̈̈te. -

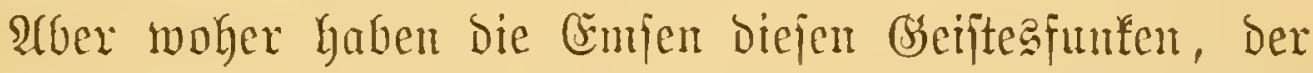
alferbinge aud aus ifrem faltenreidhen Bsefirn hervorblibst, und warum haben es gerabe diefe unfdeitbaren Rerfe fo meit

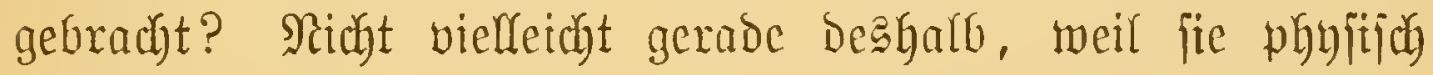
fo ftiefmütterlich bedacht find, und weil jie trob ifrer un=

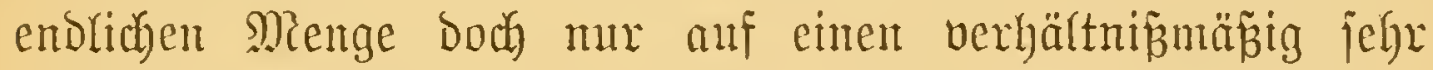
engen Sirfungatreis angemicjen mo fo, wie Mid delet jugt, von jeher bemitipigt waren, "vom 3 ufarl leben zulernen".

Serjuthen wir es mun, bas unendich bieljeitige und vielbemegte Reben biejer Thiere ganz flüdhtig zu ffizziren.

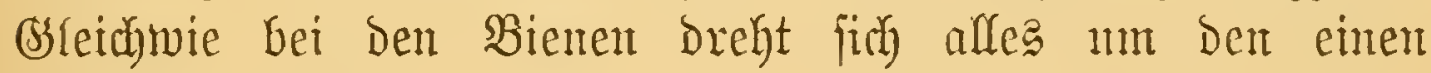
ßumtt, Die Brut.

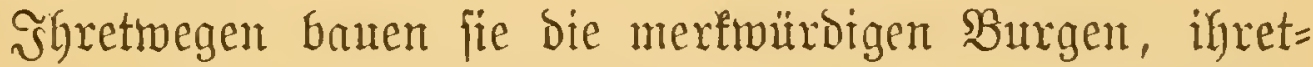
wegen unterneburen ie bie berübtigten $\Re a u b=$ mo $\mathfrak{W a n d e r}=$ züge, ifretwegen jhleppen jie anth die Sflaven herbei, und Die merfwüroige Defonomie mit bon Blattläujen hat feinen

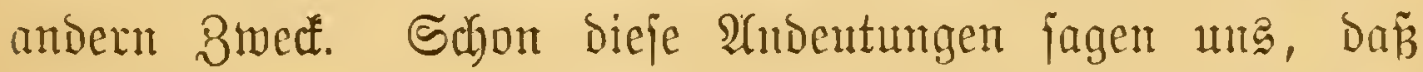
das Reben ber Âmeifen trob vielfacher fonjtiger Beziebumgen ein ganz anderes als bas der Bienen ift. 
Das Ireiben Der lebteren ift jo eintönig, wie ihr Mabentan: jebes Bienenfinb betwohnt jein eigenes Sämmer=

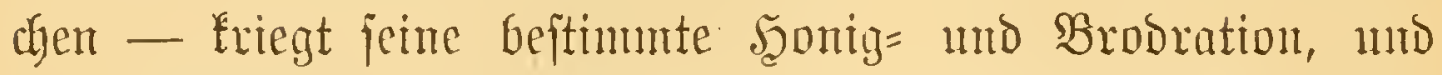

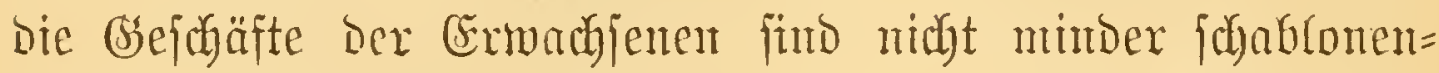
nüäzig. Die Rönigin geht von Befle zu Zelle und Yegt die (5icr; Die Arbeiter thun Degg(eichen, um zu füttern und zu

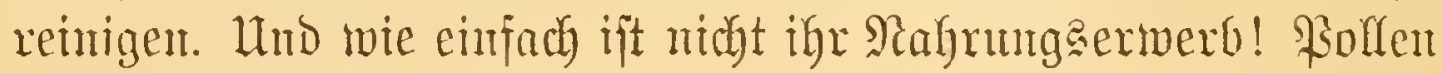

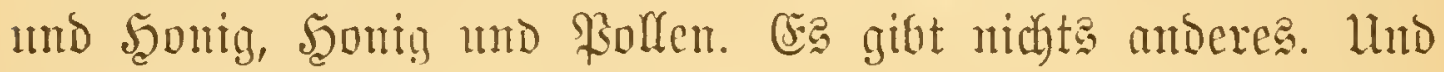
iebe Sannulerin ift anf ifren eigenen Freís, anf ifre eigene

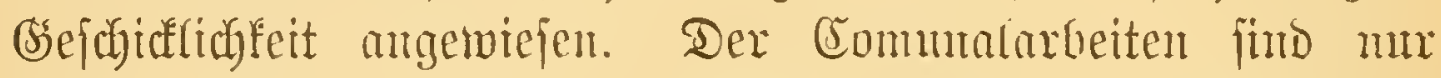
wenige; fonjt mun jedes für jidh handelu. Shr Princip ift und bribt bie ftrengite Arbeitetgeilung.

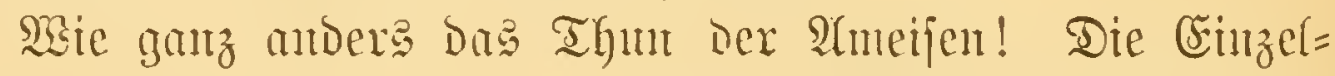
perjon bebentet fier wentg, in ifrer Berenigung aber, zu fleinen Banden ober gar zu grop̃en Seecren organifixt, leiften fie bas Unglanbliche, find fie fïrchterlich, minvioerfteblich. Die Eimmüthigfeit ijt igre Araft, Sejelligleit Das oberite

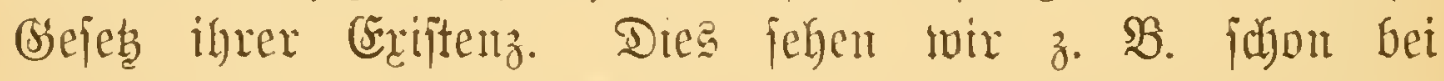

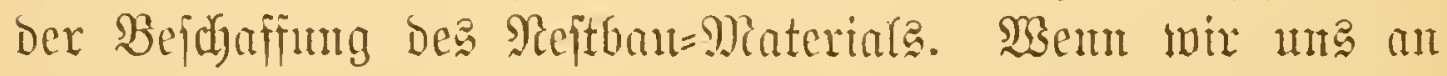
einen warmen Sommertage neben cinem Şügel der grö̉en

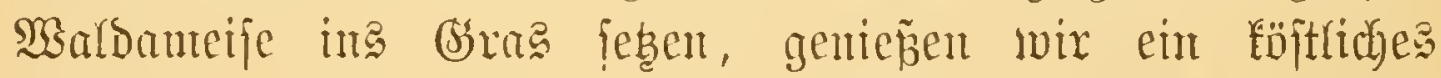
Schanfpiel. Das Rommen und Gehen ber flinfen Canjen nimunt fein Entoe. Reines fegrt nit leeren Şänden ober ridu=

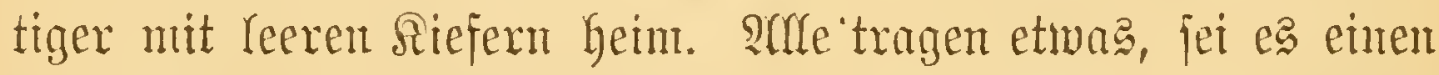
Strohbalm, eine Iammentabel, ein Bweigeldyen, ein Fleine?

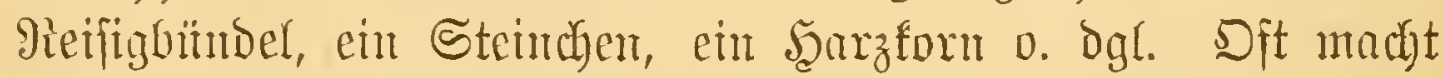
aber ein joldyex Banlieferant eimen job̈nen Fund, z. B. einen hübjchen Spahn oder Stengel, Dex pinen prädhtigen Suerbalfen

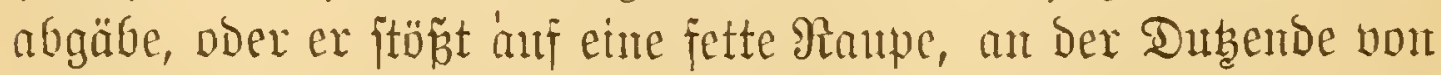
Sarben zu effen bätten, ift aber trob aller $\mathfrak{A}$ ufftrengung nidyt fähig, Das Ding weiter zu trangportiren. Wird es mu im Stid gelajien? Das verjtief́e gegen alle Anteijenregel. Die İmeije

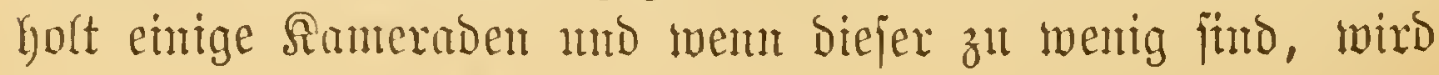


jofort ein Courier jum Sejt um Berftärfung abyejandt. Hud mm geht es an bie Rajt. Wisie Bimmerlente einen Bantm heben

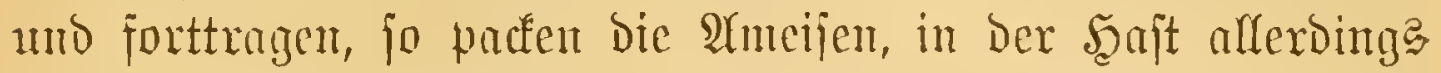

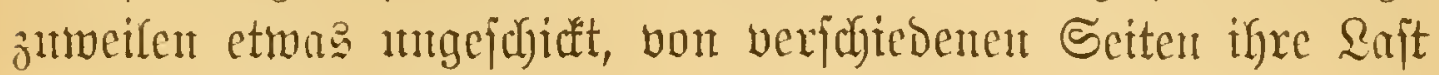
แmD jolleppen fie vorwärts. Biel Mïhe foftet es oft, eine poldhe Riejenlaft auf Den Şïgel binauf zu befördern. Doch alfes wentidet fich borthin, wo beiffe noth thut. Da wird ge=

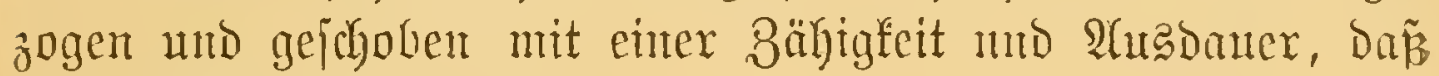
es eine wathre Frento ift.

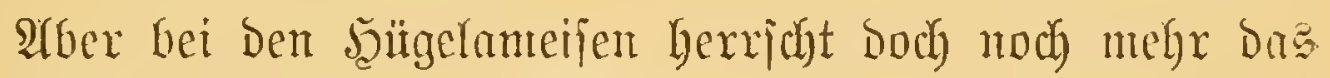
Freibenterjyjtent. Man zerftrent fich bald nadj same, baro

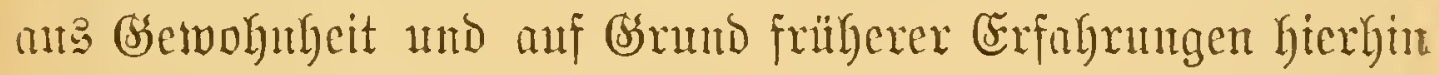
und Dortfin; jcocs nimmt, was ifm gerabe unter bie Âgen

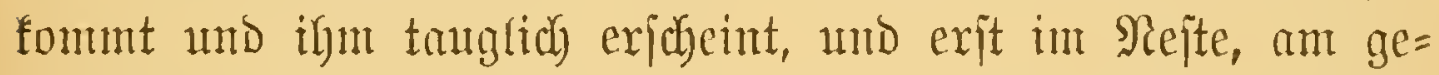
meinfamen Sanntelpunfte, wird Das, was der einzelne erworben itmo mitgebradid, als Bremeingut Der ganzen Bejellichaft anf

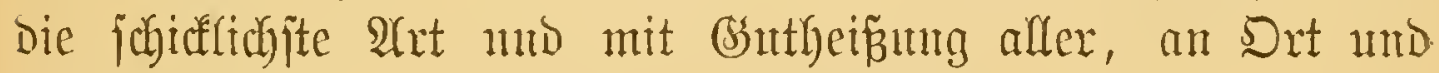
Stelle gebraibt, vertheilt uno berwerthet.

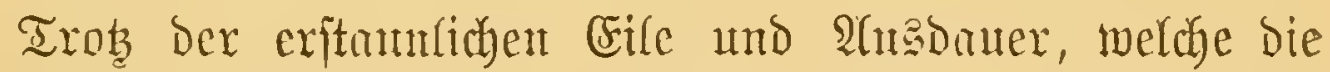
Ameifen bei der Bejorging ifrex (sejdyäte auperhalb be? Rejtes an Den Iang legen, fommen jie oft, in Folge bes un= gecigneten Terrains bod) nur langfan weiter. Man bente mux an bie Şindernifje, bie ihnen ein gewöhnticher $\mathfrak{S a l d b o b e n ~}$ bereitet. Wic viel Zeit wird nidyt Donit verloren, bis fie alle

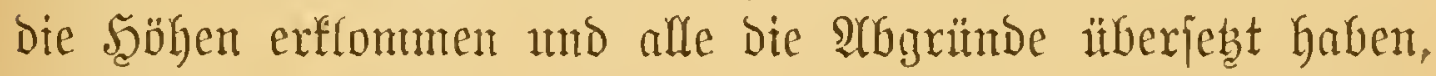
sweldye auf ifyrem $\mathfrak{S e g}$ liegen. Dft befimben fie fich thatjäcty=

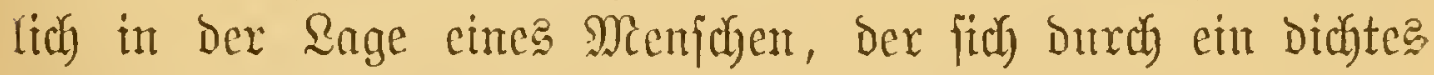
Gejtrïpp $\mathfrak{B a h n}$ (nxedyen mur langjam man ba weiter foumt. SAfein, wo auth Der Boben

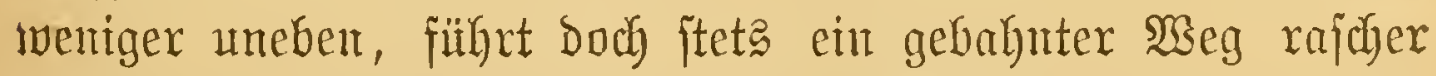

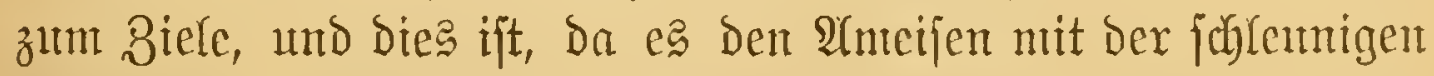
Ausfülyrung ifrer Brwedfe gewaltig Ernit ijt, wohl and ber 


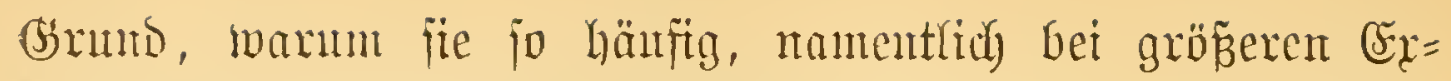

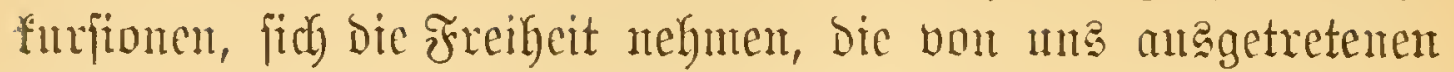

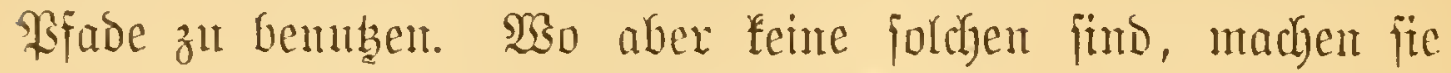

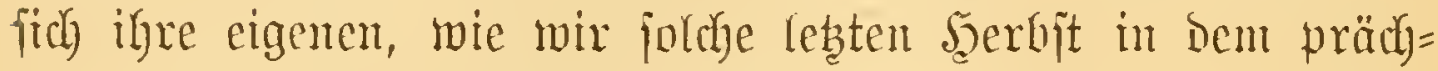
tigen Padelwalde jutichen Scharmib mo Seeferd (in Tirol) zu jehen Gelegenbeit hatten. Sberfald einer von einem frijhen Brinutein Durd)riejaten Mintse fict un anf bent grinten Shbantg cin butffer Streifen auf. WBir treten näber un jelyen ente wenigiten zwei Boll breite, in bie Eroe gegrabente gime. Wir verfolgen fie wohl ither humbert Sidritte weit Durch bie Bäume Ginturch und gclangen entolidy mit igr vor

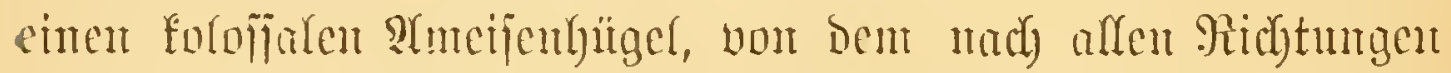
Dex $\mathfrak{B m b r o j e}$ ähnlicide uto in weiterer Entfermutg vom Bam

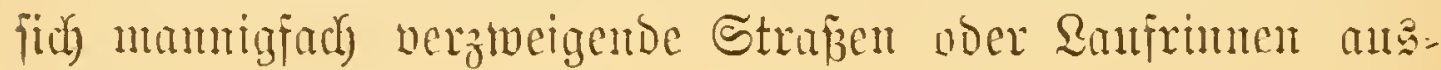
gingen.

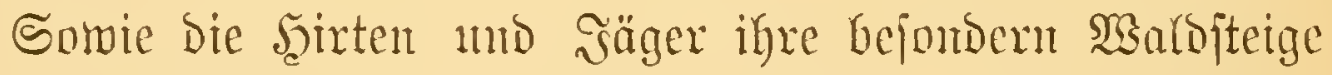
haben, jo haben fie aljo and bie Atneijen. Es bleibt aber

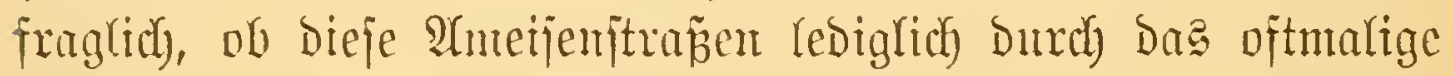
Betreten entitanden, oder ob es füntitliche D. h. mit Fleifis angelegte $\mathfrak{s e g e}$ fund. Nach Der Bejchaffentheit derjelben zut

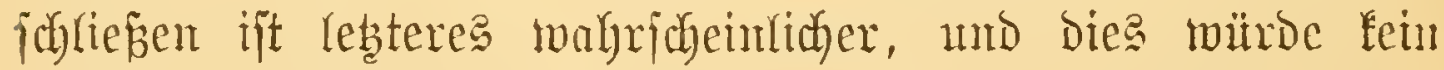

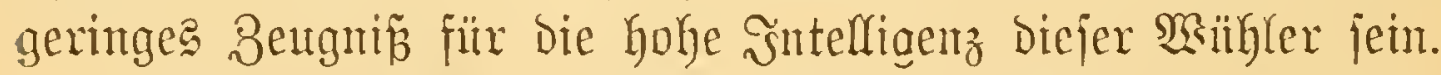

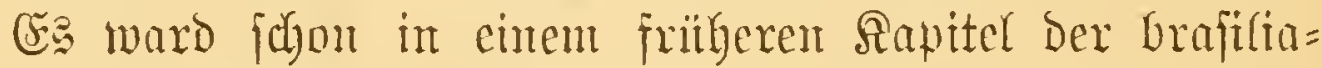
mijchen Bifitenanteijen ober Sanba's erimert, §erfe, weldye

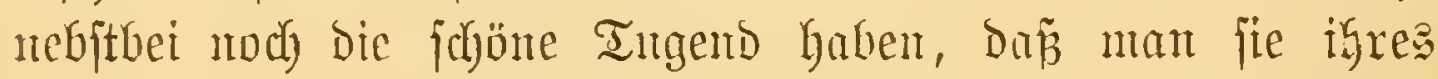

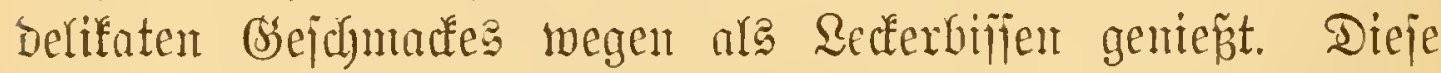

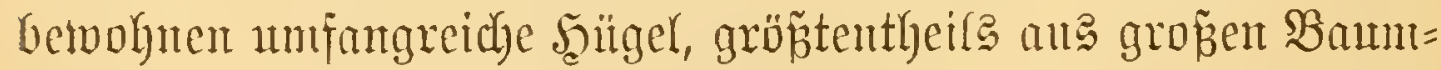

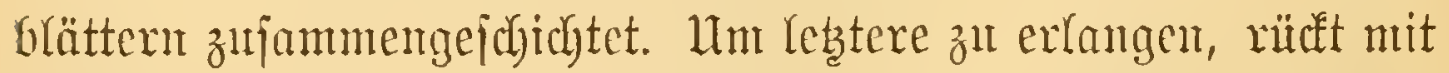

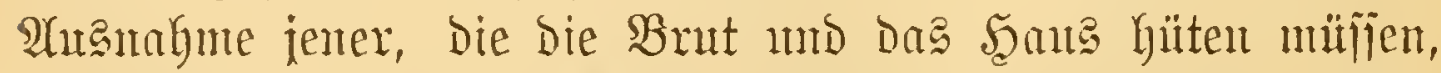
Das ganze oft in bie Miflionent zählende $\mathfrak{B}$ olf ing Feld. Sie

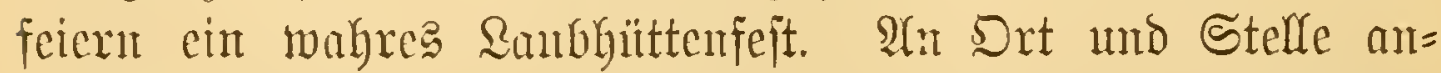
gelangt, Kfettert bann ein Theil auๆ Die Bäıme, ım bie Blättex abzuneipen, während bic unten 


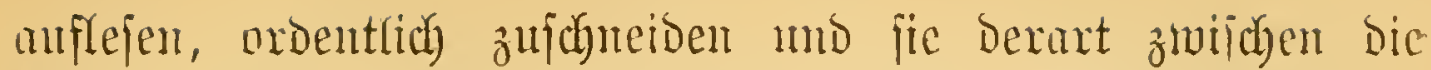
Siefer nehmen, ars went fie einten f́lemen Sontenjobirm in

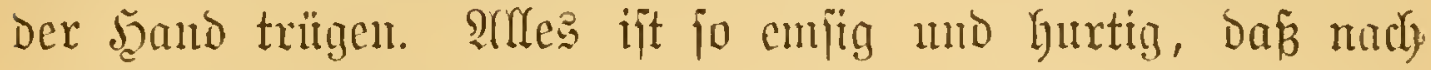
wenigen Stumben unf einten weiten Untfreis alle Bäıme ent= laubt finto und wie Bejen zum betnunt ragen.

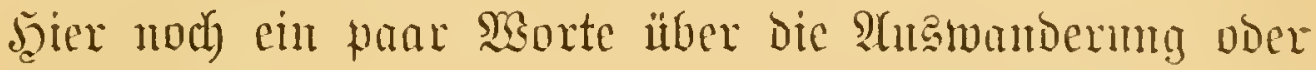

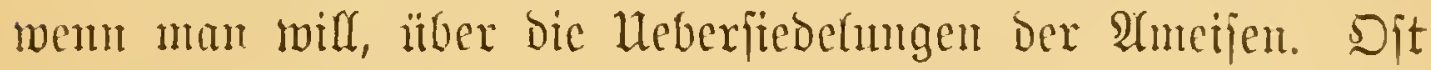

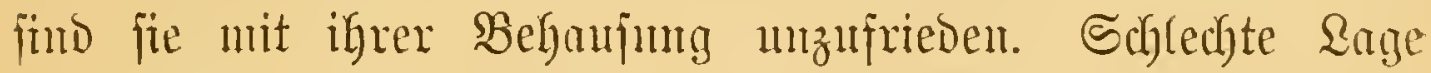
ober mižlungene Conftruction Defielben, Miangel an ergiebigen Frntterpläben, vielfache Etörungen burch ihre Feintos uno

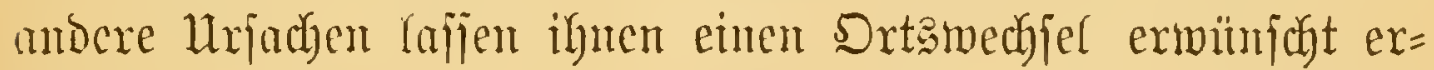

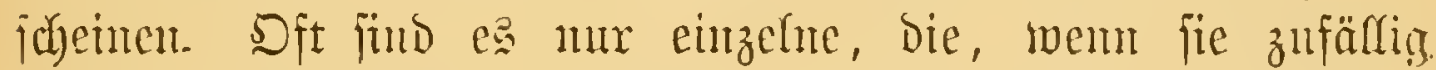
chuen befiern Pojten entbeft, ifren Rumeraben Dus $\mathfrak{A} u=$ wanberumgaprojeft anempfehlen. Bselegentlictly wiro aber aud (Ssemalt gebrandyt. Sit bie neue Station meit entéegen, jo jorgen bie "MSerbeoffiziere" fïr ein geeignete 2 abiteigequartier. Die

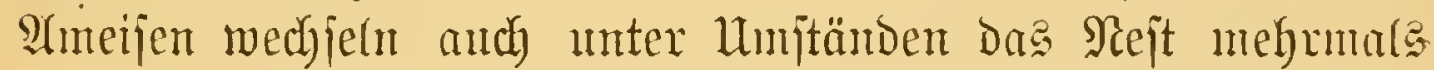
- ober felgren, wem fie von ifrer Berbefjerungamuth Durch Die Erfahrung aeheilt für, wieder renevoll in bas Schlof igrex $\mathfrak{B a ̈ t e r ~ z u r u ̈ c x . ~}$

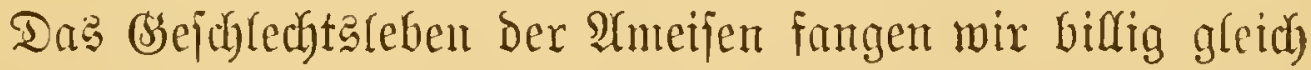

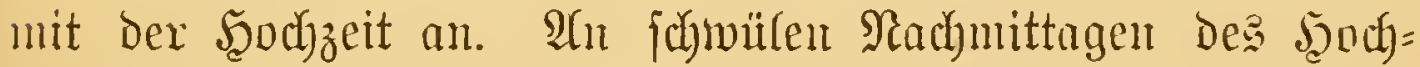
und Nachjommers fund die Âmeifenbanten oft ganz bedeçt nit

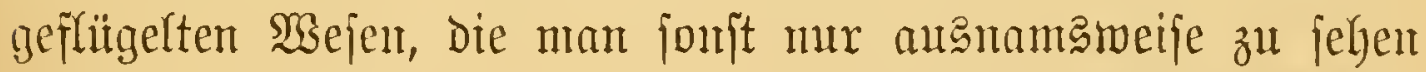

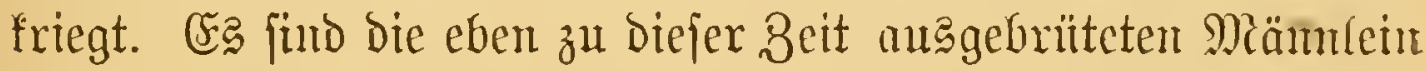
utb Weiblein, welche ibrer hujtigen Brantfahrt harren. Dies ijt eine Der jtürmifchejten und wildeiten Scenten in gauzen §erf= leben. Ssegen Sommenmtergang erheben fie fich ntit einem twirbelnden Aufbraufen — gleid) einer Fllammenjäule in bie Zuft. Sft vereinigen fich bie heirathafäligen berrjobaften

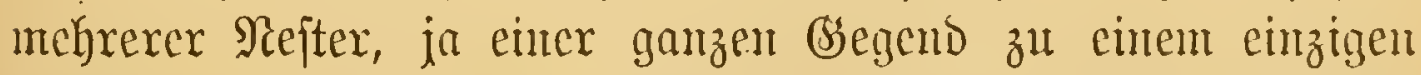
Riejenjabroarm - und es exiftiren wohlbeglanbigte Nachrichteu, 


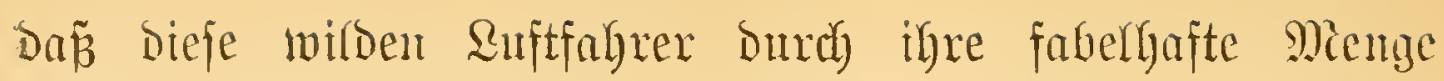
faft bie Sonne verfinftern mo fpäter, mem ihre Fhugfraft crlabmt, gleidy emem Ramoregen zux Erose fallen.

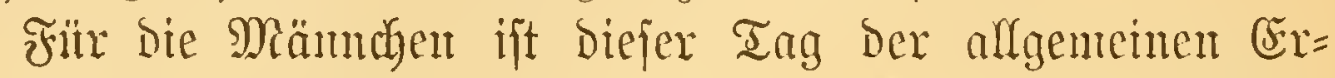

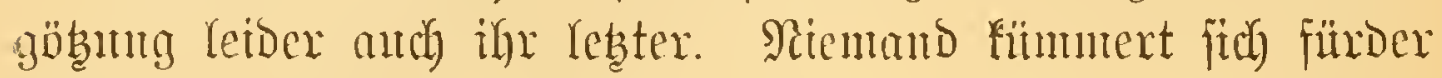

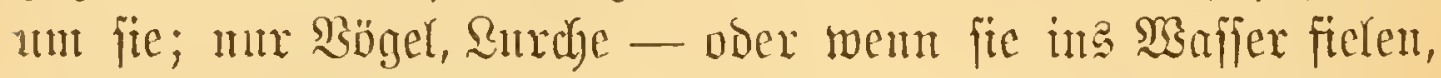

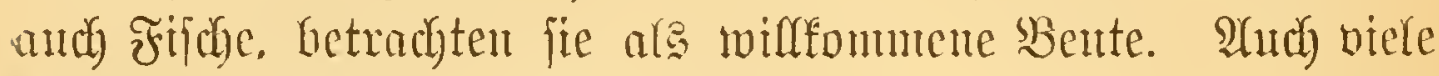

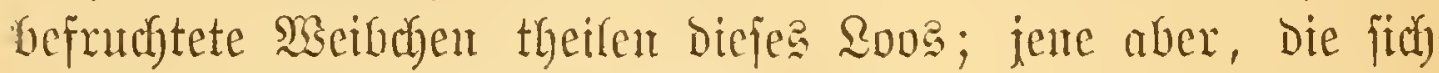

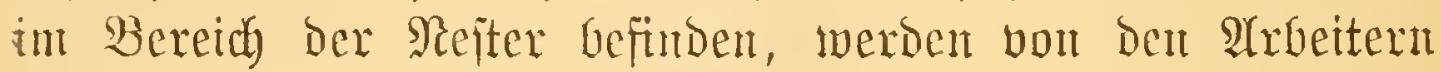
forgfältig anfgeboben mo nidyt ferten gewartfan in Das Neft

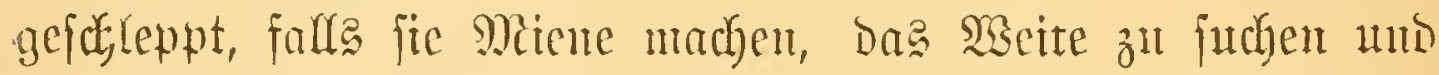
eine eigene Siblonte zu grïnden. Trob̧ biejer ftrengen Meber=

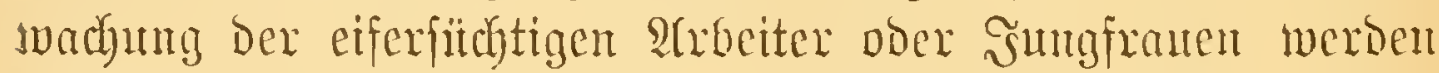
Doch in biefen Tagen tantente nenex Colonien angelegt, mobei,

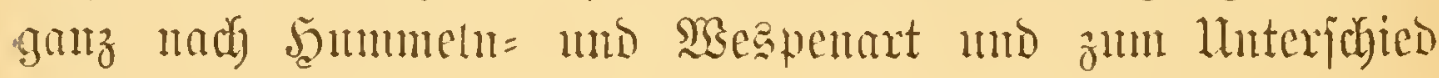
von den SBienen, häufig da

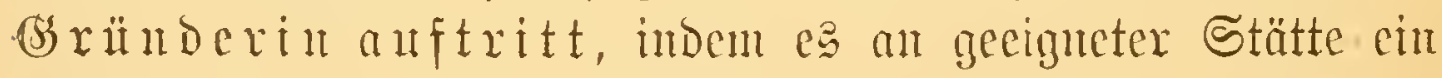

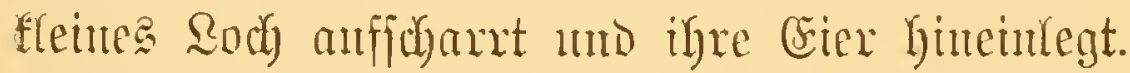

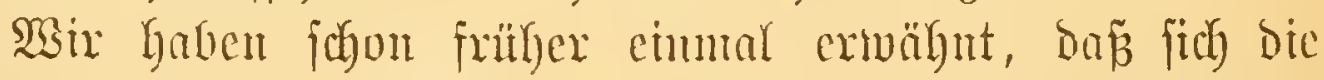

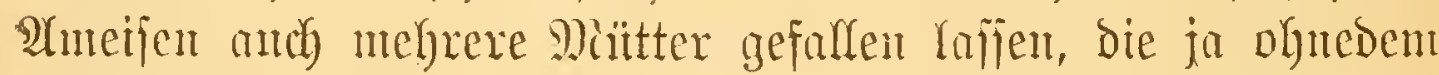

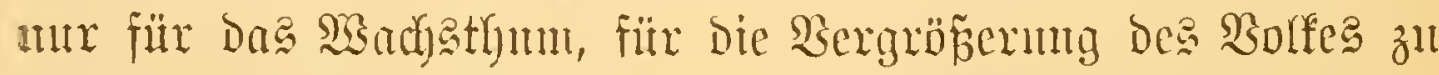
forgen, in andern Dingen aber nibt viel zul bebenten haben. Die Sheifemütter werden ziwar vortrefffich verpflegt und

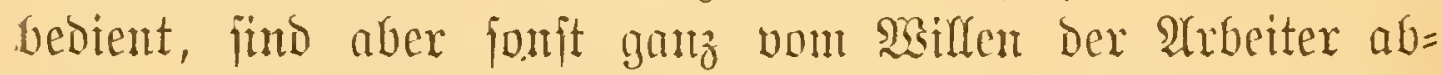
bängig, ja weroen von ifnen, wie e⿱⺈ facheint, gelegentlidf förm=

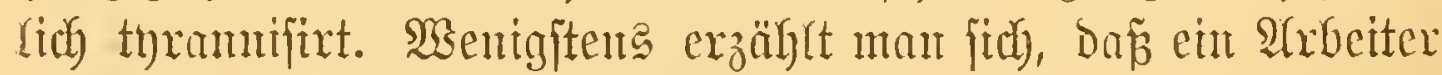

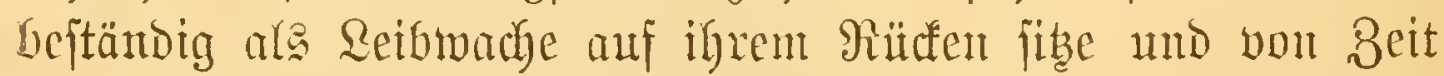

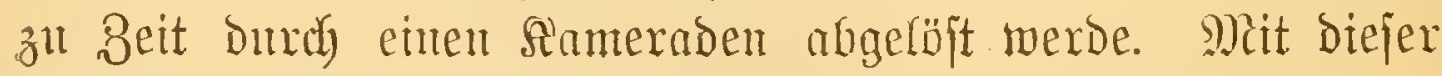

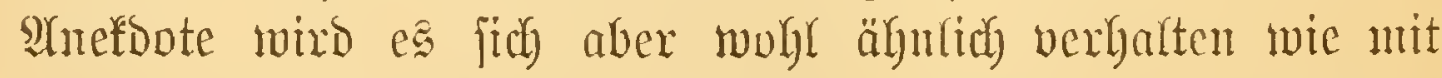

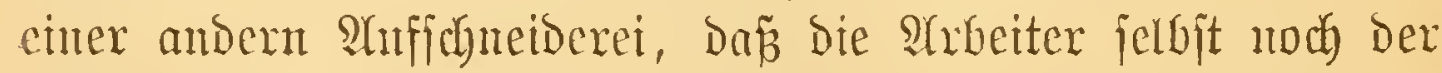

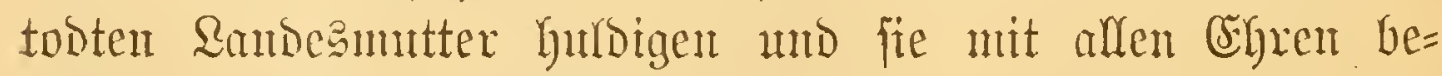
ftatten. - Dodh vorexit lajien wir jie exjt bie Eier bont fid gchen. Dies geidjieht befannt(id) nicht in bejonderen Beflen, 
pondern fie merben häuf̧chentweife an Den geeigneten Brut= pläßzen Deponirt, wobei bie Bsebärerin "bon jeweiltgen Dienft= voer Bimmerperional begleitet", in ganzen Bebände igre Rumbe madjt.

Sowie mn die flemen jub̈tterfanigen Maden ma $=$

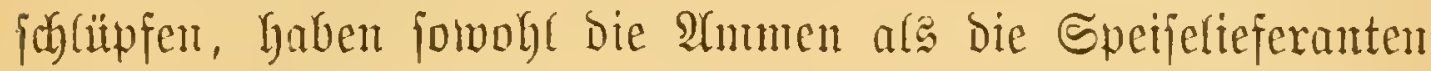
vollanf zu thum. Dieje, um bie nötgige Aeb̨ung herbeizu=

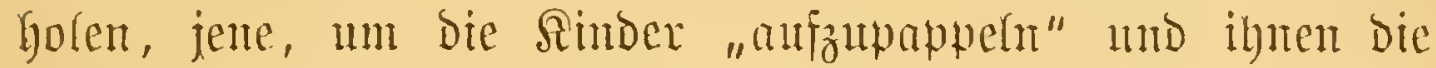

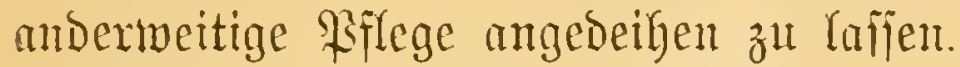

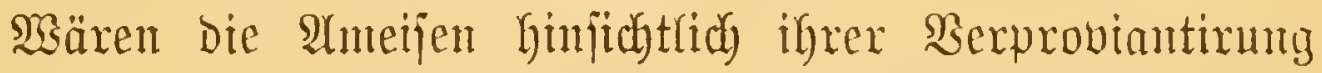
anf einen jo befdräntten CErwerb wie bie Bienen angetwiejen, jo wïroen fie niemale bieje Dominirende Stellung im Reich

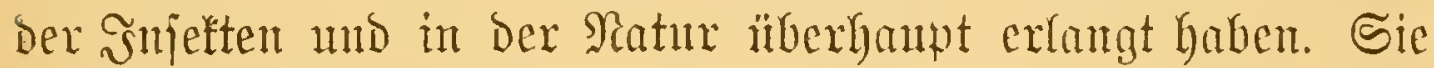
mebmen aber nit allem vorlieb, mb barum ijt dem aud ibrer Serbreitung fein Biel gejebt. — Am liebjten ejien fie aber

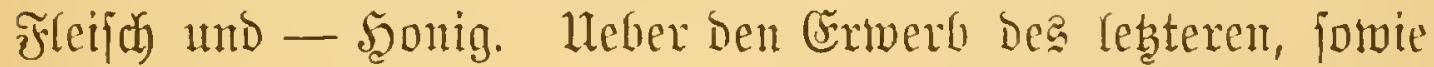
ïber bie Rornernte nody fpäter. Der erftere Artifer geht ignen nie ans. Dem fehit es an oberindifich Rerfen, muter Denen jie Den weichen Raupen mb Sarven and ifyex Sinder megen Den Sorzug geben, jo Durdywühlen jie Den Boden nach Engerlingen, Maden u. Dgt. Bezeziefer. F́nge

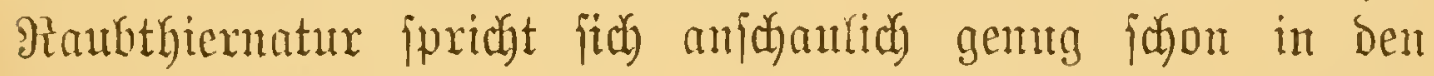

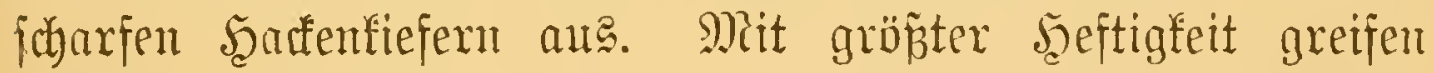
fie fich and gegenfeitig an mo frefjen zuntal bie befannten \$uppen, bic jog. "İmeijeneier" eben jo gerne twie bie ßöget. Die $\mathfrak{A}$ wamalung einer regelrechten Sdylacht zinifhen zmei

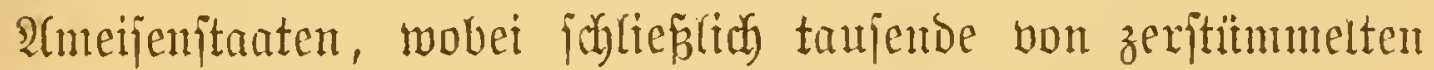
und giftbejpribten Reichen das Feld bedecfen, mag man aber bei Şuber oder Forel nadylejen.

Sełren mir mun wieder an Den häng(idgen Seerd zurn̈a*. An Rohmaterial für bic Brutfïtterung mangelt e? arjo Duxcly= ans midyt. (E⿱ 口) ijt aber Sache ber Anmen, bieje Dinge den

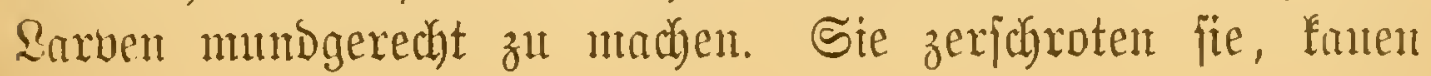


fie mb Den wieber heranfgemürgten Bräu geben fie mu ben

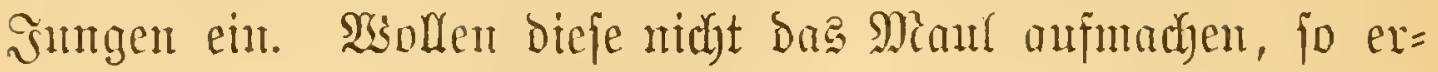
loaltent fie - wie man beubad bet haben will, emen fremblichen

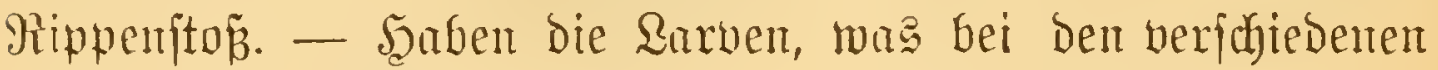

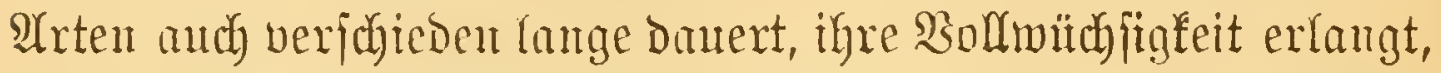
Dann fpinten fie meift cinten weiphlichen Seibencocon un fid); fie vermandeln fidt) in bie ßrappe. Mährens mun aber bie

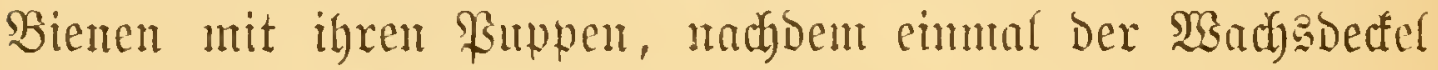
anfgelöthet ift, feinerlet Befdutwerlichfetten mehr haben, find bie Ameifenammen mit Den igrigen fortwährent geplagt.

Der Sefer hat fidf wohl cimntal einen Eingriff in cin Emfemrejt exfanbt mb geichen, wie bie Arbeiter nichts ciligeres

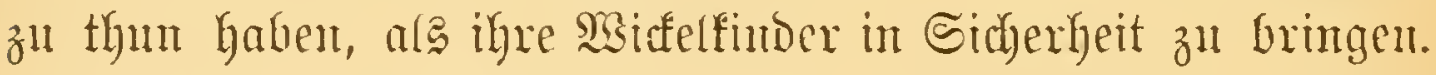

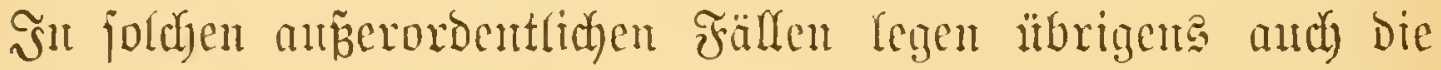
Sieferanten und Srieger Şand an, ipährent man Den Termiten=

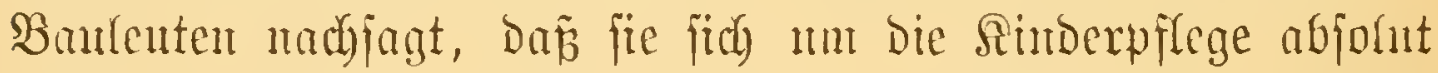
nicht fitmmern, jombern fich Damit begnïgen, bie gemadyte

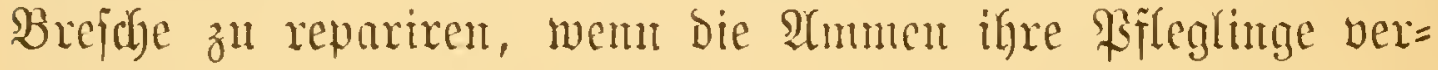

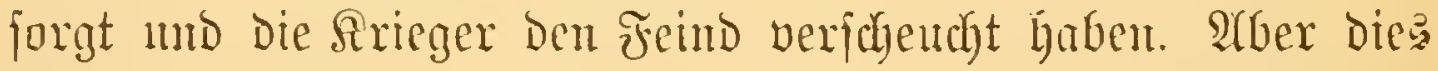

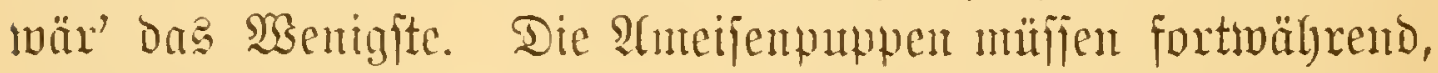

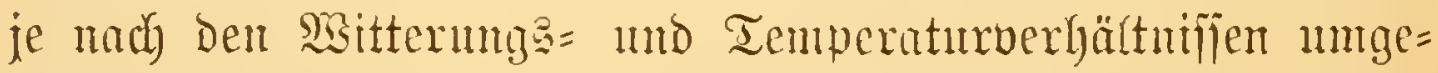
bettet, bou einem Stodfwerfe ins moere mb namentficl) aud in

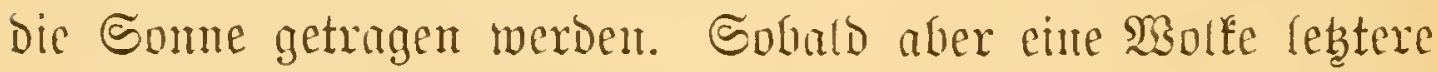
verbulitert oder ein Gegentropfen fällt, haben die Mägose

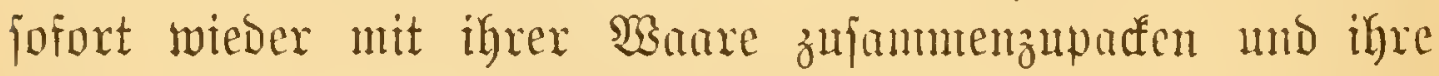

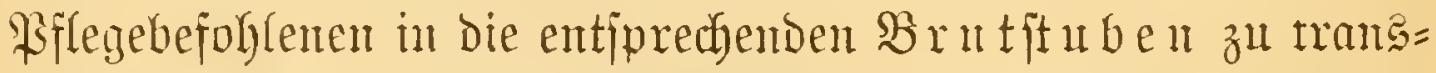
portiren. Und ungt endich bie Beit Des âtajhlüpfens herm,

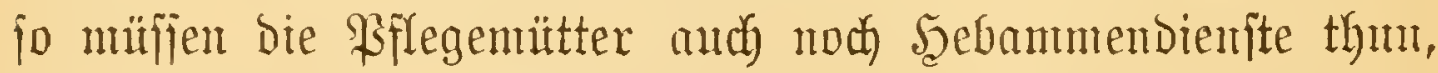

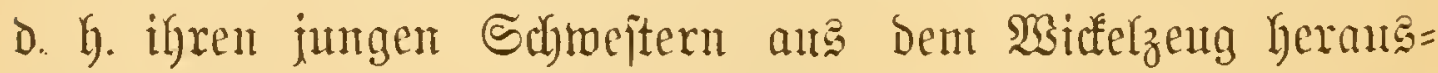
helfen. Into ijt mun enblidy bie Beit ber Rffege voritber, dam bejumt crit bie Reriode Der Erziehnng, Die Marmung vor Dunmen Streichen, die Itbriftung zux כagd, zum Bat=

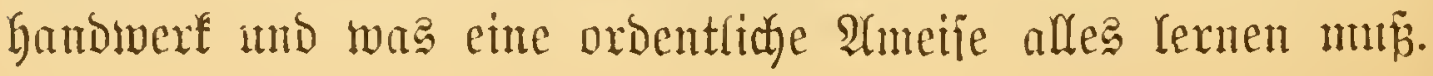


Bezüglich Der gegenfeitigen Bevormundung mb Uebertwathung in ber Ŝneifenrepublif fei mur ein einziges Faftum ermähnt.

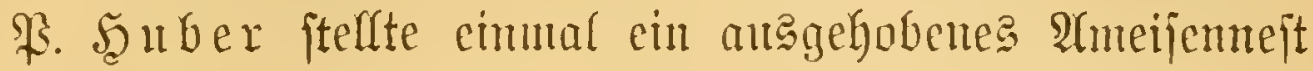

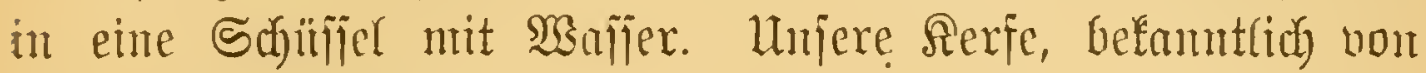
felyr Duritiger Ratur, fumen and bald in Menge an best Ramb

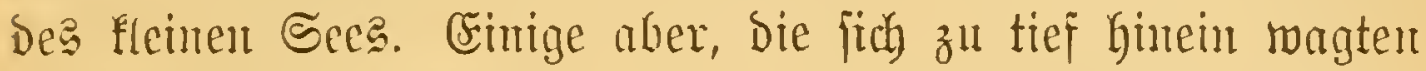
und Den Sarmugajignalen igrer vorfithtigeren Ramernden fein Bsehör jugenfen roollten, rourden mun mit setwalt gepactit mo in Das Aejt getragent. Dagegen ïbertafjen wir es anderen, bout

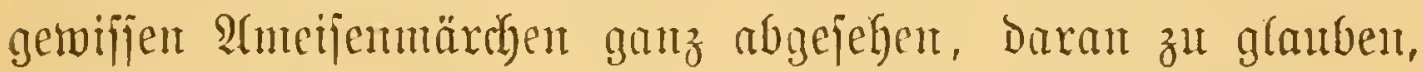

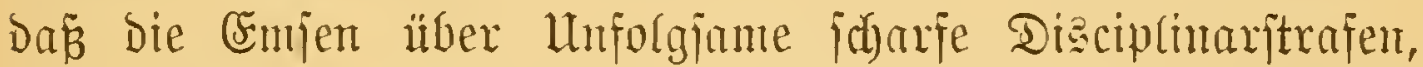

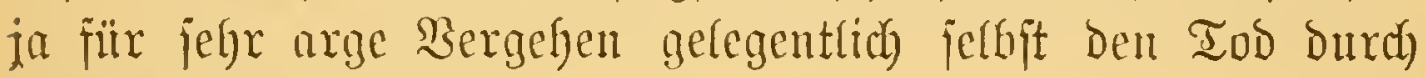
das Beil verthängert.

Dies fund jo die gewöfnliden

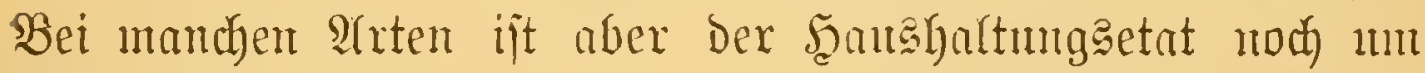

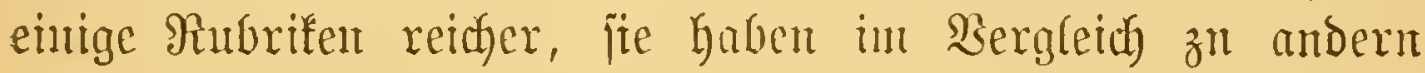
nod) mandyertei zutgelernt.

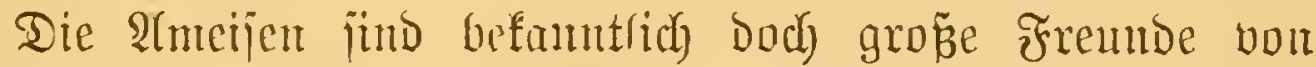

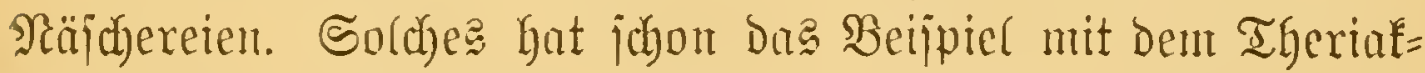
topf gezeigt; Syonig aber lieben jie ïber alles. Nianche jüb=

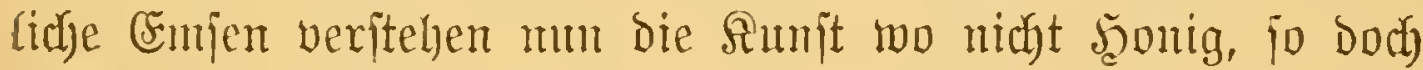
zuterereibes Mkalz zu hereiten. Bei Deu eintheimifdyen aber hat jidj Dafiir ein antoerer, weit profitablerer Snduftriezmein entroiffelt, die Bluttlans= "Senterei,. Rebtere Thiere find fleine Zufferfabrifen. Sie verwandeln Die mit ifren langen

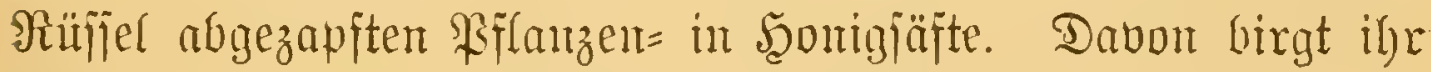

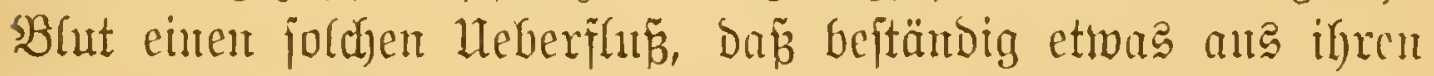

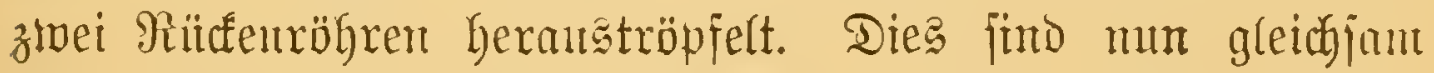

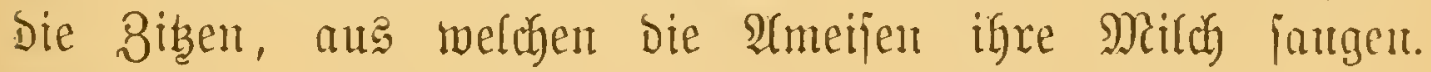
Wem e马 irgendwo auf einem SBaun oder Strauth viel joldycx Melffiíne gibt, wird man immer auth zallreidye 2 meijen ge=

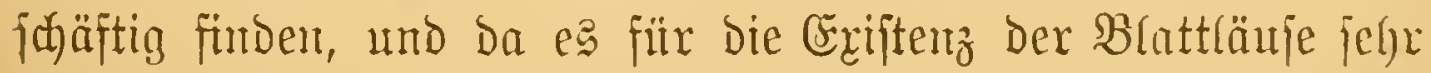
vortheilgaft ijt, wem Die getwijjen (Entleerungen Durch Die Emjan

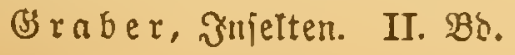


entfernt merden, fo find lebetere aur mohl gelitten. Dies haben natürlich unfere Pfiffici bald hernes gehabt umb geken

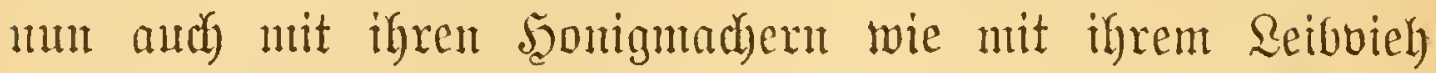
um. Sie werden an Drt und Stelle vor igren Feinton, nantentfic) vor Dem BRlattlanglömen forgfältig behjitet — ober e马 wird gar die fleine Senterei untzäınt uno jugleich, went es

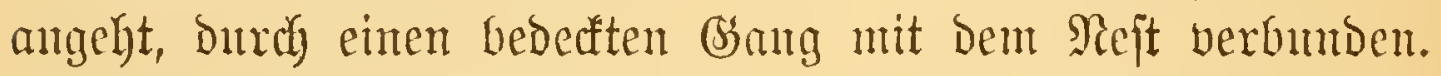

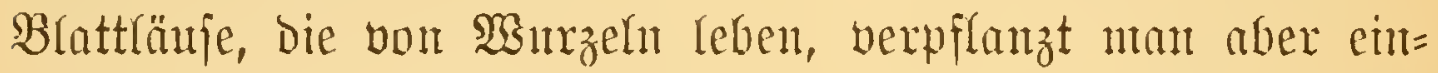

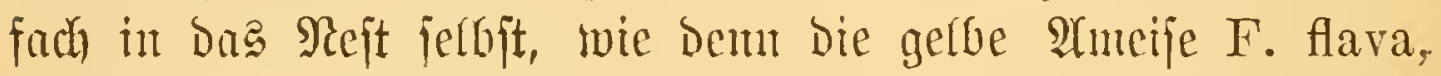

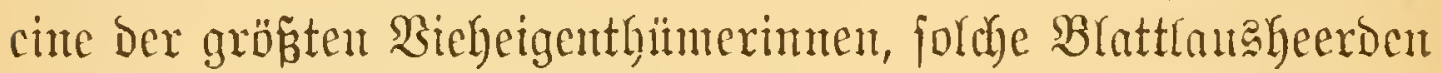
unto Brattlangftälle in Rejte hat mo für bie Brut ihres

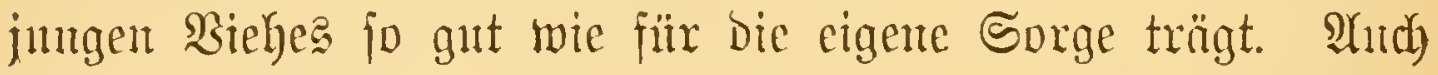
Lasius fuliginosus noto brunneus follen jtarfe Siebjtände befizen.

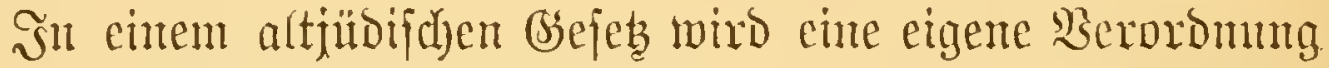
fiir ben Fall extajien, ale jenand anf jeinent sirumb mo Boden ein Roxnmagazin Der Smeifen anfert. Hub Die

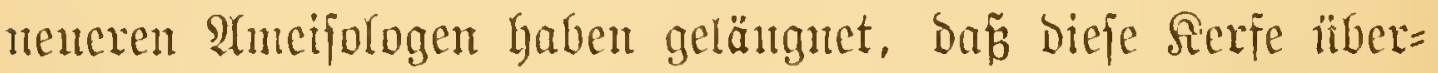
haupt Winterborräthe fanmteln, einfach ans Dem (Sinntoe, weil fie bei uns in Der falten Jahreszeit critarren unb baher aud nichts zu effen braudyen. Expt in jüngfter Beit ijt man wieder anf Dos Arte zurüffigefommen, und hat fird jpeciell ber (Eng=

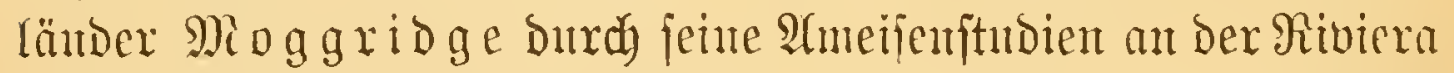
ein breibendes Berbienft ermorben. arra Sanmelanteife murde zunäajt bie in Den Eitronenterrajien borfommende Atta barbara.

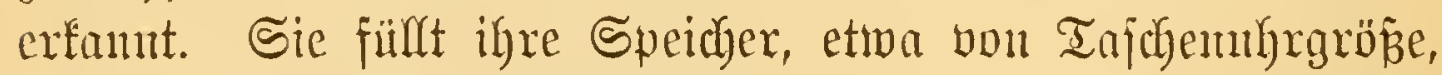
ant liebiten mit Gsetreibeförnern, auf bie fie anfänglid)

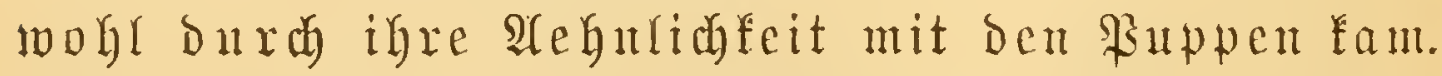
Die Reibenfidaftlicheteit im Samenfammeln erbellt am bejtent Daraus, Daf́ fie and biejen von Ferne gleidfende - Brlagperlen anfliest. Sobald Das Bretreibe ihrer Magazine zu feimen begimnt, beipen fie die Mürzelden ab und Darren es; fie find alfo Mialzfabrifanten. Moggribge glaubt, ba ż je zu biejer 
Snduftrie im ภampf ume Dafein gebradyt wurden, nämlich

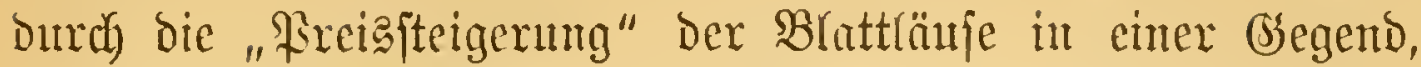

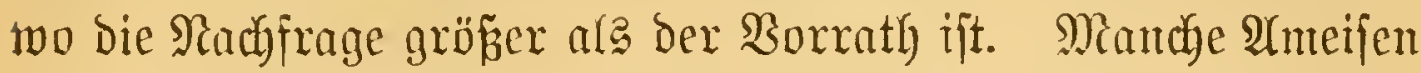
nelymen aber Samen mux gelegentlich und fehrt es arfo misht an Hebergängen żmijhen Sammtern und Nidytfammlern. Sher e? gibt nidyt blof Almeifen, weldye frembes Rorn jtehlen,

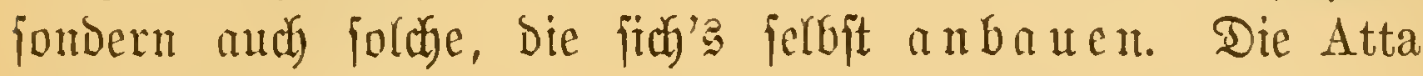
maleficiens in Texas und Miexico hat mämtict) madh Dr. Lin= fecun's Beobadytunger ein förmliches Bslacis um ihre molyl= gepflafterte Stabt, auf Dent fie eine eigene Bragart fultivirt, Deren fiejerharte weiñe Samen bann gemalzt merden.

Möblyte mant aber ichon geneigt jein, manche ber obigen Mittheilungen für ftaxt ïbertrieben anzujehen, fo wixd man

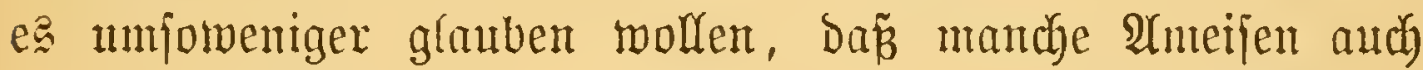

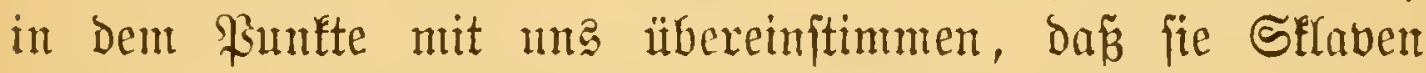

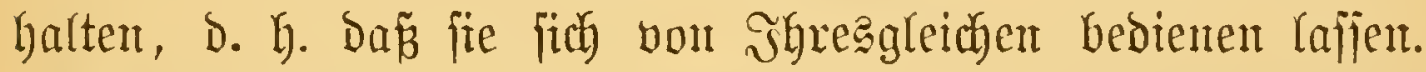
Die Thatjache jugeint aber jomohl Durch bie älteren als burch bie neueren Beobachter fonftatixt, mb zudem (iegt aud nicht ber geringite innere Brnumb vor, warum man fie bezmeifeln follte.

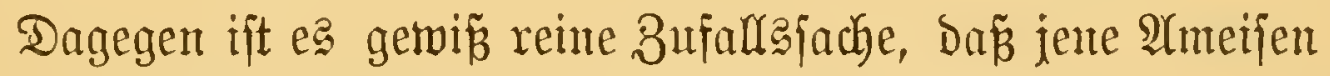
twie z. B. Polyergus rufescens, Strongylus testaceus, Formica sanguinea $\mathfrak{u}$. $\{$. w., weldye Sflaberei betreiben, won heller $\delta$. $\mathfrak{h}$. rother Farbe find, während ihre Reibeigenen F. fusca, cunicularia und caespitum dem Negerftande angehören.

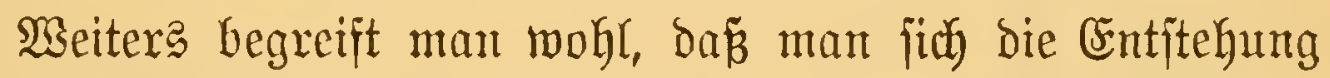

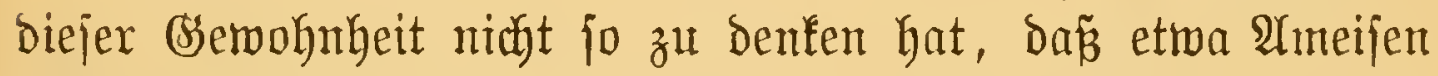
urpröblich anf bie sopee verfieten, in frembe Staater eiızu= fallen, ihre Bemohner mitzujd leppen uti fie dazu zu zroingen, ifre Rnechte zu werden.

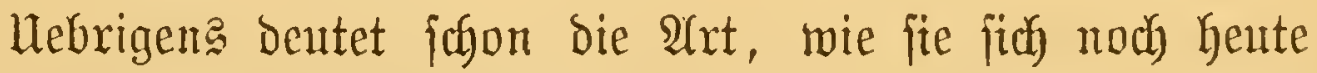

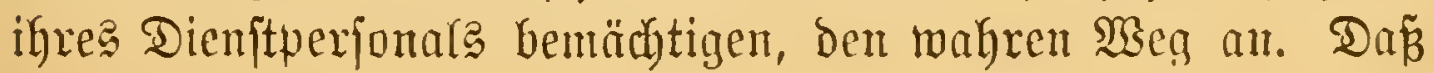




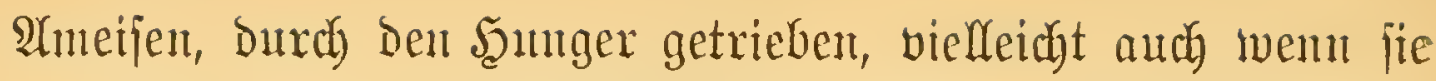

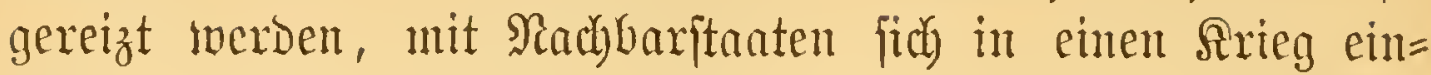

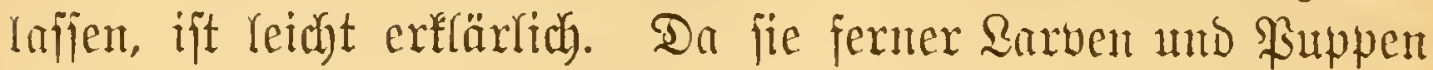

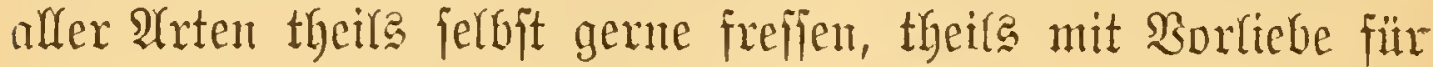
ifre eigenen Simgen ertwerben und eimjamneln, jo wirb man

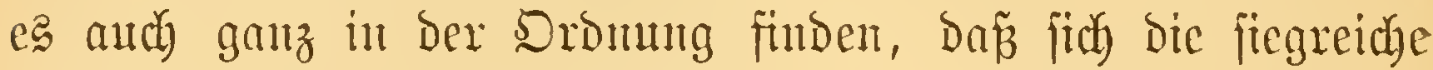
Sartei ber Rarwen mo Sasupen Der Mnterjochten bemächtigt und was nicht gleich zerfleifort wird, für den fünftigen Bedarf ins Rejt heinträgt. (5in grofaer Theil wird dort ohue 3weifel bald verfpeift werden. Einte erfleffiche $\mathfrak{A} 11$ ahd Larben jowohl

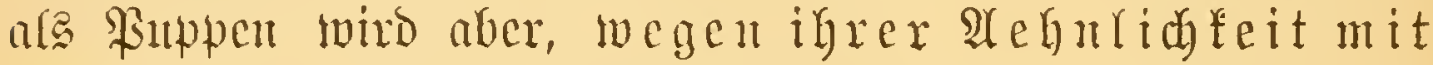
Der eigenen $B \mathfrak{n}$ t, einige Zeit unbejchäbigt breiben, ud jo ift es möglich, Daja fie fich an frember Stätte and zll voll= fonmenen Şnfeften ausbirben.

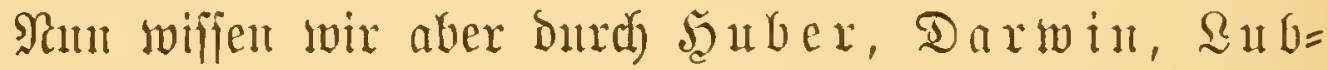
bod, Foxel t. a., Dañ bic Âmeijen âtugebörige frember Stanten nidyt miter allen Hurtänden aus igrem Neft ver=

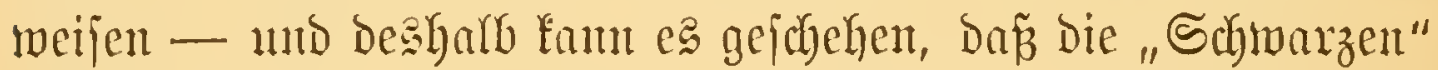
unbehellight unter Den "giothen" herumtgeken, ja lebztere fogar bei ihren verjchiedenten Bejchäftigungen begleiten und unteritïben Diirfent.

Die weitere Dromug ber Dinge gängt un dffenbar von ber relatiocu 3 ahr und Stäre fowie von ber ganzen phyjifden Berfaffug ber "Sflaven" un ihrer Dientherruab.

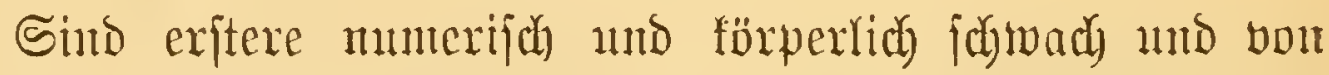

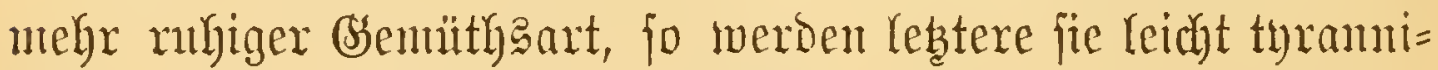

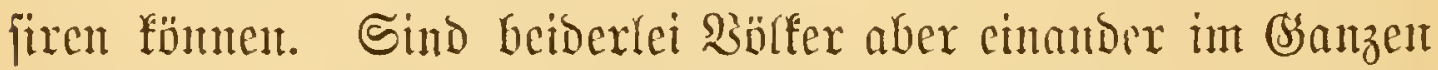

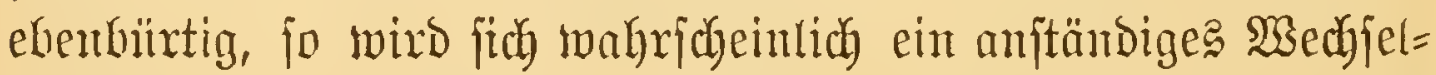
verhältuifip herausftellen; hingegen in dem Falla, two bie

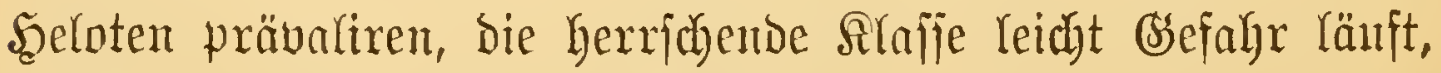
bon ibuen gehofmeiftert zu werben. 


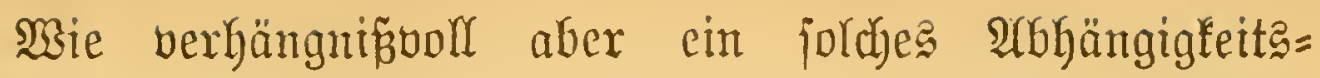
verbältniñ werben fann, bemeijen die neuejten ßerjuche

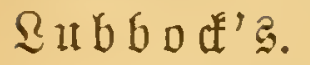

Sildividuten von Polyergus, bie fich von ifren Sflaben füttern lajjen, berbungerten, wenn lestere entfernt wurben, mitten im reidylidyjten Sentigoorrath. Sie haben einfad int Sanfe der Jahre - jo weit bringt es die Ssemolynheit! das Efjen verlernt.

Dagegen friftete er einem Polyergus über Drei Mronate Daz Reben, indem ex inm täglich für kurze Zeit einen Sflaven' zur F̋̈tterung an Die Seite gab. -

Bsemifje armeifenfamilien haben aber nidut blop igre Sflaben reipp. ihre Berbündeten, in ihren Szügeln hanjen aud Schmarober aus ifrer eigenen Sipplataft.

So findet man nady $\mathfrak{\Omega} \mathfrak{b} b o \mathfrak{b}$ bie fleine Stenamma

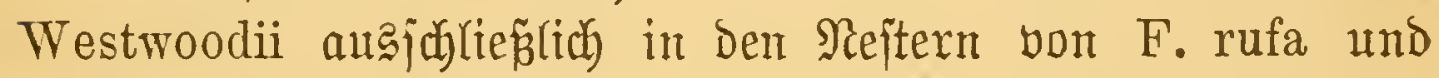
pratensis; ja fie jün gleid) Dem befamten Fleijhpolyp, Der inmer auf bem Şanje eines Crimfedlerfrebjes fist, berart an

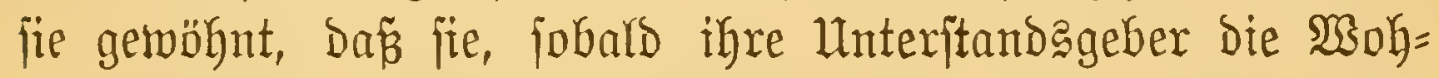
mung wedjjeln, gleidyfalls mitziehen, und hat man audh bemerft,

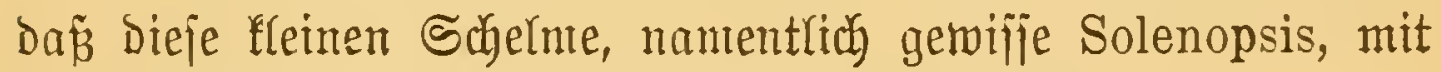
ihren sirthen alferlei Pojjenjpiele fith erlauben. 

S̃m Scrlage von $\mathfrak{R}$. Slocutbourg in Mitnchen erjujien:

\section{Dentldier ÖTovellentdiat?.}

Şerauggegeben

yon

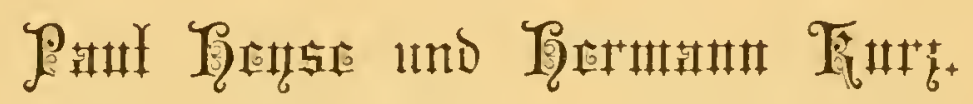

Errjchienen jint:

\section{4 בănde}

rejp. 4 Serien à 6 Bäntoe.

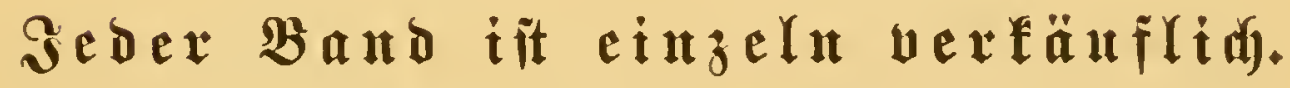

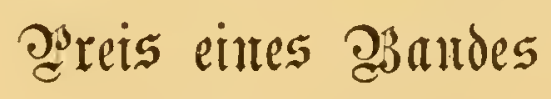

(bon ca. 20 Bogen)

broidfirt $\mathfrak{M}, 1,50-$ gefuntocn 9 , 2, 40.

Die ganze Sammlantg fant and in Doppetbäntoen (24 Bände in 12 Snmobde. gebunden) zum Gireije von 48 Marf bezogen werden. 


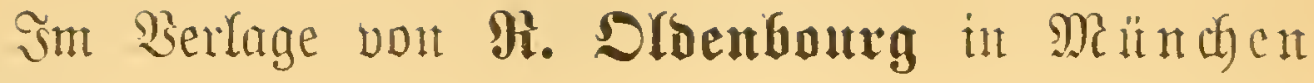
erjobien:

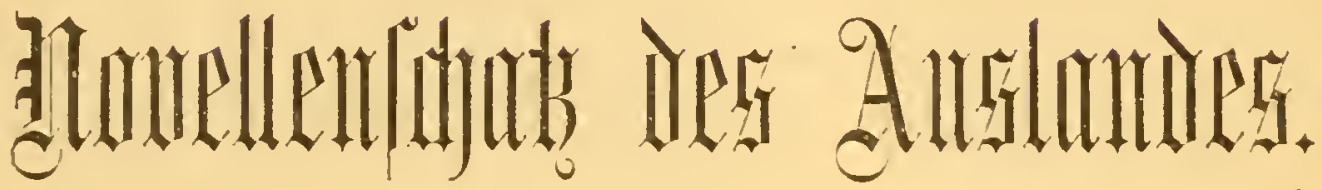

\section{nermingegeben}

vont

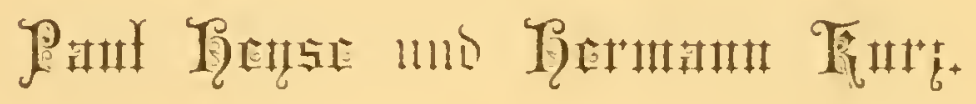

(Erjofiten find:

\section{$14 \mathfrak{B a ̈ u b c . ~}$}

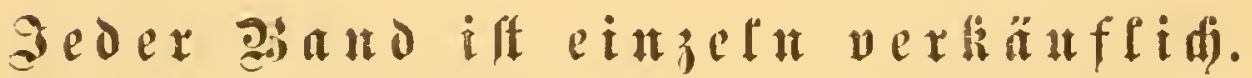

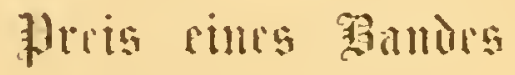

(vout cat. 20 Boggett)

brojditt Mi, 1.50-gebunden Mi. 2, 40.

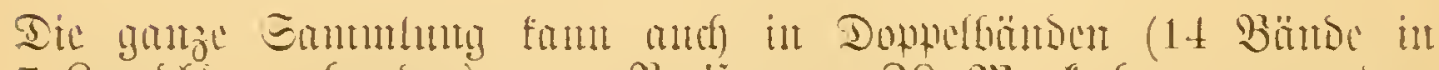

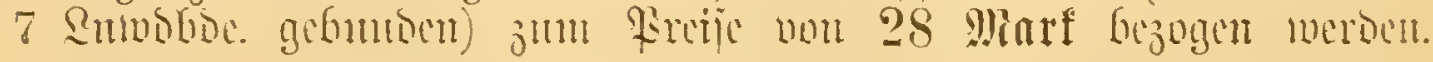




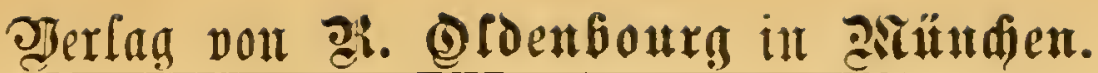

\section{Dip Mitturkriafth. \\ Gine Itaturwillentdiaftlidie S̈ofksbibliotlek.}

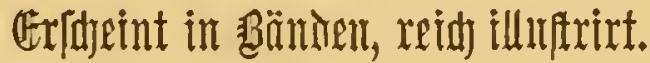

Ieder Band koftet: elegant brolfirt 3 Dilark.

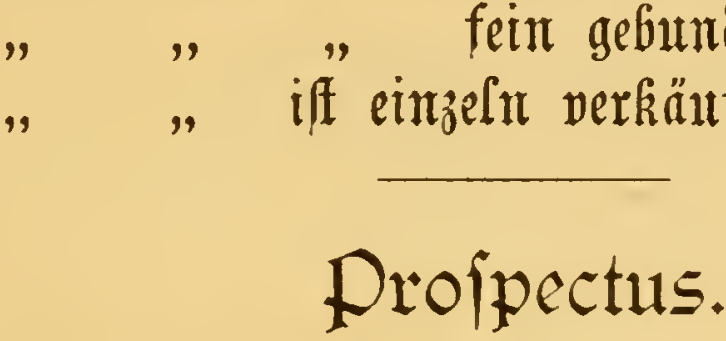

Die in Den Raturwifienidajten erworbenen (Geleke beherriden Den jufüntigen geiftigen und materiellen frortidritt Der Räıber und Bölfer; jeder (Einzelme ift an Den Fragen betheiligt, Die fid an igre $\mathfrak{A}$ nwendung tripien."

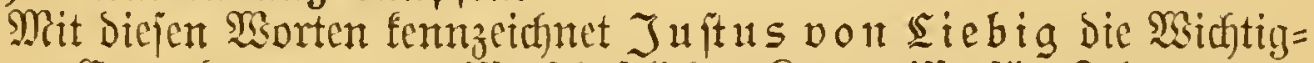

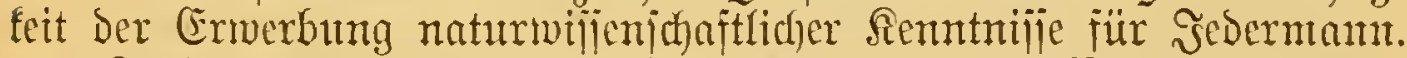

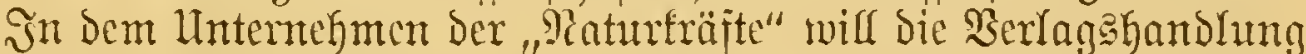

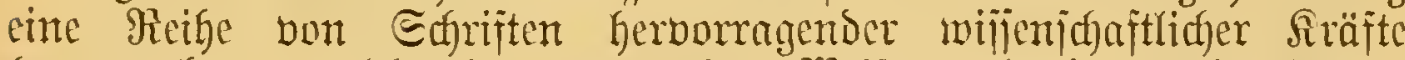

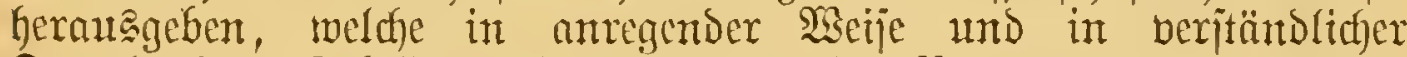

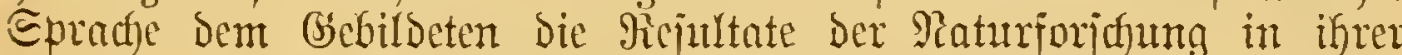

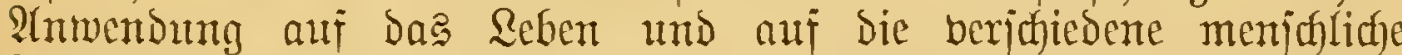
Thätigfeit borfüfren und gleiffzeitig die Sräfte Der Matur in ihrem

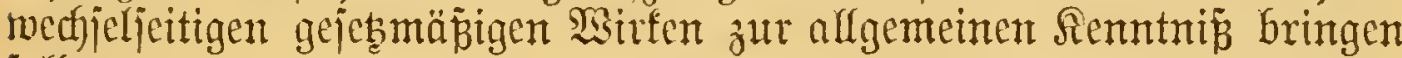
jollen.

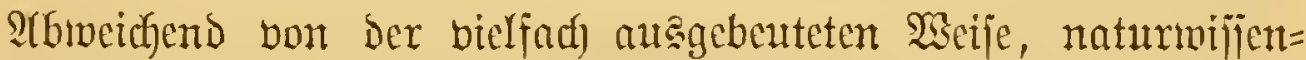

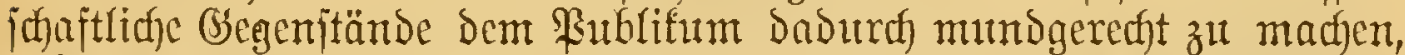

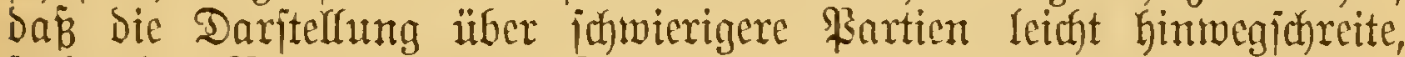

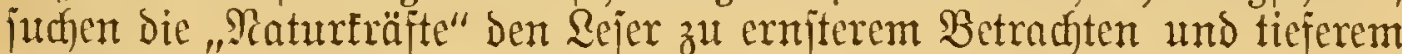
Eingehen anzuregen.

Eo bieten Die Bände Dem gereifteren Serjtande eine belehrente, Godjinterejīante Reftüre, und aud ber Fadjmant in irgens einem

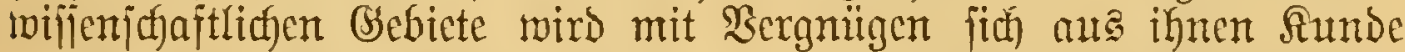
von dem erholen, was in anderen, igm fernerliegenden Theilen bes

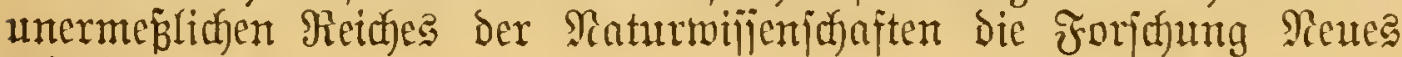
gefürocert hat. 


\section{fois jebt erffhienen 29 foünde,}

jobcr in einer Etärfe von circa 20 Drutthogen.

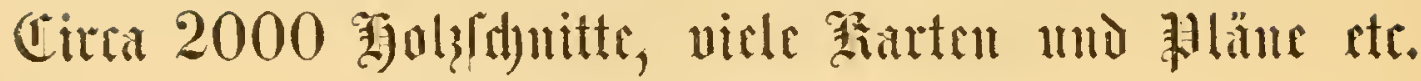 jefjutiden atno erläutern ben Tert.}

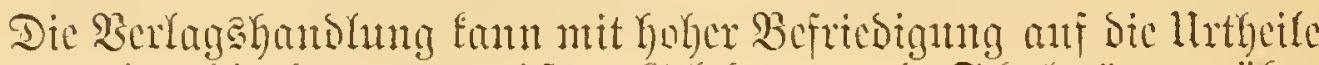

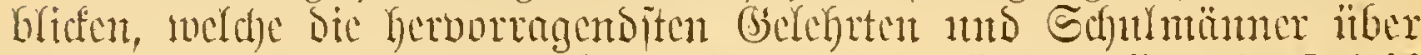

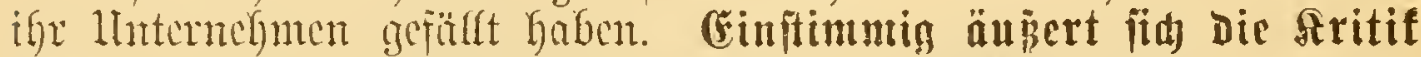

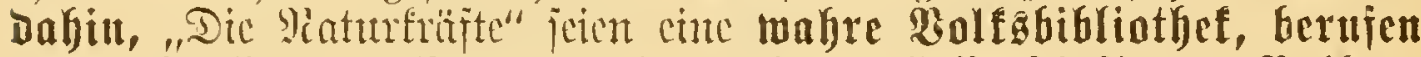

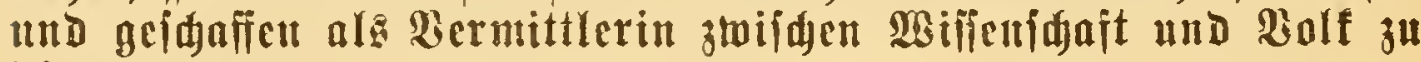
Dienen.

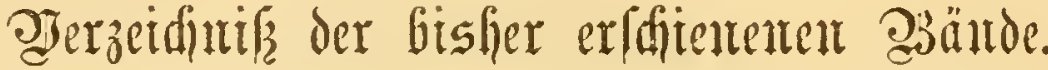

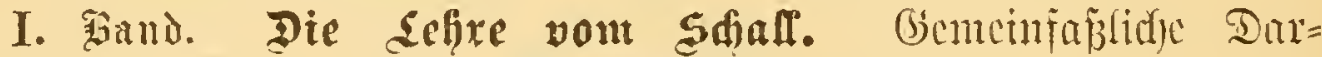

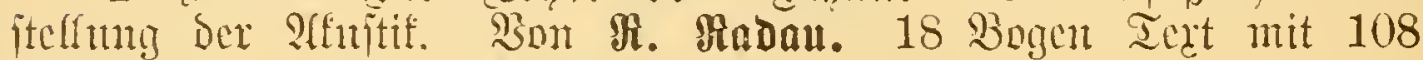

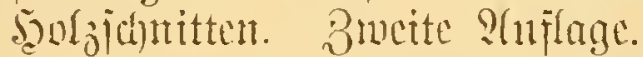

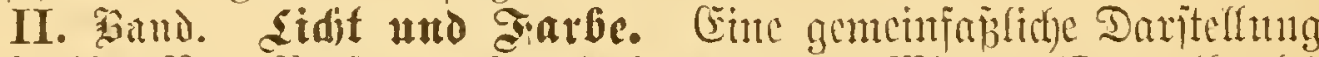

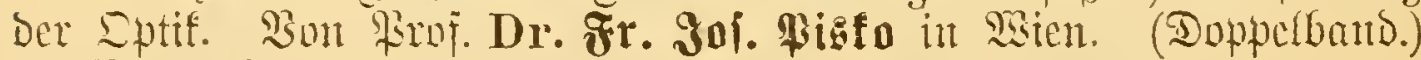

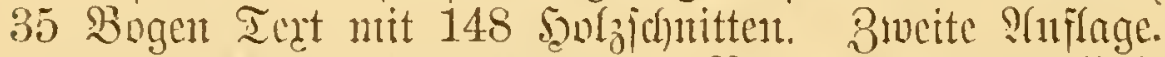

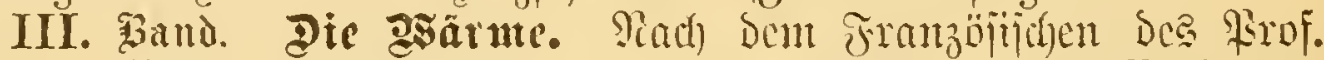

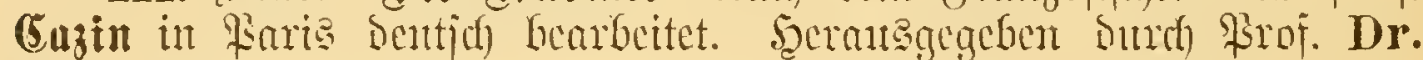

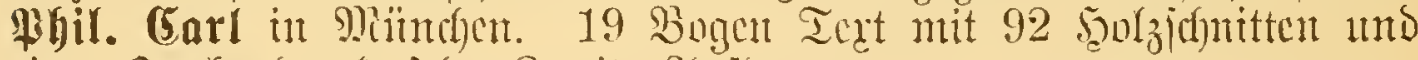
ciner sarbensundtafel. Bucite 2 tuflage.

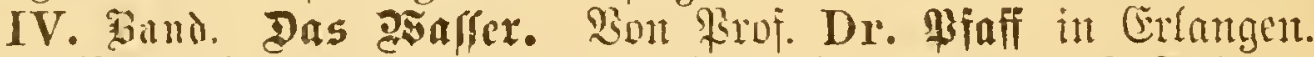

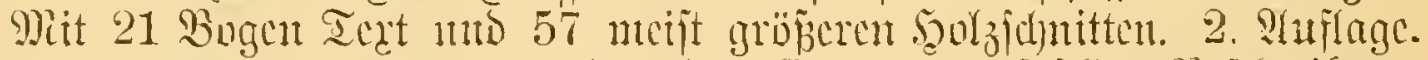

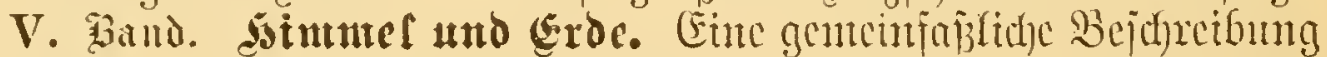

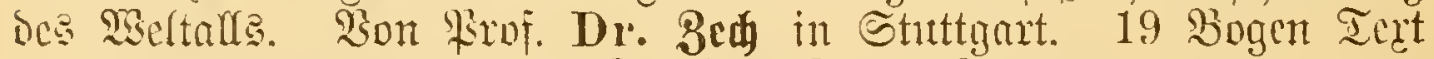

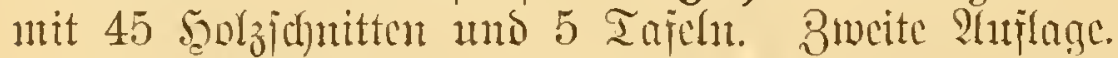

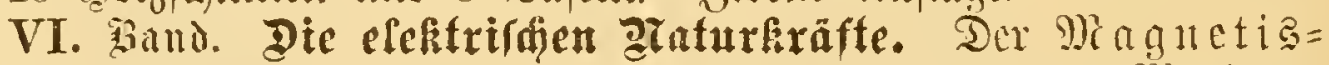
mus, bie Eleftricität, ber gafoanijae Strom. Mit ibren

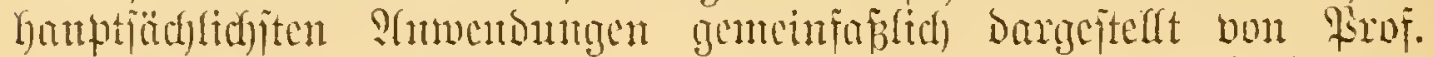

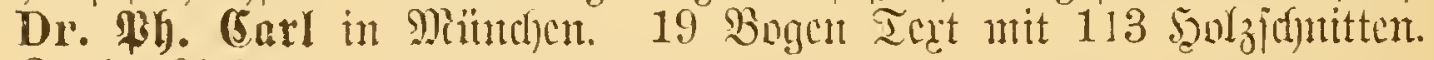
Bucite ?tuflage.

VII. Faand. Dic vufkani/dien Eridjeinungen. Son Rirof. Dr. Friedr. Pfaff in Ertangen. 21 3ugent Tert mit 37 Sgoljichnt.

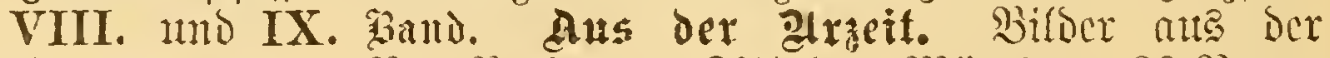

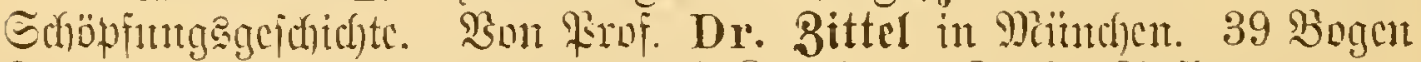

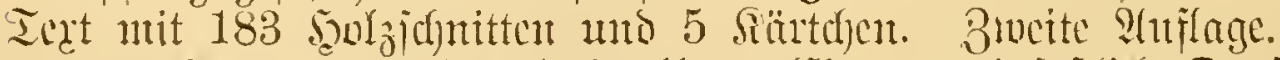

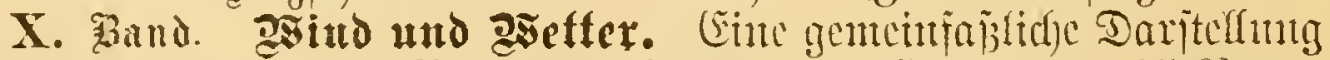

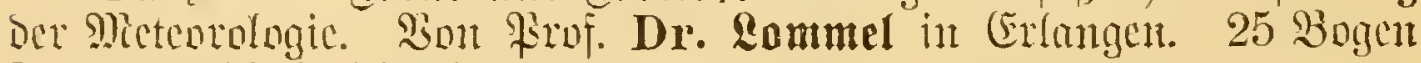
Iert mit 66 soorididnitten.

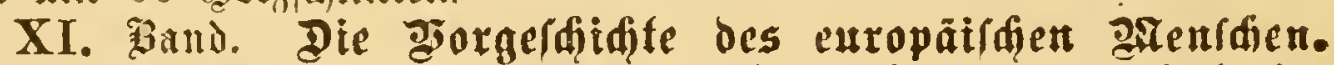

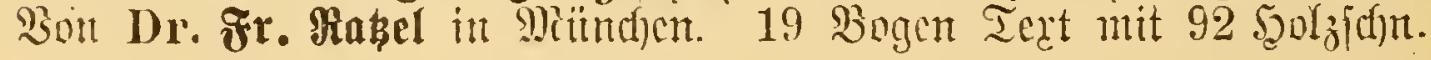




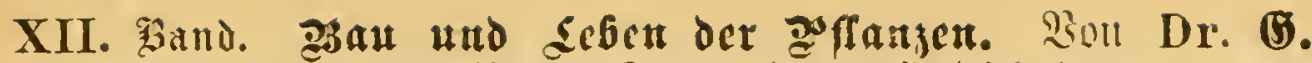

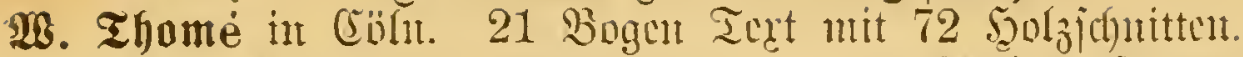

XIII. Sand. Die giredianik des mentididien \$orpers. Bont

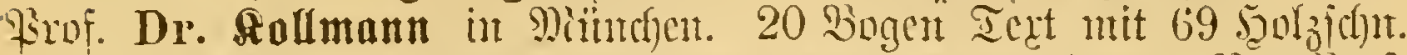

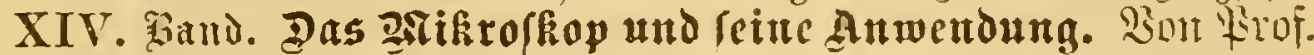

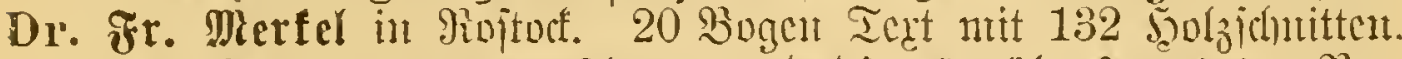
XV. Ģand. Đas Spekfaum und die Spektrafanalyie. Sout Srof. Dr. P. 3ew̆ in Etnttgart. 15 Bogen Tert mit $335001=$ id)nittent unts cinter Tafel.

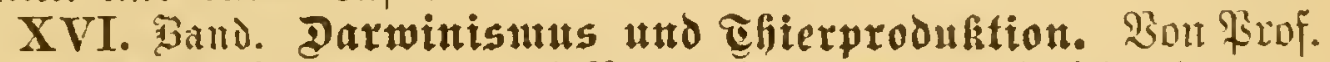

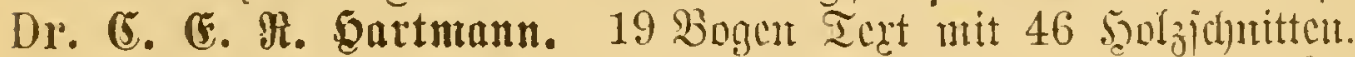

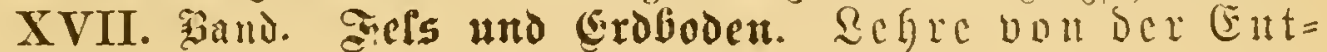

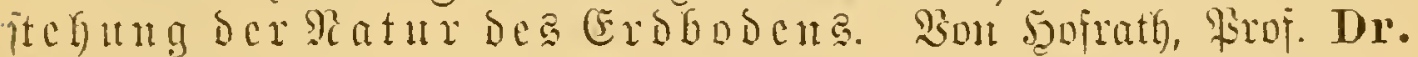

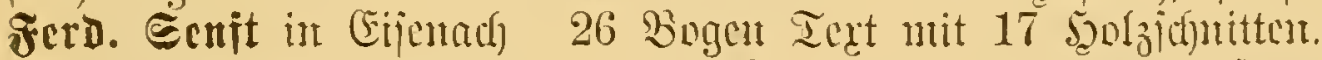

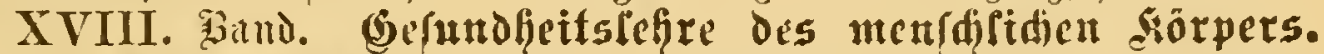

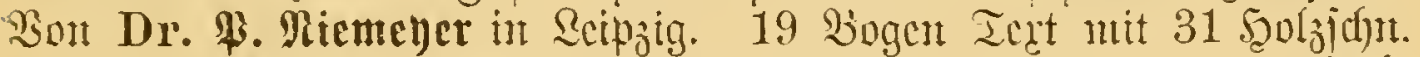

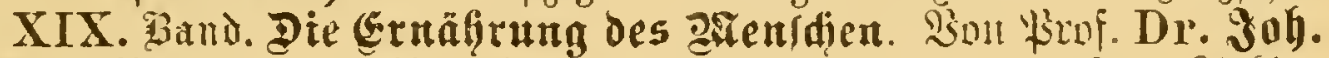

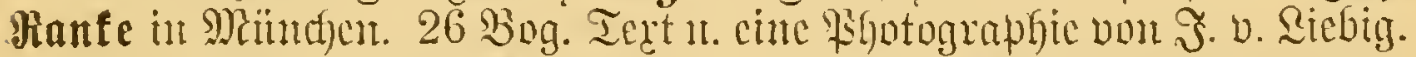

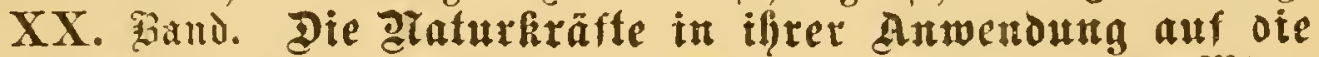
Eandwirffidaaf. \$on Dr. H.

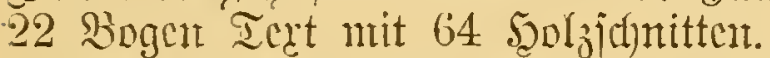

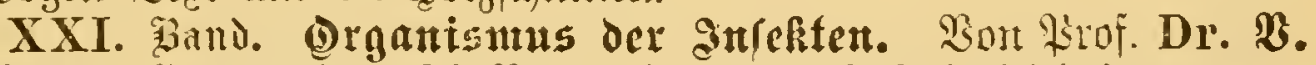

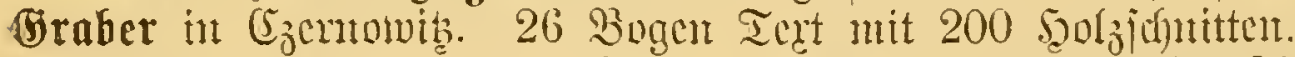

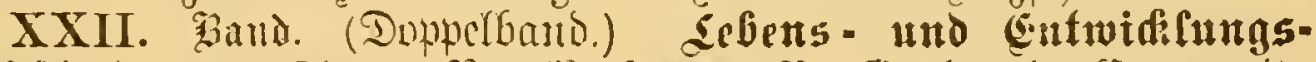

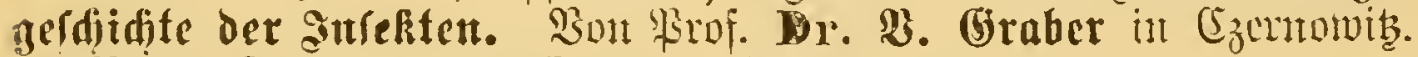
39 Bingen Tert mit 213 Drigital = 5zolzichnt.

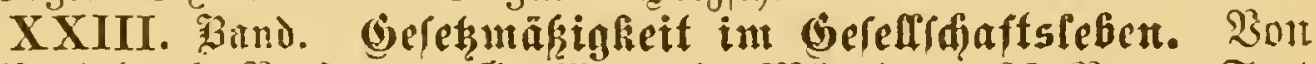

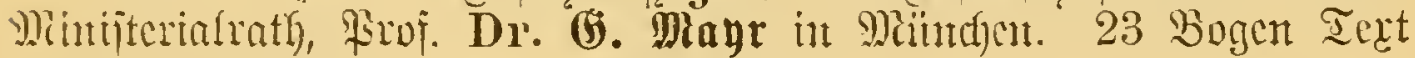
ntit $215 \mathfrak{g}_{\mathfrak{z}}$ jantitten unb 1 fiartogramm.

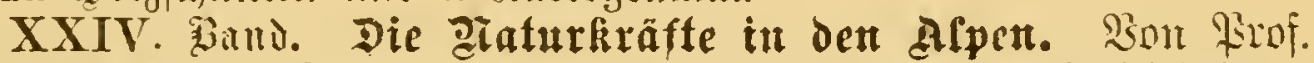

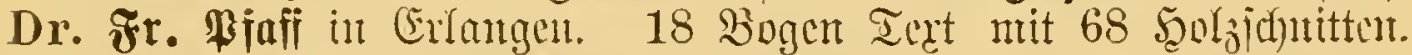

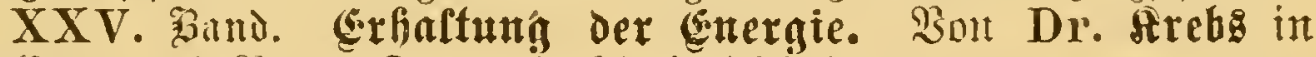

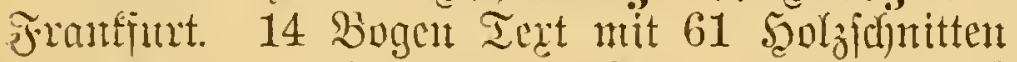

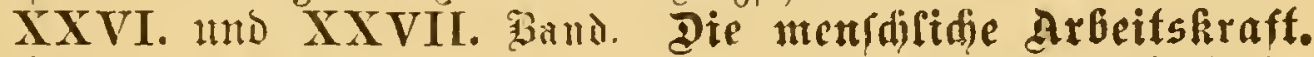

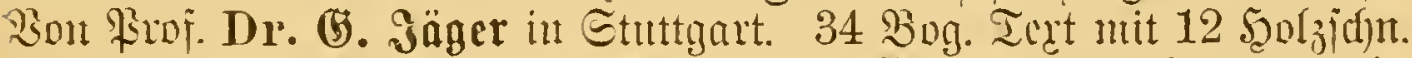

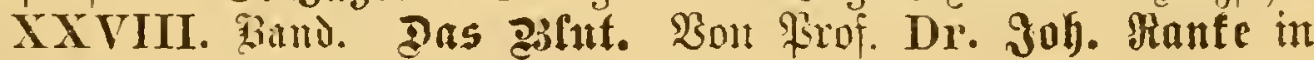

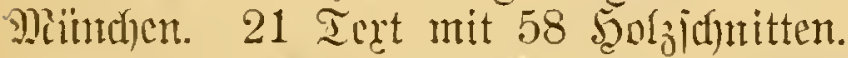

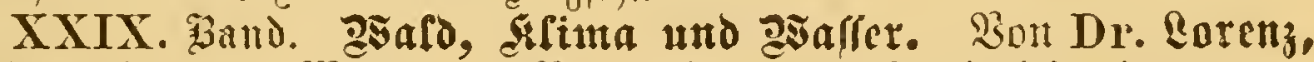

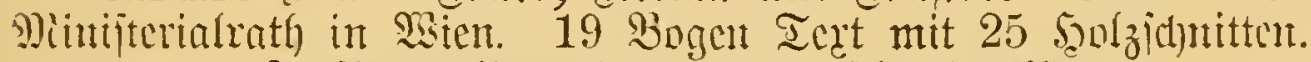

âdin

Geller, Prof. Dr. in Silel, Die \$̇arafiten.

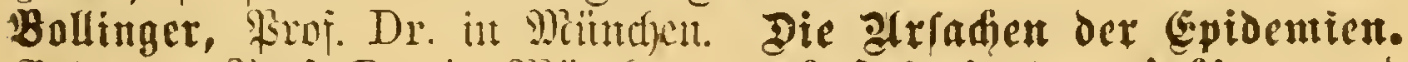

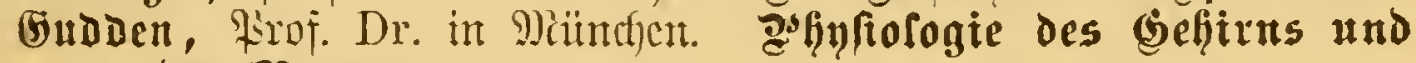
Der derven.

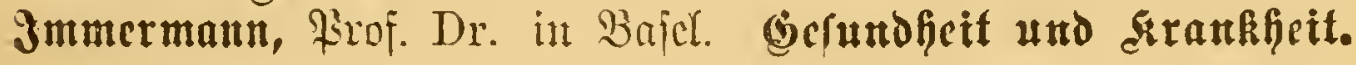




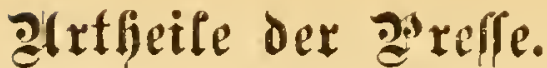

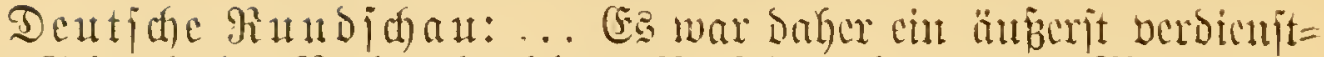

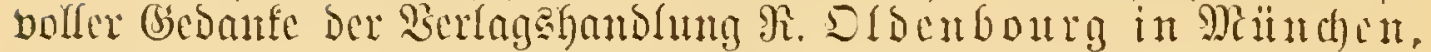

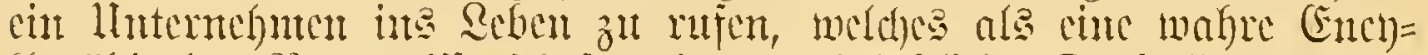

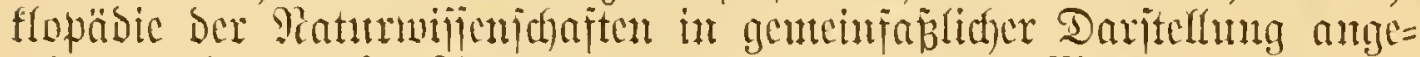

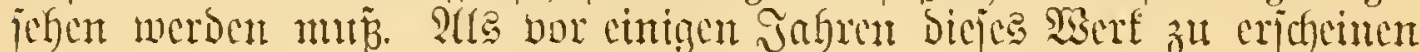

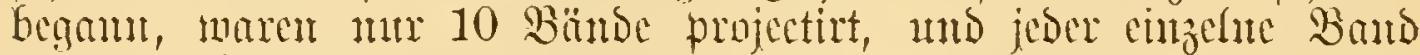
jollte cin bejimmtes Capitel auts ben ?aturwijienjaften, bon eintem bewägrten Jachnante beabeitet, enthalten. Dieje Eammlung fand cinen

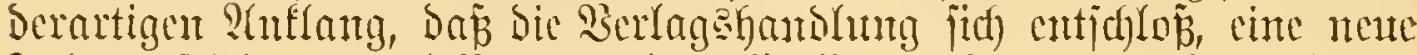

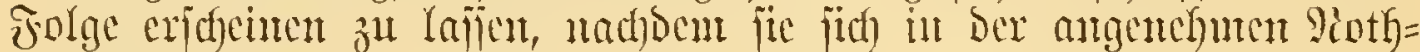

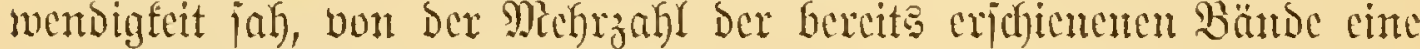

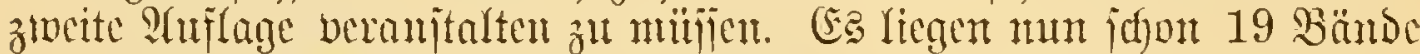

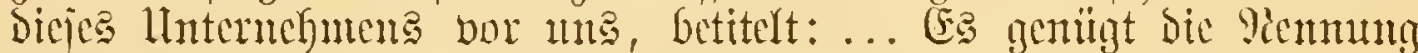

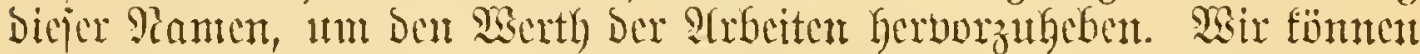

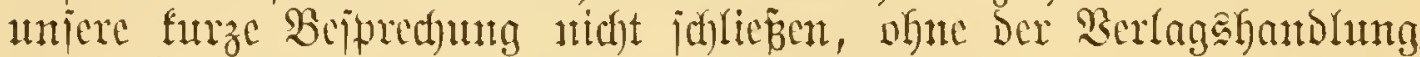

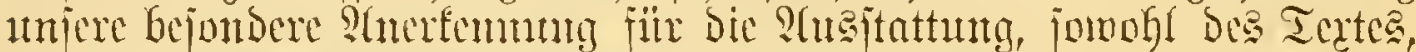

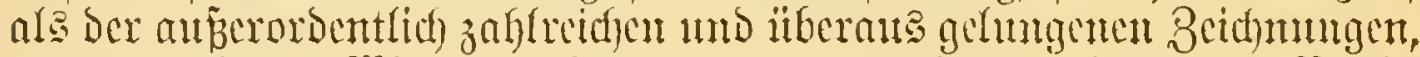

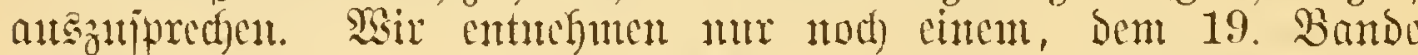

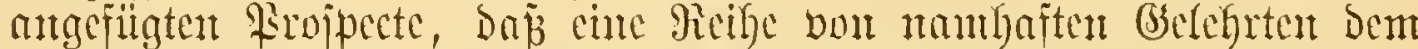

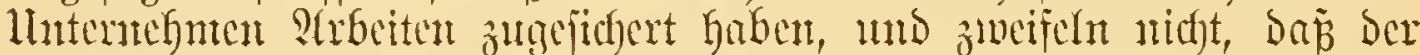
auf bicjent satge bereits crntngene Erjolg in \$Hblifun und in ber Belehrtenuelt ein jetiger bleiben mirb.

Jllutrirte Beitung: ... Dic vorliegenden Bände jeidnen jid) Durch cinc im beiten Ginne populäre Darjtelfung, weldye Durd

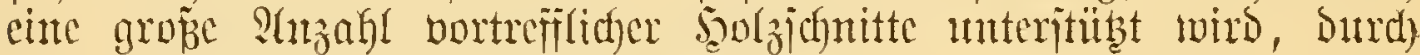
gute QGtejtattung und billigen Rreis at:.

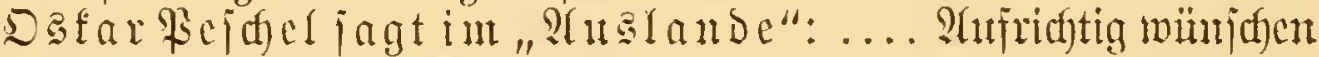

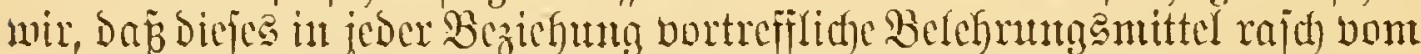

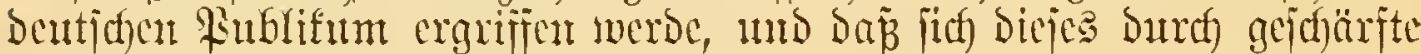

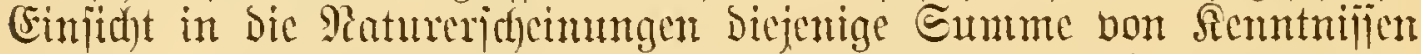
exmerbe, bie gand unerläjlich getworden ijt, wenn nidit ber jogenannte

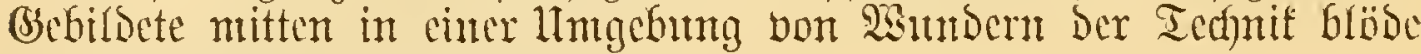
unto bäutrija) herumtappen will.

Aarl Nüller bout salle jagt iu ben, Blättern für

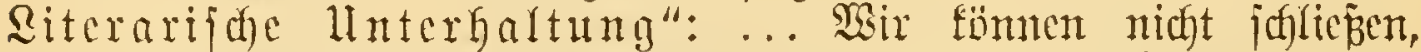
ohne Dem Serausgeber mb Berleger vbengenanter Biblinthef umere warnte Anerfennung abalutatten. Was wir bis jest bon berjelben

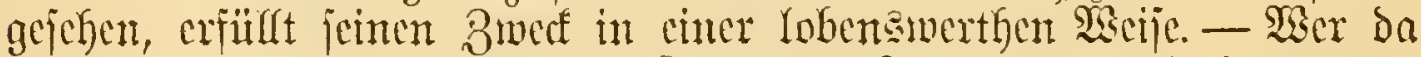

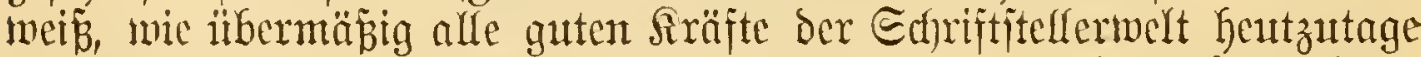
angejtrengt, ober mie vielfach fic verjagt jüb, ber wiro es betwutsern

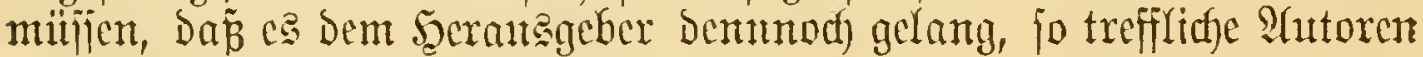
in Sejantmtosutjaland zu finden. 


\section{datarkrafte.}

Bweintojwanjigiter Bunt.

(Dopperbanto.)

$3 \mathfrak{w}$ ite $\mathfrak{s} \mathfrak{a} \mathfrak{l} \mathfrak{i t c}$ 

Sic

gite $\mathfrak{f} \mathfrak{i} \mathfrak{i}$.

3olt

Dr. Dituts Graber,

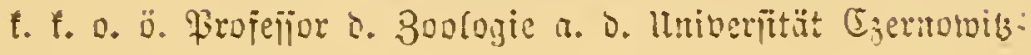

\section{3weiter Elfile}

(Doppcifonto.)

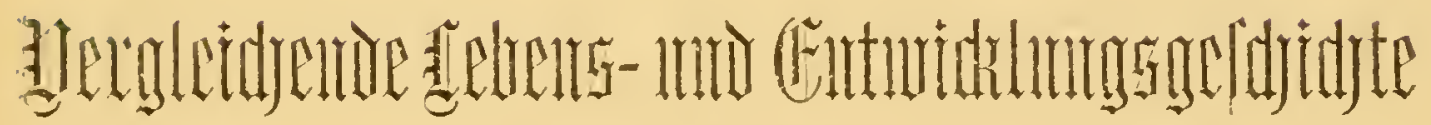 İet a्lilf phtell.}

II. Gülifte.

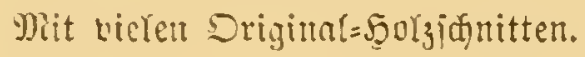

Miiutudeat.

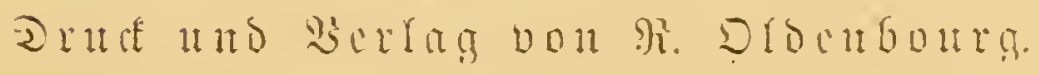

1879. 


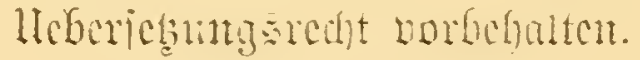




\section{Dorvort.}

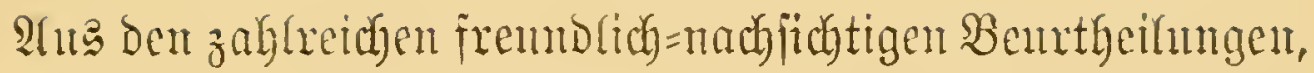

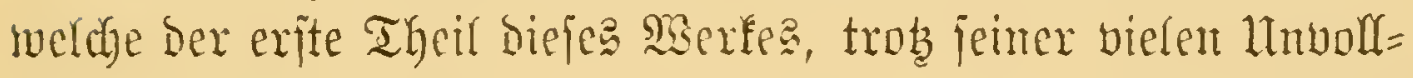
fommentgeiten, zumal in Der bentfichen mb englifichen Prefije

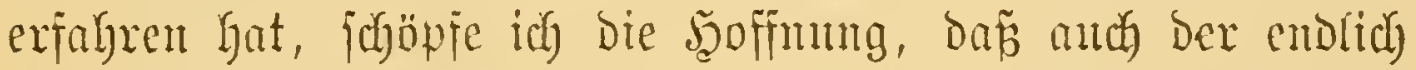
complet vorliegende Doppelband, ber die jo ungemein interejiante Gejujichte Des Rebens und fich eimigen Beifall erringent werde.

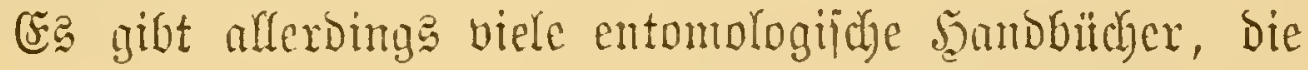
theils viel unterhaltender, theila mateidy reicher an zufanment= getragenen Ihatjacten jub, wie mpere Schrift, bie anf enten

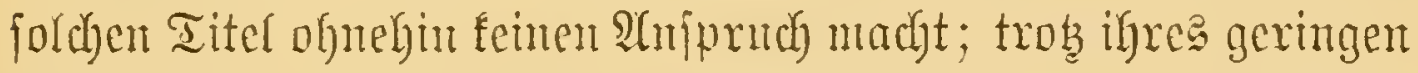

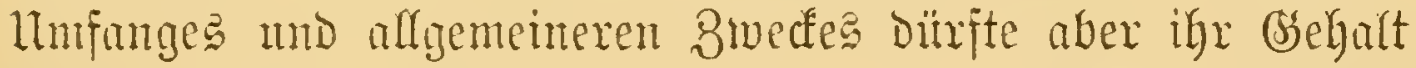

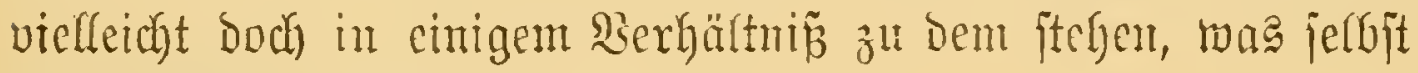
in grö̈ereren Compendien zan fintoen ijt.

Sor affem möbte aber dies zll beadyten jem. (5) lag, jabon von erjten 2 unjange an, nicht im Entferntejtent in meiner

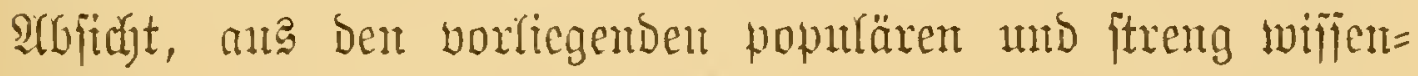

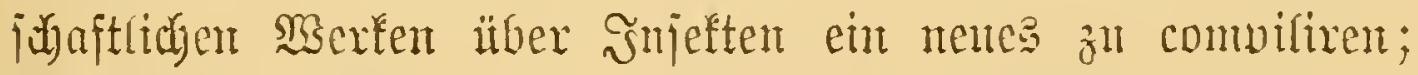

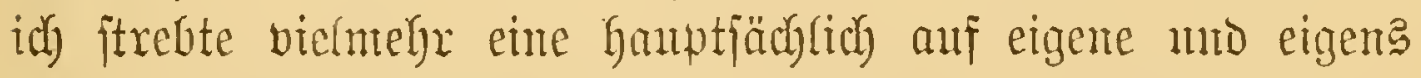
ju Dem Begufe unternommene Foxjhungen begrintote felb= f́tündige, möglichjt anjchauliche mo anregende Darjtellumg

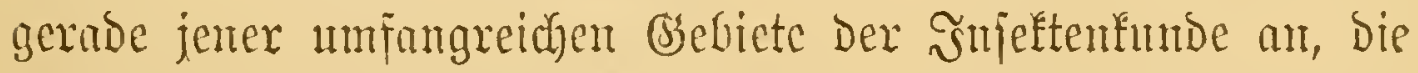

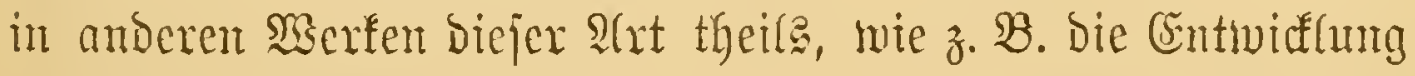
im Ei, gar nidyt behandeit, theila, wie bie Errjheinungen ber 


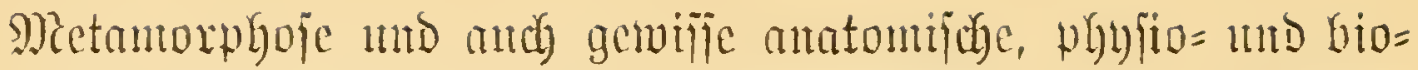

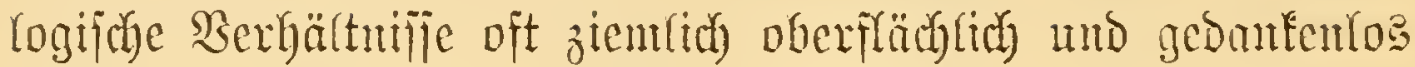
abgetban werben, umb glautot der ßerfajicr nicht bloźz zur Ropularijumg, jonbern anch) zut Ertweiterutg biejer Disciplinen Crintges beigetragen zu babon.

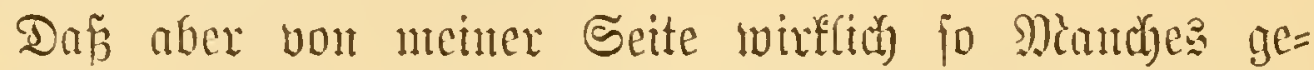

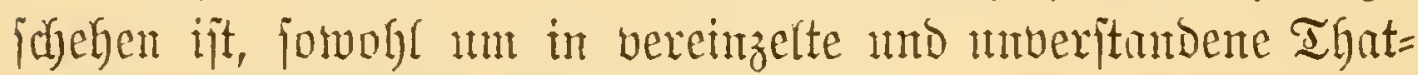

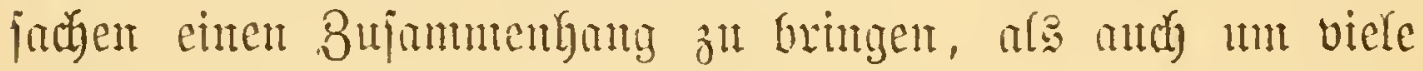

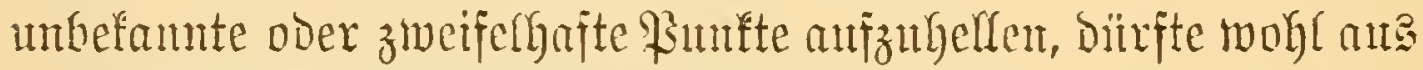

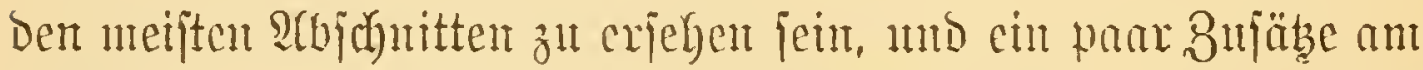

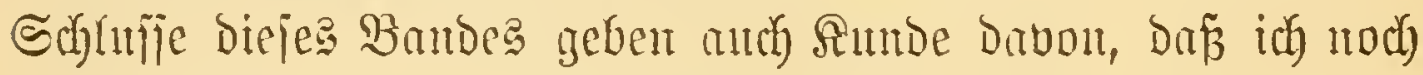
fort und fort an ber Berbejienmy bes Butches thätig bin. -

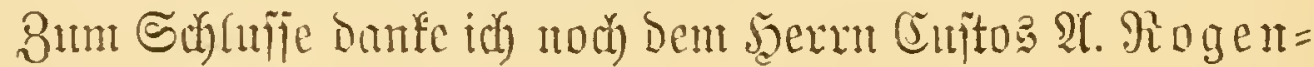
hofer für bie Fremblidfeit, wout er mix jeinerzeit bei ber

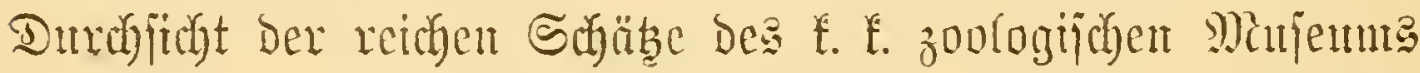

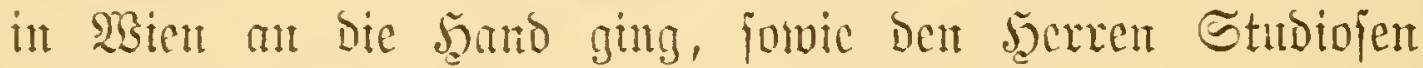

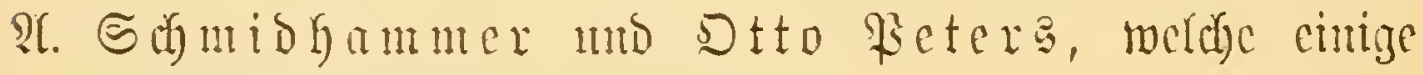

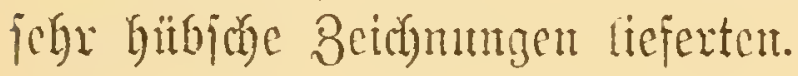

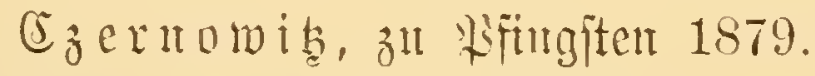

\section{g. (G)raber.}




\section{II $\mathfrak{i l} \mathfrak{a} \mathfrak{l} \mathfrak{t}$.}

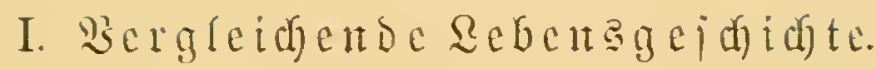

I. Siapitel:

ltmicfut . . . . . . . . . . . . 3

II. Sinpitel:

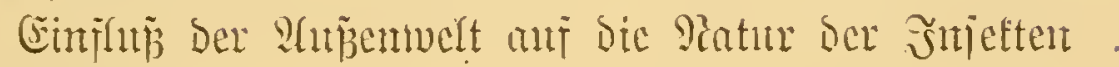

32 III. Sinpitel:

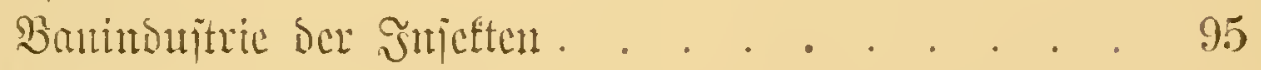
IV. Siapitel:

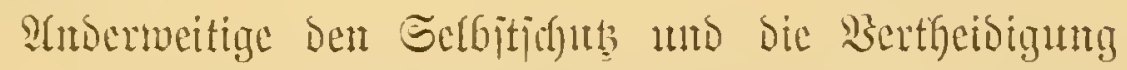

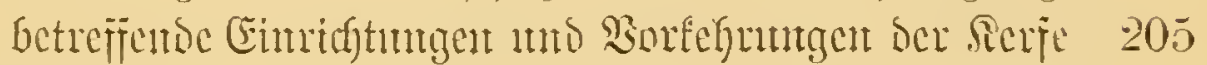
V. Sirpitel:

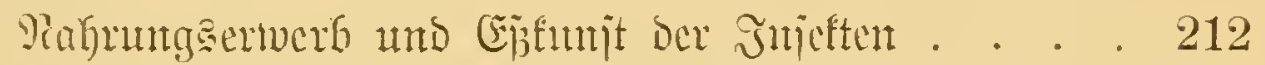
VI. Siapitel:

Gejelfinatalebat der sierie . . . . . . . . 225 VII. Siopitel:

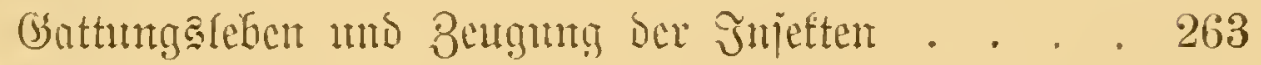
VIII. Rapitel:

Dic Jnjeften als Matummatht . . . . . . . 311

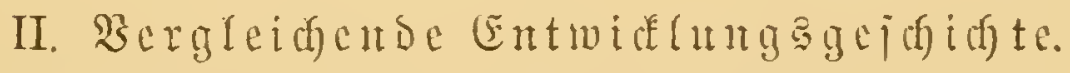

I. Ifetl: Entwidfung int (Ei (Entrigngenteic) . . . . . 371

Erite Sierändorung des Dotters . . . . . . . . 375

Scimblättcr . . . . . . . . . . . . 388

Bifsung Der Entbryonalfillfen . . . . . . . . . 409

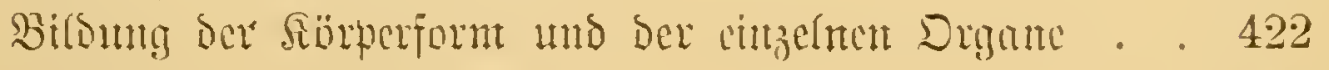

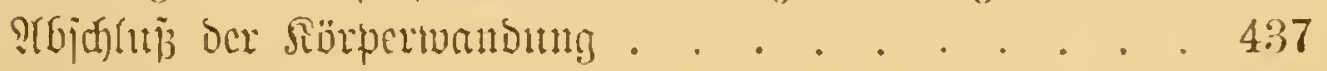


II. Theil: (Entwidefung nad) Dem Serlajien bes Esces (Rojt= cmbringeneje) . . . . . . . . . . . . 449

Edrilscrung ber Mietamorphoic:

Plfgemeine ßeränderungen . . . . . . . . . 464

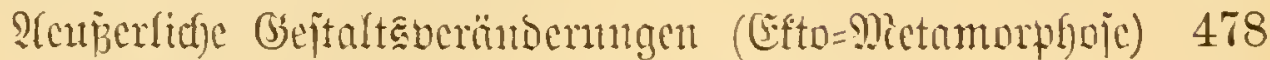

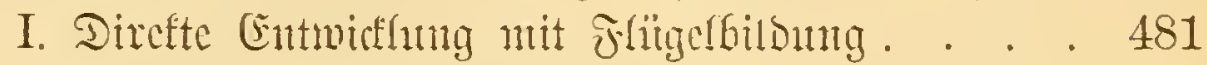

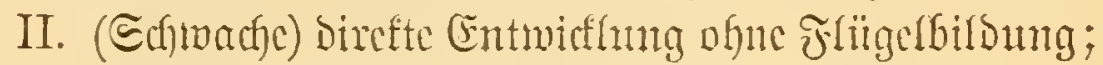

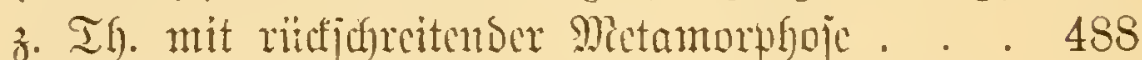

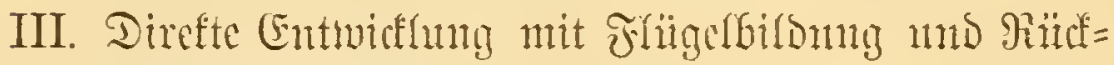
Gilonng provijorijace Drgane. . . . . . . 489

IV. Entuicflnng mit Mnctanorphoje . . . . . . 491

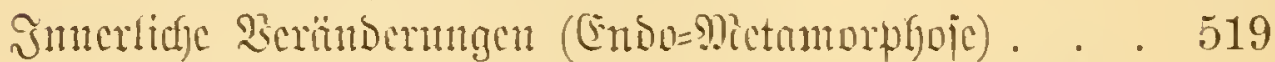

I. Jmmere Beränberung bei bon metabolijefen Jnjeften im Peframeinct . . . . . . . . 520

II. Imnerlicfe (enovgenc) Bilbung bes Jmago gemijick Buciflïgler (Minsciden) . . . . . . . . . 532

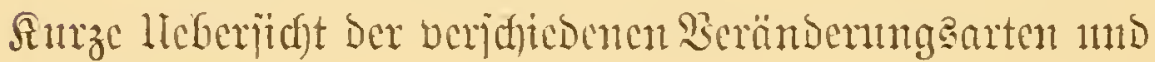

1Tebergänge . . . . . . . . . . . 559

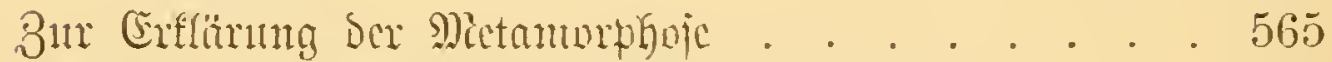

Sirtif ber millfülichen Edü̈pimgengupotheje . . . . 566

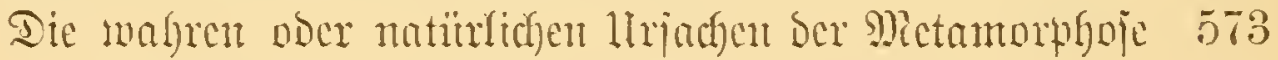

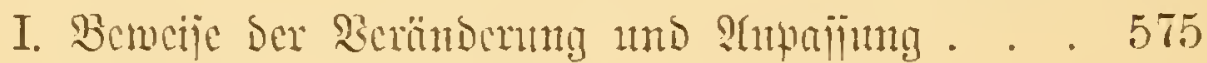

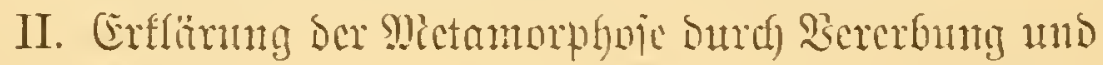
\&upaijung . . . . . . . . . 581 


\section{VII. 㞼pitel.}

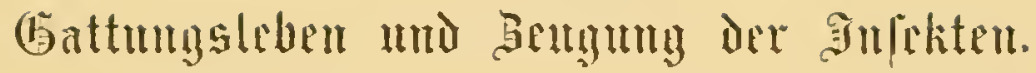

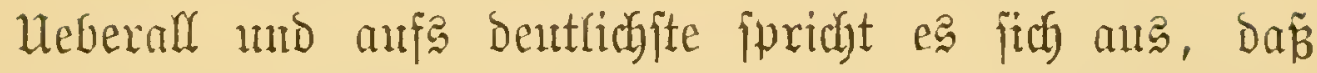

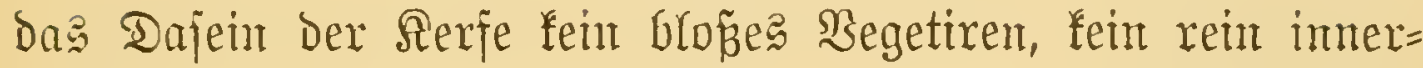

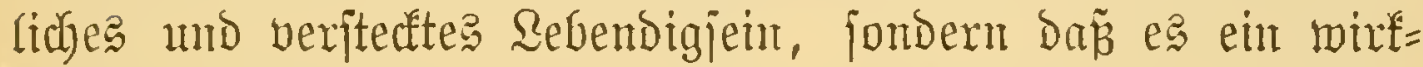
liches und nod) Dazu das betwegtejte, fräftigite und thaten= reichjte Reben ift.

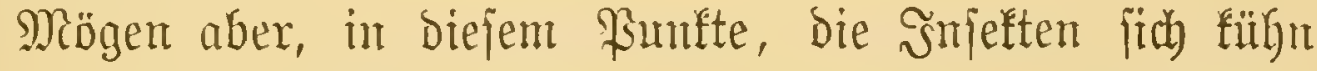
neben bie allerbolfonmenjten Rebemejen ftellen, in cinten verräth fich boch ilyre niedere Stellumg und Seerfunft: in ber

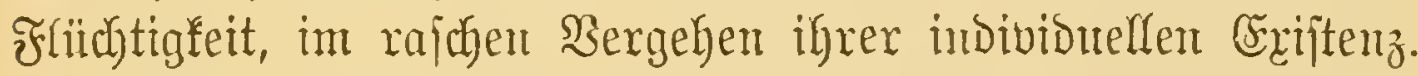

Dex gejaminte Rebertagang des Fnjefts hat, vom Stam = punft des Csinzelnen betradetet, in der That viel Tragifdes, Denn es ijt, als Indivioum genommen, fozujagen gar midhts; es exijtirt, es geminnt. SBebeutung nur in 31 jammentang mit Dem Reben Der $\mathfrak{A}$ rt.

Sici der anfänglidyen förperlichen unfertigfeit verläuft ieine Sugend überats einförmig. Die Natur zrningt ifm freilich sie

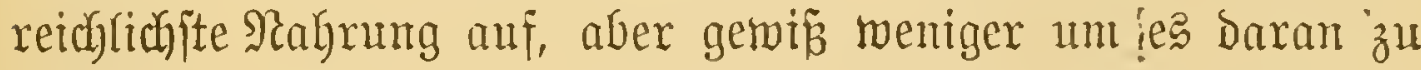
ergöben, als um es für feine fiüntige Beftinmung tüchtio zu machen. Die Rarve ift receptib, um jpäter probuttio jein zu fömten. Die Satur thut audj viel zul ihrem Schnthe, jue lehrt ihr zu bem Zwecke mamnigfache Fertigfeiten und Sünfte, Dody abermale mr, um es bejto ficherer auf Den Puntt zu bringen, "wo fie es haben will". 


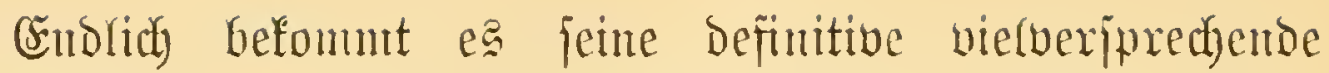
Drganifation, bie ihm eine fajöne Bufmrit eröffnete. Sum

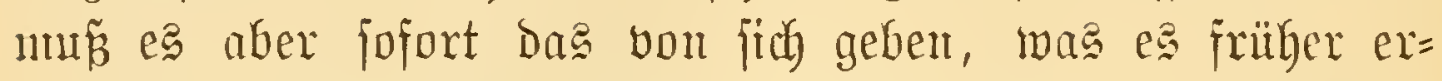

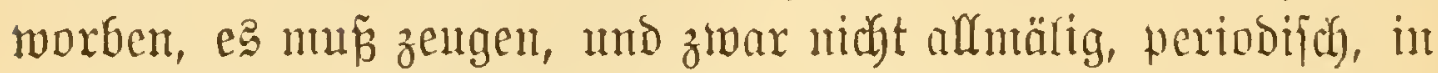
abgenefienen Beiträumen, fonbern bis zux totalen Exjdÿpfung, unt was \{peciefl Den zmueift betroffenen, Den Weibchen nod an Sraft übrig Gleibt, Das mús es aufwenden, um bie Brut zu verjorgen. Sijt es mit biejent, wie wir von friilyer wifjen,

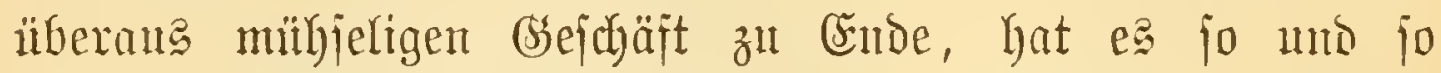

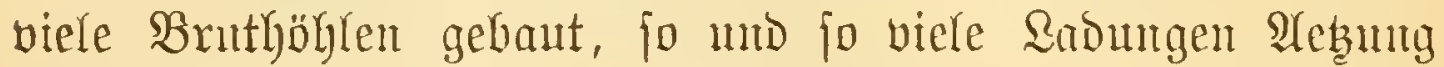

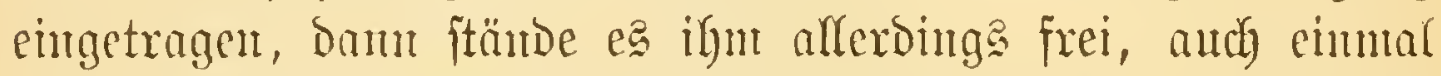
ganz für fith zuleben und ben Rejt feinex Iage angenelym

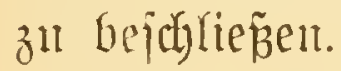

Wie aber foll bas burih bie Beugung gejdrwädhte und

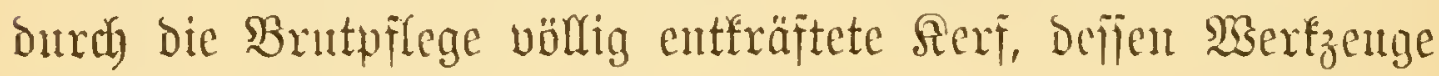
zuden in vielen Fällen äunerfit befeft geworden, ocfien Beine

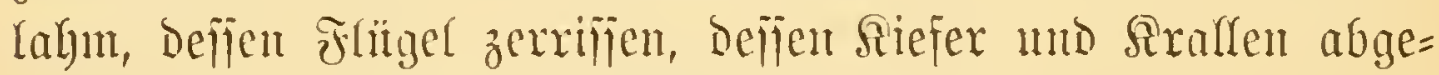
ftumpit futs, in Der Sorge um das tägliche Brod den un= augbleibliden $\Re$ ant mit ben jüngeren nod rütigen Artgendifen aufuequen? Die Funtionen Der $\mathfrak{A}$ rt erlaltug haben igu bie Fäbigkeit zur Selbiter= haltung genomen; wennes and ud lebenmödte, fo fönnte ea bod nidit.

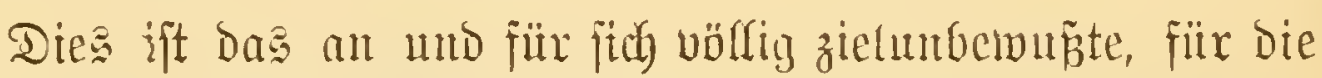

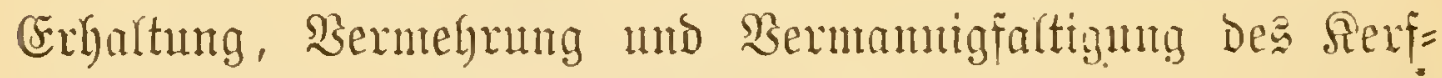
bejtandes aber äunerit żmedfentiprechende Malten ber Ratur, wobei ente Bollfommenheit bie andere hervornit: Der hohe

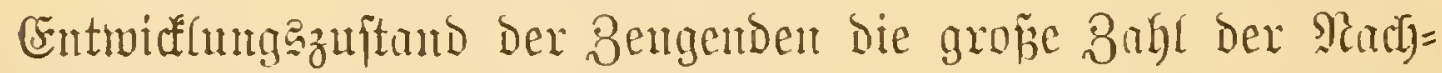
fommen und bie Miäglichfeit, fie gut zu verjorgen; leģtere aber den Bwang, dies zu thun, mo Danit die ftetig

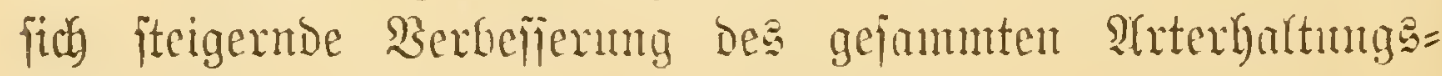
Spparate?. 


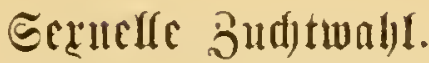

Soweit mijere Erfahrung reidht, finto alfe Snjeften,

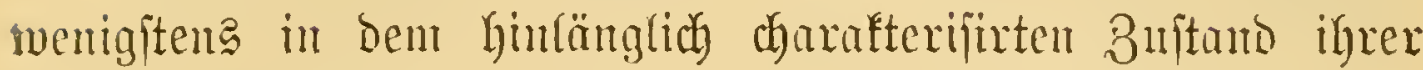

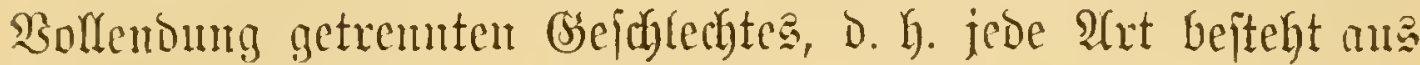

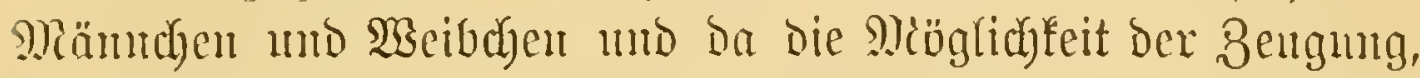
๖. h. Der Rroduftion entmidungäähiger Eier an bas Statt= füben ber Bereinigung Der beiden Scrue gefulipft ijt, jo mun

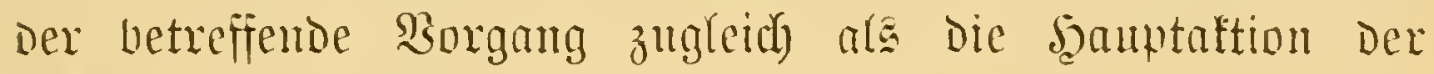
Arterhaltung bezeidhnet werben.

Huld in der That fommt alles auf biejelbe an. \$̧on

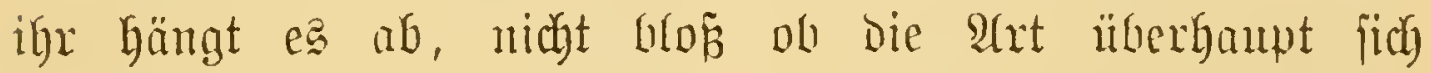
fortwflanzt ober weiter exijtirt, uno wie viele Saare mit ber Artüberfiejerung betrant jüb, es hängt babou and ab, wie Diejerbe überlicfert wirs.

\section{Dies bedarf einer angfübrlicheren Erläuterung}

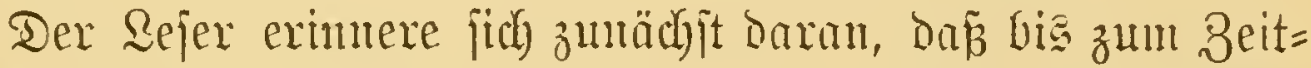
punt, wo die laufende Bseneration bie Bengungäfähigfeit erlangt, ein groperex, ja Der allergrö̈pte Theil derjelber nidyt megr am Reben ijt. Siele fanten fichon ale Enturyonen um, andere als \&arven, ein britter Theil wurbe in Puppen= zuftand Dahingeraffit mo manche musten and gleidj uach

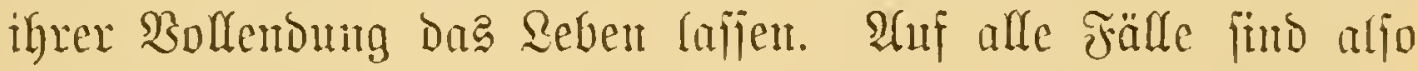
ser Heberlebemben mur äunerift menige, vielleidyt von jeber Brut mu ein einziges Bärchen - vieffeidgt aud bon viefen Bruten nur ein Männdyen ober ein Meirdyen. Das Crine aber iүt evident, ba

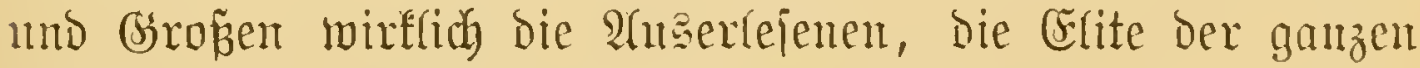

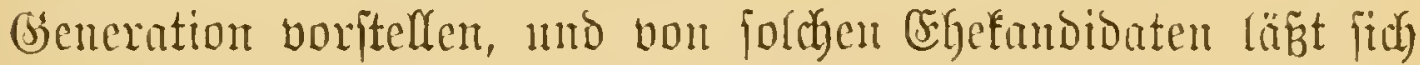

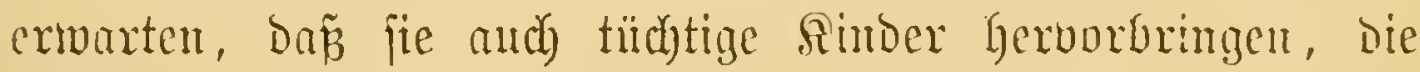

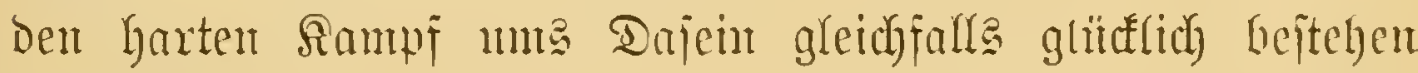
werden. 
Şier crfital fich aber der Sprud): "Biele jüb berufen,

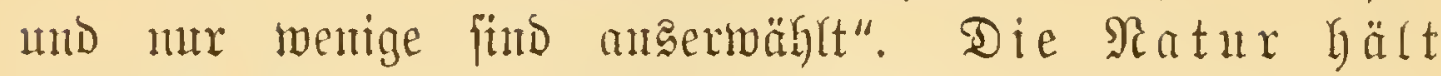

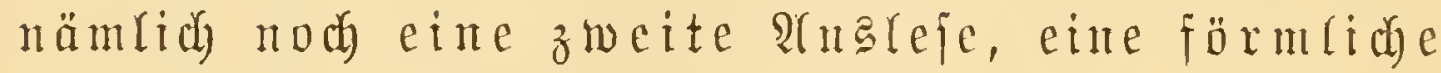
Saperarbitrirang ab.

Die Bebingung und Beranlajing für dieje lebete mo entjacidende Buthtwahl ift aber feine andere als bie ber vorgergehenden, nämlich die Seränderlicbfeit in der ganzen

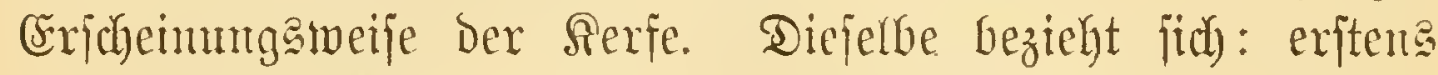

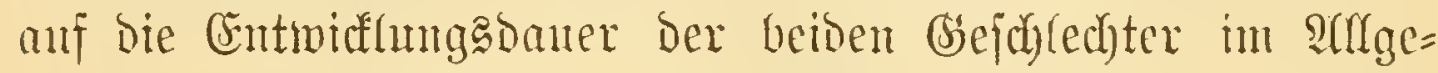
meinen jowohl, al: auf jene ber einzelnen Fnbibiduen; zweiten auf Das Bahlenverhältnif ber beiben Serug mo britteng anf die förperfiche Befchaffentheit der BBetheiligten.

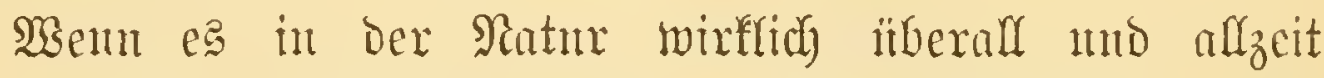
jo nett und orbentlidy herginge, wie vielfad) beganptet

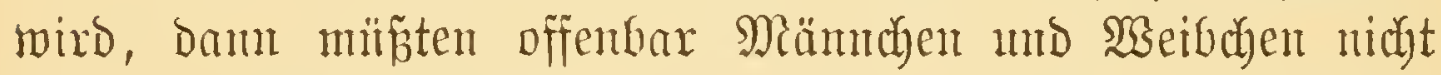

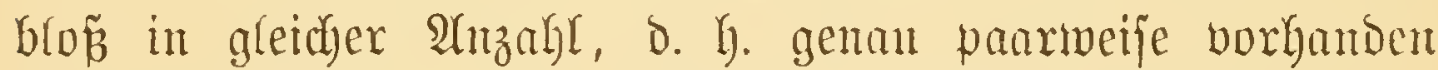
jein, jie miinsten auch möglidhit gleidyzeitig zengungabereit

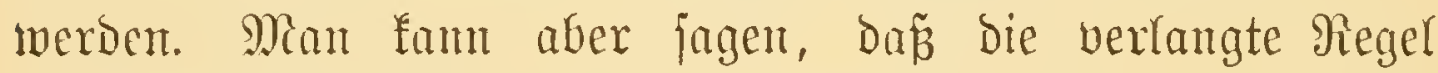

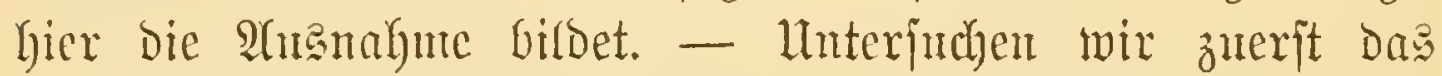

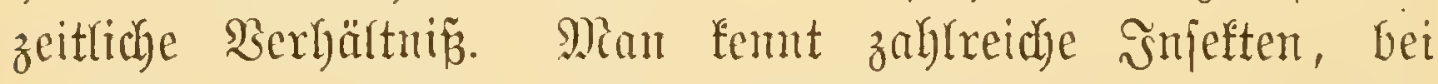

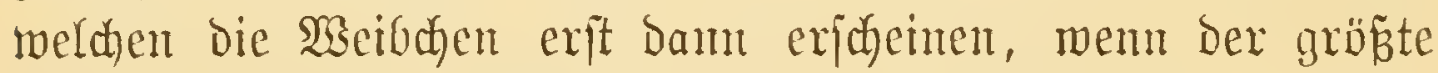
Theil ber frither reifgcworbenen Mämnthen bereits mit Tod abgegangen. Die Folge Davon ift, Daf́, von ifren übrigen

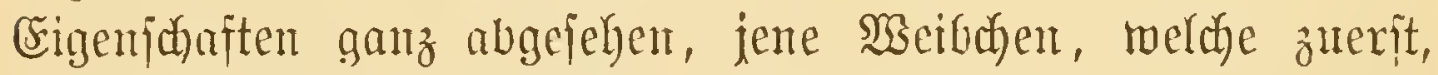
und jene Mäunden, weldye zulebt reif meroen, die meifte 2atsficht zufammenzufommen haben. Da aber bie Cigenthïm= lichleit ifrer Drganifation, bermöge sweldyer fid bie exfteren rafider und bie rebteren Yangianter entroicfeln als andere $\mathfrak{A}$ rt $=$

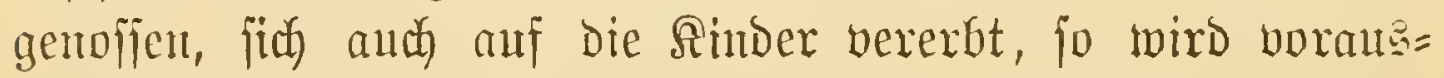

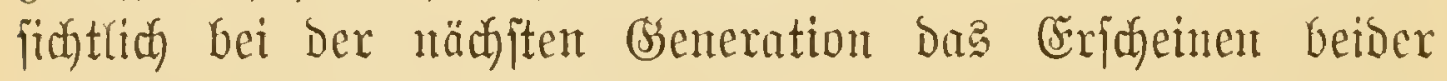
Theile näher zujammenfallen mb fo aljo lebiglich burch

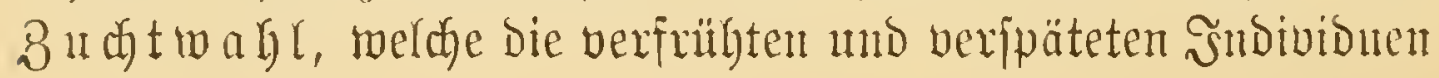


von Der Begattung ausidyliefst, cine fïr die Arterhaltung befiere Sronung Der Dinge angebahnt.

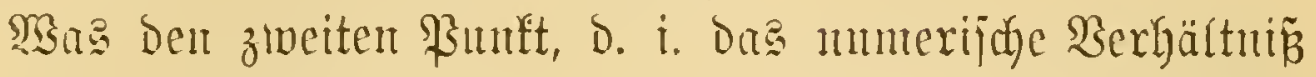
Der betoen Serus anlangt, fo fitto in ber Regel entweber itberfant mehr ober weniger Snltibionen vom einen als vom andern Befdyledyt vorbanden, oder ca tritt, bei jonjt gleider Puzahl, aud Der obige Fall Der ungleidyzeitigen Entwicklung cint.

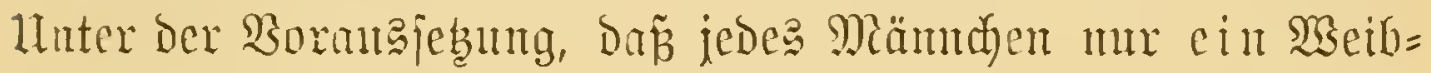
d)en befundetet, wiro bei ungleidfer 3 agh ber beiden Serus

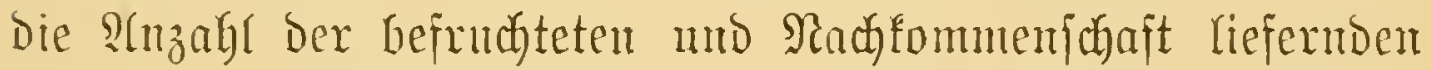
şseinchen anf alle Fälle geringer fein, als wem bei der

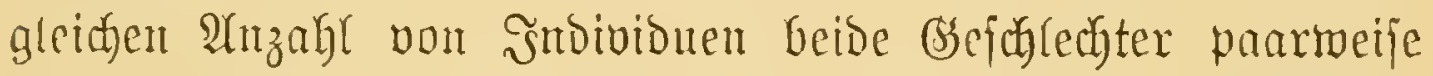
vertreten mären. So merden heippielämeije hei Halictus sexnotatus K., bei welcher $\mathfrak{5}$. Mithler unter 56 Findiviouen

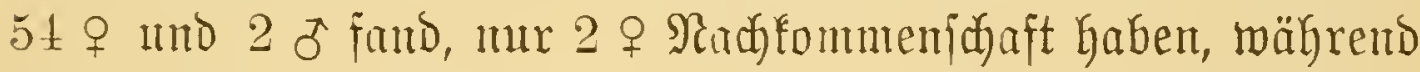
bei gleicher $\mathfrak{B}$ ertheilung $(54+2): 2=28$ eine joldje haben fömten. Ánocrerjeits werben bei Halictoides dectiventris, two unter 87 Fndibiduen fith 2 q und 85 б fanden, gleichfalls

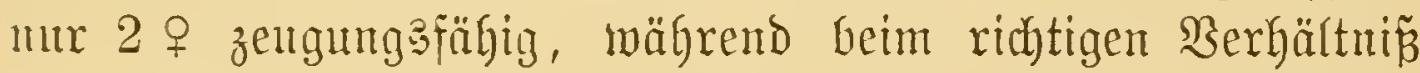
$(2+85): 2=43$ es fein fönnten, fo baź bier aljo bie Natur cinen $\mathfrak{2}$ usfall von 41 mözlichen Bruten veridhuldot.

Unterjuchen wir mun zunächjt ben leşten Der genamuten Fälle, b. i. Den, wo bie Meibchen in Der Mindorzalyl fich befinden, fo ift ber Rachtheil für die $\mathfrak{A}$ rtvermehrung offen= fundig und nidit wieber gut zu mathen. (5) fragt fich mur, ob midyt boch in gerwifiem Simme auth ein Sortheil bamit ver= fnilipft ijt. Dabei Gaben wir abernals ztwei Fälle zu unter=

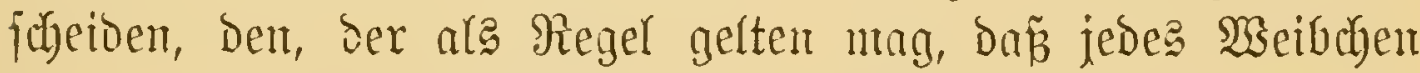
mur einen Mann zuläp̃t, und ben andern, Den wir feinterjeits bei bor Felogrifle feitgejtellt, wo ein $\mathfrak{B e i b d e n ~ b e n ~ B e j r u t ~}=$ tungğfoff mehrerer Männchen in fid aufninme.

Negnten wir zuntäbjt Den lebetere Fall und zwar unter

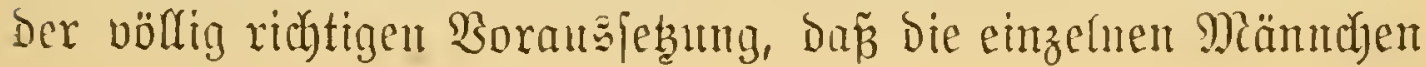


unter jid mehr wentiger verfachieden fint, jo nun man bie

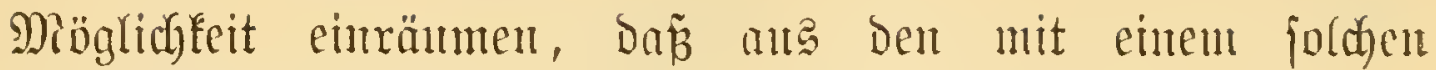
Mijid =Samen befruthteten Eiern Junge entiteben, weldye vor = ichiedente an ihren mäntichen (Erzentzern getrennt vorfoumenoe abünderungen in jith vereinigen, bie alfo von ihrent Erzentgent mehr abweichen, ala lebstere mteremander.

Da aber im arfgemeinen in keinent ber beiden Fälle ein

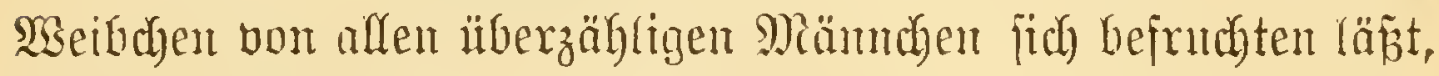
fo ift bie Sanutfrage immer bie, we(d)e dem biefer Bunt theifhaftig werdent. Wärest jie förperlich) gleidggeftellt, fo witrde offenbar dos zufällige Bujanmenjein voer 3 ulfanmentreffen entidyetoent. Da fie bies aber im âlgemeinen nicht find, jo

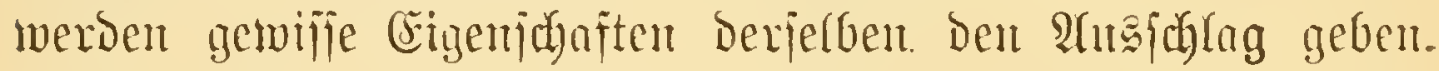
Seldye aber, bas wollen wir gleidy an eimen concreten fort exmitteln.

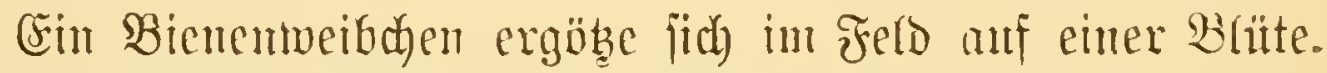
Sn iffer llmgebung und nehmen wir an, in gleidyen Diftunzen vou ihr, aber anferer Segmeite, befünden fich mehrere zeritreute

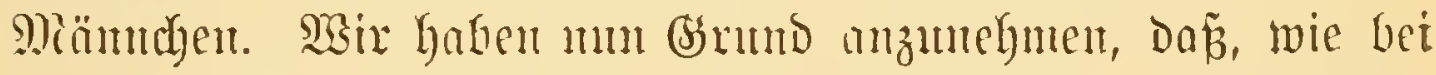
vielen andern Thieren, mud bei ben Sujetten, die Weithen

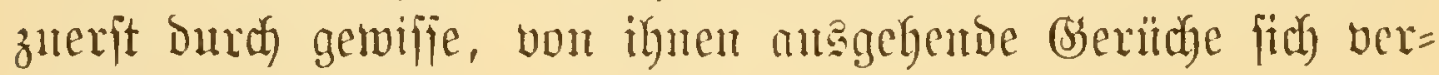
rathent.

Weldyes Mämnthen wird mu zu affererit anf bie Begen=

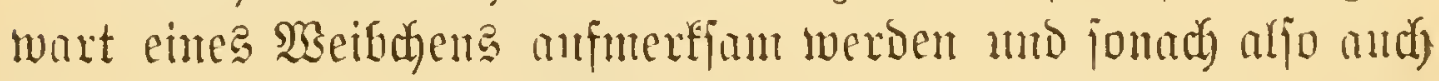

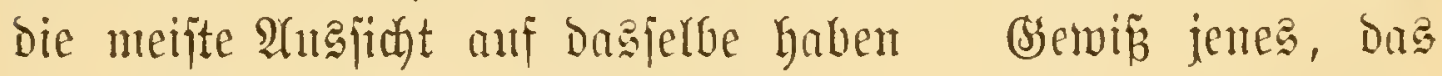

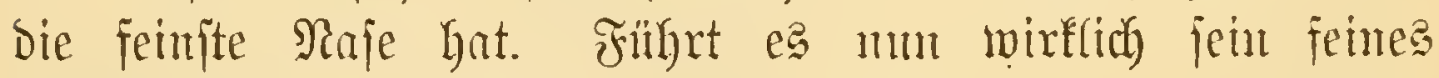
(Seruthorgan zum Biele, fo wiro fich biejes bene auth auf Die Rimber mb die folgenden Beidyledyter vererben.

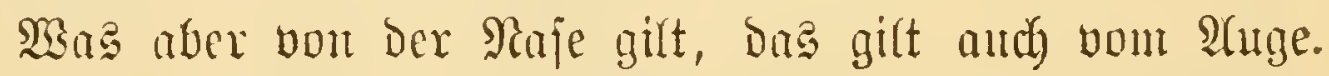
Jenex Mam, der an juärfften und zugleidy an meitejten fieht, wirb bas weibdyen aud juterit erblicfen und in Folge Defien abermals die meijten Egancen bahen. Dasjelbe ift 


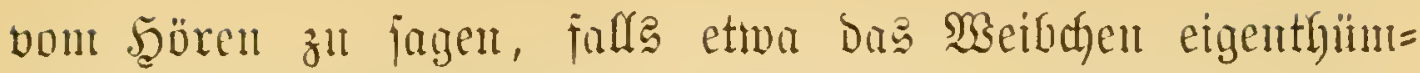

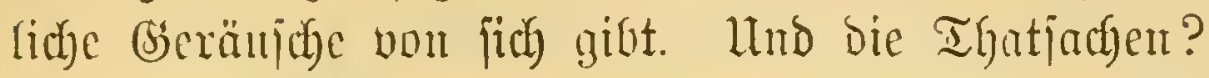

Meber bus Befjerfein ber Mäunernujen wifjen twir vor= Derfgand alferbings nichts, eben fo wentig über bie Shren, die wix ohnelin mu vermuthungasweije femen. Die Átugen aber find in Der That bei vielen Sexpuämuchen jo arffallend gröper

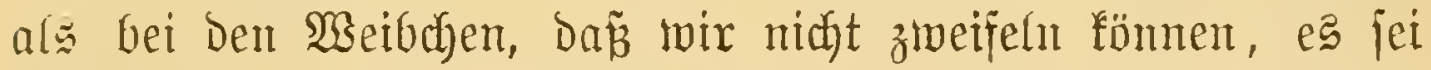
dies eine anf Den Bsejhledhtsperfehr bezügliche भuszeidumg.

Seben wir jebzt den Fall, Die freienden Bienenmämudyen rörben oder jähen bus Weibdyen gleidyzeitig, ober jie nähmen Dabon gar nidyts wahr, D. h. jie milisten exit eins fuchen gehen, weldhes möbte dam wohl zuerit ans Biel gelangen? Doch unjtreitig das, bejien Frügel ober Beine am bejten organifint wären. Die Eonjequenzen fint aber wie nben, und

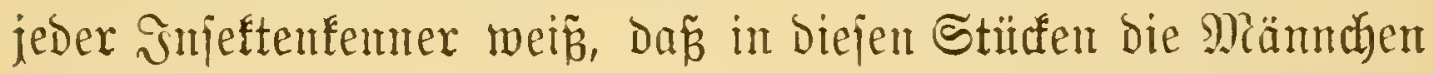
theils untereinamber, theis den Siseibdyen oft jegr überlegen find.

Dies ift Dex Rampf umb Dajen refp. unt bie füuftige Exiftenz Der art unter Den Mämnen, bevor jie nod

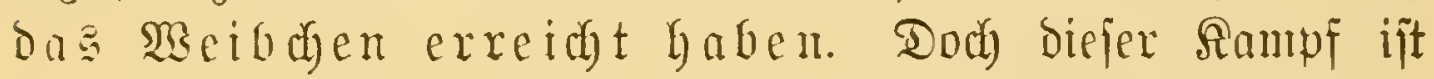

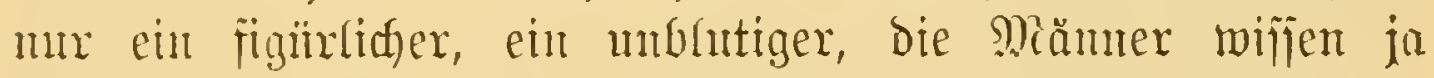
hänfig gar nichts bon einander und an wenigiten, daź fie Bibalen futo.

Seben wir mu den Fall, ber fich nicht bloź hie und da

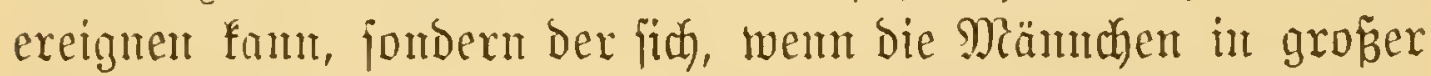
Ueberzahl jumb, jehr oft exeignen un $u \tilde{\beta}$, Daz melyrere Freier gleidzeitia anf ein $\mathfrak{B e i b c h e n ~ j o p e n , ~ w a s ~ w i r o ~ s a m ~ g e i d e h e n ? ~}$

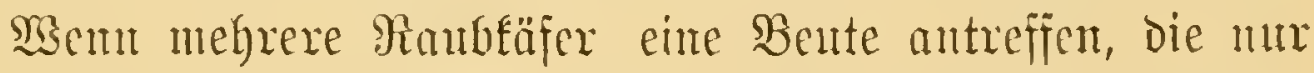

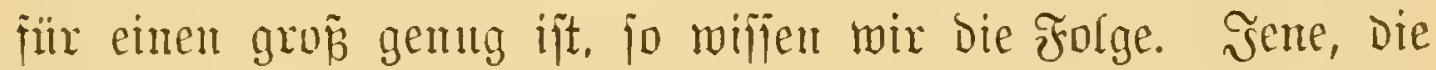

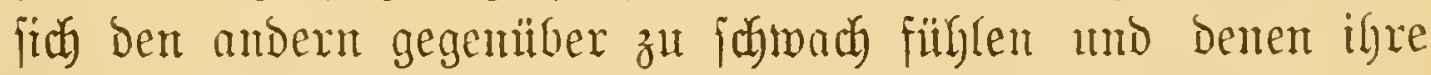

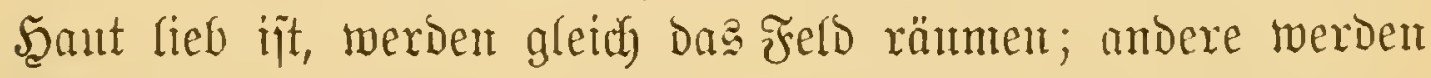
(ith) vielleidyt Durdh eine brohende Bseberde eines Rameraden

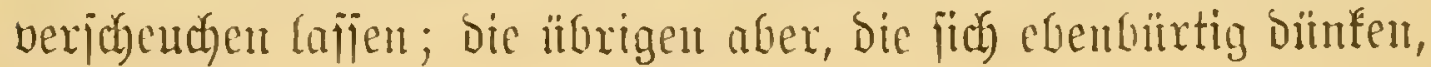


weroen fird um die Bente ranfen, und Dex ftärffite, Der bejt= bewaffnetite, Der geidjiftejte Fedhter wird Sieger bleiben.

Und jolfen wir etwa glauben, ba pinem gut gerathenen

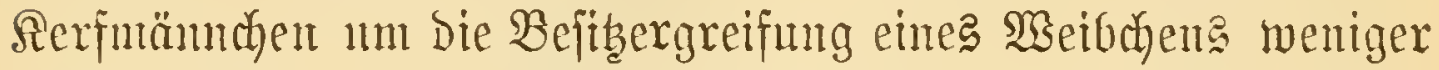

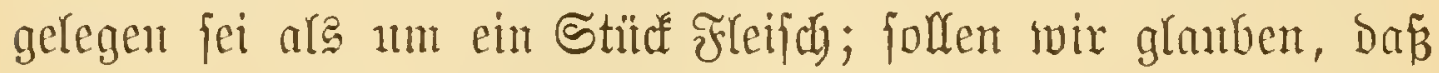
cr anf ben Bsegenitand feinte heftigiten Sertantgens freimillig

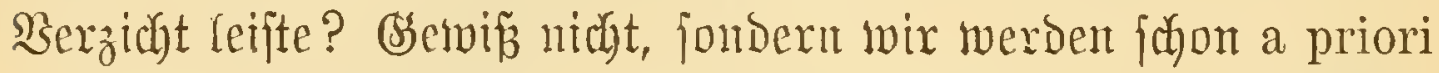

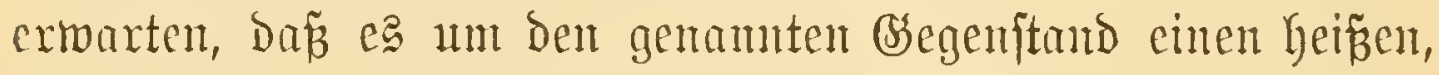
ja unter Umitänden einen blutigen Streit abjebst. Dae jodjeint

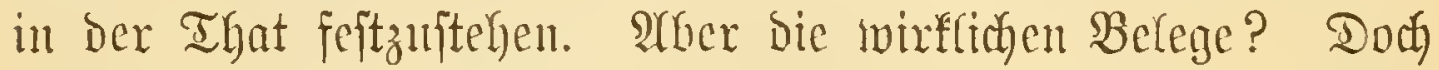

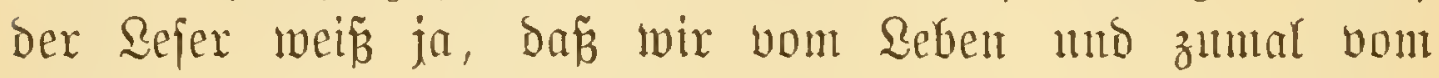

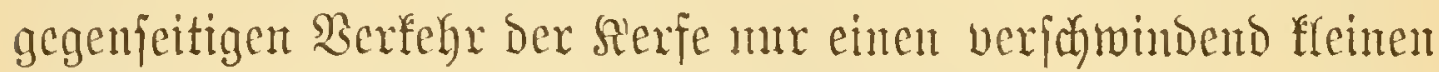
Theil femen, mo vieles anch me immer verborgen bleiben wird. Doer wie folfen wir j. B. exfagren, was, hod oben in Den Rüften, Die Bienen mo F́tiegen, die Ribellen und Falter unter fich alsmachen?

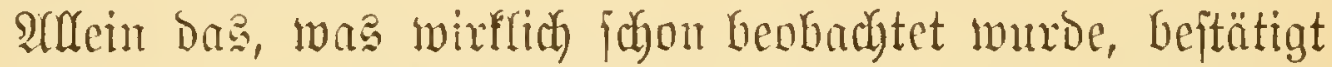

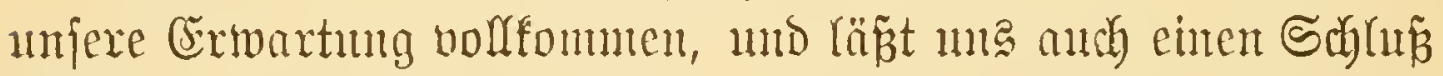
zieben anf jene Rerfe, die ung bie gewifjen Gseheimuifje now nidat verriethen.

Dañ bie Miämuchen friegerifatber Sierfe, wie Die Caraben,

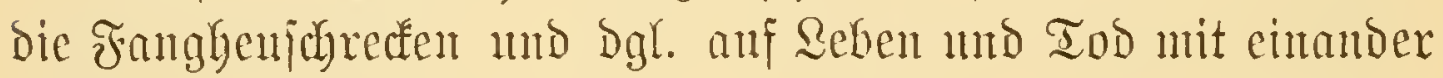
tuxniren, ifft felbjtberitändida; bie anjcheinend zabmeren Sippen,

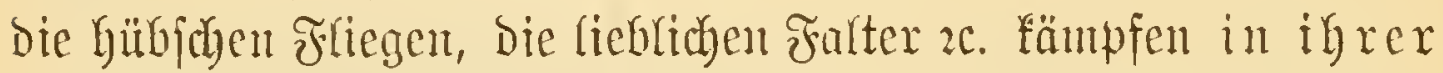

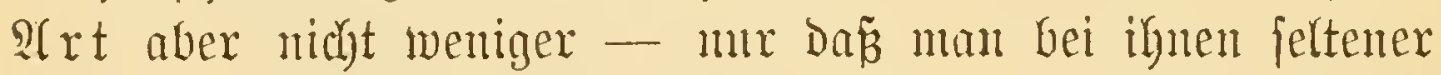
abgerifjente Frlügel, Beine, Friblex mo Dgl., vom ftattgefundenent

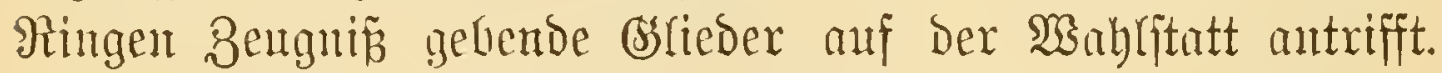
Brar originell ift mter Anderm das Berfahren gewiffer Bienen=

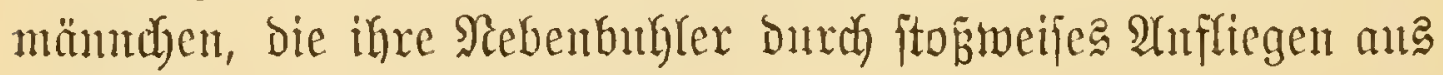
Dem Sattel zu heben fuchen.

Und weldyes Männdyen wird mun entidid ben erjtrebten Bejtb erfangen? Dhne Bweifel jente, Das ifh an meiften versient, ๖. h. Das fich um demfelben die meifte Miige hat 
foften lafjen. Die notgrwendige Confequenz Davon ijt aber,

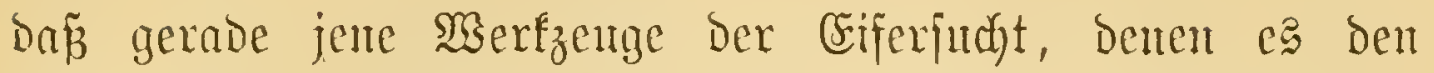
Sieg über jeine Rivalen zumädhjt verbantet, aud anf bie

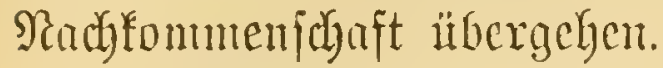

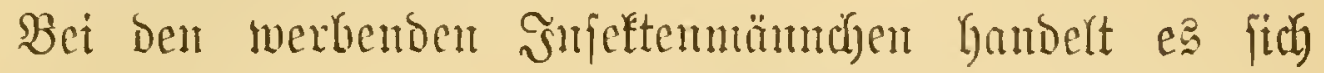
indefijen midgt allein danm, die Rebububler bei Seite zu judaffen; es ijt évenfo wichtig, fich im günftigen Montent

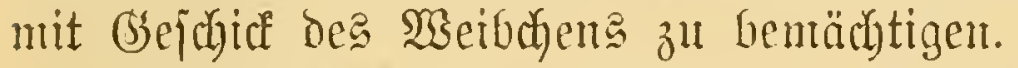

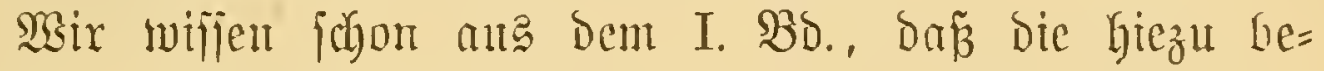
ftimmten Cimridytungen bäufig nody viel complicirtex fint

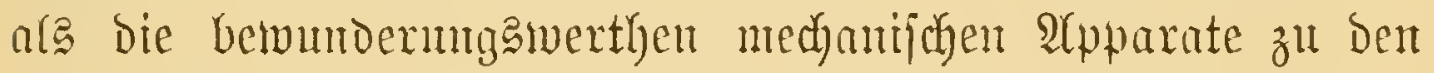
vielfachen ફ̧andolumgen ber Sirterbaltung.

Şiebei Denten die Crntomologen aber gewögntidy mux an

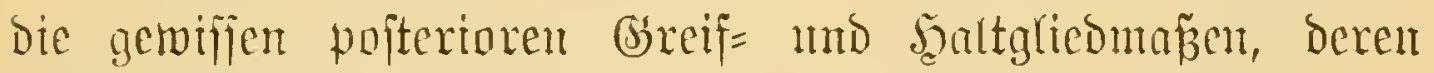
Mamnigfaltigfeit befamtlich alle Boritelfung überjteigt.

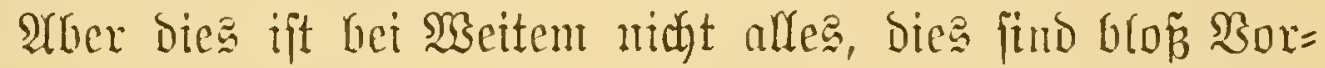

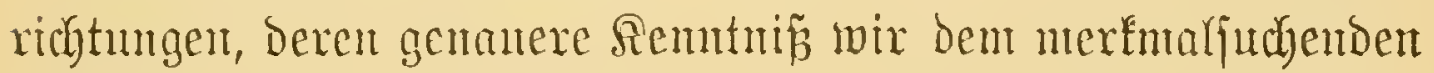
Áug' des Snftematifers verbanten.

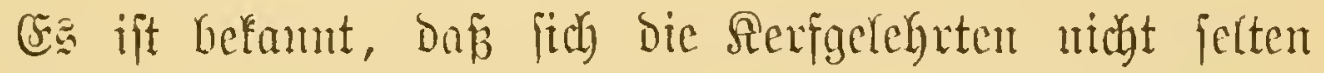
Den Ropf Darïber zerthed)en, wozu, freciell bei Den Mänthen,

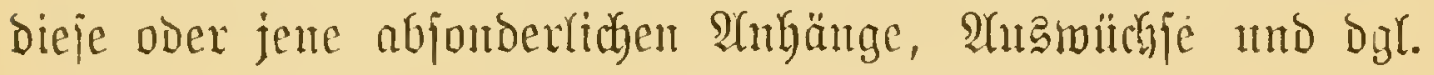
Buthaten gut fein mögen, uno fie find leidgt Dazu geneigt,

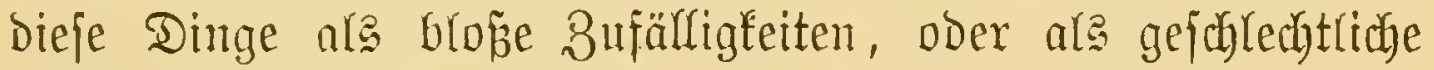

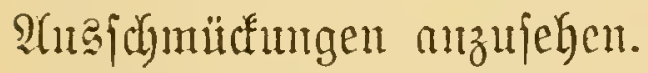

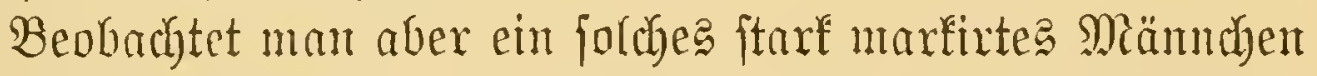
bei Der Eopulation, D. h. beurtheirt man jeine Reibrich:

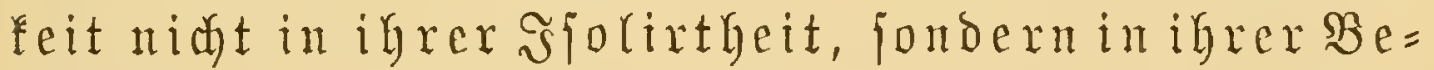

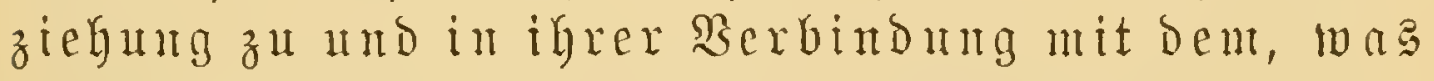

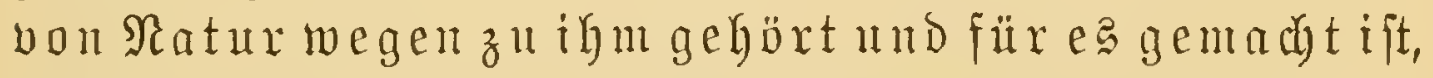

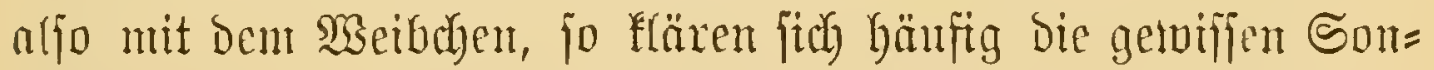
Derbarfeiten in eintem ähntidyen Simne anf wie die anffallenden Färbungen und aud bie medhantifhen AY went wix jie anf igrem natiintichen şinter = แno Untergrumbe 


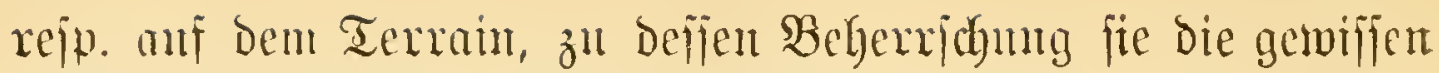

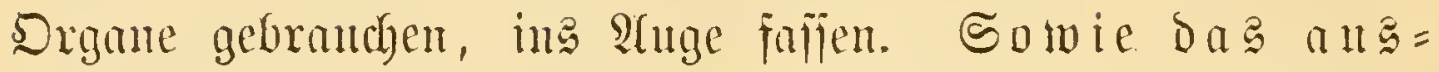

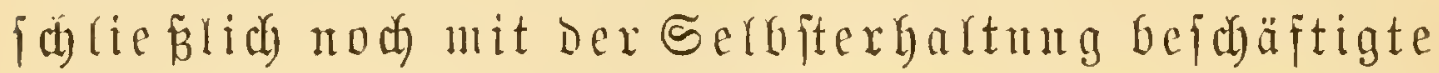
snjeft jeiner es ernägrenden umgebung angepázt ift, fo ift das in ber Fortaflanzung begriffene

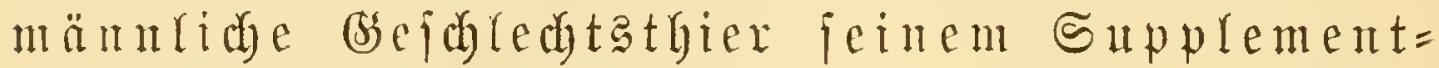

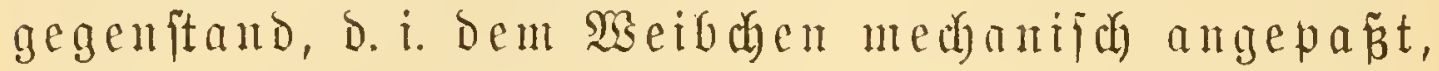
und fowie fernex im exiteren Falle die Almpaffung bald mur einte partielle, bald eine totale ijt, fo bezielgt fie fidr aud hier bald mur auf einzelne Theile, bald auf ben ge= faumten Sörper des Mämrbens, der mit der Dberflädye Des :

Ein prächtiges Beipipiel für das sieqagte gibt, nach Se. Siüller, eine Biene, die Chelostoma florisomne L. ab.

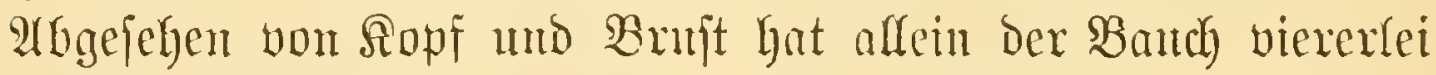

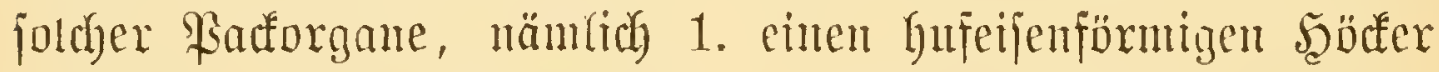
anf bom zwriten Segnent, 2, eine Dreiectige Bertiefung anf Den Dritten Ring, 3. eine Şarbitrite anf ber viertent Bandypratte mo zuguterlebt nody, am fiebenten Segment, ztwei bas weibliche Şinterende nmfafjente Dornfortjätie.

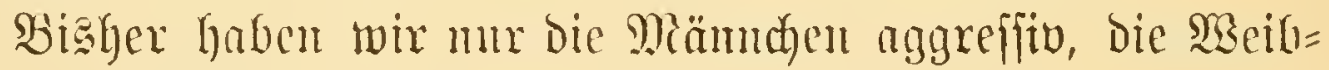

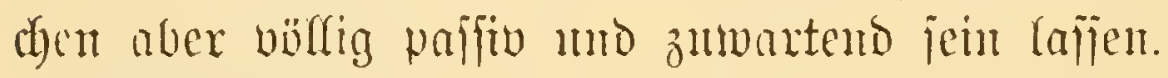

wem lebstere aber and im vorliegenden Fall, tov fie

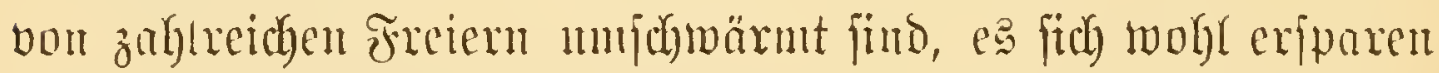

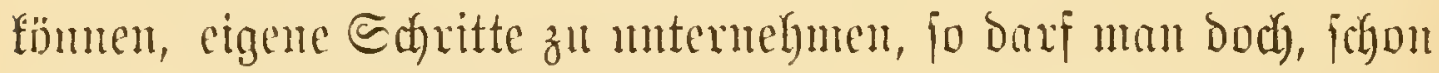

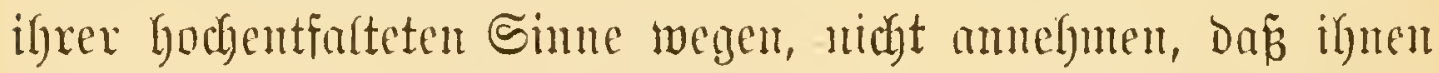

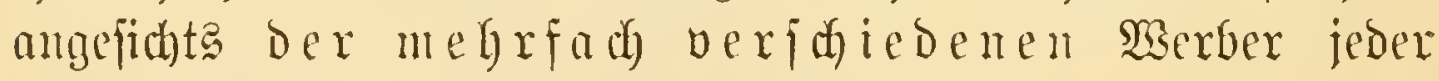

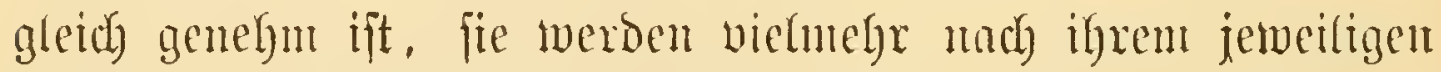
individueflen Bejchmad ihre $\mathfrak{B}$ aht treffen. Mit andern $\mathfrak{B}$ orten,

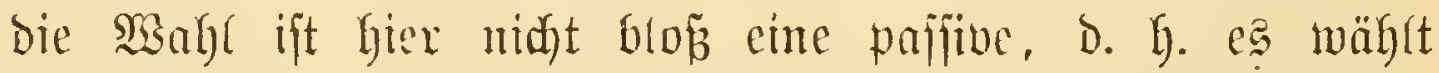

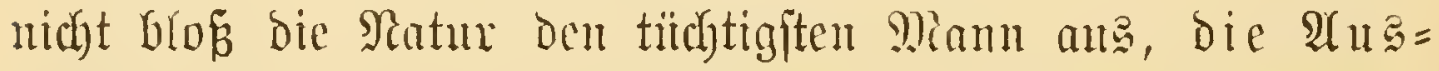
mufterung ift zum Igeil eine völlig jubjective un pexfönliche angelegengeit. 


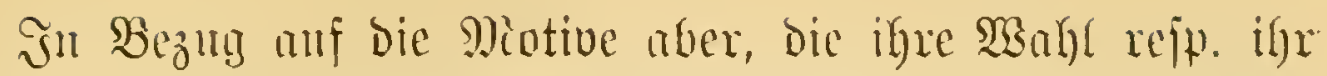

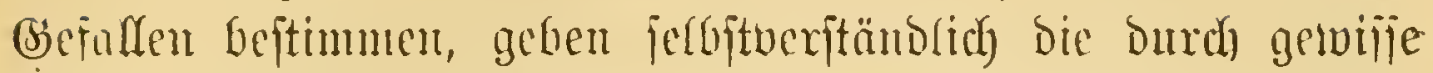

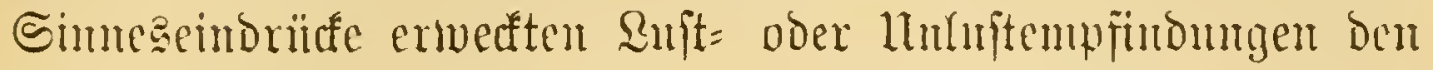
exiten Angjolag. Anfiallude Formen und Farben, aljo

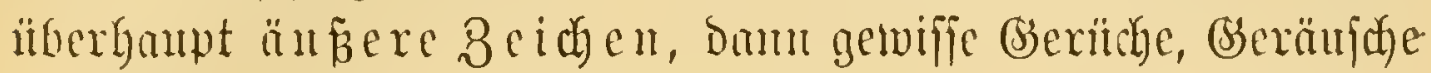
und Töne, welche bie Miämuchen probuciren, falfen nebjt ge=

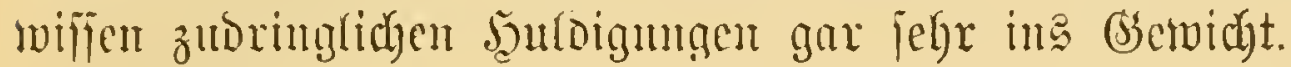

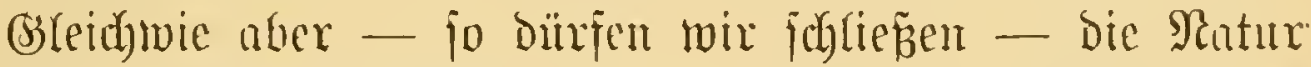

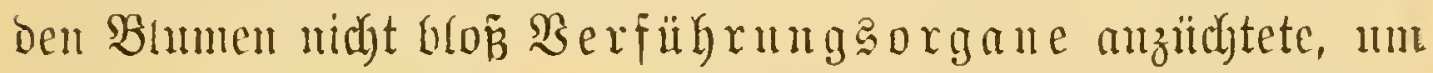

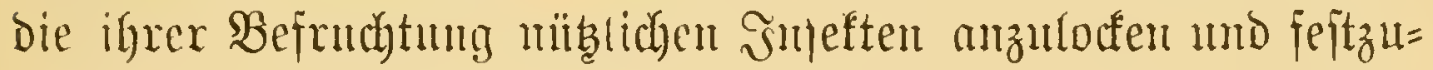

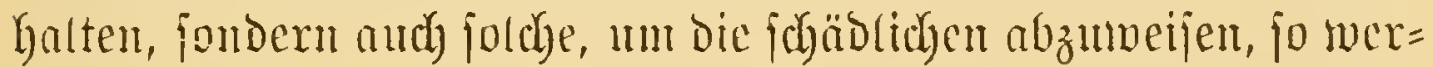

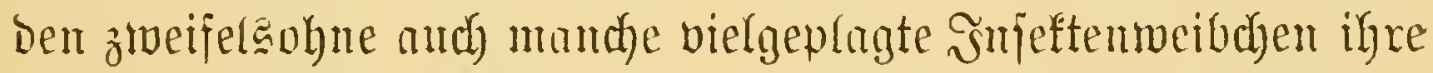

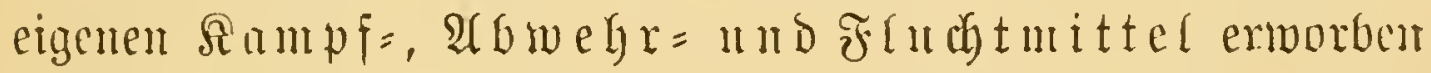
haben, weldyen madjzupilzen fïr jtrebjume Serf=Biologen ein

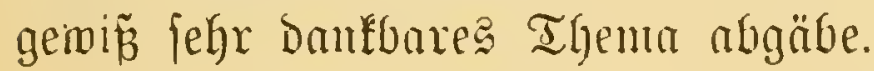

Das wären, poweit wir in biejen dunfeln Bsegenjtand

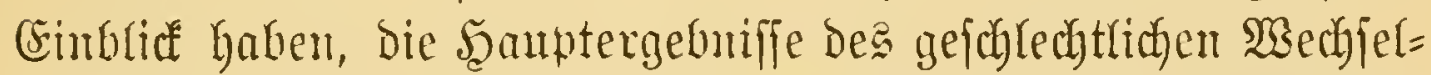

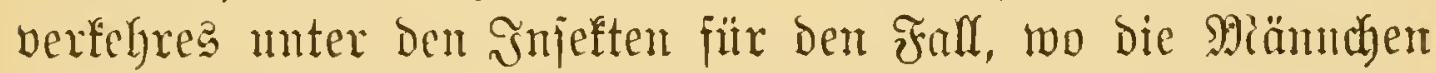
in Der Majorität füb. Num wollen wir noch furz unter = juchen, was beim entgegengejescten Fall heraustomut.

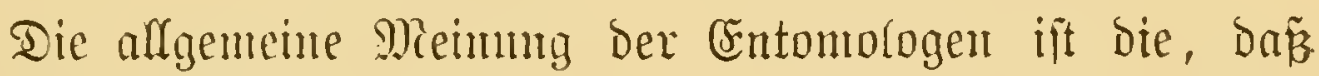
bie meijten Rerje monogam Keben. Dieje Mieinntg, ruer

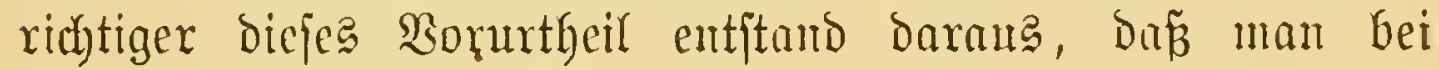

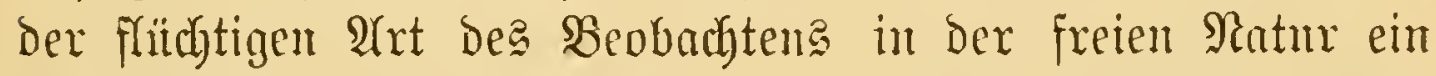
Rerfmänndes in Der Reger mur mit Einem $\mathfrak{B e i b d j e n ~ b e i = ~}$ janmen jiebt. Dies ijt aber offenbar gar lein Bemeis.

Ilm alf die $\mathfrak{B a b r b e i t ~ z u ~ f o m m e n , ~ n u ̈ ̈ p ̈ t e ~ g a n z ~ a n d e r z ~}$ berfahren werden. Die Ahtfgabe wäre Keine geringere al

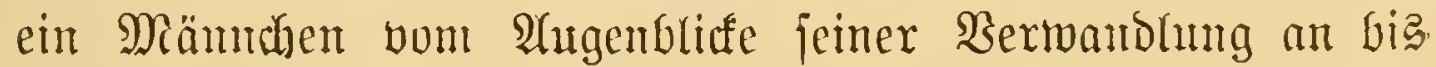
zu jeineut Ende ununterbrod) zu verfolgen mo niemalg ma Dent 2luge zu lafjen. Wer aber hat fich biaher Tage mo

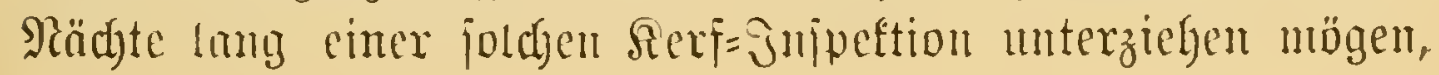


and wie toäre nun überbanpt in Stands, ein fliegendes Snjeft, 3. B. ein Bienenmänmden auf Schritt utD Sxitt zu beanf= firbtigen? Solange nan bies aber nidyt getyan hat, jollte man alles Serede fïr ntw wider bie Mronogante lieber bleiben rajient.

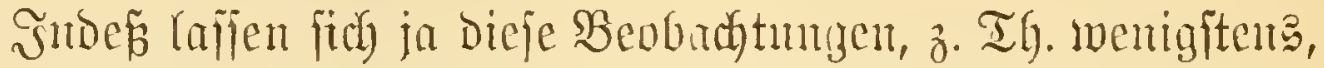
auf ganz bequente $\mathfrak{A}$ it in enuen geeigneten Räfig anjtellen. Ruf bieje art haben wir unter anberur feinerzeit conjtatirt,

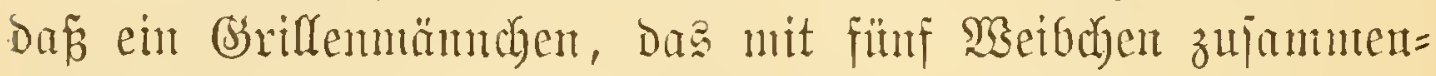
gejperrt war, fämmtliche der lebteren befrubtete, und ber

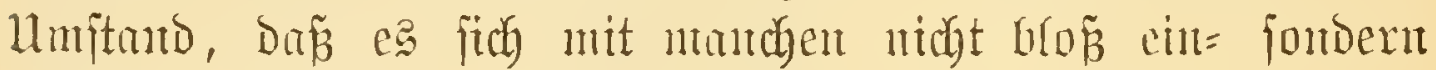

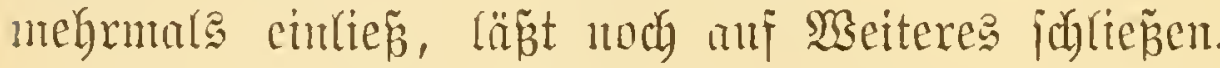

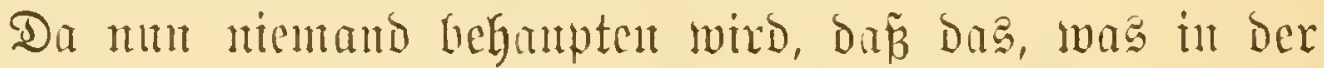

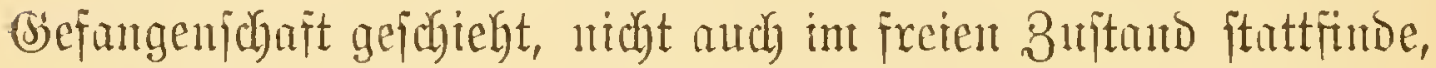
fo ijt die Bebeutung diejes Falles fïr die geiannte Bengungs= itutiftif jedenfalls in ânjwlag zu bringen.

Befänben fich unter Den oben erväbnten Briflen gleidyoiel

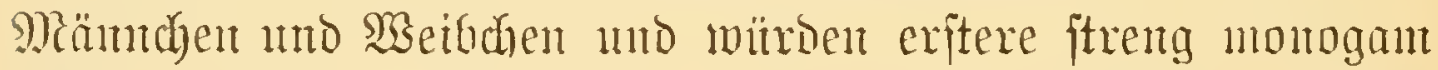
lefen, jo fömnten offenbar nux oxei Bruten entiteben. SWenn aber ant je Csines Mam fünf $\mathfrak{x e i b e r ~ e n t f a l l e n , ~ d i e ~ a l l e ~ v o n ~}$ jenem befudatet weroen, fo ergibt fich ein \$ilus oun zwei Bruten, und jo ijt flar, Daż eine joldye weiberreidye Beneration Die 2 rt viel reidglidyer fortpflanzt als eine andere.

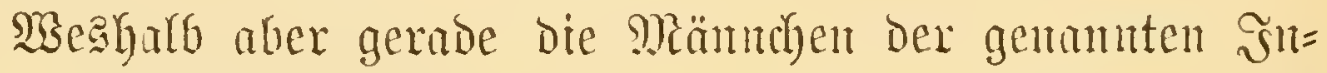
jeften zur Bolngamie himeigen, nutfjen wir den Sejer auf

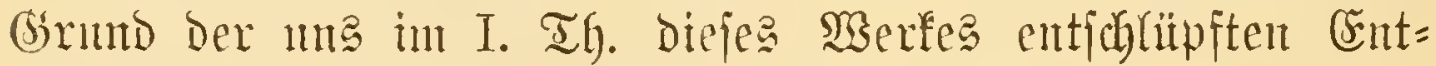
büllugen felbft exrathen laffen; Desgleidgen die Ilriache, weldye es verbindert, da ż gewifje antore, z. B. die Bienen, Biel= meiberei treiben.

Die Folgen einer foldyen gezwnugenen Monoganie

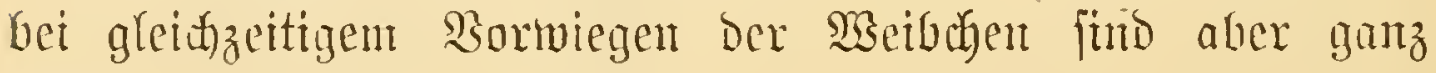
jenen analog, bie mir oben fitr Den entgegengejegten Fall 


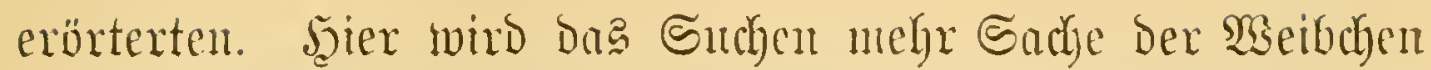

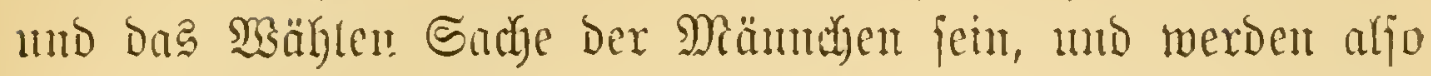

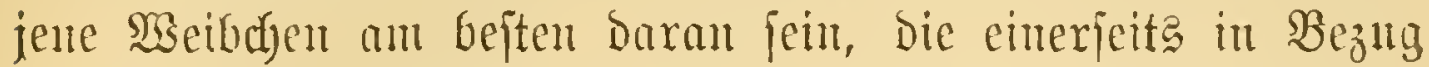

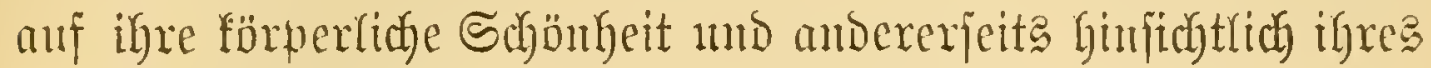
Beżehungapparates an vortheillyaftejten geftellt fint.

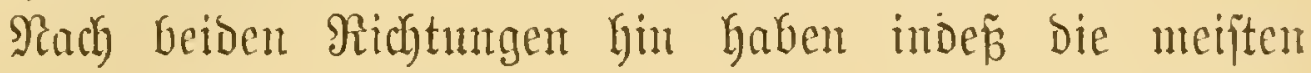
Rerfmeibdyen menig Urjadye zur Sitelfeit, unb Daraus foheint

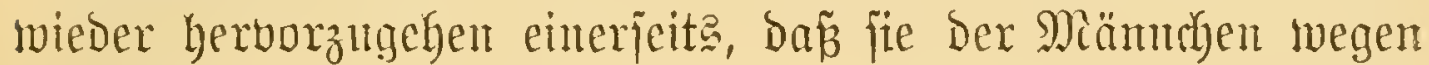

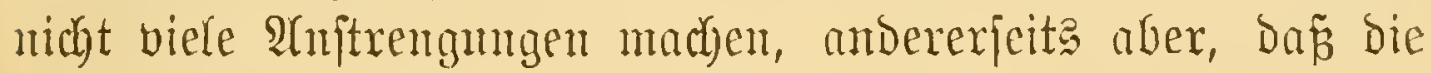
rebeteren aud nicht viel anf änfern \$runf geben.

\section{Partgenogenefi}

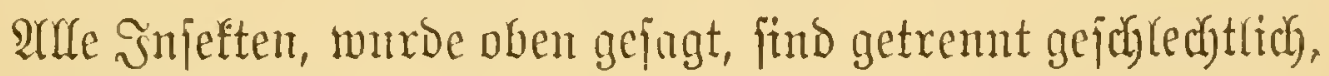
D. h. fie bejtelyen ans subivionen, weldye cier mo ans andern, welche Sperma produciren, mis es bebarf zur Fortpflanzung ber ganzen art jowohl, als auch zu jener eines Theiles ber= jerben des Bufanmenwirken aller beiden bsefdedter.

Mie (eicht einzufehen, gilt aber, ftrenge genommen, biefes Gejeb mur für jene Species, mellye man zu ver Zeit, wo fie bie Benguntgefuntion bolfführen, wirflid un zmei heterogenen

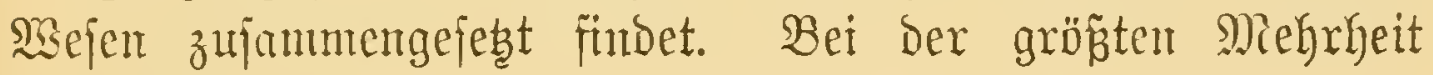
Der Aerfe ift biefe für die Beglanbigung ifrer Gistremt= geidylechtigfeit mbebingt exforberliche Beobachtung and in Der That gemadyt worben, mit ambern Morten man fennt von ben meiften Injełten bie Männden und Meibdyen und hat fich aud ïberzengt, da $\tilde{\beta}$ fie fich paaren.

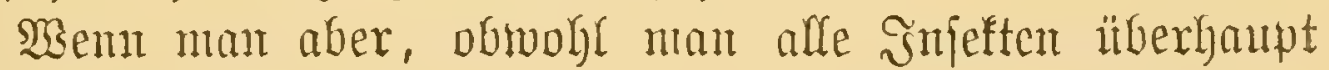
nod) nidyt fennt - Denn jedes Sabr merden nene entbect -

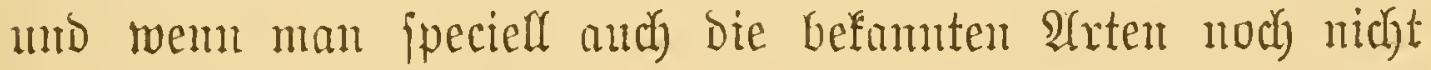
alle in Faarung, b. h. alfo in igren beiben Sertretern ge=

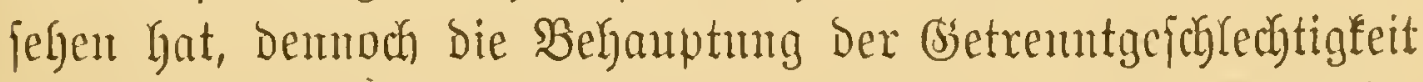
auf bie Befammityeit ausbehnt, fo ift bies eben ein Afnalogie=

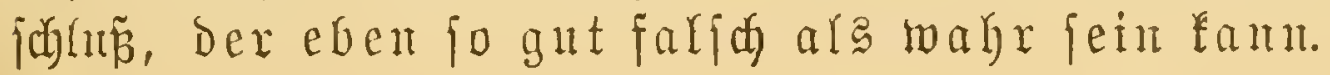


Um zunäcbit in Bezug auf Die Mnvolfftündigfeit Des Bemeismaterials für bie allgemeine (Setrenntgejhlechtigfeit ber Snfeften ein fanr Belege zu bringen, eximmern wir Daran, Dan

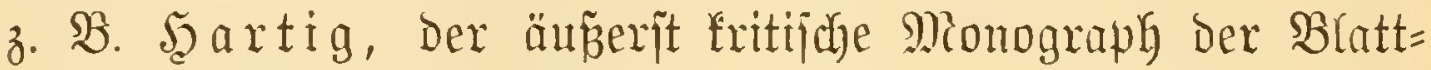
wespen, welche relatio grofe und feinesmegs veritect rebente Serfe fimb, von megr als ïber 100 Arten mux einerlei Formen

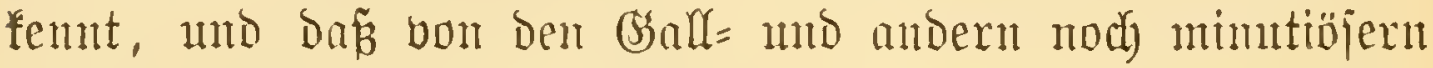

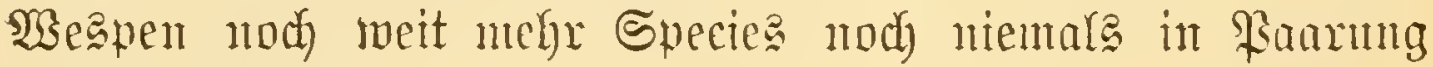
gejeyen unurben.

Die nübjite Frage ijt mu bic nach Der Natm biejer ijolirt jtehenden Bengungäwejen. Son vonnherein find 4 Fälle

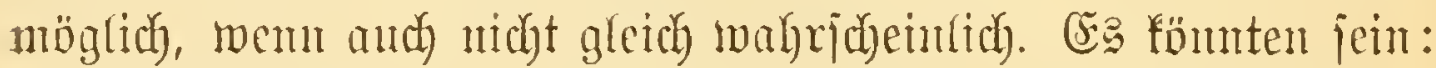

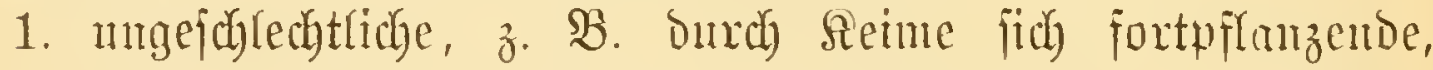

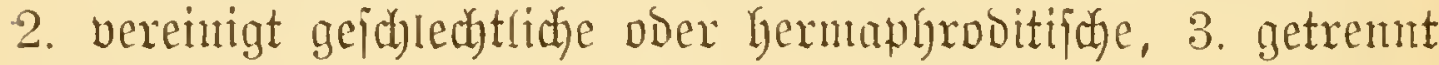
gejd)lectrtiche und dam entweder mämuliche ober weibliche

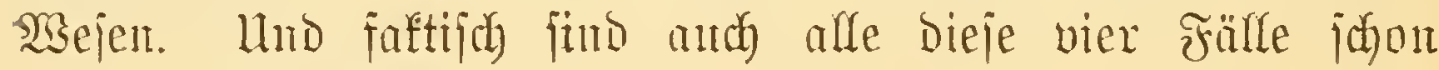
beobaditet mordert.

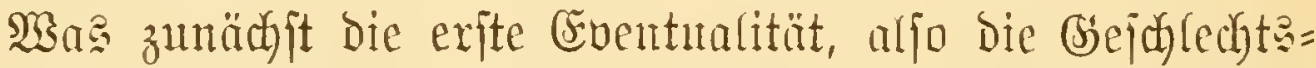
lofigfeit anlangt, jo fontmt fie aflerbings vor, jebod n nux $\mathfrak{a b}=$

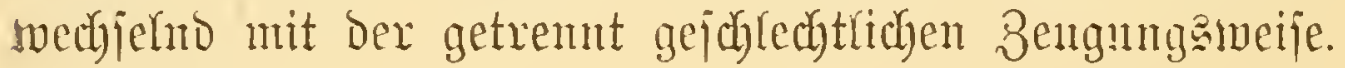

Aelynticid werhält a juyon eine Menge von Broittern, inshejondere bei Faltern,

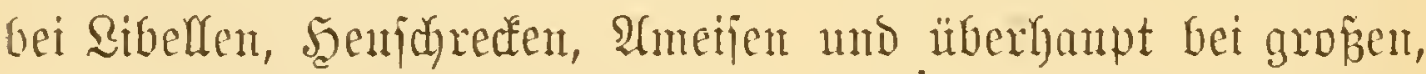

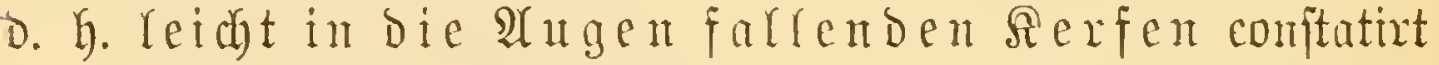
worden. Salle dieje swaren aber keme primären, aljo feine

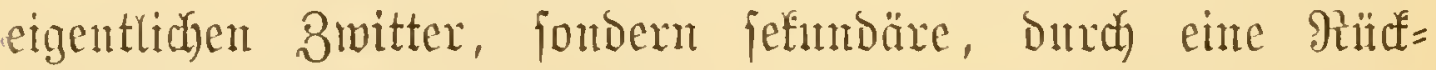

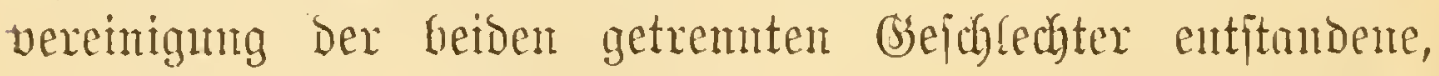
wix wollen jagen Bwirringe. Dabei ift noch Folgendes

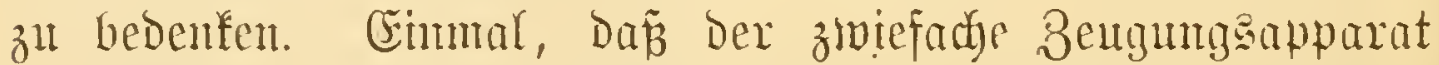
fid) jelten jo ausgeprägt zeigte, Dáz eine twirflidbe Beugung?

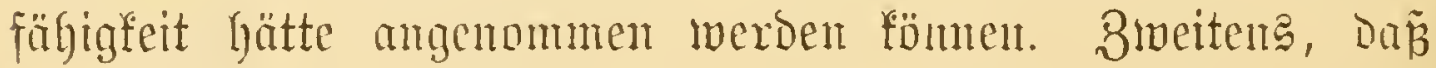
Gei biejen Zwittern itberhanpt moch miemals eine Fortpfrlanzung 


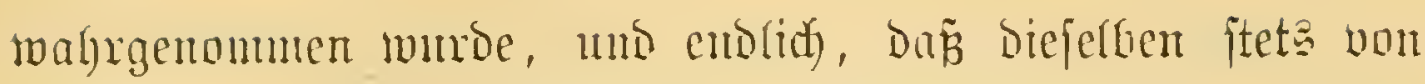
Deu betion getremuten Gejedyledytern begleitet anftreten.

Bezeichnemo ift ber oritte; aber afler Erifagrmm nach

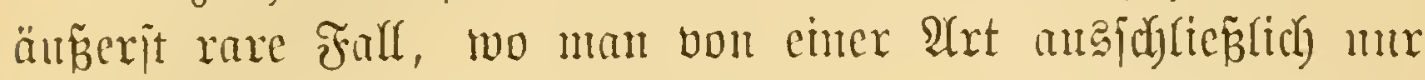
Spermaprobucenten oder Männdyen femt. Şgr Sorkandenjein

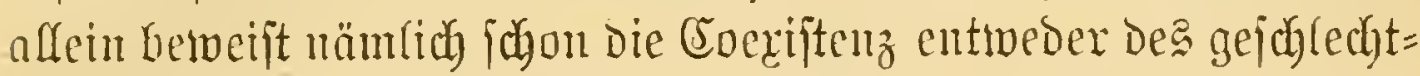

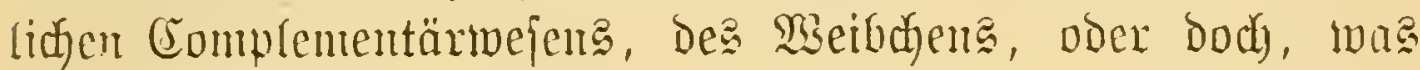
Denflar, cines ungejuledhtlidyen Bengungasmejents. Diejer Fall,

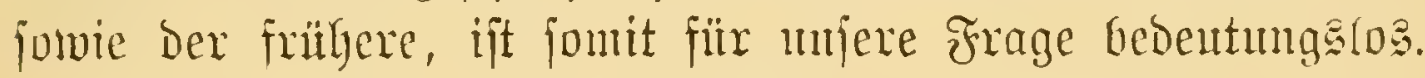
Fiñ uns ijt an interefijantejten der lebzte Fall, wo bie

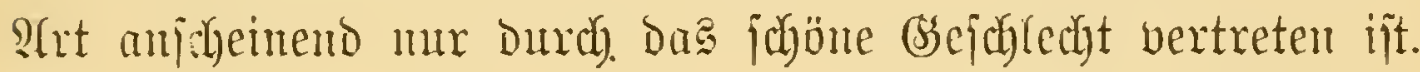
Şier geht es aber nidyt länger ofye Snoiscretion ab, e? yandelt fich nänlich um Die Frage, woran man bei Den ferfen bas cht Wreibliche erfemt, o. h. wie mo woran man bie

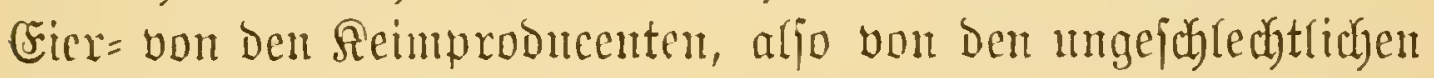
Zeugutgaswejen unterjcheibet.

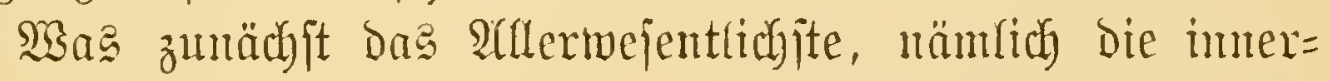
lichen Bengungagorgane betriffit, fo ijt häufig, wie bies men noch zu crörtern, weber ein geiturtficler nod ein profitolo=

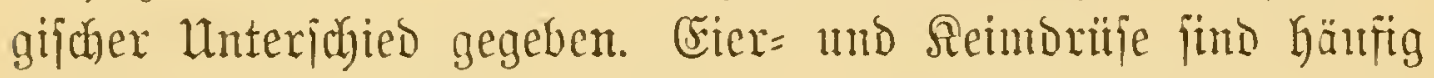

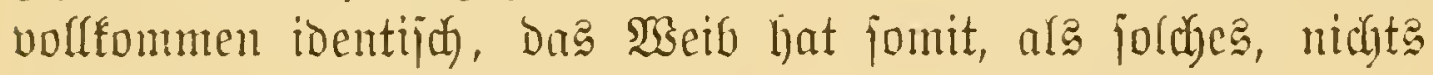
Specifijues. Das

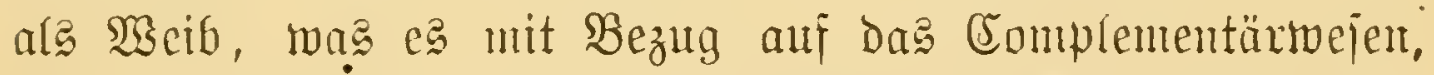

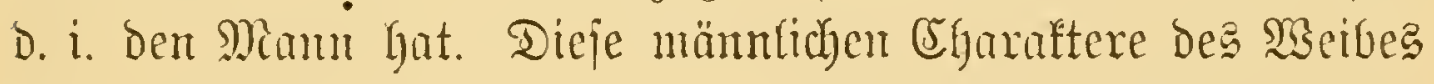
- jo wollen wir fie nemen - find aber gerade bei den meiften Rerfen jefr ausgejprodyen. Se ijt, wenn wir us mur an Das Finterliche halten, erftens dic Copulationstajche,

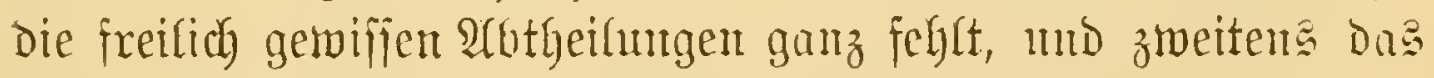

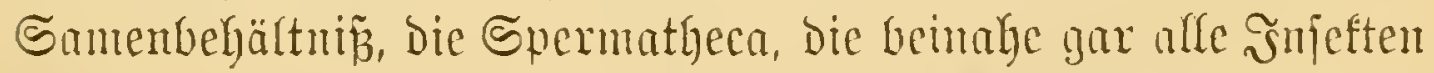
Lefizen. Demmad fömen wir jagen, ein fierfindibiomm, ons

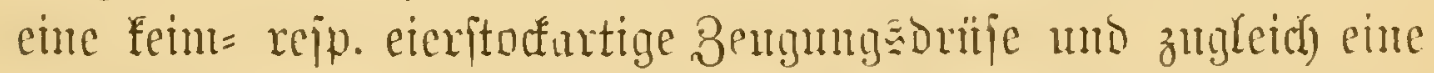

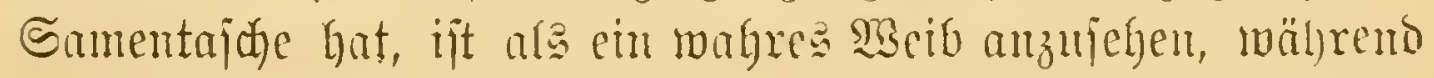
cin anderes, das kein jolches mänulidjes Merfmal m fỉ 
trägt, eben fo gut fïr ein feim= als für ein eicrprobucirenbes

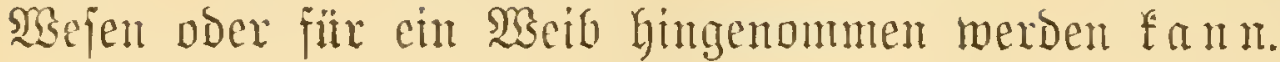

Menn mu, wie bies mirflich jo ijt, in ben obengennunten Fall, wo eine Serfart un Durch eimerlei Bengungaform ver= treten ijt, bieje aus wahren, echten şeibchen beiteht, was folgt

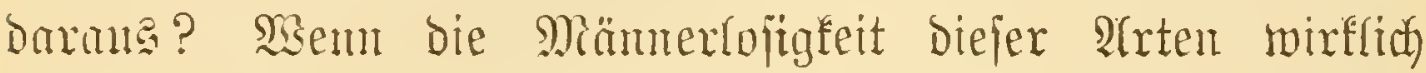

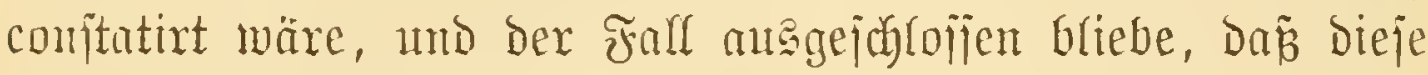

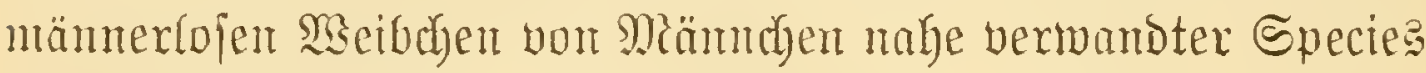

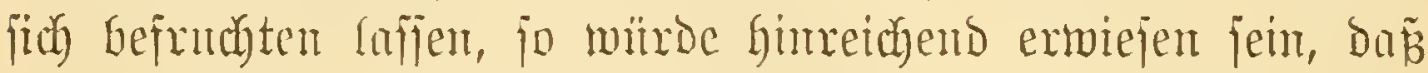

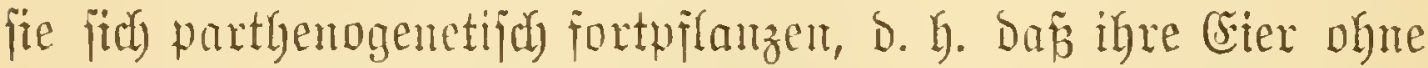
mämuliches 8uthun cben jo entroidtungesfähig twie bie jog. Reime jüto.

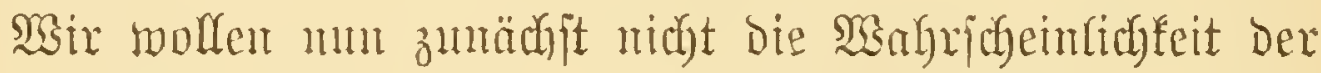
beiben gejebten Fülle und Dantit die des Statfïnoens von Parthenogenejis überhaupt unterjudyen, wir wollen mar nad)= jeben, wie und menter weldyen llnitänben jungfräuliche ober ein=

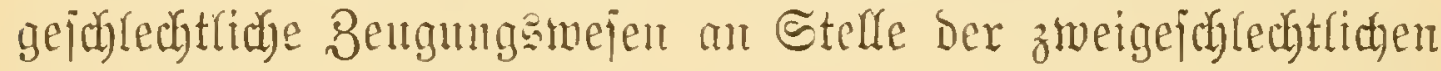
treten fönmen.

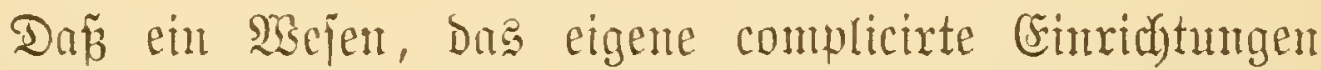
bebufs dex Bereinigung mit eimen Mranne hat, trobsem feine Bengungafunftion allein volfiührt, idseint, auf Den eriten

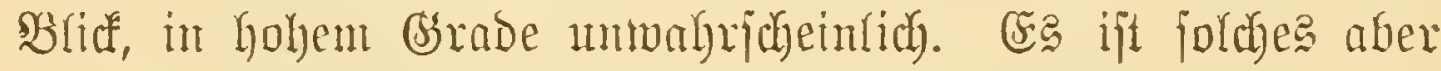

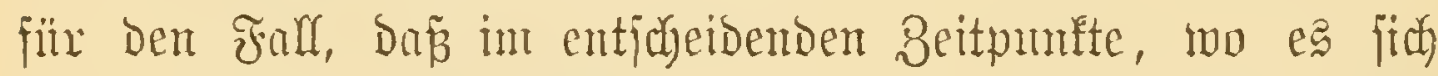
Den Nänuchen Gingugeben Den Drang hat, lebtere nimt

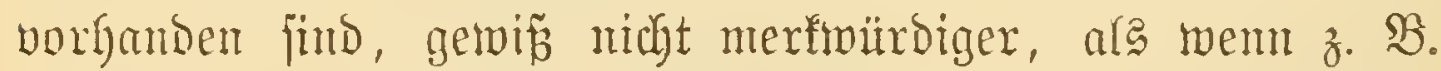

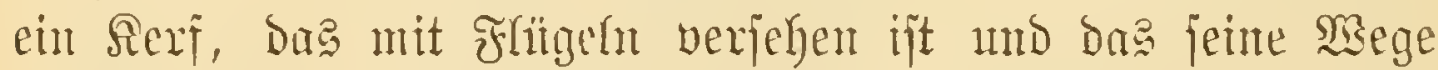

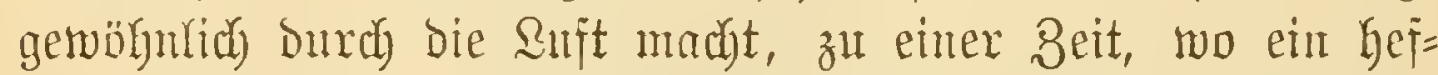

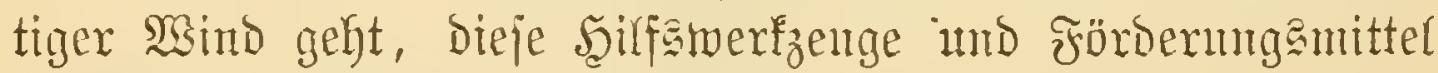
gleidjam vergefiento, zu Frn gegt.

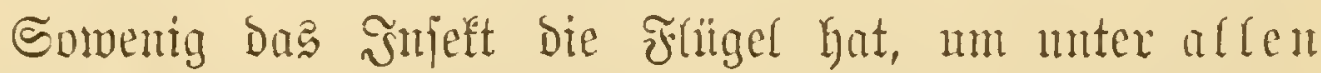
Uniftänden zu fliegen, ebenjomenig, behampten mix, hat bas Serfweibchen bie Epermatheca, um behup der Bengung untex 


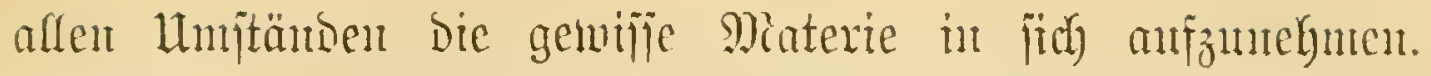
Doch Der Sergleidy, wird mant jagen, gilt nidyt.

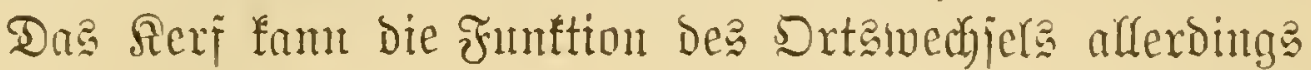

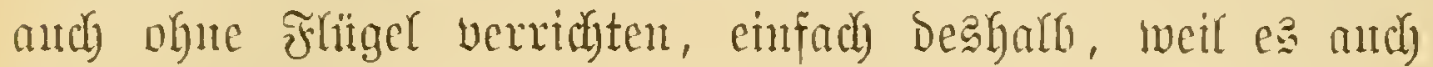
Beine hat; was aber expetst den bei den parthenogenetijan

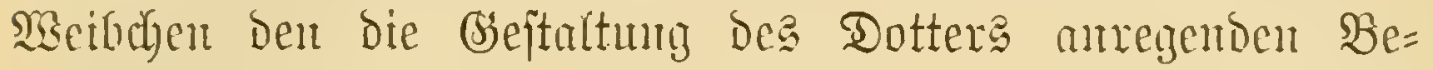
irut dytulugajtofit?

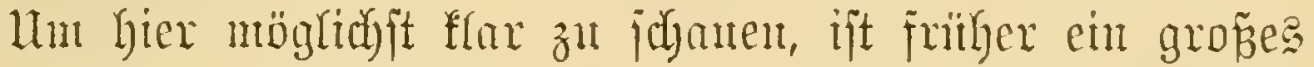
Sorutrtbeil zut überwindert.

Die Den Eiem analogen Fortpflanzungazellen ber nnge=

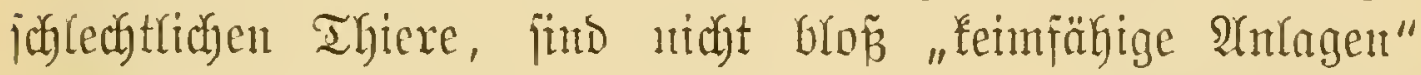
jondern wirfliche Reime - ganz ans und Durch fich jelbjt entwiffel= mo gejtaltbar. Die Trenmung ober Berlegntitg Des

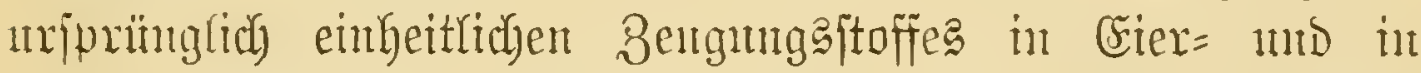
Santenzellen ift dagegent eine höhere Differenzinung, etwa

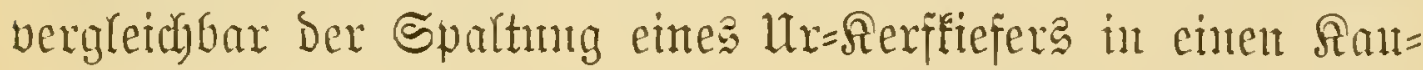

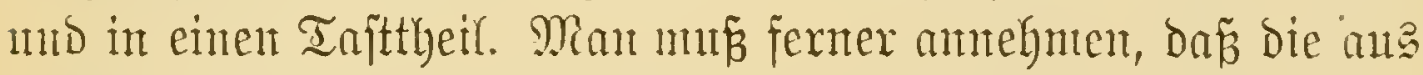
jolchen Doppel=Bengungaftoffen hervorgegangenen Sindividuen itber jeme, bie nadh Dem altent Styl entiftamben, im $\mathfrak{B o r}=$ theil waren, woburch bie anfonge durch gemifje "żufälfige"

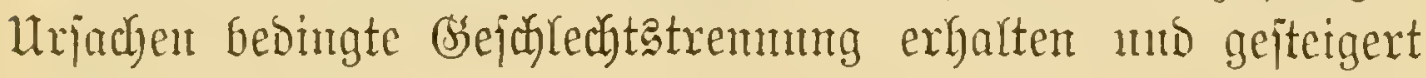
inutroe.

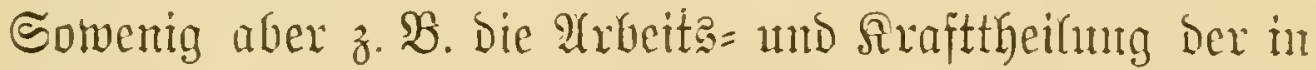
zwei Paralelitülfe zerlegten Rerbthiertiefer in alfent Fällen bie

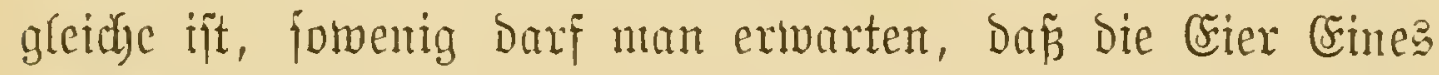

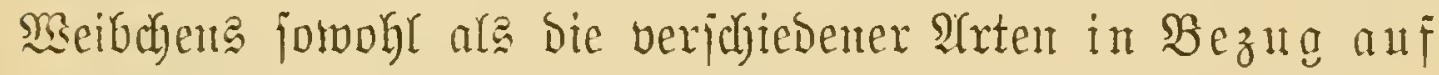
ihre jerbitändige aeimfähigleit gleid viel an ben andern Theil b. i. an ben Samen abgetreten haben. Doer andera: $\mathfrak{B a ̈ h r e n d ~ v i e l e , ~ w i r ~ b u ̈ r f e n ~ f a g e n t ~ b i e ~ m e i f t e n ~}$

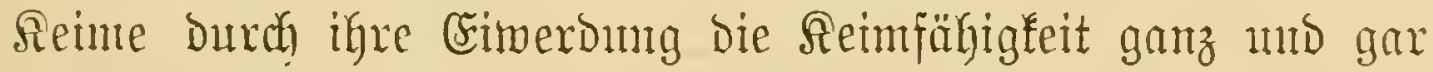

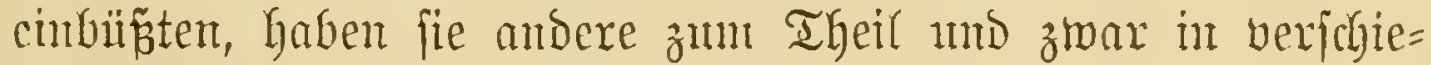
Denem Brabe erhalten, D. h. alpo, die Reimungäähigkeit ber Eier ijt nidetwas ajolutes, fondern etwas Graber, ふnjietten. II. Bל. 


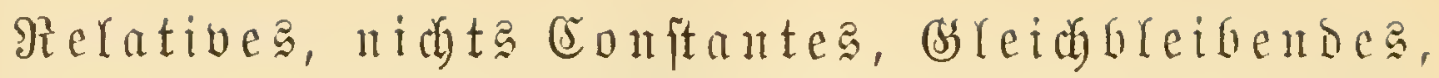
fonderu, wie alfes Drgatijue, etwa

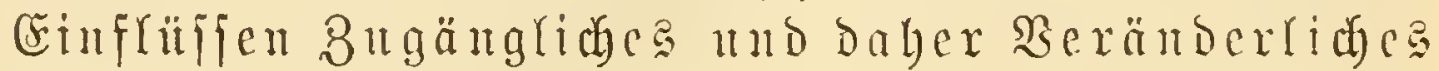

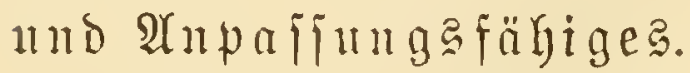

Wir fömen and fagen: So wie es Mebergänge gibt zwifden Ifierformen und Thierorganen, fo gibt es Heber= gänge vou Bengungaftoffen, von Theifroduft zur Rnoghe, von biejer zmm Reim und - ober jollen wir ba ftehen heiben? - von Reim zum - Ei.

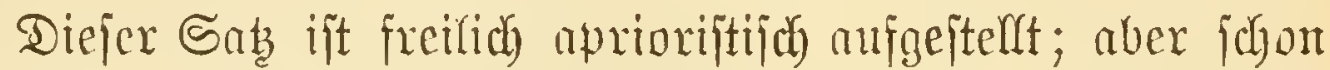
bie wenigen Thatfadyen, bie man biaker conjtatiot, bemeifen feine

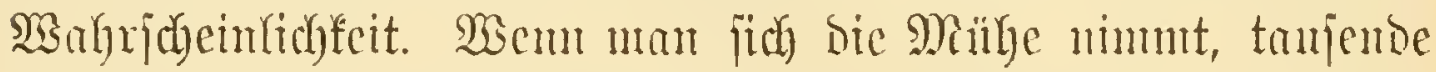
unbefrudeter Seibenpinnereicr zu unterjuthen, wird man fajt regelmäpig einige barmuter finben, bei bonen bie cint= wiffung be (Embryo melyr ober wentiger weit fortgejuritten ift,

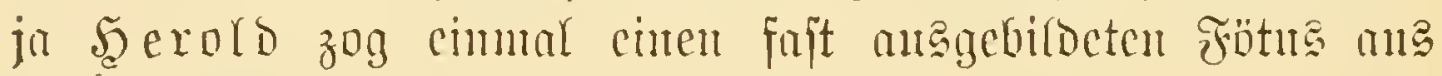
eincm forthen hervor.

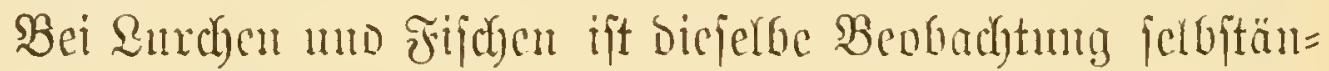

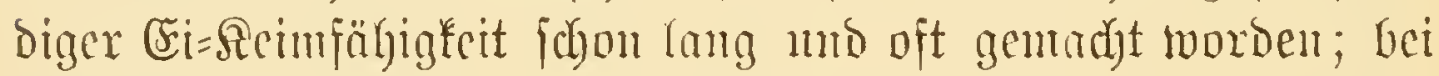

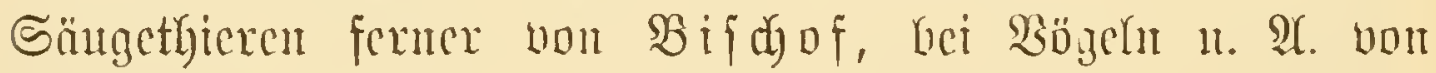

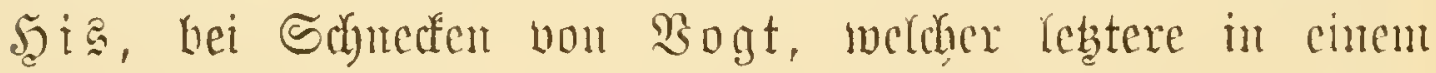
unbefrudsteten Ei vou Firola Den Enbrijo fodyon rotiren fah.

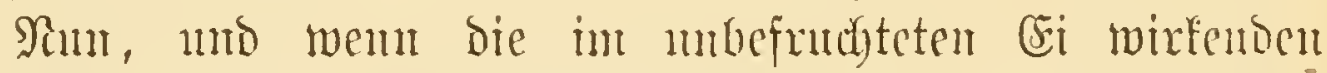
Sräfte bie Fornumg Der Dotterfingel bis zn eimen getwifjen Grabe zul bringen vermögen, warum folfen fie nidyt gelegentfich

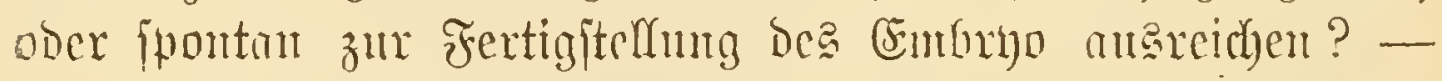

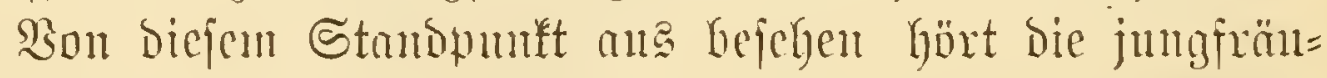

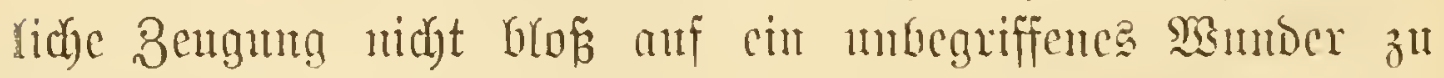
fein, fie cridgeint bielmegr ars ein nothwenbiges lucter=

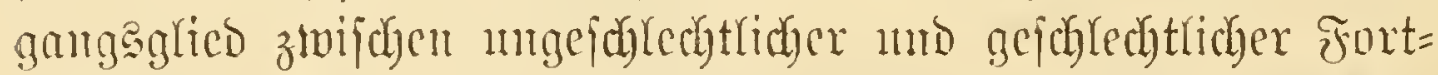

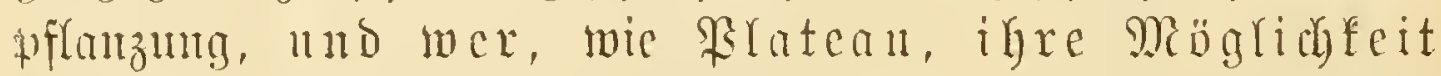

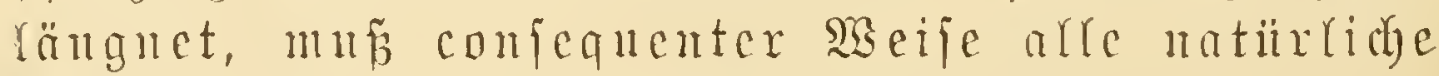
erntwialung überbant bejteciten. 
Durch weldye äuperen Bebingungen bie Simubarfeit un=

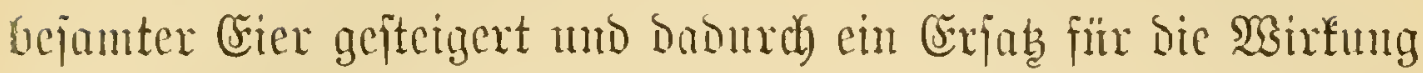
bes Spernta's gegeben suird, wifjen wix freilich ganz und gar

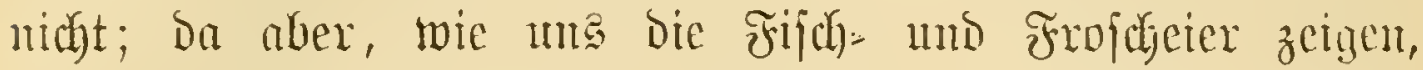
Bie beränerfidgeit ihrer Reimeraft cime That=

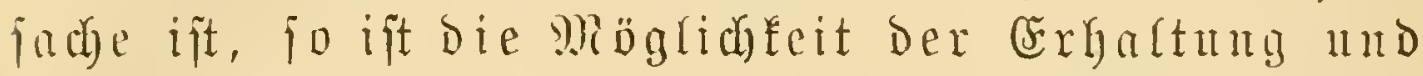
Eteigerung berjelbeu bux natürliche 3 ud twabl

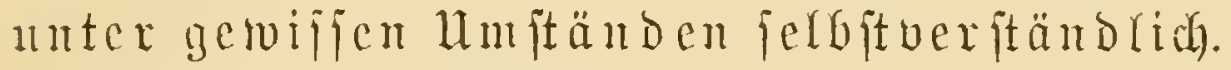

Ein foldyer lumptand ift mus eben der obengenamte, no

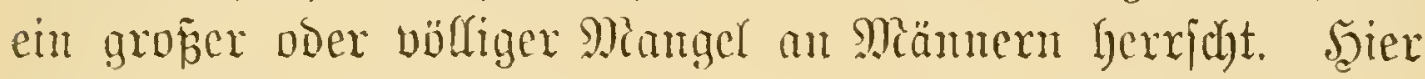

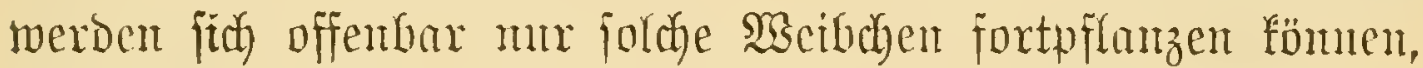
weldye dic meipte Selbjtbefruthtumgatraft in fich haben; und

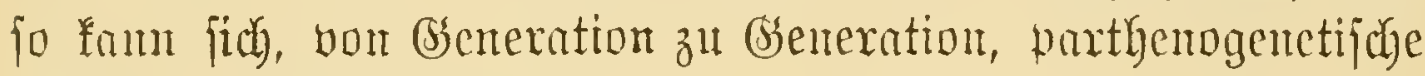
Bengung erbalten und inmer mehr befejtigen.

Wir haben jebt Dargetban, wie mo invietwcit jungfräufiche

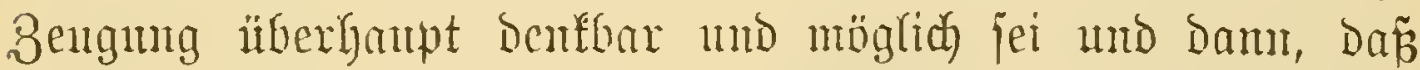
fie inßbejondere bei gewifien mämeranmen Rerfen für bie Arterhaltung faft nothwendig angentommen meroen mun.

Mebrigens hätten wir ms die vorbergehende :Betweis= fülyung für die Parthenogencjis völlig exfparen fömucu; Dem

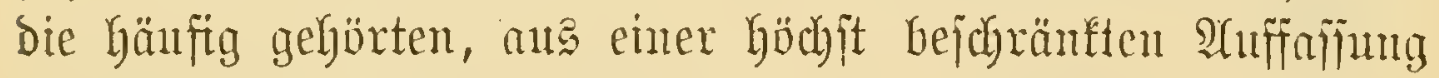
Der organifchen Satur cutfpringenden aprioriftifden Bedenfen

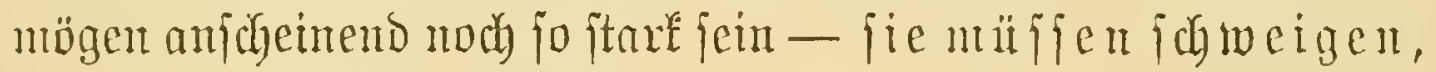
wen die Thatjachen ipreden.

Wie zu erwarten, wurden juerjt - uń zwar johon in

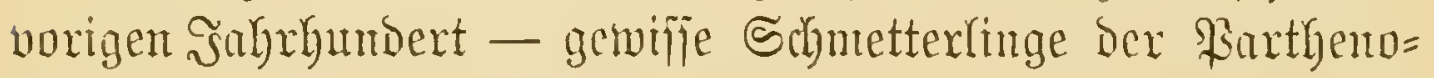
geneje bezichtigt. Bei Dom Uumjtande nämlich, Daf́ won

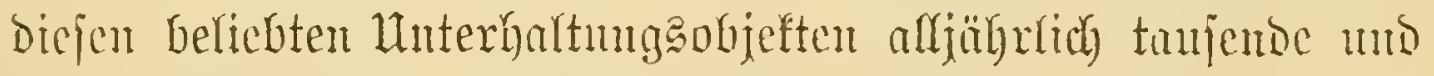
viele and ijolirt gezulditet murben, war ce faum andors

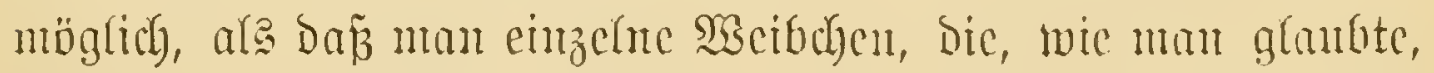

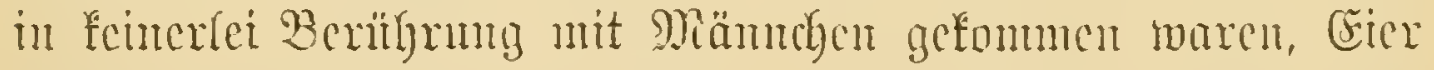
ablegen und an Denfelten jeiner Beit and Räundyen ma: iuflitipfer juth. 
Soldye gelegentlidye mb nady Damaligen Begriffen höbrat regetsoiorig expheinente Beobadytungen modeten Damn ju

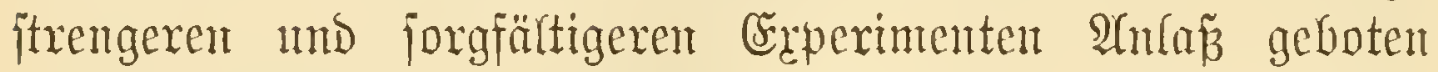
Gaben. Man bielt bie meiblichen Puppen in itrengiter Einzel= haft - Die Eier ber ausgefommenen Falter entwicfelten itid) aber trobbent; dic Barthenogenefis ichien confitatirt. Soldye Berinche ftellte unter andern $\mathfrak{A}$ ipp beim Seiden=

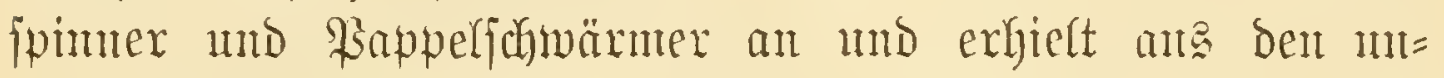

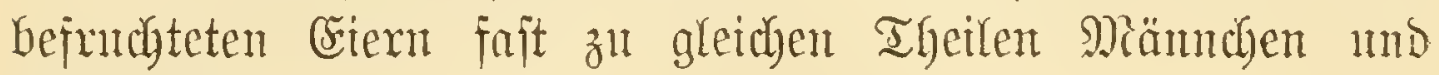
Siseibchen.

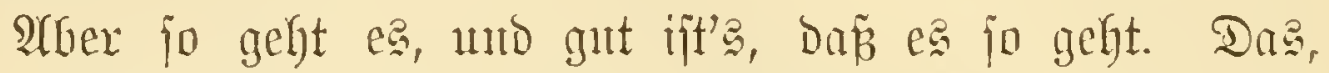
twas andere jehen oder zu jeljen glauben, will man nicht cher fïr wahr himehmen, bevor man es midht and jelbjt gejehen, bevor man fid nidyt jelbjt überzengt hat. SSie leidyt fann

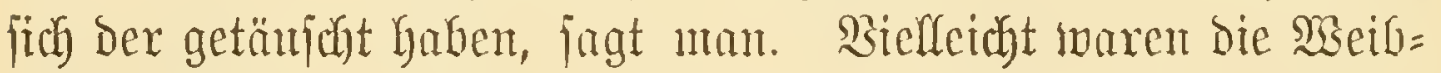
chen nidyt zux redyten Beit abgeiperrt worden. Die Farter= mämuchen find mnendlid znoringlich, möglicherweife war in

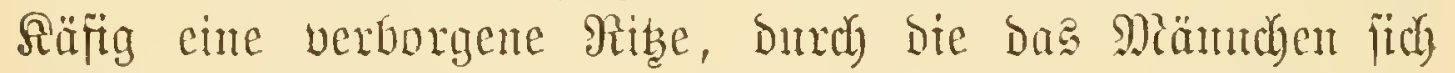
3utritt berforaffete oder Dody fein Sperma mit ifm ober mit Den fdyon gelegten Eiern in Contact bradyte.

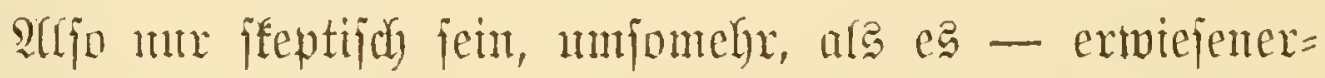

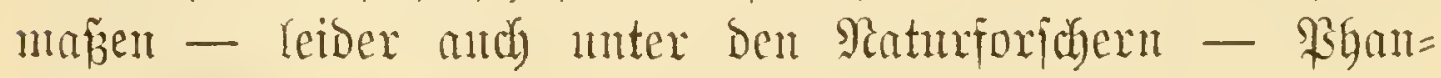
taijen gift.

Sndeffen fömen wix ung nidgt ebenjogut als ambere

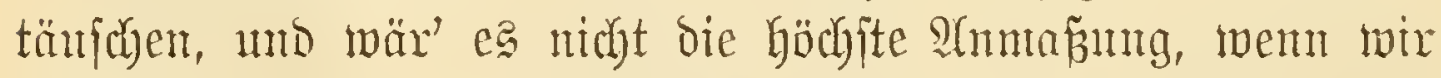
une unfehlbaver als bie hödbjten âtutoritäten anf Dent be= treffenden Felde Gielten?

Mann wix aljo z. B. cinen Sicbold, emen \&eulart, bie Davon, ob Sierfe parthenogentifich finto ober nicht fins,

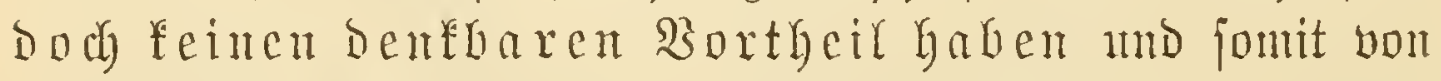
vorneberein boch gemif völfig objeftio untheilen fömnen, wem

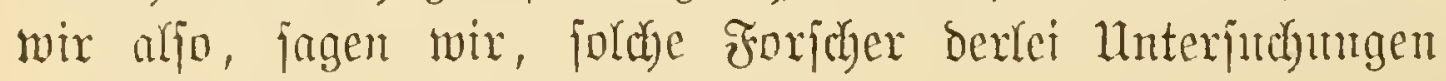


mo juar unter genalufter angabe der Methode maden jeben, gaben wix Dann ein Recht, igre Rejultate zu beztueifelı?

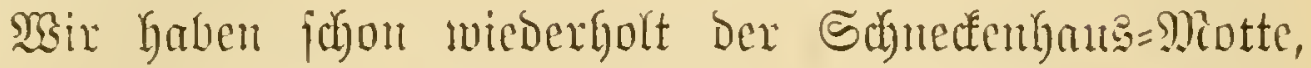
Der Cochlophora Helix Sieb. (Fig. 87 A) gebadbt. Die An=

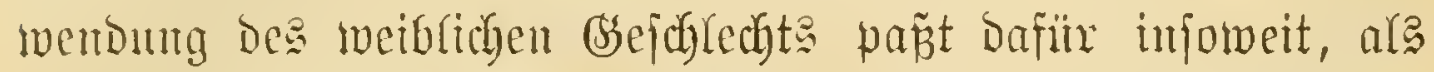
man lange Beit eben nu biejes funte. Dus NGort "Notte" aber hätte man injolnage nirbt gebranden follen; Denn bie crtuadjene Cochlophora fieht nidyts wentiger als eintem Falter

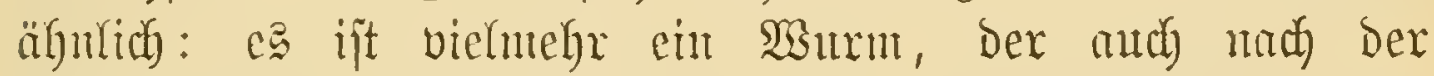
ftattgefundenen Sexpuppung aus jement Säuschen nidat beraughert.

Man findet bic betreffenden Thiere, in ntandyen Berg= gegenden jientich bäurig, anf Aräutern veridjiebener art, 3. B. חuf Lotus corniculatus, Alyssus montanus, Artemisia vulgaris u. $\{$. w.

v. Sicbold fanmelte, mit unjäglidjer Seduld, sabu: zelute bindurch Gunderte und tunjende jolcher und über: zengte fich Durdy die Section, Dañ es ranter meiblidye refp. jungfräulidye s̃udividuen

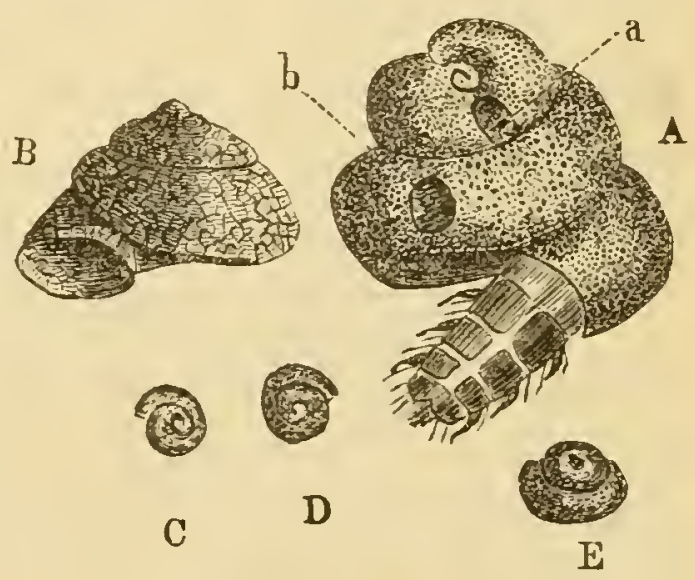

Fig. S7.

D 1. E Raupenjaf von Psyche helix Sieb., nat. (3ri. A vergx.

waren, indem ifre Samentujiche ftets vollfommen leex gejunden wurde. Dies founte aud faum anders fein; benu der un= ermübete Biologe hielt alle unter itrengiter CSlaujux, jo baf́

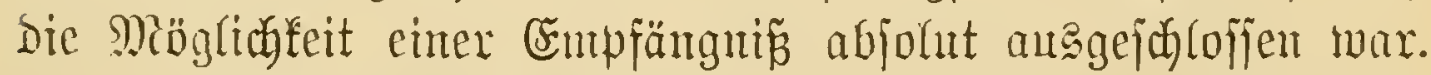
Und die Fortpfrlanzmygart? Sie ift fehx einfady. Şat Die

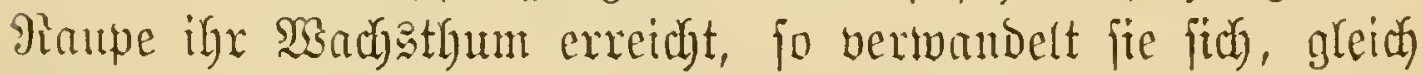
andern Falterlarven, interbalb igres Sacfes in eine Pinple,

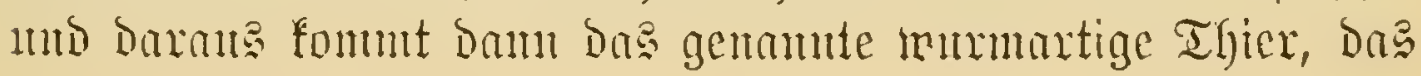




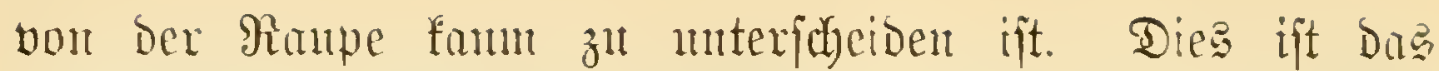

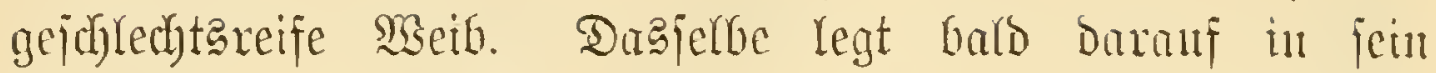

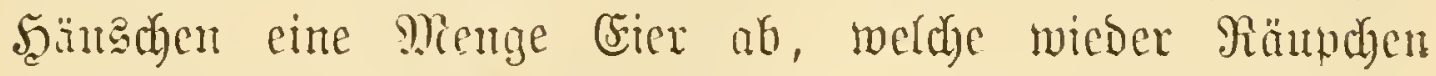
lieferm. Sebtere zeritrente fïb Dam, fpiment ifren eigenen Sack, verftärfen ihn burd) Sambförndyen mb ifre weiterin

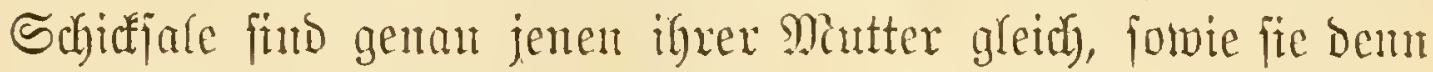
auch jelbit mieber und nach v. Siebord's Beobadytumgen

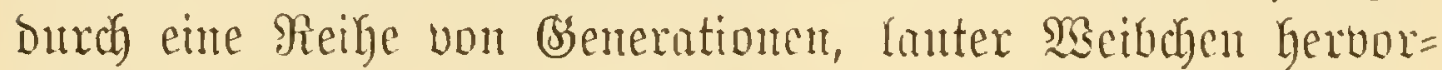
bringen.

Fïr Cochlophora Helix ijt jonnit die Rurthenogenejis

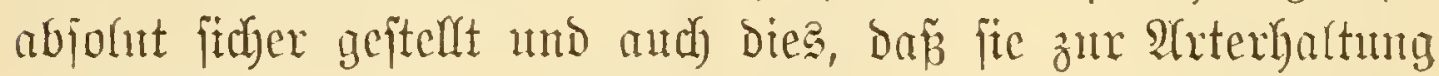
nothwendig ift; Denn, wem Siebold, an gemijien Sofulitïten

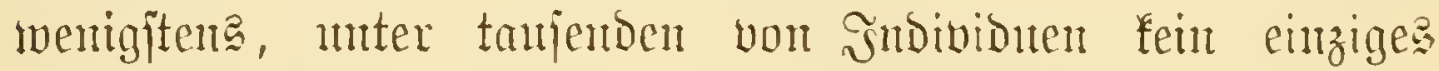

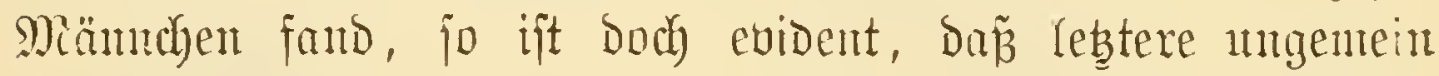
jelten jein müjjen, und falls igre Eimmirfung zur Bentung

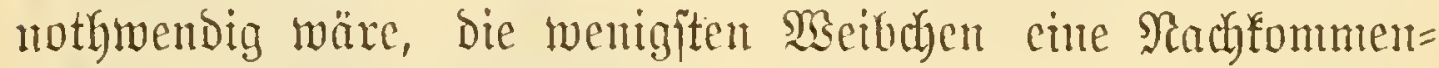

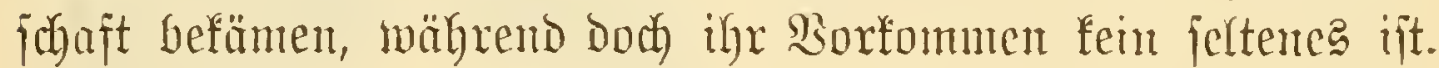

Die Exxijtenz von Helix-9Rämuchen itberhant exwaejent zu haben, ift eines ber zuhlreidyen Berbiente von Prof.

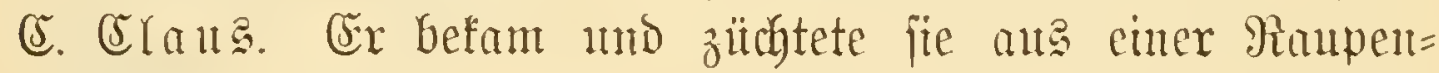

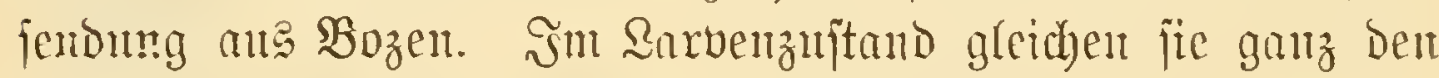
柋eibchen, haben aber etwas andere Särfe.

$\mathfrak{A}(\mathfrak{s}$ Puppen Dagegen zeigen fie fuhon bie gewijjen Falter= Entbleme, Die langen Beine, Flügel= mo FühlexfduetDent. Erwadyjen fint fie wie alle edbten Falter - nlfo ibren Gattinnen gonz muälulich. 、

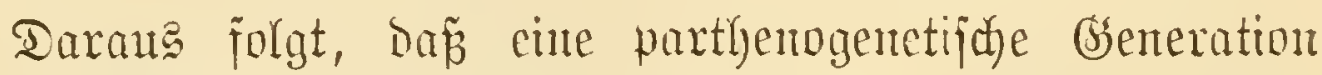

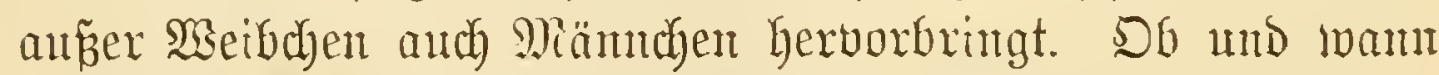
Dicje jich pararen, ob bie beiderjeitigen Sachtommen mux ans

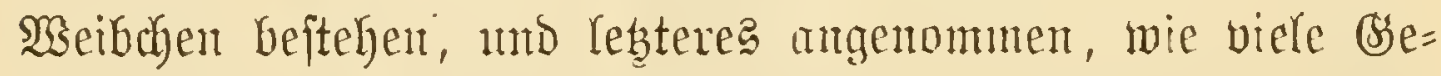
nerationen die Rarthenogenejis anthält, non all bem wiffen wir nod) gar nidigte. 


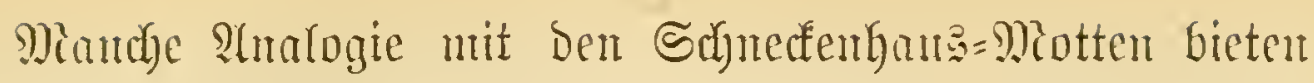

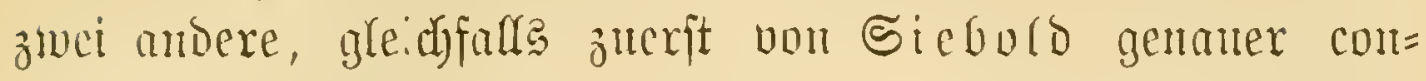
trolirte Sncfträger, bie Solenobia triquetrella uno lichenella. Sie gleidyen vielfaib den Helix, ifre Futterale, an Bretter= żämen und Bammitämmen hängend, fumb aber von bex gemöhn=

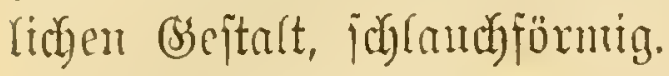

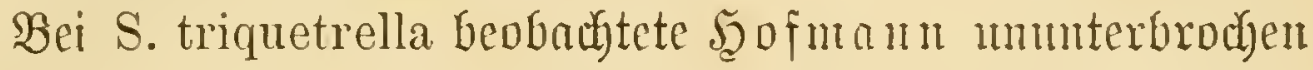
6 Sabre hindurch mu jungfräuliche Fortpflanzung, madyte aber fpäter mit ber Entbecfung der geflügelten Männlein

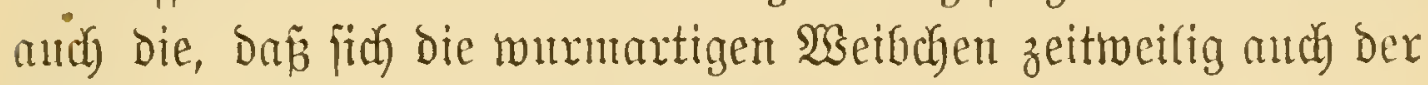
Unarmung ber leştern überlajjen, wem dieje redatzeitig, b. h.

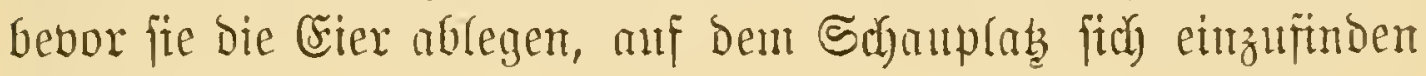
belieben.

"Unter Unmịtänden" (!) jedod) bringen es die Solenobia-

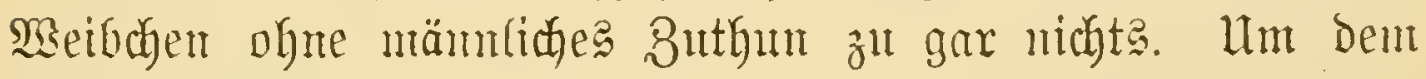
hier veritecten Şeheimmin anf bie Spur zu fommen, nahm

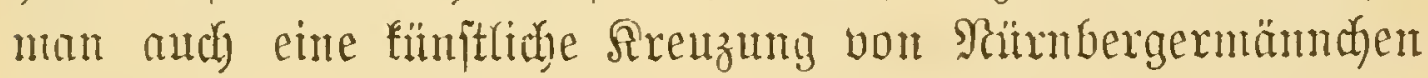
mit Miünchenerjungern vor. Das Rejultat war eine aus=

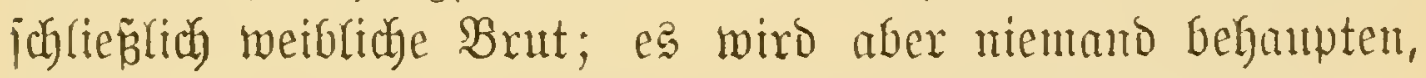

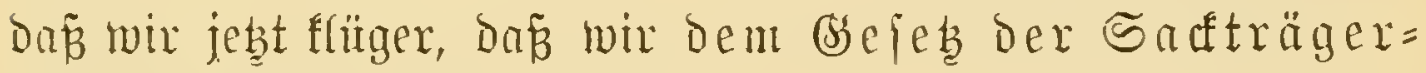
Barthenogenejis näher find.

(Fins lendytet zunädjit aus Den biaherigen Rejultaten hervor. Es genïgt midyt, wenn mu Einer oder wemt mux

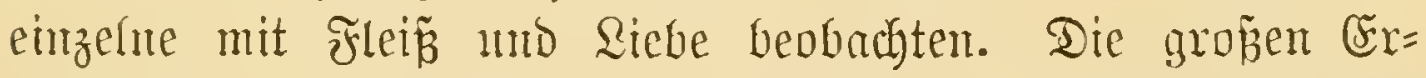

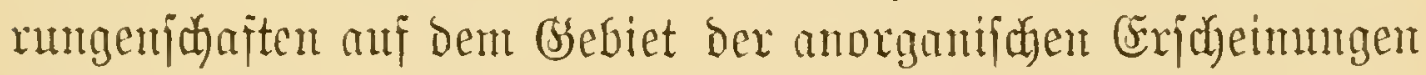

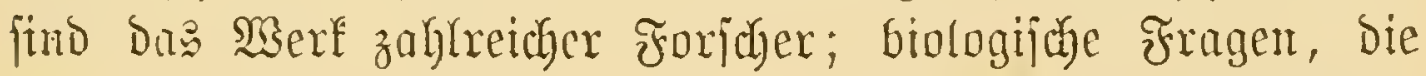

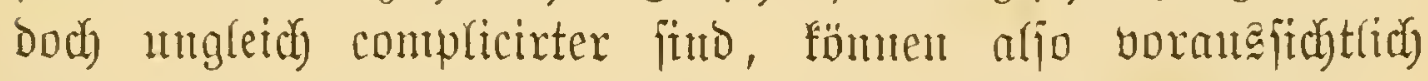

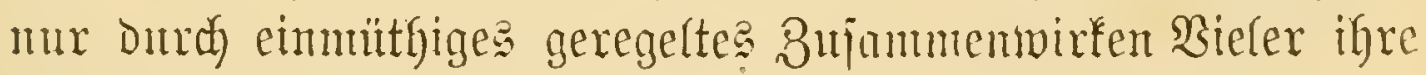
¿üpung finden.

2hts ben bisherigen Thatjachen idhemt hervorzugehen, Dañ anß unbejanten Rerfeiern, unter gewifijen ltmitüuben wonigitens, bie ju eruiren eben Sache fünjtiger Forjchung ift,

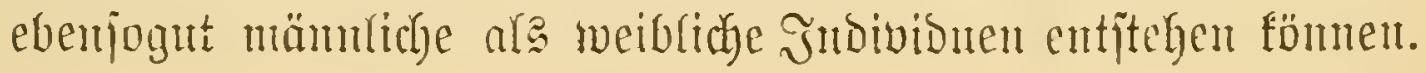




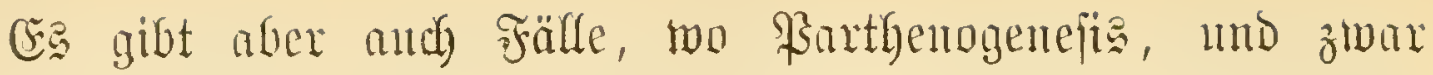
gauz regelmäpig, mu das eime der beiden Geidjledyter hervorbringt.

Eben jo interefiont als einfurd ijt das Berbalten Dex

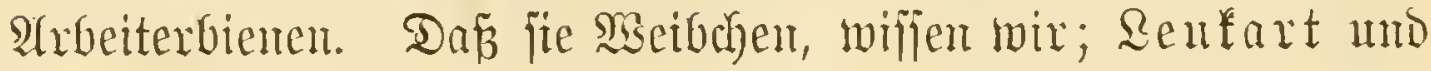
Siebold Gaben aber nadygewiejen, eimmal, dafj jie teme Samentajche haben mb dann, Daż bei der Snge ibrer Vagina aucl) cine \$anung abjolnt mbentbar wäre. Wemn jie mu, wie

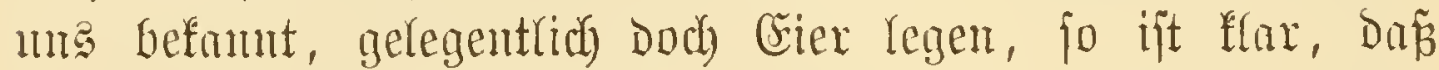

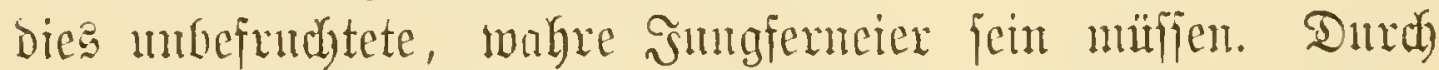
tanjende Der forgfältigiten Beobadytnugen ift aber conftutirt,

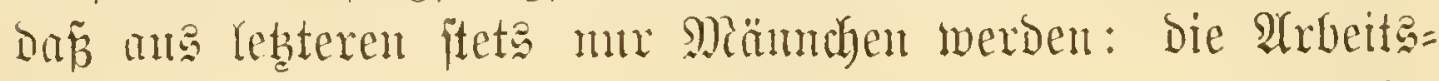
bienen fund, wie man jagt, männex= oder drobnenbrittig. Das gleidre gitt won der Rönigin. Sglre Fier find weber in Dvarim noch fpäter von cinander zu mterjaciden, d. h. jene, woldye in bie Drobnen= und jene, weldye in bie $\mathfrak{a} \mathfrak{x}=$ beiter = repp. Röniginnenzellen fonmen, fegen jich abrolnt gleids "wie ein Cá Dem moen".

S̃it die Rönigiu, aus was immex für ement Girmbe, uicht Gefruditet, fo legt fie überbant mu in Drobnenzellen.

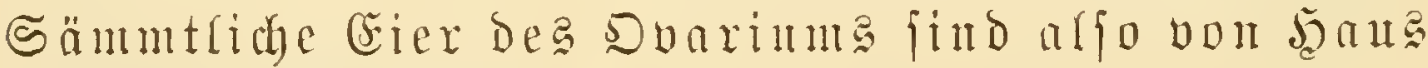

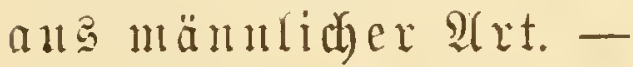

Sit jie aber befrudbtet, ift ilyre Samentajche gefüllt, Dann räß̈t jue trobsem die Drobneneiex unbefudhtet. Sn lebteren

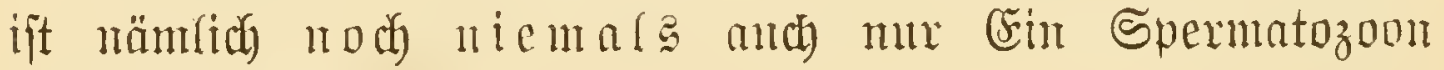
gejerjen worden.

Meiblich merden aber bieje mämulitgen Bieneneiex durch die Bejamung. Dies beweift einfach der Unifand, Dañ in allen in $\mathfrak{A}$ rbeiter $=$ repp. Söniginnenzellen Yiegenden Siern ganze Scaujen vou Spermatozpen jirf vorfinden.

Bu bejiever Befräftigung biejex Thatjache jollte man's

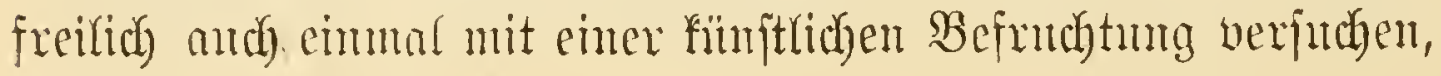


welibe ja fanon seerold mit Erfolg bei bereits gelegten Falter= eiern antgetwantst.

Einer $\mathfrak{U}$ rbeit, die an Scharfïm Dex Erfindung und Des

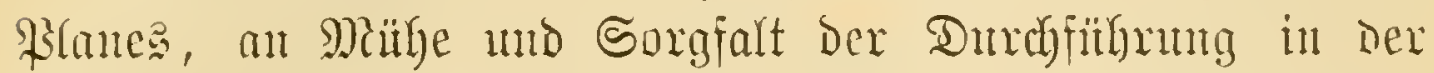
biaherigen ferf=biologifhen Riteratux wohl einzig baftedt,

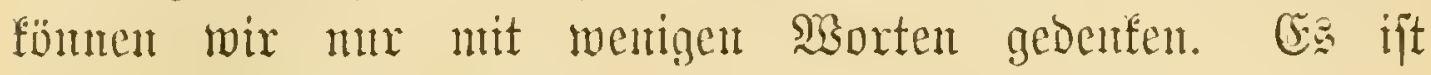
v. Siebord's Unterjudung Dex Rarthenogenejis von Polistes gallica.

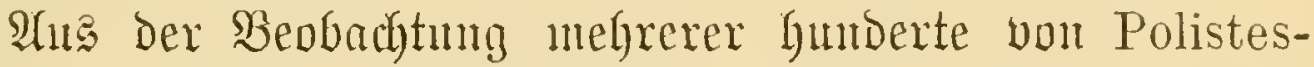
Rejtern, sie fajt tagtägliç revibirt und in Bezıg auf Den

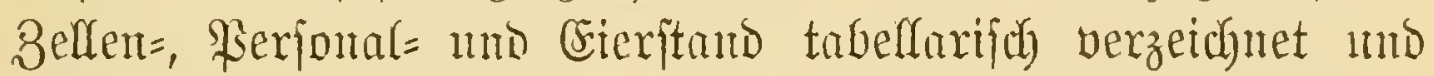
regijtrint rurben, hat jia) forgendes ergeben. Die Crier, welche die vom Borjabre her bejruchtete Rönigin in Früb= jabre legt, entmicfelui fich) zul lauter (fleimen aber wahyren und

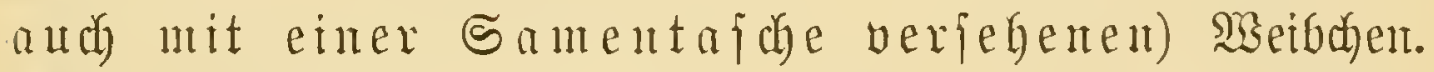

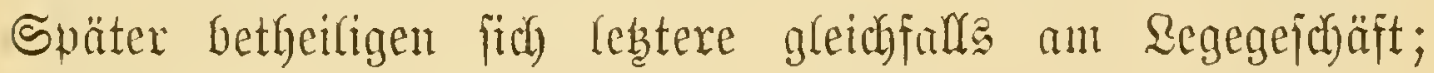
ifre (Eier - jelbftoerftändich unbefrutbtet; Denn Miännchen gibt es noch nicht - liefern genan wie bei Den Bienen Die rebteren; aud hier jutb aljo bie (unbefrudsteten) Arbei= terimten brobnenfrütig.

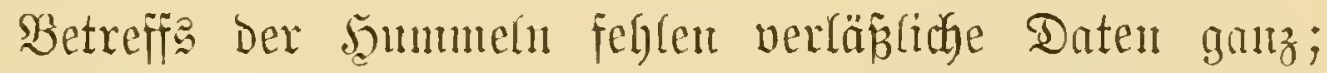
Gimficttich der ameifen liegt uns eine nene Seobarbtung Subbof's über bie Drohuenbrütigfeit unbefrudteter Arbeiter (workers) bon Formica cinerea aus Eaftelfamare vor.

Rad) allen jebt vorgefradjten Daten fömute ntan geneigt fcin zu glauben eimmal, Daż die meiften focialen Arterflitgler parthenogenetifid und Dann, da

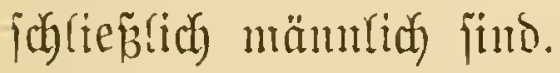

Rebeteres ift aber - uadh ben Färlen, die bisher

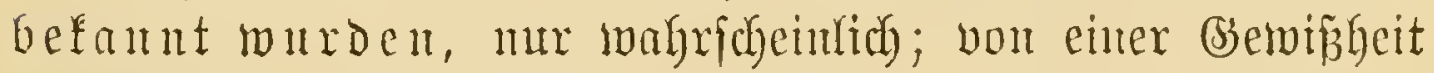
fun Deagalb feine Rebe jein, weil wir nidht ben geringften

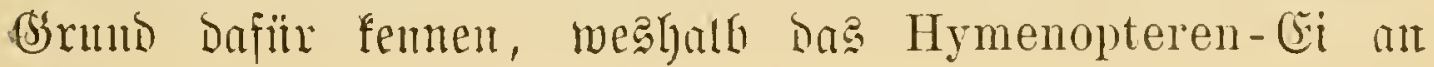




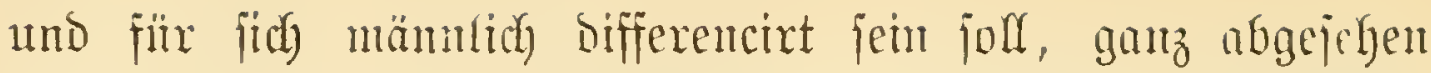

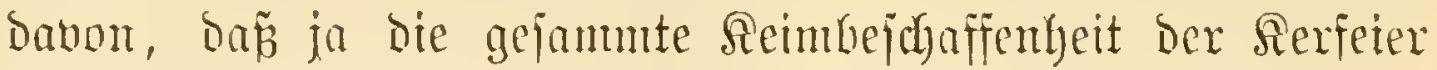
muter das allgemeine Princip ber ßeränderlibjfeit fällt.

Wie fehr wir, bei ber Menlyeit der Sache mid befoutors,

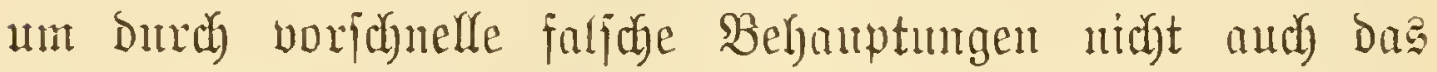

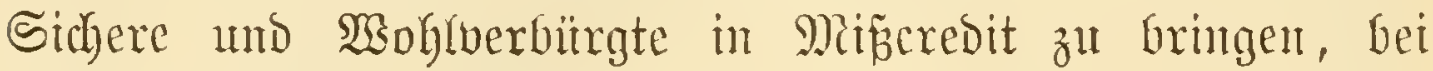
umpern Sdylinjien behutjan zu fein Itrjache haben, rehrt mu ber folgende Fall.

IMif Den Blättern Des Stadyelbeeritrautdyes (Fig. 87*)

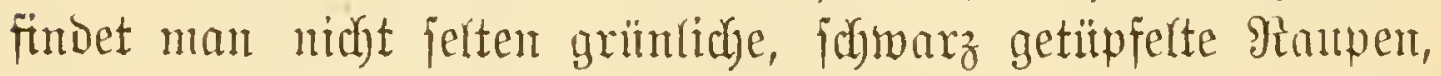
bie anggemadifen jidh in bie Eroe verfriedten, einen ovalen bräunlidben Cocon um fíd fpintmen, ans Dem Dant eine Blatt= twe spe, Der Nematus ventricosus entifeht.

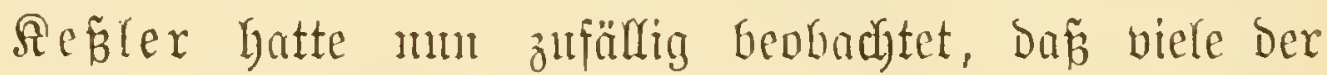

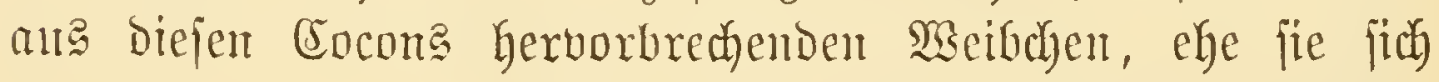
mod) mit einem Miämidyen gepant

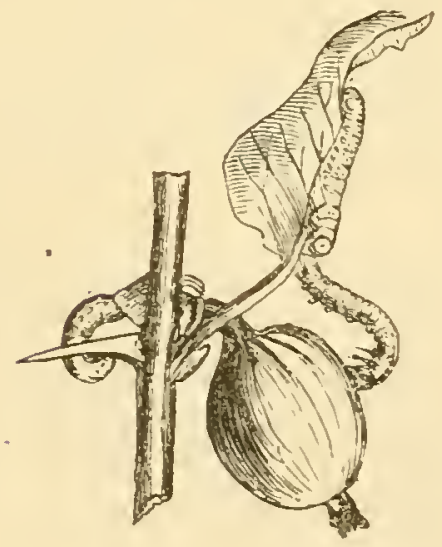

Fig. 87 .

Ctadjelberraupen onn Nematus ventricosus, nat. Gir. hatten, ifre Eier legten, Imb Dañ Darauts, arfo anf parthenogenetijudem sisege, nidgt, wie man mohl ertwarten mödyte - Mämudjen - jombern lauter sigeibeden entftanden, wälrens die Gefrubteten Nematus mud Miännd liefern.

Aud bieje Beobachtungen murden bum in grofen Style vou Siebold twiedergolt.

Er zog tarjembe vou foldyen Raupen zu Saulje in geeignteten Sïffigen uno martete die Serpuppung ab. Die grö̈̈eren Cocons, melde

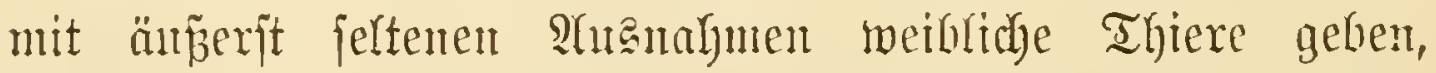

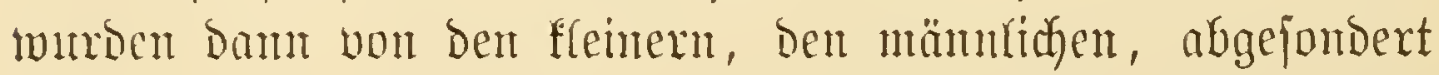
und zum Theil auth eirzeln anffewalgrt. Das Rejultat war 


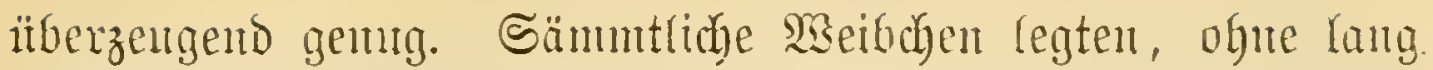
ani einen Mann ju warten, Sier - und inner murden mu Siseibden barm?

Sollten mu aber gemifje Sfeptifer alfen vorgenamten

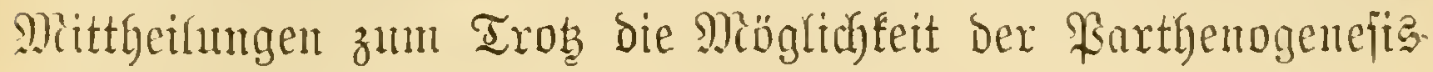
bejtreiten, fo haben jie jebenfalls bie Brflidyt, bies burch That = iachen zul bemeijen.

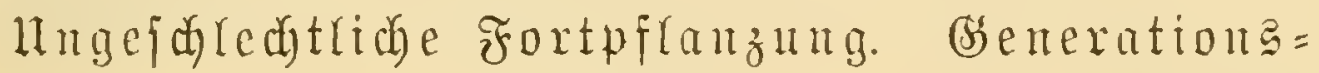
wectier.

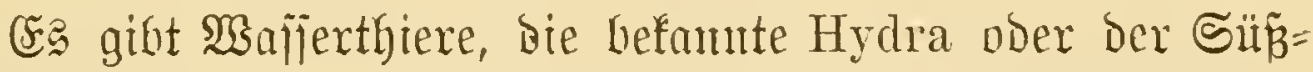
wajierpolup ijt ein foldes, vou überaus einfachem $\mathfrak{B a n}$. Fhr ganzer fïrper ijt weiter nidfta als eill afterlojer Darm, D. i. ein Shtauth, der an cinen (Ende gejchlofien und jeítgeheftet ijt, während Das andere ende offen und zum

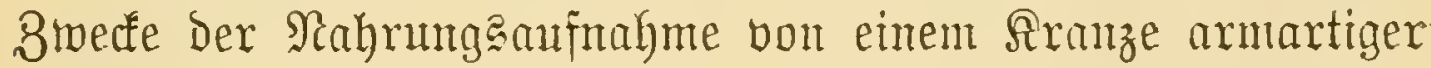
Ansftülpungen umgehen ift. Diejer niebrigen Drganijation ent= ipricht aud die Einfabheit ihrer Fortpflanzung, betwerfitelligt Durch Snospen, bie aus den Seiten biejes "PFlanzentfieres" Gerborwachjen und über firrz ober lang ein bem Mitterwejent gleidyes Bejchöpf geben.

Rentmen wir ein foldes "Siflauthtyier" A, jo wiro bie

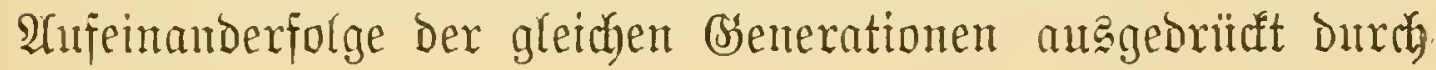
Die Reife

\section{A. A. A. A. . . .}

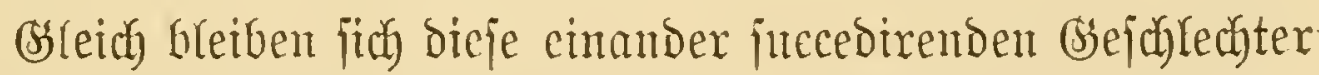
aber im ardgemeinen mux infolange, ars and ihre Rebents= bebingungen jich gleich bleiben.

Sebent wix mun Den Fall, die vom Mutterpoltyp jich los=

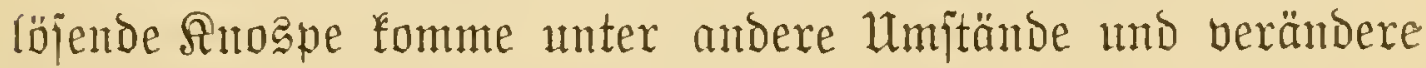
in Folge defien ihre Bejtalt $A$ in bie andere aber jegr ähn=

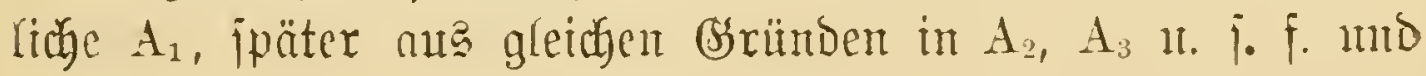


踝 fäme endlich) (im Ranfe vieter Ssenterationen, in weldyen alle Diefe entzehten Beräntorungen funmirt merben) ein SBefen hermts, das fich fobn infoweit ars eine höhere Rebensform

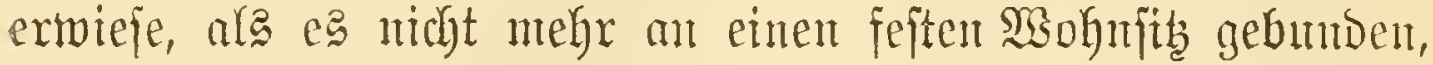

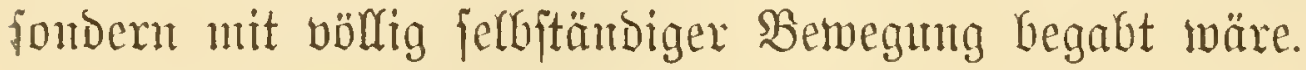

Wir jagen mu, die Form A lyat fich allmälig in bie Form $A_{n}$ verwandelt oder metamorphofirt, und bezeishen diefe nene höhere Form $A_{n}$ int Bregenjah zu Den vorangegehen= den niederen, die man $2 a r b e n$ ment, alg das (relativ!) "vollentote" Thice.

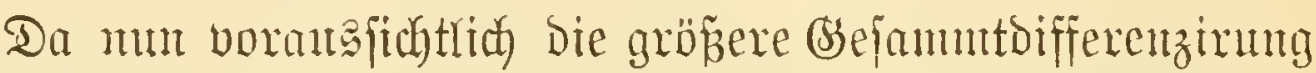
Des Rörpers aud cine Steigerung jeiner cinzelnen Futhtionen

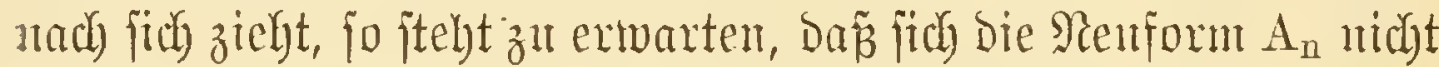

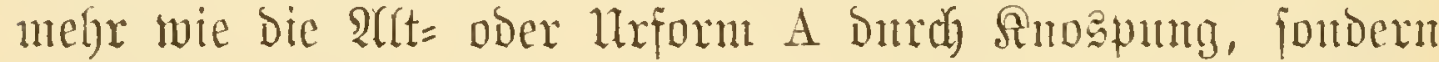
anf complicirterem $\mathfrak{s e g e}$ aljo z. $\mathfrak{B}$. Dunch befurbtete Eicr vermebrt. Die fortiareitende Metamoxphofe des Ge= fanmtthiexes ift mit andern sorten von einer pro= greffiven Metamorphofe ber Bengung begleitet.

Der Fall mu, ben roir ba gejebst, ift fein erfmbener. Es gibt in Meere wirffich in Der Biejtalt ind Fortpffanzming:

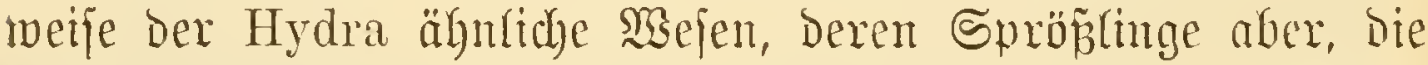

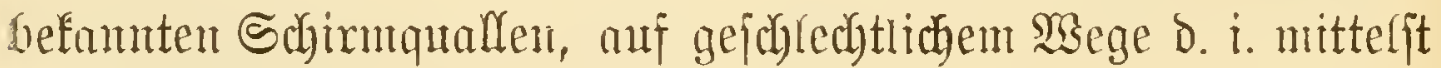
refrutdeter (sier fitch fortpflanzen.

Num ift ber Refer getwiz neugierig zu vernelymen, was

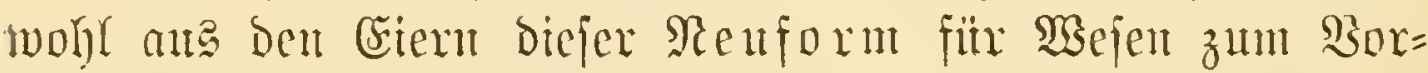
fdrein fonmen.

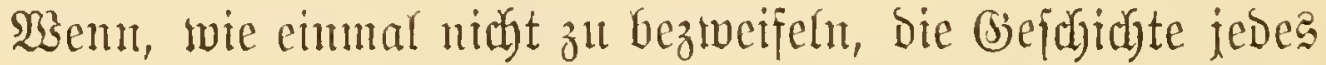
Snbivibum eine gebrängte Recapitulation, eine Wiederholung

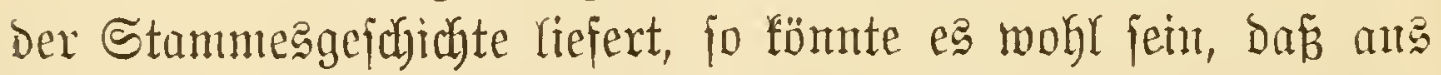
Dem Ei Der Jebzt= oder Sunflenform $A_{n}$ midyt gleidy roieder ein

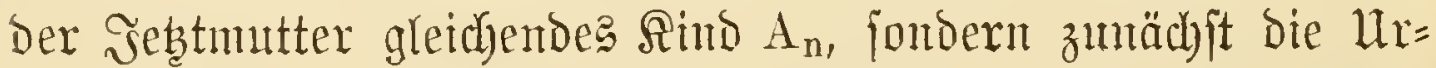
obex Einjtform A, bas wäre aljo die feitfitiente Hydra, entitimbe. 
Und vielfach gejuicht bies in ber That. Da aber bicjes erite

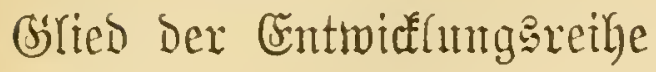

$$
A \cdot A_{1} \cdot A_{2} \cdot \ldots \cdot A_{n}
$$

wic leidyt einzujeben fich nicht umittelfar (bumch Metamtor= phoje) in bie Dunalle $A_{n}$ vermandeln fam, ba ja ber "Strmm"

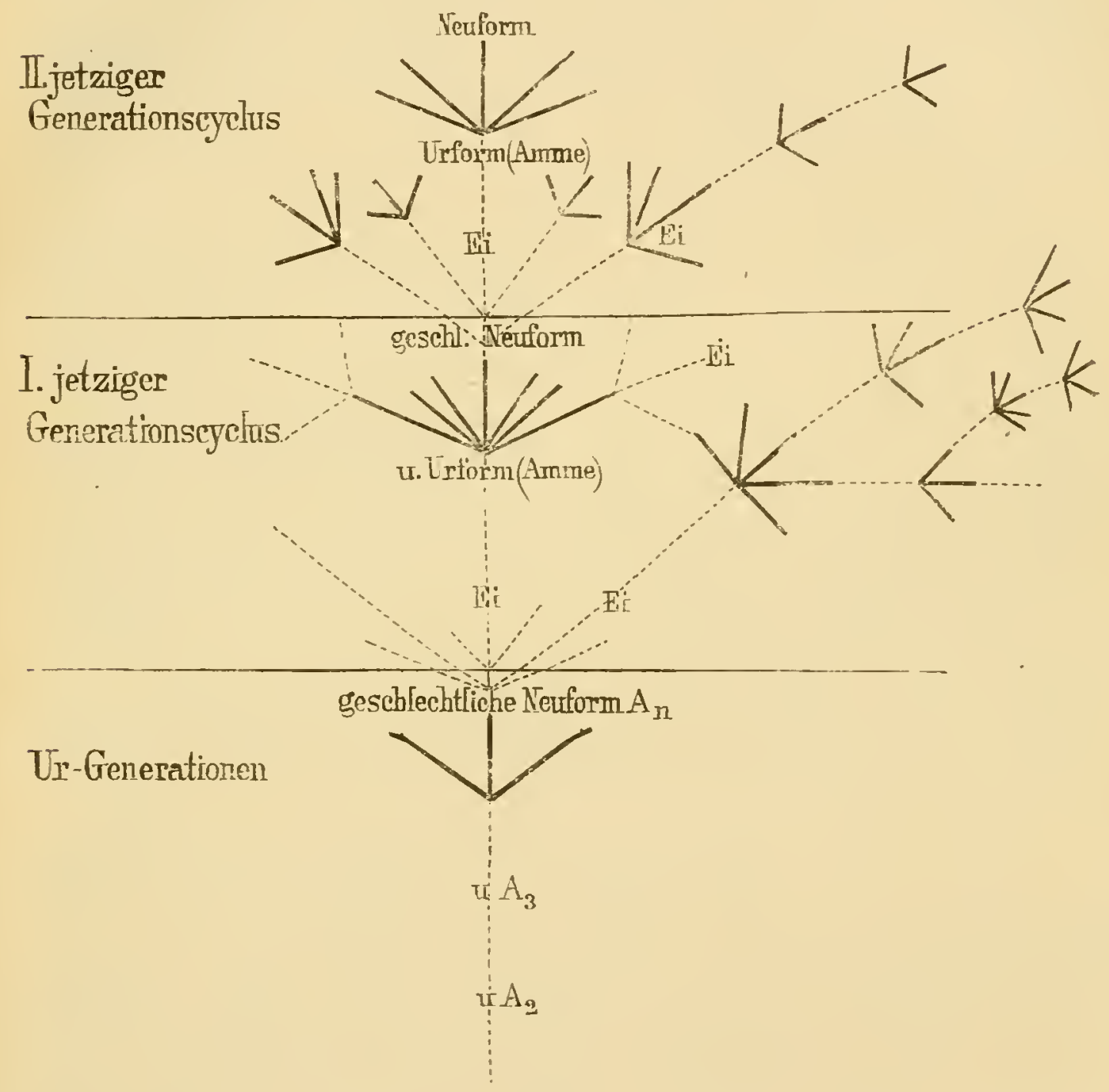

Ungeschlechtlrehe Urform ( $\left.\mathrm{uA}_{1}\right)$

Fig. 88.

Shema bes einfaden Bsenerationstwediel:

..... Gi uno saraus entịtefhente 2 (mme.

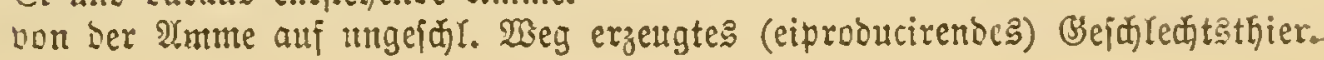




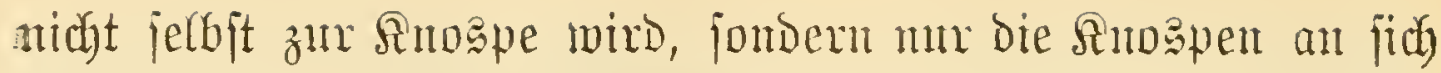

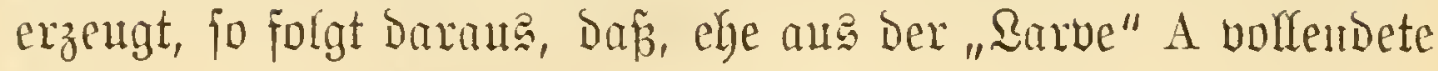
Ificre werden fömen, fie frither, wie ehmals, jelbjt erjt wroliferiren num.

Die Ren= ober Suaflenform $A_{n}$ erzengt arjo zutärbjt

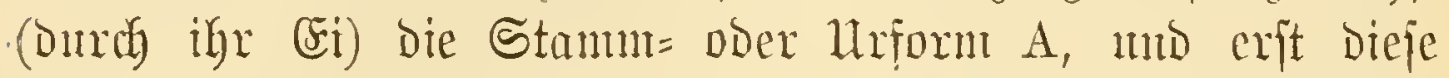
erzeugt $A_{1}, A_{2}$ it. j. F. rejp., bei abgefïrzter Metamorplyoje,

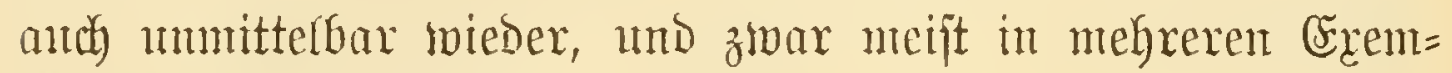
plaren, die Neuform $A_{n}$.

Dies ift aljo eime Metamorphoje, eine Medyel= folge Der Generationen. Das vollendete oder Bejolechtas=

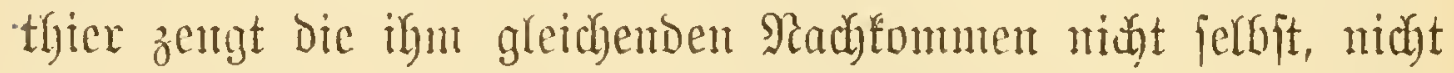
Direft, fonbern ca zengt nur bie alte Stanmmuntter, die fog. 'Amme, mo erft Dieje gibt Dem nenen Bejdyledyt Den Mriprung. Dies ift ber einfactifte Fall. - Eogut abor als bas crite (S)ied Der Durdy bie Dntogeneje wieberholten ganzen Stanm= reike jelbitändig proliferirt, ebenfo fam es auch jebes forgende

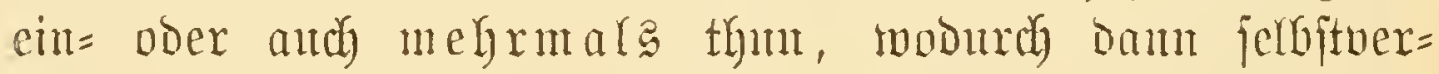
ftänolich Das ganze banmartige Shema ber chclijaten Gene= ration, swie mix es in Fig. 88 entworfen baten, now viel vertwicfelter würde.

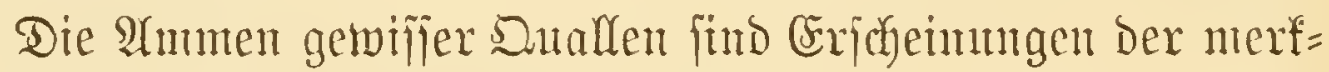

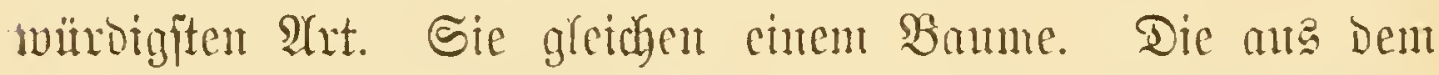

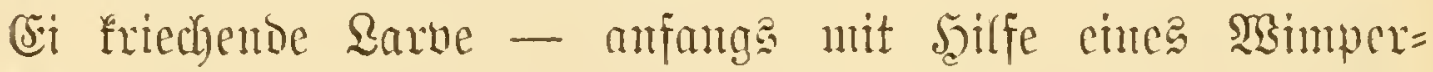

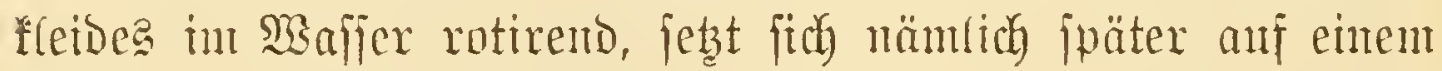

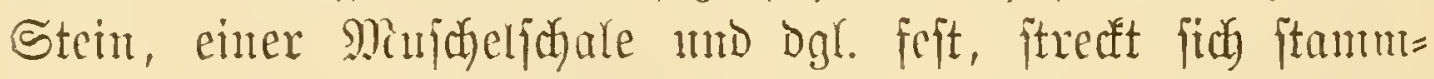

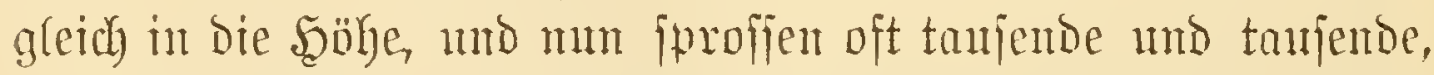

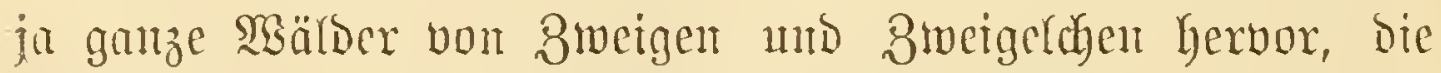

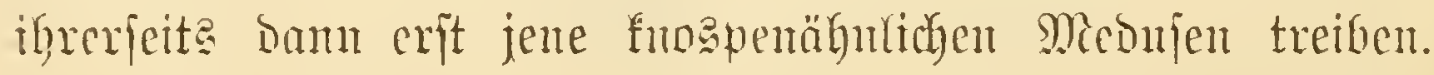

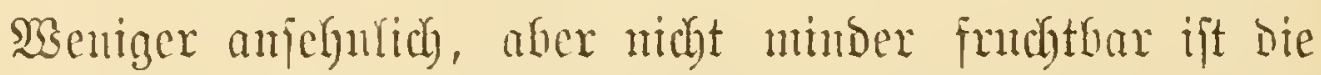

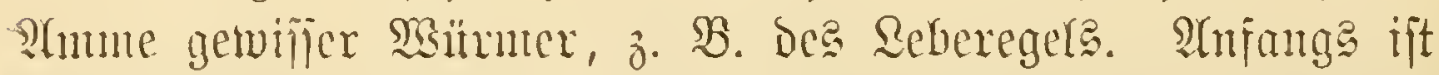

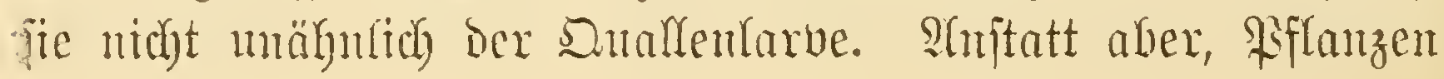




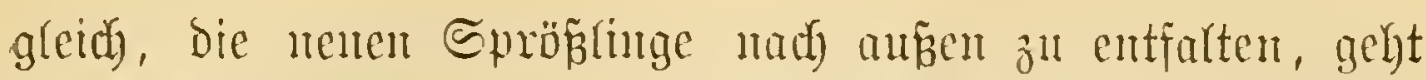
hier bie Broliferation ganz int Gebeimiten und Berborgenen bor fich.

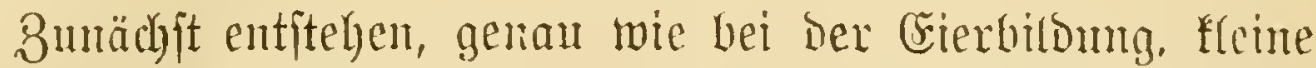
Serne, die Reimb(äschen, weldye durd) Untagerung mit

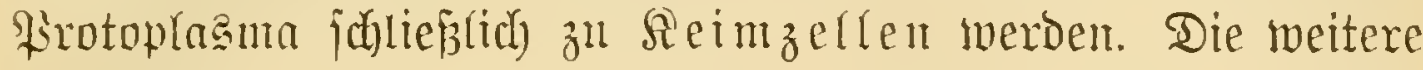

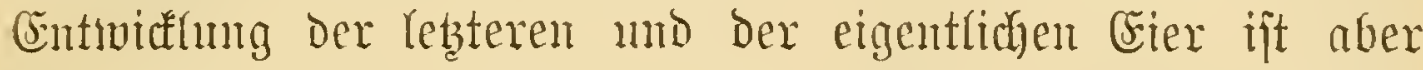
eine wejentlich verjebiedene. Die (sizefle beginnt fid erit Dann zu gejtalter, D. h. zum Entbrtyo zu bifferenziren,

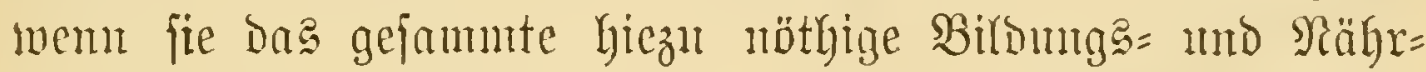
matcrial in fits anfgenommen mo Den befundutenden Samen cmpfangen hat. Ânors bie Reimzelle. Şier wird mit Der Geftaltung Des Seimftoffes nibt gewartet bie alfes beifanmen ift, bis alle Banfteine vereinigt fumb, fontern bie Fornumg begimt j(b)on an ber jutgen, joznjagen nod unreifen Reimzelle,

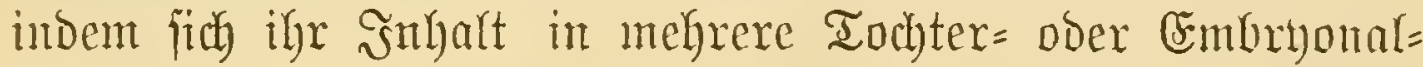
zellen jondert, bie mter beftändiger $\mathfrak{A}$ uffuahnte ans dem Stofffapital der Mintter fich vergrö̈́pen mb neuerding? theilen, jo Dañ zul ber Beit, wo bie nit einem gleityen Bilontgantateriale anggerïitete (Fizelle fid) erit zu geitalten mfängt, Gier Der Émbrbo, Das junge Ifler oder Der fiemting judon fix und fertig in ber Mutter Yiegt.

Sn ber Regel entitehen in jeder Anme jebr viele foldyer Seinte und fo ift es Gegreiffich, Daj von Der erjtent oft midyts

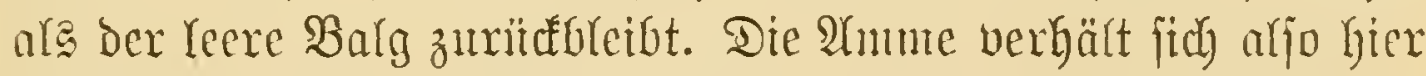
oft ähultidy wie eine Nantterzelle, bie bis anf bie Syitlle in bie Tochterzellen aufgeht. Sowic jich aber in ben Keştern oit wicder eine zweite Beffengeneration vorfindet, fo enthalten and

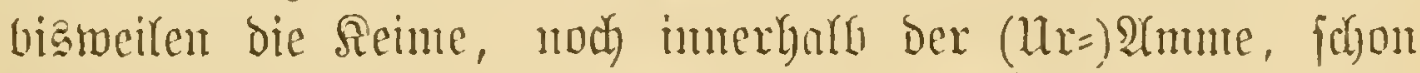

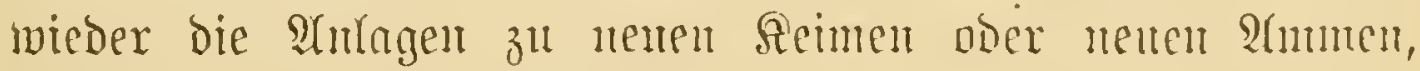

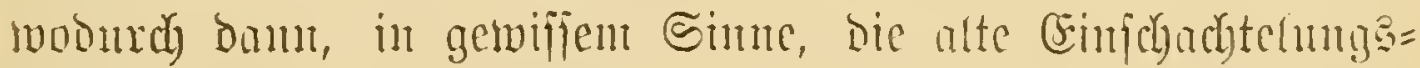
therrie wieder zul Elgren fonmut. 
Die Bortheile diejer Bermehrungämeije find jelbjtredent.

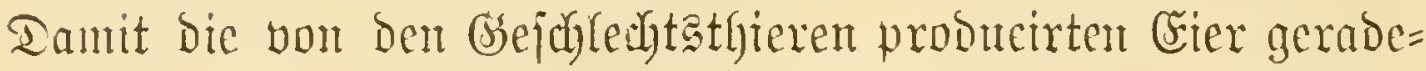

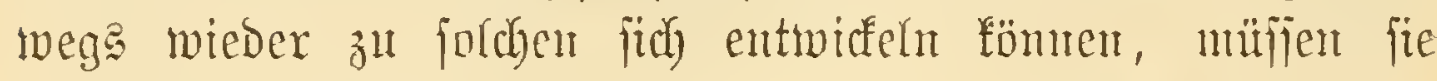
eine relativ bedentende Shajtenter von Der Matter befommen,

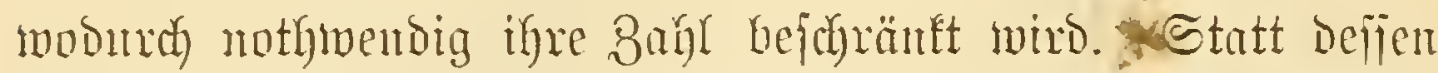

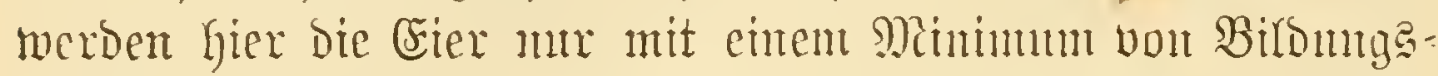

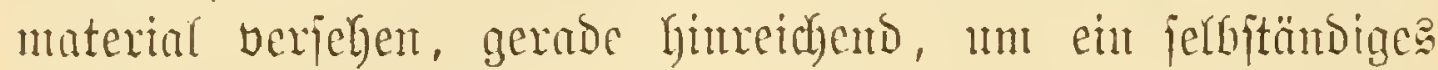

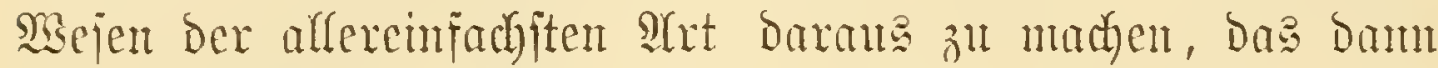
bas Fehlente fich jelbjt ertwerben mur. Salles diefes geht แun, was bein Bsejolechtathier nimmermelyr nöglidy märe,

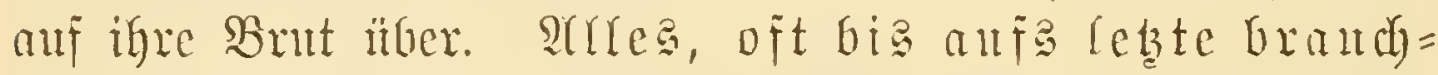
bare Atom wirb afjo 3eugunge, wird Rrobuftions=

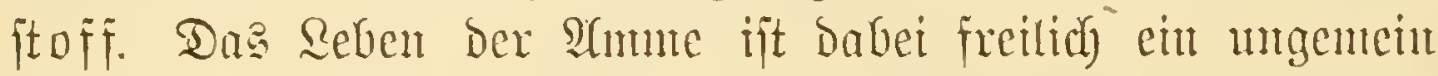
flüdhtiges - aber Daranf fommt es eben midbt an, fie ijt ja mux Mittel zun Bwed, eigentlich gar nidyte anderes als ein

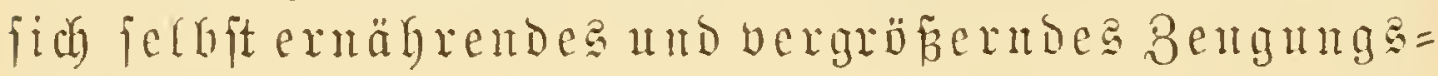
orgalt.

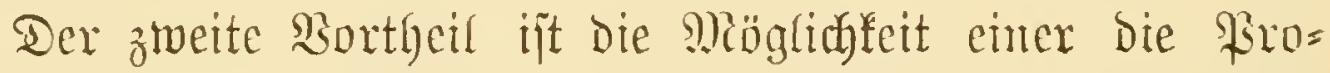
Duttivität jteigernden vieljeitigeren $\mathfrak{A}$ wbentung Der nährenden

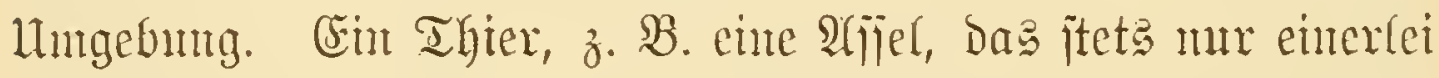

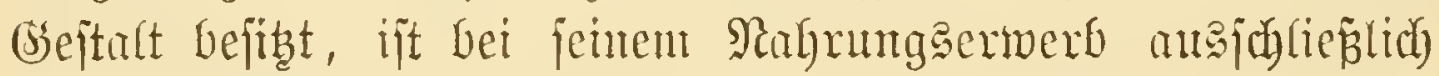
auf Das skedium bejchränt, wofïr es organtifirt ober ange=

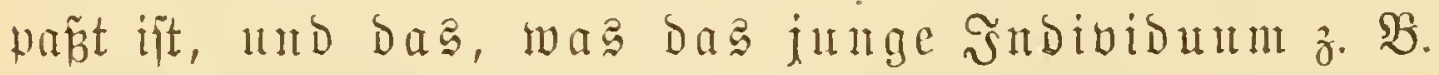

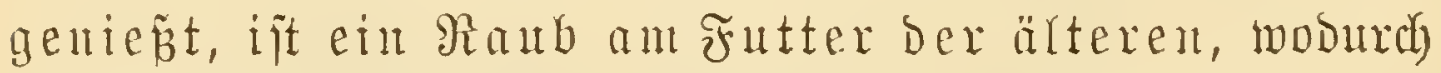

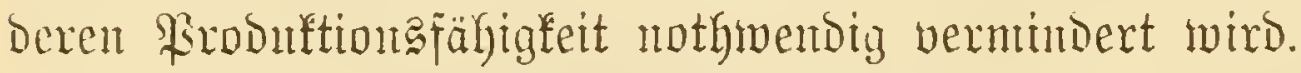

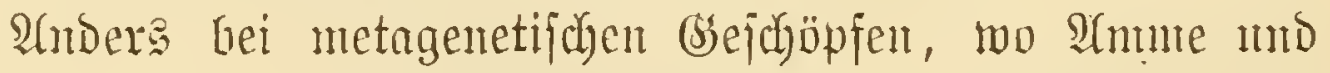

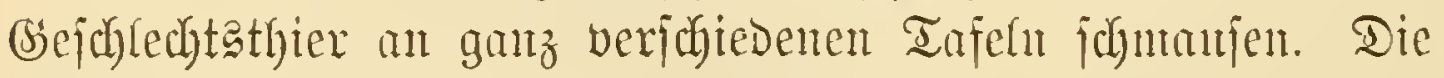
Reberegelanme z. B. beutet, jo viel jie vermat, die reichen

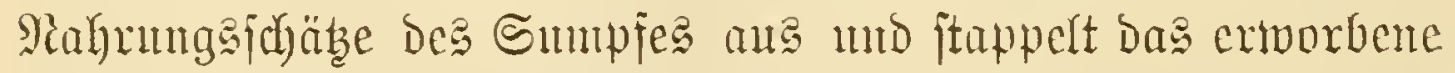
Material in ifren Remrtingen, Den famofen Cercarien auf. Sobard aber lebtere in bie Brallengänge igres wainthes ge=

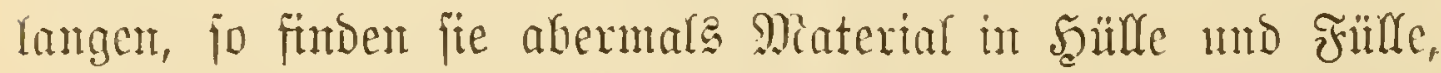
cinerjeits zur eigenen bejieren Drganifinutg, mbererfeits zux 
Froduftion ber Fier, ohne, mögen jie verzegren, wie viel inmer - Die Renten ifrex Tmmen aud ma im geringiten zu berkürzen.

Unterjuchen mix mu, intwieferne bie eben won ben Suaffen

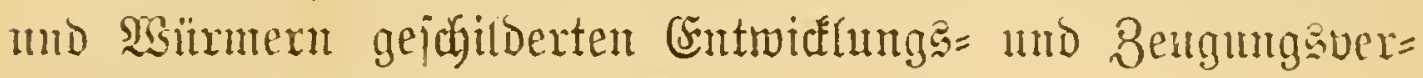

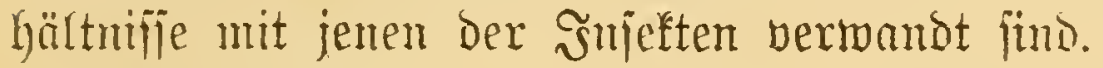

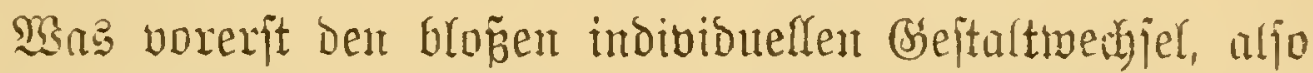
Die jogenannte Metannorpoje betrifft, jo tritt bieje befanntlich fanm too fo allgentein uno fo prägnant wie bei Den Snfeften

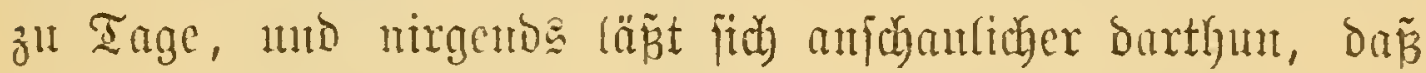
bie verfdiedenen formen, unter benen ein Thier währeno

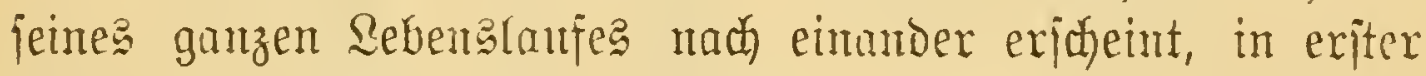

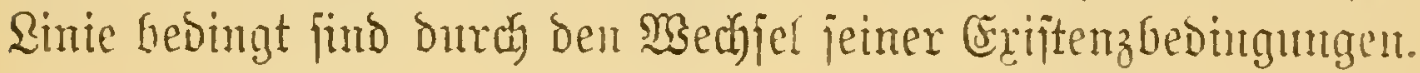

Beijtehend (Fig. 89 a) jiegt man bie erite Sebens= ober Rarbenform von Sitaris humeralis, eimem betanten @iäfer. Mian Fintoet biejes muntere Ding in Froühjonmer an ben Fingängen zll Den wben bejdriebenen Salferieen der Grobienen auj Der Saner liegen. Bei guter Brelegenheit ipringt pie Den lebtern.

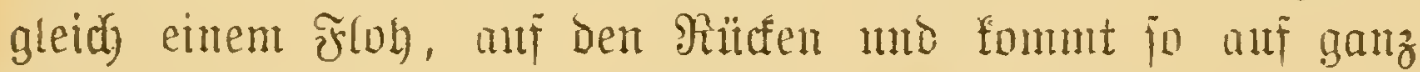

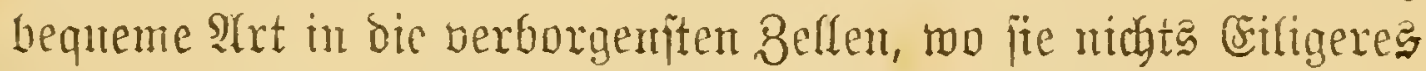
zul thu hat, als bie Eier igres gefälligen WSirthes zu ver= ipeifen. Der fluge Barafit will aber nidft bloz die Eier, er

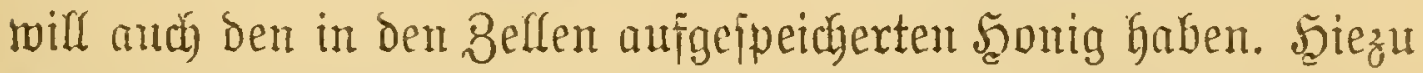
sären ihm aber offenbar bie Beine läjtig - umb fiehe da, das jchlante, glieberreiche 秥ejen verwandelt fich in eine ben Maden jeines ssirthes auffallend ähnlidye Rarve (b), die twie ein tleiner Flo

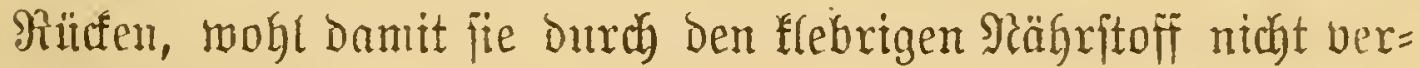
ftopit merben.

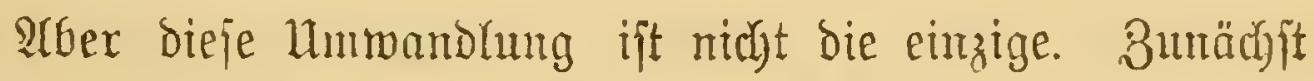
rirb, um nur furz anzudenten, eine $\mathfrak{A}$ rt Tommenpupe (c) (B) a ber, Jnielter. II. Br. 


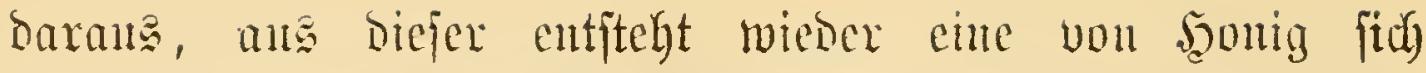
mährento Sarve (d), weldye abex, ba bor fleme fromigteich inzwijhen gejunfen, die Stigmen tiefer are bie erite haben

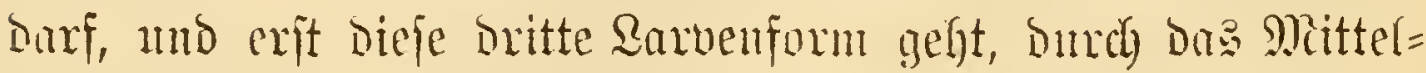

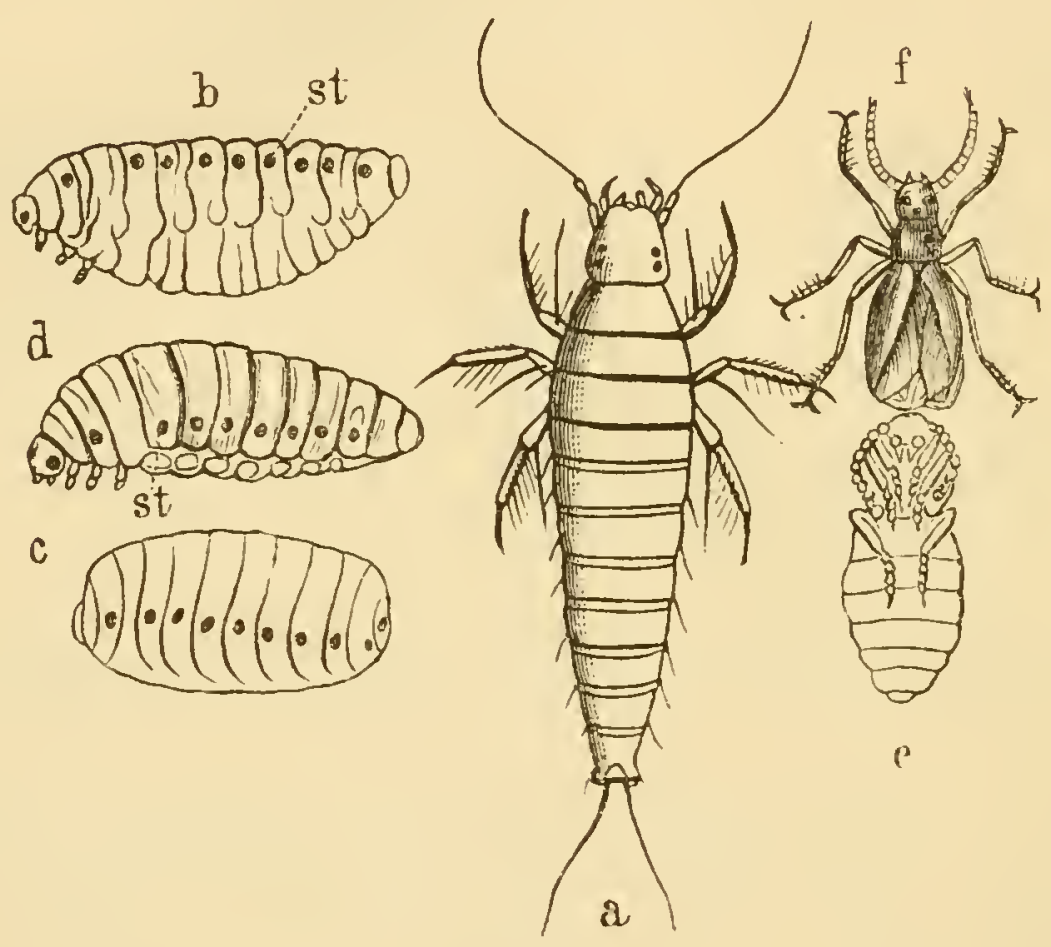

Fig. 59.

(Entwiffung vou Sitaris humeralis. Radi Fab $\mathfrak{b}$.

a Erite, arj bie Crobiente fpringente mb ifre Fier irefíende Sarbenjorm.

b 3weite, vom Sentig Der Beffen rebente arvenform (Stigmen st ganz pben

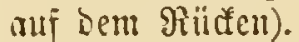

e (Erifte (probiforifde ober Sdjein $\Rightarrow$ ) Fuppe.

d Dritte, faft der ojweiten gleidjende, greidjfans von Sontig Yebenbe Garvenform (Stiģment st näher sem Bau(t)e).

c 3weite (befinitioc) Ruppe.

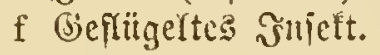

ftudium einer typifanen Räferpuppe (e), in bas vollentete Simfeft iilier.

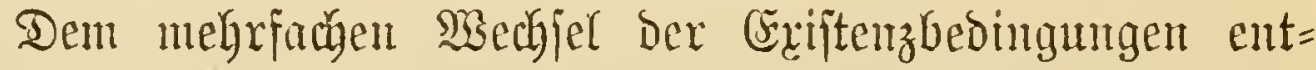

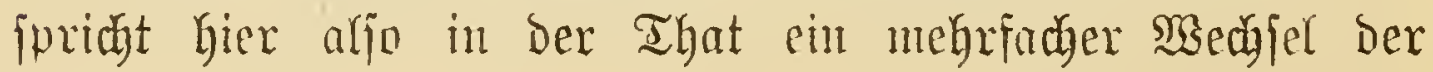


Drgunifation: Dic erite Qurve ift zm Springen, Die zmeite

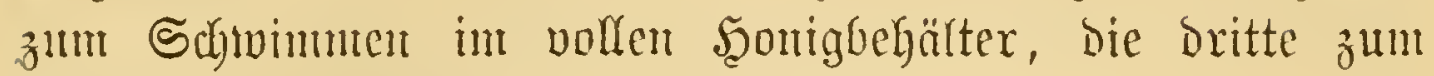

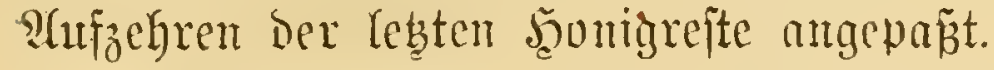

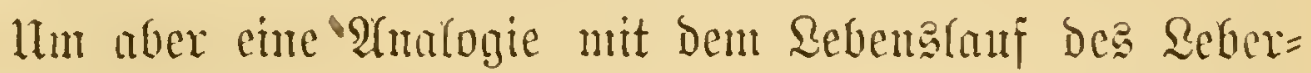

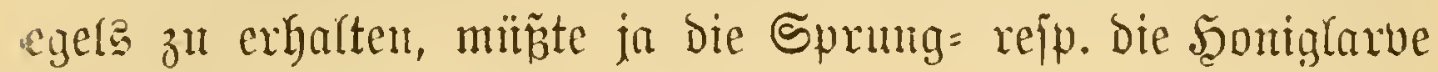
aud cine eigene Sirut erzengert.

Şeshalb bies nidyt gejchiegt, fömen mb wollen twix

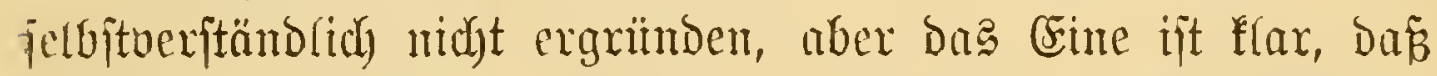

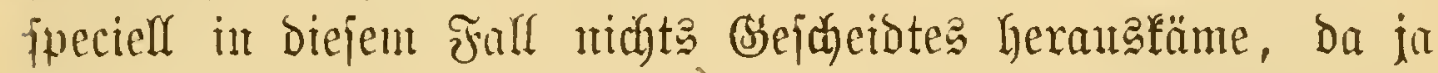

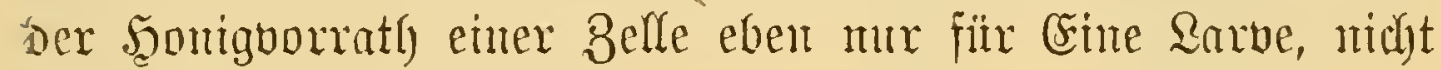
aber fïr viele ansireidyt.

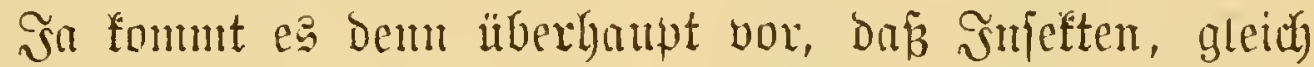

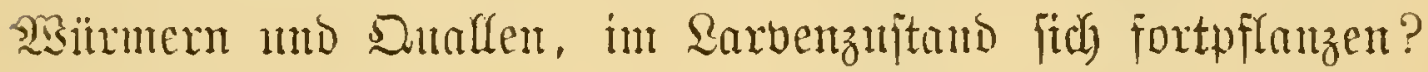

Sor etwas mentiger nla 20 Sahren würde mant Sedcm,

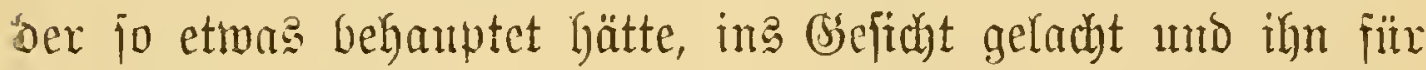
sinen Prgantajten ansgegeben haben. Şente Eemen wir freifich aud erit einten eimzigen Fall, Der jeinterzeit, wie man fich benfen mag, fein geringes Stuffeben erregte. Wir fragen aber

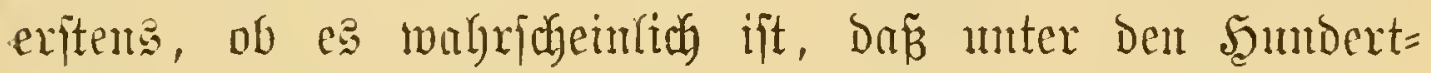

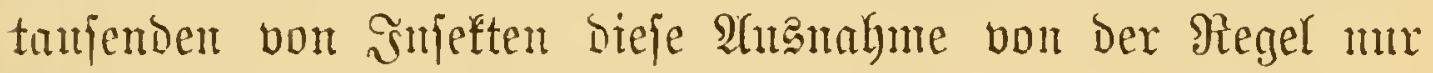
rein cinziges Mal vorfommen foll, mo bann, ob uns bie folgenden zrnutzig Salgre nicht eben fo gut eine zmeite Ent= Deflung bringen fömen, als es bie lebten thaten?

Der betreffende Fall if mu in @itze ber. Wem ber Rejer Den Durchfendyteten Bajt eines alten Baumes zerbröafelt, wird er in Der Regel eine Menge fleinter weifflicher, of́t

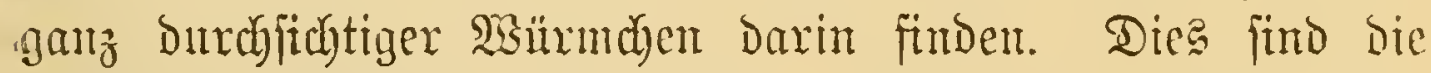
Maben beridiedener Fliegenarten. Bringt man joläe unter bas Mifroffop, fo mag man gelegentlich wohl feljen, ba

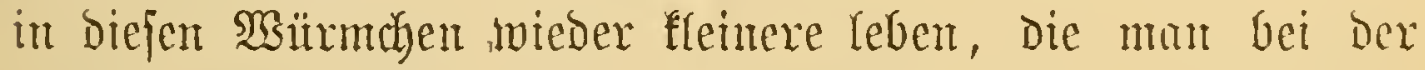

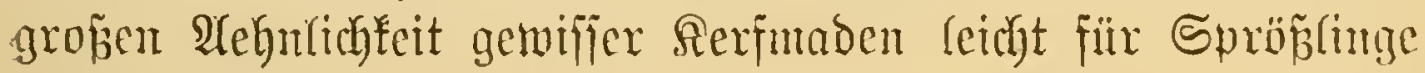

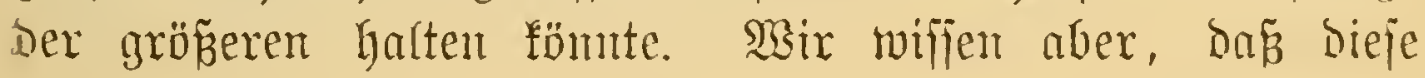




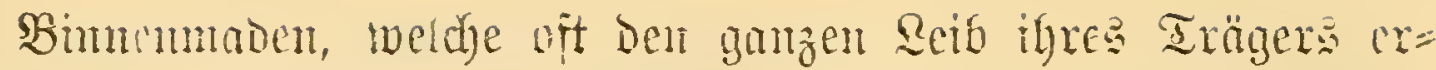

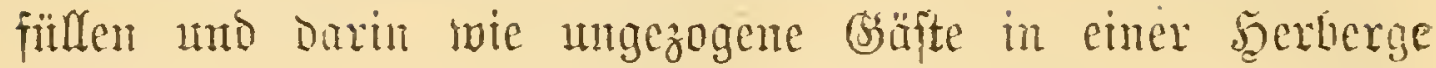
fich benthmen, von gewifien Sdymaroterferfen, nament=

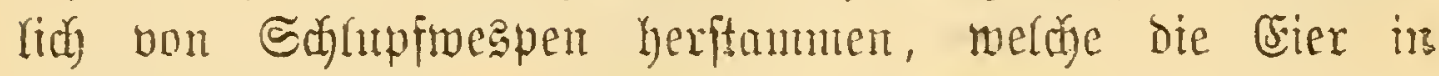

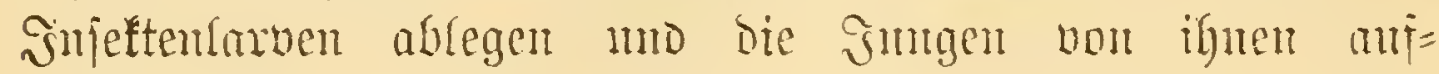
amment lajpest.

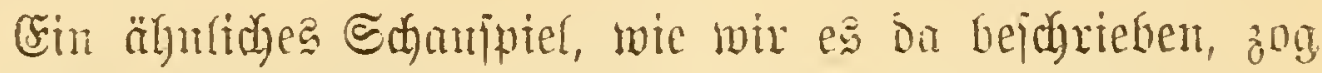

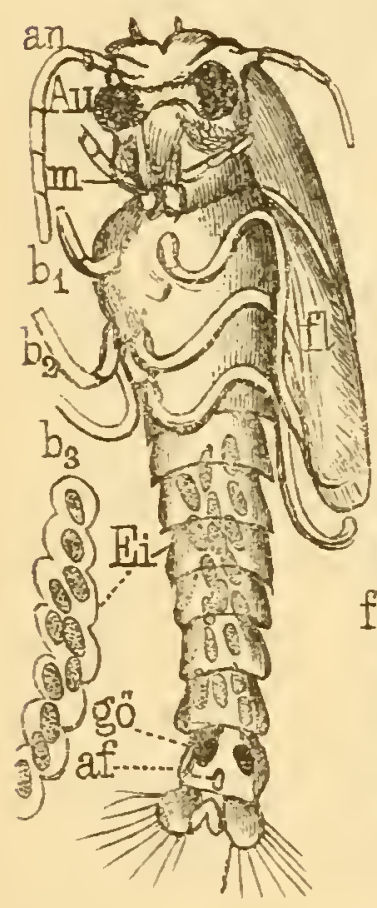

91

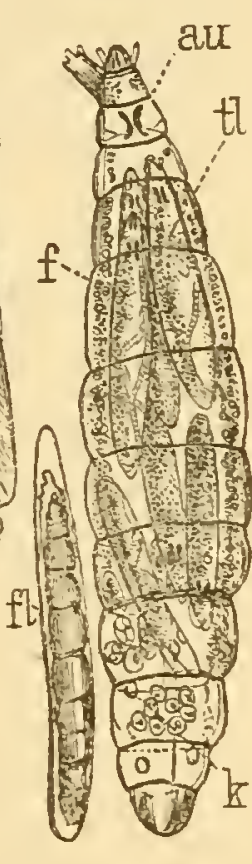

90 ริig. 90 .

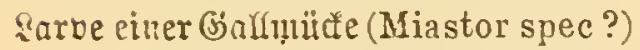
mit Todterlarven (tl) eriüllt. su Trugc, f Fettïrper, k Feimselfen.

శ్xig. 91.

Fuppe einer Feserbufamiiafe (Chironomus). gö bie beiven (bejóded,ta= öfinngen, aus toeldem bie in einem Ballertitrang eingebetteten (Fier beroorfomes. Pad : 0 . Brimm.

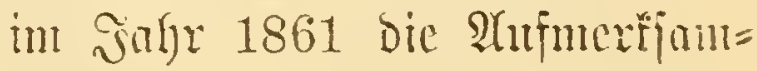
feit Des beriffmiten 3oologen

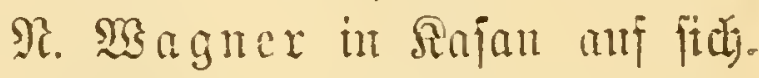

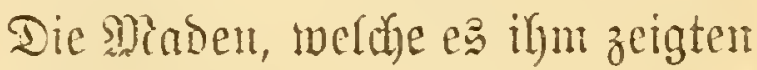
uno bon Denen eine in Fig. 90 afigebifinet ift, gatte er aus bem Bajt ciner alten alne befommen. 然驺 ifu aber gor bald in grofe sufregung berichte, war ein= mal bie Beobaditung, daṕs bie Bimenunaden bis anf das lleinfte Tetril, namentfid aber binjidt= li话 Der ganz origineffen Mimo= und Ângentilomy ifyen Trägem

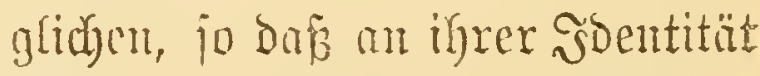
abjolut nicht länger zu zweifeln war. Angichlnggehend war aber vor artem bir Ifyatfacje, iaz Dieje Bimmen=, oder Todfterfarven wolfen wir fie jest heifen, micht von aupen hincinfanten, fondern

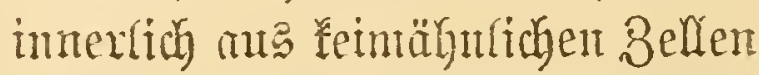

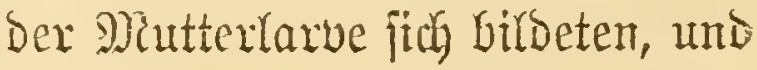
jobalo jie Den leeren Balg Der lesteren verlafjen Gatten, gleich Den Remidrändyen Dex Sangwitmer aud ihrerjeits wieder ene ähnlibe Sintenornt eraengten. 
Danf ber cifrigen Sagd, die mu, von beriftedenen Forjuen, anf bieje Wumberlarben gemadyt wurbe, entbecte fald Daranf Mieinert Diejelben Maden gleidyfalls in einer

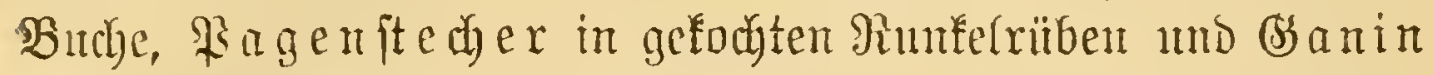

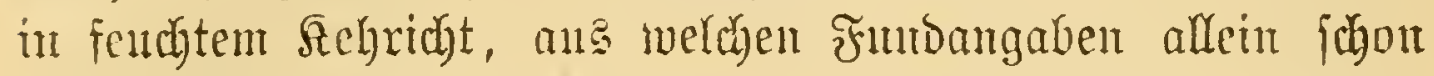

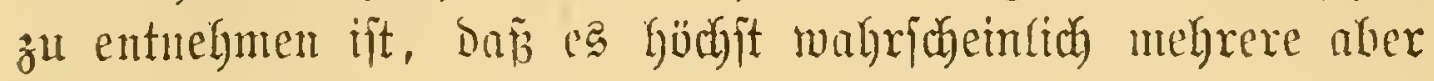
fehr make verwambte Sarten von biejen Rerfen gínt.

Durb Dic Bemülungen Me tuert's, Sentaxt's und Mecnifon's wurbe num allgemady aud ber ganze

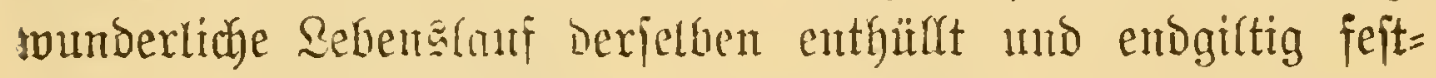

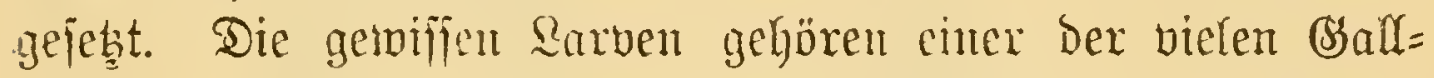

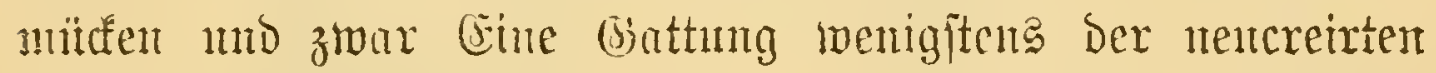
Species Miastor metraloas an. Die befrutbtete meibridae

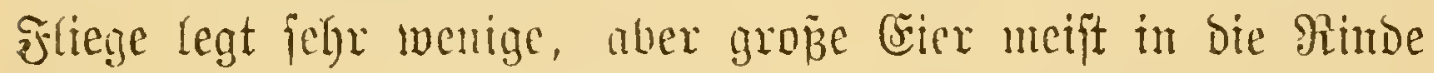
nulmiger Bäınte, Dic fid Dam nach Der gewöhntichen Regel

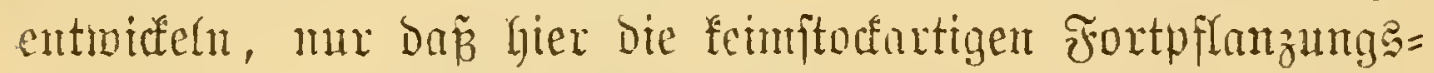
sagane jefre frügjaitig vorgebiloet weroen. Einzelte Follifel

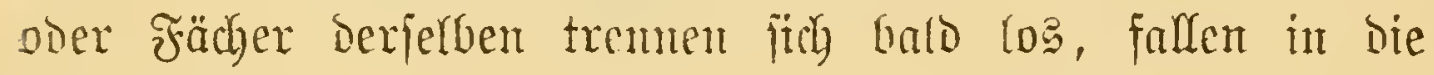
Seibeshähle und in. jedem entiteht num ein Reim, der von

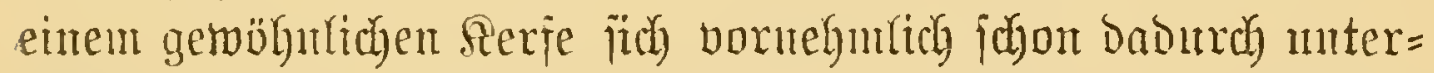
jabeibet, baz cr, unter fortonuermber Bunalyme an Material, welche hantjärblich aus bem maffigen Fettförper ftammt,

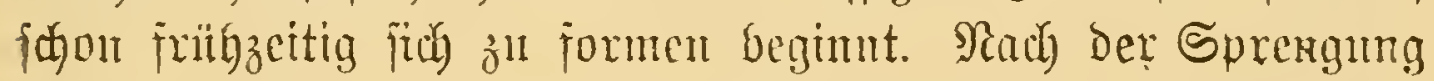

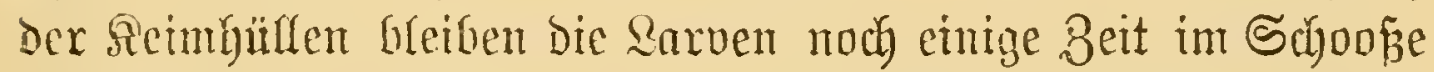

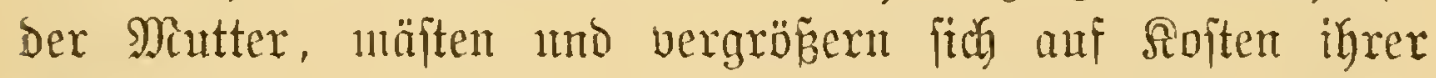
Eingeweide, und verlafien crift ben auggemeideten Balg, nach=

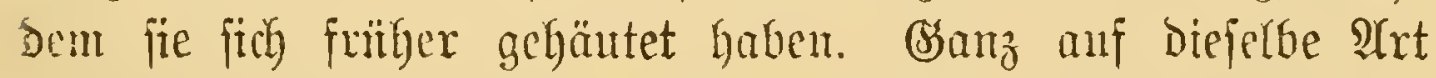
entrideln fich nun rajd ginter einamber melyrere Maden= bruten, und der $\mathfrak{A b}$ bh)

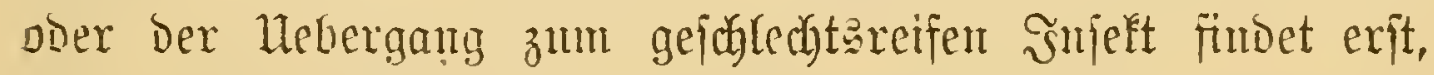

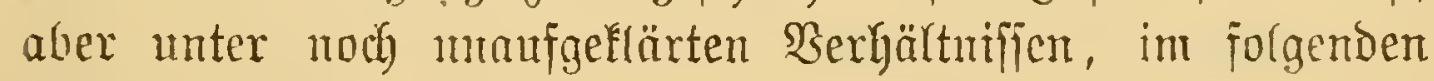
Sommer ftatt. 


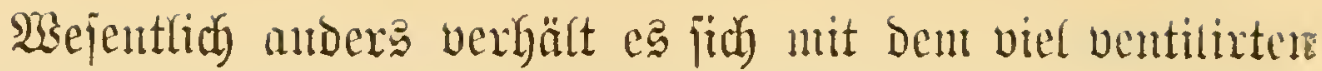
Senerationstwedjel der $\mathfrak{B l a t t}=$ ud Rindeuläuje, wo wir Sorgänge getwahr werden, bie bald jo, bald jo auggelegt werden, bie ung aber, beim redyten Ridjt bejeben, nux Den

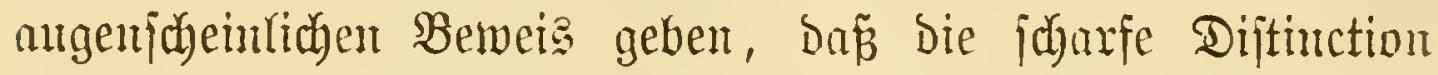

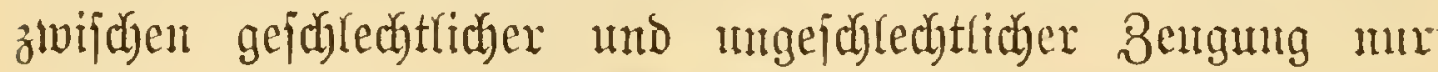

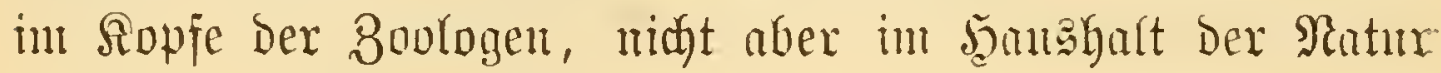
exiftixt.

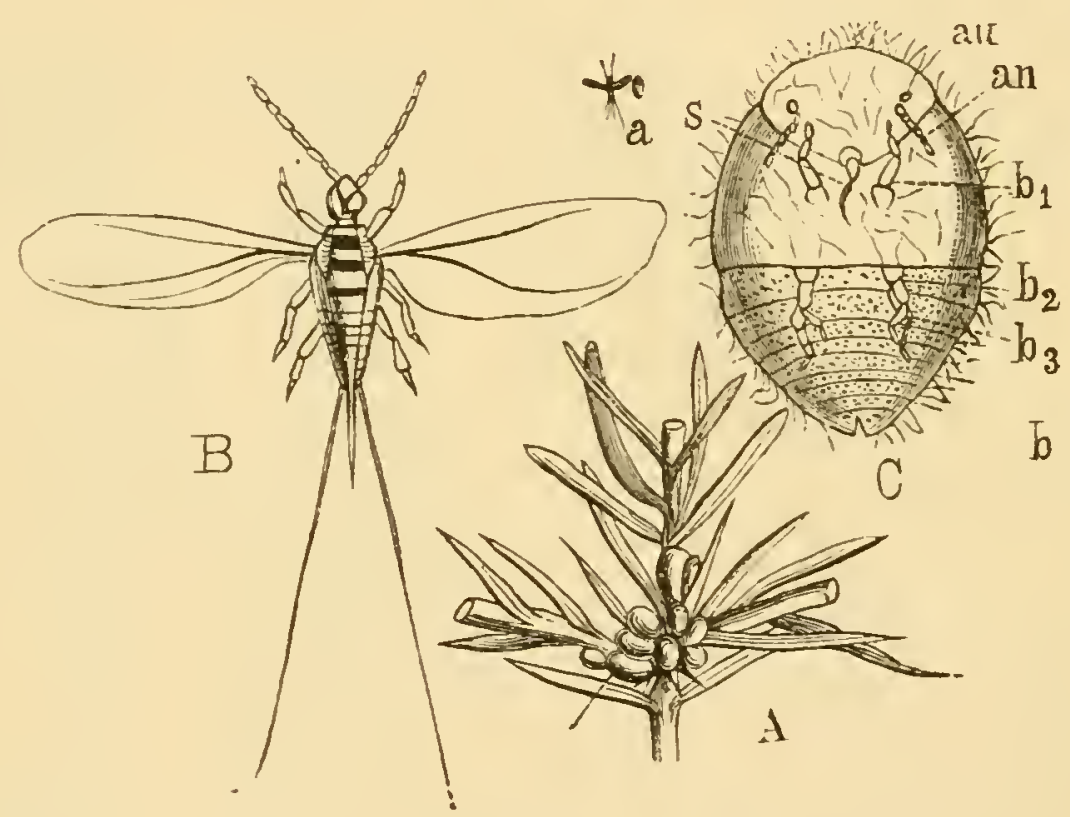

Fig. 92. Ëțilolans (Coccus spec.).

B geflügeltes $\delta$. A $q$, gleid) Beeren all sell Pabelt jitzents. C sarve ses $q$

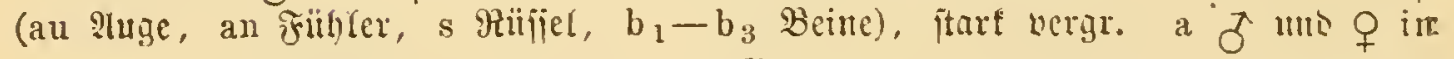
trat. अir.

Betreffe Der edbten Blattläuje ifft zu alfererjt ju con=

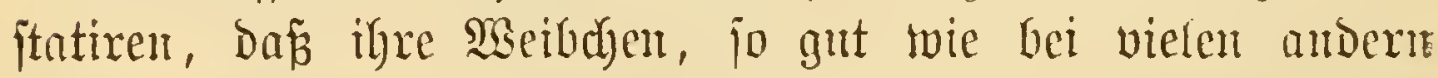

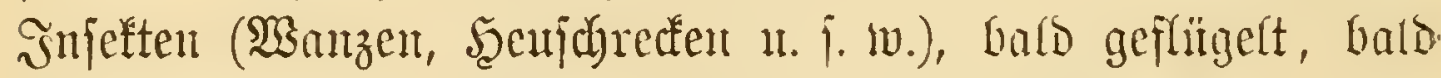
ungeflügelt find. Daraus folgt, Dá cime Blattlaus, Dic feine Frïgel hat, nidgt notfmendig twegen Dent Mangel biejer Drgane allein fïr eiste Larve gefalten werden Darf, jo westig.

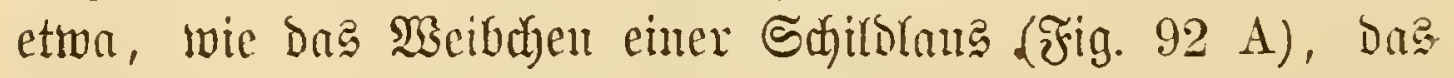

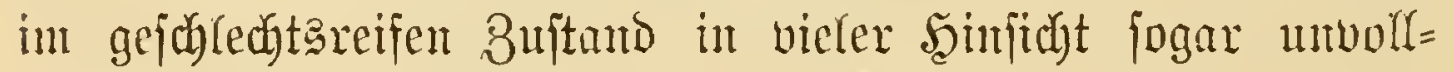
fonmencr als im Stabium der Sarve (C) ijt. 
Die edyten Blattlatsmeibdyen, fomie bie zugehörigen und fajt itets geflïgerten Mäantchen trifft ntan in Der Regel mo unter ben Serbältnifjen, wie fie die freie Ratır in unjeren Bregenden darbietet, mur im Scerbjte an. Sic begatten fich mo eritere legen Dam auf Die fünftige Futterpflanze bie

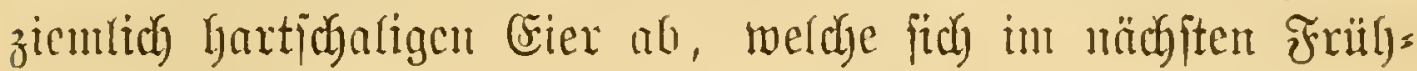

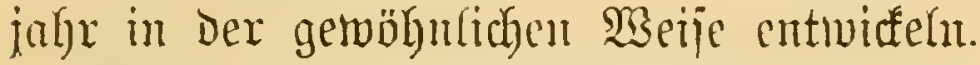

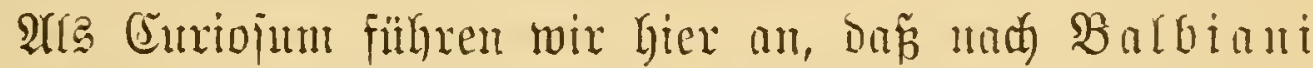

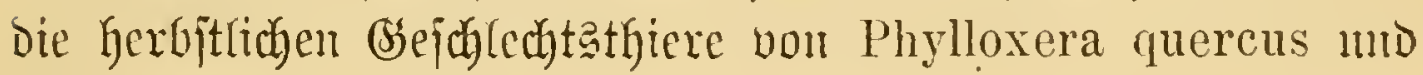

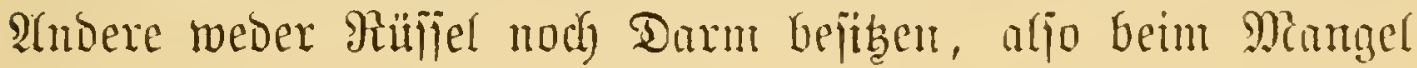
Der Selbjterhaltungargante, wenigiten in volfendeten 3 uftand,

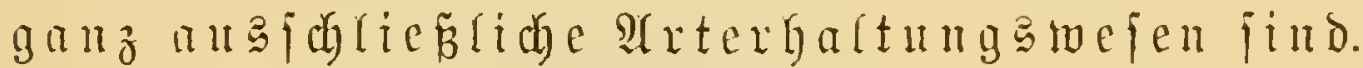

Daneben gift $c^{2}$ mieder Sndivionen, wie z. B. Die ganz abcutener(id)e Form in Fin. $93 \mathrm{C}$, bie feinerlei Beugung:

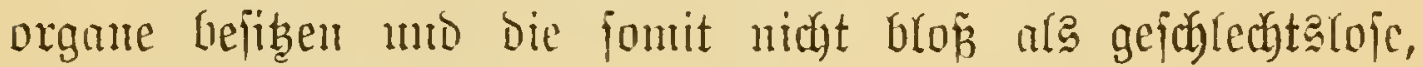

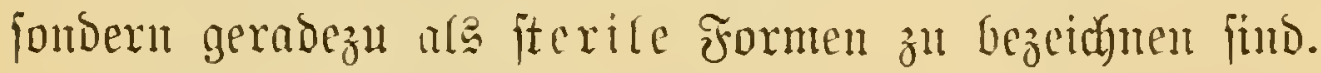

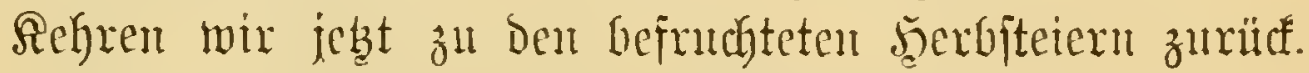

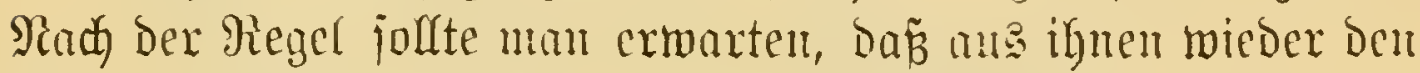

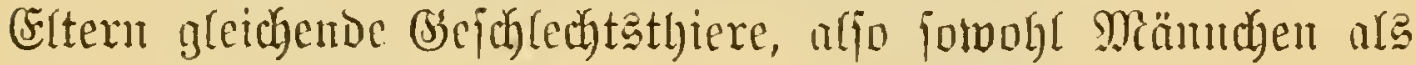
Weibden hervorgingen. Eriftere fehlen aber bis zum Seerbfte ganı mto gar, und die nenen Blattlänje, bie man jür bie lebsteren Galten möd)te, mutcridyeidon fich von ben echten

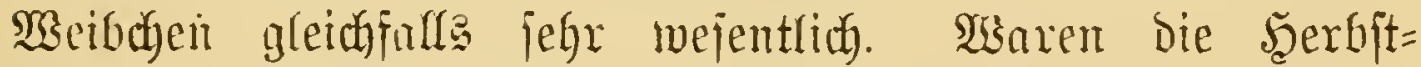
weibchen geflügelt, jo jüno bie Frühlingslänje neift ungeflügelt,

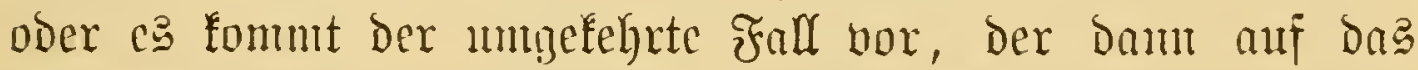

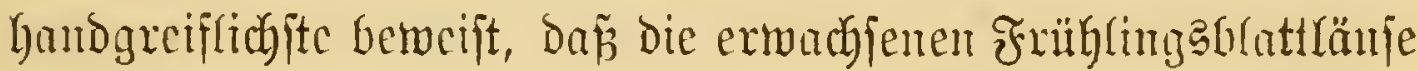

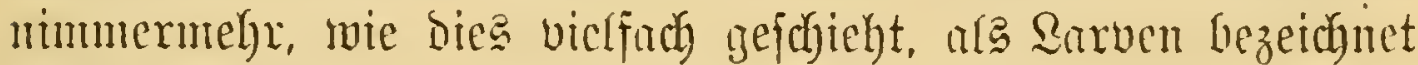
merben bïrfen.

Ein anderer and für den luneingemeirjten auffälliger llnter=

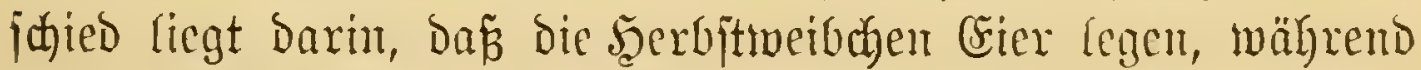

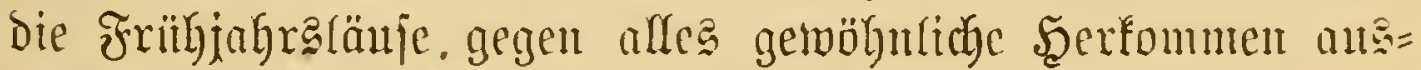
gebilbete Samge gebären. Der arft ift intereffant genug mo

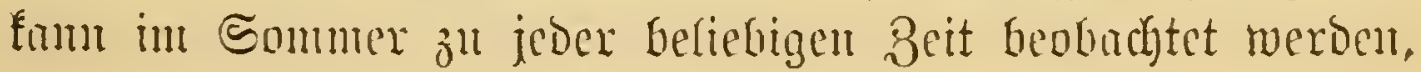


woun man fich eime mit Blattläujent intuntirte Brlanze anf Das Bimnter bringt. Da fegen wir Thiere in allen Sröpent

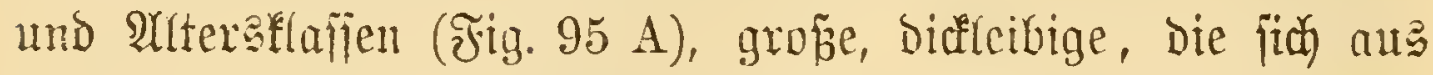

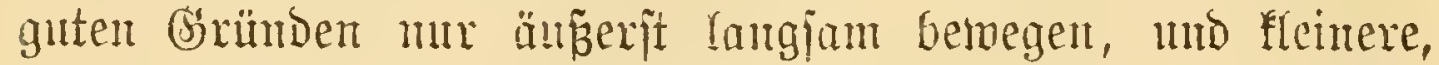
bie mmubig ani Den moblgenäfteten Seibern ber ardom bermmfpazieren.

Fininen mix nit einex supe längexe Beit eine ber exjent,

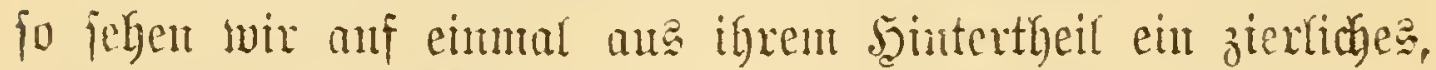

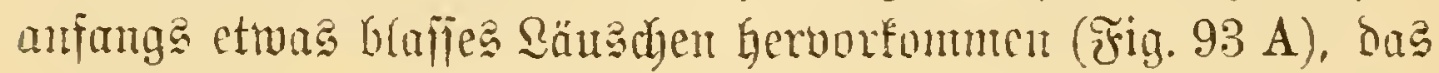

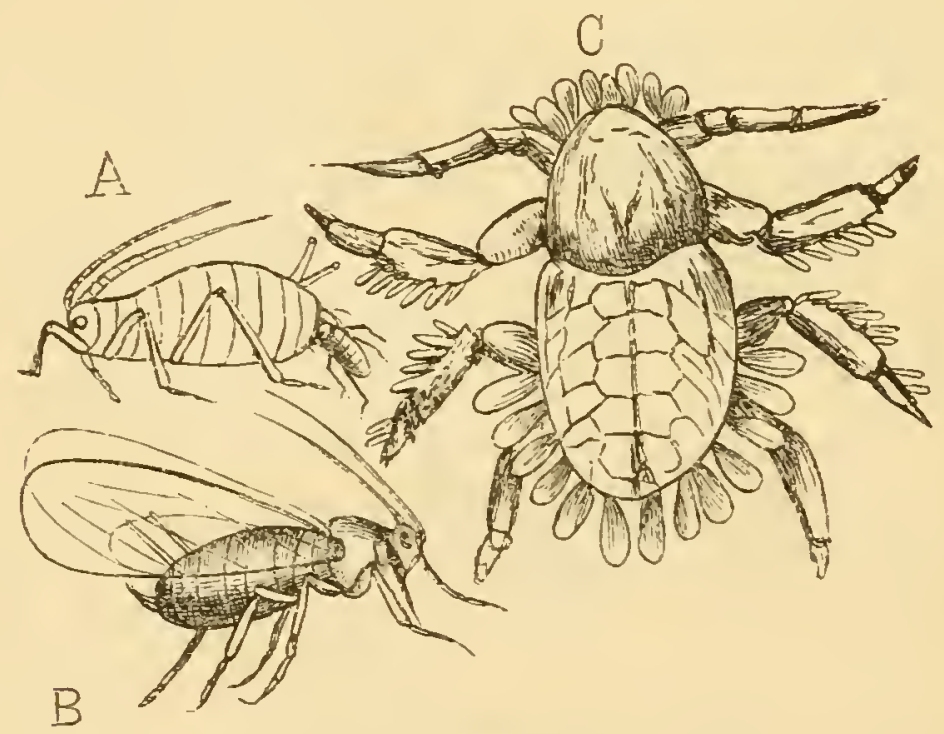

Fig. 93. B̉ Kattläuje.

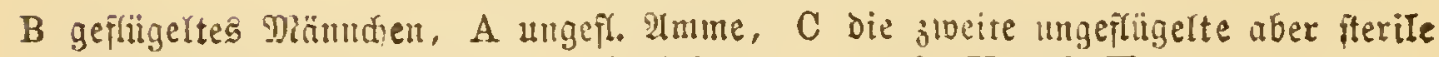
Form bon Aphis aceris (Periphyllus testudo Van d. H.), vergr.

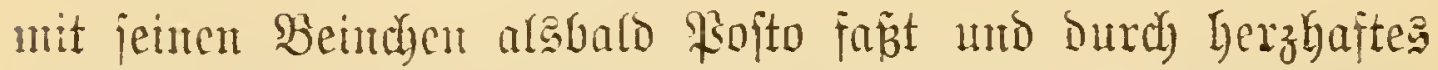
Anjtemmen und Bieben die Entbindung erleithtert. Saben wix

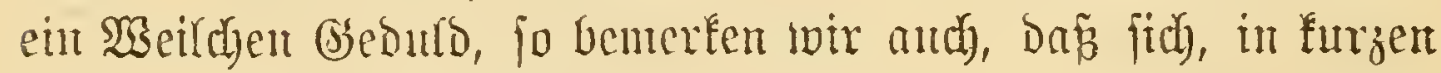

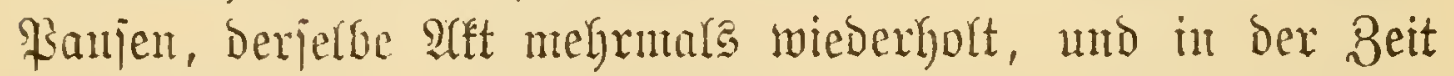
einer Stumbe fann nun bei einem und Demferben șbividum wenigftens ein Dubent folcher Giebuten crleben, wobei die Signd

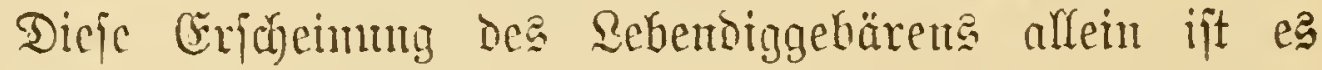

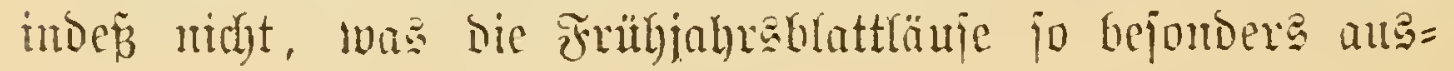


zeichnet. Aefmticlys zeigen mis näm(id) aud andere Rerie, z. B. Die Frleijuffliege, einte Schabe (Tinea vivipara), manthe

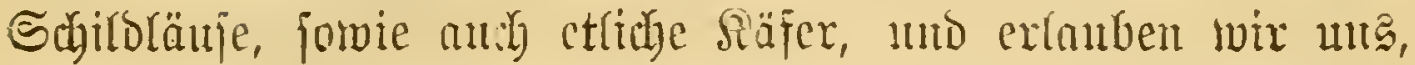
zu befferer Beranfanalibung ber Sache, in beiftehender

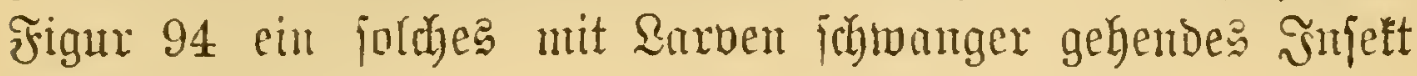
vorzuftellen.

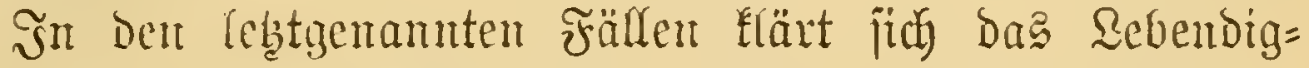

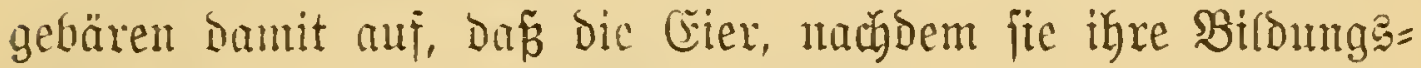
ftätte in Den Doarialfullifeln verlafjen haben, längere Bsit

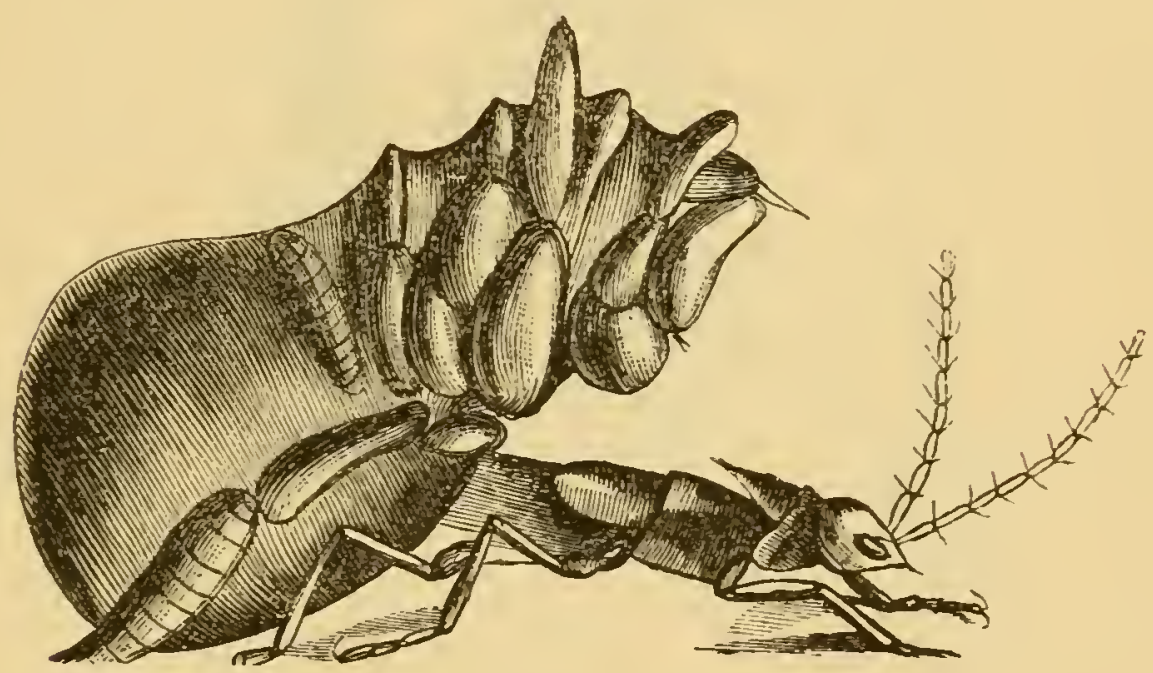

ซิig. It.

Sebendig gebärenter Räjer (Spiractha Eurymedusa) ats eintm brajilianijiden Termitenball. 1/10" (!).

als jonft in ben cilleitern verweilen unb bort, madi erfolgter Befrubtung, ifre exfte Entroiflung Durchmachen, roas unter Umitänden für bie Erhaltung ber Brut von uaheliegendem Bortheil ijt.

Unter bejonderen Serbältmijien, z. B. wem fith in eigene

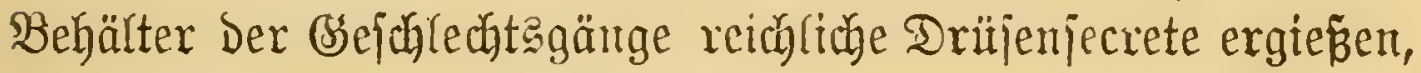
die von ben $\Omega$ arben als Nabrung afgenommen werben, fönnen rebetere noch länger in Schooje ber Miutter bleiben, ja jogar,

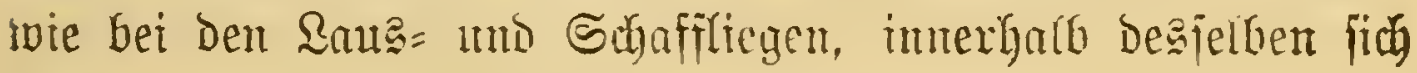

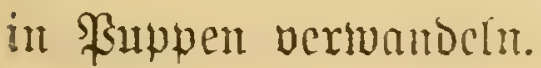




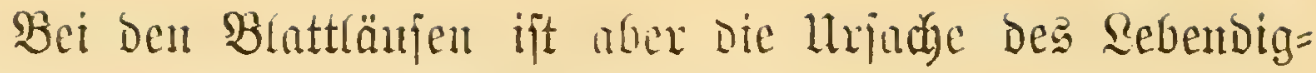
gebärents ganz eine mocre. Shre Sintgen entwideln fith

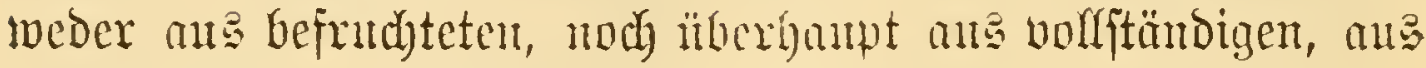

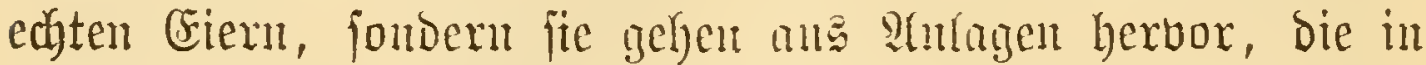

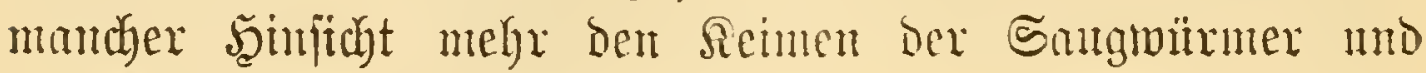
Der Miastor-@arnen entipredyen.

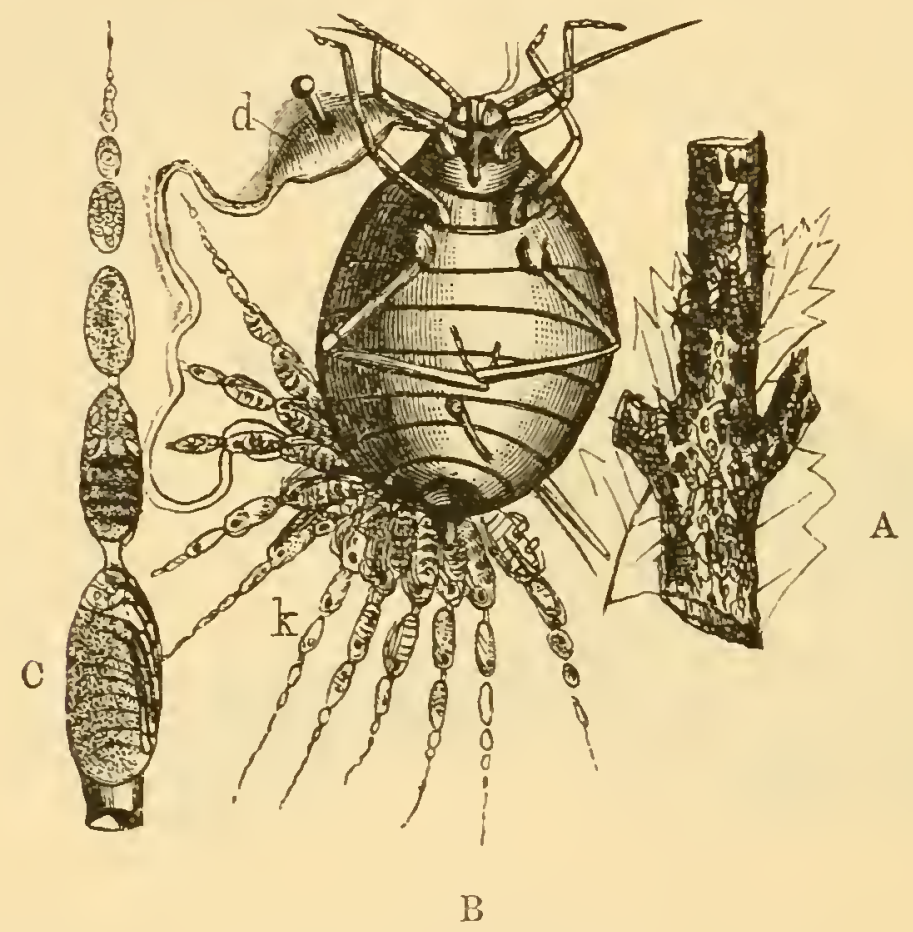

Fig. 95.

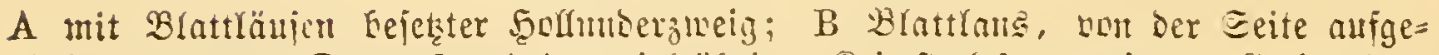

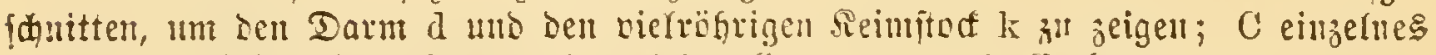
Seimrohr, sben mit sen seimbellen, unten mit Embrynten.

Fig. 95 B zeigt eine Blattluts von ber Bandfeite mit Geratapräparirtem Darm mto Beuyıngorgan. Seb̧teres, nach Ginten ungelegt, bejteht wie cin Eierftoct ans zalyl= reichen, gegen bus (Ende fict) verjüngenden Schläuthen mit perljommrartig angeordmeten Drifjentummern. Bei eimem

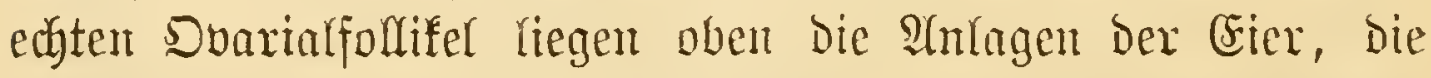
Reimzellen und unten in Den Yebsten Fä̈hern bie vollendetent

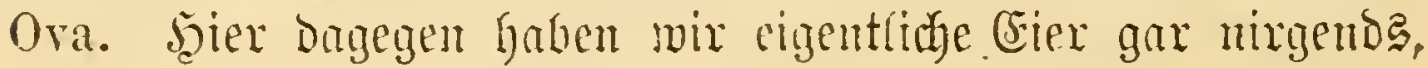


jonbern oben un Seinzellen, und unten bie jabrittweije aus denferben herworgebenden Embryonen.

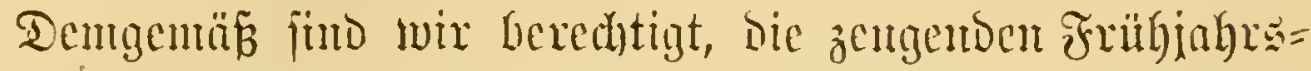

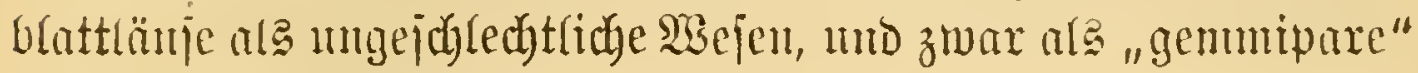
Stmunen zll bejeidynert.

Menn jich Dex Sejex bie Mïhe nimmt, einen melgelichen

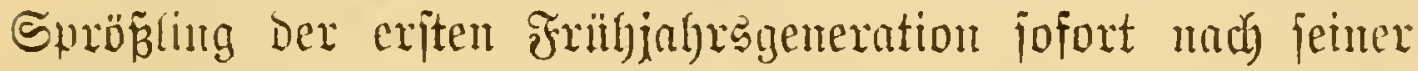
Geburt von ben übrigen abzujondern und anf eine eigene Pflanze z" übertragen, bie cr, un etwaige Mämudfen fern ju halten, mit einter silasglodfe bedeffen mag, fo erlebt er meift jobout in

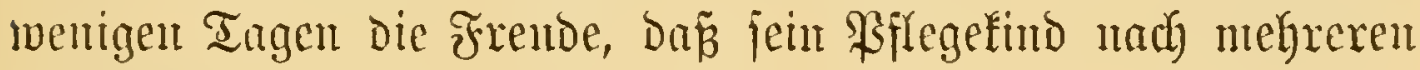

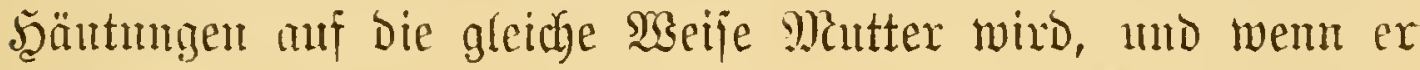
Diejes sjolirverfatgren fortiest, fan ex dosfelbe Schaupiel in Einem Sommer noch eintigentale erreben.

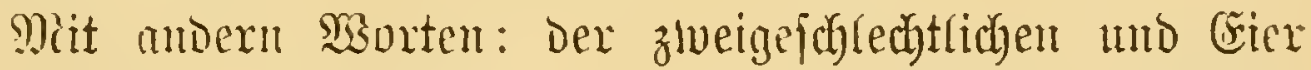
producivenden bexbitgeneration folgt eine ganze lexige m= gefibledytlidyer, lebendig gebärender mo ztwax gemmiparer Eomntergenerationen.

Fa weldbes, fragen wix mu, ift demn die gentane 3 abl

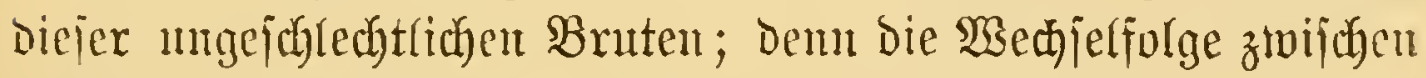
beiderlei Bsmerationen wiro Dork genan fejtgejest jein?

Das ift fie mun aber gantz mo gar nicht. Aallein gerabe

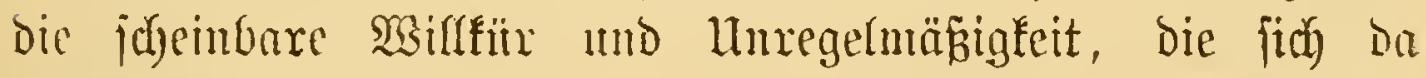
offentbart, bifbet cins der herborragenditen argimente ber 2Hupajungalegre.

Unter gleidgbleibenden Umftändou, jo jugt man, miisten auch gewijie Qebenz= mo insbejombere aljo anth bie rort=

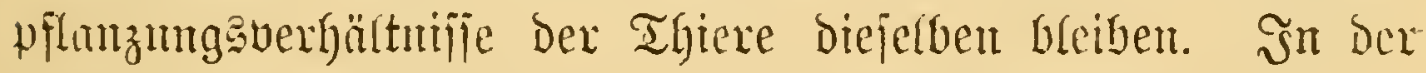

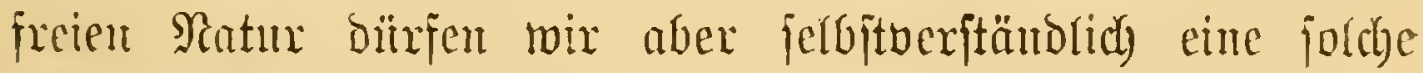
Sonjtun Des organijaden Seing nidft ermarten, Dem hier

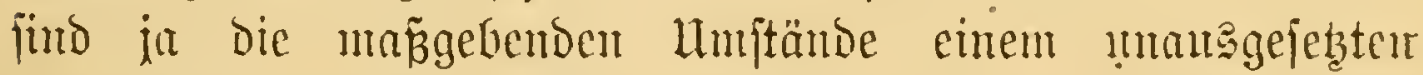

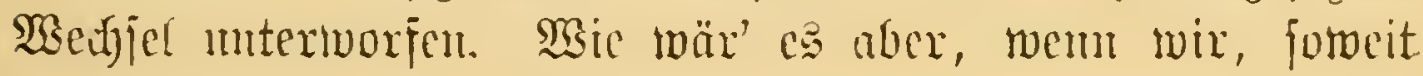




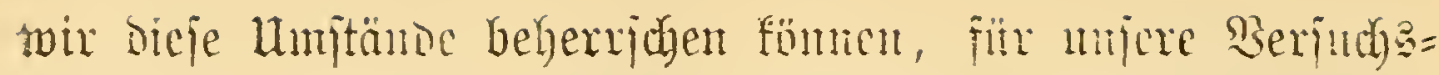

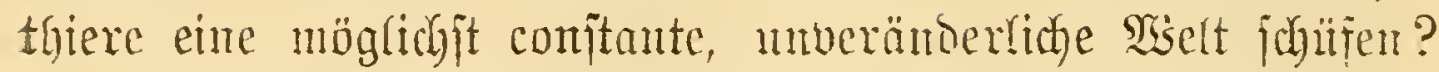

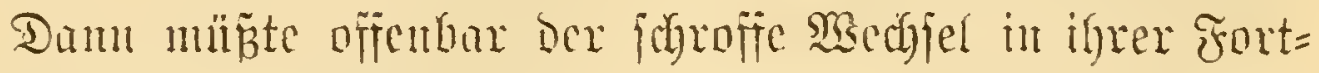

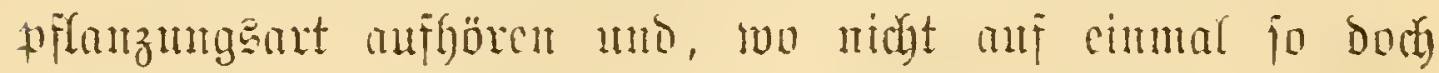

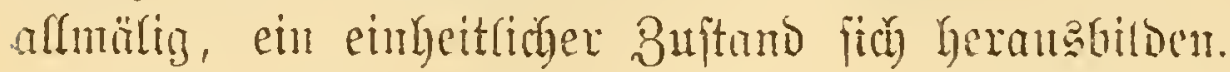

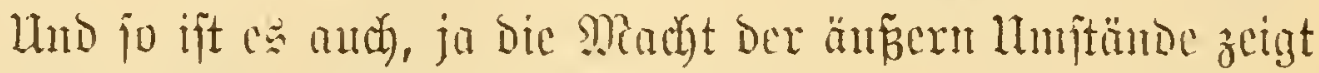

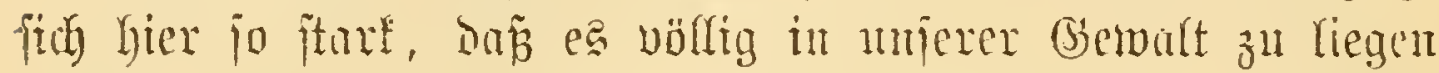
jereint, dic intermittirende anmenzengung in eine

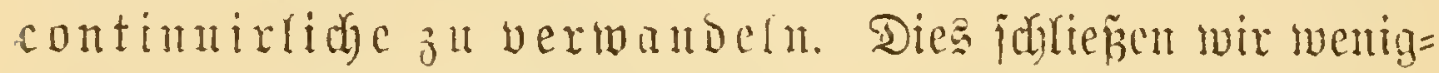

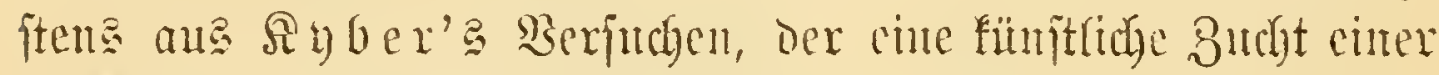

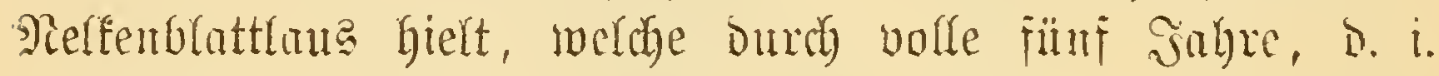

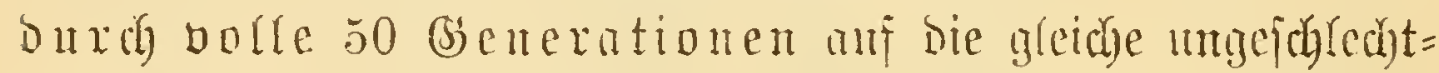
riche art jich wermehrte.

So gut wie oben bei ben sisei

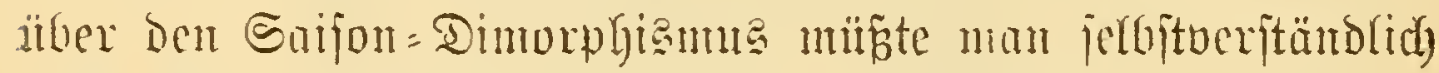
and hei Den Shlattlänjen bas entgezengejebte Experintent

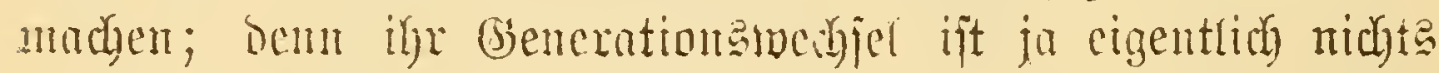
anderes als ein Enifon=Dimurphism, ars eme mit bem

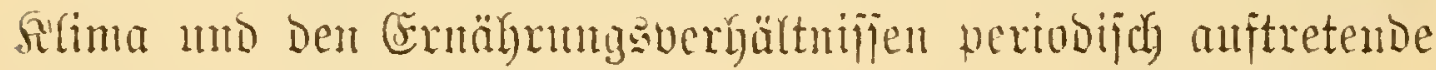
Prtpaijungsericheimng.

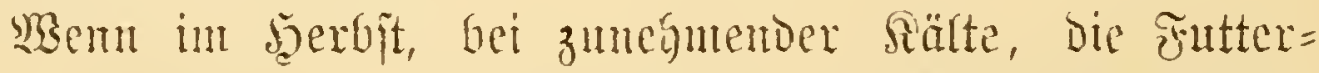
pflanzen abferten, wom ber früher meridyöplibe હäfte=

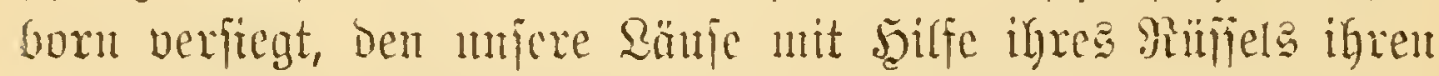

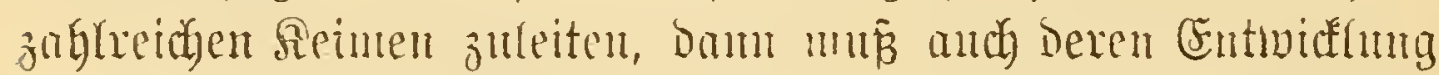
zum Stimftand fonmen mo nu werben die noch itbrigen Säfte żur Bilbung ciniger Eier vermentoet, bie, mufapielt

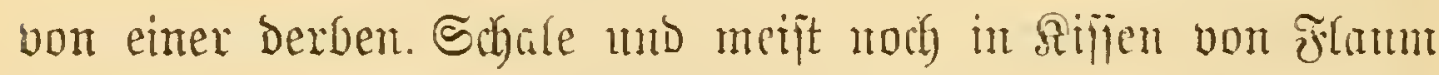

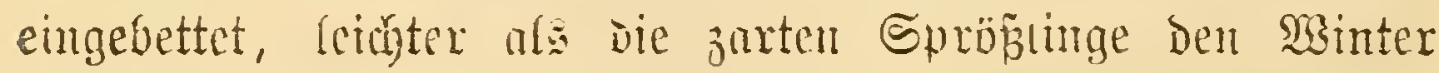
ïberoatern.

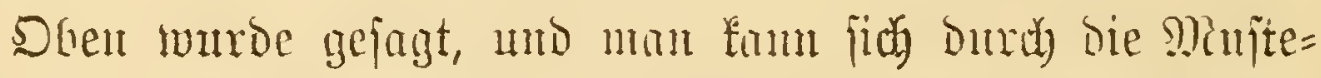

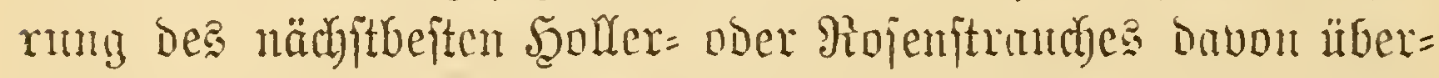

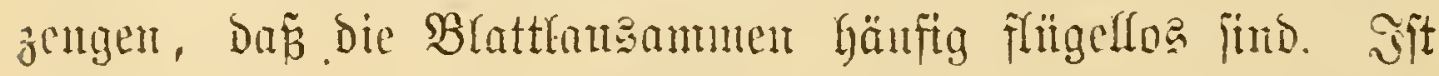

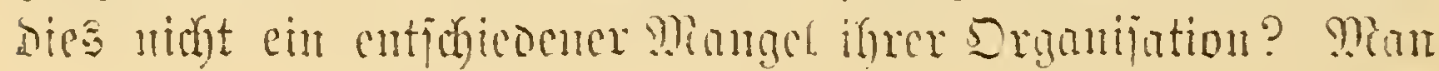




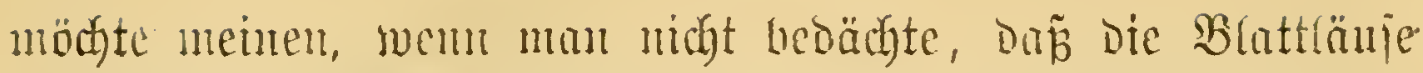
ehen Rarajiten finto, die gerabe Durdh ifre fölgellofigteit ber

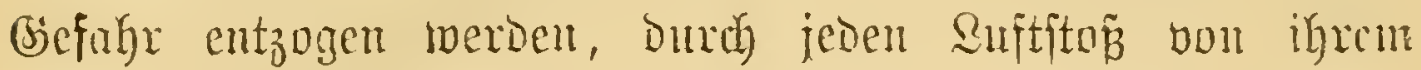

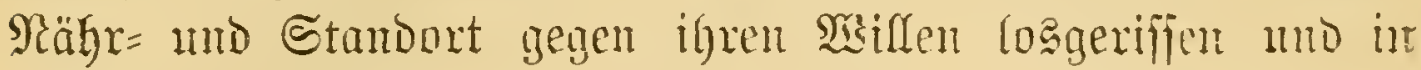
alle $\mathfrak{B i n d e}$ veriftreut jul weroen.

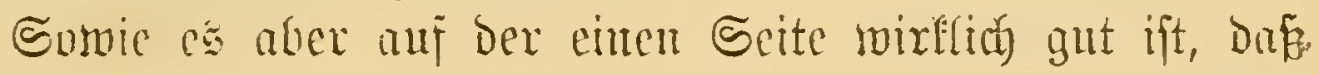
unjere Rerfider an igrer Futterpflanze ungeftört bem "itiflen

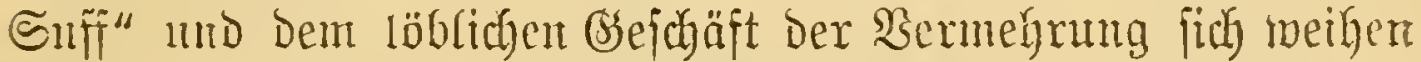
fömtn, jo ifte auf ber andern, foll ihr berïlymte

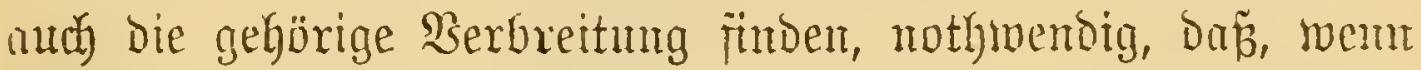

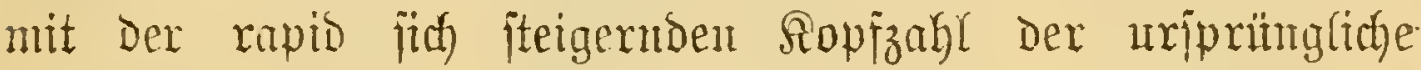

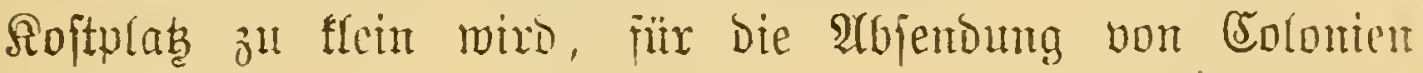
gejorgt wirb.

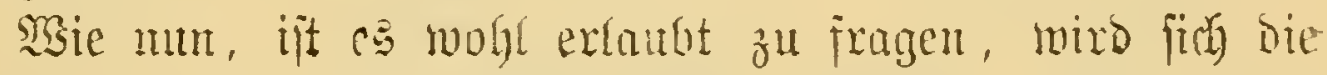

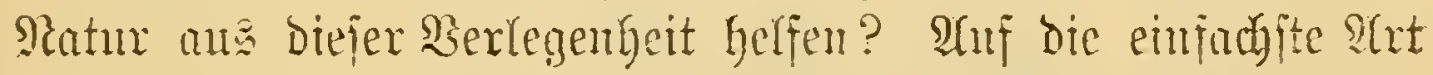

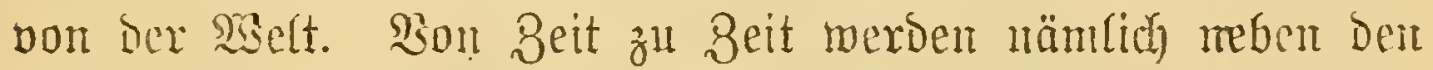
ungeflügerten Ammen, werche zur Unterhaltung dex Mnttex= colonie seftimnt find, midi) geffingelte erzentigt, bie bann mit ifren Sabingen Durdy bie Riffe jegeln mo eine nene Rieder= lajīming grimben.

23 ant unb bei melden Arten bie gefritgelten zuerit fid einfitellen, ob und in welcher Reigenfolge fie mit ben un=

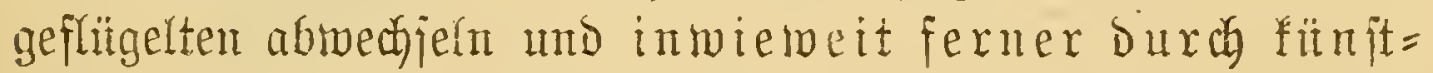

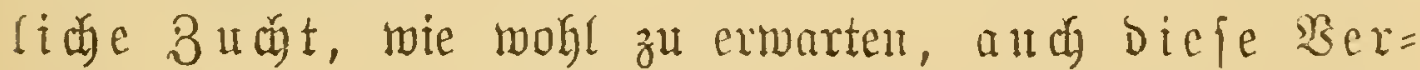
hältuifje mobificirbar jind, anf bie meijten biejer oragen

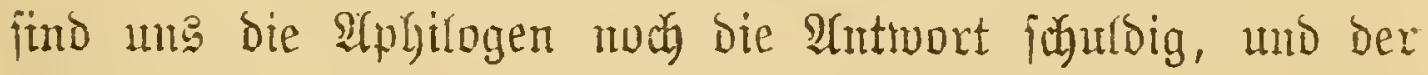

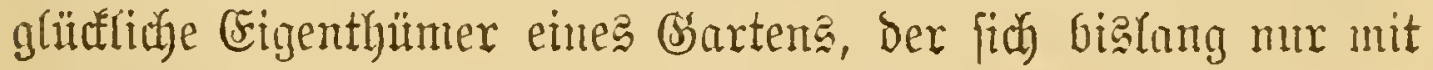

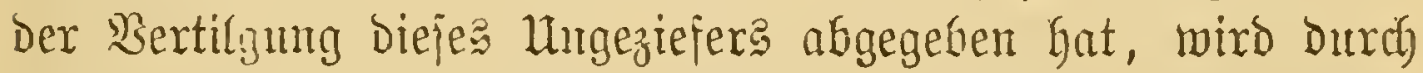
Das Giejagte vielleicht Suft betommen, basjelbe, int Jnterejie Der bebeutjamiten Fragen der Mififenjabaft, fünftig jerbit zut hegen und zu pflegen.

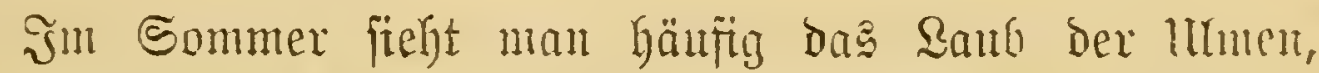
des Safelftrauthes, Der crele u. f. w. mit den manuigfaltigiten 


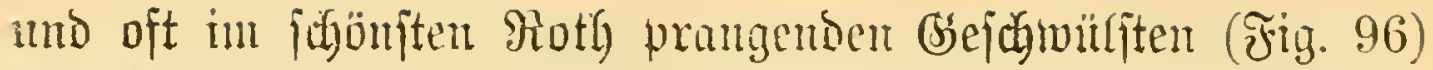

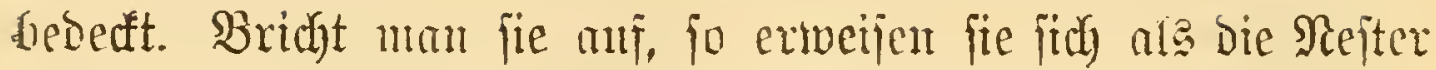
twinjiger blattlusantiger Rerfe. Dies fund bie jog. Rauballen=

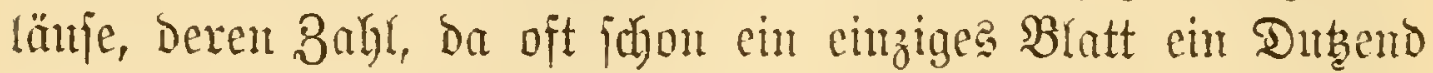

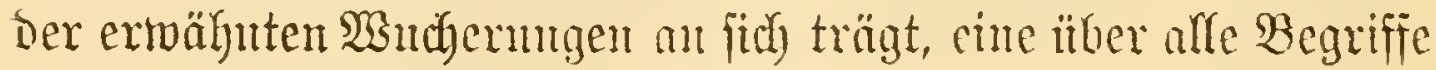
storme fein muf́.

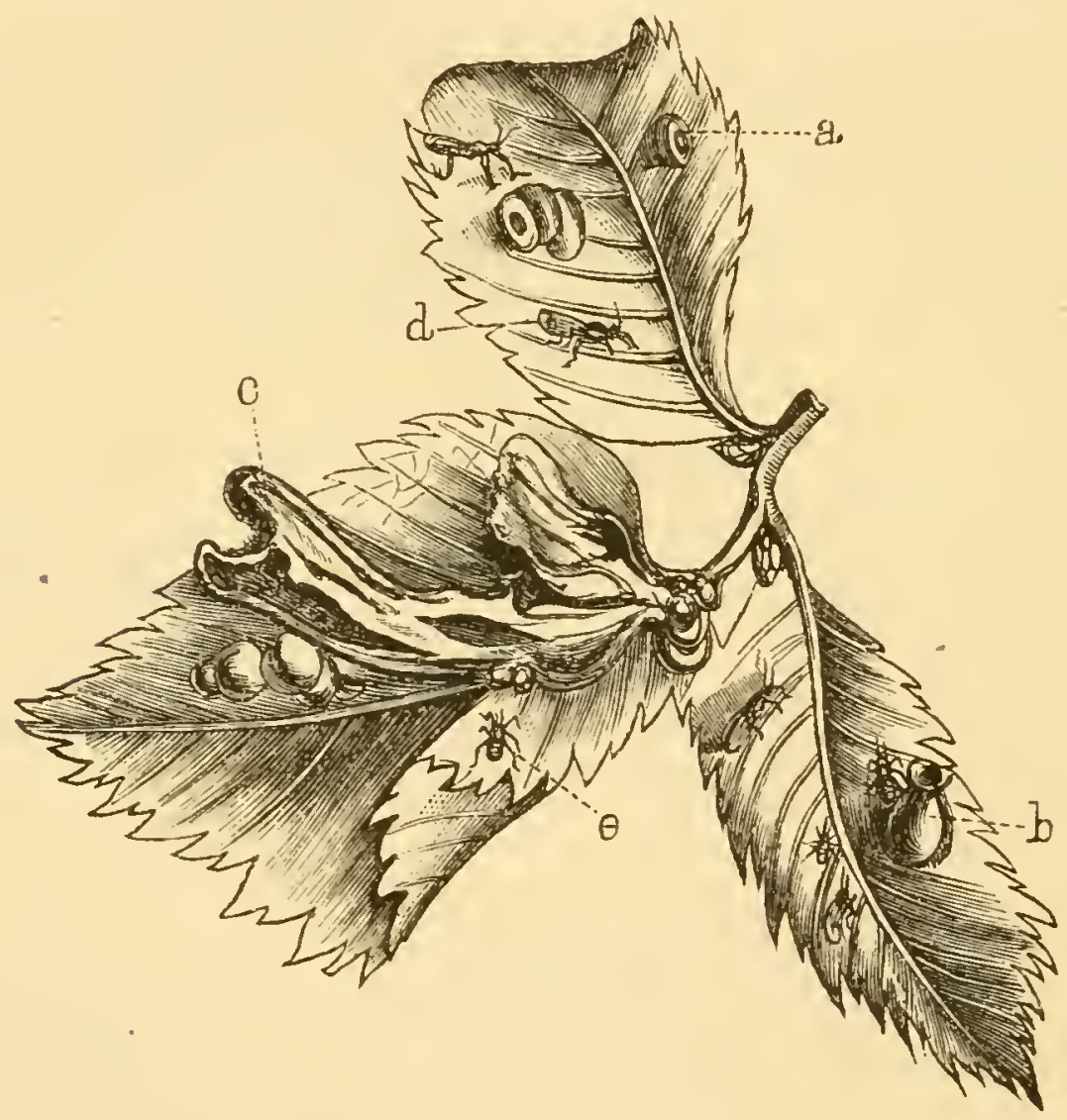

jigis. 96 .

Bur Platurgejodidte ber llimenblattrat:.

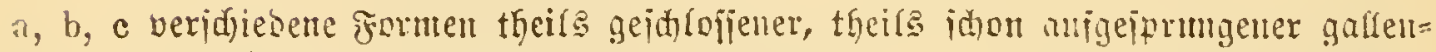

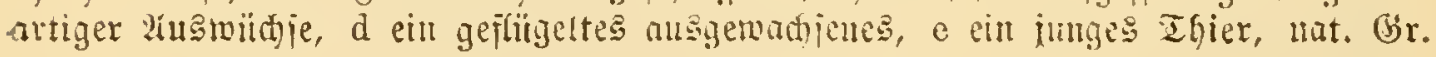

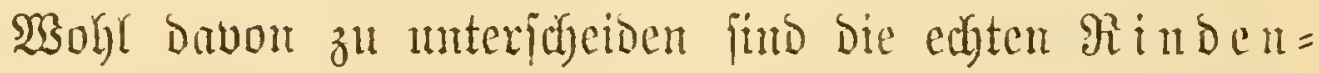
I ïnje, bie verjulebenen Chermes-9rten, wovon bie auf Der Fithte lebende Species, bie Ch. coccineus, relativ nod) am befteu befunut ift.

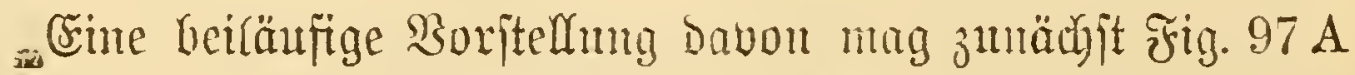
anf folgender arbbildung geben. G ftellt fie vergröpert mit 
ibren ganz darafteriftijaten, afer in Der Beichnung ctwas ju furz geratbenen Frïgeln Dor. Fenter zeigt $D$ eine

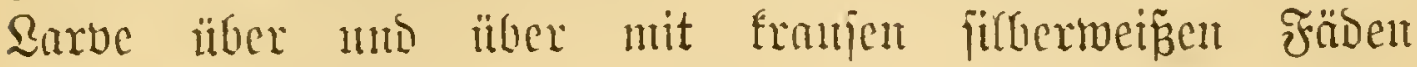

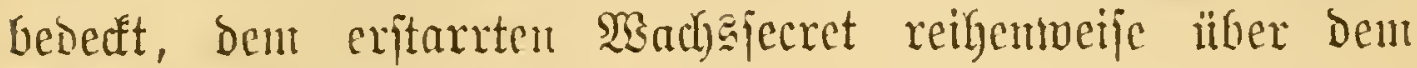
Rïten vertheilter Drijjen, bie ifnen ein franmiges, wie

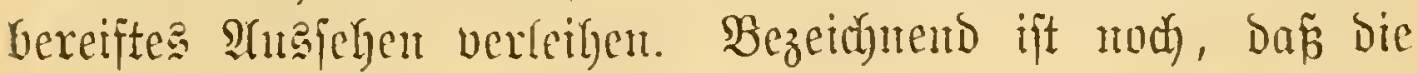

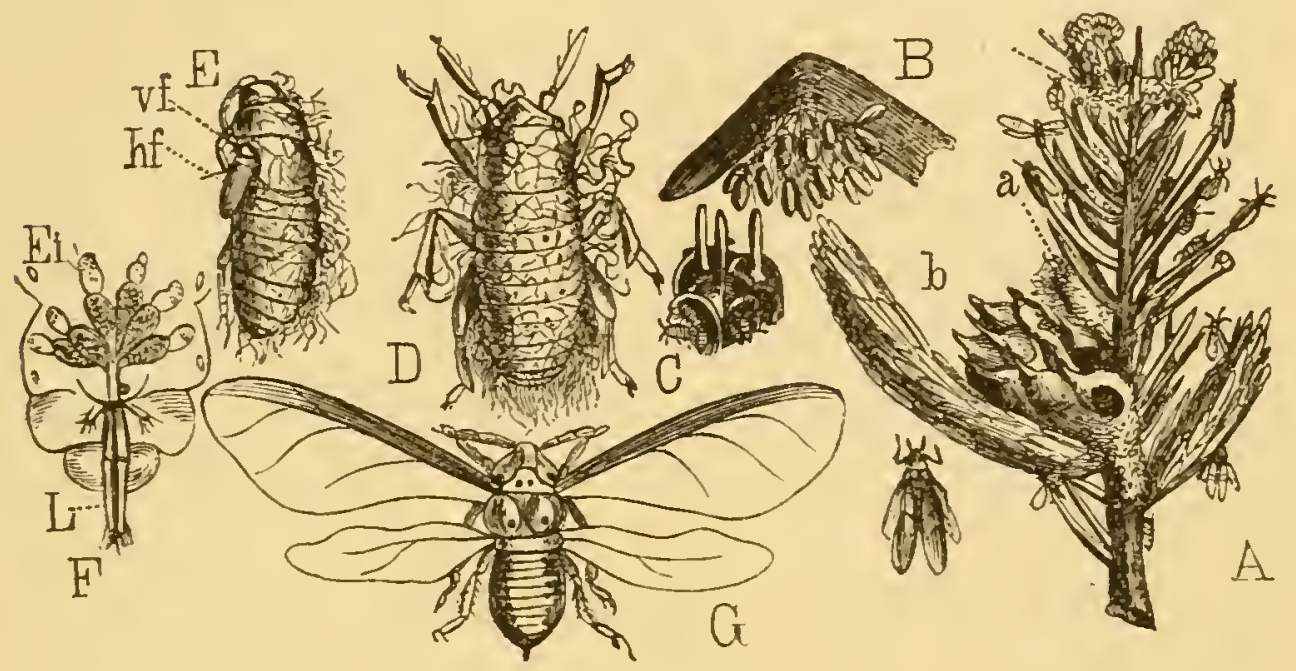

Fig. $9 \%$

3ur Thatugejud ber Fidtemrindentaus (Chermes coccineus L.).

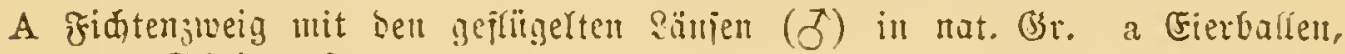
b Exeinzapjen.

B Eiergeliüne an eimer Yiasel, bergr.

C Durd) bie verbidten mo anšghöhlten :3urgeltheile ser Rabeln gebirbete Sanumert.

D Rarbe, vergröbert, mit ifren wolfartigen ?tusidgnibutugen.

E Fuppe, von Der @eite.

G Uscilligelte? $\mathfrak{B e i b}$ hen, vergr.

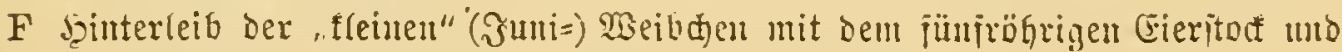

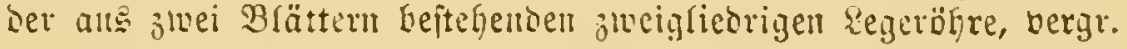

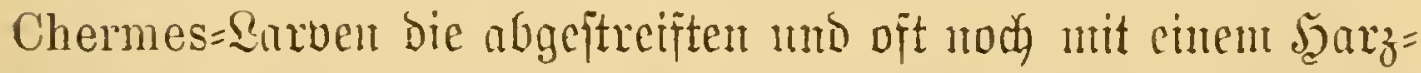

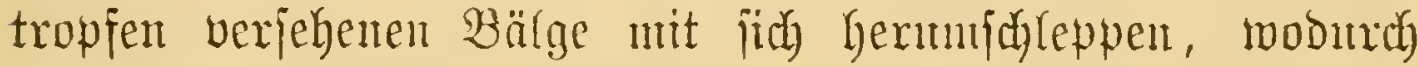

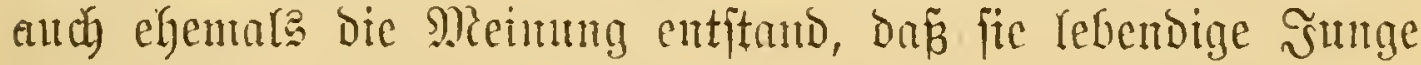

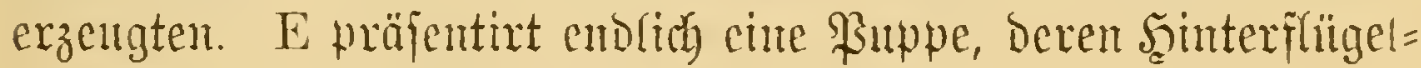
jcheiden (hf) ben vorbern (vf) vorauscilen.

Anffinllender wie die Serje jelbit fund bie von ifnen er=

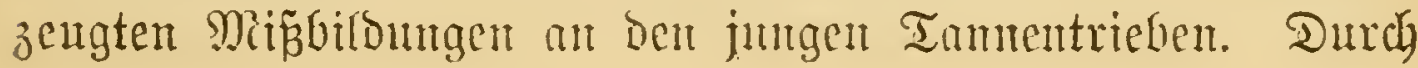


310 VII. Sapitel. Siatunggleben un Bengung ber Injeften.

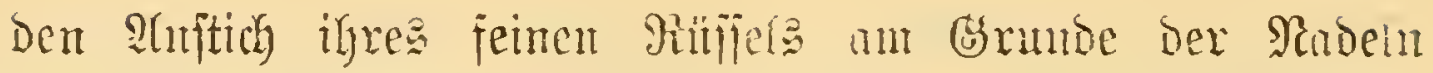

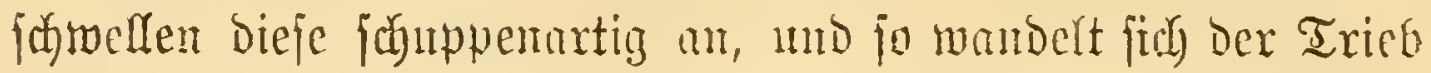

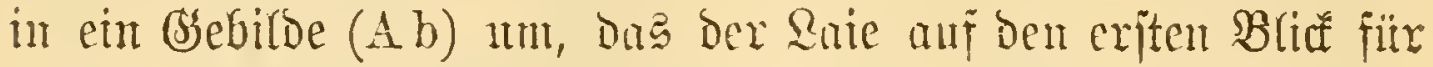
cinen Fruthtzapfen halten witroe. Dieje Scheinzapfen glïlyen

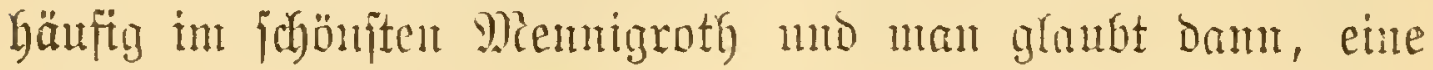

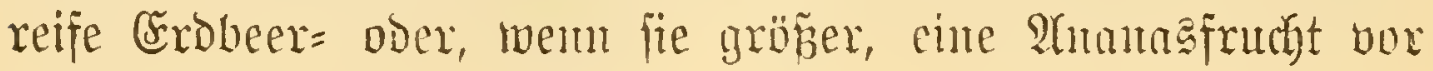
fith zul haben.

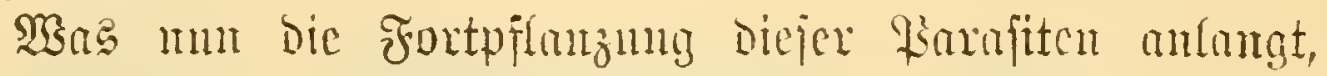

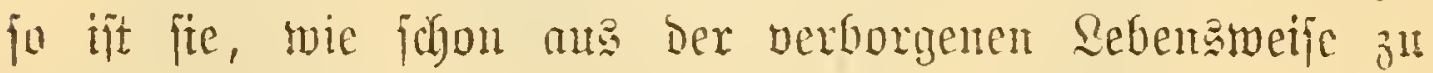

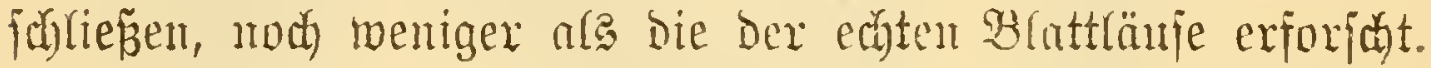

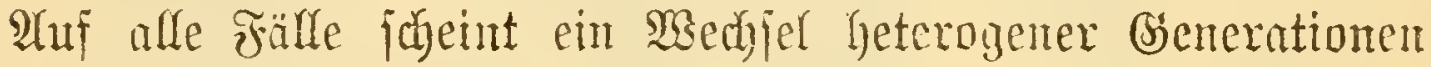

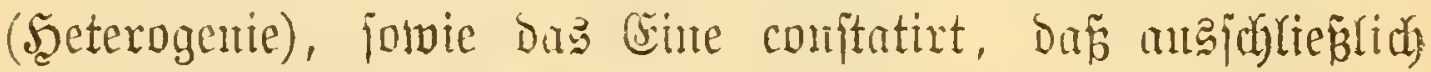
mux Ciprobuftion vorfonmt und bas bie betreffenten Bengunge=

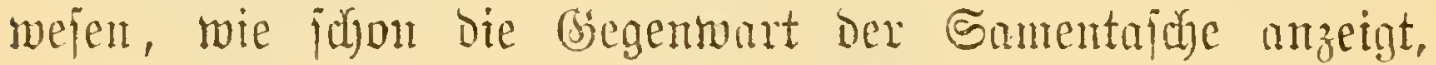

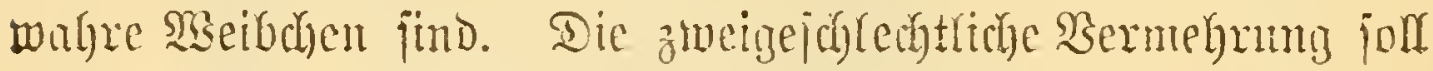

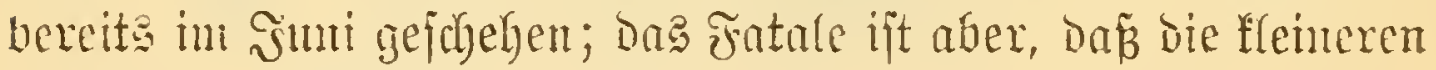

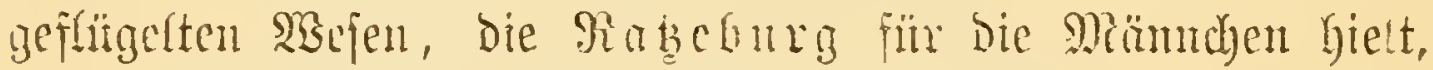
mux als zwerghafte mo zum Theil mit verfummerten Dourtim

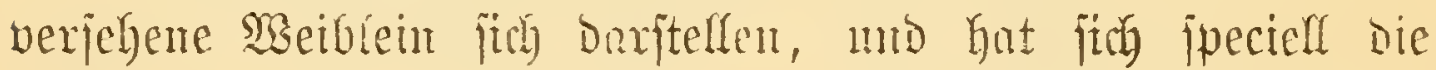

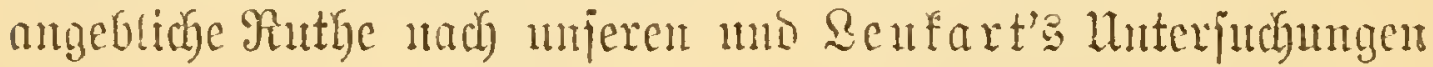

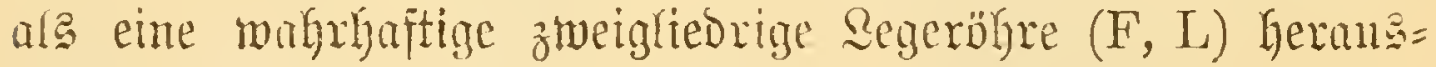
geftelft. Someit wir bie änzerit vermicfelt und and jebr

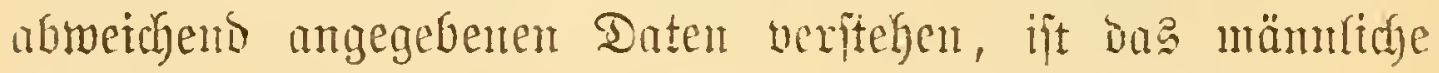
Pexponal, ftrenge genonment, noch gar utcht befant.

Dic affem Bermutyen maid) parthenogenetijach fich ent=

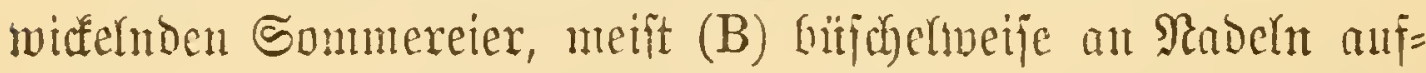

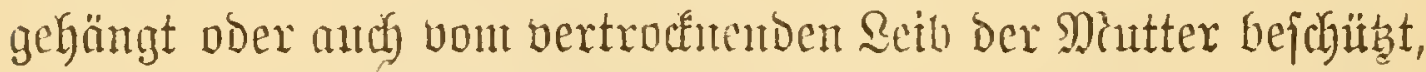
gebent bam im Frübjagr eine flitgelloje bieneration ans ent= jajieden parthenogentifirenten Mïittern, roelde gruppentweife in bejonderen Samment der Bapfen beifanmen leben (C).

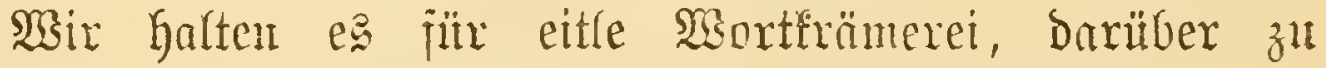
Disputiren, ob in 2̌nbetradyt oer bei ben Rindenlänjen be=

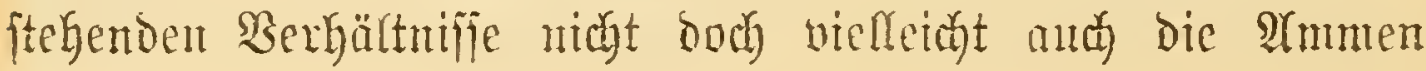




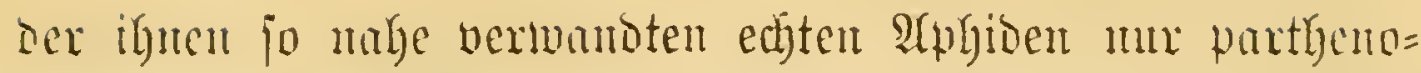

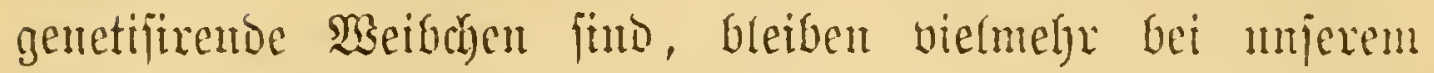

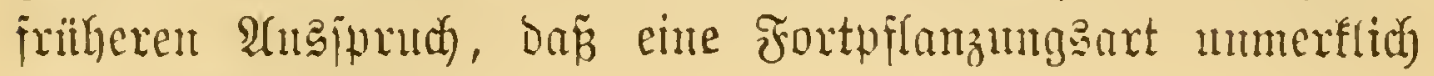
in bie andere übergegt.

Fin gantz fiir fid zu betrachtentier Fall ijt aber jeden=

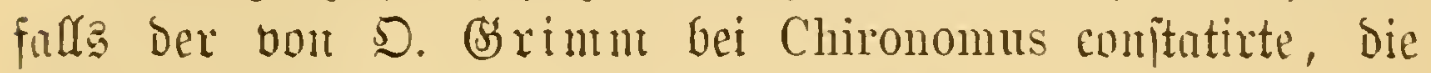

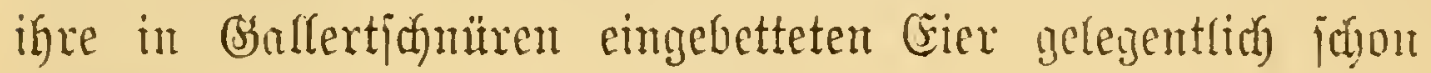
ais Pluppe (Frig. 91) vou fid) gibt.

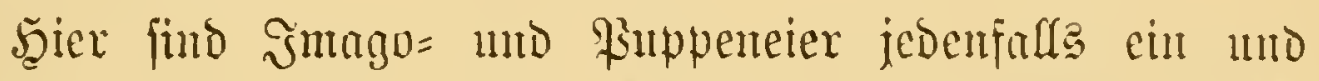

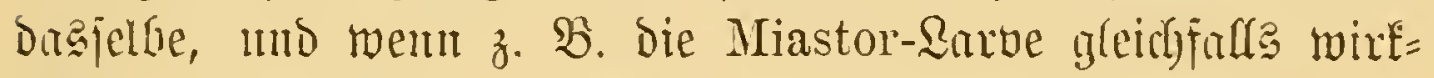

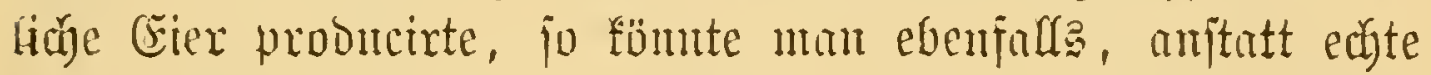

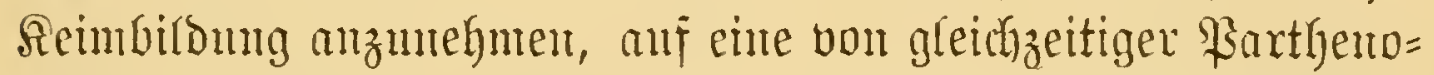

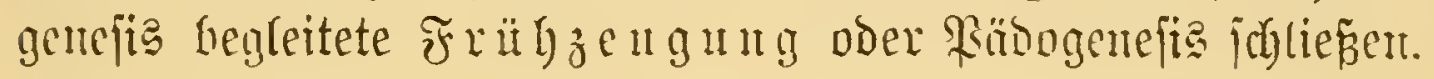

\section{E⿱乛龰apited.}

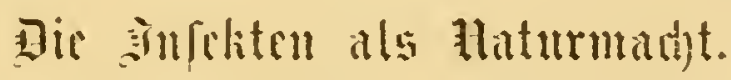

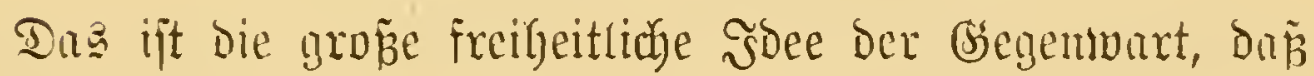

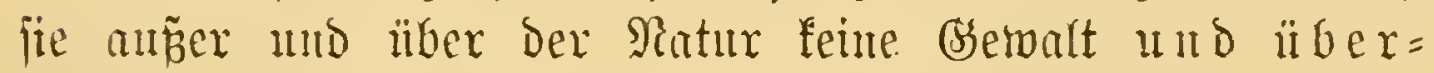
hauptein Seiu auerfennt, bañ jie alles Exiftirente,

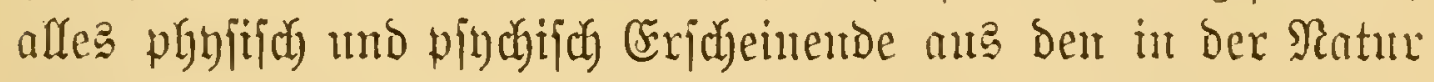

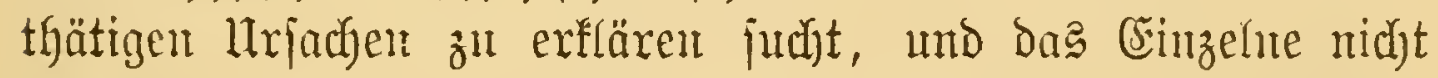
als etwas füx die Erryaltung mo die Şarmmie des Franzen

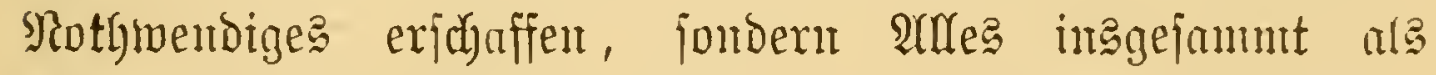
Rejultat des Zujammentwirfens ber einzelnen Raturfräfte herborgebracht jein läp̧st.

Sn bent Sime habent wir ms aud betreffs der organi=

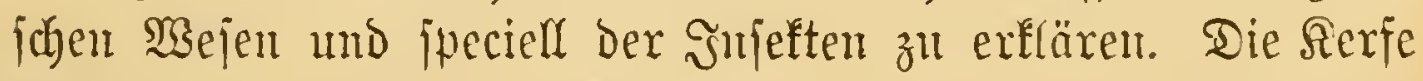

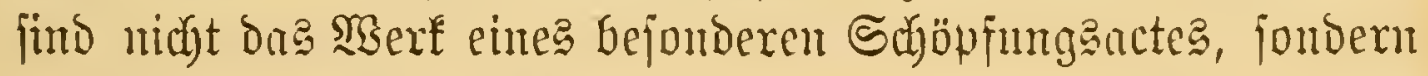

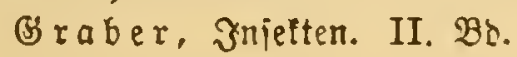


wie afles Hebrige, Das millen = mo abjichtsloje Sryengutí Der Patur. Durch restere entitamoen fic, und zwar eben zu einer Beit, wo die Girunbbobingungen zu ifrex crifterz gegeben waxen, in igr exiftixen fie, mit ihr beränoern fie fich mind werben endich twieder verjebrumben, soie viele andere

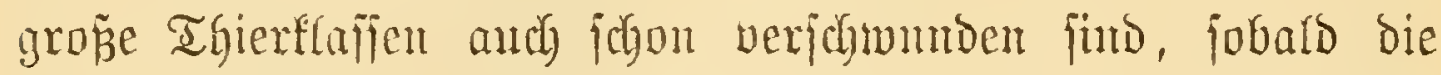
für ígren Bejtand unerläglichen Bebingungen andere gemorben.

Se mely fich aber bie latur iu irren veruanuigialtigt, dejto manuigfaltiger, defto bieljeitigex wird and die Rerfocit jid geftalten.

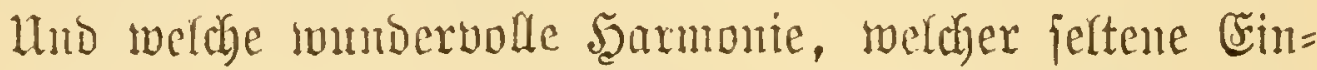
flang befteht hiex nidgt ztwijuben Den Bexurjachenden mo Den Seruxjadyten, zwijeden Den Bewirfenden und den Be= mirften, mo dies arfes ofne alle Bormabeitimmung, obue alle Beredinng, reit mux Durch den Sampf Der Siemente, Durch ben Bwang ber llmptände, durch ias allgemartige

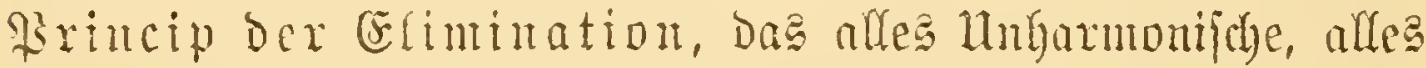
Nicbtzliammengehörige mo 马ujammenfïgbave, fanm bervor: gebracht, and wieber bejeitigt mo jo alle mit cinamber nicht zu vercinbarenden Gicgenjäge abftunpft mo ein inmer

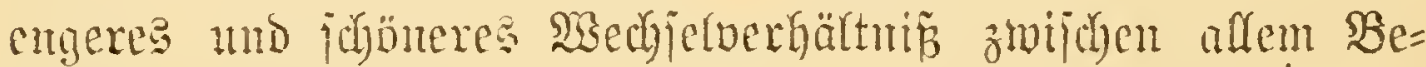
itebertoen hervorbringt.

SBie vollfommen aber die Ratur gerabe Die Snjeften Den ibnen gebotenen Bebingungen anpapt, wie jegr fie ardes in

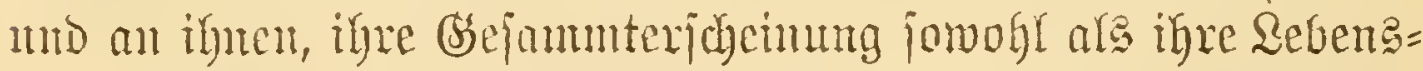
verrichtungen, ganz nach fich richtet und in bic imigite und

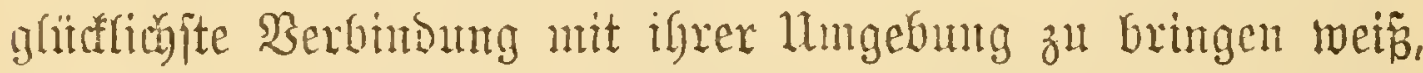

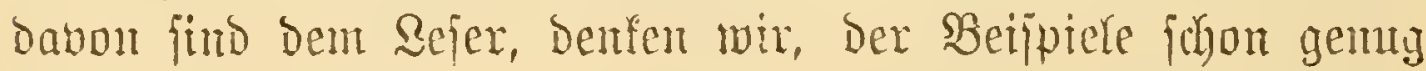
gegeben inordert.

Dody nicht barum Gandelt es fich jebt.

Rre Raturbinge, wuroe gejagt, fteben in einex bejtän=

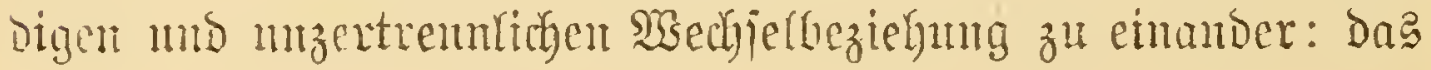




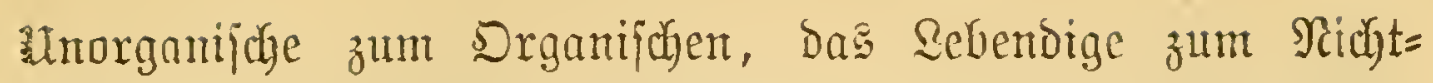
Lebenbigen, bie Pflanze zum Ilyier, bas Thier zur Pflanze,

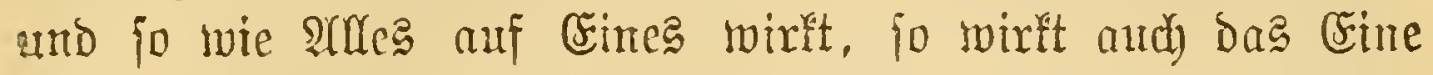

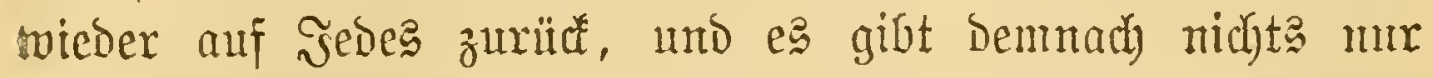

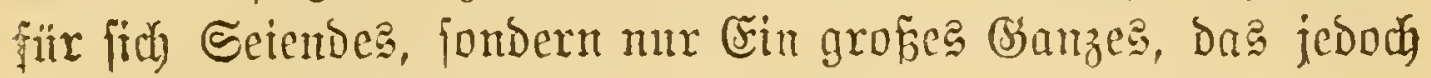
smjerm bejuränften Sim unb bscifte nur jelten ars folches zut eridjeinen pflegt.

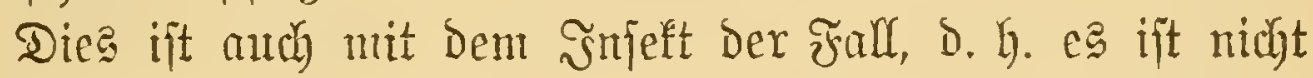

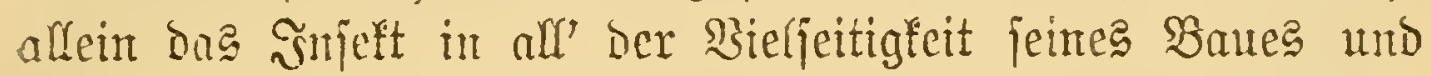

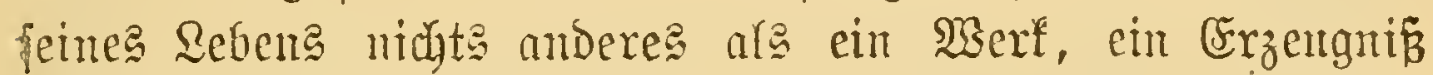
ber Natur; die Ratur ift zum Theil felbjt wieber ein Werk Der Jnjefter.

Unto man barf ee obne Bögern jagen: Unter allen bont

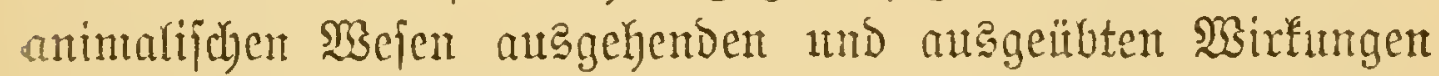
gitbt es keine berbreiteteren, feine vieljeitigeren, feine in alle

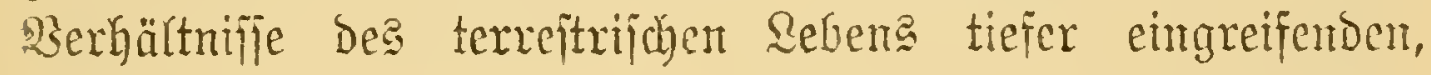
arg bie der Sinjelten.

Man Denfe vorerit mur an Bweiertei. Sinmal Daran, ba sine ganz folofijale Mafife bitden, eine Mafie, bon ber wir

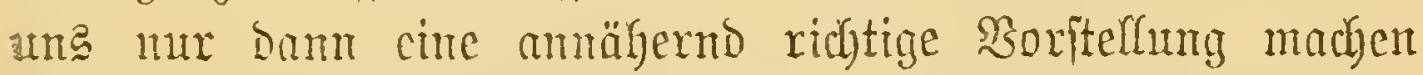

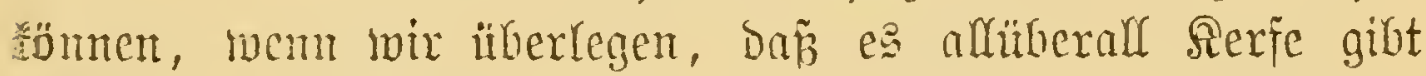
und zwar nicht bloz einige wonige mid zeritrente, fondorn

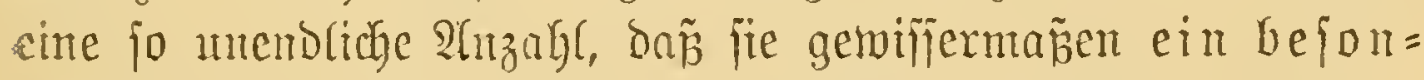

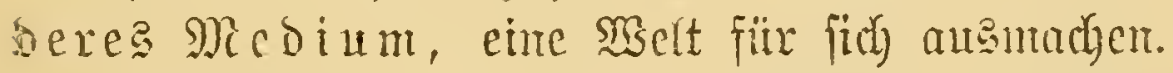

Dam ift aber, m die Madjt Der Srrfeften redyt zut

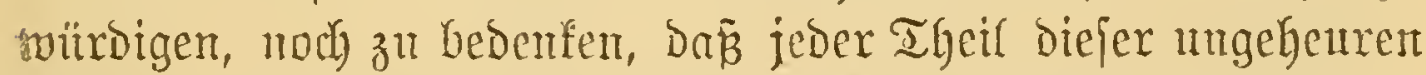

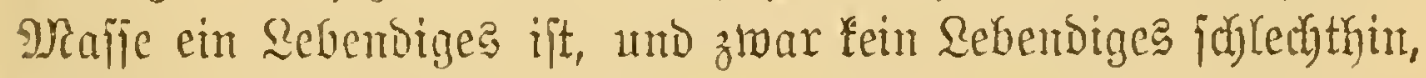
fondern bas thätigite, Das wirfingsuollfte von alfem Belebten, was wir fentment.

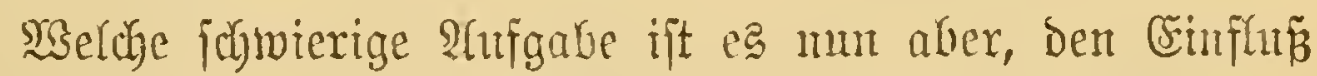

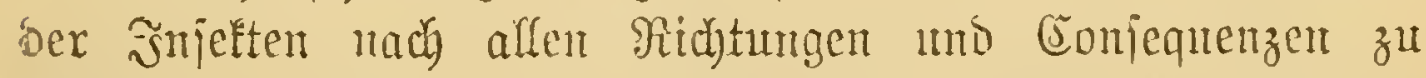
verfolgen, urb aus den uzälyligen Einzelvirfungen igre 


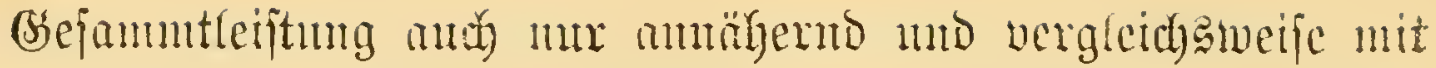

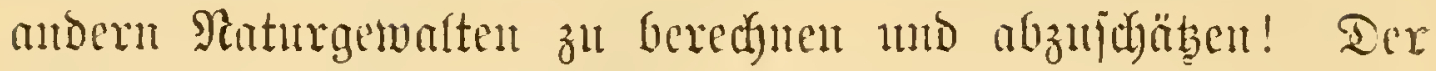
Gegenftantio ift cin unbegrenzter, einter, mit bem wir in aller 马ufunf niemala zu Ende fomment werden, aber and eber

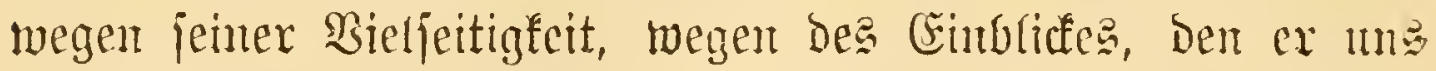
in Die Sierffitatt Der Mlaturr gejtattet, eit jo interefjanter.

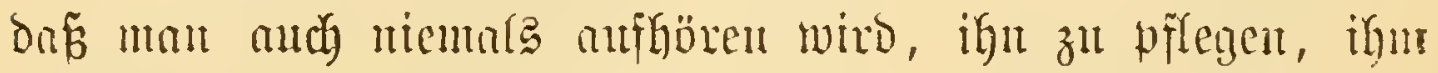

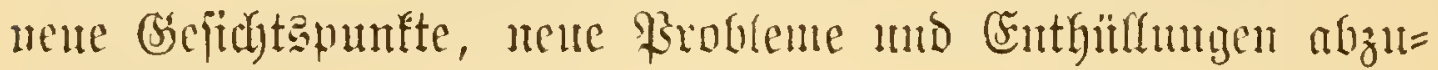
Inuifhent.

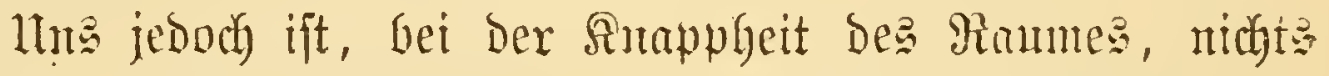
anderes zu thum berifuttet, ars an cinzelnen Bcifpielen die Sache zut veramidyanlidyen.

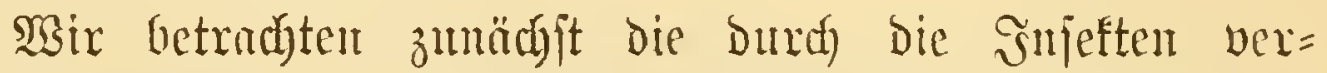

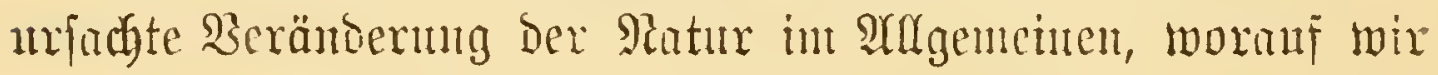

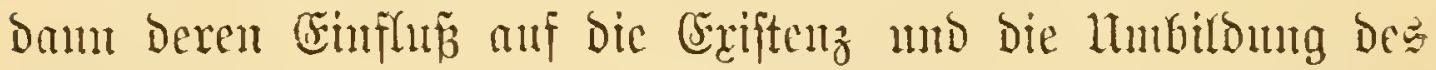

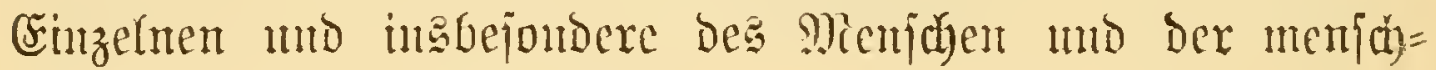
lichen Rultur ing $\mathfrak{A}$ uge fuijert.

\section{Berändoctuig ber giatur im gelfgemeinen.}

A. Beränderug ber andrgatichen Satur ober ber Bobeuber

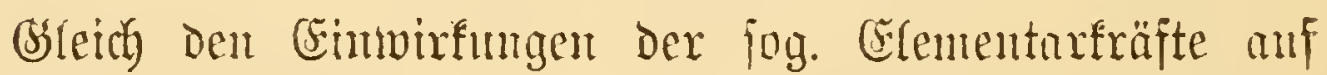
den Beftund des Raturganzen finto andi jene Der Snjeften

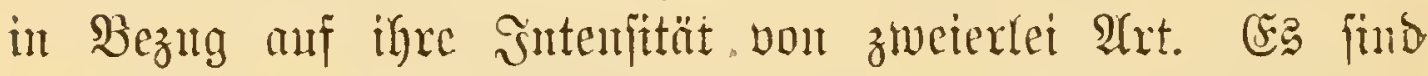
entweder ipontunte, plöbliałe, mit phänontenaler betwalt auf= tretende oder ganz afluälige, fantgiame, aber jtetig fort= arbeitcrioe.

Die Mirffamfeit ber Suffeftrn ift meift vou Der leşterent Art und gilt bies unment(id) and betreffe igres sinfluffes auf die Untgeftaltıng Der Bobentueryältnifj]e. Somie bie alts=

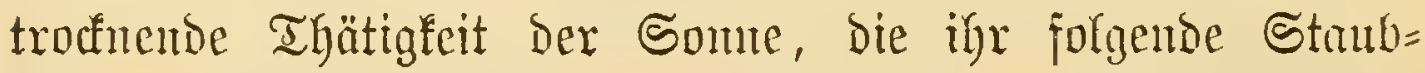

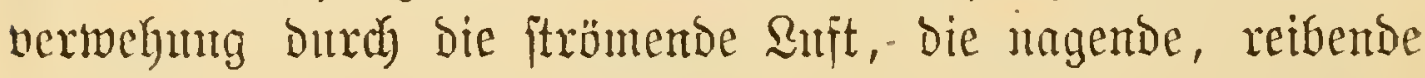

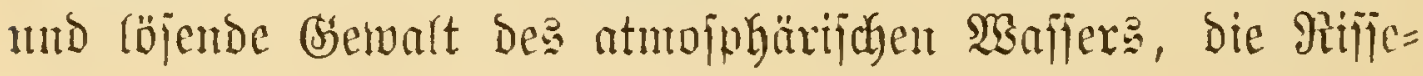




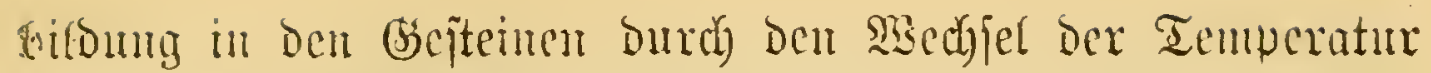

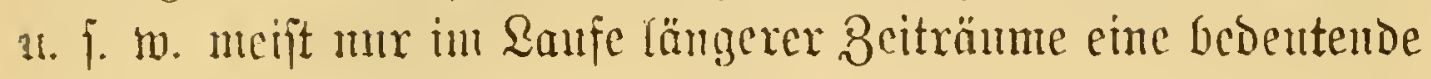
lofale limgejtartung herbormfen, während ihre momentane

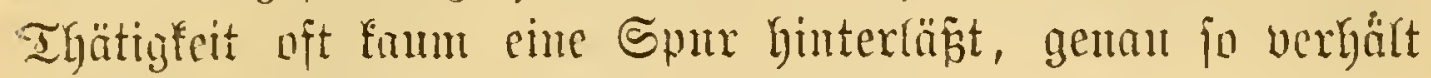
s? fich mit Dex Pionierarbeit ber Rerfe.

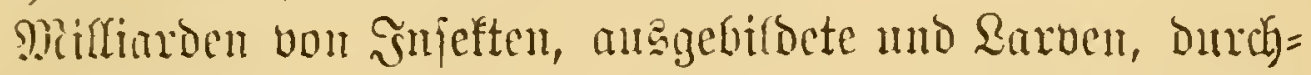

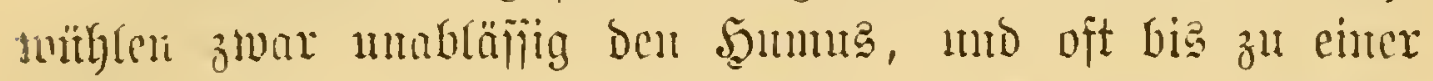

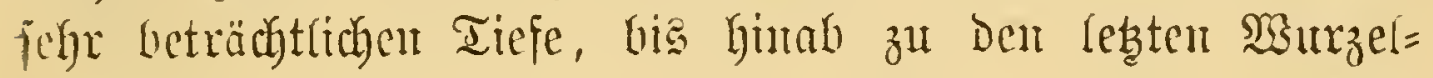
arselürfern, welde bie Riflarzen in ben Boden fenfen;

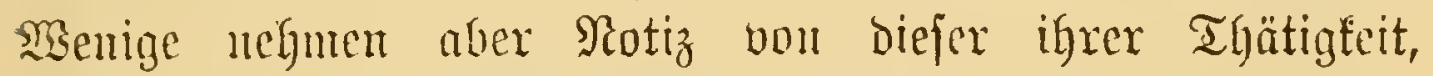

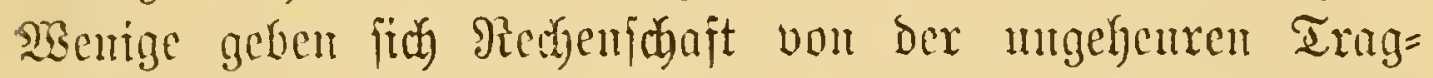

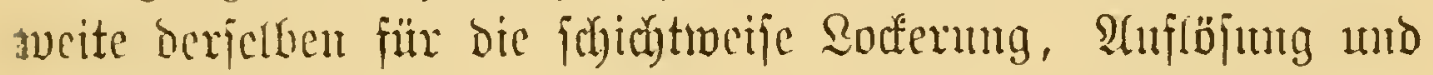
cubriche 3erftönng ber Erobberfläche. Sie bedenfen nicht,

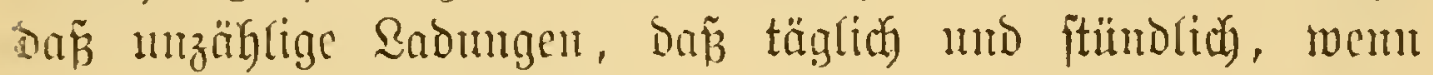

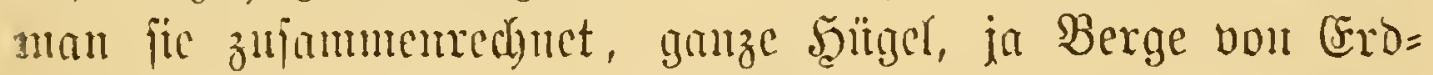
xeidy ans ber Tieje hermifgeidyafft mo bem nivellirenten

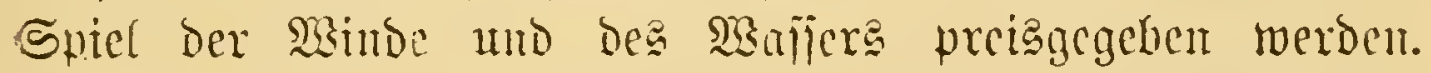

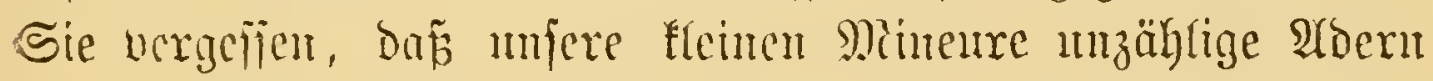

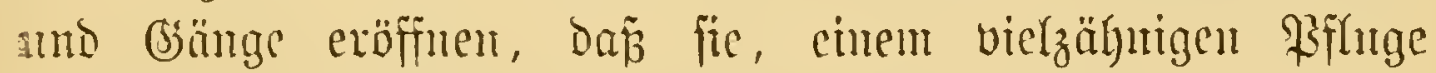
vergleidbar, dic Eroc burchadfern mo fo bas grope, ftetige

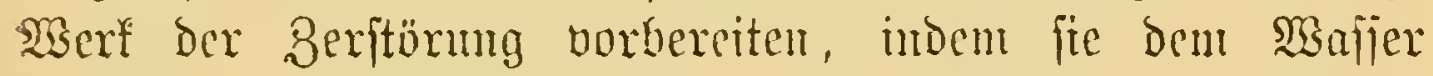
Durch) Den Durchlöberten Bboden den $\mathfrak{M e g}$ in bie Tieje bahner.

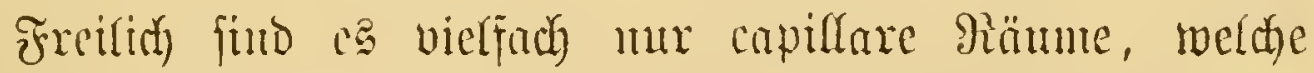
Die Rerfe fidaffen, uns in Der Riegel hutbert uts einte bichte

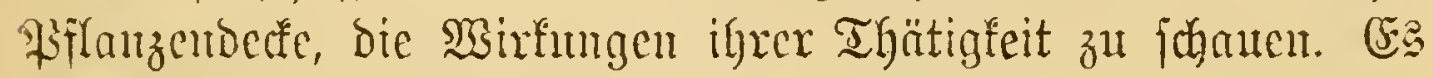

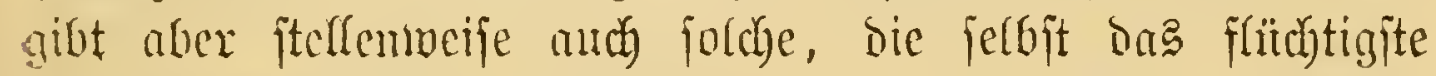

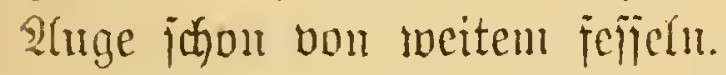

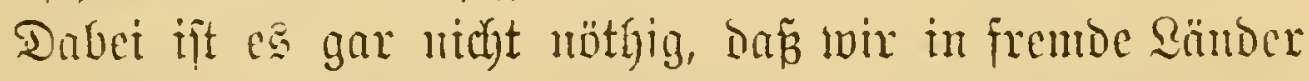

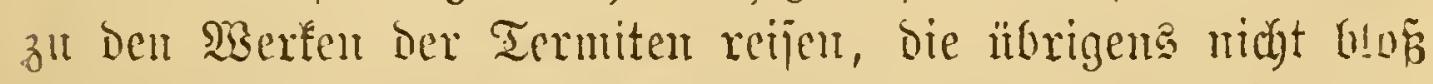
ale Berjtörer, jonbern, Den foralfen ähnlich, aud ale (Erbaner

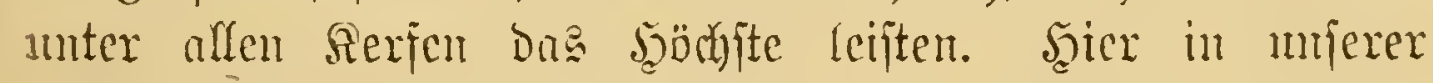

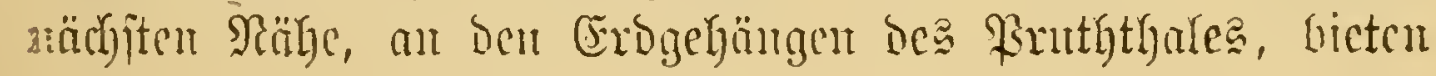


fid Dem Beidjauer bie gropartigiten Beijpiele dar. So ftehs

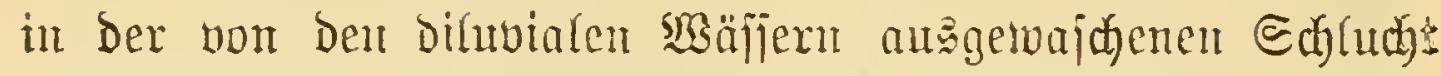
von Sabagutra eine riefige Sandbant an, bie bout bent ber:

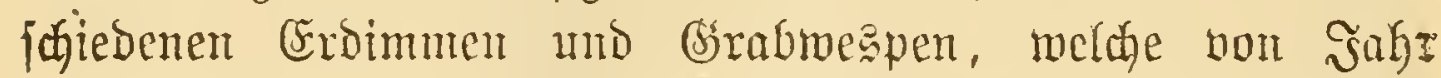
zu Sahr hier igre Brutftätten aufichlagen, ganz burdjftäblict mie ein Shinamm Durblödert erjobeint, während fich in ben Buchengehängen mebenan Taujende oft hatbefafterhoher

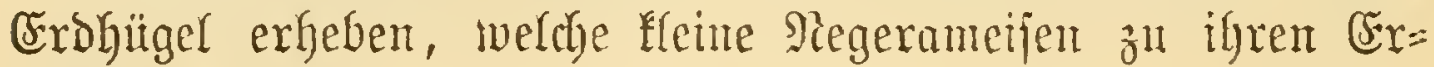
bauern baben.

DaZ gropartigite Crozeritörungämert von Rerfen, da

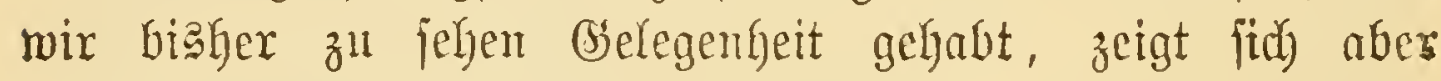
am Norbabgang bes Cecina. Der mir pout eimer joujutterm

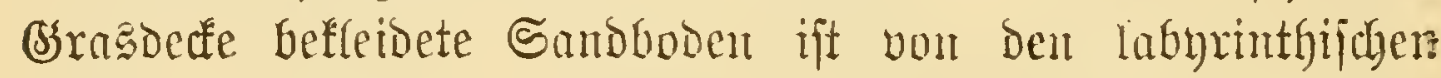

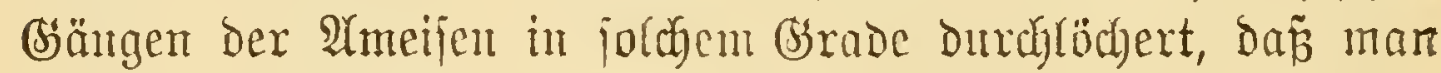
fajt bei jedem Tritte einfridyt, mo jo tragen bent mijere

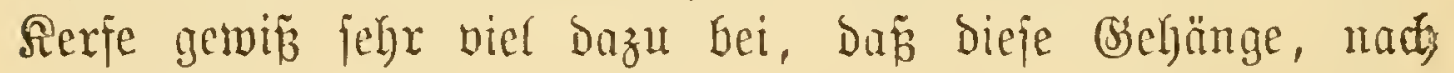
jeden jtärferen Regengnz, ber biejes ganze Rorenjyjtent mit Maijer eriüllt, ins Rutidien geratbent.

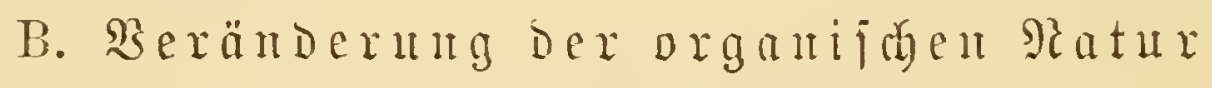

a) Duref Vertifyung verwefender Stoffe.

Die ganze Miajie abgejtorbener organijuder Snbjtanzen, welche den Eroboden bedect, ijt, wie wir wijell, cinen be=

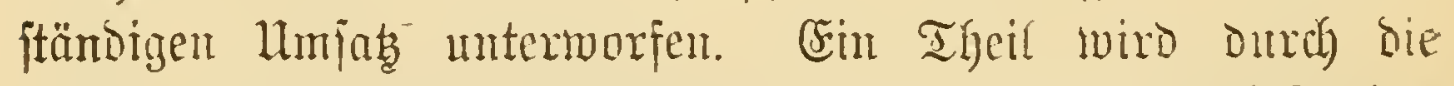

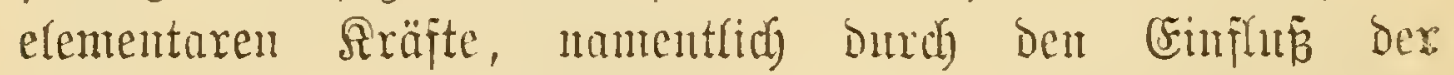
Wärme uno Der atmojpgärilicu, in jeine Grunobejtandrjeile aufgelöft. (sin anderer mirb, freilich aud in ber Reger erjt uadh vorhergehender Shalbje, von Der Bflanzcnwelt auf=

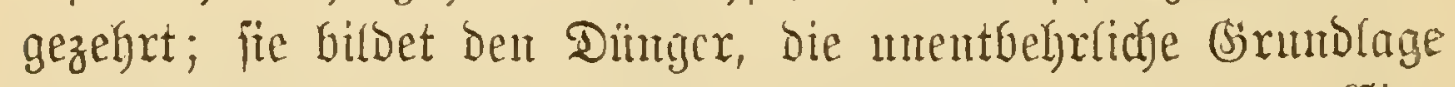

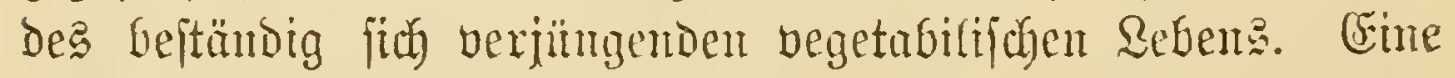
nicht hoch gentug anzujd)lagende giofle ift aber in biejem

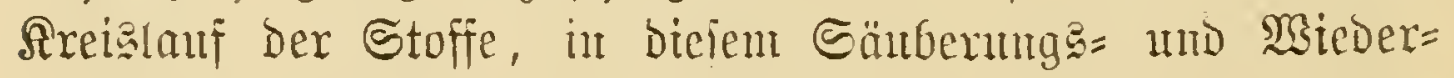
herefungaswerfe ber Ratur anth Den Serfen norbegalten. Die 
Rräfte ber Berftörung und Tuflöinng, weldye von ifuen ats: gehen, fint allerbings bei weitem nidit jo alfgementer art,

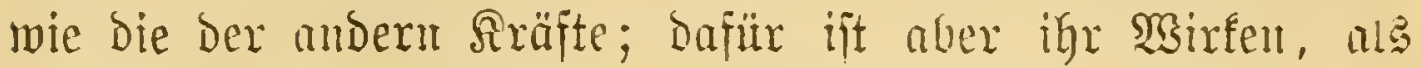
ein von belebten Beritönumganajutuen herborgebrachtes, ein viel energijueres, mmittelbareres mo baher and rajdjeres: Die Sierfe analyfiren oder atomifiren nidt; jie wälglen bas fürzefte Serfalyren: fie zertrümmern, zerjotheiden, zerhohren uno zerbeinen, und and die Reuconftituirung ber vertifgten Subjtanzen geht micht, wie bei ben Rflanzen, Den langmierigen Weg ber Bujammenjebung, Der Syntrjeje - indem jie bie todten, proteugebenden organifyen Stoffe in fich aujuegmen, verwandeln fie fie andh gleich wieder in Kebendiges Protoplasma,

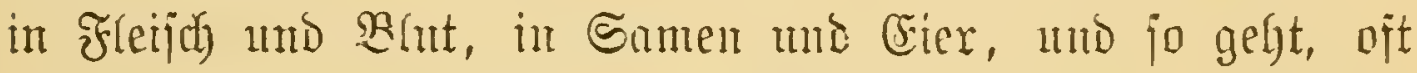

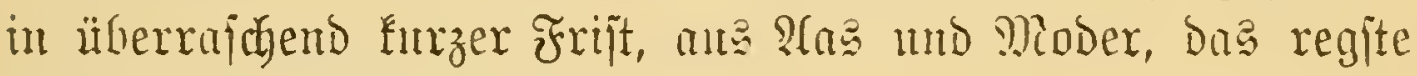
und buntefte Seben Gervor.

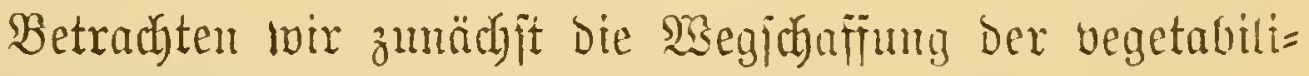
frat Sitbitanzen.

Dus Meijte mird fier bou Den Sarven geleijtet. Sm

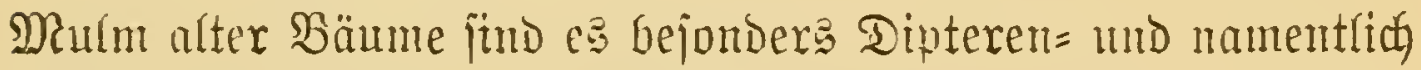
Schuacenmaden, fowie zahlzeidye Siäferlarven, z. B. von Cetonia, während Das fantente Srant= und Sanbwerf an meiften bou Sirzfflïglern, Sphäriden n. Dgl. Säfern gefrefjen wiro.

Die Sänbernng Des vegetabilijugen giciches uno nament=

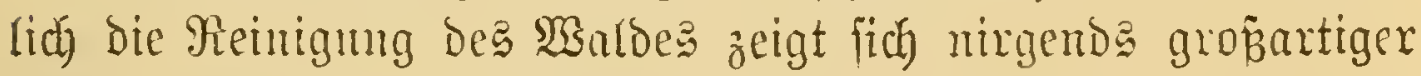
als in Den Tropen. Sobald ein Banm umfällt, ftïrzen un= zählige Scharen verjhiedener ferfe über ifu her. Die einen

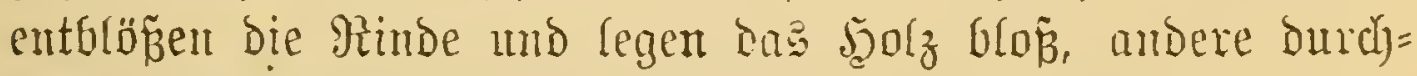
löd)ern bas rebtere jelbjt. Num dringt das

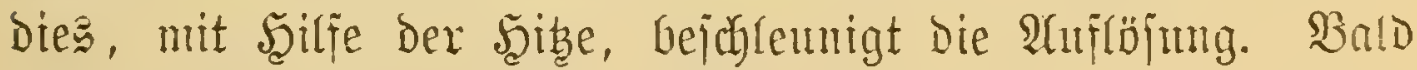

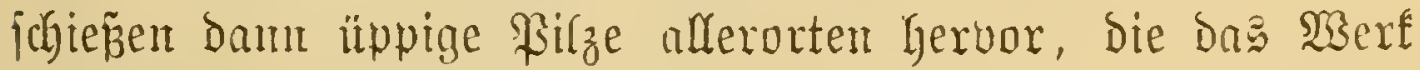
Der Beritörung fortjeben, und jo wiro, Durd das Butfun sex Serfe, bimen weniger Monnte cine gemaltige Maffe Der 
bärteften mo. zäheften Materie in Stanb zermatmt mo ciner nenen Segetation \$laz gemadyt.

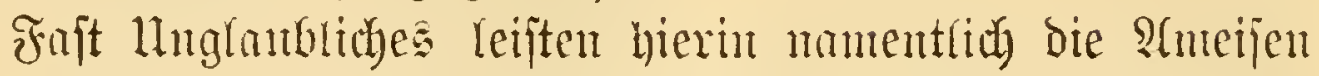
utb Iermiten, bieje verbreitetiten uno eifrigiten Sigenten Des Todes.

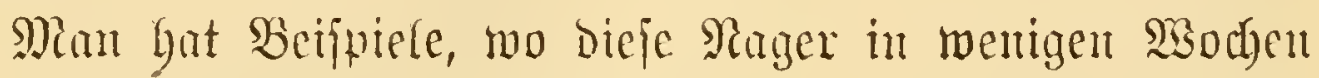
die riefigften Baunftänme anatomifirt und ganze Stäste an yölzernen Baracfen erbaut, nadjoem fie ifre Berwohner ver= trieben, fmurlos von Boben vertilgt haber. Ilno bies ift

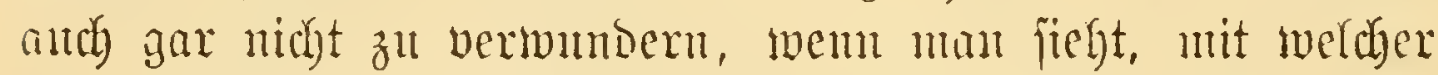

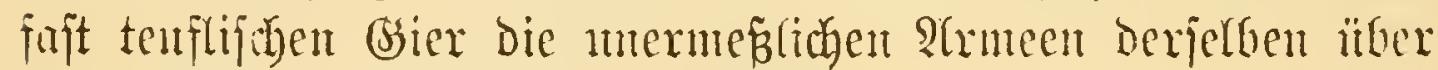
alles Beniç̧bare Gerfallen.

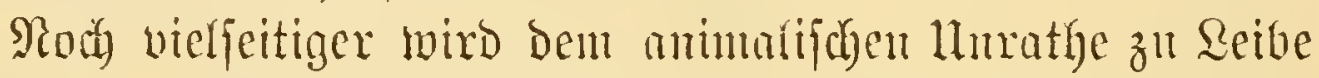

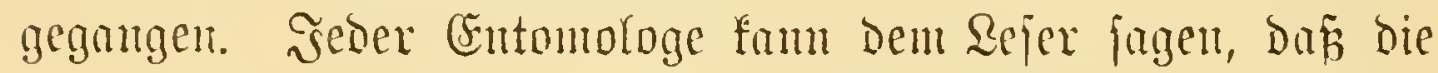

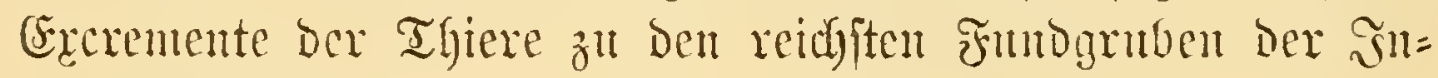
feften gehören.

$\mathfrak{B e r}$ zäglt jie auth alle bie mijanbern, went and zum

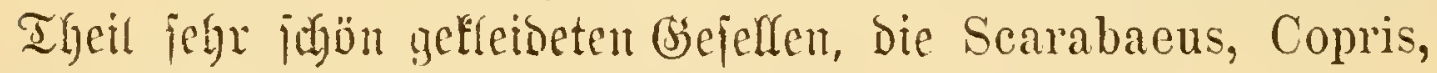
Ateuchus, Onthophagus, Die fimgflügler mo Dam Das mento= liche Seer Der Frliegen, welche Den Dung, faum gefallen, mit Dem

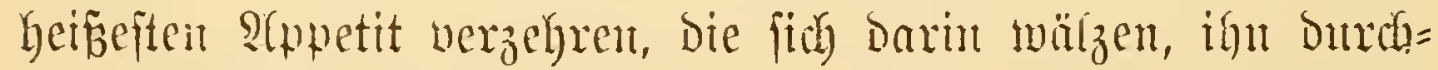

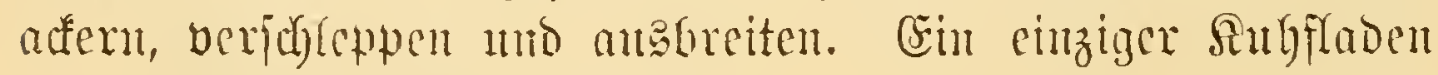
ift ju cin fleincs fierjabinet.

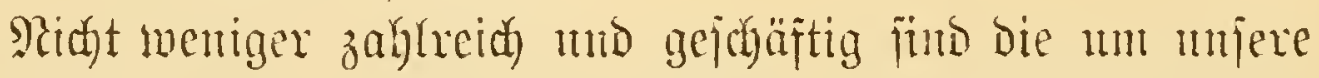

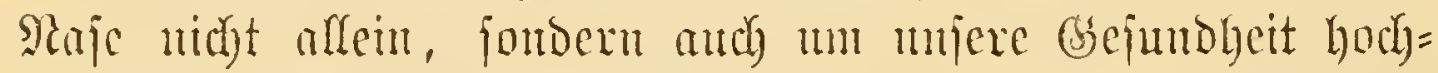
verbienten Raguertilger. Snterefiant ift Dabei bie itrenge Sqrecitetheilung.

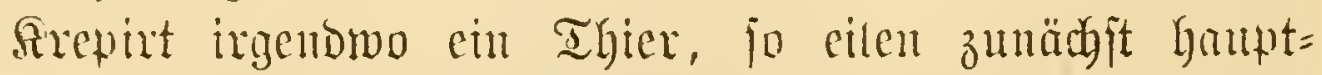

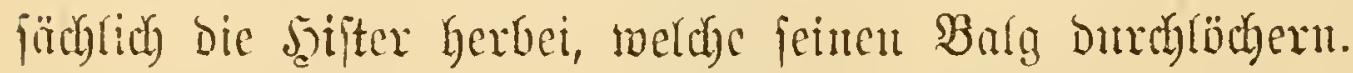

Şieranf fommen bie Fleij(d)= und andere Ffliegen mo besecken bus ara mit Mriffionen won Maben, was leidyt

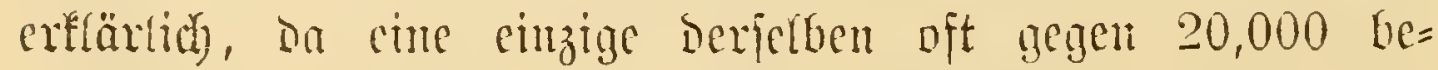
herbergt. 


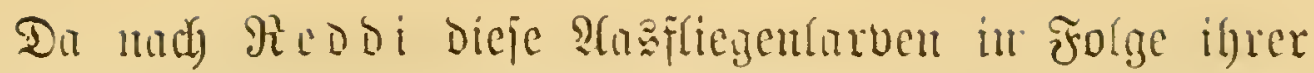

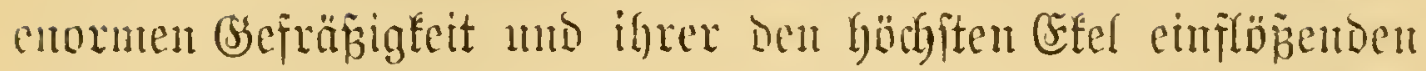

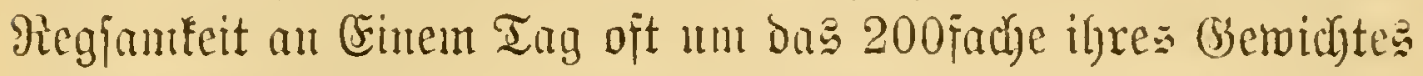

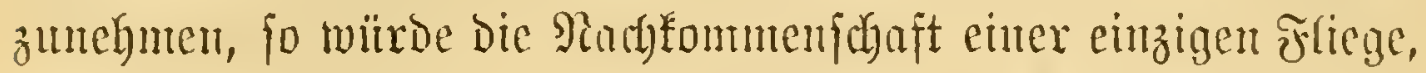

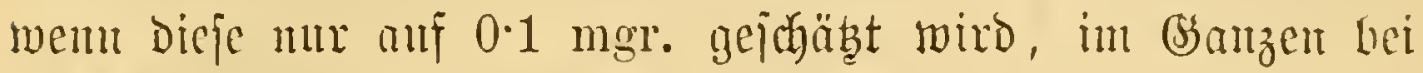

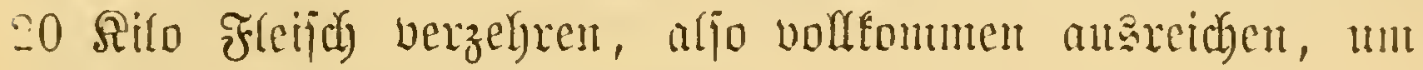

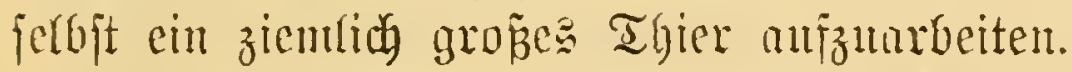

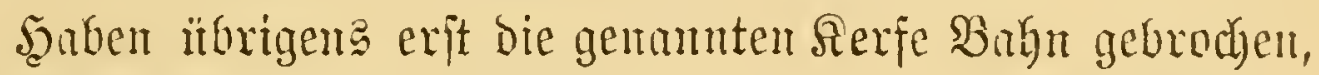
bam jeflen fich amb bald Sibaren vieler anderer, bie Necrophorus, Silphae, Dermestes 1. f. w. cin, wägresto ab utb zu

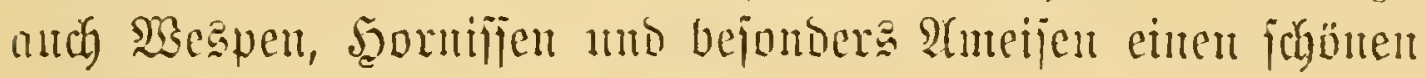
Theil wegtragen.

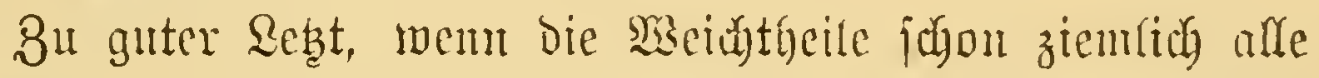

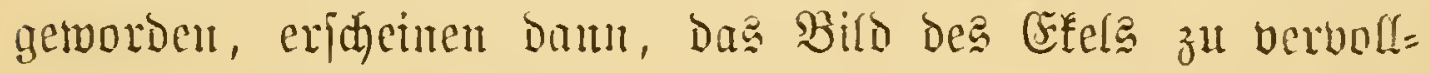

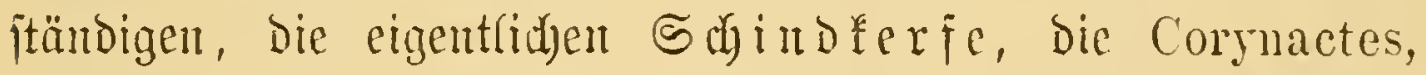

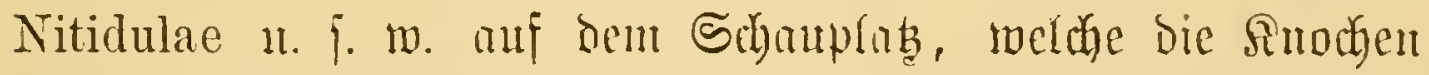

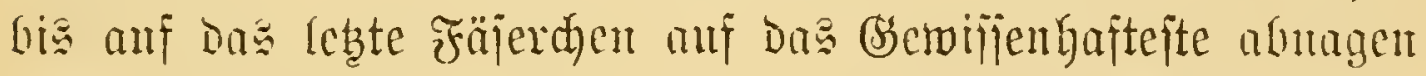

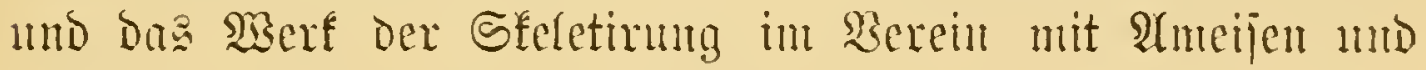

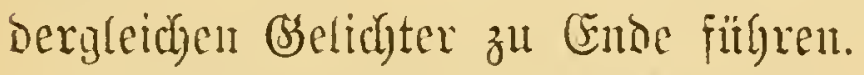

Die purificirende sirfumg Der Rerje befnt fich aber

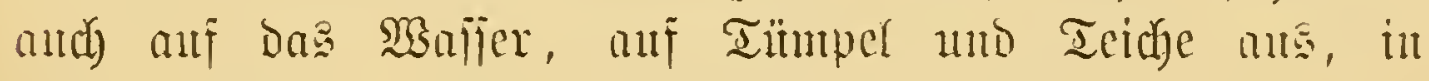
Denen, von ben ffeinen Surutern, Den Daphnien u. ₹. w.

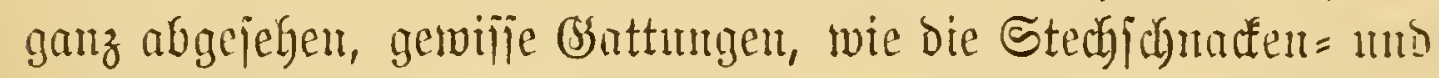

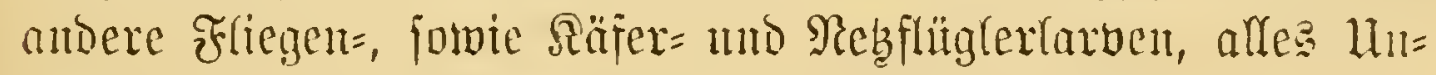
futbere, alles in Berwejung Begriffue bejeitigen.

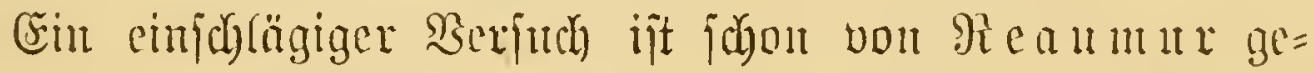

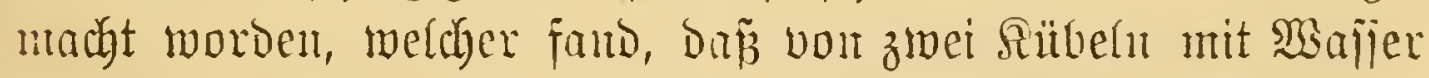

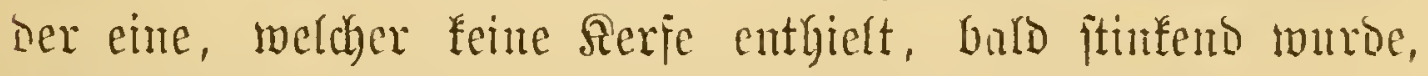

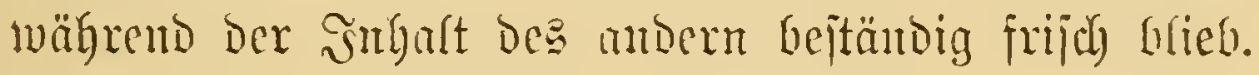

\section{b) Duref) Berfärung Der Jiffanjenweft.}

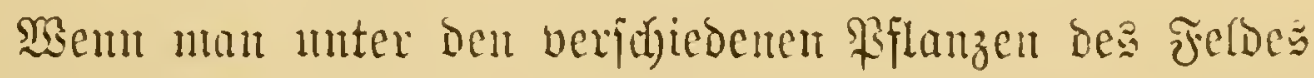

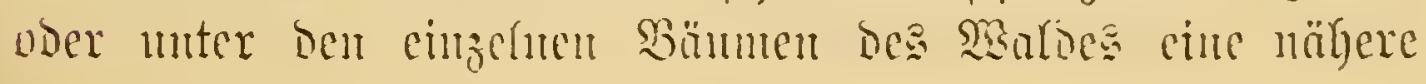




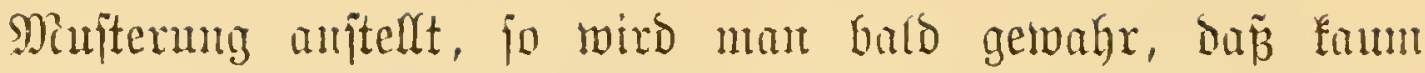

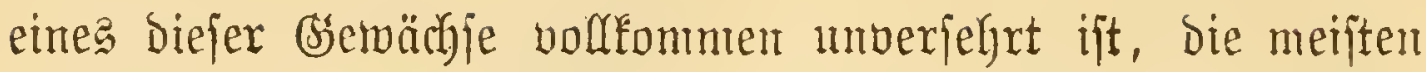
bagegen megr oder meniger von Rerfen bejouäbigt fumb, mo find es namentlich die Brätter, weldye von ifnen oft in ber ïberijten $\mathfrak{B e i j e}$ zugerichtet exicheinen.

MrMein dies gibt uns von ber pflanzenzeritörenden Thätig= feit der Serfe mur einen ganz fidwarhen Begriff.

"Ein Bübter von Seibentumern," jagt Midhelet, "glaubt im Stande zu jein, jeire Pfleglinge mit einem Maul= beerbanm befriedigen zu fömten. arber das ift norh nichts. Man bringe ifnelt ganze $\mathfrak{s a ̈ l}_{\text {ber }}$ und fie berlangen immér

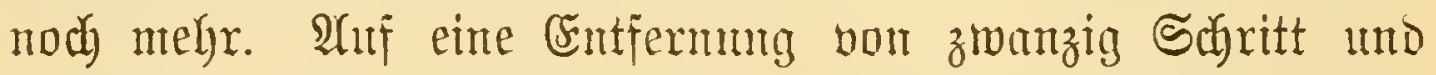
weiter hört man ein eigenthümliches mo munterbrodbenes

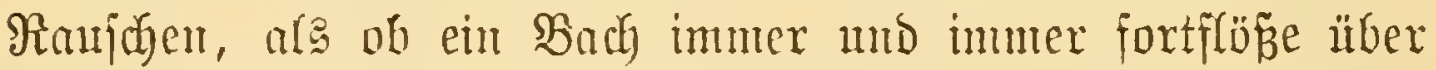

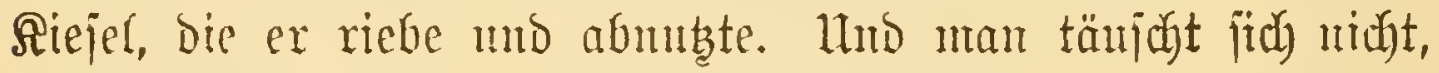
es ift in der That ein Badh, ein Sturzbach, ein mentidiber

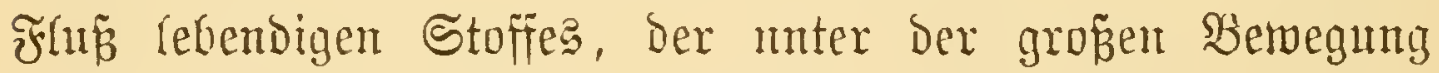

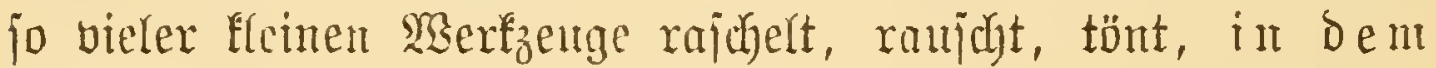

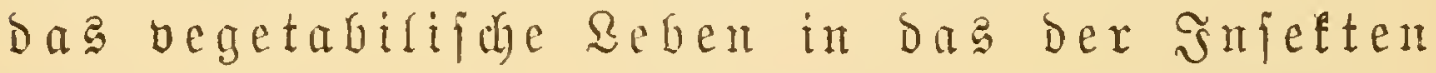
übergeht mo langian, mbejteglich mit ber Thierheit ver= johmilat." Into ift bies etwa itbertriehen?

Fallen nidyt thatfäblich jede Seande Tanjende von Blättern, Tanjende von Sititten nnter dem Babne biejer fleinten Schntter, währemd unten im (Eroieich, unferen sitifen ent=

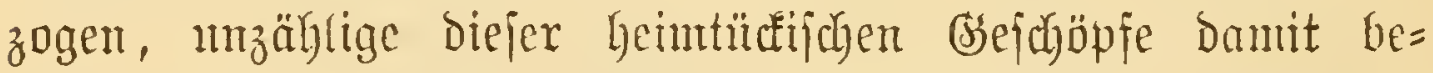
jajäftigt jüb, Durch Beritörung der Manzeh die Piflanzen von Brumb ans ju vertilgen?

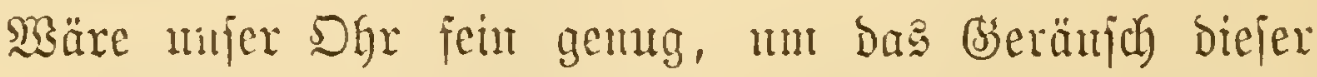
fleinen Majuinen ju vernehmen, jo witrde bie viełbejungene Stifle der Ffur zum tojenden Rärm eimes Schlarbtfeldes werden.

ltnd dies wird fie ja auch in ber That, wem bie Şeut=

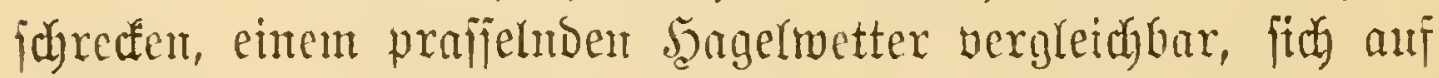

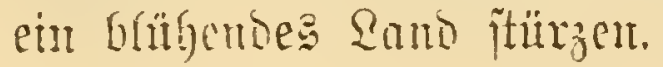


Ter fibon eimmal genamte Regener hat auggerechnet,

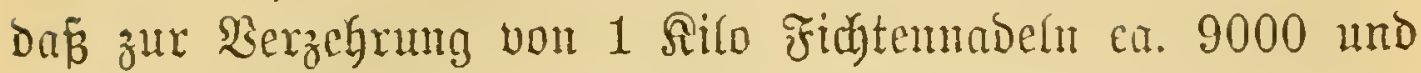

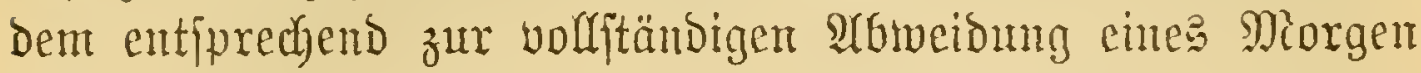
Waldes etro 300,000 Raupen exforder(id) find. Was find aber 300,000 gegen die wirflidje $3 a \mathfrak{h l}$ diejer Echaben= thicre!

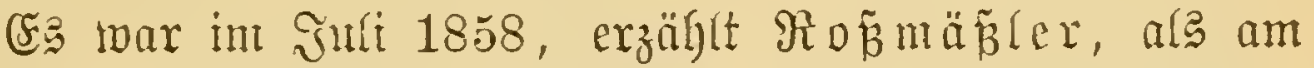

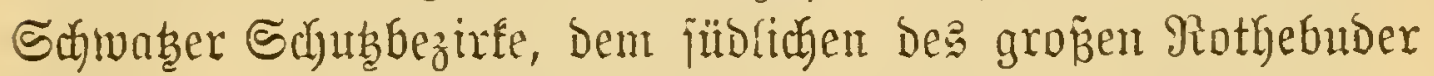

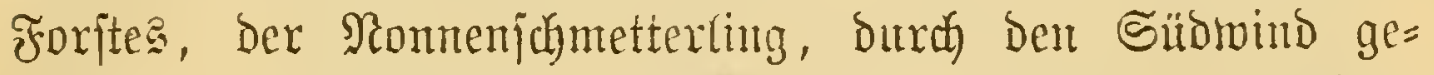
trieben, in unheilfdweren Wolfen Daher flog und in wentgen Stunden nom ganzes Mäldercomplex Bejis exgriffen Gatte. Wie ungeheuerlich bie Menge biejer Falter war, jeigt ber

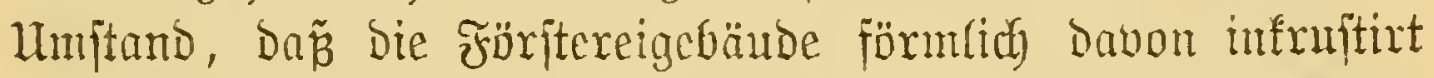
und die Sberfläble des Piltwmmjee's von Darin ertmutenen Schnettertingen mie mit meipem Scham bebect erfobien.

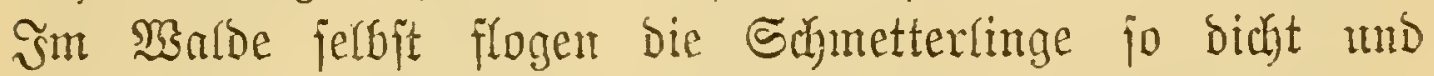
wirr Durn einander wie Sibneeflofen beim ärgiten fturm.

Diejer Mrijenüberflug der Monne aus den jüblideren

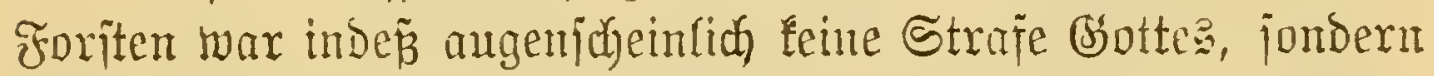

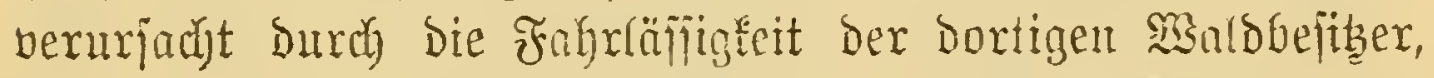
bie bas Hebel, are es roch fleit war, midyt beadyteten, mo

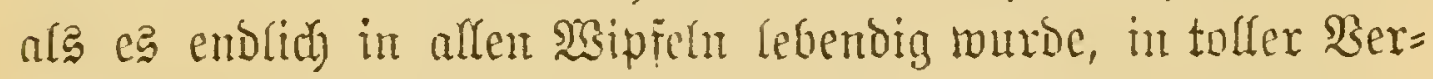

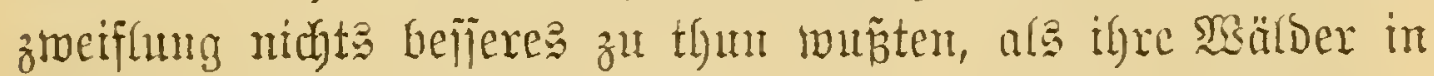
Brand zu ftecfen mo Den Feind - ifren nörofidyen Nardjearn

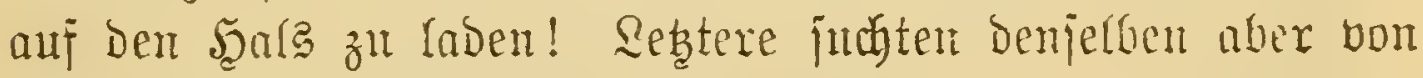

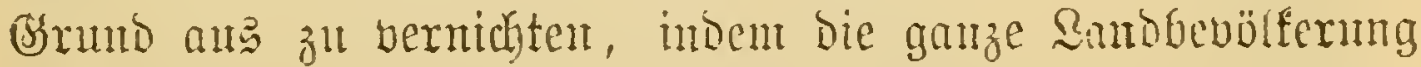
zum Einfammeln ber érier anfgefoten warbe. Teren wurben num aud bon 8. 24ugujt bis 8. Mai des folgemben Jahres gegen brei - Eentmer erbentet, twas ber jübuen 3 algr von

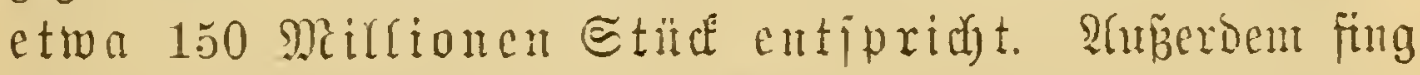

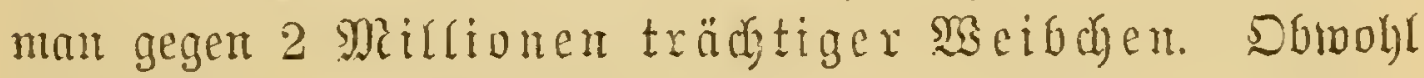

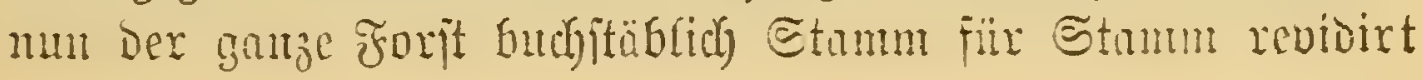




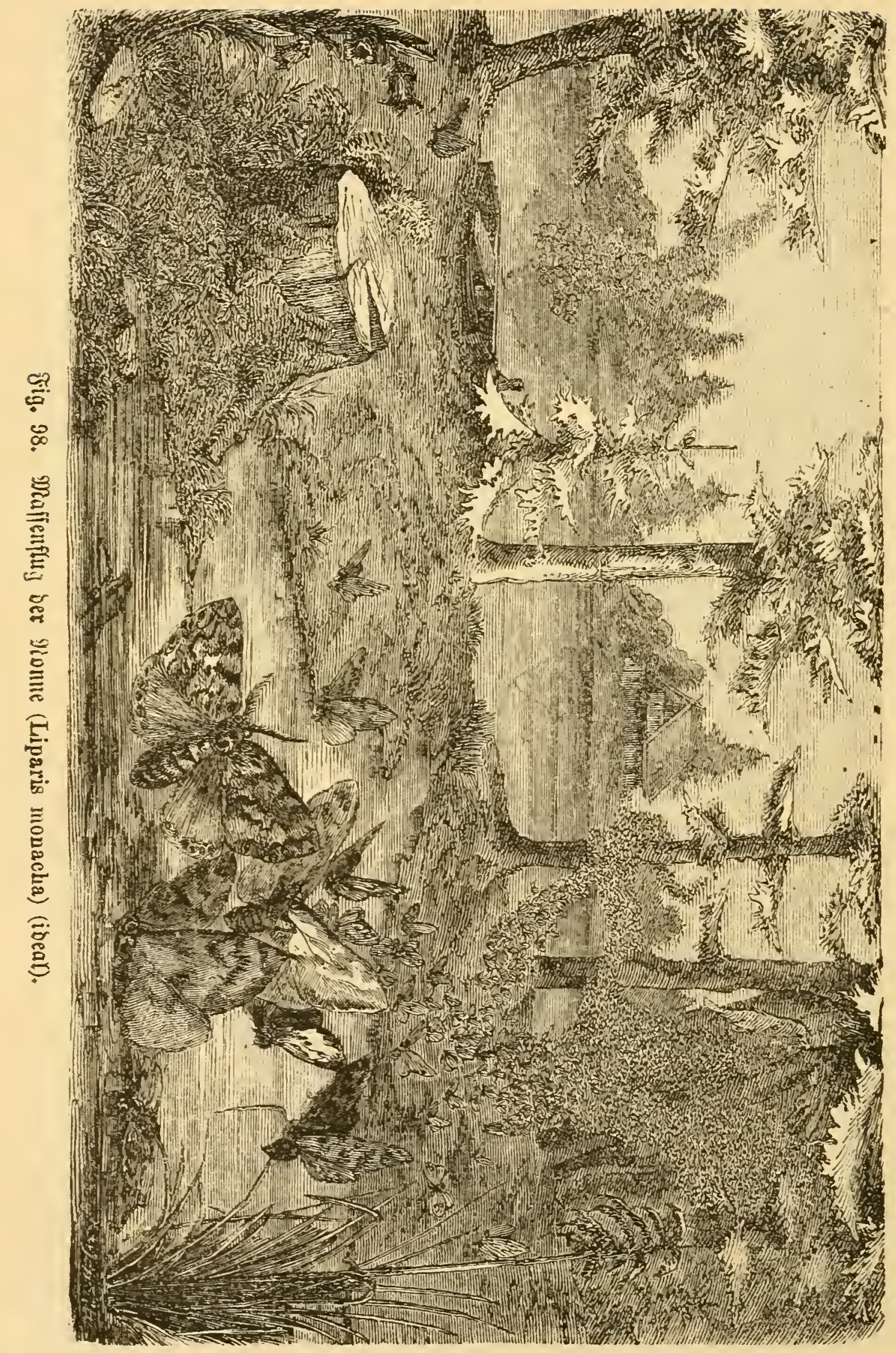




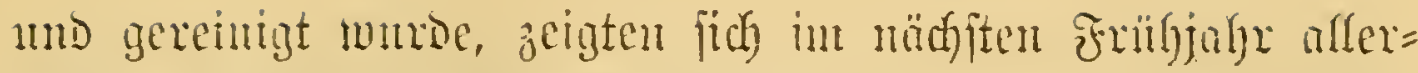

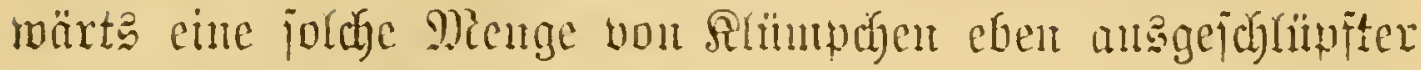

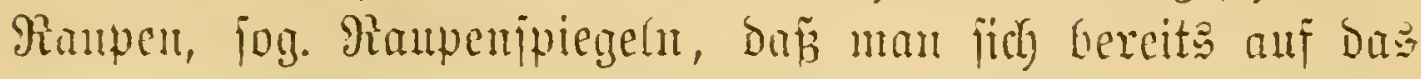

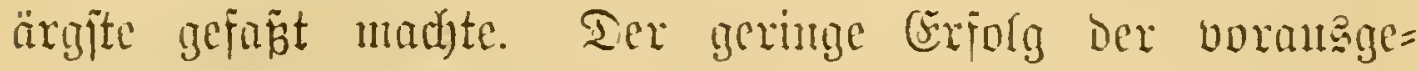
gantgenen Butbernidytung erflärt fidd zum Theil dormit, Dar

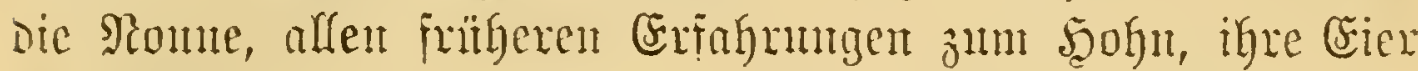

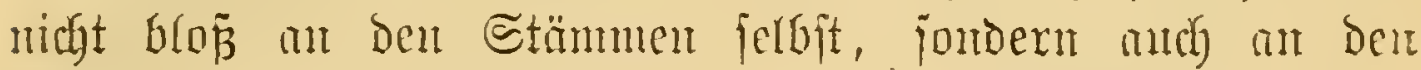

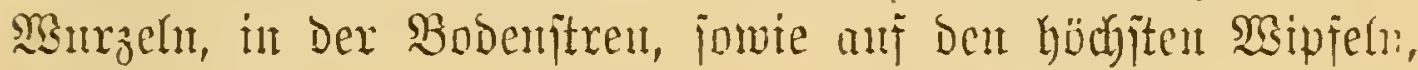

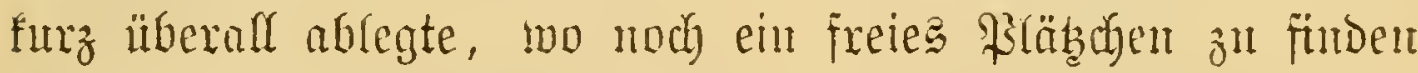

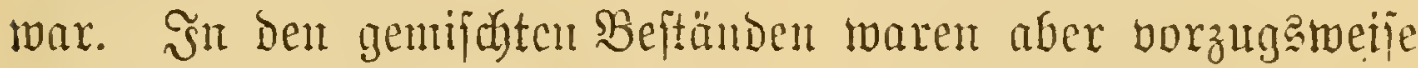

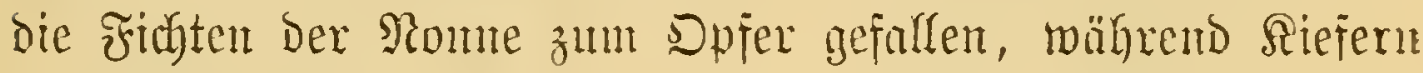

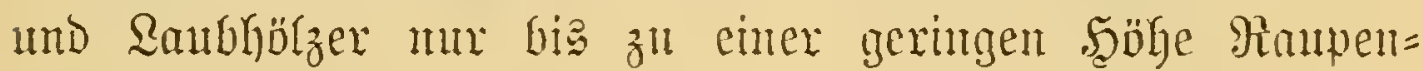
ipiegel trutgent.

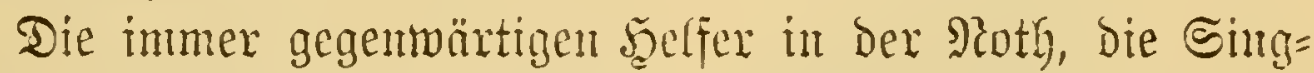

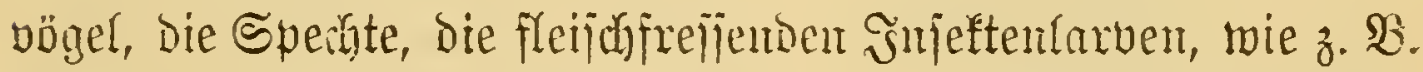
die vou Clerus, halfen zwar waffer mit - aber es half eben

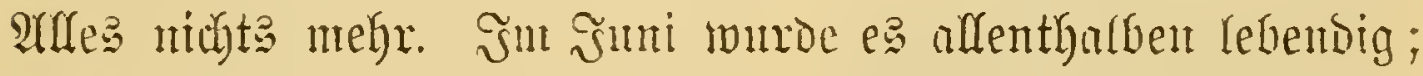

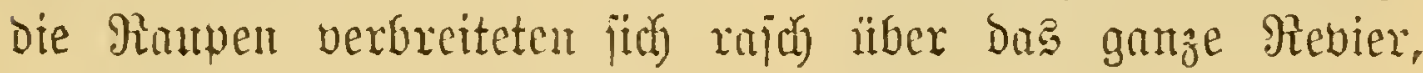

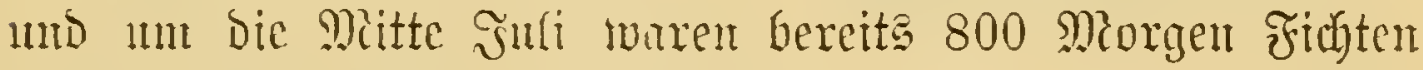

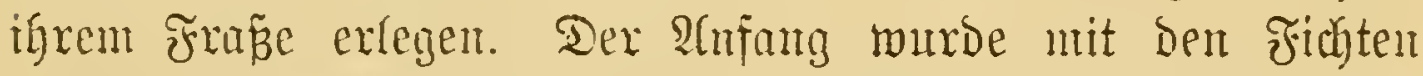

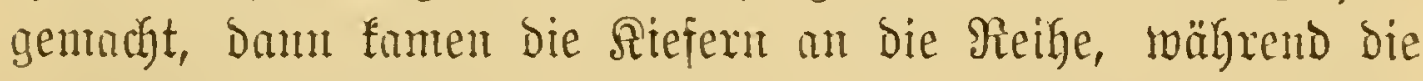

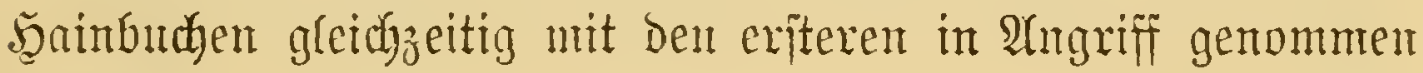
murben.

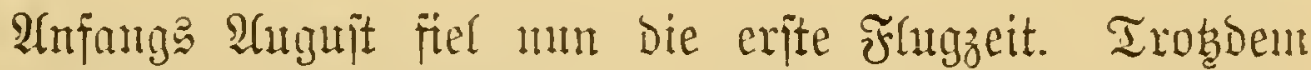

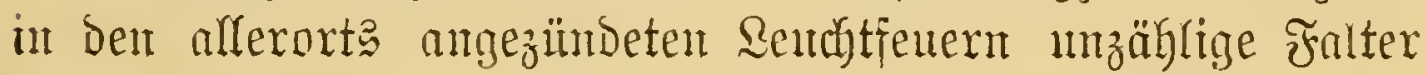

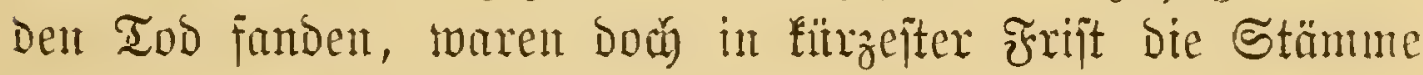
bon oben bis unten nit den frijd) abgejebenten (Ficrbanfent förm(ich infuruftirt - in in Ernanglung geeigneter Brut= ftätten wurben bie Sier jogar - gegen alfe giaifon -

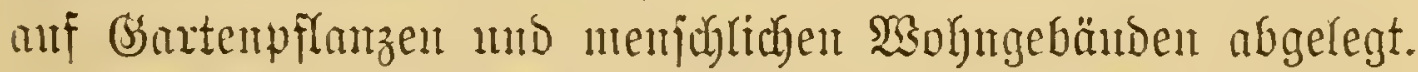

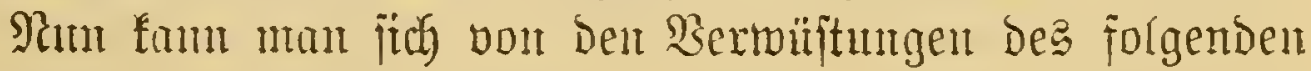
Sommers einten Begriff maden. 10,000 Mrorgen Rabel= Golzbeftand waren in wentigen Tagen fabl gefrefjen, uno 


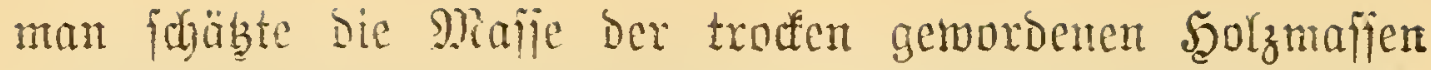
culf cime Drittel=Million Subik=

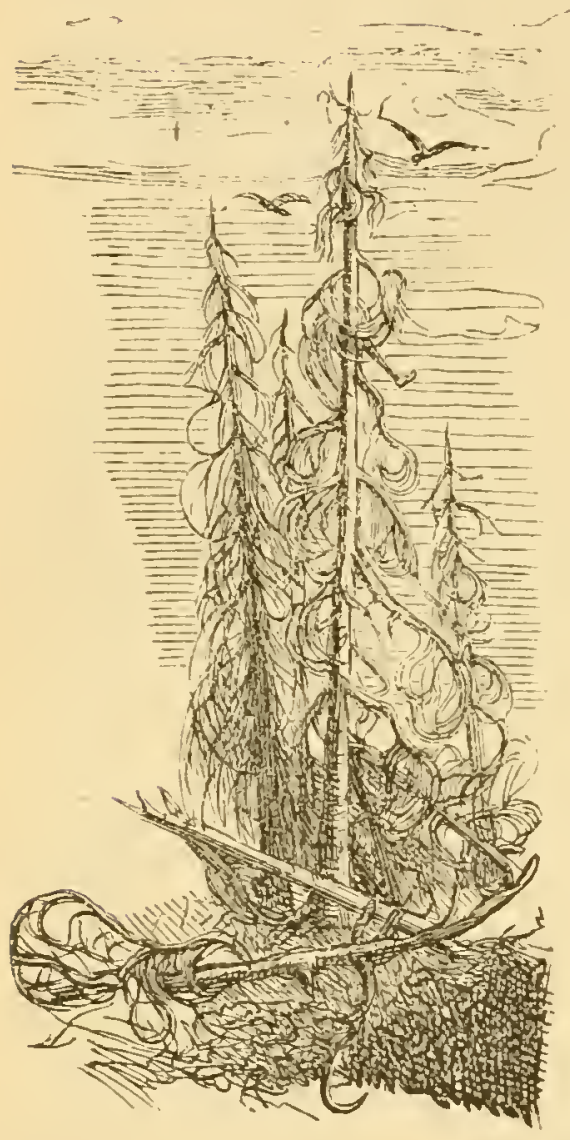

รig. 99.

Durd Die Ronnemranpe befiäbigte

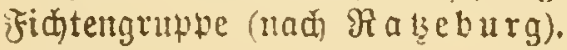
flafter! Bald griffen bie Raupen mut anch zu Den jüngeren ano jïngifen 尺ulturen und vernichteten jede Scoffintug von Grumb aus. "ŜA jüngeren Fichten. mto Gieform frimmten fich Die æBipfel unter Der Sajt ber flumpentweije Daran fibenden ßaupen, und an alfen $\mathfrak{B a ̈ u m e n t ~ h i n g e n ~ b i e ~} \mathfrak{H e j t e ~}$ abwärte. Der $\Re a \mathfrak{l}$ pentoth,

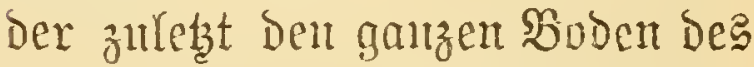
Maldes zwei bis drei Boll ho dis, ja an manthen Steflent bie peds 80 orl hod berecte, riejelte munterbrodyen, greid) cinem taren Regen, aus den frouten Dex Bäumte hè: nieber, mo bald war fajt feit grüncs Blatt, fein grüner ફ̧alm melyx ju fehen, fo meit bas

Aruge reichte."

Itnd wer benft nidgt mit Entichen an bie Berwilftungen,

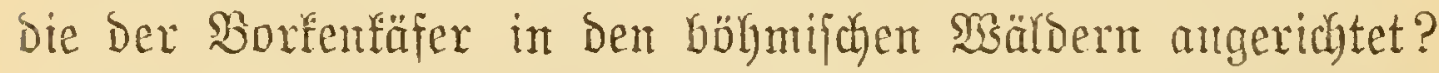

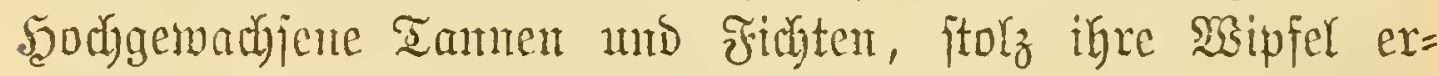
Gebent, werden heimltich von einer Schar unferer feinen Minteure ülerfallen. Bald riejelt das feine Bohrmeíl aus

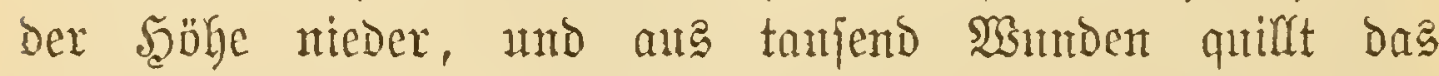
Bhut bes Santmes, das Şarz, hervor. Die Folgen lafien auth nicht lange auf fich warten. Die Rinto entfärbt fich und iclunpt fich ab, Die Rabeln vergilben und fallen zu

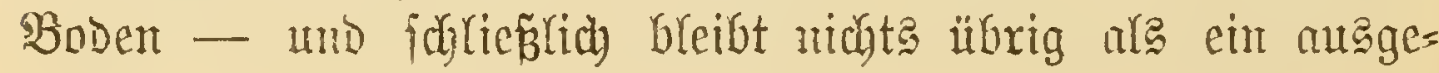


zehrter, Sïrrer Stanm mit trodfenen Btweigen, ben felbit ein fein allzu heftiger $\mathfrak{B i n b}$ ohne Mühe zu Boden wirft und in Trimmer bricht.

Und nun jhälen wir eimmal von biejer Bummleidye bie

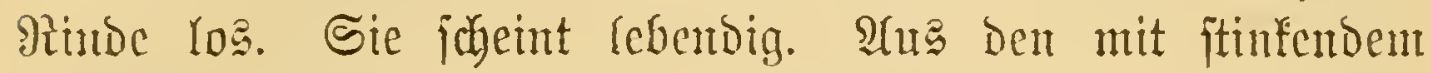

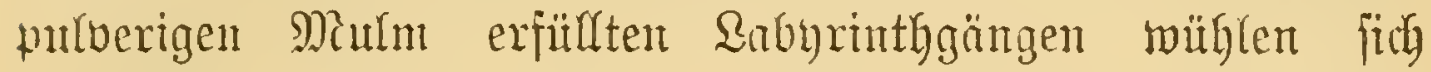
Taujente und Taufende ber flemen geflügelten Bohrer herbor, und eh' wir's me verjehen, brohen mis ifhre Eibmärme fajt zit exftifen. Sald wird audi in der That

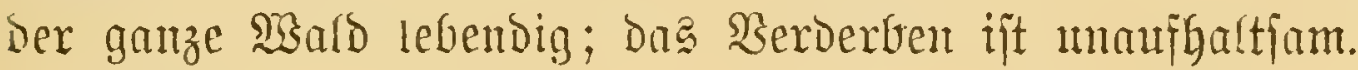

Waren es früber mur einzelne und meijt jobon ältere Bäume, die dem Berderben erlagen, jo fehen wir jeţt,

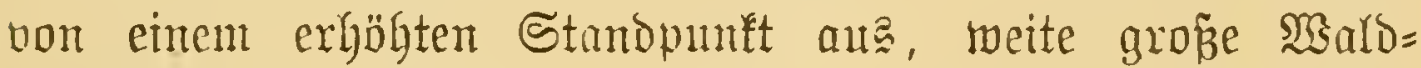
itrecent, mie bom Reif berjengt, fich röthen, uno ehe man's für möglich bält, hat bic Senthe ganze Forite ergriffen,

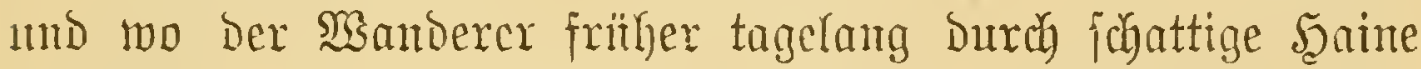
Dabinjabritt, Da zeigt fich jeinem traurigen Bricfe jest nichte

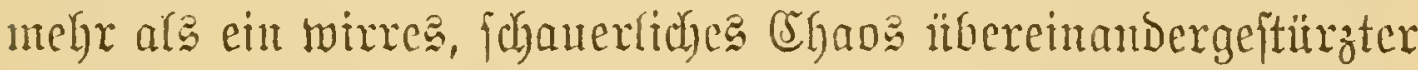

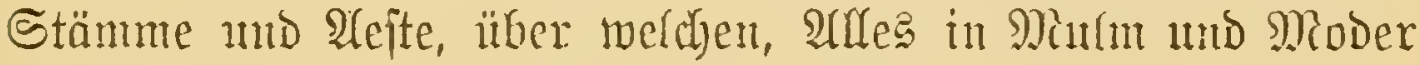
vermandelnd, Das Mulfunt emporwitidert.

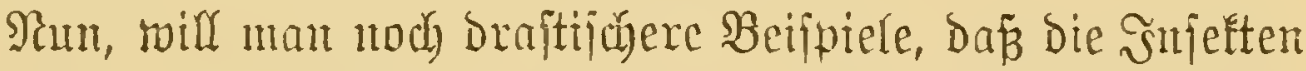
cine Der getwaltigiten Naturmäbte find, und ift angefichts fordher

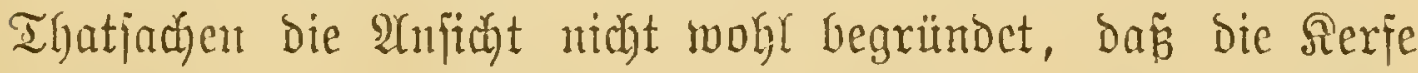
jo wie hente in Den Mrwäldern Der Tropen, aud in früheren

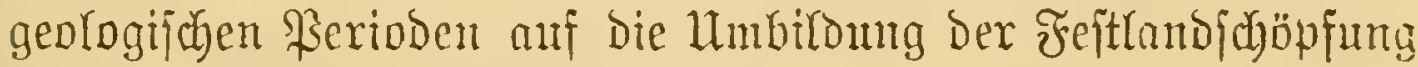

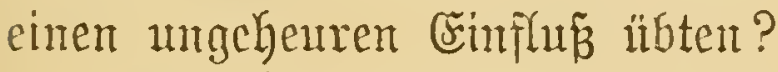

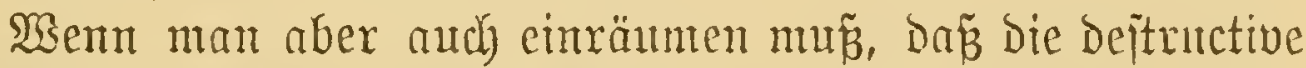
Thätigfeit ber Rerje feine abjolute ijt, ba ja fajt in ferben Mañe, als fie die eine PFflanzentart vertilgen und ausrotten, bafür andere Dejto befijer gebeihen, fo twird heutzutage boch nux mehr ein Telcologe bon Profejion jo thöridgt jein

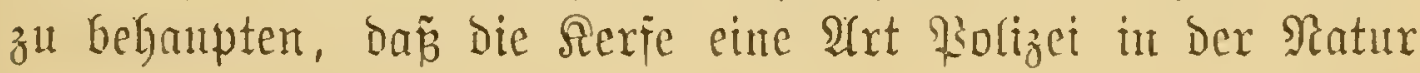




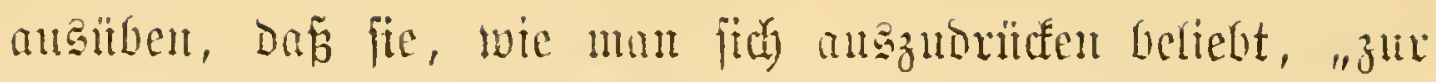

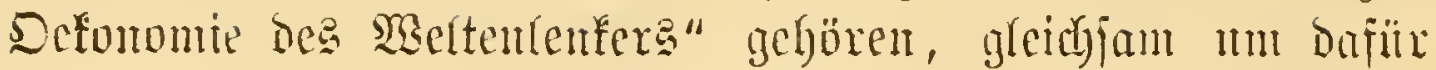

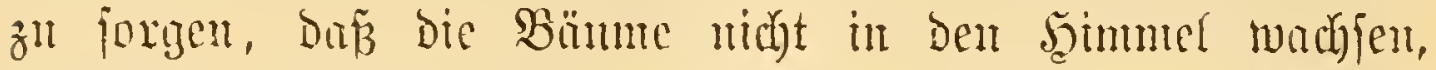
währento gejcheiote Menjchen in biejem ganzen grożartigen

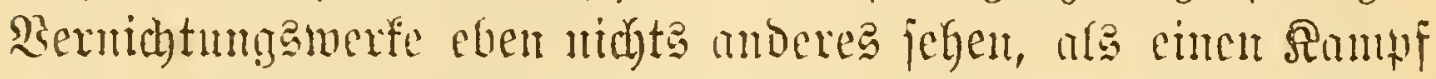

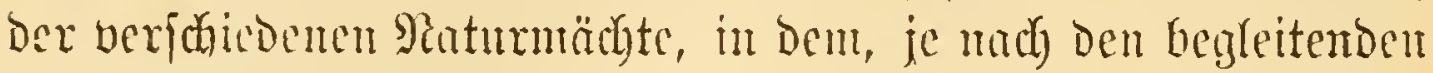

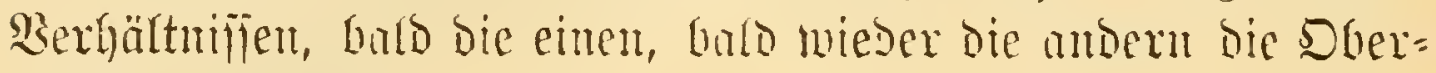
lond gemimen.

c) Duref Berftörung der efjierweft.

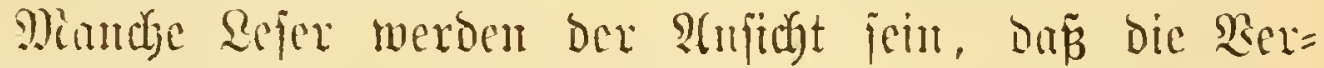

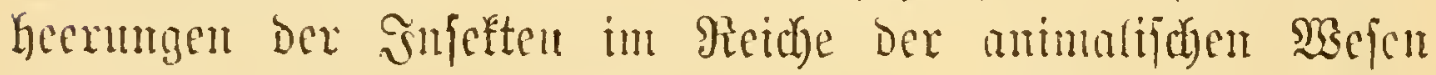
feine nemensmerthe Bebentung baten. Sie minton aber gutz mbers urtheifen, ment wir bie Thiere, welaje täglid von S̈mjeften, wir jagen nidyt anf Der ganzen Eroboberfläche,

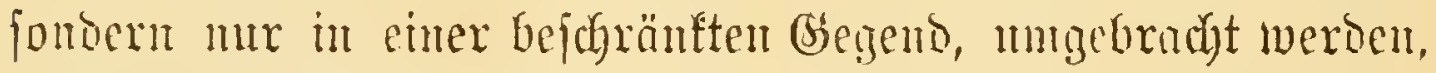

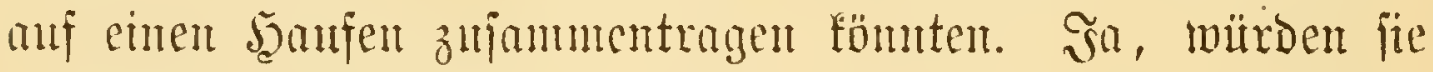
ausufen, diefe Serfe füb dod furdytbare $\mathfrak{B}$ ejen, fie wären,

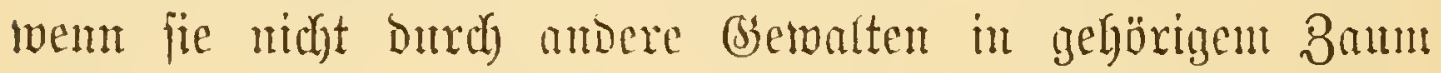

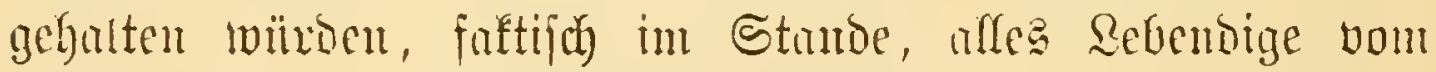

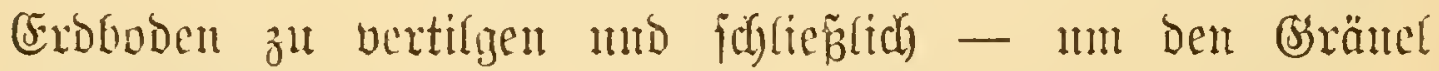
ber Berwilftung voll zu madien - jidi jelbft anfanfreffen!

Arber wentigftens, wird mun fith fagen, fint die höberen Thiere, wo nidyt vor ifyen atugriffen, fo Dody vor Der gänzfichen Berntchtmng ficher. Dody and bas ift nidyt ridytig. Mix wollen nidyt baran erimern, wie viele Mienfiben

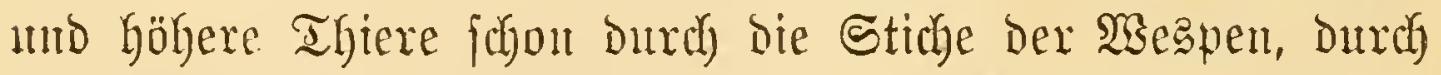

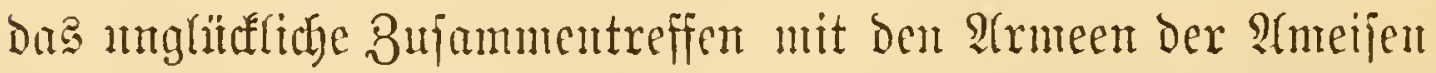
und Termiten getöbtet und zun Theil, wie glanbmürbige Beridyte erzäblen, foznfagen bei rebendigen Reibe aufgefrefien

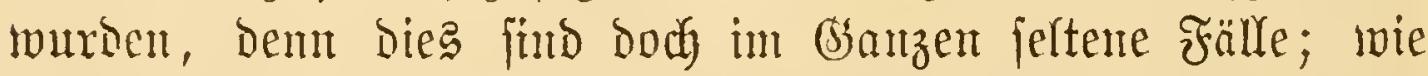
viele gröpere mo fleinere Sänger mb Sägel un deren

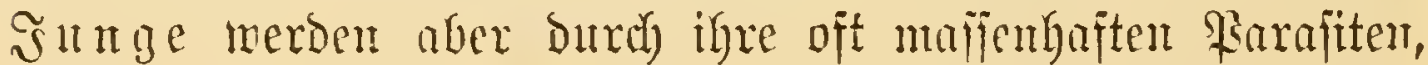


langiam zu Tobe geidumben, und wer zäh(t, vou Der Fifich= brut abgejeben, alf' bie leinteren Reptifien und \&urche, welche theilg Durch einzelne ftärfere $\Re$ erfe, z. $\mathfrak{B}$. Durch die gröpereren Shmimmfäfer, die Caraben, die Miantis u. j. w., theils Durch Den vereinigten Ûngriff mehrerer tagtäglich zerflleifabt werden!

Den ärgiten Berfolgungen find allerbing bie mirbellofen Thiere, namentich die Würmer, bie fleineren Mollıłen, in exjter Qinie aber, wenn wir vou ben arffeln, ben wentigen

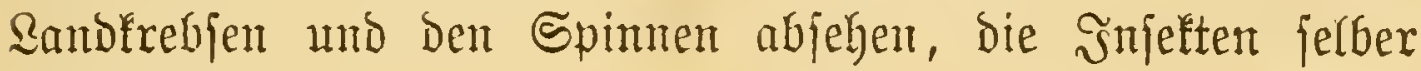
auggejeşt.

Die Bflanzentmelt, fo fömen wir dag Bsejammtmirten

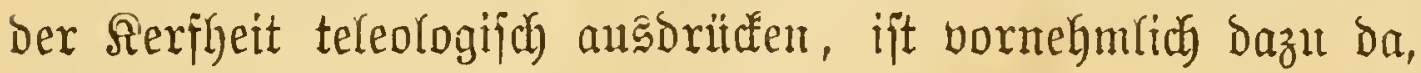

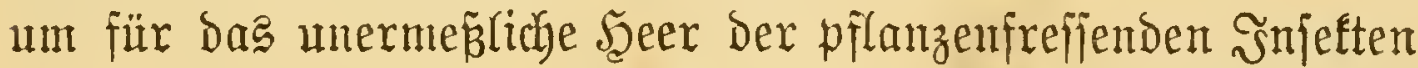

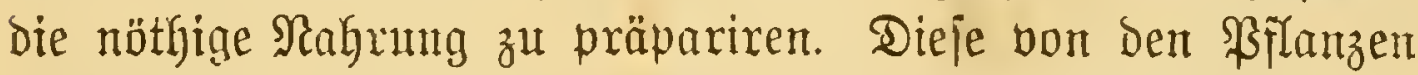

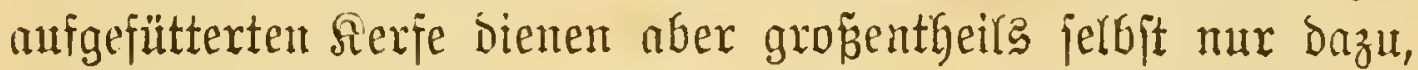
um den nidyt minder zahlreichen terifrefienden Snjeften zur Speije zu bienten, währemb lebtere zugleidy dafür Sorge tragen,

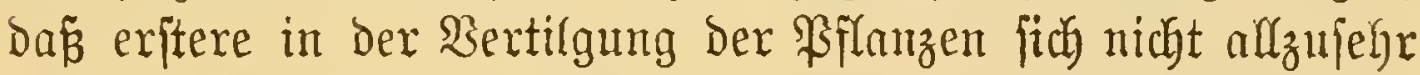

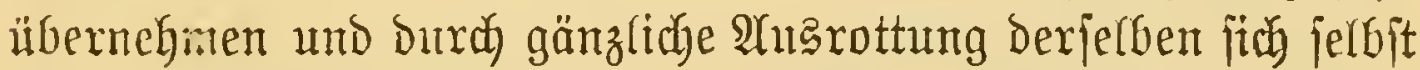
und mittelbar wiederum ben anf fie angenicjenen Infelten= freffern bie Exiftenzmittel entziegen.

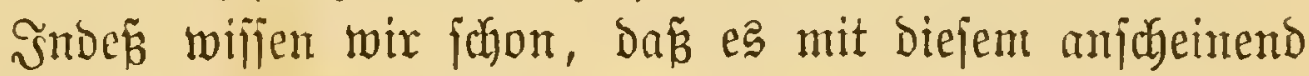
jo fein ausgeflügelten ßane nidht meit her ijt, da ja viele

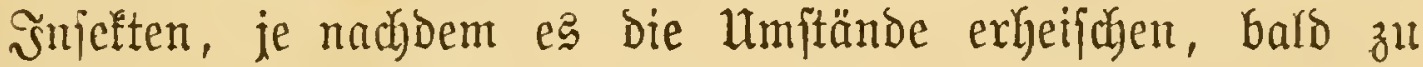
Diejer, bald zu jenter $\mathfrak{P a r t e i}$ jith johlagen.

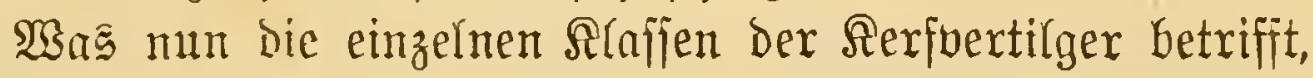
jo jind zunädjit jene zu untericheiden, weldye fie zum eigentr Gsebraud töoten und auffrefien, und Dann jene, welde fie ifrer Brut überantworten.

Unter ben erjteren gibt es mieder joldhe, bie in alfent igren Entwidfungazzuftänden Der Rerfwertifgung obliegen, wie z. B. Die meijten Rand= uno $\mathfrak{S a f j e r i n a n z e n , ~ f e r n e r ~ b i e ~ R i b e l f e n , ~}$

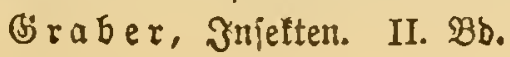




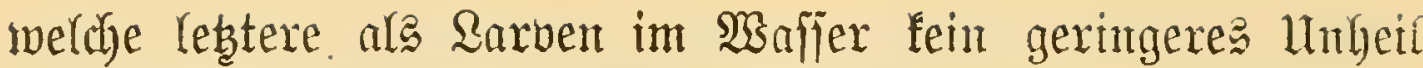
anrichten, als ppäter unter Den Ruftthieren, Dam die Fang=

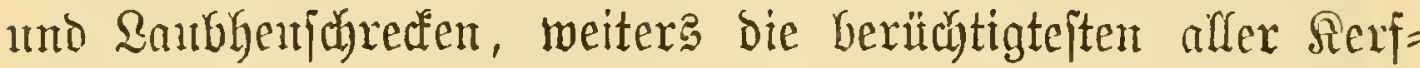
mörber, mämlich bie Carabiden, weldye zum Thyeil aud Cannibaliamnts treiben.

Andere pflegen diejes Mletiex nur ale Smagines. So z. B. bie Slmeifen, die ja faft bei allen Schandthaten fich

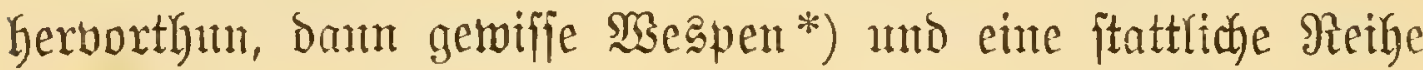
Rantbfliegen, die Asilus, die immentanbente Dioctria u. a.

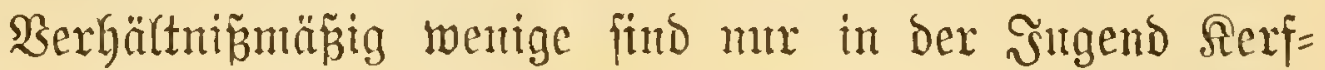
freffer. So z. B. Die Şaftlarben, weldye eine Unzahl Yäptiger uno jchäblicher Fliegen (Madoent) vertilgen, bant ingbefondere

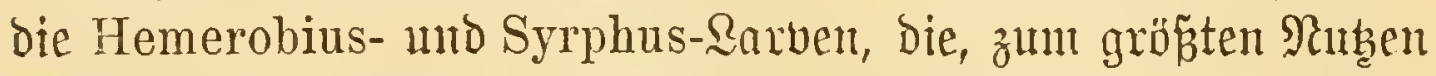
umjerex \$fflunzentulturen, unter den Bifattläufen ganz unglaub= liche Sermüjtungen anrichten.

Son Der zmeiten Srawpe finto vorab jene zu ermälnnen,

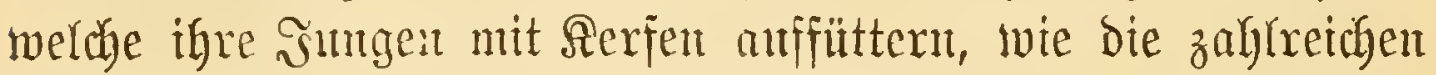
Merd $=$, Grath=, Sant = und andere einzeln and gejellig rebende Meapen.

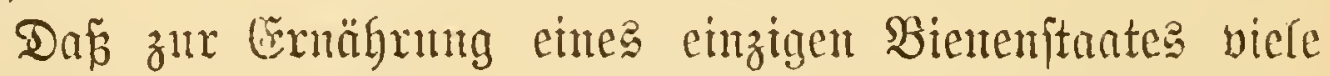
Millionen $\mathfrak{B o l l e n}=$ und fentiglabungen exforbertich fint, wirb Dem Rejer gewís eintentaten. Sam, und meint ex, bafis cine

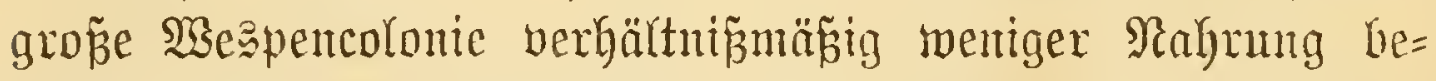
Darf? Shen haben wir jhon gehört, Da a auf einen Duabrat=

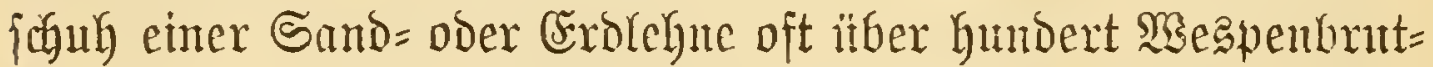
fammern entfallen. Srat nehme man fich bie Mithe, bie in einer jeden biejer Şöhlen enthaltenten, oft eng über einander

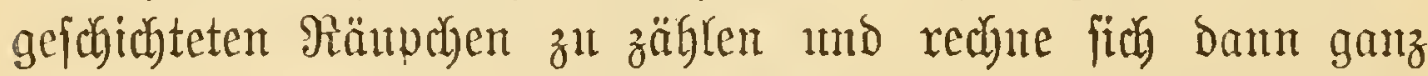
beiläuffig aus, wie viele folder Serfe von den Wespen auf

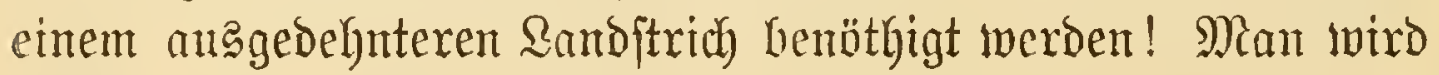

*) Sn Den Bereinigtent Staaten foll man zur Bertilgung ber griegen in ben 200 gnjtuben 5 sornifnefter aufgängen. 
Summen und Produfte ergalten, die nidyt in bie Milliouen, fonbern bie in bie Taujende ber Miflionen gehen.

Die ausgiebigften Rerfuertilger find aber oody bie Schlupf= suespen und bie Snjettenichmarober iiberhaupt.

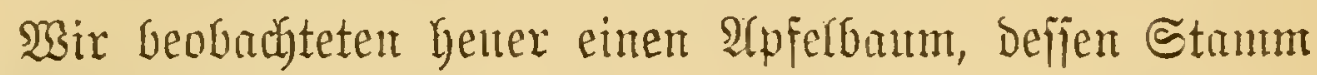

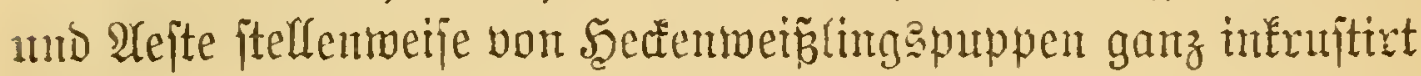

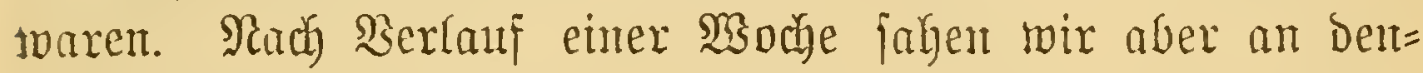

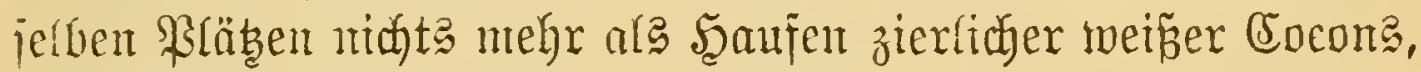
die Shilfjen, aus Denen die den Reib der \$rupen verzehrendent Sdylupfmespen hervorgegangen. Und fun e马 bod) jeber Falter=

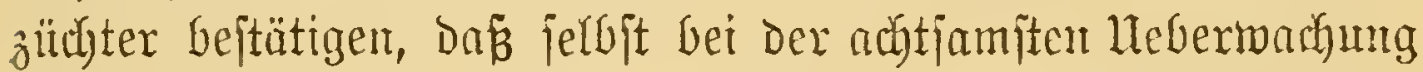

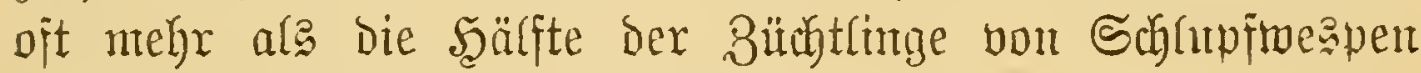
mb Shmaroberfliegen angemeibet werben.

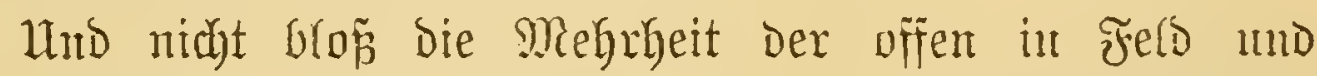

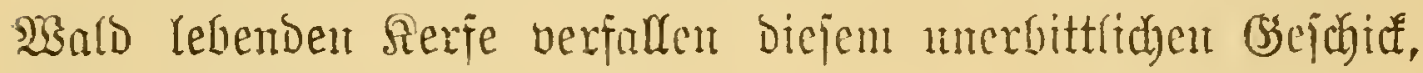
bet lebentigem Reibe ver= zebrt zu werben, fein Jmjet, utid lebe es noch jo ver= ftect, weider die Bsallmespe

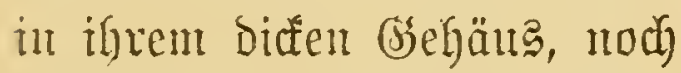
Die Erobbiente in ifrem geheimen Stollen oder bie \$appe im Didhtejtent Seíbengeĩpinntit, ijt vor der gefäbrlichen Sonde unjerer Tyranten jicher, ja,

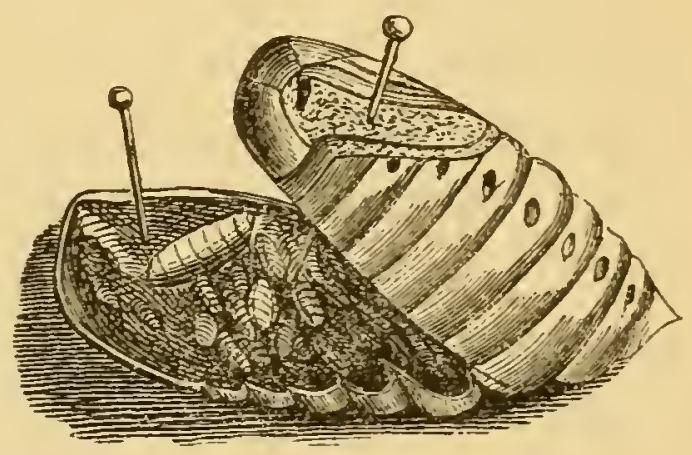

Jig. 100.

Anigeiduttene fralterbuppe, gauz vou Edmarotzerfliegen eriiul, nat. (bir. um ifrem Nament Sygre zu machen, legen ntantige jogar bie natürlidje Sheu vor bem Sajjer ab und futheat igre Spfer in Tümpeln und Bächen auf.

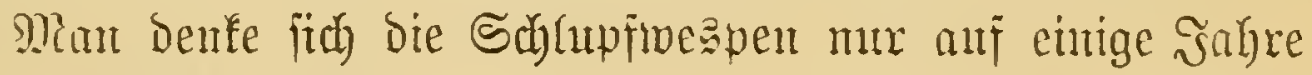
anहer Thätigfeit gejebt - und man mürobe ftauncu, was fïr

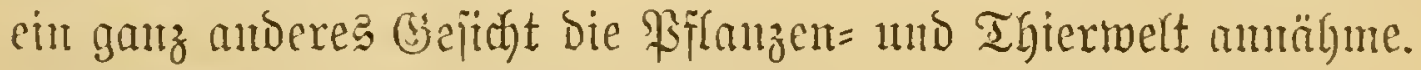
Sis itberjegt man leight; ihre Thaten aber fund riejengró, 


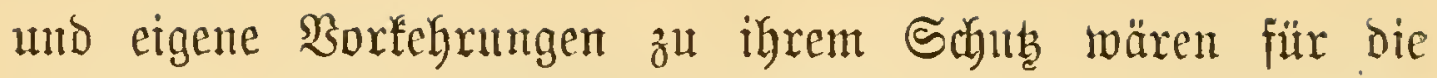

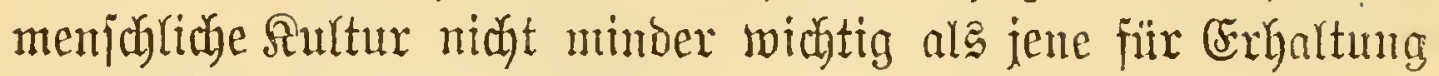
Der infeftenfreffemoen Singoöger.

\section{d) Dureff Ernäfrung Der Pftanzen.}

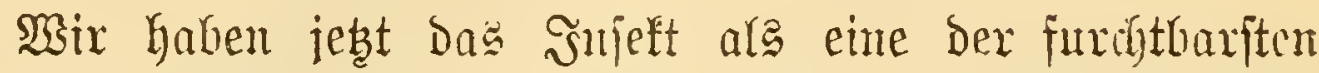
zeritörenden Mäbte Ľemien gelernt. Dieje Zeritörungãarbeit

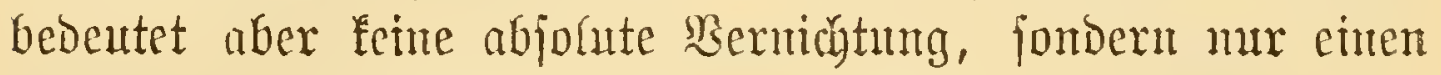
Unijab der Stoffe, und ztwar einerjeits Der lebendigent in toste und andererjeits ber tobten in Lebendige Materie. 3eritörung in engeren Sinne foun mur erjtere lumband humg genanut werben, aber aud bieje von ben Snjeften toot=

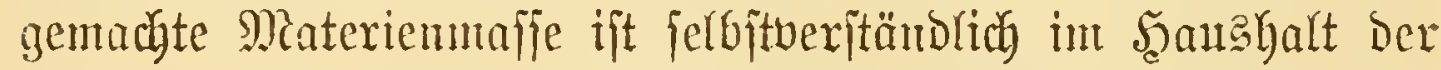
Natur Kein wirtlich todtgeidglagenes Rapital, fondern im Gegentheil die unerjöppflidye Sibaténmmer zur Erzengung neuen Rebens.

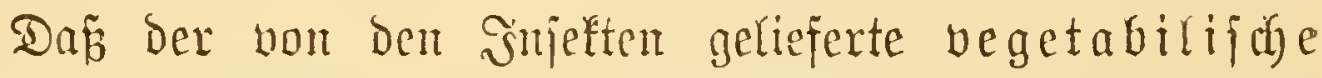
Dïng it off quantitativ ein ganz ungehenter ift, bas haben

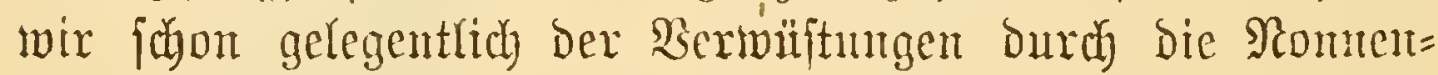
raupe exfahren, uti betreffe der Senjchredenberbeerungen

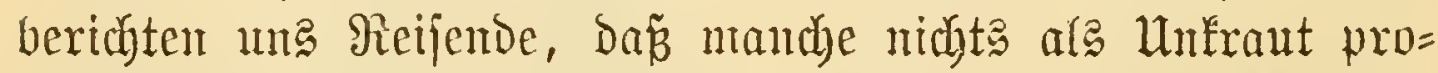

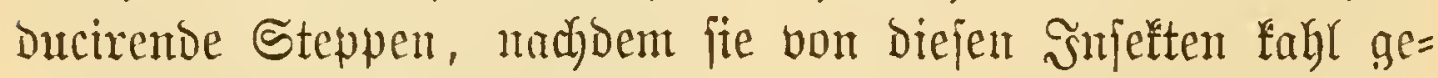
frejen unb auggiebig gedüngt worden, in wenigen Sahren sine weit üppigere uno idjönere Segetation herborbringen

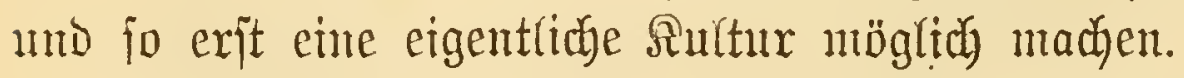

Dody aud ber von Den Injeften gelieferte animariface Dif $\operatorname{ger}$ ijt nidgt verad)tengmexth, wie wir bent nur ben

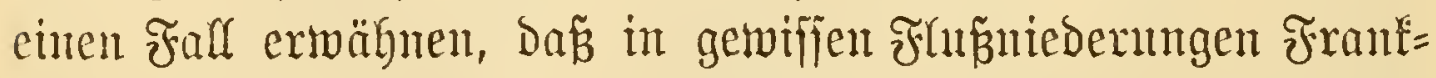

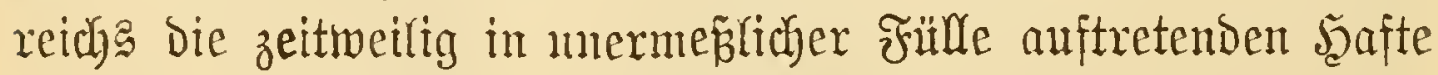
in vielen Tanjenden von $\mathfrak{B a g e n}$ auf bie Felber verführt werben.

Bwar Eemen nemengmerthen praftijchen, bafür aber einen

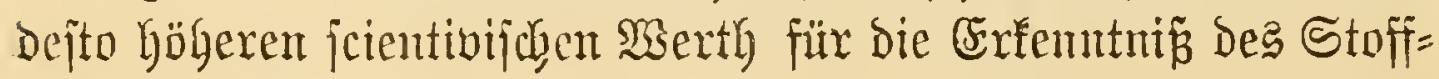


Freislanfę Der Ratux bietet bie nunentlid) in jüngfter Beit

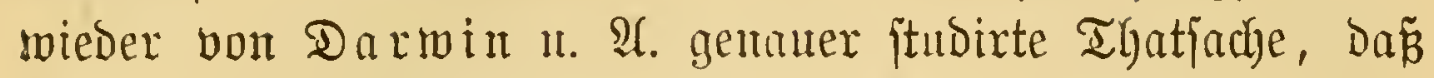

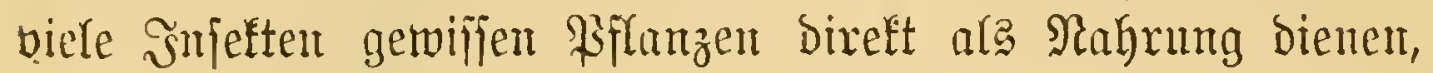

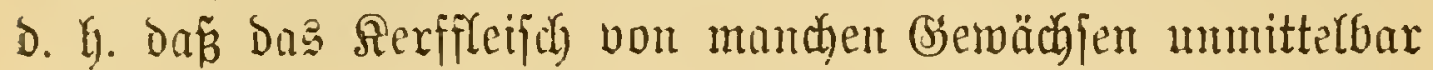
berbaut ober - wie man bic Crifideinung etwas übertrieben namute - gejrefijen wiro.

\section{e) Jutcf Ermäbrung Der Tffiete.}

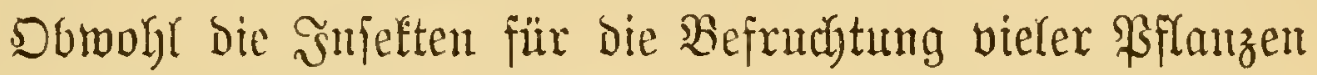

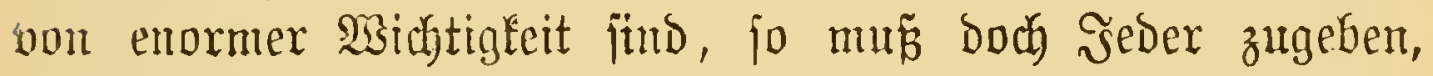
Daj trob alfedem bie meijten Słemächje wenigitens auch ohne

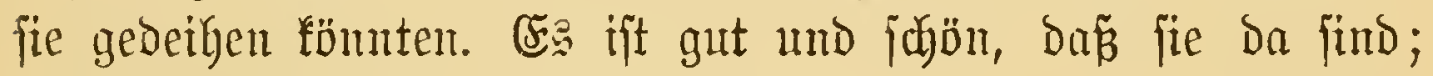
abjolut nothmendig find fie aber nicht.

Antors ift's mit Den Thieren, won Denen viele, jo wie jie eimmal eingerichtet find, olne bie Rerfe abjolut nidjt fort=

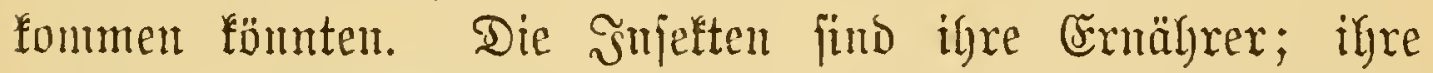

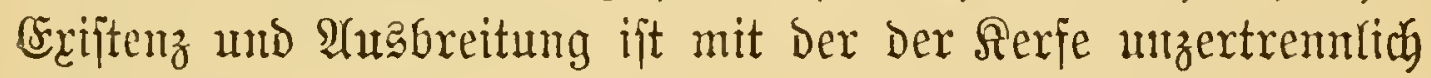
bertwadjen.

Derlei Snjeften=Conjumenten gibt es - und wir halten uns dießmal mur an bie sisirbettyiere in alfen 2 (btheilungen. Unter don Sängern ijt Das Эnjeftenfreijen viel verbreitet

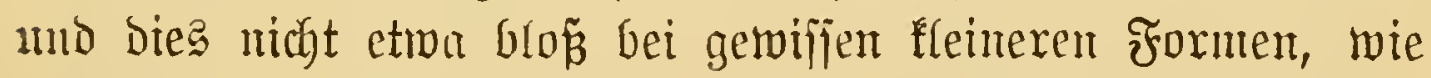
Den 2 ffen, Den Flattertbieren, כgeln, Maulwürfen, gewiffen Biberren, z. $\mathfrak{B}$. Dem anuïjanten Sconigrattel (V. mellivora)

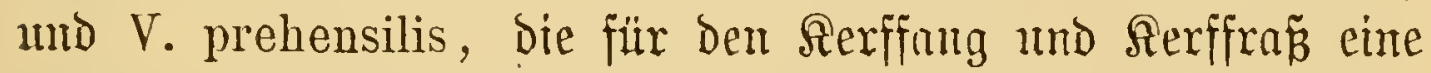
bejondere crignumg haben, foubern jelbyt gröpere und gemaltige Naturen verichmähen, wenigitens in Srmanghung von etwas Soliberem, bieje fleimen Artifel nidyt. So ijt z. B. Dadh

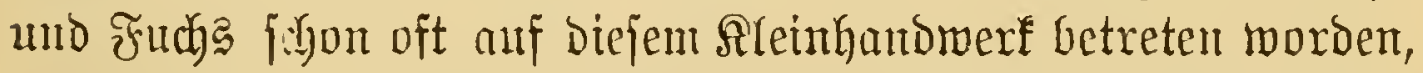
ja jelbjt Dex brummige Meifter ßebs joll fich bäufig an den Bientu vergriffen laben.

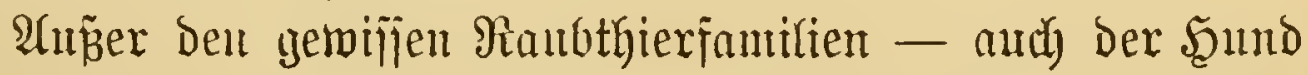

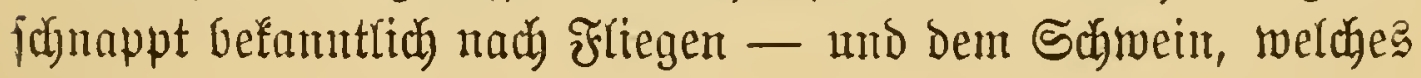




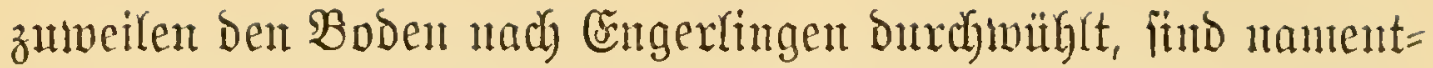
lich bie jog. Zahnlojen pafjiontrte Entonophagen. So bas

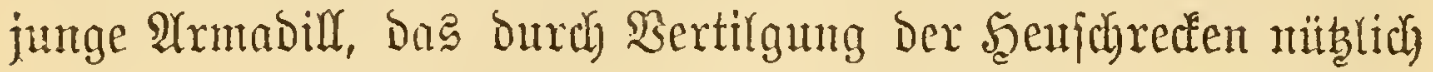
wird, in erjter sinie aber ber âmeifenfrofier (Myrmecophaga), von bem noch unten zul heridgten ift.

Unter ben böheren Thieren find aber inşupondere bie Bögel fdon berntöge ifhrer Natur fo recht eigentlich zum

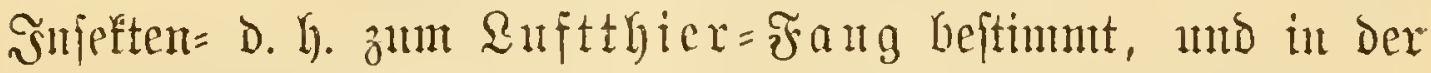

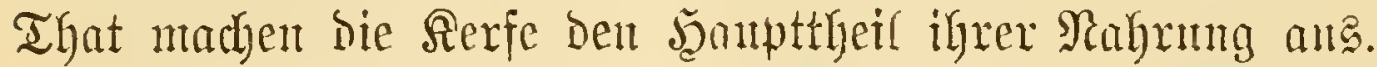

Aerffreffer gibt es fait in allen Der vielen झrbtheiluntgen

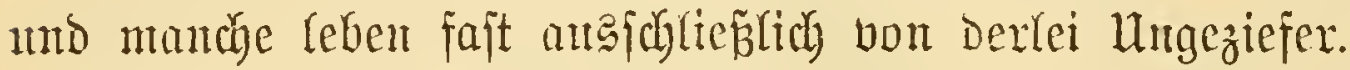

Unter Den Raubbögeln find zuntal getwiffe Falfen eifrige Rerfoertilger, jo z. B. Der Thmmfalfe, Defīat Magen oft

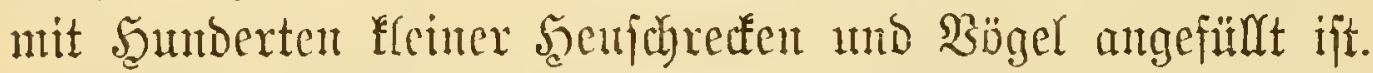

Bon Den (Sroffidunäblern Geben wir befonder: Den Maden= freffer (Crotophaga) und die Santfuähe lyerbor, welche lebztere

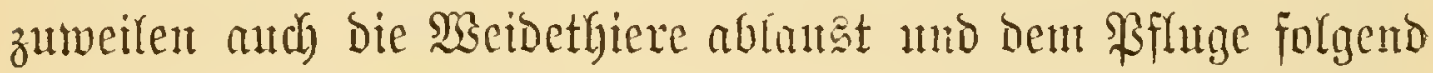

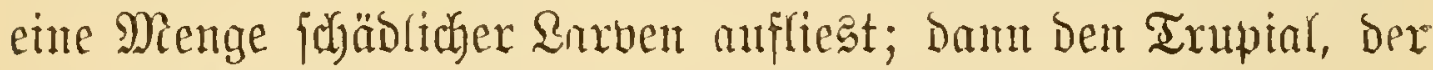

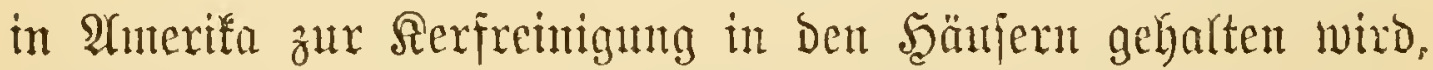
besgleichen auch Den Purpurabel, stach Defjen Bertilgung in

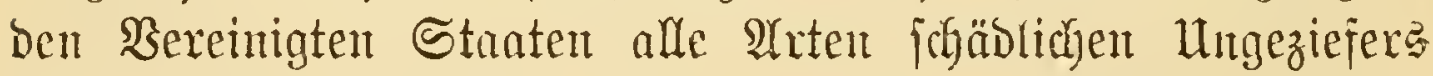
fegr ïberlyano nalymen.

S̈ntereffant ift Der Bienenfufuff (C. indicator), Der, indeni

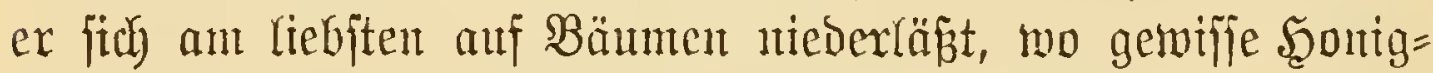
biencu nijten, Die Milden anf Deren Spur führt.

Speciell um bie $\mathfrak{S e g i d h a f f i n g ~ v i e l e r ~ f d u ̈ b l i c h e r ~ M a r b f e r f e ~}$

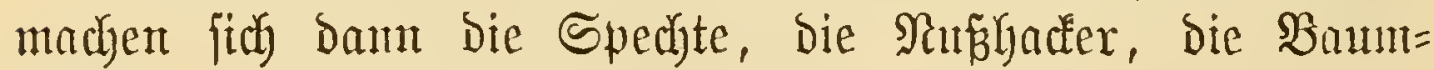

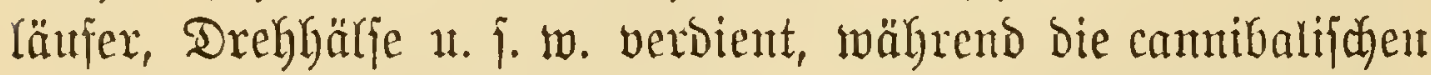
Dornoreber die ssebüjche fäubern, dabei freilid auth ntanthe nübliche Rerfe, twie die Scarabaei uno die Şumneln, ipiežen.

Die Şübnterarten fint gleichfalds eifrige Serffanmter, mD

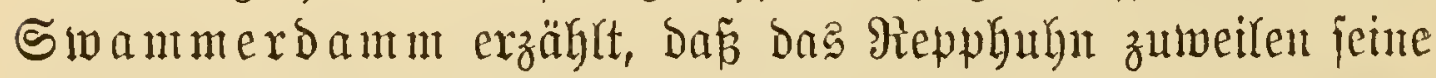
șungen zu Âmeifentejtern zu Tijobe fübrt. 
Wacil bie zaldreidften, fo aud bie midftigften Bertilger ber

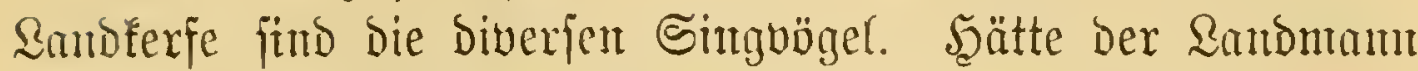
mux cine ungefähre Borftellung Davon, was für riefíge Mengen

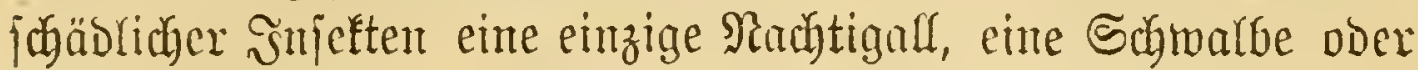
Drofiel vertilgt, ex möhte fich's, wem ihm feine Bflanzungen licb find, niemale melgr einfalten lajpen, and mur Einent biejer

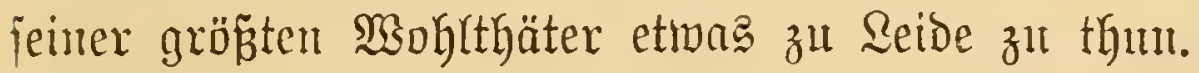

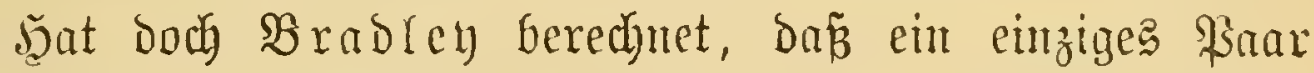

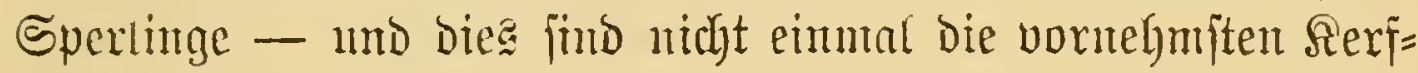
jüger - in ciner $\mathfrak{s o d}$ de gegen 4000 Raupen vertilgen fann.

Wą bie Sänger für bie Decintinuty ber Lanbferfe, das leiften bie Schaaren ber Sumpfö̈gel für jene Der Mafjerinfeften, und bie menigiten benfen wohl baran, Dañ jïb biefes Feder=

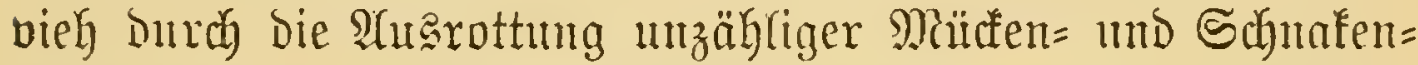

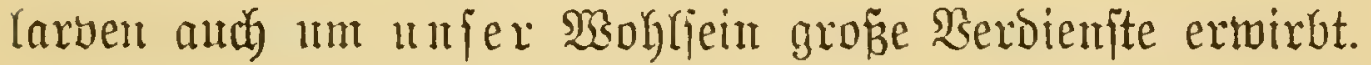

Bezeidunend ijt eine ältex Beobarbtung Sheppaxd's

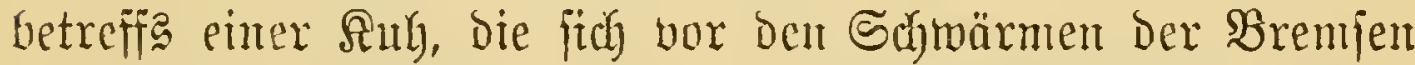
in einen Teich flübtete, wo fofort zahlreiche enten jo gefällig waren, fie bou igren Sdyntarobern zu befreien.

Un min auf bie Reptifien mo Rurche zut fommen, fo müjjen wir uns freilich mit ber allgemeinen Conftatirung ber Thatjache begnitgen, da pa nuth bon biejer Seite dent Serfent heftig zul Leibe gegnigen wirb - ja es märe angefichts ber immenfen 3 aht ber entomophagen 2 mphibien, zumal in wär $=$ meren \&ändern, erft noch bie Frage, ob fie hierin ben Rerf= jägern von Fad), ben $\mathfrak{s}$ ögeln, viel nawgeben.

Die Rerffangtünjte der Schitbfröten, Der Fröfuc u. j. m. find übrigens dem Rejer ans eigener $\mathfrak{A}$ njchaunng getänfïg;

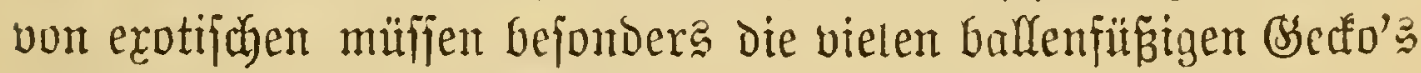

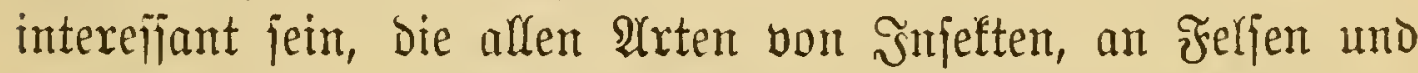

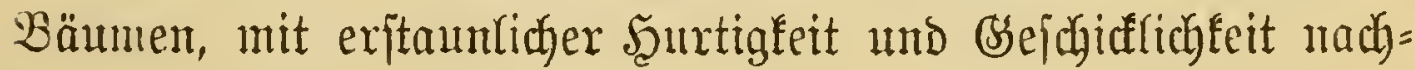
remlen. 
Bon Den Fijchen fonunen felbjtberftändich mur bie des Sitfinafiers, Gejonders bie Forellen, Salmen, Rarpfen, Efchen

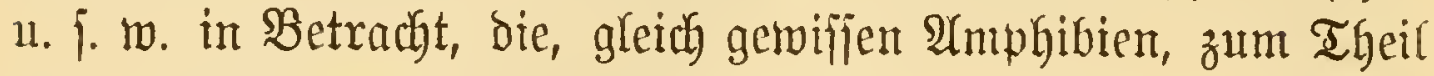

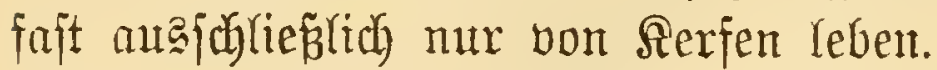

Die Larben Der Mlïfen unt Cintagafliegen fönten wir gerndezu alz die täglidje Speife, bie zu gewififen Beiten gleidy Schneflocten auf den $\mathfrak{W}$ afjerjpiegel fallenden vollendeten Rerfe Diejer Brattungen aber mit $\Re$ e a u $u \mathfrak{u}$ glcidham ars bas Mama bezeidnen, an Dem alle $\mathfrak{S a f f e r o ́}$ ewohner, grop̃ uno flein, einen gropartigen Srlymaus halten.

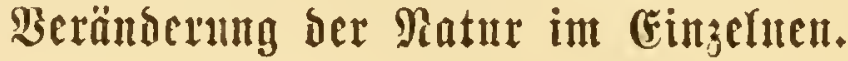

A. Utmgeftaltung ber $\mathfrak{B f}$ fanzen.

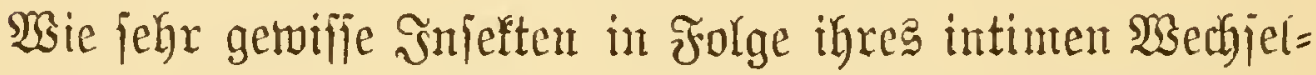
vergältniffes mit Den Bflanzen, in ifrem ganzen Mejen, in

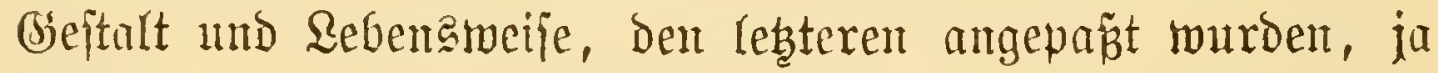
vielfach gewiffernnäen zu integrirenton Theilen, zu Drganen Der Bflanzen jerbjt werden, und fo gleidjam mit ibnen in Eirts berionmelzen, davon hat uns - wenigitens betreffs ber

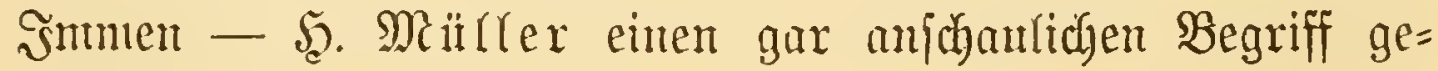
geber.

Benn aber die Pffanzen, als pafijibe Wsejen, auf bie

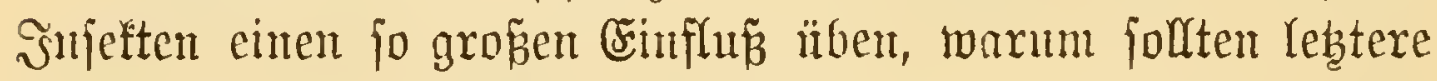
inrerjeits, als die aftio Betheiligten, an ben erjteren nicht gleichjalls bedeutende Sseftaltveränderungen herborbringen?

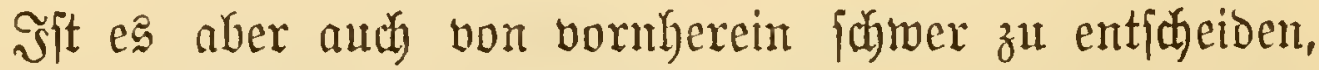
was bei ben ßflanzen Das wirflich Primitive, Endogene und Ureigene fei, und was Daran Ginterber unter bem Einflun der Snjeften entitanden ober Dazu gefommen ijt, jo ftimmen

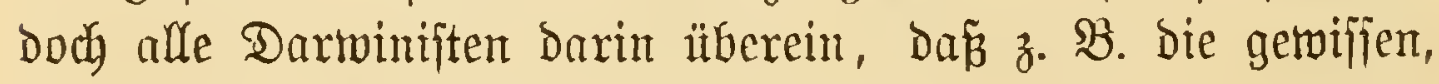
oft unendridy funftoollen und contplicirten cinriatungen ber 


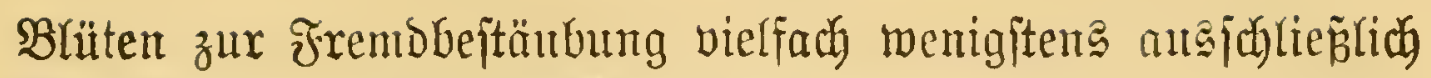
Arnuafingen an bie Srrfeften find.

Doch biejer Bjeftaltungaflecis ift mur ein Cinzelues, eine ifotirte Exfdyeinung, an ber bie Beobarbtung, amftatt auf ein Angemeineres jortzufinreiten, fo gerne baften bleibt.

Einen grozen Schritt weiter, zwar nidyt in ber exalten

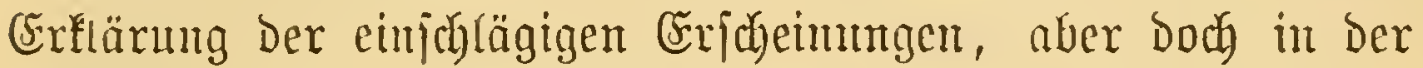

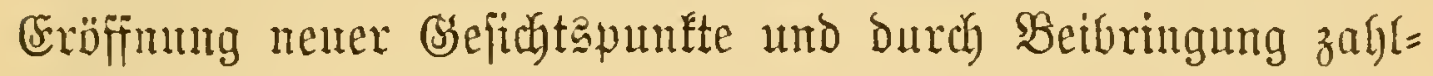
reidjer neuer Thatjachen, hat ber geniale Bflanzentoiologe Srof. Rexuer getfau.

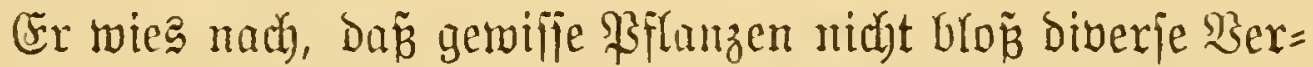
führung sorgane haben, um die zu igrer Befruhtung nöthigen Snieften herbeizuiehen und. ihnen igre widtige Mijijion zu ernöglichen und zu erleichtern, fondern baż jie, um ganz un= berufene, unnübe oder gar für bie Fortpflauzunt fichäblidfe Snjeften, wie z. $\mathfrak{B}$. Die nteiften Qarben und bie ungeflügelten (Ameijen, Blajentiübe zc.) überbaut von fich abzuhalten, aud

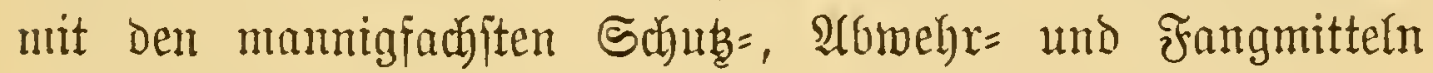
ausgeriiftet find.

Diejer Selbitichus ber Bfflanzen, namentlich gegen "an=

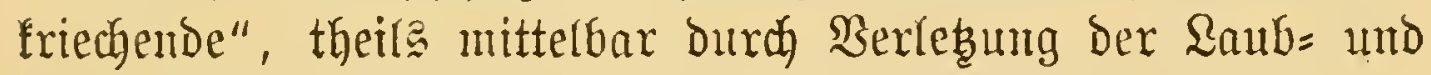
Blumenblätter, theile unmittelbar Durdy Berftörung ber Staub= und Reimorgane juäolich mirfente Rerfe, wirb auf jehr ver= juibdene Meije betwerfitelligt.

Eimmal Durbh Abjonderung widerlicher Stoffe an ben Brütentbeilen.

Diéz z: B. bei Colchicum, Parnassia, Pirola etc., Deren zwar äuñerjt verlocfend ausjehende Blumen eben megen ihrer

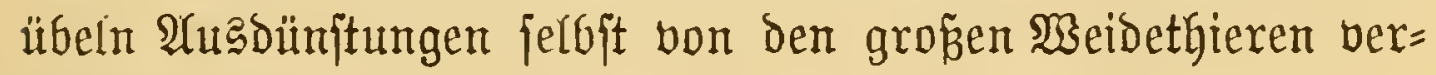
jămäht werbent.

Dann Durch ijolirende, bon den Blättern gebildete tridater= ober ichatenartige Wajferbecten, in benen bie antriechenden Rerfe zum Theil erjaufen. 
Soldbe Einridtungen finden fid z. $\mathfrak{B}$. bei viefen $\mathfrak{B} \mathfrak{r o}=$ melinceen (Billbergia, Tillandsia, Lamprococcus u. ₹. w.), Dant bei ben Sarben mb Difteln, jowie bei manthent alpinen Ssentianeen (G. lutea, pannonica), an verbreitetiten und einfachjten bargejtellt aber bei gemijien Wajjerpflanzen, 子. 28. Alisma, Hottonia, Nuphar etc., die vor flügellojent Rerfen fajt bölig fither fund.

Widftig fint Daun bie Durch llebrige Drïjen und bejondere Şarzotten gebildoten Fangapparate, wie wir fie befoutders

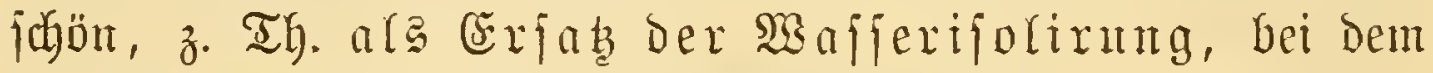
im Trodfnen vegetirenden Polygonum amphibium, bann bei gewiffen Robinien, Epimedium, Silene, Dianthus, Alsine, Holosteum it. f. w. feben.

Sicht minder vortheilhaft erweijen fid bie balb unter=, bald interbarb der Baiten befindrichen, meijt nach abwärts gerideteten und oft völig undurdyoringlichen Stadyel= mD

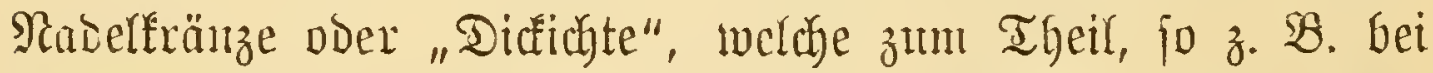
Melampyrum, zugleidy als șegtweifer biencu. Desgleidyen

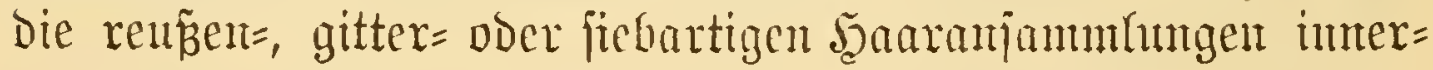

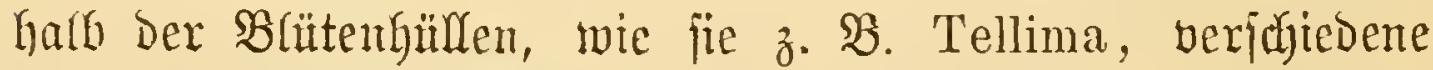
Lifien i. ;. w. auzzeichnent.

Die wirfianften und wumberlidgten Sdyutweyren werden

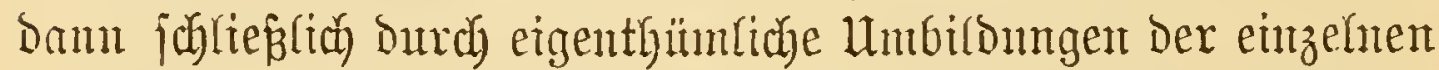
Bliutentheile jerbjt gebildet, wie Denn o. $\mathfrak{B}$. Die jog. "Sallag= baum=\$orridytutgen" bei Chelone uto Pentastemon Daber gebörent.

Docl) and bie restgentannten, gegen bie Snjpeften gemen=

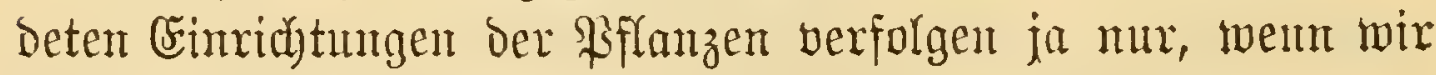

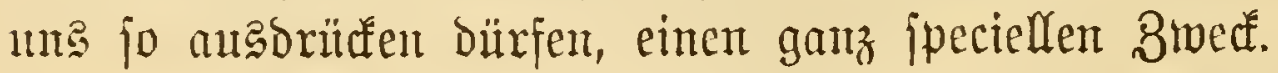

Da Die Pflanzen uidut blo jänmtlichen Theilen und Drganen, an ben $\mathfrak{B}$ lättern, Stengeln,

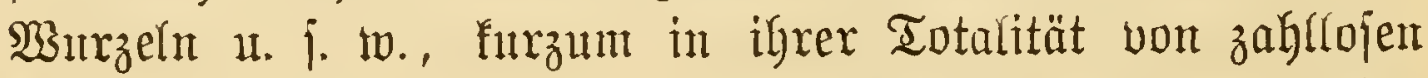
Serfen angegriffen wetoen, und es ferner, bei ifrer grof̈en 


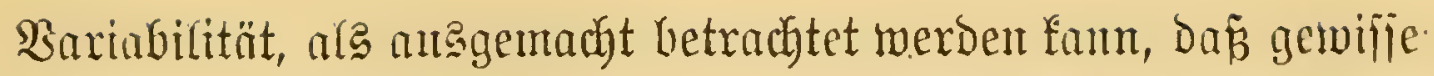

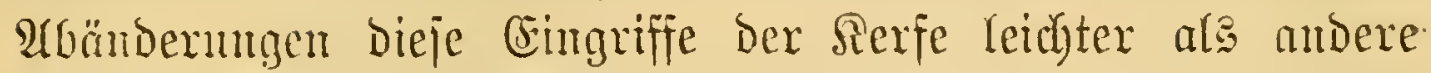
extragen, jo darf man wohl ammbmen, daź mentigftens viele vou ifncn in bicjem unatigejesten Sampje mit ihren gcjägr = lichjten Feinden cine ifre gejammte Satur oder Eelbjt= erfaltunga = Defonomic betreffende vortheilfafte äbändumg. erworben baben, bie mu in allen äıñerlichen und imter=

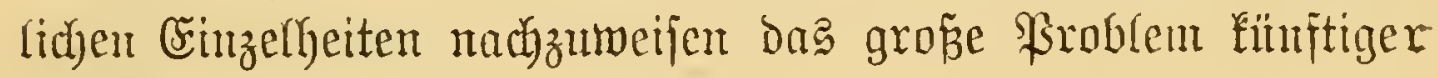
Forichung jeit nutu.

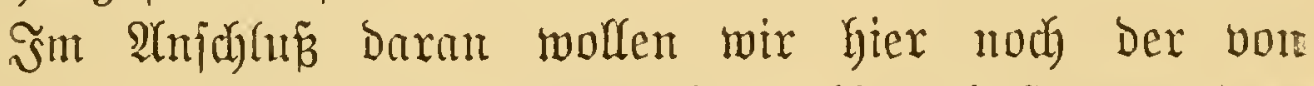

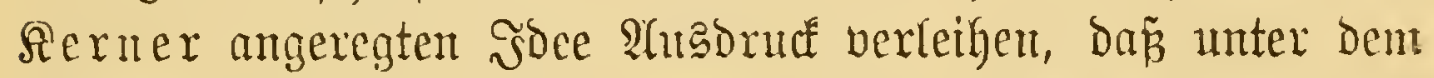

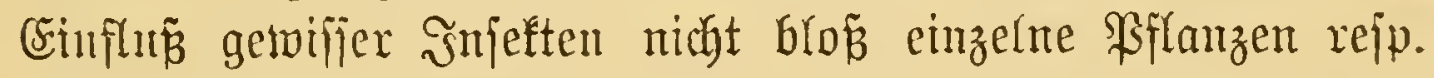
Bflanzentheile, jombern ganze groże frorengebiete, auj

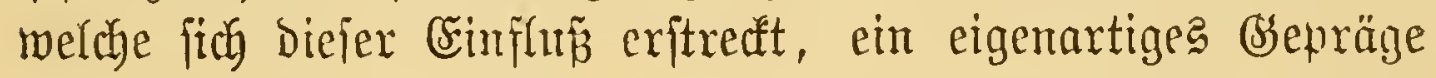
erfalten Ëmmen, Dañ fonach ber pflanzen=phyjiognomijache

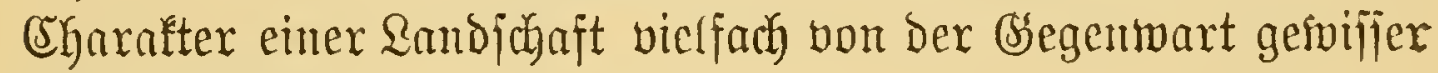
Rerje abhängt.

\section{B. Ungeitaltug Der Thiexe.}

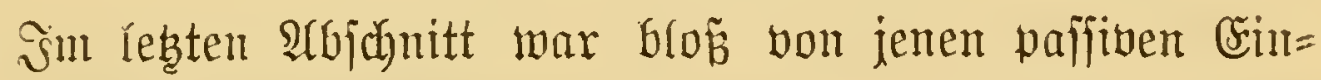

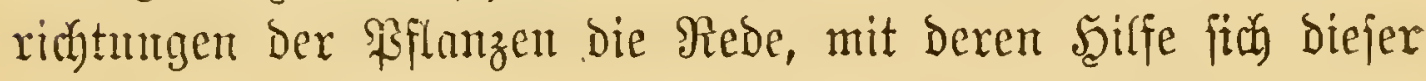
Keidende Theil Der Drganismenmelt jeine Schmarober b. i. Die

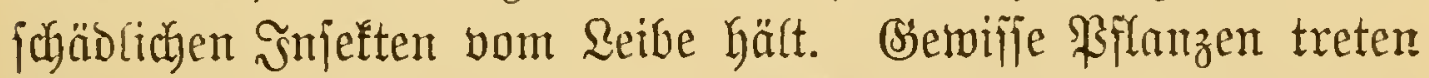

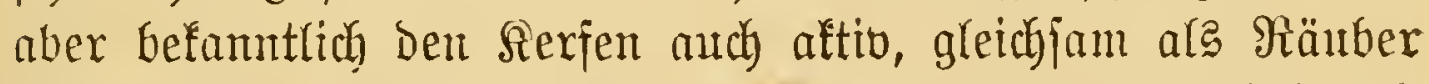
ober Miöroer entgegen, intoem f: fich von beren Fleijd) und Bhut nähren und, un berjelben habhaft zu werben, mit be= fonderen Fanggeräthen ausgerüĩtet find, Die zum Theil, wie Die nerfmüroigen Ffliegentrlappen Der Drosera, ober bie Frang=

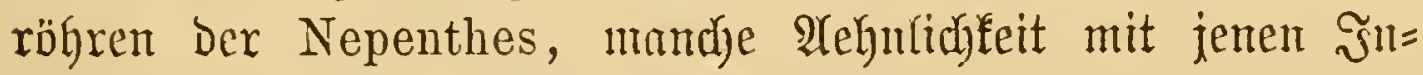
itrunenten haben, Dexen jidh bie Entomologen zux Serfjagd besienen.

Wenn aber, im bejtändigen Sampf um bie Exijtenz,

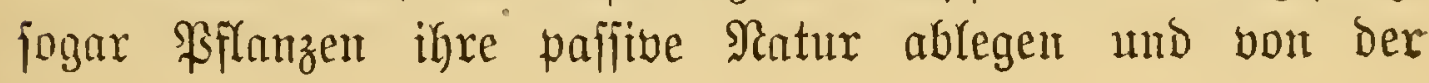




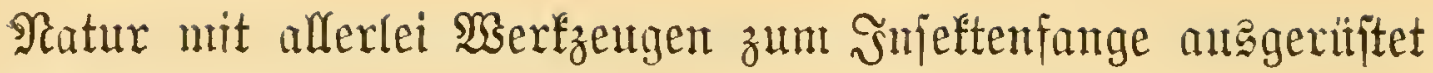
twerben, wie weit verbreitet mid vielfach müfien erjt bie $\mathfrak{A}=$ paffungen jener Thiere jein, bie von Şats als anf bie fierf= jago angewiejen jund!

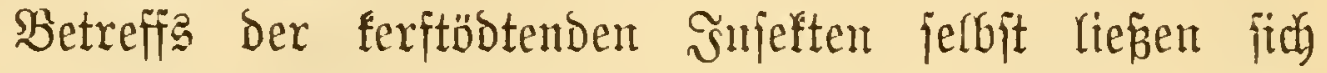
bierüber ferbjtueritändlich utzählige Belege bringen - ihr ganzer Rörper, won ben langen Fithlgönnern an, weldye zur 2Uffiphürung ihrer Spfer bienen, biz zu ben Sheeren, Zangen, Stacheln und Dolchen Des Seinterendes, womit jie diejelbent faijen ober töbten, ijt ja ein eirziger Snfeftenfang=STpparat.

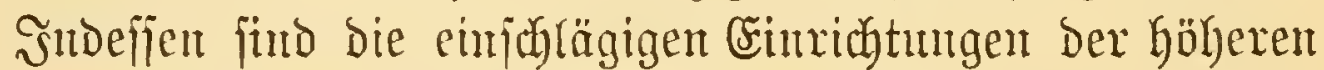
Thiere nidgt weniger zahlreich mb merftwïrdig, harren aber nob immer einer jyftematijchen Bearbeitung. Um eimen bei= 〔äufigen Begriff Davon zu geben, wird e? gentigen, einige bejonders prägnante Fälle herutgzugreifen.

Schon bon ben Säugcthieren gäbe es gentg zu jagen. Banz abgejeben von ben fïr bie Rexfingo fo prädbtig einge=

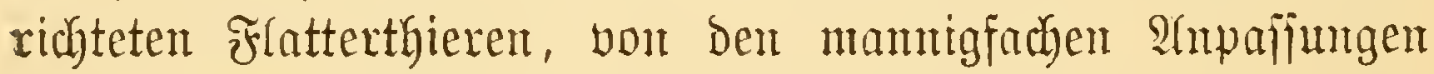
oer ftrenge jo zut nemrenden Ŝljettivoren in Bezug auf bie

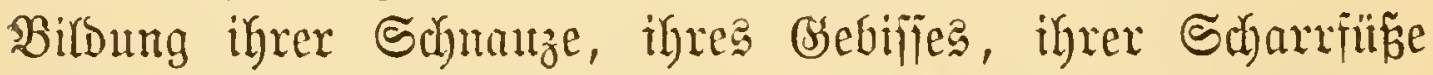
a. \{. w., weld ein unübertrefflidjer Ŝnettenjäger ift nicht Der $\mathfrak{A m e i j e n b a ̈ r ! ~}$

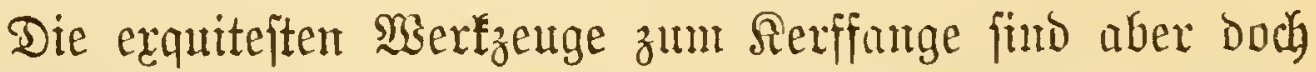
ben $\mathfrak{3}$ g̈geln zu Theil geworben. Die Flïgel zunächjt feben fie in Stand, aud Den flüdhtigiten, den Ribellen, Den Bremfen, Seummeln u. \{. w. mit Exfolg nachzujagen.

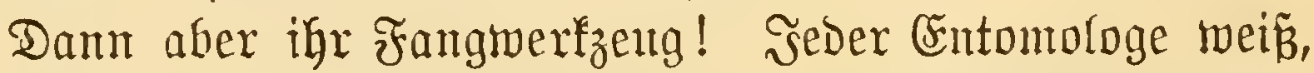

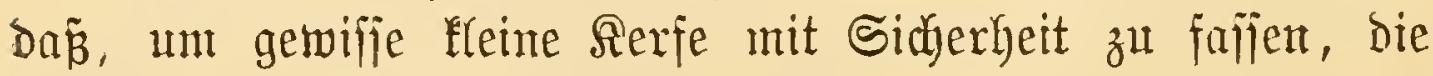
Finger häufig zu grob find, weßgalb jich Jeder zu biejent Brwecfe mit eimer feinen Pincette verjehen wirb.

Nun und weldye zwedfuäpäigeren Rerfzangen fömte e? wohl geben, als bie je nach ber Beptimmung bald itumpferen, bald fpizeren, bald geraben, bald verjobiedenartig gefrümmten, 
bald glatten, bald geferbten oder :tod) extra mit feinen (End= jpiben veriebenen Sdjuäber mijerer Sänger uno Spedite.

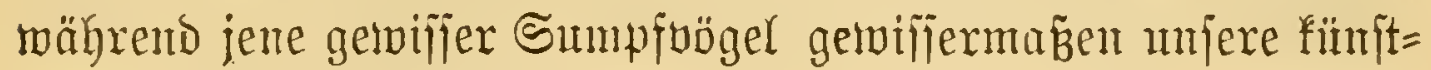
richen Träticher vertreten.

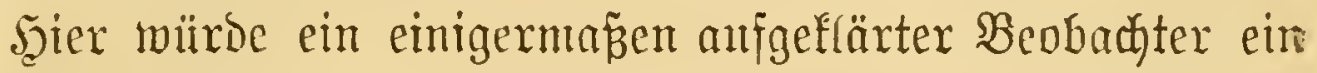
ganz föpttidyes Thema haben.

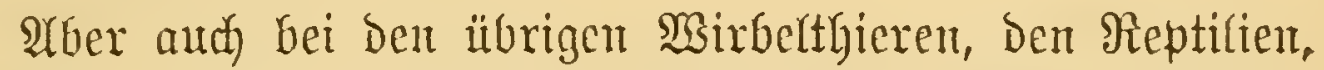
Amphifien mL Fijichen böten fich eine Menge höchjt origineller Ampaijungen Dar. WSelch' präbtiger Fangapparat ift nicht bie

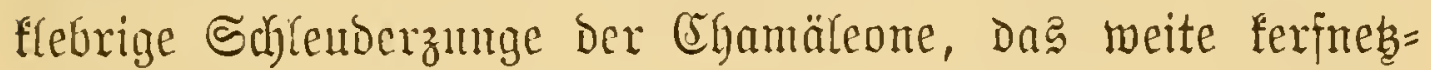
artige Maul gemiffer Rurbe und Fitidye, abgejeben von manthen auf Die Sierperfolgutg abziclenden Sciffaborridtungen, wie z. $\mathfrak{B}$. Dent breiten Fuffballen Der Bjecto's, Der Munbbarteln gewifier Fijiche u. i. เ上.

(Fin bisher nod) gar nicht fultivirtes Stmbium für fid müroen Dann, gleidh wie bei ben Rflanzen, bie gegen bie Rerf= angriffe geridateten Schus = mo $2(b$ wehrmittel beanprudjen. Daran zu żweifeln nämlich, Da witroe jo vier heipen, ala fie aud Den Siflanzen abjpredjen; man mur fie mur aufjuchen.

Das vulgärjte Suntrument biejer Art, ber lange bujajige Frlegenmedel Der Säuger ijt allen geläufig. ¿ङs wäre aber vor allem zu unterjuchen, unwicferne bie jo äuperft medhjelnden Arten Der Bedectung, Dam, ingbejondere bei Den Lurchen, die

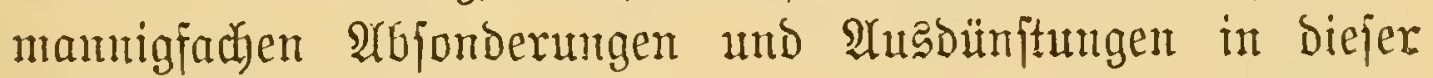
Şinficht Bedeutung haben.

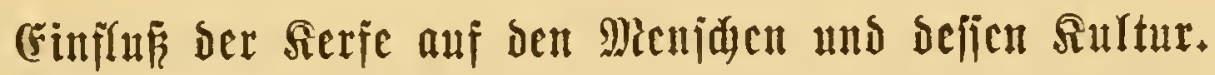

Wair benfen, ber aejer mird Durdy bie vorhergehenden,

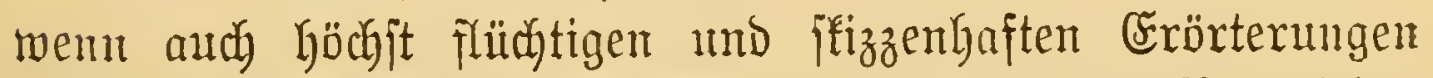

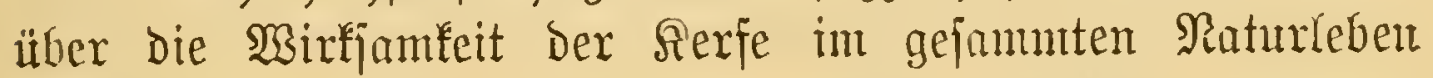
vor biejen Thieren einen getwaltigen Rejpeft befommen haben. 


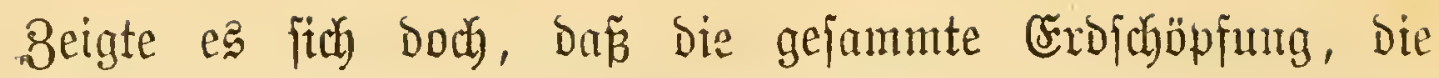

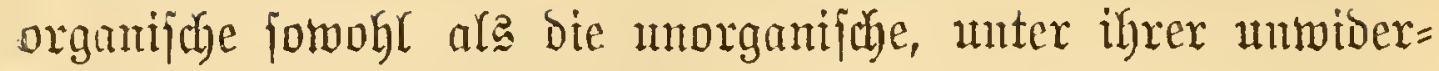
fteblichen semalt fid bengen mñ aud die erftere ofre biefe ifre furdtbaryten, ifre heim=

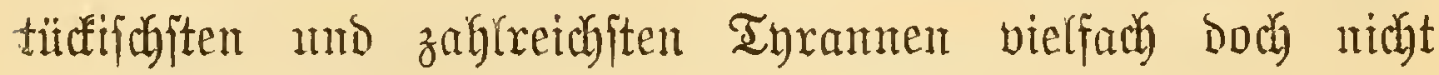
exiftixen fönnte.

Went aber, bis zu cittem gemiffen Srabe, ein groper

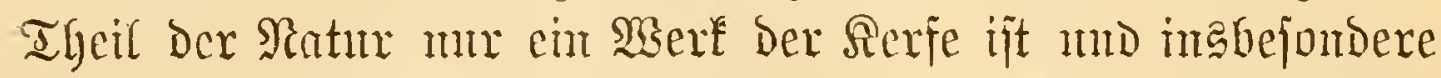
Die Exifitenz fajt fänmtlidyer Drganianten von Deren Dafein

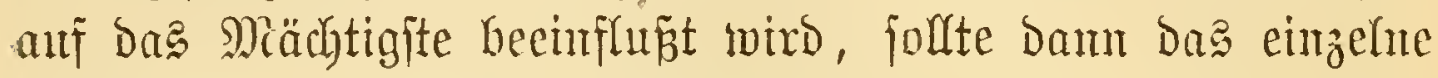

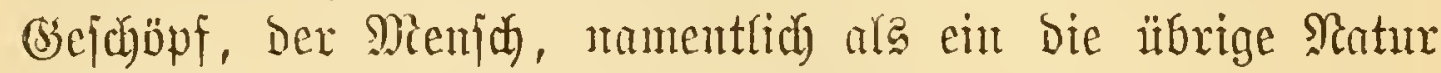
beberrichen mollendes Saejen, von biejen Thieren nidyt aud

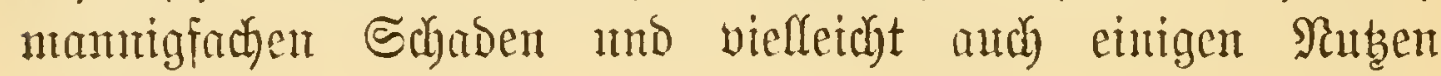
erfalyren?

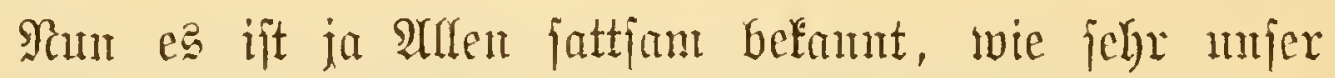

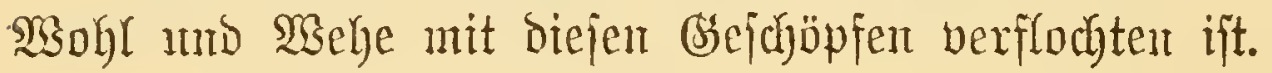

Mizaditen mag - wie fo Bieles - ber unber = ftäubige diefe Creaturen; ihre Mad aber brülut

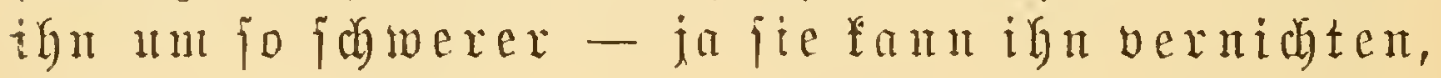
we un ex eg thut. -

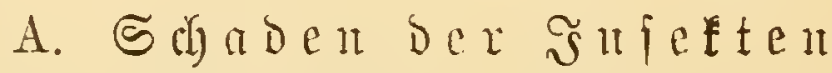

a) an unferer fierfon.

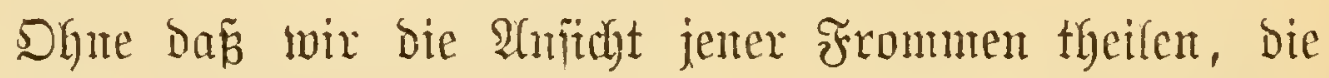

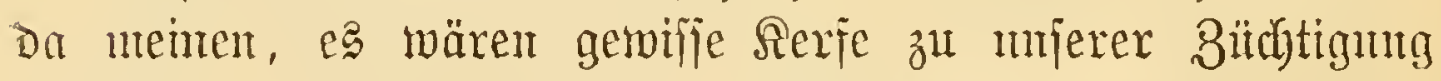

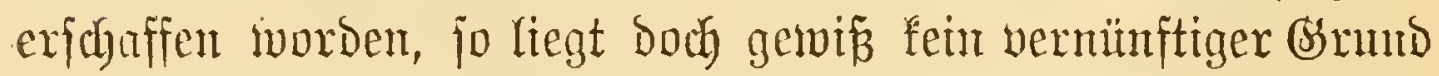

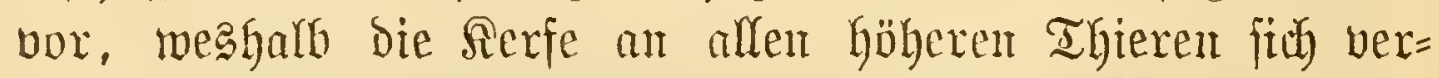
greifen, unt aber mux barm, wetl wir zufüllig die aller= wormebuften barunter find, werichonen jouten.

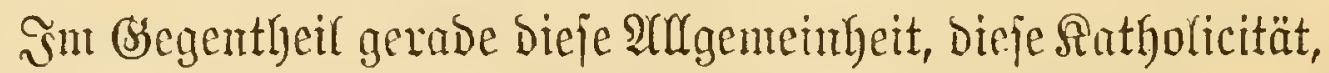

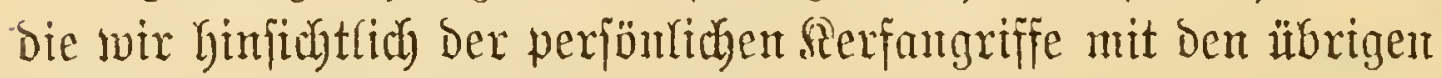

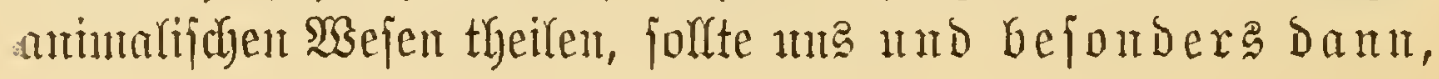


wenn.wir nicht eitmal biejer feleiten Sejen herr

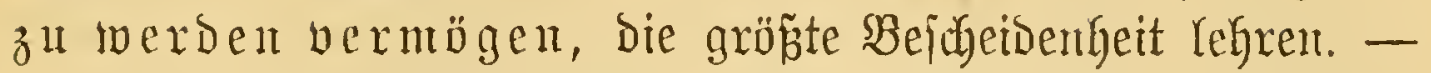

Unter Dent wentigen infeftifhen Rlaggeiftern, die zwar nidhts wentiger ars ganz originelle Sdyöpfungen, aber bod aus=

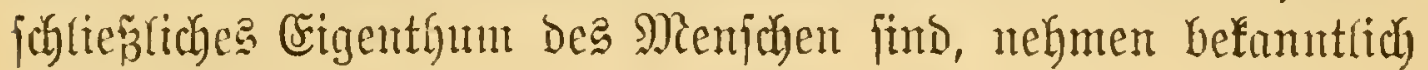
Dex Floh, Dant eit parar Satzarten, fowie Die Bettwanze, Den criten Rintg ein.

Heber eriteren wollen wir weiter gar nidyts bemerfen, als

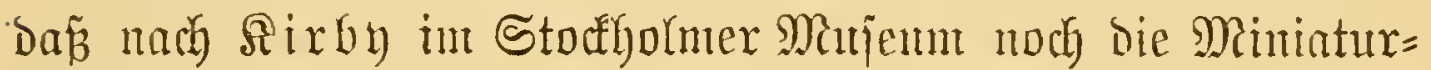
fanonen fir finden follen, wontit eine befannte Schmedent fönigin gegen bicje zubringlichen Ritter ins Fels zog.

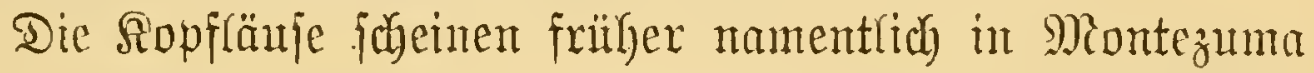
jebr berbreitet gemejen zu jein. (5) bejtand wenigitens zur Beit der Entbectung Amerifa's Darauf eine Ropfitenter, und Die Crroberex follen in bent hezïglidyen Miagazinen ganze Säufe voll biefer Scimmelägabe gefumben haben.

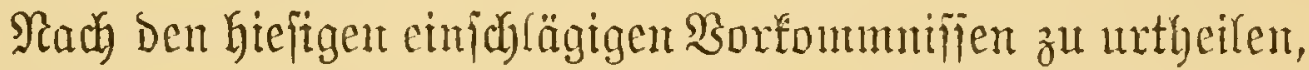
icheint biejes Itngeziefer einjt aud im "heifigen" Lanbe jefr. gebrïht zat haben.

Dasjelbe gilt vielleicht and bon der "Wandaus" (Wall-

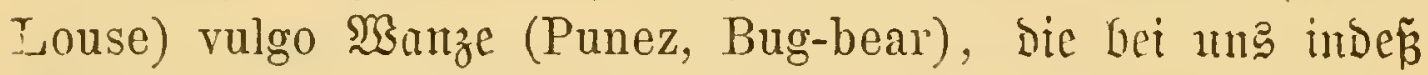
erjt jeit Dem 17. Fahrhmbert einen Namest jich ermorben.

Befährlicher wie die zahmen fund gemifje "willo" Flöhe und Manzen. Der Sandfloh, Der Wanjericorpion,

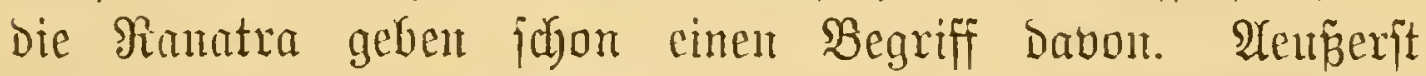

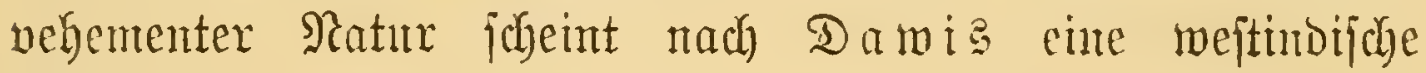
Rinderwanze, Der Reduvius serratus, zu jein. Fr erfielt von eintem einen eleftrifthen Sablag, Der ihn bis in die

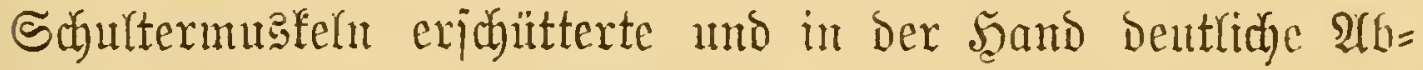

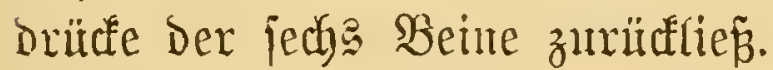

Bon ambern Blutjangern wären auß̧er den eintheintijajen Bremfen, Schnaken, Stechmühen und bergleichen zubring=

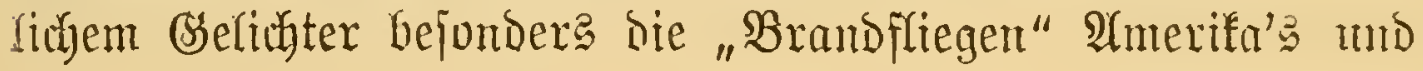


Damn die verjhiedenen Mosquito's herborzuheben. Betreffs

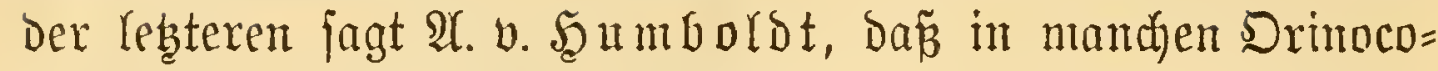

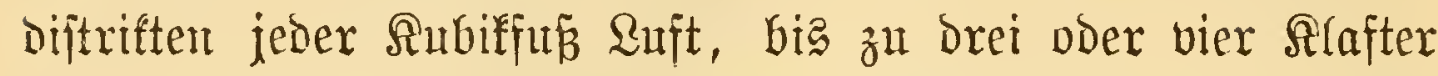
ફ̧öhe, mit einer Million foldher giftiger Blutjantger exfüllt

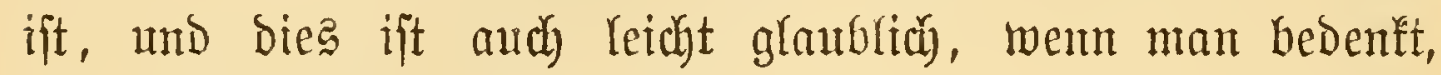

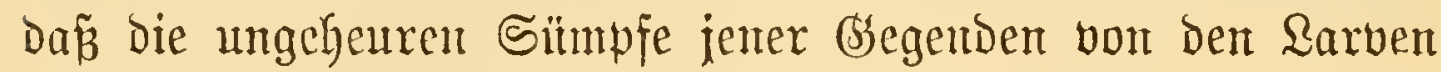
Diejer Rerje f̈̈rmlich wimmeln, indem man mit jeder Şand

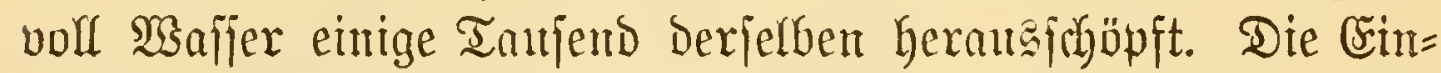
gebornen beftreichen fich bei ber arbeit mit Rehnt und graben

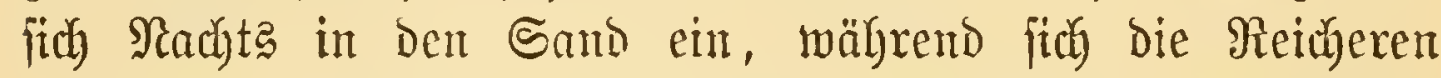
in einen hermetifh veridylofienen Schmibfaften eimperren. Sileider und jelbft bas ftärffe Rederzentg, jagt ein Reijenber, jüto gegen ihre Stedbohrer fein gröperer Sryth als bie Wolle eines Schafe马 gegen bas Mefier des Siblädters. Snterefiant

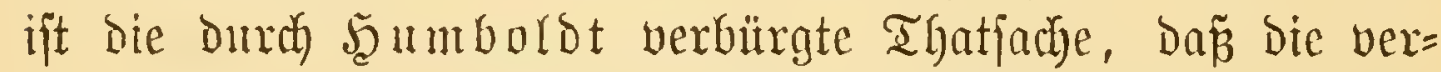

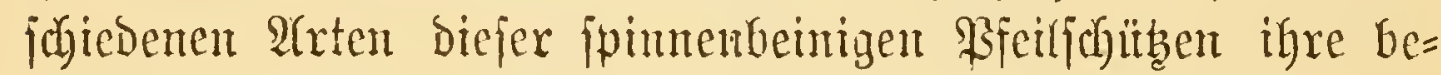

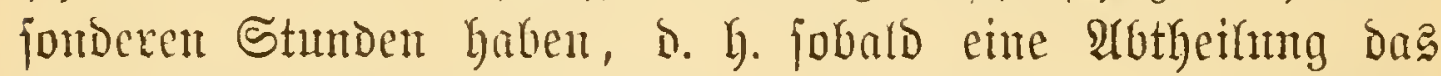

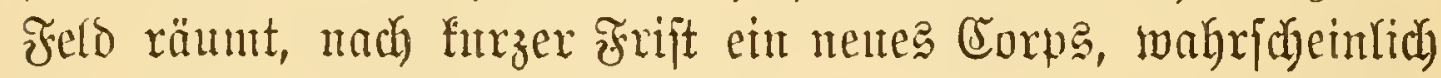
eine nene Brut, ins (sicfecht zieht.

Wie gefährlid einem die Stidye gewifjer Weapen, zumal Der Seonifis werden fümen, hat ber Rejer wohl ferbjt ex= fahren - wemn nidgt, fo hüte er jich body ja, ein Neft Der= jelben anzugreifen.

Sehr bedenfliche 8 uftände fömen ferner die \$remtyare

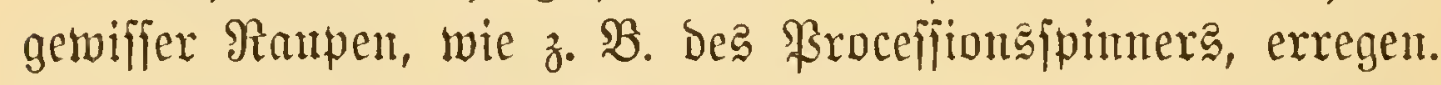
(E)in d)ronif ift nod Dą $\mathfrak{B}$ enigite.

Dás e? zum Theil auth jebr giftige Thiere biejer $\mathfrak{a r t}$ gibt, beweift Rivingitone's Beridht, wonach bie Mirden am Nanajajee ifgren lyölzernen und jorgfältig burch ein Maisblatt gefbübten Rfeilen mit Dem Saft einer Ranpe eine unfehlbar töbtriche Wirktung verteitgen. Der Eleinfte Tropfen madyt bie Bunge itarr. 
Bon jtationären Rerf= Entoparafiten jheint zwar ber Menfich ganz verichont zu jein; wir haben aber eitre Reibe ficher verbürgter Ihatjachen, Dafa zufälige cinbringlinge, namentlich Megrtourm= uno Bremienlarven, Den Tod zur Frolge hatten.

\section{b) an unferen gaustfieren.}

Mebrere unjerer Şaußthiere, wie Der Şund, die Rahe,

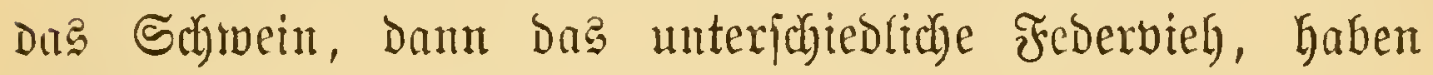

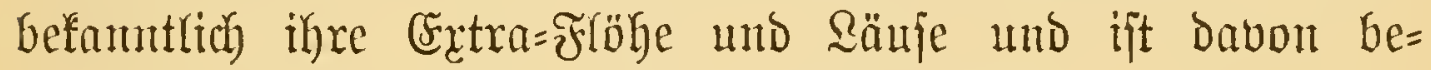
famtlich jelbit Die Biene nicht anzgeid)Lofien.

Samarober im meiteren Sinne fund dann bie Bies= fliegen, die Deitriden, oder ridhtiger beren twumartige Maben.

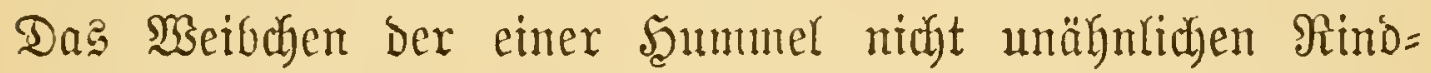
biesfliege Durchbohrt mit ifrer perjpettibartigen Regeröhre Die Rïrfenthaut Der Rinder, um Dort Die CFier unterzubringen. Die Durdy bie thierijche $\mathfrak{3 a ̈ r m e}$ bald ungebrïteten Maben

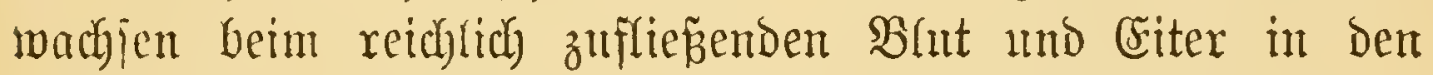

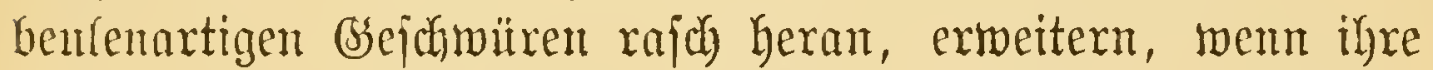

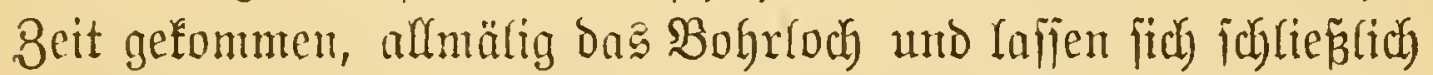
zu Boden fallen, wo ihre Berwandung exfolgt. Die Schaf= biesffiege (Oe. ovis), ein ftumpfïinniges, träges ungeziefer, legt bie (Fier in bie Rafentählen ber Schafe, wo aud bie ausktiechenden Maden igre Exiftenz friften. Sadh ungefähr fünf Monaten, wo fie ausgewachjen, führen je biejelbe Bse=

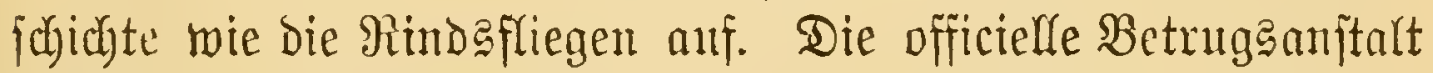

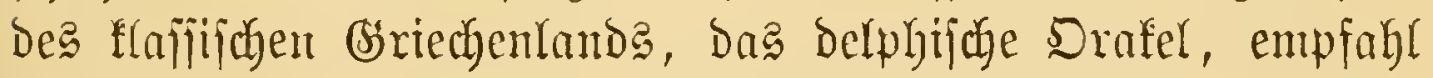
Dem Demofrates gegen bie Frallutht eine $\mathfrak{\text { Iur }}$ mit foldhen Schafsmürmern. -

Ein wahrer Cringemeibeparajit ift bie Piferdemagenbies= fliege. Die Eier merden meijt an bie Sorberbeine abgelegt. Die ausgefbrïrpften Maden Konmen Dann Durdh Belecten Der juffenden Stellen in Den Mand und Dann weiter in

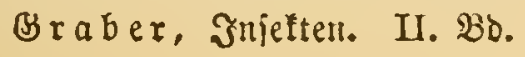


Salund und Magen, falls fie uidit etwa gar von hinten her cinmandern. Mitteljt ihrer Mundyafen bogren fie fith in bie

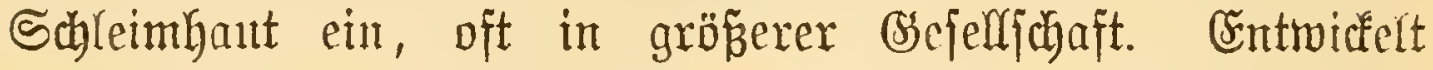
laffen fie bam los und gelangen mit ben Excrententen auj den Boden, wo jie fid einbohren und in eine jhmarze Ionne berwandeln.

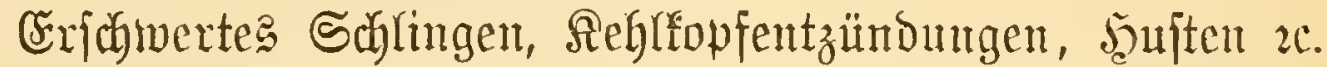

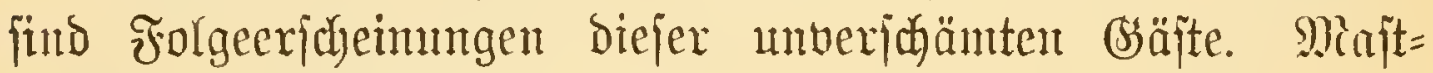
Darm= und Zwölffingerdarmbiesfliege jpredten fïr fidd.

Rothrwild und Rennthicr haben ihre cigenen Bremen. Diejen reifen wir ban die Bffrdelaugfliege (Hippobosca equina) an. Sie beunrulgigt bie Pfferde, hejonders am $\mathfrak{S}$ ars,

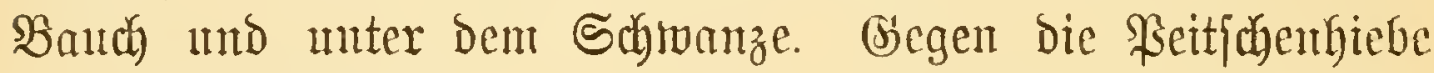

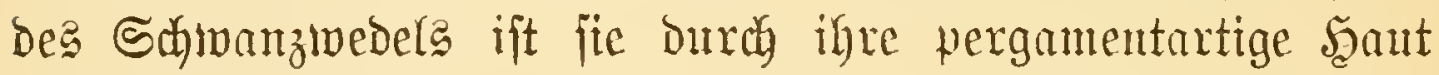

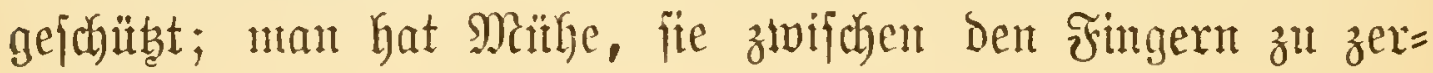
brürfent.

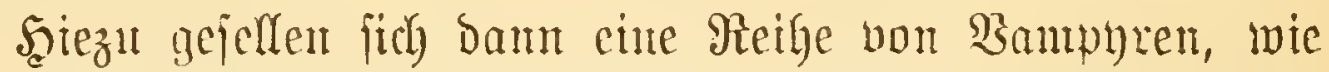
Die bivericn Tabanus, Dam bie itberang zubringficbe Stomoxys calcitrans, bie "Siemittcrmücée" (Musca meteorica) und eine Reike von Stechithnafen, von benen namentlich eine, bie Culex

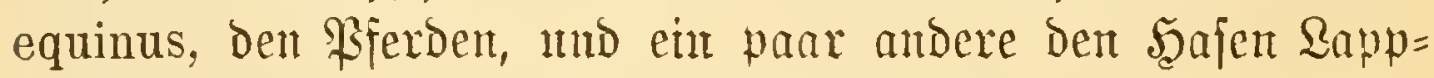

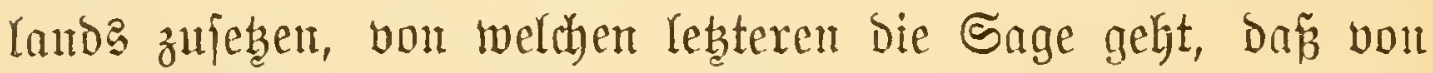
Den Drei Jungen derfelben eits burd) Rälte mo eits Durdy bie Miücent umfomnt.

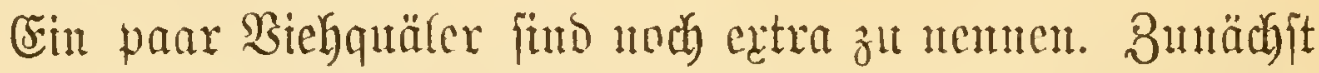
bie berïbtigte (Sollubaber Mituce (Simuliø maculata Mg.) Der

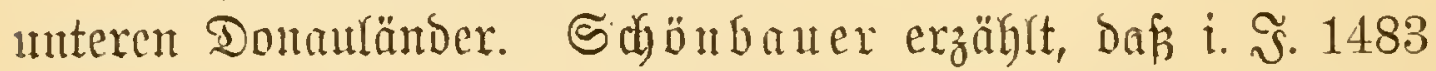
im Banat gegen 1000 gröfere Seanstyiere, Bferde, Rinder, Srameine zc., diejen unfbeinbaren Megquito's zum Spfer

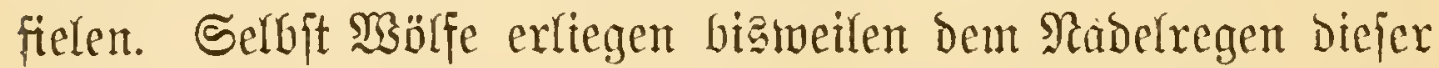

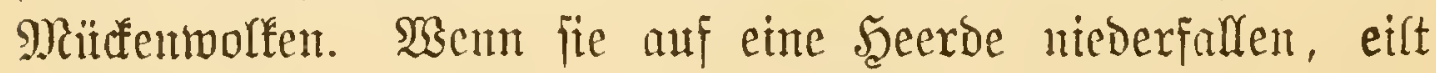

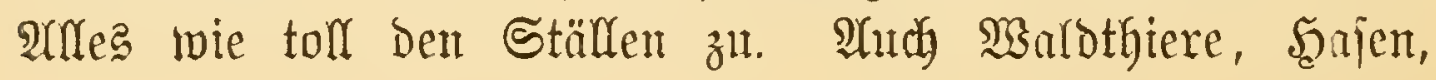




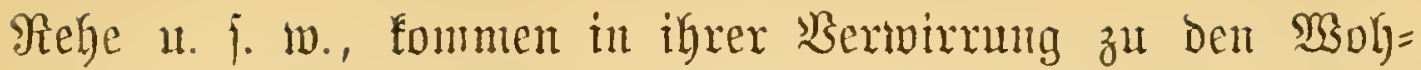

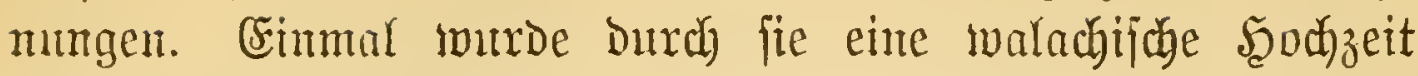
aus einamber gefprengt und bie leidyt gefleibete SBraut von biejen eiferjübtigen Bhtfangerimen febr ïbel zugeridytet.

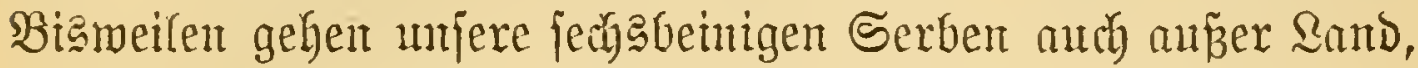
ja fie wurden ferbit in Berlin gejefen. Wober fomment dent aber Dieje Tapfern? Şly Rebenglanf ift ber ber andem

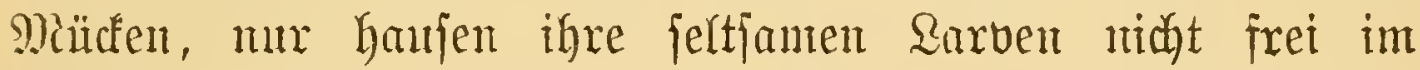

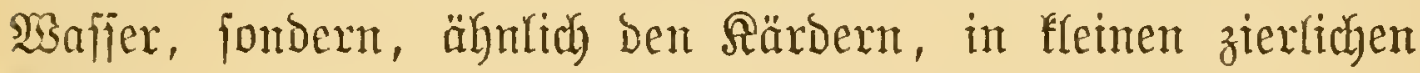
fï̈chern, mit Denen bie Riejel Der Bjebirgabäche oft aanz infermitirt find. - Saier fände jomit Das Mahnwort: "Man vertilge bå Hebel an ber Suelle", feine fundjitäbriche (s)eltung.

Weitang Die gefäbrlichjte Rlinge unter allen Rerfen füfrt die Tietjefriege (Glossinia morsitans) ane Centralafrifa.

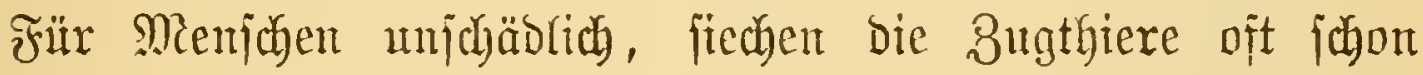
in Folge eines einzigen Stiches Dabin. Der Tod ijt fait unbermeiolich. Ramentrich icheint bas funchtbare Tjetjegift

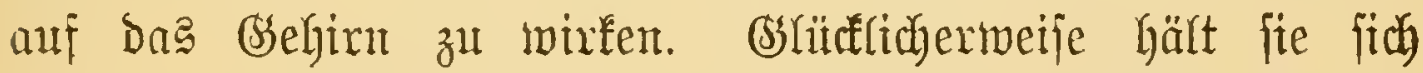
fitreng an gemiñe Dijtrifte. SBei einem unvorfithtigen Durd $=$ zug Durah einen jolden riafint aber ber Reifende jein ganzes

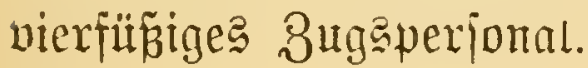

c) an unferen Speifevortätben.

Da bie Rerfe alles irgenduie Bseniefsbare angreifen uno

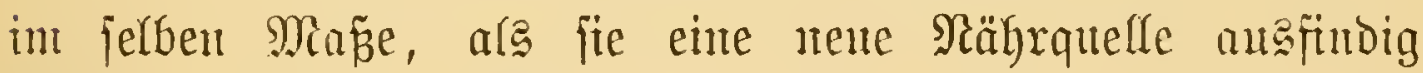

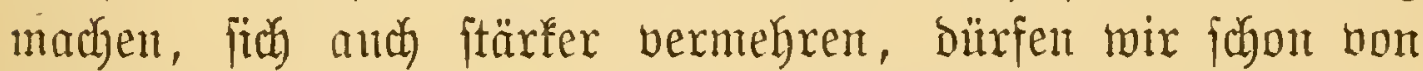
voruherein nidjt erwarten, Dás fie vielleicht mijere Nahrungs= mittel, feien e马 mu giohjtoffe ober fünjtlid zubereitete, irgenomie reipef́tiren. Und in der That gibt es aud nichts Derartiges, moes vor ifhten fitrer märe.

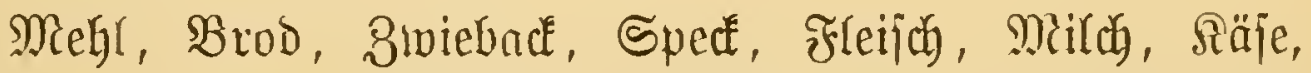

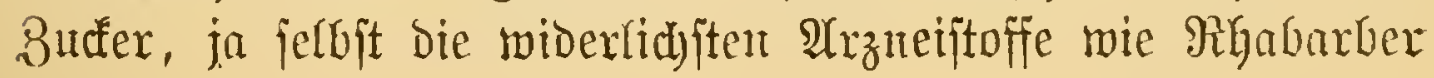


und Spium haben neben Den getwifien Snleften, wie Den

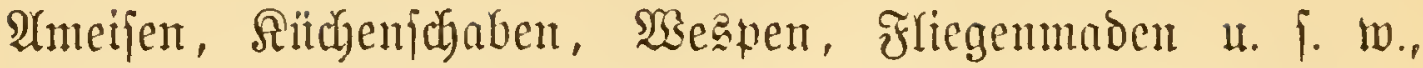
twelche ohne viel Alusmahl über stlles herfallen, meift noch ifyre bejondern Berehrer. Soldye Specialiften jüb z. B. Dermestes lardarius für Den Specf, D. panicus für Das B̉rod, Tenebrio molitor für Das Miehl, Ptinus rubellus für die fpanifdyen

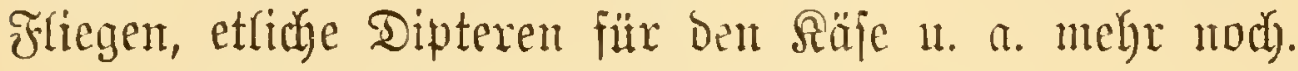

Eriter ber ärgjten, der Slomfäfer (Curculio granarius L.), jei noch bejonders erwähnt. Der "Miutterfäfer" bohrt in

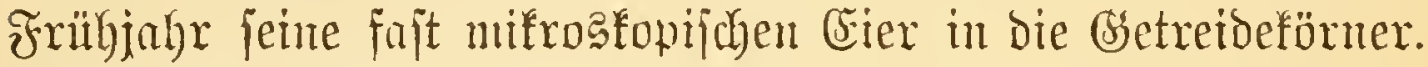
Die Sarben frefien fitch Dant ticjer cin und verpuppen fid in

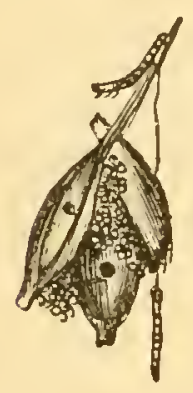

Fig. 101.

Son Sir Sormidaben= raupe (Tinea granella) ausgehbhlte $\mathfrak{w e i z e n =}$ förner, lat. Gir. Den ausgehöhlten Samen. Şm Эult ex=

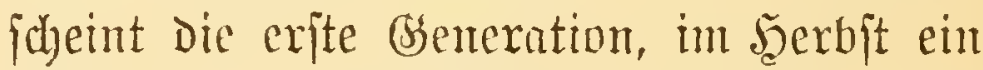
zweiter noch zableicherer Nadjichnth. Sie überwintern im Getreide oder in Riben Der Speidyer. Baldiges 2tugorefdren, iwent mun Befabr ahnt, fleipiges umichanfelst,

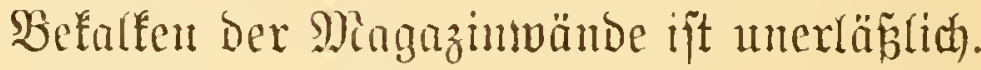

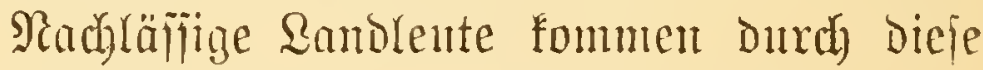
geheimen Siunder ojt fehr zu Schaden.

Dicje ganze unjubere snouftrie ift übrigens nicht ausidyliepliche Erfindung Des "Sinnmeibels", zmei ambere, Die Raupe Der Rormmotte (Tinea granella) und Der Sietreidemotte (cerealella) find $\mathfrak{B e r}=$

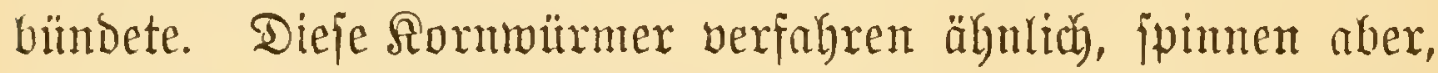

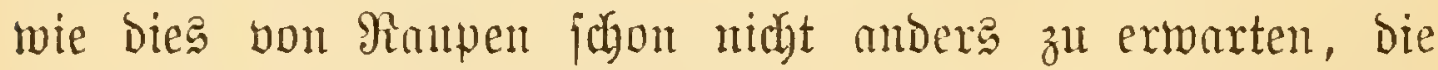
mit ifrem Unrath Geflldelten Sörner in Lleinere und Dann in gröpere Silümphen zufammen. Die Mehrzahl überwintert in Den Böben, balfen uno $\mathfrak{B a ̈ n d e n ~ b e s ~ S p e i c h e r s , ~ b a h e r ~ j o r g j a n t e ~}$ Serjtreidyen aller Riz̧en nothrwentig. Sn fełr abgelegenem (S)etreibe findet fich Der Setreide= und Der Brobfäfer (Lyctus frumentarius und Trogosita caraboides) ein. 
d) an unferen attenfitien und Wofnungen.

Die Rerfe wollen nibyt alfein wou allen arten unferer Speifeborräthe ihren Tribut haben, fie vergreifen fidy an, AYAem, was wir haben und un merth ift, einzig und alleir Gsegcriftände aus Stein, Bshas und Metalf ausgenommen.

Bunächift ift es allen Entomologen befannt, dañ fie nidgt eimmal bie jie jefbit betreffenden Shanfammlungen refpeltiren;

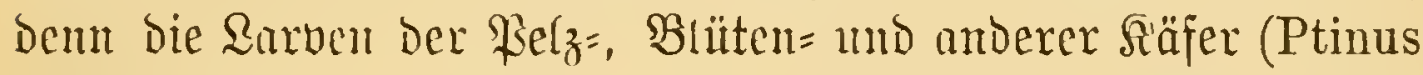
fur, Byrrhus museorum) und gewijie Motten ribten in Den Rerfmujeen oft Die greulidjiten Beriniffungen an.

Aluch unere Schriften mo Büther werden früher ober fpäter eime Speije veridhiedener Nageferfe.

So fand man in ciner alten Bibliotyef einen Stó bon nidht meniger als 27 biffen Foliobänden von einem Snljelt

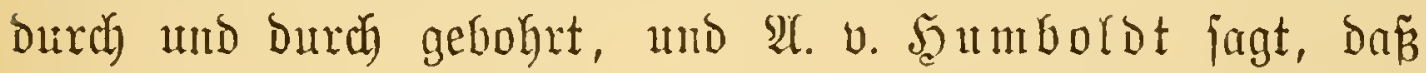

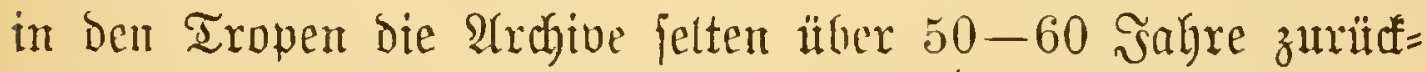
reidyen, ba fie vor ber Berftörung Durch bie Termiten lyöd)= ften in cifernen Schränfen gejdübt werben fönnen.

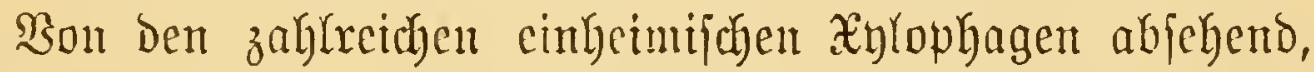

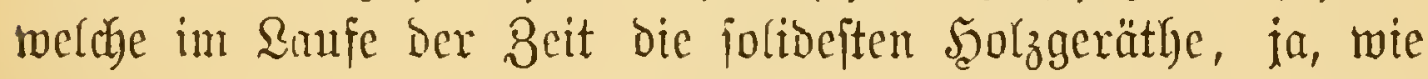
die Rarven von Cerambyx bajulus, jelbjt Blețächer Durch= Yöchern, fund es in Den wärmeren Bonen näabjt Den Ameijen

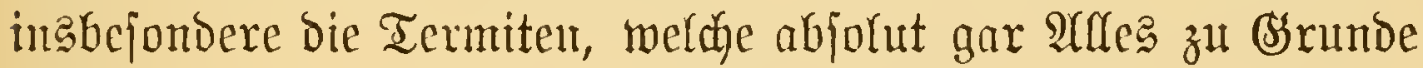
richten, umb bies etwa nicht ftürf́tweije und allmälig, fondern oft in $\ddot{n}$ berrajchend furzer Beit.

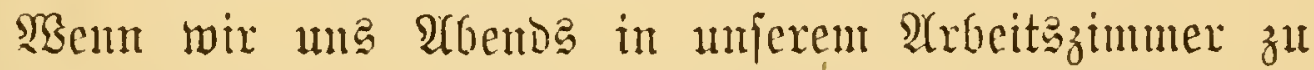
Bette legen, fo fint wir jither, an Morgen alle unjere Mten=

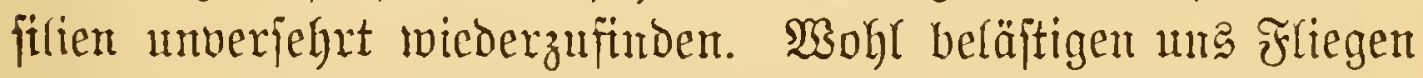

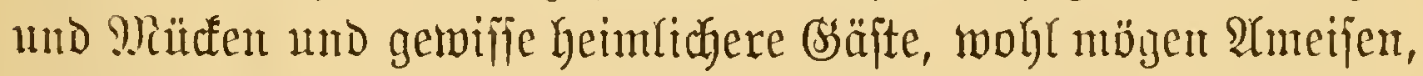

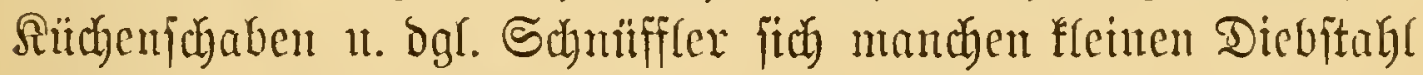

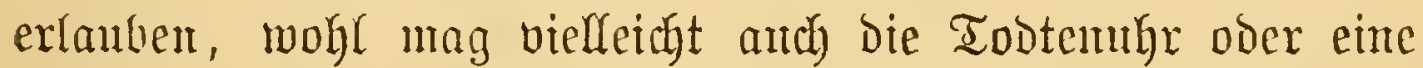
Sirenlarve in mifern Möbeln nagen und bie Pelzmotten in 


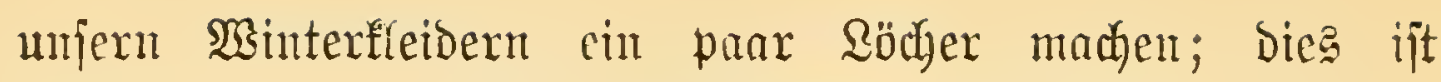
aber, unter normalen Serbältutifien, Dod, armes nidyt Der Rede werth.

Welche ganz andern Erlebuiffe madyte aber juon Mandier. Der in einem Termitenlande übernadytete.

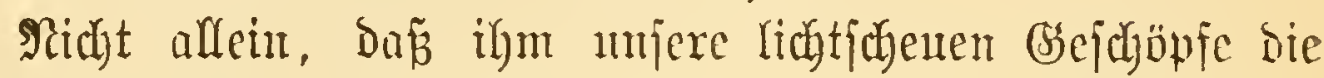

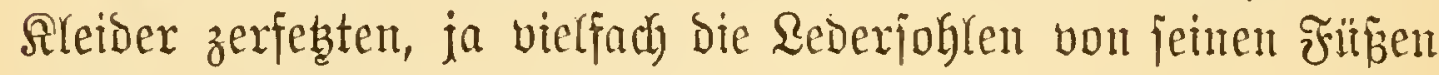

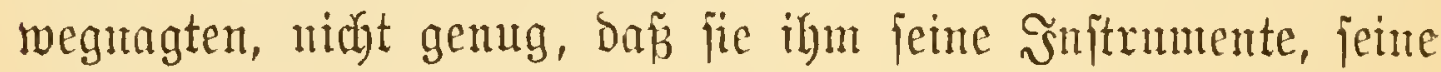
Soffer, siffen uno foptbaren Sammlungen total zerftorten, wenn ex unr ein paar SBodjen fein Bimmer bemolyte, fo brad) ifm uft bas heimlich bou diejen Sierjen hohlgefrefifente

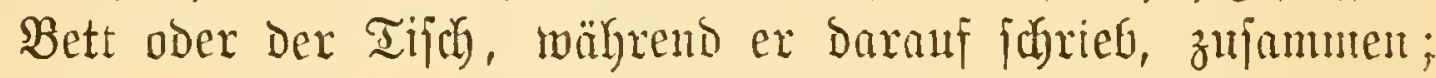

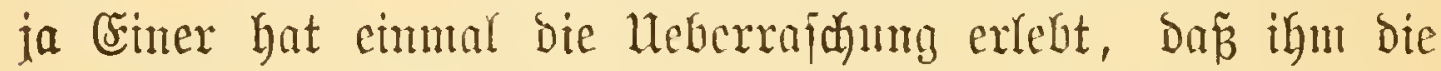

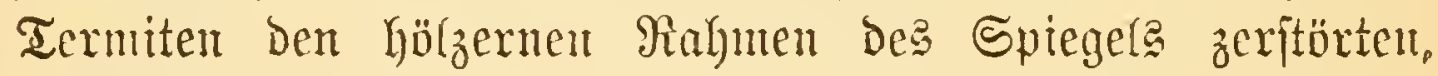

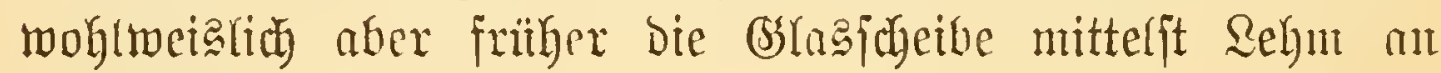
die Mianer Kitteten.

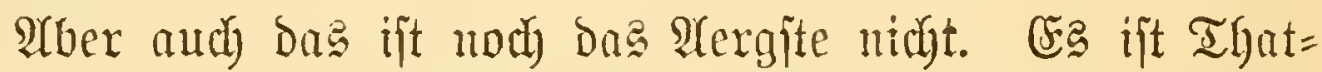
fache, dañ bie Armeen des Termes bellicosus zutweilen theice untex bie Fundamente eines Bsebändes hinab=, theile ju ben SFfoiten des Dadhes hinaufftrigen und durch luterhöhlung Desjelben jeinen Ruin herbeiführen.

Und flingt es baun jo unglaublich), Dañ fie vor längerer

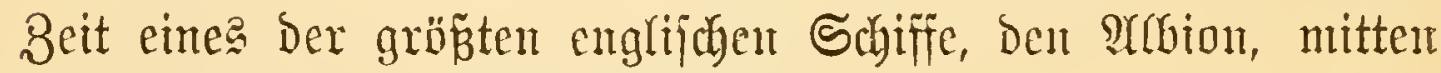
auf ber See zum Sinfen bradjten?

e) an unferen Ku(turgewäch) (en.

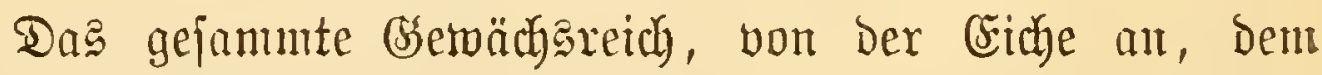
Storz Der Wälder, bis zur Sdyorffledte auf umjern Bretter= zäunen, ijt ein Eigenthum der Rerje, ulo wenn wir zahl=

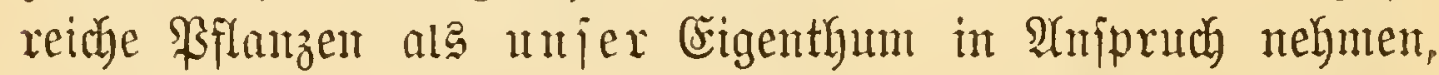

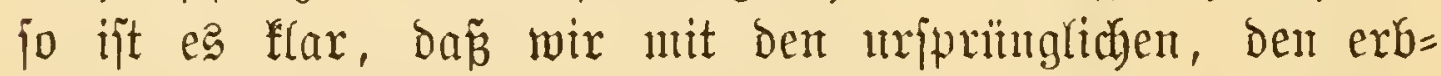
gejeffenen Bejtizen einen ununterbrochenen 尺rieg zu führen baben, bei bem wir leiber oft, trob Áufwendung aller unjerer 


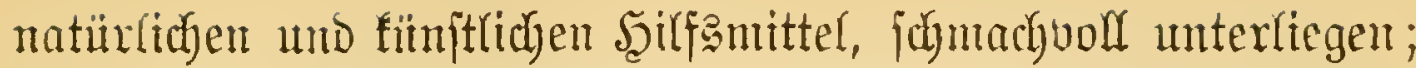

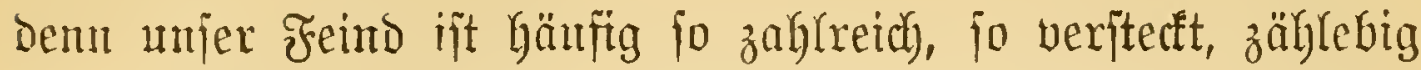

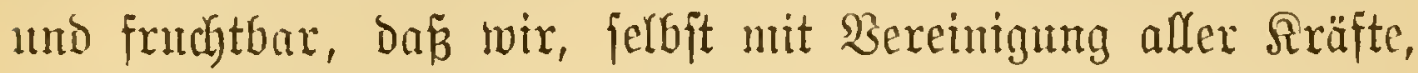

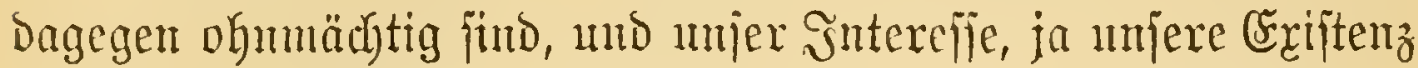

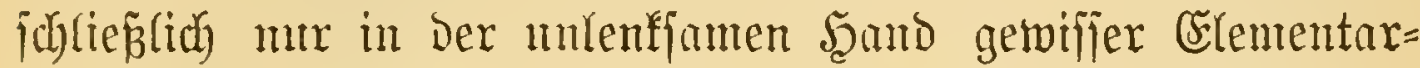
getoalten liegt, bie für ums, aber aud gegen mo Partei er= greifen fömen.

Ueber biejen Gegenitand, ber ja greidybedentend mit unjerer wichtigiten Exiftenzfrage ijt, find idjon viele SBüder, ja ganze Bibliothefen geidyrieben worben; wir rollen mux einige ber

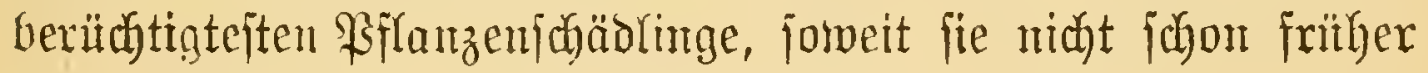
zur Sprathe famen, furz mankaft mathen.

wir heginnen mit Dent Feinden bes Ssemijjebaues.

Die kojtbaren Spargeliftofje find den Angriffen gewifjer

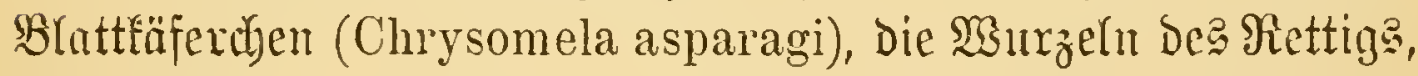
Der Niögre uno Brwiebel eintgen Friegemmaden angejebt, während ce ein Hreines Stechmanl, ber Curculio lineatus, auf die Seimblätter Der anfgehendon Bohnen abgejegen hat.

Biel Ingemang haben bie Bsartendhumen und Barten=

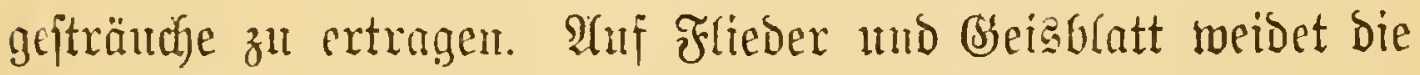

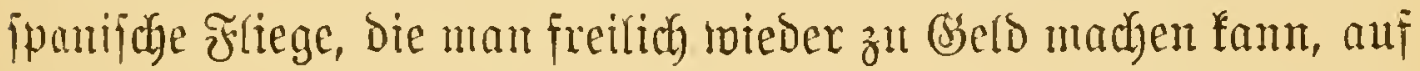

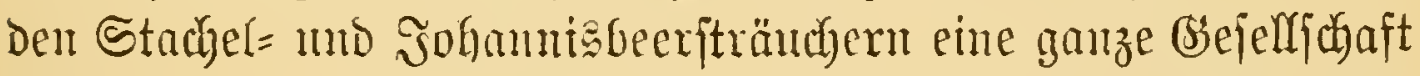

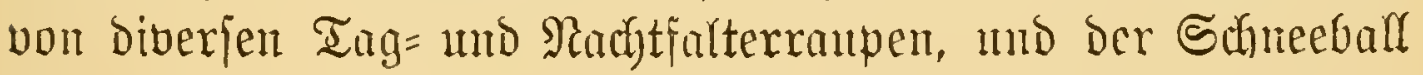
wirb vou einem eroge(hen Räfertyen (Chr. viburni) algefreffen.

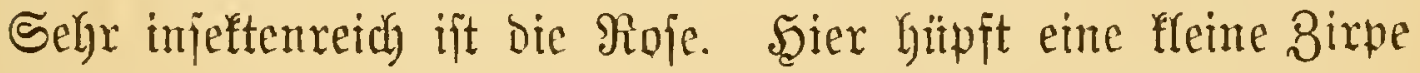
(Cicada rosae), hier meiden die flcinen (Sartentantbäfer (Melolontha horticola), mo zahlreide Raupen, Widfler und Blatt= läıje futáen aud igren Theil zat friegen.

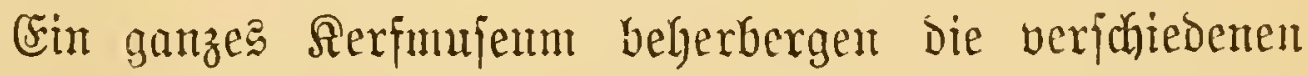
DGjtbäume, an benen, wie an allen ḩolzpflanzen, die Theifung

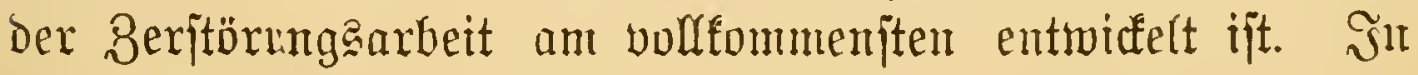

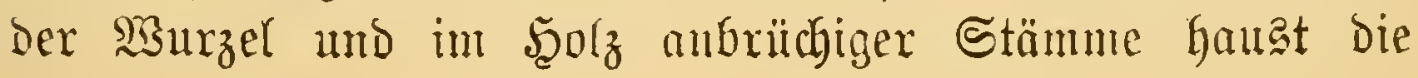


langlefige Weibentrobrexraupe, ber man mit Sdywefeldampf

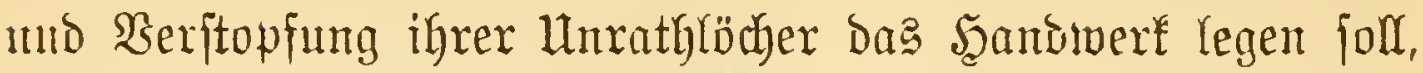

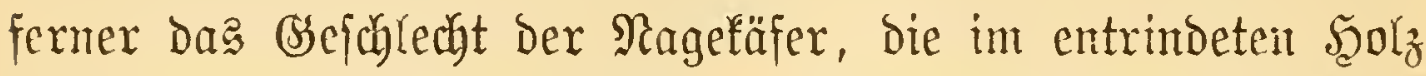
Gerumpazieren, währent die fapuzinerartigen Nup̧borfenfäfer (Eccoptogaster pruni z. B.) zwijachen Rinto und Sprint ifre feltjanten Şierogluphen meižchn, und gewiffe Borfenfäfer (B. dispar) mit igren "Fächergängen" nody ein Stüd ins

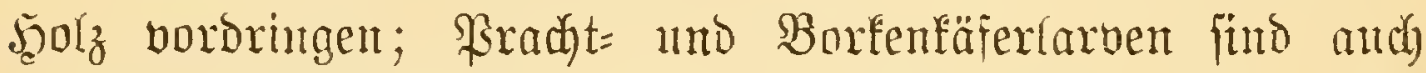

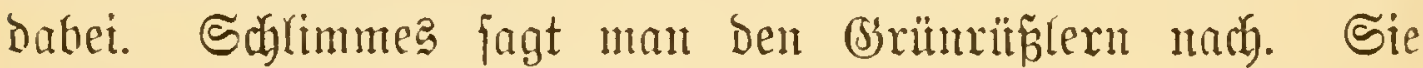
benagen $\Omega_{a u b}$ und Rnospen, Frefjen aud gerne bie Slugen

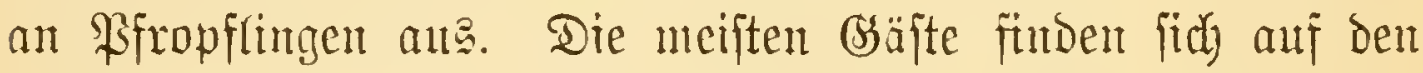

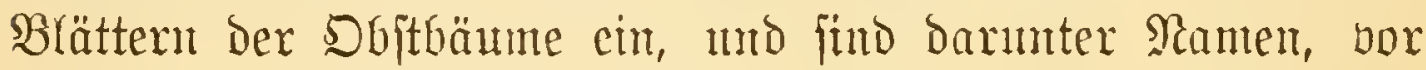

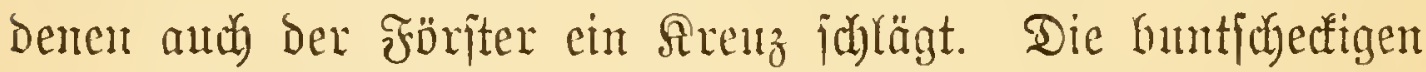
Qivrée= oder Ringelfpinnerraupen begeben fich in hellen Scanjen

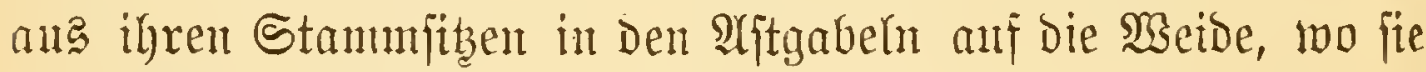

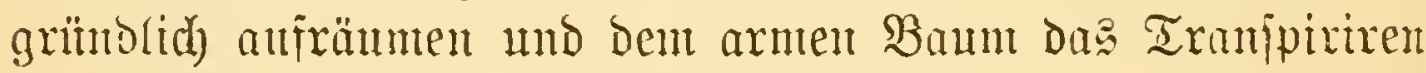

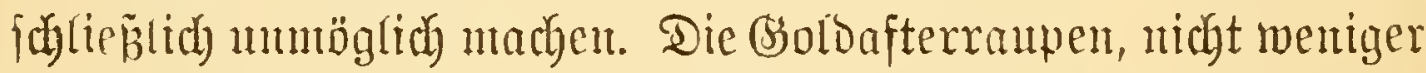

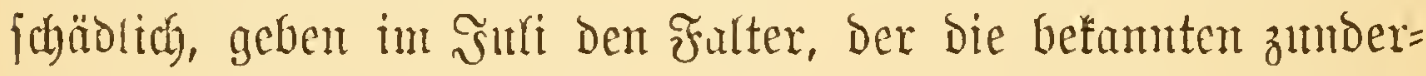
ähnlichen Eiflumpen madyt. Die jungen gäupdyen geben fid nod) in Seerbift zu fduffen und itherwintern in oft fauft= gropen Ssejpimnten. Reider gibt es Santowirthe, zumal in hiefinger Bsegend, die allen diejen Dingen ifren natïrlichen

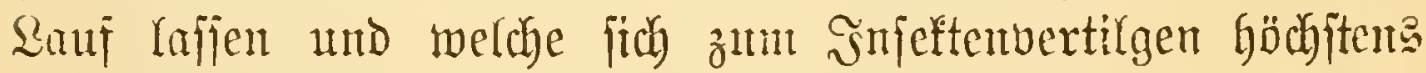

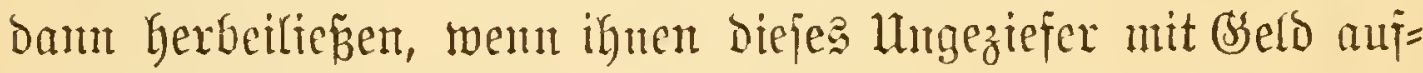
gemogen wïroe. Der Bombyx dispar mit feinen "grožen ceier=

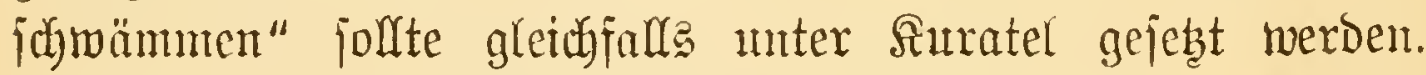
Dagejen ift ber äunerit foüälichen Blautopframpe (Noctua coeruleocephala) fdrwer beizufonment.

Einer ber alleridylimmifen (sefellen ijt Der Frostipanter, jo genamt, weil or zu feinen Hebelthaten die untuftigen

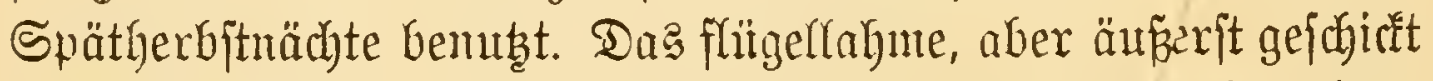

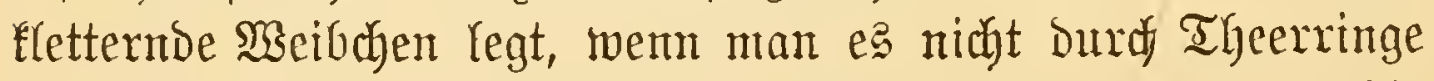
uno Dergleidyen Rräjervative am Emporfriedjen hinbert, die 
Brut an Den Baumf́no spen ab, wo fith Die jungen Räupchen

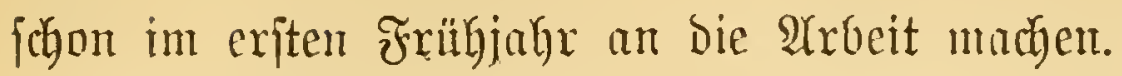

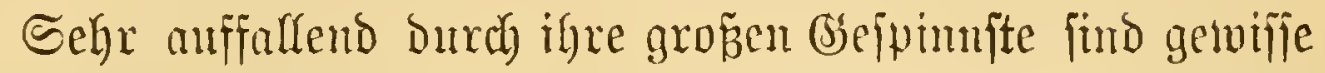
laubfrefiende Miotten, wie Tinea malinella z. $\mathfrak{B}$. Manke Dbjtbäume haben Dam noch ihre bejomberen Specialitäten.

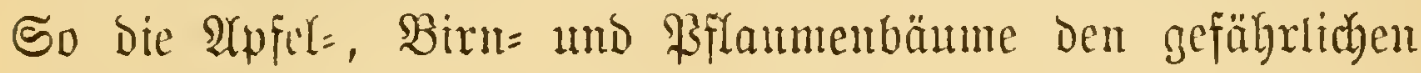

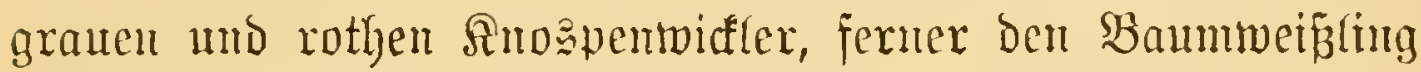
und ben befanten $\mathfrak{A p f e f b l u ̈ t e n f t e c h e r ~ ( C . ~ p o m o r u m ) . ~ D i e ~}$ Räunchen Der leģteren (Die fog. "Brenner") zerfreijen die Staubgefäpe, worauf die Bhunenblätter bram werben. Schr

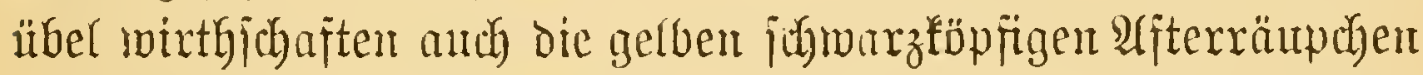
Der Birngeipinritblattwe špe (Lyda pyri). Sie halten leiber, gleich vielen undern Blattfrefijern, in ihren fothreidgen, yon ât

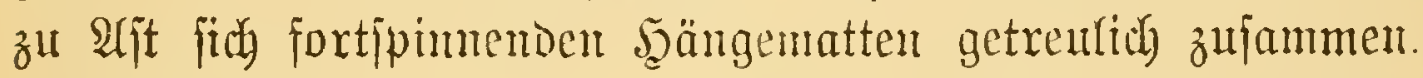
Das frübzeitige und oft majjentrafte $\mathfrak{A} b$ fallen der einge=

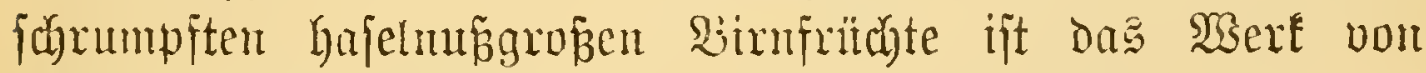

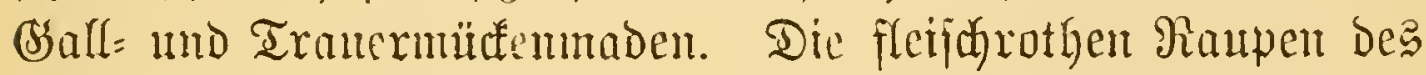
Apjelwiaflers hat ber Sejer gewi Zähnen gehabt. Diefer Irpfegoumanb überwintert an bex

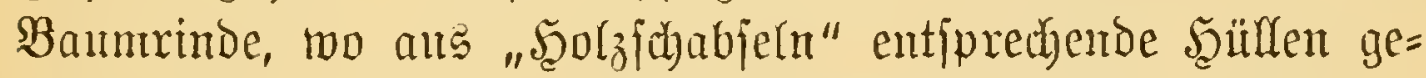
woben werden, ober, in der Dbittammer, in Wandriben.

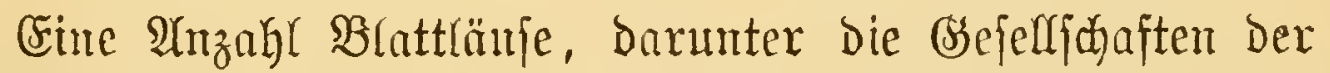
Bhutlaus Aphis lanigera, in Dumprigen Şaußgärten einten bartägnlicien Rindenanflıtg birbend, und die A. mali nit

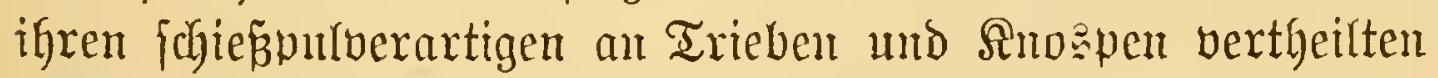
Wintereiern, zehren gleibjalls am $\mathfrak{A}$ pfelbaum.

3wei eigentyüntidye Feinte haten die Pflauntenbäume.

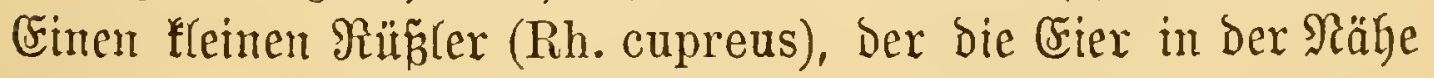
des Stielanfabes in bie junge Frumt eimbohrt, den Stengel abbein̈t und fo die Wiege ifrer Brut zu Falle bringt. Und

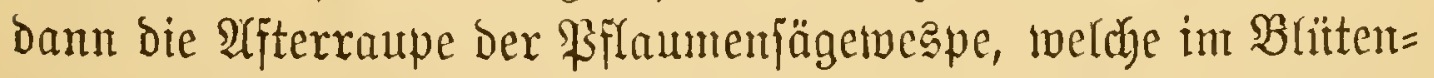

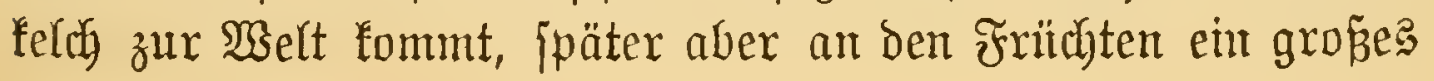


mit Uurrath gejülltes $\Omega_{0}$ a a Samzengerutid hervororingt.

Am Riridgbanm lebt wieber einer der muermetolidyent

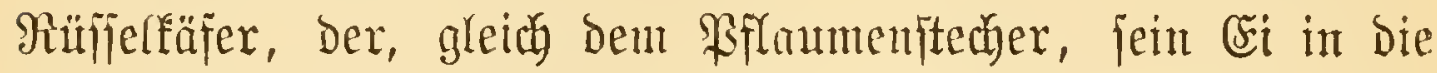
noch erbjengrofe Frutht legt und ben Stiel Durdantagt, jo baź fie, oft haufentwcife, zu Boden fällt.

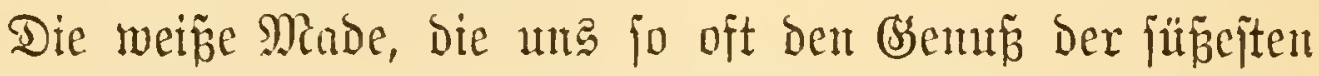
Sirjshen verbittert, went wir uts überbant eimmal auf eime

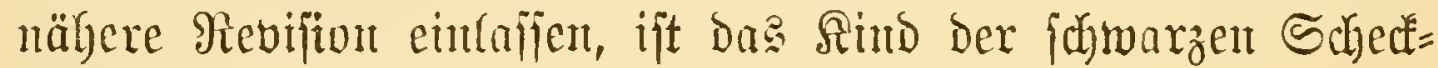
fliege (Musca cerasi).

In Den 5ajelniijen treibt, wie zu erwarten, wieder ein

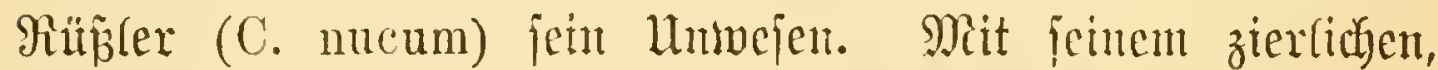
jombenartig gebogenen, fajt haarbinmen Sabnabel fabiebt er

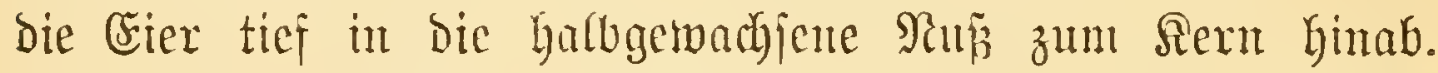

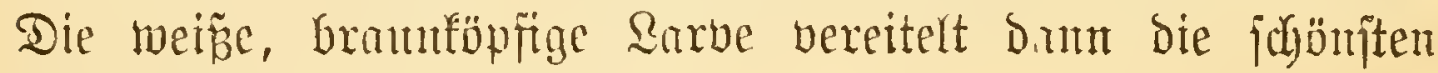
Scajehuñträume Der Simder.

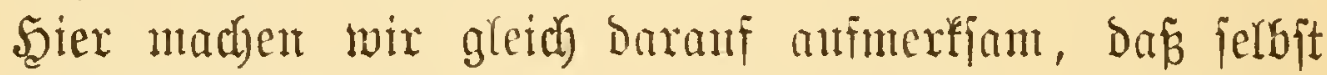

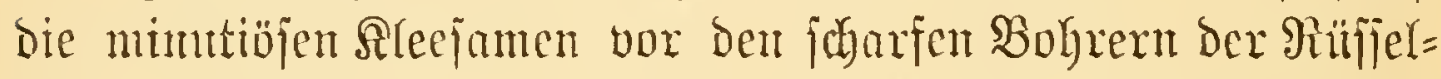
fäfer nidht fidher fints. Bu ciner tranrigen Berülymtheit hat

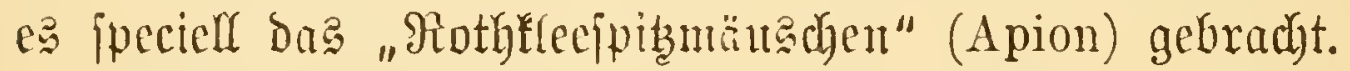

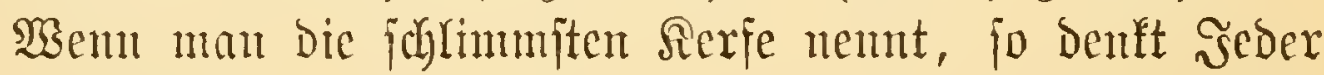
an Den Maifäfer. Seitre Rieblingghnhrung ift das Laub Der Cithe, des arbouns, Der Rof́laftanie, Der Pflammen= und

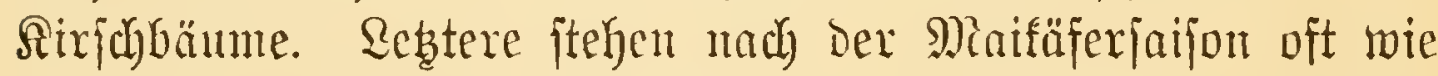
Bejen Da. Sacd Der Şochzeit, Die auf Den Bäınten gefeiert wird, gräbt fict dos Saseibchen finger= bis hanbbreit in WSiejen=, 2Yưex= ober Waldboden cin und bringt bort feine Eier, in 万̧äufchen voit 12 big 30, unter. Die jungen "Enger= linge" fommen oft judon nach einem Monat zum Sorjabein und geken mun, anfangs meijt truppweije, ibrem befannten

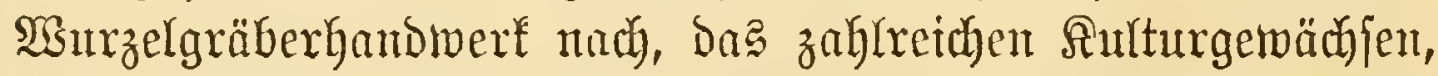

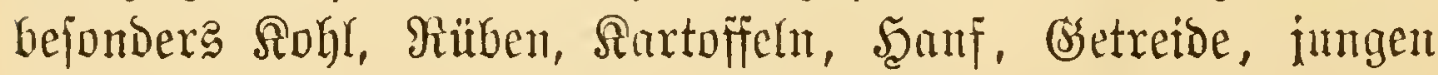

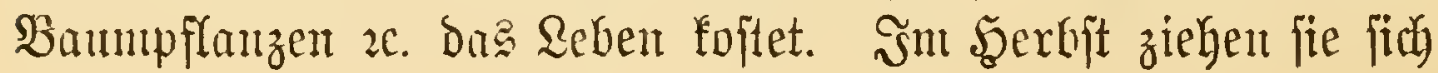




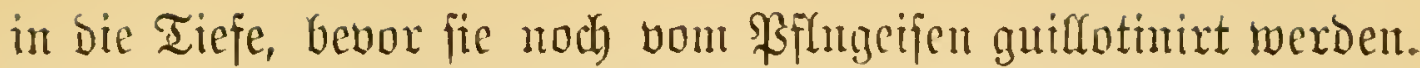

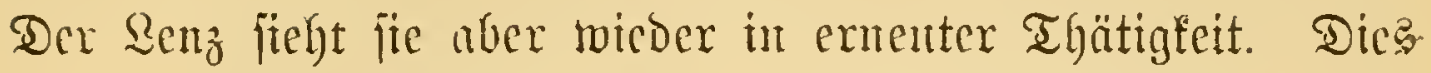

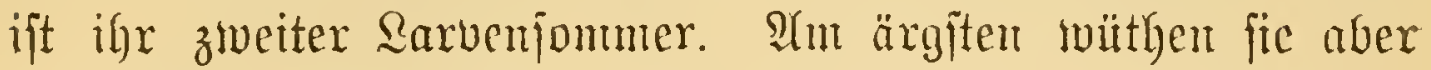
im Dritten. Эa biejem zieben jie fich num cimen Meter tief in ocn Boden Ginab utmo haxren in einex gut auggeglättetent

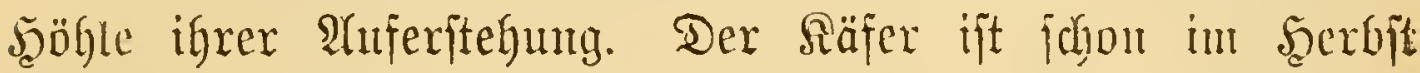

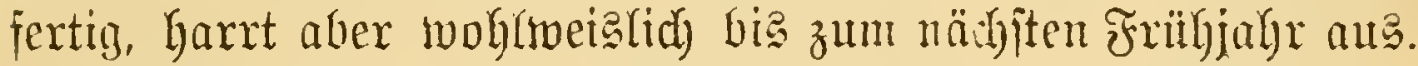
Mantige fömen ca aber nicht erwarten mo zeigen fich nod

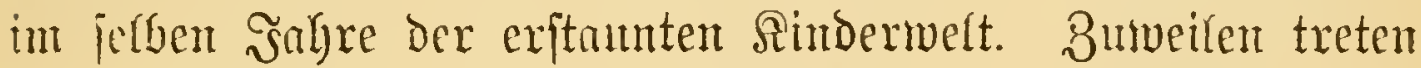

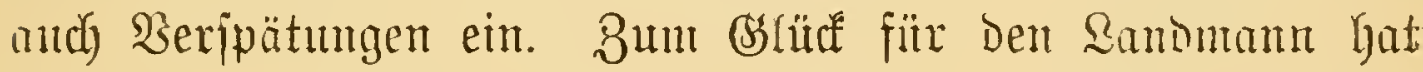
fotwohl ber Miaifäfer wie fein Engerfing jaljtreidje Feinde,

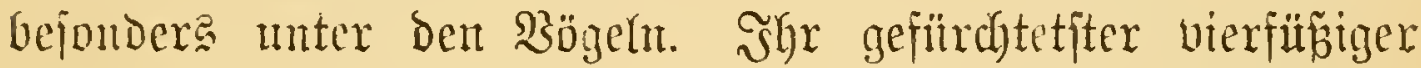

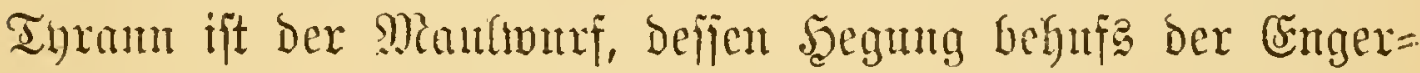

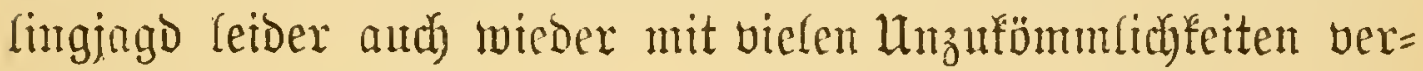
bunnen ift. Sonft ift jorgianes Riflingen und Morjens $\mathfrak{A} b=$

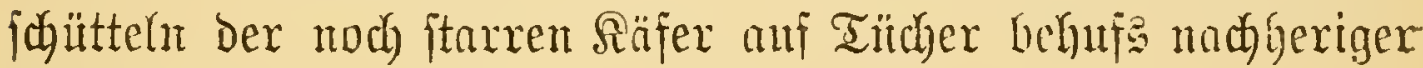
Berwendung zu Conmoit an Rlabe.

Mit Den Sentidfredfen, dic, mögen fie and nidyt manderno alftreten, Doch itetis inren Bchnt von allen feldirübten fich neymen, fün wix f(b)on nähex befinnt. Minoer Dagegen mit ben oft entietzlichen Serwiljtungen Der Winterjateneulen= ober Erd= raupe (Noctua segetum). Den Winter verbringt fie einzeln in ber Crobe und berpuppt firty im Mai, wemt fie aljo ihr werk, bie 3erftörung Der Getreide=,

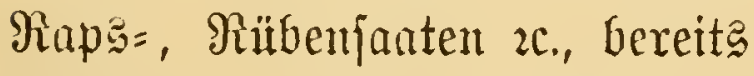
exiüllt hat. \&s ift jdyer mit biejent häß̈licjen Hebeltyätex fertig z"l werden.

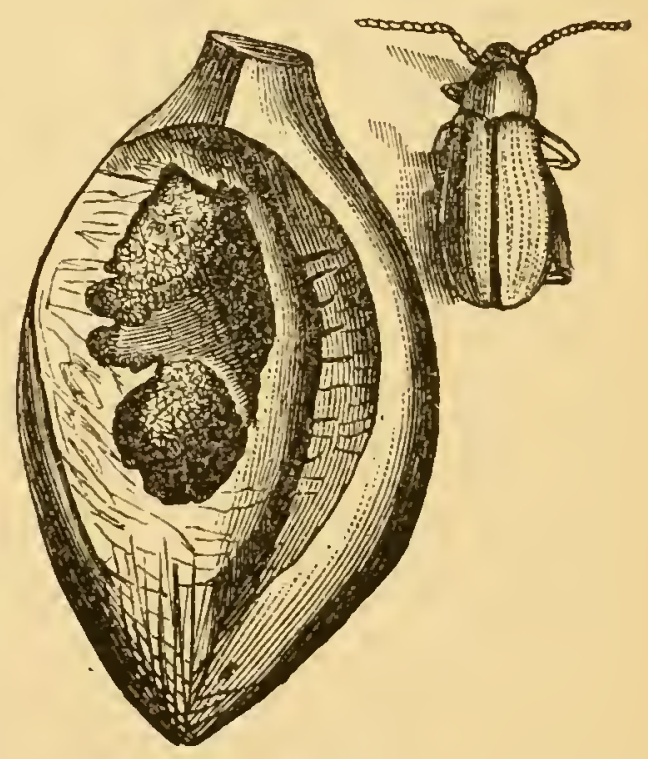

rig. 10z.

Ser Barmuáfäfer (Bruchus bactris L.) aus Brajilien, mit bent zuge=

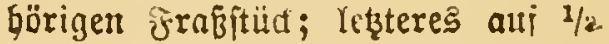
verfleinert. MBiener \$oimufeum. 
Die grïnen, weipliniirten Raupen Der Brammaenle, die zwei, biameilen aud brei Sommergenterntionen zäglt, fönnten fith an Sabäblichteit breipt mit Den Eroraupen mefien.

Biele ganz, \{pecielfe Feinde haben 9raps, Rüben und

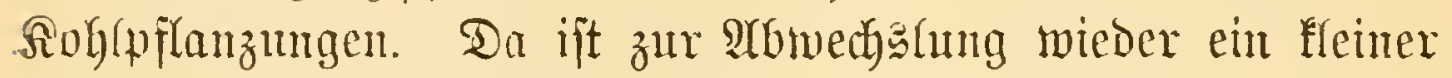

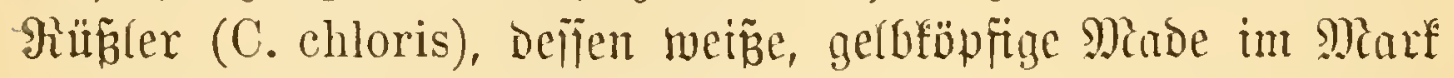

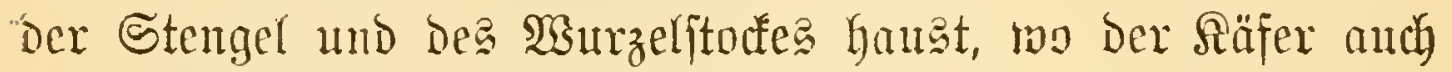
meift Den Minter znbringt. Die Rarben cines ziveiten Schnabel= fäfers (C. sulcicollis) exzengen warzentartige. SHẩmildyje an ben SGurzeln, während das Miutterferf in Den Siboten mo Bättern bohrt mo nagt. Crin Dritter Sauntfemo ift Der

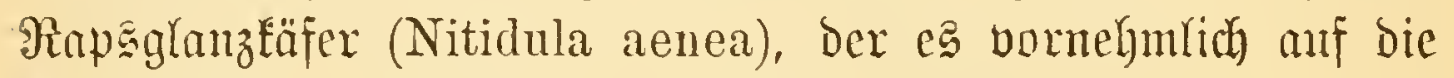
Staubgefäze abgeichen hat, wälyrent fich die Sarve mit ber fleiphigen Sibotenthülle befä́t. Fine ïheraus muntere uno

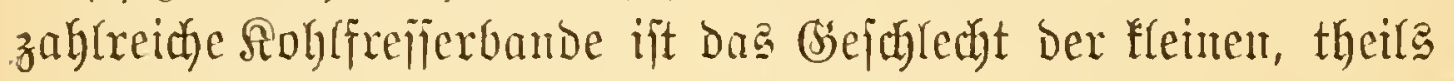
blauen, theils grïnlidhen Eroflobtëffer. Säntinge merden gutz,

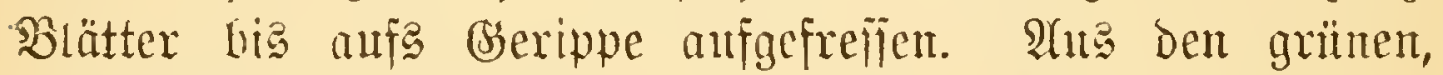

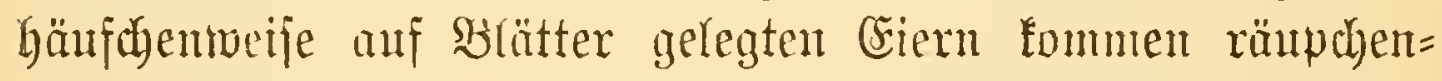
artige Rarven ljervor, bie fich auje Mintren dce Raubes ver= legen, jpäter aber aud in bie Blattitiele mo Stengel iiber $=$ mandern. Man rünt ibnen mit eigenen Majdyen, Bretter mit Igeer bejtridjen, ơ seibe.

Natïrlich fteffen auth Die Falter ifyr Eontingent. Dic

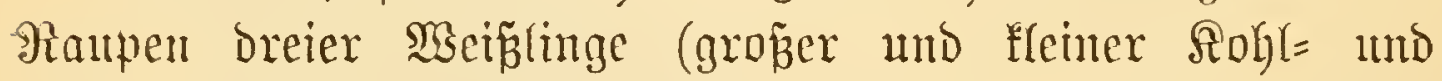

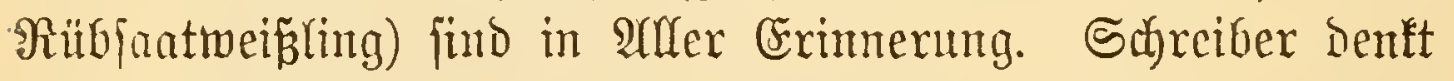

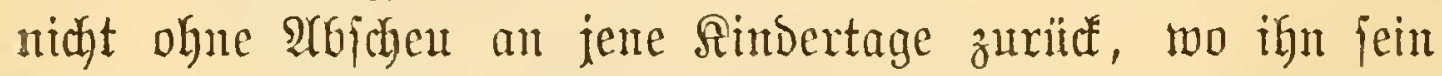

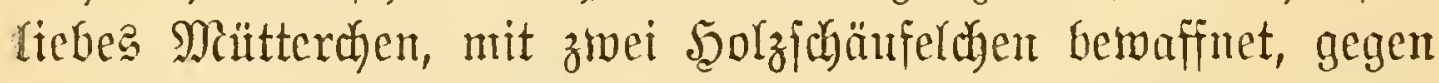
Die Sohlraupen ing Feld fhidfte. Ein par Eulenraupen (Noctua oleracea mo brassicae) fint gleidjfalls bei ber Şand; Die Der Yeszteren entzichen juth aber jeder ßerjolgung, indom

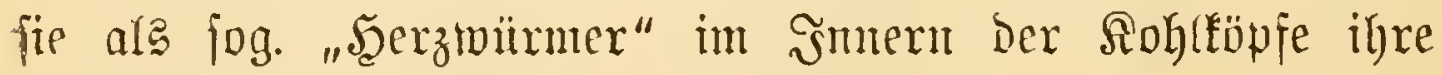
3obnung auffidslagen. 
Seltiane Sitten Gaben bie gerb= und grangeitreiften Raupen de Ringjatpfoifers (Pyralis margaritalis). Sie ipimun mehreve Schoten zujanmen uno nugen von Stefle zu Stelle cin হoch aus, als ob fie fich eine Fröte madjen mollten (Fig. 103). CFin ibünes, aber nichtasdejto= wentger mit bem allgemeinen Mafer ihres (Sejchledter behaftetes Serf ijt bie Rohl= ranze. Daj es and eine eigene $\mathbb{R} 0 \mathrm{hl}=$ fliege (M. brassicaria) gibt, Deren Made fnollige Auftreibungen ber $\mathfrak{B} u r z e l n ~ v e r=$

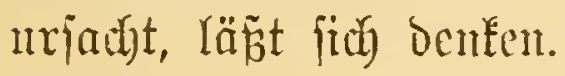

(Fin paar exquifite Feinde befibt aud ) Die Runfelrübe. Da ijt zutädbjt einer, von bem mant io etwas an menigiten ber=

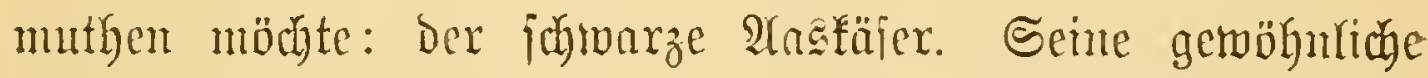

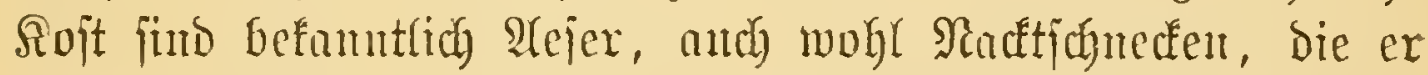

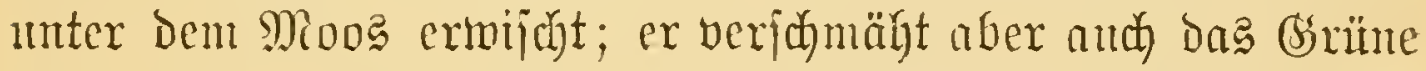

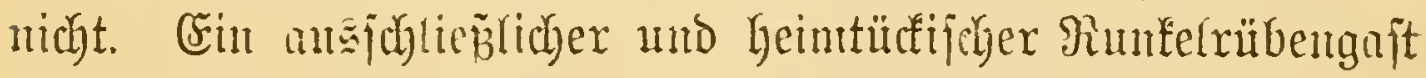

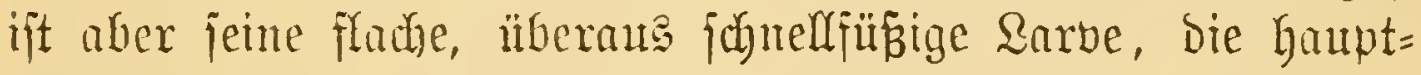

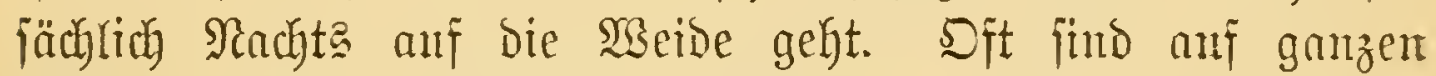

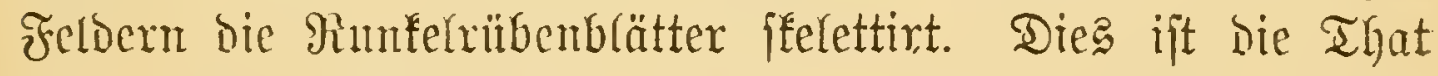
Dee nebeligen Shildfäfers (Cassida nebulosa), bejien fontor= bare Sarven anf Den Feldunfräntern haufen, wezhalb das

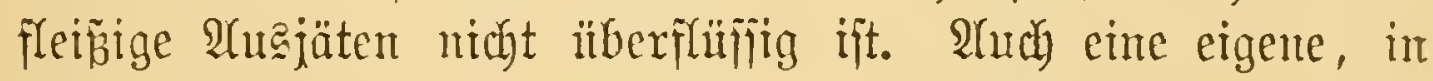
vielen Benerationen auftretende Rumfelfliege (Musca con-

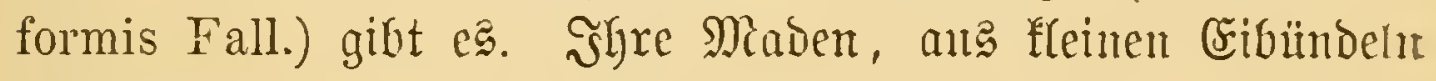

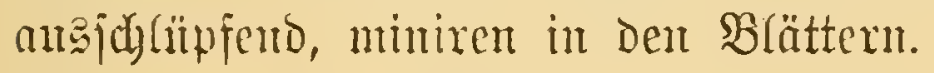

Mancherlei Rojtgänger haben die Šüljengemädje. CFinter Der befanntejten, ber es mit ber Siflanzenart nidht fo genau nimmt, ift der liniirte Graurüfler (C. lineatus). Sie zacfen die Blätter all?. 


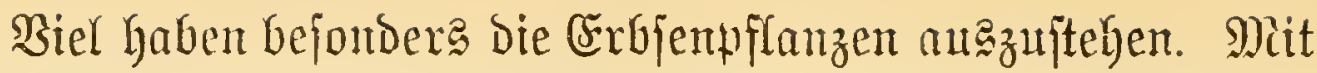
Den Samen felbjt bcjobäftigt fith wieder ein rüplerartiges Serf, Der Erbjenfäfer (Bruchus pisi), Den Die Seaugfranen oft getug zu jeben friegen, went jie die Erbjen ans Fenter jeben. W̧ent

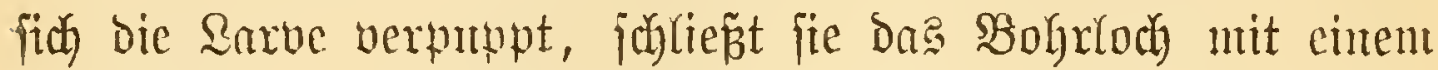

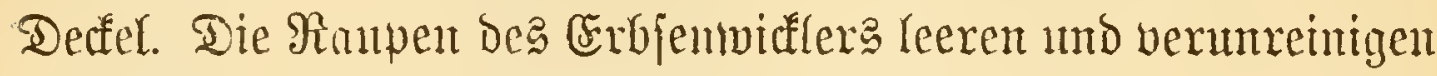
die Şülfer in toto. Âtu $\mathfrak{B l a t t l a ̈ u j e ~ j t e l l e n ~ j i c h ~ e i n ; ~ j i e ~ v e r = ~}$ urjachen ben betumiten Şonigthan.

Fin Berwandtex bee Erbjentolyeres, Bruchus granarius,

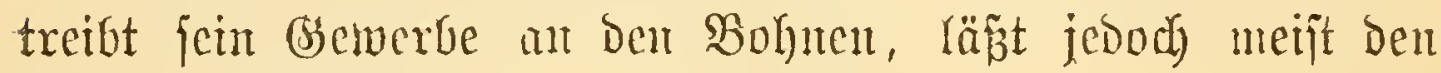
Seimling untherïtyrt.

Hnter Den Şorfenfemben füb bie ärgiten die Ranpen Des 5eopfenwurzelfpimters (B. humuli).

Die Seihe fonmt mut an bie Getreideberwijiter. Deren

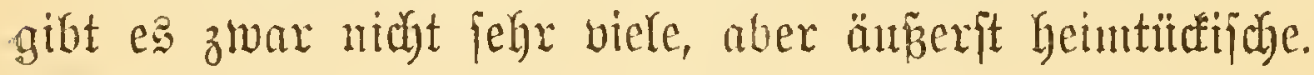

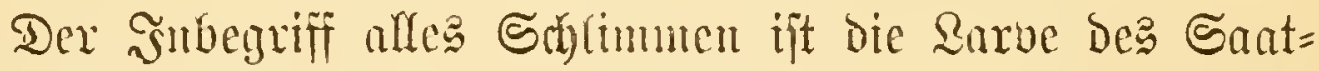
fchnellfäfers, Der Dent gerben Meblfäferlarven ähulliche Draht=

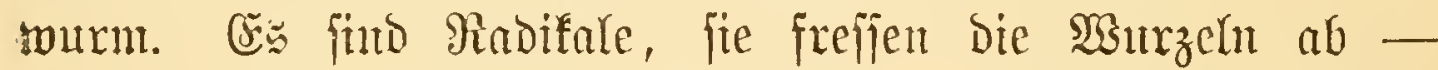
und dic Folge dovou ift tranrig gemng; dem oft mus der Adfer nen beftellt werben.

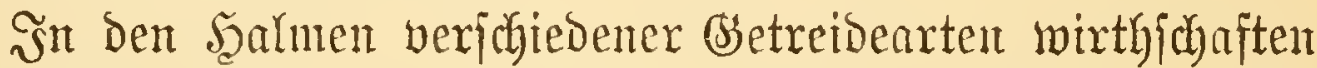

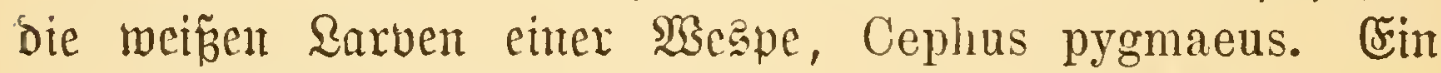
felyr berüchtigter Ssetreideberwititer, Dem Yeider fonm beizu=

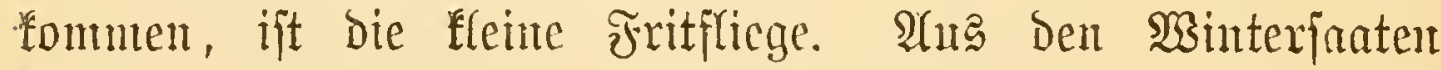
fommt fie, zeitlich in Frö̈hjabr, auf bie jumgen Sommer= pflanzungen, un Dort, an bie Unterfeite Der Brattfahuen, ihre röthlichen Eier abzulegen. Die Maden frefien fidy baun in

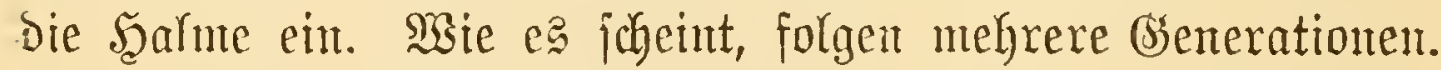

IUud bie meiften anderen Gretreidejüänder gehören zum

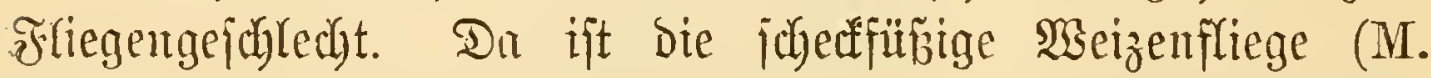
taeniopus) mit ganz eigener Sntouftrie. Die jungen Rarben

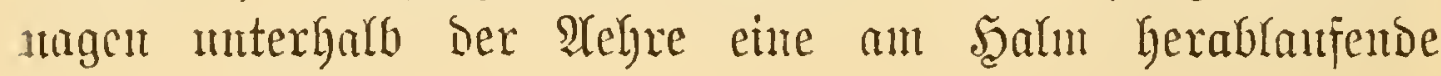




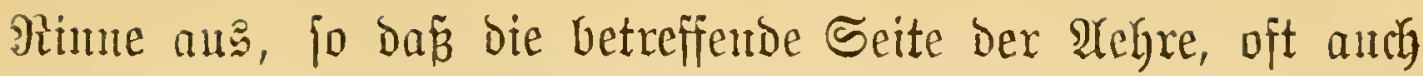
die ganze, fehr zu Schaden foumt.

Wu ber MBinterjaat manipulirt eine zmeite Sieneration, bie mit ben Fritffliegen gemeinfame Sadje

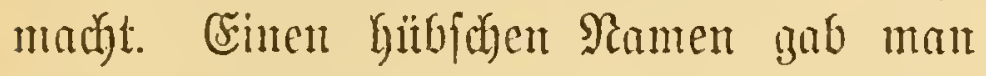
Der ipeciffifden Roggentalmumirerin : Huffämfer. Bief madyt dant! aud bie

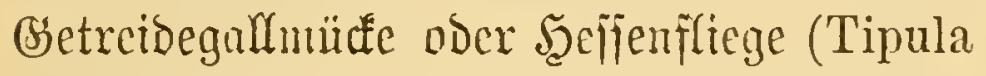
destructor) von firth reden. Die wirngigen, gax artig coftumirten "Schnäkrchen" legen bie brantrotyen cierdyen meijt paarmeife zroijchen bie Rängentmerven bes Blattes Der jungen Bflanze (Fig. 104a). Die bald ants= juhlüpfenden Maden iétagen Dan an ber

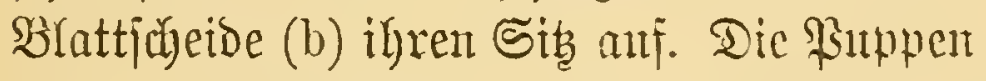

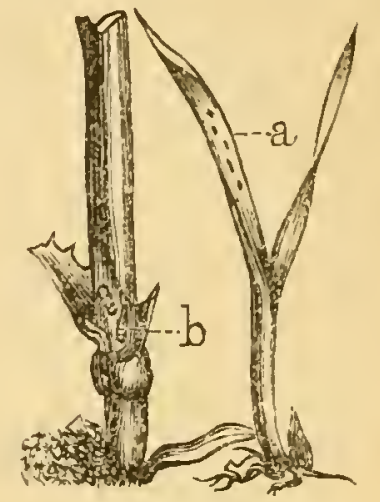

Fig. 104.

Fier (a) unb garven (b) ber Scifenfliege (Tipula destructor) auf Weizen= halmen, berfl.

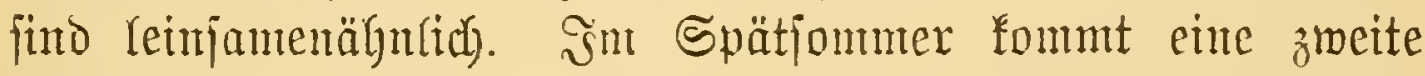
Bsenteration, bie ber Minterjant gefägrlich wird. - Die

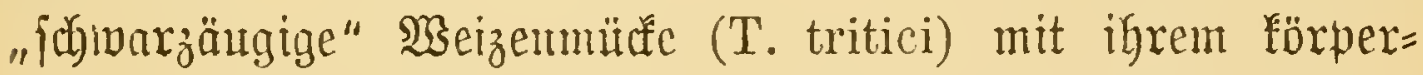

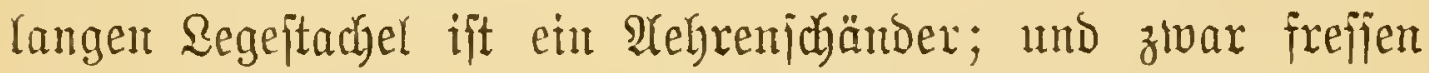

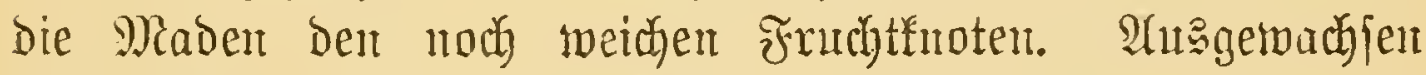

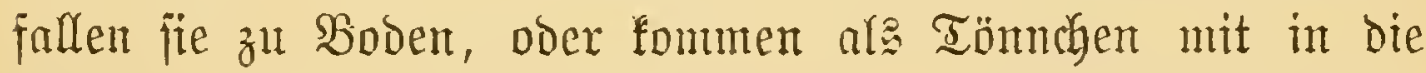

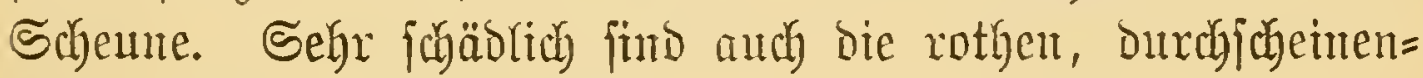
Den, gejellig Yebenton Maben ciner andern Miüce, Des jog. Bsetreibejdänders (T. cerealis). - Ein wahrgaft unver= joümtes Thier ift bann oer Bsetreibelanffäfer (Carabus

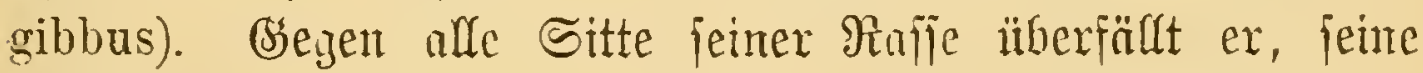
Frleifdypafïionen vergefient, bei beginnendor Bsetreibereife bes

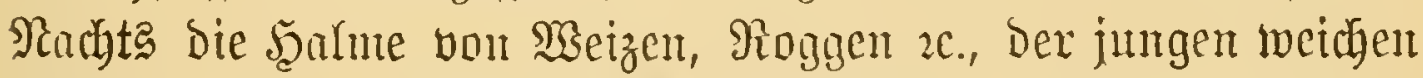
Sï̈rner regen. Seine in "̈unterirbijuen Bsängen hanjente Rarve hat ähntidye Sitten; lebtere ziebt, atm es bequenter zu haben, biameilen jogar Pffanzentheile in ihre söber.

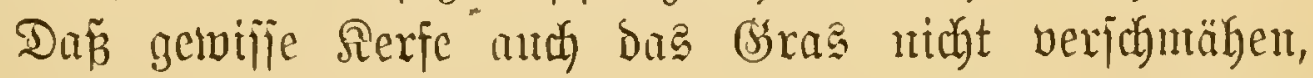

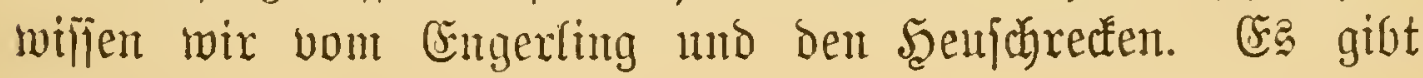




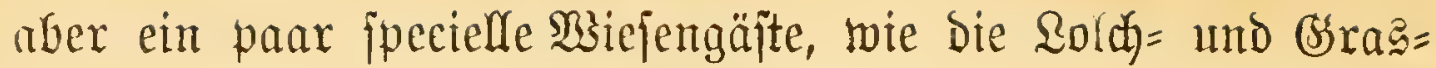
enlell, bie oft ganze Fluren fagl weiden.

Bum Bejchlnje mu noch Die Feinde Des $\mathfrak{B e i n g a x t e n s . ~}$ Drei Davon, mämlich Der Rebenjahneider (Lethrus cephalotes), Der mit feiner Sieferzange die Rebenfidoffe und Snospen ab= z'widt; ferner Der Rebenftecher (Rhynchites betuleti), Der zier= Yiche Streifen aus Den Blättern heramenagt, fomie endlich bie Raupen des Tranbentuff(ers (Tortrix uvana), die in ber eriten (beneration (Şcumurm) Die Blüten, in ber zmeiten (Sanermurm) Die Becren zujanmenjpinnt, find fabou alte Befannte.

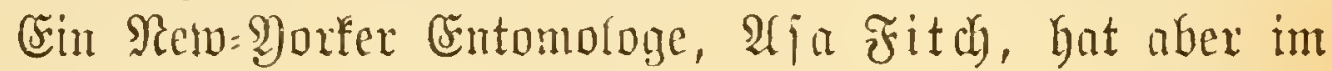
Sahr 1854 einen neuen Jebenfeind entbedt, von Dent man, angefitchts Der vielen Commifijtonen, die zu feinem Studium

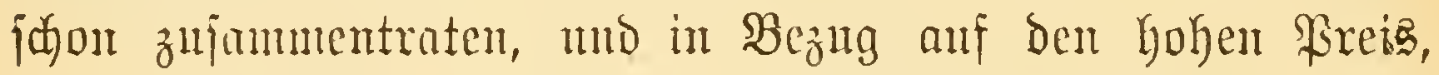
Der anf jein Reben gejest ijt, wohl fagen fam, baj es gegen=

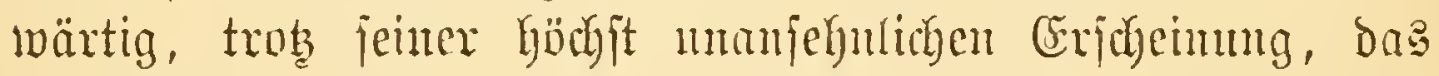
beriihmiteite Sirjeft jet. Es ijt die Rebrurzellaus, Phylloxera vastatrix Planch, oeren jüngfte furchtbare Berwilftungen, zumal in Den Mcinbergen Frantreids, aud Dem beritocfteften Ieleo=

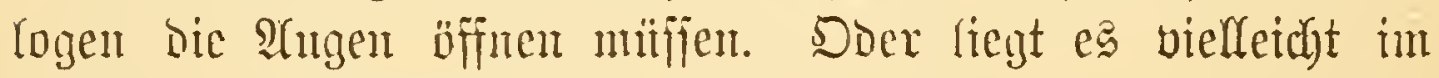

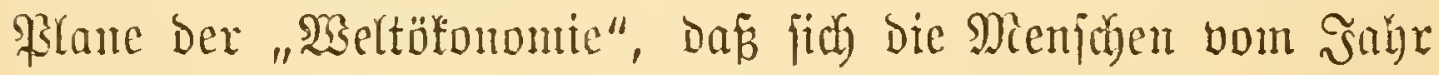
1870 Des Seiles an Das siseintrinfen abgewölnen jollen? -

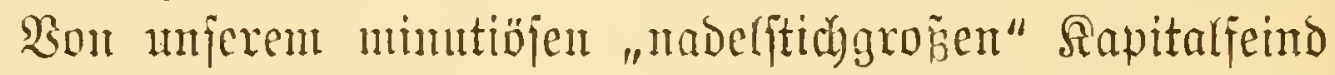
fannte man lange Beit nur Das meibliche \$serjonal, Davon aber zwei Sorten: ungeflügelte, bie grop̃e Majorität, uno geflitgelte, Die verjunwindende Minnorität. Erjtere fund wieder in zwei Rager getheilt; wir nemen fie ganz lafonifd bic

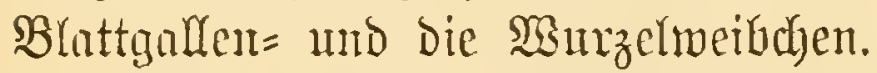

Die Dura) Den Anjtich Der Sunbgallenlänje verurfachtent

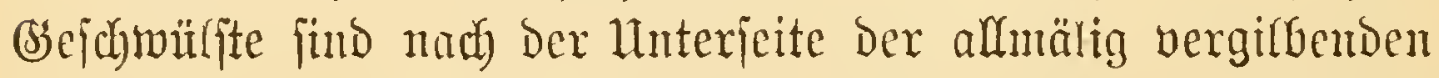
B(ätter röthlich haarige, Itach Der oberen fid in eine Spalte öfïnende twarzige, feffelartige Âstwüdfje, Die förmliche Fantilien= hämşen vorjtellen. Sie beherbergen nämlich nächjt einigen 


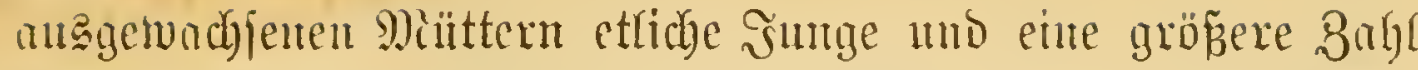

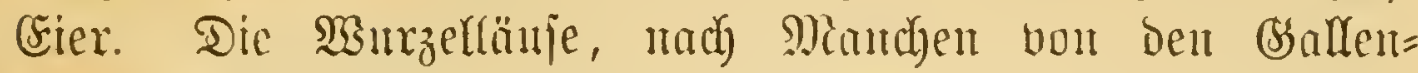
betwolynern etwas verjdicden, aljo cine bejombere Arbart,

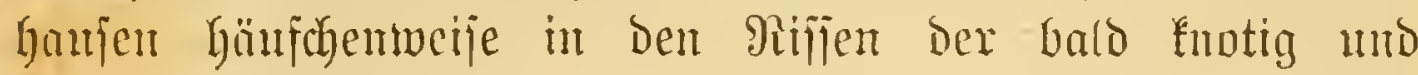

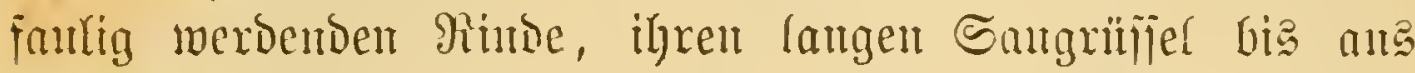

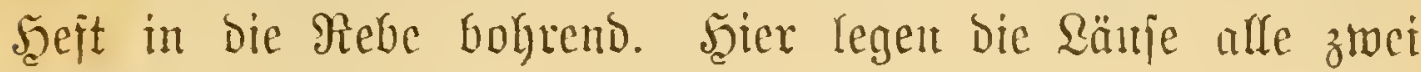

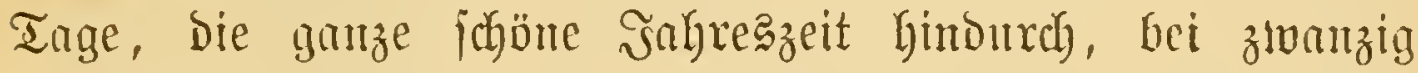

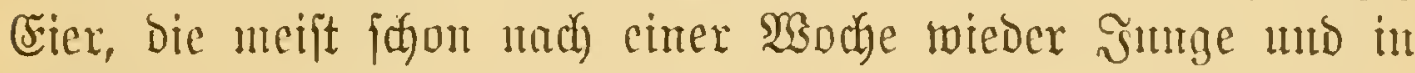

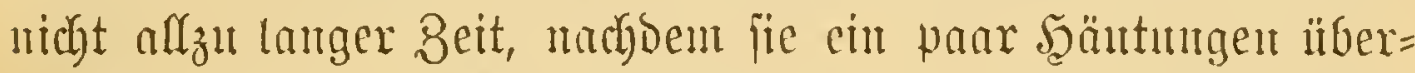

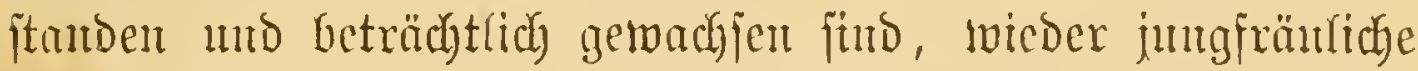
Mü̈tter geben. Die gefummte einjälyrige siad fonmenfdyaft einer "Miärz̆lang" witrbe jidy utach vorgenummenen einfachen

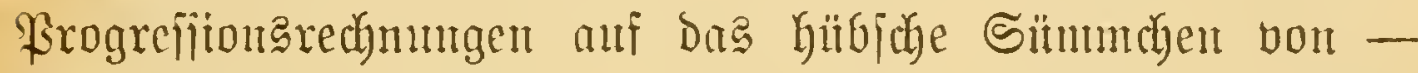
25 Milliarden belaufen. Hnter joldhen umitänden begreift

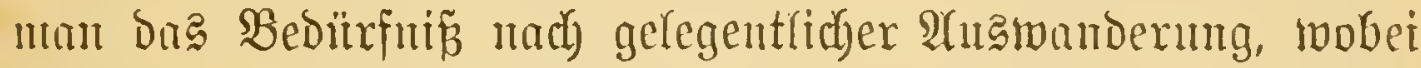
die Räufe gleich $\mathfrak{A}$ meijen über ben Boben lanfen, mit ifren

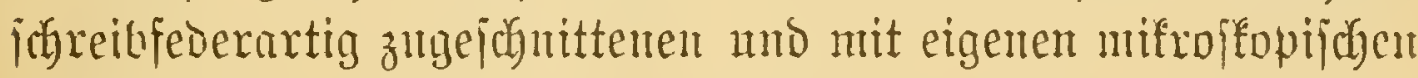

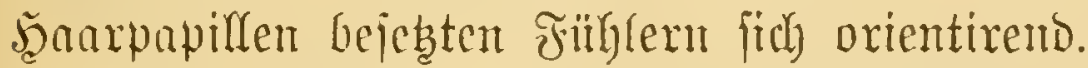

Die geflïgelten mb relativ langbeinigen Reblanmuntter geiellen fid bon Mitte Şuli an dent untgeflutgelten bei. Bueflïgelten Sunten ähntidh, werden fie und Damit bie Seudbe burch Den Sind inmer weiter und weiter verbreitet. Wie meit, Dus wird bie Bufunft lehren.

Nadh Den meneften Beobachtungen $B$ albiant's und

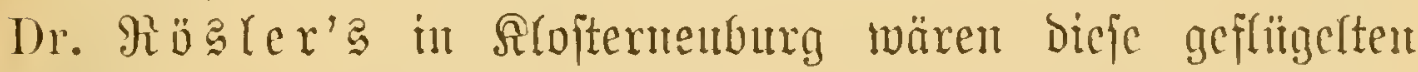
"Bigenter", werdye bei Wien aber exjt im Dltober exjheinten, die Schluggenerntion. Sic legen nut wenige, aber für bie

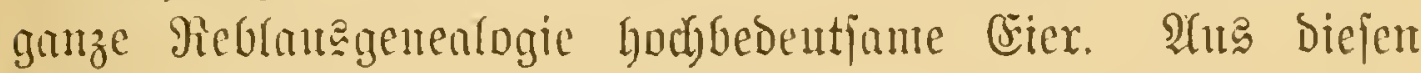
fommen nämlidy bie legitmen Stammbalter, mo zroar ans

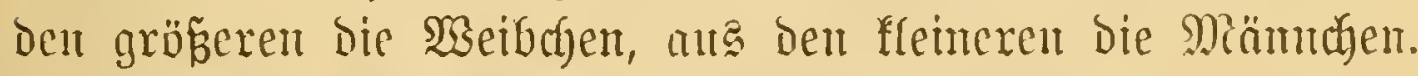

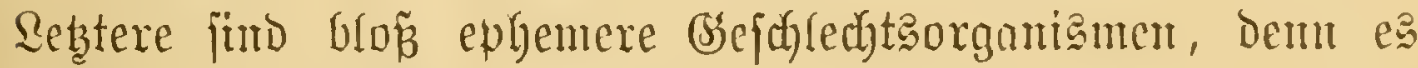

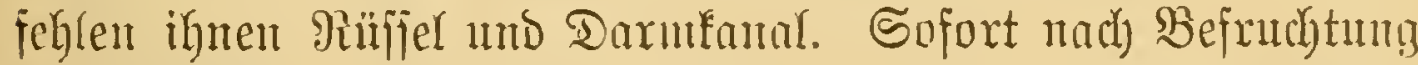
Der SSetbrben jterben fic. Sebetere, alfo bie Stammmütter, (s) raber, Tmielten. II. Bd. 
follen bis 80 Crier legen, ats Denen Dam die jungfräufich gebärenden ober "erblith befurdeten" Saeiber herborgehen.

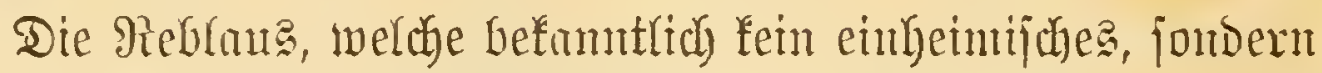

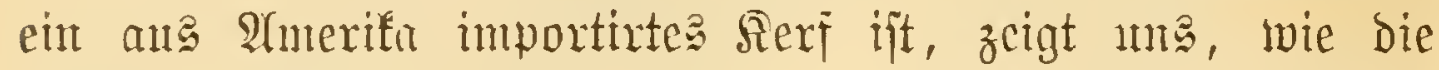

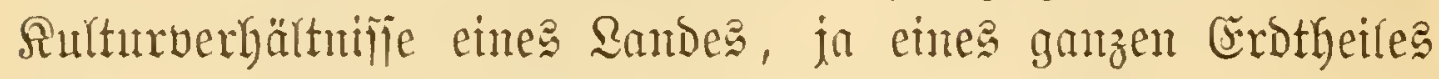
Durch "answärtige" Feimbe gejoübigt nut, went bie Phylloxera-Berkeernngen in biejem Maje fortidyreiten, auth ver= änoert weroen fömmen.

Sowie uns aher eine elende Blattlau dazu zmingen

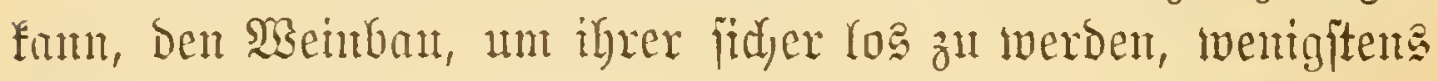

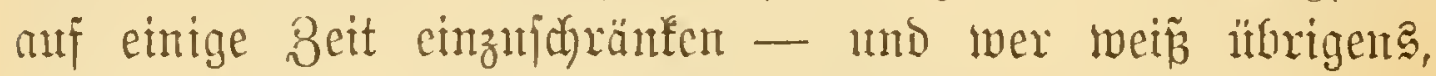
ob Dieje Aerfe Dam midgt anbere \$iflanjungen bebrohen? fo fant der Coloradofäfer, Der fdyon jeit Sangent in ben

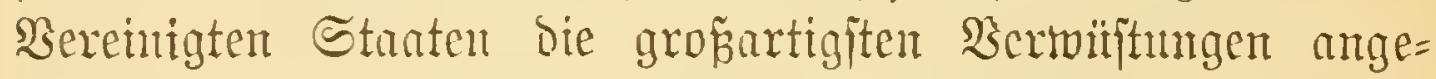

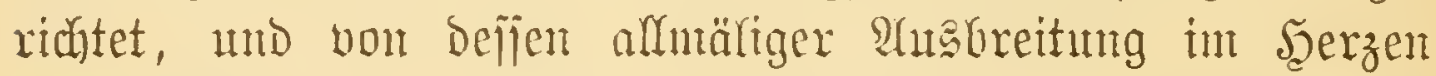

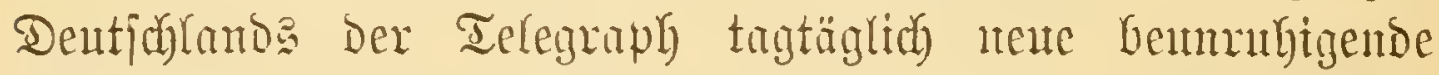
Radyridgten bringt, möglidjermeife eine antere nodi) widbtigere

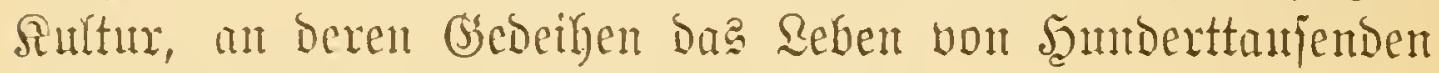
bängt, näm(ich) Den Sartoffellau gefäbroen.

\section{B. Pluten Der Snjetten.}

Die Sortbeile, weldye uns pon Den Rerfen fonmen, füt theire mittel=, theirs ummittelbare, mo weroen namentfich die

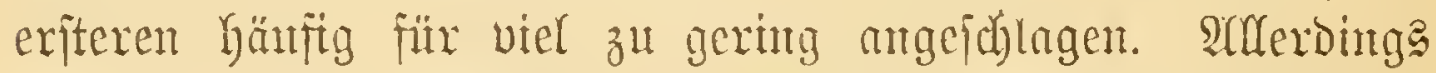

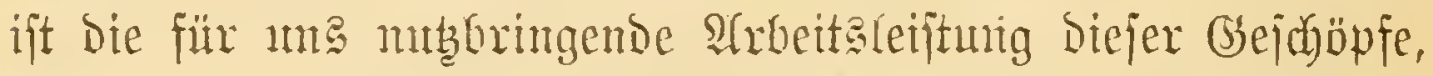

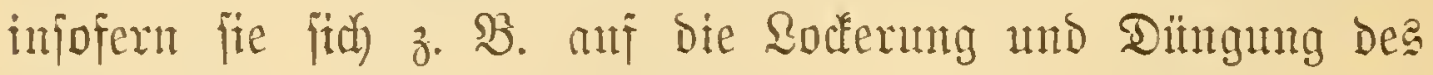
Shefexlandes, bann auf bie aluąrottung getwifjer unfräuter, auf

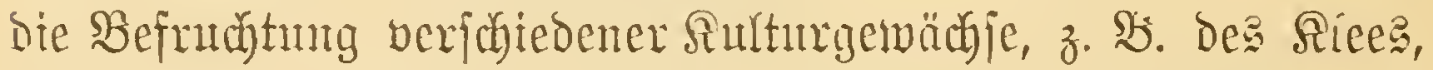
Dann anf bie Säntherung bes Şodeng nt. F. w. Gezieht, nidjt

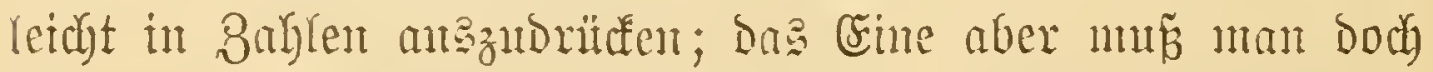

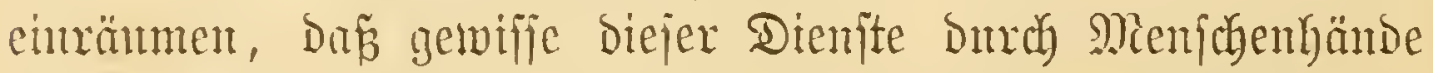

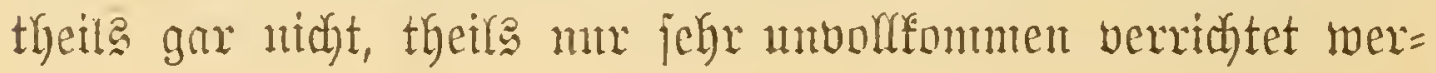




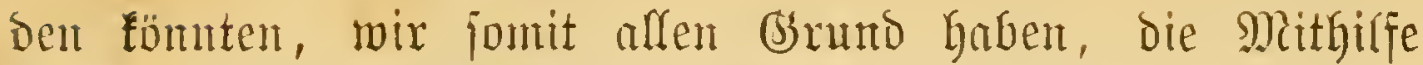
bicjer unbezahlten arbeiter Danf́bar auzuerfemen.

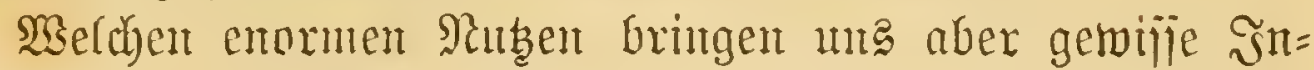

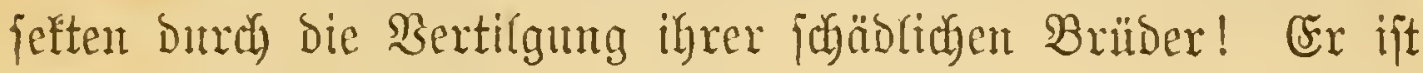

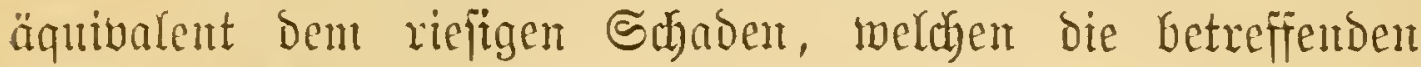
Pflanzenfrejier anfellen witrden, wem fie nidft rechtzeitig vernidytet müroen.

Die Aunbferfe mb Schlupfmeapen fund in Der That bie Erryalter, Die Schirmtnogte der Segetation und Damit miere erjten Bundeggenojien in Rampfe mit Der relebten Natur.

Da aber bon biejem nittelbaren Nuben Der Rerfe johon frither bie Rede wax, gehen wir gleich ani bie bireften Sor= theile über, bie fie ma bringen.

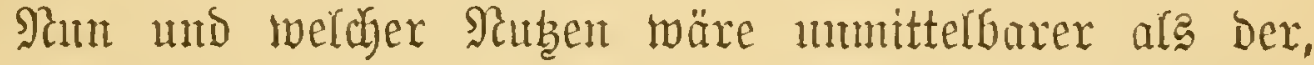
Den fie ung als Epeife gemähren? Doch Der Sejer wiro lärbeln. Sidytasoftomeniger ift es eine vielfeitig verbürgte

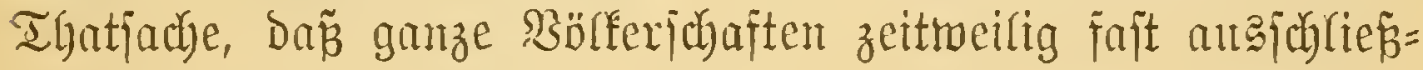

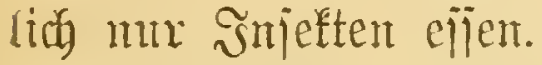

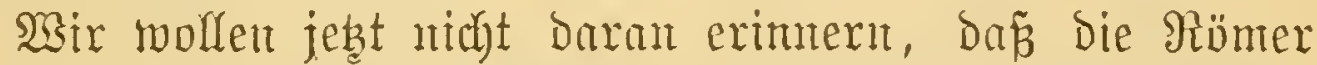
bie mit feinem Miegl gentäpteten Cossus-9łaupen für Lecfer=

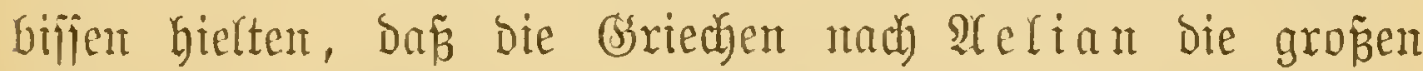

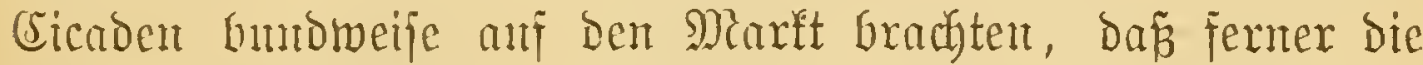

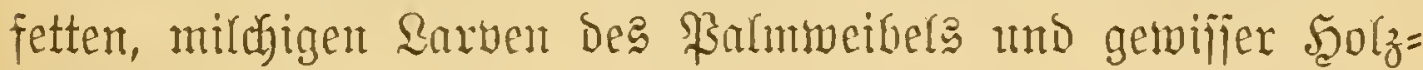

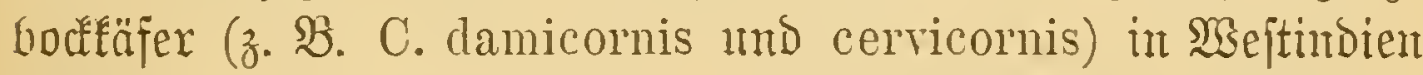

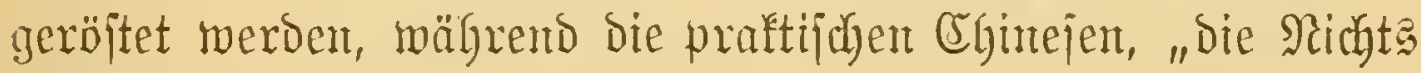
sogtwerjen", jogar bie aus bent Socon befreiten Seibempinter= puppen anf bie Tafel bringen; baz fint, wiro man fagen, ver=

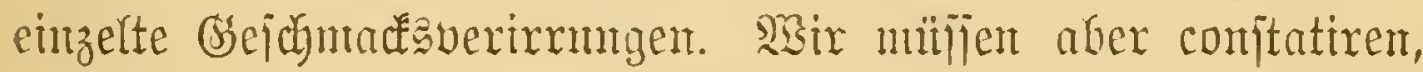

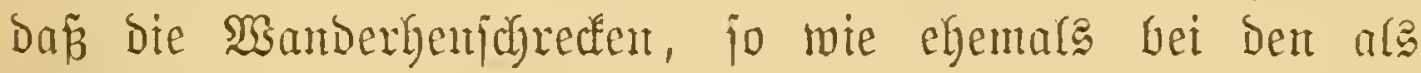
Acribophagi gejchnähten ßartferm, noch heutzutage in gemifien

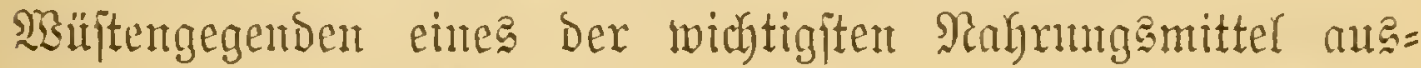
machen und jowohl, gleidy dent Termiter, roh als arị bie veridjiedenjte Weije zubereitet, gejotten, geröjtet ober zu Mehr 


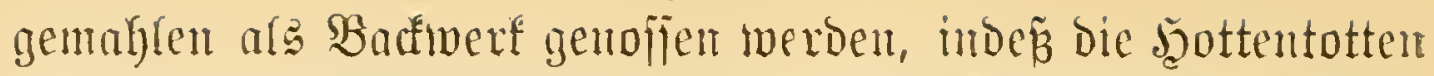

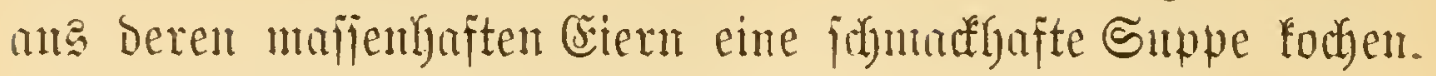

UnD milifen wir aud mit Scopoli fingen:

Quibus has delicias non invideo,

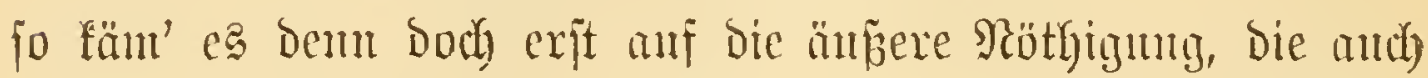

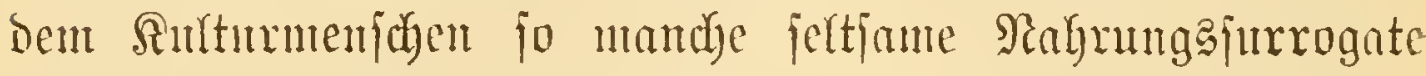

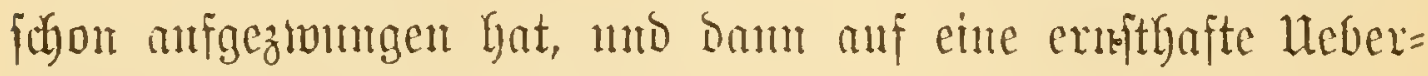
mintung gewifier Borurtheife an, hevor wir vermultigerweije

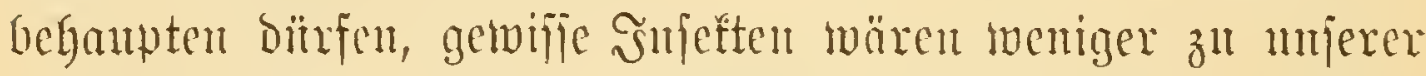

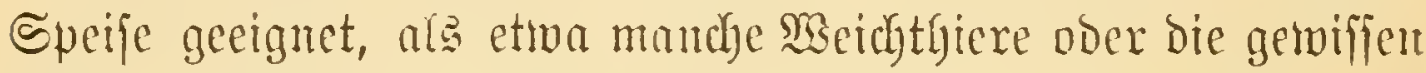
Eingemeiderwilrmer, weldye in Der Delpfanme des neapolitani=

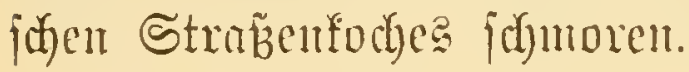

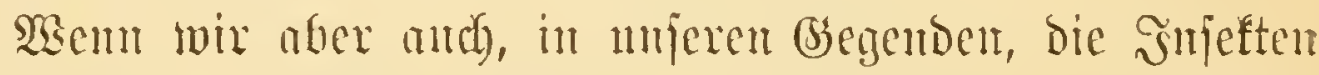

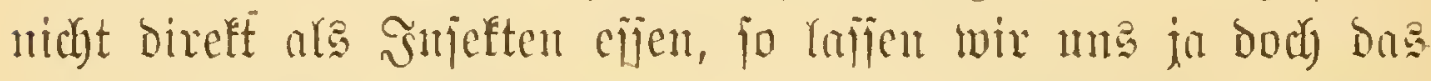

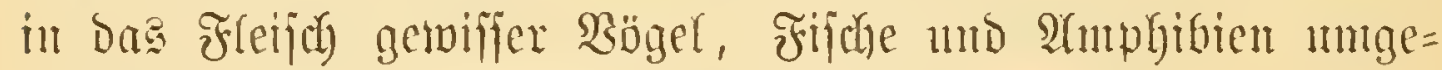
manderte Rerfprotoplasma ganz trefffich munden.

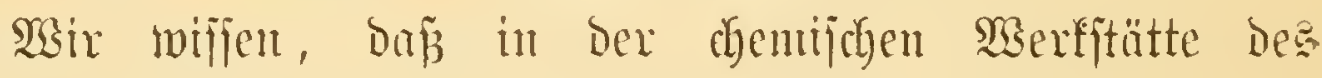
Pf̆lanzenorganisung allerlei $\mathfrak{A r z m e}=$ mo Färbejtoffe, jomie andere z" tedynijuen Zwecten widytige Materien bereitet wer= Den, mo manthe derfelben mögen aljo auth in ben 2 eif bex

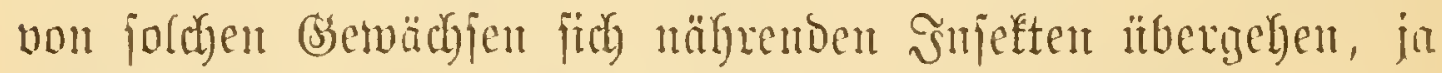
zun Theil in ifnen fïh concentriren und anffpeidgern.

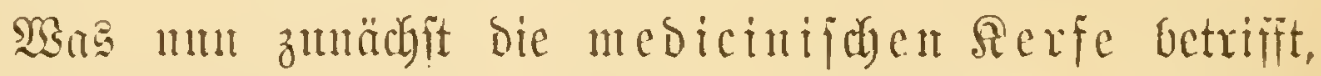
ju faben bieje feiner Beit, gleid) Den becilpfinuzen, eine vid größ̈ere Rolle gefpielt, wovon ms fpeciell ein Räfer, ber fïr Buhnf(c)merzen empfoldene Curculio antiodontalgicus in feinem

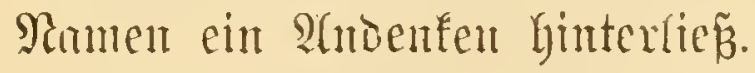

(Gegenwärtig fonmen höchftens nodh gewijie Gajenzichente Snfeften, wie bei me bie Lytta vesicatoria und bie Cetonia aurata, in mocru Rändern bie L. cinerea unb vittata, jowie Der Mylabius cichorii in Şetrucht. 
Eine bohe Bedentung baken hingegen jelbjt nod hent= zutage, wo bie orgunif(k) Rigmente immer mehr von ben mineralifach verorängt werben, bie farbjtofflicferuben (rexie.

Sowoht für bie Tinte= als für bic Berbjtoff = Snouftric in $\mathfrak{A}$ ggementen find in eriter Rinie bie von ben befannten fleimen şespdyen herritgrenden, theils int reifen (blaten),

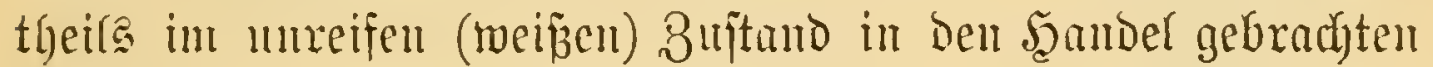

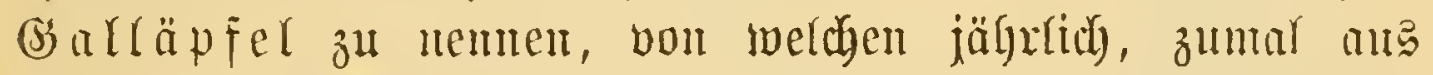

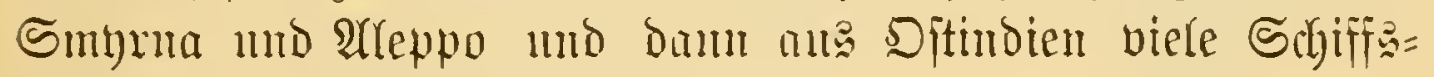
labumgen nath (Europa foumen.

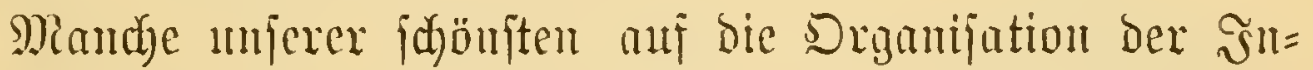
feften bezüglichen mifrojfopijagen Sräparate verbanfen befant=

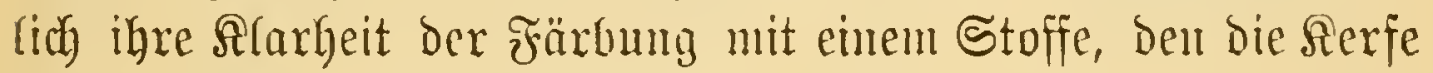
jelbit beijtellen, den Sirmin.

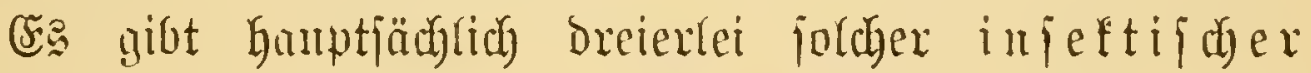
Sd a r r a d b p i guente.

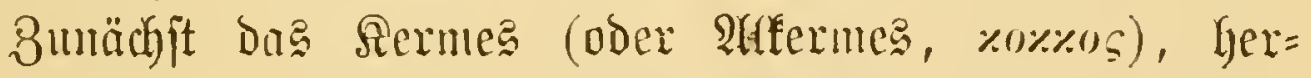
rührend von einer flemen Schilblaus (Coccus ilicis), bie auf dem Quercus coccifera, namentfich in füblichen Frantfreid) jegr häufig ift. Mit biejen jäbün Roth twmben ehemals bie berïhmten Brüff̈eler Tapeten tingirt.

Den zweiten Farbitofi liefern bie fog. polnifhen Schurlach) förner. Sie ftammen bon Coccus polonicus, meldye ant ben Wuxzeh eine befannten Untrante L., lebt. Damit färbten emilt die Tïrkinnen ifre Pägel.

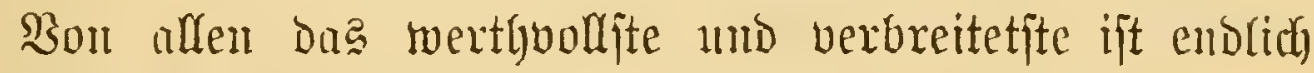

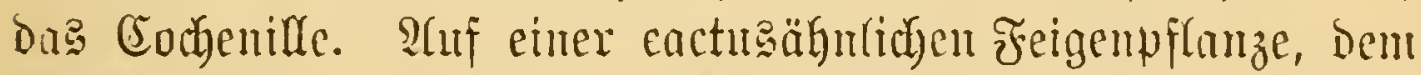
Plopal, lebt cine bejondere 2(rt Schildome (Coccus cacti), Deren im trocfenen 3ujtande rotben, runzeligen Rörnern ägnliche

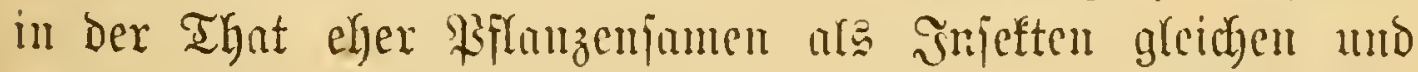
aud binkfich bis in bie menere 8eit für joldye gehalten 
murden. Die Cochenifle= Sultur wurde in Mexico bereits im 16. Sabrhmoert vorgefmben. Begenwärtig bejtegen nament= lich in Saxaca gropartige "Sopalerieen". Der Matbau gejobieft Durch Stectreijer, anf weldye Damu bie "Saat" (Semilla) in

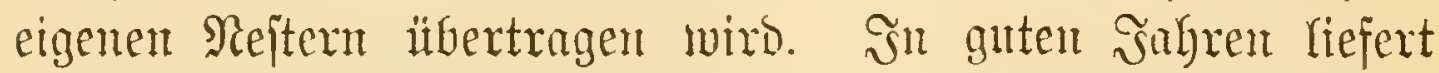

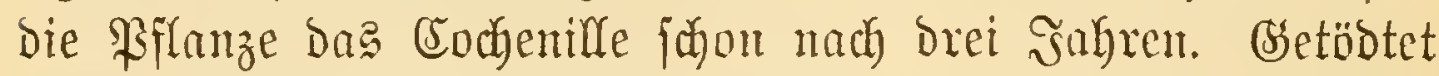

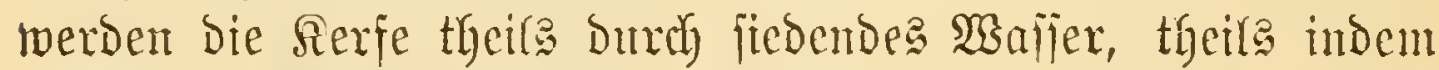

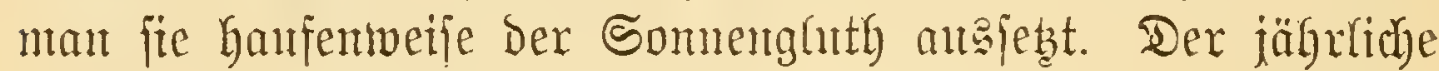

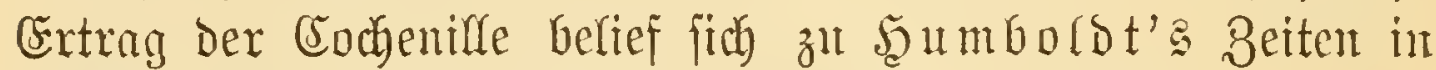
Sitdaneriffa alfein auf über brei Mrillionen Bbulden.

Fin ïberans midytiges Serfprobult ijt ber vou melyreren

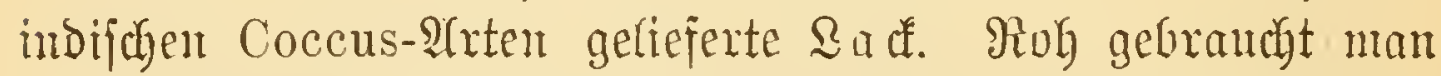
ben "3weiglac" in feinter secimat zu Schmmefgegenftänben, Dann, mit Sand vermengt, zu Exhleiffteinen und nebjthei nod) zux Tintenbereitutg. Die eiuzeluen Raffinimugajtabien Dcs=

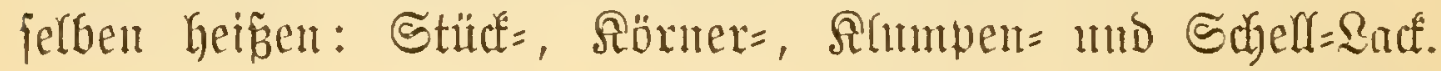
Den Merth besjelben zu berjutesenen tednifden Zwecten femt Der Rejer. Mebrigens foll ans ifm auth ein rotger Farbjtofï gemonnen werden.

Den Borjdyg geaumur's, Den oft gar materijden

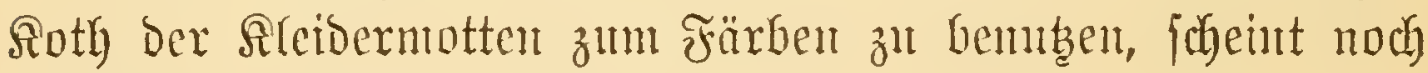
Niemant rearifint zu lyaben.

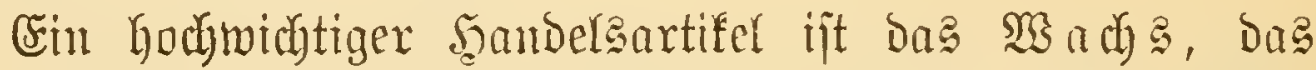
bie Ŝnjeften licfern, zu bem jedoch, twie zu jänmtlichen von biejen Thieren Gerrïhrenden Produften in lebter Sinte die Riflanzen Den Rohitoff Yiefern.

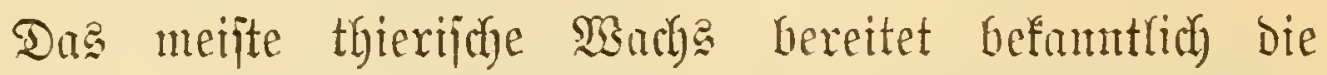

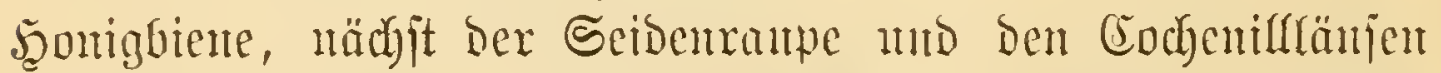

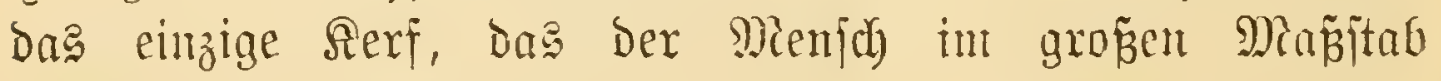
fultivint und ansucutet.

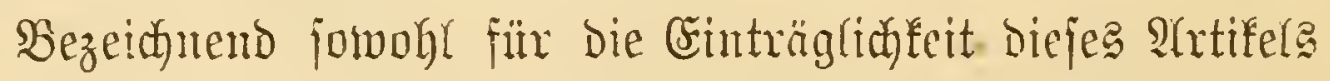

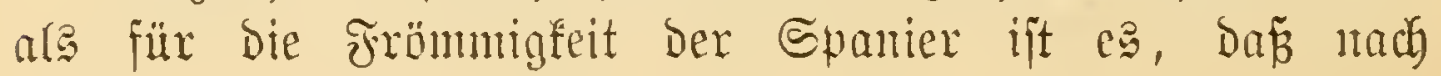




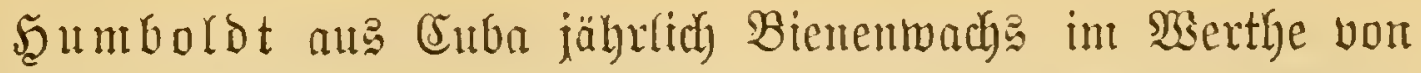
90,000 Bifo. St. madh Sitdamerifa lediglidy zux Fabrifation ber Rirchenferzen augefeülyt twurbe. Der Ssejammterport aus Cutba affein betrug gegen zwei Millionen Gurben.

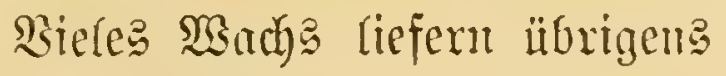
auch mehrere excotijuc Coccus-2rrten.

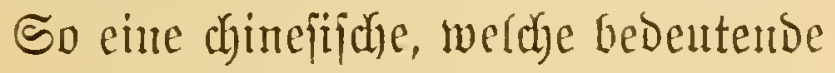

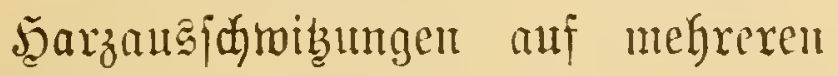
SBäunen verurjacht. Die fpibhut=

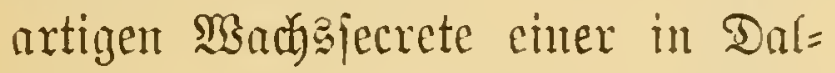
matien auf Dem Selbaum borfome menten zeigt beiptehente Figur.

Nebjtom gibt es in Craile eine majienhaft auf getwijien Driganmu= arten lebende Raupe, bie an ben

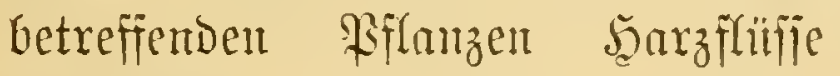
verurjadyt.

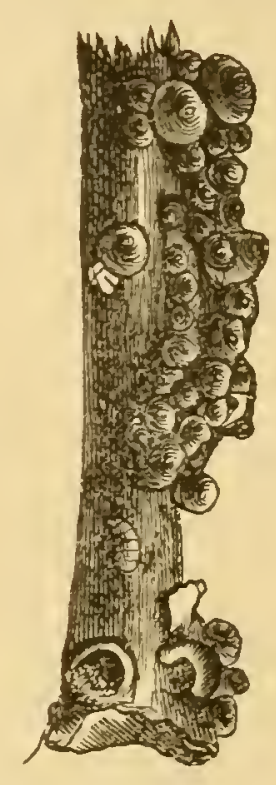

Fig. 105.

Stüct Srivenztweig, infruptirt mit

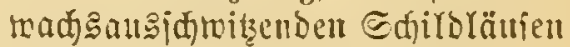
(Ceroplastes rusci L.), mat. (5rr. wiener 5oimujeun.

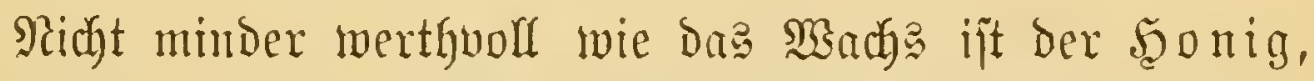
Den uns die Bienen geben, und behnte Deffen Geminmm

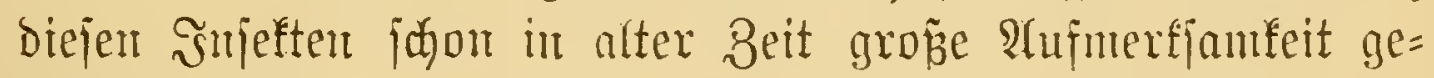
roiomet wurde.

Sowie Die heutigen Aegynter auf bem Ril ganze Rara= manen von Bienenftöcfen haben, bie jie, je nad ber Sabres=

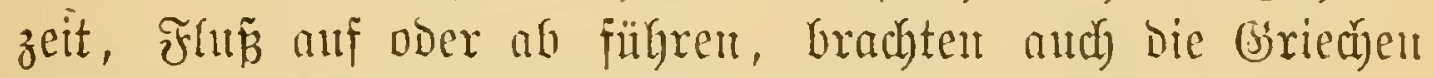

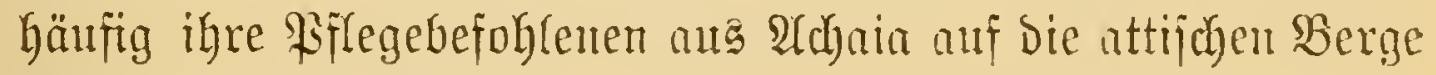
in bie Sommeririjale.

Der Şonigertrag ijt in getwifjen Bregenden ein äuñerit beträbthticher, wie Dem z. B. nath Rirtin in manthen Diftriften Sitdrufilands mo Spantens die Banern melyr ans ifren Bienenjtöcfen als ans Den Rompflanzmugn ziehen. 


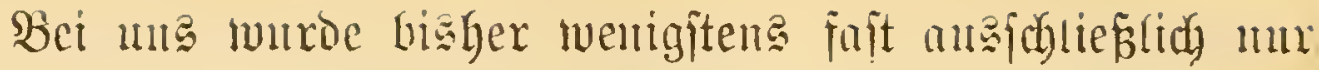
bie Apis mellifica gebalten; jiiblicher ift eine Afbart, bie

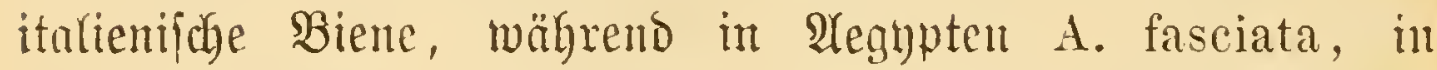
Snbien A. indica, an Sentegul A. Adansonii, anf Mandagagtar A. unicolor gezähut wurbe. Rach Fabricius wären und bejonders A. acraensis und laboriosa fur jeonigtracht zu entpjelytell.

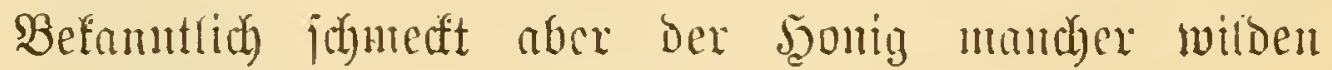

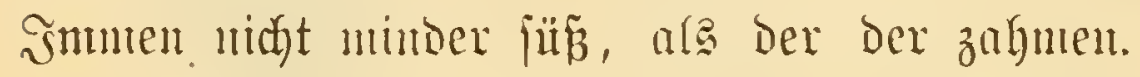

So wirs z. $\mathfrak{B}$. ans Den tranbenartigen, an Feljen häıtgenden $\mathfrak{B a b e n ~ e i t r e r ~ j o l d h e n ~ D e r ~ f a j t ~ w a j j e r f l a r e ~ " S t e i n = ~}$ honig" mo auf Der Grifer Şourbon eine leshaft grüne mo fehr gewingreiche molde Sorte getwoment.

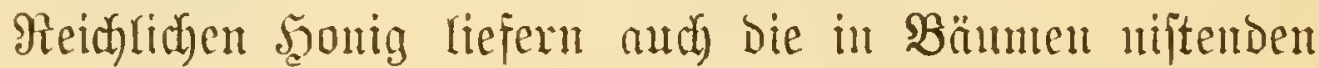
Trigona-9rten, Der manthen wilden Bölferfidaften als eiu Jeauptnahrungsmittel bient.

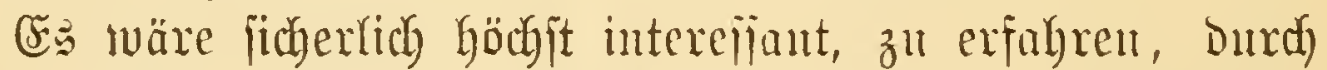
weldye Bufälle ober Durdh weldye Beobachtungen Die Mentathen

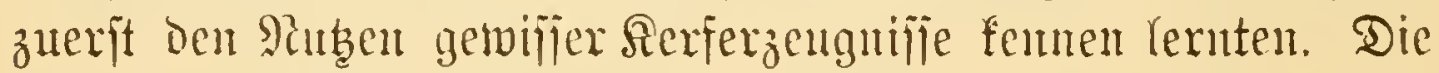
Brandjbarfeit Der Raupenfeibe fot jid aber yleidfoum won jelbjt Dar. Doer was ift natiurlicher, als baj ber Menfich,

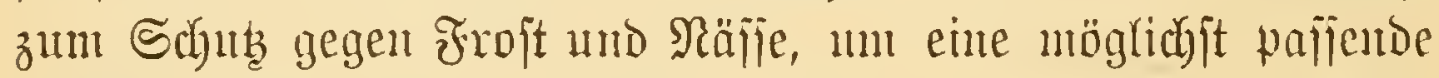

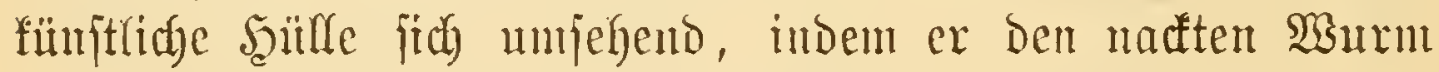

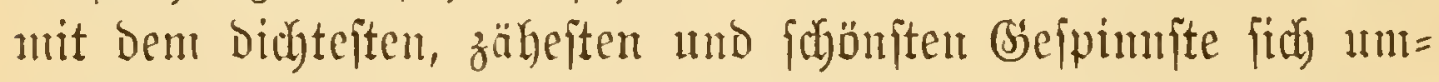
wicfeln jah, auf den Einfall fam, biejen fremben Rleidjtoff zu jeinem eigenen zu madjen?

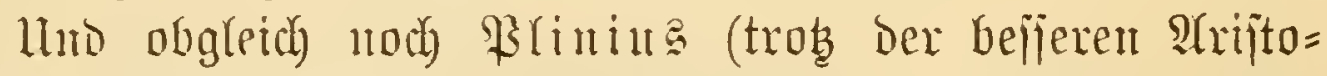

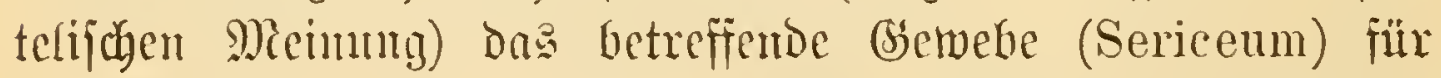
Die Eingemeide einer Epinne hielt, exzählen uns dody bie

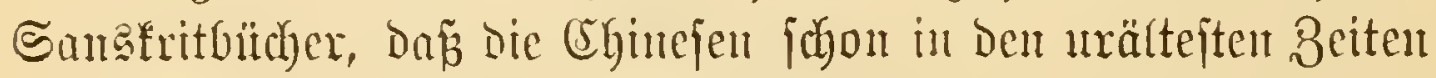

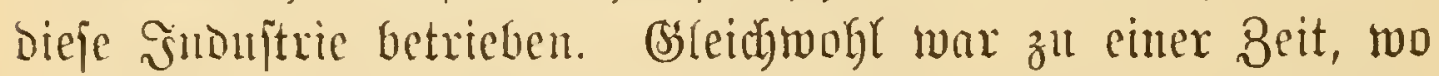

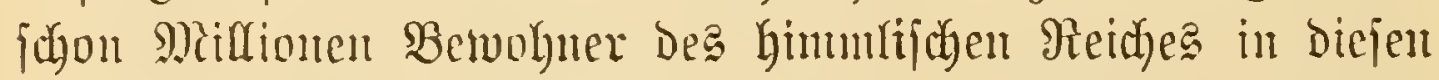

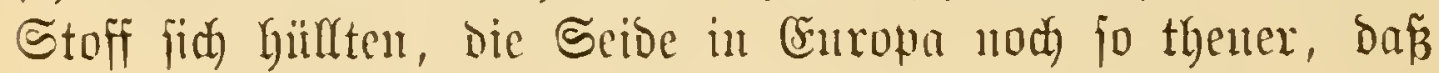


felfit die Gemahlin bes Saijers Aquecian von ibrem Gemabl

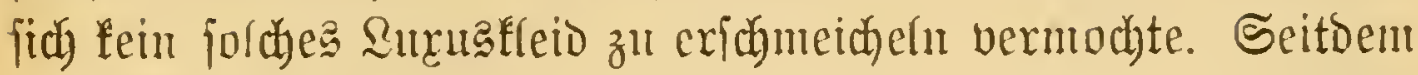

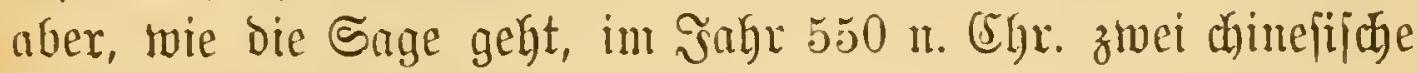
Mriffionäre die mit $\mathfrak{A}$ rgu?antgen bewadten Bombyx-Crier in

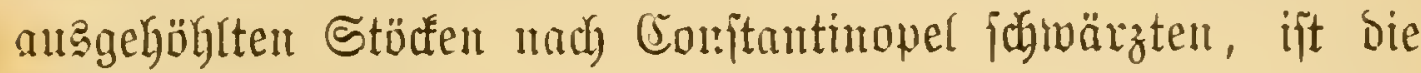
Seibenraupenzudyt unb Die Seibenindriftrie überlyant and

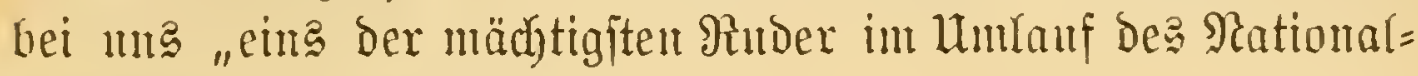
reidjthums" geworocu.

Auper ber Seide vou Bombyx mori wird in CGina juthon

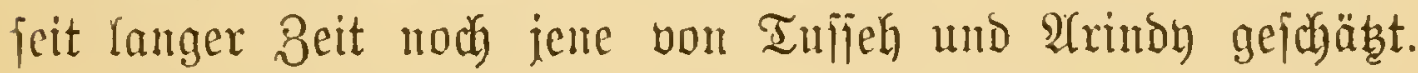
Erijtere jtamut von Dem anj Dem Šsughbebaum Kebenden

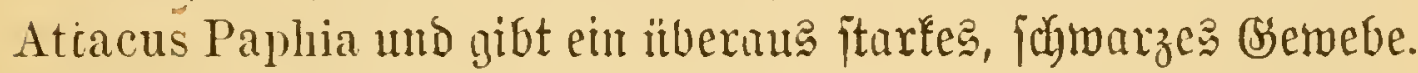

Die von $\mathfrak{A}$ rintond liefert bie auf Ricinus communis befind =

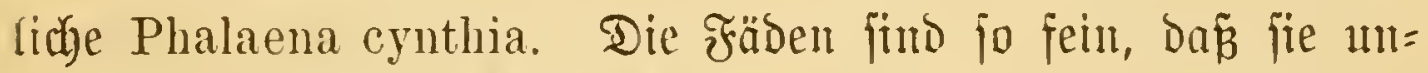
möglich abgemicfelt werben fönten. Man zerfajert bie Cocons und fpinnt jie Dann wie Baumbolle. Dafür hält bam aber and cin joldhes setwebe jo zu fagen elvig; Ein Rleio reidyt fürs ganze Reben ans.

Nebjtbei verarbeiteten die alten Meriffaner nod) bie (Sejpinnjte

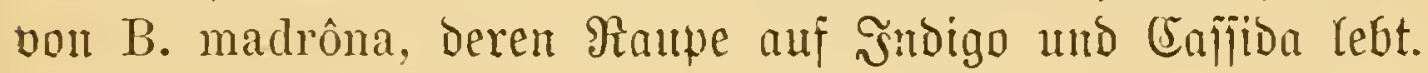

Da ber I). mori, trob Sagrhumberte alter $\mathfrak{s e r j u c h e , ~}$ abjolut nichts 2hoeres ala bie Blätter bes Miaulbeerbaumes

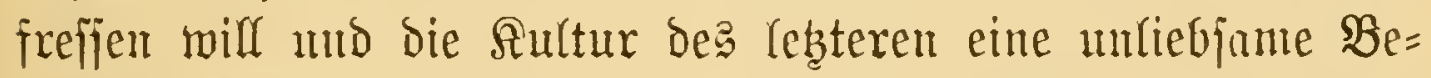
\{chränflung Des "Seidenbanes" mit jidh bringt, hat mall es and bet 1 ms mit einigen andern Spintmen probirt.

Das Meijte fobeint oer B. Pernyi zul verfwrechen, ber mit Eidyen= und Buthenlaub zufrieden ift.

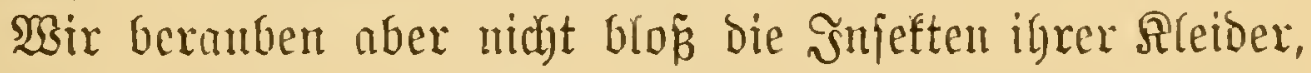
um un Daraus die eigenen zu verfertigen; die wie Dą föjt=

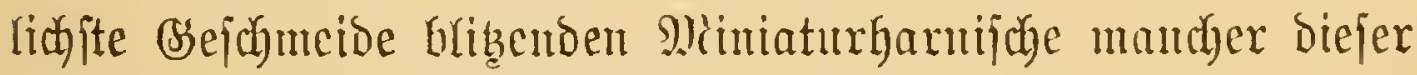

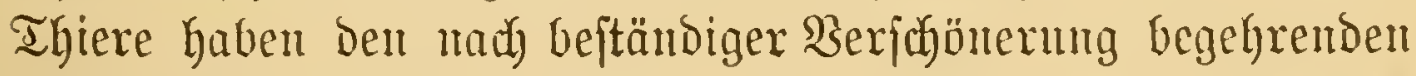

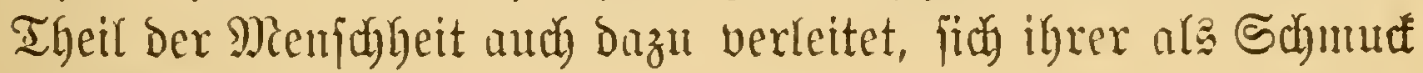
zut bedientr. 



\section{Dergleichende Entwidflungs= geforichte.}





\section{Ilycil.}

\section{soltwidklutig int Sit (Siltbrnogenefe).}

Das "omne vivum ex ovo" gilt z’war nidgt melgx für alle Thiere ganz atshahmslos, aber bod) nody für bie

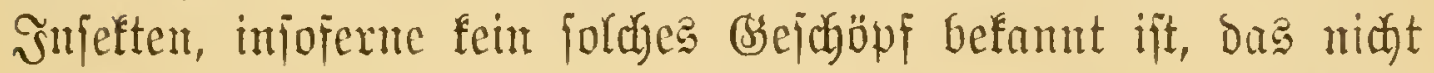

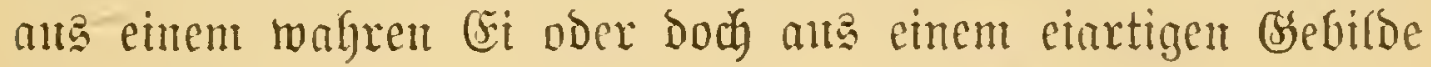
hervorginge.

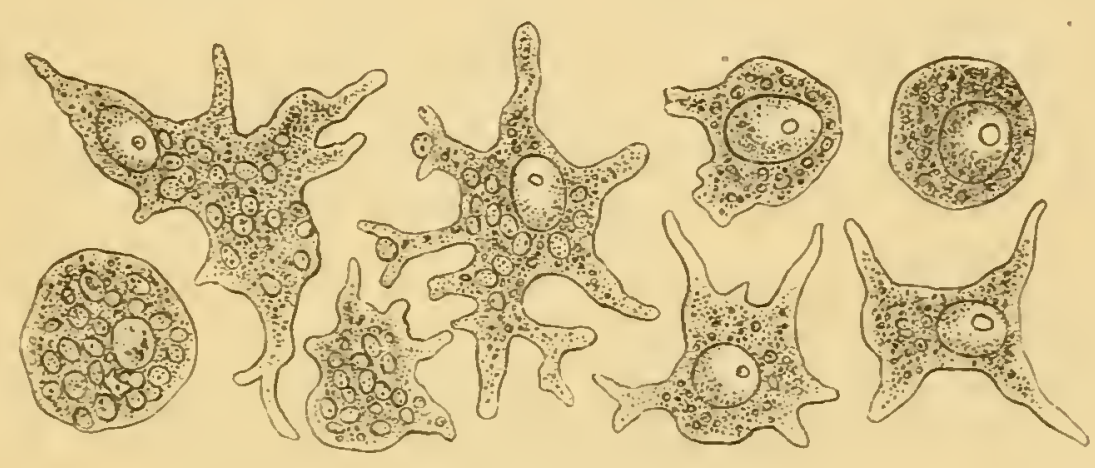

Fรig. 106. Mmöboìzeffer.

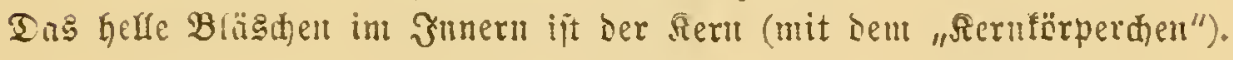

Inter cinem (si aber veriteben wir in geitaltlicher $\mathfrak{B e}=$ ziehutg nidyts Anderes als eine "Zelle", Deren "Rern" (Fig. 106)

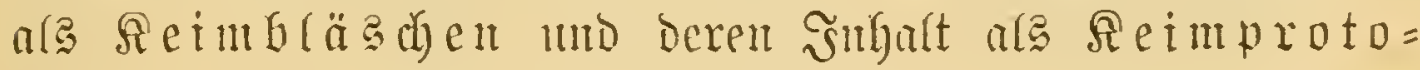
plazma oder Dotter bezeichnet wird *).

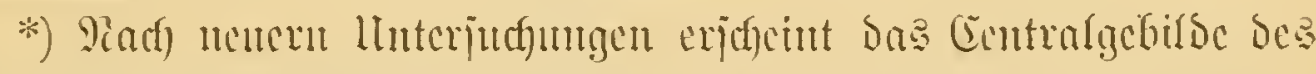

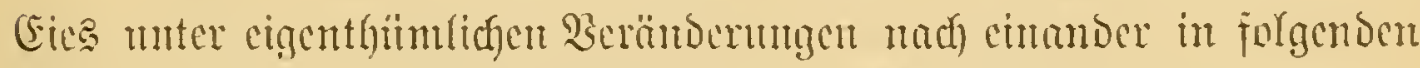

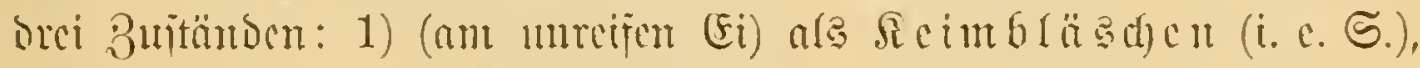

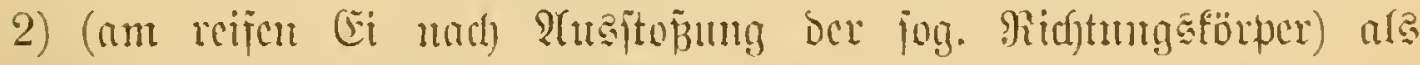

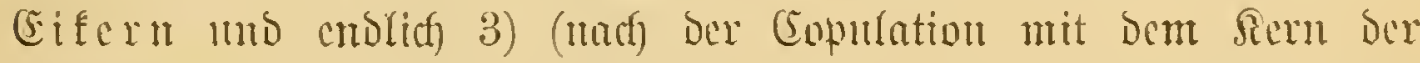

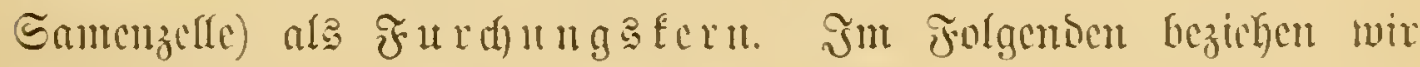

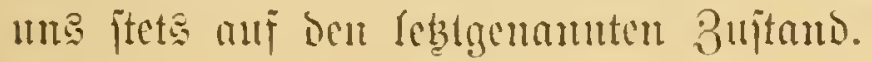


Somolk mut Das (Fi, nady Der gegebenen Defünition, zu ben allereinfachjtent Rebenggebirben gehört, fo ipridgt jich, in gewifjem Simne, Dod) fdyon an ifm bie Mannig=

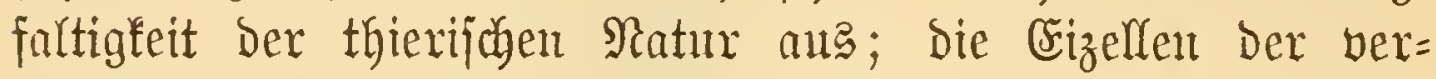
idjiebenen Thiere jüb mänlid), analog twie bie Samenzellen,

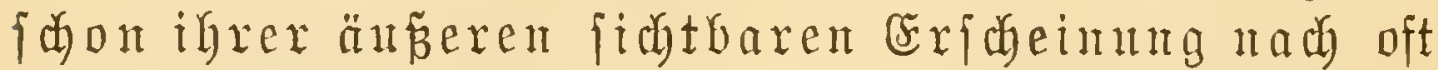
jehr berjadiedent.

Mandye niedere Thiere, twie z. $\mathfrak{B}$. Die Sdymämme, die

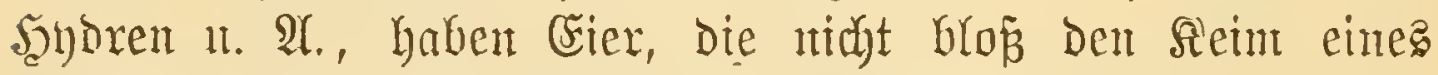
aftiven Rebents in fid) tragen, jonbern bie jelbft fidon cin

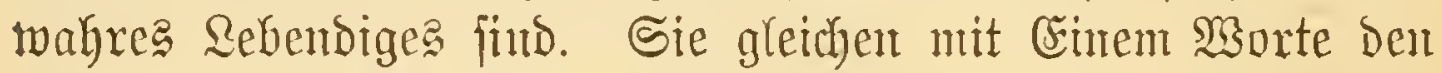

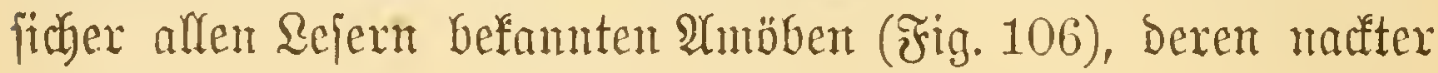
Brotoplazmaförper bejtändig feime Form medyjelt, Durd im=

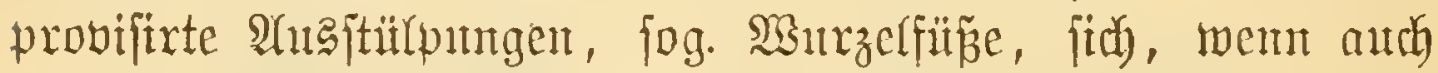

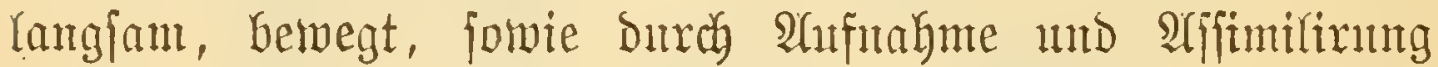
frember Stoffe fich vergräpert ober wäbjt. Soldye Eiter atemten wir baher aub̈boibe $\mathfrak{M r}=$ earer.

Die Crier vieler anberer (nieberer mid häherer) Thtere

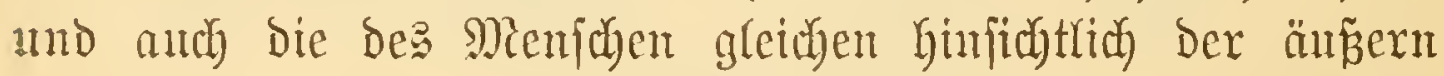
Bejchaffentreit Deas Reimprotopla:mas

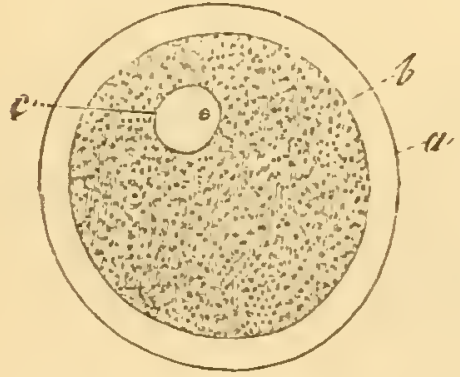

F̧ig. 107.

(Fizelle bes Menjđin, unbejuditet, 250 mar vergröjert.

a Fifürre, b Dotter, c fiein= bräs丸en mit Den! Reimfledte. fajt volfitündig ben genamnten, mux

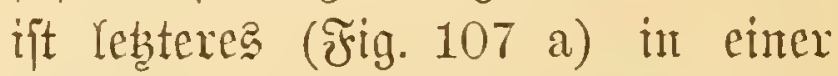
melyr ober wentiger biffen heitlle ein= geidlofiten. Soldye Seime memen wir eiutgefapielte ober cucbjtirte $\mathfrak{H} \mathfrak{x}=$ erier.

Beiderlei Mreier, bie nacten urd betweglichen jowie bie eingelapjelten und unbeweglidyen, haben vor Armem auth Das Semeinfame, daf́ bie Maffe

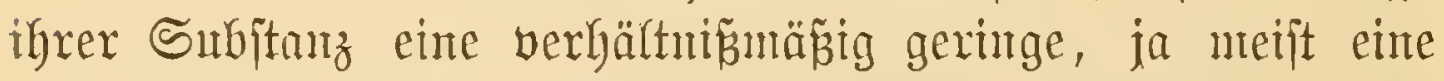

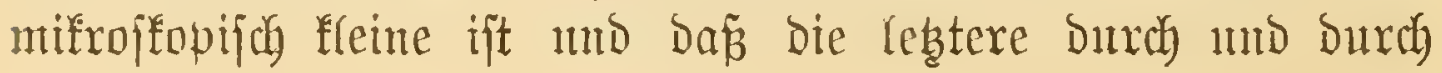


relativ gleichartig ober homogen cricheint. Da ferner bei

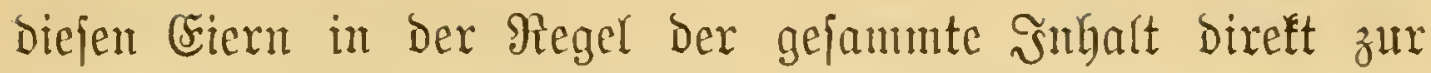
Bildung des Embryo verwendet wird, fo nemt man ifn aud Birdug gadotter.

Nun gift es nody Cier - Der Sejer Denfe an ein

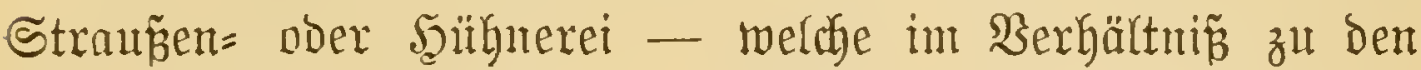

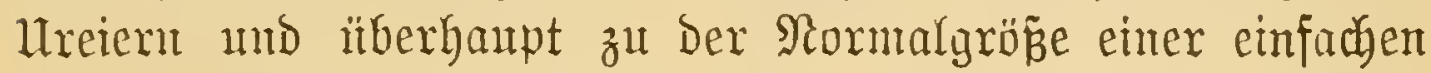
Belle jo riefige Dimenfionen haben, Dás man fabn a priori

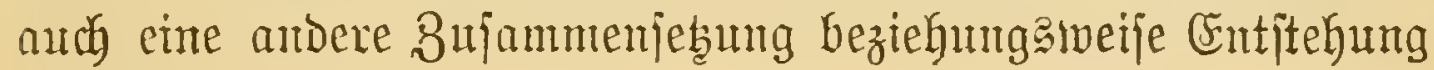

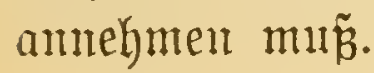

Und in ber That wein jeder Sejer, der eimnal den traubigen Cierjtot einer Jenne gejehen, Daz es Dort jehr

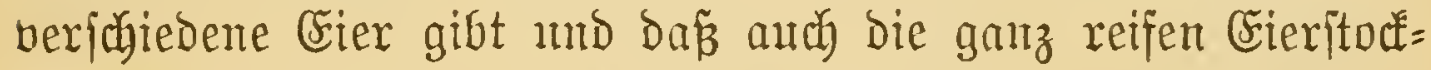
eier ganz antors als bie gelegteu aubjehen, indem u. $\mathfrak{A}$. Dą fog. Cimein erjt jpäter, bei ber Manderung durch bie Eileiter, aus bejonderen Drïfen Ginzufonmt.

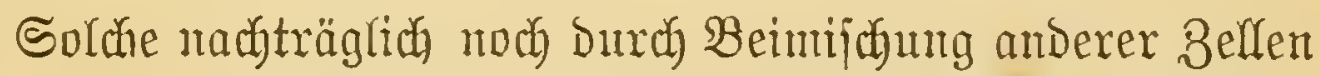
oder gemiffer Yrbjonberungen bon folchen vergröperte Frier

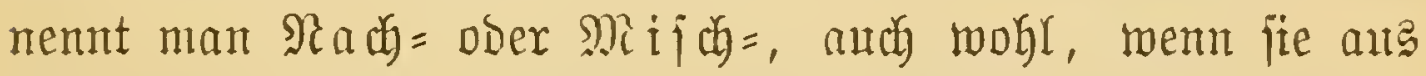
mebreren ganzen und editen Beflen entitanden, zujanmen= gefebte Fier, und Den Jnbegriff aller biejer in Das Urei

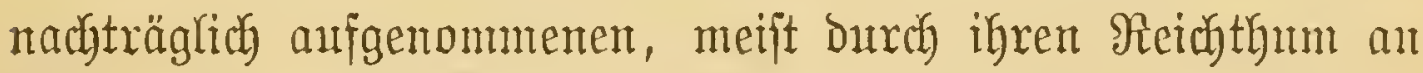
Fett und Durch eigenartige Forntheile alsggezeichneten Sub=

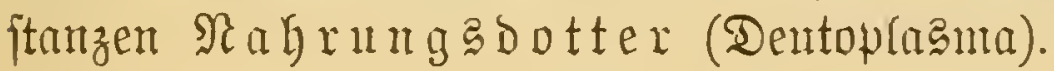

Lebzteres Desmegen, weil Derjelbe nidht dirett als Bau= material vermendet wirb, fondern mux allmälig von ben eigent=

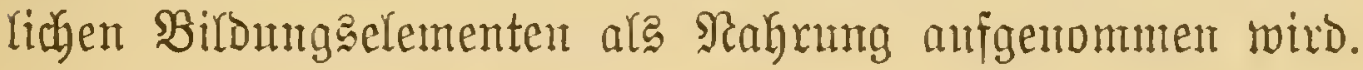

Nun, um enblid auf unfer eigentfides Thema zu fonmen, zn weldher Sategorie gehören bie Snjeftencier?

In bieje jomie anth beren Entmictung fenten zu lernen, empfehlen wir bem Rejer zux Mlaifäferjaijon joldye Thiere in 


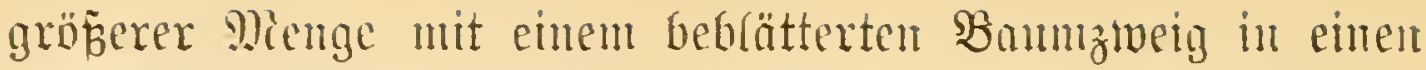
geeigneten säfig zu jperren. Bon einer gemijien Zeit an wird ex Dum alle Mergen Den Boden Desejelfen mit perl=

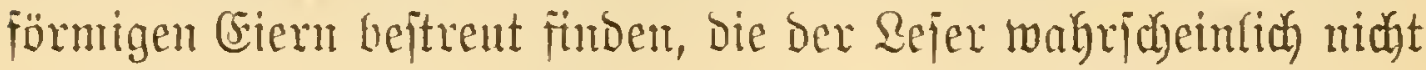

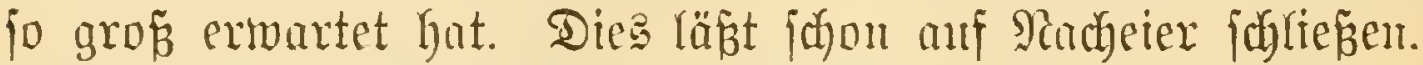

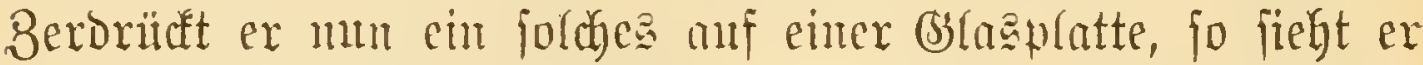

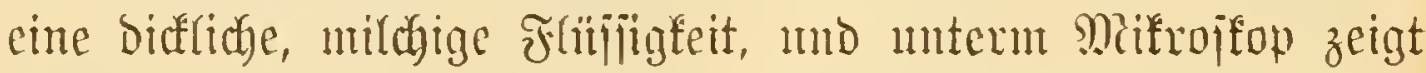

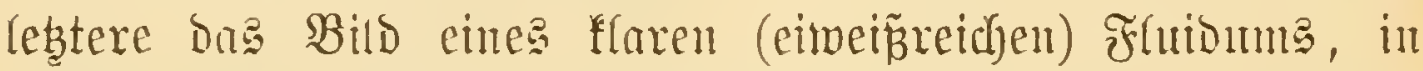
tweldyem aber anfer muzăhligen Fetttröpfdyen nod bejondere

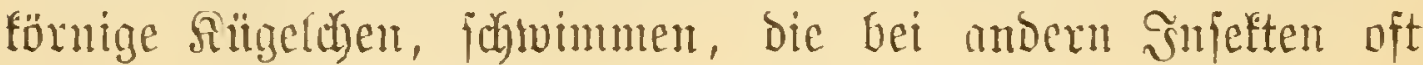

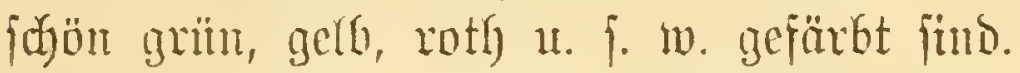

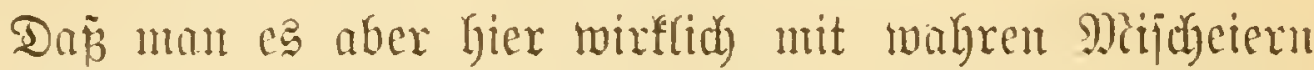
zu thut hat, offenbart fich an fogönften, wemn ntan bexen Entitefung im Erierjtocf miterinceft.

Da fiegt man ju oberjt in ber röhrenförmigen Bildungs= ftätte Eleine Sieme, die Seimbläsdyen, mn mit eimem ganz

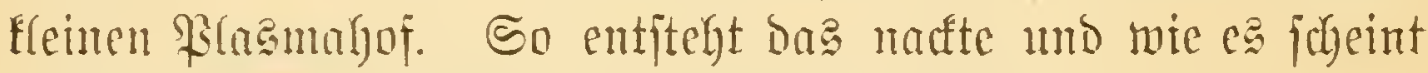

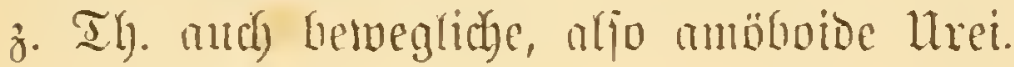

Sndem jebles mu in ber çiröbre allmälig abmärts riteft,

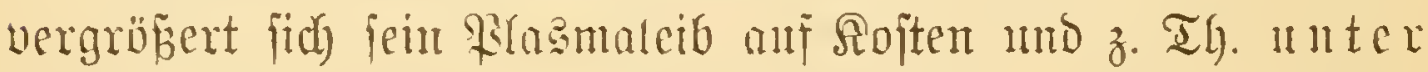

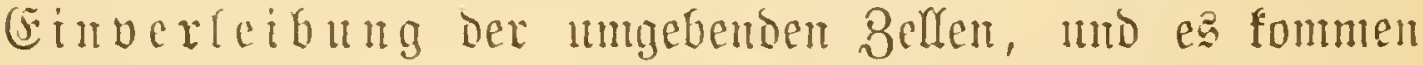
nach mo nach and bie getvifīen Fettrupfen mo Dotter= fügeldyen zum Sorjchein, ïfer Deren Mriprung man nflerding

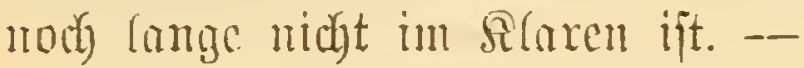

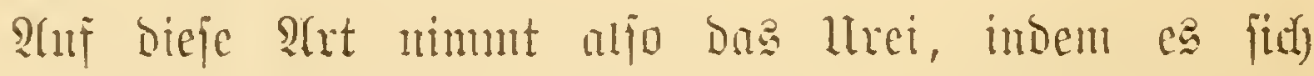
jo zul jagen mit sRahrungagotter mäjtet ober verprovinutirt,

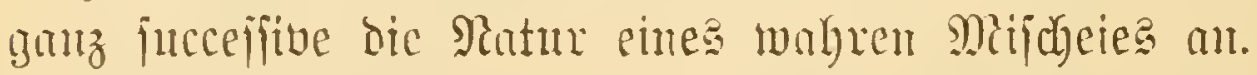

Da ber Rabrungegottex offenbar nidyte Anderes als eincu

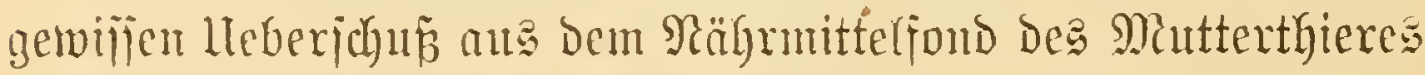
Daritellt, jo veriteht firh wohl wout felbit, onf bie relative Menge

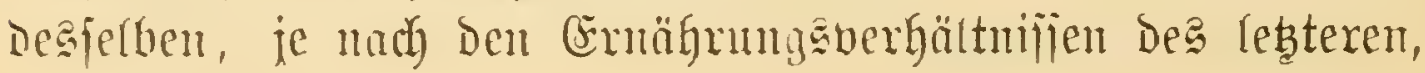


jomoht bei einer mb Derjelben Rerfart als and bei ver= idjedenen Epecies z. Th. eine jehr medjente ijt.

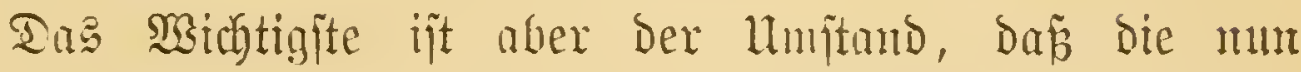

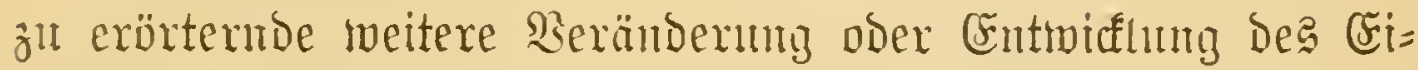
förpers gar fegr von ber Mienge mo z. Th. woht anth bout

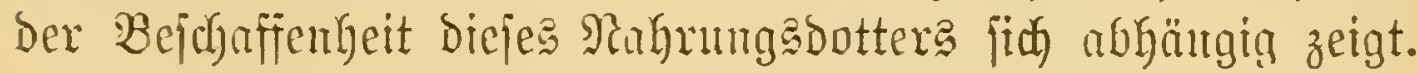

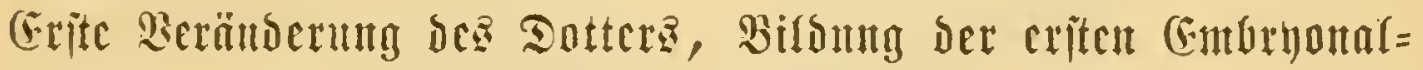
zellett utto ber Sicimblaje.

Da ber in bi zu bifbende (embryonale) Snjettenförper wie jeber högere Drgantanus ats zahlreiden Erementar= theifen, jog. Belfen, beiteht, während das (5i mur eine cinzige went aurh. häuffig aup̃erorbentlich grofe Belle barjtellt, fo hanbelt es jith jebenfallz zunächjt barmu, aus diejer eimen 8clle megrere andere zu erzengent.

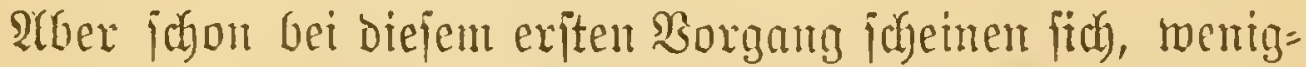

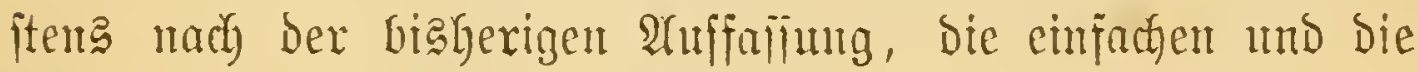
Mificheier jefr mngleich zut verhalten.

Bei ben Mreien berubt bie Sahe nuijt anf einer einfarben

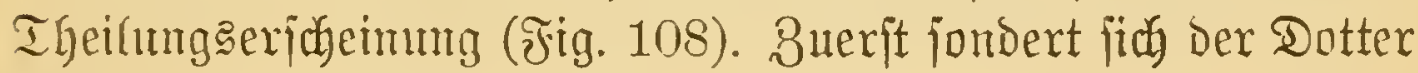
unter vorbergehender Theilung bes Rerng Durit eine immer

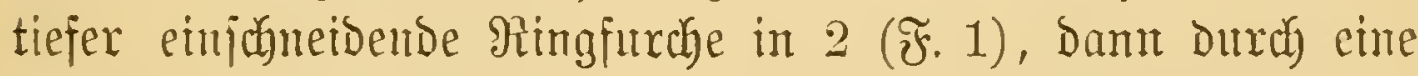
eritere freuzende in 4 (F. 2) und Durdb weitere Şalbirungen in $8,16,32,64$ u. j. m. Theiffüufe ober "Furdungătugeln", uno jo entitegt zulebt aus der einfacten cizelle ein mautbeer= artiger filumpen ("Morula") Eleinterer, aber unter jidr) ähnlicher Bellen, bie eriten Bau= ober Brmubiteme, mit welden das Fumbantent des künitigen Thieres aufgeridgtet twird. Dies nemt man mu bie totale Furaung, ntm müijen wir biejelbe, abgejeljent bon ifrer Einfadgheit, fdhon beshatb fïr die urfprünglichfte unto ältejte amfehen, weil fie vornehmlidy auth bie nieberiten Bellthiere augzeidnet.

(B) raber, Jnieften. II. $\mathfrak{B}$ b. 
Bcvor wir mu dic rinjalägigen Sexïndermugen am

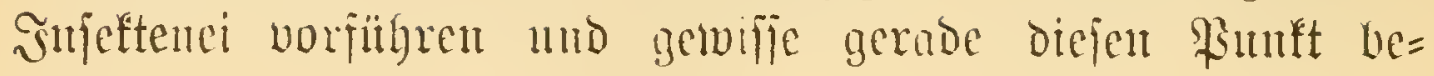
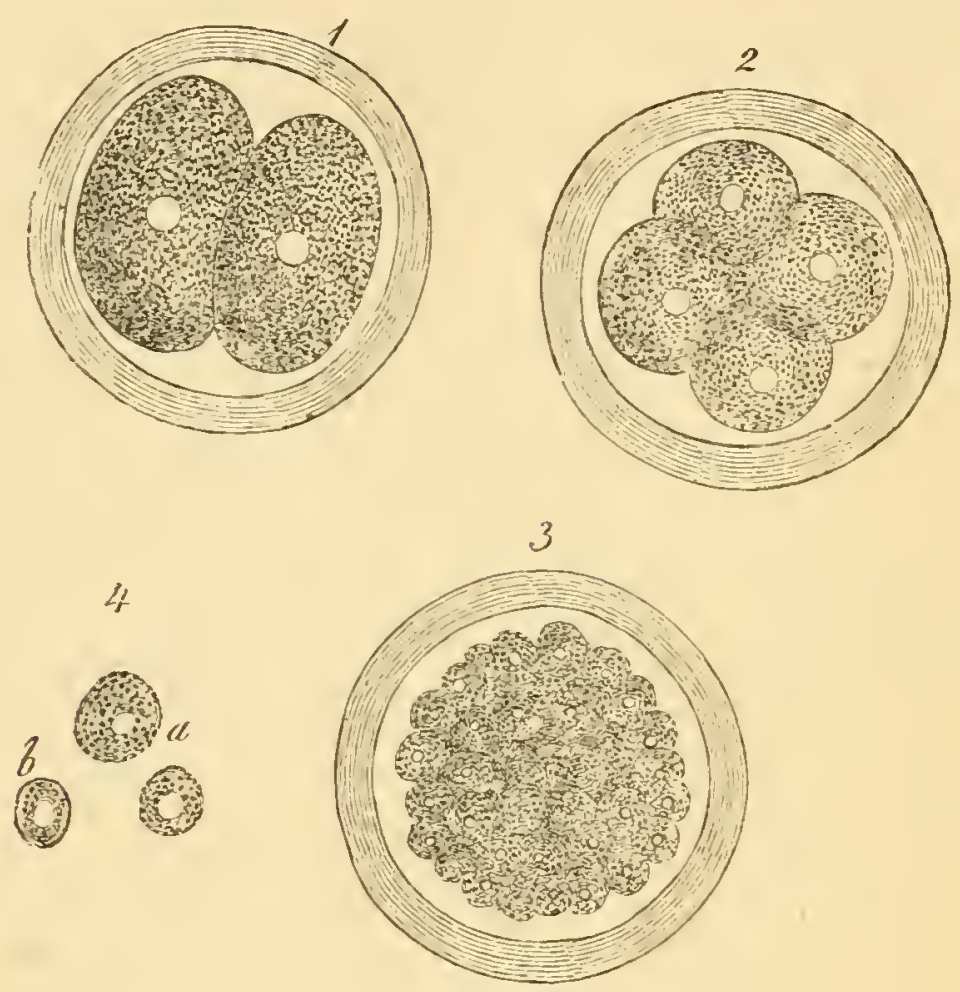

Fig. 108.

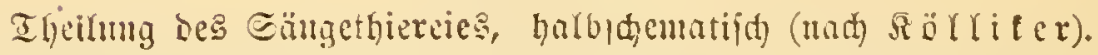

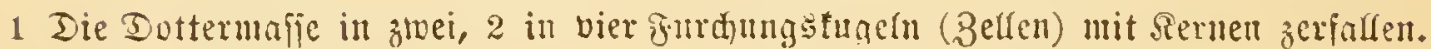

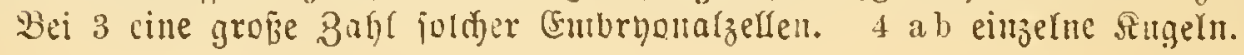

treffende 9Remutgasdifferenzen zux Sprache Exingen, woird co für bie der Entbryologie ferte ftehenden Sejer noty= wendig fein, fie in aller Sürze ïber don Bang dicjer sibijen= fichaft und bejonbers juber die gebräudblichen Metboden Der= jelben zu orientiren.

WBie die fo merfwändige fpätere Entwiafung der Şnfeften, jo Gaben aud die in Rebe ftebendon Borgänge zahlreiche

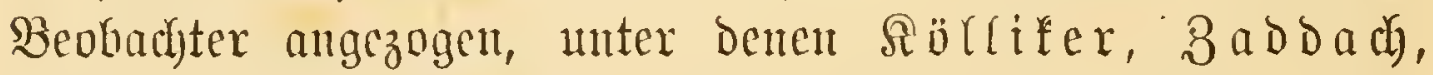
SBeisuan, Bütjdy mo Dann eite Reibe z. Th. Reutart's und Siebold's Schule angeböriger rufjifber

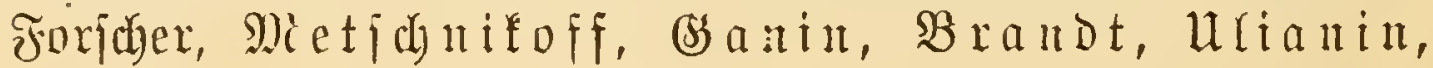




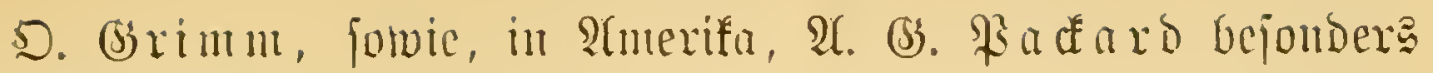
hervorragent.

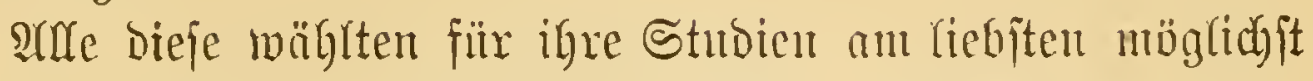
Durdjiathtige Gier, an Denen fie, ohne erjt mïbjante $3 \mathrm{er}=$

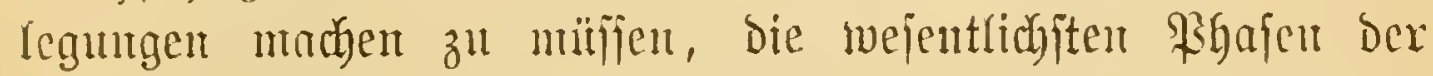
Entwifflung ganz bequent und int gebörigen $3 u f a n m e n t y a n g$ ütherichanen fomten.

Sowie man aber 3 . B. von einem brebüude, felbft went

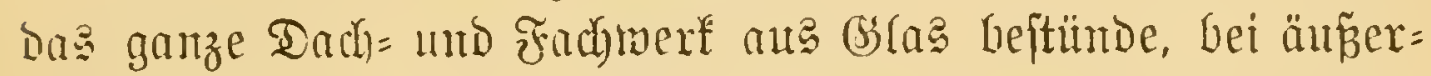

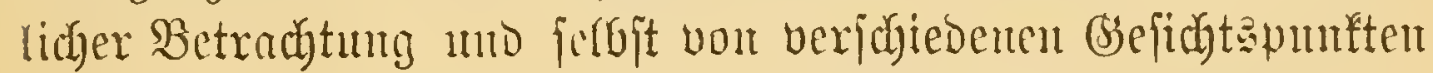

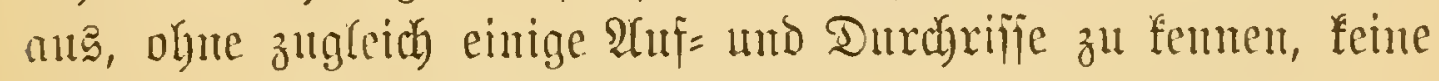
nolfommen ridytige Boritelfung über ben Bujanmentyang Der

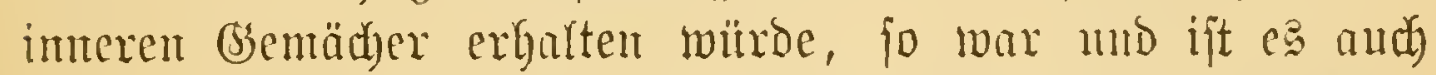

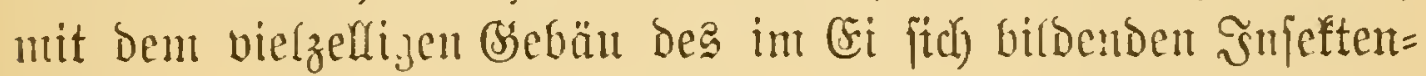
förpers. Heber då Yenzerliche, über die Miodellirung des Embryo, forvie über manche gröbere inmere Serbältuiffe geben

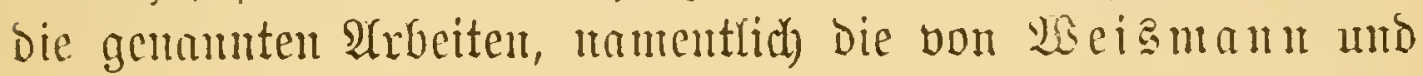
3adDach, bie flarjten and übercinftimmentiten Begriffe; fic fïlyen aber nidyt felten zu viclfach einander widerfpred

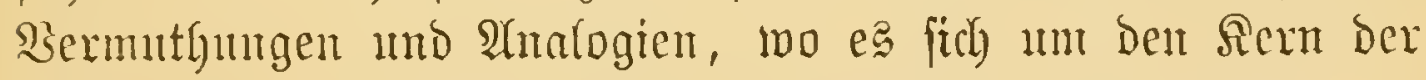
Sache, um die Erfenntnif́ des interen Bufanmenfanges, un die Bitbung und gegenfeitige Beziebung Der embryonifaben Ẽententartycile hambert.

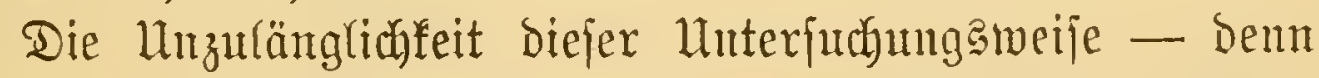
Methode faum man bies midft menten - madyt fich mun gerads bei Der Beurtheilung ber in Rebe ftehenten Borgänge an meiften füblbor.

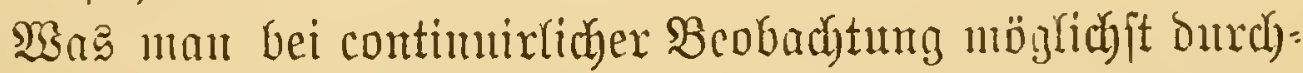
fidytiger Serfeier, z. B. jener von Chironomus nady bent ïblichent

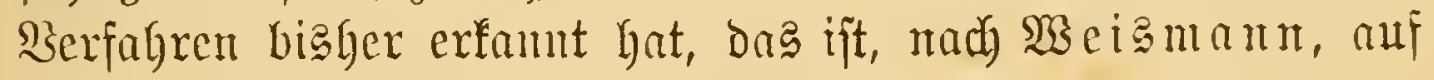
Fig. 109 zu jehent.

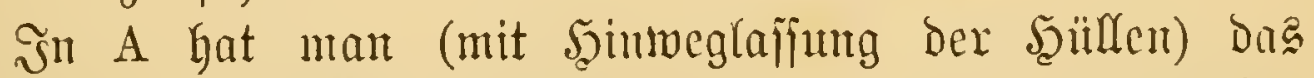
nod) ganz unentwiffelte und wegen ber gelben Dotterfïgeldyen 


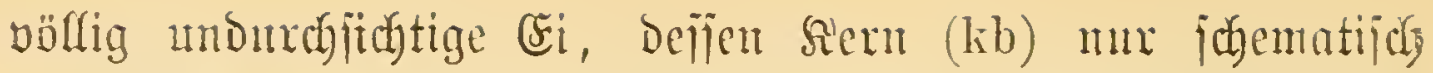
eingezeiduct ijt. B gibt Dann ein weiteres Stabium, wo jich

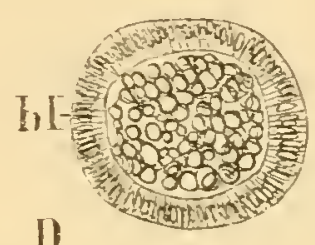

(1)

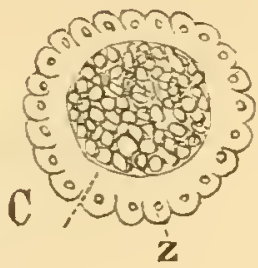

B.

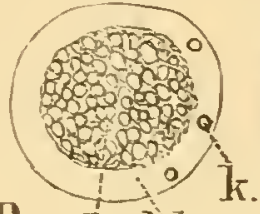

B. $n$ dio bido.

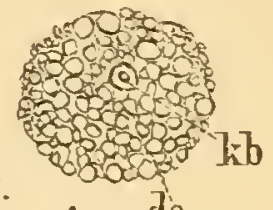

A do

テig. 109.

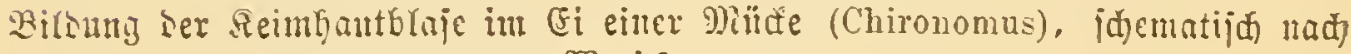
WBe i $\$$ mann.

A Ciontter (do), kb Reimbräsđen.

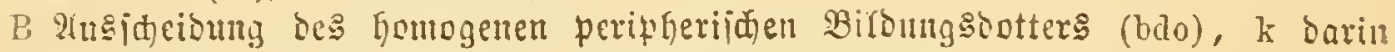
aufretende Rerne, ndo (centrałer) Nafrungsootter.

C Ier Biroungabotter (Blajten) ball jid) peripherija in Belfen (Maulbeerjorm, -Perimorula").

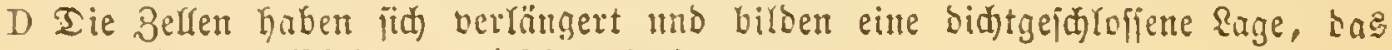
cinjuidtige Blajtorerm ("Blastnla").

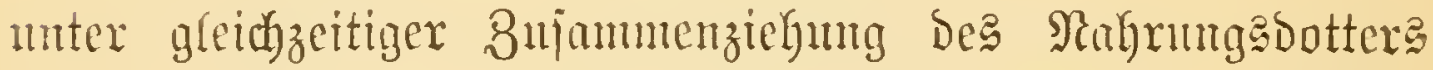
añ ber ganzen Dberfläche eine helfe hontogente Sifjidyte

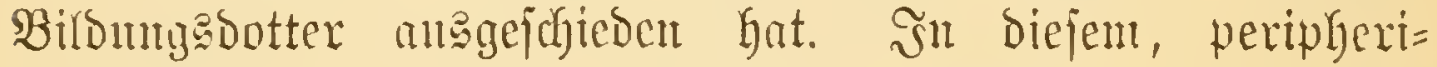

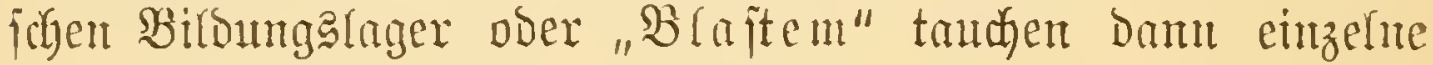
Reme (k) anf, vou benen man höbjtens vermuthen fam, da

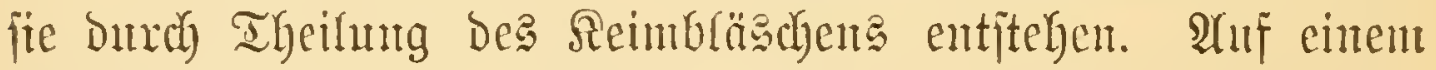
Dritten Stabinm (C) erjobeint Dam cine ganze Gsarnitux foldyer

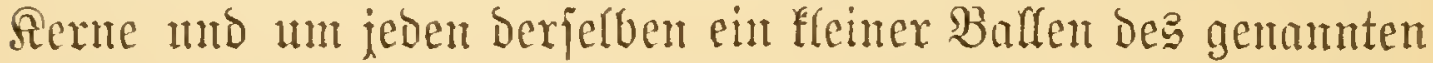

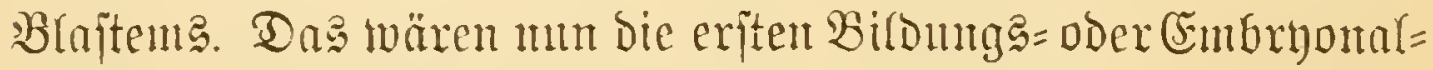

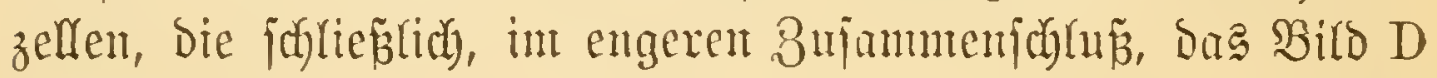
ergäbent.

Da ficf nady biejer Darjtelfung bie Formung mis Ber= legung Des Dotters mu auf eine oberflädylide Schidhte be= jaräntt, jo namnte man biejen Sorgang bie partielle mb

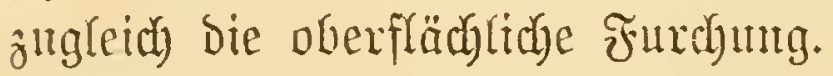

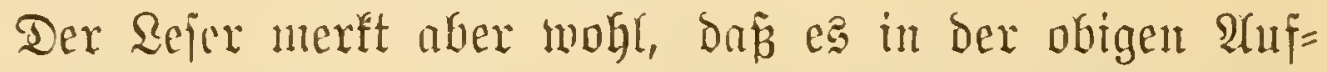

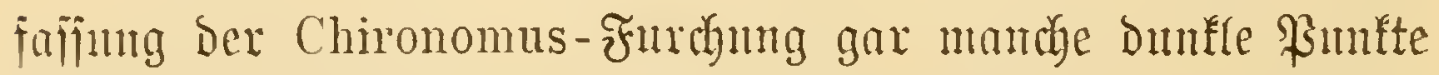

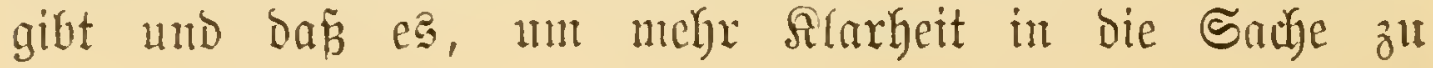


A
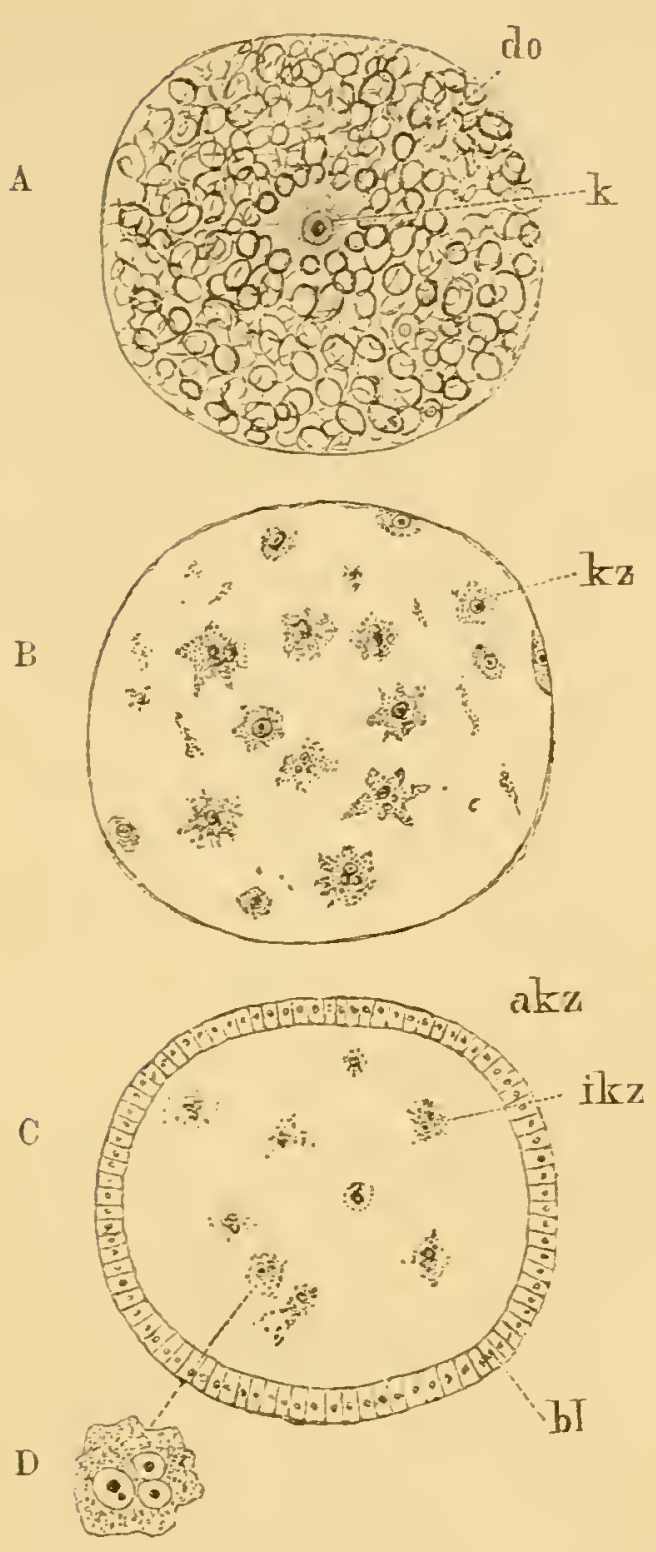

Fig. 110

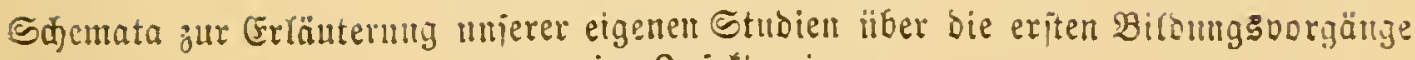
im Эorjeftenei.

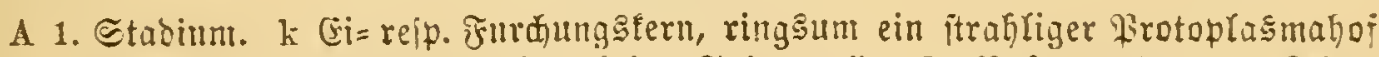

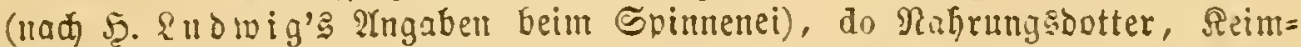
bläsden + Brotoplasmahof = llreizelle.

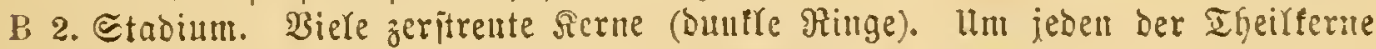

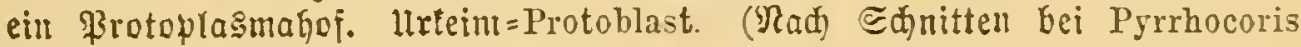
und Lina.)

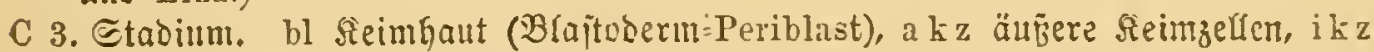
innere Seimzcllell (Centroblast), alle relatib zu groí (im llebrigen genane

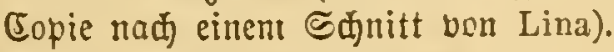

D Fine innere Sieimzelle von Pyrrhocoris ftärfer sirgröbert mit mehreren bläsđen= artigen Rernen (j. Binneutern). 
Gringen, hauptfäd)lich Darauf antäme, bas Mnterfud)ungsobjuft

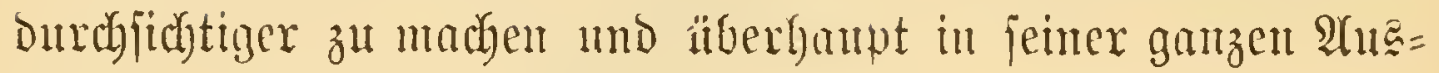
Debuutg femten zu lermen.

Dazu gibt cs mu offentrar Keim paffenderes Mittel als

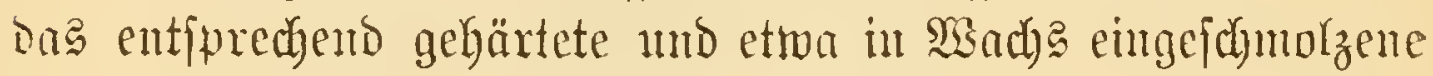
Ei in mïglidfit diume Sannitte zu zertegen, eine Methode, bie bei häheren Ihieren längit angewand, bei Snjelten aber

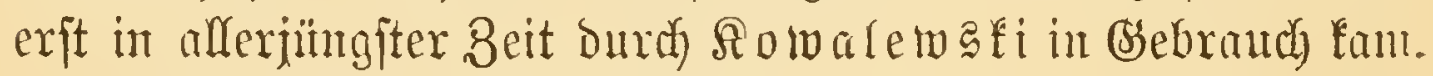

¿eiber jüb aber mitterft biejer Mietbode gerade die erften

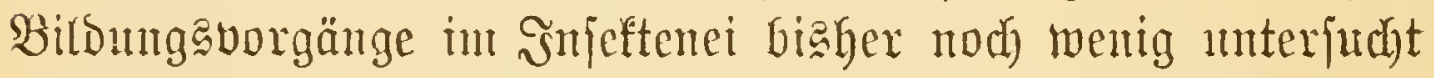
worben, und bieje Rüfe foll im Folgenten Durd bie Ergebnijie eigener Stubien ausgefüllt werden.

Bon fumbamentaler Widgtigfrit fïr bie erite Sonberung.

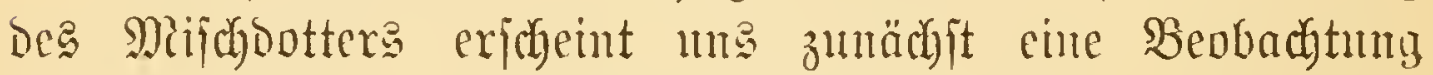

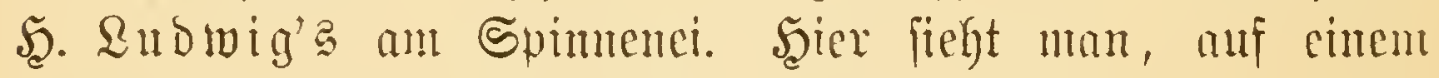

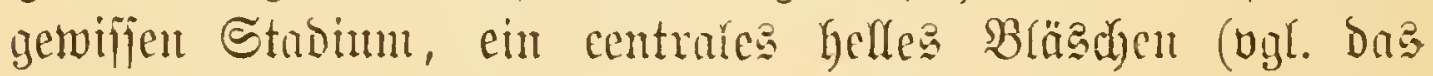

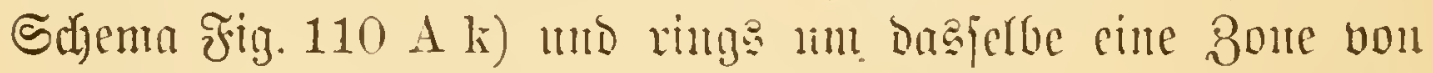

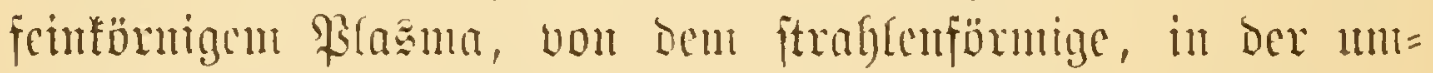
gebenden Dotterjubiturz fich verlierende Fortfäbe ansgeben.

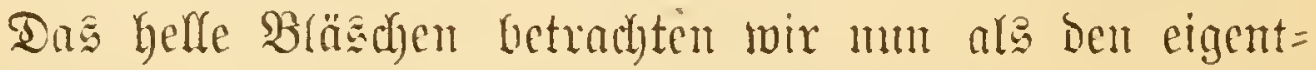

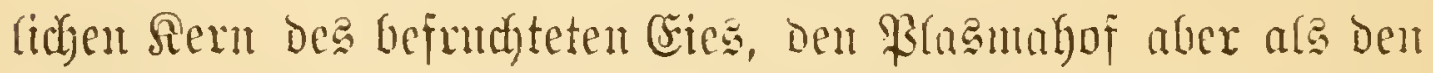
Seib Der Ilreizelle. Demund hätten wir Gier cine Sonderumg it eincn centralen Bildung $=$ (Centroplasma) und in cinen peripherijhen Alafrumgabotter (Periplasma).

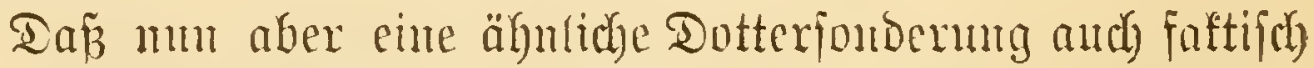
bei ben Fnfleften borfommt, jueint ans Folyendem hervor= zugehen.

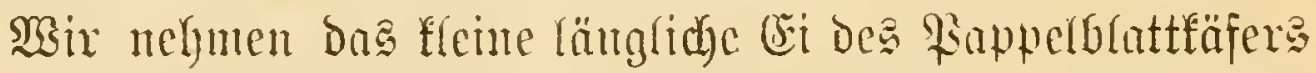

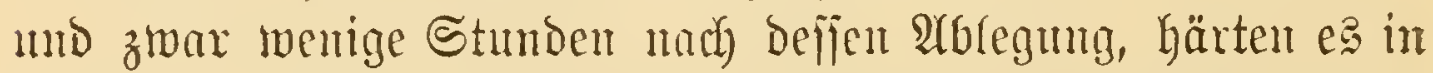
geeiguteter $\mathfrak{S e i f e}$ mo zerlegen eg bant in möglichjt bïmte Edjeiben. Iieje Schnitte färben twir muperdon mit Rifro=

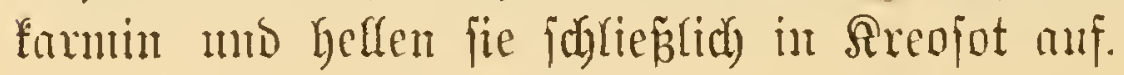


Llutex's Miftrojep getracht zeigt fich mul Folgendes (₹ig. $110 \mathrm{~B}$ ).

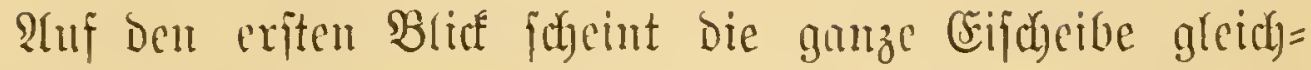
mäp̄ig vou ber \$ifrinjäure gelb gefärbt. Marjtern mir fie aber länger und recht genan, jo tanden da mo bort fleine intenfiu rothe (aljo vom Rarmin gefärbte) Rreiaflede anf, mo in cincul pätern Stabium nimmt fich Das gelbe Bsefichtsfeld

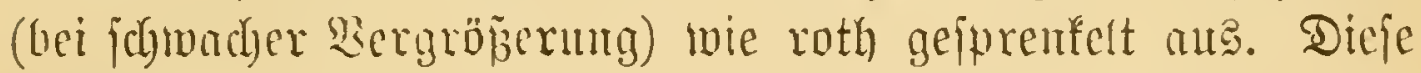
rotgen Steflen mu machen in jeber Şinfititg ganz mo gar den Eindrud vou Bellfermen und enthalten wie lebtere oft wicber

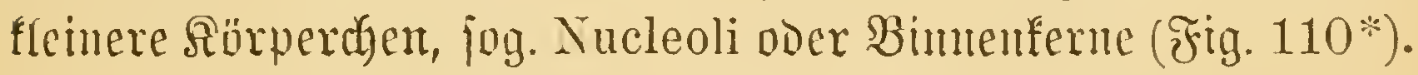

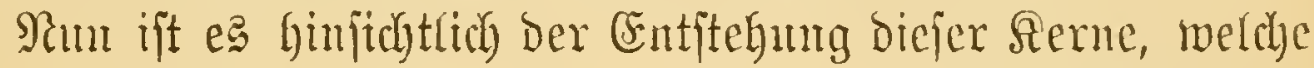
munt ant Eierjtofei noch nicht hemerft, gewin bie wahrichein=

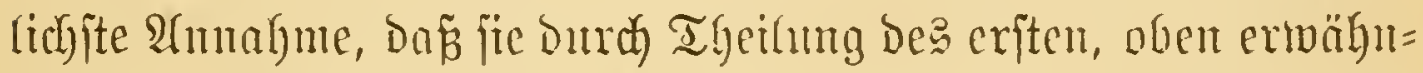

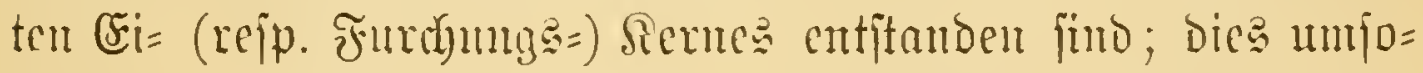
medre, als vicle biejer Rente auth faftifdy in Theilung be= griffen jino.

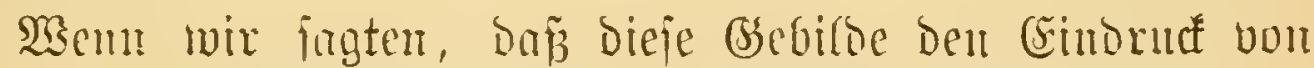
Sernen madjen, jo më̈ren mir Damit, da $\tilde{B}$ fie ganj freciell dea Sermen jener gellen gleidyen, als wellibu ifütex der (Embryo zujammengejebt erficheint.

Soláke Sifferme bahou ïbrigens aud frïbere Bevbadter gefundon und z. Th. jogar Deren atbifunit

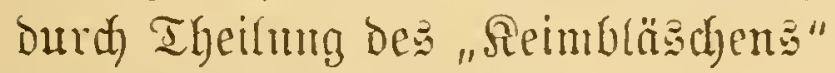
matgrideeintich gemadyt.

Böđin neu unto vou gröp̈ter Saidhtigfeit jugeint uns aber ber folgende unitand zu jecin, Da $\tilde{B}$ näm(lich dieje Sicrue midyt, wie man bisher alfgemein zu glanben

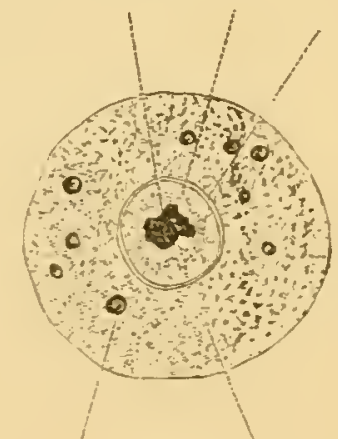

F:g. $110 \%$

(janz imge Reimbantzelle einer Imeife (Formica rufa) nad) Behanolung mit $2^{0} \%$ Eifigiaure, $\mathrm{km}$ Miembran, ks majaige ftallz beg fernz, kk nmöboicc Sernförperden, zs 3elfubftan, $F$ gerbe Fettröpichen in ocr = jerbent.

(Eriginal.) 


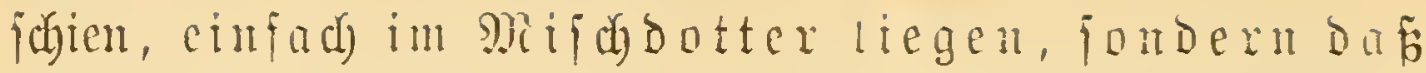
jeder von ínen von einer grö̈ren oder klement 80 ne

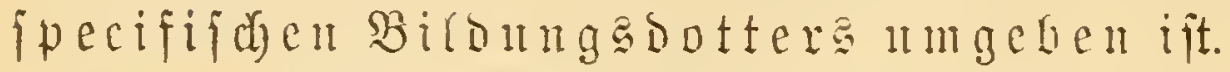

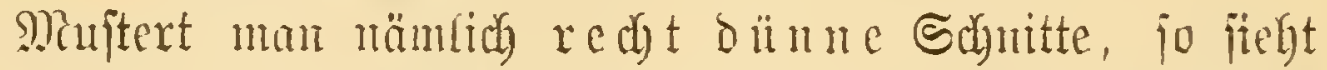
man um jeben ber rothen Areis̄lecte einen von Bifrin ungefärbt gelajienen uno saber relatio weip erjobemenden fentërnigen Prasmahof, mb biejer lestere mit fammt bem Darin einge= betteten Aern gleidyt anf ein Saar jenen edoten Tmöboid = zellen, wis fie oben auf Fig. 106 abgebilbet futr. Sn biejom Simne hat man es aljo bier nicht einfach mit Theilumgs: produlten bes cifernes, jondern mit jolden eines ganzen llieie zut thur.

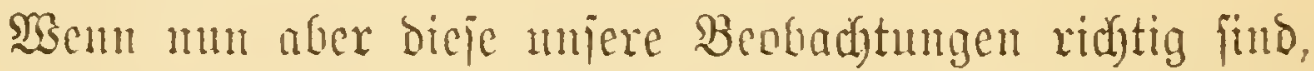

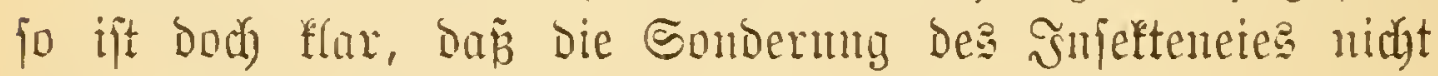

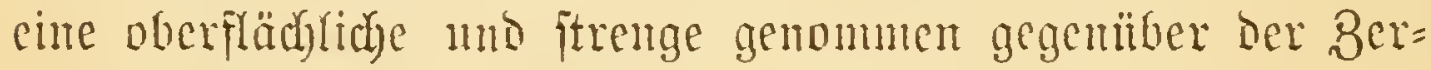
legung ber Mreier and nidht eine broz theilmcife genant werben karm.

Denfen wix un eimmal, mu bie Eadje näher zu el=

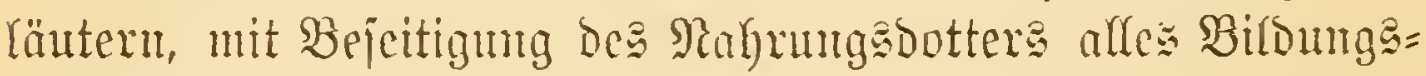
phäma un ben Gikern concentrirt, fo märe bas Gsanze offenthar eine wahre llreizelle zu nement. SMärde jid num fermer diejes at theilen und wïroen dieje Belltheile ober Theifzellen heijanmen bleiben, jo hätten wir ohne $3 \mathrm{wcifel}$ sine Irt totaler Furdumg vor m?.

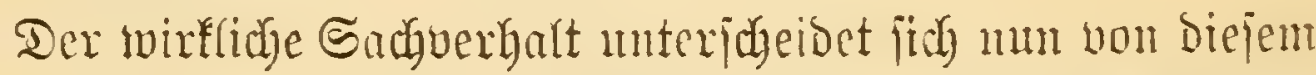

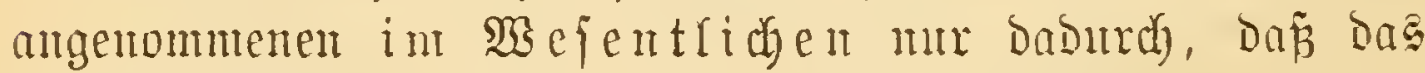
centrale ltrei mur einen relativ fleinen Brudtheil des ge=

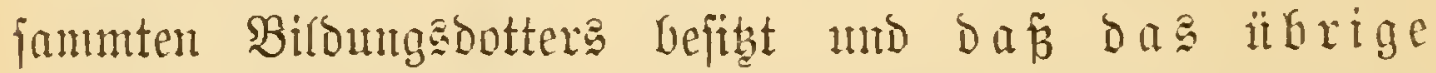

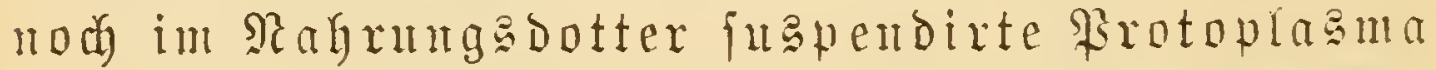

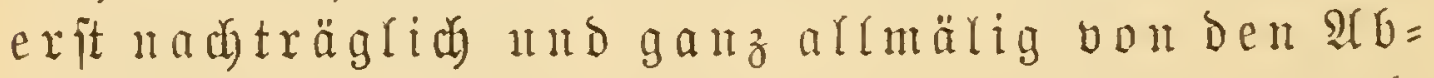
fömmlingen des lleies, d. t. bon den Embryonal= zerlen anfgentumen wits. 


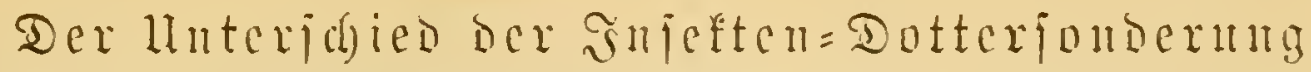

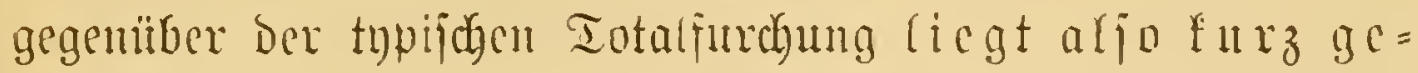
jagt weniger iu ber räumlicted alg inder zeit=

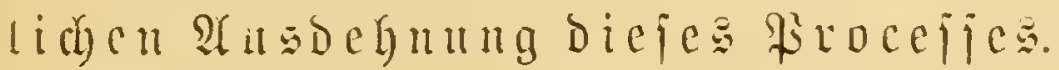

Da fid Die genumten Beflen, wie leicht zu conftatiren,

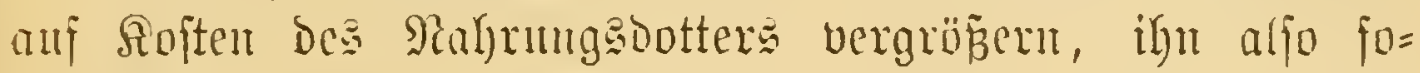
zufagen anfiejien, jo möbte man fie, num z. Th. aud ber Form twegen, mit wahren $\mathfrak{A}$ möben vergleichen; es ijt aber hervorzutheben, Dás es midyt inmer fo idyarf abgegrenzte und jelbjtändige Gsebilbe find, wie es unjer Schema andeutet, da

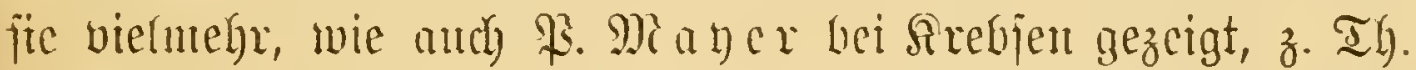

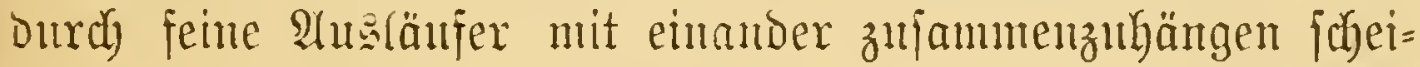

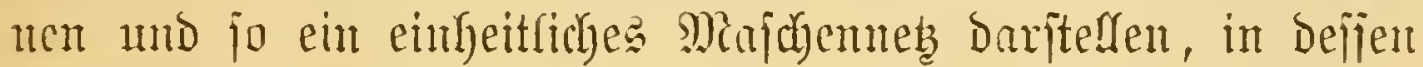

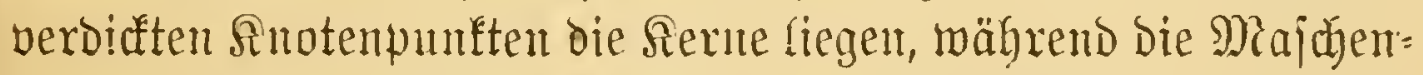

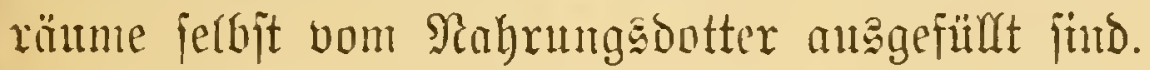

Da mir hier mmöglidy alle bie einzelnen Sdyritte, meldye Das in Der Entwifflung hegriffene Reimprotoplasma bchufs feiner weiteru ssejtaltung madyt, auch mittyun fömmen, jo miijjen wir us abermalz einen gropen Sprntrg erlauben.

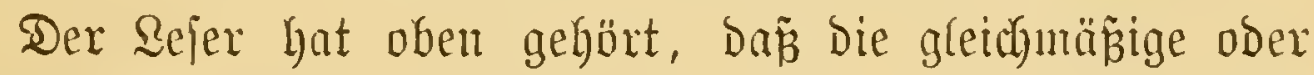

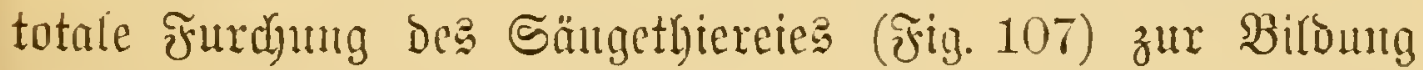

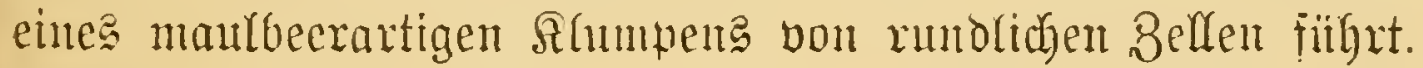

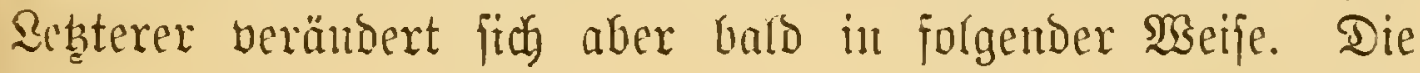
innern Belfen brängen gegen bie Dberf(äd)e, ichieben fich

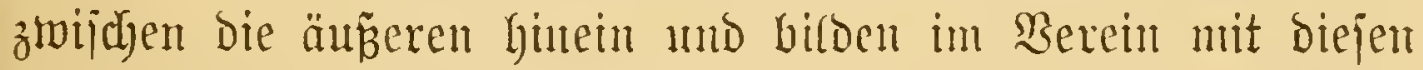
eine zujanmengängenbe aljo hautartige \&age, wälyento

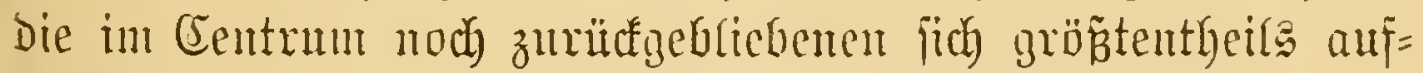
ไöjen und verflüjjigen.

Die beichriebenc cinjobidytige Belfrage ment man mun Seimbaut (B̉lajtoderm), rejp. igrer iphärijuen Gejtalt halber Reimblaje (Blastula), wäbrend ber won ifr um=

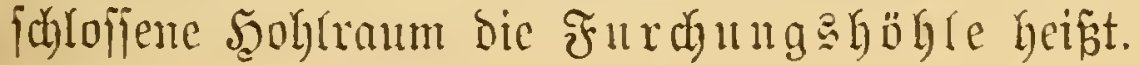




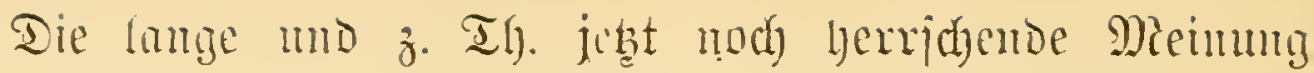
mar mun bie, do

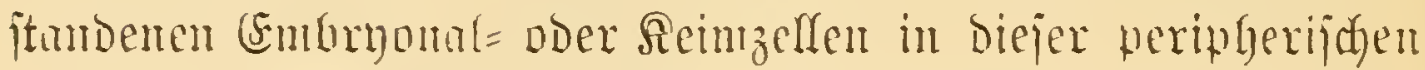

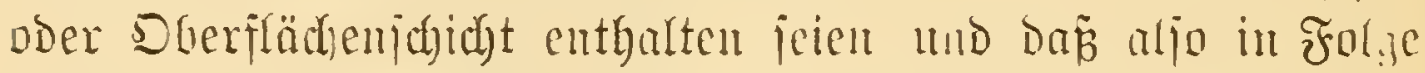
Defien aud bas Blajtoderm ben Auggangspunft für alle meitern bilbungen, fomit bu wahren Ilrfeim noer \$roto= blajt Daritelle.

Sil jïngiter Beit luat aber $\Omega$ öllifer, zuntiolyt bei ge=

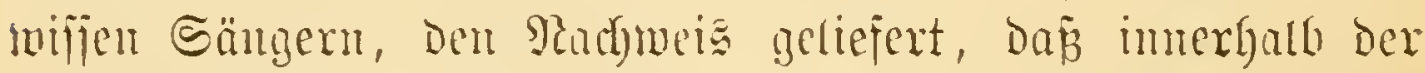

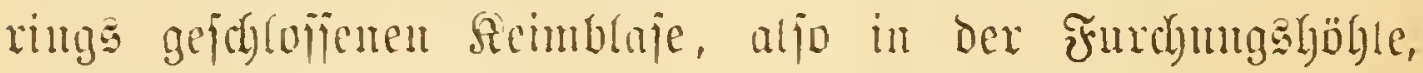

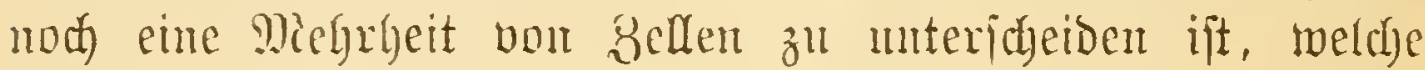

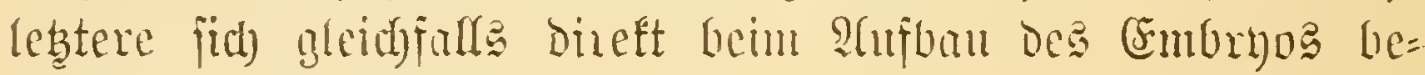
tyeiligen.

Rad) Diejer Anfibt gingen aljo aus ber Mantberform

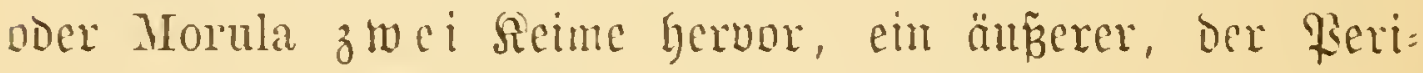
blajt oder die Sembaje, mo ein imerer, Den wir als Sentroblaft bezcidanen.

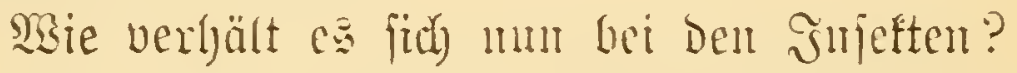

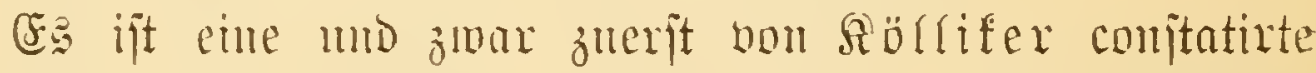

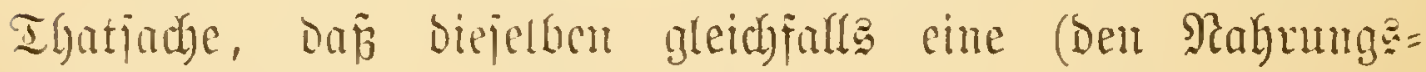
Dotter jufalenartig umjaliébente) Seimblaje hefiben, bie mir

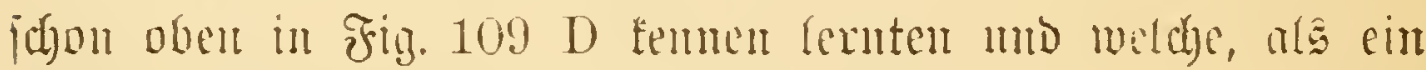

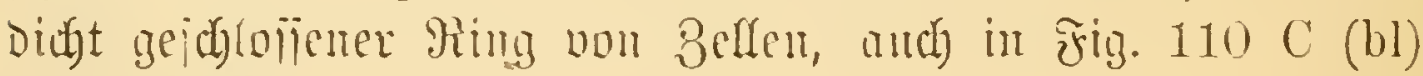
jul jebell ijt.

Waie man jicl mu, bisher wenigitens, das 8 ütude= fommen diejer Jujeftenfeimblaje erłlärte, wurde hereite früher

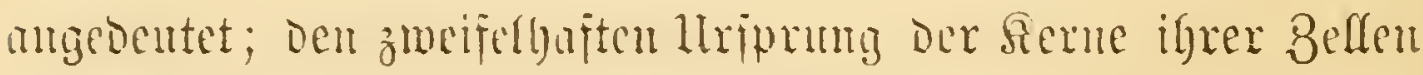
algeredhet, nabm man ganz allgemein an, Daz Der eigent= lide Seif der lebteren an der Weripherie alfo ilber= haunt bort eutfert, wo die gellen in der feim= gaut liegen.

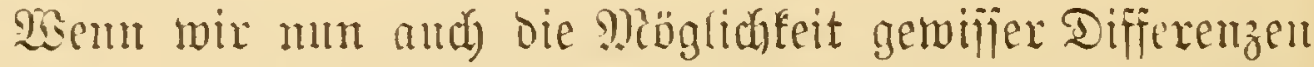

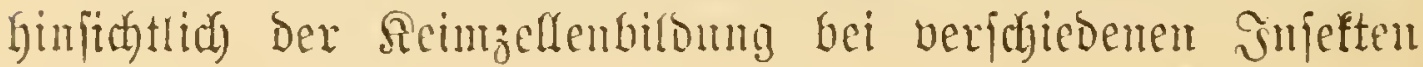




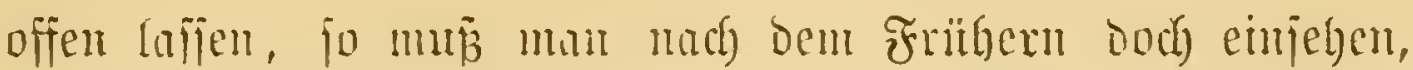
Dañ bieje Crrflärung jum menigiten midbt alfgemeine Bseltung beariprudien fam.

Geben wir in Fig. 110 anf bas Stabium B zurüa, fo finten wir wabre Zellgebilde und zwax ganz im Snmern bes

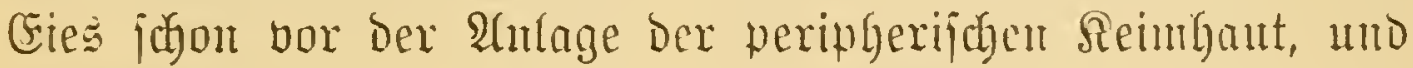
vergleichen mir neuerbinge diejen 3ujtand mit ben ganz=

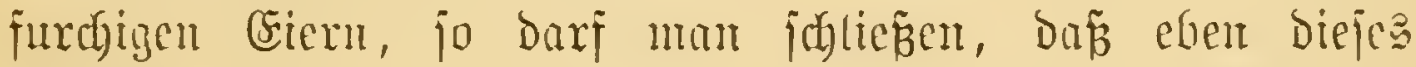
Stadium ber $\mathrm{räum}(i d)$ ud d ungejomberten Bellen ber MRulbeerform entipridyt unb Dañ ferner bie Reimblaje ähntidy

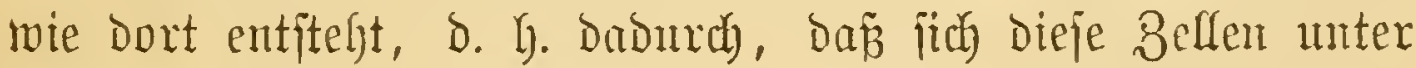
weitercr burd die Theilung ifrer fierne angebenteten $\mathfrak{B}$ er=

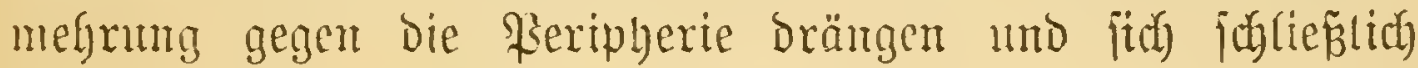
zu eimer eimjuidytigen Lage vereinigen *).

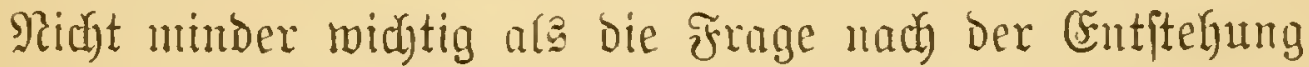
Der Sirmblaje ijt Dam bie ztweite, ob mämlich anth bier, wie alfgenein angenommen, bas Blaftoderm Alle in Allem,

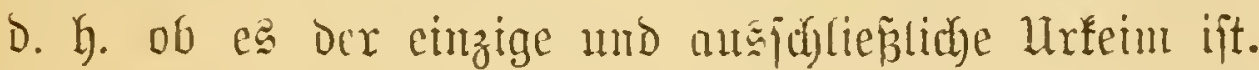

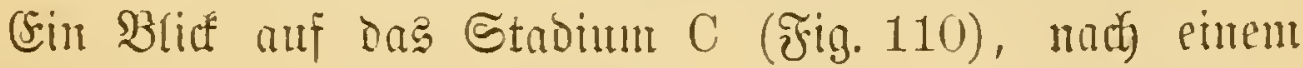
ähntich wie oben behambelten Schnitt ourd) das (ei von Lina, wirb den Rejer aber jofort boun Begentbeil ïberzengen. Er fiegt

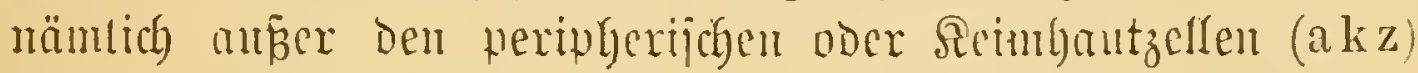
and) now imere (Efemente (ikz), uno Derent böllige Heberein=

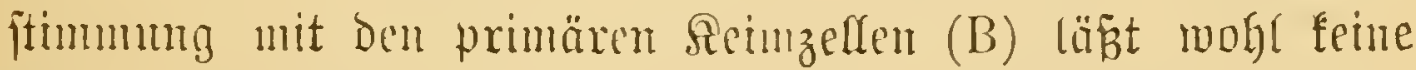

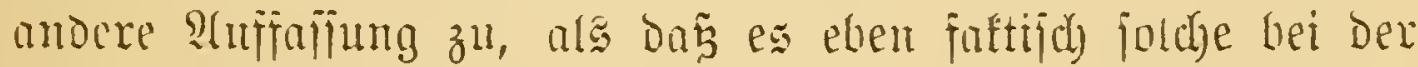

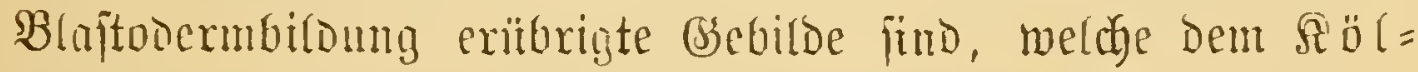
liferidyen Snneufem der Säuger entfpreduct.

Die jebt conjtutirte Thatjache, Dap bie erjte Entmickung Des

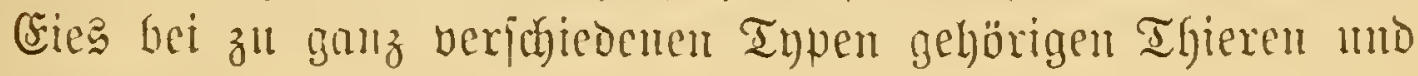

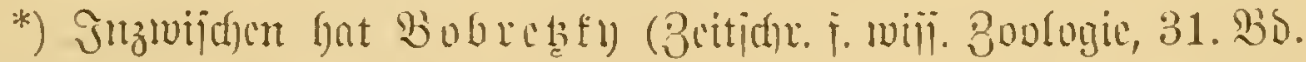

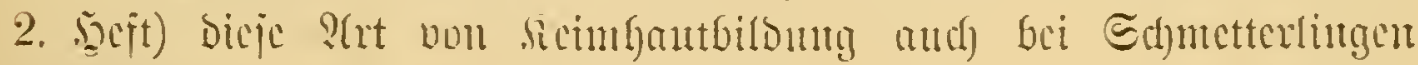
beobardetet. 


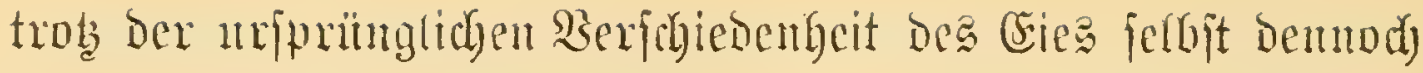
zu einem mb bempelbun Refultate, der Seimblafe (nebjt Dem

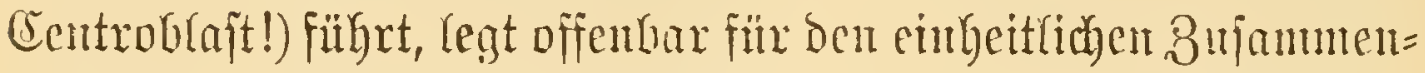
hang mo Hrfwrung Der Thierbeit fein geringe Bengnif at.

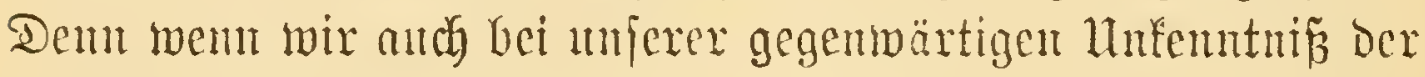

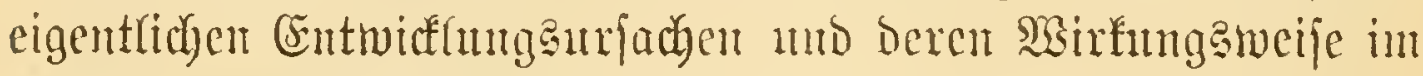

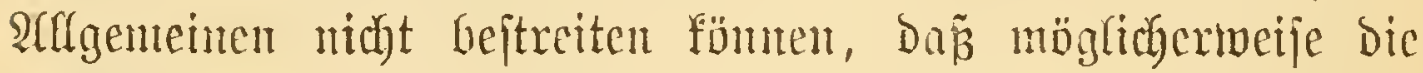

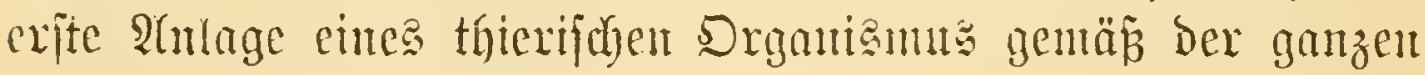
Mlatur des Reimprotoplasmas gerabe io und nid anders

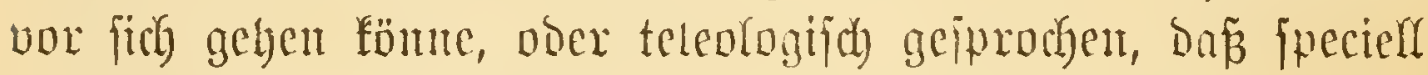
Die Bildung Der Seimbraje ein notytwendigce Mittel zur Err=

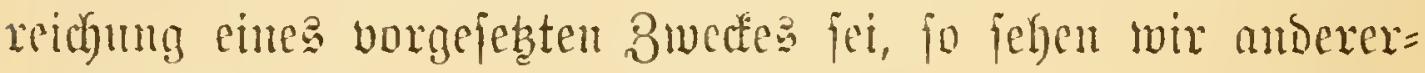
jeit: boch wiedor in jo vielent Fällen die Siatur bei ser şil= Dung verwander Iffere, und gerabe Der Juffeten, oft fo ver=

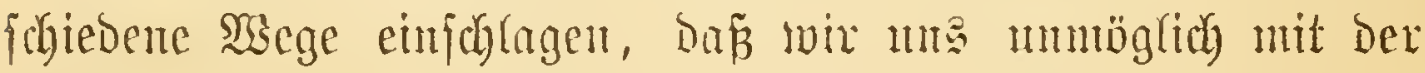

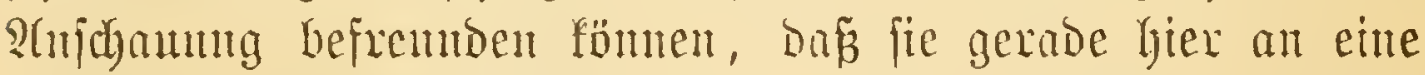

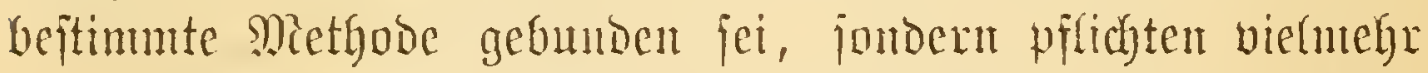

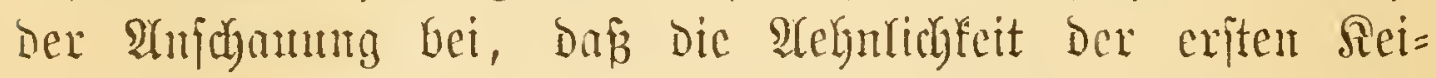

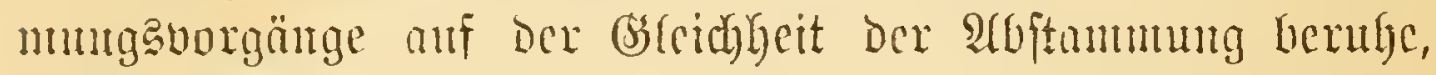
wägrento fich in gewifjen Ungleichyeiten biefes ßorganges

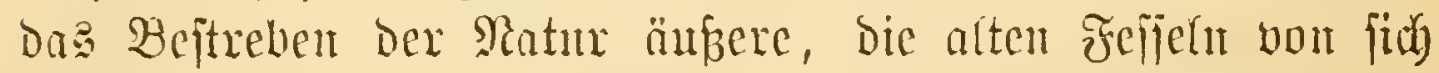
aดzuichütteln un, gemäz Den veränderten ßerbältuifjen, it neue $\mathfrak{B a h n e n}$ einzulenter.

aber, fo fam nan cimwerfen, die Remblajen ber ber:

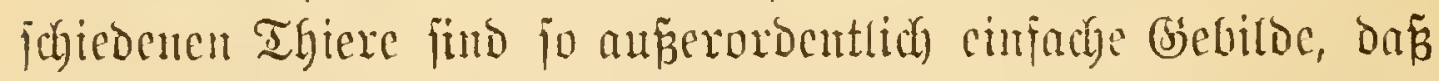
scren Breichleit elger auf cincu indifferenten, anf einten m=

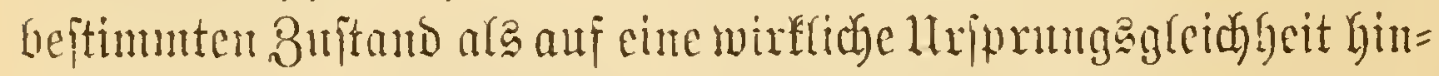

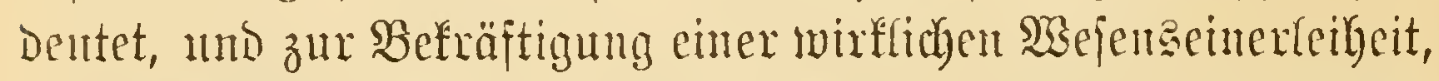
riner faftifachen Scomotypie fömnte mant jid ja faft mit bentfelben

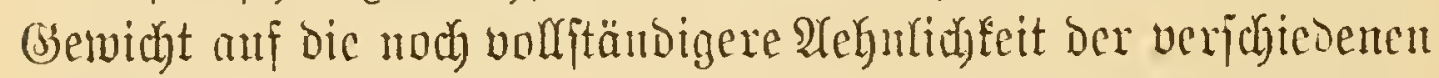

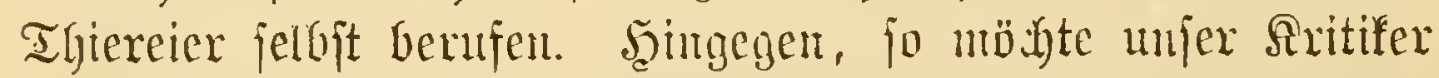
viclleicht weiter fwredien, and woir mübten ifm volltonmen

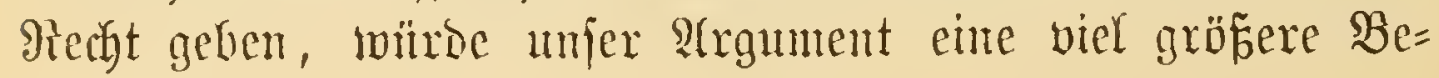


Dentuntg exfangen, wemn wix madyzuneijen int Stmose wären,

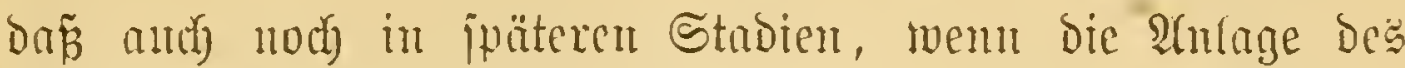
Embryo junon weiter gejuritten, wem derjelbe, im Gamzen wie in Cinzefnen, jhon eime determinirtere Bistalt ange=

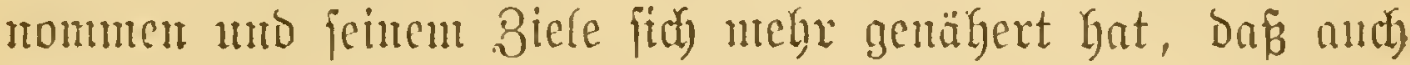
Dann nod), wentgitens in ben alfgemeinften Bügen, bie Rein=

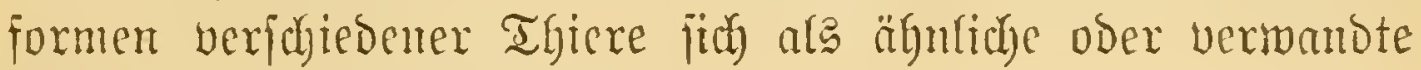
Silburngen zu erfemen gäbert.

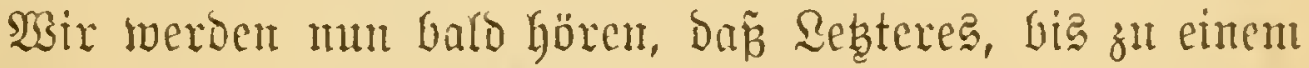

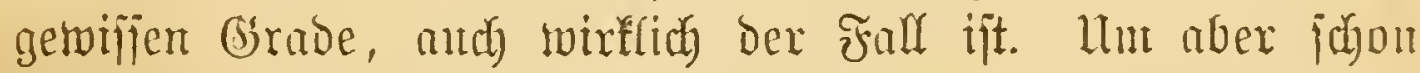

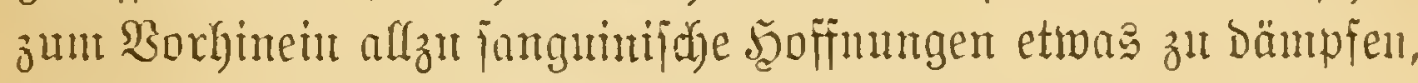
crtanthen wir uns, Den Rejer jothon an biejer Stelle auf

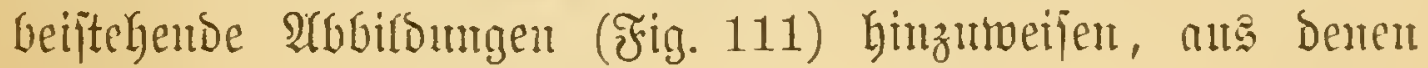
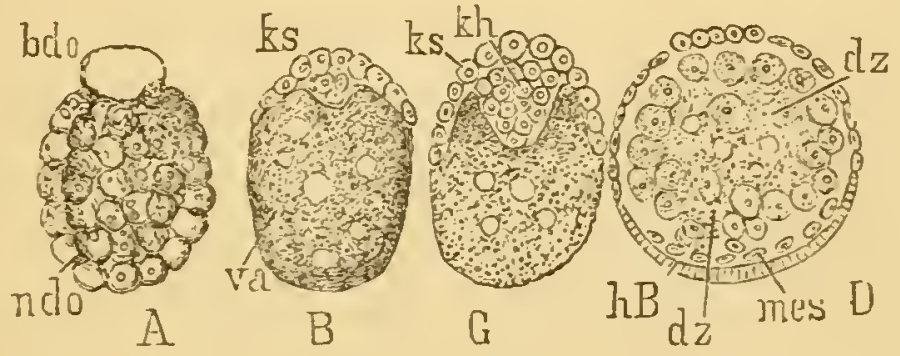

Fig. 111.

Zux Reimbilbung ser Maucrajiel (Oniscus murarius), math B o brete.t

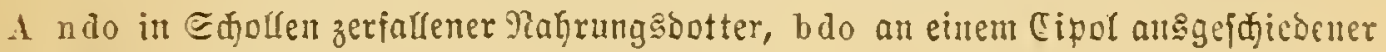

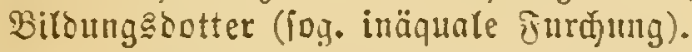

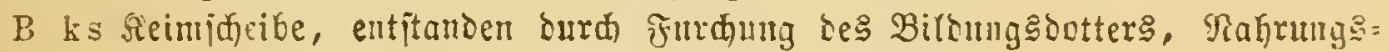
botteridollen twieder zerfalfen, va Bacuolen (?) Darin.

C $\mathrm{ks}$ einjididige Reimideibe, kh burd reale Bermegrung ifrer Beller: gebilseter in Den Dotter hineinragenter Reimbügel (Unlage des Diejo= und (Fntroerms).

D Weitere Differenzirung Der Reimanlage. hb ben ganzen Dotter eimb $\operatorname{laj}$ en= artig umfaliendes Santblatt, mes SMe jo berm, dz ing. Dotterzellen (Darm= orïjenfeim).

hervorgeht, daż gewije Den Snjelten jehr mahejtehende Thiere, wie z. B. Die Manerafjel, nicht eimmal eine typifde Reim= braje bejtisent. 


\section{Sicimblätter, "Gastrula".}

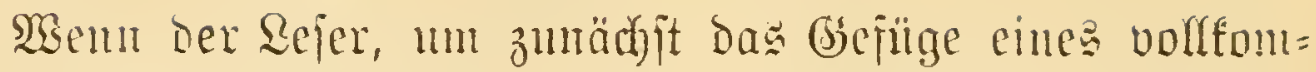
men entrvicfelten Thieres, z. B. cines Jujeftes, femen zu fernen, den Duerichnitt Dureh ein foldye in Fig. 112 anfield, fo findect cr Folgendes: 1. eincn än

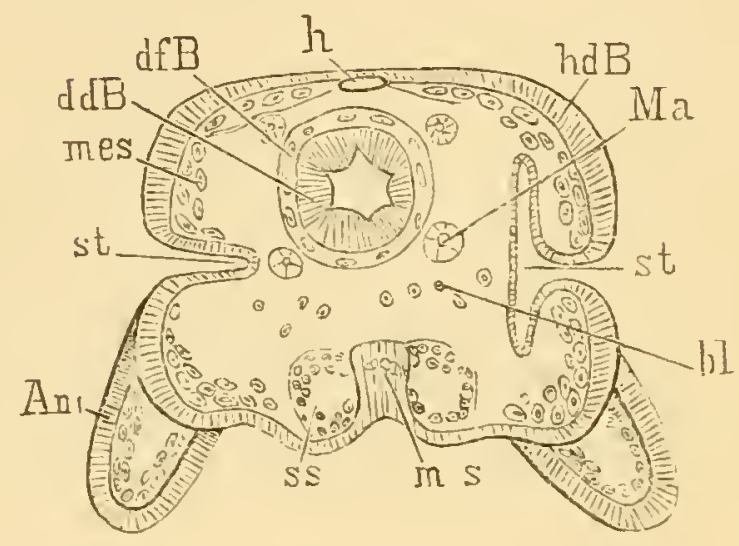

Fig. 112.

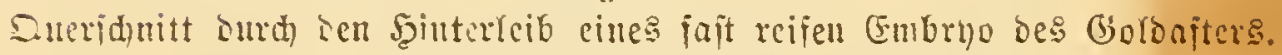

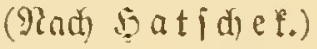

2. cin interes Roldr, Den Darm (ddB), uns 3. zwijd en

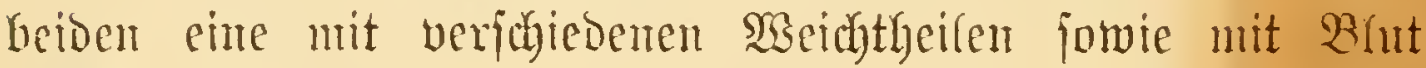
erfiullte Qeibealgöhle (bl). Bei mälycrex Betrachtung zeigt fich

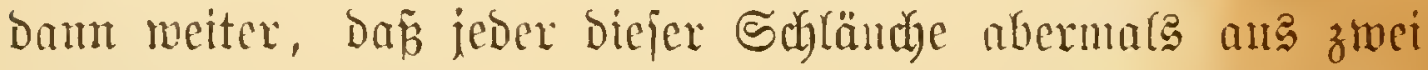
(bemebsfagen bejteht, nämtich ans einer Rage pallifabenartig neben einnor ftehender 3elfen, einem jog. Epither, no

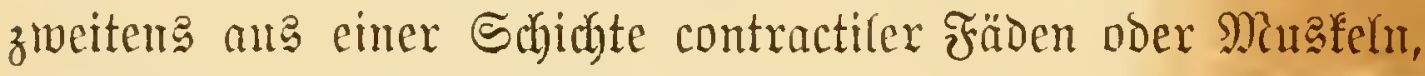
einer jog. Fajerlage.

Nard dem beitegt aljo Der fertige Rerfleib im Banzen aus vier concentrifdyen Şauptichideten, weldye bie Embryo=

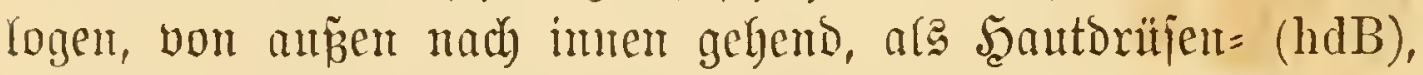
Scautfajer = (hfB), Darmijafer= (df B) und Darmbriijentage (ddB) hezeidynen.

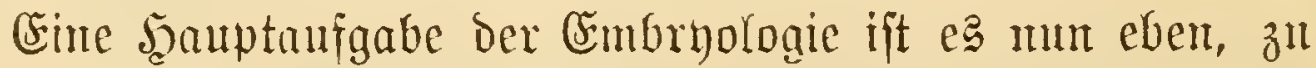

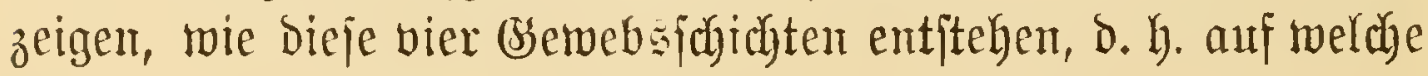


Seife jie nus Der Seimbraje obcr, wo ein joldyer vorbanben, zugleich an Dem imern Seim fith hervorbilden.

Selyr cinfach erélärte man fich bies, ehemals wentigitens mo zoll einer Beit, wo bie Entwiafung Der niederen Thiere

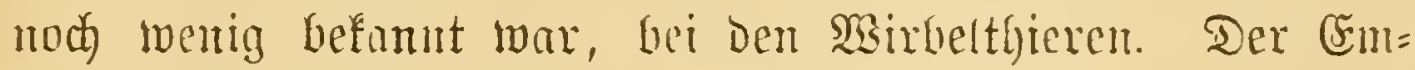
bryo entitebt hier aus cincr idheibenurtigen Seroicung ber

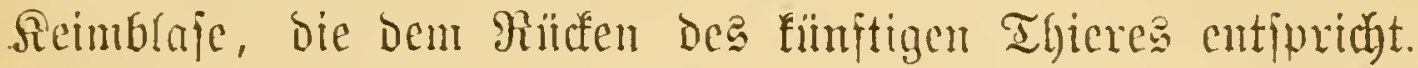
Dieje Reimideibe fparte fich mun, jo mathm man an, in zwei Sifichten, bie man igrer Bseftult mo Sage halber bas obere mo untere oder and bas amimale mb vegetative "Seimblatt" numte. Durdy Spaltumg folle jith Dann (His) jedes dicjer zwei wrintären Seimbütter mieber in żoci meitere Schichten zerlegen,

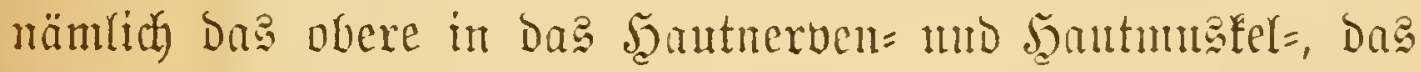
untere in Das Darnmusfel= mb Darmbrifjenblatt, monit Dunn bie ohige Sonbernng and fidgon volfzogen wäre.

Bei Der Mielyzahl Der ïbrigen Thiere ijt aber ber $30 r=$ gang jedenfalle ein ganz anderer, un jeitocm man dies wein̈, ift man and) hemilft, Die firinglätterbitbung Der Bertebraten in anderer Seije anzznlegen.

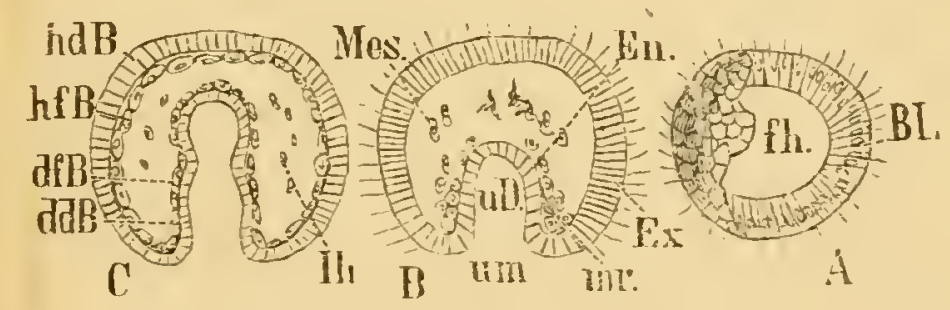

Fig. 113.

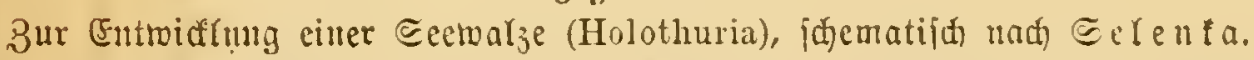

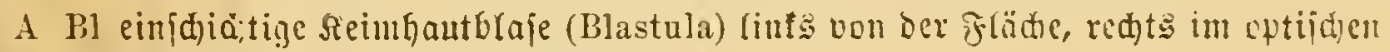
Durdjdnitt, fh Furdungshöhle.

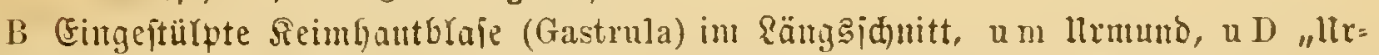
Darm", Ex Froderu (mimales), En (Fntoderm (vegetatives Reimblatt). Mus bem eingeitühten Braitoderm entitihen die Bellen IIes des Mittleren Wlattes () Mejodermi).

C Dasielbe weiter entwiffett. h d B Sautoriijenblatt (F̧oderm), d a B Iarmbrüjen= blatt (Entoderm), hf B Şautiajer=, d f B Darmajerblatt. 
Anp̌erorbentlich flar und beftimnt johent, wentigiten nad) Selenfa's Mrbeit, bie Biloung ber Seimblätter an Den völig ourdjfithtigen Crien Der Seemalzen (Fig. 113).

A zeigt ung zunäd)it, halb im Durredjidnitt, halb vort der mojaifartig gefelderten Flädte, dag Stabiunt der Reim= blaje, wobei twir zum Unterjaied gegenitber Der Säuger = mo

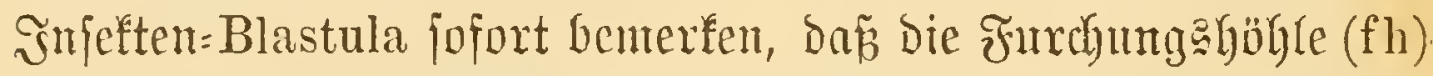
mux eine flare Flüjitgfeit, aber femerlei Bellgebilde enthält.

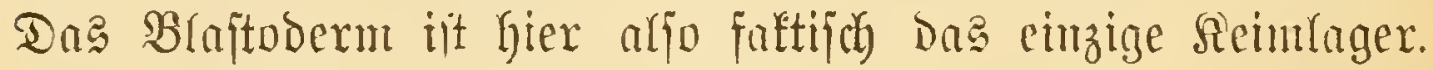

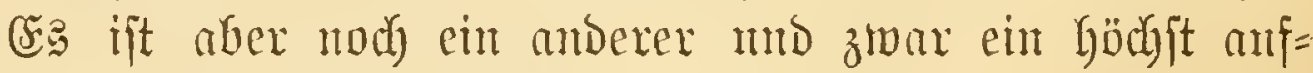
fulfertoer Mujtand zu bemerfen:

Da von bercits lebentafäbigen Embryonen ober jutgen Igieren mu bie ber höhern alfgeneiner befumt futb und

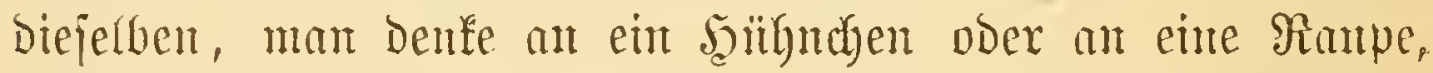

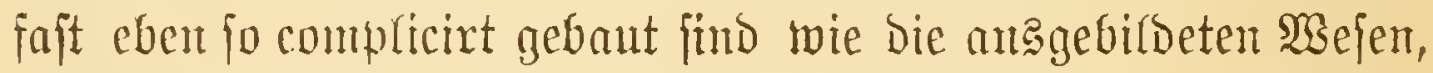
jo meint man, dáz bies bei allen Thieren jo fein mitije, b. $\mathfrak{h}$.

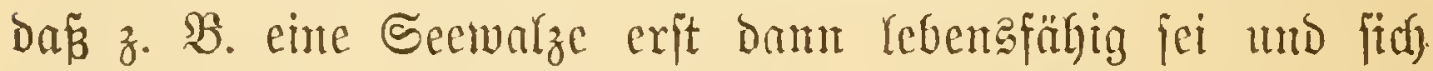
überbant als felbjtändiges Thier geriren fömte, wem $e$, ungefägr menigitens, alle die Drgane Der Mutter beftbt.

Dies ift mu gewiés ein grofeses Borurtheil, went man

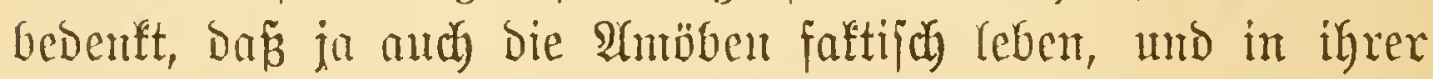

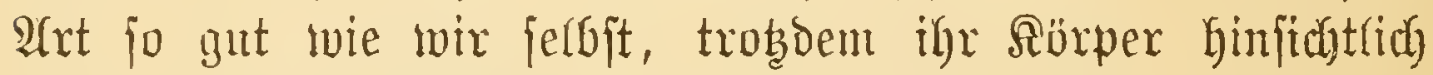
fenter Drganifationabghe mur anf ber Stufe eines cries fteht.

Went mu aber ein Thier bereits in Buftatide des Eies

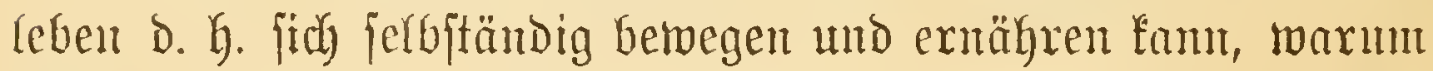
joll es bies nidyt anth auf Dem höheren Stabium einer Morula oder Blastula fömen? Num, Lebeteres ift thatjächlid bet vielon Thteren ber Fall, bie bereits in bem Stabium, wo wir fie eben fennen lernten, die Eigülle berlafien, da mit aljo

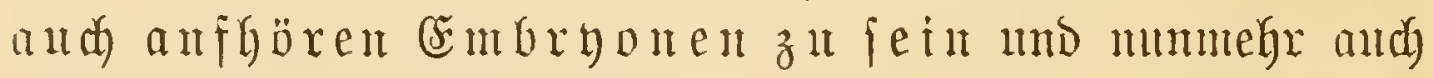
juchon ben ftolzen Titel "IIfiere" rejp. "Rarben" führen.

Das, was wir Seimblaje nemmen, ift fomit bei biejen

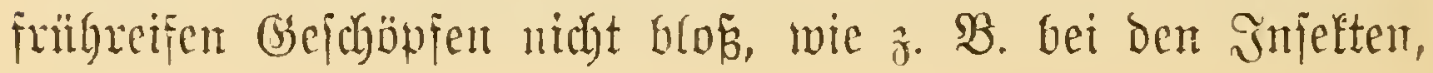




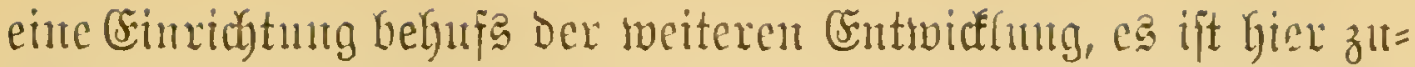

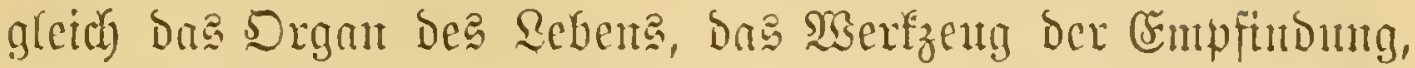
Betwegutg und Erntährung, mo fo wird fich Der Rejex, Denfent

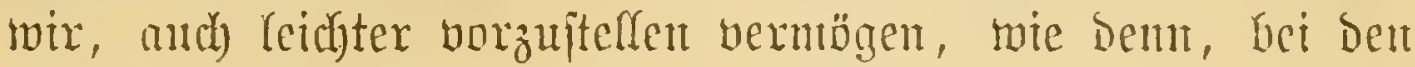
Göherent Thieren, an: einem fheintbar völlig tosten Reinte nach mo nach bie verichicdenen Energicen des Rebents fith entiviḉch fömen.

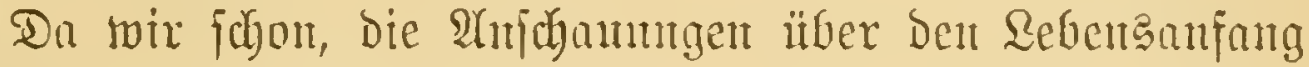

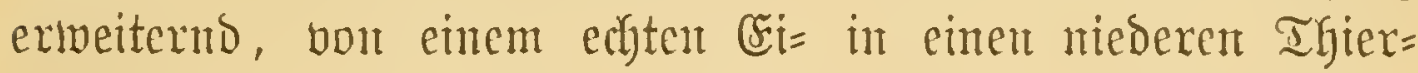
zuftand geriethen, fo fïgen wix noch bei, baj ntan joldhe $\Omega$ eim $=$ brajentyiere ans von felbjt einlentitendem Grumbe und gegenüber Dent friflyer furz erlänterten 8uftund ber Bier= blätterigfeit als "einjorjichtige" bezeidnet.

Ja, wie geht bent aber, um swieder auf unjer Thenta eit=

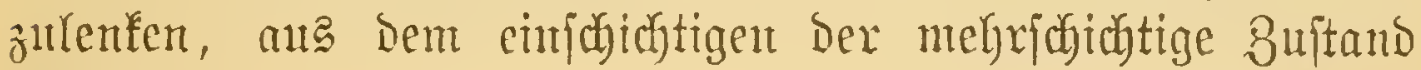
hervor?

Artfridytig gejtandent wärent wir jegr gejpant baranf, zu

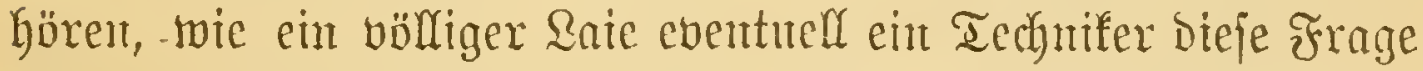

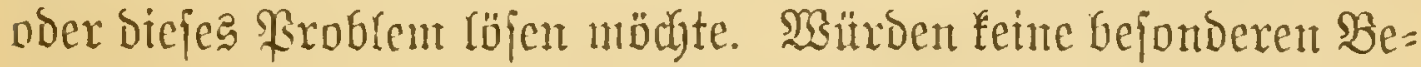
binguntgen gejtellt, fo gäbe ca freilid Der blop̃en Möglichleitent

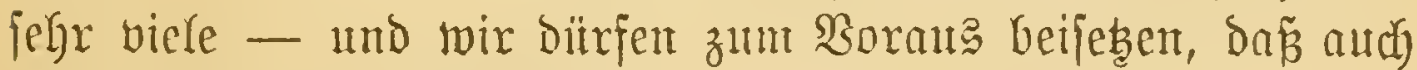

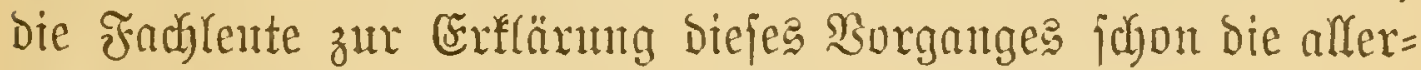
verfabiedenjten Conjuncturen angenommen haben.

Eine jefre nalgeliegende ijt bie Gereite oben ermähnte,

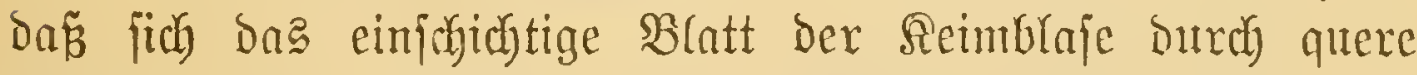
Spaltung der Bellen in ztwei Bätter zerlegt, twas mon SCbbläterung, Defamination nemt. Dies gäbe, fwäter wieder bei ben ztwei Unter = oder Secumbärblättern

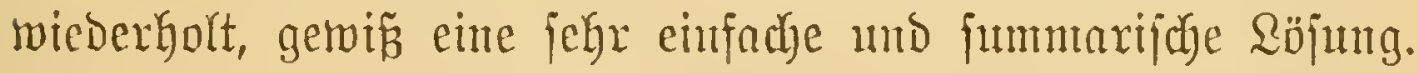
Es wïroc aber anth eine (t'jatjächlich öfter beobacbtete) par= tiefle 2 bbrätterung, wir meinten die 2rbröpung einiger Bellen, zulut Biele füfyren.

(b) raber, Эnjeften. II. 238 . 
anfe Dieje \$orgänge jebzen zunärbjt, wie man bafo ein=

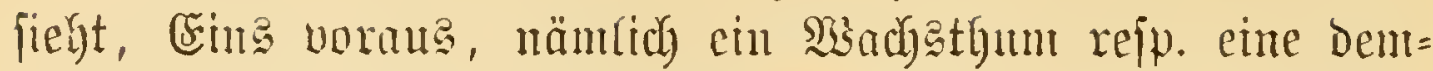
jelben folgende Theilung und Bermelyrumg ber Bellen, Eridyei= nutgen, Die ïbrigeng jobn an Der Reimblaje uno ïberbanpt wägrend der gefanmten Borentwieflung ftattfinden.

Steflent toir ms mu eimmal bor: 1) Dañ bie Reimblaje,

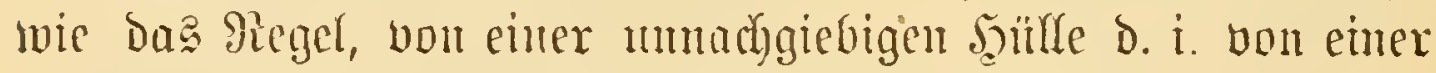

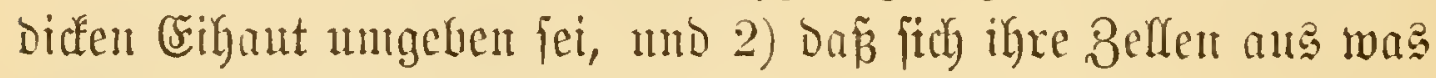
immer für einem Grumbe mur Der \&ämge nach D. i. in Der Richtung Des Reimbtajen= Rubius theilten und. Die Bellver=

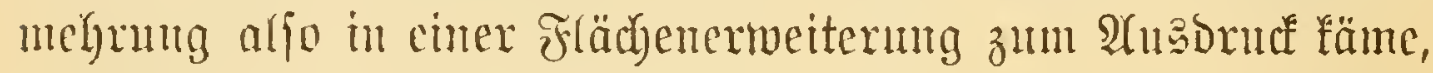
was würden Dann dicje bejonderen Bedingungen oder Buftände

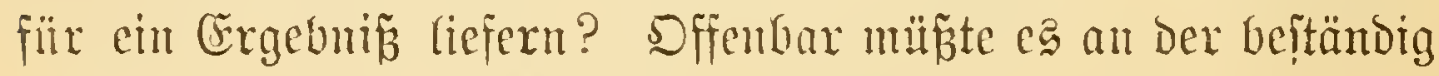

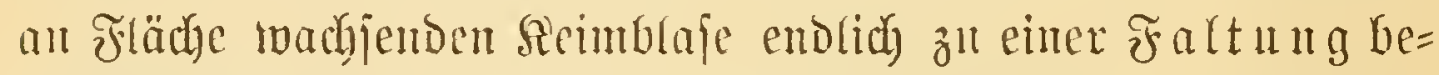

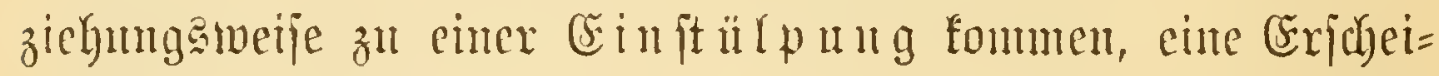

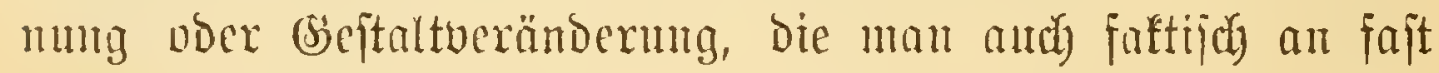
allen fräd)enthaften Bsemeben uno Drganen währeno igrex Ent= suidfung sabrutmmt.

Dáp alfo eime cinfache Miembran, cin Şantrohr ober eine

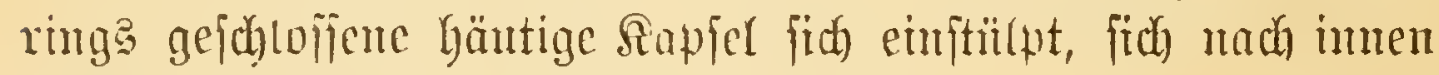
faltet, ift durchans nichts arffallendes.

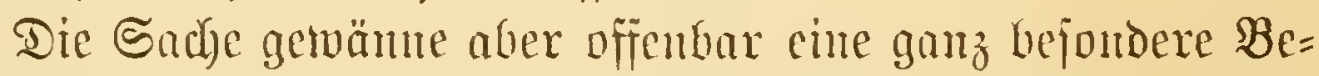

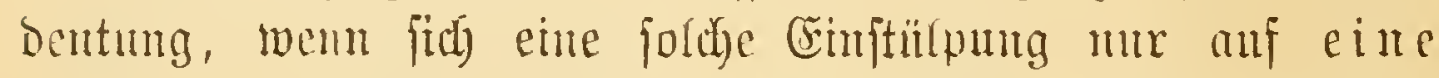
befondere Stelfe ber Reint=Membrum bejöge no wenn aus biejer einen Eistitilpung ein ganz bejonderer neuer Reim= ober Rörpertgeil herborginge.

Und bus ift mut eben, un wieder zu umperm Segen= ftand zu fommen, bei der Reimblafe dor Ecemalzen der Fall. Şicx entitegt nämlidy in Der That (ogl. Fig. 113 B) eine juldue Cinjentumg ober Solvagination, aber 1) mur an einer Eteffe mo 2), wem wix jo jagen dürfen, zu sinem ganz

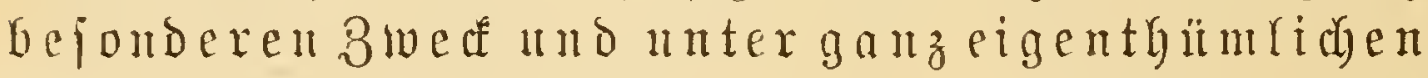
begleitenden ll mituden. 


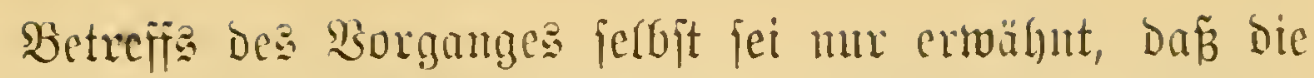

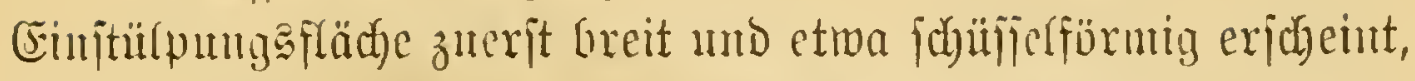
Dañ fid) aber, während die Falte fich imerlide ntehr uno melyr

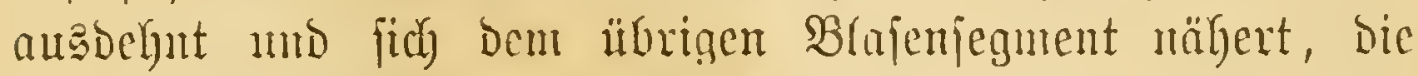

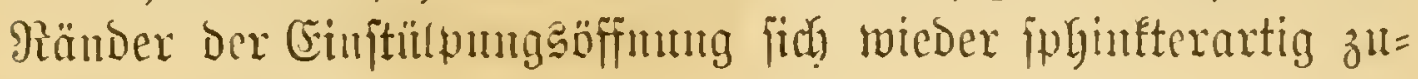
jammenziegen.

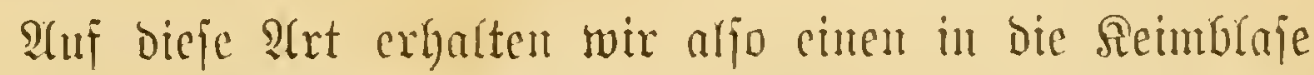

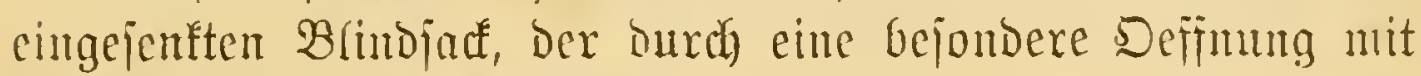
Der Âñentolt communicirt.

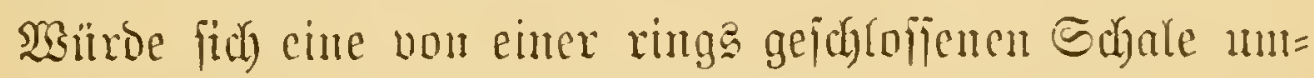
gebene Simblaje in bicjer 2trt verümbern, fo wilrben bir jebenfalls über die Bedeutung des getwijien Binnenjactes jeryr im Ungewijen jein; an einer frei lebenden Scewarzen= Blastula aber jtellt fich bie Sache in einem ganz andern Sichte Dor.

Die Reinhlafe, murde grjagt, ijt biefem Rebewejen ein

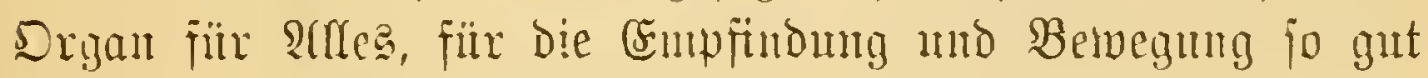
wie für die Rahrungampungme.

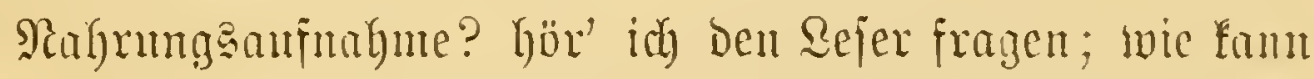
bonn in cine rings gejdolofiene Blaje etwas anfgenommen werden? Hnd ex hat Gedgt; wir hätten, da von cinem Thier

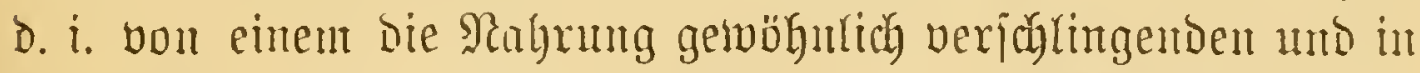

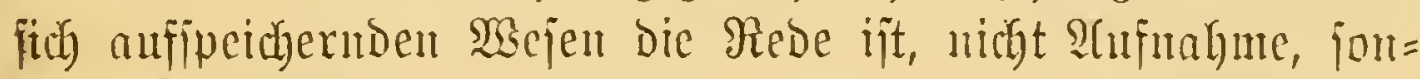
bern Âfjaugung fagen jollen.

Went der Rejer aber faftijer in ber bireften Eimfiilyrung

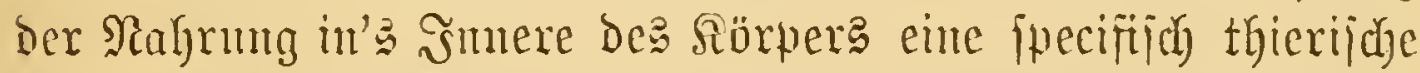

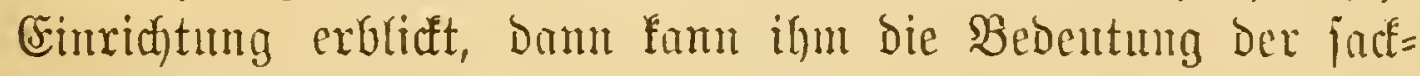

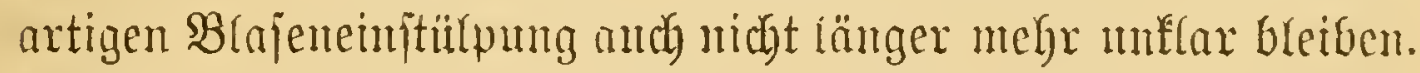
Sie bietet fich Doch von jelfit als Magen ober Darm, ïfer=

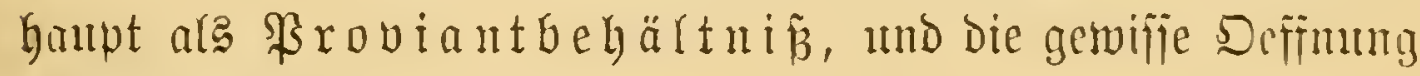
ala glyub Dar.

Und unjere Blastula erfanbt fidr) aud in Der That vom 


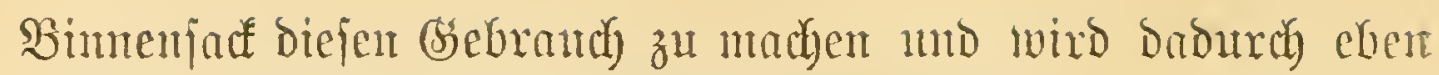

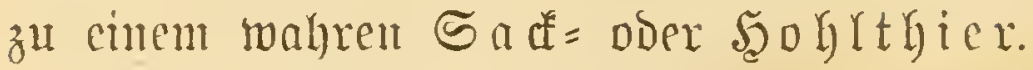

Nan itaunt in ber That über bie Cinfachert Der be=

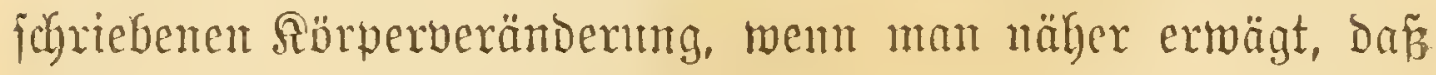

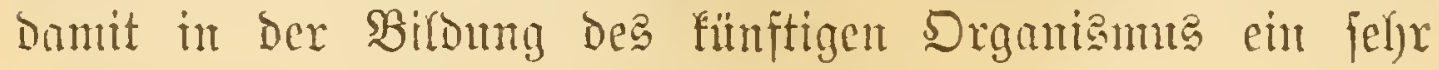
resentender Schritt vorwärts gethan ift.

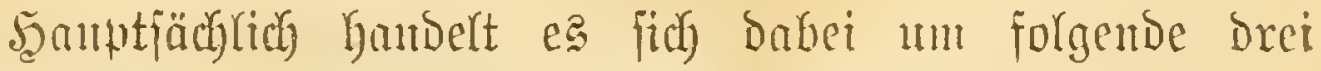
Sonderungen ober Differenzirungen. 1) Un einte rämutiche. Friilyer war mu cin Senzeres vorbanden, jebt ift baraus ein

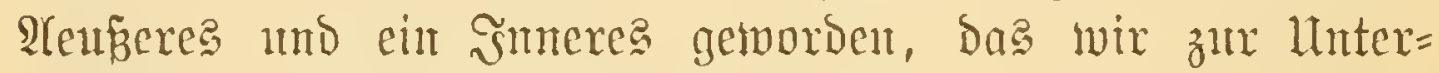

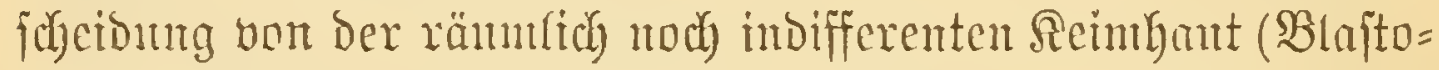

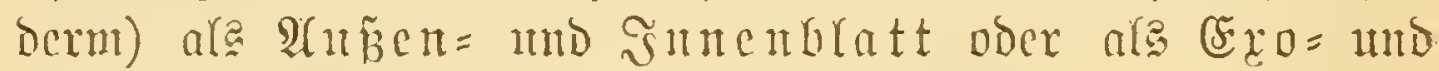
(E) IODCru bezeichnen.

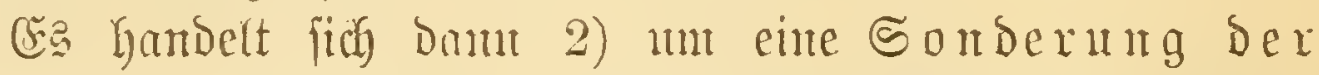
Struftur, ber Bsemebe. Die Bellen des Blaftoderms find uriprünglid) alfe gleid); fobald aber bie Eimftutpung begimnt,

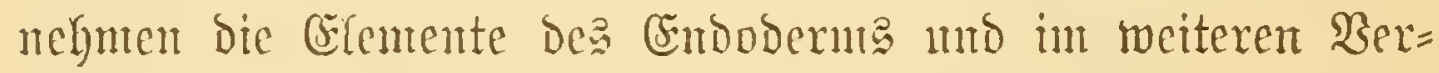
lanf and bie Des expoderme (menn anth in geringerem Brabe) einte andere Bejuaffenteit an. Sebtere breiben Dect=, Empfin=

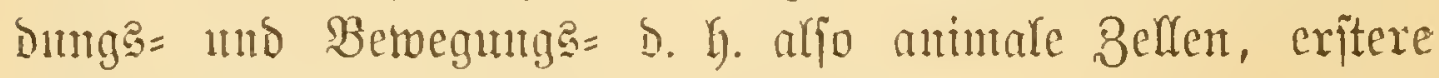
werben Berbanngazeffen oder begetative Efementarorgane, mb Dantite ift bem and bie 3., Die phyfiologifde Diffe= renzirung ober arbeitstgeilung, vou felbit als= gciprodient.

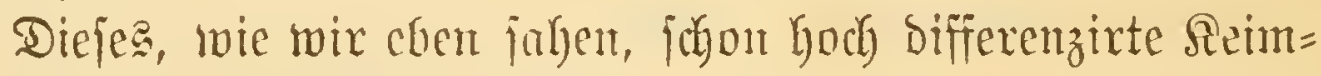
itnbium, bas Saedel "Gastrula", ๖. i. Magent= oder Saef= thier, taufte, ift es mut eben, dos wegen feiner weiten $\mathfrak{B e r}=$ breitung in faft allen Stünment bes Thierreiches, anf jene

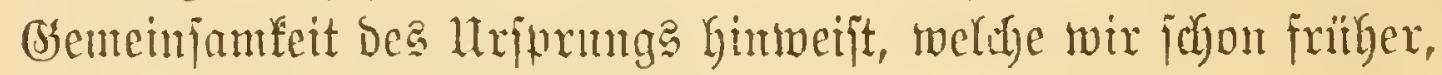
bei ser Blastula, ahnen durften. -

Ulujer Samptthema ijt befanttich. - wemn wir es wieder=

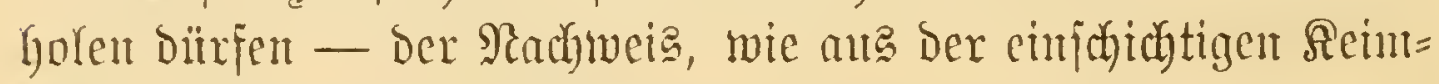

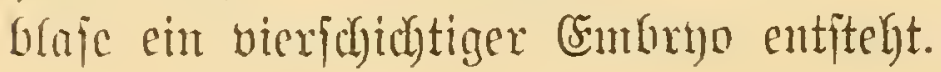


3wei biejer verfangten Sibidten twurben, fir die See= walze, bereits abgeleitet, näntid das aus gleidartigen. Pflafter= woex Epithelzellen bejefende frantblatt (Eroberm) nno bam sus im Błanzen älntidi conjtruirte Daxmorüjenblatt (Endoderm),

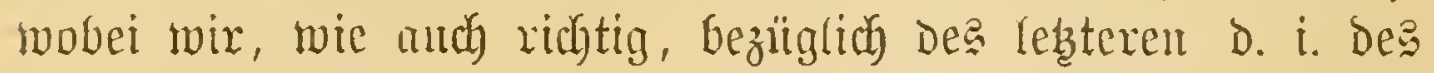

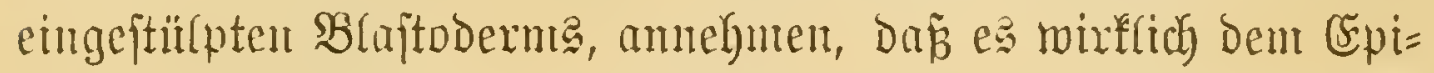
thet des befinitiven Darms entiprityt. Denmadi fehlt nod)

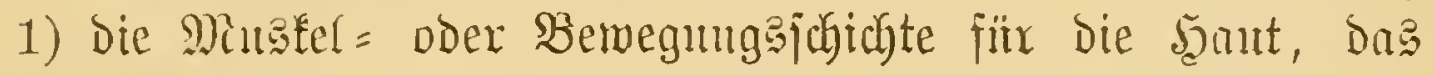

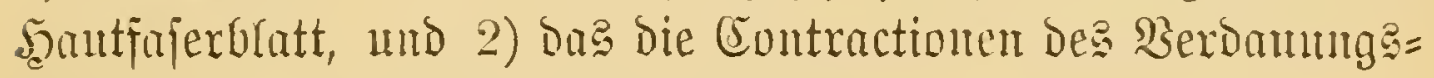
robres vermittelnde Darmjajerblatt.

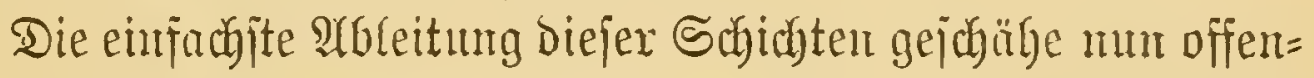
bar Durch Spaltung dex ztwei Şauptblätter - bei ben Sce= twalzen aber geben nach Selenfa alle beide aus Den immern J̧auptblatt, Dem Crmboberm, herbor, mind ztwar zutächft anf bie M̧eije, Dáj jid, , vie Fig. $113 \mathrm{~B}$ andeutet, von bejonderen 然uthexungen bes Bimenjactes einzelne Bcllen ablöjen und

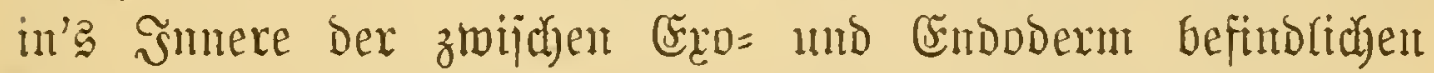

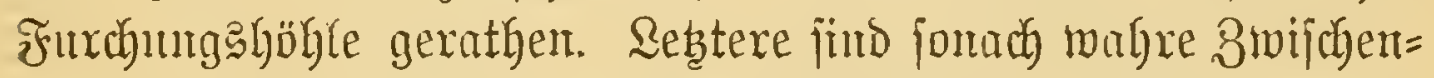
oder Mittelzellen und miro ifyre Bsejamuntyeit baher and ganz pajient als Mittelfeim ober Mejoderm bezeidnet.

Dieje Mittelzefent rufen uns mieder Fritheres in's Gre=

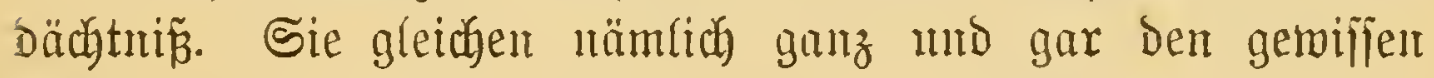
Amöboid= oder Stexnzellen, bie wir (gleichfalls in ber Fur chungahöhle) bei Den Snfeften fanden, bort aber jळon zu eimer 3eit, bevor etwas dem Endodern Sergleichbares borljan= Den ift.

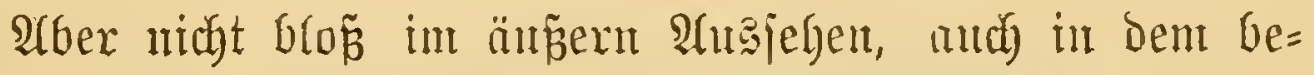
Dentungavolfen Umitand ftimnten dieje Bimtenzellen ïbereit,

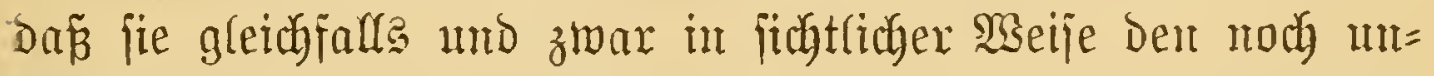
verbraudbten Dotter aufzebren und in Forge Defien fich auper=

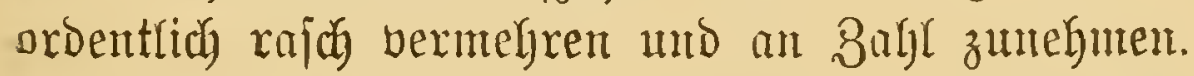

So regellos mut anfaugs alle dieje "Wantberzellen" Durch= cinanderliegen, jo auperordentlid bejtinmt ijt beren fpätere 
פufitellung, weiche jie nad) furzer Ungebuntenkeit mo frei= zügigfcit eimuehmen. Die ganze Banbe tremt fich nämlid int wabriten Sinu Des Wartes in zwei Rager, was anf Fig. $113 \mathrm{C}$ zu jegen. Die einen ajjociiren fith Dem Şantblatt (h $\mathrm{fB}$ ), bie anberen bem Darmblatt (dfB). Dies ment man mut auf gut Embryologifd bie "Spartung Deg Mefoderms"

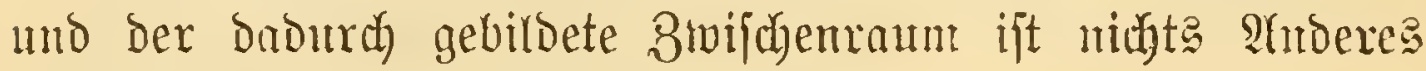
ale die Reibeagöble.

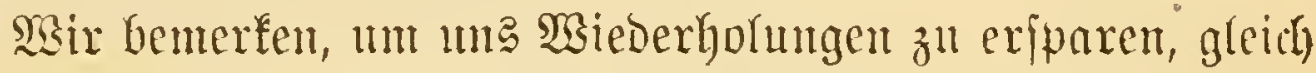

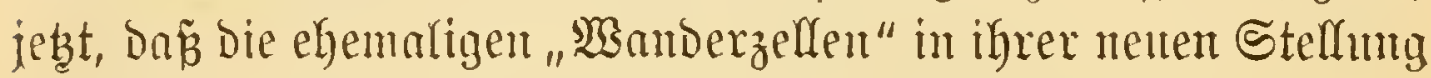
ihre frübere felb fändige Natur z. Th. anfgeben und in Den Dienjt des Gejammtorganisun tretend, in bie befamnten Ffeijdyfafern fict) ummandeln.

Nur (ains eximert nod) an ben ehemafigen 3 utand, näm= (id) Die öähigfeit Der fpontanen Bufanmenzichnng, bie aber

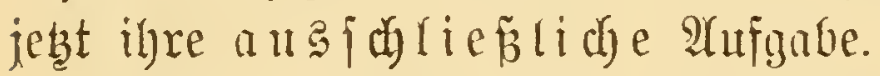

Arles in âfen genommen werden wix nun jagen, dañ

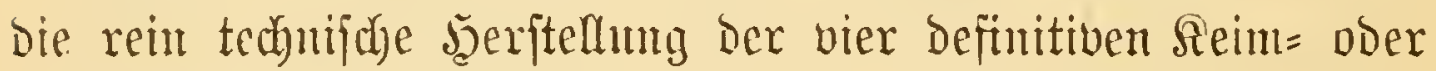
Biewebablätter Der Seewalze theifs anf Crimftülpung Der Reim=

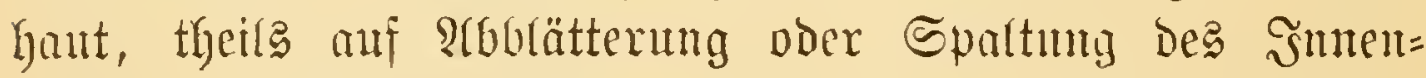
refp. Des feinerjeits wiebor bou lebzterem abgetremten Mittel= feimes berulgt.

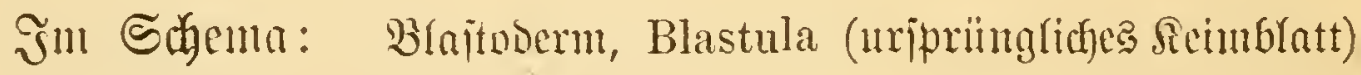

Erroderm Entodoum im w.

(1. Soutblatt) Gastrula

Miejobarm (2. Darmbrifiublatt)

(3. מุautiajurbfatt) (4. Darmiajerbratt) 


\section{Mun, wie ift es bei ben Injeften?}

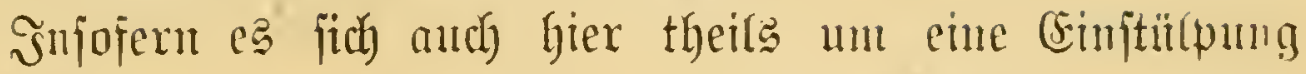

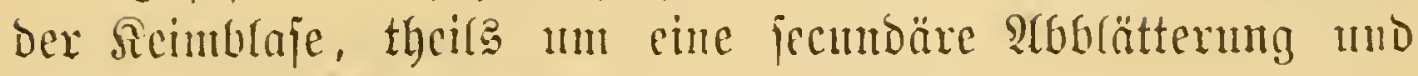
Spaltung hambelt, bari man jagen, ebenjo.

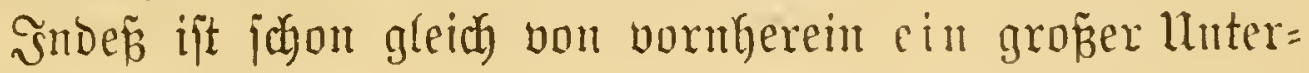
idyied herworğtheben.

Bei Der Seetbalze cutfpricht Der llmfang Der ficintbaje ank Dem llmfantg Des sambryo, in fie ift eigentfich ber Embryo

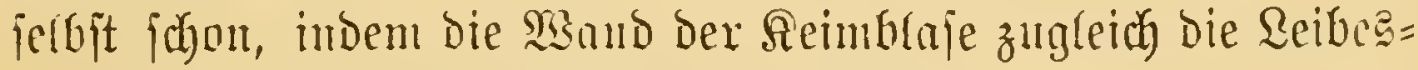
mand bes embryonalen Thieres baritellt.

Granz anders vexhält jich's, ähnlid wie bei Mirbelthieren, mit ber Injeftenfeimblaje, Die, jo möbten wir fagen, wegen

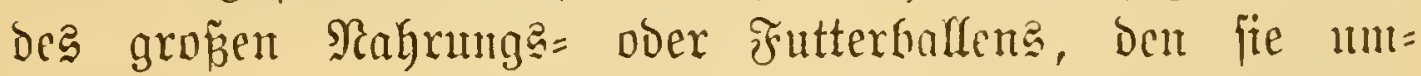

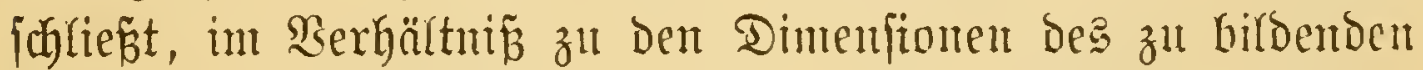
Embryo zul weitlänfig angelegt ift. Die Reimbraje ift aljo nidyt, wie bei vielen andern Igieren, ber Embrno jelbft, fie ift mur ein probijorifares bsebilde. Damit foll gejagt

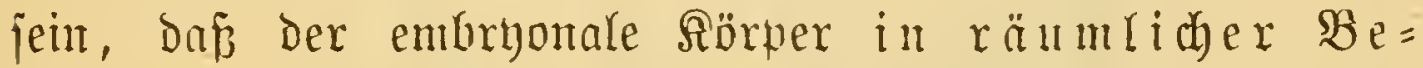
ziehnug nidgt ans ber gauze Rcimblaje entftegt, fonbern mur ans einem relatio fleinen Segment derfelben, melches Segment wir, un jeine bejtinumng ganzunzwei=

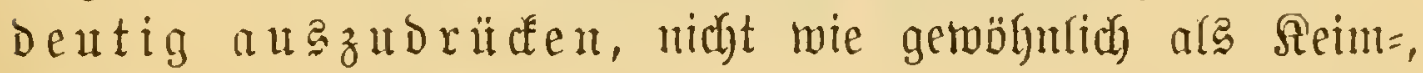
jondern, gelegentlid) menigitens, direft nlg (5mbryonal= jegment bezeidgnen werben.

Betradbtet man ein möglidjit bünnidarliges und jrifd ge=

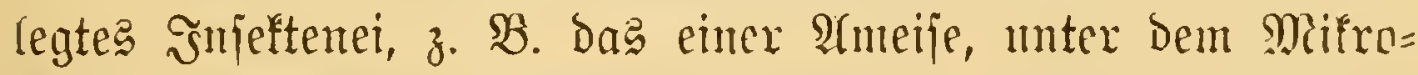
ifop bei burdyfalfendem Ridyt, jo fiebt man zunächit, mem man anf bie Dberfläche eimitellt, mur ben Dotter.

Bei länger fortgejebzter Beobndfutung bemertt man Damr,

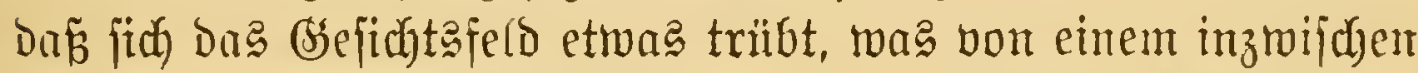

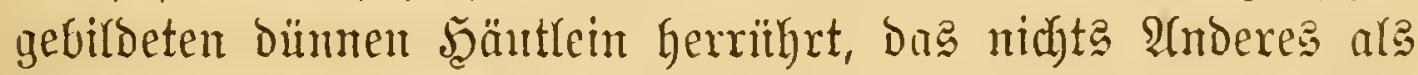
Die Reimbaut ift. Anfangs fiebt man aber nod überall ben Dotter Durdffidinmern. Sebt man aber die Beobaditumg, 


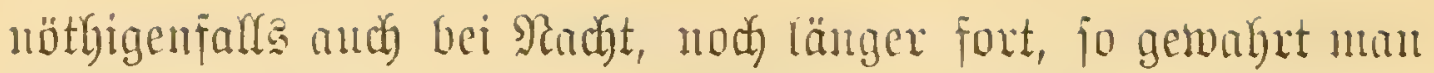
früber voer inäter an einer bejtimmten Stelle Der Reimbant einen anfangs ganz Kleinen, aber fich rajoh augheitenden

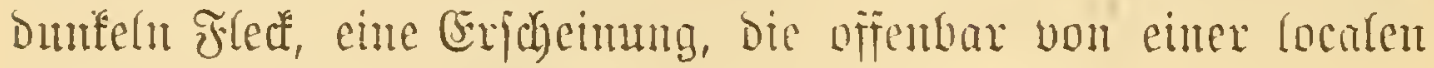

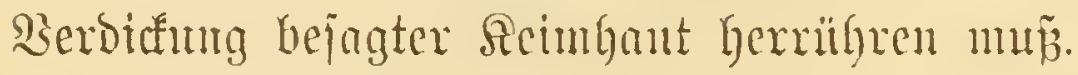

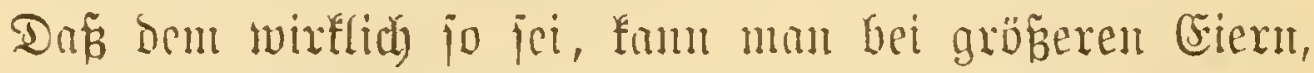

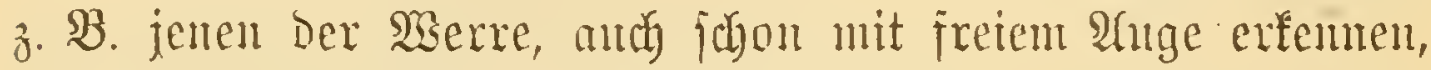

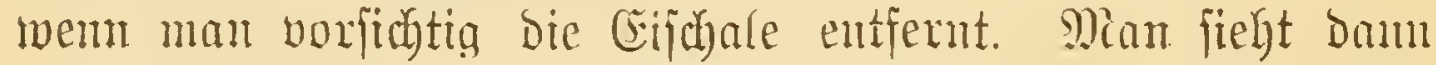

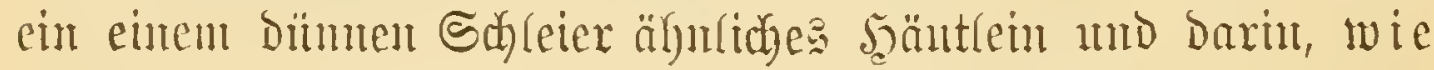

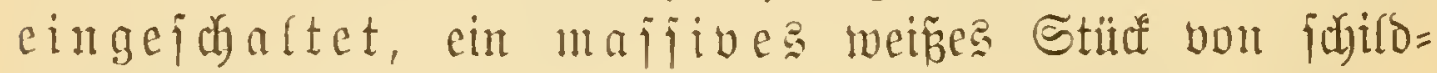
oder ftreifenartiger Form. Eriteres ift die Seimblafe, rebteres Der Embryonal= oder fieimfteif, D. i. Die früber ermähnte veroidte Stelle der Rembraje.

(5in ähntiches Bild zeigt uns auth Fig. $114 \mathrm{~A}$, Das

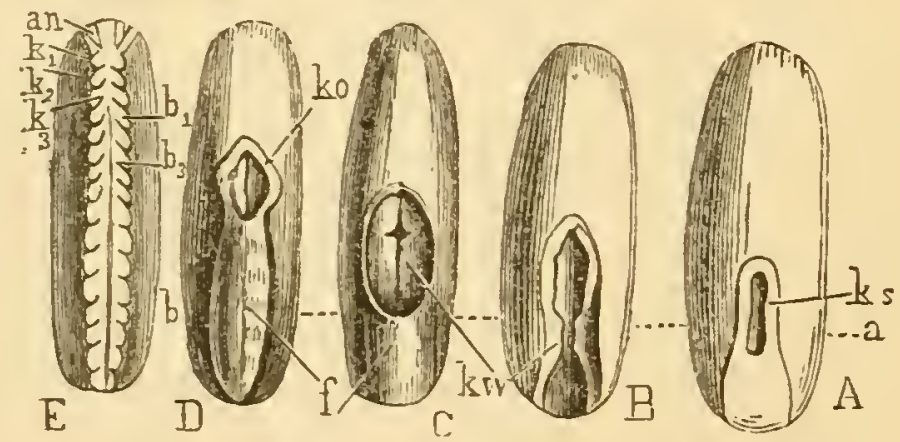

gig. 114.

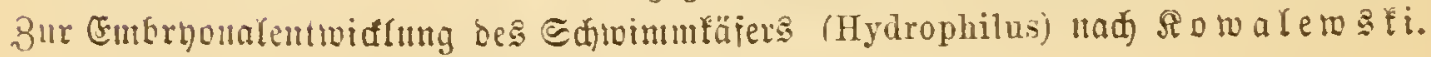
$A-E$ Fi vouber $B$ a d feite.

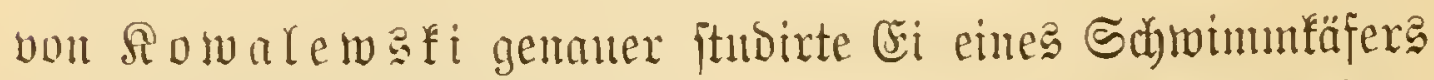
(Hydrophilus), wobei man in Der zungestartigen Africhwellung an Şinterento (ks) ben Seimftreif erfentm miro.

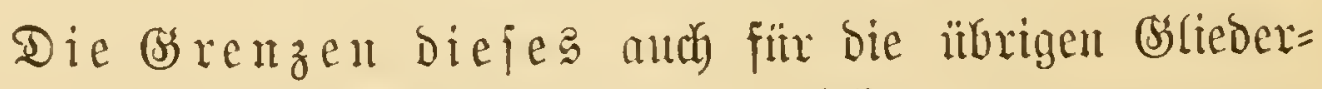

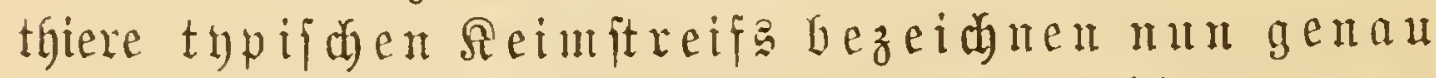

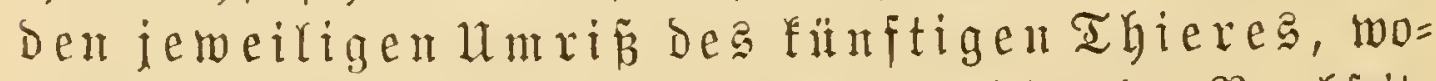

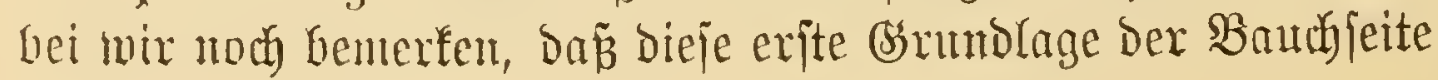


Desjelben entipridyt, baj aljo eiue Drieutiung Darüber, was,

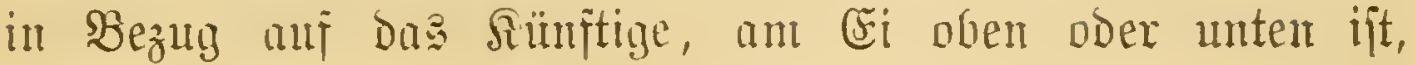
ftrenge genommen erjt nach erfolgter Differentirung biefer Embryonalanlage möglich ijt.

Die reigempeife Sergleidyung ber Figuren A, B, C, D, E

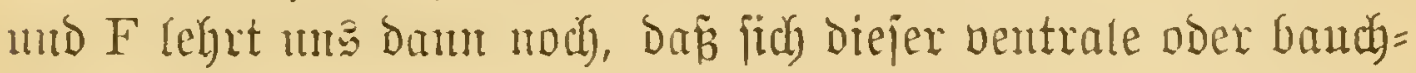

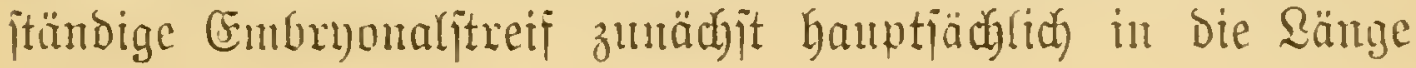
anäbelynt.

Das wäre ber erifte auffallente llnterjajed gegenïber ber Eeetralzen = Blastula.

Shan zunädjit bie Frange, wie entiteht ober morani bernht Dieje Reimblajenberditung?

(Śegenüber älteren und vie(fad) fid) triberiprechenden $\mathfrak{A}=$

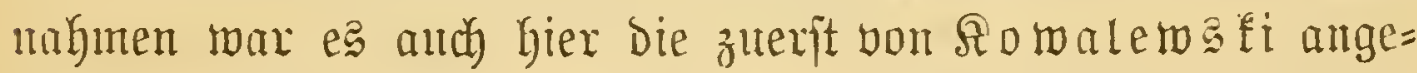

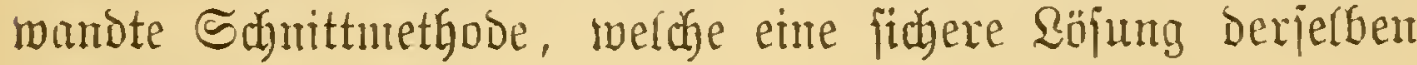
ermöglidite.

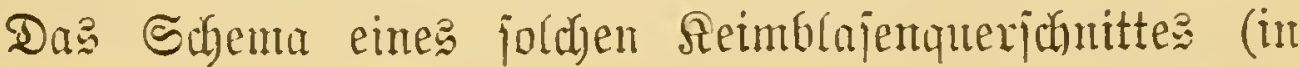
Der Region bes (Embryonalitreifa) gift F̛̃g. 115 A. Die Reim= haut bejtegt noch immer und ringsum aus einer einzigen Sdidyte von Bellen, und bie embryonale Zone bexjelben, ¿. i. Dex Reimitreif (ks) entitebt einfach dadurch, da ja bie Bel= len hier grö̈er rejp. höher jind als im übrigen Theile.

Un: borliegenden Stadium ijt ber Unterjafied zwar now gering, ex verftärft fich aber 1) Dadurch, Dá̃ bie cylinderförmigen Bellen ber Embryonalzone fich now mehr ver= rängern, und 2) Dadurd), ba $\tilde{\beta}$ g(eid)= zeitig bie Elementartheile Der übrigen

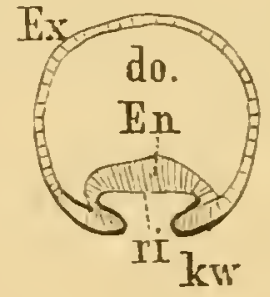

B.

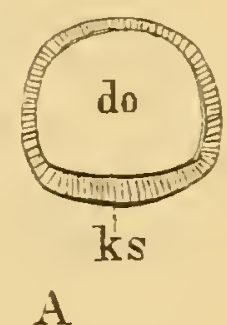

Fig. 115.

Edjemata bon fieimblajen= queriduitten.

$\Lambda$ Erites Stadium. ks Meimitreif.

B Finitülpungsitabium. Ex Froderm, En Endoderm, ri Reimrinue, kw Reim= roiilite, do viahrungsotter. 
Bone an şöhe einbünen. Sebeterer ßorgang zeigt unz zu=

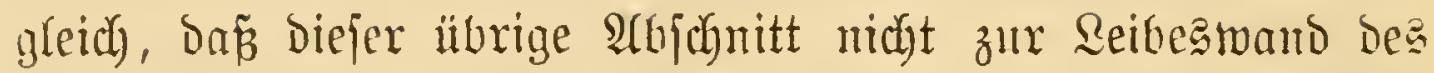

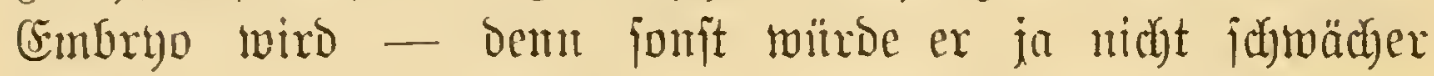
merben - Daj ex vielutegr mur zur Unibüllung des Dotters bient.

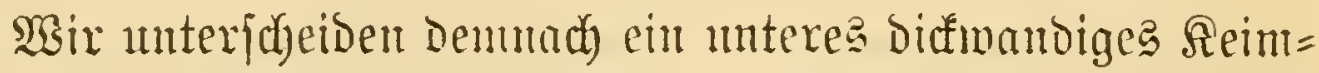
blajenjegment, bie Embryonalzone, und ein bberes bün=

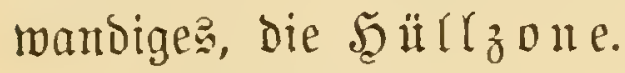

Diejelhe Sondorming mo Bejdaffentheit Der Reinthaje findet man nad) eigenen Mnterfudumgen-fajt bei allen Snfeften, audh bei jenen, benen andere einen mehridhichtigen Seimjtreif rejp. den Mangel einer Şüllzone zufdreiben. - Die ganze jebt betrad)tete Differenzinutg Der Reimblafe herulgt, wie wir

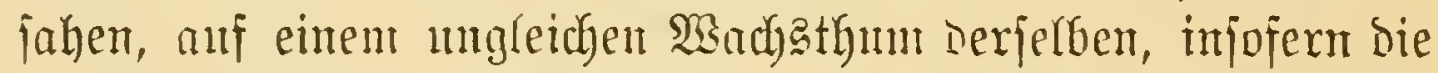

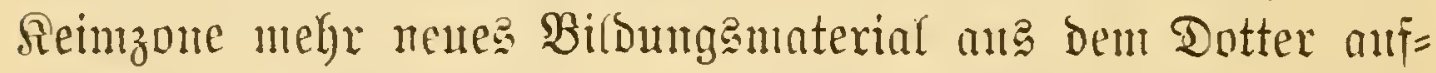

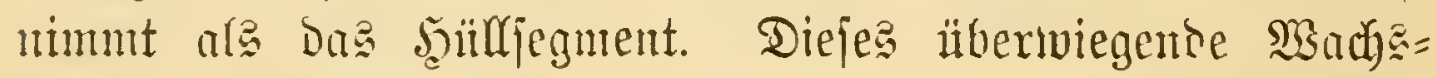

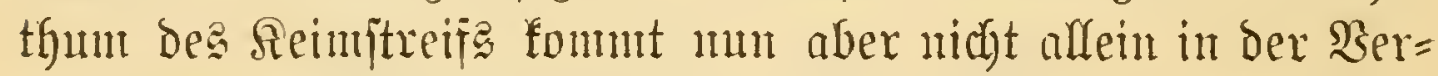
größzerung rejp. Serłängerntg feimer Belfen zum jonbern anth in einer Sermebrung Derjelben uno in Folge

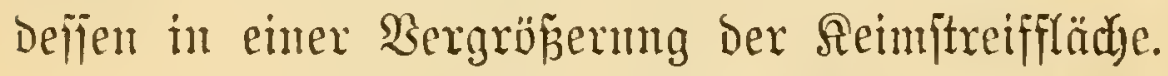

Die Flächenandeblunng einer zelligen Rlatte führt aber, wie mix jadjon früber gehört, unter getwijen Bebingıngen

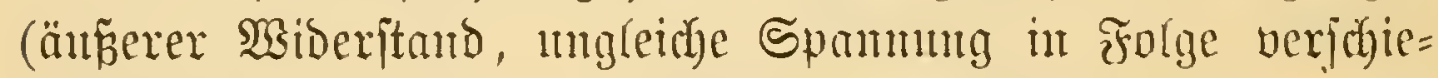
Dener Dicfe n. j. w.) zu einer Faltung beziehungăweije zu einer Cimptülpung, mo falls dies muth hier gejuähe, wäre bamit

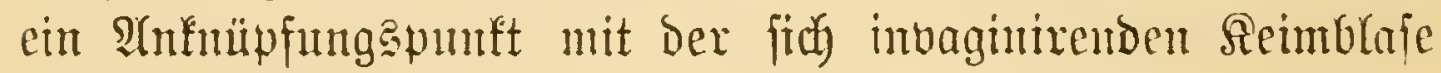
Der Seemalzen gegeben.

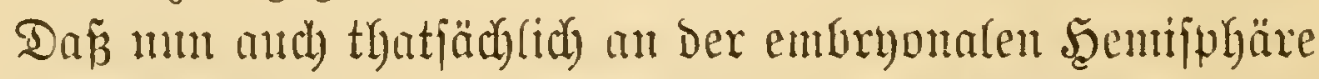
Dex Snfeftenfeintblaje cine Eirjtülpung, ober Faltung nach

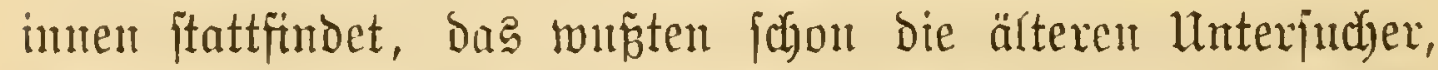

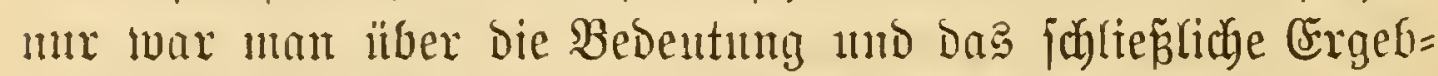

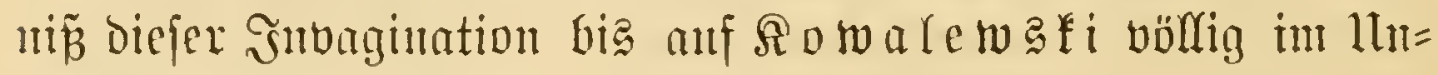
flaren. 
Seben wix bie oben begnnnene continnirfidye Beobadytung

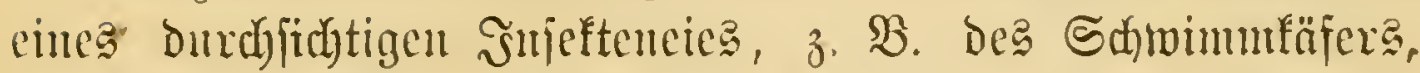
fort, fo fehen wir, don fidy ber Reimftreif baíd madj feinent

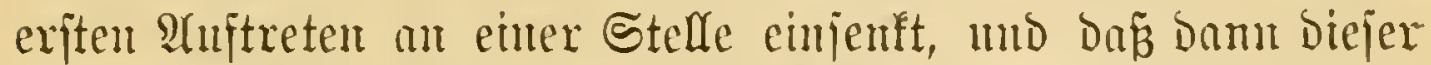
anfange meift mapfartige Cimbrud fid längs ber Mitte des Reimitreifs in cine denfellon halbirende Furdhe (Fig. $116 \mathrm{Aks}$ ),

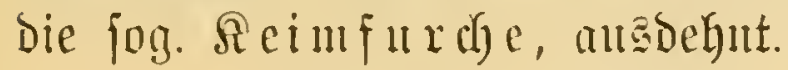

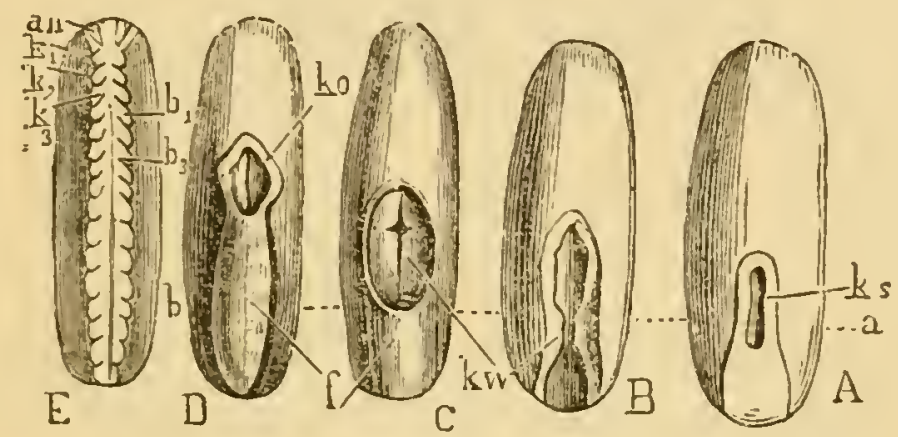

Fig. 116.

A Edirbiörmiger Hrimitiv= nder Embryonalïreijen mit ber ßrimitibrime.

B Wad)

(5) feidyzeitig mit biejer Cinjenfung des mebianen Theila erheben fich aber and die Seitentänder in Bseftalt zmeier bie Reimfurdye überragenter mb affmälig einengender (Rein=) Wäl jte (Fig. $116 \mathrm{~B} \mathrm{kw).}$

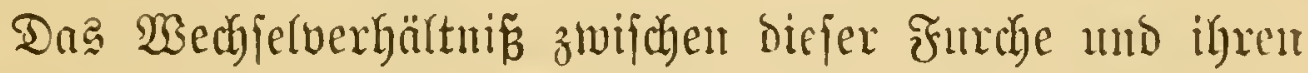
giändern ftellt fich wieber an einem Duteriduitt (Fig. 117 B) an flar= itert Dar.

Şier erfennt man mit Einem

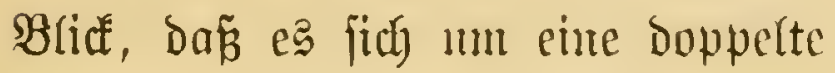
Faltung hanbelt, um eine crin= jtülpung (En), dic Sicimfurche (ri), uno baun um einte Aqugtülpurg Dex beiben Ränder, die Reimmülfte (kw).

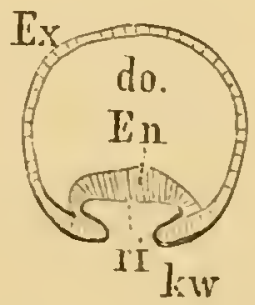

B.

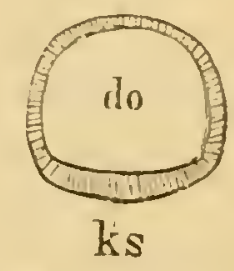

A

Fig. 117. 
Num, fragen twir ben \&ejer, ijt bie S̈njeftenfeimblaje anf biejem Stabinm nidyt eine wabre Gastrula ju menten?"

Dáp jich Die Seimblaje wirf(ich) in eimem eingejtïlpten 3ujtand befindet, wird woht Rientand läuguen, man wird aber, ganz abgejeben von Der längliden Form diejer Falte, ihre

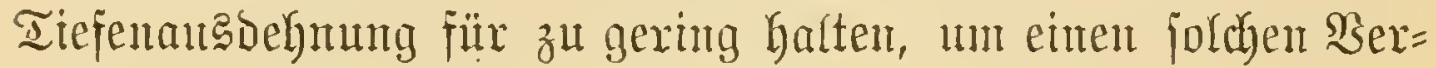
gleich mit bem Bimmenjad der Seewalze zu wagen.

Er bliffe aber jeb̧t gefülligit auf Fig. 119 A, einem mux

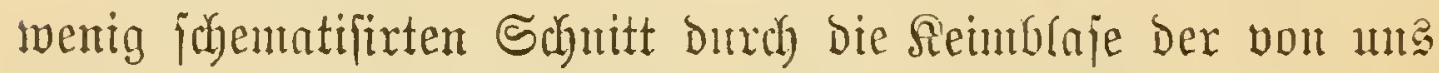
jelbit unterjuchten Lina - Sier.

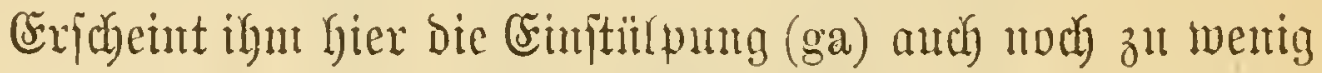
gajtrula=artig?

গAn, in biefen Fall, hoffen toir, Dünfte Dodh Die in Fig. 118 Dargejtellte simjacfung (ga*) eines ebenfalls jelbjtgejduttenten Fliegenteies Brentüge thut.

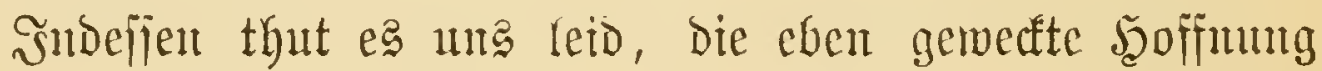

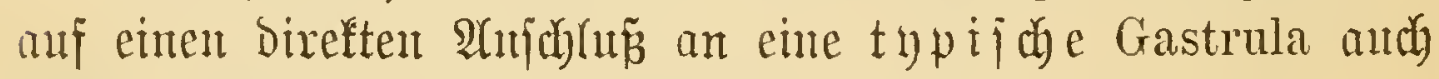
jofort wieber zerftören zu mïfjen.

Unter einer typifden Gastrula berftelden wir nad Der früberen Darjtelfung eine joldue, Derèn Bimen= jate atth moch beim fertigen Thiere einen Theil bes Serdau= ungaholframtes ober bes Darmes ausnatht, bei ber alfo,

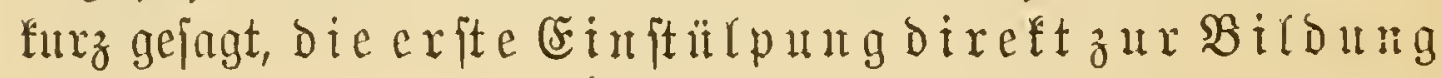
eimes bleibenden 5ohlorganes fügrt.

Dies ijt nut aber bei don Snjeften nie mo nimmer ber Fall.

Die mit einer Bellwudherung verbumbene $\mathfrak{B}$ erjent

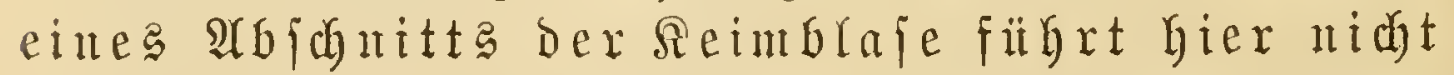
zur birbua eines bleibendea Soblorgaus, fie

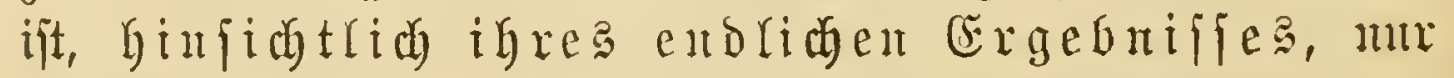

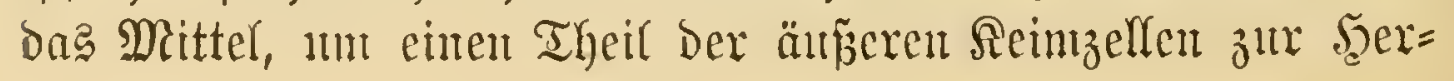




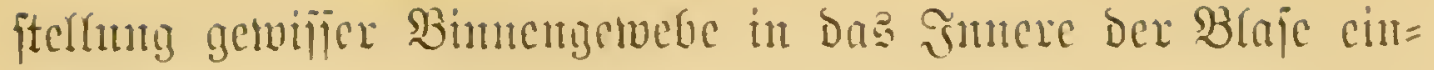
zufiitfrent.

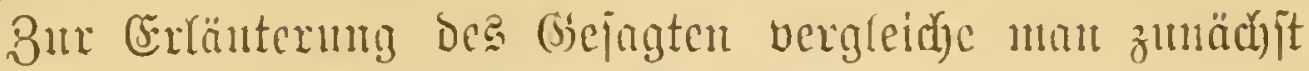
Fitg. 114 B nit C. Fn B.ift bic Sicintfurche mux in ocr Mitte

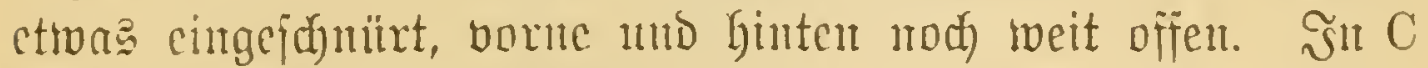
Gingegen jieht mau äuß̧erlidg mux mehr einen engen Spalt,

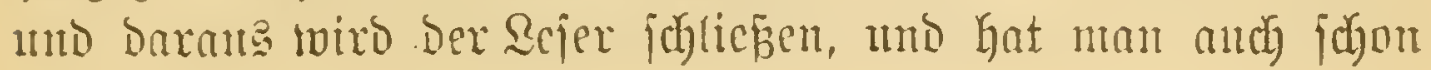

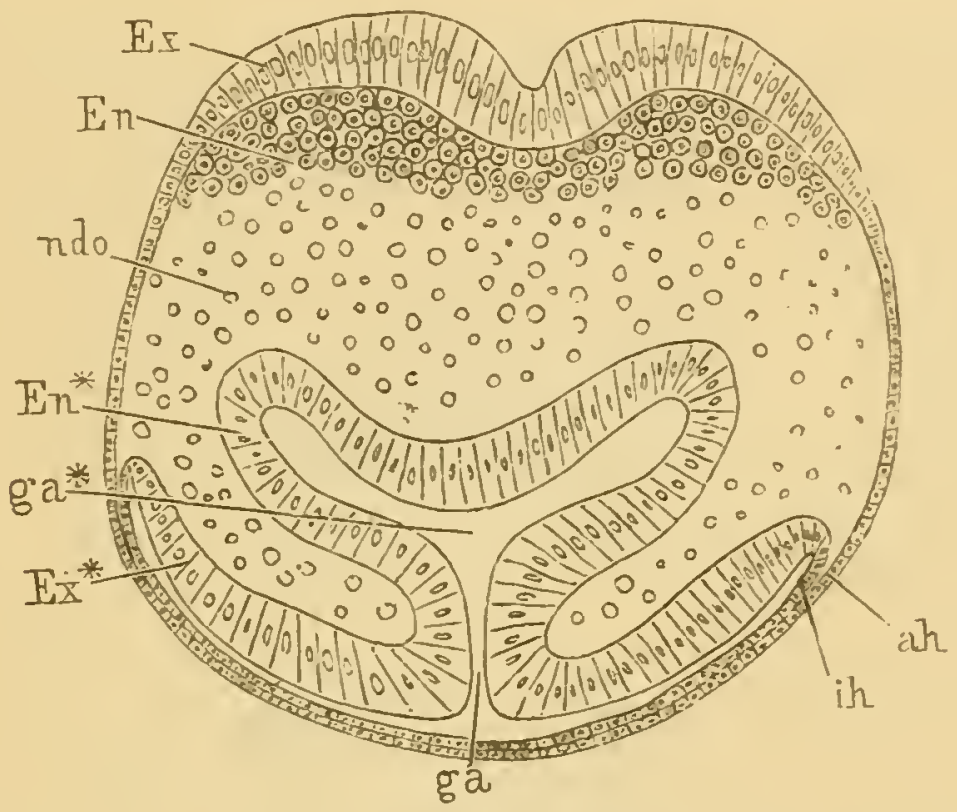

Fig. 118.

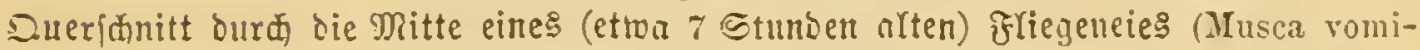
toria L.)

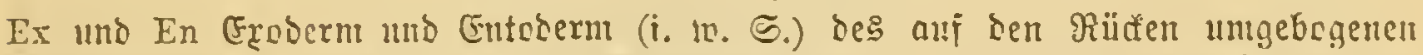
Reimftreifentes, Ex* Eroberm bes Reimitreifo, En* gaitrula=artige (Finjtülfung ber

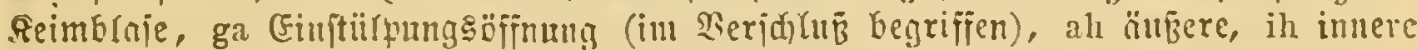
(ventrale) Embryonalhülle, nilo Dotter. Bergr. 20\%/. (Driginar.)

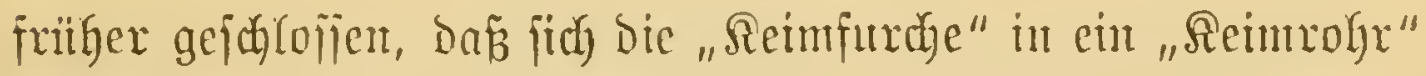
vermantelt.

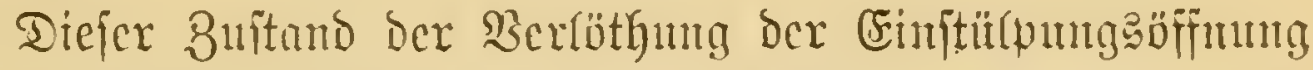
ftellt aud mijer Suerfduitt Fig. 118 bar, wo man bei ga mur modj cinte cnge Ribe ficht.

Dic Berftopfung bes "Mrmumbes" aflein witroce imber moch feinesmegs ber Gastrula cin Ende mad)en, ment fich 


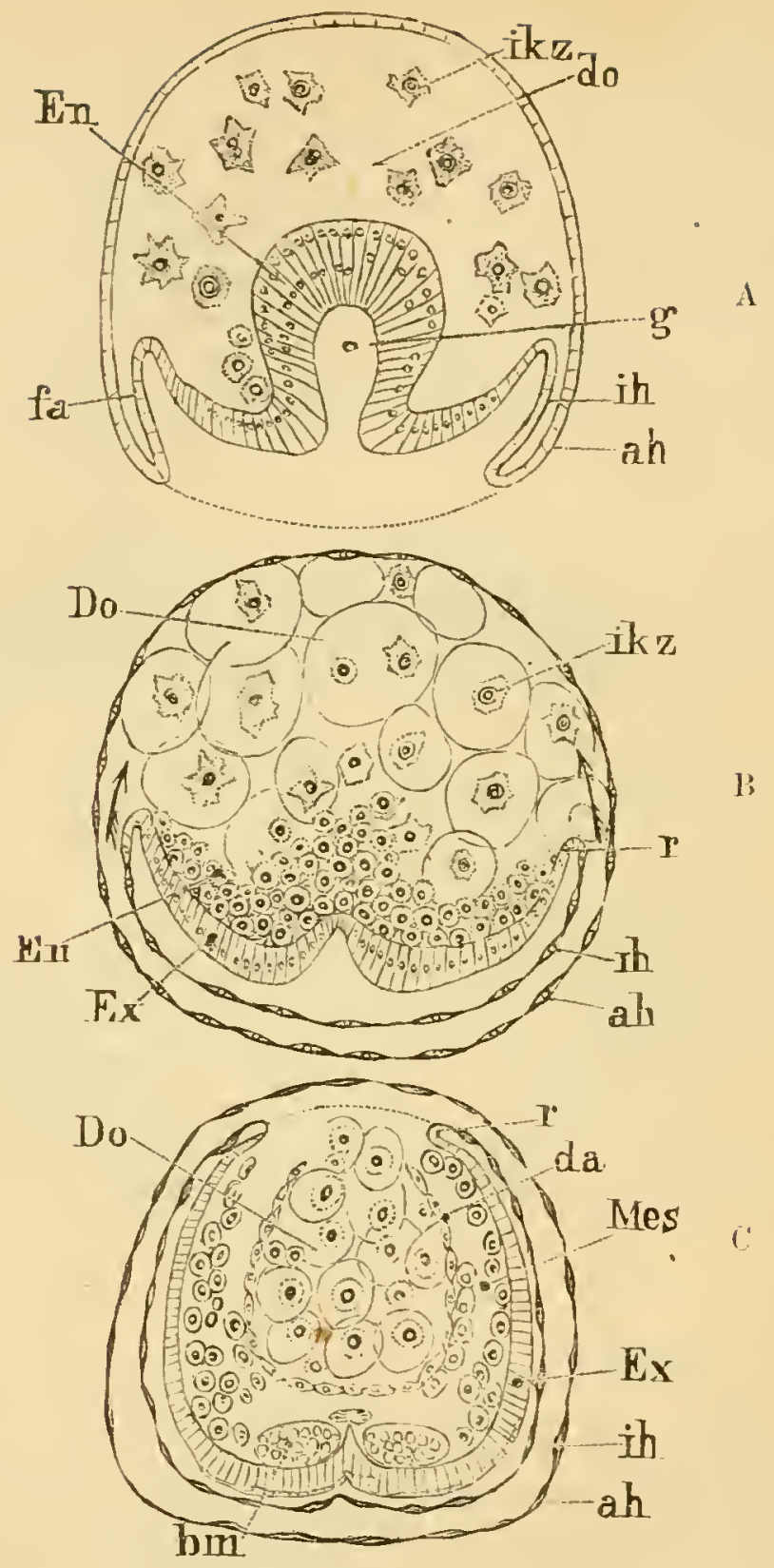

\&ig. 119 A B C.

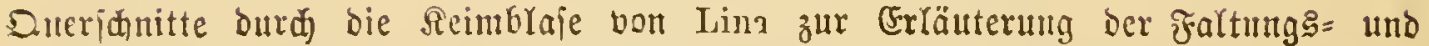
anלerer Birdungšvorgänge.

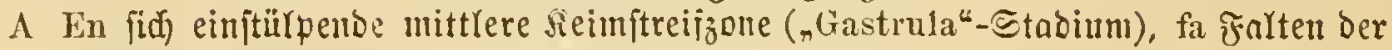

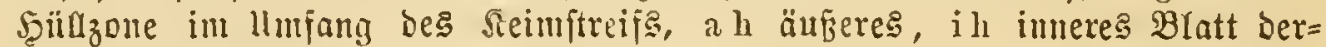
ielben, do Dotter, ikz innere seim= ober Dotterzelfell.

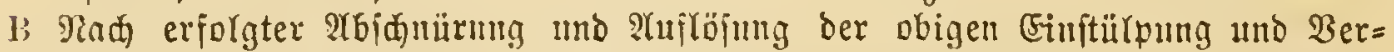
einigung ber Baudgfalten. En bas Darans entitanbene Entoberm (hier aber

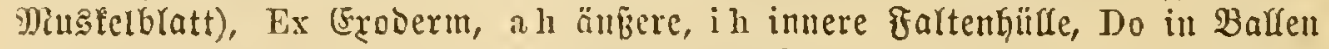
geformter Rahrungsootter, i k zellen Derielben.

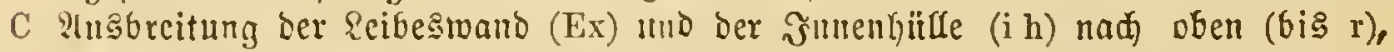
Mes Mejoberm, da Mitteroarm-(Epitgel (Eöloblajt), Do Dotter, bm Baud)=

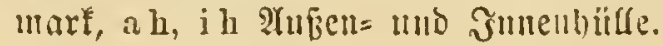




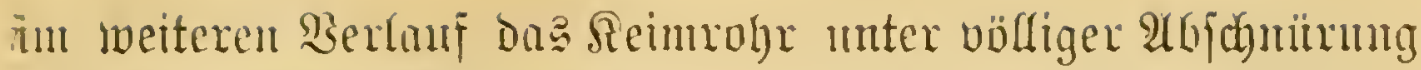

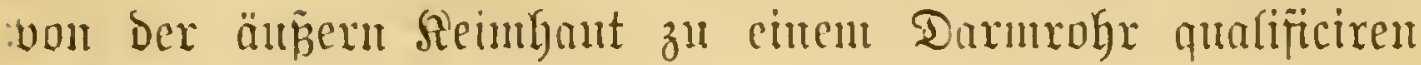
wuilroc.

Sie aber fohon bentert, gejchiebt bies ganz mo gar nidjt;

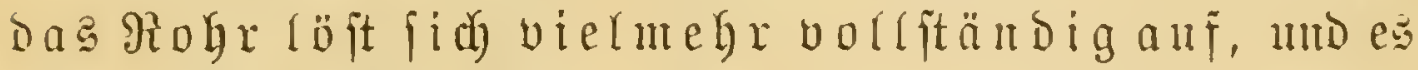
bleibt bavon nidyts ïbrig, als was man an mperent Sdyntt (F̌ig. 118) oher: bei En* fieht, nämlid) ein Şanfent rundicher Nactzellen.

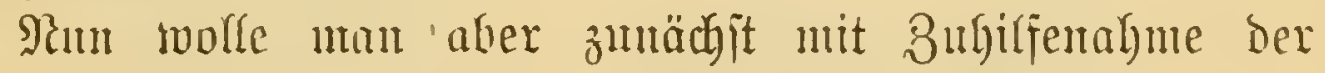
Fig. 119 B beachten, baj jegt bie Reimzone ans zmei berjchie= Denen Bellenlagern bejtert, die wir wieder, aber ledig=

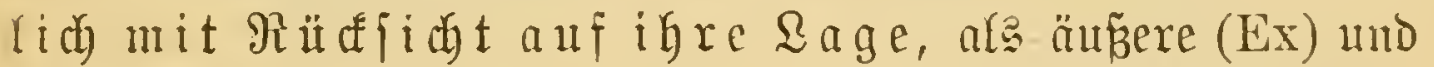

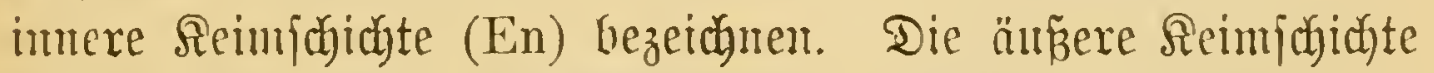
ift, wie man fieht, in Wejentlidyen Dasfelbe einfdhidhtige Epitger, wie vor ber Einftülpung, und da Dasjelbe faltijit Dir äunern Reibes= rejp. Bandhmandung de马 füntigen Thieres

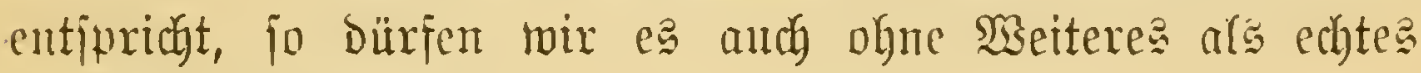
Eroderm bezeidynert.

Die Frage ijt num, was ats ber zmeiten oder innern Shidgte (En) wirb.

Sebent wir cimmal den für bie Seemalzen = Gastrula zu=

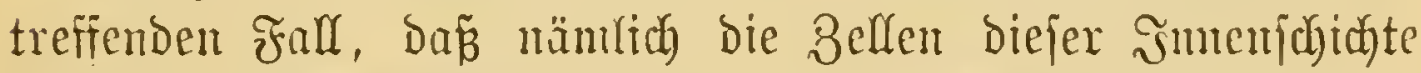
die eimzigen formelentente imergalb Der Reimblaje (Exodernt) twären, Danu wäre Deren Bejtimmung Gald erratgen, fie bildeten einfad den gemeinjamen $\mathfrak{l} r=\Re e$ eim für das $\mathfrak{F} a j e r=$ und Darm $=$ Ulatt.

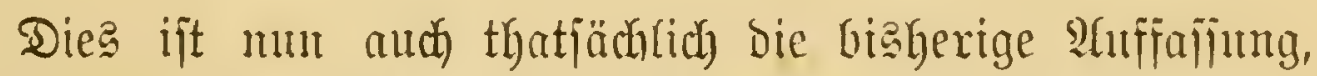

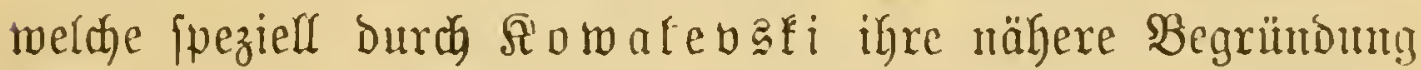
ergielt.

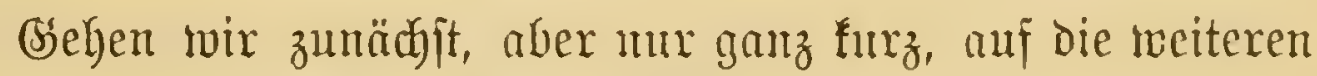

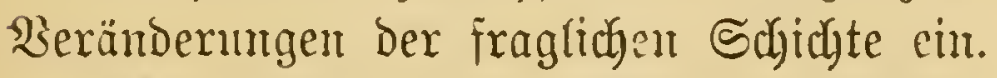

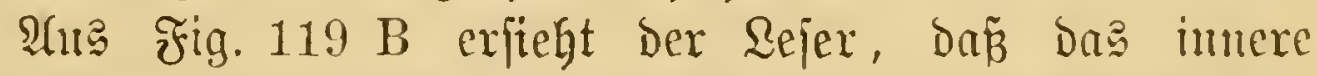

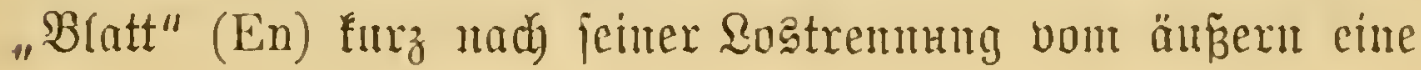




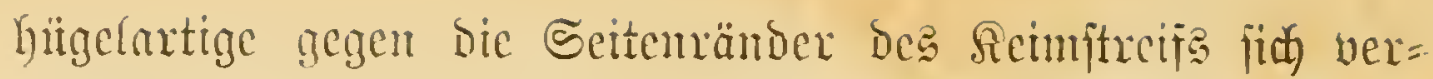
flachende Belfmafie bildot. Die betreffomben Belfen verichieben

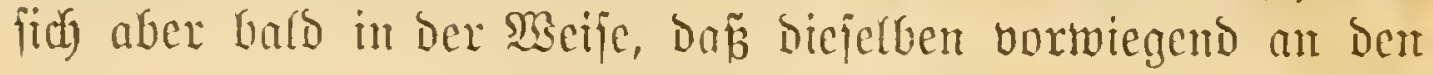
Sciten (જ̛ig. $120 \mathrm{lh}$ ) angebänft exidyeinen.

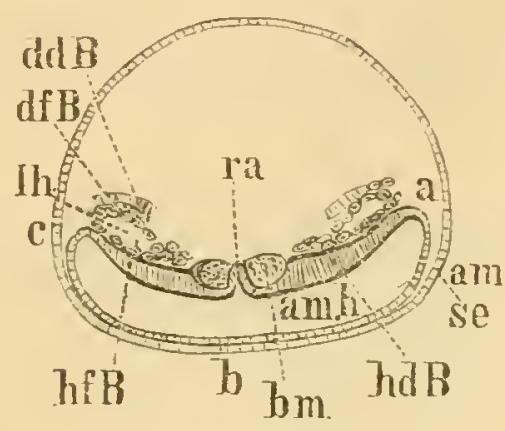

Fig. 120.

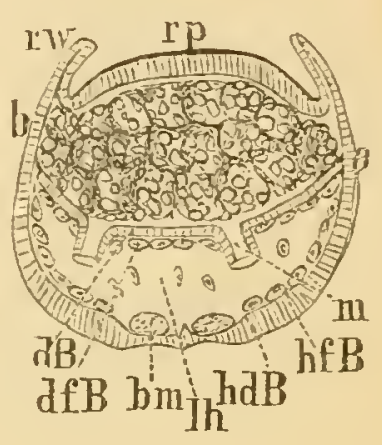

Fig. 121.

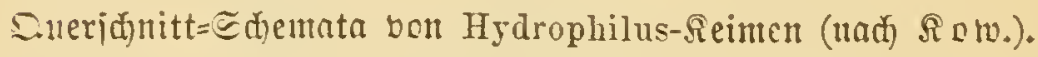

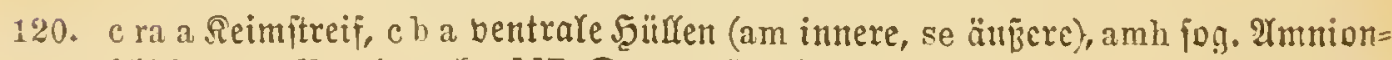
höhle, bm Banchmart, ddB Darmoriijenblatt=?nlage, df B Darmfaiers, hf B

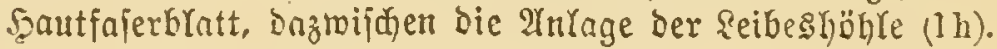

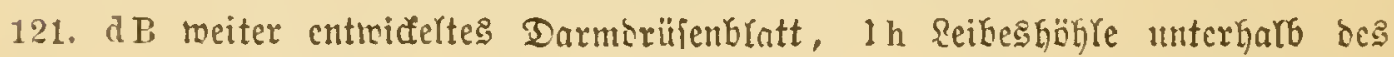

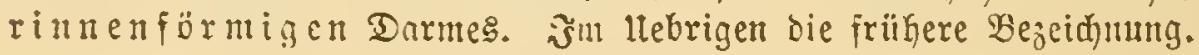

Dieje jeitlduden Bellitränge find mut in erfter Sinte bie Anlagen fïr das Bmijchengemebe mo jpeciell für bas Darm= 1mb Şautfajerblatt.

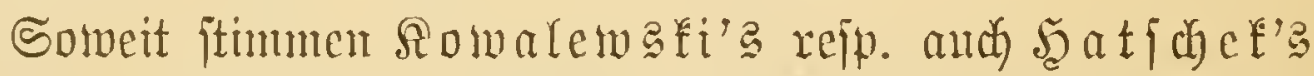
Ungaben boflfommen mit Den cigenen Befunden ïfrerein.

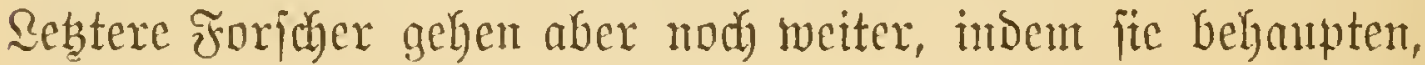
Dan ïber Dem Darmfaferblatte und aus Demjelbert Mate= rial and das Darmbriffenblatt entjtïnde und zrvar zumäcbjt

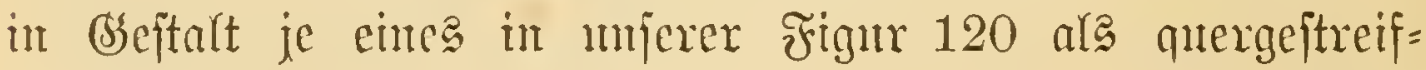
tes Banto (ddB) Dargejtellen Epitherftreifent. Dicfe beisent Seitemftreifur follten bam, vom Ranbe her, gegen bie Mitte jujammenwachjen, umb anf bicje Ârt fäme bie der offenen Darmanlage ber Mirbeltyiere ähutiche, Den Dotter vou mten

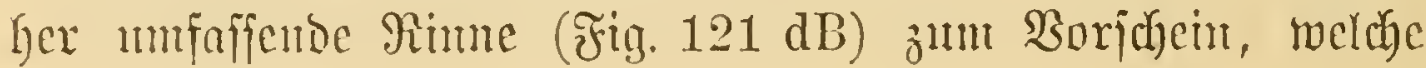




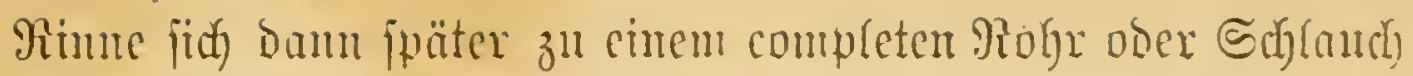
vervollitändigen sülrde.

Diejer Durmbildungaghyotheje gegenüber müjen wir mur den Sejer bor Seffem Daranf aufmerfjam mathen, Don

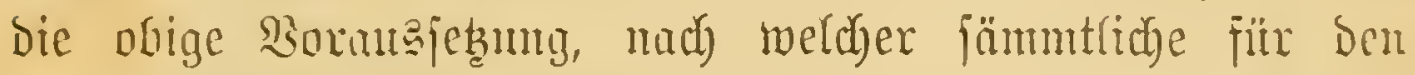

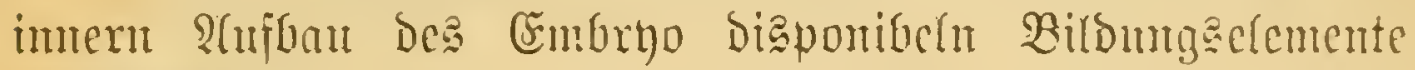

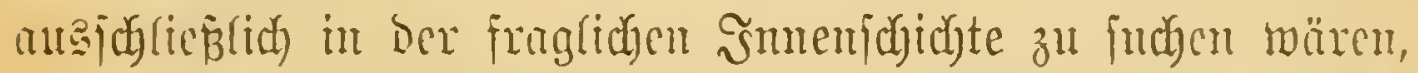

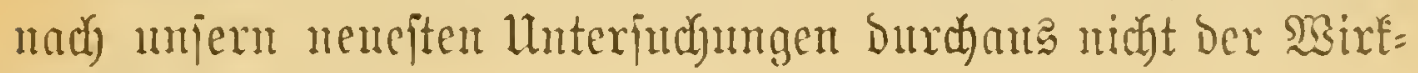
liajfeit cutfpridyt.

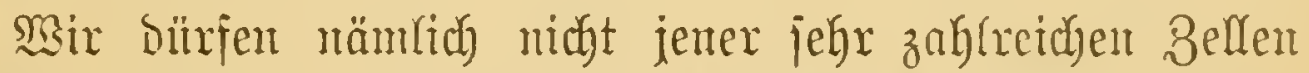

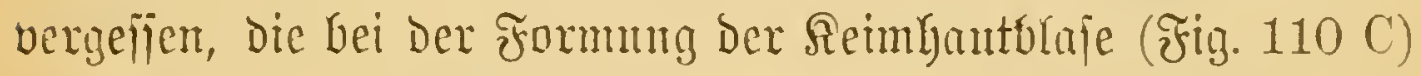
und zmar als Ritefitände der exften Embryonalzellen im

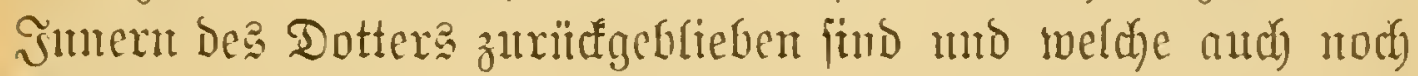
Fätex und zur Zeit Der Blajtonerm-Snoagination Dariu bor=

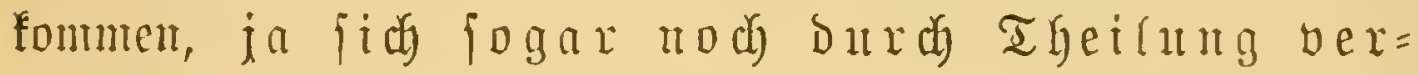
megren.

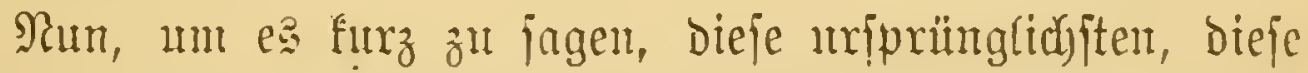
primären Bimnenzellen find ca eben, wethe bas Darmepithel ober Dus Cocloberm Gifloen, mälyrent die von ber eingejtïlpten Reimbaut abjtanmenden Elemente nidhts anderes ars das Bwijhengemebe, das Micjo= ober (Enteroderm Yiefern*).

Wab aber bie 2 at und Beije betrifft, wie bie im Dotter alferorts zeritrenten Zellen fich zu einer benjelben aljeitig unifaijenden Schidyte zujammenfügen, jo haben wir es da

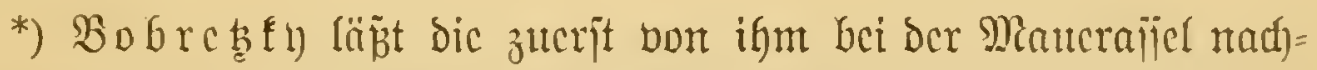

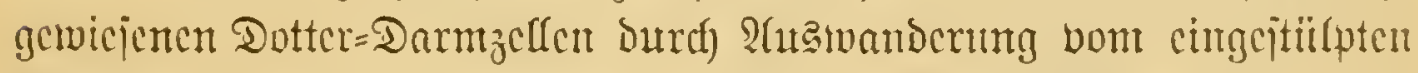
Blajtobermthcile aus entitchen Siach gewiilïn Schnitten bci Lina,

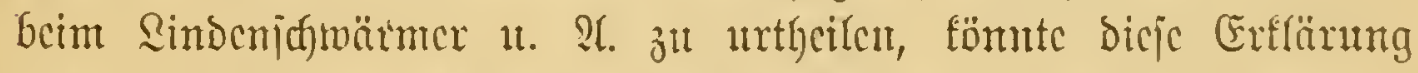

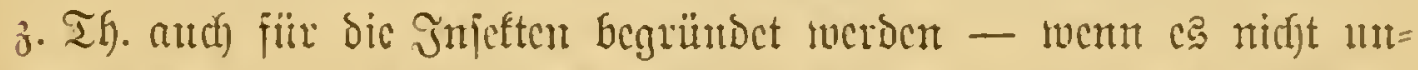

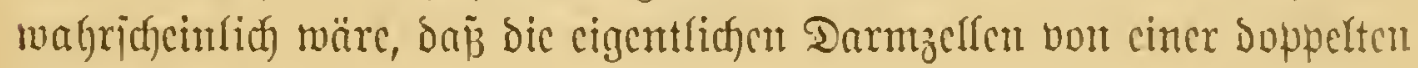
Dutclle beritamtuten.

Braber, Jnjetten. II. B̊s. 
mit cumen ganz analogen Borgang mie bet Dex SBildung ber Reintbautbraje zu thun, fenuen aber leiber nod uid bie Rxäfte, weldye eine joldye centrifugale Bewegun ber betreffenden Berren auslöen. Seier ift tod eine eigenthimtidye und meift in bie Beit Der Reinftreiffildung fallende Fridyemung ant Nabrungs: botter zu exwähnen. Sie beitebt darin, daż fich derielbe bei vielen S̈nfeften fowie audh bei andern (śliebertbieren in grof̧e ballenartige Stüfe jondert (Fig. 119 Do). Dieje bald frïher, bald ipäter auftretende räunliche Sonberung hat man als jecundäre Fuxdyug oder Segmentirung bezeidnet. S̃n= Defien entftehen, wie wir bei Lina nnd andermärts beobach = teten, Dieje Dotterbaßlen ganz nno gar nidyt burdy eine einer totalen Furahung ähnliche Berklütung ber ganzen Dottertugel,

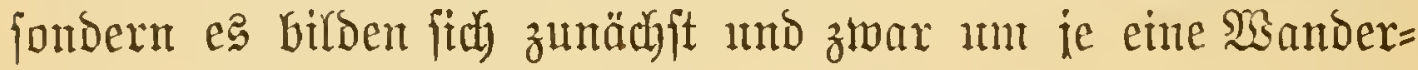
zelle infelartige (rumpen mitten in nod unge= formten Dotter und exit nady mo nady belynt fid diefe,

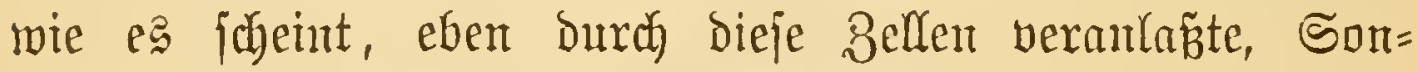
berung auf die ganze Majje ans. Statt einer einfeitlidien Dottexmaffe mit vielen eingejprengten Bellen baben wix Dann eine Bielgeit Heinerer Dottermajjen mit meift je einer Belle. Der Borgang läuft mit andern Moxten auf eine $\mathcal{I} \mathfrak{L}$ eirung ber Eruährungterritorien der einzeluen Mander= zellen binaus.

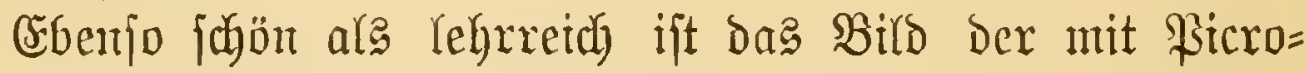
Eamin gefärbten Durdjantutte diejer Angehn. Snt Sentum liegt en rother Rreigflef, D. i. Dex Rexn Der Sanderzelle

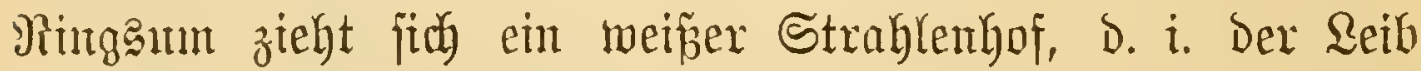
ber Belle, während die Sattututajfe Der Augel, Dex gelb ge= färbte Nabrungsotter, die Reripherie emummt.

Sm Siegenjag zu Bobrebly, der jede der gentamten Bellen mit Dent fie beherbergenden Dotterballen zu eimen

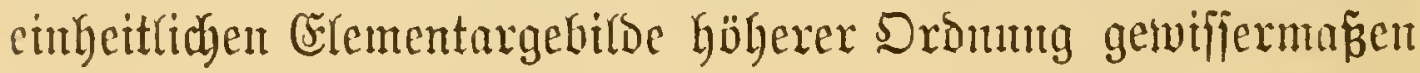




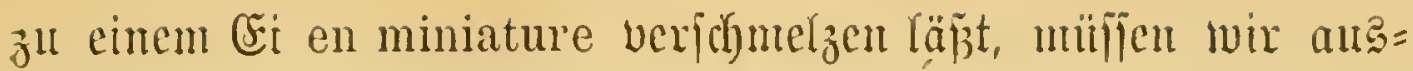
brürffich betonen, da $\tilde{\beta}$ dieje Zerten zux Zeit der

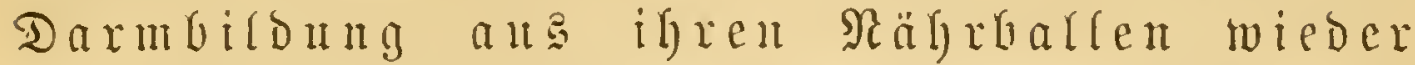

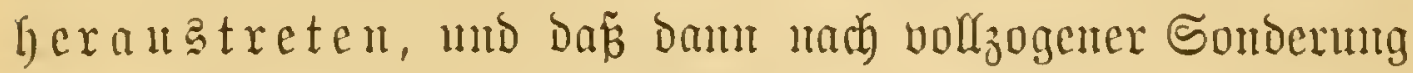
Die "Dotterzelfen" mo Dotterballen in Der Meije angeorduet

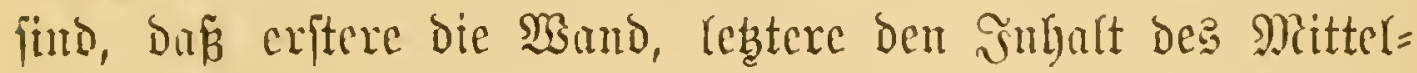
darme billost.

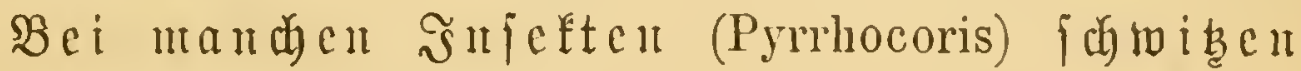
aud die cinzeluendotterfumpen nad dem $\mathfrak{A} u s=$ tritt der zerlen eine ziemlid dicfe, beutlidy doppelt= fonturirte $\mathfrak{S}_{\text {ülle }} \mathfrak{a} u s$, bic fith in Rarmin roth färbt.

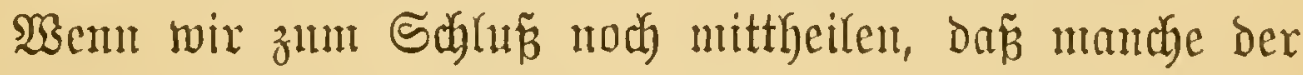
erwähnten Belfen ihren Beruf verfeh(en, d. h. im encyitirten Dotter zurüctalciben und bort zu os rumbe gebel, fo ijt bies unx ein neucr Betweis dafïr, da ja bie itrenge

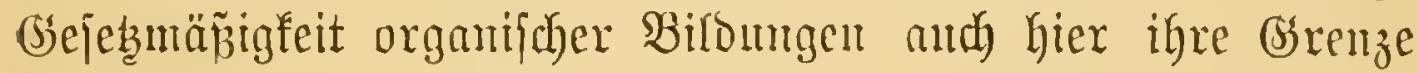
pintoet.

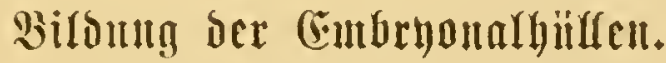

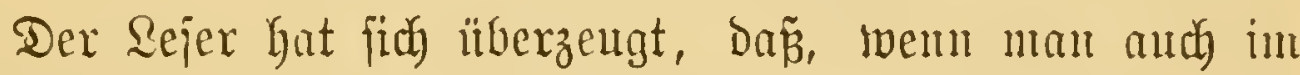
getwöhnlichen Leben jtatt "Entwicklumg" "Entfaltung" fagt,

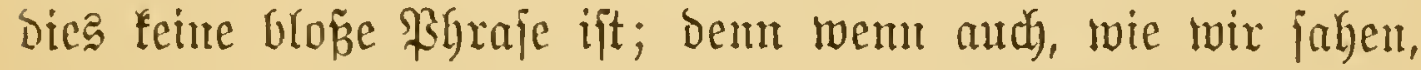
nicht alle Entwicflungaerjubeimngen auf Erweiterung, anf

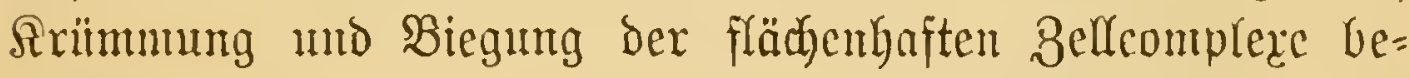
ruben, fo fund boch immerhin fehr viefe Beränderungen auf

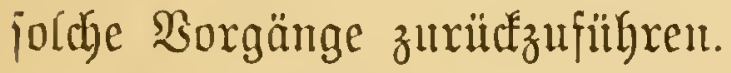

Şauptjäblith war aber bisher mux von Ciner Falte nämlich vou jener Eimjtülpung ber Reimblaje bie Rebe, aus Der bei gemifjen Thieren der Darm entiteht, währeno fie bei ben Injeften mux zux Bildung des 3mijdengemebes fillyt.

Die Seimblaje Der Thiere bildet aber micht bloñ inmere, fie erzengt aud্ äunere Falten uno zwar gelegentlid), fo icheint 


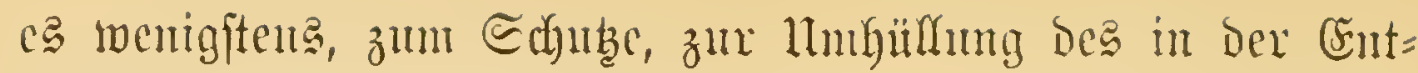

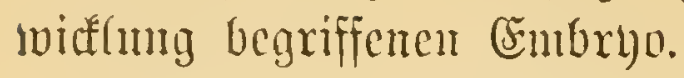

Bon ganz bejonderen Snterefie find fpeciell jene gleid $=$ fals aus Fraltungen ber Reimblafe herborgegangenen Seilllen, in bie wir felbft eimmal entgemicfelt waren, wir meincu bie Embryohülfen des Mienfalen und ber högeren Wirbeltgiere.

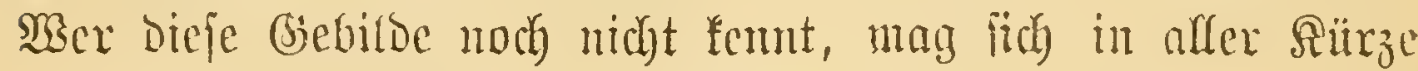
an Der Figur 122 B, einem Säuger = Ei, orientiren. Des

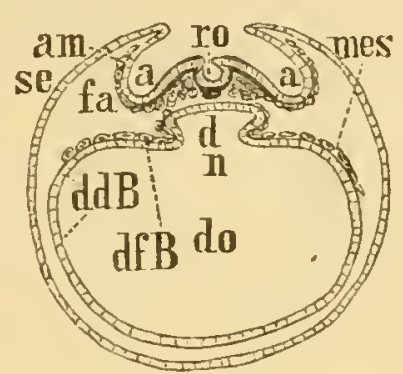

A

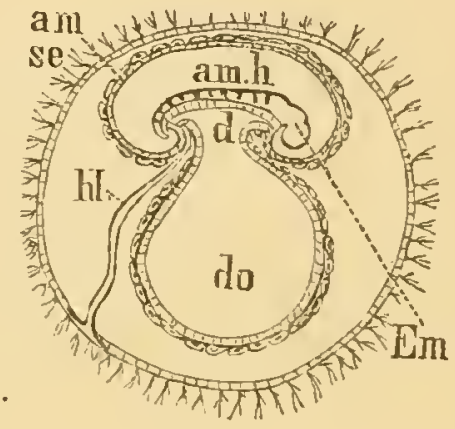

B

Fig. 122.

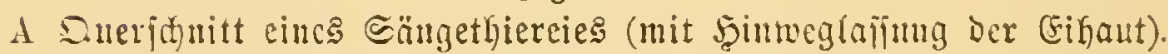

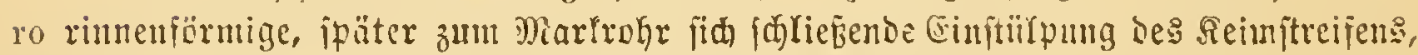
barunter (id)warzer Sireisflect) Sie llranlage Der Wirbeljänle; d Darmrime, Durd) sen Tabel $n$ mit rem Dotterfarf (do) znjammentängend; fa Falten bes äuñeren

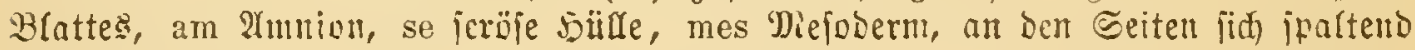

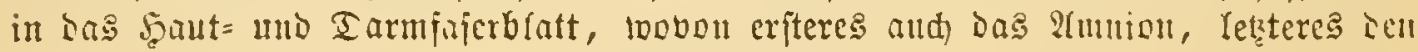
Dotterjact ausfleibet.

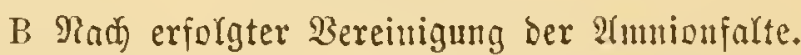

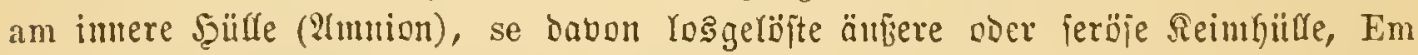

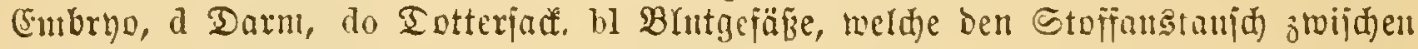
ser frudt mo bem fruchthälter (Placenta) virnittclu.

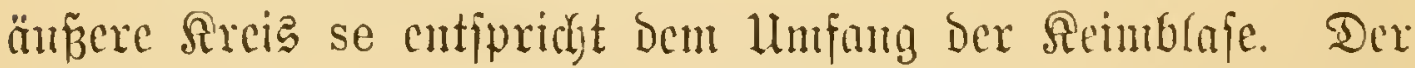
urfprïnglid Daran erzeugte Embryo felbft (Em) ift aber nur ein relatio flemer fiörper und liegt jegt ganz in smmern Derfelben, un ber an noch) offenen Darm (d) bängento Arubang (do) ift ber "Dotterfact". Wunerbem bemerłt man

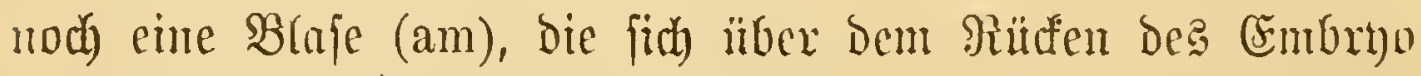
auŝpant und ganz prall mit einer mäfjerigen frtinffigfeit er= fiitult ift. 


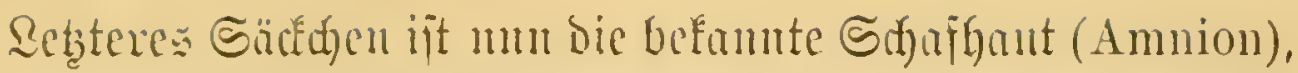

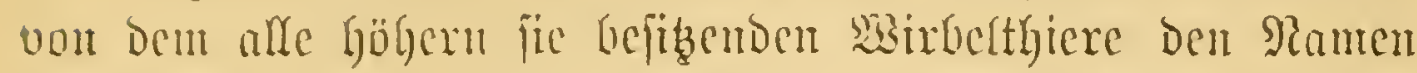

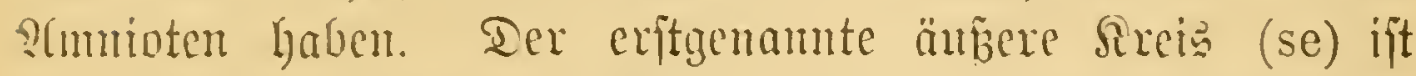
iit Dam eine zweite, für Ammion mo Dotterjacf gemeinjame fir) (cimige beillfe, die joy. "Serosa".

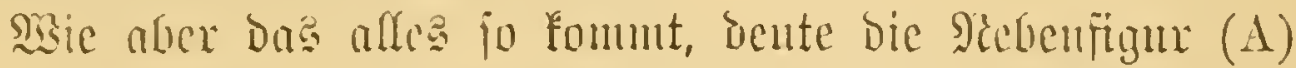
an. se ift wieder ber fiemblajemmifung, bie obere Piatte ro die jencibenförnige giüffentulage des Embruo.

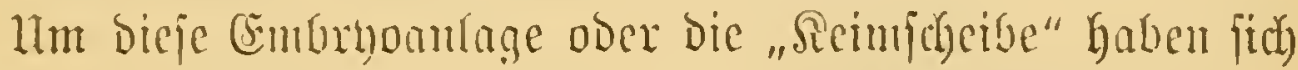
mun, toie man fieht, zwei Falten (fa) ber Seimblaje crhoben, die, swem fie ӥ̈ber dem Embryo zufammentwadyjen, bie vor= bejariebene Dopperblaje geber.

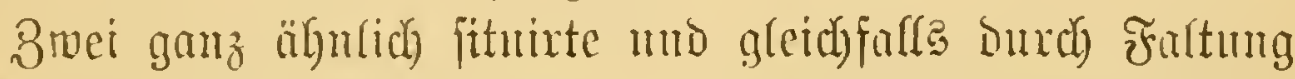

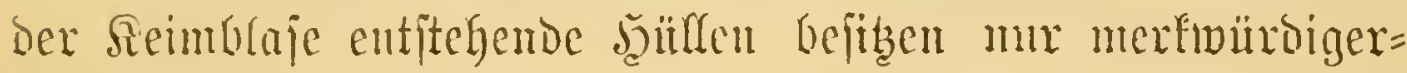
weije aud bie Snifiten.

MSix fagen "merftuilroigermeije", nidyt weil es, zmmal vom Stmopmet bex natïrlichen Budbtwaht ans, etras jo

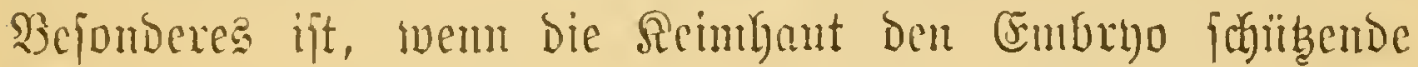
Falten anjendet, fondern bestoegen, meil gerabe bicje ed ten

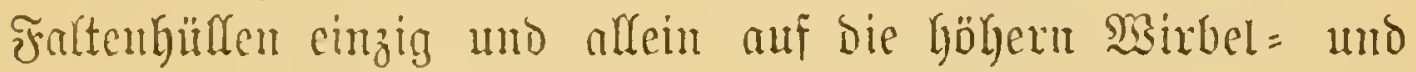

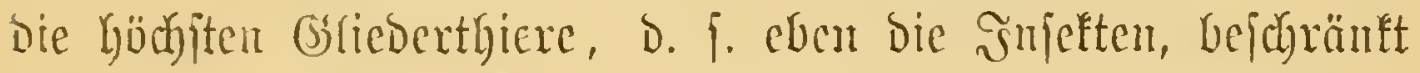

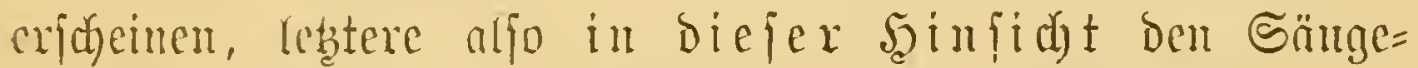
thieren ähnlidyer find als andere niebere WBirbertbicre, wie

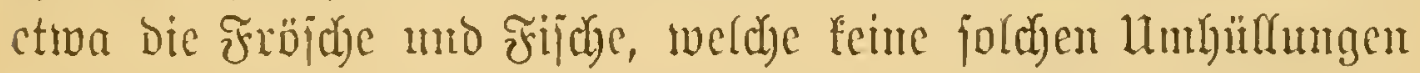
befizen. Da mu, wie and ber chen erwälynte unitand zeigt, eine nähere Sertwandifd)aft oder Şomologie biejer Şïlll= gebilde midjt firder begründet werden fann, jo haben wir es bier mieder mit einer jener burdy gleichgeridatete $\mathfrak{A} \mathfrak{n}=$ foijung erzengten Conbergenzen ober Scheingleidgeiten zu thun, wie wir joidje bei ben verfdyjedenjten Drganismen nus Srganen folyon bifter antrafen.

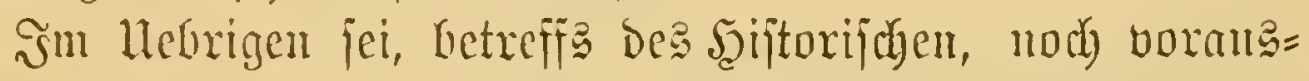

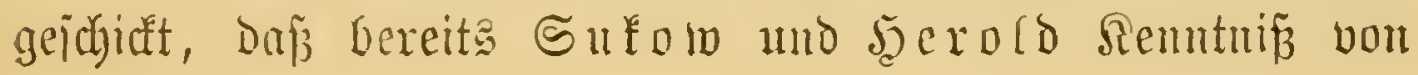




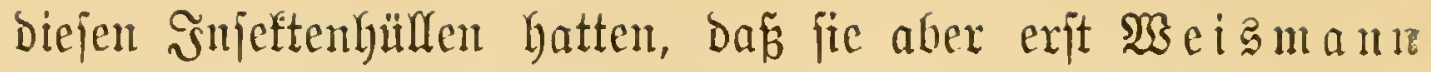
für ein= und bald barauf $\Re u p p$ fer fïr zmeijdyidytige edyte Faltentirbungen crfannte, währeno fie mo ssanin bei mandyen sulfeften z. Th. (Amnion) ge= läugnet, z. Th . (Serosa) Durch Delantination oder $\mathfrak{A} \mathfrak{b b r a ̈ t t e =}$ rung erflärt wurben, wie Demn überbaupt, namentlidy in $\mathfrak{B} e=$ zug auf Deren fpäteres Berlyalten, alle nicht auf Schnitte gegründeten $\mathfrak{A}$ uf gehen.

Durd) Den ermähnten limịtanto lajie fich aber ber Sejer nicht abidyrefien, fich mit ber Sache etwas vertraut zu madyen; Dem fie ift thatjächlich weit einfacher, als ea bei ber

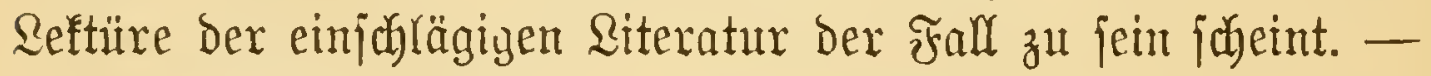

Der 2ejer nehme auf nachjtehendem Orrappenbilde ba? erfte Erbema (123) zur Şand.

Selbes zeigt die Reimblaje, jagen wir eines Räfers, anf Dem Stabium, wo jie fith bereits in eine (biffe) Reim= (kz) und in eine bünne Şüllzone (hz) gejondert hat.

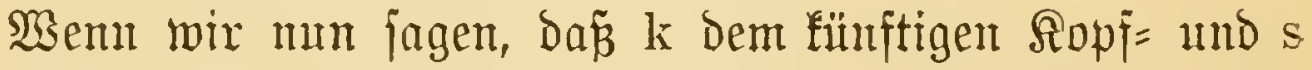
Dem Sdywanztheil des Enthryo entipridyt, fo weiñ Der Lejer

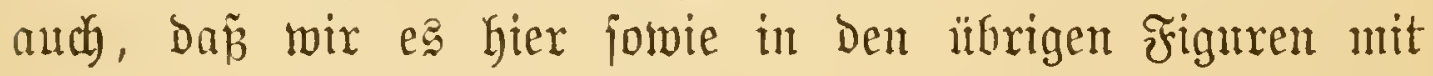

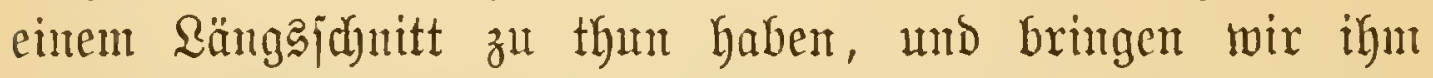

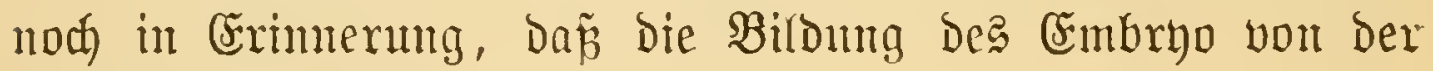
Bandjeite auggegt.

Nan vergleidje er ein fpäteres Stabium (F̧ig. 124) mit Dem frühern. Dic Beränderming ift folgende. Fürre erfte bat jich ber Ropf= und Schronatheil etwas in die Reimblaje hinein=, mo fürs zweite haben fich bie zunädyft liegenden Ränder der (Dümen) Şitllane herauggejtülpt. Demnach yaben wir an beiden Enden ober Rolen des Reimitreife zrweierlei Falten. Sine negative, weldye nad inmen geht nmo einen Theil des Reimftreifs cutfält, und cine pofitive, aus=

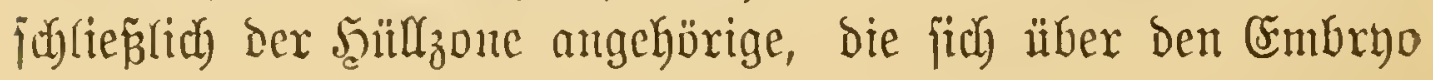



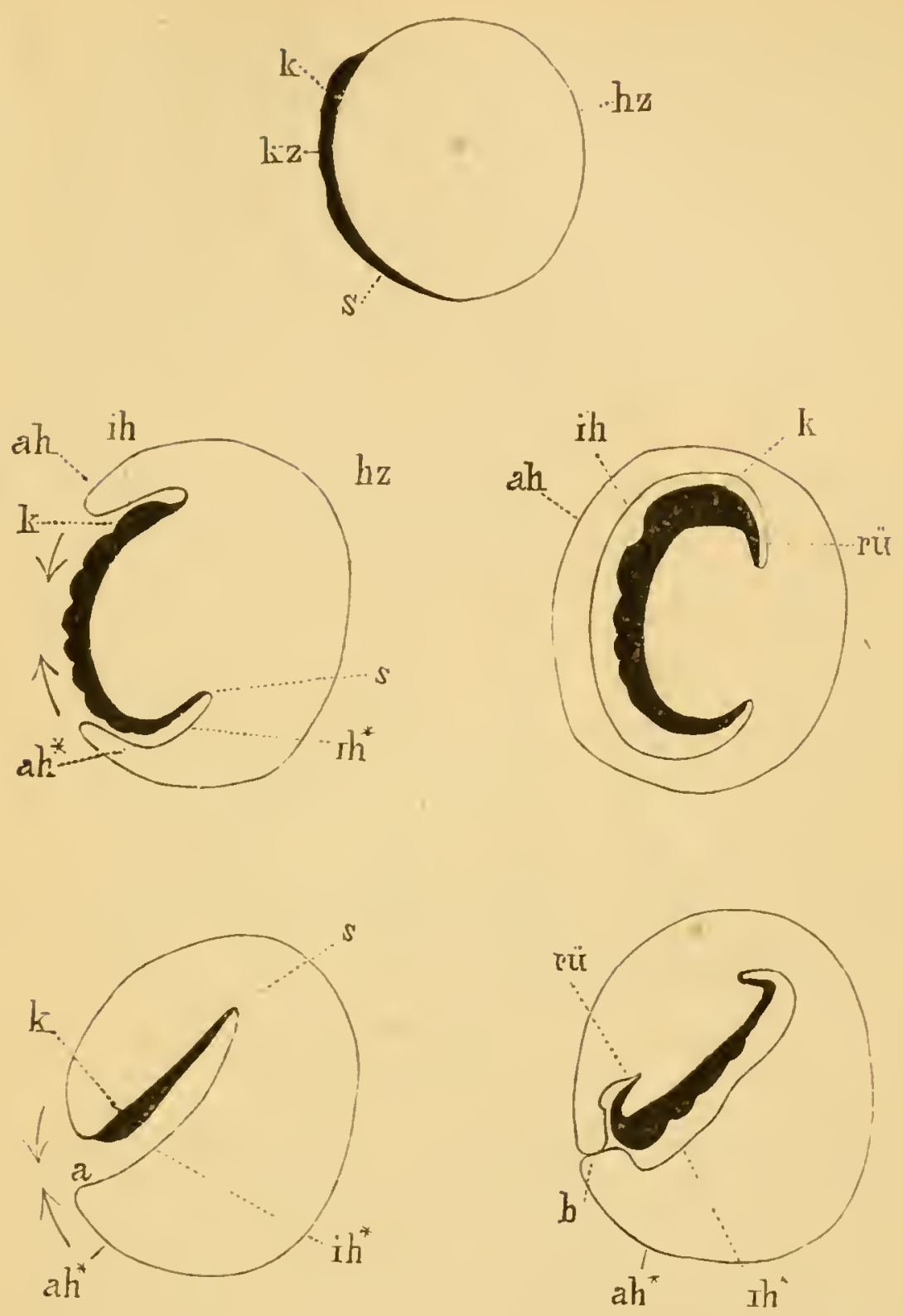

Fig. $123-127$.

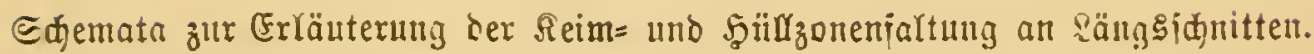

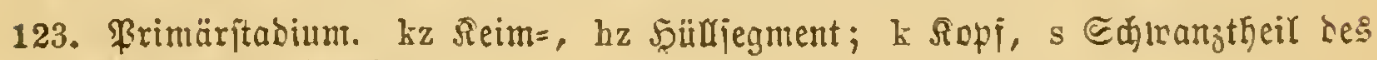
Reimitreijz (Fmbryo).

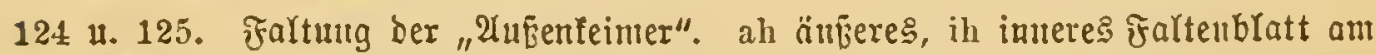

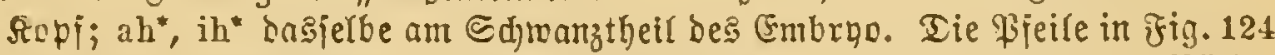

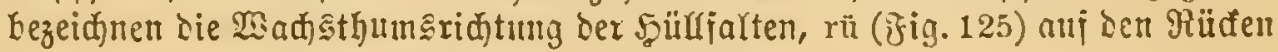
ïbergreifense innere (borjale ober negatibe) Falten.

126 1t. 127. Faltung ber "Jnnenfeimer". k Sopf, s Edtwang. Eonjtige $\mathfrak{D} e=$ zeidnung die frihthere. b (Fig. 127) burd) Bermadjung der (tleinen) Ropi=

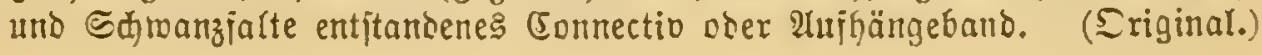




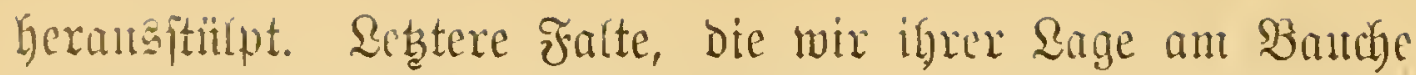
wegen bie ventrale memen, heiteht, wie erftere, ans zwei Blättern, nämlich aus einem äuñern Blatt (ah, ah*), ste

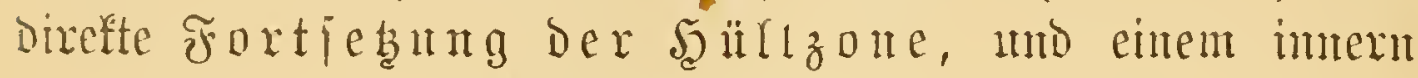

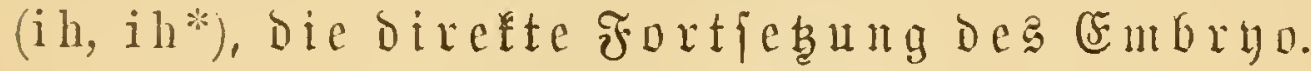

Dieje Beränderung fowie bie weitere foll der Rejer aber soo möglich felbit beobarbter, etwa am völlig burajfibtigen (Fi enter Chironomus. Legt er fid das (Fi nach unferer

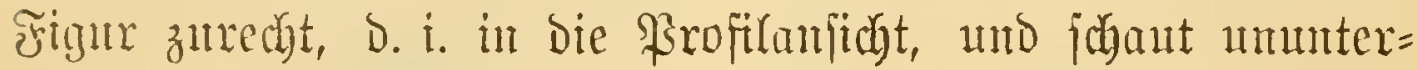
brochen einige Stunden ing Mifroffop, jo fieht ex, wie bie

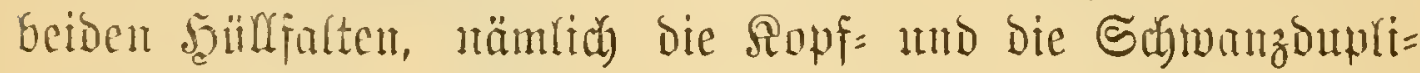

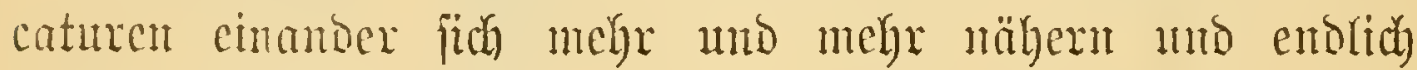
fich bereinigent.

Anfangs mird fich Der Rejer alleroings bei Der ifm recom= mandirten Beobadytung midyt gut zuredhtfintoen und Dies aus folgenten Grïnden.

Eriteng riegen bie beiben Bä̈tter Der Falten nitht fo meit ans cinander, wie es in Schema ijt, jondern z. Th. fo tnapp beifammen, da $\tilde{\beta}$ fie ohne Amwendung ber ftärkften

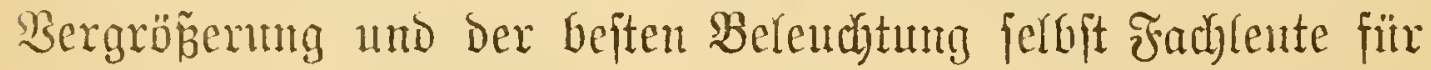
cinc Schidite Gielten und noch halten. Zweiteng find Dann Dicje Blätter, wie begreiffid), Eeine einfachen Stridbe, fondern, Da fie ja ans ber zelligen Reimblaje jtammen, Epithelien, zujammengefügt aus flachlinfenförntigen Bellen, madhen Daher

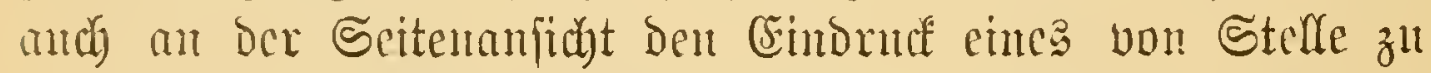
Etelle fnotig verbiften Bantoes, mobei fie zmweilen, ivent bie Berbicumgen alterniren, eine eingeitlidge Schidgte vortäujhen.

Ifm bentidfiten erfemt man Das Bsefinge diejer Blätter

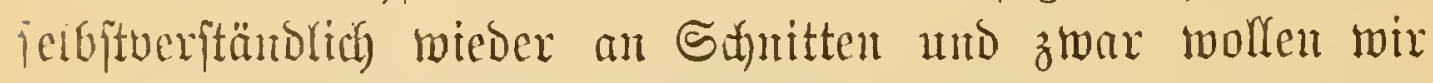

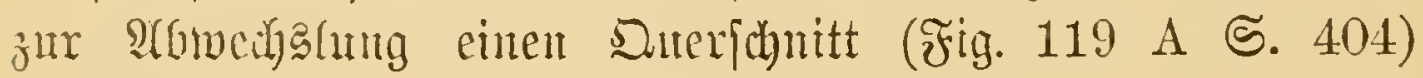
melmen.

Der Rejer wird fofort in Den beiden tajhenfürmigen Anrängen fa, ah die gewifien Falten erfemen, mo ber 


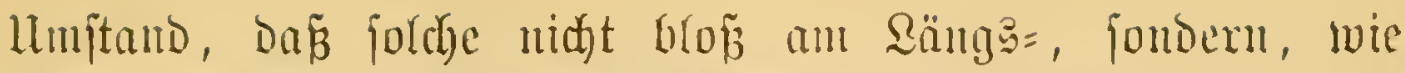

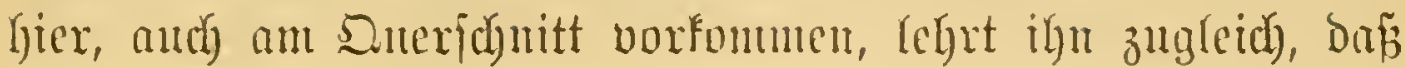

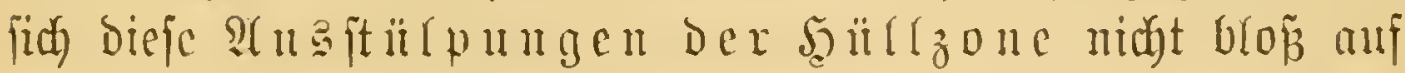
Den Ropf = und S(t)wanztheil, jondern anch anf Dic Seiten

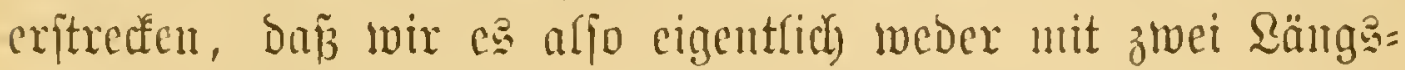
nod) mit z'vel Suerfalten, fondern mit ciner einzigen, freifich bald hier, hald bort rujdher fortidyreitenden Ring farte zu thum haben.

Nan wird man, zumal mit Şiffe emes ans Thou ober

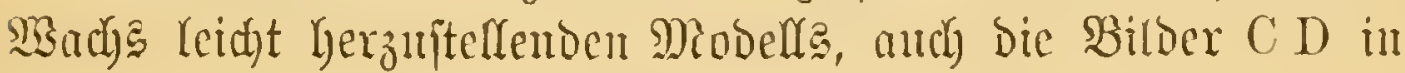

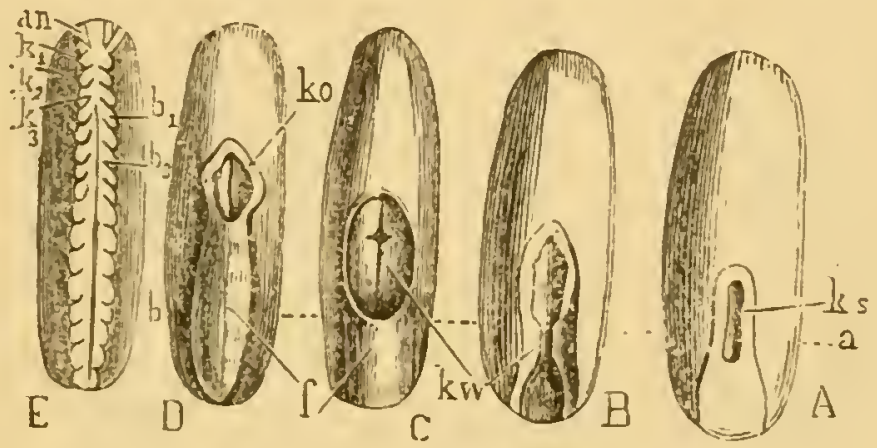

Fig. 128.

beijtehender Frigur veritegen. C zeigt Den Reimitreif Kunten von cincr Tajdye, vorn vou einem Ringamulft umgeben. Das ift eben mijere Falte, bie hier vormelymlidy an Swmanze

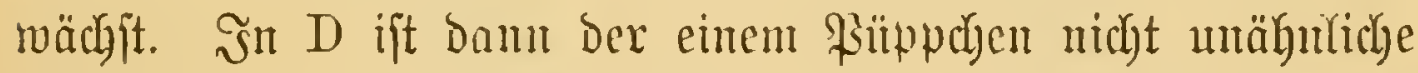
Embryo bon Der Bandjeite fhon ganz bedect, während jich

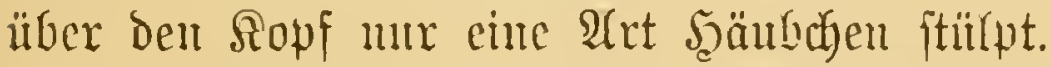

Eine jehr nahe liegende, merfmürdigermeije aber nody mie in exnitfafte $\mathfrak{A}$ rbeit genommene Frage säre die, wie benn

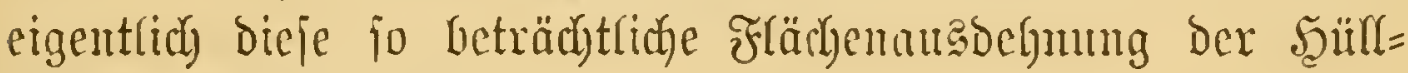
zone von Statten geht.

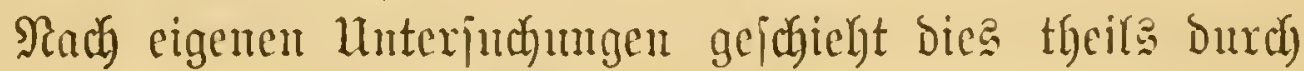
Dehnung, man fönnte fajt jagen Anzeinanderzerrung bex

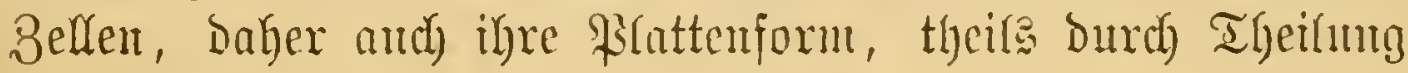




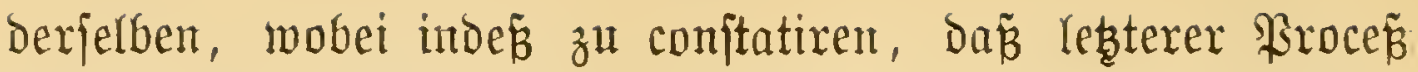
bei manden Zellen oft nur angefangen (D. h. auf Den Aern befduränft bleibt) und nicht beendigt wiro.

Wir kebren wieder zu urferen Shemen zurüf.
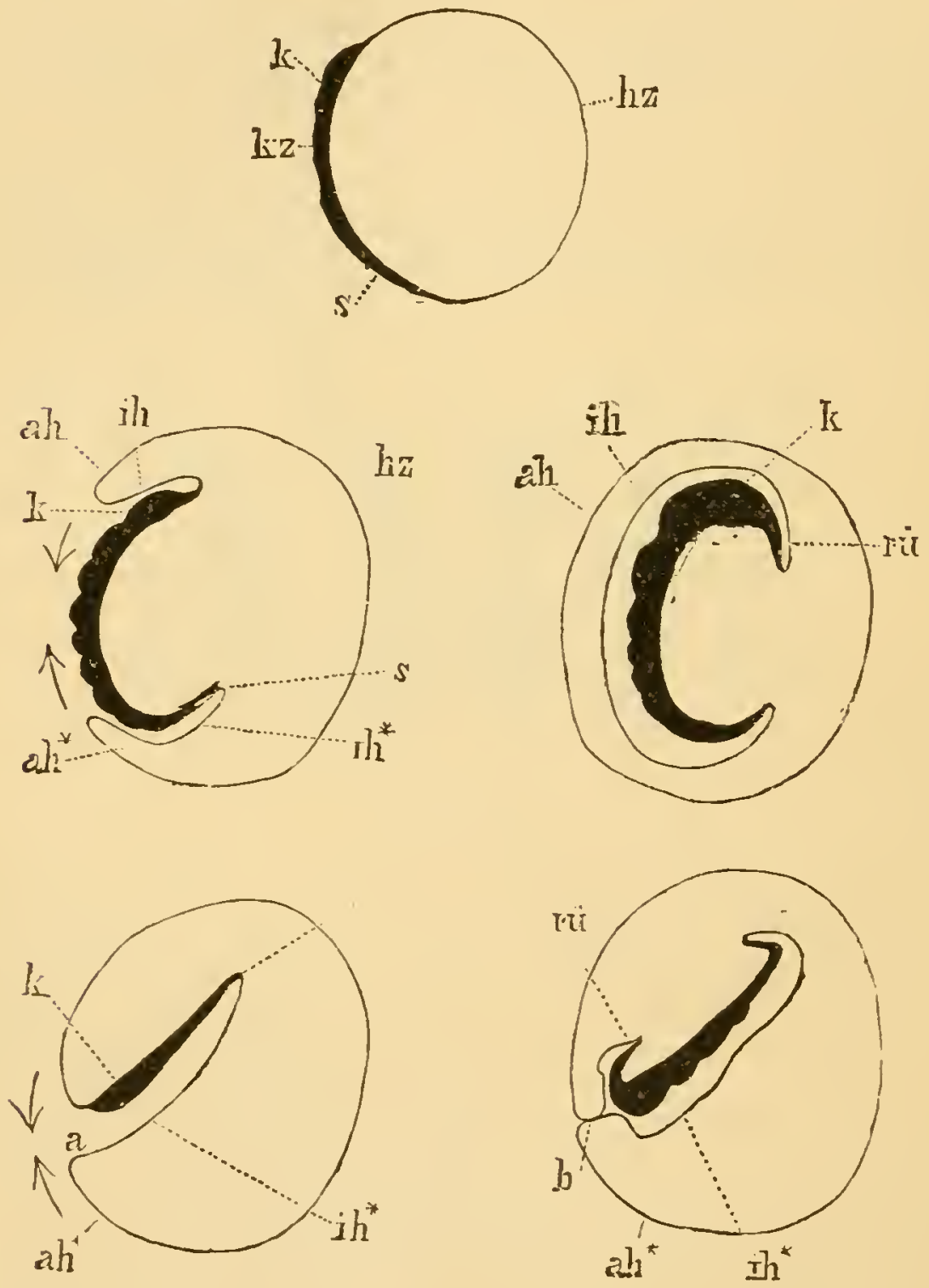

\{Fig. $123-127$.

Wem Der Rejer hei ftattfinbender Begegnung Der Ropf=

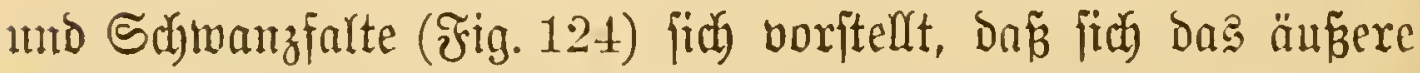
Slatt a h mit $a h^{*}$ mo Dann wieber bas intere ih mit $i h^{*}$ verbindet, fo wird er begreifen, Dñ Dam das Schema 125 
Jum Borjadein fommt. Das giejultat Der bezeiduteten Ser= einigutgameife beftegt fomit dariu, da einzigenzujammenhängenden $\mathfrak{B l a j e ~ z w e i ~ i n ~ e i m a n d e r ~}$ gejdaditelte Sä ćfe exhalten, nämlidy

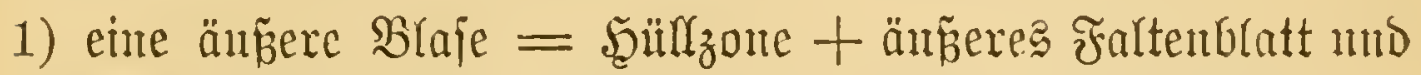
2) eine innere $\mathfrak{B l a j e}=$ Seintzune + immeres $\mathfrak{F a l t e n b l a t t . ~}$

Eritere (antalog Der Sängethier = Serofa) ift alfo ans einter blopen Şilllane des Dotters eine gemeinfame Rapjel für Dotter und Embryo geworden, während bag imere Falten= blatt mur eine "Shalbjacide", D. i. eine Den Embryo vor= Iäufig mur von der Baudfeite bebectende Seitlle barjtellt.

Wenn mu-aud Der Čmbryo bei Der Sereinigung ber Falten aus Dem Sireis Der ehemaligen Sieinblaje ausgejahaltet wiro und in Folge bejien als frei zu betrachten ijt, fo hängt er Dod bei Den meiften Injeften in Folge ber juon oben er=

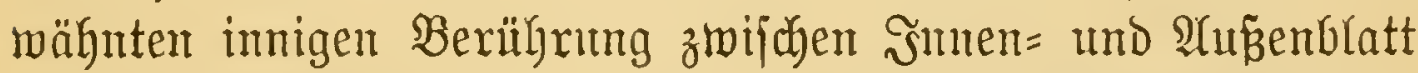

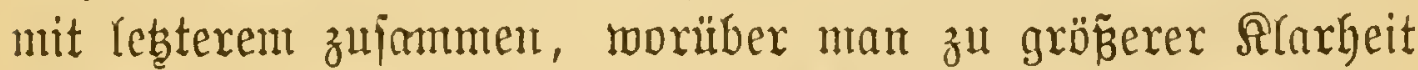
nod) Fig. 118 confultire. Şier ift a hie äuñere, ih bie imtere Şülle, bie, wie man fieht, unterhalb des Reimitreifs ganz knapp an einander liegen.

Nur bei ben Sdymetter(ingen ftehen beide Feülfen weiter von

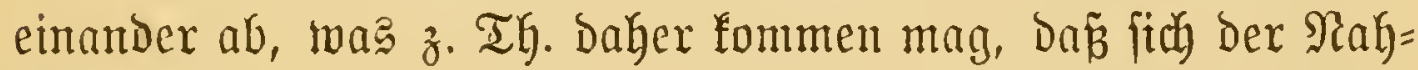
rungsootter, an ben Hubiegungäfellen de马 Entbryo in feine Scheide, dazmijiben hineinträngt.

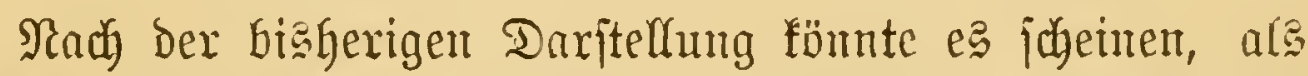
ob fich alle snfeften, soenigitens im 2 nfong, ziemlidy anf gleiche $\mathfrak{A r t}$ entrwiffelten, utb von gewijien z. Th. aud burch bie Frorm Des Cries bebingten Differenzen abgefchen ift bies aud) in hohem Srabe ber Fall.

Nux in einer $\mathfrak{B e z i e h u n g}$ ideint fujon die erjte (Embryonal= entwidfung bei gewifien Infeftengruppen fich fehr verfojieden 


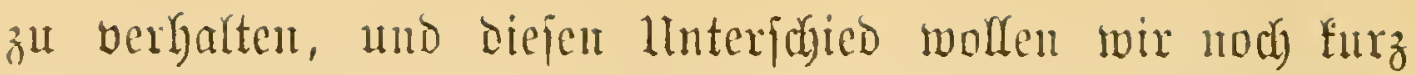

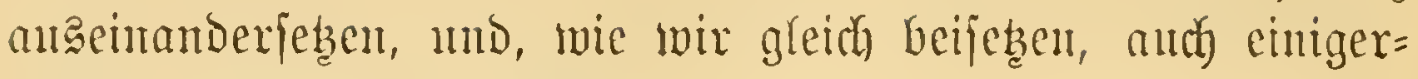

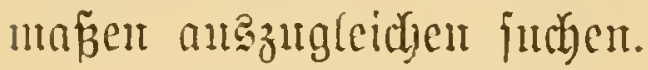

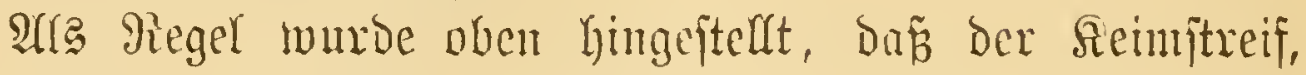
twie er fich am $\mathfrak{H} m \mathfrak{f} a \mathfrak{g}$ ber Reimblaje bifbet, and fpäter

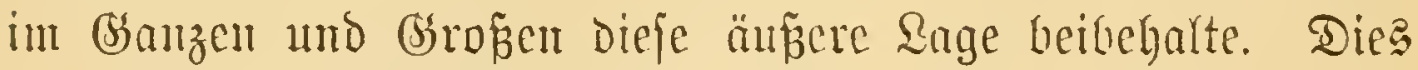

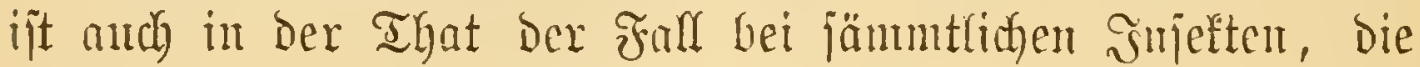
fpäter cine auffalfende Berwandung Durchmadyen, b. i. bei

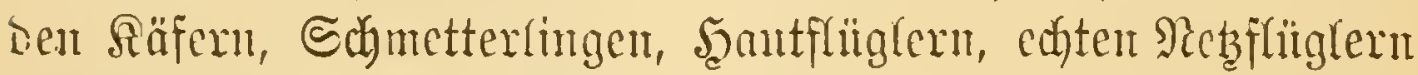
und Dipteren uto anperdem nod bei den tupifalen (Serad= flïglern.

Bei den übrigen Dagegen, D. h. Gei Den Sannubelferfen

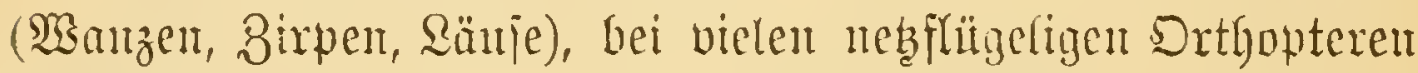

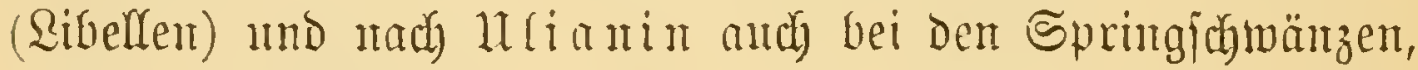
crfälyrt der Semitreif bald früher, bald ipäter eine jebr auffallende 乏ageberänderung.

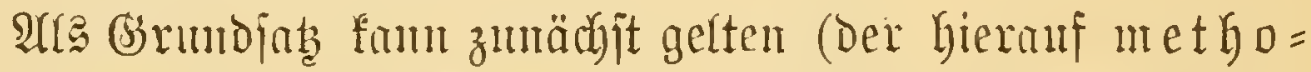

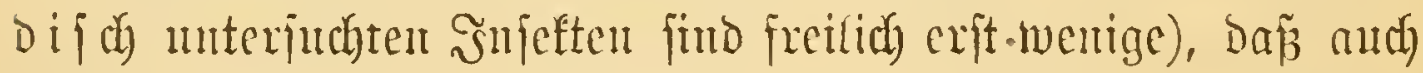

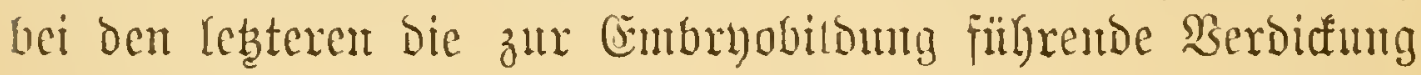

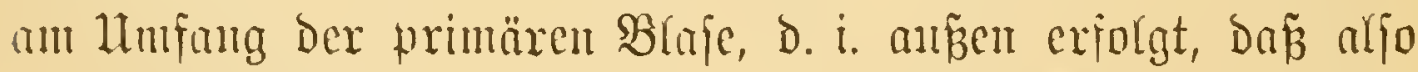
Das Reimftreiffildung: Schema Fig. 123 für alle Jufeften*) pañt.

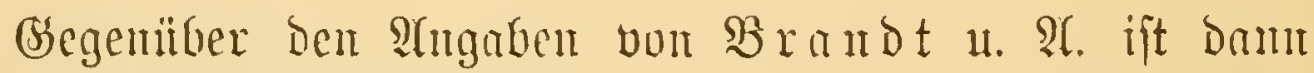

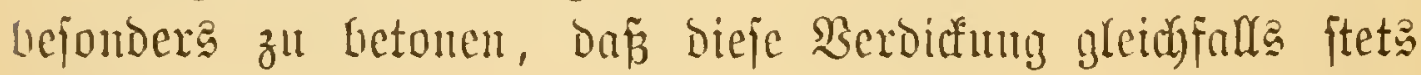
cinfochichtig ift.

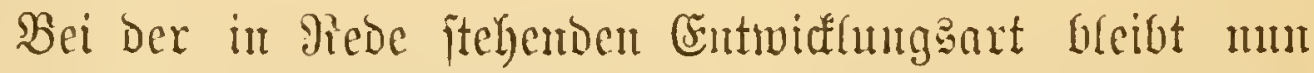
aber bie Reinzone nitht ausmendig, fonbern fie ftülpt fich) vollịtändig in das Smnere ber Blaje hiutein.

Begen diefer imterlidyen Qage bes Sieimes nent man

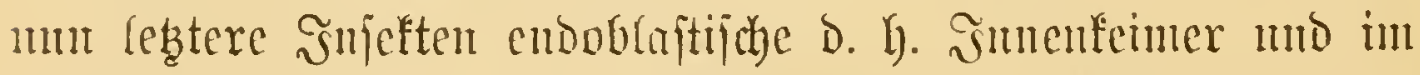

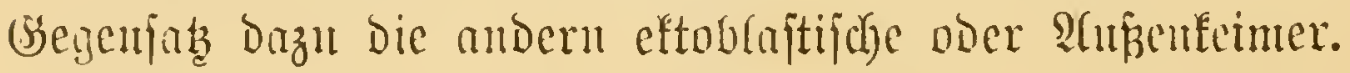

*) Dic ganz apart bajtelyenden Rteromalinen anşgenommen. 
ARad) Den bisherigen Durftellungen zumal bou Metidui= foff mb Brand wäke biejer Jmtenfeim, Dex fog. Reim= hägel, juerit cir jolider Rörper ober eine contrafte Belfmudderung, twie ties Fig. $129 \mathrm{kh}$ baritellt, und follte firly erjt

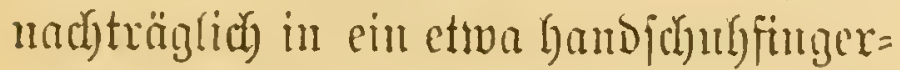
artiges 5ुohlorgan untwandeln, Deijen

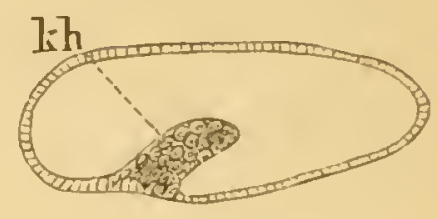

Fig. 129.

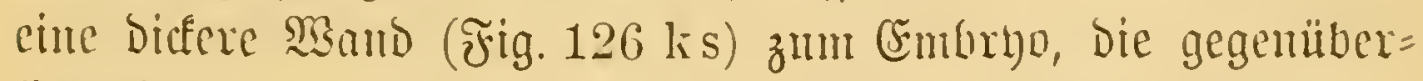
fiegende bümere (as) aber zum imeren Şüllulatt witrde.
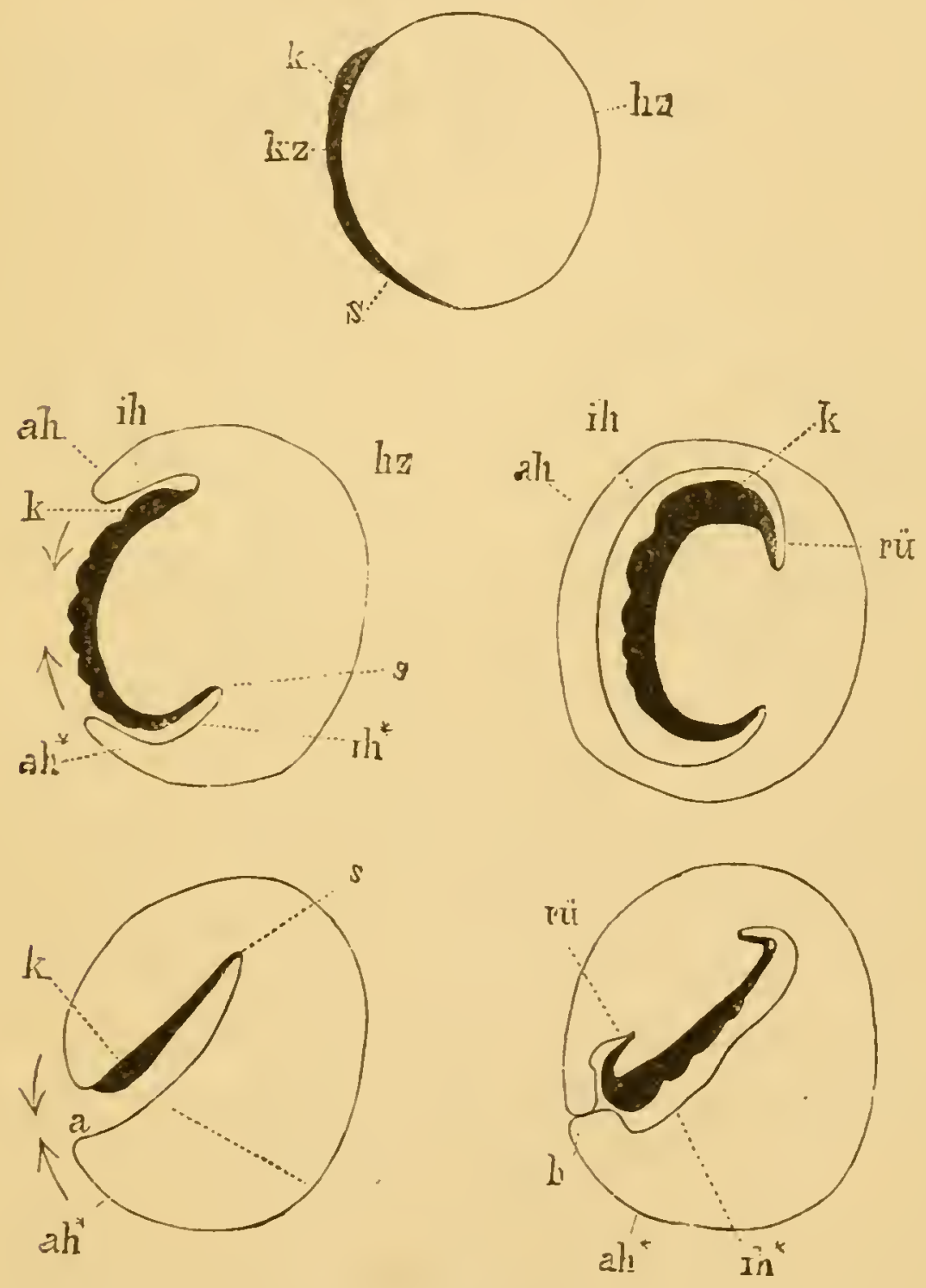

Fig. $123-127$. 


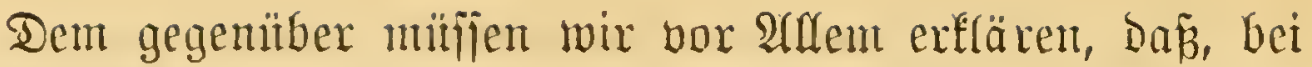

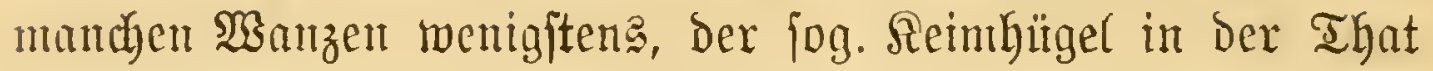
nichts Anderes are cine einfache Falte der Sieimblaje ift, bie, wie lebtere, jtets und ïberall nur aus einer einzigen Zell= ichidyte bejtefyt.

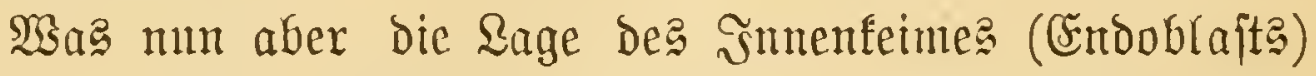
betriffi, jo bejteht aud hier feinesmegg ein fundanentaler Bse=

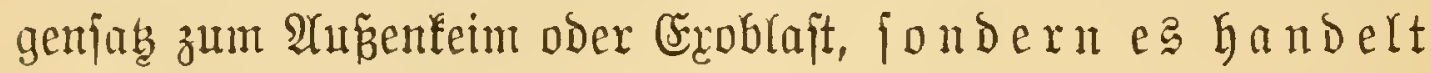
jich lediglich um grabmeife unteridiede in der

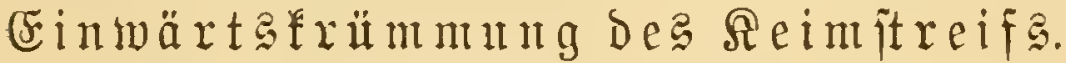

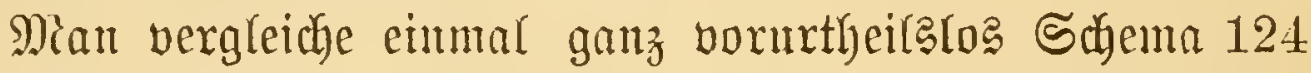

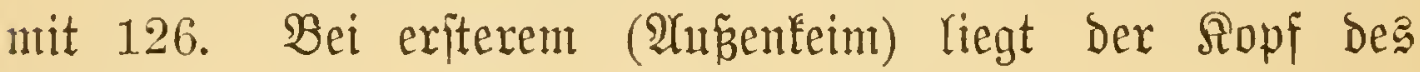
Embruo (124k) anzen, der itark eingeftülpte Shmanz (s) aber innen. Dasjelbe ift mu and beim snnenteim ber Fall

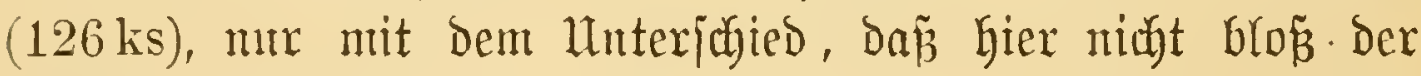

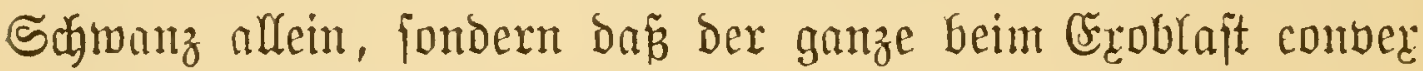

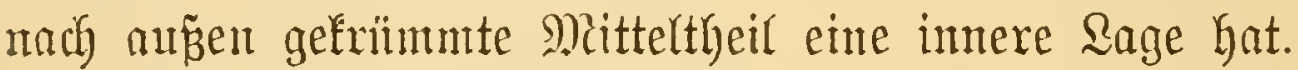

Fine Art Mebergang in biejer Seinjidyt bilden aber ge=

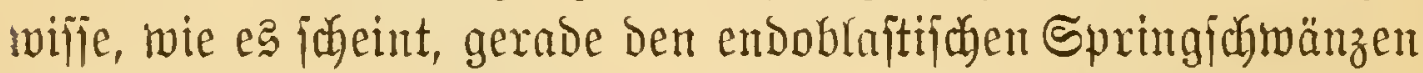

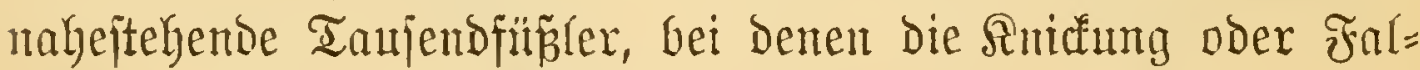
tuntg in bie Mitte bes Reimes fültt (vgl. Fig. 131).

Alber wenn wir and feine joldhen lebergänge hätten, fo

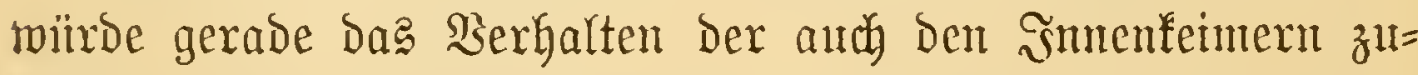
fonmenden und nun zu bejprechenden b̧üllfalten bie uahe $\mathfrak{B e r}=$

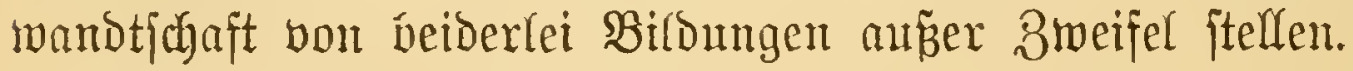

Fine abermalige $\mathfrak{S e r g l e i c h u n g}$ von 124 und 126 zeigt

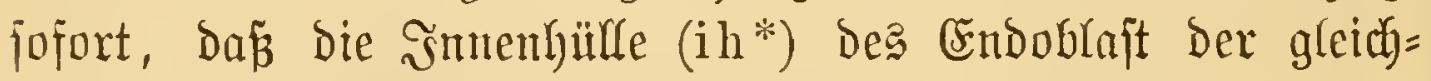

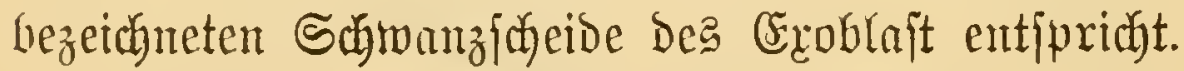

Bermin̈t wirb an Emboblajt zmädjit mux eine beutlidje Sopffalte. Da cs fich aber beint Endoblajt nux um den

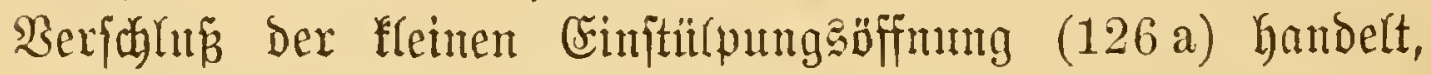
mäbrend beim Eroblajt die Falten die ganze Länge des

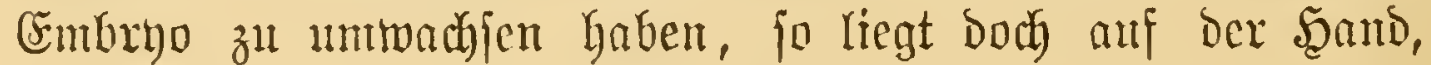




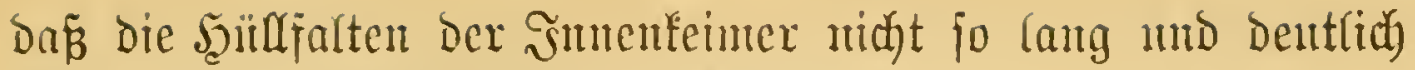
wie bie ber Mnzenfeimer jein fümnen.

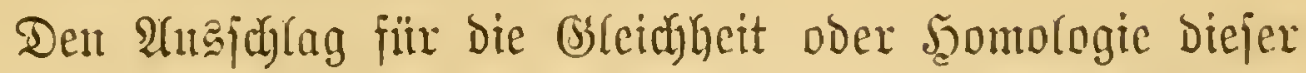
Bifdungen gibt aber die Thatfache, Dañ fich, wic aus Fig. 127 zu jeben, factija and bei ben ștutenfeimern bie Den Embryo ungrenzenton Ränder ber Şüllzone faltentartig voritülpen und

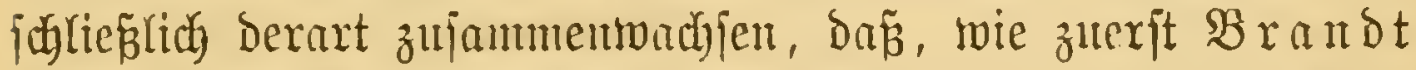
gezeigt, ber (Eutbryo idflieşlid) mur megr burd) ein unter $\mathfrak{B} e r=$

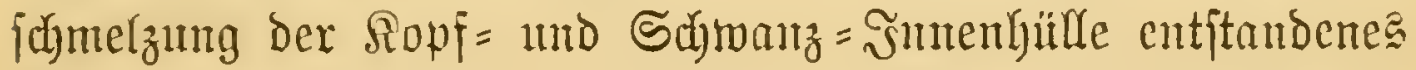
Band (c) mit ber mun gleid)falla zur Blaje ergänjten $\mathfrak{A}$ นảen=

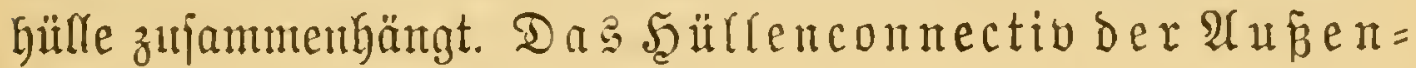
feimer erjucint aljo bei den Junenteimern nur

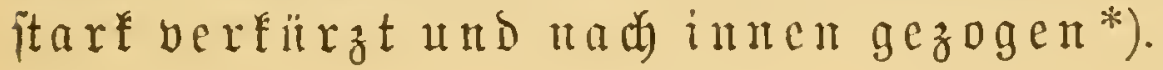

\section{0}

131
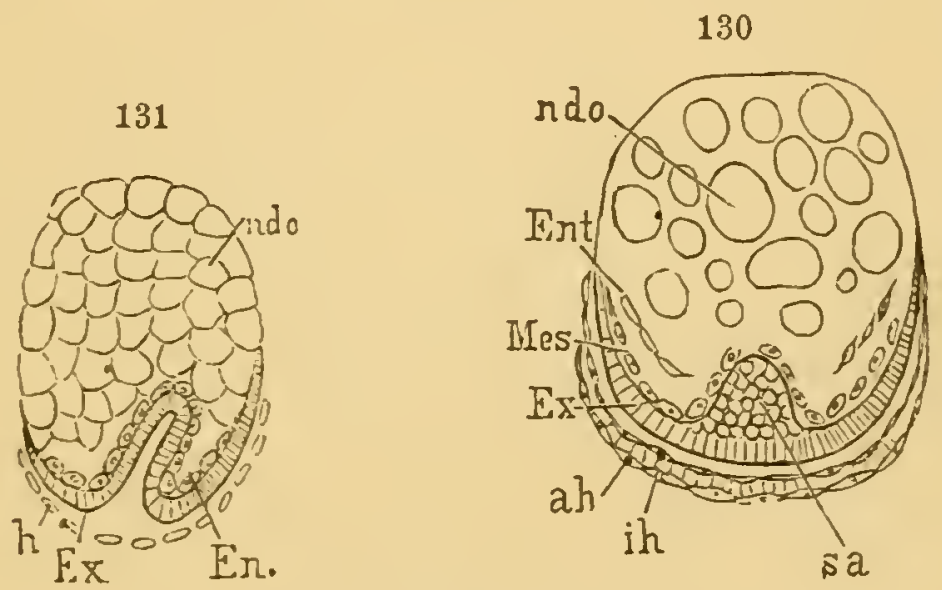

₹rig. 130.

Seimanlage bes Scorpion, jdematif nady MReçnil otw.

ndo Rabrungsbotter, an beijen unterem Pol bie ideibenartige Reimanlage entiftelt, bie allmälig ben gauzen Dotter umwädift; Ex Froderm, Jes Mejoderm, Ent Ento=

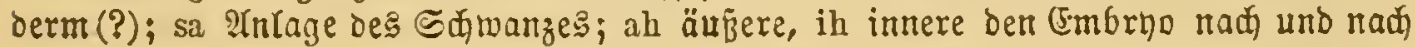

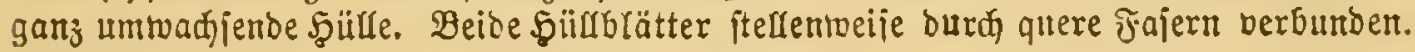

Fig. 131 .

Seimanlage eines Taujembjübrlers (Polyxenus lagurus), nad Mtecz nitom.

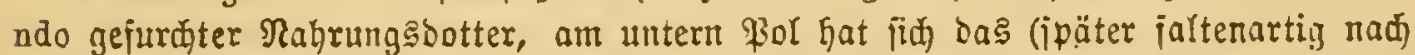
innen geittił(pte) Blajtoberm abgejonbert; Ex äuB̉eres, En inneres Blatt bes Sieim= ftreifens, h Şülle ans Iojen (?) Bellen.

*) Radf nudf nicht ganz abgejdjlojienen cigenen Unterjudungen

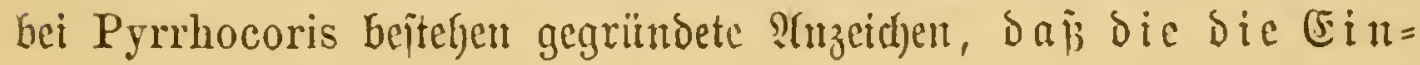




\section{Bilsuty ber Siörueriorm und ber cinjefmen Drgane.}

Serfyicden vom Rïnftler, Der, um ein Bild ober Modelf

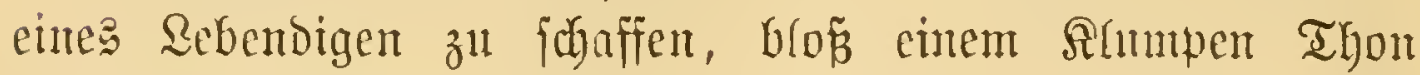

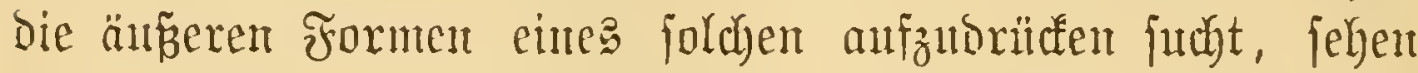
wir bie Natm bei ber Birdong Des Sriginale felbjt ver= fahrent. Entiprechend den ungleidyen Theilen, aus benten ein $D$ rgantismus aus= und intwendig beftegt, ridet fie erit Das geeignete Material für bicjelben her, und erjt, menn biefe马 beifammen, wemt auf oft gar conulicirtem $\mathfrak{s e g e ~ b i e ~}$ nöthigen Banelemtente und Brrmbgemebe aus Dem Reim= protoplasma ausgefobieden find, erjt bann farreitet fie zur Fundirung Des Werfés fellojt, bas bam oft weit raficher ale die vorbereitende $\mathfrak{A} r b e i t$ von Statten geht.

Das eigentlicke Fumbament des Snfcttenförpers ift be=

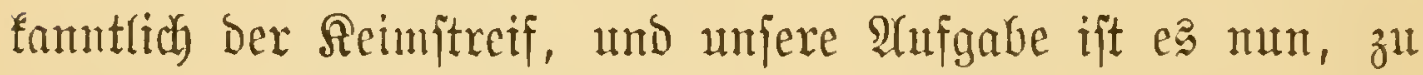
zeigen, wie biejer allmälig Form und Ssejtalt anuimmt, uno

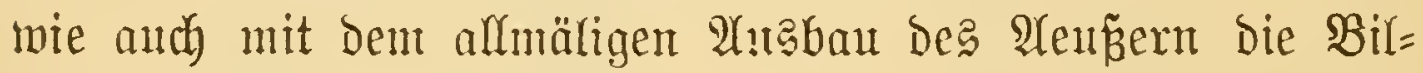
Dung ber mannigfaltigen imern Drgane ifrem endichen Biel entgegengeht.

Der Scimftreif, wie er zuerit exjheint, bezeidnet feimes=

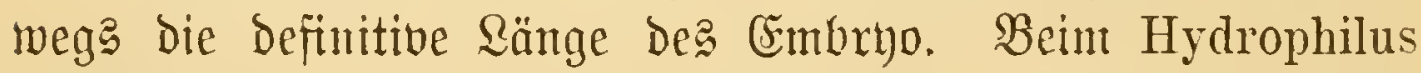
3. B. (Fig. 114 A st) ift er ganz furz und mun fitr) erift allmälig in bie Ränge ftrefen, bei ben Frliegen bingegent umipannt ex, mit Ropf und Sdywanz auf Den Rürfen um= gebogen, faft Den ganzen Dotter, und nmís fith Daber fä̈ter

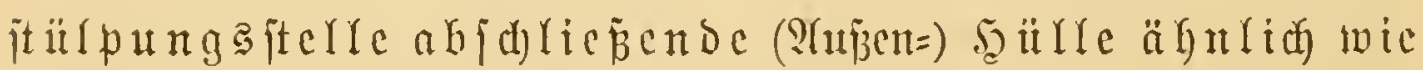
nad Metichnifoff bei Minriopoden uns Scorpio (Jig. 130, 131 h uno ah, ih) Durch locale Sabblätterung Des (ExD=

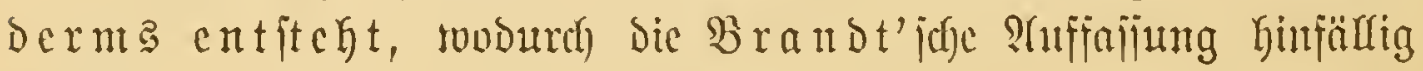
wiïro. 
mieber zufanmenziehen; Den ex entfpricht ja nur der unteren J̧entifngäre, oder Dem Baudjtycil Des Embrizo.

Befdyanen wir ung mun zumädyjt bie plaftifdye Umgejtal= tung biefes Gsebildes, mb zlwax infoweit fic jeine änţere Scyichte, Das Ectoderm, betrifft. Sie beginnt befinntfich mit einem mebianen Rängąentontef (Fig. 114 A). Dantit ift ent=

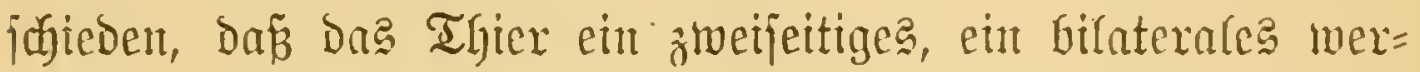
Den foll. Das Widutigite ift aber Der ztweite Schritt, Das $\mathfrak{A} u \tilde{f}=$ treten vou Duterfurchen, ober bie $\mathfrak{A}$ btheilung bes Reimftreifs in

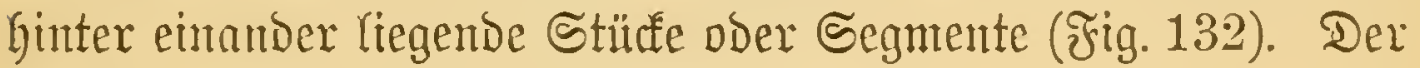
Ëmbrho qualificirt fich zum Sstiedertfier. 3u welchem ift freilich noch nicht gejagt;

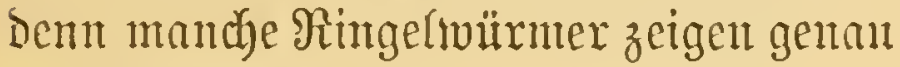
Dą গämliçe.

DG alle bieje urjegmente ober Urfomiten auf cinmal cutfteyen oder z. Th. nad einamber mo in weldyer 3ahl und Folge, ift noch lange nicht feitgeitellt, wohl aber, Dañ bei faft allen

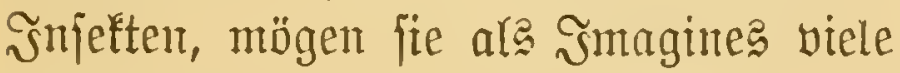

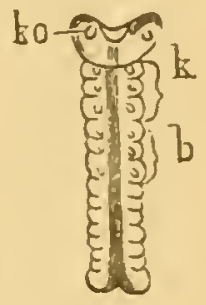

Fig. 132.

Segmentirter Reimitreif eines Falters, nadi $\mathfrak{A} 0 \mathrm{in}$. ko 1trfopi, k 3 Rieferf́pp $\dot{i}=$ jegmente, b Bruft. ober wentige freie Ringe zeigen, die $Z$ aht biefer Arbichnitte meift 18 beträgt.

Mälyremb aber auf Diefem Stabitum alle Segmente ober ridtiger Segnentpare wie bei einem extent Ringeltwum cinander vollfommen gleid ober homonom find, ift bas erite

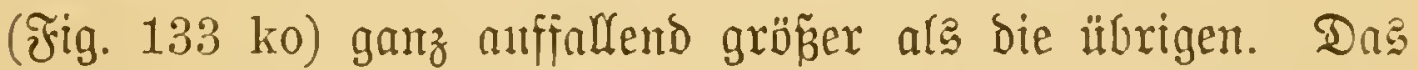

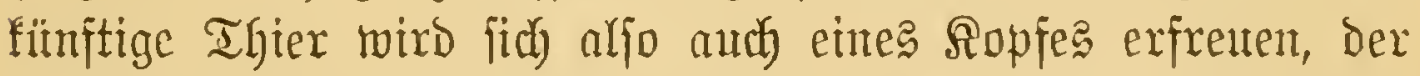
im $\mathfrak{L}$ aufe ber Dinge, wie wir hören werden, Duxch Buziehung

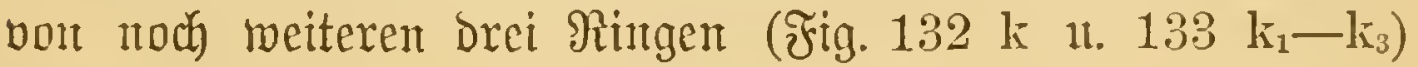
fich fogar noch bedeutend vergröß̈ern miro. Tha dem eriten

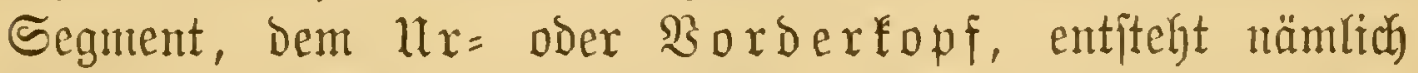

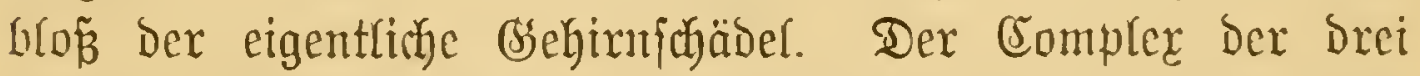

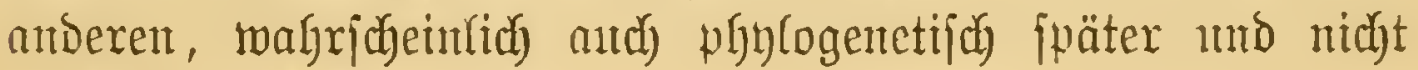
(j) raber, Jnjeften. II. Bלo. 


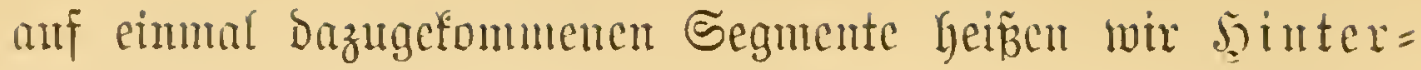
oder Sieferfopf.

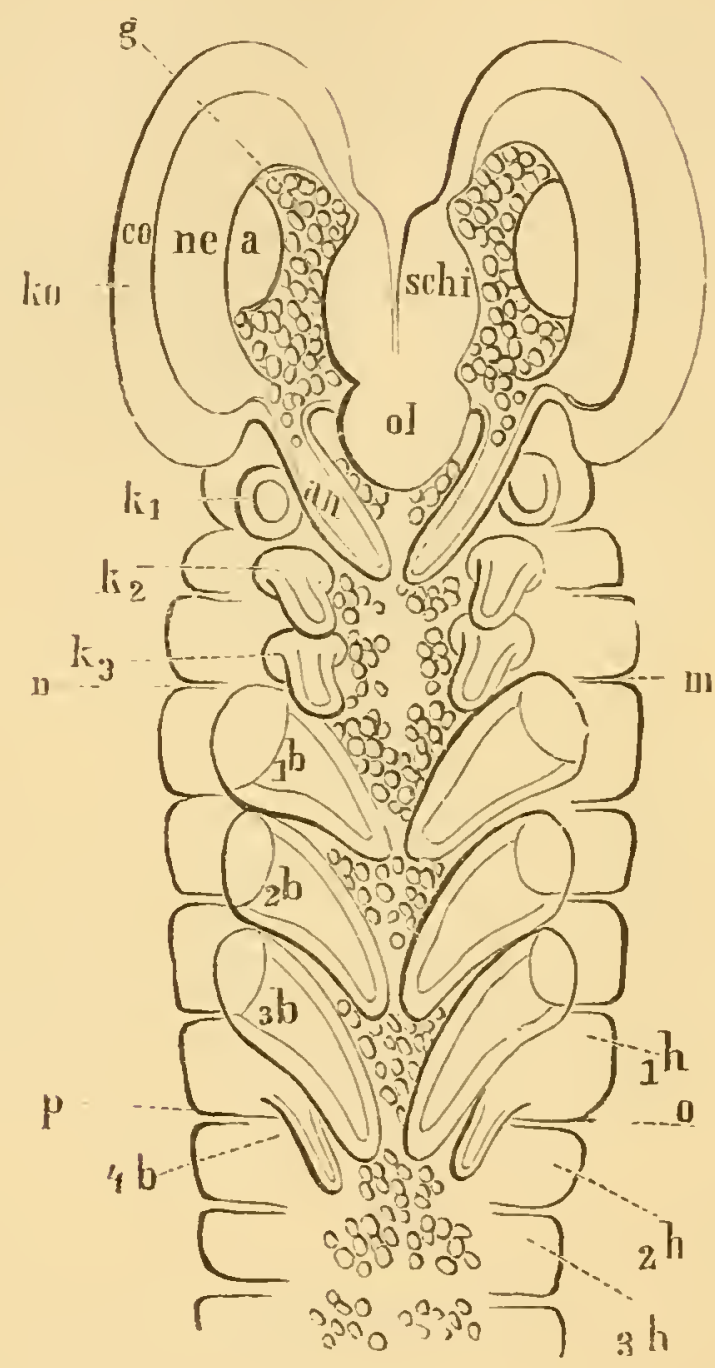

Figig. 133.

Seimitreif ion Nantis.

ko Borbertopifegment (G Gehirn, ne Reţhaut, co Cornea (ber gropent Facettauyent),

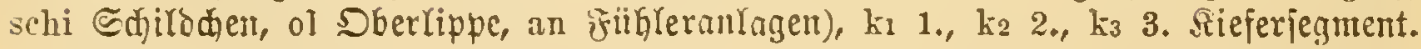
$b_{1}$ Border $=$, b2 Mittel=, b3 Siuterbruftring mit Den Ien Siefern entipredenden Bein=

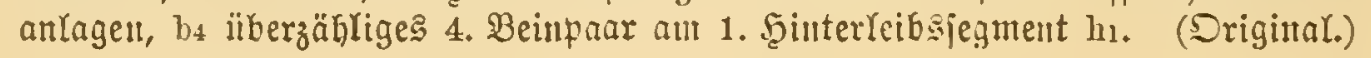

Rad einem weiteren Stadim in Fig. 134 z̆ urtheilen,

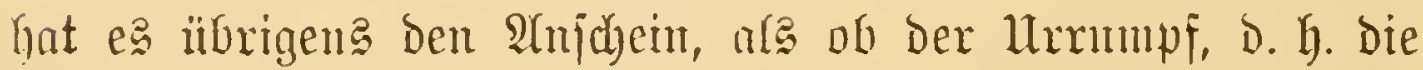

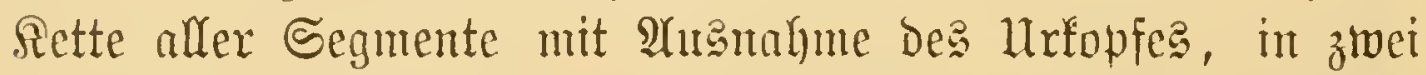
Theire fich funeiden wollte. Die vorderften 6 Reibešftincfe 


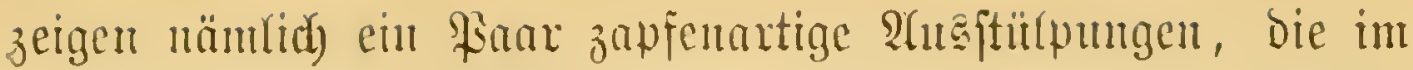

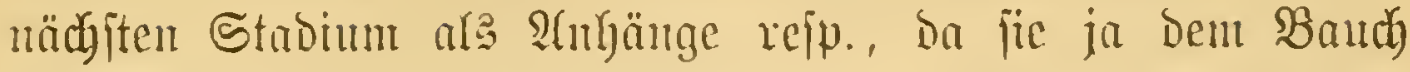

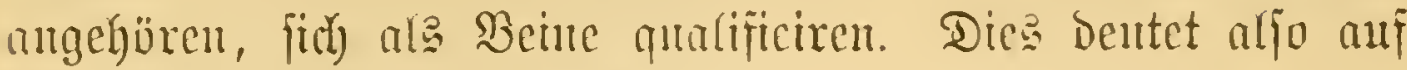
einen Sielfü̈lex. Dod) bic Sadje nimmt balb (togl. Fig. 133) cin anderes Gejicht an. Die Drei erjten Segmentmbänge $\left(k_{1}-k_{3}\right)$ swadjfen mix langjam unb breiten flein, wälyrend ifnen die übrigen $\left(b_{1}-b_{3}\right)$ voranteilen. Eritere geben eben bie Mubbeine ober Riefor, lestere bie eigentlidyen Sselywerl = zenge, eine Scheidung, die jedoch

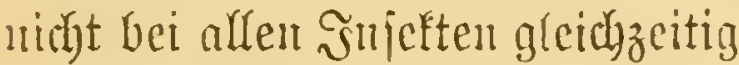
criolgte unb nody erfolgt, intom 3. $\mathfrak{3}$. Leim Calopteryx-Embryo die MRittel= unt Sinterfiefer lange Beit mehr Den Beinen ale Den Sorberfiejern gicidjichen. Die 马ahl Dex (Embrumonalbeine ijt aber wedyjelnt ; bei Hydrophilus finto

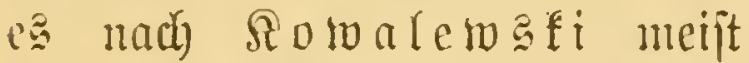
fünf, bei Mantis (ङ̌ig. $133 \mathrm{~b}_{1}$ ) wier Barare, biämeilen gleid)falls mit ber Spur eines fünfter. Die

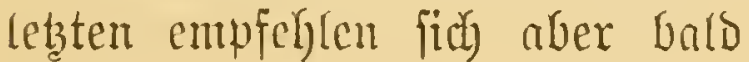
mo e bleibcu ftets mur brei

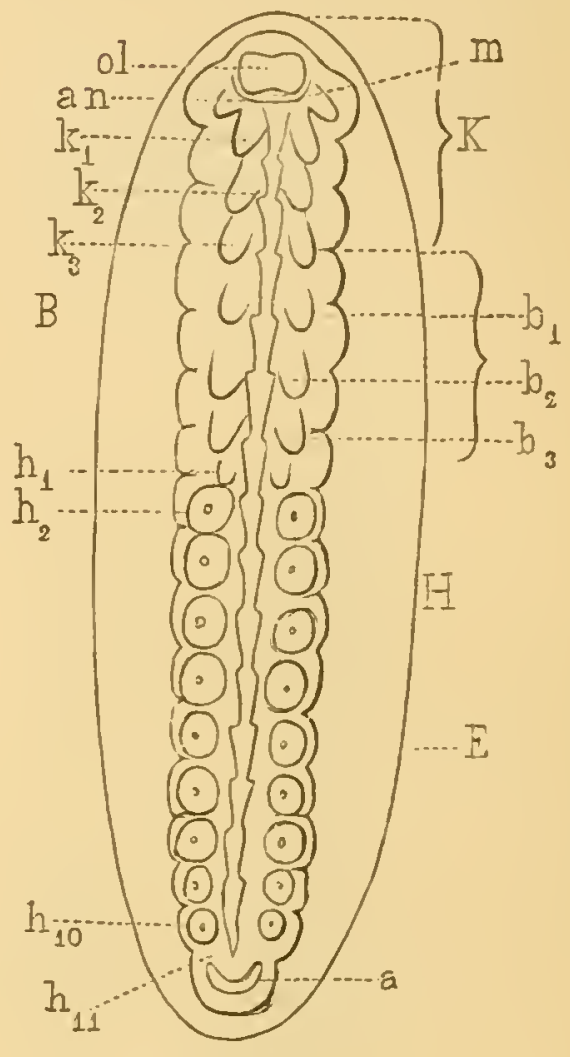

Fig. 134.

(5mbryo eines 巨đ̆winmläjers (nad) Rom.).

E IImrî́ Der Bifhant. Die ftreifen= artige seimanlage idon beutlid) iegmentirt. I Ropf, ol SberYippe, $m$ Numb, an rï̈hler, $k 1, k_{3}$ Siejer, B Brujt, b1, b3 Beine. IIm eritent Sinter Yeibsring $\left(h_{1}\right)$ Mnlage eines weiteren Ǵliesmá̉enpaares. a IIfter. itbrig. Dex Bielfïfler wixd dadurd zum Sedaz=

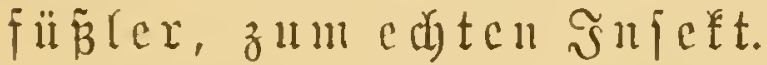

Während aber alle Snjeften als Embrignen ftets brei Dentliche Sieferpanre tragen, fintot man bei Serfen, bie als

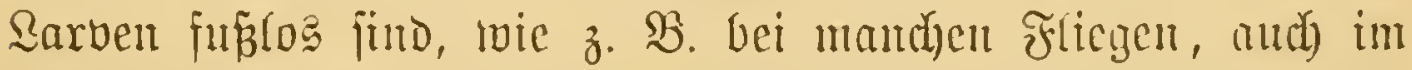
(Embryo feime ober dod) mur utbentlide Spuren bavon (f̧ig. 135). 


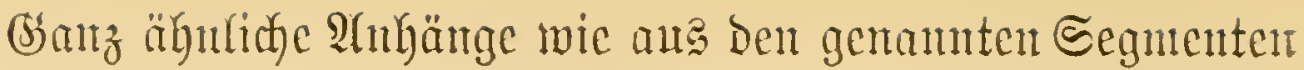

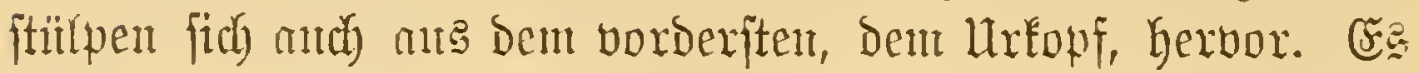

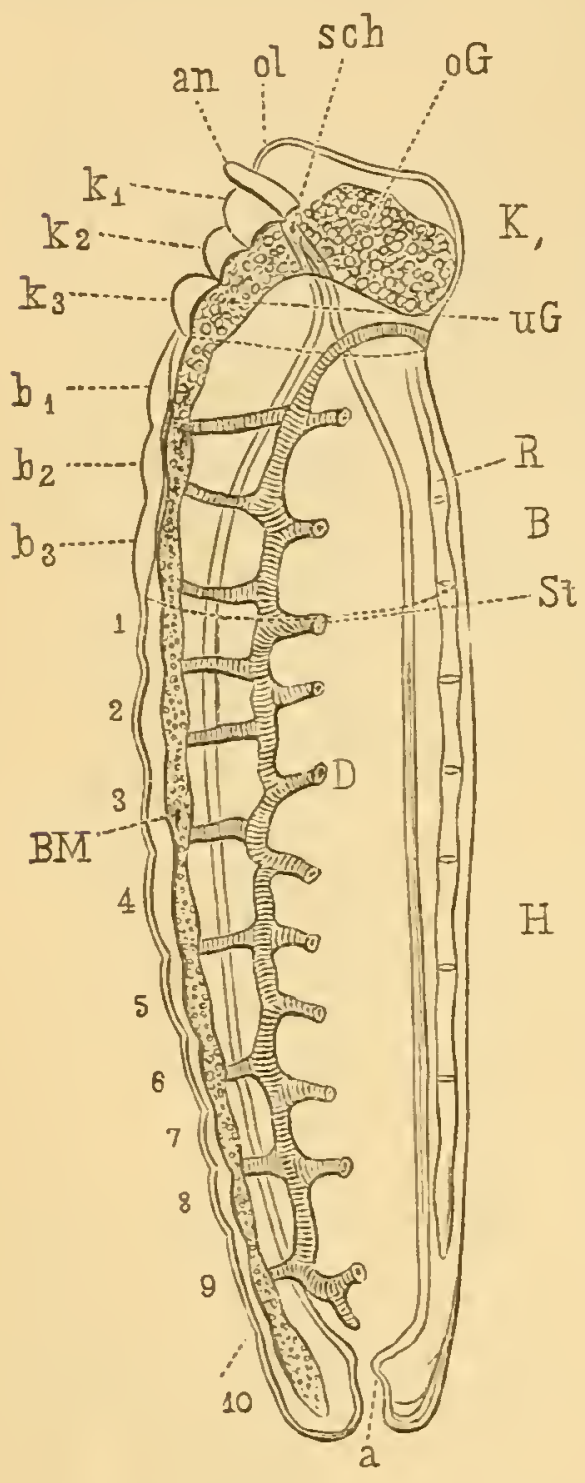

Fig. 135.

Profilamitut eines Biencnembryo (nad) Rolv.).

23ezeidnung twie in ǰig. 134. BII gegliederte Batudmarf. D Weiter Mitteloarm. St \&11ftlöder mit Den savon entipringenten \&uitröhren oder Iradjeell.

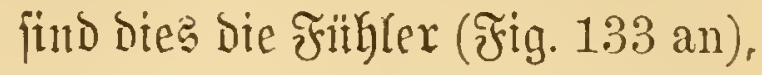
die ber Rejer nady ihrer fpäteren Stellutg toohl nicht an ber $\mathfrak{B a n t}$ )= jeite ermartet Gat. - Dả wärent zuntädyjt Die Drgane, Die Das Cro Derm an feiner $\mathfrak{A}$ ñ Nun fonment wir alf jene, bie aus demjelchen Blatte innerlicis entiteben. Derent gibt es haupt= jächlich żweierlei, nämlich bas Bautimarf, Das aus eimex $\mathfrak{A} b=$ blätteruntg bor mittleren 囚em= ftreifzone herborgeht, umb Dann eine Reifye von Driffen, bie in

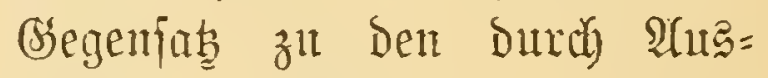
ftülprung cntitandenen äuŕeren Intyäıtgen Durd rölyrige Ein= fentungen gebilibet werden.

(Fin Blict auf den quer Durch $=$ idunittenen Reimitreif in Fitg. 136 zcigt bem হejer einen mittleren ftart verbicften Theil (ab) uno zmei bümere Rantopartieen (ac). Setstere find bie-jog. Seitenplat= ten, ats weldyen bie befaldiebe= nen $\mathfrak{A}$ rhänge entitehen, während crjterer $\mathfrak{A}$ ffdyitt bie jog. Me= Dutflar $=$ ober Şantnerventplatte. vorjtellt. Die Bellen Der lesteren find anf Diejem Stabium (A z) in Duertheilung begriffen, ber, nad) eigenen luterjutbungen,

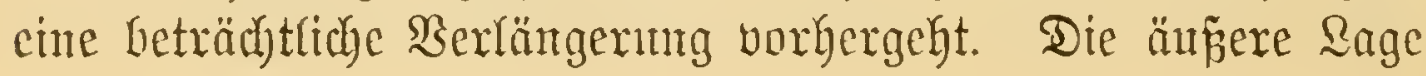


biejer Bellen (z) bilbet bas eigentlidye Şaut= bejielunngämeije

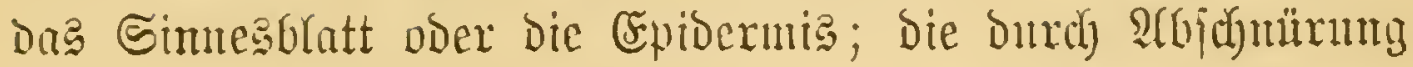
entftutidenen imteren $\left(\mathrm{z}^{\prime}\right)$ Bellen geben aber dą Centralnerben=

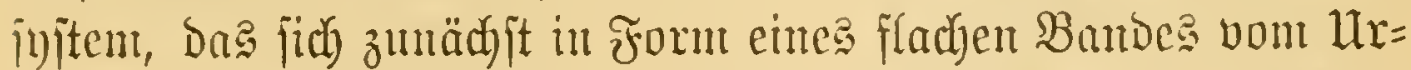

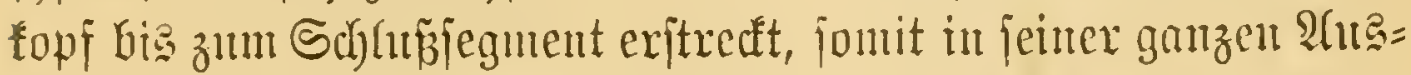

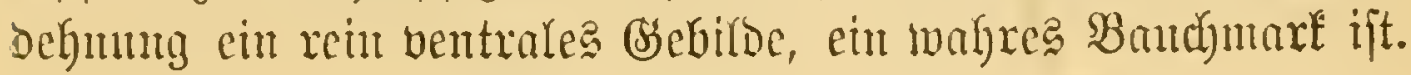

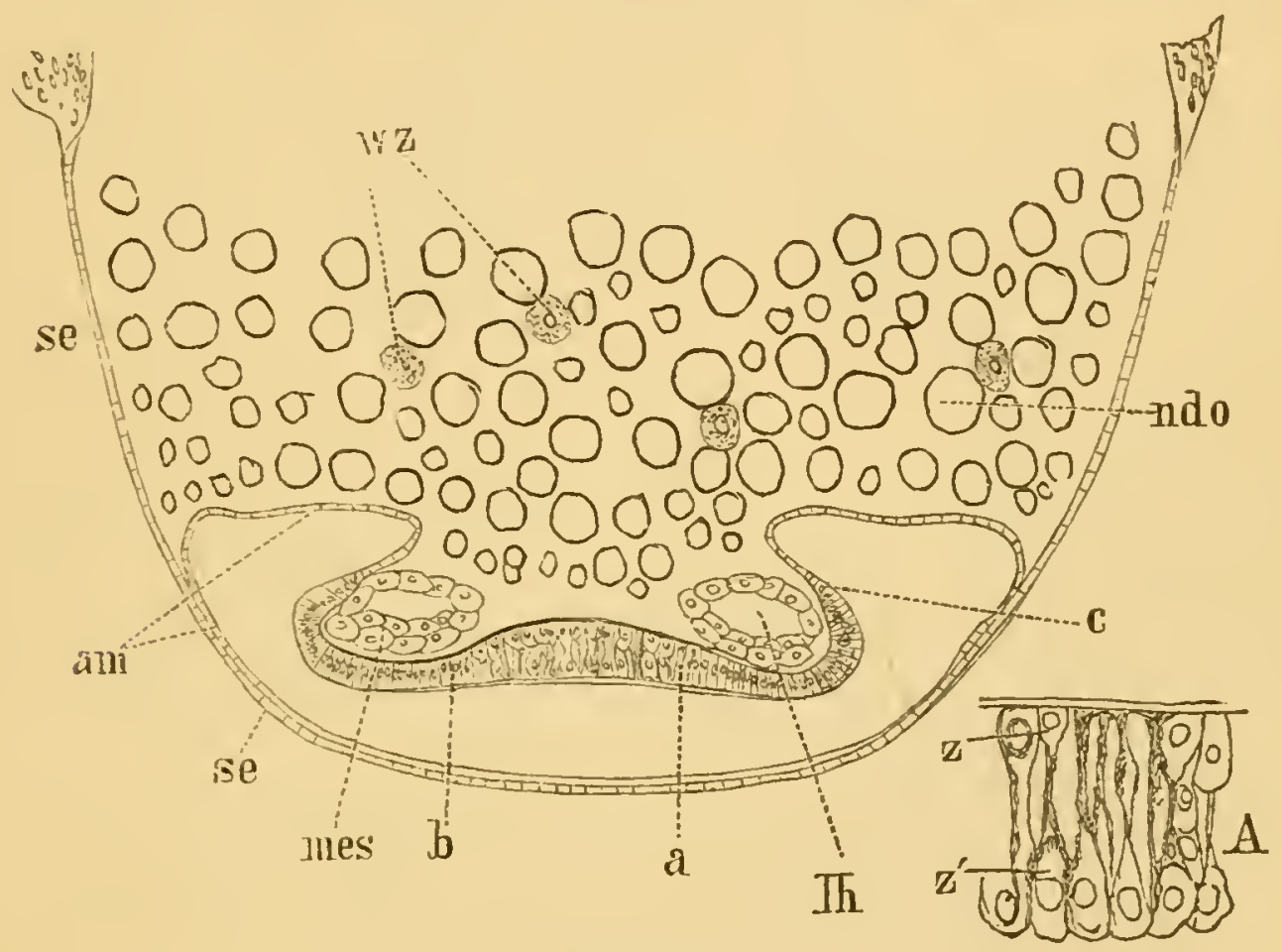

ขig. 136.

Bentraler Theil eines Suerjanittes burd, bie Sieimblaje von Mantis religiosa.

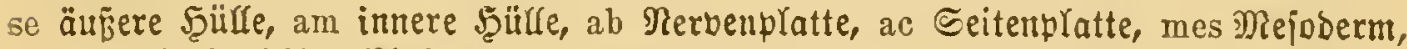

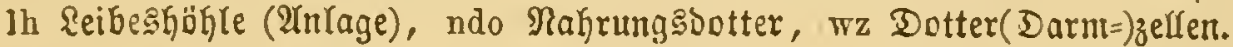

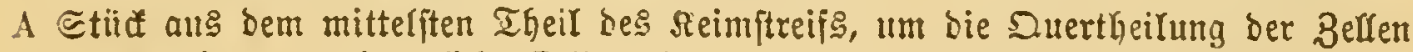
zu zeigen; z eigentlide Epidermis:=, z' bavon abgetrennte Rervenzellen.

(Driginal.)

Später fpaltet jich aber mady Seatidect biejes cine Marfbano

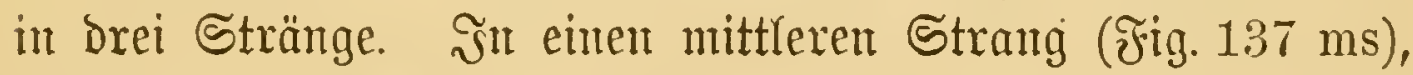
Der als eine bireltt vom Şautblatt entipringende, bei Den ein=

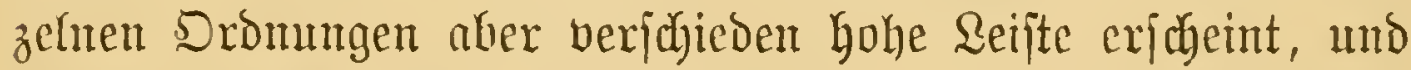
in zwei jeitliche vällig ifolirte Stränge (ss). Leţtere futo bie cigentlichen Markbänoer. Wout Segment zu Segment ber= fdumilzt aber cin Theil Des Mitterftranges mit Den lebeteren 


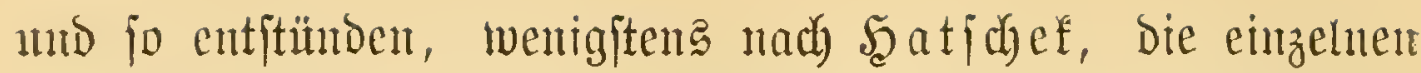
Segmentganglien, die bann burch die beibent Seitenftränge,

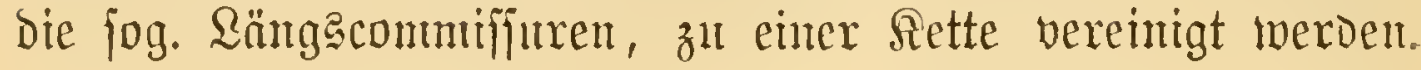

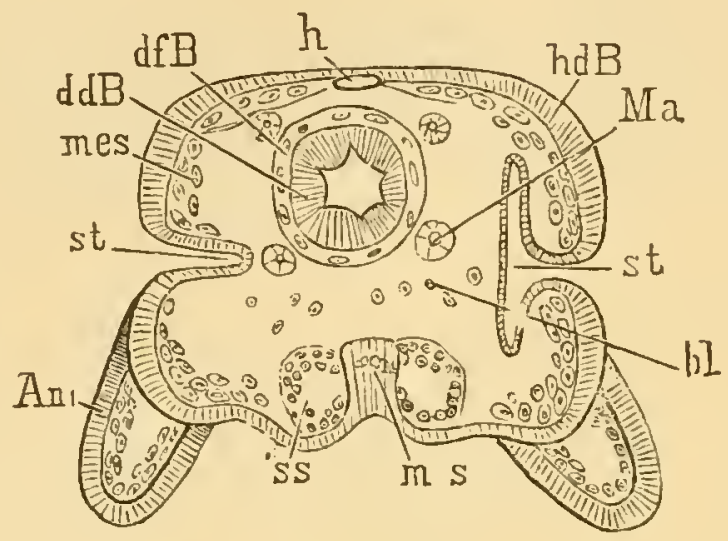

Fig. 137.

Wir namiten die gefammte Branglienfette eine ventrale

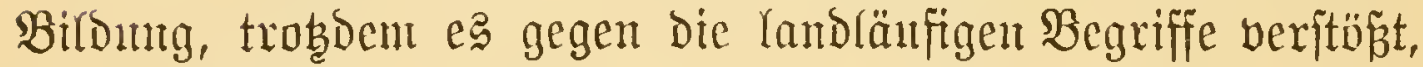

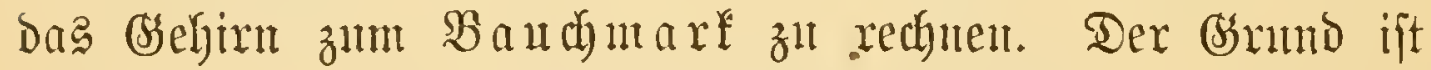

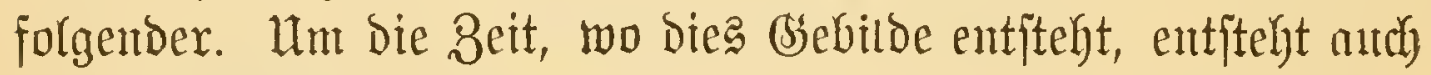
Der Mand und bie Speiferöhre, überhaupt der Borderbarm,

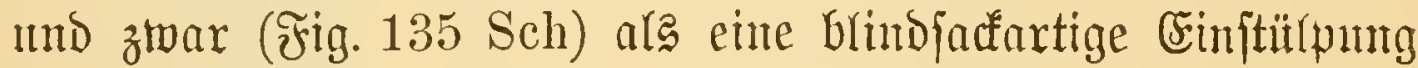
Des Exoderms zwifhen Dem erften uns zweiten Ropfiegutent.

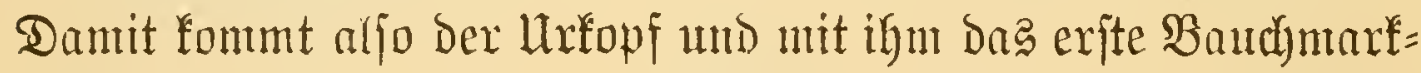
jegunent vor refp. über den Salunt. Es wird zum oberen Schlundganglion, während das ben Mittel= und Šintertiefern entfprechende Dritte und vierte Bandymarffegntent nad) ihrer fpäteren Sereinigutug das untere Bsantion liefern uno bas zweite, ben Dberfiefern entipredyende, die Berbintung beider zum jog. Salutubnerbenringe bemerkftelfigen joll.

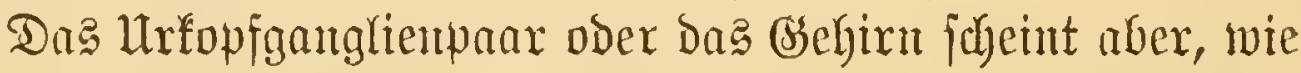

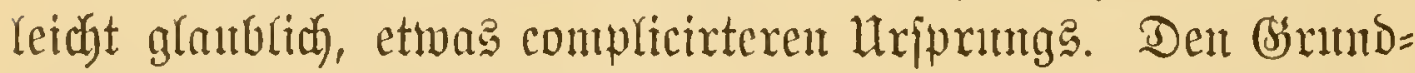

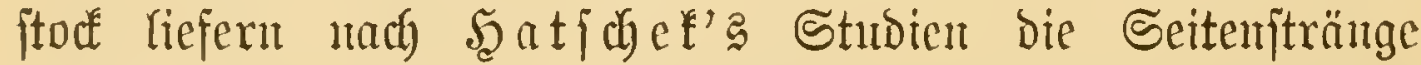
(F̧ig. $138 \mathrm{ss}$ ). Diejer vergröß̈ert fitch aber noch äunerlich durch

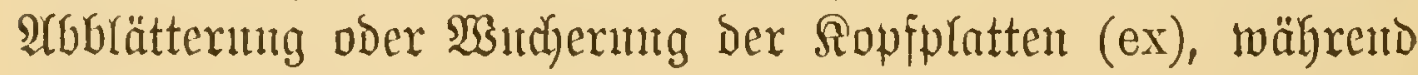
Durch eime Einftitlpung des Eroderms (fa) abermals ein netter 
Theil Ginzufonmt und bus quere (Sommifiurenjuftem zivifden beiden Şimbentiphären malyrfateinlich, zum Theil wenigiten?, Dem vou Şatide fler allerbing? nidyt erroähnten Mittelitrang (ms) jeinen ltrjprung verbantt.

Das Eroderm, mit bejien Drganifinung bix zumädufit be= jayäftigt, wurde f(d)on mehr $=$ fach als Driifenbiatt bezeid)net.

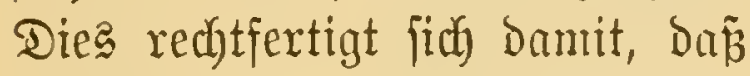
einerfeits bie gejammte Epider= mis getoifje $\mathfrak{x}$ (bjonberungen lie= fert - Die Eritimbaut z. B. ift ia midyte Anderes als ein Secret

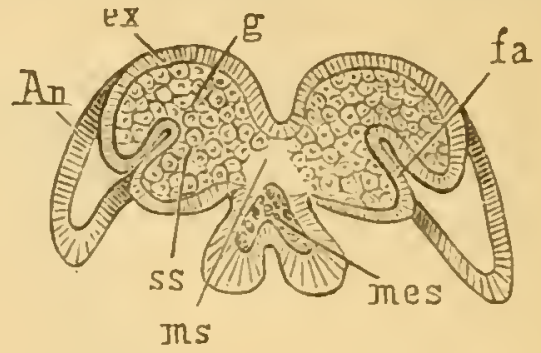

Fig. 138.

Querjunitt burdy die Borberlop: anlage des Fmbryo vom (soldafter. (Nad) 5 a t; d e t.)

ex (Froberm (Ropiepithel), g babon abgetrennte Behirnzellen, fa Bjehirn= falte, ss Ceitenjtränge, mes Mejo= berm über bem Speijerohr, An Fübleranlagen. Derjelben - আnd als mbererfeitz Durch crimftülpungen oder imere Faltungen jene \{pecifijuen Drgane der 2(bjomberumg und des Stoffmedtele entitehen, die wir ars Şautorïjen im

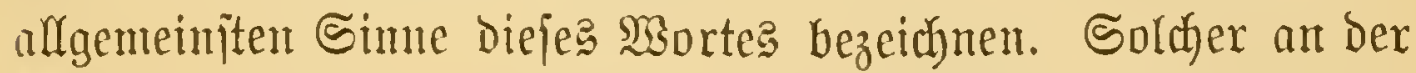

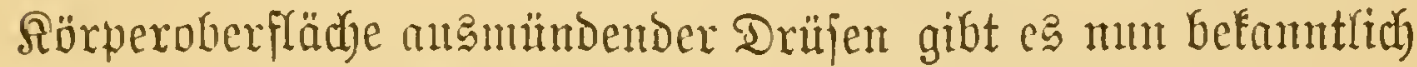
aud bei den snfeften fehr viele und mannigfartige; wir be= fabränfen uns aber auf die parrigen Mrund= und anf bis gleidfalls in duplo bon Segment zul Segment fich wieder=

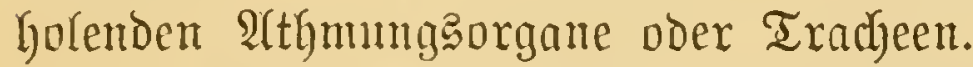

Die Mimborüfen, getwöhnlidy afs Speidyelorgane bezeichnet, fommen im arlgemeinen, jo z. B. Ficher bei ben Faltern und Bienen, in zwei \$aaren vor, wovon das vordere bem ztweiten oder Manbifeljegment, bas Gintere aber bem vierten Sopfring oder Der Unterlippe entipricht. SBei bielen Rarbe!̣ funftionirt bas

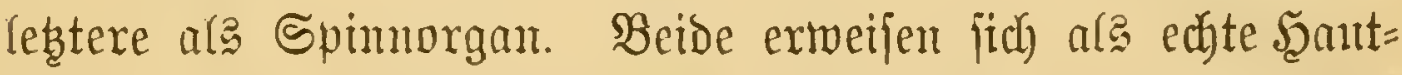
orüjent. Sie entfteben nämlid), wie jüngit wieder Şatichef gezeigt, aus einer faltenartigen Crinjtülpung bes Eroderm, bic jich) bann allntälig, oft unter melgrfachex Beräjtelung, zu

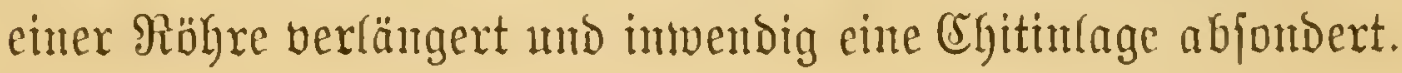




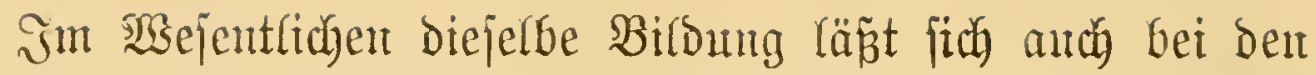
Trabeen (vgl. Fig. 139) nadiweifen, uno tach Den neuejten

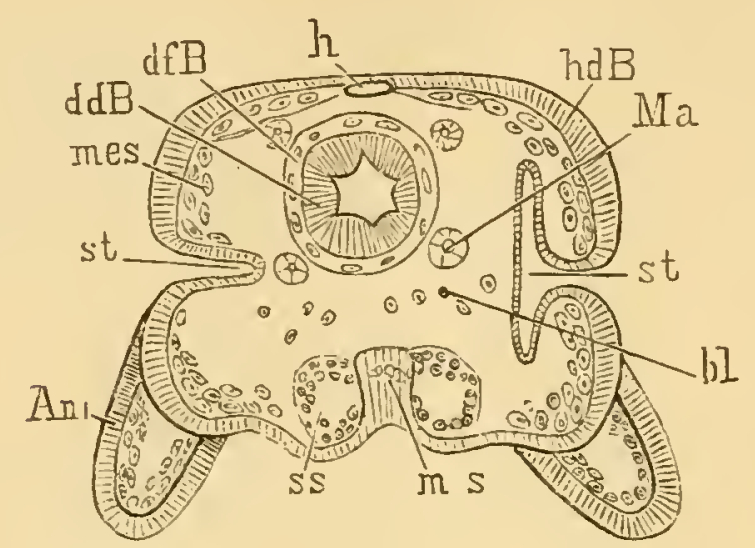

Fig. 139.

Unterjudugen von $\mathfrak{B a r n t e n t}$ ijt es aud jebr wabrideintid, da

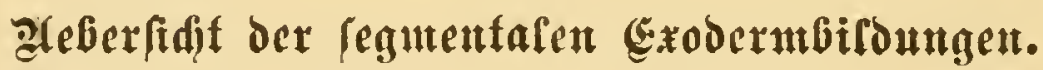

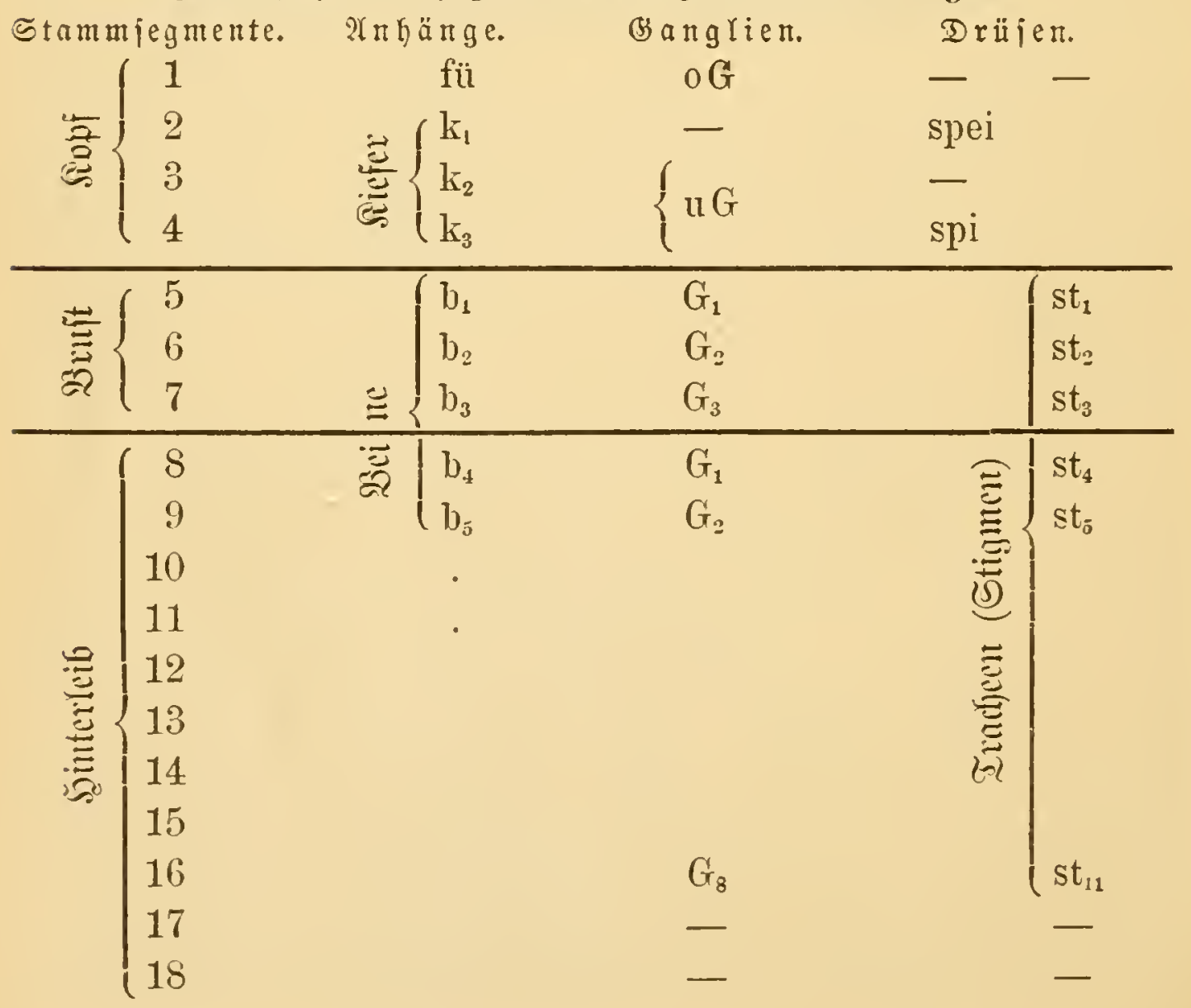




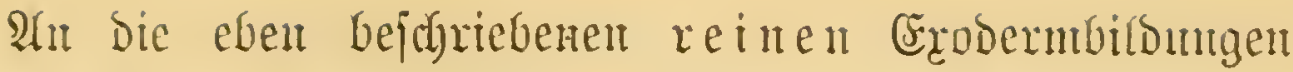
ichlię̧en wix bie Entwidfung eines hod)widytigen Bimen= organs, nämtich) bce Darmf́attales an.

Eine joüne Heberficht gibt zunächjt Der beinahe einent

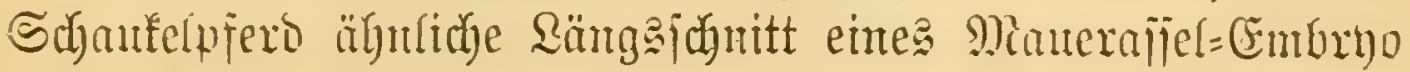
(Fig. 140).

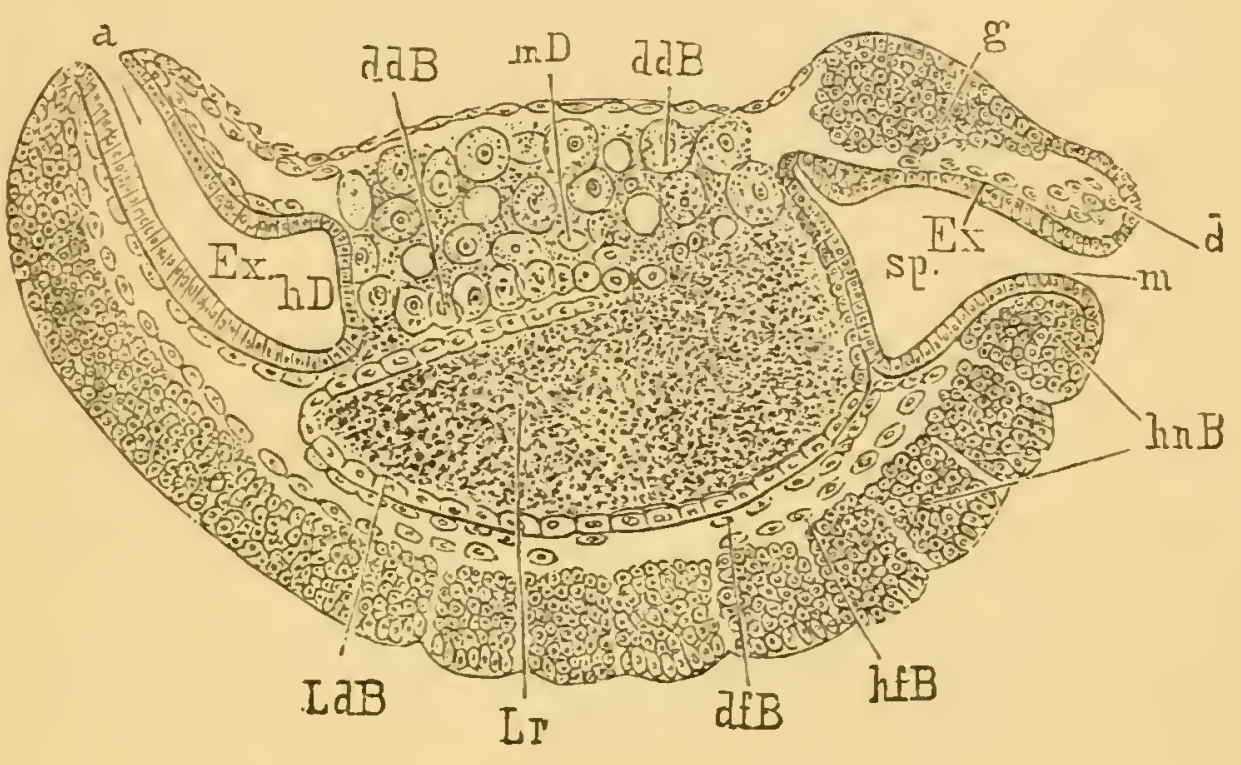

Fुig. 140.

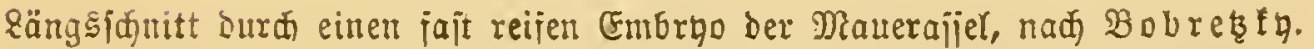
hnB mefridjidtiges und jegmentirtes Şautnervenblatt, alts bem bie Baufbecte und bie Banglientette herborgeht; vorne unb hinten geft es in bas einjujidtige Exaberm (Ex) über, burd bejien Finjtülpung ber Border= (sp) und ber Finterbarm (hD) ent= fiteht; m Mund, a Ifiter, g Bebirn, hfB Sautfajer=, dfB Darmfajerblatt, Lr Reber. jaf, $\mathrm{mD}$ Mittelbarm, ddB Darmsrüjen=, LdB \&eberbrüjenblatt.

Da vou Der Birbung eines Darmidulauches die Rede ift, jo wirb ber Rejer in Den beiben einander entgegenwadjfendent brindjactartigen Finfitïlpungen sp und $\mathrm{hD}$ ohne 3roeifel bie Anfünge eines joldhen vernuthen, fich aber wahricheinlich

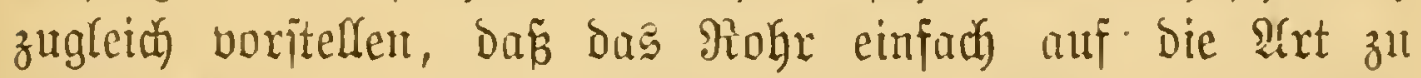
Etande fommt, Dá bie betreffenden Blindjäafe in ber Mitte Des Rörperimtern anf eimander fto itelle fird öfinell werdent.

So einfad geht bie Sadje aber nidyt ab. Die gemilifen

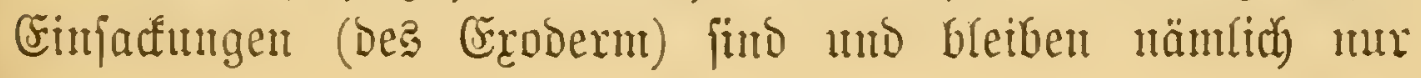


Die Enditüfe des ganzen Ranales, während Der Mitteltheif, D. i. alfo ber Darm im engeren Sinne, cinen ganz andern urjprung nimmt.

Derjelbe entiteht ans jenen im Dotter zeritrenten Bit= Dungaelementen, die wir jhon oben als Darmzellen be= zeichneten.

An umjerer FFigur (140) jtelfen biejelben (ddB) gröp̈ten= theils noch einte compacte Majie dar; mur muten bei LdB fieht man, Daź fie fereits aus dem Dotter heranggetreten fint und dañ hier bie Bildung des Drüfendarmjacfe in 3uge ift.

Dás mun aber wirffich auch bei Injeften ganz ähnliche

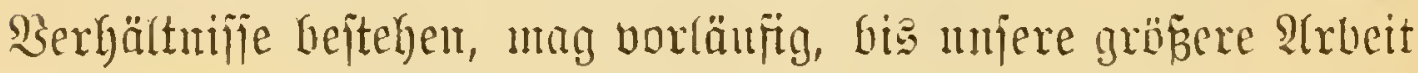

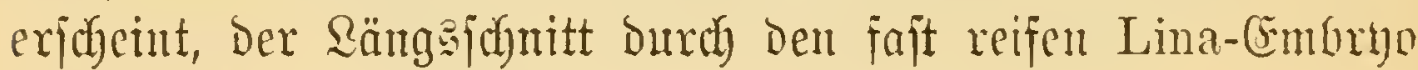
int Frig. 141 zeigent.

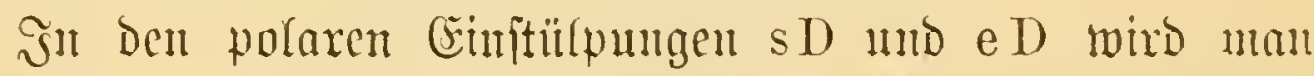

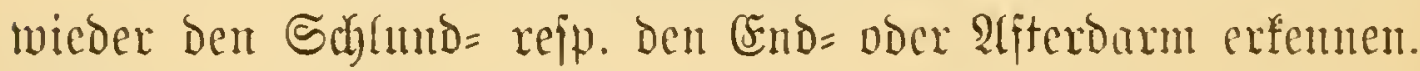
Dazmijdyen liegen unn zwei grofe weite Shajen, bie getrenten Durchichnitte Durch Den etwas gebogenen Mitteldarm. Dic

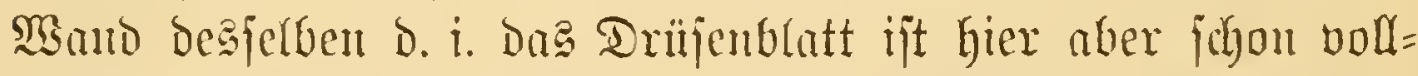

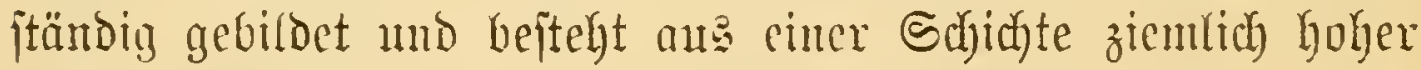

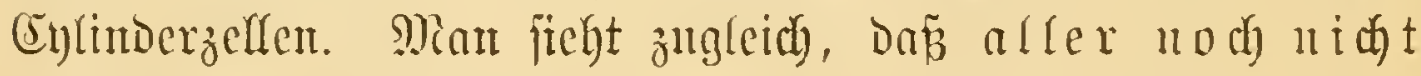
verbrauder Dotter in biejem Mitterbarm ein= gefdrlofien ijt, da Dotterjackes oertritt.

\section{Frflärung zu Jig. 141 G. 433.}

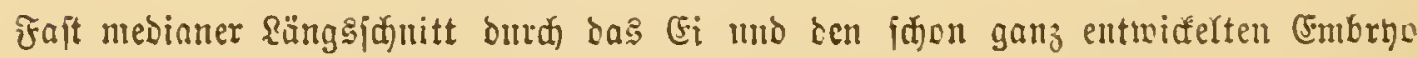
Des Rapperblattfäjers.

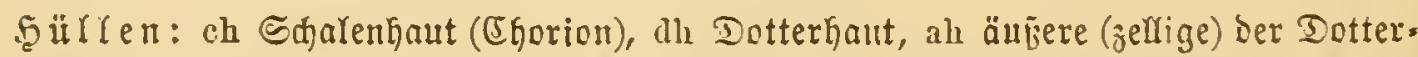
haut anliegende Reimbülle, ih innere (zellige) bem (Fntbryo fid) anjumiegende Reim=

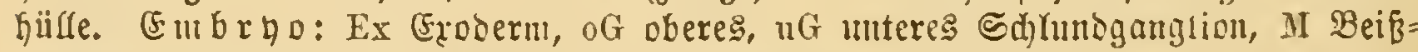

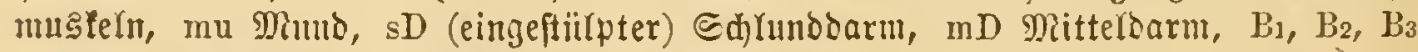
Beine, eD Entoarm, a ifiter, st_-sts tridterartige 2fnlagen ser Etiguten reip. 


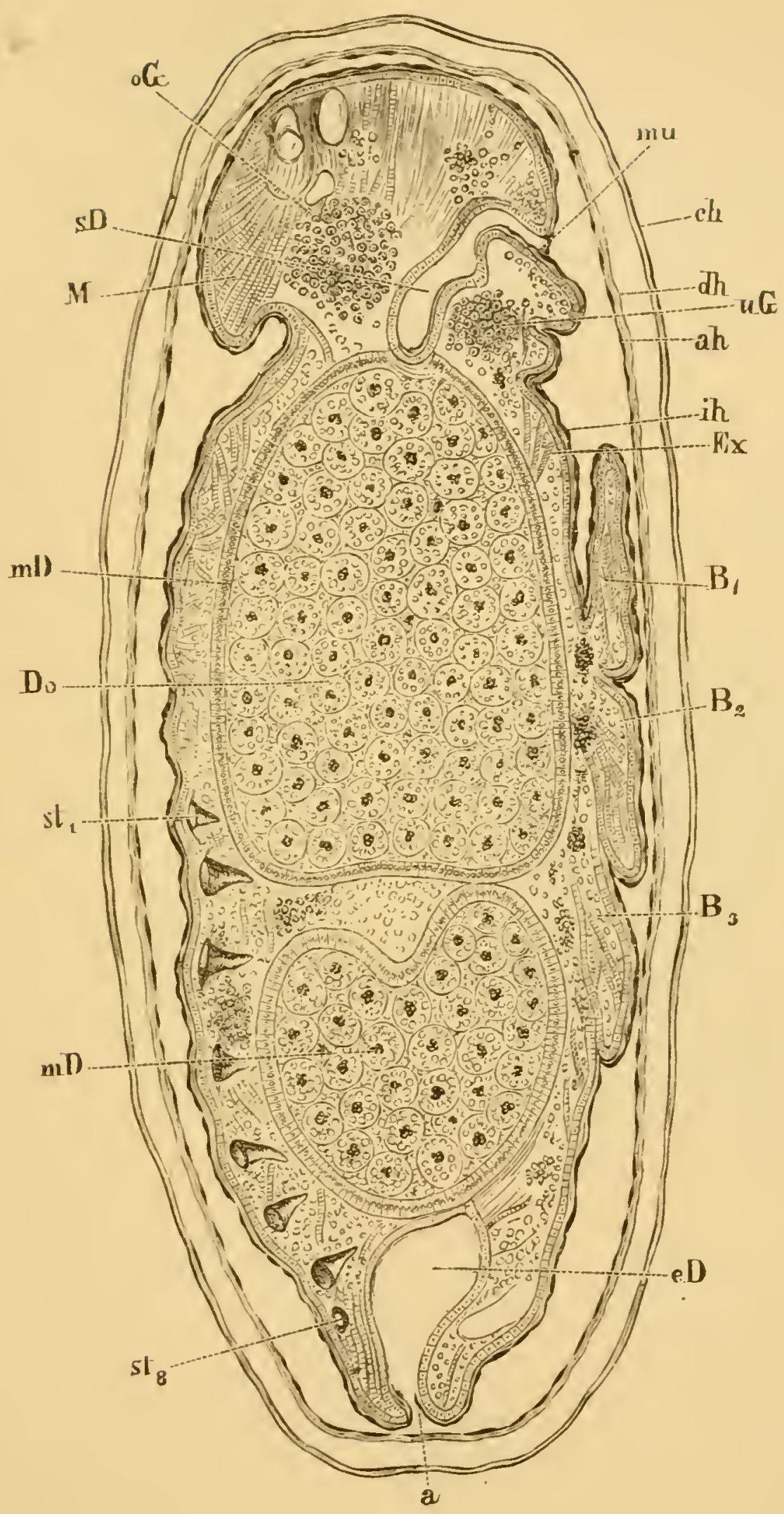

f̛ig. 141. (Erltäruแก f. ミ. 432.) 
Diejer Dotter ift ferner nod) immer in jene grofent

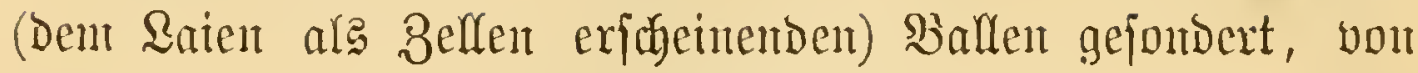

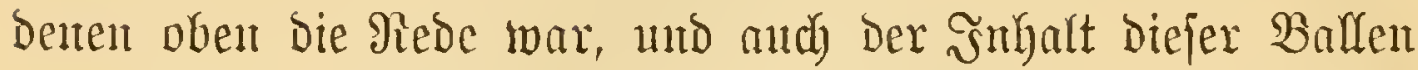
ift nod) ein ähntlidyer, D. h. man fintoet bei Dopperfärbung mit Siffrinfäure un Rarmin 1) einen rothen centralen Renn, 2) einen hellen PIasmahof und 3) an Dex Pexipherie Des lebetern bie gelb gefärbten Dotterfitgelchen.

Die Beipredung Des Mittelblattes oder Mejodern Gaben wix abfichtlich auf zuleşt gelafien, uämlich unt einfach

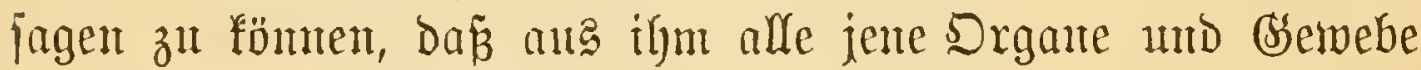
heroorgehen, welche Den Şohlraum żwifhen Dem Şaut = mo dem Darmiditanthe eimtehmen.

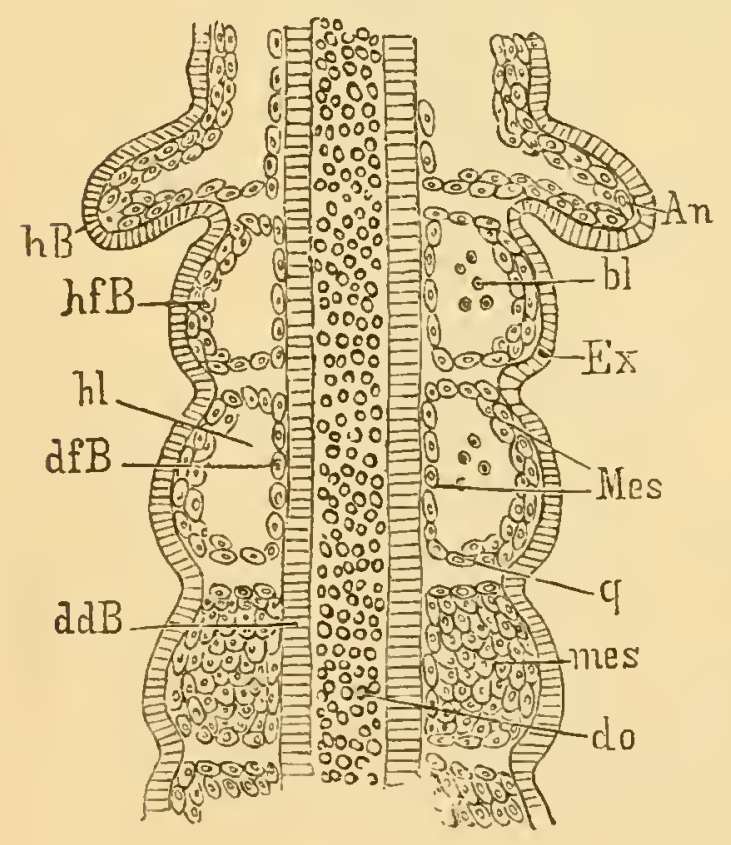

Fig. 142.

Sdiematifde Dariteflung ber Segmentirung Des mittleren Seimblattes an einem horizon=

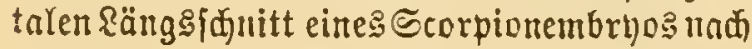
Meczuifow.

Ex Ercoberm, ddB DarmbrijjenGratt; żvija)en diefen Blättern bie hohłen "bilrfeljörmigen" Mejodermjegmente; hfB beren äußeres oder Sautfajer =, dfB beren intmeres ober Darm=

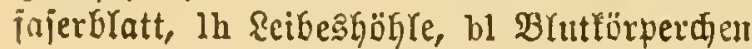
barin, do Rahrunggootter.
$\mathfrak{A m}$ Dueridhnitt in Fig. 136 fiebt Der Rejer bie erjten 2 ntlagen biejer Theile in Sisftalt zweier anfang? joliber, fpäter hobl wer= Denter Beffitränge (mes) an Den Seiten Der mittleren Reintitreifberbiffutg, aus ber bie Esanglienfette her= vorgeht. Mit Der Seg= mentixung Des Exoderm? zerfallen Dam nad) Den biaberigen angaben aud dieje Bellftränge in eine entiprechende $\mathfrak{A}$ tza abl von Stiilfen. Dies foll nach Meczuifot bejonders ant Sdywanze des Scor= pions beutlich jein, wovon Fig. 142 cin Stïlf dar = ftellt. Ex zeigt bos ge= 


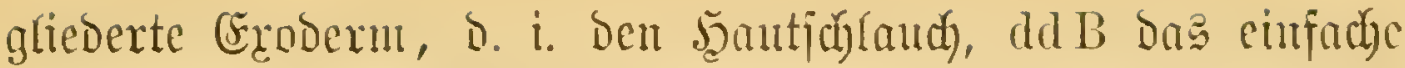
Darntrobx. Daztwijaden bemerft man an beiben Seiten bie würfelartigen Theifftilafe des Mittelbfattes. Dieje Miejoderm=

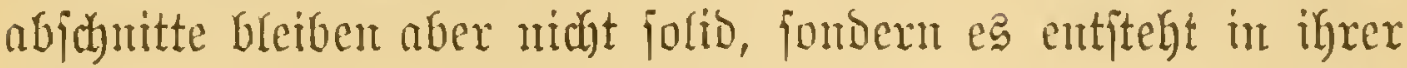
Mitte (ygl. Den vorderen Theil Der Figur), wie fdyon frither

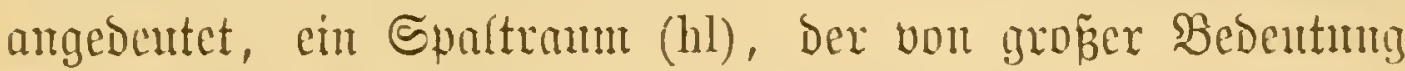

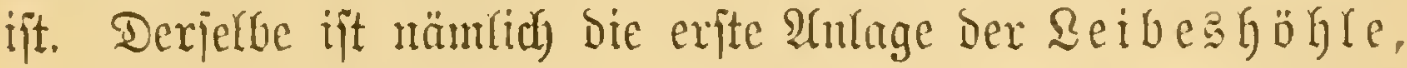
bie aljo, gantz mabhängig vom Darmjchlaud) mb meijt fduon vor bejien Bolfendung als eine einfache \&ü de im Mittel= blattentjeht.

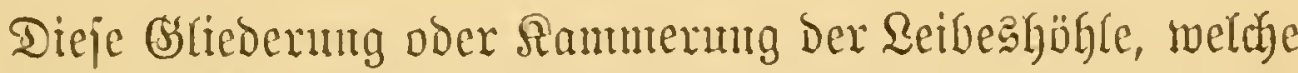
man bei gemifien Würmern zeittebens fundet, ijt aber bei ben Snjeften un ein vorïbergehentoer Bujtand, indem jich bic queten Sryeidemänto (q) jehr bard auflöjen. Das Mefodern bejteht bann in

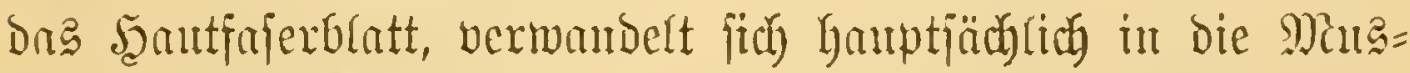
felu bes Şautifecettes und behält z. Th. ifre urfprüngliche

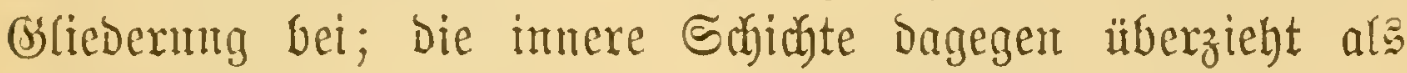

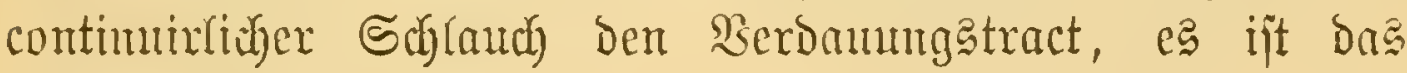
Darmifajerblatt.

2unerdem entïtehen aus bem Mittelfeim nod) folgende Sscruebe. Erjtens einmal Das Bhat, Defjen Formbejtnntotheile, bie Bhlutförperchen, als abgelöjte Miejodermzellen zut betrad)ten jints, und Dann bie Bindejubjtanzen, weldye die in ber Reibes= Göhre liegenton Drgane ïberziehen und unter eimander be= fejtigent.

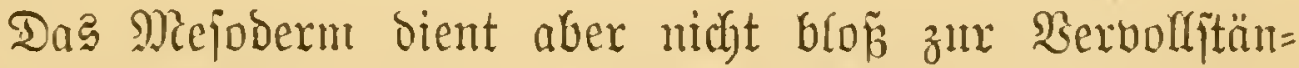

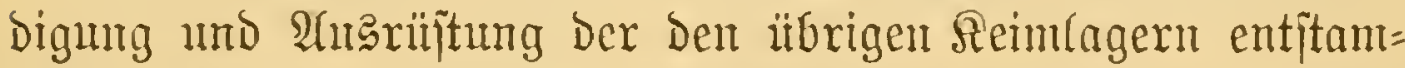
menden Drgane, e马 liejert audh jelbjtänbige Sïrpertheiłe. Dahin

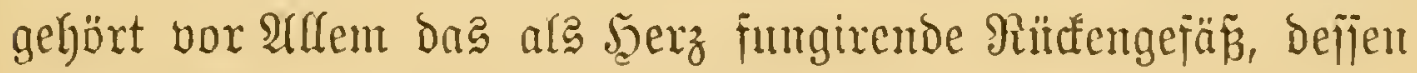

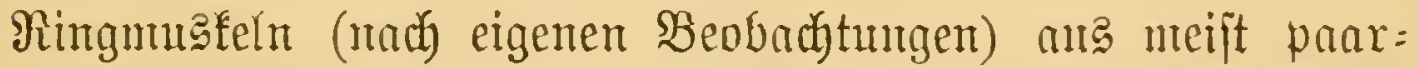
weije verichmelzenton Bellen entitehen, unb bant bic gewijie 
im erjten Band näher bejoriebene Bandyprefic. Die übrigen Bhtutbalyen Dagegen find cinfadye Spalten Des Mittellager:

Der Sejer bïrfte un vou jeden der bielen Cunzeltheile

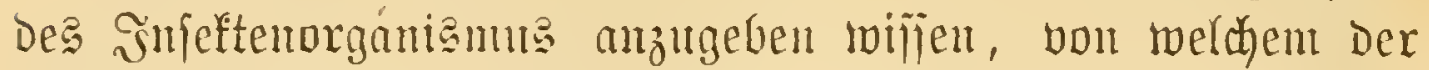
orei Bellcomplexe, in die das embrubuale Bildungamaterial ge= fondert ift, fie ibren Ilrpprung mebnen. SArr bou einem Drgan, mo zwar von einem Der interejianteiten, nänliç Dem Der

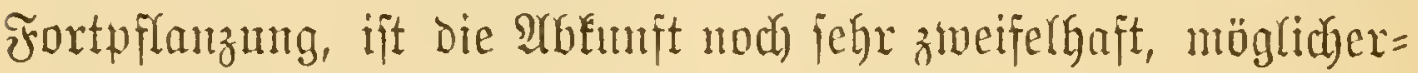
weije aber and hei ben einzelnen aththeilungen einte jefre ver= jujiedene.

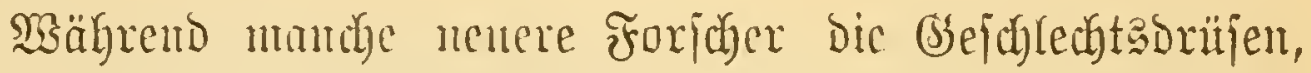

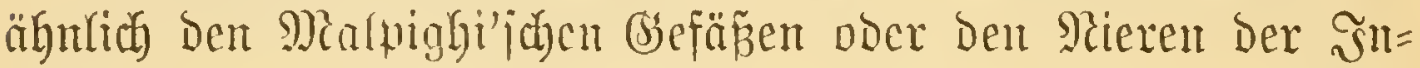
jelten, an bem Cendoarm heronxjurofjen lafjen, fie arjo auf das

143

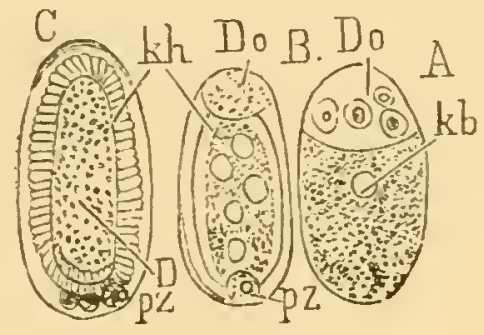

144

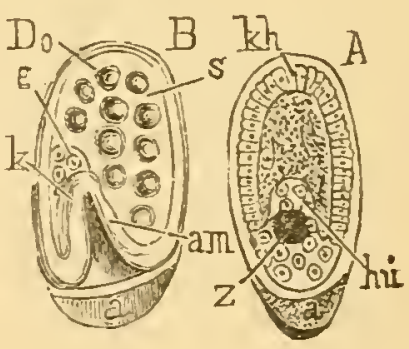

ifig. 143 .

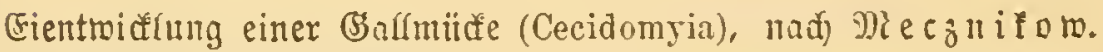

A Fi, Do Dottcr=, k Reimfad).

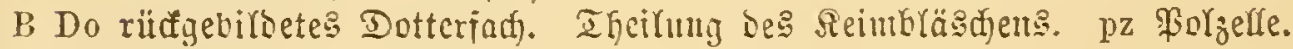

C Fertige Reimlint (kh). Folgellen vermehrt.

Fig. 14.

Fientwidftung einer Rarben gebärenden $B$ lattlans.

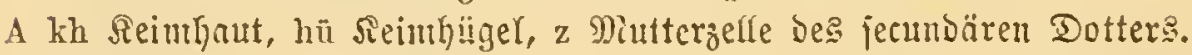

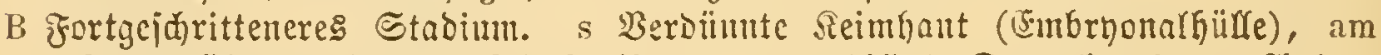

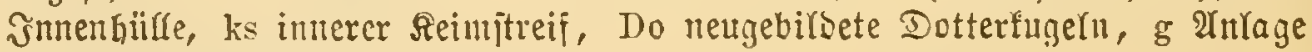
ser (sejejledtenorgane.

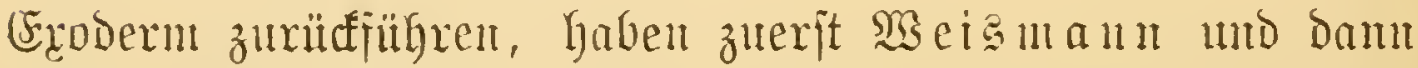

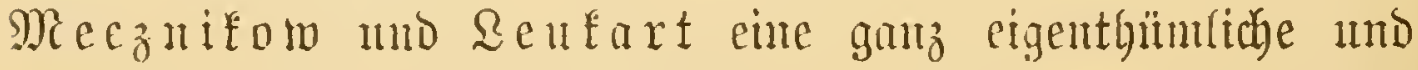
non den fiemblättern mabrängige Birbung angenomment. SRach Diejen entjtebt zu Beit ber Seintulajenbildung am 


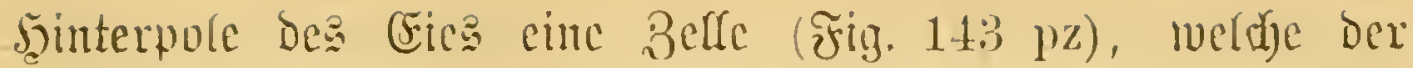
Eutbecfer desharb and al Pongelle bezeidnete.

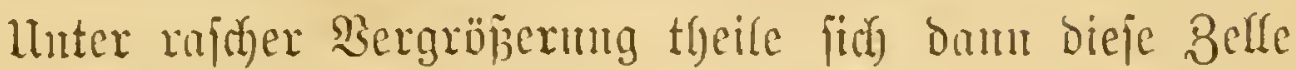

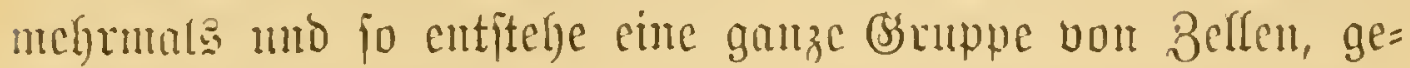

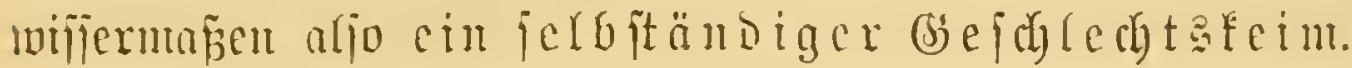

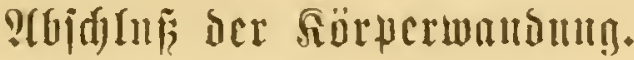

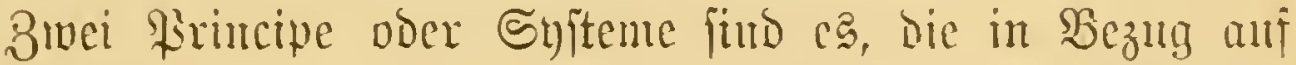

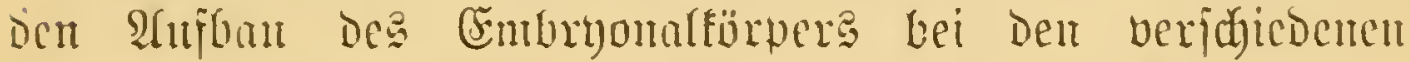
Thicren bejolgt werden, und wir bezeidynen fie furz arg ben g)

Einen gejolyloifenen Ban zeigte un z. B. Die Seemalze,

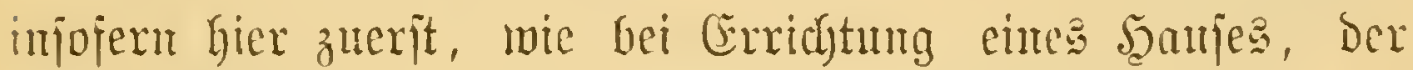
änzere Rohbau, D. i. Die gcjumnte Reibesmand des Thieres

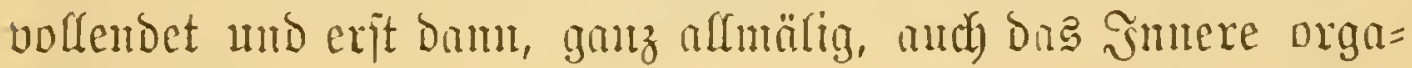
nifirt toird.

Dieje Banant ijt jebenfalls die uriprïmylidyjte, und fic ermöglidyt, wie bus Beifpich ber Seewalge zeigt, cine fehr balbige Semtbung bes Banes, D. h. eine frïlye Selbjtänbigkeit

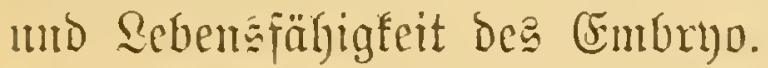

Sbwohl", z. Th. gewiz als Den angefïhrten Gründen, bicje Bannat aud) beitan bie verbreitetite ijt, jo foumt jis

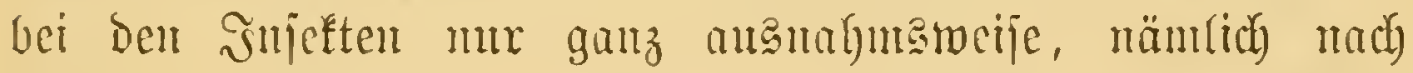
(3) a nin's idyönen Entbecfungen, bei getwifien in Den Eiern

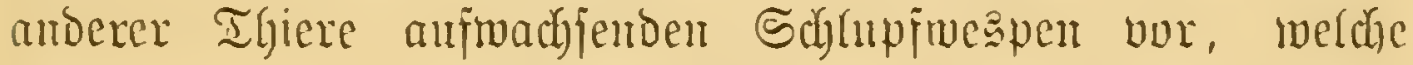
deut Seewalzen äburlich, in cinem gauz oder Doch beinabe feimblafenartigen Bujtand und Dennad) aud ganz añer= ordentlich frïl) ber (Eifant entid)(ï̈pen.

Son einer offenen Banart aber ipredhen soir Dort, wo fid) bie (Embryonalanlage nidyt ülner ben ganzen Unfantg bes Dotters erjtrect, fonderu wo ber (Embryo nit jeimer Qeibes= wand mir ein Segment Der Dotterfugel bedect min Der nod) 


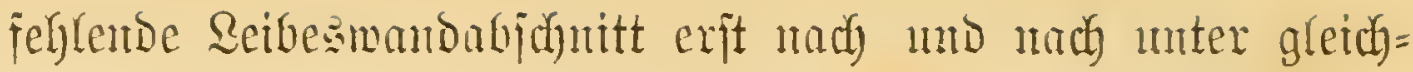

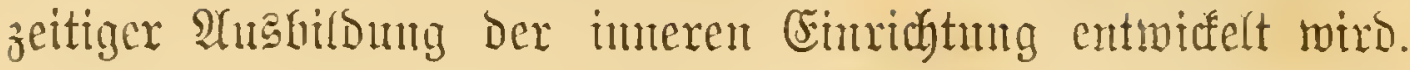

Diejen $\mathfrak{B}$ antil finden wir u. A. het Den Mirbel = und

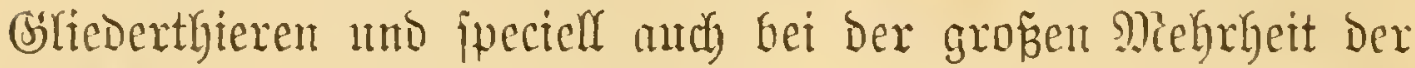

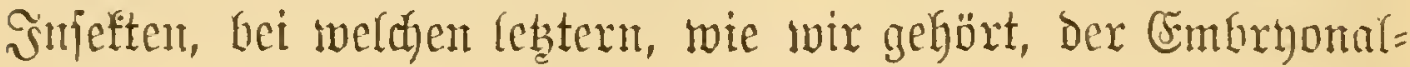
förper anfauge mu Durch Den Bandytheil vertreten ift und als eite jtreifenartig verbicte Bone Der Remblaje cricheint.

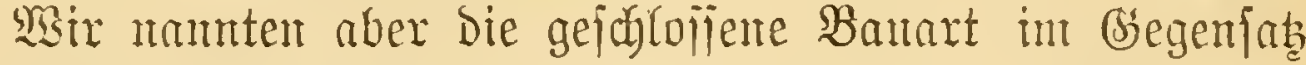
ju biejer bie uriprünglidje, weil wir faftijh bei

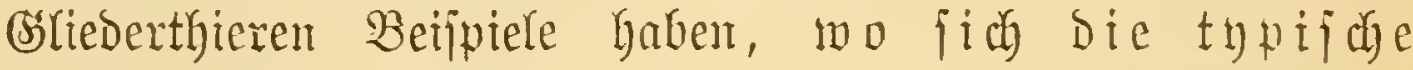
offene Embryonalanlage (Dmrdy einten Remitreif) an einen bereits lebengäbigen gefalofjenen ermbryo entmiafelt.

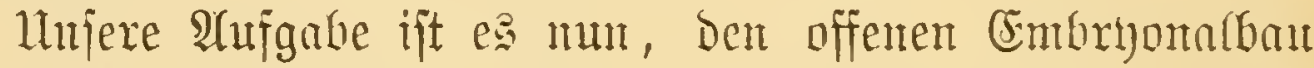
Der Smjeften nod cimmal näher zu muterjuchent und haupt=

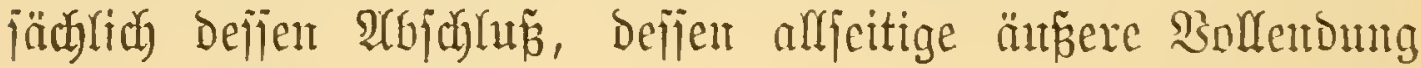
jut berfolgen.

Bur Erräutterung nelyute man zunädbjt ben Galbreifen Mäufenentbryo auf F̧ig. 145 vor. Derjelbe gleidyt, um unt? möglicbjt furz zu verftänbigen, eiuem mit Seitemippen (bie

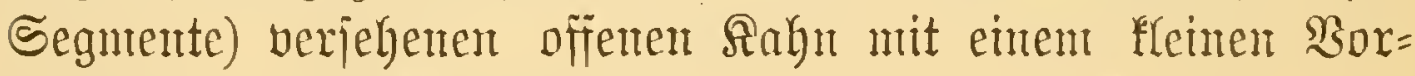
Derbect o. i. Der Siopffappe (g).

Diejer fahnartige Embryo ijt aber nibyt leer, jonbern

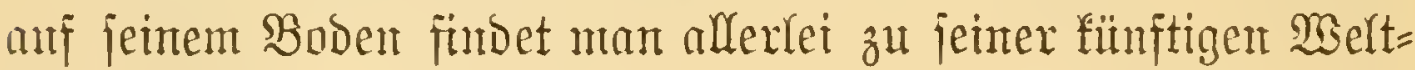

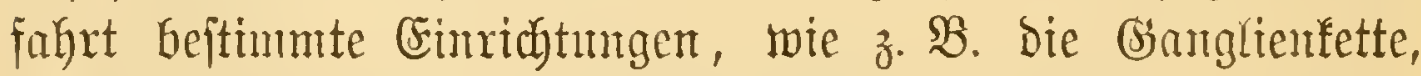

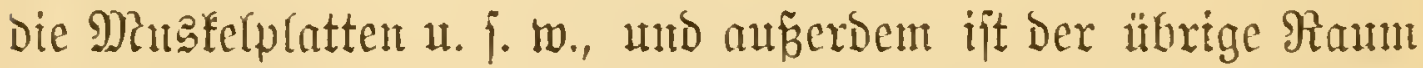

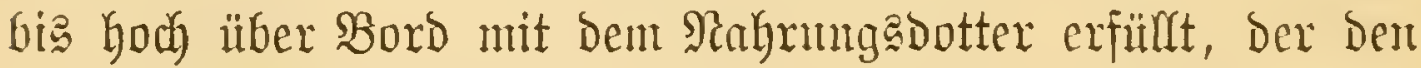
Belfen jente Miaterial liefert, mit dem jeinerzeit ein volftänoiges Berbecf gemadit mo bent entfpredyend aud bie inmere cint= richtung exgäuz̆t merden joll.

Somie mat mu meiftens eil in jeinent Dberban nod) unfertiges Şau ober, um beint Bergleidy zu bleiben, einen

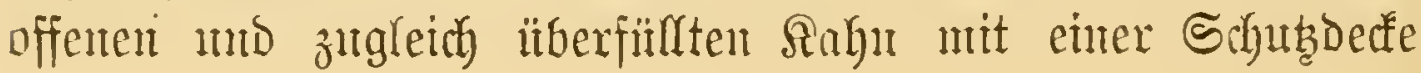




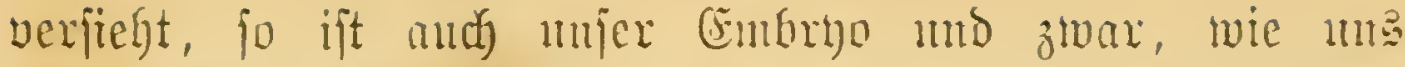

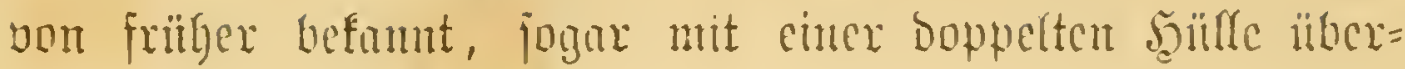

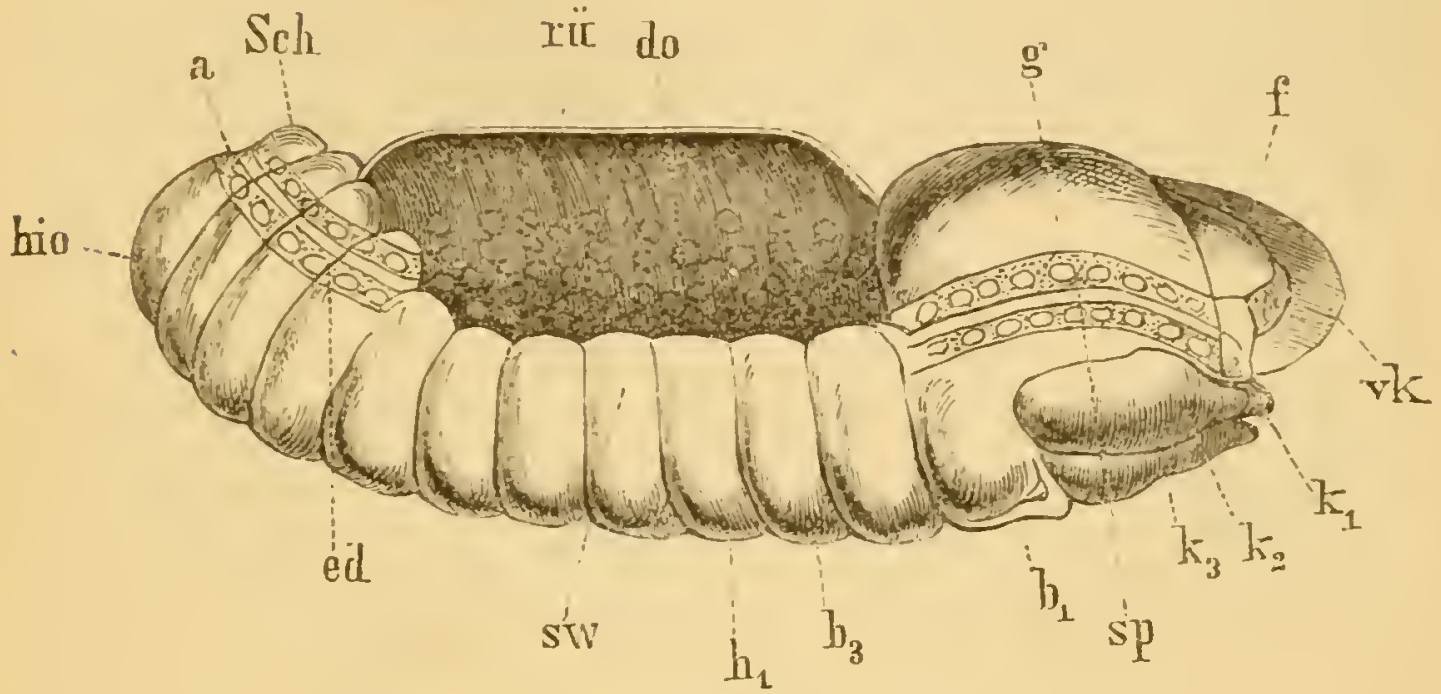

Fig. 145 .

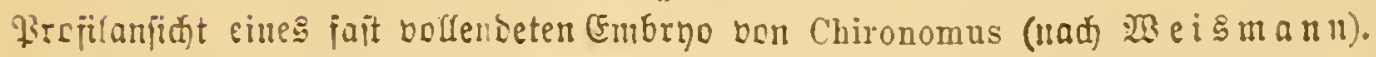

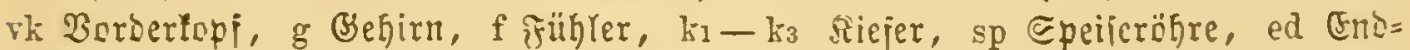
carm, Eeibe burd Finftitlpung bes Exoberms gebildet mo münien in do, ben Dotterjad (Mittelearm).

jogen, über Deren Berfalten mant utadjteffentoe Fig. 146 jut Riathe jiehe.

Die biffe, in Der Mitte eingeferbte $\Omega$ age (Ex) ift ber

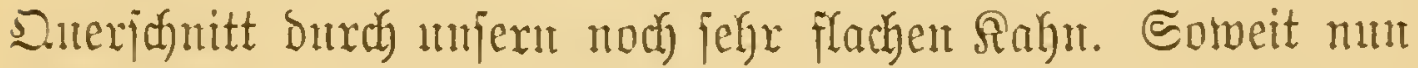

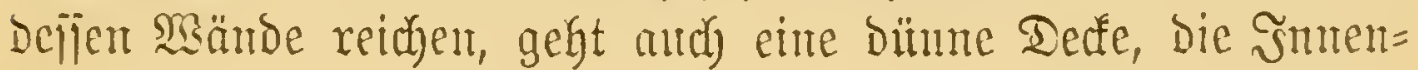

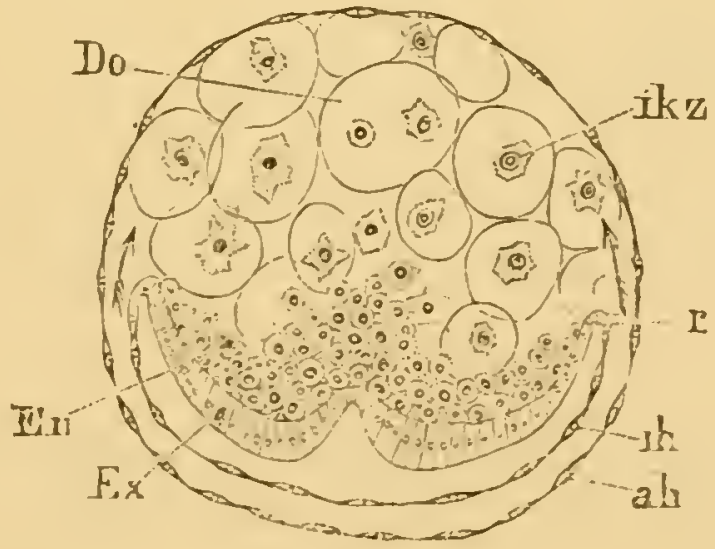

Fig. $14 \%$.

(B) raber, Injelten. II. Bos. 
bülle (ih), weldye ringsum mit Den Silgnuändern verwachjen ijt. Do ift Dam bie hoch ïber Borb aufgehäufte Sabung, weldye mitjanmt Dem (Embrun von einer zweiten Decfe, Der

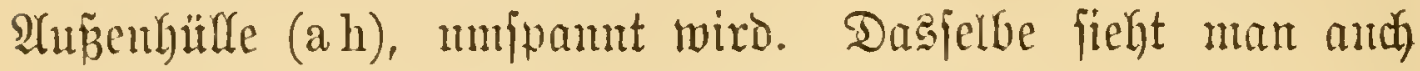

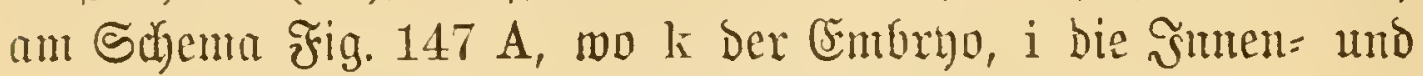

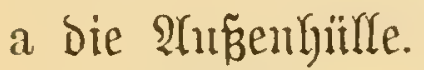
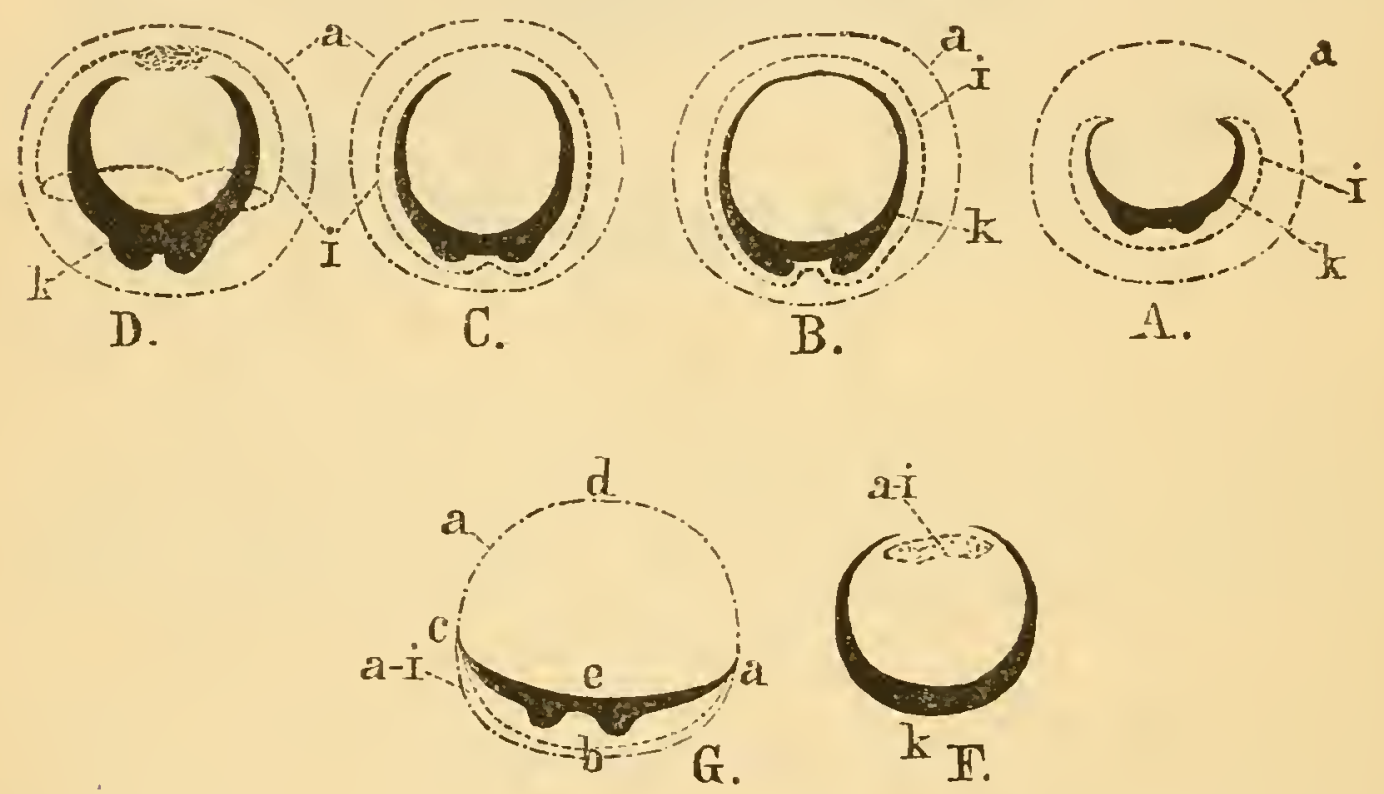

Fig. 147.

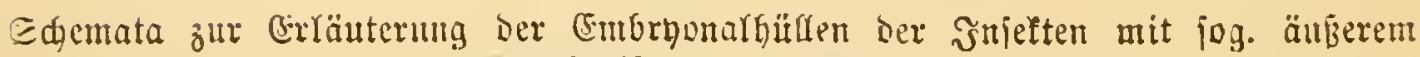
Seimftreif an Dueridnitten.

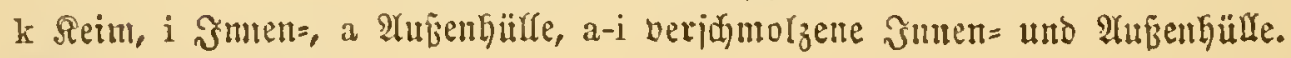

A $\mathfrak{H}$ ugenteiner Iypus.

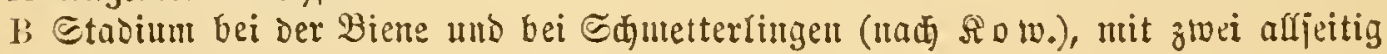
geid) Yofjenten Şiulfen.

C Stadium bei Phryganea, Donacia etc. (แa M) Mel nif.), mit abgelöitem Reimitreif.

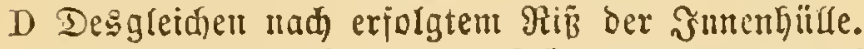

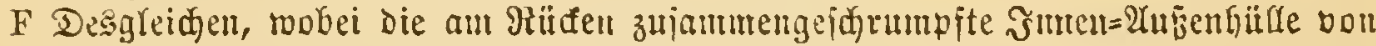

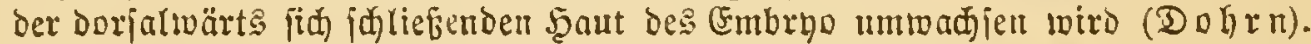

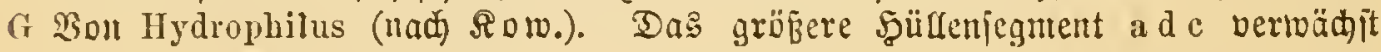

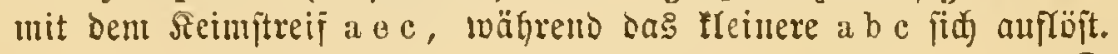

(Sriginal.)

Die Frage ijt mu, wie fid die Reibesmand des (Fmbryo am Rüufen ergäızt, wie fie aljo ans einer Riune ein completes giohr toird. 


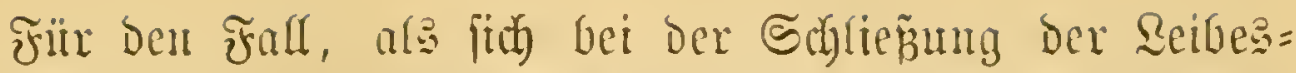

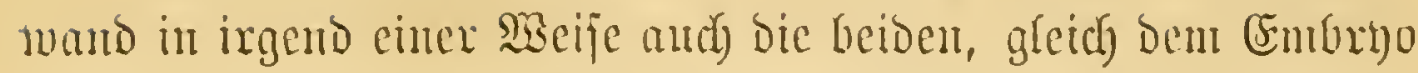
ferbjt ja maty an ber Siemblaje entitandenen şüllen bethei=

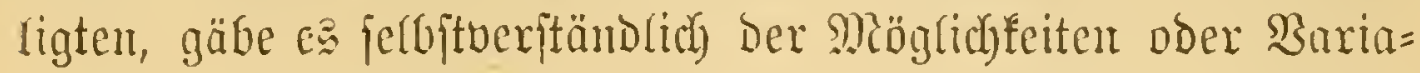
tionen wieder jegr viele, mo juefe Da, alle ober soch bie

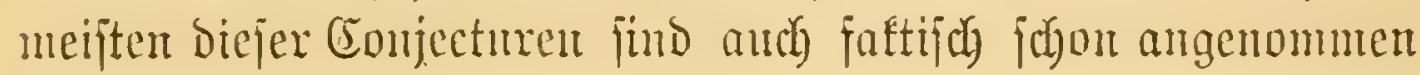
toordent.

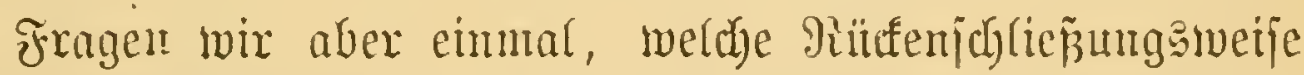
erjtens mit Riüfficht auf analoge Buitände bei Den Mirbelthieren

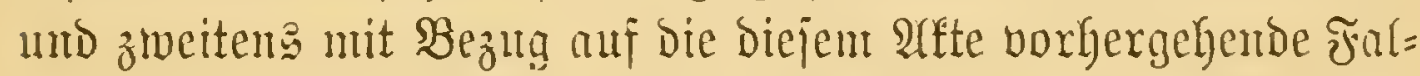
tentilloung an ber Band feite wohl bie nakeliegendite jein mörbte, jo bietet jith bie Röjung des Problems an ber lebet= crwährtes Fig. $147 \mathrm{~A}$ jo ju jagen bou jellojt dax.

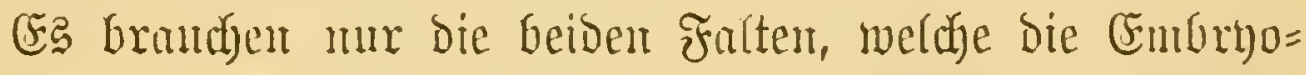

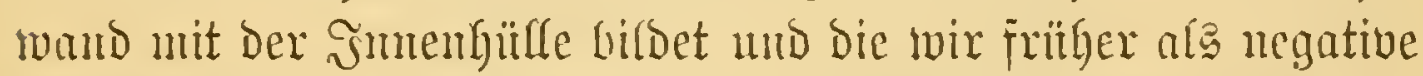

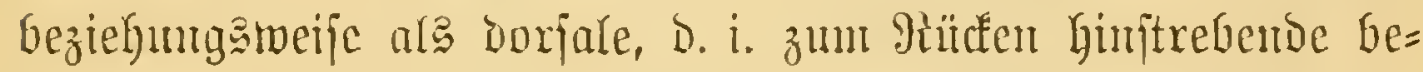
zeidyneten, nach oben ver(ängern no über Dem Dotter zu= jammentwachjen, fo erbalten mir (Fig. 147 B) gleidjzeitig 1) eine alljeitig gcidgloijene Seibesform (k) und 2) eine rebtere ringe ungebende Jumentitlle (i).

Enmberbarermcije ijt aber bieje cimfarjite $\mathfrak{Y}$ rt Der Riüfen=

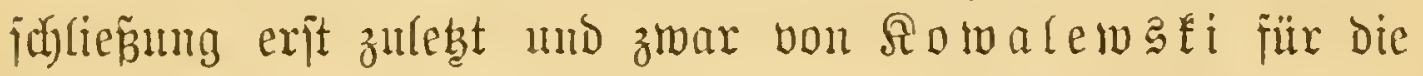
Biene uns (unter gemijifen Miodif̈icationen) aud für bie Schnet= terlinge nadygemiejen, während von bemfelben forjoger für andere Snfeften o. Th. nodj bie früheren $\mathfrak{A m n a b m e n ~ b e i b e = ~}$ Galten werden.

Auf Brumb ausgebehnter eigener Stubien find wir aber

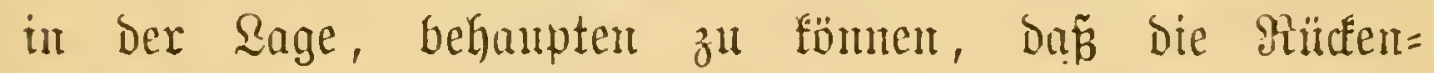

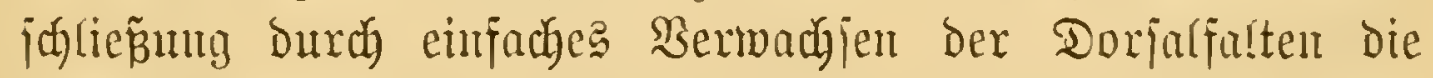
verbreitetite zu jeis jobeint und fpeciell aud bei joldyen Jnjeften (子. B. Räjern) vorfommt, dener $\Re$. jelbjt jomie ambere CEmbryologen, wie Gejombers Melnifow, ein $a b=$ weidyentes Berhalten zujdreiluen. 
3u gröperer Desttidgfeit Geliebe man die Figuren 146 A B C (von Lina) zul vergleichen. Bei B liegen Die Ränoer

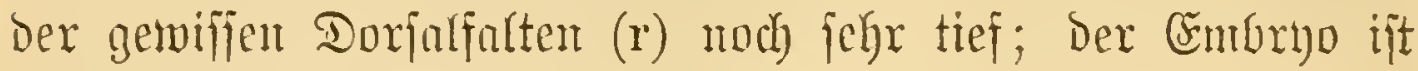
ein flacher $\Re$ ahjt.

Sie ergeben fich aber rafd in Der Ridytung Der Rfeile,

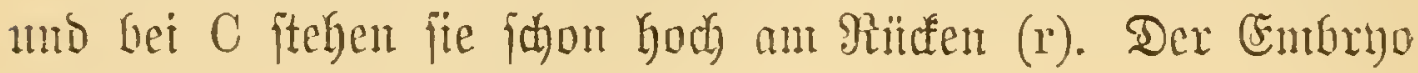
gleidyt einen ftart ïberwölbten Boote.

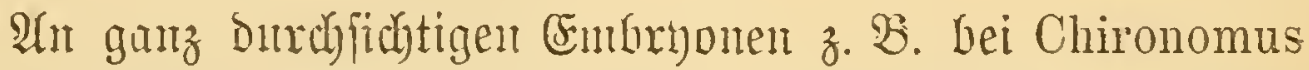
fant man ïbrigens Dieje Dorfarfalten and bireft fid vereinigen

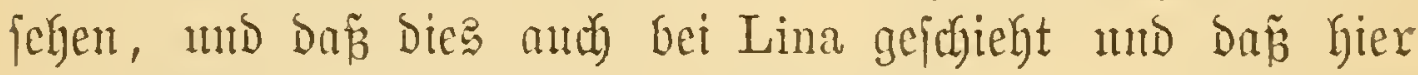
mad) erforgter Sereinigung faltifa auzer ber gejulofijenen

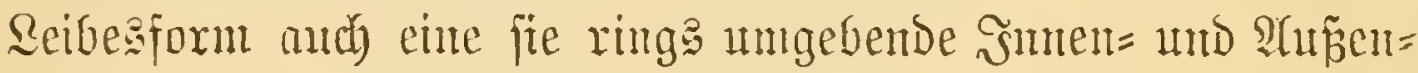

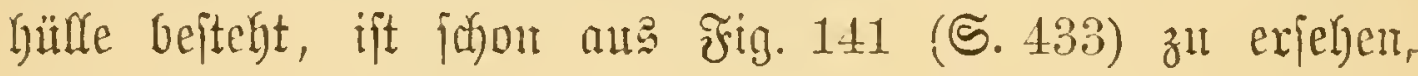

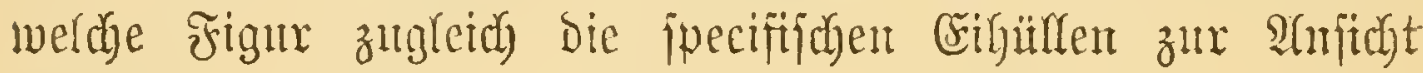
bringt.

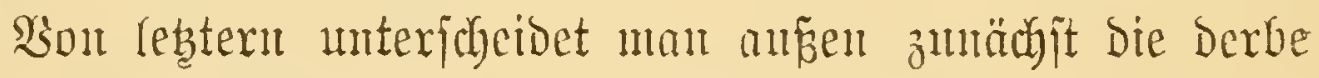
leberartige Eifagale (ch), barmif bie dïnte meijt mux an Schntiten wabutelubare Dotterbant (dh). San fommen erit bie eigentiduen Embryonulfänte. Die äuñere ber= felben (ah) liegt munittelbar ber Dotterfant an mo ift einer Den Embryo einhyüfentoen sisindel zu vergleidyen. Die imtere Seüfle hingegen (ih) gleidgt cinem zarten Sleide, Da: fich alfen Unebenheiten Des Entbryo amfdumiegt. MSix unter= icheiden Daxan einte Şantbe für Den Ropf, einen Sragen für Den Şala, eine Deafe für Den Rïlfen, Scheiden für bie Beine u. f. w. Crrjt anf bieje Miembran folgt Dam bie eigent=

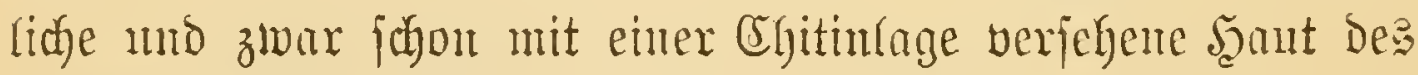
jungen Snfefta, welde in Folge der \$räparation jid bis= weilen ablöit.

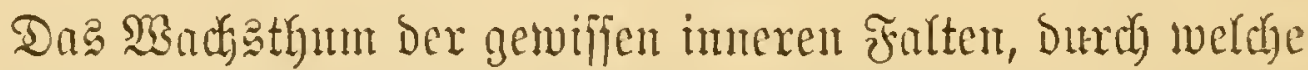
die obere Reibestound gebirbet wirb, exjolgt faft alfgemein jo,

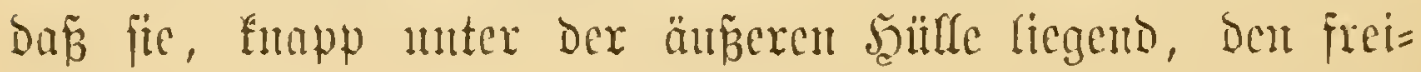

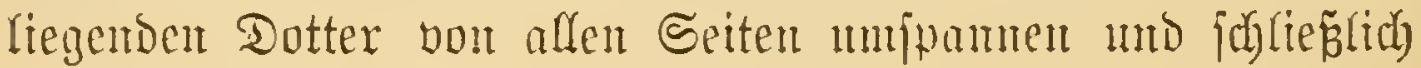




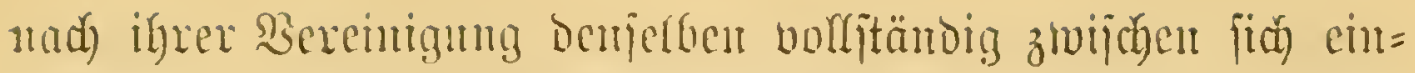

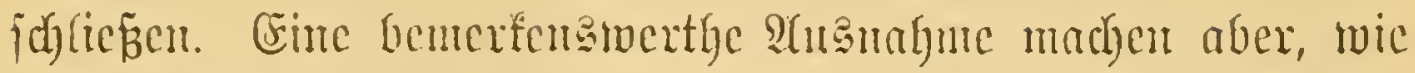
zuterit folvalcwali mo Dohru zeigten, bic Schmetter=

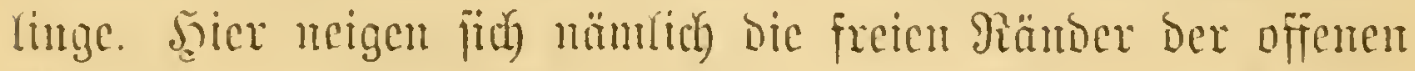

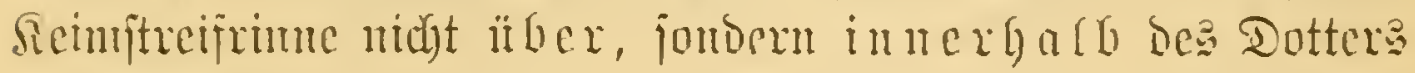

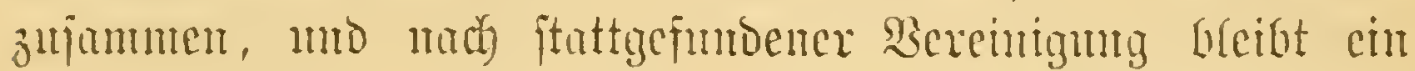

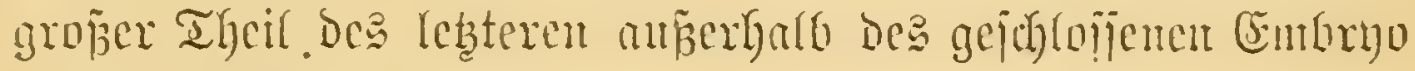
anf bem gütrfen liegen.

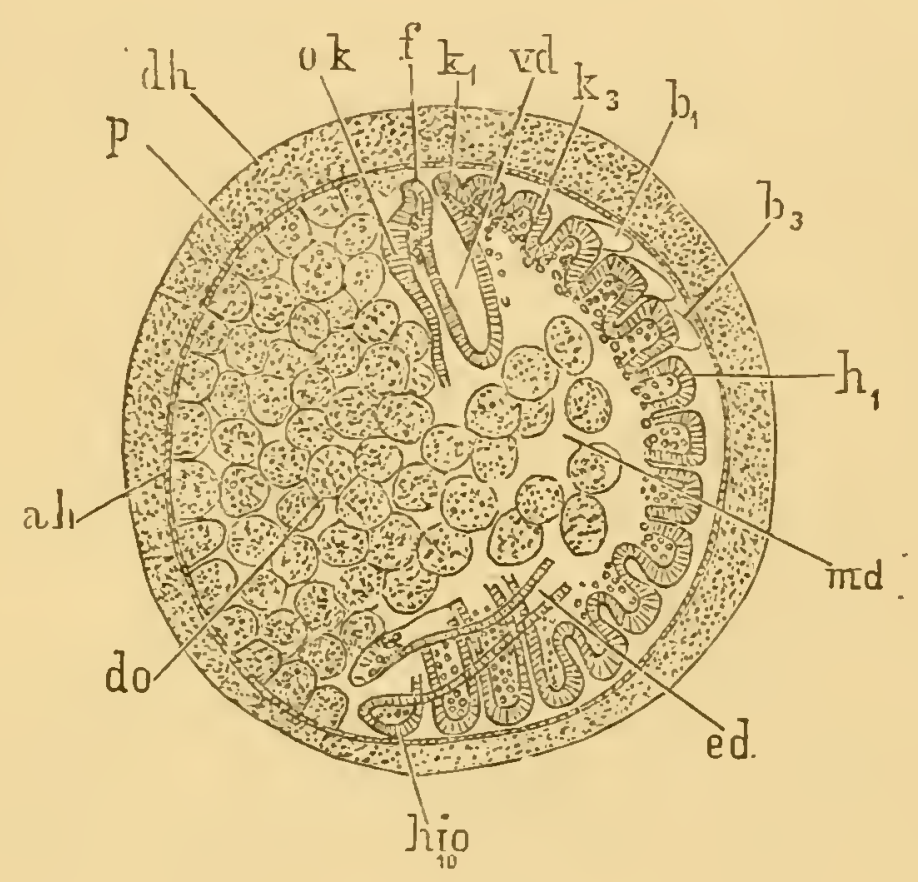

Frig. 148.

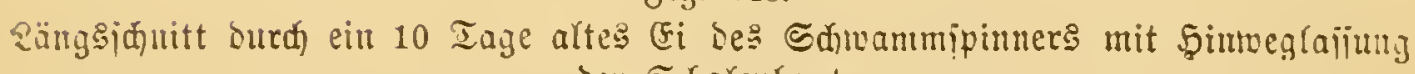
ber Edjalenhaut.

dh Dotterbaut, ah äubere Sillfe (bie intrere vom tiblographen überjehen worben),

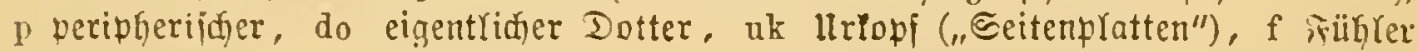
rd Glinbiafurtiger Borberbarm, $\mathrm{k}_{1}-\mathrm{k}_{3}$ Siejer $=, \mathrm{b}_{1}-\mathrm{b}_{3}$ Beinarlagen, $\mathrm{h}_{1}-\mathrm{h}_{10}$ Sinter= Yeibsringe (bie Yetzten bereits geid)(nijen), ed Endsarm, md Yünftiger Mittelbarm. (Driginal.)

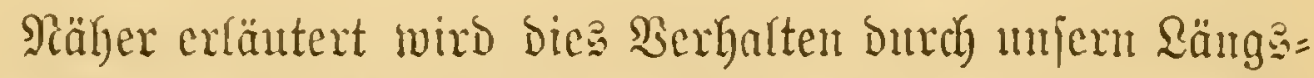

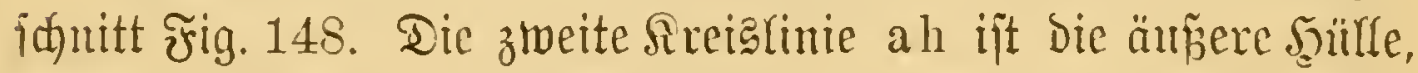
melche Den Entbryo fannut bem Dotter umgibt. Die conbere

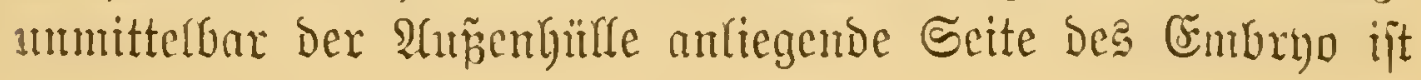




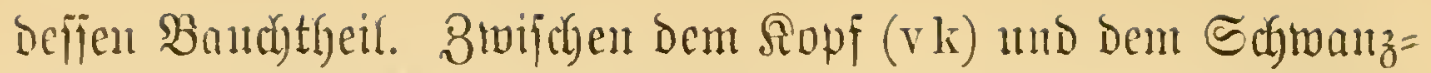

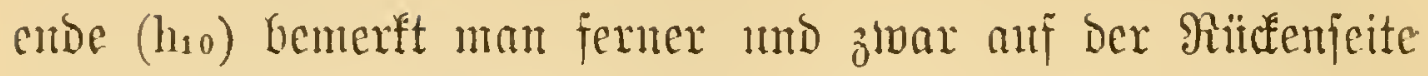

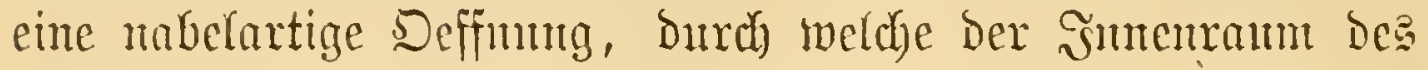

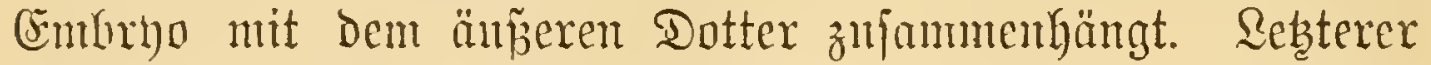

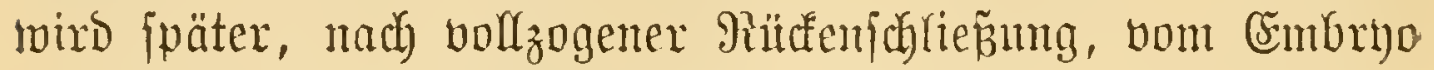
Durch ben Mumb aufgenonumen, ift aljo ein "skahrungs"= Dotter im ftrengiten Sime Dicję 涊ortę.

Die Falter zeigen nod eine andere Eigenthümlidyfeit. Wäl)=

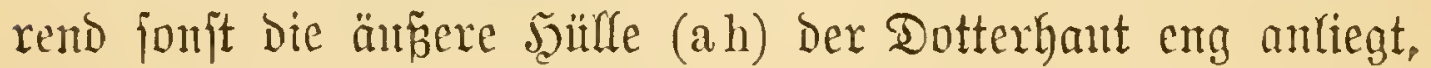
fintet man bier ganz alfgemein zwifhen dicjen Miembranen einen gröperen 3wifd)enraum, bex mit ciner am gebärteten Ei bröfelig gerumtenen Subjtanz crfüllt ijt. Mit Der äuferen Saitle jelbjt wird fpäter aud biejer periplyerifac Dotter

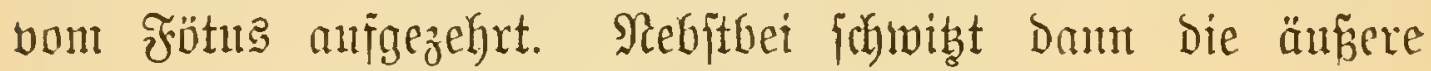
Seitlle nod eine befondere Cyitingant ats.

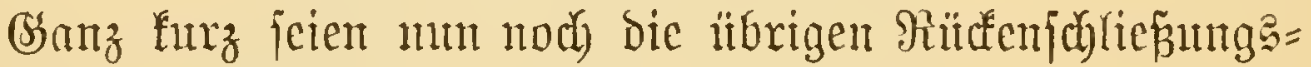
hypothejen berilfrt.

Die der ficher erwiejenen Faltumgetheorie am näbdjten

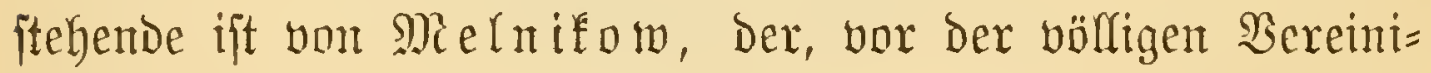
gung Der Falten, Die Rcibesmant von ber Simenthitfle fich loz= reifen und hierauf, betDerlei Micmtbranen umabhängig von

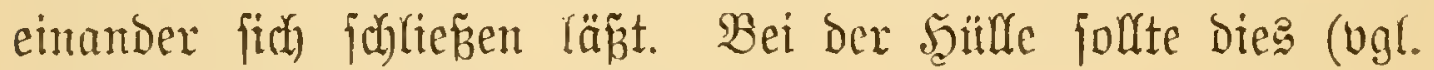
Schema $147 \mathrm{C}$ ) frïher geidyebent.

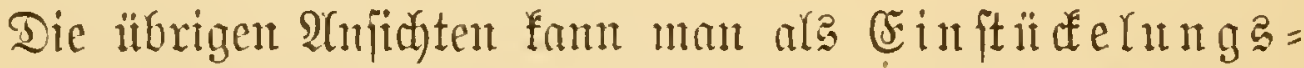
hypothejen zujamenfajien, da fie alle auf ber amabue beruben, daf der Rürfentheil Der Reibesmant bireft Durdy

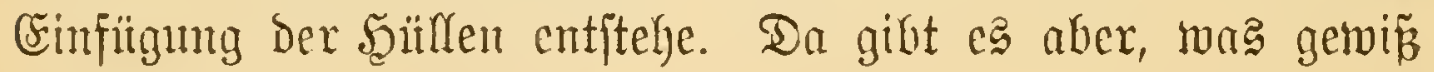

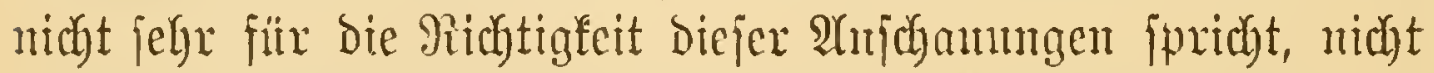
weniger als Drei Sariationen. Die Compretirnng ober $\mathfrak{A}$ u $s=$

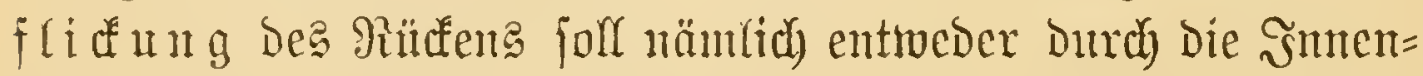

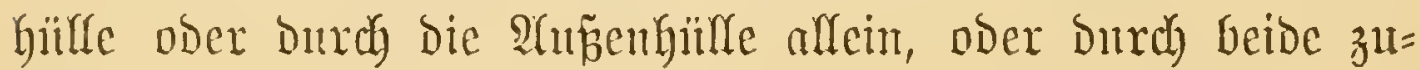
greich geideben. 
Die erjte Bartation, wntry Mccantifow vertreten, ift in

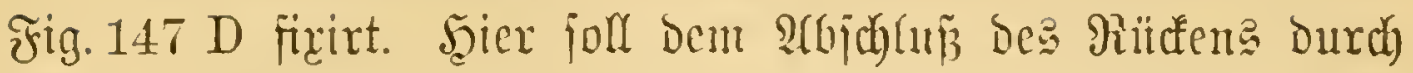

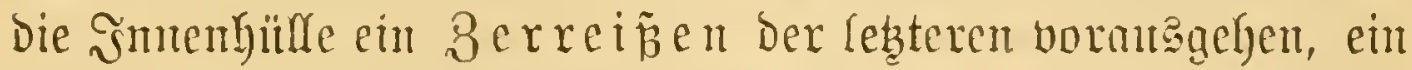
Borgang, dex and faftijh nicht jelten z. B. bei Phryganea vorfomint.

Fraglid) ift es aber nod), ob bie atte bem Berfall der

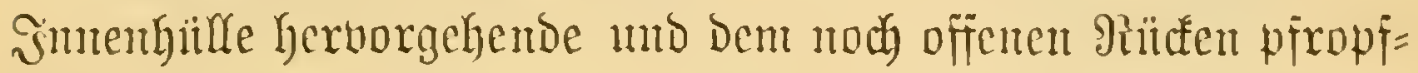
artig anffitzente Bellmajie bireft in bie Reibcsmandmg ïbergeht. -

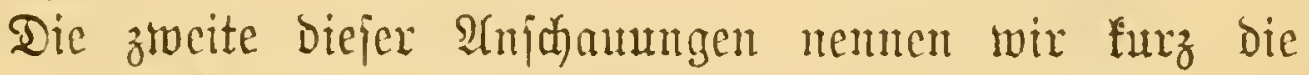

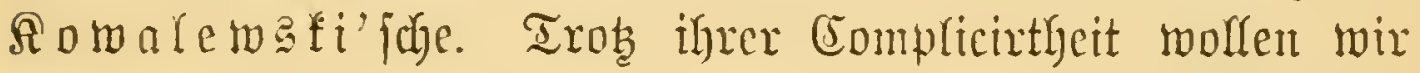

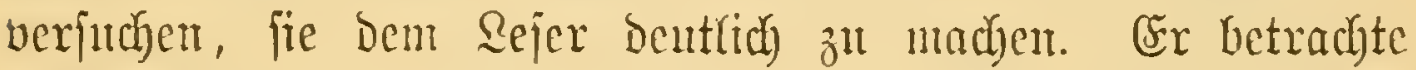
Den Ducridnitt in Fig. 147 G. Der Dunte Streif cea ijt bie Gauchjtämbige Reintanlage. Darmuter bemerft man mu

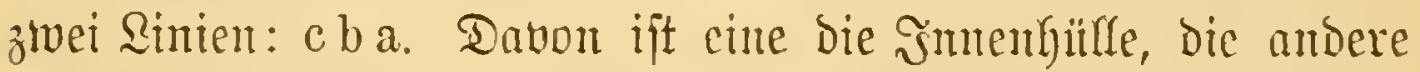

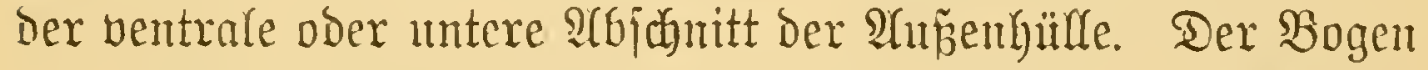
(c da) über bem Seimftreif 活 Da马 obere Segment Der $\mathfrak{A} u \tilde{B} e n=$

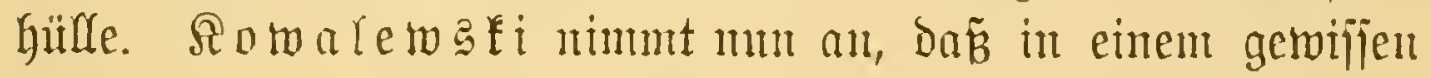
Stabium die Şülfgebilbe unter bem Reimitreif (a-i) ber $=$

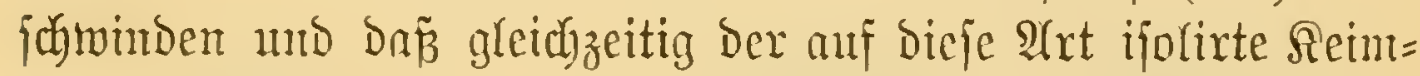
ftreif mit bem obern Theil bor äuñeren Siülle zufammentwadjpe. Der eigentliche Reimfteif wärde aljo die Baud

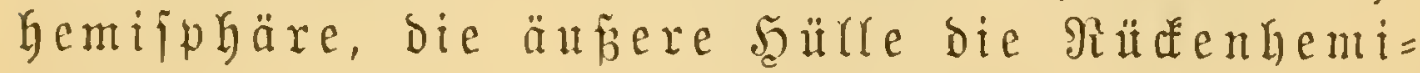
iphäre des Thiexes bilden. Die Seülle felbjt gebe aber

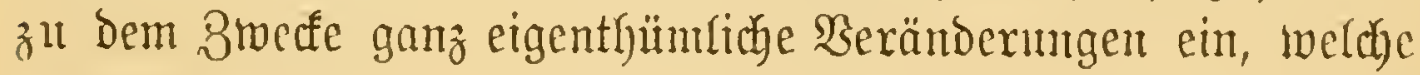
in gewifjem Sime bie früher am ßeimitreif abgelaufenen wie= berholen.

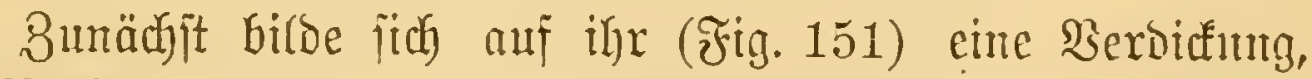
Die Riücfentatte (rp). Dann erheben fich Die Diumnen Rians= ftellen in Beftalt zmeicr Falten (rw), welde ïber Der Platte

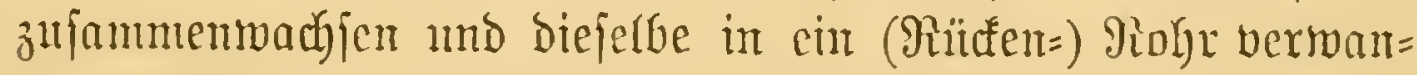

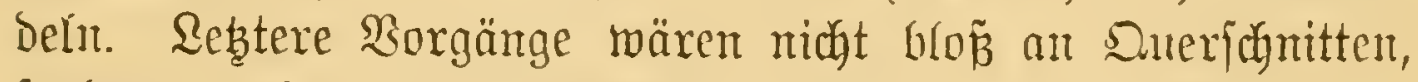

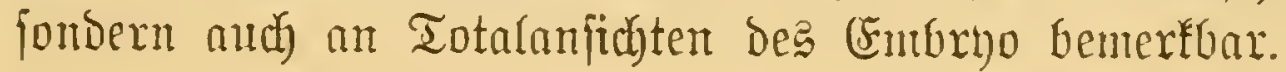




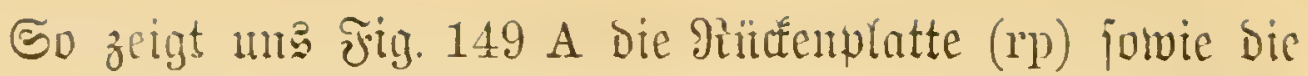
jeitliden Falten, weldhe jid hinten bei f bereits zu einem B(ind:

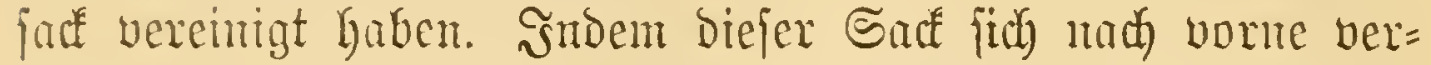

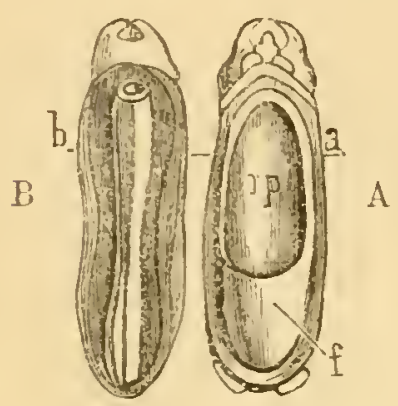

Fig. 149.

Embrgonen von Hydrophilus

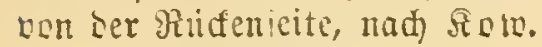

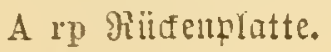

B ßiiffenrofr. längert, entitegt das bei $B$ jichtbare Dorjalrobx.

Die meiteren Beräıterungeı Diejer merfwitroigen Bildung zeigen Fig. 150 A uno B. Das ßofyr (rro)

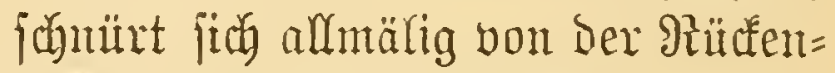

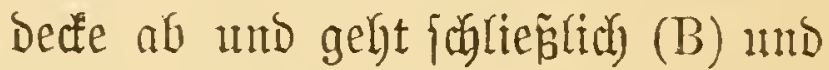
zwar inmerbalb des Darmes jpur= lo zu Grumbe.

Mir erwähnen noch flübtig,

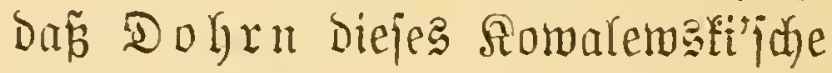

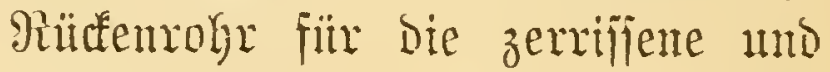

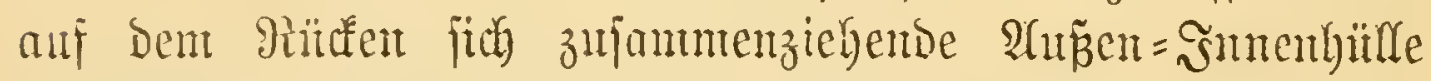

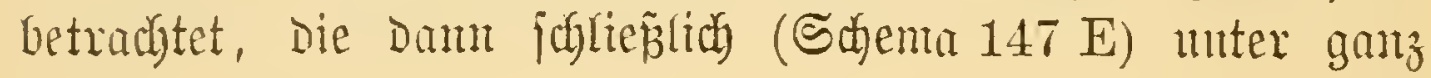

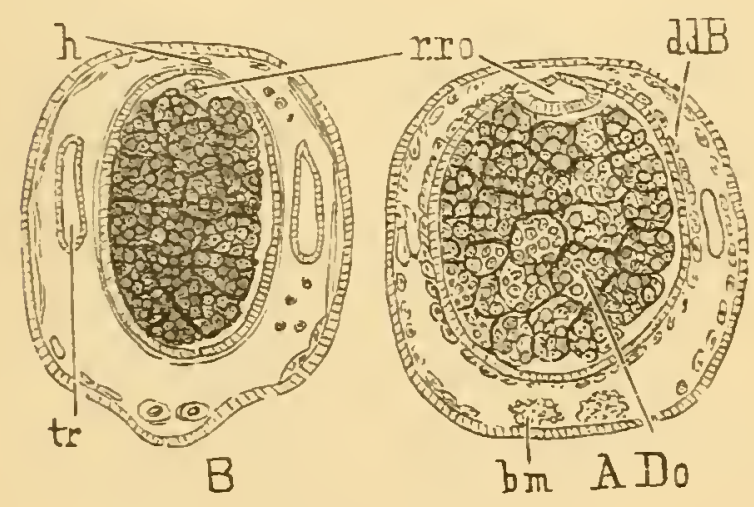

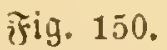

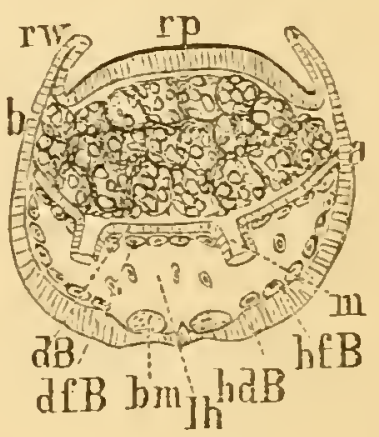

Fig. 151.

Sueridnitte burd obige Embryonen, nad Rolv.

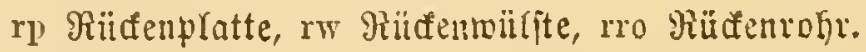

Ingetwöbulidien lintitüntoen von Der Reifrestwand übermactjen miltroe.

S6 es mu in jedem einzelnen Falle jo ober fo ijt, läpt fich a priori allerbings juber entidjeiben; Das aber barf utan 


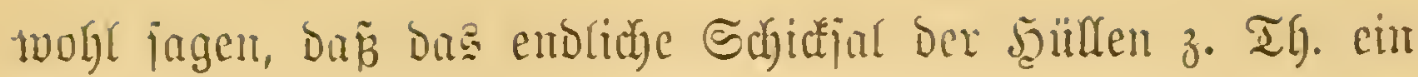
jegr verjojiedenes ijt.

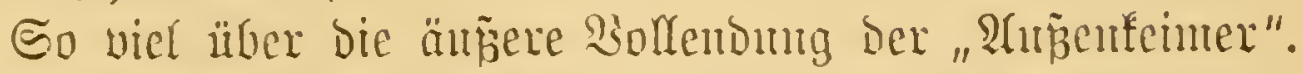

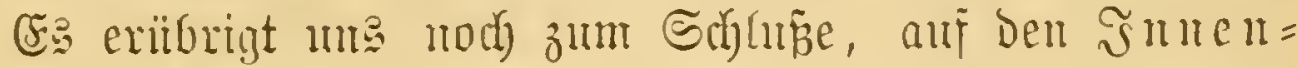

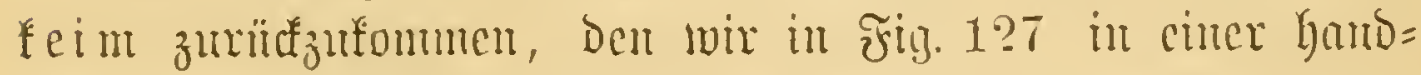

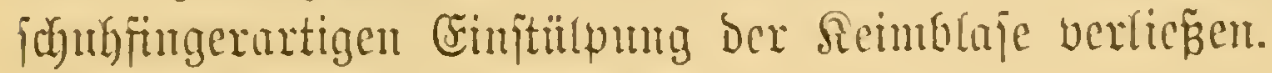

Beijtelyeude Figur $152 \mathrm{~A}$ fiifint ums mu einten joldyen, aber bis anf ben feglemben Rüufen fadon jehr entrickelten Bimenembryo ciner Sibelle nteuerbing? vor.

柋ie wird mu bicjer jei=

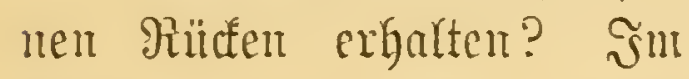
Buanzen, toie als eigentr Sdanitten zu exjegen, anf die= jelbe $\mathfrak{B e i j e ~ D . ~ h . ~ D u r d h ~ B e r = ~}$ längerung Der getwijןen (anf Fig. 127 mit $r$ angebenteten) giüufenfaltert.

\$ise Fig. 152 A zeigt, ijt aber hier nibt aller Dotter twie bei Den 2arnenfeimern

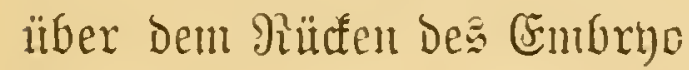
bercinigt, und ebent dies

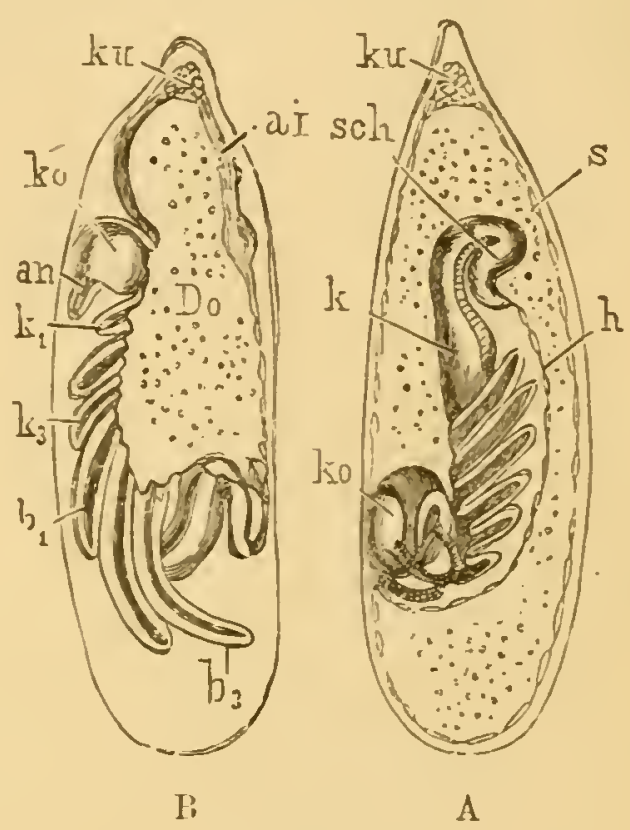

Fig. 152.

Enbrnone bon Calopterys (Ribelle) in ber (Fijdale, nad 2 . Branbt. s äubere Sülre (Reimblaje), ku futhen= artige polure Berbiafung berjelben, h innere Sïlle, ko Ropi, sch ङめtram res cmbryo.

an F̈̈̈ler, $k_{1}-k_{3}$ Riejer, $b_{1}-b_{3}$ Beine.

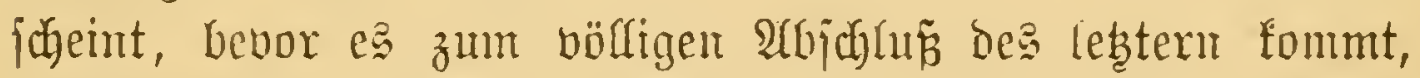
im $\mathfrak{B}$ erein mit ambern llxjachen eine auffalfende $2 a g e v e r a ̈ n b e=$ rutg nothimendig zu machen.

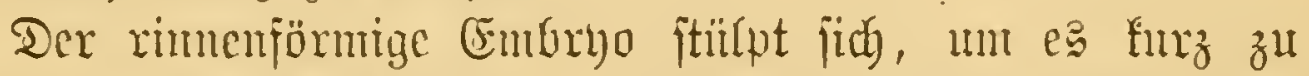
fagen, mit bem Sopf boran, aus jeiner Iajhe herbor und nimmt bic anf B bezeidynete Antentementage an, toobei, wie Durch fimptliche Smitation Diejes Borganges an einer Dop= pelblaje zu beobadten, bic gleidzeitig zerreipenocn, aber ber 


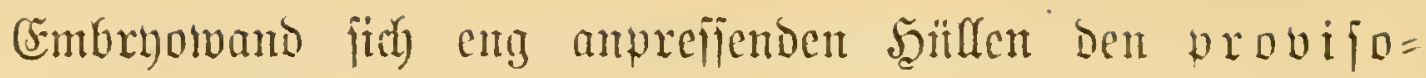

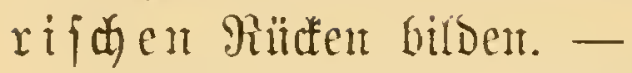

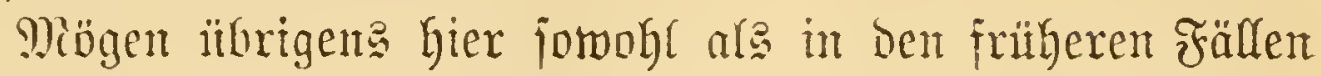
bie zelligen Şüfllen ras immer für ßeränderungen erleiden,

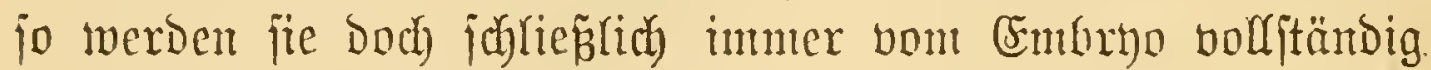
rejorbirt, unb hierin liegt ein widhtiger 1tnterjhied gegenüber Dem befanten Schicffal der amalogen Biebilde bei mandidn. Mirbelthieren. 


\section{Ifycil.}

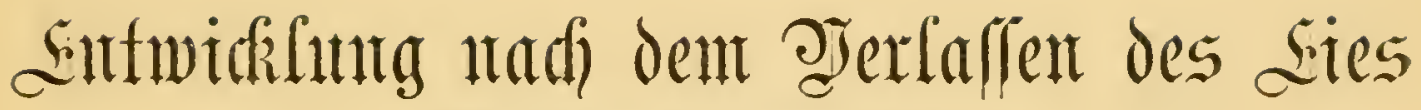 (20) ftembruogentele).}

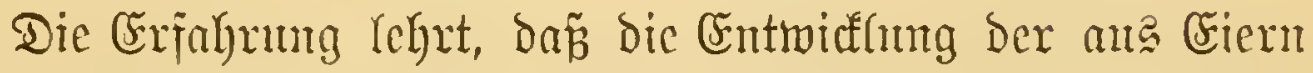

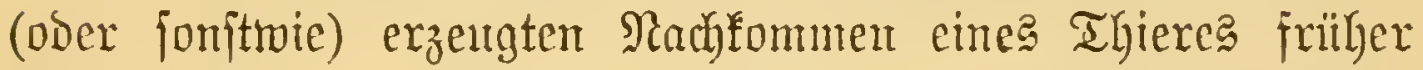

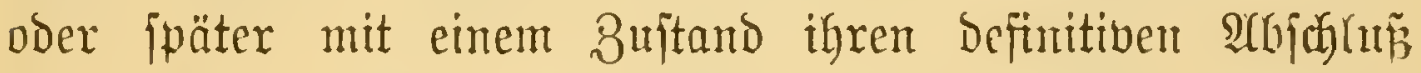
findet, ber, von unwejentfichen Modificationen abgejeljen,

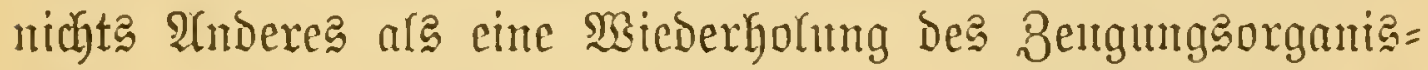
mus, ober eine Siederferifellung Des Urjprïnglichent ift. Diejen Bujtand nennt man Gefanntlidi das Reifejtabium, und

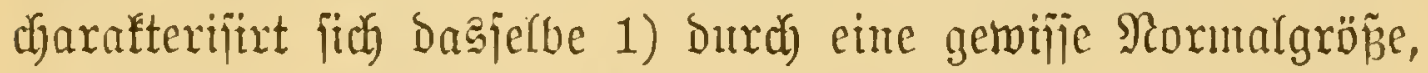
2) Durch eine bejtinmte Sörpergejtalt und 3) endich, Durch) bie Fähigfeit Der geichiechtlidyen Fortpflanzung.

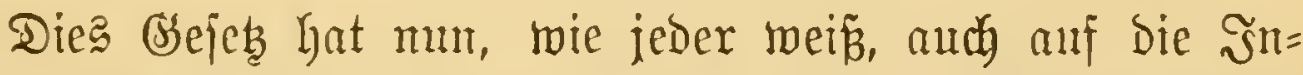

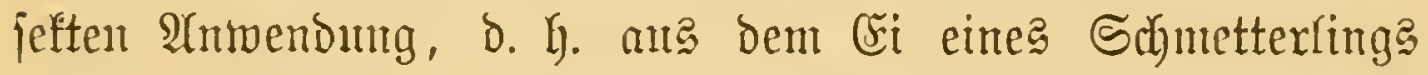
3. B. entitegt immer wieder ein Sifnmetterling, aus dem Ei ber Biene eine Biene und niemals etwas 2 mberes.

Shne ung jeb̧t zu fragen, ob Die ßorgänge währento dcr früher behandolten erjten Entmicfumgaperiode inmer bon Der

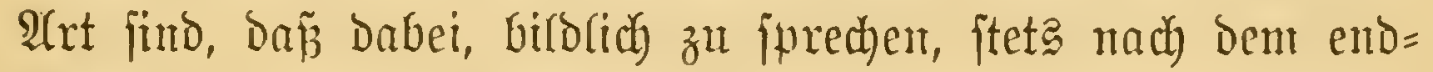
lichen Ziele hingearbeitet wird, wollen mir nummegr das lebzte Rejultat biejer Entmicftung, o. i. Den fertigen Embryo mit jeimen Eritern vergleichen. 
Und Da zeigt jid fofort eirmal, Dañ Der ausgebildete

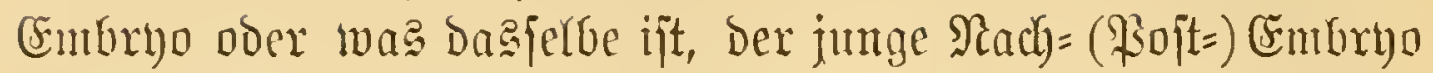

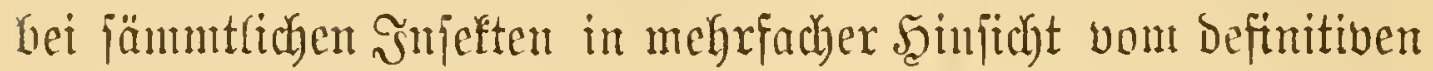

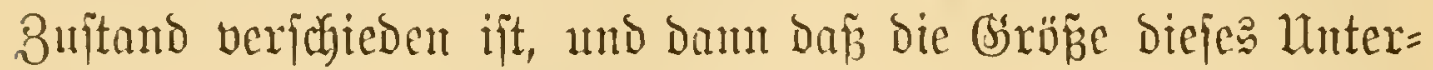

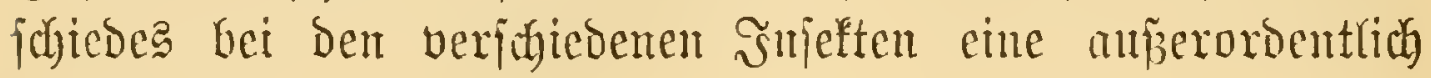
ungleidye ijt.

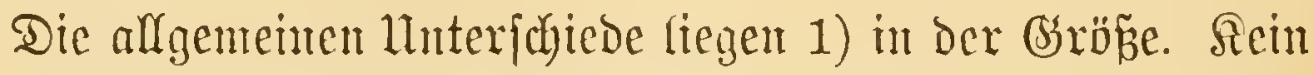

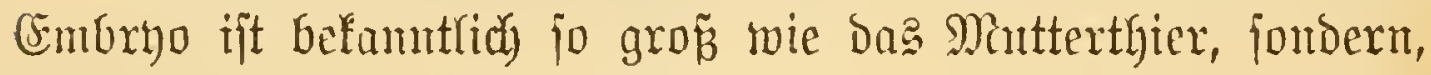

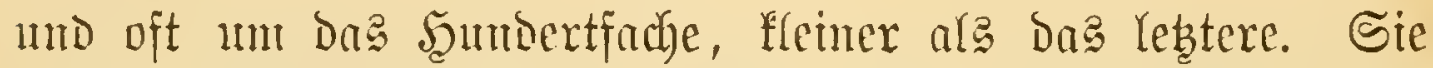
liegen Dann 2) in Der Infertigfeit Der 3eugungsorgane refp.

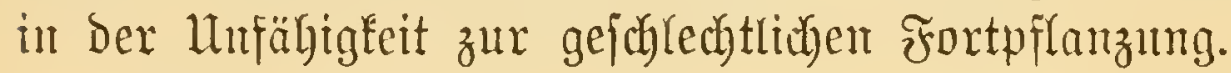

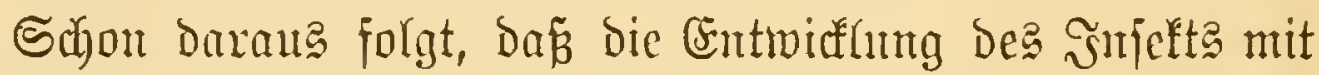

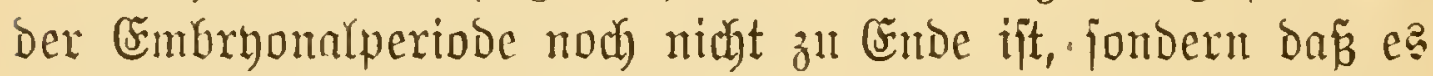
auf alfe Fälle nody wachjen und gemijije Drgane meiter

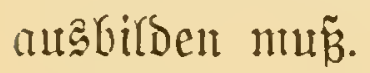

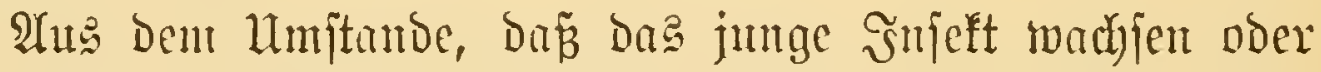

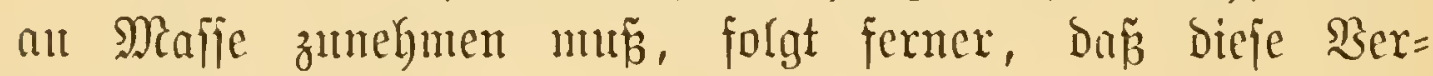
änderungen nidyt melgr an eiment nady aupen hin unthätigen Wefen vor fich gehen fömten, jombern baj bas fich meiter

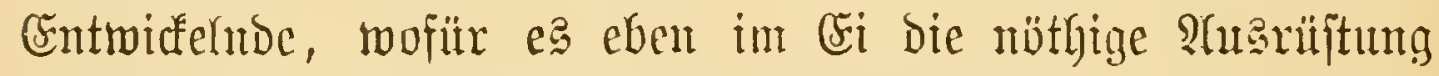

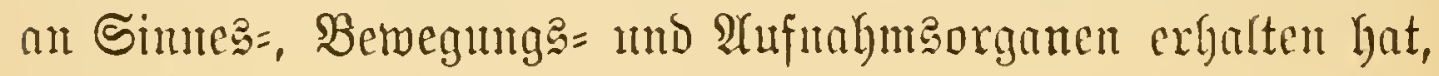
in Bufunft fiir fich jelbjt zu forgen hat.

Mit biejer, wie es jueint, Dem mïnbig gemordenen

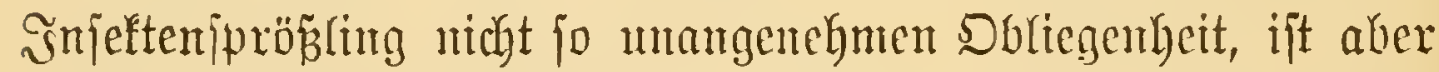

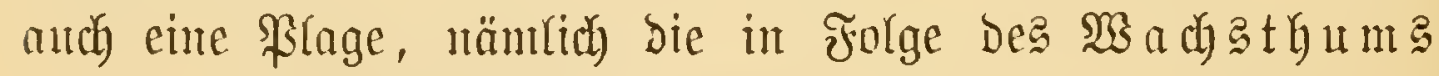

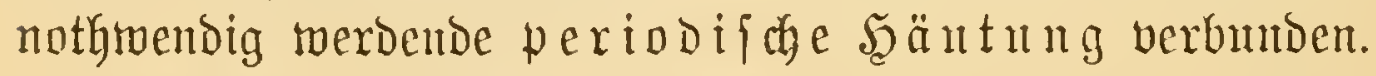

$\mathfrak{H m}$ mun auf bie bejonderen D. $\mathfrak{h}$. anf bie von $\mathfrak{A}$ rt z̆

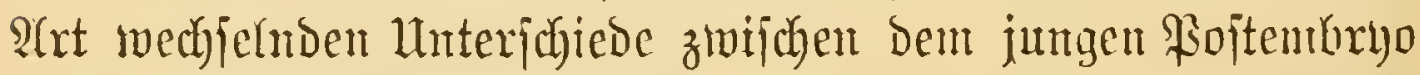

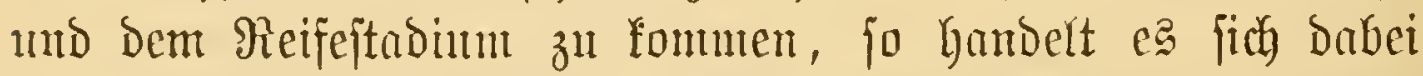
tm biverje mehr meniger auffalfende 2 bweidyungen in $\mathfrak{B}$ ezug auf Die ganze Sïrpergeitaltung, und jo miijien Dem Enditabium

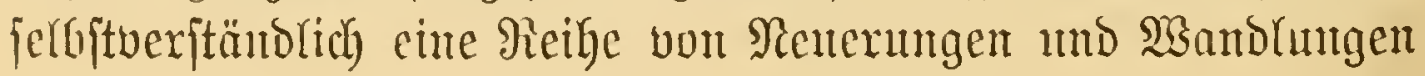




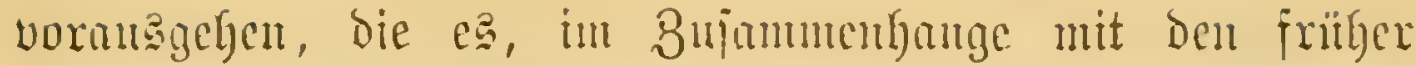

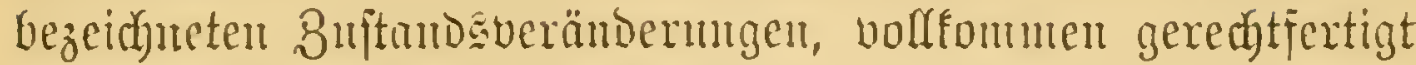
erjobeinen lafjen, dic pojtembryoualen Sorgänge un

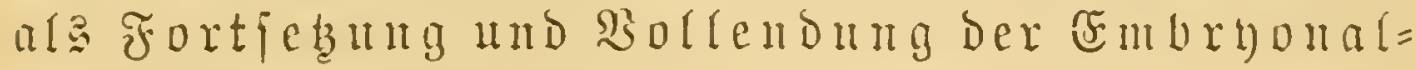
entroictung a ufaufaffer.

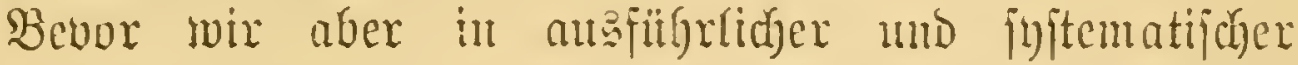

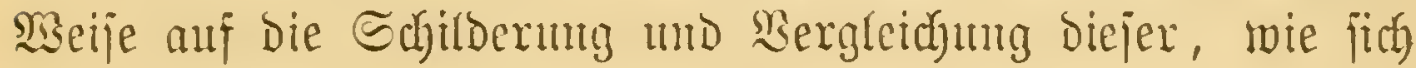

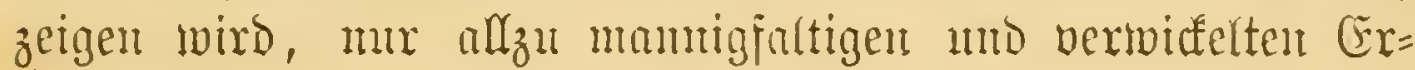

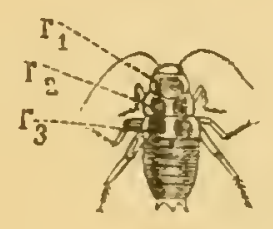

A

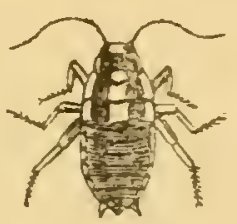

$\mathrm{B}$
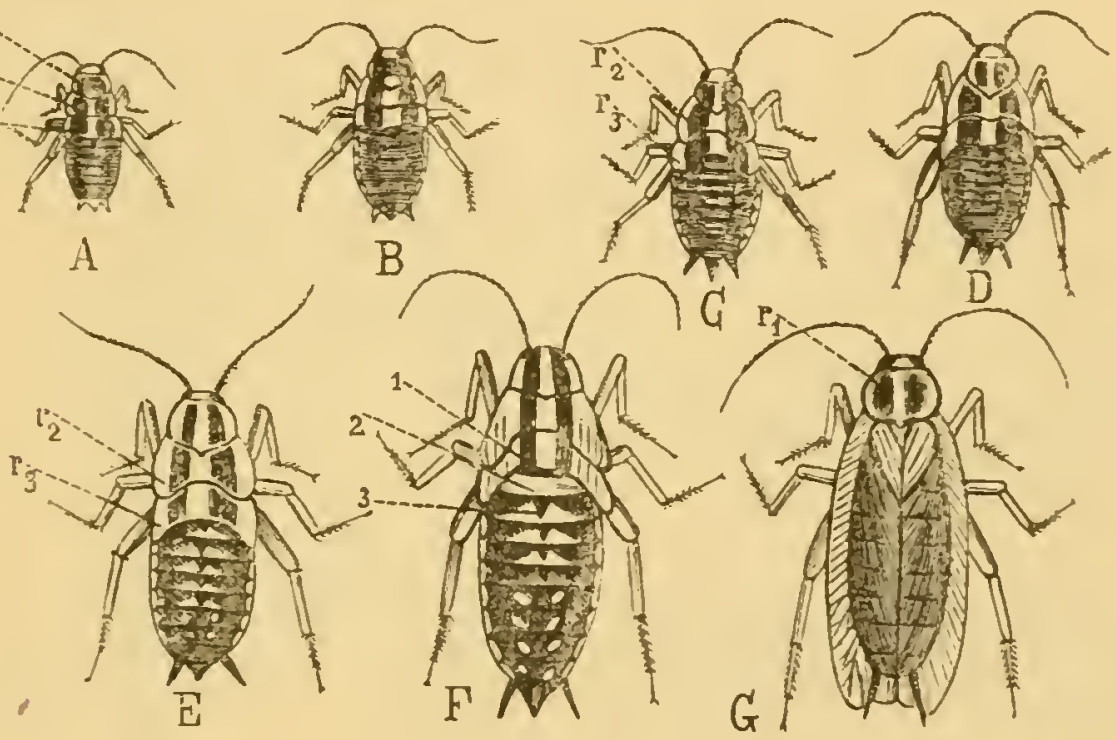

₹ij. 153.

3ur Entwicflung Ier siüdenidabe (Blatta germanica), 11/2 bergr.

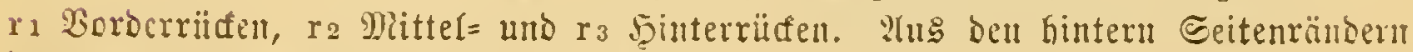

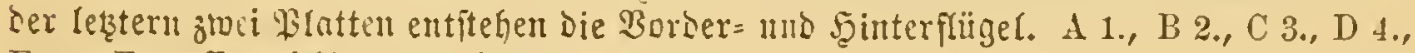

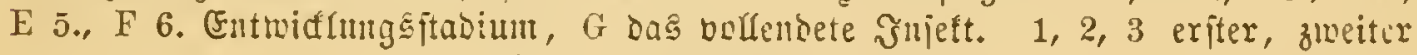
unb britter Şinterleibąring.

(Drigina!.)

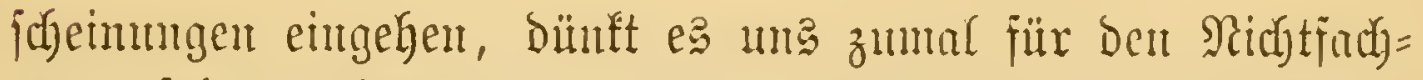
manu jegr wïnjchensemerth, ifn an Der Şand ettidyer Beifpiele ifhon zum Borfinein über einige ber midgtigiten Thatjudyen und ber barauf bezüiglichen Begriffe zu orientiren und jo auj Das Meitere vorzubereitert.

Auf voritehenden Bif́de (153) wiro junädyjt bie "freie"

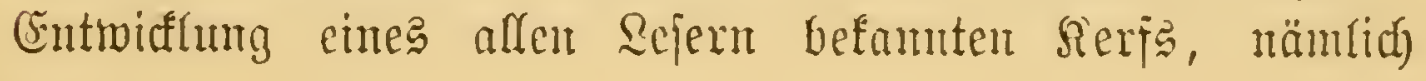




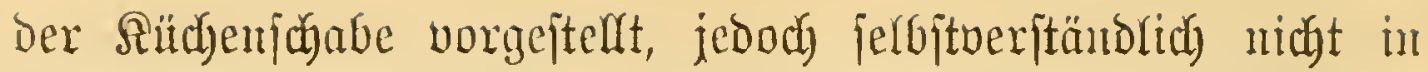
alfen cinzelnen ïberbant mtericheiobaren Bilbungzzntämben, jondern mur in fieben Durch die Şäutung marfirten Scaupt= ftadien $(A-G)$. Aud obue dieje Ybbildung weís man, dás

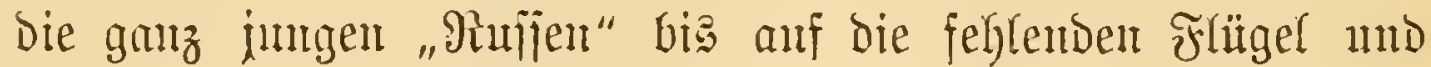
einige andere lluvoufommenlyeiten ben "Alten" greidgen, fowie,

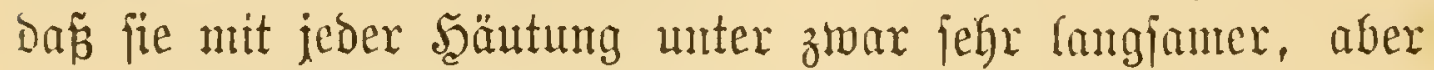

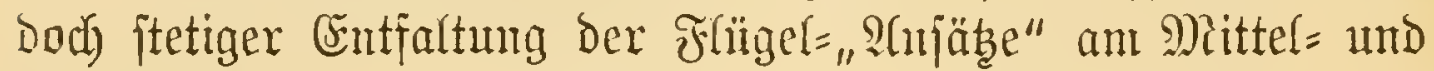
Scinterrüten $\left(r_{2}, r_{3}\right)$ Denfelben inmer ähnlidher werden.

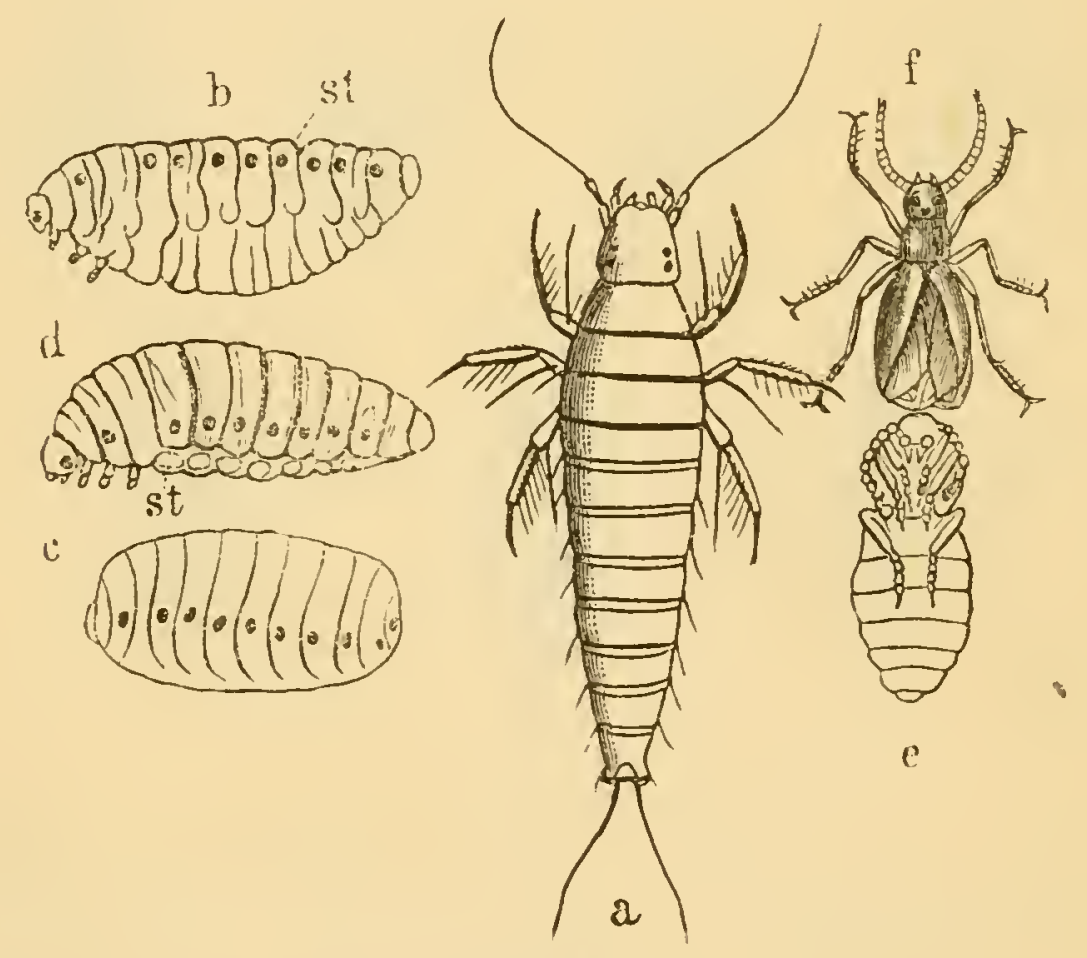

Fig. 154 .

Entwidfung vol Sitaris hmmeralis (j. Є. 296).

Da mun alle dieje Bildungáfabien - vou erjten bis zum

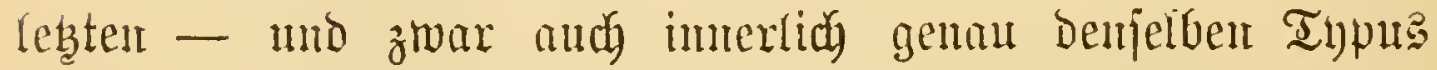
haben, jo nemen wir bieje entwiatugameife die gleidförmige ober homotypifdre.

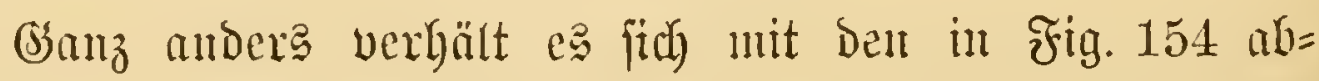

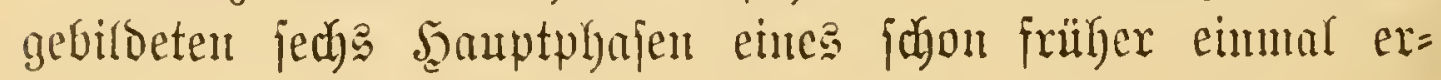




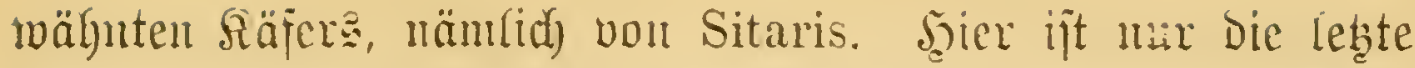

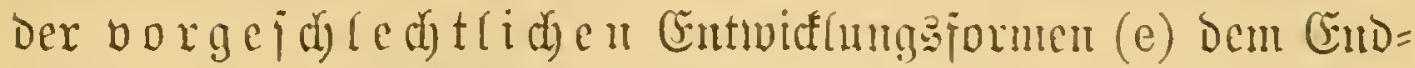
jtadum D. i. Den Sä̈er (f) älulidf, wälrum die vier vorber= gehenden (d, c, b, a) jumobl unter cimmber als aud vom lebst=

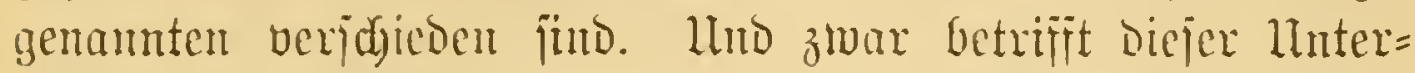

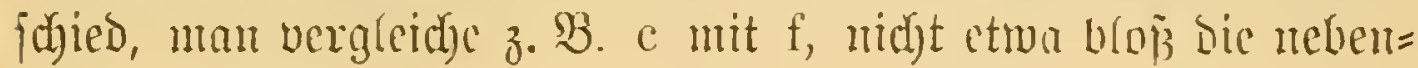

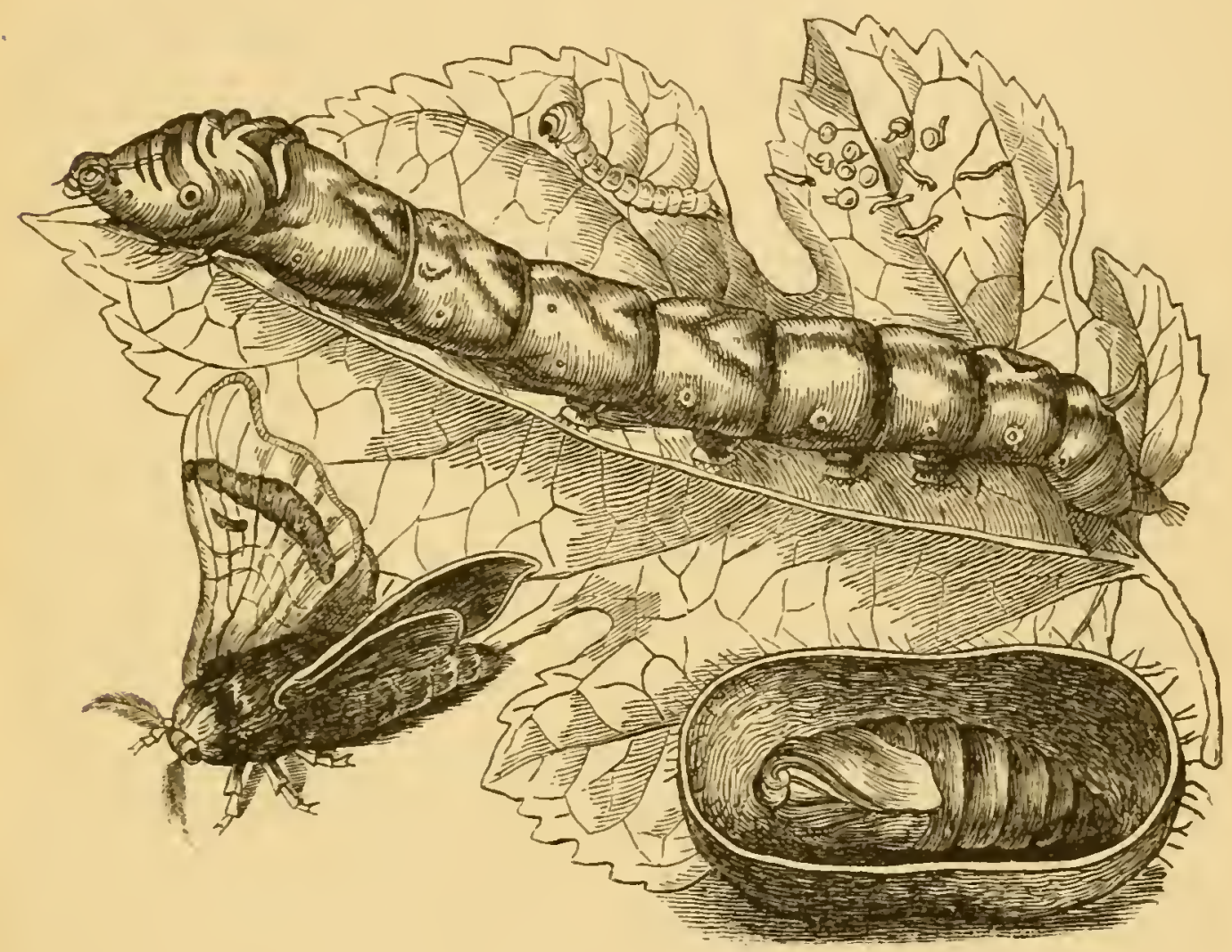

Fig. 155.

Jaupe, Huppe, Edumetterling (こciocmpimer).

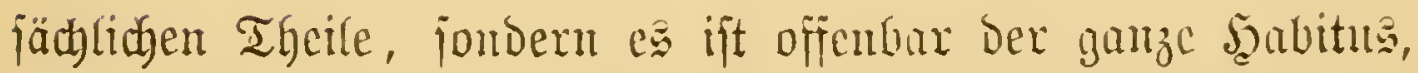

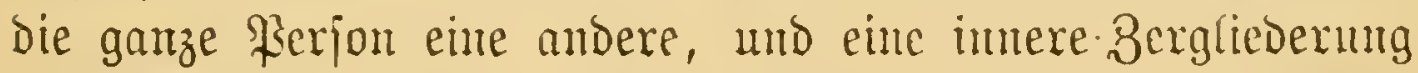
und jtüntweije Confrontimug Der Drgane vïrde gleidjalls viele und jegr bedeutende Differenzen crgeben.

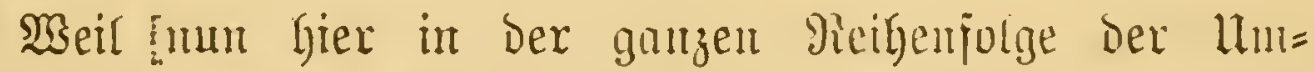
änderungen mehrere und z. Th. ganz unäbuliche, ja tupijư 
verichiebene Buptände anftueten, fo nenten wix dieje Ent=

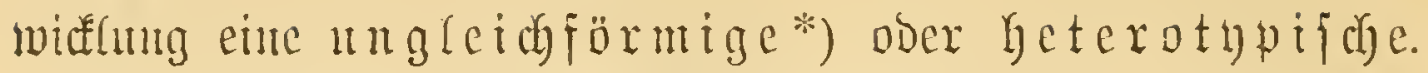

Die 2 xt bon angleidfförntiger Entwidung, wie wir fie bei Sitaris und naudjen andern S̈njeften fumben, ijt aber nidyt

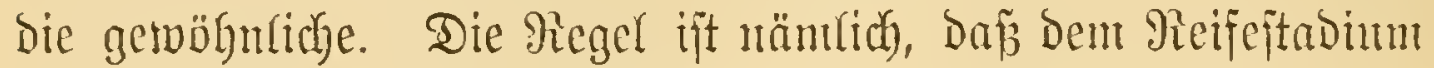
nidgt melyrere, jomberu, mentigftens unch ber vulgären âf= fajumg, mu zwei verichiedene Buftände vorkergehen.

Mian befebe jich zu Dent Brwede die Crntwidtung De: Mankeerjpiners in Fig. 155.

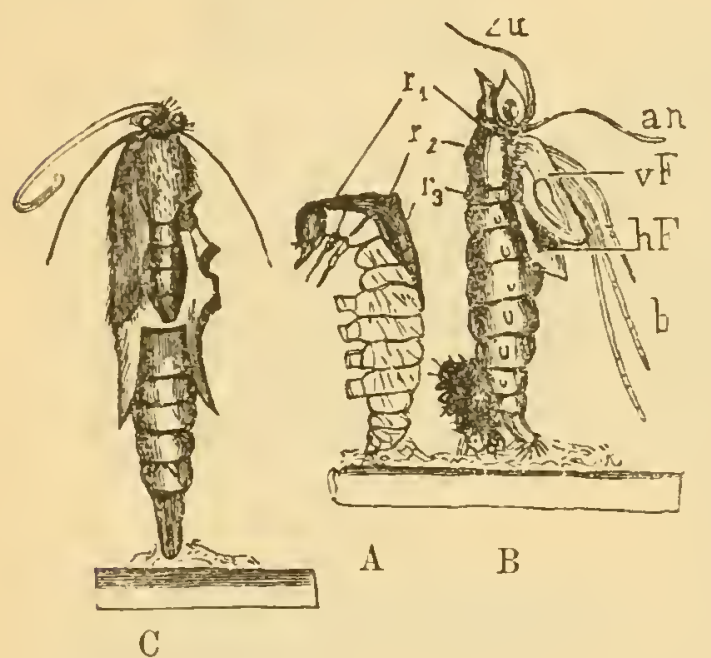

Jig. 156.

Berwandung des Refieljalters (Vanessa Urticae).

A Raupe, an einem Mjit hängens, mit an Viticten aujipringender Shitingaut. $r_{1}-r_{3}$ Border $=$, Mitte $=$, Şinterü̈den.

B Buppe, unmittelbar nad Deu 2bitreijen ber an inrer Şinterleibsipize einge= tlenmten Raupenhaut. zu Bunge, an sühler, vF Border =, hF șinterflüger, b Beine. 2ư 2antänge jrei.

NB. Reide Figuren bat man fid in bängenter sage zu benfen.

C Faltir, sie झimppcufülle verlajiens. Vrat. Br.

(Driginal.)

Inte bem Exi (gantz oben anf bent Blatt foumnt ein furz= aber vielbeinges (sejübpt, Das Danf jeiner Gsefräñatgeit fehr

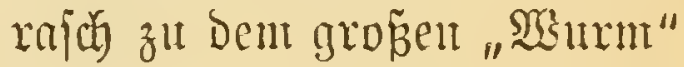
(auf Der Mitte des B (atte?) herammädft, Dex trob mehr=

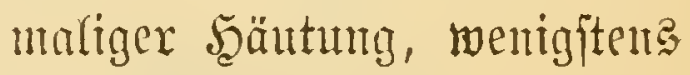
in Sintzelt, immter muer= ändert, inmer berfelbe blcibt. Da mu affe $\mathfrak{B e r a ̈ n d e x u n g e n ~}$ biejes sejente bantptiädylich mur auf Zutahne der Brröźe Gintatalanfen, fo memten wir e it a bium.

SMie Fig. 156 in Er= innerung bringt, geft mu, wem dieje Form (A) Das reste Mar bie Sant abjtreift,

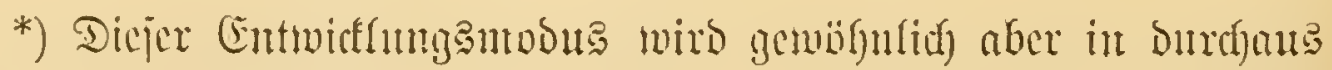

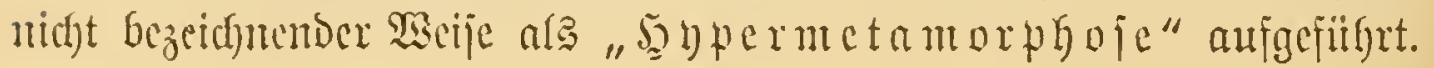




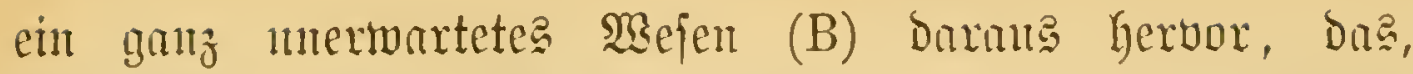
namentfich) gleidy mady ber Şäntung, dic muverfembarfte

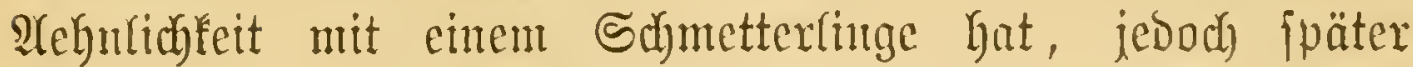
miedcr, indent feine $\mathfrak{A n}$ yänge, bie Füblex (an), Bcine (b), Frlïgel $(\mathrm{vF}, \mathrm{hF})$ u. $\{$. w. nit Der gleichzeitig erftarrenden Sörperbant vertötlyen, eimen ganz abjondertichen Cyarafter anmimunt.

(s)leich Der fritheren Form bleibt aud bieje, änzerfich betradjtet, immer biejelbe, mir baj ljier and ants nahe=

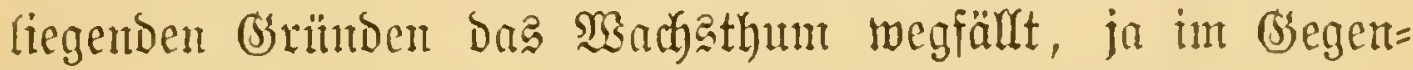
theil (vgl. Fig. 155) eine bedentende $\mathfrak{B}$ ohmmanchleinerung exfolgt.

Nachbem mu aber biejes (sejübpf eine Beit Kang wie toot Dagebargen, fpringt jeine Şant anj (C) molo hervortritt Der wargre Falter in all jeiner Farbenprad)t mo fratter $=$ lyaftigfeit.

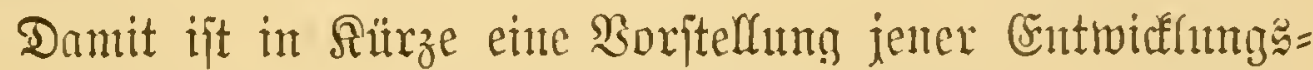
meije gegeben, die man als Metamorphoje, als Ber= wo a $b^{\natural} \mathfrak{n} \mathfrak{g}$ bezeidntet.

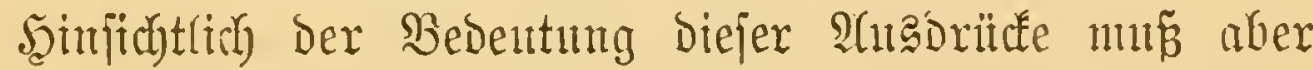

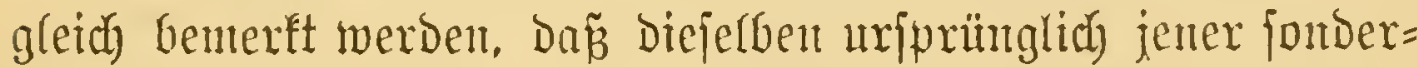

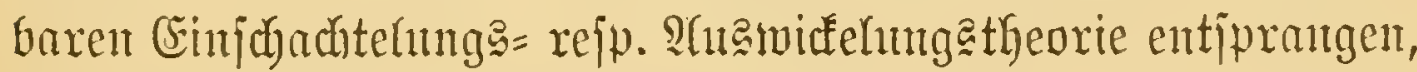
mit ber man fick bon $\mathfrak{S} i p p o n$ und Diogenes an bis her

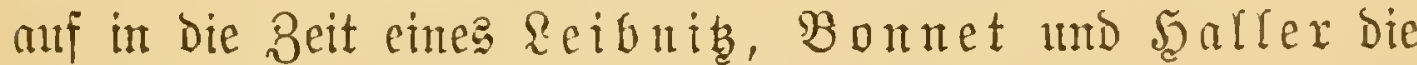
jo auffälligen Ericheimungen ber šmjeftenbildung gax bequem zu erflären jutchte. Ardes, was weroen joll, jo ftellte man jich vor, alfo audi bas vollendote snjelt ift menigitens in nuce bereits

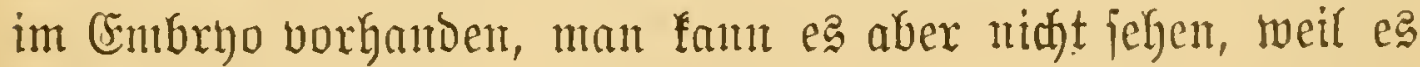

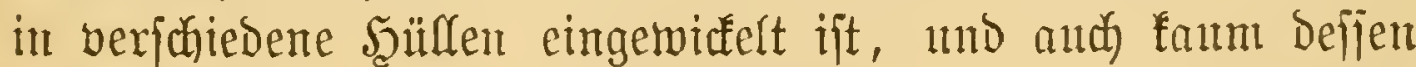
wahre Bseftalt errathen, Da bieje Şitllen ganz andere Bseitalten vortäujact. Mit andern Morten, Die Defintitive Form ober

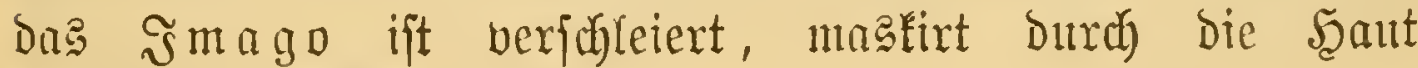
(3) raber, 3njeften. II. $\mathfrak{B}$. 


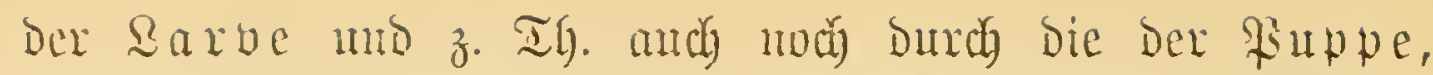
als weluge man bie Den Jimago ähnliche und mmittelbar worhergelyente Serwandungaftufe micht ganz pafiend und con= jequent bezeicinete.

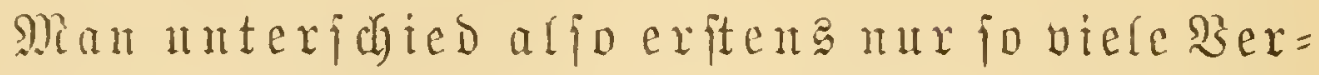

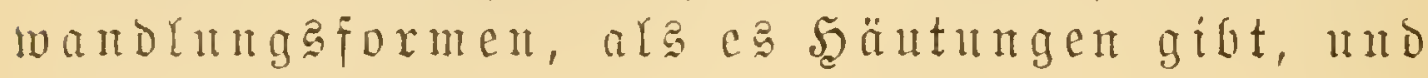
Dade te jich bieferben als gletujeitig neben un in eimander exiftirembe, jelbitänige un fadrax gejonderte 3 utiönde.

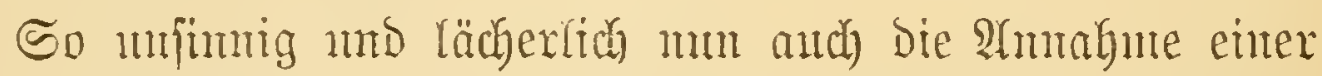

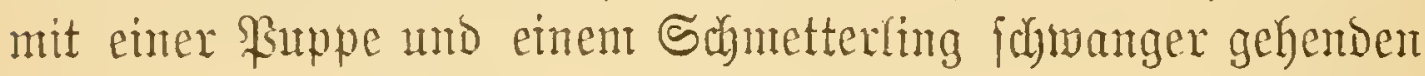

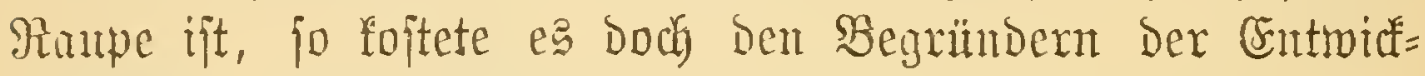

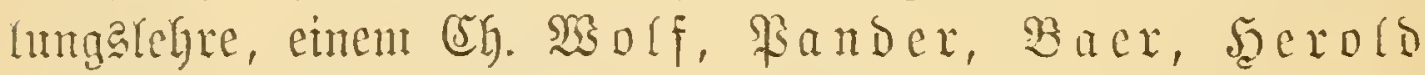

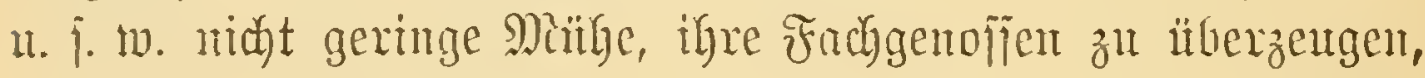
Da $\tilde{\beta}$ Die genamten Formen mux Differenzirungen mo $\mathfrak{H} n=$

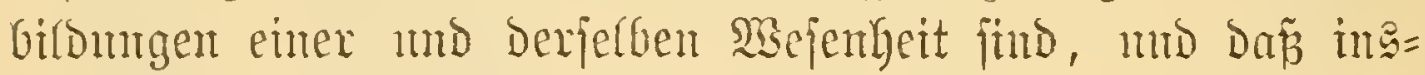

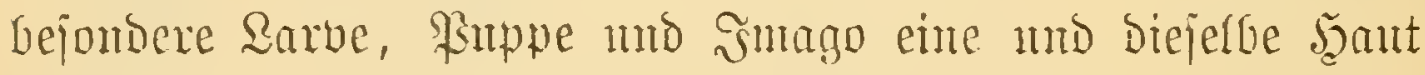

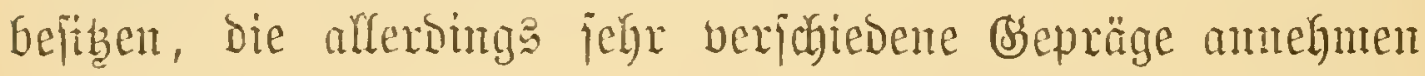
und ben entipredyeno aud jebr ungleich anajegende Chitin=

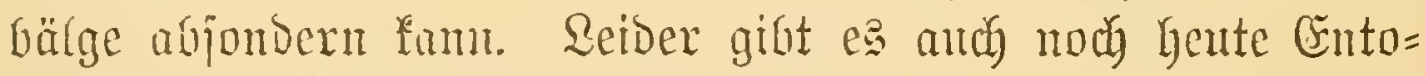

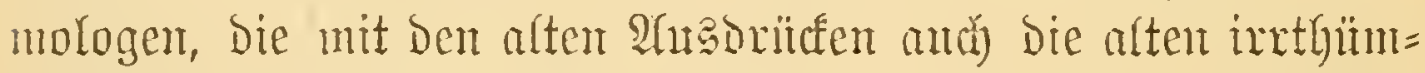

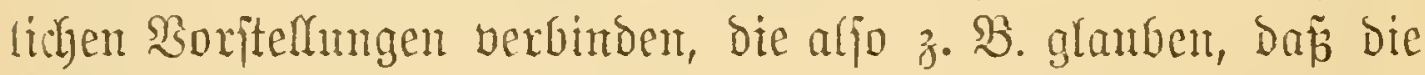

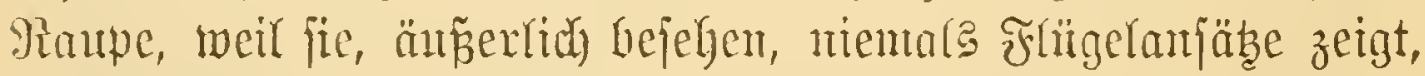

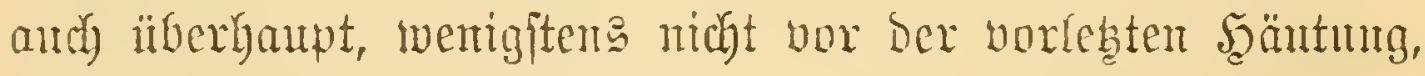

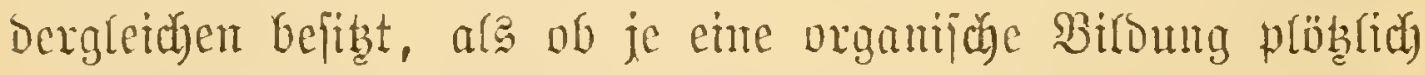
uns unvernittelt entiteryen, oder wie mit Banberidylag in eine andere fich verwandelat fömte.

Fit $x$ un gingegen find bie alten Serwandung

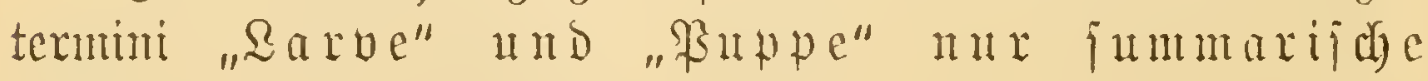
Bezeidunugen für garze lange Rethen ober Perioden fucefioe in eimander ïbergegender

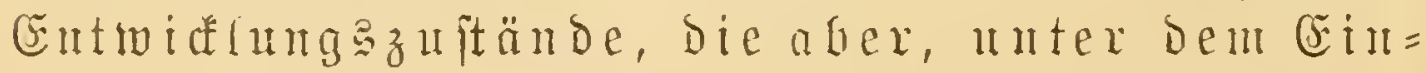


fluz der Exifteuzbebiugungu, cine getwifie

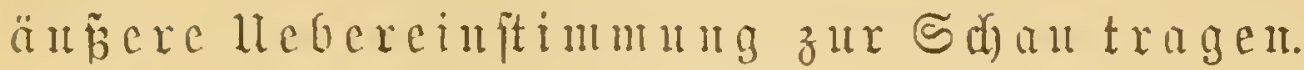

Ilun aber jull comptatiren, Dañ Die "Larbe" in Der That nux ganz alfuälig in bic "Pippe" und retztere mieber ebent

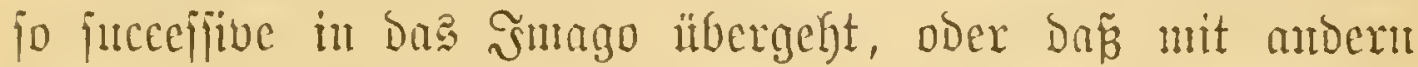

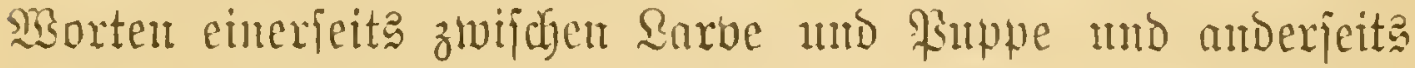

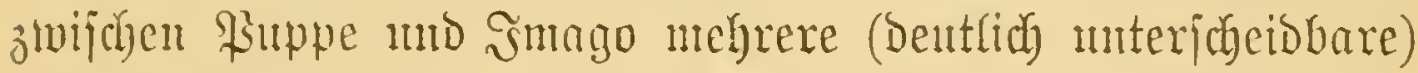
Bwijdyenjtndien liegen, bazu ift gar nidgt immer, wie ctron bei Den Schmetterlingen, einc intere Unterfudung, beziehnugs=

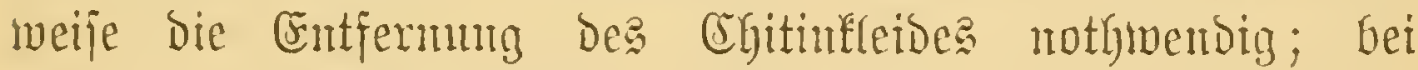

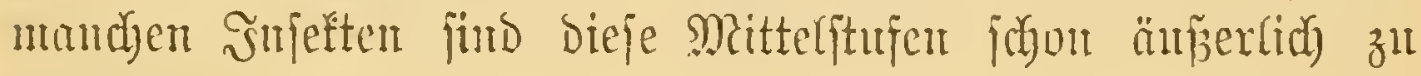
crfentuer.

Mem fich Der Rejer cine Bruttafel der Şonigbiente ver=

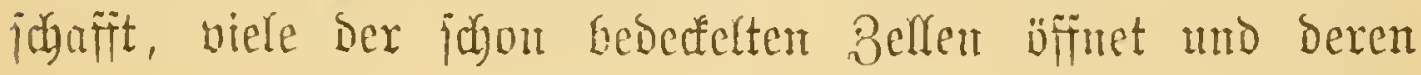

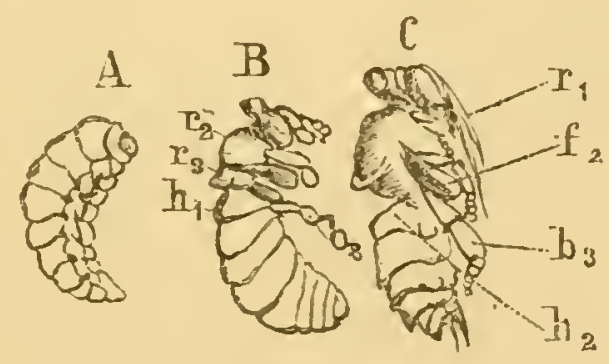

Jig. 157.

3ur Berwanthung Der Sonigbiente.

A rajt ansgetwadjene sarve.

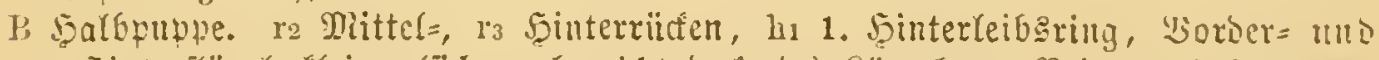

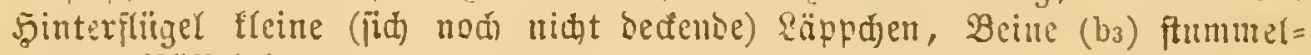
artị, Milijel furz.

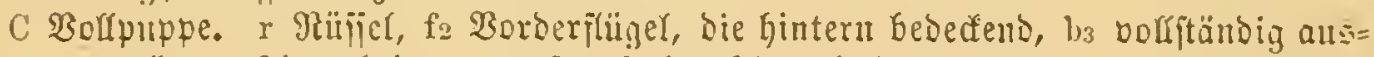
geprägtes Şinterbein, he erfter freier Şinterleibsring (Der 1. eigentlidje Ttb= bomenring ber Sarbe mit bem Bruftiorb refp. Dem Metanotum verwadien). Nat. Größ̄e.

(Driginal.)

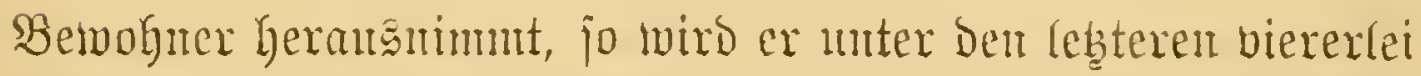

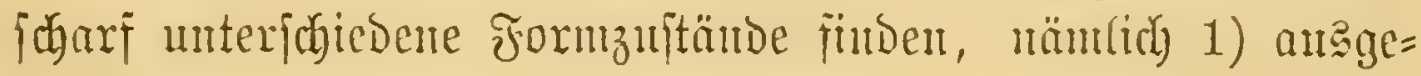

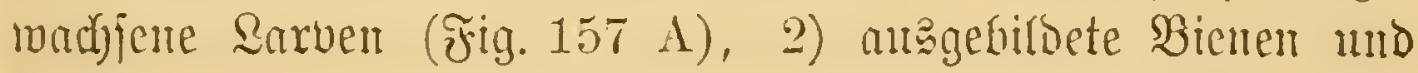


endlich 3) zwei Formen von łiupen (B und $\mathrm{C}$ ), wovon bie eine $(\mathrm{C})$ bis anf bie fleinen frlügellappen $\left(\mathrm{f}_{2}\right)$ fdudn ganz an Das Imago erimert, während bie ambere (B) zmijachen

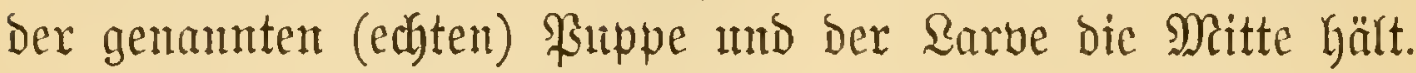

Man beadte mur Einiges. Die Sorpuppe, fo neme ich $B$, zeigt, vom Ropf abgejehent, am Stanm eine der Rarbe nod) ähnlliche, homonome (gleidartige) Segntentixung, menn autr) Der zweite Bruftring $\left(\mathrm{r}_{2}\right)$, alg Iräger Der Sorberflitgel, ichon etwas verdiat und mit bem dritten $\left(\mathrm{r}_{3}\right)$ verwachjen ift.

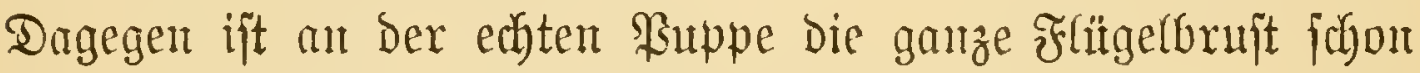
faft fo ftark wie beim కntago aufgetrieben unt mit bem

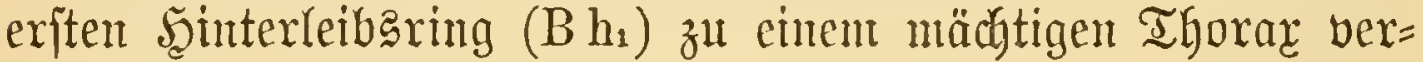
ichmorzen. Áehnlich ift's mit den Ânbängen. Bei ber edten

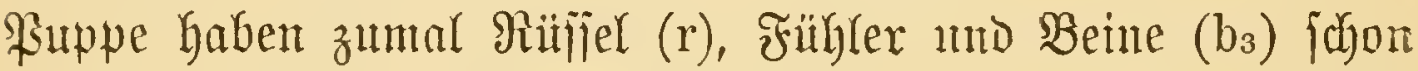
beinahe, bis anf bie feinere Modellixung, die definitive $\mathfrak{B} e=$ ¡waffentheit; bei ber Şalbpuppe hingegen find die Mlund= theife nuch furz (etwa benen einer Blattmeape vergleidjbar), Desgleiden bie Fłlïgellappen, und insbejonbere gilt bies von ben Beiten $\left(b_{3}\right)$, au Denen noch fein Tarjus zu fehen ift.

Sowie mant fich mu bei vielen biententartigen Snlfeften

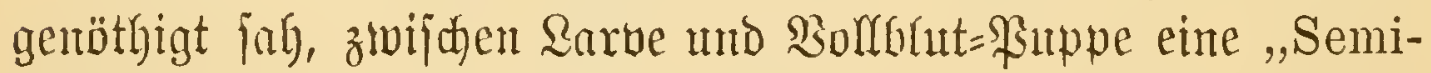
pupa" ober „Subnympha" einzufdieben, fo fpridit man bei

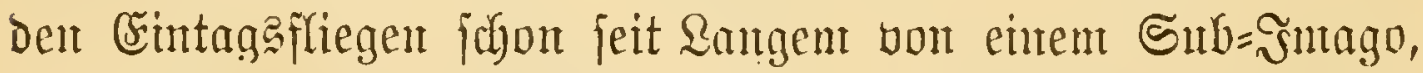
und zwar, wie allfefunnt, aus bent Brumbe, weil hier (menigitens bei einzelnen Brattungen) Dem Sntago eine Form vorausgebt, welde lebterer viel ähntidyer als Der eigentlidjen Suppe ift.

Wir haben mu zwei Scauptarten von Pojtembryogeneje

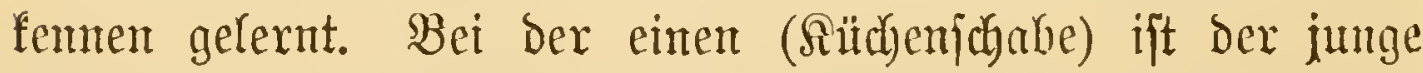

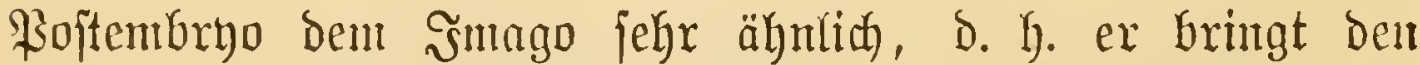
imaginalen Egarafter fibon aus bem (Fi mit, und geht

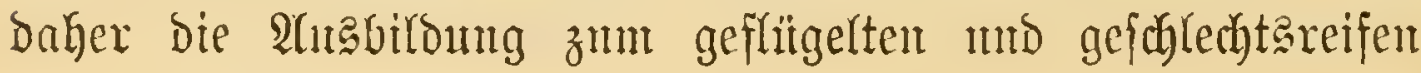




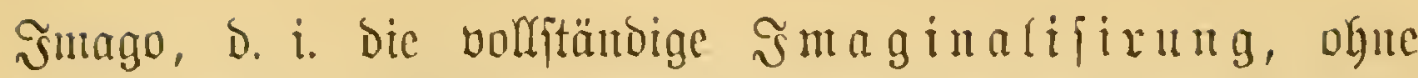
irgend weldye auffallende Beftaltueränderungen von Statten.

Man nemt bies cine Eutwiflug ohue Meta= morphoje (Ametalolie).

Bei Der zweiten $\mathfrak{A}$ rt bon Pojtembryogeneje aber (Sr)met= terling) ift Der juntge \$ojtembryo Dem Şmago jefrr muähulich,

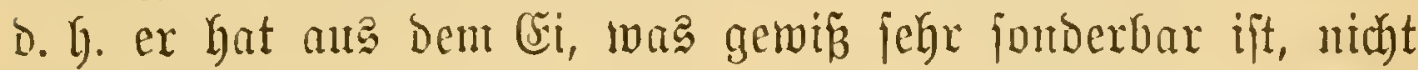
Den ribtigen, Den imaginalen Charafter, jontoen einen farjeden ober larvalen I I ppus nitgebracht, und um den exitern zu ex= balten, um, freifidy auf Ummegen, Dod) zum Definitiven Ziele zu gelangen, ift einte tief eintgreifende Huänbermng Des larbalen 3ujtandes nöthig, die Smaginalifinung beruht, wie man jugt, auf (rutwick ng mit Mietamoxphoje (Mietabolie).

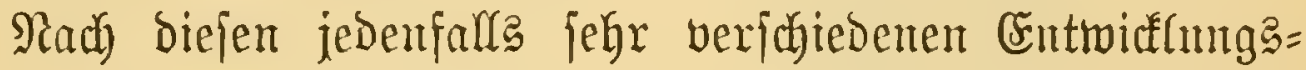

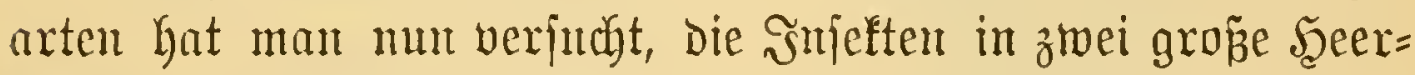
haufen zu theilen, in bie Ametabola, bie Berwandungalojen, und in bie Metabola, bie mit $\mathfrak{B e r m a n t o r n g . ~}$

Dieje Cintheilung würde natürlich voransjetsen, Daß̃ ber Pojtenbryo Der einen Bruppe itets einen rein imaginalen, Der ber andern aber einen ausgeiprod)en larbalen CGarafter hätte, ober mit ambern Morten, daź Das junge Thier ber

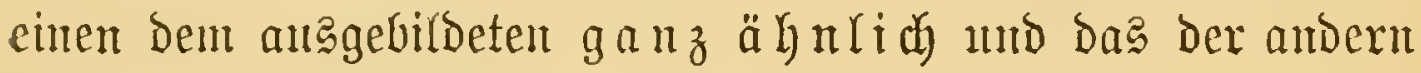

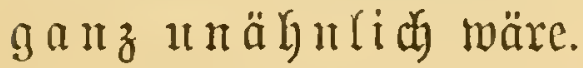

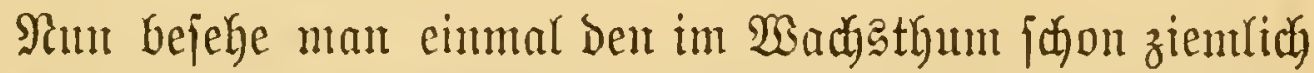
weit vorgerüdten Fojtembryo einer erintagafliege in Fig. 158.

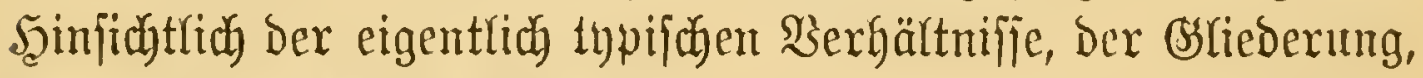

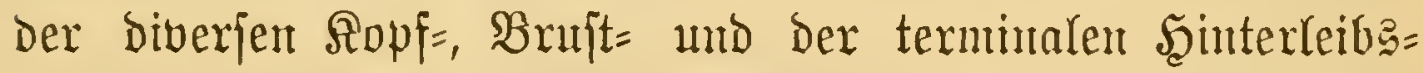

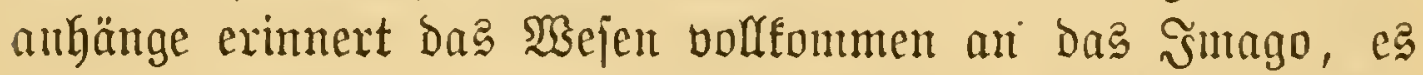
ijt alfo imaginal. Neben biejen imaginalen Mierkmalen befizst

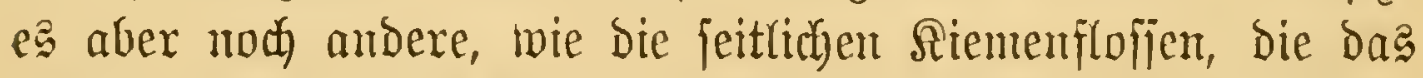

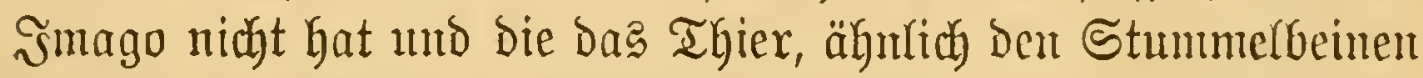
ber Raupen, überbaupt mur vorübergebend mux proviforifd, 


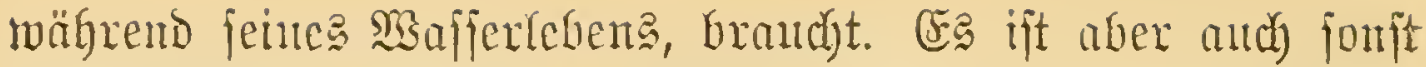
nody Mandbes ander: wie beim Șmago, z $\mathfrak{B}$. in Den Mind=

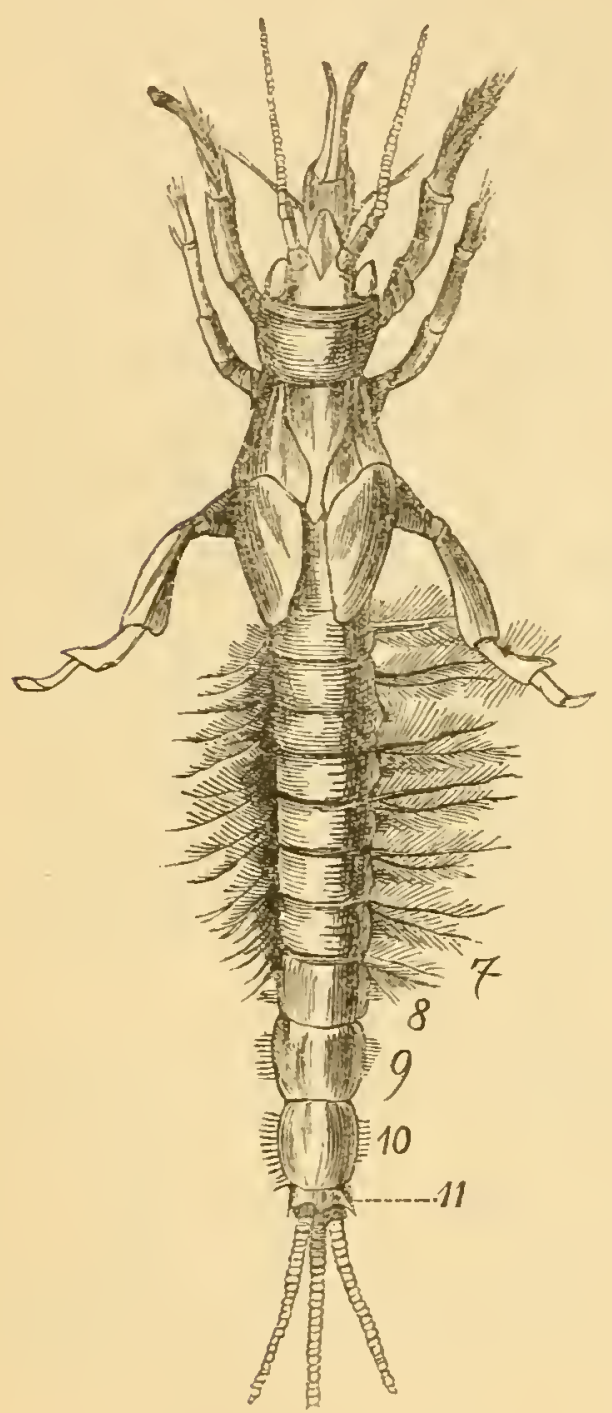

Fig. 158.

Rarbe eincr Cintrgafliege (Ephemera). 2n Den erîten 6 Seinter (cibsringen feber= artige Iradjeenficmen. (Driginal.) theilen, in Dex Befdaffentyeit Der SBeitte it. $\%$. m., mo bie vollftänbige Smaginalifirmug borulbt alfo midat blom anf dem $\mathfrak{A}$ bwerfen der genamten provijorifăsen BBifontren, jon= bern ce jüto alto toirfficle ZGänderangen ober lummand= lungen nothmentig.

Nut, ift dies cine intagi= male ober eime larbale cant= midumgsform, gejuleht bie Entwicking hiex ofue ober mit Metamorphoje?

Der Rejer wird jugen, es ift ctroas vour cimen mb aud vom Artoen vorfanton; die "junge" Ephemera ijt eine Sุalb $=\Omega$ arve mo ifree ent= widktug sinte $\mathfrak{S a l b}=\mathfrak{B e r}=$ to a

Soll aber bie an $\mathfrak{A b}=$ ftufungen uns 1Tebergängen jo reide Ratur wirffidy mux zmei voex mur brei Entwictunges= weijen Darbieten, oder ift bies nidyt auch cine fo erzmungente Diftinftion mie bic Drei= theifung in Den Buftand Der Sarbe, der Suppe mb des Эmago?

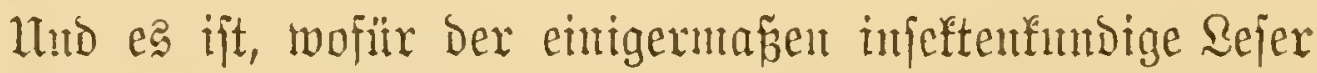
bie Belege fich felbjt geben fant, in ber I I at jo. 
So wic es feime "einfad)e" Entwidulug gibt obue unbildung, ofue licetamorabofe, jo gibt

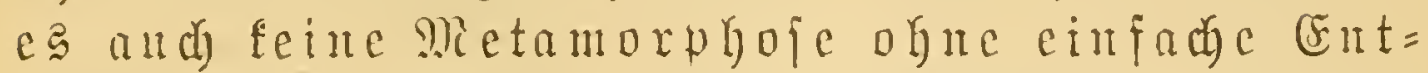
wiffung, fondern was wixtich vortommt, Das find

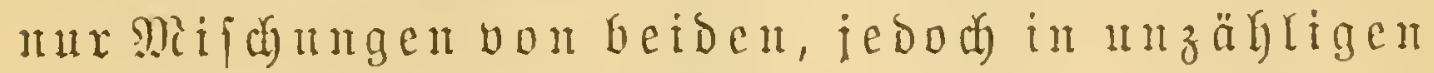
Straden ud Sdyattirngen.

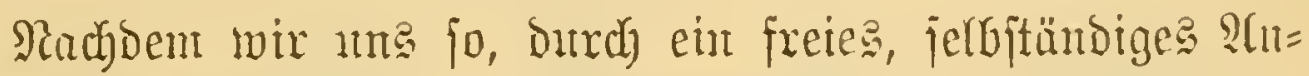

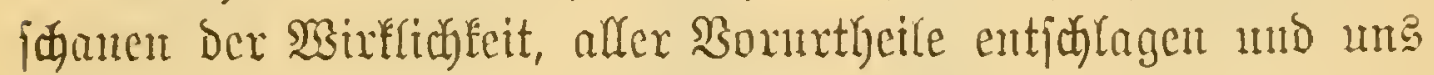
midyt mebr burch Sujteme gefuntoen fühlyen, mag bex Sejer

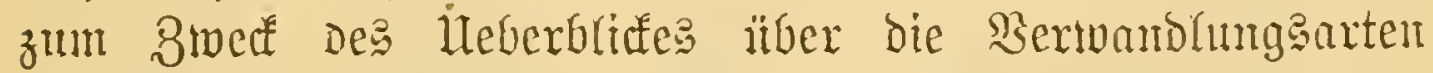
bei ben einzelnen Injeütengruppen bas nadjtehendo Tableau (F̛ig. 159) Durdjgelyen.

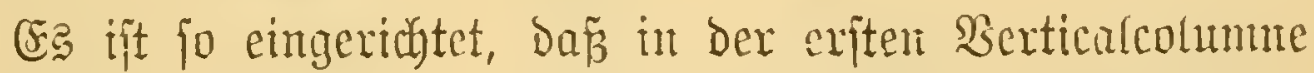

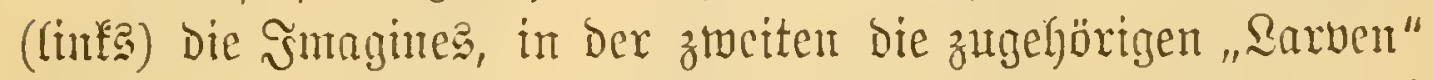
mo in Der Dritten bie "\$inpen" Ftehen, während bie nod)

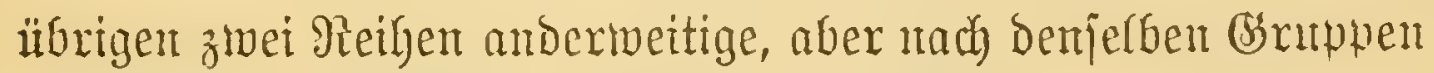
georonete Entwicflungagnutände vorführen.

Dic Bergleidyung in ber Berticalridytung gibt aljo bie Heberfidyt bei Den verjidedenen Drommgen, jene in ben Şori=

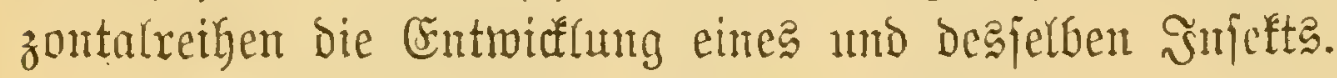

3ut oberit (a) jtebt ein flügellojer Borjtemjatwanz, b und c

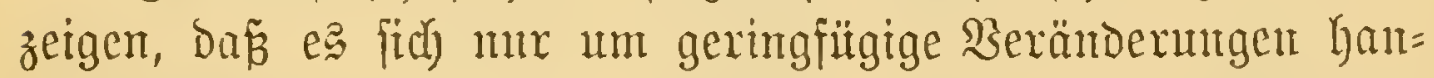
Delt (2̂metabolie). Die 2. und 3. Şorizontalreilye zeigen

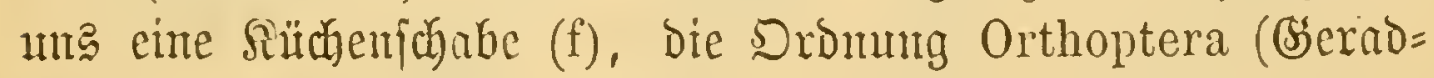
flügler) repräjentixend, dant einte Banmmanze (l) als wür:= bigite Bertreterin Der Schnabefferfe (Rhynchota). Die Ent= miffung ijt ähnlidy und bon früher befount, "Rarven" (Gier

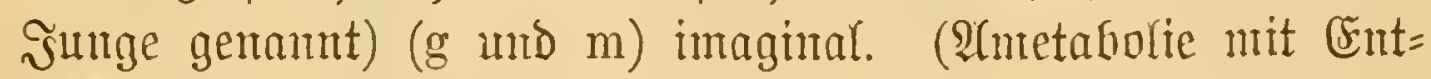
wicflung von Fr(ügelı 2 c.)

Biertenţ fiebt man (q) eine Eintagafliege (PseudoNeuroptera). Sarve, fafon borgefommen, mit proviforifden Drganert (tupifide Semimetabolie). 


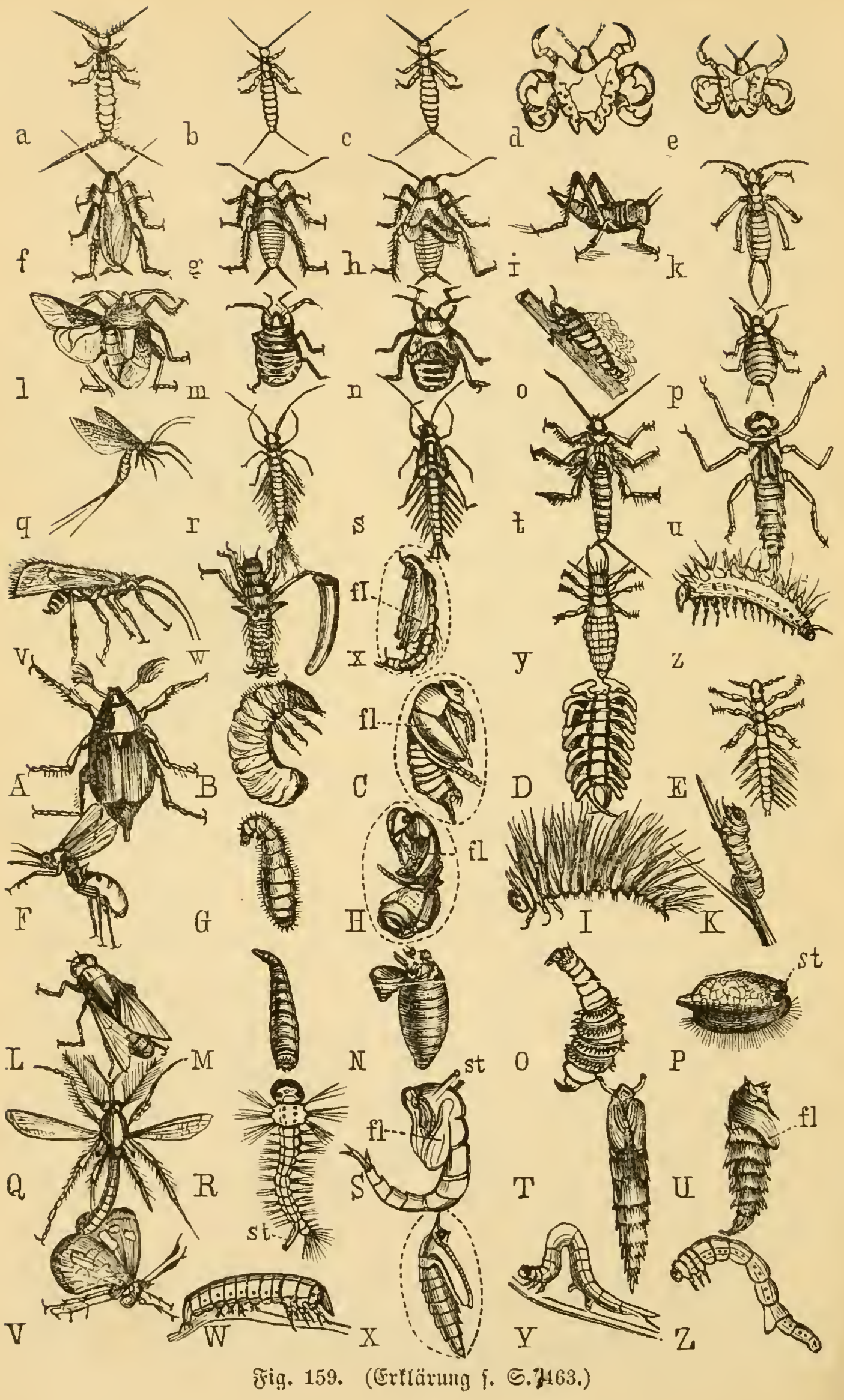




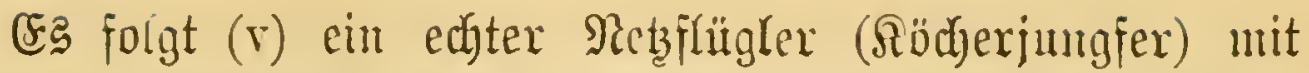

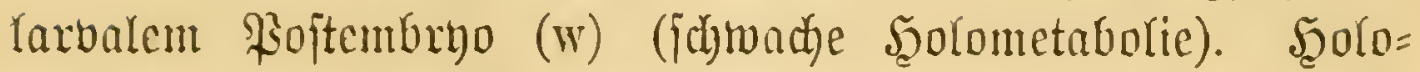
metabol, aber in jefrr ungleidyem Srade, find and alle Die übrigen: Die Säfer $(A, B)$, die Şautflügler $(F, G)$, die furzfüblerigen Zweiflïgler ( $\left.\mathrm{L}_{2}\right)$ mit "Eopflofer" Sarve oder Mabe (M), fermer bie langhörnigen Diptera $(Q, R)$ und entlidf) Die Schmetterlinge $(\mathrm{V}, \mathrm{W})$.

Betreffe Der hier zunädyjt übergegangenen \$uppen der "Sholometabolen" ift bie manther Miüfen (S) frei betweg= lich, bie ber frliegen (N) in ber verharjuten Rarventhaut eingezmängt (Tomtenpuppe mit manthen Ulebergängen auth) hei einigen $\Re a ̈ f e r n=$ Pupa coarctata). Die Sirppe mandex

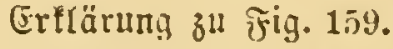

Bergleithende 3 uiammenfterlung ber freien Entwidtungs= formen einiger $\Im$ uiettentqpen.

Die einzelnen f̧orizontalcolumnen enthalten Repräjentanten je einer ber Injelten = Sauptgruppen. In Der 1. Berticalcolumne jind bie Yamagines, in ber 2. Die Earven,

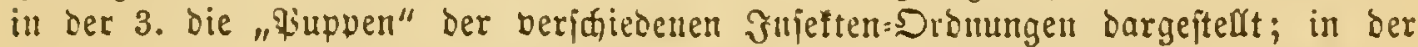
4. und 5. Berticalcolumne tommen Iann nod ein paar $\mathfrak{B e r t r e t e r ~ ( 2 a r b e ~ o b e r ~ P u p p e ) ~}$ ber betrefifenden Sronung bor.

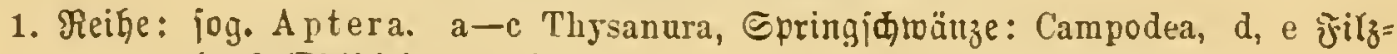
lats (Phthirius pubis).

2. Reike: Orthoptera, Berabflïgler. f-h Rüdenjabe (Blatta germanica), i junge Sdnarrheuidrede, $\mathrm{k}$ junger Shrwurm.

3. Reike: Rhynchota, Ednabelterie. I-n Baumtoanze, o Rarve ber 巨めaum= zirpe, $\mathrm{p}$ junge Blattlaus.

4. Reibe: Neuroptera orthoptera, Reţflügler. q-s Fintaggfliege, t Numphe voll Perla, u Nyniphe einer sibelle.

5. Reife: Neuroptera s. str. v-x §öherjungjer, y \&arbe von Chrysopa, z \&arve orn Bittacus.

6. Reihe: Col eoptera, Räier. A-C Maifäjer, D \&arve von Drỉlus, E \&arve von Dyticus.

7. Reihe: Hymenoptera, aberflügler. F-H Imeije, J sarve einer amerifa= nifळen, $\mathrm{K}$ einer andern $\mathfrak{B l a t t w e s p e . ~}$

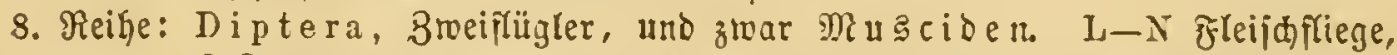
0 Rarve bon Dermatobia noxialis (ill ber Şaut oes Sgundes in Jjexifo), $\mathrm{P}$ Earbe vor. Microdon globosus (unter Piählen lebello), st Borberftignta.

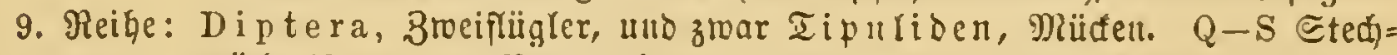
müfe (Culex), T Puppe eitter Tipula, U \&uppe von Midas clavatus.

10. Reike: Lepidoptera, Gdmetterlinge. V-X Fierlmutterialter, Y Raupe

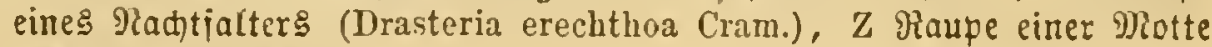
(Macaria granitata). 


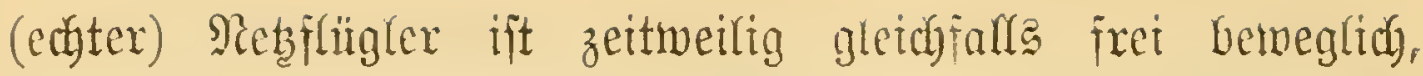

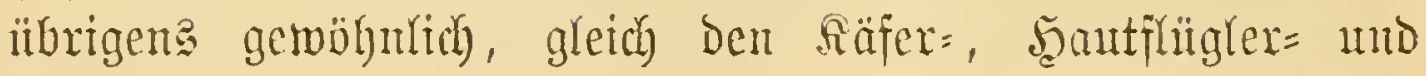
Falterpuppen, noch extra eingejponten, rons die Pimftimie in $\mathrm{x}, \mathrm{C}, \mathrm{H}$ und $\mathrm{X}$ andentet. SBei alfen fteryen bie Sistieb=

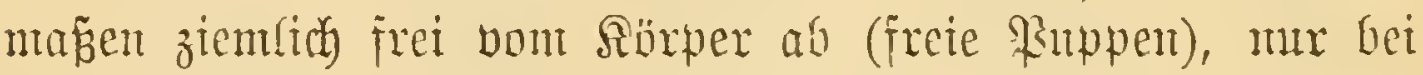
Den meiften Faltern jimb fie fpäter mit Den 9rump于 verlütget (unfreie \$iuppen).

Die Şergleidumg der \$appen einerjeits bon $c-s$,

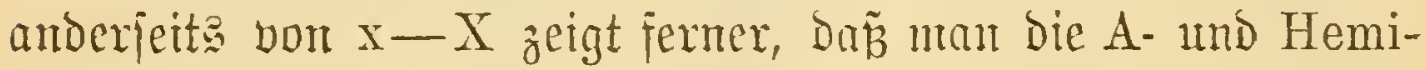
metabola von sen Holometabolis an leichteften an ifnen

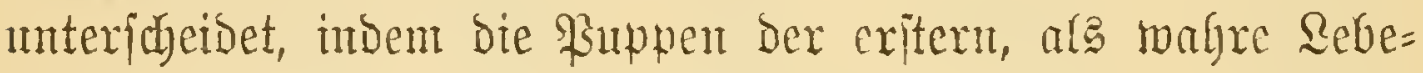

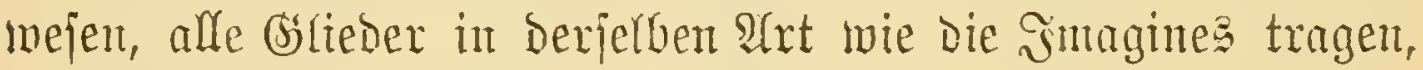
währendoen bei Den ruhenden \$ippen ber Holometabola bieje $\mathfrak{A}$ thänge einte meijt ganz vertrafte Sage baben.

\section{Sdjildernty der giletanorplofe. \\ Zllgemente Deränderungen.}

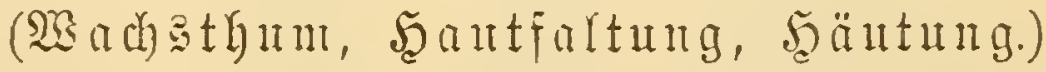

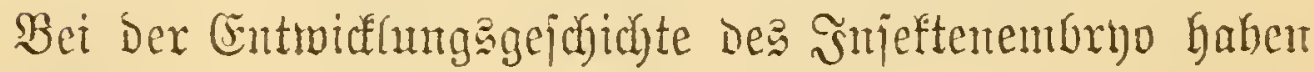

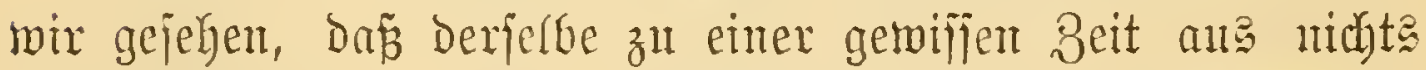
Anderen bejtegt als aus einer Nienge Kleiter Protoplasma= kïgelden, Die wir Beflen namten.

Diejes einfache Bellentugregat bifferenzint fich aber

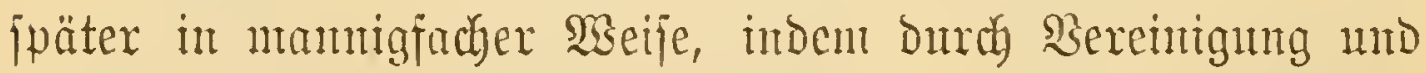

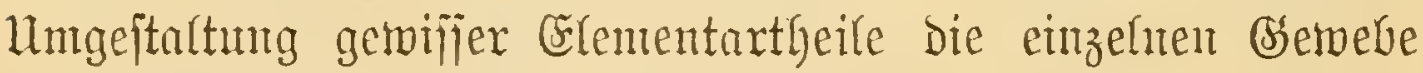
und Srgane herworgehen.

Dabei mterjibieden wir ipeciell eine $\Omega$ age von Bellen,

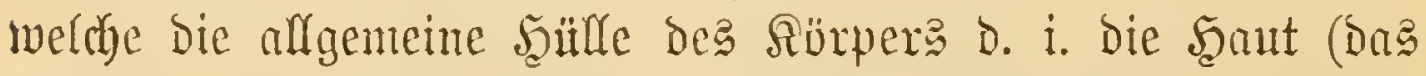
(Eroderm) Gildot, mo bant die verjajtenenten Bimnengemebe rejp. Bimenorgane. 


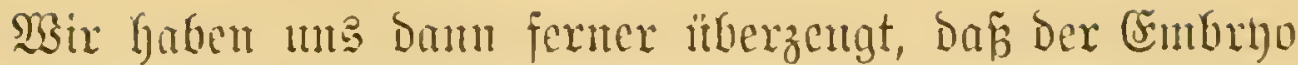

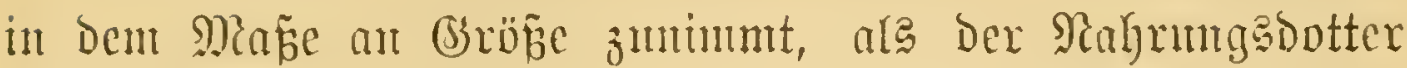

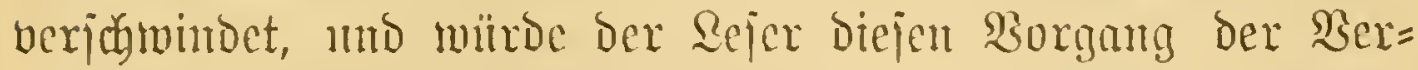

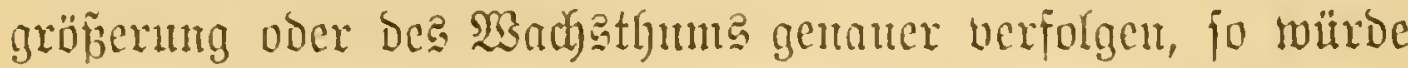

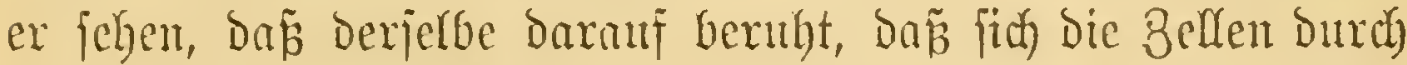

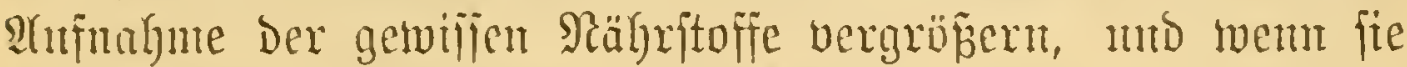
cin bejtumtes Maximum überjuritten baben, fich Durch Theifung vermelgren. Die natïrlidye Folge babont ift banu,

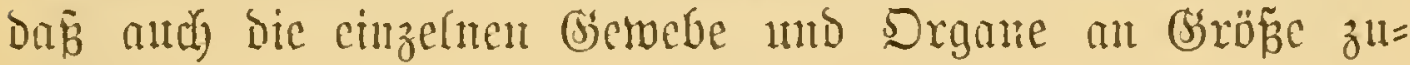
mehmen, jet es, wie bei majimgen Theilen mady allen bret

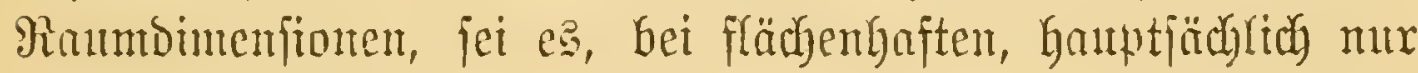

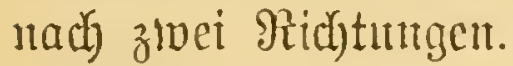

Speciell an ber Şaut ober an Dex SHrenzzellentage äuñert

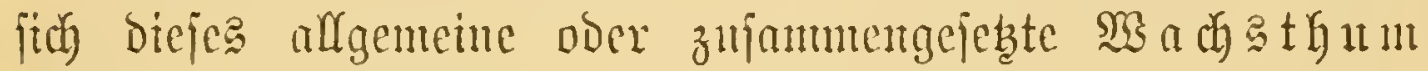

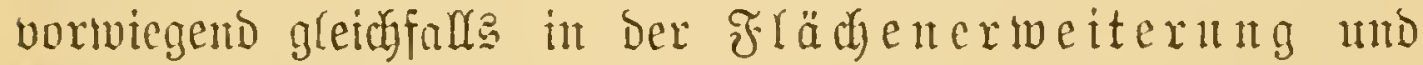

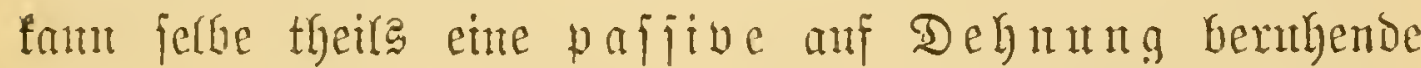
jeit, Gerborgebradyt Duxdy Den Druf des roadjenden Binnen=

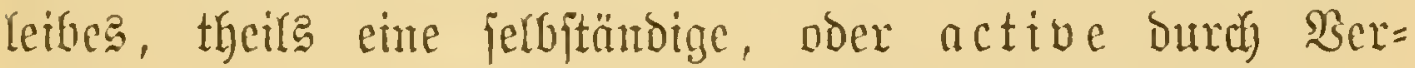
gröperung mb Berme斤rung der cigenen Bsetwebaelemente.

Wir Gehen Gier aber gerabe die Seant herbor, weil fie ja der Irägex ber Sïrpergejtalt ift utto weil hauptjädblich anf ihr jene merfmürobigen $\mathfrak{S e r a ̈ n d e r n t g e n ~ j i c h ~ a b j p i e l e n , ~ D e r e n ~ S c h i l = ~}$ berung unjer Zmea ijt, uno rair jejiften bas Hebrige voraus, um dem Sejer wieder in errmterung zu bringen,

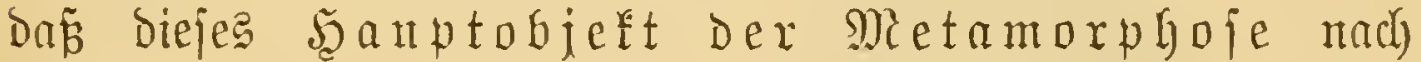
uriprung und fortoancruber Beziebung uidyt etmas vour

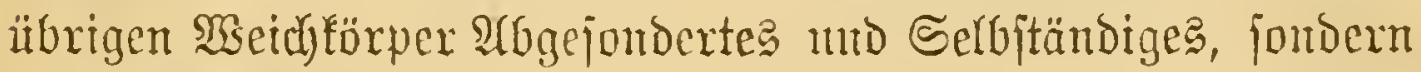

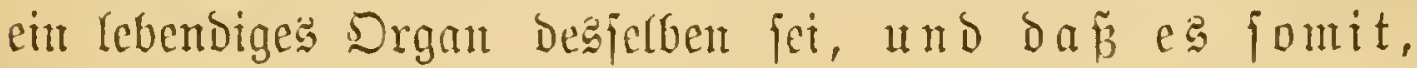

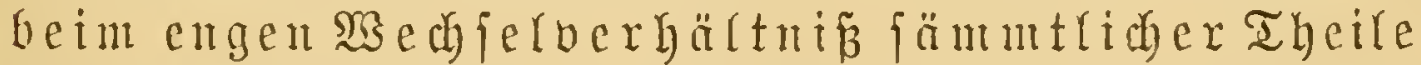

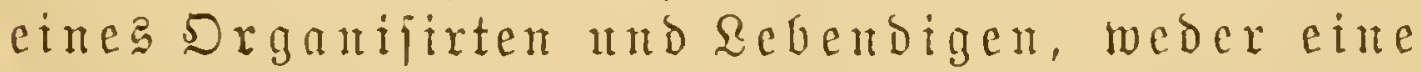

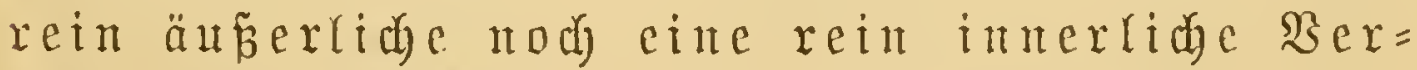
änderug ud Metamorhlofe gebeu fan. 


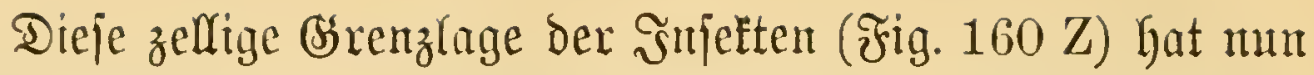
befauntlich eime ganz hejondere CEigenfichaft, nämlich bie, Da

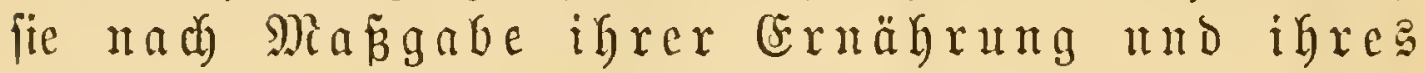
Wadjthum an ifrer Dberfläche eine bejondere rings= gejuroffene Sautidityte, eine fog. Critin-Cuticula (Cu) abjegt.

Während aber biefe Heber = ober Beifaut beim Embryo

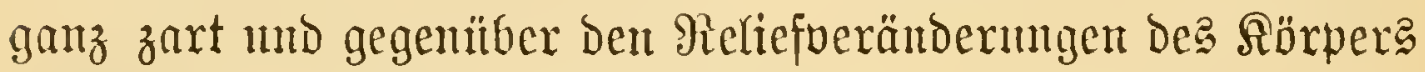
bolfonmen elaftifich ntud nachgiebig ift, nimmt fie bei ber Sarve aus mehrfachen Şründen eitte gröbere Diffe und Steifgeit an, futrz gejagt fie wird zu eitter bie

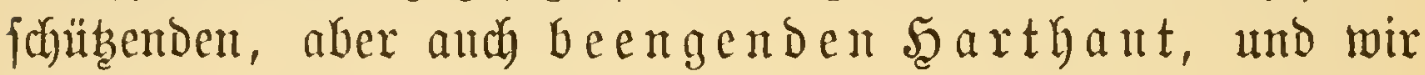

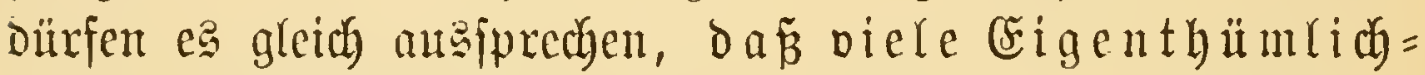
feiten ber suletenmetamorphoje eben von diejer acceforifaeu sutegumentlage herrübren.

Went wir eit jtarf wachjendes Rint in eilt enges und

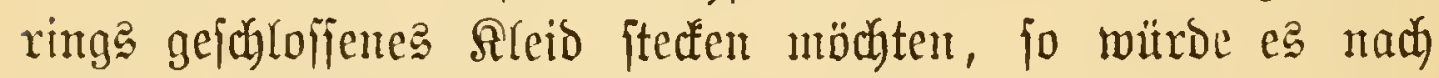
einiger Beit Dahin fommen, Dan başelbe in Folge Der innern Spanmung zerrifjen mürde.

Achnlich verbält jich's mit einer Sinfeftenlarve. Átnfangs, fo lange bie Chitiufant nody etwas efaftifa oder z. Th., wie

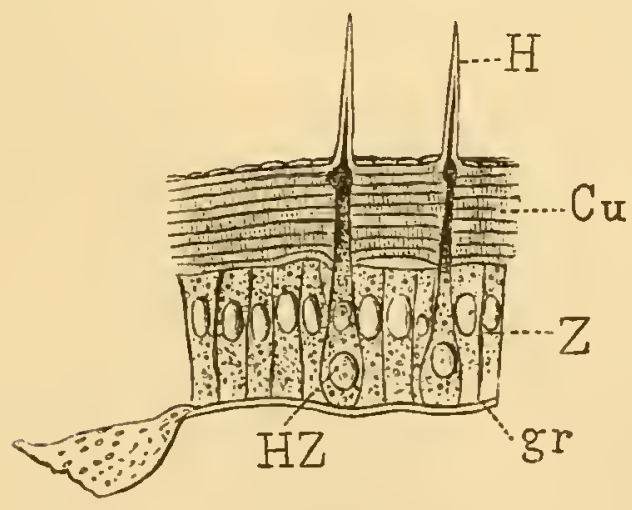

Fig. 160.

Queridnitt Durd Das Jntegunent eitte (Ehitinfäuters.

Z zellige Weidhant (Epi- nder Hypodermis), cu bie jaidtuveije abgejonoerte Cuticula.

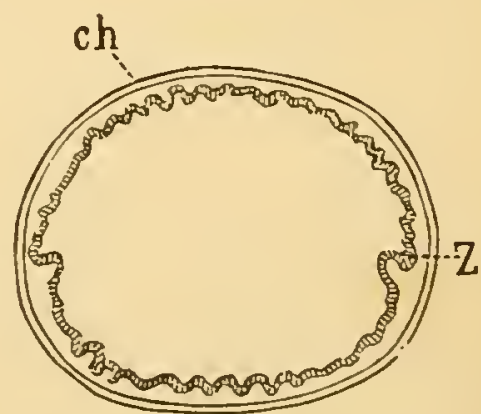

Fig. 161.

Edema Der Doppelfaut einte Jnjefts vor der Şäutung. z zelliga $\mathfrak{W}$ eimbaut (Epidermis), ch (s)itin= ober Şarthaut. 
zrwifhen Den Reibesringen, in Falten gelegt ift, famm fith Der

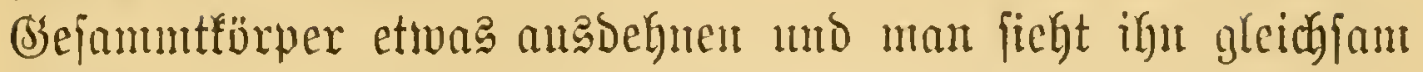
wadfjen; hat aber einmal bie Panzerlant das Marimum ifyrex

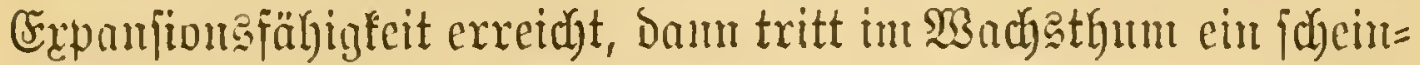
barer Stiaftand ein. Bead)ten wir aber, daź bie Rarve aud

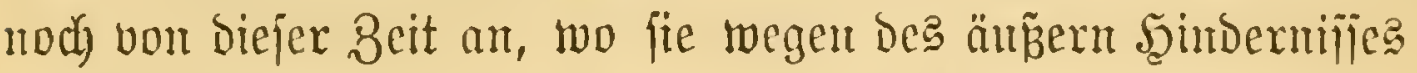

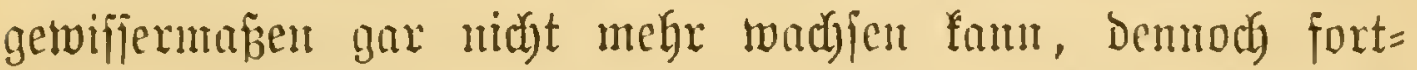

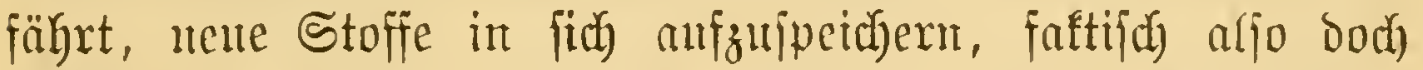

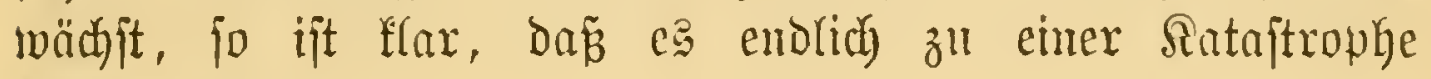
fommen mur

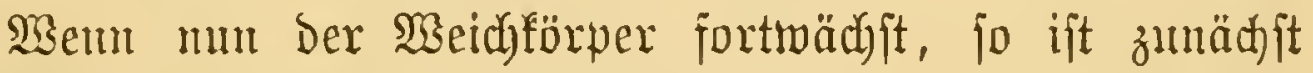

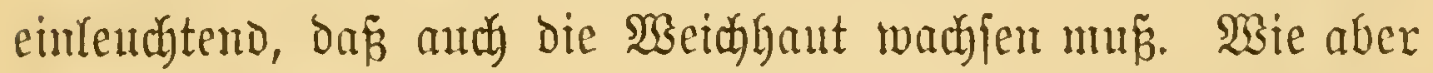

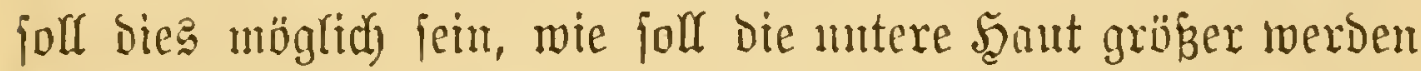
fömen, went bie obere ftarx ift? Dies liefe jich offenbar mur in Der aus Fig. 161 erfichtlichen Weije, nämlich burch Faltungen bemerfitelligen. Wie aber, muñ man weiter fragen, fann eite jolde Faltumg itattfinden, D. h. twoher fommt ber Bumadjs an Raum, in Dem joldhe Biegungen itattfinden fömen? Man fiegt, es jegt bies nothmendig eine jpontane

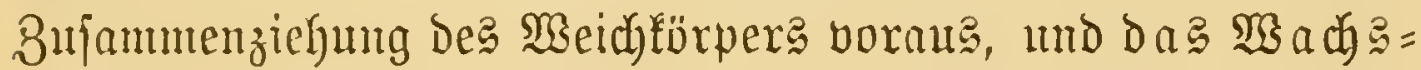
thum witroe fid alfo auf biejem Stabium wentger

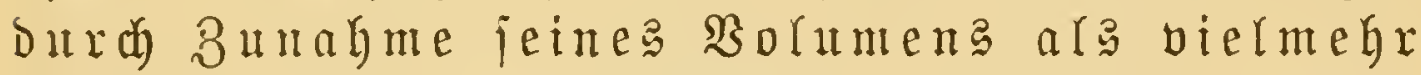
durdh 8 una me feiner Didtigkeit zeigen.

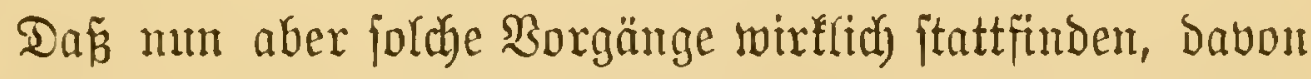

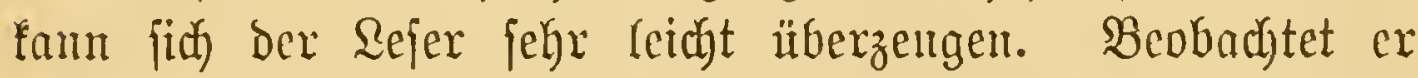

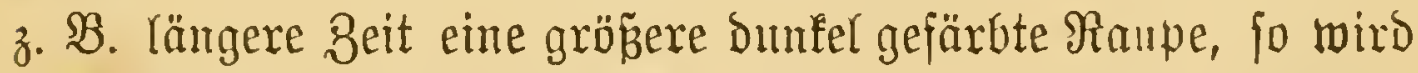
ex früher ober jpäter bemerfen, baż iłre Şant allmälig bläjīer, gleidffam welf wird und ba nach vollfänbig von Der Cuticula zurüafziegt. Entfernt er

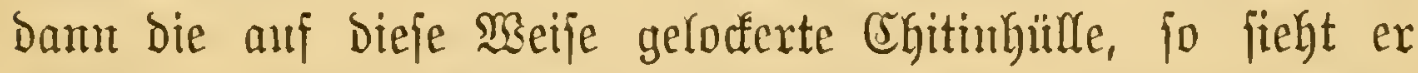
aud) Die getrijient Faltungen Der Weibhaut. Dieje Runzelı zeigen aber łeinesmegs einen fo regelmäjigen Berlau;, wie 
man viefleidgt glaubt, fonderu fie bilben oft äuñerit complicirte Figuren utb Syftcme.

Mährend ich Dies fohreibe und zufällig dic llnterjeite

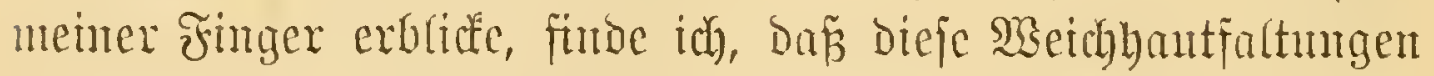
eine frappante $\mathfrak{A}$ ehntichteit mit den befanten Rimzelfyjtemen

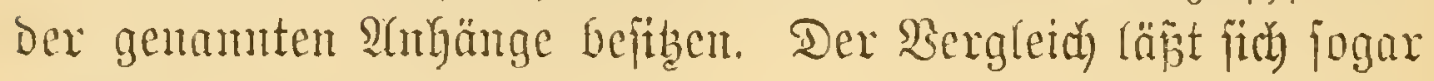
nod) weiter treiben. Sowie man an einem menfditiden Finger zumal an Der Unterjeite, anťer Den feinen Furben anf Deu einzelncm Bsfiedern and nody, an Den belenfen, tiefere und gröpere Duerfalten wahrummt, fo bat mtan aud au einer Raupe neben ben fleiten Fältelungen Der cinzeluten Ringe ober Bsirtel bie umfangreidjeren cinftïlpungen an ben 3wijachengänten zut unterfacheiden.

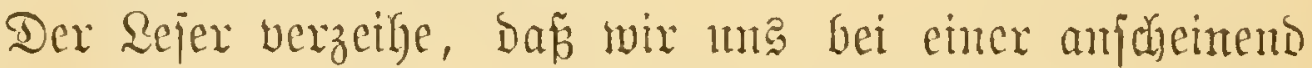
jo mbedentenden Sache noth Cänger nufbarten; allein bieje

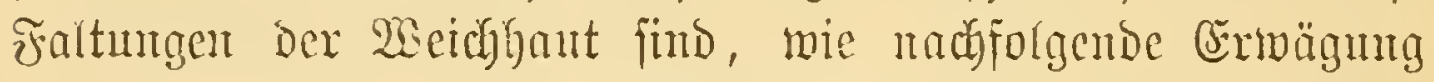

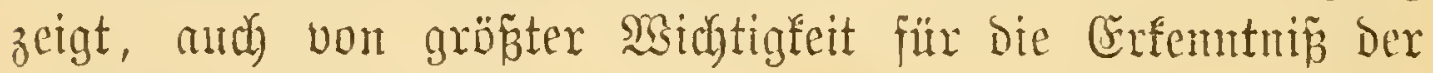
Šertwand

Die geianmte \$eränderung in Der Beftalt eines Serfo

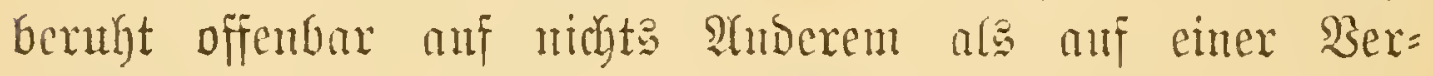

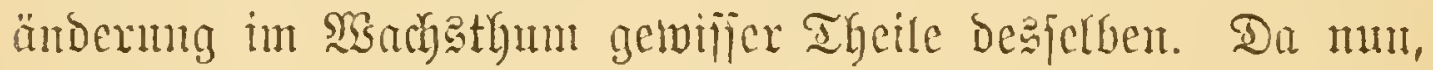

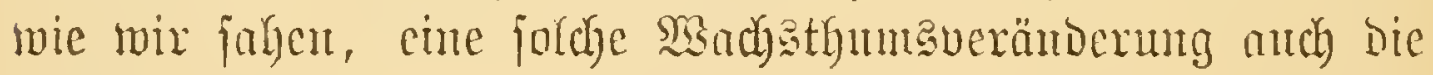

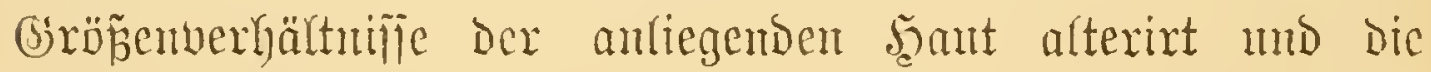

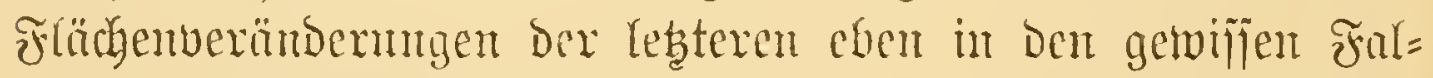

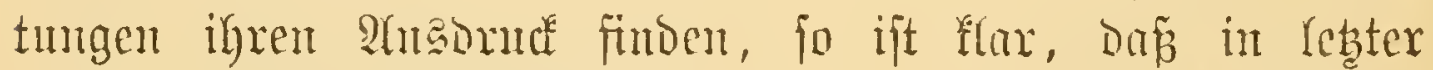
Sinie aud jede Geftaltveräuberung ber Sierfe auf

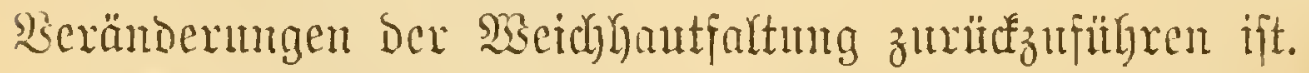

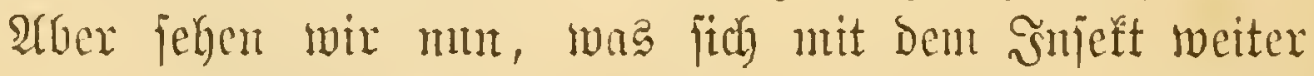

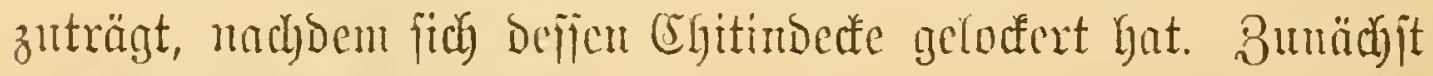

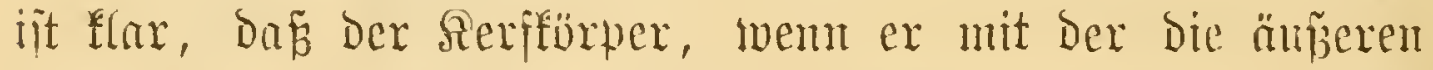
Reize vermittelnden Dberhant dic Fühlung verliert, gegen retetere felbjt mempfindich wiro, fich aljo nidyt mehr in gewohntex Scife in jeiner Untgebung oricutiren fan. $B_{e}=$ 


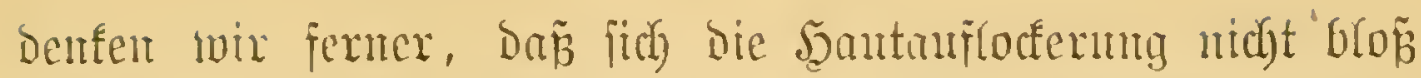

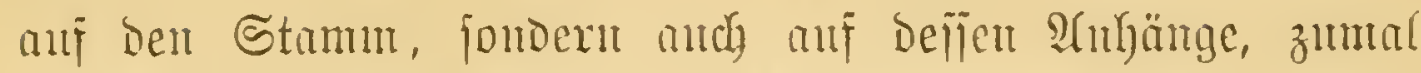

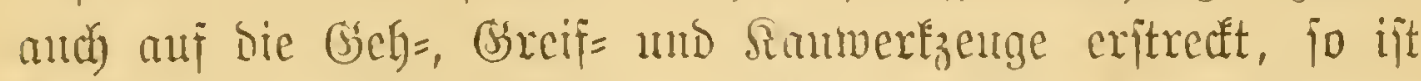

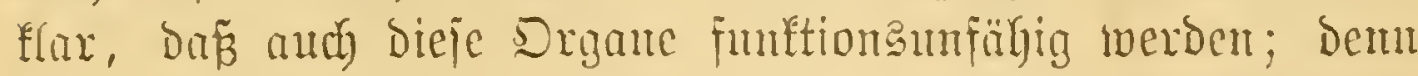
e

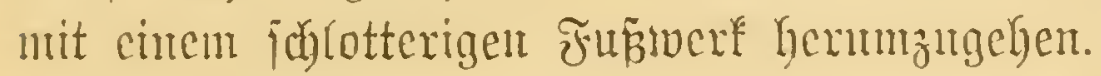

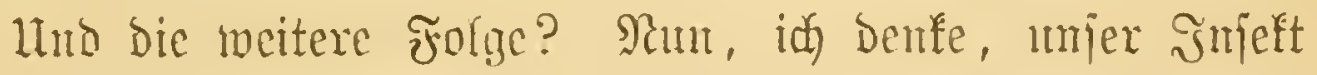

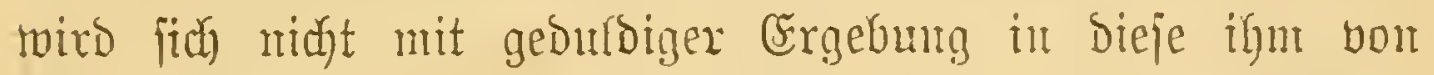
jeiner Satur aujerlegte Brongalage fïgen; im Ssegentheil, es wird fith anfaugs unrubig, ängitlich und Dam, wem

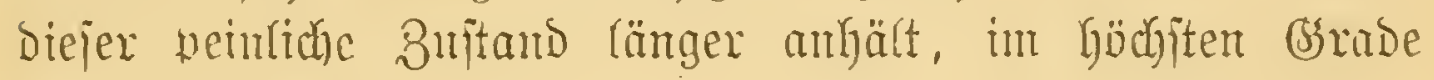
umgeberbig jeigent.

Uebrigen hängt bas Saeitere garz von ber Sejdyaffen=

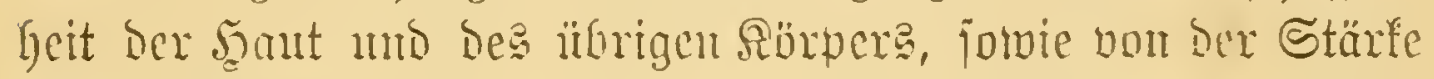

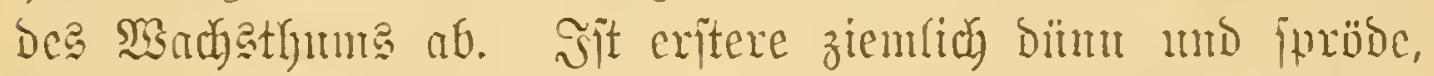
jo surd ber (Shiturbalg cinfach Durd) Den Druef bes einge=

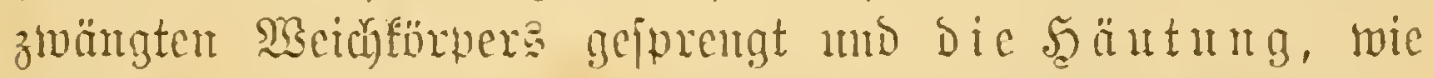

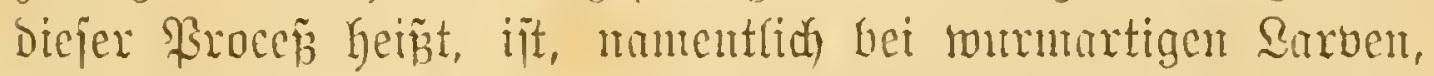

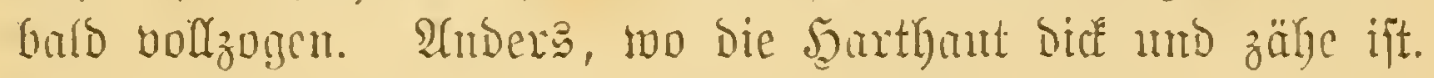

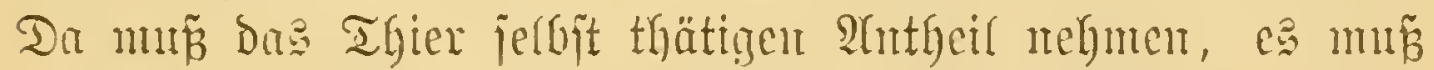

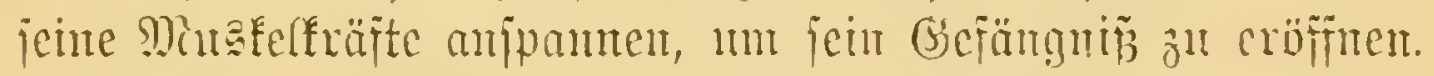

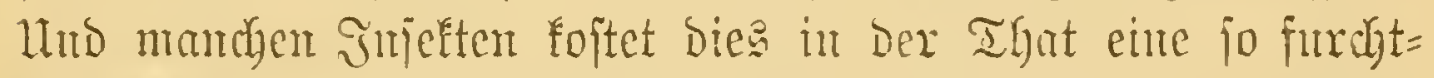

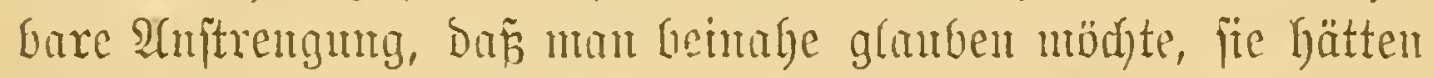

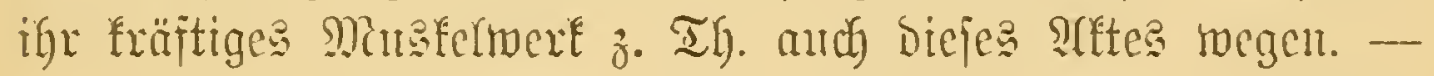

Und ijt auch ens(ic) und oft erit nady tagelangen vergeb=

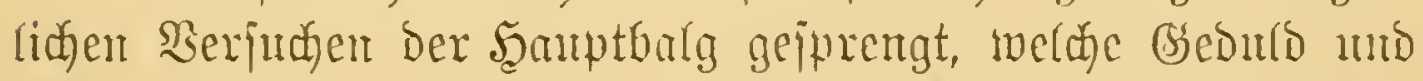
Mälye ijt noch erjorbertich, un alle bie Sturgänge - wo joldje f̈tto -, dic Fühlex, die Mumbtheile, Die Beine, Die Flügel,

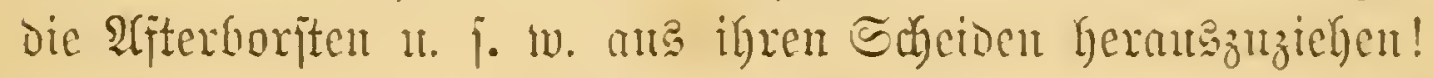

Hebrigens find die Methoden Der Şäutung fefre mannig=

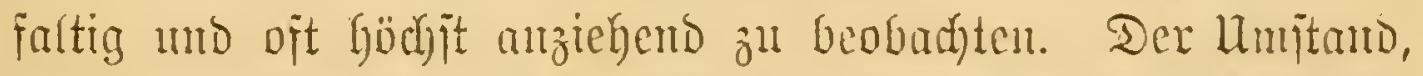

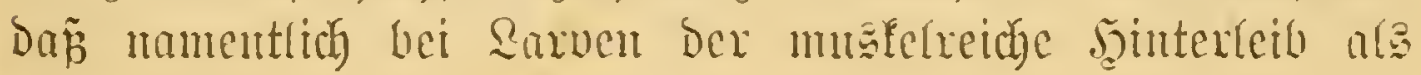




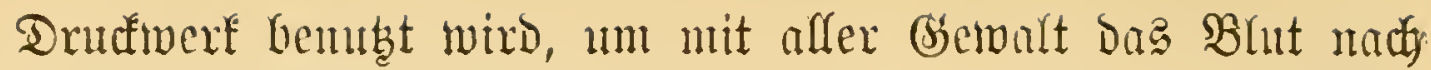

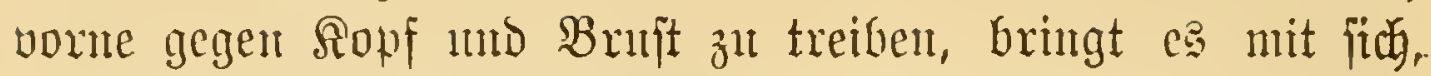

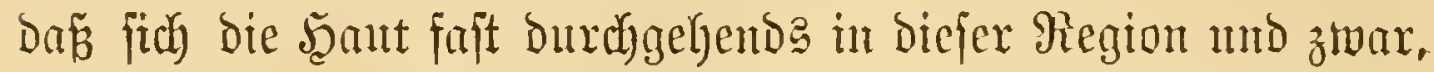
mts andern Briünen, meift oben it der Mittellinie öffnet.

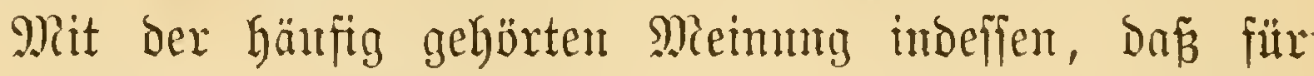

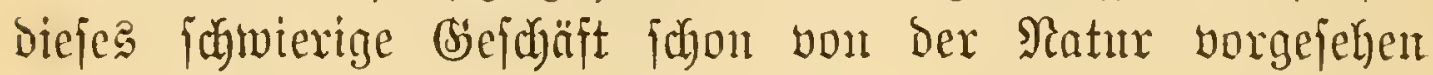

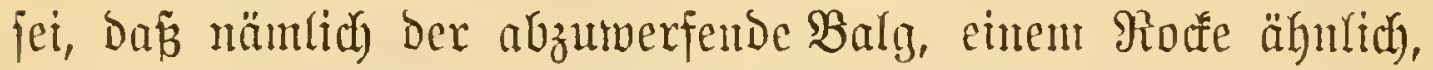
itets mit befonderen präformirten Trenmmgglinten ober "Nähten" verjegen jei, verbält es fich wie mit andern $\mathfrak{B D L}=$ urtheilen. Bei manthen Thieren ijt Durch Anpaijung ber= gleidyen thatjärblidu vorhanden, bei anbern aber ift bie cin= ridytung viel moolffonmener oder nod gar midyt auggebildet.

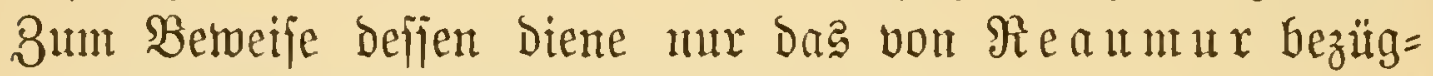
(itd) einer Zygaena filipendula erzäljlte Faltum, bie, als alfe gewölntichen ânitrengungen zux Sprengung ber Şaut ver=

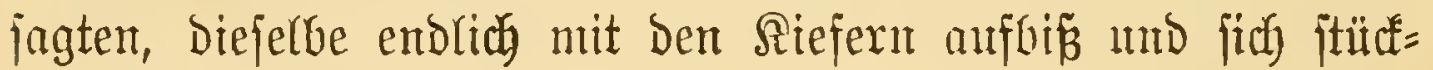
weife vom Reibe ríp.

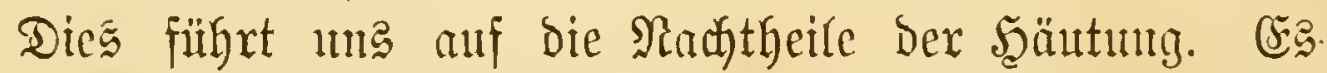
fommt gemiñ viel öfter vor als wix glauben, baj manches Snjeft feine ofeffeln ïberbaupt gar nidht zul löjen verntag und jo bei Yebendigem Leib eingejargt bleibt. Wnoere verlierent - von der Zeit ganz abgejeben - bei biejer Bselegentyeit irgend ein für's fpätere Reben nothwendigea sslied, bas, unge=

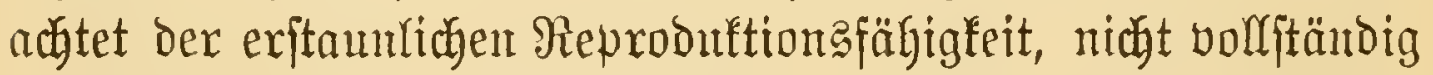

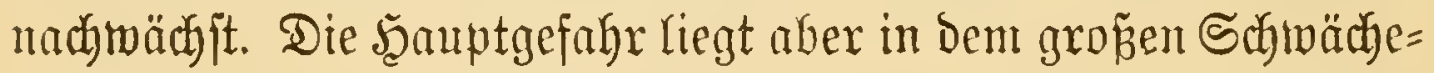
zujtand, in Dem bie Rerfe die alte Şülle verlajien; Dem e?

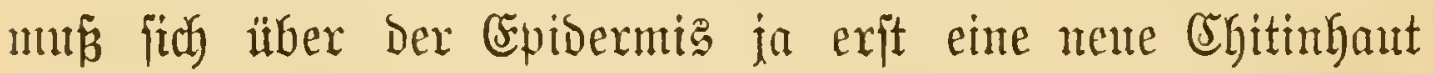
bilben, bevor fie von igren Sräften Bebranth machen fönnen, und wie biele biefer naten armen befdjöpfe erfiegen frïher Den lubirsen Dex Mitterung ober ihren zahllojen Feinden! Bergleichen wix nut bag frijh "gehäutete" Thiex mit

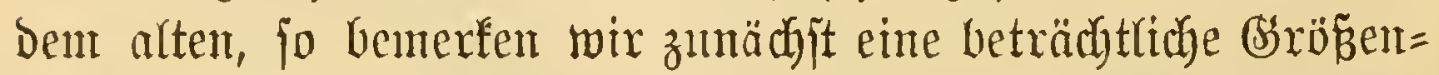

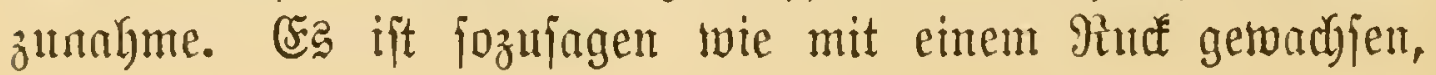


was (eid)t begreiflid), da ja nad) Entfermung des äuzeren

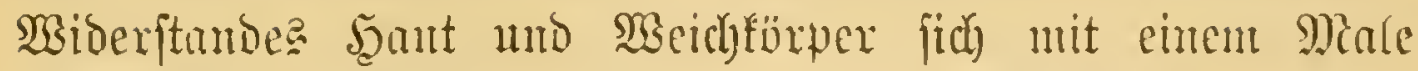

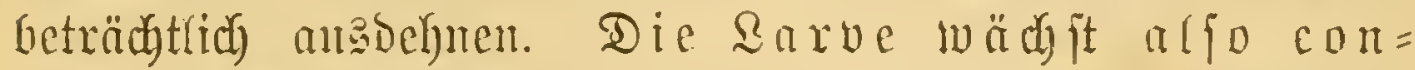
tiultixlidj fo gut wie ein anderes Thier; ihr ll mfang ändert jid aber nux periobiju. Mair fömten aud jagen, bie Didfte ber $\Omega$ arve jteigert fid bei gleidyent Bolumen

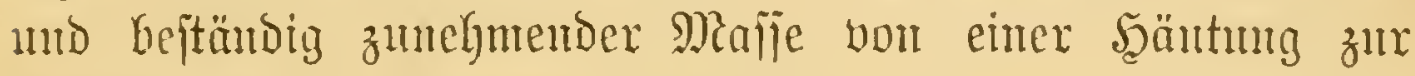
andern, jie verringert jid) aber montentan bei jedent biejer Iffte, um bann, jobard ber Şantumfang lvieber conftant geworden, neuterdings zumtuebuen.

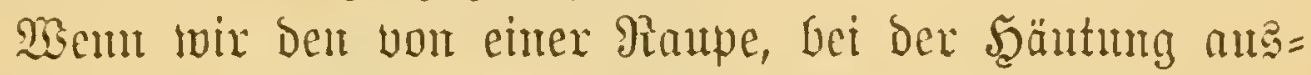
gezogenen Balg janmt defien Shthängen, Den ß̧einen, Rie=

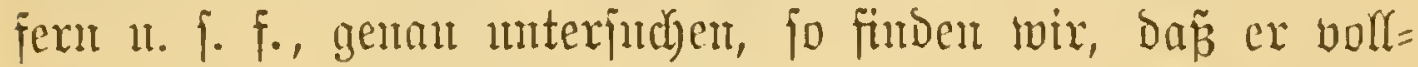

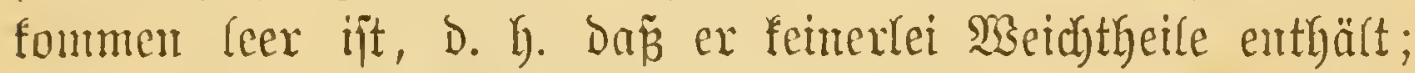
und miftern wir fermer das frijd gefjäntete Thier jelbjt, jo jeben mir - Den glïffichen Aftegung des \$rocejles vorauts=

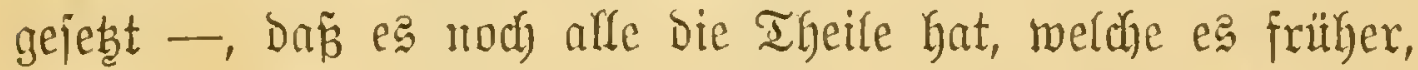

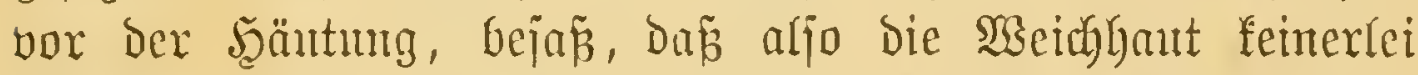

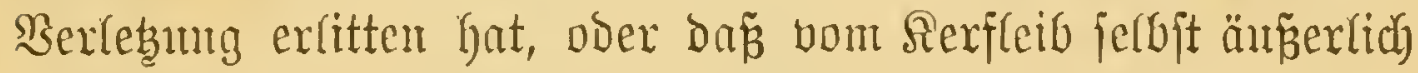
nidyts weggefonmen, nidyts verloren gegangen ijt.

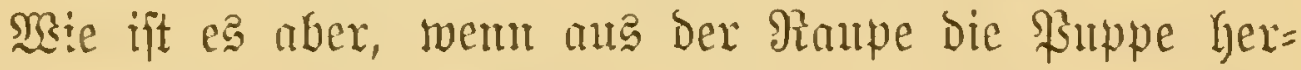
vorgegt? Bergleidyen wir letztere gegen erftere, fo finten

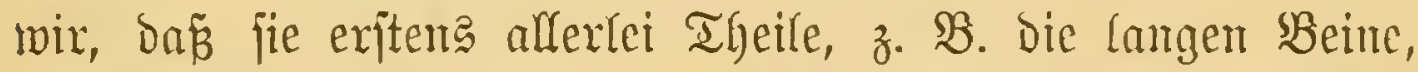

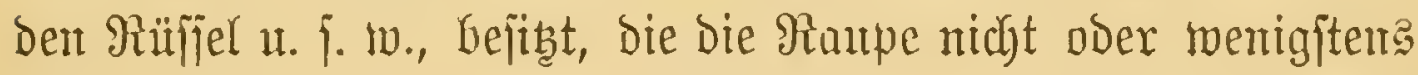

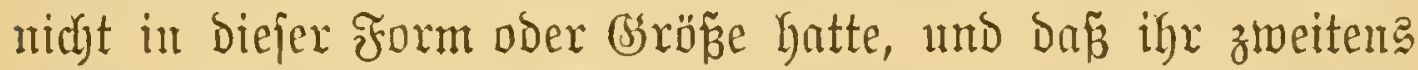

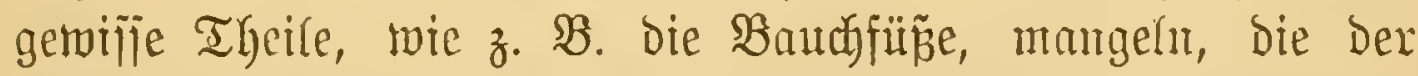

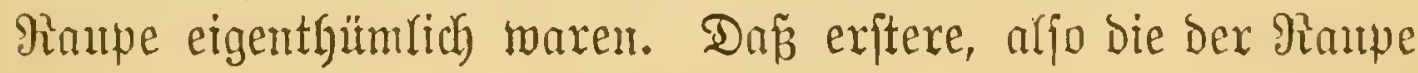
fehlenden Theire, jedoch in Bufammenthang mit Der ïbrigen

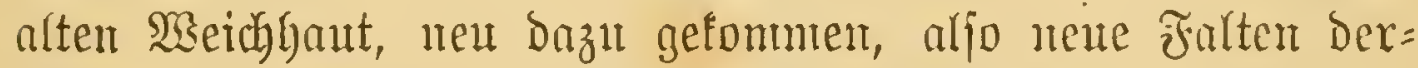
felben find, werben mir jpäter hören. Wie ftegt es aber mit

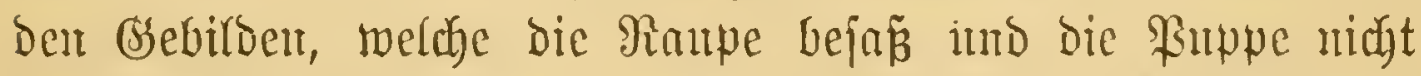

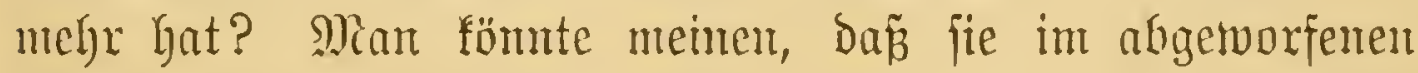

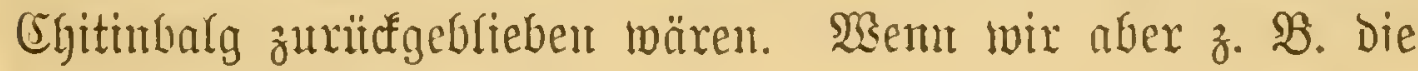

(S) raber, Injelten. II. B⿺. 


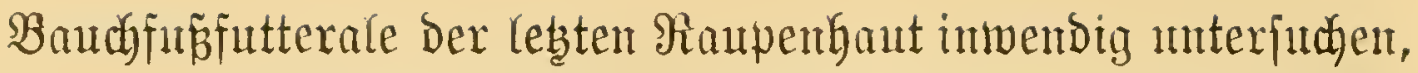
fo finden wir andh uidat eine Spur bon ben zugehörigen 3apfen des Meichförners. Darants folgt aber offentbar, Dáp

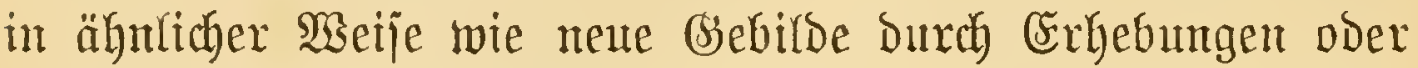

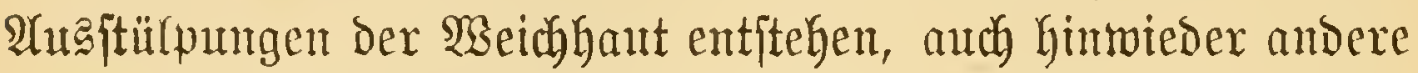

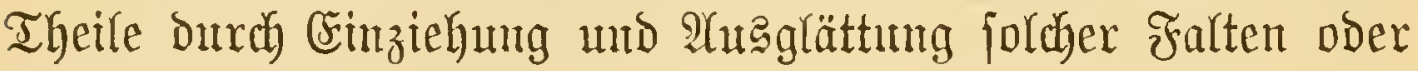

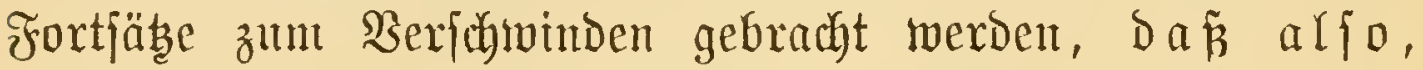

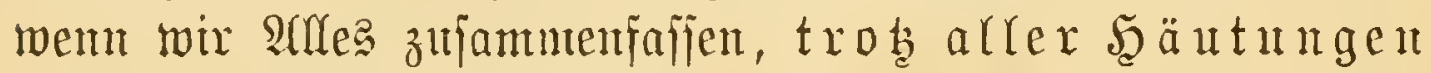
und Formberänderugen die Continutät der Weidhaut uiemars ud uirgends, aud nicht für eiuen Mioment, aufgeboben wird.

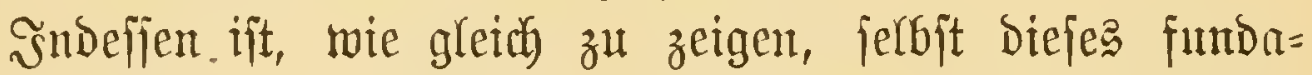

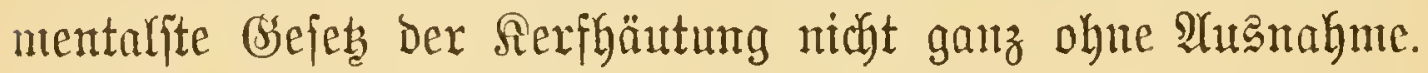

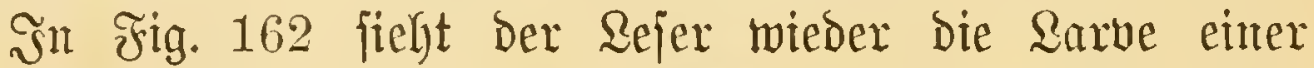
Crintagefliege nit ben eigenthümlìnen Rientenblättern $\left(k_{1}, k_{3}\right)$

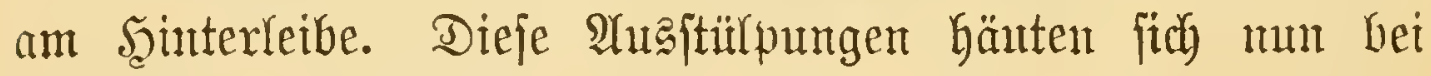
Der Larbe in ähnlicher Saeije wie andere Reibeananjänge, 3. $\mathfrak{B}$. Die Beine oder die Flügelfacheiden (VF), d. h. mit ber übrigen Efitmbant wirb audh bie Cuticula biefer Fortfäbe abgejtreift, währento ifre Eptoermis und das davon ein=

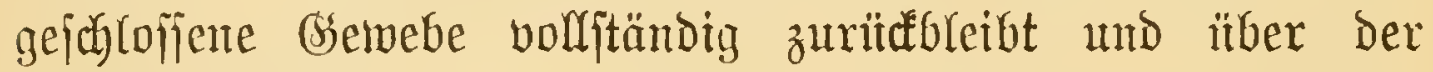
exfteren alsbald ein nenes Chitinfutteral entfebt. - Die Frage ift mut aber, was bei ber rebeten Şäutıng geidjiegt,

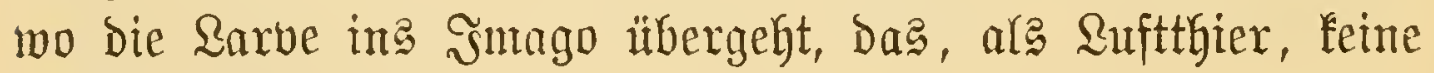
folchen Riemen hat.

Bei der Raupe, wo wir himfidttidy der obliterirenden Bauthfürpe einen ähnlichen Fall haben, ijt Dex Scergang, wie

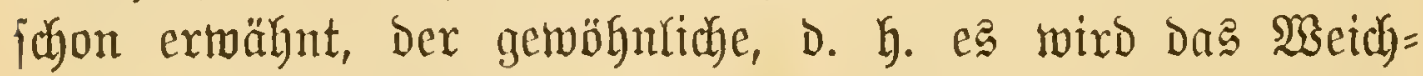
gemebe biejer Bapfen mit Der Spibermis eingezogen utb dann unr Das leere CGitinfutteral cntfernt.

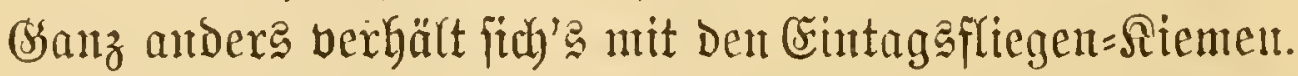
Şier wird nämlide nidgt blof das Futteral, hier wird ber

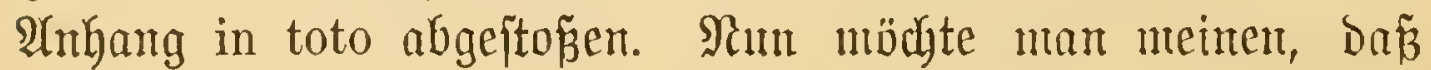


bann bei Diefer Amputation in Der Sant ber Ffiege eine

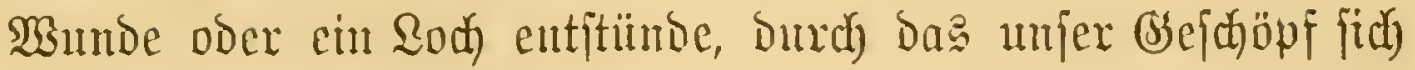

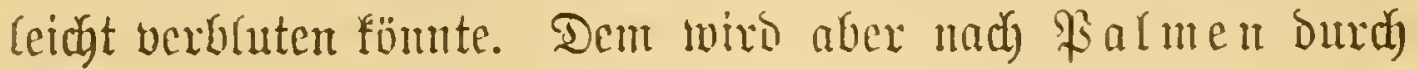

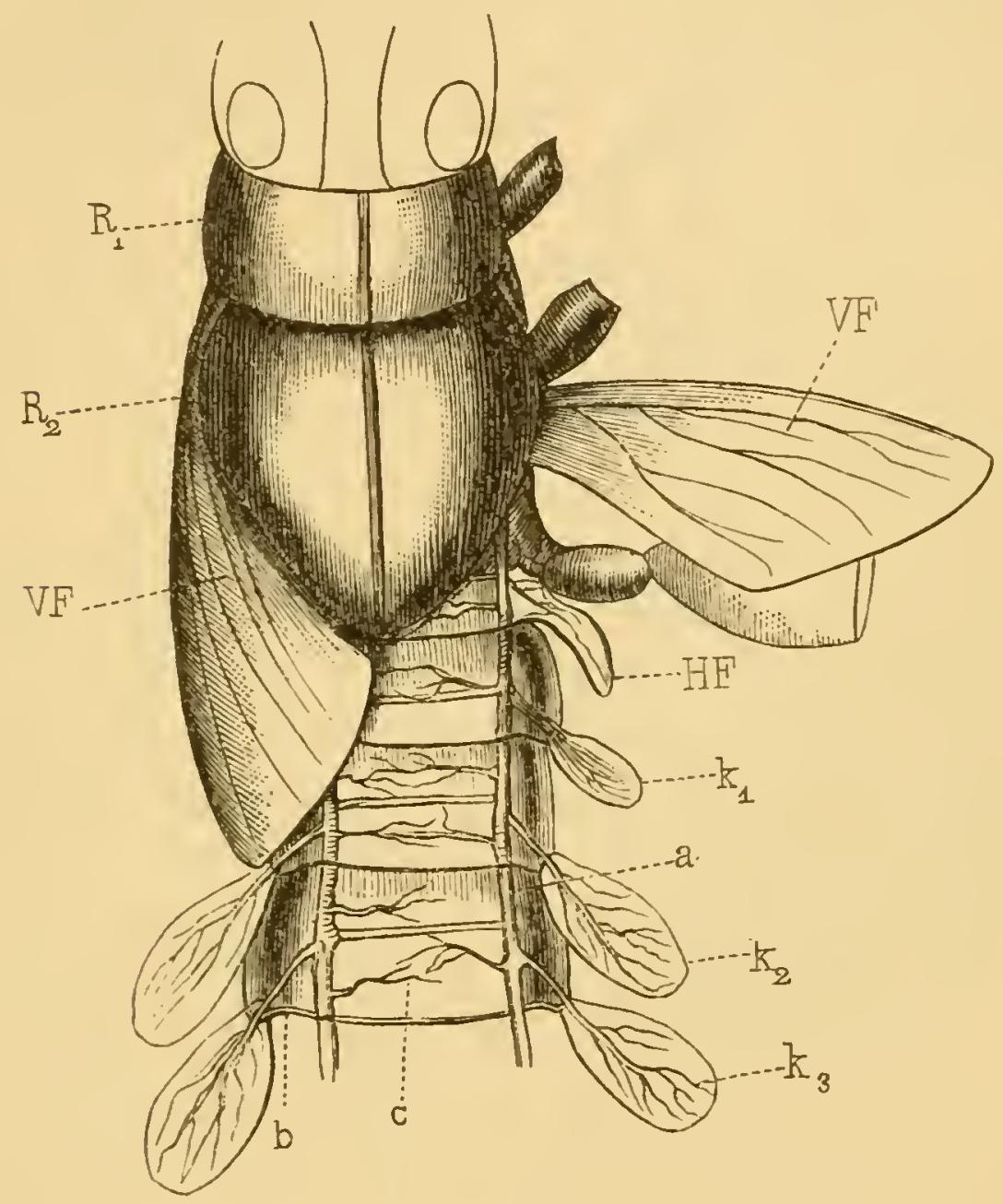

Fig. 162.

Cloeon dimidiatum, Rarbe.

VF Borber $=$, HF Şinterflügel, Gomolog Den Tradeenliemenbrättern $\left(k_{1}-k_{3}\right)$ ber Sinterleibsjegumente.

(Driginal.)

eine $\mathfrak{A}$ it Muterbindung vorgebengt, indem bie Trenmung ber Weidyaut jener der Szarthant voranggeht und bie $\mathfrak{B}$ umbe,

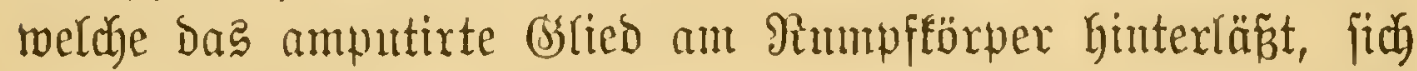

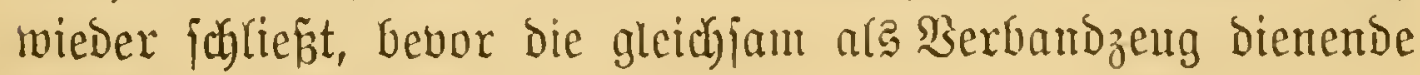
Egitingant abgenommen wiro. 


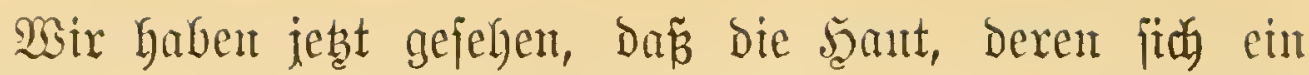
Snjeft zu gewifjen Beiten entredigt, ein genaues und treue Arbild der bseftalt ijt, die es in dem eben abjolvirten Stabium bejefien hat, mo went wir alfe die Bälge, die ein ßerf Der Reife mach ausziegt, hübju ausgeftopft ober fonft abjuitirt neben einamber auffifelften, fo befämen wir, während es felbjt unanfgaltjam jeinem Biełe entgegengeht, einen Heberbliaf über

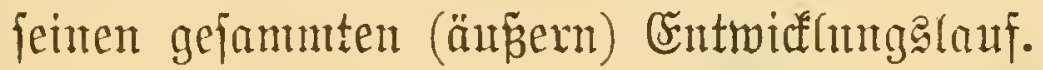

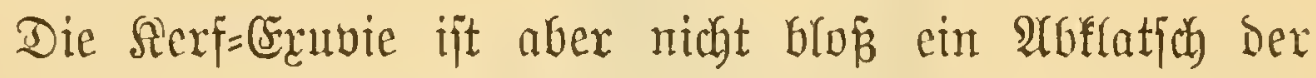

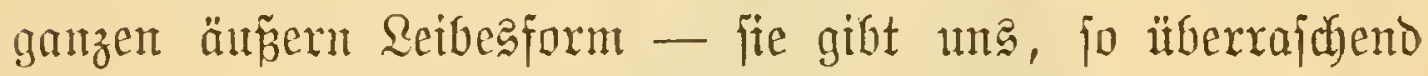

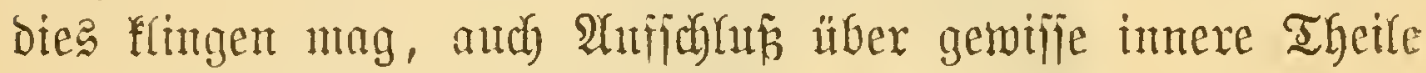
mo Cinnichtungen, bie fein Iräger bejeffen hat.

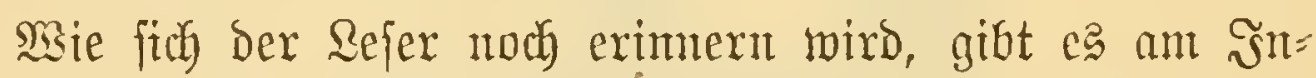
jeftenembryo einen Buftand, wo bie Şaut oder Das Eroberm nidhts atroeres als einfacher Sdylauth ober Sact ift. Die fpätere, bifferenzirte Reibesform entitebt Dann durch gewiffe Ein=

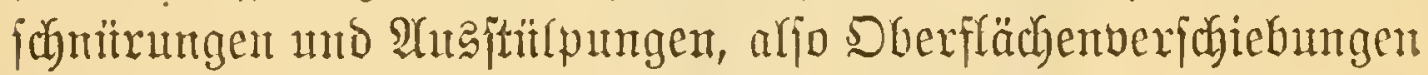

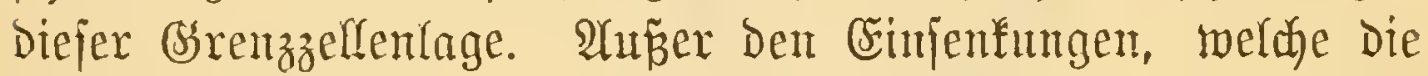

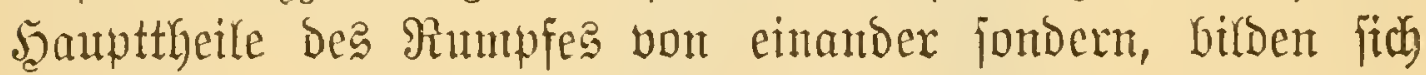
aber noch andere, tiefer in das Sörperimnere eindringenbe. So futo befantutich Borber $=$ und Şinterdarm, getwifie Mand $=$

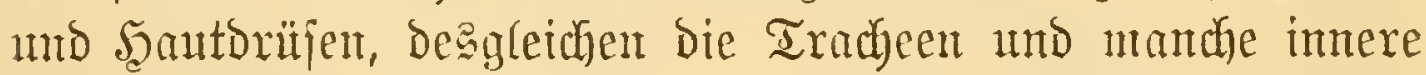

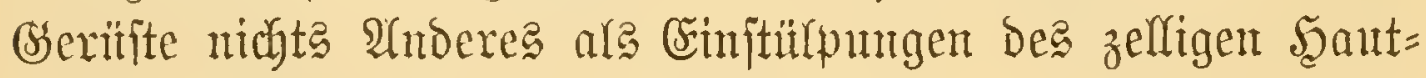
blattes. So weit afer bas lestere reidyt, mag es mut wie an

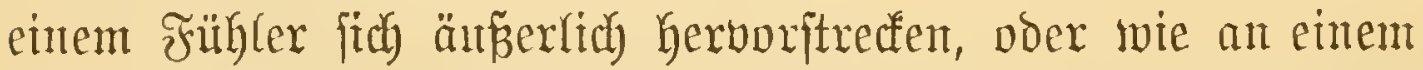
Suftrohr fich innerlich vertiefen und anghreiten, jo weit reidat

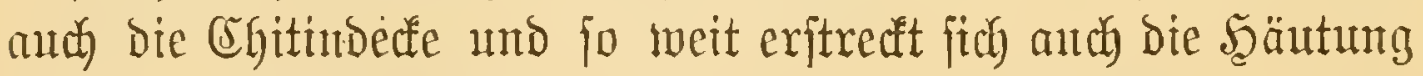

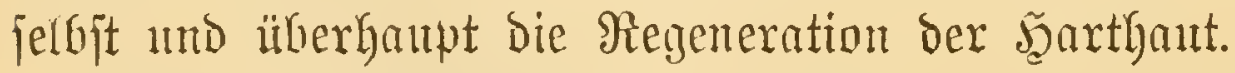

Dex Rärgåghntitt Durch eine Fliegentuppe in Fig. 163

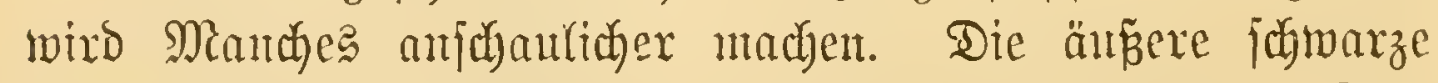

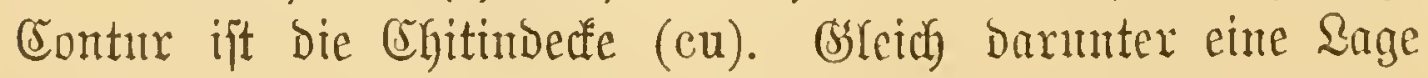

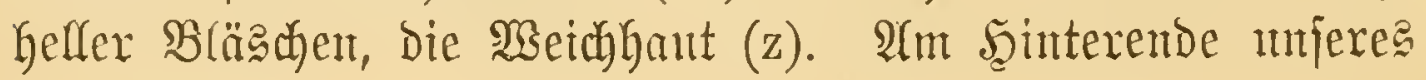




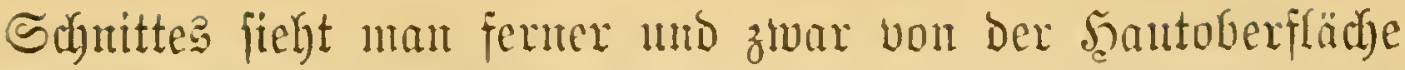

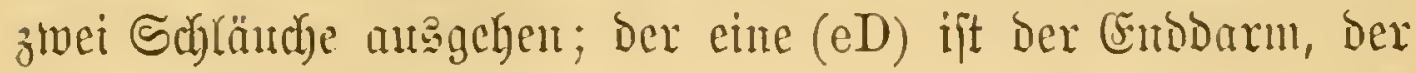
andere (St, Tr) Der grof̉e

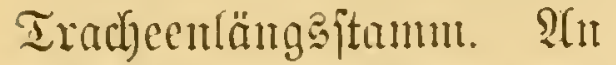
Uebeterem bemerfent wix die= jelben zwei (ssewebajujichten wie frïlyer an ber Şaut, Inur, weil es einte Ein= ftü(punty in verfehrter D D nutrg, nämlich äuñerer(ich) cinte Lage von Zellen, bie, wie man bei St jielgt, an= mittelbar in jene Der Şaut iibergegt, uno imter(ich eine alferbing feryx zarte ergitiu= haut, voul der Ginfichtticy des 3ujammentanges mit bem Sintegument Das (s)leiche gilt. an vorliegenden Schnitt bemerkt mant aber imter= halb diejer Chitinnögre nod eine zwcite z. Th. etrog zn= jammengejdyrumpfte. Dies ijt ehen die Erubie Der Irachea, unter ber fich bereits ein nener Cgitin= jud laud gebirldet hat.

Dáz aber bicje Tracheen= (Exubien aud) wirflich ent= fernt werben, bas farn mant bei ber Şäutung jefbit uno

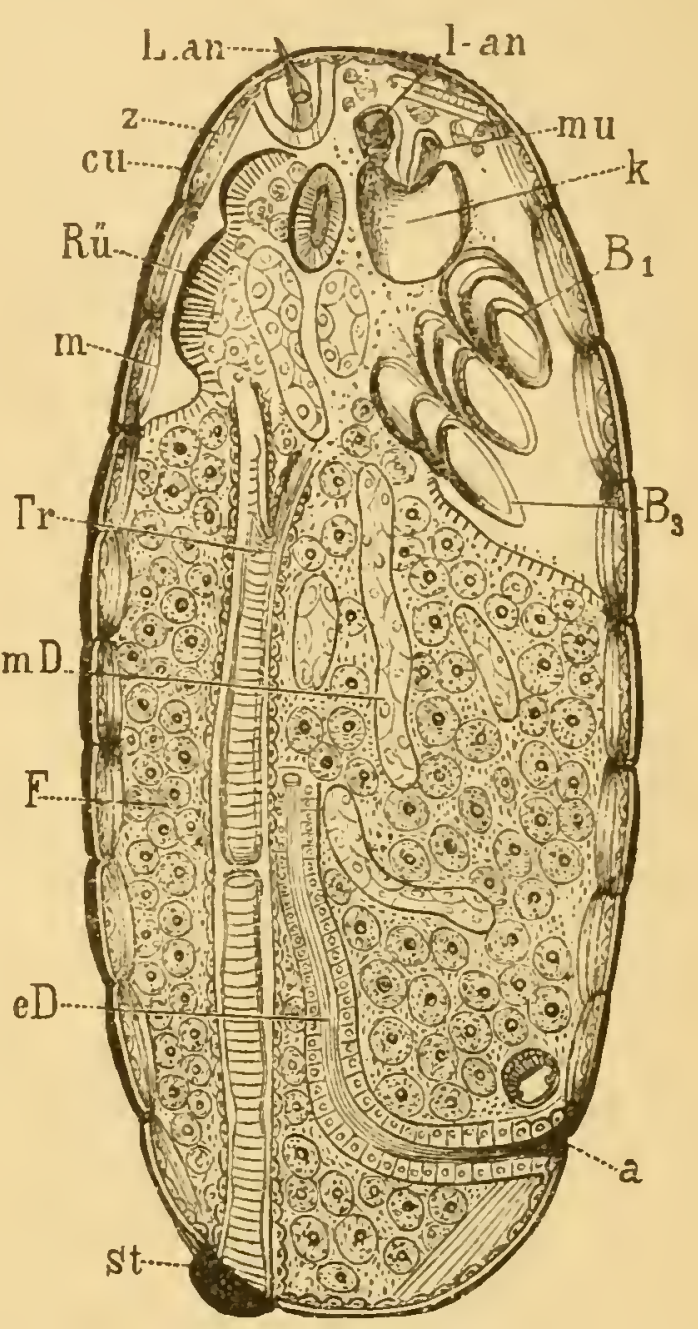

Fia. 163.

Mebiauer \&äuggiduitt burd eine zroei Tage

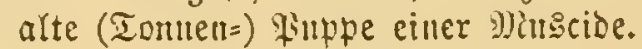

cu biffe Rarven=(E)itin=) Şant, z Epidermis (BelfGaut), $m$ legmentirter (Earben $\Rightarrow$ ) Saut= muselid)Lau币, Lan Antemne, st Etigma, Tr Trudea, a 2 ifter, eD Endoarm, mD Mittel=

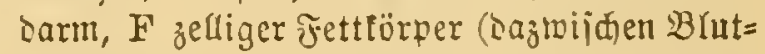
lacunert) Der \&arve; $\mathrm{k}$ fiopjanlage, mu Mimstheile, Ian zintennen, $B_{1}, B_{3}$ Beine,

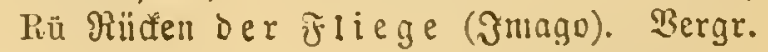
(Driginar.)

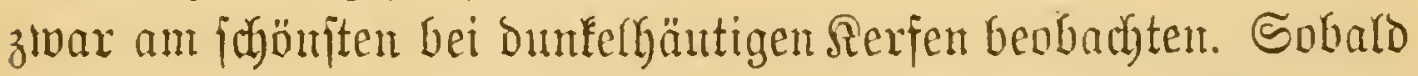
au einem folden Thier ber Balg geborjten ift, fieht mant, 
Dañ fich zwifuch beiben, und zrwar an Den Seiten, Dort wo

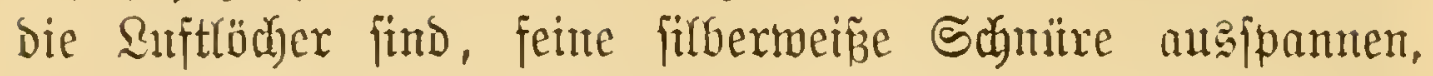

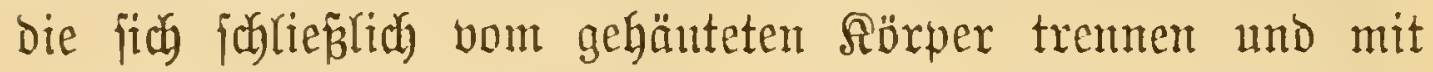
Der Errutie verfleben. Man merft wohl, daż bieje Fä̈en, Die jelbit nach vollzogener Sonberung von Şaut unb Sïrper noch einige Beit eine Serbindung unterfalten, nidjts 2 (noere? fint als bie aus Den Stigment hervorgezogenen \&uftröhren. Breiten wix nun eine polde unter Sajjer borjidytig nit Nabeln aus und bejehen fie mit ben Bergröperungaglna,

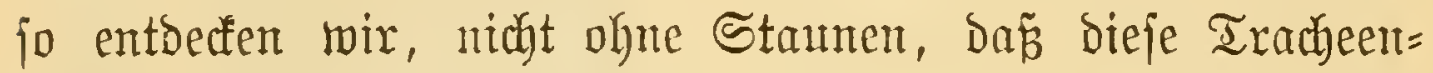

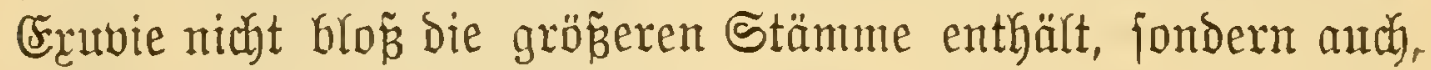
z. Th. wenigitent, bie feineren $\mathscr{A}$ ejte und 3meige, die fich

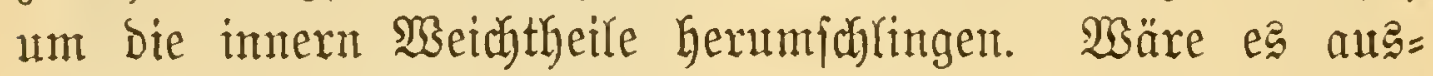
füfrbar, die vielfach abgeriffenen (snden zu unterbinden und

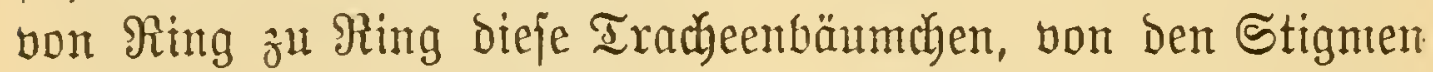
aus, mit einer farbigen Mafie zu injiciren, jo mürbe man ein ganz föftliches ßräparat befomment.

Mähremb hier und an andern Sntegumentalorganen bie

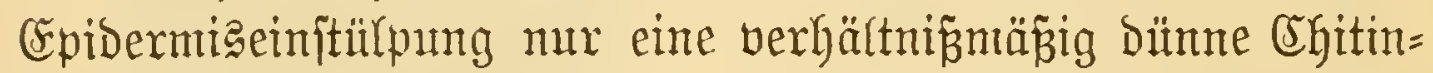
lage ausjocheidet, in Der Mitte aljo ein Scohlgang bleift, fülrt

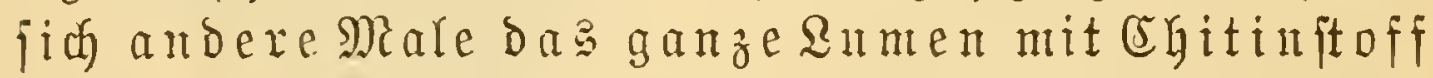
a u. So entftehen z. $\mathfrak{B}$. jene "innern". Sfelettheile uto Selnen, an benen jich bie Mugkeln anheften, und bie alle,

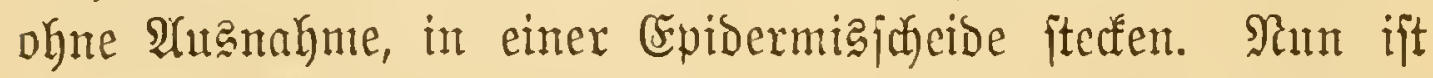

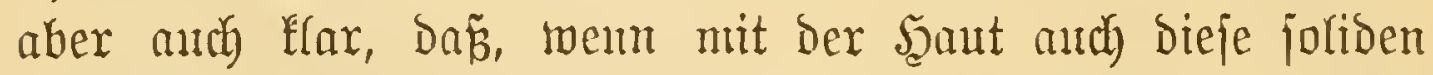
Fortiäbe aus Dem Rörper hernusgezogen weroen, an Deren Stelle jich Deffmutgen bilden und zeigen miifien, die dann erjt allmälig wieber verftopft mo gejdolofien werden.

Alünahmaneije verlöthen aber andh poldye Şanteinjtïl= purgen, bie jonft gemöhntich offen breiben. So jiebt ber Lejer an ber rebtbeiprobenen Fignux (163), Dá in Der Friegen= puppe die Crgitin= Ŝnnenthant bes Endonarmes gegen Den 
Iffer (a) zll jid verbict und an rescterer Dertfichfeit bie Deffinutg total veritopit.

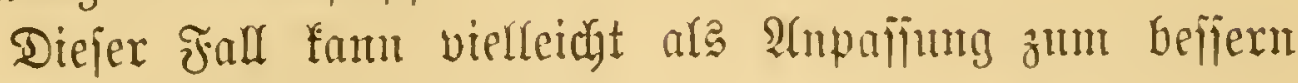
Sayub diefes Stabium geltent. 秋eit roidytiger find aber folgente Serthäıtnij̄e.

(5s wax forjon megrmala, und anth in biejem $\Re$ apiter mieser, vou

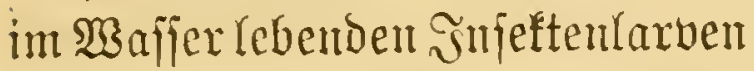
dic Rebe, bie nicht Durdy Iracheen, jonbern Durdy Riemen atgmen. Skun finoct man hier (F̧ig. 164) neben ben lebterent (d) and fidnon Die Cinnidytung zum athmen in Der Rnft, wie fie bas Smago hat,

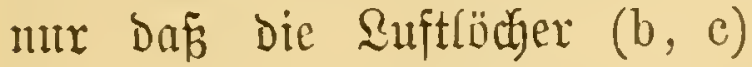
reip. Die zit Denfelben führenden Tradjeen zum Sdutze gegen Daz জ্রajier für getoöhulich ge= jufojien furd und mur bei ber Şäutung behuf̉ EntF̄ernung Der Tradeen= Exutuien momentan ge= öffinet werdent.

$\mathfrak{U m}$ mut mad) ber flitdrtigen Schildorutug ber Şäutung nod) einmal auf bie Iurjachen ber= felbest zunüqufonmen, fo ergibt fich zunächjt bie Qubängigfeit biefer

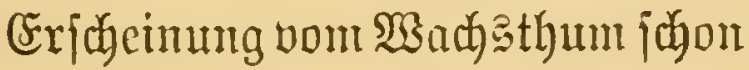
แmb ber Thatjache, baj fich bie= jelbe mur währent jener Entroict= lungaperiode mehrmalis wieder= holt, in weldyer faftifich eine

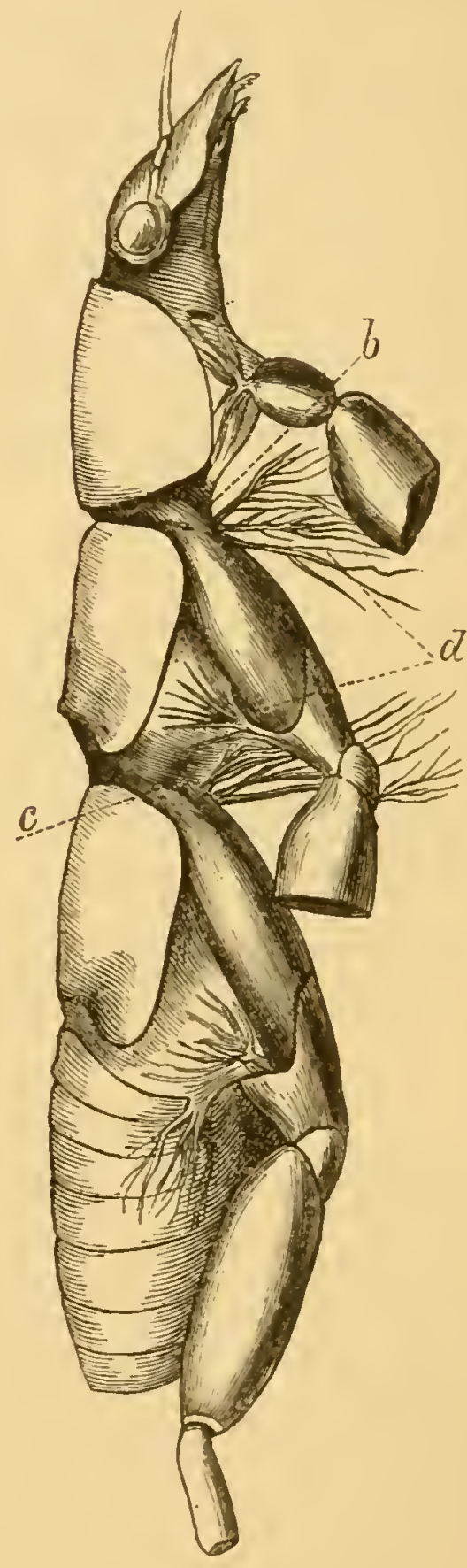

テrig. 161.

Sarbe eitter Fertice.

b uno c Suftipalten (Stigment), d quaftenförmige Iradeenfiement.

(Driginal.) 


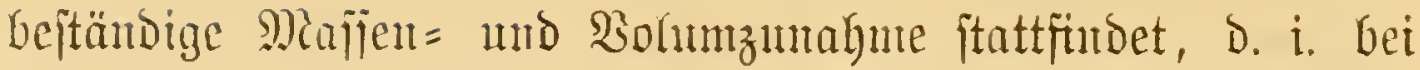

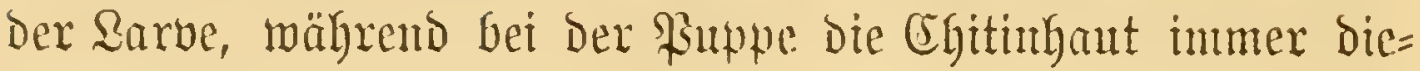
jelbe bleibt.

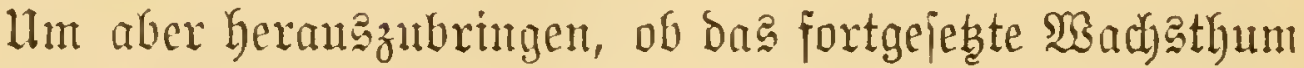

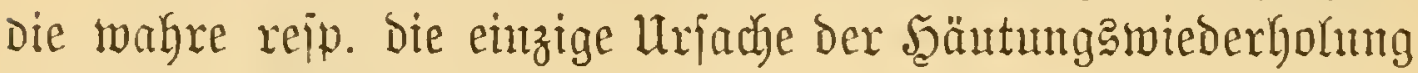
oder Der $\mathfrak{X}$ echjelyäutigfeit ift, wollen wir eimmal fragen, ob

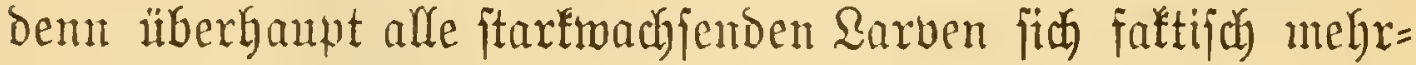

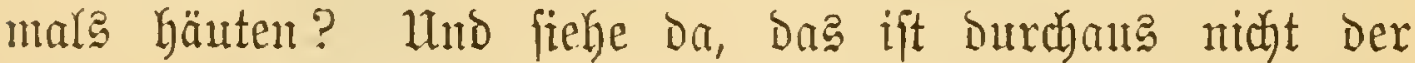
Fall. - Es⿱ gibt wenig Sarven, die fo jtarf madjfen mie bie Der Biene oder die einer $\mathfrak{A}$ a

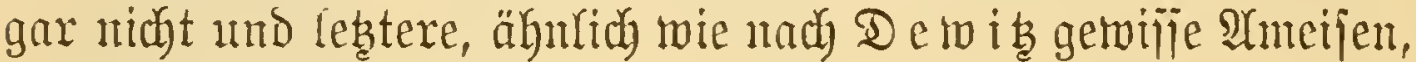
mux eimmal.

Der Umitund nun, dáp gerabe bieje a uberweitig be=

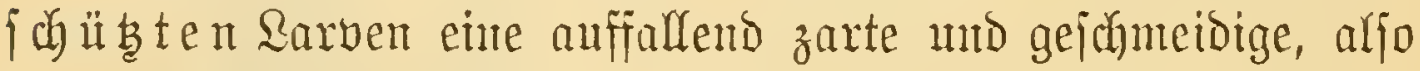
aud jegr ermeitermngäähige Sant haben, bemeift woht zur Sientüge, Daz bie Şäutung in Der That auth mit der $\mathfrak{B} e=$

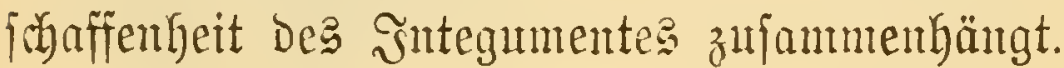

\section{Zenererliche Geftaltsvarnderungen.}

(Efto=sestamtorpfoie.)

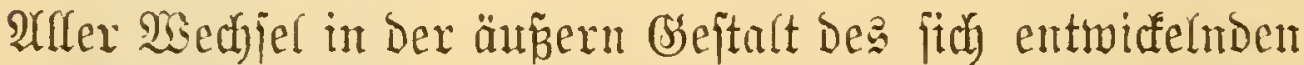
Snjeftes beruht - einige Rerfgruppen mit ganz abjomber= licher Metamorplyoje angenonmen $\cdots$ an

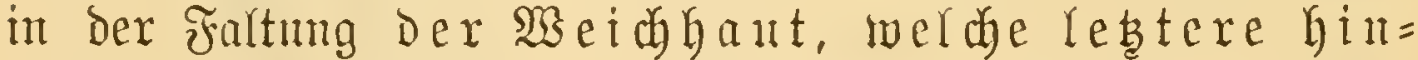

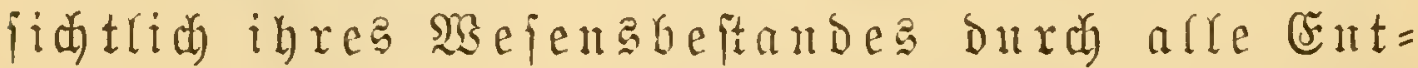
wiflungatabien himburah, bon Embruo an bis zum Smago, diejelbe bleibt.

3or Affem haben wir ms mu an einigen Beifpielen über die verjchicdenen Şanptarten biejer Meränderntngen zu

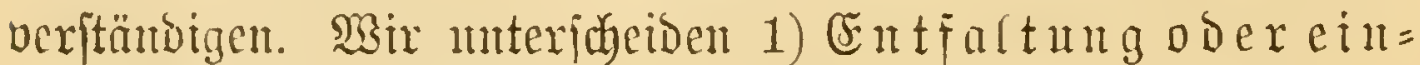
fade Entwiatung (Exaploje) mD ipeziell bie Nen= 
bildutg (Meontorphoje $=$ Meoplaje) und 2) bie eigentlidge Umformug ober Metamorphoje (Metaplaje).

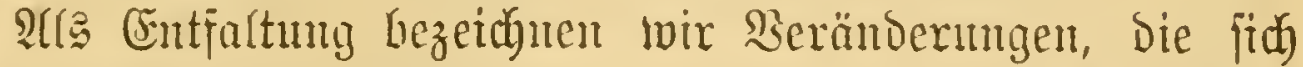
midyt anf Den Typus, fondern mur anf Die räımliche Differenzi=

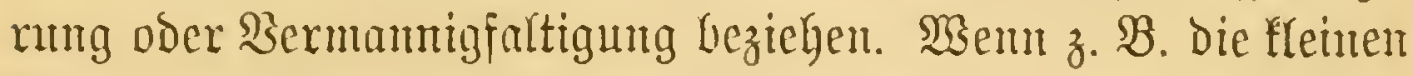

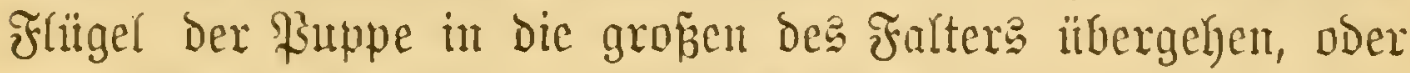

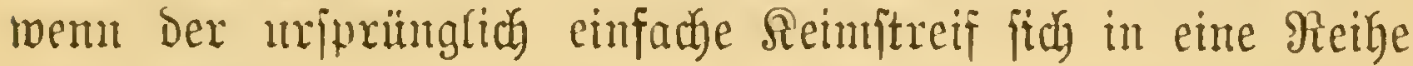
von Segmenten abgliebert, fo ift bies eine entfaltung. Speciell als skenbilbung aber bezethnen wir bie lebtere, injofern fie neue, früher gar midt angebentete Theile her=

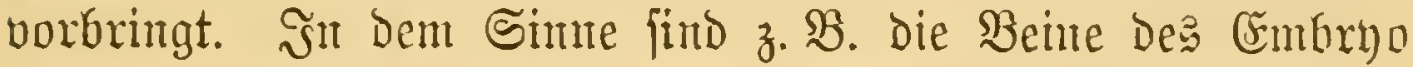
oder bie Frïgel ber Larbe aus und an Der Meidjhaut ent= faltete Reugebilde.

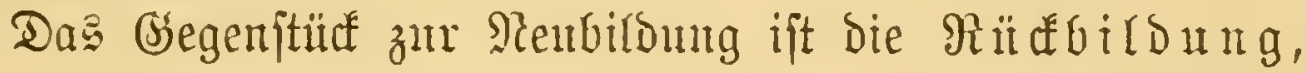
bei welcher ein früher Beftehendes fei es ganz ober zum Theil

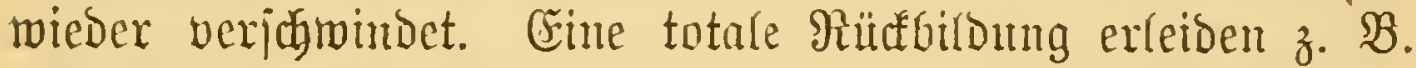

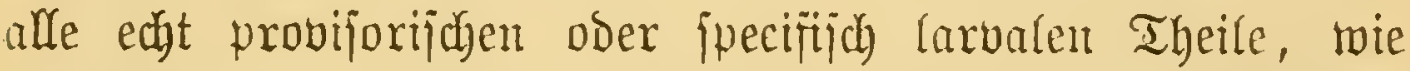

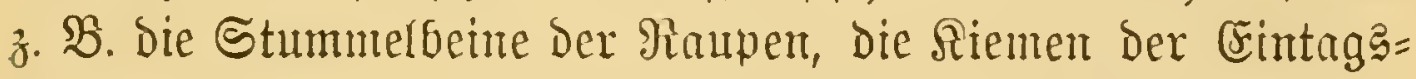
Fliegentarven; einte partielle hingegen die Dberfiefer ber

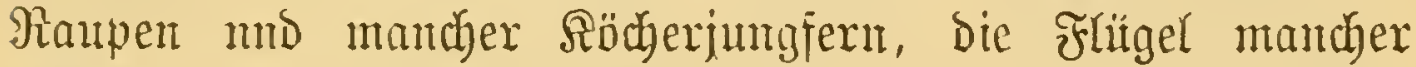
Snjeften und andere 5 rgane.

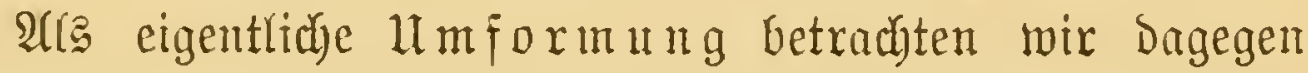
cine auf Den ganzen Şabitus bezitglidge ßexänderung eines bereits gegebenen, mehr ober weniger entralteten Theiles.

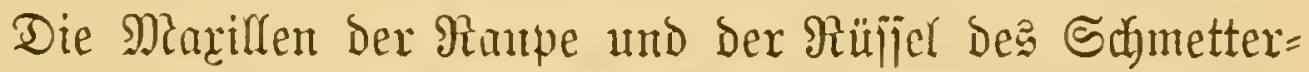

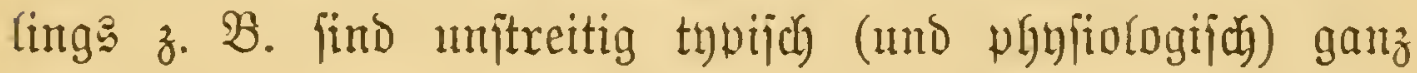
verifhiedente Dinge, Die Bildung des lebetern aus erjteren berubt alfo anf einer wahren lumformung ober metaplaje Die aber, da bie Riijijellaben viel länger alz Die Raulaben fund, zugleid) von einer entfaltug begleitet ijt.

Mian begreift übrigens jofort, baj jpecielf die Reubildung von ber llmbildung mur grabmeije verjebieden ijt, impofen ja 


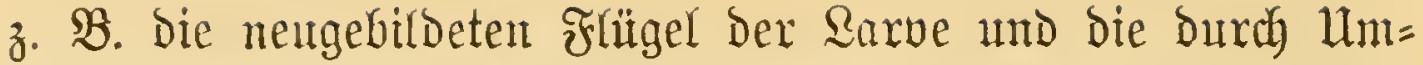

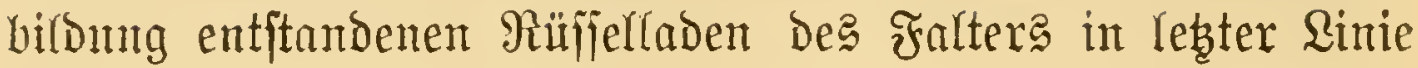
beibe ans einer gemeinjamen Sormmblage, der Saant herbor= gehen, mux Dá̉ Dies bei bent Rantenflïgeln un mittelbar, bei ben Falterrüjjelladen aber mittelbar $\mathfrak{D}$. $\mathfrak{h}$. unter $\mathfrak{D} a=$ zwifhentreten Der gianpenfanladen gefohiegt.

Sabar zu unteridheiden hat man aber zmijhen ber Reutbildung ober Reoplaje, wie soir fie Gier verjtehen, unto jenter jpäter zu erörterndent $\mathfrak{R}$ eu erze genefe, bei der gemifife imaginale Şatorgante gar midyt auts ber larbalen Weichyant, fondern ans bejonderent intmeren 2 thlagen herborgehen.

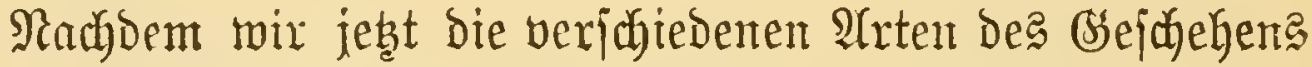
oder Statffindent Der Scantmetamorphoje auseinndorgejest, miitijen toir nody die Bedeutung oder Das Biel Derjelben in's Auge fafjen. Und da fint vornebmlich zwei Rategorien von Beräntorungen zut ntterfcheiden. Sente, melche jich auf

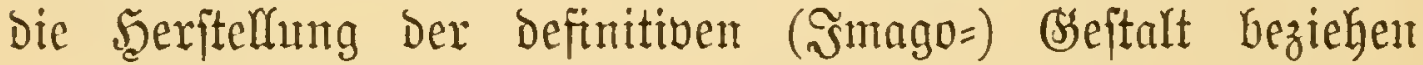
- Den Fnbegriff berjelben nannten wir jabn frïher bie Smaginalifinung -, und bant jene, weldye unr eine vorïber= gehentoe ober proviforifate Bedentung haben.

Da restere nody ipäter in 81 fanmenthang mit ber Ere flärnng Der Metamorphofe zur Sprache fommen, bejaränfent wir uts im Folgenden rebiglidy anf bie nähere Sdjilberung Der Smagintalifinutu, wobei wir mit Rüufficht anf Den $\mathfrak{l} \mathfrak{m}=$

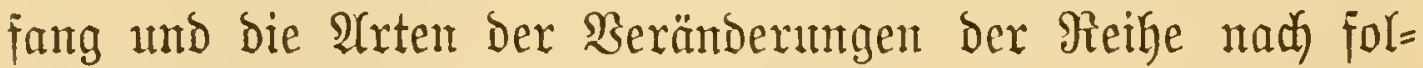
gende Utbtheilungen unteridheiden werdent.

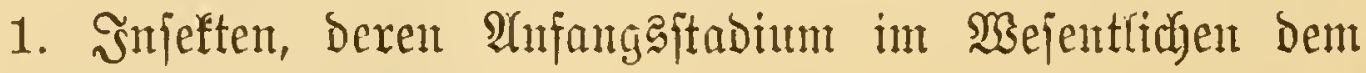
Эmago gleich ift.

Birbung Der Fflügel, leine ober geringe Rütút= Dungen. (S)leidye Rebentameije:

Bicrndflïgler, Schntabelferje, Błajinjiïler. 
2. Snjeften, Deren Shufangagfudiun ägntich wie bet 1 . Dem Smago gleich) ijt.

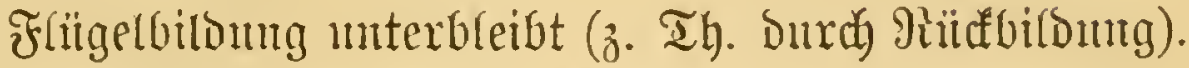
Bsicidye Rebertsweife:

sliigulloj:

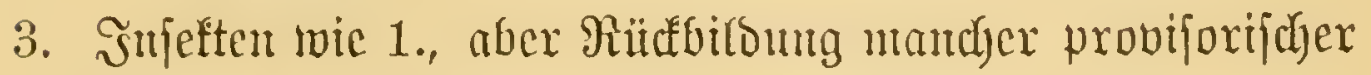
Drgane in Folge bes Miediumtuedjfels:

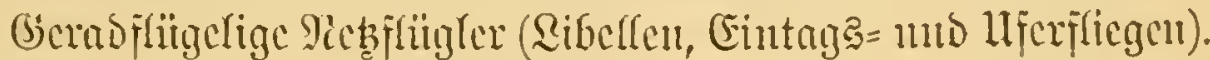

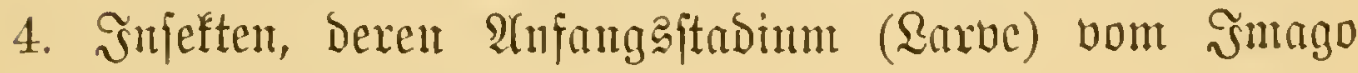
mejentlich verjujieben ijt.

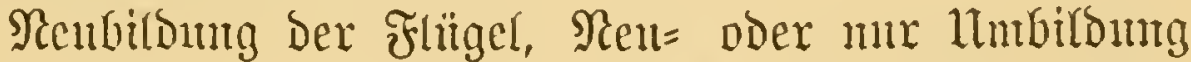
vieler anderer Drgane (z. S. Beine, Mumbtheile). Meift

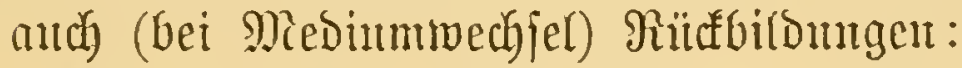

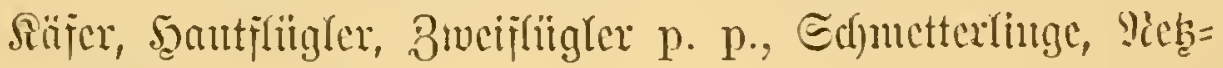
flitigler p. p.

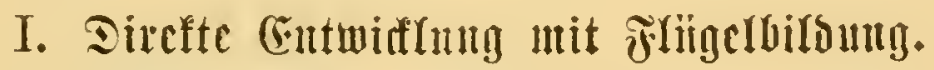

Bergleichen wir einen Repräjentanten diefer Grntppe, 3. B. cine Siübenjchabe, mit einer Biene und Dann beiberlei Typen mit einem britten gemeinjamen 3 uftand, D. i. mit Dem

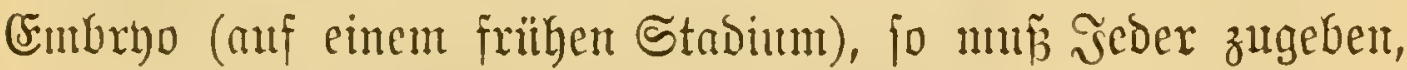

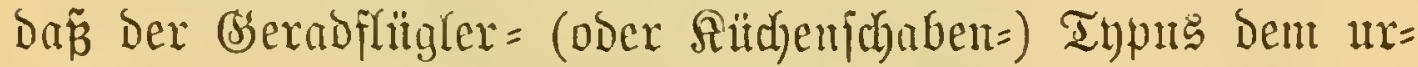
jprïnglidjen ober embryonalen 3uftand, weit näher jteht als Der Bienentypus.

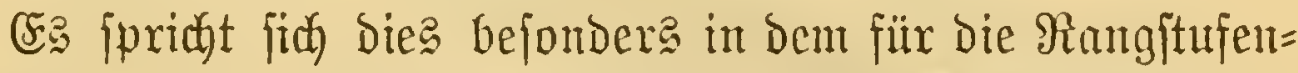

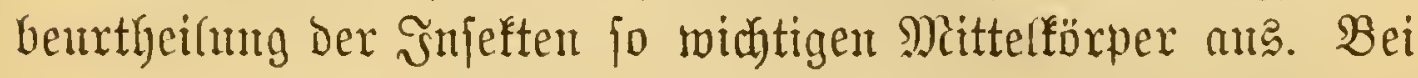

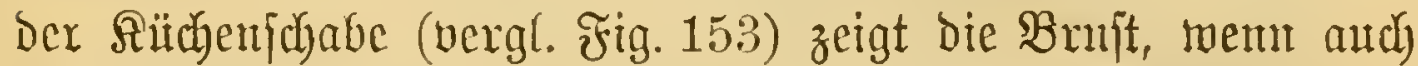

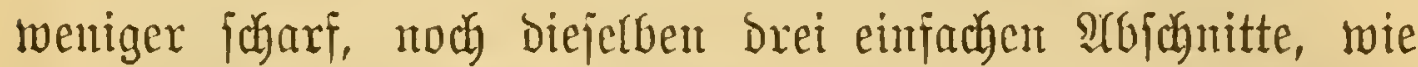

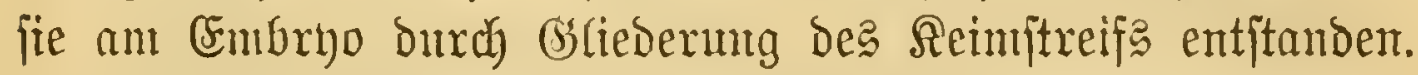
Bei der Bient Gingegen finto nidyt bloj̉ bic zwei Shinterjegmente Der Bruft unter cinantoer, jondern nod, wie woir in Fig. 157 gejehen, mit Dem criten Şinterleibaring verwadyjen, D. $\mathfrak{b}$. aljo bie primäre Rumpfglicberfette ift an Bicnenimago im 
3ufanmenthang mit ber Sräftigung und Şervollfommumug Des Ffrngapparates viel höher und ftärfer Differenzixt als beim Srerabflüglertypus. Qebterex mürde ungefähr Gimfichtlich ber Stammbifferenzirung mit ber balbpape dex Biene zu bergleiden feil, wo

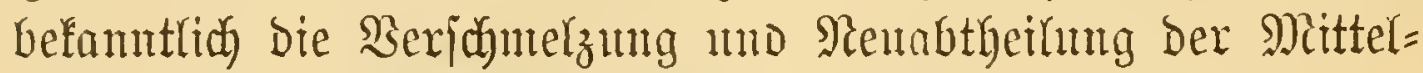
ringe erit in 8 uge ijt.

Bem mu aber Das Snago Der biejer eriten Gruppe angehörigen Serfe relatio einfaner D. i. vom urfprüngliden

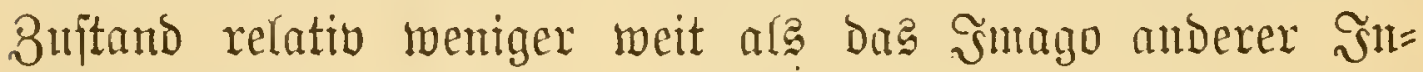

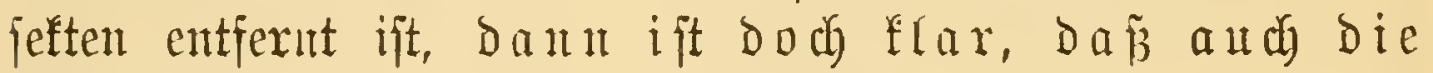
Entwiafung biefer (s)ruppe fid einfader als fonft geftalten $\mathfrak{k} \mathfrak{a} \mathfrak{u}$.

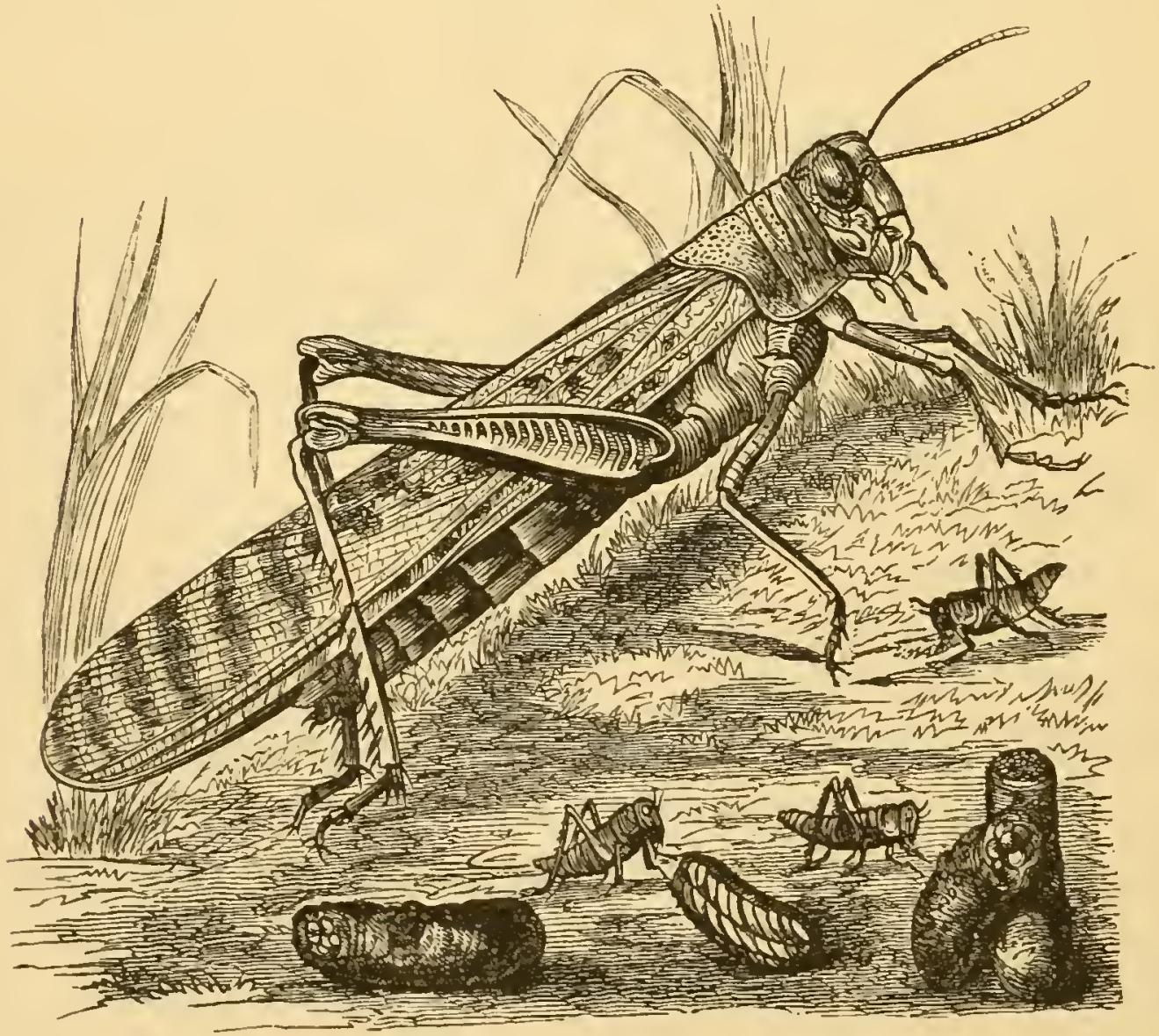

Fig. 165.

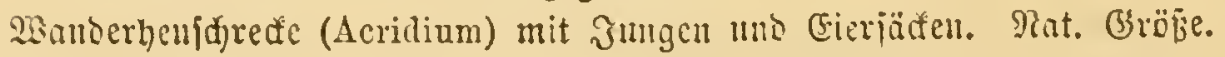


Stellen wix mu, um an Die betreffenden Berändorungen felbit zu fonmen, Die fleinen Springer unjeres Bildes (Fig. 165) ifrer Mentter gegenitber, fo ift bie Familien =, ja jelbjt bie

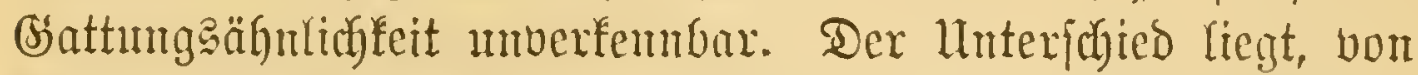
flemeren, fith allmälig anggleichenden Differenzen abgejeben,

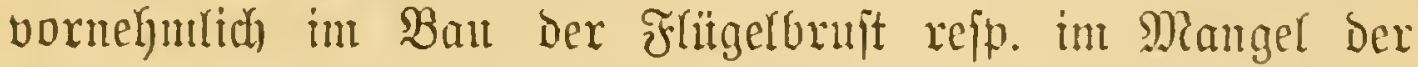
Frïgel, und mit Der Bildungämeife der leştern wollen wir

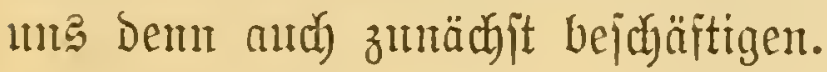

Die Sache läpst fich am Reidyteften an einem Schema verjtehen, wie wir cin joldes in Fig. 166 entworfen haben.

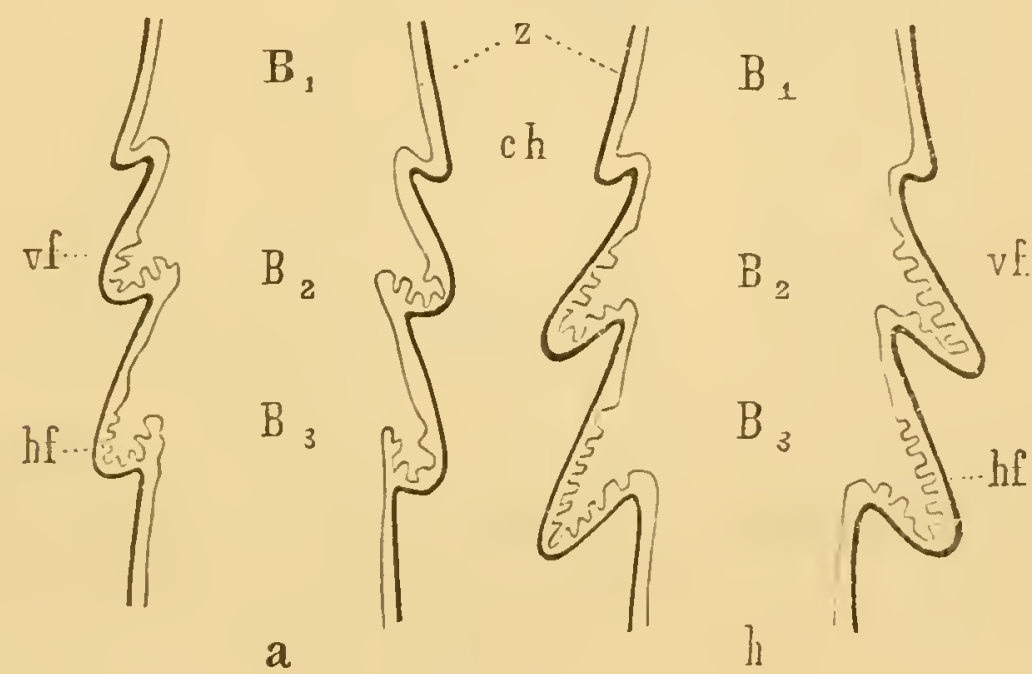

Fig. 166.

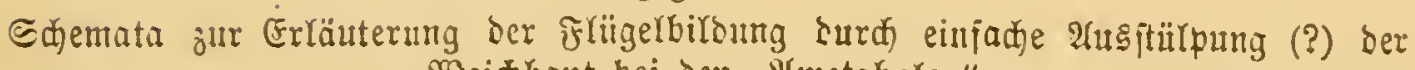
Beidhaut bei bent "îlmetabolen".

$\mathrm{B}_{1}, \mathrm{~B}_{2}, \mathrm{~B}_{3}$ Borocr=, Dittel=, Sinterbruft, rf $\mathfrak{B o r b e r =}$, hf Seinterflüger, ch Ehitin=, z zellige $\mathfrak{\text { Weichant. }}$

(Driginal.)

Darin bezeidynten $B_{1}, B_{2}, B_{3}$ bie Drei emander fajt gleidjent Brujtringe, jagen mix einex jungen Rühenjwabe. Ferner be= Dente bie äuz̃ere biffe Contux (ch) Die Cyitin= und Die innere

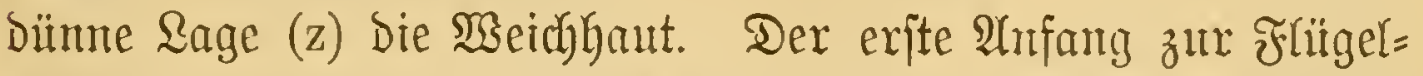

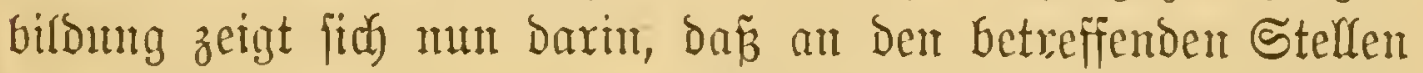

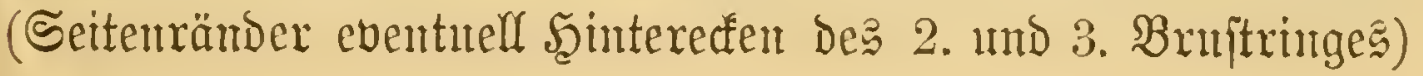


die bildungäfäbige Weichlyaut ftärfer wäd)ft und fich aud ftärfer faltet als an Dent übrigen Theilen. Bei ber näbdjten

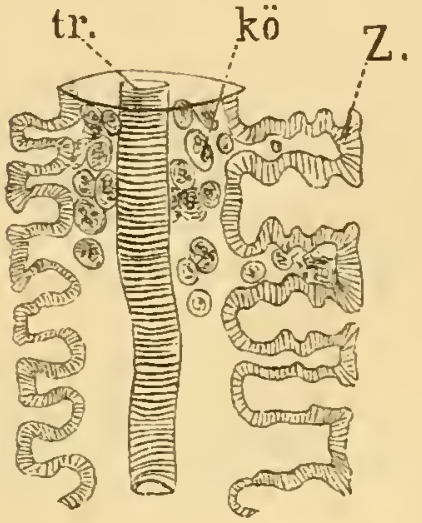

テrig. 167.

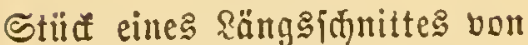
ber Flügelanlage einer ausge = wachienen Raupe.

$\mathrm{z}$ in primäre grof́c unb jecumbäre fleinere Falten gelegte Zellhant, tr Iradieen, kö ̊örnerfugeln im sumen ber frligeltajde.

(Driginal.)

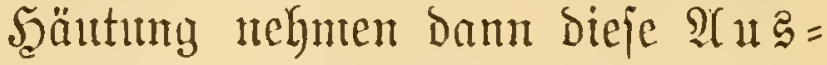

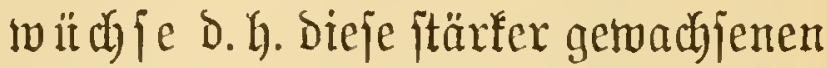
und ftärfer gefalteten Brufthauttheile die Form befonberer Rappen an, und Dies fint bie "Fl ïgelfbeiden". "Scheiben" Deamegen, weil in ifnen utach Dent gleichen Faltutugaprincip wieder meue und gröpere Flügel fich entridfelut. - So ergeben jich nadh unt mad bie in Fig. 153 und 168 reihenweife Dargejtellten Bildungen. - Sm (Einzelnen, z. B. hinfictutid des Beginmes, der Stärfe, Rajul $=$ Geit und Der uäheren 2 rt des Flügel= wadesthum gift es allerding viel= fache, aber nod wentig ftudirte Differenzen und manthe

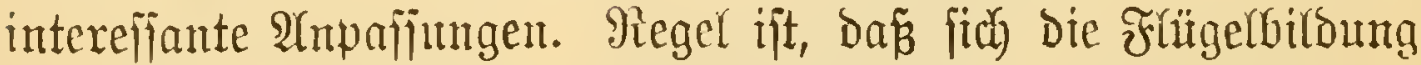
Durch mehrere Stndien hinziegt und in Bezng auf (Şrößen= entfaltung gegen Ende einen befdylennigten Bertauf nimnt.

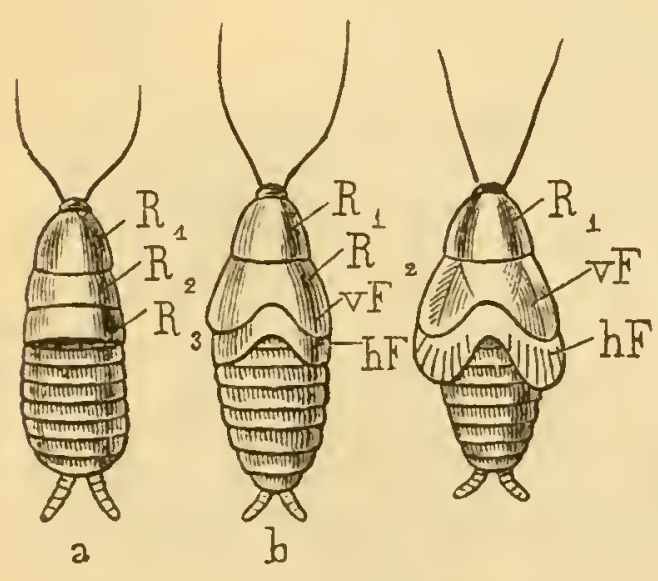

Jig. 168.

Natx Eing jei bejoutere her $=$ vorgeboben. Bei Den meiften umjerer Rerfe (wanzen, Ribel=

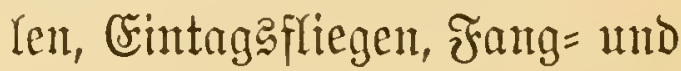
Stabhenladredfen, Dhrmürmex 1t. \{. iv.) entfteben bie Flügel wie bei ber Rübenfbabe vor= melynlich aus Den Şinterecten Der Riüctertplatten und behal= tenauth, wie Fig. 168 zeigt, bis zur Yeb̨ten Şäntung einte vortwiegento horizpntale Lage 


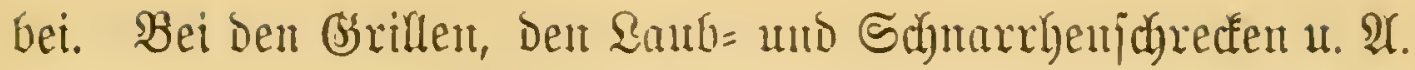
hingegen cridhemen jie (F̌ig. 169 vF, hF) als rein jeitfiche $\mathfrak{A} u=$

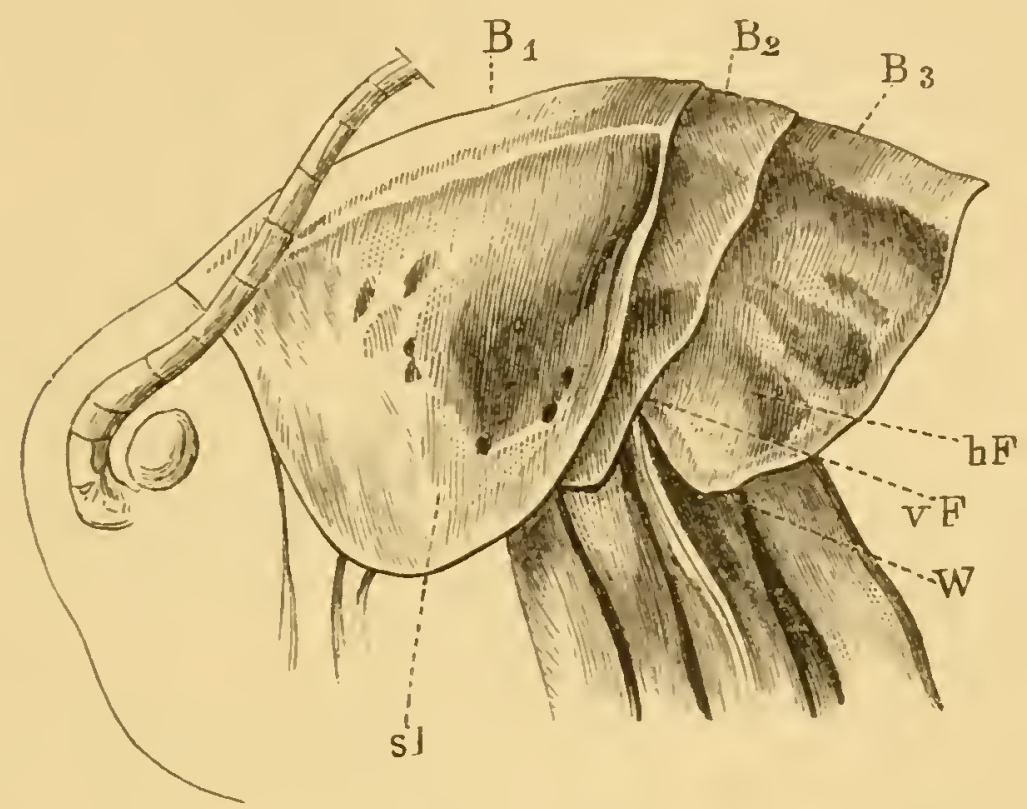

テrig. 169.

Brujtorb einer jungen \&aubheujdrede, bergr. rF, hF itnlagen ber f̧lügel, als ten

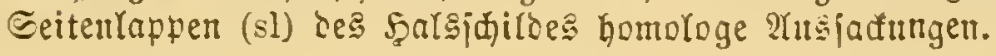

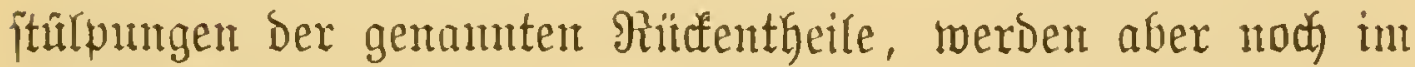

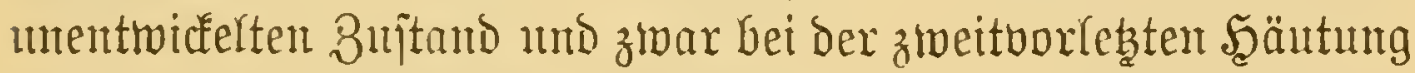

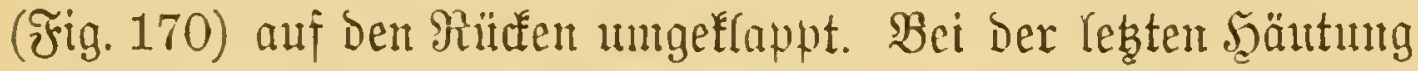

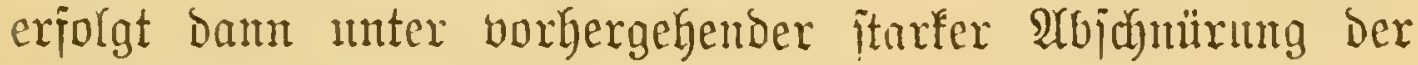
Flügeltourzel eine neue $\mathfrak{M m}=$ Drefung, biesmal um bie

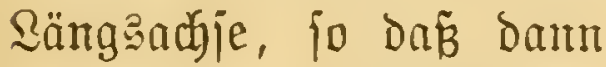

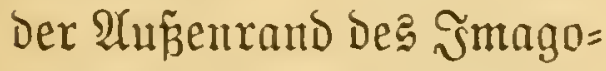
flügelᄅ Dent \$orberrant Der ieitlidjen $\mathfrak{A}$ ullage entipridyt. Bum Theil find bie? jedenfalls 2 Anpaijungen, injofern fïr einen miedergedrädten und breiten Reib die hori=
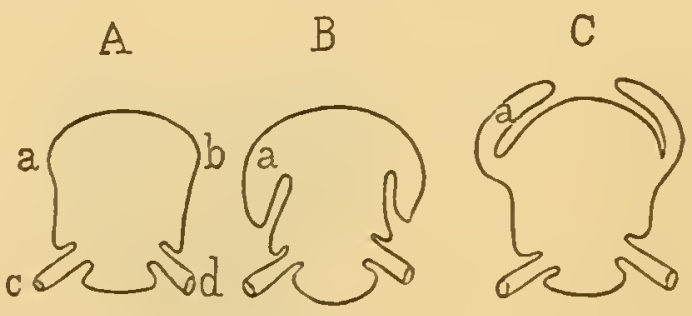

Fig. 170:

巨djematijđe Darjellnng ber Flïgelentialtung ber Şeujdreden an Durridnitten.

c, d bie bauditündigen Beine, a, b tajden= artige Falten ber $\Re$ it fertulatten, aus benen

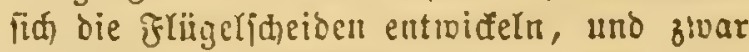
bei $\mathrm{B}$ in ifrer mrjpriingliden \&age, bei $\mathrm{C}$ nad erjolgter ltmregung auf ben ßü̈en. 
zoutale, für ciuen hoheu und funalen seib die jeitliche refp. dic verticale flügellage an= gemejfanex und bortheilhafter ift un in Folge gewifjer individueller abweidungen die eine Bildungameife aud leidst in bie andere über = gehen

Die SEntwidfung Der Flügel, ift obne Bweifel bie augen= fälligfte Formveränderung, welde nit unferen jungen Rerfen vorgeht. (5) gibt nber nod) eine andere, bie in mander Sin= fidyt für Den Bernf Des Snagos widhtiger ift. Wir meinen

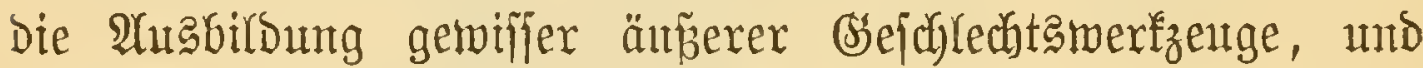
fpeciell Der inzbejonbere bei Ribellen, bei sriflen und \&aub= henjărecten jehr auffallenden Regeröhre.

Wie in exfen Band $\subseteq .224$ nachzulefen, befteht lebtere meift ans orei ßaaren von länglidgen Stücten, die von Den Baudplatten Der lebten Reibezringe auggeben. Das Nähere Der Entfteluntg zeigt Dann Fig. 178 A. Man fiebt hier ein junges, fagen wir heufdredenartiges Thier,

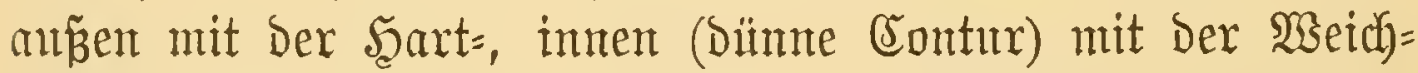
Gaut. Wie, vorne an Der B̧ruit, die Frïgel fich billden, ift

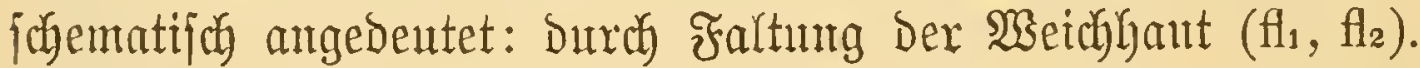
Bliffen wix mn in Die Shegend, wo beim vollendeten Tyier Der (Duxw) Punttinicn bezeidnete) Segeitadyel Gervoritebt, fo
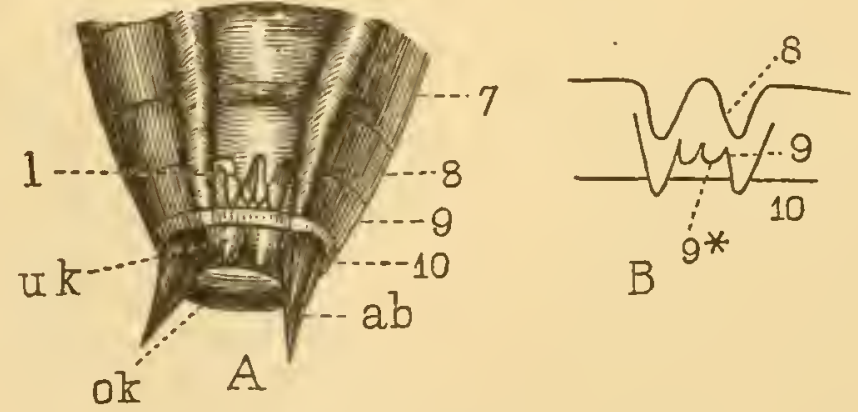

Fig. 171.

Şinterleibsende einer meiblidinen Saubbeujidrede (Odontura serricauda) im Jugendzuftand.

8, 9 zapfenartige 2mlagen ber \&egeröhre. 
bemerfen wir an miferem jungen bejdjöpf nod) gar nidhts. entfernen wir ater bie Şartgaut, fo zeigen fide 4 m an ber

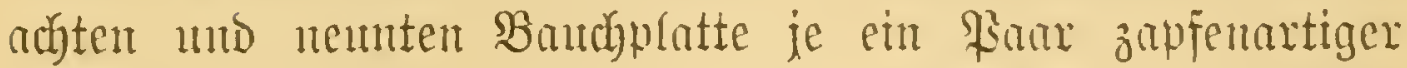
Sorfpritnge (vergl. audh Fig. 171), uto ber Rejer fieht,

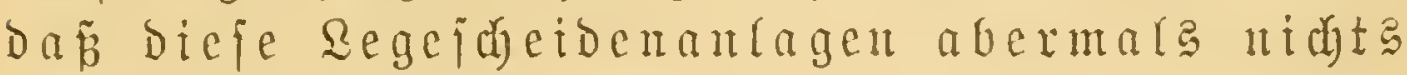
Inderes als Falteu der

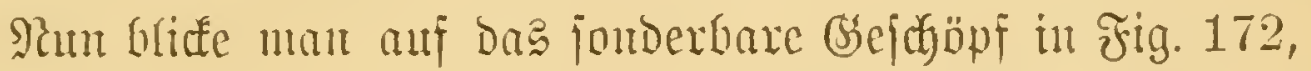

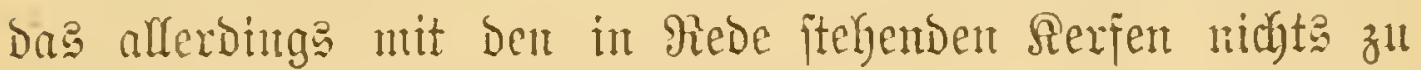
thum lyat. Selbes ift aber doch hödjit

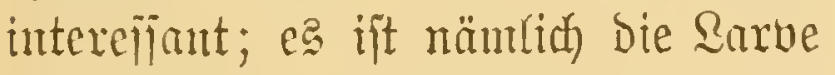
cimer mitzigen Schlupfwespe, Deren Meibdjen befantrict gleidyfalls cine segerölre haben, und ber Iejer ift gemin begierig zu erfabrem, wie letstere fiex, d. i. bei einem metabolifach Snifeft, entitegt. Naut, garz genau jo mie bei ciner Senjajredfe. Huter=

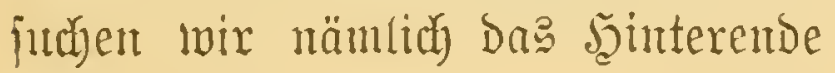
Diejer jeltfonten Rarbe, fo entoecten wir unter Der 惢eichant brei \$arare von Zapjen $\left(\mathrm{g}_{1}, \mathrm{~g}_{2}, \mathrm{~g}_{3}\right)$, Die, wie man fiebt, gatz und gar mit ben

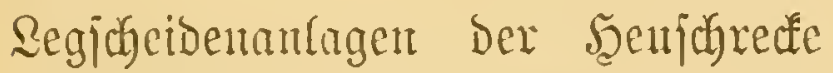
(テ̛ig. $171 \mathrm{~B}$ ) itbereimftintmen.

Dieje Ueberemftimnung aber

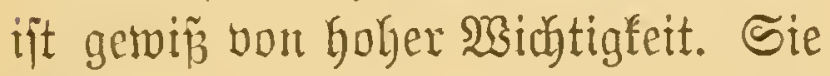

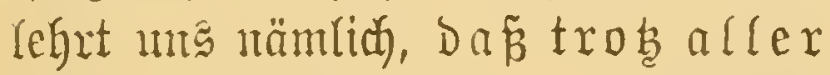
Beridiedenfeiten im Bane und in der Birdugameife

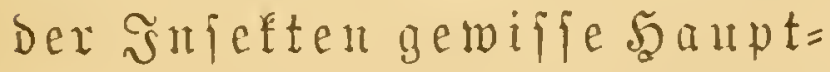

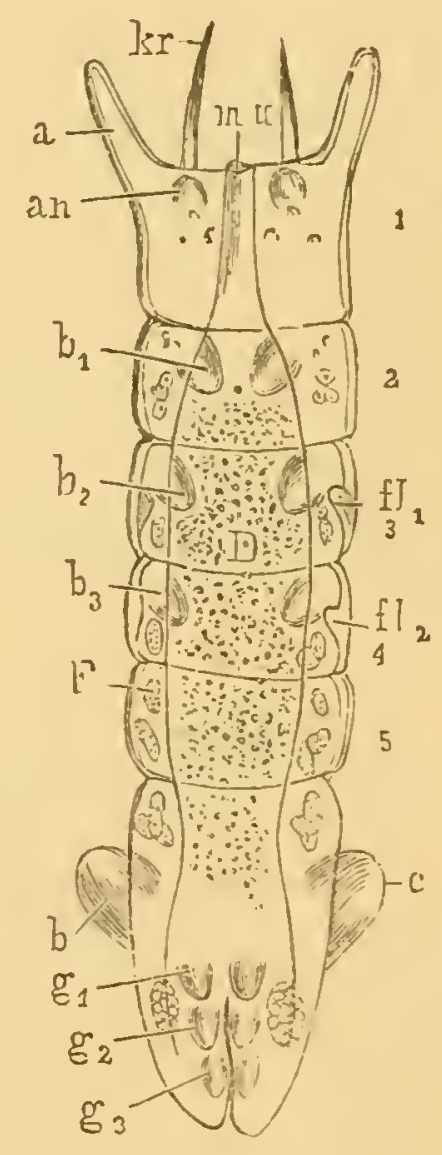

รig. 172.

Seţte Sarbenjorm bon Polynema (Sđ)lupitwespe), nad) (sianin. g1, g2, g3 2tnlagen bes sege= fachels. grumbzüge ber ertatidung bennod bei allen diejelben find.

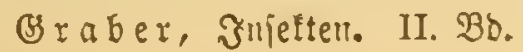


Bum Schnije nod eine Bemerfung. Die frither Getonte

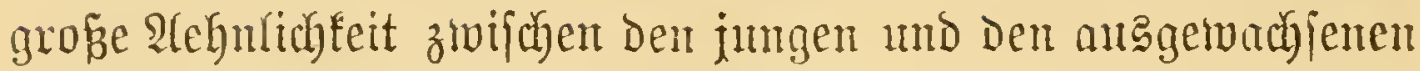

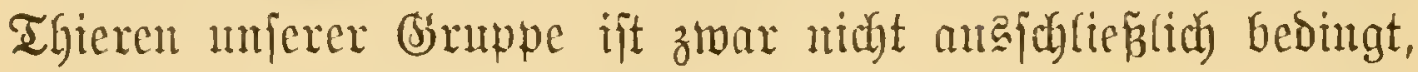
aber bod) ermögriagt burch die Hebereinftimmung in ihrer Sebenzmeife. Dies ijt aber nidyt bei allen ber jompt hieber gejtellen fierfen fo, unb benten wir babei fpeciell an ben

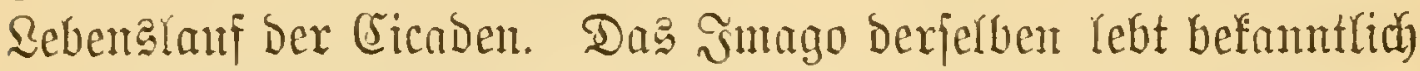
frei arf Bäumen, bie Rarbe hingegen tief in ber Erbe an

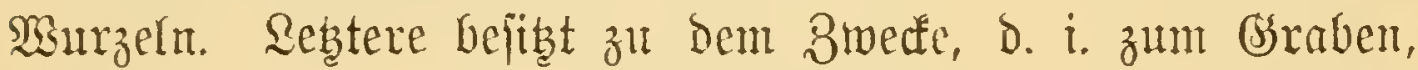

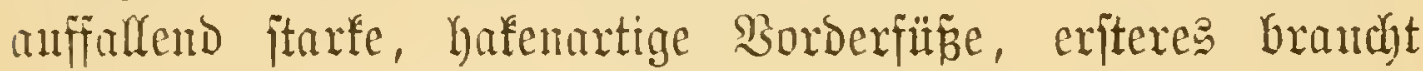

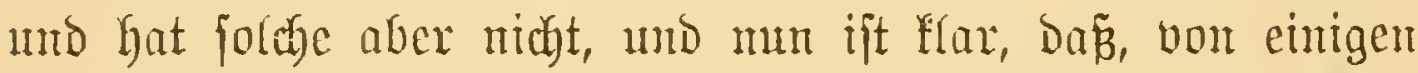

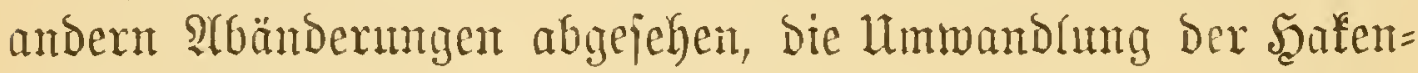

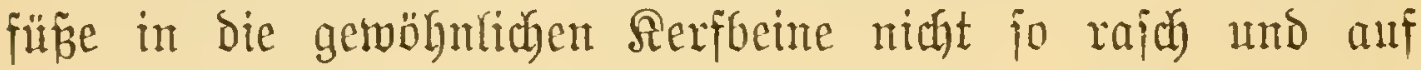
eimmal geht.

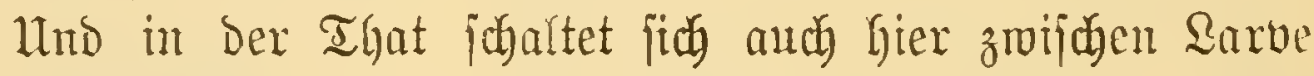
uno Jmago cine wahre, ju fogar eine "ruhende" \$uppe ein, und fo fiebt man neuerbinge, Dar bie Mamnigfaltig= feit Des Snjeftenthums alfer cintheilung und Silaffificirung ipottet.

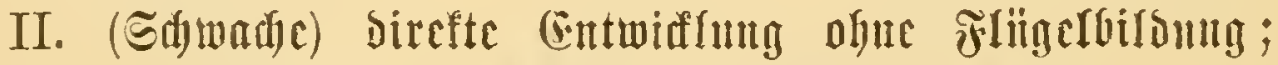

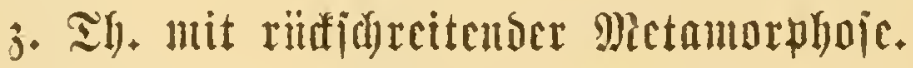

Den Smagines Der frithern Abtheilung warde madgejugt,

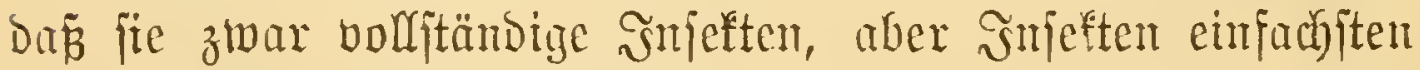
Stiles feien. Die Mritglieder Diejer Bruppe ftehen now

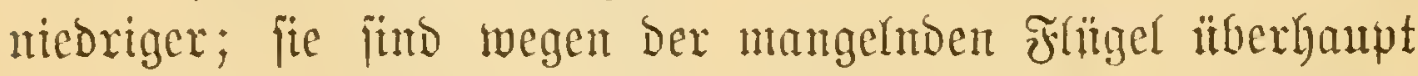
feine volftänoigen, feine ganzen S̈nfeften mehr, fondem midy

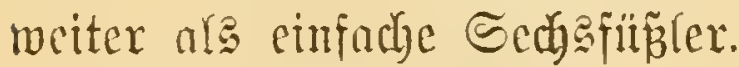

Sm Hebrigen ift ify fang ein febr mngleidyer. Wir

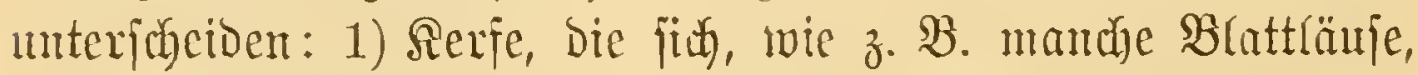

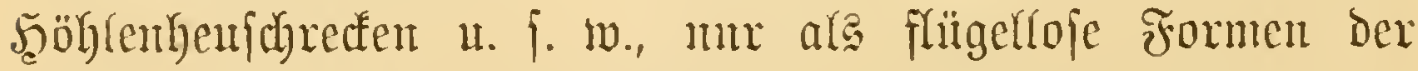

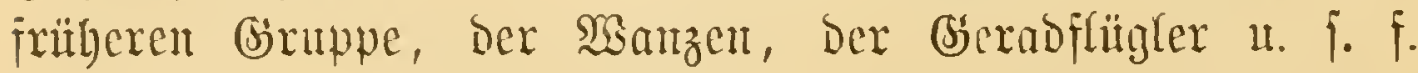
herangftellen uto, bie Sexualorgane abgeredhut, als Jmagines 
ungęähr anf Der Stufe itehen, weldye Die Sngembjtabien Der

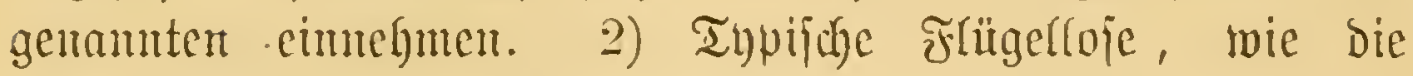
Springidhtwänze, 子. Th. gleidffalla non edht larbenartigem şabitus, indem bei manchen mr fog. Punft= mo feine

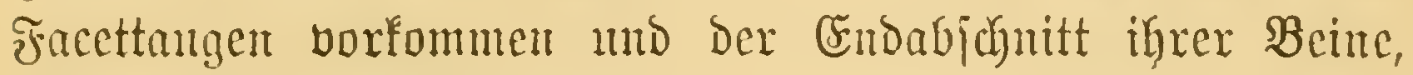
mas ganz larvenmäpig, Gistweilen nur cin Bsticd und eine Alaue hat. 3) Endich ßerfe, bie, wie bie unterjdyiedtidyen

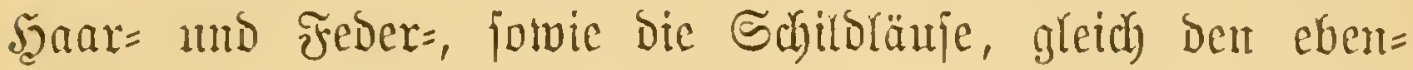
genamten nux flügelloje Formen Der erjten Brmple, jpeciell ber Schnabelferfe, fint, in Folge igrer parafitifden Rebents=

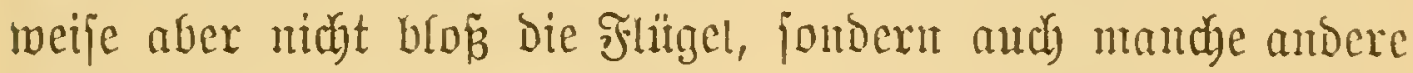
ipecififd imaginale Crarattere, wie bie zujammengejesten Shugen, bie Fintler, bic mehrghiederigen Tarjen u. Dergl, vertoren haben, und jo, wie gebürlid), auf ber langen Stufen=

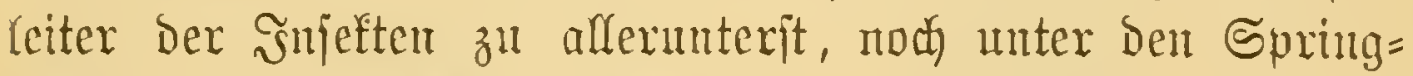
fdyänzen und ährtichem Belidater placirt merden.

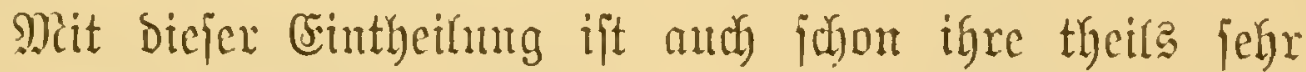
furze, theils rücfläufige Entmidfung z. Th. mit Metamorphoje angedeutet.

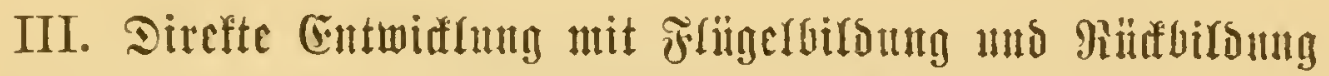 wrobijorijder Drgante.}

2inch) mit biejen ferfen (Eintagafliegen, Libellen 2 c.)

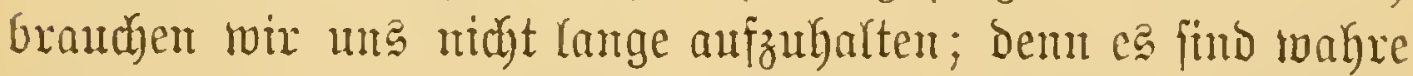

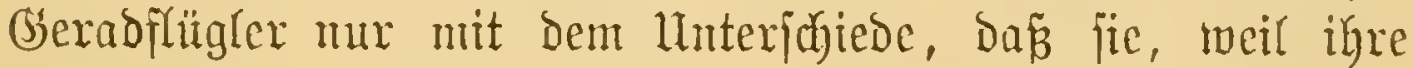

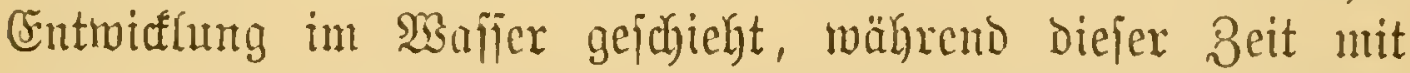
bejonderen, diejem Medium entipredjenden Drganen, nament=

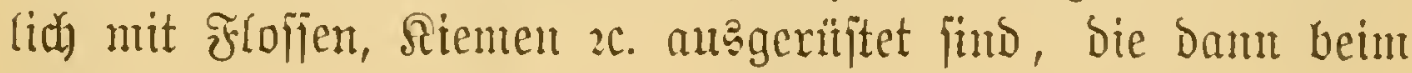
Ucbergang in bie 2uft in ber Regel abgelegt werben.

Sogleich) wir mun von biejen Rerfent jhon vieles gebört,

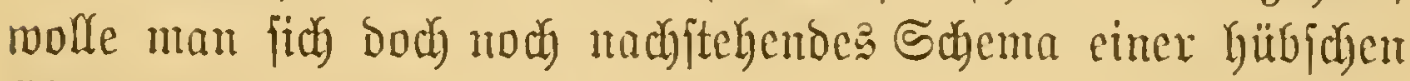
sintageffiegenlarve anjeben. 


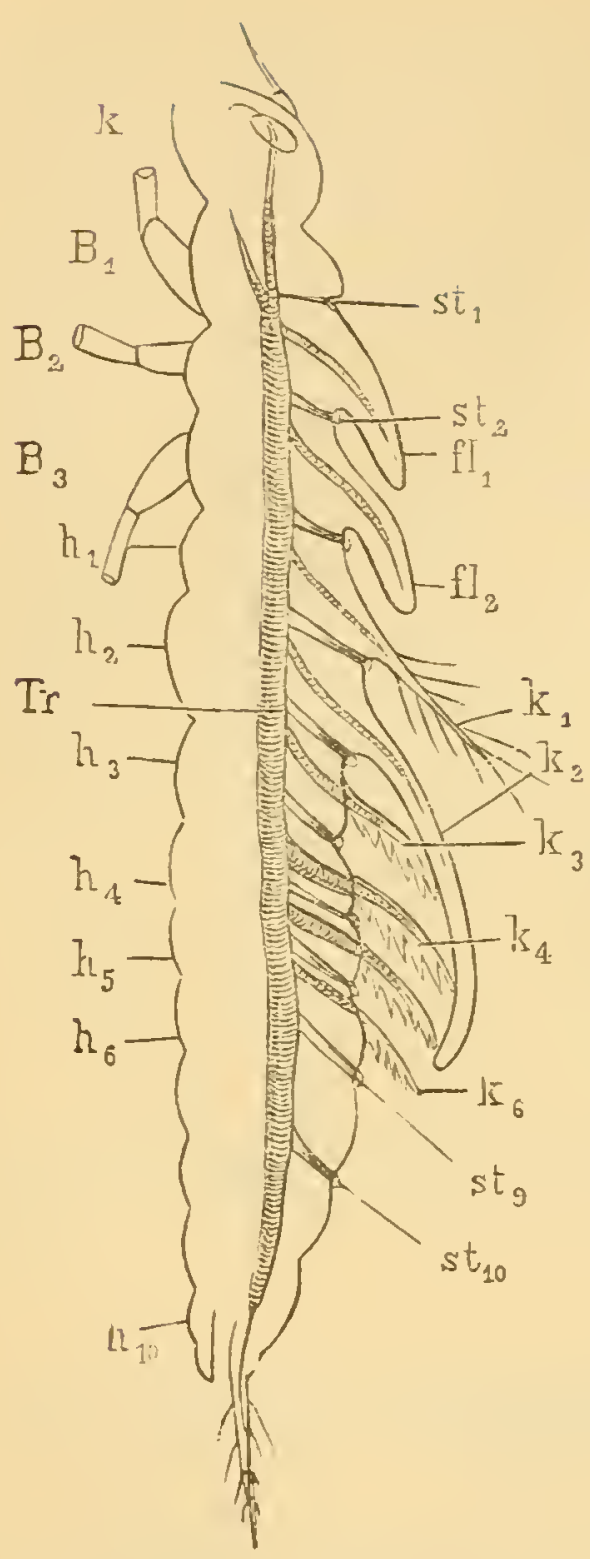

Fig. 173.

Chematifurter Mebian=Rängsinnitt ciner Fintagsfliegentarbe (Coenis).

k Siopf, B1-B3 $B_{1}$ order $=$, Mittel $=$ unb Sinterbrujt rejp. Beine, hl-h1o Sinter= leibsringe, $\mathrm{fl}_{1} \mathfrak{B}$ orber $=$, fl 2 Seinterflïgel= anlagen, kı boritenartige Sieme (?) bes 1. Sainterleibsringes, $\mathrm{k}_{2}$ al\& fiemendeffel fungirende Dorjalauŝftülpung am 2. アing, $\mathrm{k}_{3}-\mathrm{k}_{6}$ eigentlide Iraheenfiemen am $3 .$, 4., 5. uns 6. Ring; Tr Tradeenläng $=$ famm, st 1 -stio (an ber \&arve nux wäh)= rent ber Şäutung fid öffnente) Stigmen jammt Irađeen.

(Driginar.)
IIm Sorbertheil finden mix faft alles fo wie hei

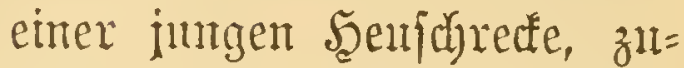
mal auth bie Frïgelanlagen $\left(\mathrm{fl}_{1}, \mathrm{fl}_{2}\right)$ Der Mittel $=\left(\mathrm{B}_{2}\right)$ umb Scinterornit $\left(B_{1}\right)$. Şäbrat jon= Derbar ijt aber Der Şinterleí. Inf Den erjten Blicf glant matt, ex jei an ber $\mathfrak{B}$ urzel ntit zwei flïgeln bedect. Dies find aber ztwei Decfell, Die vom f̧interleib jelgft, und ztwar vom zmeitent ßing cutipringen. Beobaditet man unternt Mifro= ffop Daz lebende Thier genturer, fo jieht man ferner unter biejen

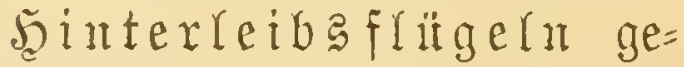
framite, Dümte Blatten nadj Irt einer S̊reisfäge fich hin = unb herbetwegen: Diez find bie Irachentfemen. Arterement be= merft man vor Den ermähnten Decfert, am eriten Şinterleibs= ring, moch ein Baar äptiger Fortjäbe. Das Schema zeigt

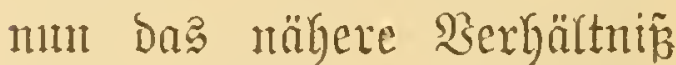
Diejer $\mathscr{A}$ nhänge. Arles fint Den Flïgeln äbnliche, aber 子. Th. vielleidyt mehr jeitfidye

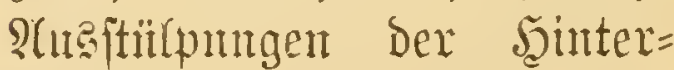
Keibsringe. Sm Dritten, vier= ten, fünften uto jeduften $\left(\mathrm{h}_{3}-\mathrm{h}_{6}\right)$ jteben junächit bic 


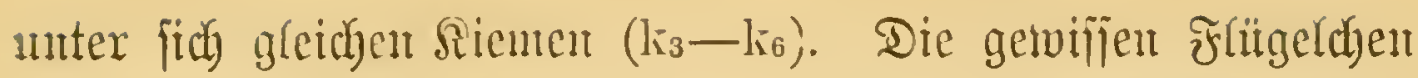

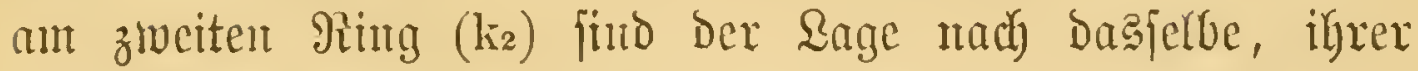

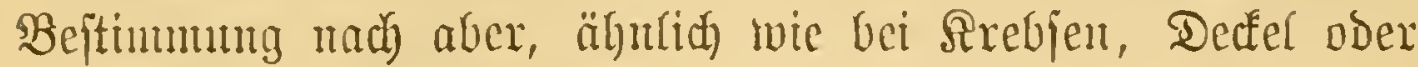
Schutzorridutungen für' biefe zarten Drgane.

IInflar bleibt Die Beftimmung Der itarren, fpieß̃igen Fort= jäbe an erjten ging (ki), anf Denten fich mit Sortiebe allertei (S)Lofentficuden anfiedeln.

Bei Dex reßzten Şäutung fallen bann and lyier auf bie

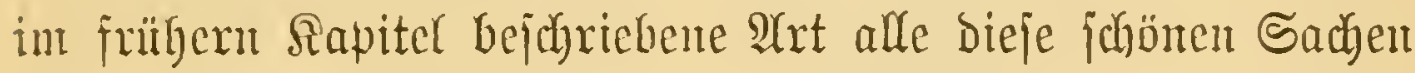
fort; Die zehn ichon vorbereiteten Stigmen $\left(\mathrm{st}_{1}\right.$ - $\mathrm{st}_{10}$ ) öffnen fith und das früber jo umjaubere Schlanmthier fliegt als nette Sicrfchen in bie Rüfte.

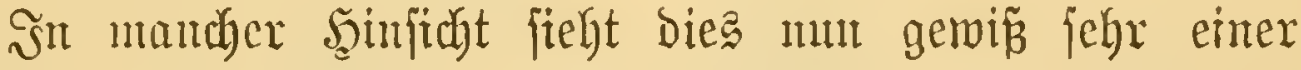

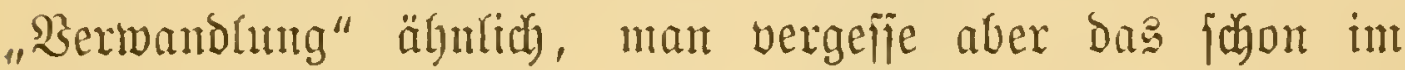

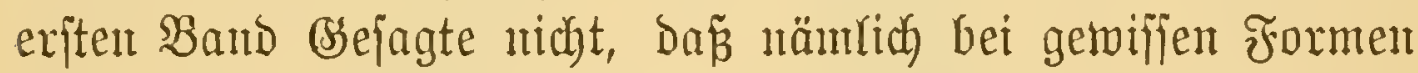
(₹̛ig. 164) Die Riemen $\mathfrak{g a r}$ uid $t$ abgemorfen werben, im Bantzen aljo, Die Frlïgel abgeredynet, Das Sintago gentu bie= jelben Ifheile wie bie "Inrue" hat.

\section{Entwiffung mit Mietannophoje.}

Dhzmar f́num ein zoologijober Sbegenftanto fo populär wie Die Metanorphoje Der Smpeften ift, fo befiken wir bod über Den Borgang, wix mödten jagen ïber bie $\mathfrak{I} e$ hinif ber

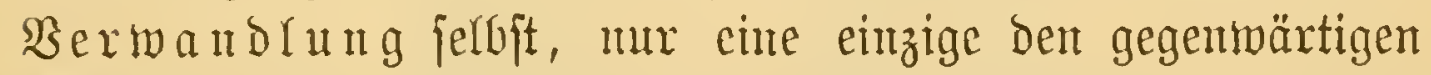

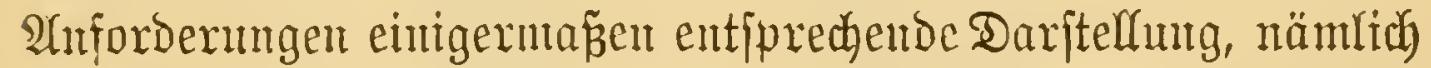

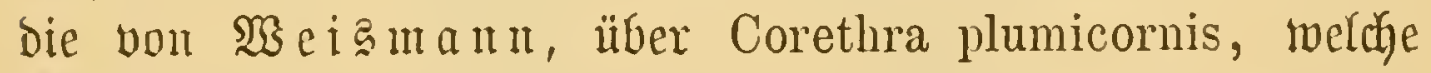

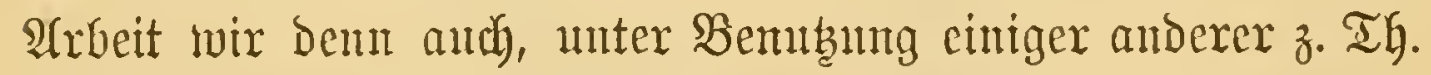
eigenter Detailftudien Der folgenden Erbilderutng zu Orrutbe legen.

Da das Biel Der Corethra-Entruiffung, refp. Das Bild ciner Miücfe alfen Rejern befaunt jein dürfte, beginten

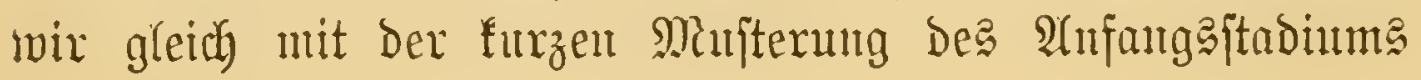




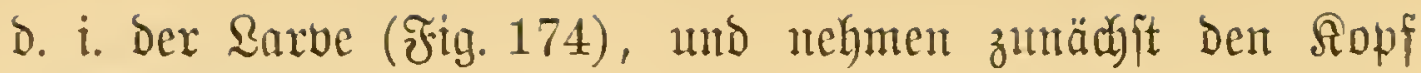
in $\mathfrak{A}$ utgenfudein.

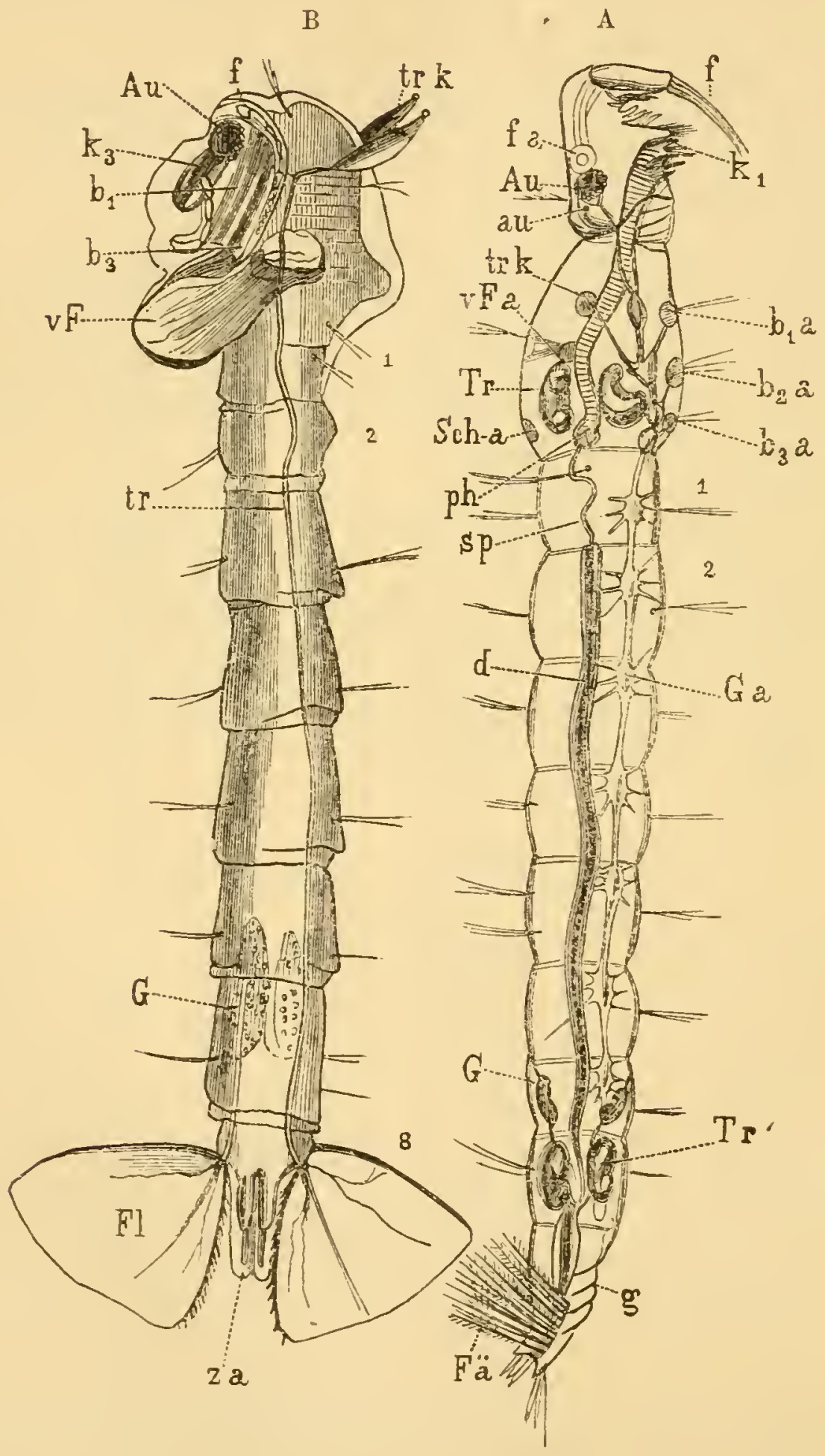

Fig. 174. (Erträrıแ! ๆ. S. 493.) 
Bon oben betradbtet zeigt Derferbe bis anf bie fahnabel=

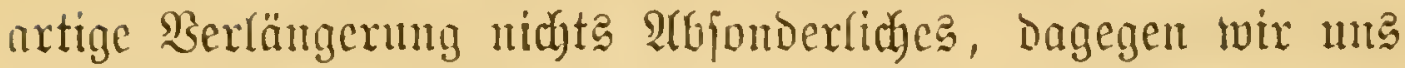
bei jeitlicher $\mathfrak{A}$ mijut cinem grimmig vorlugenden Epinnentyant gegenïber glauben. Dies rilfrt von ber eigentfïmlichen $\mathfrak{B} e=$ junaffentyeit und Stellung Der Fühter her. Mährent bieje anthänge hei andern Rerflarven meift ganz mamjegnliche, oft jogar gang in bie baut einziehbare ßorjprïnge Daritellen,

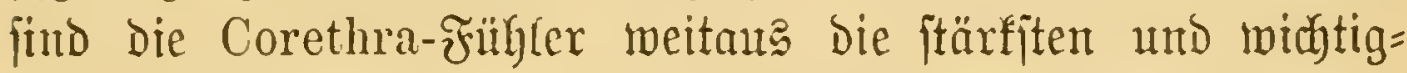

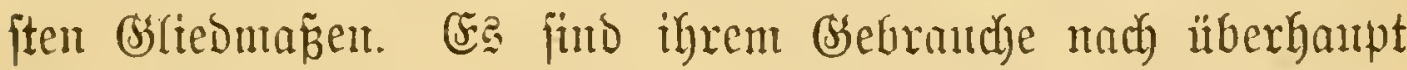
feine edbten Frilhler, fondern ben beribdtigten Spinnenf(auen ähnlidbe, nach hinten cinjolagbare Fangmerfzentge: aljo Riefer= fïhler. Sie bejtehen (F̧ig. $174 \mathrm{Af}$ ), wie jene, ans cinem Diden Stiel, tragen aber itatt Der R̂aue einen Recthen iteifer Borften. Sebt begreift man aud, warum mijere für igre lebenbe lumgebung idjwer jidytbare $\mathfrak{a} a$ rbe oft fo lange, wie fejtgebannt, an ciner Stelle vermeilt. Sie lauert auf Beute,

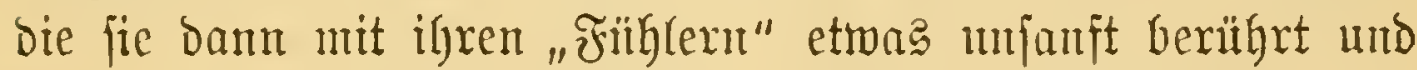
ben weiter Ginten befindichen eigentichen Mutndtheilen über= antwortet. Seştere zeigen mit $\mathfrak{H e b e r g e h u n g ~ e i n t g e r ~ t h e i l s ~}$ boriten=, theirs blattartiger 3wifdjenantänge $(\beta)$ folgende Einzelheiten: erjtens eine grö́e, lappenartige Sherlippe (ol), Dann, Die 5̧antfache, cin Paar fräftige, megrzabrige

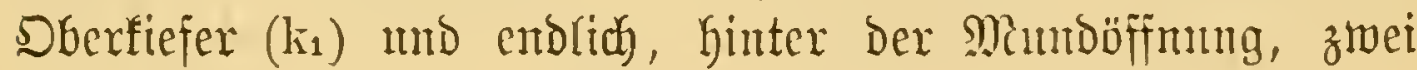

\section{Ertlärung zน ₹ig. 174.}

Bur Entmictung Ier Feberbujdmüude (Corethra plumicornis), nach $\mathfrak{W}$ e is mann.

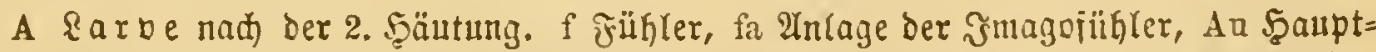
(Imago $\Rightarrow$, an Sieben=('arben $=$ ) Iuge, $\mathrm{k}_{1}$ Dberfiejer, b1 a, b2a, b3 a Inlage ber Borber $=$ Mittel= und Şinterbeine, trk Inlage ber Tradeenfieme, vFa ber $\mathfrak{B o r b e r}=$ flügel, Scha ber Edwinger (Șinterflügel), 1-9 Şinterleibsringe, Tr borbere, Tr' hintere Iradeenblajen, ph fijdreujenartiger łigarbnx, d Mittcliarm, Ga

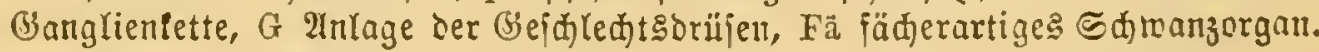
cea 12 mal bergrö̈̈ert.

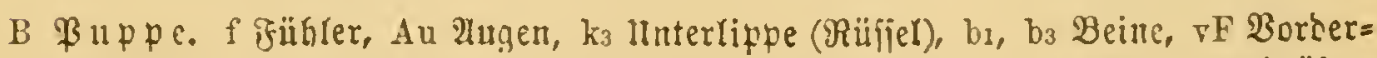

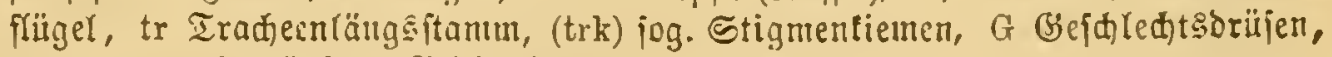

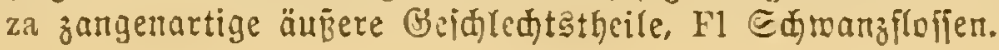


Baare von fubräberen Griffeftn: Die Unterfiefer und Unter= lippe $\left(\mathrm{k}_{2}, \mathrm{k}_{3}\right)$.

Hebergehend auf die Bruft, fo ift vorerit ber gänz̧iche Mangel von irgento meldyen Marbängen zu conftatiren; um fo auffallender erjabeint es, da in bie Drei typifanen Segmente zerlegt ift, jonbern ein einziges

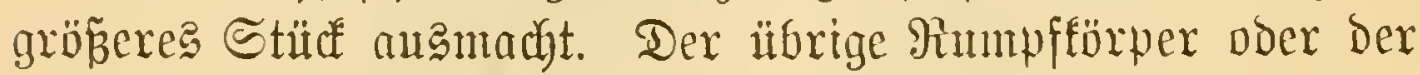

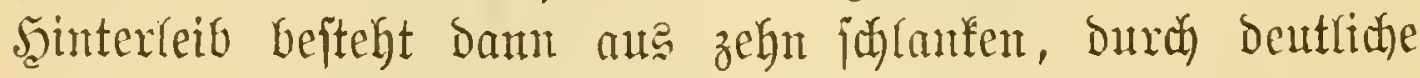
Rerben von einander gefonderten Somiten, Deren Yestes (10) fpib ausgezogen ift. Diejer Schluftheil hat mun, gleich Dem

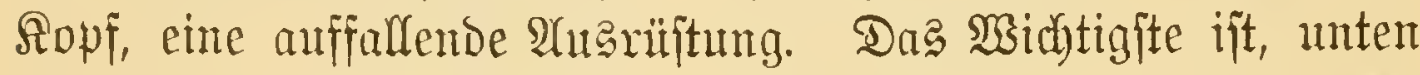
anf Der Mitterlinie, eine Art Stenerruber oder Fiofie (Fã), beitebeno an iteifen, fiebrigen Şararen, bie fï fächerartig zujammenlegen und entfalten laffen. Dazu fommen damn an Dex Reibegfpibe ferbit bie für fierflarben obligaten Griffer und Borften, alfo Stüboorridytugen für friechende Thiere, die hier ziem(id) überflüfitg erjedemen. -

Stelfen wir jest, mady itattgefundener Bejdreibung ber

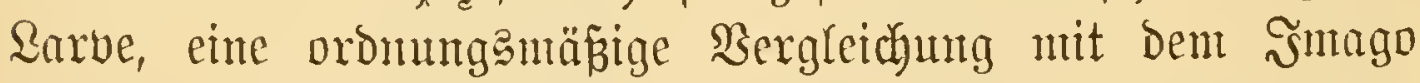
an, jo wird fich genau zeigen, was am einen Zujtand ver=

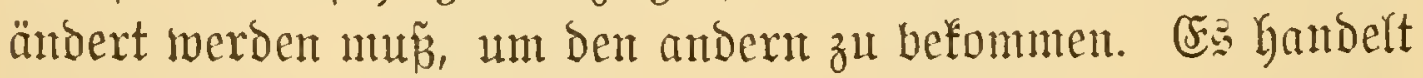
fich um breierlei: erftens um totale Entfernung gewifijer (proviforifber) Sarventheife, zweitens un die Imformung

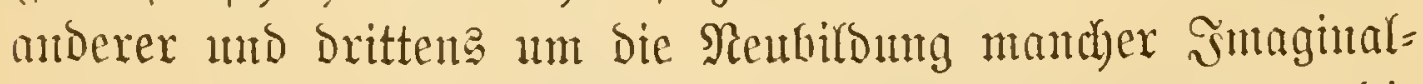
organe. 3 il entfernen find z. 3 . Der Schwanzfüher, die Endogriffel mo bie früber vergeffenten Tajtoriften an Den Rumpfringen. Huzuformen find: Sopf แmb Bruft im âlge= meinen und bann bie Ahthänge des exftexen, foweit baraus Fühter und Mimbtheile Der Mlüfe werdent.

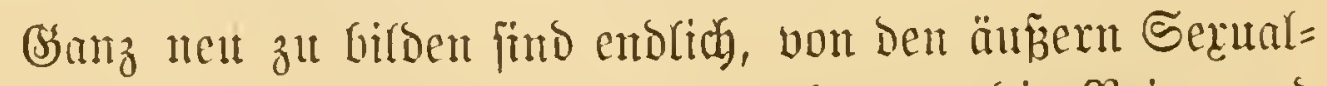
organen abjebento, fämnttiche Brultantänge: Die Beine mo Frlitgel. 
Mair beipredyen mu gleidy bie leketern, aljo bie

a. Nenbiloungen.

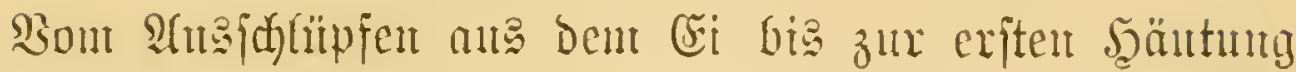

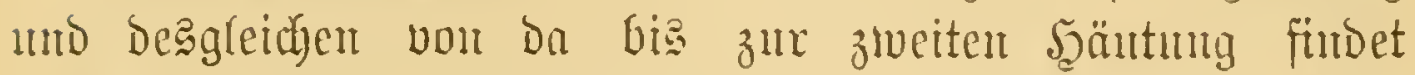
mady Weisunan an ber Brujt ber Corethra-尺arbe feine merffiche Beränderung ftatt, und abgejehen vom verfrühten

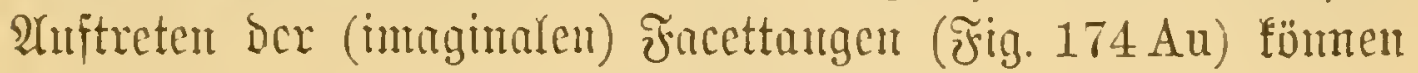

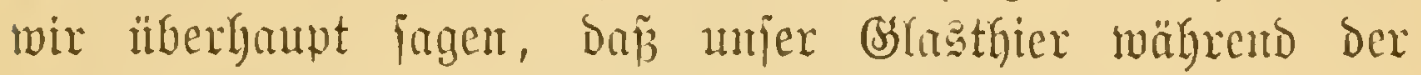
erjten ztwei Rerioden des freien Rebens den mpiprünglidyen Charafter beibelyalte.

Somie aber die żoeite Saäntung vorüber mo das leb̧te Rarvenftabium begimnt, falfen in wollfonmen ourdyfidytigen

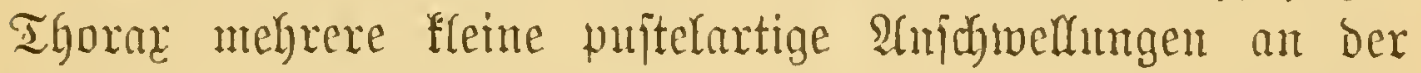

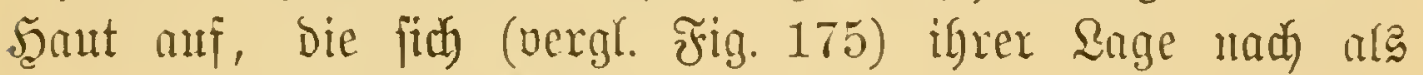
bie eriten Deutlichen $\mathfrak{A}$ nllagen Der Beine $\left(b_{1} a-b_{3} a\right)$, ferner der frlïgel ( $\mathrm{vF}$ a) und der bie Şinterflügel vertretentoen

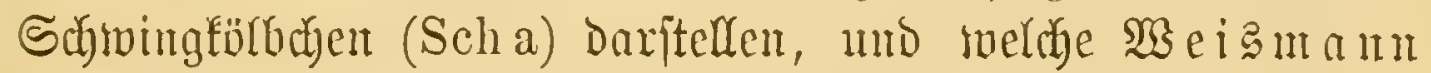

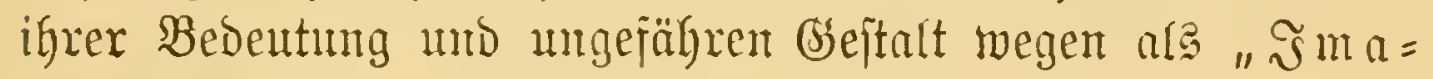
ginaricheiben" bezeichnete.

Die erjte Frage ijt mun felbjtoerjtänoblich, wie fehen bieje

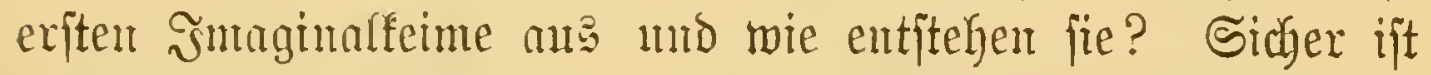

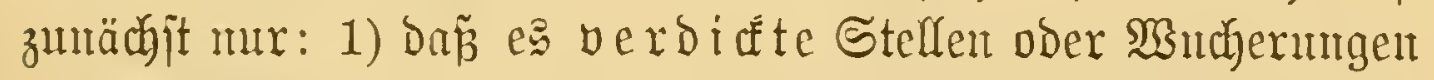

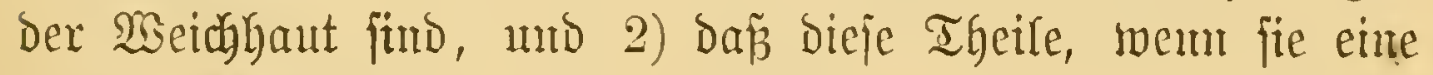
gemifife $\mathfrak{A}$ ubildung erlangt gaben, in bie umgebente bümnere Şaut hineingeitülpt exjoheinent.

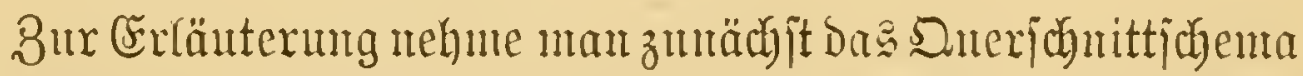

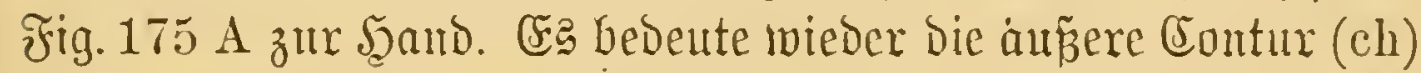

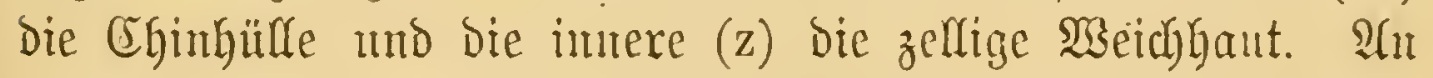
lebterer fiegt man mu oben (bei f) und unten (bei b) je ein Paar verbicter Etellen, weldye in bie untgebente bïnnere

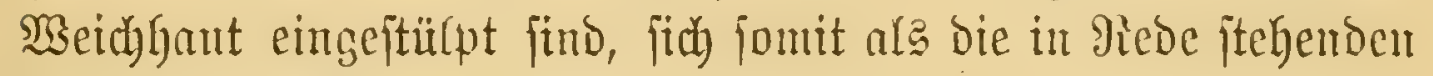
Fflügel= uno Beinantagen erweijen. 
Würde man mu bas Buftandefonmen biejer Silloungen

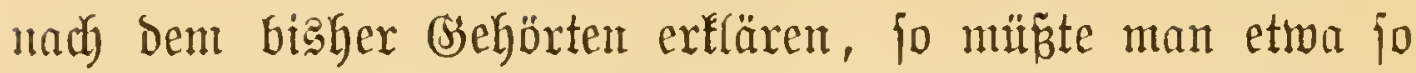
jagen. Buerjt fand an ben getwifjen Şautftellen ein ftärferes

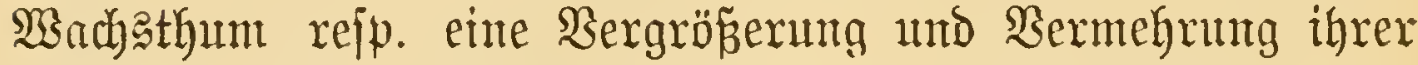

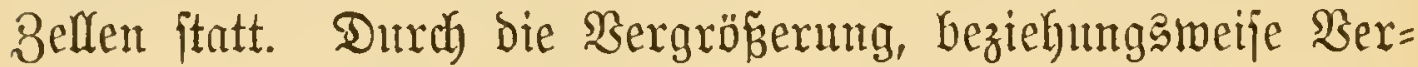

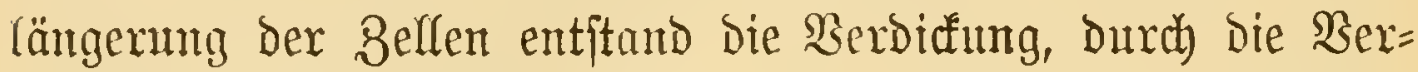
mebrung Derjelben aber bie Ermeiterung des betreffenden

A

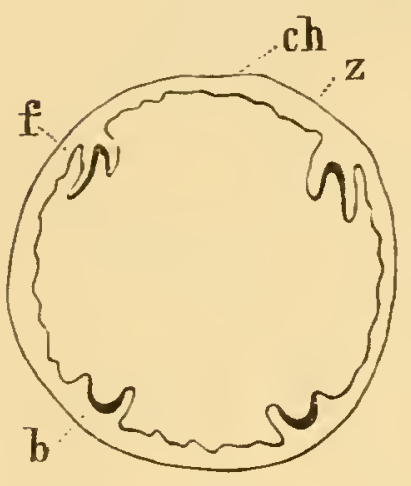

$\mathrm{D}$

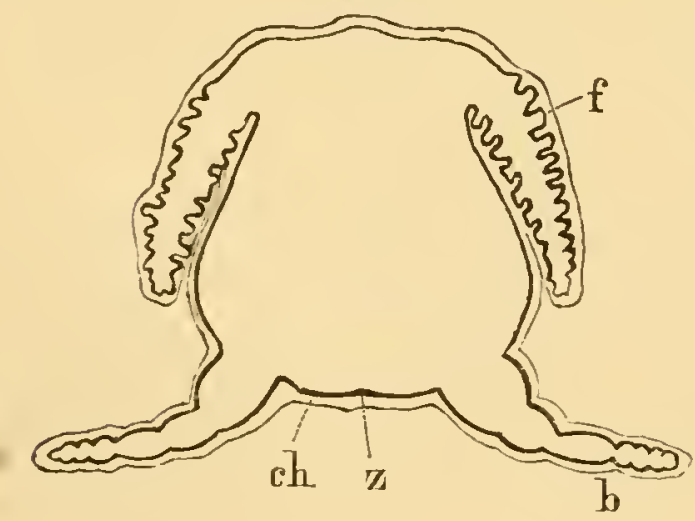

$\mathrm{B}$

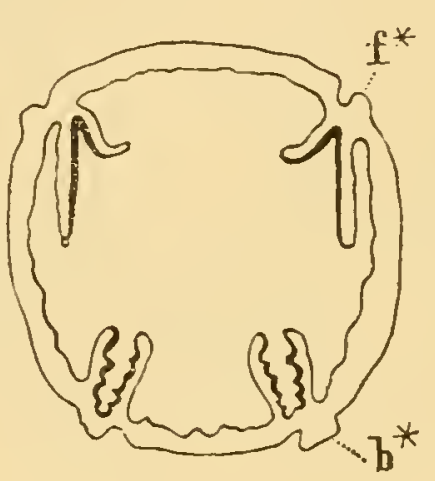

C

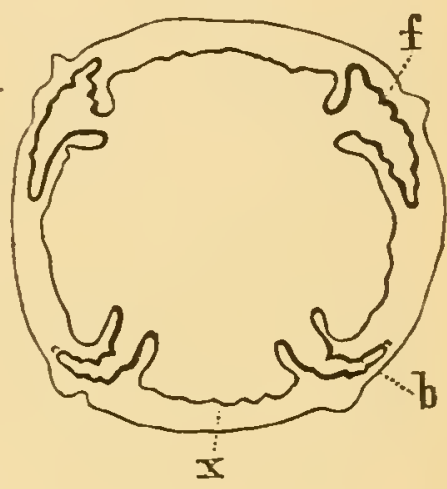

$\mathrm{E}$

fig. $175 \mathrm{~A}-\mathrm{E}$.

Sdemata zux crrläuterung Der Beine= und Flügerbildung in ber Rarbe uno \$uppe Der metaborijuen Jnjelten an Dueridnitten.

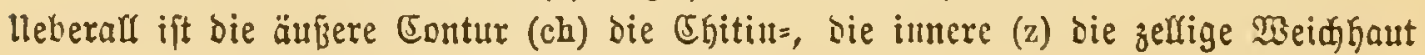
(Epidermis).

f $\mathfrak{J}$ lügel $=$, b Beinanlagent.

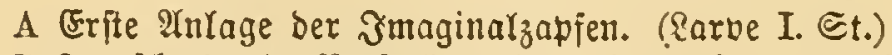

B Fortidreitende Berjentung berjelben. (Rarbe II. St.)

C Beginncnie $\mathscr{A}$ Ifftilpung Derielben. (Rarbe III. St.)

D Bollendete 2(usftülpung nad) Mbftofing ber \&arventaut. (Fuppe.)

E Stabium B mit tiejerer Finfenfung der Jmaginalfalten uno Berengerung Der (5initülpungsöfifnung. 


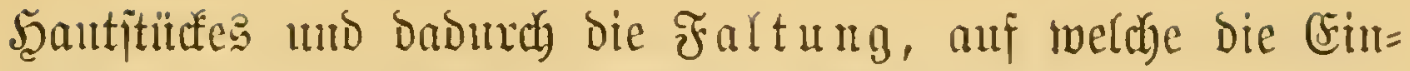

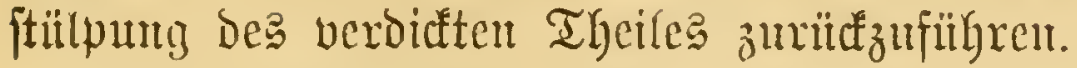

Sn jïngiter Zeit haben aber zuei nambafte Forjober,

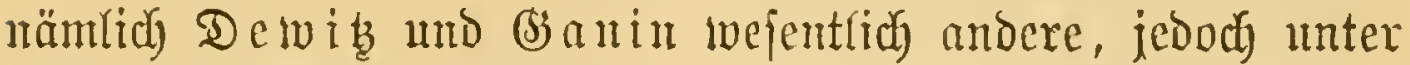
einander wieber abweid)ende Daritellungen gegeben. - $\mathfrak{u m}$

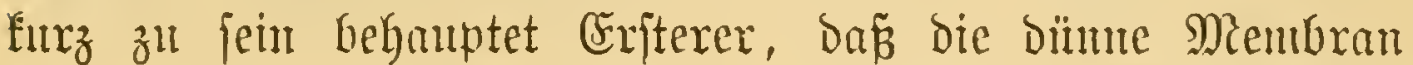

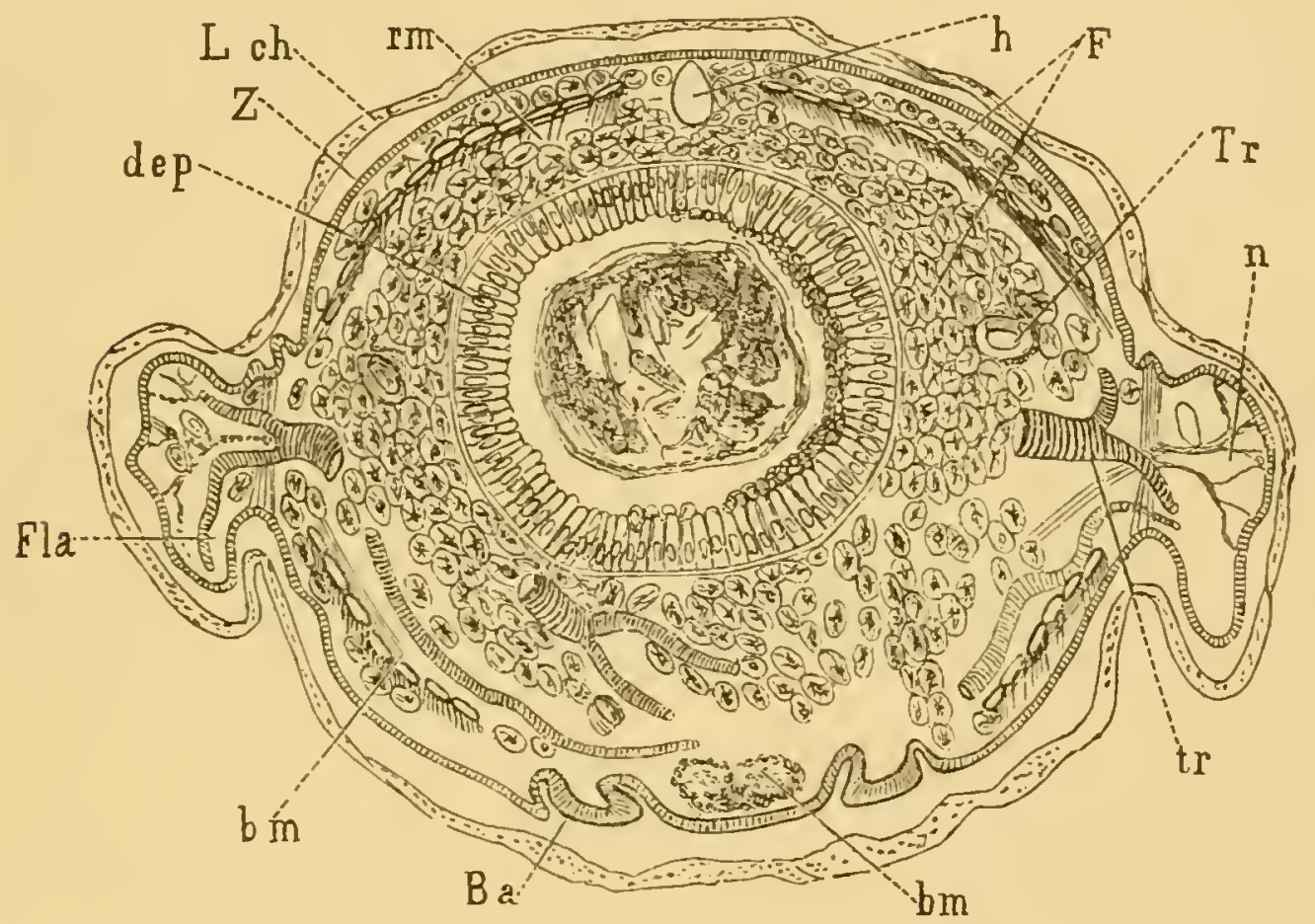

Fig. 176.

Queridnitt Durd) die Mittelbrujt eiter Rarbe der franz. Weßpe (Polistes gallica).

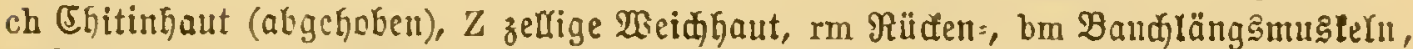
h Serz, dep Iarmepitbel, F zelfiges Binbegerwebe, Tr 1 . $\operatorname{tr}$ Iradieen, n Nerbent= entigungen au Der Şaut, bm Baudumarf, Ba Anlagen der Beine (Falten der Fpi= bermis.

(Driginal.)

ber Tafde, in welder ber berbicte Fmaginalzapfen liegt, Durdy $\mathfrak{A} b\{p a l t u \mathfrak{g}$ aus ber maffio gebadftel primären

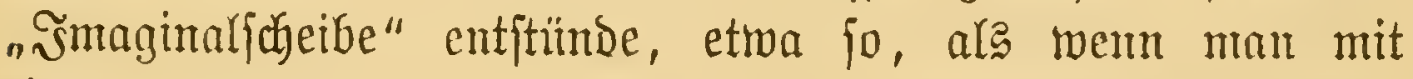
einem Scohleifen utahe Der ßrinde einen Einjtich in einen Ipfel machte.

Da fich aber, wie wir bon frïlyer mifjent, foldhe Fragen mur an bitnnen Schnitten mit Sicherheit entfdyeiden lajjen, 
fo haben wir dieje Miethode and hier und zwar bei einer Galbreifen Polistes-2arve verjutht.

Un eintem biejer Schntitte (J̧ig. 176) fam fir ber Lejer mu ein eigenes Mrtheil bitben.

3u änf̧erjt bemterft er eine zarte, vielfach verbogene

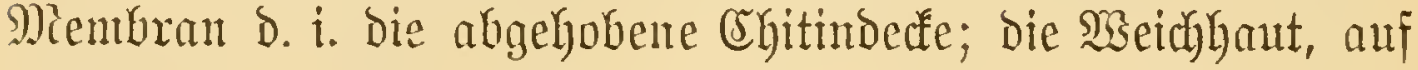
bie ç bier anfonmt, ift dann bie zweite (quergeftrichelte) Lage (z). Daran fiegt man mu, muten beiderfeits Dez Banch)= marfes $(\mathrm{bm})$, je eine auffallende, aber noch fleine Falte, offenbar bie Beinarlage.

Şier fam man fid num auf Das Dentlidjpte ïherzengen,

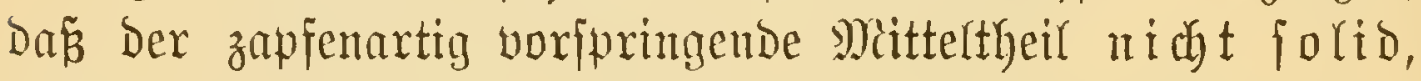

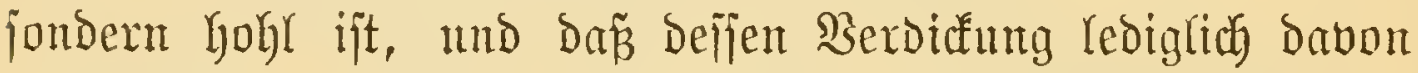

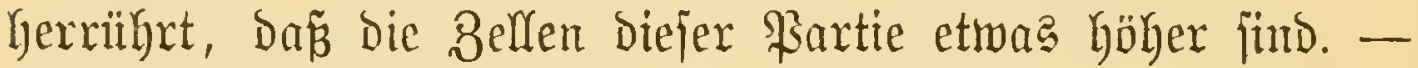

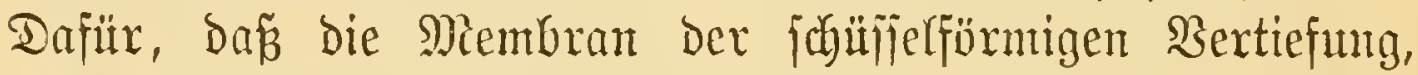
in weldyer ber Beinzapfen liegt, von lebertem Durch $\mathfrak{A}(6=$

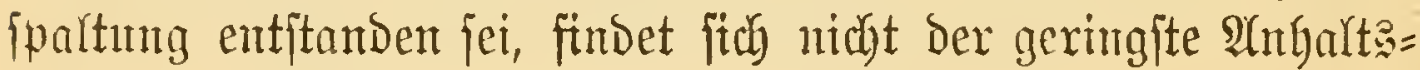
puinft.

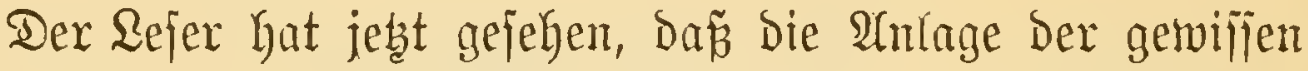
Reutbildungen bei Den metabolifdyen Rexfen (Corethra, Polistes) in $\mathfrak{B e j e n t f i c h e n ~ f e i n e ~ a m b e r e ~ i f t ~ w i e ~ b i e ~ b e r ~ F r i t g e t ~}$ hei ben ametabolifblyen (Sïchemidabe).

Ein gewiffer unterjefied zeigt fich erft bei ber weiteren

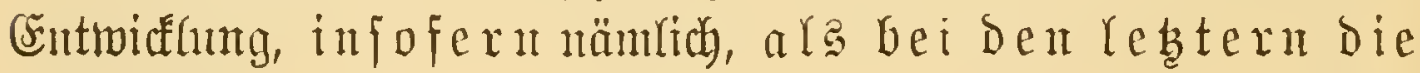

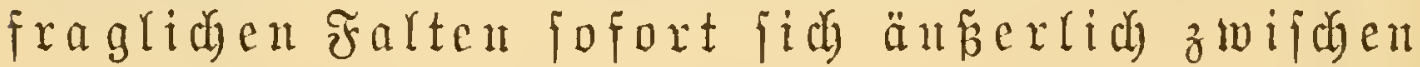

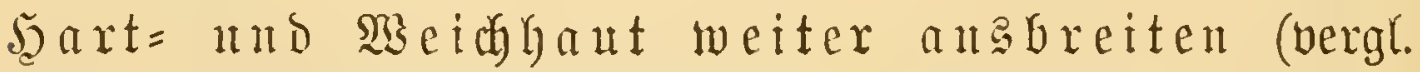
Fig. $175 \mathrm{C}$ ), während bei ben metabolijacn biejem Stadium der vorgerrfecudeu $\mathfrak{A}$ us

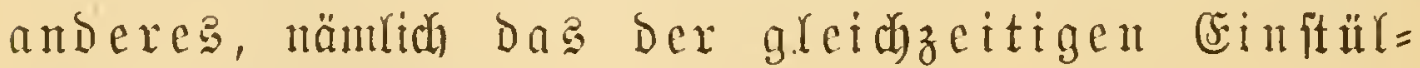
f) 1 u g (B) worlyergelyt.

Wir jagten "gleidyzeitigen" Einjtitlpung, weil in jelben Maaßze, als Der Bein= oder Fliïgelzapfen $\left(175 \mathrm{Bf} \mathrm{b}^{*}\right)$ nach anfen

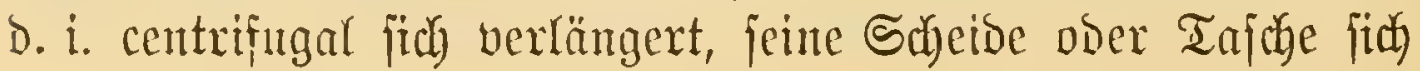




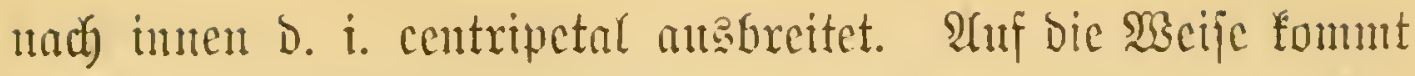

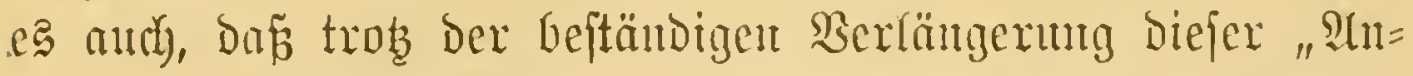
bänge" ifgre Spitze fich Doch nicht über bas Nivenu ber Meid)= gant erhebt, ja in Begentheil bismeilen beträdytlich unter Dasjelbe Gintabiutt.

Was aber eigentlid) ber (bsumb biejer combinirteu

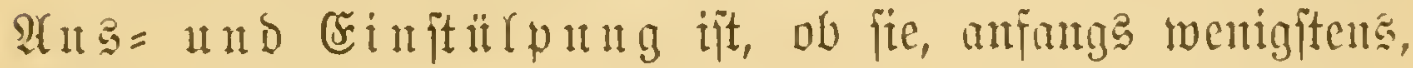

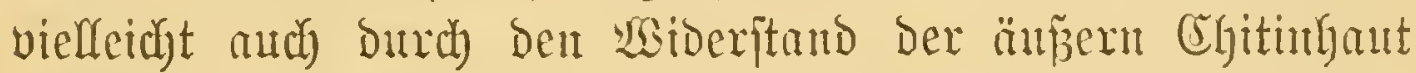

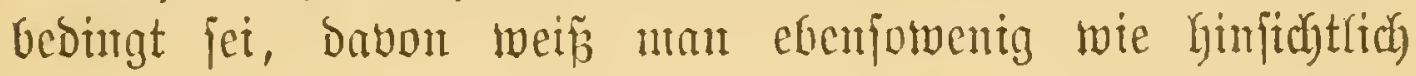

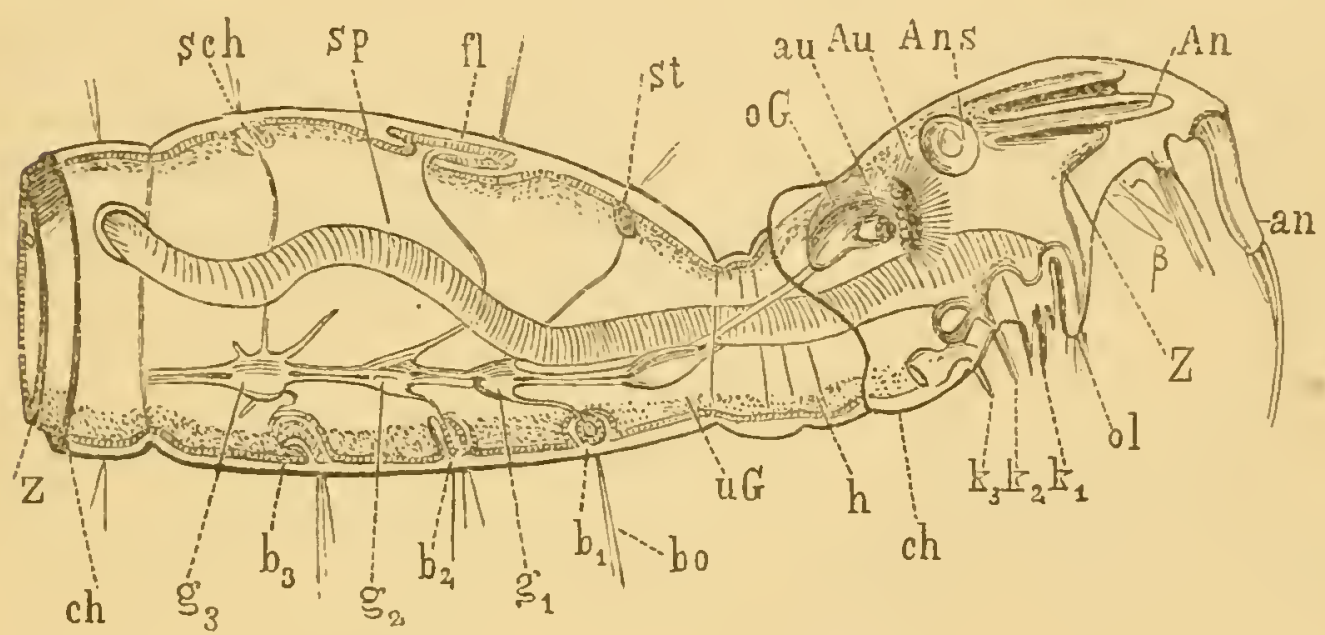

rig. 177.

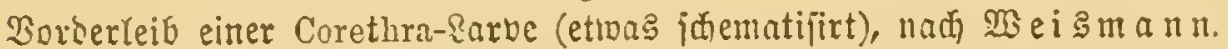

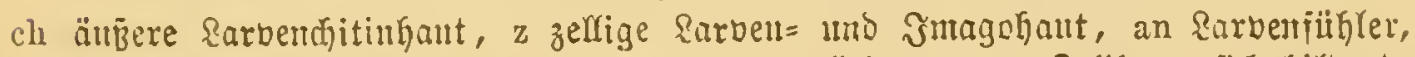
An Jmagofïhler, ill ber bon ber Eaticula zuritffigezogenen Bellyaut fich biloent,

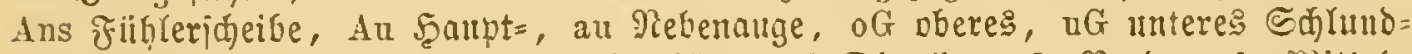

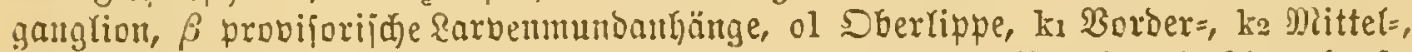

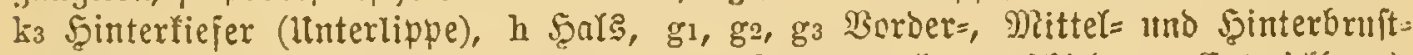
ganglion, $b_{1}, b_{2}, b_{3}$ Beinanlagen an Der Bcllhant (in verjatedener (Fnttoidung),

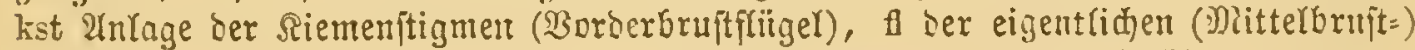
Flägel, sch ber Sabinger (jinterbruitflïgel), sp Epeijeröhre.

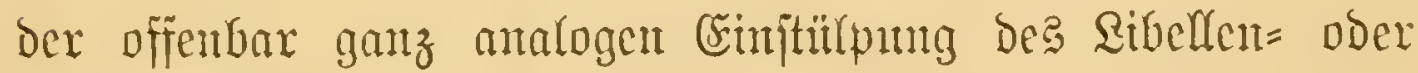

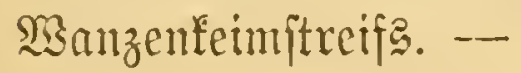

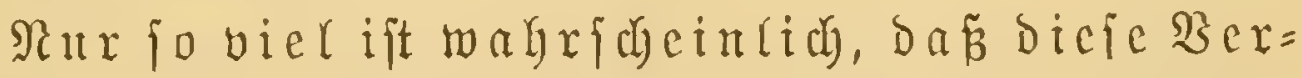

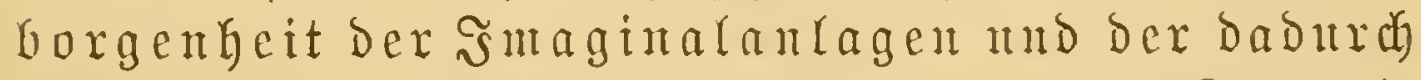
crmöglidte läugere Fortbeftald des araral= 
lebeng deu fid entwidelnden Thier unter ge= wijfen, fräter zn exwähnenden Umitänden von $\mathfrak{B} \mathfrak{o r}=$ theil feiu $\mathfrak{i} \mathfrak{a}$ ut.

Wir fommen mut anf die weitere Differenzirung und

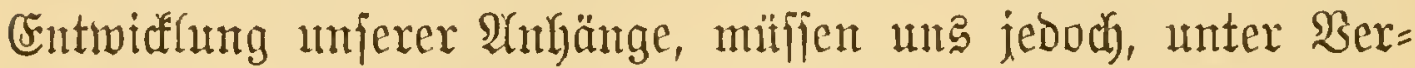

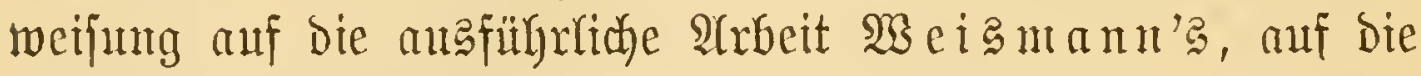

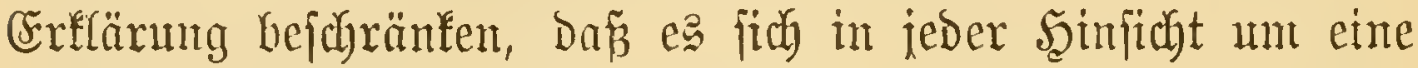
wabre Entfaltung ganoelt. Sebtere zeigt fich einmal in der fortichreitenton Berlängerung Der Unlänge, bie aus nahe= liegenten siründen, zmual an Den Bemen, zu mannigfadjen,

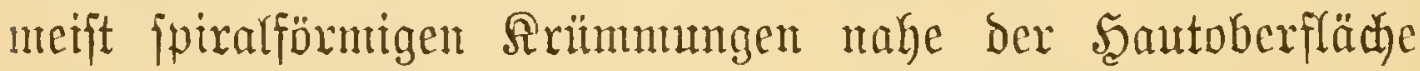
fïlyrt, und Dann in den fecundären Falten oder Runzeln,

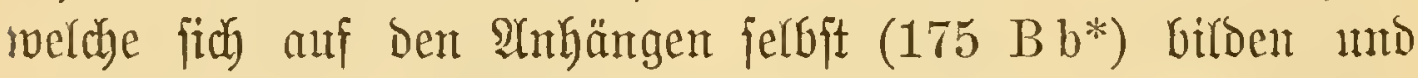
vou Deren Satur man eine ungefähre Boritellung exhält, wenn man cinen vorne zugenähten Rocfärmer in fich felbit linem= ftïlpt.

Salben aber biefe in Den Weidförper verjenlten Unlagen cinc getwifje Ausderumng exreidyt, Dann exfolgt, und z. Th.

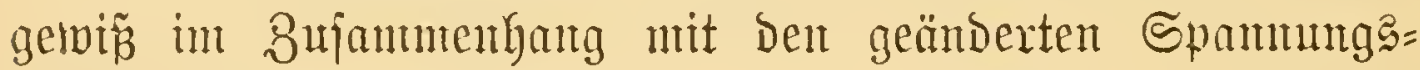
verbältuiffen Des Binnenförpers, ihre Âsftullpung, wobei fie

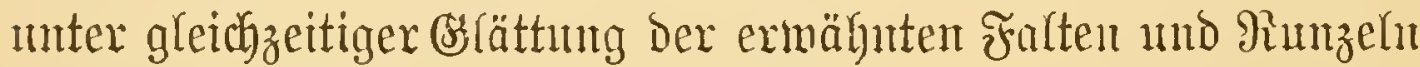
mod) weit gröper weroen, als fie in invaginirten Buftand zll jein fdyienen.

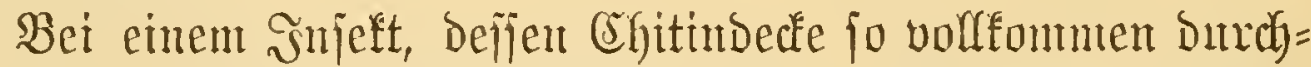
fidutig twie bei ber Corethra ift, fömen wir die jebt flïd)tig

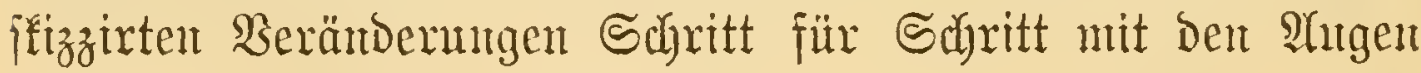

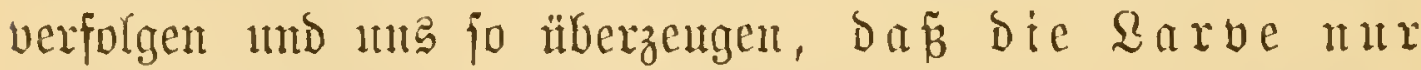
gauz alluärig auflöxt Saxbe zu feiu mb ebenjo

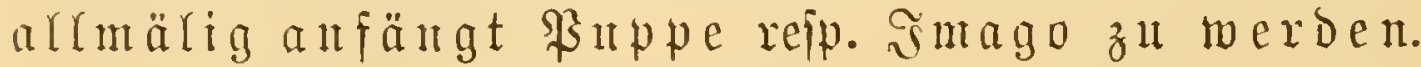

sei undurdyfidgtigen Rerfen fingegen benterten wox von allen diejen Borgängen gar nidbts, and fo fund tvix freilidy fénx exitaunt, wenn bein endidgen Arufjuringen ber 


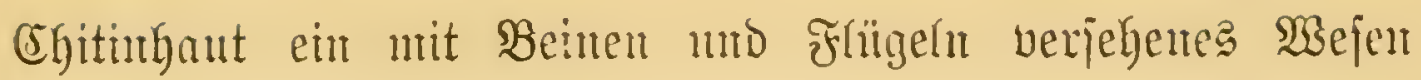
hervorfonturt.

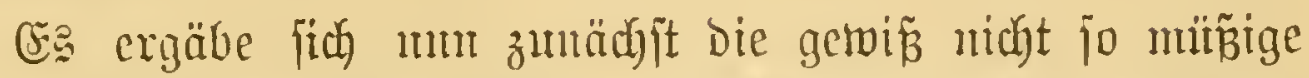

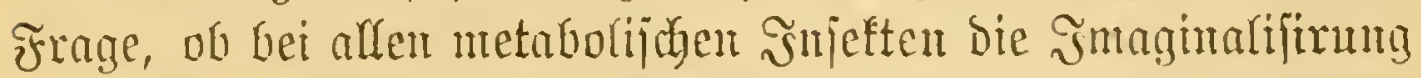
Dex Sarve relatio b. i. in Bezug anf bie gejanmite Dauer

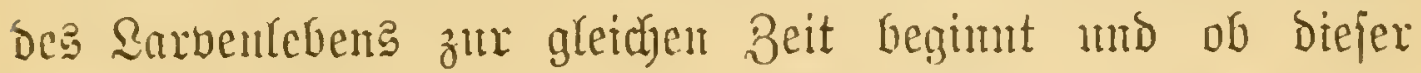
Brocé ïberall mit berjelben Bsejumindigkeit abläuft.

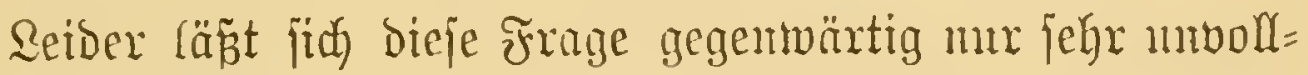
fonment beantworten, mb zrwar exitens beßhalb, weil biejer Borgang biaher mux an mentigen Formen ftubirt wurbe, und

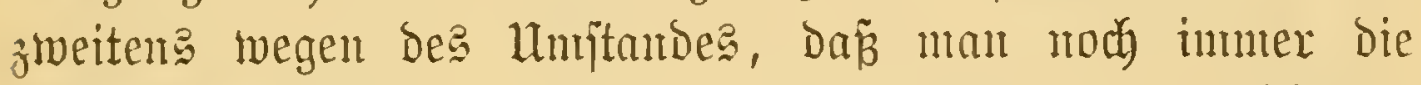

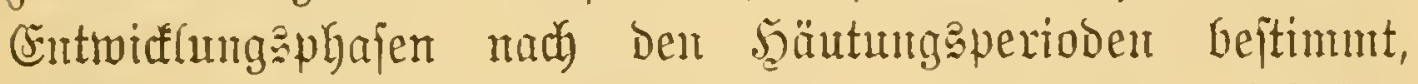

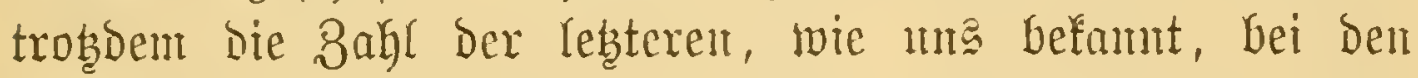

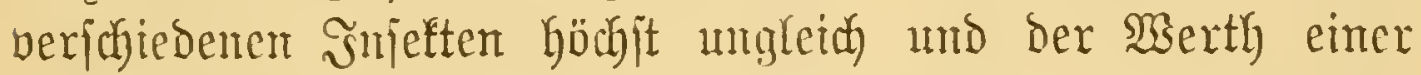
joldyen aljo ein jehr verjchiedener ift. -

Fiir manche unjerer Lejer Ditrfte Hibrigen fafon bie That=

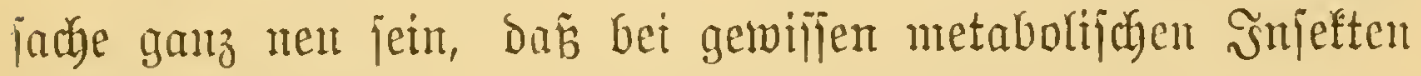

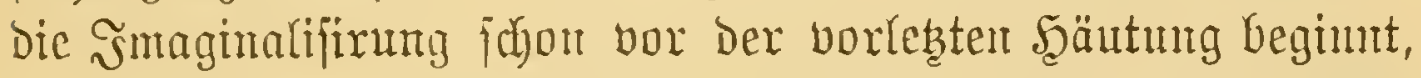
ein Umitand, Der allerdings bereits $5 \mathfrak{w}$ am merb amm mo Sexold befant war.

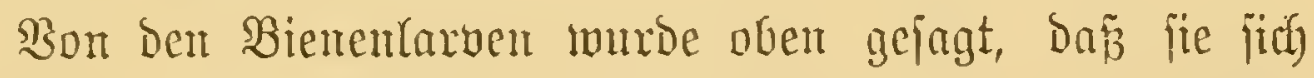
ałs Larben gar midbt häuten; bei ben Mrmeijen, mit älnulicher Zarthaut, joll bies nach Dewi is menigitents einmal gejohehen.

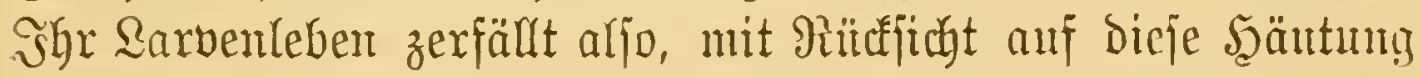
nidht in orei, wie bei Corethra, jonbern unr in zwei Rerioben.

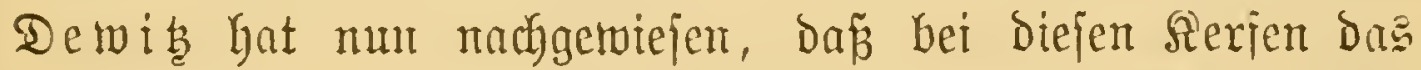
erite Stabium Der Smaginalifirung $\delta$. i. Die Ânlage unto

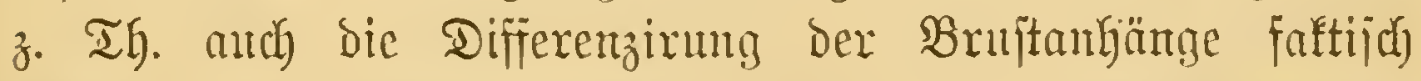
ichon vor Der exften Şäutung beginnt, Die Ëntwidfung alfo

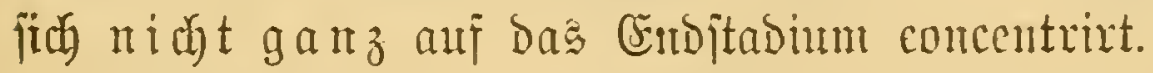

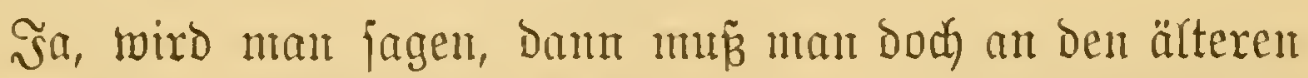

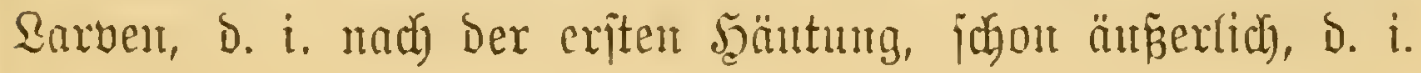




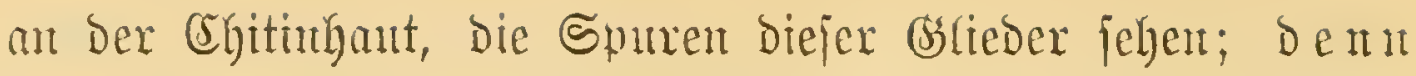
bie neue jarthat itert ja immer eimen getreueu

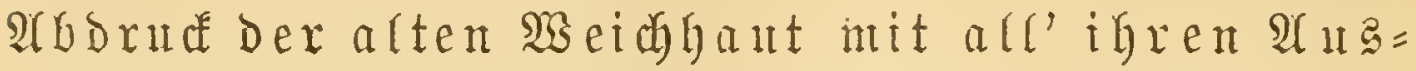
un Ei nftülpungen dar. Und dies ift aud thatfächlidy jo. Man nebme, un Darüber gauz flax zu werben, nenerdings

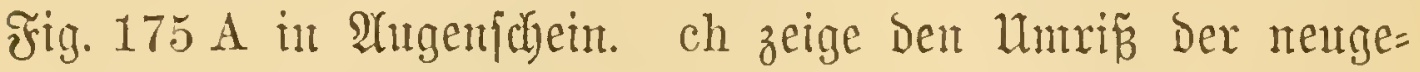
bormen ฉave. Später fartet fich die saeichlyant (z) und birben fich bie șmaginaleinjtüluntugen $(\mathrm{b}, \mathrm{f})$. (s)leidzeitig be=

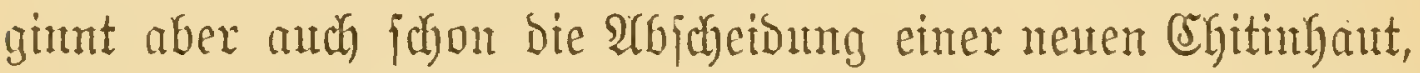

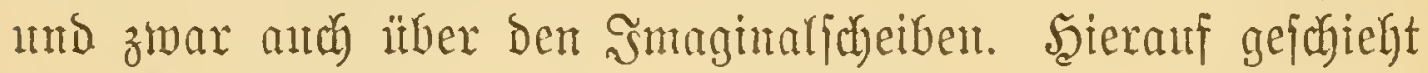
bie erjte Scäntung, D. h. Die ringan glatte Rarbenhart= Gaut (A ch) wird abgetworfen und die neue Shitingant (Fig. B und C) nit Den $\mathfrak{A b}=$ und Sindrücfen ber gewijjen Bapfen fommt zum Borjuein. Sebtere hebt fich aber, wenn wir

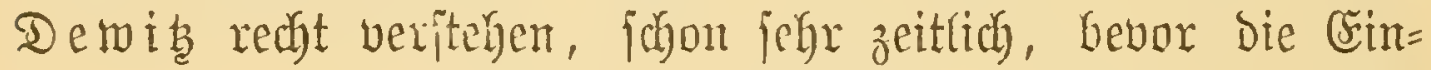

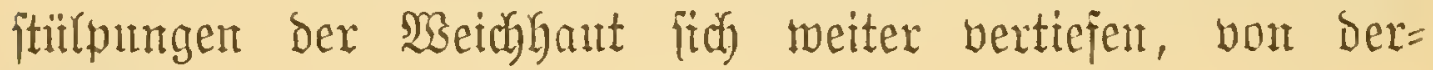
felben ab.

Die Folge Davon ijt, Daf́p Dieje neue oder zweite Rarvent=

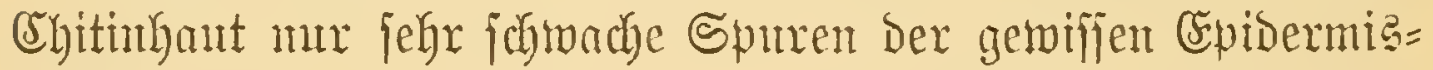

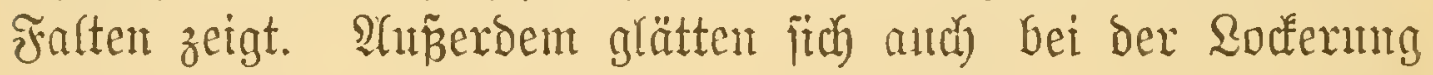
Der Searthaut die betreffenden Unebentheiten $z$. Th. aus, und jo hat man, zumal an fajt auggemacjenen \&arven, Nä̈be, diejelben $\left(\mathrm{B}, \mathrm{C} \mathrm{b}^{*}, \mathrm{f}^{*}\right)$ ïberbant wabrzmehnen.

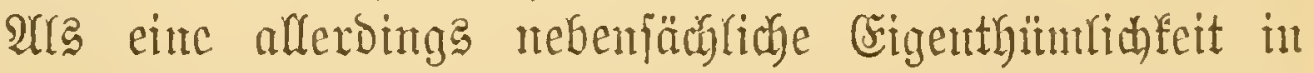
Der Meiterentwidnng Dex Aneifenbeine heben wix nod her =

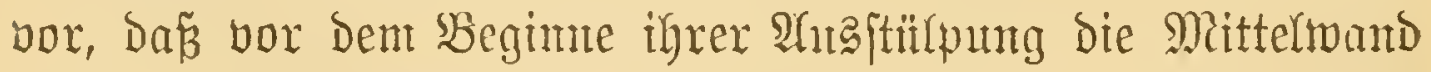

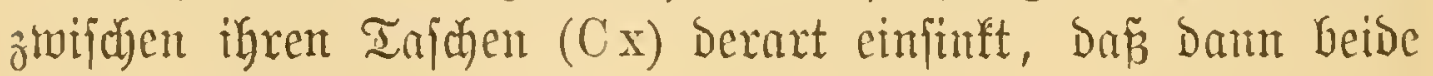
Bęine in einer genteinfanten Sirube Yiegent.

Wäbrend, wie eben gezeigt, bei ben anteijent bie Sntuginalifinung in vorlebsten Şäutungştabium beginnt, tritt fie bei Şnjeften nit öfterer şäutung, z. B. bei Sduntter= lingen, Gighweilen fajon in Der zweit= ober orittuorlebten

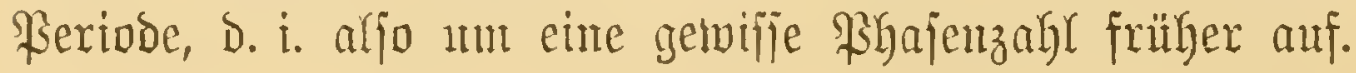


Bei Den Leştgenumten Serjen verdicut ïbrigens and Die Form Der Ertrentitätenanlagen Ertwägnung. Sede ijt befomutlich (Fig. 175 B f) eine Art Doppelfalte, D. h. fie

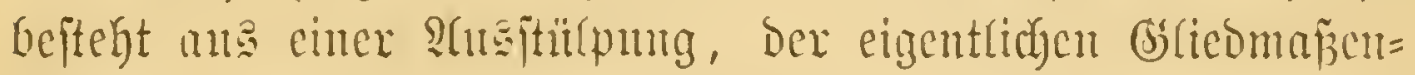

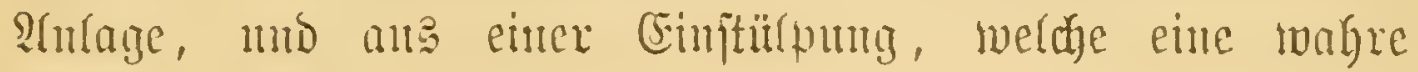
"Edjeide" ijt.

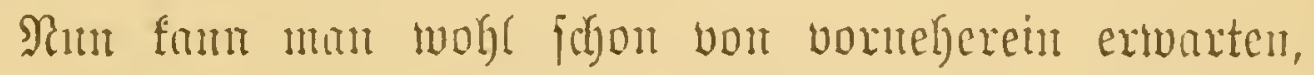

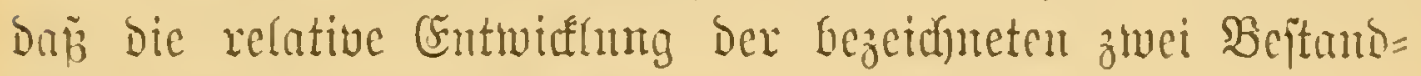
theile bei verjajicbenen Thieren cine ungleidge jein werde.

Dies zeigt fid mut and in ber That bei Den Schmetter=

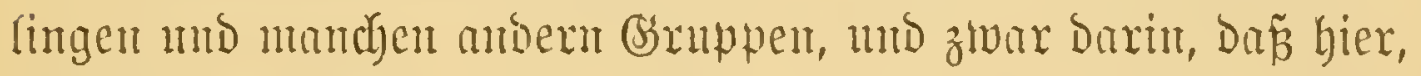

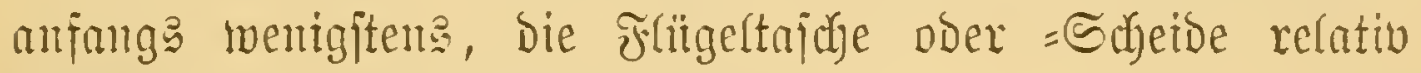
gröper ale bie frlïgelanlage jelbjt ijt.

Stelfen wir ums mu, mit Seilfe der Fig. $175 \mathrm{E}$, weiter bor, Dañ fin Der Sax́, in Dent bie tief in Den 柋eidy= förper eingejenfte Flïiglantage gleichjam aufgebängt ijt, über

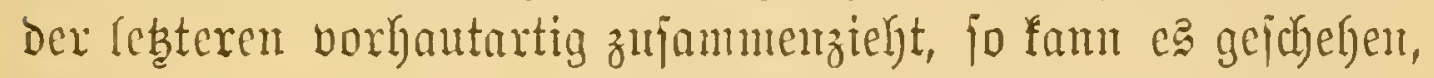

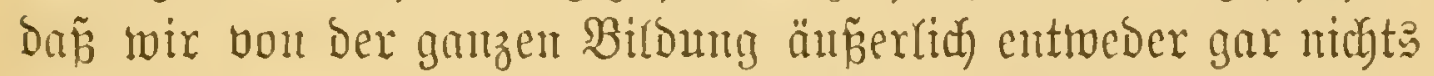
ober mux eine feime Deffunng bemerfen, mo ba pa wir in Folge Defien anch bie verjenften Snnaginalantagen jelbjt gar nidyt für

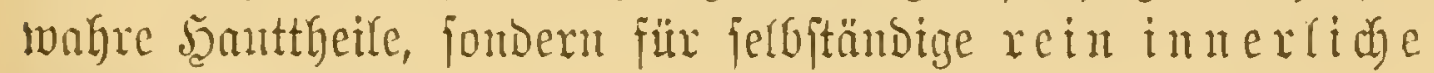
Bildungen haltert.

\section{b. Un formugen (Mietmorphoje i. e. S.).}

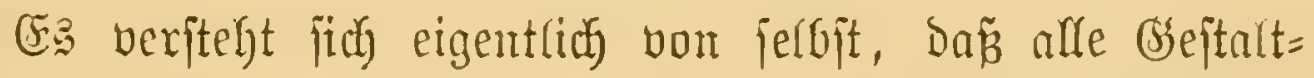

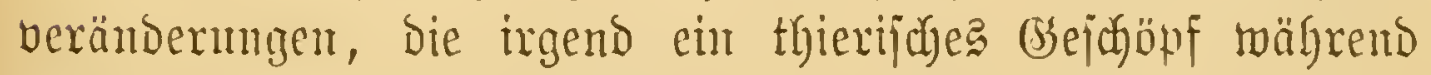

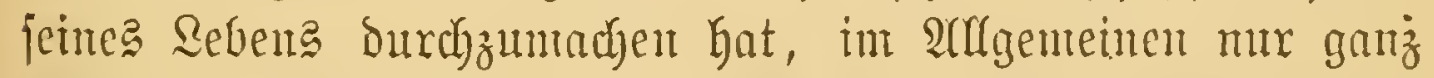

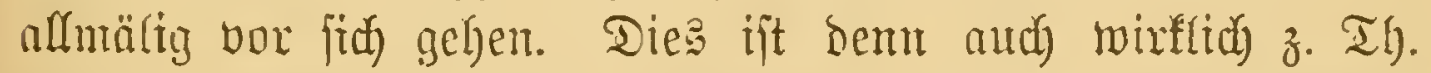
bei ben Jnfeften Der Fall, indem ja z. B. Die Flügel, welche ben Schmetterling jo anffallend von ber Raupe unter= idjeiden, nidyt jo plöbsich und unbermittelt entjtehen, Da man Die eriten anlagen Derjelben jubu bei ben jungen Raupen Gis raber, Jnjetten. II. $\mathfrak{B}$. 


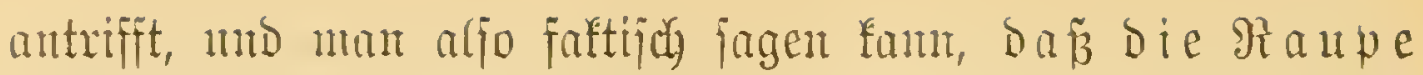
biufichtlich bex Flägel un ganz altmälig zum Schmetteriage wiro.

Eine jolde armmäligleit ber Sorwandung ift aber, obne Beeinträdjtigung bes Rebens des Ifjieres, mur bei gewifient

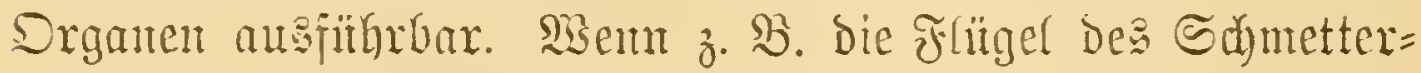
lings jigon an ber Raupe vorgebiloet werben, jo Kintort bies

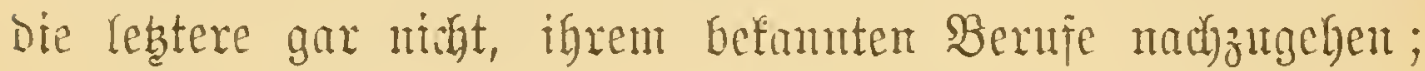

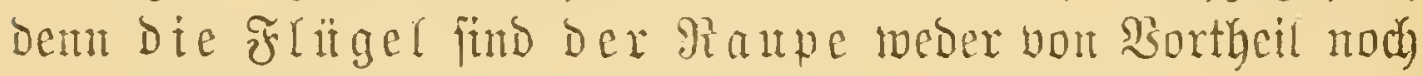

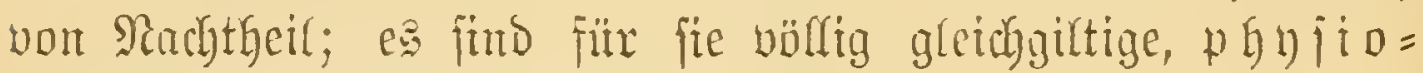
logif indifferente Birbungen.

Genan Dagjelbe wutroe der Fall fein, ment ber Saug=

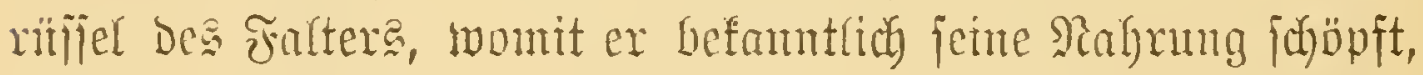

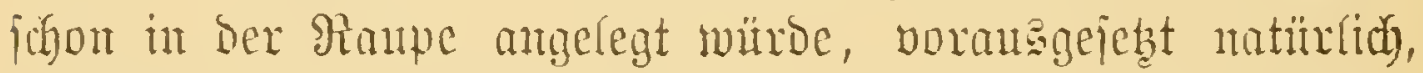
Da a Defien frühe Contwiafung nidyt andere für Das Rehen ber

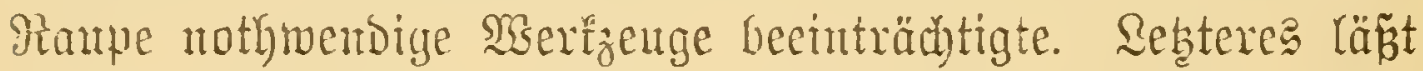

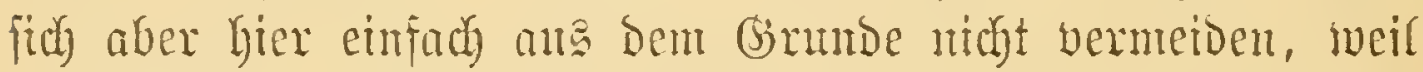

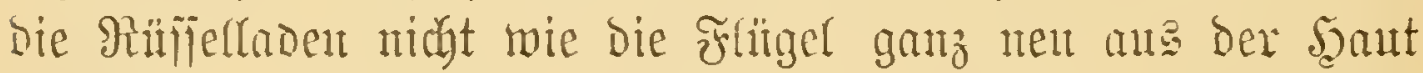
entfteben, jombern ats bereits an Der fante vorbantonen

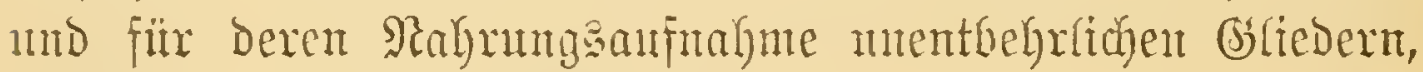

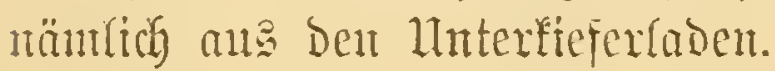

Num, wird man fagen, went ber Falterwiujel aud ntibt

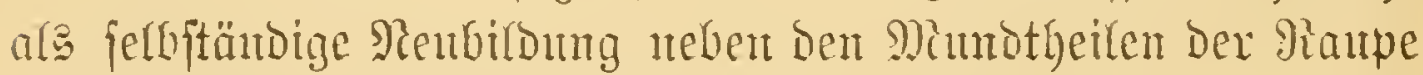

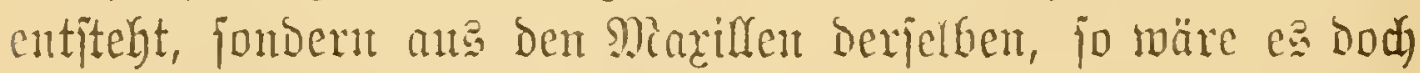
wohl möglid), Da vor fich ginge.

Nut möglich wäre bies immerfint, mo wahricheinlidy i it

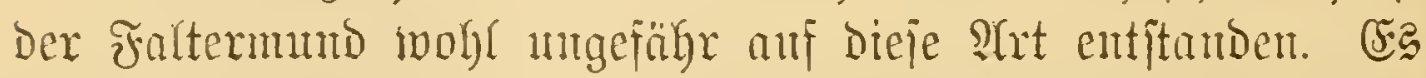
fragt fid) abex, was eine jolde afluärige s)intmometamorphoje fït eine Folge haben witrole.

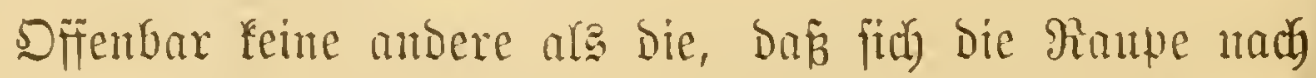

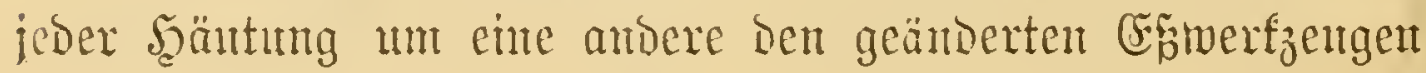




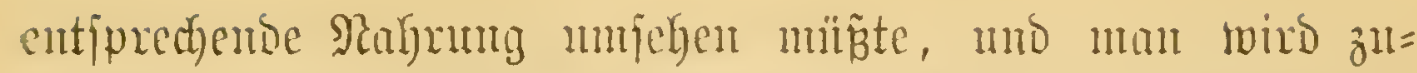

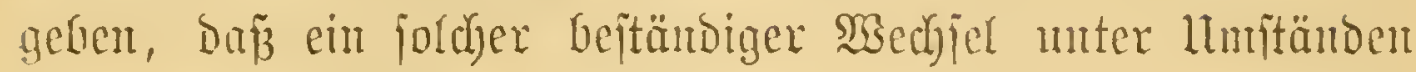

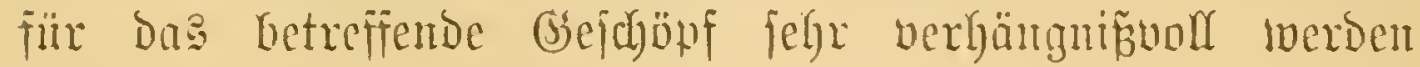

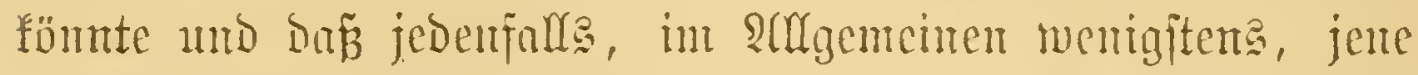
Snjeften bejer baran fint, hei welchen bieje Umänberung

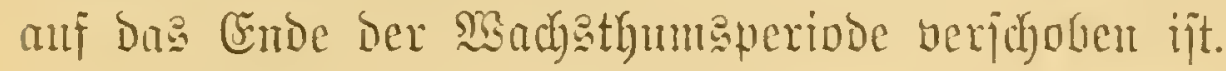

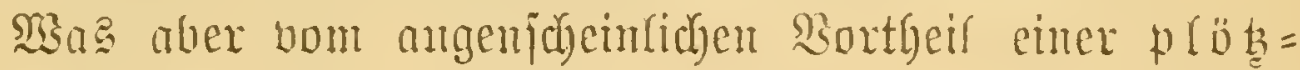

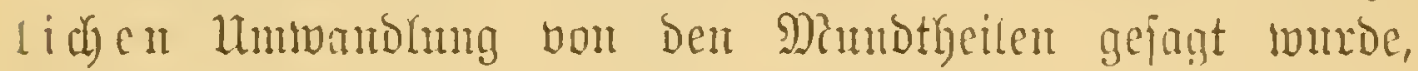
bas gilt and von vielen ambern correlativen und zujanmen= gehörigen Rebentwerlzeugen, z. B. von Den Bewegutgg= unD

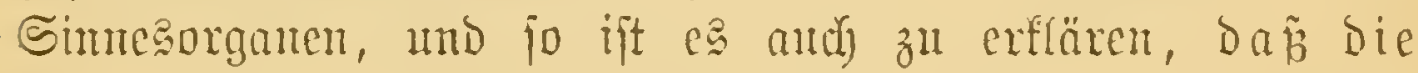

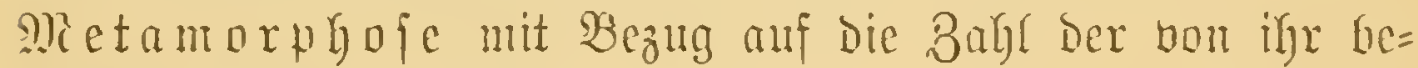
troffenen Rörpertheife meift feiue vereiuzelte, fonderu eine zujammengejeste oder cum lative ift.

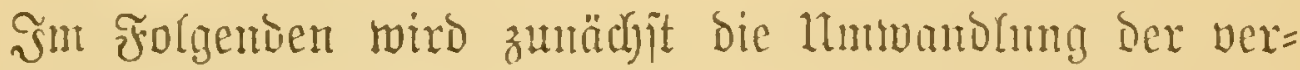

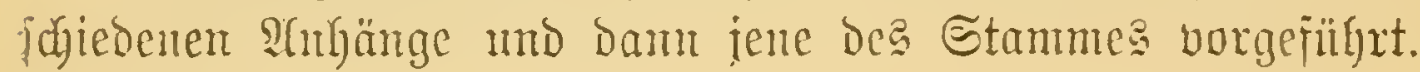

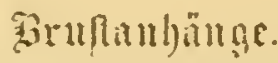

\section{Brinc.}

Şier gibt e⿱乛龰, nädjt Den Riejern, wohl bie meiften $\mathfrak{l} m=$

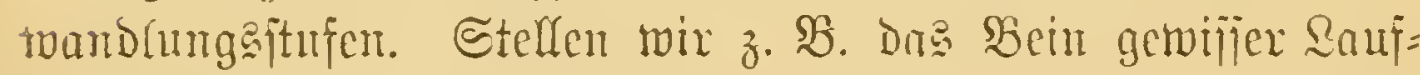
and Ranbiäfer Dem entipredjenten Drgan ifrer Sarven gegen=

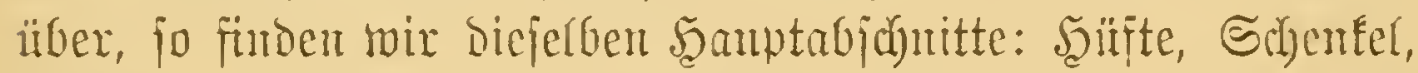

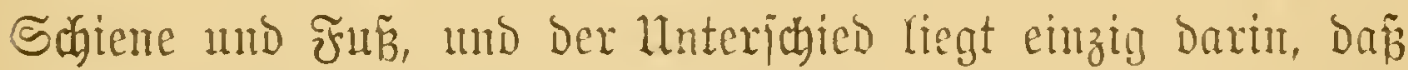
bei Der Rarbe bie Form und gegenfeitige Stellung der Cringel=

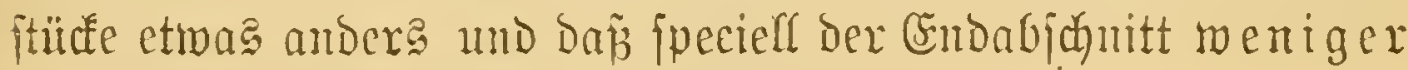
entwifert, weniger bifferencirt ift.

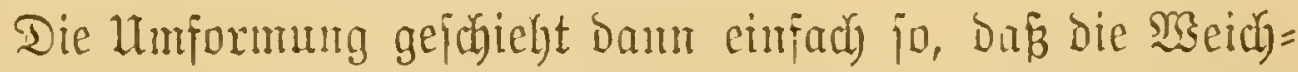

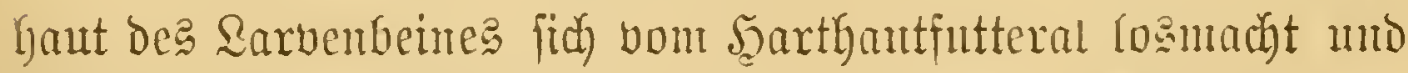

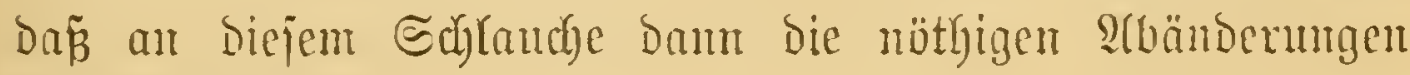
vor jidh geber. 


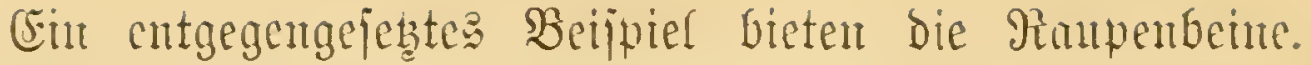

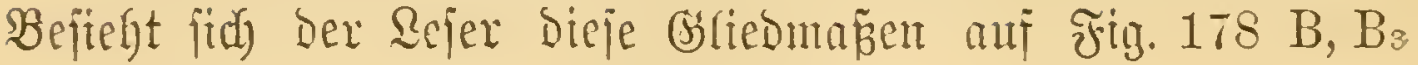

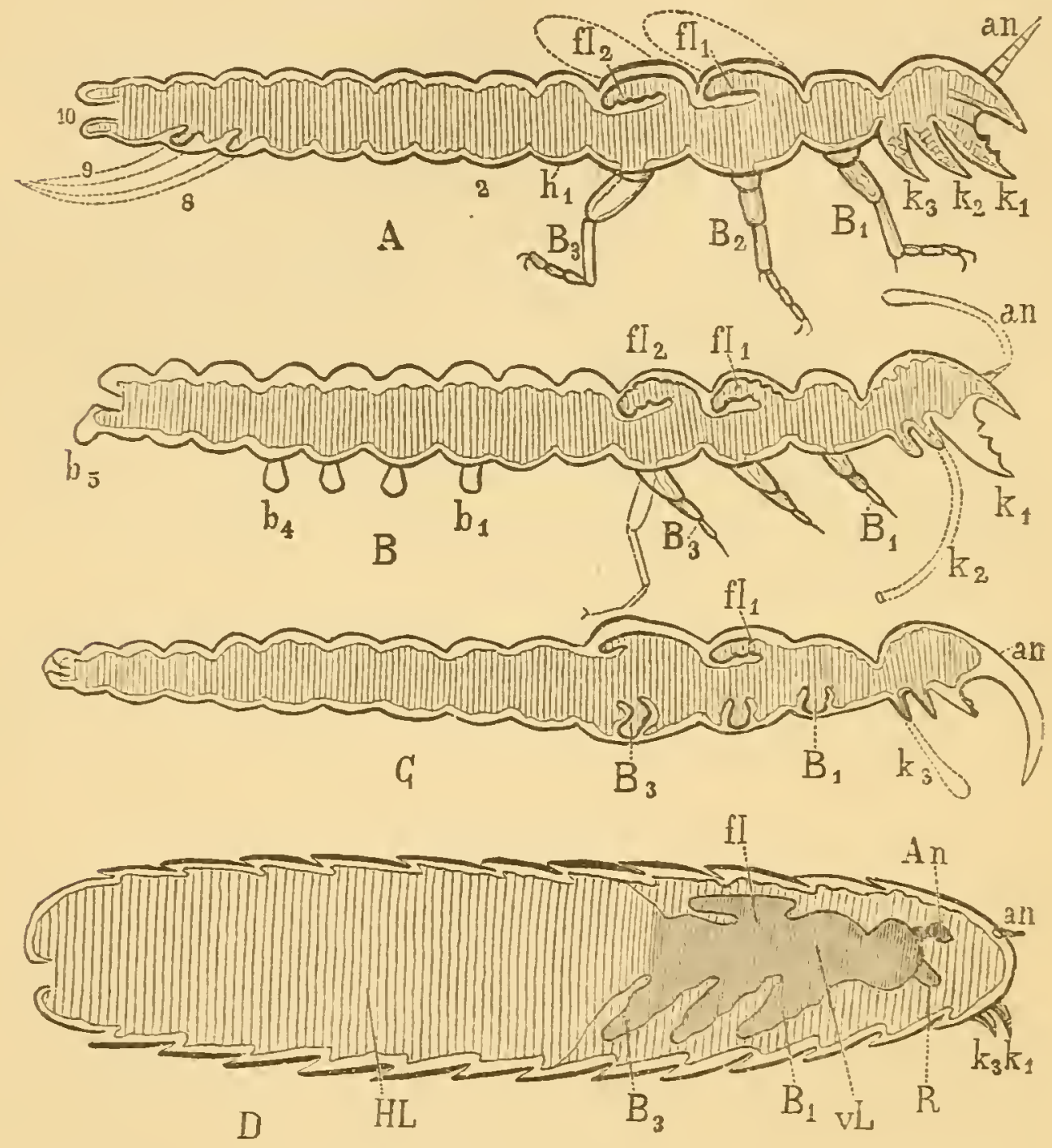

Jig. 178.

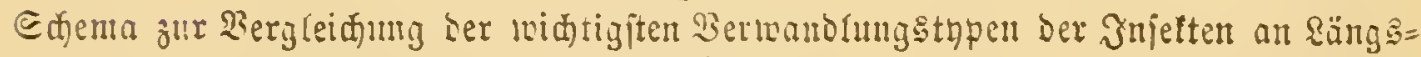
idinittent.

Iteberaff besentet bie äuB̈ere Contur Die Chitinfant Der Rarve, Die innere (gejüItelte)

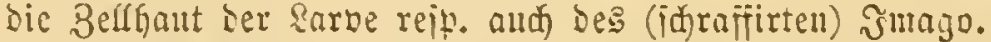

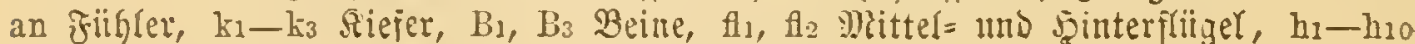

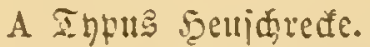
şiuterteifsringe.

B " ङduetterling.

C " Milice.

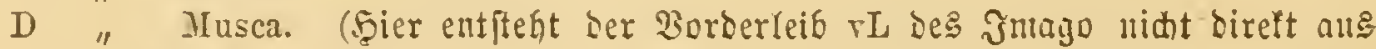
bem 2iorterteib ser Sarbe, wie bei Den übrigen Iypen, jombern ars innere Rentirlsung.)

(Sriginal.) 


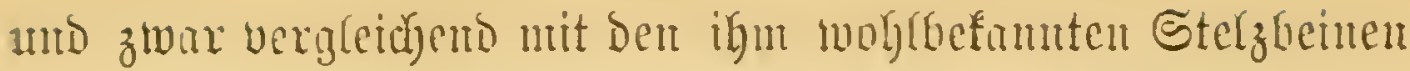

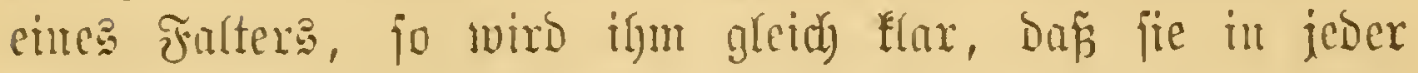

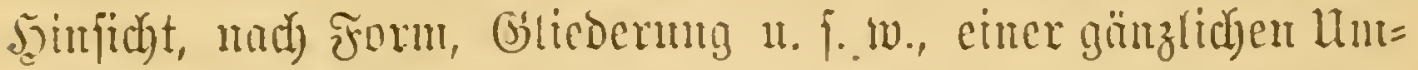

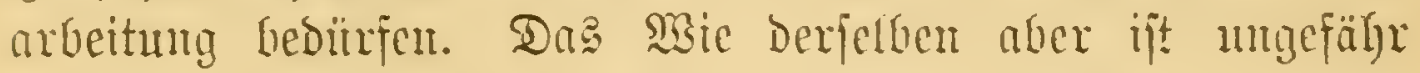

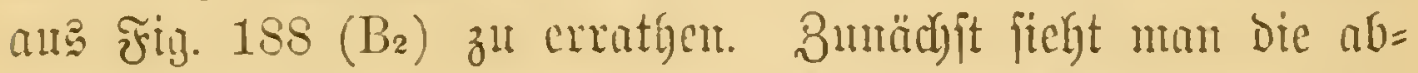

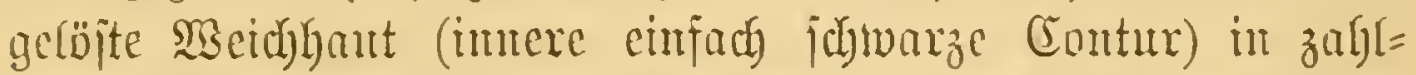
reide Falten gelegt, eine Erjobeinung, Die offenbar anf bie

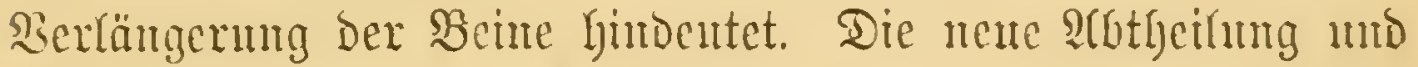
Mrodellinung beajelben fanm man aber, eben inegen biejer vielen Gunzeln, nidyt Dentfich unterideiden, jie zeigt jich erit,

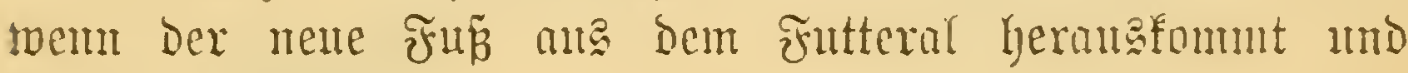
jitif ftrecten farm.

fisopfanljänge.

a. $\mathfrak{F}$ iif $\mathfrak{i} \mathfrak{c} \mathfrak{c}$.

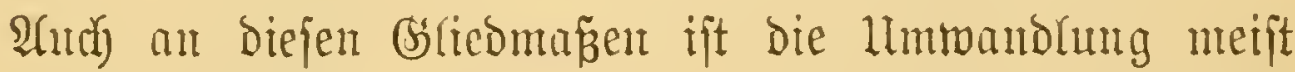

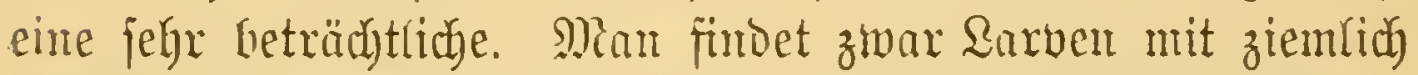
imaginalen D. i. mit fegr langen und vielgliedrigen $\mathfrak{A}$ (ntenten -

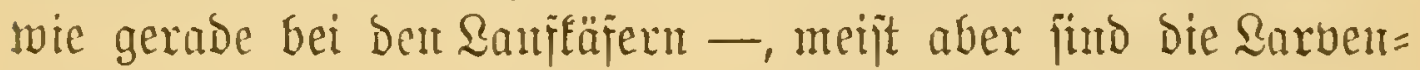
fïfler ganz unarfebnlthe 2-3 gliebrige Stummel mit etlidyen Endboriten.

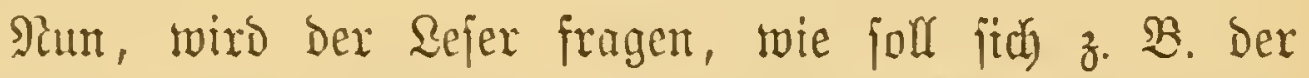
Ricjenfülyler cines Boffäfer: in winzigen Antentrenftummel

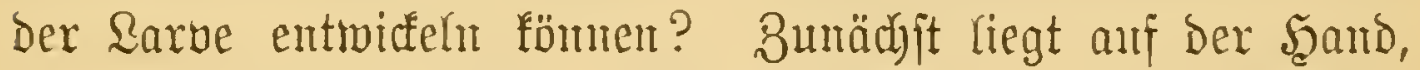

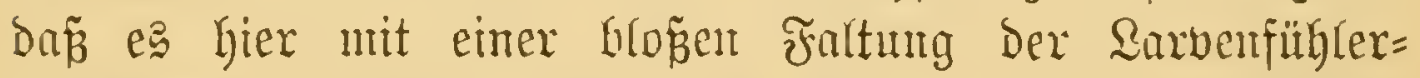

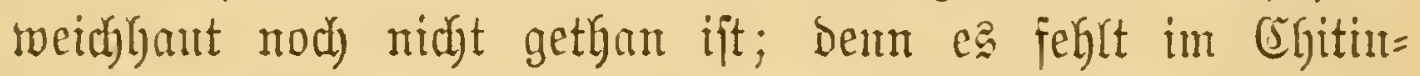
futteral abjolut ber phyjithe Raum zur SBitbung cines jo grozen Drgans. 2aljo was mu? Áfufichtig geftanden, jind biefe Bexhältuife jowie die Metamoxphoje

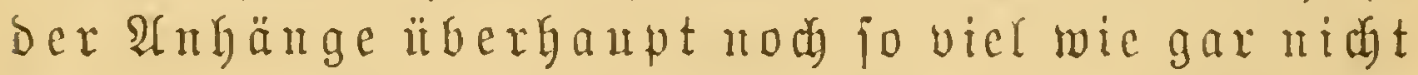
ftudirt; trobedent wollent wir's verjutyen, bem Sejer nach

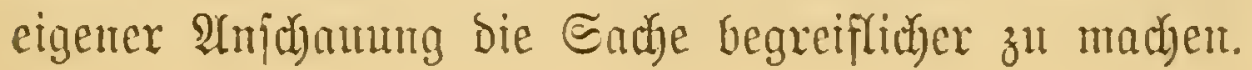


Die in einen iptben Rolben endigenden langent Füblex eines Tagfalters (Fig. 179*) fennt Der Sejer ofne Bweifel, und

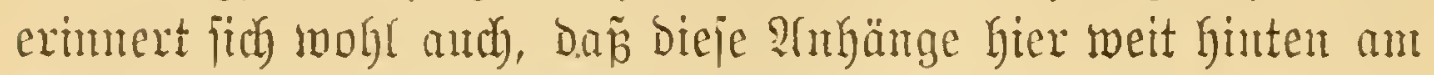
Sopf entipringen; Das Sinjolägige Der Kunpe aber ift in in Fig. 179 nabe gelegt. Er bemertet an ber ftadgeligen Syitin= frufte des Sopfes mo zwar ganz borne neben den Mcurd= theilen (bei an) einen furzen zweiglieorigen Bapfen. Das ift Der Raupenfübler. Bridat nan nut, un Dą Rïnjtige zu

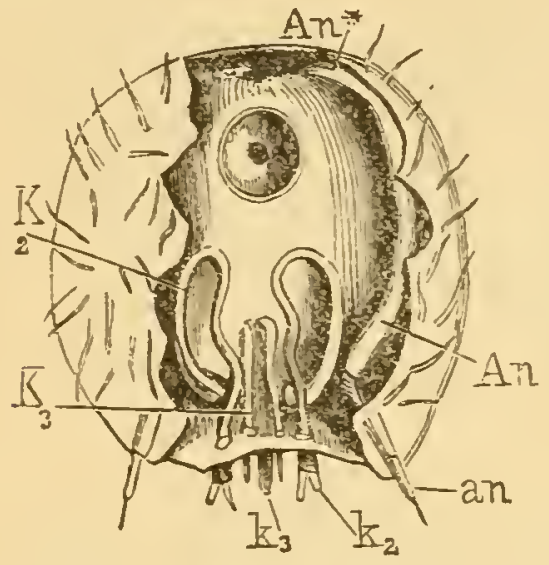

Fig. 179.

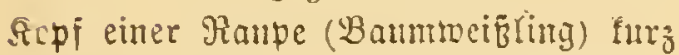
vor Der "Birpuppun", von unten gejeken. Die critinfant ijt 5 . Th. aujgebroden uns jïht nan Sen Ruppenfopl.

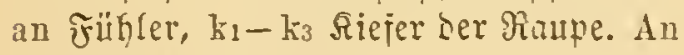
fïffler, $\mathrm{K}_{2}-\mathrm{K}_{3}$ Siejer Der Fuppe (reip. Rabialpalpen und Bunge in natïrl. Sage).

(Driginal.)

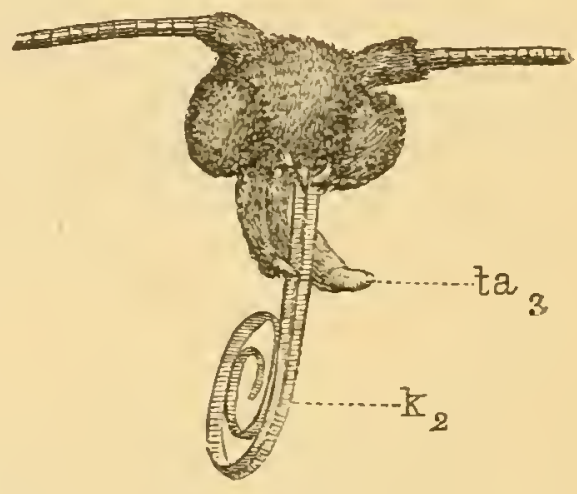

isig. $179 \%$

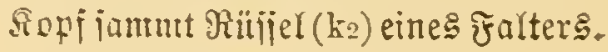
tas lluterippentajter.

jehen, an eimer giaune, furz bebor jie fich "verpupht", bieje Srufte auf, jo hat man ben nod ganz blaifen und weidyen Ruppenfopf vor jich. Betreffz Der nenen Filigler ift mun bies zut entbecfen. Die Spibe Derjelben (An) liegt in Der That im Chitinfutteral des Ranpenfïglers, es jino jomit beides faftija homologe Theile. Áber mu bie Spize; dem die gemifje

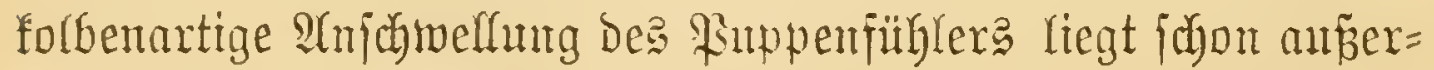
Galb der Rampenantenne, aber hart an Der Bafis Derfelben.

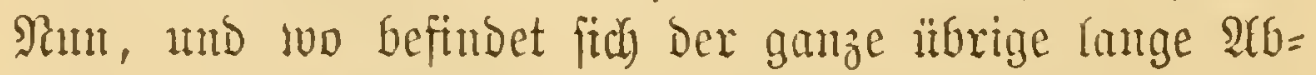

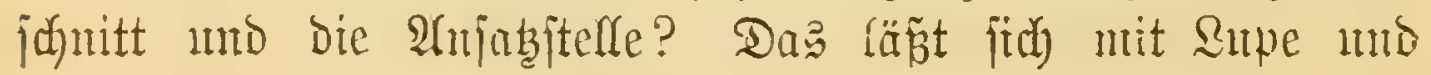


Pabel, wem man cimmal ber Sadje auf ber Spur ijt, leidyt

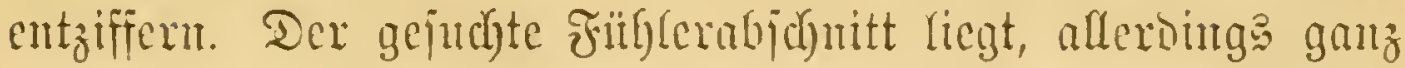
in cinc Ginute eingejent, an ben Seiten bes fiopfes, mälrento die Jujertionsiftelle ganz ginten (bei $\mathrm{An}^{*}$ ) zu juthen ijt.

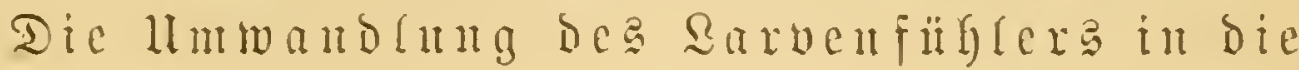

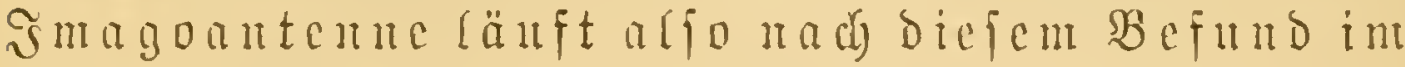

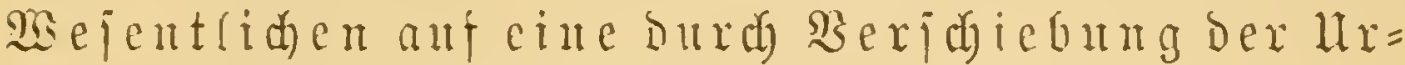
iprug

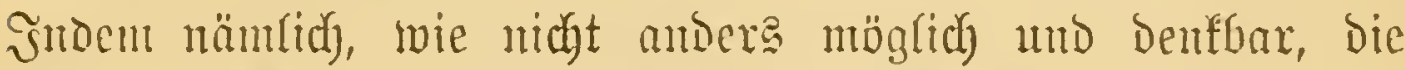

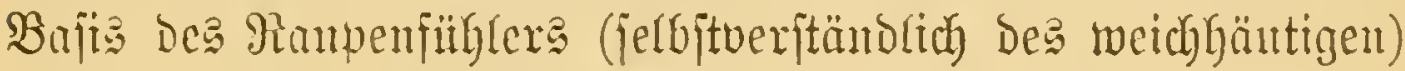

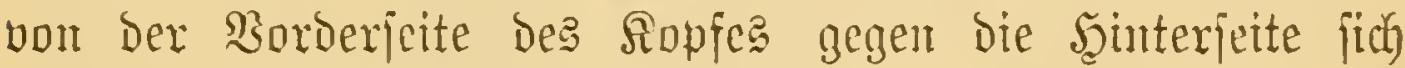
verjdyob ober jurüufag, wurbe bie entjpredgende Sänge getwomen. Dem erjten Uriprung ua i f fomit der

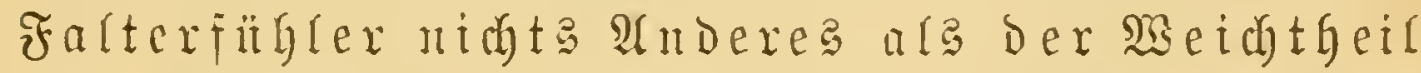
dex aranenatente; infoferu eriterer aber,

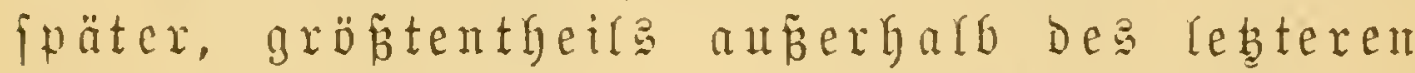

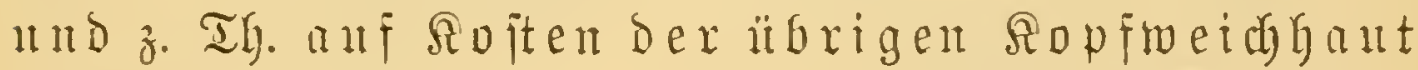
cutfegt, fan ex ar einc bejondere art bou Reugebilde gelten.

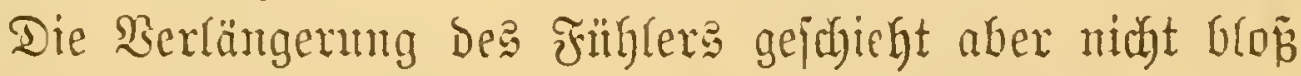
burch Serfichiebung, Durdh Burürfforlegurg ber $\mathfrak{A} n=$ fabitelle, fonderut inges = jombere auth burch fitarfe Fältelıng Der neu hinzu= getwadjjenen Strecte. Dies zeigt jich am jeföniten an cintem gecigneten Echnitt, wie Fig. 180 cinen foldhen Darftellt. (Era gegt quer Durd) Den Sinterfopi einter aus= gewarjjenen Ranpe. Die

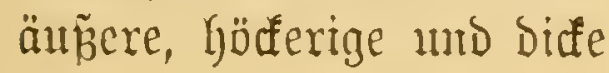

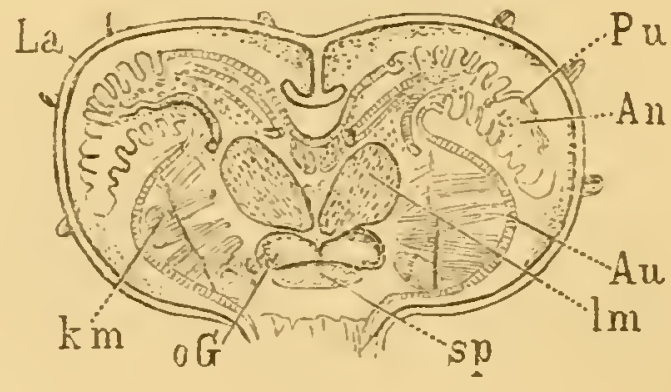

Fig. 180.

3ur Entmidfung des Edmetterfingtopfes (Bauntweibling).

Frontalidnitt (Ginter. ber Mitte bes Sopies) eitur halb ansgetradientu Raupe.

La bie von ser jelligen (Matrix) abgefobene

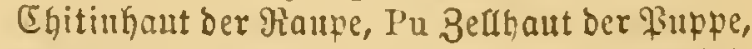
An filthler $=$, A 2 lugenanlagen, $\mathrm{km}$ SiaumuEfel= reite, Im sängannistcln, oG nberes Edirmo= ganglion, sp Eppeijeröhre. (Driginal.) 
Sage (La) ift Die Chituthant ber Sarve, bie inmere, quer=

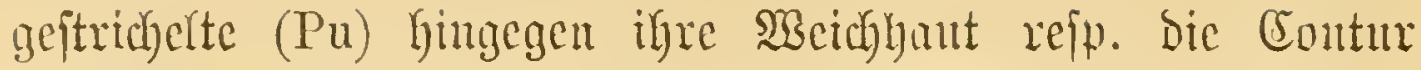

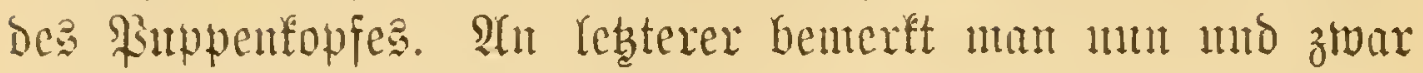
oberbalb Der vorgetwölbten Argen (Au) cin \$aar mabe bei= fammen entipringender Fortjäßze (An), die auf́cn, da fie durch

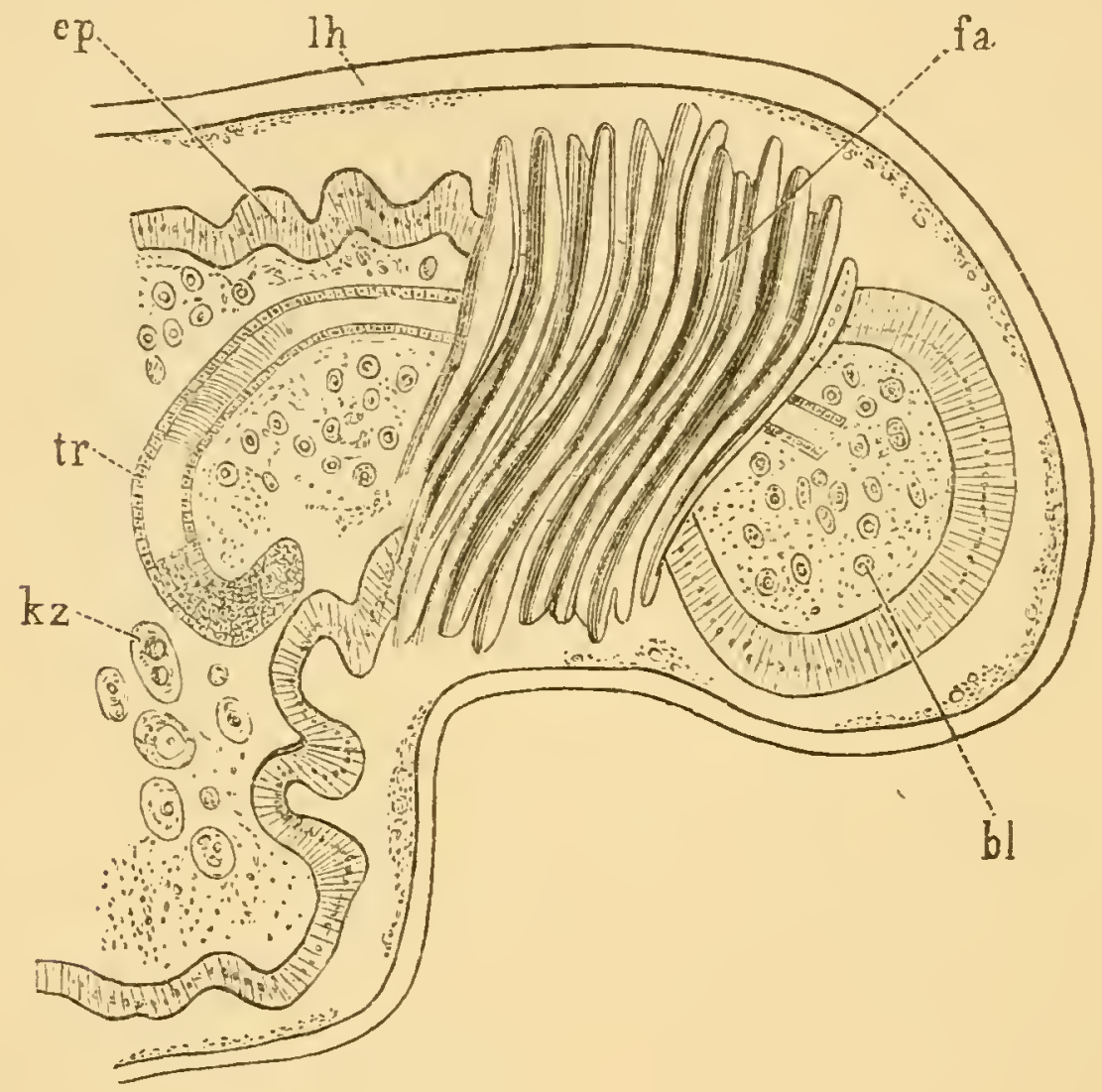

Fig. 181.

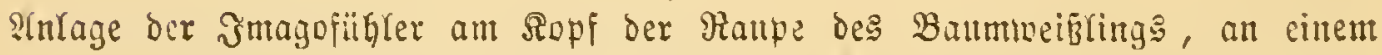
Quneriduitt.

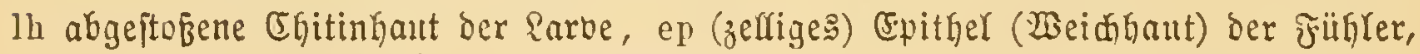
fa Falten berielben, tr Tradeenanlage, kz Röner $=$ bl Blutzellen.

(Prigittul.)

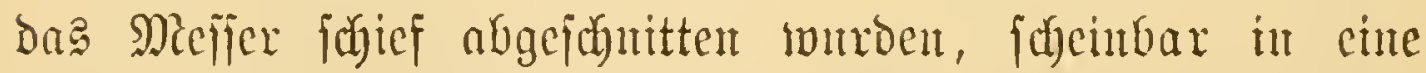

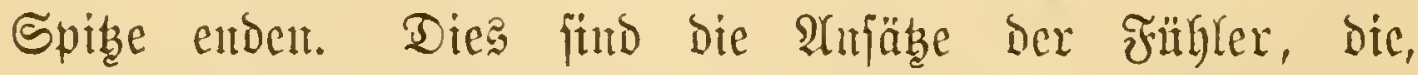

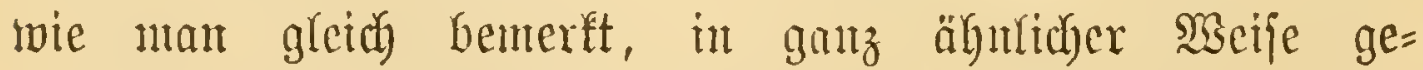

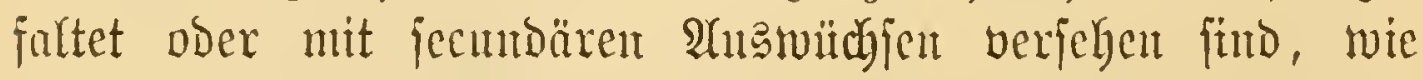
wir bies oben bei ben Beiten ntto Filïgeht fantben.

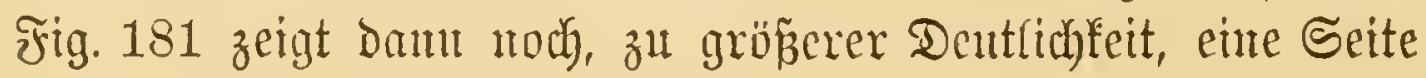




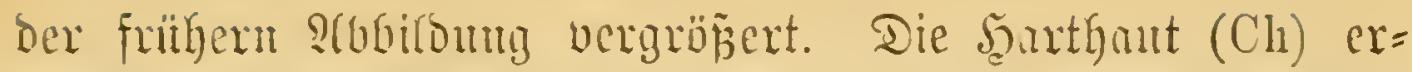
fideint als biffer Gomogener Snum, bie zellige șeidjhaut (ep) alver ift wellig gebogen mo ber barme entjpungene Fübler

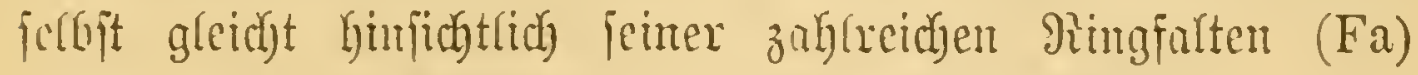

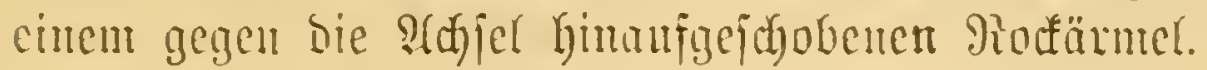

\section{b. minutitgcile.}

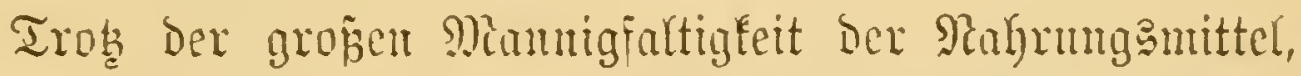

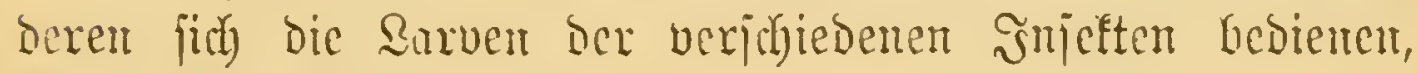
ijt Doch ify simbaptarat meijt cin zicuticl) cin= facher und einfïrmiger. STs allgemeiniter Typus fam bas "Ścbi $\tilde{\beta}^{\prime \prime}$ Der Rante (ซig. 181*) gelter. Da finden wir: 1) cin $\mathfrak{P a a r}$ fräftiger Beíñ angen $\left(k_{1}\right)$; 2) ein $\mathfrak{P a a r}$, aber gautz fidwacher, Mittel= ober Iluterfiefer (ka) mit furr $=$ zent "Fre ₹ripitien" (al, d)

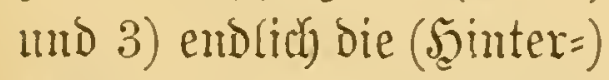
Siefer $\left(k_{3}\right)$, weldye jebon

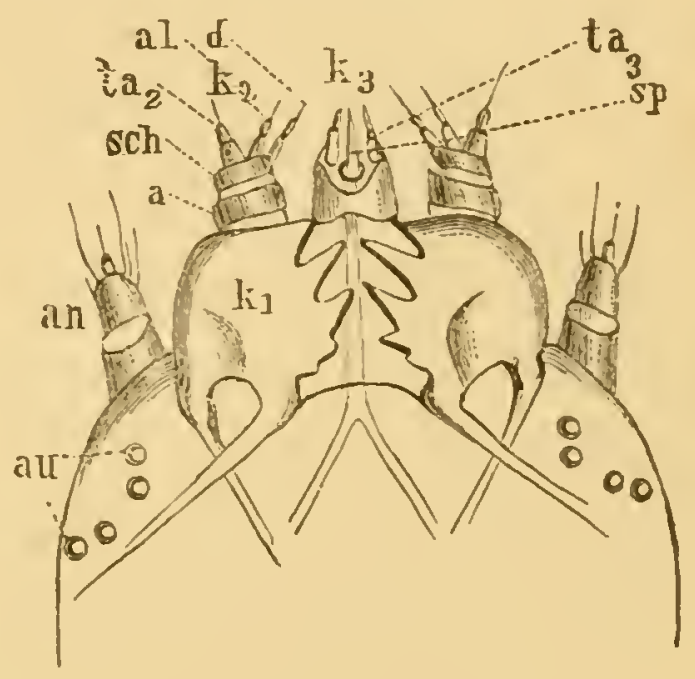

Fig. 181\%.

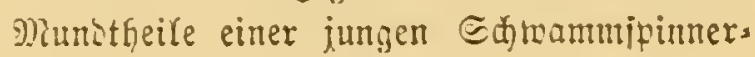
raupe. zur Epimfpule (Unterlippe) verjanolzen und mur in ben Iajtern jectoitändig find.

Bedenfen wir nun, wie fehr die Crnährungąncije ber

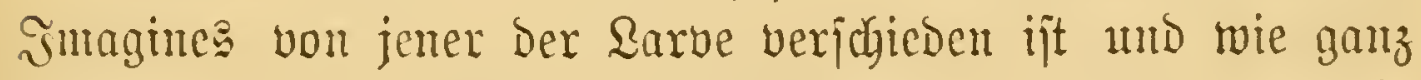

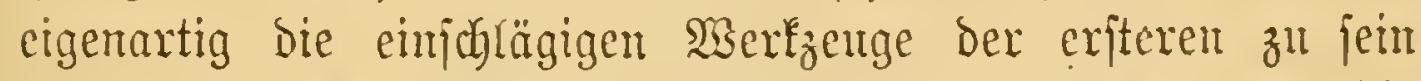

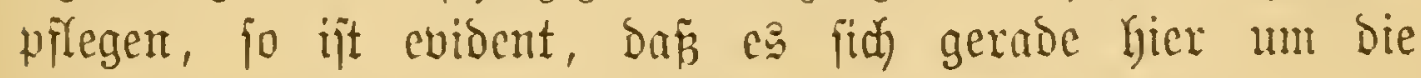
vieljeitigiten und intenfiujten Serämberungen handelt.

3u befierer Meberijut tömen wir folgende Irten unter= \{ufetbert : 
1) Bseringe, auf bölyere Differenzinung geridytete aren=

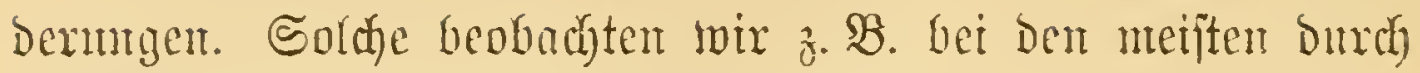

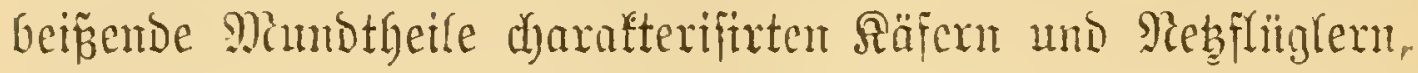
aljo bei den relatio cinfaditen metabolifara Rerfen.

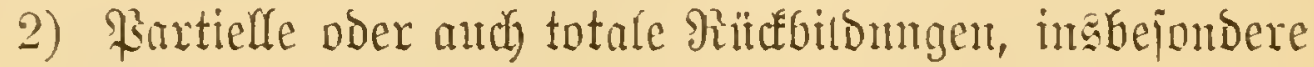

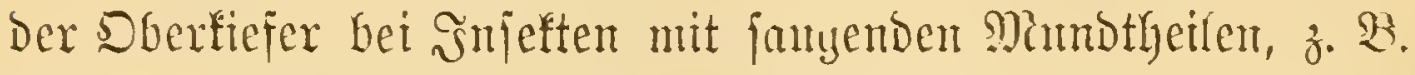
bei Den Faltern, FFliegen, aber mudh bei Ruminfeften, z. B. Den Pagrygantoen und Eukemeriben.

3) emblich llmformung ber Mrittel= ober şinterkiefer

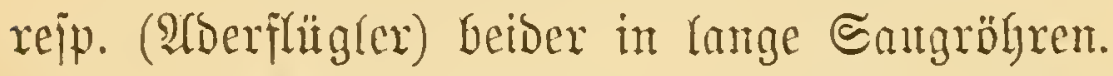

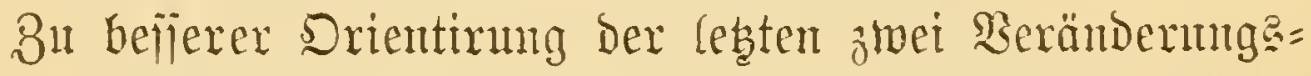
axten mebme man zumädyjt miesex bie Sdyemata in Fig. $178 \mathrm{~B}$ und C zur Scand. Falter= und Corethra-Rarve zeigent bie brei Rieferpare $k_{1}-k_{3}$. Bei beiben rebuciren fich an Imago bie

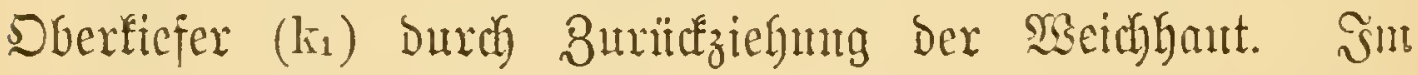
SBeiteren bemerfe man biejen Mnterjojied: Bein Falter ent=

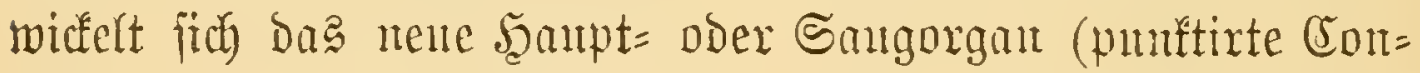

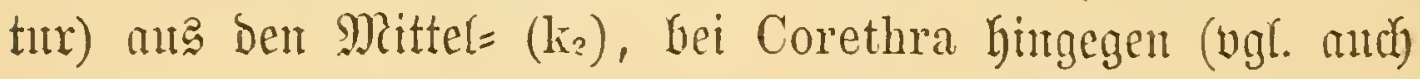
Fig. 177) aus den b̧intertiefern $\left(k_{3}\right)$, soährend die andern Theile, wenn anch in etwas veränderter Bseitalt, als Seben= organe fich forterlyalten.

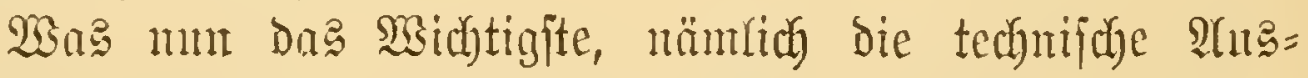
füfrung biejer Beränderungen betrifft, jo wollen wir ut:, wie bei Dex Fühlerntetamorphoje, woieder an die Rampe halten. S⿱:

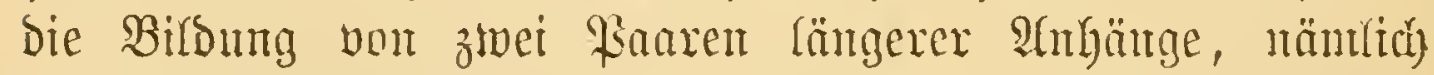
Der Unterlippentajter ( $\left.\operatorname{ta}_{3}\right)$ mb der Das Samgrohr zu=

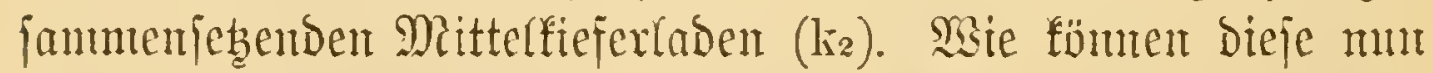

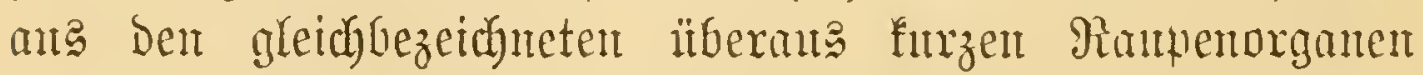
$\left(\mathrm{k}_{2}, \mathrm{k}_{3}\right)$ in Fig. 183 hervorgehen? EFin Bifíf auf Den ent=

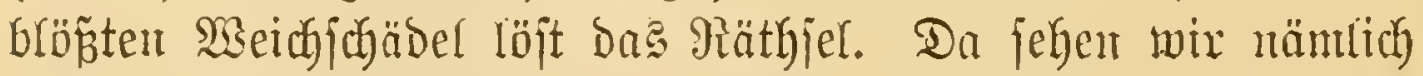

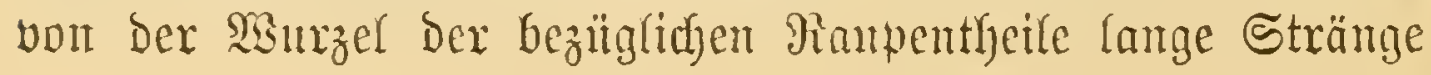




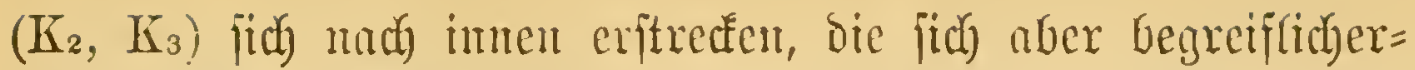

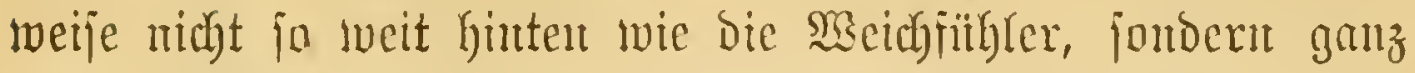
vorme imferiren uno eben ans biefem (srumbe and - un

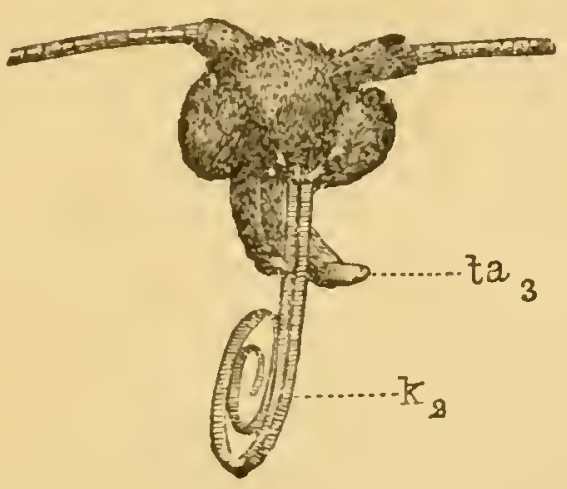

ifig. 182.

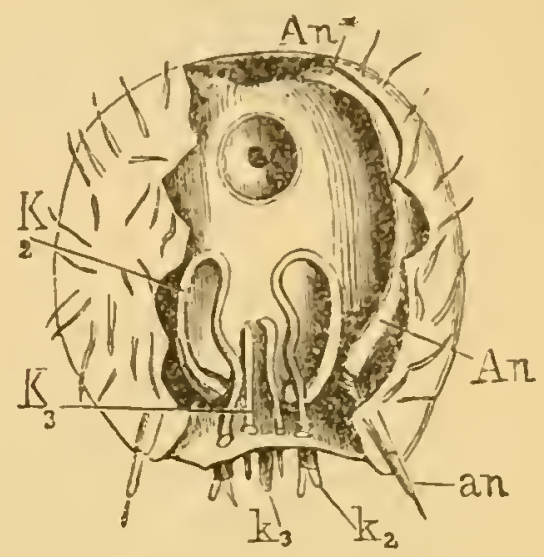

F̂ig. 183.

Demnoch die nötgige Qänge z̆l erhalten - mehrfach gebogen,

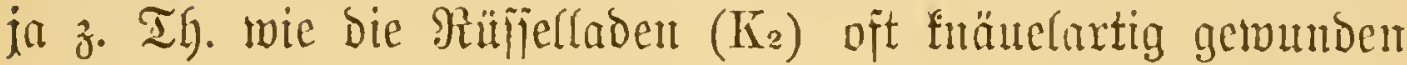
jimb.

Stamm!n.

Went wix, ım die Bröp̈c ber Stanm = Mietamorphoje zu bejtimmen, cune Raupe (Fig. $184 \mathrm{~A}$ ) mb cinen Schmetter= ling (C) neben einander legen, jo jheint der Mnterjated ein gauzz gewaltiger zu jein.

Fin's Erfte ift ber Schmetterlingftamm beinabe un bie

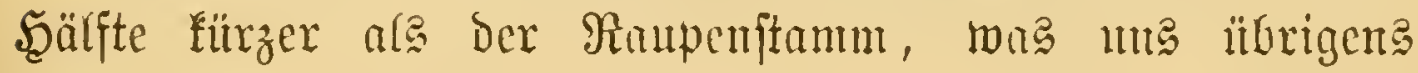

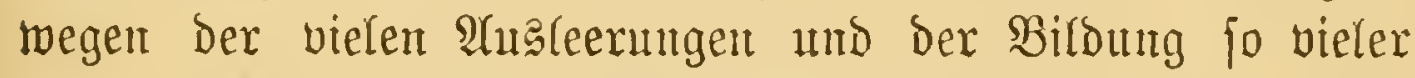

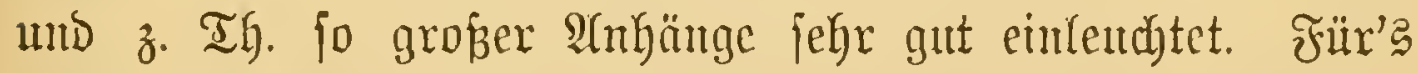
3weite ift aber bie ganze Brfiederung eine mbere. Bei Der

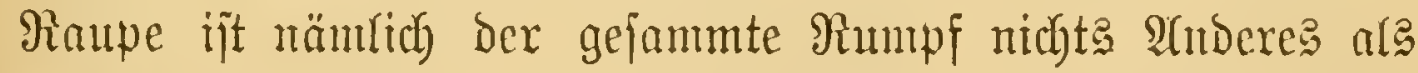
ein einziger burdi feidyte Mingferben in oreizchn greidje Bjürtel oder Somiten abgetheilter Schlund, während ber äquibalente Falteritamm in brei gröpere burch tiefe (sin= fabnitte getrennte und unter einander ganz verjojiebene $\mathfrak{A} b=$ 

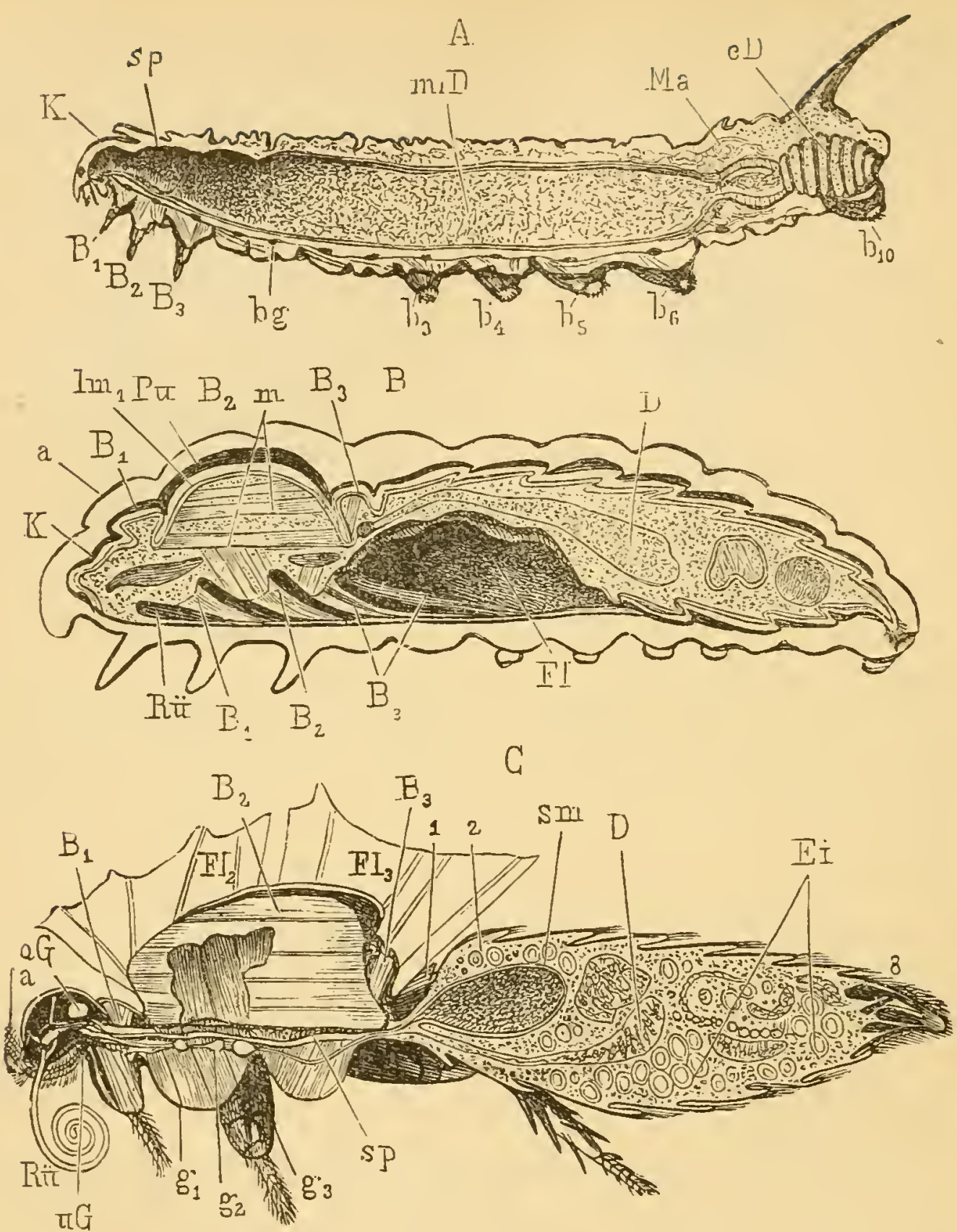

Fig. 184.

3 Mr Mietamorphofe ser Sajmetterlinge.

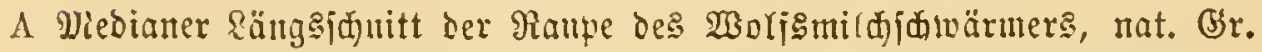

$\mathrm{K}$ Sopf, $B_{1}, B_{2}, B_{3}$ Borber=, Mittel= uno Seinterbrujt rejp. = Bein, b3-b1o Stummelbeine bes 3., 4. 2c. Sinterleibsringes, sp Epeijeröhre, $\mathrm{mD}$ Mitteloarm

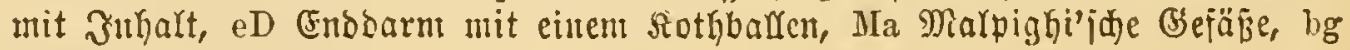
Baudganglientette.

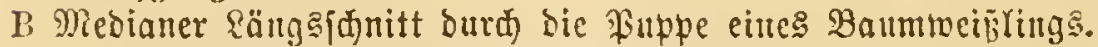

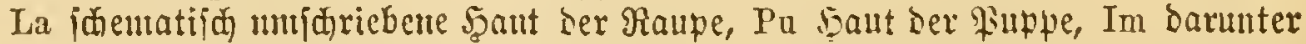

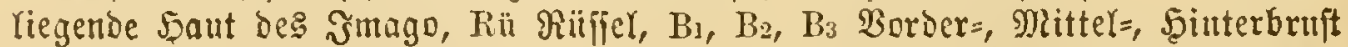

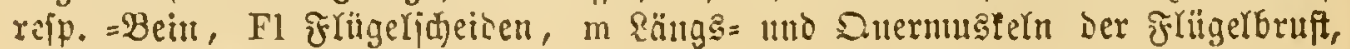
D Darm. Bergr. $3 / 1$. 


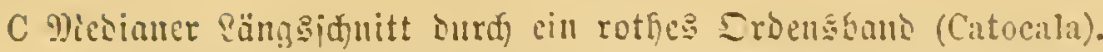

ta Sippentajter, Rü Sangriifich, oG oberes, nG unteres Edflumeganglion,

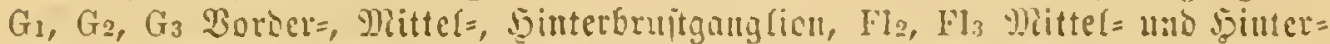

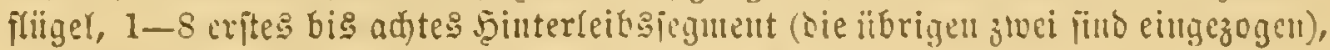
sm Eanguagen, D Darm, sp Epcijeröbre, Ei Eicrîtod. Bergr. 2'ı.

(Driginal.)

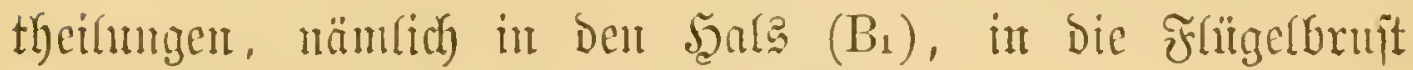
$\left(\mathrm{B}_{2}, \mathrm{~B}_{3}\right)$ und in Den șinterccib zerfälnt.

Dic Mittelfigur (B), wo wir vout anzen math imnen bie Ilmxilie von Ranpe, Puppe mb Falter neben und in einander

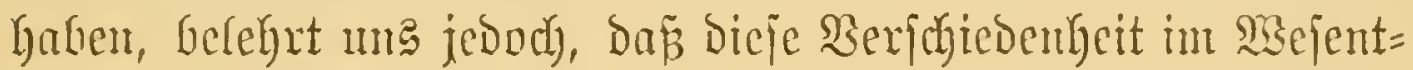

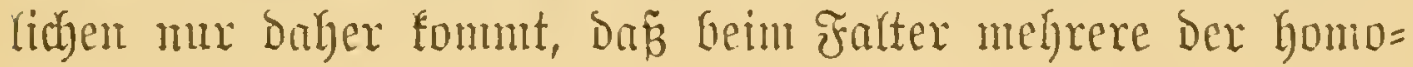
nomen Raupenftammglieber in größ̈ere Eomplere vereningt fint.

So wird der Rejer Gard Gerats haben, daź das, was

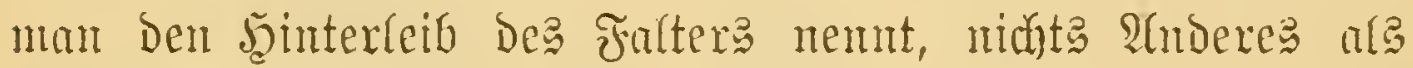
eine Bereinigung Dex zehn hinteriten Ranpenjomiten iit, bie aber beim Smago viel ftärfer in cinander gejdjoben finto.

Dic Şantumformung betrifft aber, wie mut fiebt,

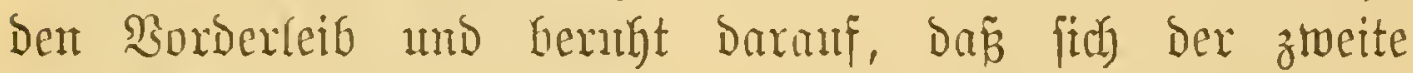
$\left(\mathrm{B}_{2}\right)$ und Danit in Bujammenfyang and ber britte Ring

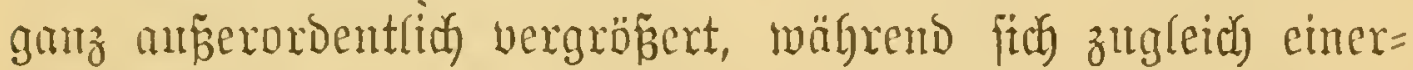

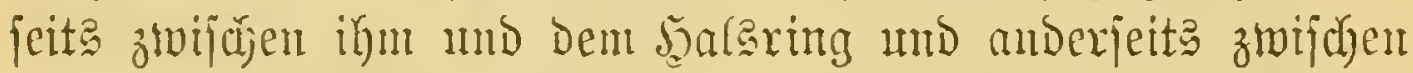
Der ganzen Flügelbruft und Dem Syinterleíb ein tiefgelyentoer

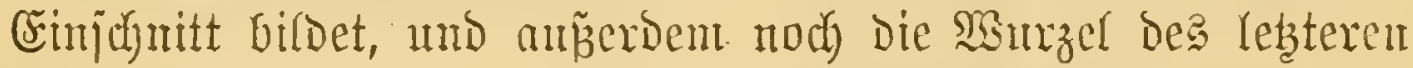
nanentfich bon unten her jtielartig zajumenja)rmmit. Beiberlei Borgänge aber, bie Erweitermngen mb die Serengerungen, fimb, wie aus ber imeriten (Smago) Sontur zu erjeken, anf

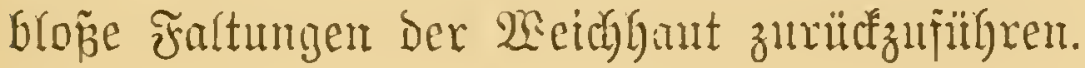

\section{Die $\mathfrak{R}$ uppe.}

Das Ergebnip aller jeşt bejdyriebenen Serändenmgen an Der Saroe ift befanntlich Die Puppe, die mn ihrerjeits

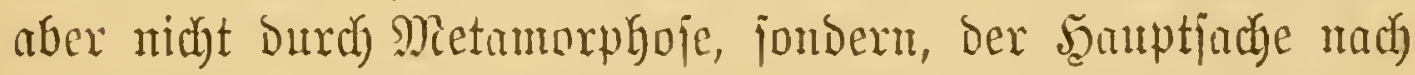

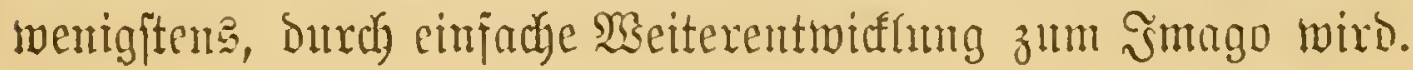




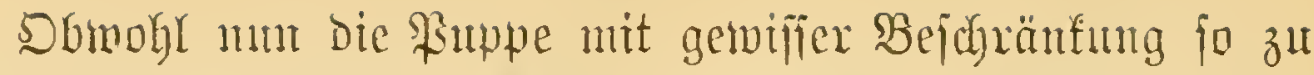

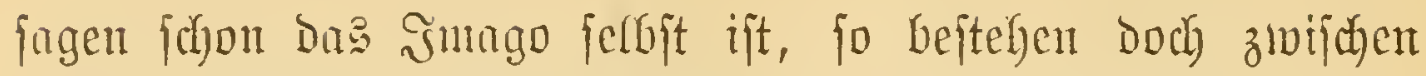
beiben mandyerlei, im Folgenden furr anzudententoe Unter= fajiede.

WSas zunäbrift Den Stamm angeht, fo ficht der Lejer aut ciner Falterpuppe (Fig. 184 B), Du汸 bier Der imaginale Cryarafter robl angedentet, aber nod bet meitent utidyt

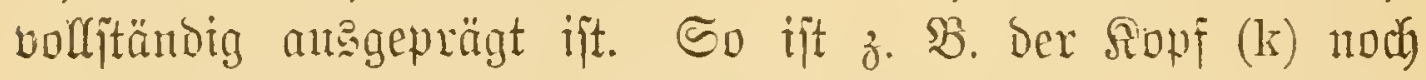

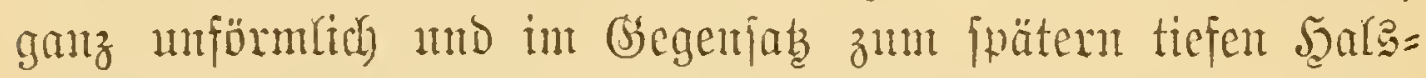

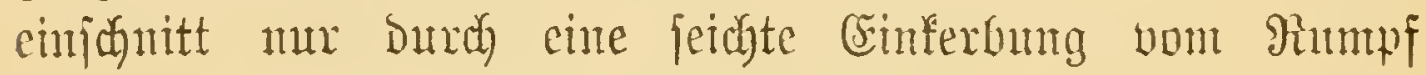

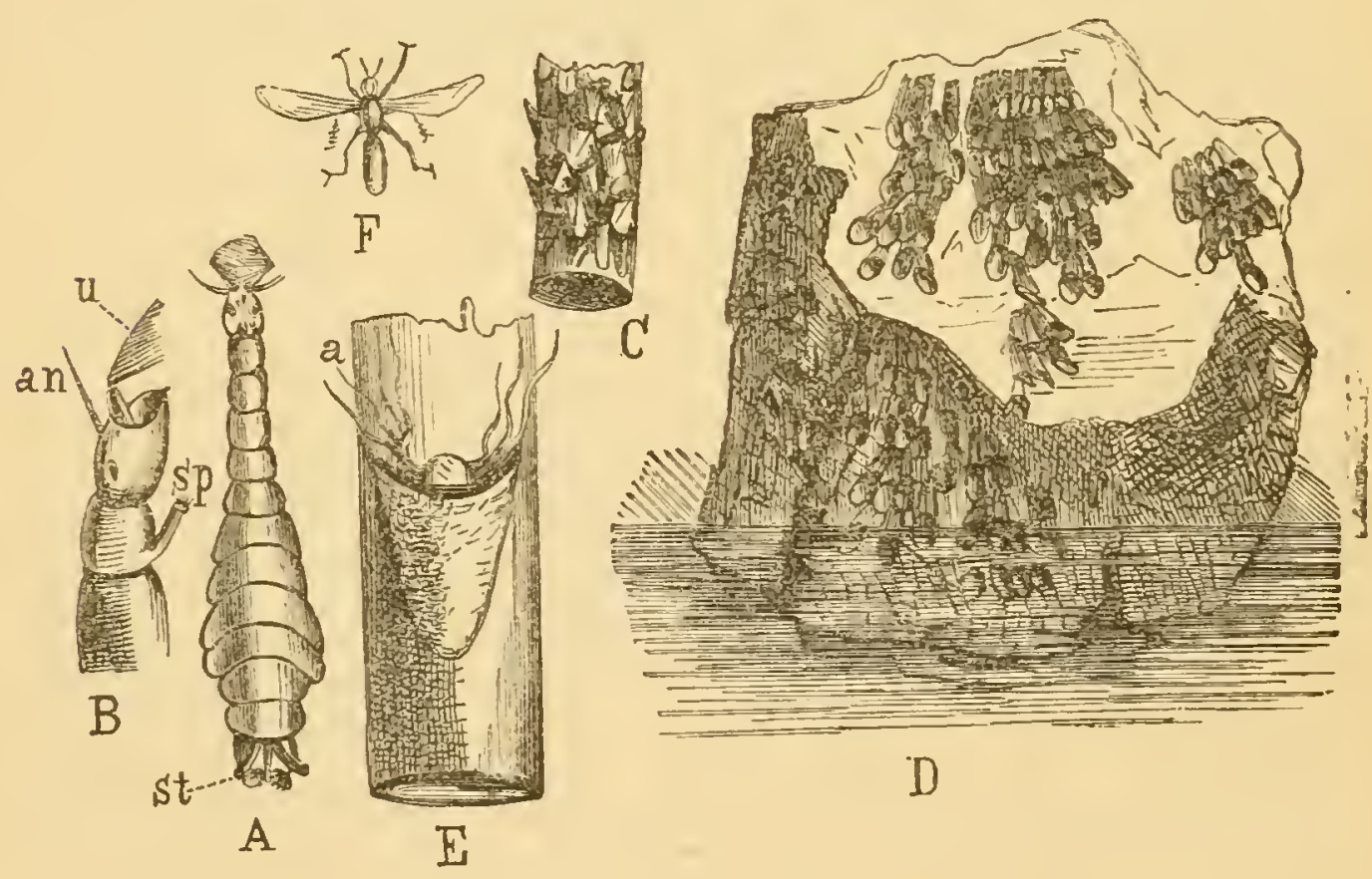

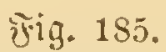

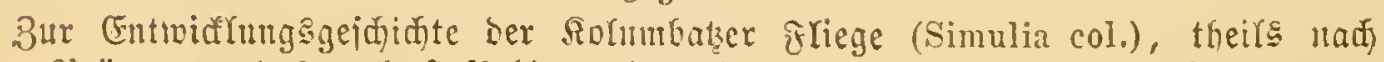

Fräparaten tes zool. Shoffabinets in Wien, theils nad Sriginalzeidunngen von Эoj. צiann.

A Sarbe mit beweglichen $\mathbb{R}$ iterftigmenröhren st.

B Deren Borberleib won ber Geite. m Niuns, u medeliörntige Ricjer (ganz analog aber nidt homolog ben Corethra-ifïhlerm), an Jibler.

C Etüd eines in wajier untergetanciten Bammineiges mit sen pergamentartigen

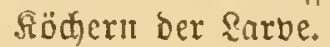

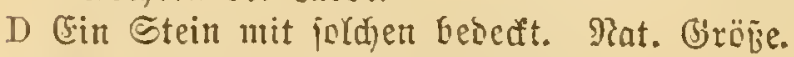

E Cine folde 3elle mit ber Pimpe.

F Friege. 


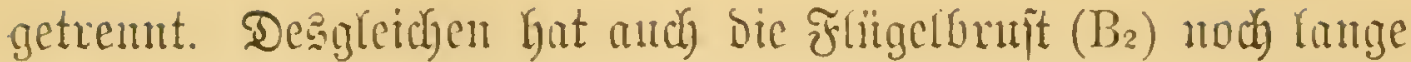

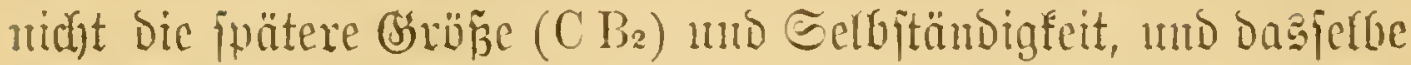
fum man an ber Corethra-Pinke (Fig. 174 B) jehen, so ber

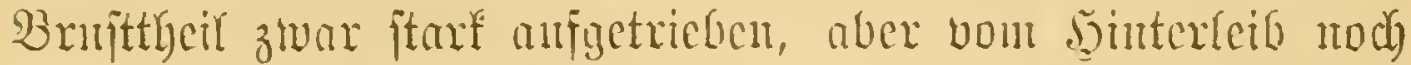

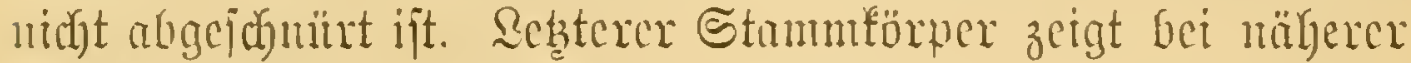
Sergleichnty and mantije Differenzen, wobei wir bon un=

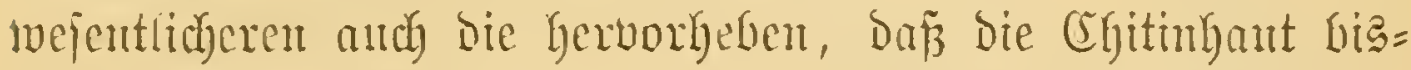
weilen noch gewijie oen Rarven fo eigentyüntiche Şare mo gionfigfeiten bejtht.

Weit vieljeitiger find nodi bie lluterfatede bei deu Ğliedmañanct.

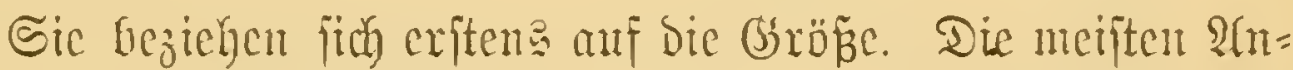

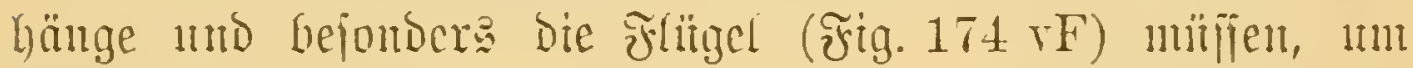

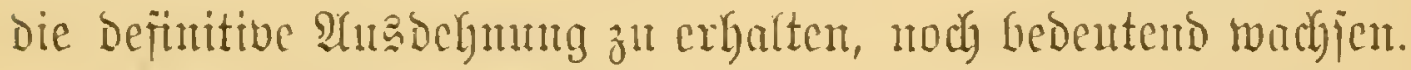

Am wichtigjten, toenigitens fïr Den ganzen S3abitns Dex

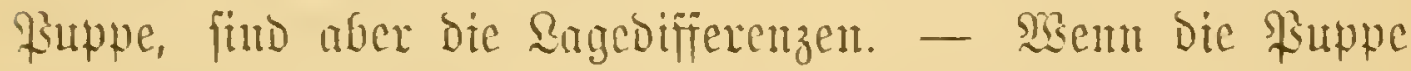

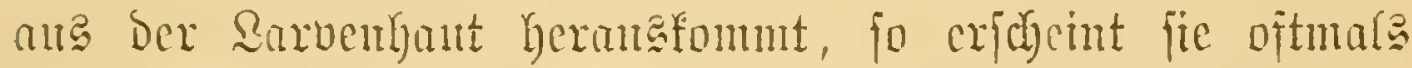
- fogar bei Siljnetterfingen - ale cin jegr lebendiges, reg= james 2 sejen, und da mu alle früber ganz bem Sörper an=

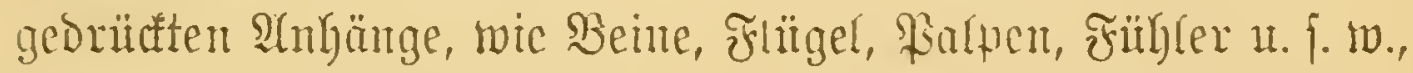

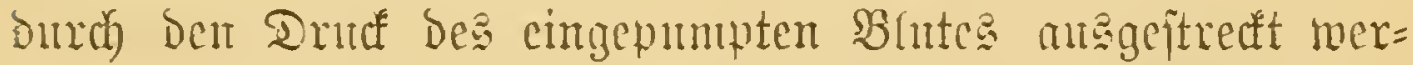

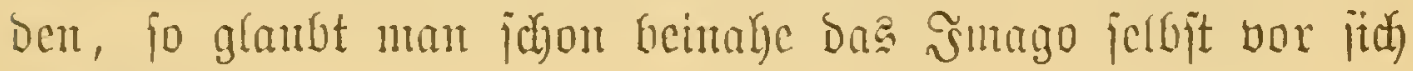
zu lyatien.

Diejer piendimaginale Bujtand gegt aber rajd vorifber, inden alle die genannten bsfieder, in Folge ber immern lunjertig=

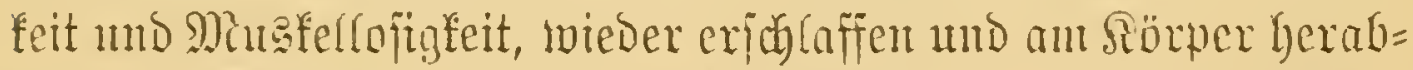

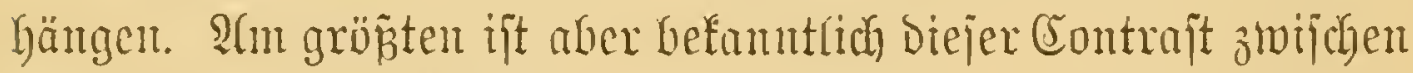

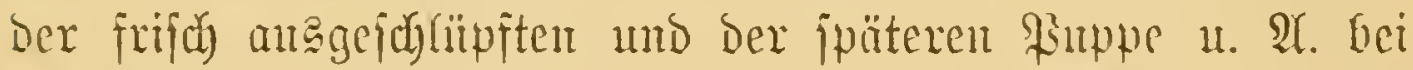

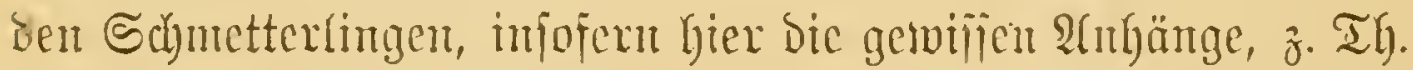

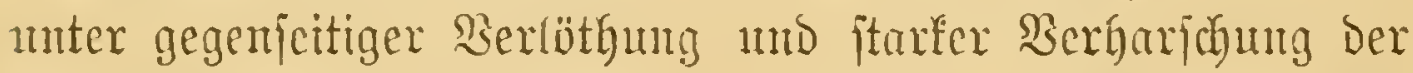

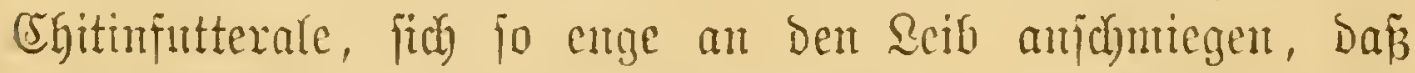
fie gax nidjt mehr als jelbjtändige Theile, foutbern mux als

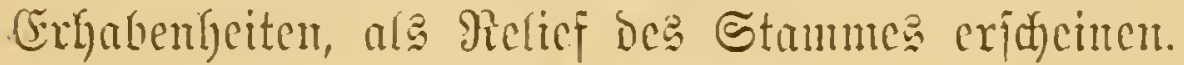


3ux ridytigen Bentheimng biejer jog. "gemeijelten"

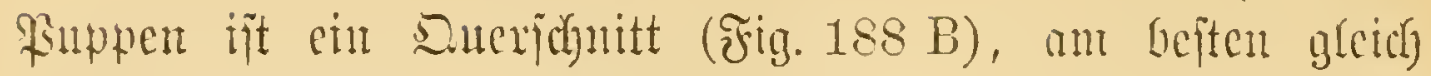
Güter ber Brujt, zux Şand zu mehmen. MRan jieht hier au

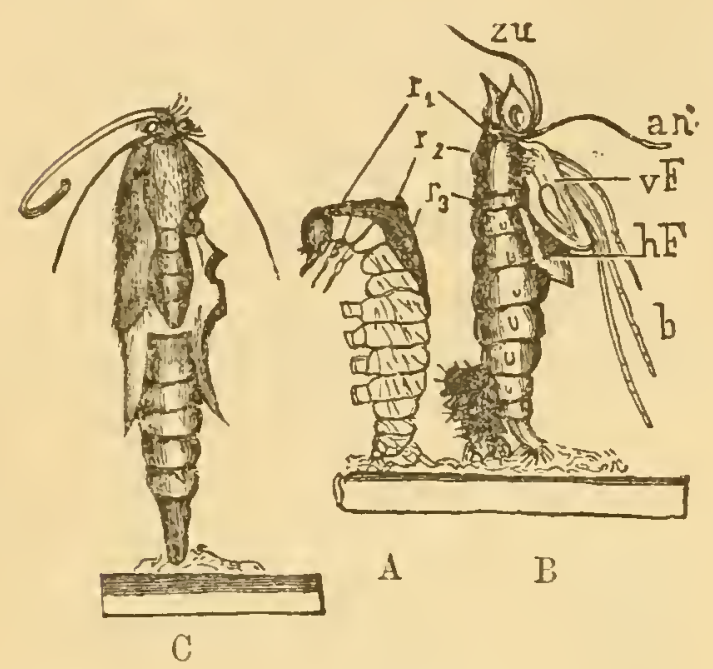

F̧ig. 186. Dor Bandufeite, żwijach ben lappenartigen Flügel= icheiben ( $\mathrm{Fl}$ ), nidgt ineniger als ad int in eine obere und untere geibe geord = nete Durchjolutte bon röh)= renartigen ergitinfuttera= len, in Jmern mit Den entiprechenden (imagina= len) Maseidgabilden. Die obere, eng gejchlofiene Reige enthält die brei Beimpare mb zwar jo,

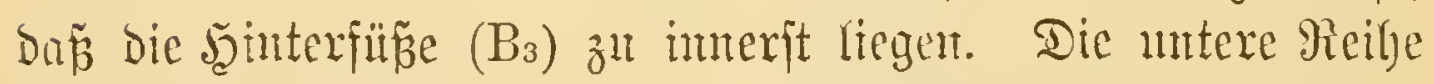
Gintgegen mmfap̃t, ganz jeitmärts, bie Füflex (an) umb näher

$\Lambda$
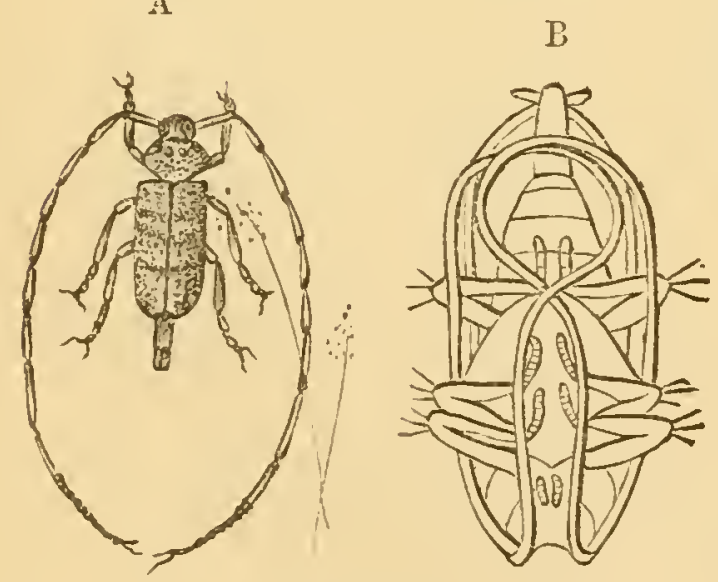

Fig. 157.

Bimmerbod.

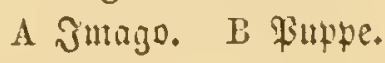
Der Mitte, unterbalb dor bintex = und Mittelbeine, Die Prïffel (rü) und Rippen= triftericheiber.

arte bieje 2unbänge bilben mut fabembar mit Dent Rumpf ein Oúnzes,

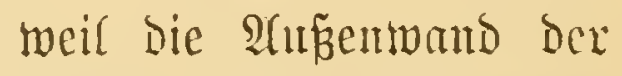
äน wie in ber Beidumng Durd Berbicuturg Der Contur ant gebentet wurbe, eine berbe Fruite bildet uno weil

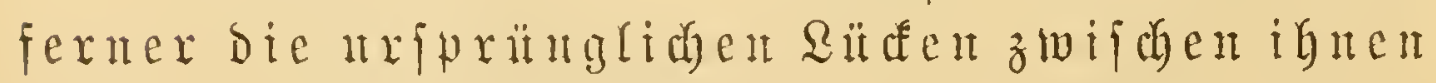

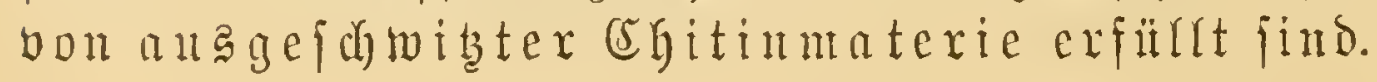




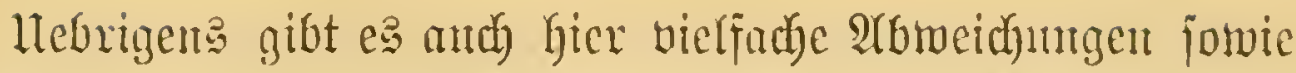
Hebergänge vom "bedeffen" in ben gewöhnlichen halb= freien Pinpenzutano, indem unter Arbern bei gewiffen

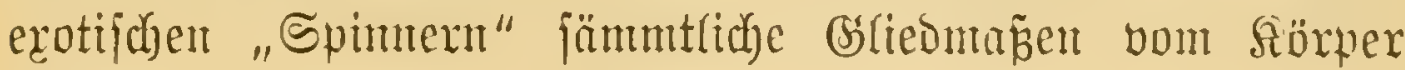
abitegen.

Die anfaflendite und jonberbarjte $\Omega$ age unter alfen Ruppengliebmazen haben aber mitreitig die lantgen Fühler

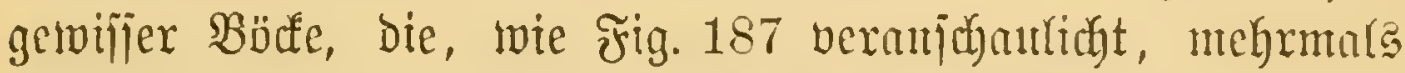
und freuzmeife ben gejanmten Sïrper umidglingen.

\section{Jnmerliche Deränderungen.}

(Endo= Mictamorpfoje.)

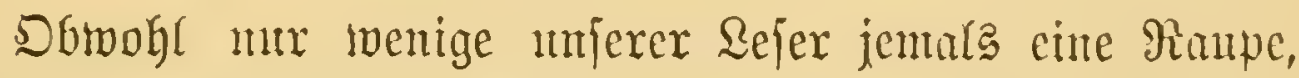
eine Buppe und cinen Sdymetterling behutg Renntnipnahne

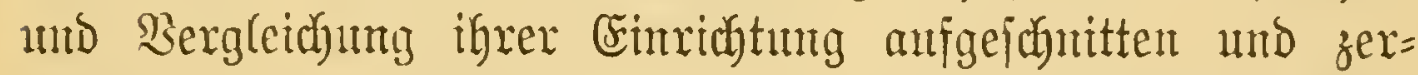
gliebert haben bitrften, jo wirb Dod jither(ide feiner baran

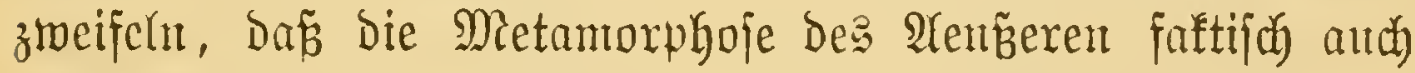
vou gemijjen Untwandungen im Snmern begleitet ijt.

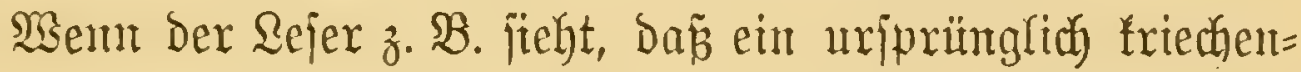

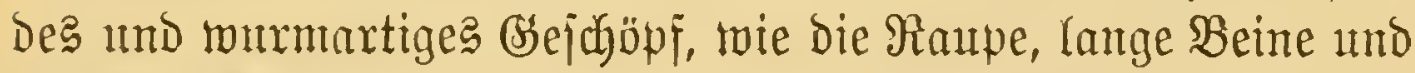
Flügel befommt, fo nur er ja einjeben, da cine andere Couftruction Der Bruft, zumal hinjidyttich Der Mirafitlatur, Der Serven u. j. w. verlangt, und eberjo wird er ohne Zreifel beim Schmetteriting, Der fich von Sennig nährt, eituen ganz andern Serbaunngapparat voratsjeben als bei Der

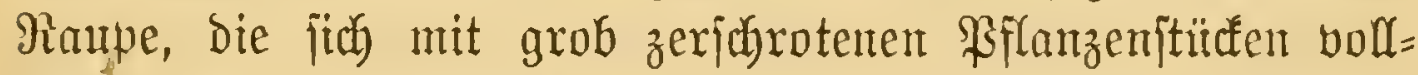
itopft, obgleid hier die Beränderung nidy fo unbedingt nothwendig erideint wie bei jenen Weidtheilen, die mit ben veränderten $\mathfrak{S} a \mathfrak{t}=$

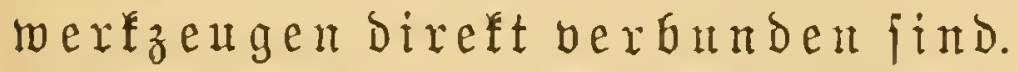

Uebergehend auf bie mähere Darjtellung biejer äunerit compricirten Berbältnifje, fo madjen wix ben Rejer fadjon im

Graber, Jnfeften. II. Bd. 
Sorbinein Darauf aufmerffam, daź bier meben Der einfachen Entwicflung und IImforntung and bielfach nodh tiefer eint= greifende Berä̈toerungen vorfommten, weldye leţtere benn aud ciner jeparaten Befprechutg besürien.

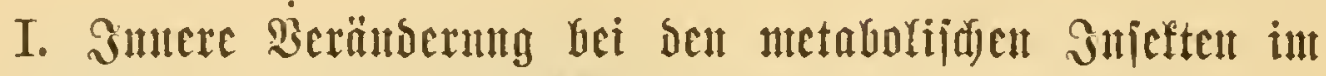 IUfgemeinert.}

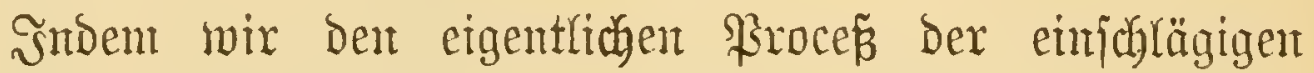

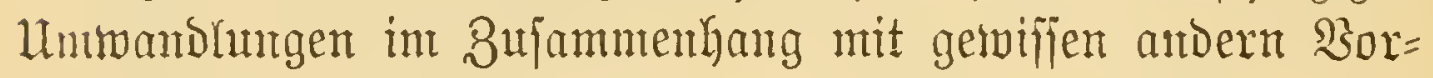
gängen fpäter exörtern wollen, ift e马 ung hier zunäbjo barum zul thun, Den Rejer an eintigent Beifpielen über Dent Mmfang Dcrjelbent zu orientiren, und in Dem Sinte selgnte man gleidy

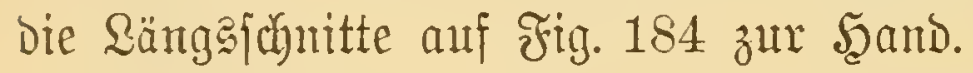

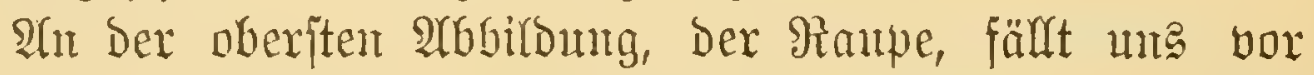
ardem eine weite mit grobzerfauten Prflanzenjtïfen erfüllte Şöhle, D. i. Der Schlumb= mo Magentoarm, auf. WSie man

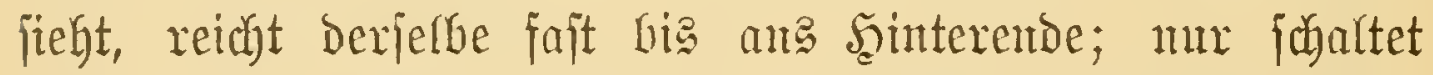

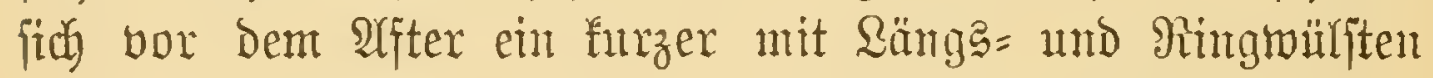
verjehener Miaftornt (eD) ein, Der Den Slotgballen bie allen Raupenmäftert wohlbefante ziertich abgeoredyjelte Fornt gibt.

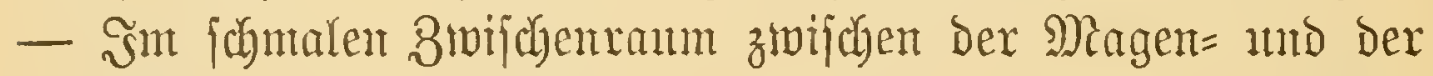
Reibeswand wird der Rejer dam, zumal am gehärtetest Ifhier,

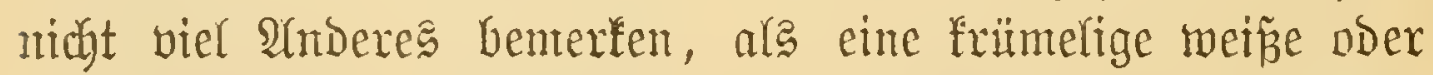
getbliche Majie. Dies ift Der fog. Fetteörper, in Dem das

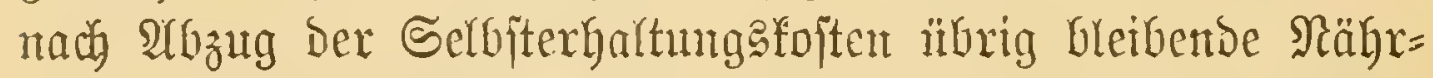
material zum Künftigen (Gefrandye bei Sen vielfachen Peu= bisbutgen aufgejpeidjert twird. Cin jorgfamer Berglieberer entbectet bant, wom toir von dent jiemlich unveränsert

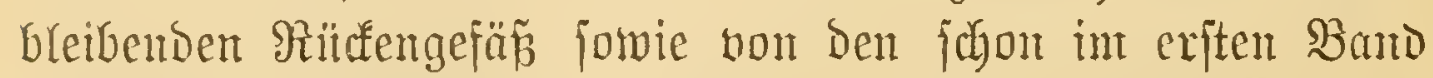
exwähnten šsutalanlagen abjegen, in biejer Fettmafje, uto zmar unterhalb bes Darmes die aus 12 Pancen ziemtian gleither Snoten zujanmenge petste und ziemlich gerabe Batch = gangrienfette (bg). Die in Dber= und Interfopf gelegenen 


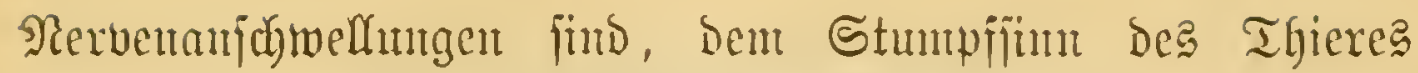

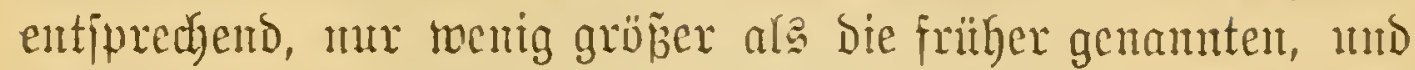

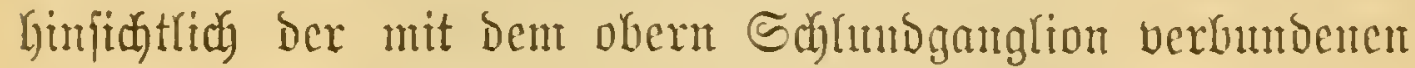
Simmearorgante wollen wix mix bic ganz minzigen aber in

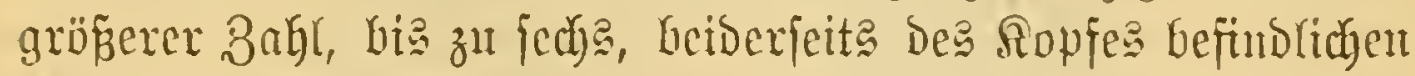
Teuglein mit ifrer Qinfe mto Dent "retinula"-artigen Perceptionsapparat herworkeben.

Son ganz fpecifijhen Ranpentonganten find Dann nod bie Spintroüfen zu benterfen: ztwei lange an Dent Seitu bes Darmes fith hinjolängelnoe Gölyren, Die, zumal gegen das Ende Der Larbenperiode, mächtig amichwelfen.

Dies wären bie eigentlidyen Fingeweios. Dazu fonment

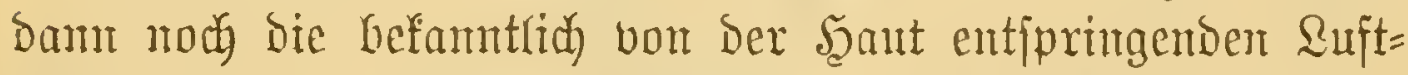

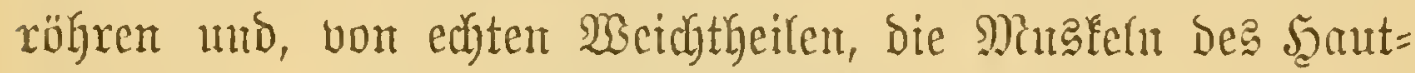

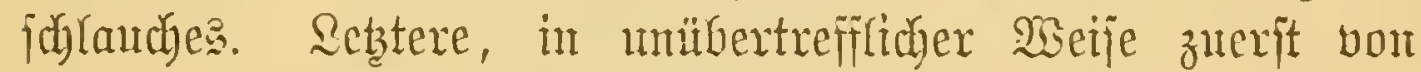
syonet analyfint und gejdifdert, bitben ein bon oring

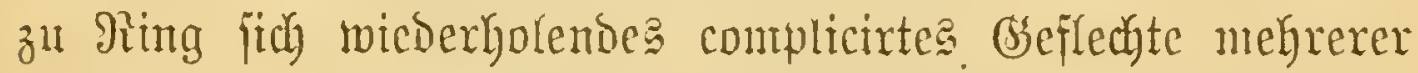

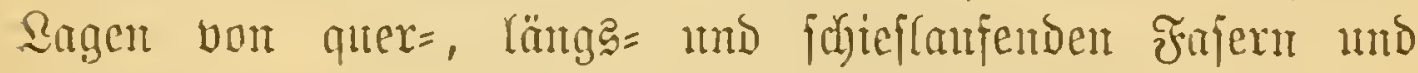
Büntoeln, bie an völlig anggetvetbeten Salg einen prädytigen 2hrbritif geber.

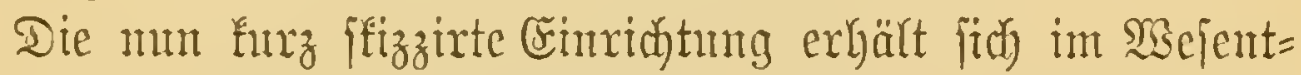
lichen bis ans Ende ber Larbenzeit, ja itrenge genommen fogar länger als ber äu $\mathfrak{B}$ ere Raupenlyabitus.

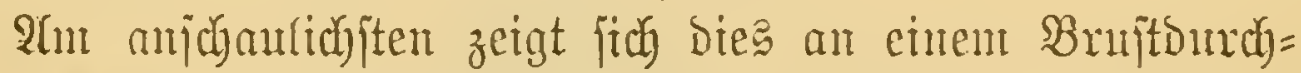

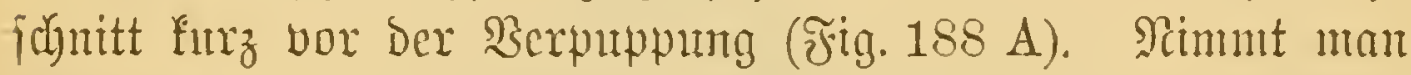
Gier Die Dornige Sarvenfaut (la) ah, jo hat man im Wejent= liden fidjon bie (in ber Beidjunng itarf gefaltete) Contur

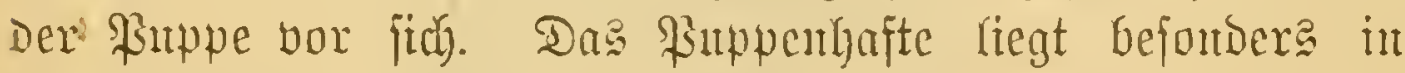
Den frlügeln (fl), weldye ala grof́e, oben epoulettartig vor=

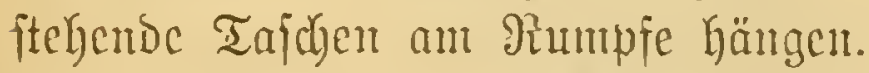

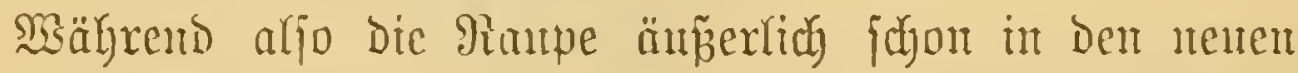
Buftamb ülergetreten, finden wir fie interfich noch ziemlich unverändert. - S̆n ber Nhitte zmädyjt liegt ein meiter 

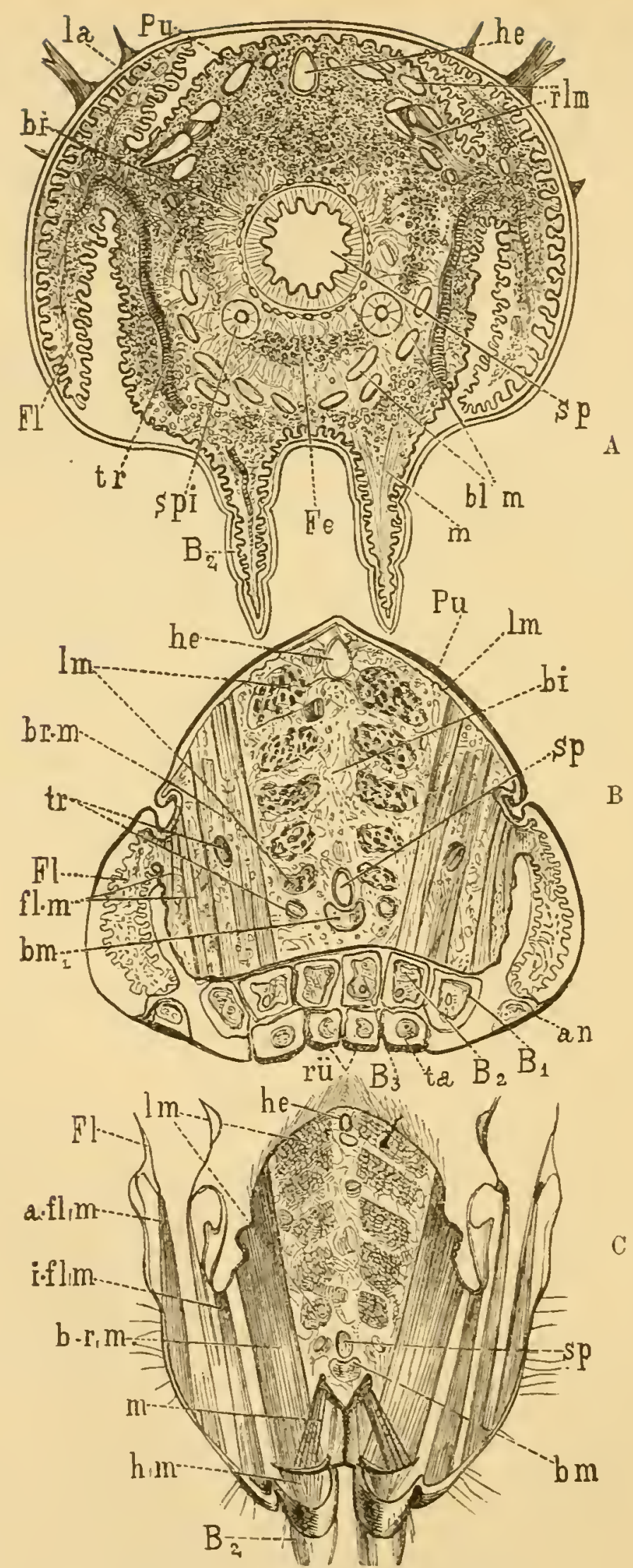

ริig. 188. (ङrtlärung ๆ. ๑. 523.) 
Sdhland) (sp), Der Mlagen, Defien hohe wellig gefaltete Drüjen= rage fanmt ben nus Säutge = mo Rintgfajern geflod)tenen

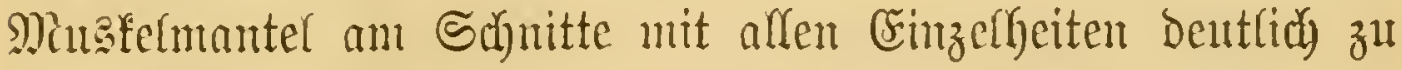

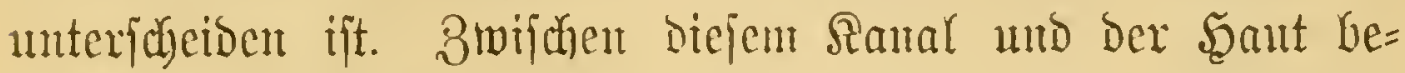
merfen mir ferner bie jud oben erwälynte, von zahlreichen

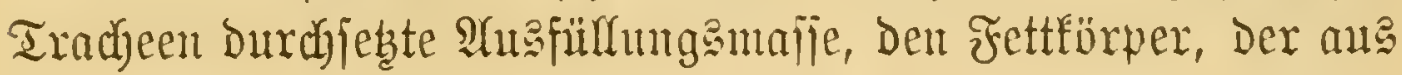
Fajerneben mit cingeftreuten z. Th. öltropfenartigen $3 \mathrm{cll}$ en bejtegt. Dody ift dies Gewebe nidat mebr jo compalt und

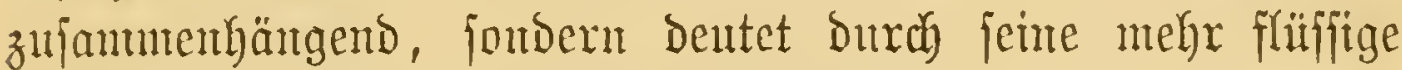

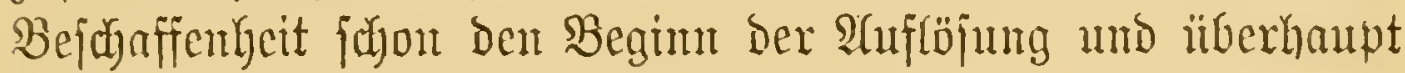
Der Künftigen Berämberungen an.

Meiters zeigen fib an Den Seiten bes Darnes bie żmei Enimmröhren (spi) und rings an ber \$eripherie mehrere

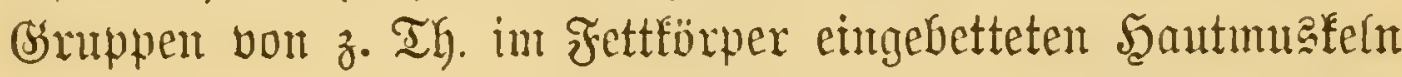
(rlm, blm). Bumal in ber Sertheilung ber Lescteren ipridgt

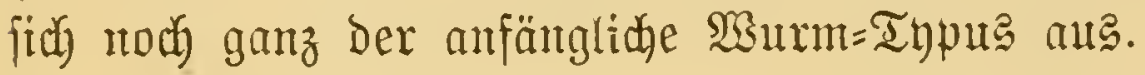

\section{Frtärung zน ₹̛ig. 188.}

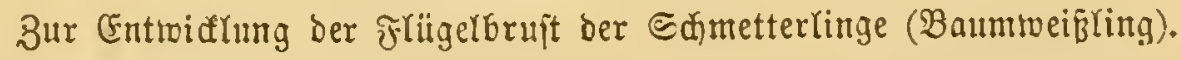

A Suerianitt Durd bie Mittelbrnjt einer Raupe furz vor ber Berpuppung.

la Dornige Sarben(ditin)Gaut, $\mathrm{Pu}$ faltige 3ellhaut ber \$ippe, F1 Borber= flügelanlagen, $\mathrm{B}_{2}$ Raupenbeine, innerhalb welder bie Falterbeine fammt ifren Mnsfeln (m) fid bilben, he Seerz, sp Speiferohr mit Ring= unb Rängammscularis,

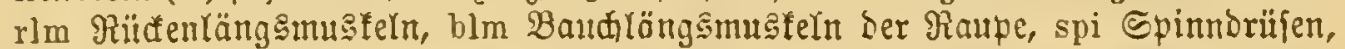
bi netzartiges Biniegemebe mit Dem (Dunfelförnigen) majïigen fettförper (Fe), tr Iradjeet.

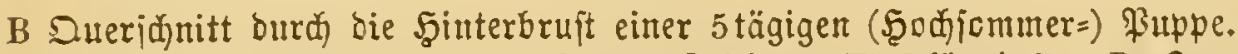

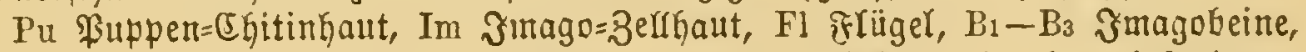

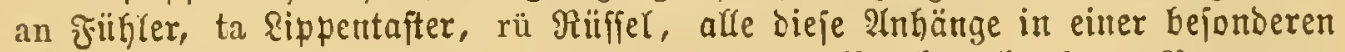

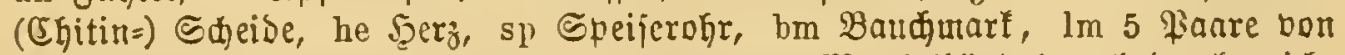

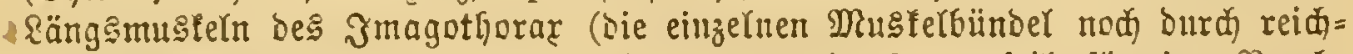
lides Bindegetwebe (bi) bon cinander getrennt), brm pieileriörmige Baud=

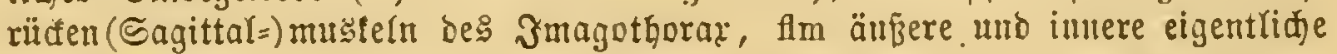
Flügelmusfeln.

C Duerjanitt burळ bie Mittelbrujt eines ausgebilbeten Falters.

Fl Flügelıurzel, a flm äußere, i flm innere frlügelmusfelu, Im 5 \$aare \&äng

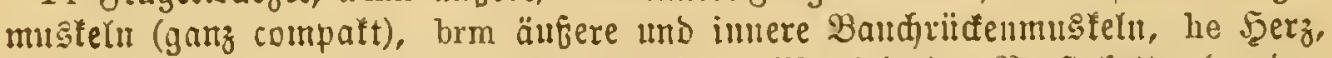
sp Epeijerohr (jehr eng), bm Baudmarf, m Mugteln ber Bruftplatte (au ber

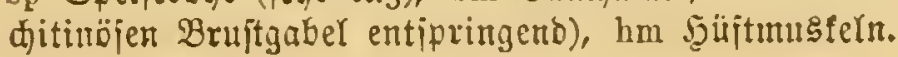

(Driginal.) 


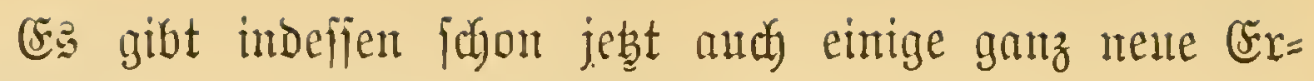
idjeintungen.

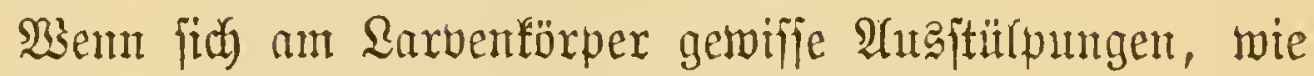
bie Frlitgel, Gilben ober wem bie idgon borhambenten larbalen Anfänge, wie bie Beine, Füflex $2 \mathcal{c}$, vergröpert werben, fo

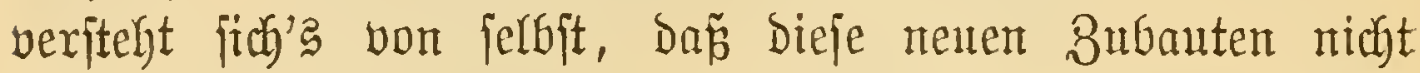
leer bleiben, fondern eine der jeweiligen Bejtinmung ent=

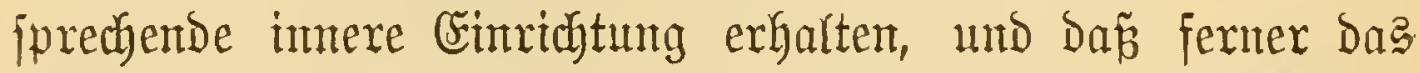
Material Giezu Dem bereits vorhandenten Bintentweidförper entnomment wirb. Snleterex $\mathfrak{S}$ injict, aljo betreff ber Entitehug Der inueren seugebilde, hat man aber ftreng zu uttericheiden zwifhen ben hiezu bienenden Birbugaftoffen im atrgemeinen und zroifden ben eigentlichen grumblcgendent $\mathfrak{B a}=$ oder $\mathfrak{B}$ ildugatementen.

Das Birbunganaterial in âfgemeinen ftnmmt $\mathfrak{o} \mathfrak{x}=$ wiegend aus Dem Bhut, Dann aus Dem Fettförper, fowie von gewijien andern Drganen und Bsemeben her. Dagegen ift Dex Urjprung ber Bildungaelemente, wie noch ausfülyr= licher im täbdten ßapitel zu erörtern, aus naheliegendent

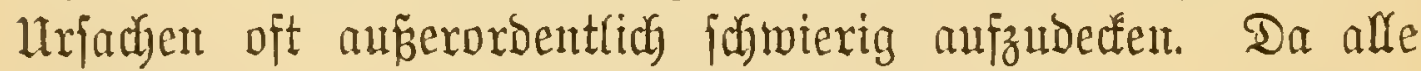
organijaden Birsungen aus Bellen herborgehen, jo wifijen

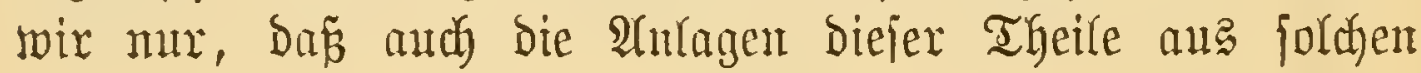

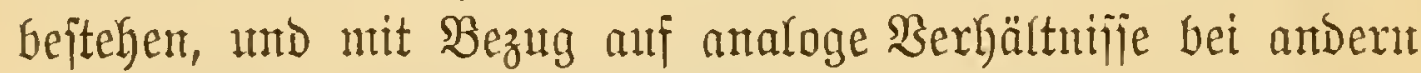

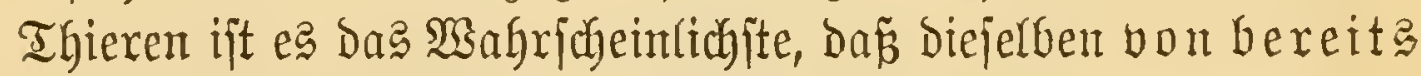
vorgandenen bereben abjtament.

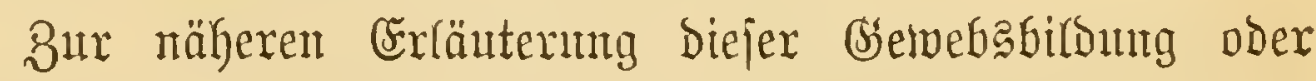
Şiftogenefe in Den imaginalen Şautauģaçungen mögen vorläufitg ein paar $\mathfrak{A}$ bbildungen bientent.

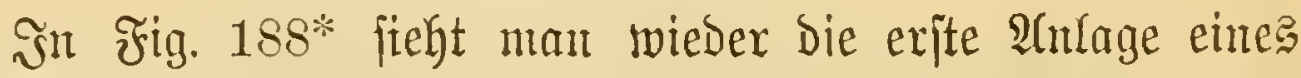
Falterfühlers. Während bie fertige Antenne mit allerlet com= pafteren Bremeben, żuntal mit zanflreidyent Maıkeln, Tradjeen, 


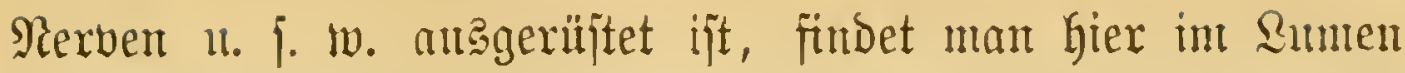

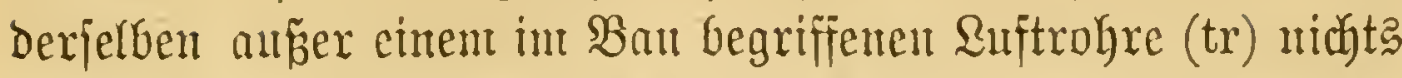

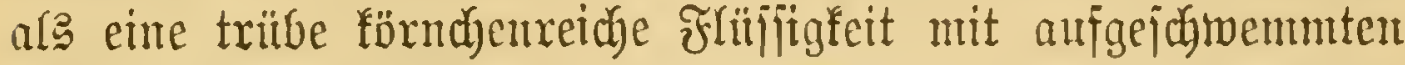

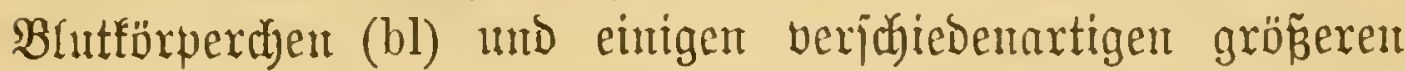

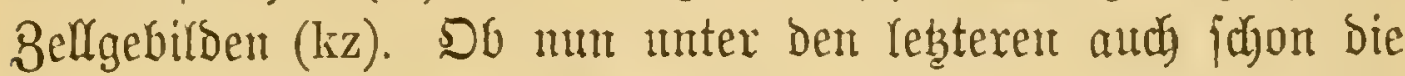
Eremente find, weldye bie Brnumblage Der genannten Setwebe

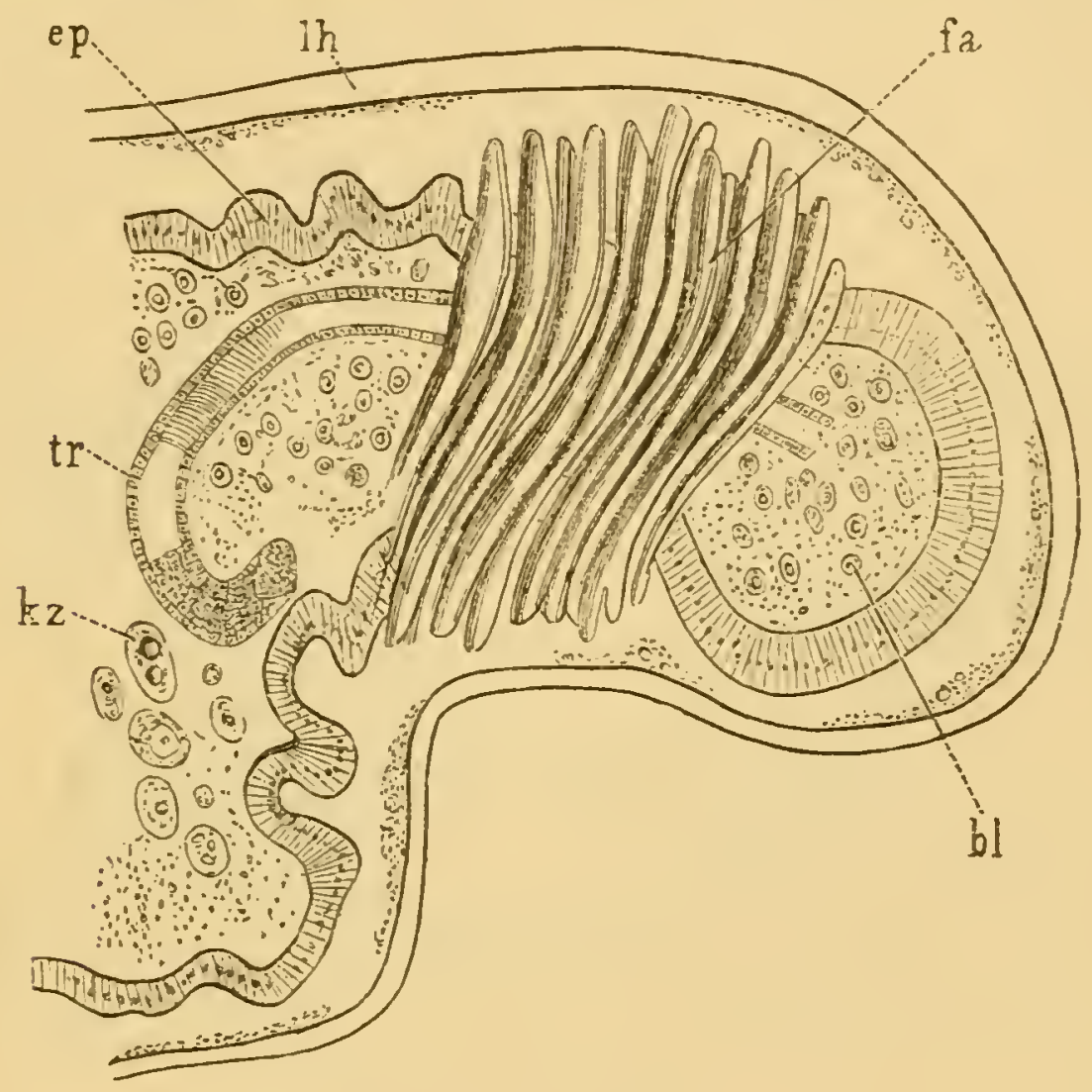

Fig. 188*.

formiren werden, ober ob bieje erjt jpäter von anderstwoher fommen, wer möbte bies entideriben? Es ijt ja Beides möglich).

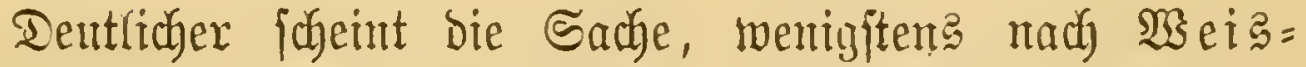
mann, an ben šmaginalbeinen Der oben gejujilderten Corethra-@arve.

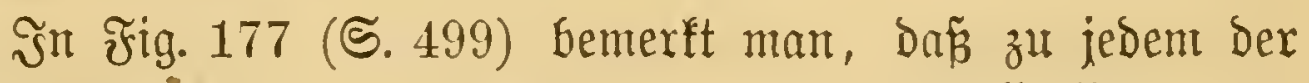
Borjtentündel $\left(b_{1}-b_{3}\right)$, bie genat an ber Stelle fiken, too 
fpäter burch die befaunte Şauteinftillnung bie Beine entitehent, ein (Simtes=) Rerv hintritt, Der bireft aus Dem zugehörigen Brultganglion $\left(\mathrm{g}_{1}-\mathrm{g}_{3}\right)$ entipringt. - Nachjtebende Frig. 189

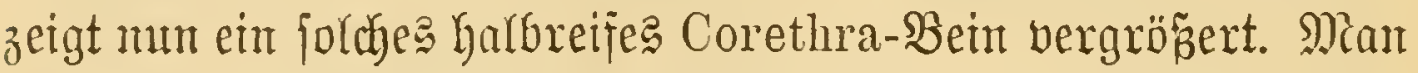

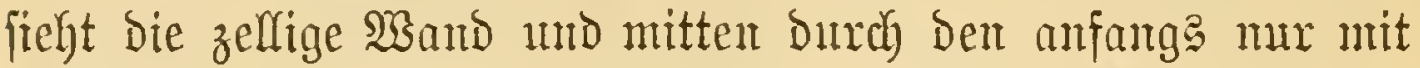
Bhut erfiülten Şohlraum Den vorermälgnten (Dumflen) SRert (n)

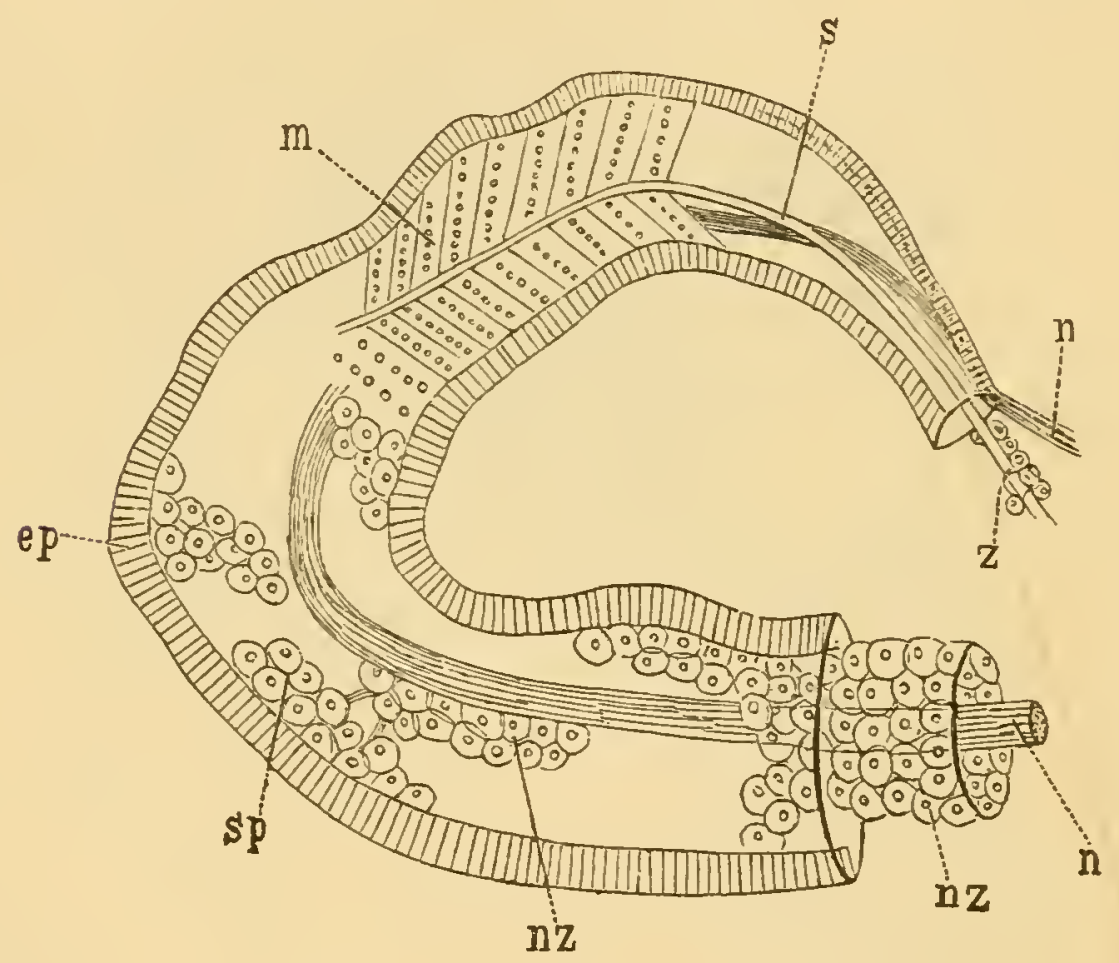

Fig. 189.

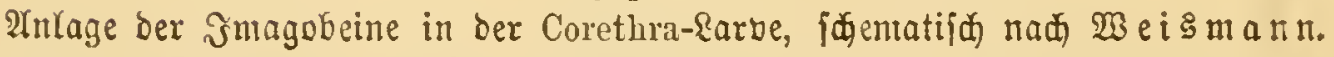

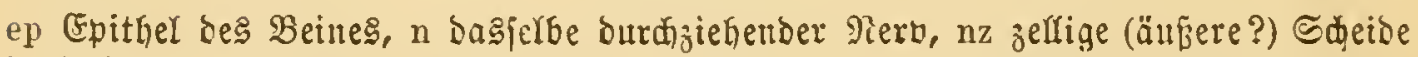
besjelben, sp Belleu vom Epithel, nz bom Neurilentm abgelöit, $m$ ats resteren Zellen hervorgehente Minfeln, s Gefne, z zelliges Futteral berielben.

jich erftrecfen. Wie bie meiftent Rerven ift auth biejer von

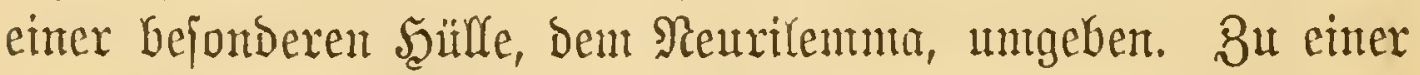

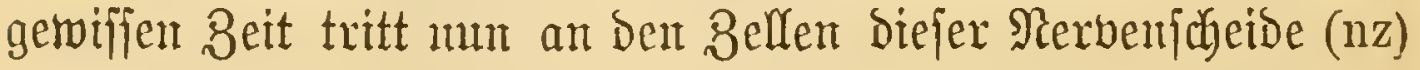

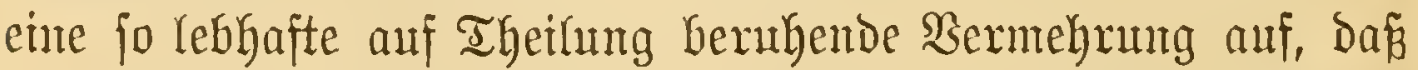

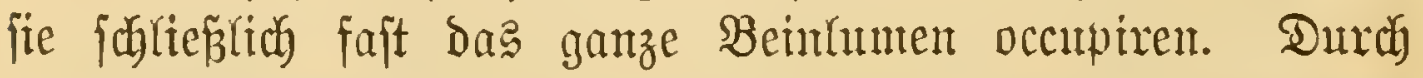
räumliche Sonberung und antbere Differentzinutugen biefer Bellen 
entitehen bam bie verfatedenen Bimnengetwebe, zumal die Mas=

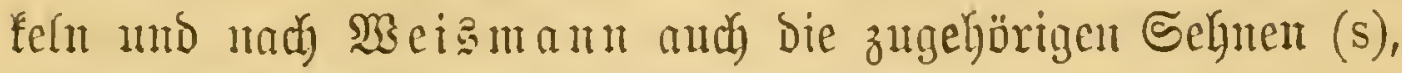
weldye foult bireft vou Seantblatt ausgeben.

Rehren trix nun nady Diejer Gijtogenetijhen Srientixung z̆ unferm Thema zurïf. Wir mollten, fpeciell bei ben Schmetterlingen, do: Man und bie Natur ber imtern lun= bitdungen femen lemen und haben zulest bie cimridutung Der Paupe an einem Brujtqueridgnitt ffizzirt. Zut einiger Servolljtänsigung mïge man nody ein Diagramm Durch Den

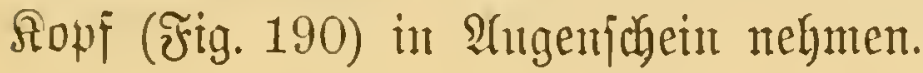

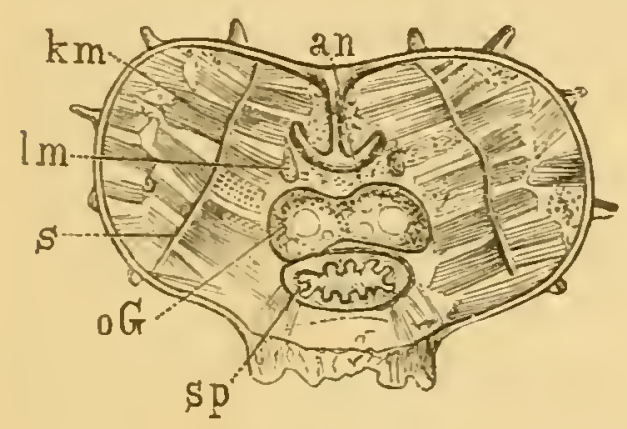

Jig. 190.

Frontaliduitt eines Raupentoples (nake Aิ. bem Sinterenbe).

an anferförmige Chitinplatte, $\mathrm{km}$ grofe Raumusfern, s Eefne icrielben, Im mediane Rängsmuslel, sp ๔peiferohr, oG Gehirn (oberes Shlungganglion).

(Driginar.)

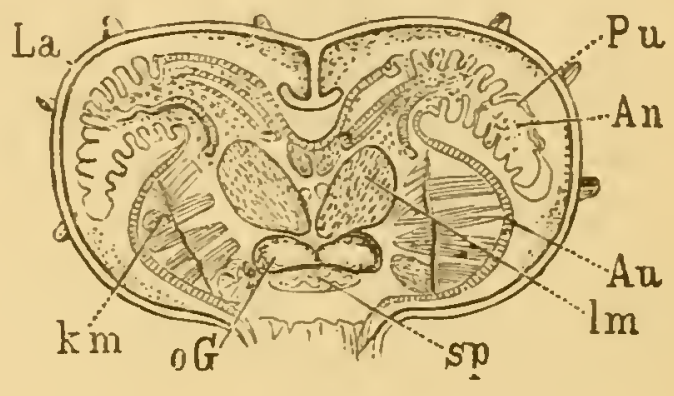

fig. 191.

Daŝjelbe furz bor ber Berpuppung. La Die von ber zelligen Matrix abgehobene Efitinfaut ber Raupe, $\mathrm{Pa}$ Bellhaut ter Buppe, An rö̈hler=, Au 2Uugenanlagen,

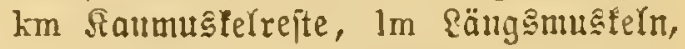
oG oberes Sđlunoganglion, sp Speije= röhre.

(Driginal.)

Bon befannterem Detail jei vor âfem die gefaltete Schlunoröbre (sp) exwähnt. Der Bwillingafnoten bart barüber ift offenbar das obere Schlundganglion, bas Bsehirn; wie man jieht, bon febr bejdeidenem umfang. Die gejammte übrige Ropifapfel enthält bagegen (wentigitend, im hintern uno

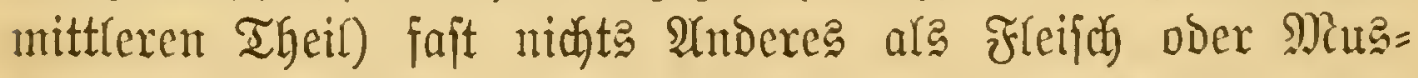
feln $(\mathrm{km})$, bie fich um je eine flïgelartige derbe Selnte (s) gruppiren. Dieje Mnafełn gehören Den fräftigen Riefenn ober Beístwerfzeugen an. 
Sergleichen twix mut, ım ung Den ganzen llmfang Dex

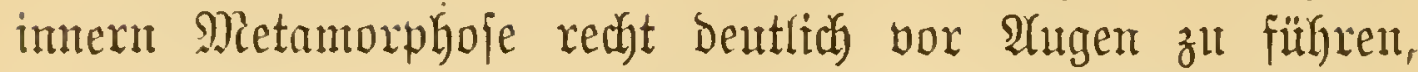
bie Drganifation Der Raupe mit ber des Sdymetterlingz

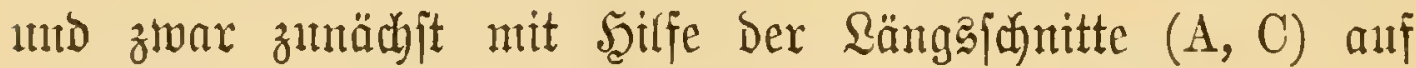
Fig. 184.

Un wieder mit Dem Mittelorgan, Dem Darm, zu be= ginnen, fo entbecfen wir ba nidyts megr von ber weiten

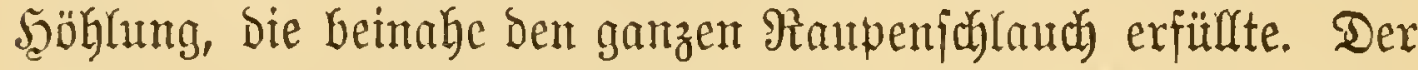
Darm, mb fpeciell Dejjen Bordertheif, hat fich ebeat aus eitem

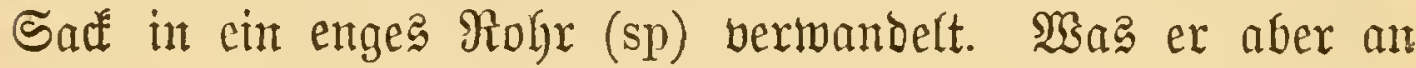
lumfantg verloren, bas ift z. Th. an হänge zugewarhjen. Mittel= mo Şinterdarm ijt nämlid nidyt megr gerabe, fondern

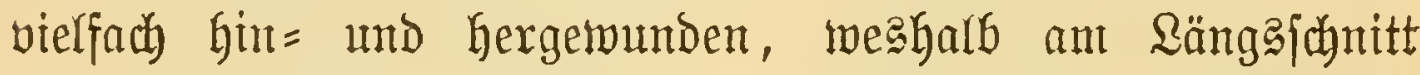

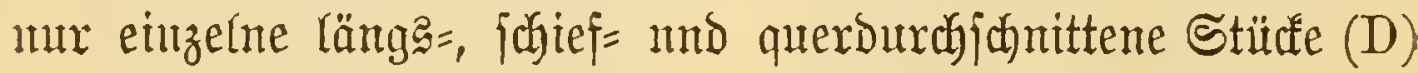

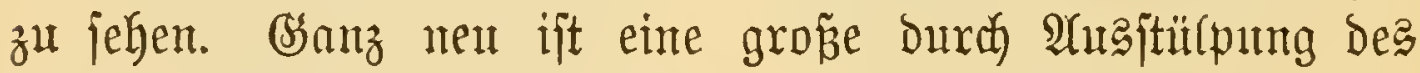
Sahlundrohres entitandente Blaje, Der fog. Sautgmagen (sm), weldyer ale Speifexefervoir zu betradjten ift. Der burch Rebuciung bes Darmboluments getwonnene Raum wirb hinten, in abgejchnürten $\mathfrak{X}$ boomen, von ben jeğt mädtig entmiffelten

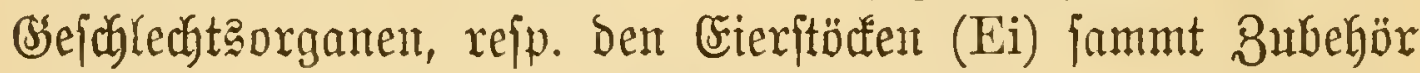

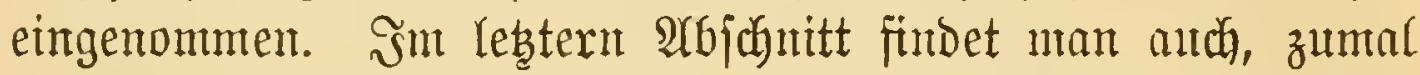

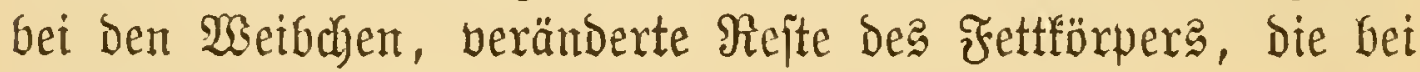
Der Entmiffumg ber Cier allmälig veridyintont.

Die augenfälligjte llmgejtaltıng hat bie Muafululatıx er= litten. A(m Deutlid) geringelten Seinterleib, Der überhant von Der Metamorphofe relatio an wenigiten betroffen wiro, hat fid im Wejentliden allerbing Der Ratpe erhalten; Dagegen zeigt unz Der imaginale $\mathfrak{S o r b e r}=$ rumpf ober bie Burft eine total berämberte Cinnichtung. Mittel= uno Şinterbrułt, wo eben bie Frlïgel jïken, birben nidyt megr einfadje Ringe mit Den nad Dom Miujter Der Şinter= leiba

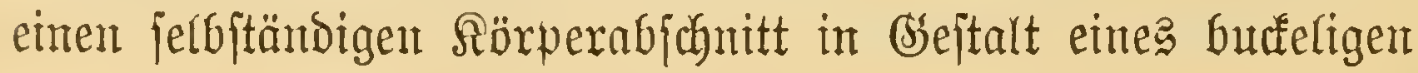


Bjebäujes (C, B), Das, befonders in feinem Dberbau, fajt auss=

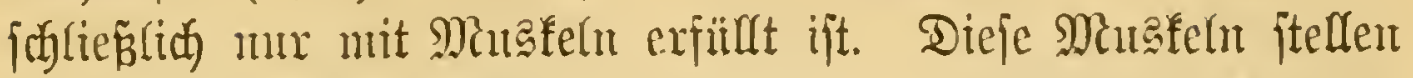
ein wohlgeoronetes Snjtem von \&ängs= und Seitentbalfen Dar.

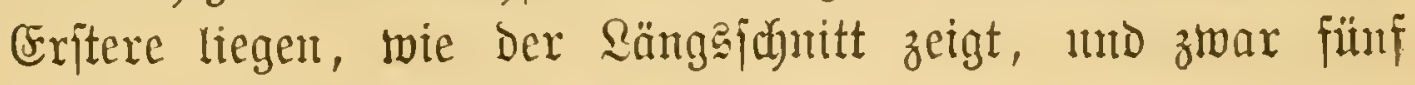
Durd tracheenreides Bindegewebe unterfrochene Etagen bildent, in Der Mitte; lebtere (an einer burdu= brodenen Stelle zu exfemtent) fabmiegen fid an bie Seiten= mände.

$\mathfrak{A}$ m fujönjtent zeigt fich biefe马 neue Mugfelwerf fotwie Der $\mathfrak{U}$ tuter= frjied im Bergleid) zur Raupen= brujt an Dueriduntitt forg. $188 \mathrm{C}$. Der Sejer erfennt in bem helfent feifförmigen Mittelraum bie fünf ßaaxe von হäıgabalfen $(\mathrm{lm})$ und Dann bie gemiffen bereits im I. BD. näher gefdutberten, theils pfeiler=, theils frangartigen Sei= termugfelı (brm, iflm, a flm), zu benent bann an ser Şaudffeite nod Diverje Beinmuafeln hinzı= fomment.

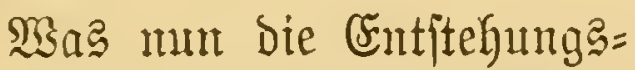
weije Diejes Mechanismus an= lanyt, fo läp̃t fich mit Sicherheit

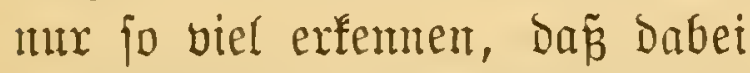
Der Fettförper eine widjtige Rolle
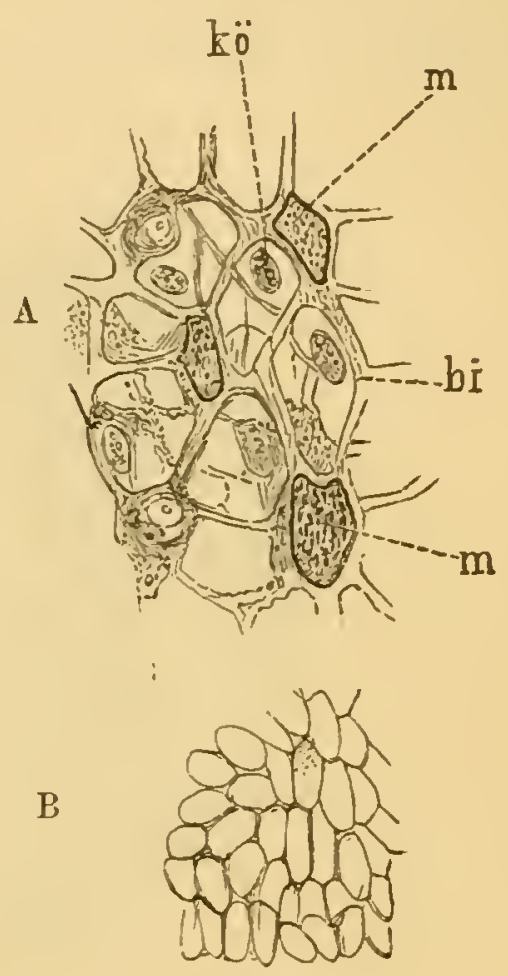

fFig. 192.

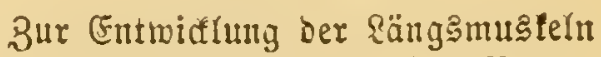
in Der Flügelbrujt ber Falter (Baum= meibling).

A Stïcf bou Duexjduitt des betr. Musfels, entiprediend Fig. $188 \mathrm{~B}$. bi nebartiges Bindegetwebe mit

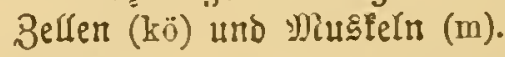

B Etüa vom Duexjhnitt beşjelber Miustels im ausgebildeten $311=$ jtano (bie Mntsleljajern zu eirtem compaften @trang vereinigt).

(Driginal.) ipielt.

Fine $\mathfrak{A}$ rt Mittelitadium, von einer $\mathfrak{B u p p e , ~ j e h t ~ m a n ~ a m ~}$

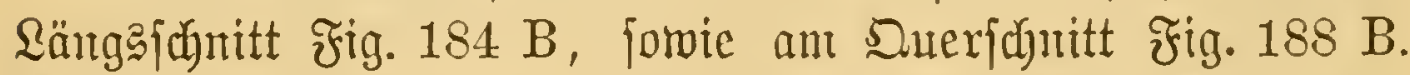

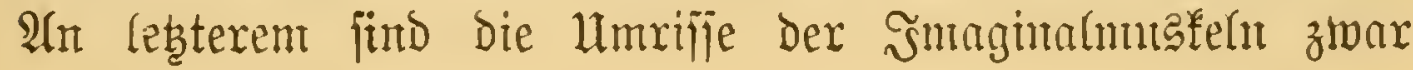


antgebeutet, ifr brefüge ijt aber nody ganz locfer, intoent fic, wie Fig. 192 zeigt, fozufagen ıur zur ફ̧älfte aus fichon fertigen Fajern $(\mathrm{m})$, zur andern Şälfte bagegen aus nod) unverarbeitetem Belfmateriale (kö) beitehen.

Darj hei einer fo bedeutenden Unmandung des imern

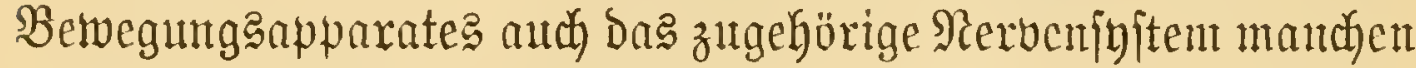

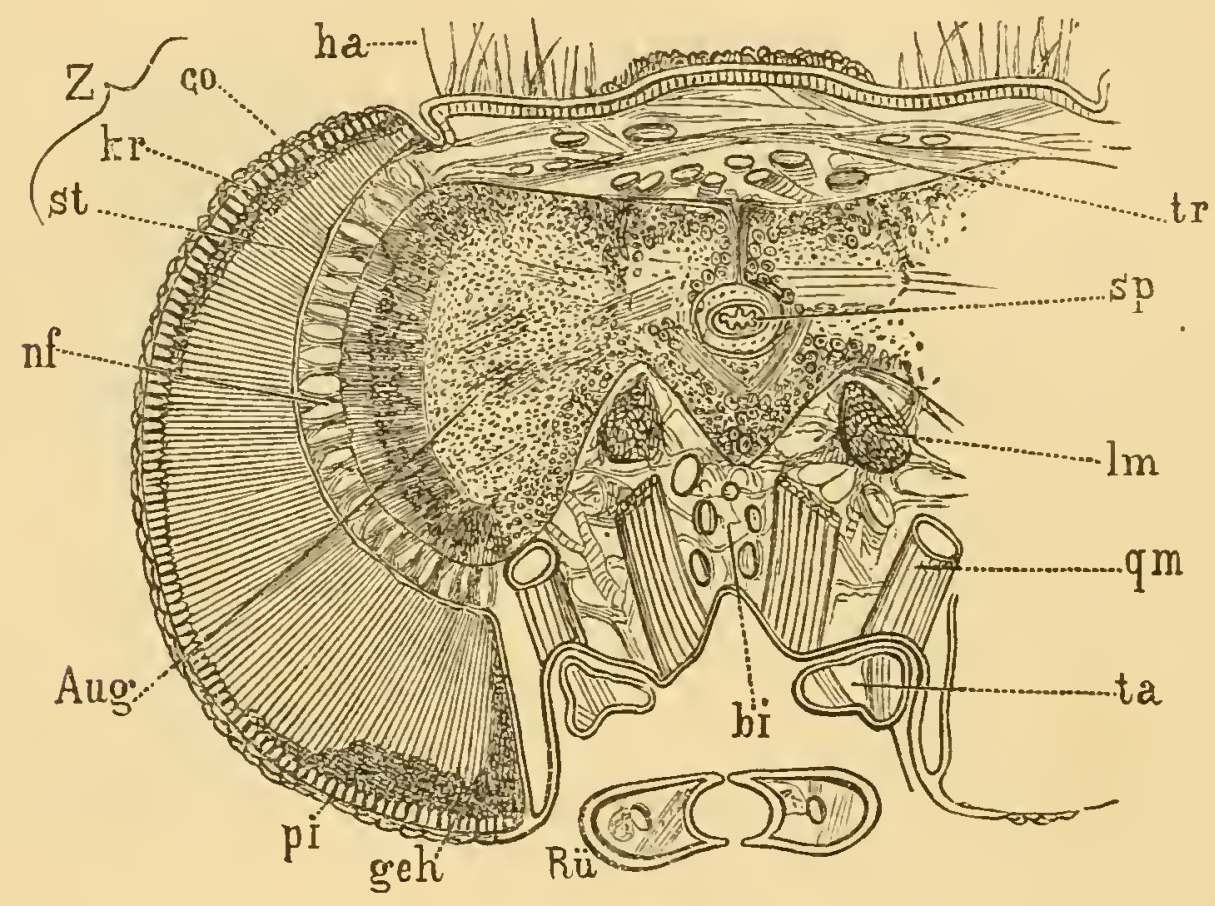

Fig. 193.

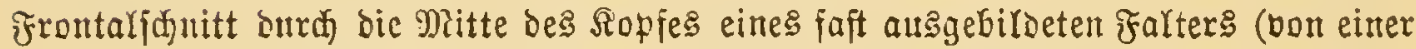

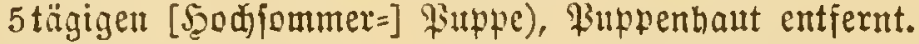

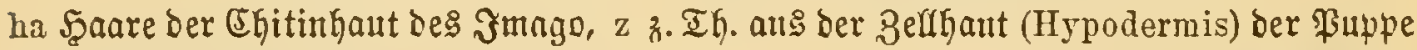

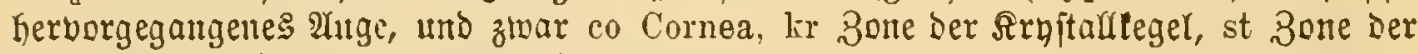

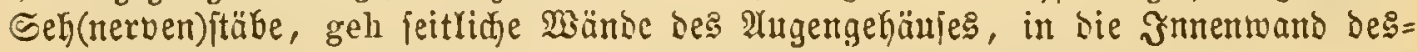

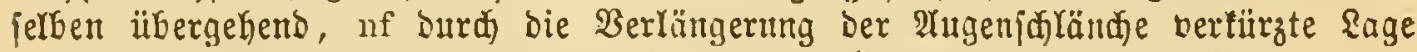

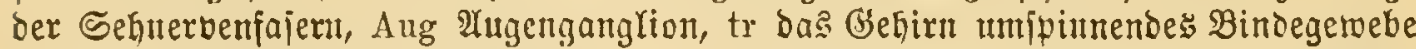

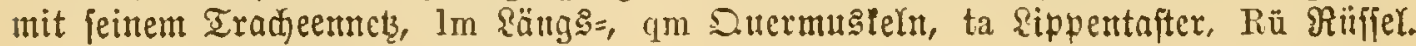

(Driginal.)

Beränterungen muterliegt, ift ferbftberftändrich. Sie beftelyen,

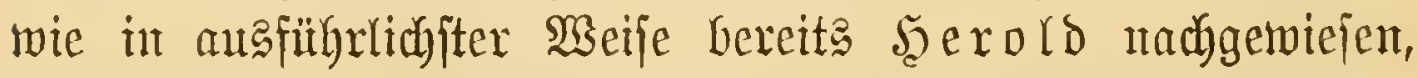
vortwiegent in Der Meduftion Der Şinterleibegnoten, fowie in

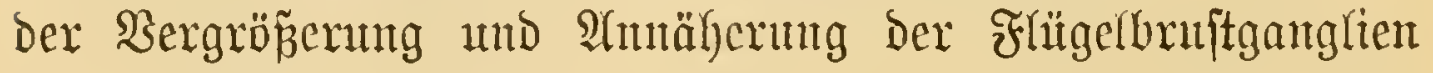
(vgl. F̌tg. $184 \mathrm{C} \mathrm{g}_{2}, \mathrm{~g}_{3}$ ). 


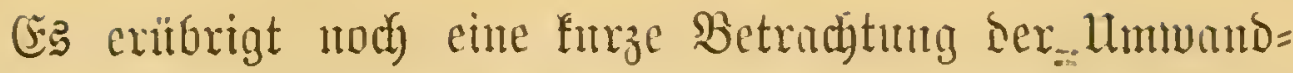
lungen in Sopftheil, bezielungşweife, da wir bie Einridytung des Raupentenfez bereits fenten, ber Sergleidy mit bem Falterhaupt.

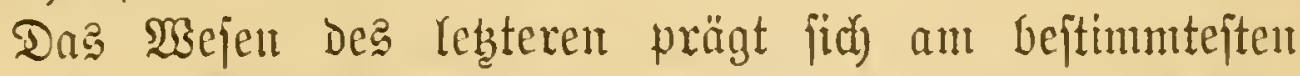
an einem Suteridnitt (Fig. 193) aus. Man beadte vor Mant Das mit

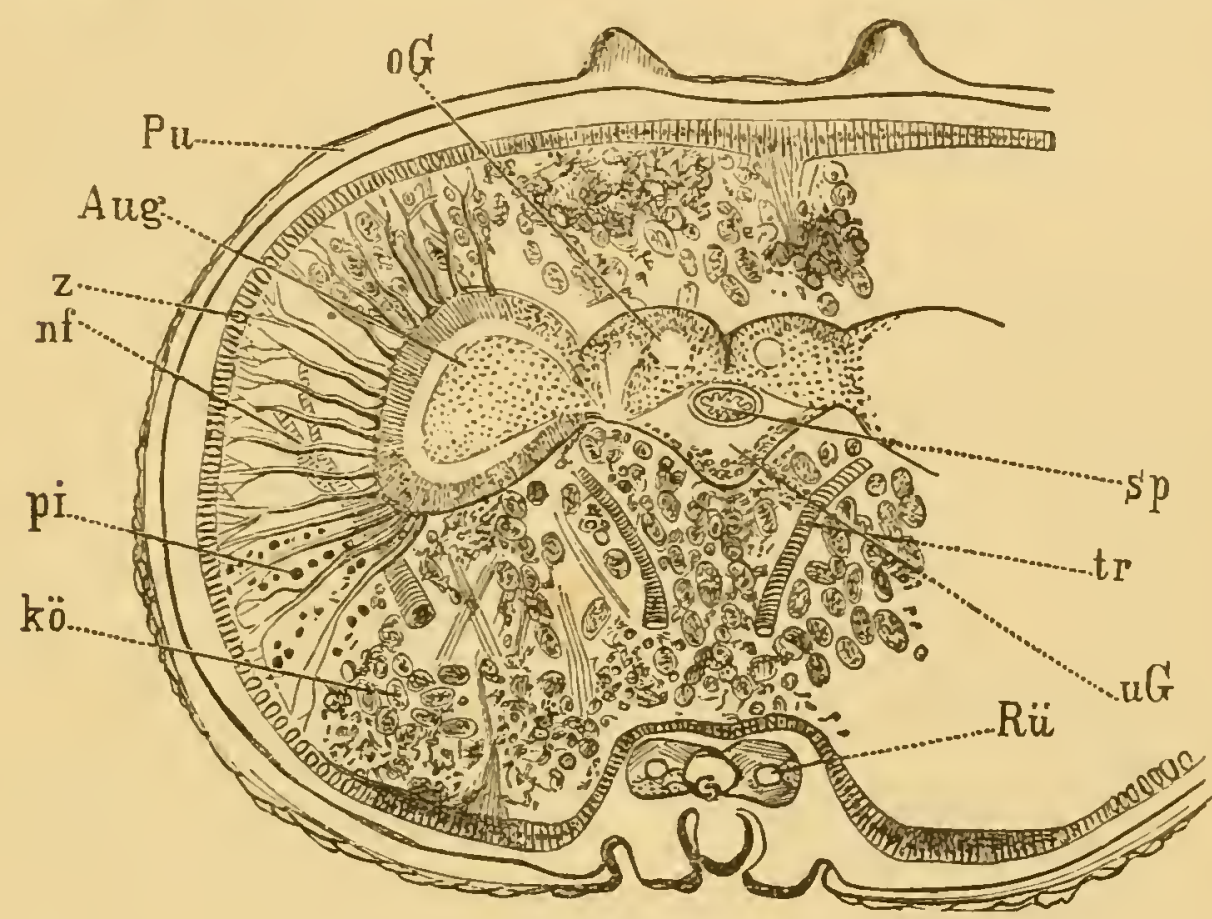

Fig. 194.

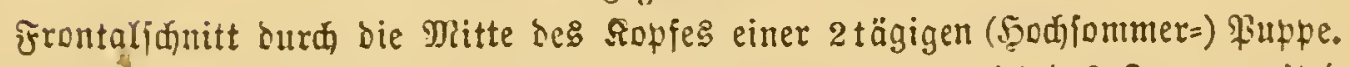
Pu abgehobene Chitinhaut ber Fuppe, z Bellhaut (Hypodermis) des Jmago mit ben

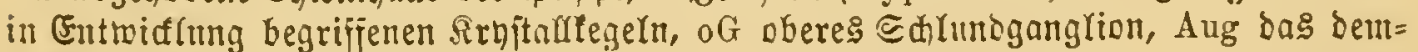
jelben anjizende grö̌e 2lugenganglion (nit jeinen berjđiebenen 3ell= unb ₹ajerlagen),

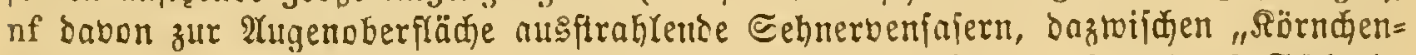

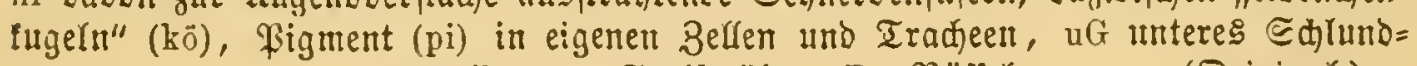
ganglion, sp EFeijeröhre, Rü Rüijer.

(Driginal.)

Der Speijeröhre (sp) Durubbohte Brehirn mit den neu himzu= gerwadjenten umfangreiden Seiten= ober antgenlappen (Aug). Dex ganze Raum ztwifden leteteren mo ber Ropfrandumg,

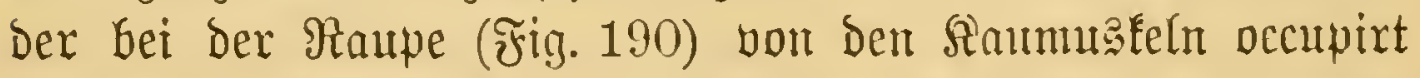

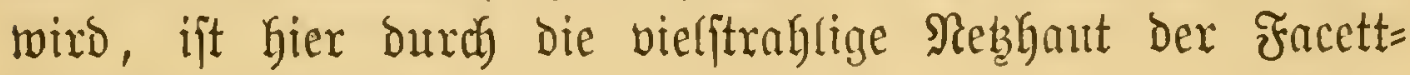
argen ausgefülut. 


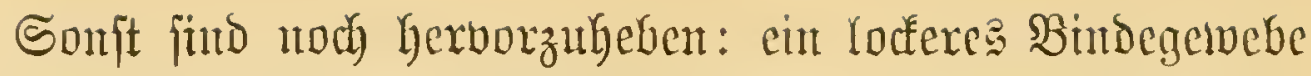
(bi) mit zahlreichen \&uftröhren (tr) unt dant geminfe haupt=

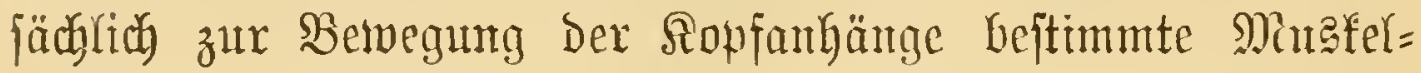
bündol $(q \mathrm{~m})$, von welchen manthe Qängagtränge $(\mathrm{lm})$ von ber Raupe (

Ein ïberats refrreiches Stabium bes Heberganges vom Raupen = in Den Falterfopf haben wir in Fig. 194 firirt. Man fiebt zuntäbjt ganz aņ̃en Dic warzige Puppenthaut $(\mathrm{Pu})$ mto Darunter bie von einer Entwitflungaphaje zux andern fidy fort erhaltende SMeidyaut ober Hypodermis. Ein Brid in šnnere führt ung in medias res Der Metanorphoje ein.

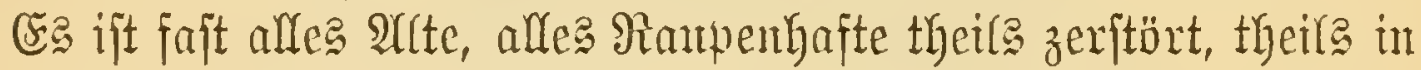
völiger Aluflöjung begriffen, unt vo!n Aetten, vont Smaginalen ijt aud noch wentig workanden.

Bei biefem Sachuerhalt wird firb ber Rejer and nidyt Yänger mehr Daxïber vermubern, da fowie bicler anderer Şnfeften, bei Denten der imtere Untbau fo plöblich gejdyiegt, fïr gemifie 8cit fo gut wie toot ift.

Şndeffen exblicfen wir mitten in Dem Egang von Trüm= mern alter Thgeile und von 2 nfüngen fünftiger Birdunaen Dod wentigitens cin Drgan, Das von biejer allgemeinen Ber=

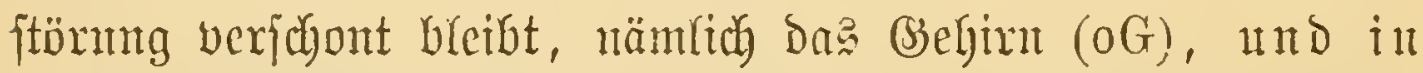
Der Contiutüt Des Centralorgang fpricht jich zu= gleid, hei arrem $\mathfrak{B e d y j e l}$ der Drganifation, bie un= uterbrodene Fortsauer un Eingeit bes aebenz $\mathfrak{a} \mathfrak{a}$.

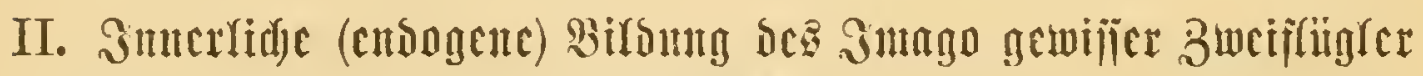
(9inciocu).

So felyr giaupe mid Schmetterling mo ülerhaupt Rarve

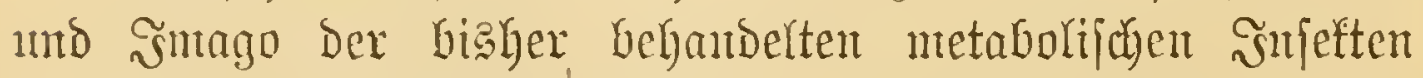

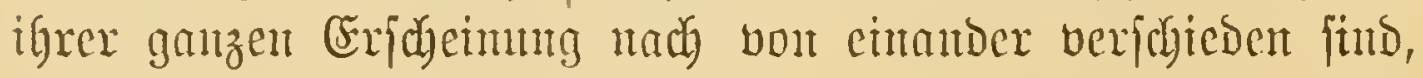

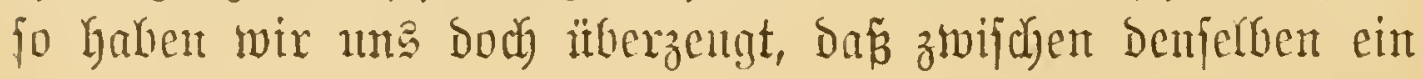


imniger und unmitterbarex 3 manmenthang bejteht, Daz ber

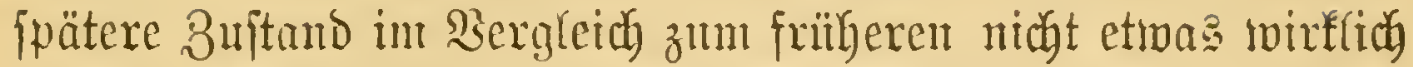

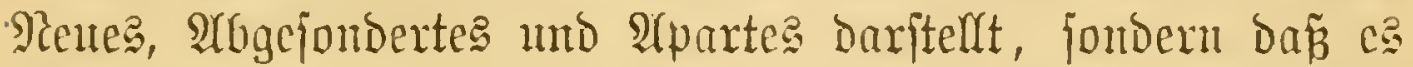

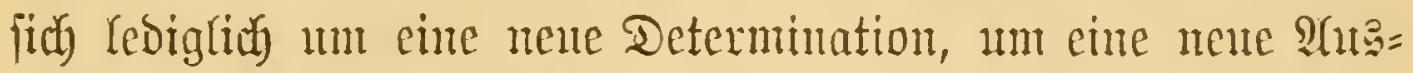
urägung cincr in ber Şauptjache mberändertich bleibenden

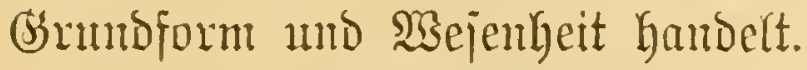

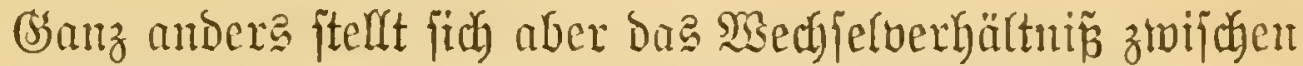
Sarve mo Smago bei getwiffen Dipteren (Mntzciden), z. B.

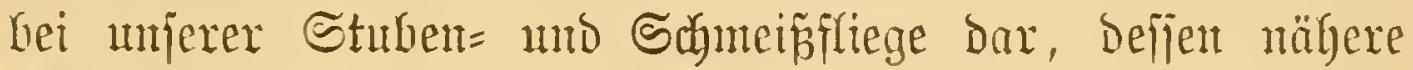

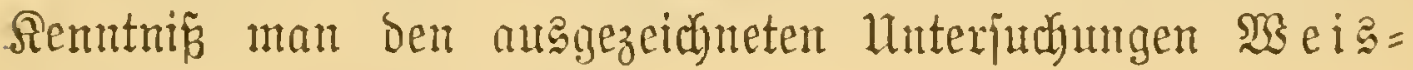
man n's (1864) verbantt.

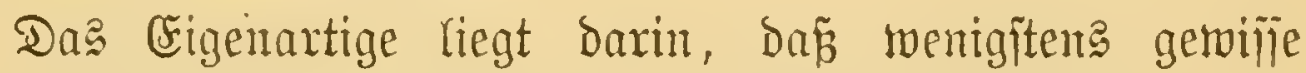

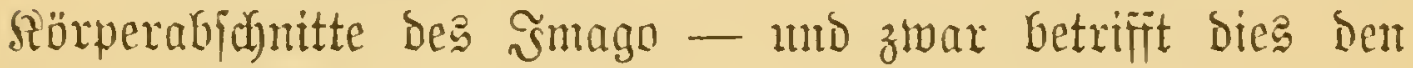
gejammten Borberleib - jidy nidit als einfache lumformungen

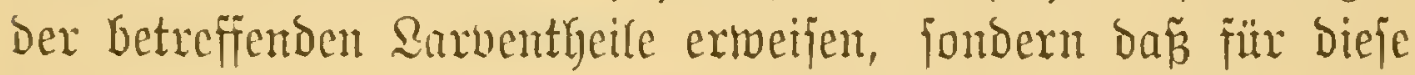
Sebildo ein ganz nener, ein vom Bejtehenden völig mab= Gärgiger $\mathfrak{A n j a n t y ~ g e j e b z t ~ m i r o ́ . ~}$

Ganz bejonders ift mody zut betonen, Dan ipeciell aud das

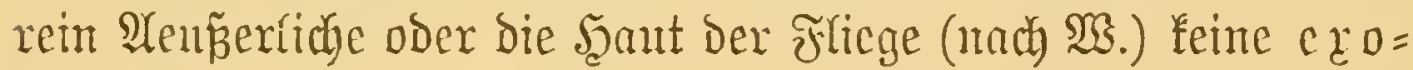
ober bermogene, bae will jagen feine ans bem Sntegument

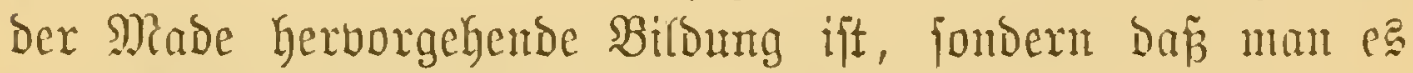
aud Gier mit cinem böltig innerfichen ober endogenen Erzeugutin zut thum hat.

Da manden mferer Sejer bieje Serhältnijie ganz un= Gefamnt fein bürften, jo miro zunädhit cine borlänfige Srien=

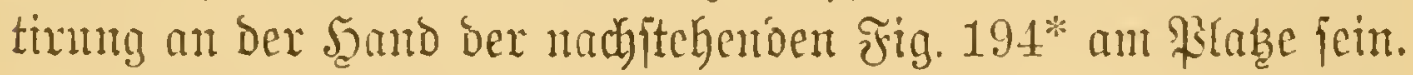

Die Drei eriten hier abgebildeten Typen $(A, B, C)$ geben Beippiele für bie berfdutcoenen Arten ober bejer Grabe Der gewöhntichen Metamorphoje, wobei bejonbere zil beadenten,

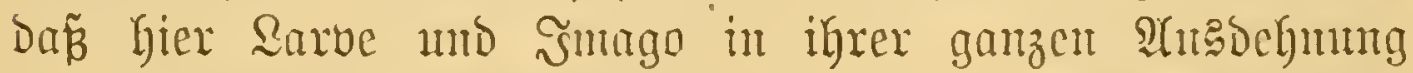

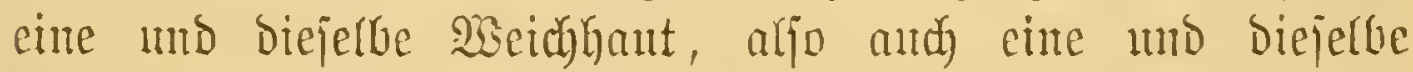
Mejenkeit bejiben. 
2rnders finbet man es beim unteriten $B$ Birbe (D), bas jid

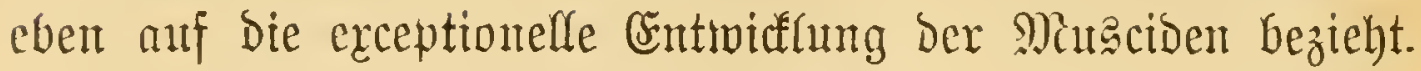
Şier haber mämlich Larbe und Smago mux einen gemein= fament Sïrpertheil, d. i. Den Şinterleib, mähremd der (Dunffer

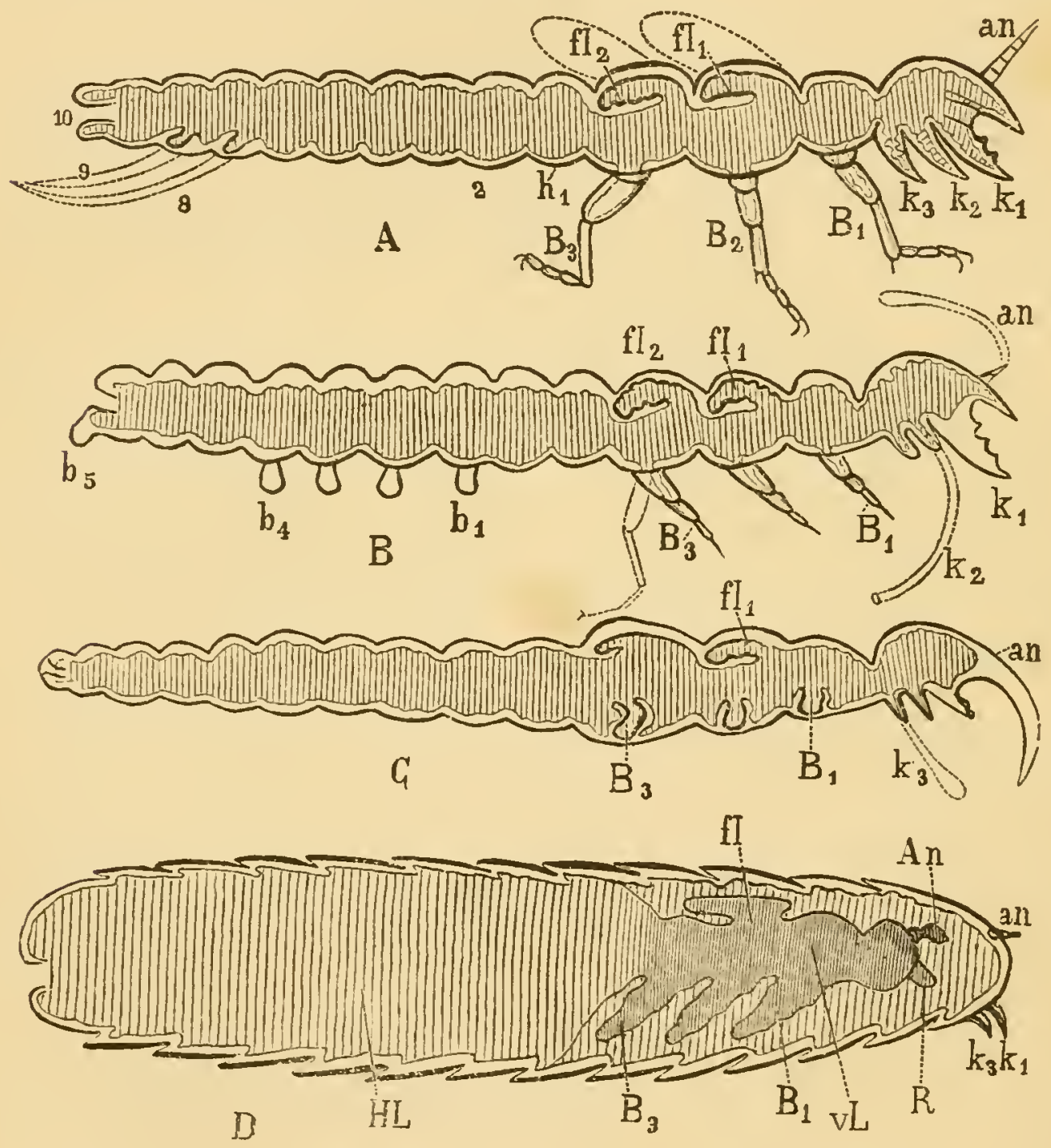

Fig. $194^{*}$.

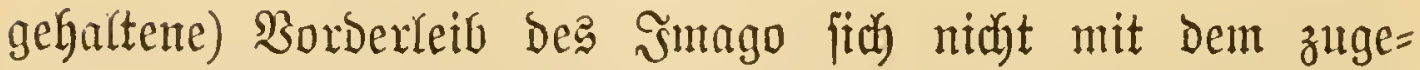
Görigen Rarventheile Decet, fonbern als ein jeparater Einfoblǘ,

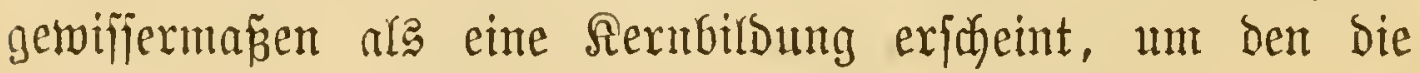
Sarbenthant die Schale ober Den Mantel Darjtellt. 


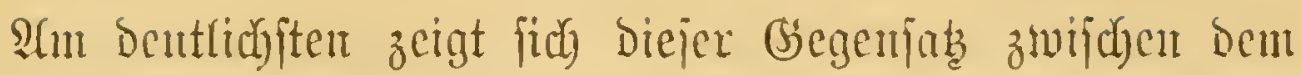
worbern und Gutern Theile Des Smagoförpers in dem llu=

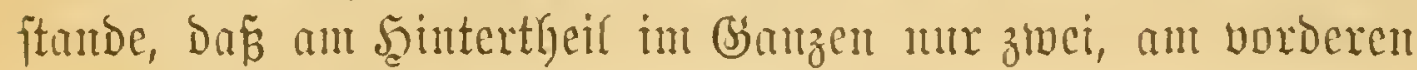
Dagegen brei verjejiebene Eonturen brjiebungameije Şautlagen

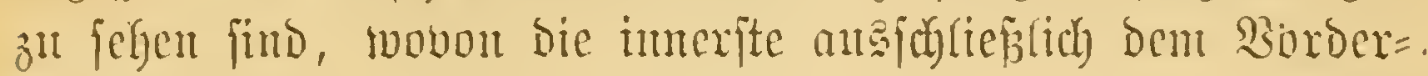

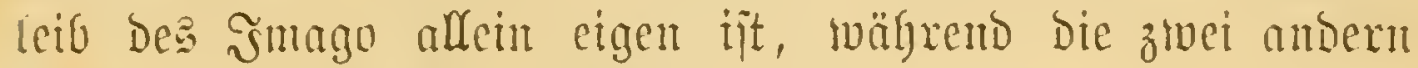

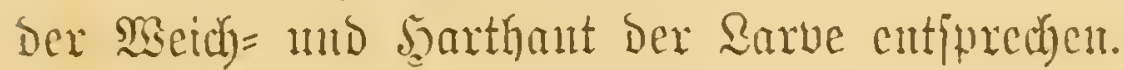

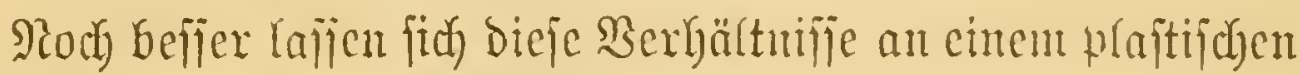
Niodell erläutern. Mlan modelt zuerit ante hant Der Ffiegenlarbe. Dam and Thon beren hauntjädylidjite Bimtenorgane. (Enblid) bifbet man aus ambers gefärbtem șadg

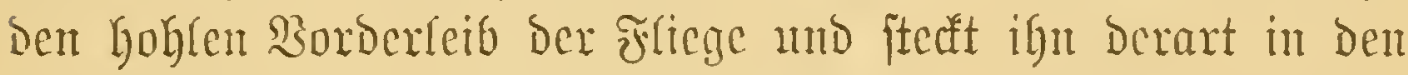
Sordertheil des (aus I I gon gemad)ten) Binnentörpers Gincin, Daj ein Theil bes leteteren imerfalb, ein anderer anjerbulb

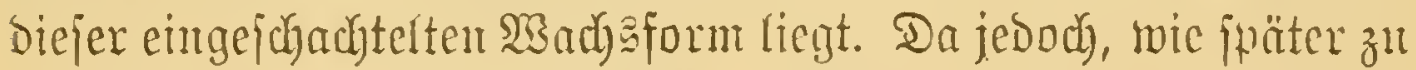
zeigen, die Afnlage des imaginalen Borberleibes feine zujanmen=

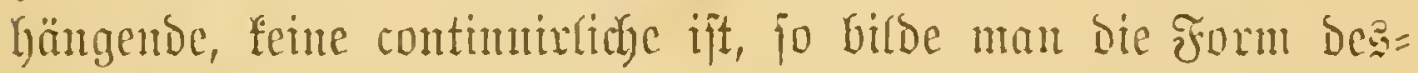
jelben nidgt an einen Stüd, jombern an melyreren Theilen,

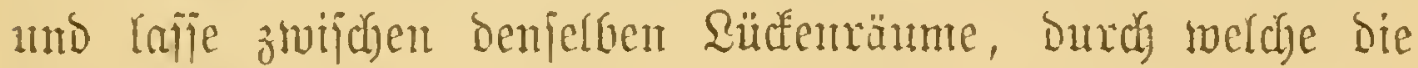

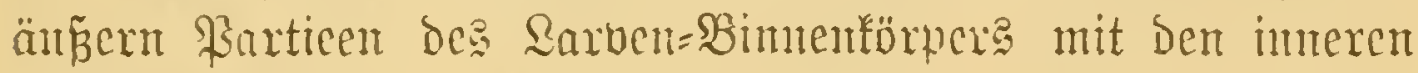

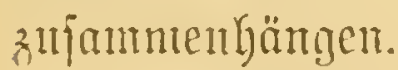

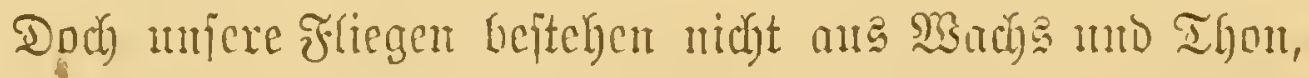
mis fo mollen wir bem baran gehen, ifyen fo mutmerbar

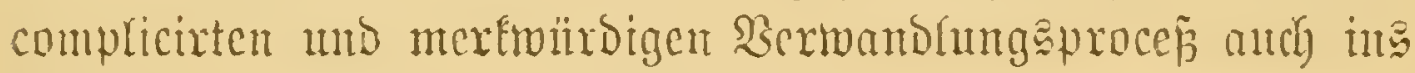
Feinere zu verfolgen und Darzujtellen.

Itm vorerjt genitgendes Material zur Interjudutung oiejer

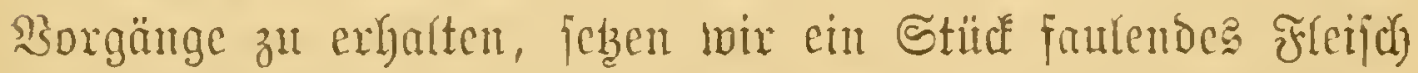

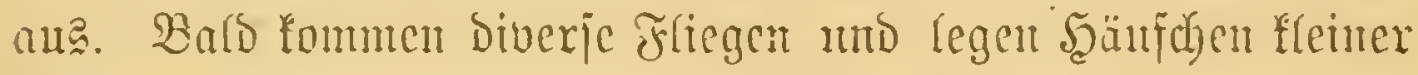

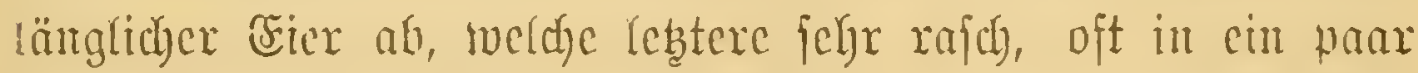
Tagen entwicfelt find. Bejeljen wir me num zutädyjt einen joldyen fajt reifen Ffiegenembrtso, fo finton wir ibut ganj uad)

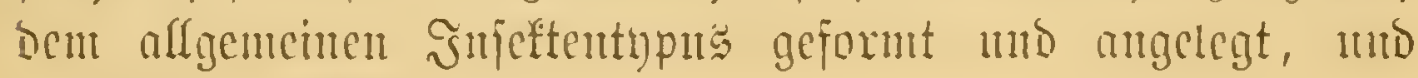
Bisaber, ơllelten. II. 80 . 
Dies Gejonders aud hinfitattich Des Ropfabjantittes, Der in die gewöhnliben vier Segmente mit je einem Bifiedmafenpar zerfällt.

Mianche Diejer Sopftgeile erfanten aber noch im Ei, thei(

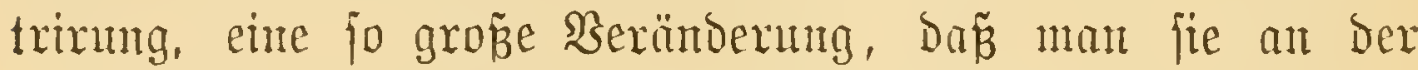

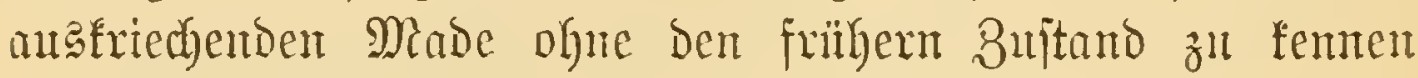
vergeblich juchen witroe.

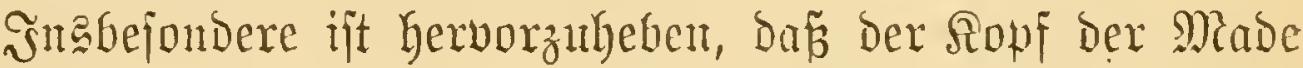
mit jeinem anffallent weit nad hinten gexïften Bsebirn gar

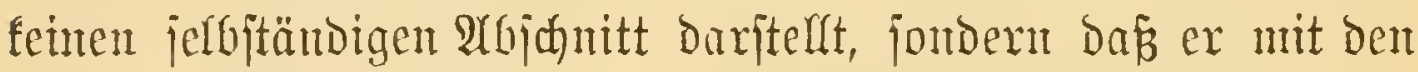
ïbrigen perjpeftivartig ant: und einziebbaren Rumpfringen zu einem vou hinten utach vorne fïh zufpibenden fegel= ober feil=

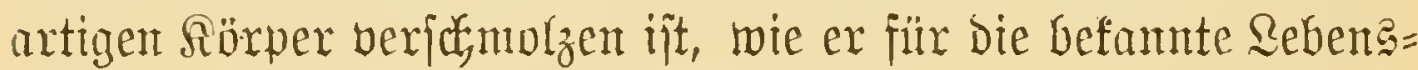

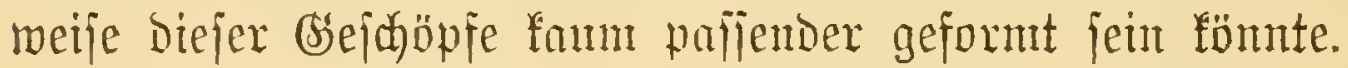

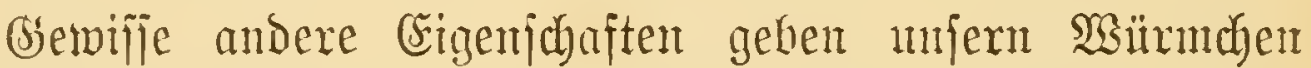
zugleidh Die Fä̈gigfeit, fich Durch bie engiten Spalten und

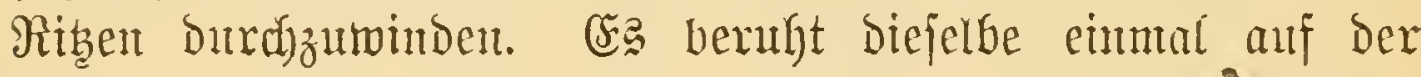
gantz erftantiden (Elafticität und Schmiegjanteit igres reid)= (ich) mit Matafelst ansgejtatteten uns mit grofen begnbaren

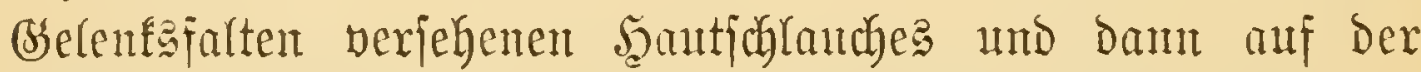

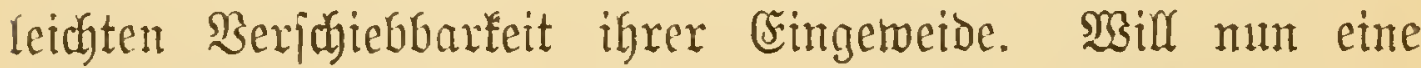
joldye Mabe ourch eine Spalte, bie meit jahmäler als fie felbjt ijt, jo bemerft mant Folgendes. Bumädjit zieben jich bie ohnelin jebr jamalen \$orderringe nuter gleidyzeitigem Buriöltreten Der Fmtentheile in einen dimmen Faben aus, Der, während Der bicfe Şiutertheil biesjeits martet, burd)

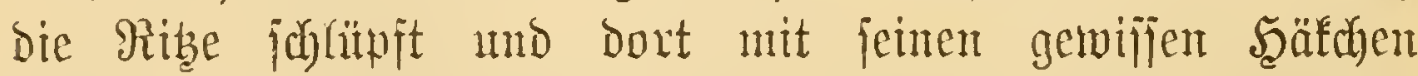

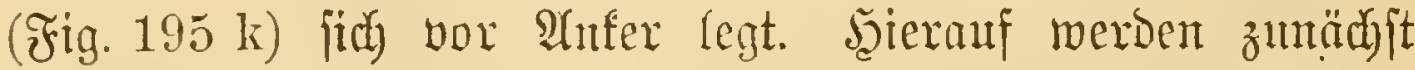
bie Eingeweide nach und nach und oft unter erjtautlicher

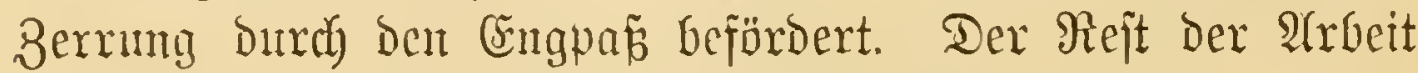
ijt Dann cine Rleinigfeit: Dex ausgemeibete D. i. nad borne 


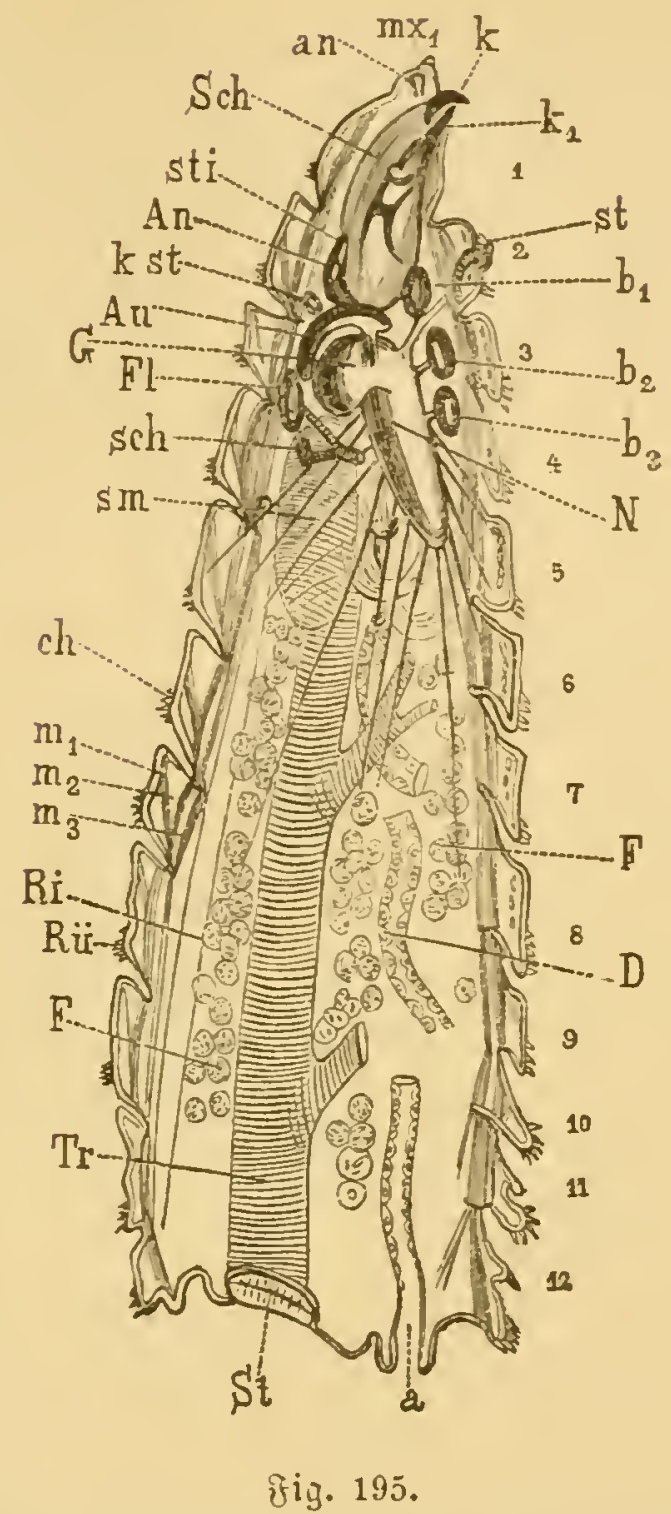

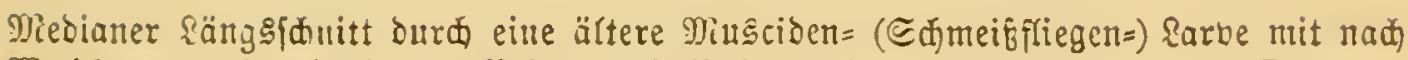

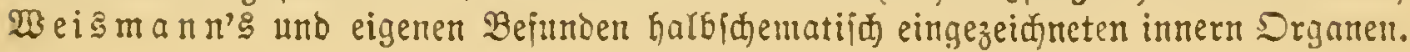
Bergr. ${ }^{6} \%$.

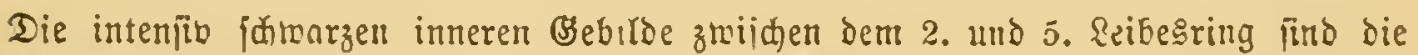
2nlagen fïr ben ganz nen zu bilsenden sopf und bie Bruft ber łliege.

1-12 Reibesringe, ch (5hitingaut (bie jie erzengende Epidermis if nidt gezeidnet),

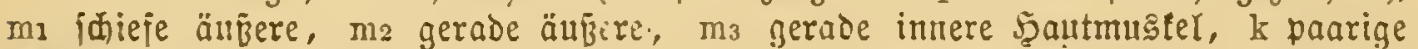

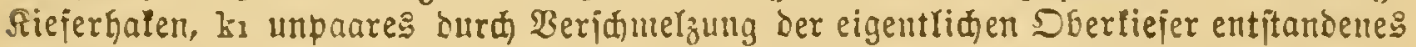
Bohrorgan, an Fühler, mxs rubimentäre Maxille, Schl ๔alundopf, st porberę Rarbenjtigma am 2. Segment, b1, b2, b3 Borber=, Mittel= und Sinterbeinanlage,

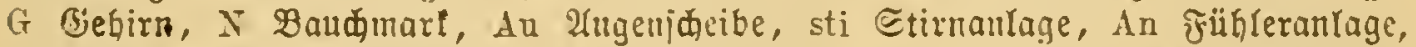

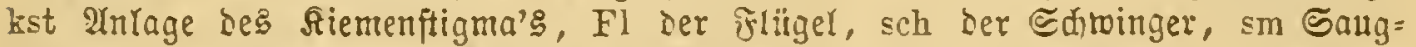
magen, D Mitteltarm, a Riter, F ivettförper, Tr Iradeenlängsfamm, St Etigma

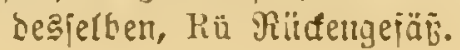




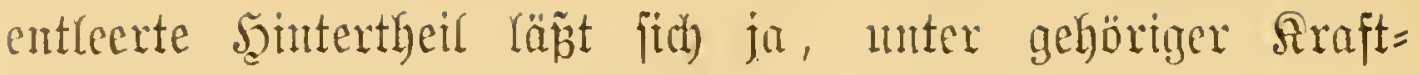
anjtrengung bes vorderen, bequent Ginüberziehen.

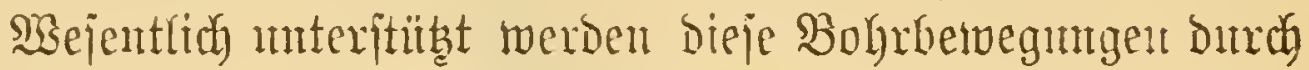
Die and manden andern wummatigen Sshmarobern eigen= thiumlichen nad hinten gerichteten Dornen, bie - man vgl. ひig. 1590 - oft franzartig Die einzelnen Pringe umppanten.

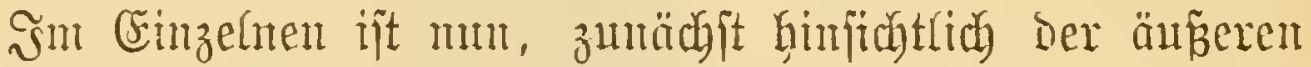
SUariijtung, das erite und das lebte Rörperjegment beadyten: werth. Eriferes ift fegelartig zugefpist und trägt mehrere theits freie, theirs cinziehbare Anthänge. Won leţteren er=

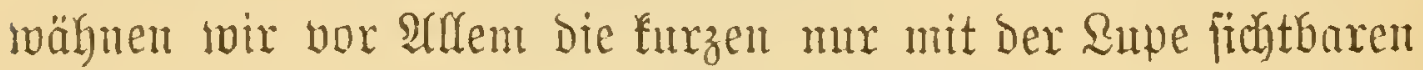

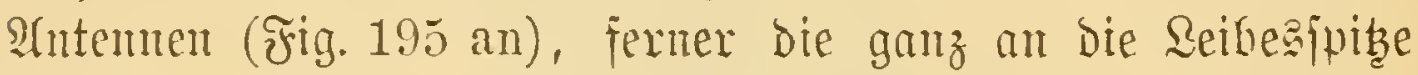
vorgefubbenen und an biejer Stclle gleidyfulls Der Drientinutg Dienenden Mittelfiejertajter $\left(\mathrm{mx}_{1}\right)$. (jileich Dabinter an ber

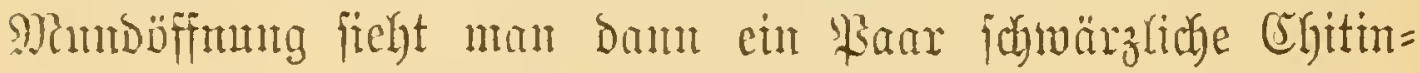
Gafen, Die, mit eimem intmen holzboctintigen bseitell wer= Gumben, Durch einen complicirten Minfefmechantam (Sch) hervorgeitopen und wiedex eingezogen werden. YY ganz jungen Naben bemerft man anzerbem an gleidyen Drte eine

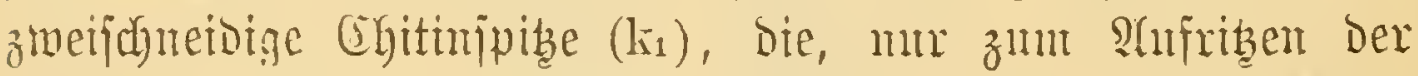

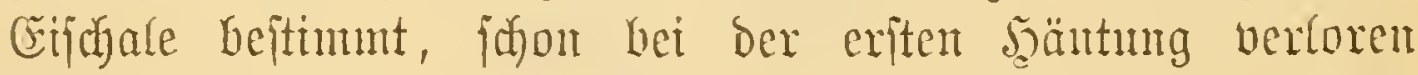

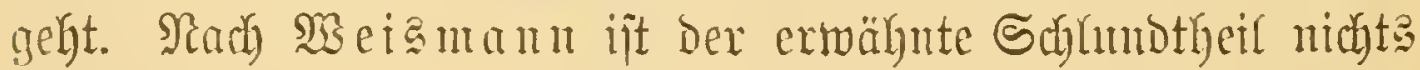
ShDeres als ber in bas zreite Segment eingeitülpte Border= forf jammt Den Mandifularjegment, und gebören bie Šmut=

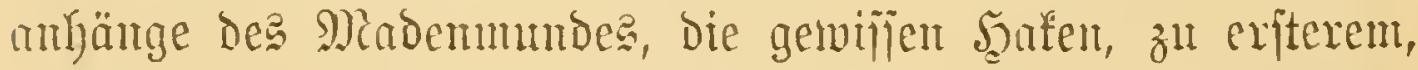
wäfremb Das unaare Doldhartige Drgan Durdi Sermachjung Der embryonalen Sberficfer entjteht. Afuf Die Wseije erflärt

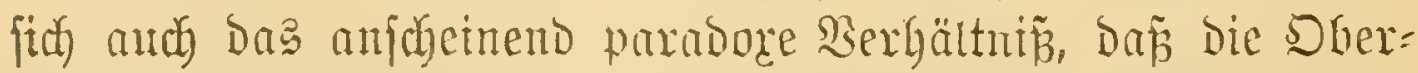
fiefer $\left(k_{1}\right)$ Ginter den Mitteffieferut ober Mariflen $\left(m_{1}\right)$ Ciegen.

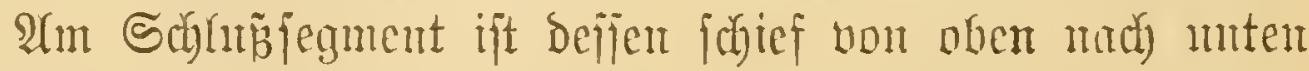

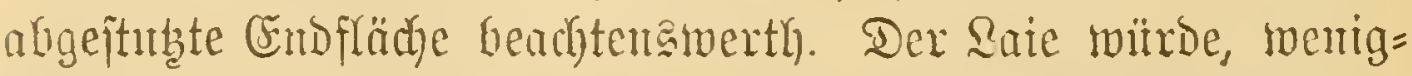

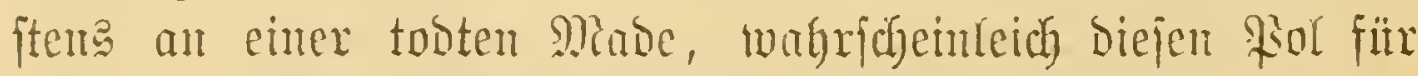

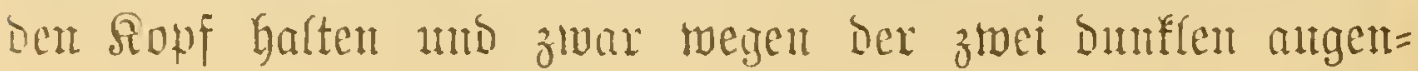


artigen Fleffe an bemijelben. Soldye Drgane brandjen aber bie Miaben nidyt, und bie vorliegenton find uidyts Mrnderes

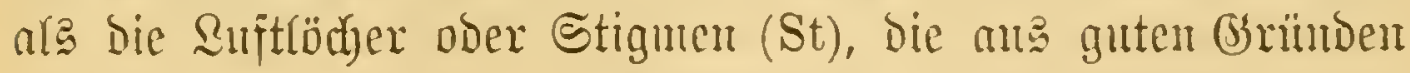
an biefe an mentigiten ber Berjtopfung angajebzte Stelle ver= legt find unb mix eine enge burch ein baarmets geidühte Athenribe Gaben. Die papillenartige Erbebung (a) gleid) unter biejer Stigmemplatte ift der affer.

Sir fonmen mut an bie imere Einriditung, mo ver=

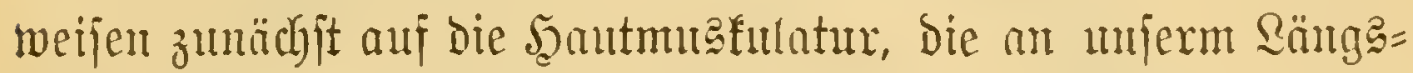
ichnitt ganlz naturgetren wiebergegeben. Sie bejtelyt von Ring

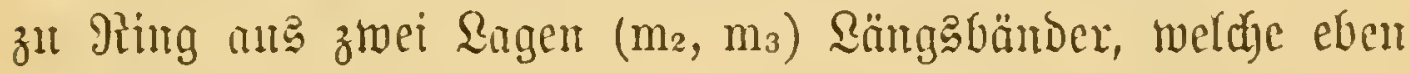
bie Segmente in citrander ziehen, jerner m. jojiejen Bintoln (m) nto endich) ante je einem Panar jeitlicher Stränge, bie aber

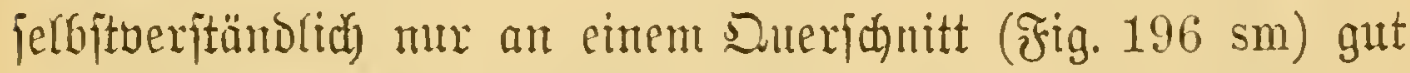

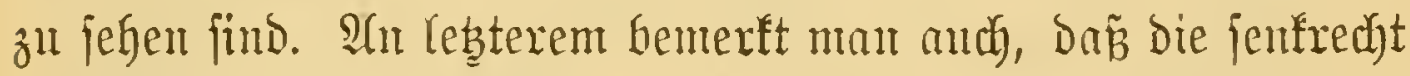

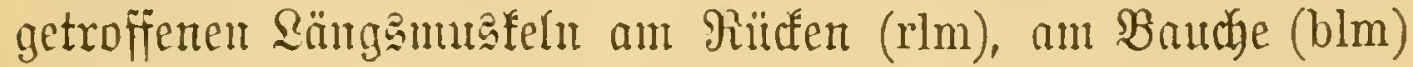
unb an ben Eeiten (oslm unb uslm), aljo ringanm ziemlich gleict)

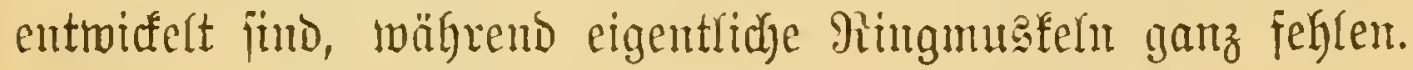

Jnt Banzen hat die Miusfulatur manches Analoge mit jener ber "Яiundwïrmex".

Bon andorn Şantorganen jei bam das Tradjeenjyjtem ermälynt. Celbes beitegt aus zmei feitlidyen bauntartig ans ben frïher bezcidyeten 2 fiteritigmen jid erhebenden und in mannig=

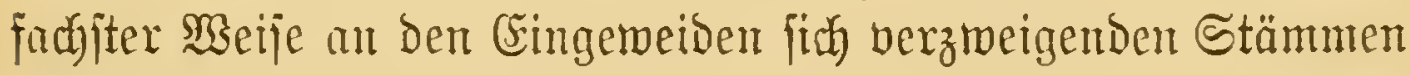

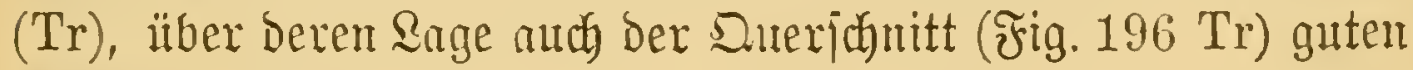

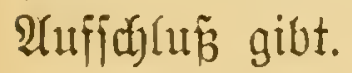

Bon auffalfenber Ränge mo Complication mamenttict) gegenüber bem bödyt einfachen Darmichlaud Der Raupen

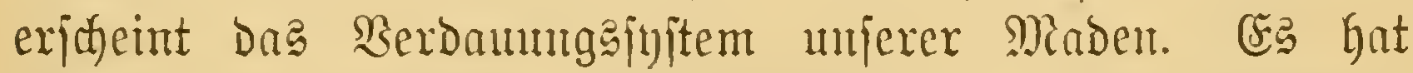

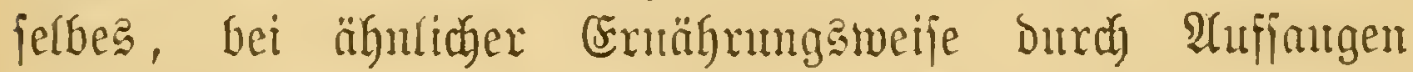
flizfifger Stoffe, jogar eine auffallembe Analogie mit bem ber

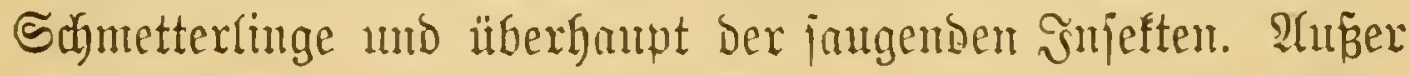

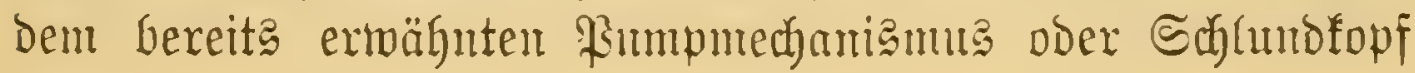


unb einem Kurzen Derbyäutigen Epeijerohr (テ̛ig. 196 Oe) ift vor $\mathfrak{A}$ flem Der abgeidumite Saugmagen (F̧ig. $195 \mathrm{sm}$ ) jowie Der

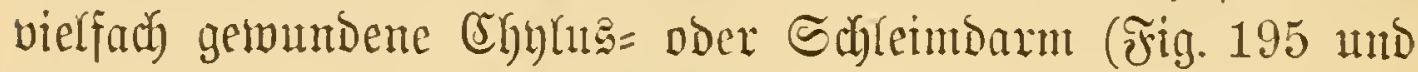
Fig. $196 \operatorname{ch} \mathrm{D}$, ch $\mathrm{D}^{1}$ ) bearbtengtwertf.

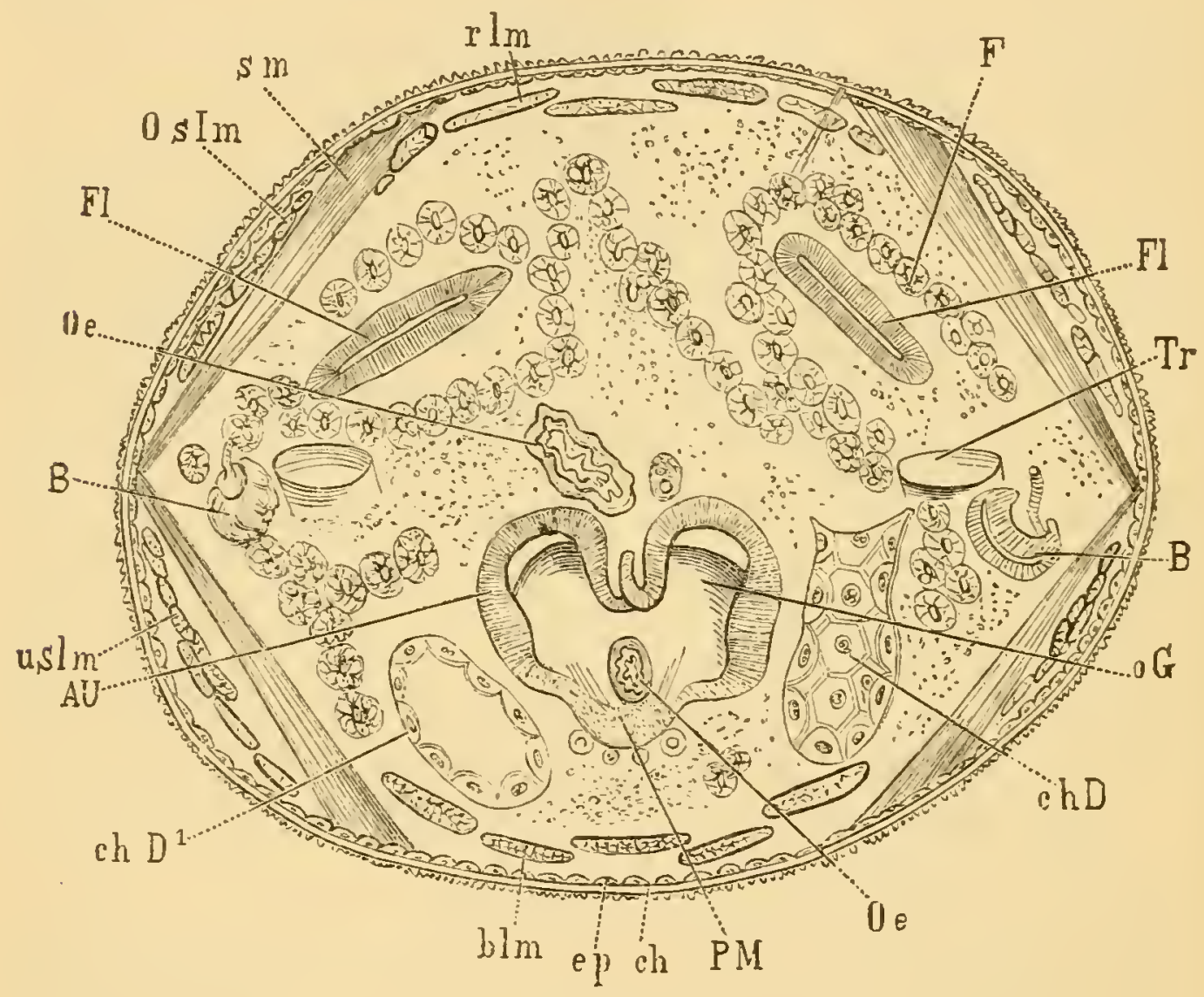

テig. 196.

Querjanitt burd ben 4. Reibesring einer Musciben=(§Yiegen=) Rarbe.

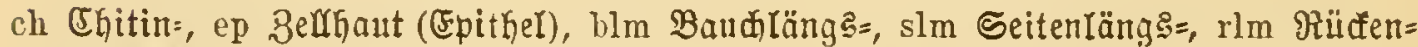

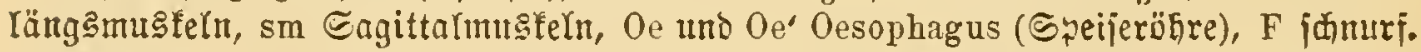

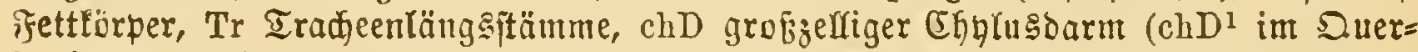
idnitt), oG oferes Sdlundoganglion (Begirn), PII Baummarf, Au Dem Biefirn (?)

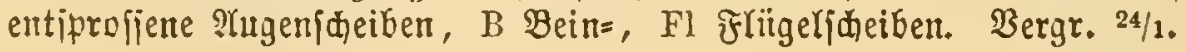

(Driginal.)

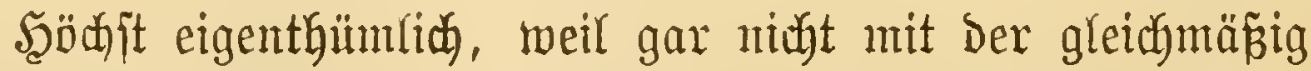

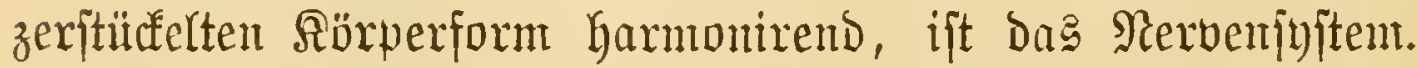
Statt einer $\Re$ ette von Granglien, wie bei Der Raupe, futden mir hier (Fig. 195) zrwijhen bem 3. un 5. Jing eine furze "piftolen= artige" Nerventmaffe (N), Deren Şandgriff $(G)$ bem Bsebirn, 
Deren ïturiger Theil dem gejammten Bandfunarf entipridyt. Som erfteren gehen Rerven vorwiegend zum Borberförper, von lebzterem zablreidye jtrafj ausgejpante Fajern zum Şuterleibe.

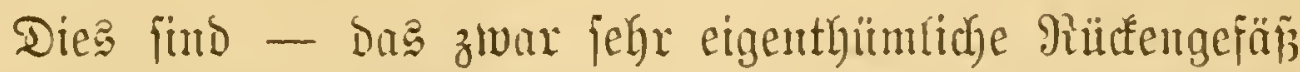
(Rü) Lajien wir ganz bei Seite - bie eigentlichen Eingeweise.

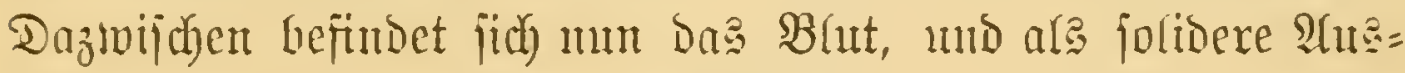
fïllung der aus gropen perlidumrartig aufgereigten Bellen bejtehende Fettfírper (F̛ig. $196 \mathrm{~F}$ ).

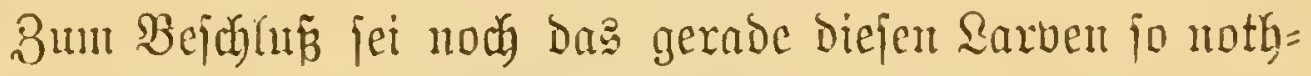

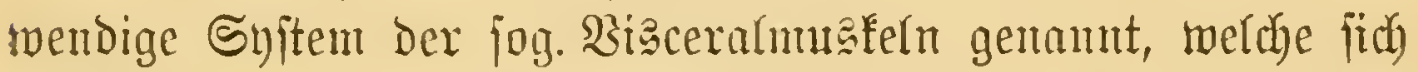
zwijhen Şant und Eingemeiben ausjpamen und die oben

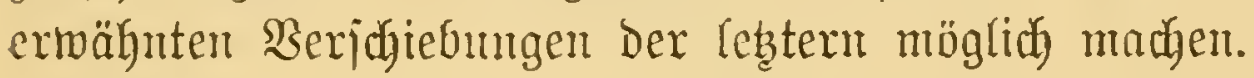

Streng genommen müpte mu, um das Biel und eimiger=

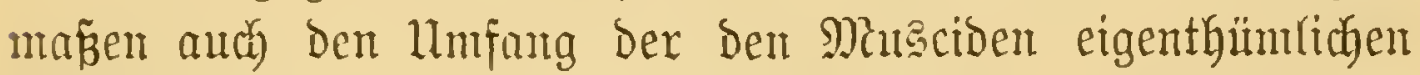
Metamorphoje zu bezeidhn, eine nähere Shillderung des Jntago

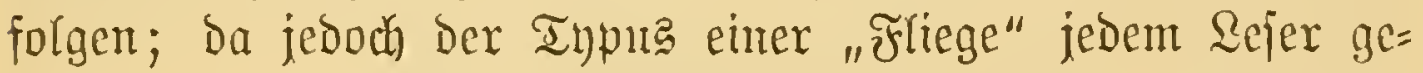
läufig, merden jolgende Şantfennzeichen genügen. Die Fliege hat im Begemfats zax Sarbe einen wohl abgejonderten Ropf mit gropen Facettuntgen, mehrgliedrigen Fühlern umb Dem be= fannten vieltheiligen Saugrüfijel. Sie bejut meiters eine gleidjalls ganz felbitändige aus orei Ringen veridynolzene Brujt, dben mit einem Flügelpaar, unten mit Den fechs Fntago= beimen. Endich foumt ifg nody ein Şintertörper zu mit z. Th. verwadyjenen, theits eingezogenen Reibearingen.

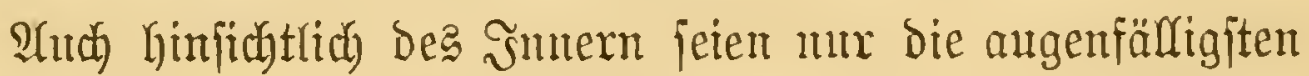

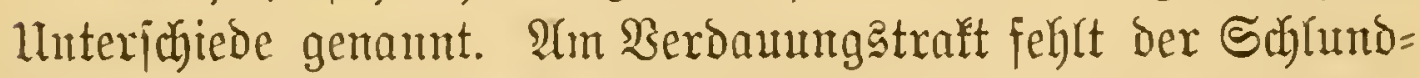
fopf und find bie ïbrigen Theile vielfach umgearbeitet. Das Nervenjuftem ift ganz anders, inden bier zum typifden Sdyhnoring nody eigene Bruft= und Reifganglien fommen.

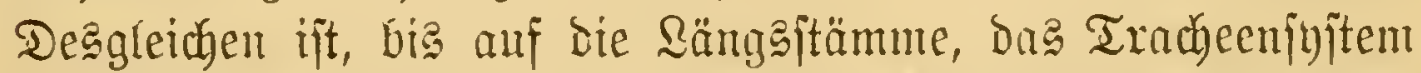
cin anderes, indent $j a$, von andern $\mathfrak{2}$ (btweidungen und ber 


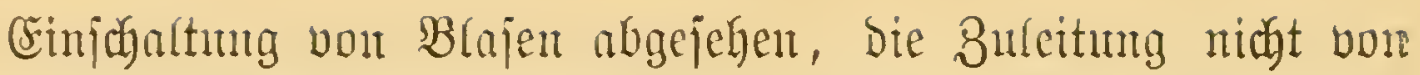
linten, jonbern von Den Eeiten her exfolgt. Am anffalfenditent

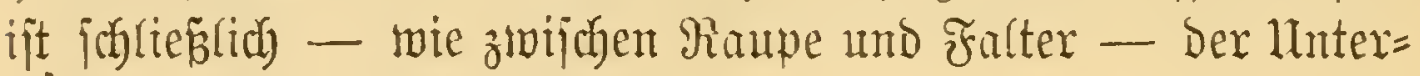

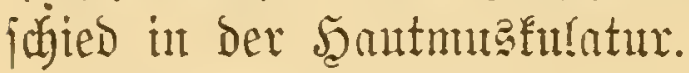

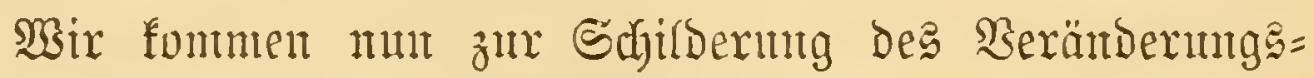

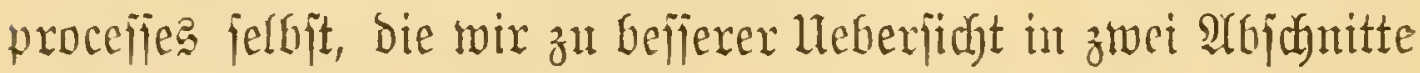
theilen werbent.

a) Anlage und Entmitumg bes imaginalen Borberleibesin ber $\mathfrak{a}$ arbe.

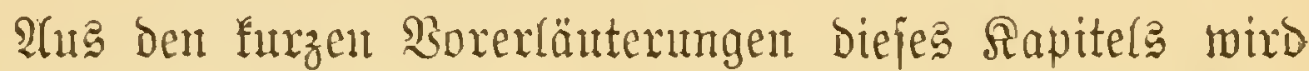

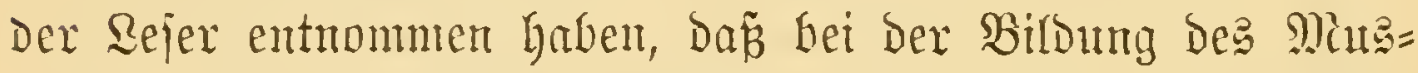

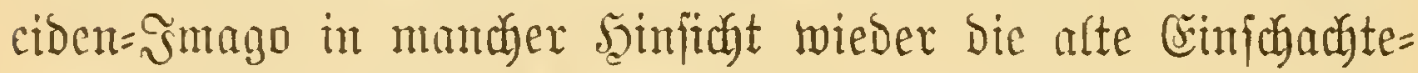

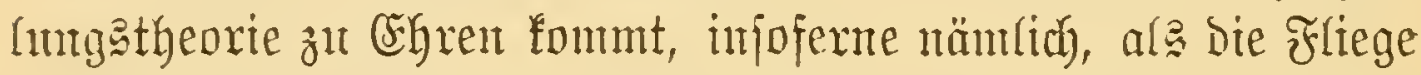

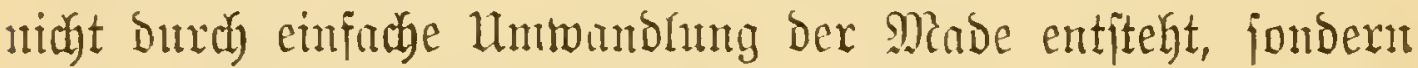

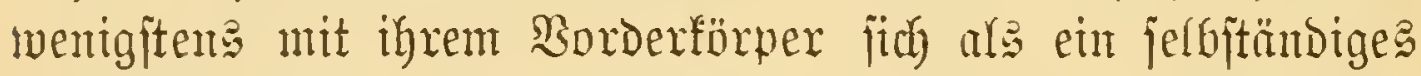

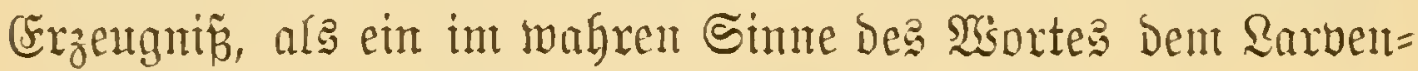
organiuntus einberleibte sejeidöpf fich Darjtellt.

Dies neue uno eigenartige Berhältniz zwifhen $\Omega$ arve

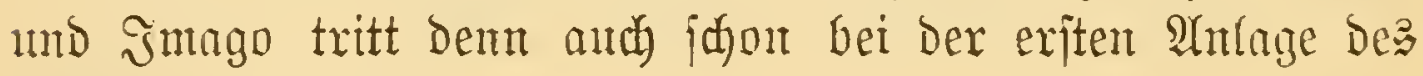
resteren zat Tage.

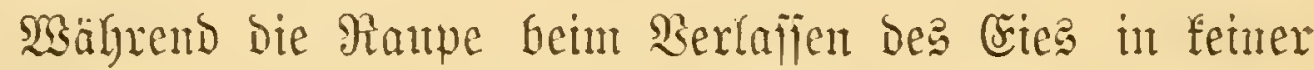
Shinjityt etwas Stnderes ift, als eben eine einfache, eime un=

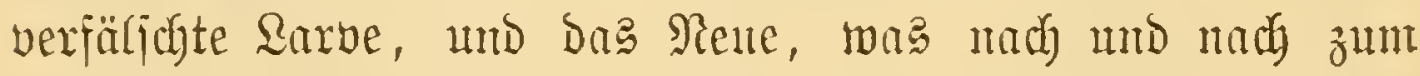
Borjachein foumt mo jie zum Schmetterlinge marbt, in lebter

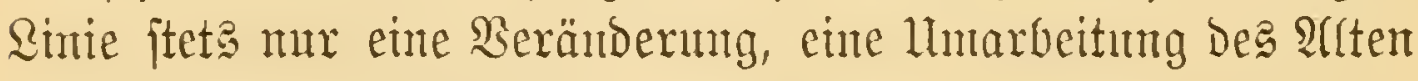

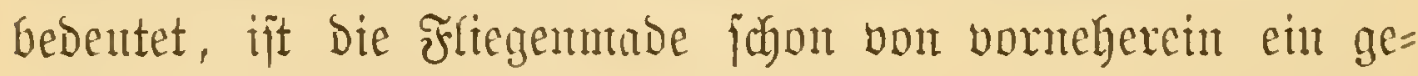
mijuter Drganisun, eine Art Doppel= oDer 3witterwejen,

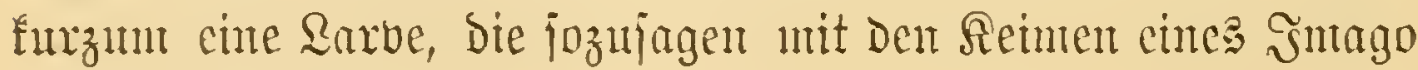
idrwanger geft.

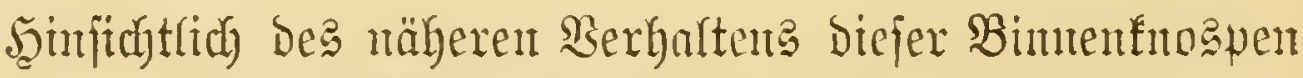

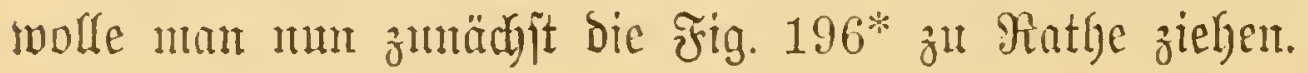




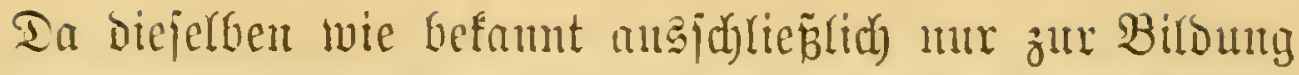
Des intuginalent Borderleibes, D. i. Der Brujt mo des Ropfes bienten, jo hat mant fie an Der Rarve and in entipredyentan

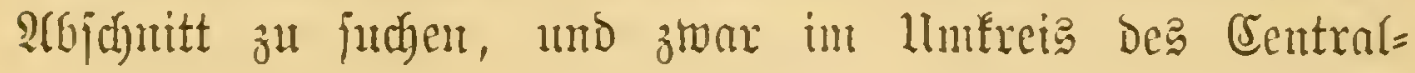

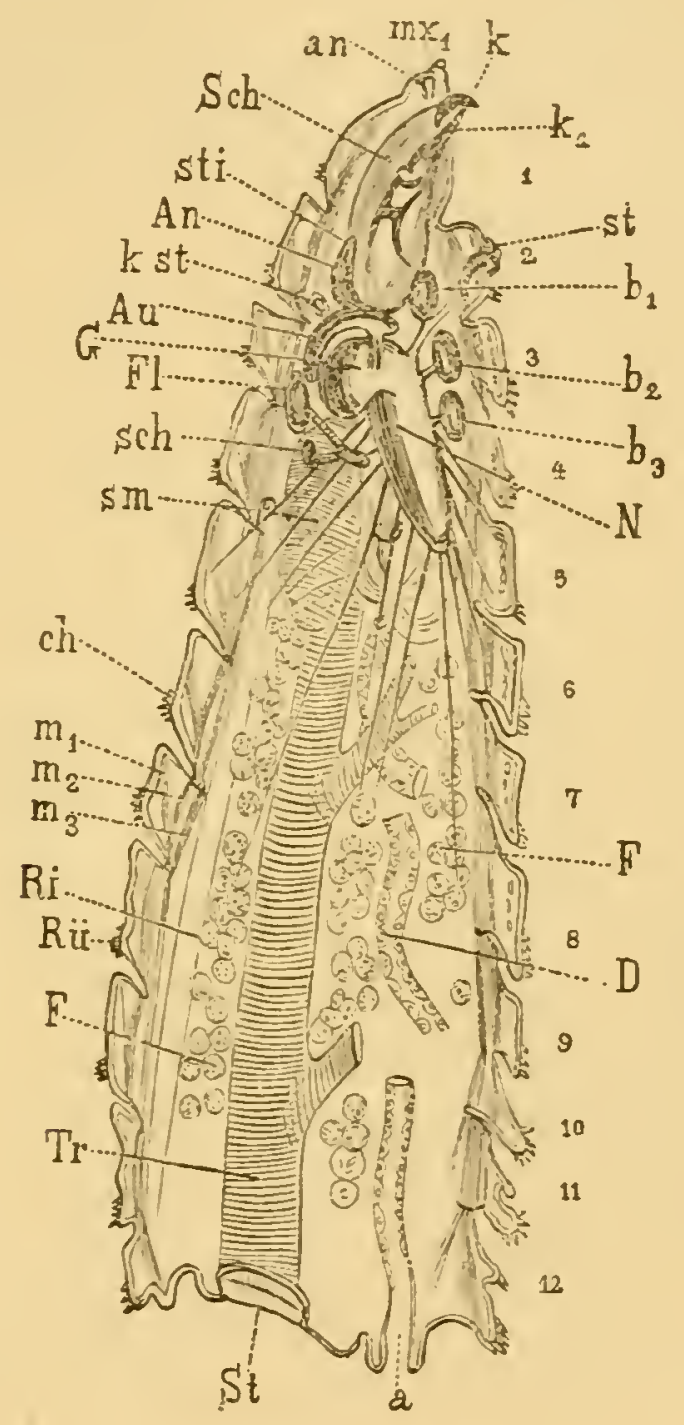

isig. $196 \%$

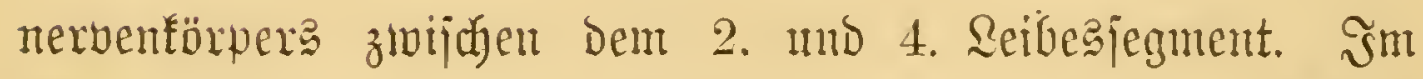
Granzen fimb beren nidyt wentiger ala fieben Panre, nämlidc)

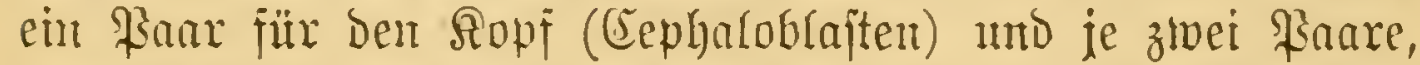

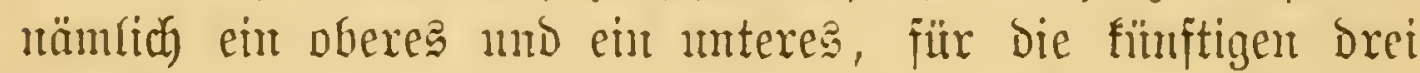
Bruftringe (Thoracoblajten). SRad Den wejentidyjten Bei= 


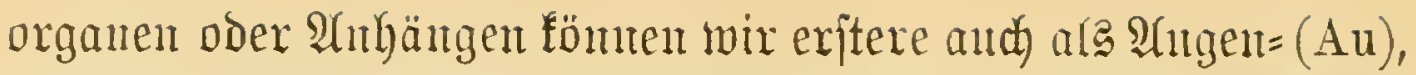

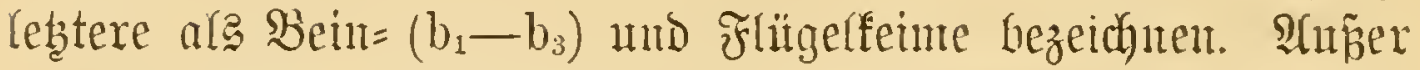
Der eigenttichen "Flügel"feimen (Fl) am Mrittelrütéen hat mant aber noch foldye für bie Sinpentigmen an Borderriüten (kst)

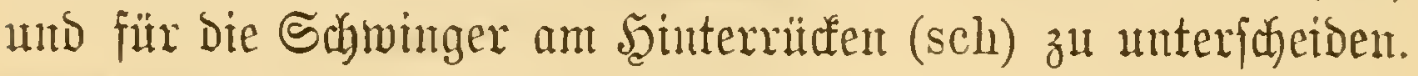

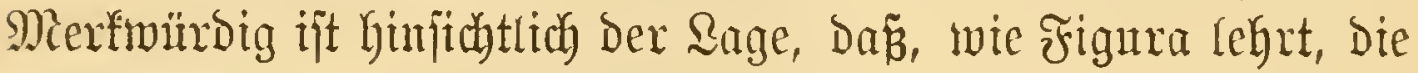
Cephaloblajten $(\mathrm{Au})$ nidat vor, jombern juifden Den Thoraco= Graften fich befinden, ber Smaginaffopf aljo feiner Alulage nadh in ber Brujt eingeidachtelt ijt.

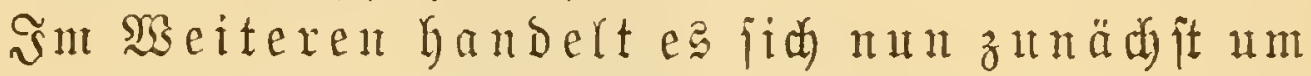
folgende zwei Carbinalfragen: 1) woher b. i. bout

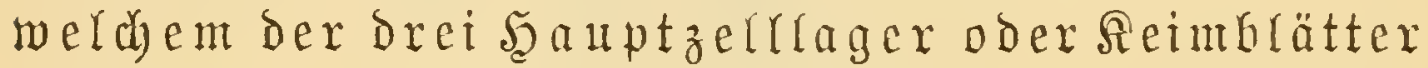
des Embryo itammenteje Reine un 2) welde Berragen ober (semebsfiditen des Smago gehen hitwiederum a

Un zuerft bie lestere Frage zll berühren, fo behauptet

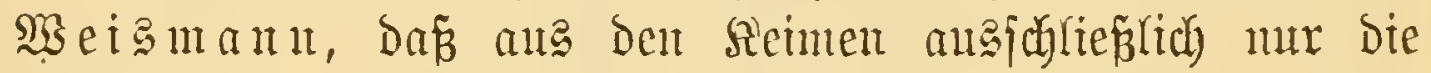
Meidifhant ober Epidermis des Smago, arfo jene Bellage

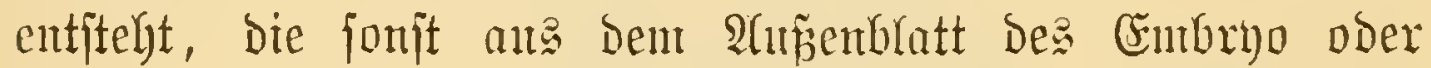
aus Dem Eftoderm hervorgeft, wogegen in neuejter Beit (b) anin bie mit mandyen Beobadyturgen $\mathfrak{B}$ ei

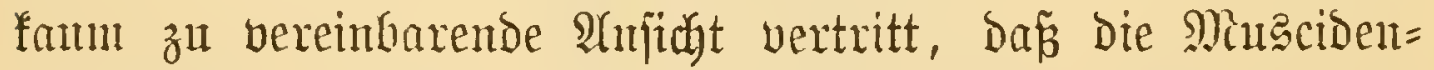
Neoblaften anferbem and mejodermatifde Birsungen ex=

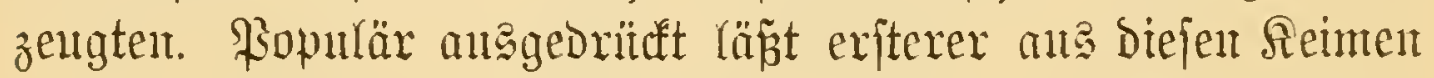

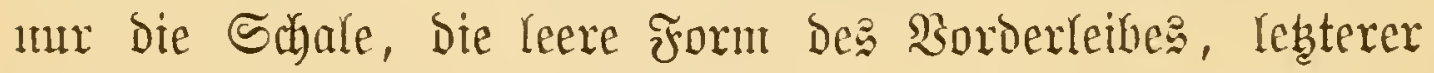

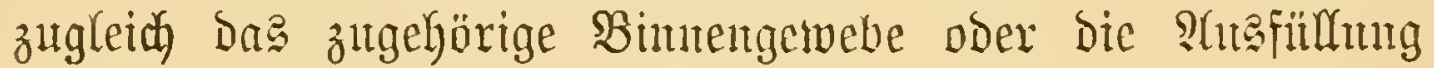
entitelent.

Wag Dan die andere Frage d. i. bie nad ben Uriprungujerer Reine aulangt, jomüzten bie=

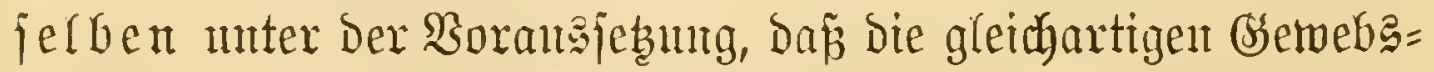
lagen Der volfenteten Thiere ftets aud ans gleichartigen oder homogentijiden Belfgruppen Des Embrtyo hervorgingen, nad

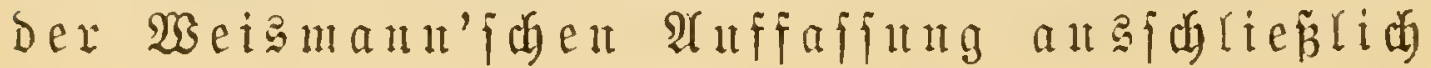




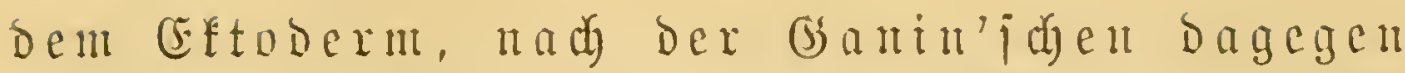
theirs dem eftoderm, theils dem Mejoderm ent= it a mu men.

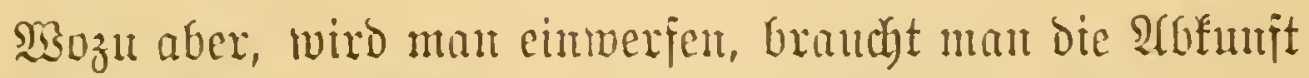

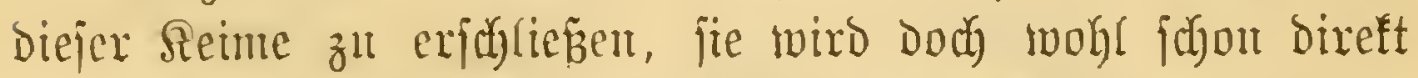
beobachtet und üher allen Zweifel jicher gejtellt jein. Sultofien

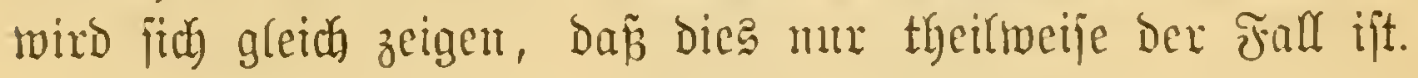

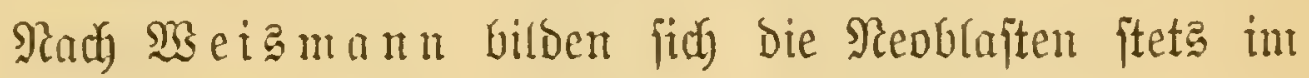
8ujanmenthang entweder mit cintent SRerb ober aber mit einer Tradjea, und nelyme man gleich zur Crrläuterung Der leştern Berbindung bie Fig. $197 \mathrm{E}$ 孔u Şand. Man fiegt da einen verzroeigten Tracheenitanm, inten mit Der Cyitin=, auñen mit Der Bcllyaut (z). An einter Stelfe benterft man bann

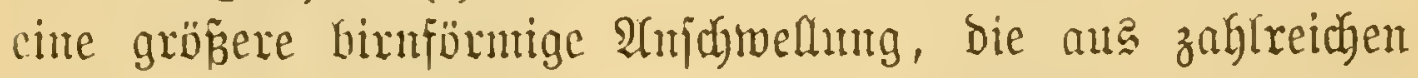
B(äabuen ober Bellen bejteht. Das ijt mut eben ein joldyer Sntaginalfeim mo zmar Der für bie obere Mittelbruft $\left(a \mathrm{~B}_{2}\right)$.

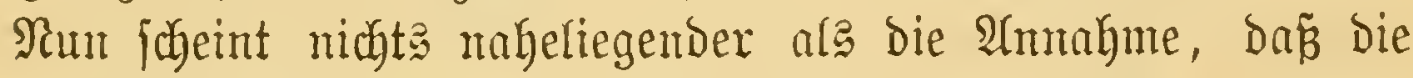

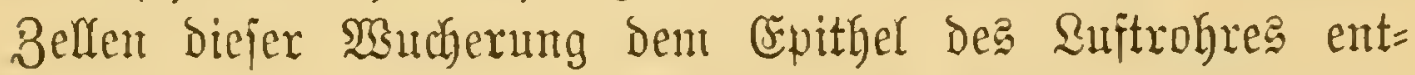

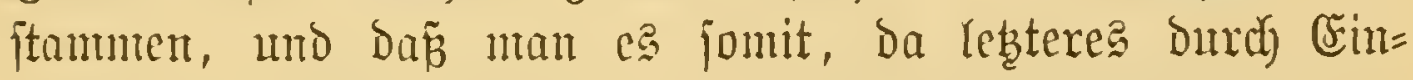
jentung Der Şaut entitegt, mit einer rohren Eftodermbildung

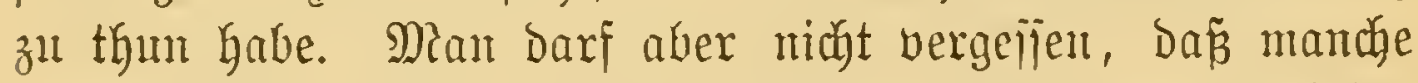
Tracheen von ciner bem Mittelblatt entitummenden Bimbe= gemebsyülle untfleibet find, bie betreffente Belfwndherung jomit ebenjogut Den eritern (eftobermatijhen) als Dem leb̧tern (mejobermatijijen) Siemebe ober möglichermeije beiben zugleid) autgehören faum.

Roch unfiderer ift Dex Uriprung jenter Seime, bie fich an Rerben entroiffelut. Fig. 197 A zeigt uns bas ijolinte Sentralmarf, Defijen zweiter (2) und Dritter (3) Nerv ganglien= artige $\mathfrak{A}$ uf Smaginalfeime und zroar bie der untern Sorder $=\left(\mathrm{u} \mathrm{B}_{1}\right)$ unt Der untern Mittelbrujt $\left(\mathrm{u} \mathrm{B}_{2}\right)$. Nady 


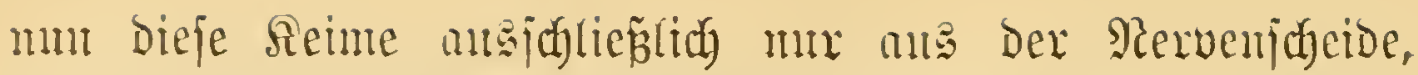
aljo aus einem Bewebe entitehen, das, wie wir im früheru
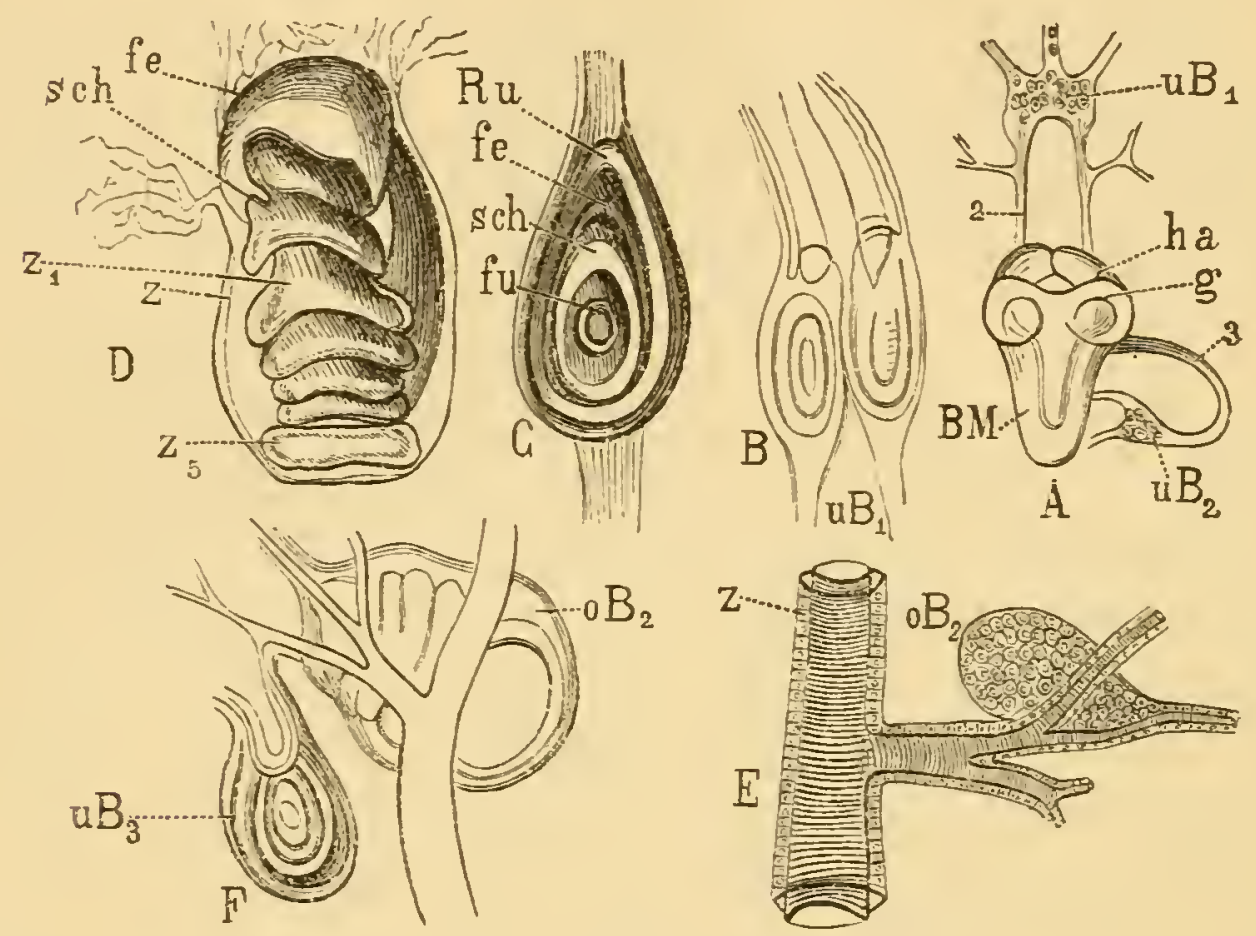

Fig. 197.

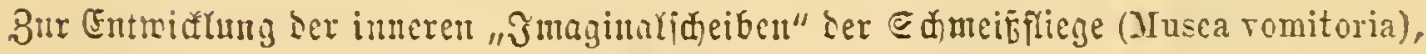
nad) Weis $\mathrm{ma}$ แ⿰

A Bebirn (G) mit Banthmart (BII) einer $0,7 \mathrm{~cm}$ Iangen \&arre.

ha "Sirnantang" over Ispfideibe, 2 ztocites Rerbenfanr Ies Bandmarfes, Daran uB1 Ynlage ber untern Borter fruft (Prothoracalidcibe), 3 orittes Terven= Faar, baran nBe Inlage ser untern Mittelbrnit (Mejothoracalideibe).

E Diejelben 2 orberbruitideifen einer $1,5 \mathrm{~cm}$ Yangen Nabe meiter entmidelt.

C Itntere Mittelbrufticheibe einer irija berwuppten Rarne.

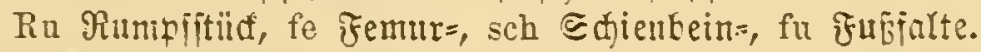

D Nittelbein mehr entmiafelt.

$z$ Sie sie Beinanlage umgebende Şülmembran (vom 2. Puftentag), $z_{1}-z_{5}$ Jufgrieber.

E Mnlage ser obern Mittelbruit (Flïgelideibe) $\left(\mathrm{oB}_{2}\right)$ an einem Tradeengmeig. $z$ bie Bellage (Tradjenepithel) non einer eken ans Iem (Ei gefrodienent sarte.

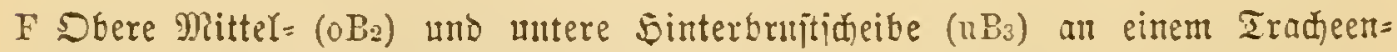
ftom ron einer ausgetondjenen garte.

Siapitel gefört, bei Corethra ganz und gar nidjt zur Billoung

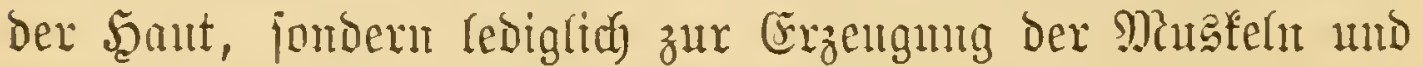
ïberfarpt Der (mejodermatijenen) Bimenjutujtanzen bient. 


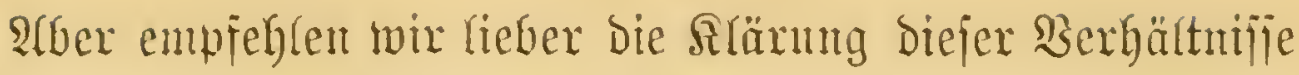

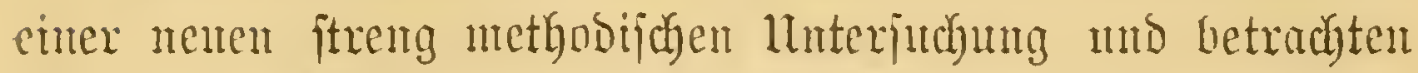

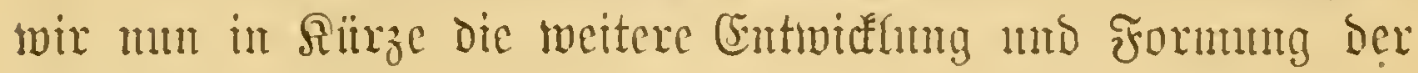
Эmaginal "icheiben".

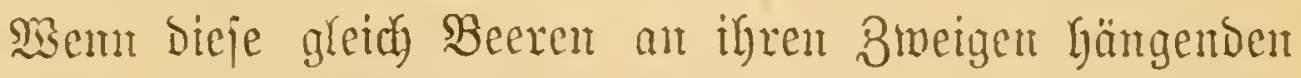

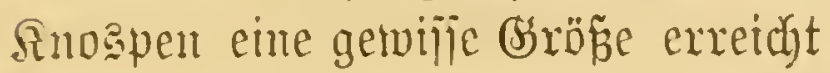
habest, jo entitelgt in ignen zunädyit cine nut Der llmgebung $\delta$. i. mit Dent Imemenm Dex Rarue com= muntirente Sebhthug. Der jolide Sieim verwandert id mit andern

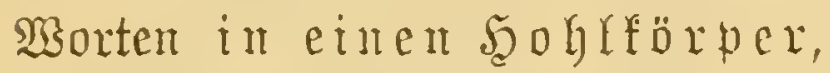

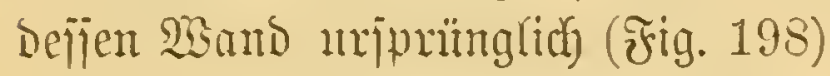
mis eimer einzigen aage holder Bellen (z) bejtergt.

2ats biefent ßerbalten, forwie ans bem lumitande, Daj bieje epithel= artige Bellage alsbald eime zientich

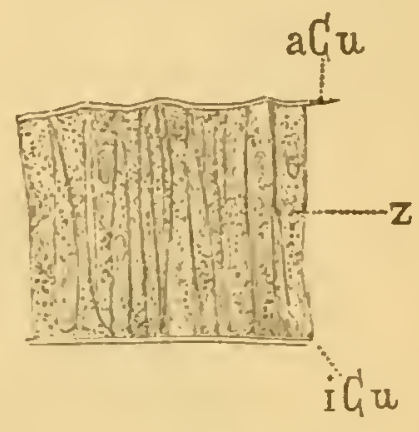

Fig. 195.

Etïd eines Sucridnittes ber frügeljheibe einer minacion= rarue.

z Continderepitbel, a $\mathrm{Cu}$ ätbere Cuticula.

(Driginal.)

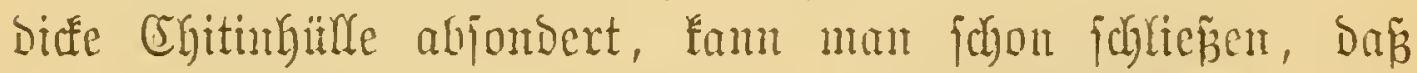

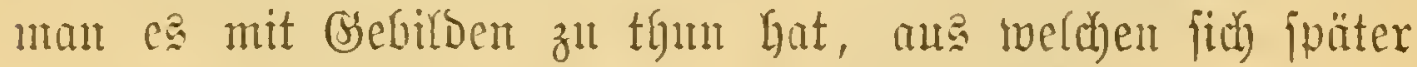

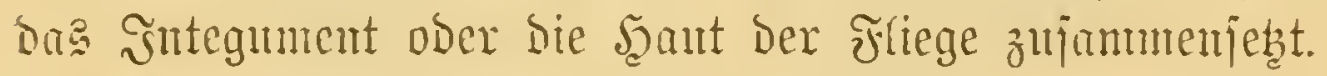

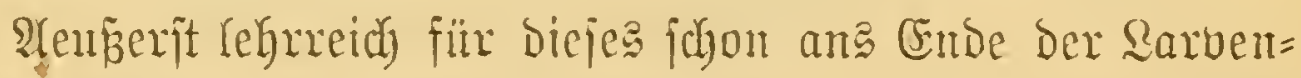
periode fallembe Stabium ijt mier mebr bejprodyencr Suer=

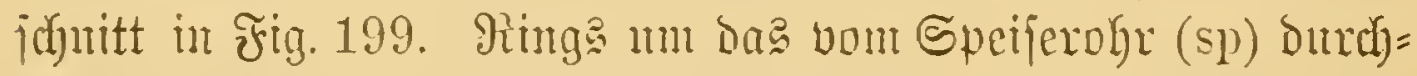
bohrte Bbehinn (oG) jiegt man zutädhjt die angenteme (Au).

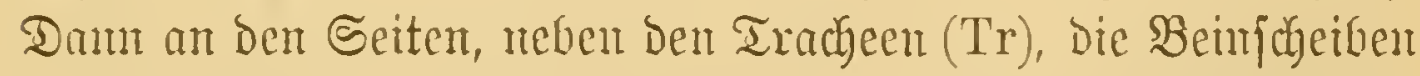

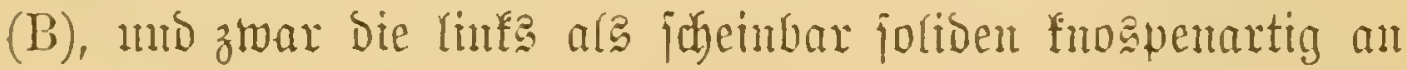
Der Trachea hängenden Sïrper, wägrent bie redfte, mitten

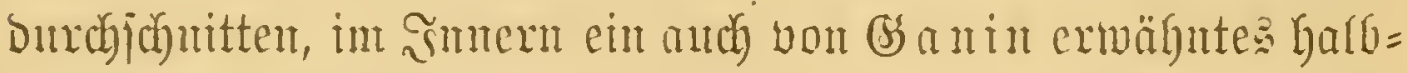
mondförmiges Sumen zeigt. Sben, bei $\mathrm{Fl}$, bat man endid

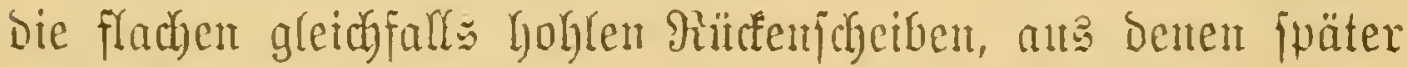

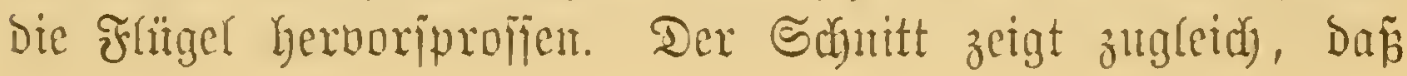




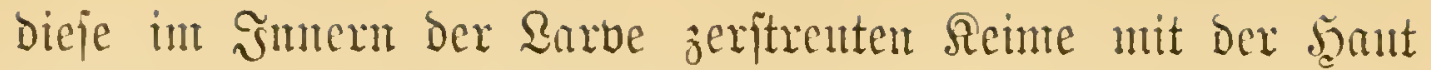
Derfelben in gar feiter bireften ßerfindung ftehen.

Mas mu bic eigentfiche Gseftaltung oder Mrodellinung biejer Siemte betrifft, fo wollen wir uts borläufitg mur auf die Beinanlagen bejaränfen. Die Sache beruht auf einfacher

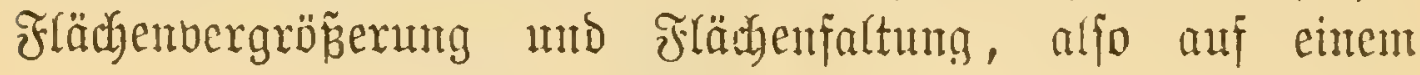

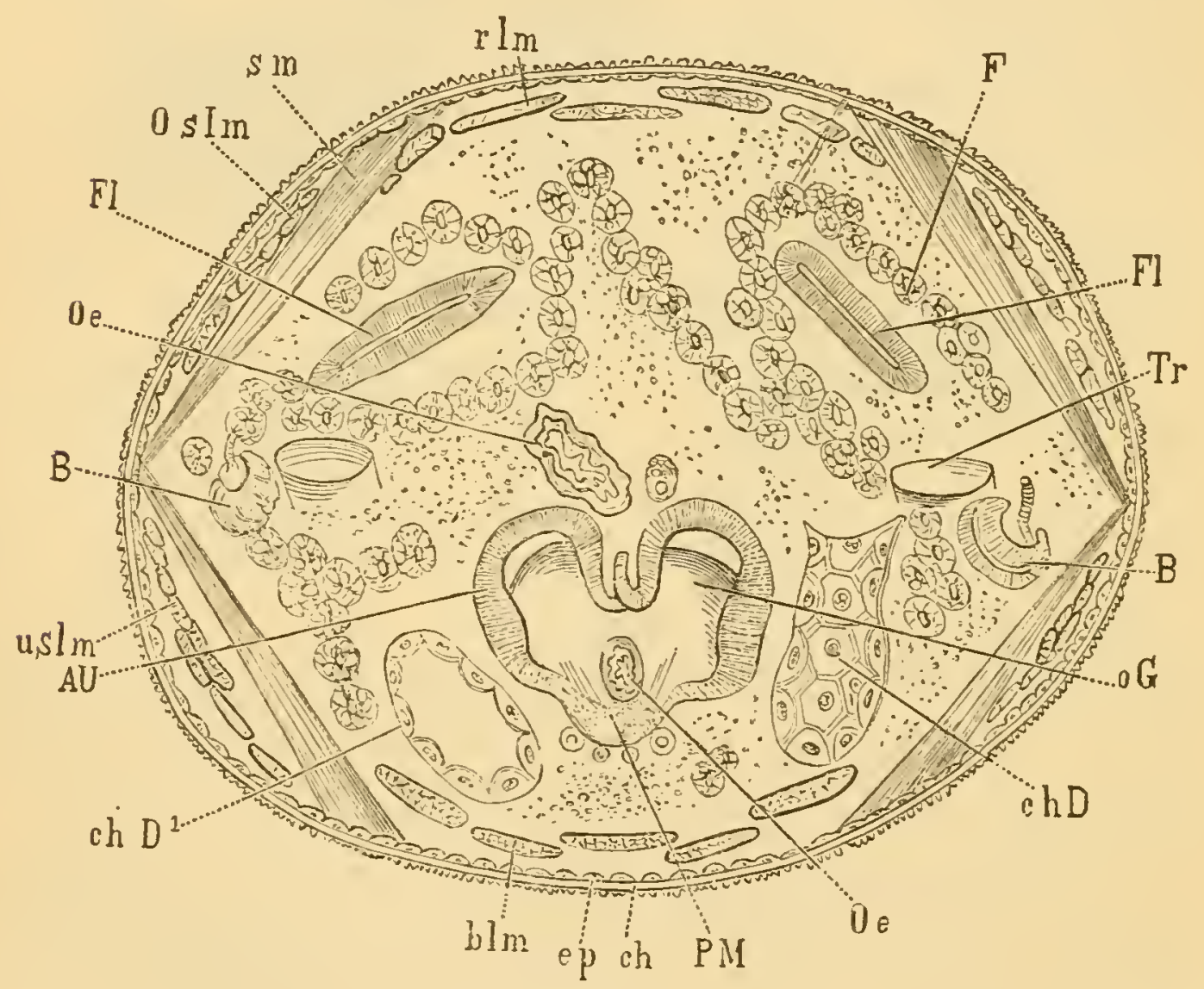

ifig. 199.

Princip, bus bei allen folduen Bildunganorgängen bie Scunt= rolle jpielt.

Am Zwillingakein in Fig. 199* B Gemerfen wix auf jeber

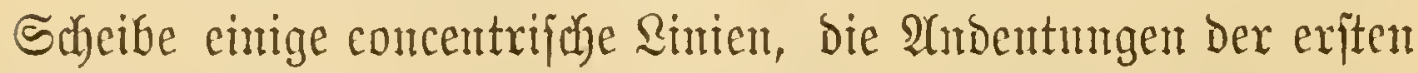
Flädbenbiegurgent. Sn $\mathrm{C}$, einem fpätern Stabium, bilbet Dann

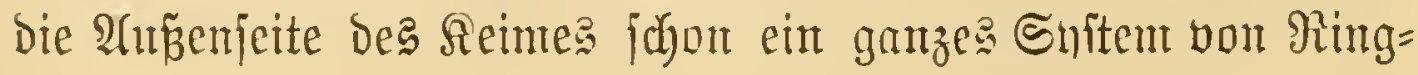


falten, bic, burch entiprechende Furdyen vou cumber getremt,

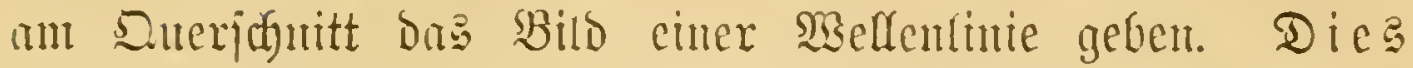

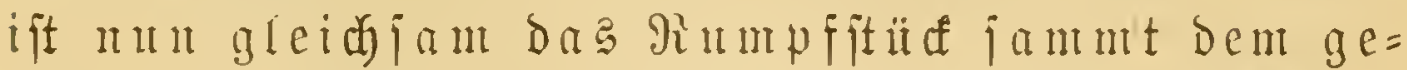
grieberten Beinaubang in ber Sorizontalprojeftion. Der Sam ber Sdyeibe cutfpridyt näm(id der Bruftwandung, mährent bie innen 3onen folgetweije die Bsticber bes Frües D. i. Des Frmutr (Fe), der Schiene (Sch) und des Tarjus (Fu) Darjtellen und Der centrule Rern Des Sranzen Die Spibe Dez
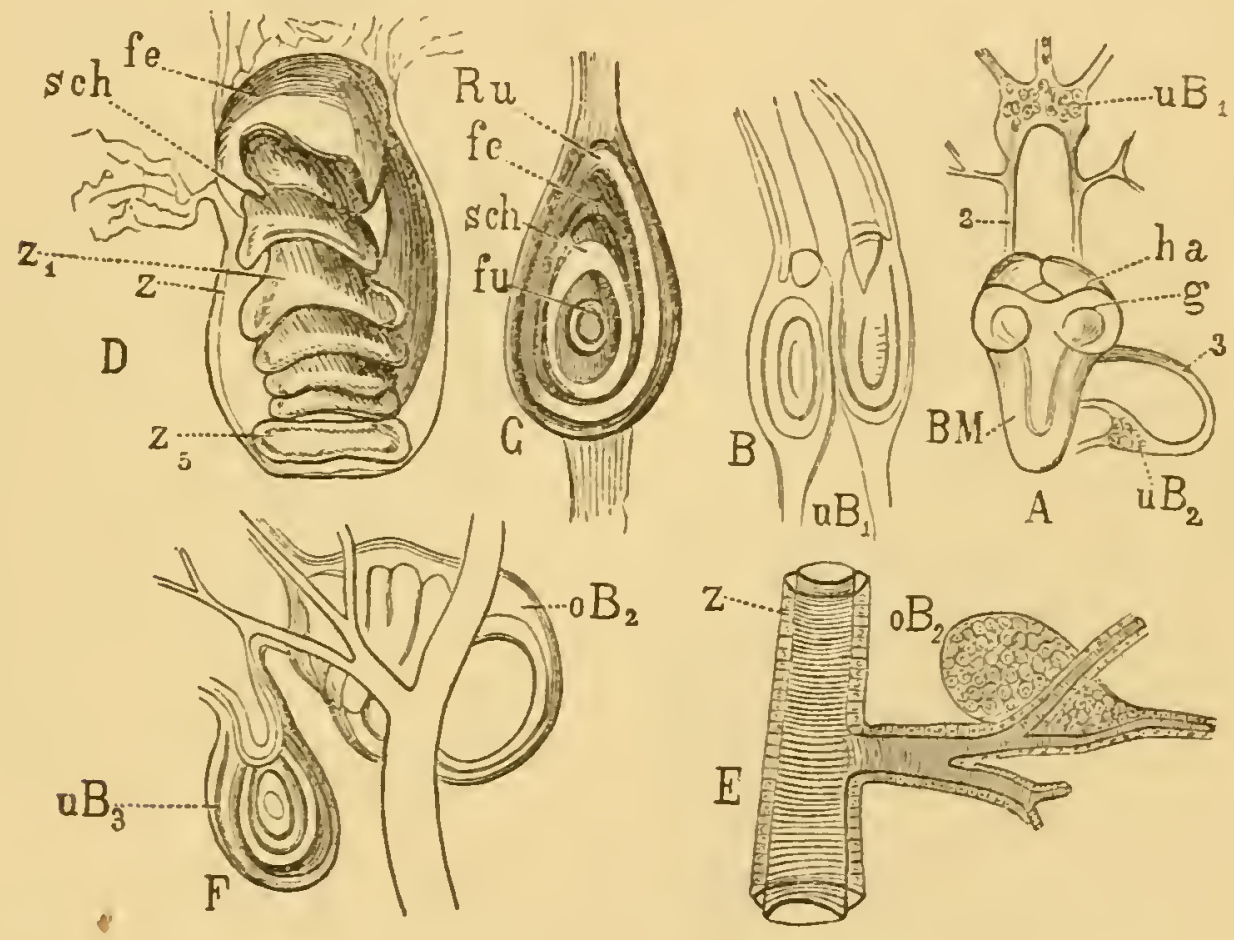

Fig. $199 *$

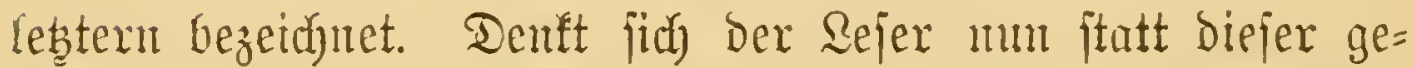
falteten Silntte eine elajtijuc Mhrieder, Deren innere Windung

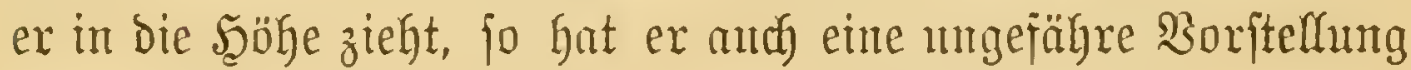
Dabon, wie allmälig aus ber flachen Echeibe ber in D abge= zeiducte $\mathfrak{A n h a n g}$ herauswächjt.

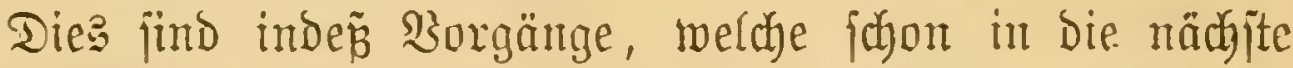
Beriode fallen. 


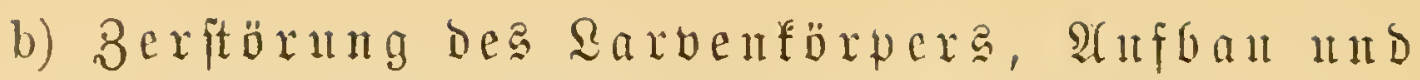

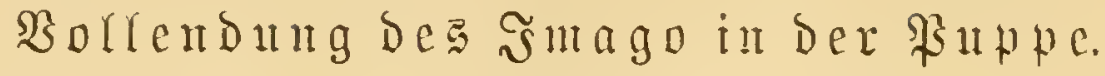

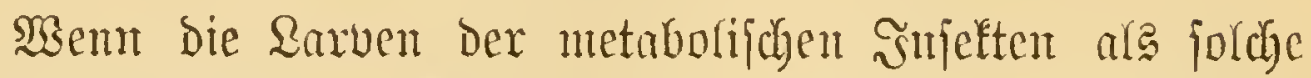

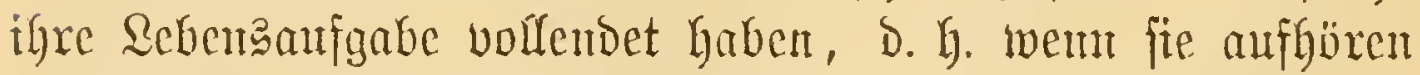
zu frefien und neues Bildungamaterial aufmipeidyern, fo

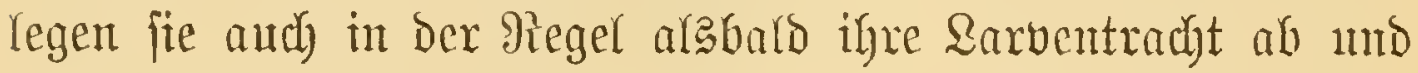
zeigen fich in eimer bom reifen Jnjelt ähulichen Bsejtalt, D. $i$.

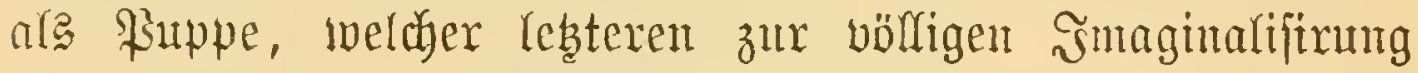

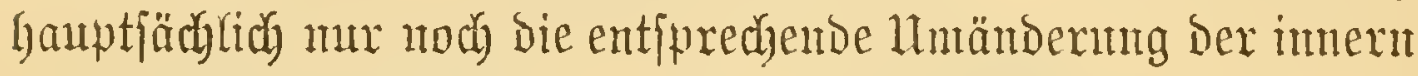
Einridgtumg nötgig ift.

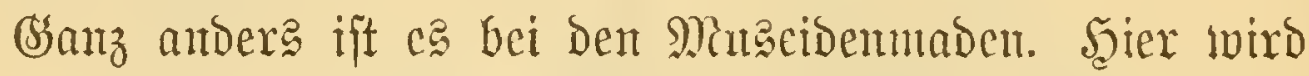
Der Hebergang vom freien ober aftiven Reben in Dest burch bie beginnende intere 1 nntwandung herbetgefübrten 3 utamb Der Untyätigfeit nicht durch cinen Şant= ober Bscitaltwechjel

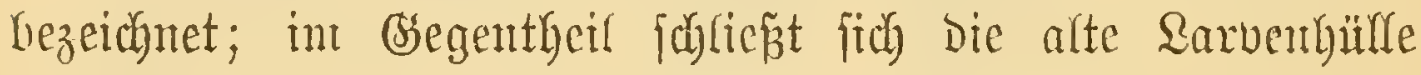
mod) enger un ben weidfürper zufammen, ja fie wirb unter gleichzeitiger Serbickung und unter Cimftillpung Des eriten

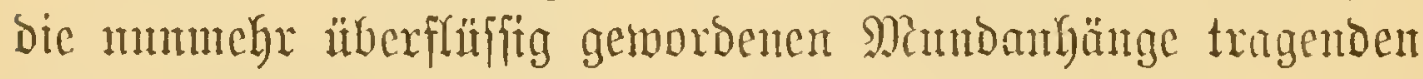
Singes, zu einer förntichen Schate ober Sapfer, in ber mu bie "Iomtenpuppe" igrem weiteren Schickal entgegen= geht.

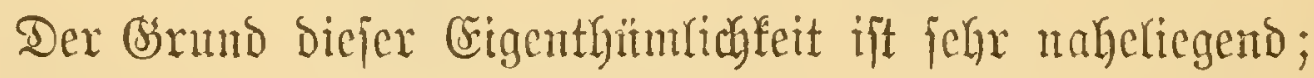

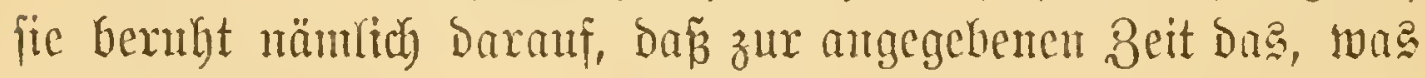

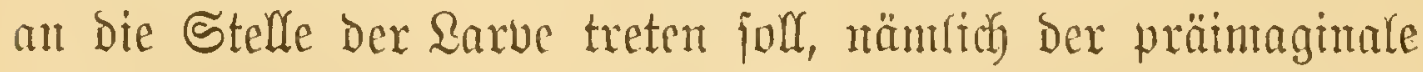
ת̈̈rper oder die Fuppe, änfer(ich) noch nidyt ganz fertig ift,

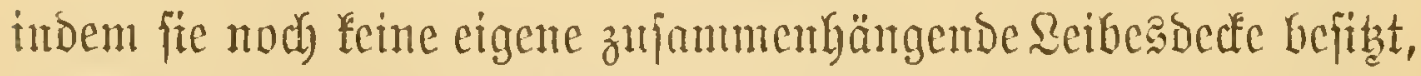

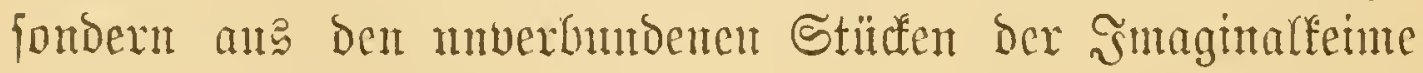
bejtegt. Mürde mut troksoen dic Rarventhant entfent, fo

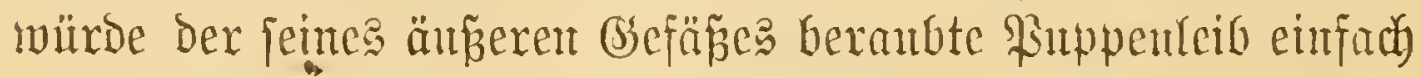
ausciuamber fallen.

Sa, unesharb aber wird ber Sarventarg nicht wenig= ftens Dant geppengt, went, was in wentigen. Tagen 


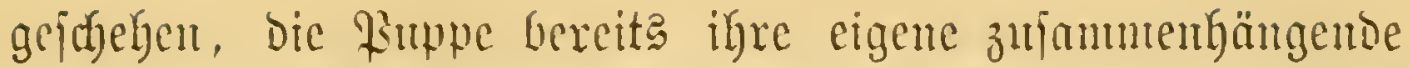

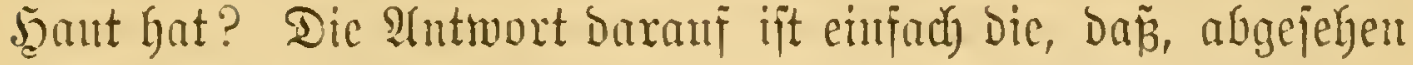
von Dejenjiocn Éfarafter einer joldyen accejporijchen Bebecfurg, bei Der jofort eintretenden Beritörnng Des innern Rarventeibes dic Drgnte, wir meinen bic Mingfeht fehlen, um bieje $\mathfrak{A}$ beit

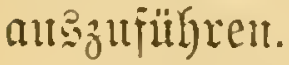

Stbex betrad)ten wir mmmehr bie weiteren Sorgänge in Diefon jelfiamen Doppelf́̈rper.

Einen jubönen Meberblif über Den exĩten Zujtand ber Sarvelt = Rimpe gibt Der Sängajubrtitt in Fin. 200. Da jefjen wir äuñerlid) junädjit bie Rarbentant, und j̧wax 1) bie bicfe Shitinlage (cu), 2) Die

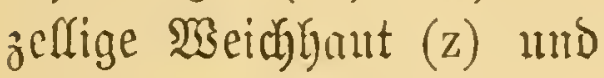

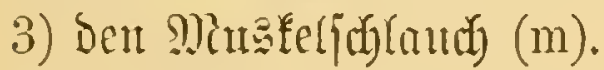
Da: Snnere zeigt ztwei 2(bidnnitte: einten burbern jelbitändigen Rörpertheil, D. i. Den Borderleín des Эmago, mb bam einen Gintern, ver mit bor Sarve zıjammenfällt.

Brwifajen Dem jelb= itändigen Ruppenvorder= Leib und ber allgemeinten bülle fimden jich aber noch gewijie ber Sarve angebörige Neichgewebe: 3. B. Bhut, Fettzellen u. $\mathfrak{A}$.

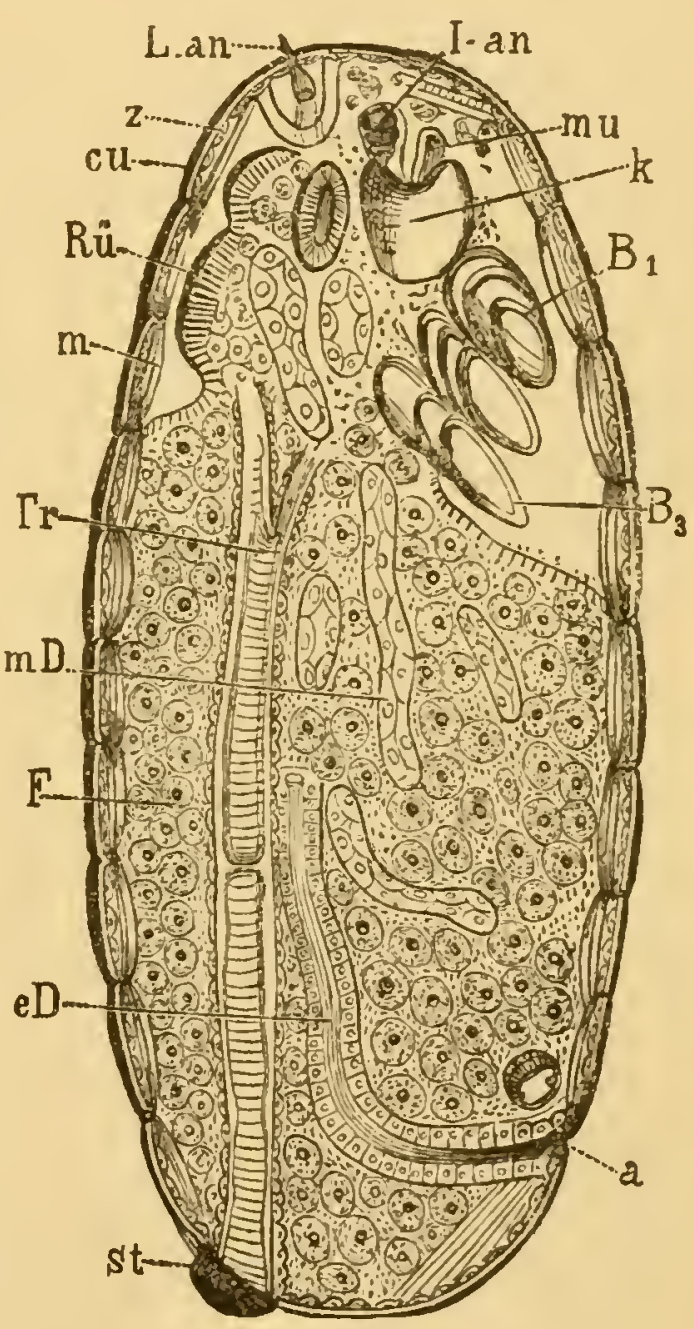

Fig. 200.

(Bgl. S. 475.)

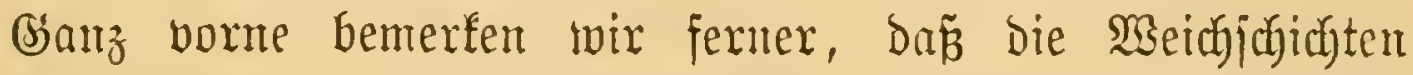

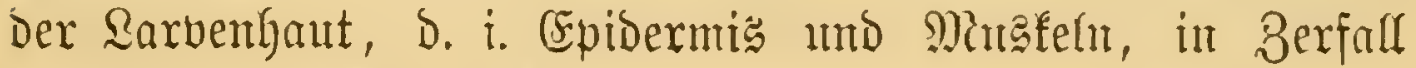
ઉ̧raber, 3njeften. II. $\mathfrak{B}$. 
Gegriffen funt. Dieje Berftörung Debnt fich Daun fehr rajd

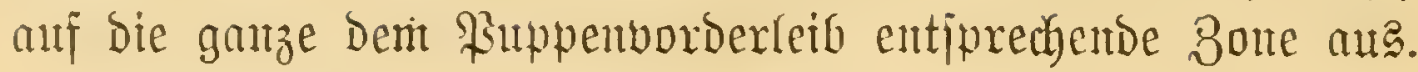

Mran beadyte mut aber vor Mmen, baź bieje mo bie ge=

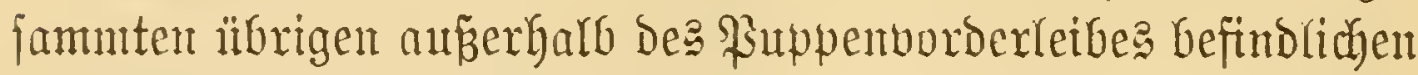

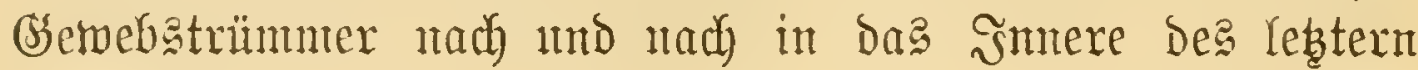
übergefirbrt werben, ba $\mathfrak{B}$ aljo aud bei biejer $\mathfrak{u} m=$

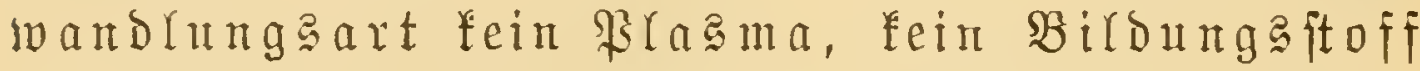
verloren geht, fouberu die Maffe des smago volrytändig jener bez angerachienen Sarben= leibeg entipridyt.

Sobald mun alle vou ber Beritörung des altent Bebältoes Gerrïfremben Materialien in Den imment Menbau ïbertragen

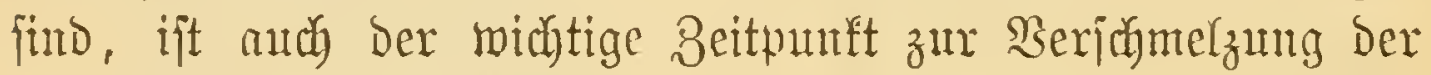

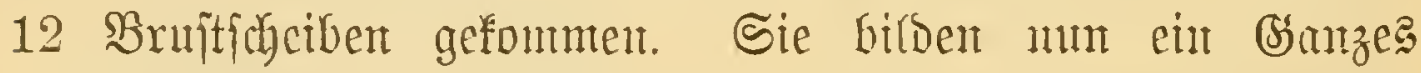

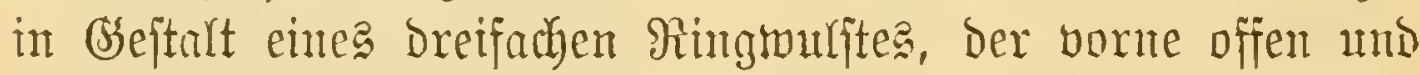
Ginten anf jtoch utidyt ganz erffärte $\mathfrak{B}$ eije mit Der Sarventhaut verbunoen ift.

Der Mopf (K) aber befundet fich, was in berjelbent Frigux nadyzujeben, noch imerbalb biejes Bruftgebäujes. Derfelbe beftegt anfangs (ogl. auth fig. $1960 \mathrm{G}$ ) aus zmei tellerartigen

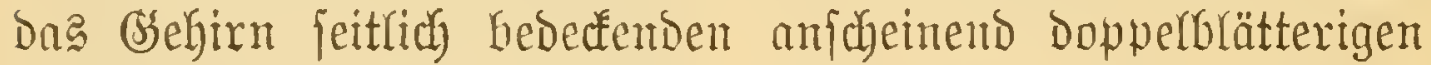

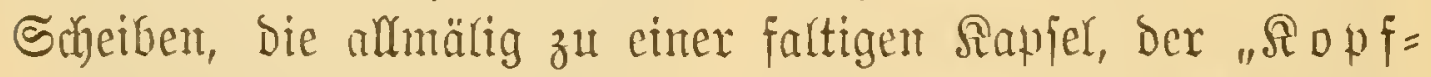
brafe", verwadyjen, weldye restere aber vorme behufg Aufuahme getwifier 3erfallaprodufte nod) lange Beit offent breiben foll.

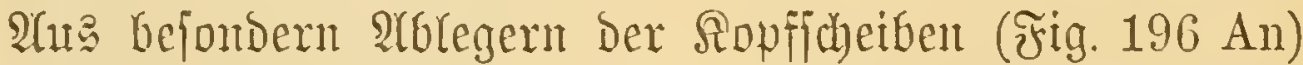
bitbent fidy Dunn, aher viel Fpäter, Der Borberforf, forvie bie

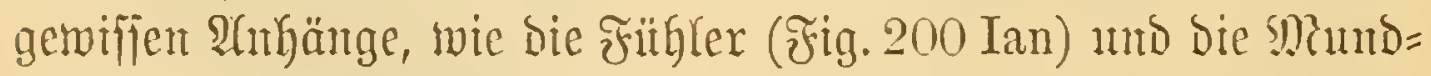
theile (mu). Daram ergibt fidy aud, da

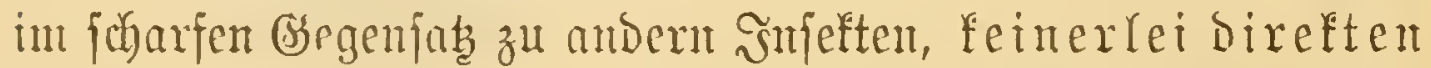
Bezug weder zu ben gleichuatigen 2 arven= no h

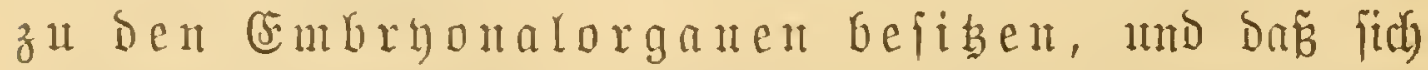

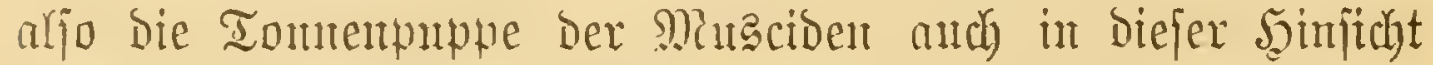
are cin wahrea Dopnelwejen herantaftellt. 


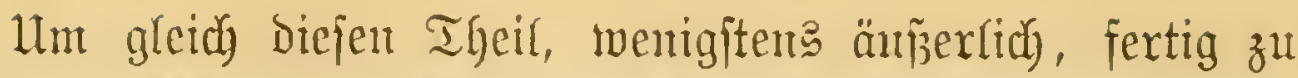

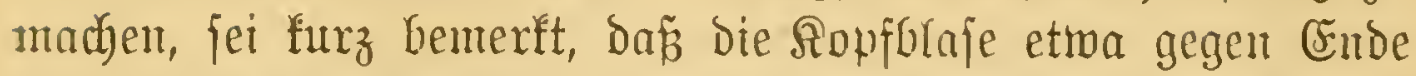
ber criten Puppentmodhe unter Bufammenziehung ies Bruft=

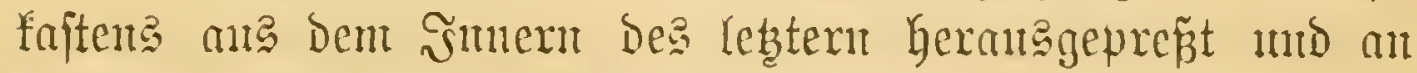
ifre Defintitive Stelle beförocert wird.

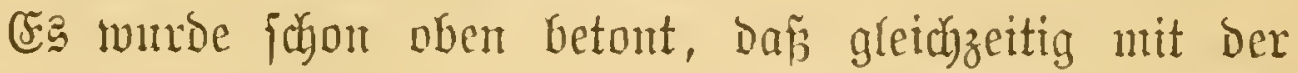

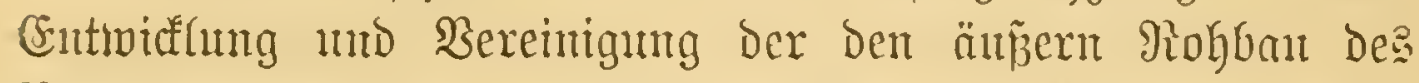
Ruppenborberleibes bildenden Stücfe getwijie peripherifde Zarbengemebe in Serfall gerathen. Weit gröpere Dintenjunten

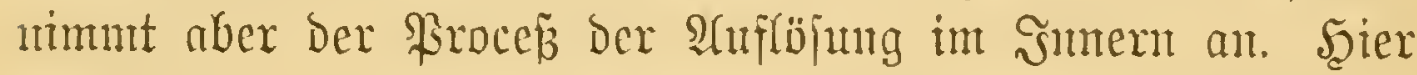
wiro mit alleiniger $\mathfrak{A}$ tinnahme bes centralen Nerveninftems Alles zerjtört, affes zertrünmert uto fozujagen fein Stein

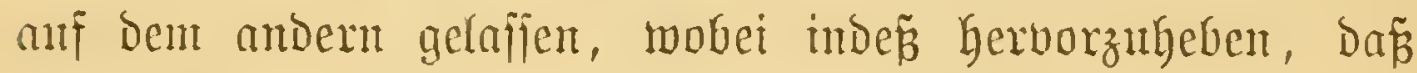
bicjer Umiturz ober bieje Degorganifation nicht alle Theile zugleich ergreift.

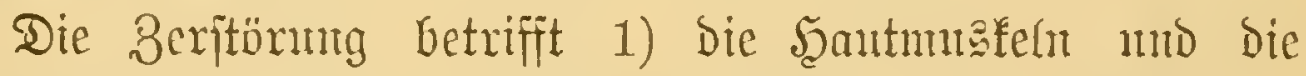
Sgantmerven, 2) Dą gejamnte Snjtent Der \&uftröbren, 3) getwije Darntheile mo 4) endlidif Den Fettförper.

Dic bezcichneten Drgane Yöjen jid zutädajt in igre Elementartheile anf, weldhe Yetztern Dann ipäter gleid Den vormiegent fajerigen Bsemeben, Den Mußnfeln und Rerven, cinent bollftändigen molefitlaren Berfall unterliegen.

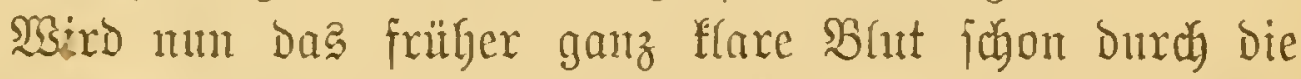
Beimijantung biejer Berfalaprodufte in hohen Grabe verun=

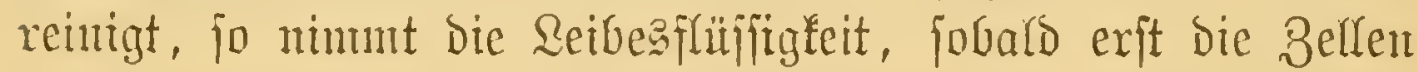
Des Fettförpers ifren suthalt entfeeren, ganz umb gar cine milchig=bränige Bejchaffentheit an mo bie Rarvenpunpe fant mun faftijach einem mit Dotter erfüllten (Fi verglichen weroen. Was mu bie in biejem "Gicuebebräı" vorfommenden

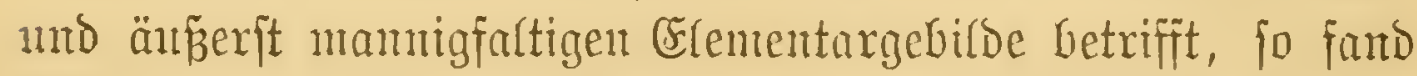
we (F̧ig. 202 A) ara "尺̈̈rnexzellen” bezeidyet. Rörnerzellen Deahalb, weil fie die Den Embrynnalzellen vergleidybaren 
Grumbelemente ober Banjteine jein jollten, aus weldyen bie nenen Smaginalorgane gebildet mitroen.

Die grope Frage ijt mut aber bie, ob aud diefe ETementar=

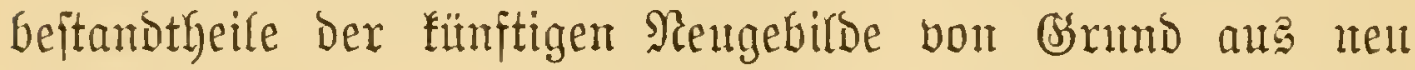
gejuaffen werden, oder ob hiezu mur gemiffe Heberrejte ber frügeren Bserwebe zur Berwendung fonment.

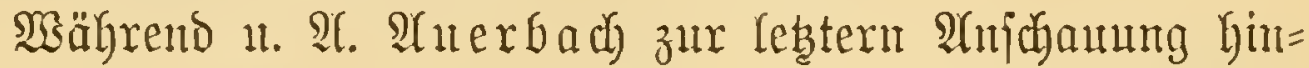

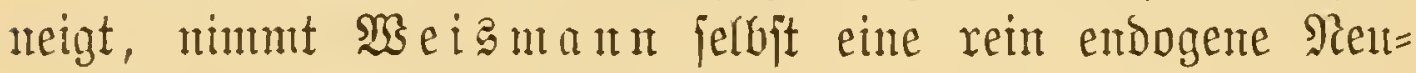
exzentulty an, umb zwar glautbt er fich überzeugt zu haben,

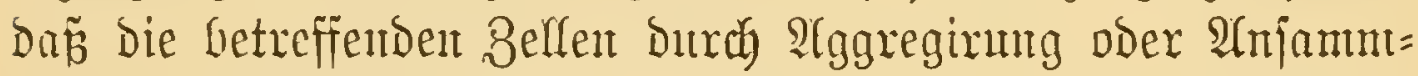
lumg jener \$íasmaförnchen entitehen, welche von molefularen Berfall Der oggenantent \&arventgeile Gerriigren.

Bevor wir mu aber anf bie Conftitnirung Der bleibenden ober imaginalen SReubildungent eingehen, utiijjen wir Den Lejer

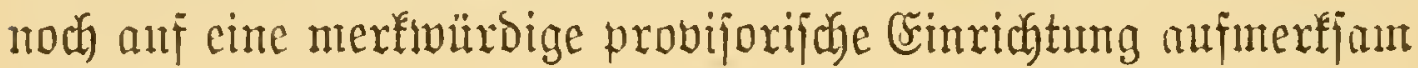
machert.

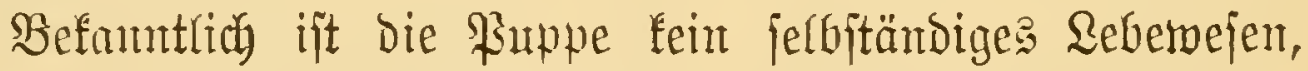

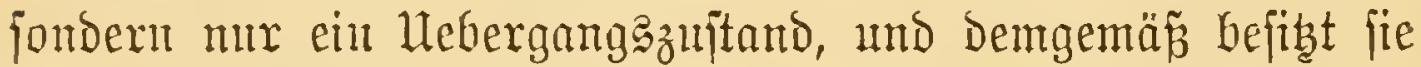
anch) in âlgemeinen feine eigene (Eimrichtung ober Drgani= jation, und bie verjobiedenen Theile, welche mant in ihr fintot, jint lesiglidy entweder lleberbleibjel der aarue ober foldje Neugebirdo, weldye für bas Smago vorbereitet merden.

IIm jo auffallender ift es mut, báp jpeciell die Musciden= Suppe mit einem imern $\mathfrak{A}$ (pparate auggerijptet ift, welder weber bei ber \&arbe, nod) bei Der Ffliege borfoumt, Der fomit

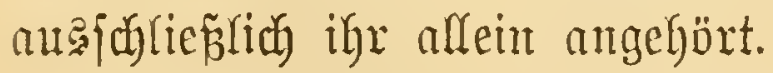

Es ijt bies ein ganz eigenartiges Iracheenitytem, aljo

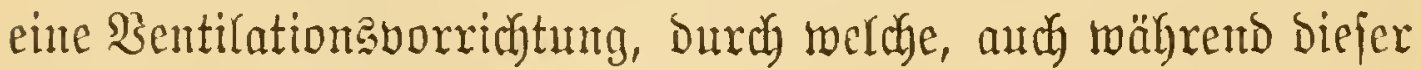
Deitruftiven Periode, bie erforderlide Drybirung oder Durd = jäueruntg ber in beftändiger Umjeb̨ung befindlidaen Bsemebe betwerfitelligt wiro.

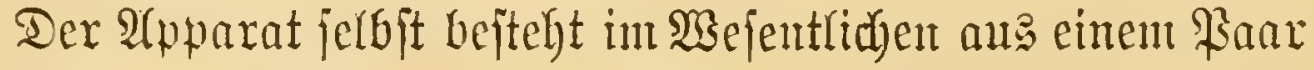
Şantjpalten oder Stigmen am 2. Leibezring (Fig. 195 st S. 537), 


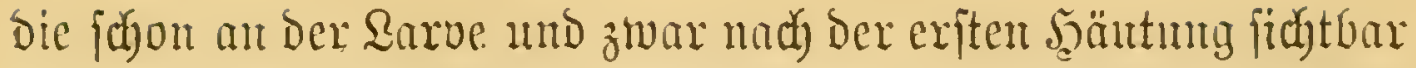

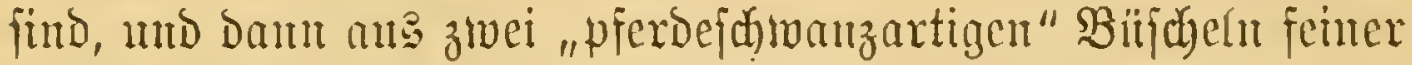
giögren, weldye gautz frei in Der Reibesflüffitgkeit fluctuiren und

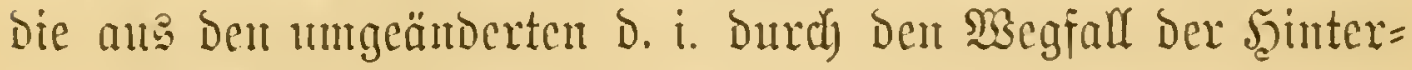

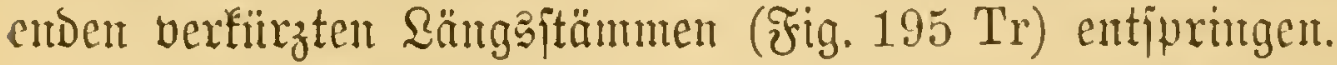

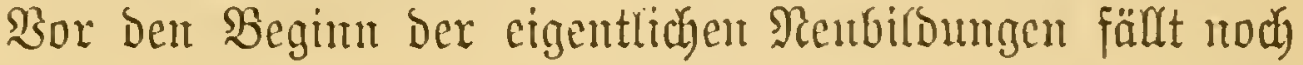

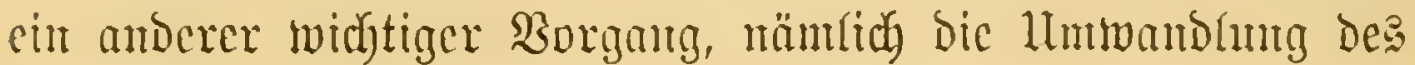
Darmf́anales. - Ëngeleitet wird biejelbe durch bie gänzlitche Berftörnng Des ভajlunbonmes, Defjen excrementartige Berfalls=
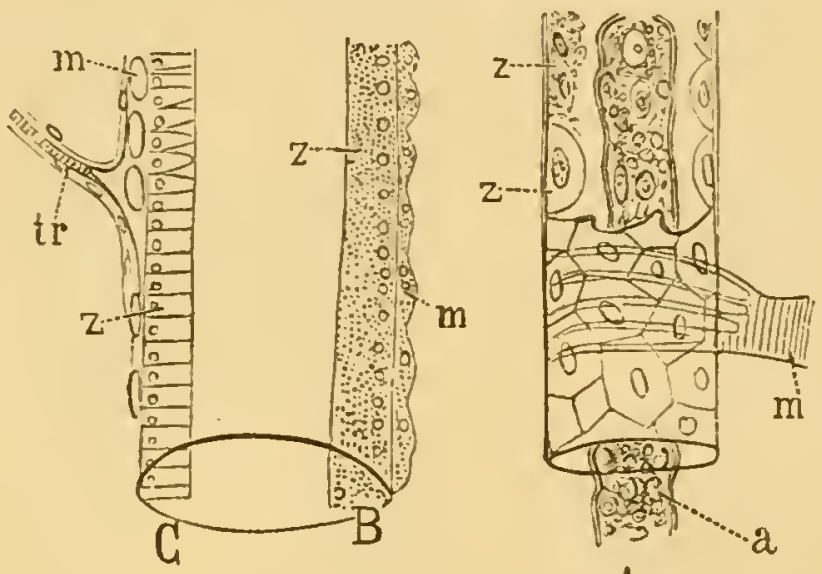

A

isig. 201.

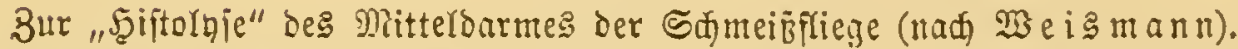

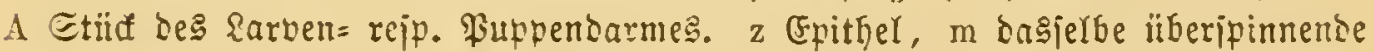
Bisceralmusteln, a tourftartige Jnhaltsmajie, ans ber Zerftörung bes Borber= Darmes, z Epithelzellen in Der Beriettung und $\mathfrak{A}$ thiöiung begrifien.

B, C Darm in ser Reubiloung. Redts z Epithel=, m MnElelblaftem; Yinf: beide

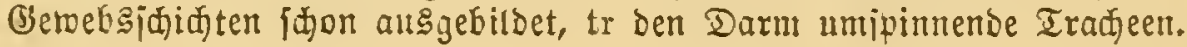

produtte (F̧ig. $201 \mathrm{~A}$ a) in Dent Mitteltraft gelangent, unt bant

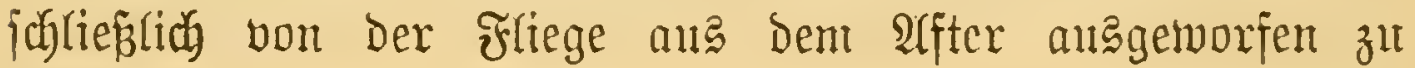
merbent.

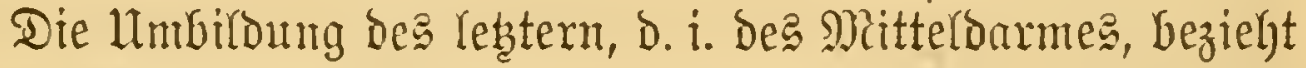

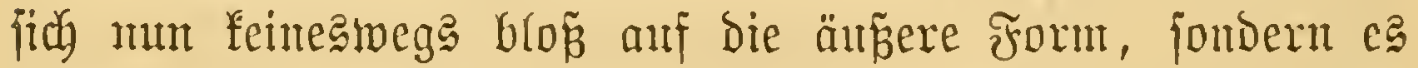

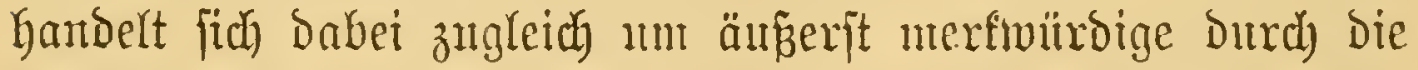
F̌iguren 201 A, B und C k゙urz zu exläuternde Struftur= veräıtoeruntgen. 
A zeigt zunäcbit cin Stür $\Omega$ arbendarm mit bem daraf =

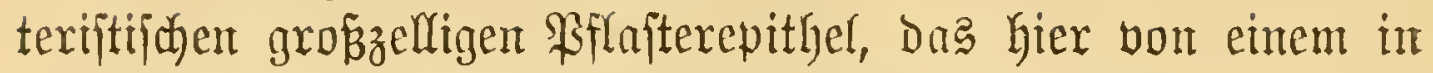
viele Aejte aufgelöftent singetweidemutakel (m) umfpant roirb. Bei $\mathrm{z}$ an Derjelben Figur bemerfen wir ferner, wie einzelme biejer Darmzellen unter fettiger Entartung und Plaben Der Bellyaut ihrent Snthalt entleeren und zerfallen. Auf bieje

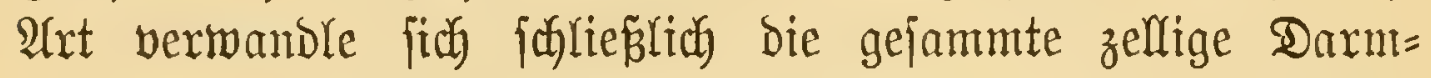
wand in eine Dem "Biajtem" Des Embrto ähnliche homogene Subjtanzlage.

Rebtere jiebt man in $B$ utb bemerft Darin eine Reige

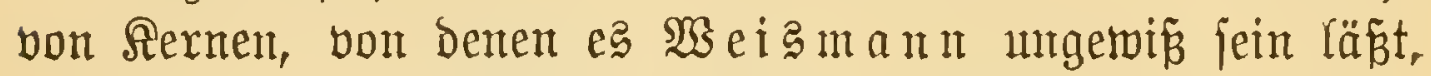
ob fie ganz neu entftanden oder als arbëmmlinge der $\Omega$ arben=

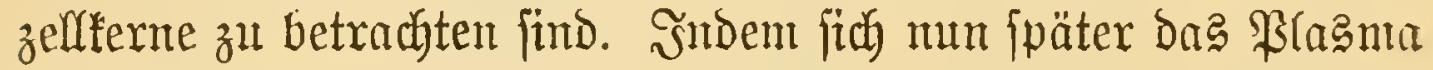
diefes. Bildungalagers um die erwähnten Sierne in fugelförmige Ballen jondert, entiteht eine neue Belfichidyte, wie fie bei $C$ jfizzint ift.

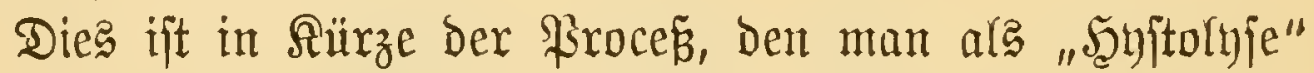

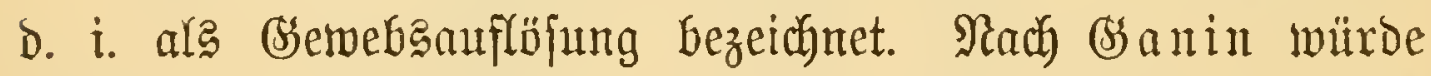
Dagegen bie Humandlung dez Darmepithels meder hier nodh

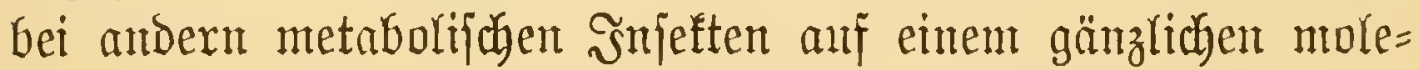
fularen Berfall der alten Daxmzelfen, fondern Kebiglidy anf einer Theilung einzelner Sarvenzellen beruhen, während mur

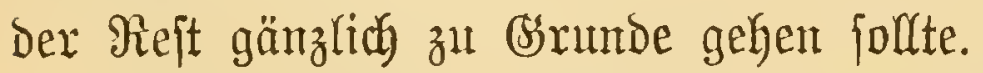

Siun fämen wir endlich) zu Den eigentfichen Neubi(bungen,

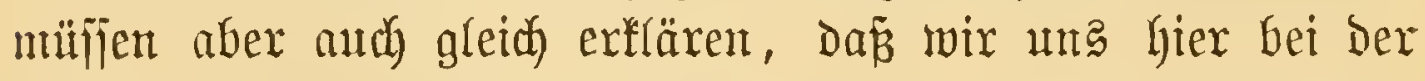
ganz aunerorbentlicten Mannigfaltigfeit unt Complicirtheit

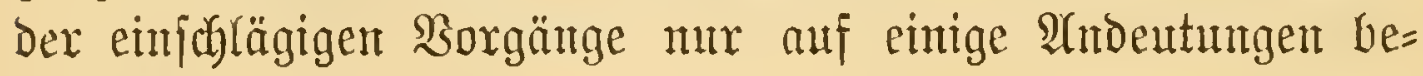
\{đdränfent.

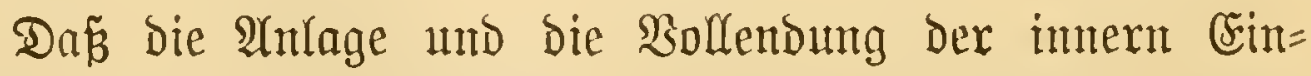
ridftung Der Fliege ein äunerft langmieriger Procez ift, geht

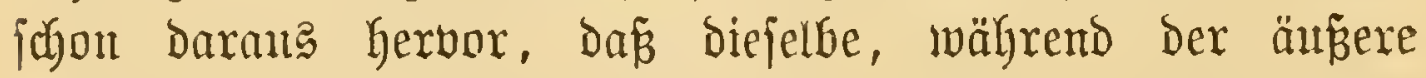
Rohban in circa 8 Tagen fertig ift, bon ba ab noch wenig= fteng 12 Iage in Anjprud nimmt, fowie Denn übergaupt, 


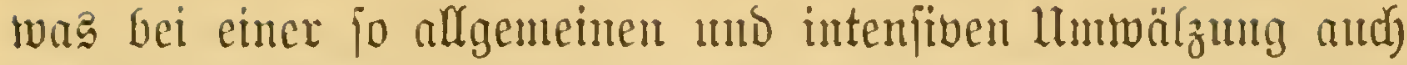
leidyt begreiflidy, Die Periode Der Pitppe megr als doppelt fo Tange wie jene Der Rarve Danert.

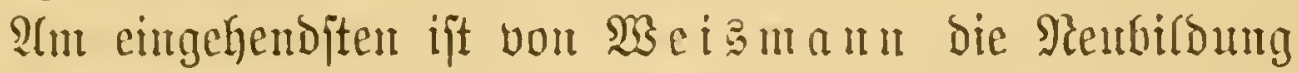
Der Mitafeln ftubirt.

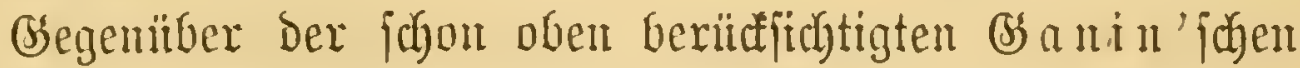

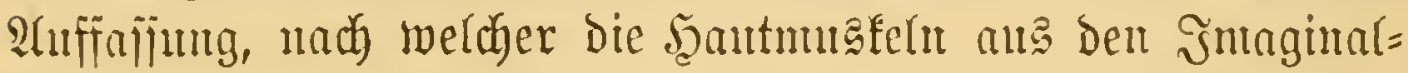
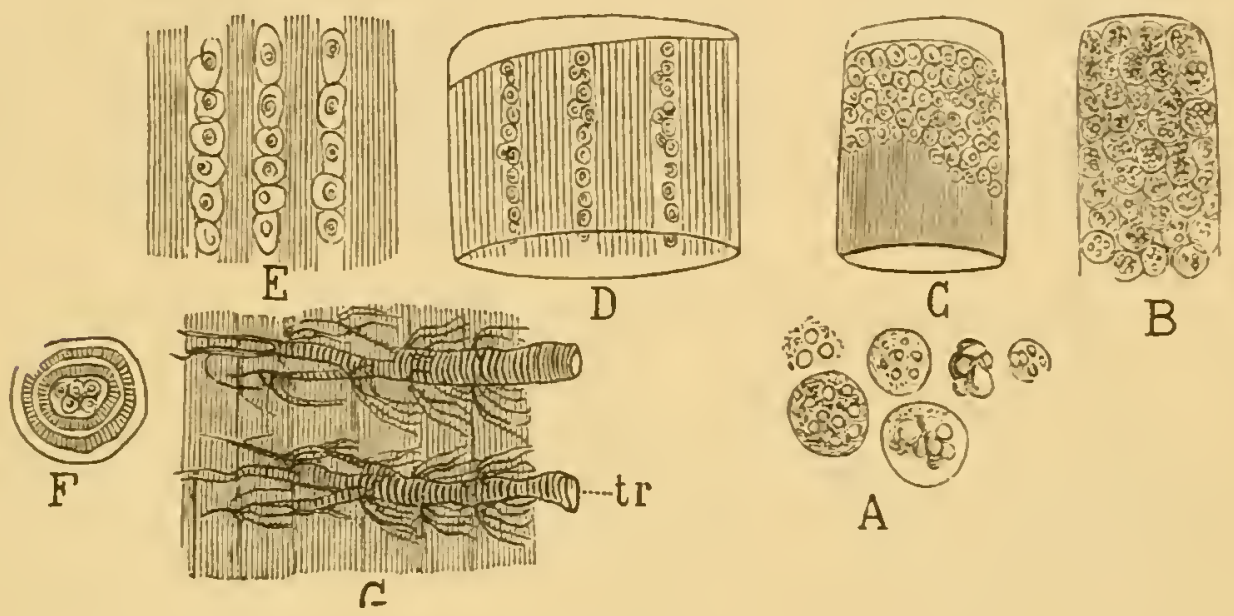

Fig. 202.

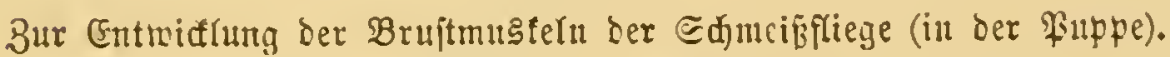
Rad) 2 e is mann.

A "Sörndjentugeln" und Bellen לe马 in Der llmbiloung begriffenen Puppenleibe:

B Etrang bon Sïrndenlugeln als exite Mulage eines Mušlel:

C Etrang von Sernen, it coutrattiler (Fleifd)jubitanz.

D Weiteres Stabium, to dic Serne in Beftalt von Säulen zroijden ber fđon fibriflir gemorbenen Fleijđjubjtanz liegen.

F Dnerjuntt eines in ber Fntnidfung begriffenen Pluslelprimitibbünols. 3u äuserit bie Muslelideide, bann ztwei Miäntel bon Musleljubftanz, in ber Mitte Die Rermiäule.

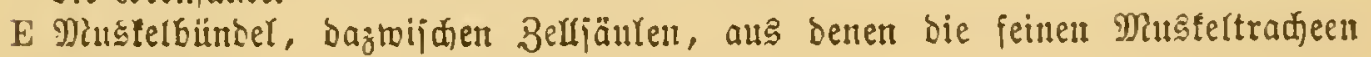
entitehen.

G Musfelbündel mit ausgebilbeten Tradeen (tr).

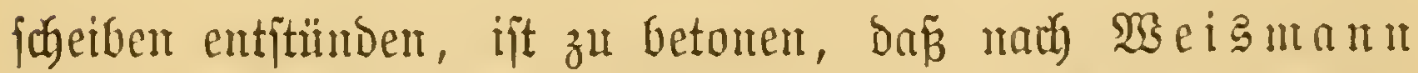
die Diverjen Sorberlcibanthänge, twie z. B. Die Beine, anfanģ

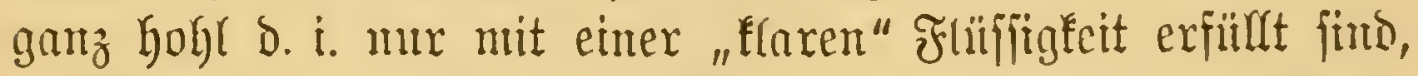

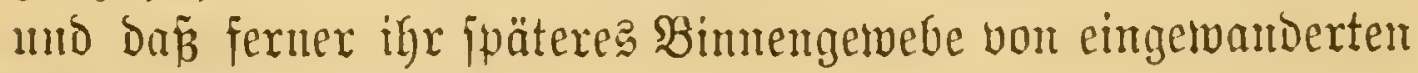
Siönexzellen herrübrt. 
Bejonber: interefiant ijt Die Bilbung Der Brujt= rejp.

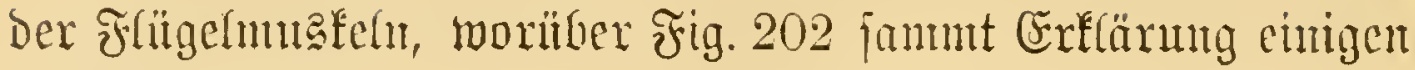
$\mathfrak{U} u f(\mathfrak{c}) \mathfrak{l} u \tilde{B}$ gibt.

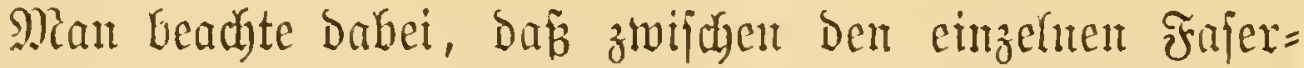

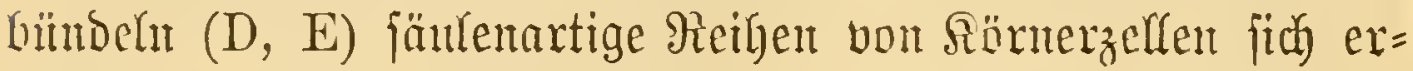

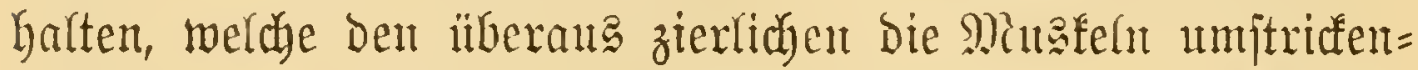

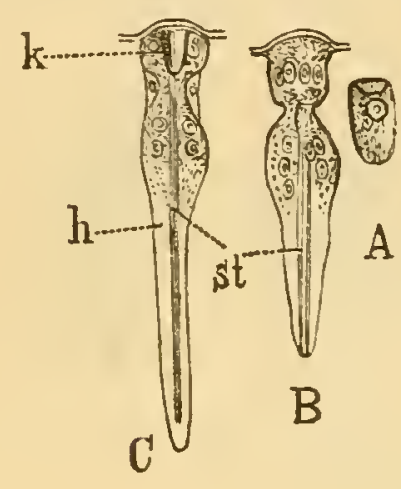

Fig. 203.

3ur Entwiaflung ber 2 Yugen= theile, nad seis mann.

A Belle ber Uryenjübibe.

B Diejerbe tn bie ?änge ge= wadjien unb in zwei $\mathfrak{A} 6=$ idnitte, ben bioptrijden und perceptiven, getheilt.

C Diejelbe, nod mebr bifie= rencirt. $\Im \mathfrak{m}$ vorbern $\mathfrak{U} \mathfrak{b}=$ junitt anfen bie Cornea, inmen ber Sryjtalfegel (k); im hintern Der Miervenjtab (st), in ser Seülle (h) ftecfent. Den Tradyeen $(G)$ Den Hrjprung geben. Sonjt entiteben bie Cesctern in aus Bellen zujammengeiebten Şohlrögren, forwie bie feinften End = zmeige, nad)

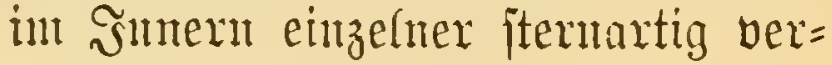
zweigter Zellgebilíde.

ltm gleich aud bie gefantunte Irachen= 2ungelegentheit abzutyut, fo fitto ba vor affem neue Buleitunge= röhren an Der Mittel= mitd Seinter= Grujt jomie an 2rbonten zu jobaffen, was nach (bsanin, entgegen ber

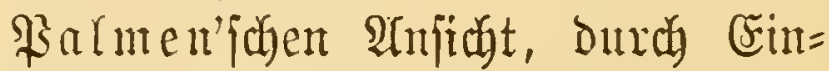
jtülpung vont Der f̧ant her gejueken foll. - Die an Centrahtuerbenjyjtent

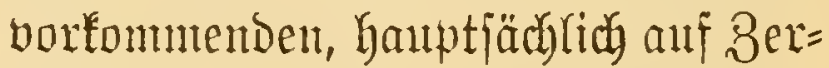
theilung oder Decentralifation be= rubenden Aenderungen wurben jofou

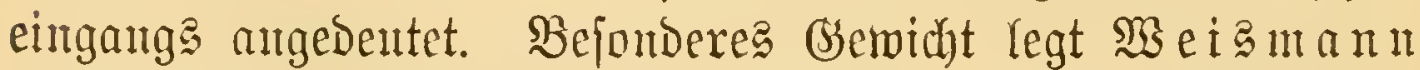
auf Den lumitand, Da

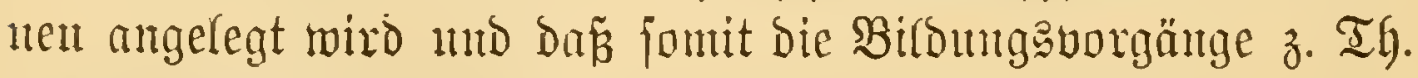
ganz unabhängig vou Centralorgan exjolgen dürjten.

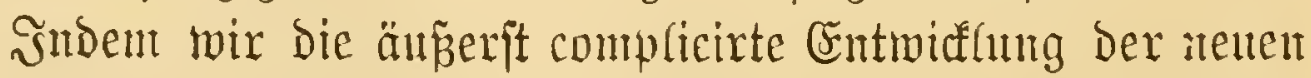
Sintresorgante (ntau jebe allenfalls Fig. 203 nady) aud hier wicder gauz unberïeffichtigt lajien, wenden wir uts zun

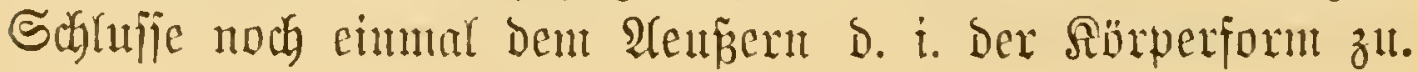


Ilnd ba hat beun Der Rejer, muter nodymaliger CFimprägung Der Fig. 200 vor anem an bies zu adyten. Der Leib der

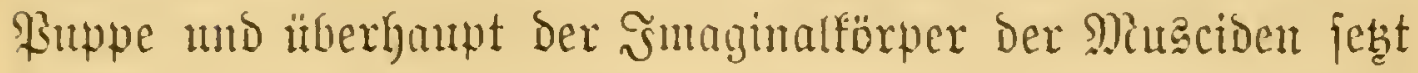

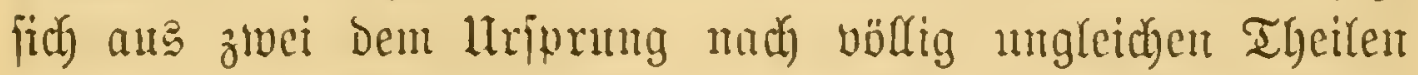
zufammen: ans bem Borberleibe, ber als endogene Reubildung

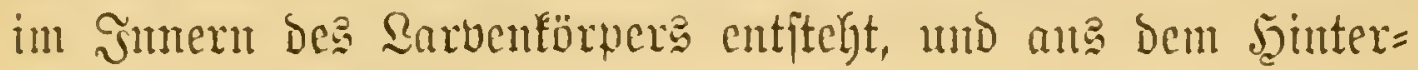
Keibe, den bie Flliege mit ber হarbe gentemfan hat.

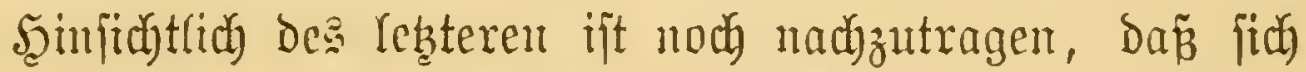
gegen Ende Der Ruppenperiode die Meidghaut des Rarven=

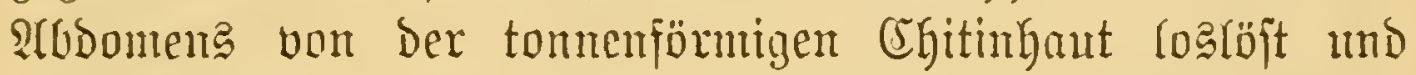
unter gewiffen, nod) genuter zu ftubirentoen Mobificationen allmälig bie Definitive Befefaltuntg annimmt.

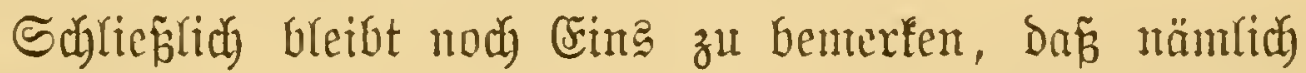
Die Weidhaut bes Puppenförpers eine zarte Critingant aus=

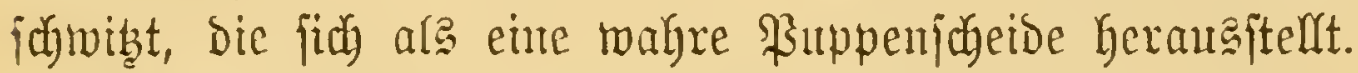

Auf bieje $\mathfrak{U}$ rt wäre aljo Die Fliege im Э̂nern der Tomen= fuppe von nidgt wentiger als von brei Critingüflen untgeben,

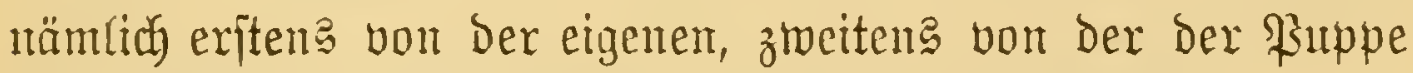
und endtich zu äuñerjt bon jener bes Sarvenförpers.

Kurje Ueberfįht der verjhiedenen Deränderungsarten und Uebergänge.

Trob unjerex mehriad) ausgeiprodenen 9 (ntipathie gegen

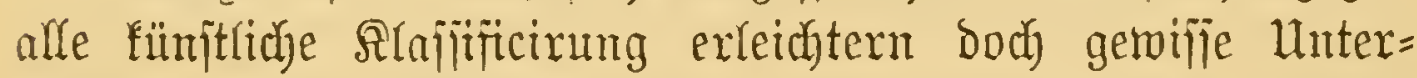
jubeioungen bie Meberfidgt über bie Mamigfaltigfeit ber Err= juheimungen, und in biejem Sime wollen wir mis nod einmal und zwar an brei Typen, Der Sühenjobabe, Dem Schmetter= ling und Der Ffliege, bie widytigiten Şauptformen ber Ent=

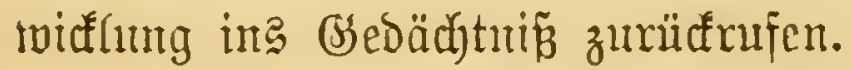

Beim erften Typus (Rühenjdabe) ijt die äunere Crnt=

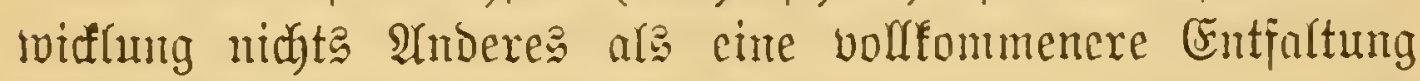

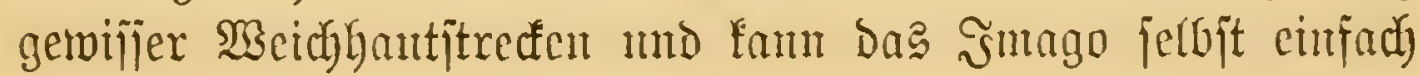




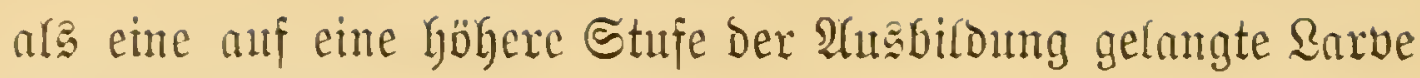
befinirt werdent.

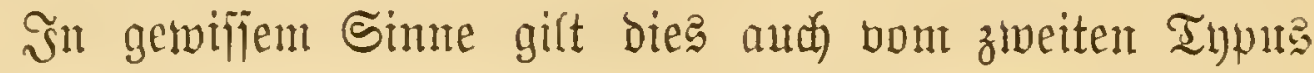

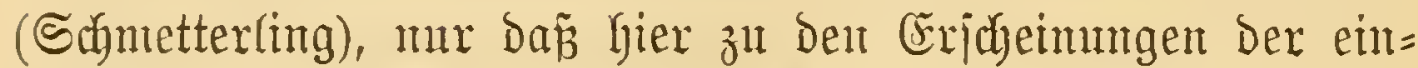
fachen und alfmäfigen Fortentwiff(nng utody bie einer hod)= grabigen und plöblichen Unformutg hinzutreten, bie, im Berein mit correfpondirenden Hmwandungen ber imtern Einrichtung, ein bejontores lebengufühiges Mittel= it a dium, nämlich dic Ruppe bedingen.

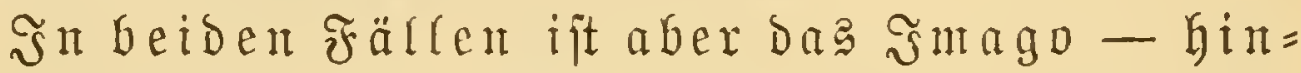
jidjtrid bez äu

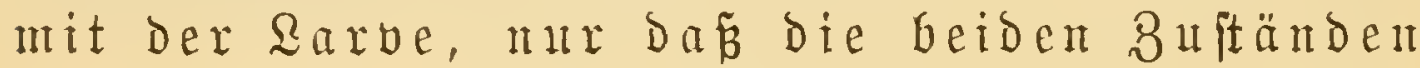
gemeinjame meidhaut beim smago theirs ent= wifeltere und neue, theils megr weniger ver= änderte Formen hat.

Beim Dritten Iypus (Musca) hingegen judeint to enig= ften mit ber $\Omega$ arve, jombern ex ijt etwag ganz Reue

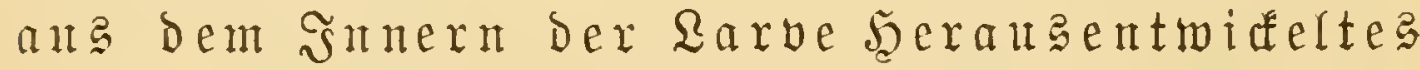

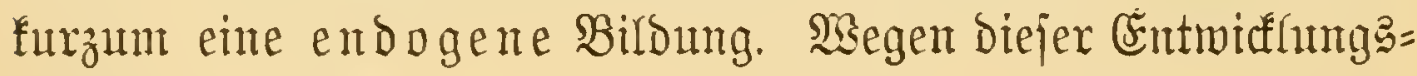

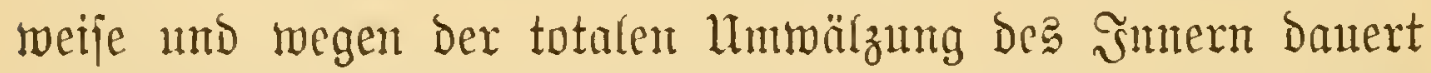
hier and bie Pröimaginalperiode am längiten und ift bie betrefiende "Larben=\$appe" abjolut leben:miähig.

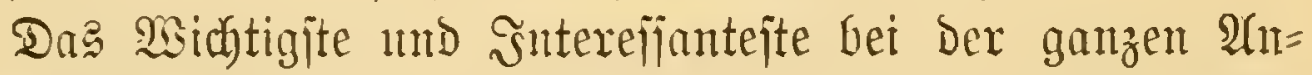

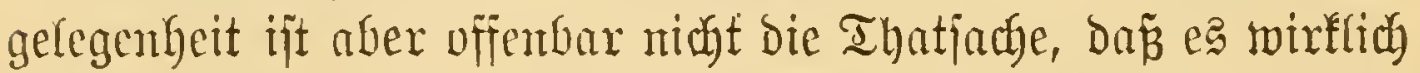
mefrere und z. Th. wie es jujeint grumbueridiedene arten vou Crntwiffung und Metanorphoje gibt, jondern vielmefr bie Frage, ob bieje bejonderen Berändernngałategorieen burd) Mittel= oder 8 wijhenformen in einander gehen und intwit fie fich. überhant als berfdiedene Miobificationen einer mo Derjelben Seränderungęmeije daritellen lajjen.

Wą mu in biejer ફ̧inficht zuächjt bie verlantgten Heber=

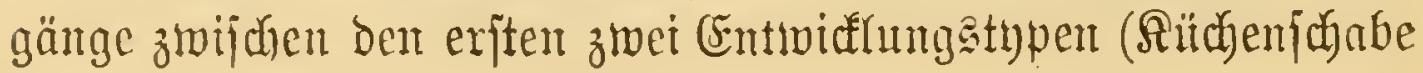


und Sdymetter(ing) betrifft, jo brauden wix mur einer= jeits au bie jtarf veränbertichen "\{metabolen" (Cicaben, (Eintagäfliegen) und anderjeits an bie wenig veränberlichen "Metabolen" (gewifife Räfer, Neb̧ritgler) zu erimern, um

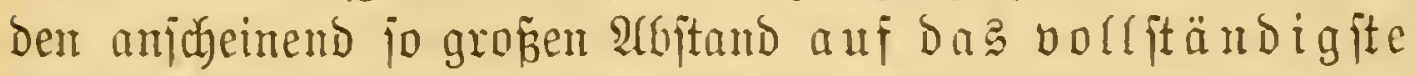

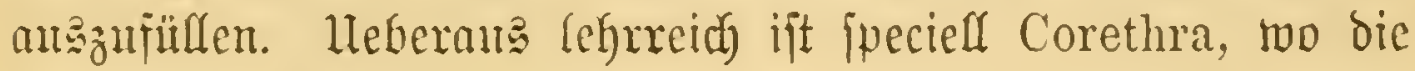

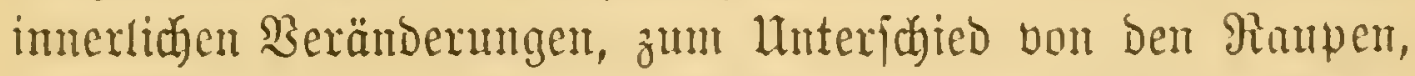

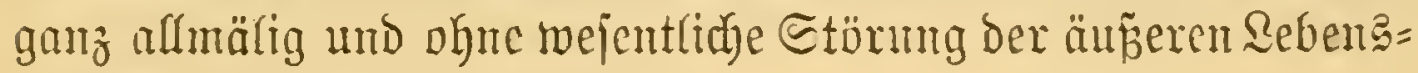
thätigkeit von Statten geben.

$\mathfrak{S O}_{\mathrm{D}}$ jind aber bic Hebergänge jwifhen ber Falter= und

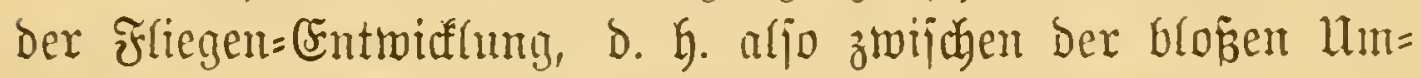
formurg unb ber bölligen Neurarzengung (NReogeneje)?

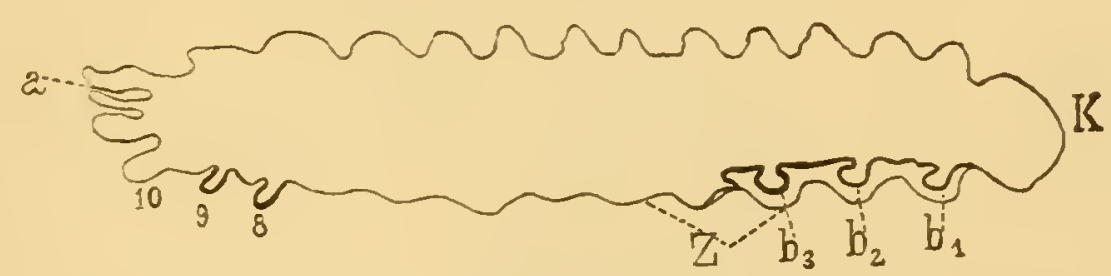

Fig. 204.

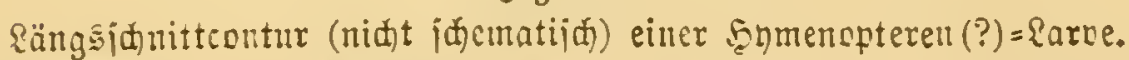
Die Düne Eontur ijt bie Weiđhaut (Epidermis) ber Iarbe, bie biffe bebeutet bie innern imaginalen Reubildungen (mit 2lusnahme von $S$ und 9 ).

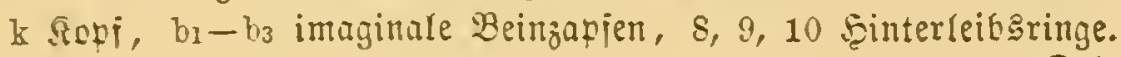

(Driginal.)

In Diejer Şinfint bürite zunädjit eine eigente Beobad)= tung millfommen jein. Sie betriffit cine mit cinem $\mathfrak{l a n}_{\mathfrak{g}}=$ geglieberten $\mathfrak{B}$ a d duar berjegene (bymenopteren=?) Sarpe, bei welder nidyt, wie bei ben fliegen, ber gejamme Borderleib, joubern mur bie Bruft jid neu zu bilbeu ideint. - Jn der naturgetrenen

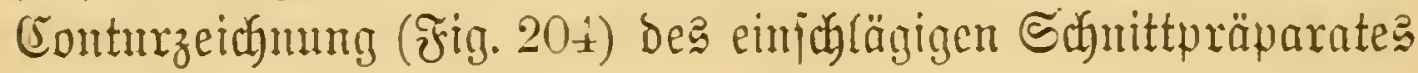

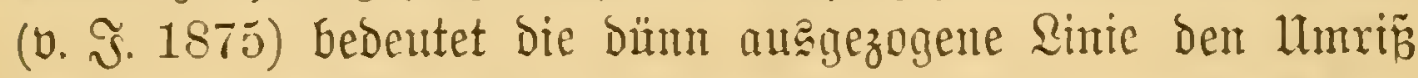

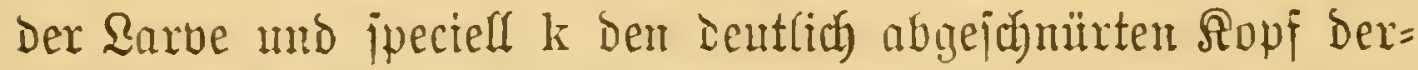
jelben, mährend bie verbicften Stellen dic imaginalen Aeu= bildungen bezeidnen. Bon leştern gegören die Zapfen 8 und 9 , 
๖. \{. die nehrbefprodyenen Anlagen Dex Regeröhre, Dex Sarben= weidbhaut an, wäbrend die Brufttheile $\left(b_{1}, b_{2}, b_{3}\right)$, unabbängig bon lebterex, aus innern Remen herborzunospen icheinen. UHafithrlicher zeigt Rebteres die Schnittfigur 205. Lch ift Die fohupige Rarvendyitinfaut (Der Bruftregion), lz die zu= gebörige abex ftrecfentreife fdy on zexfarlene Meid Gaut. Darunter fiebt mant Dann bie mit "Sörnerzellen" (kö) crfürlte Reibezhögle und barin, hinten mit dex Rarben=

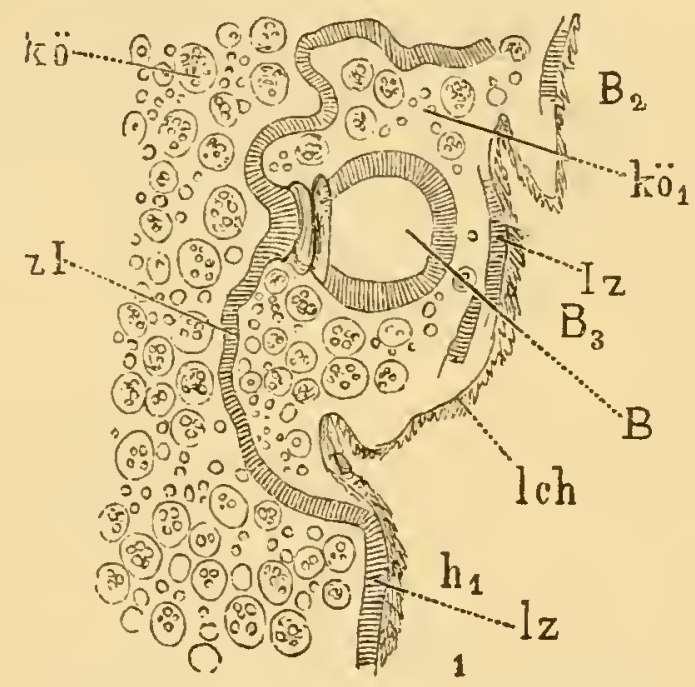

Fig. 205.

Stü \&ängsfdnitt Duró die Bruft berjelben \&arbe.

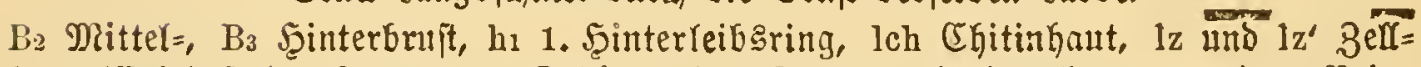

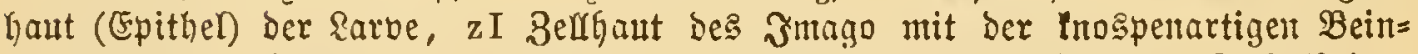

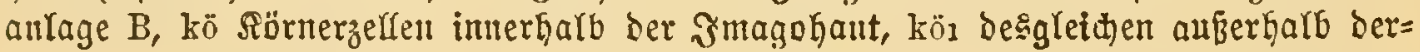
jelben, im Raum zwifjent ifr uno ber Rarventaut.

(Driginal.)

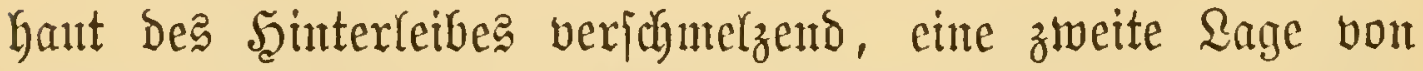

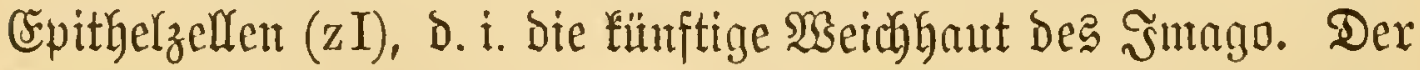
fnospenartige Boriprung (B) an rebererer ift nidhts alnderes als bie a u Beinatilage.

Der Rejer fieht aber wohl jelbjt ein, baź aud mit biefer

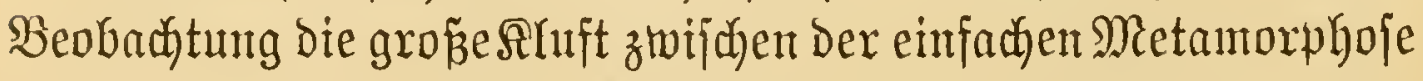
und ber entogenen (Entwidf(ung noch lange nicht ausgejüut ift. 
Mian fömute fid mu allerbinge mit ber Mmafme be=

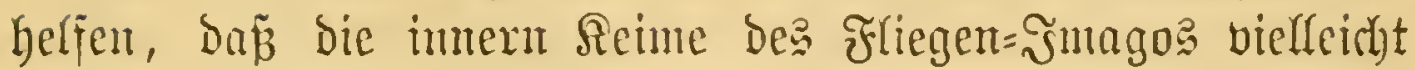

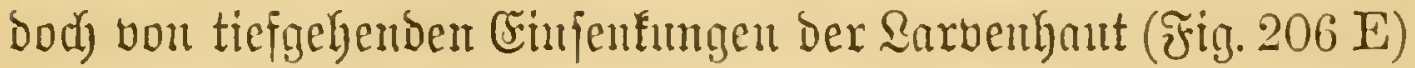
abzuleites jülo. Eime foldhe Simabme entbehrt aber vorläufig

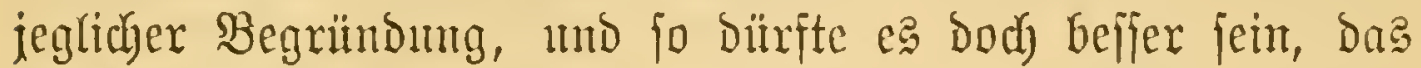
Sorfonnten einer endogenen Sufeften= Mietamorphofe eiufad) anzulerkennen, als fie mit bsemalt zu einem Sorgang umzı=

A

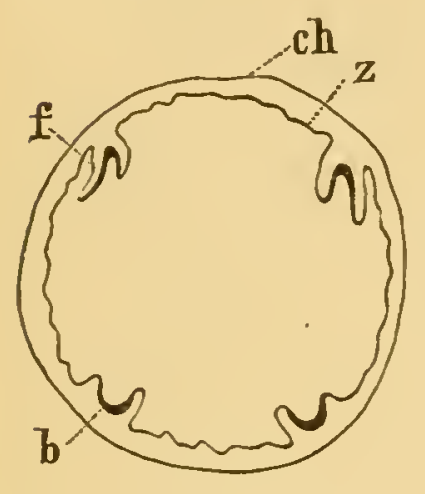

$\mathrm{D}$

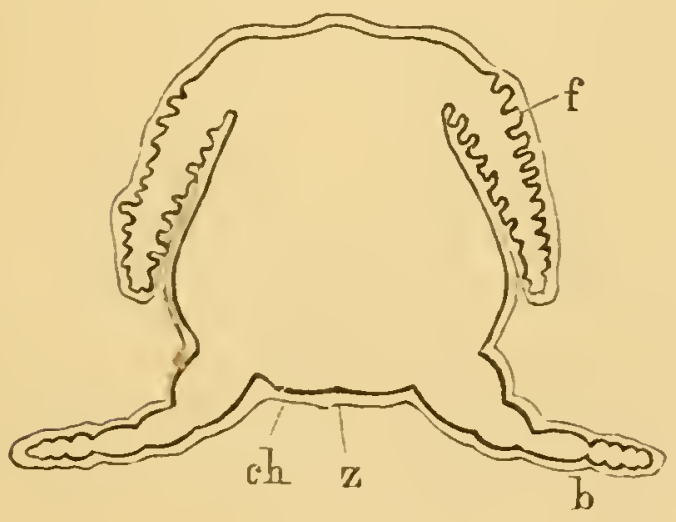

Fig. 206.

(Bgl. S. 496.)
$\mathrm{C}$

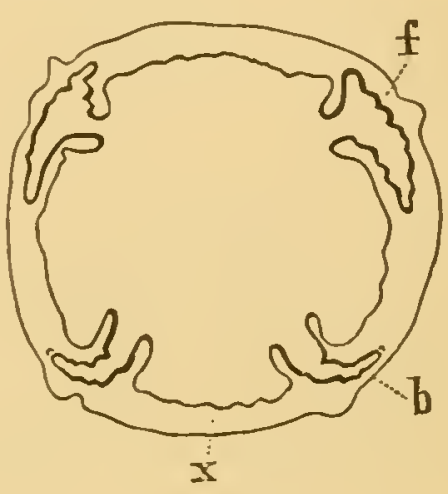

E

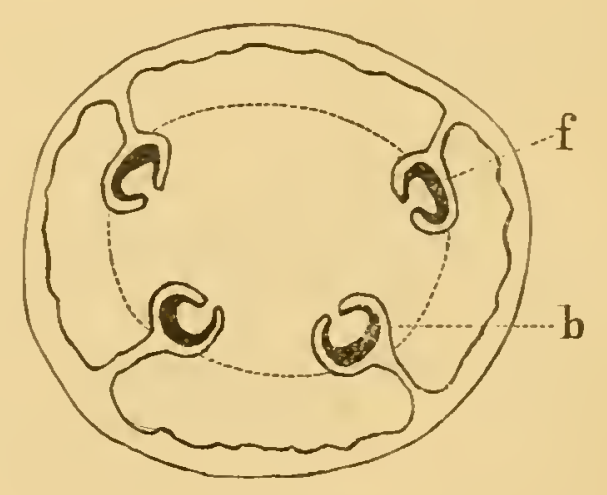

Deutein, ber mit Den biaherigen Beobadutungen nidgt übereit= ftimmt.

Den in ber 3oologie wentiger bewanderten $2 e j e r$ müfien

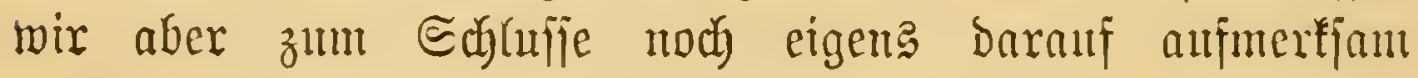

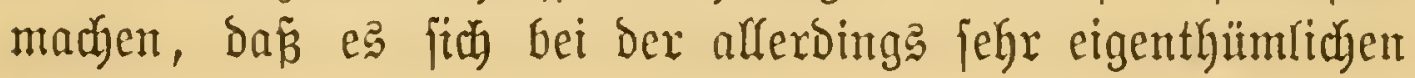




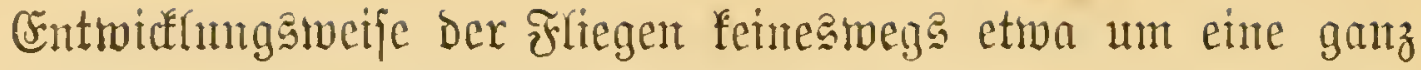

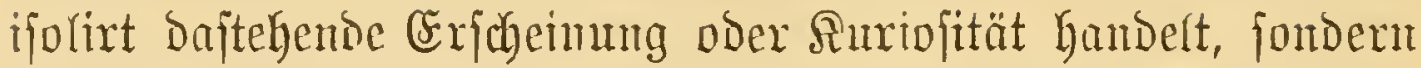
Dá̉ bei gemifjen anderen Thieren, z. B. bei Den Stadyel=

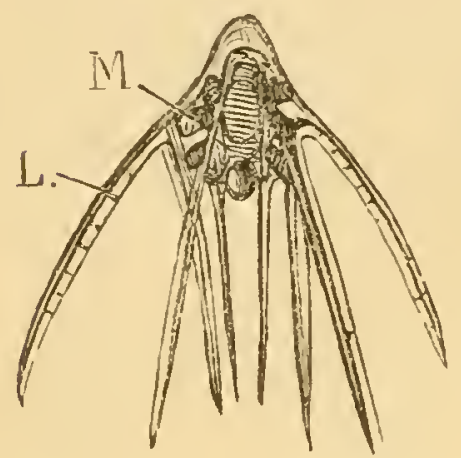

Fig. 207.

Gog. Plnteus-artige \&arvenform eines @d)langeniterttes.

Эัm llmtreis bes Magens ber Sarbe bie rojettenartig grup= pirten $\mathfrak{A}$ lagen ber Eeeiteru= arme (St). L Rarbengeitell. häutern (F̛̀g. 207), Derartige ßor= gänge etwas fehr bsemb̈hnlicyes find.

Da fier aber einerjeits das

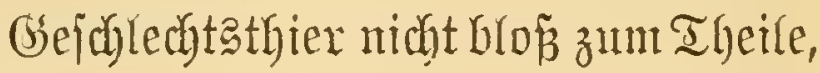
fondern in feiter gejantuten $\mathfrak{A}$ (us $=$ Debnumg als ein rein intuerliches Erzengnif exfdueint und anderfeits Die basjelbe probucirende Sarbe nach Defien $\mathfrak{B}$ ollendung z. Th. nody eine genviije Selbitäutoigfeit betwahrt, fich aljo nidyt vollfonmen exidyöpft, jo wird ber betreffende Sorgang vou Manthen ars wahrex senerations=

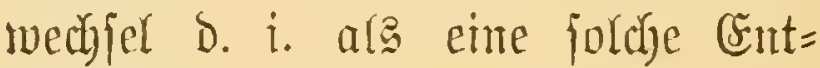
triffungs: refp. Fortpflauzungameije angejehen, bei Der bie Sarve bie Rolle einer $\mathfrak{A}$ mme fpielt.

Heberaus interefjant wäre n. $\mathfrak{A}$. aud ber Serg(eich mit Der Metamnrphofe gewiffer Sangwürmer, z. $\mathfrak{3}$. Des Monostomum mutabile, Das als Embriyo in wahren Simte des Sortes ein Doppelwejen borjtell, indem fich jene centralent Bellen, aus benen fonft gewifije Eingeweibe gebildet werben, zu einem ferbjtändigen mit Mnut Darm uto anberem $3 \mathfrak{u}=$

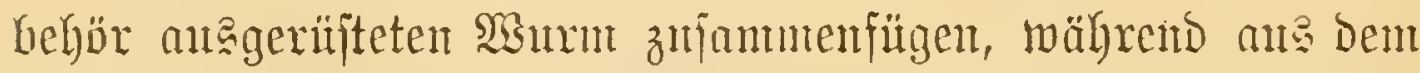

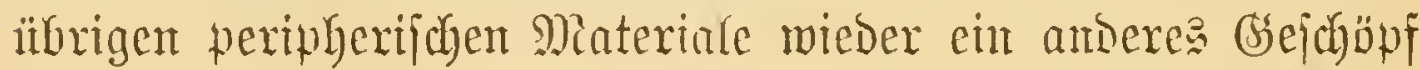
ober, wie es v. Siebold nemt, Der "Tebenbige Rerfer" hervorgeht, in welchem dor exitgenamte șm eingejulonjen ift.

Diefer ampheinent fo munderbare Fall bünfte and Dentlidy

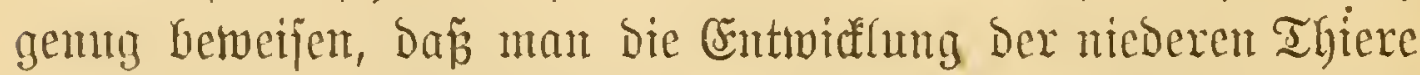
nidyt mit Dent von Den höheren entnummenten Mañ itabe mejien

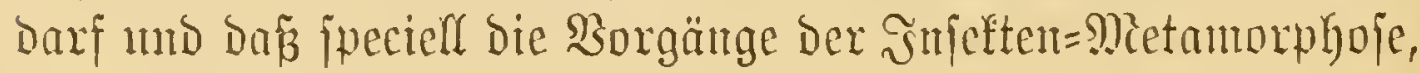




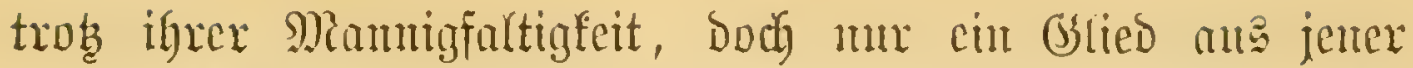

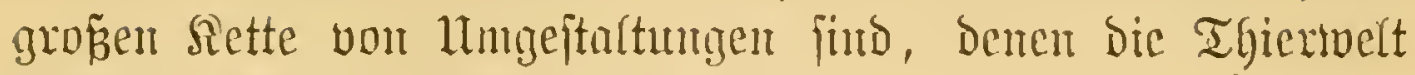
in igrer Gejammtheit morerworfen ift.

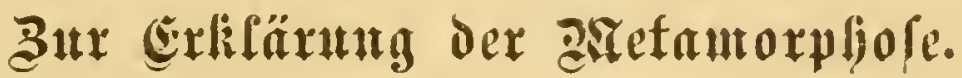

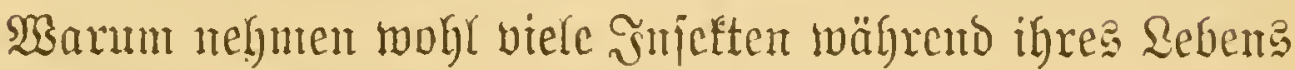

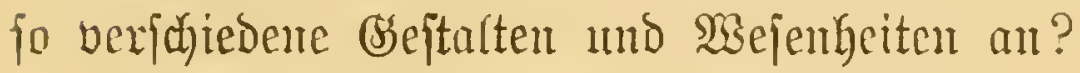

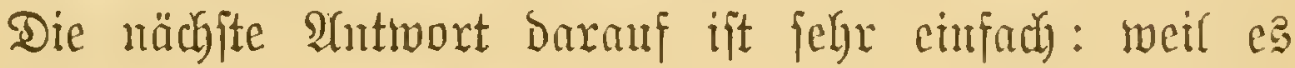

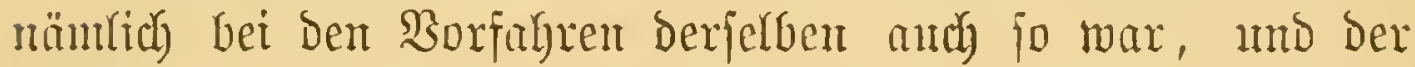

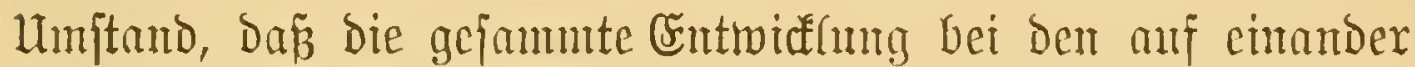

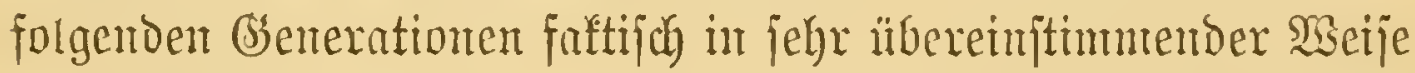

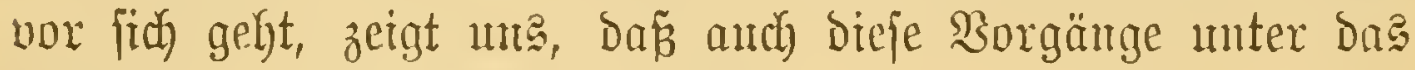

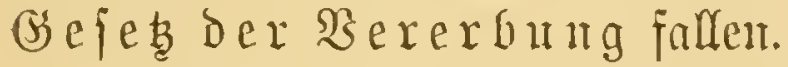

Der Lejer merft aher wohl, Dafa dieje Irt von Erffärung

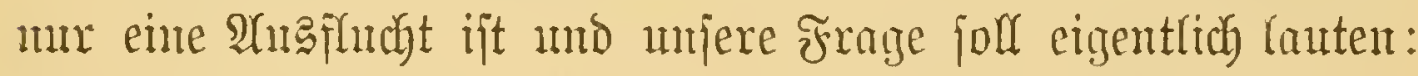
Wie find die snjeften un toie ijt deren gegen= wärtige entwidfung urfprünglid oder phylo= genctifal entitanden?*)

Da jedoch, wie wohl faum zu benterfen nöthig, bei bicjent

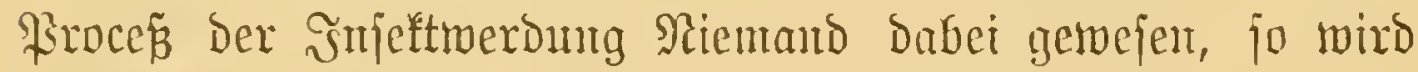
jelbitveritändich) Die madhträgliche Darjtellung ober Errflärung biejer Begebentheit, welcher Int fie and inmer fein möge, gewiffe nidyt ftreng betoeisbare $\mathfrak{A}$ mathmen madben müijen und

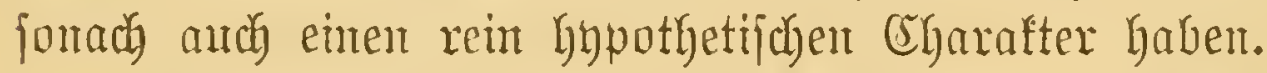

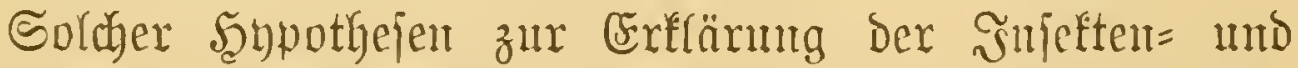

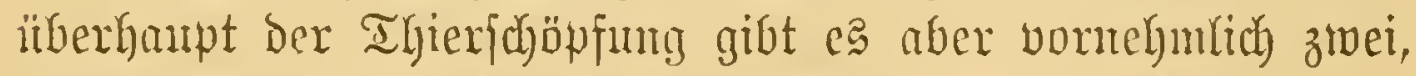

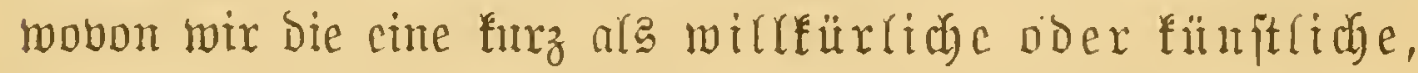
bie andere ala natürtiche Srböpfmyghynotheje bezcichnen.

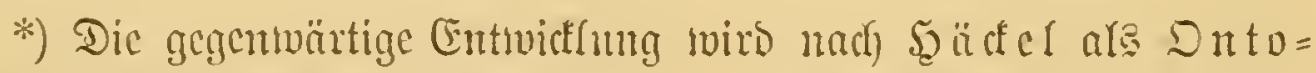
gencic, die bijtorijde als 


\section{Lritif der willfürlichen Sḑöpfungshypothefe.}

So bezeichnten wir ben leider mur alfzu verbreiteten

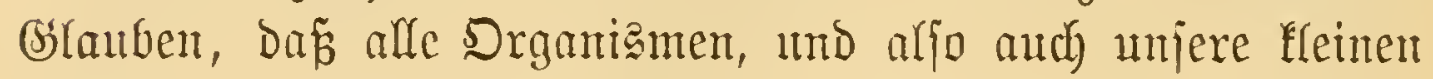
Thierchen, ihr Dajein einter ganz bejombern und ipecififichen Hrfacte oder Rraft berbanfen, bie man, antatt fie wenigitens ganz unbejtimmt und nebelhaft zu lajjen, nody mit bem be=

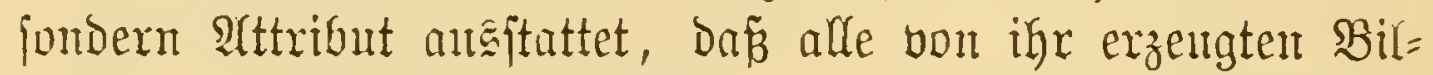
bungen in einem harmonijoben, in einem ftrentg planmäpigen ober fümftrichen Bufamunenhange mit eimander ftünoen, unt dañ jie ferner in ifrer $\mathfrak{a}$ at abjolut gut und zmeckmäfig jeient.

Fnt Folge bieịer bejonberent Bejtimmung Der „Bildunga: fraft" fümmern wir uts zutäbjt gar nicht mebr barum, ob

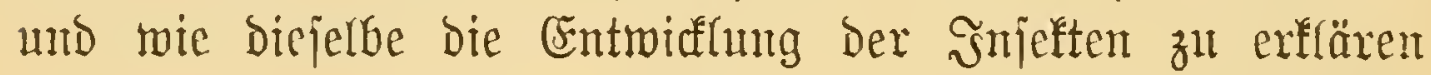
vermag, jondern fragen einfady, ob ez denn bei biejer (bie= legenbeit wirflid) jo wunderbar pranmäpig hergehe, wie man es uns glauben machen will.

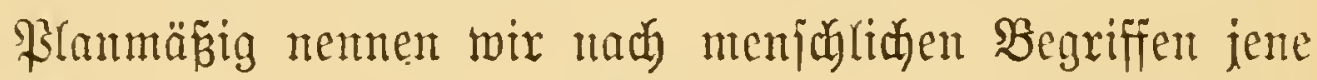
Entmiffung, bei der das zu Beftaltende, Dem Bildwerf cinte? Rünjtlers ähnlid, mit jeder Berändenung, die es exfährt, volffonmener D. i. in jeinen einzelnen Theilen bejtimmter und bentlicher wird und ant bieje Weije Dem entolichent Biele

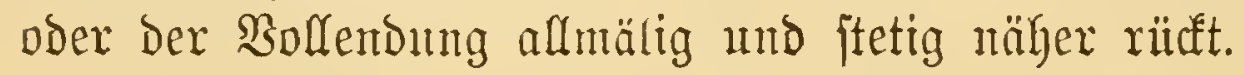

Prüfen wir mut nadj biejen Ssefidgtapunte die Ent=

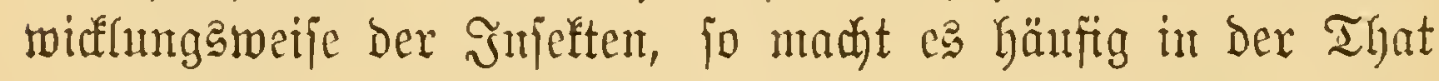

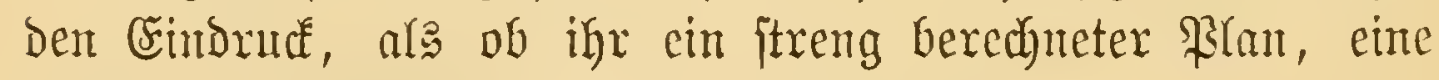
wahrbaft fünjtlerijabe soee zu Grumbe läge.

Mir eximnern zunähjt an bie oben ffizzinten Morgänge

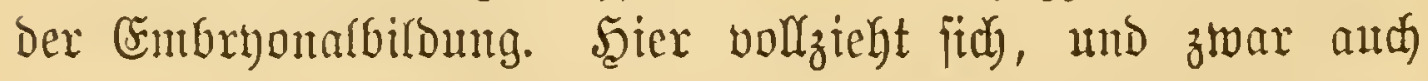
bei vielen Snjeften, beren fpätere Entmifflung fehr auffallende

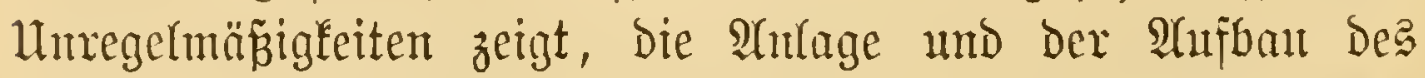
Thieres in anjheinend fo methodifher und injtematijuer 


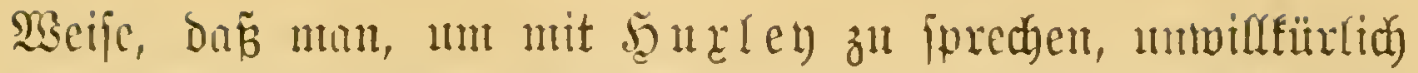
nach bex band bes Mieijters jucht, ber bieję şerf voll= bringt.

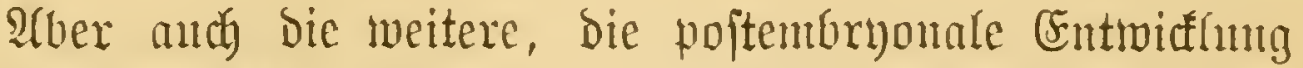
ift bei manchen Sierfen eine foldye, Daź jie, menigitens in Den

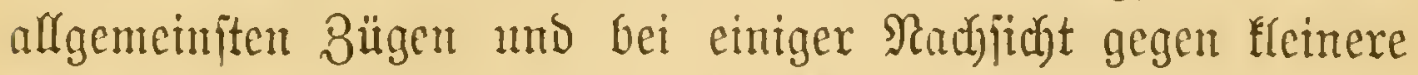
Seritöbe, als Beleg für bie fürnftiche Sdjöpfunt verwendet werden Eömte. Dem verfolgt man z. $\mathfrak{B}$. Die cinzelnen

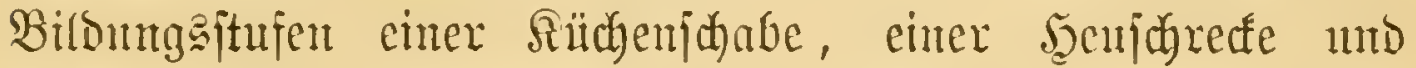

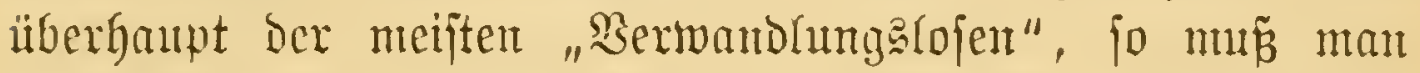

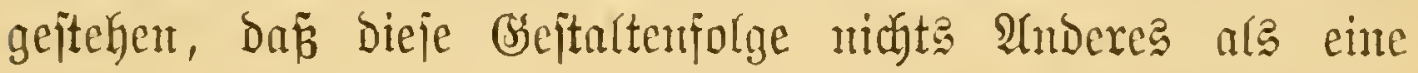
Meike oder ein Enjtem jucceffiver Entfaltmigen, Differenzi= rumgen und überhant Bervolffommunngen Darjtellt.

Reben biejer ftrengen Eonfequenz und Folgeridgtigfeit,

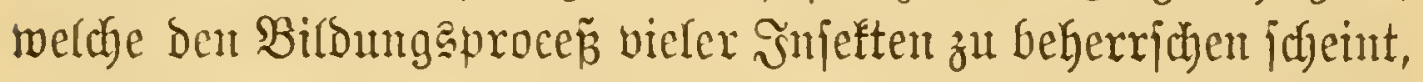
finden jidy aber and Erifheinungen, die nit Dem Brincipe

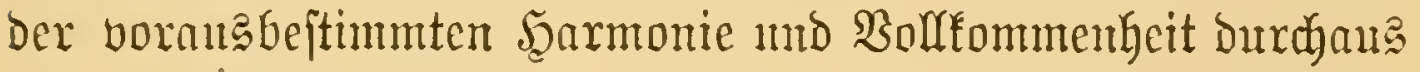
mnereinbax jind und bie baher, ba bie angenommene Syjtem= mäp̈igfeit boch jebenfalls eine allgemeine und allumfajifende

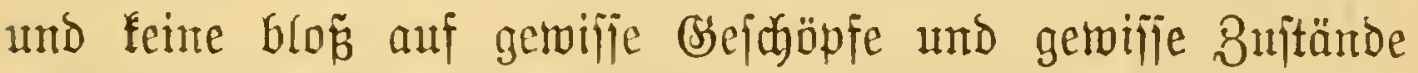

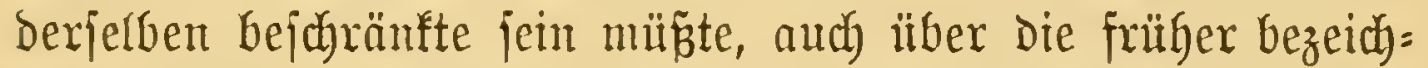

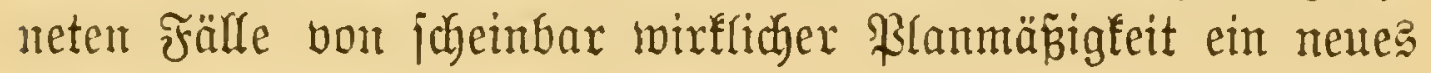
Sidjt verbreiten.

Dieje wenigitents nach ben herfönmlichen Begriffen ganz

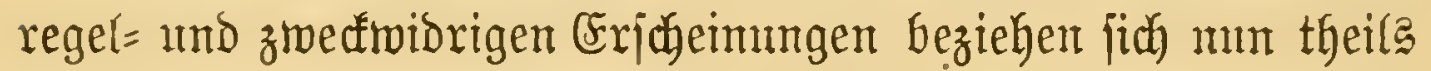

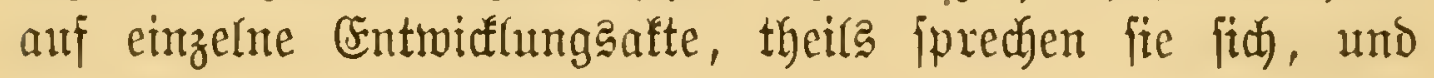
bies ijt bon ansjolaggebentor Bebeutung, in Der Bejammt= Geit injeftifher Bildungen D. i. im "Syjtem" biejer Thiere aus.

Disharmonieen Der Einzelentroidung.

Würbe ein Bitshauer, in ber 2 fbjutht bie Statue eines Mannes zu modelliren, zuerjt bie eines Pjerdes madjen und darans dann theils burch ummodelung, theils burd) (B) $r$ ber, Injeften. II. BD. 
Megnahme ober Şitzufïgung gewifjer Theile fein definitioes

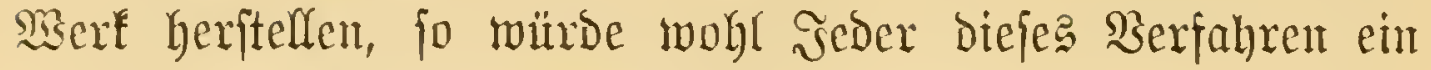

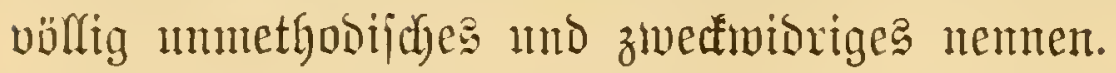

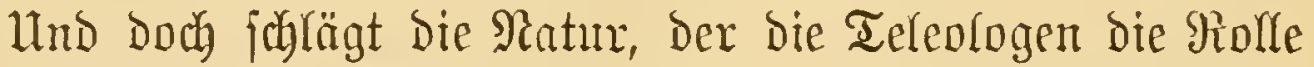

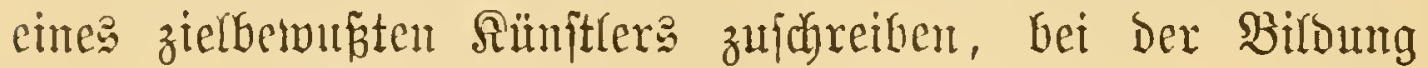
aller metabolifichen Sufeften in 柋efentfichen Denferben, ja oft cinen nody weit jonderbareren

Rekmen wir z. B. Die Gejtaltung Des Schmetterlings, jo mird man Doch zugeben, dapj Der erfte Entwurf, D. i. Die Gianpe, vour definitiven Gebirbe, Dem Falter, noch weit mebr verifteden ift ala Der Drganismus eimes Pferdes von Dem des Mertichen.

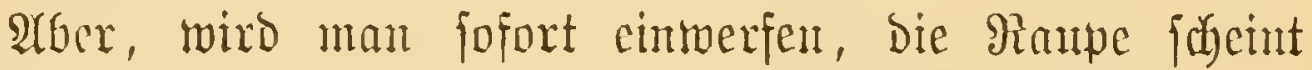

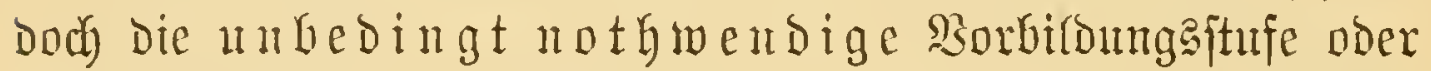
Borangfebung für ben Sdymettering zu jein, Da jich Der lebtere ftets mur aus biefer oseftalt mo niemale ans einer andern, 子. B. ans einer Miade, aus ciner Campodea-fromt o. bgl. entmicfelt.

Sollte Dem abex, fragen wix, bie Allgemeinheit in Dex

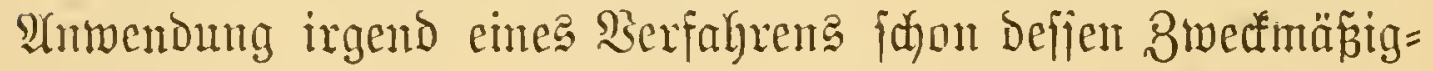

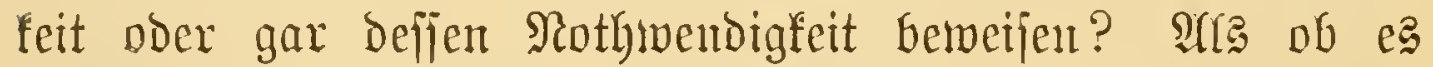
midyt anth in Bereide der menfedichen und wie wir m?

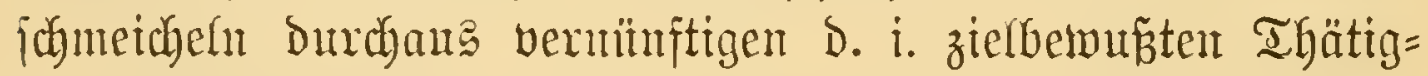
feit geutug Mcthoben gäbe, die cine fehr alfgemeine Ser= breitutg haben (oder hatten) und weldye trots alfedem vou

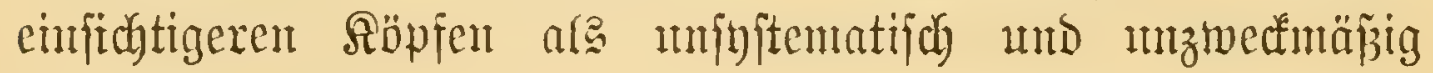
vermorfen rerbent.

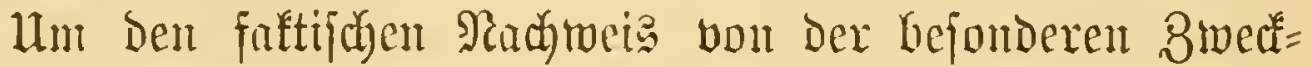

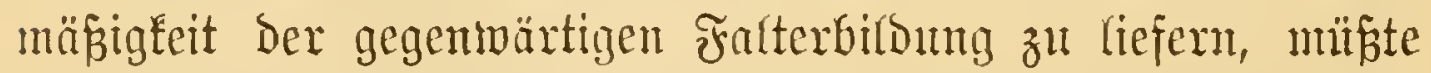
ciner bie feltente $\Re$ unft verftehen, zu zeigen, inmiefent z. $\mathfrak{b}$.

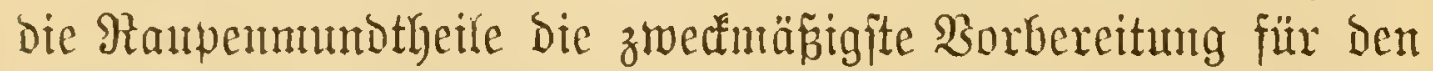

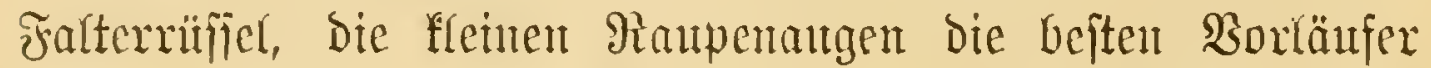

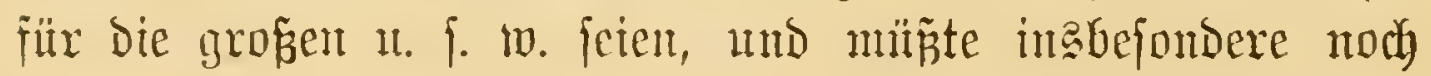


nadygewiejen werben, weld)er Sortheil fïr bic Miodelfirnmy bes Falters fpeciell me jenen Rinuenorganen, z. S. Den

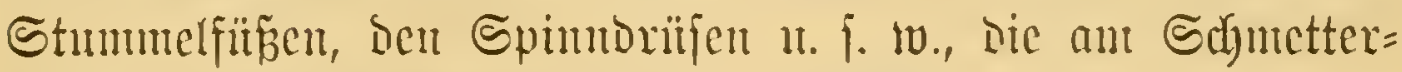
ling gar nidyt megr vorfommen, ertwächjt.

S⿱

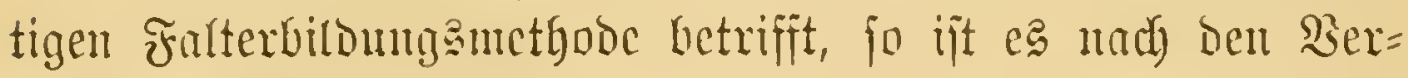

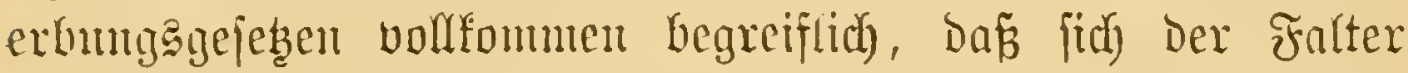
heutzutage als einem wejen entwidelt, Das meniig ober gar nichte Falterartiges an j̈̈r) hat;

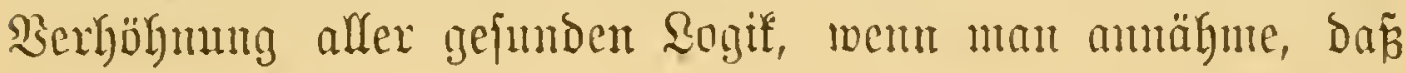

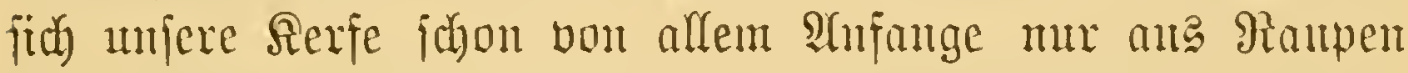
und nidht ans ambern, Den Fraltern ähnlicheren $\mathfrak{W e f e n ~ h a ̈ t t e n ~}$ entmideln fömmen. SDer, wesu nad) biejer Ámahme bic Bildung Des Schmetterlings cime Demịelben gunz mähnliche Borbildungatufe voraugfebt, warum geht daum z. B. bie

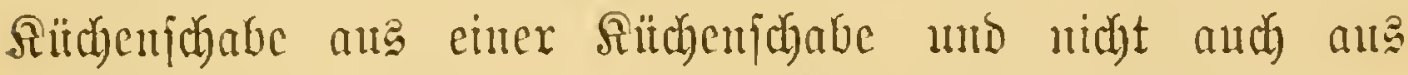
irgend einem andern gauz fremoartigen Bseichöpf hervor?

Mian förnte un allerdinga, um bie von ung angegriffenc Egre Der "verünftigen Bildurgahraft" zu retten, woranf mid mein werther Freuto, ber \$igifojoph Marty, aufmerffam

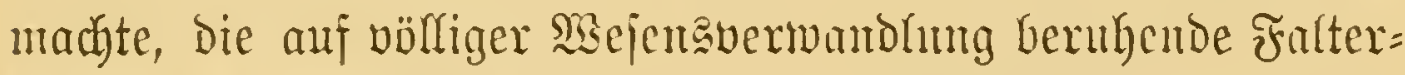

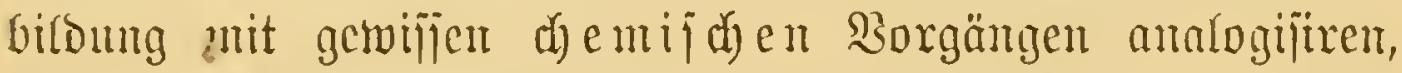
wo ja aud unter gewijīen Bebingutgen ein Rörper in cincu

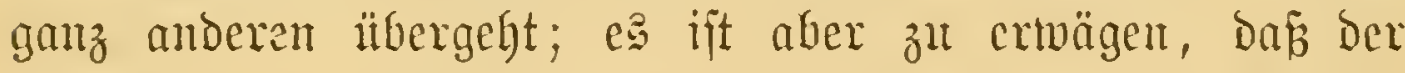
Schmetterling ja nicht alts ber Berbindung Der Gampe mit eimen andern fpäter zuzeigen, felbit cin burdh gewijie $\mathfrak{A} g e n t i e n$ ver $=$ ämbertex un in gemijien Sinne aljo and eiu zu= fammengejeter ober gemifdeter Drganismus ift.

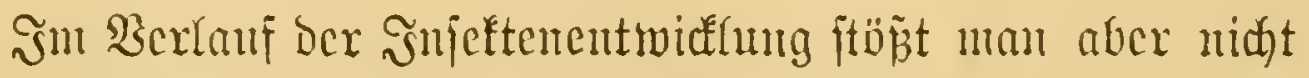
blós anf eine Menge von Morgängen, bie, un gelinde zu

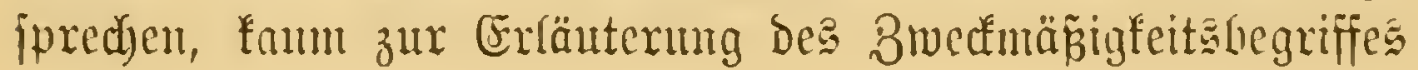




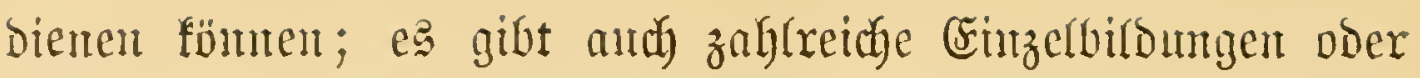
Digane, dic man mit gutem Biemijien als voljtäntoig zmedto bezeidunen famt.

Wag mödyte Der $\Omega e j e r$ wohl won einer Entwicflung halten, bei weldyer der in ber Eijdyale eingeidylofiene Embryo mefrr

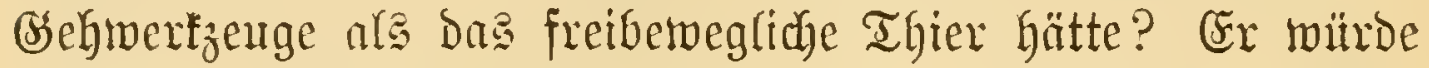

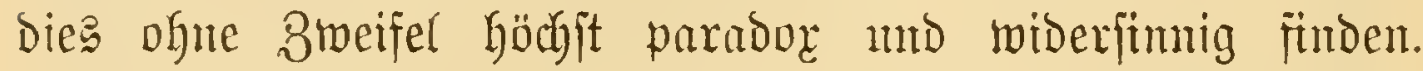
Und Doch fommt biejer Fall bei den Smjeften jegr häufị vor. Der Embrno Des Edyminmfäfer und jener Der Bsotte anbeterin*) $\mathfrak{z}^{\text {. }} \mathfrak{B}$. hat mefr Beine als bie Rarve mo als

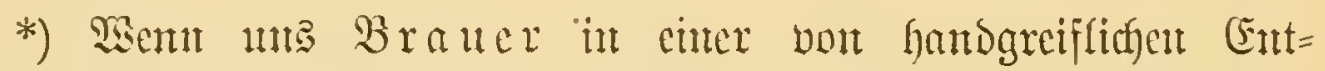

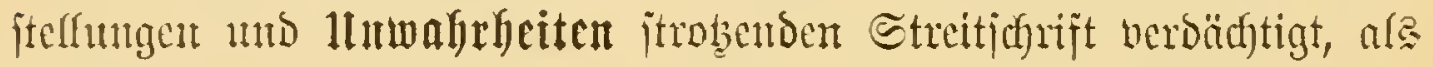

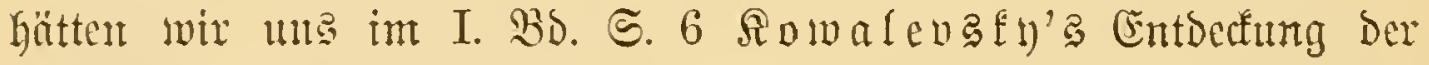
ïberzägligen (Embrunoulatbeine zulignent wolfen (!), jo ijt alt bejagter

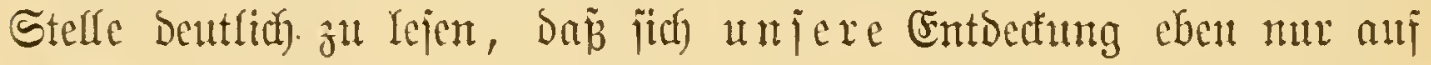

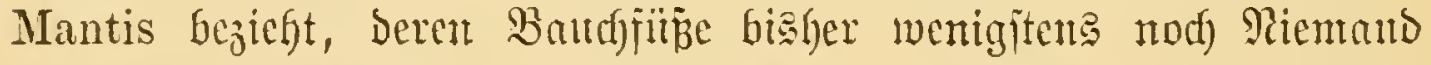

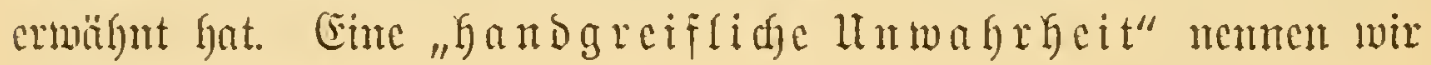

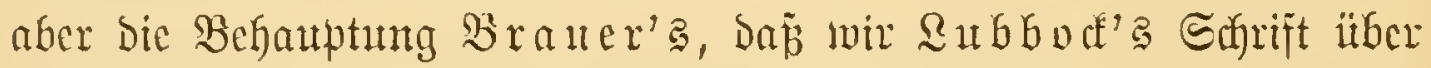

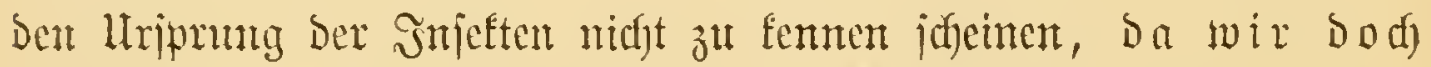
Derjelben (I. BD. S. 124) a U B D

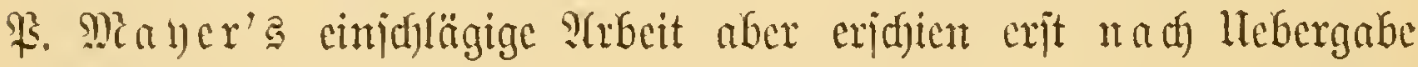

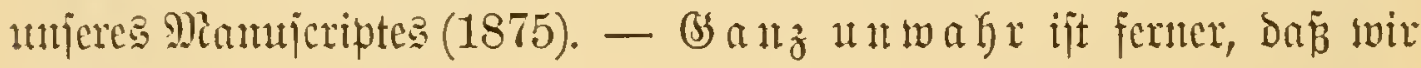
(ङ. 66 u. 67) ipeciell ber mit aboominalen Stummelbeintert ber= jelgenent Campodea unt Japyx cinte Springgabel (!!) zujd)rieben (twir gebraudften biejes Merental mutr jur Charafterijtif Der Thysanura i. w. S., wie bies u. Y. aud) (Elaus thut, und naunten als bent

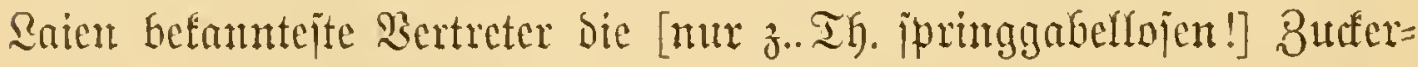

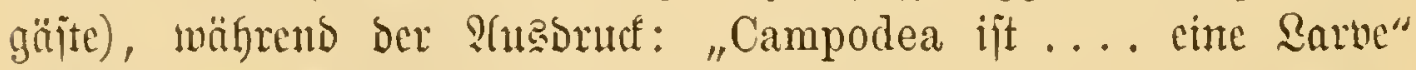
offentrar mur figürriad, wie etma: "Diejer Miant ift cin Rims", angetwendet ijt. -

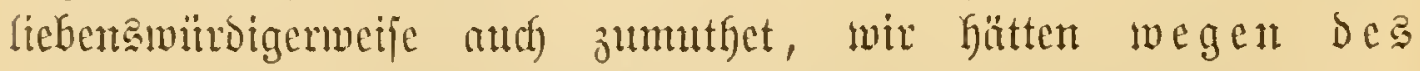

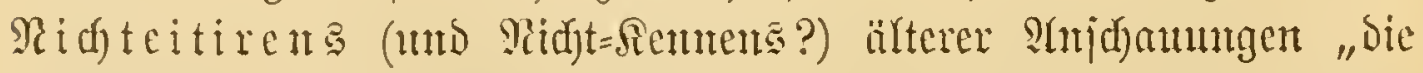

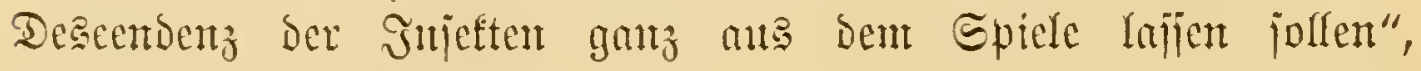

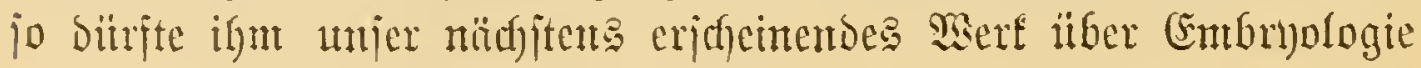


Das vollenbete Thier, mo nod cclatunter ift ber Frall bei

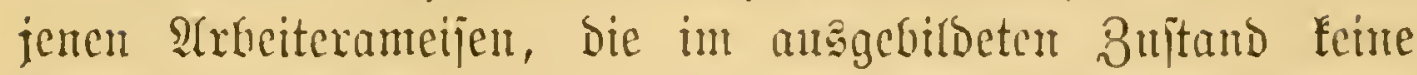
Epm von Frügeln zeigen, bei benen aber, nad) Den fabönen Interjuthungen von Dewis, Die Puppen Dant verieben finto.

Mir wären in ber That neugierig zu hören, mas woht

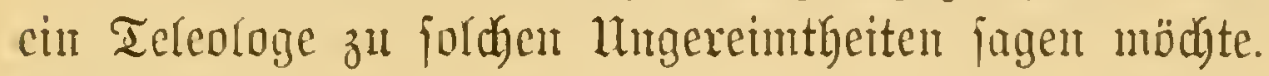

Disharmonieen im Gejammtbeftane ober "Syitem" ber snieten.

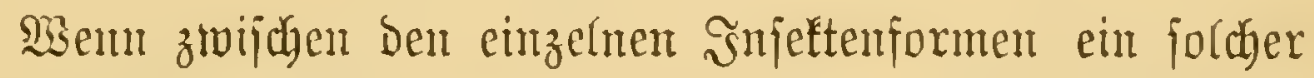

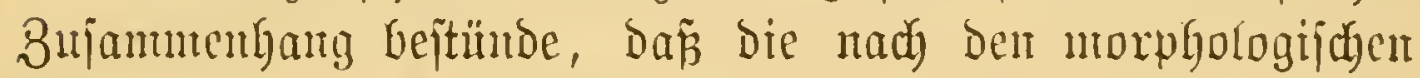
Principien ber Aebnlidyfeit gebildetent Syiteme Der Larben unto ber Smagines einander genau paralfel wären, fo witroen wir cine joldje Dronung, zumal angefictsts ber unabjebfaren Mannigfaltigkeit Diejer Mejen, in Der Igat

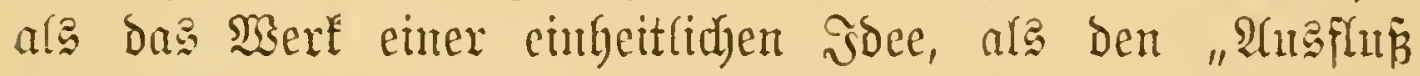
eines högern bsedanfeng" betradten müijen, ja wir wïroen

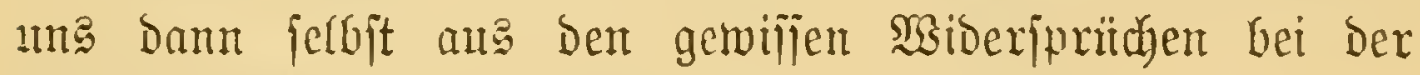
Einzelentwidfung weniger Darans madyent.

Dicje itrenge Silannäpigfeit in Bejanmtbejtande Der Smicten cxiitirt aber leioer mur im ßapf Der Teleologen;

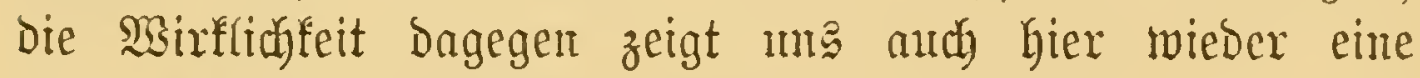
Menge pon Sncongruenzen und llngereintheiten.

Setradjten wir beifpielshalber bas Syftent ber feaut= flügler.

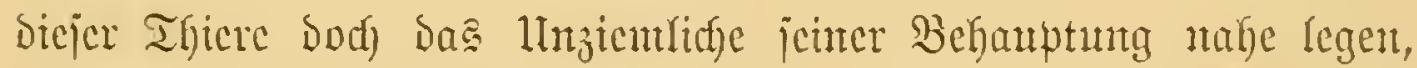

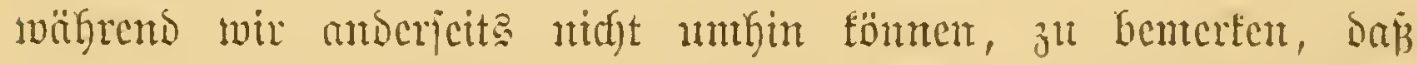

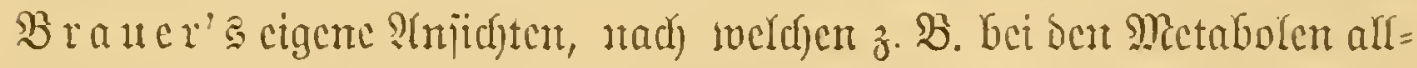

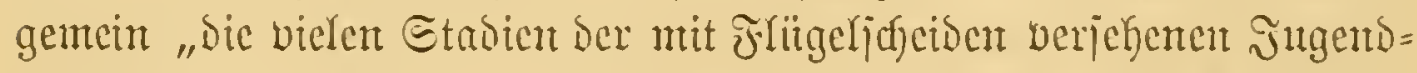

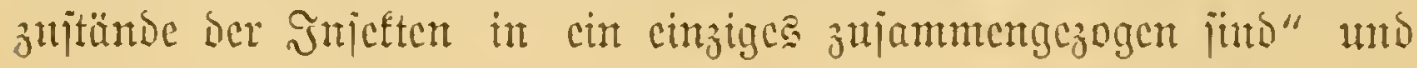
"ba

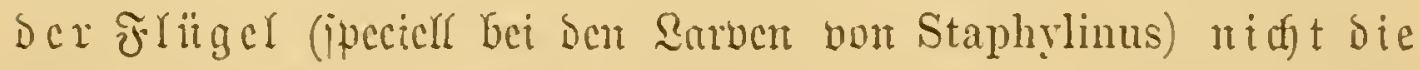

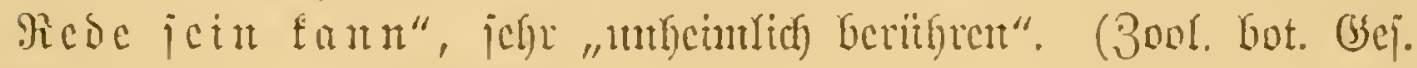

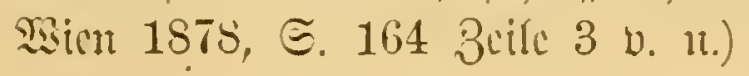


Was zutächjt Deren Şmagines betrifft, fo fam fïch Der Sejer in jeder gröpern Sammlung Keidyt ïberzengen, dar bie= jelben in jeder Seinfidat, nantentlich aber in Bezug anf Den

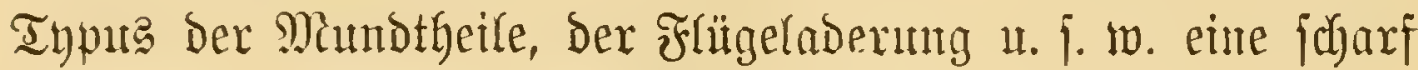
untgrengte, eine wahrhaft natürliche Grutppe birlden.

Da mut bie Rarben im âlgenteinen meniger bifferenzirte

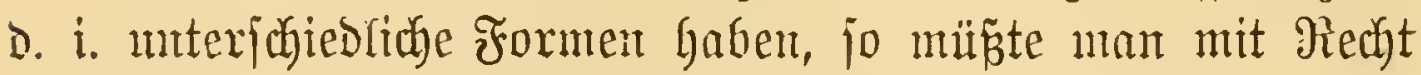

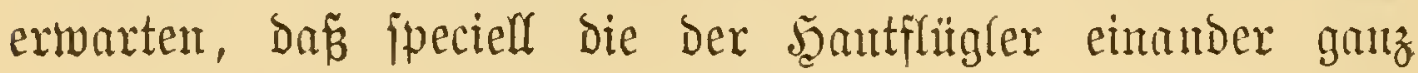

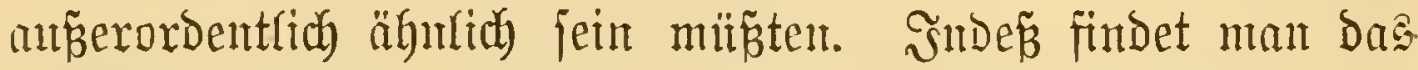
gerabe Biegentheil. Die Sarven gewijier Symenopteren, z. B. Die Der Bienten, zeigen Den Mabentypuz, andere, wie bie Der Blattmespen, Den ausgejprobeniten Furpenthabitus.

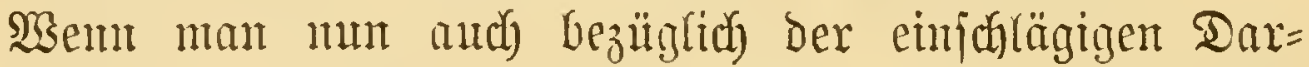

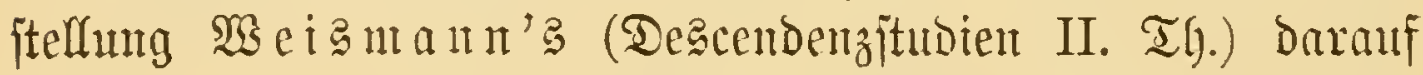
Ginweifen mñ

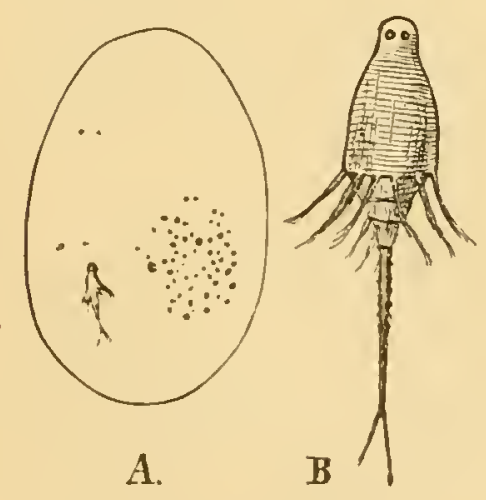

Fig. 208.

Эn Säfer(Rhynchites)eiern iđmaroteme 5̧antflügłerłarve.

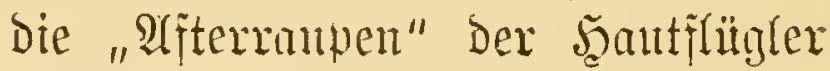
Durch gemije feimere Merfntale, z. B. int Den Mintmotheilen, ziemtich fabarf vou ben edjten Raupen Der Schmetter= linge unterfactben, mährend jie jith atberjeits eben Durch bieje und wohl nod) Durch manche andere mely veritecfte Sharaftere an bie Madon= larven Der Bienen u. $\{$. $\tilde{f}$. amf jo gifte $e$ s sock aud ganz ifolirt ba= ftelyende Forment, wir meinent nämlich foldye, die feiu Syitematifer übergaut zu dent

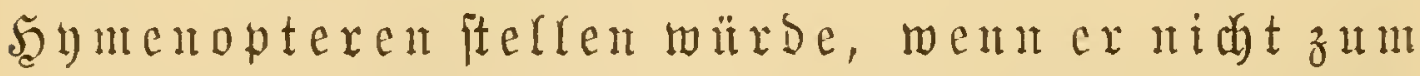

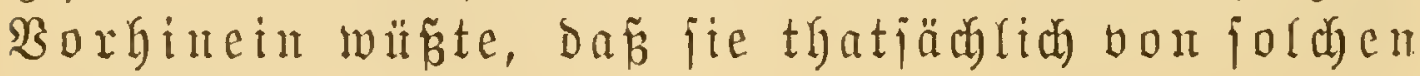
a b f t a ment.

Dber wer, mörden wir fragen, wird es etwa ber Larve in Fig. 208 oder Den jonderbaren Entwidfungagornten Der

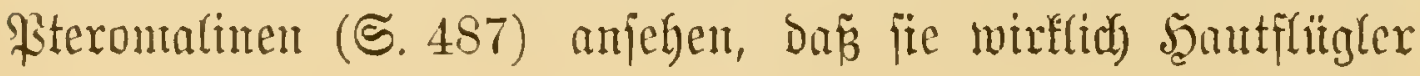


find, mo weldyes folfen Dann bie Merfunale jein, an bencu fie jidh als joldhe erfommen ooer "bejtummen" laijen? -

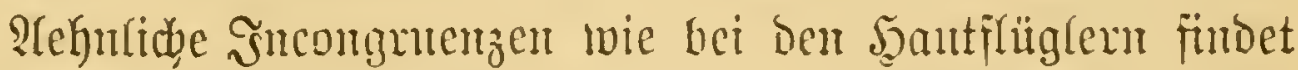
man mu and bei amoern (5ruppen, und preciell für bie Sdymetterlinge hat weizmann in ber citirten Schrift den

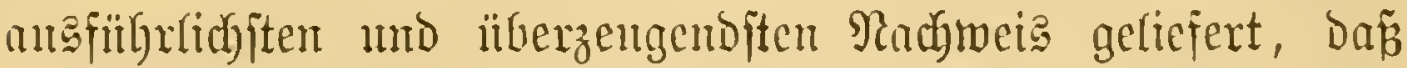

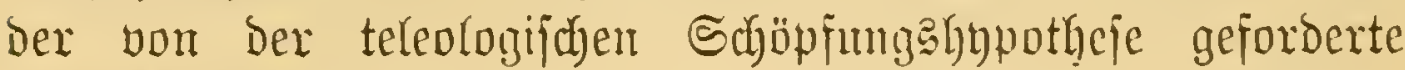
"Parallerismus" zmijhen Den Sarben unb Den Jntugines weber im ganzen હyjteme nod in ben lleiteren arbtheilutgen ju Iage tritt.

\section{Die wahren oder natürlichen Hrfahen der zretantorphoje.}

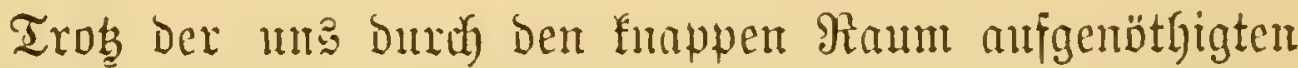
Efizzenfaftigfeit umperer Darjtellung hat fich ber Refer boch

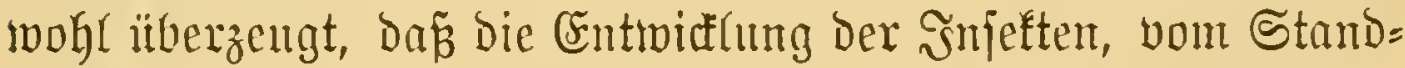
punft dex blopen Beftaltbildung aus, jomohl in Einzelnen als in Bezung anf bie Bejanmtgeit Der Formenteihen in Dex That viele Disharmoniecu unb Ungereimtheiten zeigt, und

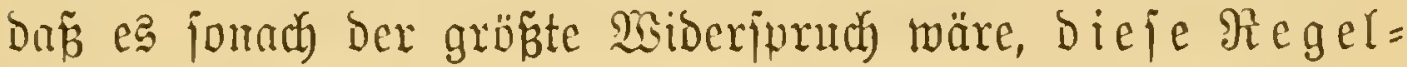

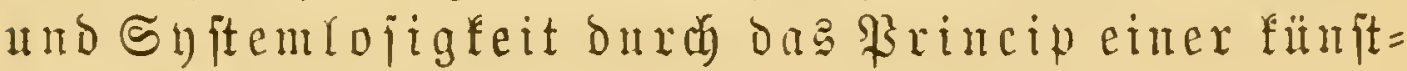

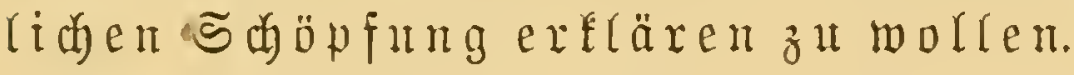

beier ijt mut aber gleidy bon Seite ber Teleologen fol= gender Erimmur zu gewärtigen. Der Sdjöpfer, werden fie jagen, hatte mit Bezug añ bic Regelung Der Snjpten=

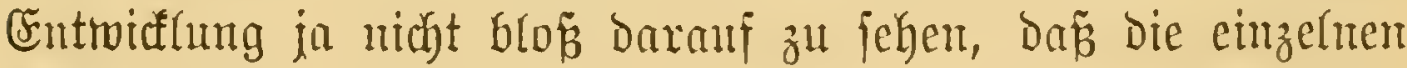
Birbungåtabien unter einander in Şaxmonte ftehen, es fam ifm vor Allem Daranf an, Diejelfon mit Den jemeitigen Bebingungen Des practijach Rebens in Uebereirjtimmung zu bringent.

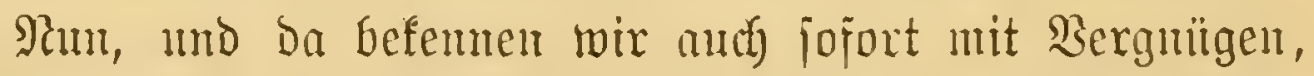

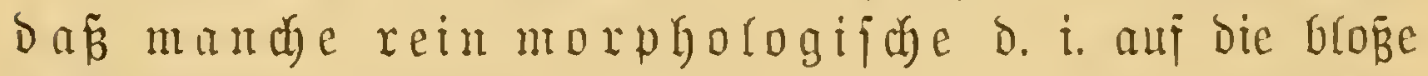
Gejtaltbildung bezügliche Disgarmonieen in ber That 
Durd biologifde Şarmonieen auggegliden, gleid $=$ fam corrigirt werden. So ift z. B. Sie Raupe, mie oben gezeigt,

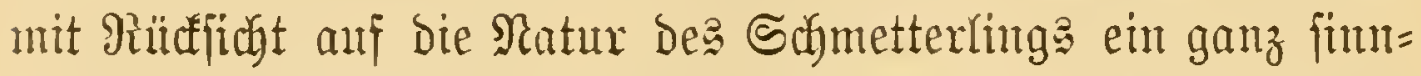

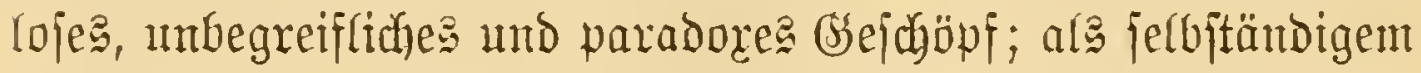
Seberwejen aber, allenfalls now mit bem jübunen Beruf, Daz zux Bilbung Des Papilio nöthige Miaterial zu fammeln, merden wir ihr alfe Utnerfenmung zu Theil werben lajien.

Damit indelien haben bie Teleologen now) lange nidat

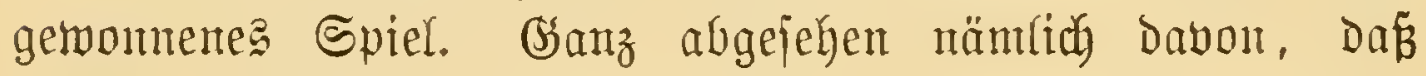

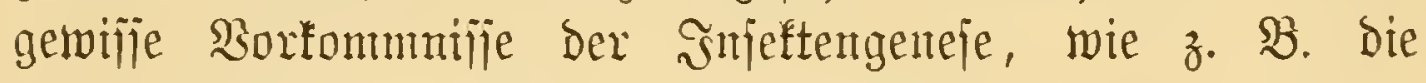

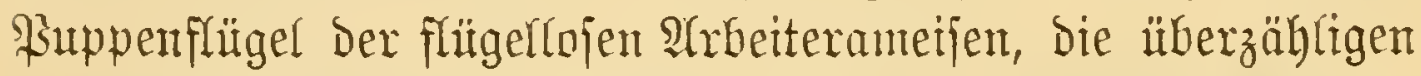

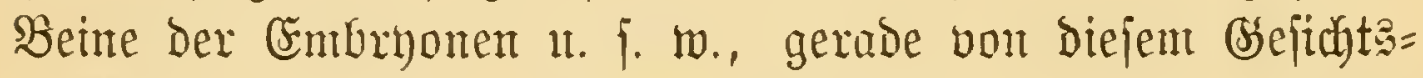
mulft aus betradytet, abjolut unverjtänd (id) bleiben, mödyten wir mas aud die Frage exlauben, waxum den der

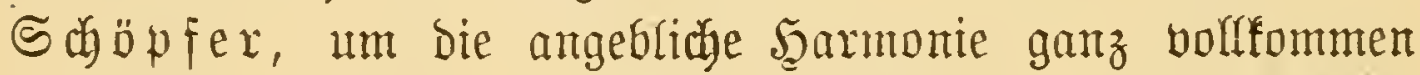
zu maden, das morphologifae Enftem der Snjeften nid mit bem biologijuen zujamenjarlen lié,

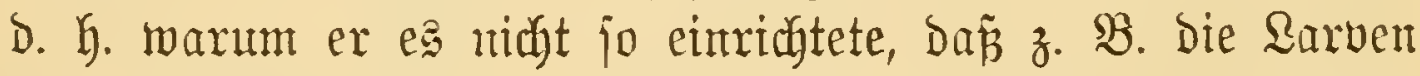
Der Ztweiflügler alle parafitijich und madenartig, jente Der Şautflügler alle pflanzenfrejiend und ranpenartig 2 . wären.

Darauf gibt e⿱乛龰 aber nur (rine Antwort, nämlid die, Dá eitre foldhe Şarmonte ben ülrigen ßerfältnifien ber Satur wiberipridyt.

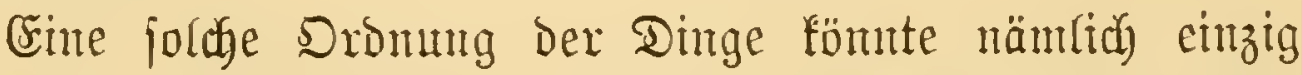

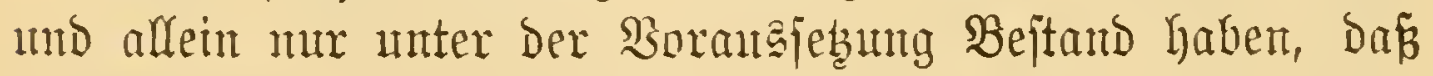
Die Bejammtheit Der Erijtenthedingungen iteta biejelbe briebe. Nun jehen wix aber tagtäglich nit eigenen $\mathfrak{H} u g e n, ~ b a \tilde{B}$

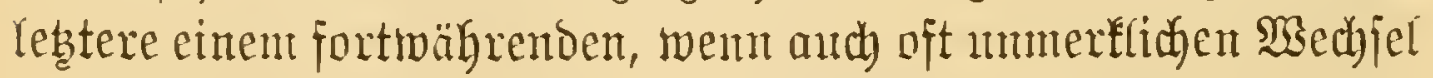
mterliegen, währent ma bie bsejhidyte Der Crobe gerabezu

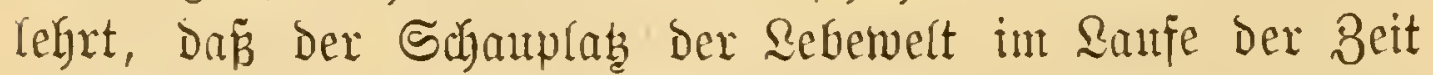
mehraache totale Beränderungen exlitten hat. Itno bamit fund

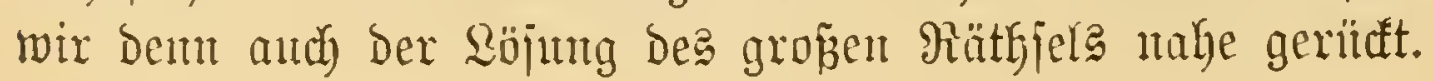


Cben Das, was dic von Den Telcologen behauptete Sarmonte

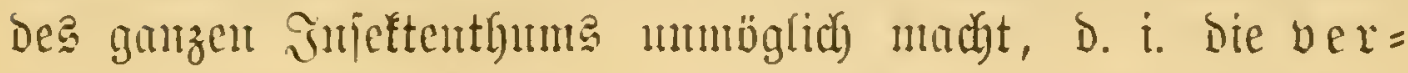

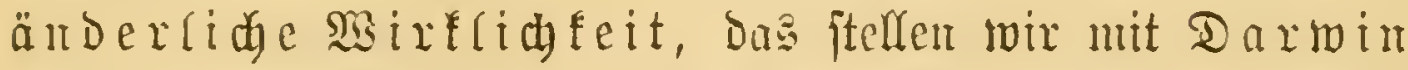

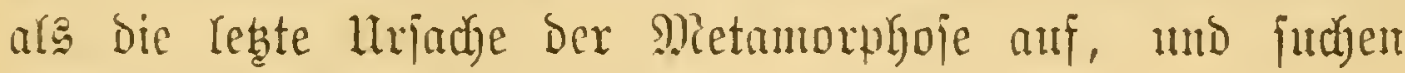
demaemäz folgende zmei Fragen zu beantworten:

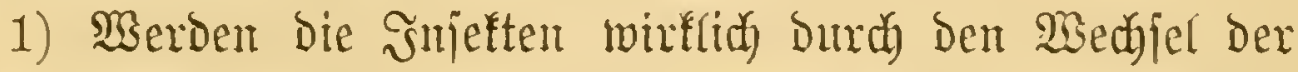

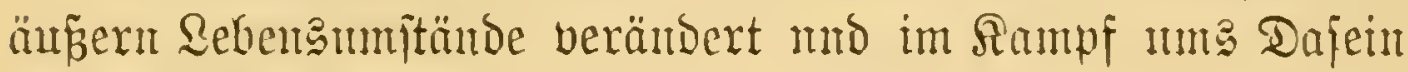
Denjelbent angepañt?

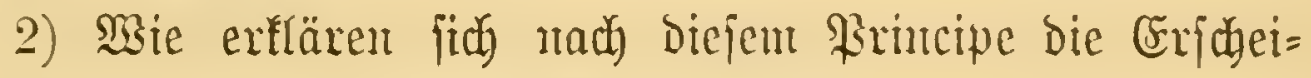
mungen ihrer gegentoärtigen Entmicklung?

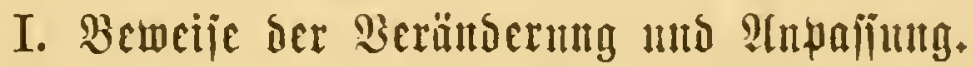

Die ganze Frage, welde uts hier bejüätigt, wäre jelbit= veritändich fofort entidjeden, wem e⿱乛龰 ung gelänge, burch

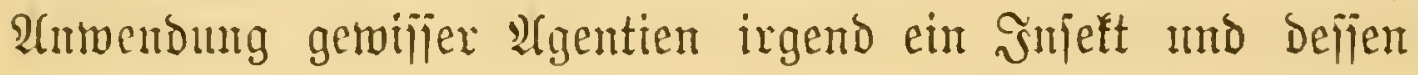

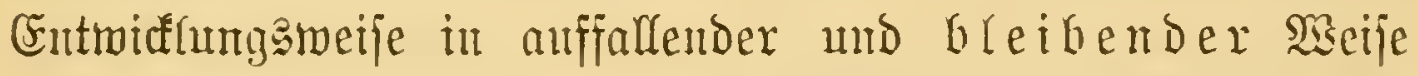

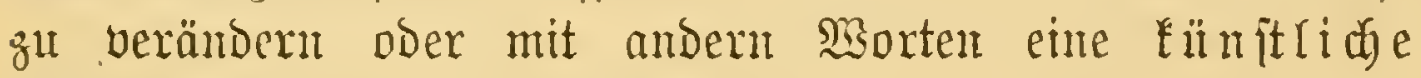
Metamorphoje herbeizuführen.

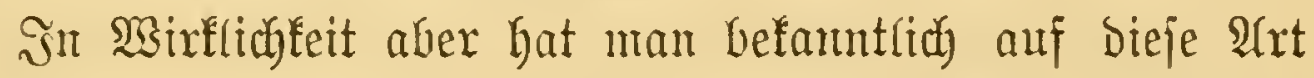
meijt mur geringfïgige ßeränberungen Der Farbe, Der Zeit)=

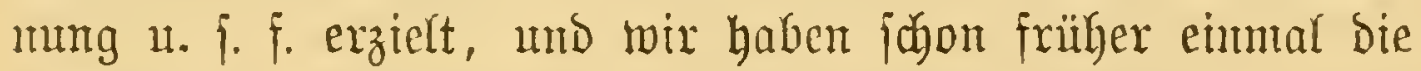

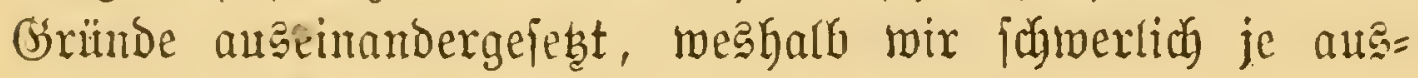
giebigere llmwand

Sit mun antd) Den bisherigen bireften Bemeijen für umpere

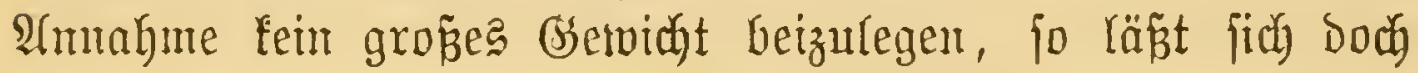
und zmar auf bas Ueberzengendite Die Richtigfeit berjelben auf inbireftem Wege bartfun.

Qehreich ijt in Diejer Beziehung zunäbjt ein Sergleid Der veridhiedenen Form= unt Rebenszuitände eines Injeftes mährent Der zmei Şatptperioden jeiner Entrocflung.

Sm Ei, two Dagjelbe ein von Der Ilukentwelt fajt gänz= (id) abgeidnittenes Dajein führt, ijt bie Entwictumg in ber Regel cine ziemlidy gleidjp̈rmige, wentigitens frei vout jo auf= 
fullenden den gauzen Şabitus verämbernben Umgeitaltutgen, wie man fie foult beobadytet.

Mit Dem Cintritt ing freie Reben Dagegen, wo bas Thier bald unter bieje, bald unter jene Berbältuifije geräth แnd ferbjt bei Der benffar größten Cinförmigfeit ber $\mathfrak{U m}=$

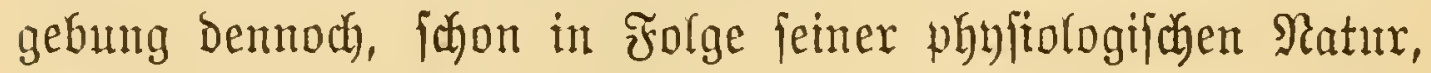
bejtändig nenten Ânregingen und Antrieben anggejeb̨t ift, beginnt auch baz Unjtäte und Beränderlide der Entwić:

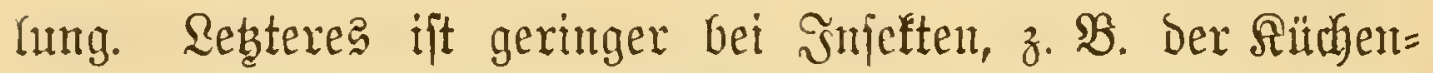
ichabe, bie unter relatio gleidbleibenden ober itationären $\mathfrak{M} m=$ jtänden aufwadbjen; e马 jteigert füh aber (Sitaris, Polynema)

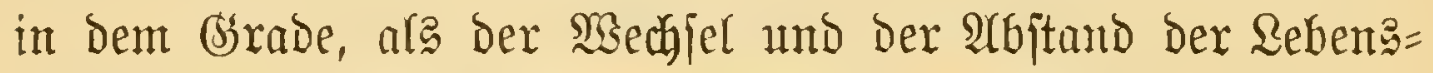
bebingungen ( $\mathfrak{A}$ ufenthalt, Nabrung $2 \mathfrak{c}$.) zuninmt.

Solt grof̌er Widtigfeit für unfere Frage fint dam die proviforifaren 5 rgane, D. h. Die gemijien zur typifich oder ererbten Normalansriftung meu Ginzuermorbenen und ganz bejonderen Exiftenzbedingungen entipredhenden bergä $\mathrm{g}=$ lidyen Eimribtungent. Sie findent fib in allen Rebensjtabien.

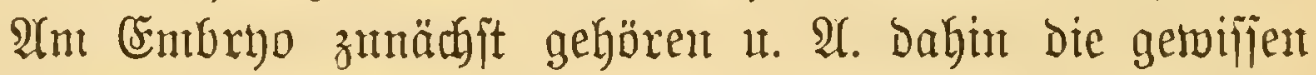

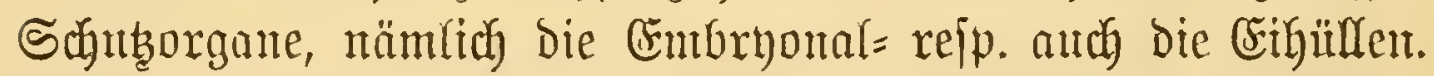

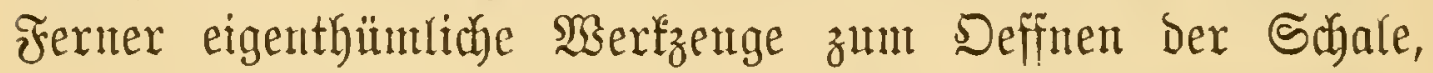
wie z. $\mathfrak{B}$. Der obenerwähnte Mumbitachel Der Fliegentude.

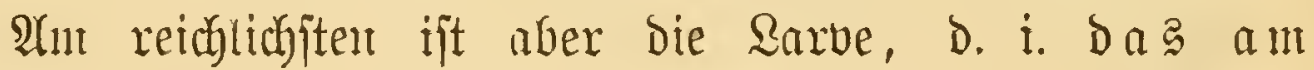
längften un a m neijten Den Einflüfjen eimer wedyjelut= Den uno feindichen 2 An

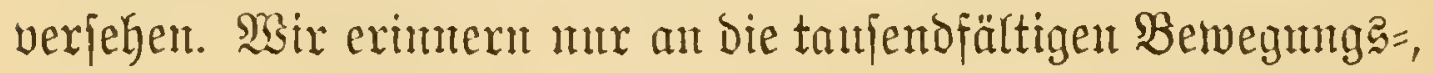
Şaft= mo Shutgorgane, fpeciell an bie Şuterfeibghafen Der Cicindela (ভ. 7.3), an Das "mantmurftabenartige" Rriectyorgan Der Chironomus*), an bie feltjanten Rlanmermerfzenge ber

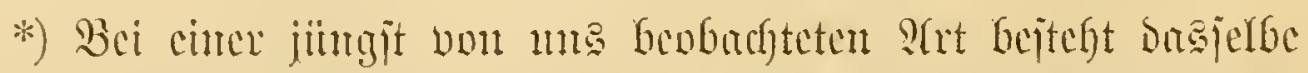

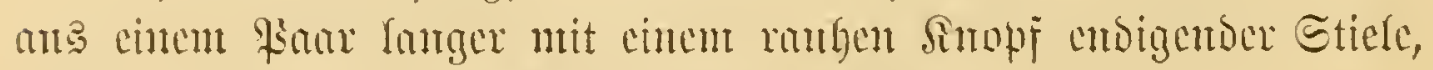

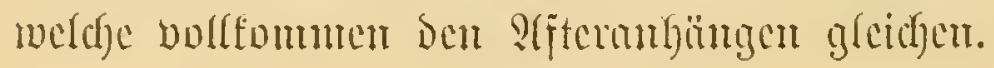


röhrenhetwohnenden Rärber (F่̧g. 159 w), an Die Dornfränze Der Ffiegenmaben (Fig. 159 o), jowie von innern Einrid)tungen

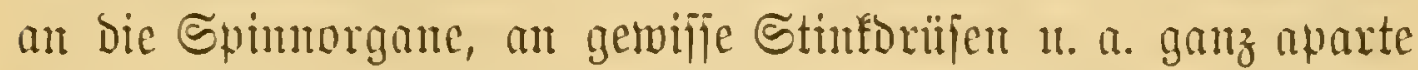

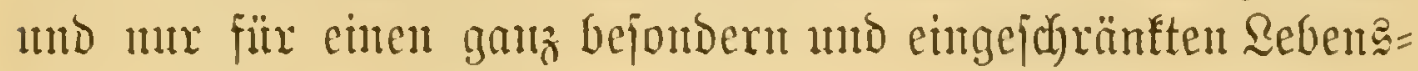
freis bejtinmte Dinge.

Auch) bie Puppe hat joldye practifdre Rebenorgane mo zluar, was ganz zur Theorie pap̃t, m jo mehr, je mehr fie mit ber Anzentwelt verfegrt, alfo je "freier" fie ift. Dies und itberfaupt bas $\mathfrak{B e j e n}$ der provijorifden Bildungen wird am

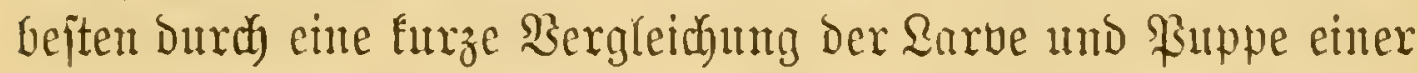

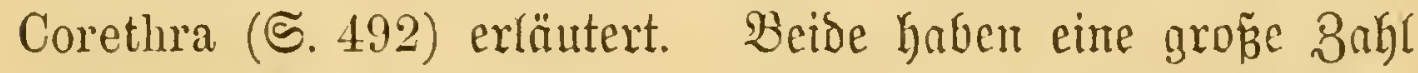
(Semeinjamteiten: bies ift Das Iypijde, Das Durd) alfe $\mathfrak{S e r}=$ sundungen Bejtehende und Breibende. Daneben hat jeoes jein Driginelles, feine Bejonderheiten, wovon wir, ınt den

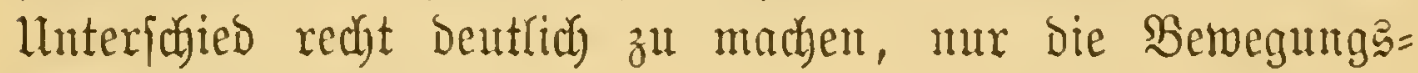
organe herborkeben.

Die Sarbe (A) nimmet befanntlidy wegen igrer zwei Tradjeenblajenpanre, wovon das eine borme, bas andere Ginten liegt, in Măfifer cine horizontale Stellung ein. Dem cutfpridyt mu, wie bei einent oride, eit berticales Stenterorgan (Fia). Die Ruppe (B) Dagegen fteht, wegen

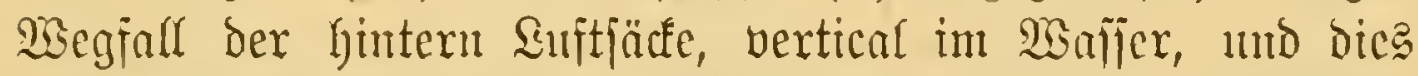
verlangt eine (hier in zmei Flügel getheilte) horizontale Sd)inamfloije (Fl).

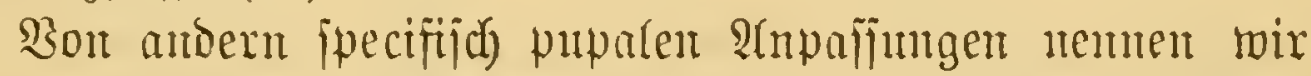
nod) bie geitielten Stigment ber freilebigen Fliegenpuppen,

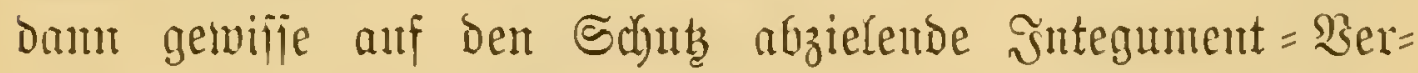
bicfungen und Raubigfeiten, wie man jie bei Fltegen, Faltern 4. 2. beobadytet.

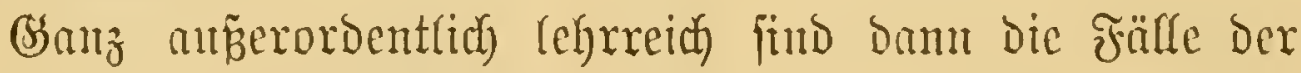
jog. $\int_{0} n=\pi n b$ Divergenz.

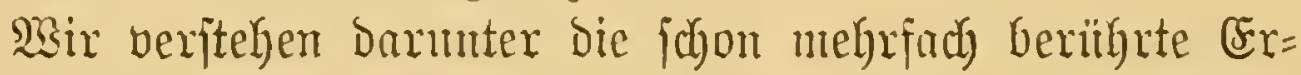

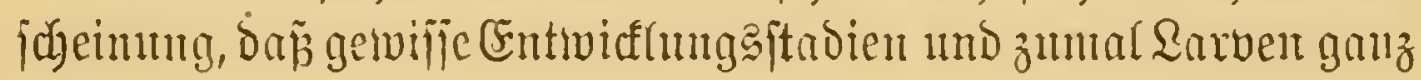


veridjtedener Drommgen unter ähnlichen Lebenahedingungen

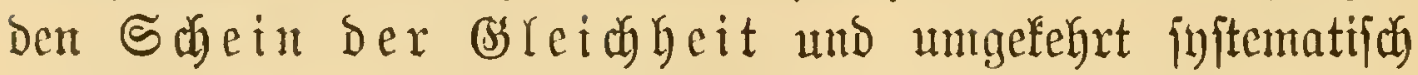
unheftehente und aud imerlid zufanmengehörige Formen unter bivergenten $\mathfrak{u n t i t a ̈ n d e n ~ d e n ~ S d y e i n ~ b e r ~} \mathfrak{H}$ ngleidheit zur Schau tragen.

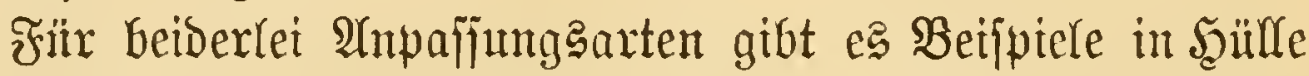

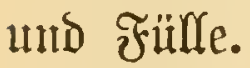

Szinfidytlich ber Convergenz eximern wir zutäd)ft an

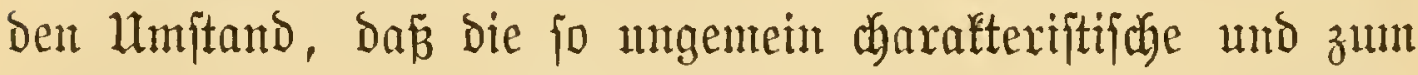

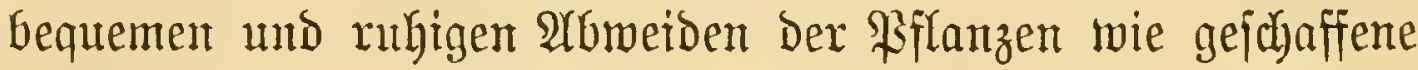
Яaupenform Der Sdymetterlinge unter meift ganz ähnlliden Lebenghedingungen aud in ber Dromung ber Scautflïgler

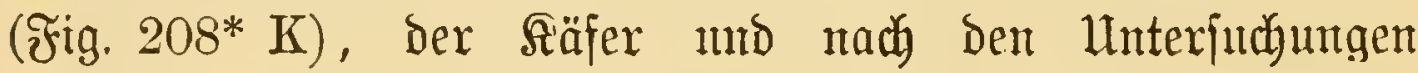
Brauer's aud bei Nekfflïglern (Panorpa, u) wiederfehrt.

Nicht minder auffaflend ift Dant bie unitreitig mur burch

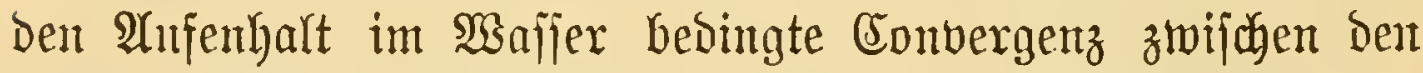
¿arven Dex Cintagaffiegen (r) und jenen gewiffer Schmimm= fäfer (Gyrinus E), Deren als Siemenflofien dienende Şinter= reibzanfänge in beiben Dromuntgen oft fo ähntidy find, als of

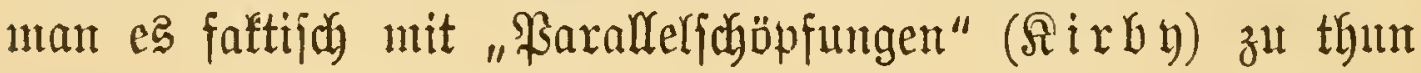
hätte.

Auch mandhe ber jog. campodeaförmigen Rarben bürften

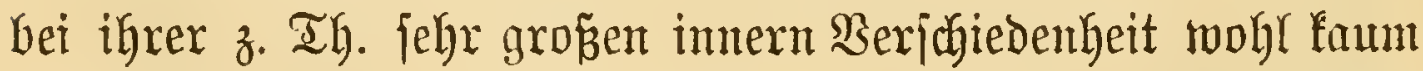

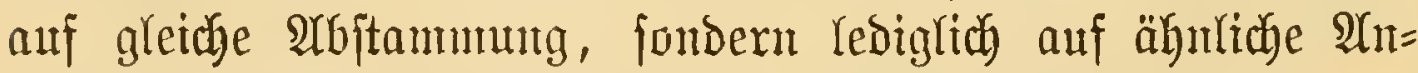

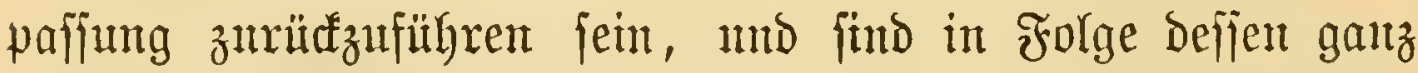
Darnach angethan, ung beim Auffuchen ber Uriprungąormen bex Snjeften auf eine farfache Fä̆hrte zul leiten.

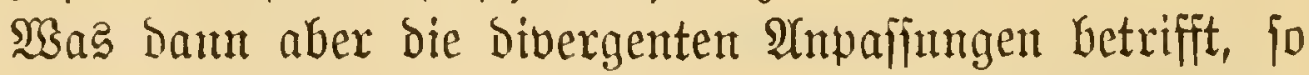

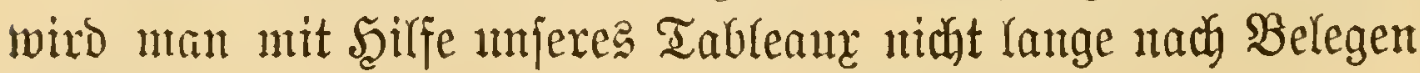
futchent.

Man nelgme beifpiclameife die Räferreihe $(\mathrm{A}-\mathrm{E})$. Da futben wix srei Rarben (B, D und E), von Denten wohl jeder

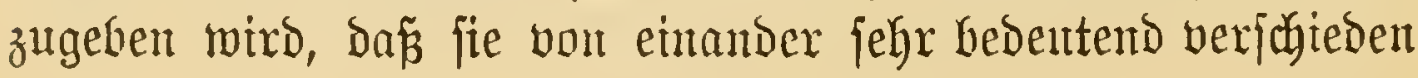




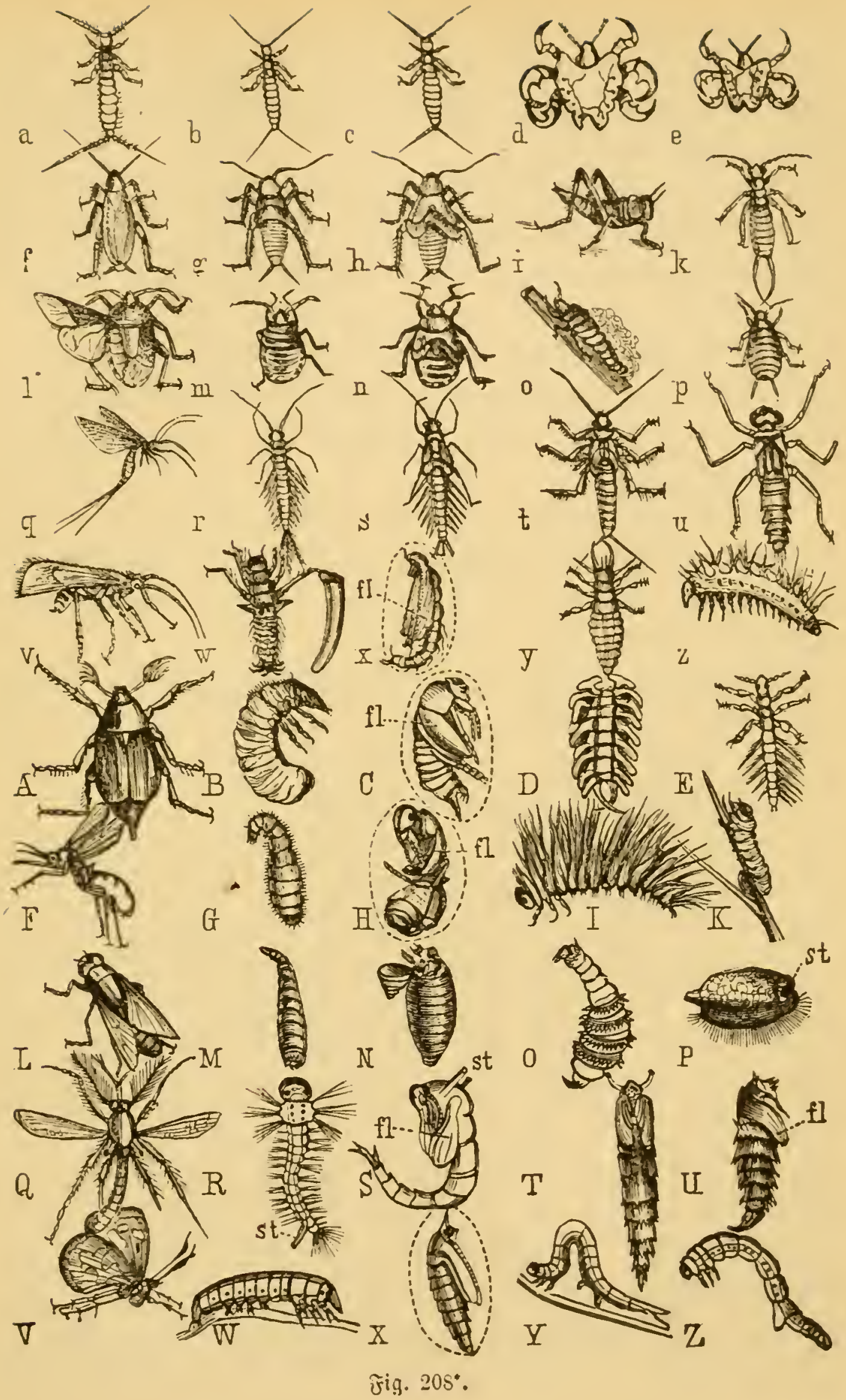




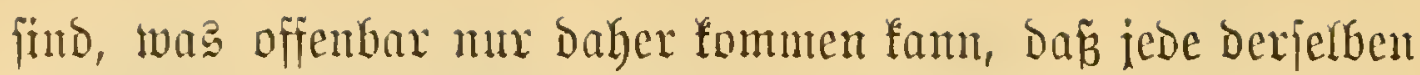
unter ganz eigenartigen Ilmftäntoen leht und benfelben in hohem Sirabe accontodirt ift.

So vegetirt befamntfic) bie Rarve $B$ als fog. Entgerling

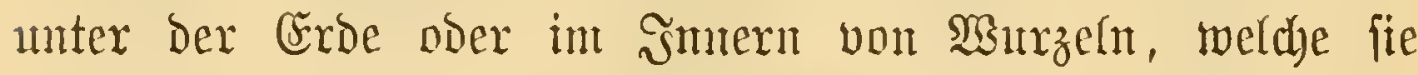

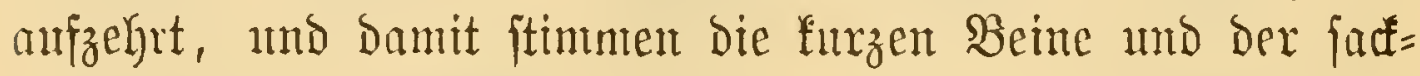
artige weiche f̧interteib.

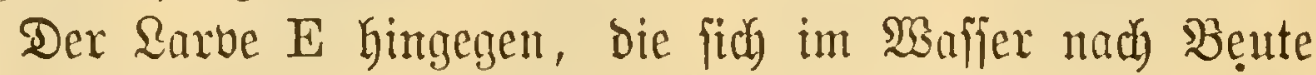
Geruntreibt, fönnten wir keine paijendere Aruzrüjtung geben, als bie fie faftifid befitest, nämlich bie mebr ermähnten Iracheenfiement.

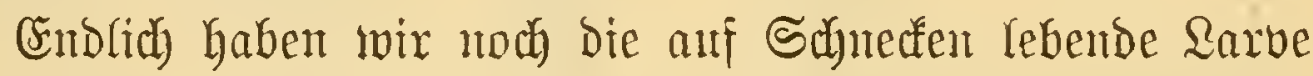
D, unto es ifft in bie Alugen ipringend, da a i igr affelartig verbreiterter Sïrper der fchtitpfrigen Unterlage feldr ange= mefien ift.

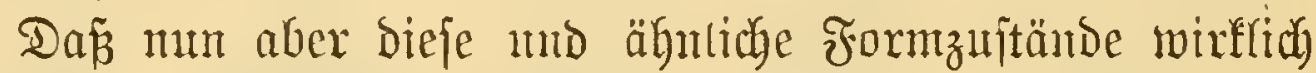
int Rampf ums Dafein erworbene noer natürlidye $\mathfrak{A}$ tr= pafjungen furd, bafïr legen ganz bejonders bie meit ver= breiteten $\mathfrak{R}$ ü

Die meijten Snjeften, ın mur Cin Beijpiel Diejer (S)attmng

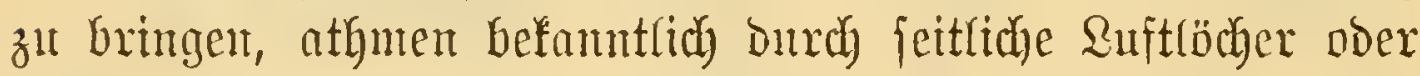
Stigmen, won benen meift zmei Paare anf bie Bruft und adyt auf Den Seinterteib entfallen, und fund die Alnlagen biefer Deffnmmen forwie Dex zugehörigen Tracheen aud in ber Regel bereits an Canbryo ausgeprägt. Sun möchte man gewi liegende Mittelftadium, D. i. Die Larbe, Dantit in gleidjer Meife verfeben wäre. Das ift aber bei mandben Snjeften, Derent Larven im $\mathfrak{B a f f e r}$ oder in antoen für ein alleitig offenes (Golopnenftifd)es) Trad)eenfuftem nngeeignteten Mesien Leben, nicht ber Fall, fondern wir finten entweder, wie bei bent Larben vieler Nebfflitgler, mandher Räfer, Sdumetterlinge u. \{. w., gar feine offenen Stigmen (apuentifid), 
Dafür aber, als edft proviforijate Birsungen, die oft $\mathfrak{e x}=$

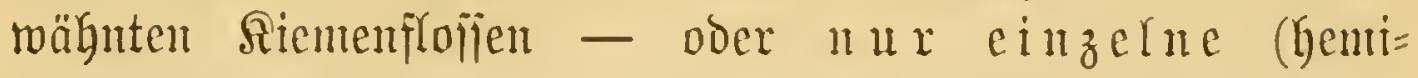

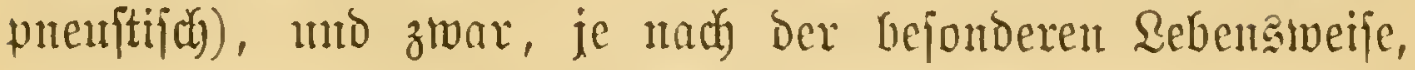
entwecoer ganz Ginten (metapneuftif(y)), wie bei Den Muasciben= maben, bei Hydrophilus, Culex u. . w., ober mur vorne (propmenftif(y), refp. (wie bei Mitaciben, Deftriden) borne und binten (amphipnenitifa).

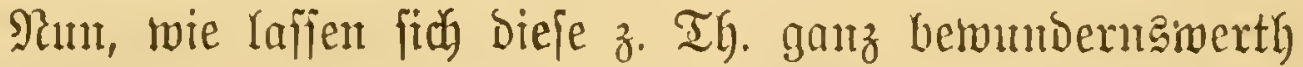

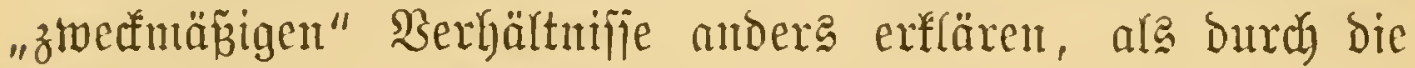

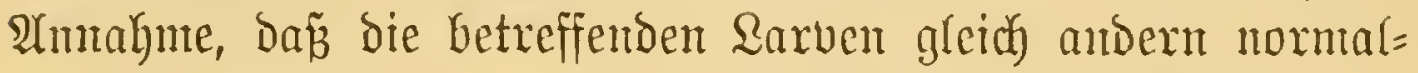

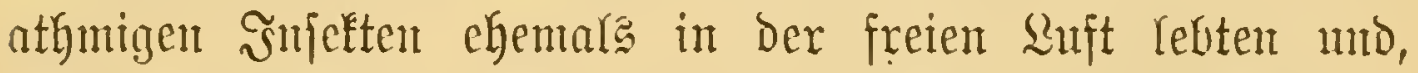

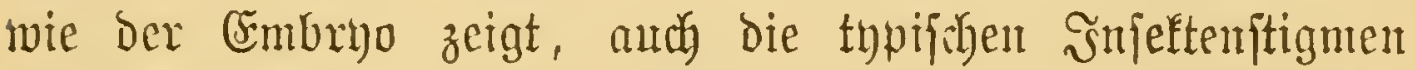

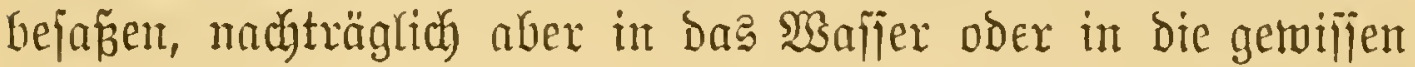

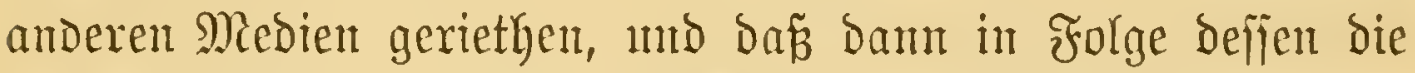
für dic geänderten Rebenaverbältnifie umvortheilfaften offenen

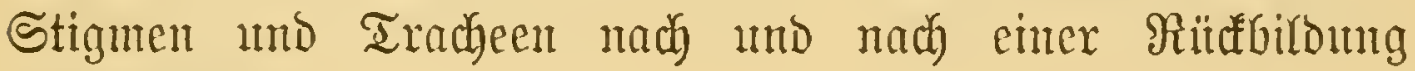
antheimfielen?

Diefe neurerichit ourch $\mathfrak{B} a$ lmen auf bas eingehendite begrünoete Sُuffaffung findet ihre glänzende Beftätigung in Dem burch benfelben Foricher gelieferten ausgedehnten Nach= weis, daf es fich bier gar nidat um ein abjolutes Felylen

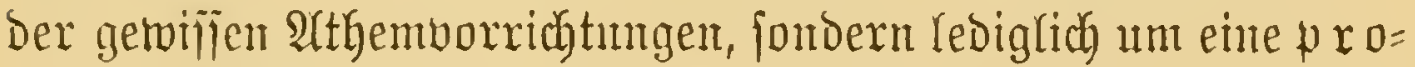

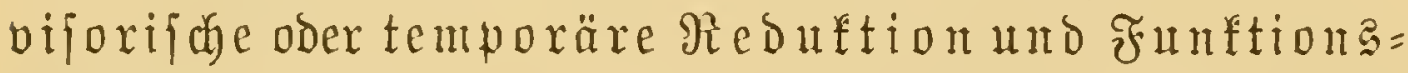
einiterrung handelt, unb es wäre in Der That des Berjuches merty, zu erproben, ob fich folche Beränderungen nicht viel=

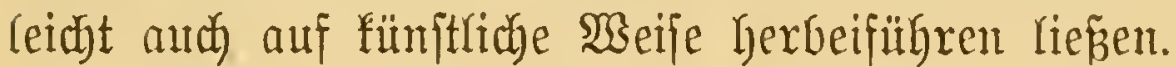

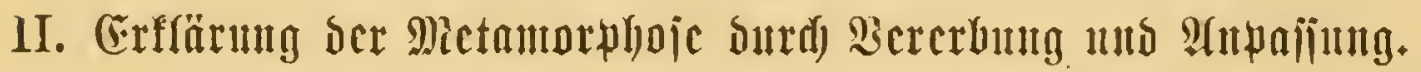

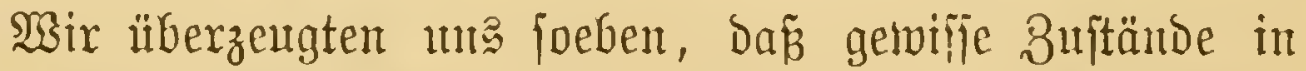
Der heutigen Entwictung Des Jndiviounms anf thatjächliche Seränderungen ber Snjeften in Qaufe der ßeit $\delta$. i. aljo anf

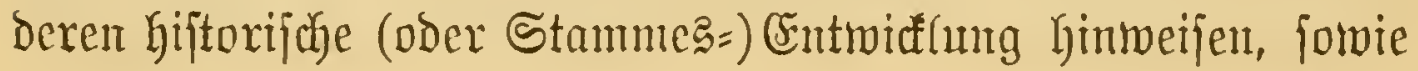


aus allem Biagerigen hervorlentedtet, Dáj bieje beisen Ent=

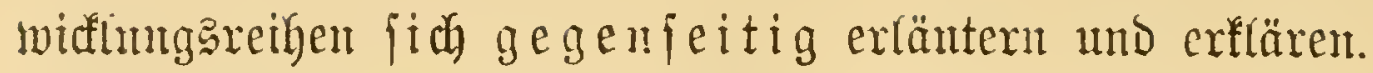

Da mur aber, ftrenge genommen, die indioibuelle

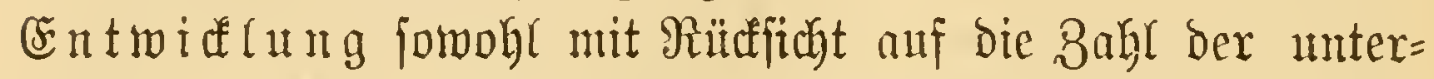

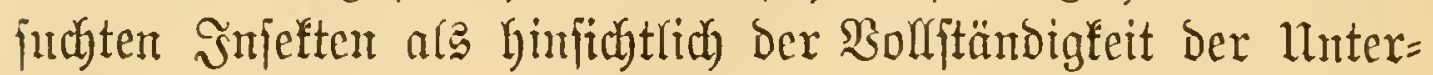
fudutg nux theilweife befant un a d d bie palä= outologifac ueberlieferung trob ber zahlreiden Funde ber lebten Fabre, eine äuźcift mangelgafte ift*), jo

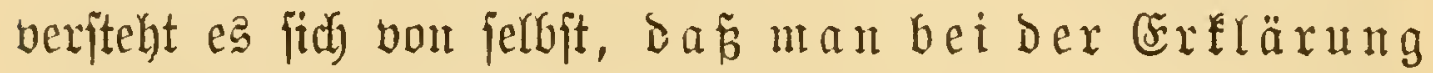
ber Mretantorphojearlenthalben auf unitbermind=

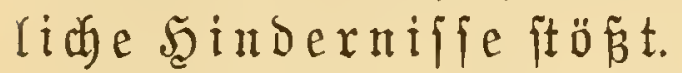

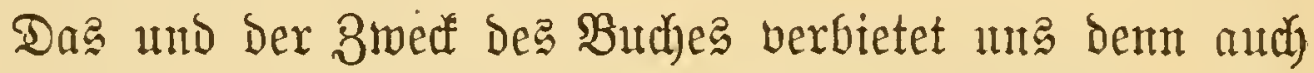
im Nadjolgenden über bie Darlegutg einiger allg e me i n e rer Biefichtapunte Ginatizugehen. **)

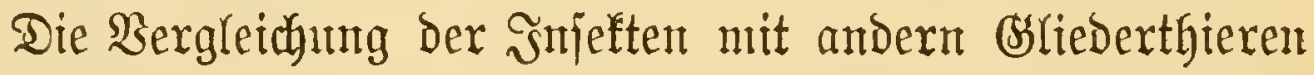

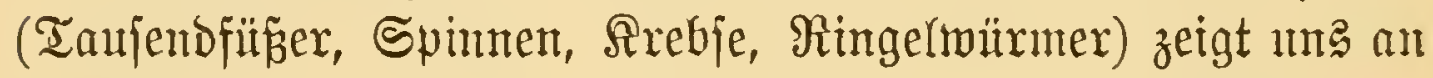

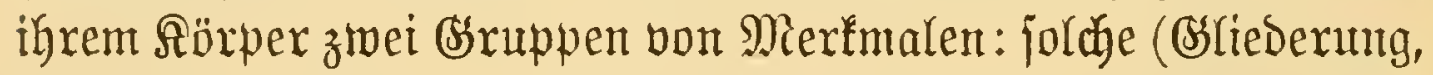
Segmentanfänge p. p. gemifije innere (Einridutmmen), bie fie mit

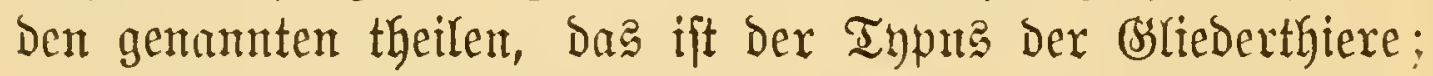

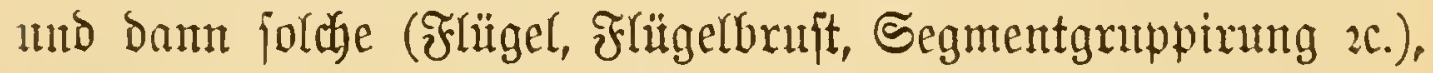

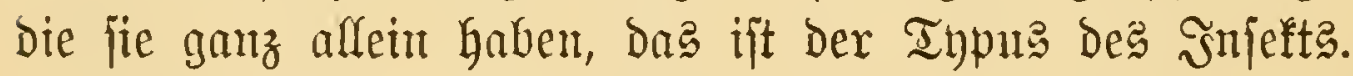

Den Tlyus des Gsliederthiers jagen wir mu, haben bie Jnfeften von einem Bsfiederthiex geerbt, ober fie ftanment bon einen mit ben betreffenten gauz a rlgemeinen Merfmalen

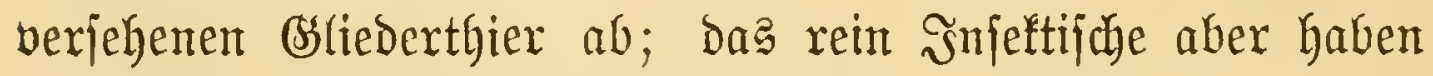

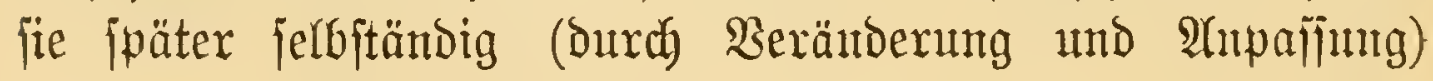

*) CEitu gebrängte Darjtellung Des gegentwärtigen Stantes jo= wie ser Siteratur bar Jnjeften=\$alïontologie gift (Memoires of the Boston Soc, of Nat. History 1879) Der beriibnte amerifaniface Ento=

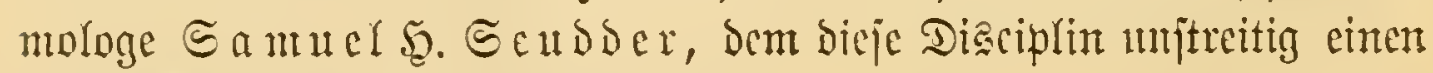

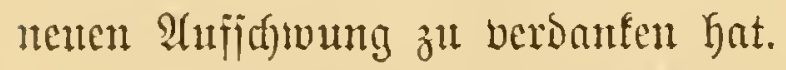

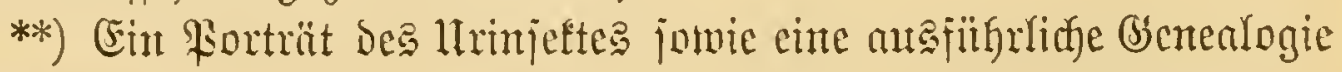

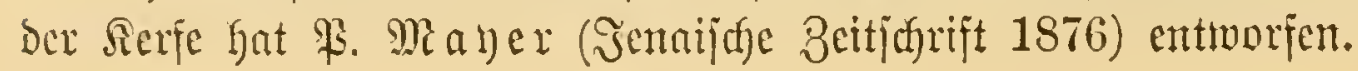




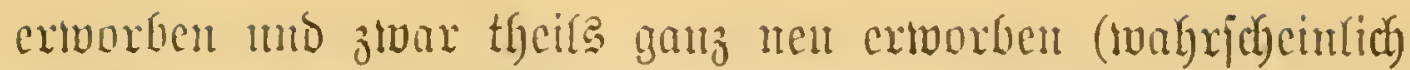

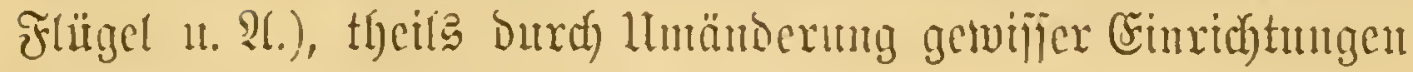
ifrer Sorfathren (Beine, Mcumbtheile :c.).

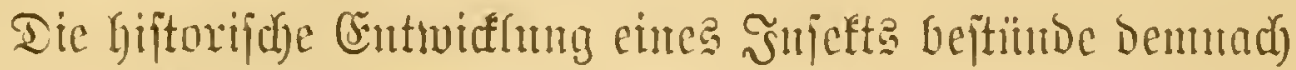

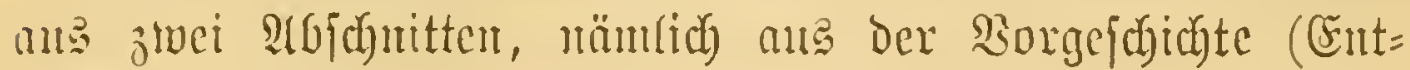

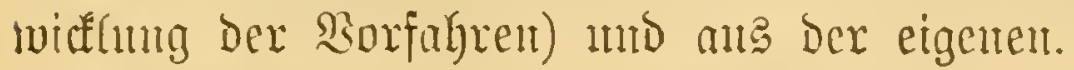

8wei äguliche Sierioben zeigt uts mut and in Der That

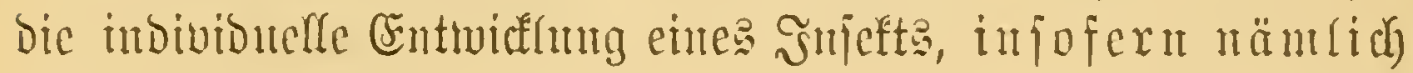

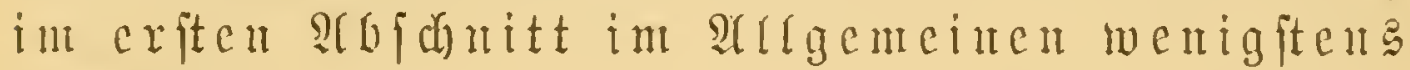

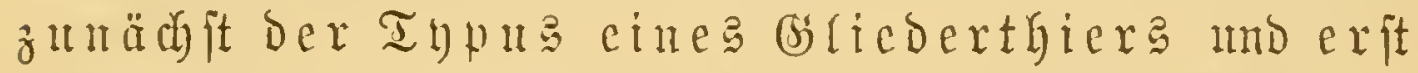

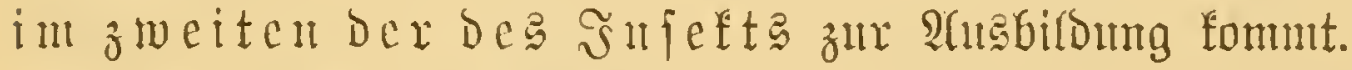

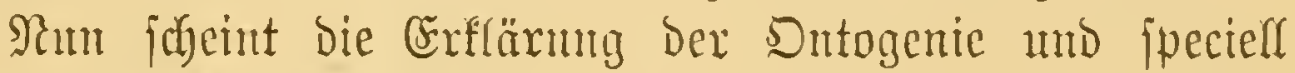

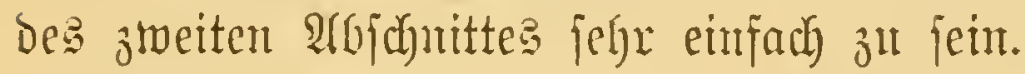

Denfen wir ums cimmal als Stamminjett ein jechis= beinige aber nod) ganz flïgerlofes sśliedertfier umb zor in jwei Exemplarent.

Die Nachfonmen bes einten Cremplars jeient im Ianfe Der

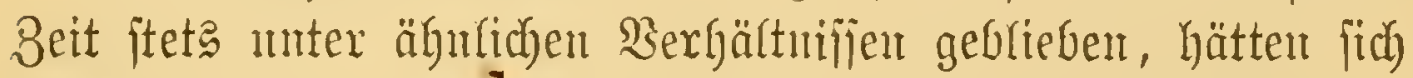
aber benjelben, in Sintof ums Dajein, immer volffommenter

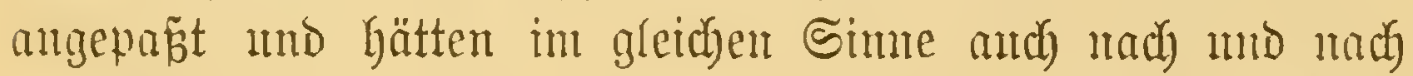
bie Fftugorgane, jowic manthe mocre imaginale Charaftere erworbert.

Die Micberfolung ocer Recapitulation biejer fuccejition

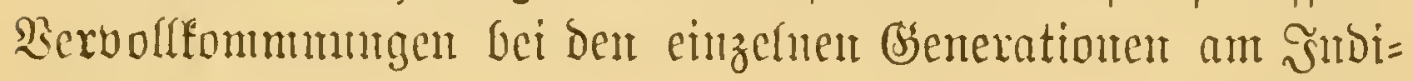
vidunm gäbe mut bas, was roir die einfache fortidgreitento Entwicflung memten.

Die PRarbfomment des andern Exemplars Dagegen wärent in Qanfe ber Beit unter jebr abweidyenden Bebingungen gerathen mo bätten in Forge Defien nach mb nady aud jebr abmeidjende

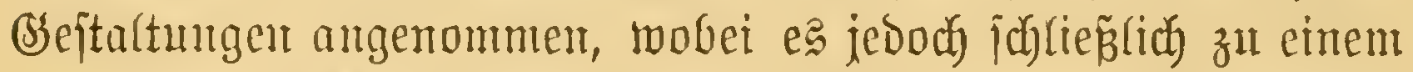

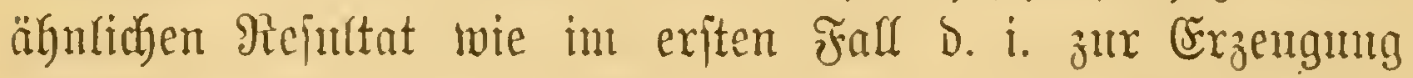
einer geflïgelten und ïberfantpt eimer edft imaginalent Biene= ration fam.

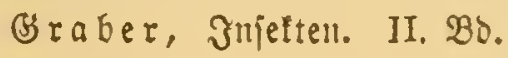




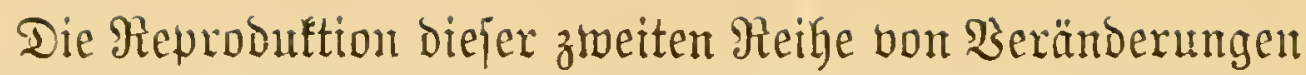

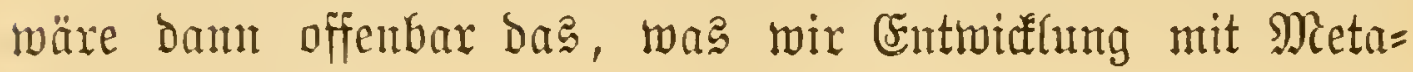
morphoje heinent.

Ja joll bem aber bie gegenwärtige Entroidfung wirflich nux eine jhablonemmäp̈ige Ancinanderreilyng früherer Form= zuitände fein?

Cine cinfache Betradytung Yehrt, Daf bies Durahaus nidat Dex Fall fein fant. SMir Dürfen nämlich n. $\mathfrak{A}$. nidht vergefien,

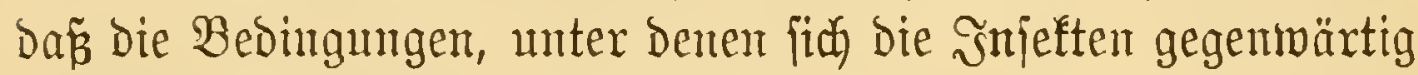
entwicfeln, vielfach ganz ambere find wie in frühern ßerioben, und unjere Sanuptanfgabe iłt ç mun eben zu zetgen, was bie indivibuelle Entwiflung von ber hiftorifden ober Stamme geididite unterfideidet, was aljo bie jpecififdue Eigen= art berjelben bebingt und a

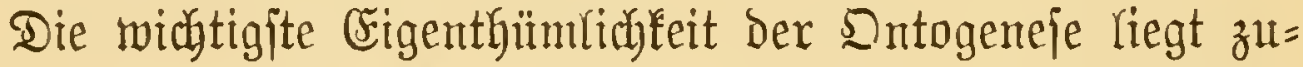

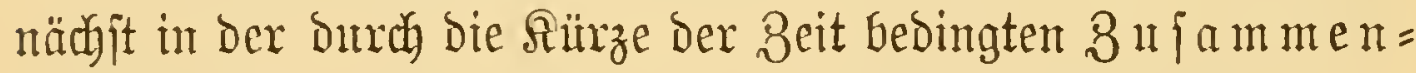

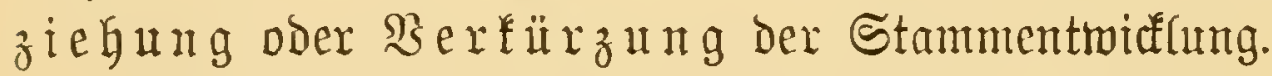

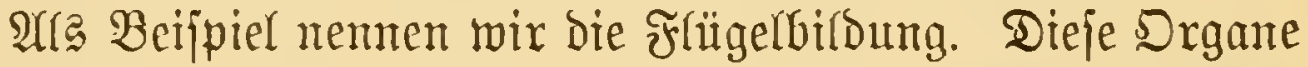

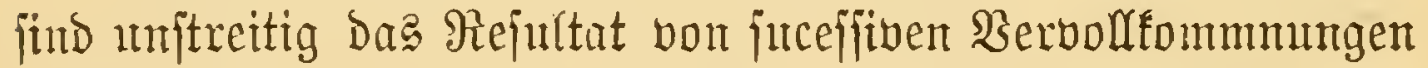
gemifier Şautfalten, bie wohl erit im হaufe zahlreider Słene= rationen jo weit gebieben find.

Snn ber Sntogeneje aber wiro biejer Procés jegr rajd

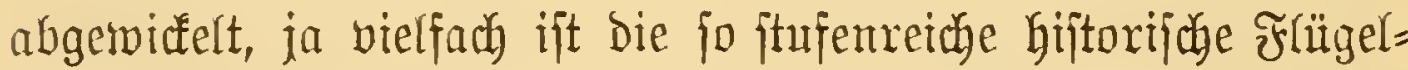
biloungaperiode ibeinbar mur Durbit ein einziges Stadium vertreter.

Fine zmeite Eigenart berugt auf einer andern erin= theirug ber erntwidugazerioden.

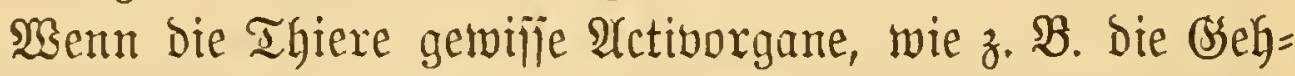

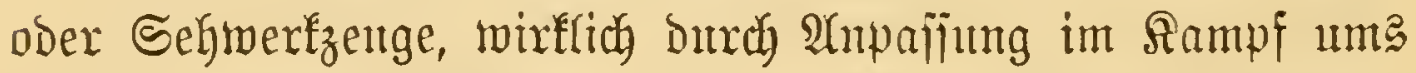
Dajein ermorben haben, jo ijt body flax, Dá biez midt im 3uftunte des Eies, wo es ja noch nidhts zu laufen und zu fehen gibt, jonbern exft juätex, während igres freien $2 e b e n s$ gejuehen jein famm. 


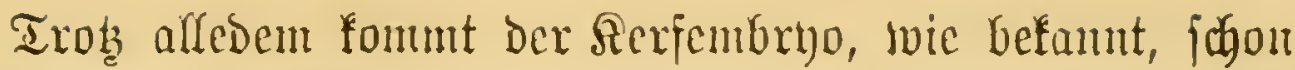
volfitändig gemappnet iuts ber Echale, ja es cutrickeln fich bereits in Ei jogar jolde Einridtungen, wie z. B. Die Facett= angen (ber Âmetubolen), bic Stigmen u. . w., weldye phylo= gentetiju gewi苗 relativ jungen Datunts find.

Bedenten wix aber, baf ein Thier und gar ein fo ungeheurer Concurrenz und Ânfeindung augejetestes, wie Das Jnjeft, jhon fïr den erften Bedarf bes freien Rebens
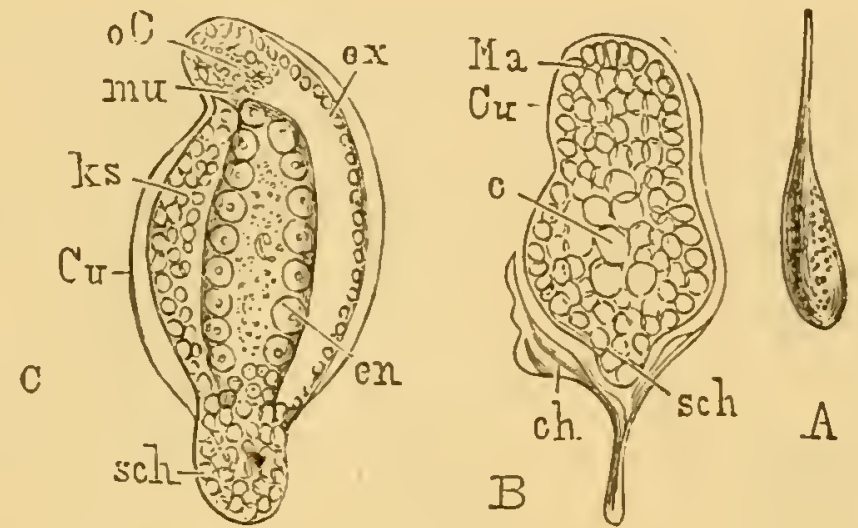

Fig. 209.

Entwialung einer Sd)lupirorspe (Polynema natans), nari) (S) a nit.

A Beftieltes Fi.

B Erite Earbenform mit Theilen ber geiprengten (Fihaut (ch). Ma Jautepitbel (Froberm), Cu bie babon abgeionberte Cuticula, c grö̈e Eentral= (Entoderm=)

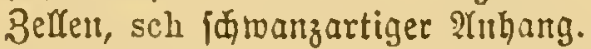

C IImmanblung in bie zweite \{arbeniorm. Anlage eines Seimftreifక (ks), Bilbung bes Darmes (en), oG Bebirngangtion, mu Mundipalte. Die Caticula (Cu) Der eriten Sarbenform ift gelodert.

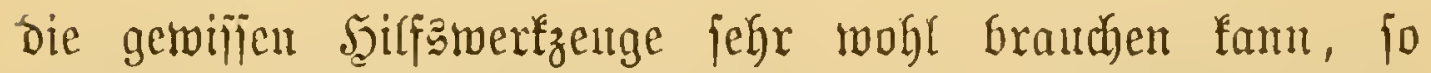

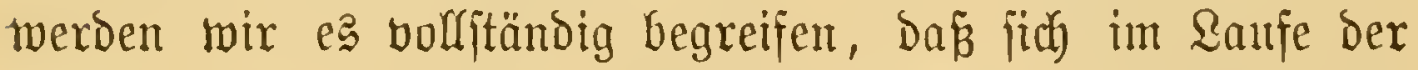

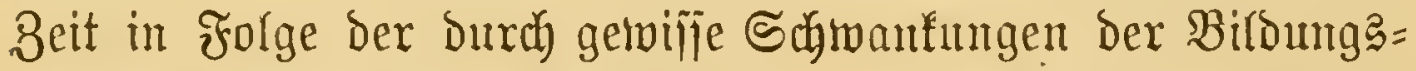

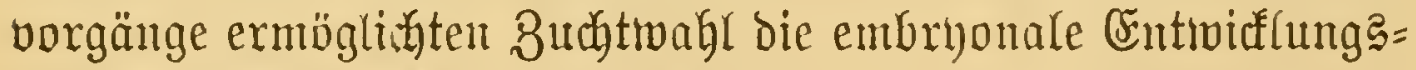
periode unter Berfiitrang Der poitembryonalen und unter $\mathfrak{B} e r=$

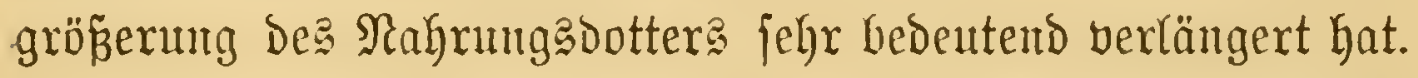

Sownie es aber für bie meiften Jnjeften voll gropent Bortheil ijt, bañ fie möglichjt jpät beziehungsmeife in einem 


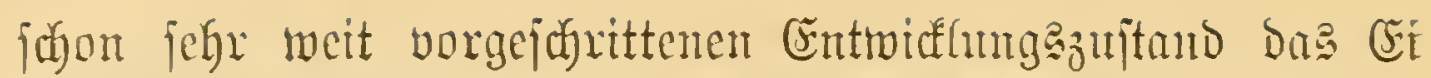
verlajien, jo taun es, jumal bei groperer Aleintheit bes Eres,

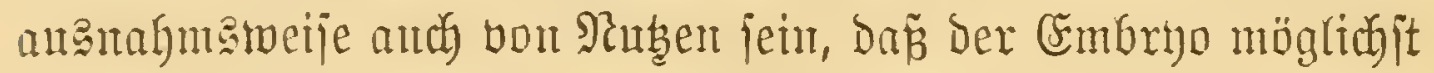

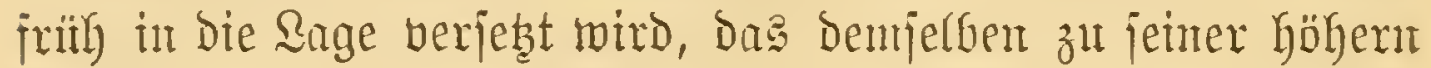

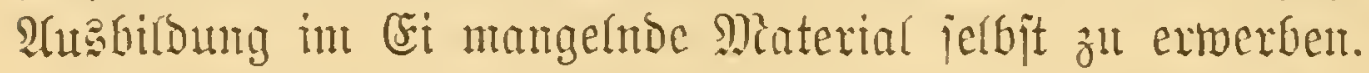

Eine Derartige ßerfitrzung Des Embryonallebens fonmt

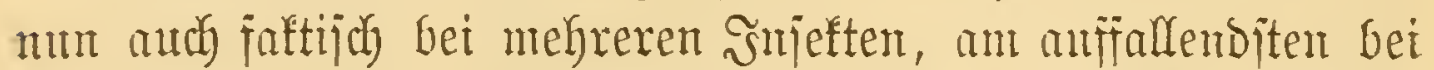

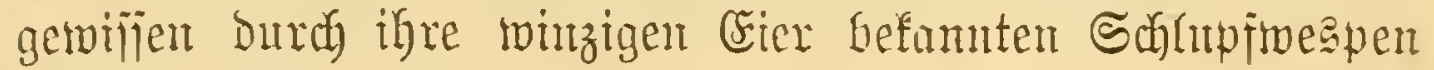
(Riterontalintert) bor.

Frig. 209 A zeigt mady (b́anim bas mit eimentangen

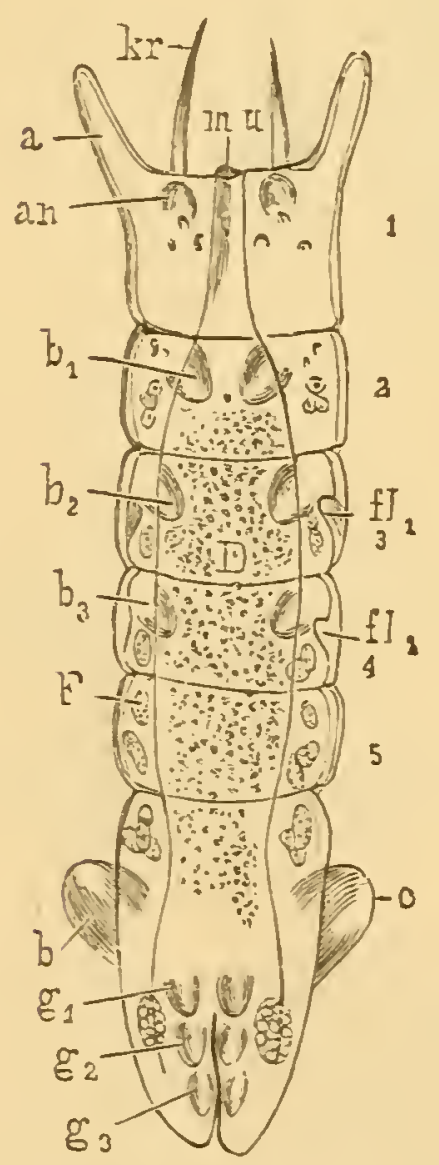

Fig. 210.

Dritte iog. Hystriobdella (eine 2 rt Blutegel) ähuliđe :arbeniorm.

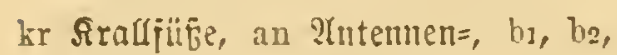
$\mathrm{b}_{3}$ Rein=, fl1, fla frlugel= unb g1, g:, g3 Genitalanlagen, F Fettförfer.
Stid verjehene ci einer foldyen (Polynema) und B bie in itber= rajuend furzer Beit Darats Gervorgehende (erjte) ミarbe. Der äup̃exn noch völlig imbifferenten Forn madi) ijt lestere aber jozujagen jelbjt now ein Eit,

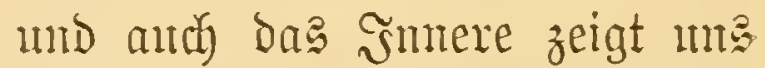
ftatt Der mannigfaltigen Drgane anderer Serflarben nidyts weiter als cinten Şatifen Bellen, bie jich jpäter (C) in eine Sountlage (ex) unb in cine cine $\mathfrak{A r t}$ Darm= Göhle forntirende Bintenlage (en) jonbern. Benannte Şöhle mo

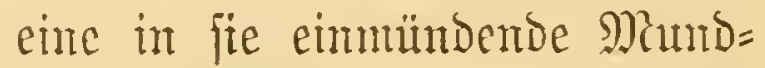
ipalte find and bie einziger Drgante, meldye Der jojon weiter entwicfelten (ober zreiten) \&urven= form zufommen und mit twel= chen ite bie ofen angebentete Fsultion Der Ernälurutg volf= ziełen. 
Das, was aubere Ŝljeften und Bsfieberthicre überhant

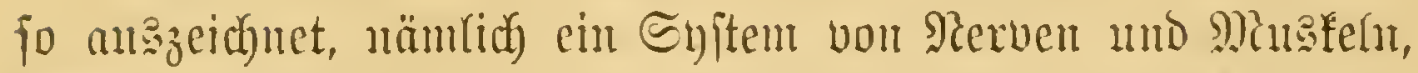
fonmt exft jpäter aus einer keimitreifartigen Serbicfung bes Bandjeroderma (ks) zum Sorichein. Die Defintitive (3.) Rarven= form ift in Fig. 210 bargeftellt.

Bei einigen antoen Riteromalinen (Platygaster z. B.) ift bie erjte anve (Fig. 211 D) wegen getwifijer an Der $\mathfrak{A b}=$

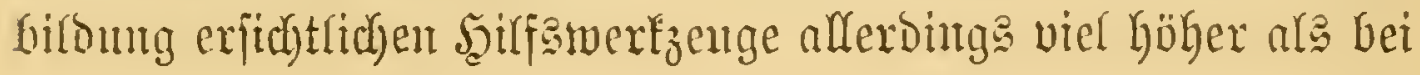
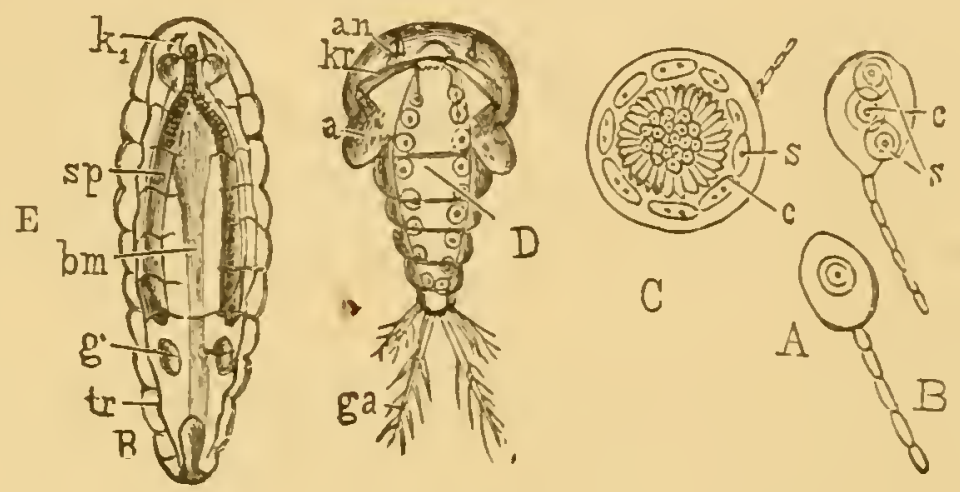

Fig. 211.

Entroiđlung einer ansern fiteromaline (Platygaster).

A ranggeftieltes Ei.

B S̆ Theilung.

C Späteres Stabium, too aus ser Centralzelle (c) ein foliber Belfhaujen, der Fmbrbo, und aus den Polarzellen (s) bie Embrbonalhülle entfanden.

D Exite, aus dem (Fi ausgejulïpite jog. chclopsartige \&arbenjorm, an Intenten,

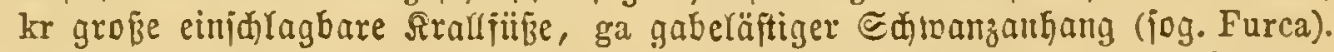

E Dritte Rarbenform. ki Dberliejer, sp grofie Speidelorüjen beiberjeits bes

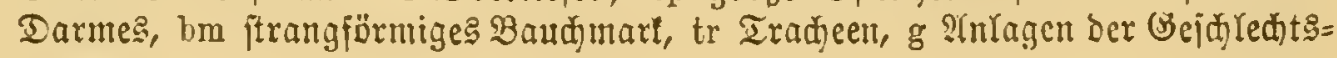
organte.

Polynema; ifr Smeres ift aber faum mentiger mangelhaft

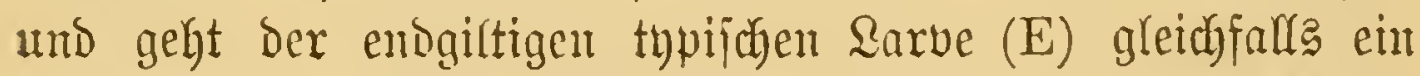
Galb puppen=, Galb embryoartiges Mitteljtabium mit Reint= \{treif vornuz.

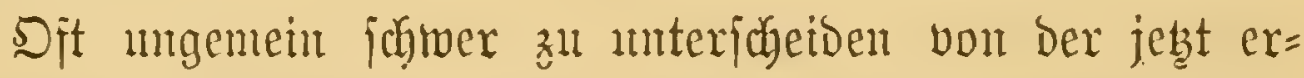
räuterten Berlängerung refp. Berfürzant cinzeluex Ent= widfungâperioben ijt bie eigentlid)e ßerjediebung berjelben, 


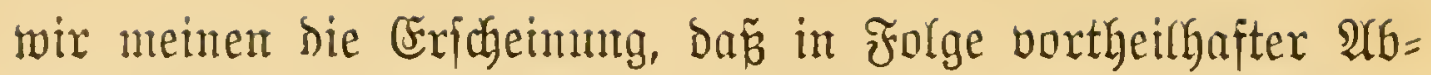

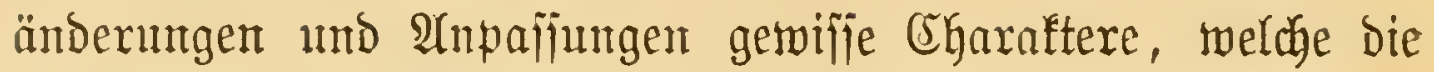
Sorfahren der Snjeften relatio fpät ermorben haben, in ber Sestentroiffung relatio frïh und ungefegrt auftreten.

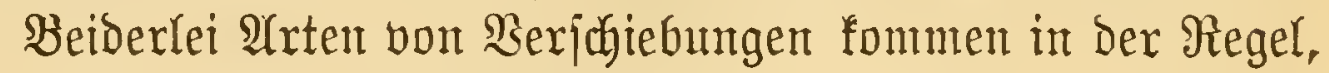
twie folgendes Beifpiel Yebrent ntag, vereint vor.

Die Flïgel nimmt mant wohl duragebends, da je ja ein

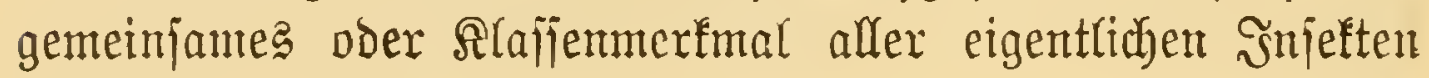
Gilden und a u bereits an ben $\Re$ erfen ber Devon= Formation ben heutigen Typus zeigen, als fehr

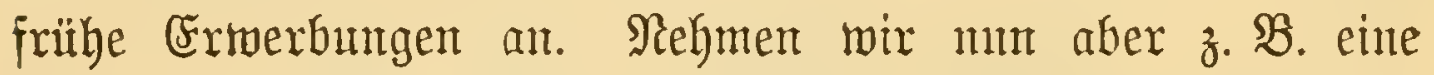
Werre, jo zeigen jich Deren flügelanlagen erjt nach einigen Şäutungen, unb bei den metabolijacn Эnjeften fomment fie,

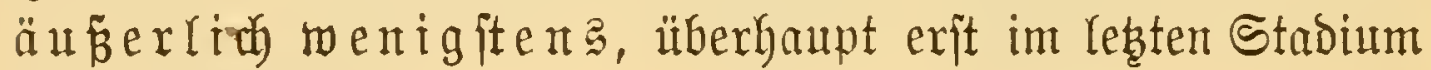
zum Borfyein.

Mir namten aber jpeciell bie $\mathfrak{B e r r e , ~ m e i l ~ m a n ~ b i e j e r ~}$

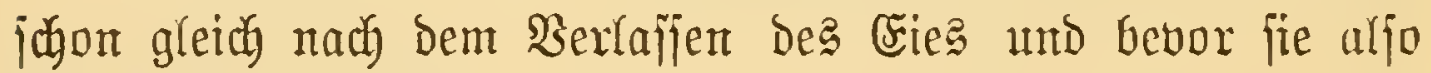

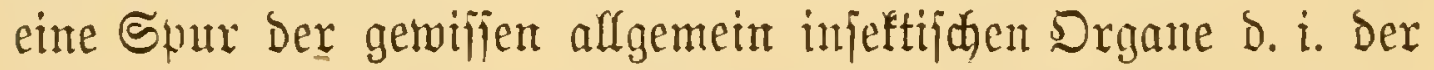
Flügel zeigt, nitht blof die Dronung und Familie, fontern faft fidon bie brattung anfemnt, zu Der fie gebört.

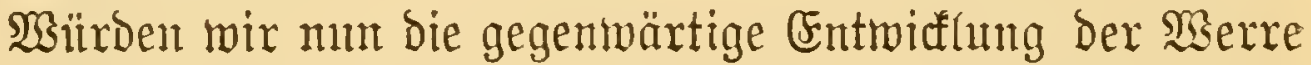
als getrene und nidgt als "gefäljoble Miedergabe ber

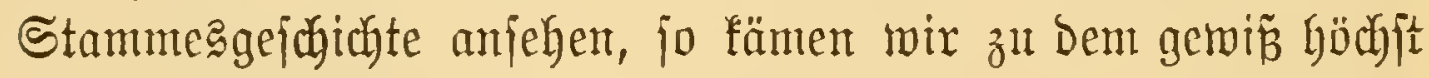

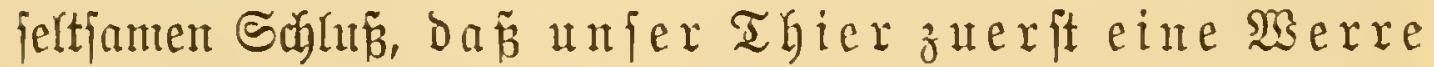
und Daun erit ein (geflitgelteg) sujelt geworden ift.

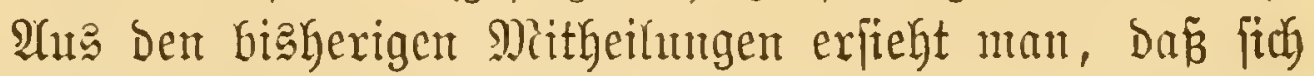

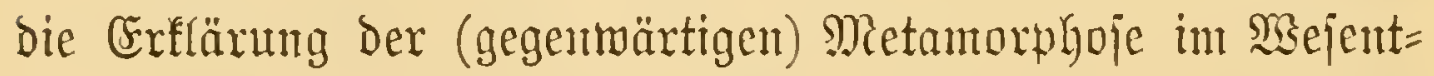
lichen um Die Frage Drebt, weldye Formzultände ober Ent=

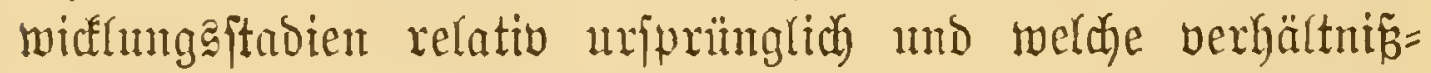
mäp̃ig neutern Datums find, mo wir wollen uns mu Darïber furz zu orientiren fud den.

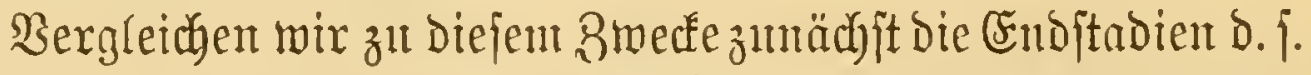

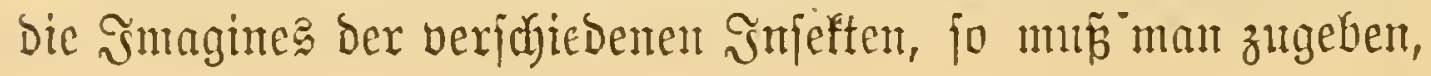




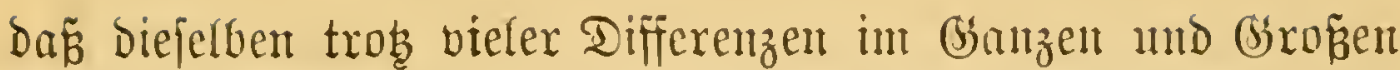

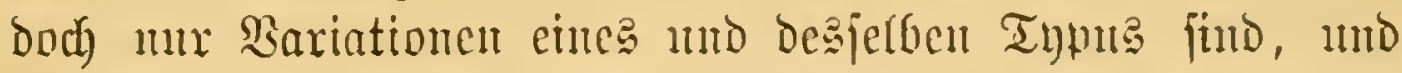

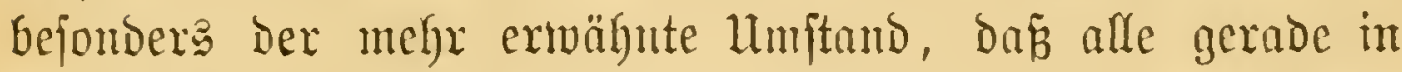
einem Merfunal, Das fein anderes Thier befitst, wir meinent

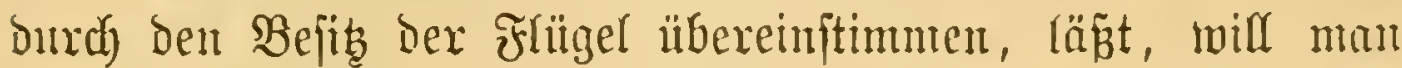

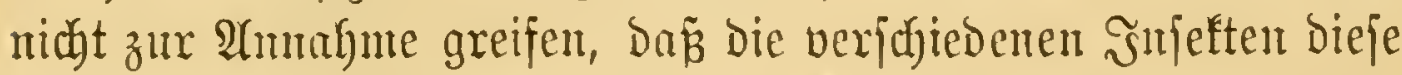
Srgane jelbjtänbig ourd conbergente Anpafintug errourbent haben,

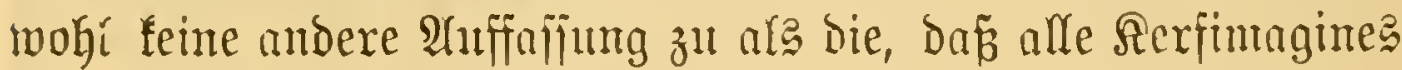
voll ciner gemeinfamen geflügełten llxform abftanmen, und

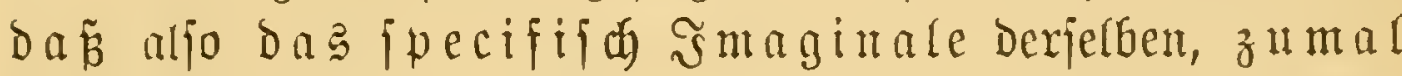
Der Flügelbejib etwas relatio uriprünglides oder frübertoorbenes ift.

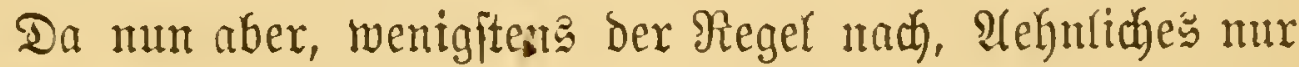

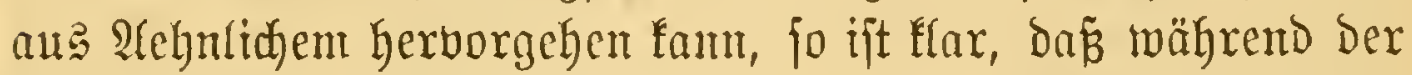
Silur=?eriode ober noch frither, mo die erften imaginalen

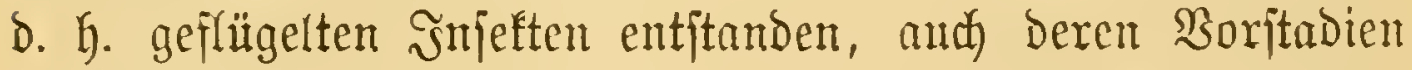
refp. Deren Rarven fowohl unter einander als and Den Smagines ähnlidu gemejen jein muñtent.

Muftern wir mut aber bie gegenmärtigen Sorftabien

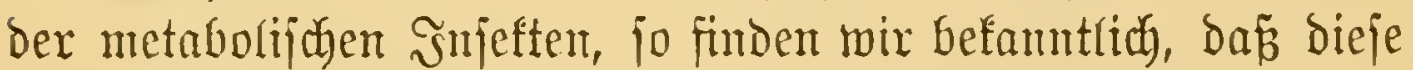

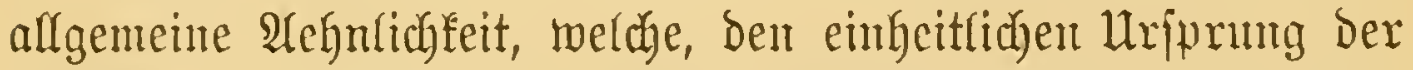
Snjeften voraugejebt, unjeres Eradjtens eimmal nothwendig

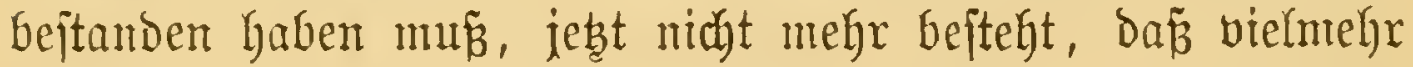

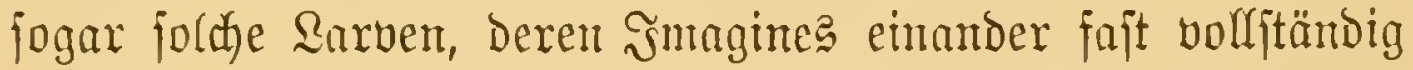

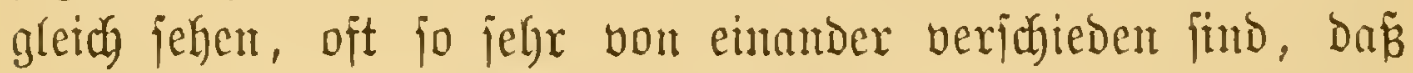

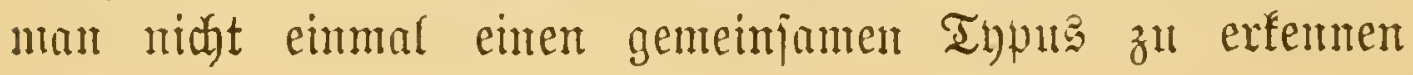
vermag.

Dieje Erjobeimung läp̈t mun offenbar feine andere Er=

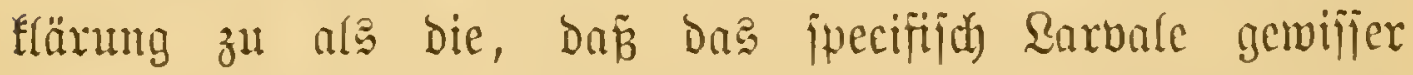
heutiger. Borjtabien relativ weit jüngeren Mrjprutg? alg

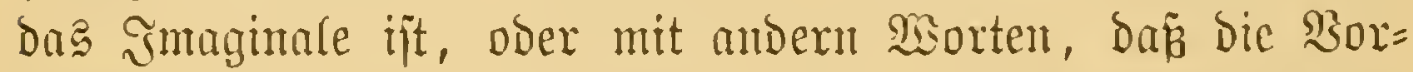
ftadien ber Jnjelten in Folge nener für fie vortheiffafter

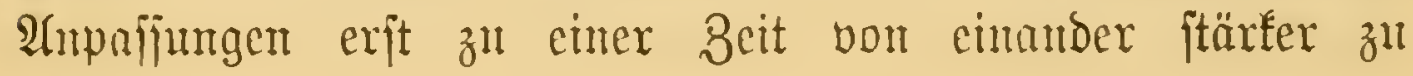


Divergiren anfingen, als bie hiftorifabe Prexiobe der Juntugi= nalfitumg idon worüber mar. *)

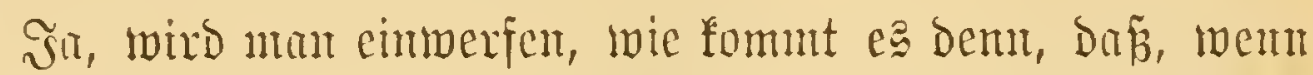

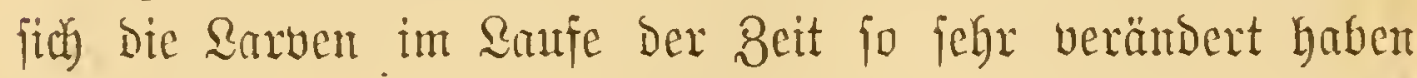

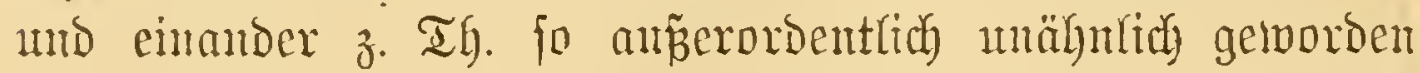
find, ifre Imagines, wie oben hehantet worden, bod) wenig=

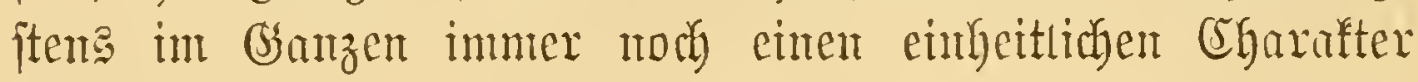
Darbietelt?

Diejer für mijere Theorie jheinthar höbjit Gedenflidye (Fimmurf findet indez in einer bereits in ber vergleidfentoen

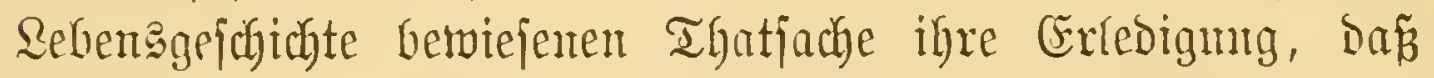

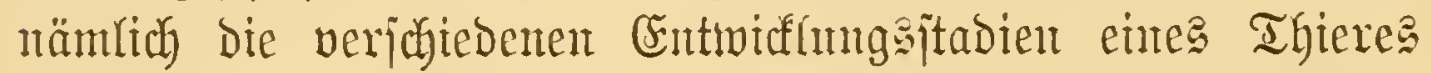
bis zu einem gewifijen brrabe ganz unabhängig von eitander

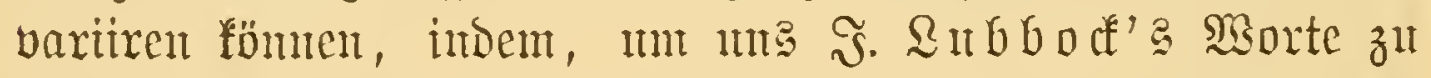

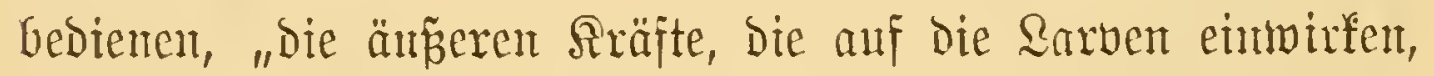
vou betten verfateden jutro, weldye die reife Form beenflujijen, und Dem entfprechend in ben Jungen Seränderungen herbor= gebradyt werben, weldye wentiger anf bie befintitue beftalt ale anf bie augenblidfichen Beditufuije Bezug haben".

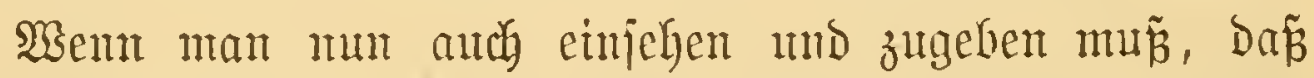

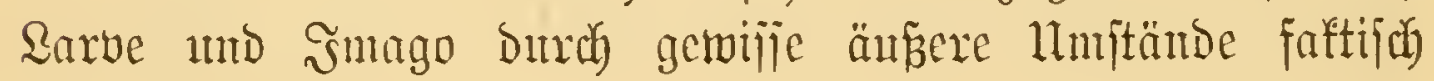

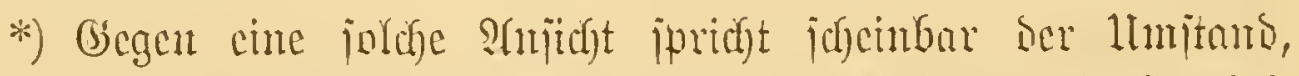

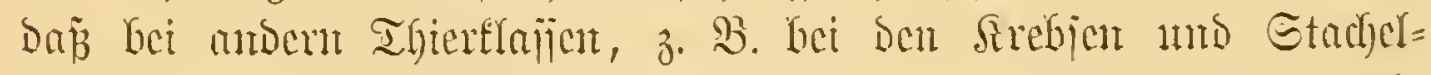

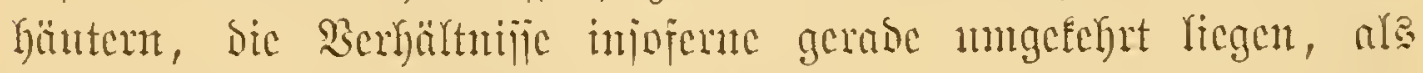

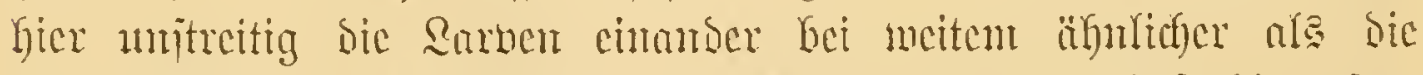

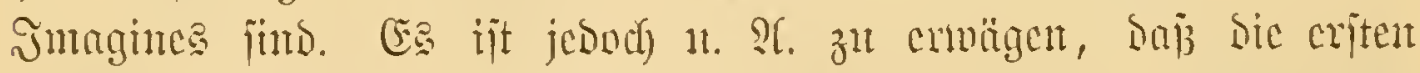

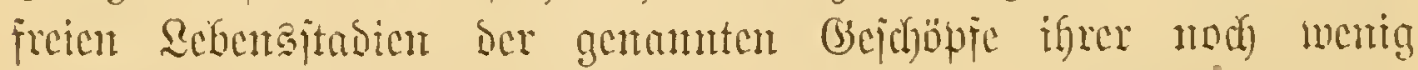
Sififerencirten Drganijation Kalber nicht mit ben meit häber itelgenden

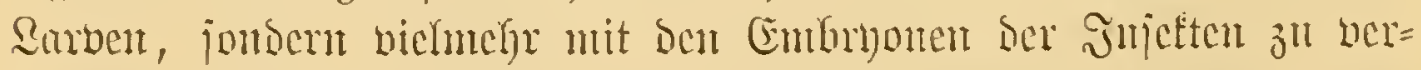

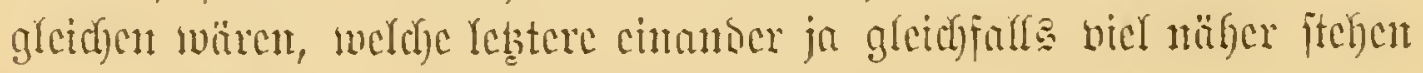
als sie Jutugines. 


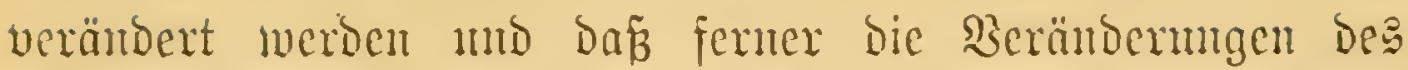
cinen Stabimes nidyt immer mud cine gleidygeridatete ober correjponbirende llungejtaltung bes andern febingt, jo breibt es

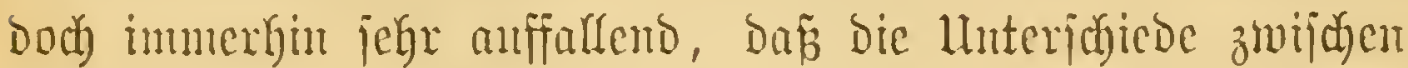

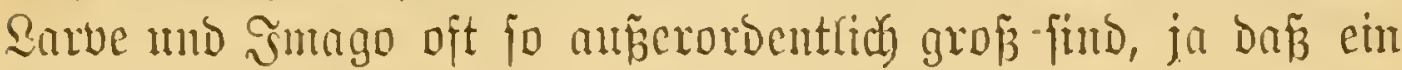
mb basferbe 柋eju nad) cinamber gerabezu contrajtixende Formen mo Rebenagewohnheiten Darbietet.

Und in ber That ijt mit Der Berührung biejer Frage Der eigentridye Rermumet Des gejammen Metamorphojen= problents getroffen - zugleidy aber and bie Belegenheit ge=

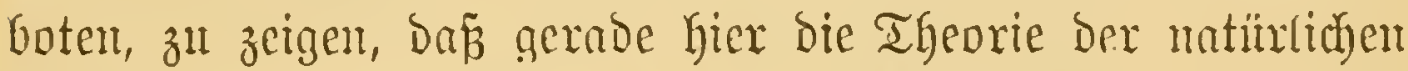
8udbtwahl bie einfadjite und bie volftommenite Röpung gibt.

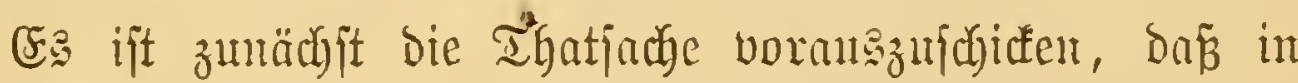
Antetradyt der ganz enormen, Der alle Begriffe überiteigenden

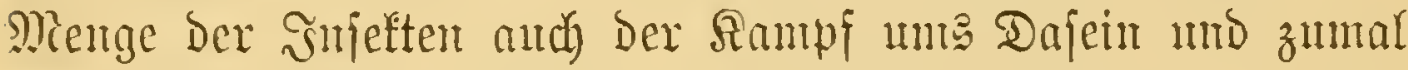

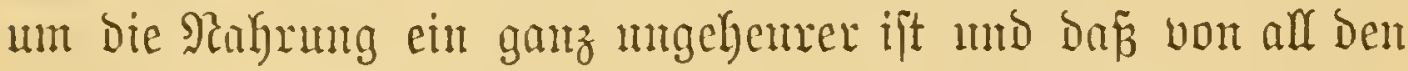

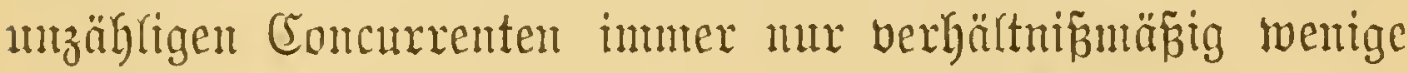

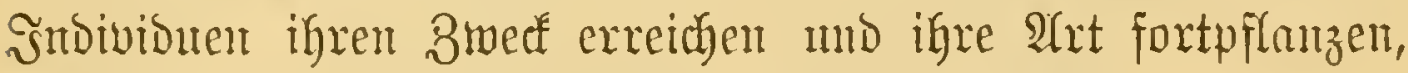
wäbrend die übrigen vorzeitig zn Srumbe gehen.

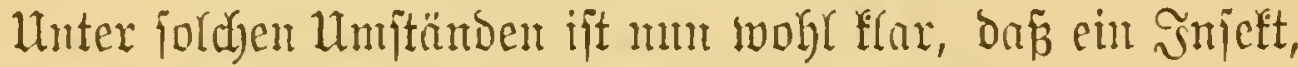

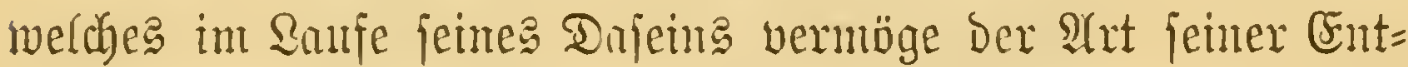
wifflung ein Doppeltes Rahrungägebiet beherridyen würoe, wir

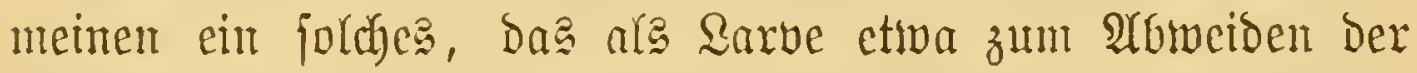

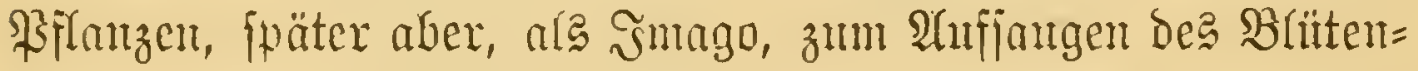

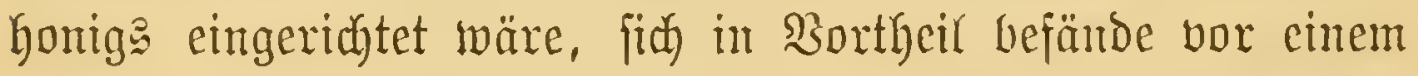
andern, bas in beiden Rebentaltern ungefägr bie gleiche D $\mathfrak{x}=$ ganifation bejäze und in Folge defjen entmeder nur Blätter fanen ober mur Sonnig faugen fömte.

Went dię aber im alfgemeinten wenigitens und frecielf

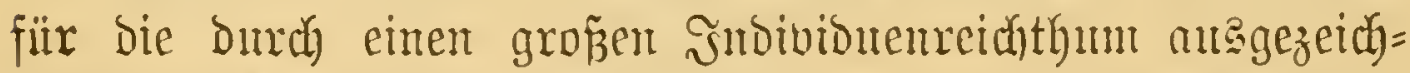
neten Snfeftenformen richtig ift, Dam ift and cintentatent,

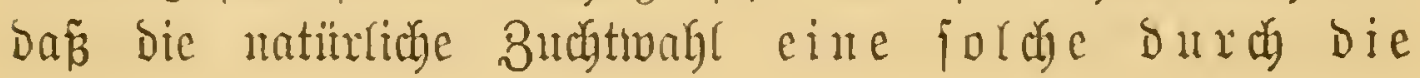


ganze Ratuxälomie gebotene Arbeita = und $\mathfrak{R a h} \mathfrak{x}$ ug geeigneter Sïrperberänderungen fräftigit unterftüben wirb,

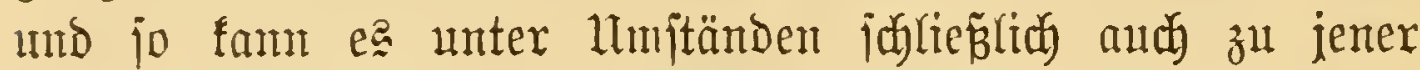
totalen $\mathfrak{B}$ edjellebigleit un $\mathfrak{B}$ edjelgejtaltigleit fommen, wie fie ja aud bei ambern Thieren, z. $\mathfrak{B}$. Gei ben

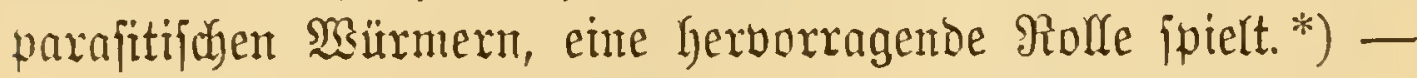

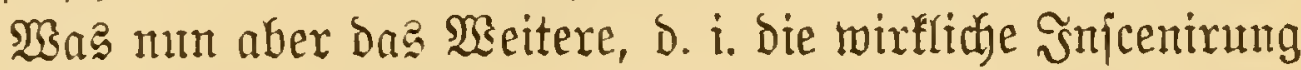
einer foldyent Segenjäblibjfeit und Sonderung zwijhen Rarbe und Smago anlangt, jo hat man da folgende Punte zut

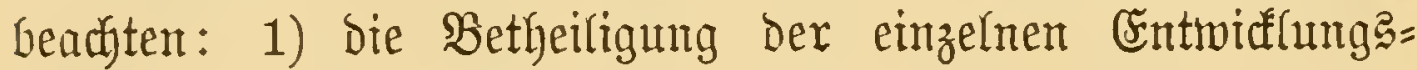

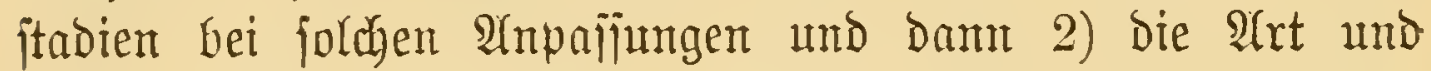
meije, wie bieje geideben und auf weldje Drgane fie fich Gauptjächlich erjtrecten.

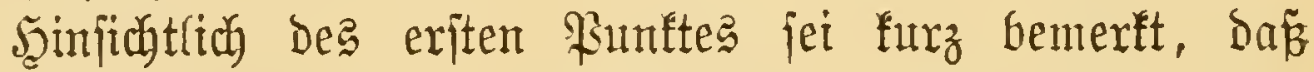

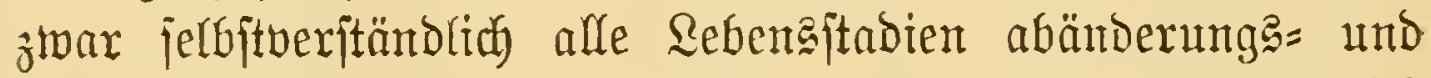

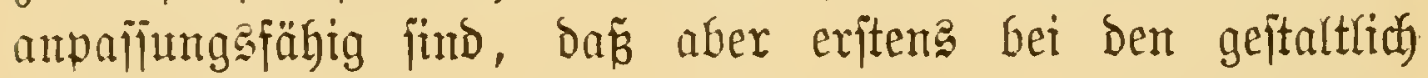

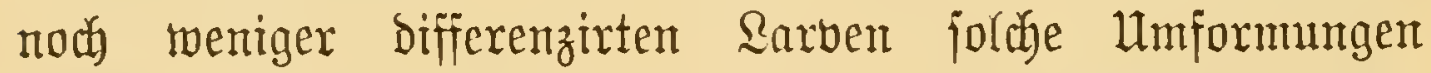
leiditer ausfühtrbar find als bei einem in morphologifider

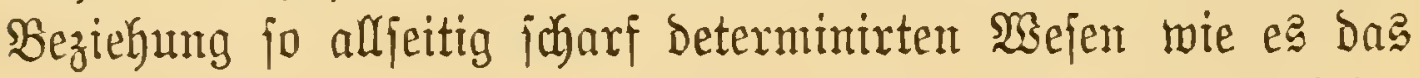

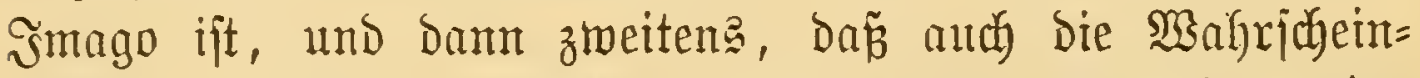

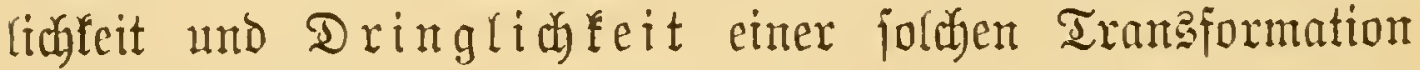
bei ben Rarben um jo gröperer ift, je länger ihr Leben im

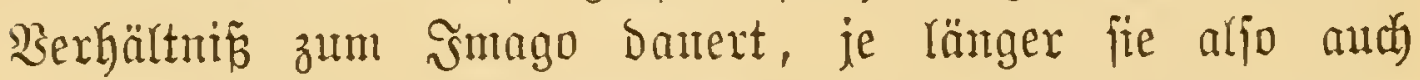

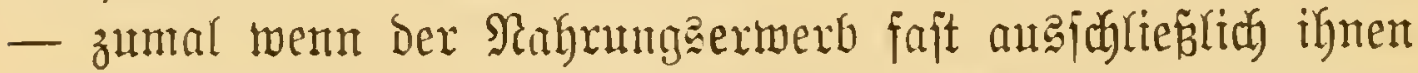
allein zufält - den unatebleiblicben Sampf ums Dafein zu füfren haben.

Mag Dann aber ben zmeiten Ristutt D. i. Die Natur biefer Anpafiutgen umb zwar fpeciell bei ber \&arbe betrifft, jo ift hiex nach Dem Frühern eine Doppelte Eridgeinntug ou

*) Schr nerjtärft mirb bicje Dinergenz Dutró die vielfältigent

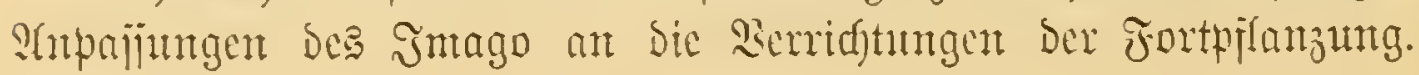




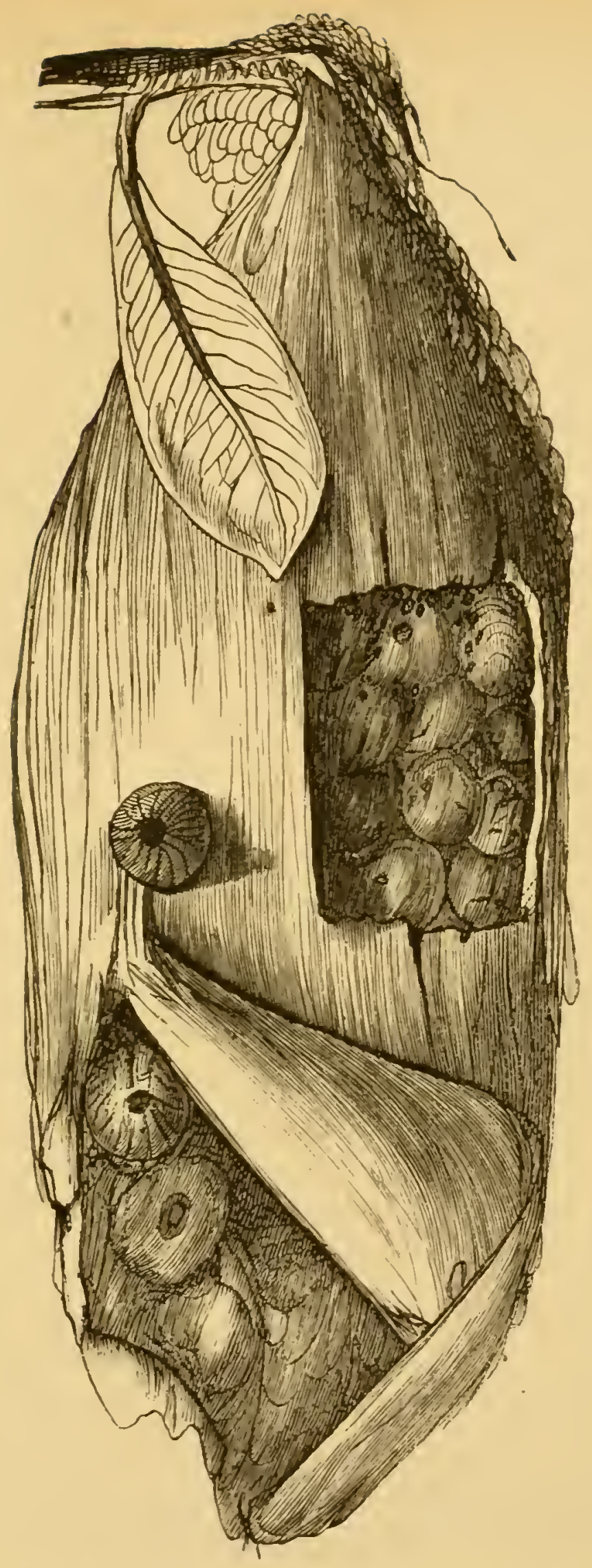

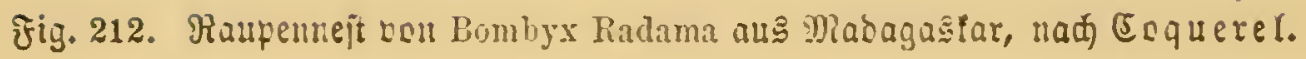




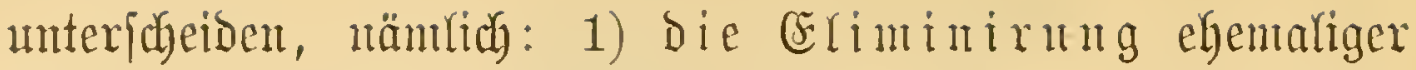
aber für bie nenen Rebenguerbältuifje zweefwibriger oder bod ïberflüffiger imaginalex charaftere, wie z. B. Der Frïgel, Dex Facettangen n. \{. w., wir nemen bię furz bie

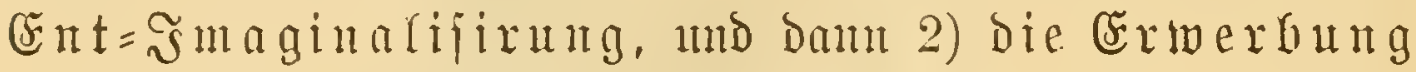
tener, wein proviforifder (sinridtugen, d. $i$, aljo

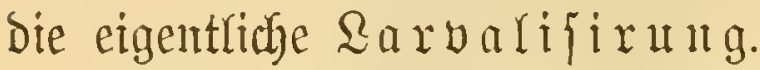

Bezüglich Der Ent= Smaginalifinung mörbten wir nod Darauf zurü̈ffommen, Daż bie verfteffte, wir meinen bie burch Cruftülpung ober gar Durd rein intertiche Reime bewerk =

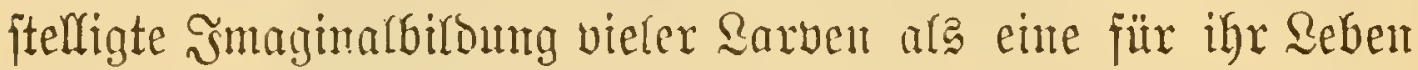
vortheilfafte Anpafjung oDer 2 bänderung zu betrachten fein Dïrfte, twährend ungefegrt z. $\mathfrak{B}$. Das frühe $\mathfrak{Z}$ uftreten ber Nebangen bei ber räuberijchen Corethra-Rarbe eine burch maheliegende Unttände exzeugte Wiederanuäherug a bag $\mathfrak{s}$ ntago bedeutet.

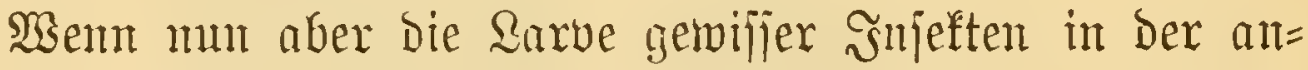
gebeuteten Weife nach mo nach ihre ehemalige unntittelbare

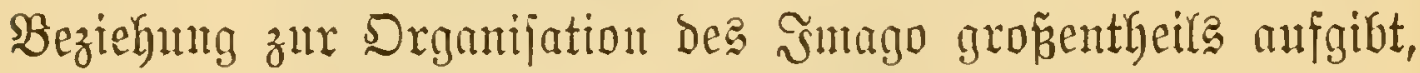
wie foll Dann aus ifre Dennody das rabtere herborgehen?

Nam, bieje Bermittlung bejorgt eben an Stelle ber eman= cipirten Rarbe ein anderes Wefen und bas ift, wie der Rejer wohl jugon errathen haben wird, die Bappe.

Da jei bent aber zunäbjit diejez herborgeboben. — Wix fömten uns fehr reidyt - und milfien es nady der Theorie -

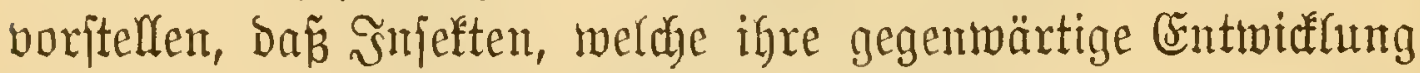

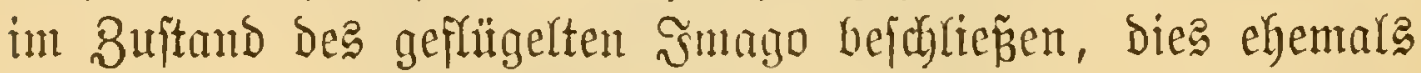
ars Rarben, fagen wix in cinem gantz oder fajt ungeflügerten

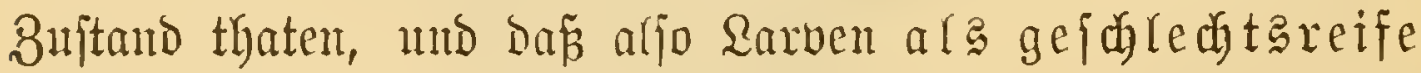
End formen mixflich cimmal gelebt haben und z. Th. nod

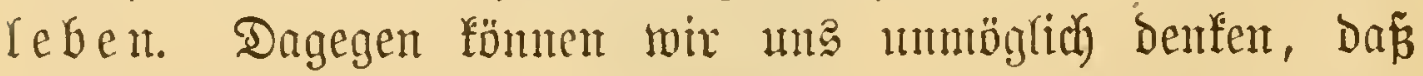

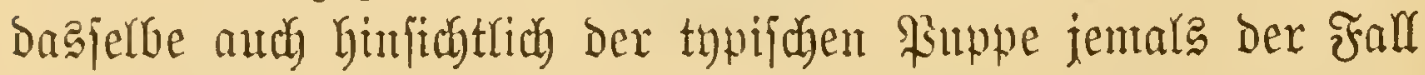
getoejen jei; Denn wie fönnte cin $\mathfrak{s e j e n , ~ w i e ~ e t w a ~ b i e ~}$ 
Tomtenpuppe der Fliege, fich fortpflangen ober ïberlyant

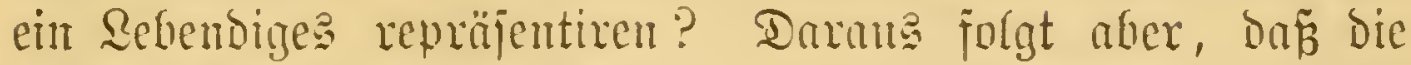

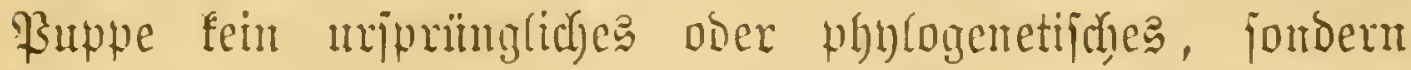
lebiglich cin jecundäres, ein ipecifij di ontogenetijacs Entwicfumgegtabium ift.

Man fum aber die Zeit und die Art Der Puppen= Birbung nod genaner bejtimmen.

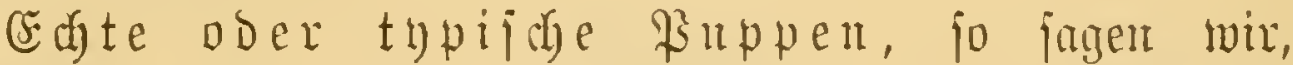
exifticen genall jo lange, als es jarle ent=

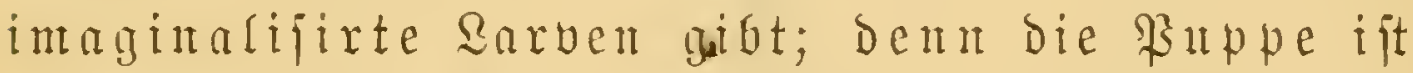
ja ebeu nidy

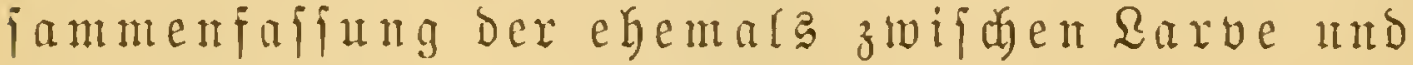
Snagu bejtanden Uebergangazutände, und biejes jpecififde biologifd um jo unjelbjtäniger, je felbitändiger und eigenartiger bie $\mathfrak{a r b e}$ ijt nnd ie höber jich ougleich bas hentige șmago ilber bas alte exhoben hat.

Bei biejer gleidjalls unter bas Princip Der $\mathfrak{A}$ rbeit: $=$

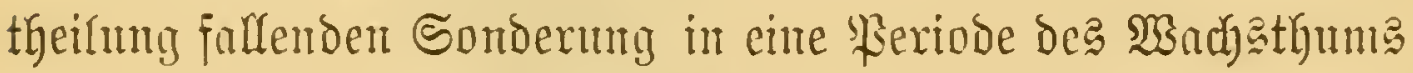
ober Der Larbe umb in eine Periobe ber $\mathfrak{B}$ ertand ober Der Płuppe ditrite aber möglichermeije nod) ein zmeiter Faftor von Bedentumty jein.

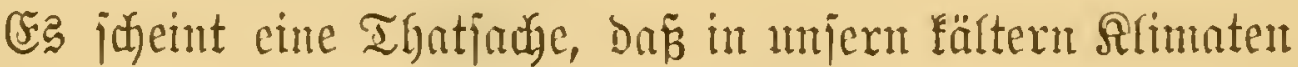
Der Zuitand Der 和upe meift in Den Wintex, in Den tropi=

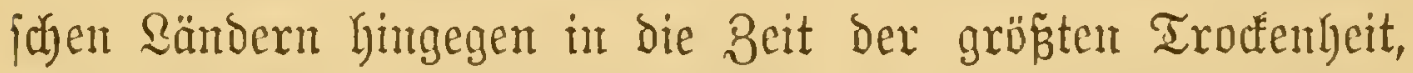
aljo beibe Male in Rerioden jüllt, wo bie für beu unter= Galt vieler Snjeftent notymentigen Bedingungen nidyt vor= Ganden jins.

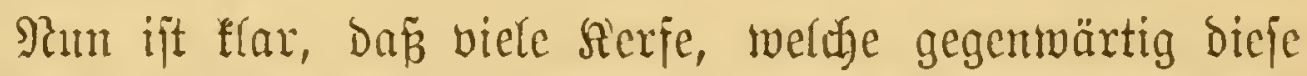

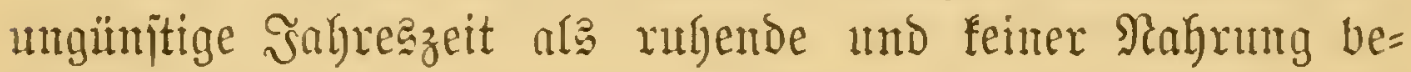

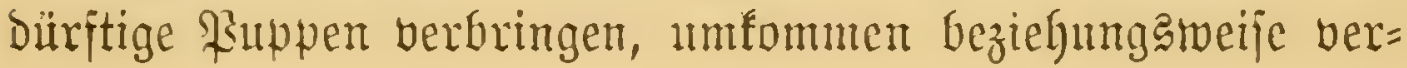


Gungern würben, wenn fie dies in einem freilebigen und nabrunģbedüritigen ßuftand thun müpten, und in diejem

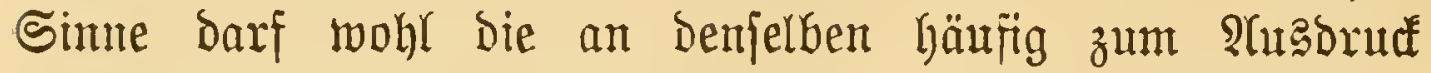
gelangende Mumificixung als eine auf ben Saub bes

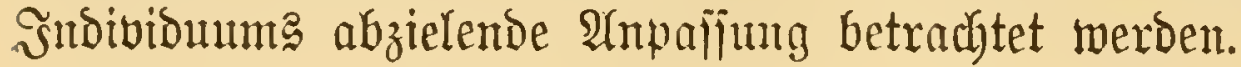

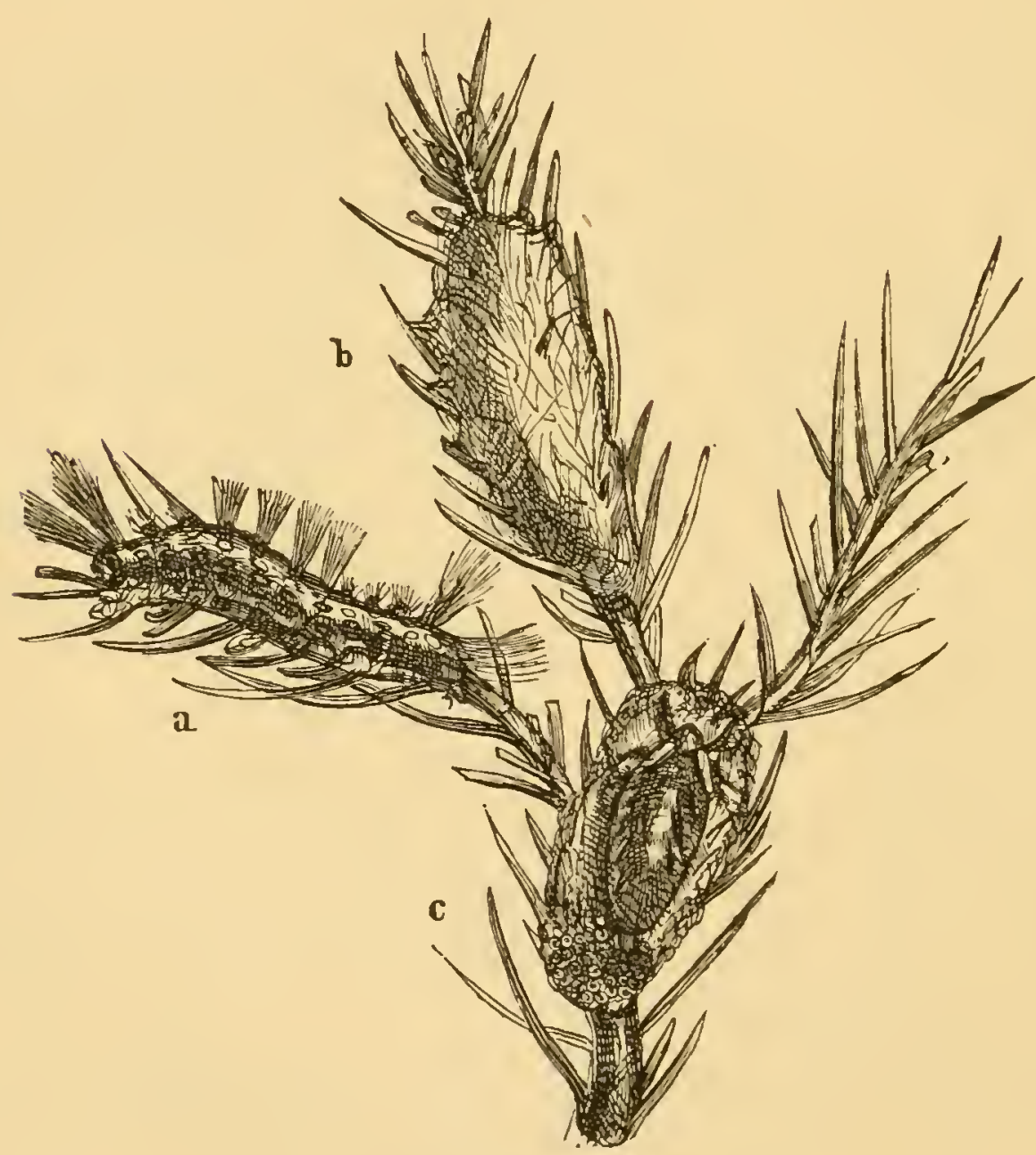

Fig. 213.

a Raupe, b eingeiponnene Puppe, c eierlegentes, jaft flügerlojes łunago bes Riejern.

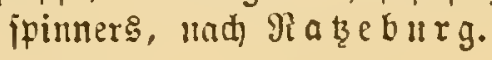

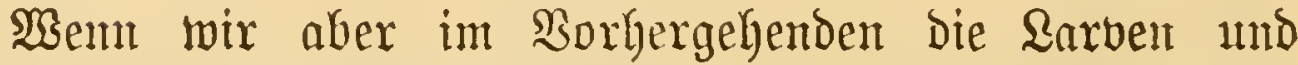

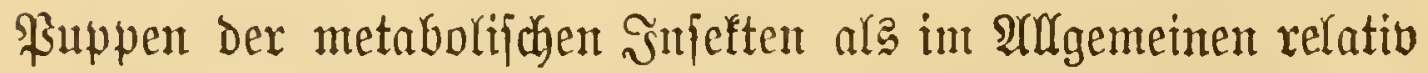
fpät entiftandene Buftände bezeidynteten, fo foll damit Ginjichtlich

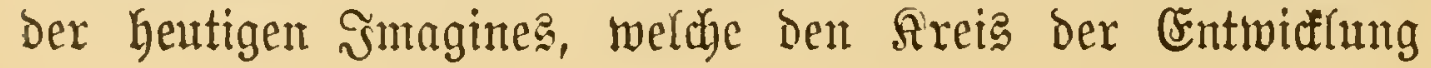




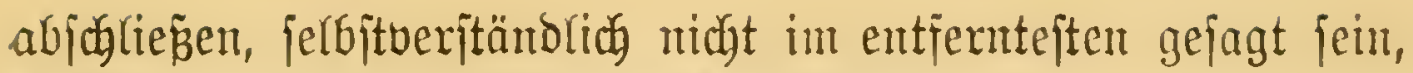

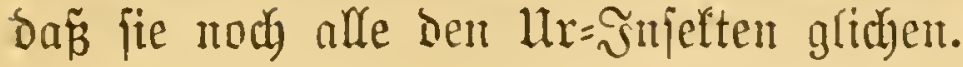

Der allgemeinfte Iypub der Yebeteren, der jeiner $\mathfrak{B}$ or $=$

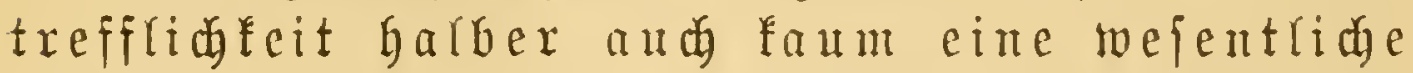

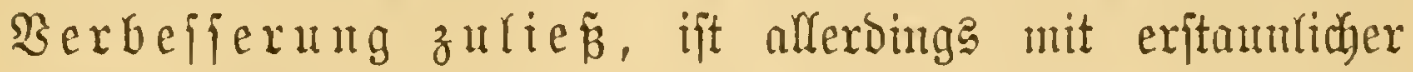
Treue bewal)rt worben; alles 1tebrige aber, bie ganze Detailausführung ijt z. Th. getwiés jüngern Uriprungs, uto

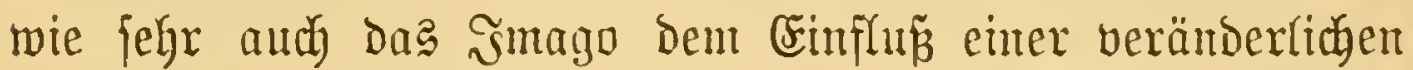
$\mathfrak{A}$ unentwelt unterliegt, bag fehen wir u. $\mathfrak{A}$. an ben Sintmen=

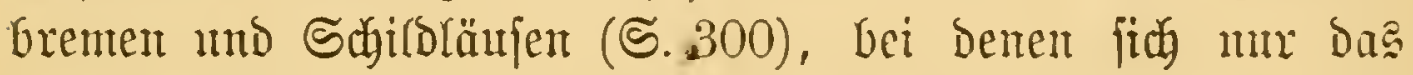
freilebige Männchen zum geflügelten Smago verwandelt, mäh)=

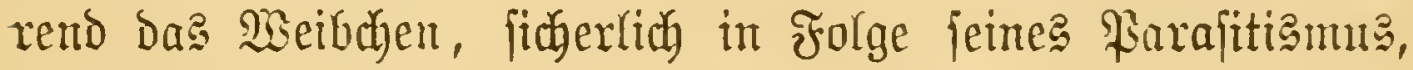
nod) unter Den Bujtand ber ミarve Gerabjant.

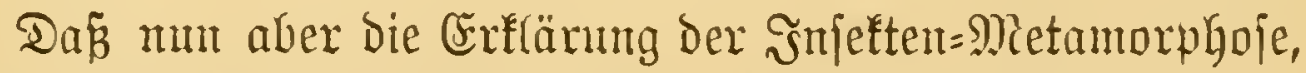
wie fie jebt flüritig ffizzirt wurbe, feinesmegs etwa, wie es Manthen jüeinen mag, jeber realen Srumblage entbehrt, bas wird fidy zum Saldifje aus folgenter Thatfache ergeber.

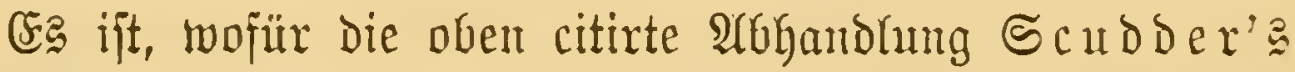
bie nöthigen Belege enthält, einfach bie, ba in in Den aller= ältejten 2 (blagerungen - vou der Silurformation an bis Gerauf zu Den burch einen faft mermeß̈liben Beitraum ge=

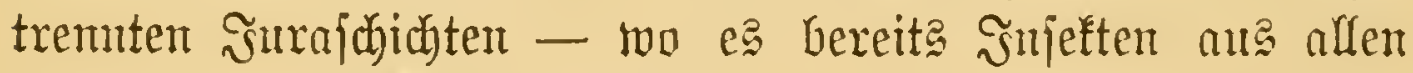

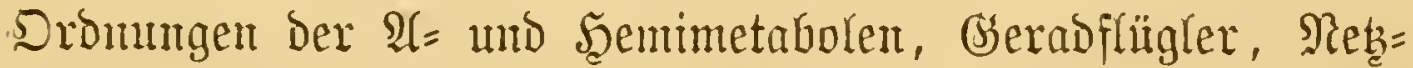
flügler, Schnabelferfe und auth Säfer in reidjter Fritlfe gab, biaher aud nibt ein einziges edyt=metabolifhes Serf, D. i. weder ein Scant= noch ein Zweiflïgler ober ein Schmetterling gejumben wurbe, und ba jener ganzen langen Periobe and nod feine typifaen arven ud Ruppen exiftirt haben. 


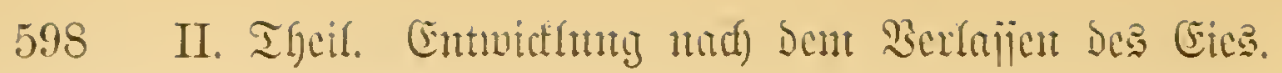

Dieje Thatjadye läв̈t mut wohl, svill man midyt zur böllig willfitrlidgen und unbegrimbeten Sygpotheje eimer mieder= holten Shöpfung bie Bufludyt nehmen, feine andere Deu=

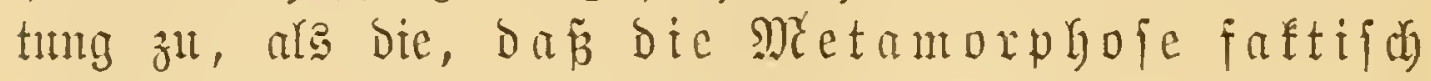

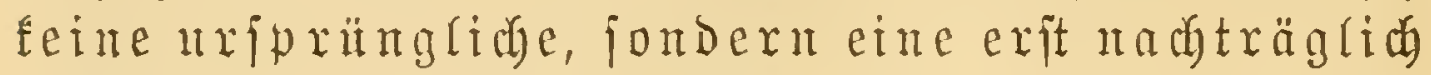

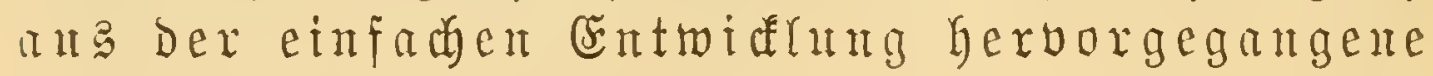
Erideciung ijt. 


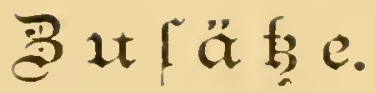

\section{Biologi佸e⿻上丨.}

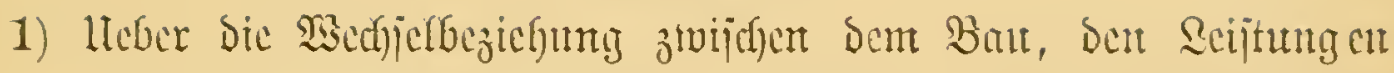

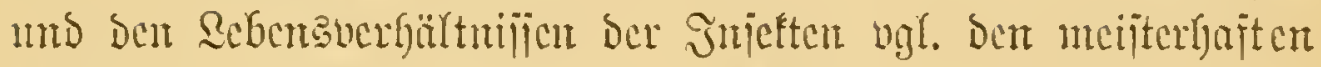

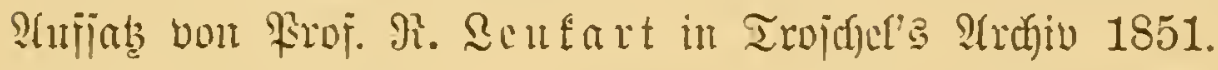

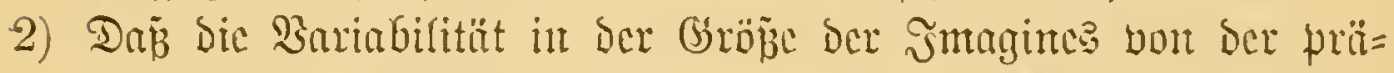

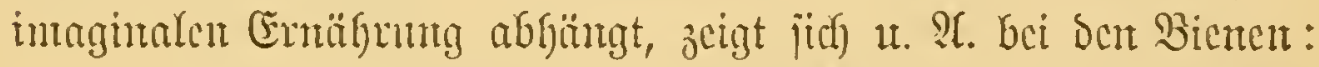

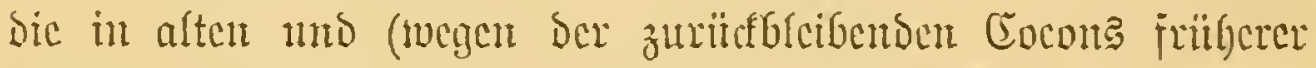
Jnjajjen) engeren Betfen aujwadjjenden werber fleincr, weil man

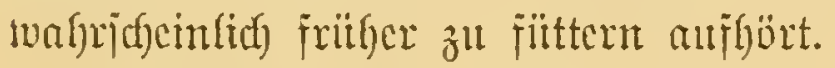

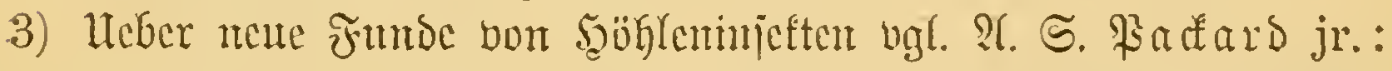
on a new cave fauna in Utah (Bulletin of the survey Vol. III. No. 1. 1877) utmo the invertebrate cave fauna of Kentucky etc. (American Naturalist 1875).

4) Heber bie Convergenz zmijgen Den Rarventwohnungen getwilier

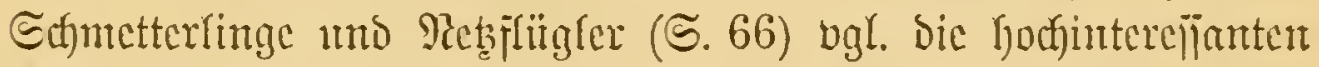

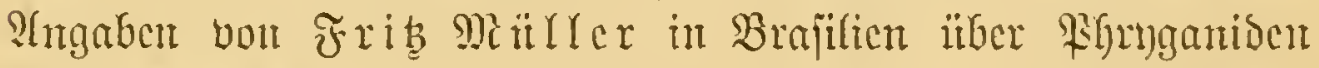
(zool. SUtzeiger 1878 uno 1879, wo man aut am rajujciten

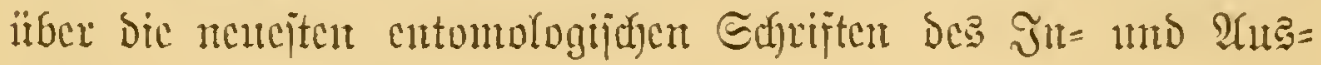
Iandes prientirt rirs).

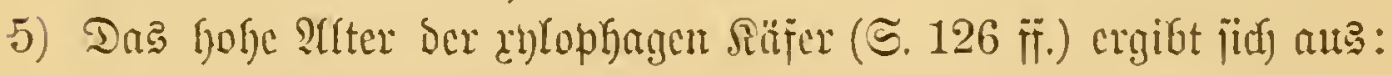
"Bois fossiles perforés par des Coléoptères" (Annales de la Soc. Ent. d. France 1877).

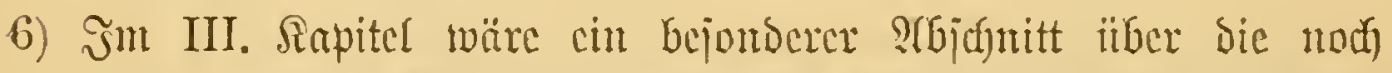

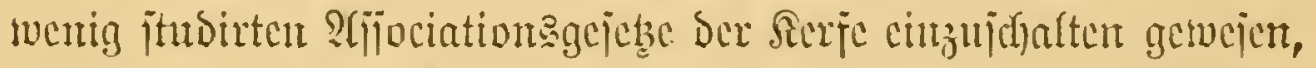

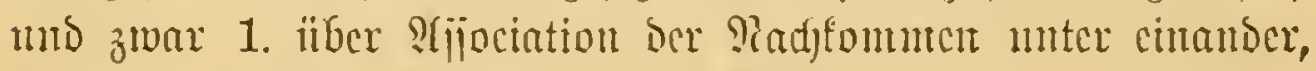
2. mit Den Eftern, 3. mit anderen Rerjen.

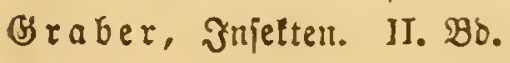




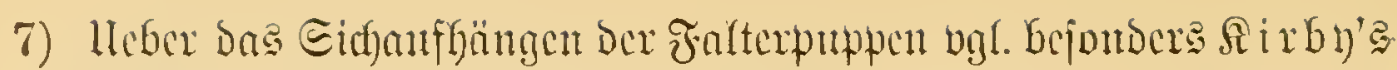

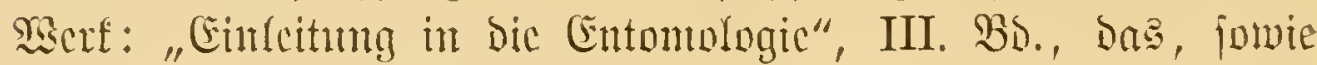

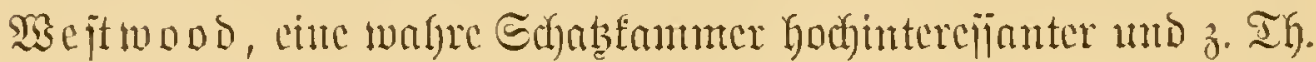

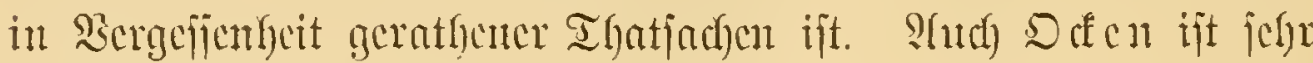

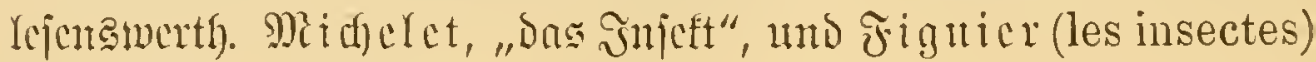
Paris 1869, populär.

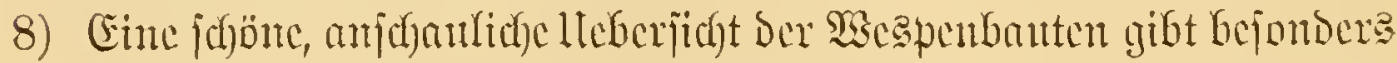
Securi de Saujfuxe in jumer "Monographie des Guêpes sociales". Paris-Genève 1858. - Dic autggezcidunt illuftrixtc

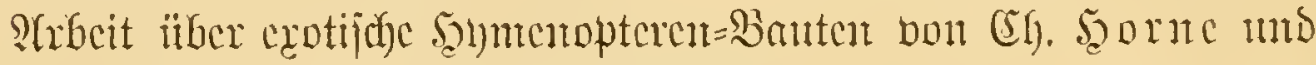
Fr. Smith (ङ. 171 ff.) ftcht in Dout "Transactions of the Zoological Society of London", Vol. VII. 1870. - Sumit vgl. nod): "Metamorphoses, mœurs et instinct des Insectes"

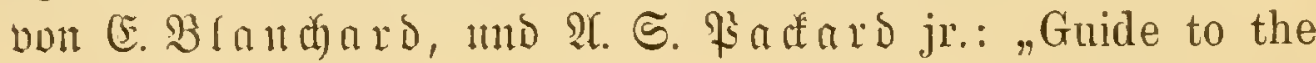
study of Insects". Salem 1872. - Sdjonc Sumundnefter bejibt Prof. Siritof in Graz, won bem aud bas anf $\subseteq .195 \mathrm{gez}$.

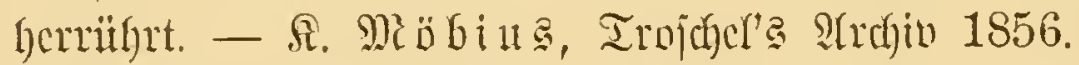

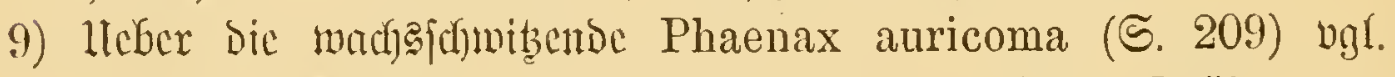

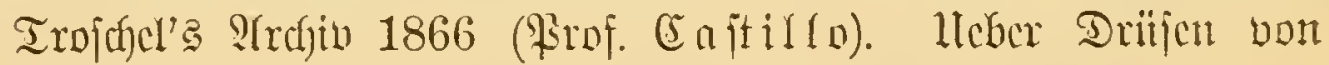
Chrysomela etc. Craus, 3citjchr. f. wifi. Bonlogic.

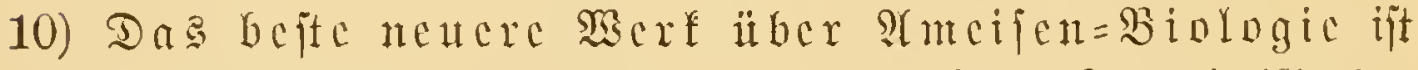
"Les fourmis de la Suisse" vout Dr. Áug. Forcl (Sicnève

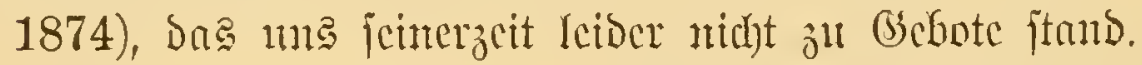

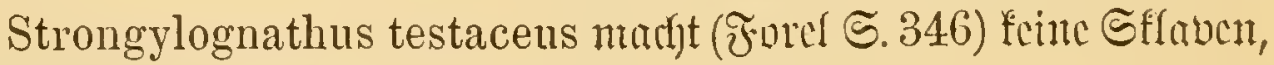
jondern lebt ale Rarajit bci Tetr. caespitum.

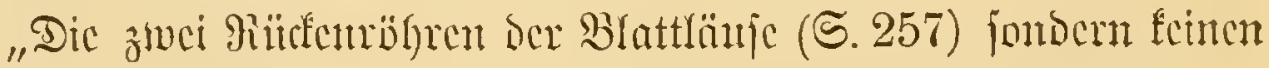

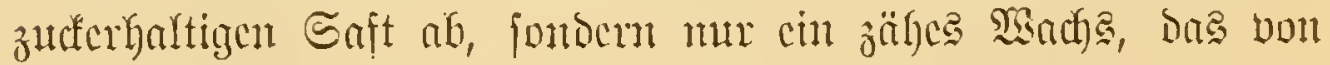

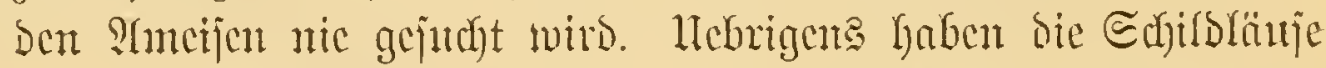
und vicle Blattlänje gax feine joldjen Rïhren und werden bod)

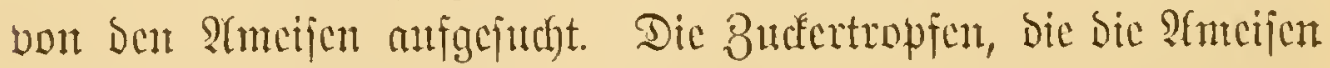

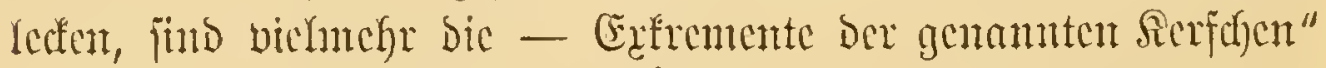
(ugl. Şuber uns Forel'z Études myrmecologiques 1875).

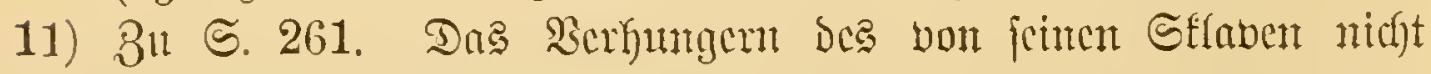
gefïtterten Polyergus mude bereits non \$guber und bant ouerit wicbex anf Grund amfangueducr Experimente vont Forel (ธ.308-310) fomptatint. 


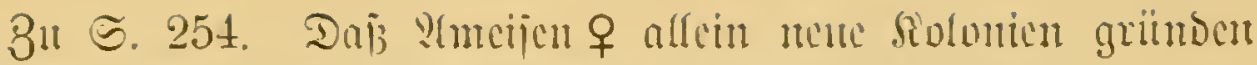

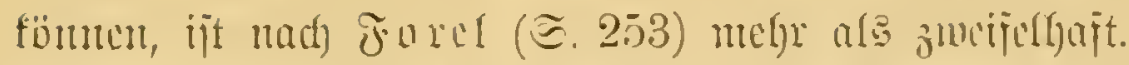

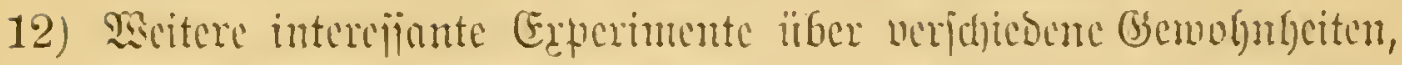

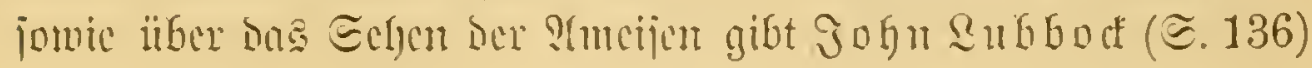
in "the Limnean Society's Journal-Zoologie", vol. XIII n. XIV.

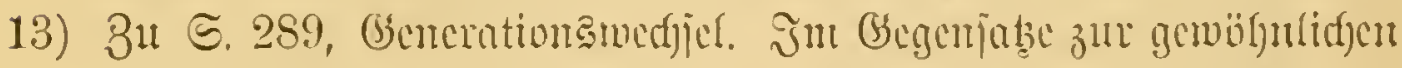

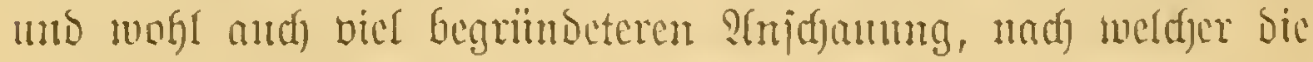

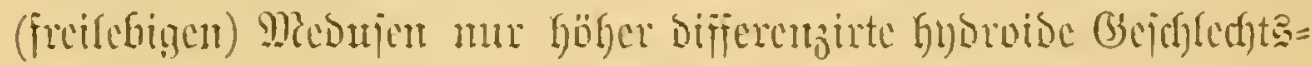

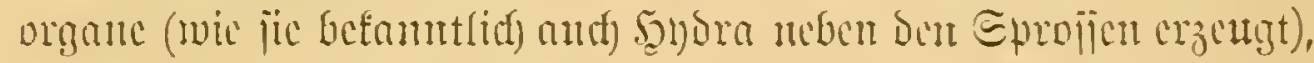

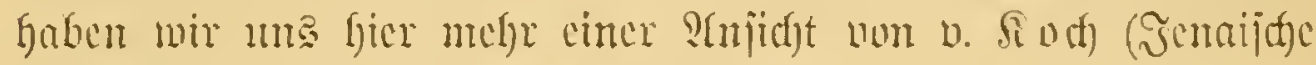
Bcitidgr. F. Piaturiv. 1872) asigeidflojien.

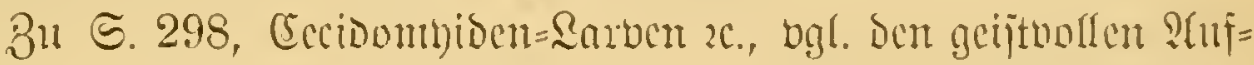
jaț bon v. B̧acr im Bulletin de l'Acad. Petersbourg, Tome IX, jomic (b) a n in's arbeit cbembajelbjt.

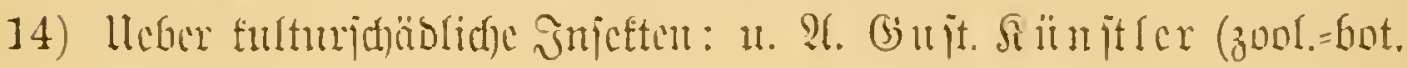
(bic. 㫮icn 1871).

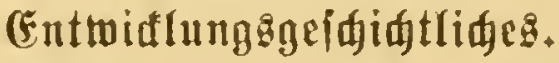

1) 3n S. 372. Das Jnjeften=(Si fant injoferne mit cincr eingc= fapielten Stmöbe vergliden weroen, als jein Jnthalt, wie wir

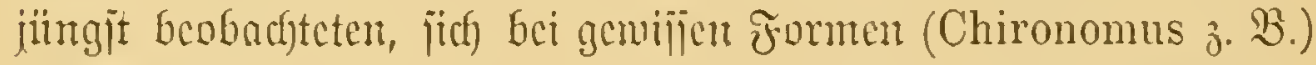

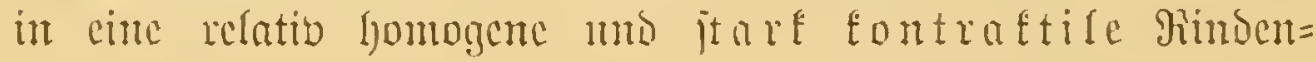

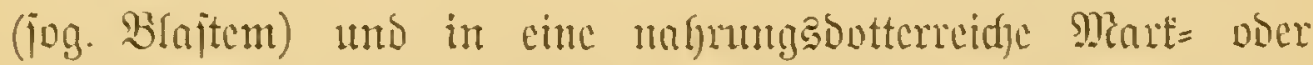

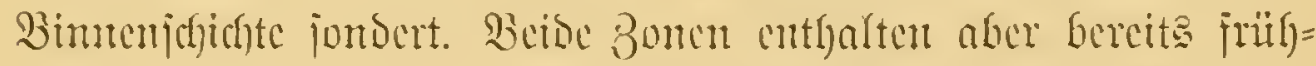

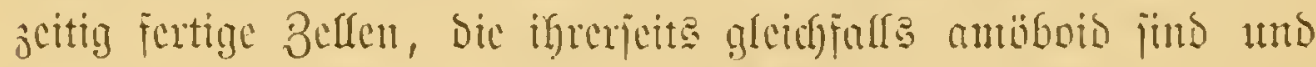
jojujagen bie Iefendige But Der Ei=?lmöbe baritellan.

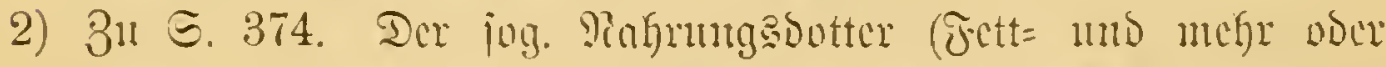

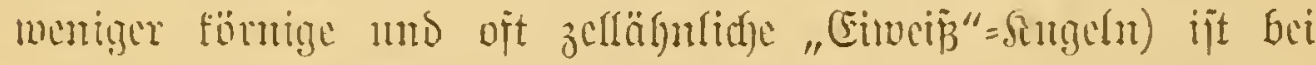

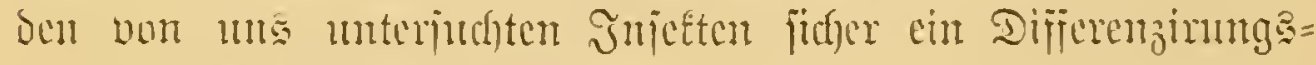
prodult bes erifiripers jelfit.

3) 3u S. 380. Heber Dic Patur und Die. Entitegung Der

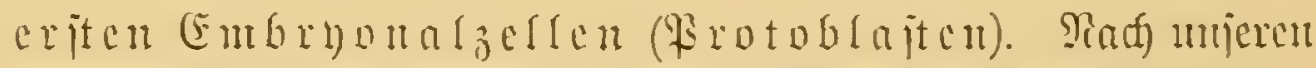

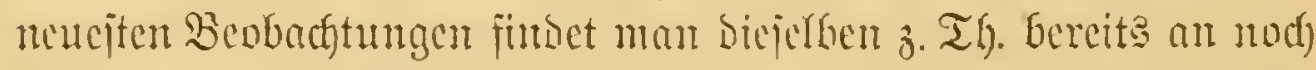

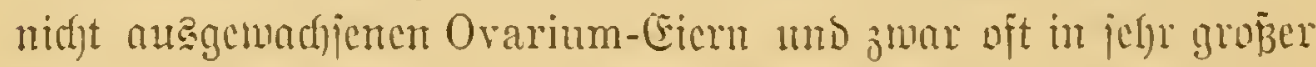

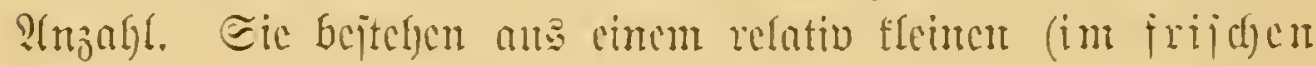

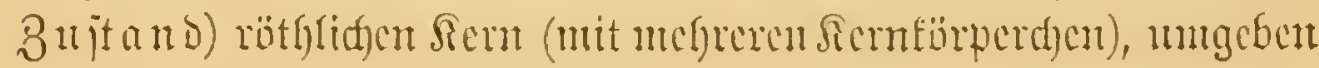


bon einem jelbitünoigen, anjangę jebr jamalen, jpäter beutlid antö=

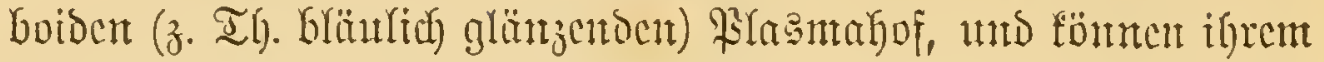

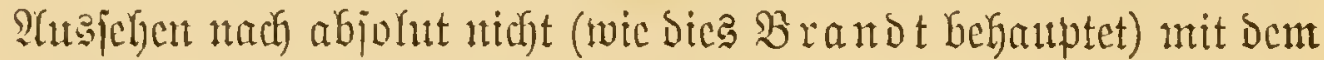

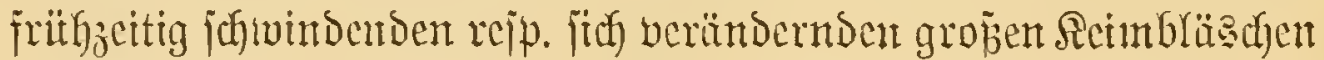

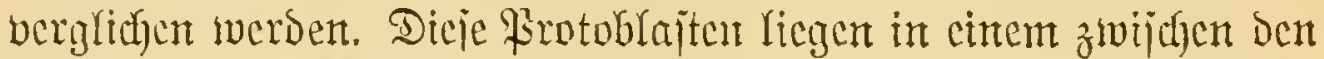
Sabrungsootterelententen fid) ausbreitenoen protoplasmatijacn

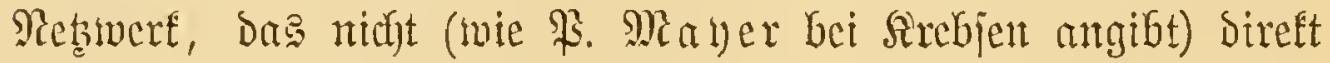
mit ben eingelagerten Rrotoblajten zujammenbängt. Rern uno

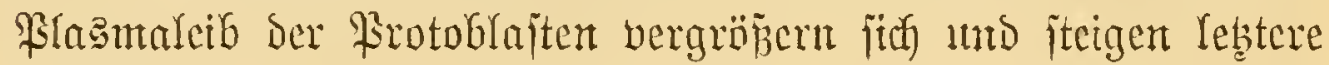
3. Ih., wie wir an lebenden ciem sireft Geobaditet, an bie Glajtemartige Dberflädye, un bas Blajtoberm (Periblait) zut bilben,

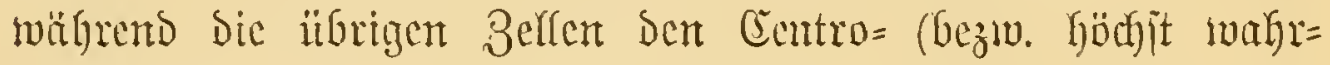

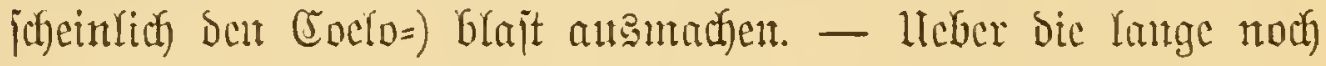

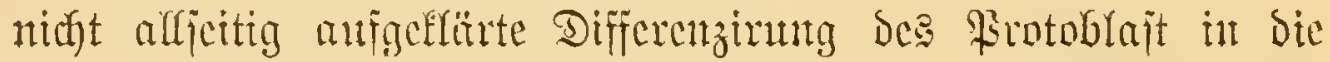

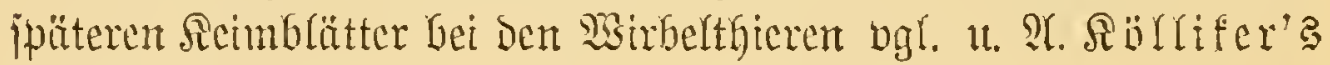

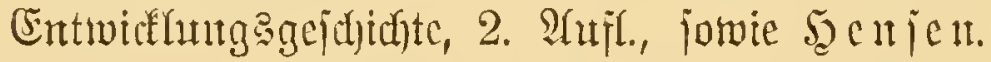

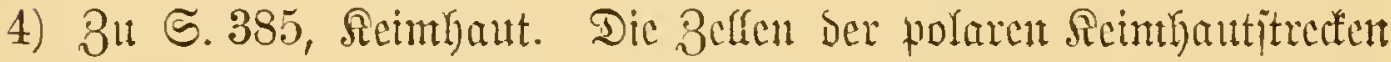
bei Chironomus zeigen (nach cigenen Beobachtungen) febr intenjïve

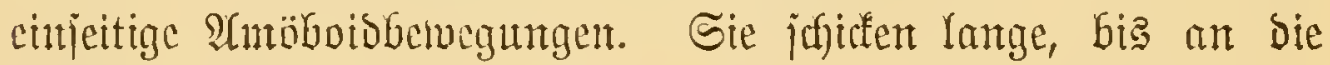

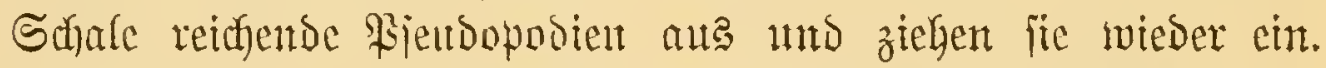

5) 3แ ธ. 409. Dic Deutung Der "Dotterf́lumpen"büllen bei Pyrrhocoris ijt faljh. Soldye bejusen bie Dotterfugeln inon

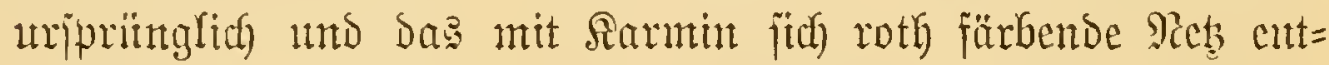
ipridyt Dem bbcrwähnten Silasma=Reticulum. Seicr fontmt cas Ḧberbaupt zu feiner Dotterballung.

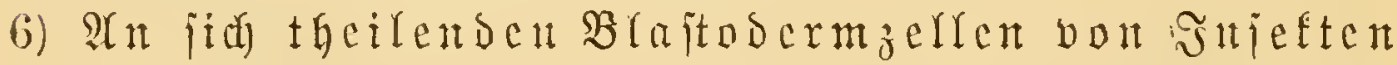
und Spinnen fouftatirten wir jüngit nad Behandung mit $2 \%$ Efjiglüure mb Bsfuccrit eine ganz unzweifel=

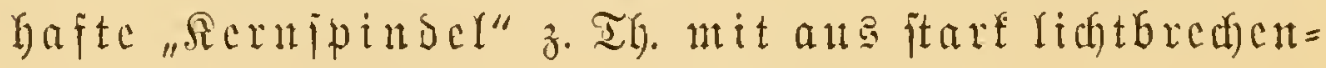

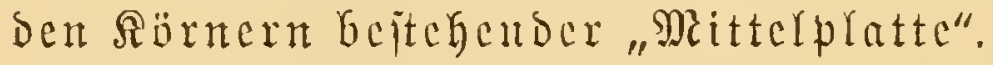

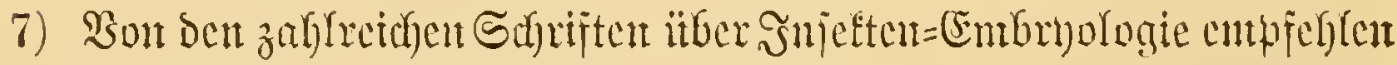

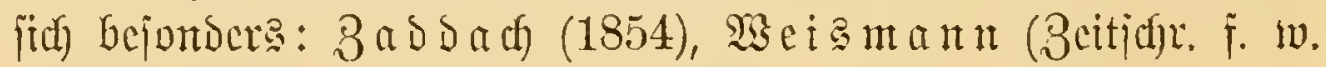

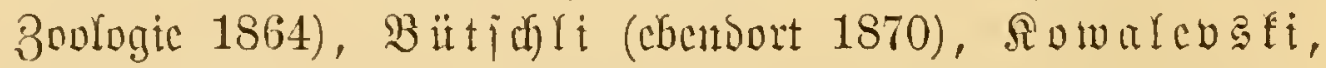

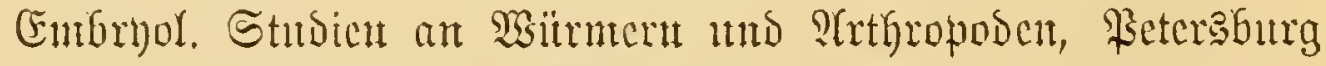
1871, fowic $\mathfrak{B}$ ran it $\mathfrak{Y}$. (Mómoires de l'Acad. Petersb. 1869).

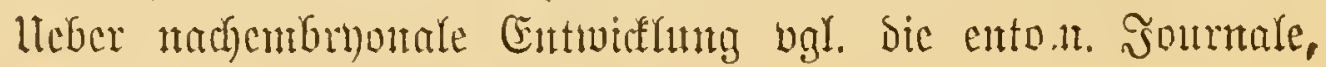




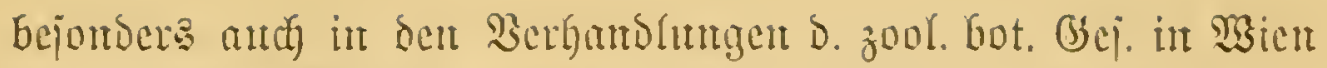

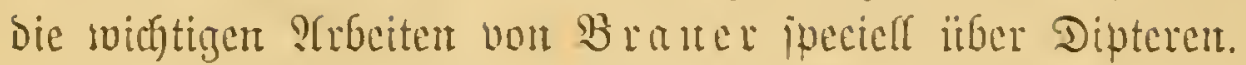

Dunt, anjer ben jonjt erwähnten: The ancestry of insects

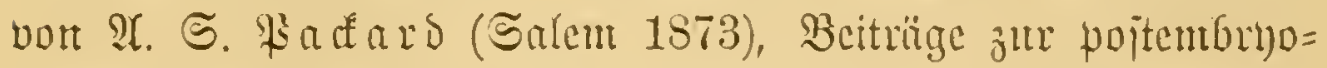

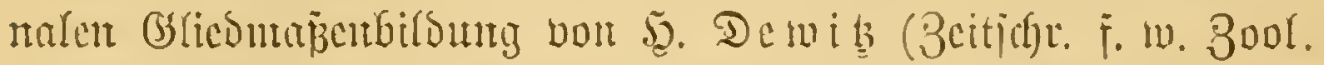

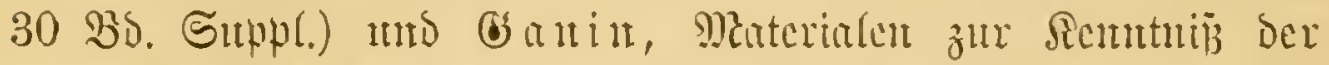

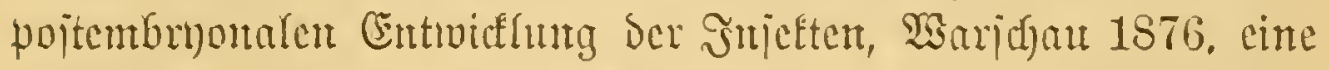

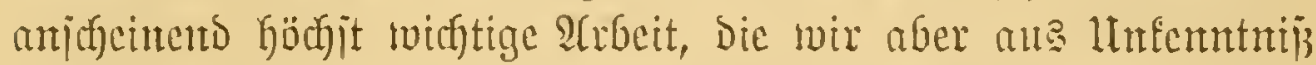

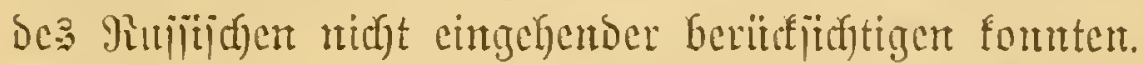

8) Betreffs der Birbug de

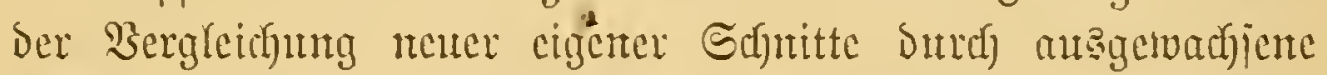

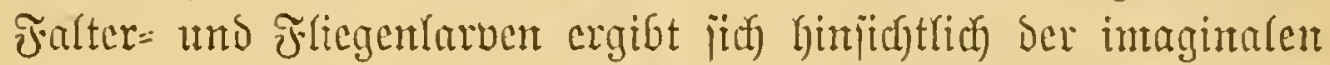

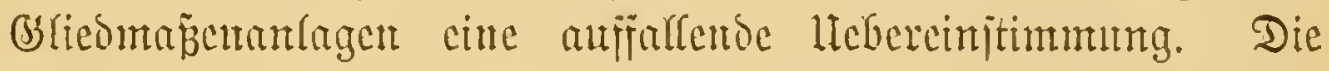

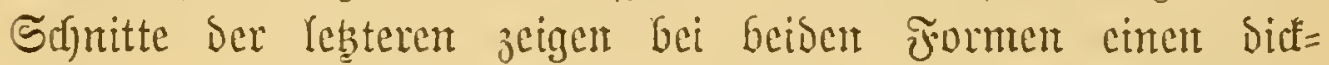

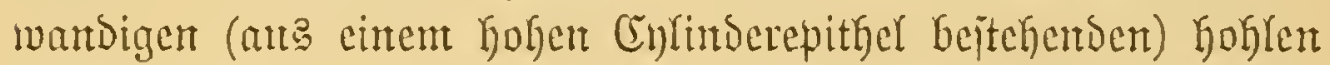
Bapien uno eine biunne pirajterepitgelartige Itmfiillung. Dies

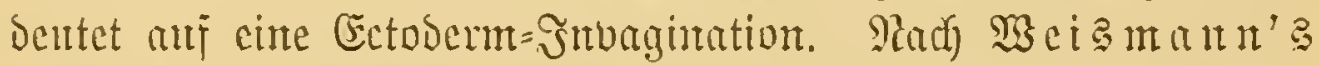

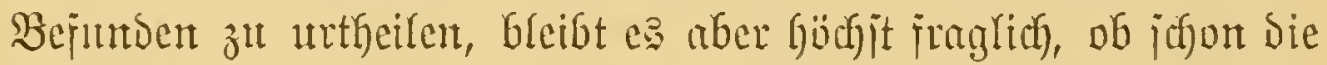
eriten SInlagen ber Fiegentętrentitïten (in ber juntgen Made)

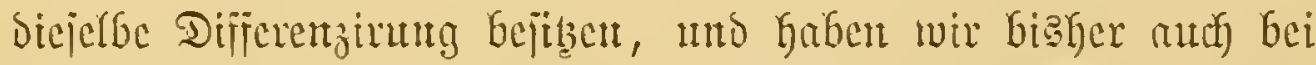

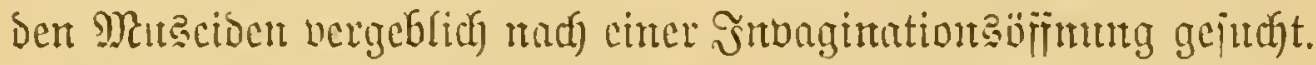

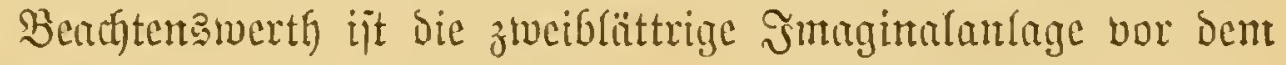
Mrabentafter (S. 475 Fig. 163 a).

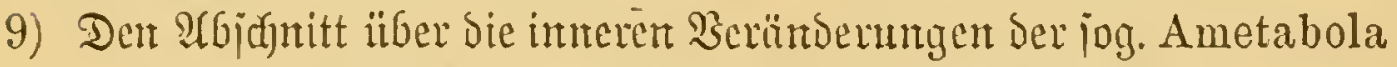
Gabent wir, obrogh er bereits gejeşt war, weggelajien.

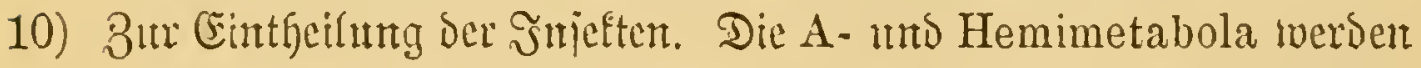

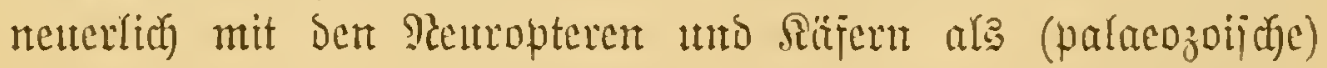
Heterometabola zujamntengejujt, benten jidf bant bie geologija)

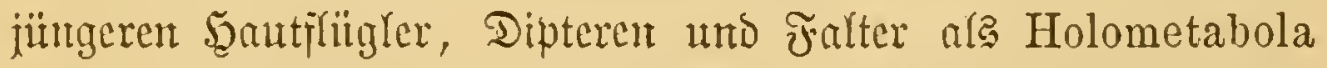

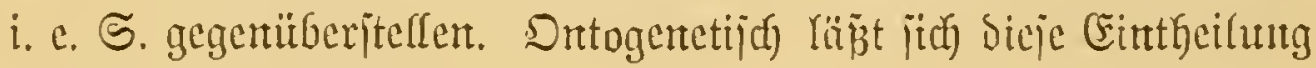
nicfst wogh redytjertigent.

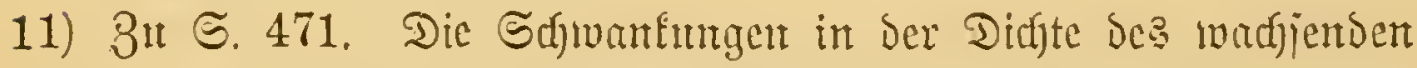
Jnjeftentërpers jitelent in engen 8 manmengange mit sem relatiben Majiergehalte desielbert. 


\section{Corrigenda.}

5. 24 ftatt recursa

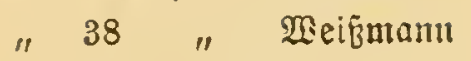

" 121 น. 123 ftatt betulae

" 259 it att Strongylus

" 259 " Sinfectm

" 259 " maleficiens (!)

" 259 Atta molefaciens $=$ Poyonomyrmex barbatus Smith.

" 264 3. 11 v. U.: "twenn es and nod) :c." ijt zu ftreiden.

" 299 " 13 v. u. ftatt Serfe ries Seriei.

" 318 " 11 b. . . ift "fajt" zoll freident.

" 327 " 12 v. o. ft a $t t$ "löunen twir" ri $e$ s "tönnte man".

" 383 "12 r. u. " Säugethiereies " mirbelthiereies.

"383 "10 v. u. " balb " z. Th.

" 391 " 10 ๖. u. " Eonjumctmen " Conjecturen.

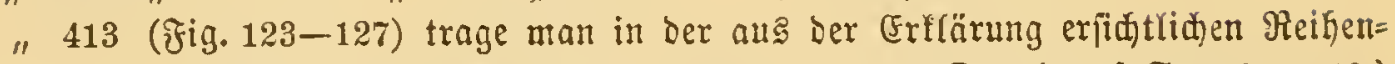
folge bie einzelnen Figuren=?ummern ein. (Deşgl. auj $§ .416 \mathrm{u}, 419$. )

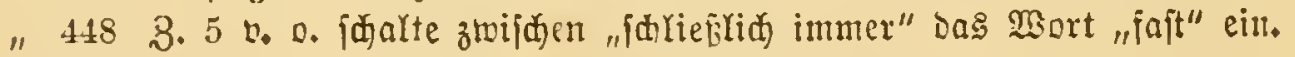

" 451 " 4 b. It. fiat "unb ber" Yies "into Die".

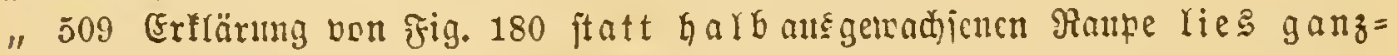
antsgernachjentu.

" 518 Fig. 187 B ift aus Berichen bes ๔eţer's anf bon sopf geftellt. 


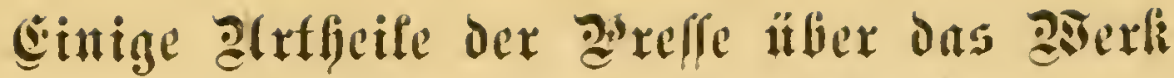 , (6) raber, Die Jiteliten."}

Der maturnifienjartliden Dolfsbibliothef: "Die Ziaturfräfte" XXI. แns XXII. Band.

Band XXI ,graber, Drganismus Der Jnfeften." Band XXII ?(bthig. $1-2$, , grober, Eeben Der Jnferten."

llcber letsteren Band, icjien Echlubabtheilung ber vorltegende

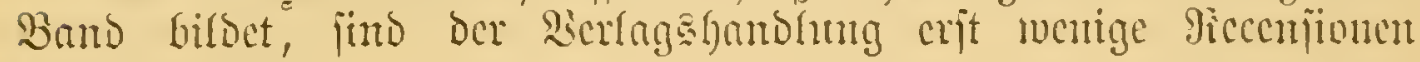
jugctommer.

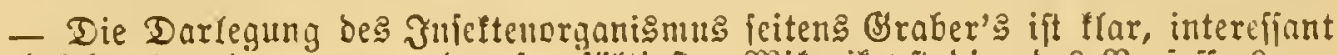
uns Gelchrend mo zeugt bon Den jorgiältigften Mifrojtopftubien bes Berjaifer:

Das neue Blatt.

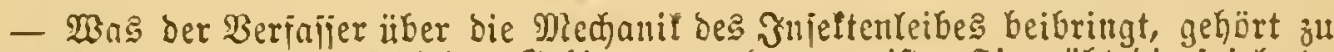
bem 2 eiten, twas ung anf Diefem Bebiete borgefomment ijt. Sier übt bie ipiclente seintigleit jeiner Spradje einen mohlthuenben Finflub auj ben \&ejer, unb jwar um jo mehr, je mehr or fï iiber bie Einfeitigfeit ses Entomologen erbebt uno jid als

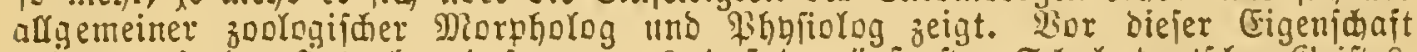
nefmen wir ben Şut $a b$ und ireuen uns, baj ber äuberiten Sđule bentiden Geijtes,

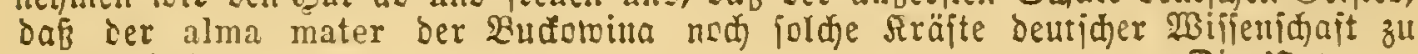
Bebote jteheu.

Die Zlatur.

- Die im Berlag bon $\Re$. Slbenbourg erjheirenbe Bolfsbibliothef ift eine ber wenigen populären Sdriftenjolgen, welde derartig zujammengejęt find, daf man jesen neu erjueinenden $\mathfrak{B a n d}$ mit einem günfigen Borurtheile in die 5ano nimmt. Diejes Brurtheil wirb wieber eimmal auf brs (jlänzendite geredtiertigt burd Den ung borYiegenden exjten Band Der "Injeften" bon (3raber. Wir itehen nidit an, ju behaupten, bafi berjelbe eines "Der beften populär geidriebent bentjden Merfe arts bem Ǵebiete ber "beiareibenben" Raturwiffenidaiten ijt. Wenn wir

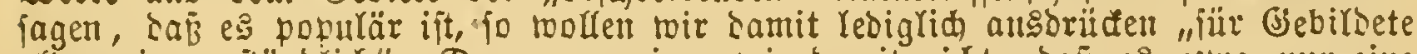

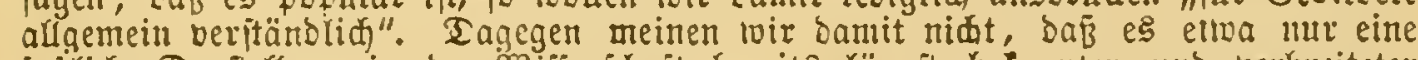

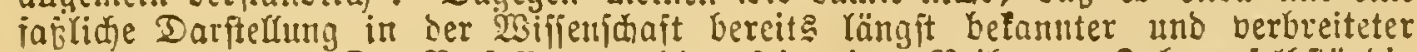

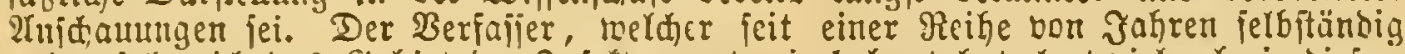
mb erfolgreid tas Gebiet ber Эnjeftenanatomie bebaut hat, regt vielnehr in Diefem Buthe and eine frifle bon eigenen bis jest unpublicirten $B$ eobađtungen nieber.

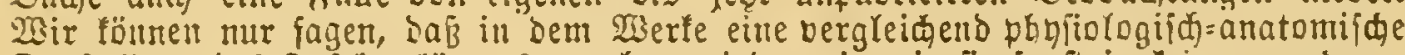

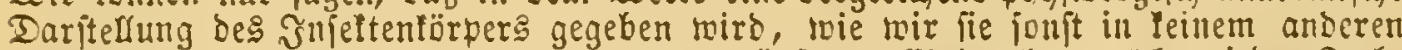
Werle finden. Siidt wenig tragen zu bom günjtigen Finbrude, welden jeser fad $=$

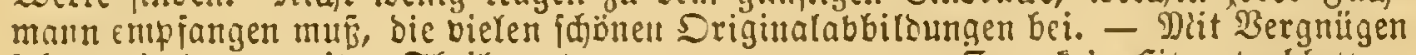
iehen wit dem zweiten Theile entgegent.

כarnde's Siteraturblatt.

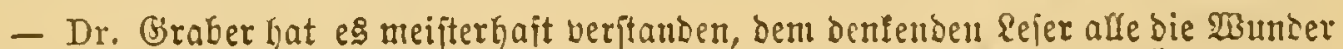

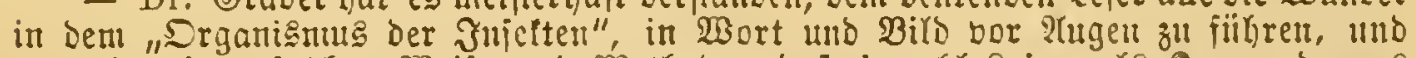

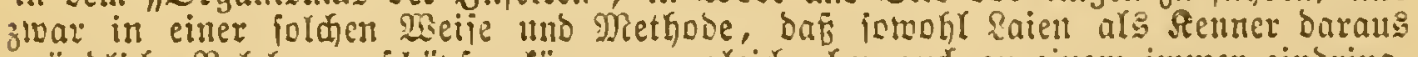
grimblide Bełehrumg föp̈pen fönnen, zugleid) aber aud zu einem immer einbring= lideren und ausgebehnteren ¿tmbium biefer romberfamen शaturen, fid angeregt fiiblen.

Eliäb̆er Biemenjüchter.

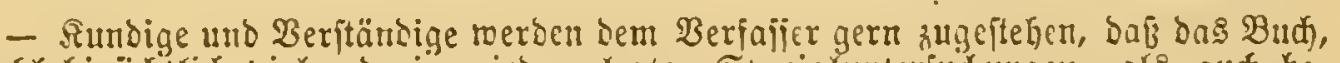

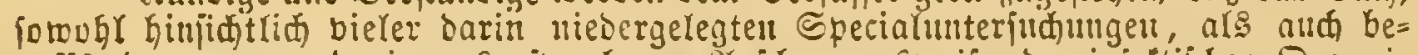

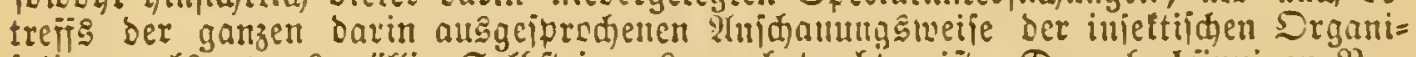

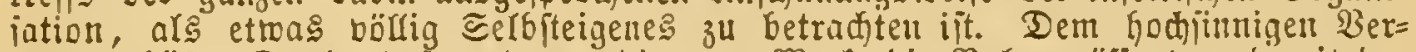

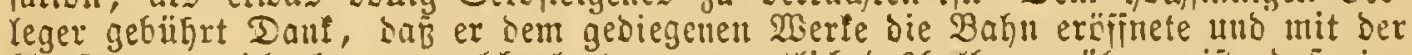

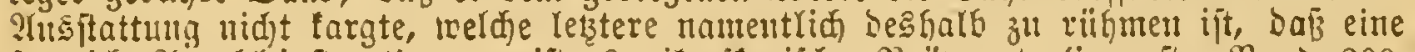

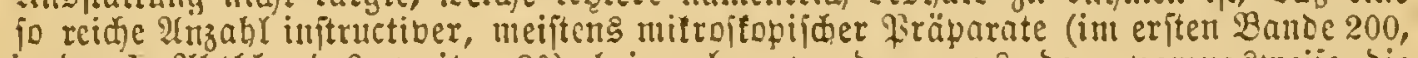

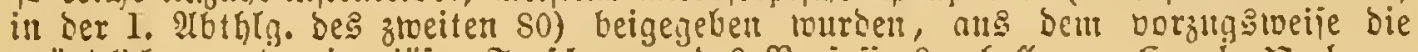

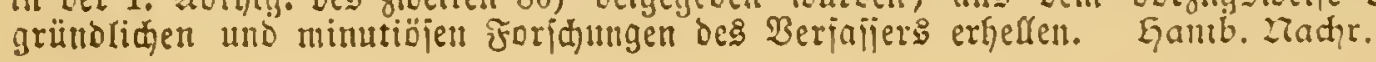




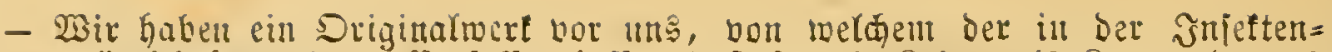

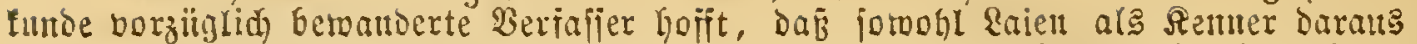
grünolide belehrung idöpien, zugleid aber aud zu einem immer einoringliderent

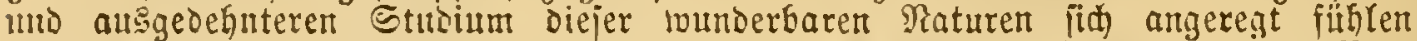

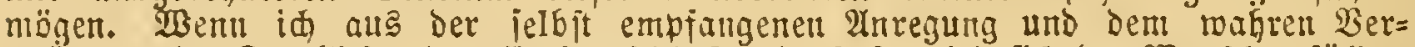

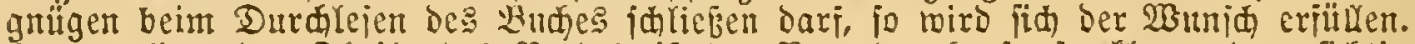

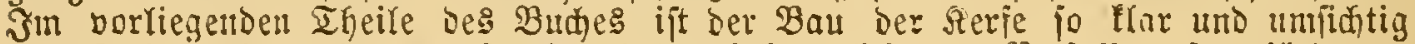

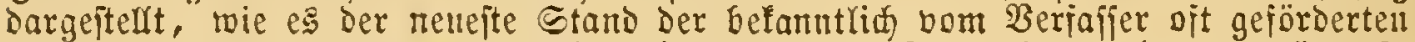
Specialmifienidaft berlangte. Int jelbit wemt ber Tept ni由t gelungen wäre, fo

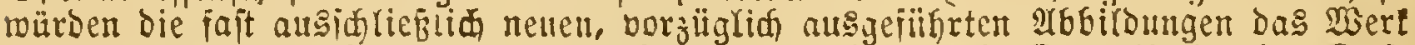
zu einer hödit beadtenimerthen Fridjeimug madjen. Die Drganiation Der Rerie

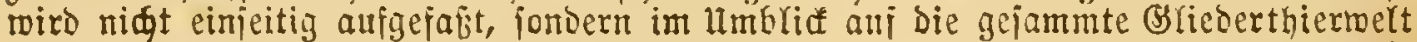

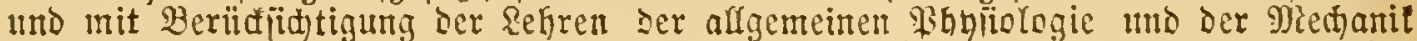

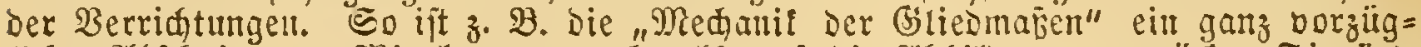

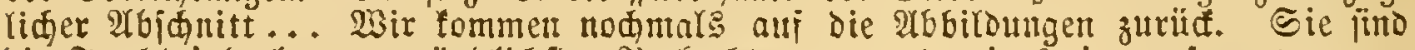
bie Frudt jahrelastger grünbliditer Beobadtungen und eines immenjen, bon me=

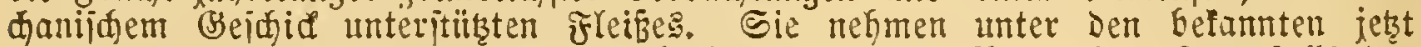

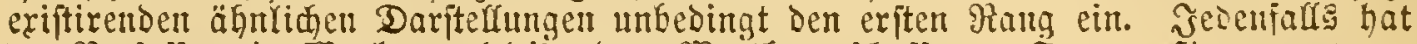
Der Berfajier ein Werf von bleibendem Werthe gejđafjen. Jenaer Siteraturjtg.

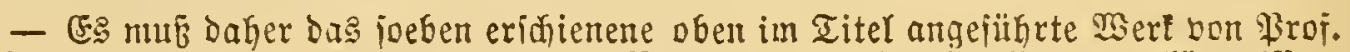
(3raber, weldes als XXI. uns XXII. Banb Dem berdienjtoolfen populär wijiens

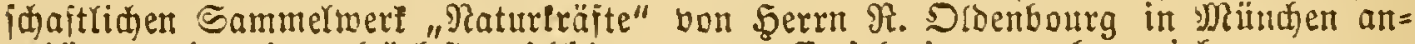

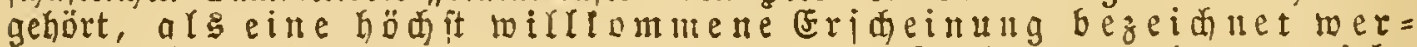
ben, und es tann basielbe fpecielr Den Fadentomologen

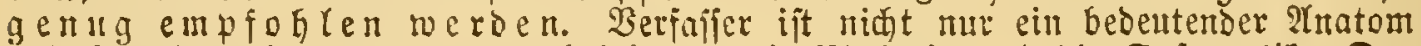
unt Sifitolog, jonoern lent aud jehr gut bie Biologie uno bie Sbitematit. Den

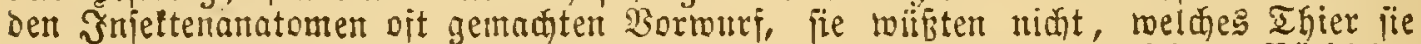

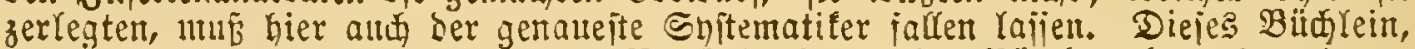
tweldes den XXI. Band ber von $\Re$. Slbenbourg in Dïnden heriuggegebenen

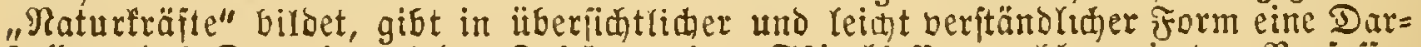

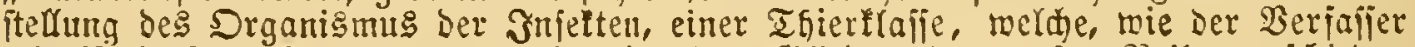
mit Recht bemerft, jtwar mur ein einzelnes Gified in Der grofent Reibe beridieden orgastijirter IGiernaturen und im (Sanzen jidh rejentlid gleid bleibens, bod eine

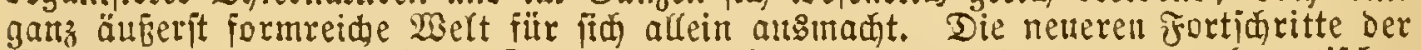

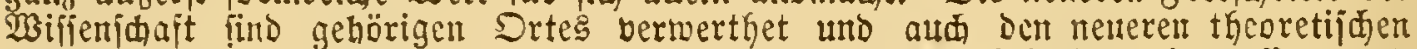

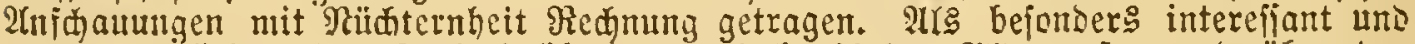

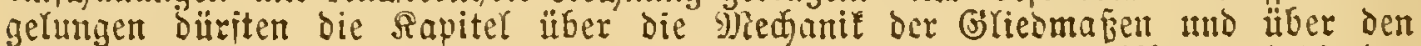
Srlentirnggapparat (bie Simestwerfyeuge) zul bezeidnen jein. 2rber aud die ser

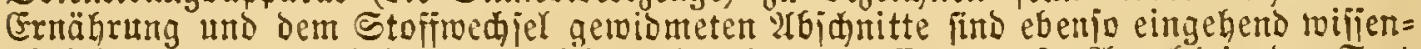

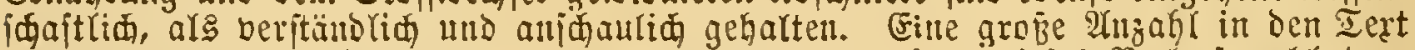
einjeorudter guter \$olzianitte trägt twejentliđ cazu bei, diejes Bub jomohl Dem

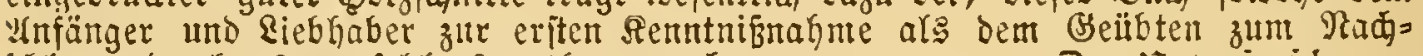

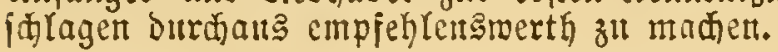

Der ziaturforicher.

- Wir itehen nidjt an, zu befaupten, daj dasielbe eines ber beften yopulär

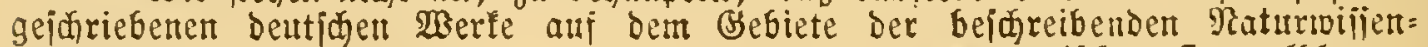
iduaiten ijt. Siterarijhes centralblatt.

-... it is therefore with unmixed pleasure that we welcome the appearance of Dr. Graber's admirable and ably-illustrated treatise. It would be impossible here to gire even an outline of the vast series of facts which the learned author has brought together, mothing relative to the organism of insects being regarded as too insignificant for careful and unwearied research; as an instance of the thoroughness of his labours we would especially call attention to his interesting observations on the action of the legs of insects when walking, a point which he seems thoroughly to hare studied and which he has amply illustrated, although many students would probably hare regarded it as a matter of little moment. In fine, the entire rolume is nost valuable, and should be esteemed as a necessary hand-book, not only by every entomologist, but by all who have the interests of natural science at heart.

The Nature. 



$\because \quad$.

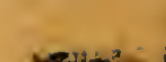


11515 
a $x^{2} y-48$ 